\title{
Water Resources Data
} for

\section{California}

\section{Water Year 1976}

Volume 1. Colorado River Basin, Southern Great Basin from Mexican Border to Mono Lake Basin, and Pacific Slope Basins from Tijuana River to Santa Maria River

U.S. GEOLOGICAL SURVEY WATER-DATA REPORT CA-76-1

Prepared in cooperation with the California Department of Water Resources and with other agencies 


\section{CALENDAR FOR WATER YEAR 1976}

1975

OCTOBER NOVEMBER DECEMBER

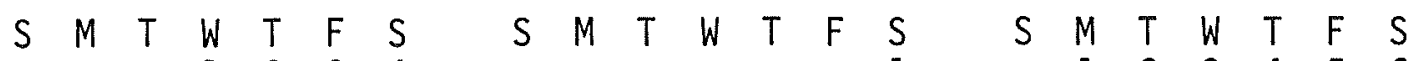

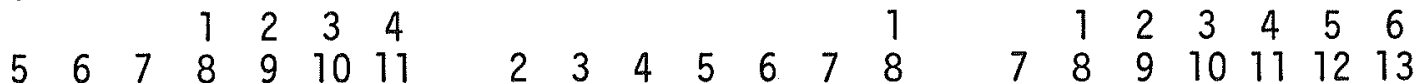

$\begin{array}{llllllllllllllllllllll}12 & 13 & 14 & 15 & 16 & 17 & 18 & 9 & 10 & 11 & 12 & 13 & 14 & 15 & 14 & 15 & 16 & 17 & 18 & 19 & 20\end{array}$

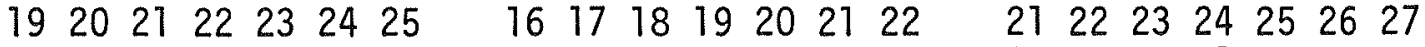
$\begin{array}{lllllllllllllllll}26 & 27 & 28 & 29 & 30 & 31 & 23 & 24 & 25 & 26 & 27 & 28 & 29 & 28 & 29 & 30 & 31\end{array}$

30

1976

JANUARY FEBRUARY MARCH

$\begin{array}{lllllllllllllllllllll}S & M & T & W & T & F & S & S & M & T & W & T & F & S & S & M & T & W & T & F & S\end{array}$ $\begin{array}{lllllllllllllllllll} & & 1 & 2 & 3 & 1 & 2 & 3 & 4 & 5 & 6 & 7 & & 1 & 2 & 3 & 4 & 5 & 6\end{array}$ $\begin{array}{llllllllllllllllllllll}4 & 5 & 6 & 7 & 8 & 9 & 10 & 8 & 9 & 10 & 11 & 12 & 13 & 14 & 7 & 8 & 9 & 10 & 11 & 12 & 13\end{array}$ $\begin{array}{lllllllllllllllllllll}11 & 12 & 13 & 14 & 15 & 16 & 17 & 15 & 16 & 17 & 18 & 19 & 20 & 21 & 14 & 15 & 16 & 17 & 18 & 19 & 20\end{array}$

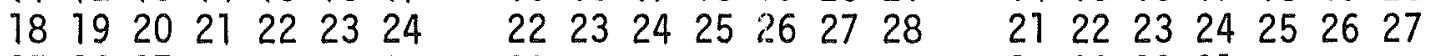

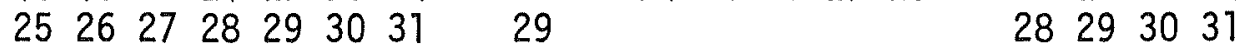

APRIL MAY JUNE

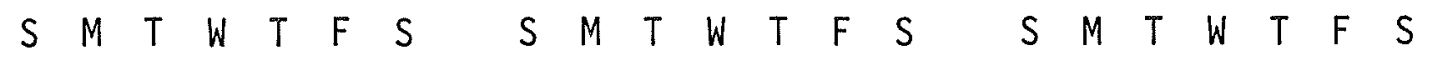

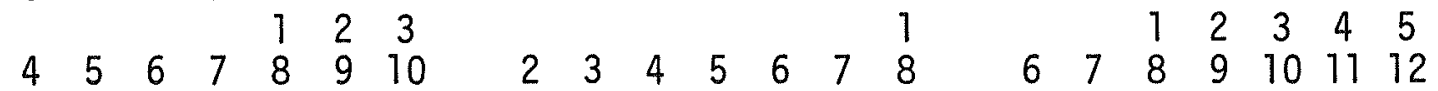
$\begin{array}{lllllllllllllllllllll}11 & 12 & 13 & 14 & 15 & 16 & 17 & 9 & 10 & 11 & 12 & 13 & 14 & 15 & 13 & 14 & 15 & 16 & 17 & 18 & 19\end{array}$ $\begin{array}{lllllllllllllllllllll}18 & 19 & 20 & 21 & 22 & 23 & 24 & 16 & 17 & 18 & 19 & 20 & 21 & 22 & 20 & 21 & 22 & 23 & 24 & 25 & 26\end{array}$

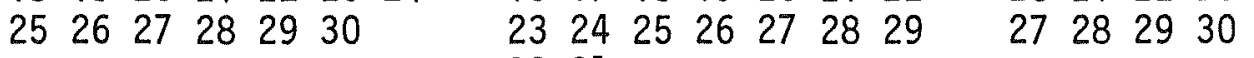
3031
$J \cup L Y$
$A \cup G \cup S T$
SEP TEMBER
$\begin{array}{llllllllllllll}S & M & T & W & T & F & S & S & M & T & W & T & F & S \\ & & & 1 & 2 & 3 & 1 & 2 & 3 & 4 & 5 & 6 & 7\end{array}$
$\begin{array}{llllllllllllllllllllll}4 & 5 & 6 & 7 & 8 & 9 & 10 & 8 & 9 & 10 & 11 & 12 & 13 & 14 & 5 & 6 & 7 & 8 & 9 & 10 & 11\end{array}$
$\begin{array}{lllllllllllllllllllll}11 & 12 & 13 & 14 & 15 & 16 & 17 & 15 & 16 & 17 & 18 & 19 & 20 & 21 & 12 & 13 & 14 & 15 & 16 & 17 & 18\end{array}$

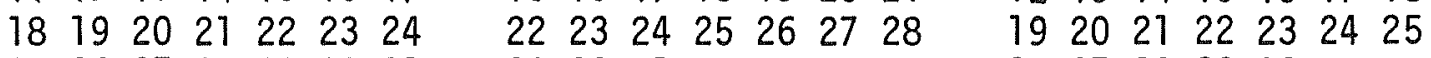

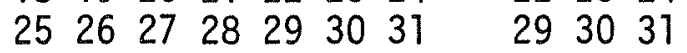
26. 27282930 


\section{Water Resources Data for California}

\section{Water Year 1976}

Volume 1. Colorado River Basin, Southern Great Basin from Mexican Border to Mono Lake Basin, and Pacific Slope Basins from Tijuana River to Santa Maria River

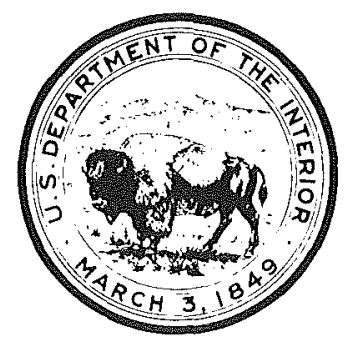

U.S. GEOLOGICAL SURVEY WATER-DATA REPORT CA-76-1

Prepared in cooperation with the California Department of Water Resources and with other agencies 
UNITED STATES DEPARTMENT OF THE INTERIOR

CECIL D. ANDRUS, Secretary

GEOLOGICAL SURVEY

V. E. McKelvey, Director
For information on the water program in California write to District Chief, Water Resources Division U.S. Geological Survey 855 Oak Grove Avenue Men1o Park, California 94025


PREFACE

This report was prepared by the U.S. Geological Survey, in cooperation with the California Department of Water Resources and with other agencies, by personnel of the California District of the Water Resources Division under the supervision of Lee R. Peterson, District Chief, and W. H. Robinson, Regional Hydrologist, Western Region.

This report is one of a series issued by state. General direction for the series is by J. S. Cragwell, Jr., Chief Hydrologist, and G. W. Whetstone, Assistant Chief Hydrologist for Scientific Publications and Data Management.

Data for California are in four volumes as follows:

Volume 1. Colorado River Basin, Southern Great Basin from Mexican Border to Mono Lake Basin, and Pacific Slope Basins from Tijuana River to Santa Maria River

Volume 2. Pacific Slope Basins from Arroyo Grande to Oregon State Line except Central Valley

Volume 3. Southern Central Valley Basins and The Great Basin from Walker River to Truckee River

Volume 4. Northern Central Valley Basins and The Great Basin from Honey Lake Basin to Oregon State Line 


\section{BIBLIOGRAPHIC DATA}

SHEET

SHEET TIIE and Subrile Water ResOurces Data for

4. Title and Subtitle Water Resources Data for California, 1976

Volume 1. Colorado River Basin, Southern Great Basin from

Mexican Border to Mono Lake Basin, and Pacific-Slope

Basins from Tijuana River to Santa Maria River

\section{Author(s)}

U.S. Geological Survey

9. Performing Organization Name and Address

U.S. Geological Survey, Water Resources Division

California District

345 Middlefield Road

Menlo Park, Calif. 94025

12. Sponsoring Organization Name and Address

U.S. Geological Survey, Water Resources Division

Ca1ifornia District

345 Middlefield Road

Menlo Park, Calif. 94025

15. Supplementary Notes

Prepared in cooperation with the California Department of Water Resources and

16. Abstracts other agencies.

Volume 1 of water resources data for the 1976 water year for California consists of records of stage, discharge, and water quality of stream; stage, contents, and water quality in lakes and reservoirs; and water levels in wells. This report contains discharge records for 243 gaging stations; stage-only record for 1 gaging station; stage and contents for 19 lakes and reservoirs; water quality for 60 stations and 2 wells; water levels for 22 observation we11s. Also included are 22 crest-stage partial-record stations. Additional water data were collected at various sites, not part of the systematic data collection program, and are published as special investigations and miscellaneous measurements. These data represent that part of the Nationa1 Water Data System operated by the U.S. Geologica1 Survey and cooperating State and Federal agencies in California.

17. Key Words and Document Analysis. 17a. Descriptors

*California, *Hydrologic data, *Surface water, *Water quality, *Ground water, Flow rate, Gaging stations, Lakes, Reservoirs, Chemical analyses, Sediment, Water temepratures, Sampling sites, water levels, water analyses.

17b. Identifiers/Open-Ended Terms

17c. COSATI Field/Group

18. Availability Statement No restriction on distribution.

This report may be purchased from:

National Technical Information Service

Springfield, VA 22161

\begin{tabular}{|c|c|}
$\begin{array}{l}\text { 19. Security Class (This } \\
\text { Report) } \\
\text { UNCLASSIFIED }\end{array}$ & $\begin{array}{c}\text { 21. No. of Pages } \\
644\end{array}$ \\
\hline $\begin{array}{l}\text { 20. Security Class (This } \\
\text { Page } \\
\text { UNCLASSIFIED }\end{array}$ & 22. Price \\
\hline
\end{tabular}




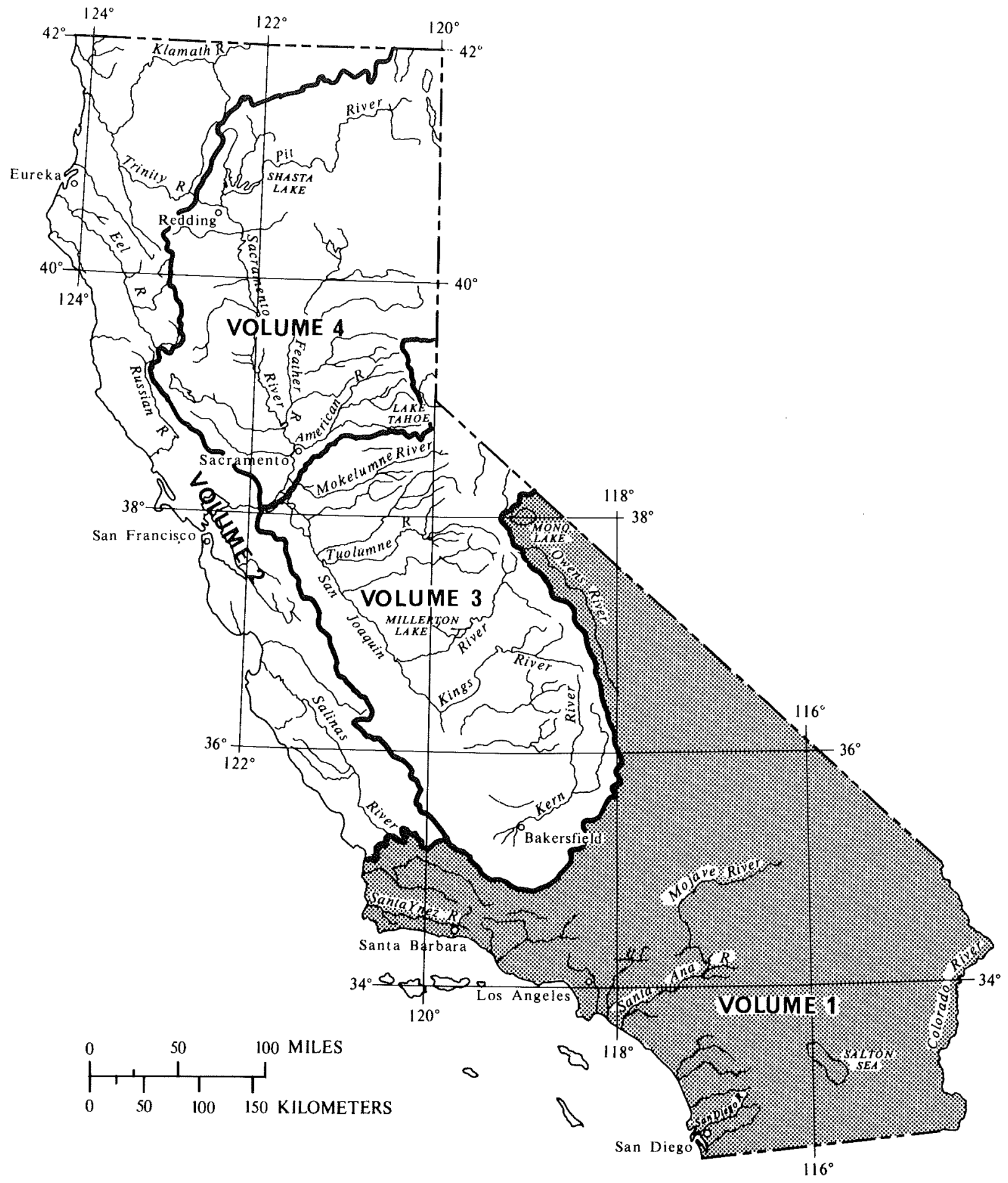

Area covered by volumes in the annual series on water-resources data for California. Area covered by this volume is shaded. 



\section{CONTENTS}

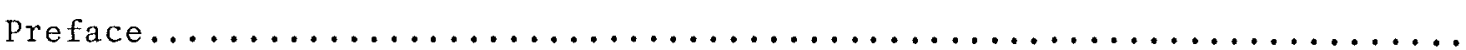

List of surface-water and water-quality stations, in downstream order,

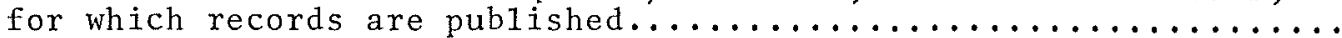

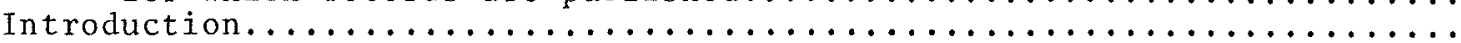

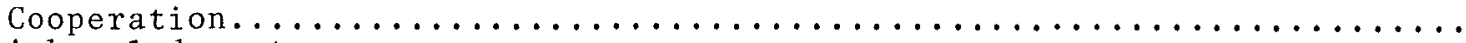

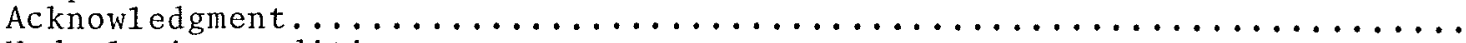

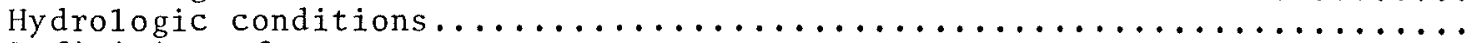

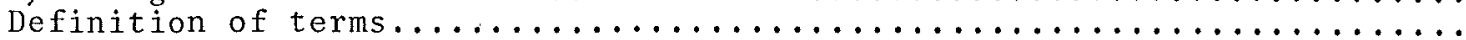

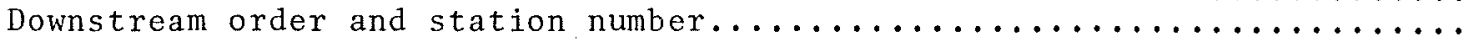

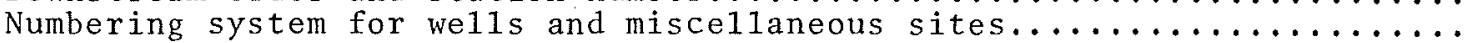

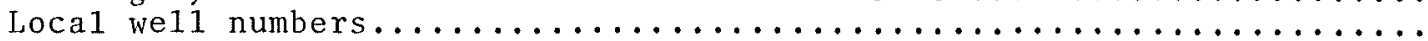

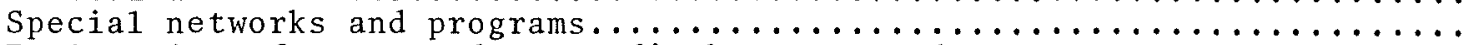

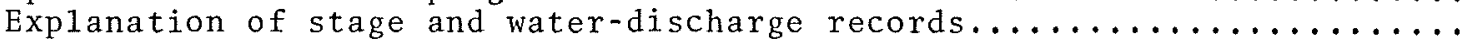

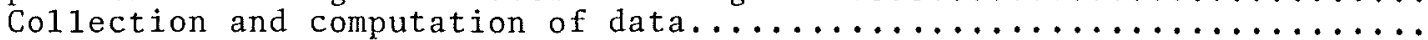

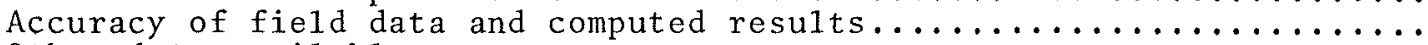

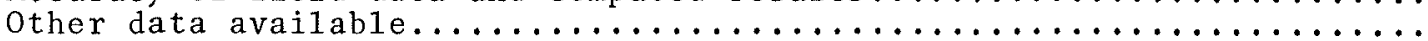
Records of discharge collected by agencies other than the

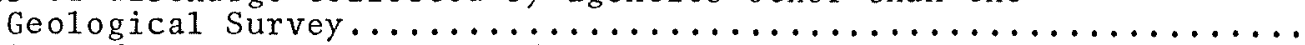

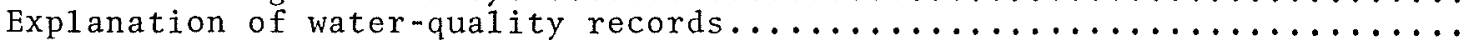

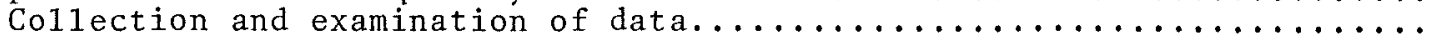

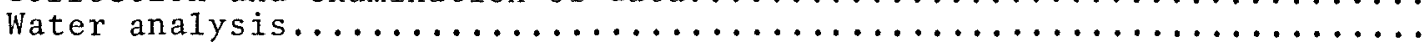

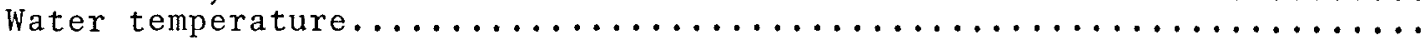

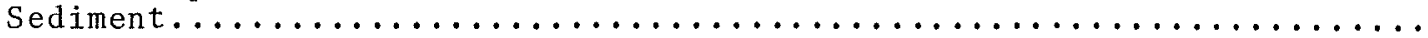

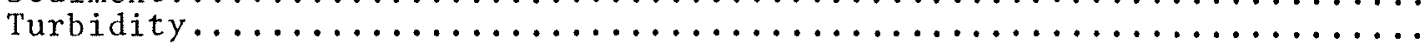

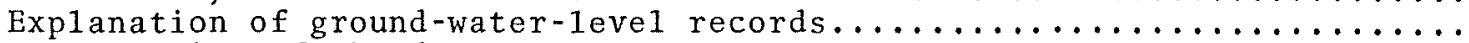

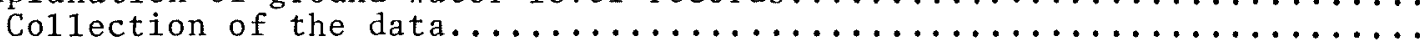

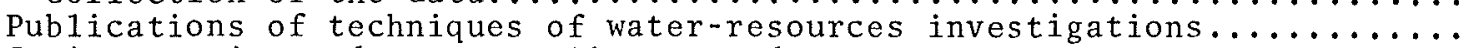

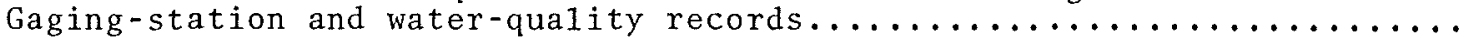
Discharge at partial-record stations and miscellaneous sites.........

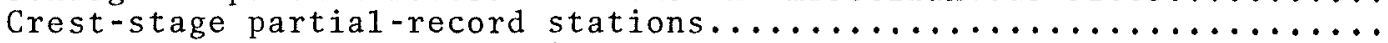

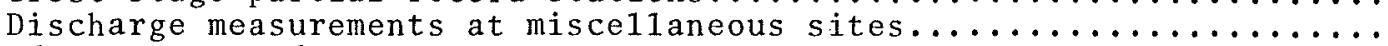

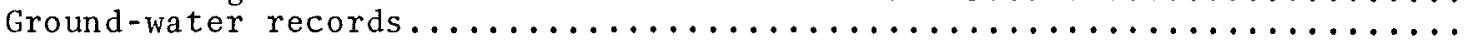

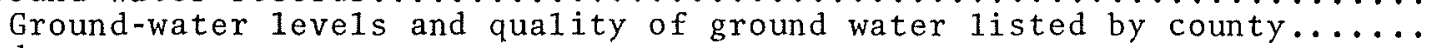

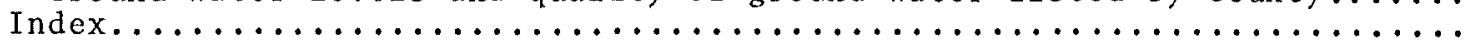




\section{ILLUSTRATIONS}

Figure 1. Map of California showing runoff for the current water year....

2. System for numbering wel1s and miscellaneous sites (1atitude

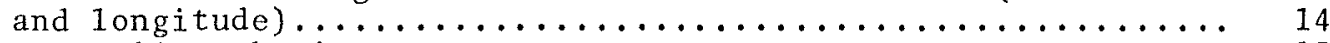

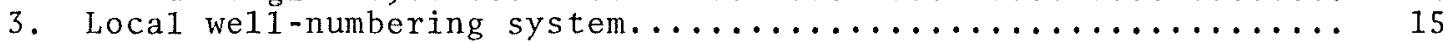

4. Schematic diagram showing gaging stations and water-quality stations on streams, diversions, and return flows between Imperial Dam and the southerly international boundary...... 161

5-6. Schematic diagrams showing diversions and storage:

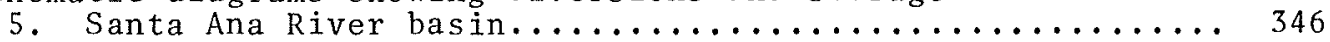

6. San Gabriel and Los Angeles River basins............... 453

TABLE

Table 1. Conversion of turbidity values, measured by Hach Turbidimeters Mode1 1860 or 2100 , from parts per mil1ion or milligrams per

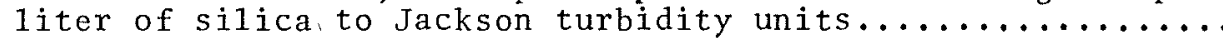


[Letters after station name designate type of data:

(d), discharge; (1), lake contents; (c), chemica1; (b), biological;

$(t)$, water temperature; and ( $s$ ), sediment]

COLORADO RIVER BASIN

COLORADO RIVER:

Colorado River below Hoover Dam, Ariz. -Nev. (dcbs).................

Colorado River below Davis Dam, Ariz.-Nev. (dc) $\ldots \ldots \ldots \ldots \ldots \ldots \ldots \ldots \ldots \ldots \ldots$

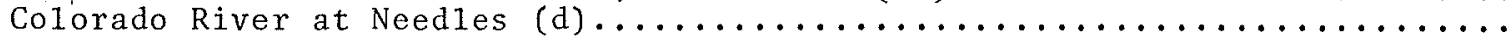

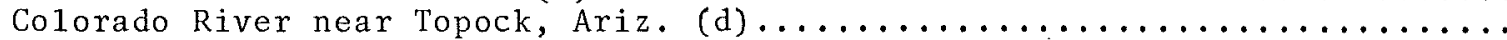

LAKE HAVASU:

DIVERSION FROM LAKE HAVASU

Colorado River aqueduct near Parker Dam, Ariz.-Calif. (dc)...........

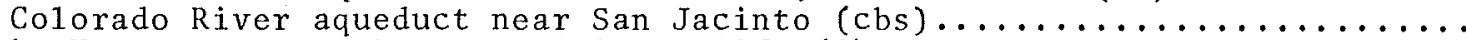

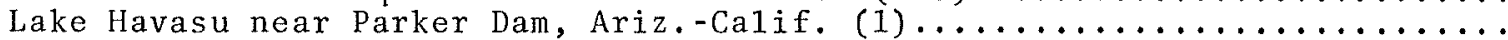

Colorado River below Parker Dam, Ariz.-Calif. (dc)..................

TRIBUTARIES AND DIVERSIONS BETWEEN PARKER DAM AND PALO VERDE DAM

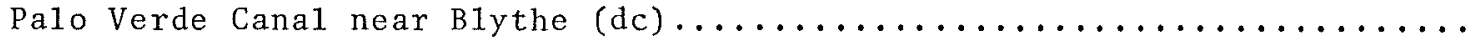

Colorado River at Palo Verde Dam, Ariz.-Calif. (d) ................

Palo Verde Irrigation District Olive Lake drain near Blythe (c) .........

Palo Verde Irrigation District Outfall drain near Palo Verde (c) .........

Pa1o Verde Irrigation District Anderson drain near Palo Verde (c) .......

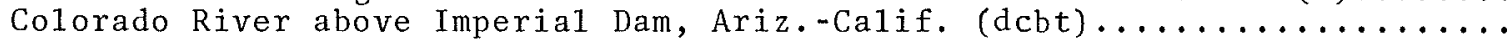

Colorado River below Imperial Dam, Ariz.-Calif. (d) .................

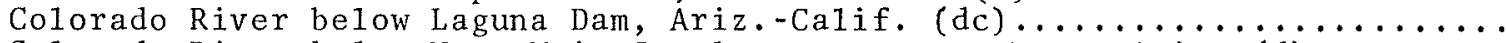

Colorado River below Yuma Main Canal wasteway, at Yuma, Ariz. (d).........

Colorado River at northerly international boundary, above Morelos Dam,

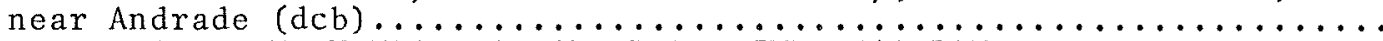

DIVERSIONS AND RETURN FLOWS AT AND BELOW IMPERIAL DAM

Gila Gravity Main Canal at Imperial Dam, Ariz.-Calif. (dct) ..........

All-American Canal near Imperial Dam, Ariz.-Calif. (d)..............

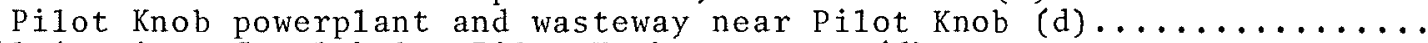

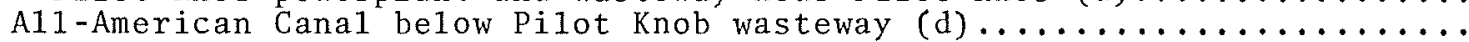

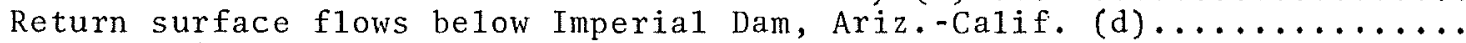
THE GREAT BASIN

PANAMINT VALLEY

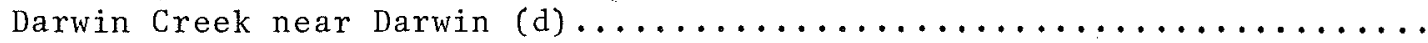

DEATH VALLEY

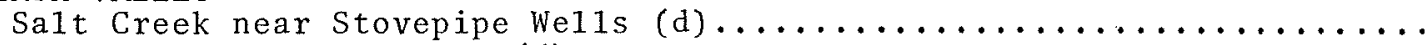

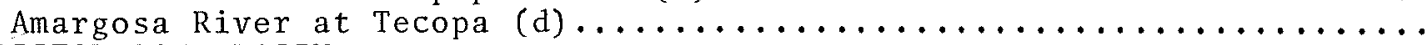

BRISTOL LAKE BASIN

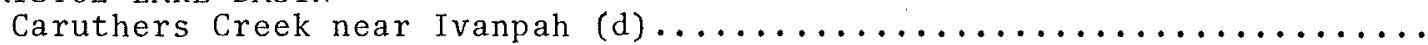

SALTON SEA BASIN

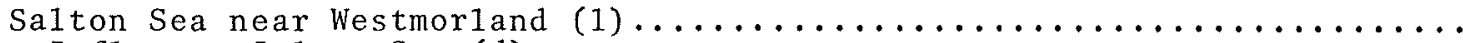

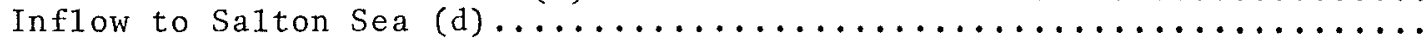

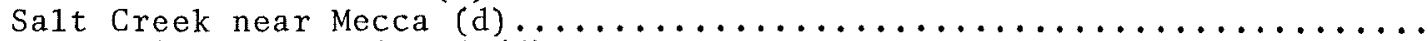

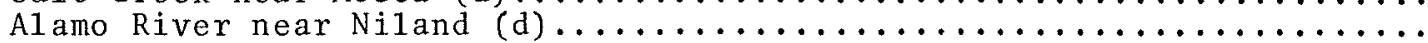

New River at international boundary, at Calexico (cbts)............

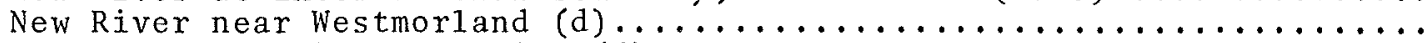

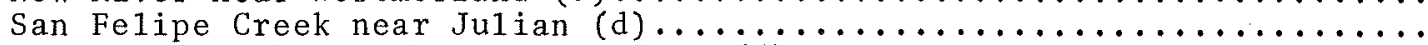

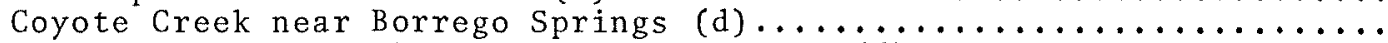

Borrego Palm Creek near Borrego Springs (d) $\ldots \ldots \ldots \ldots \ldots \ldots \ldots$ Carrizo Creek:

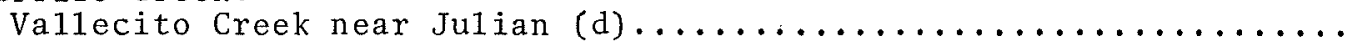

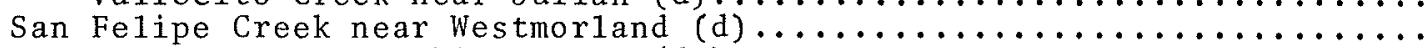

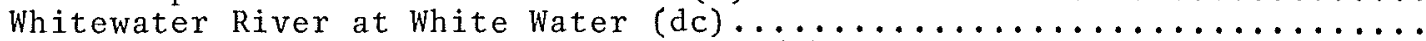

San Gorgonio River near white water (d) $\ldots \ldots \ldots \ldots \ldots \ldots \ldots \ldots$

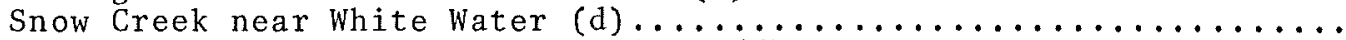

Mission Creek near Desert Hot Springs (d) $\ldots \ldots \ldots \ldots \ldots \ldots \ldots \ldots$

Chino Canyon Creek near Palm Springs (d) $\ldots \ldots \ldots \ldots \ldots \ldots \ldots \ldots$

Page

27

46

48

120

121 
THE GREAT BASIN--Continued

SALTON SEA BASSIN--Continued

New River:

Morongo Wash:

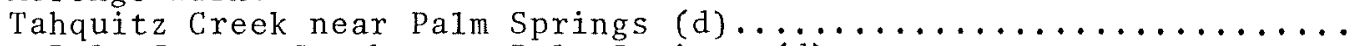

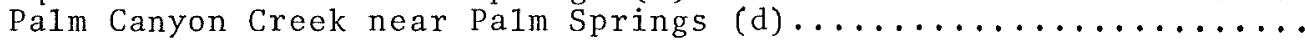

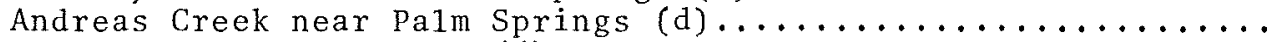

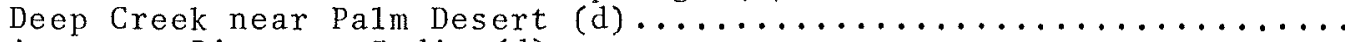

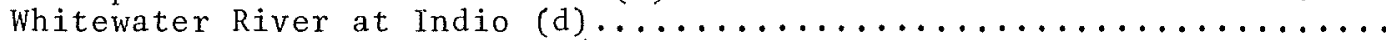

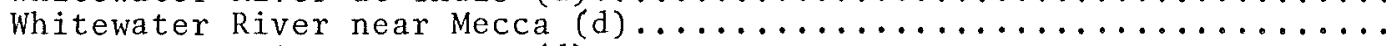

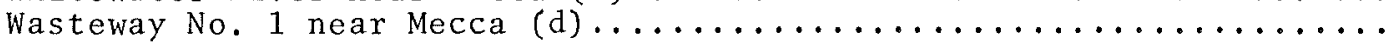
MOJAVE RIVER BASIN

Deep Creek (head of Mojave River) near Hesperia (d) $\ldots \ldots \ldots \ldots \ldots \ldots \ldots$

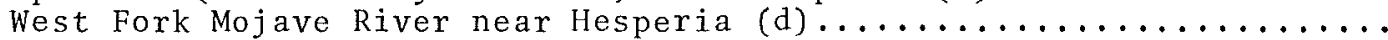

Mojave River below Forks Reservoir, near Hesperia (c) ..............

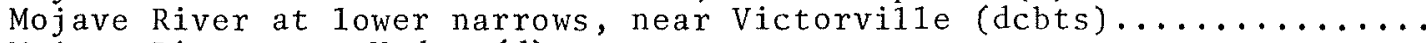

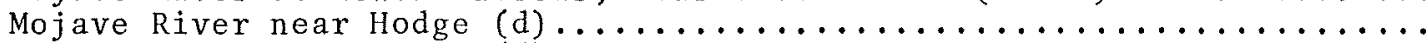

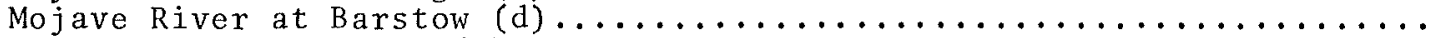

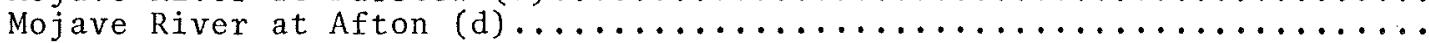

ANTELOPE VALLEY

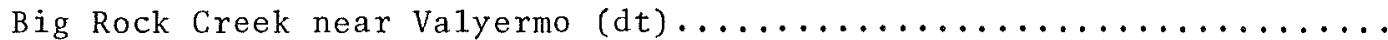

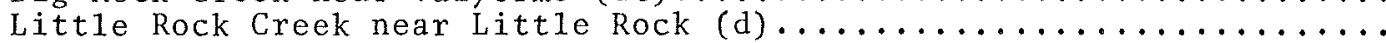

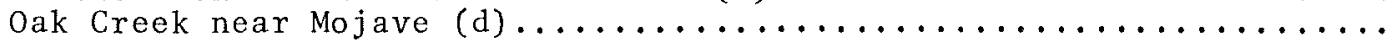

KOEHN LAKE BASIN

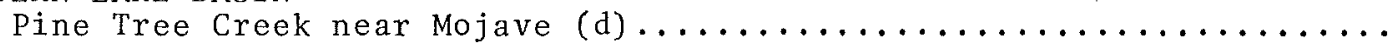
OWENS LAKE BASIN

Owens River:

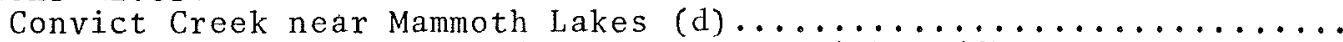

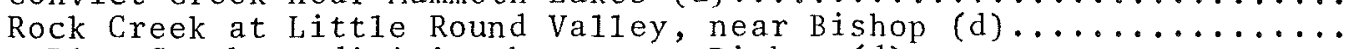

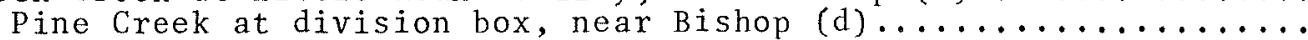

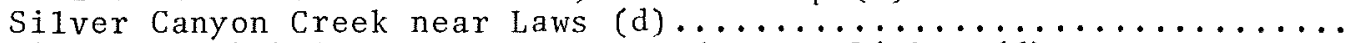

Bishop Creek below powerplant No. 6, near Bishop (d) ............

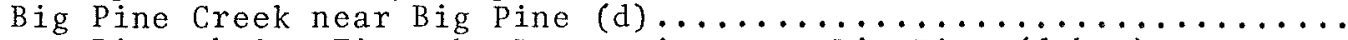

Owens River below Tinemaha Reservoir, near Big Pine (dcbts).........

Los Angeles Aqueduct at outlet at San Fernando (c) ..............

Independence Creek below Pinyon Creek, near Independence (d) ......

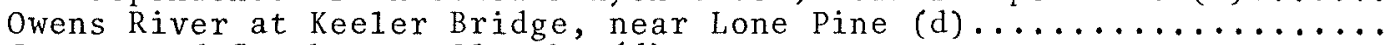

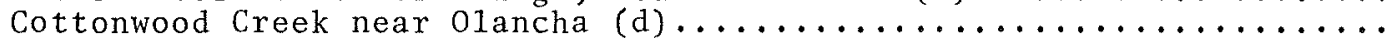

MONO LAKE BASIN

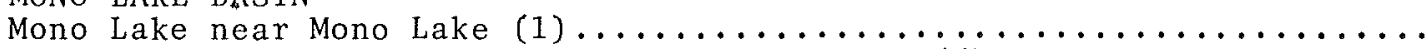

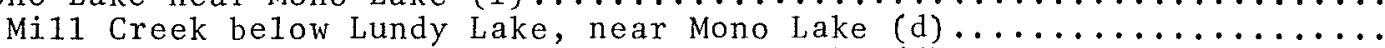

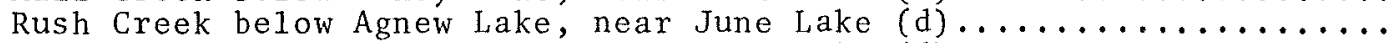

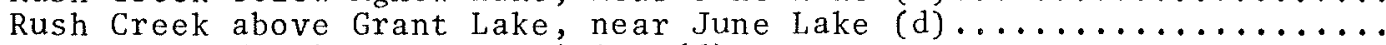

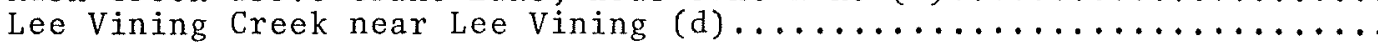

PACIFIC SLOPE BASINS IN CALIFORNIA

TIJUANA RIVER BASTN

Cottonwood Creek (head of Tijuana River) above Tecate Creek, near

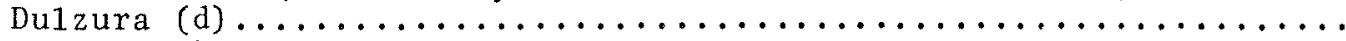

Tecate Creek:

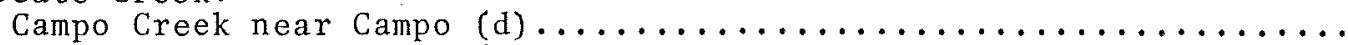

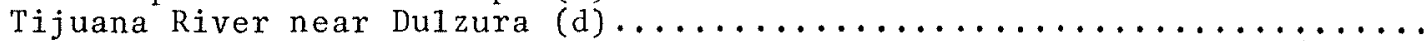

Rodriguez Reservoir at Rodriguez Dam, Baja California, Mexico (1)....

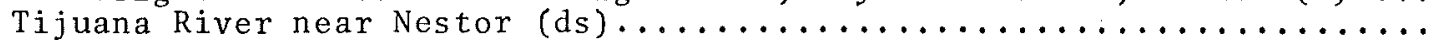
OTAY RIVER BASIN

Jamul Creek (head of otay River) near Jamul (d) ...............

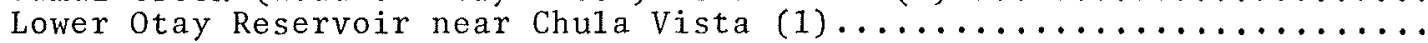

SWEETWATER RIVER BASIN

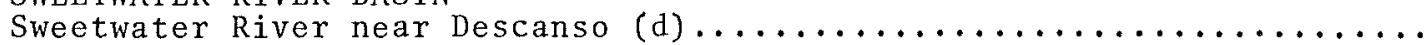

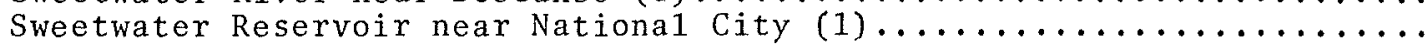

SAN DIEGO RIVER BASIN

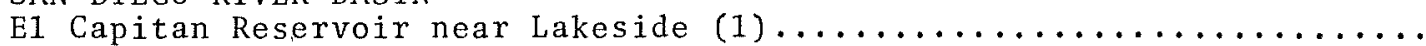

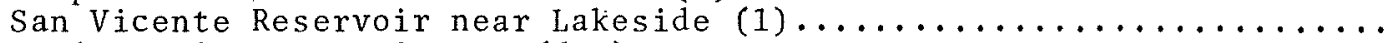

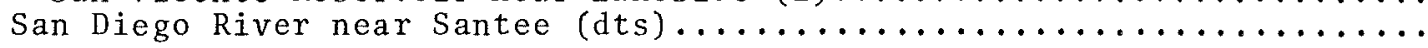

200

201

202

203

204

205

206

207

208

209

210

224

225

226

227

229

230

231

232

233

234

235

236

237

239

256

258

259

260

262

263

264

265

266 
PACIFIC SLOPE BASINS IN CALIFORNIA--Continued

LOS PENASQUTTOS CREEK BASIN

Poway Creek (head of Los Penasquitos Creek) :

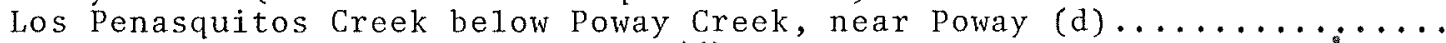

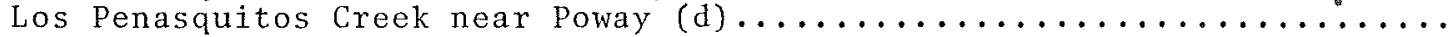

SAN DIEGUITO RIVER BASIN

Santa Ysabe1 Creek (head of San Dieguito River) near Ramona (d)........

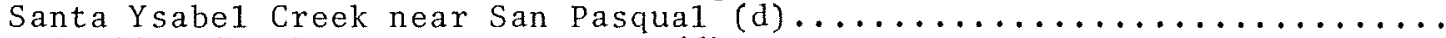

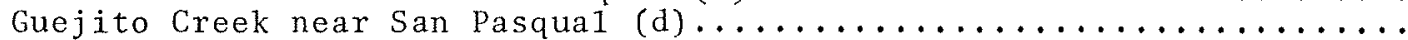

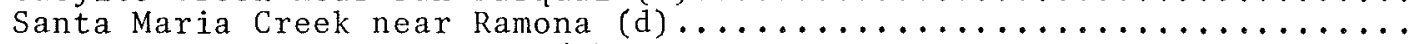
Lake Hodges near Escondido (1)

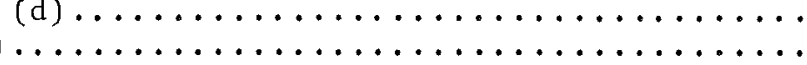
ESCONDIDO CREEK BASIN

Lake Wohlford near Escondido (1)

SAN LUIS REY RIVER BASIN

San Luis Rey River:

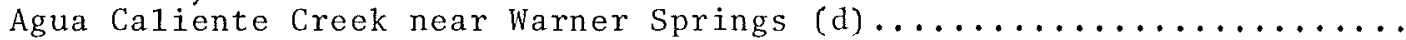

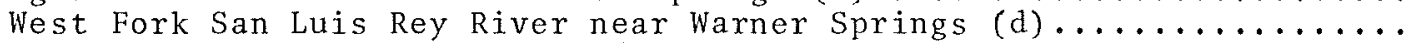

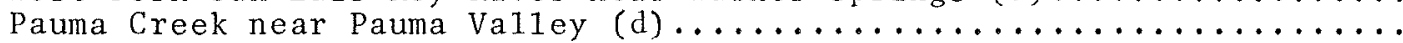

San Luis Rey River at Monserate Narrows, near Pala (d).............. Keys Creek:

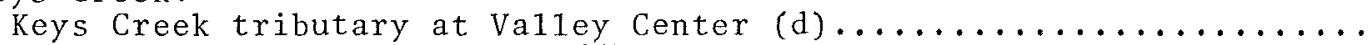

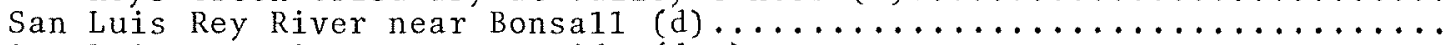

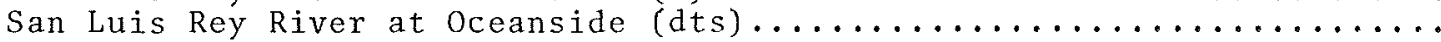

SANTA MARGARITA RIVER BASIN

Temecula Creek (head of Santa Margarita River) near Aguanga (d)........

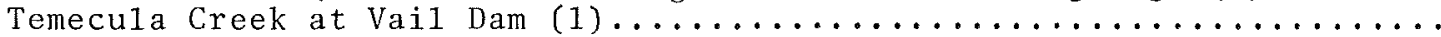

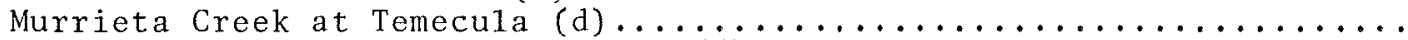

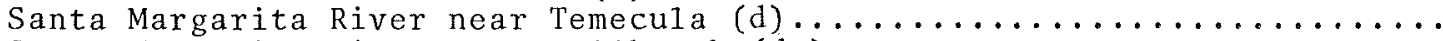

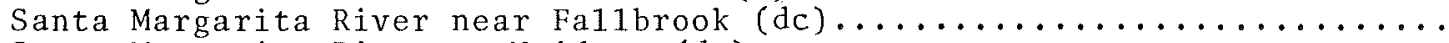

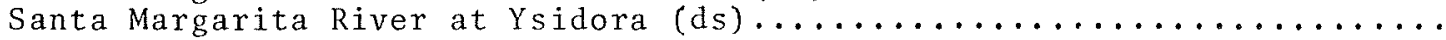

LAS FLORES CREEK BASIN

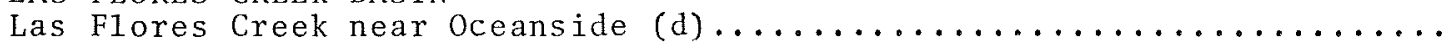

SAN JUAN CREEK BASIN

San Juan Creek at San Juan Gapistrano (dts) ................... Arroyo Trabuco:

Oso Creek at Crown Valley Parkway, near Mission Viejo (d).........

Arroyo Trabuco at San Juan Capistrano (dts).................. ALISO CREEK BASIN

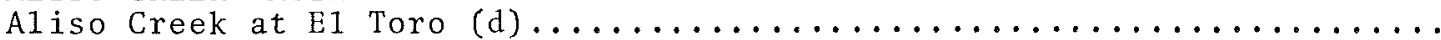

SAN DIEGO CREEK BASIN

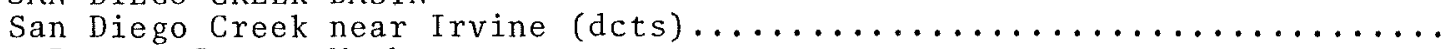
Peters Canyon Wash:

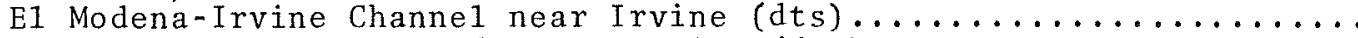

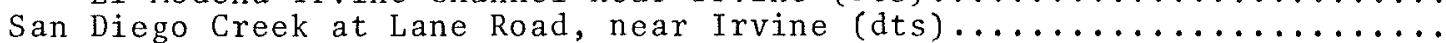

SANTA ANA RIVER BASIN

Santa Ana River:

Bear Creek:

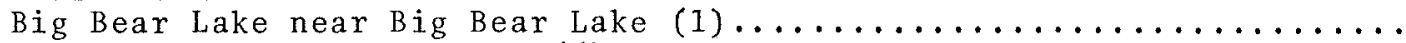

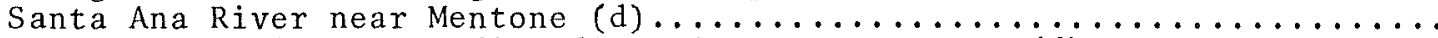

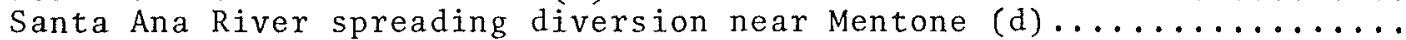

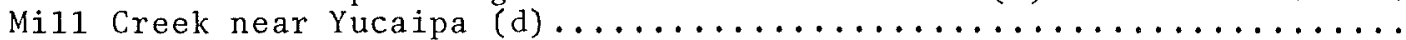

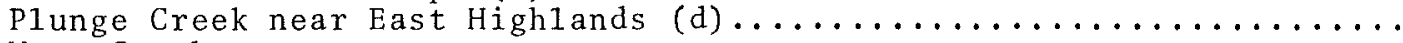
Warm Creek:

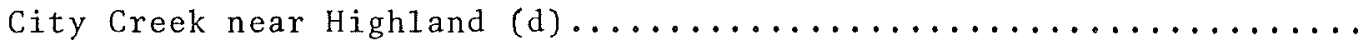

San Timoteo Creek:

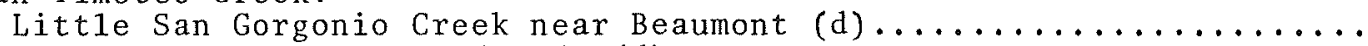

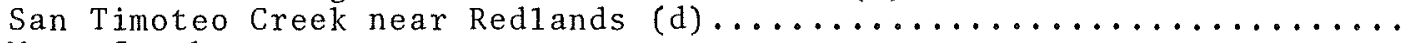
Warm Creek:

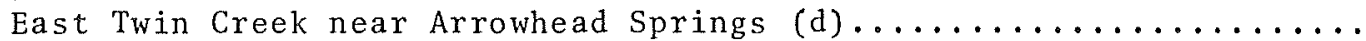

Waterman Canyon Creek near Arrowhead Springs (d) .............. 
San Bernardino Water Quality Control p1ant at San Bernardino (dc)....

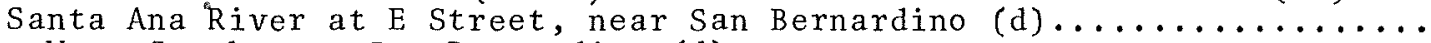

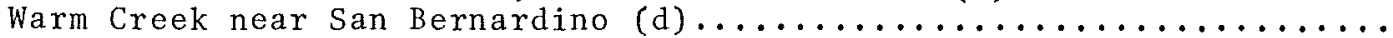

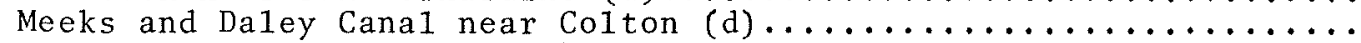

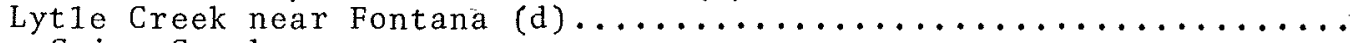
Cajon Creek:

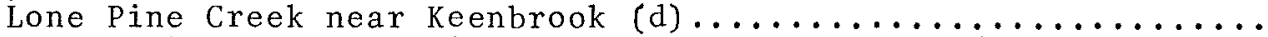

Cajon Creek below Lone Pine Creek, near Keenbrook (d)............

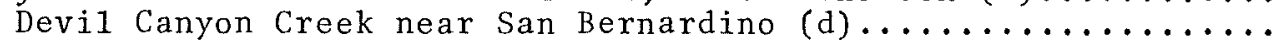

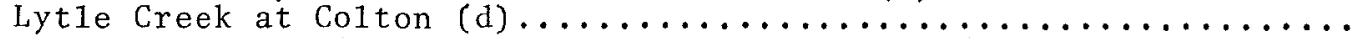

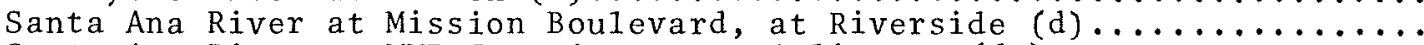

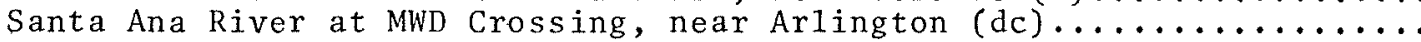

Riverside Water Qua1ity Control P1ant at Riverside Narrows, near

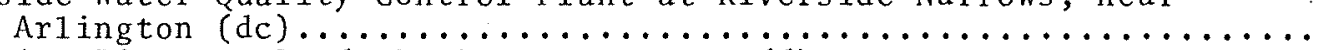

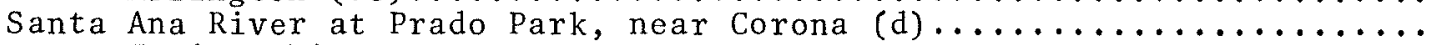

San Jacinto River:

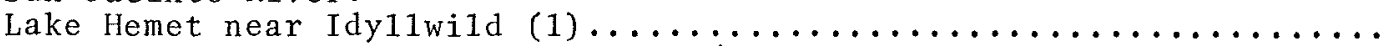

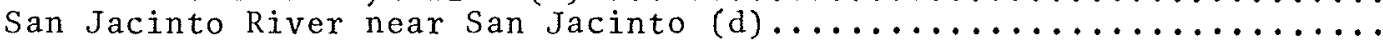

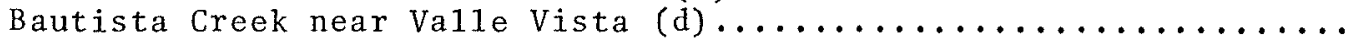

San Jacinto River at Railroad Canyon weir, near Eisinore (d) ......... Sa1t Creek at Railroad Canyon Reservoir, near Elsinore (d) ........

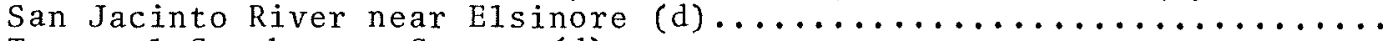

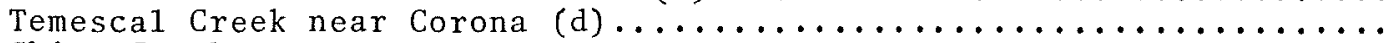

Chino Creek:

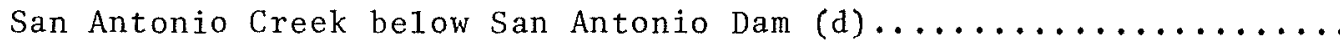
Rialto pipeline below San Antonio Dam, near Claremont (c).......

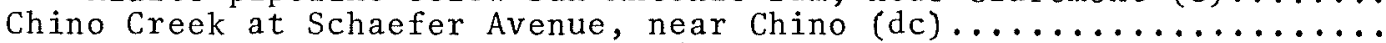

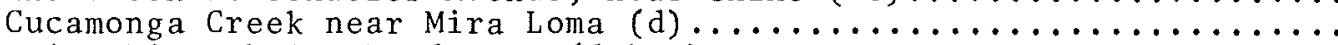

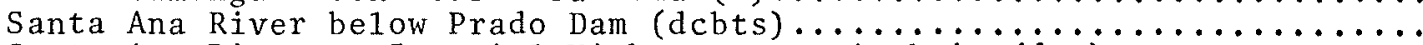

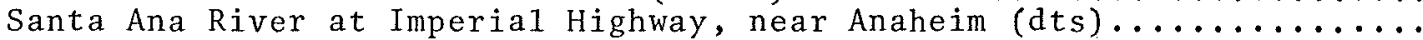

Santa Ana Spreading Diversion below Imperial Highway, near

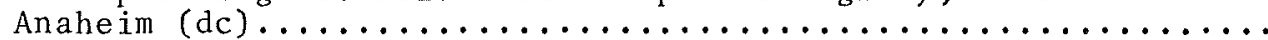

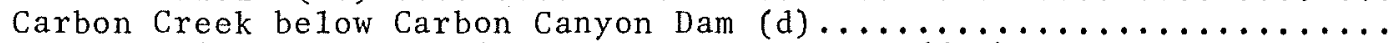

Santa Ana River near Katella Avenue, at orange (dts) ..............

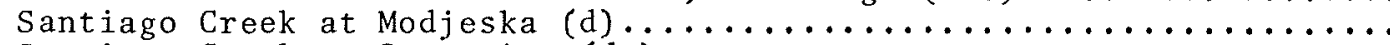

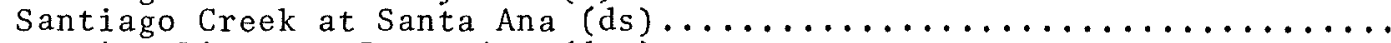

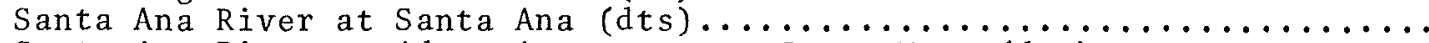

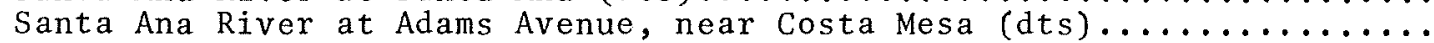

SAN GABRIEL RIVER BASIN

East Fork San Gabriel River (head of San Gabriel River) near Camp

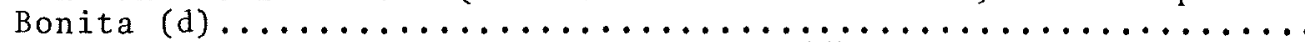

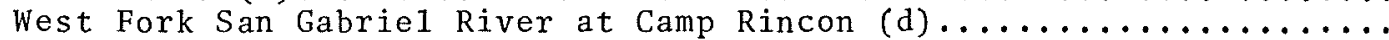

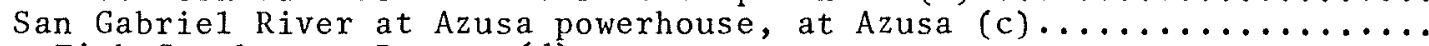

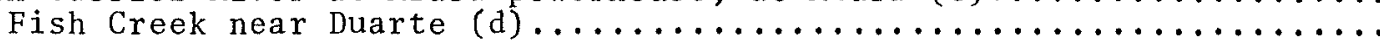

San Gabrie1 River below Santa Fe Dam, near Baldwin Park (d).........

Walnut Creek:

Dalton Creek:

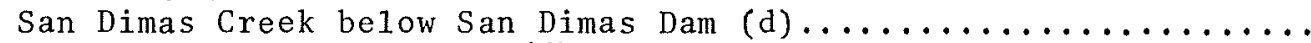

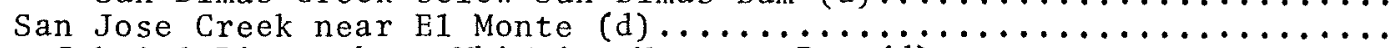

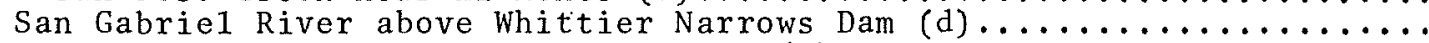

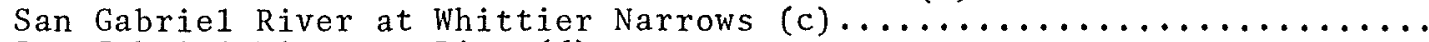

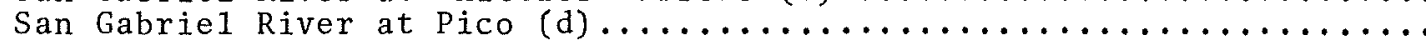

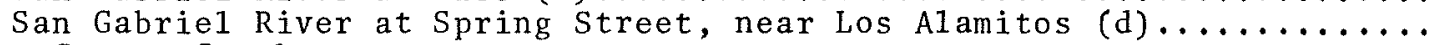

Coyote Creek:

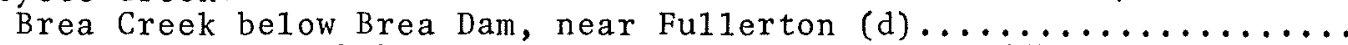

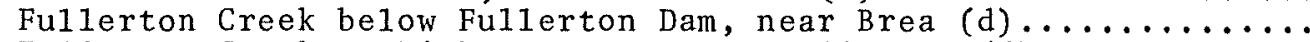

Fullerton Creek at Richman Avenue, at Fullerton (d) ............

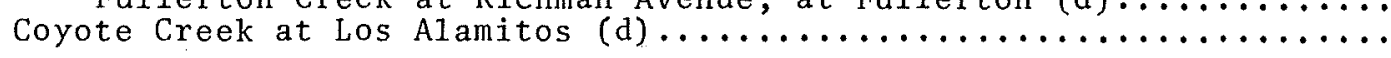


PACIFIC SLOPE BASINS IN CALIFORNIA--Continued

LOS ANGELES RIVER BASTN

Los Angeles River at Sepulveda Dam (d)

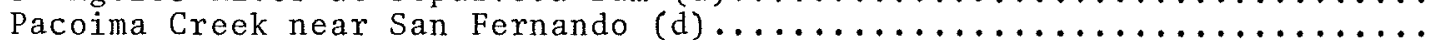

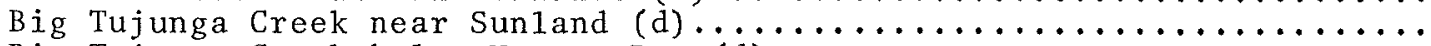

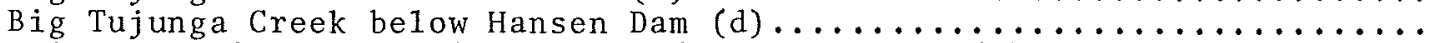

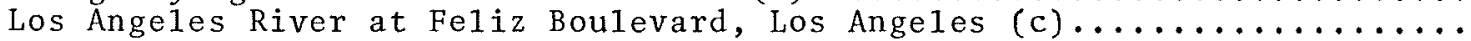

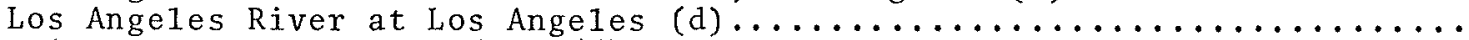

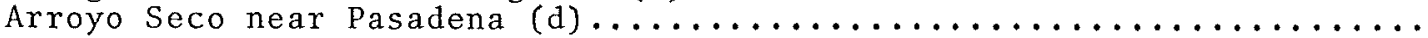

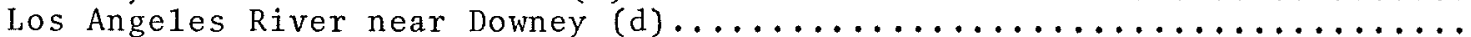

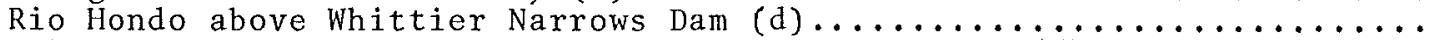

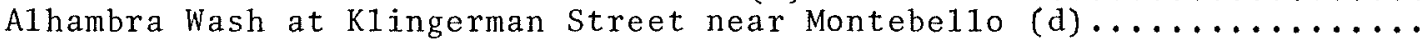

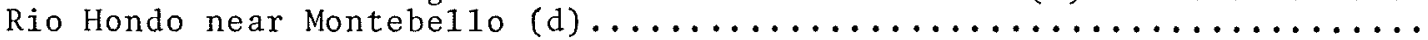

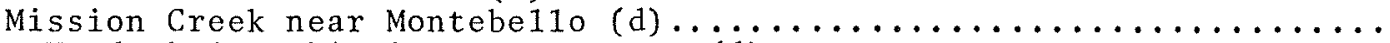
Rio Hondo below whittier Narrows Dam $(\mathrm{d}) \ldots \ldots \ldots \ldots \ldots \ldots$

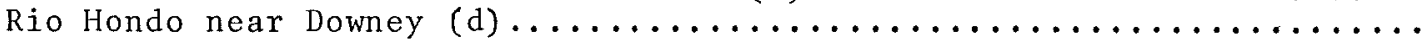

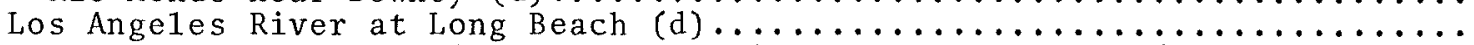
Los Angeles River at Willow Street Bridge, at Long Beach (cbts)........ BALLONA CREEK BASIN

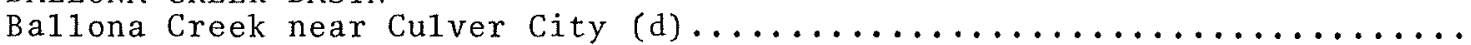
TOPANGA CREEK BASIN

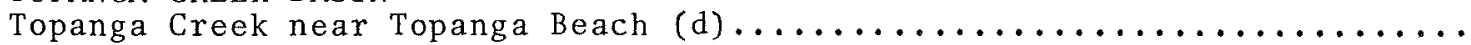
MALIBU CREEK BASIN

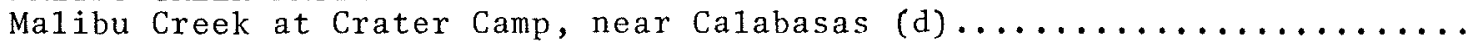
CALLEGUAS CREEK BASIN

Calleguas Creek:

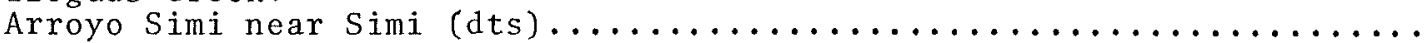

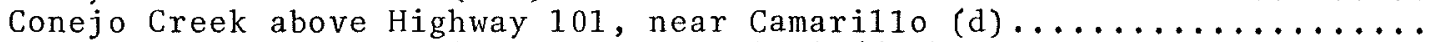

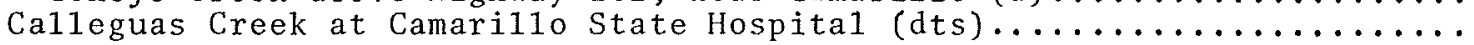
SANTA CLARA RIVER BASIN

Santa Clara River above railroad station, near Lang (d).............

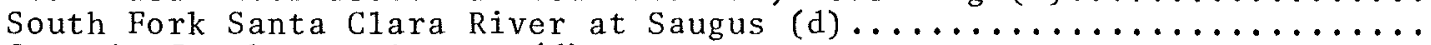

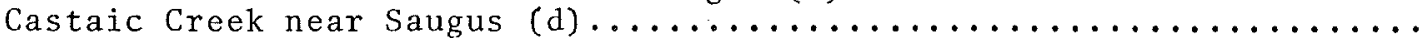
Santa C1ara River at Los Angeles-Ventura County 1 ine (dcts)............

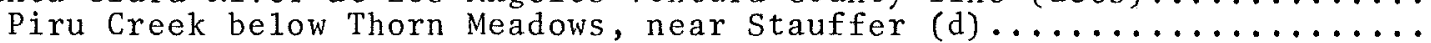
Lockwood Creek:

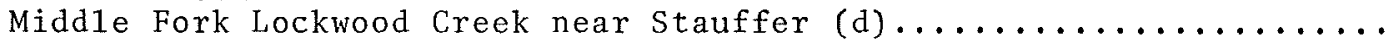

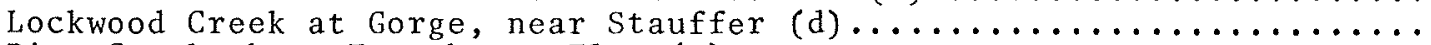

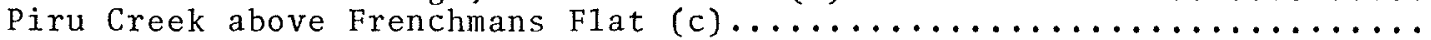

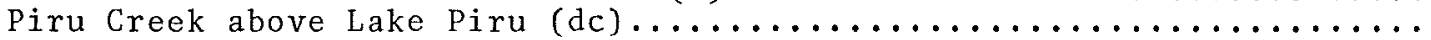

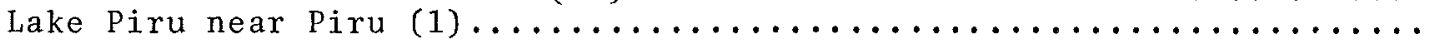

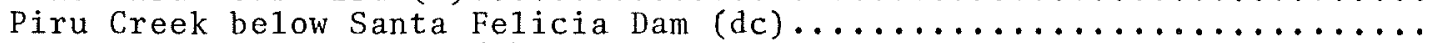

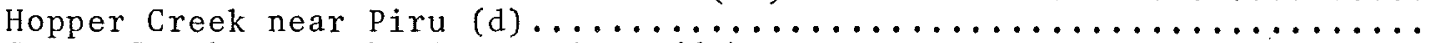

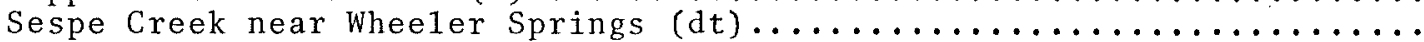

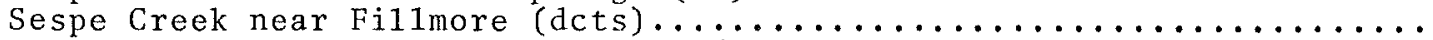

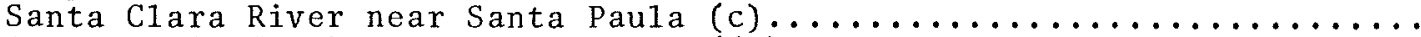

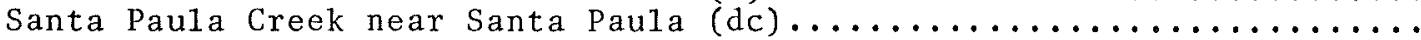

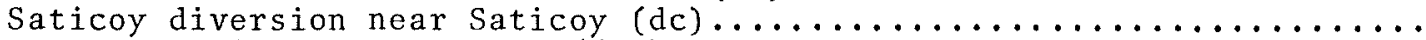

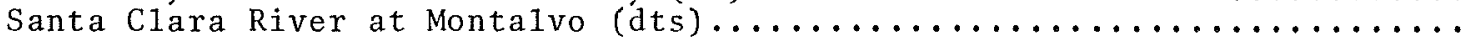
VENTURA RIVER BASIN

Matilija Creek (head of Ventura River):

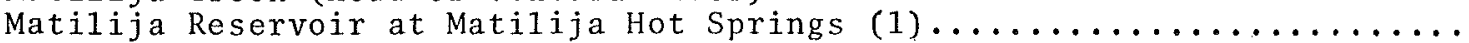

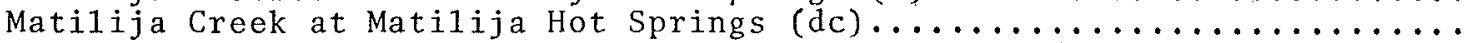

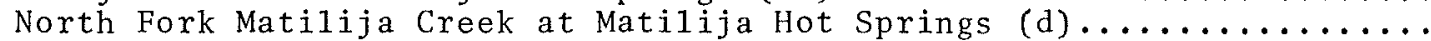

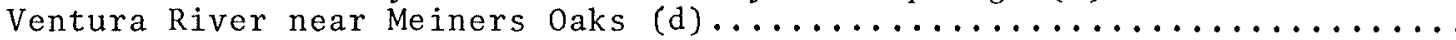

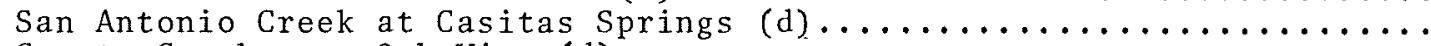

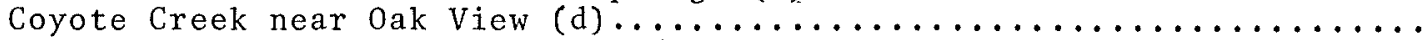

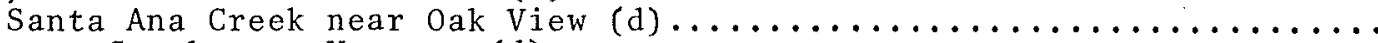

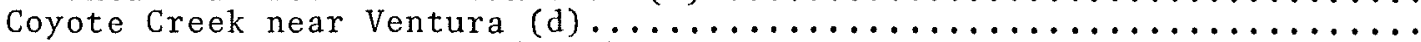

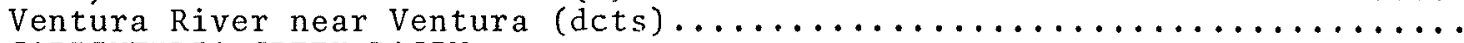
CARPINTERIA CREEK BASIN

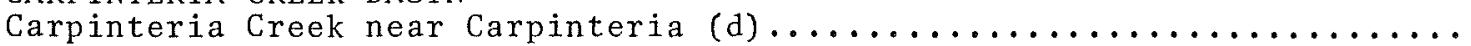
FRANKLIN CREEK BASIN

Franklin Creek at Carpinteria (d). 
PACIFIC SLOPE BASINS IN CALIFORNIA--Continued

Page MISSION CREEK BASIN

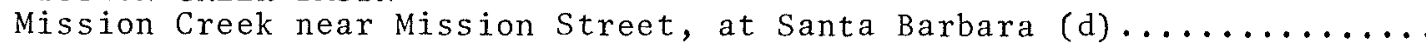
Victoria Street drain at outlet, at Santa Barbara (d) $\ldots \ldots \ldots \ldots \ldots \ldots$ ARROYO BURRO CREEK BASTN

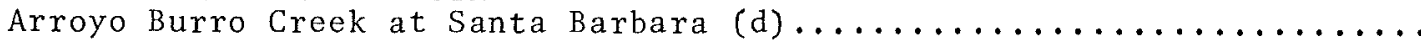

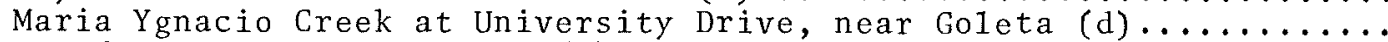

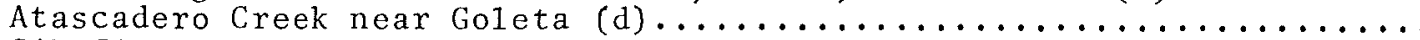
SAN JOSE CREEK BASIN

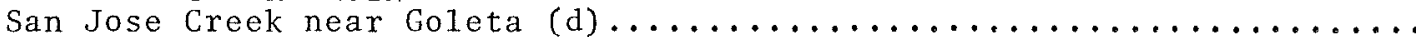

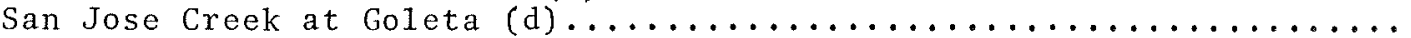
GAVIOTA CREEK BASIN

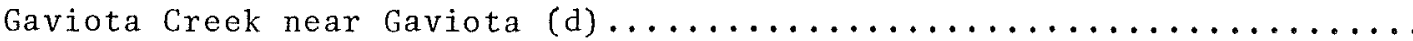
JALAMA CREEK BASIN

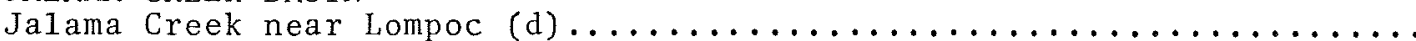
SANTA YNEZ RIVER BASIN

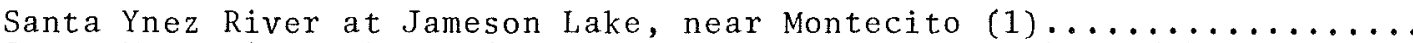

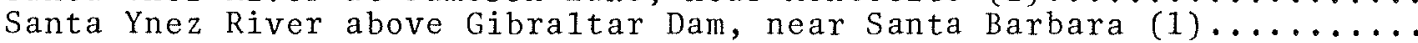
Santa Ynez River below Gibraltar Dam, near Santa Barbara (d) .......... Santa Ynez River below Los Laureles Canyon, near Santa Ynez (d).......

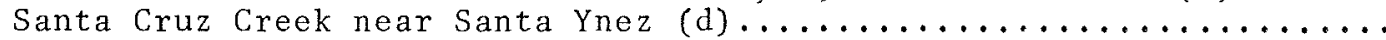

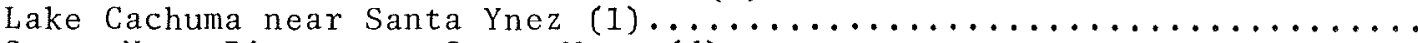

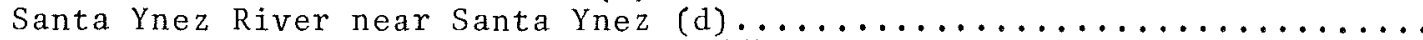

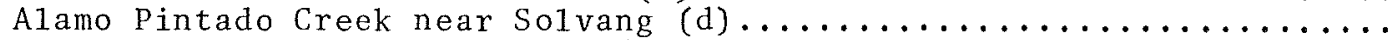

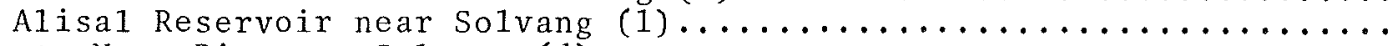

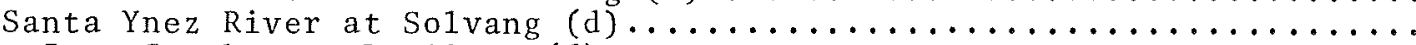

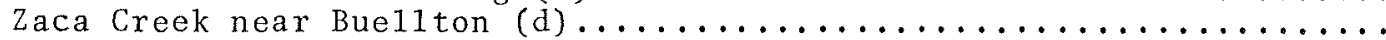

Santa Ynez River at Cooper's Reef, near Lompoc (d) ................

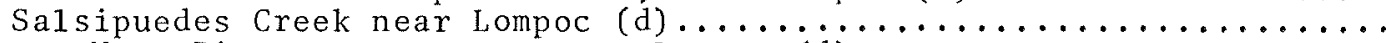

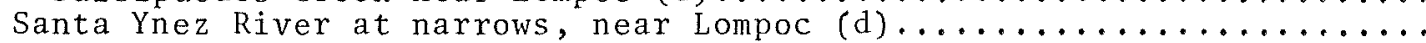

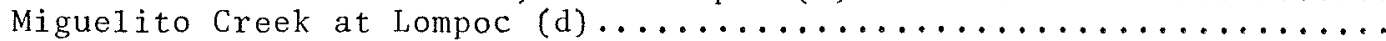

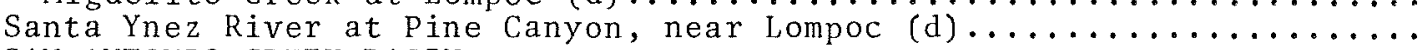
SAN ANTONIO CREEK BASIN

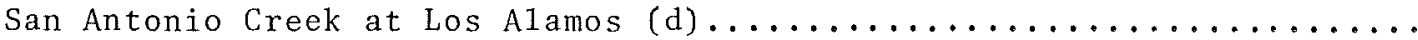

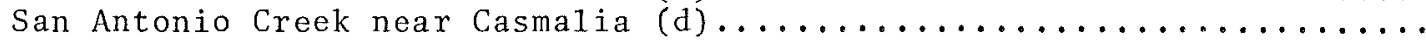
SANTA MARIA RIVER BASIN

Cuyama River (head of Santa Maria River):

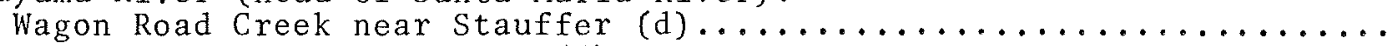

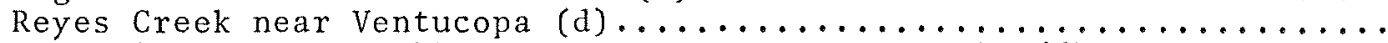

Cuyama River below Buckhorn Canyon, near Santa Maria (d)............

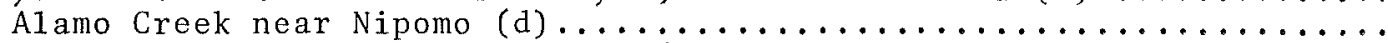

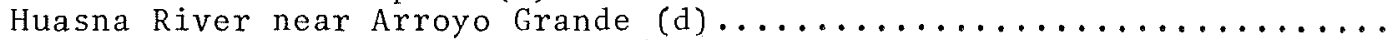

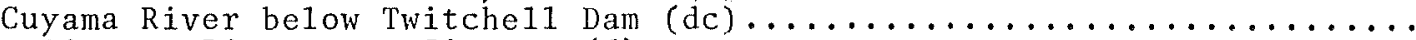

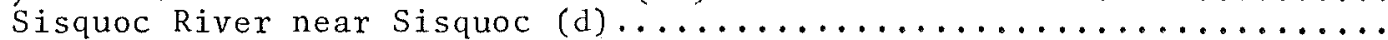

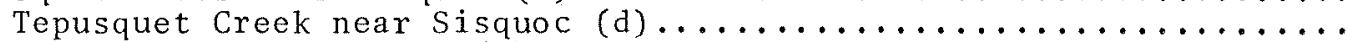

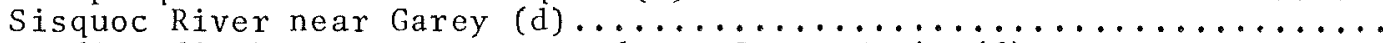

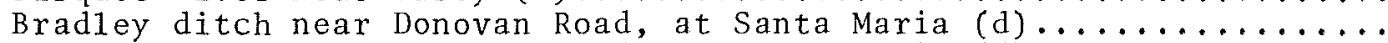

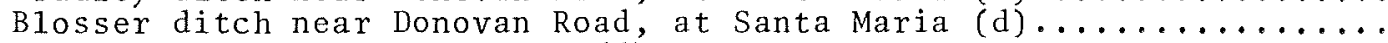

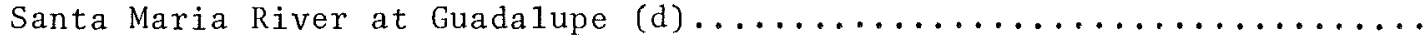




\title{
WATER RESOURCES DATA FOR CALIFORNIA, 1976
}

Volume 1

\author{
INTRODUCTION
}

Water-resources data for the 1976 water year for California consist of records of stage, discharge, and water quality of streams; stage, contents, and water quality of lakes and reservoirs; records of water levels in selected observation wells; and selected chemical analyses of ground water. Records for a few pertinent streamflow and water-quality stations in bordering states are also included. The records were collected and computed by the Water Resources Division of the U.S. Geological Survey under the direction of Lee R. Peterson, district chief; Winche11 Smith, assistant district chief for hydrologic data; and Leonard $\mathrm{N}$. Jorgensen, chief of the basic-data section. These data, a contribution to the National Water Data System, were collected by the Geological Survey and cooperating local, State, and Federal agencies in California.

Records of discharge or stage of streams and contents or stage of lakes and reservoirs were first published in a series of U.S. Geological survey watersupply papers entitled, "Surface Water Supply of the United States." Through September 30,1960 , these water-supply papers were in an annual series and then in a 5-year series for 1961-65 and 1966-70. Records of chemical quality, water temperatures, and suspended sediment were published from 1941 to 1970 in an annual series of water-supply papers entitled, "Quality of Surface Waters of the United States." Records of ground-water levels were published from 1935 to 1974 in a series of water-supply papers entitled, "Ground-Water Levels in the United States." Water-supply papers may be consulted in the libraries of the principal cities in the United States or may be purchased from Branch of Distribution, U.S. Geological Survey, 1200 South Eads Street, Arlington, VA 22202.

For water years 1961 through 1974, streamflow data were released by the Geological Survey in annual reports on a State-boundary basis. Water-quality records for water years 1964 through 1974 were similarly released, either in separate reports or in conjunction with streamflow records. Beginning with the 1975 water year, water data for streamflow, water quality, and ground water are published as an official Survey report on a State-boundary basis. These official Survey reports carry an identification number consisting of the twoletter State abbreviation, the last two digits of the water year, and the volume number. For example, this report is identified as "U.S. Geological Survey Water-Data Report CA-76-1." Water-data reports are for sale by the National Technical Information Service, U.S. Department of Commerce, Springfie1d, VA 22161. 


\section{COOPERATION}

The U.S. Geological Survey and organizations of the State of California have had cooperative agreements for the systematic collection of records since 1903. Organizations that supplied data are acknowledged in station descriptions. Organizations that assisted in collecting data through cooperative agreement with the Survey are:

Antelope Valley-East Kern Water Agency, Wallace G. Spinarski, general manager. California Department of Water Resources, R. B. Robie, director.

Casitas Municipal Water District, Robert McKinney, general manager-chief engineer.

Coachella Valley County Water District, L. O. Weeks, general manager-chief engineer.

Desert Water Agency, P. G. Payne, general manager.

Imperial Irrigation District, R. F. Carter, general manager.

Los Angeles County Flood Control District, A. E. Bruington, chief engineer.

Los Angeles Department of Water and Power, Louis H. Winnard, general manager and chief engineer.

Montecito County Water District, H. O. Neil Mendena11, general manager.

Orange County Environmenta1 Management Agency, H. G. Osborne, director.

Orange County Water District, Nei1 M. Cline, secretary-manager.

Riverside County Flood Control and Water Conservation District, J. W. Bryant, chief engineer.

San Bernardino Valley Municipal Water District, J. A. Beaver, general manager.

San Diego, City of, Water Utilities, R. W. King, director.

San Diego, County of, Department of Sanitation and Flood Contro1, C. J. Houson, director.

Santa Barbara, City of, Department of Public Works, R. W. Puddicombe, director.

Santa Barbara County Flood Control and Water Conservation District, James Stubchaer, flood-control engineer.

Santa Barbara County Water Agency, Harre11 Fletcher, board of directors chairman.

Santa Maria Valley Water Conservation District, M. F. Twitchell, secretary.

Santa Ynez River Water Conservation District, William Laranjo, president.

United Water Conservation District, R. A. Smith, general manager-chief engineer.

Ventura County Flood Control District, A. P. Stokes, engineer-manager.

Western Municipal Water District, H. A. Hicks, general manager.

Assistance in the form of funds or services was given by the Corps of Engineers, U.S. Army; U.S. Navy; Bureau of Indian Affairs, Bureau of Reclamation and National Park Service, U.S. Department of the Interior.

The following organizations aided in collecting records: Bear Valley Mutual Water Co., Metropolitan Water District of Southern California, Fontana Union Water Co., Rancho California, Southern California Edison Co., and Vista Irrigation District. 


\section{ACKNOWLEDGMENT}

Responsibility for collection of data and preparation of data reports is delegated to the three subdistrict offices in the California District of the Water Resources Division. This volume was prepared by personnel of the Laguna Niguel subdistrict office under the direction of D. H. Appe1 and Darwin Knochenmus, successive subdistrict chiefs. Special acknowledgment is made of the contribution of R. J. Longfield, T. P. Landis, and C. E. Lamb who direct the work in the hydrologic data section. Report data were provided by the Santa Barbara field office, South Coast and Desert field group, and Santa Ana field group supervised by J. A. Singer, H. E. Skjold, and H. R. Frisbie. Ground-water data were handled by Mary J. Mermod. Elenere A. Amidon and Kay L. Spiegl supervised computer processing and assisted in review of data for publication. Manuscript typing and assembly of the report was done by Julia A. Schulenburg and Gladys M. Pigage.

\section{HYDROLOGIC CONDITIONS}

Runoff during the 1976 water year in the area covered by this volume indicated a below-normal to deficient trend throughout most of the year and averaged about 50 percent of the 1941-70 median. Total runoff at selected sites for the 1976 water year is shown in figure 1 for al1 of California. Runoff in the Santa Ana River basin and other coastal basins to the south was about 50 percent of the median; runoff in the Santa Clara River basin and other coastal basins to the north was about 35 percent of the median; and runoff in the Salton Sea basin was about 65 percent of the median.

Precipitation was very erratic and mostly contraseasonal. It varied throughout the area from 250 percent of normal north of the Salton Sea to greater than 100 percent of normal over most of the lower Colorado River basin, the extreme south-central part of the state, and along the international boundary. Precipitation was about 70 percent of normal in the Mojave Desert and 80 to 100 percent of normal along the entire southern coast from Santa Barbara to San Diego.

Very little rain fell in southern California during October through December 1975, and none in January 1976, the latter occurring only one other time--January 1972--in over 100 years of record. Rainfal1 for the Los Angeles area totaled 0.59 inches $(15 \mathrm{~mm})$ since July 1 , 1975 , as compared to the average of 7.46 inches $(189 \mathrm{~mm})$. The 9 -month drought was temporarily ended by a south coastal storm during the period February 4-10, resulting in heavy precipitation in many areas of southern California. Totals ranged from 2.3 to 5.5 inches (58 to $140 \mathrm{~mm}$ ) for 1 day; 5.0 to 10.2 inches $(127$ to $259 \mathrm{~mm})$ for 3 days; and 8.7 to 15.2 inches (221 to $386 \mathrm{~mm}$ ) for the entire 7 days. Most of this 


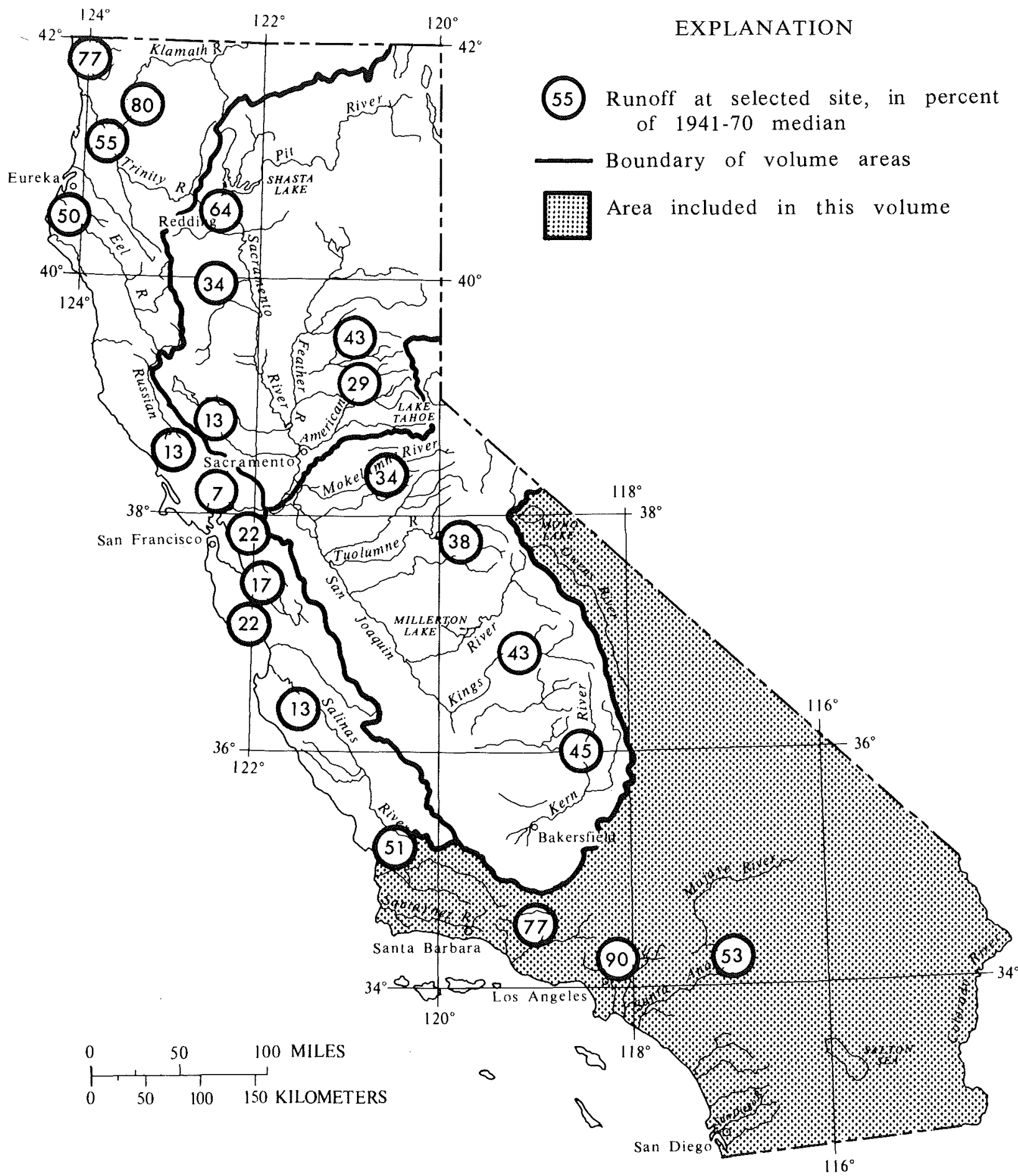

FIGURE 1,--Runoff for the current water year. 
precipitation soaked into the dry soil and only minor runoff occurred, although some mudslides were evident in the Mill Creek-Big Tujunga burn areas. Medium rains March 1 and moderate rains March 3 along the southern coastline resulted in minor runoff of some of the small streams. Runoff rapidly decreased during the period April through August and was well below normal as the statewide drought continued. Tropical storm Kathleen, the first storm system of this type since September 1939, hit the desert area near the Salton Sea September 10 and 11. Kathleen brought heavy precipitation, 10 to 11 inches (254 to $279 \mathrm{~mm}$ ) in the mountains of southern California, 2 to 3 inches ( 51 to $76 \mathrm{~mm}$ ) in the desert areas, and 1 to 2 inches ( 25 to $51 \mathrm{~mm}$ ) in the coastal plains. Significant flooding with resulting peaks of record occurred within a $60-m i l e$ radius of the Salton Sea, and the gage on San Felipe Creek near Westmorland was destroyed. Showers and thunderstorms over the desert area of southeastern California september 23 and 24 resulted in minor localized flooding. Thunderstorms in the Santa C1ara and Santa Barbara areas September 29 and 30 produced some minor runoff.

Because of the heavy September rains, Imperial, Riverside, San Bernardino, and San Diego Counties were declared storm disaster areas. The latter three, along with Los Angeles County, were also drought disaster areas during the water year.

The quality of surface water did not change appreciably throughout the entire water year. Ground-water levels in selected wells in southern California were near normal at the beginning of the water year. They remained near average until May, when they dropped below average. The heavy use of water from groundwater aquifers in some areas has lowered the water tables considerably despite the continued diversions from surface supplies.

\section{DEFINITION OF TERMS}

Terms related to streamflow, water-quality, ground-water, and other hydrologic data, as used in this report, are defined below. See also the table for converting English units to International system of units (SI) on the inside of the back cover.

Acre-foot (AC-FT, acre-ft) is the quantity of water required to cover 1 acre to a depth of 1 foot and is equivalent to 43,560 cubic feet or about 326,000 gallons or 1,233 cubic meters.

Algae are mostly aquatic single-celled, colonial, or multicelled plants, containing chlorophyll and lacking roots, stems, and leaves.

Aquifer is a geologic formation, group of formations, or part of a formation that contains sufficient saturated permeable material to yield significant quantities of water to wells and springs.

Artesian means confined and is used to describe a well in which the water level stands above the top of the aquifer tapped by a well. A flowing artesian well is one in which the water level is above the land surface.

Bacteria are the microscopic unicellular organisms, typically spherical, rodlike, or spiral and threadlike in shape, often clumped into colonies. Some bacteria cause disease, others perform an essential role in nature in the recycling of materials; for example, by decomposing organic matter into a form available for reuse by plants. 


\section{Bacteria (continued)}

Total coliform bacteria are a particular group of bacteria that are used as indicators of possible sewage pollution. They are characterized as aerobic or facultative anaerobic, gram-negative, nonspore-forming, rod-shaped bacteria which ferment lactose with gas formation within 48 hours at $35^{\circ} \mathrm{C}$. In the 1aboratory these bacteria are defined as the organisms which produce colonies within 24 hours when incubated at $35^{\circ} \mathrm{C}+1.0^{\circ} \mathrm{C}$ on $\mathrm{M}$-Endo medium (nutrient medium for bacterial growth) . Their concentrations are expressed as number of colonies per $100 \mathrm{~mL}$ of sample.

Fecal coliform bacteria are bacteria that are present in the intestines or feces of warm-blooded animals. They are often used as indicators of the sanitary quality of the water. In the laboratory they are defined as all organisms which produce blue colonies within 24 hours when incubated at $44.5^{\circ} \mathrm{C}+0.2^{\circ} \mathrm{C}$ on $\mathrm{M}-\mathrm{FC}$ medium (nutrient medium for bacterial growth). Their concentrations are expressed as number of colonies per $100 \mathrm{~mL}$ of sample.

Fecal streptoccal bacteria are bacteria found a1so in intestines of warm-blooded animals. Their presence in water is considered to verify fecal pollution. They are characterized as gram-positive, cocci bacteria which are capable of growth in brain-heart infusion broth. In the 1 aboratory they are defined as all the organisms which produce red or pink colonies within 48 hours at $35^{\circ} \mathrm{C}+1.0^{\circ} \mathrm{C}$ on $\mathrm{M}$-enterrococcus medium (nutrient medium for bacterial growth). Their concentrations are expressed as number of colonies per $100 \mathrm{~mL}$ of sample.

Bed material is the unconsolidated material of which a streambed, 1ake, pond, reservoir, or estuary bottom is composed.

Benthic organisms (invertebrates) are the group of animals inhabiting the bottom of an aquatic environment. They include a number of types of organisms, such as bacteria, fungi, insect larvae and nymphs, snails, clams, and crayfish.

Biochemical oxygen demand (BOD) is a measure of the quantity of dissolved oxygen, in milligrams per liter, necessary for the decomposition of organic matter by microorganisms, such as bacteria.

Biomass is the amount of living matter present at any given time, expressed as the mass per unit area or volume of habitat.

Ash mass is the mass or amount of residue present after the residue from the dry mass determination has been ashed in a muffle furnace at a temperature of $500^{\circ} \mathrm{C}$ for 1 hour. The ash mass values of zooplankton and phytoplankton are expressed in grams per cubic meter $\left(\mathrm{g} / \mathrm{m}^{3}\right)$, and periphyton and benthic organisms in grams per square meter $\left(\mathrm{g} / \mathrm{m}^{2}\right)$.

Dry mass refers to the mass of residue present after drying in an oven at $60^{\circ} \mathrm{C}$ for zooplankton and $105^{\circ} \mathrm{C}$ for periphyton, until the mass remains unchanged. This mass represents the total organic matter, ash and sediment, in the sample. Dry mass values are expressed in the same units as ash mass.

Organic mass or volatile mass of the living substance is the difference between the dry mass and ash mass, and represents the actual mass of the living matter. The organic mass is expressed in the same units as for ash mass and dry mass.

Wet mass is the mass of living matter plus contained water.

Bottom material: See Bed material. 
Cel1s/volume refers to the number of cells of any organism that are counted by using a microscope and grid or counting cell. Many planktonic organisms are multicelled and are counted according to the number of contained cells per sample, usually milliliters (mL) or liters (L).

Chemical oxygen demand (COD) is a measure of the chemically oxidizable material in the water and furnishes an approximation of the amount of organic and reducing material present. The determined value may correlate with natural water color or with carbonaceous organic pollution from sewage or industrial wastes.

Chlorophyl1 refers to the green pigments of plants. Chlorophy11 a and $\underline{b}$ are the two most common pigments in plants.

Color unit is produced by one milligram per liter of platinum in the form of the chloroplatinate ion. Color is expressed in units of the platinum-cobalt scale.

Contents is the volume of water in a reservoir or lake. Unless otherwise indicated, volume is computed on the basis of a level pool and does not include bank storage.

Control designates a feature downstream from the gage that determines the stage-discharge relation at the gage. This feature may be a natural constriction of the channel, an artificial structure, or a uniform cross section over a long reach of the channel.

Control structure as used in this report is a structure on a stream or canal that is used to regulate the flow or stage of the stream or to prevent the intrusion of salt water.

Cubic foot per second $\left(\mathrm{FT}^{3} / \mathrm{S}, \mathrm{ft}^{3} / \mathrm{s}\right)$, is the rate of discharge representing a volume of 1 cubic foot passing a given point during 1 second and is equivalent to approximately 7.48 gallons per second or 448.8 gallons per minute or 0.02832 cubic meters per second.

Discharge is the volume of water (or more broadly, total fluids plus suspended sediment), that passes a given point within a given period of time.

Mean discharge (MEAN) is the arithmetic mean of individual daily mean discharges during a specific period. time.

Instantaneous discharge is the discharge at a particular instant of

Dissolved refers to the amount of a substance present in true chemical solution. In practice, however, the term includes all forms of the substance that will pass through a 0.45 -micrometer membrane filter and thus may include some very small (colloidal) suspended particles. Analyses are performed on filtered samples.

Diversity index is a numerical expression of evenness of distribution of aquatic organisms. The formula for diversity index is:

$$
\bar{d}=\sum_{i=i}^{s} n_{i} \log _{2} \frac{n_{i}}{n}
$$

where $n$ is the number of individuals per taxon, $n$ is the total number of individuals, and $s$ is the total number of taxa. Diversity index values range from zero when a11 the organisms in the samples are the same to some positive number when some or all the organisms in the sample are different. 
Drainage area of a stream at a specified location is that area, measured in a horizontal plane, enclosed by a topographic divide from which direct surface runoff from precipitation normally drains by gravity into the stream above the specified point. Figures of drainage area given therein include all closed basins, or noncontributing areas, within the area unless otherwise noted.

Drainage basin is a part of the surface of the earth that is occupied by a drainage system, which consists of a surface stream or body of impounded surface water together with all tributary surface streams and bodies of impounded surface water.

$\mathrm{Ft}^{3} / \mathrm{s}$-day is the volume of water represented by a flow of 1 cubic foot per second for 24 hours. It is equivalent to 86,400 cubic feet, approximately 1.9835 acre-feet, or about 646,000 gallons or 2,445 cubic meters. It represents a runoff of approximately 0.0372 inch from 1 square mile or 0.3468 millimeter from 1 square kilometer.

Gage height (G.H.) is the water-surface elevation referred to some arbitrary gage datum. Gage height is often used interchangeably with the more general term "stage," although gage height is more appropriate when used with a reading on a gage.

Gaging station is a particular site on a stream, canal, lake, or reservoir where systematic observations of gage height or discharge are obtained.

Hardness of water is a physical-chemical characteristic that is commonly recognized by the increased quantity of soap that is required to produce 1 ather. It is attributable to the presence of alkaline earths (principally calcium and magnesium) and is expressed as equivalent calcium and carbonate $\left(\mathrm{CaCO}_{3}\right)$.

Macrophytes are the macroscopic plants in the aquatic environment. The most common macrophytes are the rooted vascular plants that are usually arranged in zones in aquatic ecosystems and restricted in the area by the extent of illumination through the water and sediment deposition along the shoreline.

Metamorphic stage refers to the stage of development that an organism exhibits during its transformation from an immature form to an adult form. This development process exists for most insects, and the degree of difference from the immature stage to the adult form varies from relatively slight to pronounced, with many intermediates. Examples of metamorphic stages of insects are egglarva-adult or egg-nymph-adult.

Methylene blue active substance (MBAS) is a measure of apparent detergents. This determination depends on the formation of a blue color when methylene blue dye reacts with synthetic detergent compounds.

Micrograms per gram (UG/G, $\mu \mathrm{g} / \mathrm{g}$ ) is a unit expressing the concentration of a chemical element as the mass (micrograms) of the element sorbed per unit mass (gram) of sediment.

Micrograms per liter (UG/L, $\mu \mathrm{g} / \mathrm{L}$ ) is a unit expressing the concentration of chemical constituents in solution as mass (micrograms) of solute per unit volume (1iter) of water. One thousand micrograms per liter is equivalent to one milligram per liter.

Milligrams per liter. (MG/L, $\mathrm{mg} / \mathrm{L}$ ) is a unit for expressing the concentration of chemical constituents in solution. Milligrams per liter represent the mass of solute per unit volume (1iter) of water. Concentration of suspended sediment also is expressed in $\mathrm{mg} / \mathrm{L}$ and is based on the mass of sediment per liter of water-sediment mixture.

Nekton are the consumers of the aquatic environment and consist of large free-swimming organisms that are capable of sustained, directed mobility. 
Organism is any living entity, such as an insect, phytoplankter, or zooplankter.

Organism count/area refers to the number of organisms collected and enumerated in a sample and adjusted to the number per unit area of the habitat, usually square meter $\left(\mathrm{m}^{2}\right)$, acre, or hectare. Periphyton, benthic organisms, and macrophytes are expressed in these terms.

Organism count/volume refers to the number of organisms collected and enumerated in a sample and adjusted to the number per sample volume, usually milliliter (mL) or liter (L). Numbers of planktonic organisms can be expressed in these terms.

Total organism count is the total number of organisms collected and enumerated in any particular sample.

Partial-record station is a site where limited streamflow data are collected systematically over a period of years for use in hydrologic analyses.

Particle size is the diameter, in millimeters $(\mathrm{mm})$, of suspended sediment or bedmaterial determined by either sieve or sedimentation methods. Sedimentation methods (pipet, bottom-withdrawal tube, visual-accumulation tube) determine fall diameter of particles in chemically dispersed distilled water.

Particle-size classification used in this report agrees with recommendations made by the American Geophysical Union Subcommittee on Sediment Terminology. The classification is as follows:

Classification

C1ay...........

Silt...........

Sand.............

Grave1........
Size $(\mathrm{mm})$

$$
\begin{gathered}
0.00024-0.004 \\
0.004-0.062 \\
0.062-2.0 \\
2.0-64.0
\end{gathered}
$$

Method of analysis

Sedimentation

Sedimentation

Sedimentation or sieve Sieve.

The particle-size distributions given in this report are not necessarily representative of all particles in transport in the stream. Most of the organic material is removed and the sample is subjected to mechanical and chemical dispersion before analysis in distilled water.

Percent composition or percent of total is a unit for expressing the ratio of a particular part of a sample or population to the total sample or population, in terms of types, numbers, weight, or volume.

Periphyton are microorganisms attached to and growing upon solid surfaces. While primarily consisting of algae, the periphyton also include bacteria, fungi, protozoa, rotifers, and other small organisms. Periphyton are useful indicators of water quality.

Pesticides are chemical compounds used to control undesirable plants and anima 1 s. Major categories of pesticides include insecticides, miticides, fungicides, herbicides, and rodenticides. Insecticides and herbicides, which control insects and plants respectively, are the two categories reported.

Picocurie (PC, pCi) is one trillionth $\left(1 \times 10^{12}\right)$ of the amount of radioactivity represented by a curie (Ci). A curie is the amount of radioactivity that yields $3.7 \times 10^{10}$ radioactive disintegrations per second. A picocurie yields $2.22 \mathrm{dpm}$ (disintegrations per minute). 
Plankton are suspended, floating, or weakly swimming organisms that live in the open water of lakes and rivers.

phytoplankton compose the plant part of the plankton. They are usually microscopic and their movement is subject to water currents. Phytoplankton growth is dependent upon solar radiation and nutrient substances. Because they are able to incorporate as well as release materials to the surrounding water, the phytoplankton have a profound effect upon the quality of the water. They are the primary food producers in the aquatic environment and are commonly known as algae.

Blue-green algae are phytoplankton organisms having a blue pigment in addition to the green pigment called chlorophyll. Blue green algae often cause nuisance conditions in water.

Diatoms are the unicellular or colonial algae having a siliceous she11. Their concentrations are expressed as number of cells $/ \mathrm{mL}$ of sample.

Green algae have chlorophyll pigments similar in color to those of higher green plants. Some forms produce algal mats or floating "moss" in lakes. Their concentrations are expressed as number of cells/mL of sample.

Zooplankton compose the animal part of the plankton. Zooplankton are capable of extensive movements within the water column and are often large enough to be seen with the unaided eye. Zooplankton are secondary consumers feeding upon bacteria, phytoplankton, and detritus. Because they are the grazers in the aquatic environment, the zooplankton are a vital part of the aquatic food web. The zooplankton community is dominated by small crustaceans and rotifers.

Polych1orinated bipheny1s (PCBs) are industrial chemicals that are mixtures of chlorinated bipheny 1 compounds having various percentages of chlorine. They are similar in structure to organochlorine insecticides.

Primary productivity is a measure of the rate at which new organic matter is formed and accumulated through photosynthetic and chemosynthetic activity of producer organisms, chiefly green plants. The rate of primary production is estimated by measuring the amount of carbon assimilated by plants (carbon method) or the amount of oxygen released (oxygen method).

Milligrams of carbon per area or volume per unit time $\left[\mathrm{mg} \mathrm{C} /\left(\mathrm{m}^{2} \cdot \mathrm{time}\right)\right.$ for periphyton and macrophytes and $\mathrm{mg} C /\left(\mathrm{m}^{3}\right.$. time)] for phytoplankton are the units for expressing primary productivity. They define the amount of carbon dioxide consumed as measured by radioactive carbon (carbon 14). The carbon 14 method is of greater sensitivity than the oxygen light-and darkbottle method, and is preferred for use in unenriched waters. Unit time may be either the hour or day, depending on the incubation period.

Milligrams of oxygen per area or volume per unit time $\left[\mathrm{mg} \mathrm{O} \mathrm{O}_{2} /\left(\mathrm{m}^{2} \cdot\right.\right.$ time $)$ for periphyton and macrophytes and $\mathrm{mg} \mathrm{O}_{2} /\left(\mathrm{m}^{3} \cdot\right.$ time $\left.)\right]$ for phytoplankton are the units for expressing primary productivity. They define production and respiration rates as estimated from changes in the measured dissolved-oxygen concentration. The oxygen 1 ight-and dark-bottle method is preferred if the rate of primary production is sufficient for accurate measurements to be made within 24 hours. Unit time may be either the hour or day, depending on the incubation period. 
Sediment is solid material that is derived mostly from disintegrated rocks and is transformed by, suspended in, or deposited from water; it includes chemical and biochemical precipitates and decomposed organic material such as humus. The quantity, characteristics, and cause of the occurrence of sediment in streams are influenced by environmental factors. Some major factors are degree of slope, length of slope, soil characteristics, land usage, and quantity and intensity of precipitation.

Bedload is the sediment that is transported in a stream by rolling, sliding, or skipping along the bed and very close to it. In this report, bedload is considered to consist of particles in transit within $0.25 \mathrm{ft}$ of the streambed.

Bedload discharge (tons per day) is the quantity of sediment, as measured by dry weight, that moves past a section as bedload in a given time.

Mean concentration is the time-weighted concentration of suspended sediment passing a stream section during a 24-hour day.

Suspended sediment is the sediment that at any given time is maintained in suspension by the upward components of turbulent currents or that exists in suspension as a colloid.

Suspended-sediment concentration is the velocity-weighted concentration of suspended sediment in the sampled zone (from the water surface to a point approximately $0.3 \mathrm{ft}$ or $0.9 \mathrm{~m}$ above the bed) expressed as milligrams of dry sediment per liter of water-sediment mixture (mg/L).

Suspended-sediment discharge (tons per day) is the rate at which dry weigh $\bar{t}$ of sediment passes a section of a stream or is the quantity of sediment, as measured by dry weight, that is discharged in a given time. It is computed by multiplying discharge times milligrams per liter times 0.0027 .

Total-sediment discharge or total-sediment load (tons per day) is the sum of suspended-sediment discharge and the bedload discharge. It is the total quantity of sediment, as measured by dry weight, that passes a section in a given time.

Sodium-adsorption-ratio (SAR) is the expression of relative activity of sodium ions in exchange reactions with soil and is an index of sodium or alkali hazard to the soil. Waters range in respect to sodium hazard from those which can be used for irrigation on almost all soils to those which are generally unsatisfactory for irrigation.

Solute is any substance derived from the atmosphere, vegetation, soil, or rocks that is dissolved in water.

Specific conductance is a measure of the ability of water to conduct an electrical current and is expressed in micromhos per centimeter at $25^{\circ} \mathrm{C}$.

Specific conductance is related to the type and concentration of ions in solution and can be used for approximating the dissolved-solids concentration in water. Commonly, dissolved solids (in milligrams per liter) is about 65 percent of the specific conductance (in micromhos). This relation is not constant from stream to stream or from well to we11, and it may even vary in the same source with changes in the composition of the water.

Stage-discharge relation is the relation between gage height (stage) and the volume of water, per unit of time, flowing in a channel. 
Substrate is the physical surface upon which an organism lives.

Natural substrate refers to any naturally occurring emersed or submersed solid surface, such as a rock or tree, upon which an organism lives.

Artificial substrate is a device which is purposely placed in a stream or lake for colonization of organisms. The artificial substrate simplifies the community structure by standardizing the substrate from which each sample is taken. Examples of artificial substrates are basket samplers (made of wire cages filled with clean streamside rocks) and miltiplate samplers (made of hardboard) for benthic-organism collection and plexiglass strips for periphyton collection.

Surface area of a lake is the area, in acres, outlined on the latest Geological Survey topographic map as the boundary of the lake and measured by a planimeter. In localities not covered by topographic maps, the areas are computed from the best maps available. Areas shown are for the lake stage at the time the map was made.

Surficial bed material is the part (upper 0.1 to $0.2 \mathrm{ft}$ ) of the bed material that is sampled by using U.S. Series Bed-Material Samplers.

Suspended (as used in tables of chemical analyses) refers to the amount (concentration) of undissolved material in a water-sediment mixture. The water-sediment mixture is associated with (or sorbed on) the material retained on a 0.45 micrometer filter.

Taxonomy is the division of biology concerned with the classification and naming of organisms. The classification of organisms is based upon a hierarchical scheme beginning with kingdom and ending with species at the base. The higher the classification level, the fewer features the organisms have in common. For example, the taxonomy of a particular mayly, Hexagenia limbata is the following:

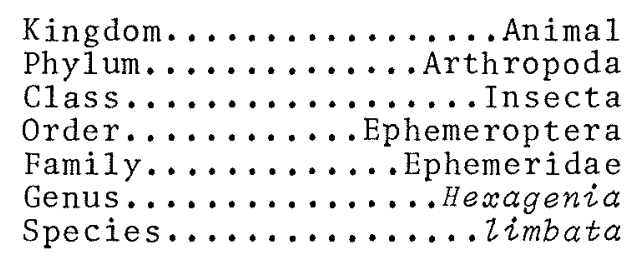

Thermograph is a thermometer that continuously and automatically records, on a chart, the water temperature of a stream. "Temperature recorder" is the term used to indicate the presence of a thermograph or a digital mechanism that records water temperature in a digital format on punched paper tape.

Time-weighted average is computed by multiplying the number of days in the sampling period by the concentrations of individual constituents for the corresponding period and dividing the sum of the products by the total number of days. A time-weighted average represents the composition of water that would be contained in a vessel or reservoir that had received equal quantities of water from the stream each day for the water year.

Tons per acre-foot indicates the dry weight of dissolved solids in 1 acre-foot of water. It is computed by multiplying the concentration in miligrams per liter by 0.00136 .

Tons per day is the quantity of a substance in solution or suspension that passes a stream section during a 24 -hour day. 
Total load (tons) is the total quantity of any individual constituent, as measured by dry mass or volume, that is dissolved in a specific amount of water (discharge) during a given time. It is computed by multiplying the total discharge, times the $\mathrm{mg} / \mathrm{L}$ of the constituent, times the factor 0.0027 , times the number of days.

Turbidity of a sample is the reduction of transparency due to the presence of particulate matter. In this report it is expressed in Jackson turbidity units (JTU).

WDR is used as an abbreviation for "Water-Data Reports" in the summary REVISIONS paragraph to refer to previously published State annual basic-data reports.

Weighted average is used in this report to indicate discharge-weighted average. It is computed by multiplying the discharge for a sampling period by the concentrations of individual constituents for the corresponding period and dividing the sum of the products by the sum of the discharges. A dischargeweighted average approximates the composition of water that would be found in a reservoir containing all the water passing a given location during the water year after thorough mixing in the reservoir.

WSP is used as an abbreviation for "Water-Supp1y Paper" in reference to previously published reports.

\section{DOWNSTREAM ORDER AND STATION NUMBER}

Since October 1, 1950, the order of 1isting hydrologic-station records in Survey reports is in a downstream direction along the main stream. All stations on a tributary entering upstream from a main-stream station are listed before that station. A station on a tributary that enters between two main-stream stations is listed between them. A similar order is followed in listing stations on first-rank, second-rank, and other ranks of tributaries. The rank of any tributary on which a station is situated with respect to the stream to which it is immediately tributary is indicated by an indention in a list of stations in the front of the report. Each indention represents one rank. This downstream order and system of indention shows which stations are on tributaries between any two stations and the rank of the tributary on which each station is situated.

As an added means of identification, each surface-water station, waterquality station, and partial-record station has been assigned a station number. These are in the same downstream order as used in this report. In assigning station numbers, no distinction is made between partial-record and continuousrecord stations; therefore, the station number for a partial-record station indicates downstream order position in a list made up of both types of stations. Water-quality stations located at or near gaging stations or partial-record stations have the same number as the gaging or partial-record station. Gaps are left between the numbers to allow for new stations that may be established; hence the numbers are not consecutive. The complete 8-digit number for each station, such as 11264500 which appears just to the left of the station name, includes the 2-digit number "11" plus the 6-digit downstream order number "264500". In this report, the records are listed in downstream order by parts. The part number refers to an area whose boundaries coincide with certain natural drainage lines. Records for California are in Part 9 (Colorado River basin), Part 10 (The Great Basin), and Part 11 (Pacific slope basins in California). Al1 records for a drainage basin encompassing more than one state could be arranged in downstream order by assembling pages from the various state reports by station number to include all records in the basin. 


\section{NUMBERING SYSTEM FOR WELLS AND MISCELLANEOUS SITES}

The 8-digit downstream-order station numbers are not assigned to wells and miscellaneous sites where only random water-quality samples or discharge measurements are taken.

The we11 and miscellaneous-site number system of the U.S. Geological Survey is based on the grid system of latitude and longitude. The system provides the geographic location of the well or miscellaneous site and a unique number for each site. The number consists of 15 digits. The first 6 digits denote the degrees, minutes, and seconds of latitude, the next 7 digits denote degrees, minutes, and seconds of longitude, and the last 2 digits (assigned sequential1y) identify the wells or other sites within a 1-second grid. See figure 2.

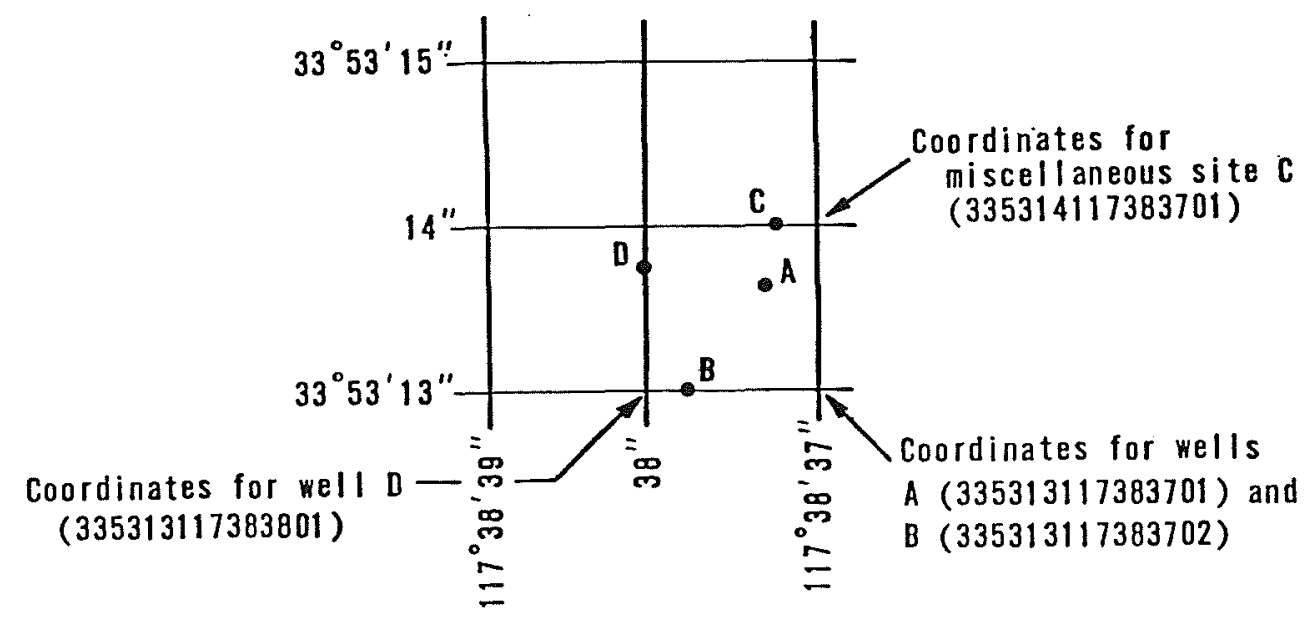

Figure 2.--System for numbering we11s and miscellaneous sites (1atitude and longitude).

\section{Loca1 We11 Numbers}

We11s and springs in California are assigned numbers according to their location on the rectangular system for the subdivision of public land. For example, in the number $5 \mathrm{~S} / 10 \mathrm{E}-22 \mathrm{Gl} \mathrm{M}$, the part of the number preceding the slash indicates the township (T.5 S.) and the number between the slash and hyphen indicates the range (R.10 E.); the digits following the hyphen indicate the section (sec.22); the letter following the section number indicates the 40-acre subdivision of the section. Within each 40-acre tract, the wells are numbered serially, as indicated by the final digit. The final letter, separated from the rest of the number by a space, indicates the base line and meridian. Baseline and meridian designations are as follows: H, Humboldt; M, Mount Diablo; $\mathrm{S}$, San Bernardino. See figure 3. 


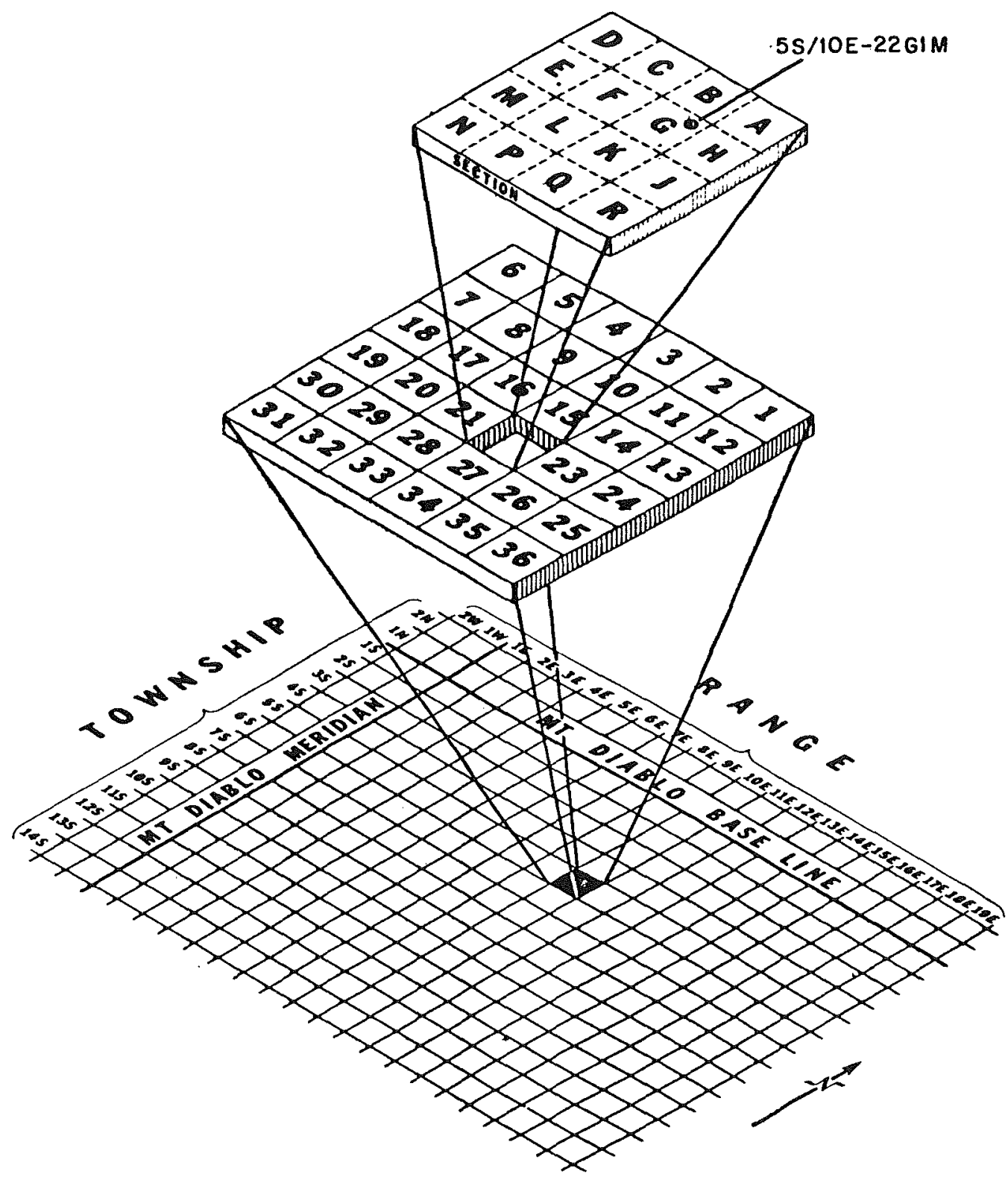

Figure 3.--Local wel1-numbering system. 


\title{
SPECIAL NETWORKS AND PROGRAMS
}

Some of the stations for which data are published in this report are included in special networks and programs. These stations are identified by their title, set in parentheses, under the station name.

Hydrologic bench-mark station is one that provides hydrologic data for a basin in which the hydrologic regimen will likely be governed solely by natural conditions. Data collected at a bench-mark station may be used to separate effects of natural from manmade changes in other basins which have been developed and in which the physiography, climate, and geology are similar to those in the undeveloped basin. Stations in this network are listed below:

\section{Volume 2:}

\section{E1der Creek near Branscomb, CA}

Volume 3:

\author{
11264500 Merced River at Happy Isles Bridge, near Yosemite, CA
}

National stream-quality accounting network is an accounting network designed by the U.S. Geological Survey to meet many of the information demands of agencies or groups involved in national or regional water-quality planning and management. Both accounting and broad-scale monitoring objectives have been incorporated in the network design. Areal configuration of the network is based on the river-basin accounting units designated by the office of Water Data Coordination in consultation with the Water Resources Council. Primary objectives of the network are (1) to depict areal variability of water-quality conditions nationwide on a year-by-year basis and (2) to detect and assess longterm changes in streamflow and stream quality. Stations in this network are listed below:

\section{Volume 1:}

09424190 Colorado River Aqueduct near San Jacinto, CA

09429500 Colorado River above Imperial Dam, AZ-CA

10254970 New River at International Boundary, at Calexico, CA

10261500 Mojave River at lower narrows, near Victorville, CA

10277400 Owens River below Tinemaha Reservoir, near Big Pine, CA

11074000 Santa Ana River below Prado Dam, CA

11103010 Los Angeles River at Willow Street Bridge, at Long Beach, CA

\section{Volume 2 :}

11152500

11467000

11530500

Salinas River near Sprecke1s, CA

Russian River near Guerneville, CA

Klamath River near Klamath, CA

Volume 3:

11250000 Friant-Kern Canal at Friant, CA

11303500 San Joaquin River near Vernalis, CA

11325500 Mokelumne River at Woodbridge, CA

Volume 4:

11447650 Sacramento River at Freeport, CA 
Pesticide program is a network of regularly sampled water-quality stations where samples are collected to determine the concentration and distribution of pesticides in streams whose waters are used for irrigation or in streams in areas where contamination could result from the application of the common $1 y$ used insecticides and herbicides. Operation of the network is a Federal interagency activity.

Radiochemical program is a network of regularly sampled water-quality stations where samples are collected to be analyzed for radiosotopes. The streams that are sampled represent major drainage basins in the conterminous United states.

Tritium network is a network of stations which has been established to provide baseline information on the occurrence of tritium in the Nation's surface waters. In addition to the surface-water stations in the network, tritium data are also obtained at a number of precipitation stations. The purpose of the precipitation stations is to provide an estimate sufficient for hydrologic studies of the tritium input to the United States.

\section{EXPLANATION OF STAGE AND WATER-DISCHARGE RECORDS}

\section{Collection and computation of data}

The base data collected at gaging stations consist of records of stage and measurements of discharge of streams and canals and records of stage, of lakes and reservoirs. In addition, observations of factors affecting the stagedischarge relation or the stage-capacity relation, weather records, and other information are used to supplement base data in determining the daily flow or volume of water in storage. Records of stage are obtained from direct readings on a nonrecording gage or from a water-stage recorder that gives a continuous graph of the fluctuations or a tape punched at selected time intervals. Measuremements of discharge are made with a current meter, using the methods adopted by the Geological Survey. These methods are described in standard textbooks, in Water-Supply Paper 888 , and in the U.S. Geological Survey Techniques of Water Resources Investigations, book 3, chapter A6.

For a stream-gaging station, rating tables giving the discharge for any stage are prepared from stage-discharge relation curves. If extensions to the rating curves are necessary to express discharge greater than measured, they are made on the basis of indirect measurements of peak discharge (such as slopearea or contracted-opening measurements, computation of flow over dams or weirs), velocity-area studies, and logarithmic plotting. The daily mean discharge is computed from gage heights and rating tables, then the monthly and yearly mean discharges are computed from the daily figures. If the stage-discharge relation is subject to change because of frequent or continual change in the physical features that form the control, the daily mean discharge is determined by the shifting-control method, in which correction factors based on individual discharge measurements and notes by engineers and observers are used in applying the gage heights to the rating tables. If the stage-discharge relation for a station is temporarily changed by the presence of aquatic growth or debris on the control, the daily mean discharge is computed by what is basically the shifting-control method.

At some stream-gaging stations the stage-discharge relation is affected by backwater from reservoirs, tributary streams, or other sources. This necessitates the use of the slope method in which the slope or fall in a reach of the stream is a factor in computing discharge. The slope or fall is obtained by means of an auxiliary gage set at some distance from the base gage. At some stations the stage-discharge relation is affected by changing stage; at these stations the rate of change in stage is used as a factor in computing discharge. 
At some stream-gaging stations the stage-discharge relation is affected by ice in the winter, and it becomes impossible to compute the discharge in the usual manner. Discharge for periods of ice effect is computed on the basis of the gage-height record and occasional winter discharge measurements. Consideration is given to the available information on temperature and precipitation, notes by gage observers and hydrologists, and comparable records of discharge

For a lake or reservoir station, capacity tables giving the contents for any stage are prepared from stage-area relation curves defined by surveys. The application of the stage to the capacity table gives the contents from which the daily, month1y, or yearly change in contents is computed.

If the stage-capacity curve is subject to changes because of deposition of sediment in the reservoir, periodic resurveys of the reservoir are necessary to define new stage-capacity curves. During the period between reservoir surveys the computed contents may be increasingly in error due to the gradual accumulation of sediment.

For some gaging stations there are periods when no gage-height record is obtained or the recorded gage height is so faulty that it cannot be used to compute daily discharge or contents. This happens when the recorder stops or otherwise fails to operate properly, intakes are plugged, the float is frozen in the we11, or for various other reasons. For such periods the daily discharges are estimated on the basis of recorded range in stage, prior and subsequent records, discharge measurements, weather records, and comparison with records for other stations in the same or nearby basins. Likewise, daily contents may be estimated on the basis of operator's $10 \mathrm{~g}$, prior and subsequent records, inflowoutflow studies, and other information.

The data in this report generally comprise a description of the station and tabulations of daily and monthly figures. For gaging stations on streams or canals a table showing the daily discharge and monthly and yearly discharge is given. For gaging stations on lakes and reservoirs a monthly summary table of stage and contents or a table showing the daily contents is given. Tables of daily mean gage heights are included for some streamflow stations and for some reservoir stations. Records are published for the water year, which begins on October 1 and ends on September 30. A calendar for the current year is shown on the reverse side of the front cover to facilitate finding the day of the week for any date.

The description of the gaging station gives the location, drainage area, period of record, notations of revisions of previously published records, type and history of gages, general remarks, average discharge, and extremes of published records. The location of the gaging station and the drainage area are obtained from the most accurate maps available. River mileage, given under "LOCATIONS" for some stations, is that determined and used by the Corps of Engineers or other agencies. Periods for which there are published records for the present station or for stations generally equivalent to the present one are given under "PERIOD OF RECORD."

Previous1y published records of some stations have been found to be in error on the basis of data or information later obtained. Revisions of such records are usually published, along with the current records, in one of the annual or compilation reports. In order to make it easier to find such revised records, a paragraph headed "REVISED RECORDS" has been added to the description of all stations for which revised records have been published. Listed therein are al1 the reports in which revisions have been published, each followed by the water years for which figures are revised in that report. In listing the water years only one number is given; for instance, 1933 stands for the water year october 1,1932 , to September 30,1933 . If no daily, month1y, or annual figures of discharge are affected by the revision, that fact is brought out by notations after the year dates as follows: "(M)" means that on $1 y$ the instantaneous maximum discharge was revised; "(m)" that on $1 y$ the instantaneous minimum 
was revised; and "(P)" that only the peak discharges were revised. If the drainage area has been revised, the report in which the revised figure was first published is given.

The type of gage currently in use, the datum of the present gage above mean sea leve1, and a condensed history of the types, locations, and datums of previous gages used during the period of record are given under "GAGE". In references to datum of gage, the phrase "mean sea level" denotes "Sea Leve1 Datum of 1929" as used by the Topographic Division of the Geological Survey, unless otherwise qualified.

Information pertaining to the accuracy of the discharge records, and to conditions that affect the natural flow at the gaging station, is given under "REMARKS"; for reservoir stations information on the dam forming the reservoir, the capacity, outlet works and spillway, and purpose and use of the reservoir is also given under "REMARKS."

The average discharge for the number of years indicated is given under "AVERAGE DISCHARGE"; it is not given for stations having fewer than 5 complete years of record or for stations where changes in water development during the period of record cause the figure to have little significance. In addition, the median of yearly mean discharges is given for stream-gaging stations having 10 or more complete years of record if the median differs from the average by more than 10 percent. Under "EXTREMES" are given: First, the extremes for the period of record; second, information available outside the period of record; and last, those for the current year. Unless otherwise qualified, the maximum discharge (or contents) is the instantaneous maximum corresponding to the crest stage obtained by use of a water-stage recorder (graphic or digita1), a creststage gage, or a nonrecording gage read at the time of the crest. If the maximum gage height did not occur on the same day as the maximum discharge (or contents), it is given separately. Similarly, the minimum is the instantaneous minimum unless otherwise qualified. For some stations peak discharges are listed with EXTREMES FOR THE CURRENT YEAR; if they are, all independent peaks (including the maximum for the year) above the selected base, with the time of occurrence and corresponding gage heights, are published in tabular format. The base discharge, which is given in the table heading, is selected so that an average of about three peaks a year will be presented. Peak discharges are not published for any canals, ditches, drains, or for any stream for which the peaks are subject to substantial control by man. Time of day is expressed in 24-hour 1ocal standard time; for example, $12: 30 \mathrm{a} . \mathrm{m}$. is $0030,1: 30 \mathrm{p.m}$. is 1330 . The minimums for these stations are published in a separate paragraph following the table of peaks.

Skeleton rating tables are published, immediately following EXTREMES, for stream-gaging stations where they serve a useful purpose and the dates of applicability can be easily identified.

The daily table for stream-gaging stations gives the mean discharge for each day and is followed by monthly and yearly summaries. In the monthly summary below the daily table, the line headed "TOTAL" gives the sum of the daily figures. The line headed "MEAN" gives the average flow in cubic feet per second during the month. The lines headed "MAX" and "MIN" give the maximum and minimum daily discharges, respectively, for the month. Discharge for the month also may be expressed in acre-feet ( 1 ine headed "AC-FT").

Footnotes to the table of daily discharges are introduced by the word "NOTE." Footnotes are used to indicate periods for which the discharge is computed or estimated by special methods because of no gage-height record, backwater from various sources, or other unusual conditions. Periods of no gage-height record are indicated if the period is continuous for a month or more or includes the maximum discharge for the year. Periods of backwater from an unusual source, of indefinite stage-discharge relation, or of any other unusual 
condition at the gage site are indicated only if they are a month or more in length and the accuracy of the records is affected. Days on which the stagedischarge relation is affected by ice are not indicated. The methods used in computing discharge for various unusual conditions have been explained in preceding paragraphs.

For most gaging stations on lakes and reservoirs the data presented comprise a description of the station and monthly summary table of stage and contents. For some reservoirs a table showing daily contents or stage is given. A skeleton table of capacity at given stages is published for all reservoirs for which records are published on a daily basis, but it is not published for reservoirs for which only monthly data are given.

Data collected at partial-record stations follow the information for continuous-record sites. Data for partial-record discharge stations are presented in two tables. The first is a table of discharge measurements at low-flow partial-record stations, and the second is a table of annual maximum stage and discharge at crest-stage stations. The tables of partial-record stations are followed by a listing of discharge measurements made at sites other than continuous-record or partial-record stations. Occasionally, a series of discharge measurements are made within a short time period to investigate the seepage gains or losses along a reach of a stream or to determine the low-flow characteristics of an area. Such measurements are also given in special tables following the tables of partial-record stations.

\section{Accuracy of field data and computed results}

The accuracy of discharge data depends primarily on (1) the stability of the stage-discharge relation or, if the control is unstable, the frequency of discharge measurements, and (2) the accuracy of observations of stage, measurements of discharge, and interpretation of records.

The station description under "REMARKS" states the degree of accuracy of the records. "Excellent" means that about 95 percent of the daily discharges are within 5 percent; "good" within 10 percent; and "fair" within 15 percent. "Poor" means that daily discharges have less than "fair" accuracy.

Figures of daily mean discharge in this report are shown to the nearest hundredth of a cubic foot per second for discharges of 1 ess than $1 \mathrm{ft}^{3} / \mathrm{s}$; to tenths between 1.0 and $10 \mathrm{ft} / \mathrm{s}$; to whole numbers between 10 and $1,000 \mathrm{ft}^{3} / \mathrm{s}$; and to 3 significant figures above $1,000 \mathrm{ft}^{3} / \mathrm{s}$. The number of significant figures used is based solely on the magnitude of the figure. The same rounding rules apply to discharge figures listed for partial-record stations and misce1laneous sites.

Discharge at many stations, as indicated by the monthly mean, may not reflect natural runoff due to the effects of diversion, consumptive use, regulation by storage, increase or decrease due to artificial causes, or to other factors. Evaporation from a reservoir is not included in the adjustments for changes in reservoir contents, unless it is so stated. Even at those stations where adjustments are made, large errors in computed runoff may occur if adjustments or losses are large in comparison with the observed discharge.

\section{Other data available}

Information of a more detailed nature than that published for most of the gaging stations, such as observations of water temperatures, discharge measurements, gage-height records, and rating tables, is on file in the district office. Also, most gaging-station records are available in computer-usable form and many statistical analyses have been made. Information on the availability of unpublished data or statistical analyses may be obtained from the district office. 
Special reports on major floods or droughts or of other hydrologic studies for the area have been issued in publications other than water-supply papers. Information relative to these reports may be obtained from the district office.

Records of discharge collected by agencies other than the Geological Survey

Records of discharge not published by the Geological Survey have been collected at numerous sites by many other Federa1, State, County, City, and 1ocal agencies and by private organizations. A listing of stream-gaging stations and the agencies operating them is published in California Department of Water Resources Bulletin 157, "Index of Stream-Gaging Stations in and Adjacent to California." The National Water Data Exchange, Water Resources Division, U.S. Geological Survey, National Center, Reston, VA 22092, maintains an index of such sites. Information on records at specific sites can be obtained upon request.

\section{EXPLANATION OF WATER-QUALITY RECORDS}

\section{Collection and examination of data}

Surface-water samples for analyses usually are collected at or near gaging stations. The water-quality records are given immediately following the discharge records at these stations.

The descriptive heading for water-quality records gives the period of record for all water-quality data; the period of daily record for properties and constituents that are measured on a daily basis (specific conductance, pH, dissolved oxygen, water temperature, sediment discharge, etc.); instrumentation; general remarks; extremes for the period of daily record; and extremes for the current year.

For ground-water records, no descriptive statements are given; however, the well number, depth of well, date of sampling and/or other pertinent data are given in the table containing the chemical analyses of the ground water.

\section{Water analysis}

Most methods for collecting and analyzing water samples are described in the U.S. Geological Survey Techniques of Water-Resources Investigations listed on a following page.

One sample can define adequately the water quality at a given time if the mixture of solutes throughout the stream cross section is homogeneous. However, the concentration of solutes at different locations in the cross section may vary widely with different rates of water discharge, depending on the source of material and the turbulence and mixing of the stream. Some streams must be sampled through several vertical sections to obtain a representative sample needed for an accurate mean concentration and for use in calculating load.

Chemical-quality data published in this report are considered to be the most representative values available for the stations 1 isted. The values reported represent water-quality conditions at the time of sampling as much as possible, consistent with available sampling techniques and methods of analysis. In the rare case where an apparent inconsistency exists between the reported $\mathrm{pH}$ value and the relative abundance of carbon dioxide species (carbonate and bicarbonate), the inconsistency is the result of a slight uptake of carbon dioxide from the air by the sample between time of measurement of $\mathrm{pH}$ in the field and determination of carbonate and bicarbonate in the laboratory. 
For chemical-quality stations equipped with digital monitors, the records consist of daily maximum, minimum, and mean values for each constituent measured and are based upon hourly punches beginning at 0100 hours and ending at 2400 hours for the day of record. More detailed records (hourly values) may be obtained from the district office.

Ground-water quality normally does not change significantly during short periods of time; infrequent sampling and analysis of ground water adequately defines ground-water quality at a given site.

\section{Water temperature}

Water temperatures are measured at most of the water-quality stations. In addition, water temperatures are taken at time of discharge measurements for water-discharge stations. For stations where water temperatures are taken manually once or twice daily, the water temperatures are taken at about the same time each day. Large streams have a small diel temperature change; shallow streams may have a daily range of several degrees and may follow closely the changes in air temperature. Some streams may be affected by waste-heat discharges.

At stations where continuously recording thermographs are present, the records consist of maximum and minimum temperatures for each day and month. Water temperatures taken at the time of discharge measurements are on file in the district office. They will be used, with all other temperature data, for reports such as the open-file reports by subregion, "Water Temperature of California Streams, $1970 . "$

\section{$\underline{\text { Sediment }}$}

Suspended-sediment concentrations are determined from samples collected by using depth-integrating samplers. Samples usually are obtained at several verticals in the cross section, or a single sample may be obtained at a fixed point and a coefficient applied to determine the mean concentration at the cross sections.

During periods of rapidly changing flow or rapidly changing concentration, samples may have been collected more frequently (twice daily or, in some instances, hourly). The published sediment discharges for days of rapidly changing flow or concentration were computed by the subdivided day method (timedischarge weighted average). Therefore, for days when the published sediment discharge value differs from the value computed as the product of discharge times mean concentration times 0.0027 , the reader can assume that the sediment discharge was computed by the subdivided day method. For periods when no samples were collected, daily loads of suspended sediment were estimated on the basis of water discharge, sediment concentrations observed immediately before and after the periods, and suspended-sediment loads for other periods of similar discharge.

At other stations, suspended-sediment samples were collected periodically at many verticals in the stream cross section. Although data collected periodically may represent conditions only at the time of observations, such data are useful in establishing seasonal relations between quality and streamflow in predicting long-term sediment-discharge characteristics of the stream.

In addition to the records of suspended-sediment discharge, estimates of bedload- and total-sediment discharge are included for some stations. Also included are particle-size distribution analyses of suspended sediment, surface bed material, and bedload material (sediment in transit within $0.25 \mathrm{ft}$ of the bed). 
Computations of monthly bedload discharges are based on the relation between instantaneous water discharge and corresponding bedload discharge for the station. Values of bedload discharge used in defining this relation are based on samples obtained by use of the Helley-Smith bedload sampler or by modified Einstein or Meyer-Peter Muller computation procedures. Application of the bedload-transport relation at a station was made on a dajly basis or subdivided-day basis.

The Helley-Smith sampler is designed to collect a time-weighted sample of the sediment moving within $0.25 \mathrm{ft}$ of the streambed. Sediment moving in this portion of the flow cannot be sampled with standard suspended-sediment samplers. It is assumed that samples obtained by this sampler represent the bedload discharge when used in coarse-material bedded streams (median diameter coarser than about $4 \mathrm{~mm}$ ) and that these data can be used in conjunction with theoretical computations to define the bedload-transport relation for a station.

Calibration of the Helley-Smith sampler has not been completed, and a trap efficiency of 1.0 has been assumed applicable to this device. Error sources in the theoretical methods, based on analysis of bed material characteristics, channel geometry, and associated hydraulic factors, are also undefined. In consequence, figures of bedload discharge must be used with caution. They are estimates, at best, and are subject to revision.

\section{Turbidity}

At some stations samples for the determination of turbidity were collected at the same frequency as samples collected for determination of suspended sediment. Turbidity, measured in Jackson turbidity units (JTU), is shown in relation to the concentration of sediment in the simultaneously collected sample.

Measured values of turbidity are significantly influenced by the type of instrument used. Turbidity values published in California reports prior to July 1966 were determined by means of a Hellige Turbidimeter and are not directly comparable with those published subsequently. Data published in parts per million as silica from July 1966 to September 1968, and in milligrams per 1iter as silica from October 1968 to September 1970, were measured with a mode1 1860 Hach Turbidimeter which is optically similar to the model $2100 \mathrm{Hach}$ Turbidimeter used from October 1970 to September 1974, and the mode1 $2100 \mathrm{~A}$ Hach Turbidimeter used since October 1974. Scales are available for those instruments providing a readout in either milligrams per liter or in Jackson turbidity units. Hence, conversion of data for the period July 1966 through September 1970, from parts per million or milligrams per liter of silica to Jackson turbidity units can be made by use of table 1 .

Table 1.-Conversion of turbidity values, measured by Hach Turbidimeters Model 1860 or 2100, from parts per million or milligrams per liter of silica to Jackson turbidity units.

Turbidity, in ppm or $\mathrm{mg} / \mathrm{L}$ Turbidity, in JTU

$\begin{array}{rr}5 & 3 \\ 10 & 6 \\ 50 & 30 \\ 100 & 55 \\ 200 & 110 \\ 500 & 240 \\ 1000 & 440\end{array}$




\section{EXPLANATION OF GROUND-WATER LEVEL RECORDS}

\section{Collection of the data}

Only ground-water-level data from a basic national network of observation wells are published herein. These water-1evel measurements are intended to provide a sampling and historical record of water-level changes in the Nation's most important aquifers.

Each we1l is identified by means of (1) a 15-digit number that is based on the grid system of latitude and longitude as shown in figure 2, and (2) a 1 local number that is provided for continuity with older reports and for other use as dictated by local needs (fig. 3).

Measurements are made in many types of wells under various conditions, but the methods of measurement are standardized to the extent possible. The equipment and measuring techniques used at each observation we11 insure that measurements at a well are of consistent accuracy and reliability.

Water-level measurements in this report are given in feet with reference to either mean sea level (msl) or land-surface datum (1sd). Mean sea level is the datum plane on which the national network of precise levels is based; 1 andsurface datum is a datum plane that is approximately at land surface at each we11. If known, the altitude of the land-surface datum above mean sea level is given in the well description. The height of the measuring point (MP above or below 1and-surface datum), if known, is given in each well description. Water levels in wells equipped with recording gages are reported for every fifth day and the end of each month (EOM).

Water leve1s are reported to as many significant figures as can be justified by the local conditions. For example, in a measurement of a depth to water of several hundred feet, the error of determining the absolute value of the total depth to water may be a few tenths of a foot, whereas the error in determining the net change of water level between successive measurements may be only a hundredth or a few hundredths of a foot. For lesser depths to water, the accuracy is greater. Accordingly, most measurements are reported to a hundredth of a foot, but some are given only to a tenth of a foot or a larger unit. 


\section{PUBLICATIONS OF TECHNIQUES OF WATER-RESOURCES INVESTIGATIONS}

Thirty-four manuals by the U.S. Geological Survey have been published to date in the series on techniques describing procedures for planning and executing specialized work in water-resources investigations. The material is grouped under major subject headings called books and is further divided into sections and chapters. For example, Section A of Book 3 (Applications of Hydraulics) is on surface water. The chapter, the unit of publication, is limited to a narrow field of subject matter. This format permits flexibility in revision and publication as the need arises. The reports listed below are for sale by the U.S. Geological Survey, Branch of Distribution, 1200 South Eads Street, Arlington, VA 22202 (authorized agent of the Superintendent of Documents, Government Printing Office). Prices are subject to change.

NOTE: When ordering any of these publications, please give the title, book number, chapter number, and "U.S. Geological Survey Techniques of Water-Resources Investigations".

1-D1. Water temperature-influential factors, field measurement, and data presentation, by H. H. Stevens, Jr. J. F. Ficke, and G. F. Smoot: USGS--TWRI Book 1, Chapter D1. 1975. 65 pages. \$1.60.

1-D2. Guidelines for collection and field analysis of ground-water samples for selected unstable constituents, by W. W. Wood: ' USGS--TWRI Book 1, Chapter D2. 1976. 24 pages. \$0.85.

2-D1. Application of surface geophysics to ground-water investigations, by A. A. R. Zohdy, G. P. Eaton, and D. R. Mabey: USGS--TWRI Book 2, Chapter D1. 1974. 116 pages. $\$ 1.90$.

2-E1. Application of borehole geophysics to water-resources investigations, by W. S. Keys and L. M. MacCary: USGS--TWRI Book 2, Chapter E1. 1971. 126 pages. $\$ 1.75$.

3-A1. General field and office procedures for indirect discharge measurements, by M. A. Benson and Tate Dalrymple: USGS--TWRI Book 3, Chapter A1. 1967. 30 pages. $\$ 0.25$.

3-A2. Measurement of peak discharge by the slope-area method, by Tate Dalyrmple Measurement of peak discharge by the slope-area method, by Tate Dalyrmple
and M. A. Benson: USGS--TWRI Book 3, Chapter A2. 1967. 12 pages. $\$ 0.20$.

3-A3. Measurement of peak discharge at culverts by indirect methods, by G. L. Bodhaine: USGS-TWRI Book 3, Chapter A3, 1968. 60 pages. $\$ 0.40$.

3-A4. Measurement of peak discharge at width contractions by indirect methods, By H. F. Matthai: USGS--TWRI Book 3, Chapter A4. 1967. 44 pages. \$1.00. 3-A5. Measurement of peak discharge at dams by indirect methods, by Harry
Hulsing: USGS--TWRI Book 3, Chapter A5, 1967. 29 pages. \$0.30.

3-A6. General procedure for gaging streams, by R. W. Carter and Jacob Davidian: USGS--TWRI Book 3, Chapter A6, 1968. 13 pages. \$0.20.

3-A7. Stage measurements at gaging stations, by T. J. Buchanan and W. P. Somers: USGS--TWRI Book 3, Chapter A7. 1968. 28 pages. $\$ 0.45$.

3-A8. Discharge measurements at gaging stations, by T. J. Buchanan and W. P. Somers: USGS--TWRI Book 3, Chapter A8. 1969. 65 pages. $\$ 1.25$.

3-A11. Measurement of discharge by moving-boat method, by G. F. Smoot and C. E. Novak: USGS--TWRI Book 3, Chapter A11. 1969.22 pages. \$0.40.

3-A12. Fiuormetric procedures for dye tracing, by J. F. Wiison, Jr.: USGS-TWRI Book 3, Chapter A12. 1968. 31 pages. $\$ 0.35$. Not current1y available.

3-B1. Aquifer-test design, observation, and data analyses, by R. W. Stallman: USGS--TWRI Book 3, Chapter B1. 1971. 26 pages. $\$ 0.70$.

3-B2. Introduction to ground-water hydraulies-a programed text for selfinstruction, by D. S. Bennett: USGS--TWRI Book 3, Chapter B2. 1976. 172 pages. $\$ 2.50$

3-C1. Fluvial sediment concepts, by H. P. Guy: USGS--TWRI Book 3, Chapter C1. 1970. 55 pages. $\$ 0.65$.

3-C2. Fiezd methods for measurement of fluvial sediment, by H. P. Guy and V. W. Norman: USGS--TWRI Book 3, Chapter C2, 1970.59 pages. $\$ 0.70$.

3-C3. Computation of fiuviat-sediment discharge, by George Porterfield: USGS-TWRI Book 3, Chapter C3: 1972. 66 pages. \$1.15. 
4-A1. Some statistical tools in hydrology, by H. C. Riggs: USGS--TWRI Book 4, Chapter A1. 1968. 39 pages. \$.30.

4-A2. Frequency curves, by H. C. Riggs: USGS--TWRI Book 4, Chapter A2. 1968 15 pages. $\$ 0.20$.

4-B1. Low-flow investigations, by H. C. Riggs: USGS--TWRI Book 4, Chapter B1. 1972. 18 pages. $\$ 0.65$.

4-B2. Storage analyses for water supply, by H. C. Riggs and C. H. Hardison: USGS--TWRI Book 4, Chapter B2. 1973. 20 pages. \$0.75.

4-B3. Regional analyses of streamflow characteristios, by $\mathrm{H}$. C. Riggs: USGS-TWRI Book 4, Chapter B3. 1973. 15 pages. \$0.75.

4-D1. Computation of rate and volume of stream depletion by wells, by C. T. Jenkins: USGS--TWRI Book 4, Chapter D1. 1970. 17 pages. $\$ 0.65$.

5-A1. Methods for collection and analysis of water samples for dissolved minerals and gases, by Eugene Brown, M. W. Skougstad, and M. J. Fishman: USGS--TWRI Book 5, Chapter AI. 1970. 160 pages. $\$ 2.40$.

5-A2. Determination of minor elements in water by emission spectroscopy, by P. R. Barnett and E. C. Mallory, Jr.: USGS--TWRI Book 5, Chapter A2. 1971. 31 pages. $\$ 0.80$.

5-A3. Methods for analysis of organio substances in water, by D. F. Goerlitz and Eugene Brown: USGS--TWRI Book 5, Chapter A3. 1972. 40 pages. $\$ 0.90$.

5-A4. Methods for oollection and analysis of aquatic biological and miorobiological samples, by K. V. Slack, R. C. Averett, P. E. Greeson, and R. G. Lipscomb: USGS--TWRI Book 5, Chapter A4. 1973. 165 pages. \$1.95.

5-A5.* Methods for determination of radioactive substances in water and fluvial sediments, by L. L. Thatcher, V. J. Janzer, and K. W. Edwards: USGS-TWRI Book 5, Chapter A5. 1977. 95 pages. $\$ 16.00$.

5-C1. Laboratory theory and methods for sediment analyses, by H. P. Guy: USGS-TWRI Book 5, Chapter C1. 1969. 58 pages. $\$ 0.65$.

7-C1. Finite-difference model for aquifer simultation in two dimensions with results of numerical experiments, by P. C. Trescott, G. F. Pinder, and S. P. Larson: USGS--TWRI Book 7, Chapter C1. 1976. 116 pages. $\$ 2.30$.

8-A1. Methods of measuring water levels in deep weils, by M. S. Garber and F. C. Koopman: USGS--TWRI Book 8, Chapter AI. 1968, 23 pages. $\$ 0.70$.

8-B2. Calibration and maintenance of vertical-axis type current meters, by G. F. Smoot and C. E. Novak: USGS--TWRI Book 8, Chapter B2. 1968. 15 pages. $\$ 0.40$.

*Looseleaf format. Available only by subscription. Additional supplements will be issued to subscribers at no extra cost. 
09421500. COLORADO RIVER BELOH HOOVER DAM, ARIZ. -NEV.

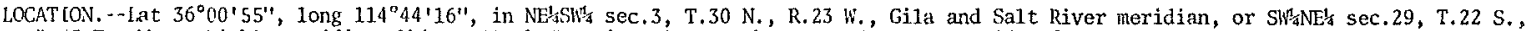
R. .5 E., Mount Diablo merjdian, Mohave-Clark Counties, in powerhouse at downstream side of Hoover Dam.

DRAINAGL AREA (REVISED).--171,700 $\mathrm{mi}^{2}\left(444,700 \mathrm{kn}^{2}\right)$, approximately, including 3,959 $\mathrm{ni}^{2}$ (10,254 $\mathrm{kn}^{2}$ ) in Great Divide basin in southert Wyoming, which is noncontributing (previously considered part of the Missouri River basin).

PERIOD OF RECORD. - -October 1933 to current year (prior to April 1934, monthly discharge only, published in kSP 1313). Published as "noar Willow Beach" 1933-39 and as "below Boulder Dan" 1939-45.

GAGE.--Totalizing flowmeters on each turbine in Hoover Dam powerholse. Prior to Nov, 1, 1939, water-stage recorder at site 9 mi (14 $\mathrm{kn})$ downstream at datum $594.8 \mathrm{ft}(181.30 \mathrm{~m})$ above mean sea level. Nov. 1, 1939, to June 30, 1958, water-stage recorder at site $0.8 \mathrm{mi}(1.3 \mathrm{~km})$ downstream at datum $600.35 \mathrm{ft}(182.987 \mathrm{~m})$ above mean sea level.

AVERAGE DISGIARGE. - -42 years $(1934-76), 13,340 \mathrm{ft}^{3} / \mathrm{s}\left(377.8 \mathrm{~m}^{3} / \mathrm{s}\right), 9,665,000 \mathrm{acre}-\mathrm{ft} / \mathrm{yr}\left(11,900 \mathrm{hm}{ }^{3} / y \mathrm{r}\right)$ unadjusted for storage in Lake lead.

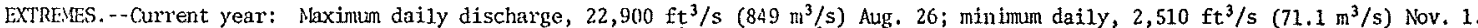
Period of record: Naxinum daily disclare, $36,000 \mathrm{ft}^{3} / \mathrm{s}\left(1,020 \mathrm{~m}^{3} / \mathrm{s}\right)$ Jan, 28,1942 ; no flow at Hoover Darl part of Feb. 10 , 1935; minimum daily discharge, $152 \mathrm{ft}^{3} / \mathrm{s}\left(4.30 \mathrm{~m}^{3} / \mathrm{s}\right) \mathrm{Feb}, 10$, 1935

REMARKS.--Flow regulated by Lake Mead since Feb. 1, 1935. Many diversions above station for irrigation, industrial, and municipal use. Records of chemical analyses for the current year are published on following pages.

COOPERATION. - -Records furmished by Bureau of Reclaniation.

DISCHARGE, IN CUBIC FEET PER SECOND, WATER YEAR OCTOBER 1975 TO SEPTEMBER 1976 MEAN VALUES

\begin{tabular}{|c|c|c|c|c|c|c|c|c|c|c|c|c|}
\hline DAY & OCT & NOV & DEC & JAN & FEB & MAR & APR & MAY & JUN & JUL & AUG & SE \\
\hline $\begin{array}{l}1 \\
2 \\
3 \\
4 \\
5\end{array}$ & $\begin{array}{r}13800 \\
12000 \\
8760 \\
6320 \\
6000\end{array}$ & $\begin{array}{l}2510 \\
2570 \\
6670 \\
8840 \\
8330\end{array}$ & $\begin{array}{r}10300 \\
7840 \\
6350 \\
7270 \\
10800\end{array}$ & $\begin{array}{r}10400 \\
13400 \\
10400 \\
9140 \\
11200\end{array}$ & $\begin{array}{r}6020 \\
10500 \\
11600 \\
11700 \\
14000\end{array}$ & $\begin{array}{l}17000 \\
16300 \\
16300 \\
15000 \\
16300\end{array}$ & $\begin{array}{l}17000 \\
15400 \\
11400 \\
11500 \\
15300\end{array}$ & $\begin{array}{r}12100 \\
7070 \\
19700 \\
19000 \\
21300\end{array}$ & $\begin{array}{r}17200 \\
17500 \\
14600 \\
12800 \\
5990\end{array}$ & $\begin{array}{l}14000 \\
15200 \\
7060 \\
6710 \\
6810\end{array}$ & $\begin{array}{r}5390 \\
15600 \\
17300 \\
16600 \\
17700\end{array}$ & $\begin{array}{r}15000 \\
17600 \\
16600 \\
11800 \\
4290\end{array}$ \\
\hline $\begin{array}{r}6 \\
7 \\
8 \\
9 \\
10\end{array}$ & $\begin{array}{l}6430 \\
6940 \\
7510 \\
9100 \\
8140\end{array}$ & $\begin{array}{r}8660 \\
10100 \\
8830 \\
7170 \\
10900\end{array}$ & $\begin{array}{l}5910 \\
6870 \\
9040 \\
7690 \\
9990\end{array}$ & $\begin{array}{r}10000 \\
6260 \\
7430 \\
6780 \\
4160\end{array}$ & $\begin{array}{r}16100 \\
7000 \\
7700 \\
11900 \\
6850\end{array}$ & $\begin{array}{l}10300 \\
10400 \\
16000 \\
17000 \\
18700\end{array}$ & $\begin{array}{l}14500 \\
16000 \\
16100 \\
14800 \\
12800\end{array}$ & $\begin{array}{r}21000 \\
18600 \\
9570 \\
8210 \\
21100\end{array}$ & $\begin{array}{r}6300 \\
13000 \\
13800 \\
13200 \\
13200\end{array}$ & $\begin{array}{r}18100 \\
16600 \\
16800 \\
14500 \\
6390\end{array}$ & $\begin{array}{r}16100 \\
7060 \\
5280 \\
16800 \\
13600\end{array}$ & $\begin{array}{r}424 \\
1770 \\
1640 \\
1420 \\
1930\end{array}$ \\
\hline $\begin{array}{l}11 \\
12 \\
13 \\
14 \\
15\end{array}$ & $\begin{array}{r}2710 \\
3350 \\
6050 \\
13400 \\
16300\end{array}$ & $\begin{array}{r}11800 \\
8540 \\
9800 \\
9010 \\
7720\end{array}$ & $\begin{array}{l}9760 \\
9810 \\
4590 \\
4200 \\
8980\end{array}$ & $\begin{array}{l}5500 \\
5710 \\
8040 \\
5520 \\
6340\end{array}$ & $\begin{array}{l}7280 \\
7340 \\
4270 \\
4240 \\
3680\end{array}$ & $\begin{array}{r}18100 \\
19900 \\
11700 \\
6150 \\
17100\end{array}$ & $\begin{array}{l}10100 \\
14600 \\
16600 \\
17400 \\
15400\end{array}$ & $\begin{array}{r}20800 \\
19400 \\
17700 \\
16400 \\
9090\end{array}$ & $\begin{array}{r}12100 \\
5890 \\
4670 \\
17600 \\
14200\end{array}$ & $\begin{array}{r}5230 \\
15400 \\
15900 \\
17500 \\
15900\end{array}$ & $\begin{array}{r}14900 \\
15900 \\
16300 \\
6770 \\
7680\end{array}$ & $\begin{array}{r}628 \\
538 \\
1420 \\
1350 \\
1310\end{array}$ \\
\hline $\begin{array}{l}16 \\
17 \\
18 \\
19 \\
20\end{array}$ & $\begin{array}{r}16900 \\
14800 \\
6080 \\
8990 \\
9760\end{array}$ & $\begin{array}{l}5630 \\
9220 \\
8520 \\
9050 \\
8360\end{array}$ & $\begin{array}{l}7370 \\
9710 \\
8510 \\
7840 \\
7640\end{array}$ & $\begin{array}{l}7470 \\
6140 \\
5420 \\
5990 \\
7180\end{array}$ & $\begin{array}{l}4310 \\
5250 \\
4070 \\
5610 \\
5570\end{array}$ & $\begin{array}{r}16900 \\
17100 \\
16700 \\
16800 \\
8570\end{array}$ & $\begin{array}{r}18000 \\
6600 \\
7030 \\
13800 \\
13200\end{array}$ & $\begin{array}{r}9210 \\
17100 \\
19400 \\
19000 \\
14800\end{array}$ & $\begin{array}{r}13400 \\
14300 \\
15000 \\
10200 \\
5050\end{array}$ & $\begin{array}{r}17800 \\
8300 \\
6190 \\
15100 \\
18300\end{array}$ & $\begin{array}{l}15800 \\
17600 \\
15700 \\
18100 \\
19700\end{array}$ & $\begin{array}{r}1270 \\
1250 \\
362 \\
334 \\
983\end{array}$ \\
\hline $\begin{array}{l}21 \\
22 \\
23 \\
24 \\
25\end{array}$ & $\begin{array}{r}10600 \\
8120 \\
8960 \\
9680 \\
8510\end{array}$ & $\begin{array}{l}8280 \\
5580 \\
6480 \\
8750 \\
9680\end{array}$ & $\begin{array}{r}6230 \\
12500 \\
10500 \\
7660 \\
5130\end{array}$ & $\begin{array}{r}6870 \\
8820 \\
10600 \\
7070 \\
6160\end{array}$ & $\begin{array}{r}3190 \\
3390 \\
9800 \\
12400 \\
15300\end{array}$ & $\begin{array}{r}9490 \\
12800 \\
14000 \\
16000 \\
14300\end{array}$ & $\begin{array}{l}16000 \\
16100 \\
18100 \\
12600 \\
10200\end{array}$ & $\begin{array}{r}14500 \\
7140 \\
7090 \\
15900 \\
20000\end{array}$ & $\begin{array}{l}14200 \\
11800 \\
13800 \\
15200 \\
13200\end{array}$ & $\begin{array}{r}19000 \\
16800 \\
18100 \\
9080 \\
5970\end{array}$ & $\begin{array}{r}11900 \\
6860 \\
19400 \\
18600 \\
20400\end{array}$ & $\begin{array}{r}10300 \\
8750 \\
10700 \\
9780 \\
3770\end{array}$ \\
\hline $\begin{array}{l}26 \\
27 \\
28 \\
29 \\
30 \\
31\end{array}$ & $\begin{array}{r}6260 \\
8400 \\
8050 \\
6130 \\
6430 \\
10300\end{array}$ & $\begin{array}{r}10500 \\
7670 \\
10700 \\
8560 \\
6510 \\
-\end{array}$ & $\begin{array}{r}8240 \\
4570 \\
5500 \\
7230 \\
11500 \\
13000\end{array}$ & $\begin{array}{r}11100 \\
10500 \\
10800 \\
11100 \\
11300 \\
9730\end{array}$ & $\begin{array}{r}16000 \\
15100 \\
11400 \\
8270 \\
- \\
=0-\end{array}$ & $\begin{array}{r}15000 \\
11200 \\
7130 \\
18100 \\
19400 \\
16900\end{array}$ & $\begin{array}{r}18900 \\
16800 \\
15200 \\
20400 \\
21600 \\
\end{array}$ & $\begin{array}{r}19000 \\
16700 \\
19800 \\
14400 \\
5010 \\
6240\end{array}$ & $\begin{array}{r}6860 \\
4790 \\
13000 \\
15000 \\
13300 \\
0.0\end{array}$ & $\begin{array}{r}17000 \\
19500 \\
16900 \\
17600 \\
19600 \\
7480\end{array}$ & $\begin{array}{r}22900 \\
21800 \\
10900 \\
8570 \\
16000 \\
13400\end{array}$ & $\begin{array}{r}379 \\
841 \\
666 \\
756 \\
557 \\
-\end{array}$ \\
\hline $\begin{array}{l}\text { TOTAL } \\
\text { MEAN } \\
\text { MAX } \\
\text { MIN } \\
\text { AC-FT }\end{array}$ & $\begin{array}{r}276780 \\
8928 \\
16900 \\
2710 \\
549000\end{array}$ & $\begin{array}{r}244940 \\
8165 \\
11800 \\
2510 \\
485800\end{array}$ & $\begin{array}{r}252530 \\
8146 \\
13000 \\
4200 \\
500900\end{array}$ & $\begin{array}{r}256530 \\
8275 \\
13400 \\
4160 \\
508800\end{array}$ & $\begin{array}{r}249840 \\
8615 \\
16100 \\
3190 \\
495600\end{array}$ & $\begin{array}{r}458640 \\
14790 \\
19900 \\
7130 \\
909700\end{array}$ & $\begin{array}{r}443430 \\
14780 \\
21600 \\
6600 \\
879500\end{array}$ & $\begin{array}{r}468330 \\
15110 \\
21300 \\
5010 \\
928900\end{array}$ & $\begin{array}{r}361150 \\
12040 \\
17600 \\
4670 \\
716300\end{array}$ & $\begin{array}{r}424820 \\
13700 \\
19600 \\
5230 \\
842600\end{array}$ & $\begin{array}{r}450610 \\
14540 \\
22900 \\
5280 \\
893800\end{array}$ & $\begin{array}{r}306870 \\
10230 \\
19300 \\
3340 \\
608700\end{array}$ \\
\hline
\end{tabular}

CAL YR 1975 TOTAL 4218430 MEAN 11560 MAX 20900 MIN 2510 AC-FT 8367000 HTR YR 1976 TOTAL 4194470 MEAN 11460 MAX 22900 MIN 2510 AC-FT 8320000 
09421500. COLORADO RIVER BELON HOOVER DAM, ARIZ.-NEV.

(National stream-quality accounting network station)

LOCATION, --Lat $36^{\circ} 00^{\prime} 38^{\prime \prime}$, long $114^{\circ} 44^{\prime} 31^{\prime \prime}$, in SW'SW/4 sec.3, T. 30 N., R. 23 W., Gila and Salt River meridian, Mohave County, Ariz., or in

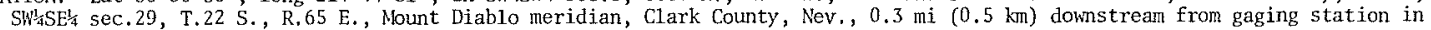
powerhouse at downstrean side of Hoover Dam.

DRAINAGE AREA (REVISED) . --171,800 $\mathrm{mi}^{2}\left(445,000 \mathrm{~km}^{2}\right)$, approximately, including $3,959 \mathrm{mi}^{2}\left(10,254 \mathrm{~km}^{2}\right)$ in Great Divide basin in southern Wyoming which is noncontributing (previously considered part of the Missouri River basin).

PERIOD OF RECORD.--Chemical analyses: October 1939 to current year.

Water temperatures: October 1941 to Septenber 1957.

\begin{tabular}{|c|c|c|c|c|c|c|c|c|c|c|c|c|}
\hline DATE & TIME. & $\begin{array}{c}\text { INSTAN- } \\
\text { TANEOUS } \\
\text { DIS- } \\
\text { CHARGE } \\
\text { (CFS) }\end{array}$ & $\begin{array}{l}\text { SPE- } \\
\text { CIFIC } \\
\text { CON- } \\
\text { DUCT- } \\
\text { ANCE } \\
\text { (MICRO- } \\
\text { MHOS) }\end{array}$ & $\begin{array}{c}P H \\
\text { (UNITS) }\end{array}$ & $\begin{array}{l}\text { TEMPER- } \\
\text { ATURE } \\
\text { (DEG C) }\end{array}$ & $\begin{array}{l}\text { TUR- } \\
\text { BID- } \\
\text { ITY } \\
\text { (JTU) }\end{array}$ & $\begin{array}{l}\text { FEO } \\
\text { COL } \\
\text { FOF } \\
\text { ICO } \\
P E \\
100\end{array}$ & $\begin{array}{l}C A L \\
\text { II- } \\
\text { KM } \\
O L \\
\text { ER } \\
\text { MLI }\end{array}$ & $\begin{array}{r}\text { STh } \\
\text { TOCO } \\
1 \mathrm{CO} \\
\text { ONI } \\
\mathrm{PH} \\
100\end{array}$ & $\begin{array}{l}\text { REP- } \\
\text { OCC I } \\
O L- \\
\text { IES } \\
\text { ER } \\
\text { MLI }\end{array}$ & $\begin{array}{l}\text { HARD- } \\
\text { NESS } \\
\text { (CA,MG) } \\
\text { (MG/L) }\end{array}$ & $\begin{array}{l}\text { NON- } \\
\text { CAR- } \\
\text { BONATE } \\
\text { HAHD- } \\
\text { NESS } \\
\text { (MG/L) }\end{array}$ \\
\hline \multicolumn{13}{|l|}{ OC $\mathrm{r}$} \\
\hline $\begin{array}{l}07 \ldots \\
08 \ldots \\
\text { NOV }\end{array}$ & $\begin{array}{l}0830 \\
0815\end{array}$ & $\begin{array}{l}8300 \\
8020\end{array}$ & $\begin{array}{r}1140 \\
--\end{array}$ & $\begin{array}{r}7.9 \\
---\end{array}$ & $\begin{array}{l}13.0 \\
14.0\end{array}$ & -1 & & $\overline{B I}$ & & $\overline{B 3}$ & $\begin{array}{r}360 \\
--\end{array}$ & $\begin{array}{r}220 \\
--\end{array}$ \\
\hline $\begin{array}{l}11 \ldots \\
12 \ldots \\
\text { DEC }\end{array}$ & $\begin{array}{l}0830 \\
0800\end{array}$ & $\begin{array}{r}23000 \\
6600\end{array}$ & 1060 & 7.2 & $\begin{array}{l}12.5 \\
12.0\end{array}$ & $\begin{array}{r}0 \\
--\end{array}$ & & $\overline{B 1}$ & & $\overline{B 1}$ & $\begin{array}{r}340 \\
--\end{array}$ & $\begin{array}{r}200 \\
--\end{array}$ \\
\hline $\begin{array}{l}09 \ldots \\
10 \cdots \\
\text { JAN }\end{array}$ & $\begin{array}{l}0900 \\
0830\end{array}$ & $\begin{array}{l}14220 \\
10820\end{array}$ & $\begin{array}{r}1070 \\
--\end{array}$ & $\begin{array}{r}6.9 \\
--\end{array}$ & $\begin{array}{l}12.5 \\
12.0\end{array}$ & $\begin{array}{r}0 \\
--\end{array}$ & & $\overline{61}$ & & $\overline{B 9}$ & $\begin{array}{r}320 \\
--\end{array}$ & $\begin{array}{c}190 \\
--\end{array}$ \\
\hline$\underset{F E H}{13 \ldots} 14 \ldots$ & $\begin{array}{l}0830 \\
0815\end{array}$ & $\begin{array}{r}16720 \\
6220\end{array}$ & 1100 & $\begin{array}{r}7.7 \\
---\end{array}$ & $\begin{array}{l}12.0 \\
12.5\end{array}$ & -1 & & $\overline{B 1}$ & & $8 \overline{10}$ & $\begin{array}{r}340 \\
--\end{array}$ & $\begin{array}{r}200 \\
-\cdots\end{array}$ \\
\hline $\begin{array}{l}10 \ldots \\
11 \ldots \\
\operatorname{MAR}\end{array}$ & $\begin{array}{l}1000 \\
1000\end{array}$ & $\begin{array}{r}9400 \\
12500\end{array}$ & $\begin{array}{r}1080 \\
--\end{array}$ & $\begin{array}{r}7.6 \\
--0\end{array}$ & $\begin{array}{l}11.5 \\
11.5\end{array}$ & $\begin{array}{r}2 \\
--\end{array}$ & & $\overline{81}$ & & 81 & $\begin{array}{r}320 \\
--\end{array}$ & $\begin{array}{r}180 \\
--\end{array}$ \\
\hline $\begin{array}{l}09 \ldots \\
10 \ldots \\
A P R\end{array}$ & $\begin{array}{l}0915 \\
0800\end{array}$ & $\begin{array}{l}23820 \\
21120\end{array}$ & 1090 & $\begin{array}{r}7.7 \\
--\end{array}$ & $\begin{array}{l}12.0 \\
12.0\end{array}$ & $\begin{array}{r}0 \\
--\end{array}$ & & $\mathrm{H}$ & & $\overline{B I}$ & $\begin{array}{r}320 \\
=-\end{array}$ & 190 \\
\hline $\begin{array}{l}13 \ldots \\
14 \ldots \\
\text { MAY }\end{array}$ & $\begin{array}{l}0830 \\
0830\end{array}$ & $\begin{array}{l}19920 \\
19150\end{array}$ & $\begin{array}{r}1080 \\
--\end{array}$ & $\begin{array}{r}7.8 \\
---\end{array}$ & $\begin{array}{l}12.5 \\
11.5\end{array}$ & -- & & $\overline{B i}$ & & $\overline{B 1}$ & $\begin{array}{r}320 \\
--\end{array}$ & $\begin{array}{r}190 \\
--\end{array}$ \\
\hline $\begin{array}{l}11 \ldots \\
\operatorname{JUN}\end{array}$ & $\begin{array}{l}0715 \\
0800\end{array}$ & $\begin{array}{l}22400 \\
21820\end{array}$ & 1090 & $\begin{array}{r}8.1 \\
--=\end{array}$ & $\begin{array}{l}12.5 \\
12.5\end{array}$ & -1 & & $\overline{B 1}$ & & 81 & $\begin{array}{r}330 \\
--\end{array}$ & $\begin{array}{r}200 \\
--\end{array}$ \\
\hline $\begin{array}{l}08 \ldots \\
09 \ldots \\
\text { JUL }\end{array}$ & $\begin{array}{l}0800 \\
0830\end{array}$ & $\begin{array}{l}13600 \\
18700\end{array}$ & $\begin{array}{r}1080 \\
--\end{array}$ & $\begin{array}{r}7.9 \\
--\end{array}$ & $\begin{array}{l}12.0 \\
12.5\end{array}$ & -- & & $\overrightarrow{B 1}$ & & $\overline{B 1}$ & $\begin{array}{r}320 \\
--\end{array}$ & $\begin{array}{r}190 \\
--\end{array}$ \\
\hline $\begin{array}{l}13 \ldots \\
14 \ldots \\
A \cup G\end{array}$ & $\begin{array}{l}0800 \\
0800\end{array}$ & $\begin{array}{l}14820 \\
18720\end{array}$ & $\begin{array}{r}1100 \\
--\end{array}$ & $\begin{array}{r}8.0 \\
--\end{array}$ & $\begin{array}{l}12.5 \\
12.5\end{array}$ & $\begin{array}{r}0 \\
--\end{array}$ & & 81 & & 89 & $\begin{array}{r}340 \\
--\end{array}$ & 200 \\
\hline $\begin{array}{l}10 \cdots \\
11 \ldots \\
\text { SEP }\end{array}$ & $\begin{array}{l}0730 \\
0800\end{array}$ & $\begin{array}{r}9250 \\
17930\end{array}$ & 1080 & $\begin{array}{r}8.0 \\
--\end{array}$ & $\begin{array}{l}15.0 \\
12.5\end{array}$ & $\begin{array}{r}0 \\
--\end{array}$ & & $\overline{B 1}$ & & $B 1$ & 340 & 200 \\
\hline $\begin{array}{l}14 \ldots \\
15 \ldots\end{array}$ & $\begin{array}{l}0800 \\
0800\end{array}$ & $\begin{array}{l}12860 \\
14020\end{array}$ & $\begin{array}{r}1070 \\
--\end{array}$ & $\begin{array}{r}8.0 \\
--\end{array}$ & $\begin{array}{l}12.5 \\
13.0\end{array}$ & -1 & & $\overline{B 10}$ & & $\overline{87}$ & $\begin{array}{r}330 \\
--\end{array}$ & 200 \\
\hline
\end{tabular}

B--Results based on non-ideal colony count. 
09421500. COLORADO RIVER BELOW HOOVER DAM, ARIZ, -NEV .--CONTINUED

MATER QUALITY DATA, WATER YEAR UCTOBER 1975 TO SEPTEMBER 1976

\begin{tabular}{|c|c|c|c|c|c|c|c|c|}
\hline & DIS - & & & DIS- & & & & \\
\hline DIS- & SOLVED & & SODIUM & $\begin{array}{l}\text { SOLVED } \\
\text { PO- }\end{array}$ & & & DIS- & $\begin{array}{l}\text { DIS- } \\
\text { SOLVED }\end{array}$ \\
\hline $\begin{array}{c}\text { SOLVED } \\
\text { CAL- }\end{array}$ & $\begin{array}{l}\text { MAG- } \\
\text { NE- }\end{array}$ & $\begin{array}{l}\text { DIS- } \\
\text { SOLVED }\end{array}$ & $\begin{array}{l}\text { AU- } \\
\text { SORP- }\end{array}$ & TAS- & BICAR- & CAR- & $\begin{array}{l}\text { DIS- } \\
\text { SOLVEO }\end{array}$ & CHLO- \\
\hline $\begin{array}{l}\text { CAL- } \\
\text { CIUN }\end{array}$ & $\begin{array}{l}\text { SE- } \\
\text { SIUM }\end{array}$ & SODIUM & TION & SIUM & BONATE & BUNATE & SULFATE & RIDE \\
\hline$(C A)$ & (MG) & (NA) & RATIO & $(k)$ & $(\mathrm{HCO} 3)$ & $(\mathrm{CO} 3)$ & $(504)$ & $(C L)$ \\
\hline$(M G / L)$ & $(M G / L)$ & (MG/L) & & $(M G / L)$ & $(M G / L)$ & $(M G / L)$ & (MG/L) & (MG/L) \\
\hline
\end{tabular}

OCT

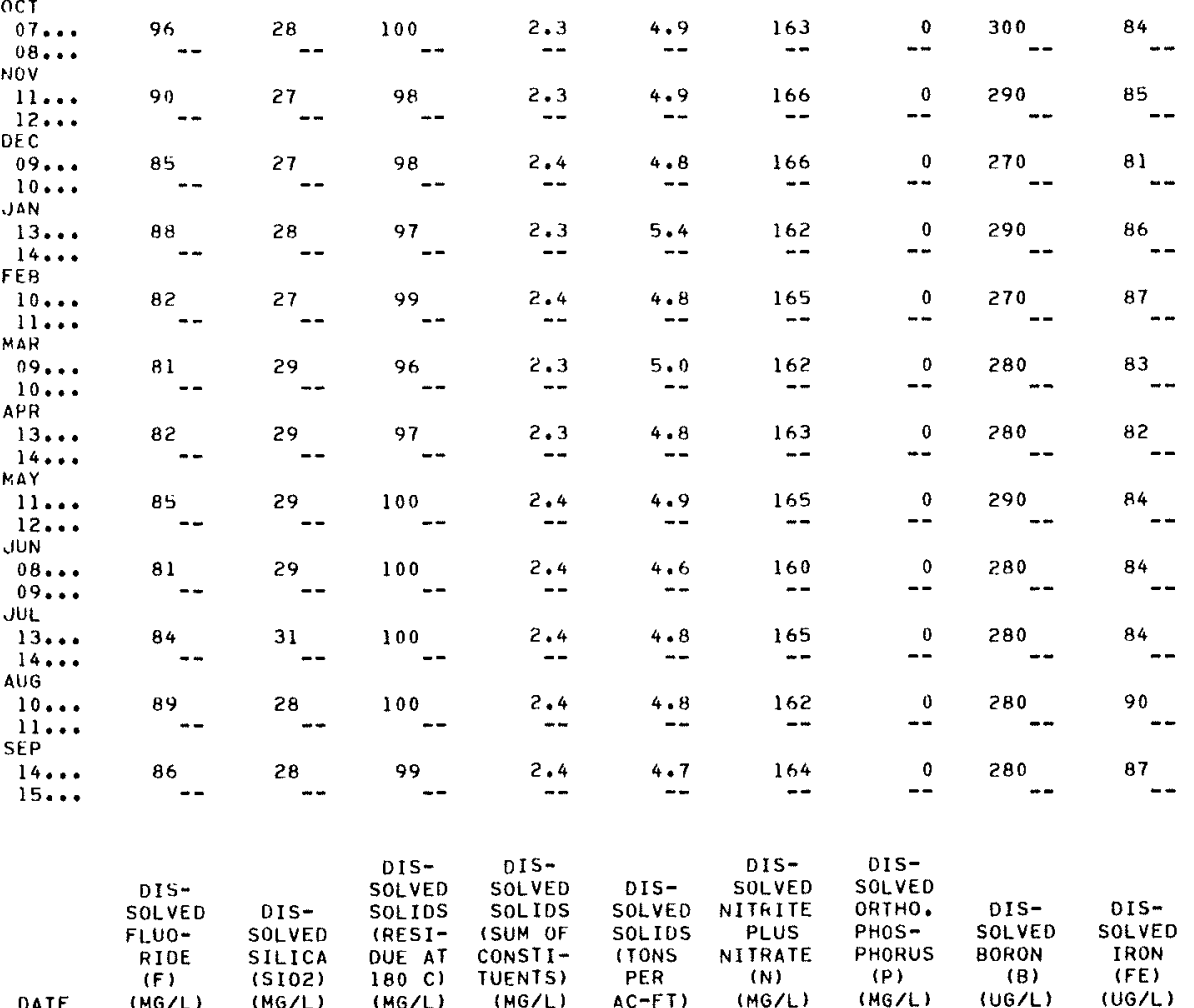

DATE

OCT

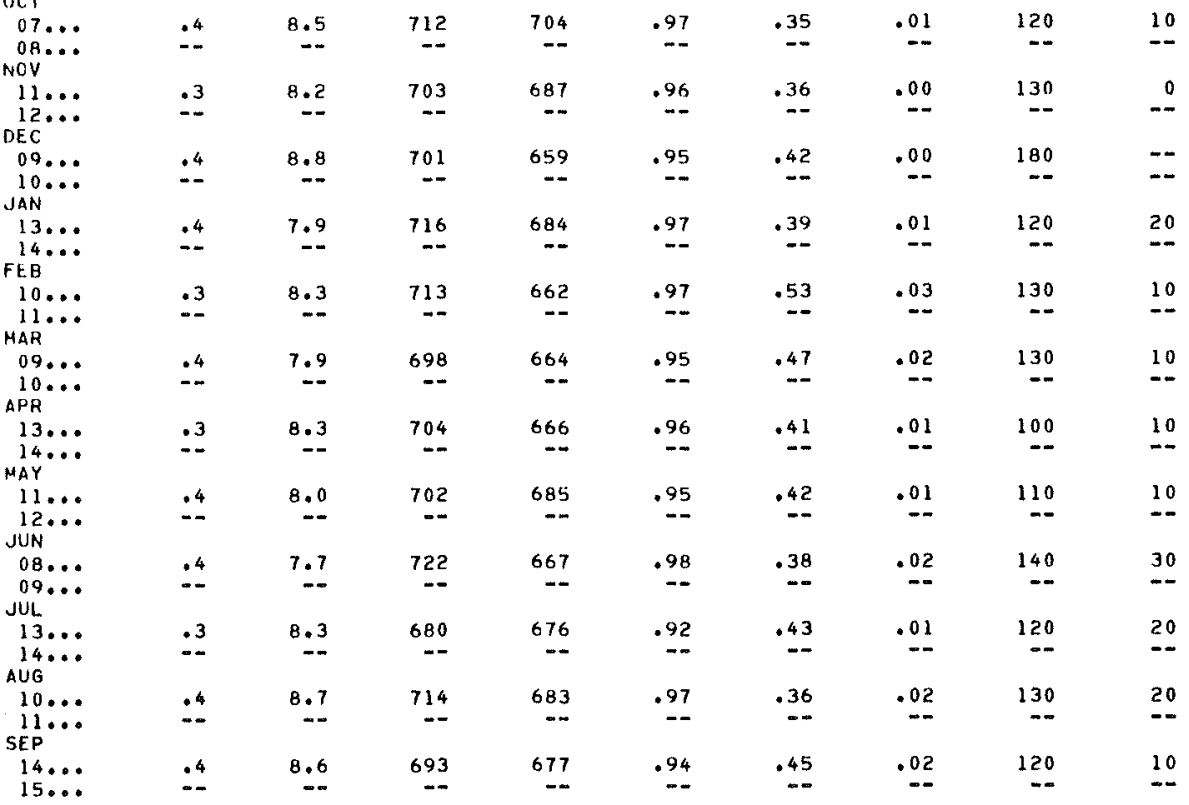


COLORADO RIVER MAIN STEM

09421500. COLORADO RIVER BELOW HOOVER DAM, ARIZ . -NEV . - CONTINUED AATEK WUALITY DATA, WATER YEAH UC:TUEER 1975 TO SEPTEMGER IS7K

\begin{tabular}{|c|c|c|c|c|c|c|c|c|}
\hline DATE & TIMF & $\begin{array}{c}\text { TOTAL } \\
\text { ARSFNIC } \\
\text { (AS) } \\
\text { (UA/L) }\end{array}$ & $\begin{array}{l}\text { DIS- } \\
\text { SOLVEO } \\
\text { AKSENIC } \\
\text { (AS) } \\
\text { (UG/L) }\end{array}$ & $\begin{array}{c}\text { UIS- } \\
\text { SOLVED } \\
\text { HORON } \\
\text { (H) } \\
\text { (UG/L) }\end{array}$ & $\begin{array}{l}\text { TOTAL } \\
\text { CAD- } \\
\text { MIUM } \\
(C D) \\
(U G / L)\end{array}$ & $\begin{array}{l}\text { UIS- } \\
\text { SULVED } \\
\text { CAD- } \\
\text { MIUM } \\
\text { (CD) } \\
(U G / L)\end{array}$ & $\begin{array}{l}\text { TUTAL } \\
\text { CHKO- } \\
\text { MIUM } \\
\text { (CK) } \\
(U G / L)\end{array}$ & $\begin{array}{l}\text { DIS- } \\
\text { SOLVEO } \\
\text { CHRO- } \\
\text { MIUM } \\
\text { (CR) } \\
\text { (UG/L) }\end{array}$ \\
\hline $\begin{array}{l}\text { nuV } \\
11 \ldots\end{array}$ & 0830 & 3 & 3 & 130 & $<10$ & 1 & 4 & 2 \\
\hline $\begin{array}{ll}11 & \ldots \\
F E_{1} & \end{array}$ & 0930 & $=-$ & $=$ & -- & - & -- & $<10$ & -- \\
\hline MAY & 100 & $r$ & & * & & & & \\
\hline${ }_{A \cup G}^{11} \ldots$ & 0715 & 4 & 4 & 110 & $<10$ & 0 & 0 & 0 \\
\hline $10 \ldots$ & 0730 & 3 & 2 & 130 & $<10$ & 1 & 0 & 0 \\
\hline
\end{tabular}

\begin{tabular}{|c|c|c|c|c|c|c|c|c|c|}
\hline UATE & $\begin{array}{l}\text { TOTAL } \\
\text { COAALT } \\
\text { (CU) } \\
\text { (UG/L) }\end{array}$ & $\begin{array}{l}\text { UIS- } \\
\text { SULVEO } \\
\text { COEALT } \\
\text { (CU) } \\
\text { (UG/L) }\end{array}$ & $\begin{array}{l}\text { TOTAL } \\
\text { COPPER } \\
\text { (CU) } \\
\text { (UG/L) }\end{array}$ & $\begin{array}{l}\text { OIS- } \\
\text { SOLVEU } \\
\text { COPPEK } \\
\text { (CU) } \\
\text { (UG/L) }\end{array}$ & $\begin{array}{l}\text { TOTAL } \\
\text { IRON } \\
\text { (FE) } \\
\text { (UG/L) }\end{array}$ & $\begin{array}{l}\text { OIS- } \\
\text { SOLVEO } \\
\text { IRON } \\
\text { (FE) } \\
\text { (UG/L) }\end{array}$ & $\begin{array}{c}\text { TOTAL } \\
\text { LEAD } \\
\text { (PG) } \\
\text { (UG/L) }\end{array}$ & $\begin{array}{l}\text { OIS- } \\
\text { SOLVEN } \\
\text { LEAD } \\
\text { (PB) } \\
\text { (UG/L) }\end{array}$ & $\begin{array}{l}\text { TOTAL } \\
\text { MAN- } \\
\text { GANESE } \\
\text { (MN) } \\
\text { (UG/L) }\end{array}$ \\
\hline \multicolumn{10}{|l|}{ NOV } \\
\hline $11 \ldots$ & $<50$ & 0 & $<10$ & 1 & 0 & 0 & $<100$ & h & 10 \\
\hline$\underset{F \in H}{11} \cdots$ & -- & $\cdots$ & -- & -- & -- & -- & - & -- & -- \\
\hline$\underset{M A Y}{10 \ldots}$ & $<50$ & 1 & $<10$ & 0 & 100 & 10 & $<100$ & 3 & 30 \\
\hline${ }_{\text {AUG }}^{11} \ldots$ & $<50$ & 0 & 20 & 3 & 40 & 10 & $<100$ & 3 & 0 \\
\hline $10 \ldots$ & $<50$ & 1 & 20 & 0 & 120 & 20 & $<100$ & 0 & 0 \\
\hline
\end{tabular}

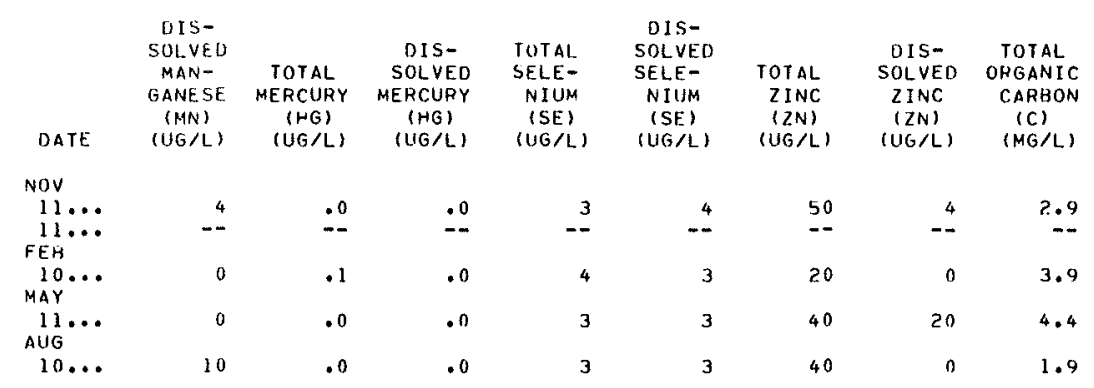

$<$ Actual value is known to be less than the value shown. 
COLORADO RIVER MAIN STEM

09421500. COLORADO RIVER BELOW HOOVER DAM, ARIZ.-NEV.--CONTINUED

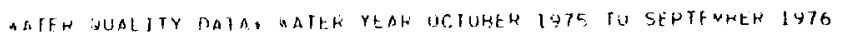

$1 \mathrm{I} \times \mathrm{H}$
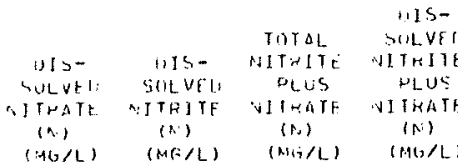

TOTAL T(IVEF)

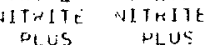

NIIKATE

(D) (Ni)

(P)

IOTAL

XJEL-

YAHL.

NITRO-

GEN

$(M G / L)$

TUTAL TOIAL

NITRO-

SEEN

(N)

$\left(M C_{3} / L\right)$

TUTAL TUTAL ORTHO.

NITHO- PHOS- PHOS-

1). 14

11430

$.34 \quad .01$

.34

- is

$.51 \quad .46$

(IvUj)

PHORUS

PHORUS
(P)

(1) 17

11... n+s

$.35 \quad .01$

.36

.36

.

.76

$.4 \mathrm{C} .00$

.47

.42

.$>1$

.63

3.8

$M G / L)$

( $M G / \mathrm{L}$

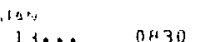

. +4 .11 140

.34

$.5 \mu$

1.0

$.54 \quad .53$

.75

1.3

4.4

.03

.01

1... 1000

.53

.00

.79

.47

.24

.63

5.8

.00

.00

nu... $11+1 b$

$.47 \quad .00$

.41

.41

$.44 \quad .90$

$2 \cdot 8$

4.0

$.00 \quad .00$

$11 \ldots 001930$

.41

.41

.42

$--$

$\rightarrow$

$-$

OH... OHOO

$.38 \quad .00 \quad .37$

$.3 \mathrm{H}$

.34

.75

$3 \cdot 3$

$.43 \quad .43$

.72

1.2

5.1

.3

.74

$3 \cdot 3$

.00

.01

$.04 \quad .03$

$.00 \quad .02$

a1ti: 0130

.36

.42

.45

.11

.55

2.4

$.03 \quad .01$

$.02 \quad .01$

$.00 \quad .02$

.02 .01

$.00 \quad .02$

$14 \ldots$ OroO

.01

.94

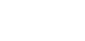

.01

.02

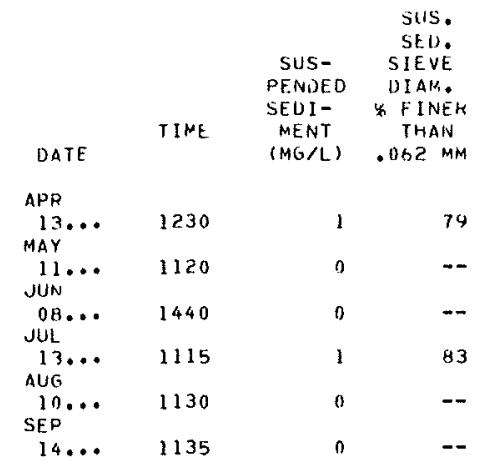


09421500. COLORADO RIVER BELOW HOOVER DAM, ARIZ, -NEV. - - CONTINUED

QUALITATIVE AND ASSOCIATED QUANTITATTVE ANALYSES OF BIOLOGICAL DATA, WATER YEAR OCTOBER 1975 TO SEPTEMBER 1976 PERIPHYTON

\begin{tabular}{|c|c|c|c|c|c|c|c|}
\hline Date & $\begin{array}{c}\text { Length of exposure } \\
\text { (days) }\end{array}$ & $\begin{array}{l}\text { Biomass } \\
\text { Dry weight }\end{array}$ & $\begin{array}{l}\left(g / m^{2}\right) \\
\text { Ash weight }\end{array}$ & $\begin{array}{c}\text { Chlorophyl1 } \\
\text { a } \\
\left(\mathrm{mg} / \mathrm{m}^{2}\right)\end{array}$ & $\begin{array}{c}\text { Ch1orophyl1 } \\
b \\
\left(\mathrm{mg} / \mathrm{m}^{2}\right)\end{array}$ & $\begin{array}{l}\text { Biomass } \\
\text { pigment } \\
\text { ratio }\end{array}$ & $\begin{array}{l}\text { Sampling } \\
\text { method }\end{array}$ \\
\hline May 11 & 28 & .308 & .154 & .741 & .061 & 210 & $\begin{array}{l}\text { Polyethylene } \\
\text { strip }\end{array}$ \\
\hline Aug. 10 & 28 & 2.80 & 1.90 & 1.10 & .036 & 820 & $\begin{array}{c}\text { Polyethylene } \\
\text { strip }\end{array}$ \\
\hline
\end{tabular}

QUALITATIVE AND ASSOCIATED QUANTITATTVE ANALYSES OF BIOLOGICAL DATA, WATER YEARS OCTOBER 1974 TO SEPTEMBBER 1976

$$
\begin{gathered}
\text { NDV. } 5,1974 \\
0800 \text { HOURS }
\end{gathered}
$$

IDENTIFICATION OF PHYTOPLANKTON

$3.800 \mathrm{CELLS} / \mathrm{ML}$

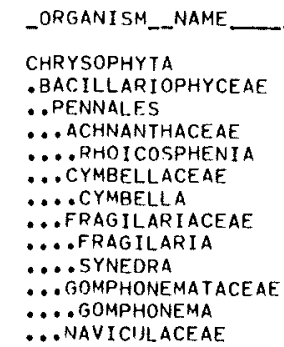

D... Navicillaceae

\section{CYANOPHYTA}

- MYXOPHYCEAE

. OSCILlatoriales

D .... OSCILLATORIA

\section{PYRRHOPHYTA}

- OINOPHYCEAE

. PERIDINIALES

\#..GLENODINIACEAE
_COMMON_NAME

DIATOMS

PF.NNATE

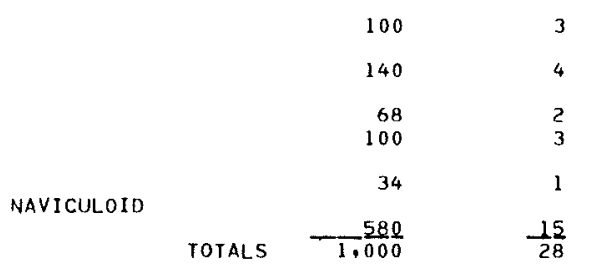

BLUE-GREEN ALGAE

F ILAMENTOUS

$$
\text { TOTALS }-\frac{2,800}{2,800}
$$$$
2,800
$$

FIRE ALGAE

DINOFLAGELLATES

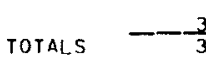

$-\frac{1}{1}$
PER_CENT

2

$1.940=0$ I VERS I TY

$\frac{72}{72} \quad 0.000=0$ IVERSITY

$0.000=0$ IVERSITY 
09421500. COLORADO RIVER BELON HOOVER DAM, ARIZ. -NEV, --CONTINUED

QUALITATIVE AND ASSOCIATED QUANTITATIVE ANALYSES OF BIOLOGICAL DATA, WATER YEARS OCTOBER 1974 TO SEPTERBER 1976

$$
\text { DEC. } 3.1974
$$

0800 HOURS

IDENTIFICATION OF PHYTONLANKTON

1,300 CELLS/ML

_ORGANISM_NAME

CHLOROPHYTA

- CHLOROPHYCEAE

- chlorococcales

. . DOCYSTACEAE

.... OOCYSTTIS

. . SCEnede smaceae

.... ACTINASTRUM

. VOLVOCALES

.. CHL amydomonadaceae

.... CHLAMYDOMONAS

\#. volvocaceae

....PANDORINA

CHRYSOPHYTA

- BACILLARI OPHYCEAE

.. CENTRALES

... COSCINODISCACEAE

.... crclotella

- PenNales

...FRAg Illariaceae

... ASTERI INELLA

. gompHONEMATACEAE

....gOMPHONEMA

... NaviculaceaE

... Navicula

... NITZSCHIACEAE

.....NITZSCHIA

CYANOPHYTA

- MYXOPHYCEAE

- CHROOCOCCALFS

.. CHROOCoccaceae

$\because$. AGMENELLUM

$\because$ @ OSCILLATORI ALES

.. OSC ILl LatoR I ACEAE

1) .... L L YNGBYa
_COMMON_NAME

GREEN ALGAE
CELLS/ML

PER_CENT

GREEN ALGAE

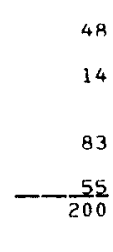

DIATOMS

CENTRIC

PENNATE

41

3

PENATE

NAVICULOIO

7
$100 \quad 8$

$14 \quad 1$

$69 \quad 5$

TOTALS<smiles>C[13CH]</smiles>

$-\frac{2}{20}$

BLUE-GREEN ALGAE

COCCOID

FILAMENTOUS

110

9

TOTALS $-\frac{690}{800}$

$\frac{55}{64}$

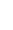

5

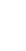

.... SYNEDRA

$1.800=$ DIVERSITY

$2.160=0$ IVERSITY

NOTE: D - DOMINANT ORGANISM; GREATER OR EQUAL TO $15 \%$ 
09421500. COLORADO RIVER BELOW HOOVER DAM, ARIZ.-NEV. - - CONTINUED QUALITATIVE AND ASSOCIATED QUANTITATIVE ANALYSES OF BIOLOGICAL DATA, WATER YEARS OCTOBER 1974 TO SEPTEMBER 1976

$$
\begin{aligned}
& \text { JAN. } 7 \text {, } 1975 \\
& 0950 \text { HOURS }
\end{aligned}
$$

IDENTIFICATION OF PHYTOPLANKTON

$1.500 \mathrm{CELLS} / \mathrm{ML}$

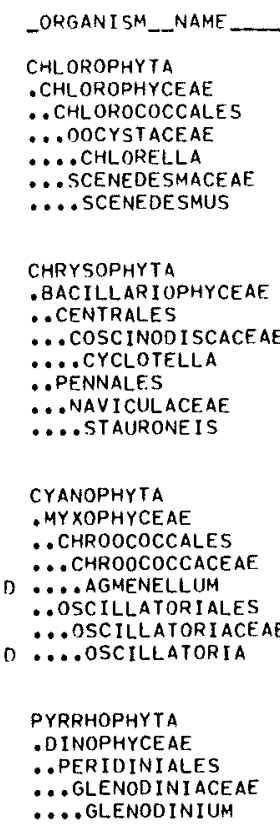

TOTALS $-\frac{1}{14} \quad-\frac{1}{1} \quad 0.000=0$ IVERSITY

NOTE: D - DOMINANT ORGANISM: GREATER OR EOUAL TO $15 \%$ 
09421500. COLORADO RIVER BELON HOOVER DAM, ARIZ. -NEV. - - CONTINUED

QUALITATIVE AND ASSOCIATED QUANTITATIVE ANALYSES OF BIOLOGICAL DATA, WATER YEARS OCTOBER 1974 TO SEPTEMBER 1976

FFR, 11,1975

0900 HOURS

IOENTIFICATION OF PHYTOPLANKTON

1.100 CELLS/ML

_OOGANISM_NAMF.

CHLOROPHYTA

- CHLOROPHYCEAF

. chlorococcales

... OOCYSTACEAE

... ANK I STrone SMUS

... SCENEDE SMACEAF

... scenedesmus

CHRYSOPHYTA

- HAC I LLAR I OPHYCEAE

- HACILLARI I
- CENTRALES

.. coscinoviscaceae

.... CYClotella

. PENNALES

... CyMHellaceae

... AMPHORA

CYANOPHYTA

- MYXOPHYCEAE

- chroococcales

. CHROOCOCCACEAE

... Anacystis

- oscillatoriales

.. OScillatoriaceae

f.... LYNGHYa
_COMMON_NAME

CELLS/ML

GDEEN ALGAE

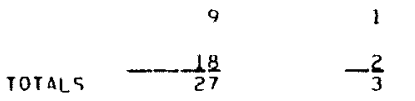

DIATOMS

CENTRIC

PFNNATE

TOTALS

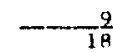

BLUE-GREEN ALGAE

Coccoid

FILAMENTOUS

TOTALS $-\frac{1+000}{1.000}$
$0.918=0$ IVERSITY

1

PER_CENT

$-\frac{1}{2}$

$1.000=$ DIVERSITY

1

$\frac{95}{96}$
$0.072=0$ IVERSITY 
09421500, COLORADO RIVER BELOW HOOVER DAM, ARIZ. -NEV. --CONTINUED

QUALITATIVE AND ASSOCIATED QUANTITATIVE ANALYSES OF BIOLOGICAL DATA, WATER YEARS OCTOBER 1974 TO SEPTEMBER 1976

MAR. $11+1975$

0815 HOURS

IDENTIF ICATION OF PHYTOPLANKTON

$71 \mathrm{CELLS} / \mathrm{ML}$

_ORGANISM_-_NAME

CHRYSOPHYTA

- BACILLARIYPHYCEAF

. CENTRALES

... COSCinod I SCACE.aE

.... MELOSIRA

. PENNALES

... Achinanthaceae

... coccone is

... NAVICULACEAE

.... Navicula

... NITZSCHIACEAE

....NITZSCHIA
_COMMON_NAME

DIA IOMS

CFNTRIC

PENNATE

NAVICILOIO

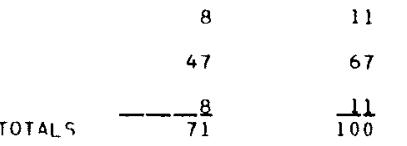

CELLS/ML OER_CENT

110

$1.447=$ DIVERSITY

MOTE: D - DOMINANT ORGANISM: GREATER OR EOUAL TO 15\%

APR. $\quad 8,1975$

0900 HDURS

IOENTIFICATION OF PHYTOPLANKION

320 CELLS/ML

_ORGANISM_NAME

CHLOROPHYTA

- CHLOROPHYCEAE

- CHI orococcales

.. SCENEDE SMACEAE

.... SCENEDESMUS

CHRYSOPHYTA

-8ACILLARIOPHYCEAE

. CENTRALES

.. coscinodiscaceae

D .... CYCLOTELLA

$\because$ PENNALES

.. ACHNANTHACEAE

... ACHNANTHES

.... coccone Is

... NAVICULACEAE

... Navicula
_COMMON__NAME

GREEN ALGAE
CELLS/ML

PER_CENT

\begin{tabular}{l} 
TOTALS \\
\cline { 3 - 4 } \\
MIATOMS
\end{tabular}

NOTE: 0 - DOMINANT ORGANISM: GREATER OR EQUAL TO $15 \%$ 
09421500. COLORADO RIVER BELON HOOVER DAM, ARIZ, -NEV.--CONTINUED

QUALITATIVE AND ASSOCIATED QUANTITATTVE ANALYSES OF BIOLOGICAL DATA, WATER YEARS OCTOBER 1974 TO SEPTENBER 1976

$$
\begin{aligned}
& \text { MAY } 6,1975 \\
& 0745 \text { HOURS }
\end{aligned}
$$

IDENTIFICATION OF PHYTOPLANKTON

64 CELLS/ML

$$
\text { _ORGANISM__NAME }
$$

CHLOROPHYTA

- CHL DROPHYCEAE

- CHLOROCOCCALFS

...OOCYSTACEAE

.... CHLORELLA

CHRYSOPHYTA

- BAC I LLAR I OPHYCE AF

. CENTRALES

... Coscinod I SCACEAe

D.... Cyclotella

. PENNALFS

... Naviculaceae

-... Navicula

... NitzSchiaceae

D .... NITZSCHIA
_COMMON_NAME GREEN ALGAE

TOTALS

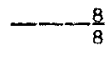

DIATOMS

CENTRIC

PENNATE

NAVICILOID

$\begin{array}{rr}32 & 50 \\ 8 & 12 \\ \text { TOTALS } \quad-\frac{16}{56} & \frac{25}{87}\end{array}$

$1.379=$ DIVERSITY

$0.000=$ DIVERS ITY

$\frac{1}{7}$

NOTE: D - DOMINANT OKGANISM: GREATER OR EQUAL TO $15 \%$

JUNE 10,1975

0800 HOURS

IDENTIFICATION OF PHYTOPLANKTON

$190 \mathrm{CELLS} / \mathrm{ML}$
_ORGANISM_NAME

CHLOROPHYTA

- CHLOROPHYCEAE

. CHLOROCOCCALFS

... OOCYSTACEAE

... OOCYSTIS

CHRYSOPHYTA

- BACILLAR I DPHYCEAE

-.PENNALES

.. Cymbel laceae

... CrMBELla

@...FRAGILARI ACEAE

0 ... Fragilaria

... naviculaceae

... Navicula
_COMMON_NAME

GREEN ALGAE

TOTALS

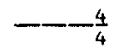

DIATOMS

PENNATE

NAVICULOIO
PER_CFNT

CELLS/ML

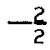

$0.000=0$ I VERS I TY

TOTAL $\frac{23}{180}$
84

$\frac{12}{98}$

NOTE: D - DOMINANT ORGANISMI GREATER OR EQUAL TO I5\% 
09421500. COLORADO RIVER BELOW HOOVER DAM, ARIZ. -NEV. - - CONTINUED

QUALITATIVE AND ASSOCIATED QUANTITATIVE ANALYSES OF BIOLOGICAL DATA, WATER YEARS OCTOBER 1974 TO SEPTEMBER 1976

OCT. 7,1975

INENTIFICATION OF PHYTOPLANKTON

610 CELLS/ML

-ORGANISM N NAME

CHLOROPHYTA - CHLOROPHYCEAE

..CHLORDCOCCALES

O. ONCYSTACEAE

?...TETRAEDRON

... SCENEDE SMACEAE

(...SCENEDESMUS

. .ULOTRICHales

...IJ Otrichaceae

D....ul Othrix

CHRYSOPHYTA

- BACILLAR IOPHYCEAE

. . CENTRALES

... COSCINODISCACEAE

..... CYCLOTELLA

....mElosira

. PENNALES

.. ACHNANTHACEAE

... RHOI COSPHENIA

... CYMBELLLACEAE

....crmbella

...diatomaceae

.... DIATOMa

:.. NAviculaceae

O...nNavicula

@..NITZSCHIACEAE

....NIIZSCHIA

CYANOPHYTA

- MYXOPHYCEAE

..OSCILLATORI ALES

$\because$ NOSTOCACEAE

... anabaenopsis

...OSCILLATOR IACEAE

0..... LYNGBYA

PYRRHOPHYTA

- DINOPHYCEAE

. . PER I ININ IALES

...PERID INIACEAE

....PERIDINIUM
_COMMON__NAME

CELLS $/ M L$

PER_CFNT

GREFN ALGAE

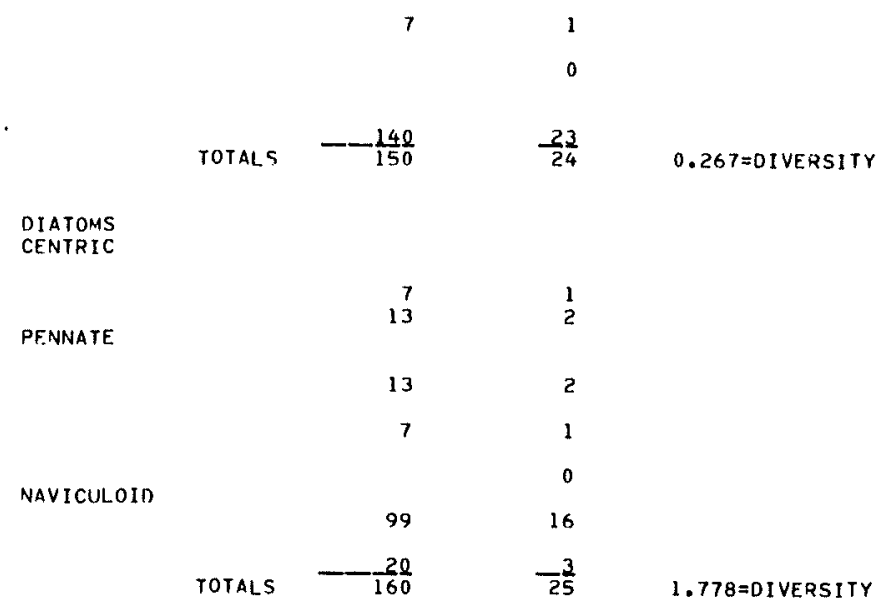

BLUE-GREEN ALGAE

F ILAMENTOUS

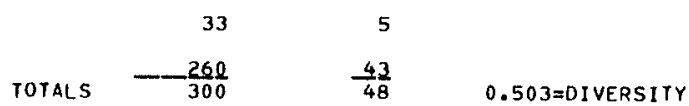

FIRE ALGAE

DINOFLAGELLATES

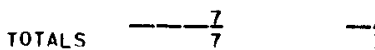

$0.000=0$ IVERSITY

NOTE: D - DOMINANT ORGANISM; GREATER OR EQUAL TO $15 \%$

L - LESS THEN 1\%: MAY NOT HAVE BEEN ACTUALLY COUNTED 
09421500. COLORADO RIVER BELON HOOVER DAM, ARIZ. -NEV. - -CONTINUED

QUALITATIVE AND ASSOCIATED QUANTITATIVE ANALYSES OF BIOLOGICAL DATA, WATER YEARS OCTOBER 1974 TO SEPTFMBER 1976

$$
\text { NOV. } 11,1975
$$

IDENTIFICATION OF PHYTOPLANKTON

610 CELLS/ML

ORGANISM NAME

CHLOROPHYTA

- CHLOROPHYCEAE

- chlorococcales

... OnCYSTACEAE

.... SELENASTRUM

CHRYSUPHYTA

- BAC ILLAR IOPHYCEAE

-. CFNTRALES

.. COSC Inod iscaceat

.... cyclotella

.... MElosira

. PENNALES

. ACHNANTHACEAE

... ACHNANTHES

L ... COCCONE IS

...FRAGILAR I ACEAE

... Fragilaria

... Naviculaceae

... Navicula

... NITZSCHIACEAE

.... NIIZSCHIA

CYANOPHYTA

- MYXOPHYCEAE

. oscillatoriales

.. Is ILllatoriacene

D.... Y YNGBYa

... oscillatoria
COMMON NAME

GREEN ALGAE

TOTALS

CELLS/ML

PER_CENT

$$
\text { TOTALS }
$$<smiles>C[Al]</smiles>

DIATOMS

CFNTRIC

PENNATE

NAVICULOIO

$\begin{array}{ll}10 & 2 \\ 21 & 3\end{array}$

$\begin{array}{lll}10 & 2 \\ & \end{array}$

$\begin{array}{lll}10 & 2 \\ 41 & 7 \\ 10 & 100\end{array}$

TOTALS $-\frac{10}{100} \quad-\frac{2}{18}$

BLUE-GREEN ALGAE

FILAMENTOUS

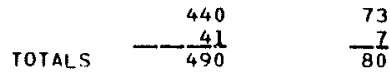

$0.420=$ DIVERSITY

NOTE: D - DOMINANT DRGANISMI GREATER OR EQUAL TO $15 \%$

L - LESS THEN 1\%; MAY NDT HAVE BEEN ACTUALLY COUNTED 
09421500. COLORADO RIVER BELOW HOOVER DAM, ARIZ, -NEV. - - CONTINUED

QUALITATIVE AND ASSOCIATED QUANTITATIVE ANALYSES OF BIOLOGICAL DATA, WATER YEARS OCTOBER 1974 TO SEPTEMBER 1976

$$
\begin{gathered}
\text { JAN. } 13.197 K \\
0830 \text { HOURS }
\end{gathered}
$$

IDENTIFICATION OF PHYTOPLANKTON

400 CELLS/ML

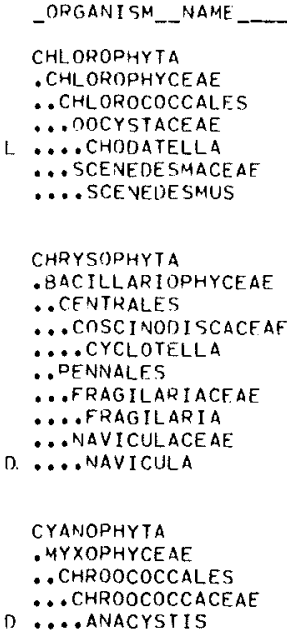

D... Anacystis

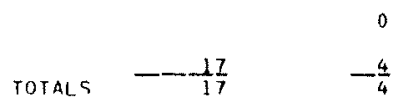

$0.000=$ DIVERSITY

DIATOMS

CENTRIC

PENNATE

NAVICULOIO

TOTALS $-\frac{59}{130} \quad \frac{15}{31}$

$1.530=$ DIVERSITY

BLUE-GREEN ALGAE

$\operatorname{coc} 010$

TOTAL

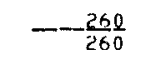

NOTE: D - DOMINANT ORGANISM: GREATER OR FQUAL TO $15 \%$

L - LESS THEN 1\%: maY NOT HAVE BEEN ACTUALLY CDUNTEO

\section{FEB. 10,1976 \\ 1000 HOURS}

IDENTIFICATION OF PHYTOPLANKTON

68 CELLS/ML

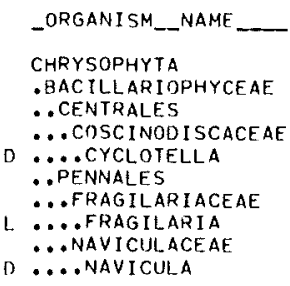

NAVICULOID

NOTE: D - DOMINANT ORGANISM; GREATER OR EQUAL TO 15\% 
09421500. COLORADO RIVER BELOW HOOVER DAM, ARIZ, -NEV, --CONTINUED

QUALITATIVE AND ASSOCIATED QUANIITATIVE ANALYSES OF BIOLOGICAL DATA, WATER YEARS OCTOBER 1974 TO SEPTEMBER 1976

HAR. 9.1970

0915 HOURS

IDENTIFICATION OF PHYTOPLANKTON

390 CELLS/ML

_ORGANISM _.NAMF

CHL OROPHYTA

- CHLOROPHYCEAE

..CHLOROCOCCALES

... 00CYSTACEA

.... OOCYSTIS

.... tetraedron

CHRYSOPHYTA

- BACILLARIOPHYCEAE

.. CFNTRALES

.. cosc inodiscacfae

$\cap . .$. CYCL OTELLA

.... MElosira

. PFNnAles

... NITZSCHIACEAE

.... NitzSCHIa

- ChRYSOPHYCEAE

.. CHRYSUMONADALES

.. ochromonadaceae

... OchRoMONAS

PYRRHOPHYTA

- DINOPHYCEAE

. PER I DIN I ALES

..peridintaceaf

. . PERIDINIIIM
_COMMON_NAME

GREEN ALGAE

TOTAL.

$\begin{array}{r}44 \\ --22 \\ \hline 66\end{array}$

17

$0.918=$ DIVERSITY

DIATOMS

CENTRIC

PENNATE

200

50

TOTALS

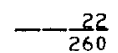

$\frac{6}{6}$

$1.041=0$ I VERS I TY

YELLOW-BROWN ALGAE

TOTALS

$--\frac{44}{44}$

11

$0.000=0$ I VERSI $T Y$

FIRE ALGAE

DINOFLAGELLATES

TOTALS $--\frac{22}{22}$

$-\frac{6}{6}$

$0.000=$ DIVERSI TY

NOTE: D - DOMINANT OFGANISM: GREATER OR EQUAL TO 15\% 
09421500. COLORADO RIVER BELON HOOVER DAM, ARIZ. -NEV, --CONTINUED

QUALITATIVE AND ASSOCIATED QUANTITATIVE ANALYSES OF BIOLOGICAL DATA, WATER YEARS OCTOBER 1974 TO SEPTEMBER 1976

AQR. 13. 1976

0830 HOURS

IDENTIFICATION OF PHYTOPLANKTON

$650 \mathrm{CELLS} / \mathrm{ML}$

_ORGANISM_NAME

CHLOROPHYTA

- CHLOROPHYCEAE

. Chlorocuccales

... OOCYSTACEAE

t. . . OOCYSTIS

. VOL Vocales

... Phacotaceae

... Phacotus

CHRYSOPHYTA

- BACILLAR IOPHYCEAE

-.PENNALES

...FRAG ILARIACEAF

... FRAGILARIA

@...

... NIITSSCHI ACEAE

@... DENTICULa

CYANOPHYTA

- MYXOPHYCEAE

. CHROOCOCCALES

.. CHROOCOCCACEAE

D ... ANACYSTIS

. Osc ILla tor I ales

. . OSC ILlLatori ace Ae

1) ... LYNGBYa
_COMMON_NAME

GREEN ALGAE

CELLS/ML

PER_CENT

TOTALS

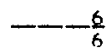

$-\frac{1}{1}$

$0.000=D I V E R S I T Y$

DIATOMS

PENNATE

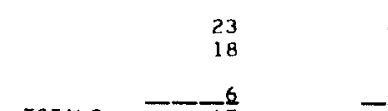

TOTALS $-\frac{6}{4} \quad-\frac{1}{8}$

BLUE-GREE $Y$ ALGAE

coccoio

Filamentous

320

49

TOTALS $-\frac{280}{590}$

$0.997=0$ I VERS I TY

NOTE: D - DOMINANT ORGANISMः GREATER OR EQUAL TO 15\%,

L - LESS THEN ITI MAY NOT HAVE BEEN ACTUALLY COUNTED 
09421500. COLORADO RIVER BELON HOOVER DAM, ARIZ.-NEV.--CONTINUED

QUALITATIVE AND ASSOCIATED QUANTITATIVE ANALYSES OF BIOLOGICAL DATA, WATER YEARS OCTOBER 1974 TO SEPTEMBER 1976

$$
\begin{aligned}
& \text { MAY } 11.1976 \\
& 0715 \text { HOURS }
\end{aligned}
$$

IOENTIFICATION OF PHYTOPLANKION

150 CELLS/ML

_ORTANISM_NAMF.

CHLOROPHYTA

- CHL DROPHYCEAE

. CHLOROCOCCALFS

... ONCYSTACEAE

.... ANK I STRODE SMUS

.... KIRCHNER IFLLA

... SCEnedesmaceae

... SCENEDESMUS

CHRYSOPHYTA

- BACILLAR I I)PHYCEAF

-. CFNTRALEs

.. coscinon I Scaceaf

.... melosira

- pennales

\#. AchNanthaceae

... ACHNANTHES

... cYMBELLacea

@... CYMBELL a

...fragillayiaceae

... ASTERIONELla

.. NAVI CULACEAE

... navicilla

... NITZSCHIACEAE

D ... NITZSCHIA

CYANOPHYTA

- MYXOPHYCEAE

. oscillatoriales

... Nostocaceae

$\because$ anabaena

\#. Oscillator I aceae

.... SPIRUL Ina
_COMMON_NAME GREEN ALGAE.

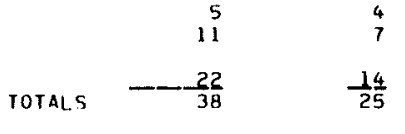

DIATOMS

CFNTRIC

PENNATE

NAVICULOID

NAviciugro

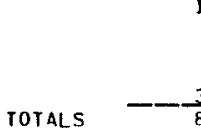

BLUE-GREEN ALGAE

F ILAMENTOUS

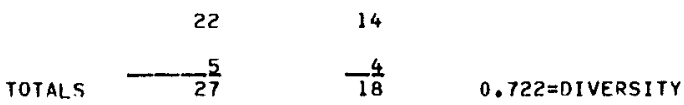

$1 \cdot 379=0$ I VERS I TY

$2.233=0$ IVERS I IY

NOTE: D - DOMINANT ORGANISM: GREATER OR EQUAL TO 15\%

JIJNE 8,1976

0800 HOUF

IDENTIFICATION OF PHYTOPLANKTON

990 CELLS/ML

$$
\text { _ORGANISM_NAME }
$$

CHRYSOPHYTA

-BACILLARIOPHYCEAE

. PENNALES

@..FRAG ILAR I ACEAE

.... SYNEDRa

... Navi Culaceae

L .... Navicula

\section{CYANOPHYTA}

- MYXOPHYCEAE

. OSCILLAT JRI ALES

.. OSCILLATORI ACEAE

0... OSCILLATORIA
_COMMON__NAME

DIATOMS

PENNATE

NAVICULOID

$0.000=$ DIVERSITY

BLUE-GREEN ALGAE

FILAMENTOUS
TOTALS

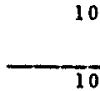

1

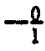

CELLS/ML PER_CENT

TOTALS $-\frac{970}{970} \quad \frac{92}{99}$

NOTE: D - DOMINANT ORGANISM; GREATER OR EQUAL TO $15 \%$

L - LESS THEN 1 \%क MAY NOT HAVE BEEN ACTUALLY COUNTED 
09421500. COLORADO RIVER BELOW HOOVER DAM, ARIZ. -NEV, --CONTINUED

QUALITATIVE AND ASSOCIATED QUANTITATIVE ANALYSES OF BIOLOGICAL DATA, WATER YEARS OCTOBER 1974 TO SEPTEMBER 1976

JIILY 13,1976

0800 HOURS

IDENTIFICATION OF PHYTOPLANKION

810 CELLS/ML

_ORGANISM_NAME

CHLOROPHYTA

- CHLOROPHYCEAE

. ChLorococcales

.. SCENEDE SMACEAE

.... SCENEDE SMus

. VOL VOCALES

... PHACOTACEAE

.... phacotus

CHRYSOPHYTA

- BACILLARI INPHYCEAF

. CENTRALES

... COSCINOD ISCACFAE

.... cyclotella

....MELOSIRA

..PEnNales

.. ACHNANTHACEAE

.... ACHNANTHES

... CYMBELL ACEAE

.... CYMBELla

$\because$ FragiLaRIACEAF

थ. . Fragilaria

... NAVICullaceae

... navicula

CYANOPHYTA

- MYXOPHYCEAE

- CHROOCOCCALES

... chrodcoccaceae

.... ANACYSTIS

. OSC ILLatoriales

... OSC ILla TORIACEA

n ... DSCILlatoria

PYRRHOPHYTA

- DI NOPHYCEAE

-DINOPHYCEAE

\#...GLENOUINIACEAE

...GLENOU INI ACEAE
_COMMON_NAME

GREEN ALGAE

TOTALS

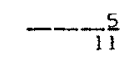

DIATOMS

CENTRIC

PENNATE

11
11
11
NAVICULOIO TOTALS -

TO

BLUE-GREEN ALGAE

$\operatorname{coc} \cos D$

FILAMENTOUS

75

9

TOIALS $=-\frac{660}{730} \quad \frac{81}{90}$

FIRE ALGAE

DINOFLAGELLATES

TOTALS
PER_CFNT<smiles>C[Te]</smiles>

$1.000=D$ IVERSITY

1

1

1

1

$-\frac{3}{8} \quad 2.418=$ DIVERSITY

NOTE: D - DOMINANT ORGANISMI GREATER OR EQUAL TO I5\% 
09421500. COLORADO RIVER BELOW HOOVER DAM, ARIZ, -NEV. --CONTINUED

QUALITATIVE AND ASSOCIATED QUANTITATIVE ANALYSES OF BIOLOGICAL DATA, NATER YEARS OCTOBER 1974 TO SEPTEMBER 1976

$$
\begin{aligned}
& \text { AIIG. } 10,1976 \\
& 0730 \text { HOURS }
\end{aligned}
$$

IDENTIFICATION OF PHYTOPLANKTON

$350 \mathrm{CELLS} / \mathrm{ML}$

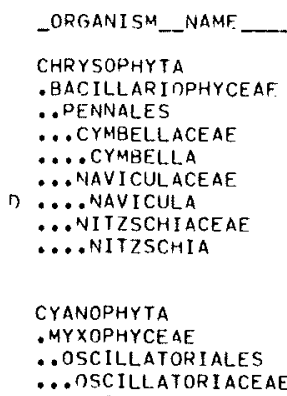

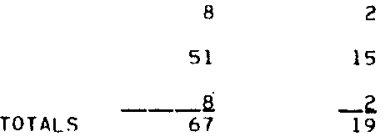

$1.061=0$ IVERSITY

BLUE-GREEN ALGAE.

FILAMENTOUS

$$
\text { TOTALS }-\frac{280}{280} \quad \frac{80}{80} \quad 0.000=0 \text { IVERSITY }
$$

NOTE: D - DOMINANT ORGANISM: GREATER OR EOUAL TO $15 \%$

SEP. 14,1976

0800 HOURS

IDENTIFICATION OF PHYTOPLANKTON

$1.900 \mathrm{CELLS} / \mathrm{ML}$

_ORGANISM_NAME

CHLOROPHYTA

- CHLOROPHYCEAE

. chlorococcales

... OOCYSTACEAE

.... OOCYSTIS

\section{CHRYSOPHYTA}

- BACILLAR I OPHYCEAE

. PENNALES

... i iatomaceae

I. ... DIatoma

... Navi Culaceae

.. Navicula

@.. NITZSCHIACEAE

... NitzSchia

CYANOPHYTA

- MYXOPHYCEAE

. OSCilla toriales

.. NOSTOCACEAE

$0 . \ldots$ CYLINDROSPERMUM

... OsCilla toriaceae

D - ... OSCILLATORIA
_COMMON_NAME

GREEN ALGAE

TOTALS

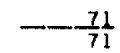

DIATOMS

PENNATE

NAVICULOIO

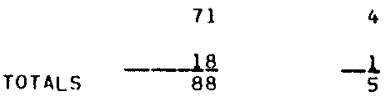

\begin{tabular}{|c|c|c|c|}
\hline & 280 & 15 & \\
\hline TOTALS & $-\frac{1}{1, \frac{400}{700}}$ & $\frac{76}{91}$ & $0.650=0$ I VERS I TY \\
\hline
\end{tabular}

BLUE-GREEN ALGAE

FILAMENTOUS

NOTE: D - DOMINANT ORGANISM; GREATER OR EQUAL TO $15 \%$

L - LESS THEN Iक: MAY NOT HAVE BEEN ACTUALIY COUNTED 
09423000. COLORADO RIVER BELON DAVIS DAM, AZ-NV.

LOCAT'ION, - Lat $35^{\circ} 11^{\prime} 30^{\prime \prime}$, long $114^{\circ} 34^{\prime} 17^{\prime \prime}$, in SE'sNEts sec.1, T.32 S., R.66 E., Mount Diablo meridian, in Nevada, Clark County, on right bank $0.5 \mathrm{mi}(0.8 \mathrm{~km})$ downstrean from Davis Dam, $29 \mathrm{mi}(47 \mathrm{~km})$ west of Kingman, Ariz., and $68 \mathrm{mi}(109 \mathrm{~km})$ downstream from lloover Dam.

DRAINAGE AREA (REVISED). - - 173, 300 $\mathrm{mi}^{2}\left(448,800 \mathrm{~km}^{2}\right)$, approximately, including 3,959 mi ${ }^{2}\left(10,254 \mathrm{~km}^{2}\right)$ in Great Divide basin in southern Woming, which is noncontributing (previously considered part of Missouri River basin)

PERIOD O: RECORD. - - June 1905 to September 1907 (published as "at Hardyville"), March 1949 to current year.

GAGE. - Water-stage recorder. Datum of gage is $500.00 \mathrm{ft}(152.40 \mathrm{~m})$ above mean sea level; gage readings have been reduced to elevations above mean sea level. 1905-7, nonrecording gage at site $4.8 \mathrm{mi}(7.7 \mathrm{~km})$ downstream at datum about $13.4 \mathrm{ft}(4.1 \mathrm{~m}) 10 \mathrm{wer}$, Mar. 16 to May 3, 1949, water-stage recorder at site $0.5 \mathrm{mi}(0.8 \mathrm{~km})$ downstream at present datum. May 4, 1949, to Feb. 24 , 1956, water-stage recorder at site $400 \mathrm{ft}(120 \mathrm{~m})$ upstream at present datum.

AVERAGE DISCHARGE. - 27 years $(1949-76), 12,560 \mathrm{ft}^{3} / \mathrm{s}\left(355.7 \mathrm{~m}^{3} / \mathrm{s}\right), 9,100,000 \mathrm{acre}-\mathrm{ft} / \mathrm{yr}(11,200 \mathrm{hm} / \mathrm{yr})$.

EXTRMES. --Current year: Maximum discharge, 25,500 ft $3 / \mathrm{s}\left(722 \mathrm{~m}^{3} / \mathrm{s}\right.$ ) Apr. 28 (elevation $505.59 \mathrm{ft}$ or $154.104 \mathrm{~m}$ ); maximan elevation, $505.61 \mathrm{ft}(154.110 \mathrm{~m})$ June 30 ; minimum dai1y discharge, $2,090 \mathrm{ft}^{3} / \mathrm{s}\left(59.2 \mathrm{~m}^{3} / \mathrm{s}\right)$ May 8 .

1905-7: Maximum daily discharge, $116,000 \mathrm{ft}^{3} / \mathrm{s}\left(3,290 \mathrm{~m}^{3} / \mathrm{s}\right)$ June 20, 1906; minimum daily, 2,850 $\mathrm{ft}^{3} / \mathrm{s}\left(80.7 \mathrm{~m}^{3} / \mathrm{s}\right) \mathrm{Jan} .5,1906$.

1949-76: Maximum discharge, 31,200 ft $3 / \mathrm{s}\left(884 \mathrm{~m}^{3} / \mathrm{s}\right) \mathrm{Apr} .22,1952$ (elevation, $513.91 \mathrm{ft}$ or $156.640 \mathrm{~m}$ ); no flow at Davis Dan parts of several days July to September 1950 and Dec, 27,1950 , when gates in dam were closed; minimum daily discharge, $285 \mathrm{ft}^{3} / \mathrm{s}$ $\left(8.07 \mathrm{~m}^{3} / \mathrm{s}\right)$ Aug. 3,1950 .

REMARKS.--Records excellent. Flow regulated by Lake Mead since Feb. 1, 1935, and by Lake Mohave since Jan. 17, 1950. Many diversions upstream for irrigation, industrial, and municipal uses. Records of chenical analyses for the current year are published on following pages.

DISCHAHGE, IN CUBIC FEET PER SECUNO, WATER YEAR OCTOBER 1975 TO SEPTEMBEH 1976 MEAN VALUES

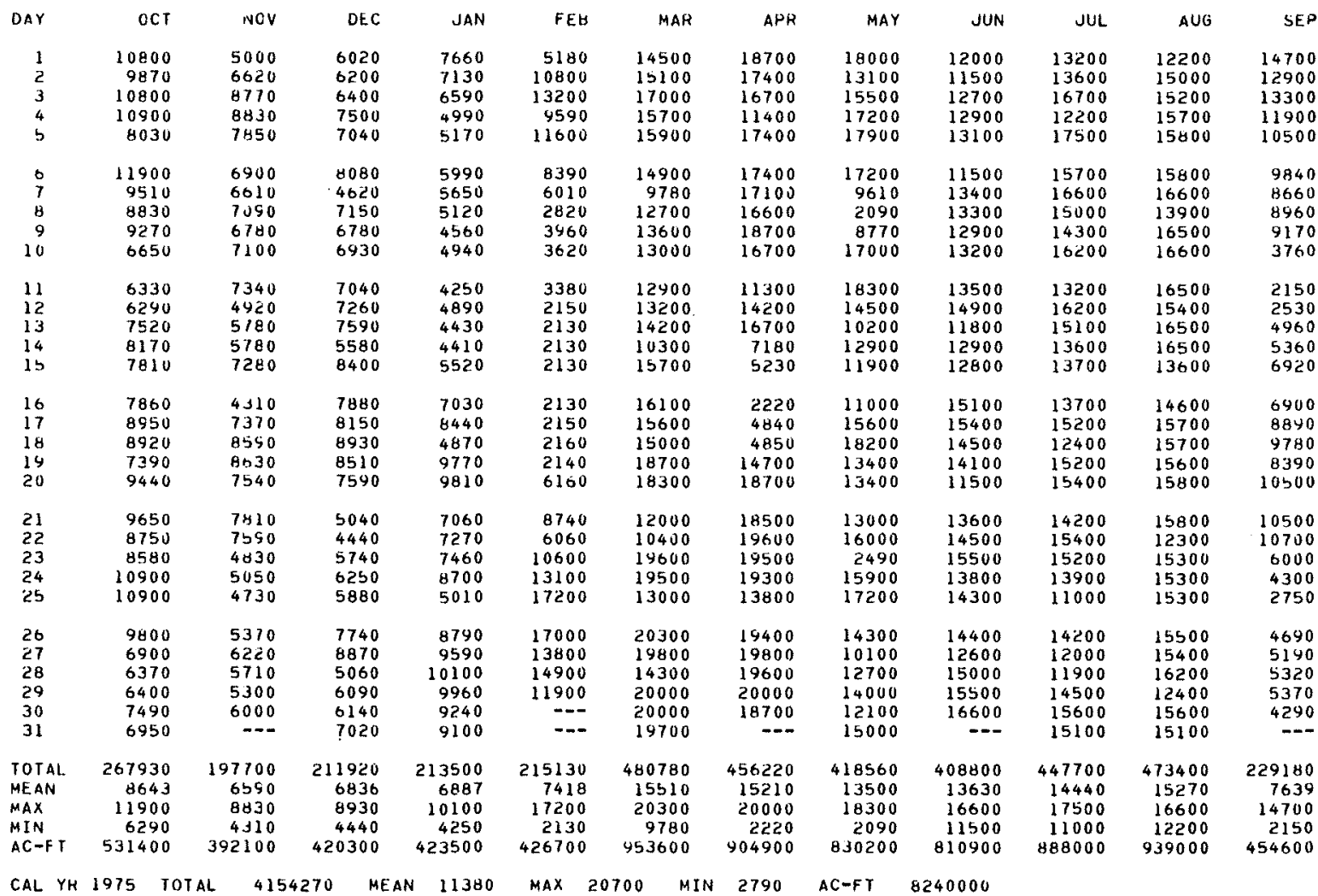

WTR YR 1976 TOTAL 4020820 MEAN 10990 MAX 20300 MIN 2090 AC-FT 7975000 
09423000. COLORADO RIVER BELON DAVIS DAM, ARIZ. -NEV.

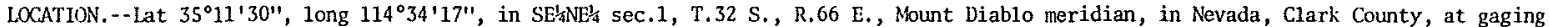
station on right bank $0.5 \mathrm{mi}(0.8 \mathrm{~km})$ downstream from Davis Dam, $29 \mathrm{mi}(47 \mathrm{~km})$ west of Kingman, Ariz., and $68 \mathrm{mi}$ (109 km) downstream from Hoover Dam.

DRAINAGE AREA (REVISED) .--173,300 $\mathrm{mi}^{2}\left(448,800 \mathrm{~km}^{2}\right)$, approximately, including $3,959 \mathrm{mi}^{2}\left(10,254 \mathrm{~km}^{2}\right)$ in Great Divide basin in southern Wyoming which is noncontributing (previously considered part of the Missouri River basin).

PERIOD OF RECORD.--Chemical analyses: July 1969 to current year.

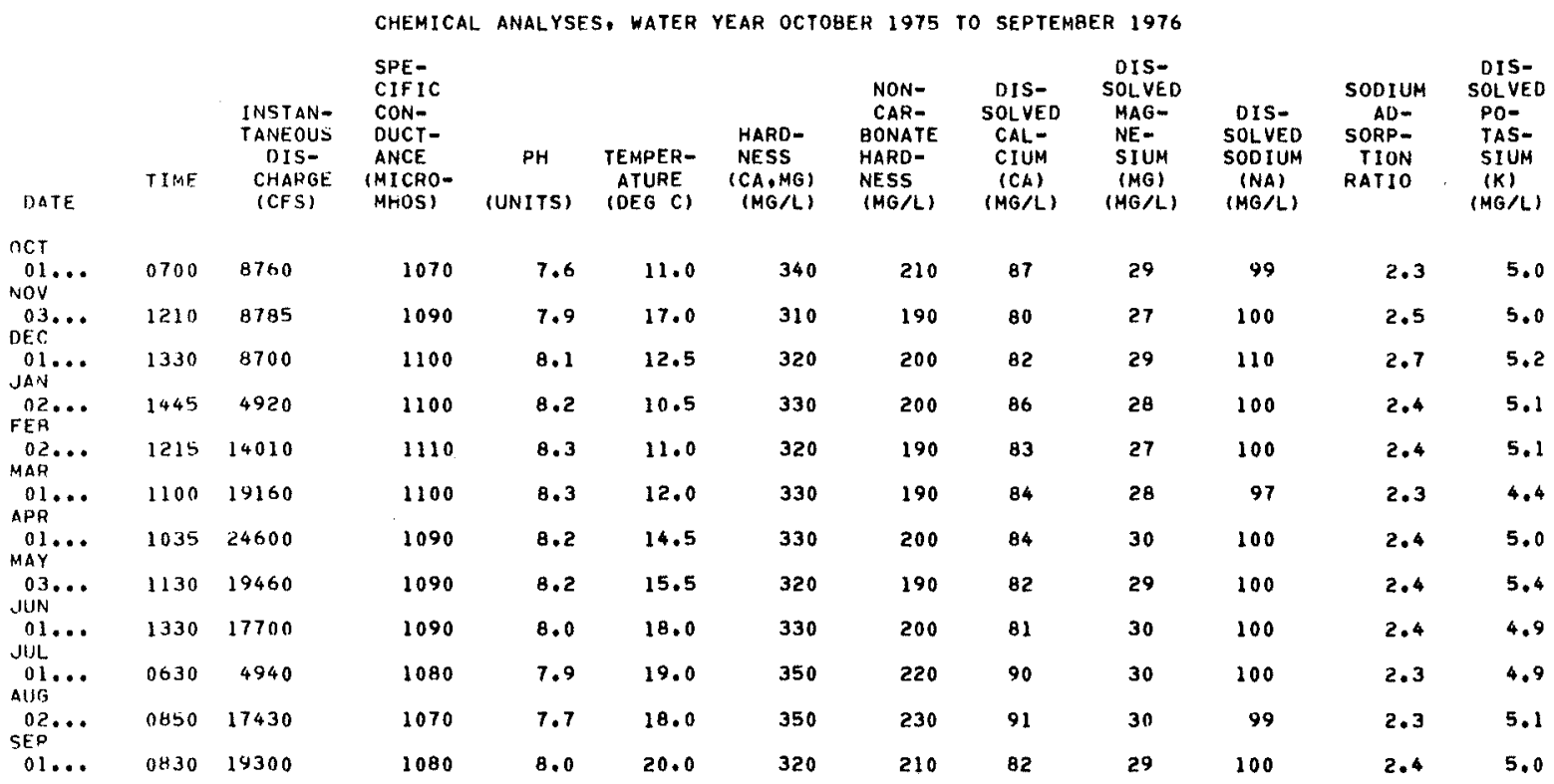

\begin{tabular}{|c|c|c|c|c|c|c|c|c|c|c|c|c|}
\hline DATF & $\begin{array}{l}\text { BICAK- } \\
\text { BONATE } \\
\text { (HCOB) } \\
\text { (MG/L) }\end{array}$ & $\begin{array}{l}\text { CAR- } \\
\text { BONATE } \\
\text { (CO3) } \\
(M G / L)\end{array}$ & $\begin{array}{l}\text { DIS- } \\
\text { SOLVEO } \\
\text { SULFATE } \\
\text { (S04) } \\
\text { (MG/L) }\end{array}$ & $\begin{array}{l}\text { DIS- } \\
\text { SOLVED } \\
\text { CHLO- } \\
\text { RIDE } \\
\text { (CL) } \\
\text { (MG/L) }\end{array}$ & $\begin{array}{l}\text { DIS- } \\
\text { SOLVED } \\
\text { FLUO- } \\
\text { RIDE } \\
(F) \\
(M G / L)\end{array}$ & $\begin{array}{l}\text { DIS- } \\
\text { SOLVED } \\
\text { SILICA } \\
\text { (SIOZ) } \\
\text { (MG/L) }\end{array}$ & $\begin{array}{l}\text { DIS- } \\
\text { SOLVED } \\
\text { SOLIDS } \\
\text { (RESI- } \\
\text { DUE AT } \\
\text { IAO C) } \\
\text { (MG/L) }\end{array}$ & $\begin{array}{l}\text { DIS- } \\
\text { SOLVED } \\
\text { SOLIDS } \\
\text { (SUM OF } \\
\text { CONSTI- } \\
\text { TUENTS) } \\
\text { (MOIL) }\end{array}$ & $\begin{array}{l}\text { DIS- } \\
\text { SOLVED } \\
\text { SOLIDS } \\
\text { TONS } \\
\text { PER } \\
\text { AC }-F T \text { T }\end{array}$ & $\begin{array}{l}\text { DIS- } \\
\text { SOLVED } \\
\text { NITRITE } \\
\text { PLUS } \\
\text { NITRATE } \\
\text { (N) } \\
\text { (MG/L) }\end{array}$ & $\begin{array}{l}\text { DIS- } \\
\text { SOLVED } \\
\text { BORON } \\
(B) \\
(U G / L)\end{array}$ & $\begin{array}{l}\text { DIS- } \\
\text { SOLVED } \\
\text { IRON } \\
\text { (FE) } \\
\text { (UG/L) }\end{array}$ \\
\hline $\begin{array}{l}\text { nct } \\
\text { ol.... } \\
\text { Nov }\end{array}$ & 158 & 0 & 290 & 86 & .2 & 7.9 & 715 & 683 & .97 & .27 & 140 & 0 \\
\hline OEC $03 .$. & 150 & 0 & 280 & 85 & .3 & 7.8 & 716 & 660 & . 97 & .14 & 130 & 40 \\
\hline JAN $^{01 \cdots}$ & 152 & 0 & 290 & 86 & .4 & 8.3 & 724 & 687 & .98 & .19 & -- & 10 \\
\hline$\underset{F E R}{02} \cdot \cdots$ & 159 & 0 & 300 & 83 & .3 & 7.8 & 718 & 691 & .98 & .46 & 130 & 0 \\
\hline MAR & 162 & 0 & 290 & 86 & .3 & 7.6 & 722 & 680 & .98 & .27 & 120 & 10 \\
\hline$\underset{A P R}{01 \cdots}$ & 163 & 0 & 290 & 87 & .5 & 8.3 & 719 & 681 & .98 & .33 & 130 & 10 \\
\hline MAY & 165 & 0 & 280 & 87 & .3 & 7.8 & 717 & 677 & .98 & .25 & 100 & 0 \\
\hline${ }_{J U N}^{03 \cdots \cdots}$ & 168 & 0 & 290 & 86 & $\cdot 3$ & 5.3 & 710 & 683 & .97 & .24 & -4 & 10 \\
\hline JUL & 156 & 0 & 290 & 88 & .4 & 7.1 & 694 & 680 & .94 & .26 & 130 & 20 \\
\hline$\underset{\text { AUS }}{01} \cdots$ & 162 & 0 & 300 & 88 & .4 & 8.7 & 710 & 704 & .97 & .54 & 120 & 0 \\
\hline$\underset{\text { SËP }}{02} \cdot . \cdot$ & 152 & 0 & 300 & 88 & .3 & 8.4 & 709 & 698 & .96 & .20 & 130 & 0 \\
\hline $01 \ldots$ & 142 & 0 & 310 & 88 & .3 & 8.4 & 710 & 694 & .97 & .22 & 130 & 10 \\
\hline
\end{tabular}


09423500. COLORADO RIVER AT NEEDLES, CALIF.

LOCATION.--Lat $34^{\circ} 51^{\prime} 06^{\prime \prime}$, long $114^{\circ} 36^{\prime} 33^{\prime \prime}$, in SE $4_{4 E^{\prime}}$ sec. 19 , T.9 N., R. 23 E., San Bernardino meridian, San Bernardino County, on right

baik at Needles, $15 \mathrm{mi}(24 \mathrm{~km})$ upstream from gaging station near Topock, Ariz., $30 \mathrm{mi}$ (48 km) downstream from Davis Dam, and 9 ? $\mathrm{mi}$
$(156 \mathrm{~km})$ downstream from Hoover Dam.

DRAINGE AREA (REVISED),--174,500 $\mathrm{mi}^{2}\left(452,000 \mathrm{~km}^{2}\right)$, approxinately, including 3,959 $\mathrm{mi}^{2}\left(10,254 \mathrm{~km}^{2}\right)$ in Great Divide basin in southern Wyoming, which is noncontributing (previously considered part of the Missouri River basin).

PERTOD OF RECORD,--April 1931 to current year (elevations only).

GAGE.- Water-stage recorder. Datum of gage is $400.00 \mathrm{ft}(121.920 \mathrm{~m})$ above mean sea level. Prior to May 15 , 1942 , at site $550 \mathrm{ft}$

$(170 \mathrm{~m})$ downstrean and May 15,1942 , to Feb. 16 , 1969 , at site $200 \mathrm{ft}(60 \mathrm{~m})$ upstream; at datum $66.23 \mathrm{ft}$ (20.187 $\mathrm{m})$ higher prior

to Jan. 12, 1952, and at present datum thereafter.

EXTRE.ES.--Current year: Maximum elevation, $475.12 \mathrm{ft}$ (144.817 m) Sept. 1; minimum, $458.69 \mathrm{ft}$ (139.809 m) Feb. 19

Period of record: Maximm elevation, $475.77 \mathrm{ft}(145.015 \mathrm{~m})$ Nov. 30, 1944; minimum, 457.84 ft (139.550 m) Feb. $26,1973$.

REWRES.- Flow regulated by Lake Mead since Feb. 1, 1935, and by Lake Mohave since Jan. 17, 1950.

REVISTONS (WATER YEARS).- -IVSP 1119: 1931-47.

MEAN ELEVATTON, IN FEET, WATER YEAR OCTOBER 1975 TO SEPTEMBER 1976

\begin{tabular}{|c|c|c|c|c|c|c|c|c|c|c|c|c|}
\hline DAY & OCT & Nov & DEC & JAN & FEB & MAR & APR & MAY & JUN & JUL & AUG & SEP \\
\hline $\begin{array}{l}1 \\
2 \\
3 \\
4 \\
5\end{array}$ & $\begin{array}{l}64.21 \\
63.76 \\
63.98 \\
64.20 \\
63.57\end{array}$ & $\begin{array}{l}61.44 \\
61.16 \\
62.37 \\
63.35 \\
62.82\end{array}$ & $\begin{array}{l}61.58 \\
61.53 \\
61.44 \\
61.93 \\
62.31\end{array}$ & $\begin{array}{l}62.34 \\
62.13 \\
61.83 \\
61.64 \\
60.56\end{array}$ & $\begin{array}{l}62.38 \\
62.34 \\
64.69 \\
64.26 \\
63.75\end{array}$ & $\begin{array}{l}64.93 \\
65.63 \\
66.51 \\
66.45 \\
66.66\end{array}$ & $\begin{array}{l}68.08 \\
67.28 \\
67.06 \\
65.96 \\
65.41\end{array}$ & $\begin{array}{l}67.63 \\
65.79 \\
66.14 \\
66.40 \\
67.11\end{array}$ & $\begin{array}{l}65.24 \\
64.90 \\
64.28 \\
65.22 \\
65.11\end{array}$ & $\begin{array}{l}65.86 \\
65.27 \\
66.44 \\
65.04 \\
66.84\end{array}$ & $\begin{array}{l}65.23 \\
64.86 \\
65.14 \\
65.98 \\
66.47\end{array}$ & $\begin{array}{l}70.65 \\
65.53 \\
65.28 \\
64.99 \\
64.62\end{array}$ \\
\hline $\begin{array}{r}6 \\
7 \\
8 \\
9 \\
10\end{array}$ & $\begin{array}{l}63.42 \\
63.89 \\
63.40 \\
63.38 \\
62.70\end{array}$ & $\begin{array}{l}62.09 \\
61.95 \\
62.02 \\
62.12 \\
61.85\end{array}$ & $\begin{array}{l}62.63 \\
61.88 \\
61.14 \\
61.63 \\
62.16\end{array}$ & $\begin{array}{l}61.06 \\
61.46 \\
61.01 \\
60.82 \\
60.48\end{array}$ & $\begin{array}{l}63.69 \\
62.45 \\
60.80 \\
59.72 \\
60.25\end{array}$ & $\begin{array}{l}65.96 \\
65.05 \\
64.14 \\
65.14 \\
65.26\end{array}$ & $\begin{array}{l}67.08 \\
66.80 \\
67.36 \\
67.26 \\
67.06\end{array}$ & $\begin{array}{l}67.14 \\
66.12 \\
60.83 \\
60.46 \\
65.08\end{array}$ & $\begin{array}{l}64.61 \\
65.08 \\
65.12 \\
65.19 \\
65.28\end{array}$ & $\begin{array}{l}66.05 \\
66.84 \\
66.14 \\
65.69 \\
66.28\end{array}$ & $\begin{array}{l}66.43 \\
66.82 \\
65.66 \\
66.65 \\
66.89\end{array}$ & $\begin{array}{l}64.17 \\
63.11 \\
62.94 \\
63.31 \\
63.07\end{array}$ \\
\hline $\begin{array}{l}11 \\
12 \\
13 \\
14 \\
15\end{array}$ & $\begin{array}{l}61.70 \\
61.59 \\
62.14 \\
62.69 \\
62.53\end{array}$ & $\begin{array}{l}62.00 \\
62.27 \\
60.80 \\
61.70 \\
61.77\end{array}$ & $\begin{array}{l}62.48 \\
61.70 \\
61.98 \\
62.07 \\
61.65\end{array}$ & $\begin{array}{l}60.63 \\
60.30 \\
60.81 \\
60.36 \\
60.45\end{array}$ & $\begin{array}{l}59.83 \\
59.43 \\
59.03 \\
59.01 \\
59.01\end{array}$ & $\begin{array}{l}64.93 \\
65.17 \\
65.10 \\
64.86 \\
65.00\end{array}$ & $\begin{array}{l}65.70 \\
64.78 \\
66.35 \\
64.96 \\
61.52\end{array}$ & $\begin{array}{l}67.09 \\
66.57 \\
65.16 \\
64.08 \\
65.02\end{array}$ & $\begin{array}{l}65.40 \\
65.65 \\
65.40 \\
64.81 \\
65.20\end{array}$ & $\begin{array}{l}65.40 \\
66.20 \\
66.07 \\
65.49 \\
65.41\end{array}$ & $\begin{array}{l}66.71 \\
66.37 \\
66.74 \\
66.81 \\
65.76\end{array}$ & $\begin{array}{l}60.38 \\
59.26 \\
59.89 \\
60.85 \\
60.71\end{array}$ \\
\hline $\begin{array}{l}16 \\
17 \\
18 \\
19 \\
20\end{array}$ & $\begin{array}{l}62.52 \\
62.63 \\
63.02 \\
62.68 \\
62.86\end{array}$ & $\begin{array}{l}61.68 \\
60.87 \\
62.33 \\
62.94 \\
62.74\end{array}$ & $\begin{array}{l}62.81 \\
62.51 \\
62.81 \\
63.51 \\
62.48\end{array}$ & $\begin{array}{l}61.56 \\
61.97 \\
62.05 \\
61.67 \\
63.78\end{array}$ & $\begin{array}{l}59.01 \\
59.01 \\
59.00 \\
58.93 \\
56.91\end{array}$ & $\begin{array}{l}66.68 \\
66.42 \\
66.06 \\
67.11 \\
67.42\end{array}$ & $\begin{array}{l}60.20 \\
59.86 \\
60.69 \\
62.70 \\
66.36\end{array}$ & $\begin{array}{l}64.19 \\
64.85 \\
66.97 \\
65.73 \\
65.44\end{array}$ & $\begin{array}{l}65.80 \\
66.24 \\
66.24 \\
65.77 \\
64.83\end{array}$ & $\begin{array}{l}65.13 \\
65.90 \\
65.26 \\
65.57 \\
66.16\end{array}$ & $\begin{array}{l}65.66 \\
66.13 \\
66.17 \\
66.48 \\
66.52\end{array}$ & $\begin{array}{l}61.99 \\
62.69 \\
63.34 \\
63.26 \\
63.01\end{array}$ \\
\hline $\begin{array}{l}21 \\
22 \\
23 \\
24 \\
25\end{array}$ & $\begin{array}{l}63.40 \\
63.31 \\
63.02 \\
63.69 \\
64.12\end{array}$ & $\begin{array}{l}62.39 \\
62.55 \\
61.86 \\
60.74 \\
60.94\end{array}$ & $\begin{array}{l}61.86 \\
61.04 \\
60.76 \\
61.36 \\
61.55\end{array}$ & $\begin{array}{l}62.97 \\
61.77 \\
62.20 \\
62.58 \\
62.15\end{array}$ & $\begin{array}{l}62.55 \\
62.27 \\
62.38 \\
64.29 \\
66.72\end{array}$ & $\begin{array}{l}66.10 \\
63.24 \\
67.48 \\
67.86 \\
64.86\end{array}$ & $\begin{array}{l}67.79 \\
67.86 \\
67.84 \\
67.90 \\
66.29\end{array}$ & $\begin{array}{l}64.98 \\
65.70 \\
63.60 \\
62.25 \\
66.39\end{array}$ & $\begin{array}{l}65.25 \\
65.65 \\
66.04 \\
65.96 \\
65.64\end{array}$ & $\begin{array}{l}65.57 \\
66.36 \\
66.20 \\
65.73 \\
65.16\end{array}$ & $\begin{array}{l}66.57 \\
65.70 \\
65.68 \\
66.26 \\
66.26\end{array}$ & $\begin{array}{l}64.07 \\
64.23 \\
64.03 \\
60.26 \\
61.15\end{array}$ \\
\hline $\begin{array}{l}26 \\
27 \\
28 \\
29 \\
30 \\
31\end{array}$ & $\begin{array}{l}64.12 \\
62.47 \\
61.93 \\
61.76 \\
62.04 \\
62.41\end{array}$ & $\begin{array}{r}60.67 \\
61.08 \\
61.14 \\
61.34 \\
60.93 \\
\end{array}$ & $\begin{array}{l}61.50 \\
62.64 \\
62.41 \\
60.95 \\
61.76 \\
61.49\end{array}$ & $\begin{array}{l}61.55 \\
63.09 \\
63.58 \\
63.86 \\
63.19 \\
63.22\end{array}$ & $\begin{array}{r}67.20 \\
65.72 \\
66.20 \\
65.50 \\
. \\
.\end{array}$ & $\begin{array}{l}66.84 \\
68.44 \\
66.21 \\
67.50 \\
68.29 \\
68.21\end{array}$ & $\begin{array}{r}67.22 \\
68.02 \\
68.05 \\
68.17 \\
67.75 \\
\ldots . .\end{array}$ & $\begin{array}{l}66.16 \\
65.12 \\
63.61 \\
65.48 \\
64.66 \\
65.14\end{array}$ & $\begin{array}{r}65.76 \\
65.38 \\
65.34 \\
65.72 \\
66.52 \\
-.-\end{array}$ & $\begin{array}{l}65.05 \\
64.97 \\
64.33 \\
65.16 \\
66.29 \\
65.94\end{array}$ & $\begin{array}{l}66.25 \\
66.39 \\
66.75 \\
65.46 \\
65.97 \\
66.26\end{array}$ & $\begin{array}{r}59.51 \\
61.24 \\
60.90 \\
61.08 \\
61.11 \\
. . .\end{array}$ \\
\hline $\begin{array}{l}\text { MEAN } \\
\text { MAX } \\
\text { MIN }\end{array}$ & $\begin{array}{l}63.00 \\
64.21 \\
61.59\end{array}$ & $\begin{array}{l}61.80 \\
63.35 \\
60.67\end{array}$ & $\begin{array}{l}61.92 \\
63.51 \\
60.76\end{array}$ & $\begin{array}{l}61.84 \\
63.86 \\
60.30\end{array}$ & $\begin{array}{l}62.01 \\
67.20 \\
58.91\end{array}$ & $\begin{array}{l}66.11 \\
68.44 \\
63.24\end{array}$ & $\begin{array}{l}65.98 \\
68.17 \\
59.86\end{array}$ & $\begin{array}{l}65.19 \\
67.63 \\
60.46\end{array}$ & $\begin{array}{l}65.42 \\
66.52 \\
64.28\end{array}$ & $\begin{array}{l}65.74 \\
66.84 \\
64.33\end{array}$ & $\begin{array}{l}66.16 \\
66.89 \\
64.86\end{array}$ & $\begin{array}{l}62.69 \\
70.65 \\
59.26\end{array}$ \\
\hline
\end{tabular}

W.TR YR 1976 MEAN 64.00 MAX 70.65 MIN 58.91

NOTE. - Add 400,00 ft to obtain elevation above mean sea leve1. 
09424000. COLORHDO RIVER NEAR TOPOCK, ARIZ.

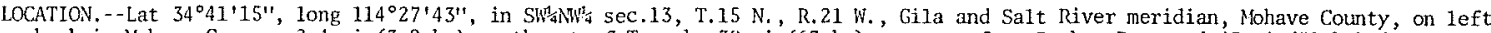
bank in Mohave Canyon, $2.4 \mathrm{mi}(3.9 \mathrm{~km})$ southeast of Topock, $39 \mathrm{mi}(63 \mathrm{~km})$ upstrean from Farker Dan, and $45 \mathrm{mi}(72 \mathrm{~km})$ downstream from Davis Dam.

DRAINAGE AREA (REVISED) . --176,300 $\mathrm{mi}^{2}\left(456,600 \mathrm{~km}^{2}\right)$, approximately, including $3,959 \mathrm{mi}^{2}\left(10,254 \mathrm{~km}^{2}\right)$ in Great Divide basin in southern Wyoming, which is noncontributing (previously considered part of the Missouri River basin).

PERIOD OF RECORD.--January 1917 to current year. Daily mean elevations published since October 1938.

GAGE.- -Water-stage recorder. Datum of gage is $423.02 \mathrm{ft}(128.936 \mathrm{~m})$ above mean sea level; gage readings have been reduced to elevations above mean sea level. Prior to Dec. 3, 1922, at site about 1 mi (2 km) upstream at different dation.

AVERAGE DISCHARGE. - - 17 years $(1917-34), 20,260 \mathrm{ft}^{3} / \mathrm{s}\left(573.8 \mathrm{~m}^{3} / \mathrm{s}\right), 14,670,000 \mathrm{acre}-\mathrm{ft} / \mathrm{rr}(18,100 \mathrm{hm} / \mathrm{yr}) ; 42 \mathrm{years}(1934-76)$, $12,860 \mathrm{ft}^{3} / \mathrm{s}\left(364.2 \mathrm{~m}^{3} / \mathrm{s}\right), 9,317,000 \mathrm{acre}-\mathrm{ft} / \mathrm{yr}\left(11,500 \mathrm{hm}^{3} / \mathrm{yr}\right)$, unadjusted.

EXTREIES.--Current year: Maximum discharge, $19,900 \mathrm{ft} / \mathrm{s}\left(564 \mathrm{~m}^{3} / \mathrm{s}\right.$ ) Mar. 31, Apr. 30 (elevation, $455.80 \mathrm{ft}$ or $138.928 \mathrm{~m}$, Mar. 31 ); minimim daily, 1,950 ft $\mathrm{ft}^{3} / \mathrm{s}\left(55.2 \mathrm{~m}^{3} / \mathrm{s}\right)$ Feb. 20 ; minimum elevation, $448.06 \mathrm{ft}(136.569 \mathrm{~m})$, Feb. 20.

1917-34: Maximum discharge probably exceeded $200,000 \mathrm{ft}^{3} / \mathrm{s}\left(5,660 \mathrm{~m}^{3} / \mathrm{s}\right)$ June 22,$1921 ;$ minimum, $1,480 \mathrm{ft}^{3} / \mathrm{s}\left(41.9 \mathrm{~m}^{3} / \mathrm{s}\right)$ Aug. 17, 1934 .

1934-76: Naximum discharge, $35,700 \mathrm{ft}^{3} / \mathrm{s}\left(1,010 \mathrm{~m}^{3} / \mathrm{s}\right)$ Jan. 29, 1942; maximum elevation, $457.37 \mathrm{ft}$ (139.406 $\left.\mathrm{m}\right) \mathrm{July} 9$, 1959 ; minimum discharge, $375 \mathrm{ft}^{3} / \mathrm{s}\left(10,6 \mathrm{~m}^{3} / \mathrm{s}\right) \mathrm{Feb}, 14,1935 ;$ minimum daily, $422 \mathrm{ft}^{3} / \mathrm{s}\left(12.0 \mathrm{~m}^{3} / \mathrm{s}\right) \mathrm{Feb} .14,1935$.

Discharge of about $300,000 \mathrm{ft}^{3} / \mathrm{s}\left(8,500 \mathrm{~m}^{3} / \mathrm{s}\right)$, based on determination at Lees Ferry gaging station, occurred about July 10 , 1884 .

Discharge estinated to be in excess of $400,000 \mathrm{ft}^{3} / \mathrm{s}\left(11,300 \mathrm{~m}^{3} / \mathrm{s}\right)$ probably occurred within the period $1857-68$ and most $1 \mathrm{ikely}$ in

1862 .

REMARKS, --Records good above $10,000 \mathrm{ft}^{3} / \mathrm{s}\left(280 \mathrm{~m}^{3} / \mathrm{s}\right)$, and fair below. Many diversions above station for irrigation, municipal, and industrial uses. Flow regulated by Lake Mead since Feb. 1, 1935, and by Lake Mohave since Jan. 17, 1950.

REVISIONS (WATER YEARS).--WSP 918: 1921, WSP 1313: 1918-19(M),

DISCHARGE, IN CUBIC FEET PER SECOND, WATER YEAR OCTOBER 1975 TO SEPTEMBER 1976 MEAN VALUES

\begin{tabular}{|c|c|c|c|c|c|c|c|c|c|c|c|c|}
\hline DAY & OCT & NOV & DEC & JAN & FEB & MAR & APR & MAY & JUN & JUL & AUG & SEP \\
\hline $\begin{array}{l}1 \\
2 \\
3 \\
4 \\
5\end{array}$ & $\begin{array}{l}10800 \\
10500 \\
10100 \\
10700 \\
10600\end{array}$ & $\begin{array}{l}6530 \\
5270 \\
6380 \\
8450 \\
8080\end{array}$ & $\begin{array}{l}5460 \\
5840 \\
5780 \\
5940 \\
6950\end{array}$ & $\begin{array}{l}6680 \\
6800 \\
6580 \\
6070 \\
4990\end{array}$ & $\begin{array}{r}8260 \\
5580 \\
10000 \\
11600 \\
9340\end{array}$ & $\begin{array}{l}11200 \\
12600 \\
13800 \\
14900 \\
14800\end{array}$ & $\begin{array}{l}18500 \\
17300 \\
16400 \\
15700 \\
12100\end{array}$ & $\begin{array}{l}17500 \\
15900 \\
14000 \\
14600 \\
16100\end{array}$ & $\begin{array}{l}13500 \\
12500 \\
11900 \\
12900 \\
12900\end{array}$ & $\begin{array}{l}14700 \\
12800 \\
13800 \\
13800 \\
13500\end{array}$ & $\begin{array}{l}13600 \\
12300 \\
14000 \\
14400 \\
14800\end{array}$ & $\begin{array}{l}14100 \\
13500 \\
12400 \\
12500 \\
11600\end{array}$ \\
\hline $\begin{array}{r}6 \\
7 \\
8 \\
9 \\
10\end{array}$ & $\begin{array}{r}8650 \\
11000 \\
9530 \\
9350 \\
8830\end{array}$ & $\begin{array}{l}7450 \\
6740 \\
6600 \\
6750 \\
6630\end{array}$ & $\begin{array}{l}6950 \\
7030 \\
4750 \\
6190 \\
6320\end{array}$ & $\begin{array}{l}4680 \\
5450 \\
5180 \\
4760 \\
4290\end{array}$ & $\begin{array}{r}10500 \\
8240 \\
5850 \\
3750 \\
4180\end{array}$ & $\begin{array}{r}14000 \\
13400 \\
9910 \\
11500 \\
12400\end{array}$ & $\begin{array}{l}15600 \\
15800 \\
16300 \\
15900 \\
16800\end{array}$ & $\begin{array}{r}16800 \\
15700 \\
9250 \\
3860 \\
9680\end{array}$ & $\begin{array}{l}12700 \\
12200 \\
12800 \\
12900 \\
12900\end{array}$ & $\begin{array}{l}14500 \\
14900 \\
14800 \\
14000 \\
14000\end{array}$ & $\begin{array}{l}14800 \\
15200 \\
14400 \\
14100 \\
15500\end{array}$ & $\begin{array}{r}10800 \\
9740 \\
8930 \\
9300 \\
9860\end{array}$ \\
\hline $\begin{array}{l}11 \\
12 \\
13 \\
14 \\
15\end{array}$ & $\begin{array}{l}7120 \\
6410 \\
6670 \\
7400 \\
7510\end{array}$ & $\begin{array}{l}6650 \\
6880 \\
5280 \\
5860 \\
5800\end{array}$ & $\begin{array}{l}6960 \\
6350 \\
6590 \\
6860 \\
5570\end{array}$ & $\begin{array}{l}4340 \\
3870 \\
4410 \\
3940 \\
3820\end{array}$ & $\begin{array}{l}3700 \\
3430 \\
2790 \\
2670 \\
2510\end{array}$ & $\begin{array}{l}11800 \\
11900 \\
12300 \\
12600 \\
10600\end{array}$ & $\begin{array}{r}15400 \\
11900 \\
13800 \\
14900 \\
8820\end{array}$ & $\begin{array}{l}15500 \\
16100 \\
13800 \\
10900 \\
12700\end{array}$ & $\begin{array}{l}13100 \\
13300 \\
13600 \\
11600 \\
12200\end{array}$ & $\begin{array}{l}14000 \\
13500 \\
14400 \\
13300 \\
12800\end{array}$ & $\begin{array}{l}15300 \\
14900 \\
14900 \\
15400 \\
14500\end{array}$ & $\begin{array}{l}5680 \\
2900 \\
3000 \\
4450 \\
4360\end{array}$ \\
\hline $\begin{array}{l}16 \\
17 \\
18 \\
19 \\
20\end{array}$ & $\begin{array}{l}7390 \\
7420 \\
8230 \\
8130 \\
7390\end{array}$ & $\begin{array}{l}6690 \\
4500 \\
6540 \\
7670 \\
7820\end{array}$ & $\begin{array}{l}7470 \\
7360 \\
7480 \\
8520 \\
7780\end{array}$ & $\begin{array}{l}5050 \\
6190 \\
7180 \\
4890 \\
8570\end{array}$ & $\begin{array}{l}2460 \\
2440 \\
2410 \\
2320 \\
1950\end{array}$ & $\begin{array}{l}14100 \\
14600 \\
14000 \\
14400 \\
16600\end{array}$ & $\begin{array}{r}6550 \\
3900 \\
4830 \\
5000 \\
12400\end{array}$ & $\begin{array}{l}11800 \\
11700 \\
15200 \\
15800 \\
13100\end{array}$ & $\begin{array}{l}13100 \\
14000 \\
14200 \\
13800 \\
12900\end{array}$ & $\begin{array}{l}12600 \\
13100 \\
13300 \\
12200 \\
13900\end{array}$ & $\begin{array}{l}12500 \\
14100 \\
14100 \\
14600 \\
14800\end{array}$ & $\begin{array}{l}6050 \\
6740 \\
8070 \\
8650 \\
7780\end{array}$ \\
\hline $\begin{array}{l}21 \\
22 \\
23 \\
24 \\
25\end{array}$ & $\begin{array}{r}8720 \\
9000 \\
8160 \\
8770 \\
10000\end{array}$ & $\begin{array}{l}7030 \\
7230 \\
6880 \\
4730 \\
4710\end{array}$ & $\begin{array}{l}6920 \\
5110 \\
4560 \\
5330 \\
5860\end{array}$ & $\begin{array}{l}8770 \\
6560 \\
6760 \\
6940 \\
7670\end{array}$ & $\begin{array}{r}5400 \\
7380 \\
5940 \\
9260 \\
12700\end{array}$ & $\begin{array}{l}16500 \\
11100 \\
11600 \\
16900 \\
16600\end{array}$ & $\begin{array}{l}16700 \\
17100 \\
17800 \\
17900 \\
16600\end{array}$ & $\begin{array}{r}12800 \\
13400 \\
13700 \\
5500 \\
14200\end{array}$ & $\begin{array}{l}12400 \\
13200 \\
13700 \\
14200 \\
13400\end{array}$ & $\begin{array}{l}13700 \\
13600 \\
14200 \\
13700 \\
12900\end{array}$ & $\begin{array}{l}14900 \\
14500 \\
12300 \\
14000 \\
14200\end{array}$ & $\begin{array}{r}9430 \\
9690 \\
10200 \\
6050 \\
5550\end{array}$ \\
\hline $\begin{array}{l}26 \\
27 \\
28 \\
29 \\
30 \\
31\end{array}$ & $\begin{array}{r}10300 \\
8530 \\
6970 \\
6450 \\
6390 \\
7230\end{array}$ & $\begin{array}{l}4500 \\
5160 \\
5650 \\
5490 \\
4980 \\
-\end{array}$ & $\begin{array}{l}5530 \\
7060 \\
7690 \\
5030 \\
5840 \\
5670\end{array}$ & $\begin{array}{l}5120 \\
7770 \\
8780 \\
9450 \\
8890 \\
8480\end{array}$ & $\begin{array}{r}15100 \\
14100 \\
13400 \\
13400 \\
\end{array}$ & $\begin{array}{l}13400 \\
18200 \\
16900 \\
14500 \\
18000 \\
18600\end{array}$ & $\begin{array}{r}14200 \\
17500 \\
18200 \\
16400 \\
18200 \\
=\end{array}$ & $\begin{array}{l}15600 \\
13500 \\
10700 \\
12600 \\
12700 \\
12200\end{array}$ & $\begin{array}{r}13800 \\
13700 \\
12900 \\
13700 \\
14600 \\
=0\end{array}$ & $\begin{array}{l}11300 \\
12700 \\
11300 \\
11800 \\
14200 \\
14100\end{array}$ & $\begin{array}{l}14200 \\
14400 \\
14900 \\
14300 \\
12500 \\
14200\end{array}$ & $\begin{array}{l}2800 \\
4780 \\
4760 \\
5020 \\
5170 \\
=-0\end{array}$ \\
\hline $\begin{array}{l}\text { TOTAL } \\
\text { MFAN } \\
\text { MAX } \\
\text { MIN } \\
\text { AC-FT }\end{array}$ & $\begin{array}{r}264250 \\
8524 \\
11000 \\
6390 \\
524100\end{array}$ & $\begin{array}{r}188930 \\
6298 \\
8450 \\
4500 \\
374700\end{array}$ & $\begin{array}{r}196750 \\
6347 \\
8520 \\
4560 \\
390300\end{array}$ & $\begin{array}{r}192930 \\
6224 \\
9450 \\
3820 \\
382700\end{array}$ & $\begin{array}{r}200660 \\
6919 \\
15100 \\
1950 \\
398000\end{array}$ & $\begin{array}{r}433710 \\
13990 \\
18600 \\
9910 \\
860300\end{array}$ & $\begin{array}{r}430500 \\
14350 \\
18500 \\
3900 \\
853900\end{array}$ & $\begin{array}{r}406890 \\
13130 \\
17500 \\
3860 \\
807100\end{array}$ & $\begin{array}{r}394600 \\
13150 \\
14600 \\
11600 \\
782700\end{array}$ & $\begin{array}{r}417400 \\
13460 \\
14900 \\
11300 \\
827900\end{array}$ & $\begin{array}{r}442600 \\
14280 \\
15500 \\
12300 \\
877900\end{array}$ & $\begin{array}{r}233860 \\
7795 \\
14100 \\
2800 \\
463900\end{array}$ \\
\hline
\end{tabular}

$\begin{array}{llllllllllll}\text { CAL YR } 1975 & \text { TOTAL } & 3957650 & \text { MEAN } & 10840 & \text { MAX } & 19500 & \text { MIN } & 3090 & \text { AC-FT } & 7850000 \\ \text { WTR YR } 1976 & \text { TOTAL } & 3803080 & \text { MEAN } & 10390 & \text { MAX } & 18600 & \text { MIN } & 1950 & \text { AC-FT } & 7543000\end{array}$ 
COLORADO RIVER MAIN STEM

09424000. COLORADO RIVER NEAR TOPOCK, ARIZ,--CONTINUED

MEAN ELEVATION, IN FEET, WATER YEAR OCTOBER 1975 TO SEPTEMBER 1976

\begin{tabular}{|c|c|c|c|c|c|c|c|c|c|c|c|c|}
\hline DAY & OCT & NCV & DE.C & JAN & FEB & MAR & $A P R$ & MAY & JUN & JUL & AUG & SEP \\
\hline $\begin{array}{l}1 \\
2 \\
3 \\
4 \\
5\end{array}$ & $\begin{array}{l}52.70 \\
52.60 \\
52.47 \\
52.69 \\
52.62\end{array}$ & $\begin{array}{l}50.92 \\
50.28 \\
50.45 \\
51.20 \\
51.64\end{array}$ & $\begin{array}{l}50.38 \\
50.58 \\
50.54 \\
50.63 \\
51.13\end{array}$ & $\begin{array}{l}51.00 \\
51.05 \\
50.95 \\
50.70 \\
50.13\end{array}$ & $\begin{array}{l}51.70 \\
50.43 \\
52.43 \\
53.00 \\
52.16\end{array}$ & $\begin{array}{l}52.86 \\
53.35 \\
53.75 \\
54.13 \\
54.12\end{array}$ & $\begin{array}{l}55.34 \\
54.95 \\
54.64 \\
54.38 \\
53.13\end{array}$ & $\begin{array}{l}54.98 \\
54.46 \\
53.84 \\
54.05 \\
54.52\end{array}$ & $\begin{array}{l}54.03 \\
53.67 \\
53.47 \\
53.82 \\
53.82\end{array}$ & $\begin{array}{l}54.33 \\
53.69 \\
54.02 \\
54.00 \\
53.89\end{array}$ & $\begin{array}{l}53.54 \\
53.08 \\
53.68 \\
53.82 \\
53.97\end{array}$ & $\begin{array}{l}53.72 \\
53.50 \\
53.11 \\
53.16 \\
52.83\end{array}$ \\
\hline $\begin{array}{r}6 \\
7 \\
8 \\
9 \\
10\end{array}$ & $\begin{array}{l}51.89 \\
52.78 \\
52.23 \\
52.17 \\
51.94\end{array}$ & $\begin{array}{l}51.36 \\
51.02 \\
50.96 \\
51.03 \\
50.97\end{array}$ & $\begin{array}{l}51.13 \\
51.16 \\
50.00 \\
50.75 \\
50.82\end{array}$ & $\begin{array}{l}49.96 \\
50.38 \\
50.24 \\
50.01 \\
49.76\end{array}$ & $\begin{array}{l}52.59 \\
51.70 \\
50.58 \\
49.44 \\
49.70\end{array}$ & $\begin{array}{l}53.82 \\
53.59 \\
52.34 \\
52.94 \\
53.26\end{array}$ & $\begin{array}{l}54.35 \\
54.42 \\
54.60 \\
54.46 \\
54.75\end{array}$ & $\begin{array}{l}54.74 \\
54.48 \\
52.49 \\
50.76 \\
52.44\end{array}$ & $\begin{array}{l}53.76 \\
53.59 \\
53.83 \\
53.86 \\
53.88\end{array}$ & $\begin{array}{l}54.21 \\
54.38 \\
54.31 \\
54.00 \\
54.00\end{array}$ & $\begin{array}{l}53.97 \\
54.12 \\
53.81 \\
53.72 \\
54.23\end{array}$ & $\begin{array}{l}52.52 \\
52.12 \\
51.81 \\
51.96 \\
52.19\end{array}$ \\
\hline $\begin{array}{l}11 \\
12 \\
13 \\
14 \\
15\end{array}$ & $\begin{array}{l}51.21 \\
50.86 \\
50.99 \\
51.34 \\
51.40\end{array}$ & $\begin{array}{l}50.98 \\
51.08 \\
50.29 \\
50.58 \\
50.56\end{array}$ & $\begin{array}{l}51.13 \\
50.84 \\
50.96 \\
51.07 \\
50.44\end{array}$ & $\begin{array}{l}49.78 \\
49.52 \\
49.82 \\
49.56 \\
49.49\end{array}$ & $\begin{array}{l}49.42 \\
49.25 \\
48.83 \\
48.74 \\
48.63\end{array}$ & $\begin{array}{l}53.05 \\
53.06 \\
53.20 \\
53.32 \\
52.61\end{array}$ & $\begin{array}{l}54.24 \\
53.00 \\
53.71 \\
54.08 \\
51.85\end{array}$ & $\begin{array}{l}54.33 \\
54.53 \\
53.87 \\
52.99 \\
53.55\end{array}$ & $\begin{array}{l}53.94 \\
54.02 \\
54.13 \\
53.43 \\
53.66\end{array}$ & $\begin{array}{l}53.98 \\
53.80 \\
54.11 \\
53.69 \\
53.49\end{array}$ & $\begin{array}{l}54.16 \\
54.01 \\
54.02 \\
54.19 \\
53.86\end{array}$ & $\begin{array}{l}50.85 \\
49.73 \\
49.61 \\
50.10 \\
50.05\end{array}$ \\
\hline $\begin{array}{l}16 \\
17 \\
18 \\
19 \\
20\end{array}$ & $\begin{array}{l}51.34 \\
51 \cdot 35 \\
51 \cdot 70 \\
51 \cdot 65 \\
51.33\end{array}$ & $\begin{array}{l}51.00 \\
49.87 \\
50.92 \\
51.45 \\
51.52\end{array}$ & $\begin{array}{l}51.37 \\
51.32 \\
51.37 \\
51.83 \\
51.51\end{array}$ & $\begin{array}{l}50.17 \\
50.76 \\
51.22 \\
50.08 \\
51.85\end{array}$ & $\begin{array}{l}48.59 \\
48.57 \\
48.55 \\
48.48 \\
48.19\end{array}$ & $\begin{array}{l}53.85 \\
54.05 \\
53.84 \\
53.98 \\
54.72\end{array}$ & $\begin{array}{l}50.88 \\
50.04 \\
50.30 \\
50.36 \\
53.35\end{array}$ & $\begin{array}{l}53.19 \\
53.10 \\
54.22 \\
54.42 \\
53.65\end{array}$ & $\begin{array}{l}53.98 \\
54.30 \\
54.36 \\
54.19 \\
53.87\end{array}$ & $\begin{array}{l}53.41 \\
53.59 \\
53.65 \\
53.22 \\
53.81\end{array}$ & $\begin{array}{l}53.14 \\
53.74 \\
53.72 \\
53.89 \\
53.96\end{array}$ & $\begin{array}{l}50.82 \\
51.12 \\
51.68 \\
51.91 \\
51.55\end{array}$ \\
\hline $\begin{array}{l}21 \\
22 \\
23 \\
24 \\
25\end{array}$ & $\begin{array}{l}51.90 \\
52.02 \\
51.67 \\
51.94 \\
52.43\end{array}$ & $\begin{array}{l}51.16 \\
51.26 \\
51.09 \\
50.00 \\
49.98\end{array}$ & $\begin{array}{l}51.11 \\
50.20 \\
49.90 \\
50.31 \\
50.59\end{array}$ & $\begin{array}{l}51.92 \\
50.94 \\
51.04 \\
51.13 \\
51.45\end{array}$ & $\begin{array}{l}50.28 \\
51.33 \\
50.63 \\
52.13 \\
53.39\end{array}$ & $\begin{array}{l}54.68 \\
52.76 \\
52.92 \\
54.82 \\
54.70\end{array}$ & $\begin{array}{l}54.70 \\
54.82 \\
55.05 \\
55.10 \\
54.65\end{array}$ & $\begin{array}{l}53.57 \\
53.69 \\
53.79 \\
51.09 \\
53.92\end{array}$ & $\begin{array}{l}53.71 \\
53.95 \\
54.14 \\
54.26 \\
53.98\end{array}$ & $\begin{array}{l}53.71 \\
53.67 \\
53.86 \\
53.70 \\
53.38\end{array}$ & $\begin{array}{l}54.00 \\
53.86 \\
53.09 \\
53.69 \\
53.76\end{array}$ & $\begin{array}{l}52.23 \\
52.34 \\
52.54 \\
50.69 \\
50.57\end{array}$ \\
\hline $\begin{array}{l}26 \\
27 \\
28 \\
29 \\
30 \\
31\end{array}$ & $\begin{array}{l}52.55 \\
51.82 \\
51.14 \\
50.84 \\
50.86 \\
51.26\end{array}$ & $\begin{array}{r}49.87 \\
50.22 \\
50.48 \\
50.40 \\
50.13 \\
.--\end{array}$ & $\begin{array}{l}50.42 \\
51.18 \\
51.45 \\
50.16 \\
50.58 \\
50.49\end{array}$ & $\begin{array}{l}50.20 \\
51.50 \\
51.94 \\
52.21 \\
51.98 \\
51.81\end{array}$ & $\begin{array}{r}54.26 \\
53.89 \\
53.67 \\
53.67 \\
=-. \\
=-\end{array}$ & $\begin{array}{l}53.62 \\
55.25 \\
54.81 \\
54.00 \\
55.19 \\
55.37\end{array}$ & $\begin{array}{r}53.85 \\
54.96 \\
55.18 \\
55.26 \\
55.20 \\
.-\end{array}$ & $\begin{array}{l}54.38 \\
53.84 \\
52.98 \\
53.69 \\
53.75 \\
53.57\end{array}$ & $\begin{array}{r}54.11 \\
54.06 \\
53.75 \\
54.03 \\
54.33 \\
. .\end{array}$ & $\begin{array}{l}52.77 \\
53.28 \\
52.74 \\
52.91 \\
53.77 \\
53.74\end{array}$ & $\begin{array}{l}53.77 \\
53.85 \\
54.00 \\
53.77 \\
53.16 \\
53.77\end{array}$ & $\begin{array}{r}49.48 \\
50.27 \\
50.26 \\
50.35 \\
50.42 \\
. . .\end{array}$ \\
\hline $\begin{array}{l}\text { MEAN } \\
\text { MAX } \\
\text { MIN }\end{array}$ & $\begin{array}{l}51.80 \\
52.78 \\
50.86\end{array}$ & $\begin{array}{l}50.79 \\
51.80 \\
49.87\end{array}$ & $\begin{array}{l}50.82 \\
51.83 \\
49.90\end{array}$ & $\begin{array}{l}50.73 \\
52.21 \\
49.49\end{array}$ & $\begin{array}{l}50.84 \\
54.26 \\
48.19\end{array}$ & $\begin{array}{l}53.81 \\
55.37 \\
52.34\end{array}$ & $\begin{array}{l}53.85 \\
55.34 \\
50.04\end{array}$ & $\begin{array}{l}53.64 \\
54.98 \\
50.76\end{array}$ & $\begin{array}{l}53.93 \\
54.36 \\
53.43\end{array}$ & $\begin{array}{l}53.71 \\
54.38 \\
52.74\end{array}$ & $\begin{array}{l}53.79 \\
54.23 \\
53.08\end{array}$ & $\begin{array}{l}51.45 \\
53.72 \\
49.48\end{array}$ \\
\hline
\end{tabular}

CAL YR 1975 MEAN 52.75 MAX 55.74 MIN 49.08

WTR YR 1976 MEAN 52.44 MAX 55.37 MIN 48.19

NOTE. - Add $400.00 \mathrm{ft}$ to obtain elevation above mean sea level. 
09424150. COLORADO RIVER AQUENUCT NEAR PARKER DAM, ARIZ. -CALIF.

LOCATION. - Lat $34^{\circ} 18^{\prime} 58^{\prime \prime}$, long $114^{\circ} 09^{\prime} 23^{\prime \prime}$, in NWbsW. sec. 28 , T.3 N., R. 27 F., San Bernardino meridian, in California, San Bernardino County, at intake pumping plant of Metropolitan Water District of Southern California on Lake Havasu, $1.8 \mathrm{mi}(2.9 \mathrm{~km})$ upstream from Parker Dam and $149 \mathrm{mi}(240 \mathrm{~km})$ downstream from Joover Dam.

PERIOD OF RECORD. --January 1939 to current year (monthly diversions only since October 1942). Published as a supplement to records

for Colorado River below Parker Dam, 1942-50. Percolation return flow (monthly flow only) October 1964 to September 1973 (discontinued); prior to October 1964 miscellaneous measurements only.

GAGE.--Venturi meters in pressure lines at intake pumping plant.

AVERAGE DISCHARGE. -37 years, $865 \mathrm{ft}^{3} / \mathrm{s}\left(24.50 \mathrm{~m}^{3} / \mathrm{s}\right), 626,700 \mathrm{acre}-\mathrm{ft} / \mathrm{yr}\left(773 \mathrm{hm}^{3} / \mathrm{yr}\right)$.

EXTRSiEs.--Period of record: Maximum daily diversion, 3,986 acre- $\mathrm{ft}\left(4.91 \mathrm{hm}^{3}\right), 2,010 \mathrm{ft}^{3} / \mathrm{s}(56.9 \mathrm{~m} / \mathrm{s})$ oct. 25 , $1970 ; \mathrm{no}$ diversion at tines.

REMARKS.--Pumping began Jan. 7, 1939. Figures of monthly diversion shown represent water pumped from Lake Havasu less return surface flow from Gene and Copper Basin Reservoirs. No water returned as surface flow from these reservoirs this year. Percolation return flow from Cene and Copper Basin Reservoirs is estimated as 14 acre-ft/day $\left(17,300 \mathrm{~m}^{3} / \mathrm{day}\right)$ or 5,110 acre-ft $\left(6.30 \mathrm{hm}^{3}\right)$ for the year for accounting purposes.

COOPERATION.--Diversion records furnished by Metropolitan Water District of Southern California.

AONTHLY DIVERSIONS, IN ACRE-FEET, WATER YEAR OCTOBER 1975 TO SEPTEMBER 1976

\begin{tabular}{|c|c|c|c|c|}
\hline \multirow[b]{2}{*}{ Month } & \multicolumn{4}{|c|}{ Diversions } \\
\hline & Maximum & Minimum & Mean & Total \\
\hline 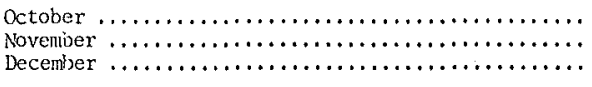 & $\begin{array}{l}2,339 \\
1,538 \\
1,583\end{array}$ & $\begin{array}{l}1,350 \\
1,254 \\
1,338\end{array}$ & $\begin{array}{l}2,207 \\
1,379 \\
1,377\end{array}$ & $\begin{array}{l}68,411 \\
41,371 \\
42,673\end{array}$ \\
\hline 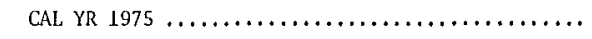 & 3,348 & 0 & 2,155 & 786,757 \\
\hline 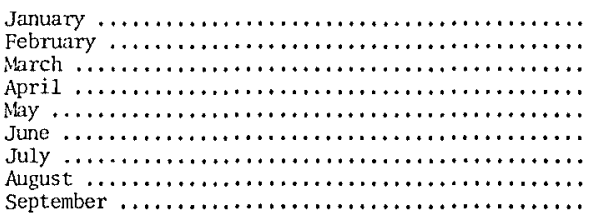 & $\begin{array}{l}2,433 \\
3,045 \\
2,341 \\
2,704 \\
2,758 \\
2,726 \\
3,212 \\
3,294 \\
2,693\end{array}$ & $\begin{array}{r}558 \\
0 \\
2,116 \\
2,103 \\
2,148 \\
2,565 \\
2,825 \\
2,949 \\
2,143\end{array}$ & $\begin{array}{l}1,574 \\
1,830 \\
2,204 \\
2,309 \\
2,511 \\
2,662 \\
3,061 \\
3,061 \\
2,422\end{array}$ & $\begin{array}{l}48,788 \\
53,077 \\
68,320 \\
69,264 \\
77,836 \\
79,845 \\
94,878 \\
94,895 \\
72,675\end{array}$ \\
\hline 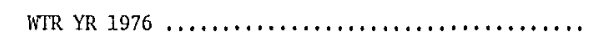 & 3,294 & 0 & 2,219 & 812,033 \\
\hline
\end{tabular}


PERIOD OF RECORD.--Chemical analyses: October 1966 to current year.

REMARKS,--Records of discharge were furnished by Metropolitan Water District of Southern California.

COOPERATION. - Chemica1-quality records were furnished by California Department of Water Resources.

CHEMICAL ANALYSES, WATER YEAR OCTOBER 1975 TO SEPTEMBER 1976

\begin{tabular}{|c|c|c|c|c|c|c|c|c|c|c|}
\hline DATE & TIME & $\begin{array}{l}\text { DIS- } \\
\text { CHARGE } \\
\text { (CFS) }\end{array}$ & $\begin{array}{l}\text { SPE- } \\
\text { CIFIC } \\
\text { CON- } \\
\text { DUCT- } \\
\text { ANCE } \\
\text { (MICRO- } \\
\text { MHOS) }\end{array}$ & $\begin{array}{c}\text { PH } \\
\text { (UNITS) }\end{array}$ & $\begin{array}{l}\text { TEMPER- } \\
\text { ATURE } \\
\text { (DEG C) }\end{array}$ & $\begin{array}{l}\text { TUR- } \\
\text { BIO- } \\
\text { ITY } \\
\text { (JTU) }\end{array}$ & $\begin{array}{l}\text { HARD- } \\
\text { NESS } \\
(C A, M G) \\
(M G / L)\end{array}$ & $\begin{array}{l}\text { NON- } \\
\text { CAR- } \\
\text { BONATE } \\
\text { HARD- } \\
\text { NESS } \\
\text { (MG/L) }\end{array}$ & $\begin{array}{c}\text { DIS- } \\
\text { SOLVED } \\
\text { CAL- } \\
\text { CIUM } \\
\text { (CA) } \\
\text { (MG/L) }\end{array}$ & $\begin{array}{l}\text { DIS- } \\
\text { SOLVE } \\
\text { HAG- } \\
\text { NE- } \\
\text { SIUM } \\
\text { (MG) } \\
\text { (MG/L }\end{array}$ \\
\hline $\begin{array}{l}\text { OCT } \\
05 \ldots . \\
\text { NOV }\end{array}$ & -- & 1124 & 1060 & 8.7 & -- & 1 & 313 & 200 & 76 & 30 \\
\hline DEC & 1450 & -- & 1070 & -- & -- & 1 & 331 & 210 & 83 & 30 \\
\hline JAN $01 \cdots$ & -- & 689 & 1070 & -- & 13.5 & $-\infty$ & 333 & 210 & 83 & 30 \\
\hline$\underset{F E B}{12} \cdots$ & 1220 & $=-$ & 1080 & -- & 10.0 & 1 & 334 & 210 & 85 & 30 \\
\hline MAR 0.9 & -- & 1089 & 1100 & $=-$ & -- & 1 & 339 & 210 & 83 & 32 \\
\hline$\underset{A P R}{08 . . .}$ & 1435 & -- & 1080 & -- & 15.5 & 3 & 336 & 210 & 86 & 30 \\
\hline MAY 04 & 1435 & - & 1090 & -- & 16.5 & 4 & 336 & 210 & 85 & 30 \\
\hline$\underset{\text { JUN }}{02} \cdots$ & -- & 1311 & 1180 & -- & 21.0 & 2 & 331 & 200 & 84 & 30 \\
\hline $14 \ldots$ & $\begin{array}{l}1445 \\
1445\end{array}$ & $=$ & $\begin{array}{l}1090 \\
1090\end{array}$ & -- & $\begin{array}{l}23.5 \\
23.5\end{array}$ & $\begin{array}{l}1 \\
1\end{array}$ & $\begin{array}{l}335 \\
335\end{array}$ & $\begin{array}{l}210 \\
210\end{array}$ & $\begin{array}{l}84 \\
84\end{array}$ & $\begin{array}{l}30 \\
30\end{array}$ \\
\hline $\begin{array}{l}\text { AUG } \\
08 \ldots\end{array}$ & & & & & 26,5 & & & & & \\
\hline $\begin{array}{l}\text { SEP } \\
14 \ldots\end{array}$ & -- & 1306 & 1060 & -- & 20.3 & 1 & 318 & 210 & 77 & 30 \\
\hline
\end{tabular}

\begin{tabular}{|c|c|c|c|c|c|c|c|c|c|}
\hline DATE & $\begin{array}{l}\text { DIS- } \\
\text { SOLVED } \\
\text { SODIUM } \\
\text { (NA) } \\
\text { (MG/L) }\end{array}$ & $\begin{array}{l}\text { PERCENT } \\
\text { SODIUM }\end{array}$ & $\begin{array}{l}\text { SOOIUM } \\
\text { AD- } \\
\text { SORP- } \\
\text { TION } \\
\text { RATIO }\end{array}$ & $\begin{array}{l}\text { DIS- } \\
\text { SOLVED } \\
\text { PO- } \\
\text { TAS- } \\
\text { SIUM } \\
\text { (K) } \\
\text { (MG/L) }\end{array}$ & $\begin{array}{l}\text { BICAR- } \\
\text { BONATE } \\
\text { (HCO3) } \\
\text { (MG/L) }\end{array}$ & $\begin{array}{l}\text { CAR- } \\
\text { BONATE } \\
(\text { CO3) } \\
(N G / L)\end{array}$ & $\begin{array}{l}\text { ALKA- } \\
\text { LINITY } \\
\text { AS } \\
\text { CACO3 } \\
\text { (MG/L) }\end{array}$ & $\begin{array}{c}\text { CARBON } \\
\text { DIOXIDE } \\
\text { (COZ) } \\
(M G / L)\end{array}$ & $\begin{array}{l}\text { DIS- } \\
\text { SOLVED } \\
\text { SULFATE } \\
\text { (SO4) } \\
(M G / L)\end{array}$ \\
\hline OCT & & & & & & & & & \\
\hline $\begin{array}{l}05 . \cdots \\
\text { NOV }\end{array}$ & 111 & 43 & 2.7 & 5.0 & 134 & 4 & 117 & .5 & 305 \\
\hline $\begin{array}{l}02 \\
D E C\end{array}$ & 103 & 40 & 2.5 & 5.0 & 148 & 0 & 121 & -- & 296 \\
\hline JaN & 104 & 40 & 2.5 & 5.0 & 149 & 0 & 122 & $-m$ & 302 \\
\hline$\underset{F E B}{12 \ldots}$ & 106 & 40 & 2.5 & 5.0 & 151 & 0 & 124 & $-\infty$ & 304 \\
\hline $\begin{array}{l}09 . \ldots \\
\text { MAR }\end{array}$ & 109 & 41 & 2.6 & 4.0 & 155 & 1 & 129 & $-\infty$ & 309 \\
\hline$\underset{A P R}{08} \cdots$ & 104 & 40 & 2.5 & 4.7 & 159 & 0 & 130 & -- & 298 \\
\hline MAY 04. & 107 & 41 & 2.5 & 5.0 & 155 & 2 & 130 & -- & 309 \\
\hline JUN & 107 & 41 & 2.6 & 4.8 & 157 & 0 & 129 & -- & 298 \\
\hline $\begin{array}{l}14 \ldots \\
30 \ldots \\
A \cup G\end{array}$ & $\begin{array}{l}106 \\
106\end{array}$ & $\begin{array}{l}40 \\
40\end{array}$ & $\begin{array}{l}2.5 \\
2.5\end{array}$ & $\begin{array}{l}5.0 \\
5.0\end{array}$ & $\begin{array}{l}159 \\
159\end{array}$ & $\begin{array}{l}0 \\
0\end{array}$ & $\begin{array}{l}130 \\
130\end{array}$ & $=$ & $\begin{array}{l}297 \\
297\end{array}$ \\
\hline$\underset{\text { SEP }}{08} \cdots$ & 107 & 42 & 2.6 & 5.0 & 133 & 1 & 111 & $-=$ & 300 \\
\hline $14 \ldots$ & 101 & 41 & 2.5 & 5.0 & 137 & 0 & 112 & -- & 292 \\
\hline
\end{tabular}


09424150 COLORADO RIVER AQUEDUCT NEAR PARKER DAM, ARI2.-CA--Continued

\begin{tabular}{|c|c|c|c|c|c|c|c|c|c|}
\hline DATE & $\begin{array}{l}\text { OIS- } \\
\text { SOLVED } \\
\text { CHLO- } \\
\text { RIDE } \\
\text { (CL) } \\
(M G / L)\end{array}$ & $\begin{array}{l}\text { DIS- } \\
\text { SOLVED } \\
\text { FLUO- } \\
\text { RIDE } \\
\text { (F) } \\
\text { (MG/L) }\end{array}$ & $\begin{array}{l}\text { DIS- } \\
\text { SOLVED } \\
\text { SILICA } \\
\text { (SIOL) } \\
\text { (MG/L) }\end{array}$ & $\begin{array}{l}\text { DIS- } \\
\text { SOLVED } \\
\text { SOLIDS } \\
\text { IRESI- } \\
\text { DUE AT } \\
\text { I80 C) } \\
\text { (MG/L) }\end{array}$ & $\begin{array}{l}\text { DIS- } \\
\text { SOLVED } \\
\text { SOLIDS } \\
\text { (SUM OF } \\
\text { CONSTI- } \\
\text { TUENTS) } \\
\text { (MG/L) }\end{array}$ & $\begin{array}{l}\text { DIS- } \\
\text { SOLVED } \\
\text { SOLIDS } \\
\text { (TONS } \\
\text { PER } \\
\text { AC-FT) }\end{array}$ & $\begin{array}{l}\text { DIS- } \\
\text { SOLVED } \\
\text { SOLIDS } \\
\text { (TONS } \\
\text { PER } \\
\text { DAY) }\end{array}$ & $\begin{array}{l}\text { TOTAL } \\
\text { NON- } \\
\text { FILT- } \\
\text { RABLE } \\
\text { RESIDUE } \\
\text { (MG/L) }\end{array}$ & $\begin{array}{c}\text { TOTAL } \\
\text { NITRATE } \\
\text { (N) } \\
\text { (MG/L) }\end{array}$ \\
\hline $\begin{array}{l}\text { ocr } \\
05 . . . \\
\text { Nov }\end{array}$ & 89 & .4 & 6.6 & 694 & -- & .94 & 2110 & 3 & .00 \\
\hline $\begin{array}{c}02 \ldots \\
\mathrm{DEC}\end{array}$ & 90 & .2 & 7.6 & 689 & -- & .94 & -- & 2 & .09 \\
\hline JAN $01 . \cdots$ & 91 & .5 & 7.4 & 698 & $\cdots$ & .95 & 1300 & 4 & .04 \\
\hline $\begin{array}{c}12, \ldots \\
F E B \\
09 .\end{array}$ & 92 & .5 & 9.2 & 707 & - & .96 & 2110 & $\cdots$ & $\begin{array}{l}.11 \\
.07\end{array}$ \\
\hline $\begin{array}{r}09 . \cdots \\
\text { MAR } \\
08 . .\end{array}$ & 91 & .4 & 8,7 & 716 & & .97 & 2110 & -- & \\
\hline $\begin{array}{r}08 \ldots \\
\text { APR } \\
04 \ldots\end{array}$ & 89 & $0^{4}$ & 9.4 & - & 700 & • 95 & $-\infty$ & - & .16 \\
\hline & 89 & 3 & 4.4 & 696 & $\ldots$ & .95 & 2460 & -- & .09 \\
\hline $\begin{array}{l}J \cup N \\
14 \ldots\end{array}$ & . & 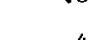 & 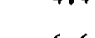 & $0>0$ & - & & & . & \\
\hline $\begin{array}{l}14 \ldots \ldots \\
30 \ldots \\
A \cup G\end{array}$ & $\begin{array}{l}90 \\
90\end{array}$ & .44 & $\begin{array}{l}6.6 \\
6.6\end{array}$ & $\begin{array}{l}700 \\
700\end{array}$ & $6 \overline{97}$ & .95 & $=$ & 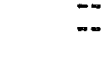 & $\begin{array}{r}.18 \\
.18\end{array}$ \\
\hline $\begin{array}{l}08 . . \\
\text { SEP }\end{array}$ & 90 & .3 & 8.0 & 684 & -- & .93 & 2830 & $\cdots$ & .00 \\
\hline $14 \ldots$ & 90 & .3 & 8.7 & 673 & -- & .92 & 2370 & 3 & .02 \\
\hline
\end{tabular}


09424190 COLORADO RIVER AQUEDUCT NEAR SAN JACINTO, CA

(Nationa 1 stream-quality accounting network station)

WATER-QUALITY RECORDS

LOCATION, - Lat $33^{\circ} 49^{\prime} 18^{\prime \prime}$, long $116^{\circ} 58^{\prime} 01^{\prime \prime}$, in NEt/ sec.15, T.4 S., R. 1 W., San Bernardino County, at west portal of San Jacinto Tunne1, $1.7 \mathrm{mi}(2.8 \mathrm{~km})$ southeast of Gilman Hot Springs, and $2.5 \mathrm{mi}(40 \mathrm{~km})$ north of San Jacinto.

PERIOD OF RECORD. - Water year 1975 to current year.

CHEMICAL ANALYSES: Water year 1975 to current year.

SEDIMENT RECORDS: Water year 1975 to current year (partial-record station).

REMARKS.--Discharge values were furnished by Metropolitan Water District from the aqueduct records.

CHEMICAL ANALYSES, WATER YEAR OCTOBER 1975 TO SEPTEMRER 1976

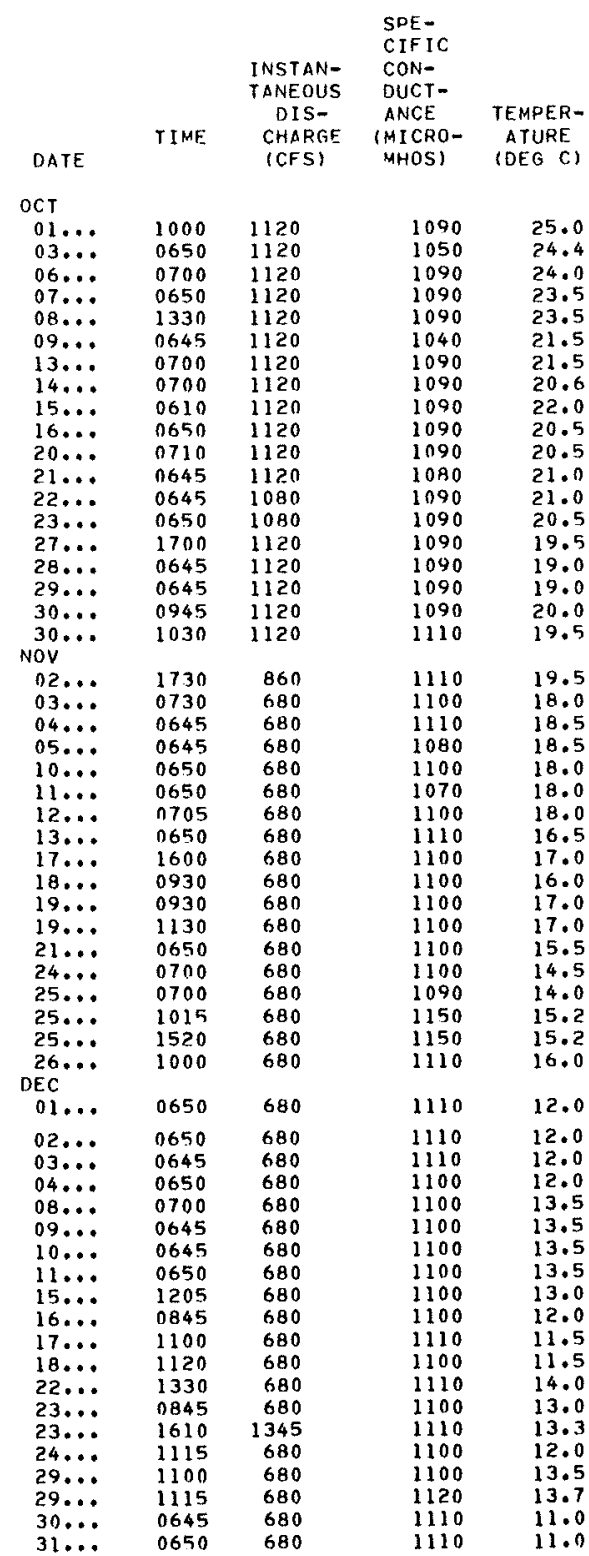


09424190 COLORADO RIVER AQUEDUCT NEAR SAN JACINTO, CA--Continued

CHEMICAL ANALYSES, HATER YEAR OCTOBER 1975 TO SEPTEMBER 1976

\begin{tabular}{|c|c|c|c|c|}
\hline DATE & I IME & $\begin{array}{l}\text { INSTAN- } \\
\text { TANEOUS } \\
\text { DIS- } \\
\text { CHARGE } \\
\text { (CFS) }\end{array}$ & $\begin{array}{l}\text { SPE - } \\
\text { CIFIC } \\
\text { CON- } \\
\text { DUCT- } \\
\text { ANCE } \\
\text { (MICRO- } \\
\text { MHOS) }\end{array}$ & $\begin{array}{l}\text { TEMPER- } \\
\text { ATURE } \\
\text { (DEG C) }\end{array}$ \\
\hline $\begin{array}{r}\text { JAN } \\
05 \ldots . . \\
06 \ldots \\
07 \ldots \\
08 \ldots \\
12 \ldots \\
13 \ldots \\
14 \ldots \\
15 \ldots \\
19 \ldots \\
20 \ldots \\
21 \ldots \\
23 \ldots \\
26 \ldots \\
27 \ldots \\
28 \ldots \\
29 \ldots \\
30 \ldots \\
30 \ldots \\
\text { FEB }\end{array}$ & $\begin{array}{l}1650 \\
0700 \\
0700 \\
0645 \\
0710 \\
0830 \\
1540 \\
1500 \\
0700 \\
0940 \\
1230 \\
0730 \\
1100 \\
0900 \\
0830 \\
1100 \\
1100 \\
1115\end{array}$ & $\begin{array}{r}680 \\
680 \\
680 \\
680 \\
680 \\
680 \\
680 \\
680 \\
680 \\
680 \\
680 \\
680 \\
680 \\
870 \\
870 \\
1110 \\
1120 \\
1120\end{array}$ & $\begin{array}{l}11110 \\
11100 \\
1120 \\
1110 \\
1110 \\
1110 \\
1110 \\
1110 \\
1110 \\
1110 \\
1110 \\
1110 \\
1100 \\
1110 \\
11120 \\
1120 \\
1130 \\
1100\end{array}$ & $\begin{array}{l}11.0 \\
10.0 \\
10.0 \\
10.5 \\
10.0 \\
10.0 \\
11.0 \\
11.0 \\
10.5 \\
13.0 \\
13.0 \\
12.0 \\
13.0 \\
13.0 \\
12.0 \\
13.0 \\
13.0 \\
14.0\end{array}$ \\
\hline $02 \ldots$ & 0900 & 1120 & 1113 & 13.0 \\
\hline $\begin{array}{l}03 \ldots \\
04 \ldots \\
05 \ldots \\
09 \ldots \\
10 \ldots \\
11 \ldots \\
12 \ldots \\
24 \ldots \\
25 \ldots \ldots \\
26 \ldots \\
27 \ldots \\
27 \ldots \\
\text { MAR }\end{array}$ & $\begin{array}{l}0900 \\
1850 \\
1850 \\
0700 \\
0700 \\
0700 \\
0700 \\
1115 \\
1340 \\
0700 \\
0700 \\
1045\end{array}$ & $\begin{array}{l}1120 \\
1110 \\
1110 \\
1110 \\
1110 \\
1110 \\
1120 \\
1349 \\
1340 \\
1340 \\
1340 \\
1340\end{array}$ & $\begin{array}{l}1107 \\
1109 \\
1116 \\
1110 \\
1086 \\
1078 \\
1090 \\
1108 \\
1116 \\
1113 \\
1100 \\
1100\end{array}$ & $\begin{array}{l}13.0 \\
12.0 \\
12.0 \\
13.0 \\
13.0 \\
13.0 \\
13.0 \\
14.0 \\
12.0 \\
14.0 \\
14.0 \\
15.2\end{array}$ \\
\hline $\begin{array}{l}01 \ldots \\
02 \ldots \\
03 \ldots \\
04 \ldots \\
08 \ldots \\
09 \ldots \\
10 \ldots \\
11 \ldots \\
15 \ldots \\
16 \ldots \\
17 \ldots \\
18 \ldots \\
22 \ldots \\
23 \ldots \\
24 \ldots \\
24 \ldots \\
25 \ldots \\
29 \ldots \\
30 \ldots \\
31 \ldots \\
A P R\end{array}$ & $\begin{array}{l}1600 \\
0700 \\
0645 \\
1530 \\
1600 \\
0645 \\
0650 \\
0700 \\
0700 \\
0650 \\
0645 \\
0650 \\
0655 \\
0700 \\
0645 \\
1040 \\
0650 \\
0700 \\
0650 \\
0650\end{array}$ & $\begin{array}{l}1330 \\
1340 \\
1110 \\
1110 \\
11110 \\
11110 \\
1110 \\
11110 \\
1110 \\
11110 \\
11110 \\
11110 \\
1110 \\
11110 \\
11110 \\
11100 \\
11110 \\
11110 \\
11110 \\
11107\end{array}$ & $\begin{array}{l}1149 \\
1073 \\
1088 \\
1104 \\
1138 \\
1102 \\
1110 \\
1042 \\
1086 \\
1077 \\
1048 \\
1132 \\
1091 \\
1081 \\
1087 \\
1140 \\
1098 \\
1090 \\
1078 \\
1091\end{array}$ & $\begin{array}{l}14.0 \\
14.0 \\
14.0 \\
14.0 \\
15.0 \\
14.0 \\
14.0 \\
14.0 \\
14.0 \\
14.0 \\
14.0 \\
14.0 \\
14.0 \\
14.0 \\
16.0 \\
17.5 \\
16.0 \\
15.0 \\
16.0 \\
16.0\end{array}$ \\
\hline $\begin{array}{l}01 \ldots \\
05 \ldots \\
06 \ldots \\
07 \ldots \\
08 \ldots \\
12 \ldots\end{array}$ & $\begin{array}{l}0645 \\
0700 \\
0645 \\
0650 \\
0650 \\
0700\end{array}$ & $\begin{array}{l}11107 \\
11105 \\
11105 \\
11105 \\
11105 \\
11115\end{array}$ & $\begin{array}{l}1089 \\
1090 \\
1066 \\
1069 \\
1086 \\
1090\end{array}$ & $\begin{array}{l}16.0 \\
16.0 \\
16.0 \\
16.0 \\
17.0 \\
17.0\end{array}$ \\
\hline $\begin{array}{l}13 \ldots \\
14 \ldots \\
19 \ldots \\
20 \ldots \\
21 \ldots \\
22 \ldots \\
26 \ldots \\
27 \ldots \\
29 \ldots \\
30 \ldots\end{array}$ & $\begin{array}{l}0650 \\
0700 \\
0700 \\
0645 \\
0645 \\
0650 \\
0700 \\
0645 \\
0700 \\
1000\end{array}$ & $\begin{array}{l}11105 \\
11105 \\
11105 \\
11105 \\
11105 \\
11105 \\
13335 \\
1320 \\
1318 \\
1320\end{array}$ & $\begin{array}{l}1088 \\
1092 \\
1088 \\
1088 \\
1078 \\
1055 \\
1087 \\
1094 \\
1085 \\
1110\end{array}$ & $\begin{array}{l}18.0 \\
16.0 \\
17.0 \\
18.0 \\
18.0 \\
18.0 \\
19.0 \\
19.0 \\
19.0 \\
21.5\end{array}$ \\
\hline
\end{tabular}


09424190 COLORADO RIVER AQUEDUCT NEAR SAN JACINTO, CA--Continued

CHEMICAL ANALYSES, WATER YEAR OCTOBER 1975 TO SEPTEMRER 1976

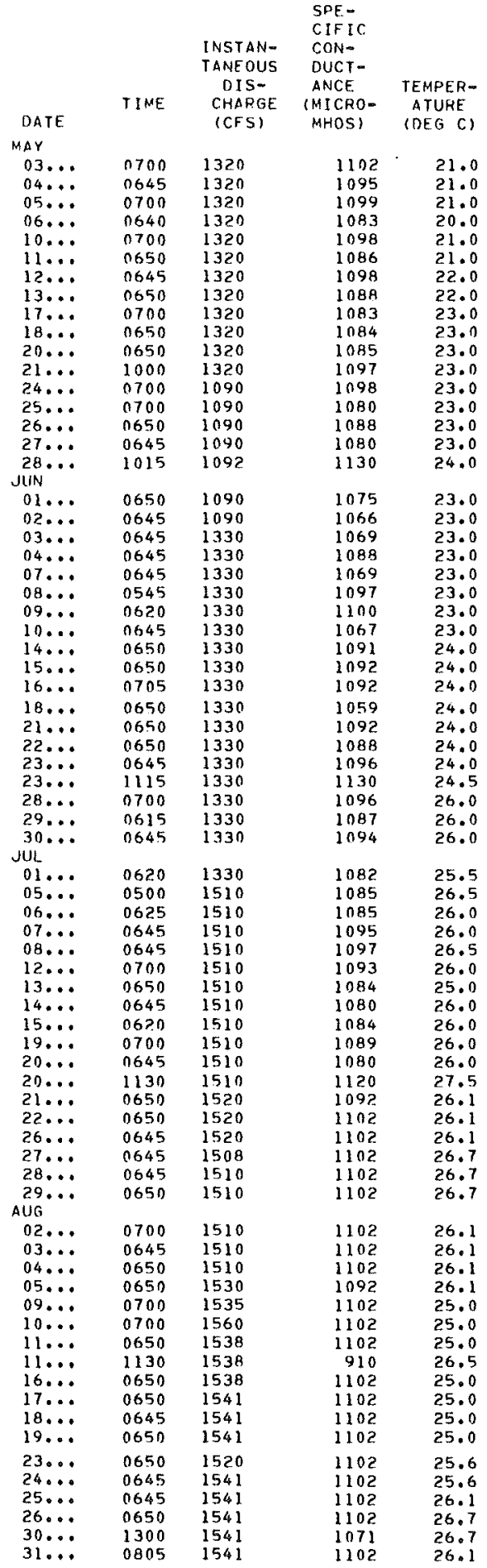


09424190 COLORADO RIVER AQUEDUCT NEAR SAN JACINTO, CA--Continued

CHEMICAL ANALYSES. WATER YEAR OCTOBER 1975 TO SEPTEMAER 1976

\begin{tabular}{|c|c|c|c|c|}
\hline DATE & TIME & $\begin{array}{l}\text { INSTAN- } \\
\text { TANEOUS } \\
\text { OIS- } \\
\text { CHARGE } \\
\text { (CFS) }\end{array}$ & $\begin{array}{l}\text { SPE- } \\
\text { CIFIC } \\
\text { CON- } \\
\text { DUCT- } \\
\text { ANCE } \\
\text { (MICHO- } \\
\text { MHOS) }\end{array}$ & $\begin{array}{l}\text { TEMPER- } \\
\text { ATURE } \\
\text { (DEG C) }\end{array}$ \\
\hline \multicolumn{5}{|l|}{ SFP } \\
\hline $01 \ldots$ & $O B 10$ & 1541 & 1102 & 26.1 \\
\hline $03 \ldots$ & 0805 & 1349 & 1102 & 26.1 \\
\hline $07 \ldots$ & 0745 & 1349 & 1102 & 26.1 \\
\hline $08 \ldots$ & 0810 & 1349 & 1102 & 26.1 \\
\hline $09 \ldots$ & 0755 & 1349 & 1102 & 26.1 \\
\hline $09 \ldots$ & 1145 & 1349 & 970 & 26.0 \\
\hline $10 \ldots$ & 0745 & 1349 & 1065 & 26.1 \\
\hline $13 \ldots$ & 0705 & 1320 & 1043 & 25.0 \\
\hline $14 \ldots$ & 0650 & 1354 & 1066 & 25.0 \\
\hline $15 \ldots$ & 0650 & 1334 & 1066 & 25.0 \\
\hline $16 \ldots$ & 0655 & 1334 & 1066 & 25.0 \\
\hline $17 \ldots$ & 0720 & 1137 & 1060 & 25.0 \\
\hline $20 \ldots$ & 0700 & 1137 & 1069 & 25.0 \\
\hline $21 \ldots$ & 0650 & 1137 & 1054 & 25.0 \\
\hline $22 \ldots$ & 0645 & 1123 & 1066 & 25.0 \\
\hline $23, \ldots$ & 0655 & 1136 & 1067 & 25.0 \\
\hline $27 \ldots$ & 0710 & 1136 & 1054 & 25.0 \\
\hline $28 \ldots$ & 0650 & 1136 & 1046 & 25.0 \\
\hline $29 \ldots$ & 1300 & 1136 & 1053 & 25.6 \\
\hline $30 \ldots$ & 0650 & 1136 & 1055 & 25.0 \\
\hline
\end{tabular}

\begin{tabular}{|c|c|c|c|c|c|c|c|c|c|c|c|c|c|}
\hline DATE & TIME & $\begin{array}{l}\text { INSIAN- } \\
\text { TANEOUS } \\
\text { DIS- } \\
\text { CHARGE } \\
\text { (CFS) }\end{array}$ & $\begin{array}{c}P H \\
\text { (UNIIS) }\end{array}$ & $\begin{array}{l}\text { TUR- } \\
\text { BID- } \\
\text { ITY } \\
\text { (JTU) }\end{array}$ & \multicolumn{2}{|c|}{$\begin{array}{l}\text { FECAL } \\
\text { COLI - } \\
\text { FORM } \\
\text { ICOL. } \\
\text { PFR }\end{array}$} & \multicolumn{2}{|c|}{$\begin{array}{l}\text { STREP- } \\
\text { TOCOCCI } \\
\text { ICOL- } \\
\text { ONIES } \\
\text { PER }\end{array}$} & $\begin{array}{l}\text { HARD - } \\
\text { NESS } \\
(C A, M G) \\
(M G / L)\end{array}$ & $\begin{array}{l}\text { NON- } \\
\text { CAR- } \\
\text { BONATE } \\
\text { HARD- } \\
\text { NESS } \\
\text { (MG/L) }\end{array}$ & $\begin{array}{l}\text { DIS- } \\
\text { SOLVED } \\
\text { CAL- } \\
\text { CIUH } \\
\text { (CA) } \\
\text { (MG/L) }\end{array}$ & $\begin{array}{l}\text { OIS- } \\
\text { SOLVED } \\
\text { MAG - } \\
\text { NE- } \\
\text { SIUM } \\
(M G) \\
(M G / L)\end{array}$ & $\begin{array}{l}\text { DIS- } \\
\text { SOLVED } \\
\text { SODIUM } \\
\text { (NA) } \\
\text { (NG/L) }\end{array}$ \\
\hline $\mathrm{OCT}$ & & & & & & & & & & & & & \\
\hline $\begin{array}{l}30 \ldots \\
\text { NOV }\end{array}$ & 1030 & 1120 & B. 4 & 0 & & 0 & & B12 & 320 & 190 & 81 & 28 & 110 \\
\hline DEC $^{25} \ldots$ & 1015 & 680 & 8.4 & 1 & & 0 & & 83 & 320 & 200 & 80 & 30 & 110 \\
\hline${ }_{\text {JAN }}^{29} \ldots$ & 1115 & 680 & 8.4 & 1 & & 0 & & 0 & 330 & 200 & 83 & 29 & 110 \\
\hline$\underset{F E R}{30} \cdots$ & 1100 & 1120 & 8.5 & 15 & & BI & & 0 & 320 & 200 & 82 & 29 & 110 \\
\hline $\begin{array}{l}27 \ldots \\
\text { MAR }\end{array}$ & 1045 & 1340 & 8.4 & 2 & & 81 & & 86 & 330 & 200 & 84 & 29 & 100 \\
\hline$\underset{A P R}{24 \ldots}$ & 1040 & 1110 & 8.6 & 1 & & 0 & & 81 & 310 & 180 & 82 & 26 & 100 \\
\hline $\begin{array}{l}30 \\
\text { MAY }\end{array}$ & 1000 & 1320 & 8.4 & 1 & & 0 & & 82 & 330 & 190 & 82 & 30 & 110 \\
\hline$\underset{\text { JUN }}{28} \cdots$ & 1015 & 1092 & 9.1 & 1 & & $-\infty$ & & -- & 340 & 210 & 85 & 30 & 110 \\
\hline$\underset{\text { JUL }}{23 . \ldots}$ & 1115 & 1330 & 8.5 & 2 & & 1 & & 11 & 340 & -- & 83 & 31 & 110 \\
\hline $\begin{array}{l}20 \\
\text { AUG }\end{array}$ & 1130 & 1510 & 8.4 & 0 & & 0 & & 87 & 340 & 210 & 86 & 31 & 110 \\
\hline $\operatorname{SEP}_{11} \cdots$ & 1130 & 1538 & 8.4 & 1 & & Bl & & B4 & 330 & 200 & 84 & 29 & 110 \\
\hline $09 \ldots$ & 1145 & 1349 & 7.7 & 1 & & 0 & & $B 9$ & 310 & 190 & 78 & 29 & 100 \\
\hline
\end{tabular}

B Results based on colony count outside the acceptable range (non-ideal colony count). 
09424190 COLORADO RIVER AQUEDUCT NEAR SAN JACINTO, CA--Continued

CHEMICAL ANALYSES, WATER YEAR OCTOBER 1975 TO SEPTEMBER 1976

\begin{tabular}{|c|c|c|c|c|c|c|c|c|c|c|c|}
\hline DATE & $\begin{array}{r}\text { PERCENT } \\
\text { SODIUM }\end{array}$ & $\begin{array}{l}\text { SOOIUM } \\
\text { AD- } \\
\text { SORP- } \\
\text { TION } \\
\text { RATIO }\end{array}$ & $\begin{array}{l}\text { DIS- } \\
\text { SOLVED } \\
\text { PO- } \\
\text { TAS- } \\
\text { SIUM } \\
\text { (K) } \\
\text { (MG/L) }\end{array}$ & $\begin{array}{l}\text { BICAR- } \\
\text { BONATE } \\
\text { (HCO3) } \\
\text { (MG/L) }\end{array}$ & $\begin{array}{l}\text { CAR- } \\
\text { BONATE } \\
\text { (CO3) } \\
(M G / L)\end{array}$ & $\begin{array}{l}\text { ALKA- } \\
\text { LINITY } \\
\text { AS } \\
\text { CACO3 } \\
\text { (MGIL) }\end{array}$ & $\begin{array}{l}\text { CARBON } \\
\text { DIOXIDE } \\
\text { (CO2) } \\
\text { (MG/L) }\end{array}$ & $\begin{array}{l}\text { DIS- } \\
\text { SOLVED } \\
\text { SILFATE } \\
\text { (SO4) } \\
\text { (MG/L) }\end{array}$ & $\begin{array}{l}\text { DIS- } \\
\text { SOLVF.D } \\
\text { CHLO- } \\
\text { RIDE } \\
\text { (CL) } \\
(M G / L)\end{array}$ & $\begin{array}{l}\text { DIS- } \\
\text { SOLVEO } \\
\text { FLUO- } \\
\text { RIDE } \\
\text { (F) } \\
(M G / L)\end{array}$ & $\begin{array}{l}\text { DIS- } \\
\text { SOLVED } \\
\text { SILICA } \\
\text { (SIOZ) } \\
\text { (MG/L) }\end{array}$ \\
\hline NCT & & & & & & & & & & & \\
\hline $\begin{array}{l}3 n . . . \\
\text { NOV }\end{array}$ & 42 & 2.7 & 5.2 & 133 & 9 & 124 & 1.0 & 290 & 92 & .3 & 7.8 \\
\hline $\begin{array}{l}25 . . \\
\text { DEC }\end{array}$ & 42 & 2.7 & 5.4 & 147 & 0 & 121 & .9 & 300 & 90 & .4 & 8.3 \\
\hline$\underset{\text { JAN }}{29 . \cdots}$ & 42 & 2.6 & 5.7 & 154 & 0 & 126 & 1.0 & 290 & 91 & .2 & 7.8 \\
\hline$\underset{F E F}{30 \ldots}$ & 42 & 2.7 & 5.0 & 155 & 0 & 127 & .8 & 300 & 91 & .3 & 7.5 \\
\hline$\underset{M A R}{27} \cdots$ & 39 & 2.4 & 4.8 & 159 & o & 130 & 1.0 & 290 & 89 & .4 & 7.9 \\
\hline$\underset{A P R}{24} \cdots$ & 41 & 2.5 & 5.5 & 159 & 0 & 130 & .6 & 280 & 89 & .3 & 7.3 \\
\hline $\begin{array}{l}30 \ldots \\
\text { MAY }\end{array}$ & 42 & 2.6 & 5.2 & 151 & 6 & 130 & 1.0 & 300 & 87 & .4 & 5.2 \\
\hline 2A... & 41 & 2.6 & 4.9 & 156 & 0 & 128 & $\cdot 2$ & 310 & 92 & .5 & 5.7 \\
\hline$\underset{\text { JUL }}{23} \cdots$ & 41 & 2.6 & 4.7 & -- & -- & -- & -- & 300 & 90 & .4 & 7.6 \\
\hline AUG & 41 & 2.6 & 5.2 & 157 & 0 & 129 & 1.0 & 290 & 91 & .3 & 8.0 \\
\hline$\underset{S F P}{11 . . .}$ & 42 & 2.6 & 5.0 & 157 & 0 & 129 & 1.0 & 300 & 90 & .3 & 8.7 \\
\hline $09 \ldots$ & 40 & 2.5 & 5.3 & 147 & 0 & 121 & 4.7 & 300 & 89 & .3 & 8.5 \\
\hline
\end{tabular}

\begin{tabular}{|c|c|c|c|c|c|c|c|c|c|c|}
\hline DATE & $\begin{array}{l}\text { DIS- } \\
\text { SOLVED } \\
\text { SOLIDS } \\
\text { (RESI- } \\
\text { DUE AT } \\
\text { IEO C) } \\
\text { (MG/L) }\end{array}$ & $\begin{array}{l}\text { OIS- } \\
\text { SOLVEO } \\
\text { SOLIDS } \\
\text { ISUM OF } \\
\text { CONSTI- } \\
\text { TUENTS) } \\
\text { (MG/L) }\end{array}$ & $\begin{array}{l}\text { DIS- } \\
\text { SOLVED } \\
\text { SOLIDS } \\
\text { (TONS } \\
\text { PER } \\
\text { AC-FT) }\end{array}$ & $\begin{array}{l}\text { OIS- } \\
\text { SOLVED } \\
\text { SOLIDS } \\
\text { (TONS } \\
\text { PER } \\
\text { DAY) }\end{array}$ & $\begin{array}{c}\text { TOTAL } \\
\text { NITRITE } \\
\text { PLUS } \\
\text { NITRATE } \\
\text { (N) } \\
\text { (MG/L) }\end{array}$ & $\begin{array}{l}\text { TOTAL } \\
\text { KJEL- } \\
\text { DAHL } \\
\text { NITRO- } \\
\text { GEN } \\
\text { (N) } \\
\text { (MG/L) }\end{array}$ & $\begin{array}{l}\text { TOTAL } \\
\text { NITRO- } \\
\text { GEN } \\
\text { (N) } \\
\text { (MG/L) }\end{array}$ & $\begin{array}{l}\text { TOTAL } \\
\text { NITRO- } \\
\text { GEN } \\
\text { (NO3) } \\
\text { (MG/L) }\end{array}$ & $\begin{array}{l}\text { TOTAL } \\
\text { PHOS- } \\
\text { PHORUS } \\
\text { (P) } \\
\text { (MG/L) }\end{array}$ & $\begin{array}{l}\text { TOTALL } \\
\text { PHYTO- } \\
\text { PLANK- } \\
\text { ION } \\
\text { (CELLS } \\
\text { PER } \\
\text { ML) }\end{array}$ \\
\hline $\begin{array}{l}\text { Oct } \\
30 \ldots\end{array}$ & & & & & & & & & & \\
\hline $\begin{array}{c}30 \\
\text { NOV }\end{array}$ & 727 & 689 & .99 & 2200 & .11 & .46 & .57 & 2.5 & .00 & 2200 \\
\hline$\underset{D E C}{25 \ldots}$ & 724 & 697 & .98 & 1330 & .15 & .38 & .53 & 2.3 & .00 & 980 \\
\hline $\operatorname{JAN}_{\text {JaN }}^{29}$ & 727 & 693 & .99 & 1340 & .17 & .39 & .56 & 2.5 & .01 & 720 \\
\hline$\underset{F F B}{30 . . .}$ & 730 & 701 & 99 & 2210 & .23 & .56 & .79 & 3.5 & .00 & 3200 \\
\hline$\underset{\text { MAR }}{27} \cdots$ & 724 & 683 & .98 & 2620 & .16 & .40 & .56 & 2.5 & .01 & 250 \\
\hline$\underset{A P R}{24 \cdots}$ & 703 & 668 & .96 & 2110 & .18 & .21 & .39 & 1.7 & .01 & 520 \\
\hline $\operatorname{MAY}_{M}^{30} \cdots$ & 720 & 700 & .99 & 2590 & .22 & .31 & .53 & 2,3 & .00 & 2300 \\
\hline$\underset{\text { JUN }}{28} \cdots$ & 730 & 715 & .99 & 2150 & .13 & .51 & .64 & 2.8 & .01 & 3800 \\
\hline${ }_{J U L}^{23} \cdots$ & $\cdots$ & -- & $\cdots$ & -- & .17 & .50 & .67 & 3.0 & .01 & 4200 \\
\hline $\begin{array}{c}20 \\
\text { AUG }\end{array}$ & 721 & 699 & .98 & 2940 & .18 & .24 & .42 & 1.9 & .00 & 2500 \\
\hline $\operatorname{sep}_{11}^{11} \cdot$ & 704 & 704 & .96 & 2920 & .14 & .34 & .48 & 2.1 & .01 & 3600 \\
\hline $09 .$. & 701 & 683 & .95 & 2550 & .13 & .55 & .68 & 3.0 & .00 & 1900 \\
\hline
\end{tabular}


09424190 COLORADO RIVER AQUEDUCT NEAR SAN JACINTO, CA--Continued

QUALITATIVE AND ASSOCIATED QUANTITATIVE ANALYSES OF BIOLOGICAL DATA, WATER YEAR OCTOBER 1975 TO SEPTEMBER 1976 PHYTOPLANKTON

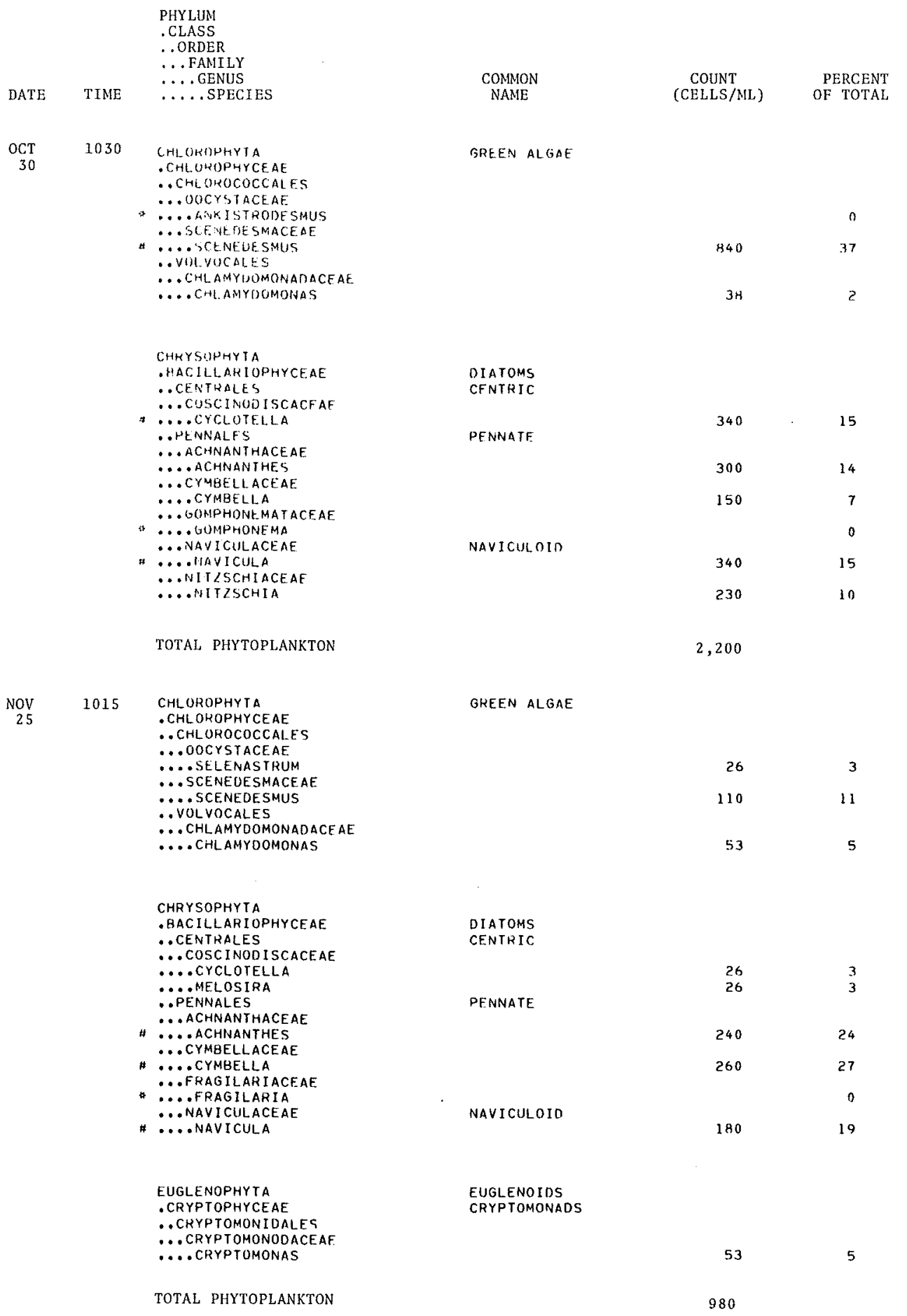

See footnotes at end of table. 
09424190 COLORADO RIVER AQUEDUCT NEAR SAN JACINTO, CA- - Continued

QUALITATIVE AND ASSOCIATED QUANTITATIVE ANALYSES OF BIOLOGICAL DATA, WATER YEAR OCTOBER 1975 TO SEPTEMBER 1976 PHYTOPLANKTON

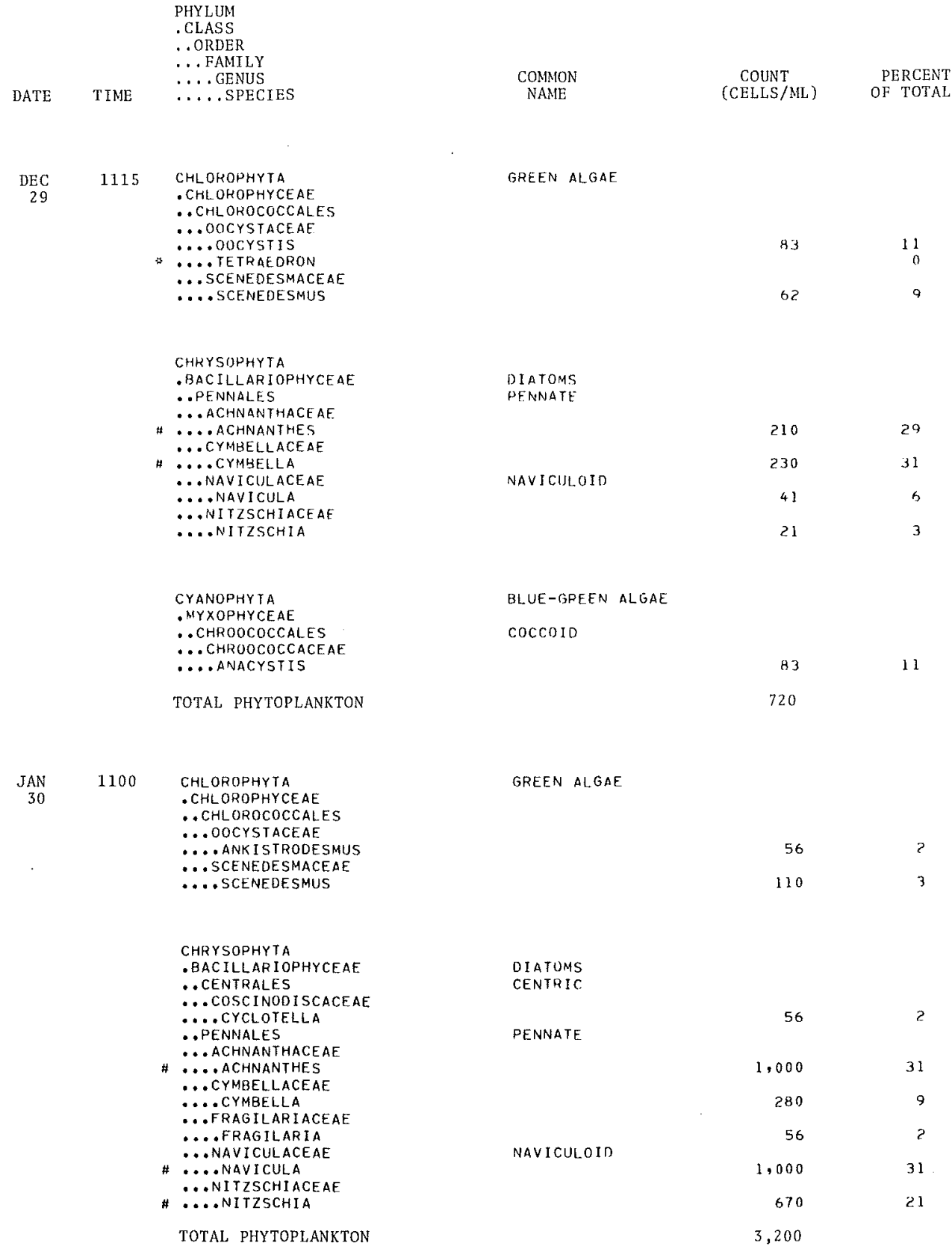

See footnotes at end of table. 
09424190 COLORADO RIVER AQUEDUCT NEAR SAN JACINTO, CA -Continued

QUALITATIVE AND ASSOCIATED QUANTITATIVE ANALYSES OF BIOLOGICAL DATA, WATER YEAR OCTOBER 1975 TO SEPTEMBER 1976 PHYTOPLANKTON

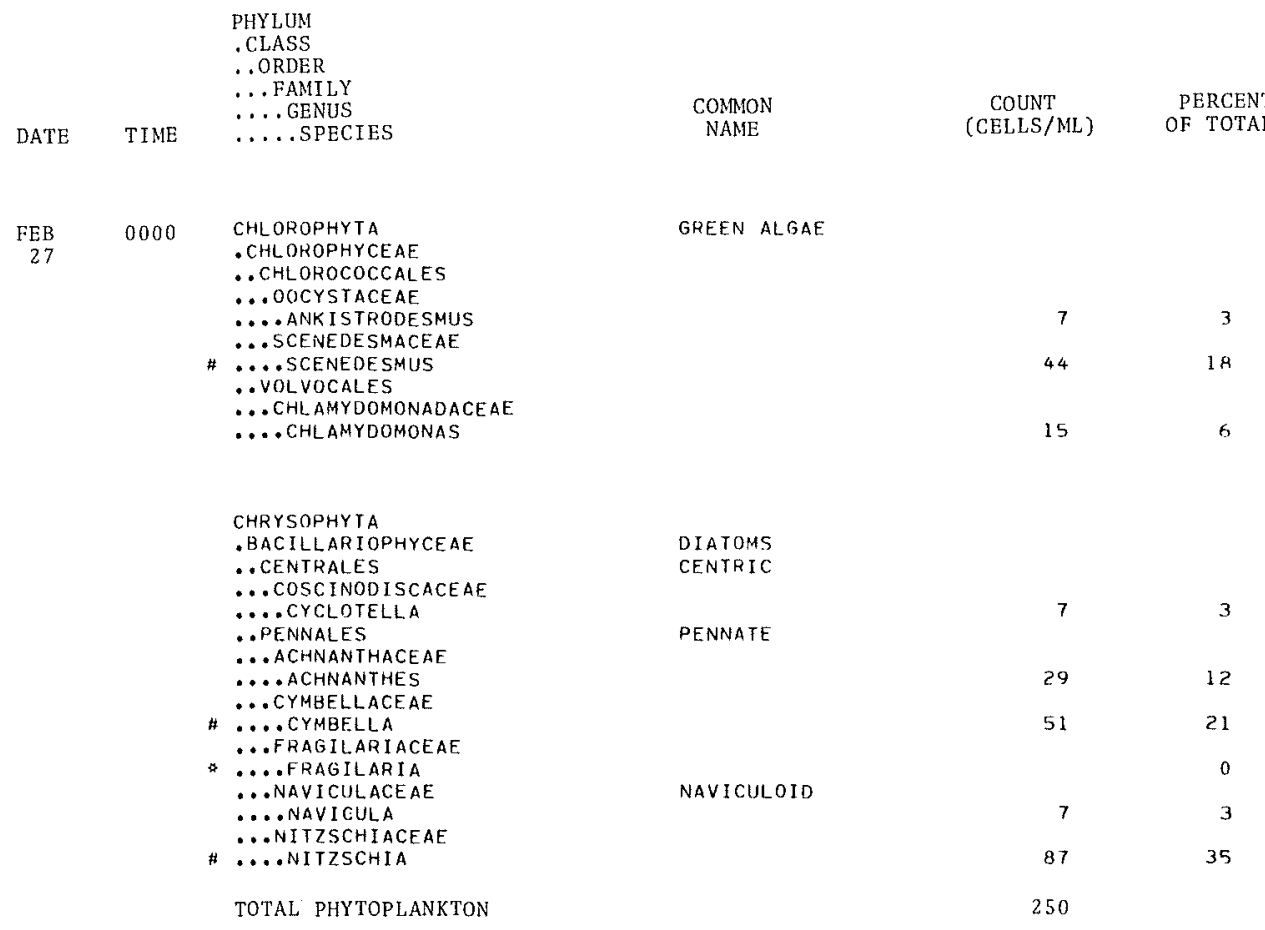

\begin{tabular}{|c|c|c|}
\hline $\begin{array}{r}\text { MAR } \\
24\end{array}$ & 1040 & $\begin{array}{l}\text { CHLOROPHYTA } \\
\text { CHLOROPHYCEAE } \\
\ldots \text { CHLOROCOCCALES } \\
\ldots \text { OOCYSTACEAE } \\
\ldots \text { ANKISTRODESMUS } \\
\ldots \text { OOOCYSTIS } \\
\ldots \text { SELENASTRUM } \\
\ldots \text { SCENEDESMACEAE } \\
\ldots \text { CRUCIGENIA } \\
\ldots \text { SCENEOESMUS } \\
\ldots \text { VOLVOCALES } \\
\ldots \text { CHLAMYDOMONADACEAE } \\
\ldots \text { CARTERIA } \\
\ldots \text { CHLAMYDOMONAS }\end{array}$ \\
\hline
\end{tabular}

GREEN ALGAE

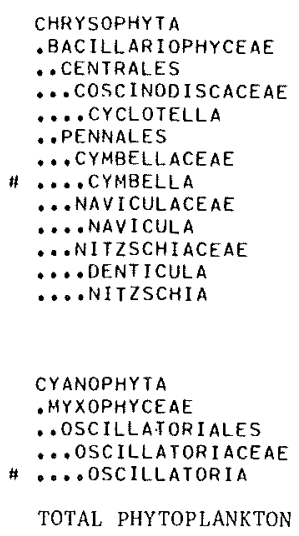

PENNATE

NAVICULOID

$\begin{array}{rr}23 & 4 \\ 92 & 18 \\ 11 & 2 \\ 11 & 2 \\ 23 & 4\end{array}$

BLUE-GREEN ALGAE

FILAMENTOUS 
09424190 COLORADO RIVER AQUEDUCT NEAR SAN JACINTO, CA--Continued

QUALITATIVE AND ASSOCIATED QUANTITATIVE ANALYSES OF BIOLOGICAL DATA, WATER YEAR OCTOBER 1975 TO SEPTEMBER 1976 PHYTOPLANKTON

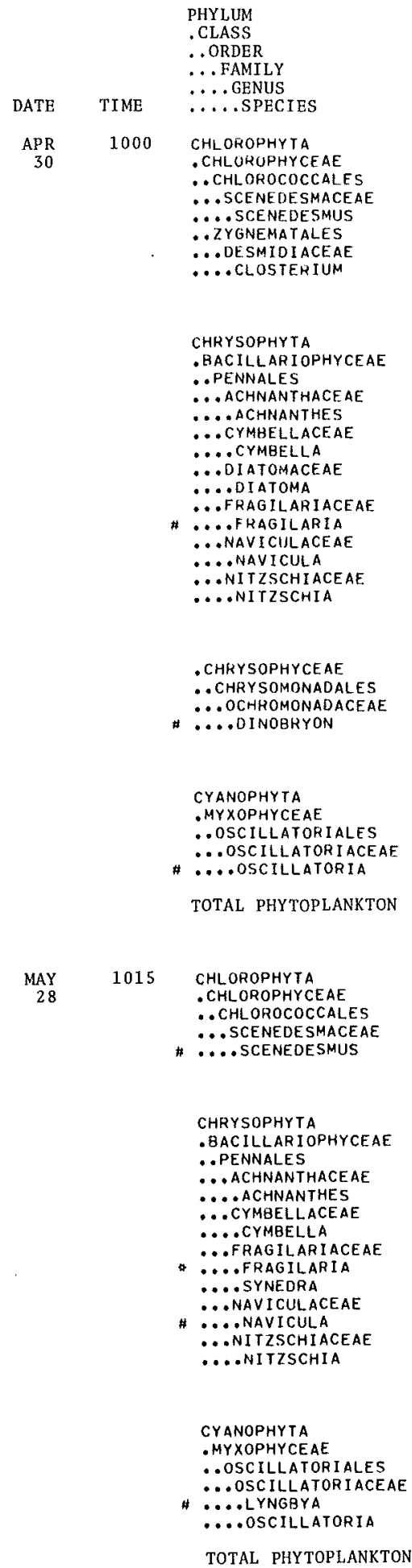

COMMON
NAME
COUNT

GREEN ALGAE

PLACODERM DESMIDS

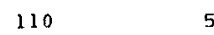

14

1

DIATOMS

PENNATE

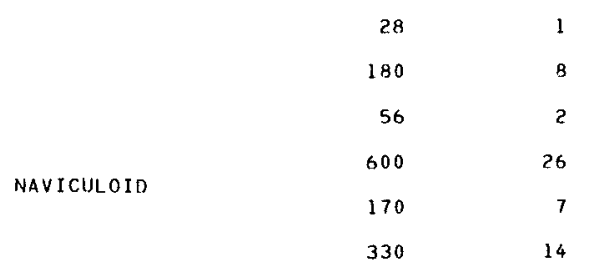

YELLOW-BROWN ALGAE

400

17

BLUE -GREEN ALGAE

FILAMENTOUS

420

18

2,300

GREEN ALGAE

600

16

DIATOMS

PENNATE

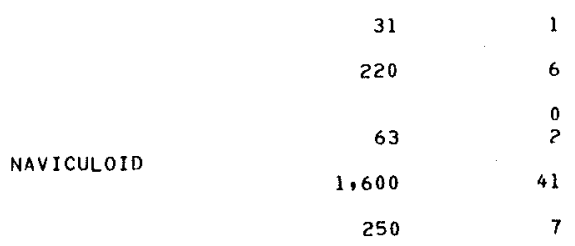

BLUE-GREEN ALGAE

FILAMENTOUS

$\begin{array}{rr}760 & 20 \\ 310 & 8 \\ 800 & \end{array}$


09424190 COLORADO RIVER AQUEDUCT NEAR SAN JACINTO, CA--Continued

QUALITATIVE AND ASSOCIATED QUANTITATIVE ANALYSES OF BIOLOGICAL DATA, WATER YEAR OCTOBER 1975 TO SEPTEMBER 1976 PHYTOPLANKTON

\begin{tabular}{|c|c|c|c|c|c|}
\hline DATE & TIME & $\begin{array}{l}\text { PHYLUM } \\
\text {. CIASS } \\
\ldots \text { ORDER } \\
\ldots \text { FAMILY } \\
\ldots \text {. GENUS } \\
\ldots \text {. SPECIES }\end{array}$ & $\begin{array}{l}\text { COMMON } \\
\text { NAME }\end{array}$ & $\begin{array}{c}\text { COUNT } \\
\text { (CELLS/ML) }\end{array}$ & $\begin{array}{l}\text { PERCENT } \\
\text { OF TOTAL }\end{array}$ \\
\hline \multirow[t]{6}{*}{$\begin{array}{r}\text { JUNE } \\
23\end{array}$} & 1115 & 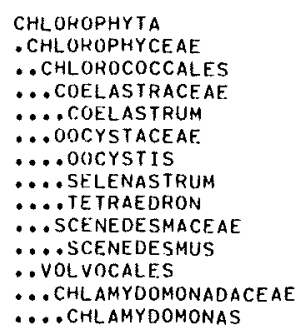 & GREEN ALGAE & $\begin{array}{r}410 \\
54 \\
54 \\
27 \\
920\end{array}$ & $\begin{array}{r}10 \\
1 \\
1 \\
1 \\
22\end{array}$ \\
\hline & & 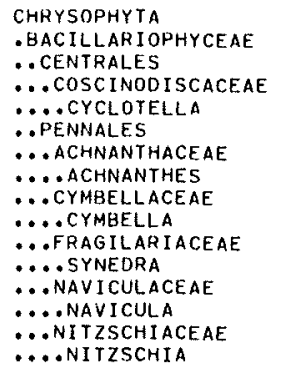 & $\begin{array}{l}\text { DIATOMS } \\
\text { CENTRIC } \\
\text { PENNATE }\end{array}$ & $\begin{array}{r}54 \\
81 \\
270 \\
81 \\
1,300 \\
350\end{array}$ & $\begin{array}{r}2 \\
6 \\
2 \\
32 \\
8\end{array}$ \\
\hline & & $\begin{array}{l}\text { CYANOPHYTA } \\
\text { MYXOPHYCEAE } \\
\ldots \text { CHROOCOCCALES } \\
\ldots \text { CHROOCOCCACEAE } \\
\ldots \text {. ANACYSTIS } \\
\ldots \text { OSCILLATORIALES } \\
\text { \#OSCILLATORIACEAE } \\
\ldots \text { OOSCILLATORIA }\end{array}$ & $\begin{array}{l}\text { BLUE-GREEN ALGAE } \\
\text { COCCOID } \\
\text { FILAMENTOUS }\end{array}$ & $\begin{array}{l}270 \\
220\end{array}$ & $\begin{array}{l}6 \\
5\end{array}$ \\
\hline & & $\begin{array}{l}\text { EUGLENOPHYTA } \\
\text { - EUGLENOPHYCEAE } \\
\text { - EUGLENALES }\end{array}$ & EUGLENOTOS & & \\
\hline & & $\begin{array}{l}\text {.. EUGLENACEAE } \\
\text {. . TRACHEL OMONAS }\end{array}$ & & 54 & 1 \\
\hline & & TOTAL PHYTOPLANKTON & & 4,200 & \\
\hline
\end{tabular}

See footnotes at end of table. 
09424190 COLORADO RIVER AQUEDUCT NEAR SAN JACINTO, CA--Continued

QUALITATIVE AND ASSOCIATED QUANTITATIVE ANALYSES OF BIOLOGICAL DATA, WATER YEAR OCTOBER 1975 TO SEPTEMBER 1976 PHYTOPLANKTON

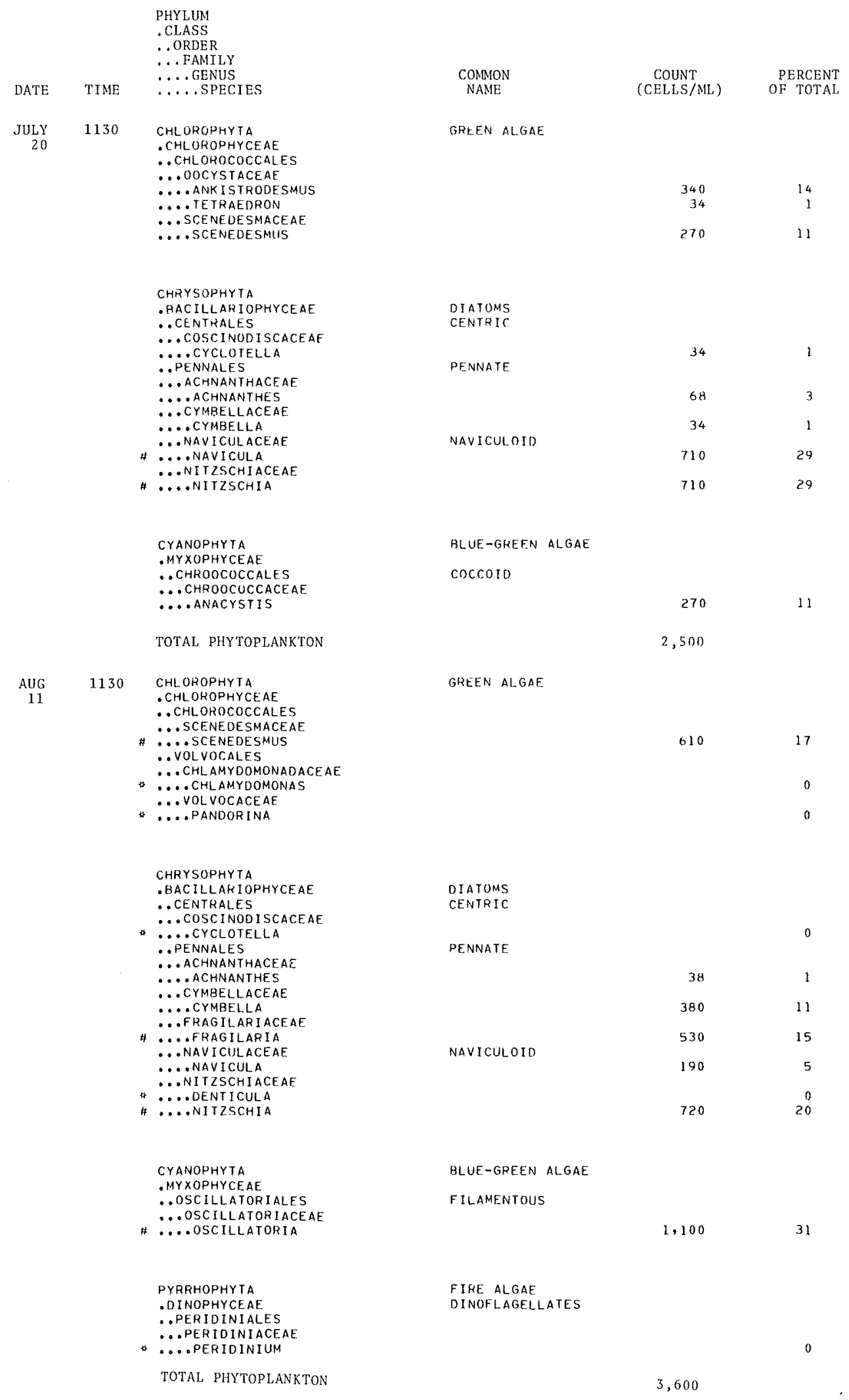


09424190 COLORADO RIVER AQUEDUCT NEAR SAN JACINTO, CA--Continued

QUALITATIVE AND ASSOCIATED QUANTITATIVE ANALYSES OF BIOLOGICAL DATA, WATER YEAR OCTOBER 1975 TO SEPTEMBER 1976 PHYTOPLANKTON

\begin{tabular}{|c|c|c|c|c|c|}
\hline & & $\begin{array}{l}\text { PHYLUM } \\
\text {. CLASS } \\
\ldots \text { ORDER } \\
\ldots \text {. FAMILY } \\
\ldots \text {. GENUS }\end{array}$ & COMMON & COUNT & PERCENT \\
\hline DATE & TIME & $\ldots$. SPECIES & NAME & (CELLS/ML) & OF TOTAL \\
\hline
\end{tabular}

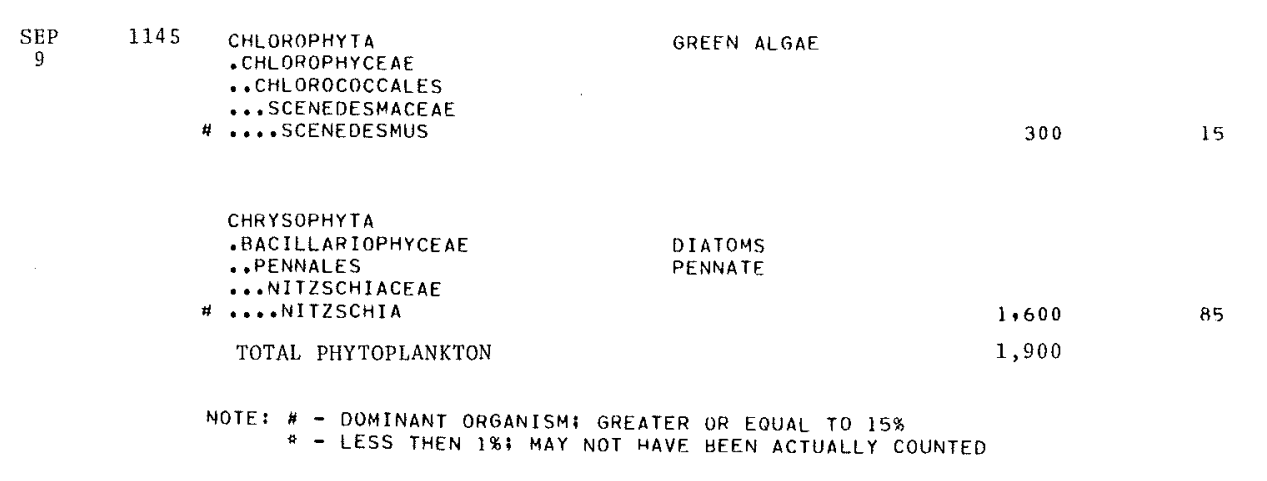

PERI PHYTON

\begin{tabular}{|c|c|c|c|c|c|c|c|c|}
\hline Date & $\begin{array}{c}\text { Length of exposure } \\
\text { (days) }\end{array}$ & Dry & weight & Ash weight & $\begin{array}{c}\text { Ch1orophyl1 } \\
\text { a } \\
\left(\mathrm{mg} / \mathrm{m}^{2}\right)\end{array}$ & $\begin{array}{c}\text { Chlorophy11 } \\
\text { b } \\
\left(\mathrm{mg} 7 \mathrm{~m}^{2}\right)\end{array}$ & $\begin{array}{l}\text { Biomass } \\
\text { pigment } \\
\text { ratio }\end{array}$ & $\begin{array}{l}\text { Sampling } \\
\text { method }\end{array}$ \\
\hline oct. 31 & .26 & & 7.8 & 6.2 & 3.5 & 0.1 & 490 & $\begin{array}{l}\text { Polyethylene } \\
\text { strip }\end{array}$ \\
\hline Mar. 24 & 37 & & 16 & 12 & 5.9 & 0.0 & 620 & $\begin{array}{l}\text { Polyethylene } \\
\text { strip }\end{array}$ \\
\hline Aug. 11 & 29 & & 11 & 8.8 & 4.1 & 0.1 & 500 & $\begin{array}{l}\text { Polyethylene } \\
\text { strip }\end{array}$ \\
\hline
\end{tabular}

CHEMICAL ANALYSES WATER YEAR OCTORER 1975 TO SFPTEMRER 1976

\begin{tabular}{|c|c|c|c|c|c|c|c|c|c|c|c|c|}
\hline DATE & TIME & $\begin{array}{c}\text { TOTAL } \\
\text { ARSENIC } \\
\text { (AS) } \\
\text { (UG/L) }\end{array}$ & $\begin{array}{c}\text { SUS- } \\
\text { PENDED } \\
\text { ARSENIC } \\
\text { (AS) } \\
\text { (UG/L) }\end{array}$ & $\begin{array}{c}\text { DIS- } \\
\text { SOLVED } \\
\text { ARSENIC } \\
\text { (AS) } \\
\text { (UG/L) }\end{array}$ & $\begin{array}{c}\text { TOTAL } \\
\text { CAD- } \\
\text { MIUH } \\
\text { (CD) } \\
\text { (UG/L) }\end{array}$ & $\begin{array}{l}\text { SUS- } \\
\text { PENDED } \\
\text { CAD- } \\
\text { MIUM } \\
\text { (CD) } \\
(U G / L)\end{array}$ & $\begin{array}{c}\text { OIS- } \\
\text { SOLVEO } \\
\text { CAD- } \\
\text { MIUM } \\
\text { (CD) } \\
\text { (UG/L) }\end{array}$ & $\begin{array}{l}\text { TOTAL } \\
\text { CHRO- } \\
\text { MIUM } \\
\text { (CR) } \\
\text { (UG/L) }\end{array}$ & $\begin{array}{l}\text { SUS- } \\
\text { PENDED } \\
\text { CHRO- } \\
\text { MIUIM } \\
\text { (CR) } \\
\text { (UG/L) }\end{array}$ & $\begin{array}{l}\text { DIS- } \\
\text { SOLVEO } \\
\text { CHRO- } \\
\text { MIUM } \\
\text { (CR) } \\
\text { (UG/L) }\end{array}$ & $\begin{array}{l}\text { TOTAL } \\
\text { COBALT } \\
\text { (CO) } \\
\text { (UG/L) }\end{array}$ & $\begin{array}{l}\text { SUS- } \\
\text { PENDED } \\
\text { COBALT } \\
\text { (CO) } \\
\text { (UG/L) }\end{array}$ \\
\hline \multicolumn{13}{|l|}{ oct } \\
\hline $\begin{array}{l}30 \ldots \\
\text { JAN }\end{array}$ & 10.30 & 3 & 0 & 3 & $<10$ & $<10$ & 0 & 0 & 0 & 0 & $<50$ & $<49$ \\
\hline $30 \cdots$ & 1100 & 2 & 0 & 2 & $<10$ & $<9$ & 1 & 0 & 0 & 0 & $<50$ & $<49$ \\
\hline $30 \ldots$ & 1000 & 3 & 0 & 3 & $<10$ & $<10$ & 0 & 0 & 0 & 0 & $<50$ & $<50$ \\
\hline $\begin{array}{l}\text { JUL } \\
20 \ldots .\end{array}$ & 1130 & 1 & 0 & 1 & $<10$ & $<9$ & 1 & 0 & 0 & 0 & $<50$ & $<50$ \\
\hline
\end{tabular}


09424190 COLORADO RTVER AQUEDUCT NEAR SAN JACINTO, CA--Continued

CHEMICAL ANALYSES, WATER YEAR OCTOBER 1975 TO SEPTEMBER 1976

\begin{tabular}{|c|c|c|c|c|c|c|c|c|c|c|c|}
\hline DATE & $\begin{array}{l}\text { OIS- } \\
\text { SOLVEO } \\
\text { COBALT } \\
\text { (CO) } \\
\text { (UG/L) }\end{array}$ & $\begin{array}{l}\text { TOTAL } \\
\text { COPPER } \\
\text { (CU) } \\
(U G / L)\end{array}$ & $\begin{array}{l}\text { SUS- } \\
\text { PENDED } \\
\text { COPPER } \\
\text { (CU) } \\
\text { (UG/L) }\end{array}$ & $\begin{array}{l}\text { DIS- } \\
\text { SOLVED } \\
\text { COPPER } \\
\text { (CU) } \\
\text { (UG/L) }\end{array}$ & $\begin{array}{l}\text { TOTAL } \\
\text { IRON } \\
\text { (FE) } \\
\text { (UG/L) }\end{array}$ & $\begin{array}{l}\text { DIS- } \\
\text { SOLVED } \\
\text { IRON } \\
\text { (FE) } \\
\text { (UG/L) }\end{array}$ & $\begin{array}{c}\text { TOTAL } \\
\text { LEAD } \\
\text { (PB) } \\
(U G / L)\end{array}$ & $\begin{array}{l}\text { SUS- } \\
\text { PENDED } \\
\text { LEAD } \\
\text { (PR) } \\
\text { (UG/L) }\end{array}$ & $\begin{array}{l}\text { DIS- } \\
\text { SOLVED } \\
\text { LEAD } \\
\text { (PB) } \\
\text { (UG/L) }\end{array}$ & $\begin{array}{l}\text { TOTAL } \\
\text { MAN- } \\
\text { GANESE } \\
\text { (MN) } \\
\text { (UG/L) }\end{array}$ & $\begin{array}{l}\text { SUS- } \\
\text { PENDED } \\
\text { MAN- } \\
\text { GANESE } \\
\text { (MN) } \\
\text { (UG/L) }\end{array}$ \\
\hline \multicolumn{12}{|l|}{ OГT } \\
\hline $\begin{array}{l}30 \ldots \\
\text { JAN }\end{array}$ & 1 & 0 & 0 & 3 & 30 & 0 & 100 & 98 & 2 & 10 & 10 \\
\hline $\begin{array}{l}30 \ldots \\
A P R\end{array}$ & 1 & $<10$ & $<5$ & 5 & 450 & 20 & $<100$ & $<96$ & 4 & 60 & 60 \\
\hline$\underset{\text { JUL }}{30 \ldots}$ & 0 & 20 & 6 & 14 & 80 & 20 & $<100$ & $<96$ & 4 & 10 & 10 \\
\hline $20 \ldots$ & 0 & 10 & 7 & 3 & 80 & 40 & $<100$ & $<94$ & 6 & 10 & 10 \\
\hline
\end{tabular}

CHEMICAL ANALYSES, HATER YEAR OCTOBER 1975 TO SEPTEMBER 1976

\begin{tabular}{|c|c|c|c|c|c|c|c|c|c|c|c|}
\hline DATE & $\begin{array}{l}\text { DIS- } \\
\text { SOLVED } \\
\text { MAN- } \\
\text { GANESE } \\
\text { (MN) } \\
\text { (UG/L) }\end{array}$ & $\begin{array}{l}\text { TOTAL } \\
\text { MEKCURY } \\
\text { (HG) } \\
\text { (UG/L) }\end{array}$ & $\begin{array}{l}\text { SUS- } \\
\text { PENDED } \\
\text { MERCURY } \\
\text { (HG) } \\
\text { (UG/L) }\end{array}$ & $\begin{array}{c}\text { DIS- } \\
\text { SOLVED } \\
\text { MERCURY } \\
\text { (HG) } \\
\text { (UG/L) }\end{array}$ & $\begin{array}{c}\text { TOTAL } \\
\text { SELE- } \\
\text { NIUM } \\
\text { (SE) } \\
\text { (UG/L) }\end{array}$ & $\begin{array}{l}\text { SUS- } \\
\text { PENDED } \\
\text { SELE- } \\
\text { NIUM } \\
\text { (SE) } \\
\text { (UG/L) }\end{array}$ & $\begin{array}{l}\text { OIS- } \\
\text { SOLVEO } \\
\text { SELE- } \\
\text { NIUM } \\
\text { (SE) } \\
\text { (UG/L) }\end{array}$ & $\begin{array}{c}\text { TOTAL } \\
\text { ZINC } \\
\text { (ZN) } \\
(U G / L)\end{array}$ & $\begin{array}{l}\text { SUS- } \\
\text { PENDED } \\
\text { ZINC } \\
\text { (ZN) } \\
\text { (UG/L) }\end{array}$ & $\begin{array}{l}\text { OIS- } \\
\text { SOLVED } \\
\text { ZINC } \\
\text { (ZN) } \\
(U G / L)\end{array}$ & $\begin{array}{l}\text { TOTAL } \\
\text { ORGANIC } \\
\text { CARBON } \\
\text { (C) } \\
\text { (MG/L) }\end{array}$ \\
\hline OCT & & & & & & & & & & & \\
\hline $\begin{array}{l}30 \\
\text { JAN }\end{array}$ & 0 & .0 & .0 & .0 & 1 & 0 & 1 & 0 & 0 & 0 & 4.6 \\
\hline$\underset{\triangle P R}{30} \cdots$ & 0 & .0 & .0 & .0 & 3 & 0 & 3 & 80 & 70 & 10 & 3.2 \\
\hline $\begin{array}{c}30 \ldots \\
\text { JUL }\end{array}$ & 0 & .0 & .0 & .0 & 3 & 0 & 3 & 40 & 20 & 20 & 5.7 \\
\hline $20 \ldots$ & 0 & .0 & .0 & .0 & 3 & 0 & 3 & 20 & 10 & 10 & 3.2 \\
\hline
\end{tabular}

PART ICLE-SIZE DISTRIBUTION OF SUSPENDED SEDIMENT, WATER YEAR OCTOBER 1975 TO SEPTEMBER 1976

\begin{tabular}{|c|c|c|c|c|c|c|}
\hline DATE & TIME & $\begin{array}{c}\text { INSTAN- } \\
\text { TANEDUS } \\
\text { OIS- } \\
\text { CHARGE } \\
\text { (CFS) }\end{array}$ & $\begin{array}{l}\text { TEMPER- } \\
\text { ATURE } \\
\text { (DEG C) }\end{array}$ & $\begin{array}{l}\text { SUS- } \\
\text { PENDED } \\
\text { SEDI- } \\
\text { MENT } \\
\text { (MG/L) }\end{array}$ & $\begin{array}{l}\text { SUS- } \\
\text { PENDED } \\
\text { SEDI- } \\
\text { MENT } \\
\text { DIS- } \\
\text { CHARGE } \\
\text { (T/OAY) }\end{array}$ & $\begin{array}{l}\text { SUS. } \\
\text { SED, } \\
\text { SIEVE } \\
\text { DIAM. } \\
\text { * FINER } \\
\text { THAN } \\
\text { TH2 MM }\end{array}$ \\
\hline OCT & & & & & & \\
\hline $\begin{array}{l}30 \ldots \\
\text { NOV }\end{array}$ & 1030 & 1120 & 19.5 & 4 & 12 & 45 \\
\hline DEC & 1520 & 680 & 15.2 & 2 & 3.7 & -- \\
\hline $\begin{array}{l}29 \\
\text { JAN }\end{array}$ & 1115 & 680 & 13.7 & 1 & 1.8 & -- \\
\hline FER & 1100 & 1120 & 13.8 & 5 & 15 & 59 \\
\hline$\underset{M A R}{27} \cdots$ & 1045 & 1340 & 15.2 & 3 & 11 & 74 \\
\hline$\underset{A P R}{24 \cdots \cdots}$ & 1040 & 1110 & 17.5 & 2 & 6.0 & 44 \\
\hline MAY & 1000 & 1320 & 21.5 & 10 & 36 & 20 \\
\hline JUN $28 \ldots$ & 1015 & 1092 & 24.0 & 10 & 29 & 54 \\
\hline$\underset{\text { JUL }}{23 . \cdots}$ & 1115 & 1330 & 24.5 & 12 & 43 & 40 \\
\hline$\underset{A \cup G}{20} \cdots$ & 1130 & 1510 & 27.5 & 2 & 8.2 & 39 \\
\hline$\underset{\text { SE.P }}{11} \cdots$ & 1130 & 1538 & 26.5 & 6 & 25 & 53 \\
\hline $09 \ldots$ & 1145 & 1349 & 26.0 & 4 & 15 & 44 \\
\hline
\end{tabular}


09427500. LAKF HAVASU NEAR PARKER DAM, ARIZ.-CALIF.

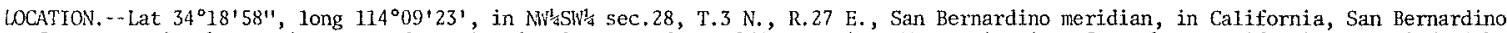
County, at intake pumping plant for Colorado River aqueduct of Metropolitan Water District of Southern California, $1.8 \mathrm{mi}$ (2.9 km) upstrean fron Parker Dan on Colorado River, and $149 \mathrm{mi}(240 \mathrm{~km})$, downstream from Hoover Dam.

DRAINGE AlKA (REVISED) .--182,700 $\mathrm{mi}^{2}\left(473,200 \mathrm{~km}^{2}\right)$, approximately, including $3,959 \mathrm{mi}^{2}\left(10,254 \mathrm{~km}^{2}\right)$ in Great Divide bas in in southern Whoming, which is noncontributing (previously considered part of the Missouri River basin).

PERION OF: RECORD.--July 1938 to current year. Published as Parker Reservoir near Parker Dam 1958.

GAGE. - Water-stage recorder. Datum of gage is $400.54 \mathrm{ft}(122.085 \mathrm{~m})$ above mean sea level. Gage readings have been reduced to elevations above mean sea level.

EXTREMES,--Ourrent year: Maximum contents, 623,400 acre- $\mathrm{ft}\left(769 \mathrm{hm}^{3}\right)$ May 8 (elevation, $450.74 \mathrm{ft}$ or $137.386 \mathrm{~m}$ ); minimum, $529,000 \mathrm{acre}-$ ft $\left(652 \mathrm{hn}^{3}\right.$ ) Feb. 24 (elevition, $445.78 \mathrm{ft}$ or $135.874 \mathrm{~m}$ )

Period of record: Maximum contents, 693,000 acre-ft $\left(854 \mathrm{hm}^{3}\right)$, by temporary use of flashboards, Apr. 18, 1943 , Jume 4 , 1953; maximum elevation, $450.77 \mathrm{ft}(137.395 \mathrm{~m})$ Jume 26, 1958; minimum contents, 71,400 acre-ft (88.0 hm $\left.{ }^{3}\right) \mathrm{June}^{25}$, 1942 (elevation, 412.09 ft or $125.605 \mathrm{~m}$ ).

REMARKS.--Lake is formed by concrete-arch dam; dam was completed and storage began July 1, 1938 . Usable capacity-based on April 1957 re-survey by Bureau of Reclamation between elevations $430.54 \mathrm{ft}(131.229 \mathrm{~m})$ and $450.54 \mathrm{ft}(137.325 \mathrm{~m})-619,400 \mathrm{acre}-\mathrm{ft}$ $\left(764 \mathrm{fm}^{3}\right)$ between elevations $400.54 \mathrm{ft}(122.085 \mathrm{~m})$, sill of regulating gates, and $450.54 \mathrm{ft}$ (137.325 m), top of regulating gates. Prior to oct. 1, 1956, different capacity table used, Dead storage, 28,600 acre-ft $\left(35.3 \mathrm{hm}^{3}\right) \mathrm{below}^{\mathrm{elevation}} 400.54 \mathrm{ft}(122.085 \mathrm{~m})$, based on original survey. About $0.07 \mathrm{ft}(0.021 \mathrm{~m})$ fall indicated between gage and parker Dam under nomal operating conditions. Drawdown below elevation $440.54 \mathrm{ft}(134.277 \mathrm{~m})$ not legally permissible except by consent of the Metropolitan Water District of Southern California or in an emergency affecting the safety of the dam. Lake is used for flood controt, power development, reregulation of river for irrigation demand, and as a basin from which water is pumped by Metropolitan Water District of Southern California to Colorado River aqueduct. Figures given herein represent usable contents. For record of diversion to Colorado River aqueduct, see record for Colorado River aqueduct near Parker Dam elsewhere in this report.

REVISIONS.--WRD Ariz, 1975: 1974 (elevation).

CONTENTS, IN ACRE-FEET, WATER YEAR OCTUBER 1975 TO SEPIEMBER 1976

INSTANTANEOUS OBSERVATIONS AT 2400

\begin{tabular}{|c|c|c|c|c|c|c|c|c|c|c|c|c|}
\hline DAY & OCT & NCV & DEC & JAN & FE8 & MAR & $A P R$ & MAY & JUN & JUL & AUG & SEP \\
\hline $\begin{array}{l}1 \\
2 \\
3 \\
4 \\
5\end{array}$ & $\begin{array}{l}575100 \\
576800 \\
575200 \\
573200 \\
571400\end{array}$ & $\begin{array}{l}558800 \\
556400 \\
553700 \\
555000 \\
558400\end{array}$ & $\begin{array}{l}554100 \\
554400 \\
552200 \\
550300 \\
549900\end{array}$ & $\begin{array}{l}545000 \\
545600 \\
547700 \\
549400 \\
547400\end{array}$ & $\begin{array}{l}546800 \\
539100 \\
537800 \\
544100 \\
550300\end{array}$ & $\begin{array}{l}536800 \\
532600 \\
533300 \\
539300 \\
544700\end{array}$ & $\begin{array}{l}567600 \\
572600 \\
576000 \\
576200 \\
570100\end{array}$ & $\begin{array}{l}598400 \\
599400 \\
595400 \\
595000 \\
599600\end{array}$ & $\begin{array}{l}616200 \\
614800 \\
615200 \\
613000 \\
612400\end{array}$ & $\begin{array}{l}606000 \\
603000 \\
600200 \\
599600 \\
597000\end{array}$ & $\begin{array}{l}569700 \\
564600 \\
563100 \\
564200 \\
566500\end{array}$ & $\begin{array}{l}562500 \\
569000 \\
570300 \\
569600 \\
569200\end{array}$ \\
\hline $\begin{array}{r}6 \\
7 \\
8 \\
9 \\
10\end{array}$ & $\begin{array}{l}565800 \\
568000 \\
568600 \\
568800 \\
567100\end{array}$ & $\begin{array}{l}561600 \\
560700 \\
560000 \\
558400 \\
558600\end{array}$ & $\begin{array}{l}549500 \\
551000 \\
547200 \\
546500 \\
546800\end{array}$ & $\begin{array}{l}546300 \\
548100 \\
550600 \\
549900 \\
549000\end{array}$ & $\begin{array}{l}560000 \\
563300 \\
563800 \\
565200 \\
568600\end{array}$ & $\begin{array}{l}549200 \\
552800 \\
549000 \\
548500 \\
551000\end{array}$ & $\begin{array}{l}572000 \\
575600 \\
580400 \\
580800 \\
582700\end{array}$ & $\begin{array}{l}608400 \\
620800 \\
615600 \\
600400 \\
595000\end{array}$ & $\begin{array}{l}610800 \\
607600 \\
608000 \\
609800 \\
611000\end{array}$ & $\begin{array}{l}599400 \\
601600 \\
605000 \\
599800 \\
593800\end{array}$ & $\begin{array}{l}565400 \\
563700 \\
560300 \\
557900 \\
557900\end{array}$ & $\begin{array}{l}573000 \\
574300 \\
574100 \\
575800 \\
586600\end{array}$ \\
\hline $\begin{array}{l}11 \\
12 \\
13 \\
14 \\
15\end{array}$ & $\begin{array}{l}561800 \\
556000 \\
550800 \\
548100 \\
549700\end{array}$ & $\begin{array}{l}560000 \\
560900 \\
560300 \\
556500 \\
553500\end{array}$ & $\begin{array}{l}549200 \\
551200 \\
551700 \\
552100 \\
546700\end{array}$ & $\begin{array}{l}547200 \\
545400 \\
545200 \\
545400 \\
545800\end{array}$ & $\begin{array}{l}569600 \\
570500 \\
566700 \\
565600 \\
565400\end{array}$ & $\begin{array}{l}554100 \\
552800 \\
550800 \\
550300 \\
543400\end{array}$ & $\begin{array}{l}583200 \\
575400 \\
583600 \\
598800 \\
602400\end{array}$ & $\begin{array}{l}601800 \\
610200 \\
613400 \\
608800 \\
606400\end{array}$ & $\begin{array}{l}610200 \\
609800 \\
610400 \\
608600 \\
606000\end{array}$ & $\begin{array}{l}589700 \\
585700 \\
585900 \\
584800 \\
584200\end{array}$ & $\begin{array}{l}558600 \\
560000 \\
558800 \\
558800 \\
558100\end{array}$ & $\begin{array}{l}593800 \\
590100 \\
582500 \\
577000 \\
572000\end{array}$ \\
\hline $\begin{array}{l}16 \\
17 \\
18 \\
19 \\
20\end{array}$ & $\begin{array}{l}550600 \\
548100 \\
545400 \\
542900 \\
540700\end{array}$ & $\begin{array}{l}551000 \\
545600 \\
545000 \\
545200 \\
549000\end{array}$ & $\begin{array}{l}545400 \\
545400 \\
546100 \\
548100 \\
549900\end{array}$ & $\begin{array}{l}543200 \\
543200 \\
544000 \\
539300 \\
541800\end{array}$ & $\begin{array}{l}566100 \\
565600 \\
562900 \\
559800 \\
551700\end{array}$ & $\begin{array}{l}542500 \\
544300 \\
545900 \\
545800 \\
548600\end{array}$ & $\begin{array}{l}597200 \\
582500 \\
569200 \\
555400 \\
555200\end{array}$ & $\begin{array}{l}601400 \\
594600 \\
595200 \\
603800 \\
607400\end{array}$ & $\begin{array}{l}606000 \\
609400 \\
613400 \\
613800 \\
611400\end{array}$ & $\begin{array}{l}579600 \\
575100 \\
572400 \\
567100 \\
567300\end{array}$ & $\begin{array}{l}554100 \\
553500 \\
553900 \\
555800 \\
555600\end{array}$ & $\begin{array}{l}572000 \\
569700 \\
569400 \\
568200 \\
563300\end{array}$ \\
\hline $\begin{array}{l}21 \\
22 \\
23 \\
24 \\
25\end{array}$ & $\begin{array}{l}541600 \\
546300 \\
548500 \\
550600 \\
554800\end{array}$ & $\begin{array}{l}548800 \\
549200 \\
552100 \\
552200 \\
552600\end{array}$ & $\begin{array}{l}554400 \\
560500 \\
557700 \\
553900 \\
552100\end{array}$ & $\begin{array}{l}547000 \\
548600 \\
548100 \\
546700 \\
546300\end{array}$ & $\begin{array}{l}547400 \\
544500 \\
534200 \\
529400 \\
530500\end{array}$ & $\begin{array}{l}551300 \\
545200 \\
536900 \\
539600 \\
545600\end{array}$ & $\begin{array}{l}559000 \\
564200 \\
567600 \\
570500 \\
574500\end{array}$ & $\begin{array}{l}605400 \\
604400 \\
607400 \\
594600 \\
601800\end{array}$ & $\begin{array}{l}608400 \\
606800 \\
607400 \\
611000 \\
610400\end{array}$ & $\begin{array}{l}567500 \\
568600 \\
569700 \\
570300 \\
568600\end{array}$ & $\begin{array}{l}556500 \\
557900 \\
555000 \\
555200 \\
556700\end{array}$ & $\begin{array}{l}562900 \\
563800 \\
576200 \\
579400 \\
587200\end{array}$ \\
\hline $\begin{array}{l}26 \\
27 \\
28 \\
29 \\
30 \\
31\end{array}$ & $\begin{array}{l}559400 \\
561800 \\
560300 \\
558600 \\
558800 \\
559200\end{array}$ & $\begin{array}{r}551200 \\
552100 \\
553500 \\
553900 \\
554600 \\
\end{array}$ & $\begin{array}{l}546100 \\
548100 \\
550300 \\
551300 \\
548500 \\
545600\end{array}$ & $\begin{array}{l}541100 \\
540900 \\
542300 \\
546300 \\
548100 \\
548600\end{array}$ & $\begin{array}{r}537700 \\
541300 \\
541100 \\
540900 \\
-\end{array}$ & $\begin{array}{l}541100 \\
545000 \\
547700 \\
546100 \\
550400 \\
558400\end{array}$ & $\begin{array}{c}568600 \\
570100 \\
576800 \\
585300 \\
592400 \\
\end{array}$ & $\begin{array}{l}613000 \\
616200 \\
610800 \\
610200 \\
611800 \\
612000\end{array}$ & $\begin{array}{r}609400 \\
608200 \\
603200 \\
599400 \\
599800 \\
=-\end{array}$ & $\begin{array}{l}565900 \\
569600 \\
569600 \\
569700 \\
570700 \\
571300\end{array}$ & $\begin{array}{l}559400 \\
559600 \\
560000 \\
561100 \\
558400 \\
560000\end{array}$ & $\begin{array}{r}583800 \\
583800 \\
583400 \\
583800 \\
584400 \\
\end{array}$ \\
\hline $\begin{array}{l}\text { MAX } \\
\text { MIN } \\
(\ddagger)\end{array}$ & $\begin{array}{l}576800 \\
540700 \\
-14200\end{array}$ & $\begin{array}{r}561600 \\
545000 \\
-4600\end{array}$ & $\begin{array}{r}560500 \\
545400 \\
-9000\end{array}$ & $\begin{array}{r}550600 \\
539300 \\
+3000\end{array}$ & $\begin{array}{r}570500 \\
529400 \\
-7700\end{array}$ & $\begin{array}{l}558400 \\
532600 \\
+17500\end{array}$ & $\begin{array}{r}602400 \\
555200 \\
+34000\end{array}$ & $\begin{array}{r}620800 \\
594600 \\
+19600\end{array}$ & $\begin{array}{r}616200 \\
599400 \\
-12200\end{array}$ & $\begin{array}{l}606000 \\
565900 \\
-28500\end{array}$ & $\begin{array}{l}569700 \\
553500 \\
-11300\end{array}$ & $\begin{array}{r}593800 \\
562500 \\
+24400\end{array}$ \\
\hline
\end{tabular}

CAL YR 1975 MAX 619200 MIN 528100 $\quad+12,300$ WTR YR 1976 MAX 620800 MIN 529400 \$ $+11,000$

$\neq$ Change in contents, in acre-feet. 
ELEVATION, IN FEET ABOVE MEAN SEA LEVEL, WATER YEAR OCTOBER 1975 TO SEPTEMBER 1976 INSTANTANEOUS OBSERVATIONS AT 2400

\begin{tabular}{|c|c|c|c|c|c|c|c|c|c|c|c|c|}
\hline DAY & OCT & Nov & DEC & JAN & FEB & MAR & APR & MAY & JUN & JUL. & AUG & SEP \\
\hline $\begin{array}{l}1 \\
2 \\
3 \\
4 \\
5\end{array}$ & $\begin{array}{l}448.28 \\
448.37 \\
448.29 \\
448.18 \\
448.09\end{array}$ & $\begin{array}{l}447.42 \\
447.29 \\
447.15 \\
447.22 \\
447.40\end{array}$ & $\begin{array}{l}447.17 \\
447.19 \\
447.07 \\
446.96 \\
446.94\end{array}$ & $\begin{array}{l}446.67 \\
446.70 \\
446.82 \\
446.91 \\
446.80\end{array}$ & $\begin{array}{l}446.77 \\
446.34 \\
446.27 \\
446.62 \\
446.96\end{array}$ & $\begin{array}{l}446.21 \\
445.98 \\
446.02 \\
446.35 \\
446.65\end{array}$ & $\begin{array}{l}447.89 \\
448.15 \\
448.33 \\
448.34 \\
448.02\end{array}$ & $\begin{array}{l}449.49 \\
449.54 \\
449.34 \\
449.32 \\
449.55\end{array}$ & $\begin{array}{l}450.38 \\
450.31 \\
450.33 \\
450.22 \\
450.19\end{array}$ & $\begin{array}{l}449.87 \\
449.72 \\
449.58 \\
449.55 \\
449.42\end{array}$ & $\begin{array}{l}448.00 \\
447.73 \\
447.65 \\
447.71 \\
447.83\end{array}$ & $\begin{array}{l}447.62 \\
447.96 \\
448.03 \\
447.99 \\
447.97\end{array}$ \\
\hline $\begin{array}{r}6 \\
7 \\
8 \\
9 \\
10\end{array}$ & $\begin{array}{l}447.79 \\
447.91 \\
447.94 \\
447.95 \\
447.86\end{array}$ & $\begin{array}{l}447.57 \\
447.52 \\
447.48 \\
447.40 \\
447.41\end{array}$ & $\begin{array}{l}446.92 \\
447.00 \\
446.79 \\
446.75 \\
446.77\end{array}$ & $\begin{array}{l}446.74 \\
446.84 \\
446.98 \\
446.94 \\
446.99\end{array}$ & $\begin{array}{l}447.48 \\
447.66 \\
447.69 \\
447.76 \\
447.94\end{array}$ & $\begin{array}{l}446.90 \\
447.10 \\
446.89 \\
446.86 \\
447.00\end{array}$ & $\begin{array}{l}448.12 \\
448.31 \\
448.56 \\
448.58 \\
448.68\end{array}$ & $\begin{array}{l}449.99 \\
450.61 \\
450.35 \\
449.59 \\
449.32\end{array}$ & $\begin{array}{l}450.11 \\
449.95 \\
449.97 \\
450.06 \\
450.12\end{array}$ & $\begin{array}{l}449.54 \\
449.65 \\
449.82 \\
449.56 \\
449.26\end{array}$ & $\begin{array}{l}447 \cdot 77 \\
447 \cdot 68 \\
447 \cdot 50 \\
447 \cdot 37 \\
447 \cdot 37\end{array}$ & $\begin{array}{l}448.17 \\
448.24 \\
448.23 \\
448.32 \\
448.89\end{array}$ \\
\hline $\begin{array}{l}11 \\
12 \\
13 \\
14 \\
15\end{array}$ & $\begin{array}{l}447.58 \\
447.27 \\
446.95 \\
446.84 \\
446.93\end{array}$ & $\begin{array}{l}447.48 \\
447.53 \\
447.50 \\
447.30 \\
447.14\end{array}$ & $\begin{array}{l}446.90 \\
447.01 \\
447.04 \\
447.06 \\
446.76\end{array}$ & $\begin{array}{l}446.79 \\
446.69 \\
446.68 \\
446.69 \\
446.71\end{array}$ & $\begin{array}{l}447.99 \\
448.04 \\
447.84 \\
447.78 \\
447.77\end{array}$ & $\begin{array}{l}447.17 \\
447.10 \\
446.99 \\
446.96 \\
446.58\end{array}$ & $\begin{array}{l}448.71 \\
448.30 \\
448.73 \\
449.51 \\
449.69\end{array}$ & $\begin{array}{l}449.66 \\
450.08 \\
450.24 \\
450.01 \\
449.89\end{array}$ & $\begin{array}{l}450.08 \\
450.06 \\
450.09 \\
450.00 \\
449.87\end{array}$ & $\begin{array}{l}449.05 \\
448.84 \\
448.85 \\
448.79 \\
448.76\end{array}$ & $\begin{array}{l}447 \cdot 41 \\
447 \cdot 48 \\
447 \cdot 42 \\
447 \cdot 42 \\
447 \cdot 38\end{array}$ & $\begin{array}{l}449.26 \\
449.07 \\
448.67 \\
448.38 \\
448.12\end{array}$ \\
\hline $\begin{array}{l}16 \\
17 \\
18 \\
19 \\
20\end{array}$ & $\begin{array}{l}446.98 \\
446.84 \\
446.69 \\
446.55 \\
446.43\end{array}$ & $\begin{array}{l}447.00 \\
446.70 \\
446.67 \\
446.68 \\
446.89\end{array}$ & $\begin{array}{l}446.69 \\
446.69 \\
446.73 \\
446.84 \\
446.94\end{array}$ & $\begin{array}{l}446.57 \\
446.57 \\
446.61 \\
446.35 \\
446.49\end{array}$ & $\begin{array}{l}447.81 \\
447.78 \\
447.64 \\
447.47 \\
447.04\end{array}$ & $\begin{array}{l}446.53 \\
446.63 \\
446.72 \\
446.71 \\
446.87\end{array}$ & $\begin{array}{l}449.43 \\
448.67 \\
447.97 \\
447.24 \\
447.23\end{array}$ & $\begin{array}{l}449.64 \\
449.30 \\
449.33 \\
449.76 \\
449.94\end{array}$ & $\begin{array}{l}449.87 \\
450.04 \\
450.24 \\
450.26 \\
450.14\end{array}$ & $\begin{array}{l}448.52 \\
448.28 \\
448.14 \\
447.86 \\
447.87\end{array}$ & $\begin{array}{l}447 \cdot 17 \\
447 \cdot 14 \\
447 \cdot 16 \\
447 \cdot 26 \\
447 \cdot 25\end{array}$ & $\begin{array}{l}448.12 \\
448.00 \\
447.98 \\
447.92 \\
447.66\end{array}$ \\
\hline $\begin{array}{l}21 \\
22 \\
23 \\
24 \\
25\end{array}$ & $\begin{array}{l}446.48 \\
446.74 \\
446.86 \\
446.98 \\
447.21\end{array}$ & $\begin{array}{l}446.88 \\
446.90 \\
447.06 \\
447.07 \\
447.09\end{array}$ & $\begin{array}{l}447.19 \\
447.51 \\
447.36 \\
447.16 \\
447.06\end{array}$ & $\begin{array}{l}446.78 \\
446.87 \\
446.84 \\
446.76 \\
446.74\end{array}$ & $\begin{array}{l}446.80 \\
446.64 \\
446.07 \\
445.80 \\
445.86\end{array}$ & $\begin{array}{l}447.02 \\
446.68 \\
446.22 \\
446.37 \\
446.70\end{array}$ & $\begin{array}{l}447.43 \\
447.71 \\
447.89 \\
448.04 \\
448.25\end{array}$ & $\begin{array}{l}449.84 \\
449.79 \\
449.94 \\
449.30 \\
449.66\end{array}$ & $\begin{array}{l}449.99 \\
449.91 \\
449.94 \\
450.12 \\
450.09\end{array}$ & $\begin{array}{l}447.88 \\
447.94 \\
448.00 \\
448.03 \\
447.94\end{array}$ & $\begin{array}{l}447 \cdot 30 \\
447 \cdot 37 \\
447 \cdot 22 \\
447 \cdot 23 \\
447 \cdot 31\end{array}$ & $\begin{array}{l}447.64 \\
447.69 \\
448.34 \\
448.51 \\
448.92\end{array}$ \\
\hline $\begin{array}{l}26 \\
27 \\
28 \\
29 \\
30 \\
31\end{array}$ & $\begin{array}{l}447.45 \\
447.58 \\
447.50 \\
447.41 \\
447.42 \\
447.44\end{array}$ & $\begin{array}{r}447.01 \\
447.06 \\
447.14 \\
447.16 \\
447.20 \\
-\end{array}$ & $\begin{array}{l}446.84 \\
446.84 \\
446.96 \\
447.02 \\
446.86 \\
446.70\end{array}$ & $\begin{array}{l}446.45 \\
446.44 \\
446.52 \\
446.74 \\
446.84 \\
446.87\end{array}$ & $\begin{array}{r}446.26 \\
446.49 \\
446.45 \\
446.46 \\
-. . \\
-.\end{array}$ & $\begin{array}{l}446.45 \\
446.67 \\
446.82 \\
446.73 \\
446.97 \\
447.40\end{array}$ & $\begin{array}{r}447.94 \\
448.02 \\
448.37 \\
448.82 \\
449.19 \\
\end{array}$ & $\begin{array}{l}450.22 \\
450.38 \\
450.11 \\
450.08 \\
450.16 \\
450.17\end{array}$ & $\begin{array}{r}450.04 \\
449.98 \\
449.73 \\
449.54 \\
449.56 \\
-\ldots\end{array}$ & $\begin{array}{l}447.80 \\
447.99 \\
447.99 \\
448.00 \\
448.05 \\
448.08\end{array}$ & $\begin{array}{l}447.45 \\
447.46 \\
447.48 \\
447.54 \\
447.40 \\
447.48\end{array}$ & $\begin{array}{r}448.74 \\
448.74 \\
448.72 \\
448.74 \\
448.77 \\
-\end{array}$ \\
\hline $\begin{array}{l}\text { MEAN } \\
\text { MAX } \\
\text { MIN }\end{array}$ & $\begin{array}{l}447.38 \\
448.37 \\
446.43\end{array}$ & $\begin{array}{l}447.18 \\
447.57 \\
446.67\end{array}$ & $\begin{array}{l}446.96 \\
447.51 \\
446.69\end{array}$ & $\begin{array}{l}446.72 \\
446.99 \\
446.35\end{array}$ & $\begin{array}{r}447.09 \\
448.04 \\
445.80\end{array}$ & $\begin{array}{l}446.72 \\
447.40 \\
445.98\end{array}$ & $\begin{array}{r}448.34 \\
449.69 \\
447.23\end{array}$ & $\begin{array}{r}449.83 \\
450.61 \\
449.30\end{array}$ & $\begin{array}{l}450.04 \\
450.38 \\
449.54\end{array}$ & $\begin{array}{l}448.67 \\
449.87 \\
447.80\end{array}$ & $\begin{array}{l}447.45 \\
448.00 \\
447.14\end{array}$ & $\begin{array}{r}448.31 \\
449.26 \\
447.62\end{array}$ \\
\hline
\end{tabular}

CAL YR 1975 MEAN 448.06 MAX 450.53 MIN 445.73 WTR YR 1976 MEAN 447.89 MAX 450.61 MIN 445.80 
09427520. COLORADO RIVER BELOH PARKER DAM, ARIZ.-CALIF.

LCCNTION, - Lat $34^{\circ} 17^{\prime} 4^{\prime \prime}$, long $114^{\circ} 08^{\prime} 22^{\prime \prime}$, in NWtsw's sec.3, T.2 N., R.27 E., San Bernardino meridian, in California, San Bernardino County, on north end of powerpliant at Parker Dan, $13 \mathrm{mi}$ (21 km) northeast of Parker, Ariz., and $14 \mathrm{mi}$ (23 km) upstream from Headgate Rock Dam.

DRAINAGE AREA (REVISED) ,--182,700 $\mathrm{mi}^{2}\left(473,200 \mathrm{~km}^{2}\right)$, approximately, including $3,959 \mathrm{mi}^{2}\left(10,254 \mathrm{~km}^{2}\right)$ in Great Divide basin in southern Wyoning, which is noncontributing (previously considered part of the Missouri River basin).

PERIOD OF RECORD. - February to September 1934 (gage heights and fragmentary discharge records), October 1934 to current year, Prior to October 1937, publishod as "near Parker, Ariz."

GAGE. - Water-stage recorder. Datun of gage is $300.54 \mathrm{ft}(91.605 \mathrm{~m})$ above mean sea leve1. Prior to Oct. 1, 1967, at site $3.8 \mathrm{mi}$ $(0.1 \mathrm{~km})$ downstream at datum $346.23 \mathrm{ft}(105.531 \mathrm{~m})$ above mean sea level.

AVERAGE DISGIARGE, -42 years, $12,070 \mathrm{ft}^{3} / \mathrm{s}\left(341.8 \mathrm{~m}^{3} / \mathrm{s}\right), 8,745,000$ acre-ft/yr $\left(10,800 \mathrm{hm}^{3} / \mathrm{yr}^{2}\right)$, unadjusted.

EXTRENES.--Current year: Maximum discharge, $19,400 \mathrm{ft}^{3} / \mathrm{s}\left(549 \mathrm{~m}^{3} / \mathrm{s}\right)$ Aug. 17 (gage height, $72.16 \mathrm{ft}$ or $\left.21.994 \mathrm{~m}\right) ; \mathrm{minimum}$ daily, $1,740 \mathrm{ft}^{3} / \mathrm{s}\left(40.3 \mathrm{~m}^{3} / \mathrm{s}\right)$ Dec. 22

Period of record: Maximum discharge, $42,400 \mathrm{ft}^{3} / \mathrm{s}\left(1,200 \mathrm{~m}^{3} / \mathrm{s}\right)$ Feb. 8,1937 ; no flow at Parker Dam for parts of several days

in 1942 when gates in dam were closed; mininn daily discharge, $1,220 \mathrm{ft}^{3} / \mathrm{s}\left(34.6 \mathrm{~m}^{3} / \mathrm{s}\right) \mathrm{Jan} .16,1974$

An umregulated discharge of probably less than $1,350 \mathrm{ft}^{3} / \mathrm{s}\left(38.2 \mathrm{~m}^{3} / \mathrm{s}\right)$ occurred Aug. 18, 1934' (1owest unregulated discharge since 1917 and probably since a much earlier date.

REWRKS.-Records excellent. Flow regulated by Lake Mead since Feb, 1,1935 , Lake Mohave since Jan. 17, 1950, and by Lake Havasu since July 1, 1938. Many diversions above station. For record of diversion to Colorado River aqueduct and return flows, see record for Colorado River aqueduct near Parker Dam, elsewhere in this report. Records of chenical analyses and water temperatures for the current water year are published on following pages.

REVISIONS (WATER YEARS), - WSP 1313: $1941(\mathrm{M})$.

DISCHARGE, IN CUBIC FEET PER SECOND, WATER YEAR OCTOBER 1975 TO SEPTEMBER 1976 MEAN VALUES

\begin{tabular}{|c|c|c|c|c|c|c|c|c|c|c|c|c|}
\hline DAY & OCT & NOV & DEC & JAN & FEB & MAR & APR & MAY & JUN & JUL. & AUG & SEP \\
\hline $\begin{array}{l}1 \\
2 \\
3 \\
4 \\
5\end{array}$ & $\begin{array}{r}9310 \\
8840 \\
9610 \\
10700 \\
10400\end{array}$ & $\begin{array}{l}5860 \\
5850 \\
7040 \\
7040 \\
5920\end{array}$ & $\begin{array}{l}4750 \\
4800 \\
6290 \\
6110 \\
6590\end{array}$ & $\begin{array}{l}6050 \\
5880 \\
4710 \\
4730 \\
5220\end{array}$ & $\begin{array}{l}8380 \\
8750 \\
8700 \\
7840 \\
6160\end{array}$ & $\begin{array}{l}12900 \\
13500 \\
12800 \\
11100 \\
11900\end{array}$ & $\begin{array}{l}13500 \\
14400 \\
14000 \\
14700 \\
14600\end{array}$ & $\begin{array}{l}13500 \\
14600 \\
14000 \\
13900 \\
12800\end{array}$ & $\begin{array}{r}10500 \\
10700 \\
9670 \\
11600 \\
11400\end{array}$ & $\begin{array}{l}11200 \\
12800 \\
13900 \\
13300 \\
13200\end{array}$ & $\begin{array}{l}13300 \\
13400 \\
13500 \\
13000 \\
12800\end{array}$ & $\begin{array}{l}11900 \\
10100 \\
11000 \\
11700 \\
11800\end{array}$ \\
\hline $\begin{array}{r}6 \\
7 \\
8 \\
9 \\
10\end{array}$ & $\begin{array}{l}9990 \\
9190 \\
7990 \\
7730 \\
8420\end{array}$ & $\begin{array}{l}5440 \\
6180 \\
6380 \\
6490 \\
5880\end{array}$ & $\begin{array}{l}6380 \\
5970 \\
6090 \\
6010 \\
5470\end{array}$ & $\begin{array}{l}5270 \\
4430 \\
3390 \\
4410 \\
4450\end{array}$ & $\begin{array}{l}5070 \\
5950 \\
4710 \\
3230 \\
1990\end{array}$ & $\begin{array}{l}11100 \\
11100 \\
11100 \\
11300 \\
10500\end{array}$ & $\begin{array}{l}14100 \\
13600 \\
13400 \\
15000 \\
15100\end{array}$ & $\begin{array}{r}11300 \\
8240 \\
10700 \\
10200 \\
10600\end{array}$ & $\begin{array}{l}11900 \\
11500 \\
11500 \\
10400 \\
10700\end{array}$ & $\begin{array}{l}12400 \\
12600 \\
12100 \\
14800 \\
15200\end{array}$ & $\begin{array}{l}14300 \\
15000 \\
15300 \\
14800 \\
14400\end{array}$ & $\begin{array}{l}7920 \\
7880 \\
7820 \\
7020 \\
3140\end{array}$ \\
\hline $\begin{array}{l}11 \\
12 \\
13 \\
14 \\
15\end{array}$ & $\begin{array}{l}8510 \\
8460 \\
7790 \\
7560 \\
5900\end{array}$ & $\begin{array}{l}5390 \\
5190 \\
4840 \\
6580 \\
6570\end{array}$ & $\begin{array}{l}5020 \\
5220 \\
5920 \\
6070 \\
7280\end{array}$ & $\begin{array}{l}4890 \\
4650 \\
4250 \\
3530 \\
3350\end{array}$ & $\begin{array}{l}1940 \\
2070 \\
3020 \\
1960 \\
1960\end{array}$ & $\begin{array}{l}10000 \\
12100 \\
12200 \\
12500 \\
13300\end{array}$ & $\begin{array}{r}14700 \\
14700 \\
9550 \\
6910 \\
5680\end{array}$ & $\begin{array}{l}11100 \\
11000 \\
10700 \\
11400 \\
12400\end{array}$ & $\begin{array}{l}12100 \\
12200 \\
12600 \\
11700 \\
12200\end{array}$ & $\begin{array}{l}15300 \\
14100 \\
13500 \\
12900 \\
12000\end{array}$ & $\begin{array}{l}14400 \\
13500 \\
14600 \\
14300 \\
14500\end{array}$ & $\begin{array}{l}2030 \\
3740 \\
5720 \\
6490 \\
6050\end{array}$ \\
\hline $\begin{array}{l}16 \\
17 \\
18 \\
19 \\
20\end{array}$ & $\begin{array}{l}6010 \\
8060 \\
8680 \\
8760 \\
7660\end{array}$ & $\begin{array}{l}6980 \\
6810 \\
6590 \\
6260 \\
5410\end{array}$ & $\begin{array}{l}7410 \\
6790 \\
6400 \\
6900 \\
6290\end{array}$ & $\begin{array}{l}5690 \\
5860 \\
6810 \\
7070 \\
6790\end{array}$ & $\begin{array}{l}1970 \\
2490 \\
3480 \\
3970 \\
6090\end{array}$ & $\begin{array}{l}13800 \\
13300 \\
12800 \\
14200 \\
14200\end{array}$ & $\begin{array}{r}6640 \\
9670 \\
10700 \\
11000 \\
12100\end{array}$ & $\begin{array}{l}12100 \\
12900 \\
12800 \\
10400 \\
10000\end{array}$ & $\begin{array}{l}11700 \\
11800 \\
12000 \\
12800 \\
13000\end{array}$ & $\begin{array}{l}14000 \\
14100 \\
13900 \\
13900 \\
12900\end{array}$ & $\begin{array}{l}13700 \\
13600 \\
13200 \\
13000 \\
14100\end{array}$ & $\begin{array}{l}5500 \\
7350 \\
7540 \\
8880 \\
9630\end{array}$ \\
\hline $\begin{array}{l}21 \\
22 \\
23 \\
24 \\
25\end{array}$ & $\begin{array}{l}7270 \\
6260 \\
6000 \\
6480 \\
6830\end{array}$ & $\begin{array}{l}6760 \\
6240 \\
5050 \\
4000 \\
3960\end{array}$ & $\begin{array}{l}4310 \\
1740 \\
5140 \\
6070 \\
6070\end{array}$ & $\begin{array}{l}6050 \\
5540 \\
6610 \\
7500 \\
7530\end{array}$ & $\begin{array}{r}7240 \\
8240 \\
9460 \\
10700 \\
10800\end{array}$ & $\begin{array}{l}14400 \\
14200 \\
14300 \\
14300 \\
14100\end{array}$ & $\begin{array}{l}13700 \\
14000 \\
15400 \\
15700 \\
15000\end{array}$ & $\begin{array}{r}12000 \\
11500 \\
10900 \\
9770 \\
9120\end{array}$ & $\begin{array}{l}12900 \\
12900 \\
12200 \\
11700 \\
12400\end{array}$ & $\begin{array}{l}12700 \\
12000 \\
12900 \\
13100 \\
12700\end{array}$ & $\begin{array}{l}13900 \\
13500 \\
13200 \\
13300 \\
12700\end{array}$ & $\begin{array}{l}9230 \\
8910 \\
5050 \\
4370 \\
2040\end{array}$ \\
\hline $\begin{array}{l}26 \\
27 \\
28 \\
29 \\
30 \\
31\end{array}$ & $\begin{array}{l}6810 \\
6850 \\
6720 \\
6340 \\
5450 \\
5670\end{array}$ & $\begin{array}{r}4090 \\
3770 \\
4570 \\
4460 \\
4210 \\
-\infty-\infty\end{array}$ & $\begin{array}{l}6550 \\
6290 \\
6350 \\
3950 \\
6660 \\
6350\end{array}$ & $\begin{array}{l}7120 \\
7210 \\
7210 \\
6830 \\
7250 \\
7590\end{array}$ & $\begin{array}{r}10900 \\
11700 \\
12600 \\
12400 \\
=\ldots\end{array}$ & $\begin{array}{l}14800 \\
15400 \\
15600 \\
14400 \\
14800 \\
14000\end{array}$ & $\begin{array}{r}15200 \\
15100 \\
13800 \\
13000 \\
13800 \\
-\infty\end{array}$ & $\begin{array}{r}8950 \\
10300 \\
11000 \\
10800 \\
10500 \\
10200\end{array}$ & $\begin{array}{r}13000 \\
13300 \\
13600 \\
14100 \\
13500 \\
\end{array}$ & $\begin{array}{r}11200 \\
10200 \\
10100 \\
9940 \\
12400 \\
12700\end{array}$ & $\begin{array}{l}12200 \\
14000 \\
13700 \\
13600 \\
13100 \\
13000\end{array}$ & $\begin{array}{r}3570 \\
3860 \\
3970 \\
3920 \\
3520 \\
-0 .\end{array}$ \\
\hline $\begin{array}{l}\text { TOTAL } \\
\text { MEAN } \\
\text { MAX } \\
\text { MIN } \\
\text { AC }=F T\end{array}$ & $\begin{array}{r}240250 \\
7750 \\
10700 \\
5450 \\
476500\end{array}$ & $\begin{array}{r}169810 \\
5660 \\
7040 \\
3770 \\
336800\end{array}$ & $\begin{array}{r}181240 \\
5846 \\
7410 \\
1740 \\
359500\end{array}$ & $\begin{array}{r}177870 \\
5738 \\
7590 \\
3350 \\
352800\end{array}$ & $\begin{array}{r}183770 \\
6337 \\
12600 \\
1940 \\
364500\end{array}$ & $\begin{array}{r}406000 \\
13100 \\
15600 \\
10000 \\
805300\end{array}$ & $\begin{array}{r}388750 \\
12960 \\
15700 \\
5680 \\
771100\end{array}$ & $\begin{array}{r}349680 \\
11280 \\
14600 \\
8240 \\
693600\end{array}$ & $\begin{array}{r}361570 \\
12050 \\
14100 \\
9670 \\
717200\end{array}$ & $\begin{array}{r}398040 \\
12840 \\
15300 \\
9940 \\
789500\end{array}$ & $\begin{array}{r}424900 \\
13710 \\
15300 \\
12200 \\
842800\end{array}$ & $\begin{array}{r}201650 \\
6722 \\
11900 \\
2030 \\
400000\end{array}$ \\
\hline
\end{tabular}


PERIOD OF RECORD. --Chemical analyses: October 1963 to current year. Water temperatures: February 1954 to August 1970.

Prior to October 1968 , published as 09428000 .

CHEMICAL ANALYSES, WATER YEAR OCTOBER 1975 TO SEPTEMBER 1976

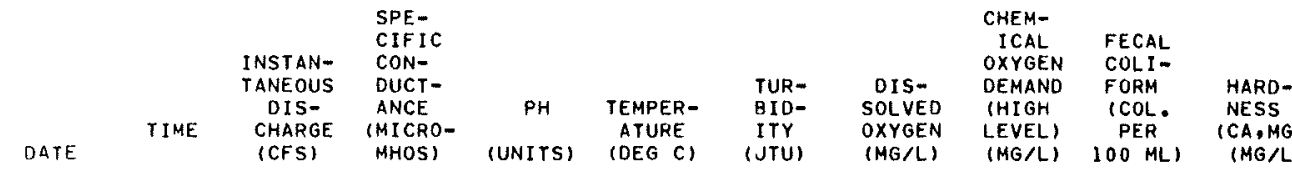

$$
\text { NCT }
$$

\begin{tabular}{|c|c|c|c|c|c|c|c|c|c|c|c|}
\hline $06 \ldots$ & 0915 & 13300 & & 1090 & 7.9 & $=-$ & -- & -- & -- & -- & \\
\hline $14 \ldots$ & 0900 & & -- & 1090 & $=$ & -- & $-\infty$ & $-\infty$ & -- & - & -0 \\
\hline $20 \ldots$ & 0800 & & -+ & 1100 & -- & $-m$ & -- & $=$ & - & $=-$ & $-\infty$ \\
\hline $28 \ldots$ & 0945 & & -- & 1100 & -- & -- & $=-$ & - & -- & $=$ & - \\
\hline NOV & & & & & & & & & & & \\
\hline $03 \ldots$ & 0815 & 4710 & & 1090 & 7.9 & -- & -- & -- & -- & -- & 330 \\
\hline $10 \ldots$ & 0430 & & $m$ & 1110 & -- & -- & -- & -- & -- & -- & - \\
\hline $17 \ldots$ & 0815 & & -- & 1100 & -- & -- & $=$ & -- & -- & -- & $-\infty$ \\
\hline $24 \ldots$ & 0930 & & -- & 1110 & -- & -- & $-m$ & -- & -- & - & - \\
\hline DEC & & & & & & & & & & & \\
\hline $91 \ldots$ & 0800 & 4430 & & 1100 & 7.9 & -- & -- & $-\infty$ & -- & -- & 330 \\
\hline $08 \ldots$ & 0800 & & -- & 1100 & -- & $-m$ & - & $m-$ & -- & -- & $=$ \\
\hline $15 \ldots$ & 1000 & & -- & 1110 & -- & -- & -- & $-\infty$ & -- & - & -- \\
\hline $21 \ldots$ & 1600 & & -- & 1110 & -- & -- & -- & -- & $=-$ & $-=$ & -- \\
\hline $29 \ldots$ & 0930 & & - & 1110 & -- & -- & $=-$ & -- & $m$ & -- & $\infty$ \\
\hline JAN & & & & & & & & & & & \\
\hline $05 \ldots$ & 0730 & & -- & 1110 & -- & $-\infty$ & - & -- & -- & -- & -- \\
\hline $12 \ldots$ & 0730 & & -- & 1120 & -- & $-=$ & -- & -- & -- & - & - \\
\hline $15 \ldots$ & 1130 & 3680 & & 1110 & 8.1 & 10.5 & 1 & 10.4 & 22 & B1 & 300 \\
\hline $19 \ldots$ & 0730 & & $\cdots$ & 1110 & - & -- & $m-$ & -- & $-\infty$ & $-\infty$ & $=$ \\
\hline $\begin{array}{r}26 \\
F E\end{array}$ & 0730 & & $-\infty$ & 1110 & -- & $-\infty$ & -- & - & - & - & - \\
\hline $02 \ldots$ & 0730 & & -- & 1110 & - & -- & - & - & - & $-\infty$ & -- \\
\hline $09 \ldots$ & 0800 & & $-\infty$ & 1110 & - & $\overline{-}$ & $-m$ & $-=$ & -- & $=$ & -- \\
\hline $12 \ldots$ & 1115 & 1740 & & 1100 & 8.2 & 12.5 & 3 & 10.2 & -- & B1 & 330 \\
\hline $17 \ldots$ & 0800 & & -- & 1100 & $=-$ & -- & -- & -- & $=-$ & -- & $-=$ \\
\hline $23 \ldots$ & 0720 & & $\cdots$ & 1100 & -- & $-\infty$ & -- & -- & $m$ & -- & -- \\
\hline MAR & & & & & & & & & & & \\
\hline $01 \ldots$ & $\begin{array}{l}0730 \\
0730\end{array}$ & & $=$ & $\begin{array}{l}1100 \\
1100\end{array}$ & $=$ & $=-$ & $=-$ & $=$ & $=$ & $=-$ & $=$ \\
\hline $11 \ldots$ & 0950 & 13200 & & 1090 & 8.3 & 13,5 & 4 & 9.6 & $-\infty$ & 1) & 330 \\
\hline $15 \ldots$ & 0730 & & -- & 1120 & - & $=-$ & $=-$ & -- & - & $=-1$ & 330 \\
\hline $29 \ldots$ & 0715 & & -- & 1090 & $=-$ & - & -- & -- & $-\infty$ & $-\infty$ & - \\
\hline$A P R$ & & & & & & & & & & & \\
\hline $05 \ldots$ & 0730 & & $-\infty$ & 1090 & -- & -- & -- & -- & $-\infty$ & -- & - \\
\hline $12 \ldots$ & 0730 & & $-\infty$ & 1100 & -- & -- & $-=$ & -- & $-\infty$ & -- & \\
\hline $15 \ldots$ & 1040 & 9330 & & 1090 & 8.3 & 16.0 & 1 & 9.6 & 14 & B1 & 350 \\
\hline $19 \ldots$ & 0730 & & $-\infty$ & 1100 & $=-$ & -- & $-\infty$ & -- & - & $-=$ & - \\
\hline $26 \ldots$ & 0730 & & $-\infty$ & 1090 & -- & -- & -- & -- & 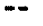 & -- & \\
\hline MAY & & & & & & & & & & & \\
\hline $03 \ldots$ & 0730 & & -- & 1090 & -- & $=$ & $m$ & $m-$ & $=$ & $-\infty$ & - \\
\hline $10 \ldots$ & 0730 & & -- & 1090 & - & $-\overline{-}$ & - & $-\overline{0}$ & $=$ & $=$ & \\
\hline $13 \ldots$ & 1040 & 8950 & & 1100 & 8,2 & 22.0 & 2 & 8.8 & 12 & BI & 330 \\
\hline $17 \ldots$ & 0730 & & $-\infty$ & 1090 & -- & -- & - & -- & - & -- & $=$ \\
\hline $24 \ldots$ & 0730 & & $=-$ & 1090 & - & $-\infty$ & $-\infty$ & $-\infty$ & -- & $-\infty$ & \\
\hline JUN & & & & & & & & & & & \\
\hline $01 \ldots$ & 0830 & & $=$ & 1090 & - & -- & -- & -- & - & - & \\
\hline $07 \ldots$ & 0730 & & $-\cdots$ & 1090 & $-\overline{0}$ & $-\overline{-}$ & $-\infty$ & $-\overline{-}$ & $=$ & $-\overline{0}$ & \\
\hline $10 \ldots$ & 1035 & 11400 & & 1090 & 7.9 & 21.5 & 1 & 7.6 & 18 & 81 & 350 \\
\hline $14 \ldots$ & 0730 & & -- & 1090 & -- & -- & -- & -- & $=-$ & $=$ & $=$ \\
\hline $21 \ldots$ & 0730 & & -- & 1090 & -- & -- & -- & $-\infty$ & $=-$ & -- & \\
\hline $28 \ldots$ & 0730 & & -- & 1100 & -- & -- & -- & -- & -- & $=-$ & \\
\hline JUL & & & & & & & & & & & \\
\hline $06 \ldots$ & 0700 & & -- & 1080 & $=-$ & -- & - & $=$ & - & -- & \\
\hline $12 \ldots$ & 0730 & & -- & 1080 & $-\infty$ & - & - & - & - & $-m$ & \\
\hline $15 \ldots$ & 1050 & 14360 & & 1080 & 7.8 & 24.0 & 1 & 6.9 & -- & $=-$ & 350 \\
\hline $19 \ldots$ & 0800 & & -- & 1080 & -- & - & -- & - & $=$ & $-\infty$ & \\
\hline $26 \ldots$ & 0730 & & -- & 1080 & - & -- & -- & -- & -- & -- & \\
\hline$A \cup G$ & & & & & & & & & & & \\
\hline $02 \ldots$ & 0730 & & -- & 1080 & $=$ & -- & -- & $-\infty$ & $=$ & $-\infty$ & \\
\hline $09 . \ldots$ & 0730 & & -- & 1070 & 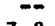 & 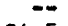 & $=$ & - & -- & $-\infty$ & \\
\hline $12 \ldots$ & 1040 & 18610 & & 1080 & 7.8 & 24.5 & 1 & 6.8 & -- & $B 2$ & 330 \\
\hline $16 \ldots$ & 0930 & & -- & 1080 & - & 21.0 & -- & $\cdots$ & $\cdots$ & -- & 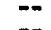 \\
\hline $23 .$. & 0930 & & - & 1080 & $-\infty$ & 24.0 & $-\infty$ & -- & -- & $=$ & \\
\hline $\begin{array}{r}30 \\
S E P\end{array}$ & 0730 & & -- & 1080 & -- & - & -- & $-\infty$ & $\cdots$ & $-\infty$ & \\
\hline $07 \ldots$ & 0730 & & $=$ & 1070 & -- & $-\infty$ & -- & - & $=$ & $=$ & \\
\hline $13 \ldots$ & 0730 & & -- & 1080 & -- & -- & -- & -- & $=-$ & -- & \\
\hline $16 \ldots$ & 1045 & 4630 & & 1070 & 7.7 & 24.5 & 1 & 6.9 & $-\infty$ & B1 & 320 \\
\hline $20 \ldots$ & 0930 & & -- & 1070 & -- & - & $-\infty$ & -- & -- & -- & \\
\hline $27 \ldots$ & 0730 & & $-\infty$ & 1060 & -- & -- & $=-$ & -- & $-\infty$ & $=$ & - \\
\hline
\end{tabular}

B Results based on colony count outside the acceptable range (non-ideal colony count) 
09427520. COLORADO RIVER BELOW PARKER DAM, ARTZ. -CALIF.--CONTINUED

CHEMICAL ANALYSES, WATER YEAR OCTOBER 1975 TO SEPTEMEER 1970

\begin{tabular}{|c|c|c|c|c|c|c|c|c|c|c|}
\hline DATE & $\begin{array}{l}\text { NON- } \\
\text { CAR- } \\
\text { BONATE } \\
\text { HARD- } \\
\text { NESS } \\
\text { (MG/L) }\end{array}$ & $\begin{array}{l}\text { DIS- } \\
\text { SOLVED } \\
\text { CAL- } \\
\text { CIUM } \\
\text { (CA) } \\
(M G / L)\end{array}$ & $\begin{array}{l}\text { DIS- } \\
\text { SOLVED } \\
\text { MAG- } \\
\text { NE- } \\
\text { SIUM } \\
(M G) \\
(M G / L)\end{array}$ & $\begin{array}{l}\text { DIS- } \\
\text { SOLVED } \\
\text { SOUIUHA } \\
\text { (NA) } \\
\text { (MG/L) }\end{array}$ & $\begin{array}{l}\text { SODIUM } \\
\text { AD- } \\
\text { SORP- } \\
\text { TION } \\
\text { RAYIO }\end{array}$ & $\begin{array}{l}\text { DIS- } \\
\text { SOLVED } \\
\text { PO- } \\
\text { TAS- } \\
\text { SIUM } \\
\text { (K) } \\
\text { (MG/L) }\end{array}$ & $\begin{array}{l}\text { BICAR - } \\
\text { BONATE } \\
\text { (HCO3) } \\
\text { (MG/L) }\end{array}$ & $\begin{array}{l}\text { CAR- } \\
\text { BONATE } \\
\text { (CO3) } \\
\text { (MG/L) }\end{array}$ & $\begin{array}{l}\text { DIS- } \\
\text { SOLVED } \\
\text { SULFATE } \\
\text { (SO4) } \\
\text { (MG/L) }\end{array}$ & $\begin{array}{l}\text { DIS- } \\
\text { SOLVED } \\
\text { CHLO- } \\
\text { RIDE } \\
\text { (CL) } \\
\text { (MG/L) }\end{array}$ \\
\hline \multicolumn{11}{|l|}{ ICT } \\
\hline $06 \ldots$ & 200 & 77 & 30 & 110 & 2.7 & 5.5 & 140 & 0 & 310 & 92 \\
\hline $14 \ldots$ & -- & -- & -- & - & -- & -- & - & -- & -- & -- \\
\hline $20 \ldots$ & - & -- & -- & $-\infty$ & $m$ & -- & -- & - & $=$ & -- \\
\hline \multicolumn{11}{|l|}{ NOV } \\
\hline $03 \ldots$ & 200 & 83 & 29 & 110 & 2.6 & 5.2 & 160 & 0 & 300 & 93 \\
\hline $10 \ldots$ & $=$ & $=$ & - & $=$ & -- & - & -- & $-\infty$ & -- & - \\
\hline $17 \ldots$ & -- & -- & -- & $=$ & -- & -- & - & - & $-\cdots$ & $-\infty$ \\
\hline${ }_{D E C}^{24} \cdots$ & -- & -- & -- & $m$ & -- & -- & -- & -- & - & -- \\
\hline $01 \ldots$ & 210 & 84 & 30 & 110 & 2.6 & 4.9 & 152 & 0 & 300 & 95 \\
\hline ט8. . . & -- & - & - & - & -- & -- & - & -- & - & - \\
\hline $1 b \ldots$ & -- & -- & -- & - & -- & -- & -- & - & -- & $\cdots$ \\
\hline $21 \ldots$ & -- & -- & $=-$ & $=-$ & - & - & -- & -- & -- & - \\
\hline Jan & -- & $-\infty$ & -- & -- & $=-$ & -- & - & -- & -- & -- \\
\hline$n 5 \ldots$ & -- & $=-$ & -- & $=$ & $=-$ & $=-$ & - & -- & -- & -- \\
\hline $12 \ldots$ & -- & -- & -- & -- & -- & -- & -- & -- & - & $=$ \\
\hline $15 \ldots$ & 170 & 73 & 28 & 110 & 2.8 & 5.4 & 153 & 0 & 310 & 90 \\
\hline $19 \ldots$ & - & -- & - & - & -- & $=$ & - & -- & - & -- \\
\hline$\underset{F E H}{2 h} \cdots$ & -- & -- & -- & $-=$ & -- & -- & -- & $-m$ & -- & -- \\
\hline $02 \ldots$ & -- & -- & -- & $-\infty$ & -- & -- & - & -- & -- & - \\
\hline $04 \ldots$ & -- & -- & -- & - & - & $m$ & $-\infty$ & -- & -- & $=$ \\
\hline $12 \ldots$ & 200 & 84 & 29 & 100 & 2.4 & 4.8 & 160 & 0 & 300 & 90 \\
\hline $17 \ldots$ & -- & - & $=-$ & - & -- & -- & - & -- & $-\infty$ & - \\
\hline$\underset{M A R}{23} \cdots$ & $=-$ & -- & $-=$ & -- & -- & -- & - & -- & -- & $m$ \\
\hline $01 \ldots$ & -- & -- & -- & -- & $=$ & -- & -- & -- & -- & - \\
\hline us.... & -- & -- & -- & -- & -- & -- & -- & $=$ & -- & $-\infty$ \\
\hline $11 \ldots$ & 190 & 83 & 29 & 100 & 2.4 & 5.0 & 166 & 0 & 300 & 86 \\
\hline $15 \ldots$ & - & - & $-\cdots$ & -- & $=-$ & $\rightarrow$ & - - & - & -- & -- \\
\hline $29 .$. & -- & -- & -- & -- & $=-$ & -- & $-\infty$ & $=$ & - & -- \\
\hline \multicolumn{11}{|l|}{$A P R$} \\
\hline 0 -... & $m$ & -- & -- & -- & $=$ & -- & $=-$ & -- & $\ldots$ & - \\
\hline $12 \ldots$ & -- & -- &.- & -- & - & - & $=-$ & -- & $=$ & $-\infty$ \\
\hline $15 \ldots$ & 220 & 86 & 34 & 100 & 2.3 & 5.0 & 165 & 0 & 300 & 92 \\
\hline $19 \ldots$ & -- & -- & - & -- & -- & - & $\cdots$ & -- & -- & $=$ \\
\hline $26 \ldots$ & -- & -- & -- & $-\infty$ & -- & -- & $=-$ & $-\infty$ & -- & $=$ \\
\hline \multicolumn{11}{|l|}{ MAY } \\
\hline $03 \ldots$ & -- & $=-$ & $-\infty$ & -- & $=-$ & $=$ & - & -- & -- & -- \\
\hline $10 \ldots$ & -- & -- & -- & -- & -- & - & $=$ & -- & -- & - \\
\hline $13 \ldots$ & 190 & 82 & 30 & 100 & 2.4 & 5.0 & 167 & 0 & 300 & 89 \\
\hline $17 \ldots$ & -- & - & $=-$ & -- & $=-$ & -- & -- & -- & -- & -- \\
\hline $24 \ldots$ & -- & -- & $-\infty$ & $-\infty$ & -- & -- & -- & $-\infty$ & $=-$ & $-\infty$ \\
\hline \multicolumn{11}{|l|}{ JUN } \\
\hline $01 \ldots$ & -- & -- & $\rightarrow$ & $=$ & $-=$ & -- & - & -- & -- & - \\
\hline $07 \ldots$ & $-\infty$ & - & - & -- & -- & - & $-=$ & -- & -- & -- \\
\hline $10 \ldots$ & 220 & $8 B$ & 31 & 110 & 2.6 & 4.6 & 160 & 0 & 310 & 91 \\
\hline $14 \ldots$ & -- & -- & -- & - & - & -- & $-\infty$ & $=-$ & - & - \\
\hline $21 \ldots$ & - & $\rightarrow$ & -- & - & -- & -- & -- & $-\infty$ & $=$ & -- \\
\hline $28 \ldots$ & - & -- & -- & $=-$ & -- & -- & - & -- & -- & - \\
\hline \multicolumn{11}{|l|}{ 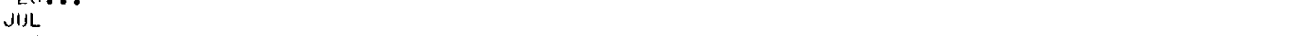 } \\
\hline $06 \ldots$ & -- & -- & $=-$ & - & -- & $=$ & $\cdots$ & $\ldots$ & $-=$ & $=$ \\
\hline $12 \ldots$ & -- & $-\infty$ & -- & -- & -- & -- & - & -- & $m$ & - \\
\hline $15 \ldots$ & 220 & 88 & 31 & 100 & 2.3 & 5.0 & 159 & 0 & 290 & 90 \\
\hline $19 \ldots$ & -- & $=$ & $=-$ & - & $=$ & -- & -- & -- & - & - \\
\hline \multicolumn{11}{|l|}{ A1J6 } \\
\hline $02 \ldots$ & $=-$ & -- & -- & -- & -- & $m$ & $m$ & $m-$ & -- & - \\
\hline $09 . \ldots$ & -- & -- & - & -- & -- & - & $m$ & $-\infty$ & -- & - \\
\hline $12 \ldots$ & 200 & 84 & 29 & 110 & 2.6 & 5.0 & 154 & 0 & 290 & 93 \\
\hline $16 \ldots$ & $=$ & $=$ & -- & $=$ & -- & $=$ & $\cdots$ & $-m$ & $=$ & -- \\
\hline $23 \ldots$ & $-\infty$ & -- & -- & $-=$ & $m$ & $-\infty$ & $=$ & -- & $=-$ & 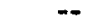 \\
\hline $30 \ldots$ & $m$ & -- & $m$ & -- & $=$ & $=$ & -- & -- & -- & $-\infty$ \\
\hline \multicolumn{11}{|l|}{ SEP } \\
\hline $07 \ldots$ & -- & -- & -- & - & -- & $=-$ & $=-$ & - & -- & $-\infty$ \\
\hline $13 \ldots$ & -- & -- & -- & - & -- & - & -- & -- & - & -- \\
\hline $16 \ldots$ & 190 & 79 & 29 & 100 & 2.4 & 5.0 & 153 & 0 & 300 & 90 \\
\hline $20 \ldots$ & - & $=$ & -- & -- & - & - & -- & $=$ & - & $=$ \\
\hline $27 \ldots$ & -- & -- & & $\ldots$ & - & -- & -- & $-=$ & -- & \\
\hline
\end{tabular}


09427520. COLORADO RIVER BELOW PARKER DAM, ARIZ. -CALIF.--CONTINUED

CHEMICAL ANALYSES, WATER YEAH OCTOBER 1975 TO SEPTEMBER 1976

\begin{tabular}{|c|c|c|c|c|c|c|c|c|c|}
\hline DATE & $\begin{array}{l}\text { DIS- } \\
\text { SOLVED } \\
\text { FLUO- } \\
\text { RIDE } \\
\text { (F) } \\
\text { (MG/L) }\end{array}$ & $\begin{array}{l}\text { DIS- } \\
\text { SOLVED } \\
\text { SILICA } \\
(S I O Z) \\
(M G / L)\end{array}$ & $\begin{array}{l}\text { DIS- } \\
\text { SOLVED } \\
\text { SOLIDS } \\
\text { (RESI- } \\
\text { DUE AT } \\
\text { I8O C) } \\
\text { (MG/L) }\end{array}$ & $\begin{array}{l}\text { DIS- } \\
\text { SOLVED } \\
\text { SOLIDS } \\
\text { (SUM OF } \\
\text { CONSTI- } \\
\text { TUENTS) } \\
\text { (MG/L) }\end{array}$ & $\begin{array}{l}\text { OIS- } \\
\text { SOLVED } \\
\text { SOLIDS } \\
\text { (TONS } \\
\text { PER } \\
\text { AC-FT) }\end{array}$ & $\begin{array}{l}\text { DIS- } \\
\text { SOLVED } \\
\text { NITRITE } \\
\text { PLUS } \\
\text { NITRATE } \\
\text { (N) } \\
\text { (MG/L) }\end{array}$ & $\begin{array}{l}\text { DIS- } \\
\text { SOLVEO } \\
\text { ORTHO. } \\
\text { PHOS- } \\
\text { PHORUS } \\
\text { (P) } \\
\text { (MG/L) }\end{array}$ & $\begin{array}{c}\text { DIS- } \\
\text { SOLVED } \\
\text { BORON } \\
\text { (B) } \\
\text { (UG/L) }\end{array}$ & $\begin{array}{l}\text { OIS- } \\
\text { SOLVEO } \\
\text { IRON } \\
\text { (FE) } \\
\text { (UG/L) }\end{array}$ \\
\hline
\end{tabular}

\begin{tabular}{|c|c|c|c|c|c|c|c|c|c|}
\hline $\mathrm{OCT}$ & & & & & & & & & \\
\hline $06 \ldots$ & .3 & 6.8 & 690 & 701 & .94 & .12 & - & 140 & 10 \\
\hline $14 \ldots$ & - & -- & 696 & - & .95 & -- & $=$ & $=$ & $-\infty$ \\
\hline $20 \ldots$ & -- & $=-$ & 704 & $=-$ & .96 & $\ldots$ & - & -- & -- \\
\hline $28 \ldots$ & - & -- & 696 & -- & .95 & $=-$ & -- & -- & -- \\
\hline Nov & & & & & & & & & \\
\hline ט... & .4 & 7.7 & 692 & 708 & .94 & .14 & $m$ & 140 & 20 \\
\hline $10 \ldots$ & -- & -- & 710 & $-\infty$ & .97 & -- & -- & - & -- \\
\hline $17 \ldots$ & -- & -- & 704 & $=-$ & .96 & - & - & -- & - \\
\hline $24 \ldots$ & -- & $-\infty$ & 712 & -- & .97 & - & - & $-\infty$ & -- \\
\hline DEC & & & & & & & & & \\
\hline $01 \ldots$ & .4 & 8.1 & 698 & 709 & .95 & .26 & - & 140 & 50 \\
\hline $08 \ldots$ & -- & - & 696 & $=-$ & .95 & -- & - & $=-$ & $-=$ \\
\hline $15 . .$. & $-=$ & $=$ & 706 & $=-$ & .96 & -- & - & $m$ & -- \\
\hline $21 . .$. & $=-$ & - & 700 & -- & .95 & $=$ & -- & -- & $=-$ \\
\hline $29 . \ldots$ & -- & $-\infty$ & 704 & -- & .96 & - & - & -- & -- \\
\hline JAN & & & & & & & & & \\
\hline $05 \ldots$ & -- & -- & 702 & $=-$ & .95 & -- & - & -- & -- \\
\hline $12 \ldots$ & $=-$ & -- & 716 & -- & .97 & - & $=$ & -- & $-\infty$ \\
\hline $15 \ldots$ & .4 & 7.8 & 735 & 701 & 1.00 & .17 & .00 & 130 & 30 \\
\hline $19 \ldots$ & -- & -- & 704 & -- & .96 & -- & - & -- & $\cdots$ \\
\hline $26 \ldots$ & -- & -- & 704 & $-\infty$ & .96 & -- & -- & -- & $=-$ \\
\hline FEH & & & & & & & & & \\
\hline $02 \ldots$ & $m$ & - & 706 & -- & .96 & -- & -- & - & - \\
\hline $09 \ldots$ & $=$ & -- & 704 & -- & .96 & $=-$ & - & -- & - \\
\hline $12 \ldots$ & .4 & 7.5 & 749 & 695 & 1.02 & .16 & .00 & 120 & 0 \\
\hline $17 \ldots$ & $=-$ & - & 704 & $=-$ & .96 & -- & -- & -- & $=$ \\
\hline $23 \ldots$ & $\rightarrow$ & $=-$ & 704 & -- & .96 & -- & -- & -- & -- \\
\hline MAR & & & & & & & & & \\
\hline $01 \ldots$ & -- & -- & 698 & $=$ & .95 & - & -- & - & -- \\
\hline $08 . .$. & -- & -- & 700 & $=-$ & .95 & - & -- & -- & $-m$ \\
\hline $11 \ldots$ & .4 & 8.3 & 731 & 695 & .99 & .20 & .01 & 130 & 10 \\
\hline $15 \ldots$ & -- & -- & 716 & $=$ & .97 & - & -- & -- & 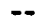 \\
\hline $\boldsymbol{2}^{4} \ldots$ & -- & $-\infty$ & 692 & -- & .94 & 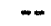 & $=-$ & $=-$ & -- \\
\hline$A P R$ & & & & & & & & & \\
\hline $05 \ldots$ & $=-$ & $=$ & 698 & -- & .95 & - & $\infty$ & $=-$ & $\infty$ \\
\hline $12 \ldots$ & -- & -- & 700 & -- & .95 & -- & $-\infty$ & -- & -- \\
\hline $15 \ldots$ & .4 & 6.3 & 719 & 706 & .98 & .20 & .00 & 130 & 10 \\
\hline $19 \ldots$ & $-m$ & -- & 698 & -- & .95 & $-m$ & -- & $-\infty$ & - \\
\hline $26 \ldots$ & -- & $m$ & 690 & -- & .94 & -- & $=$ & -- & $-\infty$ \\
\hline MÅY & & & & & & & & & \\
\hline $03 \ldots$ & - & -- & 688 & $=-$ & .94 & - & -- & $-m$ & $-\infty$ \\
\hline $10 \ldots$ & $-=$ & -- & 684 & - & .93 & $=$ & $=$ & $=$ & $=-$ \\
\hline $13 \ldots$ & .4 & 4.8 & 728 & 694 & .99 & .15 & .01 & 130 & 0 \\
\hline $17 \ldots$ & -- & -- & 678 & -- & .92 & - & - & -- & -- \\
\hline$? 4 \ldots$ & $-\infty$ & -- & 678 & $=$ & .92 & $=-$ & $-\infty$ & $=-$ & $=0$ \\
\hline JUN & & & & & & & & & \\
\hline $01 \ldots$ & -- & -- & 686 & $=-$ & .93 & $=$ & $=$ & - & $=-$ \\
\hline $07 \ldots$ & $-\infty$ & -- & 694 & -- & .94 & - & - & - & $-\infty$ \\
\hline $10 \ldots$ & .4 & 7.8 & 732 & 722 & 1.00 & $-\infty$ & - & 120 & 10 \\
\hline $14 \ldots$ & -- & - & 680 & - & .92 & - & - & -- & $\infty$ \\
\hline $21 \ldots$ & -- & - & 702 & $-m$ & .95 & - & $=$ & -- & -- \\
\hline $28 \ldots$ & 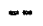 & -- & 696 & $=-$ & .95 & $=$ & $-\infty$ & -- & - \\
\hline J!/L & & & & & & & & & \\
\hline $06 \ldots$ & $-\infty$ & -- & 676 & $=$ & .92 & $=0$ & $=$ & $=-$ & $=$ \\
\hline $12 \ldots$ & $=-$ & $=$ & 676 & -- & .92 & $\cdots$ & $-\infty$ & $=-$ & $m$ \\
\hline $15 \ldots$ & .4 & 8.3 & 719 & 692 & .98 & .11 & .00 & 130 & 10 \\
\hline $19 \ldots$ & -- & - & 676 & $\cdots$ & .92 & $=$ & $-=$ & $=$ & $=-$ \\
\hline $26 \ldots$ & $-\infty$ & $-\infty$ & 676 & $-\infty$ & .92 & $-\infty$ & $=$ & $=-$ & $=$ \\
\hline$A \cup G$ & & & & & & & & & \\
\hline $02 \ldots$ & $-\infty$ & $-\infty$ & 674 & $=$ & .92 & $\infty$ & $\infty$ & $=-$ & $\infty$ \\
\hline $09 \ldots$ & $=-$ & $=\infty$ & 682 & $=-$ & .93 & $-\infty$ & $=$ & $\ldots$ & $=-$ \\
\hline $12 \ldots$ & .3 & 8.5 & 703 & 696 & .96 & .07 & .01 & 140 & 10 \\
\hline $16 \ldots$ & $=\infty$ & $-\infty$ & 688 & -- & .94 & $-m$ & $=$ & $-\infty$ & -- \\
\hline $23 \ldots$ & $=-$ & - & 684 & $-\infty$ & .93 & $\infty$ & $m$ & $=-$ & $=$ \\
\hline$\underset{\mathrm{SFP}}{30} \cdots$ & $-\infty$ & $-\infty$ & 674 & $\infty-$ & .92 & $=$ & $m$ & $=$ & $=-$ \\
\hline SEP & & & & & & & & & \\
\hline $07 \ldots$ & $\Rightarrow$ & $\infty$ & 682 & - & .93 & $=$ & $-\infty$ & $\infty$ & $-\infty$ \\
\hline $13 \ldots$ & - & $=-$ & 682 & $\infty$ & .93 & 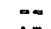 & $-\infty$ & $-\infty$ & -- \\
\hline $16 \ldots$ & .3 & 8.5 & 701 & 688 & .95 & .15 & .00 & 130 & 10 \\
\hline $20 \ldots$ & $-\infty$ & - & 676 & $m$ & .92 & $-\infty$ & $\Rightarrow$ & $\infty$ & $\infty$ \\
\hline $27 \ldots$ & $=\infty$ & $-\infty$ & 662 & $\infty$ & .90 & $=-$ & $=$ & $\infty$ & $\infty$ \\
\hline
\end{tabular}


09427520. COLORADO RIVER BELOW PARKER DAM, ARTZ. - CALIF. - CONTINUED

CHEMICAL ANALYSES, WATER YEAR OCTOBER 1975 TO SEPTEMBER 1916

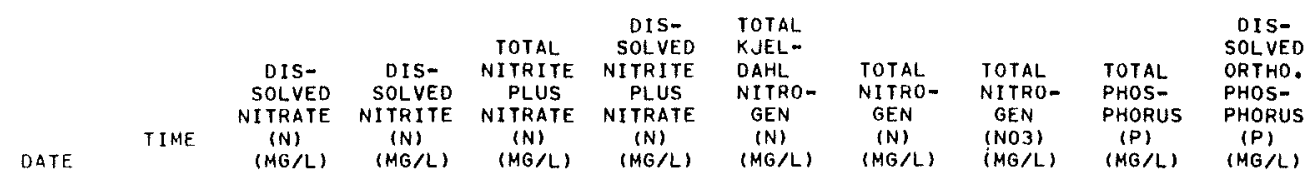

\begin{tabular}{|c|c|c|c|c|c|c|c|c|c|c|}
\hline $\begin{array}{l}\text { JAN } \\
15 \ldots . \cdots \\
F E H\end{array}$ & 1130 & .17 & .00 & .19 & .17 & .56 & .75 & 3.3 & .00 & .00 \\
\hline$\underset{M A R}{12} \cdots$ & 1115 & $\rightarrow$ & -- & .16 & .16 & .46 & .62 & 2.7 & .03 & .00 \\
\hline$\underset{A P R}{11} \cdots$ & 0950 & -- & - & .20 & .20 & .51 & .71 & 3.1 & .01 & .01 \\
\hline $\begin{array}{l}15 \ldots \\
\text { MAY }\end{array}$ & 1040 & -- & -- & .19 & .20 & .20 & . 39 & 1.7 & .09 & .00 \\
\hline$\underset{J U N N}{13} \cdots$ & 1040 & -- & -- & .21 & .15 & .27 & .48 & 2.1 & .01 & .01 \\
\hline $\begin{array}{l}10 \\
\text { JIJL }\end{array}$ & 1035 & - & -- & .18 & -- & .35 & .53 & $2 \cdot 3$ & .02 & - \\
\hline $\operatorname{Aug}_{15} \ldots$ & 1050 & $=-$ & -- & .11 & .11 & .24 & .35 & 1.6 & .01 & .00 \\
\hline$\underset{S E P}{12} \cdots$ & 1040 & -- & - & .11 & .07 & .22 & .33 & 1.5 & .02 & .01 \\
\hline $16 \ldots$ & 1045 & $-\infty$ & -- & .15 & .15 & .60 & .75 & $3 \cdot 3$ & .00 & .00 \\
\hline
\end{tabular}

\begin{tabular}{|c|c|c|c|c|c|c|c|c|c|c|}
\hline DATE & TIME & $\begin{array}{c}\text { TOTAL } \\
\text { ARSENIC } \\
\text { (AS) } \\
(U G / L)\end{array}$ & $\begin{array}{c}\text { DIS- } \\
\text { SOLVEO } \\
\text { ARSENIC } \\
\text { (AS) } \\
\text { (UG/L) }\end{array}$ & $\begin{array}{l}\text { TOTAL } \\
\text { BARIUM } \\
\text { (BA) } \\
\text { (UG/L) }\end{array}$ & $\begin{array}{c}\text { TOTAL } \\
\text { BORON } \\
\text { (B) } \\
\text { (UG/L) }\end{array}$ & $\begin{array}{l}\text { DIS- } \\
\text { SOLVEO } \\
\text { BORON } \\
\text { (B) } \\
\text { (UG/L) }\end{array}$ & $\begin{array}{l}\text { TOTAL } \\
\text { CAD- } \\
\text { MIUH } \\
\text { (CD) } \\
\text { (UG/L) }\end{array}$ & $\begin{array}{l}\text { DIS- } \\
\text { SOLVED } \\
\text { CAO- } \\
\text { HIUM } \\
\text { (CD) } \\
\text { (UG/L) }\end{array}$ & $\begin{array}{l}\text { TOTAL } \\
\text { CHRO- } \\
\text { MIUM } \\
\text { (CR) } \\
\text { (UG/L) }\end{array}$ & $\begin{array}{l}\text { HEXA- } \\
\text { VALENT } \\
\text { CHRO- } \\
\text { MIUM } \\
\text { (CR6) } \\
\text { (UG/L) }\end{array}$ \\
\hline $\begin{array}{l}\text { JAN } \\
15 \ldots \\
\text { FEH }\end{array}$ & 1130 & -- & 4 & $-\infty$ & -- & 130 & $-m$ & 0 & -- & 1 \\
\hline${ }_{\text {MAR }} 12 \ldots$ & 1115 & 3 & -- & 0 & 180 & 120 & $<10$ & 0 & 0 & -- \\
\hline${ }_{\triangle P R} 11 \ldots$ & 0950 & 2 & -- & 0 & 170 & 130 & $<10$ & 1 & 0 & $m$ \\
\hline $15 \ldots$ & 1040 & 2 & $-\infty$ & 100 & 180 & 130 & $<10$ & 1 & 0 & -- \\
\hline $\operatorname{JUN}_{13} \cdots$ & 1040 & 3 & $-\infty$ & 200 & 160 & 130 & $<10$ & 0 & 0 & $-\infty$ \\
\hline 100 & 1035 & 3 & -- & 300 & 190 & 120 & 0 & 0 & 10 & -- \\
\hline $\begin{array}{l}15 \ldots \\
\text { Aug }\end{array}$ & 1050 & 4 & -- & 100 & 200 & 130 & $<10$ & 0 & 10 & -- \\
\hline $\operatorname{SEP}^{12} \cdots$ & 1040 & 2 & -- & 0 & 170 & 140 & $<10$ & $=$ & 0 & $m$ \\
\hline $16 \ldots$ & 1045 & 3 & $-\infty$ & 100 & 180 & 130 & $<10$ & $-\cdots$ & 0 & -- \\
\hline
\end{tabular}


09427520. COLORADO RIVER BELOW PARKER DAM, ARIZ.-CALIF.--CONTINUED

CHEMICAL ANALYSES, WATER YEAR OCTOBER 1975 TO SEPTEMBER 1976

\begin{tabular}{|c|c|c|c|c|c|c|c|c|c|}
\hline DATE & $\begin{array}{l}\text { TOTAL } \\
\text { COPPER } \\
\text { (CU) } \\
\text { (UG/L) }\end{array}$ & $\begin{array}{l}\text { DIS- } \\
\text { SOLVED } \\
\text { COPPER } \\
\text { (CU) } \\
(U G / L)\end{array}$ & $\begin{array}{l}\text { TOTAL } \\
\text { IRON } \\
\text { (FE) } \\
\text { (UG/L) }\end{array}$ & $\begin{array}{l}\text { DIS- } \\
\text { SOLVED } \\
\text { IRON } \\
\text { (FE) } \\
\text { (UG/L) }\end{array}$ & $\begin{array}{c}\text { TOTAL } \\
\text { LEAD } \\
\text { (PB) } \\
\text { (UG/L) }\end{array}$ & $\begin{array}{l}\text { DIS- } \\
\text { SOLVED } \\
\text { LEAD } \\
\text { (PB) } \\
\text { (UG/L) }\end{array}$ & $\begin{array}{l}\text { TOTAL } \\
\text { MAN- } \\
\text { GANESE } \\
\text { (MN) } \\
\text { (UG/L) }\end{array}$ & $\begin{array}{l}\text { DIS- } \\
\text { SOLVED } \\
\text { MAN- } \\
\text { GANESE } \\
\text { (MN) } \\
(U G / L)\end{array}$ & $\begin{array}{c}\text { TOTAL } \\
\text { MERCURY } \\
\text { (HO) } \\
\text { (UG/L) }\end{array}$ \\
\hline $\begin{array}{l}\text { JAIN } \\
15 \ldots . \\
\text { FtB }\end{array}$ & -- & 0 & $-\infty$ & 30 & -- & 0 & -- & 0 & - \\
\hline $\begin{array}{l}F \in B \\
12 \ldots . . \\
\text { MAR }\end{array}$ & $<10$ & -- & 100 & 0 & $<100$ & -- & 20 & 0 & .0 \\
\hline$\underset{A P R}{11} \cdots$ & 20 & - & 210 & 10 & $<100$ & -- & 40 & 10 & .0 \\
\hline $\begin{array}{c}1 b \ldots \\
\text { MAY }\end{array}$ & 10 & $=$ & 120 & 10 & $<100$ & -- & 10 & 10 & .0 \\
\hline $\begin{array}{l}13 . \cdots \\
\text { JUN }\end{array}$ & 10 & -- & 40 & 0 & $<100$ & $=-$ & 10 & 0 & .0 \\
\hline $\mathrm{JUL}^{10 \cdots}$ & 1 & -- & 50 & 10 & 7 & $-\infty$ & 20 & 0 & .2 \\
\hline${ }_{A \cup G}^{15} \cdots$ & 10 & - & 100 & 10 & 100 & $-\infty$ & 30 & 20 & .0 \\
\hline $\operatorname{SEP}_{12} \cdots$ & 10 & -- & 160 & 10 & $<100$ & -- & 20 & 10 & .0 \\
\hline $16 \ldots$ & 10 & - & 30 & 10 & $<100$ & -- & 20 & 10 & .0 \\
\hline
\end{tabular}

\begin{tabular}{|c|c|c|c|c|c|c|c|c|c|}
\hline DATE & $\begin{array}{c}\text { DIS- } \\
\text { SOLVED } \\
\text { MERCURY } \\
\text { (HG) } \\
(U G / L)\end{array}$ & $\begin{array}{l}\text { TOTAL } \\
\text { SELE- } \\
\text { NIUM } \\
\text { (SE) } \\
(U G / L)\end{array}$ & $\begin{array}{l}\text { OIS- } \\
\text { SOLVED } \\
\text { SELE- } \\
\text { NIUM } \\
\text { (SE) } \\
\text { (UG/L) }\end{array}$ & $\begin{array}{l}\text { TOTAL } \\
\text { SILVER } \\
\text { (AG) } \\
(U G / L)\end{array}$ & $\begin{array}{l}\text { TOTAL } \\
\text { ZINC } \\
\text { (ZN) } \\
\text { (UG/L) }\end{array}$ & $\begin{array}{l}\text { DIS- } \\
\text { SOLVEO } \\
\text { ZINC } \\
\text { (ZN) } \\
(U G / L)\end{array}$ & $\begin{array}{l}\text { TOTAL } \\
\text { ORGANIC } \\
\text { CARBON } \\
\text { (C) } \\
\text { (MG/L) }\end{array}$ & $\begin{array}{c}\text { CYANIDE } \\
\text { (CN) } \\
\text { (MG/L) }\end{array}$ & $\begin{array}{l}\text { PHENOLS } \\
\text { (UG/L) }\end{array}$ \\
\hline $\begin{array}{l}\text { JAN } \\
15 \ldots .\end{array}$ & .0 & $\cdots$ & 3 & $-\infty$ & - & 0 & 4.0 & .00 & 1 \\
\hline $\begin{array}{l}\text { FEH } \\
12 \ldots \\
\text { MAR }\end{array}$ & -- & 2 & $\cdots$ & $<10$ & 10 & -- & 4.0 & .00 & 2 \\
\hline$\underset{A P R}{11} \ldots$ & -- & 4 & -- & $<10$ & 10 & $\cdots$ & 3.3 & .00 & 2 \\
\hline${ }_{\text {MYY }}{ }_{\text {M }}$ & -- & 5 & -- & $<10$ & 10 & -- & 3.8 & .00 & 0 \\
\hline${ }_{\text {JUN }}^{13 \ldots}$ & $\cdots$ & 3 & -- & $<10$ & 0 & $=-$ & 3.0 & .01 & 2 \\
\hline $\begin{array}{l}10 \ldots \\
\text { JUL }\end{array}$ & -- & 2 & $=$ & 0 & 20 & -- & 6.3 & .00 & 7 \\
\hline $\begin{array}{l}\text { JUL } \\
\text { AUG }\end{array}$ & - & 3 & -- & $<10$ & 20 & -- & 6.9 & .02 & 2 \\
\hline $12 \ldots$ & -- & 3 & $=$ & $<10$ & 10 & -- & 1.9 & .00 & 2 \\
\hline $16 \ldots$ & -- & 3 & $=$ & $<10$ & 10 & -- & 2.8 & .01 & 3 \\
\hline
\end{tabular}


99429000. PALO VERDF CANAL NEAR BLYTHE, CALIF.

LOCAT LON, - Lat $33^{\circ} 43^{\prime} 55^{\prime \prime}$, long $114^{\circ} 30^{\prime} 40^{\prime \prime}$, in N N ${ }^{\prime}$ NEt sec. 19 , T.5 S., R. 24 E., San Bernardino meridian, Riverside County, at canal intake structure on west side of Palo Verde Diversion Dam, $10 \mathrm{mi}(16 \mathrm{~km})$ northeast of Blythe and $44 \mathrm{mi}(71 \mathrm{~km})$ downstream from lieadgate Rock Dan.

PERIOD OF RECORD, --January 1922 to December 1923, January 1925 to current year (prior to October 1950 , monthly discharge only).

GAGE.--Recording gages above and below intakes to record head. Since May 18, 1964, recorder to show gate openings. Datum of gage is: Forebey gage, at mean sea level; tailrace gage, $274.13 \mathrm{ft}(83.555 \mathrm{~m})$ above mean sea leve1. Aug. 7 , 1950 , to Nov. 30 , 1952 , water-

stage recorder on tailrace and auxiliary recorder $0.5 \mathrm{mi}(0.8 \mathrm{~km})$ downstream and Dec. 1,1952 , to Oct. 28 , 1957 , recording gage above and below former intake structure $0.2 \mathrm{mi}(0.3 \mathrm{~km})$ upstream, at different datums.

AVERAGE IISCHARGE, -26 years $(1950-76), 1,205 \mathrm{ft}^{3} / \mathrm{s}\left(34.13 \mathrm{~m}^{3} / \mathrm{s}\right), 873,000 \mathrm{acre}-\mathrm{ft} / \mathrm{yr}\left(1,080 \mathrm{hm}^{3} / \mathrm{yr}\right)$.

EXTREES.--Period of record: Maximum daily discharge, $2,180 \mathrm{ft} \mathrm{t}^{3} / \mathrm{s}\left(61.7 \mathrm{~m}^{3} / \mathrm{s}\right)$ Aug. 7 , 1962 ; no flow at times.

REMARS.--Records good. Daily diversions computed on basis of head on intake gates and gate openings. Records published herein represent flow diverted from Colorado River for irrigation of 91784 acres $\left(371 \mathrm{~lm}^{2}\right.$ ) during the 1975 calendar year. Return flows to Colorado River are measured by 11 wasteways and drains extending throughout the project; 5 of these are equipped with waterstage recorder and Parshall flume, 3 are equipped with Sparling flowmeters. Return flows have not been subtracted; combined monthly return flows are given in table below. Records of chemical analyses for the current year are published on following pages.

REVISIONS (WATER YEARS) . - WSP 1213: 1946-48.

OISCHARGE, IN CUBIC FEET PER SECONO, WATER YEAR OCTOBER 1975 TO SEPTEMBER 1976

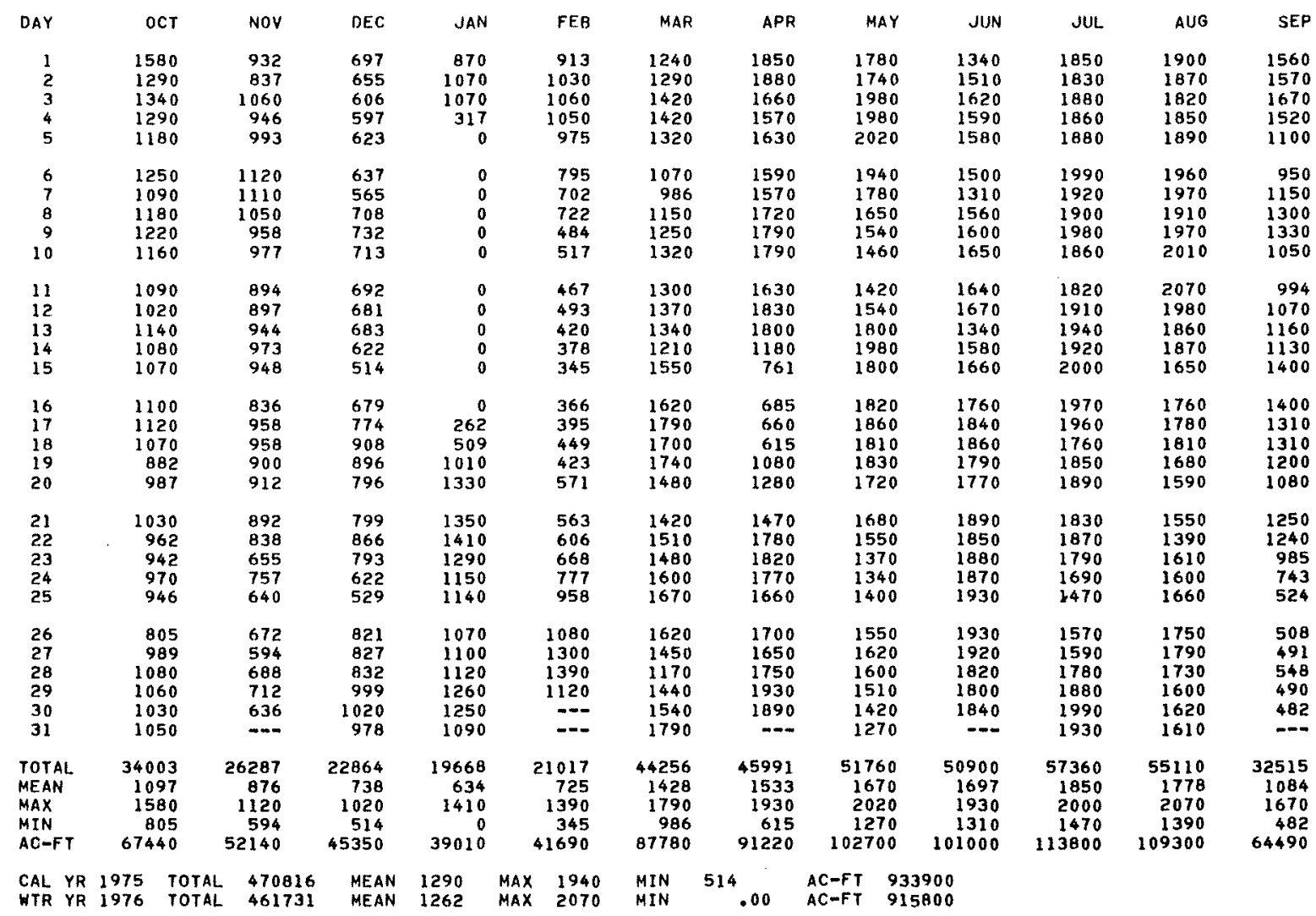


PERIOD OF RECORD,--Chemical analyses: March 1970 to current year.

REMARKS. - No flow Jan. 5-16.

CHEMICAL ANALYSES, WATER YEAR OCTOBER 1975 TO SEPTEMBER 1976

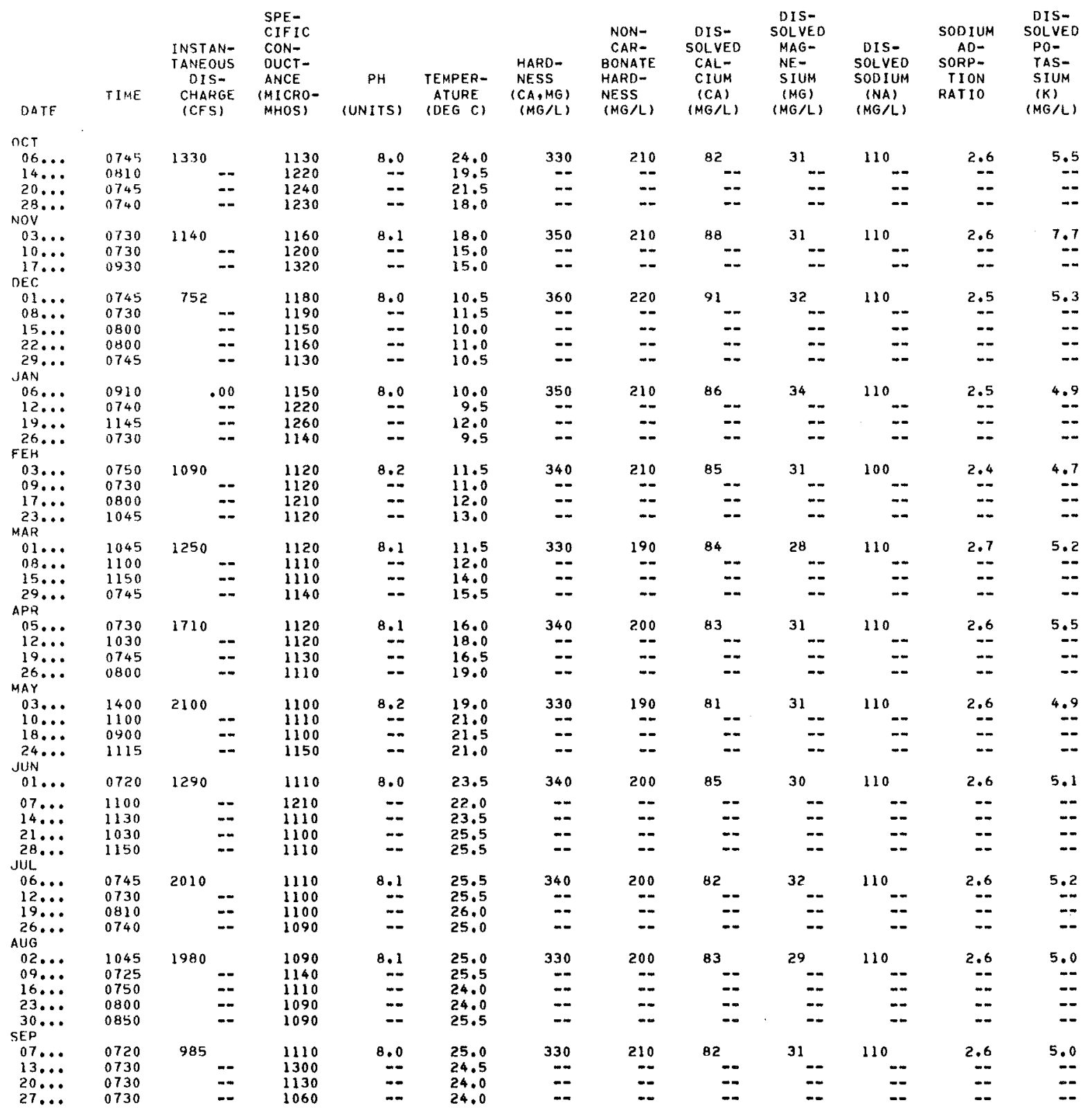


09429000. PALO VERDE CANAL NEAR BLYTHE, CALIF.--CONTINUED

CHEMICAL ANALYSES, WATER YEAR OCTOBER 1975 TO SEPTEMBER 1976

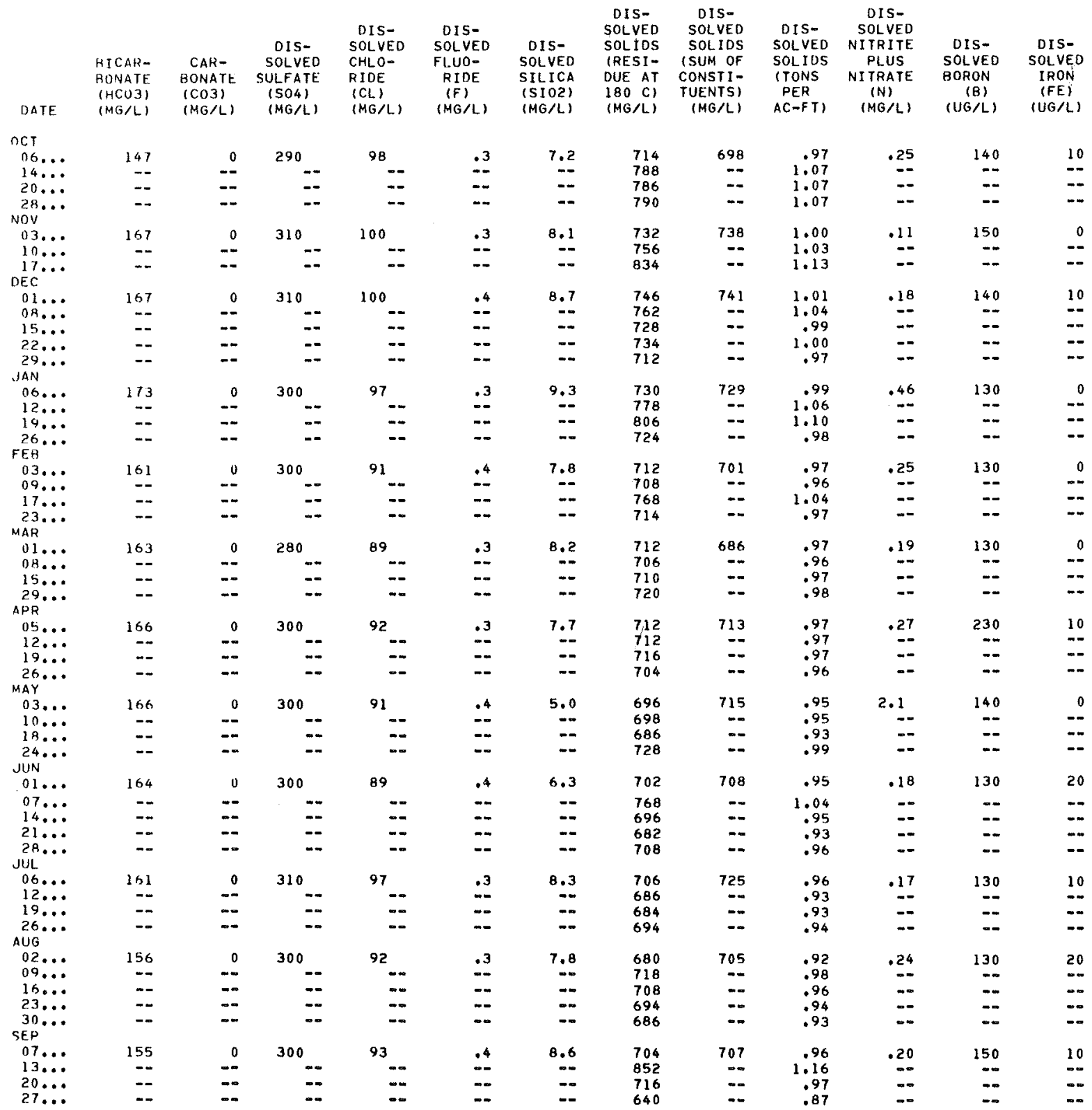


09429010 COLORADO RIVER AT PALO VERDE DAM, ARIZ. -CALIF.

LOCATION, - Lat $33^{\circ} 43^{\prime} 55^{\prime \prime}$, long $114^{\circ} 30^{\prime} 40^{\prime \prime}$, in NW.NE $\frac{1}{4}$ sec.19, T.5 S., R. 24 E., San Bernardino meridian, in CaIifornia, Riverside County, on west side of Palo Verde Diversion Dam, $10 \mathrm{mi}$ ( $16 \mathrm{~km}$ ) northeast of B1ythe, Calif., and 44 mi (71 km) downstream from Headgate Rock Dam.

DRAINAGE AREA (REVISED). - - 186,200 $\mathrm{mi}^{2}\left(482,300 \mathrm{~km}^{2}\right)$, approximately, including $3,959 \mathrm{mi}^{2}$ (10,254 km ${ }^{2}$ in $\mathrm{Great}$ Divide basin in southerm Wyoming, which is noncontributing (previously considered part of the Missouri River basin).

PERIOD OF RECORD, - -April 1969 to current year. If records (available in files of Tuscon District office) for the tho Colorado River Indian Reservation drains entering below Palo Verde Dam are added to records for this station, records equivalent to those published 1956-69 as Colorado River below Palo Verde Dan can be obtained.

GAGE, - Two water-stage recorders, one above and one below dan, to record head on gates, and water-stage recorder to record gate opening. Supplementary water-stage recorder above dam operated by Geological Survey and supplementary water-stage recorder below dam operated by Palo Verde Irrigation District. Datum of gages is at mean sea leve1.

AVERAGE DISCHARGE. --7 years, $7,355 \mathrm{ft}^{3} / \mathrm{s}\left(208.3 \mathrm{mt}^{3} / \mathrm{s}\right), 5,329,000$ acre-ft/yr $\left(6,570 \mathrm{hm}^{3} / \mathrm{yr}\right)$.

EXTREMES. --Current year: Maximum daily discharge, $12,900 \mathrm{ft}^{3} / \mathrm{s}\left(365 \mathrm{~m}^{3} / \mathrm{s}\right) \mathrm{Mar} .28 ;$ minimum daily, $1,350 \mathrm{ft} / \mathrm{s}\left(38.2 \mathrm{~m}^{3} / \mathrm{s}\right)$ Sept. 12 . Period of record: Maximum daily discharge, $13,200 \mathrm{ft}^{3} / \mathrm{s}\left(374 \mathrm{~m}^{3} / \mathrm{s}\right) \mathrm{Apr} .8,1970 ;$ minimum daily, $1,060 \mathrm{ft} / \mathrm{s}\left(30.0 \mathrm{nt}^{3} / \mathrm{s}\right)$ Nov. 24,1972 .

REMARKS. --Records good. Record does not include diversion to Palo Verde Canal. (See elsewhere in this report.) Daily discharge computed from relation between discharge, head, and gate openings. Many diversions above station for irrigation, municipal, and industrial uses. Flow regulated by Lake Mead, Lake Mojave, and Lake Havasu.

DISCHARGE, IN CUBIC FEET PER SECOND, WATER YEAR OCTOBER 1975 TO SEPTEMBER 1976 MEAN VALUES

\begin{tabular}{|c|c|c|c|c|c|c|c|c|c|c|c|c|}
\hline DAY & OCT & NOV & DEC & JAN & FEB & MAR & APR & MAY & JUN & JUL & AUG & SEP \\
\hline $\begin{array}{l}1 \\
2 \\
3 \\
4 \\
5\end{array}$ & $\begin{array}{l}8140 \\
7160 \\
6820 \\
7710 \\
8460\end{array}$ & $\begin{array}{l}4470 \\
4690 \\
4680 \\
5600 \\
5670\end{array}$ & $\begin{array}{l}3570 \\
3890 \\
3970 \\
5200 \\
5200\end{array}$ & $\begin{array}{l}5390 \\
5110 \\
4920 \\
5580 \\
5110\end{array}$ & $\begin{array}{l}6490 \\
6690 \\
7580 \\
7000 \\
6650\end{array}$ & $\begin{array}{r}10200 \\
10700 \\
10900 \\
9850 \\
9320\end{array}$ & $\begin{array}{l}10400 \\
10500 \\
11200 \\
11400 \\
12200\end{array}$ & $\begin{array}{r}10700 \\
10900 \\
10900 \\
10400 \\
9800\end{array}$ & $\begin{array}{l}7630 \\
7810 \\
7870 \\
7040 \\
8110\end{array}$ & $\begin{array}{r}9070 \\
8080 \\
10100 \\
10000 \\
10000\end{array}$ & $\begin{array}{r}9560 \\
10000 \\
10000 \\
9660 \\
9340\end{array}$ & $\begin{array}{l}9670 \\
9540 \\
8700 \\
9400 \\
9400\end{array}$ \\
\hline $\begin{array}{r}6 \\
7 \\
8 \\
9 \\
10\end{array}$ & $\begin{array}{l}8180 \\
7650 \\
6860 \\
6230 \\
5980\end{array}$ & $\begin{array}{l}4300 \\
4120 \\
4890 \\
5180 \\
5330\end{array}$ & $\begin{array}{l}5670 \\
5560 \\
5000 \\
5350 \\
4920\end{array}$ & $\begin{array}{l}5460 \\
5360 \\
4700 \\
3840 \\
4530\end{array}$ & $\begin{array}{l}5340 \\
4260 \\
5080 \\
4400 \\
2570\end{array}$ & $\begin{array}{l}9630 \\
9160 \\
8890 \\
8990 \\
9020\end{array}$ & $\begin{array}{l}11300 \\
11500 \\
10700 \\
10300 \\
12300\end{array}$ & $\begin{array}{l}9240 \\
8520 \\
6830 \\
6630 \\
7490\end{array}$ & $\begin{array}{l}8070 \\
8860 \\
8680 \\
8100 \\
6980\end{array}$ & $\begin{array}{r}9610 \\
9100 \\
9130 \\
9680 \\
11500\end{array}$ & $\begin{array}{r}9480 \\
11300 \\
11300 \\
11300 \\
10400\end{array}$ & $\begin{array}{l}8860 \\
5740 \\
5420 \\
5860 \\
5080\end{array}$ \\
\hline $\begin{array}{l}11 \\
12 \\
13 \\
14 \\
15\end{array}$ & $\begin{array}{l}6560 \\
6660 \\
6640 \\
6070 \\
5880\end{array}$ & $\begin{array}{l}4770 \\
4320 \\
4150 \\
3840 \\
5420\end{array}$ & $\begin{array}{l}4410 \\
4400 \\
3930 \\
4800 \\
5710\end{array}$ & $\begin{array}{l}4780 \\
4920 \\
4780 \\
4220 \\
3940\end{array}$ & $\begin{array}{l}1720 \\
1520 \\
2030 \\
2360 \\
1810\end{array}$ & $\begin{array}{r}8000 \\
7640 \\
9680 \\
9900 \\
10100\end{array}$ & $\begin{array}{r}11800 \\
11500 \\
11000 \\
7380 \\
5550\end{array}$ & $\begin{array}{l}8260 \\
8440 \\
8860 \\
7920 \\
8400\end{array}$ & $\begin{array}{l}7530 \\
8790 \\
8930 \\
9100 \\
8880\end{array}$ & $\begin{array}{r}11700 \\
10700 \\
10600 \\
10000 \\
9240\end{array}$ & $\begin{array}{l}10400 \\
10200 \\
10000 \\
10800 \\
10700\end{array}$ & $\begin{array}{l}1830 \\
1350 \\
2390 \\
3460 \\
3490\end{array}$ \\
\hline $\begin{array}{l}16 \\
17 \\
18 \\
19 \\
20\end{array}$ & $\begin{array}{l}4440 \\
4620 \\
6270 \\
7030 \\
7180\end{array}$ & $\begin{array}{l}5700 \\
5800 \\
5480 \\
5430 \\
5100\end{array}$ & $\begin{array}{l}5980 \\
6040 \\
5580 \\
5180 \\
5350\end{array}$ & $\begin{array}{l}3630 \\
4980 \\
5190 \\
5210 \\
4960\end{array}$ & $\begin{array}{l}1720 \\
1900 \\
2010 \\
2830 \\
3510\end{array}$ & $\begin{array}{l}10700 \\
10800 \\
10300 \\
10500 \\
11700\end{array}$ & $\begin{array}{l}4960 \\
5770 \\
8630 \\
9010 \\
8850\end{array}$ & $\begin{array}{r}8720 \\
8900 \\
10100 \\
9150 \\
7590\end{array}$ & $\begin{array}{l}8270 \\
8030 \\
8150 \\
8450 \\
9370\end{array}$ & $\begin{array}{r}9360 \\
10600 \\
11000 \\
10800 \\
10100\end{array}$ & $\begin{array}{r}10900 \\
10200 \\
10100 \\
9790 \\
10300\end{array}$ & $\begin{array}{l}3660 \\
4120 \\
5230 \\
5430 \\
6940\end{array}$ \\
\hline $\begin{array}{l}21 \\
22 \\
23 \\
24 \\
25\end{array}$ & $\begin{array}{l}6130 \\
5700 \\
4790 \\
4740 \\
5130\end{array}$ & $\begin{array}{l}4540 \\
5710 \\
5460 \\
4240 \\
3190\end{array}$ & $\begin{array}{l}4810 \\
2680 \\
1760 \\
4500 \\
5460\end{array}$ & $\begin{array}{l}4880 \\
4400 \\
4430 \\
5000 \\
5710\end{array}$ & $\begin{array}{l}4980 \\
5980 \\
7080 \\
8590 \\
8650\end{array}$ & $\begin{array}{l}11800 \\
11600 \\
11900 \\
11300 \\
12000\end{array}$ & $\begin{array}{l}10100 \\
10800 \\
11300 \\
12700 \\
11600\end{array}$ & $\begin{array}{l}7900 \\
9260 \\
9250 \\
6420 \\
7360\end{array}$ & $\begin{array}{l}9480 \\
9180 \\
9250 \\
8500 \\
8170\end{array}$ & $\begin{array}{r}9920 \\
9480 \\
9530 \\
10100 \\
10700\end{array}$ & $\begin{array}{r}10700 \\
10600 \\
10100 \\
9920 \\
9730\end{array}$ & $\begin{array}{l}7100 \\
6970 \\
7500 \\
4500 \\
5450\end{array}$ \\
\hline $\begin{array}{l}26 \\
27 \\
28 \\
29 \\
30 \\
31\end{array}$ & $\begin{array}{l}5680 \\
5540 \\
5500 \\
5400 \\
5120 \\
4170\end{array}$ & $\begin{array}{c}3200 \\
3390 \\
3230 \\
3580 \\
3530 \\
-0-\end{array}$ & $\begin{array}{l}5370 \\
5760 \\
5580 \\
4860 \\
3480 \\
5020\end{array}$ & $\begin{array}{l}5890 \\
5420 \\
5380 \\
5370 \\
4910 \\
5750\end{array}$ & $\begin{array}{r}8950 \\
8880 \\
9380 \\
10600 \\
\ldots 0 \\
-0\end{array}$ & $\begin{array}{l}11100 \\
12600 \\
12900 \\
12200 \\
12200 \\
11700\end{array}$ & $\begin{array}{r}10900 \\
12400 \\
11900 \\
10000 \\
10500 \\
0.0\end{array}$ & $\begin{array}{l}7300 \\
6380 \\
7680 \\
8600 \\
8660 \\
8240\end{array}$ & $\begin{array}{r}8690 \\
9320 \\
9540 \\
9750 \\
10100 \\
-0-\end{array}$ & $\begin{array}{r}10200 \\
8740 \\
7250 \\
6630 \\
7010 \\
9220\end{array}$ & $\begin{array}{r}9160 \\
9130 \\
10400 \\
10300 \\
10100 \\
9660\end{array}$ & $\begin{array}{l}2770 \\
3610 \\
3620 \\
3920 \\
3290 \\
-\end{array}$ \\
\hline $\begin{array}{l}\text { TOTAL } \\
\text { MEAN } \\
\text { MAX } \\
\text { MIN } \\
\text { AC-FT }\end{array}$ & $\begin{array}{r}192440 \\
6208 \\
8460 \\
4170 \\
381700\end{array}$ & $\begin{array}{r}139010 \\
4634 \\
5800 \\
3190 \\
275700\end{array}$ & $\begin{array}{r}148990 \\
4806 \\
6040 \\
1760 \\
295500\end{array}$ & $\begin{array}{r}153750 \\
4960 \\
5890 \\
3630 \\
305000\end{array}$ & $\begin{array}{r}150560 \\
5192 \\
10600 \\
1520 \\
298600\end{array}$ & $\begin{array}{r}327280 \\
10560 \\
12900 \\
7640 \\
649200\end{array}$ & $\begin{array}{r}308450 \\
10280 \\
12700 \\
4960 \\
611800\end{array}$ & $\begin{array}{r}266800 \\
8606 \\
10900 \\
6380 \\
529200\end{array}$ & $\begin{array}{r}256430 \\
8548 \\
10100 \\
6980 \\
508600\end{array}$ & $\begin{array}{r}299150 \\
9650 \\
11700 \\
6630 \\
593400\end{array}$ & $\begin{array}{r}315510 \\
10180 \\
11300 \\
9130 \\
625800\end{array}$ & $\begin{array}{r}164300 \\
5477 \\
9670 \\
1350 \\
325900\end{array}$ \\
\hline $\begin{array}{l}\text { CAL YR } \\
\text { WTR YR }\end{array}$ & $\begin{array}{l}975 \\
976\end{array}$ & $\begin{array}{l}28 \\
27\end{array}$ & $\begin{array}{l}50 \\
70\end{array}$ & $\begin{array}{l}7732 \\
7439\end{array}$ & $\begin{array}{ll}\operatorname{MAX} & 1 \\
\operatorname{MAX} & 1\end{array}$ & $\begin{array}{l}\text { MIN } \\
\text { MIN }\end{array}$ & $\begin{array}{l}1760 \\
1350\end{array}$ & $\begin{array}{l}C-F T \\
C-F T\end{array}$ & $\begin{array}{l}8000 \\
0000\end{array}$ & & & \\
\hline
\end{tabular}


09429130. PALO VERDE IRRTGATION DISTRICT OLIVE LAKE DRAIN NFAR BLYTHE, CALIF.

LOCATION. - Lat $33^{\circ} 40^{\prime} 36^{\prime \prime}$, Iong $114^{\circ} 32^{\prime} 09^{\prime \prime}$, in SW' SWl sec.1, T.6 S., R. 23 E., San Bernardino meridian, Riverside County, 0.3 mi (0.5 km) upstream from mouth, and $5 \mathrm{mi}(8 \mathrm{~km})$ northeast of B1ythe.

PERIOD OF RECORD.--Chemical analyses: October 1968 to September 1970 (partial-record station), October 1970 to current year.

RFMARKS, - Unpublished miscellaneous chemical analyses for water years 1962-68 available from district office in Tucson, Ariz.

CHEMICAL ANALYSES, WATER YEAR OCTOBER 1975 TO SEPTEMBER 1976

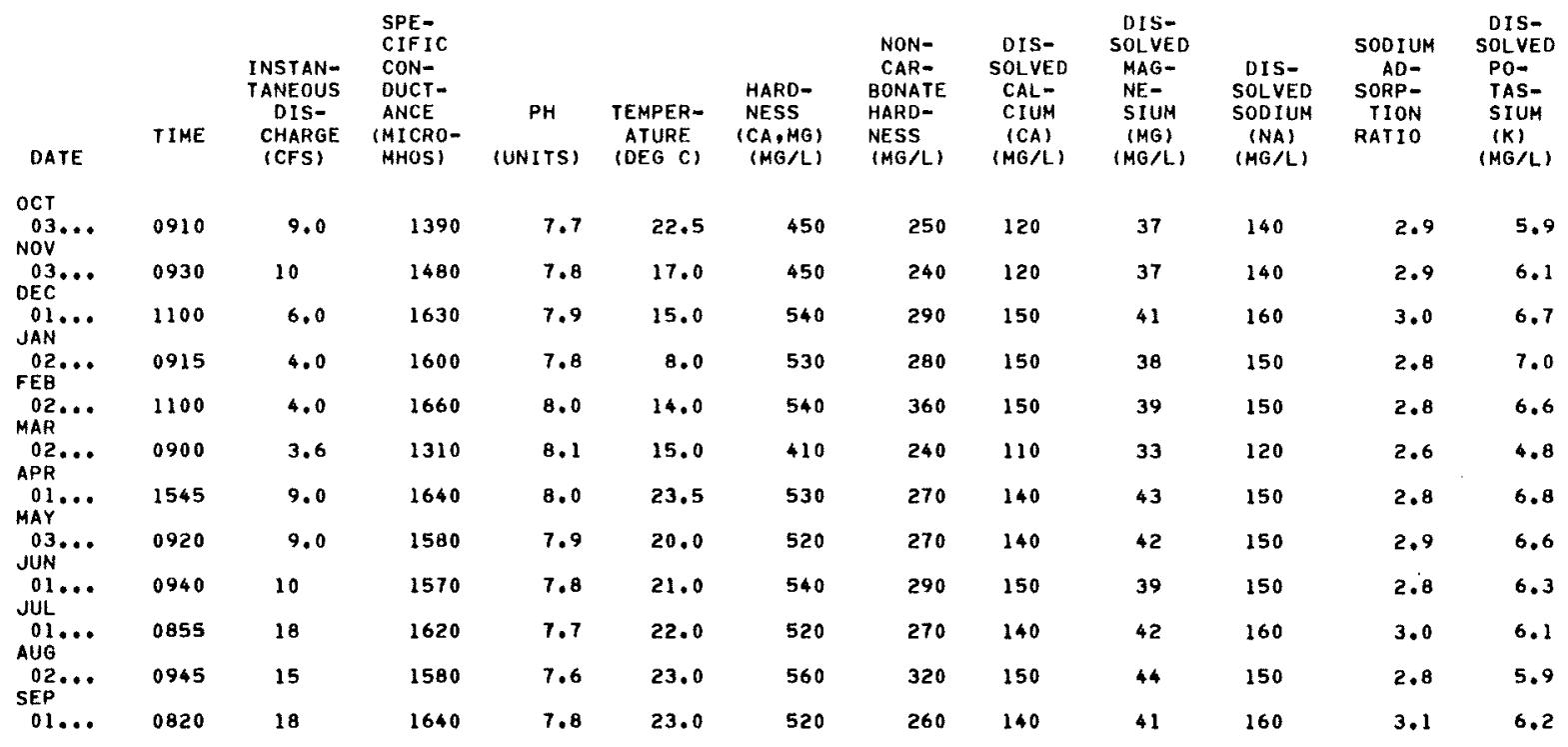

\begin{tabular}{|c|c|c|c|c|c|c|c|c|c|c|c|c|}
\hline DAIE & $\begin{array}{l}\text { BICAR- } \\
\text { BONATE } \\
\text { (HCO3) } \\
\text { (HG/L) }\end{array}$ & $\begin{array}{l}\text { CAR- } \\
\text { BONATE } \\
\text { (CO3) } \\
\text { (MG/L) }\end{array}$ & $\begin{array}{l}\text { DIS- } \\
\text { SOLVEO } \\
\text { SULFATE } \\
\text { (SO4) } \\
\text { (MG/L) }\end{array}$ & $\begin{array}{l}\text { DIS- } \\
\text { SOLYED } \\
\text { CKLO- } \\
\text { RIDE } \\
\text { ICL) } \\
\text { (HG/L) }\end{array}$ & $\begin{array}{l}\text { DIS- } \\
\text { SOLVED } \\
\text { FLUO- } \\
\text { RIOE } \\
\text { (F) } \\
\text { (HG/L) }\end{array}$ & $\begin{array}{l}\text { DIS- } \\
\text { SOLVED } \\
\text { SILICA } \\
\text { (SIO2) } \\
\text { (MG/L) }\end{array}$ & $\begin{array}{l}\text { DIS- } \\
\text { SOLVEO } \\
\text { SOLIDS } \\
\text { (RESI- } \\
\text { DUE AT } \\
\text { IBO C) } \\
\text { (MG/L) }\end{array}$ & $\begin{array}{l}\text { DIS- } \\
\text { SOLVED } \\
\text { SOLIDS } \\
\text { (SUM OF } \\
\text { CONSII- } \\
\text { TUENTS) } \\
\text { (MG/L) }\end{array}$ & $\begin{array}{l}\text { DIS- } \\
\text { SOLVED } \\
\text { SOLIDS } \\
\text { (TONS } \\
\text { PER } \\
\text { AC-FT) }\end{array}$ & $\begin{array}{l}\text { OIS- } \\
\text { SOLVED } \\
\text { NITRITE } \\
\text { PLUS } \\
\text { NITRATE } \\
\text { (N) } \\
\text { (HG/L) }\end{array}$ & $\begin{array}{c}\text { DIS- } \\
\text { SOLVED } \\
\text { BORON } \\
\text { (B) } \\
(U G / L)\end{array}$ & $\begin{array}{l}\text { DIS- } \\
\text { SOLVED } \\
\text { IRON } \\
\text { (FE) } \\
\text { (UG/L) }\end{array}$ \\
\hline OCT & & & & & & & & & & & & \\
\hline noy... & 242 & 0 & 370 & 120 & .3 & 13 & 944 & 927 & 1.28 & .35 & 180 & 0 \\
\hline $\begin{array}{l}03 \ldots \\
\text { DEC }\end{array}$ & 264 & 0 & 380 & 120 & .3 & 14 & 998 & 949 & 1.36 & .19 & 170 & 50 \\
\hline JAN $\cdots$ & 307 & 0 & 450 & 130 & .4 & 18 & 1080 & 1110 & 1.47 & .31 & 190 & 160 \\
\hline$\underset{F E B}{02 \ldots}$ & 303 & 0 & 440 & 120 & .3 & 16 & 972 & 1070 & 1.32 & .18 & 170 & 10 \\
\hline MAR & 212 & 0 & 450 & 140 & .4 & 16 & 1040 & 1060 & 1.41 & .24 & 180 & 70 \\
\hline $02 \ldots$ & 211 & 0 & 350 & 110 & .5 & 11 & 852 & 844 & 1.16 & .17 & 160 & 10 \\
\hline MAY $\cdots$ & 307 & 0 & 390 & 130 & .4 & 17 & 1070 & 1030 & 1.46 & .14 & 180 & 10 \\
\hline JUN... & 305 & 0 & 440 & 140 & .4 & 16 & 1000 & 1090 & 1.36 & .19 & 160 & 20 \\
\hline JuL... & 297 & 0 & 420 & 130 & .3 & 16 & 1050 & 1060 & 1.43 & .35 & 170 & 10 \\
\hline OU1... & 305 & 0 & 410 & 150 & .4 & 17 & 1070 & 1080 & 1.46 & .21 & 180 & 20 \\
\hline $\begin{array}{c}02 . . . \\
\text { SEP }\end{array}$ & 287 & 0 & 420 & 140 & .4 & 17 & 1060 & 1070 & 1.44 & .25 & 180 & 10 \\
\hline 01. & 313 & 0 & 410 & 140 & .4 & 18 & 1090 & 1070 & 1.48 & .31 & 190 & 20 \\
\hline
\end{tabular}


09429220. PALO VERDE iRRIGATION DISTRICT OUTFALL DRAIN NEAR PALO VERDE, CALIF.

LOCATION, - Lat $33^{\circ} 21^{\circ} 41^{\prime \prime}$, long $114^{\circ} 43^{\prime} 20^{\prime \prime}$, in SE $45 E^{t}$ sec. 26 , T.9 S., R. 21 E, , San Bernardino meridian, Imperial County, at gaging station, at State Highway 78 bridge, $3.3 \mathrm{mi}(5.3 \mathrm{~km})$ upstream from mouth, and $5 \mathrm{mi}$ (8 km) south of Palo Verde.

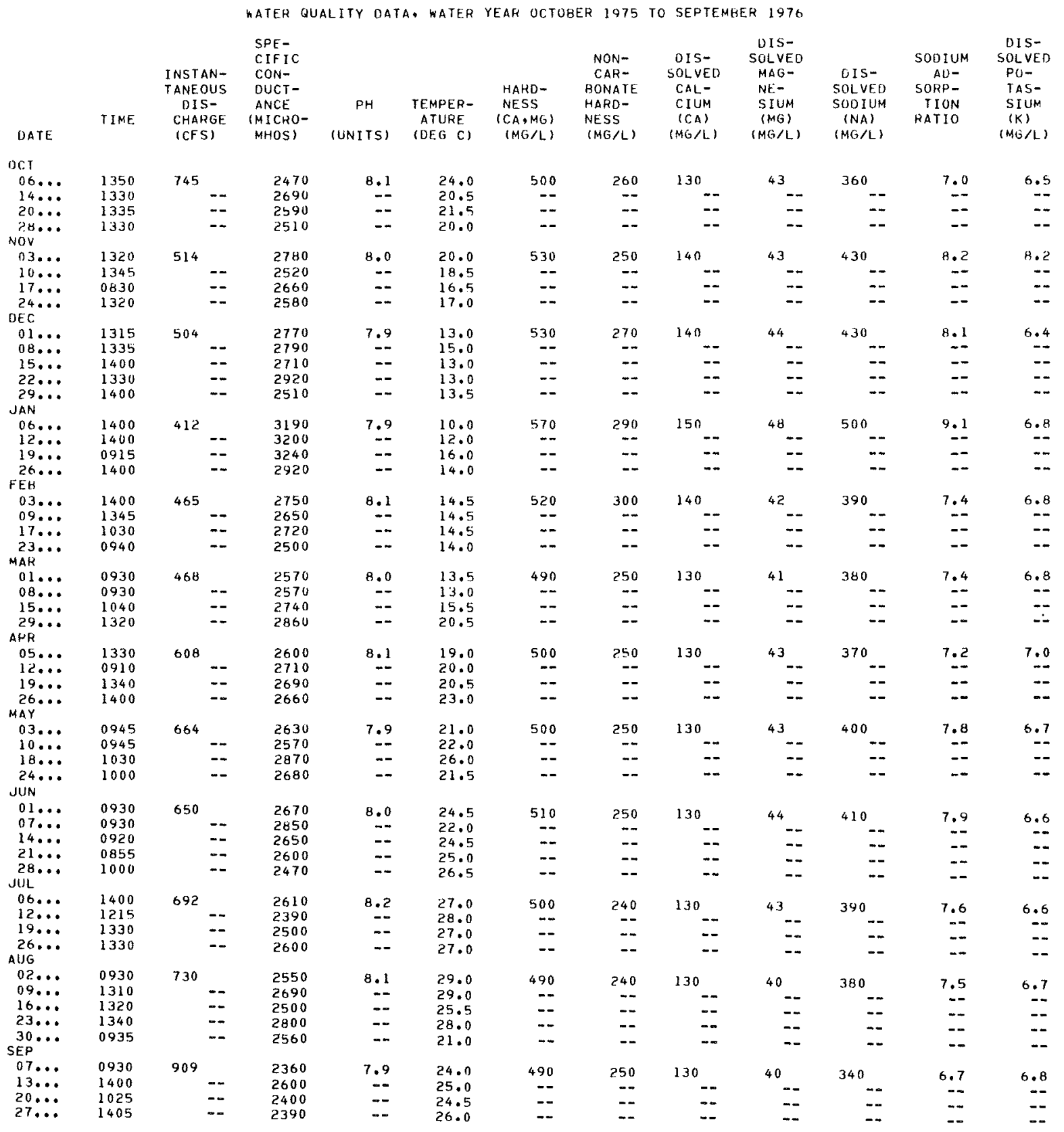


09429220. PALO VERDE IRRIGATION DISTRICT OUTFALL DRAIN NEAR PALO VERDE, CALIF. - -CONTINUED

PERIOD OF RECORD.--Chemical analyses: October 1968 to current year.

REMAARS.--Unpublished miscellaneous chemical analyses for water years 1962-68 available from district office in Tucson, Ariz

WATER QUALITY DATA, WATER YEAR OCTOBER 1975 TO SEPTEMBER 1976

OC

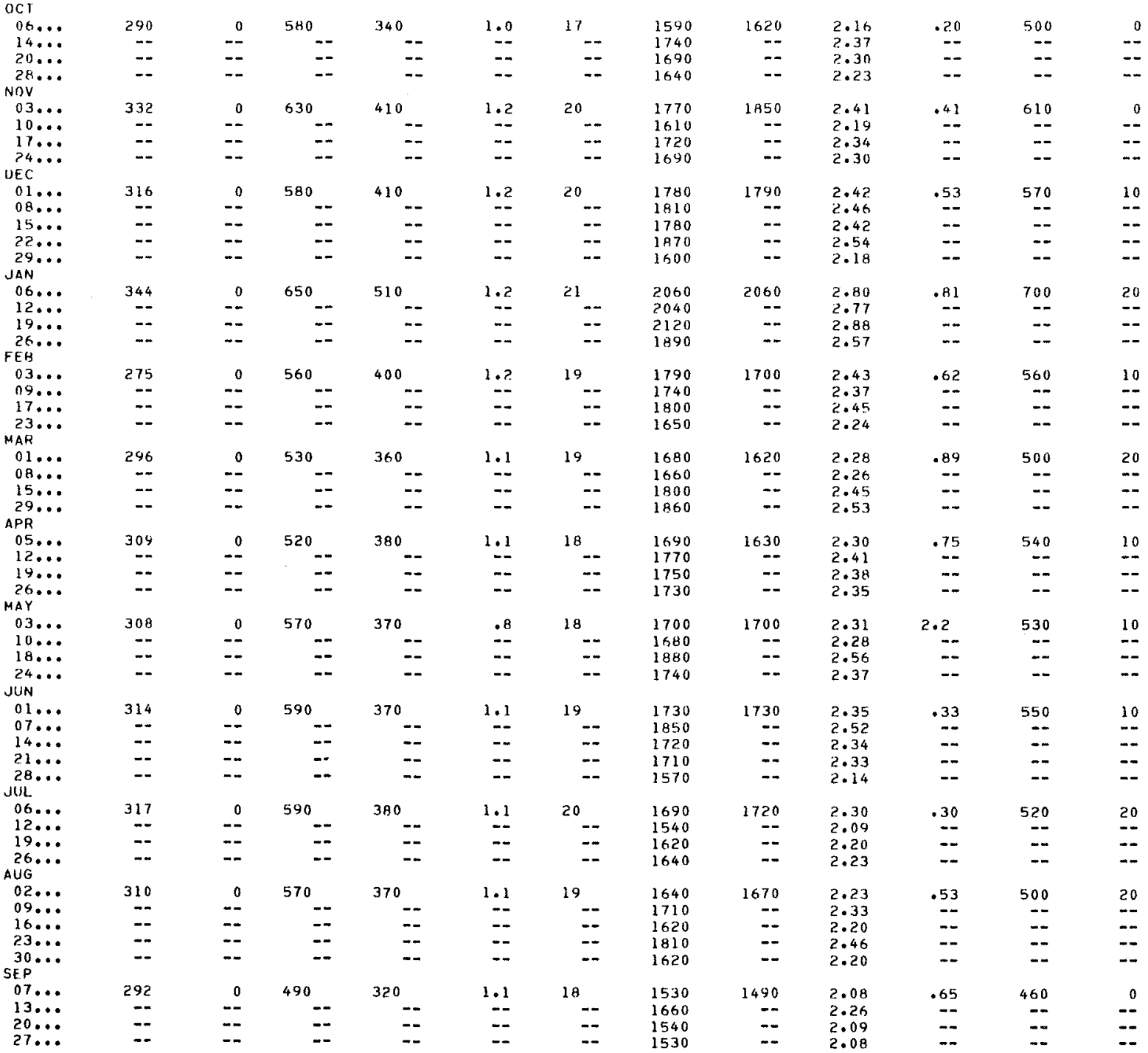


LOCATION,--Lat $33^{\circ} 21^{\prime} 19^{\prime \prime}$, long $114^{\circ} 43^{\prime} 00^{\prime \prime}$, in Sw't sec.36, T.9 S., R. 21 E., San Bernardino meridian, Imperial County, $0.1 \mathrm{mi}(0.2 \mathrm{~km}$ ) upstream from pump into Outfall drain, and $5.5 \mathrm{mi}(8.8 \mathrm{~km})$ south of Palo Verde.

PERIOD OF RECORD,--Chemical analyses: Water year 1969 (partial-record station), October 1969 to current year.

REMARKS.--Unpublished miscellaneous chemical analyses for water years 1966-68 available from district office in Tucson, Ariz.

NATER QUALITY DATA, WATER YEAR OCTOBEP 1975 TO SEPTEMEER 1976

\begin{tabular}{|c|c|c|c|c|c|c|c|c|c|c|c|c|}
\hline DATE & TIME. & $\begin{array}{l}\text { INSTAN- } \\
\text { TANEOUS } \\
\text { DIS- } \\
\text { CHARGE } \\
\text { (CFS) }\end{array}$ & $\begin{array}{l}\text { SPE- } \\
\text { CIFIC } \\
\text { CON- } \\
\text { DUCT- } \\
\text { ANCE } \\
\text { (MICRO- } \\
\text { MHOS) }\end{array}$ & $\begin{array}{c}\mathrm{PH} \\
\text { (UNITS) }\end{array}$ & $\begin{array}{l}\text { TEMPER- } \\
\text { ATURE } \\
\text { (DEG C) }\end{array}$ & $\begin{array}{l}\text { HAKD- } \\
\text { NESS } \\
\text { (CA,MG) } \\
(M G / L)\end{array}$ & $\begin{array}{l}\text { NON- } \\
\text { CAR- } \\
\text { BONATE } \\
\text { HARD- } \\
\text { NESS } \\
(M G / L)\end{array}$ & $\begin{array}{l}\text { DIS- } \\
\text { SOLVED } \\
\text { CAL- } \\
\text { CIUM } \\
\text { (CA) } \\
\text { (MG/L) }\end{array}$ & $\begin{array}{l}\text { DIS- } \\
\text { SOLVED } \\
\text { MAG- } \\
\text { NE- } \\
\text { SIUM } \\
\text { (MG) } \\
\text { (MG/L) }\end{array}$ & $\begin{array}{l}\text { DIS- } \\
\text { SOLVED } \\
\text { SODIUM } \\
\text { (NA) } \\
\text { (MG/L) }\end{array}$ & $\begin{array}{l}\text { SODIUM } \\
\text { AD- } \\
\text { SORP- } \\
\text { TION } \\
\text { RATIO }\end{array}$ & $\begin{array}{l}\text { DIS- } \\
\text { SOLVEO } \\
\text { PO- } \\
\text { TAS- } \\
\text { SIUM } \\
\text { (K) } \\
\text { (HG/L) }\end{array}$ \\
\hline OCI & & & & & & & & & & & & \\
\hline Nov & 1430 & 2.2 & 3080 & 7.9 & 25.0 & 420 & 0 & 100 & 42 & 570 & 12 & 5.6 \\
\hline $\begin{array}{l}03 \ldots \\
\mathrm{DEC}\end{array}$ & 1055 & 2.2 & 3100 & 8.1 & 19.5 & 270 & 0 & 59 & 29 & 630 & 17 & $4 \cdot 8$ \\
\hline$\underset{\text { JAN }}{01} \cdots$ & 1300 & 2.3 & 3700 & 8.0 & 14.0 & 430 & 0 & 96 & 47 & 650 & 14 & 7.6 \\
\hline$\underset{F E H}{02} \cdots$ & 1200 & .00 & 2910 & 8.0 & 16.0 & 200 & 0 & 47 & 20 & 600 & 18 & 4.4 \\
\hline $\begin{array}{c}02 \ldots \\
\text { MAR }\end{array}$ & 1435 & 1.2 & 2540 & 7.9 & 20.5 & 250 & 0 & 59 & 26 & 470 & 13 & 5.1 \\
\hline$\stackrel{01}{01} \cdots$ & 1505 & .56 & 2760 & 7.9 & 19.0 & 210 & 0 & 48 & 22 & 520 & 16 & 4.7 \\
\hline MAY $01 \ldots$ & 1555 & 1.6 & 2730 & 7.9 & 23.0 & 210 & 0 & 47 & 23 & 530 & 16 & $4 \cdot 3$ \\
\hline${ }_{\text {JUL }}^{01} \cdots$ & 1430 & 1.4 & 2780 & 8.0 & -- & 280 & 0 & 63 & 30 & 510 & 13 & 7.6 \\
\hline$\underset{A \cup G}{01} \cdots$ & 1040 & 2.0 & 1450 & 7.5 & 29.0 & 260 & 200 & 52 & 31 & 190 & 5.2 & 9.9 \\
\hline $\begin{array}{l}02 \ldots \\
\text { SEP }\end{array}$ & 1345 & 1.2 & 2710 & 7.4 & 29.0 & 330 & 0 & 77 & 34 & 530 & 13 & 7.6 \\
\hline $01 \ldots$ & 1530 & .00 & 3500 & 7.8 & 32.0 & 560 & 22 & 120 & 63 & 600 & 11 & 16 \\
\hline DATE & $\begin{array}{l}\text { BICAR- } \\
\text { BONATE } \\
\text { (HCO3) } \\
\text { (MG/L) }\end{array}$ & $\begin{array}{l}\text { CAR- } \\
\text { BONATE } \\
\text { (CO3) } \\
(M G / L)\end{array}$ & $\begin{array}{l}\text { OIS- } \\
\text { SULVED } \\
\text { SULFATE } \\
\text { (SO4) } \\
\text { (MG/L) }\end{array}$ & $\begin{array}{l}\text { DIS- } \\
\text { SOLVED } \\
\text { CHLO- } \\
\text { RIDE } \\
(\mathrm{CL}) \\
(M G / L)\end{array}$ & $\begin{array}{l}\text { DIS- } \\
\text { SOLVED } \\
\text { FLUO- } \\
\text { RIDE } \\
\text { (F) } \\
(M G / L)\end{array}$ & $\begin{array}{l}\text { DIS- } \\
\text { SOLVED } \\
\text { SILICA } \\
\text { (SIOZ) } \\
\text { (MG/L) }\end{array}$ & $\begin{array}{l}\text { DIS- } \\
\text { SOLVEU } \\
\text { SOL IDS } \\
\text { (RESI- } \\
\text { DUE AT } \\
180 \mathrm{C}) \\
(M G / L)\end{array}$ & $\begin{array}{l}\text { DIS- } \\
\text { SOLVED } \\
\text { SOLIDS } \\
\text { (SUM OF } \\
\text { CONSTI- } \\
\text { TUENTS) } \\
\text { (MG/L) }\end{array}$ & $\begin{array}{l}\text { DIS- } \\
\text { SOLVED } \\
\text { SOLIDS } \\
\text { (TONS } \\
\text { PER } \\
\text { AC-FT) }\end{array}$ & $\begin{array}{l}\text { DIS- } \\
\text { SOLVED } \\
\text { NITRITE } \\
\text { PLUS } \\
\text { NITRATE } \\
\text { (N) } \\
\text { (MG/L) }\end{array}$ & $\begin{array}{c}\text { DIS- } \\
\text { SOLVED } \\
\text { BORON } \\
\text { (B) } \\
\text { (UG/L) }\end{array}$ & $\begin{array}{l}\text { DIS- } \\
\text { SOLVED } \\
\text { IRON } \\
\text { (FE) } \\
(U G / L)\end{array}$ \\
\hline $\begin{array}{l}\mathrm{oct} \\
01 \ldots\end{array}$ & & & & & & & & & 376 & & & \\
\hline NOV & 340 & & 100 & 340 & 1.3 & 22 & 2030 & 2050 & 2.76 & .07 & 840 & 20 \\
\hline $\begin{array}{l}03 . . . \\
\text { DEr }\end{array}$ & 534 & 0 & 660 & 360 & 2.0 & 23 & 2020 & 2030 & 2.75 & .08 & 970 & 150 \\
\hline $\begin{array}{l}02 \ldots \\
F E B\end{array}$ & 519 & 0 & 580 & 310 & 1.5 & 22 & 1950 & 1840 & 2.52 & $\cdot 22$ & 930 & 210 \\
\hline $\begin{array}{l}02 \ldots \\
\text { MAR }\end{array}$ & 478 & 0 & 550 & 250 & 1.7 & 21 & 1640 & 1620 & 2.23 & .08 & 750 & 160 \\
\hline${ }_{A P R}^{01} \cdots$ & 524 & 0 & 550 & 260 & 2.1 & 23 & 1760 & 1690 & 2.39 & .06 & 840 & 140 \\
\hline MAY $01 \cdots$ & 515 & 0 & 530 & 260 & 2.0 & 23 & 1710 & 1670 & $2 \cdot 33$ & .06 & 820 & 220 \\
\hline$\underset{\text { JUN }}{03 \ldots}$ & 521 & 0 & 580 & 260 & 1.9 & 22 & 1720 & 1710 & $2 \cdot 34$ & .03 & 680 & 360 \\
\hline $\begin{array}{l}01 \ldots \\
\text { JUL. }\end{array}$ & 552 & 0 & 570 & 290 & 1.6 & 23 & 1770 & 1770 & 2.41 & 1.4 & 800 & 140 \\
\hline$\underset{\text { AUG }}{01 \ldots}$ & 75 & 0 & 350 & 140 & .6 & 15 & 946 & 897 & 1.29 & 16 & 260 & 100 \\
\hline SE... & 592 & 0 & 550 & 270 & 1.4 & 28 & 1780 & 1800 & 2.42 & 1.9 & 790 & 300 \\
\hline $01 \ldots$ & 655 & 0 & 710 & 430 & 1.0 & 30 & 2340 & 2310 & 3.18 & 2.5 & 870 & 80 \\
\hline
\end{tabular}


09429490. COLORADO RIVER ABOVE IMPERIAL DAM, ARIZ. -CALIF.

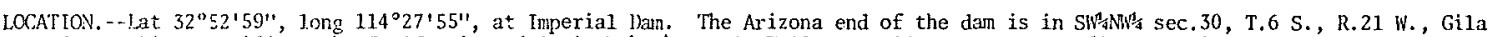
and Salt River meridian; the Califormia end is in NW'SW sec.9, T.15 S., R.24 E., San Bernardino meridian. Imperial Dam is 5 mi $(8 \mathrm{kin})$ upstream from Laguna Dan, $15 \mathrm{mi}(24 \mathrm{~km})$ northeast of Yuma, Ariz., $90 \mathrm{mi}$ (i45 km) downstream from Palo Verde Dam, and $147 \mathrm{mi}$ (237 lim) downstrean fron Parker Dam.

DRMNGGE AREA (REVISFD). - - 188,500 $\mathrm{mi}^{2}\left(488,200 \mathrm{~km}^{2}\right)$, approximntely, including $3,959 \mathrm{mi}^{2}\left(10,254 \mathrm{~km}^{2}\right)$ in Great Divide basin in southern Hyoming, which is noncontributing (previously considered part of the Missouri River basin).

PLIRIOD Ol. RECORD,--1903-34 (yerrly discharge only, published in WSP 1313), July 1934 to current year (monthly discharge only since October 1942). Prior to October 1942 published as "near Picacho, Calif." October 1942 to September 1971 published as "at Inperial Dann" (monthly discharge shom as "flow reaching Imperial Dam," listed as supplement to "flow passing Imperial Dam").

GAGE,-Nno. This record is synthesized from records of several other stations (sce REMARKS). July 13, 1934, to Sept. 30, 1942, water-stage recorder at sitc $14.5 \mathrm{mi}(23.3 \mathrm{~km})$ upstrean at datum $167.38 \mathrm{ft}(51.017 \mathrm{~m})$ above mean sea 1evei.

AVERAGE I ISCTARGE. - -42 year's $(1934-76), 11,110 \mathrm{ft}^{3} / \mathrm{s}\left(314.6 \mathrm{~m}^{3} / \mathrm{s}\right), 8,049,000 \mathrm{acre}-\mathrm{ft} / \mathrm{yr}(9,920 \mathrm{hm} / \mathrm{yr})$.

EXTREVES, - 1934-76: Maximun discharge, 40,800 $\mathrm{ft}^{3} / \mathrm{s}\left(1,160 \mathrm{~m}^{3} / \mathrm{s}\right)$ Sept. 5, 1939; minimum, $538 \mathrm{ft}^{3} / \mathrm{s}\left(15.2 \mathrm{~m}^{3} / \mathrm{s}\right)$ Aug. 3,$1934 ;$ minimum daily since regulation of Hoover Dam began, $1,450 \mathrm{ft}^{3} / \mathrm{s}\left(41.1 \mathrm{~m}^{3} / \mathrm{s}\right) \mathrm{Feb} .17,1935$.

REMARKS.--Records show rlow of Colorado River reaching Imperial Dam, and are based on combined monthly total flow of Colorado River below Imperial Dan (sta 09429500), A11-American Canal near Imperial Dam (sta 09523000), Gila Gravity Main Canal at Imperial Darn (sta 09522500 ), and diversions to Mittry Lake. Records for 1903-34 and for October 1942 to September 1960 were computed as combined flow of Colorado River at Yuma (sta 09521000) and the canals diverting at Imperial and Laguna Dans, less the flow of Cila River near Dome (sta 095205(0); for some of these periods drainage and waste return flows and channel losses between the gaging staticns and Imperial Dam wore considered, and for other poriods they were neglected. Records for July 1934 to September 1942 show daily discharge of Colorado River at gaging station near Picacho, Calif.

Natural flow of Colorado River at this point affected by transmountain diversions, storage reservoirs, power developments, grotud-water withdrawals, and diversions for irrigation, municipal, and industrial uses, and return flows from irrigated areas. Diversions to Mittry Lake, which began June 23, 1970, are included in river records in table below. Additional regulation, begin:ing Jan. 31,1966 , to equalize supplies for downstream water users, is provided by pumped storage in reservoir on Senator Wash, about $2 \mathrm{mi}(3 \mathrm{~km})$ upstream from Imperial Dam. Monthend contents of Senator Wash Reservoir-capacity; 13,840 acre-ft (17.1 $\left.\mathrm{hm}^{3}\right)$-is given in table below. Records of chemical analyses for the current water year are given on following pages .

COOPERATION.--Records of Sparling meter readings of diversion to Mittry Lake and contents of Senator Wash Reservoir furnished by Bureau of Reclamation.

COLORADO RIVER ABOVE IMPERIAL DAM, DTVERSIONS TO MITTRY LAKE, AND MONTHEND CONTENTS OF SENATOR WASH RESERVOIR, WATER YEAR OCTOBER 1975 TO SEPTEMBER 1976

\begin{tabular}{|c|c|c|c|c|}
\hline \multicolumn{5}{|c|}{ Discharge of Colorado River } \\
\hline Month & $\begin{array}{l}\text { Mean } \\
\text { (cubic feet } \\
\text { per second) }\end{array}$ & $\begin{array}{l}\text { Runoff in } \\
\text { acre-feet }\end{array}$ & $\begin{array}{l}\text { Diversions to } \\
\text { Mittry Lake } \\
\text { (acre-feet)* }\end{array}$ & $\begin{array}{l}\text { Monthend contents, } \\
\text { Senator Wash Reservoir } \\
\text { (acre-feet) }\end{array}$ \\
\hline 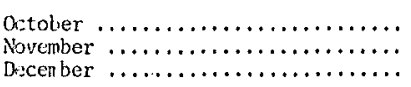 & $\begin{array}{l}7,314 \\
5,606 \\
5,669\end{array}$ & $\begin{array}{l}449,700 \\
333,600 \\
348,600\end{array}$ & $\begin{array}{l}395 \\
348 \\
429\end{array}$ & $\begin{array}{l}5,270 \\
0,1+0 \\
3,5010\end{array}$ \\
\hline CAL YR $1975 \ldots \ldots \ldots \ldots \ldots \ldots$ & 8,510 & $6,161,000$ & 6,830 & $\cdot$ \\
\hline 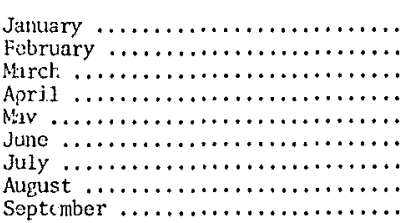 & $\begin{array}{r}5,549 \\
5,696 \\
10,700 \\
11,410 \\
9,624 \\
9,354 \\
10,530 \\
10,890 \\
7,555\end{array}$ & $\begin{array}{l}341,200 \\
327,600 \\
658,100 \\
678,800 \\
591,800 \\
556,600 \\
647,400 \\
669,900 \\
449,500\end{array}$ & $\begin{array}{l}479 \\
564 \\
631 \\
626 \\
700 \\
593 \\
634 \\
617 \\
543\end{array}$ & $\begin{array}{r}7,860 \\
1,600 \\
8,570 \\
3,730 \\
7,240 \\
6,510 \\
9,750 \\
7,720 \\
13,750\end{array}$ \\
\hline WTI: YR $1976 \ldots \ldots \ldots \ldots \ldots \ldots$ & 8,338 & $6,053,000$ & 6,560 & - \\
\hline
\end{tabular}

* Included in first two colunms of table.

NOTE.--Discharge of Colorado River, in first two colunns of table above, is combined discharge of colorado River below Imperial Dam (sta 09429500) and diversions to All-American Canal, Gila Gravity Main Canal, and Mittry Lake. 
09429490. COLORADO RTVER ABOVE IMPERIAL DAM, ARIZ.-CALIF.

(National strearn-quality accounting network, pesticide. radiochentical, and tritium network station)

LOCATION, - Lat $32^{\circ} 52^{\prime} 59^{\prime \prime}$, Iong $114^{\circ} 27^{\prime} 55^{\prime \prime}$, in NHPSW' sec.9, T.15 S., R. 24 E., San Bernardino meridian, Imperial County, Calif., above trash racks at Al1-American Canal, headworks at west end of Imperial Dam, $5 \mathrm{mi}$ (8 km) upstream from Laguna Dam, $15 \mathrm{mi}$ (24 kn) northeast of Yuma, $90 \mathrm{mi}(145 \mathrm{~km})$ downstream from Palo Verde Dan, and $147 \mathrm{mi}$ (237 kn) downstream from Parker Dam.

DRAINAGE AREA (REVISED) .--188,500 $\mathrm{mi}^{2}\left(488,200 \mathrm{~km}^{2}\right)$, approximately, including 3,959 $\mathrm{mi}^{2}\left(10,254 \mathrm{kn}^{2}\right)$ in Great Divide basin in southern Wyoring which is noncontributing (previously considered part of the Missouri River basin).

PERIOD OF RECORD, --Chenical analyses: August 1969 to current year.

Water temperatures: October 1974 to current year.
Prior to October 1971, published as sta 09429500, Colorado River at Imperial Dam, Ariz.-Calif.

WATER QUALITY DATA, WATER YEAH OCTOBER 1975 TO SEPTEMBER 1976

\begin{tabular}{|c|c|c|c|c|c|c|c|c|c|c|c|c|c|}
\hline DATE & TIME & $\begin{array}{l}\text { DIS } \\
\text { CHAR } \\
\text { ICFS }\end{array}$ & & $\begin{array}{l}\text { INSTAI } \\
\text { TANEO } \\
\text { OIS } \\
\text { CHAR } \\
\text { ICFS }\end{array}$ & & $\begin{array}{l}\text { SPE- } \\
\text { CIFIC } \\
\text { CON- } \\
\text { DUCT- } \\
\text { ANCE } \\
\text { (MICHO- } \\
\text { MHOS) }\end{array}$ & $\begin{array}{c}\text { PH } \\
\text { (UNITS) }\end{array}$ & $\begin{array}{l}\text { TEKPER- } \\
\text { ATURE } \\
\text { (DEG C) }\end{array}$ & $\begin{array}{l}\text { TUR- } \\
\text { BID- } \\
\text { IIY } \\
\text { (NFU) }\end{array}$ & $\begin{array}{l}\text { DIS- } \\
\text { SOLVED } \\
\text { OXYGEN } \\
\text { (MG/L) }\end{array}$ & $\begin{array}{l}\text { CHEM- } \\
\text { ICAL } \\
\text { OXYGEN } \\
\text { DEMAND } \\
\text { (HIGH } \\
\text { LEVEL) } \\
\text { (MG/L) }\end{array}$ & $\begin{array}{c}\text { FEC } \\
\text { COL } \\
\text { FOR } \\
1 \mathrm{CO} \\
\text { PE } \\
100\end{array}$ & $\begin{array}{l}\text { CAL } \\
\text { LI- } \\
\text { RM } \\
\text { OL. } \\
\text { ER } \\
M L\end{array}$ \\
\hline \multicolumn{14}{|l|}{$\begin{array}{l}\text { OCT } \\
\text { 06... }\end{array}$} \\
\hline $\begin{array}{l}06 \ldots \\
07 \ldots\end{array}$ & $1400^{--}$ & 8575 & -- & & $\overline{-}$ & 1300 & 8.1 & -- & -2 & - & $\rightarrow$ & & $=$ \\
\hline $07 \ldots$ & 1420 & & -- & 8860 & & 1340 & 7.6 & 23.5 & -- & 8.6 & 14 & & 42 \\
\hline $13 \ldots$ & -- & 7258 & & & -- & 1330 & 8.1 & $=-$ & 4 & 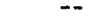 & -- & & $\rightarrow$ \\
\hline $20 \ldots$ & -- & 6760 & & & -- & 1360 & 8.2 & - & 3 & -- & - & & $=$ \\
\hline $21 \cdots$ & 1045 & & -- & 7053 & & $=$ & $8-\overline{5}$ & $21 \cdot 5$ & $+\overrightarrow{3}$ & $=$ & 11 & & $=$ \\
\hline \multicolumn{14}{|l|}{$\begin{array}{l}27 \ldots \\
\text { Nov }\end{array}$} \\
\hline $03 \ldots$ & -- & 2890 & & & -- & 1410 & 8.2 & -- & 1 & -- & -- & & -- \\
\hline $10 \ldots$ & - & 5280 & & & -- & 1400 & 8.1 & - & 2 & $-\overline{0}$ & -5 & & -- \\
\hline $11 \ldots$ & 1330 & & -- & 5770 & & 1360 & 8.2 & 25.5 & $-\overline{-}$ & 8.0 & 9 & & 28 \\
\hline $17 \ldots$ & $=$ & 6000 & & & $=$ & $\begin{array}{l}1370 \\
1360\end{array}$ & $\begin{array}{l}8.2 \\
8.2\end{array}$ & $\overline{--}$ & $\begin{array}{l}2 \\
3\end{array}$ & $\overline{--}$ & 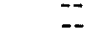 & & $=$ \\
\hline $\begin{array}{l}24 \ldots \ldots \\
24 \ldots\end{array}$ & $1100^{--}$ & 6060 & -- & 6110 & - & $\begin{array}{r}1360 \\
-0\end{array}$ & $\begin{array}{r}8.2 \\
--.\end{array}$ & 13.0 & $\rightarrow-$ & - & 12 & & - \\
\hline \multicolumn{14}{|l|}{ OEC } \\
\hline $01 \ldots$ & $=$ & 4460 & & & -- & 1460 & 8.1 & - & 4 & -- & -- & & -- \\
\hline $08 .$. & -- & 5940 & & & -- & 1340 & $8 \cdot 1$ & -- & 4 & -- & $-\overline{0}$ & & $\overline{-}$ \\
\hline $09 \ldots$ & 1330 & & -- & 6130 & & 1390 & $8 \cdot 3$ & 14.5 & $\overline{5}$ & 9.3 & 8 & & $=$ \\
\hline $15 . \cdots$ & -- & 6010 & & & -- & 1400 & 8.2 & -- & 5 & -- & $\overline{-}$ & & $=$ \\
\hline $22 \ldots$ & - & 6640 & & & -- & 1310 & 8,1 & $-\overline{5}$ & 2 & $-\infty$ & $\overline{3}$ & & $=$ \\
\hline $23 \cdot \cdots$ & 1210 & & -- & 6310 & & $\overline{-}$ & $-\overline{-}$ & 13.5 & $=$ & -- & 33 & & $=$ \\
\hline \multicolumn{10}{|l|}{ JAN } & & - & & - \\
\hline $05 \ldots$ & -- & 5020 & & & -- & 1340 & 8.2 & -- & 2 & - & $\cdots$ & & -- \\
\hline $12 \ldots$ & - & 5070 & & & - & 1410 & $8 \cdot 3$ & -- & 3 & -- & -- & & - \\
\hline $14 \ldots$ & 0930 & & -- & 5660 & & 1360 & 8.3 & 10.0 & -- & 9.4 & 15 & & 84 \\
\hline $19 \ldots$ & -- & 5710 & & & -- & 1390 & 8.2 & -- & 2 & - & $=$ & & $=$ \\
\hline $26 \ldots$ & - & 5860 & & & - & 1330 & 8.1 & $\overline{0}$ & -6 & $=-$ & 15 & & - \\
\hline$\underset{F E A}{27} \cdots$ & 1100 & & - & 6140 & & $\cdots$ & -- & 11.0 & - & $-\infty$ & 15 & & - \\
\hline $02 \ldots$ & - & 6440 & & & $\cdots$ & 1330 & 8.2 & $-\infty$ & 3 & -- & $-\infty$ & & -- \\
\hline $09 \ldots$ & -- & 4120 & & & -- & 1350 & 8.1 & $-\overline{-}$ & 4 & -- & -- & & - \\
\hline $11 \ldots$ & 0915 & & -- & 4580 & & 1340 & 8.2 & 15.0 & $-\overline{-}$ & 8.6 & 9 & & 70 \\
\hline $16 \ldots$ & $=$ & 2950 & & & -- & 1570 & 8.1 & - & 4 & - & -- & & - \\
\hline $23 \ldots$ & -- & 6330 & & & $-\infty$ & 1380 & 8.2 & $-\bar{a}$ & 4 & $=$ & $-\frac{7}{8}$ & & $=$ \\
\hline$\underset{\mu_{A R}}{24 \cdots}$ & 1100 & & -- & 7510 & & -- & -- & 14.0 & -- & -- & 8 & & - \\
\hline $01 \ldots$ & - & 5910 & & & - & 1220 & 8.3 & -- & 4 & -- & -- & & -- \\
\hline $08 \ldots$ & -- & 9400 & & & -- & 1240 & 8.2 & $-\overline{-}$ & 8 & - & - & & -- \\
\hline $10 \ldots$ & 1110 & & -- & 9570 & & 1310 & 8.2 & 16.0 & -- & 9.5 & 15 & & B12 \\
\hline $15 \ldots$ & -- & $\$ 730$ & & & - & 1240 & 8.2 & -- & 6 & -- & -- & & $m$ \\
\hline $22 \ldots$ & -- & 11300 & & & -- & 1220 & 8.2 & -- & 6 & -- & - & & - \\
\hline $23 \ldots$ & 1130 & & -- & 11900 & & $\overline{-0}$ & $\overrightarrow{\vec{j}}$ & 14.0 & -- & -- & 2 & & - \\
\hline $29 \ldots$ & $-\cdots$ & $1 \approx 700$ & & & - & 1220 & 8.1 & -- & 4 & -- & -- & & $-\infty$ \\
\hline \multicolumn{14}{|l|}{$\triangle P B$} \\
\hline $12 \ldots$ & - & 12200 & & & - & 1230 & B.2 & -- & 8 & -- & -- & & - \\
\hline $14 \ldots$ & 0855 & & -- & 9470 & & 1260 & 7.9 & 17.0 & -- & 9.0 & 5 & & 36 \\
\hline $19 \ldots$ & -- & 8380 & & & -- & 1360 & 8.2 & -- & 5 & -- & -- & & - \\
\hline $26 \ldots$ & -- & 12800 & & & -- & 1220 & 8.2 & - & 3 & -- & -- & & - \\
\hline MAY & 1035 & & -- & 13300 & & -- & -- & 20.5 & -- & -- & 14 & & - \\
\hline $07 \ldots$ & -- & 11500 & & & -- & 1250 & 8.3 & -- & 3 & -- & -- & & -- \\
\hline $10 \ldots$ & -- & 8500 & & & -- & 1320 & B. 2 & -- & 11 & -- & -- & & - \\
\hline $12 \ldots$ & 0920 & & - & 9098 & & 1300 & 8.2 & 25.0 & - & 7.9 & 2 & & 38 \\
\hline $17 \ldots$ & -- & 9340 & & & -- & 1290 & 8.3 & -- & 4 & -- & -- & & - \\
\hline $24 \ldots$ & $-\cdots$ & 9140 & & & $=-$ & 1260 & 8.3 & -- & 2 & -- & -- & & -- \\
\hline $2 h \ldots$ & 1030 & & -- & 9420 & & $=-$ & $\overline{-}$ & 23.0 & $\overline{2}$ & $=-$ & 9 & & $=$ \\
\hline JUN 31. & -- & 8830 & & & -- & 1290 & 8,1 & -- & 3 & $+\infty$ & -- & & $\cdots$ \\
\hline $07 \ldots$ & -- & 8810 & & & -- & 1270 & 8.3 & $\rightarrow-$ & 2 & -- & $-\cdots$ & & -- \\
\hline $09 \ldots$ & 0445 & & -- & 9320 & & 1290 & 8.1 & 24.5 & - & 8.1 & 16 & & 20 \\
\hline $14 \ldots$ & -- & 9430 & & & $-\infty$ & 1260 & 8.3 & -- & 3 & -- & -- & & -- \\
\hline $21 \ldots$ & $-\infty$ & 9460 & & & -- & 1280 & 8.3 & -- & 2 & -- & +- & & -- \\
\hline $2 \mathrm{H} \ldots$ & -- & 5530 & & & -- & 1260 & 8.3 & - & 2 & -- & -- & & - \\
\hline JUL & & & & & & & & & & & & & \\
\hline $\begin{array}{l}05 \ldots \\
12 \ldots\end{array}$ & $=-$ & $\begin{array}{r}\$ 720 \\
10500\end{array}$ & & & $=-$ & $\begin{array}{l}1240 \\
1220\end{array}$ & $\begin{array}{l}8.1 \\
8.3\end{array}$ & $\overline{--}$ & $\begin{array}{l}3 \\
5\end{array}$ & -- & 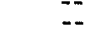 & & $m$ \\
\hline $14 \ldots$ & 0915 & & -- & 11860 & & 1280 & 8.1 & 27.5 & -- & 7.5 & 3 & & -- \\
\hline $14 \ldots$ & -- & 10700 & & & -- & 1230 & 8.2 & -- & 2 & -- & -- & & -- \\
\hline $26 \ldots$ & -- & 10400 & & & -- & 1220 & 8.2 & - & 3 & - & $-\overline{-}$ & & -- \\
\hline$\underset{\text { avis }}{27} \cdots$ & 1010 & & -- & 9960 & & -- & - & 28.5 & -- & -- & 11 & & - \\
\hline $02 \ldots$ & -- & 9810 & & & -- & 1270 & 8.3 & -- & 3 & -- & $-\infty$ & & - \\
\hline $09 \ldots$ & -- & 11200 & & & -- & 1230 & 8.1 & -- & 3 & -- & -- & & -- \\
\hline $11 \ldots$ & 0930 & & - & 11660 & & 1200 & 8.0 & 27.5 & $-\overline{-}$ & 7.7 & 21 & & 860 \\
\hline $16 \ldots$ & -- & 11200 & & & -- & 1240 & 8.3 & -- & 2 & - & -- & & -- \\
\hline $23 \ldots$ & -+ & 11540 & & & - & 1230 & 8.3 & -- & 3 & -- & -- & & -- \\
\hline $24 \ldots$ & 1045 & & -- & 11690 & & $=$ & -- & 28.0 & - & -- & 19 & & - \\
\hline $3 n \ldots$ & -- & 10500 & & & $-\infty$ & 1230 & 8.3 & -- & 3 & -- & - & & - \\
\hline
\end{tabular}

B Results based on non-ideal colony count. 
09429490. COLORADO RIVER ABOVE IMPERIAL DAM, ARIZ.-CALIF,--CONTINUED

EXTREMES. --Current year:

Specific conductance: Maximum daily, 1,650 micromhos Feb. 19; minimum daily, 939 micromhos Sept. 26

Water temperatures: Maximum daily, $31.0^{\circ} \mathrm{C}$ July 29,31 , Aug. 1 ; minimum daily, $9.0^{\circ} \mathrm{C}$ Jan. 4.

periot of record:

Specific conductance: Maximum dail $y, 1,880$ micromhos Nov. 21, 1969; minimum daily, 939 micromhos Sept. $26,1976$.

Water temperatures: Maximum daily, 31.0 $0^{\circ} \mathrm{C}$ Aug. 5,1975 , July 29, 31, Aug. 1, 1976; minimum daily, 9.0 ${ }^{\circ} \mathrm{C}$ Dec. 26,1974, Jan. $4,1976$.

REMARKS.--Stream discharges reported with analyses represent total flow reaching Imperial Dan. Daily temperature and specific-conductance

record furnished by Bureau of Reclanation. Since January 1971, daily specific-conductance measurements have been made using a
composite of four water samples taken at 6-hour intervals. Composites of four water samples per day are analyzed for major chemical constituents. Tritium analyses available from U.S. Geological Survey, Water Resources Division, Reston, Virginia.

WATER QUALITY DATA, WATER YEAR OCTOBER 1975 TO SEPTEMBER 1976

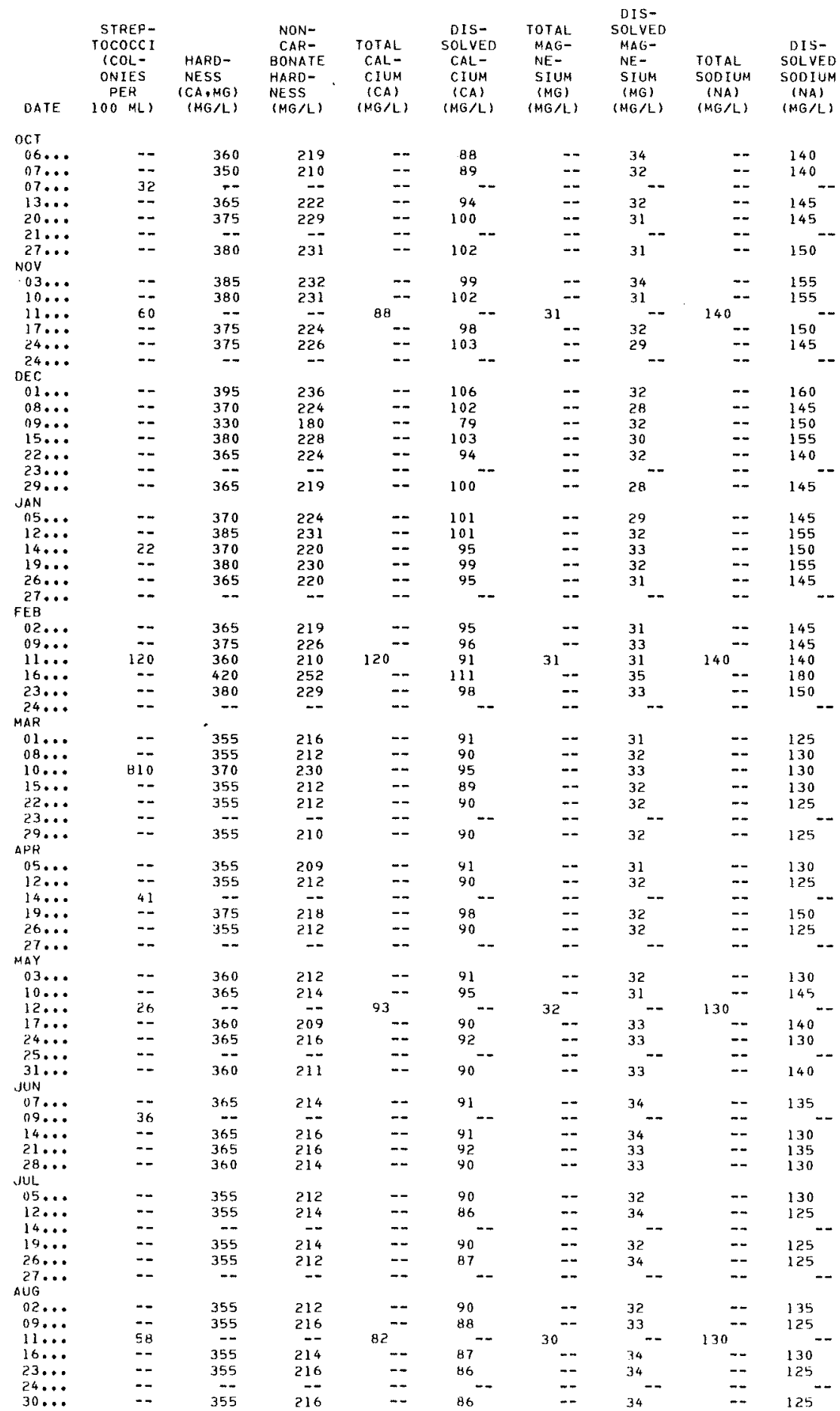

B Results based on non-ideal colony count. 
COLORADO RIVER MAIN STEN

09429490. COLORADO RIVER ABOVE IMPERIAL DAM, ARIZ.-CALIF.--CONTINUED

WATEK GUALITY DATA, WATER YEAR OCTOBER 1975 TO SEPTEMBER 1976

\begin{tabular}{|c|c|c|c|c|c|c|c|c|c|}
\hline DATE & $\begin{array}{l}\text { SOOIUM } \\
\text { AU- } \\
\text { SORP- } \\
\text { TIUN } \\
\text { KATIO }\end{array}$ & $\begin{array}{l}\text { TOTAL } \\
\text { PO- } \\
\text { TAS- } \\
\text { SIUM } \\
\text { (K) } \\
\text { (MG/L) }\end{array}$ & $\begin{array}{l}\text { OIS- } \\
\text { SOLVEO } \\
\text { PO- } \\
\text { TAS- } \\
\text { SIUM } \\
\text { (K) } \\
\text { (MG/L) }\end{array}$ & $\begin{array}{l}\text { BICAR- } \\
\text { BONATE } \\
\text { (HCO3) } \\
\text { (MG/L) }\end{array}$ & $\begin{array}{l}\text { CAR - } \\
\text { RONATE } \\
\text { (CO3) } \\
\text { (MG/L) }\end{array}$ & $\begin{array}{l}\text { DIS- } \\
\text { SOLVED } \\
\text { SULFATE } \\
\text { (SO4) } \\
\text { (MG/L) }\end{array}$ & $\begin{array}{l}\text { DIS- } \\
\text { SOLVEO } \\
\text { CHLO- } \\
\text { RIOE } \\
\text { (CL) } \\
(M G / L)\end{array}$ & $\begin{array}{l}\text { DIS- } \\
\text { SOLVED } \\
\text { FLUO- } \\
\text { RIUE } \\
\text { (F) } \\
\text { (MG/L) }\end{array}$ & $\begin{array}{l}\text { OIS- } \\
\text { SOLVEU } \\
\text { SILICA } \\
\text { (SIOZ) } \\
\text { (MG/L) }\end{array}$ \\
\hline \multicolumn{10}{|l|}{$n C \mathrm{~T}$} \\
\hline $06 \ldots$ & 3.2 & -- & 5.9 & 172 & 0 & 345 & 118 & .5 & 10 \\
\hline $07 \ldots$ & $3 \cdot 2$ & $=-$ & 5.3 & 172 & - & 340 & 130 & .3 & 8.8 \\
\hline $07 \ldots$ & $\cdots$ & -- & -- & -- & -- & - & -- & $-\overline{-}$ & $=$ \\
\hline $13 \ldots$ & 3.3 & -- & 5.6 & 174 & 0 & 350 & 125 & .5 & 9.0 \\
\hline $20 \ldots$ & 3.2 & -- & 6.3 & 178 & 0 & 355 & 130 & .5 & 8.0 \\
\hline $21 \ldots$ & -- & -- & - & $=-$ & -- & -- & -- & -- & - \\
\hline $27 \ldots$ & 3.3 & -- & 5.6 & 182 & 0 & 360 & 132 & .6 & 10 \\
\hline \multicolumn{10}{|l|}{ NoV } \\
\hline $03 \ldots$ & 3.4 & -- & 5.6 & 186 & 0 & 365 & 139 & .6 & 11 \\
\hline $10 \ldots$ & 3.4 & $-\infty$ & 5.6 & 182 & 0 & 365 & 135 & .5 & 9.0 \\
\hline $11 \ldots$ & -- & 4.7 & -- & - & -- & $=-$ & -- & -- & -- \\
\hline $17 \ldots$ & 3.4 & -- & 5.2 & 184 & 0 & 355 & 130 & .5 & 10 \\
\hline $24 \ldots$ & 3.3 & -- & 5.4 & 182 & 0 & 350 & 132 & .5 & 10 \\
\hline $24 \ldots$ & $=-$ & -- & -- & -- & -- & - & -- & -- & -- \\
\hline \multicolumn{10}{|l|}{ OEC } \\
\hline $01 \ldots$ & 3.5 & -- & 5.2 & 194 & 0 & 380 & 140 & .5 & 9.0 \\
\hline $08 \ldots$ & 3.3 & -- & 5.0 & 178 & 0 & 350 & 128 & .5 & 10 \\
\hline $09 \ldots$ & 3.6 & -- & 5.3 & 178 & $-\sim$ & 340 & 130 & .4 & 9.2 \\
\hline $15 \ldots$ & 3.5 & -- & 5.4 & 186 & 0 & 365 & 135 & .5 & 10 \\
\hline $22 \ldots$ & 3.2 & -- & 5.2 & 172 & 0 & 345 & 122 & .5 & 10 \\
\hline $23 \ldots$ & - & -- & -- & - & -- & -- & - & - & - \\
\hline $29 \ldots$ & $3 \cdot 3$ & -- & 5.2 & 178 & 0 & 345 & 125 & .5 & 10 \\
\hline JAN & & & & & & & & & \\
\hline $05 \ldots$ & 3.3 & -- & 5.4 & 178 & 0 & 350 & 128 & .4 & 8.0 \\
\hline $12 \ldots$ & 3.4 & $-\pi$ & 5.4 & 188 & 0 & 36.5 & 140 & .5 & 7.0 \\
\hline $14 \ldots$ & 3.4 & $-\infty$ & 5.3 & 181 & -- & 360 & 140 & .4 & 8.9 \\
\hline $19 \ldots$ & 3.5 & -- & 5.6 & 186 & 0 & 360 & 135 & .5 & 9.0 \\
\hline $26 \ldots$ & 3.3 & -- & 5.6 & 176 & 0 & 345 & 128 & .4 & 9.0 \\
\hline $27 \ldots$ & -- & $\cdots$ & -- & - & - & $=$ & -- & $-\infty$ & - \\
\hline FEH & & & & & & & & & \\
\hline $02 \ldots$ & 3.3 & $-\infty$ & 5.2 & 178 & 0 & 345 & 126 & .4 & 10 \\
\hline $09 \ldots$ & 3.3 & -- & 5.0 & 182 & 0 & 350 & 131 & .4 & 9.0 \\
\hline $11 \ldots$ & 3.2 & $4 . B$ & 5.0 & 181 & -- & 340 & 130 & .4 & 8.8 \\
\hline $16 \ldots$ & 3.8 & -- & 5.4 & 204 & 0 & 390 & 170 & .5 & 10 \\
\hline $23 \ldots$ & 3.3 & -- & 5.0 & 184 & 0 & 360 & 132 & .6 & 8.9 \\
\hline $74 \ldots$ & -- & $-\infty$ & -- & - & -- & -- & $=$ & - & - \\
\hline MAR & & & & & & & & & \\
\hline $01 \ldots$ & 2.9 & -- & $5 \cdot 2$ & 170 & 0 & 330 & 105 & .4 & 10 \\
\hline $08 \ldots$ & 3.0 & -- & 5.0 & 174 & 0 & 330 & 108 & .5 & 8.0 \\
\hline $10 \ldots$ & 2.9 & $-\infty$ & 5.2 & 179 & 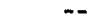 & 330 & 120 & .4 & 8.9 \\
\hline $15 \ldots$ & 3.0 & -- & 5.4 & 174 & 0 & 330 & 109 & .5 & 8.8 \\
\hline $22 \ldots$ & 2.9 & -- & 5.4 & 174 & 0 & 330 & 102 & .5 & 9.1 \\
\hline $23 \ldots$ & -- & -- & -- & $-\infty$ & -- & - & -- & -- & - \\
\hline $29 \ldots$ & 2.9 & -- & 5.2 & 176 & 0 & 330 & 102 & .5 & 8.6 \\
\hline$\triangle P R$ & & & & & & & & & \\
\hline $05 \ldots$ & 3.0 & -- & $5 \cdot 2$ & 178 & 0 & 330 & 108 & .5 & 8.2 \\
\hline $12 \ldots$ & 2.9 & -- & 5.6 & 174 & 0 & 330 & 105 & .5 & 6.8 \\
\hline $14 \ldots$ & $=$ & -- & -- & -- & -- & -- & -- & - & - \\
\hline $19 \ldots$ & 3.4 & -- & 5.6 & 192 & 0 & 350 & 131 & .5 & 6.8 \\
\hline $26 \ldots$ & 2.9 & -- & 5.2 & 174 & 0 & 330 & 102 & .4 & 6.0 \\
\hline $27 \ldots$ & -- & -- & -- & -- & -- & -- & - & -- & -- \\
\hline MAY & & & & & & & & & \\
\hline $03 \ldots$ & 3.0 & -- & 4.8 & 180 & 0 & 335 & 110 & .4 & 6.2 \\
\hline $10 \ldots$ & 3.3 & -- & 5.0 & 184 & 0 & 345 & 124 & .5 & 6.5 \\
\hline $12 \ldots$ & $\cdots$ & 5.8 & -- & -- & - & -- & -- & -- & - \\
\hline $17 \ldots$ & 3.2 & $-\infty$ & 5.6 & 184 & 0 & 340 & 118 & .6 & 5.5 \\
\hline $24 \ldots$ & 3.0 & -- & 5.5 & 182 & 0 & 335 & 112 & .5 & 7.2 \\
\hline $25 \ldots$ & -- & -- & -- & -- & -- & -- & -- & - & -- \\
\hline $31 \ldots$ & 3.2 & -- & 5.3 & 182 & 0 & 340 & 118 & .5 & 7.5 \\
\hline JUN & & & & & & & & & \\
\hline $07 \ldots$ & 3.1 & -- & 5.6 & 184 & 0 & 335 & 114 & .5 & 7.2 \\
\hline $09 \ldots$ & -- & -- & -- & -- & - & -- & - & -- & -- \\
\hline $14 \ldots$ & 3.0 & -- & 5.4 & 182 & 0 & 335 & 112 & .5 & 7.5 \\
\hline $21 \ldots$ & 3.1 & - & 5.0 & 182 & 0 & 340 & 114 & .4 & 9.0 \\
\hline $28 \ldots$ & 3.0 & -- & 5.4 & 178 & 0 & 335 & 112 & .5 & 8.8 \\
\hline JUL & & & & & & & & & \\
\hline $05 \ldots$ & 3.0 & -- & 5.7 & 174 & 0 & 330 & 110 & .5 & 7.5 \\
\hline $12 \ldots$ & 2.9 & -- & 5.7 & 172 & 0 & 330 & 105 & .5 & 7.5 \\
\hline $14 \ldots$ & -- & -- & 5.4 & $=$ & -- & -- & -- & -- & -- \\
\hline $19 .$. & 2.9 & -- & 5.7 & 172 & 0 & 330 & 108 & .4 & 8.0 \\
\hline $26 \ldots$ & 2.9 & $\cdots$ & 5.8 & 174 & 0 & 330 & 105 & .4 & B. 0 \\
\hline $27 \ldots$ & -- & -- & -- & - & -- & -- & -- & -- & -- \\
\hline AUG & & & & & & & & & \\
\hline $02 \ldots$ & 3.1 & - & 5.6 & 174 & 0 & 335 & 115 & .5 & 9.5 \\
\hline $09 \ldots$ & 2.9 & -- & 5.6 & 170 & 0 & 330 & 109 & .4 & 9.0 \\
\hline $11 \ldots$ & -- & 4.6 & - & -- & -- & -- & -- & -- & - \\
\hline $16 \ldots$ & 3.0 & -- & 6.0 & 172 & 0 & 330 & 111 & .4 & 8.0 \\
\hline $23 \ldots$ & 2.9 & -- & 5.7 & 170 & 0 & 330 & 139 & .5 & 8.0 \\
\hline $24 \ldots$ & - & - & -- & $-\infty$ & -- & - & $=-$ & -- & - \\
\hline $30 \ldots$ & 2.9 & -- & 5.3 & 170 & 0 & 330 & 108 & .5 & 9.5 \\
\hline
\end{tabular}


09429490. COLORADO RIVER ABOVE IMPERIAL DAM, ARIZ .-CALIF.--CONTINUED

WATEN UUALITY DATA, WATER YEAH OCTOBEH 197510 SEPTEMBER 1976

\begin{tabular}{|c|c|c|c|c|c|c|c|c|c|}
\hline DATE & $\begin{array}{l}\text { DIS- } \\
\text { SOLVEO } \\
\text { SOLIUS } \\
\text { (RESI- } \\
\text { DUE AT } \\
\text { I80 C) } \\
\text { (MG/L) }\end{array}$ & $\begin{array}{l}\text { TOTAL } \\
\text { FILT- } \\
\text { RABLE } \\
\text { HESIDUE }\end{array}$ & $\begin{array}{l}\text { DIS- } \\
\text { SOLVED } \\
\text { SOL IDS } \\
\text { (SUM OF } \\
\text { CONSTI- } \\
\text { TUENTS) } \\
\text { (MG/L) }\end{array}$ & $\begin{array}{l}\text { DIS- } \\
\text { SOLVED } \\
\text { SOLIDS } \\
\text { (TONS } \\
\text { PER } \\
\text { AC } \rightarrow F Y)\end{array}$ & $\begin{array}{c}\text { TOTAL } \\
\text { NON- } \\
\text { FILT- } \\
\text { RABLE } \\
\text { RESIDUE } \\
\text { (MG/L) }\end{array}$ & $\begin{array}{l}\text { DIS- } \\
\text { SULVEO } \\
\text { NITRAYE } \\
\text { (N) } \\
\text { (MG/L) }\end{array}$ & $\begin{array}{l}\text { DIS- } \\
\text { SOLVED } \\
\text { ORTHO. } \\
\text { PHOS- } \\
\text { PHORUS } \\
\text { (P) } \\
(M G / L)\end{array}$ & $\begin{array}{c}\text { DIS- } \\
\text { SOLVED } \\
\text { BORON } \\
\text { (H) } \\
\text { (UG/L) }\end{array}$ & $\begin{array}{l}\text { DIS- } \\
\text { SOLVED } \\
\text { IHON } \\
\text { (FE) } \\
(1+G / L)\end{array}$ \\
\hline \multicolumn{10}{|l|}{ กCT } \\
\hline $06 \ldots$ & 432 & -- & 827 & 1.13 & - & .07 & - & -- & $=$ \\
\hline $\begin{array}{l}07 \ldots \\
07 \ldots\end{array}$ & $=$ & -- & 831 & 1.13 & -- & $=$ & .00 & $\begin{array}{l}180 \\
170\end{array}$ & - \\
\hline $13 \ldots$ & 446 & -- & 848 & 1.15 & - & .11 & - & - & - \\
\hline $20 \ldots$ & 478 & -- & 864 & 1.19 & - & -- & -- & $-m$ & -- \\
\hline $21 \ldots$ & -- & -- & -- & -- & 24 & -- & -- & -- & - \\
\hline \multicolumn{10}{|l|}{ NOV } \\
\hline $03 \ldots$ & 900 & $=$ & 901 & 1.22 & $=$ & .14 & $=$ & $=$ & $=-$ \\
\hline $\begin{array}{l}10 \ldots \\
11 \ldots\end{array}$ & $\begin{array}{r}\text { as? } \\
--\end{array}$ & $=$ & $\begin{array}{r}893 \\
---\end{array}$ & 1.21 & 3 & -- & .00 & 190 & $\overline{0}$ \\
\hline $17 \ldots$ & 872 & -- & 873 & 1.19 & -- & .34 & -- & $=$ & - \\
\hline $24 \ldots$ & 380 & $-\infty$ & 867 & 1.20 & -- & .38 & - & -- & -- \\
\hline $24 \ldots$ & -- & $\rightarrow$ & -- & -- & 11 & .21 & .03 & 190 & -- \\
\hline \multicolumn{10}{|l|}{$D \in C$} \\
\hline $01 \ldots$ & 940 & -- & 930 & 1.28 & - & .23 & $-\infty$ & -- & $\cdots$ \\
\hline $08 \ldots$ & $B \in 0$ & -- & 858 & 1.17 & -- & .25 & -- & $=$ & -- \\
\hline $09 \ldots$ & -- & -- & 835 & 1.14 & 10 & -- & .01 & 160 & 0 \\
\hline $15 \ldots$ & 906 & $-\infty$ & 897 & 1.23 & -- & .29 & -- & -- & - \\
\hline $22 \ldots$ & 346 & -- & 834 & 1.15 & -- & .09 & -- & -- & -- \\
\hline $23 \ldots$ & -- & -- & - & -- & 13 & .17 & .01 & 190 & $=-$ \\
\hline $29 \ldots$ & 352 & -- & 848 & 1.16 & -- & .29 & -- & -- & - \\
\hline \multicolumn{10}{|l|}{ JAN } \\
\hline $05 \ldots$ & $\$ 68$ & -- & 857 & 1.18 & -- & .41 & -- & -- & -- \\
\hline $12 \ldots$ & 934 & -- & 900 & 1.27 & -- & .18 & -- & $\overline{-}$ & - \\
\hline $14 \ldots$ & -- & 970 & 883 & 1.20 & 5 & .16 & .01 & 200 & 0 \\
\hline $19 \ldots$ & 858 & -- & 890 & 1.22 & -- & .41 & -- & -- & $-\infty$ \\
\hline $26 \ldots$ & 864 & -- & 848 & 1.18 & -- & .34 & -- & -- & - \\
\hline $27 \ldots$ & -- & -- & -- & $=$ & 12 & -- & -- & $-\infty$ & -- \\
\hline $02 \ldots$ & 844 & -- & 846 & 1.15 & -- & .18 & $-\infty$ & -- & $\cdots$ \\
\hline $09 . \ldots$ & 364 & -- & 860 & 1.18 & -- & .20 & -- & - & -- \\
\hline $11 \ldots$ & -- & -- & 837 & 1.14 & 14 & $=$ & .01 & 160 & 10 \\
\hline $16 \ldots$ & 1010 & -- & 1000 & 1.37 & -- & .29 & -- & -- & - \\
\hline $23 \ldots$ & 906 & -- & 879 & 1.23 & -- & .11 & -- & -- & -- \\
\hline $24 \ldots$ & -- & -- & $-\infty$ & -- & 7 & - & - & -- & -- \\
\hline \multicolumn{10}{|l|}{$M A R$} \\
\hline $01 \ldots$ & 780 & -- & 782 & 1.06 & $-\infty$ & .14 & $-\infty$ & -- & - \\
\hline $08 \ldots$ & 788 & -- & 791 & 1.07 & $=$ & .34 & -- & -- & -- \\
\hline $10 \ldots$ & -- & $-\infty$ & 812 & 1.10 & 27 & .24 & .01 & 160 & 10 \\
\hline $15 \ldots$ & 796 & -- & 791 & 1.08 & - & .16 & -- & -- & -- \\
\hline $22 \ldots$ & 778 & -- & 781 & 1.06 & -- & .23 & -- & -- & -- \\
\hline $23 \ldots$ & -- & -- & -- & -- & 24 & $-\cdots$ & -- & -- & $m$ \\
\hline $29 . \ldots$ & 782 & -- & 782 & 1.06 & - & .32 & -- & -- & -- \\
\hline \multicolumn{10}{|l|}{$A P R$} \\
\hline $05 \ldots$ & 794 & -- & 793 & 1.08 & -- & .23 & -- & $-m$ & -- \\
\hline $12 \ldots$ & 780 & $m$ & 783 & 1.06 & -- & .41 & -- & -- & -- \\
\hline $14 \ldots$ & -- & $-\infty$ & -- & -- & 16 & -- & .00 & 170 & -- \\
\hline $19 \ldots$ & 870 & -- & 870 & 1.18 & -- & .25 & -- & -- & -- \\
\hline $26 \ldots$ & 778 & -- & 777 & 1.06 & -- & .16 & -- & -- & - \\
\hline MAY 27 & -- & -- & -- & -- & 25 & -- & -- & -- & -- \\
\hline $03 \ldots$ & 796 & -- & 799 & 1.08 & - & .18 & -- & -- & - \\
\hline $10 \ldots$ & 838 & -- & 844 & 1.14 & $=$ & .29 & -- & -- & $-\infty$ \\
\hline $12 \ldots$ & -- & -- & - & - & 22 & -- & .00 & 170 & 0 \\
\hline $17 \ldots$ & 822 & - & 824 & $1 \cdot 12$ & -- & .11 & -- & -- & -- \\
\hline $24 \ldots$ & 806 & -- & 806 & 1.10 & $=$ & .25 & -- & -- & -- \\
\hline $25 \ldots$ & -- & -- & -- & $=$ & 23 & -- & -- & $-\infty$ & -- \\
\hline $31 \ldots$ & 828 & -- & 825 & 1.13 & - & .11 & -- & -- & -- \\
\hline JUN & & & & & & & & & \\
\hline $07 \ldots$ & 810 & -- & 814 & 1.10 & -- & .20 & -- & -- & -- \\
\hline $09 \ldots$ & - & -- & - & - & 17 & -- & .00 & 160 & -- \\
\hline $14 \ldots$ & 802 & -- & 806 & 1.09 & -- & .23 & -- & -- & -- \\
\hline $21 \ldots$ & 824 & -- & 819 & 1.12 & -- & .18 & -- & -- & -- \\
\hline $28 \ldots$ & 804 & $-\rightarrow$ & 803 & 1.09 & -- & .14 & -- & - & $=$ \\
\hline JUL & & & & & & & & & \\
\hline $05 \ldots$ & 790 & - & 792 & 1.07 & - & .14 & -- & - & $=$ \\
\hline $12 \ldots$ & 786 & $\overline{0}$ & 779 & 1.07 & $-\pi$ & .11 & -- & $=$ & - \\
\hline $14 \ldots$ & $\overline{--}$ & $\begin{array}{r}840 \\
--\end{array}$ & $\overline{\bar{n}}$ & $-\infty$ & -3 & $\overline{-}$ & .00 & 170 & $=$ \\
\hline $\begin{array}{l}19 \ldots \\
26 \ldots\end{array}$ & $\begin{array}{l}784 \\
782\end{array}$ & $=$ & $\begin{array}{l}785 \\
782\end{array}$ & 1.07 & $=$ & .11 & $=$ & $=-$ & $=$ \\
\hline $\begin{array}{l}26 \ldots \\
27 \ldots\end{array}$ & 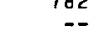 & - & $\begin{array}{r}18 c \\
--2\end{array}$ & $\begin{array}{c}1.06 \\
=-\end{array}$ & 14 & -- & - & -- & - \\
\hline AUG & & & & & & & & & \\
\hline $02 \ldots$ & 808 & -- & 809 & 1.10 & 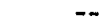 & .09 & -- & -- & $\cdots$ \\
\hline $09 \ldots$ & 790 & $m$ & 784 & 1.07 & -- & .11 & -- & -- & -- \\
\hline $11 \ldots$ & -- & -- & -- & - & 4 & .13 & .01 & 170 & 10 \\
\hline $16 \ldots$ & 790 & -- & 792 & 1.07 & - & .09 & -- & $-\infty$ & $=$ \\
\hline $23 \ldots$ & 780 & -- & 783 & 1.06 & -- & .11 & $=$ & -- & -- \\
\hline $24 \ldots$ & $=-$ & -- & -- & -- & 13 & -- & - & -- & -- \\
\hline $30 \ldots$ & 784 & -- & 783 & 1.07 & -- & .09 & -- & -- & -- \\
\hline
\end{tabular}


COLORADO RIVER MAIN STEI

09429490. COLORADO RTVER ABOVE IMPERTAL DAM, ARIZ.-CALIF.--CONTINUED

WATER UUALITY DATA, WATER YEAK OCTOBER 1975 TO SEPTEMBER 1976

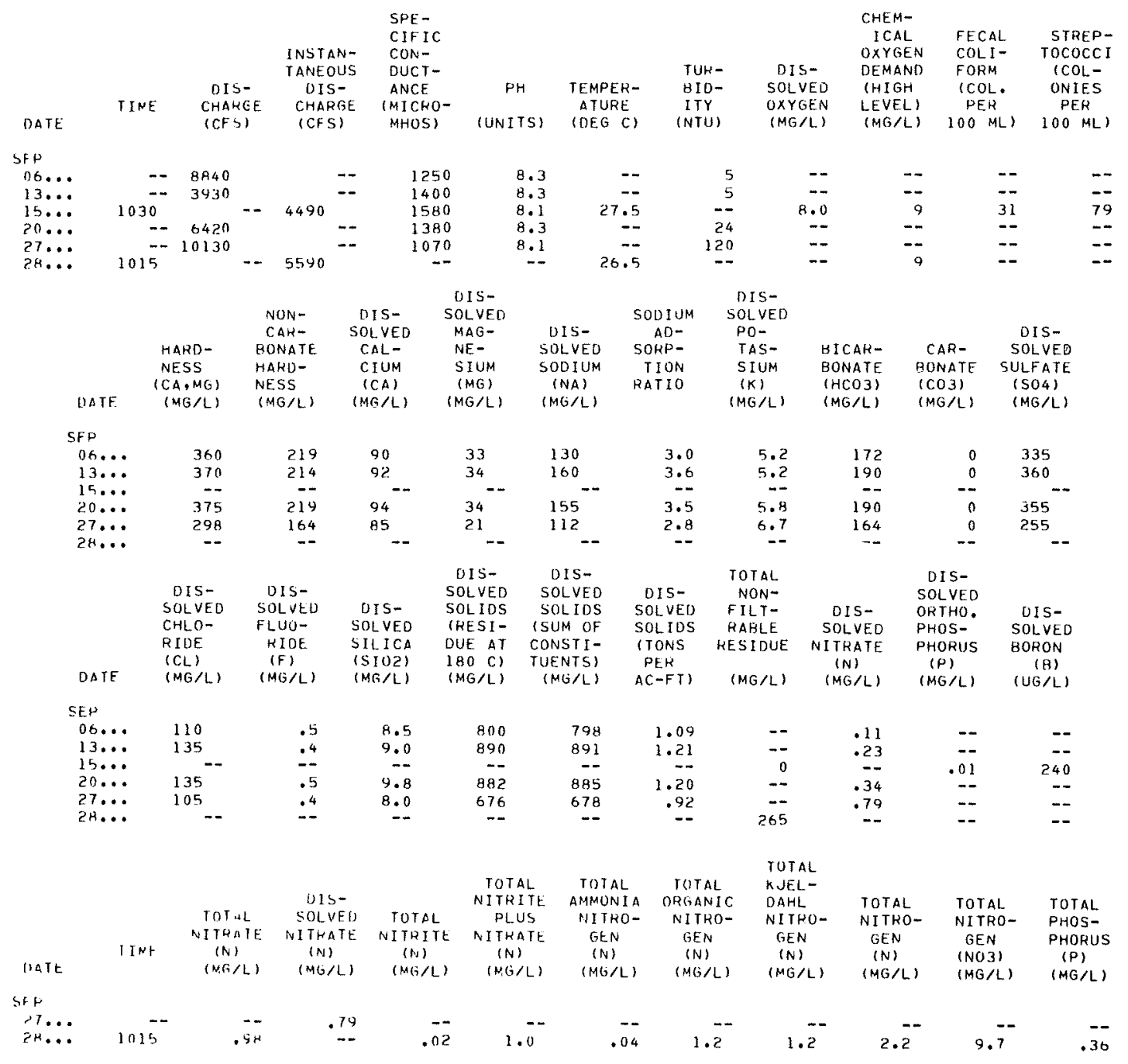


09429490. COLORADO RIVER ABOVE IMPERIAL DAM, ARIZ.-CALIF.--CONTINUED

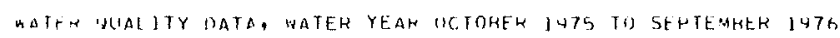

\begin{tabular}{|c|c|c|c|c|c|c|c|c|}
\hline TIATE & IInt & $\begin{array}{l}\text { TUTAL } \\
\text { NITPATE } \\
\text { (A) } \\
\text { (MEAL) }\end{array}$ & $\begin{array}{l}\text { HIS- } \\
\text { SOLVED } \\
\text { NIINATF } \\
\text { (N) } \\
(M G / L)\end{array}$ & $\begin{array}{l}\text { TOTAL } \\
\text { NITHICE } \\
\text { (N) } \\
\text { (MG/L) }\end{array}$ & $\begin{array}{l}\text { UIS- } \\
\text { SOLVEU } \\
\text { SITRITE } \\
\text { (WI) } \\
\text { (MSIL) }\end{array}$ & $\begin{array}{c}\text { TOTAL } \\
\text { MTHITE } \\
\text { PLIIS } \\
\text { MIIAIE } \\
\text { (IV) } \\
\text { (MS/L) }\end{array}$ & $\begin{array}{l}\text { OIS- } \\
\text { SOLVEU } \\
\text { ATHITE } \\
\text { PLUS } \\
\text { NITHATE } \\
\text { (NI) } \\
\text { (MUIL) }\end{array}$ & $\begin{array}{l}\text { TUTAL } \\
\text { AMMONIA } \\
\text { NITRO- } \\
\text { GEN } \\
\text { (N) } \\
(N G / L)\end{array}$ \\
\hline \multicolumn{9}{|l|}{ nr:T } \\
\hline inh.... & -- & - & .07 & -- & $=$ & -- & -- & - \\
\hline i) $1 \ldots$ & 1420 & .10 & -- & .00 & .00 & .10 & .10 & .03 \\
\hline $13 \ldots$ & -- & - & .11 & - & -- & -- & $=$ & - \\
\hline $\cos _{1} \cdots$ & 1645 & .119 & - & .111 & -- & .10 & - & .01 \\
\hline $113 \ldots$ & -- & -- & .14 & 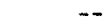 & $-\infty$ & -- & -- & -- \\
\hline $11 \ldots$ & 1330 & .15 & -- & .191 & .01 & . IA & .16 & .04 \\
\hline $17 \ldots$ & -- & -- & .34 & -- & -- & -- & -- & -- \\
\hline$? 4 \ldots$ & -- & -- & $.3 A$ & -- & - & - & - & -- \\
\hline $\begin{array}{l}24, \ldots \\
\text { BEC }\end{array}$ & 1100 & .21 & .21 & .01 & .01 & .22 & .22 & $.0 ?$ \\
\hline$n 1 \ldots$ & -- & -- & .23 & -- & -- & $\ldots$ & -- & -- \\
\hline $08 \ldots$ & - & -- & .75 & - & -- & -- & -- & -- \\
\hline$n ч . .$. & 1330 & .14 & -- & .01 & .01 & & .14 & .04 \\
\hline $15 . .$. & - & $-\ldots$ & .79 & $-\infty$ & - & -- & -- & - \\
\hline $27 \ldots$ & -- & - & -1) & $m$ & - & -- & -- & -- \\
\hline $23 . \ldots$ & $1 \geqslant 10$ & .17 & .17 & .00 & . & .17 & .17 & .03 \\
\hline \multicolumn{8}{|l|}{$J \Delta N$} & - \\
\hline $115 \ldots$ & -- & - - & .41 & -- & -- & -- & - & -- \\
\hline $12 \ldots$ & -- & - & .14 & -- & - & $=$ & -- & -- \\
\hline $14 \ldots$ & by 30 & $.1 \mathrm{H}$ & in & .010 & .01 & .18 & .15 & .01 \\
\hline$l y \ldots$ & -- & -- & .41 & -- & $=$ & -- & -- & 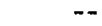 \\
\hline ग.... & -- & -- & .34 & -- & -- & -- & -- & -- \\
\hline $27 \ldots$ & $11 \% 0$ & .211 & $-\infty$ & . (11 & $\ldots$ & .21 & -- & $.0 ?$ \\
\hline \multicolumn{9}{|l|}{ FAH } \\
\hline$\|<\ldots$ & - & -- & .17 & -- & $=$ & -- & -- & -- \\
\hline $119 . \ldots$ & $-\infty$ & $=-$ & .20 & -- & -- & -- & - & - \\
\hline $11 \ldots$ & nylt & $.2 h$ & -- & .01 & .01 & .27 & .26 & .01 \\
\hline It.... & $-\infty$ & -- & .29 & $\ldots$ & - & - & -- & -- \\
\hline $3 \ldots$ & - & -- & .11 & -- & -- & -- & - & - \\
\hline $24 \ldots$ & 1100 & .19 & - & .111 & - & .20 & $-\rightarrow$ & .01 \\
\hline $01 \ldots$ & $-\cdots$ & -- & .14 & -- & -- & - & -- & - \\
\hline$\| \mathrm{H} \ldots$ & - & -- & .34 & -- & -- & - & - & - \\
\hline $111 \ldots$ & 1110 & .23 & .24 & .01 & .00 & .24 & 4.6 & .02 \\
\hline $15 \ldots$ & -- & - & .16 & 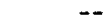 & -- & -- & -- & -- \\
\hline$p>\ldots$ & - & $=-$ & .23 & -- & -- & -- & -- & -- \\
\hline $23 \ldots$ & 1130 & .27 & -- & .01 & - & .28 & -- & .07 \\
\hline$P y \ldots$ & -- & - & .37 & -- & -- & -- & -- & -- \\
\hline \multicolumn{9}{|l|}{ APQ } \\
\hline $05 \ldots$ & -- & - &.$? 3$ & -- & -- & -- & -- & -- \\
\hline $12 \ldots$ & -- & $\rightarrow$ & .41 & - & -- & - & -- & -- \\
\hline $14 \ldots$ & 0455 & .74 & -- & .00 & . 111 & .24 & .25 & .00 \\
\hline $19 \ldots$ & - & -- & .25 & -- & -- & - & - & - \\
\hline $2 n \ldots$ & $-\cdots$ & -- & .16 & -- & -- & -- & -- & -- \\
\hline $27 \ldots$ & 1035 & .13 & -- & .01 & -- & .14 & - & .0 .3 \\
\hline \multicolumn{9}{|l|}{$M A Y$} \\
\hline $05 \ldots$ & -- & -- & .18 & -- & -- & - & -- & -- \\
\hline $10 \ldots$ & - & $=$ & .29 & - & - & -- & - & -- \\
\hline $12 \ldots$ & 0420 & .22 & - & .00 & .01 & .22 & .22 & .02 \\
\hline $17 \ldots$ & - & - & .11 & -- & - & - & - & - \\
\hline $34 \ldots$ & -- & -- & .25 & -- & -- & $\rightarrow-$ & - & -- \\
\hline ; & 1030 & .11 & -- & .01 & -- & .12 & -- & .00 \\
\hline $31 \ldots$ & -- & - & .11 & - & -- & - & -- & - \\
\hline \multicolumn{9}{|l|}{ Juts } \\
\hline $97 \ldots$ & -- & -- &.$P n$ & - & -- & - & -- & - \\
\hline$n y \ldots$ & 0445 & .14 & -- & .01 & .01 & . 1n & .16 & .01 \\
\hline $14 \ldots$ & -- & -- & .23 & -- & - & -- & -- & - \\
\hline$? 1 \ldots$ & $=-$ & -- & .14 & -- & -- & -- & $=-$ & -- \\
\hline ?н... & - & -- & .14 & -- & -- & $\rightarrow$ & -- & -- \\
\hline JUL & & & & & & & & \\
\hline $05 \ldots$ & -- & -- & .14 & -- & -- & $\cdots$ & -- & $\rightarrow$ \\
\hline $12 \ldots$ & -- & - & .11 & -- & -- & -- & -- & -- \\
\hline $14 \ldots$ & 0915 & .11 & - & .00 & .00 & .11 & .10 & .01 \\
\hline $19 .$. & - & - & .11 & - & - & $\ldots$ & -- & - \\
\hline $26 \ldots$ & - & -- & .09 & -- & -- & -- & -- & -- \\
\hline $27 \ldots$ & 1010 & .13 & -- & .00 & -- & .13 & -- & .00 \\
\hline Allo & & & & & & & & \\
\hline $02 \ldots$ & -- & - & .49 & - & -- & $=-$ & -- & -- \\
\hline $09 . \ldots$ & -- & - & . Il & - & -- & $\rightarrow-$ & -- & - \\
\hline $11 \ldots$ & 0930 & .14 & .13 &.$n 1$ & .00 & .15 & .13 & .00 \\
\hline $16 \ldots$ & - & -- & .179 & - & -- & - & -- & -- \\
\hline $33 \ldots$ & -- & - & .11 & -- & -- & $=$ & - & - \\
\hline $24 \ldots$ & 1045 & .07 & -- & .00 & -- & .07 & - & .00 \\
\hline${ }_{S E P} 30 \cdots$ & - & - & .09 & - & -- & -- & -- & $=-$ \\
\hline $76 \ldots$ & -- & -- & .11 & -- & $=-$ & -- & -- & -- \\
\hline $13 \ldots$ & -- & -- & .23 & -- & -- & -- & -- & - \\
\hline $15 \ldots$ & 1030 & .06 & -- & .00 & .00 & .06 & .08 & .00 \\
\hline $20 \ldots$ & -- & - & .34 & -- & -- & -- & -- & - \\
\hline
\end{tabular}


COLORADO RIVER MAIN STEM

09429490. COLORADO RIVER ABOVE IMPERIAL DAM, ARIZ.-CALIF.--CONTINUED

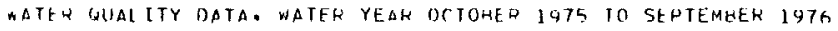

\begin{tabular}{|c|c|c|c|c|c|c|c|}
\hline DAFE & $\begin{array}{l}\text { TOTAL } \\
\text { OHSANIC } \\
\text { NITRO- } \\
\text { GEN } \\
\text { (N) } \\
\text { IMG/I.) }\end{array}$ & $\begin{array}{l}\text { TOTAL } \\
\text { KJFL- } \\
\text { DAPL } \\
\text { NIYRO- } \\
\text { GEN } \\
\text { (N) } \\
\text { (MOLL) }\end{array}$ & $\begin{array}{l}\text { TOTAL } \\
\text { MITHO- } \\
\text { GEN } \\
\text { (N) } \\
\text { (MG/L) }\end{array}$ & $\begin{array}{l}\text { TUTAL } \\
\text { MITHO- } \\
\text { GEN } \\
\text { (NU3) } \\
\text { (NGSL) }\end{array}$ & $\begin{array}{l}\text { rutat } \\
\text { HHOS- } \\
\text { PHOKUS } \\
\text { (H) } \\
\text { (MG/L) }\end{array}$ & $\begin{array}{l}\text { UIS- } \\
\text { SOL- } \\
\text { VEO- } \\
\text { FHOS- } \\
\text { PHOPUS } \\
\text { (P) } \\
\text { (MG,L) }\end{array}$ & $\begin{array}{l}\text { DIS- } \\
\text { SOLVED } \\
\text { OHTHU. } \\
\text { PHOS- } \\
\text { PHORUS } \\
\text { (P) } \\
\text { (MG/L) }\end{array}$ \\
\hline OCT & & & & & & & \\
\hline of.... & -- & -- & -- & -- & -- & -- & - \\
\hline $07 \ldots$ & .27 & .30 & .40 & 1.8 & $.0<$ & - & .00 \\
\hline $13 \ldots$ & -- & -- & -- & - & -- & $=$ & $=$ \\
\hline 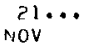 & .44 & .45 & .55 & 2.4 & .00 & -- & -- \\
\hline $03 .$. & -- & -- & -- & -- & -- & -- & -- \\
\hline $11 \ldots$ & . 26 & .31 & .46 & 2.0 & .01 & .00 & $.0 n$ \\
\hline $17 \ldots$ & -- & -- & -- & - & -- & - & $\cdots$ \\
\hline $24 \ldots$ & -- & -- & -7 & -- & $\cdots$ & -- & -- \\
\hline $24 .$. & $.4 \mathrm{~h}$ & $.4 \mathrm{H}$ & .70 & 3.1 & .00 & -- & .03 \\
\hline OEC & & & & & & & \\
\hline$n 1 \ldots$ & $=$ & $=-$ & -- & -- & -- & $=-$ & -- \\
\hline $\begin{array}{l}n+\ldots \\
n 9 \ldots\end{array}$ & . &.$\overline{32}$ & .51 & $2 . \overline{3}$ &.$\overline{0 u}$ & $=$ &.$\overline{0}$ \\
\hline $15 \ldots$ & $\cdots$ & - & - & - & -- & -- & - \\
\hline $2 ? \ldots$ & -- & -- & -- & - & -- & - & -- \\
\hline $27 \ldots$ & .14 & .17 & .34 & 1.5 & .02 & -- & .01 \\
\hline$>4 \ldots$ & -. & - & -- & -- & -- & -- & $\cdots$ \\
\hline$\checkmark \Delta N$ & & & & & & & \\
\hline $05 \ldots$ & $=$ & $=$ & $=-$ & $=$ & -- & $=$ & $=$ \\
\hline $14 \ldots$ & .57 & .58 & .76 & 3.4 & .00 & - & .01 \\
\hline $19 \ldots$ & -- & -- & -- & -- & -- & -- & -- \\
\hline ph.... & -- & -- & -- & -- & -- & - & - \\
\hline $27 . .$. & .45 & .47 & .68 & 3.0 & .00 & -- & -- \\
\hline$F F H$ & $-\infty$ & -- & -- & -- & -- & $-\rightarrow$ & -- \\
\hline $0 y . .$. & - & -- & $=$ & $\ldots$ & - & - & $=$ \\
\hline $11 \ldots$ & . 52 & .53 & - & 3.5 & .03 & .00 & .01 \\
\hline $1+\ldots$ & -- & - & -- & - & -- & - & $\cdots$ \\
\hline$? 3 \ldots$ & -- & - & -- & - & -- & -- & - \\
\hline $24 \ldots$ & .20 & .21 & .41 & 1.3 & .012 & - & -- \\
\hline $\begin{array}{l}\text { MAR } \\
01 . . .\end{array}$ & -- & -- & -- & -- & - & -- & - \\
\hline$n n_{0} .$. & - & - & - & 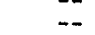 & $=$ & - & $=$ \\
\hline $10 \ldots$ & .45 & .47 & .71 & 3.1 & .03 & -- & .01 \\
\hline $15 \ldots$ & - & -- & - & - & -- & - & -- \\
\hline $22 \ldots$ & -- & -- & -- & -- & -- & - & $\cdots$ \\
\hline $23 \ldots$ & .45 & .47 & b & 1.3 & .05 & -- & -- \\
\hline $29 \ldots$ & -- & - & - & -- & -- & -- & -- \\
\hline$\triangle P R$ & & & & & & & \\
\hline $05 . .$. & $\because$ & -- & -- & $=$ & $=-$ & -- & -- \\
\hline $\begin{array}{l}12 \ldots \\
14 \ldots\end{array}$ & .33 &.$\overline{33}$ & .57 & $2 . \overline{5}$ & .17 & $\overline{--}$ &.$\overline{.00}$ \\
\hline $19 . .$. & - & - & - & - & - & - & -0 \\
\hline $26 \ldots$ & - & -- & - & $=$ & -- & $\rightarrow$ & -- \\
\hline $27 \ldots$ & .34 & $.4 ?$ & .56 & 2.5 & .05 & - & -- \\
\hline MAr & & & & & & & \\
\hline $03 \ldots$ & $=$ & $=$ & $=$ & $=$ & $=$ & $\because$ & $=-$ \\
\hline $10 \ldots$ & .31 & .33 & .55 & 2.4 &.$\overline{05}$ & .02 &.$\overline{00}$ \\
\hline $17 \ldots$ & -. & $\ldots$ & - & -- & -- & -- & -- \\
\hline$>4 \ldots$ & -- & -- & -- & -. & -. & -- & -. \\
\hline $25 \ldots$ & .40 & .40 & .52 & 2.3 & .01 & -- & -- \\
\hline $31 \ldots$ & -- & -- & $\cdots$ & $\cdots$ & $\cdots$ & -- & -- \\
\hline $\begin{array}{c}J 10 \\
07 \ldots\end{array}$ & -- & - & -- & -- & -- & -- & - \\
\hline $09 \ldots$ & .63 & .64 & .80 & 3.5 & .13 & -- & .00 \\
\hline $14 \ldots$ & -. & - & -- & - & -. & -- & - \\
\hline $21 \ldots$ & - & -- & - & -- & -- & $\cdots$ & -- \\
\hline$>\mu \ldots$ & -- & -- & -- & -- & - & - & -- \\
\hline JIIL & & & & - & - & - & - \\
\hline $\begin{array}{l}15, \ldots \\
12 \ldots\end{array}$ & -- & $\overline{--}$ & $=$ & $=$ & $=-$ & $=$ & $=-$ \\
\hline $14 \ldots$ & .02 & .03 & .14 & . A? & .03 & -- & .00 \\
\hline $19 \ldots$ & -- & -- & -- & -- & -- & -- & -- \\
\hline $26 \ldots$ & -- & -- & -- & -- & -- & - & -- \\
\hline $27 \cdots$ & .41 & .41 & .54 & 2.4 & .03 & -- & $\cdots$ \\
\hline & & & & & & & \\
\hline $\begin{array}{l}n ? \ldots \\
n 9 . . .\end{array}$ & $\because$ & $=$ & $=$ & $=$ & $=$ & $=$ & $=$ \\
\hline $11 \ldots$ & .24 & .24 & .39 & 1.7 & .02 & .01 & .01 \\
\hline $16 \ldots$ & -. & -- & -- & - & -- & -- & -- \\
\hline $23 \ldots$ & 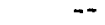 & -- & - & -- & - & -- & -- \\
\hline $24 \ldots$ & .64 & .64 & .71 & 3.1 & .02 & $=-$ & -- \\
\hline $30 .$. & -- & -- & -- & - & -- & -- & -- \\
\hline SEP & -- & -- & -- & -- & -- & - & -- \\
\hline $13 \ldots$ & -- & -- & -- & -- & -- & -- & $\cdots$ \\
\hline $15 \ldots$ & .51 & .51 & .57 & 2.5 & .01 & -- & .01 \\
\hline
\end{tabular}


09429490. COLORADO RIVER ABOVE IMPERIAL DAM, ARIZ,-CALIF,--CONTINUED

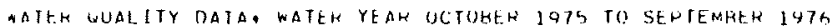

\begin{tabular}{|c|c|c|c|c|c|c|c|c|}
\hline & & & & & & BIS- & & OIS- \\
\hline & & & DIS- & {$[+1)-$} & TUTAL & SOL VEO & TOTAL & $S o) \in V t$ \\
\hline & & 11)TAL & SOLVEO & SULVEU & $C A B-$ & CAD- & $\mathrm{CHRO}-$ & CHKO- \\
\hline & TIHE & $\begin{array}{c}\text { ARSFNIC } \\
(\triangle S)\end{array}$ & $\begin{array}{c}\text { AKSENIC } \\
\text { (AS) }\end{array}$ & $\begin{array}{c}\text { MURUN } \\
(H)\end{array}$ & $\begin{array}{l}M\{U M \\
(\mathrm{C} \theta)\}\end{array}$ & $\begin{array}{l}M I U M \\
(C D)\end{array}$ & $\begin{array}{l}\text { IIUM } \\
\text { (CH) }\end{array}$ & $\begin{array}{l}M I U M \\
(C R)\end{array}$ \\
\hline ATt & & $(11 \% / L)$ & $(U(, / L)$ & $(U G / L)$ & $(1) G / L)$ & $(1) G / L)$ & $(1) 0 / L)$ & $(U G / L)$ \\
\hline
\end{tabular}

UCI

\begin{tabular}{|c|c|c|c|c|c|c|c|c|}
\hline 1) $7 \ldots$ & 1420 & -- & $\rightarrow$ & 170 & $\cdots$ & -- & - & - \\
\hline $21 \ldots$ & 1045 & -- & -- & -- & $=-$ & - & -- & - \\
\hline vov & . & & & & & & & \\
\hline $11 \ldots$ & 1350 & 2 & 2 & 140 & 10 & 2 & 6 & 0 \\
\hline$? 4 \ldots$ & 1100 & -- & -- & 150 & - & -- & -- & -- \\
\hline \multicolumn{9}{|l|}{$D E C$} \\
\hline$n 4 \ldots$ & 1330 & -- & -- & 150 & -- & -- & -- & - \\
\hline $23 \ldots$ & 1210 & -- & -- & 190 & -- & -- & -- & $=$ \\
\hline \multicolumn{9}{|l|}{ JAN } \\
\hline $14 \ldots$ & 0450 & -- & $-m$ & 200 & -- & -- & $=-$ & -- \\
\hline $27 \ldots$ & 1100 & -- & -- & -- & -- & $=-$ & -- & -- \\
\hline \multicolumn{9}{|l|}{ FEH } \\
\hline $11 \ldots$ & 0415 & 3 & 3 & 160 & $<10$ & 0 & 0 & 0 \\
\hline $24 \ldots$ & 1100 & -- & - & -- & -- & -- & -- & -- \\
\hline \multicolumn{9}{|l|}{ MAN } \\
\hline $10 \ldots$ & 1110 & -- & -- & 160 & -- & -- & -- & -- \\
\hline \multirow{2}{*}{\multicolumn{9}{|c|}{$A P_{N}$}} \\
\hline & & & & & & & & \\
\hline $27 \ldots$ & 1035 & -- & $m$ & - & - & -- & $=-$ & - \\
\hline \multicolumn{9}{|l|}{ MAY } \\
\hline $12 \ldots$ & 0920 & 4 & 3 & 170 & $<10$ & 0 & 0 & 0 \\
\hline $25 \ldots$ & 10,30 & -- & -- & -- & $\rightarrow$ & -- & $-\cdots$ & - \\
\hline \multicolumn{9}{|l|}{ Jijw } \\
\hline $04 \ldots$ & 0445 & -- & - & 160 & -- & $=-$ & -- & - \\
\hline \multicolumn{9}{|l|}{ JUL } \\
\hline $14 \ldots$ & 0415 & -- & -- & 170 & - & -- & -- & -- \\
\hline $27 \ldots$ & 1010 & -- & -- & $\rightarrow$ & -- & $-\cdots$ & -- & -- \\
\hline \multicolumn{9}{|l|}{ AllG } \\
\hline $11 \ldots$ & 0930 & 2 & 2 & 170 & $<10$ & 0 & 10 & 0 \\
\hline $24 \ldots$ & 1045 & $=-$ & -- & -- & - & $=$ & -- & -- \\
\hline \multicolumn{9}{|l|}{ SEP } \\
\hline $15 \ldots$ & 1030 & -- & -- & 240 & -- & -- & -- & -- \\
\hline $2 \mathrm{H} \ldots$ & $101 \mathrm{~b}$ & -- & -- & -- & -- & -- & -- & - \\
\hline
\end{tabular}

\begin{tabular}{|c|c|c|c|c|c|c|c|c|c|}
\hline & & UIS- & & DIS- & & DIS- & & DIS- & TOTAL \\
\hline & $\begin{array}{l}\text { TOTAL } \\
\text { CORALT }\end{array}$ & $\begin{array}{l}\text { SOLVED } \\
\text { CUBALT }\end{array}$ & $\begin{array}{l}\text { TOTAL } \\
\text { COPPER }\end{array}$ & $\begin{array}{l}\text { SOLVED } \\
\text { COPPER }\end{array}$ & $\begin{array}{l}\text { TOTAL } \\
\text { IKON }\end{array}$ & $\begin{array}{l}\text { SOLVED } \\
\text { IHON }\end{array}$ & $\begin{array}{r}\text { TOTAL } \\
\text { LEADD }\end{array}$ & $\begin{array}{c}\text { SOLVED } \\
\text { LEAD }\end{array}$ & $\begin{array}{l}\text { MAN- } \\
\text { GANESE }\end{array}$ \\
\hline IAIE & $\begin{array}{c}(C O) \\
(U G / L)\end{array}$ & $\begin{array}{c}(C O) \\
(U G / L)\end{array}$ & $\begin{array}{c}(C U) \\
(U G / L)\end{array}$ & $\begin{array}{c}\text { (CU) } \\
(U G / L)\end{array}$ & $\begin{array}{c}(F E) \\
(U G / L)\end{array}$ & $\begin{array}{c}(F E) \\
(U G / L)\end{array}$ & $\begin{array}{c}(P B) \\
(N G / L)\end{array}$ & $\begin{array}{c}(F F) \\
(U G / L)\end{array}$ & $\begin{array}{c}(H N) \\
(U G / L)\end{array}$ \\
\hline
\end{tabular}

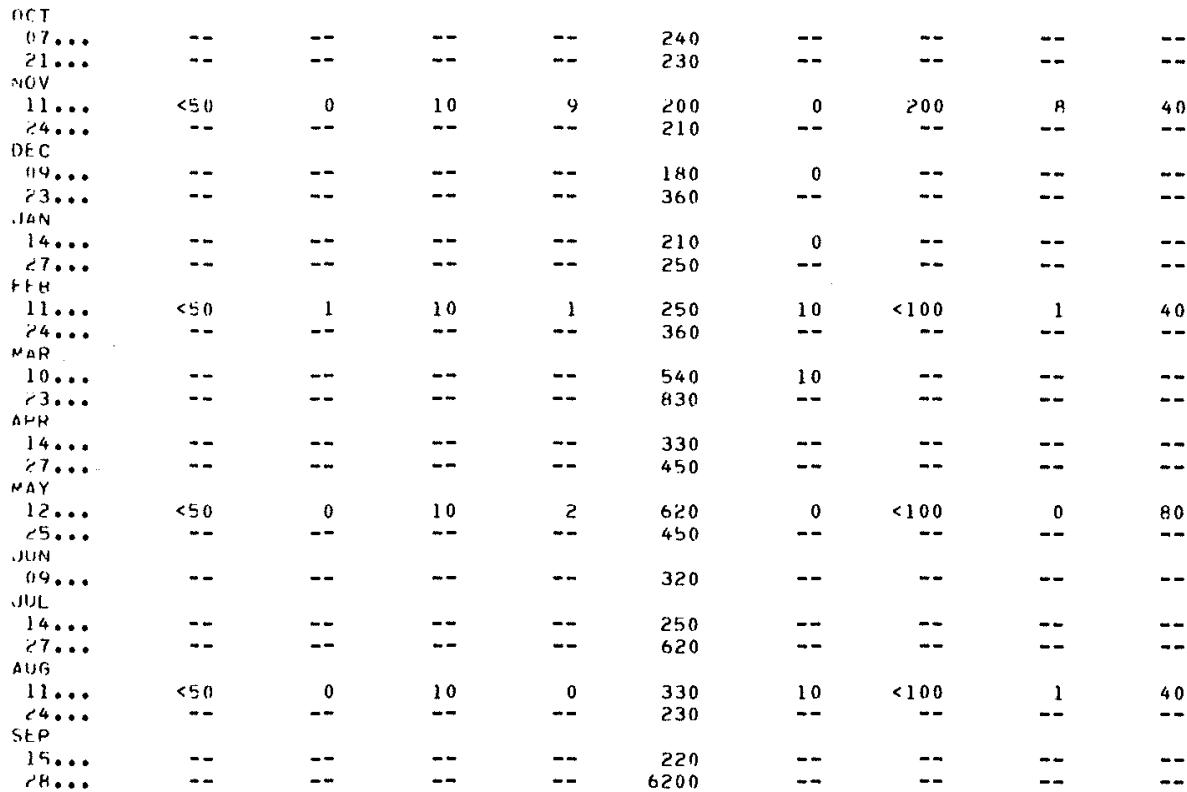

< Actual value is known to be less than the value shown. 
09429490, COLORADO RIVER ABOVE INPERIAL DAM, ARIZ.-CALIF.--CONTINUED AATEH WULLITY DATA. WATER YLAR UCTUBEF 197 S TO SEPIENEEK ISTh

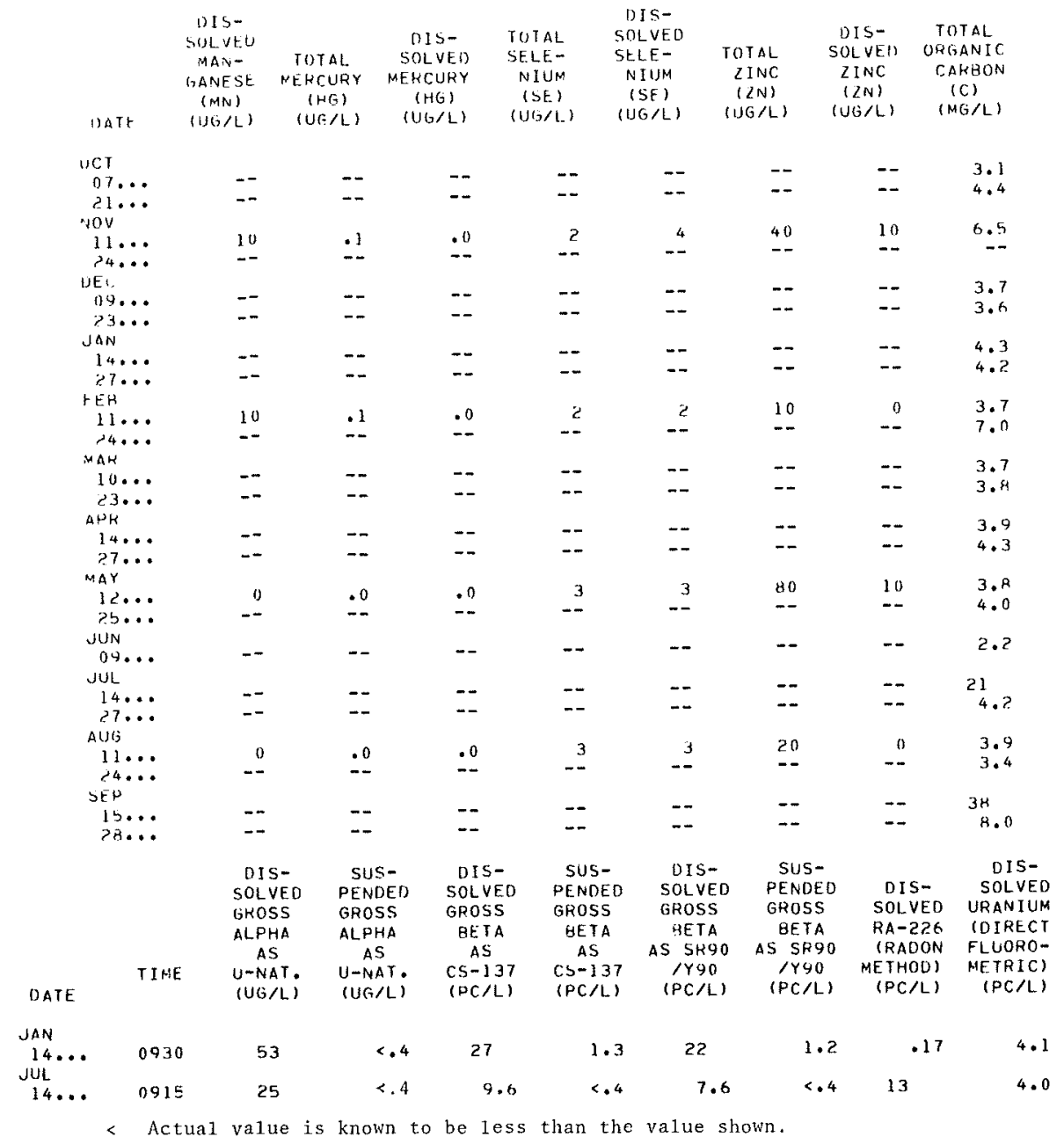


09429490. COLORADO RIVER ABOVE IMPERIAL DAM, ARIZ, CALIF.--CONTINUED

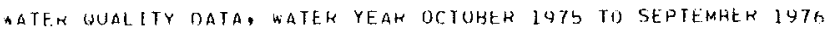

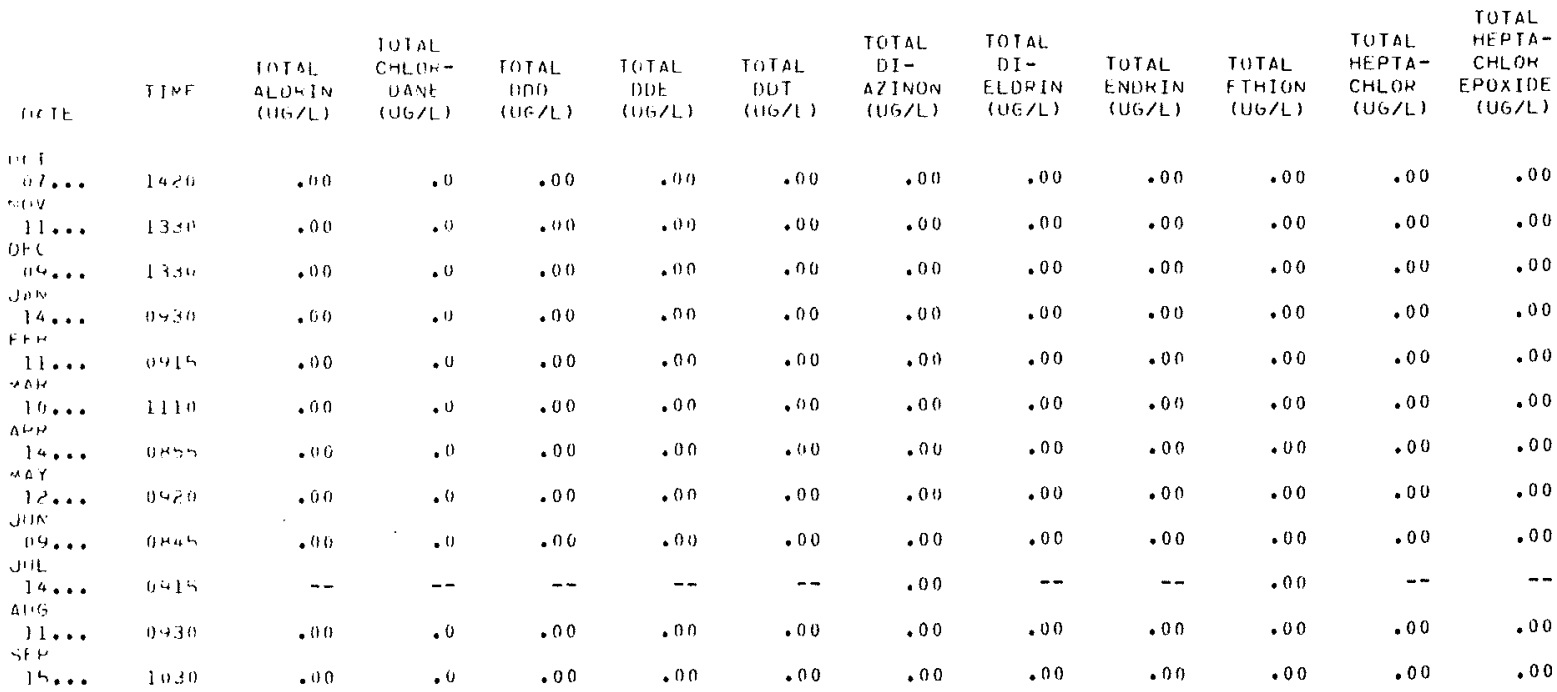

\begin{tabular}{|c|c|c|c|c|c|c|c|c|c|c|c|}
\hline fort & 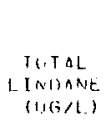 & $\begin{array}{l}\text { WOTAL } \\
\text { NALA- } \\
\text { IHIUA } \\
\text { (UGCL) }\end{array}$ & $\begin{array}{l}\text { TUTAL } \\
\text { ME. THYL } \\
\text { HAKA- } \\
\text { YHION } \\
(U(\mathrm{~L} / \mathrm{L})\end{array}$ & $\begin{array}{l}\text { TOTAL } \\
\text { MFTHYL } \\
\text { THI- } \\
\text { THION } \\
\text { IUGAL) }\end{array}$ & $\begin{array}{l}\text { TOTAL } \\
\text { PARA- } \\
\text { THION } \\
(U G / L)\end{array}$ & $\begin{array}{l}\text { TOTAL } \\
\text { TUX- } \\
\text { AHHENE } \\
\text { (UG/L) }\end{array}$ & $\begin{array}{c}\text { TUTAL } \\
\text { FHI- } \\
\text { THION } \\
(U G / L)\end{array}$ & $\begin{array}{l}\text { TOTAL } \\
2,4-0 \\
(U G / L)\end{array}$ & $\begin{array}{c}\text { TOTAL } \\
2,4,5-T \\
\text { (UG/L) }\end{array}$ & $\begin{array}{l}\text { TOTAL } \\
\text { SILVEX } \\
\text { (IIG/L) }\end{array}$ & $\begin{array}{l}\text { TOTAL } \\
P C H \\
\text { (UA }\end{array}$ \\
\hline $4 \pi$ & & & & & & & & & & & \\
\hline $\cos \ldots$ & .011 & . 00 & .00 & .00 & .00 & 0 & .00 & .00 & .00 & .00 & .0 \\
\hline${ }_{\operatorname{lif}} 11 \ldots$ & .00 & .00 & .00 & .00 & .00 & 0 & .00 & .00 & .00 & .00 & .0 \\
\hline nis.... & .00 & .00 & .00 & .00 & .00 & 0 & .00 & .00 & .00 & .00 & .0 \\
\hline$\underset{f+1}{14}$ & .00 & .00 & .00 & .00 & .00 & $n$ & .00 & .00 & .00 & .00 & .0 \\
\hline $\ln _{a 1} 1 \ldots$ & .011 & .00 & .00 & .00 & .00 & 0 & .00 & .00 & .00 & .00 & .0 \\
\hline$\underset{\text { ncite }}{10} \ldots$ & .00 & .00 & .00 & .00 & .00 & 0 & .00 & .00 & .00 & .00 & .0 \\
\hline $14 \ldots$ & .010 & .00 & .00 & .00 & .00 & 0 & .00 & .00 & .00 & .00 & .0 \\
\hline$\underset{n=0}{A \rightarrow \infty}$ & .011 & .00 & .00 & .00 & .00 & 0 & .00 & .00 & $.0 n$ & .00 & .0 \\
\hline $\begin{array}{l}1.4 \ldots \\
\sqrt{3}+1 .\end{array}$ & .011 & -- & .00 & .00 & .00 & 0 & .00 & .00 & .00 & .00 & .0 \\
\hline$\underset{\text { arte- }}{14 \ldots}$ & -- & .00 & .00 & .00 & .00 & -- & .00 & .08 & .01 & .00 & $-\infty$ \\
\hline${ }_{\text {sf }}^{11} \ldots$ & .00 & .00 & .00 & .00 & .00 & 0 & .00 & .00 & .00 & .00 & .0 \\
\hline $15 \ldots$ & .00 & .00 & .00 & .00 & .00 & 0 & .00 & .00 & .00 & .00 & .0 \\
\hline
\end{tabular}


09429490. COLORADO RIVER ABOVE IMPERIAL DAM, ARIZ. -CALIF.--CONTINUED

TEMPERATURE (DEG. C) OF WATEK, WATER YEAR OCTUBER 1975 TO SEPTEMBER 1976

\begin{tabular}{|c|c|c|c|c|c|c|c|c|c|c|c|c|}
\hline OAY & $O C T$ & NOV & OEC & JAN & FEE & MAR & APK & MAY & JUN & JUL & AUG & SEP \\
\hline $\begin{array}{l}1 \\
2 \\
3 \\
4 \\
5\end{array}$ & $\begin{array}{l}26.5 \\
26.5 \\
26.5 \\
26.5 \\
26.5\end{array}$ & $\begin{array}{l}20.0 \\
20.0 \\
20.0 \\
20.0 \\
20.0\end{array}$ & $\begin{array}{l}12.0 \\
13.5 \\
13.5 \\
14.5 \\
15.0\end{array}$ & $\begin{array}{r}11.0 \\
9.5 \\
9.5 \\
9.0 \\
10.0\end{array}$ & $\begin{array}{l}15.0 \\
15.0 \\
14.5 \\
14.5 \\
15.0\end{array}$ & $\begin{array}{l}16.5 \\
16.5 \\
15.5 \\
15.0 \\
14.5\end{array}$ & $\begin{array}{l}18.5 \\
18.5 \\
14.0 \\
19.0 \\
18.5\end{array}$ & $\begin{array}{l}22.0 \\
23.5 \\
23.5 \\
23.0 \\
23.5\end{array}$ & $\begin{array}{l}26.0 \\
26.5 \\
26.5 \\
26.5 \\
26.5\end{array}$ & $\begin{array}{l}30.0 \\
29.0 \\
29.0 \\
29.0 \\
29.0\end{array}$ & $\begin{array}{l}31.0 \\
30.0 \\
29.0 \\
29.0 \\
29.0\end{array}$ & $\begin{array}{l}30.0 \\
29.0 \\
29.0 \\
29.5 \\
29.5\end{array}$ \\
\hline $\begin{array}{r}6 \\
7 \\
8 \\
9 \\
10\end{array}$ & $\begin{array}{l}26.5 \\
25.0 \\
24.0 \\
24.0 \\
24.0\end{array}$ & $\begin{array}{l}20.0 \\
20.0 \\
20.0 \\
19.5 \\
19.0\end{array}$ & $\begin{array}{l}15.0 \\
15.0 \\
15.0 \\
15.0 \\
14.0\end{array}$ & $\begin{array}{l}11.0 \\
11.0 \\
11.0 \\
11.0 \\
10.5\end{array}$ & $\begin{array}{l}15.0 \\
15.0 \\
16.0 \\
16.5 \\
16.5\end{array}$ & $\begin{array}{l}15.0 \\
15.0 \\
15.5 \\
16.0 \\
16.5\end{array}$ & $\begin{array}{l}19.5 \\
19.0 \\
19.5 \\
19.5 \\
20.0\end{array}$ & $\begin{array}{l}22.0 \\
22.0 \\
22.0 \\
23.5 \\
24.5\end{array}$ & $\begin{array}{l}26.5 \\
26.5 \\
26.5 \\
26.5 \\
25.5\end{array}$ & $\begin{array}{l}30.0 \\
30.0 \\
30.5 \\
30.5 \\
30.0\end{array}$ & $\begin{array}{l}29.0 \\
29.5 \\
29.5 \\
29.5 \\
29.5\end{array}$ & $\begin{array}{l}29.0 \\
28.5 \\
29.0 \\
28.5 \\
28.0\end{array}$ \\
\hline $\begin{array}{l}11 \\
12 \\
13 \\
14 \\
15\end{array}$ & $\begin{array}{l}24.5 \\
23.5 \\
23.0 \\
22.0 \\
21.5\end{array}$ & $\begin{array}{l}19.5 \\
17.0 \\
16.5 \\
16.0 \\
16.0\end{array}$ & $\begin{array}{l}15.0 \\
15.0 \\
15.0 \\
14.0 \\
12.0\end{array}$ & $\begin{array}{l}11.5 \\
12.0 \\
11.5 \\
12.0 \\
11.5\end{array}$ & $\begin{array}{l}15.5 \\
16.0 \\
16.0 \\
16.5 \\
16.5\end{array}$ & $\begin{array}{l}16.5 \\
16.0 \\
15.5 \\
16.5 \\
16.5\end{array}$ & $\begin{array}{l}20.0 \\
20.0 \\
20.0 \\
19.5 \\
19.5\end{array}$ & $\begin{array}{l}24.5 \\
25.5 \\
26.0 \\
26.5 \\
26.5\end{array}$ & $\begin{array}{l}25.5 \\
25.5 \\
26.5 \\
26.5 \\
26.5\end{array}$ & $\begin{array}{l}30.0 \\
29.5 \\
30.5 \\
29.5 \\
29.5\end{array}$ & $\begin{array}{l}30.0 \\
29.5 \\
29.0 \\
26.5 \\
27.0\end{array}$ & $\begin{array}{l}27.0 \\
29.0 \\
28.5 \\
29.0 \\
29.0\end{array}$ \\
\hline $\begin{array}{l}16 \\
17 \\
18 \\
19 \\
20\end{array}$ & $\begin{array}{l}21.5 \\
21.5 \\
23.0 \\
23.0 \\
23.0\end{array}$ & $\begin{array}{l}16.5 \\
16.5 \\
16.5 \\
15.0 \\
15.5\end{array}$ & $\begin{array}{l}11.5 \\
11.5 \\
13.5 \\
12.0 \\
11.5\end{array}$ & $\begin{array}{l}13.0 \\
13.5 \\
14.0 \\
14.5 \\
13.5\end{array}$ & $\begin{array}{l}16.5 \\
17.0 \\
17.0 \\
18.5 \\
16.5\end{array}$ & $\begin{array}{l}16.5 \\
17.0 \\
16.5 \\
16.5 \\
16.5\end{array}$ & $\begin{array}{l}17.0 \\
16.5 \\
18.0 \\
18.5 \\
20.5\end{array}$ & $\begin{array}{l}26.5 \\
26.5 \\
26.5 \\
26.5 \\
20.0\end{array}$ & $\begin{array}{l}26.5 \\
26.5 \\
27.0 \\
28.5 \\
29.5\end{array}$ & $\begin{array}{l}29.5 \\
29.0 \\
29.0 \\
29.0 \\
29.5\end{array}$ & $\begin{array}{l}26.5 \\
28.0 \\
27.0 \\
27.0 \\
27.0\end{array}$ & $\begin{array}{l}28.0 \\
28.0 \\
28.0 \\
28.0 \\
27.0\end{array}$ \\
\hline $\begin{array}{l}21 \\
22 \\
23 \\
24 \\
25\end{array}$ & $\begin{array}{l}23.0 \\
23.5 \\
21.0 \\
20.0 \\
19.0\end{array}$ & $\begin{array}{l}15.0 \\
15.0 \\
15.0 \\
14.5 \\
15.0\end{array}$ & $\begin{array}{l}13.0 \\
13.5 \\
14.5 \\
14.0 \\
14.5\end{array}$ & $\begin{array}{l}13.5 \\
13.5 \\
13.5 \\
14.0 \\
14.0\end{array}$ & $\begin{array}{l}15.5 \\
15.0 \\
15.0 \\
15.0 \\
16.0\end{array}$ & $\begin{array}{l}16.0 \\
16.5 \\
18.0 \\
18.5 \\
18.5\end{array}$ & $\begin{array}{l}21.0 \\
20.5 \\
21.0 \\
21.5 \\
21.5\end{array}$ & $\begin{array}{l}26.0 \\
26.0 \\
26.0 \\
25.5 \\
25.0\end{array}$ & $\begin{array}{l}29.5 \\
29.0 \\
28.0 \\
27.0 \\
28.0\end{array}$ & $\begin{array}{l}29.5 \\
29.0 \\
29.5 \\
30.0 \\
30.0\end{array}$ & $\begin{array}{l}28.0 \\
29.0 \\
29.5 \\
30.5 \\
30.0\end{array}$ & $\begin{array}{l}27.0 \\
27.0 \\
27.0 \\
25.5 \\
25.5\end{array}$ \\
\hline $\begin{array}{l}26 \\
27 \\
28 \\
29 \\
30 \\
31\end{array}$ & $\begin{array}{l}18.0 \\
18.5 \\
20.0 \\
21.0 \\
21.0 \\
20.0\end{array}$ & $\begin{array}{r}14.5 \\
14.5 \\
14.5 \\
13.0 \\
13.0 \\
-. .-\end{array}$ & $\begin{array}{l}13.5 \\
13.5 \\
13.0 \\
12.0 \\
13.0 \\
11.0\end{array}$ & $\begin{array}{l}14.0 \\
13.0 \\
13.0 \\
13.0 \\
12.0 \\
14.0\end{array}$ & $\begin{array}{r}16.0 \\
16.5 \\
16.5 \\
17.0 \\
\ldots \ldots\end{array}$ & $\begin{array}{l}18.5 \\
18.0 \\
18.0 \\
18.0 \\
18.0 \\
18.0\end{array}$ & $\begin{array}{l}21 \cdot 5 \\
22.0 \\
21.5 \\
21.5 \\
22.0 \\
---\end{array}$ & $\begin{array}{l}25.5 \\
26.0 \\
26.0 \\
25.5 \\
26.5 \\
25.5\end{array}$ & $\begin{array}{r}28.5 \\
29.5 \\
30.0 \\
30.5 \\
30.0 \\
-.-0\end{array}$ & $\begin{array}{l}30.5 \\
30.5 \\
30.5 \\
31.0 \\
30.0 \\
31.0\end{array}$ & $\begin{array}{l}30.0 \\
30.0 \\
30.5 \\
30.5 \\
30.5 \\
30.5\end{array}$ & $\begin{array}{r}25.0 \\
26.0 \\
27.0 \\
27.0 \\
27.0 \\
-\end{array}$ \\
\hline NTH & 23.0 & 17.0 & 13.5 & 12.0 & 16.0 & 16.5 & 20.0 & 25.0 & 27.5 & 30.0 & 29.0 & 28.0 \\
\hline
\end{tabular}

YEAR MAX $31.0 \quad$ MIN $9.0 \quad$ MEAN 21.5

SPECIFIC CONDUCTANCE (MICROMHOS/CM AT 25 DEG. C), WATER YEAR OCTOBER 1975 TO SEPTEMBER 1976 MEAN VALUES

\begin{tabular}{|c|c|c|c|c|c|c|c|c|c|c|c|c|}
\hline DAY & OCT & NCV & DEC & JAN & FEB & MAR & $A P R$ & MAY & JUN & JUL & AUG & SEP \\
\hline $\begin{array}{l}1 \\
2 \\
3 \\
4 \\
5\end{array}$ & $\begin{array}{l}1280 \\
1290 \\
1310 \\
1310 \\
1330\end{array}$ & $\begin{array}{l}1360 \\
1400 \\
1410 \\
1390 \\
1400\end{array}$ & $\begin{array}{l}1490 \\
1470 \\
1450 \\
1450 \\
1430\end{array}$ & $\begin{array}{l}1420 \\
1380 \\
1350 \\
1320 \\
1340\end{array}$ & $\begin{array}{l}1330 \\
1320 \\
1300 \\
1280 \\
1280\end{array}$ & $\begin{array}{l}1220 \\
1220 \\
1230 \\
1200 \\
1220\end{array}$ & $\begin{array}{l}1250 \\
1240 \\
1250 \\
1230 \\
1230\end{array}$ & $\begin{array}{l}1280 \\
1240 \\
1250 \\
1240 \\
1240\end{array}$ & $\begin{array}{l}1290 \\
1290 \\
1290 \\
1310 \\
1300\end{array}$ & $\begin{array}{l}1260 \\
1250 \\
1270 \\
1270 \\
1240\end{array}$ & $\begin{array}{l}1280 \\
1270 \\
1240 \\
1240 \\
1240\end{array}$ & $\begin{array}{l}1220 \\
1240 \\
1260 \\
1260 \\
1260\end{array}$ \\
\hline $\begin{array}{r}6 \\
7 \\
8 \\
9 \\
10\end{array}$ & $\begin{array}{l}1300 \\
1290 \\
1290 \\
1300 \\
1330\end{array}$ & $\begin{array}{l}1370 \\
1340 \\
1380 \\
1430 \\
1400\end{array}$ & $\begin{array}{l}1370 \\
1360 \\
1330 \\
1240 \\
1220\end{array}$ & $\begin{array}{l}1310 \\
1320 \\
1350 \\
1360 \\
1390\end{array}$ & $\begin{array}{l}1300 \\
1300 \\
1340 \\
1360 \\
1340\end{array}$ & $\begin{array}{l}1250 \\
1230 \\
1250 \\
1250 \\
1250\end{array}$ & $\begin{array}{l}1230 \\
1210 \\
1250 \\
1250 \\
1260\end{array}$ & $\begin{array}{l}1240 \\
1270 \\
1280 \\
1290 \\
1310\end{array}$ & $\begin{array}{l}1310 \\
1280 \\
1270 \\
1280 \\
1280\end{array}$ & $\begin{array}{l}1240 \\
1250 \\
1250 \\
1260 \\
1290\end{array}$ & $\begin{array}{l}1260 \\
1270 \\
1260 \\
1230 \\
1220\end{array}$ & $\begin{array}{l}1240 \\
1210 \\
1230 \\
1300 \\
1370\end{array}$ \\
\hline $\begin{array}{l}11 \\
12 \\
13 \\
14 \\
15\end{array}$ & $\begin{array}{l}1340 \\
1350 \\
1330 \\
1330 \\
1330\end{array}$ & $\begin{array}{l}1380 \\
1370 \\
1370 \\
1420 \\
1430\end{array}$ & $\begin{array}{l}1280 \\
1350 \\
1360 \\
1390 \\
1410\end{array}$ & $\begin{array}{l}1420 \\
1410 \\
1410 \\
1380 \\
1390\end{array}$ & $\begin{array}{l}1360 \\
1390 \\
1520 \\
1580 \\
1630\end{array}$ & $\begin{array}{l}1250 \\
1270 \\
1280 \\
1280 \\
1240\end{array}$ & $\begin{array}{l}1250 \\
1230 \\
1250 \\
1230 \\
1250\end{array}$ & $\begin{array}{l}1330 \\
1290 \\
1270 \\
1290 \\
1310\end{array}$ & $\begin{array}{l}1300 \\
1330 \\
1290 \\
1250 \\
1250\end{array}$ & $\begin{array}{l}1250 \\
1220 \\
1230 \\
1240 \\
1230\end{array}$ & $\begin{array}{l}1230 \\
1230 \\
1240 \\
1240 \\
1240\end{array}$ & $\begin{array}{l}1350 \\
1350 \\
1420 \\
1540 \\
1630\end{array}$ \\
\hline $\begin{array}{l}16 \\
17 \\
18 \\
19 \\
20\end{array}$ & $\begin{array}{l}1360 \\
1370 \\
1390 \\
1420 \\
1360\end{array}$ & $\begin{array}{l}1420 \\
1370 \\
1340 \\
1330 \\
1390\end{array}$ & $\begin{array}{l}1370 \\
1320 \\
1310 \\
1320 \\
1330\end{array}$ & $\begin{array}{l}1410 \\
1440 \\
1440 \\
1370 \\
1340\end{array}$ & $\begin{array}{l}1550 \\
1550 \\
1610 \\
1650 \\
1590\end{array}$ & $\begin{array}{l}1250 \\
1230 \\
1230 \\
1240 \\
1250\end{array}$ & $\begin{array}{l}1330 \\
1360 \\
1390 \\
1340 \\
1280\end{array}$ & $\begin{array}{l}1300 \\
1280 \\
1280 \\
1280 \\
1240\end{array}$ & $\begin{array}{l}1260 \\
1250 \\
1290 \\
1290 \\
1280\end{array}$ & $\begin{array}{l}1260 \\
1270 \\
1250 \\
1230 \\
1230\end{array}$ & $\begin{array}{l}1240 \\
1240 \\
1230 \\
1240 \\
1240\end{array}$ & $\begin{array}{l}1510 \\
1460 \\
1450 \\
1470 \\
1370\end{array}$ \\
\hline $\begin{array}{l}21 \\
22 \\
23 \\
24 \\
25\end{array}$ & $\begin{array}{l}1320 \\
1310 \\
1350 \\
1370 \\
1380\end{array}$ & $\begin{array}{l}1370 \\
1360 \\
1400 \\
1360 \\
1350\end{array}$ & $\begin{array}{l}1320 \\
1310 \\
1340 \\
1440 \\
1580\end{array}$ & $\begin{array}{l}1340 \\
1320 \\
1330 \\
1360 \\
1380\end{array}$ & $\begin{array}{l}1570 \\
1480 \\
1340 \\
1310 \\
1260\end{array}$ & $\begin{array}{l}1220 \\
1220 \\
1220 \\
1220 \\
1210\end{array}$ & $\begin{array}{l}1280 \\
1290 \\
1260 \\
1240 \\
1230\end{array}$ & $\begin{array}{l}1270 \\
1300 \\
1290 \\
1260 \\
1270\end{array}$ & $\begin{array}{l}1270 \\
1250 \\
1240 \\
1240 \\
1230\end{array}$ & $\begin{array}{l}1230 \\
1240 \\
1240 \\
1240 \\
1230\end{array}$ & $\begin{array}{l}1240 \\
1230 \\
1230 \\
1240 \\
1250\end{array}$ & $\begin{array}{l}1340 \\
1280 \\
1280 \\
1150 \\
1040\end{array}$ \\
\hline $\begin{array}{l}26 \\
27 \\
28 \\
29 \\
30 \\
31\end{array}$ & $\begin{array}{l}1400 \\
1380 \\
1360 \\
1360 \\
1350 \\
1350\end{array}$ & $\begin{array}{r}1400 \\
1410 \\
1450 \\
1490 \\
1490 \\
-0 .\end{array}$ & $\begin{array}{l}1500 \\
1340 \\
1350 \\
1340 \\
1350 \\
1380\end{array}$ & $\begin{array}{l}1340 \\
1310 \\
1310 \\
1340 \\
1320 \\
1310\end{array}$ & $\begin{array}{l}1240 \\
1260 \\
1230 \\
1240 \\
=- \\
-=-\end{array}$ & $\begin{array}{l}1220 \\
1220 \\
1230 \\
1220 \\
1230 \\
1240\end{array}$ & $\begin{array}{c}1230 \\
1260 \\
1230 \\
1230 \\
1250 \\
-0-\end{array}$ & $\begin{array}{l}1290 \\
1310 \\
1320 \\
1320 \\
1310 \\
1290\end{array}$ & $\begin{array}{c}1290 \\
1270 \\
1250 \\
1250 \\
1230 \\
-\end{array}$ & $\begin{array}{l}1220 \\
1220 \\
1220 \\
1250 \\
1280 \\
1280\end{array}$ & $\begin{array}{l}1250 \\
1280 \\
1270 \\
1240 \\
1230 \\
1220\end{array}$ & $\begin{array}{r}935 \\
1120 \\
1230 \\
1320 \\
1380 \\
-\end{array}$ \\
\hline NTH & 1340 & 1390 & 1370 & 1360 & 1400 & 1240 & 1260 & 1280 & 1270 & 1250 & 1240 & 1310 \\
\hline
\end{tabular}


09429490. COLORADO RIVER ABOVE IMPERIAL DAM, ARIZ.-CALIF.--CONTINUED

QUALITATIVE AND ASSOCIATED QUANTITATIVE ANALYSES OF BIOLOGICAL DATA, WATER YEAR OCTOBER 1975 TO SEPTEMBER 1976 PERIPHYTON

\begin{tabular}{|c|c|c|c|c|c|c|c|}
\hline Date & $\begin{array}{c}\text { Length of exposure } \\
\text { (days) }\end{array}$ & $\begin{array}{l}\text { Biomass } \\
\text { Dry weight }\end{array}$ & $\begin{array}{l}\left(\mathrm{g} / \mathrm{m}^{2}\right) \\
\text { Ash weight }\end{array}$ & $\begin{array}{c}\text { Chlorophy } 11 \\
\text { a } \\
\left(\mathrm{mg} / \mathrm{m}^{2}\right)\end{array}$ & $\begin{array}{c}\text { Chlorophyl1 } \\
\mathrm{b} \\
\left(\mathrm{mg} / \mathrm{m}^{2}\right)\end{array}$ & $\begin{array}{l}\text { Biomass } \\
\text { pigment } \\
\text { ratio }\end{array}$ & $\begin{array}{l}\text { Sampling } \\
\text { method }\end{array}$ \\
\hline Nov. 11 & 35 & 2.20 & 1.40 & 21.0 & 6.80 & 38 & $\begin{array}{l}\text { Polyethylene } \\
\text { strip }\end{array}$ \\
\hline Feb. 11 & 28 & 11.0 & 8.20 & 8.70 & .000 & 320 & $\begin{array}{c}\text { Polyethylene } \\
\text { strip }\end{array}$ \\
\hline May & 28 & 4.39 & .923 & 2.05 & .000 & 1700 & $\begin{array}{c}\text { Polyethylene } \\
\text { strip }\end{array}$ \\
\hline Sept. 15 & 35 & 3.08 & 1.15 & 2.70 & .000 & 710 & $\begin{array}{l}\text { Polyethylene } \\
\text { strip }\end{array}$ \\
\hline
\end{tabular}

QUALITATIVE AND ASSOCIATED QUANTITATIVE ANALYSES OF BIOLOGICAL DATA, WATER YEARS OCTOBER 1974 TO SEPTEMBER 1976

OCT. 9,1974

IDENTIFICATION OF PHYTOPLANKTON

8,800 CELLS/ML

_ORSANISM_NAMF

CHLOROPHYTA

CHLOROPHYCEAE

. CHLOROCOCCALES

... SCENEDE SMACEAE

.... CRUCI IGENIA

... SCENEDESMUS

- VOL VOCALES

... CHLAMYdomonadaceae

... ChL amyoomonas

CHRYSOPHYTA

BACILLARIOPHYCEAE

- centrales

.. COSCINOD I SCACEAE

.... CYClotella

..DENNALES

... ACHNANTHACEAE

L... ACHNANTHES

... COCCONEIS

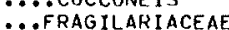

... Fragilaria

... NITZSCHIACEA

.... NITZSCHIA

- CHRYSOPHYCEAE

. CHRYSOMONADALES

@. MALLOMONADACEAE

L .... MALLOMONAS

CYANOPHYTA

- MYXOPHYCEAE

. OSCILLATORI ALES

... NOSTOCACEAE

... ANABAENA

... OsCILLATORI ACEAE

0 .... LYNGBYa
_COMMON_NAME

CELLS/ML

PER_CENT

GREEN ALGAE

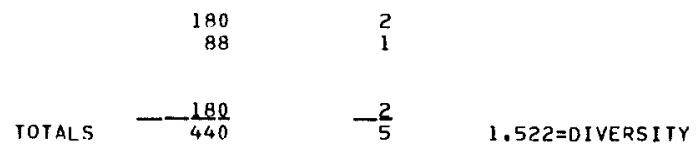

DIATOMS

CENTRIC

PENNATE

$1+100$

13

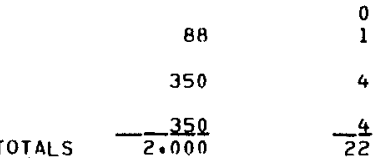

0

4

TOTALS

YELLOW-BROWN ALGAE

TOTALS

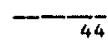

$-\frac{0}{0}$

$0.000=D$ I VERS I TY

BLUE-GREEN ALGAE

F ILAMENTOUS

\begin{tabular}{|c|c|c|}
\hline & 440 & 5 \\
\hline TOTALS & $-\frac{5,900}{6,400}$ & $\frac{67}{72}$ \\
\hline
\end{tabular}

$0.362=0 I$ IVRSI TY

NOTE: D - DOMINANT ORGANISM: GREATER OR EQUAL TO $15 \%$

L - LESS THEN 18; MAY NOT HAVE BEEN ACTUALLY COUNTED 
09429490. COLORADO RIVER ABOVE IMPERIAL DAM, ARIZ.-CALIF.--CONTINUED

QUALITATIVE AND ASSOCIATED QUANTITATIVE ANALYSES OF BIOLOGICAL DATA, WATER YEARS OCTOBER 1974 TO SEPTEMBER 1976

$$
\text { Nov. } 5,1974
$$

1330 HOURS

IDENTIFICATION OF PHYTOPLANKTON

$1,900 \mathrm{CELLS} / \mathrm{ML}$

_ORGANISM__NAME

CHLOROPHYTA

- CHLOROPHYCEAE

- CHLOROCOCCALES

. oOcYSTACEAE

.... ANK I STRODE SMUS

.... CLOSTERIOPSIS

CHRYSOPHYTA

- BACILLARI OPHYCEAF

. CENTRales

. coscinod Iscaceae

ח... CYCLOTELLA

.... MELOSIRA

-. PENNales

.. AchNanthaceae

.... coccone Is

... FRAG IL LR I ACEAE

... SYNEDRa

... Naviculaceae

... Navicula

... NITZSCHIACEAE

D.... NITZSCHIA

... SuRIRELlaceaE

.... CYMATOPLEURA

\section{EUGLENOPHYTA}

- EUGLENOPHYCEAE

. Eugeenales

... EuglenaceaE
_COMMON_NAME

GREEN ALGAE
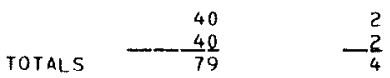

$1.000=$ DIVERSITY

DIATOMS

CENTRIC

PENNATE

NAVICULOIO

NAVICULOIO

TOTALS - $\frac{40}{1.800} \quad \frac{2}{93}$

EUGLENOIOS

TOTALS
560
600

70

79

79

360

$1, \frac{4}{800}$

$--\frac{40}{40}$ $-\frac{2}{2}$

$0.000=D I V E R S I T Y$ 
09429490. COLORADO RIVER ABOVE IMPERIAL DAM, ARIZ.-CALIF.--CONTINUED

QUALITATIVE AND ASSOCIATED QUANTITATIVE ANALYSES OF BIOLOGICAL DATA, WATER YEARS OCTOBER 1974 TO SEPTEMBER 1976

DFC. 3, 1974

1300 HOURS

IDENTIF ICATION OF PHYTOPLANKTON

$970 \mathrm{CELLS} / \mathrm{ML}$

_ORGANISM_NAME

CHLOROPHYTA

- CHLOROPHYCEAE

- CHL orococcales

... OOCYSTACEAE

.... CHLORELLA

... SCENEUE SMACEAE

... ACTINASTRUM

.

. vole trastrim

@. chl amydromonadaceae

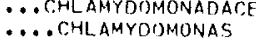

CHRYSOPHYTA

- BACILLAR I OPHYCEAE

. centrale

.. coscinodiscaceae

D.... CYClotella

... Melosira

-. PENNALES

...FRAGillariaceaf

n .... SYNEDRA

. NAV I cillaceae

.... Navicula

.. NITZSChIACEAE

.... NITZSCHIA

CYANOPHYTA

- MYXOPHYCEAE

. OSCILLATORI ALFS

... OSC ILLa TOR I aceae

.... SPIRIULINA

EUGLENOPHYTA

- EUGLENOPHYCEAE

-. Euglenales

... Eliglenacear

.....Fuglena

TOTALS

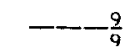

COMMON VAME

GREEN ALGAE.

TOTALS

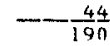

DIATOMS

CENTRIC

PFNNATE

NAVICULOID

TOTALS

BLUE-GREEN ALGAE

FILAMENTOUS

TOTALS

$--\frac{9}{9}$

EUGLENOIOS
CELLS/ML

DER_CENT

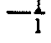

$0.000=0$ IVEQSITY

NOIE: D - DOMINANT ORGANISM: GREATER OR FOUAL TO IS\% 
09429490. COLORADO RIVER ABOVE IMPERTAL, DAM, ARIZ. -CAEIF.--CONTINUED

QUALITATIVE AND ASSOCIATED QUANTITATIVE ANALYSES OF BIOLOGICAL DATA, WATER YEARS OCTOBER 1974 TO SEPTEMBER 1976

JAN. 7,1979

1330 HOUPS

IDENTIFICATION OF PHYTOPLANKION

$180 \mathrm{CELLS} / \mathrm{ML}$

_OREANISM_NAME

CHLOROPHYTA

- CHLOROPHYCEAE

- CHLOROCOCCALES

- SCENEDE SMACEAF

.... SCENEDESMUS

. VOLVOCALES

- Chl一MYDOMONADACEAF

... ChLamydomonas

CHRYSOPHYTA

- BaCILLAR I OPHYCEAE

. . CF.NTRALES

- . COSCINODISCACEAF

n ..... C.YCLOTFLLA

. PEnNales

. Achnanthaceae

... cocconeIs

... naviculaceae

... AMPHIPRORA

... grros I gima

.... NAVICUl A

.. NITZSCHIACEAE

D ....NITZSCHIA

- CMRYSOPHYCEAE

- CHRYSOMONADALES

.... In Inokryon

PYRRHOPHYTA

- DINOPHYCEAE

. PER IDINI ALES

... GLENODINIIJM
_COMMON_NAME

GREEN ALGAE

TOTALS - - $\frac{-4}{0} \quad-\frac{2}{11}$

CELLS/ML

PER_CENT

16

9

$0.722=$ DIVERSITY

DIATOMS

CENTRIC

PFNNATE

53

29

...GLENODINIACEAE

NAVICILOIO

TOTALS

$\begin{array}{rr}20 & 11 \\ 8 & 4 \\ 4 & 2 \\ 41 & 22\end{array}$

YFLLOW-BROWN ALGAF

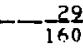

TOTALS

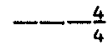

$-\frac{2}{2}$

$0.000=$ DIVERS I TY

FIRF ALGAE

DINOFLAGELLATES

TOIALS

1

22

$\frac{16}{84}$

$2.233=0$ IVERSITY

NOTE: 0 - DOMINANT ORGANISM: GREATER OR FOUAL TO $15 \%$ 
09429490, COLORADO RIVER ABOVE IMPERIAL DAM, ARIZ,-CALIF.--CONTIMJED

QUALITATIVE AND ASSOCIATED QUANTITATIVE ANALYSES OF BIOLOGICAL DATA, NATER YEARS OCTOBER 1974 TO SEPTEMBER 1976

FER. 11,1975

1345 HOURS

IDENTIFICATION OF PHYTOPLANKTON

$4.400 \mathrm{CELLS} / \mathrm{ML}$

_ORGANISM_NAME

CHLOROPHYTA

- CHLOROPHYCEAE

. CHLOROCUCCALES

.. ONCYSTACEAE

... CHIORELLA

-. SCENEDE SMACEAE

... SCENEDE SMUS

CHRYSOPHYTA

-BACILLARIOPHYCEAE

. Centrales

... coscindod I SCACEAE

.... CYCLOTELLA

-. Pennales

.. Di atomaceae

... ol atoma

... Fragilariaceae

.... SYMEDDRa

.. NITZSCHIACEAE

....NITZSCHIA

CYANOPHYTA

- mYXOPHYCEAE

. oscillatori ales

. oscillator taceae
COMMON_NAME

GREEN ALGAE

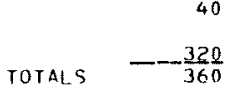

DIATOMS

CENTRIC

PENNATE

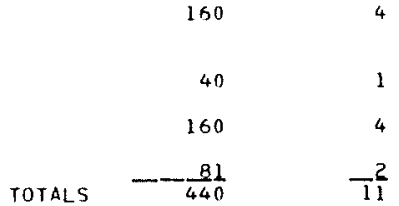

BLUE-GREEN ALGAE

FILAMFNTOUS

1

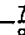

PER_CENT

$0.503=0$ IVERSITY

$1.823=0$ I VERS ITY

TOTALS $\quad-\frac{32600}{3.600} \quad \frac{82}{82} \quad 0.000=0$ IVERSITY

NOTE: D - DOMINANT ORGANISM; GREATER OR FQUAL TO 15\% 
09429490. COLORADO RIVER ABOVE IMPERIAL DAM, ARIZ.-CALIF.--CONTINUED

QUALITATIVE AND ASSOCIATED QUANTITATIVE ANALYSES OF BIOLOGICAL DATA, WATER YEARS OCTOBER 1974 TO SEPTEMBER 1976

$$
\begin{aligned}
& \text { MAR. } 11,1975 \\
& 1235 \text { HDURS }
\end{aligned}
$$

IDENTIFICATION OF PHYTOPLANKTON

Q.500 CELLS/ML

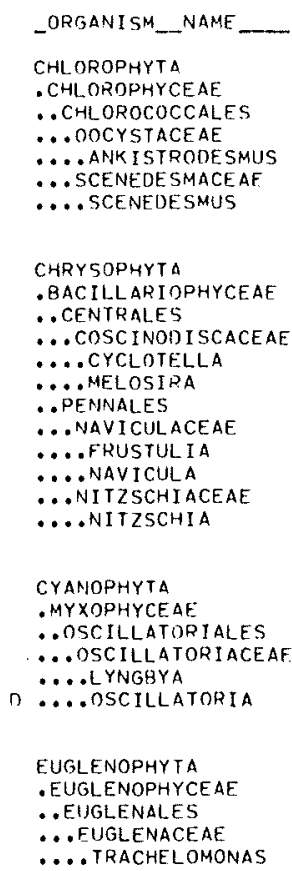

TOTALS

TOTALS - $\begin{array}{r}6.700 \\ 7.000\end{array}$

3
71
74

$0.224=0$ IVERS I TY

EUGLENOIDS $-\frac{1}{1}$

$0.000=0$ IVERS ITY

NOIE: O - DOMINANT ORGANISM; GREATER OR EQUAL TO $15 \%$ 
09429490. COLORADO RIVER ABOVE IMPERIAL DAM, ARI2.-CALIF.--CONTINUED

QUALITATIVE AND ASSOCIATED QUANTTTATIVE ANALYSES OF BIOLOGICAL DATA, WATER YEARS OCTOBER 1974 TO SEPTEMBER 1976

APR. B, 1975

1400 HOURS

IDENTIFICATION OF PHYTOPLANKTON

2,700 CELLSTML

_ORGANISM_NAME

CHLOROPHYTA

- CHLOROPHYCEAE

. chlorococcalf

... OOCYSTACEAe

@... ANKISTRODESMUS

- .

-. scenede smaceae

. . SCENEDE SML

..vol vocalf

... CHL amyoomonadace a

.... CHL AMYDOMONAS

CHRYSOPHYTA

- BACILLARTOPHYCEAE

. CENTRALES

-. coscinourscacfaf

D .... CYCLOTELLA

O...MELOSI

. PFNnales

. AchNanthes

- .

...Fragilariaceae

... FRAGILARIA

... Naviculacea

. . . Navicula

... NIT ZSCHIACEAE

....NITZSCHIA
_COMMON_NAME

GREEN ALGAE
CELLS/ML.

PER_CENT

DIATOMS

CFNIRIC

PFNNATE

NAVICISOID

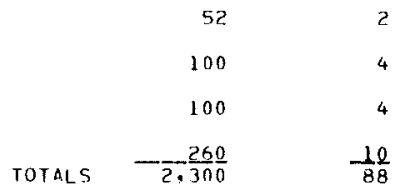

$1 \cdot 379=$ DIVERSITY

33
35

2

1. $933=$ D I VERSITY 
09429490, COLORADO RIVER ABOVE IMPERIAI DAM, ARIZ, -CALIF.--CONTINUED

QUALITATIVE AND ASSOCIATED QUANTITATIVE ANALYSES OF BIOLOGICAL DATA, WATER YEARS OCTOBER 1974 TO SEPTEMBER 1976

$$
\begin{aligned}
& \text { MAY } 5 \text {, } 1975 \\
& 1345 \text { HNURS }
\end{aligned}
$$

IDENTIFICATION OF PHYTOPLANKTON

2,300 CELLS/ML.

_ORGANISM_NAME

CHRYSOPHYTA

- Bacillarinphyceae

- CENTRALEs

... cosc INODISCACEAE

.... CYCLITTLLLA

.... MELDSIHA

..PENNALFS

-. AchNanthaceae

... cocconf is

... Cymerellaceae

.... CYMAMLLA

... ni atomaceae

... ditatoma

. . FRAGil AR I ACFAF

.. frragilaria

. gomphonfmatace af.

... gomphonema

. Naviculacfae

... havicula

... NITZSCHIACEAF

....NITZSCHIA

- CHRYSOPHYCEAE - ChRY SOMONADALES

. oc orromonanaceaf

.... I I vohryon
_COMHON_NAME

OIATOMS

CENTRIC

PFNNATE

66

130

66

200

NAVICULOID

66

200

TOTALS $-\frac{200}{2,200}$

YFLLOW-BROWN ALGAF.

TOTALS
PER_CENT

53

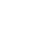

6

3

9

3

9

$-\frac{2}{8}$

$2.277=$ DIVERS I TY

$-\frac{3}{3}$

$0.000=$ DIVERS ITY 
09429490. COLORADO RTVER ABOVE IMPERIAL DAM, ARIZ .-CALIF.--CONTINUED

QUALITATIVE AND ASSOCIATED QUANTITATIVE ANALYSES OF BIOLOGICAL DATA, WATER YEARS OCTOBER 1974 TO SEPTEMBER 1976

$$
\begin{aligned}
& \text { JINE } 10,1975 \\
& 1335 \text { HOURS }
\end{aligned}
$$

IDENTIFICATION OF PHYTOPLANKTON

410 CELLS/ML

_ORGANISM_NAMF

CHLOROPHYTA

- CHLOROPHYCEAE

-. CHL OROCOCCALE

-.. CHARACIACEAE

.... SCHQOEDERIA

. SCENEDE SMACEAE

... Scenfoesmus

avilvorales

\#. Chl amyodmonadace ae

.... Chl amyodomonas

CHRY SOPHYTA

- BACILLARI IOPHYCEAF

. CFNTRALES

.. cosc inoujscaceaf

... CYClotella

. PFinnales

. . DI atomaceae

... DIATOMa

...FRAGillariace ae

... SYYNEORA

... NAVICIULACEAF

.... mastoglota

n .... . Navicula

@...nitzschtaceae

n .... NITISCHIA
_COMMON_NAME

GREEN ALGAE

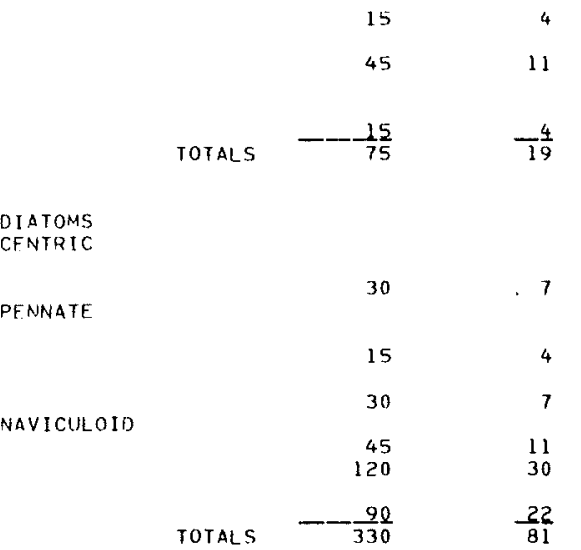

$2.266=0$ IVERSI TY

NOTE: $\cap$ - DOMINANT ORGANISMI GREATER OR EQUAL TO 15\% 
09429490. COLORADO RIVER ABOVE IMPERIAL DAM, ARIZ. -CALIF.--CONTINUED

QUALITATIVE AND ASSOCIATED QUANTITATIVE ANALYSES OF BIOLOGICAL DATA, WATER YEARS OCTOBER 1974 TO SEPTEMBER 1976

กC. 7,1975

1420 HOURS

II)ENTIFICATION DF PHYTOPLANKTON

3.300 CELLS/ML

_ORGANISH_NAMF

CHL OROPHYTA

- CMLOROPHYCEAE

- CHLOROCOCCALFS

... nocystaceae

... ANK I ST RODE SMUS

.... CLDSTERIOPSIS

... I I CTYOSPHAER IUM

...KIRCHNERIFLLA

\#. SCENEDE SMACEAE

\#. SCENEDE SMacea

... SCENEDESMUS

. VOL VOCAlFs

... CHL AMYDOMONADACEAE

... C. ChL amydomonas

. ZY YNEMATALES

. odesmid i acEaf

1. ... STAURASTRUM

CHRYSOPHYTA

- BACILLAR I OPHYCEAF

. Centrales

. ANAIJLACEAE

... TERPSINOF

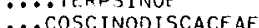

.... cyclotella

....melosira

. Pf.NNALF.

... ACHNANTHACEAE

.... COCCONE JS

... Rho I cosphenia

...Frafo I ARIACEAF

... Fragillaria

... SYMEDDRa

... NAaviculaceae

1. ... gYRosigma

.... Navicula

... Nitzschiaceae

.... NIIZSCHIA

CYANOPHYTA

- MYXOPHYCEAE

. CHROOCOCCALES

... CHROOCOCCACEA

n .... agmenellum

. . . ANACYSTIS

. osc illatoriales

... NOSToCACEAE

... ApHani zomenon
COMMON NAME

CELLS/ML

PER_CENT

GREEN ALGAF

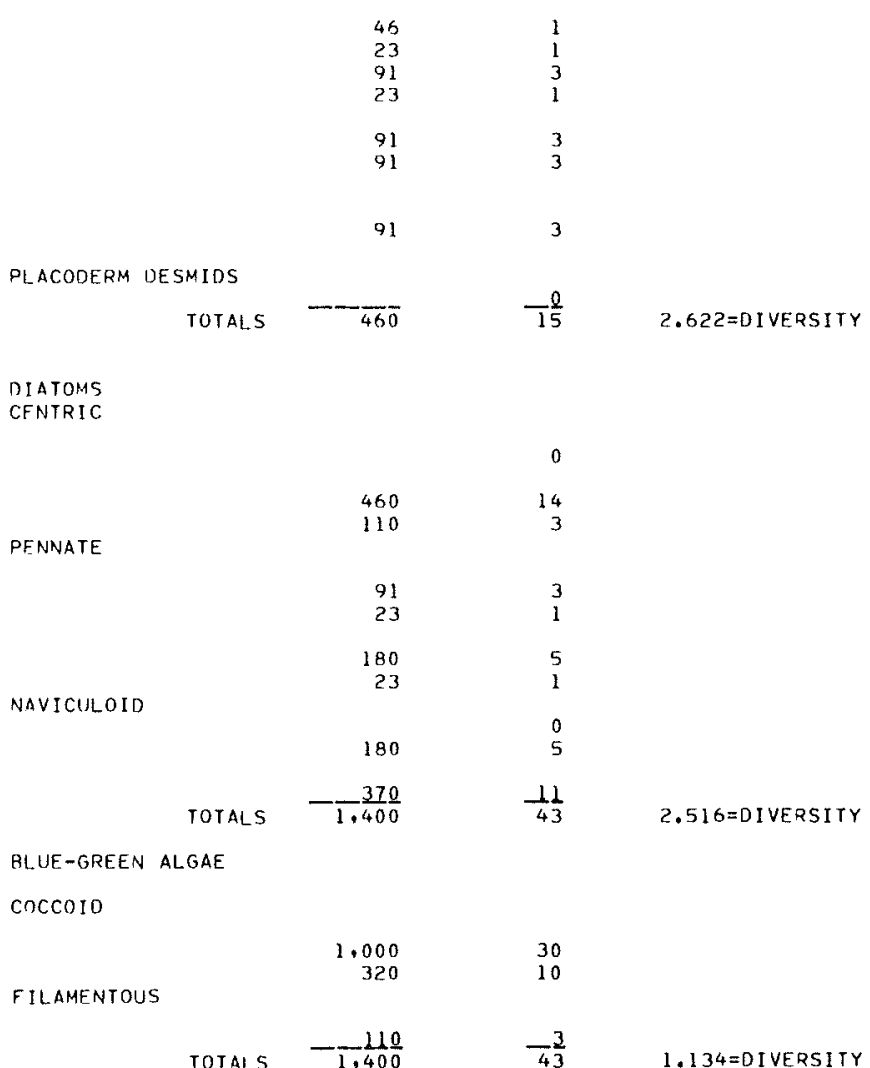

NOTE: D - DOMINANT ORGANISM; GREATER OR EQUAL IO 15\%

L - LESS THEN IF: MAY NOT HAVE BEEN ACTUALLY COUNTED 
09429490. COLORADO RIVER ABOVE IMPERIAL DAM, ARIZ.-CALIF.--CONTINUED

QUALITATIVE AND ASSOCIATED QUANTTTATIVE ANALYSES OF BIOLOGICAL DATA, WATER YEARS OCTOBER 1974 TO SEPTEMBER 1976

NOV. 11,1975

1330 HOURS

IOENTIFICATION OF PHYTOPLANKION

1.100 CELLS/ML

_ORGANISM_NAME

CHLOROPHYTA

- CHLOROPHYCEAE

. CHLOROCOCCALFS

. SCENEOE SMACEAE

.... SCENEOE SHIJS

1 ... TETRASTRHM

. VOL VOCALES

$\because$. Chl amydumonadacFae

... ChL. amy DOMONAS

CHRYSOPHYTA

- BACILLARIOPUYCE AF

. CFNTRALES

... COSCINODISCACEAE

1) .... CYCLOTELLA

.... Melosira

OPfNnales

... ACHNANTHACEAE

.... ACHNANTHES

. . cOcconeIs

... CYMBELLLACEAE

$\because$... CYMABELLA

... II I ITMACEAE

1. ... Di ATOMA

...funoti aceae

.... enunotia

... Naviculaceae

... navicula

@. Nitzschiaceae

n.... NITZSCHIA

CYANOPHYTA

- MYXOPHYCEAE

. OSC ILLA TORI ALES

... NOSTOCACEAE

... CYLINDROSPERMUM

... OSCILLATORIACEAE

... OSCILLatoria

1. .... SPIRUE INA

EUGLENOPHYTA

- EUGLENOPHYCEAE

. EIJgLENALES

... EUIGLENACEAE $\rightarrow$ COMMON_NAME

GREEN ALGAE

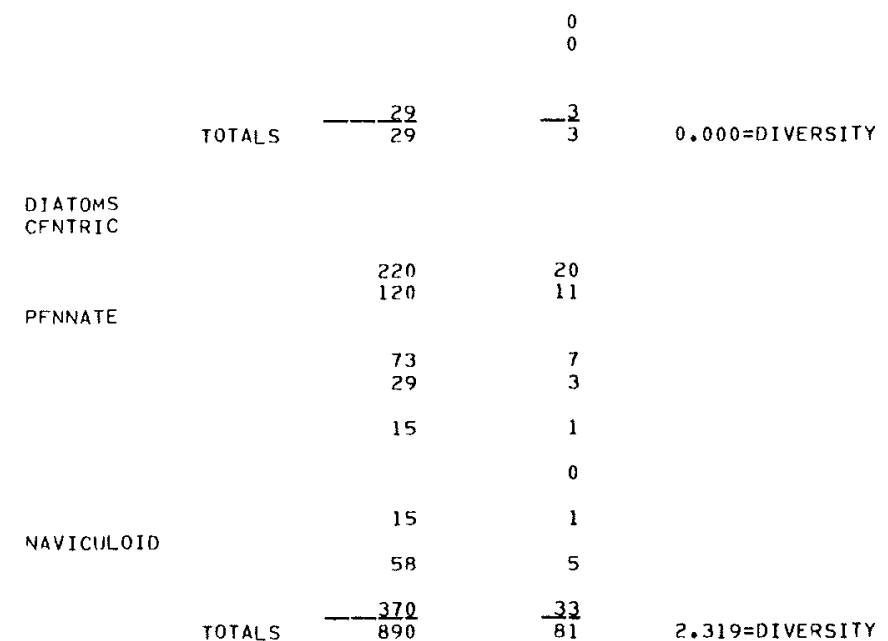

BLUE-GREEN ALGAE

FILAMENTOUS

$\begin{array}{rr}120 & 11 \\ 73 & 7 \\ \text { TOTALS } & -\frac{0}{190}\end{array}$

11

$-\frac{7}{18}$

$0.961=D I$ VERSITY

EUGLENOIOS

NOTE: D - DOMINANT ORGANISM: GREATER OR EQUAL TO 15\%

L - LESS THEN IS: MAY NOT HAVE BEEN ACTUALLY COUNTED 
09429490. COLORADO RIVER ABOVE IMPERIAL DAM, ARIZ.-CALIF.--CONTINUED

QUALITATIVE AND ASSOCIATED QUANIITATIVE ANALYSES OF BIOLOGICAL DATA, WATER YEARS OCTOBER 1974 TO SEPTEMBER 1976

DEC. 9,1975

1330 HNURS

IDENTIFICATION OF PHYTOPLANKTON

820 CELLS/ML

_OPGANISM NAME

CHLOROPHYTA

- CHIOROPHYCEAE

. CHLOROCOCCALES

.. OOCYSTACEAE

.... ANK ISTRONESMUS

-... TETRAEDRON

. SCENEDE SYACEAE

.... SCENEDESMUS

CHRYSOPHYTA

- Bac Ill LaR IOPHyceae

.. CENTRALES

.. COSCINodiscaceae

.... cyclotella

. PENnales

... ACHNANTHACEAE

... ACHNDNTHES

… ACHNANTHES

.. Cymbellaceae

... CYMBELLA

.. somphonemataceae

.... gOMPHONEMA

... NAV I CULACEAE

D .... Navicula

1. .... NE I I IUM

....P InNUllaria

... NITZSCHIACEAE

n $\because$... NITZSChIA

.. SURIREllaceae

.... SURIRELLA

CYANOPHYTA

- MYXOPHYCEAE

. oscillatoriales

... oscillatori a ceae

1. .... SPIRULINA

EUGLENOPHYTA

- CRYPTOPHYCEAE

- CRYPTOMONIDALES

- cryptomonodacea

1. .... CRYPTOMONAS

- El\}GL ENOPHYCEAE

. Fuglenale

... EugGenNaCEAE

.... Fuglena
C COMMON NAME

GREEN ALGAE

CELLS/ML

PER_CENT

\begin{tabular}{rr}
26 & 3 \\
13 & 2 \\
TOTALS & -26 \\
\hline 65 & $-\frac{3}{8}$
\end{tabular}

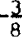

$1.522=$ DIVERSITY

DI A TOMS

CENTRIC

PENNATE

78

10

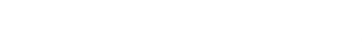

$78-10$

52

13

NAVICULOID

210

13

210

TOTALS $-\frac{13}{730}$

BLUE-GREEN ALGAE

FILAMENTOUS

EUGLENOIDS

CRYPTOMONADS
10
8

6

2

25

0

25

$\frac{2}{90}$

$2.618=0$ I VERS I TY

NOTE: D - DOMINANI ORGANISM: GREATER OR EQUAL TO $15 \%$

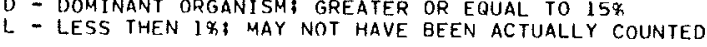


09429490. COLORADO RIVER ABOVE MPERIAL DAM, ARIZ,-CALIF.--CONTINUED

QUALITATIVE AND ASSOCIATED QUANTITATIVE ANALYSES OF BIOLOGICAL DATA, WATER YEARS OCTOBER 1974 TO SEPTEMBER 1976

JAN. 14,1976

0930 HDURS

IDENTIFICATION OF PHYTOPLANKTON

780 CELLS/ML

_ORGANISM_NAME

_COMMON__NAME

CELLS/ML

PER_CENT

CHRYSOPHYTA

- BACILLARI OPHYCEAE

. CENTRALEs

-IATOMS

CENFRIC

.... CYCLOTELLA

:- PenNales

.. Achnan Thaceae

@... ACHNANANTHFS

.... cocconeis

\#. COCCONE IS

L $\because$.. AMPHORA

... cYMBELLA

... I I atomaceae

.... DI ATOMa

$\because$. Fragilar I ACEaE

0...FRagillaria

... GOMPHONEMATACEAF

.... gomphoneva

... Naviculaceae

O...nnavicula

PENNATE

0

... NITZSCHIACEAE

.... NITZSChIa

.. sur IRELLACEAE

.... surirella

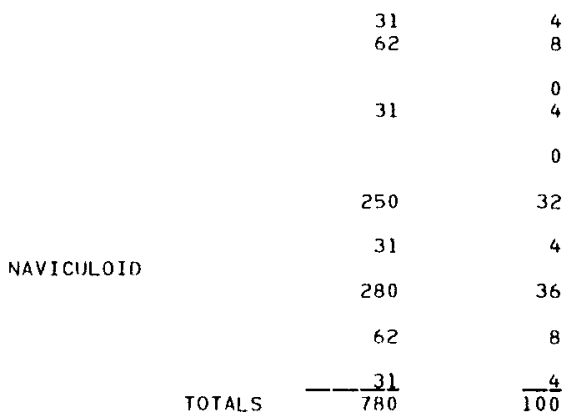

CYANOPHYTA

BLUE-GREEN ALGAE

- MYXOPHYCEAE

. OSC ILlatori ales

.. OSCILLATORIACEAF

FILAMENTOUS

$2 \cdot 383=$ D I VERSITY

I. .... SPIRUL INA

NOTE: D - DOMINANT ORGANISM GREATER OR EQUAL TO 15\%

L - LESS THEN I\%; MAY NOT HAVE BEEN ACTUALLY COUNTED 
09429490. COLORADO RIVER ABOVE IMPERIAL, DAM, ARIZ.-CALIF.--CONTINUED

QUALITATIVE AND ASSOCIATED QUANTITATIVE ANALYSES OF BIOLOGICAL DATA, WATER YEARS OCTOBER 1974 TO SEPTEMBER 1976

FER. 11,1976

0915 HDURS

IDENTIFICATION OF PHYTOPLANKTON

710 CELLS/ML

_ORGANISM_NAME

CHLOROPHYTA

- CHLOROPHYCEAE

-. CHLOROCOCCAL.FS

-. SCENEDESMACEAF

$n$.... SCENEDF SMus

CHRYSOPHYTA

- BAC ILLAR IOPHYCEAF

.. CENTRALES

$\ldots$ COSCINDDISCACFAF

... CyClotella

l. ...MELLOSIPA

@. PENACHALES

.... ACHNANTHES

.... COCCONE is

1. ... RHOI COSPHENIA

... CYMBELlaACEAE

1. ... AMPHORA

.... crmálla

... DIATOMACEAe

l. .... DI Atoma

. . Fragillariaceae

....Fragilaria

. gomphonemataceae

-...gOMPHONFMA

... NAVICULACEAE

... NAMPHIPLEURA

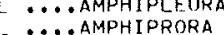

1. ... AMPHIPRORA

1. ... CALONEIS

... gYrosigma

... TROPIDONE IS

@NITZSCHIACEAE

....hANTZSCHIA

.... NITZSCHIA

CYANOPHYTA

- HYXOPHYCEAE

. OSCILLATORI ALES

.. OSCILLATORIACEAE

I. ... SPIRULINA

FUG FNOPHYTA

- CRYPTOPHYCEAE

. CRYPTOMONIDALES

1.... CQYPTOMONAS
_COMMON_NAME

CELLS/ML

GREFN ALGAE

TOTALS

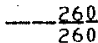

6
0

PENNATE

NAVICULOID

DIATOMS
CFNTRIC
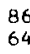

12
9
0

0

21

3

0

21

21

150

TOTALS

$--\frac{4}{450}$

BLUE-GREEN ALGAE

FILAMENTOUS

EUGLENOIDS

CRYPTOMONADS
PER_CENT

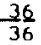

$0.000=0$ IVERSITY

NOTE: D - DOMINANT ORGANISM; GREATER OR EQUAL TO 15\%

L. - LESS THEN 1 \$ : MAY NOT HAVE BEEN ACTUALLY COUNTED 
09429490. COLORADO RIVER ABOVE IMPERIAL DAM, ARIZ, -CALIF, - -CONTINUED

QUALITATIVE AND ASSOCIATED QUANTITATIVE ANALYSES OF BIOLOGICAL DATA, WATER YEARS OCTOBER 1974 TO SEPTEMBER 1976

MAR. 10,1976

1110 HOURS

IDENTIFICATION OF PHYTOPLANKTON

$1,800 \mathrm{CELLS} / \mathrm{ML}$

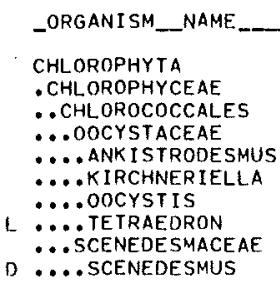

_COMMON__NAME

CELLS/ML

GREEN ALGAE

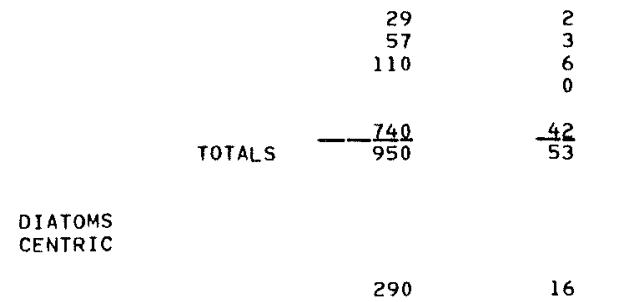

PENNATE

29

29

NAVICULOID

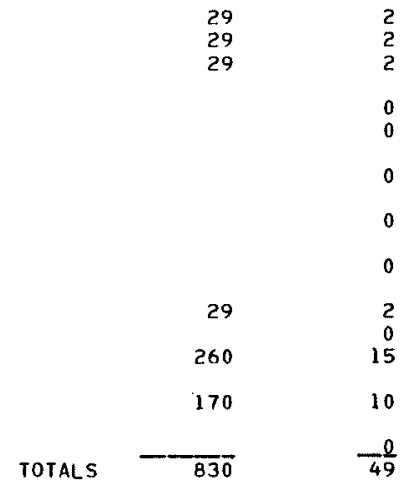

EUGLENOIDS \\ 10}

PER_CENT
$1.038=0$ IVERS ITY

NOTE: O - OOMINANT ORGANISM: GREATER OR EQUAL TO 15\%

L - LESS THEN IO: MAY NOT HAVE BEEN ACTUALLY COUNTED 
09429490. COLORADO RIVER ABOVE IMPERIAL DAM, ARIZ.-CALIF,--CONTINUED

QUALITATIVE AND ASSOCIATED QUANTITATIVE ANALYSES OF BIOLOGICAL DATA, WATER YEARS OCTOBER 1974 TO SEPTEMBER 1976

APR. 14,1976

0855 HNURS

IDENTIFICATION OF PHYTOPLANKTON

$1.200 \mathrm{CELLS} / \mathrm{ML}$

_ORGANISM NAME

CHLOROPHYTA

- CHI OROPHYCEAE

. CHL orococcales

... OOCYSTACEAE

.... ANKISTRODESMUS

.. SCENEDESMACEAE

....ACTINASTRUM

.... scenedesmus

CHRYSOPHYTA

-BAC ILLARIOPHYCEAE

. CENTRALES

.. coscinod Iscaceae

.....mELOSIRA

. PENNALES

... ACHNANTHACEAE

1. .... COCCONEIS

L....RHOI COSPHENIA

... CYMBELLLACEAE

.... cymbella

... DI ATOMaCEa

... Diatoma

. Frag ILAR I ACEAE

... Frag ILARIA

.. gOMPHONFMATACEAE

I. ....GOMPHONEMA

... Navi culaceae

... CALONEIS

... Navicilla

.... PINNULARI A

... NITZSChIACEAE

... NI TZSCHIA

- CHRYSOPHYCEAE

. CHRYSOMONADALES

. ochromonadacEaE

.... DINOBRYON
_COMMON_NAME

CELLS/ML

PER_CENT

GREEN ALGAE

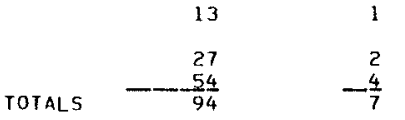

$1 \cdot 379=0$ IVERSITY

DIATOMS

CENTRIC

PENNATE

120

10

$\begin{array}{rr} & 0 \\ 54 & 0 \\ 27 & 4 \\ 630 & 53 \\ & 0\end{array}$

NAVICULOID

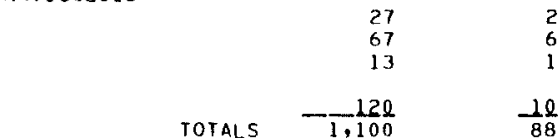

$1.978=$ DIVERSITY

YELLOW-BROWN ALGAE

TOTALS

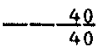

$-\frac{3}{3}$

$0.000=D I V E R S I T Y$

NOTE: 0 - DOMINANT ORGANISM: GREATER OR EQUAL TO $15 \%$

L - LESS THEN I\%: MAY NOT hAVE BEEN ACTUALLY COUNTED 
09429490. COLORADO RIVER ABOVE IMPERIAL. DAM, ARTZ.-CALIF.--CONTINUED

QUALITATIVE AND ASSOCIATED QUANTITATIVE ANALYSES OF BIOLOGICAL DATA, WATER YEARS OCTOBER 1974 TO SEPTEMBER 1976

APR, 14, 1976

0915 HOURS

IOENTIFICATION OF PHYTOPLANKION

2,900 CELLS/ML

_ORTANISM_NAME

CHI OROPHYTA

- CHLOROPHYCEAE

. CHLUROCOCCALFS

.. SCENEDE SMACEAE

... SCENEDE SMUJ

- VOL VOCALFS

... CHL AMYOOMONADACF AF

.... ChL amydomonas

CHRYSOPHYTA

- BACILLARIOPHYCEAF

- . CENTRALES

. COSCINODISCACEAF

D ... crclotella

- PenNales

. achnanthaceae

.... ACHNANTHES

.. cymell aceae

... AMPHORA

... CyMBELla

...FoAg IL LR IACEAE

... SYNEDRA

. gomphonemataceaE

....gOMPHONEMA

... NAVICUlaceae

L.... CALONEIS

... Navicula

... NITZSCHIACEAE

.... NITZSCHIA

_COMMON_NAME

CELLS/ML

PER_CENT

GREEN ALGAE

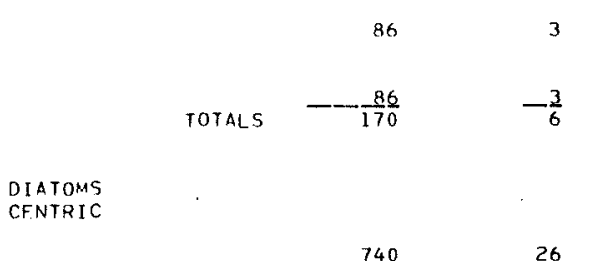

PENNATE

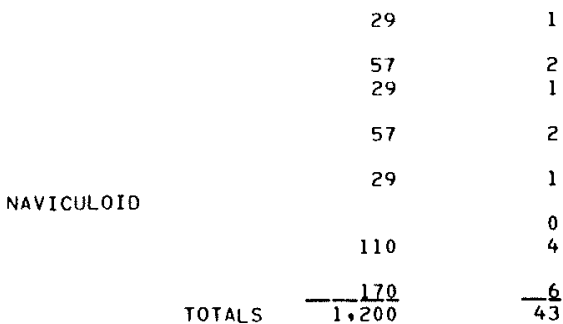

BLUE-GREEN ALGAE

CYANOPHYTA

- MYXOPHYCEAE

- ChRoococCales

.. CHROOCOCCACEAE

.... ANACYSTIS

.... coccochloris

- Öcoccochloris

..oscillatoriaceat

D ... OSCILlatoria

EUGLENOPHYTA

- EUGLENOPHYCEAE

. Euglenalf

... Eugl.enaceae

I. ... EUGLENA

COCCOID

$\begin{array}{rrr}340 & 12 \\ 57 & 2\end{array}$

FILAMENTOUS

TOTALS $-\frac{1.100}{1,500}$

$\frac{37}{51}$

$1.010=D$ I VERSITY

NOTE: D - DOMINANT ORGANISM: GREATER OR EQUAL TO 15\%

L. - LESS THEN 1\%: MAY NOT hAVE BEEN ACTUALLY COUNTED 
09429490. COLORADO RIVER ABOVE IMPERIAL DAM, ARIZ.-CALIF.--CONTINUED

QUALITATIVE AND ASSOCIATED QUANTITATIVE ANALYSES OF BIOLOGICAL DATA, WATER YEARS OCTOBER 1974 TO SEPTEMBER 1976

$$
\begin{aligned}
& \text { JINE } 9,1976 \\
& 0845 \text { HOURS }
\end{aligned}
$$

IOENTIFICATION OF PHYTOPLANKION

2,400 CFLLS/ML

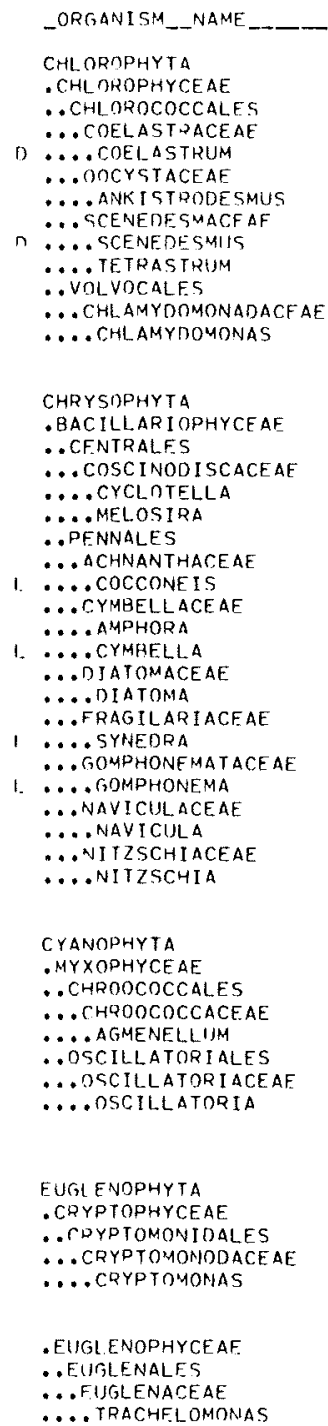

$0.000=0$ IVERSITY

NOTE: 0 - DOMINANT ORGANISH: GREATER OR EQUAL TO $15 \%$

L - LESS THFN I\%; MAY NOT HAVE BEEN ACTUALLY COUNTED 
09429490. COLORADO RIVER ABOVE IMPERIAL DAM, ARIZ, -CALIF.--CONTINUED

QUALITATIVE AND ASSOCIATED QUANTITATIVE ANALYSES OF BIOLOGICAL. DATA, WATER YEARS OCTOBER 1974 TO SEPTEMBER 1976

A1J6. 11,1976

0930 HOURS

IDENTIFICATION OF PHYTOPLANKTON

6,400 CELLS/ML

_ORGANISM_NAME

CHLOROPHYTA

- CHIOROPHYCEAE

. CHL OROCOCCALES

... OOCYSTACEAE

.... ANKISTRODESMUS

... SCENEDE SMACEAE

.... CRLICIGENIA

.... SCENEDESMUS

. volvocal.es

... CHL AMYOOMONADACFAE

I.... CHLAMYOOMONAS

CHRYSOPHYTA

- PACILLARIOPHYCEAF

- . CENTRALES

. COSCINOD I SCACEAE

... . CYClotelLa

- PenNales

...FRAGILARI ACEAE

... SYYNEDRa

... NaviculaceaE

... navicula

... Nitzschiaceae

.... NITZSCHIA

CYANOPHYTA

- MYXOPHYCEAE

- ChROOCOCCALES

... CHRDOCOCCACEAE

... Agmenellum

@oscillatoriales

. oscillatori aceae

D...0.0SCILLATORIA

1.... SPIRLLINA

EUGLENOPHYTA

- CRYPTOPHYCEAE

- CRYPTOMONIDALES

... CRYPTOMONODACEAe

... CRYPTOMONAS
_COMMON_NAME

CELLS/ML

PER_CENT

GREEN ALGAE

120

470

1.000

TOTALS -

DIATOMS

CENTRIC

PENNATE

NAVICULOYO

TOTALS

BLUE-GREEN ALGAE

CoccoIo

FILAMENTOUS

$$
\begin{array}{rr}
3,400 & 53 \\
\text { TOTALS } & -\frac{0}{3,900}
\end{array}
$$

$0.599=0$ I VERS I TY

EUGLENOIOS

CRYPTOMONADS

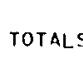

NOTE: D - DOMINANT ORGANISM: GREATER OR EQUAL TO $15 \%$

L - LESS THEN 1\%: MAY NOT HAVE BEEN aCTUALLY COUNTEO 
09429490. COLORADO RIVER ABOVE IMPERIAL DAM, ARIZ.-CALIF,--CONTINUED

QUALITATIVE AND ASSOCIATED QUANTITATIVE ANALYSES OF BIOLOGICAL DATA, WATER YEARS OCTOBER 1974 TO SEPTEMBER 1976

SEP. 15,1976
1030 HOURS

IDENTIFICATION OF PHYTOPLANKTON

$15+000$ CELLS/ML
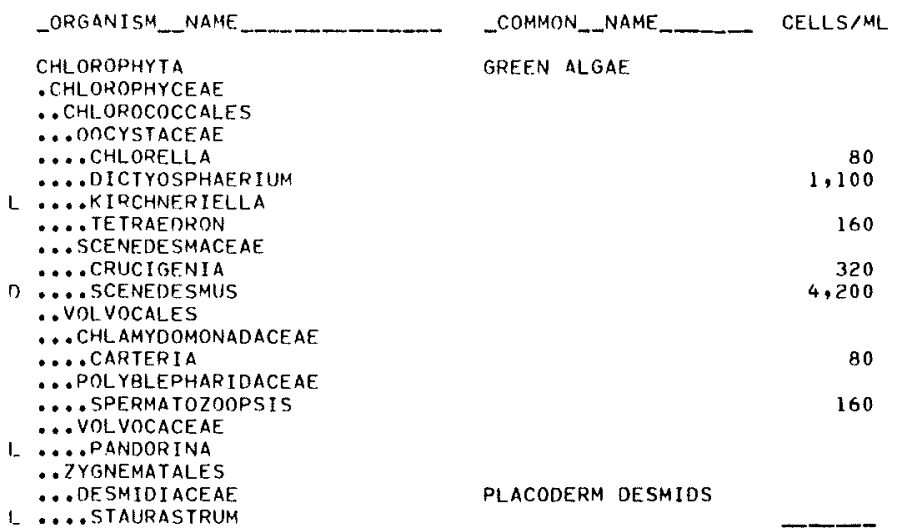

PLACODERM DESMIDS

TOTALS

$1.488=0$ IVERS I TY

OIATOMS

CENTRIC

PENNATE

NAVICULOID

400

3

80

1

0

TOTALS $-\frac{480}{2,400}$

$-\frac{3}{16}$

1.501 =0 I VERSI TY

YELLOW-BROWN ALGAE

TOTALS<smiles>C[18Br]</smiles><smiles>CC(C)(C)C</smiles>

$0.000=$ DIVERSITY

BLUE-GREEN ALGAE

coccoin

FILAMENTOUS

2,000

EUGLENOIOS

CRYPTOMONADS

rotALs

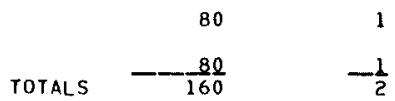

$1.000=$ DIVERSITY

NOTE: D - DOMINANT ORGANISM: GREATER OR EQUAL TO $15 \%$

L - LESS THEN 1 \%: MAY NOT HAVE BEEN ACTUALLY COUNTEO 
09429500. COLORADO RIVER BELOW IMPERTAL DAM, ARTZ,-CALIF.

LOCATION,--Forebay gage: Lat $32^{\circ} 52^{\prime} 59^{\prime \prime}$, long $114^{\circ} 27^{\prime} 57^{\prime \prime}$, in NW:SW sec.9, T.15 S., R.24 E., San Bernardino meridian, in California, Imperial County, near Al1-American Canal headworks at west end of Imperial Dam, 5 mi ( 8 km) upstream from Laguna Dam, $15 \mathrm{mi}$ ( 24 km) northeast of Yuna, $90 \mathrm{mi}(145 \mathrm{~km})$ downstream from Palo Verde Dam, and $147 \mathrm{mi}(237 \mathrm{~km})$ downstream from Parker Dan.

DRAINAGE AREA (REVISED) . - -188,500 $\mathrm{mi}^{2}\left(488,200 \mathrm{~km}^{2}\right)$, approximately, including $3,959 \mathrm{mi}^{2}\left(10,254 \mathrm{~km}^{2}\right)$ in Great Divide basin in southem Wyoming, which is noncontributing (previously considered part of the Missouri River basin).

PERIOD OF RECORD, - -October 1960 to current year. Prior to October 197I published as "at Imperial Dam." Records of flow reaching Imperial Dam, fomerly published with this station, are now published separately as sta 09429490, Colorado River above Imperial Dam.

GAGE, - Water-stage recorder in forebay, 12 calibrated gates on California sluiceway, 8 calibrated gates on Gila sluiceway, and calibrated manometer on each discharge pipe from desilting basin. Datum of forebay gage is $162.00 \mathrm{ft}$ ( $49.378 \mathrm{~m}$ ) above mean sea leve1 (Bureau of Reclamation bench mark).

EXTREMES. --Current year: Maximum daily discharge, 3,680 $\mathrm{ft}^{3} / \mathrm{s}\left(104 \mathrm{~m}^{3} / \mathrm{s}\right) \mathrm{Sept}, 26 ;$ minimtm daily, $214 \mathrm{ft} / \mathrm{s}\left(6.06 \mathrm{~m}^{3} / \mathrm{s}\right) \mathrm{Nov}, 24-30$. 1969

Period of record: Maximum daily discharge, $5,040 \mathrm{ft}^{3} / \mathrm{s}\left(143 \mathrm{~m}^{3} / \mathrm{s}\right) \mathrm{Mar} .3,1970 ; \operatorname{minimum~daily,~} 27 \mathrm{ft}^{3} / \mathrm{s}\left(0.76 \mathrm{~m}^{3} / \mathrm{s}\right) \mathrm{Dec} .15-18$,

REMARKS. - -Records good. Records of daily discharge show flow of Colorado River passing Imperial Dam, and include water released to river through California and Gila sluiceways, sludge from desilting basins returned to river, and leakage through dam. For records of flow reaching Imperial Dam see sta 09429490

Flow of Colorado river regulated by many reservoirs, principally Lake Mead, since 1935. Many diversions from Colorado River and tributaries above station. Diversion to Mittry Lake and monthend contents of Senator Wash Reservoir also are now published with sta 09429490

COOPERATION.--Records of gate openings furnished by Bureau of Reclamation. Records of sludge return flow from desilting basins furnished by Imperial Irrigation District.

DISCHARGE, IN CUBIC FEET PER SECONO, WATER YEAR OCTOBER 1975 TO SEPTEMBER 1976

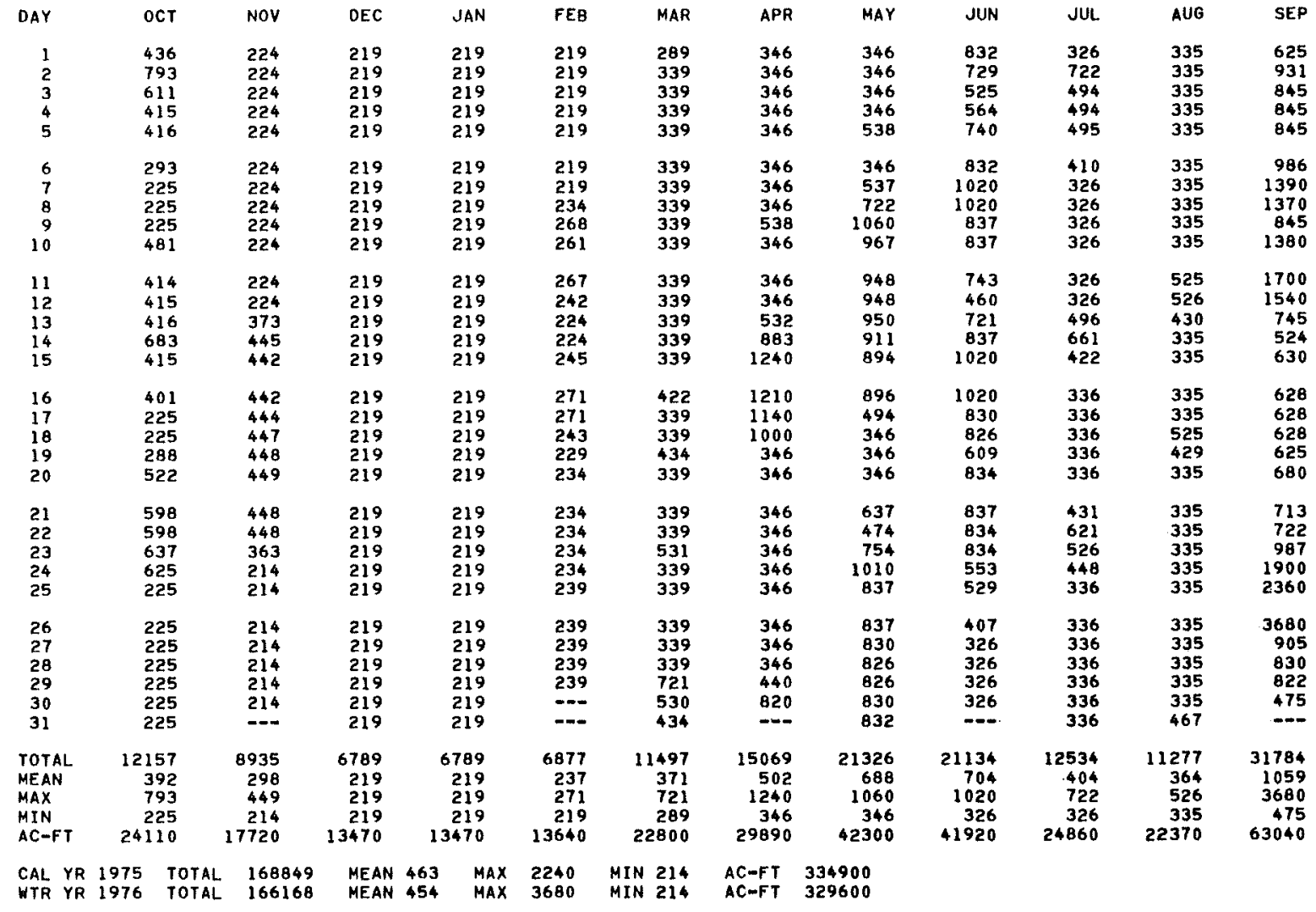


09429600. COLORACA RIVER BFLOH LAGINA DAM, ARIZ. -CALIF.

LOCATION.--Iat $32^{\circ} 48^{\prime} 44^{\prime \prime}$, long $114^{\circ} 30^{\prime} 51^{\prime \prime}$, in SE $\mathrm{ANE}^{\mathrm{t}} \mathrm{sec} .35$, T.15 S, , R. 23 E., San Bernardino meridian, in California, Imperial County, on right bank $1.4 \mathrm{mi}(2.3 \mathrm{~km})$ downstrean from Laguna Dam, $2.8 \mathrm{mi}(4.5 \mathrm{~km})$ northeast of Bard, Calif., and $10 \mathrm{mi}(16 \mathrm{~km})$ northeast of Yuila, Ariz.

DRAIMAGE AREA (REVISED).--188,600 $\mathrm{mi}^{2}\left(488,500 \mathrm{~km}^{2}\right)$, approximately, including $3,959 \mathrm{mi}^{2}\left(10,254 \mathrm{~km}^{2}\right)$ in Great Divide basin in southern Woming, which is noncontributing (previously considered part of the Missouri River basin).

PERIOD OF RECORD, - -December 1971 to current year.

GAGE. - Water-stage recorder. Datun of gage is $120.84 \mathrm{ft}(36.832 \mathrm{~m})$, above mean sea level (Bureau of Reclanation bench mark).

EXTREMES.--Current year: Maximut discharge, $4,050 \mathrm{Ft}^{3} / \mathrm{s}\left(115 \mathrm{~m}^{3} / \mathrm{s}\right)$ Sept. 26 (gage height, $12.4 \mathrm{ft}$ or $3.78 \mathrm{~m}$, from high-water mark on gage we1I); ninimum daily, $156 \mathrm{ft}^{3} / \mathrm{s}\left(4.42 \mathrm{~m}^{3} / \mathrm{s}\right) \mathrm{Feb} .7$.

period of record: Maxinium discharge, $4,050 \mathrm{ft}^{3} / \mathrm{s}\left(115 \mathrm{~m}^{3} / \mathrm{s}\right)$ Sept. 26, 1976 (gage height, $12.4 \mathrm{ft}$ or $3.78 \mathrm{~m}$, from high-water Jark on gage well); minindu daily, $71 \mathrm{ft}^{3} / \mathrm{s}\left(2.01 \mathrm{~m}^{3} / \mathrm{s}\right)$ May 29,1973 .

RIEARTS, --Records good. Naturaj. Flow of Colorado River at this point is affected by transmountain diversions, storage reservoirs, power develoments, grotind-water withdrawals, diversions for irrigation, municipal and industrial uses, and return flows from irrigated areas. Flow past station consists mainly of water released through Imperial Dam, sludge from the desilting basins at Imperial Dam, seepage through Inperial Dam, and seepage from the All-American Canal and the Gila Gravity Main Canal. Records of chenical analyses for the current year are published on following pages.

DISCHARGE, IN CUBIC FEET PER SECOND, WATER YEAR OCTOBER 1975 TO SEPTEMBER 1976 MEAN VALUES

\begin{tabular}{|c|c|c|c|c|c|c|c|c|c|c|c|c|}
\hline DAY & OCT & Nov & DEC & JAN & FEB & MAR & APR & MAY & JUN & JUL. & AUG & SEP \\
\hline $\begin{array}{l}1 \\
2 \\
3 \\
4 \\
5\end{array}$ & $\begin{array}{l}452 \\
468 \\
508 \\
520 \\
480\end{array}$ & $\begin{array}{l}258 \\
463 \\
412 \\
445 \\
485\end{array}$ & $\begin{array}{l}269 \\
269 \\
258 \\
232 \\
235\end{array}$ & $\begin{array}{l}427 \\
302 \\
293 \\
288 \\
288\end{array}$ & $\begin{array}{l}258 \\
274 \\
520 \\
502 \\
477\end{array}$ & $\begin{array}{l}347 \\
395 \\
405 \\
395 \\
372\end{array}$ & $\begin{array}{l}293 \\
296 \\
325 \\
463 \\
606\end{array}$ & $\begin{array}{l}325 \\
325 \\
447 \\
526 \\
514\end{array}$ & $\begin{array}{l}917 \\
921 \\
847 \\
742 \\
777\end{array}$ & $\begin{array}{l}340 \\
427 \\
578 \\
363 \\
354\end{array}$ & $\begin{array}{l}552 \\
400 \\
357 \\
367 \\
377\end{array}$ & $\begin{array}{l}643 \\
732 \\
839 \\
852 \\
862\end{array}$ \\
\hline $\begin{array}{r}6 \\
7 \\
8 \\
9 \\
10\end{array}$ & $\begin{array}{l}432 \\
407 \\
385 \\
397 \\
402\end{array}$ & $\begin{array}{l}405 \\
304 \\
307 \\
299 \\
288\end{array}$ & $\begin{array}{l}235 \\
213 \\
225 \\
232 \\
240\end{array}$ & $\begin{array}{l}215 \\
169 \\
171 \\
178 \\
180\end{array}$ & $\begin{array}{l}271 \\
156 \\
162 \\
171 \\
160\end{array}$ & $\begin{array}{l}362 \\
242 \\
225 \\
337 \\
342\end{array}$ & $\begin{array}{l}564 \\
420 \\
367 \\
329 \\
310\end{array}$ & $\begin{array}{r}523 \\
511 \\
707 \\
1080 \\
1060\end{array}$ & $\begin{array}{l}938 \\
882 \\
858 \\
868 \\
868\end{array}$ & $\begin{array}{l}371 \\
343 \\
423 \\
656 \\
580\end{array}$ & $\begin{array}{l}372 \\
372 \\
370 \\
354 \\
344\end{array}$ & $\begin{array}{l}866 \\
1190 \\
1440 \\
1010 \\
1160\end{array}$ \\
\hline $\begin{array}{l}11 \\
12 \\
13 \\
14 \\
15\end{array}$ & $\begin{array}{l}425 \\
417 \\
420 \\
432 \\
440\end{array}$ & $\begin{array}{l}288 \\
279 \\
235 \\
237 \\
240\end{array}$ & $\begin{array}{l}242 \\
248 \\
263 \\
255 \\
250\end{array}$ & $\begin{array}{l}169 \\
173 \\
180 \\
187 \\
182\end{array}$ & $\begin{array}{l}184 \\
266 \\
245 \\
245 \\
250\end{array}$ & $\begin{array}{l}377 \\
410 \\
412 \\
405 \\
407\end{array}$ & $\begin{array}{r}317 \\
325 \\
332 \\
494 \\
1150\end{array}$ & $\begin{array}{r}1060 \\
1060 \\
1060 \\
1050 \\
959\end{array}$ & $\begin{array}{l}896 \\
823 \\
739 \\
784 \\
837\end{array}$ & $\begin{array}{l}419 \\
364 \\
346 \\
333 \\
333\end{array}$ & $\begin{array}{l}337 \\
334 \\
349 \\
354 \\
354\end{array}$ & $\begin{array}{r}1680 \\
1630 \\
952 \\
747 \\
716\end{array}$ \\
\hline $\begin{array}{l}16 \\
17 \\
18 \\
19 \\
20\end{array}$ & $\begin{array}{l}440 \\
425 \\
407 \\
477 \\
606\end{array}$ & $\begin{array}{l}237 \\
242 \\
245 \\
240 \\
248\end{array}$ & $\begin{array}{l}250 \\
250 \\
250 \\
250 \\
255\end{array}$ & $\begin{array}{l}175 \\
198 \\
237 \\
242 \\
242\end{array}$ & $\begin{array}{l}285 \\
290 \\
266 \\
227 \\
387\end{array}$ & $\begin{array}{l}344 \\
344 \\
354 \\
367 \\
347\end{array}$ & $\begin{array}{r}1200 \\
1120 \\
1050 \\
770 \\
690\end{array}$ & $\begin{array}{l}935 \\
907 \\
613 \\
394 \\
376\end{array}$ & $\begin{array}{l}851 \\
872 \\
851 \\
844 \\
819\end{array}$ & $\begin{array}{l}299 \\
331 \\
504 \\
657 \\
549\end{array}$ & $\begin{array}{l}347 \\
344 \\
405 \\
564 \\
543\end{array}$ & $\begin{array}{l}686 \\
744 \\
697 \\
682 \\
746\end{array}$ \\
\hline $\begin{array}{l}21 \\
22 \\
23 \\
24 \\
25\end{array}$ & $\begin{array}{l}656 \\
697 \\
694 \\
505 \\
250\end{array}$ & $\begin{array}{l}250 \\
250 \\
255 \\
255 \\
255\end{array}$ & $\begin{array}{l}261 \\
269 \\
274 \\
266 \\
477\end{array}$ & $\begin{array}{l}242 \\
248 \\
250 \\
253 \\
253\end{array}$ & $\begin{array}{l}505 \\
417 \\
315 \\
312 \\
315\end{array}$ & $\begin{array}{l}352 \\
352 \\
359 \\
410 \\
558\end{array}$ & $\begin{array}{l}644 \\
541 \\
418 \\
382 \\
373\end{array}$ & $\begin{array}{l}334 \\
448 \\
728 \\
875 \\
875\end{array}$ & $\begin{array}{l}861 \\
861 \\
861 \\
865 \\
809\end{array}$ & $\begin{array}{l}382 \\
370 \\
357 \\
349 \\
359\end{array}$ & $\begin{array}{l}523 \\
500 \\
430 \\
380 \\
385\end{array}$ & $\begin{array}{r}764 \\
756 \\
708 \\
1300 \\
1870\end{array}$ \\
\hline $\begin{array}{l}26 \\
27 \\
28 \\
29 \\
30 \\
31\end{array}$ & $\begin{array}{l}250 \\
250 \\
250 \\
250 \\
250 \\
250\end{array}$ & $\begin{array}{l}242 \\
225 \\
237 \\
269 \\
269 \\
-\cdots\end{array}$ & $\begin{array}{l}494 \\
253 \\
253 \\
255 \\
422 \\
485\end{array}$ & $\begin{array}{l}250 \\
250 \\
250 \\
250 \\
253 \\
258\end{array}$ & $\begin{array}{l}334 \\
332 \\
302 \\
282 \\
-\cdots \\
---\end{array}$ & $\begin{array}{l}435 \\
370 \\
367 \\
344 \\
347 \\
327\end{array}$ & $\begin{array}{l}364 \\
361 \\
361 \\
337 \\
346 \\
---\end{array}$ & $\begin{array}{l}886 \\
938 \\
938 \\
935 \\
924 \\
921\end{array}$ & $\begin{array}{l}550 \\
385 \\
367 \\
358 \\
349 \\
-\end{array}$ & $\begin{array}{l}354 \\
349 \\
334 \\
317 \\
452 \\
621\end{array}$ & $\begin{array}{l}380 \\
372 \\
375 \\
302 \\
215 \\
397\end{array}$ & $\begin{array}{r}3300 \\
1320 \\
977 \\
982 \\
679 \\
-\infty\end{array}$ \\
\hline $\begin{array}{l}\text { YOTAL } \\
\text { MEAN } \\
\text { MAX } \\
\text { MIN } \\
\text { AC-FT }\end{array}$ & $\begin{array}{r}13242 \\
427 \\
697 \\
250 \\
26270\end{array}$ & $\begin{array}{r}8664 \\
289 \\
485 \\
225 \\
17190\end{array}$ & $\begin{array}{r}8630 \\
278 \\
494 \\
213 \\
17120\end{array}$ & $\begin{array}{r}7253 \\
234 \\
427 \\
169 \\
14390\end{array}$ & $\begin{array}{r}8710 \\
300 \\
520 \\
156 \\
17280\end{array}$ & $\begin{array}{r}11410 \\
368 \\
558 \\
225 \\
22630\end{array}$ & $\begin{array}{r}15548 \\
518 \\
1200 \\
293 \\
30840\end{array}$ & $\begin{array}{r}23234 \\
749 \\
1080 \\
325 \\
46080\end{array}$ & $\begin{array}{r}23200 \\
773 \\
938 \\
349 \\
46020\end{array}$ & $\begin{array}{r}12814 \\
413 \\
657 \\
299 \\
25420\end{array}$ & $\begin{array}{r}12055 \\
389 \\
564 \\
215 \\
23910\end{array}$ & $\begin{array}{r}31530 \\
1051 \\
3300 \\
643 \\
62540\end{array}$ \\
\hline
\end{tabular}


09429600. COLORADO RIVER BELOW LAGUNA DAM, ARIZ. -CALIF.

LOCATION, - Lat $32^{\circ} 48^{\prime} 44^{\prime \prime}$, long $114^{\circ} 30^{\prime} 51^{\prime \prime}$, in SE $\frac{1}{4} \mathrm{NE}^{\prime} \mathrm{sec} .35$, T.15 S., R.23 E., San Bernardino meridian, in California, Imperial County, at gaging station on right bank, $1.4 \mathrm{mi}(2.3 \mathrm{~km})$ downstream from Laguna Dam, $2.8 \mathrm{mi}(4.5 \mathrm{~km})$ northeast of Bard, Calif., and $19 \mathrm{mi}$

$(16 \mathrm{~km})$ northeast of Yuma, Ariz.

WATER QUALITY DATA, WATER YEAH OCTOBER 1975 TO SEPTEMBER 1976

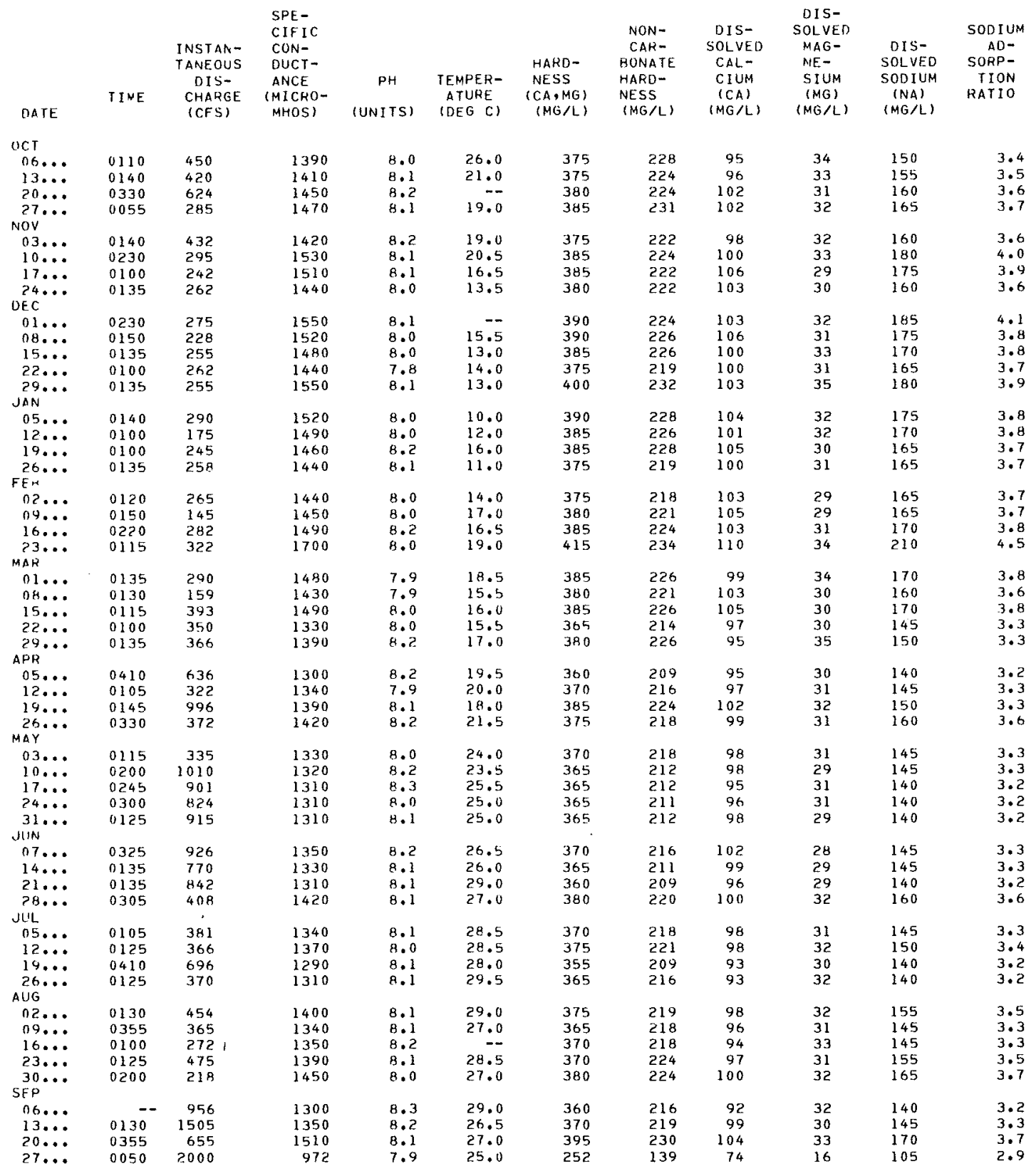


09429600. COLORADO RIVER BELON LAGUNA DAM, ARIZ. -CALIF, --CONTINUED

DRAINAGE AREA (REVISED), $\cdots 188,600 \mathrm{mi}^{2}\left(488,500 \mathrm{~km}^{2}\right)$, approximately, including $3,959 \mathrm{mi}^{2}\left(10,254 \mathrm{~km}^{2}\right)$ in Great Divide basin in southern Wyoming which is noncontributing (previously considered part of the Missouri River basin).

PERIOD OF RECORD.--Chemical analyses: July 1972 to current year.

WATER GUALITY DATA, WATER YEAK OCTOBER 1975 TO SEPTEMBEK 1976

\begin{tabular}{|c|c|c|c|c|c|c|c|c|c|c|c|}
\hline DATE & $\begin{array}{l}\text { OIS- } \\
\text { SOLVEU } \\
\text { PO- } \\
\text { TAS- } \\
\text { SIUM } \\
\text { (K) } \\
\text { (MG/L) }\end{array}$ & $\begin{array}{l}\text { HICAR- } \\
\text { HONATE } \\
\text { (HCUB) } \\
\text { (MG/L) }\end{array}$ & $\begin{array}{l}\text { CAR- } \\
\text { BONATE } \\
\text { (CO3) } \\
\text { (MG/L) }\end{array}$ & $\begin{array}{l}\text { DIS- } \\
\text { SOLVED } \\
\text { SULFATF } \\
\text { (SOA) } \\
\text { (MG/L) }\end{array}$ & $\begin{array}{l}\text { DIS- } \\
\text { SOLVED } \\
\text { CHLO- } \\
\text { PIDE } \\
\text { (CL) } \\
\text { (MG/L) }\end{array}$ & $\begin{array}{l}\text { DIS- } \\
\text { SOLVED } \\
\text { FLUO- } \\
\text { RIDE } \\
\text { (F) } \\
\text { (MG/L) }\end{array}$ & $\begin{array}{l}\text { DIS- } \\
\text { SOLVEO } \\
\text { SILICA } \\
\text { (SIOL) } \\
\text { (MG/L) }\end{array}$ & $\begin{array}{l}\text { DIS- } \\
\text { SOLVED } \\
\text { SOLIDS } \\
\text { (HESI- } \\
\text { DUE AI } \\
180 \text { C) } \\
\text { (MG/L) }\end{array}$ & $\begin{array}{l}\text { DIS- } \\
\text { SOLVEO } \\
\text { SOLIUS } \\
\text { (SUM OF } \\
\text { CONSII- } \\
\text { TUENTS) } \\
\text { (MGLL) }\end{array}$ & $\begin{array}{l}\text { DIS- } \\
\text { SOLVED } \\
\text { SOLIDS } \\
\text { (IONS } \\
\text { PER } \\
\text { AC-FI) }\end{array}$ & $\begin{array}{l}\text { DIS- } \\
\text { SOLVED } \\
\text { NITRATE } \\
\text { (N) } \\
\text { (MG/L) }\end{array}$ \\
\hline OCT & & & & & & & & & & & \\
\hline $\begin{array}{l}06 \ldots \\
13 \ldots \\
20 \ldots \\
27 \ldots\end{array}$ & $\begin{array}{l}6.1 \\
5.8 \\
6.3 \\
5.6\end{array}$ & $\begin{array}{l}180 \\
184 \\
1>0 \\
188\end{array}$ & $\begin{array}{l}0 \\
0 \\
0 \\
0\end{array}$ & $\begin{array}{l}360 \\
360 \\
365 \\
370\end{array}$ & $\begin{array}{l}135 \\
138 \\
145 \\
152\end{array}$ & $\begin{array}{l}.5 \\
.6 \\
.5 \\
.6\end{array}$ & $\begin{array}{l}12 \\
12 \\
12 \\
12\end{array}$ & $\begin{array}{l}890 \\
912 \\
948 \\
936\end{array}$ & $\begin{array}{l}882 \\
89 ? \\
916 \\
932\end{array}$ & $\begin{array}{l}1.21 \\
1.24 \\
1.29 \\
1.27\end{array}$ & $\begin{array}{r}.07 \\
.11 \\
-- \\
--\end{array}$ \\
\hline NOV & & & & & & & & & & & \\
\hline $\begin{array}{l}03 \ldots \\
10 \ldots \\
17 \ldots \\
24 \ldots \\
D E C\end{array}$ & $\begin{array}{l}5.6 \\
5.6 \\
5.4 \\
5.0\end{array}$ & $\begin{array}{l}186 \\
196 \\
198 \\
192\end{array}$ & $\begin{array}{l}0 \\
0 \\
0 \\
0\end{array}$ & $\begin{array}{l}365 \\
380 \\
375 \\
365\end{array}$ & $\begin{array}{l}141 \\
162 \\
155 \\
142\end{array}$ & $\begin{array}{l}.6 \\
.6 \\
.6 \\
.6\end{array}$ & $\begin{array}{l}11 \\
12 \\
12 \\
11\end{array}$ & $\begin{array}{l}904 \\
964 \\
968 \\
920\end{array}$ & $\begin{array}{l}905 \\
970 \\
958 \\
914\end{array}$ & $\begin{array}{l}1.23 \\
1.32 \\
1.32 \\
1.25\end{array}$ & $\begin{array}{l}-- \\
.38 \\
.38\end{array}$ \\
\hline $\begin{array}{l}01 \ldots \\
08 \ldots \\
15 \ldots \\
22 \ldots \\
29 \ldots\end{array}$ & $\begin{array}{l}5.4 \\
5.4 \\
5.6 \\
5.4 \\
5.4\end{array}$ & $\begin{array}{l}202 \\
200 \\
154 \\
150 \\
204\end{array}$ & $\begin{array}{l}0 \\
0 \\
0 \\
0 \\
0\end{array}$ & $\begin{array}{l}380 \\
375 \\
370 \\
355 \\
375\end{array}$ & $\begin{array}{l}166 \\
160 \\
155 \\
148 \\
170\end{array}$ & $\begin{array}{l}.6 \\
.6 \\
.5 \\
.5 \\
.5\end{array}$ & $\begin{array}{l}12 \\
12 \\
11 \\
11 \\
11\end{array}$ & $\begin{array}{r}994 \\
968 \\
964 \\
968 \\
1000\end{array}$ & $\begin{array}{l}985 \\
965 \\
942 \\
911 \\
981\end{array}$ & $\begin{array}{l}1.35 \\
1.32 \\
1.31 \\
1.32 \\
1.36\end{array}$ & $\begin{array}{l}.23 \\
.23 \\
.29 \\
.16 \\
.23\end{array}$ \\
\hline $\begin{array}{r}\text { JAN } \\
\quad 15 \ldots \\
12 \ldots \\
19 \ldots \\
26 \ldots \\
\text { FEH }\end{array}$ & $\begin{array}{l}5.6 \\
5.6 \\
5.8 \\
5.9\end{array}$ & $\begin{array}{l}198 \\
154 \\
192 \\
150\end{array}$ & $\begin{array}{l}0 \\
0 \\
0 \\
0\end{array}$ & $\begin{array}{l}375 \\
370 \\
365 \\
360\end{array}$ & $\begin{array}{l}160 \\
155 \\
152 \\
148\end{array}$ & $\begin{array}{l}.5 \\
.5 \\
.5 \\
.5\end{array}$ & $\begin{array}{l}11 \\
12 \\
10 \\
10\end{array}$ & $\begin{array}{l}904 \\
942 \\
926 \\
918\end{array}$ & $\begin{array}{l}963 \\
943 \\
930 \\
916\end{array}$ & $\begin{array}{l}1.31 \\
1.28 \\
1.26 \\
1.25\end{array}$ & $\begin{array}{r}.41 \\
.18 \\
.32 \\
.29\end{array}$ \\
\hline $\begin{array}{l}02 \ldots \\
09 \ldots \\
16 \ldots \\
23 \ldots \\
M A R\end{array}$ & $\begin{array}{l}5.4 \\
5.2 \\
5.2 \\
5.4\end{array}$ & $\begin{array}{l}152 \\
144 \\
156 \\
220\end{array}$ & $\begin{array}{l}0 \\
0 \\
0 \\
0\end{array}$ & $\begin{array}{l}360 \\
360 \\
365 \\
400\end{array}$ & $\begin{array}{l}148 \\
150 \\
158 \\
200\end{array}$ & $\begin{array}{l}.5 \\
.5 \\
.5 \\
.6\end{array}$ & $\begin{array}{l}10 \\
11 \\
11 \\
12\end{array}$ & $\begin{array}{r}916 \\
952 \\
948 \\
1080\end{array}$ & $\begin{array}{r}916 \\
922 \\
942 \\
1080\end{array}$ & $\begin{array}{l}1.25 \\
1.29 \\
1.29 \\
1.47\end{array}$ & $\begin{array}{r}.14 \\
.14 \\
.29 \\
.11\end{array}$ \\
\hline $\begin{array}{l}01 \ldots \\
08 \ldots \\
15 \ldots \\
22 \ldots \\
29 \ldots \\
A P R\end{array}$ & $\begin{array}{l}5.6 \\
5.6 \\
5.6 \\
5.6 \\
5.6\end{array}$ & $\begin{array}{l}194 \\
194 \\
194 \\
184 \\
188\end{array}$ & $\begin{array}{l}0 \\
0 \\
0 \\
0 \\
0\end{array}$ & $\begin{array}{l}360 \\
355 \\
360 \\
340 \\
345\end{array}$ & $\begin{array}{l}162 \\
148 \\
162 \\
125 \\
142\end{array}$ & $\begin{array}{l}.6 \\
.5 \\
.6 \\
.6 \\
.5\end{array}$ & $\begin{array}{l}11 \\
11 \\
11 \\
9.8 \\
9.2\end{array}$ & $\begin{array}{l}954 \\
912 \\
942 \\
848 \\
886\end{array}$ & $\begin{array}{l}939 \\
911 \\
941 \\
845 \\
877\end{array}$ & $\begin{array}{l}1.30 \\
1.24 \\
1.28 \\
1.15 \\
1.20\end{array}$ & $\begin{array}{r}.23 \\
.34 \\
.14 \\
.23 \\
.32\end{array}$ \\
\hline $\begin{array}{l}05 \ldots \\
12 \ldots \\
19 \ldots \\
26 \ldots \\
M \Delta Y\end{array}$ & $\begin{array}{l}5.2 \\
6.1 \\
5.7 \\
5.4\end{array}$ & $\begin{array}{l}184 \\
188 \\
196 \\
192\end{array}$ & $\begin{array}{l}0 \\
0 \\
0 \\
0\end{array}$ & $\begin{array}{l}335 \\
340 \\
350 \\
355\end{array}$ & $\begin{array}{l}120 \\
128 \\
135 \\
145\end{array}$ & $\begin{array}{l}.5 \\
.5 \\
.5 \\
.5\end{array}$ & $\begin{array}{l}8.5 \\
9.9 \\
9.0 \\
8.2\end{array}$ & $\begin{array}{l}826 \\
860 \\
890 \\
904\end{array}$ & $\begin{array}{l}826 \\
85 ? \\
88 ? \\
900\end{array}$ & $\begin{array}{l}1.12 \\
1.17 \\
1.21 \\
1.23\end{array}$ & $\begin{array}{l}.23 \\
.34 \\
.25 \\
.16\end{array}$ \\
\hline $\begin{array}{l}03 \ldots \\
10 \ldots \\
17 \ldots \\
24 \ldots \\
31 \ldots \\
\text { JUN }\end{array}$ & $\begin{array}{l}5.0 \\
5.0 \\
5.5 \\
5.5 \\
5.3\end{array}$ & $\begin{array}{l}186 \\
186 \\
186 \\
188 \\
186\end{array}$ & $\begin{array}{l}0 \\
0 \\
0 \\
0 \\
0\end{array}$ & $\begin{array}{l}340 \\
340 \\
340 \\
340 \\
340\end{array}$ & $\begin{array}{l}127 \\
124 \\
120 \\
120 \\
120\end{array}$ & $\begin{array}{l}.5 \\
.5 \\
.6 \\
.5 \\
.6\end{array}$ & $\begin{array}{l}7.2 \\
6.9 \\
6.7 \\
8.0 \\
7.5\end{array}$ & $\begin{array}{l}842 \\
840 \\
826 \\
836 \\
830\end{array}$ & $\begin{array}{l}846 \\
841 \\
831 \\
835 \\
833\end{array}$ & $\begin{array}{l}1.15 \\
1.14 \\
1.12 \\
1.14 \\
1.13\end{array}$ & $\begin{array}{l}.18 \\
.18 \\
.11 \\
.23 \\
.09\end{array}$ \\
\hline $\begin{array}{l}07 \ldots \\
14 \ldots \\
21 \ldots \\
28 \ldots \\
\text { JUL }\end{array}$ & $\begin{array}{l}5.6 \\
5.4 \\
5.0 \\
5.5\end{array}$ & $\begin{array}{l}188 \\
188 \\
184 \\
196\end{array}$ & $\begin{array}{l}0 \\
0 \\
0 \\
0\end{array}$ & $\begin{array}{l}345 \\
340 \\
340 \\
355\end{array}$ & $\begin{array}{l}128 \\
125 \\
120 \\
145\end{array}$ & $\begin{array}{r}.5 \\
.5 \\
.4 \\
.5\end{array}$ & $\begin{array}{l}9.0 \\
9.1 \\
9.0 \\
9.8\end{array}$ & $\begin{array}{l}862 \\
842 \\
840 \\
904\end{array}$ & $\begin{array}{l}857 \\
847 \\
831 \\
905\end{array}$ & $\begin{array}{l}1.17 \\
1.15 \\
1.14 \\
1.23\end{array}$ & $\begin{array}{r}.20 \\
.25 \\
.18 \\
.14\end{array}$ \\
\hline $\begin{array}{l}05 \ldots \\
12 \ldots \\
19 \ldots \\
26 \ldots \\
A 116\end{array}$ & $\begin{array}{l}5.8 \\
6.0 \\
5.7 \\
6.0\end{array}$ & $\begin{array}{l}186 \\
188 \\
178 \\
182\end{array}$ & $\begin{array}{l}0 \\
0 \\
0 \\
0\end{array}$ & $\begin{array}{l}340 \\
345 \\
335 \\
335\end{array}$ & $\begin{array}{l}128 \\
135 \\
118 \\
125\end{array}$ & $\begin{array}{l}.5 \\
.5 \\
.5 \\
.5\end{array}$ & $\begin{array}{l}8.8 \\
9.2 \\
10 \\
11\end{array}$ & $\begin{array}{l}856 \\
881 \\
816 \\
842\end{array}$ & $\begin{array}{l}850 \\
869 \\
821 \\
833\end{array}$ & $\begin{array}{l}1.16 \\
1.20 \\
1.11 \\
1.15\end{array}$ & $\begin{array}{r}.11 \\
.11 \\
.11 \\
.09\end{array}$ \\
\hline $\begin{array}{l}02 \cdots \\
09 \cdots \\
16 \cdots \\
23 \ldots \\
30 \ldots \\
\text { SEP }\end{array}$ & $\begin{array}{l}6.0 \\
5.8 \\
6.2 \\
5.8 \\
5.6\end{array}$ & $\begin{array}{l}190 \\
180 \\
186 \\
178 \\
190\end{array}$ & $\begin{array}{l}0 \\
0 \\
0 \\
0 \\
0\end{array}$ & $\begin{array}{l}350 \\
340 \\
345 \\
350 \\
355\end{array}$ & $\begin{array}{l}142 \\
130 \\
130 \\
142 \\
155\end{array}$ & $\begin{array}{l}.5 \\
.5 \\
.5 \\
.5 \\
.5\end{array}$ & $\begin{array}{l}12 \\
10 \\
8.8 \\
11 \\
11\end{array}$ & $\begin{array}{l}886 \\
854 \\
852 \\
884 \\
918\end{array}$ & $\begin{array}{l}890 \\
848 \\
855 \\
881 \\
919\end{array}$ & $\begin{array}{l}1.20 \\
1.16 \\
1.16 \\
1.20 \\
1.25\end{array}$ & $\begin{array}{l}.11 \\
.11 \\
.09 \\
.14 \\
.14\end{array}$ \\
\hline $\begin{array}{l}06 \ldots \\
13 \ldots \\
20 \ldots \\
27 \ldots\end{array}$ & $\begin{array}{l}5.6 \\
5.6 \\
6.1 \\
6.4\end{array}$ & $\begin{array}{l}176 \\
184 \\
202 \\
138\end{array}$ & $\begin{array}{l}0 \\
0 \\
0 \\
0\end{array}$ & $\begin{array}{l}340 \\
350 \\
375 \\
230\end{array}$ & $\begin{array}{r}121 \\
125 \\
155 \\
94\end{array}$ & $\begin{array}{l}.6 \\
.5 \\
.5 \\
.4\end{array}$ & $\begin{array}{r}9.5 \\
9.5 \\
11 \\
7.8\end{array}$ & $\begin{array}{l}828 \\
856 \\
950 \\
606\end{array}$ & $\begin{array}{l}828 \\
857 \\
956 \\
605\end{array}$ & $\begin{array}{r}1.13 \\
1.16 \\
1.29 \\
.82\end{array}$ & $\begin{array}{l}.09 \\
.34 \\
.23 \\
.81\end{array}$ \\
\hline
\end{tabular}


09521100. COLORADO RIVER BELOW YUMA MAIN CANAL

WASTEWAY, AT YUMA, ARIZ.

LOCATION.--Lat $32^{\circ} 43^{\prime} 54^{\prime \prime}$, long $114^{\circ} 37^{\prime} 55^{\prime \prime}$, in SWHS sec.26, T.16 S., R. 22 E., San Bernardino meridian, in California, Imperial

County, on right bank' $1,000 \mathrm{ft}(305 \mathrm{~m})$ downstream from Yuma Main Canal wasteway, $0.6 \mathrm{mi}$ (1.0 kn) downstream from former gaging station on Colorado River at Yuma, $1.1 \mathrm{mi}(1.8 \mathrm{~km})$ northwest of post office in Yuma, $5.2 \mathrm{mi}(8.4 \mathrm{~km})$ downstrean from Gila River, and $6.4 \mathrm{mi}(10.3 \mathrm{~km})$ upstream from northerly international boundary.

DRAINAGE AREA (REVISED). $--246,500 \mathrm{mi}^{2}\left(638,400 \mathrm{~km}^{2}\right)$, approximately, including all closed basins entirely within the drainage boundary, also, $3,959 \mathrm{mi}^{2}\left(10,254 \mathrm{~km}^{2}\right)$ in Great Divide basin in southern wyoming (previously considered part of the Missouri River basin).

PERTOD OF RECORD,--October 1963 to current year. If records for Yuma Main Canal wasteway at Yuna (sta 09525000) and Reservation Main Drain No. 4 (sta 09530000) are subtracted from records at this station, records equivalent to those published $1902-64$ as "Colorado River at Yuna" (sta 09521000) can be obtained.

GAGE. - Water-stage recorder. Datum of gage is $101.99 \mathrm{ft}(31.087 \mathrm{~m})$ above mean sea level.

AVERAGE DISCHARGE, - -13 years, $847 \mathrm{ft}^{3} / \mathrm{s}\left(23.99 \mathrm{~m}^{3} / \mathrm{s}\right), 613,700 \mathrm{acre}-\mathrm{ft} / \mathrm{yr}\left(757 \mathrm{hm}^{3} / \mathrm{yr}\right)$.

EXTREMES. - Current year: Maximum discharge, $3,000 \mathrm{ft}^{3} / \mathrm{s}\left(85.0 \mathrm{~m}^{3} / \mathrm{s}\right.$ ) Sept. 27 (gage height, $14.69 \mathrm{ft}$ or $4.478 \mathrm{~m}$ ); minimu daily, $392 \mathrm{ft}^{3} / \mathrm{s}\left(11.1 \mathrm{~m}^{3} / \mathrm{s}\right)$ Jan. 7 .

Period of record: Maximum discharge, 5,040 ft $\mathrm{ft}^{3} / \mathrm{s}\left(143 \mathrm{~m}^{3} / \mathrm{s}\right.$ ) Mar. 3, 1970 (gage height, $15.05 \mathrm{ft}$ or $4.587 \mathrm{~m}$ ); minimum daily, $260 \mathrm{ft}^{3} / \mathrm{s}\left(7,36 \mathrm{~m}^{3} / \mathrm{s}\right)$ Jan. 17,1970 .

Maximum gage height since at least $1878,34.0 \mathrm{ft}\left(10.4 \mathrm{~m}\right.$ ) Jan. 22,1916 (discharge, $250,000 \mathrm{ft}^{3} / \mathrm{s}$ or $7,080 \mathrm{~m}^{3} / \mathrm{s}$ ), at former gaging station at Yuma.

REMARKS, - -Records excellent above $1,000 \mathrm{ft}^{3} / \mathrm{s}\left(28.3 \mathrm{~m}^{3} / \mathrm{s}\right)$ and good below. Natura1 flow of stream affected by transmountain diversions, storage reservoirs, power developments, ground-water withdrawals and diversions for irrigation, municipal and industrial uses, and return flows from irrigated areas.

DISCHARGE, IN CUBIC FEET PER SECOND, WATER YEAR OCTOBER 1975 TO SEPTEMBER 1976 MEAN VALUES

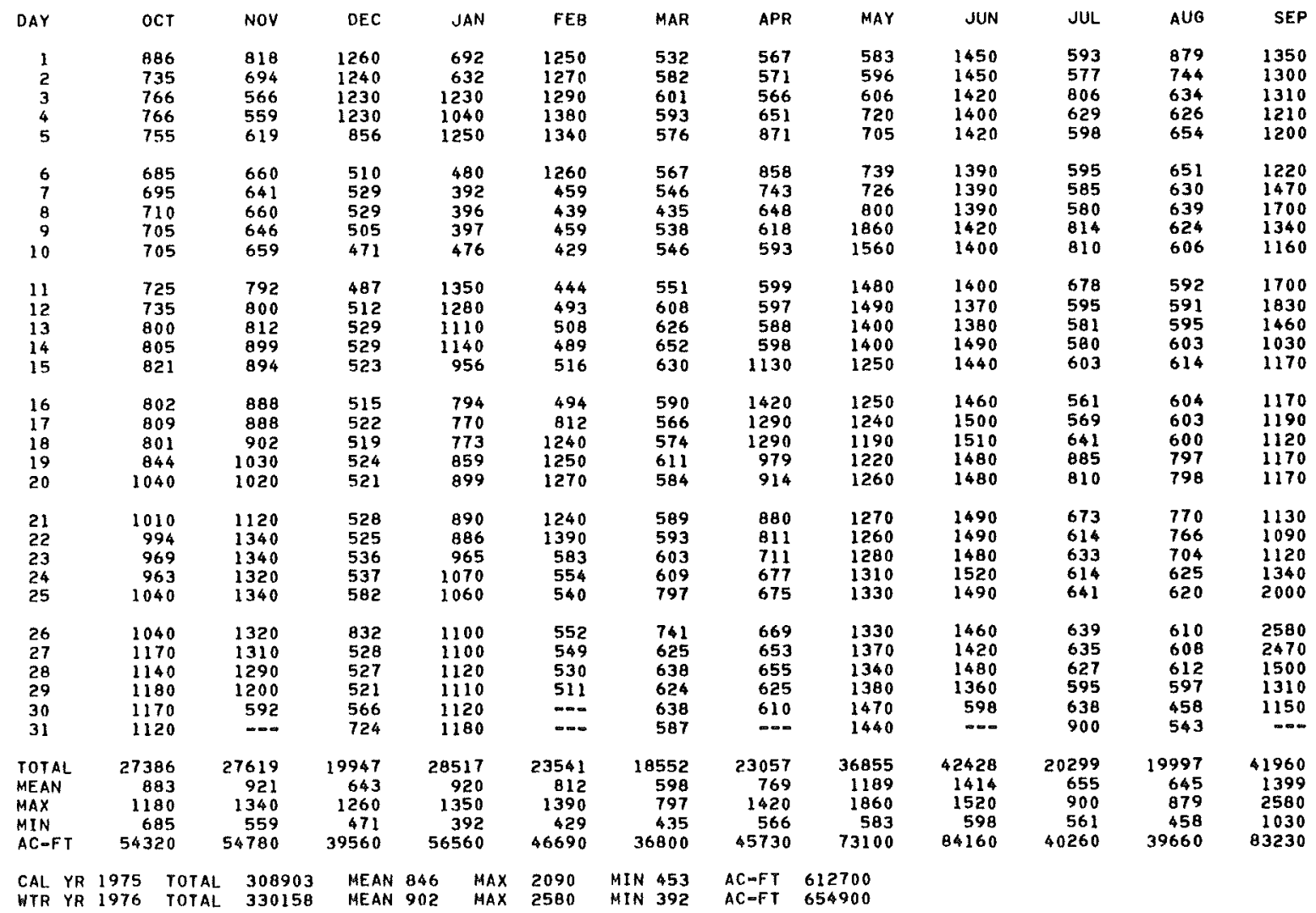


09522000. COLORADO RIVER AT NORTHERLY INTERNATIONAL BOUNDARY ABOVE MORELOS DAM, NEAR ANDRADE, CALIF.

LCCATICN.--Lat $32^{\circ} 43^{\prime} 07^{\prime \prime}$, long $114^{\circ} 43^{\prime} 05^{\prime \prime}$, in NCkSE 4 sec.21, T.8 S., R.24 W., Gila and Salt River meridian, in Arizona, Yuma County, on left bank at northerly international bolndary, $0.5 \mathrm{mi}(0.8 \mathrm{~km})$ east of' Andrade, $1.1 \mathrm{mi}$ (1.8 km) upstream from Morelos Dam, $1 . I \mathrm{mi}(1.8 \mathrm{~km})$ downstream from Rockwood Gate, and $6.4 \mathrm{mi}(10.3 \mathrm{~km})$ downstream from gaging station on Colorado River below Yuma

DRAINAGE AREA (REVISED) . - 246,700 $\mathrm{mi}^{2}\left(639,000 \mathrm{~km}^{2}\right)$, approximately, including all closed basins entirely within the drainage boundary, also $3,959 \mathrm{mi}^{2}\left(10,254 \mathrm{~km}^{2}\right)$ in Great Divicle basin in southern Wyoning (previously considered part of the Missouri River basin).

PERIOD OF RECORD. - -January 1950 to current year. Prior to October 1958 published as "at international boundary."

GAGE. - Nater-stage recorder. Datum of gage is at mean sea leve1. Supplementary water-stage recorder $1,680 \mathrm{ft}(510 \mathrm{~m}) \mathrm{upstrean}$ at same dattrit.

EXTKFIE: - Current year: Maximum discharge, $8,930 \mathrm{ft}^{3} / \mathrm{s}\left(253 \mathrm{~m}^{3} / \mathrm{s}\right)$ Sept 27 ; maximum elevation, $112.56 \mathrm{ft}(34.307 \mathrm{~m})$ Sept. $26 ;$ minimum disciarge, $745 \mathrm{ft}^{3} / \mathrm{s}\left(21.0 \mathrm{~m}^{3} / \mathrm{s}\right)$ Nov. $4 ;$ minimum elevation, $102.23 \mathrm{ft}(31.160 \mathrm{~m})$ Nov. 4.

piriod of record: Maximum discharge, $25,390 \mathrm{ft}^{3} / \mathrm{s}\left(719 \mathrm{~m}^{3} / \mathrm{s}\right)$ Jan. 1, 1953; maximum elevation, $114.24 \mathrm{ft}(34.820 \mathrm{~m}) \mathrm{Jan}$. 28 , 1958, ninimum discharge, $495 \mathrm{ft}^{3} / \mathrm{s}\left(14.0 \mathrm{~m}^{3} / \mathrm{s}\right)$ Sept, 28, 1970; minimum elevation, $101.82 \mathrm{ft}(31.035 \mathrm{~m}) \mathrm{Sept}$. 18,1971 .

REMAKS. - This record shows water passing northerly international boundary. Minor diversions to the United States below this station by ploming fron ground water for irrigation in the floodway between river and Yuma levee. Records of chemical analyses for the current year are published on following pages.

COOPERATION.--Records fumished by International Boundary and Water Commission, U.S. Section (monthly sumnary figures rounded in accordance with Geological Survey standard practice).

DISCHARGE, IN CUBIC FEET PER SECOND, WATER YEAR OCTOBER 1975 TO SEPTEMBER 1976 MEAN VALUES

\begin{tabular}{|c|c|c|c|c|c|c|c|c|c|c|c|c|}
\hline DAY & OCT & NOV & DEC & JAN & FEB & MAR & APR & MAY & JUN & JUL & AUG & SEP \\
\hline $\begin{array}{l}1 \\
2 \\
3 \\
4 \\
5\end{array}$ & $\begin{array}{r}1140 \\
945 \\
945 \\
955 \\
945\end{array}$ & $\begin{array}{r}1090 \\
909 \\
779 \\
761 \\
815\end{array}$ & $\begin{array}{l}1510 \\
1490 \\
1500 \\
1490 \\
1660\end{array}$ & $\begin{array}{l}1920 \\
1770 \\
1360 \\
1180 \\
1430\end{array}$ & $\begin{array}{l}1410 \\
1450 \\
1460 \\
1550 \\
1560\end{array}$ & $\begin{array}{l}2790 \\
2500 \\
2240 \\
2200 \\
2220\end{array}$ & $\begin{array}{l}3500 \\
3660 \\
3640 \\
3650 \\
3870\end{array}$ & $\begin{array}{l}2230 \\
2090 \\
2070 \\
1940 \\
1960\end{array}$ & $\begin{array}{l}1550 \\
1540 \\
1530 \\
1510 \\
1540\end{array}$ & $\begin{array}{l}1970 \\
1940 \\
2000 \\
2020 \\
2010\end{array}$ & $\begin{array}{l}2270 \\
2220 \\
2240 \\
2230 \\
2230\end{array}$ & $\begin{array}{l}1450 \\
1450 \\
1460 \\
1370 \\
1370\end{array}$ \\
\hline $\begin{array}{r}6 \\
7 \\
8 \\
9 \\
10\end{array}$ & $\begin{array}{l}875 \\
875 \\
875 \\
890 \\
885\end{array}$ & $\begin{array}{l}832 \\
833 \\
835 \\
825 \\
815\end{array}$ & $\begin{array}{l}1670 \\
1660 \\
1670 \\
1670 \\
1660\end{array}$ & $\begin{array}{l}1750 \\
1620 \\
1640 \\
1600 \\
1630\end{array}$ & $\begin{array}{l}1540 \\
1680 \\
1700 \\
1770 \\
1980\end{array}$ & $\begin{array}{l}2240 \\
2280 \\
2540 \\
2620 \\
2600\end{array}$ & $\begin{array}{l}3860 \\
3870 \\
3870 \\
3850 \\
3880\end{array}$ & $\begin{array}{l}1960 \\
1970 \\
1940 \\
1740 \\
1680\end{array}$ & $\begin{array}{l}1550 \\
1500 \\
1530 \\
1560 \\
1540\end{array}$ & $\begin{array}{l}2030 \\
2030 \\
2030 \\
2050 \\
2100\end{array}$ & $\begin{array}{l}2220 \\
2220 \\
2230 \\
2220 \\
2240\end{array}$ & $\begin{array}{l}1370 \\
1440 \\
1800 \\
1520 \\
2600\end{array}$ \\
\hline $\begin{array}{l}11 \\
12 \\
13 \\
14 \\
15\end{array}$ & $\begin{array}{l}895 \\
885 \\
945 \\
975 \\
985\end{array}$ & $\begin{array}{r}945 \\
955 \\
965 \\
1040 \\
1050\end{array}$ & $\begin{array}{l}1670 \\
1750 \\
1760 \\
1720 \\
1950\end{array}$ & $\begin{array}{l}1460 \\
1460 \\
1280 \\
1280 \\
1120\end{array}$ & $\begin{array}{l}2560 \\
1790 \\
1910 \\
1920 \\
1920\end{array}$ & $\begin{array}{l}2600 \\
2600 \\
2700 \\
2810 \\
2880\end{array}$ & $\begin{array}{l}3860 \\
3770 \\
3770 \\
4620 \\
7050\end{array}$ & $\begin{array}{l}1570 \\
1570 \\
1490 \\
1470 \\
1370\end{array}$ & $\begin{array}{l}1550 \\
1540 \\
1550 \\
1640 \\
1630\end{array}$ & $\begin{array}{l}2120 \\
2250 \\
2250 \\
2250 \\
2270\end{array}$ & $\begin{array}{l}2230 \\
2180 \\
2180 \\
2190 \\
2200\end{array}$ & $\begin{array}{l}4790 \\
3780 \\
1850 \\
1220 \\
1300\end{array}$ \\
\hline $\begin{array}{l}16 \\
17 \\
18 \\
19 \\
20\end{array}$ & $\begin{array}{r}975 \\
985 \\
975 \\
995 \\
1190\end{array}$ & $\begin{array}{l}1050 \\
1050 \\
1060 \\
1180 \\
1170\end{array}$ & $\begin{array}{l}1930 \\
2030 \\
2050 \\
2060 \\
2110\end{array}$ & $\begin{array}{r}960 \\
918 \\
925 \\
985 \\
1040\end{array}$ & $\begin{array}{l}1780 \\
1630 \\
1390 \\
1390 \\
1410\end{array}$ & $\begin{array}{l}2910 \\
2910 \\
2940 \\
2940 \\
2980\end{array}$ & $\begin{array}{l}6420 \\
4240 \\
3150 \\
3210 \\
3040\end{array}$ & $\begin{array}{l}1320 \\
1340 \\
1310 \\
1310 \\
1360\end{array}$ & $\begin{array}{l}1630 \\
1660 \\
1680 \\
1640 \\
1660\end{array}$ & $\begin{array}{l}2250 \\
2280 \\
2280 \\
2360 \\
2370\end{array}$ & $\begin{array}{l}2180 \\
2190 \\
2160 \\
2080 \\
2080\end{array}$ & $\begin{array}{l}1320 \\
1330 \\
1300 \\
1330 \\
1300\end{array}$ \\
\hline $\begin{array}{l}21 \\
22 \\
23 \\
24 \\
25\end{array}$ & $\begin{array}{l}1180 \\
1170 \\
1150 \\
1160 \\
1230\end{array}$ & $\begin{array}{l}1260 \\
1470 \\
1500 \\
1490 \\
1510\end{array}$ & $\begin{array}{l}2110 \\
2230 \\
2270 \\
2240 \\
2280\end{array}$ & $\begin{array}{l}1030 \\
1040 \\
1120 \\
1220 \\
1220\end{array}$ & $\begin{array}{l}1380 \\
1560 \\
1830 \\
2140 \\
2410\end{array}$ & $\begin{array}{l}3010 \\
3090 \\
3150 \\
3220 \\
3220\end{array}$ & $\begin{array}{l}3030 \\
2990 \\
2910 \\
2970 \\
2900\end{array}$ & $\begin{array}{l}1360 \\
1370 \\
1370 \\
1410 \\
1450\end{array}$ & $\begin{array}{l}1660 \\
1670 \\
1640 \\
1670 \\
1700\end{array}$ & $\begin{array}{l}2360 \\
2370 \\
2290 \\
2280 \\
2290\end{array}$ & $\begin{array}{l}2100 \\
2110 \\
2230 \\
2230 \\
2230\end{array}$ & $\begin{array}{l}1310 \\
1260 \\
1300 \\
2400 \\
5350\end{array}$ \\
\hline $\begin{array}{l}26 \\
27 \\
28 \\
29 \\
30 \\
31\end{array}$ & $\begin{array}{l}1230 \\
1360 \\
1340 \\
1400 \\
1370 \\
1360\end{array}$ & $\begin{array}{c}1510 \\
1490 \\
1500 \\
1500 \\
1670 \\
-0-\end{array}$ & $\begin{array}{l}2320 \\
2330 \\
2340 \\
2450 \\
2490 \\
2310\end{array}$ & $\begin{array}{l}1240 \\
1270 \\
1260 \\
1270 \\
1280 \\
1340\end{array}$ & $\begin{array}{r}2700 \\
3010 \\
3110 \\
3080 \\
=-\end{array}$ & $\begin{array}{l}3190 \\
3180 \\
3180 \\
3220 \\
3200 \\
3140\end{array}$ & $\begin{array}{r}2870 \\
2670 \\
2530 \\
2530 \\
2530 \\
-\end{array}$ & $\begin{array}{l}1450 \\
1470 \\
1450 \\
1460 \\
1550 \\
1540\end{array}$ & $\begin{array}{c}1630 \\
1640 \\
1650 \\
1650 \\
1870 \\
-\end{array}$ & $\begin{array}{l}2290 \\
2330 \\
2370 \\
2370 \\
2310 \\
2310\end{array}$ & $\begin{array}{l}2220 \\
2180 \\
2130 \\
1920 \\
1730 \\
1750\end{array}$ & $\begin{array}{r}5810 \\
7880 \\
2840 \\
1500 \\
1210 \\
=--\end{array}$ \\
\hline $\begin{array}{l}\text { TOTAL } \\
\text { MEAN } \\
\text { MAX } \\
\text { MIN } \\
\text { AC-FT }\end{array}$ & $\begin{array}{r}33085 \\
1067 \\
1400 \\
875 \\
65620\end{array}$ & $\begin{array}{r}33859 \\
1129 \\
1670 \\
761 \\
67160\end{array}$ & $\begin{array}{r}60380 \\
1948 \\
2490 \\
1490 \\
119800\end{array}$ & $\begin{array}{r}40618 \\
1310 \\
1920 \\
918 \\
80570\end{array}$ & $\begin{array}{r}55020 \\
1097 \\
3110 \\
1380 \\
109100\end{array}$ & $\begin{array}{r}87300 \\
2816 \\
3220 \\
2200 \\
173200\end{array}$ & $\begin{array}{r}108710 \\
3624 \\
7050 \\
2530 \\
215600\end{array}$ & $\begin{array}{r}49570 \\
1599 \\
2230 \\
1310 \\
98320\end{array}$ & $\begin{array}{r}48310 \\
1610 \\
1870 \\
1500 \\
95820\end{array}$ & $\begin{array}{r}68430 \\
2207 \\
2370 \\
1940 \\
135700\end{array}$ & $\begin{array}{r}66820 \\
2155 \\
2270 \\
1730 \\
132500\end{array}$ & $\begin{array}{r}66210 \\
2207 \\
7880 \\
1210 \\
131300\end{array}$ \\
\hline
\end{tabular}


09522000. COLORADO RIVER AT NORTHERLY INTERNATIONAL BOUNDARY, ABOVE MORELOS DAM, NEAR ANDRADE, CALIF.

(National stream-quality accounting network and pesticide station)

LOCATION.--Lat $32^{\circ} 43^{\circ} 07^{\prime \prime}$, long $114^{\circ} 43^{\prime} 05^{\prime \prime}$, in NEs $\mathrm{SE}^{\mathrm{t}}$ sec.21, T.8 S., R. 24 W., Gila and Salt River meridian, in Arizona, Yuna County, at gaging station on left bank, at northerly international boundary, $0.5 \mathrm{mi}(0.8 \mathrm{~km})$ east of Andrade, $1.1 \mathrm{mi}(1.8 \mathrm{~km})$ upstream from Morelos Dam, $1.1 \mathrm{mi}(1.8 \mathrm{~km})$ downstream from Rockwood Gate, $20.7 \mathrm{mi}(33.3 \mathrm{~km})$ upstream from southerly international boundary, and $21 \mathrm{mi}(34 \mathrm{~km})$ downstream from Laguna Dam.

DRAINAGE AREA (REVISED) . - 246,700 $\mathrm{mi}^{2}\left(640,000 \mathrm{~km}^{2}\right)$, approximately, including $3,959 \mathrm{mi}^{2}\left(10,254 \mathrm{~km}^{2}\right)$ in Great Divide basin in southern Wyoming which is noncontributing (previously considered part of the Missouri River basin).

WATEK QUALITY DATA, WATER YEAR OCTOBER 1975 TO SEPTEMRER 1976

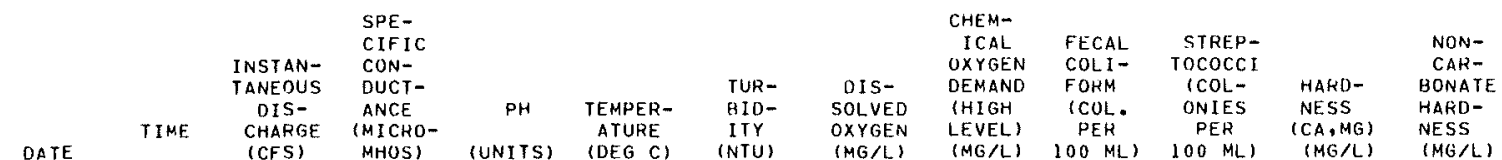

oc

\begin{tabular}{|c|c|c|c|c|c|c|c|c|c|c|c|c|}
\hline $06 \ldots$ & 0900 & 895 & 1670 & 8.0 & 24.0 & 4 & -- & -- & -- & -- & 425 & 248 \\
\hline $07 \ldots$ & 0850 & 865 & 1700 & 7.9 & 22.0 & -- & 7.6 & 13 & 150 & 170 & -- & -- \\
\hline $14 \ldots$ & 0830 & 985 & 1640 & 8.1 & - & 3 & -- & $=-$ & -- & -- & 420 & 246 \\
\hline $20 \ldots$ & 0830 & 1210 & 1640 & 8.2 & $-\infty$ & 5 & - & $=-$ & -- & -- & 420 & 246 \\
\hline $21 \ldots$ & 0825 & 1170 & $=-$ & $-=$ & 20.5 & - & -- & $B$ & -- & $=-$ & $-\cdots$ & -- \\
\hline$\underset{10 \mathrm{~V}}{28 . \cdots}$ & 0830 & 1340 & 1620 & 8.2 & - & 4 & -- & - & $=-$ & - & 415 & 244 \\
\hline $03 \ldots$ & 0830 & 780 & 1730 & 8.1 & 18.5 & 2 & -- & $-\infty$ & -- & - & 430 & 248 \\
\hline $10 \ldots$ & 0830 & 815 & 1770 & 8.1 & -- & 3 & - & -- & $=-$ & - & 440 & 253 \\
\hline $11 \ldots$ & 0830 & 955 & 1760 & 8.2 & 16.5 & -- & 7.8 & 11 & 170 & 260 & -- & -- \\
\hline $17 \ldots$ & 0835 & 1050 & 1720 & 8.2 & 16.5 & 5 & - & -- & -- & -- & 430 & 248 \\
\hline$\underset{\mathrm{EC}}{24} \cdots$ & 0900 & 1500 & 1600 & 8.0 & 12.5 & 5 & -- & 12 & -- & -- & 420 & 250 \\
\hline $01 \ldots$ & 0830 & 1490 & 1670 & 8.0 & - & 9 & -- & -- & -- & -- & 430 & 253 \\
\hline $08 \ldots$ & 0840 & 1670 & 1610 & 8.1 & 15.0 & 7 & -- & - & -- & -- & 415 & 244 \\
\hline $09 \ldots$ & 0830 & 1660 & 1660 & 8.2 & 15.5 & -- & 8.3 & 10 & -- & -- & $-\infty$ & $-\infty$ \\
\hline $15 \ldots$ & 0830 & 1960 & 1590 & 8.1 & 14.0 & 5 & - & -- & -- & - & 410 & 242 \\
\hline $22 \ldots$ & 0830 & 2186 & 1530 & 8.0 & 13.5 & 3 & - & $=$ & -- & $=-$ & 400 & 241 \\
\hline $23 \ldots$ & 1015 & 2290 & -- & - & 15.0 & -- & -- & 40 & -- & -- & - & - \\
\hline $29 \ldots$ & 0845 & 2475 & 1530 & 8.0 & - & 7 & $-\infty$ & $=-$ & -- & -- & 400 & 240 \\
\hline $\begin{array}{l}\text { JAN } \\
05 \ldots .\end{array}$ & & & & 8.1 & 9.0 & 7 & -- & -- & 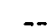 & $-\infty$ & 405 & 238 \\
\hline $12 \ldots$ & 0845 & 1470 & 1640 & 8.0 & 11.0 & 8 & $=$ & - & - & - & $\begin{array}{l}403 \\
420\end{array}$ & 248 \\
\hline $13 \ldots$ & 0830 & 1280 & 1620 & 7.9 & 10.5 & - & 10.3 & 12 & 38 & 190 & - & - \\
\hline $19 \ldots$ & 0830 & 995 & 1720 & 8.2 & 13.5 & 3 & -- & -- & - & -- & 430 & 250 \\
\hline $26 \ldots$ & 0845 & 1240 & 1630 & 8.1 & - & 6 & - & -- & -- & -- & 420 & 250 \\
\hline $27 \ldots$ & 0830 & 1300 & -- & -- & 13.0 & -- & -- & 12 & - & $=$ & -- & -- \\
\hline EB & & & & & & & & & & & & \\
\hline $02 \ldots$ & 0830 & 1460 & 1570 & 8.0 & 13.5 & 7 & -- & - & -- & + & 405 & 240 \\
\hline $09 \ldots$ & 0840 & 1800 & 1580 & 8.2 & -- & 7 & - & $-m$ & -- & - & 405 & 238 \\
\hline $10 \ldots$ & 0835 & 1700 & 1600 & 8.0 & 16.5 & - & 8.3 & 11 & 100 & 60 & -- & -- \\
\hline $17 \ldots$ & 0845 & 1720 & 1740 & 8.2 & -- & 2 & - & -- & -- & - & 435 & 250 \\
\hline $23 \ldots$ & 0905 & 1790 & 1720 & 8.1 & 16.5 & 5 & -- & -- & -- & -- & 430 & 250 \\
\hline $24 \ldots$ & 0835 & 2160 & + & -- & 15.5 & - & -- & 13 & -- & -- & -- & -- \\
\hline AAR & & & & & & & & & & & & \\
\hline $01 \ldots$ & 0845 & 2790 & 1440 & 8.1 & 17.0 & 9 & - & -- & - & -- & 390 & 234 \\
\hline $08 \ldots$ & 0830 & 2590 & 1380 & 8.1 & 16.0 & 10 & -- & - & -- & -- & 385 & 231 \\
\hline $09 \ldots$ & 0835 & 2590 & 1520 & $8 \cdot 1$ & 16.5 & -- & 8.5 & 22 & 140 & 40 & $\overline{-}$ & -- \\
\hline $15 \ldots$ & 0840 & 2900 & 1500 & 8.0 & 16.0 & 10 & -- & -- & -- & -- & 395 & 234 \\
\hline $22 \ldots$ & 0845 & 3160 & 1410 & 8.1 & 19.0 & 20 & -- & -- & -- & -- & 385 & 231 \\
\hline $23 \ldots$ & 0830 & 3090 & $=$ & $=$ & 18.5 & -- & -- & $B$ & - & -- & - & -- \\
\hline $29 \ldots$ & 0830 & 3260 & 1400 & 8.0 & 18.0 & 10 & -- & - & -- & - & 385 & 231 \\
\hline $05 \ldots$ & 0845 & 3770 & 1380 & 8.1 & - & 14 & -- & -- & - & -- & 380 & 226 \\
\hline $12 \ldots$ & 0830 & 3790 & 1390 & 8.0 & - & 10 & - & -- & - & -- & 380 & 224 \\
\hline $13 \ldots$ & 0830 & 3820 & 1440 & 8.0 & 17.5 & - & 8.0 & 11 & 38 & 63 & -- & -- \\
\hline $19 \ldots$ & 0845 & 3300 & 1500 & 8.1 & 20.5 & 12 & -- & $-\cdots$ & -- & $\rightarrow$ & 400 & 231 \\
\hline $26 \ldots$ & 0845 & 2880 & 1450 & 8.2 & 21.5 & 20 & - & - & -- & -- & 395 & 238 \\
\hline $27 \ldots$ & 0835 & 2650 & - & - & 20.0 & -- & -- & 14 & -- & - & $=$ & - \\
\hline $03 \ldots$ & 0830 & 2080 & 1490 & 8.0 & - & 9 & -- & $=-$ & -- & $=-$ & 395 & 234 \\
\hline $10 \ldots$ & 0830 & 1710 & 1510 & 8.1 & 23.5 & 20 & - & -- & -- & -- & 400 & 238 \\
\hline $11 \ldots$ & 0830 & 1600 & 1570 & 8.0 & 23.5 & -- & 7.5 & 14 & 87 & 400 & - & - \\
\hline $17 \ldots$ & 0830 & 1400 & 1520 & $B \cdot 1$ & -- & 11 & -- & $\cdots$ & - & - & 400 & 232 \\
\hline $24 \ldots$ & 0830 & 1410 & 1560 & 8.1 & -- & 7 & -- & $=-$ & $\rightarrow$ & -- & 405 & 238 \\
\hline $25 \ldots$ & 0830 & 1370 & - & - & 22.0 & -- & -- & 59 & -- & -- & - & -- \\
\hline JUN & & & & & & & & & & & & \\
\hline $01 \ldots$ & 0830 & 1560 & 1540 & 8.1 & -- & 5 & -- & -- & -- & -- & 400 & 231 \\
\hline $07 \ldots$ & 0830 & 1530 & 1540 & 8.0 & 25.5 & 10 & - & - & -- & - & 400 & 231 \\
\hline $08 \ldots$ & 0830 & 1530 & 1560 & 8.0 & 24.0 & -- & 7.4 & 29 & 110 & 200 & $=-$ & - \\
\hline $14 \ldots$ & 0830 & 1630 & 1540 & 8.1 & 24.5 & 10 & -- & -- & - & -- & 400 & 230 \\
\hline $21 \ldots$ & 0830 & 1670 & 1520 & 8.1 & -- & 9 & -- & - & -- & - & 400 & 234 \\
\hline $28 \ldots$ & 0830 & 1640 & 1550 & 8.1 & -- & 8 & -- & -- & - & -- & 400 & 232 \\
\hline$J U L$ & & & & & & & & & & & & \\
\hline $06 \ldots$ & 0830 & 2050 & 1480 & 8.0 & 26.5 & 7 & -- & -- & -- & - & 395 & 234 \\
\hline $12 \ldots$ & 0830 & 2250 & 1440 & 8.2 & -- & 6 & -- & - & - & $=$ & 390 & 232 \\
\hline $13 \ldots$ & 0955 & 2250 & 1470 & 7.7 & 27.0 & -- & 7.0 & 5 & -- & -- & - & -- \\
\hline $19 \ldots$ & 0840 & 2380 & 1480 & 8.2 & 28.5 & 9 & -- & -- & -- & -- & 395 & 238 \\
\hline $26 \ldots$ & 0820 & 2280 & 1460 & 8.1 & 26.5 & 10 & -- & -- & -- & -- & 395 & 238 \\
\hline $27 \ldots$ & 0830 & 2360 & -- & -- & 29.0 & -- & - & 11 & -- & -- & - & - \\
\hline 02 & & & & & & & & & & & & \\
\hline $\begin{array}{l}02 \ldots \\
09 \ldots\end{array}$ & 0420 & 2180 & 1580 & 8.2 & 26.5 & 9 & - & - & - & - & 405 & 242 \\
\hline $09 \ldots$ & 0830 & 2220 & 1470 & 8.2 & 27.0 & 9 & -- & -- & -- & -- & 390 & 234 \\
\hline $10 \ldots$ & 0835 & 2220 & 1440 & 7.9 & 27.0 & -- & 6.6 & 10 & 60 & 34 & -- & -- \\
\hline $16 \ldots$ & 0840 & 2220 & 1480 & 8.2 & -- & 8 & -- & -- & -- & $=$ & 395 & 239 \\
\hline $23 \ldots$ & 0430 & 2240 & 1440 & 8.4 & 28.0 & 9 & $\cdots$ & -- & -- & -- & 385 & 232 \\
\hline $24 \ldots$ & 0845 & 2250 & $=-$ & -- & 27.0 & -- & -- & $y$ & $\rightarrow$ & -- & -- & - \\
\hline $30 \ldots$ & 0840 & 1750 & 1460 & 8.2 & 28.0 & 7 & -- & - & - & -- & 385 & 229 \\
\hline $07 \ldots$ & 0830 & 1330 & 1470 & 8.2 & $=$ & 5 & $=-$ & -- & -- & -- & 390 & 231 \\
\hline
\end{tabular}


09522000. COLORADO RIVER AT NORTHERLY INTERNATIONAL, BOUNDARY,

ABOVE MORELOS DAM, NEAR ANDRADE, CALAF.--CONTINUED

PERIOD OF RECORD, - Chemical analyses: October 1968 to current year.

EXTREMES. --Current year:

Specific conductance: Maximum, 1,820 micromhos Feb. 20; minimu, 1,020 micromhos Sept. 27.

Period of record:

Specific conductance (1969-74): Maximum, 2,230 micromhos Dec. 9, 1969; minimum, 1,020 micromhos Sept. $27,1976$.

REMARKS.--Unpublished chemica1 analyses (continuing record) for water years 1961-68 available from district office in Tucson, Ariz.

WATER GUALITY DATA, WATER YEAR OCTOBER 1975 TO SEPTEMBER 1976

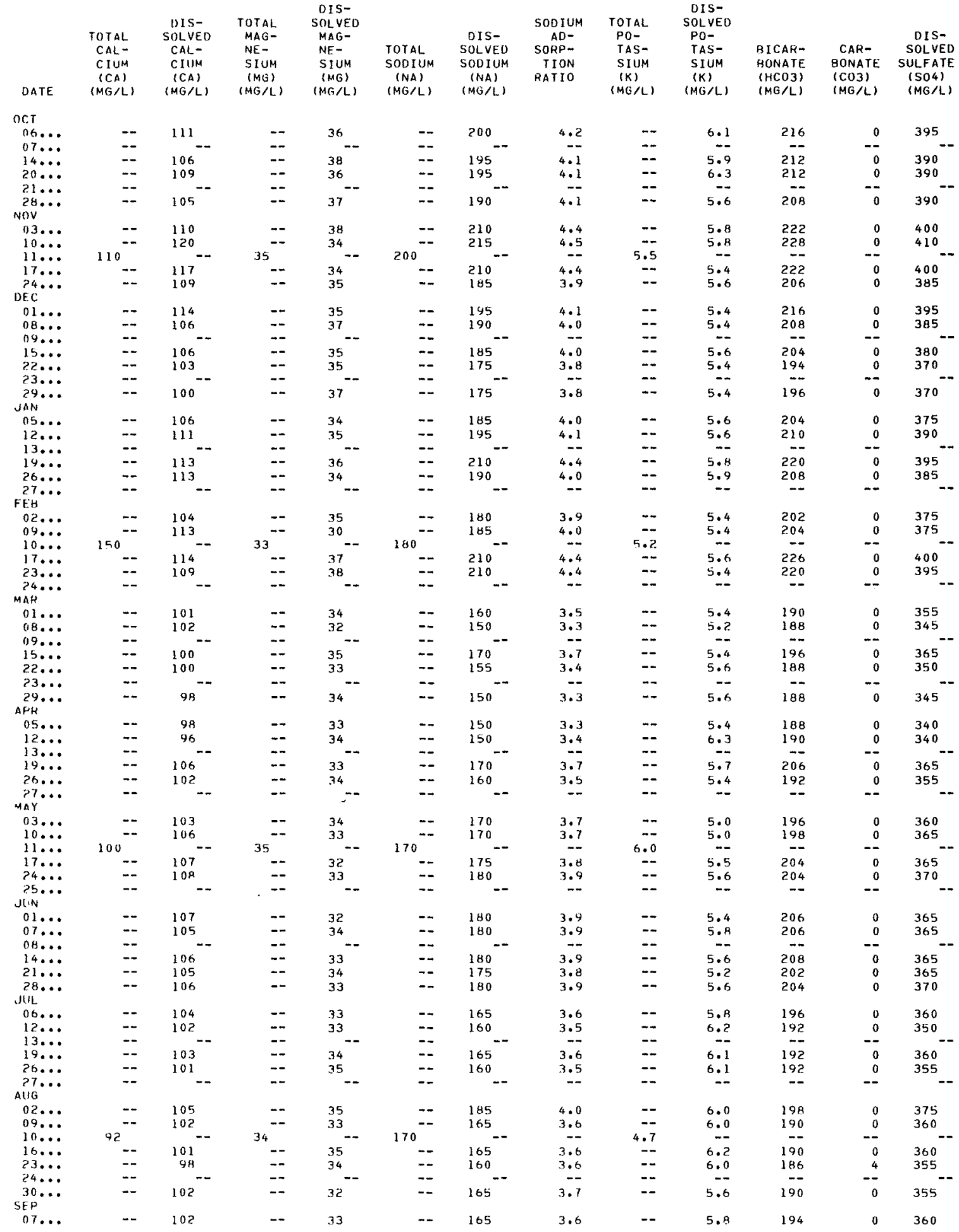


09522000. COLORADO RIVER AT NORTHERLY INTERNATIONAL BOUNDARY, ABOVE MORELOS DAAI, NEAR ANDRADE, CALIF.--CONTINUED

MAIER QUALITY DATA, WATER YEAR OCTOBER 1975 TO SEPTEMHER $197 \mathrm{~K}$

\begin{tabular}{|c|c|c|c|c|c|c|c|c|c|c|c|}
\hline DATE & $\begin{array}{l}\text { CIIS- } \\
\text { SOLVED } \\
\text { CHLO- } \\
\text { HIOE } \\
(C L) \\
(M G / L)\end{array}$ & $\begin{array}{l}\text { DIS- } \\
\text { SOLVED } \\
\text { FLUO- } \\
\text { RIDE } \\
\text { (F) } \\
\text { (MG/L) }\end{array}$ & $\begin{array}{l}\text { DIS- } \\
\text { SOLVED } \\
\text { SILICA } \\
\text { (SIOZ) } \\
\text { (MG/L) }\end{array}$ & $\begin{array}{l}\text { DIS- } \\
\text { SOLVED } \\
\text { SOLIDS } \\
\text { (RESI- } \\
\text { DUE AT } \\
180 \text { C) } \\
(M E / L)\end{array}$ & $\begin{array}{l}\text { DIS- } \\
\text { SOLVED } \\
\text { SOLIOS } \\
\text { (SUM OF } \\
\text { CONSTI- } \\
\text { TUENTS) } \\
\text { (MGLL) }\end{array}$ & $\begin{array}{l}\text { DIS- } \\
\text { SOLVED } \\
\text { SULIDS } \\
\text { (FUNS } \\
\text { PER } \\
\text { AC-FT) }\end{array}$ & $\begin{array}{c}\text { TOTAL } \\
\text { NON- } \\
\text { FILT- } \\
\text { HABLE } \\
\text { RESIOUE } \\
\text { (MG/L) }\end{array}$ & $\begin{array}{l}\text { OIS- } \\
\text { SOLVED } \\
\text { NITRATE } \\
\text { (N) } \\
(M G / L)\end{array}$ & $\begin{array}{l}\text { OIS- } \\
\text { SOLVEO } \\
\text { OHTHO. } \\
\text { PHOS- } \\
\text { PHORUS } \\
(\beta) \\
(M G / L)\end{array}$ & $\begin{array}{c}\text { DIS- } \\
\text { SOLVED } \\
\text { RORON } \\
\text { (H) } \\
\text { (UG/L) }\end{array}$ & $\begin{array}{l}\text { DIS- } \\
\text { SULVED } \\
\text { IRON } \\
\text { (FE) } \\
(U G / L)\end{array}$ \\
\hline \multicolumn{12}{|l|}{$O C T$} \\
\hline$n 6 \ldots$ & 195 & .5 & 12 & 1070 & 1060 & 1.46 & - & .20 & -- & -- & -- \\
\hline $07 \ldots$ & -- & -- & -- & -- & -- & -- & 20 & -- & .04 & 250 & -- \\
\hline $14 \ldots$ & 180 & .6 & 12 & 1050 & $\begin{array}{l}1040 \\
1040\end{array}$ & 1.43 & -- & $\cdot 38$ & -- & $=-$ & $=$ \\
\hline $\begin{array}{l}20 \ldots \\
21 \ldots\end{array}$ & 188 & $\because 5$ & $13=$ & $\begin{array}{r}1050 \\
--\end{array}$ & 1040 & $\begin{array}{r}1.43 \\
-2-\end{array}$ & 36 & -- & -- & $-\infty$ & - \\
\hline $28 \ldots$ & 185 & .7 & 14 & 1030 & 1030 & 1.40 & -- & -- & -- & -- & -- \\
\hline \multicolumn{12}{|l|}{ NOV } \\
\hline $03 \ldots$ & $20 \%$ & .7 & 14 & 1110 & 1100 & 1.51 & -- & .00 & -- & -- & -- \\
\hline $10 \ldots$ & 212 & .6 & 12 & 1130 & 1120 & 1.54 & -- & -- & -- & -- & - \\
\hline $11 \ldots$ & -- & -- & -- & -- & $-\infty$ & $m-$ & $B$ & -- & $.0 \mathrm{~K}$ & 390 & 10 \\
\hline $17 \ldots$ & 205 & .5 & 12 & 1110 & 1090 & 1.51 & -- & .38 & -- & $-m$ & $=-$ \\
\hline OEC & 180 & .6 & 12 & 1030 & 1020 & 1.40 & 12 & .41 & .05 & 250 & -- \\
\hline $01 \ldots$ & $19 \pi$ & .6 & 12 & 1070 & 1060 & 1.46 & $\cdots$ & .29 & -- & -- & - \\
\hline DE... & 185 & .6 & 12 & 1030 & 1020 & 1.40 & $\rightarrow$ & .32 & -- & -- & - \\
\hline $09 \ldots$ & - & $=-$ & - & -- & -- & - & 13 & .23 & $.0 ?$ & 230 & -- \\
\hline $15 \ldots$ & 180 & .5 & 12 & 1020 & 1010 & 1.39 & -- & .36 & -- & -- & -- \\
\hline $22 \ldots$ & 168 & .6 & 12 & 982 & 906 & 1.34 & -- & .23 & -- & -- & -- \\
\hline $23 \ldots$ & -- & -- & -- & - & -- & -- & 17 & .23 & .02 & 210 & -- \\
\hline $29 \ldots$ & $1 \in B$ & .5 & 11 & 978 & 966 & 1.33 & -- & .38 & -- & $=-$ & - \\
\hline \multicolumn{12}{|l|}{ JAN } \\
\hline$n 5 \ldots$ & 178 & .6 & 13 & 998 & 1000 & 1.36 & -- & .63 & -- & $-m$ & -- \\
\hline $12 \ldots$ & 188 & .6 & 12 & 1040 & 1040 & 1.41 & -- & .32 & -- & -- & -- \\
\hline $13 \ldots$ & -- & -- & -- & - & -- & -- & 12 & .23 & .04 & 240 & -- \\
\hline $19 \ldots$ & 208 & .6 & 14 & 1100 & 1040 & 1.50 & - & .63 & - & -- & -- \\
\hline $26 \ldots$ & 180 & .5 & 13 & 1030 & 1030 & 1.40 & -- & .36 & -- & -- & - \\
\hline $27 \ldots$ & -- & - & $=$ & -- & -- & - & 7 & - & -- & -- & - \\
\hline FEH & & & & & & & & & & & \\
\hline $02 \ldots$ & 178 & .5 & 13 & 1020 & 992 & 1.39 & -- & .32 & -- & -- & -- \\
\hline $09 . \ldots$ & $18 ?$ & .6 & 12 & 1010 & 1000 & 1.37 & -- & .36 & -- & -- & -- \\
\hline $10 \ldots$ & -- & -- & $=-$ & -- & -- & -- & 6 & .33 & .04 & 230 & 0 \\
\hline $17 \ldots$ & 210 & .5 & 11 & 1140 & 1100 & 1.55 & -- & .27 & -- & -- & -- \\
\hline $23 \ldots$ & 208 & .6 & 13 & 1100 & 1090 & 1.50 & -- & .41 & -- & -- & -- \\
\hline $24 \ldots$ & -- & $-\infty$ & -- & -- & - & $=$ & 12 & -- & -- & -- & -- \\
\hline MAH & & & & & & & & & & & \\
\hline $01 \ldots$ & 152 & .5 & 11 & 910 & 914 & 1.24 & -- & .27 & -- & -- & $-m$ \\
\hline $08 \ldots$ & 140 & .5 & 8.5 & 884 & 878 & 1.20 & -- & .45 & -- & -- & $-\infty$ \\
\hline $09 \ldots$ & -- & - & - & -- & -- & -- & 37 & .27 & .02 & 210 & -- \\
\hline $15 \ldots$ & 165 & .6 & 11 & 958 & 950 & 1.30 & -- & .25 & -- & -- & $\rightarrow$ \\
\hline $22 \ldots$ & 145 & .5 & 11 & 900 & 894 & 1.22 & -- & .29 & -- & -- & -- \\
\hline $73 \ldots$ & -- & - & -- & -- & -- & -- & 26 & $=-$ & -- & $-=$ & -- \\
\hline $29 \ldots$ & 145 & .5 & 11 & 890 & 884 & 1.21 & -- & .32 & -- & -- & - \\
\hline$A \sim R$ & & & & & & & & & & & \\
\hline $05 \ldots$ & 142 & .5 & 9.0 & 482 & 873 & 1.20 & -- & .38 & -- & -- & -- \\
\hline $12 \ldots$ & 142 & .5 & 11 & $\mathrm{BHB}$ & 876 & 1.21 & -- & .4 .3 & -- & $-\infty$ & -- \\
\hline $13 \ldots$ & - & $-\infty$ & -- & -- & -- & -- & 23 & -- & .03 & 180 & $\rightarrow$ \\
\hline $19 \ldots$ & 158 & .6 & 9.8 & 962 & 951 & 1.31 & -- & .34 & -- & -- & $=-$ \\
\hline $26 \ldots$ & 155 & .5 & 8.6 & 918 & 916 & 1.25 & -- & .23 & -- & -- & -- \\
\hline$? 7 \ldots$ & - & -- & -- & -- & -- & -- & 18 & -- & -- & -- & - \\
\hline$M \Delta Y$ & & & & & & & & & & & \\
\hline $03 \ldots$ & 165 & . 5 & 8.2 & 952 & 944 & 1.29 & -- & .27 & -- & -- & -- \\
\hline $10 \ldots$ & 168 & .6 & 9.6 & 962 & 956 & 1.31 & -- & .27 & +- & -- & -- \\
\hline $11 \ldots$ & -- & -- & $-\infty$ & - & -- & - & 21 & -- & .02 & 210 & 40 \\
\hline $17 \ldots$ & 158 & .5 & 7.8 & 972 & 962 & 1.32 & -- & .23 & -- & - & -- \\
\hline $24 \ldots$ & 179 & .6 & 9.5 & 992 & 980 & 1.35 & $-=$ & .32 & -- & -- & -- \\
\hline $25 \ldots$ & + & $\therefore$ & - & - & - & -- & 9 & - & -- & -- & -- \\
\hline JIIN & & & & & & & & & & & \\
\hline $01 \ldots$ & 172 & .6 & 9.5 & 978 & 974 & 1.33 & -- & .23 & $\rightarrow$ & -- & -- \\
\hline $07 \ldots$ & 172 & .5 & 10 & 978 & 975 & 1.33 & -- & .29 & -- & -- & -- \\
\hline$n 8 \ldots$ & - & - & -- & -- & -- & - & 31 & -- & .01 & 200 & -- \\
\hline $14 \ldots$ & 172 & .5 & 11 & 980 & 977 & 1.33 & -- & .34 & -- & -- & -- \\
\hline $21 \ldots$ & 168 & .5 & 11 & 970 & 965 & 1.32 & -- & .34 & -- & -- & -- \\
\hline $28 \ldots$ & 175 & .6 & 10 & 974 & 982 & 1.32 & -- & .29 & -- & -- & -- \\
\hline JilL & & & & & & & & & & & \\
\hline $06 \ldots$ & 162 & .5 & 9.0 & 936 & 938 & 1.27 & -- & .27 & -- & - & -- \\
\hline $12 \ldots$ & 155 & .5 & 9.5 & 916 & 912 & 1.25 & -- & .23 & -- & -- & - \\
\hline $13 \ldots$ & $\ldots$ & - & -- & -- & -- & -- & 6 & -- & .03 & 210 & -- \\
\hline $19 .$. & 167 & .5 & 10 & 936 & 936 & 1.27 & -- & .16 & -- & -- & $=$ \\
\hline $26 . \ldots$ & 160 & .5 & 11 & 932 & 925 & 1.27 & -- & .25 & -- & -- & -- \\
\hline$>7 \ldots$ & - & -- & -- & -- & -- & -- & 8 & -- & - & -- & -- \\
\hline$A \cup G$ & & & & & & & & & & & \\
\hline$\pi 2 \ldots$ & 182 & .6 & 12 & 1000 & 1000 & 1.36 & -- & .20 & - & -- & - \\
\hline $09 \ldots$ & 160 & .5 & 10 & 928 & 931 & 1.26 & -- & .16 & -- & -- & -- \\
\hline $10 \ldots$ & - & -- & - & -- & - & -- & 14 & .20 & .02 & 220 & 20 \\
\hline $16 \ldots$ & 162 & .5 & 10 & 936 & 935 & 1.27 & -- & .23 & -- & -- & -- \\
\hline $23 \ldots$ & 152 & .5 & 11 & 924 & 914 & 1.26 & -- & .23 & -- & -- & - \\
\hline $24 \ldots$ & -- & -- & -- & -- & -- & -- & 16 & -- & -- & -- & -- \\
\hline $30 \ldots$ & $15^{\circ}$ & .5 & 12 & 926 & 925 & 1.26 & -- & .16 & -- & -- & $=-$ \\
\hline SFP & & & & & 033 & 1.29 & $=-$ & 18 & -- & -- & -- \\
\hline $07 \ldots$ & 160 & $\cdot 6$ & 10 & 948 & $\$ 33$ & $1 \cdot 29$ & -- & $\cdot 18$ & - & -- & - \\
\hline
\end{tabular}


09522000. COLORADO RIVER AT NORTHERLY INTERNATIONAL BOUNDARY, ABOVE MORELOS DAM, NEAR ANDRADE, CALIF.--CONTINUED

AATER UUALITY DATA, WATER YEAK OCTUBER 1975 TO SEPTEMGER 1976

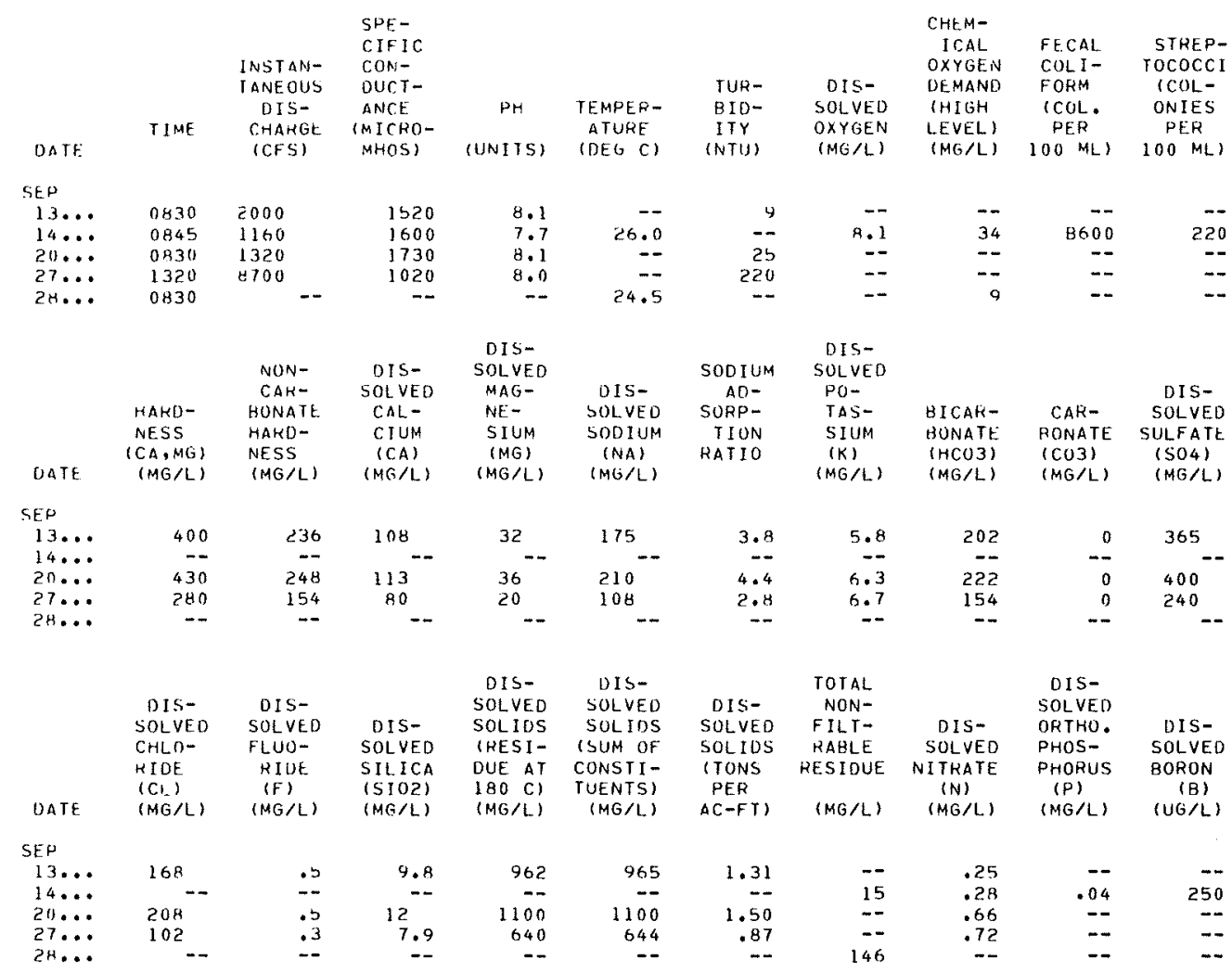

B Results based on non-ideal colony count. 
09522000. COLORADO RIVER AT NORTHERLY INTERNATIONAL BOUNDARY, ABOVE MORELOS DAM, NEAR ANDRADE, CALIF.--CONTINUED

WATER GUALITY DATA. WATER YEAR OCTOBER 1975 TO SEPTEMREH 1976

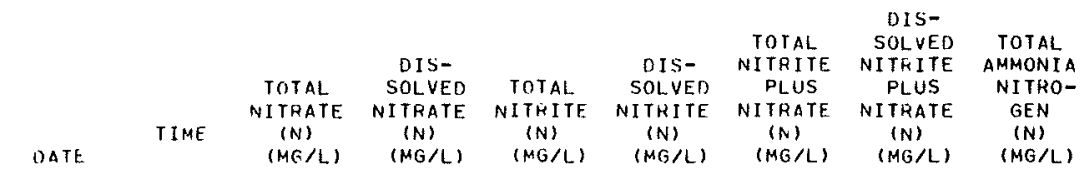

\begin{tabular}{|c|c|c|c|c|c|c|c|c|}
\hline \multicolumn{9}{|l|}{$O C T$} \\
\hline Bh... & $0 Y 00$ & -- & .20 & $-\infty$ & -- & -- & $-\cdots$ & $\cdots$ \\
\hline $07 \ldots$ & 0850 & .18 & -- & .01 & .01 & .19 & .19 & .03 \\
\hline $14 \ldots$ & 0430 & -- & . 3A & -- & $\rightarrow$ & -- & -- & -- \\
\hline $21 \ldots$ & 0825 & .17 & -- & .02 & -- & .19 & -- & .12 \\
\hline \multicolumn{9}{|l|}{ NOV } \\
\hline $03 \ldots$ & 0830 & -- & .00 & $=-$ & -- & -- & -- & -- \\
\hline $11 \ldots$ & 0830 & .27 & -- & .03 & .03 & .30 & .30 & .17 \\
\hline $17 \ldots$ & $083 \mathrm{~b}$ & -- & $.3 B$ & -- & -- & -- & -- & -- \\
\hline $24 \ldots$ & 0900 & .29 & .41 & .02 & .02 & . 31 & .31 & .14 \\
\hline \multicolumn{9}{|l|}{$\mathrm{DEC}$} \\
\hline $01 \ldots$ & 0830 & -- & .29 & - & -- & -- & -- & - \\
\hline$O H_{\ldots} \ldots$ & 0840 & -- & .32 & $-\overline{-}$ & -- & -- & -- & -- \\
\hline $09 \ldots$ & 0830 & .24 & .23 & .01 & .01 & .25 & .24 & .15 \\
\hline $15 \ldots$ & 0830 & -- & .36 & -- & -- & -- & -- & - \\
\hline $22 \ldots$ & 0830 & -- & .23 & -- & $\cdots$ & $-\cdots$ & -- & -- \\
\hline $23 \ldots$ & 1015 & .25 & .23 & .01 & .00 & .26 & .23 & .11 \\
\hline $29 \ldots$ & 0845 & -- & $\cdot 3 A$ & -- & -- & -- & -- & - \\
\hline \multicolumn{9}{|l|}{ JAN } \\
\hline $05 \ldots$ & 0845 & -- & .63 & -- & -- & -- & -- & -- \\
\hline $12 \ldots$ & 0845 & -- & .32 & $=-$ & -- & $=-$ & -- & -- \\
\hline $13 \ldots$ & 0830 & .23 & .23 & .01 & .01 & .24 & .24 & .14 \\
\hline $19 \ldots$ & 0830 & -- & .63 & -- & -- & -- & -- & -- \\
\hline $26 . \ldots$ & 0845 & -- & .36 & -- & $-\infty$ & $\cdots$ & -- & -- \\
\hline $27 \ldots$ & 0830 & .33 & -- & .02 & -- & .35 & $-\infty$ & .13 \\
\hline FEB & & & & & & & & \\
\hline $02 \ldots$ & 0830 & -- & .32 & -- & -- & -- & $-\infty$ & -- \\
\hline $09 \ldots$ & 0840 & -- & .36 & -- & -- & -- & $-\infty$ & - \\
\hline $10 \ldots$ & 0835 & .32 & .33 & .02 & .01 & .34 & .34 & .14 \\
\hline $17 \ldots$ & 0845 & $-\cdots$ & .27 & -- & -- & -- & -- & -- \\
\hline $23 \ldots$ & 0905 & -- & .41 & -- & -- & -- & -- & $-\rightarrow$ \\
\hline $24 \ldots$ & 0835 & .27 & -- & .01 & -- & .28 & -- & .05 \\
\hline MAR & & & & & & & & \\
\hline $01 \ldots$ & 0845 & - & .27 & -- & -- & -- & -- & - \\
\hline$O B \ldots$ & 0830 & -- & .45 & -- & -- & -- & -- & -- \\
\hline $09 \ldots$ & 0835 & .29 & .27 & .01 & .01 & .30 & .28 & .09 \\
\hline $15 \ldots$ & 0840 & -- & .25 & -- & -- & -- & -- & -- \\
\hline $22 \ldots$ & 0845 & - & .29 & -- & $\cdots$ & -- & -- & - \\
\hline $23 \ldots$ & 0830 & .31 & -- & .01 & -- & .32 & -- & .10 \\
\hline $29 \ldots$ & 0830 & $-\infty$ & .32 & -- & -- & -- & -- & -- \\
\hline$A P K$ & & & & & & & & \\
\hline $05 \ldots$ & 0845 & $-\infty$ & $\cdot 38$ & -- & -- & -- & -- & - \\
\hline $12 \ldots$ & 0830 & $-\infty$ & .43 & -- & -- & - & -- & -- \\
\hline $13 \ldots$ & 0830 & .24 & -- & .01 & .01 & .25 & .25 & .10 \\
\hline $19, \ldots$ & $0 \$ 45$ & -- & .34 & -- & - & -- & -- & - \\
\hline $26 \ldots$ & 0845 & -- & .23 & -- & $-\infty$ & -- & - & $=$ \\
\hline $27 \ldots$ & 0835 & .22 & -- & .01 & -- & .23 & -- & .06 \\
\hline MAY & & & & & & & & \\
\hline$n 3 \ldots$ & 0830 & $-\infty$ & .27 & - & -- & -- & -- & - \\
\hline $10 \ldots$ & 0830 & -- & .27 & -- & -- & -- & $=-$ & - \\
\hline $11 \ldots$ & 0830 & .26 & -- & .01 & .01 & .27 & .26 & .02 \\
\hline $17 \ldots$ & 0830 & -- & .23 & -- & -- & -- & -- & - \\
\hline $24 \ldots$ & 0830 & -- & .32 & -- & -- & - & -- & -- \\
\hline $25 \ldots$ & 0830 & .18 & -- & .04 & -- & .22 & -- & .09 \\
\hline JUN & & & & & & & & \\
\hline $01 \ldots$ & 0830 & -- & .23 & -- & $-\infty$ & $-m$ & -- & - \\
\hline $07 \ldots$ & 0830 & -- & .29 & -- & - & -- & $=$ & -- \\
\hline$O B \ldots$ & 0830 & .22 & -- & .02 & .02 & .24 & .23 & .05 \\
\hline $14 \ldots$ & 0830 & -- & .34 & $=-$ & - & -- & -- & - \\
\hline $21 \ldots$ & 0830 & -- & .34 & - & $-\infty$ & -- & - & - \\
\hline $28 \ldots$ & 0830 & - & .29 & -- & -- & -- & -- & - \\
\hline$J U L$ & & & & & & & & \\
\hline $06 \ldots$ & 0830 & -- & .27 & -- & -- & -- & $=-$ & -- \\
\hline $12 \ldots$ & 0830 & -- & .23 & -- & -- & -- & -- & - \\
\hline $13 \ldots$ & 0955 & .15 & -- & .00 & .00 & .15 & .19 & .07 \\
\hline $19 \ldots$ & 0840 & - & .16 & -- & -- & -- & $=-$ & - \\
\hline $26 \ldots$ & 0820 & -- & .25 & -- & -- & $-\infty$ & -- & -- \\
\hline $27 \ldots$ & 0830 & .21 & - & .01 & -- & .22 & -- & .06 \\
\hline AUG & & & & & & & & \\
\hline $02 \ldots$ & 0820 & -- & .20 & -- & -- & -- & -- & -- \\
\hline $09 \ldots$ & 0830 & -- & .16 & -- & -- & 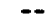 & -- & -- \\
\hline $10 \ldots$ & 0835 & .31 & .20 & .00 & .00 & .31 & .20 & .06 \\
\hline $16 \ldots$ & 0840 & -- & .23 & -- & -- & -- & -- & - \\
\hline $23 \ldots$ & 0830 & -- & .23 & - & -- & -- & -- & - \\
\hline $24 \ldots$ & 0845 & .13 & - & .00 & -- & .13 & -- & .05 \\
\hline $30 \ldots$ & 0840 & -- & .16 & -- & -- & -- & -- & -- \\
\hline SEP & & & & & & & & \\
\hline $07 \ldots$ & 0830 & $=-$ & .18 & -- & -- & -- & $=-$ & -- \\
\hline $13 \ldots$ & 0830 & -- & .25 & -- & -- & $-\infty$ & $-\cdots$ & -- \\
\hline $14 \ldots$ & 0845 & .32 & .28 & .02 & .02 & .34 & .30 & .12 \\
\hline $20 \ldots$ & 0830 & -- & .66 & -- & -- & -- & -- & - \\
\hline $27 \ldots$ & 1320 & -- & .72 & -- & -- & $-\infty$ & -- & -- \\
\hline
\end{tabular}


09522000. COLORADO RIVER AT NORTHERLY INTERNATIONAL BOUNDARY, ABOVE MORELOS DAM, NEAR ANDRADE, CALIF,--CONTINUED

WATER QUALITY DATA, WATER YEAR OCTOBER 1975 TO SEPTEMBER 1976

\begin{tabular}{|c|c|c|c|c|c|c|c|}
\hline DATE & $\begin{array}{l}\text { TOTAL } \\
\text { ORGANIC } \\
\text { NITRD- } \\
\text { GEN } \\
\text { (N) } \\
\text { (MG/L) }\end{array}$ & $\begin{array}{l}\text { TOTAL } \\
\text { KJEL- } \\
\text { DAHL } \\
\text { NITRO- } \\
\text { GEN } \\
\text { (N) } \\
\text { (HG/L) }\end{array}$ & $\begin{array}{l}\text { TOTAL } \\
\text { NITRO- } \\
\text { GEN } \\
\text { (N) } \\
\text { (MG/L) }\end{array}$ & $\begin{array}{l}\text { TOTAL } \\
\text { NITRO- } \\
\text { GEN } \\
\text { (NO3) } \\
\text { (MG/L) }\end{array}$ & $\begin{array}{l}\text { TOTAL } \\
\text { PHOS- } \\
\text { PHORUS } \\
\text { (P) } \\
\text { (MG } / L)\end{array}$ & $\begin{array}{l}\text { DIS- } \\
\text { SOL- } \\
\text { VED- } \\
\text { PHOS- } \\
\text { PHOQUS } \\
\text { (P) } \\
\text { (MG/L) }\end{array}$ & $\begin{array}{l}\text { DIS- } \\
\text { SOLVED } \\
\text { ORTHO. } \\
\text { PHOS- } \\
\text { PHORUS } \\
\text { (P) } \\
\text { (MG/L) }\end{array}$ \\
\hline \multicolumn{8}{|l|}{ UCT } \\
\hline $06 \ldots$ & -- & - & - & - & - & -- & -- \\
\hline $\begin{array}{l}07 \ldots \\
14 \ldots\end{array}$ & .53 & .56 & +75 & $\begin{array}{c}3.3 \\
-2 .\end{array}$ & .08 & $=$ & .04 \\
\hline $21 \ldots$ & .54 & .66 & .85 & 3.8 & .05 & -- & -- \\
\hline \multicolumn{8}{|l|}{ NOV } \\
\hline $\begin{array}{l}03 \ldots \\
11 \ldots \\
17 \ldots \\
24 \ldots\end{array}$ & $\begin{array}{r}.-5 \\
.93 \\
.34\end{array}$ & $1 . \overline{1}$ & $\begin{array}{c}1 .- \\
-79 \\
.79\end{array}$ & $\begin{array}{c}6 . \overline{2} \\
-- \\
3.5\end{array}$ & .0 .10 & .07 & $\begin{array}{r}.06 \\
.05\end{array}$ \\
\hline \multicolumn{8}{|l|}{ DEC } \\
\hline $01 \ldots$ & $=$ & $=$ & $=$ & $=$ & $=$ & 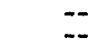 & $=$ \\
\hline $09 .$. & .14 & .29 & .54 & 2.4 & .05 & - & .02 \\
\hline $15 \ldots$ & $m$ & -- & -- & -- & $-\infty$ & -- & $-m$ \\
\hline $22 \ldots$ & -- & -- & -- & - & -- & -- & -- \\
\hline $23 \ldots$ & .22 & .33 & .59 & 2.6 & .06 & -- & .02 \\
\hline$\underset{\text { JAN }}{29} \cdots$ & $\rightarrow$ & -- & -- & -- & - & - & - \\
\hline $05 \ldots$ & -- & -- & -- & - & -- & $=-$ & -- \\
\hline $12 \ldots$ & -- & $=-$ & -- & $=-$ & - & -- & $-\infty$ \\
\hline $13 \ldots$ & .52 & .66 & .90 & 4.0 & .06 & - & .04 \\
\hline $19 \ldots$ & -- & -- & -- & -- & -- & $=$ & -- \\
\hline $26 \ldots$ & -- & -- & $=-$ & $-\infty$ & - & - & -- \\
\hline$\underset{F E B}{27}$ & .97 & 1.1 & 1.5 & 6.4 & .06 & - & $-m$ \\
\hline $02 \ldots$ & -- & -- & $m$ & -- & $=-$ & -- & -- \\
\hline $09 \ldots$ & -- & -- & -- & -- & -- & -- & -- \\
\hline $10 \ldots$ & .81 & .95 & $1 \cdot 3$ & 5.7 & .05 & .04 & .04 \\
\hline $17 \ldots$ & -- & -- & -- & - & -- & -- & -- \\
\hline $23 \ldots$ & $m$ & - & -- & -- & $-\cdots$ & $\infty$ & - \\
\hline $24 \ldots$ & .24 & .29 & .57 & 2.5 & .04 & - & -- \\
\hline \multicolumn{8}{|l|}{ MAP } \\
\hline $01 \ldots$ & $-\infty$ & -- & -- & - & $-\infty$ & - & -- \\
\hline $08 \ldots$ & -- & - & -- & -- & -- & - & -- \\
\hline $09 \ldots$ & .62 & .71 & 1.0 & 4.5 & .07 & - & .02 \\
\hline $15 \ldots$ & -- & -- & -- & -- & $-\infty$ & -- & $\cdots$ \\
\hline $22 \ldots$ & -- & - & $\cdots$ & - & -- & -- & -- \\
\hline $23 \ldots$ & .46 & .56 & .88 & 3.9 & .09 & -- & -- \\
\hline $29 \ldots$ & $-\cdots$ & $-\infty$ & -- & -- & - & -- & -- \\
\hline \multicolumn{8}{|l|}{$A P R$} \\
\hline $05 \ldots$ & -- & -- & -- & - & -- & -- & - \\
\hline $12 \ldots$ & -- & $-m$ & -- & $-\cdots$ & -- & -- & - \\
\hline $13 \ldots$ & .22 & .32 & .57 & 2.5 & .05 & $\cdots$ & .03 \\
\hline $19 \ldots$ & -- & - & -- & - & -- & - & - \\
\hline $26 \ldots$ & - & -- & -- & -- & -- & -- & -- \\
\hline $27 \ldots$ & .62 & .68 & .91 & 4.0 & .06 & $m$ & -- \\
\hline MAY & & & & & & & \\
\hline $03 \ldots$ & -- & -- & $\cdots$ & - & -- & -- & -- \\
\hline $10 \ldots$ & - & -- & -- & -- & - & -- & - \\
\hline $11 \ldots$ & .26 & .28 & .55 & 2.4 & .10 & .05 & .02 \\
\hline $17 \ldots$ & $-\infty$ & -- & $-\infty$ & -- & - & -- & -- \\
\hline $24 \ldots$ & $\cdots$ & -- & -- & - & -- & - & -- \\
\hline $25 \ldots$ & .41 & .50 & .72 & 3.2 & .05 & -- & -- \\
\hline \multicolumn{8}{|l|}{ JUN } \\
\hline $01 \ldots$ & - & -- & -- & - & -- & -- & -- \\
\hline $07 \ldots$ & - & - & -- & - & -- & -- & - \\
\hline $08 \ldots$ & .25 & .30 & .54 & 2.4 & .04 & - & .01 \\
\hline $14 \ldots$ & -- & -- & - & -- & $\rightarrow$ & -- & -- \\
\hline $21 \ldots$ & -- & - & -- & - & - & - & -- \\
\hline $28 \ldots$ & -- & - & -- & - & -- & - & - \\
\hline \multicolumn{8}{|l|}{ JUL } \\
\hline $06 \ldots$ & -- & - & - & -- & -- & - & -- \\
\hline $12 \ldots$ & -- & -- & -- & - & $-\infty$ & -- & -- \\
\hline $13 \ldots$ & .29 & .36 & .51 & 2.3 & .06 & $\cdots$ & .03 \\
\hline $19 \ldots$ & - & -- & -- & -- & -- & $=-$ & -- \\
\hline $26 \ldots$ & -- & - & - & - & -- & $\cdots$ & - \\
\hline $27 \ldots$ & .37 & .43 & .65 & 2.9 & .04 & $m$ & -- \\
\hline AUG & & & & & & & \\
\hline $02 \ldots$ & - & -- & -- & $-\infty$ & $=$ & -- & -- \\
\hline $09 \ldots$ & -- & -- & -- & $=-$ & -- & - & -- \\
\hline $10 \ldots$ & .46 & .52 & .83 & 3.7 & .04 & .02 & .02 \\
\hline $16 \ldots$ & -- & -- & - & - & -- & -- & -- \\
\hline $23 \ldots$ & -- & -- & -- & -- & -- & $=$ & - \\
\hline $24 \ldots$ & .31 & .36 & .49 & 2.2 & .07 & -- & -- \\
\hline $30 \ldots$ & -- & - & - & -- & -- & $=-$ & -- \\
\hline SEP & & & & & & & \\
\hline $07 \ldots$ & -- & -- & -- & -- & -- & -- & -- \\
\hline $13 \ldots$ & -- & $=-$ & - & -- & -- & - & $-\infty$ \\
\hline $14 \ldots$ & .10 & .22 & .56 & 2.5 & .08 & - & .04 \\
\hline $20 \ldots$ & -- & - - & -- & -- & -- & -- & -- \\
\hline $27 \ldots$ & - & -- & $\infty$ & -- & - & -- & $=$ \\
\hline
\end{tabular}


09522000. COLORADO RIVER AT NORTHERLY INTERNATIONAL BOUNDARY, ABOVE MORELOS DAM, NEAR ANDRADE, CALIF..-CONTINUED

W $\triangle$ TER UUALITY DATA, WATER YEAH OCTOBER 1975 TO SEPTEMBER 1976

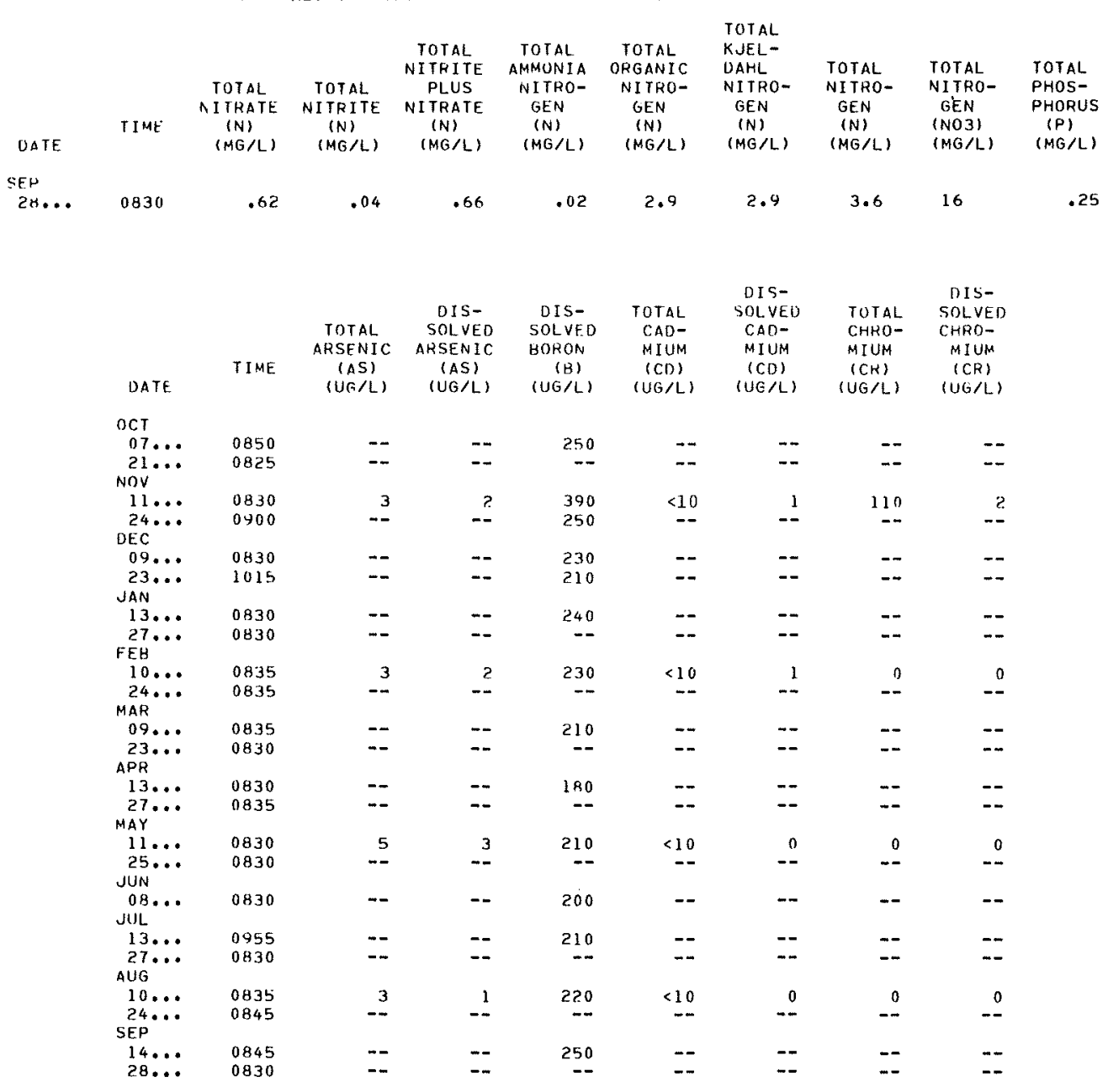


09522000. COLORADO RIVER AT NORTHERLY INTERNATIONAL BOINDARY, ABOVE MORELOS DAM, NEAR ANDRADE, CALIF, --CONTINUED

WATER GUALITY DATA, WATER YEAM OCTURER 1975 TO SEPTEMHER I976

\begin{tabular}{|c|c|c|c|c|c|c|c|c|c|}
\hline UATE & $\begin{array}{l}\text { TOTAL } \\
\text { COBALT } \\
\text { (CU) } \\
\text { (UG/L) }\end{array}$ & $\begin{array}{l}\text { UIS- } \\
\text { SOEVEO } \\
\text { COHALF } \\
\text { (CO) } \\
\text { (UG/L) }\end{array}$ & $\begin{array}{l}\text { TOTAL } \\
\text { COPPER } \\
\text { (CU) } \\
\text { (UG/L) }\end{array}$ & $\begin{array}{l}\text { OIS- } \\
\text { SOLVED } \\
\text { COPPEH } \\
\text { (CU) } \\
\text { (UG/L) }\end{array}$ & $\begin{array}{l}\text { TUTAL } \\
\text { IRON } \\
\text { (FE) } \\
\text { (UG/L) }\end{array}$ & $\begin{array}{l}\text { DIS- } \\
\text { SOLVED } \\
\text { IRON } \\
\text { (FE) } \\
\text { (UG/L) }\end{array}$ & $\begin{array}{l}\text { TOTAL } \\
\text { LEAE } \\
\text { (PA) } \\
(U G / L)\end{array}$ & $\begin{array}{l}\text { DIS- } \\
\text { SOLVEO } \\
\text { LEAO } \\
\text { (PA) } \\
(\cup G / L)\end{array}$ & $\begin{array}{l}\text { TOTAL } \\
\text { MAN- } \\
\text { GANESE } \\
\text { (MN) } \\
\text { (UG/L) }\end{array}$ \\
\hline$\| C T$ & & & & & & & & & \\
\hline $07 \ldots$ & -- & -- & -- & -- & 750 & -- & -- & -- & -- \\
\hline $21 \ldots$ & $=$ & -- & -- & - & 430 & -- & -- & -- & $-\infty$ \\
\hline $11 \ldots$ & $<50$ & 0 & 10 & 5 & 430 & 10 & $<100$ & 4 & 150 \\
\hline $\begin{array}{l}24 \ldots \\
b+c\end{array}$ & -- & - & -- & -- & 500 & -- & -- & -- & -- \\
\hline U9... & -- & -- & -- & - & 170 & -- & -- & - & -- \\
\hline$\underset{\text { JAN }}{23} \cdots$ & -- & $-\infty$ & -- & -- & 290 & $-\infty$ & $\rightarrow$ & -- & -- \\
\hline $13 \ldots$ & -- & -- & -- & - & - & -- & -- & -- & -- \\
\hline FEA & - & -- & -- & -- & 240 & -- & -- & -- & $=-$ \\
\hline $10 \ldots$ & $<50$ & 1 & $<10$ & 1 & 220 & 0 & $<100$ & 1 & 90 \\
\hline${ }_{M A H}^{24} \ldots$ & -- & -- & -- & -- & 340 & -- & -- & -- & -- \\
\hline $09 \ldots$ & -- & -- & $-m$ & -- & 1 & -- & -- & -- & $m$ \\
\hline$\underset{\triangle P R}{23} \cdots$ & -- & -- & -- & -- & 710 & -- & -- & -- & -- \\
\hline $13 \ldots$ & -- & -- & -- & -- & 380 & -- & -- & -- & -- \\
\hline $\begin{array}{r}27 \ldots \\
M A Y\end{array}$ & $=-$ & -- & -- & -- & 660 & -- & -- & -- & -- \\
\hline $11 \ldots$ & $<50$ & $\mathbf{0}$ & 10 & 1 & 870 & 40 & $<100$ & 0 & 210 \\
\hline $25 \ldots$ & -- & -- & -- & -- & 440 & -- & $=-$ & $-\infty$ & -- \\
\hline $\begin{array}{l}08 . . \\
\text { JUL }\end{array}$ & -- & -- & -- & $-\infty$ & 770 & -- & -- & -- & -- \\
\hline $13 \ldots$ & -- & -- & -- & -- & 360 & -- & -- & $-\infty$ & - \\
\hline$\underset{A \cup G}{27} \cdots$ & -- & -- & -- & $\cdots$ & 260 & $-\infty$ & -- & -- & \\
\hline $10 \ldots$ & $<50$ & 0 & $<10$ & 0 & 400 & 20 & $<100$ & 1 & 80 \\
\hline $24 \ldots$ & -- & -- & -- & -- & 340 & -- & $-\infty$ & -- & -- \\
\hline SEP & & & & & & & & & \\
\hline $\begin{array}{l}14 \ldots \\
28, \ldots\end{array}$ & -- & -- & $=-$ & $=$ & $\begin{array}{r}530 \\
3900\end{array}$ & -- & $-\infty$ & -- & $\overline{--}$ \\
\hline
\end{tabular}

\begin{tabular}{|c|c|c|c|c|c|c|c|c|}
\hline DATE & $\begin{array}{l}\text { DIS- } \\
\text { SOLVED } \\
\text { MAN- } \\
\text { GANESE } \\
\text { (MN) } \\
\text { (UG/L) }\end{array}$ & $\begin{array}{c}\text { TOTAL } \\
\text { MERCURY } \\
(H G) \\
(U G / L)\end{array}$ & $\begin{array}{c}\text { DIS- } \\
\text { SOLVED } \\
\text { MERCURY } \\
\text { (HG) } \\
(U G / L)\end{array}$ & $\begin{array}{l}\text { TOTAL } \\
\text { SELE- } \\
\text { NIUM } \\
\text { (SE) } \\
\text { (UG/L) }\end{array}$ & $\begin{array}{l}\text { DIS- } \\
\text { SOLVED } \\
\text { SELE- } \\
\text { NIUM } \\
\text { (SE) } \\
\text { (UG/L) }\end{array}$ & $\begin{array}{l}\text { TOIAL } \\
\text { ZINC } \\
(Z N) \\
(U G / L)\end{array}$ & $\begin{array}{l}\text { DIS- } \\
\text { SOLVED } \\
\text { ZINC } \\
\text { (ZN) } \\
(U G / L)\end{array}$ & $\begin{array}{c}\text { TOOAL } \\
\text { ORGANIC } \\
\text { CARBON } \\
\text { (C) } \\
\text { (MGG })\end{array}$ \\
\hline OCT & & & & & & & & \\
\hline $\begin{array}{l}07 \ldots . \\
21 \ldots\end{array}$ & $\overline{--}$ & $=$ & $=$ & $\because$ & $\bar{z}$ & $=$ & $\because-$ & $\begin{array}{l}3.2 \\
2.7\end{array}$ \\
\hline & & & & & & & & \\
\hline $24 \ldots$ & -- & :- & :- & $-\therefore$ & -3 & 30 & 20 & $\begin{array}{l}6.7 \\
3.6\end{array}$ \\
\hline $09 \ldots$ & -- & $\cdots$ & -- & -- & -- & -- & -- & 3.2 \\
\hline${ }_{\text {JAN }}^{23} \cdots$ & -- & -- & -- & -- & -- & -- & -- & 13 \\
\hline $13 \ldots$ & -- & -- & -- & -- & -- & -- & -- & 3.8 \\
\hline FEB & & & & & & & & \\
\hline $\begin{array}{l}10 \ldots \\
24 \ldots\end{array}$ & 20 & $\because 0$ & $\therefore$ & -- & -3 & 10 & -0 & $\begin{array}{l}3.5 \\
3.5\end{array}$ \\
\hline & -- & & & & & & & \\
\hline $23 \cdots \cdots$ & -- & -- & - & -- & -- & -- & -- & 2.8 \\
\hline $13 \ldots$ & -- & -- & -- & -- & -- & -- & -- & 3.3 \\
\hline$\underset{\text { MAY }}{27}$ & -- & -- & -- & -- & -- & -- & -- & 3.3 \\
\hline${ }_{25}^{11} \ldots$ & 10 & 0 & 0 & 3 & 3 & 0 & 0 & 6.2 \\
\hline JUN & & & & & & & & \\
\hline JUL & 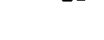 & - & -- & 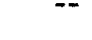 & -- & -- & -- & 3.4 \\
\hline $\begin{array}{l}13 \ldots \\
27 \ldots\end{array}$ & $=$ & $\because$ & $=$ & $=-$ & $=$ & $\because=$ & $\bar{z}$ & $<1.3$ \\
\hline $\begin{array}{l}\text { AUG } \\
10 . . .\end{array}$ & & & & & & & & \\
\hline $\begin{array}{r}240: 0 \\
0\end{array}$ & -- & -1 & $\because-0$ & -- & -- & 20 & -. & $\begin{array}{l}\begin{array}{l}3.5 \\
3.0\end{array} \\
3.0\end{array}$ \\
\hline $14 \ldots$ & & & & & & & & \\
\hline $28 \ldots$ & -- & -- & -- & -- & -- & -- & -- & 7.9 \\
\hline
\end{tabular}

< Actual value is known to be less than the value shown. 
09522000. COLORADO RIVER AT NORTHERLY INTERNATIONAL BOUNDARY, ABOVE MORELOS DAM, NEAR ANDRADE, CALIF,--CONTINUED

WATER UUALITY DATA, WATER YEAK OCTUBER 1975 TO SEPTEMBER 1976

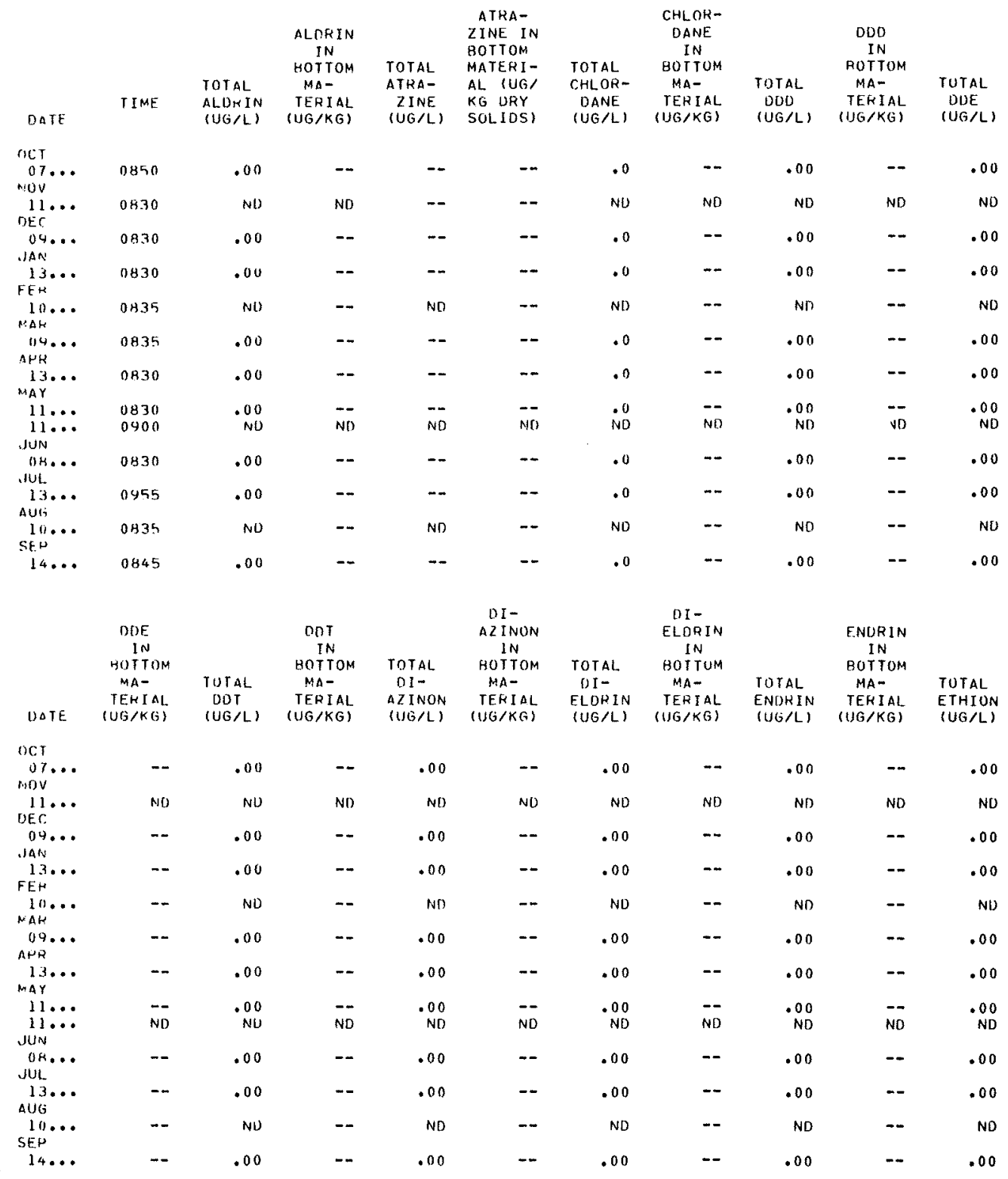


09522000, COLORADO RIVER AT NORTHERLY INTERNATIONAL BOUNDARY, ABOVE MORELOS DAM, NEAR ANDRADE, CALIF.--CONTINUED

WATEK QUALITY DATA, WATER YEAK OCTOBER 1975 TO SEPTEMBER 1976

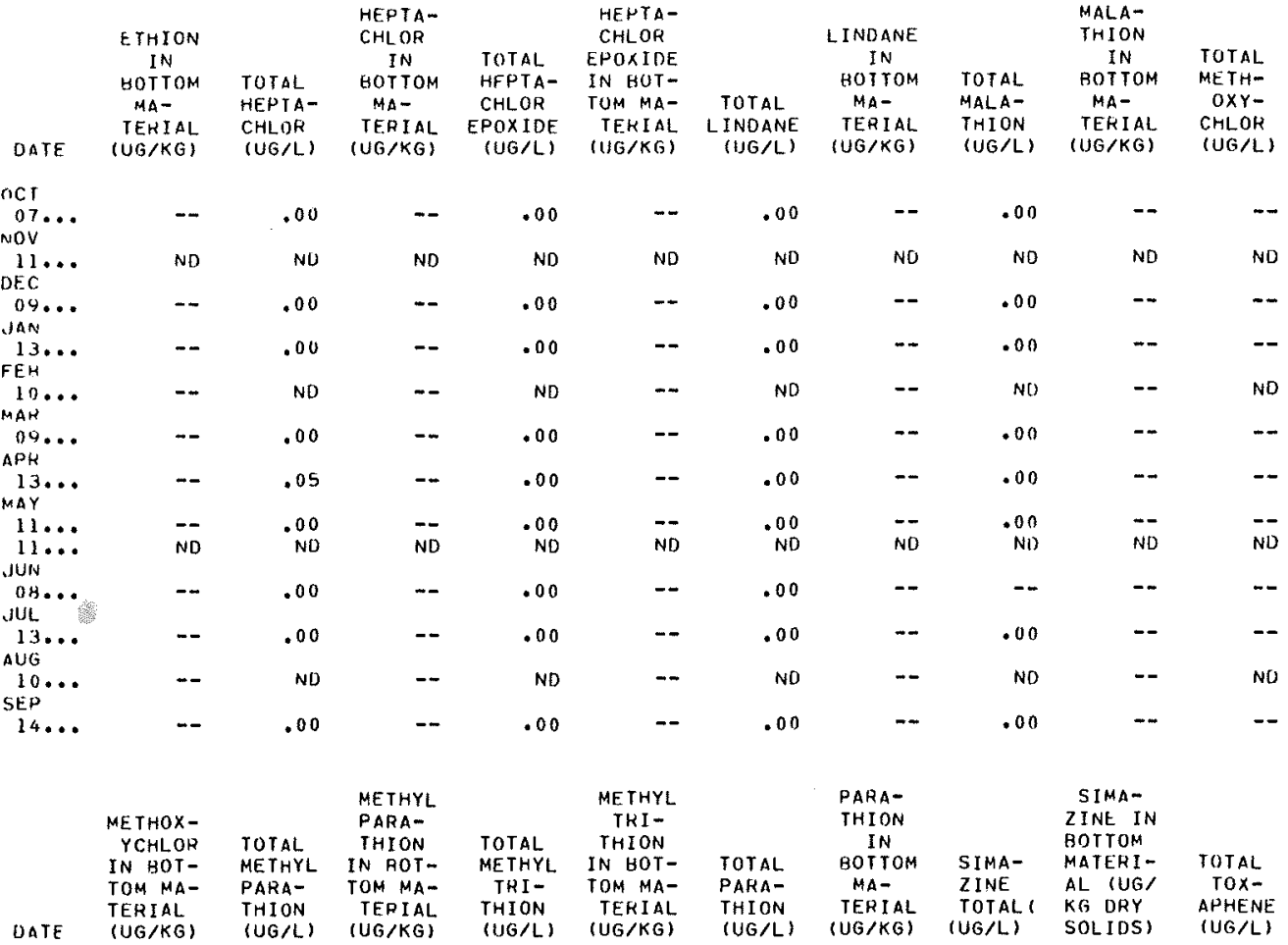

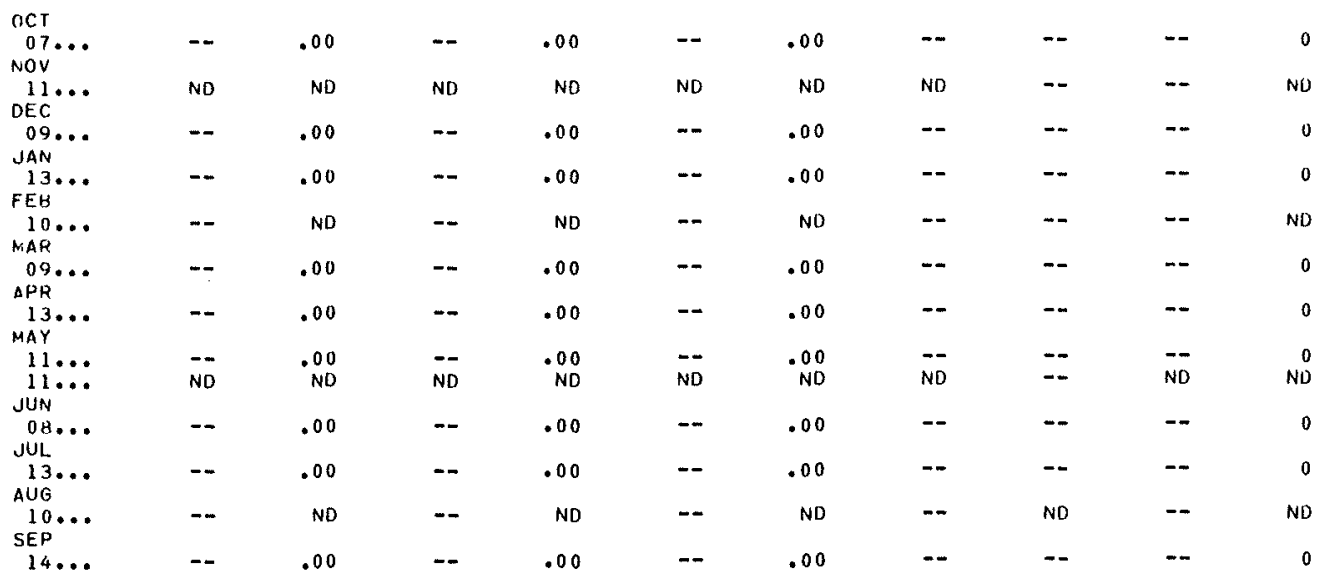

ND Material specifically analyzed for but not detected. 
09522000. COLORADO RIVER AT NORTHERLY INTERNATIONAL, BOUNDARY, ABOVE MDRELOS DAM, NEAR ANDRADE, CALIF.--CONTINUED

WaTER Quality DATA, WATER YEAK OCTOBER 1975 TO SEPTEMBER 1976

\begin{tabular}{|c|c|c|c|c|c|c|c|c|c|c|}
\hline DATE & $\begin{array}{l}\text { TOX- } \\
\text { APHENE } \\
\text { IN } \\
\text { BOTTOM } \\
\text { MA- } \\
\text { TERIAL } \\
\text { (UG/KG) }\end{array}$ & $\begin{array}{l}\text { TOTAL } \\
\text { TRI- } \\
\text { THION } \\
\text { (UG/L) }\end{array}$ & $\begin{array}{l}\text { TRI- } \\
\text { THION } \\
\text { IN } \\
\text { BOTTOM } \\
\text { MA- } \\
\text { TERIAL } \\
\text { (UG/KG) }\end{array}$ & $\begin{array}{l}\text { TOTAL } \\
2,4-D \\
\text { (UG/L) }\end{array}$ & $\begin{array}{c}2,4-0 \\
1 N \\
\text { BOTTOM } \\
\text { MA- } \\
\text { TERIAL } \\
\text { (UG/KG) }\end{array}$ & $\begin{array}{c}\text { TOTAL } \\
2,4,5-T \\
\text { (UG/L) }\end{array}$ & $\begin{array}{c}2,4,5-T \\
\text { IN } \\
\text { BOTTOM } \\
\text { MA- } \\
\text { TERIAL } \\
\text { (UG/KG) }\end{array}$ & $\begin{array}{l}\text { TOTAL } \\
\text { SILVEX } \\
\text { (UG/L) }\end{array}$ & $\begin{array}{l}\text { SILVEX } \\
\text { IN } \\
\text { ROTTOM } \\
\text { MA- } \\
\text { TERIAL } \\
\text { (UG/KG) }\end{array}$ & $\begin{array}{l}\text { TOTAL } \\
\text { PCB } \\
\text { (UG/L) }\end{array}$ \\
\hline $\begin{array}{l}0 \mathrm{CT} \\
07 \ldots\end{array}$ & -- & .00 & -- & .00 & -- & .00 & -- & .00 & -- & .0 \\
\hline $\begin{array}{l}\text { Nov } \\
11 \ldots . .\end{array}$ & ND & ND & ND & .80 & -- & .00 & $\rightarrow$ & .00 & $-\infty$ & .0 \\
\hline OEC & & & & & & & & & & \\
\hline $\begin{array}{l}09 \ldots \\
\text { JAN }\end{array}$ & $\rightarrow$ & .00 & -- & .00 & -- & .00 & -- & .00 & -- & .0 \\
\hline$\underset{F E B}{13} \ldots$ & -- & .00 & -- & .00 & -- & .00 & -- & .00 & -- & .0 \\
\hline${ }_{\text {MAR }}^{10} \ldots$ & -- & NO & -- & NO & -- & ND & -- & ND & -- & .0 \\
\hline$\underset{A P R}{09} \cdot \ldots$ & -- & .00 & $-\infty$ & .00 & - & .00 & $-\infty$ & .00 & $-\infty$ & .0 \\
\hline $\begin{array}{l}13 . \cdots \\
\text { MAY }\end{array}$ & -- & .00 & -- & .00 & -- & .00 & -- & .00 & -- & .0 \\
\hline $11 \ldots$ & - & .00 & -- & .00 & - & .00 & -- & .00 & -- & .0 \\
\hline$\underset{\text { JUN }}{11} \cdots$ & NO & ND & ND & ND & ND & $\mathrm{NO}$ & ND & NO & ND & $=-$ \\
\hline $\begin{array}{l}08 . . . \\
\text { JuL. }\end{array}$ & -- & .00 & -- & .00 & -- & .00 & $-\infty$ & .00 & -- & .0 \\
\hline$\underset{A U G}{13} \ldots$ & -- & .00 & $-\infty$ & .01 & -- & .00 & -- & .00 & -- & .0 \\
\hline$\underset{\operatorname{SEP}}{10 \ldots}$ & $-m$ & NO & -- & ND & -- & ND & -- & ND & -- & .0 \\
\hline $14 \ldots$ & -- & .00 & -- & .31 & -- & .00 & $m$ & .00 & -- & .0 \\
\hline
\end{tabular}

ND Material specifically analyzed for but not detected.

SPECIFIC CONDUCTANCE (MICROMHOS/CM AT 25 DEG. C), WATER YEAR OCTOBER 1975 TO SEPTEMBER 1976 ONCE-DAILY

\begin{tabular}{|c|c|c|c|c|c|c|c|c|c|c|c|c|}
\hline DAY & OCT & NOV & DEC & JAN & FEB & MAR & $A P R$ & MAY & JUN & JUL & $A \cup 6$ & SEP \\
\hline $\begin{array}{l}1 \\
2 \\
3 \\
4 \\
5\end{array}$ & $\begin{array}{l}1610 \\
1700 \\
1640 \\
1620 \\
1630\end{array}$ & $\begin{array}{l}1660 \\
1770 \\
1730 \\
1770 \\
1730\end{array}$ & $\begin{array}{l}1670 \\
1670 \\
1670 \\
1700 \\
1640\end{array}$ & $\begin{array}{l}-150 \\
1650 \\
1650 \\
1690 \\
1580\end{array}$ & $\begin{array}{l}1560 \\
1570 \\
1620 \\
1570 \\
1590\end{array}$ & $\begin{array}{l}1440 \\
1450 \\
1430 \\
1430 \\
1450\end{array}$ & $\begin{array}{l}1460 \\
1390 \\
1390 \\
1390 \\
1380\end{array}$ & $\begin{array}{l}1500 \\
1480 \\
1490 \\
1480 \\
1470\end{array}$ & $\begin{array}{l}1540 \\
1530 \\
1530 \\
1540 \\
1560\end{array}$ & $\begin{array}{l}1470 \\
1510 \\
1570 \\
1540 \\
1520\end{array}$ & $\begin{array}{l}1550 \\
1580 \\
1530 \\
1510 \\
1490\end{array}$ & $\begin{array}{l}1540 \\
1490 \\
1480 \\
1510 \\
1530\end{array}$ \\
\hline $\begin{array}{r}6 \\
7 \\
8 \\
9 \\
10\end{array}$ & $\begin{array}{l}1670 \\
1700 \\
1690 \\
1610 \\
1670\end{array}$ & $\begin{array}{l}1780 \\
1770 \\
1740 \\
1750 \\
1770\end{array}$ & $\begin{array}{l}1630 \\
1560 \\
1610 \\
1590 \\
1580\end{array}$ & $\begin{array}{l}1560 \\
1550 \\
1560 \\
1580 \\
1580\end{array}$ & $\begin{array}{l}1620 \\
1580 \\
1610 \\
1580 \\
1560\end{array}$ & $\begin{array}{l}1450 \\
1480 \\
1380 \\
1470 \\
1440\end{array}$ & $\begin{array}{l}1400 \\
1390 \\
1390 \\
1410 \\
1400\end{array}$ & $\begin{array}{l}1500 \\
1490 \\
1510 \\
1560 \\
1510\end{array}$ & $\begin{array}{l}1510 \\
1540 \\
1550 \\
1540 \\
1550\end{array}$ & $\begin{array}{l}1480 \\
1470 \\
1480 \\
1490 \\
1470\end{array}$ & $\begin{array}{l}1490 \\
1510 \\
1470 \\
1470 \\
1450\end{array}$ & $\begin{array}{l}1530 \\
1470 \\
1490 \\
1410 \\
1500\end{array}$ \\
\hline $\begin{array}{l}11 \\
12 \\
13 \\
14 \\
15\end{array}$ & $\begin{array}{l}1700 \\
1690 \\
1670 \\
1640 \\
1630\end{array}$ & $\begin{array}{l}1740 \\
1730 \\
1730 \\
1690 \\
1700\end{array}$ & $\begin{array}{l}1580 \\
1590 \\
1570 \\
1600 \\
1590\end{array}$ & $\begin{array}{l}1600 \\
1640 \\
1650 \\
1640 \\
1670\end{array}$ & $\begin{array}{l}1530 \\
1560 \\
1590 \\
1600 \\
1680\end{array}$ & $\begin{array}{l}1440 \\
1460 \\
1480 \\
1530 \\
1500\end{array}$ & $\begin{array}{l}1430 \\
1390 \\
1390 \\
1420 \\
1300\end{array}$ & $\begin{array}{l}1550 \\
1530 \\
1540 \\
1500 \\
1520\end{array}$ & $\begin{array}{l}1520 \\
1510 \\
1540 \\
1540 \\
1510\end{array}$ & $\begin{array}{l}1500 \\
1440 \\
1450 \\
1470 \\
1490\end{array}$ & $\begin{array}{l}1440 \\
1450 \\
1460 \\
1470 \\
1480\end{array}$ & $\begin{array}{l}1390 \\
1420 \\
1520 \\
1620 \\
1680\end{array}$ \\
\hline $\begin{array}{l}16 \\
17 \\
18 \\
19 \\
20\end{array}$ & $\begin{array}{l}1630 \\
1640 \\
1670 \\
1670 \\
1640\end{array}$ & $\begin{array}{l}1730 \\
1720 \\
1690 \\
1600 \\
1600\end{array}$ & $\begin{array}{l}1600 \\
1570 \\
1530 \\
1550 \\
1530\end{array}$ & $\begin{array}{l}1690 \\
1700 \\
1740 \\
1720 \\
1670\end{array}$ & $\begin{array}{l}1710 \\
1740 \\
1720 \\
1770 \\
1820\end{array}$ & $\begin{array}{l}1460 \\
1470 \\
1430 \\
1430 \\
1410\end{array}$ & $\begin{array}{l}1310 \\
1380 \\
1440 \\
1500 \\
1540\end{array}$ & $\begin{array}{l}1510 \\
1520 \\
1560 \\
1610 \\
1600\end{array}$ & $\begin{array}{l}1480 \\
1490 \\
1500 \\
1510 \\
1530\end{array}$ & $\begin{array}{l}1500 \\
1510 \\
1530 \\
1480 \\
1480\end{array}$ & $\begin{array}{l}1480 \\
1480 \\
1460 \\
1470 \\
1460\end{array}$ & $\begin{array}{l}1730 \\
1800 \\
1730 \\
1720 \\
1730\end{array}$ \\
\hline $\begin{array}{l}21 \\
22 \\
23 \\
24 \\
25\end{array}$ & $\begin{array}{l}1640 \\
1590 \\
1580 \\
1600 \\
1560\end{array}$ & $\begin{array}{l}1590 \\
1560 \\
1560 \\
1600 \\
1570\end{array}$ & $\begin{array}{r}1530 \\
1530 \\
1520 \\
1530 \\
-\end{array}$ & $\begin{array}{l}1650 \\
1660 \\
1630 \\
1600 \\
1620\end{array}$ & $\begin{array}{l}1780 \\
1770 \\
1720 \\
1590 \\
1560\end{array}$ & $\begin{array}{l}1430 \\
1410 \\
1410 \\
1400 \\
1430\end{array}$ & $\begin{array}{l}1510 \\
1490 \\
1490 \\
1460 \\
1450\end{array}$ & $\begin{array}{l}1580 \\
1650 \\
1600 \\
1560 \\
1490\end{array}$ & $\begin{array}{l}1520 \\
1520 \\
1510 \\
1500 \\
1500\end{array}$ & $\begin{array}{l}1480 \\
1500 \\
1510 \\
1510 \\
1500\end{array}$ & $\begin{array}{l}1460 \\
1450 \\
1440 \\
1430 \\
1430\end{array}$ & $\begin{array}{l}1680 \\
1640 \\
1590 \\
1460 \\
1270\end{array}$ \\
\hline $\begin{array}{l}26 \\
27 \\
28 \\
29 \\
30 \\
31\end{array}$ & $\begin{array}{l}1670 \\
1620 \\
1620 \\
1600 \\
1600 \\
1610\end{array}$ & $\begin{array}{c}1570 \\
1610 \\
1630 \\
1700 \\
1640 \\
=-0\end{array}$ & $\begin{array}{l}1610 \\
1650 \\
1540 \\
1530 \\
1510 \\
1520\end{array}$ & $\begin{array}{l}1630 \\
1590 \\
1570 \\
1570 \\
1590 \\
1560\end{array}$ & $\begin{array}{r}1480 \\
1440 \\
1450 \\
1430 \\
-- \\
---\end{array}$ & $\begin{array}{l}1420 \\
1410 \\
1410 \\
1400 \\
1390 \\
1400\end{array}$ & $\begin{array}{r}1450 \\
1470 \\
1470 \\
1450 \\
1470 \\
\end{array}$ & $\begin{array}{l}1540 \\
1530 \\
1540 \\
1580 \\
1550 \\
1550\end{array}$ & $\begin{array}{c}1540 \\
1550 \\
1550 \\
1540 \\
1490 \\
-\end{array}$ & $\begin{array}{l}1460 \\
1460 \\
1470 \\
1460 \\
1500 \\
1540\end{array}$ & $\begin{array}{l}1430 \\
1450 \\
1480 \\
1490 \\
1460 \\
1470\end{array}$ & $\begin{array}{r}1240 \\
1020 \\
1260 \\
1450 \\
1550 \\
\end{array}$ \\
\hline MEAN & 1640 & 1680 & 1580 & 1630 & 1610 & 1440 & 1430 & 1540 & 1520 & 1490 & 1470 & 1520 \\
\hline
\end{tabular}

YEAR

MAX 1820

MIN

1020

MEAN

1550 
09522000, COLORADO RIVER AT NORTIERLY INTERNATIONAL BOUNDARY,

ABOVE MORELOS DAN, NEAR ANDRADE, CALIF.--CONTINUED

QUALITATIVE AND ASSOCIATED QUANTITATIVE ANALYSES OF BIOLOGICAL DATA, WATER YEAR OCTOBER 1975 TO SEPTEMBER I976 PERI PHYTON

\begin{tabular}{|c|c|c|c|c|c|c|c|}
\hline Date & $\begin{array}{c}\text { Length of exposure } \\
\text { (days) }\end{array}$ & $\begin{array}{l}\text { Biomass } \\
\text { Dry weight }\end{array}$ & $\begin{array}{l}\left(\mathrm{g} / \mathrm{m}^{2}\right) \\
\text { Ash weight }\end{array}$ & $\begin{array}{c}\text { Chlorophyl1 } \\
\text { a } \\
\left(\mathrm{mg} / \mathrm{m}^{2}\right)\end{array}$ & $\begin{array}{c}\text { Chlorophyl1 } \\
\mathrm{b} \\
\left(\mathrm{mg} / \mathrm{m}^{2}\right)\end{array}$ & $\begin{array}{l}\text { Biomass } \\
\text { pigment } \\
\text { ratio }\end{array}$ & $\begin{array}{l}\text { Sampling } \\
\text { method }\end{array}$ \\
\hline Nov. 11 & 35 & 4.90 & 2.80 & 29.0 & 5.80 & 72 & $\begin{array}{l}\text { Polyethylene } \\
\text { strip }\end{array}$ \\
\hline Feb. 10 & 28 & 8.30 & 3.50 & 16.0 & .800 & 300 & $\begin{array}{c}\text { Polyethylene } \\
\text { strip }\end{array}$ \\
\hline May & 28 & 55.8 & 45.7 & 1.34 & .359 & 7500 & $\begin{array}{c}\text { Polyethylene } \\
\text { strip }\end{array}$ \\
\hline Sept. 14 & 35 & 19.5 & 15.6 & 40.6 & 4.48 & 96 & $\begin{array}{c}\text { Polyethylene } \\
\text { strip }\end{array}$ \\
\hline
\end{tabular}

QUALITATIVE AND ASSOCIATED QUANTITATIVE ANAEYSES OF BIOLOGICAL DATA, WATER YEARS OCTOBER 1974 TO SEPTEMBER 1976 OCT. 9,1974

0830 HOURS

IDENTIFICATION OF PHYTOPLANKION

8.300 CELLS/ML

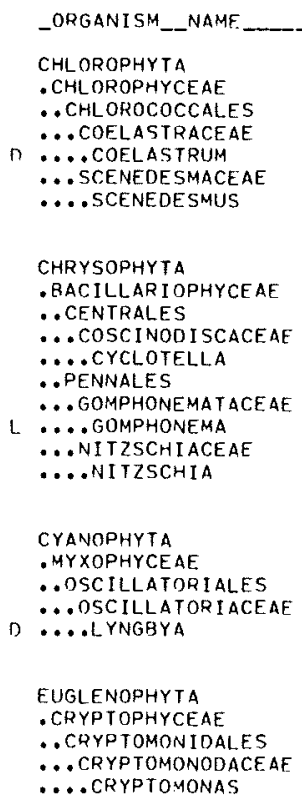

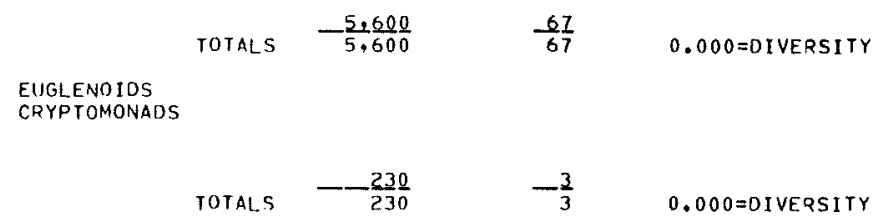

NOTE: D - DOMINANT ORGANISM; GREATER OR ENUAL TO 15* L - LESS THEN ID: MAY NOT HAVE BEEN ACTUALLY COUNTED 
09522000. COLORADO RIVER AT NORTHERLY INTERNATIONAL BOUNDARY,

ABOVE MORELOS DAM, NEAR ANDRADE, CALIF,--CONTINUED

QUALITATIVE AND ASSOCIATED QUANTITATIVE ANALYSES OF BIOLOGICAL DATA, WATER YEARS OCTOBER 1974 TO SEPTEMBER 1976

Nov. 5,1974

0815 HOURS

IDENTIFICATION OF PHYTOPLANKTON

$11,000 \mathrm{CELLS} / \mathrm{ML}$

_ORGANISM_NAME

CHLOROPHYTA

- CHL OROPHYCEAE

. CHLOROCOCCALES

... SCENEDESMACEAE

.... SCENEDESMUS

CHRYSOPHYTA

- bacillar I ophyceae

- CENTRALES

... COSC INODISCACEAE

D ..... CYCLOTELLA

D.....MElosira

\#PENANALES

. NAviculaceae

....NAVicula

... Nitzschiaceae

.... NITZSCHIA

\section{CYANOPHYTA}

- MYXOPHYCEAE

. OSCILLaturi ales

... OSCILlatoriaceaf.

D.... L YNGGYYa
_COMMON_NAME

GPEEN ALGAE

TOTALS

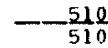

DIATOMS

CENTRIC

PENNATE
NAVICULOID

NAVICULOID

TOTALS

BLUE-GREEN ALGAE

FILAMENTOUS

TOTALS $\quad-\frac{2,100}{2,100} \quad \frac{19}{19} \quad 0.000=$ DIVERSITY

NOTE: D - DOMINANT ORGANISM: GREATER OR EQUAL TO 15\% 
09522000, COLORADO RIVER AT NORTHERLY INTERNATIONAL BOINDARY,

ABOVE MORELOS DAM, NEAR ANDRADE, CALIF.--CONTINUED

QUALITATIVE AND ASSOCIATED QUANTITATIVE ANALYSES OF BIOLOGICAL DATA, WATER YEARS OCTOBER 1974 TO SEPIEMBER 1976

$$
\begin{gathered}
\text { DF.C. } \\
\text { OB } 30 \text { HOURS }
\end{gathered}
$$

IDENTIFICATION OF PHYTOPLANKTON

6,600 CELLS/ML

_ORGANISM_NAME

CHLOROPHYTA

- CHLOROPHYCEAE

. vol vocalf.s

... CHL AMYDOMONAdACEAE

.... CHLAMYDOMONAS

CHRYSOPHYTA

- BACILLAR I OPHYCEAE

- CENTRALES

@ CENTRALES

O... COSCINODISCUS

0 .... MELOSIRA

. PENNALES

...Fragilariaceae

... SYNEERA

... Naviculaceae

. . NAVI CULA

... PInNul ar I a

... NI IzSCHIACEAE

.... NITZSCHIA

CYANOPHYTA

- MYXOPHYCEAE

. OSCILla AORI ILES

.. OSCILlatoriaceae

D .... L L YNGaYa

... oscillatmria

EUGLENOPHYTA

- EUGLENOPHYCEAE

.. EUGlenal.es

.. Euglenaceae

... Euglena
_COMMON__NAME

CELLS/ML

GREEN ALGAE

TOTALS

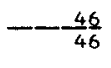

DIATOMS

CENTRIC

PENNATE

NAVICULOIO

1.900

\begin{tabular}{|c|c|c|}
\hline & 140 & 2 \\
\hline & $\begin{array}{r}180 \\
46\end{array}$ & $\begin{array}{l}3 \\
1\end{array}$ \\
\hline TOTALS & $-\frac{91}{600}$ & $\frac{1}{69}$ \\
\hline
\end{tabular}

1,900
2,200

BLUE-GREEN ALGAE

FILAMENTOISS

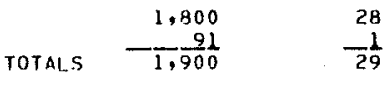

$0.276=0 I V E R S I T Y$

EUGLENOIOS

TOTALS

$-\frac{46}{46}$

$-\frac{1}{1}$

$0.000=0$ I VERS ITY

NOTE: 0 - DOMINANT ORGANISM: GREATER OR EQUAL TO 15\%

JAN. 7, 1975

0855 HOURS

IDENTIFICATION OF PHYTOPLANKTON

500 CELLS/ML

ORGANISM NAME

_COMMON__NAME

CELLS/ML.

PER_CENT

CHRYSOPHYTA

- BACILLARI OPHYCEAE

-. CENTRALES

. . coscindo Iscaceae

D :... Cyclotella

. PENNALES

... ACHNANTHACEAE

... coccone IS

... CYMBELlaceaE

... CYMBELLACEA

.... AMPHORPHONEMATACEAE

.... gOMPHONEMa

... NAVI CULACEAE

D....navicula

... NItZsChIAceae

n .... NITZSCHIA
DIATOMS

CENTRIC

PENNATE

110

22

NAVICULOID

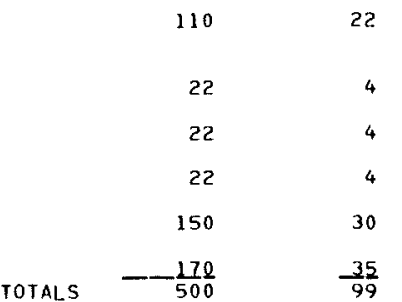

NOTE: D - DOMINANT ORGANISM: GREATER OR EQUAL TO 15\% 
09522000, COLORADO RIVER AT NORTHERLY INTERNATIONAL BOUNDARY, ABOVE MORELOS DAM, NEAR ANDRADE, CALTF.--CONTINUED

QUALITATIVE AND ASSOCIATED QUANTITATIVE ANALYSES OF BIOLOGICAL DATA, WATER YEARS OCTOBER 1974 TO SEPTEMBER 1976

FEB. 11,1975

0900 HOURS

IDENTIFICATION OF PHYTOPLANKTON

2,600 CELLS/ML

_ORGANISM_NAME

_COMMON__NAME

CELLS/ML

PER_CENT

CHLOROPHYTA

GREEN ALGAE

- CHLOROPHYCEAE

-. CHL orococcales

... OOCYSTACEAE

....TETRAEDRON

... SCENEDESMACFAF

.... SCENEDESMus

$\because$ VOL VOCALES

$\because$ CHLAMYDOMONADACEAE

.... CHL amyoOmonas

CHRYSOPHYTA

-BACILLARIOPHYCEAE

- PEENNALES

...Fragilariaceae

.....H.ARCUS

- CENTRALES

... coscinodiscace AF

..... CYCLOTELLA

....MELOSIRA

. PENNALES

.. ACHNANTHACEAE

... coccone 1 S

... cymbel Laceae

.... AMphora

...ot atomaceae

.... DI ATOMa

...FRAG ILARI ACEAE

\#.. SYNEDRA

... Navicul aceaf

... Navicula

.. NIT ZSCHIACEaf

... . HantzSchia

... NITZSCHIA

TOTALS

20

120

5

CYANOPHYTA

- MYXOPHYCEAE

. Oscilla tori ales

\#0SCILLATORI ALES

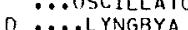

n .... oscillatoria

DIATOMS

PENNATE

CENTRIC

1

$\begin{array}{rrr}200 & 8 \\ 61 & 2\end{array}$

PENNATE

412

20

$20 \quad 1$

NAVICULOIO

100

4

160

$\begin{array}{rr}20 & \frac{310}{960} \\ \text { TOTALS } & -\frac{1}{38}\end{array}$

$2.700=$ DIVERSITY

BLUE-GREEN ALGAE

FILAMENTOUS

\begin{tabular}{|c|c|c|c|}
\hline & $\begin{array}{r}610 \\
820 \\
\end{array}$ & $\begin{array}{l}24 \\
32 \\
\end{array}$ & \\
\hline TOTALS & 1,400 & 56 & $0.985=$ DIVEQSITY \\
\hline
\end{tabular}

NOTE: D - DOMINANT ORGANISM; GREATER OR EQUAL TO $15 \%$ 
09522000. COLORADO RIVER AT NORTHERLY INTERNATIONAL BOUNDARY,

ABOVE MORELOS DAM, NEAR ANDRADE, CALIF, -CONTINUED

QUALITATIVE AND ASSOCIATED QUANTITATIVE ANALYSES OF BIOLOGICAL DATA, WATER YEARS OCTOBER 1974 TO SEPTEMBER 1976

MAR, 11,1975

0000 HOURS

IDFNTIFICATION OF PHYTOPLANKTON

5,900 CELLS/ML

_ORGANISM NAME

CHLOROPHYTA

- CHL OROPHYCEAE

-. Chlorococcales

... OOCYSTACFAe

... ANK ISTRODESMUS

CHRYSOPHYTA

- BAC I LLAR I OPHYCEAF

.. PENNALES

...FUnOTI ACEAE

.... Eunotia

... Naviculaceae

.... Navi CULA

.... Ne IDIUM

... NITZSCHIACEAE

....NIIZSCHIA

CYANOPHYTA

- MYXOPHYCEAE

CHROOCOCCALES

... Chroococcaceae

... ANACYSTIS

. Oscillatoriales

.. OSCILla tori aCEAE

D . . oscillatoria
_COMMON_NAME.

GREEN ALGAE

TOTALS

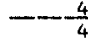

DIATOMS

PENNATE

NAVICULOID

86
130
43
TOTALS - $-\frac{86}{340}$

BLUE-GREEN ALGAE

COCCOID

FILAMENTOUS

43

TOTALS $-\frac{5,400}{5,400}$
PER_CENT

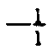

$0.000=$ DIVERS I TY

1

2

$-\frac{1}{5}$

$1.906=$ DIVERSITY

NOTE: D - DOMINANT ORGANISM; GREATER OR EQUAL TO 15\%

APR, 8,1975

0945 HOURS

IDENTIFICATION OF PHYTOPLANKTON

$880 \mathrm{CELLS} / \mathrm{ML}$

_ORGANISM _. NAME

COMMON__NAME

CELLS/ML

PER_CENT

CHRYSOPHYTA

- BACILLAR I aphyceae

. CENTRALES

.. coscinodiscaceae

0 .... CYCLOTELLA

D .... MELOSIRA

$\because$ PENNALES

$\because$ A ACHNANTHACEAE

$\because$... COCCONEIS

. . Fragilariaceae

... ASTER I ONELLA

—. GOMPHONEMATACEAE

... gOMPhONEMa

$\because$ NAVICULACEAE

... AMPHIPRORA

.... DIPLONEIS

$0 \because$.. DIPLIONE I CULA

@. NITZSCHIACEAE

@... NITZSCHIA
DIATOMS

CENTRIC

PENNATE

\begin{tabular}{rrr}
37 & 4 \\
110 & 12 \\
NAVICULOID & 73 & 8 \\
18 & 2 \\
18 & 2 \\
150 & 17 \\
& & 18 \\
\hline & TOTALS & $-\frac{2}{99}$
\end{tabular}

$0.067=$ DIVERS I TY

NOTE: D - DOMINANT ORGANISM 
09522000. COLORADO RIVER AT NORTHERLY INTERNATIONAL BOUNDARY,

ABOVE MORELOS DAM, NEAR ANDRADE, CALIF, --CONTINUED

QUALITATIVE AND ASSOCIATED QUANTITATIVE ANALYSES OF BIOLOGICAL DATA, WATER YEARS OCTOBER 1974 TO SEPTEMBER 1976

MAY 6,1975

0805 HOURS

IDENTIFICATION OF PHYTOPLANKTON

$1,600 \mathrm{CELLS/ML}$

_ORGANISM_NAME

CHLOROPHYTA

- CHLOROPHYCEAE

. Chlorococcales

.. OOCYSTACEAE

... ANKISTRODE SMUS

... SCENEDESMACEAE

. . scenEdesmus

- TFTRASPORALES

..PALMELLACEAE

.... GLOEOCYSTIS

CHRYSOPHYTA

- BAC I LLAR I OPHYCEAE

- CENTRales

. COSCINODISCACEAE

... coscinodiscus

D .... CYCLOTELLA

D.... MELOSIRA

- PENival

. Achnanthaceae

... ACHNANTHES

... CYMBELLACEAE

... cymbella

.. DI L tomaceae

... D Ia toma

. . NAVICULACEAE

... CALONEIS

... Navicula

. . NITZSCHIACEAe

.... NITZSCHIA

CYANOPHYTA

- MYXOPHYCEAE

. OSC ILLATORIALES

. oscillatoriaceae

.... PhormidIUM
_COMMON_N NAME

CELLS/ML

GREEN ALGAE

$\begin{array}{rr}42 & 3 \\ 42 & 3 \\ \text { TOTALS }-\frac{21}{100} & -\frac{1}{7}\end{array}$

$1.522=0$ IVERSI TY

DI ATOMS

CENTRIC

PENNATE

$\begin{array}{rr}21 & 1 \\ 710 & 46 \\ 270 & 18\end{array}$

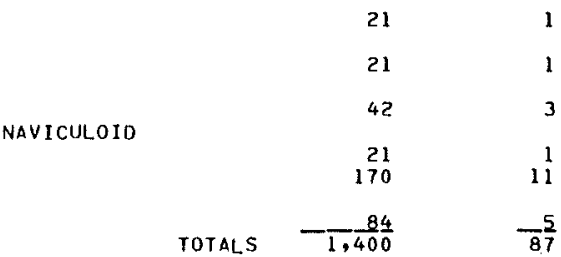

BLUE-GREEN ALGAE

FILAMENTOUS

TOTALS $-\frac{84}{84} \quad-\frac{5}{5} \quad 0.000=$ DIVERSITY

NOTE: D - DOMINANT ORGANISM; GREATER OR EQUAL TO 15\% 
09522000. COLORADO RIVER AT NORTHERLY INTERNATIONAL BOUNDARY, ABOVE MORELOS DAM, NEAR ANDRADE, CALIF..-CONTINUED

QUALITATIVE AND ASSOCIATED QUANTITATIVE ANALYSES OF BIOLOGICAL DATA, WATER YEARS OCTOBER 1974 TO SEPTEMBER 1976

JUNE 10,1975

0830 HOURS

IDENTIF ICATION OF PHYTOPLANKTON

4,200 CELLS/ML

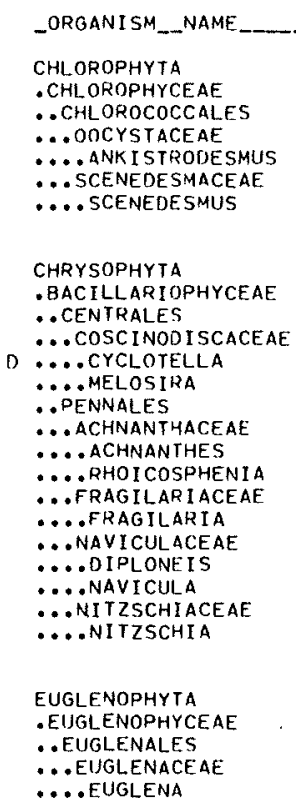

TOTALS $-\frac{100}{100}$

$100 \quad 3$

NAVICULOID

210

5

$\begin{array}{ll}100 & 3 \\ 310 & 8\end{array}$

TOTALS $-\frac{420}{3.400} \quad \frac{10}{85}$

EUGLENOIOS

$-\frac{100}{100} \quad-\frac{3}{3} \quad 0.000=$ DIVERSITY

NOTE: D - DOMINANT ORGANISMI GREATER OR EQUAL TO 15\% 
09522000. COLORADO RIVER AT NORTHERLY INTERNATIONAL BOUNDARY, ABOVE MORELOS DAM, NEAR ANDRADE, CALIF.--CONTINUED

QUALITATIVE AND ASSOCIATED QUANTITATIVE ANALYSES OF BIOLOGICAL DATA, WATER YEARS OCTOBER 1974 TO SEPTEMBER 1976

OCT. 7, 1975

0850 HOURS

IDENTIFICATION OF PHYTOPLANKTON

$13,000 \mathrm{CELLS} / \mathrm{ML}$

_ORGANISM_.NAME

CHLOROPHYTA

- CHLOROPHYCEAE

. CHL orococcales

... CHARACIACEAE

.... SCHROEDER I A

... OOCYSTACEAe

.... DICTYOSPHAER IUM

.... SELENASTRUM

... TETRAEDRON

.. SCENEDESMACEAE

... CPUCIgENI A

.... SCENEDESMUS

.. VOL VOCALES

... CHLAMYDOMONADACEAE

.... CHL AMYDOMONAS

CHRYSOPHYTA

- BACILLARIOPHYCEAE

-. CENTRALES

.. coscinod I SCACEAE

... . Cyclotella

D.... MELosiga

..PENNALES

... ACHNANTHACEAE

... COCCONE IS

... CyMBELLACEAE

.... AMPHORA

.... crmbella

.. Fragilariaceae

... Fragilaria

...gomphonemataceae

... gOMPhonema

... Nav I culaceae

L .... GYROSIGMA

... Navi cula

... NI TZSCHIACEAE

.... NITZSCHIA

- CHRYSOPHYCEAE

.. CHRYSOMONADALES

... OChROMONADACEAE

.... OCHROMONAS

CYANOPHYTA

- MYXOPHYCEAE

-. chroococcales

.. CHROOCOCCACEAE

... A Agmenellum

\# osc illatoriales

\#. OSC ILLATORIACEAE

$0 \because$ oscillatoria
_COMMON_NAME

CELLS/ML

GREEN ALGAE

$\begin{array}{rr}100 & 1 \\ 1,200 & 10 \\ 100 & 1 \\ 100 & 1 \\ 420 & 3 \\ 210 & 2\end{array}$

TOTALS

$-\frac{520}{2,700}$

$-\frac{4}{22}$

$2.215=$ DIVERSITY

DIATOMS

CENTRIC

PENNATE

1,100

2,000

9

210

210

620

210

100

620

rotALS

$-\frac{12100}{6,200}$

$2.676=$ D I VERS ITY

YELLOW-BROWN ALGAE

TOTALS $-\frac{100}{100}$

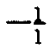

$0.000=0$ I VERS I TY

BLUE-GREEN ALGAE

coccolo

F ILAMENTOUS

1,700

13

TOTALS $-\frac{2,300}{3,900} \quad \frac{18}{31}$

$0.982=0$ IVERSI TY

NOTE: D - DOMINANT ORGANISM: GREATER OR EQUAL TO $15 \%$

L - LESS THEN 1\%; MAY NOT have BEEN ACTUALly COUNTED 
09522000, COLORADO RIVER AT NORTHERLY INIERNATIONAL BOUNDARY,

ABOVE MORELOS DAM, NEAR ANDRADE, CALIF.--CONTINUED

QUALITATIVE AND ASSOCIATED QUANTITATIVE ANALYSES OF BIOLOGICAL DATA, WATER YEARS OCTOBER 1974 TO SEPTEMBER 1976

NOV. 11,1975

0830 HOURS

IDENTIFICATION OF PHYTOPLANKTON

$3,600 \mathrm{CELLS} / \mathrm{ML}$

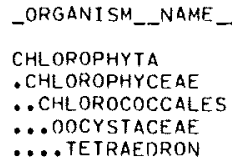

_COMMON__NAME CELLS/ML

PER_CENT

GREEN ALGAE

TOTALS

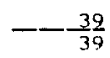

DIATOHS

CFNTRIC

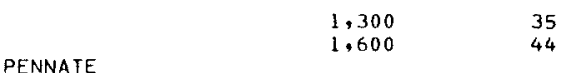

NAVICULOID

$\begin{array}{rrr} & 77 & 2 \\ & 39 & 1 \\ 230 & 6 \\ \text { TOTALS } & -\frac{77}{3,300} & -\frac{2}{90}\end{array}$

BLUE-GREEN ALGAE

FILAMENTOUS

TOTALS
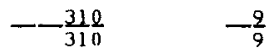

$0.000=D I V E R S I T Y$

NOTE: D - DOMINANT ORGANISM: GREATER OR EQUAL TO $15 \%$

DEC. 9, 1975

0830 HOURS

IOENTIFICATION OF PHYTOPLANKTON

$860 \mathrm{CELLS} / \mathrm{ML}$

ORGANISM NAME

CHLOROPHYTA

-CHLOROPHYCEAE

. Volvocales

... CHL AMYDOMONADACEAE

.... CHLAMYDOMONAS

CHRYSOPHYTA

- BAC ILLAR I OPHYCEAE

. CENTRALES

.. cosc inod I SCACEAe

.... cyclotella

D .... MELOSIRA

.. PENNALES

... ACHNANTHACEAE

... COCCONE IS

$\because$ CYMBELLACEAE

... AMPHORA

...Fragilariaceae

L....FRAGILARIA

... Naviculaceae

.... AMPHIPRORA

D.... NAVICULA

... StauRone Is

... NITZSCHIACEAE

@...n Nitzschia

... Sirrirellaceae

.... SuRtrella
_COMMON NAME

GREEN ALGAE

TOTALS

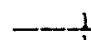

DIATOMS

CENTRIC

PENNATE

$\begin{array}{rl}89 & 10 \\ 390 & 45\end{array}$

$\begin{array}{rrr}15 & 2 \\ \text { NAVICULOID } & 15 & 2 \\ & 15 & 0 \\ 150 & 2 \\ 15 & 17 \\ 150 & 2 \\ & & 17 \\ & \text { TOTALS } & -\frac{15}{95}\end{array}$

$0.000=0$ IVERSITY

$1.637=$ DIVERS ITY 
09522000. COLORADO RIVER AT NORTHERL,Y INTERNATIONAL BOUNDARY, ABOVE MORELOS DAM, NEAR ANDRADE, CALIF.--CONTINUED

QUALITATIVE AND ASSOCIATED QUANTITATIVE ANALYSES OF BIOLOGICAL DATA, WATER YEARS OCTOBER 1974 TO SEPTEMBER 1976

$$
\begin{gathered}
\text { JAN } 13,1976 \\
0830 \text { HOURS }
\end{gathered}
$$

IDENTIFICATION DF PHYTOPLANKTON

$$
1.200 \text { CELLS/ML }
$$

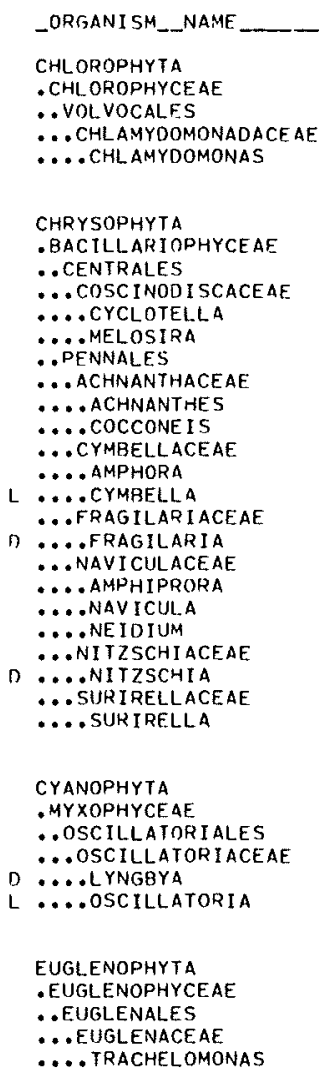

CHRYSOPHYTA

- BAC TLLARIOPHYCEAE

. CENTRALES

$\because$ COSCINODISCACEAE

.... CYCLOTELLA

... MEL osira

. PENNALE

... ACHNANTHACEAE

.... ACHNANTHES

... coccone is

... CYMBELLACEAE

.... AMPHORA

.... CYMrella

@. Fragilariaceae

0...FragILARIa

... Navi culaceae

.... AMPHIPRORA

... NAV ICULAa

.... NEIDIUM

... NITZSCHIACEAE

.... NITZSChIa

... SURR I RELL ACEAE

... surtrella

CYANOPHYTA

- MYXOPHYCEAE

. OSCILlatoriales

. oscillator I ACEAE

... L YNGGYa

L ... OSCILLATORIA

EUGLENOPHYTA

- EUGLENOPHYCEAE

.. Euglenales

...EUGLENACEAE

... trachelomonas

_COMMON_NAME

CELLS/ML

PER_CENT

GREEN ALGAE

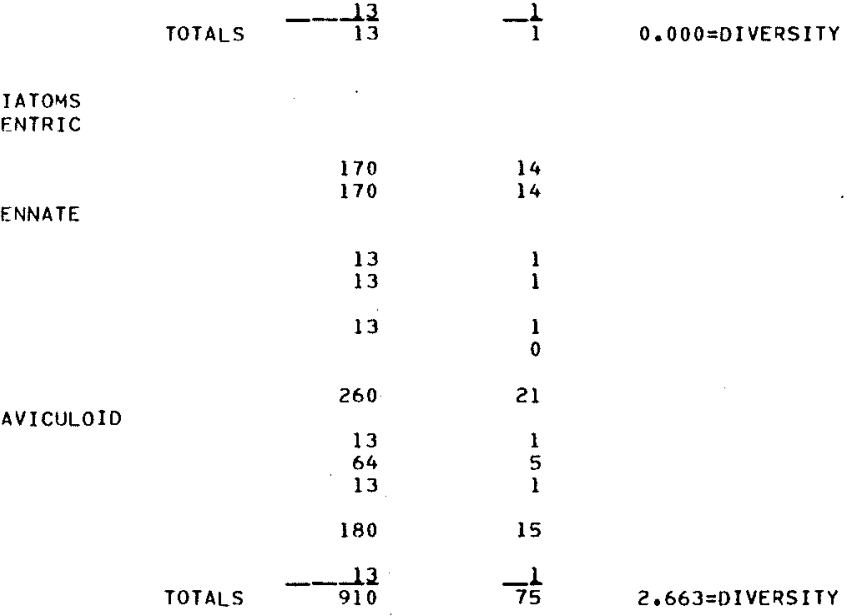

BLUE-GREEN ALGAE

FILAMENTOUS

TOTALS $\quad-\frac{26}{26} \quad-\frac{2}{2} \quad 0.000=$ DIVERSITY

NOTE: D - DOMINANT ORGANISMI GREATER OR EQUAL TO $15 \%$

L. - LESS THEN 1\%: MAY NOT HAVE BEEN ACTUALLY COUNTED 
09522000. COLORADO RIVER AT NORTHERLY INTERNATIONAL BOUNDARY,

ABOVE MORELOS DAM, NEAR ANDRADE, CALIF.--CONTIMUED

QUALITATIVE AND ASSOCIATED QUANTITATIVE ANALYSES OF BIOLOGICAL DATA, WATER YEARS OCTOBER 1974 TO SEPTEMBER 1976

$$
\begin{gathered}
\text { FFR. } 10,1976 \\
0835 \text { HOURS }
\end{gathered}
$$

IOFNTIFICATION OF PHYTOPLANKTON

560 CELLS/ML

_DRTANISM_NAMF.

CHLOROPHYTA - CHL DROPHYCEAE

- Chlorococcales

... nocrstaceae.

... Ank Istronesmu

... SCENEDE SMACEAE

I.... SCENEDESMUIS

\section{CHRYSOPHYTA} -8AC ILLARI OPHYCEAF

. CENTRALFS

... COSCINODI SCACF AF

D... CYCLOTELLa

L....MELOSIZA

PENNALES

... Achnanthaceae

$0 .$. ACHNANFHFS

I. ... COCCONF IS

... CYMBELLACFAE

... AMPHORA

.. Diatomaceat

... DIatoma

...FRagillariacFae

... frag Illaria

@. Naviculaceae

@.. AMPHIPRURA

... calone Is

... Navicul.

... NITZSCHIACEAE

.... NITZSCHIa

... SUR IRELLaceae

L .....SURIRELLA

_COMMON_NAME

CELLS/HL

PER_CENT

GPEFN ALGAE

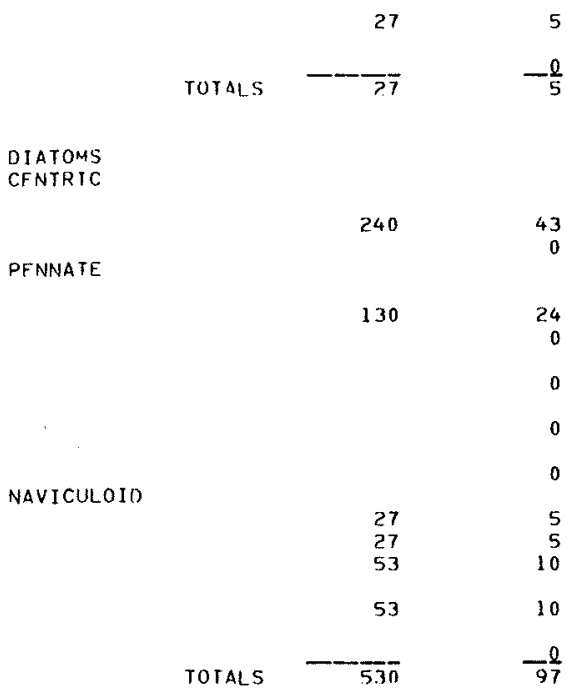

BL.UE-GREEN ALGAE

CYANOPHYTA

- MYXOPHYCEAE

. OSCILla TuRI ALES

... OSCILLATORIACEAE

FIL.AMENTOUS

L .... OSCILLATORIA

NOTE: D - DOMINANT ORGANISM: GREAIER OR EQUAL TO IS\%

L - LESS THEN 1\%: MAY NOT HAVE BEEN ACTUALLY COUNTED

MAR. 9,1976

0835 HOURS

IDENTIFICATION OF PHYIOPLANKION

$610 \mathrm{CELLS/ML}$

_ORGANISM_..NAME

CHRYSOPHYTA

- BACILLAR IOPHYCEAE

. centrales

. coscinodiscaceaf

.... cyclotella

¿PENNALES

. Achnanthaceae

... ACHNANTHES

.... COCCONEIS

... RHOI COSPHENIA

CyMBELlaceae

$1 . .$. AMPHORA

$\because$ CYMBELLA

... CYMBELLA

... gOMPHONEMA

@... NAVICULACEAE

... Calone Is

.... Navicula

... NITZSCHIACEAE

-... NITZSCHIA

- SURIRELlaceaE

L ... . CYMATOPLEURA
_COMMON__NAME

CELLS/ML

PER_CENT

DIATOMS

CENTRIC

PFNNATE

NAVICULOID
53

$\begin{array}{rrr} & 53 & 9 \\ 27 & 4 \\ 53 & 9 \\ 27 & 4 \\ & 0 \\ 27 & 4 \\ 27 & 4 \\ & 320 & 52 \\ \text { TOTALS } & 80 & 13 \\ & -610 & -9 \\ & & 99\end{array}$

$0.000=0$ I VERS I TY
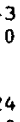

5
5

10

$2.115=$ DIVERS ITY

NOTE: 0 - DOMINANY ORGANISM: GREATER OR EQUAL TO $15 \%$

- LESS THEN 1\%; MAY NOT HAVE BEEN ACTUALLY COUNTED 
09522000. COLORADO RIVER AT NORTHERLY INIERNATIONAL BOUNDARY, ABOVE MORELOS DAM, NEAR ANDRADE, CALIF.--CONTINUED

QUALITATIVE AND ASSOCIATED QUANTITATIVE ANALYSES OF BIOLOGICAL DATA, WATER YEARS OCTOBER 1974 TO SEPTEMBER 1976

$$
A D R, 13,1976
$$

0830 HOURS

IDENTIFICATION OF PHYTOPLANKION

2,100 CELLS/ML

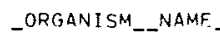

L - LESS THEN 1\%: MAY NOT HaVE BEen aCTUALLY COUNTED

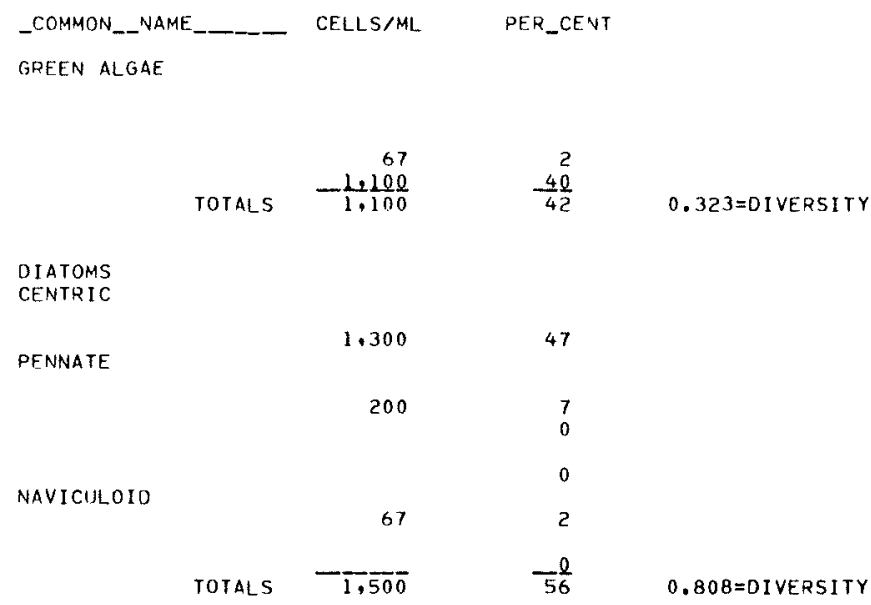

$0.808=D$ I VERS I TY

FILAMENTOUS

\section{MAY 11,1976 \\ 0830 HOURS}

IDENTIF ICATION OF PHYTOPLANKTON'

7.900 CELLS/ML
CHLOROPHYTA

- CHLOROPHYCEAE

. CHL orocuccales

.. OOCYSTACEAE

....ANKISTRODESMUS

... SELENASTRUM

... SCENEDESMACEAE

... . SCENEDESMUS

. ZYGNEMATALES

L ... DOCSMADIACEAE

\section{CHRYSOPHYTA}

- BACILLARIOPHYCEAE

. CENTRales

. COSCINODISCACEAE

D ... CYCLOTELLA

D .... MELOSIra

apenNales

...FRAG ILARI ACEAE

L ... SYNEORA

.. navi culaceae

... NAVI CUla

... NITZSCHIACEAE

.... NITZSCHIA
_COMMON__NAME GREEN ALGAE

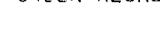

TOTALS

$-\pi \cdot 100$

3,600

DIATOMS

CFNTRIC

PENNATE

CELLS/ML

PER_CENT

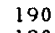

190

$\frac{2}{2}$

750

10

NAVICULOID
10

$\frac{7}{86}$

NOTE: 0 - DOMINANT OPGANISM; GREATER OR EQUAL TO $15 \%$ 
09522000. COLORADO RIVER AT NORTHERLY INTERNATIONAL BOUNDARY,

ABOVE MORELOS DAM, NEAR ANDRADE, CALIF,--CONTINUED

QUALITATIVE AND ASSOCIATED QUANTITATIVE ANALYSES OF BIOLOGICAL DATA, WATER YEARS OCTOBER 1974 TO SEPTEMBER 1976

$$
\begin{gathered}
\text { JUNE } 8,1976 \\
0830 \text { HOURS }
\end{gathered}
$$

IDENTIFICATION OF PHYTOPLANKTON

1.800 CELLS/ML

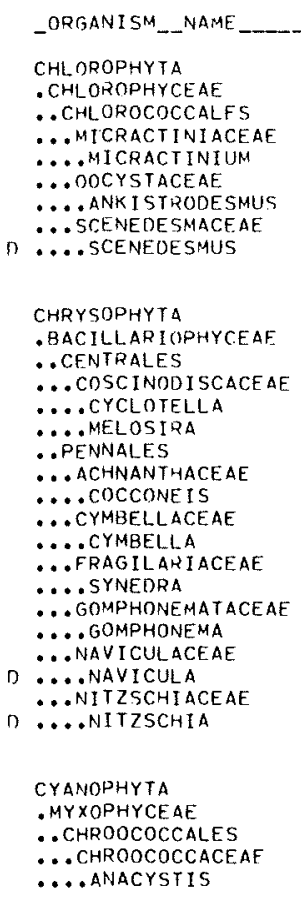

NAVICULOID

BLUE-GREEN ALGAE

$\operatorname{coccoIo}$

TOTALS $-\frac{120}{120} \quad-\frac{7}{7} \quad 0.000=0$ IVERSITY 
09522000. COLORADO RIVER AT NORTHERLY INTERNATIONAL BOUNDARY,

ABOVE MORELOS DAM, NEAR ANDRADE, CALIF.--CONTINUED

QUALITATIVE AND ASSOCIATED QUANTITATIVE ANALYSES OF BIOLOGICAL DATA, WATER YEARS OCTOBER 1974 TO SEPTEMBER 1976

JULY 13, 1976

0955 HOURS

IDENTIFICATION OF PHYTOPLANKTON

$3.000 \mathrm{CELLS} / \mathrm{ML}$

_ORGAVISM NAME

CHLOROPHYTA

.CHLOROPHYCEAE

-. Chlorococcales

... OOCYSTACEAE

... ANKISTPODE SMUS

-...TETRAEDRON

... SCENEDESMACEAE

n)... SCENEDESMUS

CHRYSOPHYTA
BACILLARIOPHYCEAE

- CFNTRALES

.. COSCINODI SCACFAE

.... CYCLOTELLA

....MTELOSIPA

-...MELOSI

... CYMBELLACEAF

. cymerla

... fragillari acea

... . Fragillaria

.... SYINEDRA

...NAVICULACEAE

- . omphtprora

-... namavicula

... NAVICULA

$n$.... NITZSCHIA
_COMMON_NAME

CELLS/ML

GREEN ALGAE

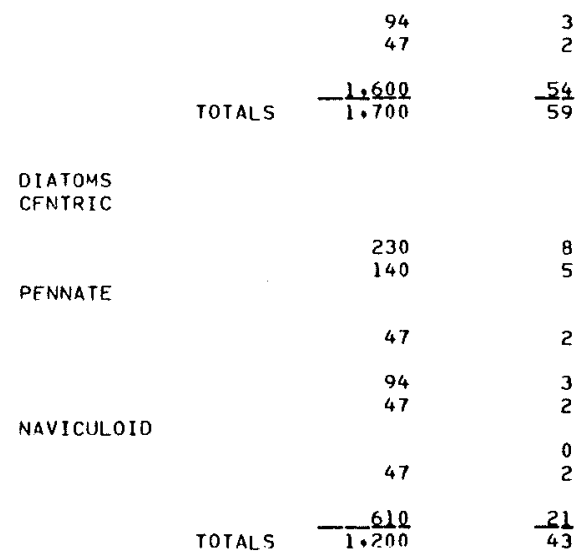

2.144=DIVERS I TY

NOTE: D - DOMINANT ORGANISM; GREATER OR EQUAL TO 15\%

l. - LESS THEN $1 \%$ : MAY NOT HAVE BEEN ACTUALLY COUNTED 
09522000, COLORADO RIVER AT NORTHERLY INTERNATIONAL BOUNDARY,

ABOVE MORELOS DAM, NEAR ANDRADE, CALIF. - -CONTINUED

QUALITATIVE AND ASSOCIATED QUANTITATIVE ANALYSES OF BIOLOGICAL DATA, WATER YEARS OCTOBER 1974 TO SEPTEMBER 1976

AUG. 10,1976

0835 HOURS

IDENTIFICATION OF PHYTOPLANKTON

$1,500 \mathrm{CELLS} / \mathrm{ML}$

_QRGANISM_NAME

CHLOROPHYTA

- CHLOROPHYCEAE

.. CHLOROCOCCALES

... OOCYSTACEAE

.... ANKI STRODESMUS

\#. SCENEOESMACEAE

.... SCENEDESMUS

. VOL VOCALES

$\because$... CHLAMYDOMONADACEAE

.... ChLAMYDOMONAS

CHRYSOPHYTA

- BACILLARI OPHYCEAE

-. CENTRALES

... COSCINODISCACEAE

.... CYClotella

.... MEL OSIRA

. PENNALES

.. ACHNANTHACEAE

... coccone ls

@. Fragilar Iaceae

@...frag Illaria

... NAV I CulaceaE

... AMPHIPRORA

-... navicula

... NITZSCHIACEAE

D .... NITZSCHIA

CYANOPHYTA

MYXOPHYCEAE

. MYXOPHYCEAE

... Chroococcaceae

.... AnacYstis

. OSCILlatoriales

.. OSC ILla for Iaceae

.... LYNGGYYa

D... OsCillatoria

... SPIRULINA

EUGLENOPHYTA

- CRYPTOPHYCEAE

. CRYPTOMONIDALES

... CRYPTOCHRYSIDACEAE

... CHROOMONAS
_COMMON_NAME

GREEN ALGAE

PER_CENT

$-\frac{21}{250}$

16

$1.241=$ DIVERSITY

DIATOMS

CENTRIC

PENNATE

TOTALS

$-\frac{260}{660}$

BLUE-GREEN ALGAE

COCCOID

FILAMENTOUS

21

1

150
400
$--\frac{11}{580}$

10
27

$\frac{1}{39}$

$1 \cdot 150=0$ I VERS I TY

EUGLENOIDS

CRYPTOMONADS

TOTALS $-\frac{11}{11} \quad-\frac{1}{1} \quad 0.000=$ DIVERSITY

NOTE: D - DOMINANT ORGANISM; GREATER OR EQUAL TO $15 \%$ 
09522000. COLORADO RIVER AT NORTHERLY INTERNATIONAL BOUNDARY, ABOVE MORELOS DAM, NEAR ANDRADE, CALIF. - - CONTINUED

QUALITATIVE AND ASSOCIATED QUANTITATIVE ANALYSES OF BIOLOGICAL DATA, WATER YEARS OCTOBER 1974 TO SEPTEMBER 1976

$$
\text { SFP. } 14 \cdot 1976
$$

0845 HOURS

IDENTIFICATION OF PHYTOPLANKTON

$15.000 \mathrm{CELLS} / \mathrm{ML}$

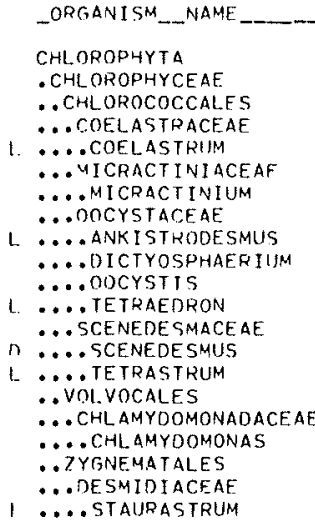

NOTE: D - OOMINANT ORGANISM; GREATER OR EQUAL TO IS\% 
09522500. GILA GRAVITY MAIN CANAL AT IMPERIAL DAM, ARIZ,-CALIF.

LOCATION. - -Lat $32^{\circ} 52^{\prime} 34^{\prime \prime}$, long $114^{\circ} 27^{\prime} 18^{\prime \prime}$, in SE $4 \mathrm{SW}_{4}^{\prime}$ sec.30, T.6 S., R. 21 W., Gila and Salt River meridian, Yuma County, on right bank $3,200 \mathrm{ft}(975 \mathrm{~m})$ downstream from intake at east end of Imperia1 Dam.

PERIOD OF RECORD. --August 1943 to current year.

GAGE. - Water-stage recorder. Datum of gage is $160.00 \mathrm{ft}(48.768 \mathrm{~m})$ above mean sea level.

AVEFAGE DISCHARGE, - -17 years $(1959-76), 1,216 \mathrm{ft}^{3} / \mathrm{s}\left(34.44 \mathrm{~m}^{3} / \mathrm{s}\right), 881,000 \mathrm{acre}-\mathrm{ft} / \mathrm{yr}\left(1,090 \mathrm{hm}^{3} / \mathrm{yr}^{2}\right)$

EXTTENES,--Period of record: Maximun daily discharge, $2,240 \mathrm{ft}^{3} / \mathrm{s}\left(63.4 \mathrm{~m}^{3} / \mathrm{s}\right)$ May 25 , 1965; no flow at canal intake at tines in several years when intake gates were closed.

REMMRKS. - Records excellent except those below $100 \mathrm{ft}^{3} / \mathrm{s}\left(2.8 \mathrm{~m}^{3} / \mathrm{s}\right)$, which are fair. Gila Gravity Main Canal diverts water from Colorado River at left end of Imperial Dam for irrigation of lands in the Gila Project area in Arizona. Diversions to this canal began Aug. 17, 1943. Diversions to North Gila Valley from this canal began Dec. 16, 1954. During the 1975 calendar year, water was used for irrigation of 103,354 acres $\left(418 \mathrm{~km}^{2}\right)$ divided as follows: North and South Gila Valleys, 16,217 acres

$\left(65.6 \mathrm{~km}^{2}\right)$; Yuma Mesa Division, 18,412 acres $\left(74.5 \mathrm{~km}^{2}\right)$; Wellton-Mohawk Division, 65,529 acres (265 km²); Yuna Mesa Auxiliary. Division, 3,196 acres $\left(12.9 \mathrm{~km}^{2}\right)$. Records of chemical analyses and water temperatures for the current water year are published on following pages.

DISCHARGE, IN CUBIC FEET PER SECOND, WATER YEAR OCTOBER 1975 TO SEPTEMBER 1976 MEAN VALUES

\begin{tabular}{|c|c|c|c|c|c|c|c|c|c|c|c|c|}
\hline DAY & OCT & NOV & DEC & JAN & FEB & MAR & APR & MAY & JUN & JUL & AUG & SEP \\
\hline $\begin{array}{l}1 \\
2 \\
3 \\
4 \\
5\end{array}$ & $\begin{array}{r}1700 \\
1730 \\
1440 \\
1200 \\
925\end{array}$ & $\begin{array}{l}742 \\
447 \\
860 \\
909 \\
958\end{array}$ & $\begin{array}{r}3.0 \\
2.8 \\
2.7 \\
2.7 \\
177\end{array}$ & $\begin{array}{l}738 \\
914 \\
954 \\
653 \\
696\end{array}$ & $\begin{array}{l}667 \\
1090 \\
1230 \\
1380 \\
1060\end{array}$ & $\begin{array}{l}1490 \\
1730 \\
1860 \\
1560 \\
1450\end{array}$ & $\begin{array}{l}1860 \\
1530 \\
1540 \\
1130 \\
1730\end{array}$ & $\begin{array}{l}1600 \\
1290 \\
1730 \\
1710 \\
1830\end{array}$ & $\begin{array}{l}1500 \\
1610 \\
1560 \\
1520 \\
1260\end{array}$ & $\begin{array}{l}2040 \\
1950 \\
1580 \\
1030 \\
1680\end{array}$ & $\begin{array}{l}1220 \\
1810 \\
1920 \\
2010 \\
2100\end{array}$ & $\begin{array}{l}1980 \\
1930 \\
1820 \\
1630 \\
1330\end{array}$ \\
\hline $\begin{array}{r}6 \\
7 \\
8 \\
9 \\
10\end{array}$ & $\begin{array}{l}1560 \\
1780 \\
1690 \\
1600 \\
1200\end{array}$ & $\begin{array}{r}1070 \\
927 \\
858 \\
609 \\
925\end{array}$ & $\begin{array}{r}883 \\
677 \\
1270 \\
1250 \\
1050\end{array}$ & $\begin{array}{l}692 \\
606 \\
578 \\
504 \\
441\end{array}$ & $\begin{array}{r}1050 \\
924 \\
705 \\
735 \\
917\end{array}$ & $\begin{array}{r}996 \\
886 \\
1310 \\
1390 \\
1460\end{array}$ & $\begin{array}{l}1870 \\
1770 \\
1650 \\
1430 \\
1280\end{array}$ & $\begin{array}{r}1810 \\
1470 \\
1370 \\
881 \\
1550\end{array}$ & $\begin{array}{r}992 \\
1370 \\
1660 \\
1680 \\
1560\end{array}$ & $\begin{array}{l}1900 \\
1990 \\
1870 \\
1850 \\
1730\end{array}$ & $\begin{array}{l}1980 \\
1860 \\
1650 \\
1960 \\
2120\end{array}$ & $\begin{array}{r}1690 \\
1560 \\
1780 \\
1490 \\
640\end{array}$ \\
\hline $\begin{array}{l}11 \\
12 \\
13 \\
14 \\
15\end{array}$ & $\begin{array}{r}1020 \\
962 \\
1070 \\
1210 \\
1350\end{array}$ & $\begin{array}{r}1120 \\
1320 \\
1110 \\
853 \\
749\end{array}$ & $\begin{array}{r}1040 \\
785 \\
603 \\
608 \\
953\end{array}$ & $\begin{array}{l}413 \\
723 \\
915 \\
896 \\
814\end{array}$ & $\begin{array}{l}775 \\
637 \\
442 \\
277 \\
287\end{array}$ & $\begin{array}{r}1450 \\
1120 \\
871 \\
718 \\
952\end{array}$ & $\begin{array}{r}1010 \\
1380 \\
1540 \\
1340 \\
790\end{array}$ & $\begin{array}{l}1580 \\
1560 \\
1450 \\
1390 \\
1110\end{array}$ & $\begin{array}{l}1660 \\
1470 \\
1030 \\
1620 \\
1570\end{array}$ & $\begin{array}{l}1400 \\
1900 \\
2040 \\
2020 \\
1920\end{array}$ & $\begin{array}{l}2150 \\
2130 \\
2020 \\
1930 \\
1650\end{array}$ & $\begin{array}{r}807 \\
768 \\
1490 \\
1450 \\
1510\end{array}$ \\
\hline $\begin{array}{l}16 \\
17 \\
18 \\
19 \\
20\end{array}$ & $\begin{array}{r}1380 \\
999 \\
799 \\
546 \\
954\end{array}$ & $\begin{array}{r}728 \\
1130 \\
1320 \\
1400 \\
1270\end{array}$ & $\begin{array}{r}1200 \\
1220 \\
1190 \\
1220 \\
893\end{array}$ & $\begin{array}{l}807 \\
653 \\
410 \\
832 \\
923\end{array}$ & $\begin{array}{l}287 \\
476 \\
541 \\
544 \\
648\end{array}$ & $\begin{array}{l}1420 \\
1480 \\
1570 \\
1250 \\
1130\end{array}$ & $\begin{array}{r}706 \\
357 \\
462 \\
1350 \\
1640\end{array}$ & $\begin{array}{r}858 \\
1550 \\
1630 \\
1620 \\
1420\end{array}$ & $\begin{array}{l}1730 \\
1710 \\
1770 \\
1410 \\
1090\end{array}$ & $\begin{array}{l}1980 \\
1480 \\
1210 \\
1810 \\
1790\end{array}$ & $\begin{array}{l}1910 \\
2040 \\
1910 \\
1910 \\
1940\end{array}$ & $\begin{array}{l}1560 \\
1180 \\
1160 \\
1080 \\
1520\end{array}$ \\
\hline $\begin{array}{l}21 \\
22 \\
23 \\
24 \\
25\end{array}$ & $\begin{array}{r}1000 \\
1050 \\
1010 \\
884 \\
537\end{array}$ & $\begin{array}{l}1240 \\
1070 \\
1310 \\
1510 \\
1330\end{array}$ & $\begin{array}{r}458 \\
637 \\
370 \\
52 \\
23\end{array}$ & $\begin{array}{l}943 \\
717 \\
634 \\
365 \\
190\end{array}$ & $\begin{array}{r}619 \\
619 \\
1000 \\
924 \\
885\end{array}$ & $\begin{array}{l}1070 \\
1540 \\
1470 \\
1660 \\
1580\end{array}$ & $\begin{array}{l}1720 \\
1740 \\
1580 \\
1420 \\
1230\end{array}$ & $\begin{array}{r}1550 \\
1030 \\
890 \\
1220 \\
1420\end{array}$ & $\begin{array}{l}1490 \\
1570 \\
1780 \\
1950 \\
1830\end{array}$ & $\begin{array}{l}1870 \\
1930 \\
1820 \\
1520 \\
1140\end{array}$ & $\begin{array}{l}1530 \\
1360 \\
1960 \\
1940 \\
1900\end{array}$ & $\begin{array}{r}1630 \\
1490 \\
1500 \\
980 \\
519\end{array}$ \\
\hline $\begin{array}{l}26 \\
27 \\
28 \\
29 \\
30 \\
31\end{array}$ & $\begin{array}{r}547 \\
1080 \\
883 \\
899 \\
1010 \\
770\end{array}$ & $\begin{array}{r}679 \\
16 \\
7.3 \\
4.1 \\
3.4 \\
-. .0\end{array}$ & $\begin{array}{l}312 \\
289 \\
387 \\
499 \\
768 \\
511\end{array}$ & $\begin{array}{l}570 \\
807 \\
834 \\
790 \\
988 \\
765\end{array}$ & $\begin{array}{r}1120 \\
1270 \\
992 \\
764 \\
--- \\
-0 .\end{array}$ & $\begin{array}{l}1530 \\
1270 \\
1200 \\
1580 \\
1830 \\
1870\end{array}$ & $\begin{array}{l}1750 \\
1950 \\
1970 \\
1970 \\
1630 \\
-0 .\end{array}$ & $\begin{array}{r}1530 \\
1530 \\
1450 \\
1250 \\
858 \\
1420\end{array}$ & $\begin{array}{c}1580 \\
1320 \\
1570 \\
1870 \\
1940 \\
-\ldots-\end{array}$ & $\begin{array}{l}1710 \\
1400 \\
1420 \\
1500 \\
1560 \\
1470\end{array}$ & $\begin{array}{l}1940 \\
1920 \\
1820 \\
1490 \\
1880 \\
1980\end{array}$ & $\begin{array}{l}318 \\
594 \\
715 \\
603 \\
674 \\
-\infty\end{array}$ \\
\hline $\begin{array}{l}\text { TOTAL } \\
\text { MEAN } \\
\text { MAX } \\
\text { MIN } \\
\text { AC-FT }\end{array}$ & $\begin{array}{r}34785 \\
1122 \\
1780 \\
537 \\
69000\end{array}$ & $\begin{array}{r}26474.8 \\
882 \\
1510 \\
3.4 \\
52510\end{array}$ & $\begin{array}{r}19336.2 \\
624 \\
1270 \\
2.7 \\
38350\end{array}$ & $\begin{array}{r}21765 \\
702 \\
988 \\
190 \\
43170\end{array}$ & $\begin{array}{r}22865 \\
788 \\
1380 \\
277 \\
45350\end{array}$ & $\begin{array}{r}42693 \\
1377 \\
1870 \\
718 \\
84680\end{array}$ & $\begin{array}{r}43325 \\
1444 \\
1970 \\
357 \\
85940\end{array}$ & $\begin{array}{r}43557 \\
1405 \\
1830 \\
858 \\
86400\end{array}$ & $\begin{array}{r}46672 \\
1556 \\
1950 \\
992 \\
92570\end{array}$ & $\begin{array}{r}52510 \\
1694 \\
2040 \\
1030 \\
104200\end{array}$ & $\begin{array}{r}57940 \\
1869 \\
2150 \\
1220 \\
114900\end{array}$ & $\begin{array}{r}37398 \\
1247 \\
1980 \\
318 \\
74180\end{array}$ \\
\hline
\end{tabular}

$\begin{array}{llllllllll}\text { CAL YR } 1975 & \text { TOTAL } & 466665.0 & \text { MEAN } & 1279 & \text { MAX } & 2060 & \text { HIN } 2.7 & \text { AC-FT } & 925600\end{array}$ 
LOCATION. - - Lat $32^{\circ} 52^{\prime} 34^{\prime \prime}$, long $114^{\circ} 27^{\prime} 18^{\prime \prime}$, in SE ${ }^{\prime}$ SW' sec.30, T.6 S., R. 21 W., Gila and Salt River meridian, in Arizona, Yuna County, at gaging station on right bank, $0.6 \mathrm{mi}(1.0 \mathrm{~km})$ downstream from intake at east end of Imperial Dam.

PERIOD OF RECORD.--Chemical analyses: October 1967 to current year (partial-record station).

Water temperatures: January 1956 to current year.

EXTREMES, --Current year:

Water temperatures: Maxinum, $30.0^{\circ} \mathrm{C}$ July $9,26-28,30,31$; minimum, $8.5^{\circ} \mathrm{C}$ on several days during January.

Period of record:

Water temperatures: Maximum, $33.0^{\circ} \mathrm{C}$ Aug. 29-31, 1970; minimum, 7.0 $\mathrm{C}$ Jan. 13-17, 1964, Jan. 4-7, 1971

REMARKS.--Temperature probe above water surface Nov. 27 to Dec. 4. Unpublished chemical analyses (partial record) for water years $1965-67$ available from district office in Tucson, Ariz.

WATER WUALITY DATA, WATER YEAH OCTOBER 1975 TO SEPTEMBER 1976

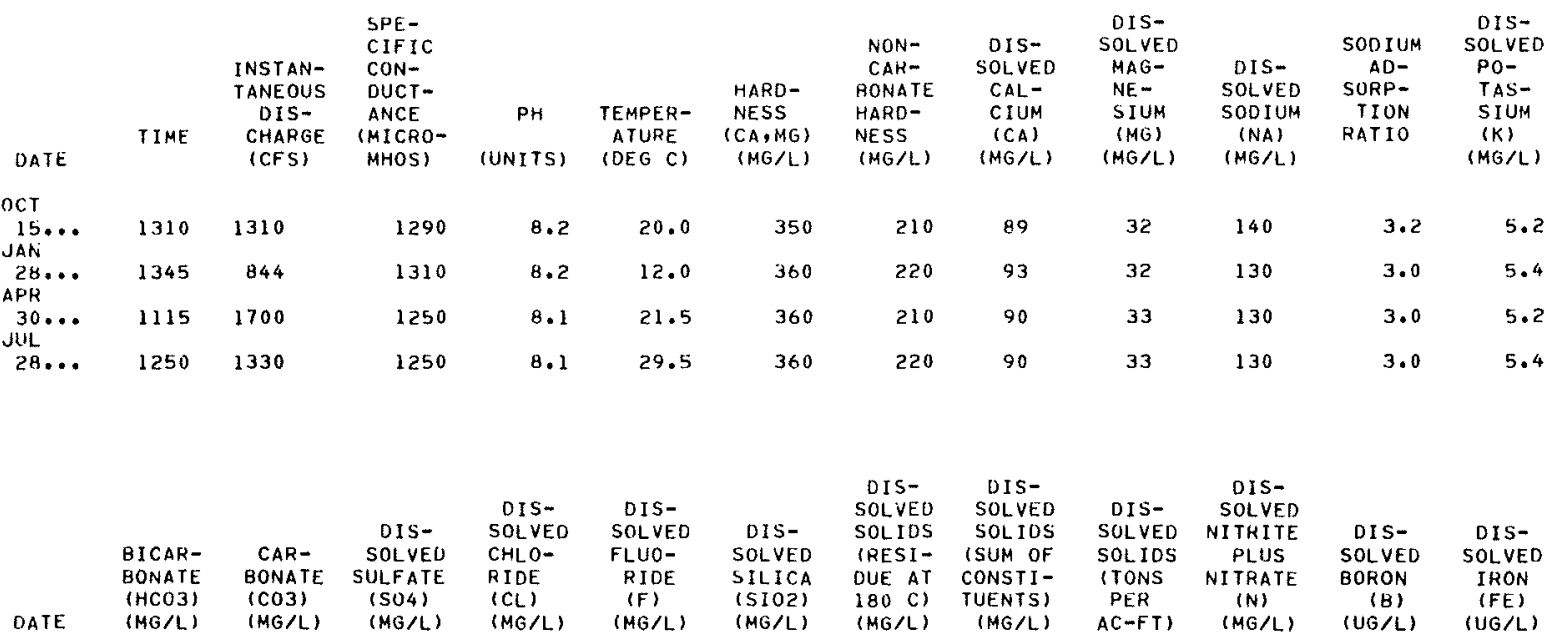

$0 \mathrm{CT}$

JAN $175 \quad 340 \quad 120$

28... $\quad 176$

$30 \ldots 183$

$0 \quad 330$

120

$\begin{array}{ll}.5 & 9.0 \\ .4 & 8.5 \\ .4 & 5.4 \\ .5 & 9.9\end{array}$

869
86
82
79

823
808
795
795

$\begin{array}{ll}1.18 & .13 \\ 1.17 & .35 \\ 1.12 & .15 \\ 1.09 & .11\end{array}$

180

170

160

120

160

20 
09522500. GILA GRAVITY MAIN CANAL AT IMPERIAL DAM, ARIZ.-CALIF.--CONIINUED

TEMPERATURE (DEG. C) OF WATER, WATER YEAR OCTOBER 1975 TO SEPTEMBER 1976

DCTOAEK

$\begin{array}{rr}\text { NAX } & \text { MIN } \\ 25.5 & 25.0 \\ 25.0 & 25.0 \\ 25.0 & 25.0 \\ 25.0 & 25.0 \\ 25.0 & 25.0\end{array}$

DECEMBER

$\begin{array}{cc}\text { MAX } & \text { MIN } \\ 18.5 & 18.5 \\ 18.5 & 18.5 \\ 18.5 & 18.5 \\ 18.5 & 18.5 \\ 18.5 & 18.5\end{array}$

\section{$\begin{array}{ll}25.0 & 24.5 \\ 24.5 & 23.5\end{array}$ \\ 23.5}

$2 \hat{2} \cdot 0$

22.0

$\begin{array}{ll}22.0 & 22.0 \\ 27.0 & 22.0\end{array}$

25.0

$21.0 \quad 21.0$

\section{$20.0 \quad 20.0$}

$\begin{array}{ll}20.0 & 20.0 \\ 20.0 & 20.0 \\ 20.0 & 20.0 \\ 20.0 & 20.0\end{array}$

$\begin{array}{ll}20.0 & 20.0 \\ 20.5 & 20.0\end{array}$

\section{$20.5 \quad 20.5$}

$\begin{array}{ll}20.5 & 20.5 \\ 20.5 & 20.0\end{array}$

$\begin{array}{ll}20.5 & 20.0 \\ 20.0 & 18.5 \\ 19.5 & 18.0\end{array}$

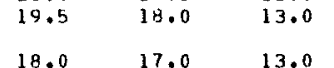

$\begin{array}{lll}18.0 & 17.0 & 13.0 \\ 17.0 & 17.0 & -\end{array}$

$\begin{array}{ll}17.0 & 17.0 \\ 18.0 & 17.0\end{array}$

$\begin{array}{ll}18.0 & 17.0 \\ 19.0 & 18.0 \\ 19.0 & 19.0\end{array}$

19.0

25.5

\subsection{5}

18.5
18.0

18.5
18.0

18.0
18.0
17.0

$\begin{array}{llll}17.0 & 16.5 & 13.0 & 13.0 \\ 16.5 & 15.5 & 13.0 & 13.0\end{array}$

$\begin{array}{llll}17.5 & 15.5 & 13.0 & 13.0 \\ 15.5 & 15.0 & 13.0 & 13.0\end{array}$

$15.0 \quad 15.0 \quad 13.0$

$\begin{array}{llll}15.0 & 15.0 & 12.0 & 11.0\end{array}$

$\begin{array}{llll}15.0 & 15.0 & 11.0 & 10.0 \\ 15.0 & 15.0 & 10.0 & 10.0\end{array}$

$\begin{array}{llll}15.0 & 15.0 & 10.0 & 10.0 \\ 15.0 & 15.0 & 10.0 & 10.0\end{array}$

$\begin{array}{lll}15.0 & 14.5 & 10.5\end{array}$

10.5

12.0
11.5

$\begin{array}{ll}11.5 & 11.5 \\ 11.5 & 11.5\end{array}$

11.5

$\begin{array}{ll}11.5 & 11.0 \\ 11.0 & 11.0\end{array}$

13.0

\begin{tabular}{cc} 
MAX & MIN \\
--- & --- \\
-- & --- \\
\hdashline$-\overline{0}$ & $--\overline{0}$ \\
13.0 & 13.0
\end{tabular}

JANUARY

FEBRUARY

MARCH

10.0
10.5

11.0
10.0
8.5
8.5
8.5

\section{MIN}

10.0

$$
\begin{aligned}
& 8.5 \\
& 8.5 \\
& 8.5
\end{aligned}
$$

8.5
8.5

$\begin{array}{ll}12.5 & 12.5 \\ 13.0 & 12.5\end{array}$

$\begin{array}{ll}13.0 & 12.5 \\ 13.0 & 13.0\end{array}$

$13.0 \quad 13.0$

13.0
13.0

8.5
8.5
9.0

8.5
8.5

\section{$8 \cdot 5$
$B \cdot 5$}

8.5
8.5
8.5

13.5

13.5
14.0
14.0

13.5
13.5
14.0

$8.5 \quad 14.0 \quad 14.0$

14.5
15.0

14.0
14.5

8.5
8.5

8.5
8.5

8.5

8.5

8.5

$\begin{array}{ll}8.5 & 15.0 \\ 6.5 & 14.5\end{array}$

15.0
14.5
14.5

15.0

14.5

14.5
14.5
14.5

14.5
14.5

14.5
15.0

9.0
9.5
10.5

15.0

15.0
15.5

8.5
9.0
9.5
10.5

15.5
15.5
15.5
16.0

15.5

15.5
15.5

11.0
11.0

10.5
11.0

16.0
16.0

15.5

$11.0 \quad 15.5$

$\begin{array}{llll}10.5 & 10.5 & 11.0 & 11.0 \\ 12.0 & 10.5 & 11.0 & 11.0 \\ 12.0 & 12.0 & 11.0 & 11.0\end{array}$

$12.0-12.0$

11.5

11.5

11.0
11.5

$\begin{array}{ll}14.5 & 14.0 \\ 14.0 & 13.5\end{array}$

$\begin{array}{ll}14.0 & 13.5 \\ 14.0 & 13.5 \\ 14.5 & 14.0\end{array}$

11.5

$\begin{array}{lll}11.5 & 11.5 & 11.5 \\ 11.5 & 11.5 & 11.5 \\ 11.5 & 11.5 & 11.5\end{array}$

$\begin{array}{ll}11.5 & 11.0 \\ 11.5 & 11.5\end{array}$

14.5

14.5

14.5

$\begin{array}{rrr}11.0 & 15.0 & 14.5 \\ 11.5 & 15.0 & 15.0 \\ 11.5 & -.0 & -.--\end{array}$

12.5

11.5

$10.0 \quad 12.5$

8.5

16.0

12.5

TEMPEHATURE (DEG. C) OF WATER, WATER YEAR OCTOBER 1975 TO SEPTEMBER 1976

APRIL

MAY

JUNE

JULY

AUGUST

SEPTEMBER

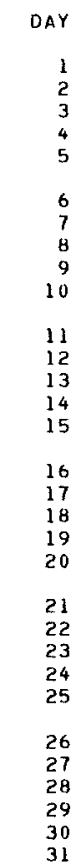

MONTH

\begin{tabular}{|c|c|}
\hline $\operatorname{NAX}$ & MIN \\
\hline $\begin{array}{l}16.5 \\
17.0 \\
17.0 \\
17.0 \\
17.0\end{array}$ & $\begin{array}{l}16.5 \\
16.5 \\
17.0 \\
17.0 \\
16.0\end{array}$ \\
\hline $\begin{array}{l}16.5 \\
17.0 \\
18.0 \\
18.0 \\
18.5\end{array}$ & $\begin{array}{l}16.0 \\
16.0 \\
17.0 \\
18.0 \\
18.0\end{array}$ \\
\hline $\begin{array}{l}18.5 \\
18.5 \\
18.5 \\
18.0 \\
18.0\end{array}$ & $\begin{array}{l}18.5 \\
18.5 \\
18.0 \\
18.0 \\
16.0\end{array}$ \\
\hline $\begin{array}{l}16.0 \\
16.0 \\
16.5 \\
18.0 \\
19.0\end{array}$ & $\begin{array}{l}16.0 \\
15.0 \\
15.0 \\
16.5 \\
18.0\end{array}$ \\
\hline $\begin{array}{l}19.5 \\
20.0 \\
20.5 \\
21.0 \\
21.0\end{array}$ & $\begin{array}{l}19.0 \\
19.5 \\
20.0 \\
20.5 \\
20.5\end{array}$ \\
\hline $\begin{array}{l}21.0 \\
20.5 \\
20.0 \\
20.0 \\
20.0\end{array}$ & $\begin{array}{l}20.5 \\
20.0 \\
20.0 \\
20.0 \\
20.0\end{array}$ \\
\hline
\end{tabular}

MAX
21.5
21.5
21.5
21.5
21.5
21.5
21.0
21.0
22.0
23.0
24.5
25.0
25.0
25.0
25.0

$M I N$
20.0
21.5
21.5
21.5
21.5
21.0
21.0
21.0
20.5
21.5
23.0
24.5
24.5
25.0
24.5

$\begin{array}{rr}\text { MAX } & \text { MIN } \\ 24.5 & 24.5 \\ 25.0 & 24.5 \\ 25.0 & 25.0 \\ 25.0 & 25.0\end{array}$

MAX

MIN

MAX

MIN

$29.0 \quad 28.0$

$28.5 \quad 27.0$

$\begin{array}{ll}27.5 & 27.0 \\ 27.0 & 26.5\end{array}$

29.529 .0

$29 \cdot 5$

$28.5 \quad 27.0$

28.0

27.0

27.0

$\begin{array}{llll}25.0 & 25.0 & 28.5 & 27.0 \\ 25.0 & 25.0 & 29.0 & 28.5\end{array}$

27.0

27.0

$\begin{array}{ll}28.0 & 27.0 \\ 28.0 & 27.0\end{array}$

$28.0 \quad 27.0$

$\begin{array}{ll}25.0 & 25.0 \\ 25.0 & 24.5\end{array}$

$\begin{array}{ll}29.5 & 28.5 \\ 30.0 & 29.5\end{array}$

$29.5 \quad 29.0$

$25.0 \quad 23.0$

$\begin{array}{ll}29.0 & 28.5 \\ 28.5 & 28.0 \\ 28.5 & 27.0\end{array}$

25.0

25.0
25.0

23.5

24.0
24.5

28.5

27.0

$\begin{array}{ll}29.0 & 28.0 \\ 29.0 & 28.5\end{array}$

$\begin{array}{lll}28.5 & 27.0 & 28.5\end{array}$

$\begin{array}{ll}28.5 & 27.0 \\ 28.5 & 28.0\end{array}$

27.0
26.0

27.0
26.0
25.0

25.0

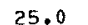

25.0

\section{0}

28.5
28.5

$25.0 \quad 25.0$

$25.0 \quad 24.5$

$$
\begin{array}{r}
25.0 \\
25.5
\end{array}
$$

$25.5 \quad 24.5$

$\begin{array}{ll}27.0 & 25.5 \\ 28.0 & 27.0\end{array}$

28.5
27.0

$\begin{array}{ll}28.5 & 25.5 \\ 27.0 & 26.0\end{array}$

$\begin{array}{ll}28.5 & 27.0 \\ 28.5 & 27.0\end{array}$

24.5

24.5
25.0

$\begin{array}{ll}25.5 & 25.0 \\ 26.0 & 25.0\end{array}$

26.0
26.0

25.0
25.5

$\begin{array}{llll}28.5 & 28.0 & 26.5 & 26.0 \\ 28.5 & 28.0 & 28.0 & 26.5 \\ 29.0 & 28.0 & 28.5 & 27.0\end{array}$

$\begin{array}{ll}24.5 & 24.0 \\ 24.5 & 24.0\end{array}$

$24.0 \quad 24.0 \quad 28.0$

24.0

24.0

27.0

28.0

$26.0 \quad 29.0$

25.5

29.0

28.0

29.0

28.5

28.5
29.0

28.5
28.5

$\begin{array}{ll}24.0 & 23.5 \\ 25.0 & 24.0\end{array}$

$28.0 \quad 26.0$

$30.0 \quad 29.0$

$\begin{array}{ll}29.0 & 28.5 \\ 29.0 & 28.5\end{array}$

$\begin{array}{ll}29.0 & 28.5 \\ 29.5 & 28.5\end{array}$

$29.5 \quad 29.0$

$\begin{array}{ll}29.5 & 29.0 \\ 29.5 & 29.0\end{array}$

$29.5 \quad 24.5$

24.5

26.5

$15.5 \quad 15.0$

$\begin{array}{ll}15.5 & 15.0 \\ 15.0 & 14.5\end{array}$

$\begin{array}{ll}14.5 & 14.0 \\ 14.0 & 14.0\end{array}$

$14.0 \quad 14.0$

$14.5 \quad 14.0$

$15.0 \quad 14.5$

$15.0 \quad 15.0$

$15.0 \quad 15.0$

$15.0 \quad 15.0$

$15.0 \quad 15.0$

$15.0 \quad 15.0$

$15.5 \quad 15.0$

$\begin{array}{ll}15.5 & 15.0 \\ 15.5 & 15.0\end{array}$

$15.5 \quad 15.0$

$15.0 \quad 15.0$

$15.5 \quad 15.0$

$\begin{array}{ll}16.0 & 15.5 \\ 16.5 & 16.0\end{array}$

$17.0 \quad 16.5$

$17.0 \quad 16.5$

$17.0 \quad 17.0$

$16.5 \quad 16.5$

$\begin{array}{ll}16.5 & 16.5 \\ 16.5 & 16.5\end{array}$

$17.0 \quad 14.0$

$29.0 \quad 28.0 \quad 30.0 \quad 29.0$

$\begin{array}{llll}29.0 & 28.5 & 29.5 & 29.5 \\ 29.0 & 28.5 & 30.0 & 29.0\end{array}$

29.0

23.0

30.0

$30.0 \quad 8.5$ 
LOCATION.--Lat $32^{\circ} 52^{\prime} 17^{\prime \prime}$, long $114^{\circ} 28^{\prime} 47^{\prime \prime}$, in SElaW's sec.17, T. 15 S., R. 24 E., San Bernardino meridian, in California, Inperial County, on left bank $6,000 \mathrm{ft}(1,829 \mathrm{~m})$ downstream from intake at west end of Imperia1 Dam and $13.7 \mathrm{mi}$ (22.0 km) upstream from tumout to Yuna Main Canal.

PERIOD OF RECORO.--October 1938 to current year. Prior to October 1939 monthly discharge only, published in wSP 1313.

GAGE. - Water-stage recorder. Datum of gage is $150.00 \mathrm{ft}(45.720 \mathrm{~m}$ ) above mean sea level (subject to undetermined changes caused by earthquake of May 18, 1940). Since Aug. 21, 1952, auxiliary water-stage recorder $18.5 \mathrm{mi}(29.8 \mathrm{~km})$ downstream from base gage.

AVEFAGE DISCHARGE, --35 years $(1941-76), 6,937 \mathrm{ft}^{3} / \mathrm{s}\left(196.5 \mathrm{~m}^{3} / \mathrm{s}\right), 5,026,000$ acre-ft/yr $(6,200 \mathrm{hm} / \mathrm{yr})$.

EXTKEMES. - Period of record: Maximan daily discharge, $13,500 \mathrm{ft}^{3} / \mathrm{s}\left(382 \mathrm{~m}^{3} / \mathrm{s}\right)$, Apr. 16, 1938 ; no flow at times.

REMARS.--Records excellent. A11-Anerican Canal diverts water from Colorado River at Imperial Dam. Water is used for power development and for irrigation in Yuma, Coachella, and Imperial Valleys. Water can be released back to the river through pilot Knob powcrplant and wasteway for power, regulatory purposes, or for downstream use in Mfexico. First diversion to All-American Canal began October 1938, but prior to October 1940 was used only for priming cana1.

COOPERATION.--Gage-height record furnished by Imperial Irrigation District.

DISCHARGE, IN CUBIC FEET PER SECONO, WATER YEAR OCTOBER 1975 TO SEPTEMBER 1976 MEAN VALUES

\begin{tabular}{|c|c|c|c|c|c|c|c|c|c|c|c|c|}
\hline DAY & $\mathrm{OCT}$ & NOV & OEC & JAN & FEB & MAR & APR & MAY & JUN & JUL & AUG & SEP \\
\hline $\begin{array}{l}1 \\
2 \\
3 \\
4 \\
5\end{array}$ & $\begin{array}{l}7010 \\
6680 \\
6440 \\
6370 \\
6180\end{array}$ & $\begin{array}{l}4950 \\
4520 \\
4480 \\
4350 \\
4650\end{array}$ & $\begin{array}{l}4190 \\
3980 \\
4180 \\
4430 \\
4440\end{array}$ & $\begin{array}{l}4640 \\
4740 \\
4160 \\
3840 \\
3980\end{array}$ & $\begin{array}{l}4980 \\
5070 \\
5460 \\
6010 \\
6310\end{array}$ & $\begin{array}{l}8150 \\
8580 \\
8640 \\
9070 \\
8950\end{array}$ & $\begin{array}{r}10500 \\
10300 \\
10300 \\
9980 \\
10000\end{array}$ & $\begin{array}{l}9790 \\
9370 \\
9650 \\
9510 \\
9630\end{array}$ & $\begin{array}{l}6800 \\
6780 \\
6930 \\
6910 \\
7000\end{array}$ & $\begin{array}{l}8310 \\
8420 \\
8150 \\
7600 \\
7550\end{array}$ & $\begin{array}{l}7150 \\
7600 \\
7680 \\
7960 \\
8400\end{array}$ & $\begin{array}{l}8200 \\
8030 \\
7960 \\
7410 \\
6730\end{array}$ \\
\hline $\begin{array}{r}6 \\
7 \\
8 \\
9 \\
10\end{array}$ & $\begin{array}{l}6620 \\
6820 \\
6750 \\
6720 \\
6510\end{array}$ & $\begin{array}{l}4940 \\
4610 \\
4300 \\
3920 \\
4070\end{array}$ & $\begin{array}{l}4550 \\
4330 \\
4450 \\
4560 \\
4850\end{array}$ & $\begin{array}{l}4690 \\
4930 \\
5400 \\
5250 \\
4730\end{array}$ & $\begin{array}{l}5600 \\
4480 \\
3970 \\
3250 \\
3160\end{array}$ & $\begin{array}{l}8280 \\
7640 \\
7850 \\
7760 \\
7850\end{array}$ & $\begin{array}{l}10100 \\
10300 \\
10500 \\
10500 \\
10500\end{array}$ & $\begin{array}{l}9260 \\
8760 \\
7610 \\
6150 \\
5960\end{array}$ & $\begin{array}{l}6270 \\
6410 \\
6530 \\
6720 \\
6830\end{array}$ & $\begin{array}{l}8050 \\
8430 \\
9020 \\
8520 \\
8750\end{array}$ & $\begin{array}{l}8790 \\
8950 \\
8980 \\
8900 \\
9010\end{array}$ & $\begin{array}{l}6330 \\
6750 \\
6250 \\
5660 \\
4610\end{array}$ \\
\hline $\begin{array}{l}11 \\
12 \\
13 \\
14 \\
15\end{array}$ & $\begin{array}{l}6200 \\
5870 \\
5750 \\
5670 \\
5670\end{array}$ & $\begin{array}{l}4340 \\
4470 \\
4420 \\
4430 \\
4320\end{array}$ & $\begin{array}{l}4960 \\
4880 \\
4850 \\
4510 \\
4790\end{array}$ & $\begin{array}{l}3940 \\
4060 \\
4080 \\
4200 \\
3970\end{array}$ & $\begin{array}{l}3760 \\
2890 \\
2800 \\
2830 \\
2710\end{array}$ & $\begin{array}{l}7830 \\
7700 \\
7930 \\
7740 \\
8360\end{array}$ & $\begin{array}{r}10300 \\
10400 \\
10100 \\
8680 \\
9280\end{array}$ & $\begin{array}{l}6250 \\
6330 \\
6650 \\
6770 \\
6930\end{array}$ & $\begin{array}{l}6600 \\
6800 \\
6560 \\
6890 \\
6950\end{array}$ & $\begin{array}{l}8650 \\
8790 \\
9040 \\
9210 \\
9250\end{array}$ & $\begin{array}{l}9110 \\
9180 \\
9150 \\
8870 \\
8460\end{array}$ & $\begin{array}{l}4650 \\
3590 \\
2300 \\
2590 \\
2660\end{array}$ \\
\hline $\begin{array}{l}16 \\
17 \\
18 \\
19 \\
20\end{array}$ & $\begin{array}{l}5490 \\
5400 \\
5350 \\
5150 \\
5170\end{array}$ & $\begin{array}{l}4260 \\
4510 \\
4670 \\
4730 \\
4590\end{array}$ & $\begin{array}{l}4900 \\
5370 \\
5690 \\
5390 \\
5310\end{array}$ & $\begin{array}{l}3960 \\
4010 \\
4030 \\
4530 \\
4840\end{array}$ & $\begin{array}{l}2500 \\
2420 \\
2270 \\
2900 \\
3190\end{array}$ & $\begin{array}{l}8580 \\
9030 \\
9010 \\
9170 \\
9360\end{array}$ & $\begin{array}{l}7520 \\
5750 \\
5340 \\
6700 \\
7460\end{array}$ & $\begin{array}{l}7040 \\
7320 \\
7880 \\
8120 \\
8260\end{array}$ & $\begin{array}{l}7150 \\
7380 \\
7190 \\
7520 \\
6880\end{array}$ & $\begin{array}{l}8730 \\
8730 \\
8470 \\
8510 \\
8850\end{array}$ & $\begin{array}{l}8900 \\
9050 \\
8920 \\
8840 \\
8820\end{array}$ & $\begin{array}{l}3070 \\
3210 \\
3230 \\
3800 \\
4170\end{array}$ \\
\hline $\begin{array}{l}21 \\
22 \\
23 \\
24 \\
25\end{array}$ & $\begin{array}{l}5250 \\
5360 \\
5040 \\
5100 \\
5050\end{array}$ & $\begin{array}{l}4590 \\
4650 \\
4350 \\
4240 \\
4270\end{array}$ & $\begin{array}{l}5230 \\
5630 \\
5430 \\
3890 \\
3140\end{array}$ & $\begin{array}{l}4910 \\
5170 \\
4940 \\
4860 \\
4780\end{array}$ & $\begin{array}{l}3330 \\
3540 \\
5050 \\
6290 \\
7320\end{array}$ & $\begin{array}{r}9220 \\
9390 \\
9810 \\
10000 \\
10200\end{array}$ & $\begin{array}{r}8420 \\
9380 \\
9480 \\
9840 \\
10000\end{array}$ & $\begin{array}{l}7970 \\
7440 \\
6840 \\
6910 \\
7150\end{array}$ & $\begin{array}{l}7060 \\
7440 \\
7510 \\
7550 \\
7330\end{array}$ & $\begin{array}{l}8850 \\
8610 \\
8140 \\
8180 \\
7960\end{array}$ & $\begin{array}{l}8760 \\
8610 \\
8940 \\
9160 \\
9190\end{array}$ & $\begin{array}{l}4650 \\
5020 \\
5260 \\
5250 \\
7550\end{array}$ \\
\hline $\begin{array}{l}26 \\
27 \\
28 \\
29 \\
30 \\
31\end{array}$ & $\begin{array}{l}4880 \\
5090 \\
5190 \\
5500 \\
5740 \\
5570\end{array}$ & $\begin{array}{r}4270 \\
4210 \\
4270 \\
4030 \\
4190 \\
-0-\end{array}$ & $\begin{array}{l}3950 \\
4670 \\
5250 \\
5770 \\
6270 \\
5570\end{array}$ & $\begin{array}{l}4920 \\
4940 \\
5080 \\
5190 \\
5240 \\
5230\end{array}$ & $\begin{array}{r}7980 \\
8370 \\
8480 \\
8240 \\
-\infty \\
-\infty\end{array}$ & $\begin{array}{l}10100 \\
10100 \\
10100 \\
10200 \\
10300 \\
10400\end{array}$ & $\begin{array}{r}10400 \\
10600 \\
10500 \\
10300 \\
10100 \\
-0-0\end{array}$ & $\begin{array}{l}6820 \\
6560 \\
6340 \\
6430 \\
6780 \\
6630\end{array}$ & $\begin{array}{r}7490 \\
7420 \\
7560 \\
7690 \\
8350 \\
-\infty\end{array}$ & $\begin{array}{l}8290 \\
8370 \\
8480 \\
8100 \\
7590 \\
7420\end{array}$ & $\begin{array}{l}8740 \\
8570 \\
8550 \\
8130 \\
8240 \\
8580\end{array}$ & $\begin{array}{r}7160 \\
8650 \\
4330 \\
4000 \\
4110 \\
-0-\end{array}$ \\
\hline $\begin{array}{l}\text { TOTAL } \\
\text { MEAN } \\
\text { MAX } \\
\text { MIN } \\
\text { AC-FT }\end{array}$ & $\begin{array}{r}179590 \\
5793 \\
7010 \\
4880 \\
356200\end{array}$ & $\begin{array}{r}132600 \\
4420 \\
4950 \\
3920 \\
263000\end{array}$ & $\begin{array}{r}149410 \\
4820 \\
6270 \\
3140 \\
296400\end{array}$ & $\begin{array}{r}143230 \\
4620 \\
5400 \\
3840 \\
284100\end{array}$ & $\begin{array}{r}135160 \\
4661 \\
8480 \\
2270 \\
268100\end{array}$ & $\begin{array}{r}277300 \\
8945 \\
10400 \\
7640 \\
550000\end{array}$ & $\begin{array}{r}283530 \\
9451 \\
10600 \\
5340 \\
562400\end{array}$ & $\begin{array}{r}233110 \\
7520 \\
9790 \\
5960 \\
462400\end{array}$ & $\begin{array}{r}212500 \\
7083 \\
8350 \\
6270 \\
421500\end{array}$ & $\begin{array}{r}261020 \\
8420 \\
9250 \\
7420 \\
517700\end{array}$ & $\begin{array}{r}268190 \\
8651 \\
9190 \\
7150 \\
532000\end{array}$ & $\begin{array}{r}157180 \\
5239 \\
8650 \\
2300 \\
311800\end{array}$ \\
\hline
\end{tabular}


09527000. PILOT KNOB POWERPLANT AND WASTEWAY NEAR PILOT KNOB, CALIF.

LOCATION.--Lat $32^{\circ} 44^{\prime} 15^{\prime \prime}$, long $114^{\circ} 42^{\prime} 56^{\prime \prime}$, in NWts SW/ sec. 25, T.16 S., R. 21 E., San Bernardino meridian, Imperial County, 2 mi (3 km) east of sumuit of Pilot Knob, $6 \mathrm{mi}\left(10^{\prime} \mathrm{kml}\right)$ west of Yuma Ariz., and $20.8 \mathrm{mi}$ ( $\left.33.5 \mathrm{~km}\right)$ downstream from intake of A11-American Canal at Imperial Dam.

PERTOD OF RECORD.--February 1939 to current year. Prior to October 1943 month1y discharge only, published in wSP 1313. Prior to October 1956, published as Pilot Knob wasteway near Pilot Knob.

GAGE.--Totalizing flowneter on each turbine, In addition, water-stage recorder in forebay on right bank of All-American Canal (also used as auxiliary gage for sta 09527500); tailrace gage with remote recorder logged hourly in control house; calibrated wicket gates for turbine flow and calibrated bypass gates for wasteway flow which are logged for each change. Datim of forebay staff gage is $150.00 \mathrm{ft}(45.720 \mathrm{~m})$; that of tailrace staff gage is $0.00 \mathrm{ft}(0.000 \mathrm{~m})$; elevation of sil1 of bypass gates is $147.88 \mathrm{ft}$ $(45.074 \mathrm{mil})$ above mean sea level.

EXTREMES.--Period of record: Maximum daily discharge, $8,350 \mathrm{ft}^{3} / \mathrm{s}\left(236 \mathrm{~m}^{3} / \mathrm{s}\right)$ Jan. 26 , 1958; no flow for long periods .

REMARKS. - Records excellent above $1,200 \mathrm{ft}^{3} / \mathrm{s}\left(34.0 \mathrm{~m}^{3} / \mathrm{s}\right)$ and good below. Daily discharge conputed from flowneter equipment or from head and gate openings on wicket gates. Records show water released through Pilot Knob powerplant and wasteway from All-American Canal and returned to Colorado River through Rockwood gates. Pilot Knob wasteway completed in sumner of 1938 and first flow occurred Feb. 5, 1939. Pilot Knob powerplant was completed in January 1957 and first flow occurred Jan. 14, 1957. See table below for monthly return flow by pilot Knob wasteway only.

COOPERATION.--Midnight readings of flometer, recorder graph of forebay, and record of tailrace elevation and gate openings furnished by Imperia1 Irrigation District.

DISCHARGE, IN CUBIC FEET PER SECOND, WATER YEAR OCTOBER 1975 TO SEPTEMBER 1976 MEAN VALUES

\begin{tabular}{|c|c|c|c|c|c|c|c|c|c|c|c|}
\hline DAY & $O C T$ & NOV & DEC & JAN & FEB & MAR & APR & MAY & JUN & JUL. & AUG \\
\hline $\begin{array}{l}1 \\
2 \\
3 \\
4 \\
5\end{array}$ & & $\begin{array}{l}0 \\
0 \\
0 \\
0 \\
0\end{array}$ & $\begin{array}{r}0 \\
0 \\
0 \\
0 \\
565\end{array}$ & $\begin{array}{r}1050 \\
954 \\
0 \\
0 \\
42\end{array}$ & $\begin{array}{l}0 \\
0 \\
0 \\
0 \\
0\end{array}$ & $\begin{array}{l}2090 \\
1760 \\
1520 \\
1480 \\
1500\end{array}$ & $\begin{array}{l}2770 \\
2830 \\
2830 \\
2760 \\
2760\end{array}$ & $\begin{array}{l}1600 \\
1460 \\
1450 \\
1150 \\
1200\end{array}$ & $\begin{array}{l}0 \\
0 \\
0 \\
0 \\
0\end{array}$ & $\begin{array}{l}1260 \\
1250 \\
1090 \\
1240 \\
1290\end{array}$ & $\begin{array}{l}1310 \\
1370 \\
1500 \\
1520 \\
1500\end{array}$ \\
\hline $\begin{array}{r}6 \\
7 \\
8 \\
9 \\
10\end{array}$ & & $\begin{array}{l}0 \\
0 \\
0 \\
0 \\
0\end{array}$ & $\begin{array}{l}1010 \\
1010 \\
1010 \\
1010 \\
1010\end{array}$ & $\begin{array}{r}1030 \\
1020 \\
1040 \\
999 \\
978\end{array}$ & $\begin{array}{r}43 \\
1010 \\
1060 \\
1120 \\
1500\end{array}$ & $\begin{array}{l}1540 \\
1640 \\
2020 \\
1940 \\
1870\end{array}$ & $\begin{array}{l}2760 \\
2860 \\
2940 \\
3000 \\
3080\end{array}$ & $\begin{array}{r}1160 \\
1170 \\
1140 \\
0 \\
0\end{array}$ & $\begin{array}{l}0 \\
0 \\
0 \\
0 \\
0\end{array}$ & $\begin{array}{l}1320 \\
1330 \\
1350 \\
1110 \\
1150\end{array}$ & $\begin{array}{l}1480 \\
1500 \\
1520 \\
1480 \\
1540\end{array}$ \\
\hline $\begin{array}{l}11 \\
12 \\
13 \\
14 \\
15\end{array}$ & & $\begin{array}{l}0 \\
0 \\
0 \\
0 \\
0\end{array}$ & $\begin{array}{l}1020 \\
1070 \\
1070 \\
1060 \\
1250\end{array}$ & $\begin{array}{l}0 \\
0 \\
0 \\
0 \\
0\end{array}$ & $\begin{array}{l}1970 \\
1180 \\
1240 \\
1300 \\
1220\end{array}$ & $\begin{array}{l}1880 \\
1820 \\
1900 \\
1980 \\
2070\end{array}$ & $\begin{array}{l}3010 \\
3010 \\
2970 \\
4000 \\
5920\end{array}$ & $\begin{array}{l}0 \\
0 \\
0 \\
0 \\
0\end{array}$ & $\begin{array}{l}0 \\
0 \\
0 \\
0 \\
0\end{array}$ & $\begin{array}{l}1300 \\
1520 \\
1550 \\
1590 \\
1540\end{array}$ & $\begin{array}{l}1550 \\
1490 \\
1470 \\
1430 \\
1440\end{array}$ \\
\hline $\begin{array}{l}16 \\
17 \\
18 \\
19 \\
20\end{array}$ & & $\begin{array}{l}0 \\
0 \\
0 \\
0 \\
0\end{array}$ & $\begin{array}{l}1220 \\
1330 \\
1370 \\
1380 \\
1410\end{array}$ & $\begin{array}{l}0 \\
0 \\
0 \\
0 \\
0\end{array}$ & $\begin{array}{r}1140 \\
715 \\
0 \\
0 \\
0\end{array}$ & $\begin{array}{l}2110 \\
2170 \\
2160 \\
2130 \\
2200\end{array}$ & $\begin{array}{l}4520 \\
2490 \\
1750 \\
2140 \\
2030\end{array}$ & $\begin{array}{l}0 \\
0 \\
0 \\
0 \\
0\end{array}$ & $\begin{array}{l}0 \\
0 \\
0 \\
0 \\
0\end{array}$ & $\begin{array}{l}1570 \\
1590 \\
1540 \\
1380 \\
1460\end{array}$ & $\begin{array}{l}1440 \\
1460 \\
1440 \\
1200 \\
1200\end{array}$ \\
\hline $\begin{array}{l}21 \\
22 \\
23 \\
24 \\
25\end{array}$ & & $\begin{array}{l}0 \\
0 \\
0 \\
0 \\
0\end{array}$ & $\begin{array}{l}1380 \\
1530 \\
1520 \\
1500 \\
1520\end{array}$ & $\begin{array}{l}0 \\
0 \\
0 \\
0 \\
0\end{array}$ & $\begin{array}{r}0 \\
41 \\
1100 \\
1460 \\
1750\end{array}$ & $\begin{array}{l}2230 \\
2280 \\
2340 \\
2370 \\
2170\end{array}$ & $\begin{array}{l}2120 \\
2150 \\
2210 \\
2290 \\
2200\end{array}$ & $\begin{array}{l}0 \\
0 \\
0 \\
0 \\
0\end{array}$ & $\begin{array}{l}0 \\
0 \\
0 \\
0 \\
0\end{array}$ & $\begin{array}{l}1590 \\
1680 \\
1580 \\
1600 \\
1580\end{array}$ & $\begin{array}{l}1220 \\
1210 \\
1400 \\
1450 \\
1430\end{array}$ \\
\hline $\begin{array}{l}26 \\
27 \\
28 \\
29 \\
30 \\
31\end{array}$ & & $\begin{array}{r}0 \\
0 \\
0 \\
39 \\
940 \\
\end{array}$ & $\begin{array}{l}1240 \\
1610 \\
1640 \\
1780 \\
1780 \\
1370\end{array}$ & $\begin{array}{l}0 \\
0 \\
0 \\
0 \\
0 \\
0\end{array}$ & $\begin{array}{r}2080 \\
2330 \\
2440 \\
2390 \\
-\ldots \\
\end{array}$ & $\begin{array}{l}2230 \\
2330 \\
2300 \\
2370 \\
2330 \\
2420\end{array}$ & $\begin{array}{c}2220 \\
2000 \\
1870 \\
1910 \\
1890 \\
-\end{array}$ & $\begin{array}{l}0 \\
0 \\
0 \\
0 \\
0 \\
0\end{array}$ & $\begin{array}{r}0 \\
0 \\
0 \\
0 \\
1160 \\
-00\end{array}$ & $\begin{array}{l}1600 \\
1650 \\
1700 \\
1700 \\
1620 \\
1360\end{array}$ & $\begin{array}{l}1400 \\
1390 \\
1330 \\
1150 \\
1100 \\
1120\end{array}$ \\
\hline $\begin{array}{l}\text { TOTAL } \\
\text { MEAN } \\
\text { MAX } \\
\text { MIN } \\
\text { AC-FT }\end{array}$ & $\begin{array}{l}0 \\
0 \\
0 \\
0 \\
0\end{array}$ & $\begin{array}{r}979 \\
32.6 \\
940 \\
0 \\
1940\end{array}$ & $\begin{array}{r}34665 \\
1118 \\
1780 \\
0 \\
68760\end{array}$ & $\begin{array}{r}7113 \\
229 \\
1050 \\
0 \\
14110\end{array}$ & $\begin{array}{r}27089 \\
934 \\
2440 \\
0 \\
53730\end{array}$ & $\begin{array}{r}63150 \\
2037 \\
2420 \\
1480 \\
125300\end{array}$ & $\begin{array}{r}81290 \\
2710 \\
5920 \\
1750 \\
161200\end{array}$ & $\begin{array}{r}10330 \\
333 \\
1600 \\
0 \\
20490\end{array}$ & $\begin{array}{r}1160 \\
38.7 \\
1160 \\
0 \\
2300\end{array}$ & $\begin{array}{r}45090 \\
1455 \\
1700 \\
1090 \\
89440\end{array}$ & $\begin{array}{r}43040 \\
1388 \\
1550 \\
1100 \\
85370\end{array}$ \\
\hline
\end{tabular}

$\begin{array}{llllllllll}\text { CAL YR } 1975 & \text { TOTAL } & 335431 & \text { MEAN } 919 & \text { MAX } & 3720 & \text { MIN O } & \text { AC-FT } & 665300 \\ \text { WTR YR } 1976 & \text { TOTAL } & 332586 & \text { MEAN } 909 & \text { MAX } & 5920 & \text { MIN } 0 & \text { AC-FT } & 659700\end{array}$ 
LOCATION.--Lat $32^{\circ} 44^{\prime} 07^{\prime \prime}$, long $114^{\circ} 43^{\prime} 23^{\prime \prime}$, in $\mathrm{NWH}_{4} \mathrm{SE} \mathrm{E}^{1 /}$ sec. 26 , T.16 S., R. 21 E., San Bernardino meridian, Imperial County, on left bank $0.4 \mathrm{mi}(0.6 \mathrm{~km})$ downstrean from Pilot Knob wasteway, $6 \mathrm{mi}$ (10 km) west of Yuna, Ariz., $15 \mathrm{mi}$ (24 km) upstream fron turnout to Coachella Cana1, and $21.2 \mathrm{mi}(34.1 \mathrm{~km})$ downstrean from intake at Imperial Dam.

PERIOD OF RECORD.--October 1961 to current year.

GAGE.- Water-stage recorder. Datum of gage is $150.00 \mathrm{ft}(45.720 \mathrm{~m})$ above mean sea leve1. Auxiliary water-stage recorder on right bank $0.4 \mathrm{mi}(0.6 \mathrm{~km})$ upstrean used to detemine head on pilot Knob check gates (also used as forebay gage for sta 09527000 , Pilot Knob powerplant and wasteway). Datum of auxiliary gage is $150.00 \mathrm{ft}(45.720 \mathrm{~m})$ above mean sea level.

AVERAGE DISCHARGE. - 15 years, $4,729^{\circ} \mathrm{ft}^{3} / \mathrm{s}\left(133.9 \mathrm{~m}^{3} / \mathrm{s}\right), 3,426,000$ acre-ft $/ \mathrm{yr}\left(4,220 \mathrm{~mm}^{3} / \mathrm{yr}\right)$.

EXTREMES.--Period of record: Maximum daily discharge, $7,610 \mathrm{ft}^{3} / \mathrm{s}\left(216 \mathrm{~m}^{3} / \mathrm{s}\right)$ April 27, 28, 1976 ; no flow Jan. 4 , 1967.

REMARKS.--Records excellent. Water is used for power development at three sites below station, and for irrigation in Coachella and Imperial Valleys.

COOPERATION, - Gage-height record and $\log$ of gate operation furnished by Imperial Irrigation District.

DISCHARGE, IN CUBIC FEET PER SECOND, WATER YEAR OCTOBER 1975 TO SEPTEMBER 1976 MEAN VALUES

\begin{tabular}{|c|c|c|c|c|c|c|c|c|c|c|c|c|}
\hline DAY & OCT & NOV & DEC & JAN & FEB & MAR & APR & MAY & JUN & JUL & AUO & SEP \\
\hline $\begin{array}{l}1 \\
2 \\
3 \\
4 \\
5\end{array}$ & $\begin{array}{l}6000 \\
5850 \\
5710 \\
5730 \\
5620\end{array}$ & $\begin{array}{l}4240 \\
4280 \\
4230 \\
4080 \\
4160\end{array}$ & $\begin{array}{l}3050 \\
2870 \\
2980 \\
3050 \\
2980\end{array}$ & $\begin{array}{l}3300 \\
3330 \\
3070 \\
2970 \\
2880\end{array}$ & $\begin{array}{l}3940 \\
3900 \\
4310 \\
4740 \\
4800\end{array}$ & $\begin{array}{l}5420 \\
6090 \\
6320 \\
6540 \\
6420\end{array}$ & $\begin{array}{l}6760 \\
6640 \\
6660 \\
6700 \\
6740\end{array}$ & $\begin{array}{l}7400 \\
7340 \\
7540 \\
7540 \\
7530\end{array}$ & $\begin{array}{l}5720 \\
5600 \\
5670 \\
5730 \\
5840\end{array}$ & $\begin{array}{l}6000 \\
6120 \\
6090 \\
5730 \\
5580\end{array}$ & $\begin{array}{l}5420 \\
5640 \\
5520 \\
5660 \\
5760\end{array}$ & $\begin{array}{l}6710 \\
6790 \\
6800 \\
6510 \\
5980\end{array}$ \\
\hline $\begin{array}{r}6 \\
7 \\
8 \\
9 \\
10\end{array}$ & $\begin{array}{l}5820 \\
5830 \\
5750 \\
5850 \\
5680\end{array}$ & $\begin{array}{l}4100 \\
3850 \\
3670 \\
3340 \\
3340\end{array}$ & $\begin{array}{l}2900 \\
2800 \\
2850 \\
2870 \\
3150\end{array}$ & $\begin{array}{l}3100 \\
3260 \\
3730 \\
3640 \\
3020\end{array}$ & $\begin{array}{l}4190 \\
2780 \\
2380 \\
1720 \\
1210\end{array}$ & $\begin{array}{l}\mathbf{5 8 8 0} \\
\mathbf{5 3 4 0} \\
5150 \\
5150 \\
5210\end{array}$ & $\begin{array}{l}6650 \\
6610 \\
6440 \\
6500 \\
6510\end{array}$ & $\begin{array}{l}7360 \\
7010 \\
6120 \\
5310 \\
5190\end{array}$ & $\begin{array}{l}\mathbf{5 5 9 0} \\
5570 \\
5570 \\
5600 \\
5380\end{array}$ & $\begin{array}{l}5810 \\
5900 \\
6250 \\
6250 \\
6510\end{array}$ & $\begin{array}{l}6080 \\
6280 \\
6420 \\
6360 \\
6350\end{array}$ & $\begin{array}{l}5480 \\
5540 \\
5190 \\
4700 \\
2230\end{array}$ \\
\hline $\begin{array}{l}11 \\
12 \\
13 \\
14 \\
15\end{array}$ & $\begin{array}{l}5410 \\
5160 \\
5110 \\
4850 \\
4820\end{array}$ & $\begin{array}{l}3410 \\
3500 \\
3470 \\
3480 \\
3510\end{array}$ & $\begin{array}{l}3270 \\
3210 \\
3190 \\
3030 \\
3040\end{array}$ & $\begin{array}{l}2600 \\
2760 \\
2720 \\
2820 \\
2880\end{array}$ & $\begin{array}{l}1200 \\
1130 \\
1080 \\
1200 \\
1030\end{array}$ & $\begin{array}{l}5180 \\
5130 \\
5230 \\
5260 \\
5610\end{array}$ & $\begin{array}{l}6290 \\
6320 \\
6000 \\
3980 \\
2770\end{array}$ & $\begin{array}{l}5320 \\
5420 \\
5750 \\
5950 \\
6190\end{array}$ & $\begin{array}{l}5220 \\
5500 \\
5370 \\
5520 \\
5530\end{array}$ & $\begin{array}{l}6400 \\
6350 \\
6450 \\
6550 \\
6590\end{array}$ & $\begin{array}{l}6460 \\
6470 \\
6430 \\
6390 \\
6380\end{array}$ & $\begin{array}{r}657 \\
1110 \\
1420 \\
1540 \\
1400\end{array}$ \\
\hline $\begin{array}{l}16 \\
17 \\
18 \\
19 \\
20\end{array}$ & $\begin{array}{l}4700 \\
4600 \\
4580 \\
4470 \\
4450\end{array}$ & $\begin{array}{l}3500 \\
3620 \\
3590 \\
3580 \\
3590\end{array}$ & $\begin{array}{l}3110 \\
3500 \\
3690 \\
3440 \\
3430\end{array}$ & $\begin{array}{l}3160 \\
3250 \\
3270 \\
3550 \\
3680\end{array}$ & $\begin{array}{r}1010 \\
982 \\
1220 \\
1600 \\
2010\end{array}$ & $\begin{array}{l}5860 \\
6170 \\
5980 \\
6150 \\
6270\end{array}$ & $\begin{array}{l}2510 \\
2820 \\
3280 \\
4110 \\
4820\end{array}$ & $\begin{array}{l}6270 \\
6640 \\
6720 \\
6610 \\
6760\end{array}$ & $\begin{array}{l}5600 \\
5750 \\
5650 \\
5980 \\
5710\end{array}$ & $\begin{array}{l}6180 \\
6210 \\
6080 \\
6180 \\
6370\end{array}$ & $\begin{array}{l}6640 \\
6720 \\
6600 \\
6560 \\
6560\end{array}$ & $\begin{array}{l}1820 \\
1970 \\
2000 \\
2470 \\
2930\end{array}$ \\
\hline $\begin{array}{l}21 \\
22 \\
23 \\
24 \\
25\end{array}$ & $\begin{array}{l}4450 \\
4550 \\
4310 \\
4270 \\
4010\end{array}$ & $\begin{array}{l}3530 \\
3460 \\
3240 \\
3050 \\
3000\end{array}$ & $\begin{array}{l}3480 \\
3660 \\
3460 \\
2090 \\
1340\end{array}$ & $\begin{array}{l}3870 \\
4100 \\
3840 \\
3700 \\
3750\end{array}$ & $\begin{array}{l}2420 \\
2590 \\
3240 \\
3840 \\
4510\end{array}$ & $\begin{array}{l}6230 \\
6180 \\
6380 \\
6610 \\
6900\end{array}$ & $\begin{array}{l}5530 \\
6160 \\
6300 \\
6600 \\
6920\end{array}$ & $\begin{array}{l}6560 \\
6210 \\
5890 \\
5920 \\
6090\end{array}$ & $\begin{array}{l}5870 \\
6110 \\
6100 \\
5980 \\
5820\end{array}$ & $\begin{array}{l}6230 \\
5970 \\
5720 \\
5840 \\
5860\end{array}$ & $\begin{array}{l}6560 \\
6560 \\
6600 \\
6610 \\
6590\end{array}$ & $\begin{array}{l}3400 \\
3780 \\
4120 \\
3260 \\
3390\end{array}$ \\
\hline $\begin{array}{l}26 \\
27 \\
28 \\
29 \\
30 \\
31\end{array}$ & $\begin{array}{l}3930 \\
3870 \\
3900 \\
4090 \\
4220 \\
4280\end{array}$ & $\begin{array}{r}3020 \\
3050 \\
2920 \\
2940 \\
2840 \\
\\
-\end{array}$ & $\begin{array}{l}2370 \\
2680 \\
3230 \\
3490 \\
3940 \\
3800\end{array}$ & $\begin{array}{l}3790 \\
3720 \\
3770 \\
3890 \\
3930 \\
4070\end{array}$ & $\begin{array}{r}4850 \\
5070 \\
5220 \\
5260 \\
- \\
-\end{array}$ & $\begin{array}{l}6730 \\
6650 \\
6760 \\
6870 \\
6950 \\
6930\end{array}$ & $\begin{array}{l}7270 \\
7610 \\
7610 \\
7480 \\
7300 \\
-\end{array}$ & $\begin{array}{l}\mathbf{5 8 3 0} \\
\mathbf{5 6 4 0} \\
\mathbf{5 5 3 0} \\
\mathbf{5 5 7 0} \\
5830 \\
\mathbf{5 6 7 0}\end{array}$ & $\begin{array}{r}5870 \\
5800 \\
5810 \\
6030 \\
6080 \\
-\end{array}$ & $\begin{array}{l}5920 \\
5820 \\
5830 \\
5520 \\
5150 \\
5300\end{array}$ & $\begin{array}{l}6260 \\
6210 \\
6280 \\
6230 \\
6270 \\
6330\end{array}$ & $\begin{array}{r}2960 \\
3280 \\
3180 \\
3350 \\
3380 \\
\end{array}$ \\
\hline $\begin{array}{l}\text { TOTAL } \\
\text { MEAN } \\
\text { MAX } \\
\text { MIN } \\
\text { AC }-F T\end{array}$ & $\begin{array}{r}151870 \\
4899 \\
6000 \\
3870 \\
301200\end{array}$ & $\begin{array}{r}105590 \\
3520 \\
4280 \\
2840 \\
209400\end{array}$ & $\begin{array}{r}95950 \\
3095 \\
3940 \\
1340 \\
190300\end{array}$ & $\begin{array}{r}105420 \\
3401 \\
4100 \\
2600 \\
209100\end{array}$ & $\begin{array}{r}83432 \\
2877 \\
5260 \\
982 \\
165500\end{array}$ & $\begin{array}{r}187550 \\
6050 \\
6950 \\
5130 \\
372000\end{array}$ & $\begin{array}{r}177890 \\
5930 \\
7610 \\
2510 \\
352800\end{array}$ & $\begin{array}{r}194710 \\
6281 \\
7540 \\
5190 \\
386200\end{array}$ & $\begin{array}{r}171570 \\
5719 \\
6110 \\
5220 \\
340300\end{array}$ & $\begin{array}{r}186760 \\
6025 \\
6590 \\
5150 \\
370400\end{array}$ & $\begin{array}{r}195200 \\
6297 \\
6720 \\
5420 \\
387200\end{array}$ & $\begin{array}{r}107347 \\
3578 \\
6800 \\
657 \\
212900\end{array}$ \\
\hline
\end{tabular}

$\begin{array}{lllllllllll}\text { CAL YR } 1975 & \text { TOTAL } & 1818890 & \text { MEAN } & 4983 & \text { MAX } & 7380 & \text { MIN } & 1340 & \text { AC-FT } & 3608000 \\ \text { WTR YR } 1976 & \text { TOTAL } & 1763289 & \text { MEAN } & 4818 & \text { MAX } & 7610 & \text { MIN } & 657 & \text { AC-FT } & 3497000\end{array}$ 
Return surface flows below Imperial Dam, Ariz.-Calif.

Between Inperial Dam and the international boundary return surface flows from irrigated areas enter the Colorado River through many drains and wasteways in Arizona and California. Other return flows enter the Gila River below the gaging station near Dome (09520500). In addition, return flows collected by the Main Drain and East Main Canal are delivered across the international boundary for use in Hexico.

Diversions for irrigation in the Gila Project in Arizona are made at Imperial Dam by the Gila Gravity Main Canal. (See sta 09522500.) Diversions for the Yuma Project in Arizona and California are made at Imperial Dam by the Al1-American Canal (see sta 09523000) and by the Yuma Main Canal. (See stas 09524000 and 09525500.) See p. for records of diversions.

See figure 4 on p. 161 for a schematic diagram showing location of diversions and return flows.

09525000. YUMA MAIN CANAL WASTEWAY.--See daily table elsewhere in this report.

09527000. PILOT KNOB POHERPLANT AND NASTEWAY.--See daily table elsewhere in this report.

09527900. MIITRY LAKE OUTLET CHANNEL.

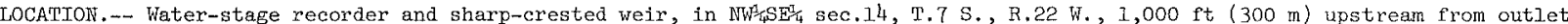
to Colorado River and Laguna Dam.

PERTOD OF RECORD.--Monthly discharge October 1974 to current year.

REMARKS.--Record shows return f'low to Colorado River from Mittry Lake. Prior to Nov, 6, 1974, records furnished by Bureau of Reclamation.

09528600. LAGUNA CANAL WASTEWAY.

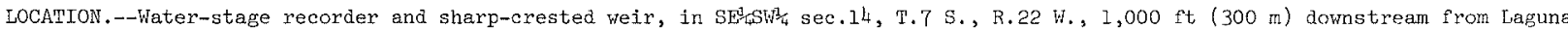
Dam and $0.7 \mathrm{mi}(1.1 \mathrm{~km})$ upstream from out let to Colorado River.

PERIOD OF RECORD,--Monthly discharge October 1960 to current year.

REMARKS.--Record shows waste water from North Gila Valley Irrigation District returned to Colorado River. Flow record computed from standard weir rating.

09528800. TEVEH CANAL WASTEWAY,

LOCATION.--Water-stage recorder and sharp-crested weir, in SE⿺辶. Colorado River.

PERIOD OF RECORD, --MonthIy discharge October 1960 to current year.

REMARKS.--Record shows waste water from North Gila Valley Irrigation District returned to Colorado River.

09529000. NORTH GILA DRAIN NO. 1.

LOCATION, --Water-stage recorder, in SEl $5.5 \mathrm{mi}(8.8 \mathrm{~km})$ downstream from Laguna Dam. No gage prior to Oct. 16, 1974 .

PERIOD OF RECORD.--Monthly discharge Octobex 1960 to current year.

REMARKS.--Record shows waste water from North Gila Valley Irrigation District returned to Colorado River. Prior to Oct. 16, 1974, flow records were computed by interpolation between discharge measurements made monthly.

09529050. NORTH GIIA DRAIN NO. 3.

LOCATION, --Drain enters wasteway to Gila River in NEtanel sec.18, T.8 s., R.21 W., 1,000 ft (300 m) upstream rrom Gila River.

PERIOD OF RECORD,--Monthly discharge April 1962 to current year.

REMARKS.--Record shows seepage from Gila Gravity Main Canal. There is no gage; records are computed by interpolation between discharge measurements made montıly.

09529100. FORTUNA WASTEWAY.

EOCATION,--Water-stage recorder and sharp-crested weir, in NE⿺ sec.30, T.8 S., R.2l V., I.3 mi (2.1 km) upstream from Gila River.

PERIOD OF RECORD. - Monthily discharge October 1960 to September 1963, October 1964 to current year.

REMARKS.--Record shows waste water spilled from Gila Gravity Main Canal; flow rarely reaches Gila River.

09529150. NORTH GILA MAIN CANAL WASTEWAY.

LOCATION.--Water-stage recorder in NE⿺WW/ sec.22, T.8 S., R.22 W., 1,000 ft (300 m) upstream from outlet to Gila River. Prior to

July I966 water-stage recorder and sharp-crested weir, $1 \mathrm{mi}(1.6 \mathrm{~km}$ ) upstream from outlet to Gila River.

PERIOD OF RECORD.--Monthly discharge October 1960 to current year.

REMARKS.--Record shows waste water from North Gila Valley Irrigation District. Prior to July 1966 record shows waste water less flow diverted for irrigation between gage and Gila River.

09529160. SOUTH GILA PUMP OUTLET CHAHNEL NO. 3.

LOCATION.-Water-stage recorder in NW/4E sec.22, T.8 S., R.22W., $0.5 \mathrm{mi}(0.8 \mathrm{~km})$ upstream from outlet to Gila River. Prior to Aug. I, 1965, record obtained by Badger total-flow meter about 500 ft (150 m) downstream.

PERIOD OF RECORD.--Monthly discharge January 1965 to current year. 
09529200. BRUCE CHURCH DRATN.

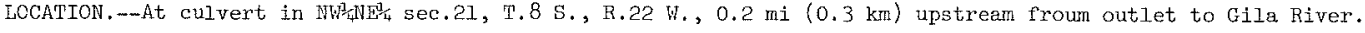

PERIOD OF RECORD.--Monthly discharge April 1962 to current year.

REMARKS.--Record shows seepage water from parts of secs.15, 16, and 21 (Bruce Church Ranch). Flow computed by interpolation between discharge measurements; prior to Nov. 30, 1970 , flow determined from pump rating.

09529240. SOUTH GILA PUMP OUTLET CHANNEL NO. 2.

LOCATION,--Water-stage recorder in SWl-WW/4 sec.28, T.8 S., R.22 W., $0.6 \mathrm{mi}(1.0 \mathrm{~km})$ upstream from outlet to Gila River; prior to Oct. 18, 1965, outlet was to Wellton-Hohawk Main Oulet Drain. Prior to Aug. 1, I965, Sparling meter at outlet to WelltonMohawk Main Outlet Drain.

PRRIOD OF RECORD.--Monthly discharge January 1962 to current year.

REMARKS.--Record shows water pumped from wells in South Gila Valley Unit and conveyed by concrete channel to the Gila River.

09529250. BRUCE CHURCH WASTEWAY.

LOCATION.--Water-stage recorder and sharp-crested weir, in SE4SEl sec.20, T.8 S., R.22 E., 500 ft (150 m) upstrearn from outiet to Gila River

PERIOD OF RECORD.--Monthly discharge October 1960 to current year.

REMARKS.---Record shows vaste water from North Gila, Valiey Irrigation District returned to Gila River.

09529300. WELLTON-MOHAWK MATN OUTLET DRALN (CONVEYANCE CHANHEL).

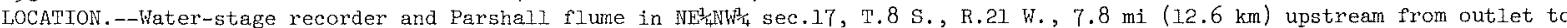
Gila River (M.O.D.E. I), which is $0.6 \mathrm{mi}(1.0 \mathrm{~km})$ upstream from mouth of Gila River. Prior to Feb. 20 , 1962 , gage heights measured from reference point on measuring bridge. Prior to oct. 1, 1974, gage located I,000 ft (300 m) upstream without Parshall flume.

PERIOD OF RECORD, --Monthly discharge Oetober 1960 to current year.

REMARKS...-Record shows water pumped from numerous wells in Wellton-Mohawk Irrigation and Drainage District to Iower the water table. Flow can be discharged to the Gila River or Colorado River by any one of or combination of three outlets. These outlets are known as: M.O.D.E. I (release to Gila River about $8.0 \mathrm{mi}$ (13 km) below station); M.0.D.E. 2 (see sta 09531800), release to Colorado River above Morelos Dam; and M.O.D.E. 3 (see sta 09531900), release to CoIorado River below Morelos Dam. For water year 1976,61 acre-ft $\left(75,200 \mathrm{~m}^{3}\right)$ was released to Gila River through M.O.D.E. 1.

09529360. SOUTH GILA PUNP OUTLET CHANEEL NO. 1.

LOCATION.-Water-stage recorder in SW. WE $\mathrm{sec} .30, \mathrm{~T} .8 \mathrm{~S}, \mathrm{R} .22 \mathrm{~W}, 0.2 \mathrm{mi}(0.3 \mathrm{~km})$ upstream from outlet to Gila River, which is $0.6 \mathrm{mi}(1.0 \mathrm{~km})$ upstream from mouth of Gila River. Prior to Aug. 1, 1965, Sparling flowmeter 300 f'eet (90 m) upstream.

PERIOD OF RECORD, -.-Monthly discharge August 1961 to current year.

REMARKS.--Record shows water pumped from vells in South Gila Valley Unit and conveyed by concrete channel to Gila River.

09529400. SOUTH GILA. DRAIIN NO. 2 .

LOCATION,-Near center of sec.24, T.8 S, R.23 W., at outlet to Colorado River. Prior to Oct. 1, 1969, Sparling flowmeter at same site.

PERIOD OF RECORD, -.-Monthly discharge October 1960 to current year.

REMARKS.--Record shows ground-water drainage and occasional waste water from South Gila valley Unit returned to Colorado River. There is no gage; flow record computed by interpolation between discharge measurements made monthly.

09529420. SOUTH GTEA TERMTNAL WASTEWAY.

LOCATION.--Water-stage recorder and Parshall flume in SWlawl/ sec.36, T.8 S., R.23 W., 2.0 mi (3.2 km) upstream from outlet to Colorado River. Prior to Aug. 1, 1965, total-flow meter at same site.

PERIOD OF RECORD, - Monthly discharge March 1965 to current year.

REMARKS.--Record shows waste water from South Gila Canal of South Gila Valley Unit returned to Colorado River.

09529440. SOUTH GTLA PUMP OUTLET CHANNEL HO. 4.

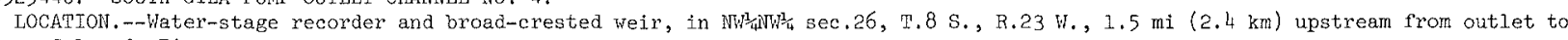
Colorado River.

PERIOD OF RECORD.--Monthly discharge July 1965 to current year.

REMARKS.--Record shows water pumped from tells in South Gila Valley Unit and conveyed by concrete-lined channel to Colorado River.

09529600. RESERVATION DRAIN NO. 7.

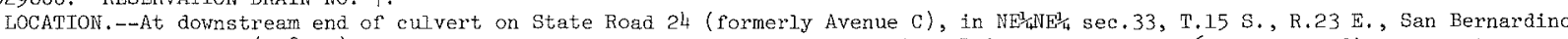
meridian, $0.5 \mathrm{mi}(0.8 \mathrm{~km})$ upstream from outlet to Reservation Main Drain. Prior to 0ct. 1 , 1969 , nonrecording gage at same site.

PERIOD OF RECORD, --Monthiy discharge March 1966 to eurrent year.

REMARKS.--Record shows drainage water from sec.34, T.15 S., R.23 E., and is used vith sta 09529700 to determine seepage frorn AllAmerican Canal. There is no gage; flow record computed by interpolation between discharge measurements made monthy. Beginning June 20, 1967, Imperial Irrigation District makes discharge measurements weekly. 
Return surface flows below Imperial Dam, Ariz.-Calif.--Continued

09529700. RESERVATION MAIN DRAIN NO. 6.

IOCATION.--Nonrecording gage on upstream right piling of Stallnacker Road Bridge (formerly 9 th Street Bridge), in SE 45 W sec.32, T.15 S., R.23 E., San Bernardino meridian.

PERIOD OF RECORD. - MOnthly discharge March 1966 to current year.

REMARKS.--Record shows waste and drainage water from the Reservation Division, and is used with sta 09529600 to determine seepage from All-American Canal, which parallels drain for $4 \mathrm{mi}(6.4 \mathrm{~km})$. Flow record computed by interpolation between discharge measurements made monthly, The Imperial Irrigation District makes discharge measurements weekly.

09529800. RESERVATION DRAIN NO. 2.

LOCATION.--At upstream side of bridge on White Road (formerly 8 th Street), in SW/NW/4 sec.6, T.16 S., R.23 E., San Bernardino meridian, $0.9 \mathrm{mi}(1.4 \mathrm{~km})$ upstream from outlet to Reservation Main Drain.

PERIOD OF RECORD, - Monthly discharge March 1966 to current year.

REMARKS.--Record used to compute seepage from AlI-American Canal in see.31, T.15 S., R.22 E. There is no gage; flow record computed by interpolation between discharge measurements made monthly. The Imperial Irrigation District makes discharge measurements weekly.

09529900. RESERVATTON DRAIN NO. 3.

LOCATION, - At Jackson Road Bridge (formerly 5th Street Bridge), in SEthEt/4 sec.10, T.I6 S., R.22 E., San Bernardino meridian, $1.0 \mathrm{mi}(1.6 \mathrm{~km})$ upstream from outlet to Reservation Main Drain.

PERIOD OF RECORD,--Monthly discherge March 1966 to current year.

REMARKS.--Record used to compute seepage from All-American Canal upstream from Yuma Main Canal. There is no gage; flow record computed by interpolation between discharge measurements made monthly. Imperial Irrigation District makes discharge measurements weekIy.

09530000. RESERVATION MATN DRAIN NO. 4.

LOCATION (REVISED). - Water-stage recorder in Ntw from railroad culvert. Prior to January 1937, no gage. January 1937 to Apr. 16, I94I, nonrecording gages at eulvert 500 ft $(150 \mathrm{~m}$ ) downstream at different datuns. Apr. 16, 1941, to Dec. 16, 1971, water-stage recorder at eulvert $500 \mathrm{ft}$ (150 $\mathrm{m}$ ) downstream. May 29, 1974, to Feb. 2, 1976, water-stage recorder with vane meter at present site. Flow enters Yuma Main Canal wasteway channel $200 \mathrm{ft}(60 \mathrm{~m})$ downstream from spillway structure. Prior to May 1955 it entered $500 \mathrm{ft}$ (I50 m) upstream from outlet of Yuma Main Canal wasteway in SE⿺辶W $W_{4}^{1}$ sec.26, T.16 S., R.22 E., San Bernardino meridian.

PERTOD OF RECORD.--Monthly discharge January 1913 to April 1920, October 1921 to March 1925 , January 1934 to current year.

(calender year discharge only 1934-36). Priox to October 1955, Published as California drainage canal.

REMARKS.--Record shows waste and drainage water from area east of Yuma Main Canal on Reservation Division. Since 1939, seepage from AlI-American Canal has caused large increase. Flow is not included in the record of Yuma Main Canal wasteway.

09530200. YUMA MESA OUTIET DRAIN

LOCATION.-Venturi meter with recorder in SE 4 SW sec.28, T.16 S., R.22 E., San Bernardino meridian, in Arizona, Yuma County, 0.3 mi $(0.5 \mathrm{~km})$ from outlet to Colorado River.

PERIOD OF RECORD. --Monthly discharge July 1970 to current year.

REMARKS.--Record shows water pumped from velis on the Yuma Mesa and conveyed by underground conduit to Colorado River.

COOPERATION.--Records furnished by Bureau of Reclamation prior to Juty $21,1972$.

09530400. RESERVATION DRATN NO. II

LOCATION. --At outlet to Drain 8-B (Araz drain), in NE⿺𠃊ted/ sec.19, T.16 S., R.22 E., San Bernardino meridian.

PERIOD OF RECORD.--lionthly discharge March 1966 to current year.

REMARKS.--Record shows drainage from sec.20, T.16 S., R.22 E. Flow at this station, with that at sta 09530500, is used to determine seepage from All-American Canal. There is no gage; flow record computed by interpolation between discharge measurements made monthly. Beginning June 20, 1967, Tmperial Irrigation District makes discharge measurements veekly.

09530500. DRAIN 8-B.

LOCATION.--.Enters Colorado River in NEtwh sec.30, T.16 S., R.22 E., San Bernardino meridian, 4 mi (6.4 km) downstream from outlet of Yuma Main Canal wastevay.

PERTOD OF RECORD.--Monthly discharge March 1948 to current year. Prior to October 1955, published as Araz drain.

REMARKS.--Record shows seepage from All-American Canal, and waste and drainage water west of Yuma Main Canal on the Reservation Division. Flow at this station, with that at sta 09530400 , is used to determine seepage from All-American Canal. There is no gage, but due to fairly constant drainage, flow record is computed by interpolation between discharge measurements made monthly. Imperial Irrigation District makes discharge measurements weekly at site $1,000 \mathrm{ft}(300 \mathrm{~m})$ upstream.

09531800. MATN OUTLET DRAIN EXTENSION ABOVE MORELOS DAM (M.O.D.E. 2)

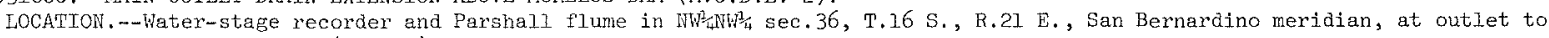
Colorado River, $1.7 \mathrm{mi}(2.7 \mathrm{~km})$ upstream from Worelos Dam.

PERIOD OF RECORD, --Monthly discharge November 1965 to current year.

REMARKS.--Record shows water conveyed to Colorado River $1.7 \mathrm{mi}(2.7 \mathrm{~km})$ above Morelos Dam, from numerous drainage vells in WelltonWohawk Irrigation and Drainage District. (See also stas 09529300 and 09531900. ) 
09531850. COOPER WASTEWAY.

LOCATION.--Water-stage recorder and weir, in $\mathrm{NE}_{4}^{\mathrm{t}} \mathrm{NE} \frac{\mathrm{m}}{4} \mathrm{sec} .28, \mathrm{~T} .8 \mathrm{~S} ., \mathrm{R} .24 \mathrm{~W}, 0.6 \mathrm{mi}(1.0 \mathrm{~km})$ upstream from Morelos Dam. Prior to

July 14, 1971, at site $1 \mathrm{mi}(1.6 \mathrm{~km})$ downstream.

PERIOD OF RECORD,--Monthly discharge January 1934 to current year.

REMARKS,--Record shows waste water from Valley Division returned to Colorado River.

COOPERATION.--Record furnished by International Boundary and Water Commission (U.S. Section).

09531900. MAIN OUTLET DRATN EXTENSTON BELOW MORELOS DAM (M.O.D.E 3).

LOCATION. - Water-stage recorder and Parshall flume in $\mathrm{N}_{4}^{2} \mathrm{SE}^{\frac{1}{4}}$ sec.28, T.8 S., R.24 H., at outlet to Colorado River just downstream from Morelos Dam.

PERIOD OF RECORD.--Monthly discharge November 1965 to current year.

REMARKS,--Record shows water conveyed to Colorado River below Morelos Dam, from numerous drainage wells in Wellton-Mohawk Irrigation and Drainage District. (See also stas 09529300, 0953I800.)

COOPERATION.--Record furnished by International Boundary and Water Commission (U.S. Section).

09532500. ELEVEN MILE WASTEWAY.

LOCATION, - Water-stage recorder and regulating gate in SElutw sec.8, T.9 S., R. 24 W., $3.2 \mathrm{mi}$ (5.1 km) downstream from Morelos Dam. PERIOD OF RECORD,--Monthly discharge January 1924 to current year.

REMARKS,--Record shows waste water from Valley Division returned to Colorado River.

COOPERATION.--Record furnished by International Boundary and Water Commission (U.S. Section).

09533000. TWENTY-ONE MILE WASTEWAY.

LOCATION, --Water-stage recordex and weir in NEWW sec.35, T.10 S., R.25 W., $0.6 \mathrm{mi}$ (1.0 km) upstream from outlet to Colorado River, which is $2.4 \mathrm{mi}(3.9 \mathrm{~km})$ upstream from southerly international boundary and $2.6 \mathrm{mi}$ (4.2 km) northwest of San Luis, Ariz. Prior to May I, 1971, water-stage recorder and Parshail flume at site $200 \mathrm{ft}(60 \mathrm{~m})$ upstream.

PERIOD OF RECORD.--Monthly discharge March 1939 to current year.

REMARKS.--Record shows waste water from Valley Division returned to Colorado River.

COOPERA'PION.--Record furnished by International Boundary and Water Commission (U.S. Section).

09534000. MAIN DRAIN.

LOCATION,--Flowmeters in discharge pipes at pumping plant in SElWE sec.11, T.11 S., R.25 W., $0.4 \mathrm{mi}(0.6 \mathrm{~km})$ west of San Luis, Ariz, Prior to Apr. 1, 1969, rated pumps with forebay and afterbay gages to measure head.

PERIOD OF RECORD.-Monthly discharge January 1919 to current year.

REMARKS.--Record shows flow which consists mostly of drainage water from the Valley Division which is pumped across the ArizonaSonora boundary for use in Mexico. Flowmeters checked by discharge measurements made by International Boundary and Water Commission (U.S. Section).

COOPERATION,--Record furnished by International Boundary and Water Commission (U.S. Section).

09534300. WEST MAIN CANAL WASTEWAY.

LOCATION.-Water-stage recorder and weir, in NWHEt/ sec.11, T.II S., R.25 W., 0.3 mi (0.5 km) upstream from outlet to Main drain, and $0.4 \mathrm{mi}(0.6 \mathrm{~km})$ west of San Luis, Ariz. Prior to Aug. 1, 1975 , at site 150 ft (46 m) upstrearn from outlet to Main drain.

PERIOD OF RECORD.--Monthly discharge February 1971 to current year.

REMARKS, --Record shows waste water from Valley Division which is discharged across the Arizona-Sonora boundary for use in Mexico. COOPERATION.--Record furnished by International Boundary and Water Commission (U.S. Section)

09534500. EAST MAIN CANAT WASTEWAY.

I,OCATION. - Water-stage recorder and veir, in Nhtsw. sec.l2, T.11 S., R.25 W., $0.3 \mathrm{mi}$ (0.5 km) upstream from outlet to Main arain, and $0.2 \mathrm{mi}(0.3 \mathrm{~km})$ west of San Luis, Ariz.

PERIOD OF RECORD.--Monthly discharge January 1924 to June 1928, January 1932 to December 1933 , Apri1 1935 to current year. Calendar year estimates 1934 and 1935, published in WSP 1313.

REMARKS,--Record shows amount of unused water at the extreme end of the Valley Division which is discharged across the ArizonaSonora boundary for use in Mexico.

COOPERATION.--Record furnished by International Boundary and Water Commission (U.S. Section). 
Return surface flows below Imperial Dam, Ariz.-Calif.--Continued

MONTHEY RETURN FLOWS, IN ACRE-FEET, WATER YEAR OCTOBER 1975 TO SEPTEMBER 1976

\begin{tabular}{|c|c|c|c|c|c|c|}
\hline Month & $\begin{array}{c}\text { Mittry Lake } \\
\text { Outlet Channel } \\
09527900\end{array}$ & $\begin{array}{c}\text { Laguna Cana.1 } \\
\text { wasteway } \\
09528600\end{array}$ & $\begin{array}{c}\text { Levee Canal } \\
\text { wasteway } \\
09528800\end{array}$ & $\begin{array}{l}\text { Noxth Gila } \\
\text { Drain No. I } \\
09529000\end{array}$ & $\begin{array}{l}\text { North Gila } \\
\text { Drain No. } 3 \\
09529050\end{array}$ & $\begin{array}{l}\text { Fortuna } \\
\text { wasteway } \\
09529100\end{array}$ \\
\hline October $\ldots \ldots \ldots \ldots \ldots \ldots \ldots \ldots$ & 633 & 0 & 106 & 504 & 0 & 30 \\
\hline November $\ldots \ldots \ldots \ldots \ldots \ldots \ldots$ & 541 & .02 & 161 & 540 & 0 & 34 \\
\hline December $\ldots \ldots \ldots \ldots \ldots \ldots \ldots$ & 839 & .4 & 131 & 308 & 0 & 35 \\
\hline CAL YR $1975 \ldots \ldots \ldots \ldots \ldots \ldots$ & 9,560 & 7.0 & 1,560 & 4,800 & 13 & 397 \\
\hline January $\ldots \ldots \ldots \ldots \ldots \ldots \ldots \ldots$ & 626 & 6.5 & 137 & 256 & 0 & 39 \\
\hline February $\ldots \ldots \ldots \ldots \ldots \ldots \ldots$ & 742 & .7 & 139 & 424 & 0 & 32 \\
\hline March $\ldots \ldots \ldots \ldots \ldots \ldots \ldots$ & 720 & 1.2 & 148 & 364 & 0 & 34 \\
\hline April $\ldots \ldots \ldots \ldots \ldots \ldots \ldots \ldots$ & 766 & .4 & 158 & 461 & 0 & 28 \\
\hline May $\ldots \ldots \ldots \ldots \ldots \ldots \ldots \ldots$ & 724 & 1.8 & 272 & 478 & 0 & 30 \\
\hline June $\ldots \ldots \ldots \ldots \ldots \ldots \ldots \ldots$ & 530 & .4 & 178 & 425 & 0 & 45 \\
\hline July $\ldots \ldots \ldots \ldots \ldots \ldots \ldots \ldots$ & 788 & 0 & 128 & 560 & .3 & 45 \\
\hline August $\ldots \ldots \ldots \ldots \ldots \ldots \ldots \ldots$ & 1,630 & 0 & 157 & 720 & .3 & 46 \\
\hline 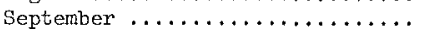 & 1.360 & 3.6 & 172 & 710 & 0 & 40 \\
\hline WIR YR $1976 \ldots \ldots \ldots \ldots \ldots$ & 9,900 & 15 & 1,890 & 5,750 & 0.6 & 438 \\
\hline
\end{tabular}

\begin{tabular}{|c|c|c|c|c|c|}
\hline Month & $\begin{array}{l}\text { North Gila } \\
\text { Main Canal } \\
\text { wasteway } \\
09529150\end{array}$ & $\begin{array}{c}\text { South Gila } \\
\text { Pump Outlet } \\
\text { Channel No. } 3 \\
09529160\end{array}$ & $\begin{array}{c}\text { Bruce Church } \\
\text { Drain } \\
09529200\end{array}$ & $\begin{array}{c}\text { South Gila } \\
\text { Pump Outlet } \\
\text { Channel No. } 2 \\
09529240\end{array}$ & $\begin{array}{c}\text { Bruce Church } \\
\text { vasteway } \\
09529250\end{array}$ \\
\hline October $\ldots \ldots \ldots \ldots \ldots \ldots \ldots \ldots \ldots$ & 82 & 0 & 91 & 408 & 2.0 \\
\hline 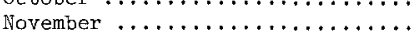 & 104 & 0 & 43 & 386 & 12 \\
\hline December $\ldots \ldots \ldots \ldots \ldots \ldots \ldots$, & 49 & 0 & $3]$ & 2,000 & 2.7 \\
\hline CAL YR $1975 \ldots \ldots \ldots \ldots \ldots$ & 745 & 7,140 & 784 & 18,150 & 82 \\
\hline January $\ldots \ldots \ldots \ldots \ldots \ldots \ldots \ldots \ldots$ & 21 & 266 & 41 & 1,150 & 1.8 \\
\hline February $\ldots \ldots \ldots \ldots \ldots \ldots \ldots$ & 43 & 389 & 33 & 1,520 & 21 \\
\hline March $\ldots \ldots \ldots \ldots \ldots \ldots \ldots$ & 56 & 2,240 & 39 & 2,220 & 1.4 \\
\hline Apri1 $\ldots \ldots \ldots \ldots \ldots \ldots \ldots$ & 71 & 2,070 & 30 & 1,870 & 15 \\
\hline May $\ldots \ldots \ldots \ldots \ldots \ldots \ldots \ldots$ & 38 & 298 & 38 & 1,280 & 0 \\
\hline June $\ldots \ldots \ldots \ldots \ldots \ldots \ldots$ & 45 & 18 & 52 & 1,740 & 22 \\
\hline July $\ldots \ldots \ldots \ldots \ldots \ldots \ldots$ & 34 & 2,500 & 66 & 2,100 & 0 \\
\hline August $\ldots \ldots \ldots \ldots \ldots \ldots \ldots$ & 56 & 779 & 60 & 1,780 & 5.4 \\
\hline September $\ldots \ldots \ldots \ldots \ldots \ldots \ldots$ & 88 & 7.8 & 54 & 1,170 & .4 \\
\hline WTR YR $1976 \ldots \ldots \ldots \ldots \ldots \ldots$ & 685 & 6,560 & 578 & 17,610 & 84 \\
\hline
\end{tabular}

\begin{tabular}{|c|c|c|c|c|c|}
\hline Month & $\begin{array}{c}\text { Wellton-Mohawk } \\
\text { Main Outlet } \\
\text { Drain } \\
09529300 \\
\end{array}$ & $\begin{array}{c}\text { South Gila } \\
\text { Punp Outlet } \\
\text { Channel No. I } \\
09529360\end{array}$ & $\begin{array}{c}\text { South Gila } \\
\text { Drain No. } 2 \\
09529400\end{array}$ & $\begin{array}{l}\text { South Gila } \\
\text { Terminal } \\
\text { wasteway } \\
09529420 \\
\end{array}$ & $\begin{array}{c}\text { South Gila } \\
\text { Pump Outlet } \\
\text { Channel No. } 4 \\
\text { og529440 }\end{array}$ \\
\hline October $\ldots \ldots \ldots \ldots \ldots \ldots \ldots$ & 18,500 & 2,200 & 0 & 32 & 4.3 \\
\hline November $\ldots \ldots \ldots \ldots \ldots \ldots \ldots$ & 18,220 & 1,960 & 18 & 35 & .2 \\
\hline December $\ldots \ldots \ldots \ldots \ldots \ldots \ldots$ & 18,740 & 2,460 & 18 & 19 & 0 \\
\hline CAI YR $1975 \ldots \ldots \ldots \ldots \ldots$ & 210,200 & 28,260 & 192 & 331 & 1,080 \\
\hline 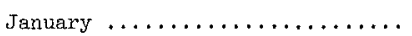 & 18,170 & 2,060 & 18 & 51 & .2 \\
\hline February $\ldots \ldots \ldots \ldots \ldots \ldots \ldots$ & 7,820 & 2,540 & 25 & 28 & 0 \\
\hline March $\ldots \ldots \ldots \ldots \ldots \ldots \ldots$ & 18,180 & 2,760 & 11 & 38 & 195 \\
\hline April $\ldots \ldots \ldots \ldots \ldots \ldots \ldots$ & 10,960 & 2,550 & 0 & 56 & 0 \\
\hline May $\ldots \ldots \ldots \ldots \ldots \ldots \ldots \ldots$ & 18,950 & 2,660 & 0 & 83 & 153 \\
\hline June $\ldots \ldots \ldots \ldots \ldots \ldots \ldots \ldots \ldots$ & 18,130 & 2,700 & 0 & 22 & 116 \\
\hline JuIy $\ldots \ldots \ldots \ldots \ldots \ldots \ldots \ldots$ & 18,660 & 2,650 & 0 & 42 & 493 \\
\hline August $\ldots \ldots \ldots \ldots \ldots \ldots \ldots$ & 19,070 & 2,530 & 18 & 11. & 327 \\
\hline 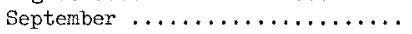 & 17,670 & 2,360 & 30 & 57 & .3 \\
\hline WTR $\mathrm{YR} 1976 \ldots \ldots \ldots \ldots \ldots$ & $203, \pm 00$ & 29,430 & 138 & 474 & 1,290 \\
\hline
\end{tabular}

HOTE.--Yearly totals given above have been computed from total cfs-days and may differ slightly from the summetion of monthly total acre-feet on occasion. 
Return surface flows below Imperial Dam, Ariz.-Calif.--Continued

MONTHLY RETURN FLOWS, IN ACRE-FEET, WATER YEAR OCTOBER 1975 TO SEPTEMBER 1976

\begin{tabular}{|c|c|c|c|c|c|c|}
\hline Honth & $\begin{array}{c}\text { Reservation } \\
\text { Drain No. } 7 \\
09529600\end{array}$ & $\begin{array}{c}\text { Reservation } \\
\text { Main Drain } \\
\text { 10. } 6 \\
09529700\end{array}$ & $\begin{array}{c}\text { Reservation } \\
\text { Drain No. } 2 \\
09529800\end{array}$ & $\begin{array}{l}\text { Reservation } \\
\text { Drain No. } 3 \\
09529900\end{array}$ & $\begin{array}{l}\text { Reservation } \\
\text { Main Drain } \\
\text { No. } 4 \\
09530000\end{array}$ & $\begin{array}{l}\text { Yuma Mesa } \\
\text { Outlet Drain } \\
09530200\end{array}$ \\
\hline October $\ldots \ldots \ldots \ldots \ldots \ldots \ldots \ldots$ & 98 & 1,200 & 29 & 273 & 3,850 & 4,540 \\
\hline November $\ldots \ldots \ldots \ldots \ldots \ldots \ldots$ & 77 & 1,090 & 41 & 222 & 3,550 & 4,430 \\
\hline Deceriber $\ldots \ldots \ldots \ldots \ldots \ldots$ & 60 & 968 & 18 & 189 & 3,460 & 4,480 \\
\hline CAL YR $1975 \ldots \ldots \ldots \ldots \ldots$ & 1,130 & 12,140 & 184 & 2,720 & 40,710 & 56,280 \\
\hline January $\ldots \ldots \ldots \ldots \ldots \ldots \ldots \ldots \ldots$ & 63 & 922 & 6.1 & 212 & 3,270 & 4,370 \\
\hline February $\ldots \ldots \ldots \ldots \ldots \ldots \ldots$ & 55 & 813 & 5.8 & 238 & 3,020 & 3,290 \\
\hline 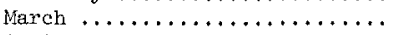 & 85 & 912 & 16 & 252 & 3,820 & 4,230 \\
\hline April $\ldots \ldots \ldots \ldots \ldots \ldots$ & 101 & 966 & 23 & 258 & 3,860 & 2,640 \\
\hline May $\ldots \ldots \ldots \ldots \ldots \ldots \ldots \ldots$ & 109 & 1,130 & 26 & 300 & 4,050 & 4,500 \\
\hline June $\ldots \ldots \ldots \ldots \ldots \ldots \ldots \ldots$ & 1.13 & 1,130 & 12 & 273 & 3,760 & 4,430 \\
\hline July $\ldots \ldots \ldots \ldots \ldots \ldots \ldots \ldots$ & 112 & 1,200 & 12 & 264 & 3,540 & 4,410 \\
\hline August $\ldots \ldots \ldots \ldots \ldots \ldots \ldots$ & 130 & 1,250 & 16 & 285 & 3,690 & 4,490 \\
\hline September $\ldots \ldots \ldots \ldots \ldots \ldots$ & 1.29 & 1,200 & 18 & 307 & 3,900 & 2,250 \\
\hline WIR YR $1976 \ldots \ldots \ldots \ldots \ldots$ & 1,130 & 12,780 & 223 & 3,070 & 43,790 & 48,080 \\
\hline
\end{tabular}

\begin{tabular}{|c|c|c|c|c|c|}
\hline Month & $\begin{array}{l}\text { Reservation } \\
\text { Drain No. I1 } \\
09530400\end{array}$ & $\begin{array}{c}\text { Drain } 8-B \\
09530500\end{array}$ & $\begin{array}{l}\text { M.O.D.E. } 2 \\
\text { (above } \\
\text { Morelos Dam) } \\
09531800\end{array}$ & $\begin{array}{c}\text { Cooper } \\
\text { wasteway } \\
09531850\end{array}$ & $\begin{array}{c}\text { M.O.D.E. } 3 \\
\text { (below } \\
\text { Morelos Dam) } \\
09531900\end{array}$ \\
\hline October $\ldots \ldots \ldots \ldots \ldots \ldots \ldots \ldots$ & 43 & 218 & 0 & 79 & 19,110 \\
\hline November $\ldots \ldots \ldots \ldots \ldots \ldots \ldots$ & 52 & 256 & 0 & 72 & 18,420 \\
\hline 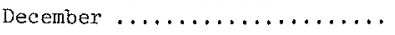 & 49 & 247 & 0 & 80 & 19,120 \\
\hline CAI YR $1975 \ldots \ldots \ldots \ldots \ldots$ & 369 & 2,080 & 0 & 766 & $2] 4,700$ \\
\hline Januery $\ldots \ldots \ldots \ldots \ldots \ldots \ldots$ & 35 & 221 & 0 & 112 & 18,720 \\
\hline February $\ldots \ldots \ldots \ldots \ldots \ldots \ldots$ & 29 & 155 & 0 & 64 & 7,840 \\
\hline March $\ldots \ldots \ldots \ldots \ldots \ldots \ldots$ & 45 & 189 & 0 & 58 & 18,470 \\
\hline April $\ldots \ldots \ldots \ldots \ldots \ldots \ldots$ & 59 & 186 & 0 & 95 & 10,870 \\
\hline Nay $\ldots \ldots \ldots \ldots \ldots \ldots \ldots$ & 58 & 204 & 0 & 126 & 19,090 \\
\hline June $\ldots \ldots \ldots \ldots \ldots \ldots \ldots$ & 55 & 220 & 0 & 60 & 18,060 \\
\hline July $\ldots \ldots \ldots \ldots \ldots \ldots \ldots$ & 61 & 234 & 0 & 107 & 18,830 \\
\hline August $\ldots \ldots \ldots \ldots \ldots \ldots \ldots$ & 58 & 240 & 0 & 45 & 19,190 \\
\hline September $\ldots \ldots \ldots \ldots \ldots \ldots$ & 60 & 244 & 0 & 25 & 17,860 \\
\hline WER YR $1976 \ldots \ldots \ldots \ldots \ldots$ & 604 & 2,610 & 0 & 923 & 205,600 \\
\hline
\end{tabular}

\begin{tabular}{|c|c|c|c|c|c|}
\hline Wonth & $\begin{array}{l}\text { Eleven Mile } \\
\text { nasteway } \\
09532500\end{array}$ & $\begin{array}{c}\text { Twenty-one } \\
\text { Mile wasteway } \\
09533000\end{array}$ & $\begin{array}{c}\text { Main Drain } \\
09534000\end{array}$ & $\begin{array}{c}\text { West Main } \\
\text { Canal wasteway } \\
09534300\end{array}$ & $\begin{array}{c}\text { East Main } \\
\text { Canal wasteway } \\
09534500\end{array}$ \\
\hline October $\ldots \ldots \ldots \ldots \ldots \ldots \ldots$ & 45 & 0.6 & 8,580 & 424 & 705 \\
\hline November $\ldots \ldots \ldots \ldots \ldots \ldots$ & 243 & 0.2 & 7,550 & 506 & 658 \\
\hline December $\ldots \ldots \ldots \ldots \ldots \ldots$ & 62 & 0 & 7,290 & 550 & 591 \\
\hline CAL YR $1975 \ldots \ldots \ldots \ldots \ldots$ & 1,140 & 9.8 & 93,160 & 5,970 & 7,650 \\
\hline January $\ldots \ldots \ldots \ldots \ldots \ldots \ldots$ & 27 & 0 & 6,810 & 565 & 690 \\
\hline February $\ldots \ldots \ldots \ldots \ldots \ldots$ & 185 & 27 & 6,500 & 537 & 388 \\
\hline 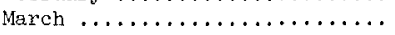 & 59 & 1.0 & 7,610 & 453 & 549 \\
\hline April $\ldots \ldots \ldots \ldots \ldots \ldots \ldots$ & 133 & 0 & 8,260 & 466 & 549 \\
\hline 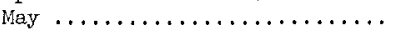 & 8 & 0 & 8,280 & 434 & 628 \\
\hline 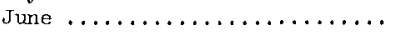 & 163 & 0 & 7,820 & 464 & 462 \\
\hline July $\ldots \ldots \ldots \ldots \ldots \ldots \ldots$ & 29 & 0 & 8,390 & 461. & 436 \\
\hline August $\ldots \ldots \ldots \ldots \ldots \ldots \ldots$ & 161 & 0 & 8,560 & 436 & 421 \\
\hline September $\ldots \ldots \ldots \ldots \ldots \ldots \ldots$ & 22 & 0 & 8,350 & 768 & 799 \\
\hline WLR YR $1976 \ldots \ldots \ldots \ldots \ldots$ & 1,140 & 29 & 94,000 & 6,060 & 6,880 \\
\hline
\end{tabular}

NOTE.--Yearly totals given above have been computed from total cfs-days and may differ sitghtiy from the summetion of monthly total acre-feet on occasion. 


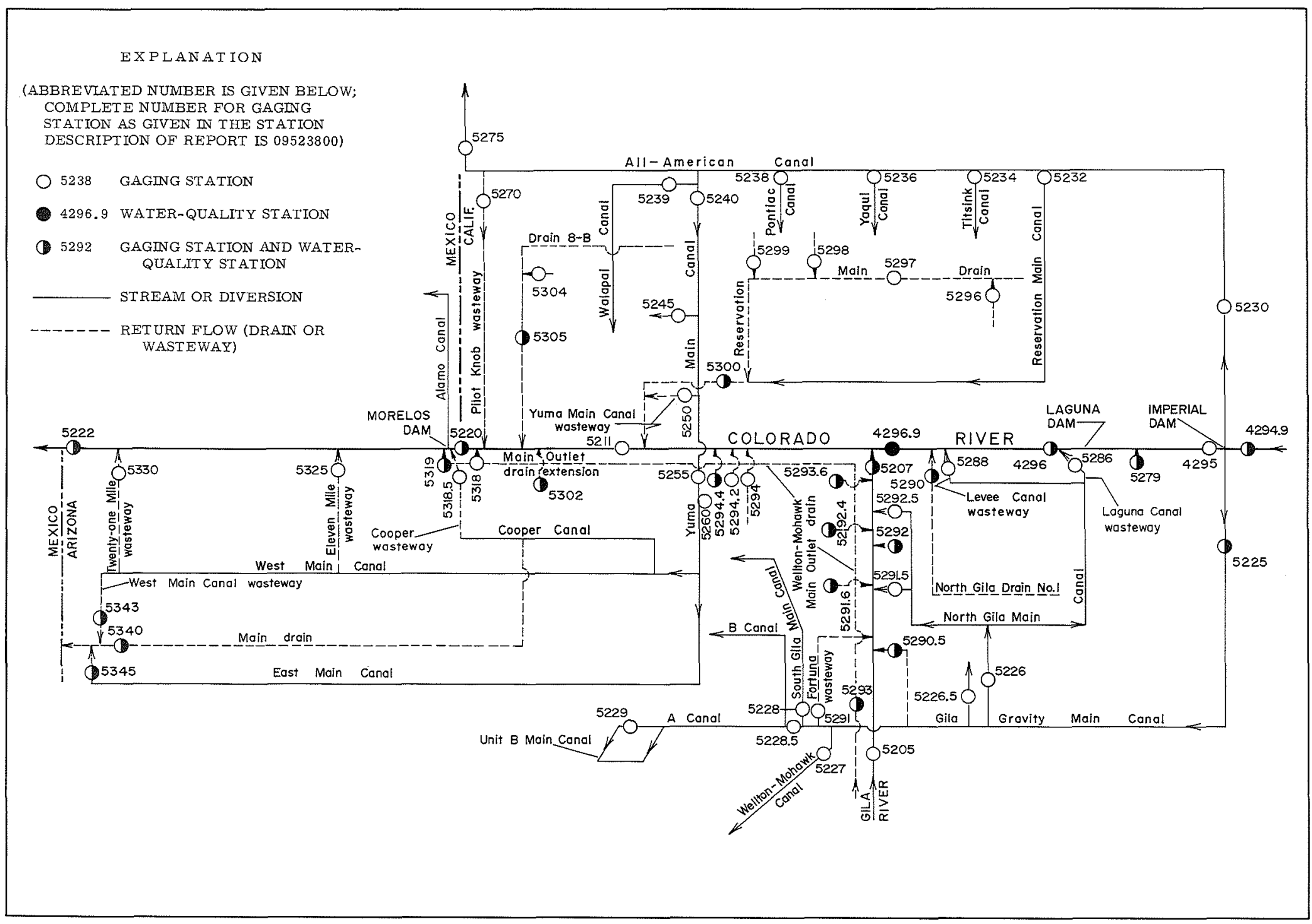

FIGURE 4. --SCHEMATIC DIAGRAM SHOWING GAGING STATIONS AND WATER-QUALITY STATIONS ON STREAMS, DIVERSIONS, AND RETURN FLOWS BETWEEN IMPERIAL DAM AND THE SOUTHERLY INTERNATIONAL BOUNDARY. 
LOCATION, - Lat $36^{\circ} 19^{\prime} 14^{\prime \prime}$, long $117^{\circ} 31^{\prime} 23^{\prime \prime}$, in NW/4SE $\frac{1}{4}$ SWl sec. 34, T. 18 S., R. 41 E., Inyo County, on 1 eft bank 510 ft $(155 \mathrm{~m})$ downstream from Darwin Falls, $1.6 \mathrm{mi}(2.6 \mathrm{~km})$ upstream from unnamed tributary, and $5.2 \mathrm{mi}$ ( $8.4 \mathrm{~km})$

DRAINAGE AREA. $-173 \mathrm{mi}^{2}\left(448 \mathrm{~km}^{2}\right)$

PERIOD OF RECORD. - October 1962 to current year.

GAGE.- Water-stage recorder. Altitude of gage is $2,640 \mathrm{ft}(805 \mathrm{~m})$, from topographic map. Prior to Aug. 6 , 1970, at site $190 \mathrm{ft}(58 \mathrm{~m})$ downstream at same datum.

REMARKS, - Records poor. No regulation above station. Town of Darwin pumps water above station for municipal suppIy.

AVERAGE DISCHARGE. - - 14 years, $0.44 \mathrm{ft}^{3} / \mathrm{s}\left(0.012 \mathrm{~m}^{3} / \mathrm{s}\right), 319 \mathrm{acre}-\mathrm{ft} / \mathrm{yr}\left(393,000 \mathrm{~m}^{3} / \mathrm{yr}^{\mathrm{r}}\right)$.

EXTREMES FOR PERIOD OF RECORD. - Maximum discharge, 4,400 $\mathrm{ft}^{3} / \mathrm{s}\left(125 \mathrm{~m}^{3} / \mathrm{s}\right) \mathrm{Jan}$. 25, 1969, gage height, $8.40 \mathrm{ft}$ $(2.560 \mathrm{~m})$, at site then in use, from floodmarks, on basis of slope-conveyance measurement of maximum flow. minimum daily, $0.05 \mathrm{ft}^{3} / \mathrm{s}\left(0.001 \mathrm{~m}^{3} / \mathrm{s}\right)$ Aug. 30 to Sept. 4,1969 .

EXTREMES OUTSIDE PERIOD OF RECORD.--Maximum gage height, $20.42 \mathrm{ft}(6.224 \mathrm{~m})$, present site, from floodmarks, date and discharge unknown.

EXTREMES FOR CURRENT YEAR, --Peak discharges above base of $10 \mathrm{ft}^{3} / \mathrm{s}\left(0.28 \mathrm{~m}^{3} / \mathrm{s}\right)$ and maximum (*), from rating curve extended above $0.6 \mathrm{ft}^{3} / \mathrm{s}\left(0.017 \mathrm{~m}^{3} / \mathrm{s}\right)$ on basis of velocity-area study at gage height $5.49 \mathrm{ft}(1.673 \mathrm{~m})$ :

\begin{tabular}{|c|c|c|c|c|c|}
\hline Date & Time & $\begin{array}{r}\text { Disch } \\
\left(\mathrm{ft}^{3} / \mathrm{s}\right)\end{array}$ & $\left(\mathrm{m}^{3} / \mathrm{s}\right)$ & $\begin{array}{l}\text { Gage } \\
\text { (ft) }\end{array}$ & $\begin{array}{r}\text { height } \\
\text { (m) }\end{array}$ \\
\hline $\begin{array}{lr}\text { May } & 6 \\
\text { July } & 17\end{array}$ & $\begin{array}{l}1630 \\
0530\end{array}$ & $\begin{array}{r}* 107 \\
23.4\end{array}$ & $\begin{array}{l}3.03 \\
0.66\end{array}$ & $\begin{array}{l}4.78 \\
3.76\end{array}$ & $\begin{array}{l}1.457 \\
1.146\end{array}$ \\
\hline
\end{tabular}

Minimum daily discharge, $0.18 \mathrm{ft}^{3} / \mathrm{s}\left(0.005 \mathrm{~m}^{3} / \mathrm{s}\right)$ several days in March and April.

DISCHARGE, IN CUBIC FEET PER SECOND, WATER YEAR OCTOBER 1975 TO SEPTEMBER 1976 MEAN VALUES

\begin{tabular}{|c|c|c|c|c|c|c|c|c|c|c|c|c|}
\hline DAY & OCT & NOV & DEC & JAN & FEB & MAR & APR & MAY & JUN & JUL & AUG & SEP \\
\hline $\begin{array}{l}1 \\
2 \\
3 \\
4 \\
5\end{array}$ & $\begin{array}{l}.24 \\
.24 \\
.24 \\
.24 \\
.24\end{array}$ & $\begin{array}{r}.27 \\
.27 \\
.27 \\
.27 \\
.24\end{array}$ & $\begin{array}{l}.27 \\
.27 \\
.24 \\
.24 \\
.24\end{array}$ & $\begin{array}{r}.24 \\
.24 \\
.24 \\
.24 \\
.24\end{array}$ & $\begin{array}{r}.21 \\
.21 \\
.21 \\
.21 \\
.21\end{array}$ & $\begin{array}{r}.21 \\
.21 \\
.21 \\
.21 \\
.21\end{array}$ & $\begin{array}{r}.18 \\
.18 \\
.18 \\
.21 \\
.21\end{array}$ & $\begin{array}{r}.19 \\
.19 \\
.19 \\
.21 \\
.24\end{array}$ & $\begin{array}{r}.24 \\
.24 \\
.21 \\
.21 \\
.21\end{array}$ & $\begin{array}{r}.27 \\
.24 \\
.24 \\
.24 \\
.21\end{array}$ & $\begin{array}{r}.27 \\
.24 \\
.27 \\
.27 \\
.24\end{array}$ & $\begin{array}{r}.25 \\
.25 \\
.25 \\
.25 \\
.24\end{array}$ \\
\hline $\begin{array}{r}6 \\
7 \\
8 \\
9 \\
10\end{array}$ & $\begin{array}{r}.24 \\
.27 \\
.27 \\
.27 \\
.27\end{array}$ & $\begin{array}{r}.24 \\
.24 \\
.24 \\
.24 \\
.24\end{array}$ & $\begin{array}{l}.24 \\
.24 \\
.24 \\
.24 \\
.24\end{array}$ & $\begin{array}{l}.24 \\
.24 \\
.24 \\
.24 \\
.24\end{array}$ & $\begin{array}{r}.32 \\
.31 \\
.34 \\
.37 \\
.27\end{array}$ & $\begin{array}{r}.21 \\
.21 \\
.21 \\
.21 \\
.21\end{array}$ & $\begin{array}{l}.21 \\
.21 \\
.21 \\
.21 \\
.21\end{array}$ & $\begin{array}{l}5.9 \\
.79 \\
.48 \\
.40 \\
.36\end{array}$ & $\begin{array}{r}.24 \\
.24 \\
.27 \\
.27 \\
.30\end{array}$ & $\begin{array}{r}.21 \\
.21 \\
.21 \\
.21 \\
.21\end{array}$ & $\begin{array}{r}.27 \\
.27 \\
.30 \\
.30 \\
.30\end{array}$ & $\begin{array}{r}.24 \\
.24 \\
.24 \\
.24 \\
.50\end{array}$ \\
\hline $\begin{array}{l}11 \\
12 \\
13 \\
14 \\
15\end{array}$ & $\begin{array}{r}.27 \\
.27 \\
.27 \\
.27 \\
.32\end{array}$ & $\begin{array}{l}.24 \\
.24 \\
.24 \\
.24 \\
.24\end{array}$ & $\begin{array}{l}.24 \\
.25 \\
.27 \\
.27 \\
.27\end{array}$ & $\begin{array}{l}.24 \\
.24 \\
.24 \\
.24 \\
.24\end{array}$ & $\begin{array}{l}.27 \\
.26 \\
.24 \\
.21 \\
.21\end{array}$ & $\begin{array}{l}.21 \\
.21 \\
.18 \\
.19 \\
.21\end{array}$ & $\begin{array}{l}.21 \\
.18 \\
.23 \\
.23 \\
.20\end{array}$ & $\begin{array}{r}.30 \\
.27 \\
.27 \\
.27 \\
.27\end{array}$ & $\begin{array}{r}.33 \\
.30 \\
.30 \\
.24 \\
.24\end{array}$ & $\begin{array}{r}.21 \\
.24 \\
.24 \\
.21 \\
.21\end{array}$ & $\begin{array}{r}.30 \\
.27 \\
.27 \\
.33 \\
.30\end{array}$ & $\begin{array}{r}.30 \\
.27 \\
.24 \\
.24 \\
.24\end{array}$ \\
\hline $\begin{array}{l}16 \\
17 \\
18 \\
19 \\
20\end{array}$ & $\begin{array}{r}.30 \\
.30 \\
.30 \\
.27 \\
.27\end{array}$ & $\begin{array}{l}.24 \\
.24 \\
.24 \\
.24 \\
.24\end{array}$ & $\begin{array}{r}.26 \\
.27 \\
.27 \\
.27 \\
.27\end{array}$ & $\begin{array}{l}.24 \\
.24 \\
.24 \\
.24 \\
.24\end{array}$ & $\begin{array}{r}.21 \\
.21 \\
.21 \\
.21 \\
.21\end{array}$ & $\begin{array}{r}.21 \\
.21 \\
.20 \\
.18 \\
.18\end{array}$ & $\begin{array}{l}.21 \\
.21 \\
.23 \\
.20 \\
.20\end{array}$ & $\begin{array}{l}.24 \\
.24 \\
.24 \\
.27 \\
.30\end{array}$ & $\begin{array}{l}.24 \\
.21 \\
.21 \\
.21 \\
.21\end{array}$ & $\begin{array}{r}.27 \\
1.6 \\
.44 \\
.52 \\
.52\end{array}$ & $\begin{array}{l}.27 \\
.27 \\
.27 \\
.27 \\
.27\end{array}$ & $\begin{array}{l}.24 \\
.24 \\
.24 \\
.24 \\
.24\end{array}$ \\
\hline $\begin{array}{l}21 \\
22 \\
23 \\
24 \\
25\end{array}$ & $\begin{array}{l}.30 \\
.30 \\
.24 \\
.24 \\
.26\end{array}$ & $\begin{array}{l}.24 \\
.24 \\
.24 \\
.24 \\
.24\end{array}$ & $\begin{array}{l}.27 \\
.27 \\
.27 \\
.27 \\
.27\end{array}$ & $\begin{array}{l}.21 \\
.21 \\
.21 \\
.21 \\
.21\end{array}$ & $\begin{array}{l}.21 \\
.21 \\
.21 \\
.21 \\
.21\end{array}$ & $\begin{array}{r}.18 \\
.18 \\
.18 \\
.18 \\
.18\end{array}$ & $\begin{array}{l}.20 \\
.20 \\
.20 \\
.20 \\
.18\end{array}$ & $\begin{array}{r}.30 \\
.30 \\
.30 \\
.30 \\
.33\end{array}$ & $\begin{array}{r}.21 \\
.21 \\
.24 \\
.24 \\
.24\end{array}$ & $\begin{array}{r}.52 \\
.36 \\
.33 \\
.30 \\
.24\end{array}$ & $\begin{array}{l}.27 \\
.27 \\
.26 \\
.26 \\
.26\end{array}$ & $\begin{array}{r}.27 \\
.27 \\
.27 \\
.33 \\
.33\end{array}$ \\
\hline $\begin{array}{l}26 \\
27 \\
28 \\
29 \\
30 \\
31\end{array}$ & $\begin{array}{l}.27 \\
.27 \\
.27 \\
.27 \\
.27 \\
.27\end{array}$ & $\begin{array}{l}.24 \\
.25 \\
.27 \\
.27 \\
.27 \\
-.2\end{array}$ & $\begin{array}{r}.27 \\
.27 \\
.24 \\
.24 \\
.24 \\
.24\end{array}$ & $\begin{array}{l}.21 \\
.21 \\
.21 \\
.21 \\
.21 \\
.21\end{array}$ & $\begin{array}{l}.21 \\
.21 \\
.21 \\
.21 \\
-.- \\
---\end{array}$ & $\begin{array}{l}.18 \\
.18 \\
.19 \\
.23 \\
.21 \\
.20\end{array}$ & $\begin{array}{l}.21 \\
.21 \\
.21 \\
.21 \\
.21 \\
.-2\end{array}$ & $\begin{array}{l}.30 \\
.27 \\
.24 \\
.27 \\
.24 \\
.24\end{array}$ & $\begin{array}{r}.24 \\
.24 \\
.24 \\
.21 \\
.24 \\
-.0\end{array}$ & $\begin{array}{r}.27 \\
.33 \\
.30 \\
.27 \\
.27 \\
.40\end{array}$ & $\begin{array}{l}.26 \\
.26 \\
.26 \\
.26 \\
.25 \\
.25\end{array}$ & $\begin{array}{r}.36 \\
.36 \\
.40 \\
.44 \\
.40 \\
.0 .\end{array}$ \\
\hline $\begin{array}{l}\text { TOTAL } \\
\text { MEAN } \\
\text { MAX } \\
\text { MIN } \\
\text { AC-FT }\end{array}$ & $\begin{array}{r}B .32 \\
.27 \\
.32 \\
.24 \\
17\end{array}$ & $\begin{array}{r}7.42 \\
.25 \\
.27 \\
.24 \\
15\end{array}$ & $\begin{array}{r}7.95 \\
.26 \\
.27 \\
.24 \\
16\end{array}$ & $\begin{array}{r}7.11 \\
.23 \\
.24 \\
.21 \\
14\end{array}$ & $\begin{array}{r}6.79 \\
.23 \\
.37 \\
.21 \\
13\end{array}$ & $\begin{array}{r}6.17 \\
.20 \\
.23 \\
.18 \\
12\end{array}$ & $\begin{array}{r}6.14 \\
.20 \\
.23 \\
.18 \\
12\end{array}$ & $\begin{array}{r}14.71 \\
.47 \\
5.9 \\
.19 \\
29\end{array}$ & $\begin{array}{r}7.23 \\
.24 \\
.33 \\
.21 \\
14\end{array}$ & $\begin{array}{r}10.30 \\
.33 \\
1.6 \\
.21 \\
20\end{array}$ & $\begin{array}{r}8.41 \\
.27 \\
.33 \\
.24 \\
17\end{array}$ & $\begin{array}{r}8.62 \\
.29 \\
.50 \\
.24 \\
17\end{array}$ \\
\hline
\end{tabular}

CAL YR 1975 TOTAL 88.44 MEAN .24 MAX .37 MIN .13 AC-FT 175 WTR YR 1976 TOTAL 99.17 MEAN .27 MAX 5.99 MIN 118 AC-FT 197 
10251100 SALT CREEK NEAR STOVEPIPE WELLS, CA

LOCATION.--Lat $36^{\circ} 35^{\prime} 58^{\prime \prime}$, long $117^{\circ} 00^{\prime} 46^{\prime \prime}$, in NE's sec.6, T.16 S., R. 46 E., Inyo County, Death Valley Nationa1

Monument, on left bank $3.0 \mathrm{mi}(4.8 \mathrm{~km})$ 'southeast of intersection of State Highway 190 and Stovepipe Wells Road, and $7.4 \mathrm{mi}(11.9 \mathrm{~km})$ east of Stovepipe Wells Hotel.

DRAINAGE AREA. --Indeterminate.

PERTOD OF RECORD.--February 1974 to current year.

GAGE. - Water-stage recorder and parsha11 flume. Altitude of gage is -180 ft (-55 m), from topographic map.

REMARKS. - Records fair. No regulation or diversion above station.

EXTREMES FOR PERIOD OF RECORD.--Maximum discharge, $363 \mathrm{ft}^{3} / \mathrm{s}\left(10.3 \mathrm{~m}^{3} / \mathrm{s}\right)$ Feb. 9 , 1976 , gage height, $4.81 \mathrm{ft}$ $(1.466 \mathrm{~m})$ based on slope-conveyance measurement of peak flow, minimum daily, $0.06 \mathrm{ft}^{3} / \mathrm{s}(0.002 \mathrm{~m} / \mathrm{s})$

June $16,24,25,1974$, Sept. 15,1976 .

EXTREMES FOR CURRENT YEAR. - Peak discharges above base of $5.0 \mathrm{ft} / \mathrm{s}\left(0.14 \mathrm{~m}^{3} / \mathrm{s}\right)$ and maximum (*), based on slope-conveyance measurement of peak flow:

\begin{tabular}{|c|c|c|c|c|c|c|c|c|c|}
\hline Date & Time & $\begin{array}{c}\text { Discharge } \\
\left(\mathrm{ft}^{3} / \mathrm{s}\right)\left(\mathrm{m}^{3} / \mathrm{s}\right)\end{array}$ & $\begin{array}{l}\text { Gage height } \\
\text { (ft) }(\mathrm{m})\end{array}$ & Date & Time & $\begin{array}{r}\text { Disc } \\
\left(\mathrm{ft}^{3} / \mathrm{s}\right.\end{array}$ & $\left(\mathrm{m}^{3} / \mathrm{s}\right)$ & $\begin{array}{l}\text { Gage } \\
(\mathrm{ft})\end{array}$ & $\begin{array}{r}\text { height } \\
(\mathrm{m})\end{array}$ \\
\hline $\begin{array}{l}\text { Feb }, 7 \\
\text { Feb. } 9\end{array}$ & $\begin{array}{l}1315 \\
1245\end{array}$ & $\begin{array}{l}7.22 \\
10.3\end{array}$ & $\begin{array}{l}1.405 \\
1.466\end{array}$ & Sept. 10 & 1930 & 269 & 7.62 & 4.64 & 1.414 \\
\hline
\end{tabular}

Minimum daily discharge, $0.06 \mathrm{ft}^{3} / \mathrm{s}\left(0.002 \mathrm{~m}^{3} / \mathrm{s}\right)$ Sept. 15 .

OISCHARGE, IN CUBIC FEET PER SECOND, WATER YEAR OCTOBER 1975 TO SEPTEMBER 1976 MEAN VALUES

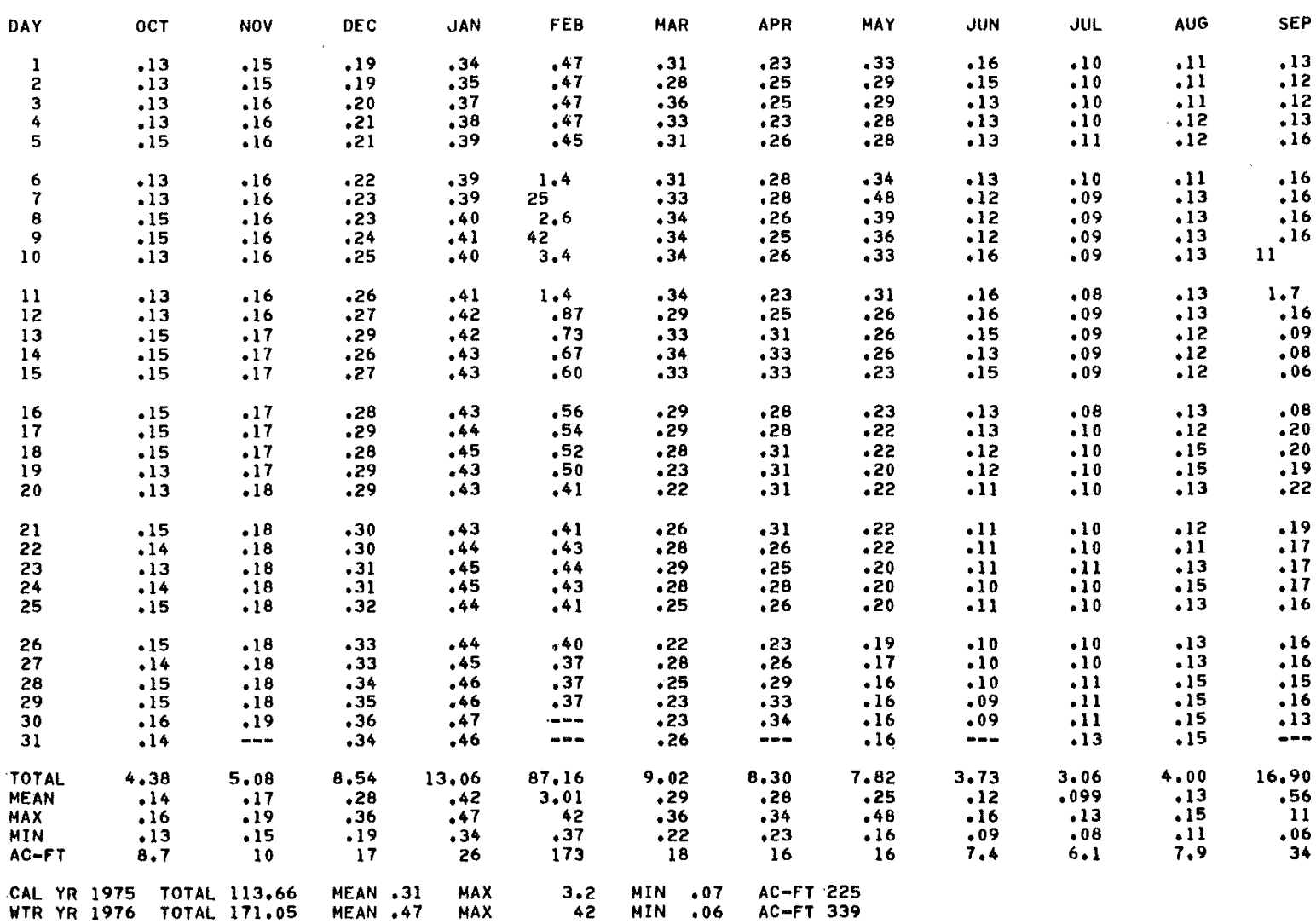


LOCATION. - - Lat $35^{\circ} 50^{\prime} 53^{\prime \prime}$, long $116^{\circ} 13^{\prime} 43^{\prime \prime}$, in NW/4W/4SE $\frac{1}{4}$ sec.9, T.20 N., R. 7 E., Inyo County, on right bank 20 ft

$(6 \mathrm{~m})$ upstrean from county road, and $0.2 \mathrm{mi}(0.3 \mathrm{~km})$ west of Tecopa.

PERIOD OF RECORD. - October 1961 to current year.

GAGE. - Water-stage recorder and culvert control. Altitude of gage is $1,310 \mathrm{ft}$ (399 m), from topographic map.

REMARKS.--Records poor. No regulation. City of Tecopa pumps water for municipal use upstream. No gage height

record July 1 to September 16.

AVERAGE DISCHARGE. - -15 years, $2.75 \mathrm{ft}^{3} / \mathrm{s}\left(0.078 \mathrm{~m}^{3} / \mathrm{s}\right), 1,990 \mathrm{acre}-\mathrm{ft} / \mathrm{yr}\left(2.45 \mathrm{hm} / \mathrm{yr}^{3}\right)$

EXTREMES FOR PERIOD OF RECORD.--Maximum discharge, 5,000 $\mathrm{ft}^{3} / \mathrm{s}\left(142 \mathrm{~m}^{3} / \mathrm{s}\right)$, estimated, Feb. 26 , 1969 , gage height,

$18.34 \mathrm{ft}(5.590 \mathrm{~m})$, from floodmark; no flow at times in most years.

EXTREMES FOR CURRENT YEAR. - Peak discharges above base of $15 \mathrm{ft}^{3} / \mathrm{s}\left(0.42 \mathrm{~m}^{3} / \mathrm{s}\right)$ and maximum (*), from rating

curve extended above $32 \mathrm{ft} / \mathrm{s}\left(0.91 \mathrm{~m}^{3} / \mathrm{s}\right)$ on basis of slope-area measurement at gage height $13.9 \mathrm{ft}(4.24 \cdot \mathrm{m})$

\begin{tabular}{|c|c|c|c|c|c|c|c|c|c|c|}
\hline Date & Time & $\begin{array}{l}\text { Discharge } \\
\left(\mathrm{ft}^{3} / \mathrm{s}\right)\left(\mathrm{Im}^{3} / \mathrm{s}\right)\end{array}$ & $\begin{array}{l}\text { Gage } \\
\text { (ft) }\end{array}$ & $\begin{array}{l}\text { eight } \\
\text { (m) }\end{array}$ & Date & Time & $\begin{array}{r}\text { Disch } \\
\left(\mathrm{ft}^{3} / \mathrm{s}\right)\end{array}$ & $\stackrel{\operatorname{rge}}{\left(\mathrm{m}^{3} / \mathrm{s}\right)}$ & $\begin{array}{l}\text { Gage } \\
(\mathrm{ft})\end{array}$ & $\begin{array}{l}\text { height } \\
\text { (m) }\end{array}$ \\
\hline $\begin{array}{lr}\text { Feb. } & 9 \\
\text { Feb. } & 11 \\
\text { May } & 7\end{array}$ & $\begin{array}{l}0700 \\
0215 \\
1800\end{array}$ & $\begin{array}{l}6.26 \\
8.58 \\
0.62\end{array}$ & $\begin{array}{l}6.20 \\
6.97 \\
4.12\end{array}$ & $\begin{array}{l}1.890 \\
2.124 \\
1.256\end{array}$ & $\begin{array}{ll}\text { Sept. } 11 \\
\text { Sept. } 24 \\
\text { Sept. } 26\end{array}$ & $\begin{array}{l}\text { Unknown } \\
0145 \\
1745\end{array}$ & $\begin{array}{r}725 \\
32 \\
\times 1060\end{array}$ & $\begin{array}{c}20.5 \\
0.91 \\
30.0\end{array}$ & $\begin{array}{r}11.73 \\
4.28 \\
13.19\end{array}$ & $\begin{array}{l}3.575 \\
1.305 \\
4.020\end{array}$ \\
\hline
\end{tabular}

Minimum daily discharge, no flow oct. 1-4.

DISCHARGE, IN CUAIC FEET PER SECOND, WATER YEAR OCTOBER 1975 TO SEPTEMBER 1976 MEAN VALUES

\begin{tabular}{|c|c|c|c|c|c|c|c|c|c|c|c|c|}
\hline DAY & OCT & NOV & DEC & JAN & FEB & MAR & APR & MAY & JUN & JUL & AUG & SEP \\
\hline $\begin{array}{l}1 \\
2 \\
3 \\
4 \\
5\end{array}$ & $\begin{array}{ll}0 & \\
0 & \\
0 & \\
0 & \\
& .01\end{array}$ & $\begin{array}{l}.05 \\
.06 \\
.11 \\
.15 \\
.12\end{array}$ & $\begin{array}{l}1.5 \\
1.8 \\
1.9 \\
2.1 \\
2.5\end{array}$ & $\begin{array}{l}1.3 \\
1.2 \\
.81 \\
1.2 \\
1.7\end{array}$ & $\begin{array}{l}2.4 \\
2.5 \\
2.6 \\
2.5 \\
2.2\end{array}$ & $\begin{array}{l}1.0 \\
.66 \\
1.4 \\
1.6 \\
1.8\end{array}$ & $\begin{array}{l}.58 \\
.66 \\
.58 \\
.52 \\
.58\end{array}$ & $\begin{array}{r}.19 \\
.15 \\
.12 \\
.11 \\
.11\end{array}$ & $\begin{array}{l}.06 \\
.05 \\
.05 \\
.05 \\
.05\end{array}$ & $\begin{array}{l}.02 \\
.02 \\
.02 \\
.02 \\
.02\end{array}$ & $\begin{array}{l}.01 \\
.01 \\
.01 \\
.01 \\
.01\end{array}$ & $\begin{array}{l}.01 \\
.01 \\
.01 \\
.01 \\
.01\end{array}$ \\
\hline $\begin{array}{r}6 \\
7 \\
8 \\
9 \\
10\end{array}$ & $\begin{array}{l}.01 \\
.01 \\
.01 \\
.01 \\
.01\end{array}$ & $\begin{array}{l}.09 \\
.09 \\
.12 \\
.17 \\
.27\end{array}$ & $\begin{array}{l}2.5 \\
2.1 \\
1.9 \\
1.5 \\
1.6\end{array}$ & $\begin{array}{l}1.7 \\
2.0 \\
1.9 \\
2.1 \\
3.3\end{array}$ & $\begin{array}{l}3.9 \\
19 \\
18 \\
109 \\
133\end{array}$ & $\begin{array}{l}1.6 \\
1.2 \\
1.1 \\
1.4 \\
1.4\end{array}$ & $\begin{array}{l}.58 \\
.75 \\
.75 \\
.58 \\
.58\end{array}$ & $\begin{array}{l}.11 \\
4.7 \\
2.6 \\
.75 \\
.35\end{array}$ & $\begin{array}{l}.05 \\
.05 \\
.05 \\
.05 \\
.05\end{array}$ & $\begin{array}{l}.01 \\
.01 \\
.01 \\
.01 \\
.01\end{array}$ & $\begin{array}{l}.01 \\
.01 \\
.01 \\
.01 \\
.01\end{array}$ & $206^{.01} .01$ \\
\hline $\begin{array}{l}11 \\
12 \\
13 \\
14 \\
15\end{array}$ & $\begin{array}{l}.02 \\
.02 \\
.02 \\
.02 \\
.02\end{array}$ & $\begin{array}{l}.40 \\
.30 \\
.20 \\
.35 \\
.40\end{array}$ & $\begin{array}{l}1.7 \\
1.6 \\
1.7 \\
2.0 \\
1.1\end{array}$ & $\begin{array}{l}3.4 \\
3.8 \\
3.4 \\
3.1 \\
2.5\end{array}$ & $\begin{array}{r}205 \\
65 \\
30 \\
15 \\
8.2\end{array}$ & $\begin{array}{l}1.2 \\
1.6 \\
.93 \\
.93 \\
1.0\end{array}$ & $\begin{array}{l}.52 \\
.40 \\
.45 \\
.66 \\
.75\end{array}$ & $\begin{array}{l}.20 \\
.11 \\
.09 \\
.11 \\
.07\end{array}$ & $\begin{array}{l}.06 \\
.06 \\
.06 \\
.04 \\
.05\end{array}$ & $\begin{array}{l}.01 \\
.01 \\
.01 \\
.01 \\
.01\end{array}$ & $\begin{array}{l}.01 \\
.01 \\
.01 \\
.01 \\
.01\end{array}$ & $\begin{array}{r}665 \\
527 \\
317 \\
125 \\
33\end{array}$ \\
\hline $\begin{array}{l}16 \\
17 \\
18 \\
19 \\
20\end{array}$ & $\begin{array}{l}.02 \\
.02 \\
.02 \\
.02 \\
.02\end{array}$ & $\begin{array}{l}.23 \\
.35 \\
.23 \\
.23 \\
.35\end{array}$ & $\begin{array}{r}.90 \\
.99 \\
.98 \\
1.1 \\
1.1\end{array}$ & $\begin{array}{l}2.8 \\
2.9 \\
2.8 \\
3.3 \\
2.3\end{array}$ & $\begin{array}{l}5.2 \\
3.6 \\
2.9 \\
2.3 \\
1.7\end{array}$ & $\begin{array}{l}.93 \\
1.1 \\
.93 \\
.66 \\
.75\end{array}$ & $\begin{array}{l}.93 \\
.93 \\
.66 \\
.66 \\
.58\end{array}$ & $\begin{array}{l}.07 \\
.06 \\
.05 \\
.04 \\
.06\end{array}$ & $\begin{array}{l}.04 \\
.04 \\
.05 \\
.04 \\
.03\end{array}$ & $\begin{array}{l}.01 \\
.01 \\
.01 \\
.01 \\
.01\end{array}$ & $\begin{array}{l}.01 \\
.01 \\
.01 \\
.01 \\
.01\end{array}$ & $\begin{array}{l}.60 \\
.46 \\
.38 \\
.30 \\
.20\end{array}$ \\
\hline $\begin{array}{l}21 \\
22 \\
23 \\
24 \\
25\end{array}$ & $\begin{array}{l}.02 \\
.03 \\
.03 \\
.03 \\
.03\end{array}$ & $\begin{array}{l}.45 \\
.58 \\
.66 \\
.93 \\
.45\end{array}$ & $\begin{array}{l}1.3 \\
1.3 \\
1.9 \\
1.7 \\
1.4\end{array}$ & $\begin{array}{l}1.8 \\
1.9 \\
2.2 \\
2.6 \\
2.3\end{array}$ & $\begin{array}{l}1.3 \\
1.5 \\
1.5 \\
1.4 \\
1.5\end{array}$ & $\begin{array}{l}.66 \\
.66 \\
.66 \\
.66 \\
.58\end{array}$ & $\begin{array}{l}.58 \\
.40 \\
.35 \\
.35 \\
.35\end{array}$ & $\begin{array}{l}.07 \\
.09 \\
.07 \\
.06 \\
.06\end{array}$ & $\begin{array}{l}.02 \\
.02 \\
.02 \\
.02 \\
.02\end{array}$ & $\begin{array}{l}.01 \\
.01 \\
.01 \\
.01 \\
.01\end{array}$ & $\begin{array}{l}.01 \\
.01 \\
.01 \\
.01 \\
.01\end{array}$ & $\begin{array}{r}.23 \\
.17 \\
7.13 \\
52^{.2}\end{array}$ \\
\hline $\begin{array}{l}26 \\
27 \\
28 \\
29 \\
30 \\
31\end{array}$ & $\begin{array}{l}.03 \\
.03 \\
.02 \\
.04 \\
.07 \\
.07\end{array}$ & $\begin{array}{l}.45 \\
1.1 \\
1.2 \\
1.1 \\
1.2 \\
-\ldots\end{array}$ & $\begin{array}{l}1.4 \\
1.5 \\
1.8 \\
1.9 \\
1.6 \\
1.8\end{array}$ & $\begin{array}{l}1.9 \\
1.9 \\
2.0 \\
2.2 \\
2.3 \\
2.6\end{array}$ & $\begin{array}{l}1.7 \\
2.0 \\
1.9 \\
1.6 \\
-2 . \\
--.\end{array}$ & $\begin{array}{l}.45 \\
.58 \\
.58 \\
.75 \\
.58 \\
.66\end{array}$ & $\begin{array}{l}.15 \\
.12 \\
.15 \\
.20 \\
.23 \\
-.0\end{array}$ & $\begin{array}{l}.06 \\
.06 \\
.05 \\
.05 \\
.06 \\
.05\end{array}$ & $\begin{array}{l}.03 \\
.05 \\
.04 \\
.03 \\
.02 \\
.-2\end{array}$ & $\begin{array}{l}1.0 \\
.03 \\
.02 \\
.01 \\
.01 \\
.01\end{array}$ & $\begin{array}{l}.01 \\
.01 \\
.01 \\
.01 \\
.01 \\
.01\end{array}$ & $\begin{array}{r}581 \\
196 \\
40 \\
28 \\
12\end{array}$ \\
\hline $\begin{array}{l}\text { TOTAL } \\
\text { MEAN } \\
\text { MAX } \\
\text { MIN } \\
\text { AC } \sim F T\end{array}$ & $\begin{array}{r}.66 \\
.021 \\
.07 \\
0 \\
1.3\end{array}$ & $\begin{array}{r}12.39 \\
.41 \\
1.2 \\
.05 \\
25\end{array}$ & $\begin{array}{r}50.17 \\
1.62 \\
2.5 \\
.90 \\
100\end{array}$ & $\begin{array}{r}71.21 \\
2.30 \\
3.8 \\
.81 \\
141\end{array}$ & $\begin{array}{r}648.4 \\
22.4 \\
205 \\
1.3 \\
1290\end{array}$ & $\begin{array}{r}30.01 \\
.97 \\
1.8 \\
.45 \\
60\end{array}$ & $\begin{array}{r}15.58 \\
.52 \\
.93 \\
.12 \\
31\end{array}$ & $\begin{array}{r}10.73 \\
.35 \\
4.7 \\
.04 \\
21\end{array}$ & $\begin{array}{l}1.25 \\
.042 \\
.06 \\
.02 \\
2.5\end{array}$ & $\begin{array}{r}1.38 \\
.045 \\
1.0 \\
.01 \\
2.7\end{array}$ & $\begin{array}{r}.31 \\
.010 \\
.01 \\
.01 \\
.6\end{array}$ & $\begin{array}{r}2791.76 \\
93.1 \\
665 \\
.01 \\
5540\end{array}$ \\
\hline
\end{tabular}

CAL YR 1975 TOTAL 256.11 MEAN .70 MAX 13 MIN O AC-FT 508

WTR YR 1976 TOTAL 3633.85 MEAN 9.93 MAX 665 MIN 0 AC-FT 7210 
10252550 CARUTHERS CREEK NEAR IVANPAH, CA

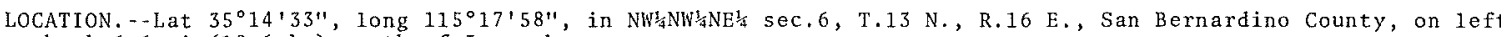
bank 6.6 mi $(10.6 \mathrm{~km})$ south of Ivanpah.

DRAINAGE AREA. $-1.13 \mathrm{mi}^{2}\left(2.93 \mathrm{~km}^{2}\right)$.

PERIOD OF RECORD, - October 1963 to current year.

GAGE. - Water-stage recorder. Altitude of gage is $5,640 \mathrm{ft}(1,719$ m), from topographic map.

REMARKS.--Records poor. No regulation or diversion above station.

AVERAGE DISCHARGE.- -13 years, $0.068 \mathrm{ft}^{3} / \mathrm{s}\left(0.002 \mathrm{~m}^{3} / \mathrm{s}\right), 49 \mathrm{acre}-\mathrm{ft} / \mathrm{yr}\left(60,400 \mathrm{~m}^{3} / \mathrm{yr}^{2}\right)$

EXTREMES FOR PERTOD OF RECORD. - Maximum discharge, $518 \mathrm{ft}^{3} / \mathrm{s}\left(14.7 \mathrm{~m}^{3} / \mathrm{s}\right)$ Aug. 25 , 1969 , gage height, $4.77 \mathrm{ft}$

$(1.454 \mathrm{~m})$, on basis of slope-conveyance measurement of maximum flow; no flow most of each year.

EXTREMES FOR CURRENT YEAR, - - Peak discharges above base of $10 \mathrm{ft}^{3} / \mathrm{s}\left(0.283 \mathrm{~m}^{3} / \mathrm{s}\right)$ and maximum (*):

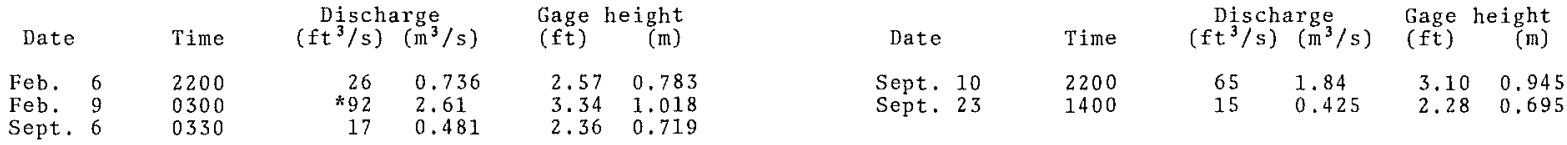

Minimum daily discharge, no flow most of year.

DISCHARGE, IN CURIC FEET PER SECOND, WATER YEAR OCTOBER 1975 TO SEPTEMBER 1976 MEAN VALUES

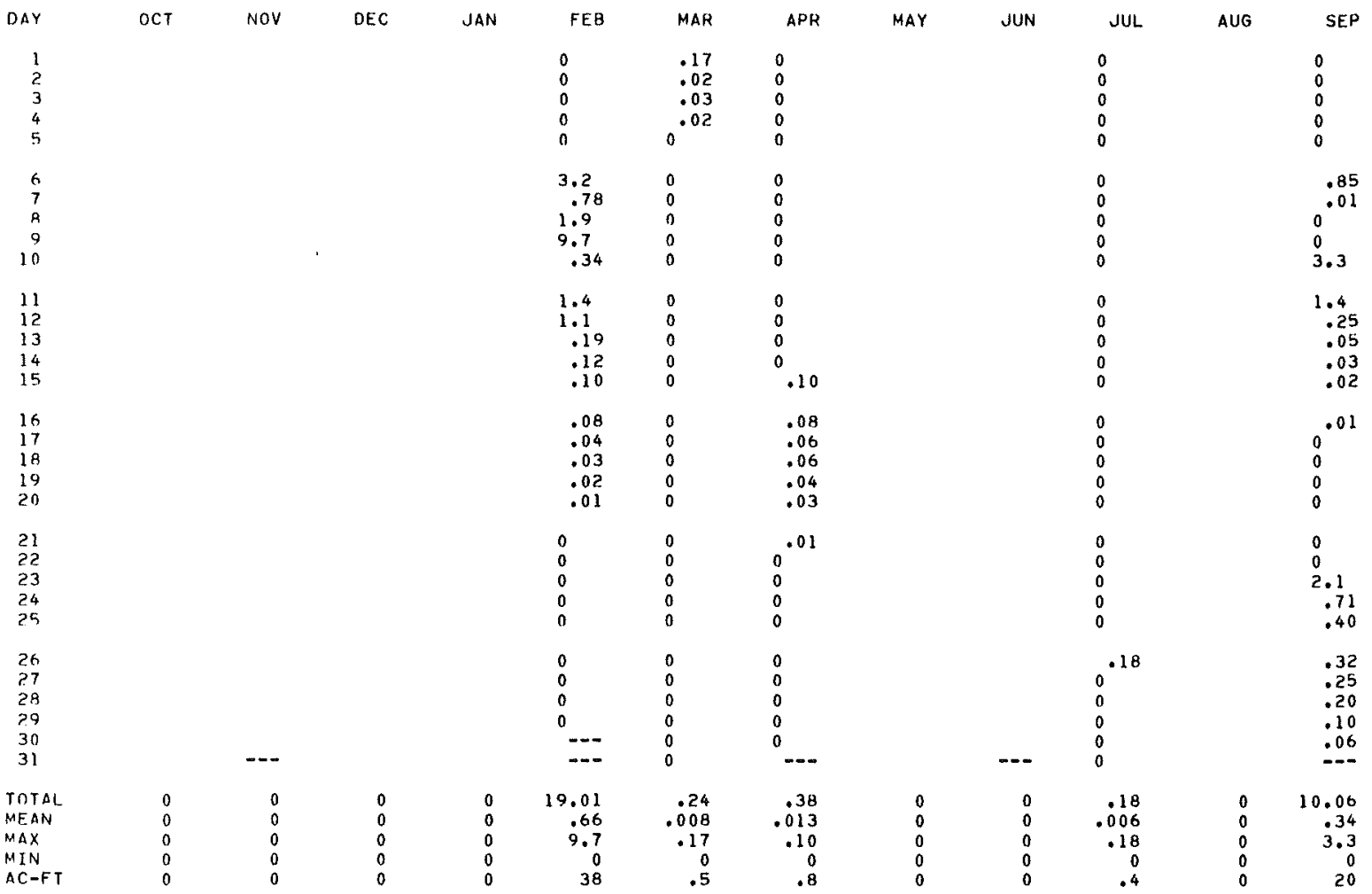

$\begin{array}{llllllll}\text { CAL YR } 1975 & \text { TOTAL } 2.21 & \text { MEAN } .0060 & \text { MAX } & .27 & \text { MIN } 0 & \text { AC-FT } 4.4 \\ \text { WTR YR } 1976 & \text { TOTAL } 29.87 & \text { MEAN } .082 & \text { MAX } 9.7 & \text { MIN } 0 & \text { AC-FT } 59\end{array}$ 
LOCATION, - Lat $33^{\circ} 11^{\prime} 37^{\prime \prime}$, long $115^{\circ} 49^{\prime} 54^{\prime \prime}$, in $N E^{\frac{1}{4} S E \frac{1}{4} S W^{1}}$ sec. 21 , T.11 S., R.11 E., Imperial County, at outer end of third mooring pier'from western shore at Sandy Beach, and 15.5 mi (24.9 km) northwest of Westmorland.

DRAINAGE AREA. $-8,360 \mathrm{mi}^{2}\left(21,650 \mathrm{~km}^{2}\right)$, approximately.

PERIOD OF RECORD.--November 1904 to current year. Records prior to 1932 are pub1ished in WSP 735.

GAGE. - Water-stage recorder. Datum of gage is $250.00 \mathrm{ft}(76.2 \mathrm{~m})$ below mean sea 1 eve1; gage readings have been converted to elevations below mean sea leve1. See WSP 1734 for history of changes prior to Mar. 2 , 1956 .

REMARKS. - Bottom of sea is $277.7 \mathrm{ft}(84.64 \mathrm{~m})$ below mean sea level. See wsp 300 , 735 , and 918 for condensed history of Salton Sea.

EXTREMES FOR PERIOD OF RECORD. - Maximum elevation, $195.9 \mathrm{ft}$ ( 59.71 fl) below mean sea 1 evel in February and March 1907; minimum since $1906,251.6 \mathrm{ft}(76.69 \mathrm{~m})$ below mean sea level in November 1924.

EXTREMES FOR CURRENT YEAR. - Maximum elevation, $229.5 \mathrm{ft}(69.95 \mathrm{~m})$ below mean sea level, Sept. $29-30$; minimum, $231.1 \mathrm{ft}(70.44 \mathrm{~m})$ below mean sea leve1, Oct. 31 , Nov, $1-2,27-29$.

MEAN DAILY MONTHEND ELEVATIONS, IN FEET, BELOW MEAN SEA LEVEL, WATER YEAR OCTOBER 1975 TO SEPTEMBER 1976

Date

Sept. $30 \ldots \ldots \ldots \ldots \ldots \ldots \ldots \ldots \ldots$

oct. $31 \ldots \ldots \ldots \ldots \ldots \ldots \ldots \ldots \ldots \ldots$

Nov. $\quad 30 \ldots \ldots \ldots \ldots \ldots \ldots \ldots \ldots \ldots \ldots \ldots \ldots$

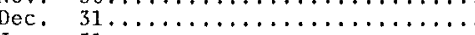

Jan. $31 \ldots \ldots \ldots \ldots \ldots \ldots \ldots \ldots$

Feb. $29 \ldots \ldots \ldots \ldots \ldots \ldots \ldots \ldots \ldots$

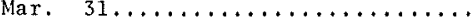

$$
\begin{gathered}
\text { Elevation } \\
\text { (feet) }
\end{gathered}
$$

230.9

231.1

231.1

230.9
230.6

230.6
230.1

229.8
Date

Apr.

May

June

Aug.

\section{INFLOW TO SALTON SEA}

Salton Sea, located near the northeast corner of Imperial County, is a closed basin consisting of 8,360 mi $\left(21,650 \mathrm{~km}^{2}\right)$.

The following table shows monthly and annual inflow, in acre-feet, for the water year 0ctober 1975 to September 1976 and the calendar year January to December 1975. Inflow from Imperial Valley is the sum of flows in Alamo River (station 10254730), New River (station 10255550), 33 drains and wasteways, and since 0ctober 1967 San Felipe Creek (station 10255885). Since October 1967 inflow from Coachella valley is the sum of flows in Whitewater River (station 10259540), Salt Creek (station 10254050), and 21 drains. Flow in Whitewater River and Salt Creek was measured at gaging stations. Discharge from the drains was furnished by Coachella County Water District (see Salton Sea basin for other flows to the sea). Table also shows amount of flow in Alamo and New Rivers contributed by Mexico as furnished by Imperial Irrigation District. Ungaged drains and natural runoff also contribute inflow to the sea.

\begin{tabular}{|c|c|c|c|c|c|c|c|c|c|c|c|c|}
\hline & oct. & Nov. & Dec. & Jan. & Feb. & Mar. & Apr. & May & June & July & Aug. & Sept. \\
\hline & & & & & & & & & & & & \\
\hline rial Va11ey & 111700 & 88490 & 86540 & 90670 & 85880 & 126200 & 124200 & 125200 & 90540 & 92850 & 94220 & 151900 \\
\hline che11a Valle & 15880 & 14560 & 13000 & 14770 & 17030 & 17110 & 16120 & 17280 & 13830 & 14900 & 15730 & 23540 \\
\hline
\end{tabular}

$\begin{array}{llll}\text { Total cal } & \text { yr } & 1975 & 1,404,600 \text { ac-ft } \\ \text { Total wtr yr } 1976 & 1,462,100 \text { ac-ft }\end{array}$

FLOW FROM MEXICO AT INTERNATIONAL BOUNDARY

\begin{tabular}{|c|c|c|c|c|c|c|c|c|c|c|c|c|}
\hline $\begin{array}{l}\text { Alamo River } \\
\text { New River }\end{array}$ & $\begin{array}{r}108 \\
6790\end{array}$ & $\begin{array}{r}94 \\
6500\end{array}$ & $\begin{array}{r}107 \\
7710\end{array}$ & $\begin{array}{r}106 \\
9100\end{array}$ & $\begin{array}{r}108 \\
10280\end{array}$ & $\begin{array}{r}127 \\
9380\end{array}$ & $\begin{array}{r}118 \\
10630\end{array}$ & $\begin{array}{r}103 \\
10280\end{array}$ & $\begin{array}{r}80 \\
6230\end{array}$ & $\begin{array}{r}60 \\
6380\end{array}$ & $\begin{array}{r}67 \\
6670\end{array}$ & $\begin{array}{r}94 \\
9900\end{array}$ \\
\hline $\begin{array}{l}\text { Cal yт 1975: } \\
\text { Ca1 yт 1975: }\end{array}$ & $\begin{array}{l}\text { Alamo Ri } \\
\text { New Rive }\end{array}$ & & $\begin{array}{r}1,570 \\
99,770\end{array}$ & $\begin{array}{l}a c-f t \\
a c-f t\end{array}$ & $\begin{array}{l}\text { Wtr y } \\
\text { Wtr y }\end{array}$ & $\begin{array}{l}1976: \\
1976:\end{array}$ & & $\begin{array}{l}, 170 \mathrm{a} \\
, 850 \mathrm{a}\end{array}$ & & & & \\
\hline
\end{tabular}


10254050 SALT CREEK NEAR MECCA, CA

LOCATION. - Lat $33^{\circ} 26^{\prime} 49^{\prime \prime}$, long $115^{\circ} 50^{\prime} 33^{\prime \prime}$, in NE/4SESW/4 sec. 28 , T.8 S., R. 11 E., Riverside County, on pier of Southern pacific Railroad bridge, $0.3 \mathrm{mi}(0.5 \mathrm{~km})$ upstream from mouth, and $16 \mathrm{mi}$ (26 $\mathrm{km})$ southeast of Mecca.

DRAINAGE AREA. $-269 \mathrm{mi}^{2}\left(697 \mathrm{~km}^{2}\right)$.

PERTOD OF RECORD.--January 1961 to current year.

GAGE. - Water-stage recorder. Altitude of gage is $230 \mathrm{ft}(70.1 \mathrm{~m})$ below mean sea leve1 (from topographic map).

REMARKS.--Records fair. No regulation or diversion above station. Flow sustained by irrigation seepage.

AVERAGE DISCHARGE, - -15 years, $6.49 \mathrm{ft}^{3} / \mathrm{s}\left(0.184 \mathrm{~m}^{3} / \mathrm{s}\right), 4,700 \mathrm{acre}-\mathrm{ft} / \mathrm{yr}\left(5.80 \mathrm{hm} \mathrm{m}^{3} / \mathrm{yr}^{2}\right)$

EXTREMES FOR PERIOD OF RECORD.--Maximum discharge, $9,900 \mathrm{ft}^{3} / \mathrm{s}\left(280 \mathrm{~m}^{3} / \mathrm{s}\right) \mathrm{Sept}, 24,1976, \mathrm{gage}$ height, $14.3 \mathrm{ft}$ $(4.359 \mathrm{~m})$, from rating curve extended above $20 \mathrm{ft} / \mathrm{s}\left(0.57 \mathrm{~m}^{3} / \mathrm{s}\right)$ on basis of contracted-opening measurement at gage height $14.3 \mathrm{ft}(4.359 \mathrm{~m})$; minimum daily, $0.40 \mathrm{ft}^{3} / \mathrm{s}\left(0.01 \mathrm{~m}^{3} / \mathrm{s}\right) \mathrm{Aug} .10,1966$.

EXTREMES FOR CURRENT YEAR. - Maximum discharge, $9,900 \mathrm{ft}^{3} / \mathrm{s}\left(280 \mathrm{~m}^{3} / \mathrm{s}\right)$ Sept. 24, gage height, $14.3 \mathrm{ft}$ (4.359 m), from rating curve extended above $20 \mathrm{ft}^{3} / \mathrm{s}\left(0.57 \mathrm{ml}^{3} / \mathrm{s}\right)$ on basis of contracted-opening measurement of peak

flow; minimum daily, $1.3 \mathrm{ft}^{3} / \mathrm{s}\left(0.037 \mathrm{~m}^{3} / \mathrm{s}\right)$ June 24,25 and 28 .

DISCHARGE, IN CUBIC FEET PER SECOND, WATER YEAR OCTOBER 1975 TO SEPTEMBER 1976

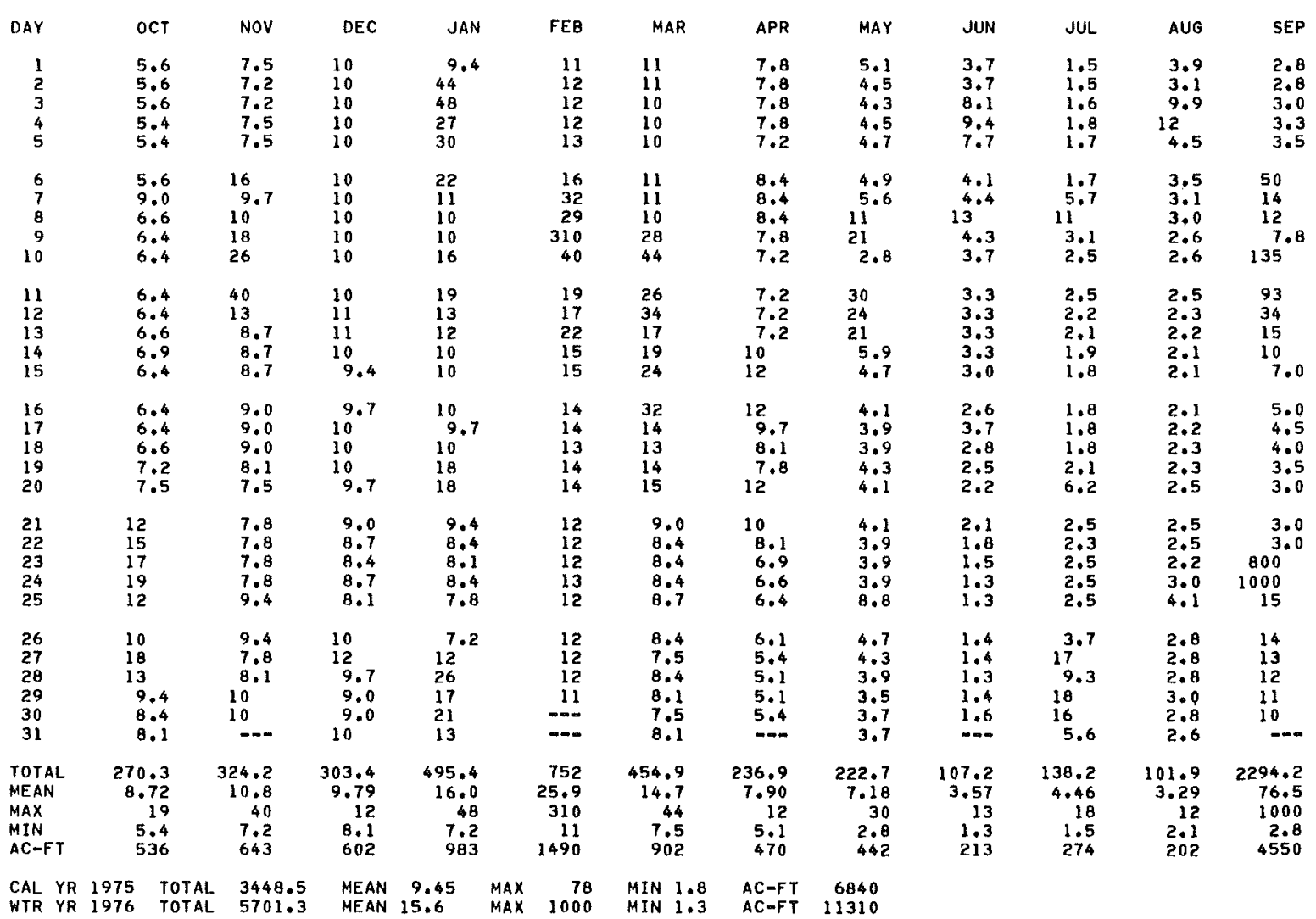


10254730 ALAMO RIVER NEAR NILAND, CA

LOCATION, - Lat $33^{\circ} 12^{\prime} 03^{\prime \prime}$, long $115^{\circ} 36^{\prime} 07^{\prime \prime}$, in NELSWHEt sec. 22 , T.11 S., R.13 E., Imperial County, on Ieft bank $0.6 \mathrm{mi}(1.0 \mathrm{~km})$ upstrean from mouth, and $5.8 \mathrm{mi}(9.3 \mathrm{~km})$ southwest of Niland.

PERIOD OF RECORD. --January 1943 to current year. Monthly discharge only for January 1943 to September 1960 , pub-

lished in WSP 1734 .

GAGE.--Water-stage recorder. Altitude of gage is $235 \mathrm{ft}(72 \mathrm{~m}$ ) below mean sea 1 evel (from topographic map).

REMARKS,--Records good. Discharge represents seepage and return flow from irrigated areas.

COOPERATION. - Records furnished by Imperial Irrigation District and reviewed by the Geological Survey.

EXTREMES FOR PERIOD OF RECORD, - Maximum daily discharge, $2,080 \mathrm{ft}^{3} / \mathrm{s}\left(58.9 \mathrm{~m}^{3} / \mathrm{s}\right) \mathrm{Nov}^{2}, 27,1967$; minimum

daily, $288 \mathrm{ft}^{3} / \mathrm{s}\left(8.16 \mathrm{~m}^{3} / \mathrm{s}\right) \mathrm{Jan} .2,1966$.

DISCHARGE, IN CUBIC FEET PER SECOND, WATER YEAR OCTOBER 1975 TO SEPTEMBER 1976 MEAN VALUES

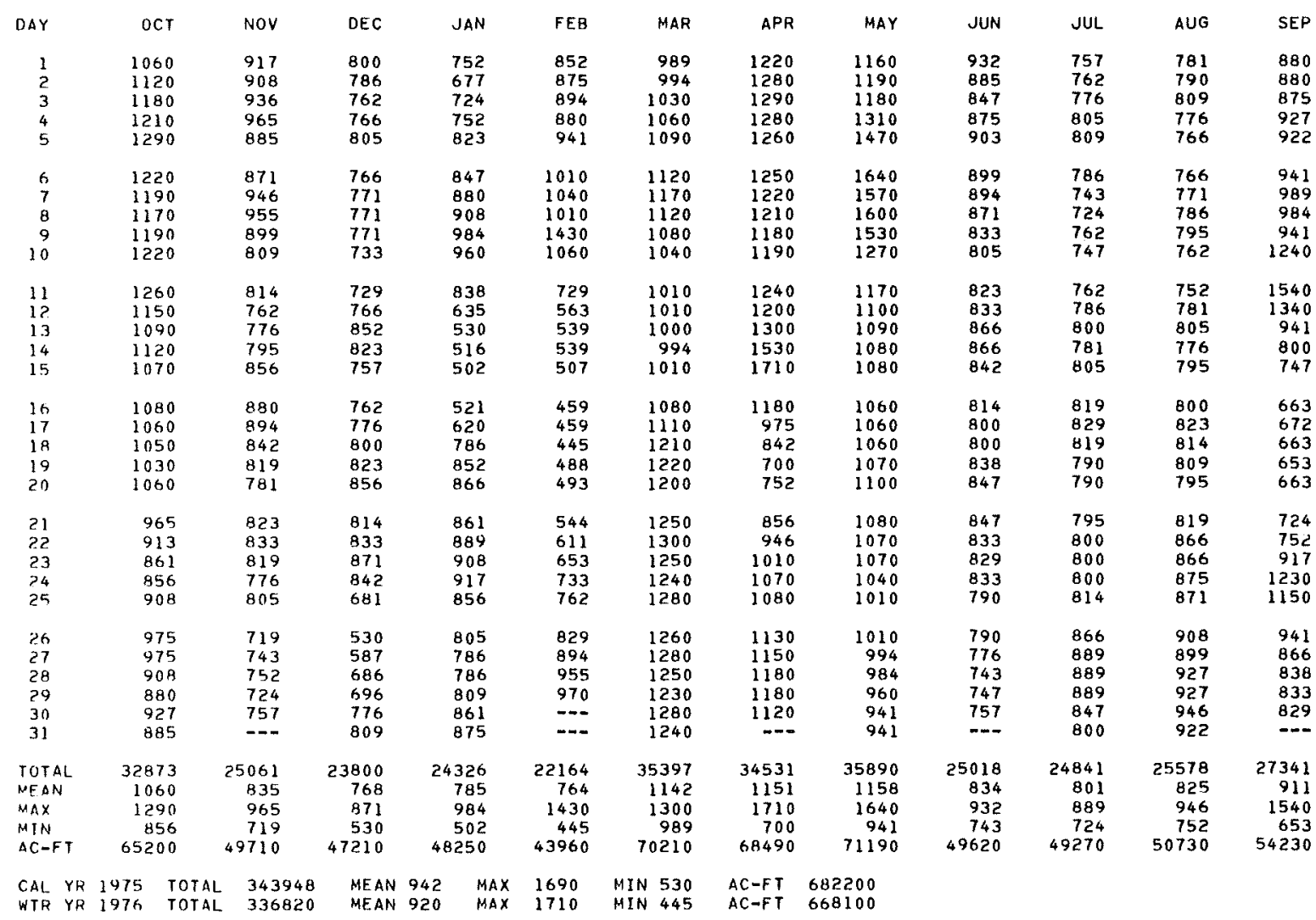


10254970 NEW RIVER AT INTERNATIONAL BOUNDARY, AT CALEXICO, CA (National stream-quality accounting network station)

LOCATION. - Lat $32^{\circ} 39^{\prime} 57^{\prime \prime}$, long $115^{\circ} 30^{\prime} 08^{\prime \prime}$, in NEs $4 W_{4}$ SEs sec.14, T.17 S., R.14 E., TmperiaI County, at gaging station at Second Street bridge, $0.2 \mathrm{mi}(0.3 \mathrm{~km})$ downstream from international boundary, and 0.2 mi ( $0.3 \mathrm{~km})$
west of Calexico.

PERIOD OF RECORD. - Water years 1969 to 1971,1973 to current year.

CHEMICAL ANALYSES: August 1969 to July 1971, February 1973 to current year.

WATER TEMPERATURES: Water year 1974 to current year.

SEDIMENT RECORDS: Water year 1975 to current year (partial-record station).

PERIOD OF DAILY RECORD.--

SPECIFIC CONDUCTANCE: October 1973 to current year.

WATER TEMPERATURES: October 1973 to current year.

INSTRUMENTATION.--Specific-conductance recorder since October 1973 . Temperature recorder since October 1973.

REMARKS,--Periods of missing conductivity and temperature data due to equipment malfunction or fouled probe. Discrepency between total and dissolved concentrations due to analytical techniques.

COOPERATION. - Discharge records were furnished by Imperial Irrigation District.

EXTREMES FOR PERIOD OF DAILY RECORD. -

SPECIFIC CONDUCTANCE: Maximum recorded, 9,830 micromhos Aug. 8, 1976; minimum recorded, 3,400 micromhos June 2,1975

WATER TEMPERATURES: Maximum recorded, $36.5^{\circ} \mathrm{C}$ Sept. 13, 14, 1976; minimun recorded, $11.0^{\circ} \mathrm{C} \mathrm{Feb.} 22,1975$.

EXTREMES FOR CURRENT YEAR.-

SPECIFIC CONDUCTANCE: Maximum recorded, 9,830 micromhos Aug. 8; minimum recorded, 4,130 micromhos Feb. 18. WATER TEMPERATURES: Maximum recorded, $36.5^{\circ} \mathrm{C}$ Sept. 13,14 ; minimum recorded, $13.0^{\circ} \mathrm{C}$ Nov. 29 to Dec. 3 .

CHEMICAL ANALYSES, WATER YEAR OCTOBER 1975 TO SEPTEMBER 1976

\begin{tabular}{|c|c|c|c|c|c|c|c|c|c|}
\hline DATE & TIHE & $\begin{array}{l}\text { INSTAN- } \\
\text { TANEOUS } \\
\text { DIS- } \\
\text { CHARGE } \\
\text { (CFS) }\end{array}$ & $\begin{array}{l}\text { SPE- } \\
\text { CIFIC } \\
\text { CON- } \\
\text { OUCT- } \\
\text { ANCE } \\
\text { (MICRO- } \\
\text { MHOS) }\end{array}$ & $\begin{array}{c}\mathrm{PH} \\
\text { (UNITS) }\end{array}$ & $\begin{array}{l}\text { TEMPER- } \\
\text { ATURE } \\
\text { (DEG C) }\end{array}$ & $\begin{array}{l}\text { DIS- } \\
\text { SOLVED } \\
\text { SOLIDS } \\
\text { (RESI- } \\
\text { DUE AT } \\
1 B 0 \text { C) } \\
\text { (MG/L) }\end{array}$ & $\begin{array}{l}\text { DIS- } \\
\text { SOLVED } \\
\text { SOLIDS } \\
\text { (SUM OF } \\
\text { CONSTI- } \\
\text { TUENTS) } \\
\text { (MG L ) }\end{array}$ & $\begin{array}{l}\text { DIS- } \\
\text { SOLVED } \\
\text { SOLIDS } \\
\text { (TONS } \\
\text { PER } \\
\text { AC-FT) }\end{array}$ & $\begin{array}{l}\text { DIS- } \\
\text { SOLVED } \\
\text { SOLIDS } \\
\text { (TONS } \\
\text { PER } \\
\text { DAY) }\end{array}$ \\
\hline OCT & & & & & & & & & \\
\hline $\begin{array}{l}06 \ldots \\
\text { Nov }\end{array}$ & 1500 & 120 & 6600 & 7.8 & 28.0 & 4260 & 4040 & 5.79 & 1380 \\
\hline DEC & 1500 & 113 & 6400 & 7.6 & 16.5 & 4730 & 4710 & 6.43 & 1440 \\
\hline JAN & 1500 & 128 & 5200 & 7.8 & 16.0 & 4580 & 4480 & 6.23 & 1580 \\
\hline$\underset{F E B}{27} \cdots$ & 1430 & 148 & 7400 & 7.8 & 16.0 & 4380 & 4110 & 5.96 & 1750 \\
\hline$\underset{\text { MAR }}{17} \cdots$ & 1400 & 213 & 6300 & 7.3 & 18.0 & 4400 & 4180 & 5.98 & 2530 \\
\hline $\begin{array}{l}03 \ldots \\
16 \cdots \\
A P R\end{array}$ & $\begin{array}{l}1100 \\
1400\end{array}$ & $\begin{array}{l}162 \\
147\end{array}$ & $\begin{array}{l}7310 \\
9200\end{array}$ & $\begin{array}{l}7.9 \\
8.0\end{array}$ & $\begin{array}{l}15.0 \\
20.0\end{array}$ & $\begin{array}{l}4750 \\
4420\end{array}$ & $\begin{array}{l}4520 \\
4800\end{array}$ & $\begin{array}{l}6.46 \\
6.01\end{array}$ & $\begin{array}{l}2080 \\
1750\end{array}$ \\
\hline $\begin{array}{l}07 \ldots \\
13 \ldots \\
\text { MAY }\end{array}$ & $\begin{array}{l}1130 \\
1500\end{array}$ & $\begin{array}{l}154 \\
195\end{array}$ & $\begin{array}{l}8200 \\
8200\end{array}$ & $\begin{array}{l}7.9 \\
8.0\end{array}$ & $\begin{array}{l}20.5 \\
18.0\end{array}$ & $\begin{array}{l}5500 \\
4850\end{array}$ & $\begin{array}{l}5060 \\
4540\end{array}$ & $\begin{array}{l}7.48 \\
6.60\end{array}$ & $\begin{array}{l}2290 \\
2550\end{array}$ \\
\hline $\begin{array}{l}05 \ldots \\
11 \ldots \\
\text { JUN }\end{array}$ & $\begin{array}{l}1120 \\
1400\end{array}$ & $\begin{array}{l}158 \\
249\end{array}$ & $\begin{array}{l}7860 \\
5998\end{array}$ & $\begin{array}{l}7.7 \\
7.4\end{array}$ & $\begin{array}{l}25.0 \\
27.5\end{array}$ & $\begin{array}{l}5330 \\
3790\end{array}$ & $\begin{array}{l}4810 \\
3910\end{array}$ & $\begin{array}{l}7.25 \\
5.15\end{array}$ & $\begin{array}{l}2270 \\
2550\end{array}$ \\
\hline $\begin{array}{l}01 \ldots \\
02 \cdots \\
29 \cdots \\
\text { JUL }\end{array}$ & $\begin{array}{l}1400 \\
1110 \\
1400\end{array}$ & $\begin{array}{r}128 \\
130 \\
97\end{array}$ & $\begin{array}{l}6569 \\
6950 \\
8293\end{array}$ & $\begin{array}{l}7.5 \\
7.7 \\
7.6\end{array}$ & $\begin{array}{l}27.5 \\
25.5 \\
32.0\end{array}$ & $\begin{array}{l}4900 \\
4530 \\
5850\end{array}$ & $\begin{array}{l}4800 \\
4280 \\
5730\end{array}$ & $\begin{array}{l}6.66 \\
6.16 \\
7.96\end{array}$ & $\begin{array}{l}1690 \\
1590 \\
1530\end{array}$ \\
\hline $\begin{array}{l}07 \cdots \\
21 \cdots \\
27 \cdots \\
\text { AUS }\end{array}$ & $\begin{array}{l}1140 \\
0815 \\
0730\end{array}$ & $\begin{array}{r}91 \\
121 \\
122\end{array}$ & $\begin{array}{l}8850 \\
8800 \\
7955\end{array}$ & $\begin{array}{l}7 .-8 \\
7.6\end{array}$ & $\begin{array}{r}31.0 \\
7.8 \\
29.0\end{array}$ & $\begin{array}{r}50 \\
5650 \\
5190\end{array}$ & $\begin{array}{r}-0 \\
5340 \\
5190\end{array}$ & $\begin{array}{r}7.08 \\
7.06\end{array}$ & $\begin{array}{l}1850 \\
1710\end{array}$ \\
\hline $\begin{array}{l}04 \ldots \\
31 \ldots \\
\text { SEP }\end{array}$ & $\begin{array}{l}1130 \\
0700\end{array}$ & $\begin{array}{l}117 \\
110\end{array}$ & $\begin{array}{l}8570 \\
6800\end{array}$ & $\begin{array}{l}7.8 \\
7.7\end{array}$ & $\begin{array}{l}26.5 \\
29.5\end{array}$ & $\begin{array}{l}5470 \\
4740\end{array}$ & $\begin{array}{l}5210 \\
4620\end{array}$ & $\begin{array}{l}7.44 \\
6.45\end{array}$ & $\begin{array}{l}1730 \\
1410\end{array}$ \\
\hline $\begin{array}{l}01 \ldots \\
21 \ldots\end{array}$ & $\begin{array}{l}1120 \\
1710\end{array}$ & $\begin{array}{l}112 \\
123\end{array}$ & $\begin{array}{l}7650 \\
7400\end{array}$ & $\begin{array}{l}7.9 \\
7.9\end{array}$ & $\begin{array}{l}26.5 \\
29.0\end{array}$ & $\begin{array}{l}4990 \\
4710\end{array}$ & $\begin{array}{l}4670 \\
4550\end{array}$ & $\begin{array}{l}6.79 \\
6.41\end{array}$ & $\begin{array}{l}1510 \\
1560\end{array}$ \\
\hline
\end{tabular}


10254970 NEW RIVER AT INTERNATIONAL, BOUNDARY, AT CALEXICO, CA--Continued

CHEMICAL ANALYSES, WATER YEAR OCTOBER 1975 TO SEPTEMBER 1976

\begin{tabular}{|c|c|c|c|c|c|c|c|c|c|c|c|c|}
\hline DATE & TIME & $\begin{array}{l}\text { INSTAN- } \\
\text { TANEOUS } \\
\text { DIS- } \\
\text { CHARGE } \\
\text { (CFS) }\end{array}$ & $\begin{array}{l}\text { TUR=- } \\
\text { BIO- } \\
\text { ITY } \\
\text { (JTU) }\end{array}$ & $\begin{array}{c}\text { FECAL } \\
\text { COLI- } \\
\text { FORM } \\
\text { (COL. } \\
\text { PER } \\
100 \mathrm{ML} \text { ) }\end{array}$ & $\begin{array}{l}\text { STREP- } \\
\text { TOCOCCI } \\
\text { (COL- } \\
\text { ONIES } \\
\text { PER } \\
100 \mathrm{ML} \text { ) }\end{array}$ & $\begin{array}{l}\text { HARD- } \\
\text { NESS } \\
(\mathrm{CA}, M G) \\
(M G / L)\end{array}$ & $\begin{array}{l}\text { NON- } \\
\text { CAR- } \\
\text { BONATE } \\
\text { HARD- } \\
\text { NESS } \\
\text { (MG/L) }\end{array}$ & $\begin{array}{l}\text { DIS- } \\
\text { SOLVED } \\
\text { CAL- } \\
\text { CIUM } \\
\text { (CA) } \\
\text { (MG/L) }\end{array}$ & $\begin{array}{l}\text { DIS- } \\
\text { SOLVED } \\
\text { MAG- } \\
\text { NE- } \\
\text { SIUM } \\
\text { (MG) } \\
\text { (MG/L) }\end{array}$ & $\begin{array}{l}\text { DIS- } \\
\text { SOLVED } \\
\text { SODIUM } \\
\text { (NA) } \\
\text { (MG/L) }\end{array}$ & $\begin{array}{r}\text { PERCENT } \\
\text { SODIUM }\end{array}$ & $\begin{array}{l}\text { SOOIUM } \\
\text { AD }= \\
\text { SORP- } \\
\text { TION } \\
\text { RATIO }\end{array}$ \\
\hline$O C T$ & & & & & & & & & & & & \\
\hline NOV & 1500 & 120 & 15 & 6700000 & 390000 & 1100 & 830 & 230 & 120 & 1000 & 66 & 13 \\
\hline${ }_{D E C}^{18} \cdots$ & 1500 & 113 & 16 & 2300000 & 300000 & 1100 & 850 & 260 & 120 & 1200 & 68 & 15 \\
\hline $\begin{array}{l}0 B \cdots \\
\text { JAN }\end{array}$ & 1500 & 128 & 15 & 1100000 & -- & 1100 & 870 & 250 & 120 & 1200 & 68 & 16 \\
\hline$\underset{F E B}{27} \cdots$ & 1430 & 148 & 15 & 2500000 & 3600000 & 1200 & 880 & 250 & 130 & 1000 & 64 & 13 \\
\hline $17 \ldots$ & 1400 & 213 & 15 & 700000 & 150000 & 1200 & 940 & 260 & 130 & 1000 & 64 & 13 \\
\hline $\begin{array}{l}03 \ldots \\
16 \ldots \\
A P A\end{array}$ & $\begin{array}{l}1100 \\
1400\end{array}$ & $\begin{array}{l}162 \\
147\end{array}$ & $-\infty$ & $\begin{array}{l}813000 \\
537000\end{array}$ & $\begin{array}{l}100000 \\
134000\end{array}$ & $\begin{array}{l}1360 \\
1300\end{array}$ & $\begin{array}{l}1100 \\
1000\end{array}$ & $\begin{array}{l}296 \\
280\end{array}$ & $\begin{array}{l}151 \\
150\end{array}$ & $\begin{array}{l}1110 \\
1200\end{array}$ & $\begin{array}{l}63 \\
65\end{array}$ & $\begin{array}{l}13 \\
14\end{array}$ \\
\hline $\begin{array}{r}07 \ldots \\
13 \ldots \\
\text { MAY }\end{array}$ & $\begin{array}{l}1130 \\
1500\end{array}$ & $\begin{array}{l}154 \\
195\end{array}$ & 27 & 8200000 & $\begin{array}{r}420000 \\
80000\end{array}$ & $\begin{array}{l}1420 \\
1400\end{array}$ & $\begin{array}{l}1150 \\
1000\end{array}$ & $\begin{array}{l}310 \\
280\end{array}$ & $\begin{array}{l}157 \\
160\end{array}$ & $\begin{array}{l}1280 \\
1100\end{array}$ & $\begin{array}{l}65 \\
62\end{array}$ & $\begin{array}{l}15 \\
13\end{array}$ \\
\hline $\begin{array}{l}05 \ldots \\
11 \ldots\end{array}$ & $\begin{array}{l}1120 \\
1400\end{array}$ & $\begin{array}{l}158 \\
249\end{array}$ & 20 & $\begin{array}{r}2000000 \\
74000\end{array}$ & $\begin{array}{r}1100000 \\
40000\end{array}$ & $\begin{array}{l}1380 \\
1000\end{array}$ & $\begin{array}{r}1110 \\
780\end{array}$ & $\begin{array}{l}284 \\
220\end{array}$ & $\begin{array}{l}163 \\
110\end{array}$ & $\begin{array}{r}1210 \\
930\end{array}$ & $\begin{array}{l}65 \\
64\end{array}$ & $\begin{array}{l}14 \\
13\end{array}$ \\
\hline $\begin{array}{l}01 \ldots \\
02 \ldots \\
29 \cdots \\
\text { JUL }\end{array}$ & $\begin{array}{l}1400 \\
1110 \\
1400\end{array}$ & $\begin{array}{r}128 \\
130 \\
97\end{array}$ & $-\frac{3}{10}$ & $\begin{array}{r}700000 \\
4200000 \\
-\end{array}$ & $\begin{array}{r}400000 \\
2000000 \\
80000\end{array}$ & $\begin{array}{l}1300 \\
1210 \\
1400\end{array}$ & $\begin{array}{r}1000 \\
959 \\
1100\end{array}$ & $\begin{array}{l}260 \\
254 \\
280\end{array}$ & $\begin{array}{l}150 \\
140 \\
160\end{array}$ & $\begin{array}{l}1200 \\
1070 \\
1500\end{array}$ & $\begin{array}{l}66 \\
65 \\
69\end{array}$ & $\begin{array}{l}15 \\
13 \\
18\end{array}$ \\
\hline $\begin{array}{r}21 \ldots \\
27 \ldots \\
\text { AUG }\end{array}$ & $\begin{array}{l}0815 \\
0730\end{array}$ & $\begin{array}{l}121 \\
122\end{array}$ & 30 & 420000 & 240000 & $\begin{array}{l}1260 \\
1200\end{array}$ & $\begin{array}{r}1060 \\
960\end{array}$ & $\begin{array}{l}270 \\
250\end{array}$ & $\begin{array}{l}143 \\
130\end{array}$ & $\begin{array}{l}1420 \\
1400\end{array}$ & $\begin{array}{l}69 \\
70\end{array}$ & $\begin{array}{l}17 \\
18\end{array}$ \\
\hline $\begin{array}{r}04 \ldots \\
\text { SEP }\end{array}$ & $\begin{array}{l}1130 \\
0700\end{array}$ & $\begin{array}{l}117 \\
110\end{array}$ & -3 & $\begin{array}{r}5100000 \\
20000\end{array}$ & 60000 & $\begin{array}{l}1190 \\
1200\end{array}$ & $\begin{array}{r}975 \\
1000\end{array}$ & $\begin{array}{l}260 \\
260\end{array}$ & $\begin{array}{l}132 \\
140\end{array}$ & $\begin{array}{l}1390 \\
1200\end{array}$ & $\begin{array}{l}69 \\
67\end{array}$ & $\begin{array}{l}18 \\
15\end{array}$ \\
\hline $\begin{array}{l}01 \ldots \\
21 \ldots\end{array}$ & $\begin{array}{l}1120 \\
1710\end{array}$ & $\begin{array}{l}112 \\
123\end{array}$ & 10 & $\begin{array}{r}1400000 \\
248000\end{array}$ & 220000 & $\begin{array}{l}1200 \\
1200\end{array}$ & $\begin{array}{l}977 \\
960\end{array}$ & $\begin{array}{l}254 \\
260\end{array}$ & $\begin{array}{l}138 \\
140\end{array}$ & $\begin{array}{l}1200 \\
1200\end{array}$ & $\begin{array}{l}67 \\
67\end{array}$ & $\begin{array}{l}15 \\
15\end{array}$ \\
\hline
\end{tabular}

\begin{tabular}{|c|c|c|c|c|c|c|c|c|c|c|c|c|}
\hline DATE & $\begin{array}{l}\text { DIS- } \\
\text { SOLVED } \\
\text { PO- } \\
\text { TAS- } \\
\text { SIUM } \\
\text { (K) } \\
\text { (HG/L) }\end{array}$ & $\begin{array}{l}\text { BICAR- } \\
\text { BONATE } \\
\text { (HCO3) } \\
\text { (HG/L) }\end{array}$ & $\begin{array}{l}\text { CAR- } \\
\text { BONATE } \\
\text { (CO3) } \\
\text { (HG/L) }\end{array}$ & $\begin{array}{l}\text { ALKA- } \\
\text { LINITY } \\
\text { AS } \\
\text { CACO3 } \\
\text { (MG/L) }\end{array}$ & $\begin{array}{l}\text { CARBON } \\
\text { DIOXIDE } \\
\text { (COZ) } \\
\text { (MG/L) }\end{array}$ & $\begin{array}{l}\text { DIS- } \\
\text { SOLVED } \\
\text { SULFATE } \\
\text { (SO\&) } \\
\text { (MG/L) }\end{array}$ & $\begin{array}{l}\text { DIS- } \\
\text { SOLVED } \\
\text { CHLO- } \\
\text { RIDE } \\
(C L) \\
(M G / L)\end{array}$ & $\begin{array}{l}\text { DIS- } \\
\text { SOLVED } \\
\text { FLUO- } \\
\text { RIDE } \\
(F) \\
(M G / L)\end{array}$ & $\begin{array}{l}\text { DIS- } \\
\text { SOLVED } \\
\text { SILICA } \\
\text { (SIO2) } \\
\text { (MG/L) }\end{array}$ & $\begin{array}{c}\text { TOTAL } \\
\text { NI TRITE } \\
\text { PLUS } \\
\text { NI TRATE } \\
\text { (N) } \\
\text { (MG/L) }\end{array}$ & $\begin{array}{l}\text { DIS- } \\
\text { SOLVED } \\
\text { NITRITE } \\
\text { PLUS } \\
\text { NITRATE } \\
\text { (N) } \\
\text { (MG/L) }\end{array}$ & $\begin{array}{l}\text { TOTAL. } \\
\text { AMMONIA } \\
\text { NITRO- } \\
\text { GEN } \\
\text { (N) } \\
\text { (MG/L) }\end{array}$ \\
\hline $\mathrm{OCT}$ & & & & & & & & & & & & \\
\hline $\begin{array}{l}06 \ldots \\
\text { NOV }\end{array}$ & 47 & 286 & 0 & 235 & 7.3 & 780 & 1700 & .6 & 18 & .02 & .02 & 4.8 \\
\hline JAN & 77 & 307 & 0 & 252 & 7.8 & 730 & 1900 & .6 & 19 & 5.5 & 5.5 & 4.5 \\
\hline FEB $27 \ldots$ & 33 & 340 & 0 & 279 & 8.6 & 800 & 1700 & .6 & 15 & .83 & .57 & 4.0 \\
\hline MAR & 42 & 300 & 0 & 246 & 24 & 780 & 1800 & .6 & 12 & .72 & 1.3 & 3.5 \\
\hline $\begin{array}{l}03 \ldots \\
16 \ldots \\
A P R\end{array}$ & $\begin{array}{l}34 \\
67\end{array}$ & $\begin{array}{l}316 \\
330\end{array}$ & $\begin{array}{l}0 \\
0\end{array}$ & $\begin{array}{l}259 \\
271\end{array}$ & $\begin{array}{l}6.4 \\
5.3\end{array}$ & $\begin{array}{l}900 \\
890\end{array}$ & $\begin{array}{l}1860 \\
2000\end{array}$ & $\begin{array}{r}1.0 \\
.6\end{array}$ & $\begin{array}{l}13 \\
16\end{array}$ & 4.3 & 6.0 & $2.6^{-1}$ \\
\hline $\begin{array}{l}07 \ldots \\
13 \ldots \\
\text { MAY }\end{array}$ & $\begin{array}{l}64 \\
64\end{array}$ & $\begin{array}{l}330 \\
\mathbf{3 8 1}\end{array}$ & $\begin{array}{l}0 \\
0\end{array}$ & $\begin{array}{l}271 \\
313\end{array}$ & $\begin{array}{l}6.6 \\
6.1\end{array}$ & $\begin{array}{l}930 \\
820\end{array}$ & $\begin{array}{l}2140 \\
1900\end{array}$ & $\begin{array}{r}1.0 \\
.6\end{array}$ & $\begin{array}{l}17 \\
17\end{array}$ & .00 & 1.9 & 4.9 \\
\hline $\begin{array}{l}05 \ldots \\
11\end{array} \ldots$ & $\begin{array}{r}37 \\
100\end{array}$ & $\begin{array}{l}330 \\
274\end{array}$ & $\begin{array}{l}0 \\
0\end{array}$ & $\begin{array}{l}271 \\
225\end{array}$ & $\begin{array}{l}11 \\
17\end{array}$ & $\begin{array}{l}915 \\
790\end{array}$ & $\begin{array}{l}2020 \\
1600\end{array}$ & .8 & $\begin{array}{l}17 \\
17\end{array}$ & .80 & .80 & $3.2^{-\infty}$ \\
\hline $\begin{array}{l}01 \ldots \\
02 \ldots \cdots \\
29 \cdots \cdots \\
\text { JUL }\end{array}$ & $\begin{array}{r}50 \\
42 \\
110\end{array}$ & $\begin{array}{l}296 \\
306 \\
275\end{array}$ & $\begin{array}{l}0 \\
0 \\
0\end{array}$ & $\begin{array}{l}243 \\
251 \\
226\end{array}$ & $\begin{array}{l}15 \\
9.8 \\
11\end{array}$ & $\begin{array}{l}940 \\
840 \\
920\end{array}$ & $\begin{array}{l}2000 \\
1760 \\
2600\end{array}$ & $\begin{array}{r}.0 \\
1: 0\end{array}$ & $\begin{array}{l}22 \\
17 \\
26\end{array}$ & $\begin{array}{r}5.7 \\
.51\end{array}$ & $\begin{array}{r}5.6 \\
-.=\end{array}$ & $\begin{array}{r}4.4 \\
0-\end{array}$ \\
\hline $\begin{array}{l}21 \ldots \\
27 \ldots \\
A \cup G\end{array}$ & $\begin{array}{l}108 \\
110\end{array}$ & $\begin{array}{l}248 \\
241\end{array}$ & $\begin{array}{l}0 \\
0\end{array}$ & $\begin{array}{l}203 \\
198\end{array}$ & 15 & $\begin{array}{l}840 \\
830\end{array}$ & $\begin{array}{l}2410 \\
2300\end{array}$ & $\begin{array}{r}1.0 \\
.7\end{array}$ & $\begin{array}{l}26 \\
28\end{array}$ & $\therefore 1$ & $3.7^{-\infty}$ & .92 \\
\hline $\begin{array}{l}04 \ldots \\
31 \ldots \\
\text { SEP }\end{array}$ & $\begin{array}{r}120 \\
71\end{array}$ & $\begin{array}{l}262 \\
232\end{array}$ & $\begin{array}{l}0 \\
0\end{array}$ & $\begin{array}{l}215 \\
190\end{array}$ & $\begin{array}{l}6.6 \\
6.6\end{array}$ & $\begin{array}{l}790 \\
790\end{array}$ & $\begin{array}{l}2360 \\
2000\end{array}$ & .7 & $\begin{array}{l}28 \\
27\end{array}$ & .48 & $3.1^{-1}$ & $2.9^{-\infty}$ \\
\hline $\begin{array}{l}01 \ldots \\
21 \ldots\end{array}$ & $\begin{array}{l}68 \\
49\end{array}$ & $\begin{array}{l}272 \\
322\end{array}$ & $\begin{array}{l}0 \\
0\end{array}$ & $\begin{array}{l}223 \\
264\end{array}$ & $\begin{array}{l}5.5 \\
6.5\end{array}$ & $\begin{array}{l}845 \\
800\end{array}$ & $\begin{array}{l}2000 \\
1900\end{array}$ & $\begin{array}{r}1.0 \\
.6\end{array}$ & $\begin{array}{l}26 \\
20\end{array}$ & .08 & $4.2^{-0}$ & $4.8^{-\infty}$ \\
\hline
\end{tabular}


10254970 NEW RIVER AT INTERNATIONAL BOUNDARY, AT CALEXICO, CA--Continued

CHEMICAL ANALYSES, WATER YEAR OCTOBER 1975 TO SEPTEMBER 1976

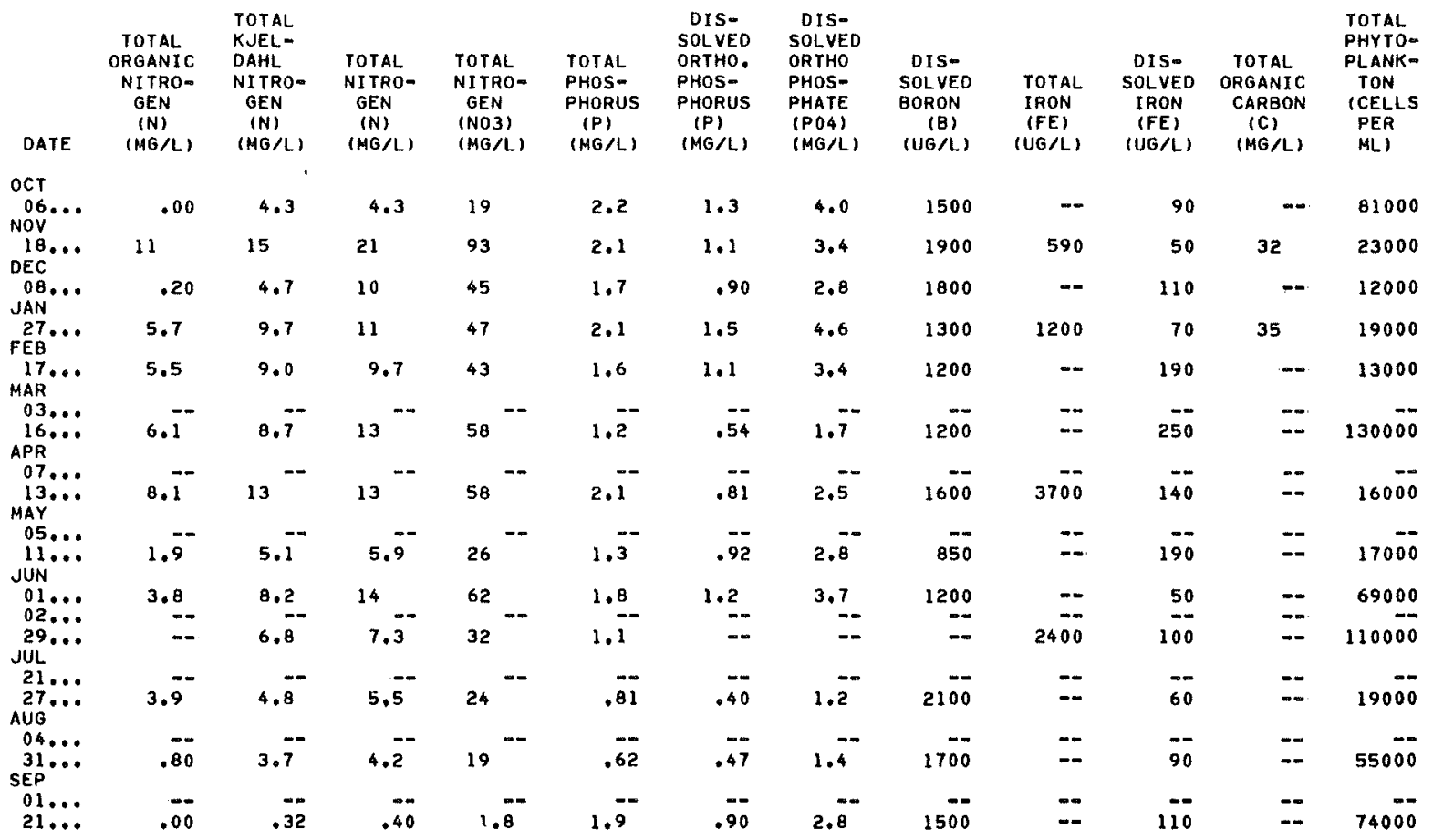


10254970 NEW RIVER AT INTERNATIONAL BOUNDARY, AT CALEXICO, CA--Continued

QUALITATIVE AND ASSOGIATED QUANTITATIVE ANALYSES OF BIOLOGICAL DATA, WATER YEAR OCTOBER 1975 TO SEPTEMBER 1976 PHYTOPLANKTON

\begin{tabular}{|c|c|c|c|c|c|}
\hline DATE & TIME & $\begin{array}{l}\text { PHYLUM } \\
\text {. CLASS } \\
\ldots \text { ORDER } \\
\ldots \text {. FAMILY } \\
\ldots \text {. GENUS } \\
\ldots \text {. . SPECIES }\end{array}$ & $\begin{array}{l}\text { COMMON } \\
\text { NAME }\end{array}$ & $\begin{array}{c}\text { COUNT } \\
\text { (CELLS/ML) }\end{array}$ & $\begin{array}{l}\text { PERCENT } \\
\text { OF TOTAL }\end{array}$ \\
\hline \multirow[t]{5}{*}{$\begin{array}{r}\text { OCT } \\
6\end{array}$} & 0000 & 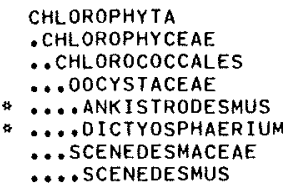 & GREEN ALGAE & 1,100 & $\begin{array}{l}0 \\
0 \\
1\end{array}$ \\
\hline & & 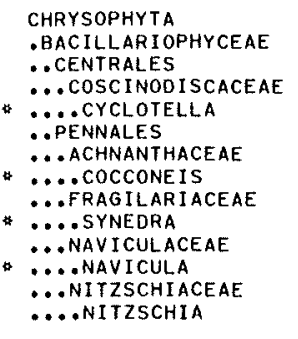 & $\begin{array}{l}\text { DIATOMS } \\
\text { CENTRIC } \\
\text { PENNATE }\end{array}$ & 800 & $\begin{array}{l}0 \\
0 \\
0 \\
0 \\
1\end{array}$ \\
\hline & & 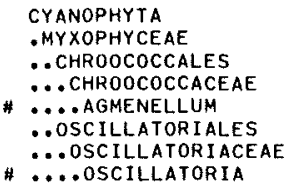 & $\begin{array}{l}\text { BLUE-GREEN ALGAE } \\
\text { COCCOIO } \\
\text { FILAMENTOUS }\end{array}$ & $\begin{array}{l}34,000 \\
43,000\end{array}$ & 54 \\
\hline & & $\begin{array}{l}\text { EUGLENOPHYTA } \\
\text { EUGLENOPHYCEAE } \\
\text {. EUGLENALES } \\
\text { \#. EUGLENACEAE } \\
\text {. . EEUGLENA }\end{array}$ & EUGLENOIDS & 530 & 1 \\
\hline & & TOTAL PHYTOPLANKTON & & 80,000 & \\
\hline
\end{tabular}

See footnotes at end of table. 
10254970 NEW RIVER AT INTERNATIONAL BOUNDARY, AT CALEXICO, CA-Continued

QUALITATIVE AND ASSOCIATED QUANTITATIVE ANALYSES OF BIOLOGICAL DATA, WATER YEAR OCTOBER 1975 TO SEPTEMBER 1976 PHYTOPLANKTON

\begin{tabular}{|c|c|c|c|}
\hline DATE & TIME & & $\begin{array}{l}\text { PHYLUM } \\
. \text { CLASS } \\
\ldots \text { ORDER } \\
\ldots \text { FAMILY } \\
\ldots \text { GENUS } \\
\ldots \text {... SPECIES }\end{array}$ \\
\hline \multirow[t]{5}{*}{$\begin{array}{r}\text { NOV } \\
18\end{array}$} & 0000 & * & $\begin{array}{l}\text { CHLOROPHYTA } \\
\text {. CHLOROPHYCEAE } \\
\ldots \text { VOL VOCALES } \\
\ldots \text { CHLAMYDOMONADACEAE } \\
\ldots \text {. . CHLAMYDOMONAS }\end{array}$ \\
\hline & & 4 & $\begin{array}{l}\text { CHRYSOPHYTA } \\
\text { BACILLARIOPHYCEAE } \\
\ldots \text { CENTRALES } \\
\ldots \text { COSCINODISCACEAE } \\
\ldots \text {. CYCLOTELLA } \\
\ldots \text { PENNALES } \\
\ldots \text { ACHNANIHACEAE } \\
\ldots \text { COCCONEIS } \\
\ldots \text { CYMBELLACEAE } \\
\ldots \text { AMPHORA } \\
\ldots \text {. CYMBELLA } \\
\ldots \text { GOMPHONEMATACEAE } \\
\ldots \text {. GOMPHONEMA } \\
\ldots \text { NAVICULACEAE } \\
\ldots \text { NAVICULA } \\
\ldots \text { NITZSCHIACEAE } \\
\ldots \text { NITZSCHIA }\end{array}$ \\
\hline & & \# & $\begin{array}{l}\text { CYANOPHYTA } \\
\text {.MYXOPHYCEAE } \\
\ldots \text { CHROOCOCCALES } \\
\ldots \text { CHROOCOCCACEAE } \\
\ldots \text {. AGMENELLUM } \\
\ldots \text { OSCILLATORIALES } \\
\ldots \text { OSCILLATORIACEAE } \\
\ldots \text {.. OSCILLATORIA }\end{array}$ \\
\hline & & * & $\begin{array}{l}\text { EUGLENOPHYTA } \\
\text { EUGLENOPHYCEAE } \\
\text { \#EUGLENALES } \\
\text { \#. EUGLENACEAE } \\
\text {. . E EUGLENA }\end{array}$ \\
\hline & & & TOTAL PHYTOPLANKTON \\
\hline
\end{tabular}

$\begin{array}{lcr}\text { COMMON } & \text { COUNT } & \text { PERCENT } \\ \text { NAME } & \text { (CELLS/ML) } & \text { OF TOTAL }\end{array}$

GREEN ALGAE

DIATOMS

CENIRIC

PENNATE

190

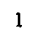

0

... coccone IS

-

. A cYMBEL

GOMPHONEMATACEAE

....GOMPHONEMA

.. NAV I CULACEAE

\%. NITZSChitaceae

...NITZSCHIA

NAVICULOIO

$190 \quad 1$

290

$290 \quad 1$

BLUE-GREEN ALGAE

Coccolo

FILAMENTOUS

22,000

EUGLENOIOS

EUGLENOPHYTA

- EUGLENOPHYCEAE
\#UUGLENALES

\#... Euglenalena

TOTAL PHYTOPLANKTON 
10254970 NEW RIVER AT INTERNATIONAL BOUNDARY, AT CALEXICO, CA--Continued

QUALITATIVE AND ASSOCIATED QUANTTTATIVE ANALYSES OF BIOLOGICAL DATA, WATER YEAR OCTOBER 1975 TO SEPTEMBER 1976

PHYTOPLANKTON

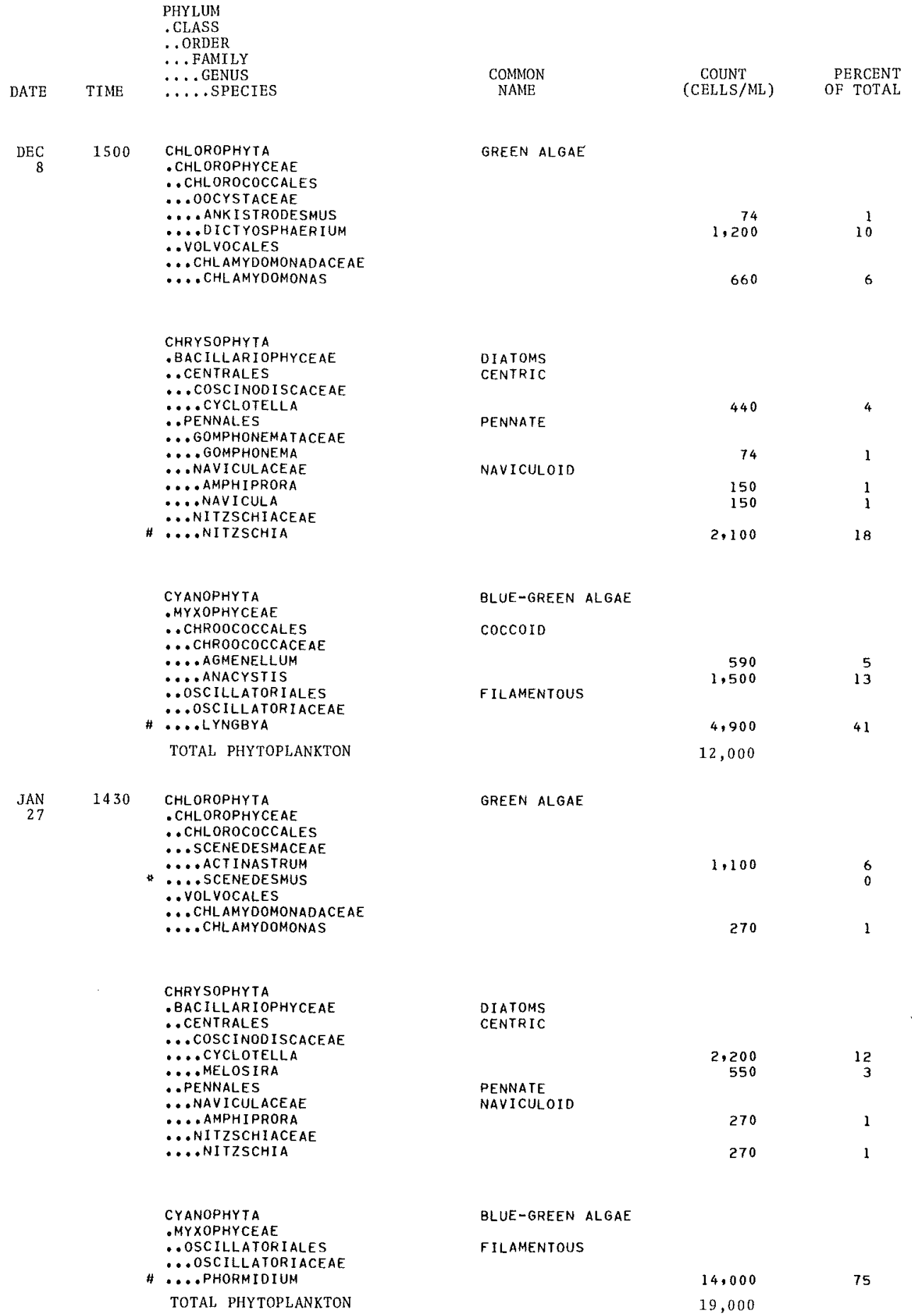

See footnotes at end of table. 
10254970 NEW RIVER AT INTERNATIONAL BOUNDARY, AT CALEXICO, CA--Continued

QUALITATIVE AND ASSOCIATED QUANTITATIVE ANALYSES OF BIOLOGICAL DATA, WATER YEAR OCTOBER 1975 TO SEPTEMBER 1976 PHYTOPLANKTON

\begin{tabular}{|c|c|c|c|c|c|}
\hline DATE & TIME & $\begin{array}{l}\text { PHYLUM } \\
\text {. CLASS } \\
\ldots \text { ORDER } \\
\ldots \text { FAMILY } \\
\ldots \text {. GENUS } \\
\ldots \ldots \text { SPECIES }\end{array}$ & $\begin{array}{l}\text { COMMON } \\
\text { NAME }\end{array}$ & $\begin{array}{c}\text { COUNT } \\
\text { (CELLS/ML) }\end{array}$ & $\begin{array}{l}\text { PERCENT } \\
\text { OF TOTAL }\end{array}$ \\
\hline $\begin{array}{r}\text { FEB } \\
17\end{array}$ & 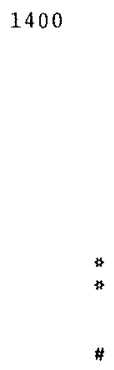 & 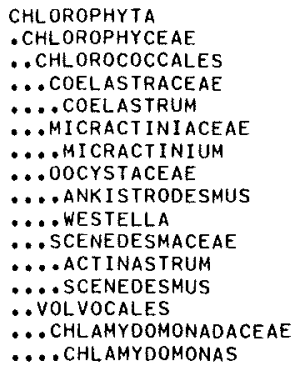 & GREEN ALGAE & $\begin{array}{l}660 \\
660 \\
250 \\
580\end{array}$ & $\begin{array}{l}5 \\
5 \\
2 \\
4 \\
0 \\
0\end{array}$ \\
\hline & \# & $\begin{array}{l}\text { CHRYSOPHYTA } \\
\text { BACILLARIOPHYCEAE } \\
\ldots \text { CENTRALES } \\
\ldots \text { COSCINODISCACEAE } \\
\ldots \text { CYCLOTELLA } \\
\ldots \text {. MELOSIRA } \\
\ldots \text { PENNALES } \\
\ldots \text { ACHNANTHACEAE } \\
\ldots \text { RHOI COSPHENIA } \\
\ldots \text { CYMBELLACEAE } \\
\ldots \text {. AMPHORA } \\
\ldots \text { CYMBELLA } \\
\ldots \text { DIATOMACEAE } \\
\ldots \text { DIATOMA } \\
\ldots \text { NAVICULACEAE } \\
\ldots \text { AMPHIPRORA } \\
\ldots \text { NAVICULA } \\
\ldots \text { NITZSCHIACEAE } \\
\ldots \text { NITZSCHIA }\end{array}$ & $\begin{array}{l}\text { DIATOMS } \\
\text { CENTRIC } \\
\text { PENNATE }\end{array}$ & $\begin{array}{r}82 \\
82 \\
\\
82 \\
160 \\
490\end{array}$ & $\begin{array}{r}28 \\
1 \\
0 \\
1 \\
1 \\
0 \\
1 \\
1 \\
4\end{array}$ \\
\hline & 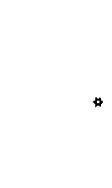 & $\begin{array}{l}\text { CYANOPHYTA } \\
\text {.MYXOPHYCEAE } \\
\ldots \text { CHROOCOCCALES } \\
\ldots \text { CHROOCOCCACEAE } \\
\ldots \text {. ANACYSTIS } \\
\ldots \text { OSCILLATORIALES } \\
\ldots \text { OSCILLATORIACEAE } \\
\ldots \text { O. LYNGBYA }\end{array}$ & $\begin{array}{l}\text { BLUE-GREEN ALGAE } \\
\text { COCCOID } \\
\text { FILAMENTOUS }\end{array}$ & 410 & $\begin{array}{l}0 \\
3\end{array}$ \\
\hline & $\#$ & .... OSCILLATORIA & & 3,700 & 28 \\
\hline & & $\begin{array}{l}\text { EUGLENOPHYTA } \\
\text { EUGLENOPHYCEAE } \\
\text {. EUGLENALES } \\
\text { @. EUGLENACEAE } \\
\text {. . EUGLENA }\end{array}$ & EUGLENOIDS & 82 & 1 \\
\hline & & TOTAL PHYTOPLANKTON & & 13,000 & \\
\hline
\end{tabular}

See footnotes at end of table. 
10254970 NEW RIVER AT INTERNATIONAL BOUNDARY, AT CALEXICO, CA--Continued

QUALITATIVE AND ASSOCIATED QUANTITATIVE ANALYSES OF BIOLOGICAL DATA, WATER YEAR OCTOBER 1975 TO SEPTEMBER 1976

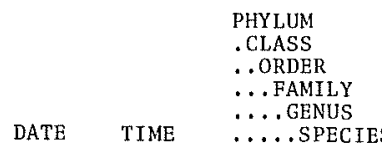

DATE TIME $\ldots$.

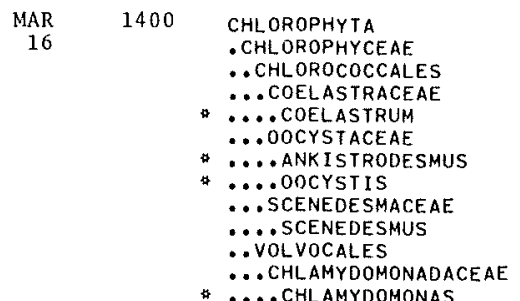

*... Chl amydomonas

CHRYSOPHYTA

- BAC ILLARI OPHYCEAE

. CENTRALES

... COSC InOd Is Caceae

.... CYCLOTELLA

-. PENNALES

... ACHNANTHACEAe

* ... COCCONEIS

- ... Rho I cosphenta

.. gomphonemataceae

* ... gohPhONEMa

.. Naviculaceae

* ... AMPHIPRORA

* .... Navicula

... NITZSChIACEAE

- ... Nitzschia

... SURIRELLACEAE

*... Surirella

CYANOPHYTA

- MYXOPHYCEAE

- chroococcales

$\because$ CHROOCOCCACEAE

.... Anacystis

. oscillatoriales

. . OsCillatoriaceae

\# ... oscillatoria

EUGLENOPHYTA

- EUGLENOPHYCEAE

. EUglenales

... Euglenaceae

- .... PHACUS

COMMON

NAME

COUNT

(CELLS/ML)

PERCENT

OF TOTAL

GREEN ALGAE

DIATOMS

CENTRIC

PENNATE

3,300

2

730

0

1

0

NAVICULOID

0

0

0

0

0

BLUE-GREEN ALGAE

COCCOID

F ILAMENTOUS

1,800

1

120,000

94

EUGLENOIDS

TOTAL PHYTOPLANKTON 
10254970 NEW RIVER AT INTERNATIONAL BOUNDARY, AT CALEXICO, CA--Continued

QUALITATIVE AND ASSOCIATED QUANTITATIVE ANALYSES OF BIOLOGICAL DATA, WATER YEAR OCTOBER 1975 TO SEPTEMBER 1976 PHYTOPLANKTON

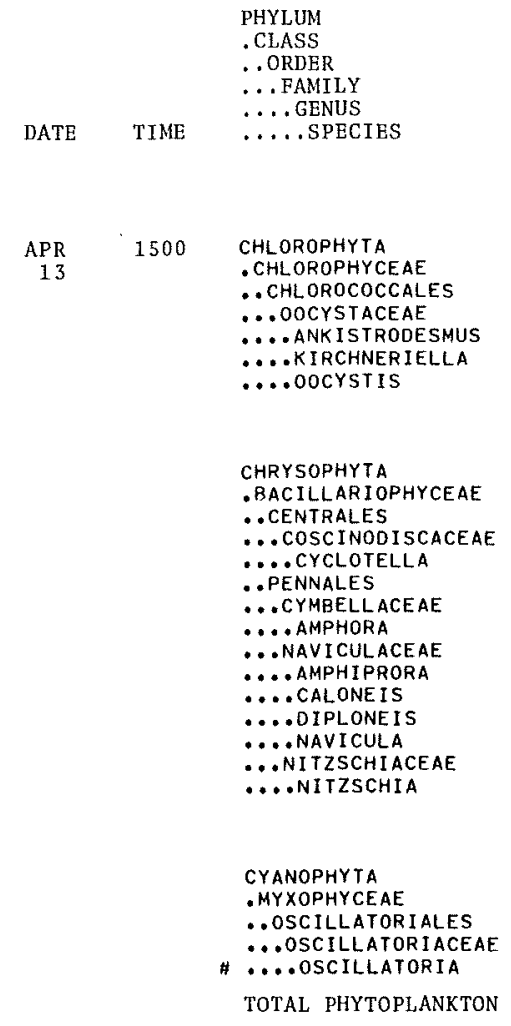

$\begin{array}{lcr}\text { COMMON } & \text { COUNT } & \text { PERCENT } \\ \text { NAME } & \text { (CELLS } / M L) & \text { OF TOTAL }\end{array}$

GREEN ALGAE

$\begin{array}{lrr} & 580 & 4 \\ & 150 & 1 \\ & 580 & 4 \\ & & \\ & & \\ \text { DIATOMS } & & \\ \text { CENTRIC } & & 5 \\ \text { PENNATE } & 730 & \\ & & 2 \\ \text { NAVICULOID } & 290 & 1 \\ & 150 & 1 \\ & 150 & 1 \\ & 150 & 11\end{array}$

BLUE-GREEN ALGAE

FILAMENTOUS

$10.000 \quad 65$

16,000

See footnotes at end of table. 
10254970 NEW RIVER AT INTERNATIONAL BOUNDARY, AT CALEXICO, CA--Continued

QUALITATIVE AND ASSOCIATED QUANTITATIVE ANALYSES OF BIOLOGICAL DATA, WATER YEAR OCTOBER 1975 TO SEPTEMBER 1976

PHYTOPLANKTON

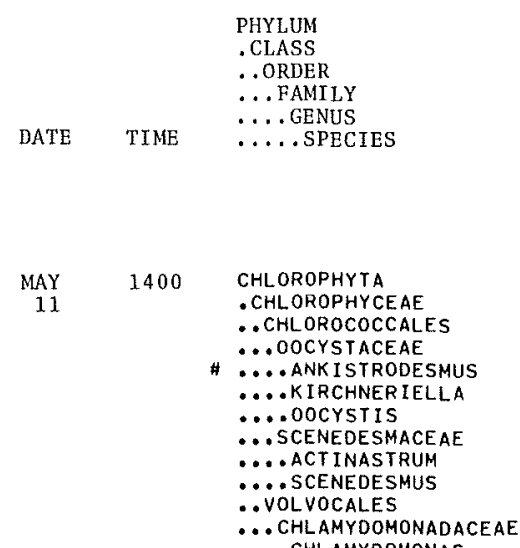

COMMON
NAME

GREEN ALGAE

.... CHLAMYDOMONAS

CHRYSOPHYTA

- BAC ILLAR I OPHYCEAE

..CENTRALES

... COSC InOd ISCACEAE

..... CYCLOTELLA

....melos IRa

? PENNALES

$\because$... CYMBELLACEAE

:... AMPHORA

...naviculateEae

... Navicula

... NITZSCHIACEAE

.... NITZSCHIA

CYANOPHYTA

-MYXOPHYCEAE

.. CHROOCOCCALES

... CHROOCOCCACEAE

.... AGMENELLUM

.... ANACYSTIIS

. OSCILLATORIALES

...0SCILlatoriaceae

* ...oosc illatoria

EUGLENOPHYTA

- EUGLENOPHYCEAE

...EUGLENALES

... Euglenaceae

.... TRACHEL OMONAS

TOTAL PHYTOPLANKTON

DIATOMS

CENTRIC

PENNATE

NAVICULOID

COCCOID

FILAMENTOUS

EUGLENOIOS
COUNT

(CELLS/ML)

PERCENT
OF TOTAL

$\begin{array}{rr}4,300 & 25 \\ 710 & 4 \\ 610 & 4 \\ 300 & 2 \\ 1,300 & 8 \\ & \\ 1,600 & \end{array}$

300

200

2

100

1

100

1

710

4

BLUE-GREEN ALGAE

1.600

10

4,100

24

410

2

See footnotes at end of table.

17,000 
10254970 NEW RIVER AT INTERNATIONAL BOUNDARY, AT CALEXICO, CA--Continued QUALITATIVE AND ASSOCIATED QUANTITATIVE ANALYSES OF BIOLOGICAL DATA, WATER YEAR OCTOBER 1975 TO SEPTEMBER 1976 PHYTOPLANKTON

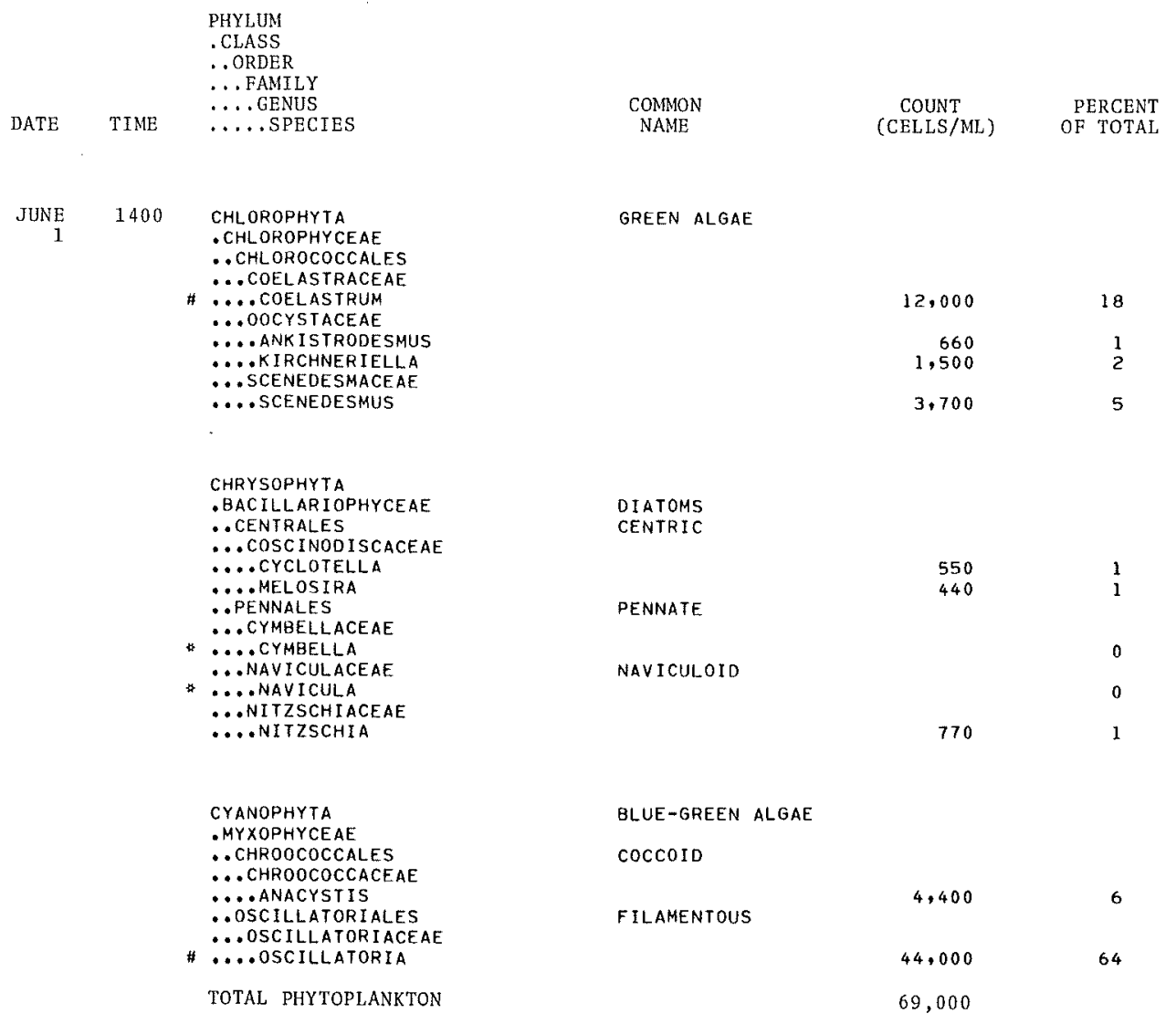

See footnotes at end of table. 
QUALITATIVE AND ASSOCIATED QUANTITATIVE ANALYSES OF BIOLOGICAL DATA, WATER YEAR OCTOBER 1975 TO SEPTEMBER 1976 PHYTOPLANKTON

\begin{tabular}{|c|c|c|c|}
\hline DATE & TIME & & $\begin{array}{l}\text { PHYLUM } \\
. \text { CLASS } \\
\ldots \text { ORDER } \\
\ldots \text {. FAMILY } \\
\ldots \text {. GENUS } \\
\ldots \text {. . SPECIES }\end{array}$ \\
\hline $\begin{array}{r}\text { JUNE } \\
29\end{array}$ & 1400 & $\#$ & 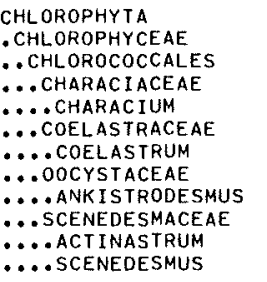 \\
\hline & & * & $\begin{array}{l}\text { CHRYSOPHYTA } \\
\text { BACILLARIOPHYCEAE } \\
\ldots \text { CENTRALES } \\
\ldots \text { COSCINODISCACEAE } \\
\ldots \text { CYCLOTELLA } \\
\ldots \text { PENNALES } \\
\ldots \text { CYMBELLACEAE } \\
\ldots \text { AMPHORA } \\
\ldots \text { AYYMBELLA } \\
\ldots \text { NITZSCHIACEAE } \\
\ldots \text { NITZSCHIA } \\
\ldots \text { SURIRELLACEAE } \\
\ldots \text {. SURIRELLA }\end{array}$ \\
\hline & & $\#$ & $\begin{array}{l}\text { CYANOPHYTA } \\
\text {. MYXOPHYCEAE } \\
\text {. CHROOCOCCALES } \\
\ldots \text { CHROOCOCCACEAE } \\
\text {. } \text {. AGMENELLUM } \\
\text { OSCILLATORIALES } \\
\text {. OOSCILLATORIACEAE } \\
\text {. OSCILLATORIA }\end{array}$ \\
\hline & & & TOTAL PHYTOPLANKTON \\
\hline
\end{tabular}

\section{COMMON \\ NAME}

GREEN ALGAE

DI ATOMS

CENTRIC

PENNATE

550

$\begin{array}{rr}23,000 & 22 \\ 1,100 & 1 \\ 2,200 & 2 \\ 3,300 & 3\end{array}$

BLUE-GREEN ALGAE

COCCOID

FILAMENTOUS

$\begin{array}{cc}\text { COUNT } & \text { PERCENT } \\ \text { (CELLS/ML) } & \text { OF TOTAL }\end{array}$

$\begin{array}{ll}2,700 & 0 \\ 0 \\ \\ 3 \\ 0\end{array}$

See footnotes at end of table. 
10254970 NEW RIVER AT INTERNATIONAL BOUNDARY, AT CALEXICO, CA--Continued

QUALITATIVE AND ASSOCIATED QUANTITATIVE ANALYSES OF BIOLOGICAL DATA, WATER YEAR OCTOBER 1975 TO SEPTEMBER 1976 PHYTOPLANKTON

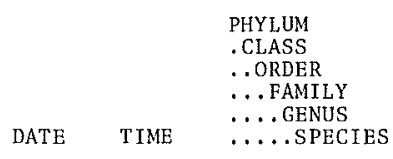

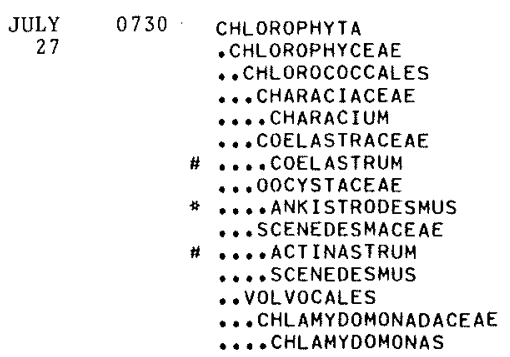

CHRYSOPHYTA

- BACILLARIOPHYCEAE

. CENTRALES

.. coscinod Iscaceae

*... crClotella

..pennales

... Crmbellaceae

* ... cymbella

...NITZSChIACEAE

.... NITZSCHIA

CYANOPHYTA

- MYXOPHYCEAE

. Chroococcales

... CHROOCOCCACEAE

.... Agmenellum

. OSCILLATORI ALES

. OSCILlatori Iaceae

* ... . LYNGBYa

... oscillatoria

TOTAL PHYTOPLANKTON
COMMON

NAME
PERCENT

OF TOTAL

GREEN ALGAE

$\begin{array}{rr}170 & 1 \\ 5,400 & 28 \\ & 0 \\ 5,500 & 29 \\ 120 & 1 \\ 690 & 4\end{array}$

DIATOMS

CENTRIC

PENNATE

0

0

120

1

BLUE-GREEN ALGAE

$\operatorname{coccoID}$

FILAMENTOUS

1,200

6

3,500

2,500

18

19,000

See footnotes at end of table. 
PHYTOPLANKTON

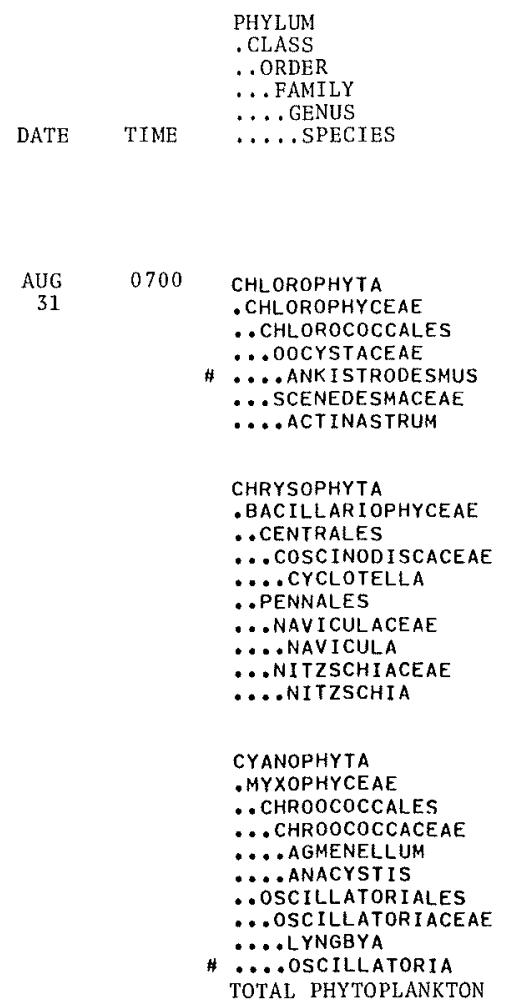

SEP $\quad 1330$

21
CHLOROPHYTA

- CHLOROPHYCEAE

. CHLorococcales

... COELASTRACEAE

... COELASTRUM

. oocYsTaceaE

* ... ANK I STROOESMUS

... SCENEDESMACEA

.... SCENEDESMUS

CHRYSOPHYTA

- BACILLARI OPHYCEAE

.CENTRALES

. . Coscinodiscaceae

.... cyclotella

. PENNALES

.. Naviculaceae

.... Navicula

... NITZSCHIACEAE

.... NITZSCHIA

CYANOPHYTA

- MYXOPHYCEAE

- ChrOdCoccales

... CHROOCOCCACEAE

*... AGMENELLUM

.... ANACYSTIS

- OSCILLATORI ALES

... OSC ILLATOR I ACEAE

.... OsCILLATORIa

TOTAL PHYTOPLANKTON

$\begin{array}{ccc}\text { COMMON } & \text { COUNT } & \text { PERCENT } \\ \text { NAME } & \text { (CELLS/ML) } & \text { OF TOTAL }\end{array}$

GREEN ALGAE

$\begin{array}{rr}11,000 & 20 \\ 1,000 & 2\end{array}$

DIATOMS

CENTRIC

PENNATE

2,500

5

NAVICULOID

$\begin{array}{ll}130 & 0 \\ 130 & 0\end{array}$

BLUE-GREEN ALGAE

$\operatorname{COCCOID}$

FILAMENTOUS

$\begin{array}{rl}3,000 & 5 \\ 510 & 1\end{array}$

1,000

36.000

55,000

$6 \frac{2}{6}$

GREEN ALGAE

$\begin{array}{rr}1,400 & 2 \\ 17,000 & 23 \\ 340 & 0\end{array}$

DIATOMS

CENTRIC

PENNATE

NAVICULOID

1700

9.500

13

BLUE-GREEN ALGAE

CoccoID

FILAMENTOUS

33,000

33,000
2,400

44
3

11.000

14

NOTE: \# DOMINANT ORGANISM GREATER OR EQUAL TO $15 \%$

74,000

\footnotetext{
* - LESS THEN 1\%; MAY NOT HAVE BEEN aCTUALLY COUNTED
} 
10254970 NEW RIVER AT INTERNATIONAL BOUNDARY, AT CALEXICO, CA--Continued

CHEMICAL ANALYSES, WATER YEAR OCTOBER 1975 TO SEPTEMBER 1976

\begin{tabular}{|c|c|c|c|c|c|c|c|c|c|c|c|}
\hline DATE & TIME & $\begin{array}{c}\text { TOTAL } \\
\text { ARSENIC } \\
\text { (AS) } \\
\text { (UG/L) }\end{array}$ & $\begin{array}{c}\text { SUS- } \\
\text { PENDED } \\
\text { ARSENIC } \\
\text { (AS) } \\
\text { (UG/L) }\end{array}$ & $\begin{array}{l}\text { DIS- } \\
\text { SOLVED } \\
\text { ARSENIC } \\
\text { (AS) } \\
\text { (UG/L) }\end{array}$ & $\begin{array}{l}\text { TOTAL } \\
\text { CAD- } \\
\text { MIUM } \\
\text { (CD) } \\
\text { (UG/L) }\end{array}$ & $\begin{array}{c}\text { SUS- } \\
\text { PENDED } \\
\text { CAD- } \\
\text { MIUM } \\
\text { (CD) } \\
(U G / L)\end{array}$ & $\begin{array}{l}\text { DIS- } \\
\text { SOLVED } \\
\text { CAD- } \\
\text { MIUH } \\
\text { (CD) } \\
(U G / L)\end{array}$ & $\begin{array}{l}\text { TOTAL } \\
\text { CHRO } \\
\text { MIUN } \\
\text { (CR) } \\
\text { (UG/L) }\end{array}$ & $\begin{array}{l}\text { SUS- } \\
\text { PENDED } \\
\text { CHRO- } \\
\text { MIUM } \\
\text { (CR) } \\
\text { (UG/L) }\end{array}$ & $\begin{array}{l}\text { DIS- } \\
\text { SOLVED } \\
\text { CHRO- } \\
\text { MIUM } \\
\text { (CR) } \\
\text { (UG/L) }\end{array}$ & $\begin{array}{l}\text { TOTAL. } \\
\text { COBALT } \\
\text { (CO) } \\
\text { (UG/L) }\end{array}$ \\
\hline \multicolumn{12}{|l|}{ Nov } \\
\hline$\underset{\text { JAN }}{18} \ldots$ & 1500 & 9 & 2 & 7 & $<10$ & $<10$ & 0 & 20 & 10 & 10 & 330 \\
\hline APR & 1430 & 14 & 3 & 11 & 30 & 0 & 95 & 60 & 60 & 0 & 80 \\
\hline${ }_{\text {JUN }}^{13} \ldots$ & 1500 & 22 & 5 & 17 & 10 & 2 & 8 & 10 & 0 & 20 & $<50$ \\
\hline $29 \ldots$ & 1400 & $-\cdots$ & -- & 23 & 2 & 0 & 2 & 30 & 30 & 0 & 0 \\
\hline
\end{tabular}

\begin{tabular}{|c|c|c|c|c|c|c|c|c|c|c|}
\hline DATE & $\begin{array}{l}\text { SUS- } \\
\text { PENDED } \\
\text { COBALT } \\
\text { (CO) } \\
\text { (UG/L) }\end{array}$ & $\begin{array}{l}\text { DIS- } \\
\text { SOLVED } \\
\text { COBALT } \\
\text { (CO) } \\
\text { (UG/L) }\end{array}$ & $\begin{array}{l}\text { TOTAL } \\
\text { COPPER } \\
\text { (CU) } \\
\text { (UG/L) }\end{array}$ & $\begin{array}{l}\text { SUS- } \\
\text { PENDED } \\
\text { COPPER } \\
\text { (CU) } \\
\text { (UG/L) }\end{array}$ & $\begin{array}{l}\text { DIS- } \\
\text { SOLVED } \\
\text { COPPER } \\
\text { (CU) } \\
\text { (UG/L) }\end{array}$ & $\begin{array}{l}\text { TOTAL } \\
\text { LEAD } \\
\text { (PB) } \\
\text { (UG/L) }\end{array}$ & $\begin{array}{l}\text { SUS- } \\
\text { PENDED } \\
\text { LEAD } \\
\text { (PB) } \\
\text { (UG/L) }\end{array}$ & $\begin{array}{l}\text { DIS- } \\
\text { SOLVED } \\
\text { LEAD } \\
\text { (PB) } \\
\text { (UG/L) }\end{array}$ & $\begin{array}{l}\text { TOTAL } \\
\text { MAN- } \\
\text { GANESE } \\
\text { (MN) } \\
\text { (UG/L) }\end{array}$ & $\begin{array}{l}\text { SUS- } \\
\text { PENDED } \\
\text { MAN- } \\
\text { GANESE } \\
\text { (HN) } \\
\text { (UG/L) }\end{array}$ \\
\hline \multicolumn{11}{|l|}{ Nov } \\
\hline$\underset{\text { JAN }}{18 \cdots}$ & 330 & 0 & 40 & 37 & 3 & $<100$ & $<97$ & 3 & 170 & 10 \\
\hline$\underset{A P R}{27} \cdots$ & 79 & 1 & 20 & 11 & 9 & 140 & 140 & 3 & 200 & 40 \\
\hline $13 \cdots$ & $<48$ & 2 & 60 & 44 & 16 & 200 & 140 & 58 & 280 & 130 \\
\hline $29 \ldots$ & 0 & 0 & 78 & 72 & 6 & 51 & 49 & 2 & 300 & 110 \\
\hline
\end{tabular}

\begin{tabular}{|c|c|c|c|c|c|c|c|c|c|c|}
\hline DATE & $\begin{array}{l}\text { DIS- } \\
\text { SOLVED } \\
\text { MAN- } \\
\text { GANESE } \\
\text { (MN) } \\
\text { (UG/L) }\end{array}$ & $\begin{array}{c}\text { TOTAL } \\
\text { HERCURY } \\
\text { (HG) } \\
(U G / L)\end{array}$ & $\begin{array}{c}\text { SUS- } \\
\text { PENDED } \\
\text { MERCURY } \\
\text { (HG) } \\
(U G / L)\end{array}$ & $\begin{array}{l}\text { DIS- } \\
\text { SOLVED } \\
\text { MERCURY } \\
\text { (HG) } \\
\text { (UG/L) }\end{array}$ & $\begin{array}{l}\text { TOTAL } \\
\text { SELE- } \\
\text { NIUH } \\
\text { (SE) } \\
\text { (UG/L) }\end{array}$ & $\begin{array}{l}\text { SUS- } \\
\text { PENDED } \\
\text { SELE- } \\
\text { NIUM } \\
\text { (SE) } \\
(U G / L)\end{array}$ & $\begin{array}{l}\text { DIS- } \\
\text { SOLVED } \\
\text { SELE- } \\
\text { NIUM } \\
\text { (SE) } \\
(U G / L)\end{array}$ & $\begin{array}{c}\text { TOTAL } \\
\text { ZINC } \\
\text { (ZN) } \\
\text { (UG/L) }\end{array}$ & $\begin{array}{l}\text { SUS- } \\
\text { PENDED } \\
\text { ZINC } \\
\text { (ZN) } \\
\text { (UG/L) }\end{array}$ & $\begin{array}{l}\text { DIS- } \\
\text { SOLVED } \\
\text { ZINC } \\
\text { (ZN) } \\
\text { (UG/L) }\end{array}$ \\
\hline NOV & & & & & & & & & & 30 \\
\hline${ }_{\text {JAN }}^{18 \ldots}$ & 160 & .1 & .1 & .0 & 0 & 0 & 1 & 100 & 70 & 30 \\
\hline$\stackrel{27}{27} \cdots$ & 160 & .0 & .0 & .0 & 3 & 1 & 2 & 250 & 60 & 190 \\
\hline $13 \ldots$ & 150 & .0 & .0 & .1 & 0 & 0 & 3 & 250 & 0 & 340 \\
\hline $\begin{array}{l}\text { JUN } \\
29 \ldots\end{array}$ & 190 & .4 & .0 & .4 & 1 & 1 & 0 & 200 & 50 & 150 \\
\hline
\end{tabular}


10254970 NEW RIVER AT INTERNATIONAL BOUNDARY, AT CALEXICO, CA--Continued

SPECIFIC CONDUCTANCE (MICROMHOS/CM AT 25 DEG. C), WATER YEAR OCTOBER 1975 TO SEPTEMBER 1976

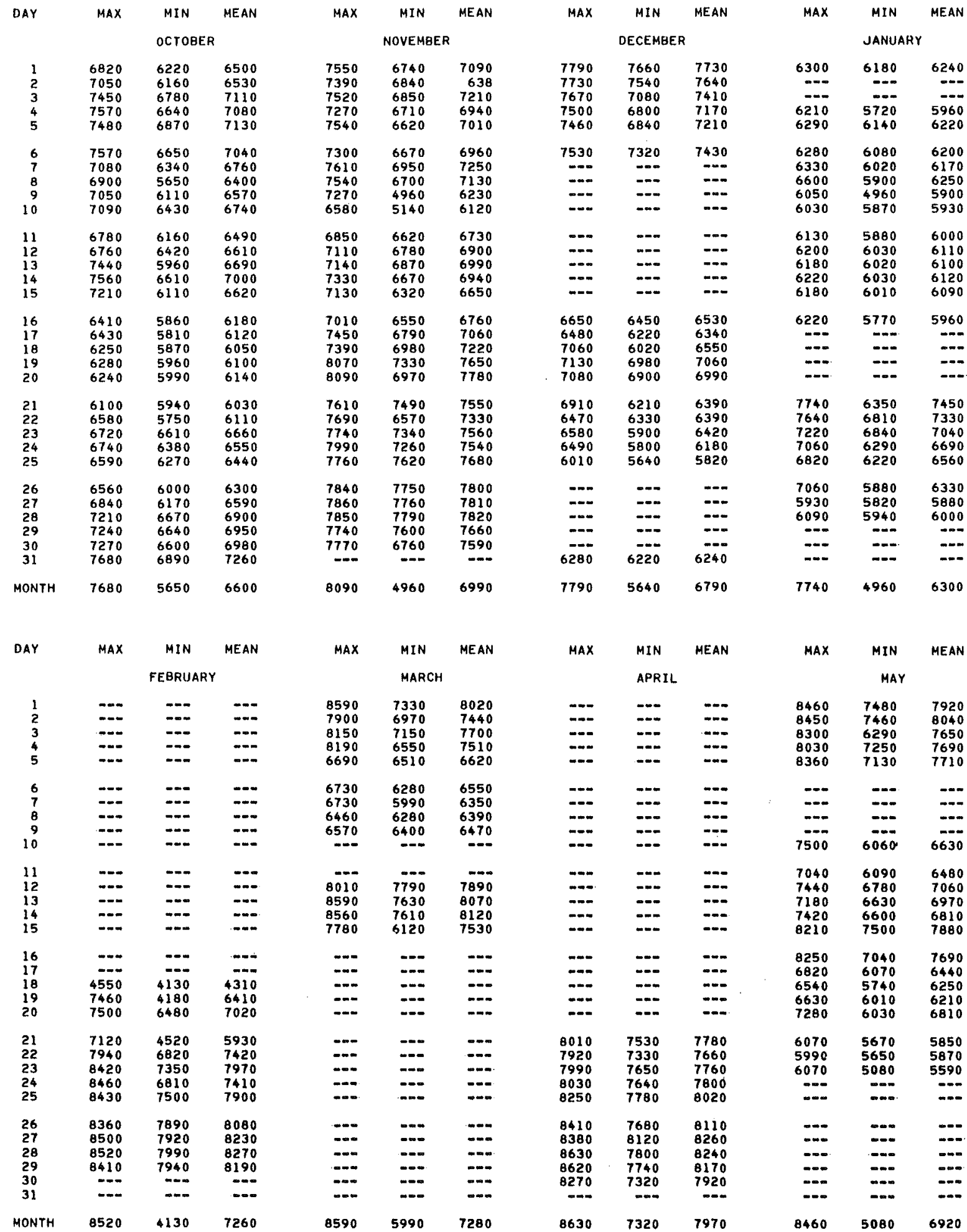


SALTON SEA BASIN

10254970 NEW RIVER AT INTERNATIONAL BOUNDARY, AT CALEXICO, CA-CONtinued

SPECIFIC CONDUCTANCE (MICROMHOS/CM AT 25 DEG, C), HATER YEAR OCTOBER 1975 TO SEPTEMEER 1976

\begin{tabular}{|c|c|c|c|c|c|c|c|c|c|c|c|c|}
\hline DAY & $\operatorname{MAX}$ & HIN & MEAN & MAX & MIN & MEAN & MAX & MIN & MEAN & MAX & MIN & MEAN \\
\hline \multicolumn{4}{|c|}{ JUNE } & \multicolumn{3}{|c|}{ JULY } & \multicolumn{3}{|c|}{ AUGUST } & \multicolumn{3}{|c|}{ SEPTEMBER } \\
\hline $\begin{array}{l}1 \\
2 \\
3 \\
4 \\
5\end{array}$ & $\begin{array}{l}7410 \\
7120 \\
7960 \\
8010 \\
8450\end{array}$ & $\begin{array}{l}5130 \\
6560 \\
6530 \\
7260 \\
7610\end{array}$ & $\begin{array}{l}6220 \\
6800 \\
7220 \\
7660 \\
7930\end{array}$ & $\begin{array}{r}9800 \\
9650 \\
8690\end{array}$ & $\begin{array}{l}9230 \\
9350 \\
8260 \\
8350 \\
8320\end{array}$ & $\begin{array}{r}-1- \\
9350 \\
8810 \\
8510\end{array}$ & $\begin{array}{l}9290 \\
8400 \\
7780 \\
7470 \\
9580\end{array}$ & $\begin{array}{l}6240 \\
6460 \\
7110 \\
7070 \\
6770\end{array}$ & $\begin{array}{l}7770 \\
7600 \\
7410 \\
7210 \\
7570\end{array}$ & $\begin{array}{l}=-\infty \\
m=- \\
=-\infty \\
=-\infty\end{array}$ & $\begin{array}{l}=-\infty \\
=-\infty \\
=-\infty\end{array}$ & 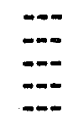 \\
\hline $\begin{array}{r}6 \\
7 \\
8 \\
9 \\
10\end{array}$ & $\begin{array}{l}8580 \\
8950 \\
8660 \\
8450 \\
9230\end{array}$ & $\begin{array}{l}7790 \\
8400 \\
7350 \\
7780 \\
8220\end{array}$ & $\begin{array}{l}8230 \\
8690 \\
8410 \\
8160 \\
8600\end{array}$ & $\begin{array}{l}8690 \\
9600 \\
8620 \\
8420 \\
8560\end{array}$ & $\begin{array}{l}8150 \\
7800 \\
7940 \\
7890 \\
7780\end{array}$ & $\begin{array}{l}8370 \\
8170 \\
8380 \\
8200 \\
8160\end{array}$ & $\begin{array}{l}9110 \\
9190 \\
9830 \\
8890 \\
7570\end{array}$ & $\begin{array}{l}7360 \\
7400 \\
6730 \\
7370 \\
6360\end{array}$ & $\begin{array}{l}8290 \\
8260 \\
8350 \\
8380 \\
7000\end{array}$ & 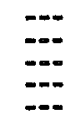 & $=$ & $\begin{array}{l}=- \\
=- \\
=- \\
=-\end{array}$ \\
\hline $\begin{array}{l}11 \\
12 \\
13 \\
14 \\
15\end{array}$ & $\begin{array}{l}9150 \\
9070 \\
9290 \\
9430 \\
8600\end{array}$ & $\begin{array}{l}8390 \\
8150 \\
8090 \\
8140 \\
7650\end{array}$ & $\begin{array}{l}8730 \\
8580 \\
8700 \\
8890 \\
8170\end{array}$ & $\begin{array}{r}8610 \\
8170 \\
7770 \\
6960 \\
-\end{array}$ & $\begin{array}{r}7840 \\
7680 \\
7080 \\
5850 \\
--0\end{array}$ & $\begin{array}{r}8100 \\
7880 \\
7400 \\
6350 \\
-\end{array}$ & $\begin{array}{l}9250 \\
8540 \\
8650 \\
6640 \\
5490\end{array}$ & $\begin{array}{l}6770 \\
6040 \\
6020 \\
5340 \\
5170\end{array}$ & $\begin{array}{l}8210 \\
7820 \\
6940 \\
5850 \\
5320\end{array}$ & $\begin{array}{l}=- \\
=- \\
=- \\
=-\end{array}$ & $=$ & $=$ \\
\hline $\begin{array}{l}16 \\
17 \\
18 \\
19 \\
20\end{array}$ & $\begin{array}{r}8800 \\
9540 \\
9700 \\
-0 \\
-\end{array}$ & $\begin{array}{l}8410 \\
8300 \\
8740 \\
8910 \\
8820\end{array}$ & $\begin{array}{r}8590 \\
8680 \\
9350 \\
\\
\ldots\end{array}$ & 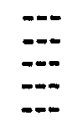 & $=$ & $\begin{array}{l}-\infty \\
m-\infty \\
-\infty \\
-\infty\end{array}$ & $\begin{array}{l}9280 \\
8580 \\
8750 \\
9090 \\
9030\end{array}$ & $\begin{array}{l}5280 \\
7880 \\
7310 \\
7540 \\
7630\end{array}$ & $\begin{array}{l}7540 \\
8220 \\
7830 \\
8350 \\
8290\end{array}$ & $\begin{array}{l}-\infty \\
=-\infty \\
-\infty \\
-\infty \\
-\infty\end{array}$ & $\begin{array}{l}-\infty \\
-\infty \\
=-\infty \\
=-\infty \\
=-\infty\end{array}$ & $=$ \\
\hline $\begin{array}{l}21 \\
22 \\
23 \\
24 \\
25\end{array}$ & $\begin{array}{l}=- \\
=- \\
=-\end{array}$ & $\begin{array}{l}9320 \\
9990 \\
9990 \\
9990 \\
9680\end{array}$ & $=$ & $=$ & $\begin{array}{l}=-\infty \\
=-\infty \\
=-\infty \\
=-\infty\end{array}$ & $=$ & $\begin{array}{l}8250 \\
8160 \\
7370 \\
7500 \\
7590\end{array}$ & $\begin{array}{l}7390 \\
7030 \\
7110 \\
6980 \\
7310\end{array}$ & $\begin{array}{l}7900 \\
7450 \\
7260 \\
7190 \\
7440\end{array}$ & $\begin{array}{l}8260 \\
7530 \\
7130 \\
6860\end{array}$ & $\begin{array}{l}7130 \\
7060 \\
6670 \\
6410\end{array}$ & $\begin{array}{l}7710 \\
7290 \\
6890 \\
6600\end{array}$ \\
\hline $\begin{array}{l}26 \\
27 \\
28 \\
29 \\
30 \\
31\end{array}$ & $\begin{array}{l}m-= \\
m=0 \\
=-0\end{array}$ & $\begin{array}{r}9840 \\
8860 \\
8780 \\
9510 \\
9100 \\
-\end{array}$ & $\begin{array}{l}=- \\
=- \\
=-\end{array}$ & $\begin{array}{l}8620 \\
7590 \\
8740 \\
9060 \\
8690 \\
9020\end{array}$ & $\begin{array}{l}5620 \\
6240 \\
6470 \\
7090 \\
7700 \\
5940\end{array}$ & $\begin{array}{l}7590 \\
6810 \\
7760 \\
8510 \\
8120 \\
7900\end{array}$ & $\begin{array}{r}7340 \\
7300 \\
7880 \\
=- \\
- \\
-\end{array}$ & $\begin{array}{r}6890 \\
6140 \\
6770 \\
-\end{array}$ & $\begin{array}{r}7110 \\
6700 \\
7270 \\
\end{array}$ & $\begin{array}{c}7090 \\
7050 \\
6160 \\
5790 \\
6030 \\
-\end{array}$ & $\begin{array}{c}6740 \\
6080 \\
5810 \\
5400 \\
5430 \\
-\end{array}$ & $\begin{array}{l}6920 \\
66110 \\
6020 \\
5550 \\
5680\end{array}$ \\
\hline MONTH & 9700 & 5130 & 8200 & 9800 & 5620 & 8020 & 9830 & 5170 & 7520 & 8260 & 5400 & 6590 \\
\hline YEAR & 9830 & 4130 & 7150 & & & & & & & & & \\
\hline
\end{tabular}

TEMPERATURE (DEG, C) OF WATER, WATER YEAR OCTOBER 1975 TO SEPTEMBER 1976

\begin{tabular}{|c|c|c|c|c|c|c|c|c|c|c|c|c|}
\hline \multirow[t]{2}{*}{ DAY } & MAX & MIN & MEAN & $\operatorname{MAX}$ & MIN & MEAN & MAX & MIN & MEAN & MAX & MIN & MEAN \\
\hline & \multicolumn{3}{|c|}{ OCTOBER } & \multicolumn{3}{|c|}{ NOVEMBER } & \multicolumn{3}{|c|}{ DECEMBER } & & JANUA & \\
\hline $\begin{array}{l}1 \\
2 \\
3 \\
4 \\
5\end{array}$ & $\begin{array}{l}29.5 \\
29.5 \\
30.0 \\
30.0 \\
29.5\end{array}$ & $\begin{array}{l}26.0 \\
26.5 \\
26.5 \\
26.5 \\
25.5\end{array}$ & $\begin{array}{l}27.5 \\
28.0 \\
28.0 \\
28.0 \\
27.5\end{array}$ & $\begin{array}{l}22.0 \\
22.0 \\
23.0 \\
23.0 \\
22.5\end{array}$ & $\begin{array}{l}18.0 \\
18.0 \\
18.5 \\
19.0 \\
19.0\end{array}$ & $\begin{array}{l}20.0 \\
20.0 \\
20.5 \\
20.5 \\
20.5\end{array}$ & $\begin{array}{l}16.0 \\
16.5 \\
16.5 \\
16.5 \\
17.5\end{array}$ & $\begin{array}{l}13.0 \\
13.0 \\
13.0 \\
13.5 \\
14.5\end{array}$ & $\begin{array}{l}14.5 \\
14.5 \\
15.0 \\
15.0 \\
16.0\end{array}$ & & & \\
\hline $\begin{array}{r}6 \\
7 \\
8 \\
9 \\
10\end{array}$ & $\begin{array}{l}28.5 \\
26.0 \\
27.5 \\
27.5 \\
28.5\end{array}$ & $\begin{array}{l}25.5 \\
23.5 \\
22.5 \\
24.0 \\
24.5\end{array}$ & $\begin{array}{l}26.5 \\
25.0 \\
24.5 \\
25.5 \\
26.5\end{array}$ & $\begin{array}{l}24.0 \\
23.5 \\
23.5 \\
23.0 \\
21.5\end{array}$ & $\begin{array}{l}19.5 \\
19.5 \\
19.0 \\
19.5 \\
18.5\end{array}$ & $\begin{array}{l}22.0 \\
22.0 \\
21.5 \\
21.5 \\
20.0\end{array}$ & $\begin{array}{l}17.5 \\
17.5 \\
17.5 \\
18.0 \\
18.0\end{array}$ & $\begin{array}{l}14.0 \\
14.5 \\
14.0 \\
14.5 \\
14.5\end{array}$ & $\begin{array}{l}16.0 \\
16.0 \\
16.0 \\
16.0 \\
16.0\end{array}$ & & & \\
\hline $\begin{array}{l}11 \\
12 \\
13 \\
14 \\
15\end{array}$ & $\begin{array}{l}28.0 \\
25.0 \\
25.5 \\
25.0 \\
25.5\end{array}$ & $\begin{array}{l}23.5 \\
21.5 \\
21.5 \\
21.5 \\
21.0\end{array}$ & $\begin{array}{l}26.0 \\
23.0 \\
23.0 \\
23.0 \\
23.0\end{array}$ & $\begin{array}{l}21.5 \\
21.0 \\
20.0 \\
19.5 \\
19.5\end{array}$ & $\begin{array}{l}19.0 \\
17.5 \\
17.0 \\
16.5 \\
16.5\end{array}$ & $\begin{array}{l}20.0 \\
19.0 \\
18.5 \\
18.0 \\
18.0\end{array}$ & $\begin{array}{r}18.0 \\
=- \\
=-\end{array}$ & $\begin{array}{r}15.0 \\
0 \\
-0\end{array}$ & $\begin{array}{r}16.5 \\
- \\
=- \\
=-\end{array}$ & & & \\
\hline $\begin{array}{l}16 \\
17 \\
18 \\
19 \\
20\end{array}$ & $\begin{array}{l}25.5 \\
25.5 \\
25.5 \\
26.5 \\
24.5\end{array}$ & $\begin{array}{l}20.5 \\
20.5 \\
21.5 \\
22.0 \\
21.5\end{array}$ & $\begin{array}{l}23.0 \\
23.5 \\
23.5 \\
23.5 \\
23.0\end{array}$ & $\begin{array}{l}19.5 \\
20.5 \\
18.0 \\
17.5 \\
18.0\end{array}$ & $\begin{array}{l}16.5 \\
17.0 \\
16.0 \\
14.5 \\
14.0\end{array}$ & $\begin{array}{l}18.0 \\
18.0 \\
17.0 \\
16.0 \\
16.0\end{array}$ & $=$ & $\begin{array}{l}-\infty \\
=-- \\
=-- \\
=-\infty \\
-\infty=\end{array}$ & $\begin{array}{l}m \\
=-\infty \\
=-\infty \\
=-\infty \\
=-\infty\end{array}$ & . & & \\
\hline $\begin{array}{l}21 \\
22 \\
23 \\
24 \\
25\end{array}$ & $\begin{array}{l}24.5 \\
25.0 \\
23.0 \\
21.5 \\
21.5\end{array}$ & $\begin{array}{l}20.5 \\
22.0 \\
20.5 \\
18.5 \\
18.0\end{array}$ & $\begin{array}{l}23.0 \\
23.5 \\
21.5 \\
20.5 \\
20.0\end{array}$ & $\begin{array}{l}18.0 \\
18.0 \\
17.5 \\
18.0 \\
18.0\end{array}$ & $\begin{array}{l}14.5 \\
14.0 \\
14.0 \\
14.0 \\
14.5\end{array}$ & $\begin{array}{l}16.5 \\
16.0 \\
16.0 \\
16.0 \\
16.5\end{array}$ & $\begin{array}{l}-\infty \\
-\infty \\
-\infty \\
-\infty\end{array}$ & $\begin{array}{l}-\infty \\
=-\infty \\
-\infty \\
=-\infty \\
-\infty\end{array}$ & $\begin{array}{l}=- \\
=-\infty \\
=-\infty\end{array}$ & & & \\
\hline $\begin{array}{l}26 \\
27 \\
28 \\
29 \\
30 \\
31\end{array}$ & $\begin{array}{l}21.5 \\
22.5 \\
22.5 \\
22.5 \\
22.5 \\
21.5\end{array}$ & $\begin{array}{l}18.0 \\
18.5 \\
19.0 \\
19.0 \\
19.0 \\
18.5\end{array}$ & $\begin{array}{l}19.5 \\
20.5 \\
21.0 \\
21.0 \\
21.0 \\
20.0\end{array}$ & $\begin{array}{r}17.5 \\
17.5 \\
16.5 \\
16.0 \\
16.5 \\
-\infty .\end{array}$ & $\begin{array}{l}14.5 \\
14.5 \\
14.5 \\
13.0 \\
13.0 \\
-0.0\end{array}$ & $\begin{array}{r}16.5 \\
16.0 \\
15.5 \\
14.5 \\
15.0 \\
-\end{array}$ & $\begin{array}{l}=-\infty \\
=-\infty \\
=-\infty \\
=-\infty\end{array}$ & $\begin{array}{l}=-\infty \\
=-\infty \\
=-\infty \\
=-\infty \\
=-\infty\end{array}$ & $\begin{array}{l}-0 \\
=0 \\
-\infty \\
-\infty\end{array}$ & & & \\
\hline MONTH & 30.0 & 18.0 & 23.5 & 24.0 & 13.0 & 18.0 & 18.0 & 13.0 & 15.5 & & & \\
\hline
\end{tabular}




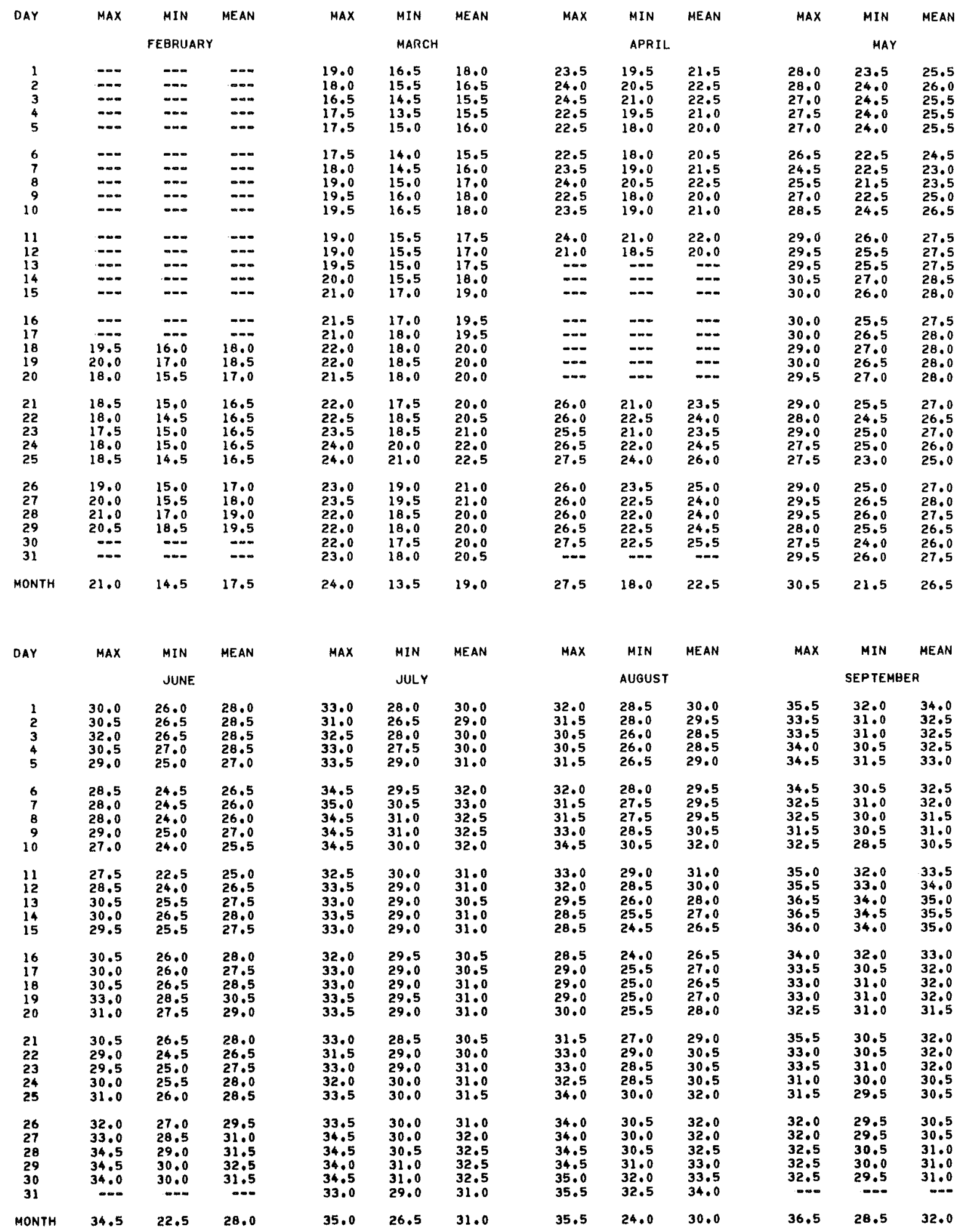


10254970 NEW RIVER AT INTERNATIONAL BOUNDARY, AT CALEXICO, CA--Continued

PARTICLE-SIZE DISTRIBUTION OF SUSPENDED SEDIMENT, WATER YEAR OCTOBER 1975 TO SEPTEMBER 1976

\begin{tabular}{|c|c|c|c|c|c|c|c|}
\hline DATE & TIME & $\begin{array}{c}\text { INSTAN- } \\
\text { TANEOUS } \\
\text { OIS- } \\
\text { CHARGE } \\
\text { (CFS) }\end{array}$ & $\begin{array}{l}\text { TEHPER- } \\
\text { ATURE } \\
\text { (DEG C) }\end{array}$ & $\begin{array}{l}\text { SUS- } \\
\text { PENDED } \\
\text { SEDI- } \\
\text { MENT } \\
\text { (MG/L) }\end{array}$ & $\begin{array}{c}\text { SUS- } \\
\text { PENDED } \\
\text { SEDI- } \\
\text { MENT } \\
\text { DIS- } \\
\text { CHARGE } \\
\text { (T/DAY) }\end{array}$ & $\begin{array}{r}\text { SUS } \\
\text { SED } \\
\text { SIEV } \\
\text { DIAM } \\
\times \text { FIN } \\
\text { THA } \\
.062\end{array}$ & $\begin{array}{l}S . \\
D \text { : } \\
V E \\
M \text {. } \\
N E R \\
A N \\
\text { AN }\end{array}$ \\
\hline \multicolumn{8}{|l|}{ OCT } \\
\hline Nov & 1500 & 120 & 28.0 & 74 & 24 & & $-\infty$ \\
\hline${ }_{D E C}^{18} \cdots$ & 1500 & 113 & 16.5 & 45 & 14 & & $=$ \\
\hline$\underset{\text { JAN }}{08 \ldots}$ & 1500 & 128 & 16.0 & 78 & 27 & & -- \\
\hline$\underset{F E B}{27} \cdots$ & 1430 & 148 & 16.0 & 71 & 28 & & - \\
\hline MAR & 1400 & 213 & 18.0 & 121 & 70 & & 54 \\
\hline$\underset{A P R}{16 \ldots}$ & 1400 & 147 & 20.0 & 114 & 45 & & $=$ \\
\hline $\begin{array}{l}13 \\
\text { MAY }\end{array}$ & 1500 & 195 & 18.0 & 183 & 96 & & 75 \\
\hline$\underset{\text { JUN }}{11} \cdots$ & 1400 & 249 & 27.5 & 429 & 288 & & - \\
\hline $\begin{array}{l}01 \ldots \\
29 \ldots \\
\text { JUL }\end{array}$ & $\begin{array}{l}1400 \\
1400\end{array}$ & $\begin{array}{r}128 \\
97\end{array}$ & $\begin{array}{l}27.5 \\
32.0\end{array}$ & $\begin{array}{l}170 \\
207\end{array}$ & $\begin{array}{l}59 \\
54\end{array}$ & & $=$ \\
\hline AUG $27 . \cdots$ & 0730 & 122 & 29.0 & 259 & 85 & & $-=$ \\
\hline$\underset{S E P}{31} \cdots$ & 0700 & 110 & 29.5 & 52 & 15 & & 37 \\
\hline $21 \ldots$ & 1710 & 123 & 29.0 & 144 & 48 & & 21 \\
\hline
\end{tabular}




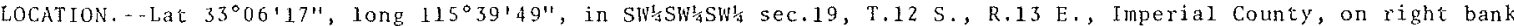
$3.5 \mathrm{mi}(5.6 \mathrm{~km})$ upstrean from mouth, and $5.2 \mathrm{mi}(8.4 \mathrm{~km})$ northwest of Westmorland.

PERIOD OF RECORD. - January 1943 to current year. Monthly discharge only for January 1943 to September 1960 , published in WSP 1734 .

GAGE. - Water-stage recorder. Altitude of gage is $220 \mathrm{ft}(67 \mathrm{~m})$ below mean sea level (from topographic map). REMARKS. - Records good below $1500 \mathrm{ft}^{3} / \mathrm{s}\left(42.5 \mathrm{~m}^{3} / \mathrm{s}\right)$, fair above. Discharge represents seepage and return flow from irrigated areas.

COOPERATION. - - Records furnished by Imperial Irrigation District and reviewed by the Geological Survey.

EXTREMES FOR PERIOD OF RECORD.--Maximum daily discharge, (estimated) $2,500 \mathrm{ft}^{3} / \mathrm{s}\left(70.8 \mathrm{~m}^{3} / \mathrm{s}\right) \mathrm{Sept}$. 13 , 1976 (from Tropical Storn Kathleen); minimum daily, $293 \mathrm{ft}^{3} / \mathrm{s}\left(8.30 \mathrm{~m}^{3} / \mathrm{s}\right) \mathrm{Jan} .6,1967$.

DISCHARGE, IN CUBIC FEET PER SECOND, WATER YEAR OCTOBER 1975 TO SEPTEMBER 1976 HEAN VALUES

\begin{tabular}{|c|c|c|c|c|c|c|c|c|c|c|c|c|}
\hline DAY & OCr & NOV & DEC & JAN & FEB & MAR & APR & MAY & JUN & JUL & AUG & SEP \\
\hline $\begin{array}{l}1 \\
2 \\
3 \\
4 \\
5\end{array}$ & $\begin{array}{l}636 \\
613 \\
603 \\
603 \\
584\end{array}$ & $\begin{array}{l}538 \\
549 \\
613 \\
596 \\
584\end{array}$ & $\begin{array}{l}528 \\
521 \\
492 \\
534 \\
532\end{array}$ & $\begin{array}{l}534 \\
513 \\
553 \\
659 \\
559\end{array}$ & $\begin{array}{l}592 \\
584 \\
564 \\
543 \\
609\end{array}$ & $\begin{array}{l}666 \\
681 \\
676 \\
730 \\
695\end{array}$ & $\begin{array}{l}730 \\
730 \\
750 \\
776 \\
758\end{array}$ & $\begin{array}{l}740 \\
772 \\
724 \\
716 \\
736\end{array}$ & $\begin{array}{l}578 \\
601 \\
611 \\
598 \\
574\end{array}$ & $\begin{array}{l}521 \\
534 \\
532 \\
542 \\
511\end{array}$ & $\begin{array}{l}530 \\
507 \\
517 \\
519 \\
530\end{array}$ & $\begin{array}{l}536 \\
568 \\
574 \\
590 \\
576\end{array}$ \\
\hline $\begin{array}{r}6 \\
7 \\
8 \\
9 \\
10\end{array}$ & $\begin{array}{l}636 \\
641 \\
645 \\
666 \\
697\end{array}$ & $\begin{array}{l}568 \\
584 \\
574 \\
578 \\
547\end{array}$ & $\begin{array}{l}519 \\
555 \\
521 \\
481 \\
479\end{array}$ & $\begin{array}{l}504 \\
449 \\
388 \\
442 \\
507\end{array}$ & $\begin{array}{l}626 \\
664 \\
580 \\
797 \\
785\end{array}$ & $\begin{array}{l}704 \\
685 \\
651 \\
659 \\
634\end{array}$ & $\begin{array}{l}738 \\
726 \\
732 \\
750 \\
746\end{array}$ & $\begin{array}{l}785 \\
826 \\
800 \\
754 \\
738\end{array}$ & $\begin{array}{l}598 \\
561 \\
555 \\
540 \\
532\end{array}$ & $\begin{array}{l}513 \\
534 \\
494 \\
502 \\
523\end{array}$ & $\begin{array}{l}521 \\
487 \\
494 \\
547 \\
543\end{array}$ & $\begin{array}{r}574 \\
685 \\
787 \\
641 \\
1500\end{array}$ \\
\hline $\begin{array}{l}11 \\
12 \\
13 \\
14 \\
15\end{array}$ & $\begin{array}{l}677 \\
645 \\
636 \\
621 \\
563\end{array}$ & $\begin{array}{l}511 \\
505 \\
494 \\
485 \\
464\end{array}$ & $\begin{array}{l}498 \\
542 \\
526 \\
509 \\
509\end{array}$ & $\begin{array}{l}545 \\
592 \\
640 \\
615 \\
643\end{array}$ & $\begin{array}{l}613 \\
574 \\
525 \\
483 \\
481\end{array}$ & $\begin{array}{l}601 \\
624 \\
638 \\
687 \\
643\end{array}$ & $\begin{array}{l}772 \\
750 \\
766 \\
859 \\
914\end{array}$ & $\begin{array}{l}718 \\
732 \\
732 \\
679 \\
674\end{array}$ & $\begin{array}{l}545 \\
586 \\
600 \\
582 \\
559\end{array}$ & $\begin{array}{l}542 \\
555 \\
540 \\
545 \\
521\end{array}$ & $\begin{array}{l}523 \\
557 \\
563 \\
566 \\
540\end{array}$ & $\begin{array}{r}1800 \\
2200 \\
2500 \\
1880 \\
691\end{array}$ \\
\hline $\begin{array}{l}16 \\
17 \\
18 \\
19 \\
20\end{array}$ & $\begin{array}{l}607 \\
613 \\
643 \\
662 \\
607\end{array}$ & $\begin{array}{l}477 \\
528 \\
532 \\
528 \\
551\end{array}$ & $\begin{array}{l}526 \\
525 \\
519 \\
517 \\
515\end{array}$ & $\begin{array}{l}611 \\
570 \\
596 \\
549 \\
536\end{array}$ & $\begin{array}{l}534 \\
515 \\
504 \\
488 \\
446\end{array}$ & $\begin{array}{l}640 \\
677 \\
698 \\
664 \\
672\end{array}$ & $\begin{array}{l}720 \\
615 \\
647 \\
668 \\
681\end{array}$ & $\begin{array}{l}702 \\
687 \\
666 \\
681 \\
683\end{array}$ & $\begin{array}{l}500 \\
490 \\
475 \\
500 \\
534\end{array}$ & $\begin{array}{l}534 \\
517 \\
502 \\
498 \\
540\end{array}$ & $\begin{array}{l}590 \\
570 \\
519 \\
528 \\
532\end{array}$ & $\begin{array}{l}557 \\
505 \\
496 \\
483 \\
494\end{array}$ \\
\hline $\begin{array}{l}21 \\
22 \\
23 \\
24 \\
25\end{array}$ & $\begin{array}{l}600 \\
603 \\
617 \\
617 \\
607\end{array}$ & $\begin{array}{l}526 \\
507 \\
515 \\
523 \\
540\end{array}$ & $\begin{array}{l}559 \\
555 \\
566 \\
598 \\
528\end{array}$ & $\begin{array}{l}549 \\
551 \\
561 \\
568 \\
580\end{array}$ & $\begin{array}{l}459 \\
504 \\
530 \\
564 \\
572\end{array}$ & $\begin{array}{l}728 \\
744 \\
728 \\
728 \\
740\end{array}$ & $\begin{array}{l}611 \\
553 \\
592 \\
647 \\
704\end{array}$ & $\begin{array}{l}681 \\
676 \\
649 \\
683 \\
693\end{array}$ & $\begin{array}{l}530 \\
519 \\
536 \\
509 \\
483\end{array}$ & $\begin{array}{l}517 \\
557 \\
570 \\
536 \\
559\end{array}$ & $\begin{array}{l}543 \\
568 \\
566 \\
543 \\
534\end{array}$ & $\begin{array}{l}481 \\
466 \\
473 \\
561 \\
772\end{array}$ \\
\hline $\begin{array}{l}26 \\
27 \\
28 \\
29 \\
30 \\
31\end{array}$ & $\begin{array}{l}596 \\
538 \\
563 \\
540 \\
566 \\
576\end{array}$ & $\begin{array}{l}509 \\
542 \\
515 \\
485 \\
487 \\
-\infty-\infty\end{array}$ & $\begin{array}{l}463 \\
509 \\
525 \\
504 \\
538 \\
545\end{array}$ & $\begin{array}{l}532 \\
545 \\
504 \\
53 \$ \\
561 \\
580\end{array}$ & $\begin{array}{l}502 \\
613 \\
643 \\
649 \\
0-2\end{array}$ & $\begin{array}{l}760 \\
766 \\
768 \\
772 \\
772 \\
742\end{array}$ & $\begin{array}{l}722 \\
698 \\
706 \\
714 \\
716 \\
-\infty\end{array}$ & $\begin{array}{l}677 \\
645 \\
636 \\
626 \\
611 \\
596\end{array}$ & $\begin{array}{l}515 \\
528 \\
507 \\
505 \\
507 \\
=-\end{array}$ & $\begin{array}{l}574 \\
594 \\
607 \\
603 \\
580 \\
586\end{array}$ & $\begin{array}{l}532 \\
545 \\
557 \\
564 \\
561 \\
557\end{array}$ & $\begin{array}{l}578 \\
534 \\
511 \\
534 \\
530 \\
\end{array}$ \\
\hline $\begin{array}{l}\text { TOTAL } \\
\text { MEAN } \\
M A X \\
M I N \\
\text { AC }-F Y\end{array}$ & $\begin{array}{r}19021 \\
614 \\
697 \\
538 \\
37730\end{array}$ & $\begin{array}{r}15955 \\
532 \\
613 \\
464 \\
31650\end{array}$ & $\begin{array}{r}16238 \\
524 \\
598 \\
463 \\
32210\end{array}$ & $\begin{array}{r}17070 \\
551 \\
659 \\
388 \\
33860\end{array}$ & $\begin{array}{r}16623 \\
573 \\
797 \\
446 \\
32970\end{array}$ & $\begin{array}{r}21573 \\
696 \\
772 \\
601 \\
42790\end{array}$ & $\begin{array}{r}21491 \\
716 \\
914 \\
553 \\
42630\end{array}$ & $\begin{array}{r}21718 \\
701 \\
826 \\
596 \\
43080\end{array}$ & $\begin{array}{r}16258 \\
542 \\
611 \\
475 \\
32250\end{array}$ & $\begin{array}{r}16783 \\
541 \\
607 \\
494 \\
33290\end{array}$ & $\begin{array}{r}16753 \\
540 \\
590 \\
487 \\
33230\end{array}$ & $\begin{array}{r}24077 \\
803 \\
2500 \\
466 \\
47760\end{array}$ \\
\hline
\end{tabular}


10255700 SAN FELJPE CREEK NEAR JULIAN, CA

LOCATION, - Lat $33^{\circ} 07^{\prime} 07^{\prime \prime}$, long $116^{\circ} 26^{\circ} 04^{\prime \prime}$, San Diego County, in Anza-Borrego Desert State Park, on 1 eft bank under bridge on State Highway 78 in Sentenac Canyon, $1.0 \mathrm{mi}(1.6 \mathrm{~km})$ upstream from Grapevine Canyon, and $10 \mathrm{mi}$ (16 km) northeast of Julian.

DRAINAGE AREA. $-89.2 \mathrm{mi}^{3}\left(231.0 \mathrm{~km}^{2}\right)$.

PERIOD OF RECORD, --August 1958 to curient year.

GAGE. - Water wtage recorder and concrete low-water control. Datum of gage is $1,872.69 \mathrm{ft}$ (570.796 m) above mean sea leve1.

REMARKS.--Records good. No regulation or diversion above station.

AVERAGE DISCHARGE. - -18 years, $0.23 \mathrm{ft}^{3} / \mathrm{s}\left(0.007 \mathrm{~m}^{3} / \mathrm{s}\right), 167 \mathrm{acre}-\mathrm{ft} / \mathrm{yr}\left(205,900 \mathrm{n}^{3} / \mathrm{yr}^{3}\right)$.

EXTREMES FOR PERIOD OF RECORD. - Maximum discharge, $1,050 \mathrm{ft}^{3} / \mathrm{s}\left(29.7 \mathrm{~m}^{3} / \mathrm{s}\right) \mathrm{Aug}, 22,1967, \mathrm{gage} \mathrm{height}, 4.08 \mathrm{ft}$

$(1.244 \mathrm{~m})$, fron rating curve extended above $12 \mathrm{ft} / \mathrm{s}\left(0.34 \mathrm{~m}^{3} / \mathrm{s}\right)$ on basis of slope-area measurenent at gage height $3.50 \mathrm{ft}(1.067 \mathrm{~m}) ;$ no flow for many days in each year.

EXTREMES FOR CURRENT YEAR. - peak discharge above base of $50 \mathrm{ft}^{3} / \mathrm{s}\left(1.42 \mathrm{~m}^{3} / \mathrm{s}\right)$ and $\mathrm{maximum}, 143 \mathrm{ft}{ }^{3} / \mathrm{s}\left(4.05 \mathrm{~m}{ }^{3} / \mathrm{s}\right)$ Sept. 10, gage height, $2.61 \mathrm{ft}(0.796 \mathrm{~m})$; no flow many days.

DISCHARGE, IN CUBIC FEET PER SECONO, HATER YEAR OCTOBER 1975 TO SEPTEMBER 1976 MEAN VALUES

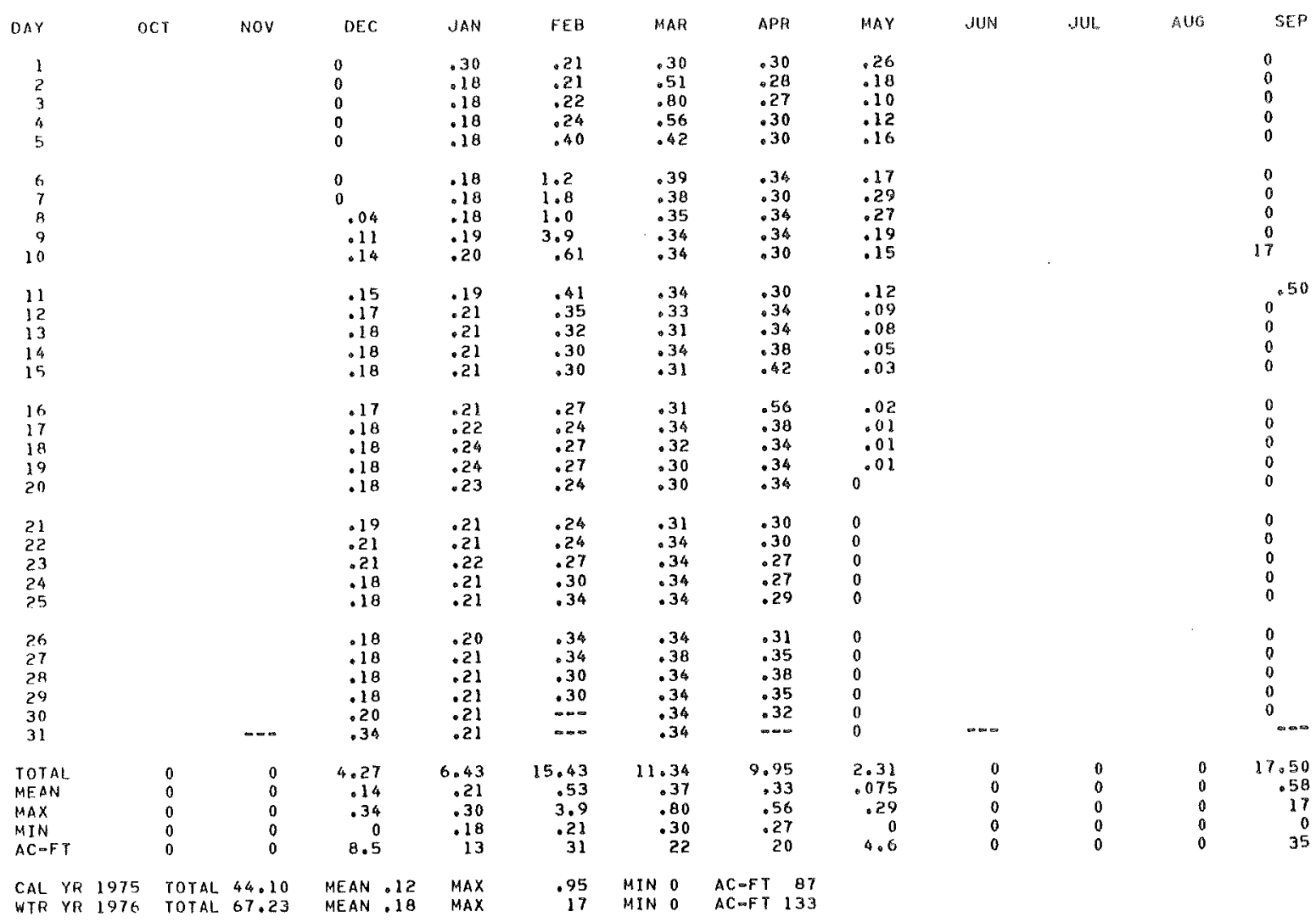




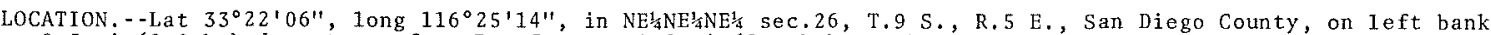
$0.5 \mathrm{mi}(0.8 \mathrm{~km})$ downstream from Box Canyon, $1.8 \mathrm{mi}(2.9 \mathrm{~km})$ northwest of Rancho De Anza, and $8.2 \mathrm{mi}$ (13.2 km) northwest of Borrego Springs.

DRAINAGE AREA. $--144 \mathrm{mi}^{2}\left(373 \mathrm{~km}^{2}\right)$.

PERIOD OF RECORD.--October 1950 to current year. Monthly discharge only for October and November 1950 , published in WSP 1734 .

REVISED RECORDS, - -WDR CA-72-1: 1969, 1971.

GAGE. - Water-stage recorder. Altitude of gage is 1,250 ft (381 m), from topographic map. Prior to Mar. 24 , 1967, at site $0.6 \mathrm{mi}(1.0 \mathrm{~km})$ upstream at different datum.

REMARKS, - Records poor. No regulation above station. Diversion about $0.5 \mathrm{mi}$ ( $0.8 \mathrm{~km})$ upstream for irrigation below station since January 1973 .

AVERAGE DISCHARGE. - -26 years, $1.82 \mathrm{ft}^{3} / \mathrm{s}\left(0.052 \mathrm{~m}^{3} / \mathrm{s}\right), 1,320 \mathrm{acre}-\mathrm{ft} / \mathrm{yr}\left(1.63 \mathrm{hm}^{3} / \mathrm{yr}^{2}\right)$.

EXTREMES FOR PERIOD OF RECORD.--Maximum discharge, 3,800 $\mathrm{ft}^{3} / \mathrm{s}\left(108 \mathrm{~m}^{3} / \mathrm{s}\right) \mathrm{July} 28$, 1951 , gage height, $14.14 \mathrm{ft}$ $(4.310 \mathrm{~m})$, from floodmarks, site and datum then in use, on basis of slope-area measurement of maximum flow; no flow at times in some years.

EXTREMES FOR CURRENT YEAR, - Maximum discharge, $2,300 \mathrm{ft}^{3} / \mathrm{s}\left(65.1 \mathrm{~m}^{3} / \mathrm{s}\right)$ Sept. 10 (time unknown), gage height, $14.5 \mathrm{ft}(4.42 \mathrm{~m})$, no other peak above base of $50 \mathrm{ft}^{3} / \mathrm{s}\left(1.42 \mathrm{~m}^{3} / \mathrm{s}\right)$, from rating curve extended above $2.0 \mathrm{ft} / \mathrm{s}$ $\left(0.06 \mathrm{~m}^{3} / \mathrm{s}\right)$ on basis of slope-area measurement at gage height $13.85 \mathrm{ft}(4.221 \mathrm{~m}) ; \mathrm{minimum}$ daily, $0.05 \mathrm{ft} / \mathrm{s}$ $\left(0.001 \mathrm{~m}^{3} / \mathrm{s}\right)$ for many days.

DISCHARGE, IN CUBIC FEET PER SECOND, HATER YEAR OCTOBER 1975 TO SEPTEMBER 1976 MEAN VALUES

\begin{tabular}{|c|c|c|c|c|c|c|c|c|c|c|c|c|}
\hline DAY & OCT & NOV & DEC & JAN & FEB & MAR & $A P R$ & MAY & JUN & JUL & AUG & SEP \\
\hline $\begin{array}{l}1 \\
2 \\
3 \\
4 \\
5\end{array}$ & $\begin{array}{l}.05 \\
.05 \\
.05 \\
.05 \\
.05\end{array}$ & $\begin{array}{l}.05 \\
.05 \\
.05 \\
.05 \\
.05\end{array}$ & $\begin{array}{l}.05 \\
.05 \\
.05 \\
.05 \\
.05\end{array}$ & $\begin{array}{l}.60 \\
.55 \\
.50 \\
.50 \\
.50\end{array}$ & $\begin{array}{r}.50 \\
.50 \\
.50 \\
.50 \\
1.0\end{array}$ & $\begin{array}{l}.50 \\
.75 \\
1.3 \\
1.0 \\
.75\end{array}$ & $\begin{array}{l}.60 \\
.70 \\
.70 \\
.70 \\
.70\end{array}$ & $\begin{array}{l}.50 \\
.50 \\
.50 \\
.50 \\
.50\end{array}$ & $\begin{array}{l}.10 \\
110 \\
110 \\
110 \\
.10\end{array}$ & $\begin{array}{l}.05 \\
.05 \\
.05 \\
.05 \\
.05\end{array}$ & $\begin{array}{l}.70 \\
.70 \\
.70 \\
.70 \\
.70\end{array}$ & $\begin{array}{l}.50 \\
.50 \\
.50 \\
.50 \\
.50\end{array}$ \\
\hline $\begin{array}{r}6 \\
7 \\
8 \\
9 \\
10\end{array}$ & $\begin{array}{l}.05 \\
.05 \\
.05 \\
.05 \\
.05\end{array}$ & $\begin{array}{l}.05 \\
.05 \\
.05 \\
.05 \\
.05\end{array}$ & $\begin{array}{l}.05 \\
.05 \\
.05 \\
.05 \\
.05\end{array}$ & $\begin{array}{l}.50 \\
.50 \\
.50 \\
.50 \\
.50\end{array}$ & $\begin{array}{l}1.5 \\
2.5 \\
1.5 \\
6.0 \\
1.5\end{array}$ & $\begin{array}{l}.75 \\
.65 \\
.60 \\
.60 \\
.60\end{array}$ & $\begin{array}{l}.70 \\
.70 \\
.70 \\
.70 \\
.70\end{array}$ & $\begin{array}{l}.50 \\
.50 \\
.45 \\
.40 \\
.40\end{array}$ & $\begin{array}{r}.10 \\
110 \\
10 \\
10 \\
110\end{array}$ & $\begin{array}{l}.05 \\
.05 \\
.05 \\
.05 \\
.05\end{array}$ & $\begin{array}{l}.70 \\
.70 \\
.70 \\
.70 \\
.70\end{array}$ & $\begin{array}{r}.50 \\
.50 \\
.50 \\
.50\end{array}$ \\
\hline $\begin{array}{l}11 \\
12 \\
13 \\
14 \\
15\end{array}$ & $\begin{array}{l}.05 \\
.05 \\
.05 \\
.05 \\
.05\end{array}$ & $\begin{array}{l}.05 \\
.05 \\
.05 \\
.05 \\
.05\end{array}$ & $\begin{array}{l}.05 \\
.05 \\
.05 \\
.10 \\
.20\end{array}$ & $\begin{array}{l}.50 \\
.50 \\
.50 \\
.50 \\
.50\end{array}$ & $\begin{array}{l}.60 \\
.50 \\
.50 \\
.50 \\
.50\end{array}$ & $\begin{array}{l}.60 \\
.60 \\
.60 \\
.60 \\
.60\end{array}$ & $\begin{array}{l}.70 \\
.70 \\
.70 \\
.70 \\
.70\end{array}$ & $\begin{array}{l}.40 \\
.40 \\
.35 \\
.30 \\
.30\end{array}$ & $\begin{array}{r}.10 \\
.10 \\
.10 \\
.10 \\
.10\end{array}$ & $\begin{array}{l}.05 \\
.05 \\
.05 \\
.05 \\
.05\end{array}$ & $\begin{array}{l}.70 \\
.70 \\
.70 \\
.70 \\
.60\end{array}$ & $\begin{array}{l}1.0 \\
.20 \\
.10 \\
.10 \\
.10\end{array}$ \\
\hline $\begin{array}{l}16 \\
17 \\
18 \\
19 \\
20\end{array}$ & $\begin{array}{l}.05 \\
.05 \\
.05 \\
.05 \\
.05\end{array}$ & $\begin{array}{l}.05 \\
.05 \\
.05 \\
.05 \\
.05\end{array}$ & $\begin{array}{l}.20 \\
.20 \\
.20 \\
.20 \\
.20\end{array}$ & $\begin{array}{l}.50 \\
.50 \\
.50 \\
.50 \\
.50\end{array}$ & $\begin{array}{l}.50 \\
.50 \\
.50 \\
.50 \\
.50\end{array}$ & $\begin{array}{l}.60 \\
.60 \\
.60 \\
.60 \\
.60\end{array}$ & $\begin{array}{l}.90 \\
.70 \\
.60 \\
.60 \\
.60\end{array}$ & $\begin{array}{l}.30 \\
.30 \\
.30 \\
.25 \\
.20\end{array}$ & $\begin{array}{l}.08 \\
.06 \\
.05 \\
.05 \\
.05\end{array}$ & $\begin{array}{l}.05 \\
.05 \\
.05 \\
.05 \\
.05\end{array}$ & $\begin{array}{l}.60 \\
.60 \\
.60 \\
.60 \\
.60\end{array}$ & $\begin{array}{l}.10 \\
110 \\
110 \\
110 \\
.10\end{array}$ \\
\hline $\begin{array}{l}21 \\
22 \\
23 \\
24 \\
25\end{array}$ & $\begin{array}{l}.05 \\
.05 \\
.05 \\
.05 \\
.05\end{array}$ & $\begin{array}{l}.05 \\
.05 \\
.05 \\
.05 \\
.05\end{array}$ & $\begin{array}{l}.20 \\
.20 \\
.20 \\
.20 \\
.30\end{array}$ & $\begin{array}{l}.50 \\
.50 \\
.50 \\
.50 \\
.50\end{array}$ & $\begin{array}{l}.50 \\
.50 \\
.50 \\
.50 \\
.50\end{array}$ & $\begin{array}{l}.60 \\
.60 \\
.60 \\
.60 \\
.60\end{array}$ & $\begin{array}{l}.60 \\
.60 \\
.60 \\
.60 \\
.60\end{array}$ & $\begin{array}{l}.20 \\
.20 \\
.20 \\
.20 \\
.20\end{array}$ & $\begin{array}{l}.05 \\
.05 \\
.05 \\
.05 \\
.05\end{array}$ & $\begin{array}{l}.05 \\
.05 \\
.05 \\
.05 \\
.95\end{array}$ & $\begin{array}{l}.60 \\
.60 \\
.60 \\
.60 \\
.50\end{array}$ & $\begin{array}{r}.10 \\
.10 \\
1.5 \\
.90 \\
.70\end{array}$ \\
\hline $\begin{array}{l}26 \\
27 \\
28 \\
29 \\
30 \\
31\end{array}$ & $\begin{array}{l}.05 \\
.05 \\
.05 \\
.05 \\
.05 \\
.05\end{array}$ & $\begin{array}{l}.05 \\
.05 \\
.05 \\
.05 \\
.05 \\
.05\end{array}$ & $\begin{array}{l}.30 \\
.30 \\
.30 \\
.30 \\
.30 \\
.60\end{array}$ & $\begin{array}{l}.50 \\
.50 \\
.50 \\
.50 \\
.50 \\
.50\end{array}$ & $\begin{array}{l}.50 \\
.50 \\
.50 \\
.50 \\
-.- \\
-.-0\end{array}$ & $\begin{array}{l}.60 \\
.60 \\
.60 \\
.60 \\
.60 \\
.60\end{array}$ & $\begin{array}{l}.60 \\
.55 \\
.50 \\
.50 \\
.50 \\
.50\end{array}$ & $\begin{array}{l}.20 \\
.15 \\
110 \\
.10 \\
.10 \\
.10\end{array}$ & $\begin{array}{l}.05 \\
.05 \\
.05 \\
.05 \\
.05 \\
.05\end{array}$ & $\begin{array}{r}.80 \\
.70 \\
.70 \\
.70 \\
.70 \\
.70\end{array}$ & $\begin{array}{r}.50 \\
.50 \\
.50 \\
.50 \\
.50 \\
.50\end{array}$ & $\begin{array}{l}.70 \\
.70 \\
.70 \\
.70 \\
.70 \\
-.0\end{array}$ \\
\hline $\begin{array}{l}\text { TOTAL } \\
\text { MEAN } \\
\text { MAX } \\
\text { MIN } \\
\text { AC-FT }\end{array}$ & $\begin{array}{r}1.55 \\
.050 \\
.05 \\
.05 \\
3.1\end{array}$ & $\begin{array}{r}1.50 \\
.050 \\
.05 \\
.05 \\
3.0\end{array}$ & $\begin{array}{r}4.95 \\
.16 \\
.40 \\
.05 \\
9.8\end{array}$ & $\begin{array}{r}15.65 \\
.50 \\
.60 \\
.50 \\
31\end{array}$ & $\begin{array}{r}25.60 \\
.88 \\
6.0 \\
.50 \\
51\end{array}$ & $\begin{array}{r}20.10 \\
.65 \\
1.3 \\
.50 \\
40\end{array}$ & $\begin{array}{r}19.45 \\
.65 \\
.90 \\
.50 \\
39\end{array}$ & $\begin{array}{r}9.60 \\
.31 \\
.50 \\
.10 \\
19\end{array}$ & $\begin{array}{r}2.29 \\
.076 \\
.10 \\
.05 \\
4.5\end{array}$ & $\begin{array}{r}6.45 \\
.21 \\
.95 \\
.05 \\
13\end{array}$ & $\begin{array}{r}19.30 \\
.62 \\
.70 \\
.50 \\
38\end{array}$ & $\begin{array}{r}38.30 \\
1.28 \\
25 \\
.10 \\
76\end{array}$ \\
\hline
\end{tabular}

$\begin{array}{lllllll}\text { CAL YR } 1975 & \text { TOTAL } 178.21 & \text { MEAN .49 } & \text { HAX } 65 & \text { MIN } 0 & \text { AC-FT } 353 \\ \text { HTR YR } 1976 & \text { TOTAL } 164.74 & \text { HEAN } 45 & \text { MAX 25 } & \text { MIN .05 AC-FT } 327\end{array}$ 
10255810 BORREGO PALM CREEK NEAR BORREGO SPRINGS, CA

LOCATION. - Lat $33^{\circ} 16^{\prime} 44^{\prime \prime}$, long $116^{\circ} 25^{\prime} 45^{\prime \prime}$, in Anza-Borrego Desert State Park, San Diego County, on 1eft bank $3.3 \mathrm{mi}(5.3 \mathrm{~km})$ northwest of Borrego Springs.

DRAINAGE AREA. $-21.8 \mathrm{mi}^{2}\left(56.5 \mathrm{~km}^{2}\right)$.

PERIOD OF RECORD, - October 1950 to current year. Prior to October 1960 , published as "Palm Canyon Creek Ilear Borrego Springs." Monthly discharge only for October to Novenber 1950, published in WSP 1734.

GAGE, - Water-stage recorder. Altitude of gage is 1,200 ft (366 m), from topographic map.

REMARKS.--Records good. No regulation or diversion above station.

AVERAGE DISCHARGE. - -26 years, $0.31 \mathrm{ft}^{3} / \mathrm{s}\left(0.009 \mathrm{~m}^{3} / \mathrm{s}\right), 225 \mathrm{acre}-\mathrm{ft} / \mathrm{yr}\left(277,000 \mathrm{~m}^{3} / \mathrm{yr}^{2}\right)$.

EXTREMES FOR PERIOD OF RECORD.--Maximun discharge, $2,000 \mathrm{ft}^{3} / \mathrm{s}\left(56.6 \mathrm{~m}^{3} / \mathrm{s}\right)$, estimated, Aug. 23 , 1955, gage height, $9.9 \mathrm{ft}(3.02 \mathrm{~m})$ from floodmarks; no flow for several months in each year.

EXTREMES FOR CURRENT YEAR.--MaXimum discharge, $13 \mathrm{ft}^{3} / \mathrm{s}\left(0.37 \mathrm{~m}^{3} / \mathrm{s}\right) \mathrm{Feb} .9$, gage height, $2.55 \mathrm{ft}(0.777 \mathrm{~m})$, no peak above base of $15 \mathrm{ft}^{3} / \mathrm{s}$; no flow most of year.

DISCHARGE, IN CUBIC FEET PER SECOND, WATER YEAR OCTOBER 1975 TO SEPTEMBER 1976 MEAN VALUES

\begin{tabular}{|c|c|c|c|c|c|c|c|c|c|c|c|c|}
\hline DAY & $O C T$ & Nov & $D E C$ & JAN & FEB & MAR & APR & MAY & JUN & JUL & AUG & SEP \\
\hline $\begin{array}{l}1 \\
2 \\
3 \\
4 \\
5\end{array}$ & & & & & $\begin{array}{l}0 \\
.01 \\
.01 \\
.02 \\
.46\end{array}$ & $\begin{array}{l}.38 \\
1.0 \\
1.3 \\
.81 \\
.80\end{array}$ & $\begin{array}{r}.17 \\
.18 \\
.15 \\
.15 \\
.15\end{array}$ & $\begin{array}{l}.05 \\
.04 \\
.04 \\
.03 \\
.03\end{array}$ & & & & $\begin{array}{l}0 \\
0 \\
0 \\
0 \\
0\end{array}$ \\
\hline $\begin{array}{r}6 \\
7 \\
8 \\
9 \\
10\end{array}$ & & & & & $\begin{array}{l}1.9 \\
3.2 \\
2.1 \\
7.2 \\
3.5\end{array}$ & $\begin{array}{l}.71 \\
.65 \\
.64 \\
.59 \\
.57\end{array}$ & $\begin{array}{r}.17 \\
.16 \\
.16 \\
.15 \\
.14\end{array}$ & $\begin{array}{l}.03 \\
.03 \\
.03 \\
.02 \\
.02\end{array}$ & & & & $\begin{array}{l}0 \\
0 \\
0 \\
0 \\
1.4\end{array}$ \\
\hline $\begin{array}{l}11 \\
12 \\
13 \\
14 \\
15\end{array}$ & & & & & $\begin{array}{l}1.7 \\
1.1 \\
.80 \\
.67 \\
.59\end{array}$ & $\begin{array}{r}.54 \\
.49 \\
.42 \\
.29 \\
.27\end{array}$ & $\begin{array}{r}.13 \\
.17 \\
.18 \\
.33 \\
.53\end{array}$ & $\begin{array}{l}.02 \\
.01 \\
.01 \\
.01 \\
0\end{array}$ & & & & $\begin{array}{l}0 \\
0 \\
0 \\
0 \\
0\end{array}$ \\
\hline $\begin{array}{l}16 \\
17 \\
18 \\
19 \\
20\end{array}$ & & & & & $\begin{array}{l}.53 \\
.48 \\
.43 \\
.38 \\
.35\end{array}$ & $\begin{array}{r}.25 \\
.24 \\
.23 \\
.22 \\
.21\end{array}$ & $\begin{array}{r}1.2 \\
.56 \\
.35 \\
\cdot 30 \\
\cdot 25\end{array}$ & $\begin{array}{l}0 \\
0 \\
0 \\
0 \\
0\end{array}$ & & & & $\begin{array}{l}0 \\
0 \\
0 \\
0 \\
0\end{array}$ \\
\hline $\begin{array}{l}21 \\
22 \\
23 \\
24 \\
25\end{array}$ & & & & & $\begin{array}{l}.32 \\
.29 \\
.29 \\
.26 \\
.25\end{array}$ & $\begin{array}{r}.19 \\
117 \\
116 \\
.15 \\
.14\end{array}$ & $\begin{array}{r}.22 \\
.20 \\
.17 \\
.14 \\
.12\end{array}$ & $\begin{array}{l}0 \\
0 \\
0 \\
0 \\
0\end{array}$ & & & & $\begin{array}{l}0 \\
0 \\
0 \\
0 \\
0\end{array}$ \\
\hline $\begin{array}{l}26 \\
27 \\
28 \\
29 \\
30 \\
31\end{array}$ & & $\cdots$ & & & $\begin{array}{l}.23 \\
.23 \\
.24 \\
.23 \\
-.-1 \\
--\infty\end{array}$ & $\begin{array}{r}.14 \\
.15 \\
.17 \\
.16 \\
.15 \\
.16\end{array}$ & $\begin{array}{r}.10 \\
.09 \\
.08 \\
.06 \\
.06 \\
.0\end{array}$ & $\begin{array}{l}0 \\
0 \\
0 \\
0 \\
0 \\
0\end{array}$ & $-\infty$ & & & $\begin{array}{l}0 \\
0 \\
0 \\
0 \\
0 \\
\end{array}$ \\
\hline $\begin{array}{l}\text { TOTAL } \\
\text { MEAN } \\
\text { MAX } \\
\text { MIN } \\
\text { AC }-F T\end{array}$ & $\begin{array}{l}0 \\
0 \\
0 \\
0 \\
0\end{array}$ & $\begin{array}{l}0 \\
0 \\
0 \\
0 \\
0\end{array}$ & $\begin{array}{l}0 \\
0 \\
0 \\
0 \\
0\end{array}$ & $\begin{array}{l}0 \\
0 \\
0 \\
0 \\
0\end{array}$ & $\begin{array}{r}27.77 \\
.96 \\
7.2 \\
0 \\
55\end{array}$ & $\begin{array}{r}12.35 \\
.40 \\
i .3 \\
.14 \\
24\end{array}$ & $\begin{array}{r}6.82 \\
.23 \\
i .2 \\
.06 \\
14\end{array}$ & $\begin{array}{r}.37 \\
.012 \\
.05 \\
0 \\
.7\end{array}$ & $\begin{array}{l}0 \\
0 \\
0 \\
0 \\
0\end{array}$ & $\begin{array}{l}0 \\
0 \\
0 \\
0 \\
0\end{array}$ & $\begin{array}{l}0 \\
0 \\
0 \\
0 \\
0\end{array}$ & $\begin{array}{r}1.49 \\
.050 \\
1.4 \\
0 \\
3.0\end{array}$ \\
\hline
\end{tabular}

CAL YR 1975 TOTAL 32.67 MEAN .090 MAX 2.3 MIN 0 ACWFT 65

WTR YR 1976 TOTAL 48.80 MEAN 13 MAX 7.2 MIN O AC-FT 97 


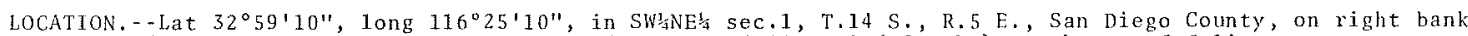
$0.2 \mathrm{mi}(0.3 \mathrm{~km})$ downstream from Cottonwood Wash, and $12.6 \mathrm{mi}(20.3 \mathrm{~km})$ southeast of Julian.

DRAINAGE AREA. $--39.7 \mathrm{mi}^{2}\left(102.8 \mathrm{~km}^{2}\right)$.

PERIOD OF RECORD.--October 1963 to current year.

GAGE. - Water-stage recorder. Altitude of gage is $1,950 \mathrm{ft}(594 \mathrm{~m})$ above mean sea level (from topographic map).

REMARKS.--Records poor. No regulation or diversion above station.

AVERAGE DISCHARGE . - -13 years, $0.12 \mathrm{ft}^{3} / \mathrm{s}\left(0,003 \mathrm{~m}^{3} / \mathrm{s}\right), 87$ acre-ft/yr $\left(107,000 \mathrm{~m}^{3} / \mathrm{yr}^{3}\right)$.

EXTRENES FOR PERIOD OF RECORD.--Maxinum discharge, $1,160 \mathrm{ft}^{3} / \mathrm{s}\left(32.9 \mathrm{~m}^{3} / \mathrm{s}\right)$ Sept. 10 , 1976 , gage height, $6.30 \mathrm{ft}$

$(1.920 \mathrm{~m})$, from average between high-water mark in wel1 and D.P. I., from rating curve extended above 0.10 ft $3 / \mathrm{s}$

$\left(0.003 \mathrm{~m}^{3} / \mathrm{s}\right)$ on basis of slope-area study of maximuil flow; no flow at times in some years.

EXTREMES FOR CURRENT YRAR.--Peak discharges above base of $15, \mathrm{ft}^{3} / \mathrm{s}\left(0.43 \mathrm{~m}^{3} / \mathrm{s}\right)$ and maximum (*), from $\mathrm{rating}$ extended above $0.10 \mathrm{ft}^{3} / \mathrm{s}\left(0.003 \mathrm{~m}^{3} / \mathrm{s}\right)$ on basis of slope-area measurement of peak flow:

\begin{tabular}{|c|c|c|c|c|c|c|c|c|c|c|}
\hline Date & Time & $\begin{array}{c}\text { Discharge } \\
\left(\mathrm{ft}^{3} / \mathrm{s}\right)\left(\mathrm{m}^{3} / \mathrm{s}\right)\end{array}$ & $\begin{array}{l}\text { Gage } \\
(\mathrm{ft})\end{array}$ & $\begin{array}{l}\text { eight } \\
\text { (II) }\end{array}$ & Date & Time & $\begin{array}{c}\text { Discha } \\
\left(f t^{3} / s\right)\end{array}$ & $\left(\mathrm{m}^{3} / \mathrm{s}\right)$ & $\begin{array}{l}\text { Gage } \\
(\mathrm{ft})\end{array}$ & $\begin{array}{r}\text { he ight } \\
\text { (m) }\end{array}$ \\
\hline $\begin{array}{lr}\text { Feb. } & 8 \\
\text { July } & 25\end{array}$ & $\begin{array}{l}2200 \\
1700\end{array}$ & $\begin{array}{l}0.57 \\
6.00\end{array}$ & $\begin{array}{l}2.39 \\
5.23\end{array}$ & $\begin{array}{l}0.729 \\
1.594\end{array}$ & Sept. 10 & 1100 & $* 1160$ & 32.9 & 6.30 & 1.920 \\
\hline
\end{tabular}

Minimum daily discharge, $0.01 \mathrm{ft}^{3} / \mathrm{s}\left(<0.001 \mathrm{~m}^{3} / \mathrm{s}\right)$ Aug. 4, 5, Sept, 6-9.

DISCHARGE, IN CUBIC FEET PER SECOND, WATER YEAR OCTOBER 1975 TO SEPTEMBER 1976 MEAN VALUES

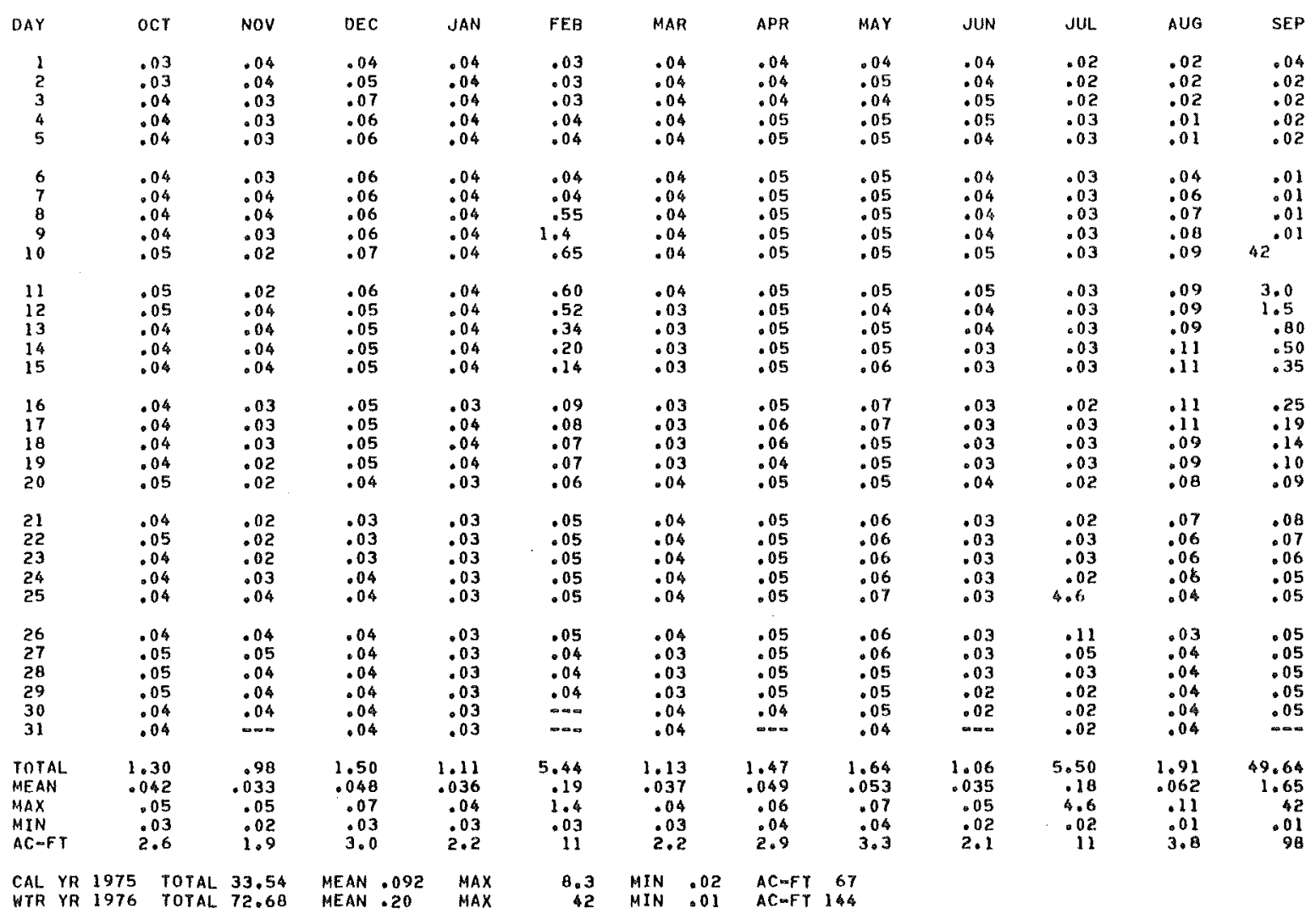


10255885 SAN FELIPE CREEK NEAR WESTMORLAND, CA

LOCATION, - Lat $33^{\circ} 07^{\prime} 25^{\prime \prime}$, long $115^{\circ} 51^{\prime} 08^{\prime \prime}$, in NW/4W/4 sec.17, T.12 S., R.11 E., Imperial County, on Ieft bank $320 \mathrm{ft}(98 \mathrm{~m})$ downstream from U.S. Highway 99 , and $14.6 \mathrm{mi}(23.5 \mathrm{~km})$ northwest of Westmorland.

DRAINAGE AREA. $-1,693 \mathrm{mi}^{2}\left(4,385 \mathrm{~km}^{2}\right)$.

PERIOD OF RECORD, - -December 1960 to current year.

GAGE. - Water-stage recorder and crest-stage gage. Altitude of gage is 190 ft ( $58 \mathrm{~m}$ ) below mean sea 1 evel, from topographic map.

REMARKS, - -Records poor. No regulation above station, Diversion and pumping for domestic use and irrigation in Borrego Valley $25 \mathrm{mi}(40 \mathrm{~km})$ upstream.

AVERAGE DISCHARGE. - -15 years (water years $1962-76), 6.88 \mathrm{ft}^{3} / \mathrm{s}\left(0.195 \mathrm{~m}^{3} / \mathrm{s}\right), 4,980 \mathrm{acre}-\mathrm{ft} / \mathrm{yr}\left(6.14 \mathrm{hm}^{3} / \mathrm{y}^{\mathrm{r}}\right)$.

EXTREMES FOR PERIOD OF RECORD.--Maximum discharge, 100,000 $\mathrm{ft}^{3} / \mathrm{s}\left(2,830 \mathrm{~m}^{3} / \mathrm{s}\right) \mathrm{Sept}$. 10, 1976 , gage height, $19.0 \mathrm{ft}(5.79 \mathrm{~m})$, from rating curve extended above $11 \mathrm{ft}^{3} / \mathrm{s}\left(0.31 \mathrm{~m}^{3} / \mathrm{s}\right)$ on basis of contractedopening measurement combined with road overflow at peak gage height; no flow for some months in each year.

EXTRENES FOR CURRENT YEAR. - Peak discharges above base of $200 \mathrm{ft}^{3} / \mathrm{s}\left(5.66 \mathrm{~m}^{3} / \mathrm{s}\right)$ and maximum $(*)$, from rating curve extended as explained above:

\begin{tabular}{|c|c|c|c|c|c|c|c|}
\hline Date & Time & $\begin{array}{c}\text { Discharge } \\
\left(\mathrm{ft}^{3} / \mathrm{s}\right)\left(\mathrm{m}^{3} / \mathrm{s}\right)\end{array}$ & $\begin{array}{l}\text { Gage height } \\
\text { (ft) }\end{array}$ & Date & Time & $\begin{array}{c}\text { Discharge } \\
\left(\mathrm{ft}^{3} / \mathrm{s}\right)\left(\mathrm{m}^{3} / \mathrm{s}\right)\end{array}$ & $\begin{array}{r}\text { Gage height } \\
(\mathrm{ft})\end{array}$ \\
\hline Feb. $\quad 9$ & 0100 & 81.00 & 3.136 & Sept. 10 & Unknown & $* 100,000$ & 19.0 \\
\hline July 26 & 1800 & 48.99 & 2.780 & Sept. 23 & 2315 & 11300 & 11.6 \\
\hline
\end{tabular}

Minimum daily discharge, no flow many months.

DISCHARGE, IN CUBIC FEET PER SECOND, HATER YEAR OCTOBER 1975 TO SEPTEMBER 1976

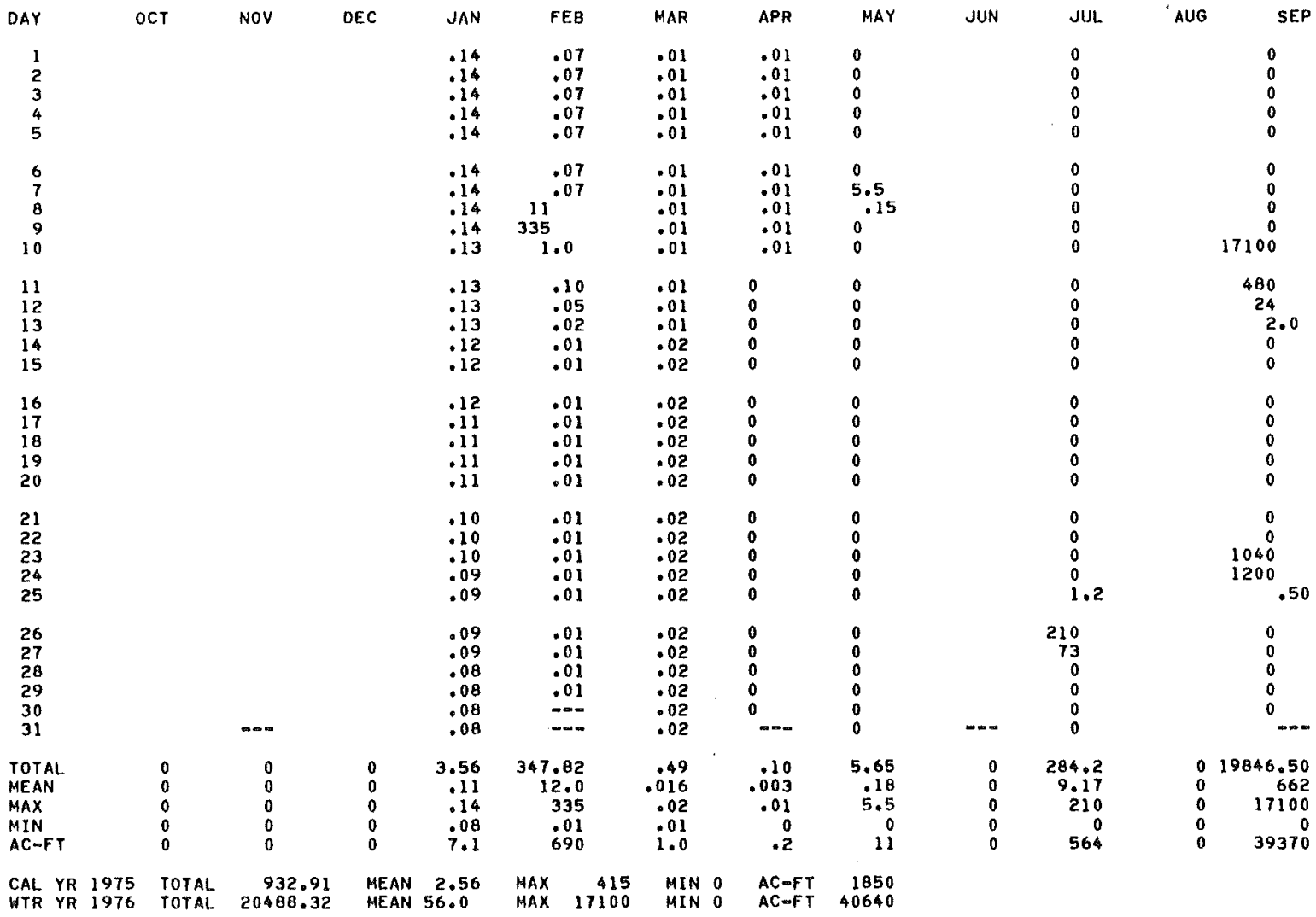




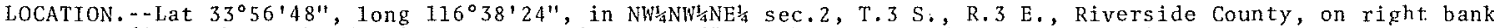

$1.5 \mathrm{mi}(2.4 \mathrm{~km})$ north of White Water, and $3.5 \mathrm{mi}(5.6 \mathrm{~km})$ upstream from San Gorgonio River.

DRAINAGE AREA. $-57.5 \mathrm{mi}^{2}\left(148.9 \mathrm{~km}^{2}\right)$, revised.

WATER-DISCHARGE RECORDS

PERIOD OF RECORD.--October 1948 to current yeat.

GAGE.- Water-stage recorder on river; water-stage recorder and Cipolletti weir on diversion 500 ft (152 $\mathrm{m}$ ) downstream. Datum of river gage is $1,610 \mathrm{ft}(491 \mathrm{ml})$ above mean sea leve1. Feb. 24,1950, to

Sept. 30, 1952, and Apr. 13, 1960, to June 19, 1968, supplementary gages at different sites and datums

within $200 \mathrm{ft}(61 \mathrm{~m})$ of base gage. Since Aug. 12, i969, supplementary gage at site $1.5 \mathrm{mi}$ (2.4 km) downstream at different datum.

REMARKS.--Records poor. No gage-height record Feb. 9-10, Feb. 28 to Mar. 8, April 1-30, July $1-30$. White Water Mutual Water Co. diverts 50 ft $(15 \mathrm{~m})$ downstream. Monthly discharge is combined with flow from infiltration line that bypasses station. No regulation above station. Water is diverted out of basin about 15 mi (24 km) upstream to powerplants in San Gorgonio River basin and then to an area north of Banning for irrigation.

One smal1 diversion for domestic use and one for irrigation are made 2 to $3 \mathrm{mi}(3.2 \mathrm{to} 4.8 \mathrm{~km}) \mathrm{upstream}$.

COOPERATION.--Records of bypass in infiltration line were furnished by White Water Mutual Water Co.; records of diversion, $15 \mathrm{mi}(24 \mathrm{~km})$ upstream, were furnished by Southern California Edison Co.

AVERAGE DISCHARGE.--River on $1 \mathrm{y}: 28$ years, $15.6 \mathrm{ft}^{3} / \mathrm{s}\left(0.442 \mathrm{~m}^{3} / \mathrm{s}\right), 11,300 \mathrm{acre}-\mathrm{ft} / \mathrm{yr}(13.9 \mathrm{hm} / \mathrm{yr})$ Combined river and infiltration line: 27 years (water years $1950-76), 17.1 \mathrm{ft}^{3} / \mathrm{s}^{\left(0.484 \mathrm{~m}^{3} / \mathrm{s}\right)}$ 12,390 acre-ft/yr $\left(15.3 \mathrm{hm}^{3} / \mathrm{yr}\right)$.

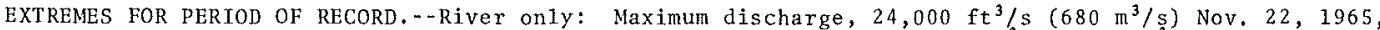
gage height, $13.60 \mathrm{ft}(4.145 \mathrm{~m})$, from rating curve extended above $660 \mathrm{ft}^{3} / \mathrm{s}$ (18.7 $\left.\mathrm{m}^{3} / \mathrm{s}\right)$ on basis of field estimate of maximum flow; no flow at times in some years.

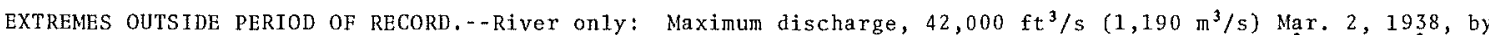
slope-area measurement of peak flow, at site $2.5 \mathrm{mi}(4.0 \mathrm{~km})$ upstream, drainage area, $51.4 \mathrm{mi}^{2}\left(133 \mathrm{~km}^{2}\right)$.

EXTREMES FOR CURRENT YEAR,--River only: Peak discharges above base of $100 \mathrm{ft}^{3} / \mathrm{s}\left(2.83 \mathrm{~m}^{3} / \mathrm{s}\right)$ and $\mathrm{maximum}^{(*)}$, based on slope-conveyance measurement of peak flow:

\begin{tabular}{lrrrrr} 
Date & Time & \multicolumn{2}{c}{ Discharge } & \multicolumn{2}{c}{ Gage height } \\
& $\left(\mathrm{ft}^{3} / \mathrm{s}\right)$ & $\left(\mathrm{m}^{3} / \mathrm{s}\right)$ & $(\mathrm{ft})$ & $(\mathrm{m})$ \\
Feb. 8 & 1830 & 218 & 6.17 & 13.76 & 4.194 \\
Sept. 10 & 2100 & $* 477$ & 13.5 & 15.66 & 4.773
\end{tabular}

Minimum daily discharge, $0.90 \mathrm{ft}^{3} / \mathrm{s}\left(0.026 \mathrm{~m}^{3} / \mathrm{s}\right)$ Sept. $28-30$.

OISCHARGE, IN CUBIC FEET PER SECOND, HATER YEAR OCTOBER 1975 TO SEPTEMBER 1976 MEAN VALUES

\begin{tabular}{|c|c|c|c|c|c|c|c|c|c|c|c|c|}
\hline DAY & OCT & NOV & DEC & JAN & FEB & MAR & APR & MAY & JUN & JUL & AUO & SEP \\
\hline $\begin{array}{l}1 \\
2 \\
3 \\
4 \\
5\end{array}$ & $\begin{array}{l}6.0 \\
6.0 \\
5.9 \\
5.9 \\
5.8\end{array}$ & $\begin{array}{l}7.7 \\
8.0 \\
7.7 \\
8.3 \\
8.3\end{array}$ & $\begin{array}{l}9.0 \\
9.0 \\
9.0 \\
9.0 \\
9.0\end{array}$ & $\begin{array}{l}5.9 \\
5.9 \\
5.9 \\
5.9 \\
5.9\end{array}$ & $\begin{array}{l}5.5 \\
5.3 \\
5.9 \\
6.1 \\
6.5\end{array}$ & $\begin{array}{l}45 \\
15 \\
55 \\
20 \\
10\end{array}$ & $\begin{array}{l}5.0 \\
5.0 \\
5.0 \\
4.5 \\
4.5\end{array}$ & $\begin{array}{l}4.0 \\
4.0 \\
4.0 \\
3.5 \\
3.5\end{array}$ & $\begin{array}{l}3.0 \\
3.0 \\
3.0 \\
3.0 \\
2.5\end{array}$ & $\begin{array}{l}1.2 \\
1.2 \\
1.2 \\
1.2 \\
1.2\end{array}$ & $\begin{array}{l}1.0 \\
1.0 \\
1.0 \\
1.0 \\
1.0\end{array}$ & $\begin{array}{l}1.0 \\
1.0 \\
1.0 \\
1.0 \\
1.0\end{array}$ \\
\hline $\begin{array}{r}6 \\
7 \\
8 \\
9 \\
10\end{array}$ & $\begin{array}{l}5.8 \\
5.7 \\
5.7 \\
5.7 \\
5.5\end{array}$ & $\begin{array}{l}7.1 \\
6.3 \\
6.5 \\
6.5 \\
6.5\end{array}$ & $\begin{array}{l}9.0 \\
9.0 \\
9.0 \\
9.0 \\
9.0\end{array}$ & $\begin{array}{l}5.9 \\
5.9 \\
5.9 \\
5.9 \\
5.9\end{array}$ & $\begin{array}{r}28 \\
96 \\
105 \\
20 \\
15\end{array}$ & $\begin{array}{l}7.0 \\
6.5 \\
6.0 \\
6.0 \\
5.5\end{array}$ & $\begin{array}{l}4.5 \\
4.0 \\
4.0 \\
4.0 \\
4.0\end{array}$ & $\begin{array}{l}3.5 \\
3.5 \\
3.5 \\
3.5 \\
3.5\end{array}$ & $\begin{array}{l}2.5 \\
2.5 \\
2.5 \\
2.5 \\
2.5\end{array}$ & $\begin{array}{l}1.2 \\
1.2 \\
1.2 \\
1.2 \\
1.2\end{array}$ & $\begin{array}{l}1.0 \\
1.0 \\
1.0 \\
1.0 \\
1.0\end{array}$ & $\begin{array}{r}1.0 \\
1.0 \\
1.0 \\
1.5 \\
140\end{array}$ \\
\hline $\begin{array}{l}11 \\
12 \\
13 \\
14 \\
15\end{array}$ & $\begin{array}{l}5.3 \\
5.7 \\
5.9 \\
5.7 \\
5.3\end{array}$ & $\begin{array}{l}6.5 \\
6.5 \\
7.4 \\
8.3 \\
7.4\end{array}$ & $\begin{array}{l}9.0 \\
9.5 \\
9.9 \\
10 \\
12\end{array}$ & $\begin{array}{l}5.7 \\
5.7 \\
5.5 \\
5.5 \\
5.5\end{array}$ & $\begin{array}{l}10 \\
9.0 \\
6.0 \\
7.5 \\
7.0\end{array}$ & $\begin{array}{l}5.5 \\
5.5 \\
5.0 \\
5.0 \\
5.0\end{array}$ & $\begin{array}{l}4.0 \\
4.0 \\
4.0 \\
4.0 \\
6.0\end{array}$ & $\begin{array}{l}3.5 \\
3.5 \\
3.5 \\
3.5 \\
3.5\end{array}$ & $\begin{array}{l}2.0 \\
2.0 \\
2.0 \\
2.0 \\
2.0\end{array}$ & $\begin{array}{l}1.2 \\
1.2 \\
1.2 \\
1.2 \\
1.2\end{array}$ & $\begin{array}{l}1.0 \\
1.0 \\
1.0 \\
1.0 \\
1.0\end{array}$ & $\begin{array}{r}128 \\
10 \\
5.0 \\
3.0 \\
2.0\end{array}$ \\
\hline $\begin{array}{l}16 \\
17 \\
18 \\
19 \\
20\end{array}$ & $\begin{array}{l}5.5 \\
6.0 \\
6.1 \\
5.9 \\
5.9\end{array}$ & $\begin{array}{l}7.1 \\
7.1 \\
7.4 \\
7.4 \\
7.4\end{array}$ & $\begin{array}{c}11 \\
9.9 \\
8.9 \\
8.6 \\
8.6\end{array}$ & $\begin{array}{l}5.5 \\
5.3 \\
5.3 \\
5.3 \\
5.7\end{array}$ & $\begin{array}{l}6.5 \\
6.0 \\
5.5 \\
5.5 \\
5.5\end{array}$ & $\begin{array}{l}4.5 \\
4.5 \\
4.5 \\
4.5 \\
4.5\end{array}$ & $\begin{array}{l}6.5 \\
5.5 \\
5.0 \\
5.0 \\
5.0\end{array}$ & $\begin{array}{l}3.0 \\
3.0 \\
3.0 \\
3.0 \\
3.0\end{array}$ & $\begin{array}{l}1.5 \\
1.5 \\
1.5 \\
1.5 \\
1.5\end{array}$ & $\begin{array}{l}1.2 \\
1.1 \\
1.0 \\
1.0 \\
1.0\end{array}$ & $\begin{array}{l}1.0 \\
1.0 \\
1.0 \\
1.0 \\
1.0\end{array}$ & $\begin{array}{l}1.5 \\
1.4 \\
1.4 \\
1.4 \\
1.4\end{array}$ \\
\hline $\begin{array}{l}21 \\
22 \\
23 \\
24 \\
25\end{array}$ & $\begin{array}{l}5.3 \\
5.3 \\
4.7 \\
4.9 \\
4.9\end{array}$ & $\begin{array}{l}7.4 \\
7.7 \\
7.7 \\
7.1 \\
7.1\end{array}$ & $\begin{array}{l}8.9 \\
11 \\
11 \\
10 \\
7.1\end{array}$ & $\begin{array}{l}5.9 \\
5.9 \\
5.9 \\
5.9 \\
5.7\end{array}$ & $\begin{array}{l}5.5 \\
5.5 \\
5.5 \\
5.5 \\
5.5\end{array}$ & $\begin{array}{l}4.5 \\
5.0 \\
5.0 \\
5.0 \\
5.5\end{array}$ & $\begin{array}{l}5.0 \\
4.5 \\
4.5 \\
4.5 \\
4.5\end{array}$ & $\begin{array}{l}3.0 \\
3.0 \\
3.0 \\
3.0 \\
3.0\end{array}$ & $\begin{array}{l}1.5 \\
1.5 \\
1.5 \\
1.5 \\
1.5\end{array}$ & $\begin{array}{l}1.0 \\
1.0 \\
1.0 \\
1.0 \\
1.0\end{array}$ & $\begin{array}{l}1.0 \\
1.0 \\
1.0 \\
1.0 \\
1.0\end{array}$ & $\begin{array}{l}1.4 \\
1.1 \\
1.1 \\
5.0 \\
2.0\end{array}$ \\
\hline $\begin{array}{l}26 \\
27 \\
28 \\
29 \\
30 \\
31\end{array}$ & $\begin{array}{r}4.5 \\
4.3 \\
4.5 \\
5.3 \\
8.4 \\
14\end{array}$ & $\begin{array}{r}7.1 \\
9.3 \\
13 \\
9.0 \\
9.0 \\
-0.0\end{array}$ & $\begin{array}{l}6.5 \\
6.3 \\
5.7 \\
5.7 \\
5.7 \\
5.7\end{array}$ & $\begin{array}{l}5.7 \\
5.7 \\
5.9 \\
6.1 \\
5.9 \\
5.7\end{array}$ & $\begin{array}{l}5.0 \\
5.0 \\
5.0 \\
5.0 \\
=- \\
-\infty\end{array}$ & $\begin{array}{l}5.5 \\
5.5 \\
5.5 \\
5.5 \\
5.5 \\
5.0\end{array}$ & $\begin{array}{l}4.5 \\
4.0 \\
4.0 \\
4.0 \\
4.0 \\
-\infty\end{array}$ & $\begin{array}{l}3.0 \\
3.0 \\
3.0 \\
3.0 \\
3.0 \\
3.0\end{array}$ & $\begin{array}{l}1.2 \\
1.2 \\
1.2 \\
1.2 \\
1.2 \\
-\infty+\infty\end{array}$ & $\begin{array}{l}1.0 \\
1.0 \\
1.0 \\
1.0 \\
1.0 \\
1.0\end{array}$ & $\begin{array}{l}1.0 \\
1.0 \\
1.0 \\
1.0 \\
1.0 \\
1.0\end{array}$ & $\begin{array}{r}1.0 \\
1.0 \\
.90 \\
.90 \\
.90 \\
0=\end{array}$ \\
\hline $\begin{array}{l}\text { TOTAL } \\
\text { MEAN } \\
\text { MAX } \\
\text { MIN } \\
\text { AC=FT }\end{array}$ & $\begin{array}{r}181.4 \\
5.85 \\
14 \\
4.3 \\
360\end{array}$ & $\begin{array}{r}229.8 \\
7.66 \\
13 \\
6.3 \\
456\end{array}$ & $\begin{array}{r}271.0 \\
8.74 \\
12 \\
5.7 \\
538\end{array}$ & $\begin{array}{r}178,3 \\
5.75 \\
6.1 \\
5.3 \\
354\end{array}$ & $\begin{array}{r}411.3 \\
14.2 \\
105 \\
5.0 \\
816\end{array}$ & $\begin{array}{r}282.0 \\
9.10 \\
55 \\
4.5 \\
559\end{array}$ & $\begin{array}{r}137.0 \\
4.57 \\
6.5 \\
4.0 \\
272\end{array}$ & $\begin{array}{r}102.0 \\
3.29 \\
4.0 \\
3.0 \\
202\end{array}$ & $\begin{array}{r}58.0 \\
1.93 \\
3.0 \\
1.2 \\
115\end{array}$ & $\begin{array}{r}34.3 \\
1.11 \\
1.2 \\
1.0 \\
68\end{array}$ & $\begin{array}{r}31.0 \\
1.00 \\
1.0 \\
1.0 \\
61\end{array}$ & $\begin{array}{r}319.90 \\
10.7 \\
140 \\
890 \\
635\end{array}$ \\
\hline $\begin{array}{l}\text { (a) } \\
\text { (b) }\end{array}$ & $\begin{array}{r}410 \\
72\end{array}$ & $\begin{array}{r}512 \\
71\end{array}$ & $\begin{array}{r}598 \\
80\end{array}$ & $\begin{array}{r}423 \\
72\end{array}$ & $\begin{array}{r}866 \\
47\end{array}$ & $\begin{array}{r}611 \\
72\end{array}$ & $\begin{array}{r}312 \\
64\end{array}$ & $\begin{array}{l}262 \\
104\end{array}$ & $\begin{array}{r}170 \\
70\end{array}$ & $\begin{array}{r}101 \\
53\end{array}$ & $\begin{array}{l}97 \\
53\end{array}$ & $\begin{array}{r}675 \\
37\end{array}$ \\
\hline
\end{tabular}

CAL YR 1979 TOTAL 2593.70 MEAN 7.11 MAX 49 MIN 3.8 AC-FT $5140 \quad$ AC-FT a 5774

WTR YR 1976 TOTAL 2236.00 MEAN 6.11 MAX 140 MIN .90 AC-FT $44 \$ 0$ AC-FT a 5037 
10256000 WHITEWATER RIVER AT WHITE WATER, CA--Continued

PERIOD OF RECORD.-

CHEMICAL ANALYSES: Water year 1967 to current year.

COOPERATION, - Chemical-quality records were furnished by California Department of Water Resources.

CHEMICAL ANALYSES, WATER YEAR OCTOBER 1975 TO SEPTEMBER 1976

\begin{tabular}{|c|c|c|c|c|c|c|c|c|}
\hline DATE & TIME & $\begin{array}{l}\text { SPE- } \\
\text { CIFIC } \\
\text { CON- } \\
\text { OUCT- } \\
\text { ANCE } \\
\text { (MICRO- } \\
\text { MHOS) }\end{array}$ & $\begin{array}{c}\text { PH } \\
\text { (UNITS) }\end{array}$ & $\begin{array}{l}\text { TEMPER- } \\
\text { ATURE } \\
\text { (DEG C) }\end{array}$ & $\begin{array}{l}\text { TUR- } \\
\text { BID- } \\
\text { ITY } \\
\text { (JTU) }\end{array}$ & $\begin{array}{l}\text { DIS- } \\
\text { SOLVED } \\
\text { OXYGEN } \\
\text { (MG/L) }\end{array}$ & $\begin{array}{l}\text { HARD- } \\
\text { NESS } \\
(C A, M G) \\
(M G / L)\end{array}$ & $\begin{array}{l}\text { NON- } \\
\text { CAR- } \\
\text { GONATE } \\
\text { HARD- } \\
\text { NESS } \\
(M G / L)\end{array}$ \\
\hline & & & & & & & & \\
\hline
\end{tabular}

\begin{tabular}{|c|c|c|c|c|c|c|c|c|}
\hline $\begin{array}{l}\text { DEC } \\
15 \ldots . \\
\text { MAR }\end{array}$ & 1000 & 259 & 8.2 & 9.0 & 10 & 10.7 & 180 & 18 \\
\hline$\underset{\text { JUN }}{22} \cdots$ & 0900 & 350 & 8.0 & 14.5 & 30 & 9.4 & 187 & 18 \\
\hline $21 \ldots$ & 0900 & 400 & 7.6 & 19.5 & 2 & 8.0 & 189 & 13 \\
\hline
\end{tabular}

\begin{tabular}{|c|c|c|c|c|c|c|c|c|c|}
\hline DATE & $\begin{array}{l}\text { DIS- } \\
\text { SOLVED } \\
\text { CAL- } \\
\text { CIUM } \\
\text { (CA) } \\
\text { (MG/L) }\end{array}$ & $\begin{array}{l}\text { DIS- } \\
\text { SOLVED } \\
\text { MAG- } \\
\text { NE- } \\
\text { SIUH } \\
\text { (MG) } \\
\text { (MG/L) }\end{array}$ & $\begin{array}{l}\text { DIS- } \\
\text { SOLVED } \\
\text { SODIUM } \\
\text { (NA) } \\
\text { (MG/L) }\end{array}$ & $\begin{array}{r}\text { PERCENT } \\
\text { SODIUM }\end{array}$ & $\begin{array}{r}\text { SOOIUM } \\
\text { AD- } \\
\text { SORP- } \\
\text { TION } \\
\text { RATIO }\end{array}$ & $\begin{array}{l}\text { DIS - } \\
\text { SOLVED } \\
\text { PO- } \\
\text { TAS- } \\
\text { SIUM } \\
\text { (K) } \\
\text { (MG/L) }\end{array}$ & $\begin{array}{l}\text { BICAR- } \\
\text { BONATE } \\
\text { (HCO3) } \\
\text { (MO/L) }\end{array}$ & $\begin{array}{l}\text { CAR- } \\
\text { BONATE } \\
\text { (CO3) } \\
(M G / L)\end{array}$ & $\begin{array}{l}\text { ALKA- } \\
\text { LINITY } \\
\text { AS } \\
\text { CACO3 } \\
\text { (MG/L) }\end{array}$ \\
\hline $\begin{array}{l}\text { OEC } \\
15 \ldots \\
\text { MAR }\end{array}$ & 54 & 11 & 13 & 13 & .4 & 5.5 & 198 & 0 & 162 \\
\hline$\underset{\text { JUN }}{22} \cdots$ & 54 & 12 & 13 & 13 & .4 & $4 \cdot 3$ & 206 & 0 & 169 \\
\hline $21 \ldots$ & 54 & 13 & 15 & 14 & .5 & 4.7 & 215 & 0 & 176 \\
\hline
\end{tabular}

\begin{tabular}{|c|c|c|c|c|c|c|c|c|}
\hline DATE & $\begin{array}{c}\text { CARBON } \\
\text { OIOXIDE } \\
\text { (COZ) } \\
\text { (MG/L) }\end{array}$ & $\begin{array}{l}\text { DIS- } \\
\text { SOLVED } \\
\text { SULFATE } \\
\text { (SO4) } \\
\text { (HG/L) }\end{array}$ & $\begin{array}{l}\text { DIS- } \\
\text { SOLVED } \\
\text { CHLO- } \\
\text { RIOE } \\
\text { (CL) } \\
\text { (MG/L) }\end{array}$ & $\begin{array}{l}\text { DIS- } \\
\text { SOLVED } \\
\text { FLUO- } \\
\text { RIDE } \\
\text { (F) } \\
(M G / L)\end{array}$ & $\begin{array}{l}\text { DIS- } \\
\text { SOLVED } \\
\text { SOLIDS } \\
\text { (RESI- } \\
\text { DUE AT } \\
180 \text { C) } \\
(M G / L)\end{array}$ & $\begin{array}{l}\text { DIS- } \\
\text { SOLVED } \\
\text { SOLIDS } \\
\text { (TONS } \\
\text { PER } \\
\text { AC-FT) }\end{array}$ & $\begin{array}{c}\text { TOTAL } \\
\text { NITRATE } \\
\text { (N) } \\
\text { (MG/L) }\end{array}$ & $\begin{array}{c}\text { DIS- } \\
\text { SOLVED } \\
\text { BORON } \\
\text { (B) } \\
\text { (UG/L) }\end{array}$ \\
\hline $\begin{array}{l}\text { DEC } \\
15 \ldots\end{array}$ & 2.0 & 40 & 3.9 & 1.0 & 2598 & 3.53 & .74 & 0 \\
\hline $\begin{array}{l}\text { MAR } \\
22 \cdot \cdots \\
\text { JUN }\end{array}$ & 3.3 & 39 & 2.8 & .9 & 226 & .31 & .84 & 40 \\
\hline $21 \ldots$ & 8.6 & 36 & 5.0 & 1.1 & 239 & .33 & .34 & 0 \\
\hline
\end{tabular}




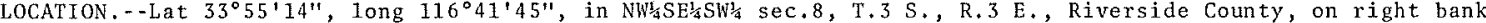
$0.2 \mathrm{mi}(0.3 \mathrm{~km})$ south of Interstate Highway 10 , and $3.4 \mathrm{mi}(5.5 \mathrm{~km})$ west of town of White Water.

DRAINAGE AREA, $\cdots+154 \mathrm{mi}^{2}\left(399 \mathrm{~km}^{2}\right)$.

PERIOD OF RECORD, - February 1966 to current year.

GAGE. - Water-stage recorder. A1titude of gage is $1,320 \mathrm{ft}(402 \mathrm{~m})$, from topographic map. Prior to Mar. 19, 1968 , flood-hydrograph recorder.

REMARKS.--Records poor. No regulation or diversion above station.

AVERAGE DISCHARGE. - - 10 years, $1.35 \mathrm{ft}^{3} / \mathrm{s}\left(0.038 \mathrm{~m}^{3} / \mathrm{s}\right), 980$ acre-ft/yr $\left(1.21 \mathrm{hm}^{3} / \mathrm{yr}\right)$.

EXTREMES FOR PERIOD OF RECORD. - Maximum discharge, $7,250 \mathrm{ft}^{3} / \mathrm{s}\left(205 \mathrm{~m}^{3} / \mathrm{s}\right) \mathrm{Jan}, 25,1969$, gage height, $6.0 \mathrm{ft}$

$(1.83 \mathrm{~m})$, from floodmarks, on basis of slope-area measurement of maximum flow; no flow most of each year.

EXTREMES OUTSIDE PERIOD OF RECORD, - -Flood of Nov, 23, 1965, reached a stage of $6.10 \mathrm{ft}(1.859 \mathrm{~m})$, from floodmarks, discharge, $4,500 \mathrm{ft}^{3} / \mathrm{s}\left(127 \mathrm{~m}^{3} / \mathrm{s}\right)$, on basis of slope-area measurement.

EXTREMES FOR CURRENT YEAR.--Peak discharges above base of $50 \mathrm{ft}^{3} / \mathrm{s}\left(1.42 \mathrm{~m}^{3} / \mathrm{s}\right)$ and maximum $(*)$, on basis of slope-conveyance measurement of peak flow:

\begin{tabular}{|c|c|c|c|c|c|c|c|c|c|c|c|}
\hline Date & Time & $\begin{aligned} \operatorname{Disc} \\
\left(\mathrm{ft}^{3} / \mathrm{s}\right.\end{aligned}$ & $\begin{array}{l}x g e \\
\left(\mathrm{~m}^{3} / \mathrm{s}\right)\end{array}$ & $\begin{array}{l}\text { Gage } \\
(\mathrm{ft})\end{array}$ & 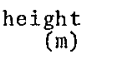 & Date & Time & $\begin{array}{r}\operatorname{Disc} \\
\left(\mathrm{ft}^{3} / \mathrm{s}\right.\end{array}$ & $\begin{array}{l}\mathrm{rge} \\
\left(\mathrm{m}^{3} / \mathrm{s}\right)\end{array}$ & $\begin{array}{l}\text { Gage } \\
\text { (ft })\end{array}$ & $\begin{array}{r}\text { height } \\
(\mathrm{m})\end{array}$ \\
\hline $\begin{array}{cc}\text { Feb. } & 9 \\
\text { Mar. } & \end{array}$ & $\begin{array}{l}0330 \\
2000\end{array}$ & $\begin{array}{r}135 \\
66\end{array}$ & $\begin{array}{l}3.82 \\
1.87\end{array}$ & $\begin{array}{l}2.50 \\
2.00\end{array}$ & $\begin{array}{l}0.762 \\
0.610\end{array}$ & $\begin{array}{l}\text { Sept. } 10 \\
\text { Sept. } 24\end{array}$ & $\begin{array}{l}\text { Unknown } \\
\text { Unknown }\end{array}$ & $\begin{array}{r}* 1680 \\
890\end{array}$ & $\begin{array}{l}47.6 \\
25.2\end{array}$ & $\begin{array}{l}3.77 \\
3.12\end{array}$ & $\begin{array}{l}1.149 \\
0.951\end{array}$ \\
\hline
\end{tabular}

Minimum daily discharge, no f1ow most of year.

DISCHARGE, IN CUBIC FEET PER SECOND, WATER YEAR OCTOBER 1975 TO SEPTEMBER 1976 MEAN VALUES

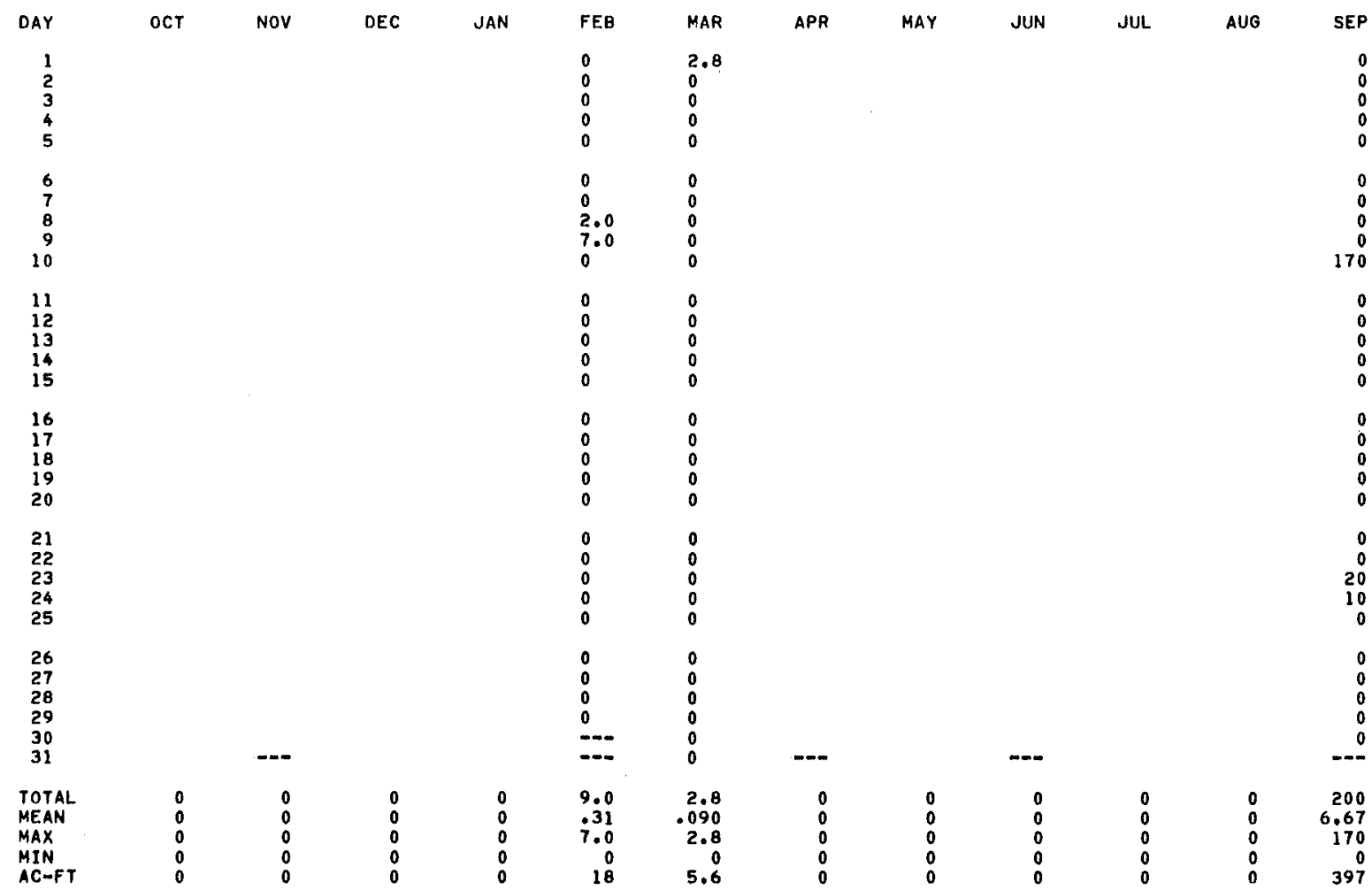

CAL YR 1975 TOTAL 22.72 MEAN .062 MAX 17 MIN O AC-FT 45 
10256500 SNOW CREEK NEAR WHITE WATER, CA

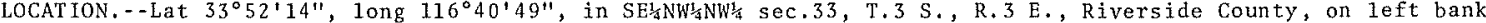
$300 \mathrm{ft}(91 \mathrm{~m})$ upstream from Southern Pacific Railroad diversion dam, 300 ft (91 m) downstream from East Fork, $2.5 \mathrm{mi}(4.0 \mathrm{~km})$ upstream from mouth, and $4.4 \mathrm{mi}(7.1 \mathrm{~km})$ southwest of white Water.

DRAINAGE AREA, $--10.8 \mathrm{mi}^{2}\left(28.0 \mathrm{~km}^{2}\right)$.

PERIOD OF RECORD, - -July to December 1921, May 1922 to February 1927, December 1927 to September 1931 , October 1959 to current year. Yearly discharge only for 1930 , published in WSp 1314.

GAGE, - Water-stage recorder. Altitude of gage is $2,000 \mathrm{ft}(610 \mathrm{~m})$, from topographic map. Prior to September 1931 , at various sites within $500 \mathrm{ft}(152 \mathrm{~m})$ of present site at different datums. September 1931 to Oct. 6 , 1970 , at site $250 \mathrm{ft}(76 \mathrm{~m})$ downstream at datum $15.9 \mathrm{ft}(4.85 \mathrm{~m})$ lower.

REMARKS.--Records poor. No gage-height record Dec. 22 to Jan. 22, Sept. 10-30, No regulation or diversion above station. Palm springs water Co. diverts $50 \mathrm{ft}(15 \mathrm{~m})$ downstream, generally taking the entire base flow.

AVERAGE DISCHARGE. - -24 years (water years $1923-26,1929-31,1960-76), 8.09 \mathrm{ft}^{3} / \mathrm{s}\left(0.229 \mathrm{~m}^{3} / \mathrm{s}\right), 5,860 \mathrm{acre}-\mathrm{ft} / \mathrm{yr}$ $\left(7.23 \mathrm{hm}^{3} / \mathrm{yr}\right)$.

EXTREMES FOR PERIOD OF RECORD. - Maximum discharge, $13,000 \mathrm{ft}^{3} / \mathrm{s}\left(368 \mathrm{~m}^{3} / \mathrm{s}\right) \mathrm{Jan}, 25,1969, \mathrm{gage}$ height, $27.4 \mathrm{ft}$ $(8.32 \mathrm{~m})$, from floodmarks, present datum, from rating curve extended above $55 \mathrm{ft} / \mathrm{s}$ ( $1.56 \mathrm{~m} / \mathrm{s}$ ) on basis of slope-area measurement of maximum flow; minimum daily, $2.1 \mathrm{ft} / \mathrm{s}\left(0.059 \mathrm{~m}^{3} / \mathrm{s}\right) \mathrm{Jun} 23-27,5 \mathrm{st}$. 5-11, 1961 .

EXTREMES FOR CURRENT YEAR. - -Peak discharges above base of $50 \mathrm{ft}^{3} / \mathrm{s}\left(1.42 \mathrm{~m}^{3} / \mathrm{s}\right)$ and maximum (*), from rating

curve extended above $100 \mathrm{ft}^{3} / \mathrm{s}\left(2.83 \mathrm{~m}^{3} / \mathrm{s}\right)$ on basis of area-velocity measurenent of peak flow at gage height 21.88 ft $(6.669 \mathrm{~m})$ :

\begin{tabular}{|c|c|c|c|c|}
\hline Date & Time & $\begin{array}{c}\text { Discharge } \\
\left(\mathrm{ft}^{3} / \mathrm{s}\right)\left(\mathrm{m}^{3} / \mathrm{s}\right)\end{array}$ & $\begin{array}{l}\text { Gage } 1 \\
(\mathrm{ft})\end{array}$ & $\begin{array}{l}\text { leight } \\
(\mathrm{m})\end{array}$ \\
\hline $\begin{array}{l}\text { Feb. } \\
\text { Sept. } 10\end{array}$ & $\begin{array}{l}1145 \\
\text { Unknown }\end{array}$ & $\begin{array}{l}4.729 \\
113.3\end{array}$ & $\begin{array}{l}18.21 \\
21.88\end{array}$ & $\begin{array}{l}5.550 \\
6.669\end{array}$ \\
\hline
\end{tabular}

Minimum daily discharge, $2.8 \mathrm{ft}^{3} / \mathrm{s}\left(0.079 \mathrm{~m}^{3} / \mathrm{s}\right)$ Aug. $8,10-14,28$.

DISCHARGE, IN CUBIC FEET PER SECOND, WATER YEAR OCTOBER 1975 TO SEPTEMBER 1976 MEAN VALUES

\begin{tabular}{|c|c|c|c|c|c|c|c|c|c|c|c|c|}
\hline DAY & OCT & NOV & DEC & JAN & FEB & MAR & APR & MAY & JUN & JUL & AUG & SEP \\
\hline $\begin{array}{l}1 \\
2 \\
3 \\
4 \\
5\end{array}$ & $\begin{array}{l}3.0 \\
3.0 \\
3.0 \\
3.0 \\
3.0\end{array}$ & $\begin{array}{l}3.6 \\
3.4 \\
3.3 \\
3.3 \\
3.3\end{array}$ & $\begin{array}{l}4.5 \\
5.0 \\
4.5 \\
4.3 \\
4.0\end{array}$ & $\begin{array}{l}3.6 \\
3.6 \\
3.6 \\
3.6 \\
3.6\end{array}$ & $\begin{array}{l}3.4 \\
3.4 \\
3.6 \\
4.8 \\
6.7\end{array}$ & $\begin{array}{l}40 \\
21 \\
25 \\
11 \\
8.5\end{array}$ & $\begin{array}{l}5.1 \\
5.1 \\
5.1 \\
5.3 \\
5.1\end{array}$ & $\begin{array}{l}7.3 \\
8.1 \\
8.6 \\
8.0 \\
8.1\end{array}$ & $\begin{array}{l}6.4 \\
6.3 \\
6.3 \\
5.9 \\
5.7\end{array}$ & $\begin{array}{l}3.7 \\
3.6 \\
3.5 \\
3.5 \\
3.5\end{array}$ & $\begin{array}{l}3.1 \\
3.0 \\
3.0 \\
3.0 \\
3.0\end{array}$ & $\begin{array}{l}3.0 \\
3.0 \\
3.2 \\
3.3 \\
3.5\end{array}$ \\
\hline $\begin{array}{r}6 \\
7 \\
8 \\
9 \\
10\end{array}$ & $\begin{array}{l}3.0 \\
3.0 \\
3.0 \\
3.0 \\
3.0\end{array}$ & $\begin{array}{l}3.3 \\
3.3 \\
3.3 \\
3.3 \\
3.3\end{array}$ & $\begin{array}{l}4.0 \\
4.0 \\
4.0 \\
3.8 \\
3.8\end{array}$ & $\begin{array}{l}3.6 \\
3.6 \\
3.5 \\
3.5 \\
3.5\end{array}$ & $\begin{array}{l}9.9 \\
8.2 \\
81 \\
28 \\
12\end{array}$ & $\begin{array}{l}7.0 \\
6.5 \\
6.5 \\
6.4 \\
6.2\end{array}$ & $\begin{array}{l}5.0 \\
4.9 \\
4.9 \\
4.8 \\
4.9\end{array}$ & $\begin{array}{l}8.1 \\
17 \\
12 \\
11 \\
10\end{array}$ & $\begin{array}{l}5.5 \\
5.4 \\
5.3 \\
5.3 \\
5.4\end{array}$ & $\begin{array}{l}3.6 \\
3.5 \\
3.6 \\
3.5 \\
3.5\end{array}$ & $\begin{array}{l}2.9 \\
2.9 \\
2.8 \\
2.9 \\
2.9\end{array}$ & $\begin{array}{r}3.8 \\
3.6 \\
3.5 \\
3.6 \\
460\end{array}$ \\
\hline $\begin{array}{l}11 \\
12 \\
13 \\
14 \\
15\end{array}$ & $\begin{array}{l}3.0 \\
3.0 \\
3.0 \\
3.0 \\
3.0\end{array}$ & $\begin{array}{l}3.3 \\
3.3 \\
3.3 \\
3.3 \\
3.3\end{array}$ & $\begin{array}{l}3.8 \\
3.8 \\
3.8 \\
3.8 \\
3.8\end{array}$ & $\begin{array}{l}3.5 \\
3.4 \\
3.4 \\
3.4 \\
3.4\end{array}$ & $\begin{array}{l}8.5 \\
6.1 \\
5.1 \\
5.5 \\
5.3\end{array}$ & $\begin{array}{l}6.0 \\
5.8 \\
5.7 \\
5.7 \\
5.6\end{array}$ & $\begin{array}{l}5.0 \\
5.1 \\
5.3 \\
5.2 \\
5.9\end{array}$ & $\begin{array}{l}9.9 \\
10 \\
10 \\
10 \\
10\end{array}$ & $\begin{array}{l}5.2 \\
5.0 \\
4.9 \\
4.9 \\
4.7\end{array}$ & $\begin{array}{l}3.6 \\
3.5 \\
3.5 \\
3.6 \\
3.4\end{array}$ & $\begin{array}{l}2.8 \\
2.8 \\
2.8 \\
2.8 \\
2.9\end{array}$ & $\begin{array}{r}170 \\
80 \\
40 \\
20 \\
15\end{array}$ \\
\hline $\begin{array}{l}16 \\
17 \\
18 \\
19 \\
20\end{array}$ & $\begin{array}{l}3.0 \\
3.0 \\
3.0 \\
3.0 \\
4.2\end{array}$ & $\begin{array}{l}3.3 \\
3.3 \\
3.3 \\
3.3 \\
3.3\end{array}$ & $\begin{array}{l}3.8 \\
3.8 \\
3.8 \\
3.8 \\
3.8\end{array}$ & $\begin{array}{l}3.4 \\
3.4 \\
3.4 \\
3.4 \\
3.4\end{array}$ & $\begin{array}{l}5.2 \\
5.0 \\
4.8 \\
4.7 \\
4.8\end{array}$ & $\begin{array}{l}5.6 \\
5.7 \\
6.0 \\
6.2 \\
6.0\end{array}$ & $\begin{array}{l}6.3 \\
5.5 \\
5.5 \\
5.6 \\
5.6\end{array}$ & $\begin{array}{l}10 \\
9.6 \\
9.2 \\
9.4 \\
9.1\end{array}$ & $\begin{array}{l}4.7 \\
4.7 \\
4.8 \\
4.9 \\
4.8\end{array}$ & $\begin{array}{l}3.4 \\
3.3 \\
3.2 \\
3.1 \\
3.1\end{array}$ & $\begin{array}{l}3.0 \\
3.0 \\
3.0 \\
3.0 \\
3.0\end{array}$ & $\begin{array}{l}10 \\
7.0 \\
6.0 \\
5.5 \\
5.0\end{array}$ \\
\hline $\begin{array}{l}21 \\
22 \\
23 \\
24 \\
25\end{array}$ & $\begin{array}{l}3.8 \\
3.5 \\
3.5 \\
3.5 \\
3.5\end{array}$ & $\begin{array}{l}3.3 \\
3.3 \\
3.3 \\
3.4 \\
3.5\end{array}$ & $\begin{array}{l}3.7 \\
3.7 \\
3.7 \\
3.7 \\
3.7\end{array}$ & $\begin{array}{l}3.3 \\
3.3 \\
3.3 \\
3.3 \\
3.3\end{array}$ & $\begin{array}{l}5.9 \\
8.3 \\
7.0 \\
5.0 \\
5.0\end{array}$ & $\begin{array}{l}5.8 \\
5.7 \\
5.6 \\
5.7 \\
5.7\end{array}$ & $\begin{array}{l}6.0 \\
6.7 \\
7.0 \\
7.2 \\
8.0\end{array}$ & $\begin{array}{l}8.0 \\
7.5 \\
7.2 \\
7.0 \\
6.8\end{array}$ & $\begin{array}{l}4.4 \\
4.2 \\
4.0 \\
4.0 \\
3.9\end{array}$ & $\begin{array}{l}3.1 \\
3.3 \\
3.4 \\
3.3 \\
3.3\end{array}$ & $\begin{array}{l}3.0 \\
3.0 \\
2.9 \\
3.0 \\
3.0\end{array}$ & $\begin{array}{l}5.0 \\
5.0 \\
5.0 \\
40 \\
15\end{array}$ \\
\hline $\begin{array}{l}26 \\
27 \\
28 \\
29 \\
30 \\
31\end{array}$ & $\begin{array}{l}3.5 \\
3.5 \\
3.5 \\
3.5 \\
4.0 \\
3.6\end{array}$ & $\begin{array}{l}3.6 \\
3.7 \\
3.7 \\
3.8 \\
4.0 \\
-.-\end{array}$ & $\begin{array}{l}3.7 \\
3.7 \\
3.7 \\
3.7 \\
3.6 \\
3.6\end{array}$ & $\begin{array}{l}3.3 \\
3.3 \\
3.3 \\
3.3 \\
3.3 \\
3.4\end{array}$ & $\begin{array}{l}5.0 \\
4.5 \\
4.5 \\
4.5 \\
-.- \\
---\end{array}$ & $\begin{array}{l}5.9 \\
5.7 \\
5.6 \\
5.4 \\
5.3 \\
5.2\end{array}$ & $\begin{array}{l}8.2 \\
7.5 \\
7.1 \\
6.8 \\
6.9 \\
-.-7\end{array}$ & $\begin{array}{l}6.8 \\
7.0 \\
7.1 \\
6.9 \\
6.5 \\
6.4\end{array}$ & $\begin{array}{l}3.8 \\
3.8 \\
3.8 \\
3.7 \\
3.8 \\
-.-\end{array}$ & $\begin{array}{l}3.3 \\
3.4 \\
3.4 \\
3.2 \\
3.2 \\
3.2\end{array}$ & $\begin{array}{l}2.9 \\
2.9 \\
2.8 \\
2.9 \\
3.0 \\
2.9\end{array}$ & $\begin{array}{r}9.0 \\
7.0 \\
6.0 \\
27 \\
8.3 \\
-\end{array}$ \\
\hline $\begin{array}{l}\text { TOTAL } \\
\text { MEAN } \\
\text { MAX } \\
\text { MIN } \\
\text { AC-FT }\end{array}$ & $\begin{array}{r}100.6 \\
3.25 \\
4.2 \\
3.0 \\
200\end{array}$ & $\begin{array}{r}102.0 \\
3.40 \\
4.0 \\
3.3 \\
202\end{array}$ & $\begin{array}{r}120.4 \\
3.88 \\
5.0 \\
3.6 \\
239\end{array}$ & $\begin{array}{r}106.2 \\
3.43 \\
3.6 \\
3.3 \\
211\end{array}$ & $\begin{array}{r}265.7 \\
9.16 \\
81 \\
3.4 \\
527\end{array}$ & $\begin{array}{r}258.0 \\
6.32 \\
40 \\
5.2 \\
512\end{array}$ & $\begin{array}{r}176.6 \\
5.89 \\
8.2 \\
4.8 \\
350\end{array}$ & $\begin{array}{r}272.6 \\
8.79 \\
17 \\
6.4 \\
541\end{array}$ & $\begin{array}{r}145.5 \\
4.85 \\
6.4 \\
3.7 \\
289\end{array}$ & $\begin{array}{r}105.3 \\
3.40 \\
3.7 \\
3.1 \\
209\end{array}$ & $\begin{array}{r}90.8 \\
2.93 \\
3.1 \\
2.8 \\
180\end{array}$ & $\begin{array}{r}976.3 \\
32.5 \\
460 \\
3.0 \\
1940\end{array}$ \\
\hline
\end{tabular}

CAL YR 1975 TOTAL 1785.3 MEAN 4.89 MAX 16 MIN 2.6 AC-FT 3540 WTR YR 1976 TOTAL 2720.0 MEAN 7.43 MAX 460 MIN 2.8 AC-FT 5400 
LOCATION, - Lat $34^{\circ} 00^{\prime} 40^{\prime \prime}$, long $116^{\circ} 37^{\prime} 38^{\prime \prime}$, in NE $\frac{1}{4} \mathrm{SW}^{\frac{1}{4}} \mathrm{sec} .12, \mathrm{~T} .2 \mathrm{~S} .$, R. 3 E., Riverside County, in Mission Creek Indian Reservation, $0,6 \mathrm{mi}(1.0 \mathrm{~km})$ downstream from West Fork, and $6.8 \mathrm{mi}$ (10.9 km) northwest of Desert Hot Springs.

DRAINAGE AREA. $--35.7 \mathrm{mi}^{2}\left(92.5 \mathrm{~km}^{2}\right)$.

PERIOD OF RECORD.--October 1967 to current year.

GAGE.- Water-stage recorder with rain-gage attachment. Altitude of gage is 2,400 ft (732 m), from topographic map.

REMARKS.--Records fair. Slight regulation of low flow by two small dams with a combined capacity of about 3 acre-ft $\left(3,700 \mathrm{~m}^{3}\right), 2 \mathrm{mi}(3 \mathrm{~km})$ above station. Precipitation, in inches, for the 1975 water year was as follows: October, 0.90 ; November, 0.20 ; December, 1.1 ; February, $0.60 ;$ March, 0.80; Apri1, 1.1; July, 0.10; September, 0.10. These were inadvertently left out of the 1975 report.

EXTREMES FOR PERIOD OF RECORD. - Maximum discharge, 1,660 $\mathrm{ft}^{3} / \mathrm{s}\left(47.0 \mathrm{~m}^{3} / \mathrm{s}\right) \mathrm{Jan}$. 25 , 1969 , gage height, $6.40 \mathrm{ft}$ $(1.951 \mathrm{~m})$ on basis of slope-area measurement of maximum flow; no flow for long periods in most years.

EXTREMES FOR CURRENT YEAR. - Maximum discharge, $9.8 \mathrm{ft}^{3} / \mathrm{s}\left(0.28 \mathrm{~m}^{3} / \mathrm{s}\right)$ Feb. 9 , gage height, $2.32 \mathrm{ft}(0.707 \mathrm{~m})$, no peak above base of $50 \mathrm{ft}^{3} / \mathrm{s}\left(1.42 \mathrm{~m}^{3} / \mathrm{s}\right)$; minimum daily, no flow most of year.

DISCHARGE, IN CUBIC FEET PER SECOND, WATER YEAR OCTOBER 1975 TO SEPTEMBER 1976 MEAN VALUES

\begin{tabular}{|c|c|c|c|c|c|c|c|c|c|c|c|c|}
\hline DAY & ocr & NOV & DEC & JAN & FEB & MAR & APR & MAY & JUN & JUL & AUG & SEP \\
\hline $\begin{array}{l}1 \\
2 \\
3 \\
4 \\
5\end{array}$ & & & & & $\begin{array}{l}0 \\
0 \\
0 \\
0 \\
0\end{array}$ & $\begin{array}{l}.72 \\
.64 \\
.76 \\
.64 \\
.45\end{array}$ & $\begin{array}{l}.23 \\
.23 \\
.23 \\
.37 \\
.37\end{array}$ & $\begin{array}{l}.06 \\
.04 \\
.05 \\
.06 \\
.08\end{array}$ & & & & \\
\hline $\begin{array}{r}6 \\
7 \\
8 \\
9 \\
10\end{array}$ & & & & & $\begin{array}{l}0 \\
1.73 \\
5.8 \\
2.2\end{array}$ & $\begin{array}{l}.54 \\
.45 \\
.45 \\
.54 \\
.64\end{array}$ & $\begin{array}{r}.29 \\
.23 \\
.18 \\
.23 \\
.18\end{array}$ & $\begin{array}{l}.11 \\
.18 \\
.11 \\
.08 \\
.06\end{array}$ & & & & \\
\hline $\begin{array}{l}11 \\
12 \\
13 \\
14 \\
15\end{array}$ & & & & & $\begin{array}{r}.90 \\
.64 \\
.36 \\
.31 \\
.54\end{array}$ & $\begin{array}{l}.64 \\
.54 \\
.54 \\
.37 \\
.37\end{array}$ & $\begin{array}{l}.18 \\
.23 \\
.37 \\
.54 \\
.64\end{array}$ & $\begin{array}{l}.04 \\
.02 \\
.02 \\
.01 \\
.02\end{array}$ & & & & \\
\hline $\begin{array}{l}16 \\
17 \\
18 \\
19 \\
20\end{array}$ & & & & & $\begin{array}{r}.37 \\
.29 \\
.23 \\
.29 \\
.37\end{array}$ & $\begin{array}{l}.29 \\
.23 \\
.23 \\
.23 \\
.18\end{array}$ & $\begin{array}{l}.54 \\
.45 \\
.37 \\
.23 \\
.23\end{array}$ & $\begin{array}{l}.01 \\
.02 \\
.01 \\
.01 \\
.01\end{array}$ & & & & \\
\hline $\begin{array}{l}21 \\
22 \\
23 \\
24 \\
25\end{array}$ & & & & & $\begin{array}{l}.16 \\
.18 \\
.23 \\
.18 \\
.14\end{array}$ & $\begin{array}{l}.18 \\
.14 \\
.11 \\
.14 \\
.14\end{array}$ & $\begin{array}{l}.14 \\
.18 \\
.18 \\
.11 \\
.08\end{array}$ & ${ }^{.01}$ & & & & \\
\hline $\begin{array}{l}26 \\
27 \\
28 \\
29 \\
30 \\
31\end{array}$ & & $=-$ & & & $\begin{array}{l}.08 \\
.06 \\
.05 \\
.05 \\
.0 \\
.-.-\end{array}$ & $\begin{array}{l}.18 \\
.16 \\
.10 \\
.29 \\
.23 \\
.29\end{array}$ & $\begin{array}{l}.14 \\
.18 \\
.18 \\
.11 \\
.08 \\
-=-\end{array}$ & $\begin{array}{l}0 \\
0 \\
0 \\
0 \\
0 \\
0\end{array}$ & $-\infty$ & & & $=-$ \\
\hline $\begin{array}{l}\text { TOTAL } \\
\text { MEAN } \\
\text { MAX } \\
\text { MIN } \\
\text { AC-FT }\end{array}$ & $\begin{array}{l}0 \\
0 \\
0 \\
0 \\
0\end{array}$ & $\begin{array}{l}0 \\
0 \\
0 \\
0 \\
0\end{array}$ & $\begin{array}{l}0 \\
0 \\
0 \\
0 \\
0\end{array}$ & $\begin{array}{l}0 \\
0 \\
0 \\
0 \\
0\end{array}$ & $\begin{array}{r}15.56 \\
.54 \\
5.8 \\
0 \\
31\end{array}$ & $\begin{array}{r}11.41 \\
.37 \\
.76 \\
.10 \\
23\end{array}$ & $\begin{array}{r}7.70 \\
.26 \\
.64 \\
.08 \\
15\end{array}$ & $\begin{array}{r}1.02 \\
.033 \\
.18 \\
0 \\
2.0\end{array}$ & $\begin{array}{l}0 \\
0 \\
0 \\
0 \\
0\end{array}$ & $\begin{array}{l}0 \\
0 \\
0 \\
0 \\
0\end{array}$ & $\begin{array}{l}0 \\
0 \\
0 \\
0 \\
0\end{array}$ & $\begin{array}{l}0 \\
0 \\
0 \\
0 \\
0\end{array}$ \\
\hline (a) & 0 & .60 & 0 & 0 & 1.5 & .90 & .30 & .50 & 0 & 0 & 0 & 2,1 \\
\hline
\end{tabular}


10257710 CHINO CANYON CREEK NEAR PALM SPRINGS, CA

LOCATION. - Lat $33^{\circ} 50^{\prime} 21^{\prime \prime}$, Iong $116^{\circ} 36^{\prime} 45^{\prime \prime}$, in SWLSWNWta sec.7, T, 4 S, R. 4 E., Riverside County, on 1eft bank $800 \mathrm{ft}(244 \mathrm{~m})$ downstream from tram building, $3.7 \mathrm{mi}(6.0 \mathrm{~km})$ west of Highway 111 on road leading to Palm Springs aerial tramway and $5.5 \mathrm{mi}(8.8 \mathrm{~km})$ west of palm Springs.

DRAINAGE AREA. $--3.88 \mathrm{mi}^{2}\left(10.05 \mathrm{~km}^{2}\right)$.

PERIOD OF RECORD.--October 1974 to current year.

GAGE. - Water-stage recorder. Altitude of gage is 2,500 ft $(762 \mathrm{~m})$, from topographic map.

REMARKS, - Records poor. Two diversions for the city of palm springs $0.5 \mathrm{mi}(0.8 \mathrm{~km}) \mathrm{upstream}$.

EXTREMES FOR PERIOD OF RECORD.--Maximum discharge, $240 \mathrm{ft}^{3} / \mathrm{s}\left(6.80 \mathrm{~m}^{3} / \mathrm{s}\right)$ Sept. 10,1976, gage height, $5.90 \mathrm{ft}$ $(1.798 \mathrm{~m})$, from floodmark, from rating curve extended above $0.25 \mathrm{ft}^{3} / \mathrm{s}(0.007 \mathrm{~m} / \mathrm{s})$ on basis of siope-area measurement of maximum flow; no flow for several months in each year.

EXTREMES FOR CURRENT YEAR, - Maximum discharge, $240 \mathrm{ft}^{3} / \mathrm{s}\left(6.80 \mathrm{~m}^{3} / \mathrm{s}\right)$ Sept. 10,1976 , gage height, $5.90 \mathrm{ft}$ $(1.798 \mathrm{~m})$, from floodmark, from rating curve extended above $0.25 \mathrm{ft}^{3} / \mathrm{s}\left(0.007 \mathrm{~m}^{3} / \mathrm{s}\right)$ on basis of slope-area measurement of maximum flow; no flow most of year.

DISCHARGE, IN CUBIC FEET PER SECOND, HATER YEAR OCTOBER 1975 TO SEPTEMBER 1976

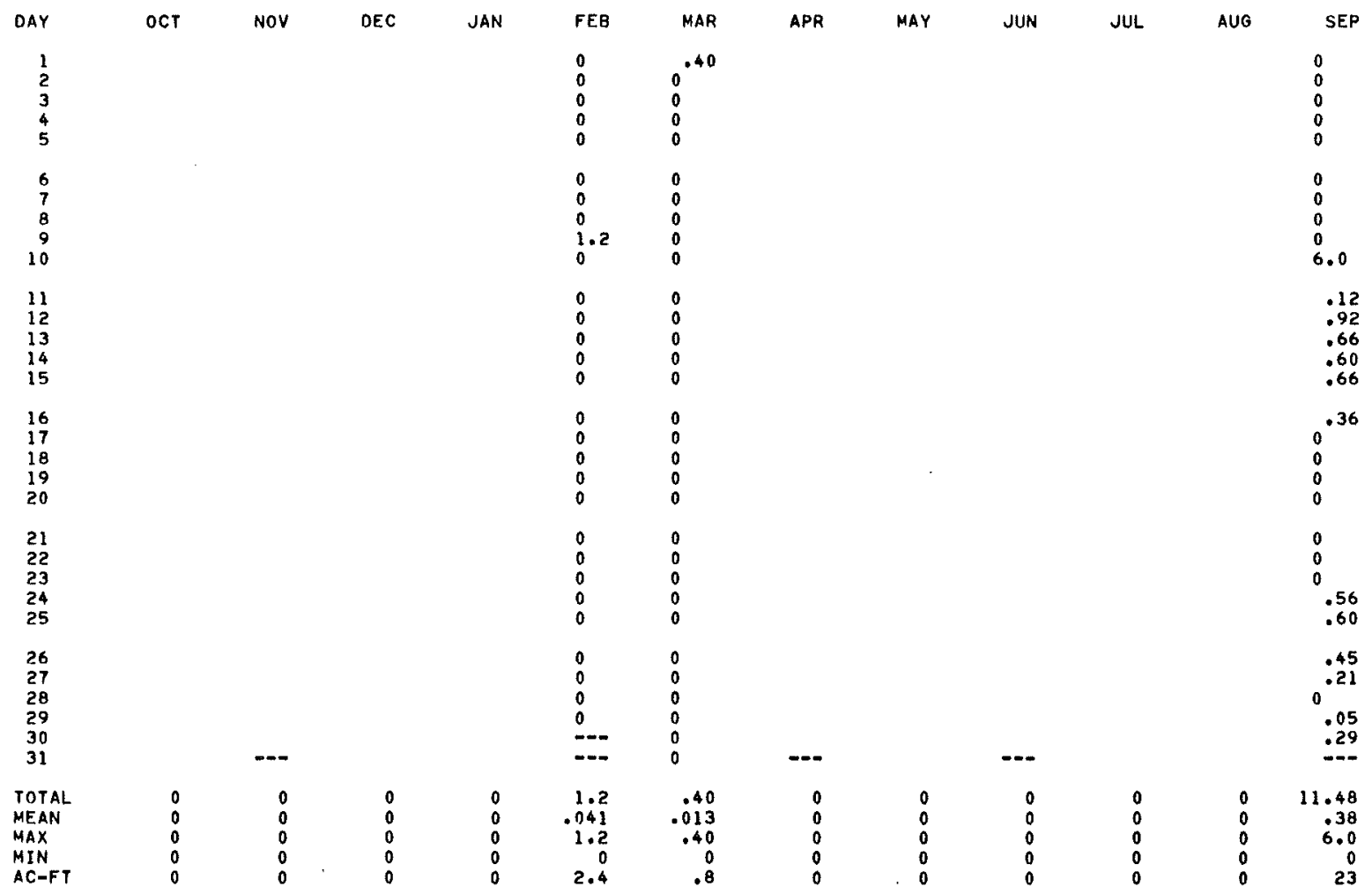

$\begin{array}{lllllllll}\text { CAL YR } 1975 & \text { TOTAL } 0.02 & \text { MEAN } .0001 & \text { MAX } .01 & \text { MIN } 0 & \text { AC-FT } .0 \\ \text { WTR YR } 1976 & \text { TOTAL } 13.08 & \text { MEAN } .036 & \text { MAX } 6.0 & \text { MIN } 0 & \text { AC-FT } 26\end{array}$ 


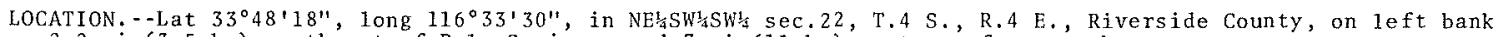
$2.2 \mathrm{mi}(3.5 \mathrm{~km})$ southwest of Palm Springs, and $7 \mathrm{mi}(11 \mathrm{~km})$ upstream from mouth.

DRATNAGE AREA. $--16.8 \mathrm{mi}^{2}\left(43.5 \mathrm{~km}^{2}\right)$.

PERIOD OF RECORD. - October 1947 to current year.

GAGE. - Water-stage recorder. Datum of gage is $762.5 \mathrm{ft}(232.41 \mathrm{~m}$ ) above mean sea level (levels by Riverside County Flood Control District). Prior to Aug, 25, 1970, at datum 2.00 ft $(0.610 \mathrm{~m}) \mathrm{higher}$.

REMARKS. - Records poor. No regulation or diversion above station.

AVERAGE DISCHARGE, -29 years, $3.62 \mathrm{ft}^{3} / \mathrm{s}\left(0.103 \mathrm{~m}^{3} / \mathrm{s}\right), 2,620 \mathrm{acre}-\mathrm{ft} / \mathrm{yr}(3.23 \mathrm{hm} / \mathrm{yr})$.

EXTREMES FOR PERIOD OF RECORD. - Maximum discharge, 2,900 $\mathrm{ft}^{3} / \mathrm{s}\left(82.1 \mathrm{~m}^{3} / \mathrm{s}\right)$ Nov. 22 , $1965, \mathrm{Jan}$. 25 , 1969, gage height, $12.34 \mathrm{ft}(3.761 \mathrm{~m})$, from rating curve extended above $80 \mathrm{ft}^{3} / \mathrm{s}\left(2.27 \mathrm{~m}^{3} / \mathrm{s}\right)$ on basis of $\mathrm{s} 1$ ope-area measurements at gage heights $8.45 \mathrm{ft}(2.576 \mathrm{~m})$ and $10.34 \mathrm{ft}(3.152 \mathrm{~m})$ site and datum then in use; no flow for parts of each year. EXTREMES FOR CURRENT YEAR. - Maximum discharge, $256 \mathrm{ft}^{3} / \mathrm{s}\left(7.25 \mathrm{~m}^{3} / \mathrm{s}\right)$ Sept. 10 (1500 hrs), gage height, $7.40 \mathrm{ft}$
$(2.256 \mathrm{~m})$, no other peak above base of $50 \mathrm{ft}^{3} / \mathrm{s}\left(1.42 \mathrm{~m}^{3} / \mathrm{s}\right)$, from rating curve extended above 10 ft ${ }^{3} / \mathrm{s}$

$\left(0.28 \mathrm{~m}^{3} / \mathrm{s}\right)$ on basis of slope-area measurement made at gage height of $10.32 \mathrm{ft}$ ( $\left.3.145 \mathrm{~m}\right) ; \mathrm{no}$ flow $0 \mathrm{ct}$. 1 to Dec. 26 , July 6 to Sept, 9.

DISCHARGE, IN CUBIC FEET PER SECOND, WATER YEAR OCTOBER 1975 TO SEPTEMBER 1976 MEAN VALUES

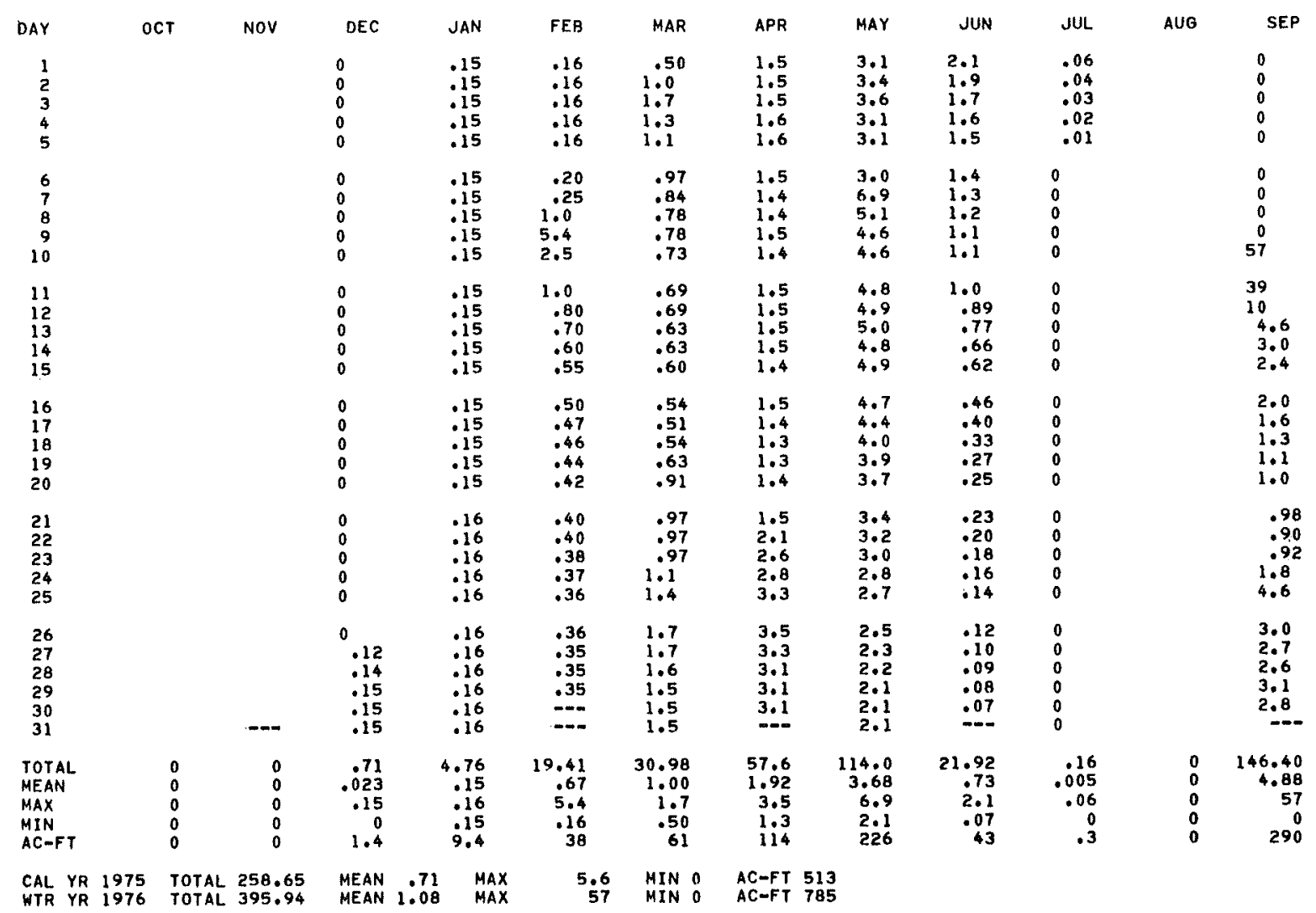


10258500 PALM CANYON CREEK NEAR PALM SPRINGS, CA

LOCATION. - Lat $33^{\circ} 44^{\prime} 42^{\prime \prime}$, long $116^{\circ} 32^{\circ} 05^{\prime \prime}$, in NE $\frac{1}{4} W^{1} \mathrm{SE}^{\frac{1}{4}}$ sec.11, T. $5 \mathrm{~S}$, , R. 4 E, Riverside County, on right bank

$0.8 \mathrm{mi}(1.3 \mathrm{~km})$ upstrean from Murray Canyon Creek, and $6 \mathrm{mi}(10 \mathrm{~km})$ south of Palm Springs.

DRAINAGE AREA, $--93.3 \mathrm{mi}^{2}\left(241.6 \mathrm{~km}^{2}\right)$.

PERIOD OF RECORD. - -January 1930 to January 1942, October 1947 to current year.

GAGE.--Water-stage recorder. A1titude of gage is $700 \mathrm{ft}(213 \mathrm{~m})$, from topographic map. Prior to Jan. 14, 1942 , at datum $0.2 \mathrm{ft}(0.06 \mathrm{~m})$ higher.

REMARKS, --Records fair, No regulation or diversion above station.

AVERAGE DISCHARGE,--40 years (water years $1931-41,1948-76), 3.22 \mathrm{ft}^{3} / \mathrm{s}\left(0.091 \mathrm{~m}^{3} / \mathrm{s}\right), 2,330$ acre-ft/yr $\left(2.87 \mathrm{hm}^{3} / \mathrm{Yr}\right)$.

EXTREMES FOR PERIOD OF RECORD.- Maximum discharge, $4,050 \mathrm{ft}^{3} / \mathrm{s}\left(115 \mathrm{~m}^{3} / \mathrm{s}\right) \mathrm{Sept}$. 10 , 1976 , gage height, $6.81 \mathrm{ft}$ $(2.076 \mathrm{~m})$, from rating curve extended above $20 \mathrm{ft} / \mathrm{s}(0.57 \mathrm{~m} / \mathrm{s})$ on basis of slope-area measurement of maximum flow; no flow for several months in most years.

EXTREMES FOR CURRENT YEAR. - -Peak discharges above base of $100 \mathrm{ft} / \mathrm{s}\left(2.83 \mathrm{~m}^{3} / \mathrm{s}\right)$ and maximum (*), from rating curve extended above $20 \mathrm{ft} / \mathrm{s}(0.57 \mathrm{~m} / \mathrm{s})$ on basis of slope-area measurement of maximum fiow:

\begin{tabular}{|c|c|c|c|c|c|c|c|c|c|c|}
\hline Date & Time & $\begin{array}{l}\text { Discharge } \\
\left(\mathrm{ft}^{3} / \mathrm{s}\right)\left(\mathrm{m}^{3} / \mathrm{s}\right)\end{array}$ & $\begin{array}{l}\text { Gage } \\
\text { (ft) }\end{array}$ & $\begin{array}{r}\text { height } \\
\text { (III) }\end{array}$ & Date & Time & $\begin{array}{r}\text { Disc } \\
\left(\mathrm{ft}^{3} / \mathrm{s}\right.\end{array}$ & $\begin{array}{l}\mathrm{rge} \\
\left(\mathrm{m}^{3} / \mathrm{s}\right)\end{array}$ & $\begin{array}{l}\text { Gage } \\
(\mathrm{ft})\end{array}$ & $\begin{array}{r}\text { height } \\
\text { (m) }\end{array}$ \\
\hline $\begin{array}{lr}\text { Feb. } & 9 \\
\text { Sept. } & 10\end{array}$ & $\begin{array}{l}0500 \\
1230\end{array}$ & $115^{4.93}$ & $\begin{array}{l}2.73 \\
6.81\end{array}$ & $\begin{array}{l}0.832 \\
2.076\end{array}$ & Sept. 23 & 1700 & 628 & 17.8 & 3.79 & 1.155 \\
\hline
\end{tabular}

Minimum daily discharge, no flow for several months.

DISCHARGE, IN CUBIC FEET PER SECOND, WATER YEAR OCTOBER 1975 TO SEPTEMBER 1976 MEAN VALUES

\begin{tabular}{|c|c|c|c|c|c|c|c|c|c|c|c|c|c|}
\hline DAY & OCT & NoV & DEC & & JAN & FEB & MAR & APR & MAY & JUN & JUL & AUG & SEP \\
\hline $\begin{array}{l}1 \\
2 \\
3 \\
4 \\
5\end{array}$ & & & & & & $\begin{array}{l}0 \\
0 \\
0 \\
0 \\
0\end{array}$ & $\begin{array}{l}.16 \\
2.1 \\
7.6 \\
2.6 \\
1.8\end{array}$ & $\begin{array}{l}0 \\
0 \\
0 \\
0 \\
0\end{array}$ & $\begin{array}{l}0 \\
0 \\
0 \\
0 \\
0\end{array}$ & & & & $\begin{array}{l}0 \\
0 \\
0 \\
0 \\
0\end{array}$ \\
\hline $\begin{array}{r}6 \\
7 \\
8 \\
9 \\
10\end{array}$ & & & & & & $\begin{array}{c}0 \\
0 \\
0 \\
63 \\
9.9\end{array}$ & $\begin{array}{l}1.3 \\
1.2 \\
1.0 \\
.90 \\
.80\end{array}$ & $\begin{array}{l}0 \\
0 \\
0 \\
0 \\
0\end{array}$ & $\begin{array}{l}0 \\
1.9 \\
0.37 \\
0\end{array}$ & & & & $\begin{array}{r}0 \\
0 \\
0 \\
0 \\
526\end{array}$ \\
\hline $\begin{array}{l}11 \\
12 \\
13 \\
14 \\
15\end{array}$ & & & & & & $\begin{array}{l}1.2 \\
.42 \\
.20 \\
.07 \\
.02\end{array}$ & $\begin{array}{l}.73 \\
.63 \\
.48 \\
.48 \\
.42\end{array}$ & $\begin{array}{l}0 \\
0 \\
0 \\
0 \\
.01\end{array}$ & $\begin{array}{l}0 \\
0 \\
0 \\
0 \\
0\end{array}$ & & & & $\begin{array}{l}25 \\
2.0 \\
0 \\
0 \\
0\end{array}$ \\
\hline $\begin{array}{l}16 \\
17 \\
18 \\
19 \\
20\end{array}$ & & & & & & $\begin{array}{l}0 \\
0 \\
0 \\
0 \\
0\end{array}$ & $\begin{array}{l}.37 \\
.32 \\
.25 \\
.20 \\
.07\end{array}$ & $\begin{array}{l}.20 \\
.05 \\
0 \\
0 \\
0\end{array}$ & $\begin{array}{l}0 \\
0 \\
0 \\
0 \\
0\end{array}$ & & & & $\begin{array}{l}0 \\
0 \\
0 \\
0 \\
0\end{array}$ \\
\hline $\begin{array}{l}21 \\
22 \\
23 \\
24 \\
25\end{array}$ & & & & & & $\begin{array}{l}0 \\
0 \\
0 \\
0 \\
0\end{array}$ & $\begin{array}{l}.06 \\
0 \\
0 \\
0\end{array}$ & $\begin{array}{l}0 \\
0 \\
0 \\
0 \\
0\end{array}$ & $\begin{array}{l}0 \\
0 \\
0 \\
0 \\
0\end{array}$ & & & & $\begin{array}{c}0 \\
0 \\
27 \\
3.3 \\
.36\end{array}$ \\
\hline $\begin{array}{l}26 \\
27 \\
28 \\
29 \\
30 \\
31\end{array}$ & & $-\infty$ & & & & $\begin{array}{l}0 \\
0 \\
0 \\
0 \\
\end{array}$ & $\begin{array}{l}0 \\
0 \\
0 \\
0 \\
0 \\
0\end{array}$ & $\begin{array}{l}0 \\
0 \\
0 \\
0 \\
0 \\
-\end{array}$ & $\begin{array}{l}0 \\
0 \\
0 \\
0 \\
0 \\
0\end{array}$ & $-\infty$ & & & $\begin{array}{r}.18 \\
.10 \\
0.01 \\
0 . .-\end{array}$ \\
\hline $\begin{array}{l}\text { TOTAL } \\
\text { MEAN } \\
\text { MAX } \\
\text { MIN } \\
\text { AC-FT }\end{array}$ & $\begin{array}{l}0 \\
0 \\
0 \\
0 \\
0\end{array}$ & $\begin{array}{l}0 \\
0 \\
0 \\
0 \\
0\end{array}$ & $\begin{array}{l}0 \\
0 \\
0 \\
0 \\
0\end{array}$ & & $\begin{array}{l}0 \\
0 \\
0 \\
0 \\
0\end{array}$ & $\begin{array}{r}74.81 \\
2.58 \\
63 \\
0 \\
148\end{array}$ & $\begin{array}{r}23.48 \\
.76 \\
7.6 \\
0 \\
47\end{array}$ & $\begin{array}{r}.26 \\
.009 \\
.20 \\
0 \\
.5\end{array}$ & $\begin{array}{r}2.27 \\
.073 \\
1.9 \\
0 \\
4.5\end{array}$ & $\begin{array}{l}0 \\
0 \\
0 \\
0 \\
0\end{array}$ & $\begin{array}{l}0 \\
0 \\
0 \\
0 \\
0\end{array}$ & $\begin{array}{l}0 \\
0 \\
0 \\
0 \\
0\end{array}$ & $\begin{array}{r}584.15 \\
19.5 \\
526 \\
0 \\
1160\end{array}$ \\
\hline
\end{tabular}




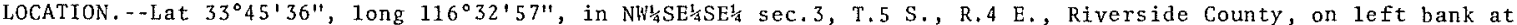
Bureau of Indian Affairs diversion dam, $1.1 \mathrm{mi}(1.8 \mathrm{~km})$ above mouth, and $5.1 \mathrm{mi}(8.2 \mathrm{~km}) \mathrm{south}$ of Pa1m $5 p \mathrm{ings}$ DRAINAGE AREA. $-8.61 \mathrm{mi}^{2}\left(22.30 \mathrm{~km}^{2}\right)$.

PERIOD OF RECORD.--October 1948 to current year.

GAGE. - Water-stage recorder and concrete control. Altitude of gage is $800 \mathrm{ft}$ ( $244 \mathrm{~m}$ ), from topographic map, Prior to Mar. 25, 1949, reference point at same site at different datum.

REMARKS,--Records poor. No regulation above station. One small diversion for domestic use about 1 mi (2 km) above station. No gage-height record July 7 to Sept. 16.

AVERAGE DISCHARGE. - 28 years, $2.07 \mathrm{ft}^{3} / \mathrm{s}\left(0.059 \mathrm{~m}^{3} / \mathrm{s}\right), 1,500 \mathrm{acre}-\mathrm{ft} / \mathrm{yr}\left(1.85 \mathrm{hm}^{3} / \mathrm{yr}^{2}\right.$.

EXTREMES FOR PERIOD OF RECORD.--Maximum discharge, $1,960 \mathrm{ft}^{3} / \mathrm{s}\left(55.5 \mathrm{~m}^{3} / \mathrm{s}\right) \mathrm{Aug}$. 31 , 1954 , gage height, $7.11 \mathrm{ft}$

$(2.167 \mathrm{~m})$, from rating curve extended above $80 \mathrm{ft} / \mathrm{s}(2.27 \mathrm{~m} / \mathrm{s})$ on basis of slope-area measurement of maximum flow; no flow at times in some years.

EXTREMES FOR CURRENT YEAR. --Peak discharges above base of $30 \mathrm{ft}^{3} / \mathrm{s}\left(0.85 \mathrm{~m}^{3} / \mathrm{s}\right)$ and maximum(*), on basis of slope-area measurement of peak flow:

\begin{tabular}{|c|c|c|c|c|c|}
\hline Date & Time & $\begin{array}{r}\text { Discl } \\
\left(\mathrm{ft}^{3} / \mathrm{s}\right)\end{array}$ & $\underset{\left(\mathrm{m}^{3} / \mathrm{s}\right)}{\mathrm{rge}}$ & $\begin{array}{l}\text { Gage } \\
\text { (ft) }\end{array}$ & $\begin{array}{r}\text { height } \\
\text { (II) }\end{array}$ \\
\hline $\begin{array}{lr}\text { eb. } & 9 \\
\text { ept. } & 10\end{array}$ & $\begin{array}{l}0315 \\
\text { Unknown }\end{array}$ & $\begin{array}{r}32.0 \\
* 225\end{array}$ & $\begin{array}{l}0.91 \\
6.37\end{array}$ & $\begin{array}{l}2.03 \\
2.90\end{array}$ & \\
\hline
\end{tabular}

Minimum daily discharge, $0.30 \mathrm{ft}^{3} / \mathrm{s}\left(0.009 \mathrm{~m}^{3} / \mathrm{s}\right)$ Sept. $6-9$.

DISCHARGE, IN CUBIC FEET PER SECOND, WATER YEAR OCTOBER 1975 TO SEPTEMBER 1976 MEAN VALUES

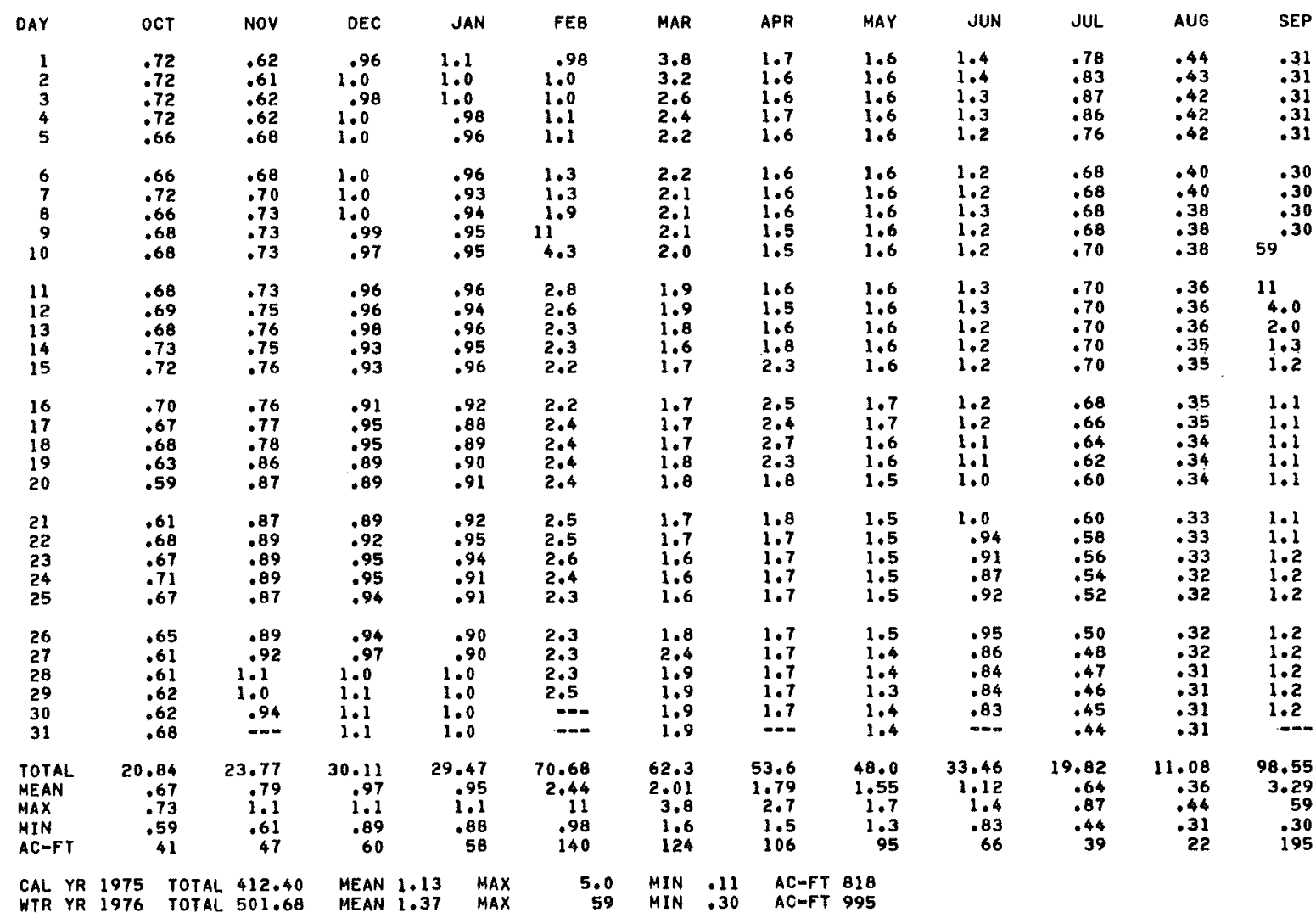


10259200 DEEP CREEK NEAR PALM DESERT, CA

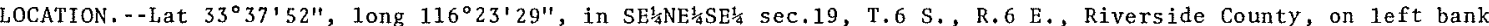

$500 \mathrm{ft}(152 \mathrm{~m})$ downstream from unnamed tributary, and $6.3 \mathrm{mli}$ (10.1 km) south of Palm Desert.

DRAINAGE AREA. $--30.6 \mathrm{mi}^{2}\left(79.3 \mathrm{~km}^{2}\right)$.

PERIOD OF RECORD. - -May 1962 to current year.

GAGE.--Water-stage recorder. Altitude of gage is $1,440 \mathrm{ft}(439 \mathrm{~m})$, from topographic map.

REMARKS.--Records poor. No gage-height record Dec. 29 to Mar. 23, Apr. 7-29, May 8 to June 6, Sept. 10-29.

No regulation or diversion above station.

AVERAGE DISCHARGE . - -14 years, $0.72 \mathrm{ft}^{3} / \mathrm{s}\left(0.020 \mathrm{~m}^{3} / \mathrm{s}\right), 522$ acre-ft/yr $\left(644,000 \mathrm{~m}^{3} / \mathrm{yr}^{2}\right)$

EXTREMES FOR PERIOD OF RECORD. - Maximum discharge, $7,100 \mathrm{ft}^{3} / \mathrm{s}\left(201 \mathrm{~m}^{3} / \mathrm{s}\right)$ Sept. 10, 1976, gage height, $7.84 \mathrm{ft}$ $(2.390 \mathrm{~m})$, recorded in gage we11, $9.85 \mathrm{ft}(3.002 \mathrm{~m})$ from floodmarks, from rating curve extended above

$3.3 \mathrm{ft}^{3} / \mathrm{s}\left(0.093 \mathrm{~m}^{3} / \mathrm{s}\right)$ on basis of slope-area measurements at gage heights $2.68 \mathrm{ft}(0.817 \mathrm{~m}), 5.15 \mathrm{ft}$

$(1.570 \mathrm{~m})$, and $7.84 \mathrm{ft}(2.390 \mathrm{~m})$; no flow for much of each year.

EXRREMES FOR CURRENT YEAR. - Peak discharges above base of $20 \mathrm{ft} / \mathrm{s}\left(0.57 \mathrm{~m}^{3} / \mathrm{s}\right)$ and maximum (*), from $\mathrm{rating}$ curve extended above $3.3 \mathrm{ft}^{3} / \mathrm{s}\left(0.093 \mathrm{~m}^{3} / \mathrm{s}\right)$ on basis of slope-area measurements at gage heights $2.68 \mathrm{ft}$ $(0.817 \mathrm{~m}), 5.15 \mathrm{ft}(1.570 \mathrm{~m})$, and $7.84 \mathrm{ft}(2.390 \mathrm{~m}):$

\begin{tabular}{|c|c|c|c|c|c|c|c|c|}
\hline Date & Time & $\begin{array}{c}\text { Discharge } \\
\left(\mathrm{ft}^{3} / \mathrm{s}\right)\left(\mathrm{m}^{3} / \mathrm{s}\right)\end{array}$ & $\begin{array}{l}\text { Gage height } \\
(\mathrm{ft})\end{array}$ & Date & Time & $\begin{array}{c}\text { Disch } \\
\left(\mathrm{ft}^{3} / \mathrm{s}\right)\end{array}$ & $\left(\mathrm{m}^{3} / \mathrm{s}\right)$ & $\begin{array}{l}\text { Gage } \\
(f t)\end{array}$ \\
\hline $\begin{array}{l}\text { Feb. } \\
\text { Sept, } \quad 10\end{array}$ & $\begin{array}{l}\text { Unknown } \\
1300\end{array}$ & $\begin{array}{r}920 \\
* 7100\end{array}$ & $\begin{array}{l}1.487 \\
2.390\end{array}$ & Sept. 23 & Unknown & 96 & 2.72 & 3.15 \\
\hline
\end{tabular}

No flow for much of year.

DISCHARGE, IN CUBIC FEET PER SECOND, WATER YEAR OCTOBER 1975 TO SEPTEMBER 1976 MEAN VALUES

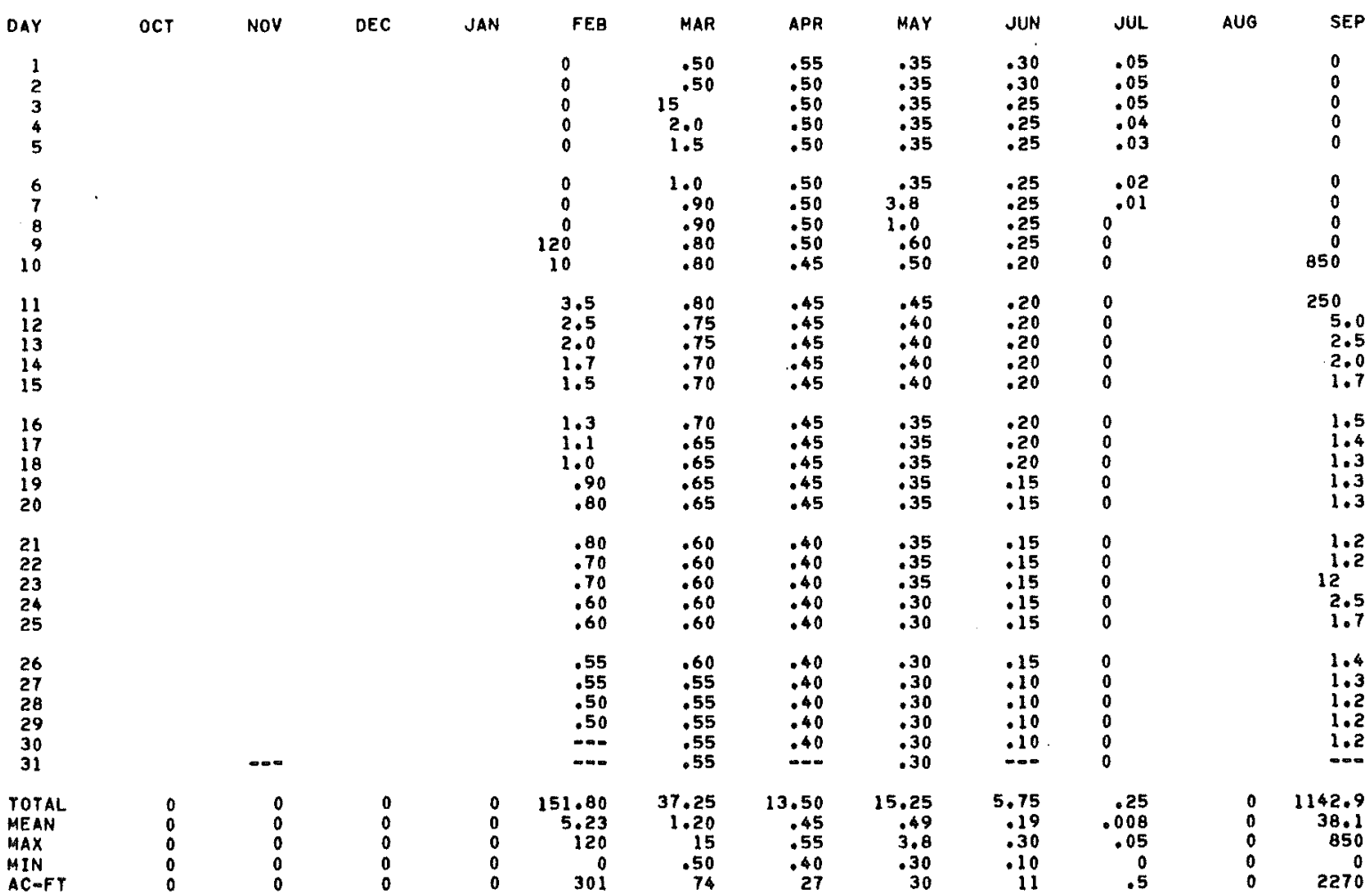

CAL YR 1975 TOTAL 26.04 MEAN .071 MAX 11 MIN 0 AC-FT 52

UTR YR 1976 TOTAL 1366.70 MEAN 3.73 MAX 850 MIN 0 ACMFT 2710 


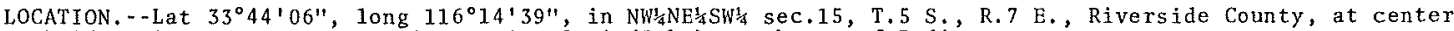
bridge pier on Interstate Highway $10,2 \mathrm{mi}(3 \mathrm{~km})$ northwest of Indio.

DRAINAGE AREA. $--1,073 \mathrm{mi}^{2}\left(2,779 \mathrm{~km}^{2}\right)$.

PERTOD OF RECORD.--March 1966 to current year.

GAGE. - Water-stage recorder and crest-stage gage. Altitude of gage is 5 ft (2 m), from topographic map.

REMARKS.--Records poor. No gage-height record Feb, 20 to Mar, 3, Apr. 5 to June 8 , Sept. 10 (1300 hrs) to Sept. 13. No regulation above station. Water diverted from tributary streams fro municipal supply in vicinity of Palm Springs. At times water is released at Coachella Canal crossing, $0.8 \mathrm{mi}(1.3 \mathrm{~km})$ upstream. AVERAGE DISCHARGE. -10 years, $3.02 \mathrm{ft}^{3} / \mathrm{s}\left(0.086 \mathrm{~m}^{3} / \mathrm{s}\right), 2,190 \mathrm{acre}-\mathrm{ft} / \mathrm{yr}^{2}\left(2.70 \mathrm{hm} / \mathrm{yr}^{3}\right)$.

EXTREMES FOR PERIOD OF RECORD.--Maximum discharge, $11,400 \mathrm{ft}^{3} / \mathrm{s}\left(323 \mathrm{~m}^{3} / \mathrm{s}\right), \mathrm{Jan}$. 25, 1969, gage height $14.41 \mathrm{ft}$ $(4.392 \mathrm{~m})$, from rating curve extended above $1,300 \mathrm{ft}^{3} / \mathrm{s}\left(36.8 \mathrm{~m}^{3} / \mathrm{s}\right)$ on basis of slope-area measurement at gage height $15.3 \mathrm{ft}(4.66 \mathrm{~m})$; no flow all or most of each year.

EXTREMES OUTSIDE PERIOD OF RECORD.--Flood of March 2 or 3,1938 , reached a discharge of $29,000 \mathrm{ft}^{3} / \mathrm{s}(821 \mathrm{~m} / \mathrm{s})$, on basis of slope-area measurement at site $4.5 \mathrm{mi}(7.2 \mathrm{~km})$ upstream. F1ood of November 22 , 1965 , reached a stage of $15.3 \mathrm{ft}(4.66 \mathrm{~m})$ from floodmarks, discharge $14,100 \mathrm{ft}^{3} / \mathrm{s}\left(399 \mathrm{~m}^{3} / \mathrm{s}\right)$ on basis of siope-area measurement of peak flow.

EXTREMES FOR CURRENT YEAR. - Maximum discharge, $8,300 \mathrm{ft}^{3} / \mathrm{s}\left(235 \mathrm{~m}^{3} / \mathrm{s}\right)$ Sept. 10 (1400 hrs), gage height, $12,4 \mathrm{ft}$ $(3.78 \mathrm{~m})$ on basis of slope-area measurement of peak flow, no other peak above base of $200 \mathrm{ft} \mathrm{b}^{3} / \mathrm{s}(5.66 \mathrm{~m} / \mathrm{s})$; no flow for most of year.

OISCHARGE, IN CUBIC FEET PER SECOND, WATER YEAR OCTOBER 1975 TO SEPTEMBER 1976 MEAN VALUES

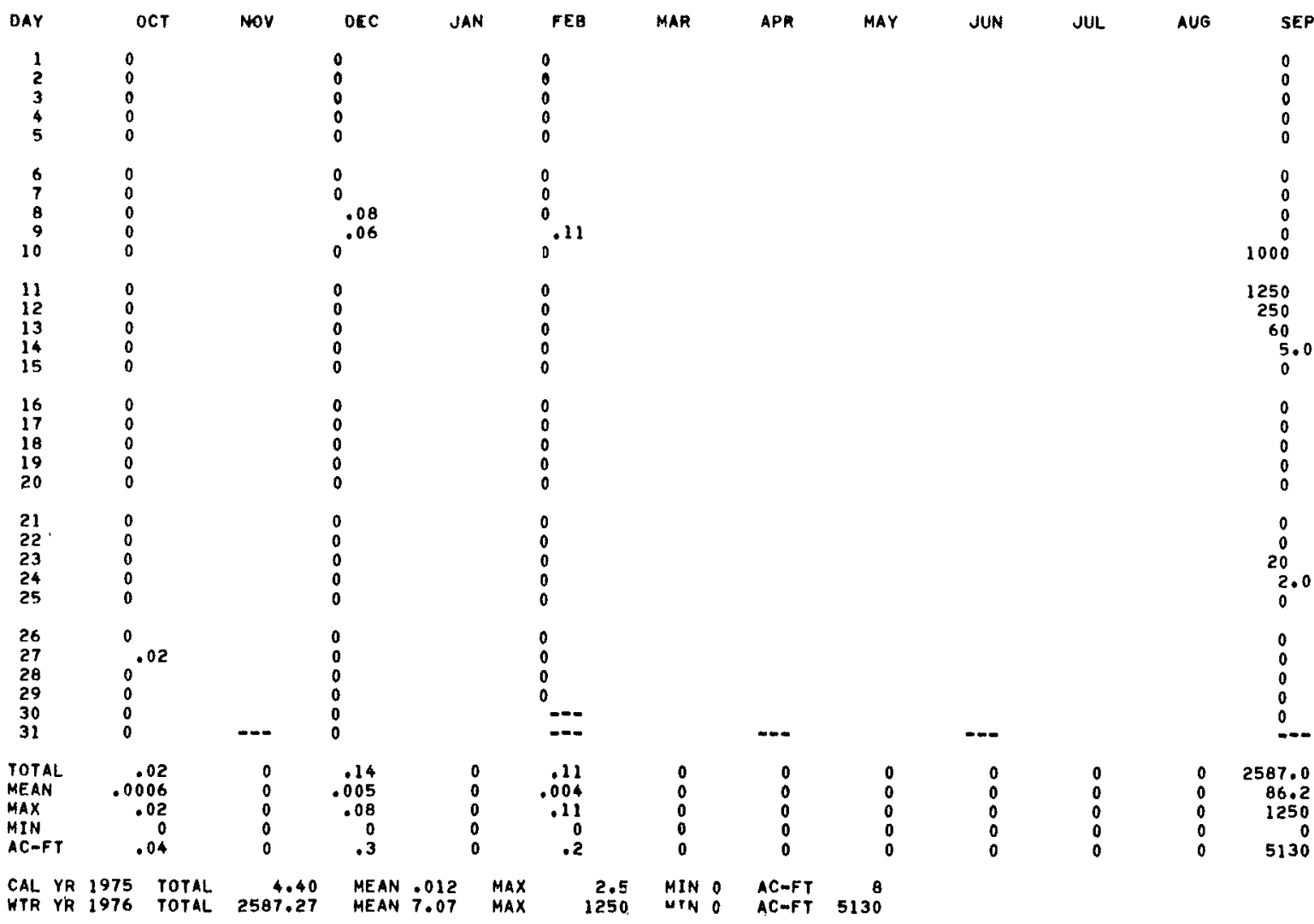


10259540 WHITEWATER RIVER NEAR MECCA, CA

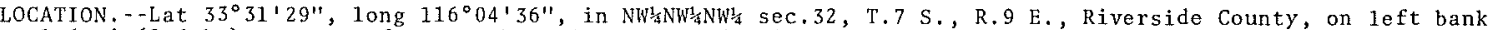
$1.6 \mathrm{mi}(2.6 \mathrm{~km})$ upstream from mouth at Salton Sea (revised), and $3.3 \mathrm{mi}$ ( $5.3 \mathrm{~km})$ south of Mecca.

DRAINAGE AREA. $-1,495 \mathrm{mi}^{2}\left(3,872 \mathrm{~km}^{2}\right)$, revised.

PERIOD OF RECORD.--October 1960 to current year.

GAGE.--Water-stage recorder. Datum of gage is $221.00 \mathrm{ft}(67.361 \mathrm{~m})$ below mean sea level (levels by Coachella County Water District). Oct. 1, 1960, to Mar. 22, 1967 , at site $1.3 \mathrm{mi}$ (2.1 km) downstream and Mar. 23 , 1967,

to Ju1y 22,1970 , at site $0.7 \mathrm{mi}(1,1 \mathrm{~km})$ downstream at different $1.3 \mathrm{mi}$ (

REMARKS. - Records poor. Most of the flow represents seepage and return flow from irrigated areas.

COOPERATION. --Sixty-five discharge measurements were furnished by Coachella Valley County Water District.

EXTREMES FOR PERIOD OF RECORD. - Maximum daily discharge, $2,500 \mathrm{ft}^{3} / \mathrm{s}\left(70.8 \mathrm{~m}^{3} / \mathrm{s}\right)$, estimated, Jan. 25 , 1969 ; minimum daily, $37 \mathrm{ft}^{3} / \mathrm{s}\left(1.05 \mathrm{~m}^{3} / \mathrm{s}\right)$ Nov. $25-29,1960$

DISCHARGE, IN CUBIC FEET PER SECOND, WATER YEAR OCTOBER 1975 TO SEPTEMBER 1976 MEAN VALUES

\begin{tabular}{|c|c|c|c|c|c|c|c|c|c|c|c|c|}
\hline DAY & OCT & NoV & DEC & JAN & FEB & MAR & APR & MAY & JUN & JUL & AUG & SEP، \\
\hline $\begin{array}{l}1 \\
2 \\
3 \\
4 \\
5\end{array}$ & $\begin{array}{l}140 \\
147 \\
159 \\
157 \\
157\end{array}$ & $\begin{array}{l}140 \\
144 \\
145 \\
157 \\
145\end{array}$ & $\begin{array}{l}145 \\
137 \\
136 \\
135 \\
136\end{array}$ & $\begin{array}{l}132 \\
130 \\
136 \\
138 \\
128\end{array}$ & $\begin{array}{l}172 \\
172 \\
156 \\
159 \\
162\end{array}$ & $\begin{array}{l}154 \\
147 \\
155 \\
155 \\
155\end{array}$ & $\begin{array}{l}168 \\
168 \\
180 \\
180 \\
182\end{array}$ & $\begin{array}{l}182 \\
184 \\
165 \\
161 \\
170\end{array}$ & $\begin{array}{l}131 \\
138 \\
147 \\
144 \\
135\end{array}$ & $\begin{array}{l}128 \\
123 \\
134 \\
140 \\
138\end{array}$ & $\begin{array}{l}146 \\
155 \\
146 \\
145 \\
146\end{array}$ & $\begin{array}{l}130 \\
135 \\
151 \\
147 \\
141\end{array}$ \\
\hline $\begin{array}{r}6 \\
7 \\
8 \\
9 \\
10\end{array}$ & $\begin{array}{l}160 \\
159 \\
159 \\
154 \\
152\end{array}$ & $\begin{array}{l}140 \\
140 \\
137 \\
135 \\
134\end{array}$ & $\begin{array}{l}137 \\
138 \\
125 \\
136 \\
136\end{array}$ & $\begin{array}{l}129 \\
130 \\
142 \\
149 \\
147\end{array}$ & $\begin{array}{l}173 \\
178 \\
188 \\
299 \\
212\end{array}$ & $\begin{array}{l}162 \\
166 \\
161 \\
156 \\
156\end{array}$ & $\begin{array}{l}169 \\
168 \\
168 \\
168 \\
169\end{array}$ & $\begin{array}{l}173 \\
200 \\
175 \\
180 \\
173\end{array}$ & $\begin{array}{l}134 \\
132 \\
126 \\
114 \\
119\end{array}$ & $\begin{array}{l}131 \\
113 \\
117 \\
123 \\
131\end{array}$ & $\begin{array}{l}150 \\
161 \\
170 \\
157 \\
150\end{array}$ & $\begin{array}{l}130 \\
140 \\
126 \\
122 \\
800\end{array}$ \\
\hline $\begin{array}{l}11 \\
12 \\
13 \\
14 \\
15\end{array}$ & $\begin{array}{l}156 \\
156 \\
150 \\
145 \\
140\end{array}$ & $\begin{array}{l}131 \\
130 \\
135 \\
135 \\
138\end{array}$ & $\begin{array}{l}134 \\
133 \\
132 \\
131 \\
131\end{array}$ & $\begin{array}{l}150 \\
254 \\
152 \\
152 \\
151\end{array}$ & $\begin{array}{l}196 \\
191 \\
184 \\
174 \\
169\end{array}$ & $\begin{array}{l}162 \\
154 \\
155 \\
162 \\
162\end{array}$ & $\begin{array}{l}169 \\
170 \\
168 \\
165 \\
174\end{array}$ & $\begin{array}{l}173 \\
178 \\
178 \\
185 \\
188\end{array}$ & $\begin{array}{l}114 \\
109 \\
131 \\
132 \\
125\end{array}$ & $\begin{array}{l}136 \\
129 \\
130 \\
131 \\
144\end{array}$ & $\begin{array}{l}154 \\
159 \\
160 \\
164 \\
160\end{array}$ & $\begin{array}{l}900 \\
290 \\
230 \\
211 \\
205\end{array}$ \\
\hline $\begin{array}{l}16 \\
17 \\
18 \\
19 \\
20\end{array}$ & $\begin{array}{l}140 \\
140 \\
140 \\
140 \\
140\end{array}$ & $\begin{array}{l}135 \\
130 \\
129 \\
126 \\
135\end{array}$ & $\begin{array}{l}130 \\
130 \\
129 \\
134 \\
134\end{array}$ & $\begin{array}{l}165 \\
152 \\
144 \\
212 \\
144\end{array}$ & $\begin{array}{l}160 \\
165 \\
150 \\
155 \\
161\end{array}$ & $\begin{array}{l}156 \\
162 \\
166 \\
160 \\
164\end{array}$ & $\begin{array}{l}181 \\
173 \\
168 \\
159 \\
162\end{array}$ & $\begin{array}{l}184 \\
186 \\
191 \\
193 \\
184\end{array}$ & $\begin{array}{r}107 \\
95 \\
106 \\
129 \\
140\end{array}$ & $\begin{array}{l}151 \\
157 \\
160 \\
147 \\
141\end{array}$ & $\begin{array}{l}157 \\
149 \\
147 \\
150 \\
161\end{array}$ & $\begin{array}{l}205 \\
205 \\
199 \\
191 \\
169\end{array}$ \\
\hline $\begin{array}{l}21 \\
22 \\
23 \\
24 \\
25\end{array}$ & $\begin{array}{l}140 \\
140 \\
140 \\
150 \\
147\end{array}$ & $\begin{array}{l}145 \\
146 \\
147 \\
142 \\
145\end{array}$ & $\begin{array}{l}125 \\
125 \\
131 \\
132 \\
129\end{array}$ & $\begin{array}{l}142 \\
144 \\
149 \\
147 \\
136\end{array}$ & $\begin{array}{l}160 \\
161 \\
172 \\
156 \\
161\end{array}$ & $\begin{array}{l}157 \\
154 \\
157 \\
164 \\
162\end{array}$ & $\begin{array}{l}173 \\
175 \\
175 \\
175 \\
174\end{array}$ & $\begin{array}{l}177 \\
177 \\
174 \\
172 \\
161\end{array}$ & $\begin{array}{l}151 \\
149 \\
142 \\
144 \\
144\end{array}$ & $\begin{array}{l}140 \\
135 \\
147 \\
151 \\
146\end{array}$ & $\begin{array}{l}159 \\
155 \\
149 \\
135 \\
135\end{array}$ & $\begin{array}{l}154 \\
149 \\
206 \\
277 \\
176\end{array}$ \\
\hline $\begin{array}{l}26 \\
27 \\
28 \\
29 \\
30 \\
31\end{array}$ & $\begin{array}{l}144 \\
146 \\
140 \\
141 \\
149 \\
144\end{array}$ & $\begin{array}{l}146 \\
151 \\
145 \\
147 \\
146 \\
-\end{array}$ & $\begin{array}{l}119 \\
136 \\
135 \\
124 \\
129 \\
140\end{array}$ & $\begin{array}{l}137 \\
140 \\
146 \\
156 \\
162 \\
166\end{array}$ & $\begin{array}{l}151 \\
166 \\
164 \\
160 \\
-0 .\end{array}$ & $\begin{array}{l}156 \\
164 \\
165 \\
164 \\
157 \\
156\end{array}$ & $\begin{array}{l}169 \\
172 \\
175 \\
181 \\
182 \\
-\end{array}$ & $\begin{array}{l}161 \\
156 \\
155 \\
154 \\
141 \\
134\end{array}$ & $\begin{array}{l}138 \\
131 \\
132 \\
124 \\
124 \\
-0\end{array}$ & $\begin{array}{l}134 \\
123 \\
119 \\
126 \\
128 \\
140\end{array}$ & $\begin{array}{l}131 \\
136 \\
141 \\
146 \\
152 \\
137\end{array}$ & $\begin{array}{l}159 \\
173 \\
159 \\
156 \\
162 \\
-\end{array}$ \\
\hline $\begin{array}{l}\text { TOTAL } \\
\text { MEAN } \\
\text { MAX } \\
\text { MIN } \\
\text { AC-FT }\end{array}$ & $\begin{array}{r}4572 \\
147 \\
160 \\
140 \\
9070\end{array}$ & $\begin{array}{r}4201 \\
140 \\
157 \\
126 \\
8330\end{array}$ & $\begin{array}{r}4104 \\
132 \\
145 \\
119 \\
8140\end{array}$ & $\begin{array}{r}4562 \\
147 \\
212 \\
128 \\
9050\end{array}$ & $\begin{array}{r}5027 \\
173 \\
299 \\
150 \\
9970\end{array}$ & $\begin{array}{r}4926 \\
159 \\
166 \\
147 \\
9770\end{array}$ & $\begin{array}{r}5160 \\
172 \\
182 \\
159 \\
10230\end{array}$ & $\begin{array}{r}5365 \\
173 \\
200 \\
134 \\
10640\end{array}$ & $\begin{array}{r}3887 \\
130 \\
151 \\
95 \\
7710\end{array}$ & $\begin{array}{r}4193 \\
135 \\
160 \\
113 \\
8320\end{array}$ & $\begin{array}{r}4663^{\prime} \\
150 \\
170 \\
131 \\
9250\end{array}$ & $\begin{array}{r}6598 \\
220 \\
900 \\
122 \\
13090\end{array}$ \\
\hline
\end{tabular}

CAL YR 1975 TOTAL 49639 MEAN 136 MAX 180 MIN 102 AC 102 TE 98460

$\begin{array}{llllllllll}\text { CAL YR } 1975 & \text { TOTAL } & 49639 & \text { MEAN } 136 & \text { MAX } 180 & \text { HIN } 102 & \text { AC }-F T & 98460 \\ \text { HTR YR } 1976 & \text { TOTAL } & 57258 & \text { MEAN } 156 & \text { MAX } 900 & \text { MIN } & 95 & \text { AC-FT } & 113600\end{array}$ 


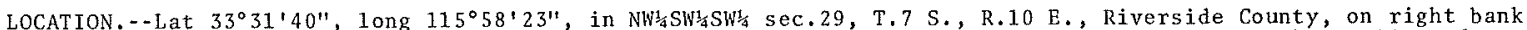
of channe1, $1,000 \mathrm{ft}(300 \mathrm{~m})$ upstream from mouth, $2,250 \mathrm{ft}(686 \mathrm{~m})$ downstream from State Highway 111 , and $6.6 \mathrm{mi}(10.6 \mathrm{~km})$ southeast of Mecca.

PERIOD OF RECORD.--February 1966 to current year.

GAGE. - Water-stage recorder. A1titude of gage is $220 \mathrm{ft}$ (67.1 m) below mean sea level (from topographic map). REMARKS.--Records poor. Discharge represents seepage and return flows from irrigated areas. At times water is wasted from Coachella Cana1.

EXTREMES FOR PERIOD OF RECORD. - Maximum daily discharge, $473 \mathrm{ft}^{3} / \mathrm{s}\left(13.4 \mathrm{~m}^{3} / \mathrm{s}\right) \mathrm{May} .9$, 1976 ; minimum daily, $1.4 \mathrm{ft}^{3} / \mathrm{s}\left(0.04 \mathrm{~m}^{3} / \mathrm{s}\right)$ May 20,1975 .

DISCHARGE, IN CUBIC FEET PER SECOND, WATER YEAR OCTOBER 1975 TO SEPTEMBER 1976

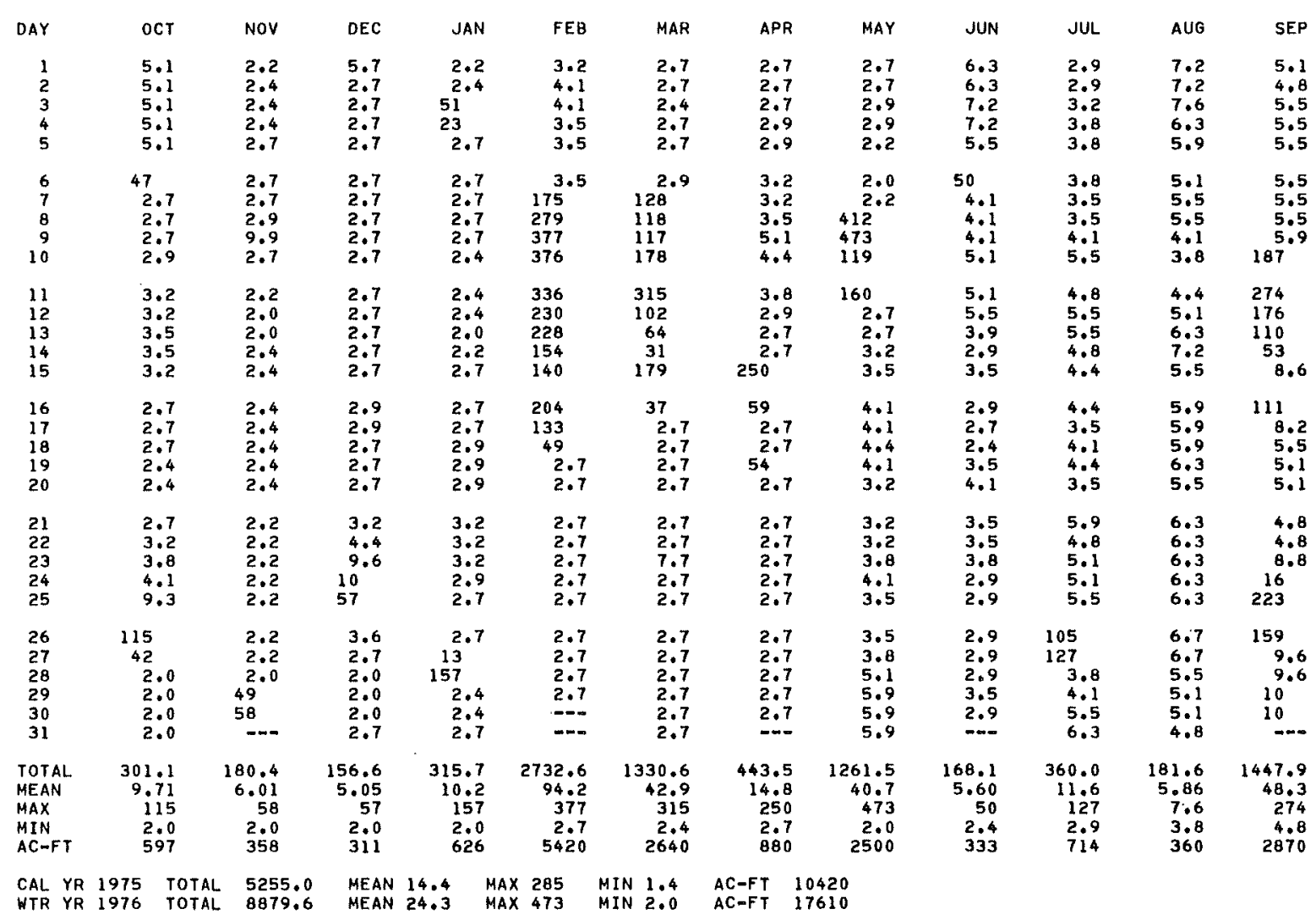


10260500 DEEP CREEK NEAR HESPERIA, CA

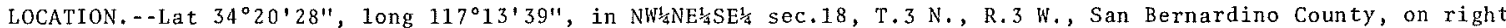
bank $0.5 \mathrm{mi}(0.8 \mathrm{~km})$ upstream from confluence with West Fork Mojave River, and $7 \mathrm{mi}$ (11 km) southeast of Hesperia.

DRAINAGE AREA. $-134 \mathrm{mi}^{2}\left(347 \mathrm{~km}^{2}\right)$, revised.

PERIOD OF RECORD. - October 1904 to September 1922 , October 1929 to current year. Month1y discharge on 1y prior to January 1930 , published in WSP 1314.

GAGE. - Water-stage recorder. Broad-crested weir since December 1938. Altitude of gage is 3,050 ft ( $930 \mathrm{~m}$ ), from topographic map. See WSP 1314 for history of change prior to Dec. $10,1938$.

REMARKS.--Records fair. Slight regulation by Lake Arrowhead, capacity, 48,000 acre-ft (59.2 hm ${ }^{3}$ ), used principally for recreation.

AVERAGE DISCHARGE, -65 years, $65.7 \mathrm{ft}^{3} / \mathrm{s}\left(1.861 \mathrm{~m}^{3} / \mathrm{s}\right), 47,600 \mathrm{acre}-\mathrm{ft} / \mathrm{yr}\left(58.7 \mathrm{hm} / \mathrm{yr}^{3}\right)$.

EXTREMES FOR PERIOD OF RECORD,--Maximum discharge, $46,600 \mathrm{ft}^{3} / \mathrm{s}\left(1,320 \mathrm{~m}^{3} / \mathrm{s}\right)$ Mar, 2 , 1938 , based on slope-area measurement of maximum flow; no flow JuIy 17,18 , 1961 .

EXTREMES FOR CURRENT YEAR. - Peak discharges above base of $400 \mathrm{ft}^{3} / \mathrm{s}\left(11.3 \mathrm{~m}^{3} / \mathrm{s}\right)$ and maximum $(*)$ :

\begin{tabular}{|c|c|c|c|c|c|c|c|c|}
\hline Date & Time & $\begin{array}{c}\text { Discharge } \\
\left(\mathrm{ft}^{3} / \mathrm{s}\right)\left(\mathrm{m}^{3} / \mathrm{s}\right)\end{array}$ & $\begin{array}{l}\text { Gage height } \\
\text { (ft) (m) }\end{array}$ & Date & Time & $\begin{array}{c}\text { Discharge } \\
\left(\mathrm{ft}^{3} / \mathrm{s}\right)\left(\mathrm{m}^{3} / \mathrm{s}\right)\end{array}$ & $\begin{array}{l}\text { Gage } \\
(\mathrm{ft})\end{array}$ & $\begin{array}{r}\text { height } \\
\text { (m) }\end{array}$ \\
\hline $\begin{array}{l}\text { Feb. } 9 \\
\text { Mar. } 1\end{array}$ & $\begin{array}{l}0145 \\
1915\end{array}$ & $\begin{array}{r}104 \\
28.9\end{array}$ & $\begin{array}{l}1.561 \\
1.079\end{array}$ & Sept. 11 & 0600 & * 5050 & 5.77 & 1.759 \\
\hline
\end{tabular}

Minimum daily discharge, $0.53 \mathrm{ft}^{3} / \mathrm{s}\left(0.015 \mathrm{~m}^{3} / \mathrm{s}\right)$ Sept. 2 .

DISCHARGE, IN CUBIC FEET PER SECOND, WATER YEAR OCTOBER 1975 TO SEPTEMBER 1976 MEAN VALUES

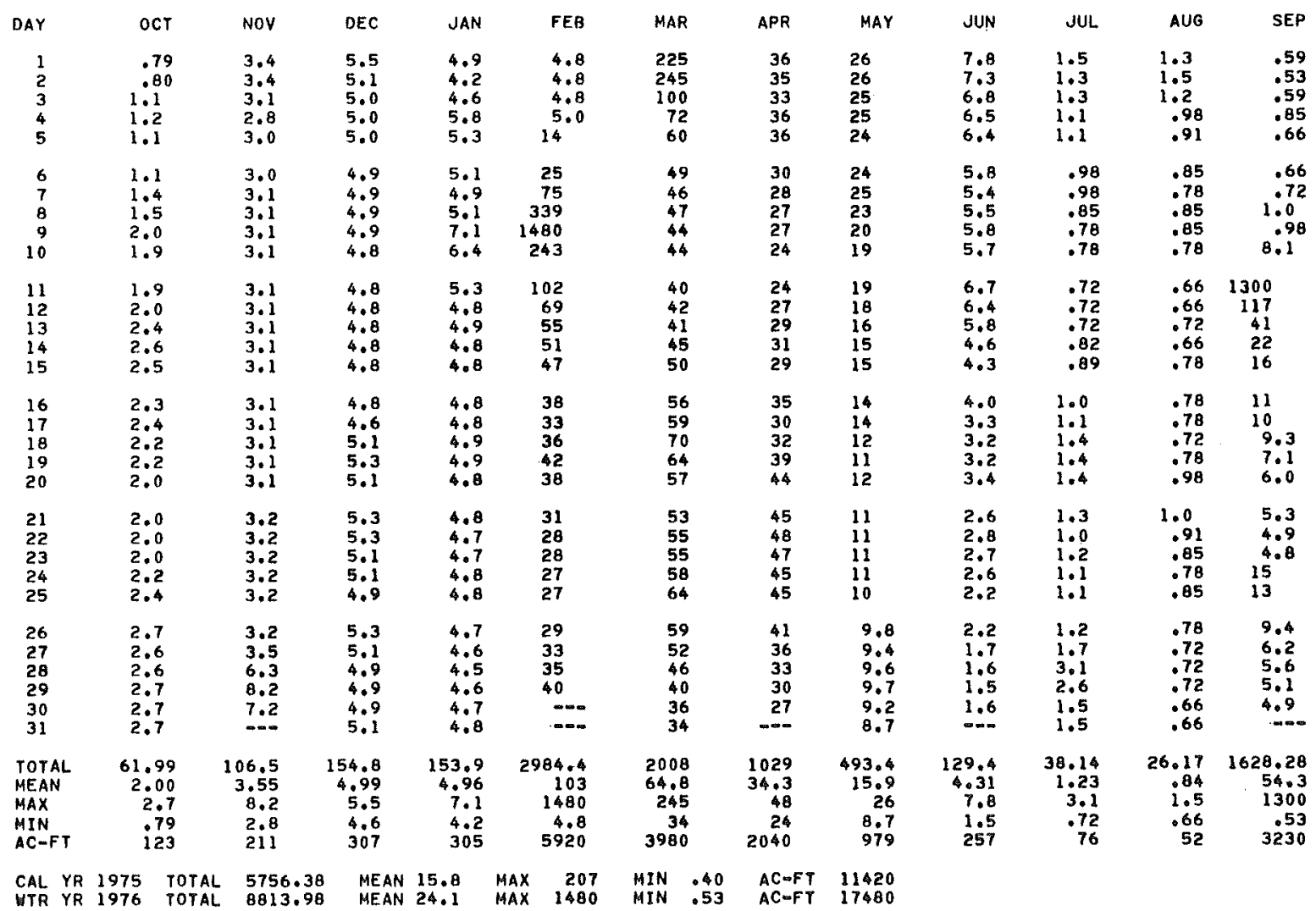


LOCATION. - Lat $34^{\circ} 20^{\prime} 20^{\prime \prime}$, long $117^{\circ} 15^{\prime} 25^{\prime \prime}$, in NW/ NW $1_{4}$ sec. 24 , T. 3 N., R. 4 W. , San Bernardino County, on left bank on upstream wingwall of concrete double box culvert on Arrowhead Lake Road, $0.1 \mathrm{mi}(0.2 \mathrm{~km})$ northeast of junction with Highway $174,4.5 \mathrm{mi}(7.2 \mathrm{~km})$ downstream from Cedar Springs Dam, and $6.5 \mathrm{mi}(10.5 \mathrm{~km})$ southeast of Hesperia.

DRAINAGE AREA, $-70.3 \mathrm{mi}^{2}\left(182 \mathrm{~km}^{2}\right)$.

PERIOD OF RECORD. - October 1904 to September 1922, October 1929 to September 1971, October 1974 to current year.

GAGE.- Water-stage recorder. Altitude of gage is $3,040 \mathrm{ft}(927 \mathrm{~m})$, from topographic map. Prior to June 30 , 1922 , nonrecording gage on water-stage recorder $1.6 \mathrm{mi}(2.6 \mathrm{~km})$ downstream at different datum. June 30 , 1922 to September 1971 , water-stage recorder $1.5 \mathrm{mi}(2.4 \mathrm{~km})$ downstream at different datum. June 30 , i942 to Apr. 14,1966 , at datum $2.00 \mathrm{ft}(0.61 \mathrm{~m})$ higher than datum then in use.

REMARKS,--Records fair. Regulation upstrean at Cedar Springs Dam since 1972.

AVERAGE DISCHARGE. - 60 years (water years $1905-22,1930-71), 39.4 \mathrm{ft}^{3} / \mathrm{s}\left(102 \mathrm{~m}^{3} / \mathrm{s}\right), 28,550 \mathrm{acre}-\mathrm{ft} / \mathrm{yr}$ $\left(35.2 \mathrm{hm}^{3} / \mathrm{yr}\right)$.

EXTREMES FOR PERIOD OF RECORD, --Maximum discharge, $26,100 \mathrm{ft}^{3} / \mathrm{s}\left(739 \mathrm{~m}^{3} / \mathrm{s}\right) \mathrm{Mar} .2,1938$, by slope-area measurement of maximum flow; no flow for several months in each year.

EXTREMES FOR CURRENT YEAR, --Maximum discharge, $1,510 \mathrm{ft}^{3} / \mathrm{s}\left(42.8 \mathrm{~m}^{3} / \mathrm{s}\right)$ Feb, 9 , gage height, $5,41 \mathrm{ft}(1.649 \mathrm{~m})$; no flow most of year.

DISCHARGE, IN CUBIC FEET PER SECOND, WATER YEAR OCTOBER 1975' TO SEPTEMBER 1976 MEAN VALUES

\begin{tabular}{|c|c|c|c|c|c|c|c|c|c|c|c|c|}
\hline DAY & OCT & Nov & DEC & JAN & FEB & MAR & $A P R$ & MAY & JUN & JUL & AUG & SEP \\
\hline $\begin{array}{l}1 \\
2 \\
3 \\
4 \\
5\end{array}$ & & & & & $\begin{array}{l}0 \\
0 \\
0 \\
0 \\
0\end{array}$ & $\begin{array}{l}48 \\
98 \\
27 \\
21 \\
13\end{array}$ & $\begin{array}{l}8.2 \\
7.8 \\
8.2 \\
12 \\
11\end{array}$ & $\begin{array}{l}3.9 \\
2.7 \\
1.7 \\
4.1 \\
3.7\end{array}$ & & & & $\begin{array}{l}0 \\
0 \\
0 \\
0 \\
0\end{array}$ \\
\hline $\begin{array}{r}6 \\
7 \\
8 \\
9 \\
10\end{array}$ & & & & & $\begin{array}{r}51 \\
103 \\
205 \\
886 \\
174\end{array}$ & $\begin{array}{l}12 \\
14 \\
13 \\
12 \\
14\end{array}$ & $\begin{array}{l}8.6 \\
3.7 \\
3.4 \\
3.0 \\
2.6\end{array}$ & $\begin{array}{l}5.0 \\
5.9 \\
5.3 \\
4.7 \\
1.5\end{array}$ & & & & $\begin{array}{l}0 \\
0 \\
0 \\
0 \\
3.9\end{array}$ \\
\hline $\begin{array}{l}11 \\
12 \\
13 \\
14 \\
15\end{array}$ & & & & & $\begin{array}{r}144 \\
107 \\
57 \\
51 \\
47\end{array}$ & $\begin{array}{l}12 \\
11 \\
12 \\
11 \\
12\end{array}$ & $\begin{array}{l}3.2 \\
3.4 \\
3.7 \\
3.2 \\
1.6\end{array}$ & $\begin{array}{l}0 \\
0 \\
0 \\
0 \\
0\end{array}$ & & & & $\begin{array}{l}92 \\
11 \\
5.0 \\
3.5 \\
3.9\end{array}$ \\
\hline $\begin{array}{l}16 \\
17 \\
18 \\
19 \\
20\end{array}$ & & & & & $\begin{array}{l}42 \\
47 \\
31 \\
33 \\
37\end{array}$ & $\begin{array}{l}14 \\
14 \\
12 \\
13 \\
13\end{array}$ & $\begin{array}{l}3.3 \\
.06 \\
0 \\
0 \\
0\end{array}$ & $\begin{array}{l}0 \\
0 \\
0 \\
0 \\
0\end{array}$ & & & & $\begin{array}{c}18 \\
6.0 \\
3.0 \\
0 \\
0\end{array}$ \\
\hline $\begin{array}{l}21 \\
22 \\
23 \\
24 \\
25\end{array}$ & & & & & $\begin{array}{l}31 \\
35 \\
33 \\
28 \\
25\end{array}$ & $\begin{array}{l}13 \\
15 \\
16 \\
16 \\
15\end{array}$ & $\begin{array}{l}1.5 \\
4.7 \\
5.3 \\
5.3 \\
5.0\end{array}$ & $\begin{array}{l}0 \\
0 \\
0 \\
0 \\
0\end{array}$ & & & & $\begin{array}{l}0 \\
0 \\
0 \\
0 \\
0\end{array}$ \\
\hline $\begin{array}{l}26 \\
27 \\
28 \\
29 \\
30 \\
31\end{array}$ & & $\ldots$ & & & $\begin{array}{r}26 \\
27 \\
22 \\
21 \\
-- \\
--0\end{array}$ & $\begin{array}{l}14 \\
15 \\
14 \\
13 \\
11 \\
11\end{array}$ & $\begin{array}{l}4.1 \\
4.7 \\
4.7 \\
4.4 \\
4.4 \\
.--0\end{array}$ & $\begin{array}{l}0 \\
0 \\
0 \\
0 \\
0 \\
0\end{array}$ & $-\infty$ & & & $\begin{array}{l}0 \\
0 \\
0 \\
0 \\
0 \\
--\end{array}$ \\
\hline $\begin{array}{l}\text { TOTAL } \\
\text { MEAN } \\
\text { MAX } \\
\text { MIN } \\
\text { AC }-F T\end{array}$ & $\begin{array}{l}0 \\
0 \\
0 \\
0 \\
0\end{array}$ & $\begin{array}{l}0 \\
0 \\
0 \\
0 \\
0\end{array}$ & $\begin{array}{l}0 \\
0 \\
0 \\
0 \\
0\end{array}$ & $\begin{array}{l}0 \\
0 \\
0 \\
0 \\
0\end{array}$ & $\begin{array}{r}2263 \\
78.0 \\
886 \\
0 \\
4490\end{array}$ & $\begin{array}{r}549 \\
17.7 \\
98 \\
11 \\
1090\end{array}$ & $\begin{array}{r}131.06 \\
4.37 \\
12 \\
0 \\
260\end{array}$ & $\begin{array}{r}38.5 \\
1.24 \\
5.9 \\
0 \\
76\end{array}$ & $\begin{array}{l}0 \\
0 \\
0 \\
0 \\
0\end{array}$ & $\begin{array}{l}0 \\
0 \\
0 \\
0 \\
0\end{array}$ & $\begin{array}{l}0 \\
0 \\
0 \\
0 \\
0\end{array}$ & $\begin{array}{r}146.3 \\
4.88 \\
92 \\
0 \\
290\end{array}$ \\
\hline
\end{tabular}

CAL YR 1975 TOTAL 2319.04 MEAN 6.35 MAX 170 MIN O AC-FT 4600 WTR YR 1976 TOTAL 3127.86 MEAN 8.55 MAX 886 MIN 0 AC-FT 6200 
10261100 MOJAVE RIVER BELOW FORKS RESERVOIR, NEAR HESPERIA, CA

WATER-QUALITY RECORDS

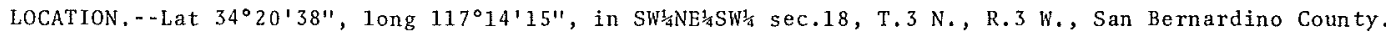
DRAINAGE AREA. $-211 \mathrm{mi}^{2}\left(546 \mathrm{~km}^{2}\right)$.

PERIOD OF RECORD. -

CHEMICAL ANALYSES: October 1966 to September 1968, water years 1969-71, 1974 to current year.

COOPERATION.--Chemical analyses were furnished by California Department of Water Resources, discharge furnished by Corps of Engineers.

CHEMICAL ANALYSES, WATER YEAR OCTOBER 1975 TO SEPTEMBER 1976

\begin{tabular}{|c|c|c|c|c|c|c|c|c|c|}
\hline DATE & TIME & $\begin{array}{l}\text { INSTAN- } \\
\text { TANEOUS } \\
\text { DIS- } \\
\text { CHARGE } \\
\text { (CFS) }\end{array}$ & $\begin{array}{l}\text { SPE- } \\
\text { CIF IC } \\
\text { CON- } \\
\text { DUCT- } \\
\text { ANCE } \\
\text { (MICRO- } \\
\text { MHOS) }\end{array}$ & $\begin{array}{c}\mathrm{PH} \\
\text { (UNITS) }\end{array}$ & $\begin{array}{l}\text { TEMPER- } \\
\text { ATURE } \\
\text { (DEG C) }\end{array}$ & $\begin{array}{l}\text { TUR- } \\
\text { BID- } \\
\text { ITY } \\
\text { (JTU) }\end{array}$ & $\begin{array}{l}\text { DIS- } \\
\text { SOLVED } \\
\text { OXYGEN } \\
\text { (MG/L) }\end{array}$ & $\begin{array}{l}\text { HARD- } \\
\text { NESS } \\
\text { (CA,MG) } \\
(M G / L)\end{array}$ & $\begin{array}{l}\text { NON- } \\
\text { CAR- } \\
\text { BONATE } \\
\text { HARD- } \\
\text { NESS } \\
\text { (MG/L) }\end{array}$ \\
\hline \multicolumn{10}{|l|}{ NOV } \\
\hline$\underset{F E B}{19}$ & 1400 & 42 & 410 & 7.6 & 8.5 & 2 & 11.0 & 78 & 0 \\
\hline$\underset{A P R}{04} \ldots$ & 0930 & 69 & 290 & 7.7 & 9.0 & 3 & 10.5 & 81 & 0 \\
\hline$\underset{\text { JUL }}{21} \cdots$ & 0945 & 134 & 150 & 7.6 & 13.0 & 3 & 9.8 & 44 & 0 \\
\hline $28 \ldots$ & 1220 & $-m$ & 420 & B.1 & 25.5 & 0 & 7.2 & 94 & 0 \\
\hline
\end{tabular}

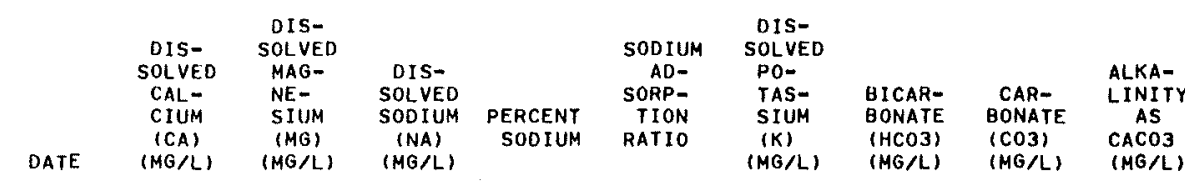

\begin{tabular}{|c|c|c|c|c|c|c|c|c|}
\hline $\begin{array}{l}\text { Nov } \\
19 . \ldots \\
\text { FEB }\end{array}$ & 26 & 3.2 & 48 & 56 & 2.4 & 3.9 & 101 & 0 \\
\hline $\begin{array}{l}04 \ldots \\
\text { APR }\end{array}$ & 27 & 3.3 & 36 & 48 & 1.7 & 2.7 & 112 & 0 \\
\hline$\underset{\text { JUL }}{21} \cdots$ & 16 & 1.1 & 14 & 40 & .9 & 1.2 & 63 & 0 \\
\hline $28 \ldots$ & 30 & 4.5 & 57 & 56 & 2.6 & 3.1 & 133 & 0 \\
\hline
\end{tabular}

\begin{tabular}{|c|c|c|c|c|c|c|c|c|c|}
\hline OATE & $\begin{array}{c}\text { CARBON } \\
\text { DIOXIDE } \\
\text { (CO2) } \\
\text { (MG/L) }\end{array}$ & $\begin{array}{l}\text { DIS- } \\
\text { SOLVED } \\
\text { SULFATE } \\
\text { (SO4) } \\
\text { (MG/L) }\end{array}$ & $\begin{array}{l}\text { OIS- } \\
\text { SOLVED } \\
\text { CHLO- } \\
\text { RIDE } \\
\text { (CL) } \\
\text { (MG/L) }\end{array}$ & $\begin{array}{l}\text { OIS- } \\
\text { SOLVED } \\
\text { FLUO- } \\
\text { RIDE } \\
\text { (F) } \\
\text { (MG/L) }\end{array}$ & $\begin{array}{l}\text { OIS- } \\
\text { SOLVED } \\
\text { SOLIOS } \\
\text { (RESI- } \\
\text { DUE AT } \\
\text { IBO C) } \\
\text { (MG/L) }\end{array}$ & $\begin{array}{l}\text { OIS- } \\
\text { SOLVED } \\
\text { SOLIOS } \\
\text { (TONS } \\
\text { PER } \\
\text { AC=FT) }\end{array}$ & $\begin{array}{l}\text { DIS- } \\
\text { SOLVED } \\
\text { SOLIDS } \\
\text { (TONS } \\
\text { PER } \\
\text { DAY) }\end{array}$ & $\begin{array}{c}\text { TOTAL } \\
\text { NITRATE } \\
\text { (N) } \\
\text { (MG/L) }\end{array}$ & $\begin{array}{c}\text { DIS- } \\
\text { SOLVEO } \\
\text { BORON } \\
\text { (B) } \\
\text { (UG/L) }\end{array}$ \\
\hline NOV & & & & & & & & & 1 \\
\hline$\underset{F E B}{19} \cdots$ & 4.1 & 56 & 18 & 2.5 & 265 & .36 & 30.1 & 2.7 & 160 \\
\hline$\underset{A P R}{04} \cdots$ & 3.6 & 39 & 14 & 2.3 & 186 & .25 & 34.7 & 1.4 & 50 \\
\hline$\underset{\text { JUL }}{21} \cdots$ & 2.5 & 84 & 9.6 & .6 & 82 & .11 & 29.7 & .29 & 110 \\
\hline $28 \ldots$ & 1.7 & 86 & 13 & 3.4 & 209 & .28 & $=$ & .04 & 260 \\
\hline
\end{tabular}


10261500 MOJAVE RIVER AT LOWER NARROWS, NEAR VICTORVILLE, CA (National stream-quality accounting network station)

LOCATION. - Lat $34^{\circ} 34^{\prime} 23^{\prime \prime}$, long $117^{\circ} 19^{\prime} 11^{\prime \prime}$, in SW $W_{4} W^{\prime} \frac{1}{4} S E^{\frac{1}{4}}$ sec.29, T.6 N., R.4 W., San Bernardino County, on 1eft bank $650 \mathrm{ft}(198 \mathrm{~m})$ upstream from bridge on county road, formerly U.S. Highway 66 , $0.6 \mathrm{mi}$ (1.0 km) downstream from Atchison, Topeka, and Santa Fe Railway bridge, $3 \mathrm{mi}$ ( $5 \mathrm{~km}$ ) northwest of Victorville, and $33 \mathrm{mi}$ ( $53 \mathrm{~km}$ ) downstream from Silverwood Lake.

DRAINAGE AREA. - $-513 \mathrm{mi}^{2}\left(1,329 \mathrm{~km}^{2}\right)$, revised.

WATER-DISCHARGE RECORDS

PERIOD OF RECORD, - February 1899 to September 1906 , October 1930 to current year. Month1y discharge on 1 y for January to September 1906, October, November 1930, published in WSP 1314. Prior to October 1936, pub1ished as "at Victorville" and as "near Victorville" in 1937.

GAGE.--Water-stage recorder. Datum of gage is $2,643.01 \mathrm{ft}(805.589 \mathrm{~m})$ above mean sea level. See WSP 1314 for history of gage changes prior to Mar. 28, 1938. Mar. 28, 1938, to Apr. 14, 1966, at site 350 ft (107 m) upstream at datum $5.00 \mathrm{ft}(1.52 \mathrm{~m})$ higher; Apr. 14, 1966, to July 17, 1969, at site $350 \mathrm{ft}$ (107 m) upstream at datum $3.00 \mathrm{ft}(0.91 \mathrm{~m})$ higher.

REMARKS.--Records fair, except for period of no gage-height record Aug, 6 to Sept. 14 which are poor: Regulation by Lake Árrowhead, capacity, 48,000 acre-ft $\left(59,2 \mathrm{hm}^{3}\right)$ used principal1y for recreation, Silverwood Lake, capacity, $78,0.00$ acre-ft $\left(96.2 \mathrm{hm}^{3}\right)$ used for the storage and distribution of imported water and recreation, and by Mojave Forks Reservoir since June 1970, capacity, 89,700 acre-ft (111 hm ${ }^{3}$ ) with ungated opening, capacity, $23,500 \mathrm{ft}^{3} / \mathrm{s}\left(666 \mathrm{~m}^{3} / \mathrm{s}\right)$. Since 1970 effluent from Mojave State Fish Hatchery diverted to Spring Valley Lake. Diversions and pumping for irrigation of about 5,000 acres $\left(20.2 \mathrm{~km}^{2}\right)$ above station.

AVERAGE DISCHARGE. - -53 years (water years $1900-06,1931-76), 71.6 \mathrm{ft} / \mathrm{s}\left(2.028 \mathrm{~m}^{3} / \mathrm{s}\right), 51,870 \mathrm{acre}-\mathrm{ft} / \mathrm{yr}^{3}$ $\left(64.0 \mathrm{hm}^{3} / \mathrm{yr}\right)$.

EXTREMES FOR PERIOD OF RECORD. - Maximum discharge, $70,600 \mathrm{ft}^{3} / \mathrm{s}\left(2,000 \mathrm{~m}^{3} / \mathrm{s}\right)$ Mar. 2 , 1938, gage height, $23.7 \mathrm{ft}$ $(7.22 \mathrm{~m})$, present datum, from rating curve extended above $10,000 \mathrm{ft} / \mathrm{s}\left(283 \mathrm{~m}^{3} / \mathrm{s}\right)$ on basis of $\mathrm{s} 10 \mathrm{pe}-\mathrm{area}$ measurement of maximum flow; minimum daily, $3.4 \mathrm{ft}^{3} / \mathrm{s}\left(0.096 \mathrm{~m}^{3} / \mathrm{s}\right)$ July 25,1975 .

EXTREMES FOR CURRENT YEAR. - -Maximum discharge, $325 \mathrm{ft}^{3} / \mathrm{s}\left(9.20 \mathrm{~m}^{3} / \mathrm{s}\right)$ Sept. 10, gage height, $3.27 \mathrm{ft}(0.997 \mathrm{~m})$ minimum daily, $11 \mathrm{ft}^{3} / \mathrm{s}\left(0.31 \mathrm{~m}^{3} / \mathrm{s}\right)$ Oct. $2-4$.

DISCHARGE, IN CUBIC FEET PER SECOND, WATER YEAR OCTOBER 1975 TO SEPTEMBER 1976 MEAN VALUES

\begin{tabular}{|c|c|c|c|c|c|c|c|c|c|c|c|c|}
\hline DAY & $\mathrm{OCT}$ & Nov & DEC & JAN & FEB & MAR & APR & MAY & JUN & JUL & AUG & SEP \\
\hline $\begin{array}{l}1 \\
2 \\
3 \\
4 \\
5\end{array}$ & $\begin{array}{l}12 \\
11 \\
11 \\
11 \\
12\end{array}$ & $\begin{array}{l}19 \\
19 \\
18 \\
19 \\
20\end{array}$ & $\begin{array}{l}24 \\
25 \\
25 \\
27 \\
27\end{array}$ & $\begin{array}{l}29 \\
33 \\
29 \\
26 \\
25\end{array}$ & $\begin{array}{l}29 \\
29 \\
30 \\
37 \\
30\end{array}$ & $\begin{array}{l}44 \\
42 \\
45 \\
39 \\
38\end{array}$ & $\begin{array}{l}34 \\
34 \\
34 \\
34 \\
32\end{array}$ & $\begin{array}{l}27 \\
26 \\
27 \\
27 \\
29\end{array}$ & $\begin{array}{l}21 \\
23 \\
23 \\
21 \\
23\end{array}$ & $\begin{array}{l}19 \\
21 \\
20 \\
19 \\
21\end{array}$ & $\begin{array}{l}18 \\
19 \\
21 \\
23 \\
24\end{array}$ & $\begin{array}{l}19 \\
19 \\
19 \\
19 \\
19\end{array}$ \\
\hline $\begin{array}{r}6 \\
7 \\
8 \\
9 \\
10\end{array}$ & $\begin{array}{l}13 \\
13 \\
14 \\
15 \\
16\end{array}$ & $\begin{array}{l}19 \\
19 \\
19 \\
20 \\
19\end{array}$ & $\begin{array}{l}25 \\
25 \\
24 \\
25 \\
25\end{array}$ & $\begin{array}{l}26 \\
26 \\
26 \\
30 \\
32\end{array}$ & $\begin{array}{r}37 \\
42 \\
66 \\
124 \\
179\end{array}$ & $\begin{array}{l}37 \\
37 \\
37 \\
35 \\
37\end{array}$ & $\begin{array}{l}34 \\
32 \\
32 \\
32 \\
32\end{array}$ & $\begin{array}{l}29 \\
30 \\
29 \\
27 \\
26\end{array}$ & $\begin{array}{l}21 \\
21 \\
20 \\
21 \\
23\end{array}$ & $\begin{array}{l}23 \\
24 \\
19 \\
20 \\
23\end{array}$ & $\begin{array}{l}23 \\
22 \\
21 \\
19 \\
19\end{array}$ & $\begin{array}{r}19 \\
19 \\
19 \\
19 \\
200\end{array}$ \\
\hline $\begin{array}{l}11 \\
12 \\
13 \\
14 \\
15\end{array}$ & $\begin{array}{l}16 \\
16 \\
17 \\
17 \\
17\end{array}$ & $\begin{array}{l}19 \\
20 \\
20 \\
21 \\
21\end{array}$ & $\begin{array}{l}25 \\
25 \\
26 \\
26 \\
25\end{array}$ & $\begin{array}{l}35 \\
34 \\
29 \\
29 \\
27\end{array}$ & $\begin{array}{l}56 \\
50 \\
47 \\
49 \\
47\end{array}$ & $\begin{array}{l}35 \\
35 \\
35 \\
34 \\
34\end{array}$ & $\begin{array}{l}35 \\
32 \\
34 \\
32 \\
37\end{array}$ & $\begin{array}{l}29 \\
24 \\
24 \\
24 \\
24\end{array}$ & $\begin{array}{l}23 \\
23 \\
20 \\
18 \\
17\end{array}$ & $\begin{array}{l}23 \\
20 \\
23 \\
24 \\
23\end{array}$ & $\begin{array}{l}19 \\
19 \\
19 \\
19 \\
19\end{array}$ & $\begin{array}{l}56 \\
38 \\
36 \\
35 \\
35\end{array}$ \\
\hline $\begin{array}{l}16 \\
17 \\
18 \\
19 \\
20\end{array}$ & $\begin{array}{l}16 \\
16 \\
17 \\
17 \\
17\end{array}$ & $\begin{array}{l}23 \\
23 \\
21 \\
21 \\
23\end{array}$ & $\begin{array}{l}25 \\
25 \\
25 \\
25 \\
26\end{array}$ & $\begin{array}{l}27 \\
27 \\
27 \\
26 \\
26\end{array}$ & $\begin{array}{l}47 \\
45 \\
44 \\
42 \\
41\end{array}$ & $\begin{array}{l}34 \\
34 \\
32 \\
34 \\
34\end{array}$ & $\begin{array}{l}38 \\
37 \\
35 \\
37 \\
32\end{array}$ & $\begin{array}{l}24 \\
23 \\
24 \\
25 \\
25\end{array}$ & $\begin{array}{l}17 \\
17 \\
15 \\
15 \\
14\end{array}$ & $\begin{array}{l}21 \\
20 \\
19 \\
19 \\
20\end{array}$ & $\begin{array}{l}19 \\
19 \\
19 \\
19 \\
19\end{array}$ & $\begin{array}{l}38 \\
38 \\
38 \\
39 \\
39\end{array}$ \\
\hline $\begin{array}{l}21 \\
22 \\
23 \\
24 \\
25\end{array}$ & $\begin{array}{l}16 \\
16 \\
17 \\
18 \\
18\end{array}$ & $\begin{array}{l}23 \\
24 \\
24 \\
24 \\
23\end{array}$ & $\begin{array}{l}25 \\
32 \\
30 \\
29 \\
29\end{array}$ & $\begin{array}{l}26 \\
26 \\
26 \\
27 \\
27\end{array}$ & $\begin{array}{l}39 \\
39 \\
42 \\
42 \\
38\end{array}$ & $\begin{array}{l}35 \\
35 \\
34 \\
32 \\
32\end{array}$ & $\begin{array}{l}31 \\
31 \\
30 \\
31 \\
31\end{array}$ & $\begin{array}{l}24 \\
23 \\
23 \\
23 \\
23\end{array}$ & $\begin{array}{l}14 \\
14 \\
15 \\
17 \\
17\end{array}$ & $\begin{array}{l}19 \\
19 \\
21 \\
21 \\
23\end{array}$ & $\begin{array}{l}19 \\
19 \\
19 \\
19 \\
19\end{array}$ & $\begin{array}{l}39 \\
39 \\
39 \\
51 \\
45\end{array}$ \\
\hline $\begin{array}{l}26 \\
27 \\
28 \\
29 \\
30 \\
31\end{array}$ & $\begin{array}{l}17 \\
19 \\
19 \\
18 \\
18 \\
20\end{array}$ & $\begin{array}{r}23 \\
21 \\
23 \\
23 \\
24 \\
-\infty\end{array}$ & $\begin{array}{l}30 \\
30 \\
30 \\
29 \\
30 \\
29\end{array}$ & $\begin{array}{l}27 \\
31 \\
30 \\
30 \\
30 \\
29\end{array}$ & $\begin{array}{r}41 \\
38 \\
39 \\
41 \\
-\infty \\
-\infty\end{array}$ & $\begin{array}{l}32 \\
32 \\
34 \\
34 \\
34 \\
34\end{array}$ & $\begin{array}{r}32 \\
30 \\
29 \\
29 \\
27 \\
-\infty \times\end{array}$ & $\begin{array}{l}21 \\
21 \\
21 \\
23 \\
23 \\
23\end{array}$ & $\begin{array}{l}18 \\
18 \\
18 \\
19 \\
18 \\
-\infty\end{array}$ & $\begin{array}{l}21 \\
21 \\
19 \\
18 \\
18 \\
19\end{array}$ & $\begin{array}{l}19 \\
19 \\
19 \\
19 \\
19 \\
19\end{array}$ & $\begin{array}{r}56 \\
56 \\
56 \\
54 \\
54 \\
-0\end{array}$ \\
\hline $\begin{array}{l}\text { TOTAL } \\
\text { MEAN } \\
\text { MAX } \\
\text { MIN } \\
\text { AC-FY }\end{array}$ & $\begin{array}{r}490 \\
15.8 \\
20 \\
11 \\
972\end{array}$ & $\begin{array}{r}635 \\
21.2 \\
24 \\
18 \\
1260\end{array}$ & $\begin{array}{r}928 \\
26.7 \\
32 \\
24 \\
1640\end{array}$ & $\begin{array}{r}878 \\
28.3 \\
35 \\
25 \\
1740\end{array}$ & $\begin{array}{r}1430 \\
49.3 \\
179 \\
29 \\
2840\end{array}$ & $\begin{array}{r}1100 \\
35.5 \\
45 \\
32 \\
2180\end{array}$ & $\begin{array}{r}980 \\
32.7 \\
38 \\
27 \\
1940\end{array}$ & $\begin{array}{r}771 \\
24.9 \\
30 \\
21 \\
1530\end{array}$ & $\begin{array}{r}564 \\
18.8 \\
23 \\
14 \\
1120\end{array}$ & $\begin{array}{r}640 \\
20.6 \\
24 \\
18 \\
1270\end{array}$ & $\begin{array}{r}608 \\
19.6 \\
24 \\
18 \\
1210\end{array}$ & $\begin{array}{r}1252 \\
42.7 \\
200 \\
19 \\
2480\end{array}$ \\
\hline
\end{tabular}

$\begin{array}{llrrrrrrr}\text { CAL YR } 1975 & \text { TOTAL } & 7970.5 & \text { MEAN } 21.8 & \text { MAX } 47 & \text { MIN } & 3.4 & \text { AC-FT } & 15810 \\ \text { HTR YR } 1976 & \text { TOTAL } 10176.0 & \text { MEAN } 27.6 & \text { MAX } 200 & \text { MIN } & 11 & A C-F T & 20180\end{array}$ 
PERIOD OF RECORD. - -Water years 1967 to current year.

CHEMICAL ANALYSES: Water years 1967 to current year; water years $1969-74$ (partial-record station). WATER TEMPERATURES: March 1962 to water year 1965, June 1975 to current year.

SEDIMENT RECORDS: Water year 1975 to current year.

PERTOD OF DATLY RECORD.-

SPECIFIC CONDUCTANCE: June 1975 to current year.

WATER TEMPERATURES: March 1962 to September $196 \dot{5}$, June 1975 to current year.

INSTRUMENTATION.--Specific-conductance recorder since June 1965 . Temperature recorder from March 1962 to September 1965 and since June 1975

REMARKS.--Periods of missing conductivity and temperature data were due to equipment malfunction.

COOPERATION.--The letter "A" following a date indicates chemical-quality data that was furnished by California Department of Water Resources.

EXTREMES FOR PERIOD OF DAILY RECORD. - -

SPECIFIC CONDUCTANCE: Maximum recorded, 726 micromhos Jan. 23, 1976; minimum recorded, 396 micromhos Mar. 3, 1976

WATER TEMPERATURES: Maximum, $34.5^{\circ} \mathrm{C} \mathrm{July} \mathrm{23,} \mathrm{Aug,} \mathrm{14,} \mathrm{1962;} \mathrm{minimum,} \mathrm{3.} 0^{\circ} \mathrm{C} \mathrm{Jan,} 2,1976$.

EXTREMES FOR CURRENT YEAR -

SPECIFIC CONDUCTANCE: Maximum recorded, 726 micromhos Jan. 23; minimum recorded, 396 mictomhos Mar. 3. WATER TEMPERATURES: Maximum recorded, $31.0^{\circ} \mathrm{C}$ June 18 and July 21 ; minimum recorded, $3.0^{\circ} \mathrm{C} \mathrm{Jan.} 2$.

CHEMICAL AHALYSES, HATER YEAR OCTOBER 1975 TO SEPTEMBER 1976

\begin{tabular}{|c|c|c|c|c|c|c|c|c|c|}
\hline DATE & T IME & $\begin{array}{l}\text { INSTAN- } \\
\text { TANEOUS } \\
\text { DIS- } \\
\text { CHARGE } \\
\text { (CFS) }\end{array}$ & $\begin{array}{l}\text { SPE- } \\
\text { CIFIC } \\
\text { CON= } \\
\text { DUCT- } \\
\text { ANCE } \\
\text { (MICRO- } \\
\text { MHOS) }\end{array}$ & $\begin{array}{c}P H \\
\text { (UNITS) }\end{array}$ & $\begin{array}{l}\text { TEMPER- } \\
\text { ATURE } \\
\text { (DEG C) }\end{array}$ & $\begin{array}{l}\text { DIS- } \\
\text { SOLVED } \\
\text { SOLIDS } \\
\text { (RESI } \\
\text { DUE AT } \\
180 \mathrm{C}) \\
(\mathrm{MG} / \mathrm{L})\end{array}$ & $\begin{array}{l}\text { DIS- } \\
\text { SOLVED } \\
\text { SOLIDS } \\
\text { (SUM OF } \\
\text { CONSTI - } \\
\text { TUENTS) } \\
\text { (HG/L) }\end{array}$ & $\begin{array}{l}\text { DIS- } \\
\text { SOLVED } \\
\text { SOLIDS } \\
\text { (TONS } \\
\text { PER } \\
\text { AC-FT) }\end{array}$ & $\begin{array}{l}\text { DIS- } \\
\text { SOLVED } \\
\text { SOLIDS } \\
\text { (TONS } \\
\text { PER } \\
\text { DAY) }\end{array}$ \\
\hline $\begin{array}{l}\text { OCT } \\
31 . . . \\
\text { NOV }\end{array}$ & 1030 & 11 & 595 & 8.1 & 17.8 & 353 & 349 & .48 & 10.5 \\
\hline $\begin{array}{c}19 \ldots . . \\
26 \ldots \\
D E C\end{array}$ & $\begin{array}{l}1130 \\
1055\end{array}$ & $\begin{array}{l}20 \\
23\end{array}$ & $\begin{array}{l}610 \\
590\end{array}$ & $\begin{array}{l}7.8 \\
8.2\end{array}$ & $\begin{array}{l}13.0 \\
12.8\end{array}$ & $\begin{array}{l}389 \\
349\end{array}$ & 337 & $\begin{array}{r}.53 \\
.47\end{array}$ & $\begin{array}{l}21.0 \\
21.7\end{array}$ \\
\hline $\begin{array}{l}30 \cdots \\
\text { JAN }\end{array}$ & 1100 & 30 & 575 & 7.9 & 14.8 & 336 & 334 & .46 & 27.2 \\
\hline$\underset{F E B}{29} \cdots$ & 1115 & 29 & 565 & 8.1 & 14.6 & 340 & 325 & .46 & 26.6 \\
\hline$\underset{\text { MAR }}{24 \ldots \ldots}$ & $\begin{array}{l}1130 \\
1045\end{array}$ & $\begin{array}{l}33 \\
42\end{array}$ & $\begin{array}{l}475 \\
535\end{array}$ & $\begin{array}{l}7.7 \\
8.3\end{array}$ & $\begin{array}{l}13.0 \\
16.0\end{array}$ & $\begin{array}{l}322 \\
316\end{array}$ & 317 & $\begin{array}{l}.44 \\
.43\end{array}$ & $\begin{array}{l}28.7 \\
35.8\end{array}$ \\
\hline$\underset{A P R}{25} \cdots$ & 1040 & 31 & 570 & 7.8 & 16.2 & 317 & 320 & .43 & 26.5 \\
\hline $\begin{array}{l}21 \ldots \ldots \\
29 \ldots \ldots \\
\text { MAY }\end{array}$ & $\begin{array}{l}1200 \\
1125\end{array}$ & $\begin{array}{l}33 \\
32\end{array}$ & $\begin{array}{l}485 \\
525\end{array}$ & $\begin{array}{l}7.6 \\
8.0\end{array}$ & $\begin{array}{l}22.0 \\
21.8\end{array}$ & $\begin{array}{l}292 \\
306\end{array}$ & 303 & $\begin{array}{r}.40 \\
.42\end{array}$ & $\begin{array}{l}26.0 \\
26.4\end{array}$ \\
\hline$\underset{\mathrm{JUN}}{27} \cdots$ & 1050 & 23 & 523 & $B .1$ & $24 \cdot 2$ & 320 & -- & .44 & 19.9 \\
\hline $\begin{array}{l}28 \ldots \ldots \\
\text { JUL }\end{array}$ & 1130 & 18 & 520 & 7.8 & 28.5 & $-\infty$ & -- & $-=$ & $=-$ \\
\hline$\underset{A \cup G}{13 . \ldots .}$ & $\begin{array}{l}1050 \\
1430\end{array}$ & $\begin{array}{l}24 \\
18\end{array}$ & $\begin{array}{l}\mathbf{5 5 0} \\
\mathbf{5 0 0}\end{array}$ & $\begin{array}{l}8.1 \\
7.7\end{array}$ & $\begin{array}{l}26.5 \\
28.5\end{array}$ & $\begin{array}{l}322 \\
246\end{array}$ & $\begin{array}{r}319 \\
--\end{array}$ & $\begin{array}{r}.44 \\
.33\end{array}$ & $\begin{array}{l}20.9 \\
12.0\end{array}$ \\
\hline SEP & 1315 & 19 & 460 & 7.9 & 24.5 & 311 & 323 & .42 & 16.3 \\
\hline $14 \ldots$ & 1145 & 35 & 470 & 8.2 & 24.5 & 318 & 303 & .43 & 30.1 \\
\hline
\end{tabular}


CHEMICAL ANALYSES, WATER YEAR OCTOBER 1975 TO SEPTEMEER 1976

\begin{tabular}{|c|c|c|c|c|c|c|c|c|c|c|c|}
\hline DATE & TIME & $\begin{array}{c}\text { INSTAN- } \\
\text { TANEOUS } \\
\text { DIS- } \\
\text { CHARGE } \\
\text { (CFS) }\end{array}$ & $\begin{array}{l}\text { TUR- } \\
\text { BID- } \\
\text { ITY } \\
\text { (JTU) }\end{array}$ & $\begin{array}{l}\text { DIS- } \\
\text { SOLVEO } \\
\text { OXYGEN } \\
\text { (MG/L) }\end{array}$ & $\begin{array}{c}\text { FECAL } \\
\text { COLI- } \\
\text { FORM } \\
\text { (COL. } \\
\text { PER } \\
100 \mathrm{ML} \text { ) }\end{array}$ & $\begin{array}{c}\text { STREP- } \\
\text { TOCOCCI } \\
\text { (COL- } \\
\text { ONIES } \\
\text { PER } \\
100 \mathrm{ML})\end{array}$ & $\begin{array}{l}\text { HARD- } \\
\text { NESS } \\
(C A, M G) \\
(M G / L)\end{array}$ & $\begin{array}{l}\text { NON- } \\
\text { CAR- } \\
\text { BONATE } \\
\text { HARD- } \\
\text { NESS } \\
\text { (MG/L) }\end{array}$ & $\begin{array}{l}\text { DIS- } \\
\text { SOLVED } \\
\text { CAL- } \\
\text { CIUM } \\
\text { (CA) } \\
\text { (MG/L) }\end{array}$ & $\begin{array}{l}\text { DIS- } \\
\text { SOLVED } \\
\text { MAG- } \\
\text { NE- } \\
\text { SIUM } \\
(M G) \\
(H G / L)\end{array}$ & $\begin{array}{l}\text { DIS- } \\
\text { SOLVED } \\
\text { SODIUM } \\
\text { (NA) } \\
\text { (MG/L) }\end{array}$ \\
\hline $\begin{array}{l}\text { OCT } \\
31 \ldots \\
\text { NOV }\end{array}$ & 1030 & 11 & 10 & -- & 30 & 60 & 160 & 0 & 49 & 9.6 & 58 \\
\hline $\begin{array}{l}19 \ldots . . A \\
26 \ldots \\
D E C\end{array}$ & $\begin{array}{l}1130 \\
1055\end{array}$ & $\begin{array}{l}20 \\
23\end{array}$ & $\begin{array}{l}10 \\
10\end{array}$ & 8.6 & $\ddot{84}$ & 37 & $\begin{array}{l}169 \\
170\end{array}$ & $\begin{array}{l}0 \\
0\end{array}$ & $\begin{array}{l}50 \\
48\end{array}$ & $\begin{array}{l}11 \\
11\end{array}$ & $\begin{array}{l}54 \\
53\end{array}$ \\
\hline JaN 30 & 1100 & 30 & 9 & - & 82 & 810 & 170 & 0 & 51 & 11 & 52 \\
\hline $\begin{array}{c}29 \\
\mathrm{FEB}\end{array}$ & 1115 & 29 & 10 & - & B6 & 23 & 160 & 0 & 47 & 11 & 50 \\
\hline $\begin{array}{r}04 \ldots A \\
24 \ldots A\end{array}$ & $\begin{array}{l}1130 \\
1045\end{array}$ & $\begin{array}{l}33 \\
42\end{array}$ & $\begin{array}{l}44 \\
10\end{array}$ & 8.3 & $\overline{\mathrm{B3}}$ & 816 & $\begin{array}{l}166 \\
160\end{array}$ & $\begin{array}{l}0 \\
0\end{array}$ & $\begin{array}{l}50 \\
50\end{array}$ & $\begin{array}{l}10 \\
9.6\end{array}$ & $\begin{array}{l}49 \\
46\end{array}$ \\
\hline$\underset{A P R}{25} \cdots$ & 1040 & 31 & 6 & -- & 0 & B18 & 160 & 0 & 47 & 9.5 & 47 \\
\hline $\begin{array}{r}21 \ldots . . . A \\
29 A Y\end{array}$ & $\begin{array}{l}1200 \\
1125\end{array}$ & $\begin{array}{l}33 \\
32\end{array}$ & 4 & 6.1 & $\overline{89}$ & $\overline{38}$ & $\begin{array}{l}156 \\
140\end{array}$ & $\begin{array}{l}0 \\
0\end{array}$ & $\begin{array}{l}47 \\
41\end{array}$ & $\begin{array}{l}9.1 \\
9.5\end{array}$ & $\begin{array}{l}48 \\
46\end{array}$ \\
\hline$\underset{J U N}{27} \cdots$ & 1050 & 23 & -- & - & 24 & -- & 160 & -- & 49 & 9.8 & 50 \\
\hline${ }_{J U L}^{28} \ldots$ & 1130 & 18 & 2 & - & 48 & 200 & 150 & -- & 44 & 9.6 & 48 \\
\hline $\begin{array}{r}13 \ldots \ldots \\
28 \ldots\end{array}$ & $\begin{array}{l}1050 \\
1430\end{array}$ & $\begin{array}{l}24 \\
18\end{array}$ & $\begin{array}{l}1 \\
2\end{array}$ & 4.6 & B18 & $\begin{array}{r}>300 \\
-\ldots\end{array}$ & $\begin{array}{l}160 \\
143\end{array}$ & $\begin{array}{l}0 \\
0\end{array}$ & $\begin{array}{l}47 \\
43\end{array}$ & $\begin{array}{l}9.7 \\
8.6\end{array}$ & $\begin{array}{l}50 \\
51\end{array}$ \\
\hline $\operatorname{sep}_{\text {SE... }}$ & 1315 & 19 & 2 & -- & B11 & 8286 & 140 & 0 & 44 & 8.4 & 53 \\
\hline $14 \ldots$ & 1145 & 35 & 15 & - & $>2000$ & B700 & 150 & 0 & 44 & 9.2 & 45 \\
\hline
\end{tabular}

\begin{tabular}{|c|c|c|c|c|c|c|c|c|c|c|c|}
\hline DATE & $\begin{array}{l}\text { PERCENT } \\
\text { SOOIUM }\end{array}$ & $\begin{array}{l}\text { SOOIUM } \\
\text { AD- } \\
\text { SORPO } \\
\text { TION } \\
\text { RATIO }\end{array}$ & $\begin{array}{l}\text { DIS- } \\
\text { SOLVED } \\
\text { PO- } \\
\text { TAS- } \\
\text { SIUM } \\
\text { (K) } \\
\text { (MG/L) }\end{array}$ & $\begin{array}{l}\text { BICAR- } \\
\text { BONATE } \\
\text { (HCO3) } \\
\text { (MG/L) }\end{array}$ & $\begin{array}{l}\text { CAR- } \\
\text { BONATE } \\
\text { (CO3) } \\
(M G / L)\end{array}$ & $\begin{array}{l}\text { ALKA- } \\
\text { LINITY } \\
\text { AS } \\
\text { CACO3 } \\
\text { (MG/L) }\end{array}$ & $\begin{array}{l}\text { CARBON } \\
\text { OIOXIDE } \\
\text { (CO2) } \\
\text { (MG/L) }\end{array}$ & $\begin{array}{l}\text { DIS- } \\
\text { SOLVED } \\
\text { SULFATE } \\
\text { (SO4) } \\
\text { (MG/L) }\end{array}$ & $\begin{array}{l}\text { DIS- } \\
\text { SOLVED } \\
\text { CHLOO- } \\
\text { RIDE } \\
\text { (CLL) } \\
\text { (MG/L) }\end{array}$ & $\begin{array}{l}\text { DIS- } \\
\text { SOLVED } \\
\text { FLUO- } \\
\text { RIDE } \\
(F) \\
(M G / L)\end{array}$ & $\begin{array}{l}\text { DIS- } \\
\text { SOLVED } \\
\text { SILICA } \\
\text { (SIOZ) } \\
\text { (MG/L) }\end{array}$ \\
\hline $\begin{array}{l}0 \mathrm{CT} \\
31 \ldots .\end{array}$ & 42 & 2.0 & 8.4 & 217 & 0 & 178 & 2.8 & 56 & 38 & .5 & 22 \\
\hline $\begin{array}{l}\text { NOV } \\
19 \ldots . . A \\
26 \ldots .\end{array}$ & $\begin{array}{l}40 \\
40\end{array}$ & $\begin{array}{l}1.8 \\
1.8\end{array}$ & $\begin{array}{l}7.0 \\
8.0\end{array}$ & $\begin{array}{l}212 \\
216\end{array}$ & $\begin{array}{l}0 \\
0\end{array}$ & $\begin{array}{l}174 \\
177\end{array}$ & $\begin{array}{l}5.4 \\
2.2\end{array}$ & $\begin{array}{l}54 \\
52\end{array}$ & $\begin{array}{l}35 \\
34\end{array}$ & .5 & $24^{--}$ \\
\hline $\begin{array}{l}\text { DEC } \\
30 \ldots \\
\text { JAN }\end{array}$ & 38 & 1.7 & 6.5 & 212 & 0 & 174 & 4.3 & 53 & 33 & .3 & 23 \\
\hline FEB $29 .$. & 39 & 1.7 & 5.5 & 208 & 0 & 171 & 2.6 & 54 & 32 & .5 & 22 \\
\hline $\begin{array}{c}04 \ldots . . A \\
24 \\
M A R\end{array}$ & $\begin{array}{l}38 \\
37\end{array}$ & $\begin{array}{l}1.7 \\
1.6\end{array}$ & $\begin{array}{l}5.9 \\
5.2\end{array}$ & $\begin{array}{l}207 \\
202\end{array}$ & $\begin{array}{l}0 \\
0\end{array}$ & $\begin{array}{l}170 \\
166\end{array}$ & $\begin{array}{l}6.6 \\
1.6\end{array}$ & $\begin{array}{l}54 \\
53\end{array}$ & $\begin{array}{l}30 \\
30\end{array}$ & .6 & $23^{--}$ \\
\hline${ }_{A P R}^{25} \ldots$ & 38 & 1.6 & 6.6 & 205 & 0 & 168 & 5.2 & 54 & 32 & .4 & 22 \\
\hline$\underset{M A Y}{21 . . .}$ & $\begin{array}{l}39 \\
40\end{array}$ & $\begin{array}{l}1.7 \\
1.7\end{array}$ & $\begin{array}{l}5.9 \\
5.8\end{array}$ & $\begin{array}{l}196 \\
198\end{array}$ & $\begin{array}{l}0 \\
0\end{array}$ & $\begin{array}{l}161 \\
162\end{array}$ & $\begin{array}{l}7.9 \\
3.2\end{array}$ & $\begin{array}{l}50 \\
52\end{array}$ & $\begin{array}{l}31 \\
29\end{array}$ & .6 & $22^{--}$ \\
\hline JUN $27 .$. & 39 & 1.7 & 6.0 & $\cdots$ & $\cdots$ & $\cdots$ & -- & 50 & 31 & $\cdots$ & 25 \\
\hline JUL $28 \cdots$ & 40 & 1.7 & 6.0 & -- & -- & -- & -- & 120 & 33 & .6 & 26 \\
\hline $\begin{array}{c}13 \ldots . . . \\
28, \ldots A\end{array}$ & $\begin{array}{l}40 \\
42\end{array}$ & $\begin{array}{l}1.7 \\
1.9\end{array}$ & $\begin{array}{l}5.8 \\
5.9\end{array}$ & $\begin{array}{l}200 \\
196\end{array}$ & $\begin{array}{l}0 \\
0\end{array}$ & $\begin{array}{l}164 \\
161\end{array}$ & $\begin{array}{l}2.5 \\
6.3\end{array}$ & $\begin{array}{l}49 \\
51\end{array}$ & $\begin{array}{l}33 \\
32\end{array}$ & .5 & 25 \\
\hline${ }_{S E P}^{19} \ldots$ & 43 & 1.9 & 5.9 & 196 & 0 & 161 & 3.9 & 56 & 33 & .5 & 26 \\
\hline $14 \ldots$ & 39 & 1.6 & 5.4 & 190 & 0 & 156 & 1.9 & 52 & 28 & .5 & 25 \\
\hline
\end{tabular}

B Results based on colony count outside the acceptable range (non-ideal colony count). 
10261500 MOJAVE RIVER AT LOWER NARROWS, NEAR VICTORVILLE, CA--Continued

CHEMICAL ANALYSES, WATER YEAR OCTOBER 1975 TO SEPTEMBER 1976

\begin{tabular}{|c|c|c|c|c|c|c|c|c|c|c|}
\hline DATE & $\begin{array}{c}\text { TOTAL } \\
\text { NITRATE } \\
\text { (N) } \\
\text { (MG/L) }\end{array}$ & $\begin{array}{l}\text { TOTAL } \\
\text { NITRITE } \\
\text { PLUS } \\
\text { NITRATE } \\
\text { (N) } \\
\text { (MG/L) }\end{array}$ & $\begin{array}{l}\text { TOTAL } \\
\text { KJEL- } \\
\text { DAHL } \\
\text { NITRO- } \\
\text { GEN } \\
\text { (N) } \\
\text { (MG/L) }\end{array}$ & $\begin{array}{l}\text { TOTAL } \\
\text { NITRO- } \\
\text { GEN } \\
\text { (N) } \\
\text { (MG/L) }\end{array}$ & $\begin{array}{l}\text { TOTAL } \\
\text { NITRO- } \\
\text { GEN } \\
\text { (NOB) } \\
\text { (MG/L) }\end{array}$ & $\begin{array}{l}\text { POTAL } \\
\text { PHOS- } \\
\text { PHORUS } \\
\text { (P) } \\
\text { (MG/L) }\end{array}$ & $\begin{array}{l}\text { DIS- } \\
\text { SOLVEO } \\
\text { ORTHO. } \\
\text { PHOS- } \\
\text { PHORUS } \\
\text { (P) } \\
\text { (MG/L) }\end{array}$ & $\begin{array}{l}\text { DIS- } \\
\text { SOLVED } \\
\text { ORTHO } \\
\text { PHOS- } \\
\text { PHATE } \\
\text { (PO4) } \\
\text { (HG/L) }\end{array}$ & $\begin{array}{c}\text { DIS- } \\
\text { SOLVED } \\
\text { BORON } \\
\text { (B) } \\
\text { (UG/L) }\end{array}$ & $\begin{array}{l}\text { TOTAL } \\
\text { PHYTO- } \\
\text { PLANK- } \\
\text { TON } \\
\text { (CELLS } \\
\text { PER } \\
\text { ML) }\end{array}$ \\
\hline $\begin{array}{l}\text { OCT } \\
31 \ldots . \\
\text { NOV }\end{array}$ & $m$ & .92 & 2.4 & 3.3 & 15 & .55 & - & 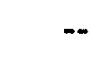 & -- & 4400 \\
\hline $\begin{array}{l}19 \ldots A \\
26 \ldots \\
D E C\end{array}$ & 2.5 & $1 . \overline{5}$ & 1.6 & 3.1 & $14^{--}$ & .42 & . 36 & 1.1 & 170 & $15 \overline{0}$ \\
\hline $\begin{array}{l}30 \ldots \\
\text { JAN }\end{array}$ & -- & 1.5 & 1.9 & 3.4 & 15 & .36 & -- & $m$ & -- & 490 \\
\hline$\underset{F E B}{29} \cdots$ & $=$ & 1.6 & 1.2 & 2.8 & 12 & .27 & $-\infty$ & -- & - & 950 \\
\hline $\begin{array}{l}04 \ldots A \\
24 \ldots \ldots \\
\text { MAR }\end{array}$ & 1.8 & 1.4 & $1.2^{-\infty}$ & $2 . \overline{6}$ & $12^{-\infty}$ & .30 & .21 & .64 & $\begin{array}{r}170 \\
-\end{array}$ & 610 \\
\hline$\underset{A P R}{25} \cdots$ & -- & 2.3 & .24 & 2.5 & 11 & .33 & -- & - & $-\infty$ & 2300 \\
\hline $\begin{array}{c}21 \ldots A \\
29 \ldots\end{array}$ & 1.8 & 1.5 & .59 & $2 . \overline{1}$ & 9.3 & .20 & .25 & $\begin{array}{r}.77 \\
-=\end{array}$ & $\begin{array}{r}120 \\
--\end{array}$ & 1600 \\
\hline $\begin{array}{l}27 \ldots \\
\text { JUN }\end{array}$ & -- & 1.8 & .25 & 2,0 & 9.1 & .28 & -- & -- & -- & 2700 \\
\hline $28 \ldots$ & -- & 1.5 & .20 & 1.7 & 7.5 & .41 & - & - & - & 2500 \\
\hline $\begin{array}{l}13 \ldots \\
28 \ldots A\end{array}$ & 1.2 & 1.5 & .17 & 1.7 & 7.4 & .33 & .39 & $1 . \overline{2}$ & 200 & $\begin{array}{r}5300 \\
--\end{array}$ \\
\hline $\begin{array}{l}19 \\
\text { SEP }\end{array}$ & $-\infty$ & 1.2 & .34 & 1.5 & 6.8 & .30 & - & $\rightarrow$ & $\rightarrow$ & 0 \\
\hline $14 \ldots$ & $\rightarrow-$ & 1.7 & 1.1 & 2.8 & 12 & .41 & - & - & $=$ & 85 \\
\hline
\end{tabular}


10261500 MOJAVE RIVER AT LOWER NARROWS, NEAR VICTORVILLE, CA--Continued

QUALITATIVE AND ASSOCIATED QUANTITATIVE ANALYSES OF BIOLOGICAL DATA, WATER YEAR OCTOBER 1975 TO SEPTEMBER 1976 PHYTOPLANKTON

\begin{tabular}{|c|c|c|c|}
\hline DATE & TIME & & $\begin{array}{l}\text { PHYLUM } \\
\text {. CLASS } \\
\ldots \text { ORDER } \\
\ldots \text { FAMILY } \\
\ldots \text {. GENUS } \\
\ldots \text {. SPECIES }\end{array}$ \\
\hline \multirow[t]{4}{*}{$\begin{array}{r}\text { OCT } \\
31\end{array}$} & 1030 & & $\begin{array}{l}\text { CHLOROPHYTA } \\
\text {. CHLOROPHYCEAE } \\
\because \text { VOL VOCALES } \\
\ldots \text { CHLAMYDOMONADACEAE } \\
\ldots \text {. CHLAMYDOMONAS }\end{array}$ \\
\hline & & $\#$ & $\begin{array}{l}\text { CHRYSOPHYTA } \\
. \text { BACILLARIOPHYCEAE } \\
\ldots \text { PENNALES } \\
\ldots \text { ACHNANTHACEAE } \\
\ldots \text { A ACHNANTHES } \\
\ldots \text { NAVI ICULACEAE } \\
\ldots \text {. NAVICULA } \\
\ldots \text { NITZSCHIACEAE } \\
\ldots \text {. NITZSCHIA }\end{array}$ \\
\hline & & $\$$ & $\begin{array}{l}\text { CYANOPHYTA } \\
\text {.MYXOPHYCEAE } \\
\text { OOSCILLATORIALES } \\
\ldots \text { OSCILLATORIACEAE } \\
\text {... OSCILLATORIA }\end{array}$ \\
\hline & & & TOTAL PHYTOPLANKTON \\
\hline
\end{tabular}

\footnotetext{
$\begin{array}{rll}\text { NOV } & 1055 & \text { CHRYSOPHYTA } \\ 26 & & \text {-BACILLARIOPHYCEAE }\end{array}$ . PENNALES ... Achnanthaceae $\because$.. ACHNANTHES .. A AOCCONE IS
.. CYMBELLACEAE $\because$... COCCONEIS $\because$ CYMBELLACEAE \#... CYMBELLA .. gOMPHONEMATACEAE

* ... gOMPHONEMA ... NaViculaceaE @. Navicula \#. NITZSCHIACEAE

\# .... NITZSCHIA TOTAL PHYTOPLANKTON
}

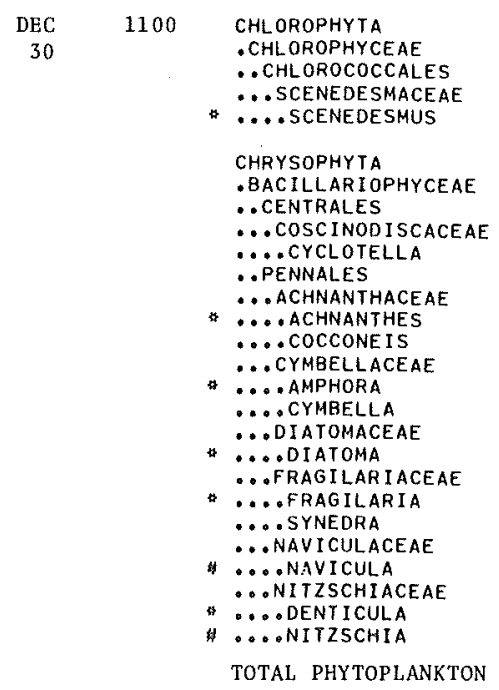

COMMON
NAME
COUNT

GREEN ALGAE

DIATOMS

PENNATE

NAVICULOID

$\begin{array}{rr}560 & 13 \\ 2,000 & 46 \\ 1,000 & 23\end{array}$

BLUE-GREEN ALGAE

FILAMENTOUS

680

4,400

15

DIATOMS

PENNATE

NAVICULOID

$\begin{array}{rr}160 & 11 \\ 39 & 3 \\ 39 & 3 \\ & 0\end{array}$

1,500

GREEN ALGAE

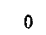

\section{DIATOMS}

CENTRIC

PENNATE.

NAVICULOID 
10261500 MOJAVE RIVER AT LOWER NARROWS, NEAR VICTORVILLE, CA--Continued

QUALITATIVE AND ASSOCIATED QUANTITATIVE ANALYSES OF BIOLOGICAL DATA, WATER YEAR OCTOBER 1975 TO SEPTEMBER 1976

PHYTOPLANKTON

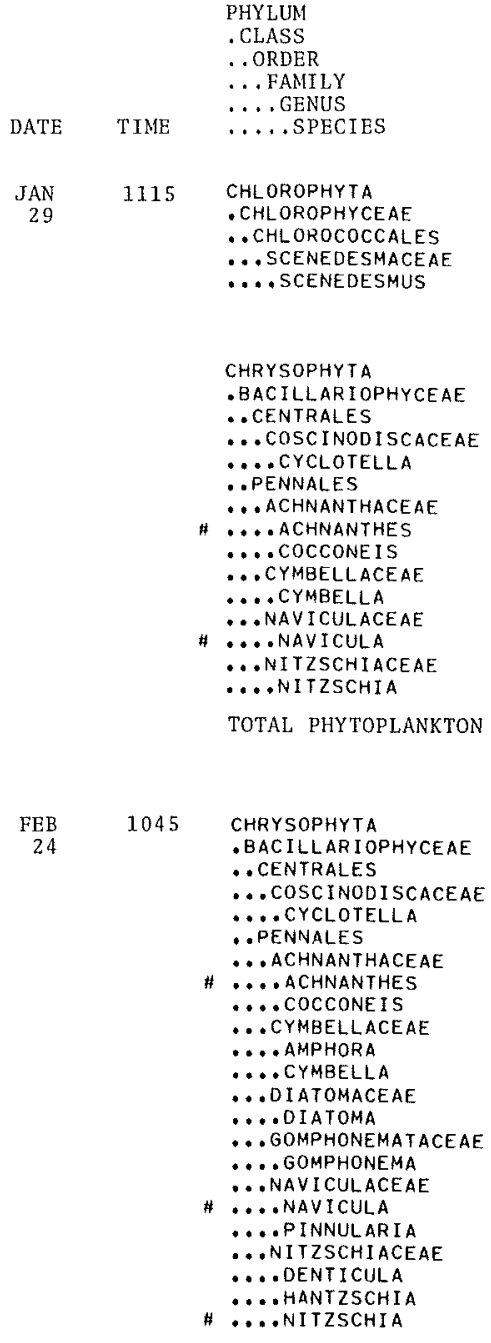

TOTAL PHYTOPLANKTON

$\begin{array}{ccr}\text { COMMON } & \text { COUNT } & \text { PERCENT } \\ \text { NAME } & \text { (CELLS/ML) } & \text { OF TOTAL }\end{array}$

GREEN ALGAE

45

5

DIATOMS

CENTRIC

PENNATE

23

2

$\begin{array}{rr}270 & 29 \\ 23 & 2\end{array}$

NAVICULOID

23

2

430

45

140

DIATOMS

CENTRIC

PENNATE

12

2

NAVICULOID

$\begin{array}{rr}120 & 20 \\ 12 & 2 \\ 12 & 2 \\ 12 & 2 \\ 25 & 4 \\ 12 & 2 \\ 160 & 27 \\ 50 & 8 \\ 12 & 2 \\ 12 & 2 \\ 160 & 27\end{array}$

610

See footnotes at end of table. 
10261500 MOJAVE RIVER AT LOWER NARROWS, NEAR VICTORVILLE, CA--Continued

QUALITATIVE AND ASSOCJATED QUANTTTATIVE ANALYSES OF BIOLOGICAL DATA, WATER YEAR OCTOBER 1975 TO SEPTEMBER 1976

PHYTOPLANKTON

\begin{tabular}{|c|c|c|}
\hline DATE & TIME & $\begin{array}{l}\text { PHYLUM } \\
\text {.CLASS } \\
\ldots \text { ORDER } \\
\ldots \text { FAMILY } \\
\ldots \text {. GENUS } \\
\ldots \text {. . SPECIES }\end{array}$ \\
\hline \multirow[t]{4}{*}{$\begin{array}{r}\text { MAR } \\
25\end{array}$} & 1040 & $\begin{array}{l}\text { CHLOROPHYTA } \\
\text {. CHLOROPHYCEAE } \\
\ldots \text { CHLOROCOCCALES } \\
\ldots \text { OOCYSTACEAE } \\
\ldots \text {. ANKISTRODESMUS }\end{array}$ \\
\hline & & 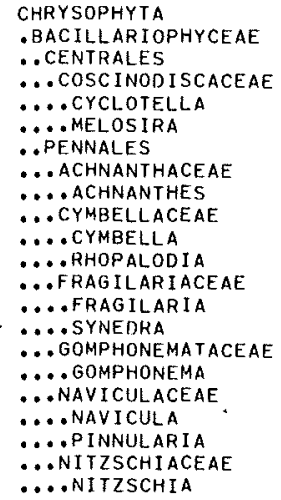 \\
\hline & & $\begin{array}{l}\text { CYANOPHYTA } \\
\text {.MYXOPHYCEAE } \\
\text { OCHROOCOCCALES } \\
\text { \#. CHROOCOCCACEAE } \\
\text { …ANACYSTIS } \\
\text {...A. INCERTA }\end{array}$ \\
\hline & & TOTAL PHYTOPLANKTON \\
\hline
\end{tabular}

$\begin{array}{ccc}\text { COMMON } & \text { COUNT } & \text { PERCENT } \\ \text { NAME } & \text { [CELLS/ML) } & \text { OF TOTAL }\end{array}$

GREEN ALGAE

20

1

DIATOMS

CENTRIC

PENNATE

$\begin{array}{crr}140 & 6 \\ 39 & 2 \\ 20 & 1 \\ 78 & 3 \\ \text { NAVICULOIO } & 39 & 0 \\ & 240 & 10 \\ & 20 & 1 \\ 250 & 11\end{array}$

BLUE-GREEN ALGAE

COCCOID

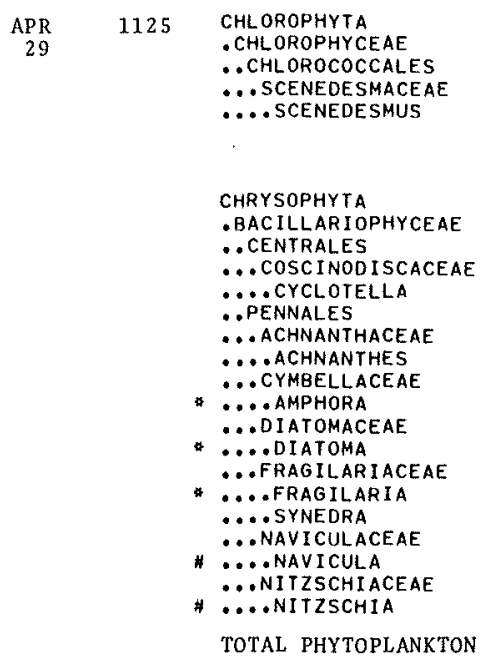

CHRYSOPHYTA - BACILLAR I OPHYCEAE .. CENTRALES ... COSCINODISCACEAE .... CYCLOTELLA ...ACHNANTHACEAE ... ACHNANTHES . CYMBELLACEAE .... AMPHORA

... DIATOMACEAE

* ... DIATOMa

.. Frag Il ar Iaceae

*...fFragilaria ... SYNEDRA

... NAVI Culaceae

*.... Navicula

..NITZSCHIACEAE

* ... NItzschia

TOTAL PHYTOPLANXTON

GREEN ALGAE

DIATOMS

CENTRIC

PENNATE

NAVICULOID

180 
10261500 MOJAVE RIVER AT LOWER NARROWS, NEAR VICTORVILLE, CA--Continued

QUALITATIVE AND ASSOCIATED QUANTITATIVE ANALYSES OF BIOLOGICAL DATA, WATER YEAR OCTOBER 1975 TO SEPTEMBER 1976 PHYTOPLANKTON

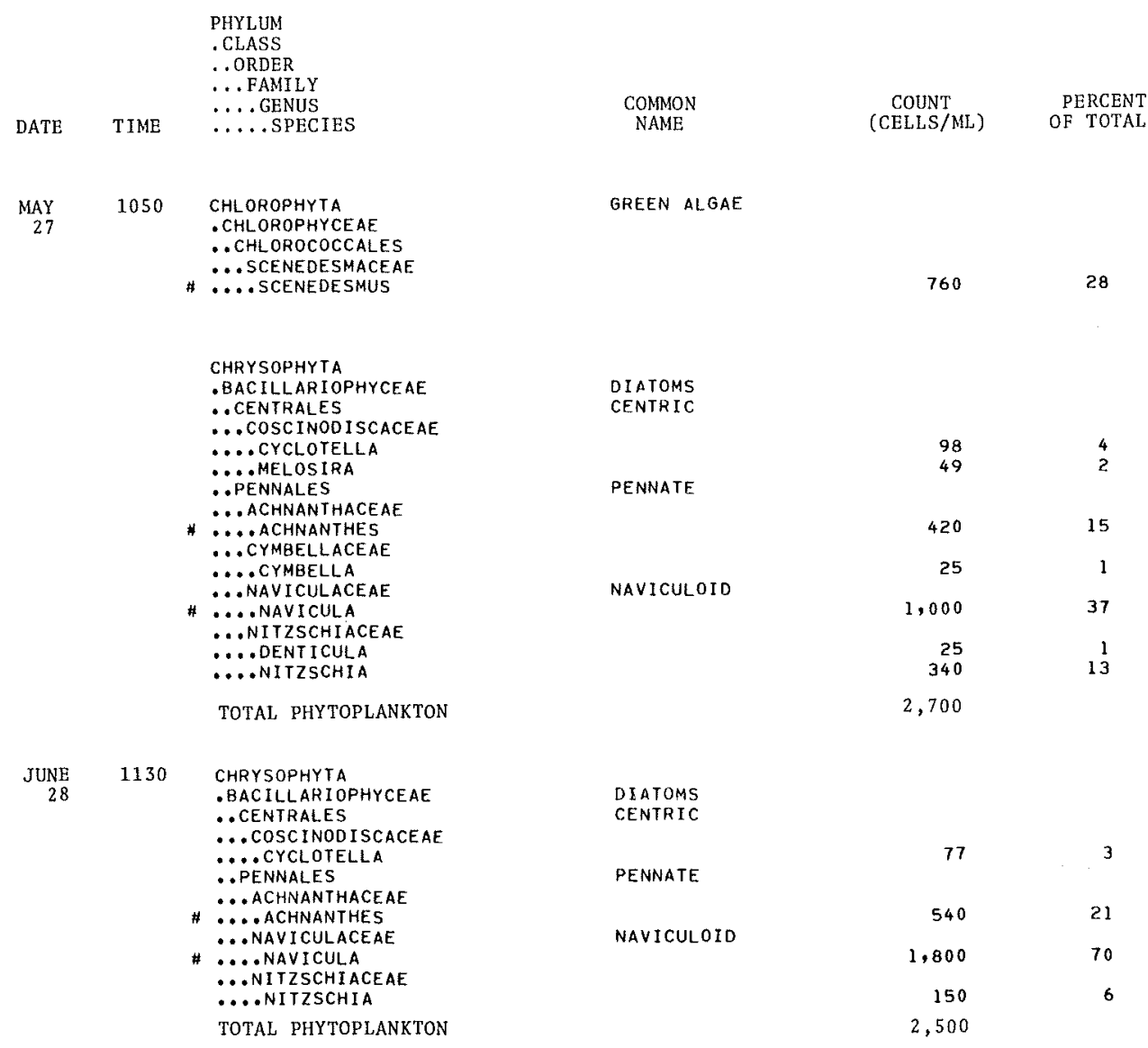

See footnotes at end of table. 
10261500 MOJAVE RIVER AT LOWER NARROWS, NEAR VICTORVILLE, CA- Continued

QUALITATIVE AND ASSOCIATED QUANTITATIVE ANALYSES OF BIOLOGICAL DATA, WATER YEAR OCTOBER 1975 TO SEPTEMBER 1976 PHYTOPLANKTON

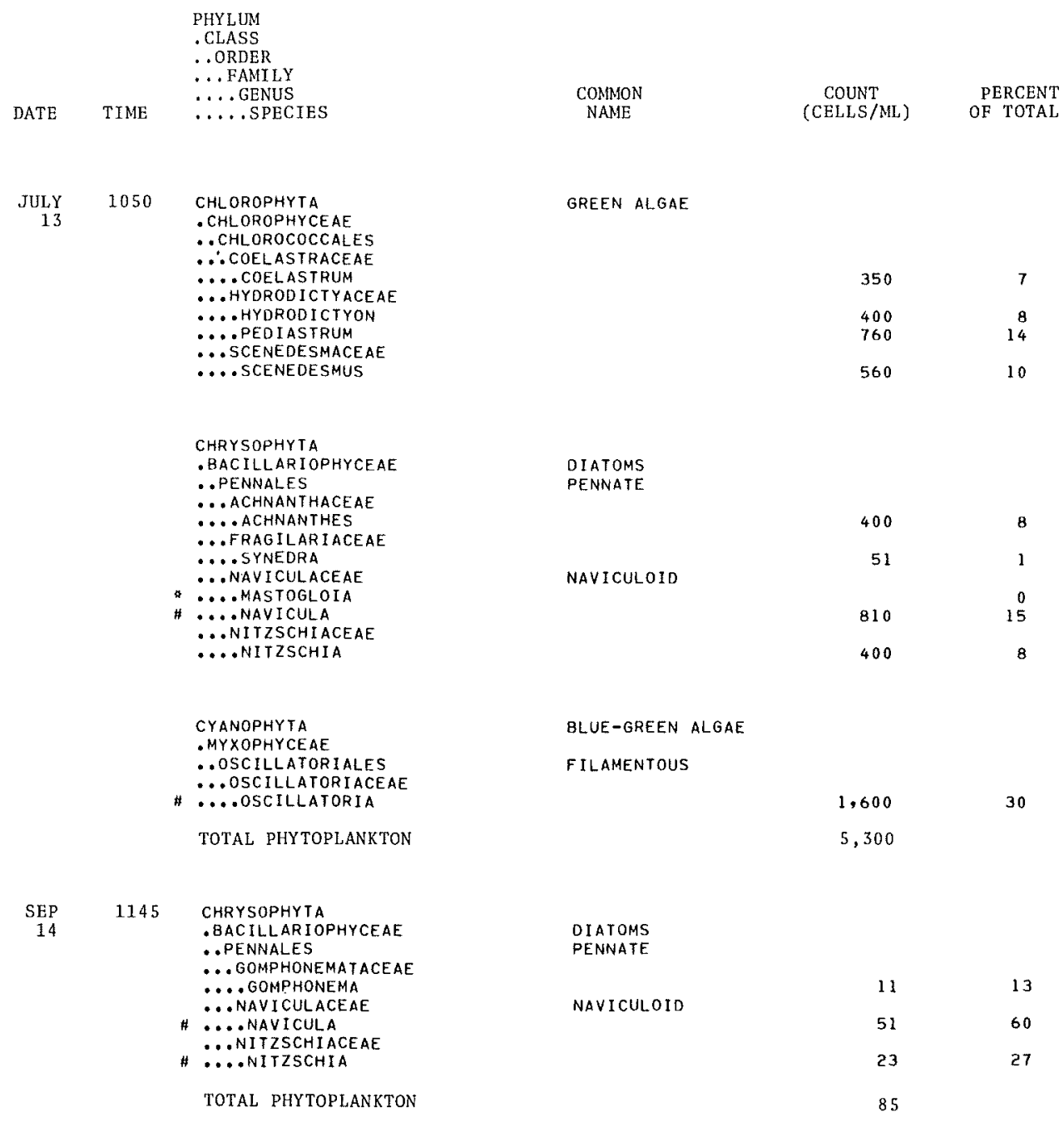

NOTE: \# - DOMINANT ORGANISM: GREATER OR EQUAL TO 15\%

* - LESS THEN $1 \%$; MAY NOT HAVE BEEN ACTUALLy COUNTED

Date

Length of exposure (days)

Sept. 26

35

Feb, $\quad 24$

29

PERI PHYTON

Bionass $\left(\mathrm{g} / \mathrm{m}^{2}\right) \quad$ Chlorophyll

Dry weight Ash weight

19

32 $\left(\mathrm{mg} \stackrel{\mathrm{a}}{\mathrm{T}}^{2}\right)$

3.9

13

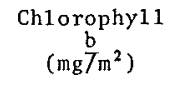

0.6

0.4
Biomass

pigment Sampling

830

430
Sampling
method

Polyethylene strip

Polyethylen 
10261500 MOJAVE RIVER AT LOWER NARROWS, NEAR VICTORVILLE, CA-COntinued

CHEMICAL ANALYSES, HATER YEAR OCTOBER 1975 TO SEPTEMBER 1976

\begin{tabular}{|c|c|c|c|c|c|c|c|c|c|c|c|c|}
\hline DATE & TIME & $\begin{array}{c}\text { TOTAL } \\
\text { ARSENIC } \\
\text { (AS) } \\
\text { (UG/L) }\end{array}$ & $\begin{array}{c}\text { SUS- } \\
\text { PENDED } \\
\text { ARSENIC } \\
\text { (AS) } \\
\text { (UG/L) }\end{array}$ & $\begin{array}{c}\text { OIS- } \\
\text { SOLVED } \\
\text { ARSENIC } \\
\text { (AS) } \\
\text { (UG/L) }\end{array}$ & $\begin{array}{c}\text { TOTAL } \\
\text { CAD- } \\
\text { MIUM } \\
\text { (CD) } \\
\text { (UG/L) }\end{array}$ & $\begin{array}{l}\text { SUS- } \\
\text { PENDED } \\
\text { CAD- } \\
\text { MIUM } \\
\text { (CD) } \\
\text { (UG/L) }\end{array}$ & $\begin{array}{l}\text { DIS- } \\
\text { SOLVED } \\
\text { CAD- } \\
\text { MIUM } \\
\text { (CD) } \\
\text { (UG/L) }\end{array}$ & $\begin{array}{l}\text { TOTAL } \\
\text { CHRO- } \\
\text { MIUM } \\
\text { (CR) } \\
\text { (UG/L) }\end{array}$ & $\begin{array}{l}\text { SUS- } \\
\text { PENDED } \\
\text { CHRO- } \\
\text { MIUM } \\
\text { (CR) } \\
\text { (UG/L) }\end{array}$ & $\begin{array}{l}\text { DIS- } \\
\text { SOLVED } \\
\text { CHRO- } \\
\text { MIUM } \\
\text { (CR) } \\
\text { (UG/L) }\end{array}$ & $\begin{array}{l}\text { TOTAL } \\
\text { COBALT } \\
\text { (CO) } \\
\text { (UG/L) }\end{array}$ & $\begin{array}{c}\text { SUS- } \\
\text { PENDED } \\
\text { COBALI } \\
\text { (CO) } \\
\text { (UG/L) }\end{array}$ \\
\hline $\begin{array}{l}\text { OCT } \\
31 \ldots \\
\text { JAN } \cdots\end{array}$ & 1030 & 6 & 1 & 5 & $<10$ & $<9$ & 1 & 80 & 70 & 10 & $<50$ & $<48$ \\
\hline$\underset{A P R}{29} \cdots$ & 1115 & 6 & 2 & 4 & $<10$ & $<9$ & 1 & 0 & 0 & 0 & $<50$ & $<49$ \\
\hline$\underset{\text { JUL }}{29}$ & 1125 & 3 & 0 & 3 & $<10$ & $<B$ & 2 & 0 & 0 & 0 & $<50$ & $<50$ \\
\hline $13 \ldots$ & 1050 & 2 & 0 & 3 & $<10$ & $<9$ & 1 & 0 & 0 & 0 & $<50$ & $<50$ \\
\hline
\end{tabular}

\begin{tabular}{|c|c|c|c|c|c|c|c|c|c|c|c|}
\hline DATE & $\begin{array}{l}\text { DIS- } \\
\text { SOLVED } \\
\text { COBALT } \\
\text { (CO) } \\
\text { (UG/L) }\end{array}$ & $\begin{array}{l}\text { TOTAL } \\
\text { COPPER } \\
\text { (CU) } \\
\text { (UG/L) }\end{array}$ & $\begin{array}{l}\text { SUS- } \\
\text { PENDED } \\
\text { COPPER } \\
\text { (CU) } \\
\text { (UG/L) }\end{array}$ & $\begin{array}{l}\text { OIS- } \\
\text { SOLVED } \\
\text { COPPER } \\
\text { (CU) } \\
\text { (UG/L) }\end{array}$ & $\begin{array}{l}\text { TOTAL } \\
\text { IRON } \\
\text { (FE) } \\
\text { (UG/L) }\end{array}$ & $\begin{array}{l}\text { DIS- } \\
\text { SOLVED } \\
\text { IRON } \\
\text { (FE) } \\
\text { (UG/L) }\end{array}$ & $\begin{array}{c}\text { TOTAL } \\
\text { LEAD } \\
\text { (PB) } \\
\text { (UG/L) }\end{array}$ & $\begin{array}{l}\text { SUS- } \\
\text { PENDED } \\
\text { LEAD } \\
\text { (PB) } \\
(U G / L)\end{array}$ & $\begin{array}{l}\text { DIS- } \\
\text { SOLVED } \\
\text { LEAD } \\
\text { (PB) } \\
\text { (UG/L) }\end{array}$ & $\begin{array}{l}\text { TOTAL } \\
\text { MAN- } \\
\text { GANESE } \\
\text { (MN) } \\
\text { (UG/L) }\end{array}$ & $\begin{array}{l}\text { SUS- } \\
\text { PENDED } \\
\text { MAN- } \\
\text { GANESE } \\
\text { (MN) } \\
(U G / L)\end{array}$ \\
\hline OCT & & & & & & & & & & & \\
\hline$\underset{\text { JAN }}{31 \cdots}$ & 2 & 20 & 16 & 4 & 1500 & 30 & $<100$ & $<97$ & 3 & 100 & 50 \\
\hline$\underset{A P R}{29} \ldots$ & 1 & $<10$ & $<7$ & 3 & 870 & 60 & $<100$ & $<98$ & 2 & 120 & 80 \\
\hline $\begin{array}{l}29 \ldots \\
\text { JUL }\end{array}$ & 0 & 20 & 16 & 4 & 900 & 20 & $<100$ & $<94$ & 6 & 280 & 260 \\
\hline $13 \ldots$ & 0 & 10 & 8 & 2 & 410 & 90 & $<100$ & $<99$ & 1 & 60 & 20 \\
\hline
\end{tabular}

\begin{tabular}{|c|c|c|c|c|c|c|c|c|c|c|c|}
\hline OATE & $\begin{array}{l}\text { DIS- } \\
\text { SOLVED } \\
\text { MAN- } \\
\text { GANESE } \\
\text { (MN) } \\
(U G / L)\end{array}$ & $\begin{array}{c}\text { TOTAL } \\
\text { MERCURY } \\
\text { (HG) } \\
\text { (UG/L) }\end{array}$ & $\begin{array}{c}\text { SUS- } \\
\text { PENDED } \\
\text { MERCURY } \\
\text { (HG) } \\
(U G / L)\end{array}$ & $\begin{array}{c}\text { DIS- } \\
\text { SOLVED } \\
\text { MERCURY } \\
\text { (HG) } \\
(U G / L)\end{array}$ & $\begin{array}{l}\text { TOTAL } \\
\text { SELE- } \\
\text { NIUM } \\
\text { (SE) } \\
\text { (UG/L) }\end{array}$ & $\begin{array}{l}\text { SUS- } \\
\text { PENDED } \\
\text { SELE- } \\
\text { NIUM } \\
\text { (SE) } \\
\text { (UG/L) }\end{array}$ & $\begin{array}{l}\text { DIS- } \\
\text { SOLVED } \\
\text { SELE- } \\
\text { NIUM } \\
\text { (SE) } \\
\text { (UG/L) }\end{array}$ & $\begin{array}{l}\text { TOTAL } \\
\text { ZINC } \\
\text { (ZN) } \\
\text { (UG/L) }\end{array}$ & $\begin{array}{l}\text { SUS- } \\
\text { PENDED } \\
\text { ZINC } \\
(Z N) \\
(U G / L)\end{array}$ & $\begin{array}{l}\text { DIS- } \\
\text { SOLVED } \\
\text { ZINC } \\
\text { (ZN) } \\
(U G / L)\end{array}$ & $\begin{array}{l}\text { TOTAL } \\
\text { ORGANIC } \\
\text { CARGON } \\
\text { (C) } \\
\text { (MG/L) }\end{array}$ \\
\hline $\begin{array}{c}\text { OCT } \\
31 \ldots \\
\text { JAN }\end{array}$ & 50 & .0 & .0 & .0 & 0 & 0 & 0 & 7 & 7 & 0 & 13 \\
\hline$\stackrel{29}{29} \cdots$ & 40 & .0 & .0 & .0 & 0 & 0 & 0 & 50 & 40 & 10 & 3.6 \\
\hline$\underset{\text { JUL. }}{29}$ & 20 & .2 & .2 & .0 & 0 & 0 & 0 & 40 & 30 & 10 & 2.1 \\
\hline $13 \ldots$ & 40 & .0 & .0 & .0 & 0 & 0 & 0 & 20 & 0 & 30 & 3.3 \\
\hline
\end{tabular}


10261500 MOJAVE RIVER AT LOWER NARROWS, NEAR VICTORVILLE, CA--Continued

SPECIFIC CONDUCTANCE (MICROMHOS/CM AT 25 DEG, C), WATER YEAR OCTOBER 1975 TO SEPTEMBER 1976

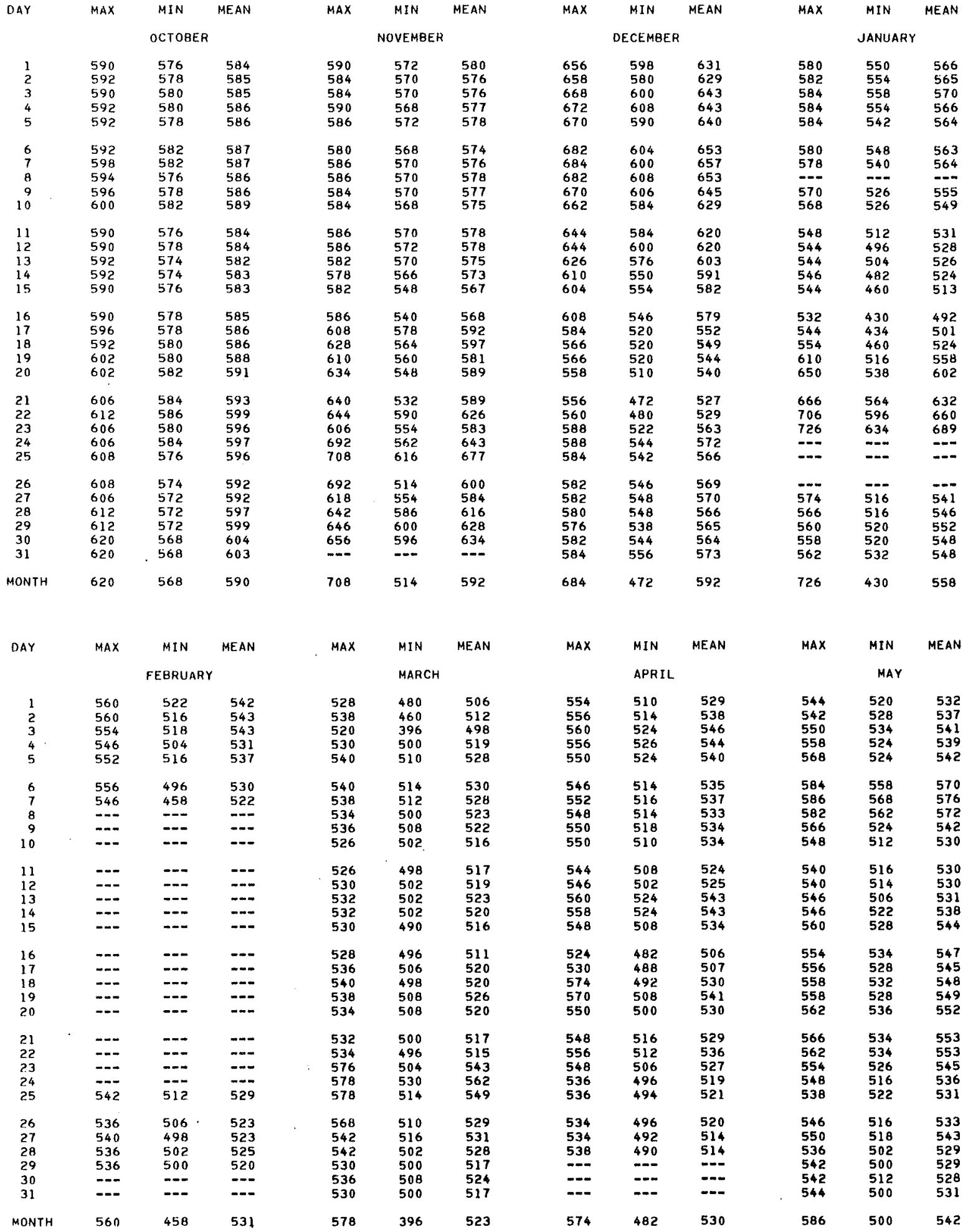


10261500 MOJAVE RIVER AT LOWER NARROWS, NEAR VICTORVILLE, CA--Continued

SPECIFIC CONDUCTANCE (MICROMHOS/CM AT 25 DEG, C), HATER YEAR OCTOBER 1975 TO SEPTEMBER 1976

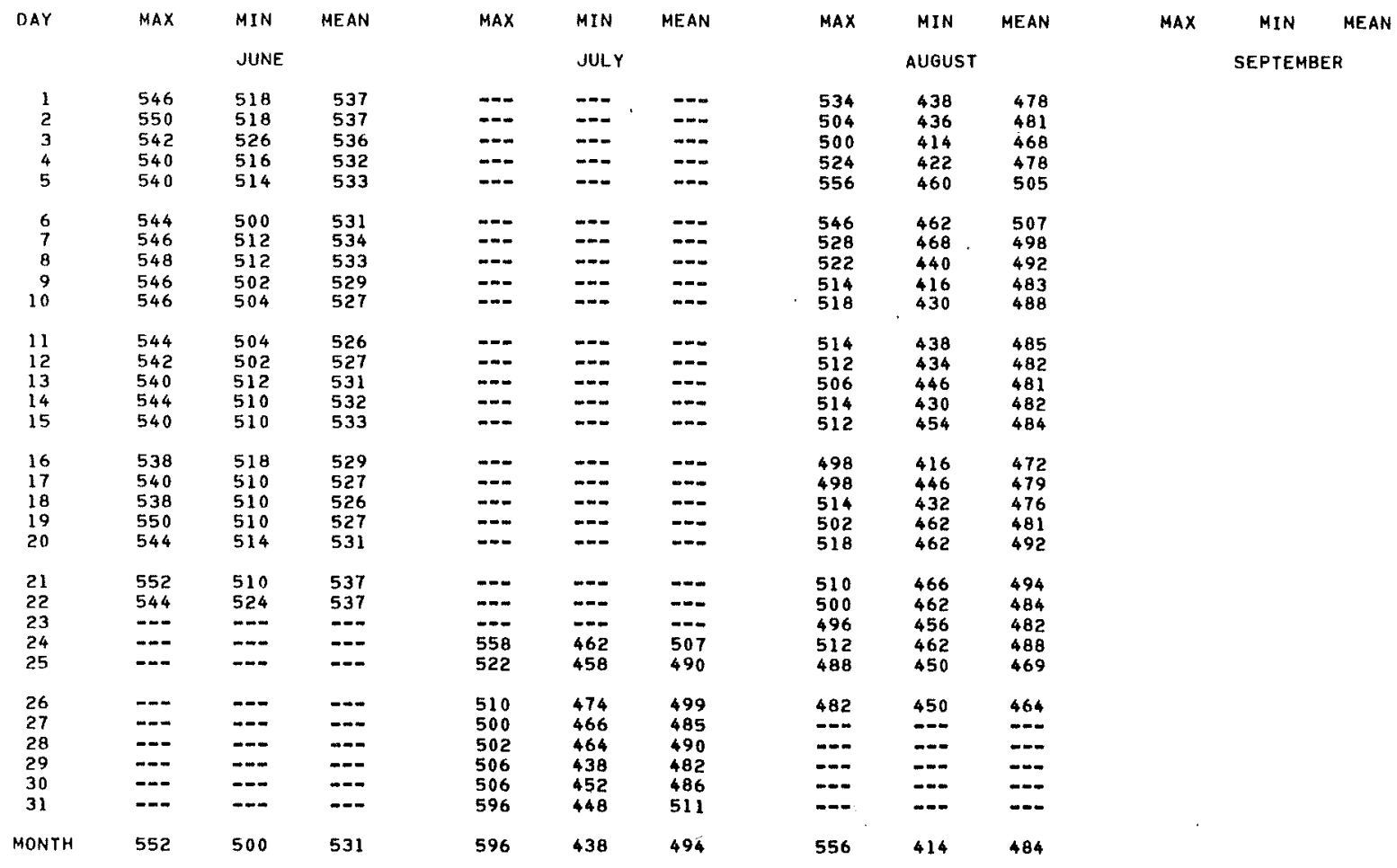

TEMPERATURE (DEG, C) OF HATER, WATER YEAR OCTOBER 1975 TO SEPTEMBER 1976

\begin{tabular}{|c|c|c|c|c|c|c|c|c|c|c|c|c|}
\hline DAY & $\operatorname{MAX}$ & MIN & MEAN & MAX & MIN & MEAN & MAX & MIN & MEAN & MAX & MIN & MEAN \\
\hline & \multicolumn{3}{|c|}{ OCTOBER } & \multicolumn{3}{|c|}{ NOVEMBER } & \multicolumn{3}{|c|}{ DECEMEER } & \multicolumn{3}{|c|}{ JANUARY } \\
\hline $\begin{array}{l}1 \\
2 \\
3 \\
4 \\
5\end{array}$ & $\begin{array}{l}27.5 \\
26.5 \\
27.0 \\
27.5 \\
27.0\end{array}$ & $\begin{array}{l}15.0 \\
15.0 \\
15.0 \\
14.5 \\
14.5\end{array}$ & $\begin{array}{l}19.5 \\
19.5 \\
19.5 \\
19.5 \\
19.0\end{array}$ & $\begin{array}{l}-m \\
-\overline{-} \\
-\overline{-} \\
-\overline{-}\end{array}$ & $=$ & $=$ & $\begin{array}{l}13.5 \\
14.5 \\
15.0 \\
15.0 \\
15.5\end{array}$ & $\begin{array}{l}7.5 \\
8.5 \\
9.0 \\
9.0 \\
9.5\end{array}$ & $\begin{array}{l}10.0 \\
11.0 \\
11.5 \\
11.5 \\
11.5\end{array}$ & $\begin{array}{l}11.5 \\
12.5 \\
13.0 \\
13.5 \\
15.0\end{array}$ & $\begin{array}{l}3.5 \\
3.0 \\
3.5 \\
4.5 \\
5.5\end{array}$ & $\begin{array}{l}6.5 \\
7.0 \\
7.5 \\
8.0 \\
9.5\end{array}$ \\
\hline $\begin{array}{r}6 \\
7 \\
8 \\
9 \\
10\end{array}$ & $\begin{array}{r}23.5 \\
21.0 \\
-\ldots- \\
--.\end{array}$ & $\begin{array}{r}15.0 \\
13.5 \\
- \\
--\end{array}$ & $\begin{array}{r}17.5 \\
16.0 \\
-0 . \\
\ldots-.\end{array}$ & $\begin{array}{l}21.0 \\
18.5 \\
19.0 \\
18.5\end{array}$ & $\begin{array}{r}0.5 \\
10.5 \\
9.5 \\
9.5\end{array}$ & $\begin{array}{r}-0 . \\
13.5 \\
13.0 \\
12.5\end{array}$ & $\begin{array}{l}14.5 \\
14.0 \\
15.0 \\
16.0 \\
16.0\end{array}$ & $\begin{array}{l}9.0 \\
8.5 \\
8.5 \\
9.0 \\
9.0\end{array}$ & $\begin{array}{l}11.0 \\
11.0 \\
11.0 \\
11.5 \\
12.0\end{array}$ & $\begin{array}{l}13.0 \\
14.0 \\
15.0 \\
14.5 \\
14.5\end{array}$ & $\begin{array}{l}6.5 \\
5.0 \\
5.0 \\
6.0 \\
6.0\end{array}$ & $\begin{array}{l}9.0 \\
8.5 \\
9.0 \\
9.0 \\
9.5\end{array}$ \\
\hline $\begin{array}{l}11 \\
12 \\
13 \\
14 \\
15\end{array}$ & $\begin{array}{l}-m- \\
-m- \\
--\infty \\
--\infty \\
-=-\end{array}$ & $\begin{array}{l}--- \\
--\overline{-} \\
--\overline{-}\end{array}$ & 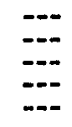 & $\begin{array}{l}17.5 \\
17.0 \\
18.0 \\
18.5 \\
18.5\end{array}$ & $\begin{array}{l}8.5 \\
7.5 \\
7.5 \\
8.0 \\
8.5\end{array}$ & $\begin{array}{l}11.5 \\
11.5 \\
11.5 \\
12.0 \\
12.5\end{array}$ & $\begin{array}{l}15.5 \\
12.5 \\
12.5 \\
11.5 \\
12.0\end{array}$ & $\begin{array}{r}10.0 \\
9.5 \\
8.5 \\
7.0 \\
5.5\end{array}$ & $\begin{array}{r}12.0 \\
11.0 \\
10.0 \\
9.0 \\
8.0\end{array}$ & $\begin{array}{l}14.0 \\
12.5 \\
13.0 \\
13.0 \\
13.0\end{array}$ & $\begin{array}{l}5.5 \\
6.5 \\
6.5 \\
6.5 \\
7.5\end{array}$ & $\begin{array}{r}9.0 \\
9.0 \\
9.5 \\
9.5 \\
10.0\end{array}$ \\
\hline $\begin{array}{l}16 \\
17 \\
18 \\
19 \\
20\end{array}$ & $\begin{array}{l}m- \\
m- \\
=- \\
---\end{array}$ & $\begin{array}{l}=- \\
=- \\
=- \\
=-\end{array}$ & $\begin{array}{l}=- \\
=- \\
=- \\
--\end{array}$ & $\begin{array}{l}17.0 \\
15.0 \\
14.0 \\
14.0 \\
14.0\end{array}$ & $\begin{array}{l}8.5 \\
9.0 \\
8.0 \\
7.0 \\
7.5\end{array}$ & $\begin{array}{l}12.0 \\
11.5 \\
10.0 \\
10.0 \\
10.0\end{array}$ & $\begin{array}{l}12.5 \\
13.0 \\
13.5 \\
13.5 \\
12.5\end{array}$ & $\begin{array}{l}5.5 \\
6.5 \\
6.5 \\
7.0 \\
7.0\end{array}$ & $\begin{array}{r}8.5 \\
9.0 \\
9.0 \\
9.5 \\
10.0\end{array}$ & $\begin{array}{l}13.5 \\
13.5 \\
13.0 \\
13.0 \\
12.5\end{array}$ & $\begin{array}{r}8.0 \\
9.0 \\
9.5 \\
10.0 \\
9.0\end{array}$ & $\begin{array}{l}10.5 \\
11.0 \\
11.0 \\
11.5 \\
10.5\end{array}$ \\
\hline $\begin{array}{l}21 \\
22 \\
23 \\
24 \\
25\end{array}$ & 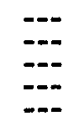 & $\begin{array}{l}=- \\
=-\infty \\
=-\infty\end{array}$ & $\begin{array}{l}=-\infty \\
-\infty \\
=-\infty \\
m-\infty \\
m-\infty\end{array}$ & $\begin{array}{l}13.5 \\
13.5 \\
13.5 \\
14.5 \\
13.5\end{array}$ & $\begin{array}{l}8.0 \\
7.5 \\
7.5 \\
8.5 \\
9.0\end{array}$ & $\begin{array}{l}10.5 \\
10.0 \\
10.5 \\
11.0 \\
11.0\end{array}$ & $\begin{array}{l}13.5 \\
12.5 \\
15.0 \\
16.0 \\
16.0\end{array}$ & $\begin{array}{l}9.5 \\
9.0 \\
7.0 \\
6.5 \\
7.0\end{array}$ & $\begin{array}{l}11.0 \\
10.5 \\
10.0 \\
10.5 \\
10.5\end{array}$ & $\begin{array}{l}12.0 \\
14.0 \\
14.0 \\
14.5 \\
16.0\end{array}$ & $\begin{array}{l}8.5 \\
9.0 \\
9.0 \\
8.5 \\
6.5\end{array}$ & $\begin{array}{l}10.0 \\
11.0 \\
11.0 \\
11.0 \\
10.0\end{array}$ \\
\hline $\begin{array}{l}26 \\
27 \\
28 \\
29 \\
30 \\
31\end{array}$ & $\begin{array}{l}=- \\
m-\infty \\
=-- \\
m-\infty \\
--\infty\end{array}$ & $\begin{array}{l}=-- \\
=-- \\
=-0 \\
=-0\end{array}$ & $\begin{array}{l}=-\infty \\
=-\infty \\
=-\infty \\
=-\infty \\
=-\infty\end{array}$ & $\begin{array}{r}15.5 \\
14.5 \\
12.0 \\
11.5 \\
13.0 \\
-. .\end{array}$ & $\begin{array}{l}9.0 \\
9.0 \\
7.0 \\
6.5 \\
6.5 \\
-.0\end{array}$ & $\begin{array}{r}11.0 \\
11.0 \\
9.5 \\
6.5 \\
9.0 \\
-.0-0\end{array}$ & $\begin{array}{l}15.5 \\
13.0 \\
15.5 \\
15.5 \\
15.0 \\
12.5\end{array}$ & $\begin{array}{l}7.0 \\
8.0 \\
7.5 \\
7.0 \\
7.5 \\
5.0\end{array}$ & $\begin{array}{r}10.5 \\
10.0 \\
10.5 \\
10.5 \\
10.0 \\
8.0\end{array}$ & $\begin{array}{l}16.0 \\
16.0 \\
17.0 \\
17.5 \\
18.0 \\
18.5\end{array}$ & $\begin{array}{l}6.0 \\
6.0 \\
6.5 \\
7.0 \\
7.5 \\
7.5\end{array}$ & $\begin{array}{l}10.5 \\
10.0 \\
10.5 \\
11.5 \\
11.5 \\
11.5\end{array}$ \\
\hline MONTH & 27.5 & 13.5 & 18.5 & 21.0 & 6.5 & 11.0 & 16.0 & 5.0 & 10.5 & 18.5 & 3.0 & 10.0 \\
\hline
\end{tabular}


TEMPERATURE (OEG. C) OF WATER, WATER YEAR OCTOBER 1975 TO SEPTEMBER 1976

\begin{tabular}{|c|c|c|c|c|c|c|c|c|c|c|c|c|}
\hline DAY & $\operatorname{MAX}$ & MIN & MEAN & $\operatorname{MAX}$ & MIN & MEAN & $\operatorname{MAX}$ & MIN & MEAN & $\operatorname{MAX}$ & MIN & MEAN \\
\hline \multicolumn{5}{|c|}{ FEBRUARY } & \multicolumn{2}{|c|}{ MARCH } & \multicolumn{3}{|c|}{ APRIL } & \multicolumn{3}{|c|}{ MAY } \\
\hline $\begin{array}{l}1 \\
2 \\
3 \\
4 \\
5\end{array}$ & & & & $\begin{array}{l}15.5 \\
16.0 \\
14.5 \\
18.5 \\
18.0\end{array}$ & $\begin{array}{l}6.5 \\
6.5 \\
6.0 \\
7.0\end{array}$ & $\begin{array}{r}9.5 \\
9.0 \\
10.5 \\
11.5\end{array}$ & $\begin{array}{l}23.5 \\
24.5 \\
21.0 \\
20.0 \\
19.5\end{array}$ & $\begin{array}{l}8.5 \\
8.5 \\
8.5 \\
8.0 \\
8.0\end{array}$ & $\begin{array}{l}14.0 \\
14.5 \\
13.0 \\
13.0 \\
12.5\end{array}$ & $\begin{array}{l}27.5 \\
25.5 \\
24.5 \\
27.5 \\
23.5\end{array}$ & $\begin{array}{l}11.5 \\
11.5 \\
12.0 \\
11.5 \\
11.5\end{array}$ & $\begin{array}{l}18.5 \\
17.5 \\
17.0 \\
18.0 \\
16.0\end{array}$ \\
\hline $\begin{array}{r}6 \\
7 \\
8 \\
9 \\
10\end{array}$ & & & & $\begin{array}{l}18.5 \\
21.0 \\
18.0 \\
19.5 \\
19.0\end{array}$ & $\begin{array}{l}6.0 \\
6.5 \\
7.5 \\
7.5 \\
8.5\end{array}$ & $\begin{array}{l}11.0 \\
12.0 \\
12.0 \\
12.0 \\
12.5\end{array}$ & $\begin{array}{l}22.5 \\
25.0 \\
18.5 \\
24.0 \\
21.5\end{array}$ & $\begin{array}{r}8.0 \\
9.0 \\
10.0 \\
8.0 \\
9.0\end{array}$ & $\begin{array}{l}14.0 \\
15.0 \\
12.5 \\
15.0 \\
14.0\end{array}$ & $\begin{array}{l}24.5 \\
22.0 \\
27.5 \\
27.5 \\
28.5\end{array}$ & $\begin{array}{l}11.0 \\
13.0 \\
12.5 \\
12.5 \\
11.5\end{array}$ & $\begin{array}{l}16.0 \\
16.5 \\
18.5 \\
19.0 \\
19.5\end{array}$ \\
\hline $\begin{array}{l}11 \\
12 \\
13 \\
14 \\
15\end{array}$ & & & & $\begin{array}{l}21.0 \\
19.5 \\
21.5 \\
21.0 \\
22.0\end{array}$ & $\begin{array}{l}7.5 \\
7.5 \\
6.5 \\
7.5 \\
8.0\end{array}$ & $\begin{array}{l}12.5 \\
12.0 \\
12.5 \\
13.0 \\
13.5\end{array}$ & $\begin{array}{l}23.5 \\
18.0 \\
20.5 \\
22.0 \\
18.5\end{array}$ & $\begin{array}{l}9.5 \\
9.5 \\
9.0 \\
8.5 \\
7.5\end{array}$ & $\begin{array}{l}14.5 \\
12.5 \\
13.0 \\
14.0 \\
12.0\end{array}$ & $\begin{array}{l}29.0 \\
28.5 \\
28.5 \\
28.0 \\
29.0\end{array}$ & $\begin{array}{l}13.5 \\
13.5 \\
12.0 \\
14.0 \\
14.0\end{array}$ & $\begin{array}{l}20.0 \\
20.0 \\
20.0 \\
20.0 \\
20.5\end{array}$ \\
\hline $\begin{array}{l}16 \\
17 \\
18 \\
19 \\
20\end{array}$ & & & & $\begin{array}{l}20.0 \\
24.0 \\
21.0 \\
18.5 \\
20.5\end{array}$ & $\begin{array}{r}9.5 \\
10.0 \\
9.5 \\
8.0 \\
7.0\end{array}$ & $\begin{array}{l}13.5 \\
15.0 \\
14.0 \\
12.0 \\
12.5\end{array}$ & $\begin{array}{l}17.5 \\
22.5 \\
22.0 \\
25.0 \\
26.5\end{array}$ & $\begin{array}{r}6.5 \\
7.0 \\
8.5 \\
9.0 \\
10.0\end{array}$ & $\begin{array}{l}11.0 \\
13.5 \\
14.5 \\
16.0 \\
17.0\end{array}$ & $\begin{array}{l}27.5 \\
27.0 \\
26.0 \\
25.5 \\
24.0\end{array}$ & $\begin{array}{l}14.0 \\
12.5 \\
13.5 \\
12.5 \\
12.0\end{array}$ & $\begin{array}{l}19.5 \\
19.0 \\
18.5 \\
17.5 \\
17.0\end{array}$ \\
\hline $\begin{array}{l}21 \\
22 \\
23 \\
24 \\
25\end{array}$ & & & & $\begin{array}{l}23.0 \\
21.5 \\
22.0 \\
23.5 \\
20.0\end{array}$ & $\begin{array}{l}7.0 \\
7.5 \\
9.0 \\
9.0 \\
8.5\end{array}$ & $\begin{array}{l}13.5 \\
14.0 \\
14.0 \\
14.5 \\
13.5\end{array}$ & $\begin{array}{l}25.5 \\
24.5 \\
26.5 \\
27.5 \\
23.0\end{array}$ & $\begin{array}{l}10.5 \\
11.0 \\
11.0 \\
11.5 \\
11.0\end{array}$ & $\begin{array}{l}16.5 \\
16.5 \\
17.5 \\
18.0 \\
16.0\end{array}$ & $\begin{array}{l}24.5 \\
27.0 \\
25.5 \\
26.0 \\
29.0\end{array}$ & $\begin{array}{l}12.0 \\
12.5 \\
13.0 \\
12.5 \\
12.5\end{array}$ & $\begin{array}{l}17.5 \\
18.5 \\
18.0 \\
18.0 \\
19.5\end{array}$ \\
\hline $\begin{array}{l}26 \\
27 \\
28 \\
29 \\
30 \\
31\end{array}$ & & & & $\begin{array}{l}23.0 \\
20.0 \\
19.0 \\
22.0 \\
23.5 \\
23.5\end{array}$ & $\begin{array}{l}8.0 \\
8.0 \\
7.0 \\
8.0 \\
7.5 \\
8.5\end{array}$ & $\begin{array}{l}14.0 \\
12.0 \\
12.0 \\
13.5 \\
14.0 \\
14.0\end{array}$ & $\begin{array}{r}24.0 \\
25.0 \\
25.5 \\
26.5 \\
27.5 \\
-.-\end{array}$ & $\begin{array}{r}9.0 \\
9.5 \\
10.0 \\
10.5 \\
10.5 \\
=--\end{array}$ & $\begin{array}{r}15.5 \\
15.5 \\
16.5 \\
17.0 \\
18.0 \\
\ldots\end{array}$ & $\begin{array}{l}29.5 \\
27.5 \\
27.0 \\
27.0 \\
27.5 \\
28.5\end{array}$ & $\begin{array}{l}13.5 \\
14.0 \\
13.5 \\
12.5 \\
12.5 \\
13.0\end{array}$ & $\begin{array}{l}20.5 \\
19.5 \\
19.0 \\
18.5 \\
19.0 \\
19.5\end{array}$ \\
\hline MONTH & & & & 24.0 & 6.0 & 12.5 & 27.5 & 6.5 & 15.0 & 29.5 & 11.0 & 18.5 \\
\hline \multirow[t]{2}{*}{ DAY } & $\operatorname{mAX}$ & $M I N$ & MEAN & $\operatorname{MAX}$ & HIN & MEAN & MAX & MIN & MEAN & $\operatorname{MAX}$ & MIN & MEAN \\
\hline & \multicolumn{3}{|c|}{ JUNE } & \multicolumn{3}{|c|}{ JULY } & \multicolumn{3}{|c|}{ AUGUST } & \multicolumn{3}{|c|}{ SEPTEMBER } \\
\hline $\begin{array}{l}1 \\
2 \\
3 \\
4 \\
5\end{array}$ & $\begin{array}{l}29.0 \\
27.5 \\
29.0 \\
28.0 \\
28.5\end{array}$ & $\begin{array}{l}13.5 \\
13.0 \\
13.0 \\
12.5 \\
12.0\end{array}$ & $\begin{array}{l}20.0 \\
19.5 \\
19.5 \\
19.0 \\
19.0\end{array}$ & $\begin{array}{l}=-\infty \\
-\infty \\
=-\infty \\
-\infty \\
-\infty\end{array}$ & $\begin{array}{l}-\infty- \\
--\infty \\
--\infty \\
--\infty \\
-\infty-\end{array}$ & $\begin{array}{l}=-\infty \\
=-\infty \\
m-\infty \\
m-\infty \\
-\infty-\infty\end{array}$ & $\begin{array}{l}25.0 \\
25.0 \\
25.5 \\
26.0 \\
25.5\end{array}$ & $\begin{array}{l}16.5 \\
16.0 \\
15.5 \\
16.0 \\
15.5\end{array}$ & $\begin{array}{l}20.0 \\
20.0 \\
20.0 \\
20.0 \\
20.0\end{array}$ & $\begin{array}{l}28.5 \\
27.0 \\
22.5 \\
27.0 \\
25.5\end{array}$ & $\begin{array}{l}16.5 \\
17.5 \\
18.0 \\
18.0 \\
17.5\end{array}$ & $\begin{array}{l}21.5 \\
21.5 \\
20.0 \\
21.5 \\
21.0\end{array}$ \\
\hline $\begin{array}{r}6 \\
7 \\
8 \\
9 \\
10\end{array}$ & $\begin{array}{l}29.0 \\
26.5 \\
25.0 \\
26.0 \\
22.0\end{array}$ & $\begin{array}{l}12.5 \\
13.5 \\
12.5 \\
13.0 \\
11.0\end{array}$ & $\begin{array}{l}19.0 \\
18.5 \\
18.0 \\
18.0 \\
15.5\end{array}$ & $\begin{array}{l}=-\infty \\
=-\infty \\
=-\infty \\
=-\infty \\
=-\infty\end{array}$ & $\begin{array}{l}--\infty \\
--\infty \\
-m \\
--\infty \\
--\infty\end{array}$ & $\begin{array}{l}m-= \\
=-\infty \\
=-\infty \\
m-\infty \\
m-\infty\end{array}$ & $\begin{array}{l}26.0 \\
26.0 \\
24.5 \\
25.5 \\
24.0\end{array}$ & $\begin{array}{l}16.0 \\
16.0 \\
16.0 \\
15.5 \\
15.5\end{array}$ & $\begin{array}{l}20.0 \\
20.5 \\
20.0 \\
20.0 \\
19.5\end{array}$ & $\begin{array}{r}24.5 \\
-0-0 \\
=-0 \\
=-0\end{array}$ & $\begin{array}{r}17.0 \\
=- \\
=- \\
=-\end{array}$ & $\begin{array}{r}20.5 \\
=-0 \\
-\ldots\end{array}$ \\
\hline $\begin{array}{l}11 \\
12 \\
13 \\
14 \\
15\end{array}$ & $\begin{array}{l}28.5 \\
29.5 \\
29.0 \\
27.5 \\
29.5\end{array}$ & $\begin{array}{l}11.0 \\
12.5 \\
13.5 \\
14.0 \\
12.5\end{array}$ & $\begin{array}{l}18.5 \\
19.5 \\
20.0 \\
20.0 \\
20.5\end{array}$ & $\begin{array}{l}--\infty \\
--\infty \\
--\infty \\
--\infty \\
--\infty\end{array}$ & $\begin{array}{l}=-\infty \\
=-\infty \\
=-- \\
=-\infty \\
=-\infty\end{array}$ & $\begin{array}{l}-\infty- \\
=\infty- \\
=-\infty \\
-\infty-\infty \\
-\infty\end{array}$ & $\begin{array}{l}26.5 \\
24.5 \\
24.5 \\
22.5 \\
23.5\end{array}$ & $\begin{array}{l}15.5 \\
16.0 \\
16.5 \\
17.0 \\
16.0\end{array}$ & $\begin{array}{l}20.5 \\
20.0 \\
20.0 \\
19.0 \\
19.0\end{array}$ & $\begin{array}{r}-.0 \\
27.5 \\
28.0 \\
26.0\end{array}$ & $\begin{array}{r}=- \\
16.5 \\
16.0\end{array}$ & $\begin{array}{r}--\infty \\
21.0 \\
19.5\end{array}$ \\
\hline $\begin{array}{l}16 \\
17 \\
18 \\
19 \\
20\end{array}$ & $\begin{array}{l}28.5 \\
30.0 \\
31.0 \\
30.0 \\
30.5\end{array}$ & $\begin{array}{l}14.5 \\
14.0 \\
14.5 \\
15.0 \\
15.0\end{array}$ & $\begin{array}{l}20.0 \\
20.5 \\
21.5 \\
21.5 \\
21.0\end{array}$ & $\begin{array}{l}27.5 \\
30.5 \\
30.0 \\
30.0 \\
30.5\end{array}$ & $\begin{array}{l}=-- \\
17.5 \\
15.5 \\
16.0 \\
16.0\end{array}$ & $\begin{array}{l}-.0 \\
22.5 \\
21.5 \\
21.5 \\
22.0\end{array}$ & $\begin{array}{l}24.5 \\
23.0 \\
23.0 \\
28.0 \\
28.5\end{array}$ & $\begin{array}{l}15.5 \\
16.5 \\
16.0 \\
16.0 \\
15.5\end{array}$ & $\begin{array}{l}19.5 \\
19.0 \\
19.0 \\
20.0 \\
20.5\end{array}$ & $\begin{array}{l}24.5 \\
25.5 \\
26.5 \\
27.0 \\
23.5\end{array}$ & $\begin{array}{l}15.0 \\
14.0 \\
14.0 \\
14.5 \\
15.5\end{array}$ & $\begin{array}{l}18.5 \\
19.0 \\
19.0 \\
19.5 \\
18.5\end{array}$ \\
\hline $\begin{array}{l}21 \\
22 \\
23 \\
24 \\
25\end{array}$ & $\begin{array}{r}29.0 \\
28.5 \\
28.5 \\
-.0 \\
\ldots-.\end{array}$ & $\begin{array}{r}14.5 \\
14.0 \\
14.0 \\
=-.\end{array}$ & $\begin{array}{r}20.5 \\
20.0 \\
-\ldots \\
=-\infty\end{array}$ & $\begin{array}{l}31.0 \\
24.0 \\
27.5 \\
29.0 \\
27.5\end{array}$ & $\begin{array}{l}16.5 \\
16.5 \\
17.5 \\
17.0 \\
18.0\end{array}$ & $\begin{array}{l}22.0 \\
20.0 \\
22.0 \\
22.5 \\
22.5\end{array}$ & $\begin{array}{l}28.0 \\
25.0 \\
28.0 \\
28.5 \\
29.0\end{array}$ & $\begin{array}{l}16.0 \\
16.0 \\
14.5 \\
15.0 \\
16.5\end{array}$ & $\begin{array}{l}20.5 \\
19.5 \\
20.0 \\
21.0 \\
21.5\end{array}$ & $\begin{array}{l}26.5 \\
26.0 \\
26.5 \\
24.5 \\
25.0\end{array}$ & $\begin{array}{l}15.5 \\
15.0 \\
16.0 \\
15.5 \\
16.0\end{array}$ & $\begin{array}{l}20.0 \\
19.0 \\
20.0 \\
18.0 \\
19.0\end{array}$ \\
\hline $\begin{array}{l}26 \\
27 \\
28 \\
29 \\
30 \\
31\end{array}$ & $\begin{array}{l}=- \\
=-\infty \\
m-\infty \\
m-\infty\end{array}$ & $\begin{array}{l}--\infty \\
=-\infty \\
=-\infty \\
=-\infty\end{array}$ & $\begin{array}{l}=-\infty \\
=-\infty \\
=-\infty \\
=-\infty \\
=-\infty\end{array}$ & $\begin{array}{l}27.0 \\
29.0 \\
28.5 \\
28.0 \\
27.5 \\
26.0\end{array}$ & $\begin{array}{l}19.5 \\
19.0 \\
19.5 \\
18.5 \\
18.0 \\
18.5\end{array}$ & $\begin{array}{l}22.0 \\
23.5 \\
23.0 \\
22.0 \\
21.5 \\
21.5\end{array}$ & $\begin{array}{l}29.0 \\
28.5 \\
29.0 \\
29.5 \\
29.0 \\
29.0\end{array}$ & $\begin{array}{l}16.0 \\
15.5 \\
16.5 \\
17.0 \\
17.5 \\
17.0\end{array}$ & $\begin{array}{l}21.0 \\
21.0 \\
22.0 \\
22.5 \\
22.5 \\
22.0\end{array}$ & $\begin{array}{r}26.0 \\
26.0 \\
24.5 \\
24.5 \\
26.0 \\
. .\end{array}$ & $\begin{array}{r}15.0 \\
15.0 \\
14.5 \\
16.5 \\
15.0 \\
-\infty\end{array}$ & $\begin{array}{l}19.0 \\
19.0 \\
18.5 \\
19.0 \\
19.0 \\
=\end{array}$ \\
\hline MONTH & 31.0 & 11.0 & 19.5 & 31.0 & 15.5 & 22.0 & 29.5 & 14.5 & 20.5 & 28.5 & 14.0 & 19.5 \\
\hline YEAR & 31.0 & 3.0 & 15.5 & & & & & & & & & \\
\hline
\end{tabular}


10261500 MOJAVE RIVER AT LOWER NARROWS, NEAR VICTORVILLE, CA--Continued

PARTICLE-SIZE DISTRIBUTION OF SUSPENDED SEDIMENT, WATER YEAR OCTOBER 1975 TO SEPTEMBER 1976

\begin{tabular}{|c|c|c|c|c|c|c|}
\hline DATE & TIME & $\begin{array}{l}\text { INSTAN- } \\
\text { TANEOUS } \\
\text { OIS- } \\
\text { CHARGE } \\
\text { (CFS) }\end{array}$ & $\begin{array}{l}\text { TEMPER- } \\
\text { ATURE } \\
\text { (DEG C) }\end{array}$ & $\begin{array}{l}\text { SUS- } \\
\text { PENDEO } \\
\text { SEDI- } \\
\text { MENT } \\
(M G / L)\end{array}$ & $\begin{array}{l}\text { SUS- } \\
\text { PENDED } \\
\text { SEDI- } \\
\text { MENT } \\
\text { DIS- } \\
\text { CHARGE } \\
\text { (T/DAY) }\end{array}$ & $\begin{array}{c}\text { SUS. } \\
\text { SED, } \\
\text { SIEVE } \\
\text { DIAM. } \\
\text { X FINER } \\
\text { THAN } \\
\text {.062 MM }\end{array}$ \\
\hline $\begin{array}{l}\text { OCT } \\
\text { 31 .... } \\
\text { NOV }\end{array}$ & 1030 & 11 & 17.8 & 103 & 3.1 & 73 \\
\hline $\begin{array}{l}26 \ldots \\
D E C\end{array}$ & 1055 & 23 & 12.8 & 78 & 4.8 & 61 \\
\hline $\begin{array}{l}30 \ldots \\
\text { JAN }\end{array}$ & 1100 & 30 & 14.8 & 91 & 7.4 & 42 \\
\hline$\underset{F E B}{29} \cdots$ & 1115 & 29 & 14.6 & 106 & 8.3 & 53 \\
\hline$\underset{\text { MAR }}{24 \cdots}$ & 1045 & 42 & 16.0 & 154 & 17 & 35 \\
\hline$\stackrel{25 \cdots \cdots}{A P R}$ & 1040 & 31 & 16.2 & 74 & 6.2 & 47 \\
\hline $29 \cdots$ & 1125 & 32 & $21 \cdot 8$ & 94 & 8.1 & 45 \\
\hline JUN $27 \cdots$ & 1050 & 23 & 24.2 & 25 & 1.6 & 31 \\
\hline$\underset{\text { JUL }}{28} \cdots$ & 1130 & 18 & 28.5 & 18 & .87 & 50 \\
\hline$\underset{\text { AUG }}{13 \ldots}$ & -1050 & 24 & 26.5 & 12 & .78 & 49 \\
\hline $\operatorname{SEP}^{19} \cdots$ & 1315 & 19 & 24.5 & 10 & .51 & 32 \\
\hline $14 \ldots$ & 1145 & 35 & 24.5 & 123 & 12 & 58 \\
\hline
\end{tabular}


LOCATION.--Lat $34^{\circ} 50^{\prime} 09^{\prime \prime}$, Iong $117^{\circ} 11^{\prime} 27^{\prime \prime}$, in SWtaSE $\frac{1}{4} \mathrm{SE} \frac{1}{6}$ sec. 28 , T.9 N., R. 3 W. , San Bernardino County, at county bridge $1.5 \mathrm{mi}(2.4 \mathrm{~km})$ north of Hodge, $10.9 \mathrm{mi}(17.5 \mathrm{~km})$ southwest of Barstow, and $44.5 \mathrm{mi}(71.6 \mathrm{~km})$ downstream from Silverwood Lake.

DRAINAGE AREA. $-1,091 \mathrm{mi}^{2}\left(2,826 \mathrm{~km}^{2}\right)$, revised.

PERIOD OF RECORD.- -October 1930 to September 1932, October 1970 to current year.

GAGE, - Water-stage recorder and crest-stage gage. Altitude of gage is 2,260 ft (689 n), from topographic map. Prior to Oct. 1, 1970 , at different datum.

REMARKS. - No flow since Aug. 3, 1974. No gage-height record Oct, 1 to Dec. 17, Sept. 16-30. Regulation by Lake Arrowhead, capacity, 48,000 acre-ft $\left(59.2 \mathrm{hm}^{3}\right)$ used principally for recreation, Silverwood Lake, capacity, 78,000 acre-ft $\left(96.2 \mathrm{hm}^{3}\right)$ used for the storage and distribution of imported water and recreation, and Mojave Forks Reservoir, capacity, 89,700 acre-ft $\left(111 \mathrm{hm}^{3}\right)$, with ungated opening, capacity, $23,500 \mathrm{ft} / \mathrm{s}(666 \mathrm{~m} / 5)$ Diversion and pumping for irrigation of about 12,000 acres $\left(48.6 \mathrm{~km}^{2}\right)$ above station.

AVERAGE DISCHARGE, - -8 years, (water years $1931-32,1971-76), 11.5 \mathrm{ft}^{3} / \mathrm{s}\left(0.326 \mathrm{~m}^{3} / \mathrm{s}\right), 8,330$ acre-ft/yr $\left(10.3 \mathrm{hm}^{3} / \mathrm{yr}^{2}\right)$.

EXTREMES FOR PERIOD OF RECORD.--Maximum discharge, $8,900 \mathrm{ft}^{3} / \mathrm{s}\left(252 \mathrm{fi}^{3} / \mathrm{s}\right)$ Feb. $9,1932, \mathrm{gage} \mathrm{height,} 5,20 \mathrm{ft}$ $(1.585 \mathrm{~m})$, datum then in use; no flow all or most of each year.

EXTREMES FOR CURRENT YEAR. - - No flow during year. 
10262500 MOJAVE RIVER AT BARSTOW, CA

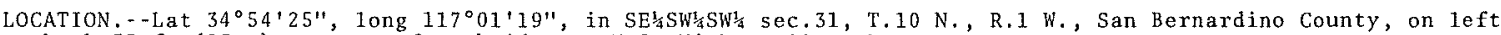
bank $75 \mathrm{ft}(23 \mathrm{~m})$ upstream from bridge on U.S. Highway 91 at Barstow.

DRAINAGE AREA. $-1,291 \mathrm{mi}^{2}\left(3,344 \mathrm{~km}^{2}\right)$, revised.

PERIOD OF RECORD, - October 1930 to current year.

GAGE. - Water-stage recorder. Datum of gage is $2,089.34(636.831 \mathrm{~m})$ above mean sea 1 evel.

REMARKS, - Records poor. Regulation by Lake Arrowhead, capacity, 48,000 acre-ft (59.2 hm ${ }^{3}$ ) used principally for recreation, Silverwood Lake, capacity, 78,000 acre-ft $\left(96.2 \mathrm{hm}^{3}\right)$ used for the storage and distribution of imported water and recreation, and Mojave Forks Reservoir, capacity, 89,700 acre-ft (111 hm ${ }^{3}$ ) with

ungated opening, capacity, $23,500 \mathrm{ft}^{3} / \mathrm{s}\left(666 \mathrm{~m}^{3} / \mathrm{s}\right)$. Diversions and pumping for irrigation of about

15,000 acres $\left(60,7 \mathrm{~km}^{2}\right)$ above station.

AVERAGE DISCHARGE. - -46 years, $22.1 \mathrm{ft}^{3} / \mathrm{s}\left(0.626 \mathrm{~m}^{3} / \mathrm{s}\right), 16,010 \mathrm{acre}-\mathrm{ft}^{2} \mathrm{yr}\left(19.7 \mathrm{hm}^{3} / \mathrm{yr}^{2}\right)$.

EXTREMES FOR PERIOD OF RECORD.--Maximum discharge, $64,300 \mathrm{ft}^{3} / \mathrm{s}\left(1,820 \mathrm{~m}^{3} / \mathrm{s}\right) \mathrm{Mar} .3,1938, \mathrm{gage} \mathrm{height,} 8.60 \mathrm{ft}$

$(2.621 \mathrm{~m})$, on basis of slope-area measurement of maximum flow; no flow for most months each year.

EXTREMES FOR CURRENT YEAR.--Maximum discharge, $12 \mathrm{ft}^{3} / \mathrm{s}\left(0.34 \mathrm{~m}^{3} / \mathrm{s}\right)$ Sept. 10 , on basis of estimate of maximum flow; no flow most of year.

DISCHARGE, IN CUBIC FEET PER SECOND, WATER YEAR OCTOBER 1975 TO SEPTEMBER 1976 MEAN VALUES

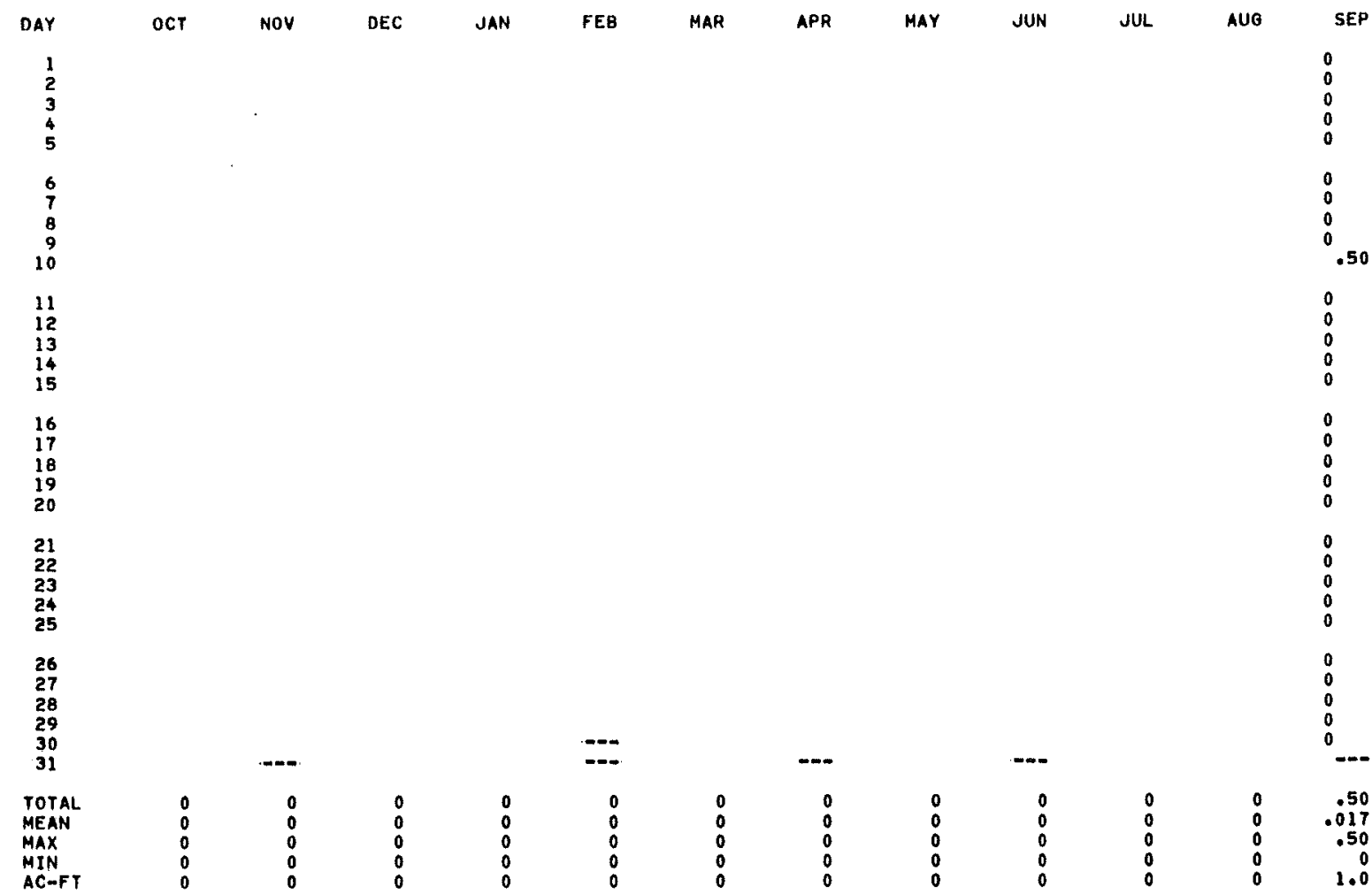

CAL YR 1975 TOTAL 0.17 MEAN .0005 HAX .17 MIN O AC-FT .3 
LOCATION, - Lat $35^{\circ} 02^{\prime} 14^{\prime \prime}$, 1ong $116^{\circ} 23^{\prime} 00^{\prime \prime}$, in SWHW $\frac{1}{4} S E^{1} 4$ sec.18, T.11 N., R. 6 E., San Bernardino County, on downstream end of right pier of Union Pacific Railroad bridge, $0.3 \mathrm{mi}(0.5 \mathrm{~km})$ west of Afton.

DRAINAGE AREA. - - $2,121 \mathrm{mi}^{2}\left(5,493 \mathrm{~km}^{2}\right)$, revised.

PERIOD OF RECORD, - -October 1929 to September 1932, October 1952 to current year. Records for the water year 1930 incomplete, yearly estimate published in WSP 1314.

GAGE. - Water-stage recorder, Datum of gage is $1,400.15 \mathrm{ft}$ (426.766 m) above mean sea 1 eve1. Dec. 21 , 1929 , to Sept. 30 , 1932, at site $1.7 \mathrm{mi}(2.7 \mathrm{~km})$ downstream at different datum.

REMARKS.--Records poor. Natural flow affected by ground-water withdrawals, diversions, municipal use, and storage in upstream reservoirs $100 \mathrm{mi}(160 \mathrm{~km})$ upstream (station 10261500).

AVERAGE DISCHARGE. - -27 years, $5.29 \mathrm{ft}^{3} / \mathrm{s}\left(0.150 \mathrm{~m}^{3} / \mathrm{s}\right), 3,830 \mathrm{acre}-\mathrm{ft} / \mathrm{yr}(4.72 \mathrm{hm} / \mathrm{yr})$.

EXTREMES FOR PERIOD OF RECORD. - Maximum discharge, 18,000 $\mathrm{ft}^{3} / \mathrm{s}\left(510 \mathrm{~m}^{3} / \mathrm{s}\right) \mathrm{Jan} .26,1969, \mathrm{gage} \mathrm{height,} 10.40 \mathrm{ft}$ $(3.170 \mathrm{~m})$, from rating curve extended above $3,200 \mathrm{ft}^{3} / \mathrm{s}(90.6 \mathrm{~m} / \mathrm{s})$ on basis of slope-area measurement of maximum fiow; no flow at times many years.

EXTREMES FOR CURRENT YEAR, - -Maximum discharge, $1,060 \mathrm{ft}^{3} / \mathrm{s}\left(30.0 \mathrm{~m}^{3} / \mathrm{s}\right)$ Sept. 11 (time unknown), gage height, $7.08 \mathrm{ft}(2.158 \mathrm{~m})$, no other peak above base of $100 \mathrm{ft}^{3} / \mathrm{s}\left(2.83 \mathrm{~m}^{3} / \mathrm{s}\right)$; minimum daily, no flow several months.

DISCHARGE, IN CUBIC FEET PER SECOND, WATER YEAR OCTOBER 1975 TO SEPTEMBER 1976 MEAN VALUES

\begin{tabular}{|c|c|c|c|c|c|c|c|c|c|c|c|c|}
\hline DAY & OCT & NOV & DEC & JAN & FEB & MAR & APR & MAY & JUN & JUL & AUG & SEP \\
\hline $\begin{array}{l}1 \\
2 \\
3 \\
4 \\
5\end{array}$ & & $\begin{array}{l}0 \\
0 \\
0 \\
0 \\
0\end{array}$ & $\begin{array}{r}.05 \\
.08 \\
.13 \\
.16 \\
.16\end{array}$ & $\begin{array}{l}.26 \\
.26 \\
.26 \\
.26 \\
.26\end{array}$ & $\begin{array}{l}.64 \\
.64 \\
.75 \\
1.0 \\
.88\end{array}$ & $\begin{array}{r}.54 \\
.54 \\
.75 \\
.64 \\
.64\end{array}$ & $\begin{array}{l}.16 \\
.16 \\
.16 \\
.16 \\
.13\end{array}$ & $\begin{array}{r}.26 \\
.26 \\
.21 \\
.21 \\
.21\end{array}$ & & & & $\begin{array}{l}0 \\
0 \\
0 \\
0 \\
0\end{array}$ \\
\hline $\begin{array}{r}6 \\
7 \\
8 \\
9 \\
10\end{array}$ & & $\begin{array}{l}0 \\
0 \\
0 \\
0 \\
0\end{array}$ & $\begin{array}{r}.21 \\
.26 \\
.32 \\
.38 \\
.38\end{array}$ & $\begin{array}{r}.26 \\
.26 \\
.32 \\
.32 \\
.32\end{array}$ & $\begin{array}{l}1.0 \\
.88 \\
1.2 \\
1.8 \\
1.0\end{array}$ & $\begin{array}{r}.64 \\
.64 \\
.64 \\
.64 \\
.64\end{array}$ & $\begin{array}{r}.21 \\
.26 \\
.26 \\
.21 \\
.16\end{array}$ & $\begin{array}{r}.21 \\
.21 \\
.32 \\
.32 \\
.32\end{array}$ & & & & $\begin{array}{l}0 \\
0 \\
0 \\
0 \\
0\end{array}$ \\
\hline $\begin{array}{l}11 \\
12 \\
13 \\
14 \\
15\end{array}$ & & $\begin{array}{l}0 \\
0 \\
0 \\
0 \\
0\end{array}$ & $\begin{array}{r}.38 \\
.38 \\
.26 \\
.13 \\
.13\end{array}$ & $\begin{array}{r}.32 \\
.32 \\
.32 \\
.32 \\
.32\end{array}$ & $\begin{array}{r}.75 \\
.75 \\
.75 \\
.64 \\
.54\end{array}$ & $\begin{array}{r}.64 \\
.54 \\
.54 \\
.54 \\
.54\end{array}$ & $\begin{array}{l}.13 \\
.10 \\
.21 \\
.64 \\
.38\end{array}$ & $\begin{array}{r}.26 \\
.21 \\
.16 \\
.16 \\
.10\end{array}$ & & & & $\begin{array}{r}79 \\
1.0 \\
.50 \\
.40 \\
.40\end{array}$ \\
\hline $\begin{array}{l}16 \\
17 \\
18 \\
19 \\
20\end{array}$ & & $\begin{array}{l}0 \\
0 \\
0 \\
0 \\
0\end{array}$ & $\begin{array}{l}.16 \\
.21 \\
.26 \\
.26 \\
.26\end{array}$ & $\begin{array}{r}.32 \\
.32 \\
.38 \\
.38 \\
.38\end{array}$ & $\begin{array}{l}.54 \\
.54 \\
.45 \\
.45 \\
.45\end{array}$ & $\begin{array}{l}.54 \\
.64 \\
.75 \\
.88 \\
.64\end{array}$ & $\begin{array}{l}.32 \\
.21 \\
.16 \\
.21 \\
.21\end{array}$ & $\begin{array}{l}.08 \\
.08 \\
.06 \\
.05 \\
.05\end{array}$ & & & & $\begin{array}{r}.35 \\
.30 \\
.25 \\
.20 \\
.15\end{array}$ \\
\hline $\begin{array}{l}21 \\
22 \\
23 \\
24 \\
25\end{array}$ & & $\begin{array}{l}0 \\
0 \\
0 \\
0 \\
0\end{array}$ & $\begin{array}{l}.26 \\
.26 \\
.26 \\
.26 \\
.26\end{array}$ & $\begin{array}{l}.38 \\
.36 \\
.26 \\
.26 \\
.21\end{array}$ & $\begin{array}{l}.45 \\
.45 \\
.45 \\
.54 \\
.54\end{array}$ & $\begin{array}{l}.32 \\
.26 \\
.26 \\
.21 \\
.21\end{array}$ & $\begin{array}{l}.21 \\
.21 \\
.21 \\
.26 \\
.26\end{array}$ & $\begin{array}{l}.05 \\
.05 \\
.05 \\
.05 \\
.05\end{array}$ & & & & $\begin{array}{l}.15 \\
.15 \\
.15 \\
.15 \\
.15\end{array}$ \\
\hline $\begin{array}{l}26 \\
27 \\
28 \\
29 \\
30 \\
31\end{array}$ & & $\begin{array}{l}0 \\
.02 \\
.05 \\
.03 \\
.04 \\
0 .-\end{array}$ & $\begin{array}{r}.26 \\
.26 \\
.32 \\
.32 \\
.52 \\
.32\end{array}$ & $\begin{array}{r}.26 \\
.38 \\
.54 \\
.54 \\
.54 \\
.64\end{array}$ & $\begin{array}{r}.64 \\
.64 \\
.64 \\
.54 \\
. .--\end{array}$ & $\begin{array}{l}.21 \\
.21 \\
.21 \\
.16 \\
.16 \\
.16\end{array}$ & $\begin{array}{l}.26 \\
.26 \\
.26 \\
.26 \\
.26 \\
.-2-\end{array}$ & $\begin{array}{l}.04 \\
.03 \\
0 \\
0 \\
0 \\
0\end{array}$ & 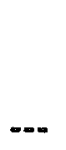 & & & $\begin{array}{r}.15 \\
.17 \\
.17 \\
.17 \\
.17 \\
-10\end{array}$ \\
\hline $\begin{array}{l}\text { TOTAL } \\
\text { MEAN } \\
\text { MAX } \\
\text { MIN } \\
\text { AC-FT }\end{array}$ & $\begin{array}{l}0 \\
0 \\
0 \\
0 \\
0\end{array}$ & $\begin{array}{r}.14 \\
.005 \\
.05 \\
0 \\
.3\end{array}$ & $\begin{array}{r}7.86 \\
.25 \\
.52 \\
.05 \\
16\end{array}$ & $\begin{array}{r}10.55 \\
.34 \\
.64 \\
.21 \\
21\end{array}$ & $\begin{array}{r}20.54 \\
.71 \\
1.8 \\
.45 \\
41\end{array}$ & $\begin{array}{r}14.93 \\
.48 \\
.88 \\
.16 \\
30\end{array}$ & $\begin{array}{r}6.89 \\
.23 \\
.64 \\
.10 \\
14\end{array}$ & $\begin{array}{r}4.06 \\
.13 \\
.32 \\
0 \\
0.1\end{array}$ & $\begin{array}{l}0 \\
0 \\
0 \\
0 \\
0\end{array}$ & $\begin{array}{l}0 \\
0 \\
0 \\
0 \\
0\end{array}$ & $\begin{array}{l}0 \\
0 \\
0 \\
0 \\
0\end{array}$ & $\begin{array}{r}84.13 \\
2.80 \\
79 \\
0 \\
167\end{array}$ \\
\hline
\end{tabular}

CAL YR 1975 TOTAL 65.78 MEAN 18 MAX 1.0 MIN 0 AC-FT 130 $\begin{array}{lllllll}\text { CAL YR } 1975 & \text { TOTAL } 65.78 & \text { MEAN } 18 & \text { MAX } & 1.0 & \text { MIN O } & \text { AC-FT } 130 \\ \text { HTR YR } 1976 & \text { TOTAL } 149.10 & \text { MEAN } & 41 & \text { MAX } & 79 & \text { MIN O }\end{array}$ 
10263500 BIG ROCK CREEK NEAR VALYERMO, CA

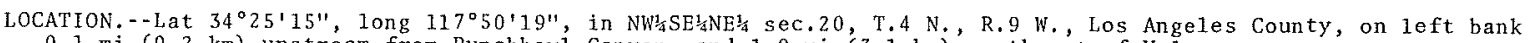
0.1 mi $(0.2 \mathrm{~km})$ upstrean from Punchbowi Canyon, and $1.9 \mathrm{mi}(3.1 \mathrm{~km})$ 'southeast of Valyermo.

DRAINAGE AREA. $-22.9 \mathrm{mi}^{2}\left(59.3 \mathrm{~km}^{2}\right)$.

WATER-DISCHARGE RECORDS

PERIOD OF RECORD. - -January 1923 to current year. Monthly discharge only for October 1937 to January 1939 , published in WSP 1314. Prior to October 1954, published as Rock Creek near Va1yermo.

GAGE. - Water-stage recorder. A1titude of gage is 4,050 ft $(1,234 \mathrm{~m})$, from topographic map. Prior to May 4, 1938 , at same site at different datums. May 4, 1938, to Jan. 26, 1939, at site $0.2 \mathrm{mi}$ (0.3 km) downstreank (below Punchbow1 Canyon) at different datum.

REMARKS.--Records poor. No regulation or diversion above station. Some infiltration into the streambed in the immediate vicinity of station.

COOPERATION.--Eighteen discharge measurements were furnished by Los Angeles County Flood Control District.

AVERAgE DISCHARgE. - -53 years (water years $1924-76), 15.6 \mathrm{ft}^{3} / \mathrm{s}\left(0.442 \mathrm{~m}^{3} / \mathrm{s}\right), 11,300 \mathrm{acre}-\mathrm{ft} / \mathrm{yr}(13.9 \mathrm{hm} / \mathrm{yr})$.

EXTREMES FOR PERIOD OF RECORD.--Maximum discharge, $8,300 \mathrm{ft}^{3} / \mathrm{s}\left(235 \mathrm{~m}^{3} / \mathrm{s}\right)$ Mar. 2 , 1938 , on basis of $\mathrm{s} 10 \mathrm{pe}-\mathrm{area}$ measurement of maximum flow; minimum daily, $0.70 \mathrm{ft}^{3} / \mathrm{s}\left(0.020 \mathrm{~m}^{3} / \mathrm{s}\right)$ Nov. 5,1951 .

EXTREMES FOR CURRENT YEAR, - Maximum discharge, $360 \mathrm{ft}^{3} / \mathrm{s}\left(10.2 \mathrm{~m}^{3} / \mathrm{s}\right)$ Sept. I1 (0530 hrs), gage height, $4.90 \mathrm{ft}$ $(1,494 \mathrm{~m})$, no other peak above base of $50 \mathrm{ft}^{3} / \mathrm{s}\left(1.42 \mathrm{~m}^{3} / \mathrm{s}\right) ; \mathrm{minimum} \mathrm{daily,} 2.9 \mathrm{ft} / \mathrm{s}(0.082 \mathrm{~m} / \mathrm{s})$

OISCHARGE, IN CUBIC FEET PER SECOND, WATER YEAR OCTOBER 1975 TO SEPTEMBER 1976 MEAN VALUES

\begin{tabular}{|c|c|c|c|c|c|c|c|c|c|c|c|c|c|c|c|}
\hline DAY & $O C$ & Tr & NOV & DEC & JAN & & FEB & & MAR & APR & MAY & JUN & JUL & AUG & SEP \\
\hline $\begin{array}{l}1 \\
2 \\
3 \\
4 \\
5\end{array}$ & $\begin{array}{l}3 . \\
3 . \\
3 . \\
3 . \\
3 .\end{array}$ & $\begin{array}{l}7 \\
7 \\
7 \\
7 \\
7\end{array}$ & $\begin{array}{l}3.6 \\
3.6 \\
3.6 \\
3.5 \\
3.5\end{array}$ & $\begin{array}{l}3.7 \\
3.7 \\
3.7 \\
3.7 \\
3.7\end{array}$ & $\begin{array}{l}3.3 \\
3.3 \\
3.3 \\
3.3 \\
3.3\end{array}$ & & $\begin{array}{l}3.1 \\
2.9 \\
2.9 \\
3.0 \\
2.9\end{array}$ & & $\begin{array}{l}11 \\
11 \\
13 \\
12 \\
11\end{array}$ & $\begin{array}{l}10 \\
10 \\
10 \\
10 \\
10\end{array}$ & $\begin{array}{l}14 \\
14 \\
15 \\
15 \\
14\end{array}$ & $\begin{array}{l}8.4 \\
8.2 \\
8.1 \\
8.1 \\
8.1\end{array}$ & $\begin{array}{l}6.5 \\
6.5 \\
6.0 \\
6.0 \\
5.7\end{array}$ & $\begin{array}{l}5.3 \\
5.3 \\
5.3 \\
5.3 \\
5.3\end{array}$ & $\begin{array}{l}4.6 \\
4.6 \\
4.9 \\
4.9 \\
4.6\end{array}$ \\
\hline $\begin{array}{r}6 \\
7 \\
8 \\
9 \\
10\end{array}$ & $\begin{array}{l}3 . \\
3 \\
3 \\
3 \\
3\end{array}$ & $\begin{array}{l}5 \\
5 \\
5 \\
5 \\
5\end{array}$ & $\begin{array}{l}3.5 \\
3.5 \\
3.8 \\
3.7 \\
3.7\end{array}$ & $\begin{array}{l}3.5 \\
3.5 \\
3.5 \\
3.5 \\
3.3\end{array}$ & $\begin{array}{l}3.3 \\
3.3 \\
3.3 \\
3.3 \\
3.3\end{array}$ & & $\begin{array}{l}10 \\
8.0 \\
28 \\
22 \\
16\end{array}$ & & $\begin{array}{l}11 \\
11 \\
11 \\
11 \\
11\end{array}$ & $\begin{array}{l}9.5 \\
8.8 \\
9.0 \\
8.8 \\
8.6\end{array}$ & $\begin{array}{l}14 \\
13 \\
12 \\
12 \\
11\end{array}$ & $\begin{array}{l}8.0 \\
7.8 \\
7.8 \\
7.8 \\
8.3\end{array}$ & $\begin{array}{l}5.7 \\
5.3 \\
5.3 \\
5.3 \\
5.7\end{array}$ & $\begin{array}{l}5.3 \\
5.3 \\
5.3 \\
5.3 \\
4.9\end{array}$ & $\begin{array}{r}4.6 \\
4.6 \\
4.6 \\
4.6 \\
30\end{array}$ \\
\hline $\begin{array}{l}11 \\
12 \\
13 \\
14 \\
15\end{array}$ & $\begin{array}{l}3 \\
3 \\
3 \\
3 \\
3 .\end{array}$ & $\begin{array}{l}5 \\
5 \\
5 \\
5 \\
5\end{array}$ & $\begin{array}{l}3.9 \\
3.8 \\
3.9 \\
3.9 \\
3.9\end{array}$ & $\begin{array}{l}3.5 \\
3.5 \\
3.7 \\
3.4 \\
3.3\end{array}$ & $\begin{array}{l}3.5 \\
3.5 \\
3.5 \\
3.5 \\
3.5\end{array}$ & & $\begin{array}{l}14 \\
13 \\
13 \\
12 \\
12\end{array}$ & & $\begin{array}{l}11 \\
11 \\
11 \\
11 \\
11\end{array}$ & $\begin{array}{l}8.5 \\
8.6 \\
8.7 \\
8.6 \\
9.4\end{array}$ & $\begin{array}{l}11 \\
13 \\
13 \\
13 \\
13\end{array}$ & $\begin{array}{l}8.3 \\
8.3 \\
7.3 \\
7.3 \\
7.0\end{array}$ & $\begin{array}{l}5.3 \\
5.3 \\
5.3 \\
5.3 \\
5.3\end{array}$ & $\begin{array}{l}4.6 \\
4.2 \\
4.2 \\
4.2 \\
4.6\end{array}$ & $\begin{array}{r}118 \\
40 \\
29 \\
22 \\
15\end{array}$ \\
\hline $\begin{array}{l}16 \\
17 \\
18 \\
19 \\
20\end{array}$ & $\begin{array}{l}3 . \\
3 . \\
3 . \\
3 .\end{array}$ & $\begin{array}{l}5 \\
5 \\
5 \\
5 \\
5\end{array}$ & $\begin{array}{l}3.9 \\
3.9 \\
3.9 \\
4.2 \\
4.2\end{array}$ & $\begin{array}{l}3.3 \\
3.3 \\
3.3 \\
3.3 \\
3.3\end{array}$ & $\begin{array}{l}3.5 \\
3.5 \\
3.5 \\
3.5 \\
3.7\end{array}$ & & $\begin{array}{l}12 \\
12 \\
11 \\
11 \\
11\end{array}$ & & $\begin{array}{l}10 \\
11 \\
11 \\
11 \\
11\end{array}$ & $\begin{array}{l}9.7 \\
10 \\
9.8 \\
10 \\
11\end{array}$ & $\begin{array}{l}13 \\
12 \\
11 \\
11 \\
11\end{array}$ & $\begin{array}{l}6.9 \\
6.8 \\
7.3 \\
7.3 \\
7.3\end{array}$ & $\begin{array}{l}5.7 \\
5.7 \\
5.7 \\
5.7 \\
5.3\end{array}$ & $\begin{array}{l}4.6 \\
4.6 \\
4.6 \\
4.9 \\
5.3\end{array}$ & $\begin{array}{l}11 \\
9.8 \\
9.2 \\
8.8 \\
8.4\end{array}$ \\
\hline $\begin{array}{l}21 \\
22 \\
23 \\
24 \\
25\end{array}$ & $\begin{array}{l}3 . \\
3 . \\
3 . \\
3 . \\
3 .\end{array}$ & & $\begin{array}{l}4.2 \\
4.2 \\
4.2 \\
4.1 \\
4.1\end{array}$ & $\begin{array}{l}3.5 \\
3.5 \\
3.5 \\
3.5 \\
3.5\end{array}$ & $\begin{array}{l}3.7 \\
3.7 \\
3.7 \\
3.7 \\
3.7\end{array}$ & & $\begin{array}{l}11 \\
11 \\
11 \\
11 \\
11\end{array}$ & & $\begin{array}{l}11 \\
11 \\
10 \\
10 \\
11\end{array}$ & $\begin{array}{l}11 \\
12 \\
12 \\
12 \\
13\end{array}$ & $\begin{array}{l}11 \\
10 \\
10 \\
10 \\
9.5\end{array}$ & $\begin{array}{l}6.9 \\
6.6 \\
6.5 \\
6.5 \\
6.5\end{array}$ & $\begin{array}{l}5.3 \\
5.7 \\
5.7 \\
5.3 \\
5.3\end{array}$ & $\begin{array}{l}5.3 \\
4.9 \\
4.6 \\
4.3 \\
4.3\end{array}$ & $\begin{array}{l}8.0 \\
7.8 \\
7.6 \\
20 \\
11\end{array}$ \\
\hline $\begin{array}{l}26 \\
27 \\
28 \\
29 \\
30 \\
31\end{array}$ & $\begin{array}{l}3 . \\
3 . \\
3 . \\
3 . \\
3 . \\
3 .\end{array}$ & $\begin{array}{l}4 \\
5 \\
5 \\
7 \\
6 \\
7\end{array}$ & $\begin{array}{l}4.1 \\
4.1 \\
3.7 \\
3.7 \\
3.7 \\
-.-\end{array}$ & $\begin{array}{l}3.5 \\
3.3 \\
3.3 \\
3.3 \\
3.3 \\
3.3\end{array}$ & $\begin{array}{l}3.5 \\
3.7 \\
3.5 \\
3.3 \\
3.3 \\
3.1\end{array}$ & & $\begin{array}{l}11 \\
11 \\
11 \\
11 \\
-\cdots-\end{array}$ & & $\begin{array}{l}11 \\
11 \\
11 \\
11 \\
10 \\
10\end{array}$ & $\begin{array}{c}13 \\
14 \\
14 \\
14 \\
14 \\
-\end{array}$ & $\begin{array}{l}9.3 \\
9.2 \\
9.3 \\
9.4 \\
9.0 \\
8.5\end{array}$ & $\begin{array}{l}6.5 \\
6.5 \\
6.5 \\
6.0 \\
6.5 \\
-.-\end{array}$ & $\begin{array}{l}5.3 \\
5.3 \\
5.3 \\
5.3 \\
5.3 \\
5.3\end{array}$ & $\begin{array}{l}4.3 \\
4.3 \\
4.3 \\
4.6 \\
4.6 \\
4.6\end{array}$ & $\begin{array}{l}8.8 \\
7.8 \\
7.2 \\
6.7 \\
6.5 \\
--.0\end{array}$ \\
\hline $\begin{array}{l}\text { TOTAL } \\
\text { MF.AN } \\
\text { MAX } \\
\text { MIN } \\
\text { AC }=F T\end{array}$ & $\begin{array}{r}109 . \\
3.5 \\
3 . \\
3 \\
21\end{array}$ & $\begin{array}{l}9 \\
5 \\
7 \\
4 \\
8\end{array}$ & $\begin{array}{r}115.6 \\
3.85 \\
4.2 \\
3.5 \\
229\end{array}$ & $\begin{array}{r}107.2 \\
3.46 \\
3.7 \\
3.3 \\
213\end{array}$ & $\begin{array}{r}107.1 \\
3.45 \\
3.7 \\
3.1 \\
212\end{array}$ & & $\begin{array}{r}318.8 \\
11.0 \\
28 \\
2.9 \\
632\end{array}$ & & $\begin{array}{r}339 \\
10.9 \\
13 \\
10 \\
672\end{array}$ & $\begin{array}{r}318.0 \\
10.6 \\
14 \\
8.5 \\
631\end{array}$ & $\begin{array}{r}360.2 \\
11.6 \\
15 \\
8.5 \\
714\end{array}$ & $\begin{array}{r}219.4 \\
7.31 \\
8.4 \\
6.0 \\
435\end{array}$ & $\begin{array}{r}171.7 \\
5.54 \\
6.5 \\
5.3 \\
341\end{array}$ & $\begin{array}{r}148.5 \\
4.79 \\
5.3 \\
4.2 \\
295\end{array}$ & $\begin{array}{r}434.6 \\
14.5 \\
118 \\
4.6 \\
862\end{array}$ \\
\hline $\begin{array}{ll}\text { CAL YR } \\
\text { WTR }\end{array}$ & $\begin{array}{l}1975 \\
1976\end{array}$ & $\begin{array}{l}\text { TOTAL } \\
\text { TOTAL. }\end{array}$ & $\begin{array}{l}2472.3 \\
2750.0\end{array}$ & $\begin{array}{l}\text { ME.AN } \\
\text { MEAN }\end{array}$ & $\begin{array}{l}6.77 \\
7.51\end{array}$ & $\begin{array}{l}\operatorname{MAX} \\
\operatorname{MAX}\end{array}$ & $\begin{array}{r}18 \\
118\end{array}$ & $\begin{array}{l}\text { HIN } \\
\text { MIN }\end{array}$ & $\begin{array}{l}3.1 \\
2.9\end{array}$ & $\begin{array}{l}A C-F T \\
A C-F T\end{array}$ & & & & & \\
\hline
\end{tabular}


WATER-QUALITY RECORDS

PERIOD OF DAILY RECORD. --

WATER TEMPERATURES: January 1962 to current year.

INSTRUMENTATION. - - Temperature recorder since January 1962.

REMARKS.--Mean values for entire year were used due to very poor circulation at the probe. periods of missing record were due to recorder malfunction.

EXTREMES FOR PERIOD OF RECORD. - -

WATER TEMPERATURES: Maximum $24.0^{\circ} \mathrm{C}$ Aug. 19, 26, 1970, July 15, 31, 1972; minimum $0.5^{\circ} \mathrm{C} \mathrm{Jan} .4,1974$.

EXTREMES FOR CURRENT YEAR.- -

WATER TEMPERATURES: Maximum recorded, $18.7^{\circ} \mathrm{C}$ July 4,$13 ;$ minimum recorded, $4.2^{\circ} \mathrm{C} \mathrm{Feb.6.}$

TEMPERATURE (OEG, C) OF WATER, WATER YEAR OCTOBER 1975 TO SEPTEMBER 1976 MEAN VALUES

\begin{tabular}{|c|c|c|c|c|c|c|c|c|c|c|c|c|}
\hline DAY & OCT & NoV & DEC & JAN & FEB & MAR & APR & MAY & JUN & JUL & AUG & SEP \\
\hline $\begin{array}{l}1 \\
2 \\
3 \\
4 \\
5\end{array}$ & $\begin{array}{l}14.0 \\
14.0 \\
14.4 \\
14.4 \\
14.2\end{array}$ & $\begin{array}{l}10.7 \\
11.0 \\
11.2 \\
11.0 \\
11.1\end{array}$ & $\begin{array}{l}9.4 \\
9.9 \\
9.7 \\
9.8 \\
9.2\end{array}$ & $\begin{array}{l}5.7 \\
5.8 \\
6.4 \\
6.9 \\
7.9\end{array}$ & $\begin{array}{r}8.9 \\
8.9 \\
10.4 \\
8.1 \\
6.4\end{array}$ & $\begin{array}{l}8.4 \\
6.1 \\
5.6 \\
6.5 \\
7.2\end{array}$ & $\begin{array}{r}10.2 \\
10.3 \\
10.3 \\
8.8 \\
9.5\end{array}$ & $\begin{array}{l}12.5 \\
12.3 \\
11.7 \\
12.1 \\
12.1\end{array}$ & $\begin{array}{l}=-0 \\
=-- \\
=-- \\
-=- \\
m--\end{array}$ & $\begin{array}{l}18.2 \\
18.4 \\
18.6 \\
18.7 \\
18.6\end{array}$ & $\begin{array}{l}15.3 \\
14.9 \\
14.8 \\
14.9 \\
14.8\end{array}$ & $\begin{array}{l}15.6 \\
15.9 \\
14.8 \\
15.6 \\
15.2\end{array}$ \\
\hline $\begin{array}{r}6 \\
7 \\
8 \\
9 \\
10\end{array}$ & $\begin{array}{l}13.5 \\
12.9 \\
11.8 \\
12.2 \\
12.4\end{array}$ & $\begin{array}{l}11.1 \\
11.0 \\
10.9 \\
10.0 \\
10.5\end{array}$ & $\begin{array}{r}8.7 \\
8.8 \\
9.2 \\
9.4 \\
10.0\end{array}$ & $\begin{array}{l}7.5 \\
7.2 \\
7.5 \\
6.1 \\
7.5\end{array}$ & $\begin{array}{l}4.2 \\
6.6 \\
7.0 \\
5.4 \\
6.4\end{array}$ & $\begin{array}{l}7.4 \\
8.1 \\
8.3 \\
8.5 \\
9.1\end{array}$ & $\begin{array}{l}10.0 \\
10.7 \\
10.1 \\
10.2 \\
10.4\end{array}$ & $\begin{array}{l}11.8 \\
11.5 \\
12.4 \\
12.6 \\
12.6\end{array}$ & $\begin{array}{l}m-- \\
-m- \\
m-- \\
--0 \\
=--\end{array}$ & $\begin{array}{l}18.1 \\
17.4 \\
17.0 \\
17.4 \\
17.4\end{array}$ & $\begin{array}{l}14.7 \\
14.8 \\
14.7 \\
14.7 \\
14.8\end{array}$ & $\begin{array}{l}15.0 \\
15.3 \\
15.3 \\
14.7 \\
14.6\end{array}$ \\
\hline $\begin{array}{l}11 \\
12 \\
13 \\
14 \\
15\end{array}$ & $\begin{array}{l}13.1 \\
11.9 \\
11.4 \\
11.4 \\
11.9\end{array}$ & $\begin{array}{r}9.4 \\
9.2 \\
9.4 \\
9.9 \\
10.3\end{array}$ & $\begin{array}{r}10.1 \\
9.5 \\
8.7 \\
7.5 \\
6.9\end{array}$ & $\begin{array}{l}7.4 \\
7.8 \\
7.7 \\
7.8 \\
8.2\end{array}$ & $\begin{array}{l}7.4 \\
7.8 \\
8.4 \\
8.8 \\
7.8\end{array}$ & $\begin{array}{l}9.3 \\
8.7 \\
8.9 \\
9.5 \\
9.7\end{array}$ & $\begin{array}{r}10.4 \\
9.9 \\
9.8 \\
9.5 \\
9.4\end{array}$ & $\begin{array}{l}12.8 \\
13.7 \\
13.9 \\
14.3 \\
14.3\end{array}$ & $\begin{array}{l}-\infty \\
=-\infty \\
-=- \\
=-\infty \\
=-\infty\end{array}$ & $\begin{array}{l}18.1 \\
18.2 \\
18.7 \\
18.1 \\
16.4\end{array}$ & $\begin{array}{l}15.0 \\
15.1 \\
15.3 \\
14.9 \\
14.7\end{array}$ & $\begin{array}{r}14.5 \\
15.3 \\
15.5 \\
-.-0 \\
--0\end{array}$ \\
\hline $\begin{array}{l}16 \\
17 \\
18 \\
19 \\
20\end{array}$ & $\begin{array}{l}12.0 \\
12.0 \\
11.9 \\
12.1 \\
13.0\end{array}$ & $\begin{array}{r}10.2 \\
9.5 \\
8.3 \\
8.1 \\
8.7\end{array}$ & $\begin{array}{l}7.1 \\
7.7 \\
7.5 \\
7.7 \\
8.0\end{array}$ & $\begin{array}{l}8.8 \\
9.2 \\
9.5 \\
8.9 \\
8.1\end{array}$ & $\begin{array}{l}8.1 \\
9.0 \\
9.0 \\
8.8 \\
7.8\end{array}$ & $\begin{array}{r}8.7 \\
10.6 \\
10.3 \\
9.6 \\
9.1\end{array}$ & $\begin{array}{r}8.6 \\
9.5 \\
10.4 \\
10.9 \\
11.4\end{array}$ & $\begin{array}{r}15.0 \\
- \\
-\end{array}$ & $\begin{array}{l}=-\infty \\
=-\infty \\
=-\infty \\
=-\infty \\
-\infty\end{array}$ & $\begin{array}{l}16.7 \\
16.5 \\
16.1 \\
16.1 \\
16.1\end{array}$ & $\begin{array}{l}14.3 \\
14.2 \\
14.8 \\
15.5 \\
17.2\end{array}$ & $\begin{array}{l}=- \\
-=- \\
-=-\end{array}$ \\
\hline $\begin{array}{l}21 \\
22 \\
23 \\
24 \\
25\end{array}$ & $\begin{array}{r}12.8 \\
12.0 \\
10.3 \\
9.7 \\
10.1\end{array}$ & $\begin{array}{l}8.7 \\
8.5 \\
8.6 \\
9.4 \\
9.7\end{array}$ & $\begin{array}{l}8.4 \\
8.2 \\
7.9 \\
8.5 \\
8.4\end{array}$ & $\begin{array}{l}8.0 \\
8.5 \\
8.7 \\
8.6 \\
7.9\end{array}$ & $\begin{array}{l}7.7 \\
8.0 \\
8.3 \\
8.7 \\
9.0\end{array}$ & $\begin{array}{r}9.4 \\
9.9 \\
10.2 \\
10.6 \\
10.3\end{array}$ & $\begin{array}{l}11.7 \\
11.6 \\
11.6 \\
12.0 \\
11.7\end{array}$ & $\begin{array}{l}-\infty \\
-\infty \\
-\infty \\
-\infty \\
-\infty\end{array}$ & $\begin{array}{l}=- \\
=- \\
17.3\end{array}$ & $\begin{array}{l}16.6 \\
14.5 \\
15.5 \\
16.2 \\
15.5\end{array}$ & $\begin{array}{l}17.6 \\
17.9 \\
17.5 \\
17.6 \\
17.9\end{array}$ & $\begin{array}{l}=- \\
=- \\
=-\end{array}$ \\
\hline $\begin{array}{l}26 \\
27 \\
28 \\
29 \\
30 \\
31\end{array}$ & $\begin{array}{l}11.4 \\
11.5 \\
10.2 \\
10.6 \\
10.7 \\
10.6\end{array}$ & $\begin{array}{r}9.3 \\
9.0 \\
7.4 \\
7.6 \\
7.6 \\
-\end{array}$ & $\begin{array}{l}8.5 \\
8.8 \\
8.9 \\
8.9 \\
8.6 \\
6.8\end{array}$ & $\begin{array}{l}7.9 \\
8.2 \\
8.8 \\
9.0 \\
9.3 \\
9.2\end{array}$ & $\begin{array}{r}9.5 \\
9.7 \\
10.0 \\
10.0 \\
1-0\end{array}$ & $\begin{array}{r}9.6 \\
9.5 \\
9.2 \\
9.6 \\
9.9 \\
10.3\end{array}$ & $\begin{array}{l}10.7 \\
10.9 \\
11.1 \\
11.6 \\
12.1\end{array}$ & $\begin{array}{l}m- \\
m- \\
m-\infty \\
m-\infty \\
m-\infty\end{array}$ & $\begin{array}{l}18.2 \\
18.5 \\
17.8 \\
18.2 \\
18.1 \\
-\end{array}$ & $\begin{array}{l}15.7 \\
15.9 \\
15.7 \\
16.0 \\
15.7 \\
15.7\end{array}$ & $\begin{array}{l}17.5 \\
17.7 \\
16.6 \\
15.9 \\
16.0 \\
16.4\end{array}$ & 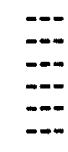 \\
\hline MONTH & 12.0 & 9.5 & 8.5 & 8.0 & 8.1 & 8.9 & 10.5 & $m$ & $-\infty$ & 16.8 & 15.7 & -- \\
\hline YEAR & MAX & 18.7 & MIN & 4.2 & MEAN & 11.3 & & & & & & \\
\hline
\end{tabular}


10264000 LITTLE ROCK CREEK NEAR LITTLE ROCK, CA

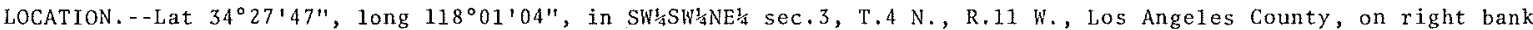
$0.3 \mathrm{mi}(0.5 \mathrm{~km})$ upstream from Santiago Creek, $1.6 \mathrm{mi}(2.6 \mathrm{~km})$ upstrean from Little Rock palmdale Irrigation District's dam, and $5 \mathrm{mi}(8 \mathrm{~km})$ south of little Rock.

DRAINAGE AREA. $-49.0 \mathrm{mi}^{2}\left(126.9 \mathrm{~km}^{2}\right)$.

PERIOD OF RECORD, - October 1930 to February 1938, May to September 1938, Apri1 1939 to'current year.

GAGE. - Water-stage recorder. Altitude of gage is 3,290 ft $(1,003 \mathrm{~m})$, from topographic map. Prior to May 1943 , at site $500 \mathrm{ft}(152 \mathrm{~m})$ downstream at different datums.

REMARKS.--Records fair. No regulation or diversion above station.

COOPERATION. - -Records furnished by Los Angeles County Flood Control District.

AVERAGE DTSCHARGE.--44 years $(1930-37,1939-76), 16.1 \mathrm{ft}^{3} / \mathrm{s}\left(0.456 \mathrm{~m}^{3} / \mathrm{s}\right), 11,660 \mathrm{acre}-\mathrm{ft} / \mathrm{yr}^{\mathrm{r}}\left(14.4 \mathrm{hm} / \mathrm{yr}^{3}\right)$.

EXTREMES FOR PERIOD OF RECORD.--Maximum discharge.--17,000 $\mathrm{ft}^{3} / \mathrm{s}\left(481 \mathrm{~m}^{3} / \mathrm{s}\right)$, estimated, Mar. 2, 1938; no flow at times in most years.

EXTREMES FOR CURRENT YEAR. - Maximum discharge, $643 \mathrm{ft}^{3} / \mathrm{s}\left(18.2 \mathrm{~m}^{3} / \mathrm{s}\right) \mathrm{Feb} .8$, gage height, $8,02 \mathrm{ft}(2.444 \mathrm{~m})$; no flow many days.

DISCHARGE, IN CUBIC FEET PER SECONO, WATER YEAR OCTOBER 1975 TO SEPTEMBER 1976 MEAN VALUES

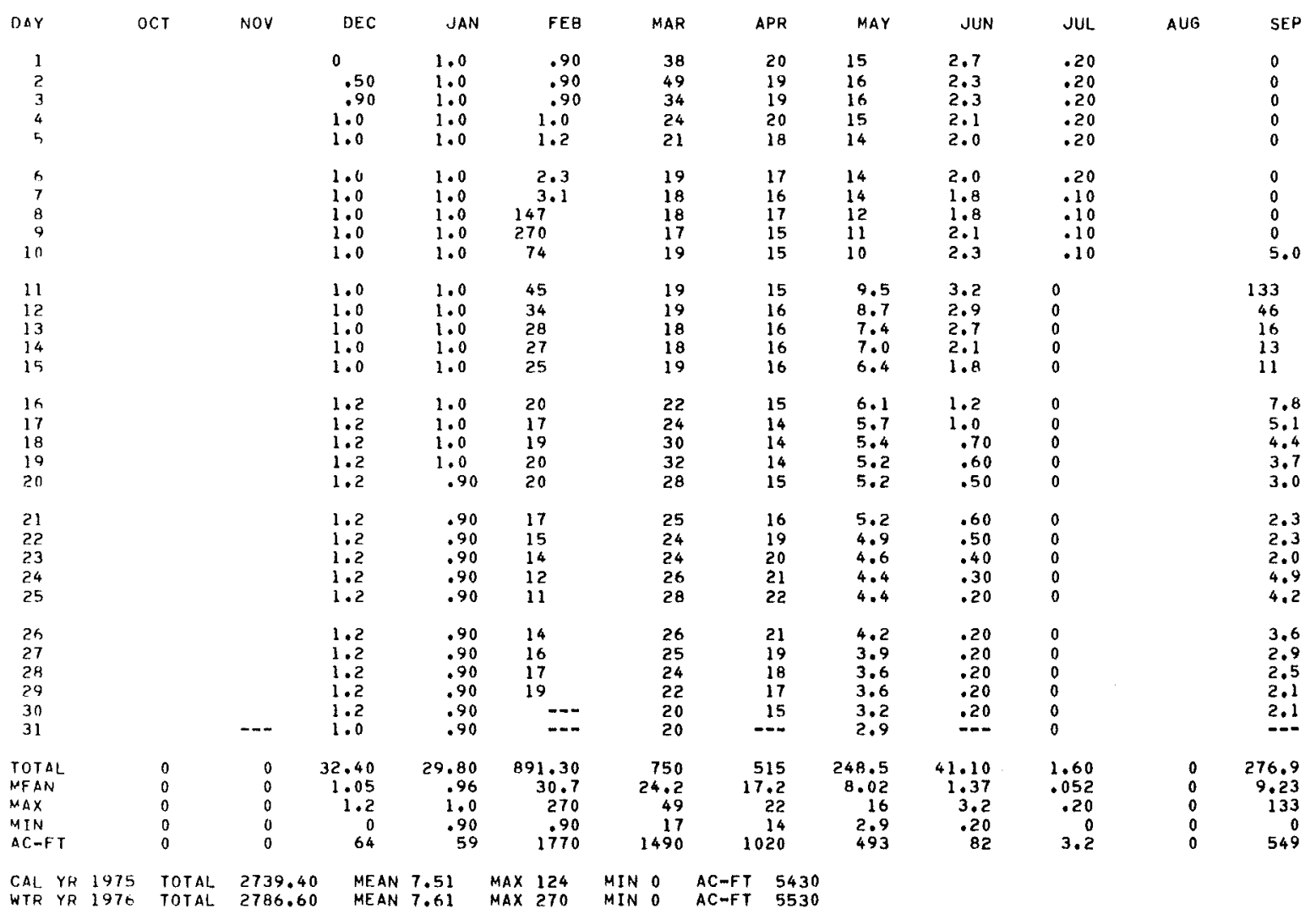


LOCATION, - Lat $35^{\circ} 03^{\prime} 00^{\prime \prime}$, long $118^{\circ} 21^{\prime} 25^{\prime \prime}$, in NW/4 sec.15, T.I1 N., R.I4 W., Kern County, on upstream right wingwall of culvert, $100 \mathrm{ft}(30 \mathrm{~m})$ downstream from unnamed tributary, $0.1 \mathrm{mi}(0.2 \mathrm{~km})$ west of junction of Oak Creek and Willow Springs Roads, and $10.5 \mathrm{mi}(16.9 \mathrm{~km})$ west of Mojave.

DRAINAGE AREA. $-15.8 \mathrm{mi}^{2}\left(40.9 \mathrm{~km}^{2}\right)$.

PERIOD OF RECORD.--August 1957 to current year.

GAGE. - Water-stage recorder. Altitude of gage is $4,100 \mathrm{ft}(1,250 \mathrm{~m})$, from topographic map.

REMARKS. - Records poor. No regulation or diversion above station.

AVERAGE DISCHARGE.--19 years, $0.67 \mathrm{ft}^{3} / \mathrm{s}\left(0.019 \mathrm{~m}^{3} / \mathrm{s}\right), 485 \mathrm{acre}-\mathrm{ft} / \mathrm{yr}\left(598,000 \mathrm{~m}^{3} / \mathrm{yr}^{2}\right)$.

EXTREMES FOR PERIOD OF RECORD. - Maximum discharge, $1,740 \mathrm{ft}^{3} / \mathrm{s}\left(49.3 \mathrm{~m}^{3} / \mathrm{s}\right)$ May 14 , 1973 , by slope-area

measurement, caused by failure of small earthen dam $4 \mathrm{mi}(6 \mathrm{~km})$ upstream during intense local thunderstorm: maximum gage height, $10.53 \mathrm{ft}(3.210 \mathrm{~m})$ May 14,1973 , ponding at culvert $0.1 \mathrm{mi}$ (0.2 km) downstream; no flow for some months in most years.

EXTREMES FOR CURRENT YEAR, - Maximum discharge, $3.1 \mathrm{ft}^{3} / \mathrm{s}\left(0.088 \mathrm{~m}^{3} / \mathrm{s}\right)$ Feb. 24, gage height $2.50 \mathrm{ft}(0.762 \mathrm{~m})$ minimum daily, $0.01 \mathrm{ft}^{3} / \mathrm{s}\left(<0.001 \mathrm{~m}^{3} / \mathrm{s}\right)$ Oct. $1-5,7,8,13-24$.

DISCHARGE, IN CUBIC FEET PER SECOND, WATER YEAR OCTOBER 1975 TO SEPTEMBER 1976 MEAN VALUES

\begin{tabular}{|c|c|c|c|c|c|c|c|c|c|c|c|c|}
\hline DAY & OCT & NOV & DEC & $J A N$ & FEB & MAR & APR & MAY & JUN & JUL & AUG & SEP \\
\hline $\begin{array}{l}1 \\
2 \\
3 \\
4 \\
5\end{array}$ & $\begin{array}{l}.01 \\
.01 \\
.01 \\
.01 \\
.01\end{array}$ & $\begin{array}{l}.03 \\
.03 \\
.04 \\
.04 \\
.05\end{array}$ & $\begin{array}{l}.04 \\
.05 \\
.04 \\
.04 \\
.04\end{array}$ & $\begin{array}{l}.04 \\
.04 \\
.04 \\
.04 \\
.04\end{array}$ & $\begin{array}{l}.02 \\
.02 \\
.03 \\
.02 \\
.02\end{array}$ & $\begin{array}{l}.11 \\
111 \\
111 \\
111 \\
111\end{array}$ & $\begin{array}{l}.10 \\
110 \\
110 \\
110 \\
.12\end{array}$ & $\begin{array}{l}.12 \\
.12 \\
.12 \\
.12 \\
.12\end{array}$ & $\begin{array}{l}.06 \\
.05 \\
.05 \\
.05 \\
.05\end{array}$ & $\begin{array}{r}.03 \\
.03 \\
.03 \\
.03 \\
.03\end{array}$ & $\begin{array}{l}.03 \\
.03 \\
.03 \\
.03 \\
.03\end{array}$ & $\begin{array}{l}.02 \\
.02 \\
.02 \\
.02 \\
.02\end{array}$ \\
\hline $\begin{array}{r}6 \\
7 \\
8 \\
9 \\
10\end{array}$ & $\begin{array}{l}.02 \\
.01 \\
.01 \\
.02 \\
.02\end{array}$ & $\begin{array}{l}.05 \\
.05 \\
.05 \\
.05 \\
.06\end{array}$ & $\begin{array}{l}.04 \\
.03 \\
.03 \\
.04 \\
.04\end{array}$ & $\begin{array}{l}.04 \\
.04 \\
.04 \\
.04 \\
.03\end{array}$ & $\begin{array}{l}.02 \\
.02 \\
.02 \\
.04 \\
.04\end{array}$ & $\begin{array}{r}10 \\
110 \\
.10 \\
.10 \\
.10\end{array}$ & $\begin{array}{r}.12 \\
.12 \\
.12 \\
.12 \\
.12\end{array}$ & $\begin{array}{l}.12 \\
.12 \\
.12 \\
.12 \\
.12\end{array}$ & $\begin{array}{l}.05 \\
.04 \\
.04 \\
.04 \\
.04\end{array}$ & $\begin{array}{r}.03 \\
.03 \\
.03 \\
.03 \\
.03\end{array}$ & $\begin{array}{l}.03 \\
.03 \\
.03 \\
.03 \\
.03\end{array}$ & $\begin{array}{l}.02 \\
.02 \\
.02 \\
.02 \\
.04\end{array}$ \\
\hline $\begin{array}{l}11 \\
12 \\
13 \\
14 \\
15\end{array}$ & $\begin{array}{l}.02 \\
.02 \\
.01 \\
.01 \\
.01\end{array}$ & $\begin{array}{l}.06 \\
.06 \\
.06 \\
.06 \\
.06\end{array}$ & $\begin{array}{l}.04 \\
.03 \\
.03 \\
.03 \\
.03\end{array}$ & $\begin{array}{l}.02 \\
.02 \\
.02 \\
.02 \\
.02\end{array}$ & $\begin{array}{l}.04 \\
.04 \\
.04 \\
.04 \\
.04\end{array}$ & $\begin{array}{r}.10 \\
.10 \\
.10 \\
.10 \\
.10\end{array}$ & $\begin{array}{l}.12 \\
.12 \\
.12 \\
.12 \\
.13\end{array}$ & $\begin{array}{l}.12 \\
.12 \\
.12 \\
.12 \\
.12\end{array}$ & $\begin{array}{l}.04 \\
.04 \\
.04 \\
.04 \\
.03\end{array}$ & $\begin{array}{r}.03 \\
.03 \\
.03 \\
.03 \\
.03\end{array}$ & $\begin{array}{l}.03 \\
.03 \\
.03 \\
.03 \\
.02\end{array}$ & $\begin{array}{l}.02 \\
.02 \\
.02 \\
.02 \\
.02\end{array}$ \\
\hline $\begin{array}{l}16 \\
17 \\
18 \\
19 \\
20\end{array}$ & $\begin{array}{l}.01 \\
.01 \\
.01 \\
.01 \\
.01\end{array}$ & $\begin{array}{l}.05 \\
.05 \\
.05 \\
.05 \\
.05\end{array}$ & $\begin{array}{l}.03 \\
.03 \\
.03 \\
.03 \\
.03\end{array}$ & $\begin{array}{l}.02 \\
.02 \\
.02 \\
.02 \\
.02\end{array}$ & $\begin{array}{l}.04 \\
.04 \\
.04 \\
.04 \\
.04\end{array}$ & $\begin{array}{r}.10 \\
.09 \\
.09 \\
.11 \\
.10\end{array}$ & $\begin{array}{l}.14 \\
.14 \\
.13 \\
.12 \\
.12\end{array}$ & $\begin{array}{r}.11 \\
.10 \\
.10 \\
.09 \\
.09\end{array}$ & $\begin{array}{l}.03 \\
.03 \\
.03 \\
.03 \\
.03\end{array}$ & $\begin{array}{r}.03 \\
.03 \\
.03 \\
.03 \\
.03\end{array}$ & $\begin{array}{l}.02 \\
.02 \\
.02 \\
.02 \\
.02\end{array}$ & $\begin{array}{l}.02 \\
.02 \\
.02 \\
.02 \\
.02\end{array}$ \\
\hline $\begin{array}{l}21 \\
22 \\
23 \\
24 \\
25\end{array}$ & $\begin{array}{l}.01 \\
.01 \\
.01 \\
.01 \\
.02\end{array}$ & $\begin{array}{l}.05 \\
.05 \\
.05 \\
.05 \\
.04\end{array}$ & $\begin{array}{r}.04 \\
.04 \\
.04 \\
.04 \\
.04\end{array}$ & $\begin{array}{l}.02 \\
.02 \\
.02 \\
.02 \\
.02\end{array}$ & $\begin{array}{l}.04 \\
.04 \\
.03 \\
.28 \\
.15\end{array}$ & $\begin{array}{r}.10 \\
110 \\
110 \\
+10 \\
+10\end{array}$ & $\begin{array}{l}.12 \\
.12 \\
.12 \\
.12 \\
.12\end{array}$ & $\begin{array}{l}.08 \\
.08 \\
.08 \\
.07 \\
.07\end{array}$ & $\begin{array}{l}.03 \\
.03 \\
.03 \\
.03 \\
.03\end{array}$ & $\begin{array}{l}.03 \\
.03 \\
.03 \\
.03 \\
.03\end{array}$ & $\begin{array}{l}.02 \\
.02 \\
.02 \\
.02 \\
.02\end{array}$ & $\begin{array}{l}.02 \\
.02 \\
.02 \\
.02 \\
.02\end{array}$ \\
\hline $\begin{array}{l}26 \\
27 \\
28 \\
29 \\
30 \\
31\end{array}$ & $\begin{array}{l}.02 \\
.02 \\
.03 \\
.03 \\
.03 \\
.03\end{array}$ & $\begin{array}{l}.05 \\
.05 \\
.05 \\
.04 \\
.04 \\
.0-\end{array}$ & $\begin{array}{l}.04 \\
.04 \\
.04 \\
.03 \\
.03 \\
.04\end{array}$ & $\begin{array}{l}.02 \\
.02 \\
.02 \\
.02 \\
.02 \\
.02\end{array}$ & $\begin{array}{r}.13 \\
112 \\
112 \\
.11 \\
-12 \\
--1\end{array}$ & $\begin{array}{r}10 \\
110 \\
110 \\
.10 \\
.10 \\
.10\end{array}$ & $\begin{array}{r}.12 \\
.12 \\
.12 \\
.12 \\
.12 \\
-.-\end{array}$ & $\begin{array}{l}.07 \\
.07 \\
.07 \\
.06 \\
.06 \\
.06\end{array}$ & $\begin{array}{l}.04 \\
.03 \\
.04 \\
.03 \\
.03 \\
-0 .\end{array}$ & $\begin{array}{l}.03 \\
.03 \\
.03 \\
.03 \\
.03 \\
.03\end{array}$ & $\begin{array}{l}.02 \\
.02 \\
.02 \\
.02 \\
.02 \\
.02\end{array}$ & $\begin{array}{l}.02 \\
.02 \\
.02 \\
.02 \\
.02 \\
.0\end{array}$ \\
\hline $\begin{array}{l}\text { TOTAL } \\
\text { MEAN } \\
\text { MAX } \\
\text { MIN } \\
\text { AC-FT }\end{array}$ & $\begin{array}{r}.47 \\
.015 \\
.03 \\
.01 \\
.9\end{array}$ & $\begin{array}{r}1.47 \\
.049 \\
.06 \\
.03 \\
2.9\end{array}$ & $\begin{array}{r}1.12 \\
.036 \\
.05 \\
.03 \\
2.2\end{array}$ & $\begin{array}{r}.01 \\
.026 \\
.04 \\
.02 \\
1.6\end{array}$ & $\begin{array}{r}1.67 \\
.058 \\
.28 \\
.02 \\
3.3\end{array}$ & $\begin{array}{r}3.14 \\
.10 \\
.11 \\
.09 \\
6.2\end{array}$ & $\begin{array}{r}3.56 \\
.12 \\
.14 \\
.10 \\
7.1\end{array}$ & $\begin{array}{r}3.06 \\
.099 \\
.12 \\
.06 \\
6.1\end{array}$ & $\begin{array}{r}1.13 \\
.038 \\
.06 \\
.03 \\
2.2\end{array}$ & $\begin{array}{r}.93 \\
.030 \\
.03 \\
.03 \\
1.8\end{array}$ & $\begin{array}{r}.76 \\
.025 \\
.03 \\
.02 \\
1.5\end{array}$ & $\begin{array}{r}.62 \\
.021 \\
.04 \\
.02 \\
1.2\end{array}$ \\
\hline
\end{tabular}

$\begin{array}{lllllllll}\text { CAL YR } 1975 & \text { TOTAL } 66.47 & \text { MEAN } 18 & \text { MAX } 1.4 & \text { MIN } .01 & \text { AC-FT } 132 \\ \text { HTR YR } 1976 & \text { TOTAL } 18.76 & \text { MEAN } .051 & \text { MAX } & .28 & \text { MIN } & 01 & \text { AC-FT } & 37\end{array}$ 
10264750 PINE TREE CREEK NEAR MOJAVE, CA

LOCATION. - Lat $35^{\circ} 13^{\prime} 50^{\prime \prime}$, long $118^{\circ} 05^{\prime} 07^{\prime \prime}$, in SW $\frac{1}{4} N^{1 / 4} S E^{\frac{1}{4}}$ sec.14, T. 31 S, R. 36 E., Kern County, on downstream side of city of Los Angeles aqueduct-siphon' pier near right bank, $0.5 \mathrm{mi}$ (0.8 km) downstream from unnamed tributary, and $13 \mathrm{mi}(21 \mathrm{~km})$ northeast of Mojave.

DRAINAGE AREA. $--33.5 \mathrm{mi}^{2}\left(86.8 \mathrm{~km}^{2}\right)$.

PERIOD OF RECORD. - -Ju1y 1958 to current year.

GAGE. - Water-stage recorder with rain-gage attachment. Altitude of gage is $2,700 \mathrm{ft}$ ( $823 \mathrm{~m}$ ), from topographic map. Prior to oct. 1, 1961, at datum $3.0 \mathrm{ft}(0.9 \mathrm{~m})$ higher.

REMARKS,--Records poor. No regulation or diversion above station.

AVERAGE DISCHARGE. - -18 years (water years $1959-76), 0.20 \mathrm{ft}^{3} / \mathrm{s}\left(0.006 \mathrm{~m}^{3} / \mathrm{s}\right), 145 \mathrm{acre-ft} / \mathrm{yr}\left(179,000 \mathrm{~m}^{3} / \mathrm{yr}\right)$.

EXTREMES FOR PERIOD OF RECORD.--Maximum discharge, $30,000 \mathrm{ft}^{3} / \mathrm{s}\left(850 \mathrm{~m}^{3} / \mathrm{s}\right)$ Aug. 23 , I961, on basis of $\mathrm{field}$ estimate of maximum flow; no flow most of each year.

EXTREMES FOR CURRENT YEAR, - Maximum discharge, $5.3 \mathrm{ft}^{3} / \mathrm{s}\left(0.15 \mathrm{~m}^{3} / \mathrm{s}\right)$ Sept. 11 , gage height, $5.01 \mathrm{ft}$ $(1.527 \mathrm{~m})$; no flow most of year.

DISCHARGE, IN CUBIC FEET PER SECOND, WATER YEAR OCTOBER 1975 TO SEPTEMBER 1976 MEAN VALUES

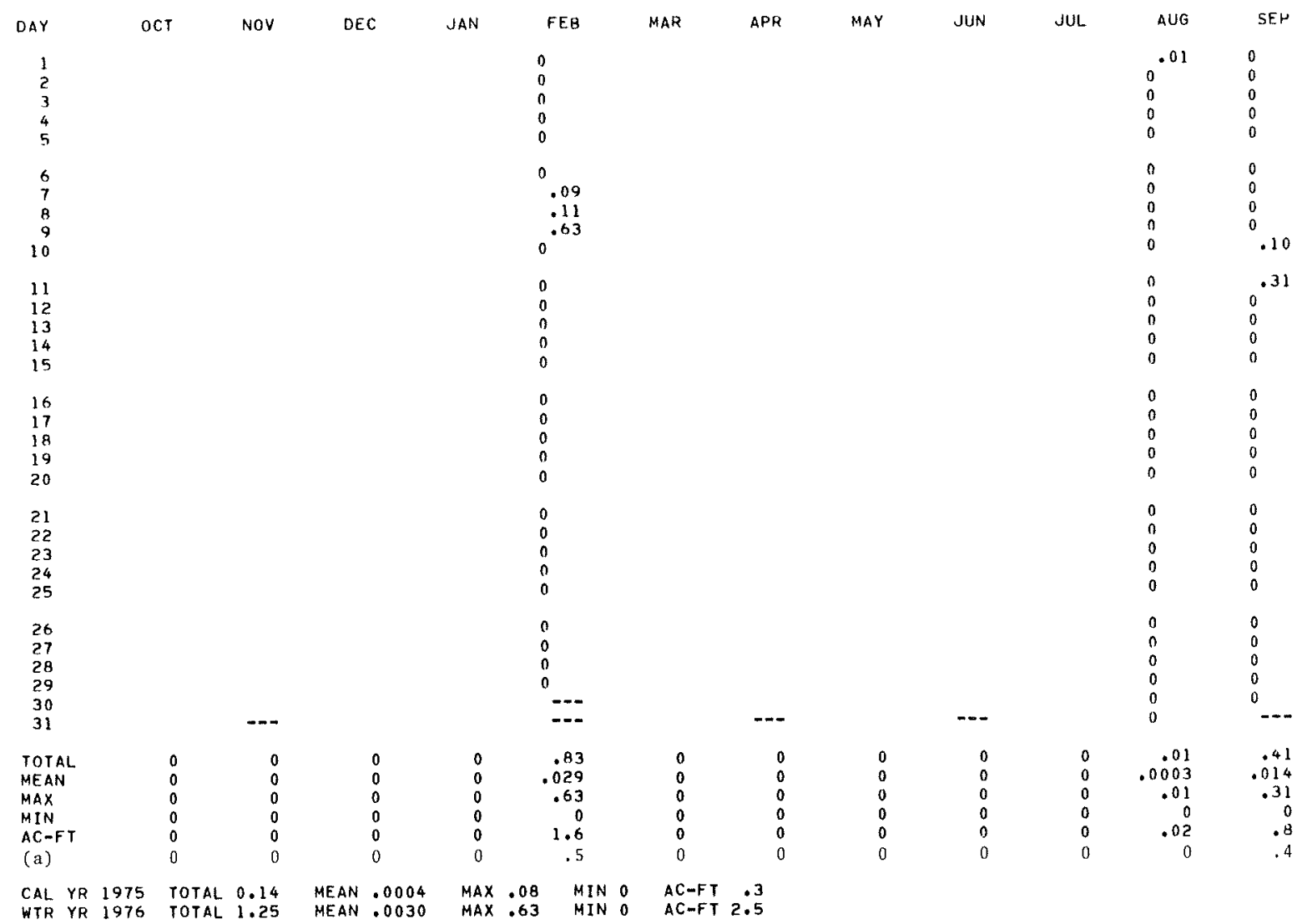

(a) Precipitation, in inches 


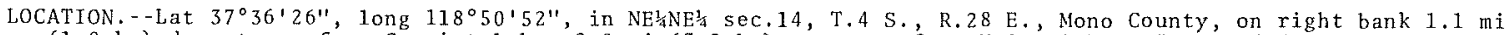
$(1.8 \mathrm{~km})$ downstream from Convict Lake, $2.0 \mathrm{mi}(3.2 \mathrm{~km})$ upstream from U.5. Highway 395 , and $7.0 \mathrm{mi}$ (11.2 km southeast of Mammoth Lakes (Ranger Station).

DRAINAGE AREA. - - $18.2 \mathrm{mi}^{2}\left(47.1 \mathrm{~km}^{2}\right)$.

PERIOD OF RECORD.--July 1925 to current year. Prior to October 1959 month1y discharge on 1 y, pub1ished in WSP 1314 and 1734 .

GAGE. - Water-stage recorder and wood control. Altitude of gage is $7,450 \mathrm{ft}(2,271 \mathrm{~m})$, from topographic map. Prior to Nov. 15, 1926, nonrecording gage at same site and datum.

REMARKS. - Records poor. Some regulation by Convict Lake above station. No diversion above station.

COOPERATION,--Records were furnished by city of Los Angeles, Department of Water and Power.

AVERAGE DISCHARGE. - -51 years, $24.4 \mathrm{ft}^{3} / \mathrm{s}\left(0.691 \mathrm{~m}^{3} / \mathrm{s}\right), 17,680 \mathrm{acre}-\mathrm{ft} / \mathrm{yr}^{\mathrm{r}}(21.8 \mathrm{hm} / \mathrm{yr})$.

EXTREMES FOR PERIOD OF RECORD, -Maximum discharge, $290 \mathrm{ft}^{3} / \mathrm{s}\left(8.21 \mathrm{~m}^{3} / \mathrm{s}\right) \mathrm{June} 29$, $1932, \mathrm{gage}$ height, $4.43 \mathrm{ft}$ $(1.350 \mathrm{~m})$; minimum daily, $1.0 \mathrm{ft}^{3} / \mathrm{s}(0.028 \mathrm{~m} / \mathrm{s})$ Sept. $20-22,1974$.

DISCHARGE, IN CUBIC FEET PER SECOND, HATER YEAR OCTOBER 1975 TO SEPTEMBER 1976 MEAN VALUES

\begin{tabular}{|c|c|c|c|c|c|c|c|c|c|c|c|c|}
\hline DAY & $\mathrm{OCT}$ & NOV & $D E C$ & JAN & FEB & MAR & $A P R$ & MAY & JUN & JUL. & AUG & SEP \\
\hline $\begin{array}{l}1 \\
2 \\
3 \\
4 \\
5\end{array}$ & $\begin{array}{l}13 \\
13 \\
13 \\
13 \\
13\end{array}$ & $\begin{array}{l}7.4 \\
7.4 \\
7.4 \\
7.4 \\
7.4\end{array}$ & $\begin{array}{l}6.4 \\
6.4 \\
6.2 \\
6.2 \\
6.0\end{array}$ & $\begin{array}{l}8.0 \\
8.0 \\
8.0 \\
8.0 \\
8.0\end{array}$ & $\begin{array}{l}8.0 \\
8.0 \\
8.0 \\
8.0 \\
8.0\end{array}$ & $\begin{array}{l}9.0 \\
10 \\
8.0 \\
9.0 \\
9.0\end{array}$ & $\begin{array}{l}7.5 \\
7.5 \\
7.1 \\
6.6 \\
6.2\end{array}$ & $\begin{array}{l}9.7 \\
9.7 \\
9.7 \\
9.8 \\
10\end{array}$ & $\begin{array}{l}27 \\
28 \\
28 \\
27 \\
27\end{array}$ & $\begin{array}{l}20 \\
20 \\
20 \\
19 \\
18\end{array}$ & $\begin{array}{l}29 \\
29 \\
28 \\
26 \\
26\end{array}$ & $\begin{array}{l}10 \\
10 \\
10 \\
10 \\
11\end{array}$ \\
\hline $\begin{array}{r}6 \\
7 \\
8 \\
9 \\
10\end{array}$ & $\begin{array}{l}13 \\
12 \\
12 \\
12 \\
12\end{array}$ & $\begin{array}{l}7.4 \\
7.4 \\
7.2 \\
7.2 \\
7.2\end{array}$ & $\begin{array}{l}6.0 \\
6.0 \\
6.0 \\
6.0 \\
6.0\end{array}$ & $\begin{array}{l}8.0 \\
7.0 \\
7.0 \\
7.0 \\
7.0\end{array}$ & $\begin{array}{l}9.0 \\
9.0 \\
9.0 \\
9.0 \\
9.0\end{array}$ & $\begin{array}{l}\mathbf{8 . 0} \\
\mathbf{8 . 0} \\
\mathbf{B . 0} \\
\mathbf{B . 0} 0 \\
\mathbf{B . 0}\end{array}$ & $\begin{array}{l}6.2 \\
6.2 \\
6.2 \\
6.2 \\
6.2\end{array}$ & $\begin{array}{l}12 \\
13 \\
14 \\
14 \\
15\end{array}$ & $\begin{array}{l}26 \\
25 \\
25 \\
25 \\
25\end{array}$ & $\begin{array}{l}17 \\
17 \\
17 \\
17 \\
16\end{array}$ & $\begin{array}{l}24 \\
23 \\
22 \\
20 \\
20\end{array}$ & $\begin{array}{l}11 \\
10 \\
10 \\
10 \\
10\end{array}$ \\
\hline $\begin{array}{l}11 \\
12 \\
13 \\
14 \\
15\end{array}$ & $\begin{array}{l}11 \\
11 \\
10 \\
9.7 \\
9.7\end{array}$ & $\begin{array}{l}7.2 \\
7.2 \\
7.2 \\
7.0 \\
7.0\end{array}$ & $\begin{array}{l}6.0 \\
6.0 \\
6.0 \\
6.0 \\
6.0\end{array}$ & $\begin{array}{l}8.0 \\
8.0 \\
9.0 \\
9.0 \\
9.0\end{array}$ & $\begin{array}{l}9.0 \\
9.0 \\
9.0 \\
9.0 \\
8.0\end{array}$ & $\begin{array}{l}8.0 \\
8.0 \\
8.0 \\
8.0 \\
7.0\end{array}$ & $\begin{array}{l}5.8 \\
5.8 \\
4.9 \\
3.6 \\
3.6\end{array}$ & $\begin{array}{l}15 \\
16 \\
18 \\
20 \\
21\end{array}$ & $\begin{array}{l}25 \\
24 \\
24 \\
23 \\
23\end{array}$ & $\begin{array}{l}16 \\
16 \\
16 \\
16 \\
16\end{array}$ & $\begin{array}{l}19 \\
18 \\
17 \\
16 \\
16\end{array}$ & $\begin{array}{l}13 \\
14 \\
15 \\
16 \\
16\end{array}$ \\
\hline $\begin{array}{l}16 \\
17 \\
18 \\
19 \\
20\end{array}$ & $\begin{array}{l}9.7 \\
9.7 \\
9.7 \\
9.7 \\
9.7\end{array}$ & $\begin{array}{l}7.0 \\
7.0 \\
7.0 \\
7.0 \\
7.0\end{array}$ & $\begin{array}{l}6.0 \\
5.8 \\
5.8 \\
5.8 \\
5.8\end{array}$ & $\begin{array}{l}9.0 \\
9.0 \\
9.0 \\
9.0 \\
9.0\end{array}$ & $\begin{array}{l}8.0 \\
8.0 \\
8.0 \\
8.0 \\
8.0\end{array}$ & $\begin{array}{l}7.0 \\
7.0 \\
7.0 \\
6.0 \\
6.0\end{array}$ & $\begin{array}{l}4.0 \\
4.4 \\
4.9 \\
6.2 \\
7.1\end{array}$ & $\begin{array}{l}25 \\
28 \\
29 \\
30 \\
30\end{array}$ & $\begin{array}{l}22 \\
23 \\
24 \\
25 \\
25\end{array}$ & $\begin{array}{l}16 \\
17 \\
16 \\
16 \\
16\end{array}$ & $\begin{array}{l}15 \\
15 \\
14 \\
14 \\
13\end{array}$ & $\begin{array}{l}16 \\
15 \\
15 \\
15 \\
14\end{array}$ \\
\hline $\begin{array}{l}21 \\
22 \\
23 \\
24 \\
25\end{array}$ & $\begin{array}{l}9.7 \\
9.7 \\
9.7 \\
9.7 \\
9.2\end{array}$ & $\begin{array}{l}7.0 \\
6.8 \\
6.8 \\
6.8 \\
6.8\end{array}$ & $\begin{array}{l}5.6 \\
5.6 \\
5.6 \\
5.6 \\
5.6\end{array}$ & $\begin{array}{l}9.0 \\
9.0 \\
8.0 \\
8.0 \\
8.0\end{array}$ & $\begin{array}{l}8.0 \\
8.0 \\
8.0 \\
8.0 \\
8.0\end{array}$ & $\begin{array}{l}6.0 \\
6.0 \\
6.0 \\
6.0 \\
7.0\end{array}$ & $\begin{array}{l}7.5 \\
8.0 \\
8.4 \\
8.8 \\
8.8\end{array}$ & $\begin{array}{l}30 \\
30 \\
29 \\
28 \\
28\end{array}$ & $\begin{array}{l}26 \\
26 \\
26 \\
25 \\
25\end{array}$ & $\begin{array}{l}15 \\
14 \\
15 \\
16 \\
17\end{array}$ & $\begin{array}{l}13 \\
13 \\
12 \\
12 \\
11\end{array}$ & $\begin{array}{l}14 \\
14 \\
14 \\
13 \\
13\end{array}$ \\
\hline $\begin{array}{l}26 \\
27 \\
28 \\
29 \\
30 \\
31\end{array}$ & $\begin{array}{l}8.7 \\
8.2 \\
8.2 \\
8.2 \\
8.2 \\
8.2\end{array}$ & $\begin{array}{l}6.8 \\
6.6 \\
6.4 \\
6.4 \\
6.4 \\
\end{array}$ & $\begin{array}{l}5.6 \\
5.6 \\
5.6 \\
5.6 \\
5.6 \\
5.6\end{array}$ & $\begin{array}{l}\text { 8.0 } \\
8.0 \\
8.0 \\
8.0 \\
8.0 \\
8.0\end{array}$ & $\begin{array}{l}7.0 \\
7.0 \\
7.0 \\
7.0 \\
-\ldots\end{array}$ & $\begin{array}{l}7.0 \\
7.0 \\
8.0 \\
8.0 \\
8.0 \\
7.0\end{array}$ & $\begin{array}{l}8.8 \\
9.3 \\
9.7 \\
9.7 \\
9.7 \\
-\end{array}$ & $\begin{array}{l}28 \\
27 \\
28 \\
28 \\
28 \\
28\end{array}$ & $\begin{array}{r}22 \\
21 \\
21 \\
21 \\
20 \\
-\end{array}$ & $\begin{array}{l}22 \\
25 \\
27 \\
27 \\
28 \\
28\end{array}$ & $\begin{array}{l}11 \\
11 \\
11 \\
11 \\
10 \\
10\end{array}$ & $\begin{array}{r}13 \\
13 \\
12 \\
12 \\
13 \\
-0\end{array}$ \\
\hline $\begin{array}{l}\text { TOTAL } \\
\text { MEAN } \\
\text { MAX } \\
\text { MIN } \\
\text { AC } \backsim F T\end{array}$ & $\begin{array}{r}323.6 \\
10.4 \\
13 \\
8.2 \\
642\end{array}$ & $\begin{array}{r}210.8 \\
7.03 \\
7.4 \\
6.4 \\
416\end{array}$ & $\begin{array}{r}182.0 \\
5.87 \\
6.4 \\
5.6 \\
361\end{array}$ & $\begin{array}{r}250.0 \\
8.19 \\
9.0 \\
7.0 \\
504\end{array}$ & $\begin{array}{r}237.0 \\
8.17 \\
9.0 \\
7.0 \\
470\end{array}$ & $\begin{array}{r}233.0 \\
7.52 \\
10 \\
6.0 \\
462\end{array}$ & $\begin{array}{r}204.9 \\
6.83 \\
9.7 \\
3.6 \\
406\end{array}$ & $\begin{array}{r}660.9 \\
21.3 \\
30 \\
9.7 \\
1310\end{array}$ & $\begin{array}{r}734 \\
24.5 \\
28 \\
20 \\
1460\end{array}$ & $\begin{array}{r}576 \\
18.6 \\
28 \\
14 \\
1140\end{array}$ & $\begin{array}{r}529 \\
17.1 \\
29 \\
10 \\
1050\end{array}$ & $\begin{array}{r}382 \\
12.7 \\
16 \\
10 \\
758\end{array}$ \\
\hline
\end{tabular}

CAL YR 1975 TOTAL 9397.7 MEAN 25.7 MAX 167 MIN 5.6 AC-FT 18640

WTR YR 1976 TOTAL 4527.2 MEAN 12.4 MAX 30 MIN 3.6 AC-FT 8980 
10265700 ROCK CREEK AT LITTLE ROUND VALLEY, NEAR BISHOP, CA

LOCATION. - Lat $37^{\circ} 33^{\prime} 15^{\prime \prime}$, long $118^{\circ} 41^{\prime} 03^{\prime \prime}$, in SE $\frac{1}{4} \mathrm{SE}^{1} \frac{\mathrm{s}}{4} \mathrm{sec} .32$, T.4 S., R. 30 E., Mono County, on right bank just upstream from diversion to Little Round Valley, $0.6 \mathrm{mi}(1.0 \mathrm{~km})$ south of Toms Place, and $20 \mathrm{mi}$ ( $32 \mathrm{~km}$ ) northwest of Bishop.

DRAINAGE AREA. $-35.8 \mathrm{mi}^{2}\left(92.7 \mathrm{~km}^{2}\right)$.

PERIOD OF RECORD. - January to December 1918, January 1920 to current year. Prior to october 1959 month1y discharge on $1 y$, published in WSP 1314 and 1734.

GAGE.--Water-stage recorder, Parsha11 flume since May 1953. Altitude of gage is $7,280 \mathrm{ft}$ (2,220 $\mathrm{m}$ ), from topographic map. See WSP 1734 for history of changes prior to May 28 , 1953.

REMARKS. - Records poor. No regulation or diversion above station.

COOPERATION.--Records were furnished by city of Los Angeles, Department of Water and Power.

AVERAGE DISCHARGE. - -56 years (water years $1921-76), 24,5 \mathrm{ft}^{3} / \mathrm{s}\left(0.694 \mathrm{~m}^{3} / \mathrm{s}\right), 17,750 \mathrm{acre}-\mathrm{ft} / \mathrm{yr}(21.9 \mathrm{hm} / \mathrm{yr})$.

EXTREMES FOR PERIOD OF RECORD, --(1926 to current year): Maximum discharge, $312 \mathrm{ft}^{3} / \mathrm{s}\left(8.84 \mathrm{~m}^{3} / \mathrm{s}\right) \mathrm{May} 30$, 1969 , gage height, $5.00 \mathrm{ft}(1.524 \mathrm{~m})$; minimum daily, $2.2 \mathrm{ft} / \mathrm{s}\left(0.062 \mathrm{~m}^{3} / \mathrm{s}\right)$ Nov. 30,1971 .

DISCHARGE, IN CUBIC FEET PER SECOND, WATER YEAR OCTOBER 1975 TO SEPTEMBER 1976 MEAN VALLES

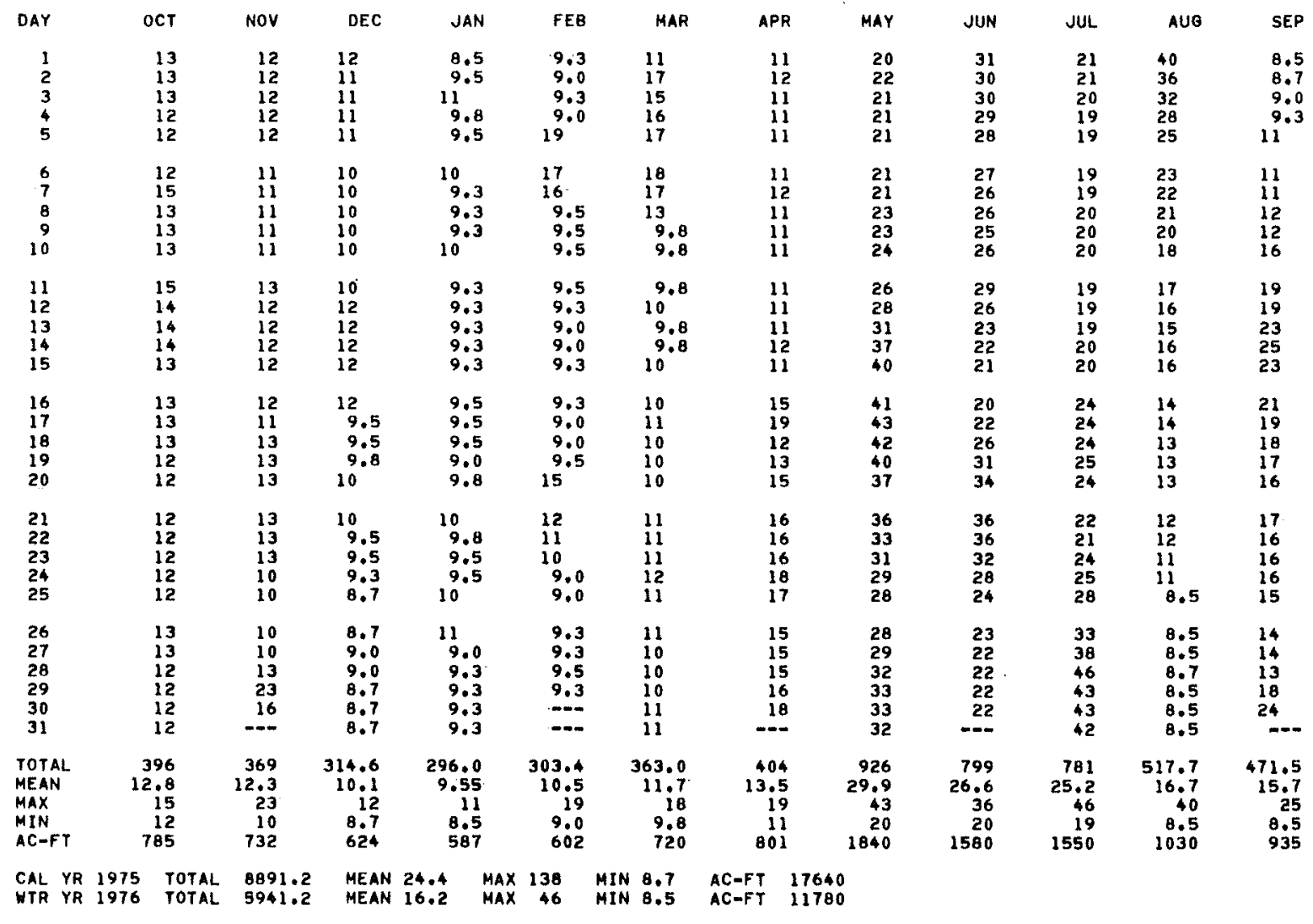




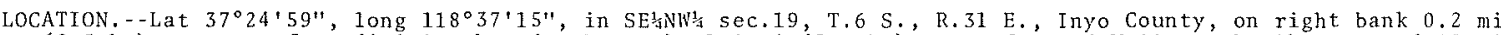

$(0.3 \mathrm{~km})$ upstream from division box (at Rovana), $1.9 \mathrm{mi}(3.1 \mathrm{~km})$ west of Round Valley schoolhouse, and $13 \mathrm{mi}$

$(21 \mathrm{~km})$ northwest of Bishop.

DRAINAGE AREA. $-36.4 \mathrm{mi}^{2}\left(94.3 \mathrm{~km}^{2}\right)$.

PERIOD OF RECORD.--October 1921 to current year. prior to October 1959 monthly discharge only, published in WSP 1314 and 1734

GAGE. - Water-stage recorder. Parshall flume since Novenber 1938. Altitude of gage is $5,280 \mathrm{ft}$ (1,609 $\mathrm{m}$ ), from topographic map.

REMARKS.--Records poor. No regulation or diversion above station.

COOPERATION, - -Records were furnished by city of Los Angeles, Department of Water and Power.

AVERAGE DISCHARGE. - -55 years, $45.2 \mathrm{ft}^{3} / \mathrm{s}\left(1.280 \mathrm{~m}^{3} / \mathrm{s}\right), 32,750 \mathrm{acre}-\mathrm{ft} / \mathrm{yr}\left(40.4 \mathrm{hm}^{3} / \mathrm{yr}^{2}\right)$.

EXTREMES FOR PERIOD OF RECORD. -Maximum discharge, $509 \mathrm{ft}^{3} / \mathrm{s}\left(14.4 \mathrm{~m}^{3} / \mathrm{s}\right)$ July 2 , 1967 , gage height, $6.05 \mathrm{ft}$

(1.844 m); minimum daily, $10 \mathrm{ft} / \mathrm{s}\left(0.28 \mathrm{~m}^{3} / \mathrm{s}\right)$ Jan. $8,1930, \mathrm{Jan} .21,1935$.

DISCHARGE, IN CUBIC FEET PER SECOND, HATER YEAR OCTOBER 1975 TO SEPTEMBER 1976 MEAN VALUES

\begin{tabular}{|c|c|c|c|c|c|c|c|c|c|c|c|c|}
\hline DAY & OCT & NOV & DEC & JAN & FEB & MAR & $A P R$ & MAY & JUN & JUL & AUG & SEP \\
\hline $\begin{array}{l}1 \\
2 \\
3 \\
4 \\
5\end{array}$ & $\begin{array}{l}26 \\
26 \\
25 \\
26 \\
26\end{array}$ & $\begin{array}{l}27 \\
27 \\
26 \\
26 \\
25\end{array}$ & $\begin{array}{l}23 \\
23 \\
22 \\
21 \\
21\end{array}$ & $\begin{array}{l}20 \\
20 \\
20 \\
20 \\
21\end{array}$ & $\begin{array}{l}21 \\
21 \\
21 \\
21 \\
21\end{array}$ & $\begin{array}{l}20 \\
20 \\
20 \\
20 \\
20\end{array}$ & $\begin{array}{l}20 \\
20 \\
20 \\
20 \\
20\end{array}$ & $\begin{array}{l}29 \\
35 \\
37 \\
37 \\
39\end{array}$ & $\begin{array}{l}67 \\
67 \\
60 \\
55 \\
53\end{array}$ & $\begin{array}{l}37 \\
35 \\
35 \\
34 \\
34\end{array}$ & $\begin{array}{l}77 \\
66 \\
57 \\
50 \\
44\end{array}$ & $\begin{array}{l}22 \\
22 \\
22 \\
23 \\
24\end{array}$ \\
\hline $\begin{array}{r}6 \\
7 \\
8 \\
9 \\
10\end{array}$ & $\begin{array}{l}27 \\
29 \\
28 \\
27 \\
28\end{array}$ & $\begin{array}{l}24 \\
25 \\
24 \\
24 \\
24\end{array}$ & $\begin{array}{l}21 \\
21 \\
21 \\
21 \\
21\end{array}$ & $\begin{array}{l}20 \\
20 \\
20 \\
19 \\
20\end{array}$ & $\begin{array}{l}22 \\
22 \\
23 \\
23 \\
22\end{array}$ & $\begin{array}{l}20 \\
21 \\
21 \\
21 \\
20\end{array}$ & $\begin{array}{l}20 \\
20 \\
19 \\
19 \\
19\end{array}$ & $\begin{array}{l}33 \\
29 \\
27 \\
32 \\
44\end{array}$ & $\begin{array}{l}52 \\
52 \\
48 \\
44 \\
43\end{array}$ & $\begin{array}{l}34 \\
33 \\
33 \\
32 \\
31\end{array}$ & $\begin{array}{l}40 \\
37 \\
36 \\
33 \\
32\end{array}$ & $\begin{array}{l}24 \\
25 \\
25 \\
24 \\
39\end{array}$ \\
\hline $\begin{array}{l}11 \\
12 \\
13 \\
14 \\
15\end{array}$ & $\begin{array}{l}30 \\
30 \\
30 \\
29 \\
28\end{array}$ & $\begin{array}{l}23 \\
23 \\
23 \\
23 \\
24\end{array}$ & $\begin{array}{l}21 \\
21 \\
22 \\
22 \\
23\end{array}$ & $\begin{array}{l}21 \\
21 \\
22 \\
22 \\
21\end{array}$ & $\begin{array}{l}21 \\
21 \\
20 \\
20 \\
20\end{array}$ & $\begin{array}{l}20 \\
20 \\
19 \\
20 \\
20\end{array}$ & $\begin{array}{l}19 \\
19 \\
20 \\
20 \\
19\end{array}$ & $\begin{array}{l}54 \\
68 \\
83 \\
94 \\
92\end{array}$ & $\begin{array}{l}42 \\
42 \\
41 \\
43 \\
46\end{array}$ & $\begin{array}{l}31 \\
31 \\
31 \\
31 \\
30\end{array}$ & $\begin{array}{l}31 \\
30 \\
29 \\
30 \\
30\end{array}$ & $\begin{array}{l}88 \\
86 \\
64 \\
53 \\
47\end{array}$ \\
\hline $\begin{array}{l}16 \\
17 \\
18 \\
19 \\
20\end{array}$ & $\begin{array}{l}27 \\
27 \\
28 \\
28 \\
28\end{array}$ & $\begin{array}{l}25 \\
25 \\
24 \\
23 \\
22\end{array}$ & $\begin{array}{l}23 \\
22 \\
21 \\
21 \\
21\end{array}$ & $\begin{array}{l}21 \\
21 \\
21 \\
21 \\
21\end{array}$ & $\begin{array}{l}20 \\
20 \\
20 \\
20 \\
20\end{array}$ & $\begin{array}{l}20 \\
20 \\
20 \\
20 \\
21\end{array}$ & $\begin{array}{l}19 \\
20 \\
21 \\
21 \\
21\end{array}$ & $\begin{array}{l}91 \\
92 \\
80 \\
67 \\
68\end{array}$ & $\begin{array}{l}53 \\
57 \\
57 \\
59 \\
60\end{array}$ & $\begin{array}{l}33 \\
37 \\
37 \\
35 \\
33\end{array}$ & $\begin{array}{l}31 \\
31 \\
29 \\
27 \\
27\end{array}$ & $\begin{array}{l}43 \\
40 \\
38 \\
37 \\
36\end{array}$ \\
\hline $\begin{array}{l}21 \\
22 \\
23 \\
24 \\
25\end{array}$ & $\begin{array}{l}27 \\
28 \\
27 \\
28 \\
28\end{array}$ & $\begin{array}{l}22 \\
21 \\
22 \\
21 \\
21\end{array}$ & $\begin{array}{l}21 \\
21 \\
21 \\
22 \\
22\end{array}$ & $\begin{array}{l}21 \\
21 \\
21 \\
22 \\
23\end{array}$ & $\begin{array}{l}20 \\
21 \\
21 \\
21 \\
21\end{array}$ & $\begin{array}{l}21 \\
21 \\
21 \\
20 \\
20\end{array}$ & $\begin{array}{l}21 \\
20 \\
20 \\
21 \\
23\end{array}$ & $\begin{array}{l}64 \\
57 \\
57 \\
63 \\
59\end{array}$ & $\begin{array}{l}56 \\
50 \\
44 \\
42 \\
41\end{array}$ & $\begin{array}{l}32 \\
31 \\
34 \\
51 \\
50\end{array}$ & $\begin{array}{l}25 \\
25 \\
25 \\
24 \\
23\end{array}$ & $\begin{array}{l}37 \\
35 \\
34 \\
33 \\
32\end{array}$ \\
\hline $\begin{array}{l}26 \\
27 \\
28 \\
29 \\
30 \\
31\end{array}$ & $\begin{array}{l}28 \\
28 \\
28 \\
28 \\
27 \\
27\end{array}$ & $\begin{array}{r}21 \\
22 \\
23 \\
23 \\
23 \\
-\end{array}$ & $\begin{array}{l}22 \\
22 \\
22 \\
22 \\
22 \\
21\end{array}$ & $\begin{array}{l}23 \\
23 \\
22 \\
21 \\
21 \\
21\end{array}$ & $\begin{array}{r}20 \\
20 \\
20 \\
20 \\
- \\
-\end{array}$ & $\begin{array}{l}20 \\
20 \\
20 \\
20 \\
20 \\
20\end{array}$ & $\begin{array}{r}24 \\
24 \\
24 \\
23 \\
24 \\
-\end{array}$ & $\begin{array}{l}69 \\
77 \\
77 \\
72 \\
67 \\
66\end{array}$ & $\begin{array}{r}41 \\
41 \\
40 \\
40 \\
38 \\
-\end{array}$ & $\begin{array}{l}53 \\
75 \\
68 \\
77 \\
65 \\
73\end{array}$ & $\begin{array}{l}23 \\
23 \\
23 \\
23 \\
23 \\
23\end{array}$ & $\begin{array}{r}31 \\
31 \\
30 \\
43 \\
57 \\
-\cdots\end{array}$ \\
\hline $\begin{array}{l}\text { YOTAL } \\
\text { MEAN } \\
\text { MAX } \\
\text { MIN } \\
\text { AC-FT }\end{array}$ & $\begin{array}{r}857 \\
27.6 \\
30 \\
25 \\
1700\end{array}$ & $\begin{array}{r}706 \\
23.5 \\
27 \\
21 \\
1400\end{array}$ & $\begin{array}{r}670 \\
21.6 \\
23 \\
21 \\
1330\end{array}$ & $\begin{array}{r}651 \\
21.0 \\
23 \\
19 \\
1290\end{array}$ & $\begin{array}{r}603 \\
20.8 \\
23 \\
20 \\
1200\end{array}$ & $\begin{array}{r}626 \\
20.2 \\
21 \\
19 \\
1240\end{array}$ & $\begin{array}{r}620 \\
20.7 \\
24 \\
19 \\
1230\end{array}$ & $\begin{array}{r}1859 \\
60.0 \\
94 \\
27 \\
3690\end{array}$ & $\begin{array}{r}1474 \\
49.1 \\
67 \\
38 \\
2920\end{array}$ & $\begin{array}{r}1276 \\
41.2 \\
77 \\
30 \\
2530\end{array}$ & $\begin{array}{r}1027 \\
33.1 \\
77 \\
23 \\
2040\end{array}$ & $\begin{array}{r}1145 \\
38.2 \\
88 \\
22 \\
2270\end{array}$ \\
\hline
\end{tabular}

CAL YR 1975 TOTAL 16527 MEAN 65.3 MAX 234 NIN 20 AC-FT 32780 WTR YR 1976 TOTAL 11514 MEAN 31.5 MAX 94 MIN 19 AC-FT 22840 
10268700 SILVER CANYON CREEK NEAR LAWS, CA

LOCATION, - Lat $37^{\circ} 24^{\prime} 28^{\prime \prime}$, long $118^{\circ} 16^{\prime} 43^{\prime \prime}$, in Inyo National Forest, Inyo County, on right bank 1.7 mi ( 2.7 km) upstream from mouth of canyon, $3.7 \mathrm{mi}(6.0 \mathrm{~km})$ east of Laws.

DRATNAGE AREA. $--19.7 \mathrm{mi}^{2}\left(51.0 \mathrm{~km}^{2}\right)$. PERIOD OF RECORD,-March 1930 to current year. Prior to October 1959 monthly discharge only, published in
WSP 1314 and 1734 .

GAGE.--Water-stage recorder and Parshall flume. Altitude of gage is $5,120 \mathrm{ft}(1,560 \mathrm{~m})$, from topographic map.

Feb. 24, 1943 , to Sept. 30, 1972 , at site $1.7 \mathrm{mi}(2.7 \mathrm{~km})$ downstream at different daturi. prior to Feb. 24.

1943, nonrecording gage and Cipolietti weir at site $3.2 \mathrm{mi}$ (5.1 km) downstream at different datum.

REMARKS. - Records poor. No regulation; occasional diversion above station.

COOPERATION, - Records were furnished by city of Los Angeles, Department of Water and power.

AVERAGE DISCHARGE. -46 years, $1.64 \mathrm{ft}^{3} / \mathrm{s}\left(0.046 \mathrm{~m}^{3} / \mathrm{s}\right), 1,190 \mathrm{acre}-\mathrm{ft} / \mathrm{yr}\left(1.47 \mathrm{hm} / \mathrm{yr}^{3}\right)$.

EXTREMES FOR PERIOD OF RECORD.--Maximum discharge, $9.6 \mathrm{ft}^{3} / \mathrm{s}\left(0.27 \mathrm{~m}^{3} / \mathrm{s}\right)$ June 16,1969 , gage height, $1.65 \mathrm{ft}$

$(0.503 \mathrm{ml})$, site and datum then in use; no flow at times in some years.

DISCHARGE, IN CUBIC FEET PER SECOND, WATER YEAR OCTOBER 1975 TO SEPTEMBER 1976 MEAN VALUES

\begin{tabular}{|c|c|c|c|c|c|c|c|c|c|c|c|c|}
\hline DAY & OCT & NOV & DEC & JAN & FEB & MAR & APR & MAY & JUN & JUL & AUB & SEP \\
\hline $\begin{array}{l}1 \\
2 \\
3 \\
4 \\
5\end{array}$ & $\begin{array}{l}1.7 \\
1.7 \\
1.7 \\
1.7 \\
1.7\end{array}$ & $\begin{array}{l}1.7 \\
1.7 \\
1.6 \\
1.6 \\
1.6\end{array}$ & $\begin{array}{l}1.6 \\
1.6 \\
1.6 \\
1.6 \\
1.6\end{array}$ & $\begin{array}{l}1.6 \\
1.6 \\
1.6 \\
1.6 \\
1.6\end{array}$ & $\begin{array}{l}1.6 \\
1.6 \\
1.6 \\
1.6 \\
1.6\end{array}$ & $\begin{array}{l}1.5 \\
1.5 \\
1.5 \\
1.5 \\
1.5\end{array}$ & $\begin{array}{l}1.7 \\
1.7 \\
1.7 \\
1.7 \\
1.7\end{array}$ & $\begin{array}{l}1.6 \\
1.6 \\
1.6 \\
1.6 \\
1.6\end{array}$ & $\begin{array}{l}1.2 \\
1.2 \\
1.2 \\
1.2 \\
1.3\end{array}$ & $\begin{array}{l}1.2 \\
1.2 \\
1.2 \\
1.2 \\
1.1\end{array}$ & $\begin{array}{r}.88 \\
.84 \\
.58 \\
.58 \\
.58\end{array}$ & $\begin{array}{r}.95 \\
.95 \\
.95 \\
.95 \\
1.1\end{array}$ \\
\hline $\begin{array}{r}6 \\
7 \\
8 \\
9 \\
10\end{array}$ & $\begin{array}{l}1.7 \\
1.7 \\
1.7 \\
1.7 \\
1.7\end{array}$ & $\begin{array}{l}1.6 \\
1.6 \\
1.6 \\
1.6 \\
1.6\end{array}$ & $\begin{array}{l}1.6 \\
1.6 \\
1.6 \\
1.6 \\
1.6\end{array}$ & $\begin{array}{l}1.6 \\
1.6 \\
1.6 \\
1.7 \\
1.7\end{array}$ & $\begin{array}{l}1.6 \\
1.6 \\
1.6 \\
1.7 \\
1.7\end{array}$ & $\begin{array}{l}1.5 \\
1.5 \\
1.5 \\
1.5 \\
1.5\end{array}$ & $\begin{array}{l}1.7 \\
1.7 \\
1.7 \\
1.7 \\
1.7\end{array}$ & $\begin{array}{l}1.6 \\
1.6 \\
1.6 \\
1.6 \\
1.5\end{array}$ & $\begin{array}{l}1.3 \\
1.3 \\
1.3 \\
1.3 \\
1.3\end{array}$ & $\begin{array}{l}1 \cdot 1 \\
1.1 \\
1.1 \\
1.1 \\
1.1\end{array}$ & $\begin{array}{l}.64 \\
.71 \\
.77 \\
.77 \\
.77\end{array}$ & $\begin{array}{l}1.1 \\
1.1 \\
1.1 \\
1.1 \\
1.1\end{array}$ \\
\hline $\begin{array}{l}11 \\
12 \\
13 \\
14 \\
15\end{array}$ & $\begin{array}{l}1.7 \\
1.7 \\
1.7 \\
1.7 \\
1.7\end{array}$ & $\begin{array}{l}1.6 \\
1.6 \\
1.6 \\
1.6 \\
1.6\end{array}$ & $\begin{array}{l}1.6 \\
1.6 \\
1.6 \\
1.6 \\
1.6\end{array}$ & $\begin{array}{l}1.7 \\
1.7 \\
1.7 \\
1.7 \\
1.7\end{array}$ & $\begin{array}{l}1.7 \\
1.7 \\
1.7 \\
1.7 \\
1.7\end{array}$ & $\begin{array}{l}1.5 \\
1.5 \\
1.5 \\
1.5 \\
1.5\end{array}$ & $\begin{array}{l}1.7 \\
1.7 \\
1.7 \\
1.7 \\
1.7\end{array}$ & $\begin{array}{l}1.5 \\
1.5 \\
1.5 \\
1.5 \\
1.5\end{array}$ & $\begin{array}{l}1.3 \\
1.3 \\
1.3 \\
1.3 \\
1.3\end{array}$ & $\begin{array}{l}1.2 \\
1.1 \\
1.2 \\
1.2 \\
1.2\end{array}$ & $\begin{array}{r}.77 \\
.81 \\
.81 \\
.84 \\
.92\end{array}$ & $\begin{array}{l}1.1 \\
1.1 \\
1.1 \\
1.1 \\
1.1\end{array}$ \\
\hline $\begin{array}{l}16 \\
17 \\
18 \\
19 \\
20\end{array}$ & $\begin{array}{l}1.7 \\
1.7 \\
1.7 \\
1.7 \\
1.7\end{array}$ & $\begin{array}{l}1.6 \\
1.6 \\
1.6 \\
1.6 \\
1.6\end{array}$ & $\begin{array}{l}1.6 \\
1.6 \\
1.6 \\
1.6 \\
1.6\end{array}$ & $\begin{array}{l}1.7 \\
1.7 \\
1.7 \\
1.7 \\
1.7\end{array}$ & $\begin{array}{l}1.7 \\
1.6 \\
1.6 \\
1.6 \\
1.6\end{array}$ & $\begin{array}{l}1.5 \\
1.5 \\
1.5 \\
1.5 \\
1.5\end{array}$ & $\begin{array}{l}1.7 \\
1.7 \\
1.7 \\
1.7 \\
1.7\end{array}$ & $\begin{array}{l}1.5 \\
1.5 \\
1.5 \\
1.5 \\
1.5\end{array}$ & $\begin{array}{l}1.3 \\
1.3 \\
1.3 \\
1.3 \\
1.3\end{array}$ & $\begin{array}{l}1.2 \\
1.1 \\
1.1 \\
1.1 \\
1.1\end{array}$ & $\begin{array}{r}.92 \\
.92 \\
.92 \\
.92 \\
.92\end{array}$ & $\begin{array}{l}1.1 \\
1.1 \\
1.1 \\
1.2 \\
1.2\end{array}$ \\
\hline $\begin{array}{l}21 \\
22 \\
23 \\
24 \\
25\end{array}$ & $\begin{array}{l}1.7 \\
1.7 \\
1.7 \\
1.7 \\
1.7\end{array}$ & $\begin{array}{l}1.6 \\
1.6 \\
1.6 \\
1.6 \\
1.6\end{array}$ & $\begin{array}{l}1.6 \\
1.6 \\
1.6 \\
1.5 \\
1.5\end{array}$ & $\begin{array}{l}1.7 \\
1.7 \\
1.6 \\
1.6 \\
1.6\end{array}$ & $\begin{array}{l}1.6 \\
1.6 \\
1.6 \\
1.6 \\
1.6\end{array}$ & $\begin{array}{l}1.5 \\
1.5 \\
1.5 \\
1.5 \\
1.5\end{array}$ & $\begin{array}{l}1.7 \\
1.7 \\
1.7 \\
1.7 \\
1.7\end{array}$ & $\begin{array}{l}1.5 \\
1.5 \\
1.5 \\
1.5 \\
1.5\end{array}$ & $\begin{array}{l}1.2 \\
1.2 \\
1.2 \\
1.2 \\
1.2\end{array}$ & $\begin{array}{r}.88 \\
.88 \\
.88 \\
.84 \\
.84\end{array}$ & $\begin{array}{r}.92 \\
.92 \\
.92 \\
.92 \\
.92\end{array}$ & $\begin{array}{l}1.2 \\
1.2 \\
1.2 \\
1.2 \\
1.2\end{array}$ \\
\hline $\begin{array}{l}26 \\
27 \\
28 \\
29 \\
30 \\
31\end{array}$ & $\begin{array}{l}1.7 \\
1.7 \\
1.7 \\
1.7 \\
1.7 \\
1.7\end{array}$ & $\begin{array}{l}1.6 \\
1.6 \\
1.6 \\
1.6 \\
1.6 \\
=-\infty\end{array}$ & $\begin{array}{l}1.5 \\
1.5 \\
1.5 \\
1.5 \\
1.5 \\
1.5\end{array}$ & $\begin{array}{l}1.6 \\
1.6 \\
1.6 \\
1.6 \\
1.6 \\
1.6\end{array}$ & $\begin{array}{l}1.6 \\
1.6 \\
1.6 \\
1.6 \\
-\infty \\
=-\infty\end{array}$ & $\begin{array}{l}1.5 \\
1.5 \\
1.5 \\
1.5 \\
1.5 \\
1.5\end{array}$ & $\begin{array}{l}1.7 \\
1.7 \\
1.7 \\
1.7 \\
1.7 \\
-0.0\end{array}$ & $\begin{array}{l}1.5 \\
1.4 \\
1.3 \\
1.3 \\
1.2 \\
1.2\end{array}$ & $\begin{array}{l}1.2 \\
1.2 \\
1.2 \\
1.2 \\
1.2 \\
--2\end{array}$ & $\begin{array}{l}.84 \\
.84 \\
.88 \\
.88 \\
.88 \\
.88\end{array}$ & $\begin{array}{r}1.1 \\
1.1 \\
1.1 \\
1.1 \\
.99 \\
.95\end{array}$ & $\begin{array}{l}1.2 \\
1.2 \\
1.2 \\
1.2 \\
1.2 \\
-=-\infty\end{array}$ \\
\hline $\begin{array}{l}\text { TOTAL } \\
\text { MEAN } \\
\text { MAX } \\
\text { HIN } \\
\text { AC-FT }\end{array}$ & $\begin{array}{r}52.7 \\
1.70 \\
1.7 \\
1.7 \\
1.05\end{array}$ & $\begin{array}{r}48.2 \\
1.61 \\
1.7 \\
1.6 \\
96\end{array}$ & $\begin{array}{r}8.8 \\
1.57 \\
1.6 \\
1.5 \\
97\end{array}$ & $\begin{array}{r}51.0 \\
1.65 \\
1.7 \\
1.6 \\
101\end{array}$ & $\begin{array}{r}47.2 \\
1.63 \\
1.7 \\
1.6 \\
94\end{array}$ & $\begin{array}{r}46.5 \\
1.50 \\
1.5 \\
1.5 \\
92\end{array}$ & $\begin{array}{r}51.0 \\
1.70 \\
1.7 \\
1.7 \\
101\end{array}$ & $\begin{array}{r}46.3 \\
1.49 \\
1.6 \\
1.2 \\
92\end{array}$ & $\begin{array}{r}37.6 \\
1.25 \\
1.3 \\
1.2 \\
75\end{array}$ & $\begin{array}{r}32.32 \\
1.04 \\
1.2 \\
.84 \\
64\end{array}$ & $\begin{array}{r}26.81 \\
.86 \\
1.1 \\
.58 \\
53\end{array}$ & $\begin{array}{r}33.60 \\
1.12 \\
1.2 \\
.95 \\
67\end{array}$ \\
\hline
\end{tabular}

CAL YR 1975 TOTAL 595.40 MEAN 1.63 MAX 1.8 AIN 1.5 AC-FT 1180

UTR YR 1976 TOTAL 522.03 MEAN 1.43 MAX 1.7 MIN .5B ACOFT 1040 


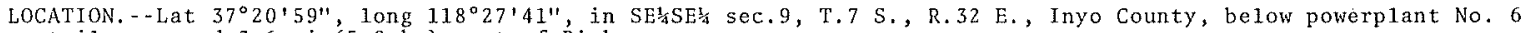
tailrace, and $3.6 \mathrm{mi}(5.8 \mathrm{~km})$ west of Bishop.

DRAINAGE AREA. - $-104 \mathrm{mi}^{2}$ or $269 \mathrm{~km}^{2}$ (natural flow).

PERIOD OF RECORD.--October 1936 to current year. Month1y and yearly mean discharges prior to october 1969, published in WSP 2127.

GAGE, - -None.

REMARKS. - Flow regulated for power development by South Lake, Lake Sabrina, and Intake No. 2 Reservoir, combined capacity, 20,660 acre-ft $\left(25.5 \mathrm{hm}^{3}\right)$ and many powerhouses. Records for "actual flow" include Bishop Creek above powerplant No. 6 tailrace and Bishop Creek powerplant No. 6 conduit. Records for "natural flow" include "actual flow" of Bishop Creek below powerplant No.6, Abelour ditch near Bishop, minus Birch-McGee diversion "actual flow" of Bishop Creek below powerplant No, 6, Abelour ditch near Bishop, minus Birch-MicGee diversi
to Bishop Creek powerplant near Bishop, and the change in contents and evaporation for South Lake, Lake Sabrina, and Intake No. 2 Reservoir.

COOPERATION.--Records furnished by Southern California Edison Co., and reviewed by the Geological Survey, in connection with a Federal Power Commission Project.

AVERAGE DISCHARGE (Actual flow). - - 41 years, $98.5 \mathrm{ft}^{3} / \mathrm{s}\left(2.790 \mathrm{~m}^{3} / \mathrm{s}\right), 71,360 \mathrm{acre}-\mathrm{ft} / \mathrm{yr}(88.0 \mathrm{hm} / \mathrm{yr})$. (Natural flow). -41 years, $105 \mathrm{ft}^{3} / \mathrm{s}\left(2.974 \mathrm{~m}^{3} / \mathrm{s}\right), 76,070$ acre-ft/yr $\left(93.8 \mathrm{hm}^{3} / \mathrm{yr}^{2}\right)$

EXTREMES (ACTUAL FLOW) FOR PERIOD OF RECORD (SINCE 1970), - Maximum daily discharge, $337 \mathrm{ft}^{3} / \mathrm{s}$ (9.54 $\mathrm{m}^{3} / \mathrm{s}$ ) June 28, 1973; minimum daily, $38 \mathrm{ft}^{3} / \mathrm{s}\left(1.08 \mathrm{~m}^{3} / \mathrm{s}\right) \mathrm{Mar}, 30,1976$.

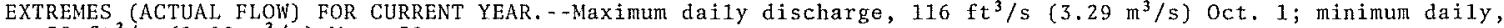
$38 \mathrm{ft}^{3} / \mathrm{s}\left(1.08 \mathrm{~m}^{3} / \mathrm{s}\right)$ Mar. 30

DISCHARGE, IN CURIC FEET PER SECOND, WATER YEAR OCTOBER 1975 TO SEPTEMBER 1976 MEAN VALUES

\begin{tabular}{|c|c|c|c|c|c|c|c|c|c|c|c|c|}
\hline DAY & OCT & Nov & DEC & JAN & FE 8 & MAR & $A P R$ & MAY & JUN & JUL & AUG & SEP \\
\hline $\begin{array}{l}1 \\
2 \\
3 \\
4 \\
5\end{array}$ & $\begin{array}{r}116 \\
96 \\
84 \\
86 \\
86\end{array}$ & $\begin{array}{l}77 \\
74 \\
72 \\
73 \\
73\end{array}$ & $\begin{array}{l}64 \\
62 \\
49 \\
49 \\
50\end{array}$ & $\begin{array}{r}91 \\
101 \\
96 \\
79 \\
72\end{array}$ & $\begin{array}{l}51 \\
51 \\
50 \\
52 \\
48\end{array}$ & $\begin{array}{l}47 \\
47 \\
47 \\
45 \\
46\end{array}$ & $\begin{array}{l}41 \\
43 \\
44 \\
43 \\
40\end{array}$ & $\begin{array}{l}54 \\
53 \\
57 \\
56 \\
55\end{array}$ & $\begin{array}{l}59 \\
61 \\
63 \\
61 \\
59\end{array}$ & $\begin{array}{l}62 \\
62 \\
62 \\
62 \\
60\end{array}$ & $\begin{array}{r}106 \\
102 \\
87 \\
80 \\
76\end{array}$ & $\begin{array}{l}79 \\
81 \\
80 \\
82 \\
82\end{array}$ \\
\hline $\begin{array}{r}6 \\
7 \\
8 \\
9 \\
10\end{array}$ & $\begin{array}{l}85 \\
87 \\
85 \\
88 \\
88\end{array}$ & $\begin{array}{l}73 \\
72 \\
73 \\
72 \\
71\end{array}$ & $\begin{array}{l}51 \\
50 \\
51 \\
50 \\
52\end{array}$ & $\begin{array}{l}71 \\
70 \\
69 \\
71 \\
70\end{array}$ & $\begin{array}{l}47 \\
52 \\
51 \\
46 \\
46\end{array}$ & $\begin{array}{l}44 \\
45 \\
46 \\
45 \\
44\end{array}$ & $\begin{array}{l}39 \\
41 \\
39 \\
39 \\
41\end{array}$ & $\begin{array}{l}55 \\
61 \\
71 \\
72 \\
61\end{array}$ & $\begin{array}{l}59 \\
59 \\
59 \\
59 \\
60\end{array}$ & $\begin{array}{l}60 \\
62 \\
60 \\
60 \\
60\end{array}$ & $\begin{array}{l}71 \\
71 \\
75 \\
79 \\
81\end{array}$ & $\begin{array}{l}79 \\
78 \\
78 \\
78 \\
85\end{array}$ \\
\hline $\begin{array}{l}11 \\
12 \\
13 \\
14 \\
15\end{array}$ & $\begin{array}{l}88 \\
89 \\
89 \\
87 \\
86\end{array}$ & $\begin{array}{l}71 \\
71 \\
72 \\
72 \\
72\end{array}$ & $\begin{array}{l}66 \\
76 \\
76 \\
75 \\
76\end{array}$ & $\begin{array}{l}71 \\
71 \\
70 \\
71 \\
71\end{array}$ & $\begin{array}{l}47 \\
49 \\
66 \\
77 \\
70\end{array}$ & $\begin{array}{l}44 \\
43 \\
43 \\
42 \\
42\end{array}$ & $\begin{array}{l}40 \\
40 \\
40 \\
41 \\
42\end{array}$ & $\begin{array}{l}56 \\
61 \\
67 \\
72 \\
72\end{array}$ & $\begin{array}{l}68 \\
63 \\
58 \\
60 \\
59\end{array}$ & $\begin{array}{l}60 \\
60 \\
61 \\
60 \\
62\end{array}$ & $\begin{array}{l}81 \\
80 \\
79 \\
79 \\
79\end{array}$ & $\begin{array}{l}85 \\
73 \\
74 \\
76 \\
80\end{array}$ \\
\hline $\begin{array}{l}16 \\
17 \\
18 \\
19 \\
20\end{array}$ & $\begin{array}{l}86 \\
86 \\
86 \\
86 \\
86\end{array}$ & $\begin{array}{l}73 \\
72 \\
72 \\
73 \\
72\end{array}$ & $\begin{array}{l}76 \\
77 \\
76 \\
76 \\
77\end{array}$ & $\begin{array}{l}70 \\
59 \\
58 \\
58 \\
59\end{array}$ & $\begin{array}{l}59 \\
43 \\
43 \\
43 \\
43\end{array}$ & $\begin{array}{l}42 \\
41 \\
41 \\
40 \\
39\end{array}$ & $\begin{array}{l}49 \\
59 \\
52 \\
41 \\
50\end{array}$ & $\begin{array}{l}73 \\
73 \\
75 \\
66 \\
68\end{array}$ & $\begin{array}{l}58 \\
63 \\
64 \\
61 \\
66\end{array}$ & $\begin{array}{l}76 \\
70 \\
66 \\
65 \\
66\end{array}$ & $\begin{array}{l}78 \\
78 \\
79 \\
80 \\
80\end{array}$ & $\begin{array}{l}77 \\
76 \\
74 \\
75 \\
74\end{array}$ \\
\hline $\begin{array}{l}21 \\
22 \\
23 \\
24 \\
25\end{array}$ & $\begin{array}{l}85 \\
85 \\
88 \\
88 \\
88\end{array}$ & $\begin{array}{l}72 \\
73 \\
70 \\
71 \\
71\end{array}$ & $\begin{array}{l}76 \\
77 \\
83 \\
92 \\
91\end{array}$ & $\begin{array}{l}57 \\
57 \\
56 \\
56 \\
56\end{array}$ & $\begin{array}{l}43 \\
43 \\
43 \\
43 \\
43\end{array}$ & $\begin{array}{l}39 \\
40 \\
40 \\
40 \\
40\end{array}$ & $\begin{array}{l}42 \\
45 \\
49 \\
46 \\
45\end{array}$ & $\begin{array}{l}65 \\
63 \\
61 \\
52 \\
56\end{array}$ & $\begin{array}{l}66 \\
62 \\
60 \\
60 \\
60\end{array}$ & $\begin{array}{l}64 \\
62 \\
67 \\
68 \\
66\end{array}$ & $\begin{array}{l}75 \\
81 \\
79 \\
81 \\
80\end{array}$ & $\begin{array}{l}79 \\
71 \\
73 \\
70 \\
71\end{array}$ \\
\hline $\begin{array}{l}26 \\
27 \\
28 \\
29 \\
30 \\
31\end{array}$ & $\begin{array}{l}92 \\
88 \\
88 \\
89 \\
87 \\
86\end{array}$ & $\begin{array}{r}71 \\
71 \\
71 \\
71 \\
72 \\
-\end{array}$ & $\begin{array}{l}77 \\
77 \\
78 \\
77 \\
77 \\
82\end{array}$ & $\begin{array}{l}58 \\
55 \\
52 \\
51 \\
51 \\
52\end{array}$ & $\begin{array}{r}41 \\
43 \\
44 \\
46 \\
-- \\
--\end{array}$ & $\begin{array}{l}40 \\
40 \\
41 \\
39 \\
38 \\
40\end{array}$ & $\begin{array}{r}48 \\
43 \\
43 \\
45 \\
50 \\
--\end{array}$ & $\begin{array}{l}58 \\
60 \\
61 \\
60 \\
61 \\
63\end{array}$ & $\begin{array}{r}60 \\
59 \\
58 \\
62 \\
60 \\
-\end{array}$ & $\begin{array}{l}66 \\
69 \\
75 \\
80 \\
86 \\
99\end{array}$ & $\begin{array}{l}80 \\
72 \\
80 \\
77 \\
80 \\
80\end{array}$ & $\begin{array}{r}71 \\
69 \\
69 \\
74 \\
93 \\
--0\end{array}$ \\
\hline $\begin{array}{l}\text { TOTAL } \\
\text { MEAN } \\
\text { MAX } \\
\text { MIN } \\
\text { AC-FI }\end{array}$ & $\begin{array}{r}2734 \\
88.2 \\
116 \\
84 \\
5420\end{array}$ & $\begin{array}{r}2163 \\
72.1 \\
77 \\
70 \\
4290\end{array}$ & $\begin{array}{r}2166 \\
69.9 \\
92 \\
49 \\
4300\end{array}$ & $\begin{array}{r}2049 \\
66.1 \\
101 \\
51 \\
4060\end{array}$ & $\begin{array}{r}1423 \\
49.1 \\
77 \\
41 \\
2820\end{array}$ & $\begin{array}{r}1310 \\
42.3 \\
47 \\
38 \\
2600\end{array}$ & $\begin{array}{r}1320 \\
44.0 \\
59 \\
39 \\
2620\end{array}$ & $\begin{array}{r}1938 \\
62.5 \\
75 \\
52 \\
3840\end{array}$ & $\begin{array}{r}1826 \\
60.9 \\
68 \\
58 \\
3620\end{array}$ & $\begin{array}{r}2058 \\
66.4 \\
99 \\
60 \\
4080\end{array}$ & $\begin{array}{r}2486 \\
80.2 \\
106 \\
71 \\
4930\end{array}$ & $\begin{array}{r}2306 \\
76.9 \\
93 \\
69 \\
4570\end{array}$ \\
\hline$(t)$ & 3010 & 2500 & 2170 & 2160 & 1970 & 2140 & 2400 & 6830 & 5850 & 5390 & 3310 & 3820 \\
\hline
\end{tabular}

CAL YR 1975 TOTAL 40209 MEAN 110 MAX 183 MIN 49 AC-FT $79750 \quad \nmid 72220$

WTR YR 1976 TOTAL 23779 MEAN 65.0 MAX 116 MIN 38 AC-FT $47170 \quad$ †41550

† Computed natural flow, in acre-feet. 
10276000 BIG PINE CREEK NEAR BIG PINE, CA

LOCATION, - Lat $37^{\circ} 08^{\prime} 42^{\prime \prime}$, long $118^{\circ} 18^{\prime} 52^{\prime \prime}$, in SW/4SW/4SE sec.24, T.9 S., R. 33 E., Inyo County, on 1eft bank $0.3 \mathrm{mi}$ $(0.5 \mathrm{~km})$ downstream from Little Pine Creek, $0.5 \mathrm{mi}(0.8 \mathrm{~km})$ downstream from powerhouse No. 3 , and $2.2 \mathrm{mi}$

$(3.5 \mathrm{~km})$ southwest of Big Pine.

DRAINAGE AREA. $-39.0 \mathrm{mi}^{2}\left(101.0 \mathrm{~km}^{2}\right)$.

PERIOD OF RECORD.--November 1907 to February 1911, January 1920 to current year; combined records of creek and diversions, June 1930 to current year. Monthly discharge only for some periods, published in wsp 1314 and 1734 .

GAGE, - Water-stage recorder and Parshall flume since April 1949 on creek; water-stage recorder and Parshal1 flume on each diversion. Altitude of creek gage is $4,500 \mathrm{ft}(1,372 \mathrm{~m})$, from topographic map. Prior to January 1923 , nonrecording gage at same site and datum. Diversion gages at different datum.

REMARKS.--Records poor. No regulation above station. Diversions above station for power and irrigation. At times since 1962 discharge from Little Pine Creek has been spread in nearby meadows and does not reach gage as surface flow. For records of combined discharge of Big Pine Creek and Giroux ditches which divert above station, see following page.

COOPERATION. - -Records were furnished by city of Los Ange1es, Department of Water and Power.

AVERAGE DISCHARGE,--Combined creek and diversions: 46 years (water years $1931-76), 40.8 \mathrm{ft}^{3} / \mathrm{s}\left(1.155 \mathrm{~m}^{3} / \mathrm{s}\right)$, 29,560 acre-ft/yr $\left(36.4 \mathrm{hm}^{3} / \mathrm{yr}\right)$.

EXTREMES FOR PERIOD OF RECORD.--Creek only: Maximum discharge, $458 \mathrm{ft}^{3} / \mathrm{s}\left(13.0 \mathrm{~m}^{3} / \mathrm{s}\right) \mathrm{July} 3$, 1932 , gage height, $6.55 \mathrm{ft}(1.996 \mathrm{~m})$; minimum daily, no flow Dec. $3-12,1935$.

Combined creek and diversions: Maximum discharge, $458 \mathrm{ft}^{3} / \mathrm{s}\left(13.0 \mathrm{~m}^{3} / \mathrm{s}\right) \mathrm{July} 3,1932 ; \mathrm{minimum} \mathrm{daily,} 6.4 \mathrm{ft}{ }^{3} / \mathrm{s}$ $\left(0.181 \mathrm{~m}^{3} / \mathrm{s}\right) \mathrm{Dec} .11,12,1935$.

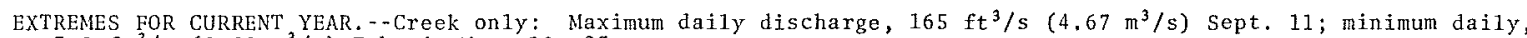
$7.9 \mathrm{ft}^{3} / \mathrm{s}\left(0.22 \mathrm{~m}^{3} / \mathrm{s}\right) \mathrm{Feb}$. 6 , Mar. 19,23 .

Combined creek and diversions: Maximum daily discharge, $173 \mathrm{ft}^{3} / \mathrm{s}\left(4.90 \mathrm{~m}^{3} / \mathrm{s}\right) \mathrm{Sept}$. 11; minimum daily,

$11 \mathrm{ft}^{3} / \mathrm{s}\left(0.31 \mathrm{~m}^{3} / \mathrm{s}\right)$ on several days in February, March, and April.

DISCHARGE, IN CUBIC FEET PER SECOND, WATER YEAR OCTOBER 1975 TO SEPTEMBER 1976 MEAN VALUES

\begin{tabular}{|c|c|c|c|c|c|c|c|c|c|c|c|c|}
\hline DAY & OCT & Nov & DEC & JAN & FEB & MAR & APR & MAY & JUN & JUL & AUG & SE \\
\hline $\begin{array}{l}1 \\
2 \\
3 \\
4 \\
5\end{array}$ & $\begin{array}{l}15 \\
14 \\
14 \\
13 \\
13\end{array}$ & $\begin{array}{l}15 \\
15 \\
14 \\
13 \\
13\end{array}$ & $\begin{array}{l}12 \\
12 \\
11 \\
12 \\
12\end{array}$ & $\begin{array}{l}9.3 \\
9.8 \\
10 \\
11 \\
11\end{array}$ & $\begin{array}{l}9.5 \\
9.5 \\
9.8 \\
9.5 \\
9.8\end{array}$ & $\begin{array}{r}9.3 \\
8.5 \\
8.7 \\
9.3 \\
10\end{array}$ & $\begin{array}{l}14 \\
14 \\
12 \\
10 \\
9.5\end{array}$ & $\begin{array}{l}15 \\
17 \\
17 \\
16 \\
17\end{array}$ & $\begin{array}{l}34 \\
37 \\
34 \\
32 \\
33\end{array}$ & $\begin{array}{l}28 \\
28 \\
30 \\
33 \\
34\end{array}$ & $\begin{array}{l}58 \\
53 \\
46 \\
41 \\
38\end{array}$ & $\begin{array}{l}34 \\
34 \\
35 \\
32 \\
33\end{array}$ \\
\hline $\begin{array}{r}6 \\
7 \\
8 \\
9 \\
10\end{array}$ & $\begin{array}{l}12 \\
14 \\
13 \\
12 \\
11\end{array}$ & $\begin{array}{l}13 \\
13 \\
14 \\
14 \\
14\end{array}$ & $\begin{array}{l}12 \\
12 \\
12 \\
11 \\
11\end{array}$ & $\begin{array}{l}9.5 \\
9.5 \\
9.5 \\
9.5 \\
9.5\end{array}$ & $\begin{array}{l}7.9 \\
11 \\
11 \\
10 \\
9.8\end{array}$ & $\begin{array}{l}9.0 \\
9.0 \\
9.0 \\
8.7 \\
9.0\end{array}$ & $\begin{array}{r}9.0 \\
9.3 \\
9.3 \\
8.7 \\
8.7\end{array}$ & $\begin{array}{l}16 \\
16 \\
16 \\
18 \\
18\end{array}$ & $\begin{array}{l}33 \\
36 \\
30 \\
26 \\
24\end{array}$ & $\begin{array}{l}43 \\
52 \\
52 \\
52 \\
54\end{array}$ & $\begin{array}{l}37 \\
35 \\
33 \\
35 \\
38\end{array}$ & $\begin{array}{l}30 \\
26 \\
25 \\
25 \\
53\end{array}$ \\
\hline $\begin{array}{l}11 \\
12 \\
13 \\
14 \\
15\end{array}$ & $\begin{array}{l}12 \\
11 \\
11 \\
10 \\
13\end{array}$ & $\begin{array}{l}13 \\
14 \\
14 \\
14 \\
14\end{array}$ & $\begin{array}{l}12 \\
12 \\
11 \\
11 \\
11\end{array}$ & $\begin{array}{l}9.5 \\
9.5 \\
9.8 \\
9.8 \\
9.8\end{array}$ & $\begin{array}{l}9.5 \\
9.3 \\
9.5 \\
9.5 \\
9.3\end{array}$ & $\begin{array}{l}8.7 \\
8.5 \\
8.5 \\
8.5 \\
8.5\end{array}$ & $\begin{array}{l}8.7 \\
8.7 \\
10 \\
11 \\
9.8\end{array}$ & $\begin{array}{l}21 \\
24 \\
27 \\
35 \\
38\end{array}$ & $\begin{array}{l}23 \\
23 \\
23 \\
27 \\
32\end{array}$ & $\begin{array}{l}61 \\
62 \\
60 \\
58 \\
55\end{array}$ & $\begin{array}{l}37 \\
37 \\
37 \\
37 \\
27\end{array}$ & $\begin{array}{r}165 \\
110 \\
62 \\
43 \\
33\end{array}$ \\
\hline $\begin{array}{l}16 \\
17 \\
18 \\
19 \\
20\end{array}$ & $\begin{array}{l}16 \\
16 \\
15 \\
15 \\
15\end{array}$ & $\begin{array}{l}14 \\
14 \\
9.8 \\
12 \\
13\end{array}$ & $\begin{array}{l}11 \\
11 \\
11 \\
11 \\
11\end{array}$ & $\begin{array}{l}9.8 \\
9.8 \\
9.5 \\
9.3 \\
9.8\end{array}$ & $\begin{array}{l}9.0 \\
9.0 \\
8.7 \\
8.7 \\
8.2\end{array}$ & $\begin{array}{l}8.7 \\
8.7 \\
8.7 \\
7.9 \\
8.2\end{array}$ & $\begin{array}{l}8.5 \\
8.7 \\
9.0 \\
8.7 \\
8.7\end{array}$ & $\begin{array}{l}39 \\
41 \\
35 \\
29 \\
29\end{array}$ & $\begin{array}{l}42 \\
44 \\
44 \\
46 \\
45\end{array}$ & $\begin{array}{r}83 \\
101 \\
67 \\
70 \\
59\end{array}$ & $\begin{array}{l}21 \\
18 \\
17 \\
15 \\
14\end{array}$ & $\begin{array}{l}28 \\
24 \\
22 \\
20 \\
20\end{array}$ \\
\hline $\begin{array}{l}21 \\
22 \\
23 \\
24 \\
25\end{array}$ & $\begin{array}{l}15 \\
14 \\
14 \\
14 \\
14\end{array}$ & $\begin{array}{l}13 \\
12 \\
12 \\
13 \\
12\end{array}$ & $\begin{array}{l}11 \\
11 \\
11 \\
11 \\
11\end{array}$ & $\begin{array}{l}9.8 \\
9.8 \\
9.8 \\
9.8 \\
9.5\end{array}$ & $\begin{array}{l}8.5 \\
8.5 \\
0.5 \\
8.2 \\
9.0\end{array}$ & $\begin{array}{l}8.5 \\
8.5 \\
7.9 \\
9.5 \\
9.0\end{array}$ & $\begin{array}{l}9.8 \\
11 \\
11 \\
12 \\
13\end{array}$ & $\begin{array}{l}29 \\
25 \\
30 \\
35 \\
31\end{array}$ & $\begin{array}{l}39 \\
31 \\
28 \\
29 \\
31\end{array}$ & $\begin{array}{l}60 \\
59 \\
62 \\
65 \\
69\end{array}$ & $\begin{array}{l}14 \\
17 \\
17 \\
18 \\
20\end{array}$ & $\begin{array}{l}20 \\
19 \\
19 \\
19 \\
18\end{array}$ \\
\hline $\begin{array}{l}26 \\
27 \\
28 \\
29 \\
30 \\
31\end{array}$ & $\begin{array}{l}15 \\
15 \\
15 \\
15 \\
15 \\
15\end{array}$ & $\begin{array}{l}12 \\
12 \\
12 \\
12 \\
14 \\
---\end{array}$ & $\begin{array}{l}11 \\
11 \\
11 \\
11 \\
9.8 \\
9.0\end{array}$ & $\begin{array}{l}9.3 \\
9.5 \\
9.5 \\
9.5 \\
9.5 \\
9.5\end{array}$ & $\begin{array}{l}9.0 \\
9.0 \\
9.0 \\
8.7 \\
=-0 \\
=-\end{array}$ & $\begin{array}{r}9.3 \\
9.3 \\
9.0 \\
9.0 \\
9.0 \\
13\end{array}$ & $\begin{array}{l}13 \\
12 \\
11 \\
11 \\
12 \\
-\end{array}$ & $\begin{array}{l}36 \\
36 \\
36 \\
34 \\
31 \\
31\end{array}$ & $\begin{array}{r}33 \\
34 \\
35 \\
32 \\
32 \\
-\end{array}$ & $\begin{array}{r}64 \\
71 \\
114 \\
103 \\
74 \\
63\end{array}$ & $\begin{array}{l}21 \\
24 \\
28 \\
31 \\
35 \\
37\end{array}$ & $\begin{array}{r}1 \\
1 \\
1 \\
2 \\
3 \\
-\end{array}$ \\
\hline $\begin{array}{l}\text { TOTAL } \\
\text { MEAN } \\
\text { MAX } \\
\text { MIN } \\
\text { AC-FT }\end{array}$ & $\begin{array}{r}426 \\
13.7 \\
16 \\
10 \\
845\end{array}$ & $\begin{array}{r}393.8 \\
13.11 \\
15 \\
9.8 \\
781\end{array}$ & $\begin{array}{r}346.8 \\
11.2 \\
12 \\
9.0 \\
688\end{array}$ & $\begin{array}{r}300.7 \\
9.70 \\
11 \\
9.3 \\
596\end{array}$ & $\begin{array}{r}266.9 \\
9.20 \\
11 \\
7.9 \\
529\end{array}$ & $\begin{array}{r}277.4 \\
0.95 \\
13 \\
7.9 \\
550\end{array}$ & $\begin{array}{r}312.1 \\
10.4 \\
14 \\
0.5 \\
619\end{array}$ & $\begin{array}{r}838 \\
27.0 \\
41 \\
15 \\
1660\end{array}$ & $\begin{array}{r}992 \\
33.1 \\
46 \\
23 \\
1970\end{array}$ & $\begin{array}{r}1886 \\
60.8 \\
114 \\
28 \\
3740\end{array}$ & $\begin{array}{r}936 \\
30.2 \\
58 \\
14 \\
1860\end{array}$ & $\begin{array}{r}1053 \\
35.1 \\
165 \\
16 \\
2090\end{array}$ \\
\hline
\end{tabular}

CAL YR 1975 TOTAL 11059.0 MEAN 30.3 MAX 183 MIN 7.4 AC-FT 21940 UTR YR 1976 TOTAL 8028.7 MEAN 21.9 MAX 165 MIN 7.9 AC-FT 15920 
10276000 BIG PINE CREEK NEAR BIG PINE, CA - Continued

COMBINED DISCHARGE, IN CUBIC FEET PER SECOND, OF BIG PINE CREEK AND UPPER AND LOWER GIROUX DITCHES, NEAR BIG PINE, CA, WATER YEAR OCTOBER 1975 TO SEPTEMBER 1976

DISCHARGE, IN CUBIC FEET PER SECOND, WATER YEAR OCTOBER 1975 TO SEPTEMBER 1976 MEAN VALUES

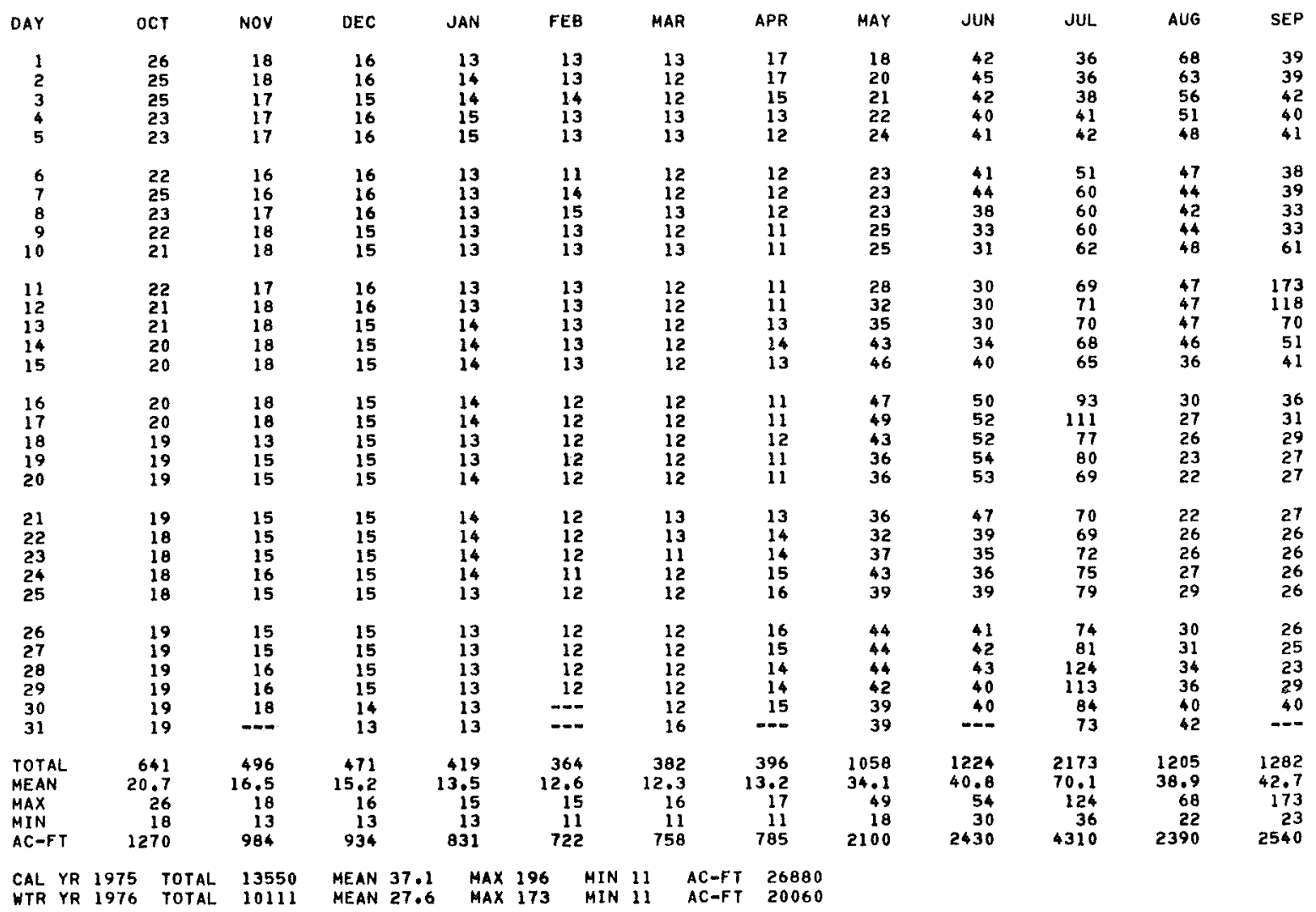


10277400 OWENS RIVER BELOW TINEMAHA RESERVOIR, NEAR BIG PINF, CA (National stream-quality accounting network station)

LOCATION, - - Lat $37^{\circ} 03^{\prime} 15^{\prime \prime}$, long $118^{\circ} 13^{\prime} 33^{\prime \prime}$, in SW'sNE' sec.26, T.10 S., R.34 E., Inyo County, about 100 ft (30 m) west of center of dam, $8.4 \mathrm{mi}(13.5 \mathrm{~km})$ southeast of Big Pine.

DRAINAGE AREA. - - I, $964 \mathrm{mi}^{2}\left(5,087 \mathrm{~km}^{2}\right)$.

WATER-DISCHARGE RECORDS

PERIOD OF RECORD,--October 1974 to current year. Since November 1951 in files of city of los Angeles, Department of Water and Power as Owens River at Tinemaha Dam.

GAGE.-Water-stage recorder and Parshall flume. Altitude of gage is $3,860 \mathrm{ft}$ ( $1,177 \mathrm{~m})$, from topographic map.

REMARKS, - Records poor. Flow regulated since 1941 by Lake Crowley, capacity, 183,500 acre-ft (226 km ${ }^{3}$ ) and several small reservoirs, combined capacity, 41,400 acre-ft $\left(51.0 \mathrm{~km}^{3}\right)$. Diversions from both main stream and tributaries. Water imported from Mono Basin since 1941 for diversion to Los Angeles Aqueduct which diverts $4 \mathrm{mi}(6 \mathrm{~km})$ downstream.

COOPERATION. - Records were furnished by city of Los Angeles, Department of Water and Power

EXTREMES FOR PERIOD OF RECORD.--Maximum daily discharge, $795 \mathrm{ft}^{3} / \mathrm{s}\left(22.5 \mathrm{~m}^{3} / \mathrm{s}\right)$ Sept, 22,$1976 ; \mathrm{minimum}$ daily, $5.0 \mathrm{ft}^{3} / \mathrm{s}\left(0.14 \mathrm{~m}^{3} / \mathrm{s}\right)$ Sept. $15,16,25-30,1976$.

DISCHARGE, IN CUBIC FEET PER SECOND, WATER YEAR OCTOBER 1975 TO SEPTEMBER 1976 MEAN VALUES

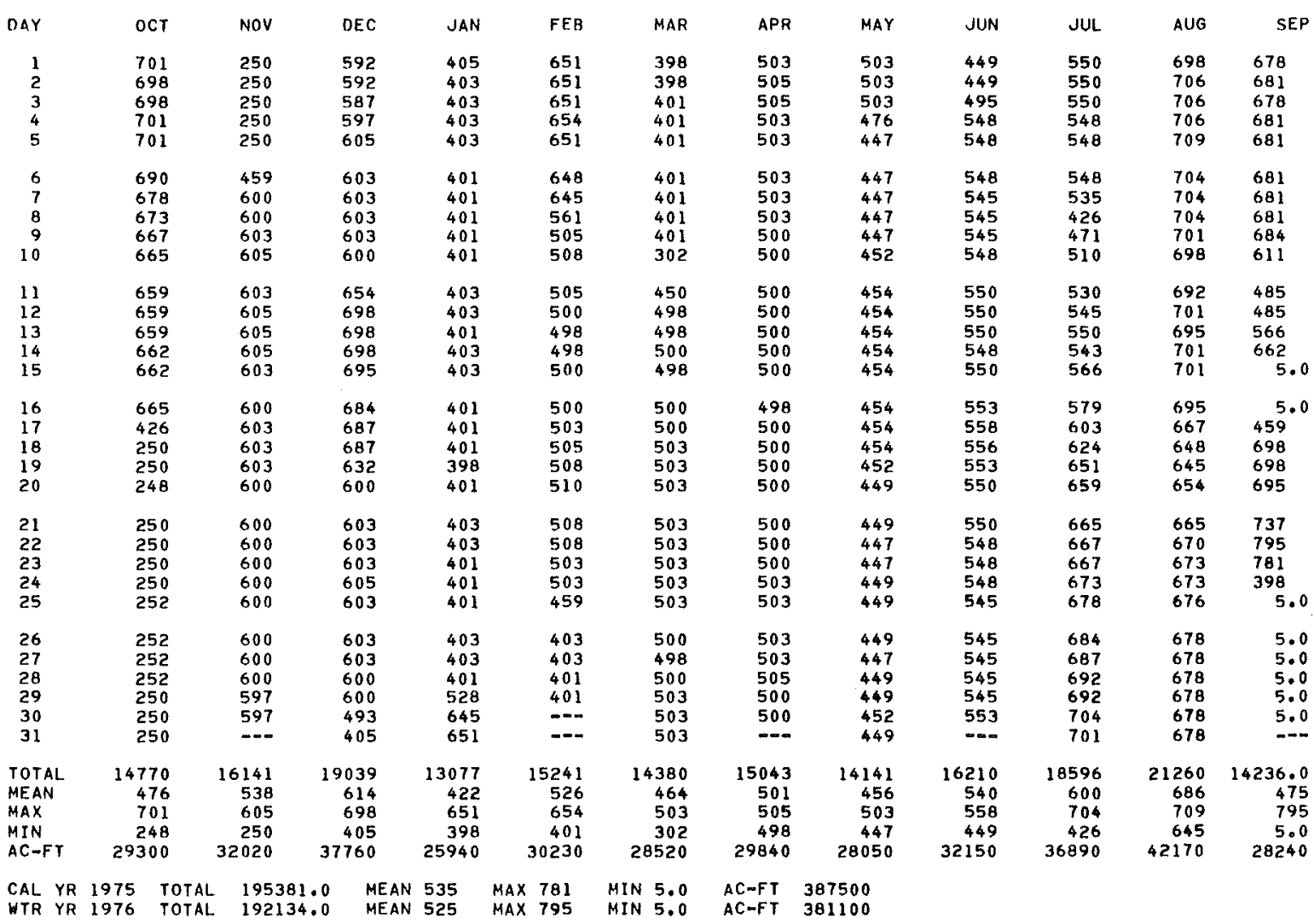


PERIOD OF RECORD. - Water year 1975 to current year.

CHEMICAL ANALYSES: Water year 1975 to current year

SEDIMENT RECORDS: Water year 1975 to current year (partial-record station).

PERIOD OF DAILY RECORD.- -

SPECIFIC CONDUCTANCE: May 1975 to current year.

WATER TEMPERATURES: February 1975 to current year.

INSTRUMENTATION. - Specific conductance recorder since May 1975. Temperature recorder since February 1975 .

REMARKS.--Aqueduct shut down sept. 15-17, 24-30. Other periods of missing temperature data due to equipment malfunction.

COOPERATION. --Pesticide samples were collected by U.S. Geological Survey and analyzed by Environmental protection Agency.

EXTREMES FOR PERIOD OF DAILY RECORD.--

SPECIFIC CONDUCTANCE: Maximum, 344 micromhos Sept, 10, 1975; minimum, 193 micromhos June 11 , 1975 ,

WATER TEMPERATURES: Maximum recorded, $25.5^{\circ} \mathrm{C}$ July 24,1976 ; minimum, $1.5^{\circ} \mathrm{C}$ Jan. 2 , 1976.

EXTREMES FOR CURRENT YEAR.--

SPECIFIC CONDUCTANCE: Maximum, 333 micromhos Feb. 14, 19; minimum, 242 micromhos 0ct. 1.

WATER TEMPERATURES: Maximum recorded, $25.5^{\circ} \mathrm{C}$ July 24 ; minimum, $1.5^{\circ} \mathrm{C}$ Jan. 2.

CHEMICAL ANALYSES, WATER YEAR OCTOBER 1975 TO SEPTEMRER 1076

\begin{tabular}{|c|c|c|c|c|c|c|c|c|c|c|c|c|c|}
\hline \multirow[b]{2}{*}{ DATE } & \multirow[t]{2}{*}{ TINE } & \multirow[t]{2}{*}{$\begin{array}{l}\text { INST AN- } \\
\text { TANEOUS } \\
\text { WIS- } \\
\text { CHARGE } \\
\text { (CF S) }\end{array}$} & \multirow{2}{*}{$\begin{array}{c}\mathrm{PH} \\
\text { (UNITS) }\end{array}$} & \multirow[t]{2}{*}{$\begin{array}{l}\text { TUP- } \\
\text { BID- } \\
\text { ITY } \\
\text { (JTU) }\end{array}$} & \multicolumn{2}{|c|}{$\begin{array}{l}\text { FFCAL } \\
\text { COLI- } \\
\text { FORM } \\
\text { ICOL. } \\
\text { PFR }\end{array}$} & \multicolumn{2}{|c|}{$\begin{array}{c}\text { STREP- } \\
\text { TOCOCCI } \\
\text { ICOL- } \\
\text { ONIES } \\
\text { PEF }\end{array}$} & \multirow[t]{2}{*}{$\begin{array}{l}\text { HARO- } \\
\text { NESS } \\
(C A, M G) \\
(M G / L)\end{array}$} & \multirow[t]{2}{*}{$\begin{array}{l}\text { NON- } \\
\text { CAR- } \\
\text { BONATE } \\
\text { HARO- } \\
\text { NESS } \\
(M G / L)\end{array}$} & \multirow[t]{2}{*}{$\begin{array}{l}\text { DIS- } \\
\text { SOLVED } \\
\text { CAL- } \\
\text { CIUM } \\
\text { (CA) } \\
\text { (MG/L) }\end{array}$} & \multirow[t]{2}{*}{$\begin{array}{l}\text { DIS- } \\
\text { SOLVED } \\
\text { MAG- } \\
\text { NE- } \\
\text { SIUM } \\
\text { (MG) } \\
\text { (MG/L) }\end{array}$} & \multirow[t]{2}{*}{$\begin{array}{l}\text { DIS- } \\
\text { SOLVEO } \\
\text { SODIUM } \\
\text { (NA) } \\
\text { (MG/L) }\end{array}$} \\
\hline & & & & & 100 & $M L)$ & 100 & $M L)$ & & & & & \\
\hline $\begin{array}{l}0,1 \\
51 . \cdots \\
\text { nov }\end{array}$ & 1510 & 250 & 8.4 & 9 & & 4 & & 8 & 68 & 0 & 21 & 3.8 & 28 \\
\hline${ }_{D F C} 18 \ldots$ & 1520 & 600 & 9.6 & 9 & & 60 & & 84 & 71 & 0 & 21 & 4.4 & 28 \\
\hline${ }_{\text {JAN }} 17 \ldots$ & 1530 & 700 & 7.7 & 3 & & 0 & & 0 & 82 & 0 & 24 & 5.4 & 31 \\
\hline$\underset{F F H}{20} \ldots$ & 1515 & 490 & R. 8 & 9 & & 0 & & 0 & 74 & 0 & 22 & 4.6 & 28 \\
\hline$\underset{M \triangle P}{25 \ldots}$ & 1445 & 400 & 8.6 & 7 & & 0 & & 0 & 87 & 0 & 27 & 4.8 & 34 \\
\hline$\underset{A O R}{31 \ldots}$ & 1410 & 500 & 8.0 & 12 & & 82 & & 0 & 74 & 0 & 22 & 4.6 & 31 \\
\hline$\underset{M A Y}{27} \cdots$ & 1505 & 500 & B. 3 & 9 & & 19 & & 17 & 73 & 0 & 22 & 4.5 & 33 \\
\hline$\underset{\text { JIIN }}{19} \cdots$ & 1610 & 450 & 8.9 & 10 & & 2 & & -- & 74 & 0 & 23 & 4.0 & 30 \\
\hline$\underset{\text { Jill }}{21 \ldots}$ & 1515 & 553 & 8.4 & 10 & & 9 & & 51 & 73 & -- & 22 & 4.3 & 33 \\
\hline$\underset{\text { A }}{21} G_{7} \ldots$ & 1505 & 665 & 8.3 & 10 & & 70 & & 143 & 78 & 0 & 24 & 4.4 & 37 \\
\hline$\underset{\text { SFP }}{P 5 \ldots}$ & 1500 & 673 & 8.0 & 10 & & 15 & & 62 & 74 & 0 & 23 & 4.1 & 35 \\
\hline $22 \ldots$ & 1630 & 805 & 8.5 & 8 & & 4 & & 14 & 76 & 0 & 23 & 4.5 & 34 \\
\hline
\end{tabular}

$B$ Results based on colony count outside the acceptable range (non-ideal colony count). 
10277400 OWENS RIVER BELOW TINEMAHA RESERVOIR, NEAR BIG PINE, CA--Continued

CHEMICAL ANALYSES, WATER YEAR OCTOBER 1975 TO SEPTEMPER 1976

\begin{tabular}{|c|c|c|c|c|c|c|c|c|c|c|c|}
\hline DATE & $\begin{array}{l}\text { PERCENT } \\
\text { SOOIUM }\end{array}$ & $\begin{array}{l}\text { SOOIUM } \\
\text { AD- } \\
\text { SURP- } \\
\text { TION } \\
\text { RATIO }\end{array}$ & $\begin{array}{l}\text { OIS- } \\
\text { SOLVED } \\
\text { PO- } \\
\text { TAS- } \\
\text { SIUM } \\
\text { (K) } \\
(M G / L)\end{array}$ & $\begin{array}{l}\text { BICAR - } \\
\text { BONATE } \\
\text { (HCO3) } \\
\text { (MG/L) }\end{array}$ & $\begin{array}{l}\text { CAR }= \\
\text { BONATE } \\
\text { (CO3) } \\
\text { (MG/L) }\end{array}$ & $\begin{array}{l}\text { ALKA- } \\
\text { LINITY } \\
\text { AS } \\
\text { CACO3 } \\
\text { (MG/L) }\end{array}$ & $\begin{array}{l}\text { CARBON } \\
\text { OIOXIDE } \\
\text { (COZ) } \\
\text { (MG/L) }\end{array}$ & $\begin{array}{l}\text { DIS- } \\
\text { SOLVEO } \\
\text { SULFATE } \\
\text { (SO4) } \\
\text { (MG/L) }\end{array}$ & $\begin{array}{l}\text { DIS- } \\
\text { SOLVED } \\
\text { CHLO- } \\
\text { RIDE } \\
\text { (CL) } \\
(M G / L)\end{array}$ & $\begin{array}{l}\text { DIS- } \\
\text { SOLVED } \\
\text { FLUO- } \\
\text { RIDE } \\
\text { (F) } \\
(M G / L)\end{array}$ & $\begin{array}{l}\text { DIS- } \\
\text { SOLVEO } \\
\text { SILICA } \\
\text { (SIOZ) } \\
\text { (MG/L) }\end{array}$ \\
\hline $\begin{array}{r}O C, T \\
21 \ldots\end{array}$ & 46 & 1.5 & 3.6 & 95 & 0 & 78 & .6 & 18 & 11 & .4 & 16 \\
\hline $\begin{array}{l}\text { NOV } \\
1 \text { R.... } \\
\text { DEC }\end{array}$ & 45 & 1.5 & 3.4 & 113 & 0 & 93 & .5 & 24 & 11 & .5 & 19 \\
\hline JAN $17 . \cdots$ & 44 & 1.5 & 4.2 & 119 & 0 & 98 & 3.8 & 27 & 13 & .4 & 20 \\
\hline$\underset{F E R}{20} \cdots$ & 44 & 1.4 & 3.6 & 123 & 0 & 101 & $\cdot 3$ & 24 & 12 & .5 & 20 \\
\hline $\begin{array}{l}25 \cdots \\
\text { MAR }\end{array}$ & 44 & 1.6 & 4.2 & 136 & 0 & 112 & .5 & 33 & 14 & .7 & 21 \\
\hline$\underset{A P R}{31} \cdots$ & 46 & 1.6 & 4.1 & 135 & 0 & 111 & 2.2 & 23 & 14 & .6 & 22 \\
\hline $\begin{array}{l}27 \ldots \\
\text { MAY }\end{array}$ & 48 & 1.7 & 4.2 & 140 & 0 & 115 & 1.1 & 21 & 14 & .6 & 21 \\
\hline$\underset{\text { JIJN }}{19} \cdots$ & 45 & 1.5 & 3.8 & 122 & 0 & 100 & .2 & 26 & 13 & .6 & 21 \\
\hline $\begin{array}{l}21 \cdots * \\
\text { JUL }\end{array}$ & 48 & 1.7 & 3.8 & $=-$ & $=$ & $=-$ & - & 18 & 13 & .8 & 24 \\
\hline AUG & 49 & 1.8 & 4.5 & 144 & 0 & 118 & 1.2 & 19 & 16 & .7 & 23 \\
\hline$\underset{\text { SFP }}{25 \cdots}$ & 49 & 1.8 & 4.1 & 145 & 0 & 119 & 2.3 & 16 & 16 & .6 & 15 \\
\hline $22 \ldots$ & 48 & 1.7 & 4.3 & 138 & 0 & 113 & .7 & 20 & 15 & .6 & 14 \\
\hline
\end{tabular}

\begin{tabular}{|c|c|c|c|c|c|c|c|c|c|c|}
\hline DATE & $\begin{array}{l}\text { DIS- } \\
\text { SOLVED } \\
\text { SOLIOS } \\
\text { (RESI- } \\
\text { DUE AT } \\
\text { IRO C) } \\
\text { (MG/L) }\end{array}$ & $\begin{array}{l}\text { OIS- } \\
\text { SOLVED } \\
\text { SOLIOS } \\
\text { (SUM OF } \\
\text { CONSTI - } \\
\text { TUENTS) } \\
\text { (MG/L) }\end{array}$ & $\begin{array}{l}\text { DIS- } \\
\text { SOLVED } \\
\text { SOLIDS } \\
\text { (TONS } \\
\text { PER } \\
\text { AC-FT) }\end{array}$ & $\begin{array}{l}\text { OIS- } \\
\text { SOLVED } \\
\text { SOLIDS } \\
\text { (TONS } \\
\text { PER } \\
\text { DAY) }\end{array}$ & $\begin{array}{c}\text { TOTAL } \\
\text { NITRITE } \\
\text { PLUS } \\
\text { NITRATE } \\
\text { (N) } \\
\text { (MG/L) }\end{array}$ & $\begin{array}{l}\text { TOTAL } \\
\text { KJEL- } \\
\text { DAHL } \\
\text { NITRO- } \\
\text { GEN } \\
\text { (N) } \\
\text { (MG/L) }\end{array}$ & $\begin{array}{l}\text { TOTAL } \\
\text { NITRO- } \\
\text { GEN } \\
\text { (N) } \\
(M G / L)\end{array}$ & $\begin{array}{l}\text { TOTAL } \\
\text { NITRO- } \\
\text { GEN } \\
\text { (NOA) } \\
\text { (MG/L) }\end{array}$ & $\begin{array}{l}\text { TOTAL } \\
\text { PHOS- } \\
\text { PHORUS } \\
\text { (P) } \\
\text { (MG/L) }\end{array}$ & $\begin{array}{l}\text { TOTAL } \\
\text { PHYTO- } \\
\text { PLANK- } \\
\text { TON } \\
\text { (CELLS } \\
\text { PER } \\
\text { ML) }\end{array}$ \\
\hline $\begin{array}{l}\text { OCT } \\
21 \ldots \\
\text { NOV }\end{array}$ & 172 & 149 & .23 & 116 & .02 & -- & - & -- & -- & 2000 \\
\hline${ }_{D E C}^{18} \cdot \cdots$ & 162 & 167 & .22 & 262 & .06 & .38 & .44 & 1.9 & .05 & 3300 \\
\hline JAN $\cdots$ & 193 & 184 & .26 & 365 & .15 & .59 & .74 & 3.3 & .05 & 720 \\
\hline$\underset{F E B}{20} \ldots$ & 178 & 175 & .24 & 192 & .09 & .58 & .67 & 3.0 & .06 & 11000 \\
\hline$\underset{\text { MAR }}{25 . .}$ & 200 & 206 & .27 & 216 & .01 & .51 & .52 & 2.3 & .06 & 9900 \\
\hline$\underset{A P R}{31} \cdots$ & 176 & 188 & .24 & 238 & .06 & .34 & .40 & 1.8 & .09 & 22000 \\
\hline$\underset{M A Y}{27} \cdots$ & 191 & 189 & .26 & 258 & .03 & .29 & .32 & 1.4 & .04 & 5600 \\
\hline JUN $19 .$. & 182 & 181 & .25 & 221 & .04 & 2.0 & 2.0 & 9.0 & .06 & 5700 \\
\hline $21 \cdots$ & -- & -- & -- & -- & .07 & .75 & .82 & 3.6 & .10 & 6300 \\
\hline${ }_{A \cup G}^{21} \cdots$ & 201 & 200 & .27 & 361 & .16 & .18 & .34 & 1.5 & .15 & 3000 \\
\hline$\underset{\text { SEP }}{25}$ & 177 & 185 & .24 & 322 & .20 & .35 & .55 & 2.4 & .09 & 630 \\
\hline $22 \ldots$ & 194 & 183 & .26 & 422 & .01 & .77 & .78 & 3.5 & .05 & 680 \\
\hline
\end{tabular}


10277400 OWENS RIVER BELOW TINEMAHA RESERVOIR, NEAR BIG PINE, CA--Continued

QUALITATIVE AND ASSOCIATED QUANTITATIVE ANALYSES OF BIOLOGICAL DATA, WATER YEAR OCTOBER 1975 TO SEPTEMBER 1976 PHYTOPLANKTON

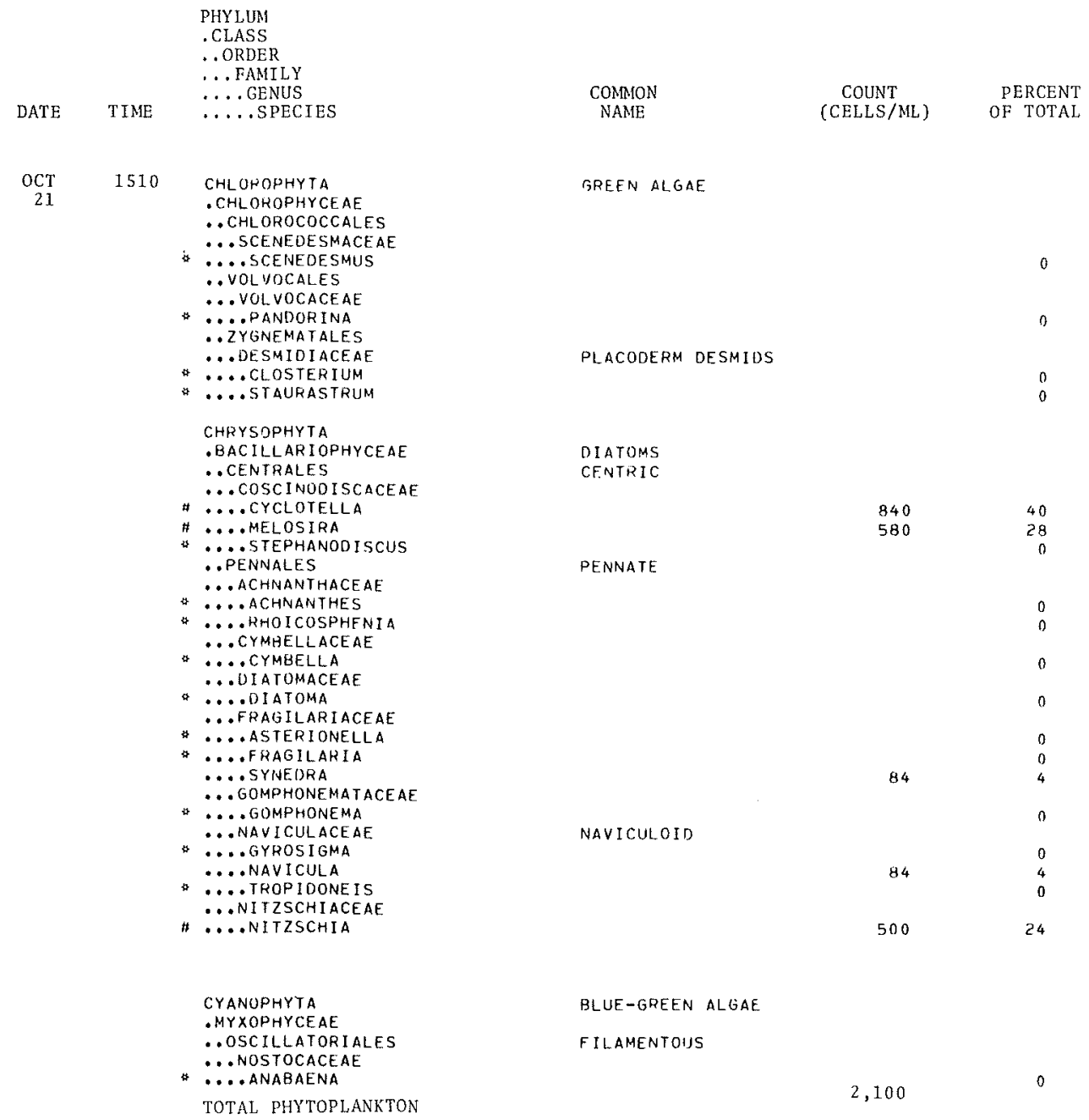

See footnotes at end of table. 
10277400 OWENS RIVER BELOW TINEMAHA RESERVOIR, NEAR BIG PINE, CA--Continued

QUALITATIVE AND ASSOCIATED QUANTITATIVE ANALYSES OF BIOLOGICAL DATA, WATER YEAR OCTOBER 1975 TO SEPTEMBER 1976 PHYTOPLANKTON

\begin{tabular}{|c|c|c|}
\hline DATE & TIME & $\begin{array}{l}\text { PHYLUA } \\
\text {. CLASS } \\
\ldots \text { ORDER } \\
\ldots \text {. FAMILY } \\
\ldots \text {. GENUS } \\
\ldots \text {. . SPECIES }\end{array}$ \\
\hline $\begin{array}{r}\text { NOV } \\
18\end{array}$ & 1520 & $\begin{array}{l}\text { CHLOROPHYTA } \\
\text {. CHLOROPHYCEAE } \\
\ldots \text { VOL VOCALES } \\
\ldots \text { CHLAMYDOMONADACEAE } \\
\ldots \text {. CHLAMYDOMONAS } \\
\ldots \text {. VOLVOCACEAE } \\
\ldots \text {. PANDORINA }\end{array}$ \\
\hline
\end{tabular}

$\begin{array}{lcr}\text { COMMON } & \text { COUNT } & \text { PERCENT } \\ \text { NAME } & \text { (CELLS/ML) } & \text { OF TOTAL }\end{array}$

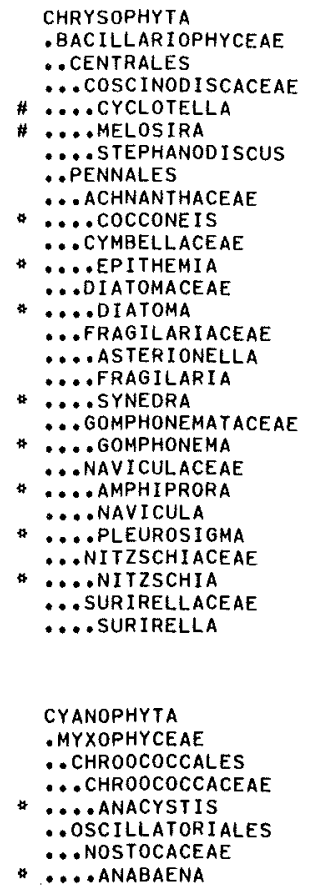

GREEN ALGAE

77

0

DIATOMS

CENTRIC

PENNATE

$\begin{array}{rr}1.400 & 42 \\ 840 & 26 \\ 77 & 2\end{array}$

NAVICULOID

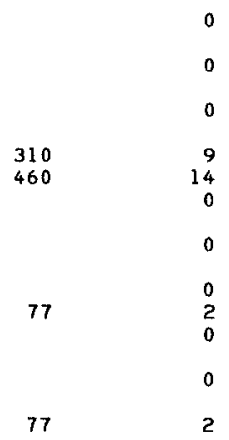

BLUE-GREEN ALGAE

$\operatorname{coc} \cos 0$

FILAMENTROUS

See footnotes at end of table. 
10277400 OWENS RIVER BELOW TINEMAHA RESERVOIR, NEAR BIG PINE, CA--Continued

QUALITATIVE AND ASSOCIATED QUANTITATIVE ANALYSES OF BIOLOGICAL DATA, WATER YEAR OCTOBER 1975 TO SEPTEMBER 1976 PHYTOPLANKTON

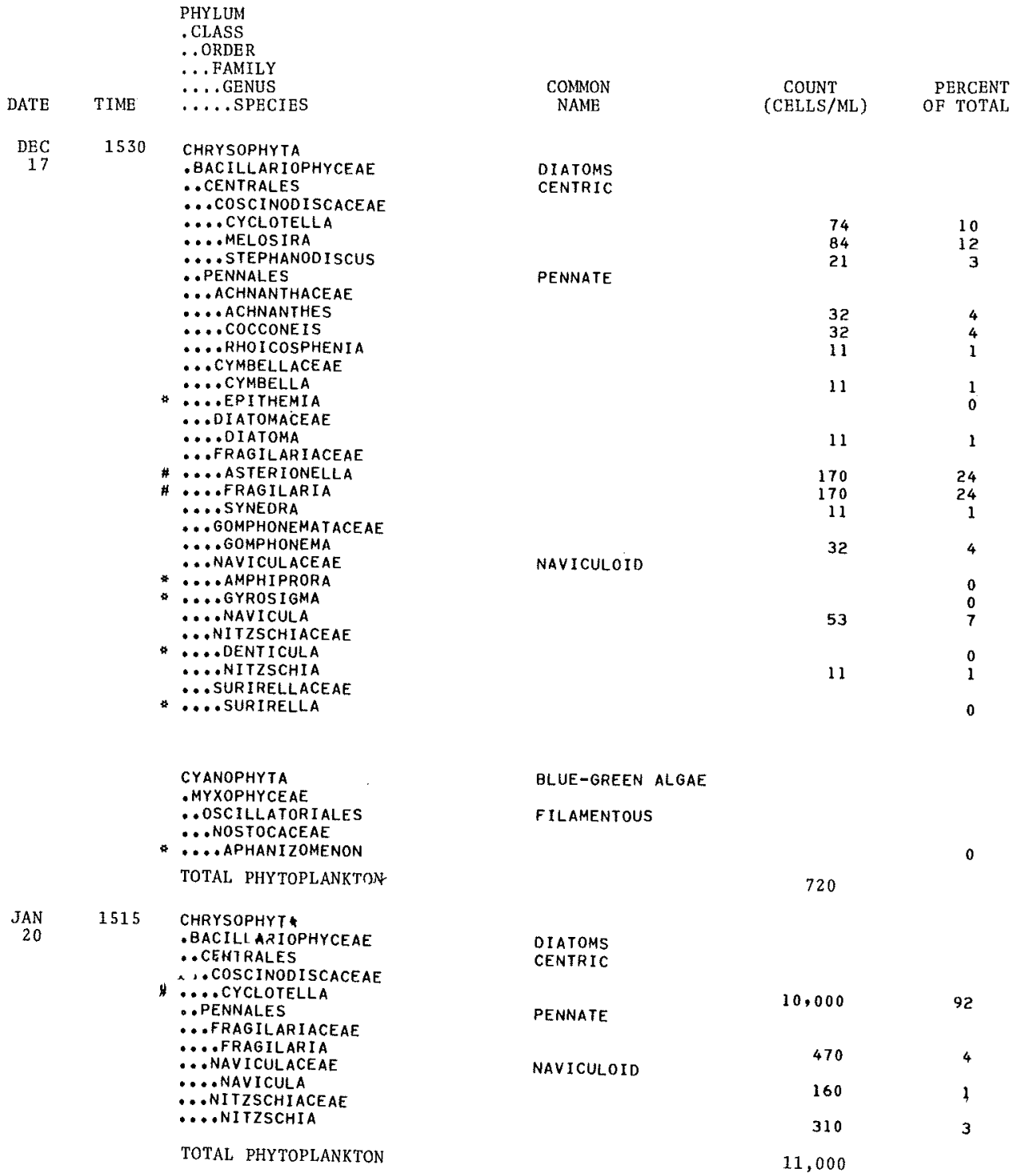

See footnotes at end of table. 
10277400 OWENS RIVER BELOW TINEMAHA RESERVOIR, NEAR BIG PINE, CA--ContinUed QUALITATIVE AND ASSOCIATED QUANTITATIVE ANALYSES OF BIOLOGICAL DATA, WATER YEAR OCTOBER 1975 TO SEPTEMBER 1976 PHYTOPLANKTON

\begin{tabular}{|c|c|c|c|c|c|}
\hline DATE & TIME & $\begin{array}{l}\text { PHYLUM } \\
\text {.CLASS } \\
\ldots \text { ORDER } \\
\ldots \text {. FAMII, } \\
\ldots \ldots \text { GENUS } \\
\ldots \ldots \text {. SPECIES }\end{array}$ & $\begin{array}{l}\text { COMMON } \\
\text { NAME }\end{array}$ & $\begin{array}{c}\text { COUNT } \\
\text { (CELLS/ML) }\end{array}$ & $\begin{array}{l}\text { PERCENT } \\
\text { OF TOTAL }\end{array}$ \\
\hline \multirow[t]{2}{*}{$\begin{array}{r}\text { FEB } \\
25\end{array}$} & 1445 & $\begin{array}{l}\text { CHLOROPHYTA } \\
\text { CHLOROPHYCEAE } \\
\ldots \text { VOLVOCALES } \\
\ldots \text { PHACOTACEAE } \\
\ldots \ldots \text { PHACOTUS }\end{array}$ & GREEN ALGAE & 88 & 1 \\
\hline & & 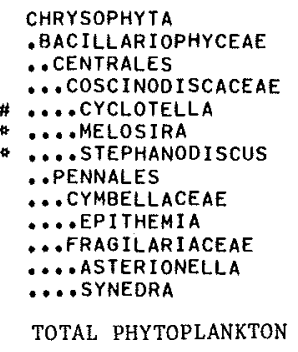 & $\begin{array}{l}\text { DIATOMS } \\
\text { CENTRIC } \\
\text { PENNATE }\end{array}$ & $\begin{array}{r}9,000 \\
88 \\
620 \\
88 \\
9,900\end{array}$ & $\begin{array}{l}1 \\
6 \\
1\end{array}$ \\
\hline $\begin{array}{r}\text { MAR } \\
31\end{array}$ & 1410 & 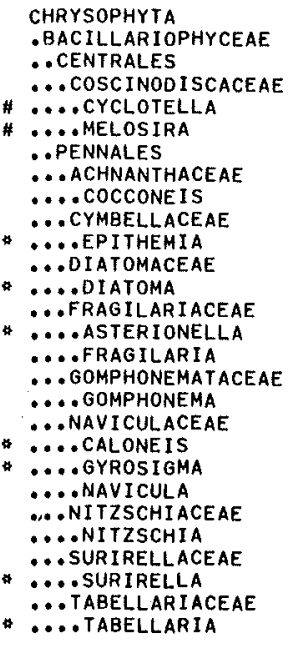 & PENNATE & $\begin{array}{r}13,000 \\
4,200 \\
210\end{array}$ & $\begin{array}{c}58 \\
19 \\
1 \\
0 \\
0 \\
0 \\
13 \\
3 \\
0 \\
0 \\
2 \\
4 \\
0\end{array}$ \\
\hline & & TOTAL PHYTOPLANKTON & & 22,000 & \\
\hline
\end{tabular}

See footnotes at end of table. 
10277400 OWENS RIVER BELOW TINEMAHA RESERVOIR, NEAR BIG PINE, CA--COntinued

QUALITATIVE AND ASSOCIATED QUANTITATIVE ANALYSES OF BIOLOGICAL DATA, WATER YEAR OCTOBER 1975 TO SEPTEMBER 1976

PHYTOPLANKTON

\begin{tabular}{|c|c|c|c|c|c|}
\hline DATE & TIME & $\begin{array}{l}\text { PHYLUM } \\
\text {. CLASS } \\
\ldots \text { ORDER } \\
\ldots \text {. FAMILY } \\
\ldots \text {. . GENUS } \\
\ldots \text {. SPECIES }\end{array}$ & $\begin{array}{l}\text { COMMON } \\
\text { NAME }\end{array}$ & $\begin{array}{c}\text { COUNT } \\
\text { (CELLS/ML) }\end{array}$ & $\begin{array}{l}\text { PERCENT } \\
\text { OF TOTAL }\end{array}$ \\
\hline \multirow[t]{12}{*}{$\begin{array}{r}\mathrm{APR} \\
27\end{array}$} & 1505 & $\begin{array}{l}\text { CHLOROPHYTA } \\
\text { CHLOROPHYCEAE } \\
\ldots \text { CHLOROCOCCALES } \\
\ldots \text { CHARACIACEAE } \\
\ldots \text {. SCHROEDERIA } \\
\ldots \text { OOCYSTACEAE } \\
\ldots \text {. ANKISTRODESMUS } \\
\ldots \text { SCENEDESMACEAE } \\
\ldots \text {. SCENEDESMUS }\end{array}$ & GREEN ALGAE & $\begin{array}{r}71 \\
210 \\
500\end{array}$ & $\begin{array}{l}1 \\
4 \\
9\end{array}$ \\
\hline & & $\begin{array}{l}\text { CHRYSOPHYTA } \\
\text {-BACILLARIOPHYCEAE } \\
\text {. CENTRALES } \\
\text {. . COSCINODISCACEAE }\end{array}$ & $\begin{array}{l}\text { DIATOMS } \\
\text { CENTRIC }\end{array}$ & & \\
\hline & \# & $\begin{array}{l}\text {... CYCLOTELLA } \\
\ldots \text { MELOSIRA } \\
\ldots \text {. STEPHANODISCUS } \\
\text {. PENNALES } \\
\text {. ACHNANTHACEAE }\end{array}$ & PENNATE & $\begin{array}{r}1,300 \\
1,900 \\
71\end{array}$ & $\begin{array}{r}23 \\
33 \\
1\end{array}$ \\
\hline & & $\begin{array}{l}\ldots \text { ACHNANTHES } \\
\ldots \text { CYMBELLACEAE }\end{array}$ & & 71 & 1 \\
\hline & & $\begin{array}{l}\text { \# \#PITHEMIA } \\
\ldots \text { FRAGILARIACEAE }\end{array}$ & & 140 & 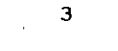 \\
\hline & & $\begin{array}{l}\text { \#FRAG ILARI A } \\
\because \text { GOMPHONEMATACEAE }\end{array}$ & & 570 & 10 \\
\hline & & $\begin{array}{l}\ldots \text {.. GOMPHONEMA } \\
\ldots \text { NAVICULACEAE }\end{array}$ & NAVICULOID & 71 & 1 \\
\hline & & $\begin{array}{l}\text {.. NAVICULA } \\
\ldots \text { NITZSCHIACEAE }\end{array}$ & & 210 & 4 \\
\hline & & $\begin{array}{l}\text {.. NIIZSCHIA } \\
\ldots \text { SURIRELLACEAE }\end{array}$ & & 210 & 4 \\
\hline & & •.. SURIRELLA & & 71 & 1 \\
\hline & & $\begin{array}{l}\text { CHRY SOPHYCEAE } \\
\because \text { CHRYSOMONADALES } \\
\because \text { OCHROMONADACEAE } \\
\cdots \text { ODINOBRYON }\end{array}$ & YELLOW-BROWN ALGAE & 210 & 4 \\
\hline & & TOTAL PHYTOPLANKTON & & 5,600 & \\
\hline
\end{tabular}

See footnotes at end of table. 
10277400 OWENS RIVER BELOW TINEMAHA RESERVOIR, NEAR BIG PINE, CA-Continued

QUALITATIVE AND ASSOCIATED QUANTITATIVE ANALYSES OF BIOLOGICAL DATA, WATER YEAR OCTOBER 1975 TO SEPTEMBER 1976

PHYTOPLANKTON

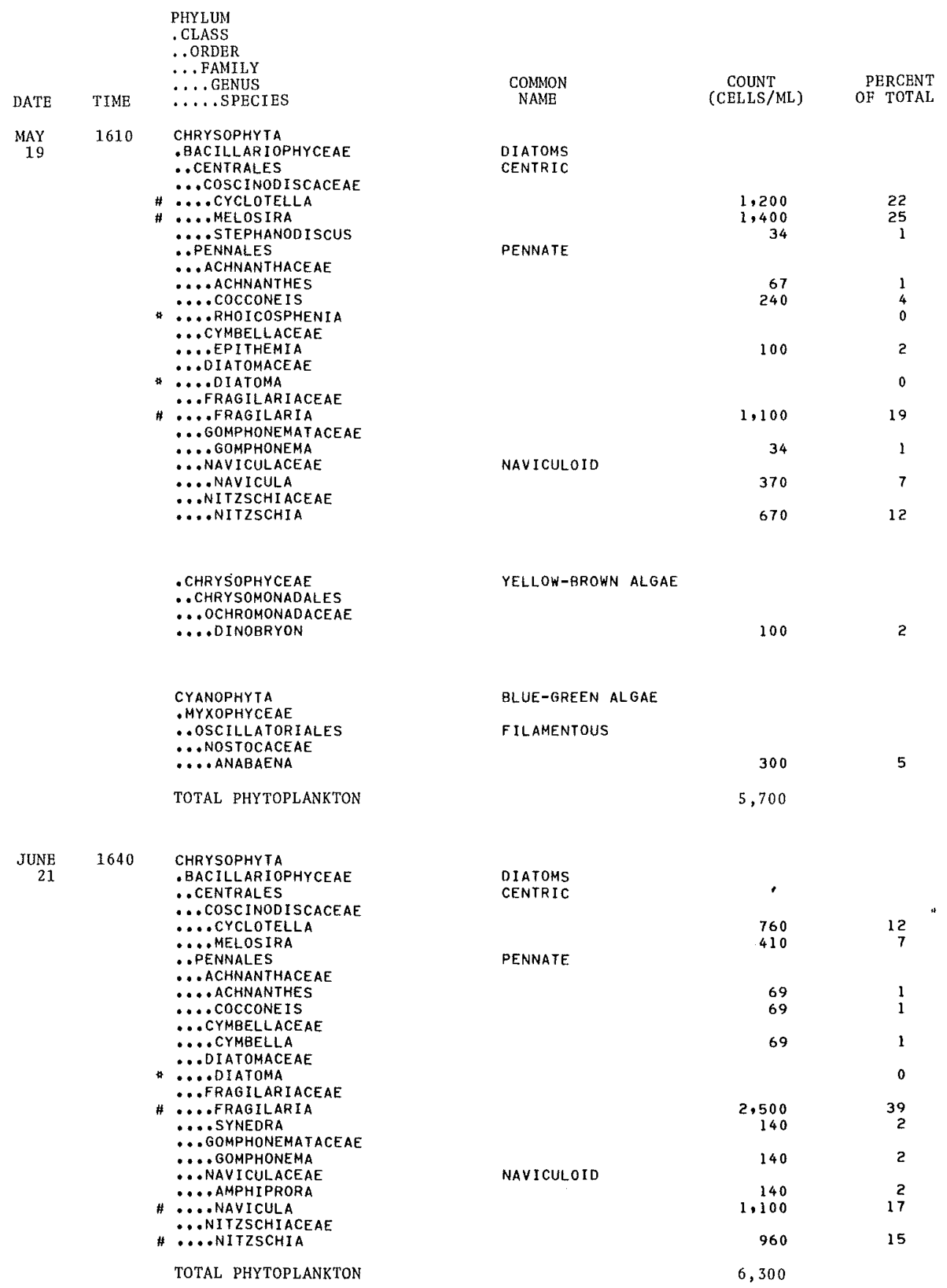

See footnotes at end of table. 
10277400 OWENS RIVER BELOW TINEMAHA RESERVOIR, NEAR BIG PINE, CA--Continued

QUALITATIVE AND ASSOCIATED QUANTITATIVE ANALYSES OF BIOLOGICAL DATA, WATER YEAR OCTOBER 1975 TO SEPTEMBER 1976

PHYTOPLANKTON

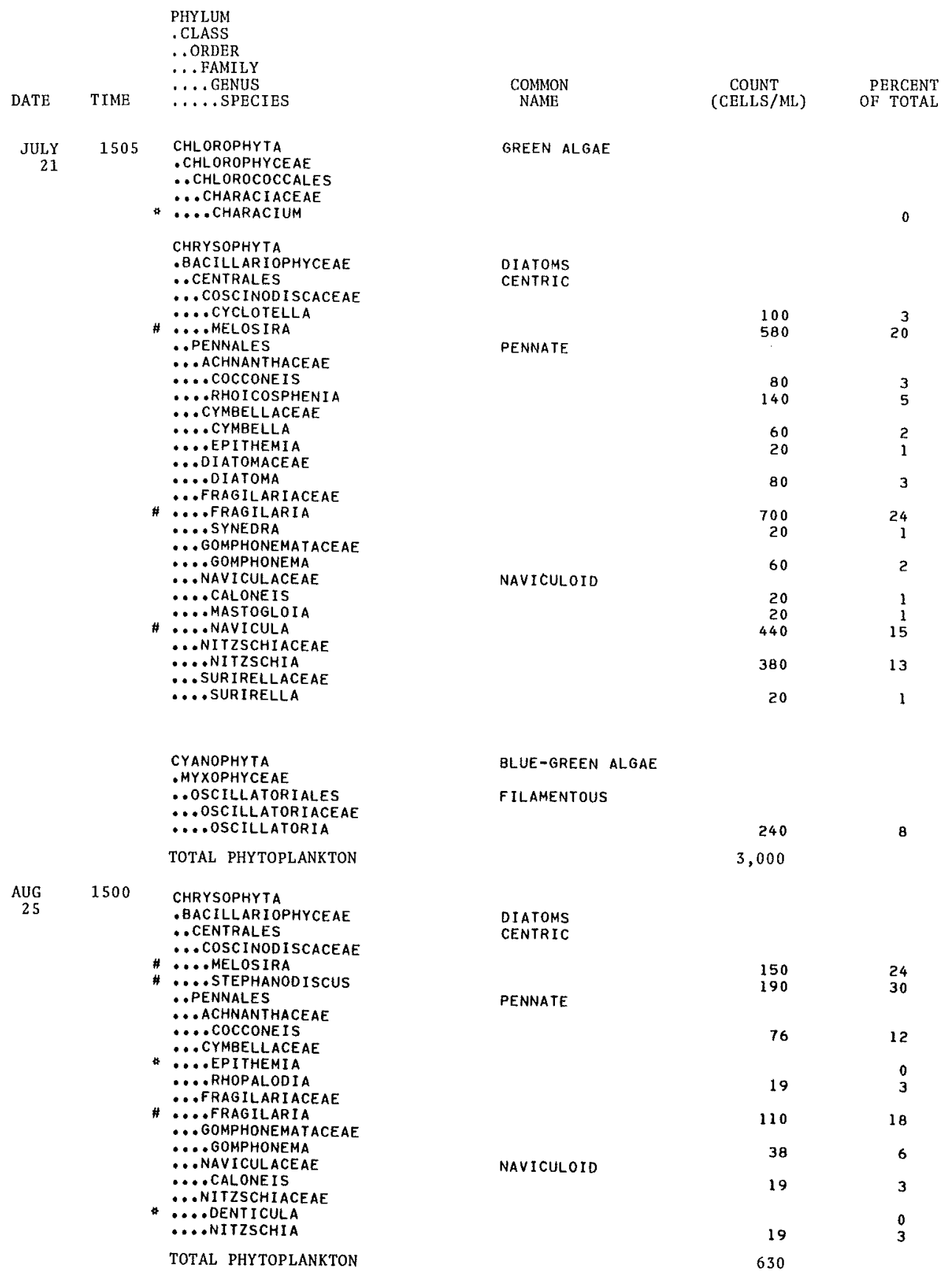

See footrotes at end of table. 
10277400 OWENS RIVER BELOW TINEMAHA RESERVOIR, NEAR BIG PINE, CA--Continued

QUALITATIVE AND ASSOCIATED QUANTITATIVE ANALYSES OF BIOLOGICAL DATA, WATER YEAR OCTOBER 1975 TO SEPTEMBER 1976 PHYTOPLANKTON

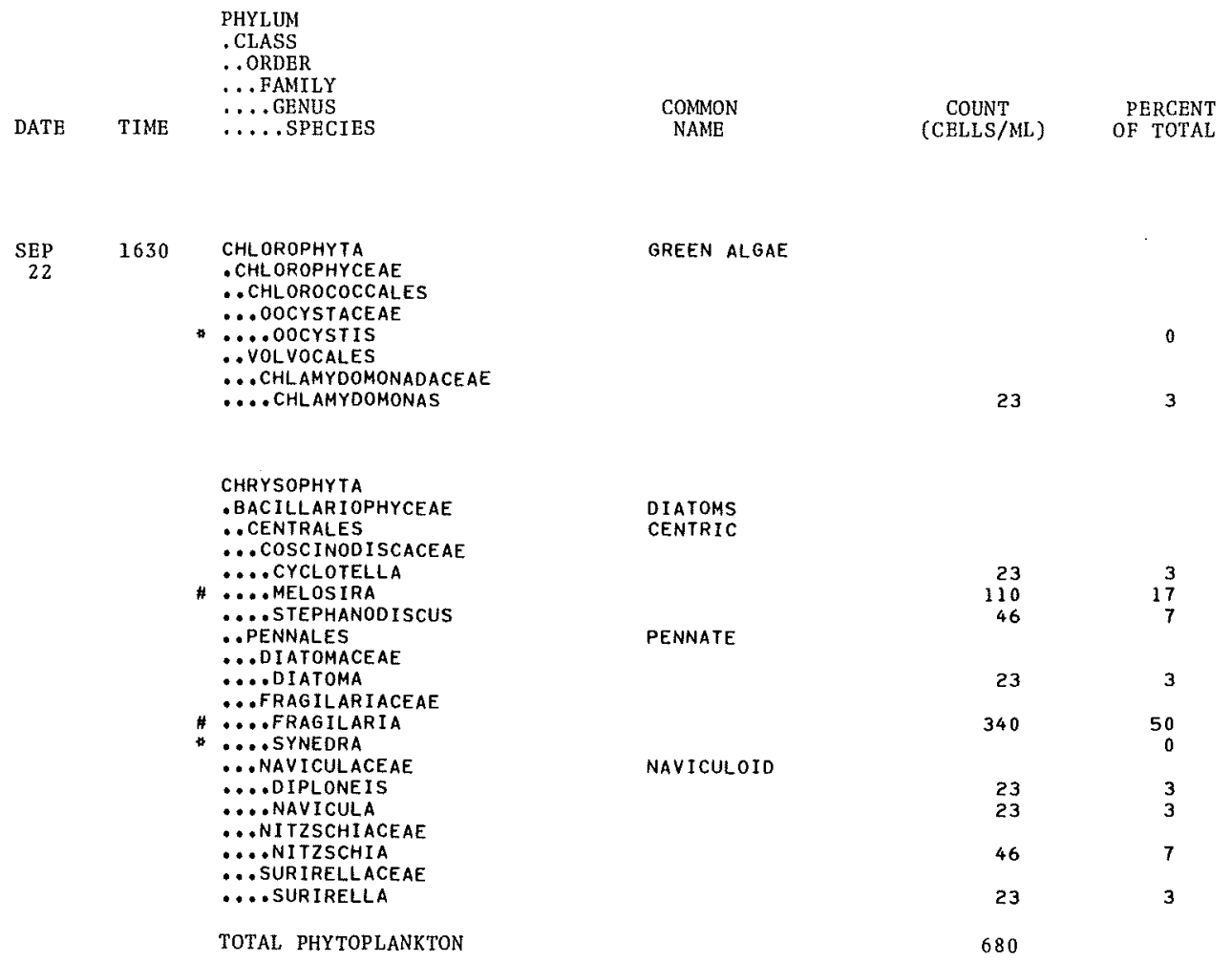

NOTE: \# - DOMINANT ORGANISM; GREATER OR EQUAL TO $15 \%$

* - LESS THEN 18; MAY NOt HAVE BEEN. ACTUALLY COUNTED

\begin{tabular}{|c|c|c|c|c|c|c|c|c|c|}
\hline \multirow[b]{2}{*}{ Date } & \multicolumn{9}{|c|}{ PERIPHYTON } \\
\hline & $\begin{array}{l}\text { Length of exposure } \\
\text { (days) }\end{array}$ & Dry & $\begin{array}{l}\text { Biomass } \\
\text { weight }\end{array}$ & $\begin{array}{l}(\mathrm{g} / \mathrm{m} \\
\mathrm{Ash}\end{array}$ & $\begin{array}{l}\left.\mathrm{m}^{2}\right) \\
\text { weight }\end{array}$ & $\begin{array}{c}\text { Ch1orophy11 } \\
\left(\mathrm{mg} / \mathrm{m}^{2}\right)\end{array}$ & $\begin{array}{c}\text { Ch1orophyl1 } \\
\text { b } \\
\left(\mathrm{mg} / \mathrm{m}^{2}\right)\end{array}$ & $\begin{array}{c}\text { Biomass } \\
\text { pigment } \\
\text { ratio }\end{array}$ & $\begin{array}{l}\text { Sampling } \\
\text { method }\end{array}$ \\
\hline Jan. 20 & 36 & & 4.2 & & 3.2 & 6.3 & 0.1 & 160 & $\begin{array}{l}\text { Polyethylene } \\
\text { strip }\end{array}$ \\
\hline $\mathrm{Feb}, 25$ & 34 & & 4.2 & & 3.8 & 1.1 & 0.1 & 360 & $\begin{array}{l}\text { Polyethylene } \\
\text { strip }\end{array}$ \\
\hline Aug. 28 & 28 & & 3.3 & & 2.5 & 0.0 & 0.0 & 0.0 & $\begin{array}{l}\text { Polyethylene } \\
\text { strip }\end{array}$ \\
\hline
\end{tabular}


CHEMICAL ANALYSES, WATER YEAR OCTOBER 1975 TO SEPTEMBER 1976

\begin{tabular}{|c|c|c|c|c|c|c|c|c|c|c|c|c|}
\hline DATE & TIME & $\begin{array}{c}\text { TOTAL. } \\
\text { ARSENIC } \\
\text { (AS) } \\
\text { (UG/L) }\end{array}$ & $\begin{array}{c}\text { SUS- } \\
\text { PENDED } \\
\text { ARSENIC } \\
\text { (AS) } \\
\text { (UG/L) }\end{array}$ & $\begin{array}{l}\text { DIS- } \\
\text { SOLVED } \\
\text { ARSENIC } \\
\text { (AS) } \\
\text { (UG/L) }\end{array}$ & $\begin{array}{c}\text { TOTAL } \\
\text { CAD- } \\
\text { MIUM } \\
\text { (CD) } \\
(U G / L)\end{array}$ & $\begin{array}{l}\text { SUS- } \\
\text { PENDED } \\
\text { CAD- } \\
\text { MIUM } \\
\text { (CD) } \\
(U G / L)\end{array}$ & $\begin{array}{l}\text { DIS- } \\
\text { SOLVED } \\
\text { CAD } \\
\text { MIUM } \\
\text { (CO) } \\
\text { (UG/L) }\end{array}$ & $\begin{array}{l}\text { TOTAL } \\
\text { CHRO- } \\
\text { MIUM } \\
\text { (CR) } \\
(U G / L)\end{array}$ & $\begin{array}{l}\text { SUS- } \\
\text { PENDED } \\
\text { CHRO- } \\
\text { MIUM } \\
\text { (CR) } \\
(U G / L)\end{array}$ & $\begin{array}{l}\text { DIS- } \\
\text { SOLVED } \\
\text { CHRO- } \\
\text { MIUM } \\
\text { (CR) } \\
\text { (UG/L) }\end{array}$ & $\begin{array}{l}\text { TOTAL } \\
\text { COBALT } \\
\text { (CO) } \\
\text { (UG/L) }\end{array}$ & $\begin{array}{l}\text { SUS- } \\
\text { PENDED } \\
\text { COBALT } \\
\text { (CO) } \\
(U G / L)\end{array}$ \\
\hline $\begin{array}{l}0 C T \\
21 . . . \\
\text { JAN }\end{array}$ & 1510 & 30 & 2 & 28 & 0 & 0 & 1 & 18 & 18 & 0 & $<50$ & $<49$ \\
\hline$\underset{A P R}{20} \cdots$ & 1515 & 24 & 4 & 20 & $<10$ & $<9$ & 1 & 0 & 0 & 0 & $<50$ & $<48$ \\
\hline$\underset{\text { JUL }}{27} \cdots$ & 1505 & 32 & 1 & 31 & $<10$ & $<9$ & 1 & 0 & 0 & 0 & $<50$ & $<50$ \\
\hline $21 \ldots$ & 1505 & 35 & 30 & 5 & $<10$ & $<9$ & 1 & 0 & 0 & 0 & $<50$ & $<50$ \\
\hline
\end{tabular}

\begin{tabular}{|c|c|c|c|c|c|c|c|c|c|c|c|}
\hline DATE & $\begin{array}{l}\text { DIS- } \\
\text { SOLVED } \\
\text { COBALT } \\
\text { (CO) } \\
\text { (UG/L) }\end{array}$ & $\begin{array}{l}\text { TOTAL } \\
\text { COPPER } \\
\text { (CU) } \\
\text { (UG/L) }\end{array}$ & $\begin{array}{l}\text { SUS- } \\
\text { PENDED } \\
\text { COPPER } \\
\text { (CU) } \\
\text { (UG/L) }\end{array}$ & $\begin{array}{l}\text { DIS- } \\
\text { SOLVED } \\
\text { COPPER } \\
\text { (CU) } \\
\text { (UG/L) }\end{array}$ & $\begin{array}{l}\text { TOTAL } \\
\text { IRON } \\
\text { (FE) } \\
\text { (UG/L) }\end{array}$ & $\begin{array}{l}\text { DIS- } \\
\text { SOLVED } \\
\text { IRON } \\
\text { (FE) } \\
\text { (UG/L) }\end{array}$ & $\begin{array}{l}\text { TOTAL } \\
\text { LEAD } \\
\text { (PB) } \\
\text { (UG/L) }\end{array}$ & $\begin{array}{l}\text { SUS- } \\
\text { PENDED } \\
\text { LEAD } \\
\text { (PB) } \\
\text { (UG/L) }\end{array}$ & $\begin{array}{l}\text { DIS- } \\
\text { SOLVED } \\
\text { LEAD } \\
\text { (PB) } \\
(U G / L)\end{array}$ & $\begin{array}{l}\text { TOTAL } \\
\text { MAN- } \\
\text { GANESE } \\
\text { (MN) } \\
\text { (UG/L) }\end{array}$ & $\begin{array}{c}\text { SUS- } \\
\text { PENDEO } \\
\text { MAN- } \\
\text { GANESE } \\
\text { (MN) } \\
(U G / L)\end{array}$ \\
\hline $\begin{array}{c}0 C T \\
21 \ldots \\
\text { JAN }\end{array}$ & 1 & 10 & 5 & 5 & 510 & 10 & $<100$ & $<99$ & 1 & 30 & 30 \\
\hline$\underset{A P R}{20} \cdots$ & 2 & $<10$ & $<6$ & 4 & 490 & 20 & $<100$ & $<93$ & 7 & 70 & 70 \\
\hline$\underset{J U L}{27} \stackrel{.}{ }$ & 0 & 10 & 5 & 5 & 880 & 70 & $<100$ & $<96$ & 4 & 50 & 50 \\
\hline $21 \ldots$ & 0 & 20 & 6 & 14 & 1500 & 60 & $<100$ & $<95$ & 5 & 60 & 3 \\
\hline
\end{tabular}

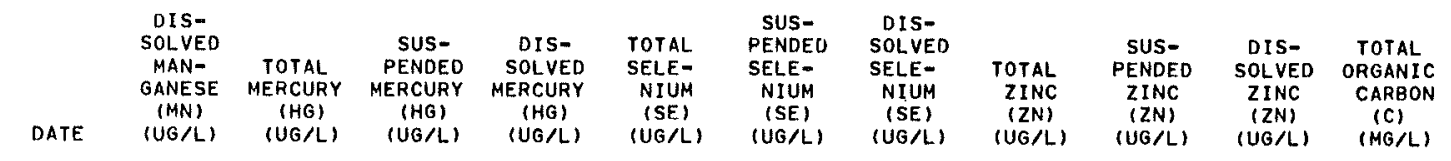
OCT

\begin{tabular}{|c|c|c|c|c|c|c|c|c|c|c|c|}
\hline${ }_{\text {JAN }}^{21} \cdots$ & 5 & .0 & .0 & .0 & - & -- & 0 & 50 & 0 & 50 & -- \\
\hline$\underset{A P R}{20} \cdots$ & 0 & .0 & .0 & .0 & 0 & 0 & 0 & 40 & 10 & 30 & 2.4 \\
\hline JUL $_{U 2}^{27} \cdots$ & 0 & .0 & .0 & .1 & 0 & 0 & 0 & 50 & 0 & 50 & 14 \\
\hline $21 \ldots$ & 30 & .0 & .0 & .0 & 0 & 0 & 0 & 40 & 30 & 10 & 5.1 \\
\hline
\end{tabular}

\begin{tabular}{|c|c|c|c|c|c|c|c|c|c|c|}
\hline DATE & TIME & $\begin{array}{l}\text { TOTAL } \\
\text { ALDRIN } \\
\text { (UG/L) }\end{array}$ & $\begin{array}{l}\text { AL:DR IN } \\
\text { IN } \\
\text { BOTTOM } \\
\text { MA- } \\
\text { TERIAL } \\
\text { (UG/KG) }\end{array}$ & $\begin{array}{l}\text { TOTAL } \\
\text { ATRA- } \\
\text { ZINE } \\
\text { (UG/L) }\end{array}$ & $\begin{array}{l}\text { ATRA- } \\
\text { ZINE IN } \\
\text { BOTTOM } \\
\text { MATERI- } \\
\text { AL (UG/ } \\
\text { KG DRY } \\
\text { SOLIDS) }\end{array}$ & $\begin{array}{l}\text { TOTAL } \\
\text { CHLOR- } \\
\text { OANE } \\
\text { (UG/L) }\end{array}$ & $\begin{array}{l}\text { CHLOR- } \\
\text { DANE } \\
\text { IN } \\
\text { BOTYOM } \\
\text { MA- } \\
\text { TERIAL } \\
\text { (UG/KG) }\end{array}$ & $\begin{array}{l}\text { TOTAL } \\
\text { DOD } \\
\text { (UG/L) }\end{array}$ & $\begin{array}{l}\text { DDD } \\
\text { IN } \\
\text { BOTTOM } \\
\text { MA- } \\
\text { TERIAL } \\
\text { (UG/KG) }\end{array}$ & $\begin{array}{l}\text { TOTAL } \\
\text { DDE } \\
\text { (UG/L) }\end{array}$ \\
\hline $\begin{array}{l}\text { NOV } \\
18 \ldots . .\end{array}$ & 1520 & ND & $=$ & $=$ & $=-$ & ND & $=$ & ND & -- & ND \\
\hline $\begin{array}{l}\text { JUN } \\
21 . . . \\
\text { AUG }\end{array}$ & 1530 & No & ND & ND & No & ND & ND & ND & ND & ND \\
\hline $25 \ldots$ & 1500 & ND & $=$ & ND & $\cdots$ & ND & $-\infty$ & ND & $-\infty$ & ND \\
\hline
\end{tabular}

ND Material specifically analyzed for but not detected. 
10277400 OWENS RIVER BELOW TINEMAHA RESERVOIR, NEAR BIG PINE, CA--Continued

CHEMICAL ANALYSES, HATER YEAR OCTOBER 1975 TO SEPTEMBER 1976

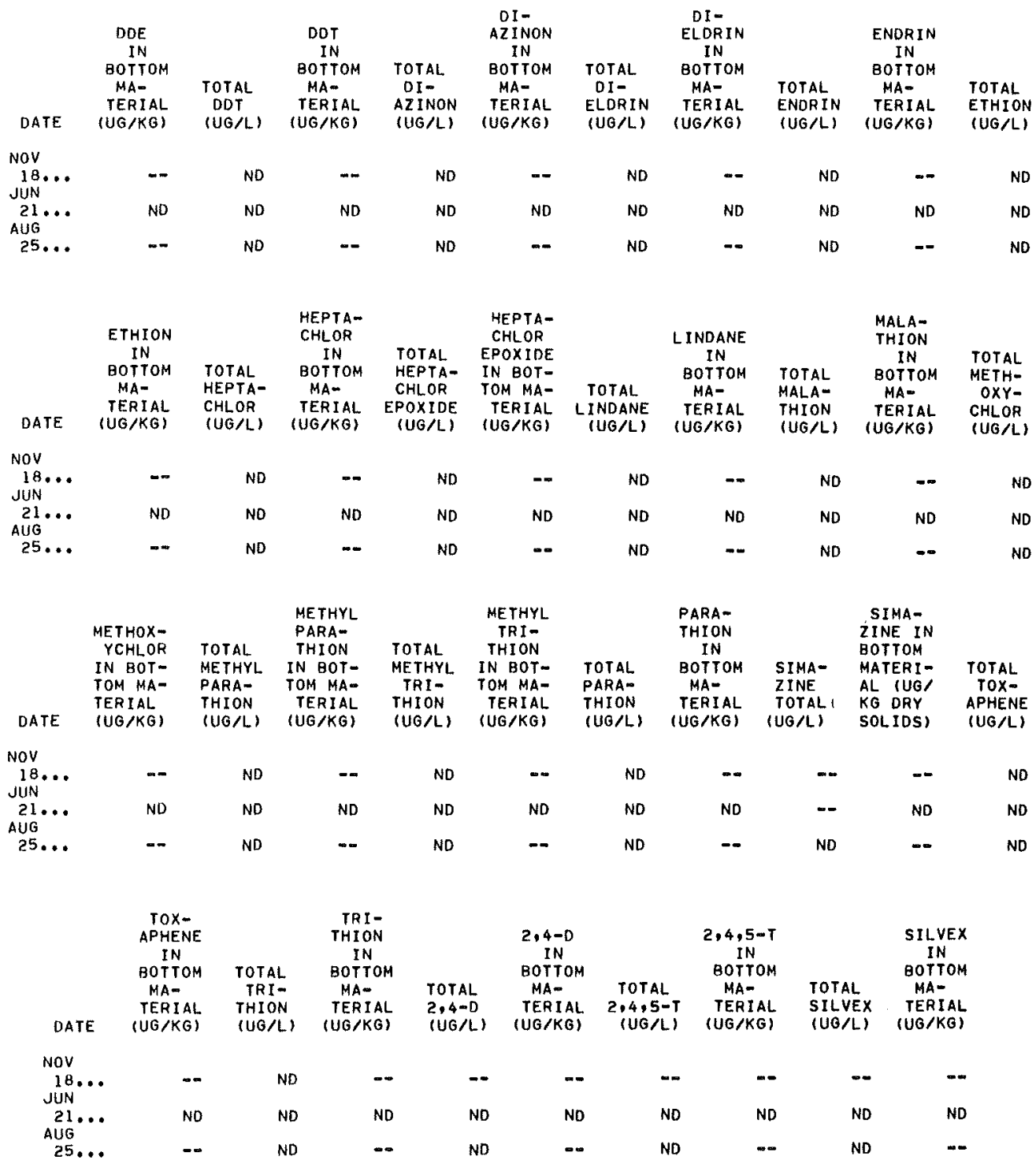

ND Material specifically analyzed for but not detected. 
10277400 OWENS RIVER BELOW TINEMAHA RESERVOIR, NEAR BIG PINE, CA--Continued SPECIFIC CONDUCTANCE (MICROMHOS/CM AT 25 DEG. C), WATER YEAR OCTOBER 1975 TO SEPTEMBER 1976

\begin{tabular}{|c|c|c|c|c|c|c|c|c|c|c|c|c|}
\hline \multirow[b]{2}{*}{ DAY } & \multicolumn{3}{|c|}{ OCTOBER } & \multicolumn{3}{|c|}{ NOVEMBER } & \multicolumn{3}{|c|}{ DECEMBER } & \multicolumn{3}{|c|}{ JANUARY } \\
\hline & MAX & MIN & MEAN & $\operatorname{MAX}$ & MIN & MEAN & $\operatorname{MAX}$ & MIN & MEAN & MAX & MIN & MEAN \\
\hline $\begin{array}{l}1 \\
2 \\
3 \\
4 \\
5\end{array}$ & $\begin{array}{l}251 \\
252 \\
255 \\
256 \\
257\end{array}$ & $\begin{array}{l}242 \\
244 \\
245 \\
253 \\
252\end{array}$ & $\begin{array}{l}246 \\
248 \\
251 \\
255 \\
255\end{array}$ & $\begin{array}{l}263 \\
264 \\
264 \\
262 \\
261\end{array}$ & $\begin{array}{l}260 \\
262 \\
261 \\
260 \\
255\end{array}$ & $\begin{array}{l}262 \\
263 \\
263 \\
261 \\
260\end{array}$ & $\begin{array}{l}267 \\
267 \\
266 \\
266 \\
268\end{array}$ & $\begin{array}{l}264 \\
264 \\
262 \\
264 \\
266\end{array}$ & $\begin{array}{l}266 \\
266 \\
264 \\
265 \\
267\end{array}$ & $\begin{array}{l}275 \\
276 \\
273 \\
274 \\
267\end{array}$ & $\begin{array}{l}272 \\
272 \\
267 \\
262 \\
261\end{array}$ & $\begin{array}{l}273 \\
274 \\
270 \\
267 \\
264\end{array}$ \\
\hline $\begin{array}{r}6 \\
7 \\
8 \\
-9 \\
10\end{array}$ & $\begin{array}{l}257 \\
259 \\
256 \\
257 \\
257\end{array}$ & $\begin{array}{l}252 \\
253 \\
253 \\
254 \\
254\end{array}$ & $\begin{array}{l}254 \\
255 \\
254 \\
255 \\
255\end{array}$ & $\begin{array}{l}264 \\
265 \\
264 \\
264 \\
263\end{array}$ & $\begin{array}{l}260 \\
262 \\
259 \\
260 \\
258\end{array}$ & $\begin{array}{l}262 \\
263 \\
262 \\
262 \\
260\end{array}$ & $\begin{array}{l}269 \\
270 \\
270 \\
272 \\
272\end{array}$ & $\begin{array}{l}267 \\
267 \\
268 \\
269 \\
270\end{array}$ & $\begin{array}{l}268 \\
269 \\
269 \\
270 \\
271\end{array}$ & $\begin{array}{l}269 \\
272 \\
274 \\
273 \\
273\end{array}$ & $\begin{array}{l}262 \\
266 \\
269 \\
271 \\
270\end{array}$ & $\begin{array}{l}266 \\
269 \\
272 \\
272 \\
272\end{array}$ \\
\hline $\begin{array}{l}11 \\
12 \\
13 \\
14 \\
15\end{array}$ & $\begin{array}{l}256 \\
256 \\
255 \\
255 \\
253\end{array}$ & $\begin{array}{l}252 \\
252 \\
251 \\
251 \\
249\end{array}$ & $\begin{array}{l}254 \\
254 \\
254 \\
253 \\
251\end{array}$ & $\begin{array}{l}267 \\
268 \\
268 \\
268 \\
269\end{array}$ & $\begin{array}{l}262 \\
263 \\
262 \\
261 \\
261\end{array}$ & $\begin{array}{l}264 \\
264 \\
265 \\
264 \\
265\end{array}$ & $\begin{array}{l}273 \\
274 \\
275 \\
275 \\
275\end{array}$ & $\begin{array}{l}270 \\
270 \\
271 \\
273 \\
269\end{array}$ & $\begin{array}{l}272 \\
273 \\
273 \\
274 \\
272\end{array}$ & $\begin{array}{l}273 \\
274 \\
273 \\
272 \\
271\end{array}$ & $\begin{array}{l}270 \\
270 \\
270 \\
269 \\
268\end{array}$ & $\begin{array}{l}272 \\
272 \\
271 \\
271 \\
270\end{array}$ \\
\hline $\begin{array}{l}16 \\
17 \\
18 \\
19 \\
20\end{array}$ & $\begin{array}{l}256 \\
255 \\
251 \\
255 \\
258\end{array}$ & $\begin{array}{l}251 \\
247 \\
246 \\
249 \\
253\end{array}$ & $\begin{array}{l}254 \\
251 \\
249 \\
253 \\
255\end{array}$ & $\begin{array}{l}265 \\
265 \\
265 \\
264 \\
264\end{array}$ & $\begin{array}{l}260 \\
260 \\
259 \\
262 \\
262\end{array}$ & $\begin{array}{l}263 \\
263 \\
262 \\
263 \\
264\end{array}$ & $\begin{array}{l}271 \\
273 \\
267 \\
265 \\
265\end{array}$ & $\begin{array}{l}267 \\
260 \\
260 \\
261 \\
258\end{array}$ & $\begin{array}{l}270 \\
270 \\
264 \\
263 \\
262\end{array}$ & $\begin{array}{l}271 \\
272 \\
272 \\
281 \\
284\end{array}$ & $\begin{array}{l}269 \\
270 \\
266 \\
269 \\
275\end{array}$ & $\begin{array}{l}270 \\
271 \\
270 \\
276 \\
280\end{array}$ \\
\hline $\begin{array}{l}21 \\
22 \\
23 \\
24 \\
25\end{array}$ & $\begin{array}{l}255 \\
256 \\
260 \\
262 \\
262\end{array}$ & $\begin{array}{l}249 \\
254 \\
256 \\
259 \\
260\end{array}$ & $\begin{array}{l}252 \\
255 \\
258 \\
260 \\
261\end{array}$ & $\begin{array}{l}265 \\
265 \\
264 \\
263 \\
264\end{array}$ & $\begin{array}{l}261 \\
261 \\
261 \\
260 \\
258\end{array}$ & $\begin{array}{l}263 \\
263 \\
263 \\
262 \\
262\end{array}$ & $\begin{array}{l}264 \\
265 \\
265 \\
265 \\
266\end{array}$ & $\begin{array}{l}259 \\
260 \\
262 \\
262 \\
260\end{array}$ & $\begin{array}{l}262 \\
263 \\
264 \\
263 \\
264\end{array}$ & $\begin{array}{l}284 \\
287 \\
287 \\
289 \\
291\end{array}$ & $\begin{array}{l}280 \\
276 \\
282 \\
282 \\
281\end{array}$ & $\begin{array}{l}282 \\
283 \\
284 \\
284 \\
287\end{array}$ \\
\hline $\begin{array}{l}26 \\
27 \\
28 \\
29 \\
30 \\
31\end{array}$ & $\begin{array}{l}260 \\
262 \\
263 \\
261 \\
265 \\
264\end{array}$ & $\begin{array}{l}254 \\
255 \\
259 \\
252 \\
260 \\
257\end{array}$ & $\begin{array}{l}258 \\
258 \\
261 \\
259 \\
263 \\
261\end{array}$ & $\begin{array}{l}265 \\
265 \\
266 \\
267 \\
267 \\
----\end{array}$ & $\begin{array}{l}262 \\
261 \\
264 \\
265 \\
265 \\
---\end{array}$ & $\begin{array}{l}263 \\
264 \\
265 \\
266 \\
266 \\
--\end{array}$ & $\begin{array}{l}265 \\
265 \\
267 \\
269 \\
271 \\
273\end{array}$ & $\begin{array}{l}262 \\
260 \\
265 \\
265 \\
268 \\
271\end{array}$ & $\begin{array}{l}263 \\
264 \\
266 \\
267 \\
269 \\
272\end{array}$ & $\begin{array}{l}291 \\
290 \\
288 \\
289 \\
292 \\
292\end{array}$ & $\begin{array}{l}286 \\
283 \\
285 \\
282 \\
286 \\
288\end{array}$ & $\begin{array}{l}288 \\
286 \\
287 \\
287 \\
290 \\
290\end{array}$ \\
\hline MONTH & 265 & 242 & 255 & 269 & 255 & 263 & 275 & 258 & 267 & 292 & 261 & 276 \\
\hline \multicolumn{4}{|c|}{ FEBRIJARY } & \multicolumn{3}{|c|}{ MARCH } & \multicolumn{3}{|c|}{ APRIL } & \multicolumn{3}{|c|}{ MAY } \\
\hline DAY & $\operatorname{MAX}$ & MIN & MEAN & $\operatorname{MAX}$ & MIN & MEAN & MAX & MIN & MEAN & $\operatorname{MAX}$ & MIN & MEAN \\
\hline $\begin{array}{l}1 \\
2 \\
3 \\
4 \\
5\end{array}$ & $\begin{array}{l}295 \\
297 \\
297 \\
298 \\
295\end{array}$ & $\begin{array}{l}291 \\
292 \\
291 \\
293 \\
291\end{array}$ & $\begin{array}{l}292 \\
294 \\
295 \\
295 \\
293\end{array}$ & $\begin{array}{l}275 \\
264 \\
312 \\
314 \\
318\end{array}$ & $\begin{array}{l}258 \\
257 \\
254 \\
307 \\
310\end{array}$ & $\begin{array}{l}264 \\
260 \\
280 \\
311 \\
313\end{array}$ & $\begin{array}{l}296 \\
294 \\
295 \\
296 \\
297\end{array}$ & $\begin{array}{l}290 \\
287 \\
288 \\
292 \\
293\end{array}$ & $\begin{array}{l}293 \\
291 \\
291 \\
294 \\
295\end{array}$ & $\begin{array}{l}298 \\
298 \\
298 \\
300 \\
301\end{array}$ & $\begin{array}{l}292 \\
294 \\
295 \\
294 \\
297\end{array}$ & $\begin{array}{l}295 \\
296 \\
297 \\
298 \\
299\end{array}$ \\
\hline $\begin{array}{r}6 \\
7 \\
8 \\
9 \\
10\end{array}$ & $\begin{array}{l}290 \\
291 \\
290 \\
292 \\
291\end{array}$ & $\begin{array}{l}287 \\
290 \\
288 \\
289 \\
287\end{array}$ & $\begin{array}{l}289 \\
291 \\
289 \\
291 \\
290\end{array}$ & $\begin{array}{l}316 \\
310 \\
316 \\
314 \\
315\end{array}$ & $\begin{array}{l}305 \\
302 \\
302 \\
304 \\
300\end{array}$ & $\begin{array}{l}310 \\
306 \\
308 \\
308 \\
305\end{array}$ & $\begin{array}{l}297 \\
296 \\
296 \\
299 \\
300\end{array}$ & $\begin{array}{l}291 \\
292 \\
294 \\
294 \\
296\end{array}$ & $\begin{array}{l}295 \\
294 \\
295 \\
296 \\
298\end{array}$ & $\begin{array}{l}301 \\
302 \\
301 \\
301 \\
300\end{array}$ & $\begin{array}{l}296 \\
297 \\
297 \\
298 \\
297\end{array}$ & $\begin{array}{l}299 \\
300 \\
299 \\
299 \\
299\end{array}$ \\
\hline $\begin{array}{l}11 \\
12 \\
13 \\
14 \\
15\end{array}$ & $\begin{array}{l}294 \\
304 \\
306 \\
333 \\
324\end{array}$ & $\begin{array}{l}290 \\
293 \\
297 \\
298 \\
306\end{array}$ & $\begin{array}{l}292 \\
295 \\
301 \\
310 \\
312\end{array}$ & $\begin{array}{l}304 \\
303 \\
309 \\
306 \\
307\end{array}$ & $\begin{array}{l}299 \\
300 \\
301 \\
299 \\
299\end{array}$ & $\begin{array}{l}302 \\
302 \\
303 \\
303 \\
303\end{array}$ & $\begin{array}{l}300 \\
299 \\
299 \\
299 \\
298\end{array}$ & $\begin{array}{l}297 \\
295 \\
298 \\
296 \\
293\end{array}$ & $\begin{array}{l}299 \\
298 \\
298 \\
297 \\
296\end{array}$ & $\begin{array}{l}304 \\
305 \\
306 \\
303 \\
305\end{array}$ & $\begin{array}{l}299 \\
299 \\
293 \\
293 \\
300\end{array}$ & $\begin{array}{l}301 \\
302 \\
301 \\
300 \\
303\end{array}$ \\
\hline $\begin{array}{l}16 \\
17 \\
18 \\
19 \\
20\end{array}$ & $\begin{array}{l}321 \\
327 \\
327 \\
333 \\
306\end{array}$ & $\begin{array}{l}309 \\
320 \\
323 \\
306 \\
274\end{array}$ & $\begin{array}{l}317 \\
323 \\
324 \\
326 \\
283\end{array}$ & $\begin{array}{l}308 \\
304 \\
303 \\
305 \\
308\end{array}$ & $\begin{array}{l}298 \\
299 \\
299 \\
299 \\
304\end{array}$ & $\begin{array}{l}302 \\
301 \\
301 \\
303 \\
306\end{array}$ & $\begin{array}{l}298 \\
300 \\
300 \\
297 \\
298\end{array}$ & $\begin{array}{l}296 \\
297 \\
295 \\
293 \\
295\end{array}$ & $\begin{array}{l}297 \\
298 \\
297 \\
296 \\
296\end{array}$ & $\begin{array}{l}305 \\
301 \\
299 \\
298 \\
296\end{array}$ & $\begin{array}{l}291 \\
284 \\
291 \\
277 \\
287\end{array}$ & $\begin{array}{l}300 \\
295 \\
296 \\
294 \\
292\end{array}$ \\
\hline $\begin{array}{l}21 \\
22 \\
23 \\
24 \\
25\end{array}$ & $\begin{array}{l}296 \\
293 \\
295 \\
300 \\
294\end{array}$ & $\begin{array}{l}281 \\
282 \\
287 \\
291 \\
287\end{array}$ & $\begin{array}{l}287 \\
289 \\
292 \\
297 \\
291\end{array}$ & $\begin{array}{l}307 \\
306 \\
300 \\
302 \\
298\end{array}$ & $\begin{array}{l}302 \\
293 \\
291 \\
295 \\
294\end{array}$ & $\begin{array}{l}305 \\
301 \\
294 \\
299 \\
296\end{array}$ & $\begin{array}{l}298 \\
299 \\
299 \\
301 \\
303\end{array}$ & $\begin{array}{l}294 \\
295 \\
296 \\
292 \\
295\end{array}$ & $\begin{array}{l}296 \\
297 \\
297 \\
297 \\
297\end{array}$ & $\begin{array}{l}295 \\
296 \\
295 \\
297 \\
296\end{array}$ & $\begin{array}{l}291 \\
288 \\
284 \\
293 \\
291\end{array}$ & $\begin{array}{l}293 \\
293 \\
293 \\
295 \\
294\end{array}$ \\
\hline $\begin{array}{l}26 \\
27 \\
28 \\
29 \\
30 \\
31\end{array}$ & $\begin{array}{l}296 \\
286 \\
275 \\
267 \\
-\infty- \\
---\end{array}$ & $\begin{array}{l}284 \\
269 \\
253 \\
255 \\
--- \\
---\end{array}$ & $\begin{array}{l}288 \\
277 \\
261 \\
259 \\
---\end{array}$ & $\begin{array}{l}298 \\
297 \\
295 \\
294 \\
296 \\
295\end{array}$ & $\begin{array}{l}292 \\
293 \\
291 \\
292 \\
290 \\
285\end{array}$ & $\begin{array}{l}295 \\
295 \\
294 \\
293 \\
294 \\
293\end{array}$ & $\begin{array}{l}306 \\
301 \\
299 \\
298 \\
297 \\
-\infty-0\end{array}$ & $\begin{array}{l}297 \\
294 \\
295 \\
295 \\
294 \\
-\end{array}$ & $\begin{array}{l}300 \\
300 \\
297 \\
296 \\
296 \\
-\end{array}$ & $\begin{array}{l}296 \\
294 \\
294 \\
297 \\
298 \\
301\end{array}$ & $\begin{array}{l}293 \\
280 \\
290 \\
294 \\
291 \\
295\end{array}$ & $\begin{array}{l}295 \\
290 \\
292 \\
295 \\
296 \\
298\end{array}$ \\
\hline MONTH & 333 & 253 & 295 & 318 & 254 & 298 & 306 & 287 & 296 & 306 & 277 & 297 \\
\hline
\end{tabular}


OWENS LAKE BASIN

$10277400^{\circ}$ OWENS RIVER BELOW TINEMAHA RESERVOIR, NEAR BIG PINE, CA--Continued

SPECIFIC CONDUCTANCE (MICROMHOS/CM AT 25 OEG. C), WATER YEAR OCTOBER 1975 TO SEPTEMBER 1976

\begin{tabular}{|c|c|c|c|c|c|c|c|c|c|c|c|c|}
\hline \multirow[b]{2}{*}{ DAY } & \multicolumn{3}{|c|}{ JUNE } & \multicolumn{3}{|c|}{ JULY } & \multicolumn{3}{|c|}{ AUGUST } & \multicolumn{3}{|c|}{ SEPTEMBER } \\
\hline & MAX & MIN & MEAN & $\operatorname{MAX}$ & MIN & MEAN & $\operatorname{MAX}$ & MIN & MEAN & MAX & MIN & MEAN \\
\hline $\begin{array}{l}1 \\
2 \\
3 \\
4 \\
5\end{array}$ & $\begin{array}{l}303 \\
305 \\
306 \\
308 \\
307\end{array}$ & $\begin{array}{l}293 \\
296 \\
292 \\
292 \\
295\end{array}$ & $\begin{array}{l}300 \\
302 \\
300 \\
303 \\
303\end{array}$ & $\begin{array}{l}314 \\
310 \\
311 \\
312 \\
313\end{array}$ & $\begin{array}{l}295 \\
300 \\
301 \\
307 \\
305\end{array}$ & $\begin{array}{l}303 \\
304 \\
306 \\
310 \\
309\end{array}$ & $\begin{array}{l}295 \\
297 \\
301 \\
302 \\
302\end{array}$ & $\begin{array}{l}286 \\
292 \\
293 \\
293 \\
296\end{array}$ & $\begin{array}{l}291 \\
294 \\
297 \\
298 \\
299\end{array}$ & $\begin{array}{l}304 \\
305 \\
305 \\
303 \\
304\end{array}$ & $\begin{array}{l}298 \\
298 \\
298 \\
296 \\
297\end{array}$ & $\begin{array}{l}301 \\
302 \\
302 \\
301 \\
299\end{array}$ \\
\hline $\begin{array}{r}6 \\
7 \\
8 \\
9 \\
10\end{array}$ & $\begin{array}{l}310 \\
313 \\
313 \\
309 \\
312\end{array}$ & $\begin{array}{l}295 \\
292 \\
295 \\
296 \\
303\end{array}$ & $\begin{array}{l}306 \\
305 \\
304 \\
302 \\
309\end{array}$ & $\begin{array}{l}309 \\
303 \\
299 \\
298 \\
294\end{array}$ & $\begin{array}{l}300 \\
294 \\
296 \\
289 \\
287\end{array}$ & $\begin{array}{l}307 \\
299 \\
298 \\
295 \\
291\end{array}$ & $\begin{array}{l}304 \\
301 \\
303 \\
303 \\
303\end{array}$ & $\begin{array}{l}292 \\
294 \\
295 \\
294 \\
295\end{array}$ & $\begin{array}{l}300 \\
299 \\
299 \\
298 \\
299\end{array}$ & $\begin{array}{l}297 \\
299 \\
302 \\
301 \\
303\end{array}$ & $\begin{array}{l}289 \\
292 \\
297 \\
299 \\
294\end{array}$ & $\begin{array}{l}292 \\
295 \\
299 \\
300 \\
299\end{array}$ \\
\hline $\begin{array}{l}11 \\
12 \\
13 \\
14 \\
15\end{array}$ & $\begin{array}{l}315 \\
307 \\
311 \\
309 \\
307\end{array}$ & $\begin{array}{l}300 \\
298 \\
304 \\
303 \\
300\end{array}$ & $\begin{array}{l}309 \\
303 \\
308 \\
307 \\
302\end{array}$ & $\begin{array}{l}296 \\
292 \\
293 \\
295 \\
298\end{array}$ & $\begin{array}{l}287 \\
284 \\
288 \\
288 \\
292\end{array}$ & $\begin{array}{l}291 \\
288 \\
290 \\
292 \\
296\end{array}$ & $\begin{array}{l}302 \\
304 \\
302 \\
304 \\
304\end{array}$ & $\begin{array}{l}296 \\
296 \\
296 \\
298 \\
298\end{array}$ & $\begin{array}{l}299 \\
299 \\
299 \\
301 \\
301\end{array}$ & $\begin{array}{l}293 \\
277 \\
290 \\
291 \\
---\end{array}$ & $\begin{array}{l}270 \\
258 \\
277 \\
281 \\
---\end{array}$ & $\begin{array}{l}279 \\
268 \\
283 \\
285 \\
---\end{array}$ \\
\hline $\begin{array}{l}16 \\
17 \\
18 \\
19 \\
20\end{array}$ & $\begin{array}{l}310 \\
308 \\
307 \\
307 \\
305\end{array}$ & $\begin{array}{l}299 \\
293 \\
291 \\
295 \\
291\end{array}$ & $\begin{array}{l}304 \\
299 \\
299 \\
302 \\
298\end{array}$ & $\begin{array}{l}300 \\
302 \\
301 \\
299 \\
298\end{array}$ & $\begin{array}{l}290 \\
291 \\
294 \\
292 \\
294\end{array}$ & $\begin{array}{l}295 \\
297 \\
298 \\
296 \\
296\end{array}$ & $\begin{array}{l}311 \\
310 \\
305 \\
305 \\
305\end{array}$ & $\begin{array}{l}303 \\
299 \\
303 \\
301 \\
302\end{array}$ & $\begin{array}{l}307 \\
305 \\
304 \\
304 \\
304\end{array}$ & $\begin{array}{l}--- \\
296 \\
300 \\
304\end{array}$ & $\begin{array}{l}--- \\
--- \\
294 \\
294 \\
299\end{array}$ & $\begin{array}{l}-- \\
295 \\
297 \\
301\end{array}$ \\
\hline $\begin{array}{l}21 \\
22 \\
23 \\
24 \\
25\end{array}$ & $\begin{array}{l}319 \\
314 \\
305 \\
308 \\
302\end{array}$ & $\begin{array}{l}291 \\
297 \\
298 \\
294 \\
293\end{array}$ & $\begin{array}{l}298 \\
305 \\
301 \\
299 \\
298\end{array}$ & $\begin{array}{l}306 \\
309 \\
308 \\
303 \\
302\end{array}$ & $\begin{array}{l}299 \\
303 \\
300 \\
295 \\
296\end{array}$ & $\begin{array}{l}303 \\
307 \\
304 \\
300 \\
300\end{array}$ & $\begin{array}{l}306 \\
307 \\
305 \\
303 \\
301\end{array}$ & $\begin{array}{l}303 \\
303 \\
299 \\
297 \\
295\end{array}$ & $\begin{array}{l}305 \\
305 \\
302 \\
300 \\
300\end{array}$ & $\begin{array}{l}303 \\
304 \\
305 \\
--- \\
---\end{array}$ & $\begin{array}{l}299 \\
297 \\
301 \\
--1-\end{array}$ & $\begin{array}{l}301 \\
303 \\
303 \\
-\ldots-\end{array}$ \\
\hline $\begin{array}{l}26 \\
27 \\
28 \\
29 \\
30 \\
31\end{array}$ & $\begin{array}{l}310 \\
303 \\
306 \\
305 \\
306 \\
-\end{array}$ & $\begin{array}{l}295 \\
295 \\
296 \\
297 \\
298 \\
-\end{array}$ & $\begin{array}{l}301 \\
299 \\
300 \\
301 \\
302 \\
-\end{array}$ & $\begin{array}{l}303 \\
302 \\
300 \\
290 \\
290 \\
293\end{array}$ & $\begin{array}{l}295 \\
293 \\
289 \\
283 \\
282 \\
285\end{array}$ & $\begin{array}{l}299 \\
298 \\
295 \\
286 \\
286 \\
289\end{array}$ & $\begin{array}{l}303 \\
301 \\
303 \\
303 \\
302 \\
303\end{array}$ & $\begin{array}{l}293 \\
296 \\
299 \\
298 \\
297 \\
298\end{array}$ & $\begin{array}{l}299 \\
299 \\
301 \\
301 \\
300 \\
301\end{array}$ & 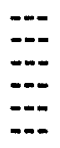 & 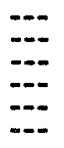 & 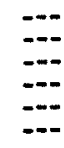 \\
\hline MONTH & 319 & 291 & 302 & 314 & 282 & 298 & 311 & 286 & 300 & -- & $m$ & -- \\
\hline
\end{tabular}

YEAR $\quad 333 \quad 242 \quad 287$

TEMPERATURE (DEG, C) OF WATER, HATER YEAR OCTOBER 1975 TO SEPTEMBER 1976

OCTOBER

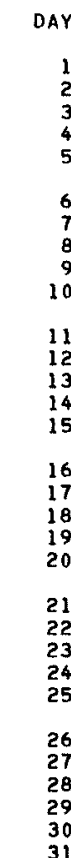

MONTH

\begin{tabular}{|c|c|c|c|c|c|c|c|c|c|c|c|}
\hline \multicolumn{3}{|c|}{ OCTOBER } & \multicolumn{3}{|c|}{ NOVEMBER } & \multicolumn{3}{|c|}{ DECEMBER } & \multicolumn{3}{|c|}{ JANUARY } \\
\hline MAX & MIN & MEAN & MAX & MIN & MEAN & MAX & MIN & MEAN & $\operatorname{MAX}$ & MIN & MEAN \\
\hline $\begin{array}{l}18.0 \\
18.0 \\
18.0 \\
18.0 \\
18.0\end{array}$ & $\begin{array}{l}17.0 \\
16.5 \\
15.5 \\
15.5 \\
15.5\end{array}$ & $\begin{array}{l}17.5 \\
17.0 \\
17.0 \\
17.0 \\
16.5\end{array}$ & $\begin{array}{r}9.0 \\
10.0 \\
10.0 \\
10.0 \\
10.5\end{array}$ & $\begin{array}{l}8.0 \\
8.0 \\
8.5 \\
9.0 \\
9.5\end{array}$ & $\begin{array}{r}8.5 \\
9.0 \\
9.5 \\
9.5 \\
10.0\end{array}$ & $\begin{array}{l}5.5 \\
6.0 \\
7.5 \\
8.0 \\
7.5\end{array}$ & $\begin{array}{l}4.0 \\
4.5 \\
6.0 \\
6.5 \\
6.5\end{array}$ & $\begin{array}{l}4.5 \\
5.5 \\
6.5 \\
7.5 \\
7.0\end{array}$ & $\begin{array}{l}3.0 \\
3.5 \\
3.5 \\
4.0 \\
4.0\end{array}$ & $\begin{array}{l}2.0 \\
1.5 \\
2.5 \\
3.0 \\
3.5\end{array}$ & $\begin{array}{l}2.5 \\
2.5 \\
3.0 \\
3.5 \\
4.0\end{array}$ \\
\hline $\begin{array}{l}17.0 \\
16.0 \\
15.0 \\
14.5 \\
14.5\end{array}$ & $\begin{array}{l}15.0 \\
13.5 \\
12.0 \\
11.5 \\
11.5\end{array}$ & $\begin{array}{l}16.0 \\
14.5 \\
13.5 \\
13.0 \\
12.5\end{array}$ & $\begin{array}{r}10.0 \\
10.0 \\
10.5 \\
10.0 \\
9.5\end{array}$ & $\begin{array}{l}9.5 \\
9.5 \\
9.5 \\
9.5 \\
9.0\end{array}$ & $\begin{array}{r}10.0 \\
9.5 \\
10.0 \\
9.5 \\
9.5\end{array}$ & $\begin{array}{l}8.0 \\
7.0 \\
7.0 \\
7.5 \\
7.5\end{array}$ & $\begin{array}{l}5.0 \\
6.0 \\
6.0 \\
6.0 \\
6.5\end{array}$ & $\begin{array}{l}7.0 \\
6.5 \\
6.5 \\
7.0 \\
7.0\end{array}$ & $\begin{array}{l}4.5 \\
4.5 \\
5.0 \\
4.5 \\
4.5\end{array}$ & $\begin{array}{l}4.0 \\
4.0 \\
4.0 \\
3.5 \\
3.5\end{array}$ & $\begin{array}{l}4.0 \\
4.5 \\
4.5 \\
4.0 \\
4.0\end{array}$ \\
\hline $\begin{array}{l}15.5 \\
14.5 \\
14.0 \\
13.5 \\
14.0\end{array}$ & $\begin{array}{r}12.0 \\
11.5 \\
10.5 \\
9.0 \\
10.5\end{array}$ & $\begin{array}{l}13.5 \\
13.0 \\
11.5 \\
11.0 \\
12.0\end{array}$ & $\begin{array}{l}9.0 \\
8.5 \\
8.5 \\
8.0 \\
8.0\end{array}$ & $\begin{array}{l}8.0 \\
8.0 \\
7.5 \\
7.5 \\
7.5\end{array}$ & $\begin{array}{l}8.5 \\
8.0 \\
8.0 \\
8.0 \\
8.0\end{array}$ & $\begin{array}{l}7.5 \\
7.5 \\
6.5 \\
4.0 \\
4.0\end{array}$ & $\begin{array}{l}6.5 \\
6.5 \\
4.5 \\
2.5 \\
2.5\end{array}$ & $\begin{array}{l}7.5 \\
7.0 \\
6.0 \\
3.0 \\
3.5\end{array}$ & $\begin{array}{l}4.5 \\
5.0 \\
5.0 \\
5.5 \\
5.5\end{array}$ & $\begin{array}{l}4.0 \\
4.5 \\
4.5 \\
4.5 \\
4.0\end{array}$ & $\begin{array}{l}4.5 \\
4.5 \\
5.0 \\
5.0 \\
4.5\end{array}$ \\
\hline $\begin{array}{l}14.0 \\
13.5 \\
12.0 \\
12.0 \\
11.5\end{array}$ & $\begin{array}{l}10.5 \\
10.5 \\
11.0 \\
10.5 \\
10.5\end{array}$ & $\begin{array}{l}12.0 \\
12.0 \\
11.5 \\
11.0 \\
11.0\end{array}$ & $\begin{array}{l}8.5 \\
8.0 \\
7.0 \\
5.0 \\
4.5\end{array}$ & $\begin{array}{l}7.5 \\
7.0 \\
5.5 \\
3.0 \\
4.0\end{array}$ & $\begin{array}{l}8.0 \\
7.5 \\
6.5 \\
4.5 \\
4.5\end{array}$ & $\begin{array}{l}4.0 \\
6.0 \\
6.0 \\
6.0 \\
6.0\end{array}$ & $\begin{array}{l}3.0 \\
3.0 \\
3.5 \\
4.0 \\
4.0\end{array}$ & $\begin{array}{l}3.5 \\
4.5 \\
5.0 \\
5.0 \\
5.0\end{array}$ & $\begin{array}{l}6.0 \\
7.0 \\
7.0 \\
6.5 \\
6.5\end{array}$ & $\begin{array}{l}4.5 \\
6.0 \\
6.0 \\
6.0 \\
5.5\end{array}$ & $\begin{array}{l}5.5 \\
6.0 \\
6.5 \\
6.5 \\
6.0\end{array}$ \\
\hline $\begin{array}{r}12.5 \\
12.5 \\
10.5 \\
9.0 \\
8.5\end{array}$ & $\begin{array}{r}11.0 \\
10.5 \\
8.5 \\
8.0 \\
7.5\end{array}$ & $\begin{array}{r}12.0 \\
11.5 \\
9.5 \\
8.5 \\
8.0\end{array}$ & $\begin{array}{l}4.5 \\
5.0 \\
6.0 \\
6.0 \\
7.0\end{array}$ & $\begin{array}{l}3.5 \\
4.0 \\
4.5 \\
5.0 \\
5.0\end{array}$ & $\begin{array}{l}4.0 \\
4.5 \\
5.0 \\
5.5 \\
6.0\end{array}$ & $\begin{array}{l}6.5 \\
5.5 \\
5.5 \\
8.0 \\
8.0\end{array}$ & $\begin{array}{l}4.0 \\
4.5 \\
4.0 \\
5.0 \\
6.0\end{array}$ & $\begin{array}{l}5.5 \\
5.0 \\
5.0 \\
6.5 \\
6.5\end{array}$ & $\begin{array}{l}6.0 \\
5.5 \\
5.5 \\
6.0 \\
6.0\end{array}$ & $\begin{array}{l}5.0 \\
5.0 \\
5.0 \\
5.0 \\
4.5\end{array}$ & $\begin{array}{l}5.5 \\
5.5 \\
5.0 \\
5.5 \\
5.5\end{array}$ \\
\hline $\begin{array}{r}9.5 \\
10.0 \\
9.5 \\
10.5 \\
10.0 \\
9.5\end{array}$ & $\begin{array}{l}8.0 \\
9.0 \\
8.0 \\
9.0 \\
9.0 \\
8.5\end{array}$ & $\begin{array}{l}8.5 \\
9.5 \\
9.0 \\
9.5 \\
9.5 \\
8.5\end{array}$ & $\begin{array}{l}7.0 \\
7.5 \\
7.0 \\
5.5 \\
5.0 \\
-.-0\end{array}$ & $\begin{array}{l}6.0 \\
6.0 \\
5.0 \\
4.5 \\
4.5 \\
-.-\end{array}$ & $\begin{array}{l}6.5 \\
6.5 \\
6.0 \\
5.0 \\
4.5 \\
-.-\end{array}$ & $\begin{array}{l}7.0 \\
6.5 \\
8.0 \\
9.0 \\
8.0 \\
5.5\end{array}$ & $\begin{array}{l}6.0 \\
5.5 \\
6.0 \\
7.0 \\
5.5 \\
3.0\end{array}$ & $\begin{array}{l}6.5 \\
6.0 \\
7.0 \\
8.0 \\
7.0 \\
4.0\end{array}$ & $\begin{array}{l}5.5 \\
5.5 \\
6.0 \\
6.5 \\
7.0 \\
7.5\end{array}$ & $\begin{array}{l}5.0 \\
4.5 \\
5.0 \\
5.5 \\
6.0 \\
6.0\end{array}$ & $\begin{array}{l}5.5 \\
5.5 \\
5.5 \\
6.0 \\
6.5 \\
6.5\end{array}$ \\
\hline 18.0 & 7.5 & 12.0 & 10.5 & 3.0 & 7.5 & 9.0 & 2.5 & 6.0 & 7.5 & 1.5 & 5.0 \\
\hline
\end{tabular}


10277400 OWENS RIVER BELOW TINEMAHA RESERVOIR, NEAR BIG PINE, CA--Continued

TEMPERATURE (DEG. C) OF HATER, WATER YEAR OCTOBER 1975 TO SEPTEMBER 1976

\begin{tabular}{|c|c|c|c|c|c|c|c|c|c|c|c|c|}
\hline \multirow[b]{2}{*}{ DAY } & \multicolumn{3}{|c|}{ FEBRUARY } & \multicolumn{3}{|c|}{ MARCH } & \multicolumn{3}{|c|}{ APRIL } & \multicolumn{3}{|c|}{ HAY } \\
\hline & $\max$ & MIN & MEAN & $\max$ & MIN & MEAN & $\max$ & MIN & MEAN & $\max$ & MIN & MEAN \\
\hline $\begin{array}{l}1 \\
2 \\
3 \\
4 \\
5\end{array}$ & $\begin{array}{l}8.0 \\
7.5 \\
8.0 \\
7.0 \\
6.0\end{array}$ & $\begin{array}{l}6.5 \\
7.0 \\
6.5 \\
6.5 \\
4.0\end{array}$ & $\begin{array}{l}7.0 \\
7: 5 \\
7: 0 \\
7: 0 \\
5: 5\end{array}$ & $\begin{array}{l}8.5 \\
7.5 \\
6.5 \\
6.0 \\
5.5\end{array}$ & $\begin{array}{l}7.5 \\
6.5 \\
5.5 \\
5.0 \\
4.5\end{array}$ & $\begin{array}{l}8.0 \\
7: 0 \\
6.0 \\
5.5 \\
5.0\end{array}$ & $\begin{array}{l}11.5 \\
12.5 \\
12.0 \\
11.5 \\
11.0\end{array}$ & $\begin{array}{l}10.0 \\
10.5 \\
11: 5 \\
10.0 \\
10.5\end{array}$ & $\begin{array}{l}11100 \\
11: 5 \\
11: 5 \\
11: 0 \\
10.5\end{array}$ & $\begin{array}{l}17: 0 \\
17: 0 \\
17: 0 \\
17: 0 \\
17: 0\end{array}$ & $\begin{array}{l}14.5 \\
15.5 \\
16.0 \\
16.0 \\
16.0\end{array}$ & $\begin{array}{l}16.0 \\
16.5 \\
16.5 \\
16.5 \\
16.5\end{array}$ \\
\hline $\begin{array}{r}6 \\
7 \\
8 \\
9 \\
10\end{array}$ & $\begin{array}{l}4.0 \\
2.5 \\
4.5 \\
5.5 \\
5.5\end{array}$ & $\begin{array}{l}2.0 \\
2.0 \\
2.5 \\
4.0 \\
3.5\end{array}$ & $\begin{array}{l}3.0 \\
2.5 \\
3.0 \\
5.0 \\
4.5\end{array}$ & $\begin{array}{l}5.5 \\
6.0 \\
6.5 \\
7.5 \\
8.5\end{array}$ & $\begin{array}{l}4.5 \\
4.5 \\
5.5 \\
6.0 \\
6.5\end{array}$ & $\begin{array}{l}5.0 \\
5.5 \\
6.0 \\
7.0 \\
7.5\end{array}$ & $\begin{array}{l}12.0 \\
13.0 \\
12.0 \\
11.5 \\
12.0\end{array}$ & $\begin{array}{l}10.5 \\
11.0 \\
10.5 \\
10.5 \\
11.0\end{array}$ & $\begin{array}{l}11.0 \\
11: 0 \\
11: 0 \\
11: 0 \\
11.5\end{array}$ & $\begin{array}{l}16.0 \\
14: 0 \\
15: 0 \\
17: 0 \\
17.5\end{array}$ & $\begin{array}{l}14.5 \\
13.0 \\
13.5 \\
15.0 \\
16.0\end{array}$ & $\begin{array}{l}15.5 \\
13.5 \\
14.0 \\
16.0 \\
17.0\end{array}$ \\
\hline $\begin{array}{l}11 \\
12 \\
13 \\
14 \\
15\end{array}$ & $\begin{array}{l}6.0 \\
6.5 \\
6.0 \\
7.5 \\
7.5\end{array}$ & $\begin{array}{l}4.5 \\
5.0 \\
5.5 \\
6.0 \\
6.5\end{array}$ & $\begin{array}{l}5.5 \\
5.5 \\
6.0 \\
6.5 \\
7.0\end{array}$ & $\begin{array}{r}9.0 \\
8.0 \\
8.0 \\
8.5 \\
10.0\end{array}$ & $\begin{array}{l}8.0 \\
7.5 \\
7.5 \\
7.5 \\
8.0\end{array}$ & $\begin{array}{l}8.5 \\
8.0 \\
8.0 \\
8.5 \\
9.0\end{array}$ & $\begin{array}{l}11.0 \\
11: 5 \\
11: 0 \\
11: 0 \\
10.5\end{array}$ & $\begin{array}{r}10.0 \\
10.0 \\
10.5 \\
10.0 \\
9.0\end{array}$ & $\begin{array}{l}10.5 \\
11: 0 \\
11: 0 \\
10.5 \\
10.0\end{array}$ & $\begin{array}{l}20.0 \\
19.5 \\
19.5 \\
20.0 \\
19.5\end{array}$ & $\begin{array}{l}17.5 \\
18.0 \\
18.5 \\
19.0 \\
18.5\end{array}$ & $\begin{array}{l}18.5 \\
18.5 \\
19.0 \\
19.5 \\
19.0\end{array}$ \\
\hline $\begin{array}{l}16 \\
17 \\
18 \\
19 \\
20\end{array}$ & $\begin{array}{l}8.0 \\
7: 5 \\
7.5 \\
7: 5 \\
6: 5\end{array}$ & $\begin{array}{l}6.5 \\
7.0 \\
7.0 \\
6.5 \\
5.5\end{array}$ & $\begin{array}{l}7.5 \\
7.5 \\
7.5 \\
7.5 \\
6.0\end{array}$ & $\begin{array}{l}11.0 \\
12.0 \\
12.0 \\
11.5 \\
11.0\end{array}$ & $\begin{array}{r}9.5 \\
10.0 \\
11.0 \\
10.5 \\
9.5\end{array}$ & $\begin{array}{l}10.0 \\
11.0 \\
11.5 \\
11.0 \\
10.0\end{array}$ & $\begin{array}{r}9.0 \\
9.0 \\
9.5 \\
11.0 \\
13.5\end{array}$ & $\begin{array}{r}6.5 \\
6.5 \\
7.5 \\
9.0 \\
10.0\end{array}$ & $\begin{array}{r}8.0 \\
7.5 \\
8.5 \\
10.0 \\
11.5\end{array}$ & $\begin{array}{l}20.0 \\
20.0 \\
20.0 \\
19.5 \\
19.5\end{array}$ & $\begin{array}{l}18.5 \\
19.5 \\
19.0 \\
19.0 \\
18.5\end{array}$ & $\begin{array}{l}19.5 \\
20.0 \\
19.5 \\
19.0 \\
19.0\end{array}$ \\
\hline $\begin{array}{l}21 \\
22 \\
23 \\
24 \\
25\end{array}$ & $\begin{array}{l}6.5 \\
7.0 \\
6.5 \\
7.0 \\
7.0\end{array}$ & $\begin{array}{l}5.5 \\
6.0 \\
6.0 \\
6.0 \\
6.5\end{array}$ & $\begin{array}{l}6.0 \\
6.5 \\
6.0 \\
6.5 \\
6.5\end{array}$ & $\begin{array}{l}11.5 \\
11.0 \\
13.5 \\
12.5 \\
12.0\end{array}$ & $\begin{array}{r}9.0 \\
10.0 \\
10.5 \\
11.0 \\
10.0\end{array}$ & $\begin{array}{l}10.0 \\
10.5 \\
11.5 \\
11.5 \\
11.0\end{array}$ & $\begin{array}{l}14.5 \\
16.0 \\
16.0 \\
16.0 \\
15.5\end{array}$ & $\begin{array}{l}13.0 \\
13.0 \\
14.0 \\
15.0 \\
14.0\end{array}$ & $\begin{array}{l}13.5 \\
14.5 \\
15.0 \\
15.5 \\
15.0\end{array}$ & $\begin{array}{l}18.5 \\
19.0 \\
19.0 \\
20.5 \\
20.5\end{array}$ & $\begin{array}{l}18.0 \\
17.5 \\
18.5 \\
18.0 \\
18.0\end{array}$ & $\begin{array}{l}18.5 \\
18.0 \\
18.5 \\
1990 \\
19.0\end{array}$ \\
\hline $\begin{array}{l}26 \\
27 \\
28 \\
29 \\
30 \\
31\end{array}$ & $\begin{array}{r}8.5 \\
8.5 \\
9.5 \\
8.5 \\
\hdashline-.\end{array}$ & \begin{tabular}{l}
6.5 \\
7.0 \\
7.5 \\
8.5 \\
\hdashline-
\end{tabular} & \begin{tabular}{l}
7.0 \\
7.5 \\
8.5 \\
8.5 \\
\hdashline.-
\end{tabular} & $\begin{array}{l}10.5 \\
11: 0 \\
11: 0 \\
10.0 \\
11: 0 \\
11.5\end{array}$ & $\begin{array}{r}9.5 \\
10.0 \\
9.5 \\
8.5 \\
9.0 \\
10.0\end{array}$ & $\begin{array}{r}10.0 \\
10.5 \\
10.0 \\
99.5 \\
9.5 \\
10.5\end{array}$ & $\begin{array}{r}14.0 \\
13.0 \\
13.5 \\
15.0 \\
15.0 \\
\cdots \cdots\end{array}$ & $\begin{array}{l}12.0 \\
11.5 \\
12.0 \\
12.5 \\
14: 0 \\
\cdots\end{array}$ & $\begin{array}{r}13.0 \\
12.0 \\
12.5 \\
13.5 \\
14.5 \\
\therefore .5\end{array}$ & $\begin{array}{l}20.0 \\
21.0 \\
21.0 \\
20.5 \\
20.0 \\
21.0\end{array}$ & $\begin{array}{l}18.5 \\
19.5 \\
19.0 \\
19.0 \\
18.5 \\
19.0\end{array}$ & $\begin{array}{l}19.0 \\
20.0 \\
20.0 \\
19.5 \\
19.5 \\
19.5\end{array}$ \\
\hline MONTH & 9.5 & 2.0 & 6.5 & 13.5 & 4.5 & 9.0 & 16.0 & 6.5 & 11.5 & 21.0 & 13.0 & 18.0 \\
\hline
\end{tabular}

TEMPERATURE (OEG. C) OF WATER, WATER YEAR OCTOBER 1975 TO SEPTEMBER 1976

\begin{tabular}{|c|c|c|c|c|c|c|c|c|c|c|c|c|}
\hline \multirow[b]{2}{*}{ DAY } & \multicolumn{3}{|c|}{ JUNE } & \multicolumn{3}{|c|}{ JULY } & \multicolumn{3}{|c|}{ AUGUST } & \multicolumn{3}{|c|}{ SEPTEMBER } \\
\hline & $\max$ & $M I N$ & MEAN & $\operatorname{MAX}$ & MIN & MEAN & $\max$ & MIN & MEAN & $\operatorname{MAX}$ & MIN & MEAN \\
\hline $\begin{array}{l}1 \\
2 \\
3 \\
4 \\
5\end{array}$ & $\begin{array}{l}21.0 \\
220.5 \\
200 \\
200 \\
20.0\end{array}$ & $\begin{array}{l}19.0 \\
19.5 \\
19.0 \\
18.5 \\
18.5\end{array}$ & $\begin{array}{l}20.0 \\
20.0 \\
19.5 \\
19.5 \\
19.5\end{array}$ & $\begin{array}{l}22.0 \\
22.5 \\
22.0 \\
23.5 \\
24.0\end{array}$ & $\begin{array}{l}18.0 \\
18.0 \\
18.5 \\
18.5 \\
19.0\end{array}$ & $\begin{array}{l}19.5 \\
19.5 \\
200.0 \\
200.5 \\
21.0\end{array}$ & $\begin{array}{l}22.0 \\
21.5 \\
22.0 \\
22.0 \\
22.0\end{array}$ & $\begin{array}{l}19.0 \\
18.5 \\
18.0 \\
17.5 \\
18.5\end{array}$ & $\begin{array}{l}20.5 \\
19.5 \\
20.0 \\
19.5 \\
20.0\end{array}$ & $\begin{array}{l}23.0 \\
22.5 \\
22.5 \\
22.5 \\
20.5\end{array}$ & $\begin{array}{l}18.5 \\
18.5 \\
18.5 \\
19.0 \\
19.0\end{array}$ & $\begin{array}{l}20.5 \\
20.0 \\
20.0 \\
20.5 \\
19.5\end{array}$ \\
\hline $\begin{array}{r}6 \\
7 \\
8 \\
9 \\
10\end{array}$ & $\begin{array}{l}20.5 \\
199.5 \\
118.5 \\
17.5 \\
15.5\end{array}$ & $\begin{array}{l}18.5 \\
18.0 \\
16.0 \\
14.5 \\
14.5\end{array}$ & $\begin{array}{l}19.5 \\
18.5 \\
17.0 \\
16.0 \\
15.0\end{array}$ & $\begin{array}{l}24.0 \\
24.0 \\
24.5 \\
24.0 \\
24.5\end{array}$ & $\begin{array}{l}19.5 \\
19.0 \\
19.0 \\
19.0 \\
20.0\end{array}$ & $\begin{array}{l}21.5 \\
21.5 \\
22.5 \\
21.5 \\
22.0\end{array}$ & $\begin{array}{l}21.5 \\
22.0 \\
22.5 \\
23.0 \\
22.5\end{array}$ & $\begin{array}{l}18.0 \\
18.0 \\
18.5 \\
19.0 \\
19.0\end{array}$ & $\begin{array}{l}19.5 \\
20.0 \\
20.5 \\
20.5 \\
20.5\end{array}$ & $\begin{array}{l}21.5 \\
22.0 \\
22.5 \\
20.0 \\
19.0\end{array}$ & $\begin{array}{l}18.0 \\
17.5 \\
18.0 \\
18.0 \\
18.0\end{array}$ & $\begin{array}{l}19.0 \\
19.5 \\
20.0 \\
19.0 \\
18.5\end{array}$ \\
\hline $\begin{array}{l}11 \\
12 \\
13 \\
14 \\
15\end{array}$ & $\begin{array}{l}18.0 \\
200 \\
20.5 \\
18.5 \\
21.0\end{array}$ & $\begin{array}{l}14.0 \\
16.5 \\
17.5 \\
16.0 \\
17.0\end{array}$ & $\begin{array}{l}16.0 \\
18.0 \\
19,0 \\
17.5 \\
19.0\end{array}$ & $\begin{array}{l}24.5 \\
24.0 \\
24.0 \\
24: 5 \\
25.0\end{array}$ & $\begin{array}{l}20.0 \\
19.0 \\
19.5 \\
20.0 \\
20.5\end{array}$ & $\begin{array}{l}22.0 \\
21.5 \\
21.5 \\
22.0 \\
22.0\end{array}$ & $\begin{array}{l}23.0 \\
23.0 \\
23.0 \\
2005 \\
20.0\end{array}$ & $\begin{array}{l}19.0 \\
1990 \\
19.0 \\
1900 \\
17.5\end{array}$ & $\begin{array}{l}20.5 \\
21.0 \\
21.0 \\
20.0 \\
19.0\end{array}$ & $\begin{array}{r}19.5 \\
20.0 \\
20.0 \\
20.0 \\
\ldots\end{array}$ & $\begin{array}{r}17.5 \\
17.5 \\
18.5 \\
19.0 \\
-\ldots 0\end{array}$ & $\begin{array}{r}18.5 \\
18.5 \\
19.5 \\
19.5 \\
-\because-9\end{array}$ \\
\hline $\begin{array}{l}16 \\
17 \\
18 \\
19 \\
20\end{array}$ & $\begin{array}{l}23.5 \\
22.5 \\
23.0 \\
22.5 \\
22.0\end{array}$ & $\begin{array}{l}18.0 \\
18.5 \\
19.5 \\
19.5 \\
19.0\end{array}$ & $\begin{array}{l}20.0 \\
20.5 \\
21.0 \\
21.0 \\
20.5\end{array}$ & $\begin{array}{l}21.5 \\
23.5 \\
24.5 \\
24.0 \\
22.5\end{array}$ & $\begin{array}{l}20.0 \\
19.0 \\
19.0 \\
19.0 \\
19.5\end{array}$ & $\begin{array}{l}20.5 \\
21.0 \\
211.5 \\
21.5 \\
20.5\end{array}$ & $\begin{array}{l}20.5 \\
20.5 \\
19.5 \\
19.5 \\
21.0\end{array}$ & $\begin{array}{l}17.0 \\
1770 \\
1770 \\
17: 0 \\
16.0\end{array}$ & $\begin{array}{l}18.5 \\
18.5 \\
18.0 \\
18.0 \\
18.5\end{array}$ & $\begin{array}{r}\cdots \\
18.0 \\
18.5 \\
18.5\end{array}$ & $\begin{array}{l}\ldots . . \\
17.0 \\
17 \% 5 \\
17.5\end{array}$ & $\begin{array}{r}\cdots \\
17.5 \\
18.0 \\
18.0\end{array}$ \\
\hline $\begin{array}{l}21 \\
22 \\
23 \\
24 \\
25\end{array}$ & $\begin{array}{l}22.0 \\
200.0 \\
20.0 \\
22.0 \\
22.5\end{array}$ & $\begin{array}{l}19.0 \\
17.0 \\
17.0 \\
17.0 \\
18.5\end{array}$ & $\begin{array}{l}20.0 \\
18.5 \\
18.5 \\
19.5 \\
20.5\end{array}$ & $\begin{array}{r}24.0 \\
23.0 \\
25.0 \\
25.5 \\
25.0\end{array}$ & $\begin{array}{r}20.0 \\
20.5 \\
20.0 \\
21.5\end{array}$ & $\begin{array}{l}21.5 \\
21.5 \\
21.5 \\
22.5 \\
24.0\end{array}$ & $\begin{array}{l}21.0 \\
20.5 \\
21.5 \\
21.5 \\
22.0\end{array}$ & $\begin{array}{l}17.5 \\
1770 \\
1770 \\
17 \% 5 \\
18.0\end{array}$ & $\begin{array}{l}19.0 \\
18.5 \\
19.0 \\
19: 0 \\
19.0\end{array}$ & $\begin{array}{r}18.0 \\
18.5 \\
19.0 \\
0.0 \\
\ldots .0\end{array}$ & \begin{tabular}{r}
17.0 \\
17.5 \\
17.5 \\
\hdashline$\ldots$ \\
0.5
\end{tabular} & $\begin{array}{r}17.5 \\
18.0 \\
18.5 \\
\cdots \\
\cdots\end{array}$ \\
\hline $\begin{array}{l}26 \\
27 \\
28 \\
29 \\
30 \\
31\end{array}$ & $\begin{array}{r}22.5 \\
23.5 \\
22.0 \\
22.0 \\
22.0 \\
-. .\end{array}$ & $\begin{array}{r}19.0 \\
19.5 \\
20.0 \\
19.5 \\
18.5 \\
-0.0\end{array}$ & $\begin{array}{r}20.5 \\
21.0 \\
21.0 \\
20.5 \\
20.0 \\
\ldots\end{array}$ & $\begin{array}{l}25.0 \\
23.0 \\
24.5 \\
23.5 \\
22.5 \\
21.0\end{array}$ & $\begin{array}{l}21.5 \\
21.5 \\
21.0 \\
21.0 \\
21.0 \\
19.5\end{array}$ & $\begin{array}{l}23.0 \\
22.0 \\
22.5 \\
22.0 \\
21.5 \\
20.0\end{array}$ & $\begin{array}{l}23.0 \\
22.0 \\
22.5 \\
23.0 \\
23.5 \\
23.0\end{array}$ & $\begin{array}{l}18.0 \\
17.5 \\
18.0 \\
18.5 \\
18.5 \\
18.5\end{array}$ & $\begin{array}{l}20.0 \\
19.5 \\
200.0 \\
20.5 \\
20.5 \\
20.5\end{array}$ & 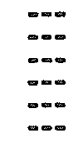 & $\begin{array}{l}\cdots \\
\cdots \\
\infty \\
\infty \\
\infty\end{array}$ & $\begin{array}{l}\cdots \\
\cdots \\
\cdots \\
\cdots \\
\cdots \\
\cdots \infty\end{array}$ \\
\hline ONTH & 23.5 & 14.0 & 19.0 & 25.5 & 18.0 & 21.5 & 23.5 & 16.0 & 19.5 & $\cdots$ & $\ldots$ & $m$ \\
\hline
\end{tabular}


10277400 OWENS RIVER BELOW TINEMAHA RESERVOIR, NEAR BIG PINE, CA - Continued

PARTICLE-SIZE DISTRIBUTTON OF SUSPENDED SEDIMENT, WATER YEAR OCTOBER 1975 TO SEPTEMBER 1976

\begin{tabular}{|c|c|c|c|c|c|c|c|}
\hline DATE & TIME & $\begin{array}{l}\text { INSTAN- } \\
\text { TANEOUS } \\
\text { DIS- } \\
\text { CHARGE } \\
\text { (CFS) }\end{array}$ & $\begin{array}{l}\text { TEMPER- } \\
\text { ATURE } \\
\text { (DEG C) }\end{array}$ & $\begin{array}{l}\text { SUS - } \\
\text { PENDED } \\
\text { SEDI - } \\
\text { MENT } \\
\text { (MG/L) }\end{array}$ & $\begin{array}{c}\text { SUS- } \\
\text { PENDED } \\
\text { SEDI- } \\
\text { MENT } \\
\text { DIS- } \\
\text { CHARGE } \\
\text { (T/OAY) }\end{array}$ & $\begin{array}{r}\text { SUS } \\
\text { SED } \\
\text { SIEVE } \\
\text { DIAM } \\
\text { X FINE } \\
\text { THAI } \\
\text { O62 }\end{array}$ & $\begin{array}{l}\text { E } \\
\text { ER } \\
\text { MM }\end{array}$ \\
\hline $\begin{array}{l}\text { OCT } \\
21 . \cdots \\
\text { NOV }\end{array}$ & 1510 & 250 & 13.2 & 20 & 14 & & 74 \\
\hline DEC & 1520 & 600 & 5.6 & 41 & 66 & & 82 \\
\hline JAN 17 & 1530 & 700 & 5.3 & 6 & 11 & & 81 \\
\hline$\underset{F E B}{20} \cdots$ & 1515 & 400 & 6.4 & 14 & 15 & & 91 \\
\hline$\underset{M A R}{25 \cdots}$ & 1445 & 400 & 7.2 & 21 & 23 & & 85 \\
\hline${ }_{A P R}^{31} \cdots$ & 1410 & 500 & 12.2 & 46 & 62 & & 80 \\
\hline MAY $27 \ldots$ & 1505 & 500 & 12.3 & 46 & 62 & & 47 \\
\hline $\begin{array}{l}19 \ldots \\
\text { JUN }\end{array}$ & 1610 & 450 & 19.6 & 34 & 41 & & 80 \\
\hline $\begin{array}{l}21 \cdots \\
\text { JUL }\end{array}$ & 1515 & 553 & 23.0 & 53 & 79 & & 82 \\
\hline${ }_{A \cup G}^{21} \cdots$ & 1505 & 665 & 23.5 & 46 & 83 & & 81 \\
\hline $\begin{array}{l}25 \ldots \\
\text { SEP }\end{array}$ & 1430 & 675 & 22.0 & 34 & 62 & & 77 \\
\hline $22 \ldots$ & 1630 & 805 & 18.5 & 21 & 46 & & $=$ \\
\hline
\end{tabular}


LOCATION.--Lat $34^{\circ} 18^{\prime} 46^{\prime \prime}$, long $118^{\circ} 29^{\prime} 32^{\prime \prime}$ (unsurveyed), Los Angeles County, in Mission de San Fernando substation at Los Angeles Aqueduct outlet at upper end of Van Norman Lake, at San Fernando.

PERIOD OF RECORD, - - Chemical analyses: Water year 1967 (partial-record station), water year 1968 to current year. REMARKS. - - Records of discharge furnished by Los Angeles Department of Water and Power.

COOPERATION. - Chemical-quality records furnished by California Department of Water Resources.

CHEMICAL ANALYSES, WATER YEAR OCTOBER 1975 TO SEPTEMBER 1976

\begin{tabular}{|c|c|c|c|c|c|c|c|c|c|}
\hline DATE & $\begin{array}{l}\text { SPE- } \\
\text { CIFIC } \\
\text { CON- } \\
\text { DUCT- } \\
\text { ANCE } \\
\text { (MICRO- } \\
\text { MHOS) }\end{array}$ & $\begin{array}{c}\text { PH } \\
\text { (UNITS) }\end{array}$ & $\begin{array}{l}\text { TEMPER- } \\
\text { ATURE } \\
\text { (DEG C) }\end{array}$ & $\begin{array}{l}\text { TUR- } \\
\text { BID- } \\
\text { ITY } \\
\text { (JTU) }\end{array}$ & $\begin{array}{l}\text { DIS- } \\
\text { SOLVED } \\
\text { OXYGEN } \\
\text { (MG/L) }\end{array}$ & $\begin{array}{l}\text { BIO- } \\
\text { CHEM- } \\
\text { ICAL } \\
\text { OXYGEN } \\
\text { DEMAND } \\
5 \text { DAY } \\
\text { (MG/L) }\end{array}$ & $\begin{array}{l}\text { HAKD- } \\
\text { NESS } \\
\text { (CA,MG) } \\
\text { (MG/L) }\end{array}$ & $\begin{array}{l}\text { DIS- } \\
\text { SOLVED } \\
\text { CAL- } \\
\text { CIUM } \\
\text { (CA) } \\
\text { (MG/L) }\end{array}$ & $\begin{array}{l}\text { DIS- } \\
\text { SOLVED } \\
\text { MAG- } \\
\text { NE- } \\
\text { SIUM } \\
\text { (MG) } \\
(M G / L)\end{array}$ \\
\hline $\begin{array}{l}\text { OCT } \\
21 \ldots . \\
\text { NOY }\end{array}$ & 332 & -- & 17.0 & 2 & 9.0 & 1.3 & $\mathbf{B B}$ & .26 & 5.9 \\
\hline$\underset{D E C}{30} \cdots$ & 293 & 8.1 & 11.0 & 4 & 10.2 & 1.4 & 80 & 24 & 4.9 \\
\hline $\begin{array}{l}23 . . . \\
\text { JAN }\end{array}$ & 394 & 8.0 & 8.0 & 4 & 8.4 & 3.4 & 80 & 24 & 4.9 \\
\hline$\underset{F E B}{22} \cdots$ & 303 & 8.0 & 7.0 & 3 & 10.2 & 2.5 & 82 & 25 & 4.9 \\
\hline$\underset{\text { MAR }}{17} \cdots$ & 295 & 7.6 & 7.0 & 3 & 10.2 & 1.9 & 82 & 24 & 5.4 \\
\hline$\stackrel{22}{22} \cdots$ & 319 & 7.8 & 10.0 & 4 & 10.4 & 1.7 & 86 & 25 & 5.6 \\
\hline $20 \ldots$ & 326 & 7.8 & 12.0 & 3 & 9,6 & .8 & 88 & 26 & 5.9 \\
\hline$\underset{J U N}{17 \ldots}$ & 327 & 7.9 & 16.0 & 4 & 7.8 & 1.4 & 86 & 25 & 5.6 \\
\hline $\begin{array}{l}21 \cdots \\
\text { JUL }\end{array}$ & 324 & 8.1 & 19.0 & 2 & 8.2 & .6 & 85 & 25 & 5.6 \\
\hline $\begin{array}{l}28 \cdots \\
\text { AU6 }\end{array}$ & 329 & 8.2 & 23.5 & 2 & 7.6 & 1.6 & 84 & 25 & 5.4 \\
\hline $\begin{array}{l}30 \ldots \\
\text { SEP }\end{array}$ & 320 & 8.3 & 23.0 & 1 & 8,0 & $1 \cdot 3$ & 80 & 23 & 5.4 \\
\hline $27 \ldots$ & 329 & - & $\infty$ & 2 & - & 1.5 & 84 & 25 & 5.4 \\
\hline
\end{tabular}

DATE (NA)

\begin{tabular}{|c|c|c|c|c|c|c|c|c|}
\hline $\begin{array}{l}\text { DIS- } \\
\text { SOLVED } \\
\text { SODIUM } \\
\text { (NA) }\end{array}$ & $\begin{array}{l}\text { PERCENT } \\
\text { SODIUM }\end{array}$ & $\begin{array}{l}\text { SOOIUH } \\
\text { AD- } \\
\text { SORP- } \\
\text { TION } \\
\text { RATIO }\end{array}$ & $\begin{array}{l}\text { DIS- } \\
\text { SOLVED } \\
\text { PO- } \\
\text { TAS- } \\
\text { SIUM } \\
\text { (K) } \\
\text { (MGL) }\end{array}$ & $\begin{array}{c}\text { ALKA- } \\
\text { LINITY } \\
\text { AS } \\
\text { CACO3 } \\
\text { (HG } / L)\end{array}$ & $\begin{array}{l}\text { DIS- } \\
\text { SOLVED } \\
\text { SULFATE } \\
\text { (SOA) } \\
\text { (MG/L) }\end{array}$ & $\begin{array}{l}\text { DIS- } \\
\text { SOLVED } \\
\text { CHLO- } \\
\text { RIDE } \\
\text { (CL) } \\
\text { (HG/L) }\end{array}$ & $\begin{array}{l}\text { DIS- } \\
\text { SOLVEO } \\
\text { FLUO- } \\
\text { RIDE } \\
\text { (F) } \\
(M G / L)\end{array}$ & $\begin{array}{l}\text { DIS- } \\
\text { SOLVED } \\
\text { SILICA } \\
\text { (SIOZ) } \\
\text { (MG/L) }\end{array}$ \\
\hline
\end{tabular}

\begin{tabular}{|c|c|c|c|c|c|c|c|c|c|}
\hline $\begin{array}{l}0 C T \\
21 . . .\end{array}$ & 35 & 45 & 1.6 & 3.5 & 118 & 21 & 15 & .5 & 24 \\
\hline $\begin{array}{l}\text { NOV } \\
30 . . . \\
\text { DEC }\end{array}$ & 28 & 42 & 1.4 & 3.2 & 108 & 18 & 13 & .5 & 22 \\
\hline $\begin{array}{l}23 \ldots \\
\text { JAN }\end{array}$ & 26 & 40 & 1.3 & 2.6 & 103 & 20 & 12 & .5 & 20 \\
\hline$\underset{F E B}{22} \cdots$ & 31 & 44 & 1.5 & 3.1 & 110 & 19 & 13 & .5 & 22 \\
\hline $\begin{array}{l}17 \ldots \\
\text { MAR }\end{array}$ & 30 & 43 & 1.4 & 3.4 & 110 & 18 & 13 & .5 & 21 \\
\hline$\underset{A P R}{22} \cdots$ & 30 & 42 & 1.4 & 3.3 & 115 & 23 & 15 & .5 & 23 \\
\hline $\begin{array}{l}20 \cdots \\
\text { MAY }\end{array}$ & 34 & 44 & 1.6 & 3.4 & 120 & 21 & 16 & .5 & 25 \\
\hline JUN $^{17 \ldots}$ & 32 & 44 & 1.5 & 3.3 & 120 & 23 & 15 & .5 & 23 \\
\hline$\underset{\text { JUL }}{21 \ldots . .}$ & 27 & 40 & 1.3 & 3.0 & 115 & 20 & 15 & .5 & 21 \\
\hline $\begin{array}{c}28 \\
\text { AUG }\end{array}$ & 36 & 47 & 1.7 & 3.5 & 123 & 16 & 17 & .6 & 22 \\
\hline $\begin{array}{l}30 \\
\text { SEP }\end{array}$ & 34 & 47 & 1.7 & 3.5 & 115 & 18 & 15 & .6 & 21 \\
\hline $27 \ldots$ & 35 & 46 & 1.7 & $\mathbf{3} \cdot \mathbf{3}$ & 120 & 17 & 16 & .6 & 19 \\
\hline
\end{tabular}


10278300 LOS ANGELES AQUEDUCT AT 'OUTLET, AT SAN FERNANDO, CA--Continued

CHEMICAL ANALYSES, WATER YEAR OCTOBER 1975 TO SEPTEMBER 1976

\begin{tabular}{|c|c|c|c|c|c|c|c|c|}
\hline DATE & $\begin{array}{c}\text { TOTAL } \\
\text { NI TRATE } \\
\text { (N) } \\
\text { (MG/L) }\end{array}$ & $\begin{array}{l}\text { TOTAL } \\
\text { KJEL- } \\
\text { DAHL } \\
\text { NITRO=- } \\
\text { GEN } \\
\text { (N) } \\
\text { (MG/L) }\end{array}$ & $\begin{array}{l}\text { DIS- } \\
\text { SOLVED } \\
\text { ORTHO. } \\
\text { PHOS- } \\
\text { PHORUS } \\
\text { (P) } \\
(M G / L)\end{array}$ & $\begin{array}{l}\text { DIS- } \\
\text { SOLVED } \\
\text { ORTHO } \\
\text { PHOS- } \\
\text { PHATE } \\
\text { (P04) } \\
\text { (MG/L) }\end{array}$ & $\begin{array}{c}\text { TOTAL } \\
\text { ARSENIC } \\
\text { (AS) } \\
\text { (UG/L) }\end{array}$ & $\begin{array}{l}\text { DIS- } \\
\text { SOLVED } \\
\text { BORON } \\
\text { (B) } \\
\text { (UG/L) }\end{array}$ & $\begin{array}{l}\text { TOTAL } \\
\text { IRON } \\
\text { (FE) } \\
\text { (UG/L) }\end{array}$ & $\begin{array}{l}\text { TOTAL } \\
\text { MERCURY } \\
\text { (HO) } \\
\text { (UG/L) }\end{array}$ \\
\hline $\begin{array}{l}\text { OCT } \\
21 \cdots \\
\text { NOV }\end{array}$ & .20 & .12 & .04 & .12 & 10 & 310 & 20 & $<.1$ \\
\hline $\begin{array}{l}30 \cdots \\
\text { DEC }\end{array}$ & .27 & .08 & .04 & .12 & 10 & 330 & 200 & $<.1$ \\
\hline JAN $23 \cdots$ & .16 & .12 & .03 & .09 & 10 & 320 & 100 & $<, 1$ \\
\hline FEB & .20 & .08 & .03 & .09 & 10 & 380 & 100 & $<.1$ \\
\hline $\begin{array}{l}17 \ldots \\
\text { MAR }\end{array}$ & .16 & .12 & .08 & .25 & 10 & 340 & 300 & - \\
\hline APR $22 \cdots$ & .09 & .00 & .05 & .15 & 40 & 390 & 40 & $<, 1$ \\
\hline$\underset{\text { MAY }}{20} \cdots$ & .20 & .12 & .07 & .21 & $<10$ & 420 & 80 & .1 \\
\hline JUN & .22 & .12 & .10 & .31 & 30 & 380 & 20 & $<.1$ \\
\hline JUL & .22 & .16 & .04 & .12 & 20 & 340 & 30 & $<.1$ \\
\hline$\underset{A U G}{28} \cdots$ & .11 & $\cdot 26$ & .15 & .46 & 20 & 430 & 40 & $<.1$ \\
\hline $\begin{array}{l}30 \cdots \\
\text { SEP }\end{array}$ & .11 & .16 & .08 & .25 & 30 & 450 & 20 & $<.1$ \\
\hline $27 \ldots$ & .09 & .16 & .04 & .12 & 20 & 410 & 40 & $<.1$ \\
\hline
\end{tabular}




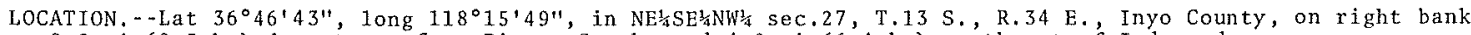
$0.2 \mathrm{mi}(0.3 \mathrm{~km})$ downstream from Pinyon Creek, and $4.0 \mathrm{mi}(6.4 \mathrm{~km})$ southwest of Independence.

DRAINAGE AREA. $--18.1 \mathrm{mi}^{2}\left(46.9 \mathrm{~km}^{2}\right)$.

PERIOD OF RECORD.--January 1923 to current year. prior to october 1959 month1y discharge only, published in WSP 1734 .

GAGE.--Water-stage recorder and Parsha11 flume (Cipolletti weir used during low flow). Altitude of gage is $5,300 \mathrm{ft}(1,615 \mathrm{~m})$, from topographic map. See WSP 1734 for history of changes prior to Dec. 13 , 1936 .

REMARKS. - Records poor. No regulation or diversion above station.

COOPERATION, - Records were furnished by city of Los Angeles, Department of Water and Power.

AVERAGE DISCHARGE, - -53 years (water years $1924-76), 12.5 \mathrm{ft}^{3} / \mathrm{s}\left(0.354 \mathrm{~m}^{3} / \mathrm{s}\right), 9,060 \mathrm{acre}-\mathrm{ft} / \mathrm{yr}(11.2 \mathrm{hm} / \mathrm{yr}$ )

EXTREMES FOR PERIOD OF RECORD. - Maximum discharge, $169 \mathrm{ft}^{3} / \mathrm{s}\left(4.79 \mathrm{~m}^{3} / \mathrm{s}\right)$ June 1 , I969, gage height, $4.45 \mathrm{ft}$

$(1.356 \mathrm{~m})$; minimum daily, $0.70 \mathrm{ft}^{3} / \mathrm{s}\left(0.020 \mathrm{~m}^{3} / \mathrm{s}\right)$ Jan. 25, 1926, Dec. 15, 1935.

EXTREMES FOR CURRENT YEAR.--Maximum daily discharge, $28 \mathrm{ft}^{3} / \mathrm{s}\left(0.79 \mathrm{~m}^{3} / \mathrm{s}\right)$ Sept. 11; minimum dai1y, $1.4 \mathrm{ft} / \mathrm{s}$

$\left(0.040 \mathrm{~m}^{3} / \mathrm{s}\right) \mathrm{Feb}, 5$.

DISCHARGE, IN CUBIC FEET PER SECOND, WATER YEAR OCTOBER 1975 TO SEPTEMBER 1976 MEAN VALUES

\begin{tabular}{|c|c|c|c|c|c|c|c|c|c|c|c|c|}
\hline DAY & OCT & NoV & DEC & JAN & FEB & MAR & APR & MAY & JUN & JUL & AUG & SEP \\
\hline $\begin{array}{l}1 \\
2 \\
3 \\
4 \\
5\end{array}$ & $\begin{array}{l}4.2 \\
4.1 \\
4.1 \\
4.1 \\
4.1\end{array}$ & $\begin{array}{l}3.6 \\
3.6 \\
3.6 \\
3.3 \\
3.3\end{array}$ & $\begin{array}{l}3.2 \\
3.1 \\
2.7 \\
2.7 \\
2.7\end{array}$ & $\begin{array}{l}3.3 \\
2.4 \\
1.9 \\
2.2 \\
2.5\end{array}$ & $\begin{array}{l}1.6 \\
1.6 \\
1.6 \\
1.5 \\
1.4\end{array}$ & $\begin{array}{l}2.7 \\
2.4 \\
2.4 \\
3.1 \\
2.7\end{array}$ & $\begin{array}{l}1.9 \\
1.9 \\
2.0 \\
2.3 \\
2.3\end{array}$ & $\begin{array}{l}4.5 \\
5.4 \\
5.9 \\
6.1 \\
6.6\end{array}$ & $\begin{array}{l}16 \\
17 \\
17 \\
16 \\
16\end{array}$ & $\begin{array}{l}11 \\
11 \\
10 \\
10 \\
9.7\end{array}$ & $\begin{array}{l}12 \\
13 \\
13 \\
13 \\
12\end{array}$ & $\begin{array}{l}4.4 \\
4.5 \\
4.5 \\
4.5 \\
4.5\end{array}$ \\
\hline $\begin{array}{r}6 \\
7 \\
8 \\
9 \\
10\end{array}$ & $\begin{array}{l}3.8 \\
4.7 \\
4.5 \\
4.4 \\
4.2\end{array}$ & $\begin{array}{l}3.3 \\
3.3 \\
3.2 \\
3.2 \\
3.3\end{array}$ & $\begin{array}{l}2.7 \\
2.5 \\
2.4 \\
2.4 \\
2.4\end{array}$ & $\begin{array}{l}2.4 \\
3.1 \\
2.2 \\
2.5 \\
2.2\end{array}$ & $\begin{array}{l}1.6 \\
3.3 \\
3.2 \\
3.1 \\
2.7\end{array}$ & $\begin{array}{l}2.4 \\
2.0 \\
1.9 \\
1.9 \\
1.8\end{array}$ & $\begin{array}{l}2.3 \\
2.3 \\
2.3 \\
2.2 \\
2.3\end{array}$ & $\begin{array}{l}7.7 \\
8.1 \\
7.5 \\
8.1 \\
9.3\end{array}$ & $\begin{array}{l}16 \\
16 \\
16 \\
16 \\
15\end{array}$ & $\begin{array}{l}9.5 \\
8.9 \\
8.9 \\
8.5 \\
8.3\end{array}$ & $\begin{array}{l}11 \\
11 \\
10 \\
9.5 \\
9.3\end{array}$ & $\begin{array}{r}4.5 \\
4.5 \\
4.5 \\
4.7 \\
11\end{array}$ \\
\hline $\begin{array}{l}11 \\
12 \\
13 \\
14 \\
15\end{array}$ & $\begin{array}{l}4.5 \\
4.5 \\
4.4 \\
4.2 \\
3.9\end{array}$ & $\begin{array}{l}3.1 \\
3.1 \\
3.1 \\
3.1 \\
3.1\end{array}$ & $\begin{array}{l}2.4 \\
2.4 \\
2.5 \\
2.5 \\
2.2\end{array}$ & $\begin{array}{l}2.4 \\
2.4 \\
2.3 \\
1.8 \\
1.8\end{array}$ & $\begin{array}{l}2.3 \\
2.3 \\
2.3 \\
2.2 \\
2.0\end{array}$ & $\begin{array}{l}1.8 \\
1.8 \\
1.8 \\
1.8 \\
1.8\end{array}$ & $\begin{array}{l}2.3 \\
2.3 \\
2.5 \\
2.5 \\
2.4\end{array}$ & $\begin{array}{l}11 \\
13 \\
15 \\
19 \\
22\end{array}$ & $\begin{array}{l}15 \\
14 \\
13 \\
13 \\
13\end{array}$ & $\begin{array}{l}8.3 \\
8.3 \\
8.3 \\
7.9 \\
7.9\end{array}$ & $\begin{array}{l}8.5 \\
8.3 \\
7.7 \\
7.9 \\
7.7\end{array}$ & $\begin{array}{l}28 \\
22 \\
22 \\
20 \\
18\end{array}$ \\
\hline $\begin{array}{l}16 \\
17 \\
18 \\
19 \\
20\end{array}$ & $\begin{array}{l}3.9 \\
3.8 \\
3.6 \\
3.5 \\
3.5\end{array}$ & $\begin{array}{l}3.1 \\
2.9 \\
2.0 \\
2.5 \\
2.5\end{array}$ & $\begin{array}{l}2.5 \\
2.5 \\
2.2 \\
2.4 \\
2.3\end{array}$ & $\begin{array}{l}1.8 \\
1.8 \\
1.8 \\
1.8 \\
1.6\end{array}$ & $\begin{array}{l}2.0 \\
2.0 \\
1.9 \\
1.9 \\
2.0\end{array}$ & $\begin{array}{l}1.8 \\
1.8 \\
1.8 \\
1.8 \\
1.8\end{array}$ & $\begin{array}{l}2.3 \\
2.4 \\
2.5 \\
2.5 \\
2.5\end{array}$ & $\begin{array}{l}21 \\
21 \\
20 \\
19 \\
18\end{array}$ & $\begin{array}{l}13 \\
14 \\
14 \\
15 \\
15\end{array}$ & $\begin{array}{l}13 \\
14 \\
11 \\
9.3 \\
8.5\end{array}$ & $\begin{array}{l}7.5 \\
7.3 \\
7.3 \\
7.5 \\
7.0\end{array}$ & $\begin{array}{l}16 \\
14 \\
13 \\
12 \\
11\end{array}$ \\
\hline $\begin{array}{l}21 \\
22 \\
23 \\
24 \\
25\end{array}$ & $\begin{array}{l}3.5 \\
3.1 \\
3.1 \\
3.1 \\
3.5\end{array}$ & $\begin{array}{l}2.5 \\
2.8 \\
2.9 \\
2.9 \\
2.8\end{array}$ & $\begin{array}{l}2.3 \\
2.2 \\
2 \cdot 2 \\
2.2 \\
2.2\end{array}$ & $\begin{array}{l}2.0 \\
2.0 \\
1.9 \\
1.7 \\
1.0\end{array}$ & $\begin{array}{l}2.0 \\
2.0 \\
1.8 \\
1.8 \\
1.7\end{array}$ & $\begin{array}{l}1.8 \\
1.8 \\
1.8 \\
1.8 \\
1.8\end{array}$ & $\begin{array}{l}2.5 \\
2.9 \\
3.1 \\
3.2 \\
3.5\end{array}$ & $\begin{array}{l}18 \\
17 \\
17 \\
17 \\
17\end{array}$ & $\begin{array}{l}15 \\
15 \\
14 \\
13 \\
13\end{array}$ & $\begin{array}{r}12 \\
7.7 \\
8.5 \\
9.5 \\
11\end{array}$ & $\begin{array}{l}6.6 \\
6.2 \\
6.2 \\
5.9 \\
5.5\end{array}$ & $\begin{array}{c}11 \\
9.7 \\
9.5 \\
12 \\
14\end{array}$ \\
\hline $\begin{array}{l}26 \\
27 \\
28 \\
29 \\
30 \\
31\end{array}$ & $\begin{array}{l}3.5 \\
3.6 \\
3.3 \\
3.5 \\
3.5 \\
3.5\end{array}$ & $\begin{array}{l}2.7 \\
2.7 \\
2.7 \\
3.1 \\
2.7 \\
-\infty\end{array}$ & $\begin{array}{l}2.2 \\
2.2 \\
2.0 \\
2.0 \\
1.9 \\
2.0\end{array}$ & $\begin{array}{l}1.7 \\
1.8 \\
1.7 \\
1.6 \\
1.6 \\
1.6\end{array}$ & $\begin{array}{l}1.8 \\
1.8 \\
1.8 \\
1.9 \\
-\infty \\
-\infty=\end{array}$ & $\begin{array}{l}1.8 \\
1.8 \\
1.8 \\
1.8 \\
1.8 \\
1.9\end{array}$ & $\begin{array}{l}3.8 \\
3.8 \\
3.3 \\
3.5 \\
3.8 \\
-\infty . \infty\end{array}$ & $\begin{array}{l}17 \\
17 \\
17 \\
17 \\
17 \\
16\end{array}$ & $\begin{array}{l}12 \\
12 \\
12 \\
11 \\
11 \\
\therefore=\infty\end{array}$ & $\begin{array}{l}11 \\
11 \\
12 \\
11 \\
11 \\
12\end{array}$ & $\begin{array}{l}5.2 \\
5.0 \\
4.9 \\
4.7 \\
4.5 \\
4.4\end{array}$ & $\begin{array}{l}13 \\
13 \\
12 \\
16 \\
18 \\
-\infty=\end{array}$ \\
\hline $\begin{array}{l}\text { YOTAL } \\
\text { MEAN } \\
\text { MAX } \\
\text { MIN } \\
\text { AC } \triangle F Y\end{array}$ & $\begin{array}{r}119.2 \\
3.85 \\
4.7 \\
3.1 \\
236\end{array}$ & $\begin{array}{r}90.0 \\
3.00 \\
3.6 \\
2.0 \\
179\end{array}$ & $\begin{array}{r}74.1 \\
2.39 \\
3.2 \\
1.9 \\
147\end{array}$ & $\begin{array}{r}63.6 \\
2.05 \\
3.3 \\
1.6 \\
126\end{array}$ & $\begin{array}{r}59.1 \\
2.04 \\
3.3 \\
1.4 \\
117\end{array}$ & $\begin{array}{r}61.2 \\
1.97 \\
3.1 \\
1.8 \\
121\end{array}$ & $\begin{array}{r}79.4 \\
2.65 \\
3.8 \\
1.9 \\
157\end{array}$ & $\begin{array}{r}435.2 \\
14.0 \\
22 \\
4.5 \\
863\end{array}$ & $\begin{array}{r}428 \\
14.3 \\
17 \\
11 \\
849\end{array}$ & $\begin{array}{r}309.0 \\
9.97 \\
14 \\
7.7 \\
613\end{array}$ & $\begin{array}{r}249.6 \\
8.05 \\
13 \\
4.4 \\
495\end{array}$ & $\begin{array}{r}355.8 \\
11.9 \\
28 \\
4.4 \\
706\end{array}$ \\
\hline
\end{tabular}

CAL YR 1975 TOTAL 3163.8 MEAN 8.67 MAX 47 HIN 1.7 AC-FT 6280

WTR YR 1976 TOTAL 2324.2 MEAN 6.35 MAX 28 HIN 1.4 AC-FT 4610 
10285700 OWENS RIVER AT KEELER BRIDGE, NEAR LONE PINE, CA

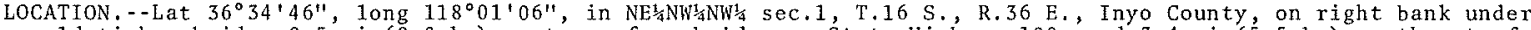
old timber bridge $0.5 \mathrm{mi}(0.8 \mathrm{~km})$ upstream from bridge on State Highway 190 , and $3.4 \mathrm{mi}(5.5 \mathrm{~km})$ southeast of Lone Pine.

DRAINAGE AREA. $-2,604 \mathrm{mi}^{2}\left(6,744 \mathrm{~km}^{2}\right)$,

PERIOD OF RECORD, - January 1927 to current year. Prior to October 1959 monthly discharge only, published in WSP 1314 and 1734 .

GAGE. - Water-stage recorder and Cipolletti weir. Altitude of gage is 3,600 ft ( $1,097 \mathrm{~m})$, from topographic map. See WSP 1734 for history of changes prior to Feb. 14, 1935, Feb, 14, 1935, to Nov. 22, 1964, water-stage recorder and Cipolletti weir at same site and datum. Nov. 23, 1964 , to June 26, 1967, nonrecording gage and Cipolletti weir at same site and datum.

REMARKS.--Records fair. Natural flow affected by storage in several reservoirs, many natural lakes, diversions for irrigation, and return flow from irrigated areas. Major portion of discharge from basin is diverted through Los Angeles Aqueduct. Discharge reported herein is wasted into Owens Lake,

COOPERATION.--Records were furnished by city of Los Angeles, Department of Water and Power.

EXTREMES FOR PERIOD OF RECORD, - Maximum daily discharge, 1,360 $\mathrm{ft}^{3} / \mathrm{s}\left(38,5 \mathrm{~m}^{3} / \mathrm{s}\right) \mathrm{June} 19$, 1969; no flow at times in some years.

DISCHARGE, IN CUBIC FEET PER SECOND, WATER YEAR OCTOBER 1975 TO SEPTEMBER 1976 MEAN VALUES

\begin{tabular}{|c|c|c|c|c|c|c|c|c|c|c|c|c|}
\hline DAY & $O C T$ & NOV & DEC & JAN & FEB & MAR & APR & MAY & JUN & JUL & AUG & SEP \\
\hline $\begin{array}{l}1 \\
2 \\
3 \\
4 \\
5\end{array}$ & $\begin{array}{l}4.2 \\
3.7 \\
3.2 \\
3.0 \\
3.0\end{array}$ & $\begin{array}{l}2.8 \\
2.8 \\
3.0 \\
3.0 \\
3.0\end{array}$ & $\begin{array}{l}4.0 \\
4.2 \\
4.2 \\
4.2 \\
4.2\end{array}$ & $\begin{array}{l}13 \\
13 \\
13 \\
12 \\
12\end{array}$ & $\begin{array}{l}8.8 \\
8.5 \\
8.5 \\
8.5 \\
8.5\end{array}$ & $\begin{array}{l}9.5 \\
9.5 \\
9.5 \\
9.5 \\
9.5\end{array}$ & $\begin{array}{l}7.0 \\
7.0 \\
7.0 \\
7.0 \\
7.0\end{array}$ & $\begin{array}{l}5.3 \\
5.3 \\
5.3 \\
5.0 \\
5.0\end{array}$ & $\begin{array}{l}2.2 \\
2.2 \\
2.0 \\
2.0 \\
1.8\end{array}$ & $\begin{array}{r}.50 \\
.50 \\
.50 \\
.50 \\
.40\end{array}$ & $\begin{array}{l}.90 \\
.80 \\
.50 \\
.40 \\
.40\end{array}$ & $\begin{array}{l}0 \\
0 \\
0 \\
0 \\
0\end{array}$ \\
\hline $\begin{array}{r}6 \\
7 \\
8 \\
9 \\
10\end{array}$ & $\begin{array}{l}2.6 \\
2.6 \\
2.6 \\
2.4 \\
2.2\end{array}$ & $\begin{array}{l}3.2 \\
3.2 \\
3.2 \\
3.5 \\
3.5\end{array}$ & $\begin{array}{l}4.2 \\
4.2 \\
4.5 \\
4.5 \\
4.5\end{array}$ & $\begin{array}{l}12 \\
12 \\
11 \\
11 \\
11\end{array}$ & $\begin{array}{l}8.0 \\
9.5 \\
11 \\
12 \\
15\end{array}$ & $\begin{array}{l}9.2 \\
9.2 \\
9.2 \\
9.2 \\
9.2\end{array}$ & $\begin{array}{l}7.0 \\
7.0 \\
7.0 \\
7.0 \\
7.0\end{array}$ & $\begin{array}{l}5.5 \\
6.7 \\
7.3 \\
7.0 \\
7.0\end{array}$ & $\begin{array}{l}1.8 \\
2.0 \\
1.6 \\
1.6 \\
1.6\end{array}$ & $\begin{array}{r}.40 \\
.30 \\
.10 \\
0 \\
0\end{array}$ & $\begin{array}{l}.30 \\
.20 \\
.20 \\
.20 \\
.10\end{array}$ & $\begin{array}{l}0 \\
0 \\
0 \\
0 \\
0\end{array}$ \\
\hline $\begin{array}{l}11 \\
12 \\
13 \\
14 \\
15\end{array}$ & $\begin{array}{l}2.2 \\
2.2 \\
2.2 \\
2.2 \\
2.4\end{array}$ & $\begin{array}{l}3.5 \\
3.5 \\
3.5 \\
3.5 \\
3.7\end{array}$ & $\begin{array}{l}4.5 \\
4.5 \\
4.5 \\
4.5 \\
4.5\end{array}$ & $\begin{array}{l}11 \\
11 \\
11 \\
11 \\
11\end{array}$ & $\begin{array}{l}16 \\
19 \\
19 \\
16 \\
15\end{array}$ & $\begin{array}{l}8.8 \\
8.8 \\
8.8 \\
8.8 \\
8.5\end{array}$ & $\begin{array}{l}6.7 \\
6.7 \\
6.7 \\
6.7 \\
6.7\end{array}$ & $\begin{array}{l}7.0 \\
6.4 \\
5.8 \\
5.5 \\
5.0\end{array}$ & $\begin{array}{l}1.8 \\
1.6 \\
1.6 \\
1.6 \\
1.4\end{array}$ & $\begin{array}{l}0 \\
0 \\
0 \\
0 \\
0\end{array}$ & $\begin{array}{l}0^{.10} \\
0 \\
0 \\
.10\end{array}$ & $\begin{array}{l}0 \\
0 \\
0 \\
0 \\
0\end{array}$ \\
\hline $\begin{array}{l}16 \\
17 \\
18 \\
19 \\
20\end{array}$ & $\begin{array}{l}2.4 \\
2.4 \\
2.4 \\
2.4 \\
2.4\end{array}$ & $\begin{array}{l}3.7 \\
4.0 \\
3.7 \\
3.7 \\
4.0\end{array}$ & $\begin{array}{l}4.5 \\
4.5 \\
4.7 \\
4.7 \\
5.0\end{array}$ & $\begin{array}{l}12 \\
12 \\
12 \\
11 \\
11\end{array}$ & $\begin{array}{l}14 \\
13 \\
13 \\
12 \\
12\end{array}$ & $\begin{array}{l}8.5 \\
8.5 \\
8.5 \\
8.2 \\
8.2\end{array}$ & $\begin{array}{l}6.7 \\
6.7 \\
7.0 \\
6.7 \\
6.7\end{array}$ & $\begin{array}{l}4.5 \\
4.2 \\
4.0 \\
3.7 \\
3.5\end{array}$ & $\begin{array}{l}1.4 \\
1.4 \\
1.2 \\
1.1 \\
1.1\end{array}$ & $\begin{array}{l}0 \\
0 \\
.10 \\
.40 \\
.30\end{array}$ & $\begin{array}{r}.30 \\
.30 \\
.20 \\
.30 \\
.40\end{array}$ & $\begin{array}{r}0 \\
17 \\
50 \\
21 \\
12\end{array}$ \\
\hline $\begin{array}{l}21 \\
22 \\
23 \\
24 \\
25\end{array}$ & $\begin{array}{l}2.4 \\
2.4 \\
2.4 \\
2.4 \\
2.4\end{array}$ & $\begin{array}{l}4.0 \\
4.0 \\
4.0 \\
4.0 \\
4.0\end{array}$ & $\begin{array}{l}5.0 \\
5.0 \\
8.5 \\
9.2 \\
10\end{array}$ & $\begin{array}{l}11 \\
10 \\
9.8 \\
9.8 \\
9.5\end{array}$ & $\begin{array}{l}11 \\
11 \\
11 \\
10 \\
10\end{array}$ & $\begin{array}{l}7.9 \\
7.9 \\
7.6 \\
7.6 \\
7.6\end{array}$ & $\begin{array}{l}6.7 \\
6.7 \\
6.7 \\
6.4 \\
6.4\end{array}$ & $\begin{array}{l}3.5 \\
3.2 \\
3.2 \\
3.0 \\
3.0\end{array}$ & $\begin{array}{r}1.1 \\
.90 \\
.80 \\
.80 \\
.80\end{array}$ & $\begin{array}{l}.20 \\
.10 \\
.10 \\
.10 \\
.10\end{array}$ & $\begin{array}{l}.40 \\
.20 \\
.20 \\
.20 \\
.10\end{array}$ & $\begin{array}{l}8.2 \\
6.1 \\
4.7 \\
4.2 \\
3.7\end{array}$ \\
\hline $\begin{array}{l}26 \\
27 \\
28 \\
29 \\
30 \\
31\end{array}$ & $\begin{array}{l}2.6 \\
2.8 \\
3.0 \\
3.0 \\
3.0 \\
2.0\end{array}$ & $\begin{array}{l}4.0 \\
4.2 \\
4.2 \\
4.2 \\
4.0 \\
-0 .\end{array}$ & $\begin{array}{l}11 \\
11 \\
12 \\
13 \\
13 \\
13\end{array}$ & $\begin{array}{l}9.5 \\
9.2 \\
9.2 \\
6.8 \\
8.8 \\
8.8\end{array}$ & $\begin{array}{l}9.8 \\
9.8 \\
9.8 \\
9.8 \\
-0 .\end{array}$ & $\begin{array}{l}7.6 \\
7.6 \\
7.3 \\
7.3 \\
7.3 \\
7.3\end{array}$ & $\begin{array}{l}6.7 \\
6.4 \\
5.8 \\
5.5 \\
5.5 \\
-\infty\end{array}$ & $\begin{array}{l}2.8 \\
2.8 \\
2.6 \\
2.6 \\
2.4 \\
2.4\end{array}$ & $\begin{array}{l}.80 \\
.60 \\
.60 \\
.50 \\
.50 \\
.-0\end{array}$ & $\begin{array}{l}.20 \\
.20 \\
.40 \\
.50 \\
.60 \\
.80\end{array}$ & $\begin{array}{l}0 \\
0 \\
0 \\
0 \\
0 \\
0\end{array}$ & $\begin{array}{l}3.5 \\
3.2 \\
2.8 \\
3.0 \\
3.0 \\
-0 .\end{array}$ \\
\hline $\begin{array}{l}\text { TOTAL } \\
\text { MEAN } \\
\text { MAX } \\
\text { MIN } \\
\text { AC-FT }\end{array}$ & $\begin{array}{r}81.9 \\
2.64 \\
4.2 \\
2.2 \\
162\end{array}$ & $\begin{array}{r}108.6 \\
3.62 \\
4.2 \\
2.8 \\
215\end{array}$ & $\begin{array}{r}199.3 \\
6.43 \\
13 \\
4.0 \\
395\end{array}$ & $\begin{array}{r}337.4 \\
10.9 \\
13 \\
8.8 \\
669\end{array}$ & $\begin{array}{r}340.3 \\
11.7 \\
19 \\
8.5 \\
675\end{array}$ & $\begin{array}{r}262.1 \\
8.45 \\
9.5 \\
7.3 \\
520\end{array}$ & $\begin{array}{r}200.1 \\
6.67 \\
7.0 \\
5.5 \\
397\end{array}$ & $\begin{array}{r}140.5 \\
4.53 \\
7.3 \\
2.4 \\
279\end{array}$ & $\begin{array}{r}40.40 \\
1.35 \\
2.2 \\
.50 \\
80\end{array}$ & $\begin{array}{r}7.30 \\
.24 \\
.80 \\
0 \\
14\end{array}$ & $\begin{array}{r}6.90 \\
.22 \\
.90 \\
0 \\
14\end{array}$ & $\begin{array}{r}142.4 \\
4.75 \\
50 \\
0 \\
282\end{array}$ \\
\hline
\end{tabular}
$\begin{array}{llllllllll}\text { CAL YR } 1975 & \text { TOTAL } & 2277.40 & \text { MEAN } 6.24 & \text { MAX } & 340 & \text { MIN } & \text { AC-FT } & 4520 \\ \text { WTR YR } 1976 & \text { TOTAL } & 1867.20 & \text { MEAN } 5.10 & \text { MAX } & 50 & \text { MIN } 0 & \text { AC-FT } & 3700\end{array}$ 
LOCATION. - Lat $36^{\circ} 26^{\prime} 20^{\prime \prime}$, long $118^{\circ} 04^{\prime} 48^{\prime \prime}$ (unsurveyed), Inyo County, Inyo National Forest, just downstream from intake to Cottonwood powerhouse, and $11.2 \mathrm{mi}(18.0 \mathrm{~km})$ north of olancha.

DRAINAGE AREA, $-40.1 \mathrm{mi}^{2}\left(103.9 \mathrm{~km}^{2}\right)$.

PERIOD OF RECORD.--January 1906 to March 1911, January 1914 to current year; combined records of creek and f1ow through powerhouse, November 1938 to current year. Monthly discharge only January 1914 to September 1959 , published in WSP 13 it and 1734 .

REVISED RECORDS, - -WDR CA-73-1: 1972.

GAGE.--Water-stage recorder and Cipolletti weir on powerhouse diversion. A1titude of gage is 4,660 ft (1,420 m), from topographic map. See WSP 1734 for history of changes prior to Oct. 31, 1938. Since May 15, 1969, supplementary gage at site $5.0 \mathrm{mi}(8.0 \mathrm{~km})$ downstream at different datum, and is presently used in computation of flow for the creek.

REMARKS. --Records poor. No regulation above station. Cottonwood powerhouse, maximum capacity, 22 ft $3 / \mathrm{s}$ $\left(0.623 \mathrm{~m}^{3} / \mathrm{s}\right)$ has diverted since Nov, 13, 1908 . Discharge figures for creek only are estimated by correlation with station $3.0 \mathrm{mi}(4.8 \mathrm{~km})$ downstream at the Los Angeles Aqueduct. For records of combined discharge of Cottonwood Creek and powerhouse, see following page.

COOPERATION.--Records were furnished by city of Los Angeles, Department of Water and Power.

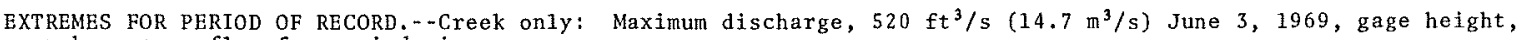

unknown; no flow for periods in some years: July $22,23,1961$.

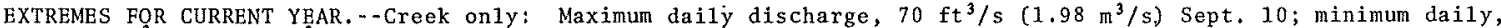
$0.20 \mathrm{ft} / \mathrm{s}\left(0.006 \mathrm{~m}^{3} / \mathrm{s}\right)$ on many days.

Combined flow: Maximum daily discharge, $82 \mathrm{ft}^{3} / \mathrm{s}\left(2.32 \mathrm{~m}^{3} / \mathrm{s}\right)$ Sept. 10; minimum daily, $3.1 \mathrm{ft}{ }^{3} / \mathrm{s}\left(0.088 \mathrm{~m}^{3} / \mathrm{s}\right)$ Aug. 31, Sept. 1, 2 .

DISCHARGE, IN CUBIC FEET PER SECOND, WATER YEAR OCTOBER 1975 TO SEPTEMBER 1976 MEAN VALUES

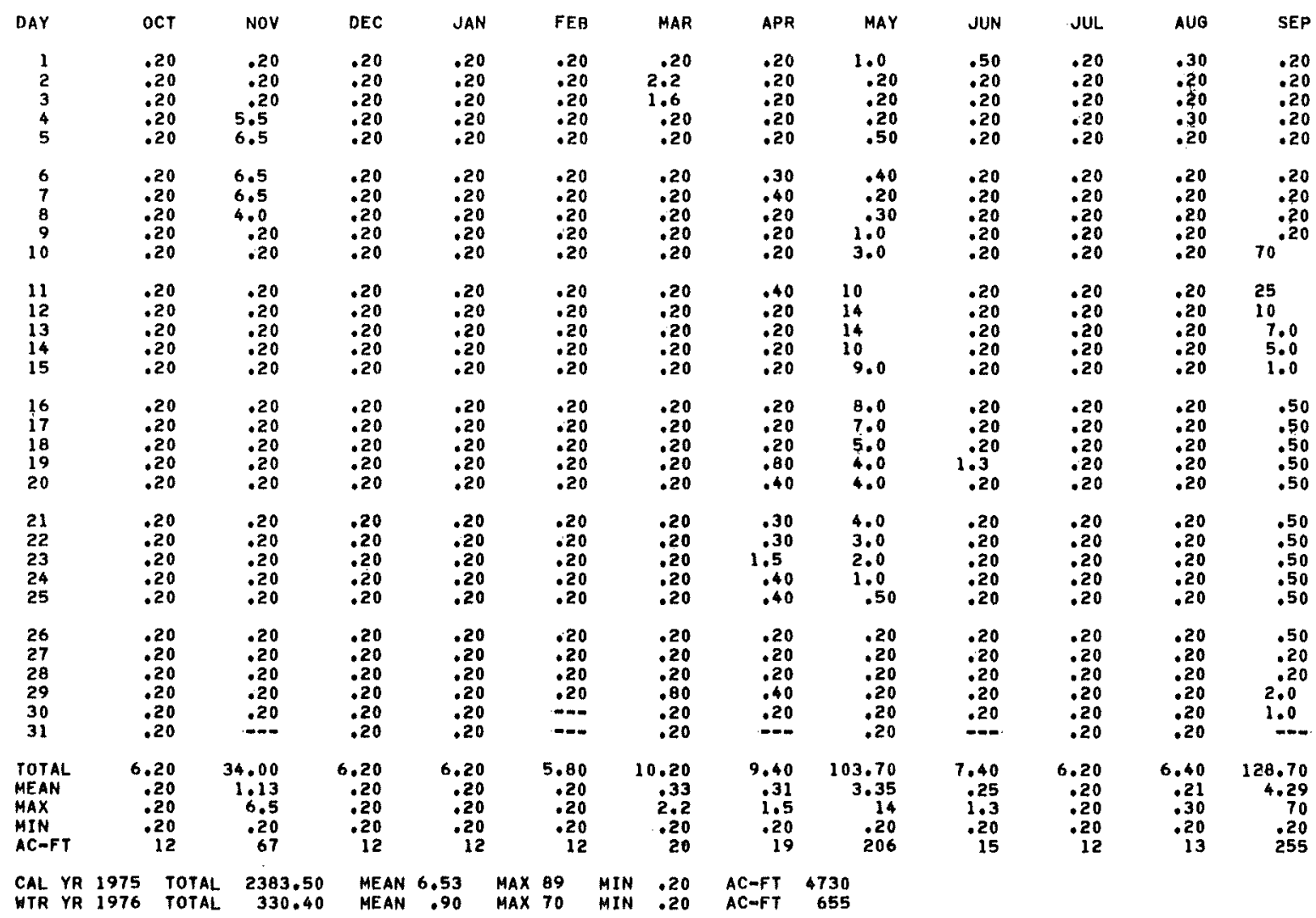


OIENS LAKE BASIN

10286000 COTTONWOOD CREEK NEAR OLANCHA, CA--Continued

COMBINED DISCHARGE, IN CUBIC FEET PER SECOND, OF COTTONWOOD CREEK AND

POWERHOUSE NEAR OLANCHA, CA, WATER YEAR OCTOBER 1975 TO SEPTEMBER 1976

DISCHARGE, IN CUBIC FEET PER SECOND, WATER YEAR OCTOBER 1975 TO SEPTEMBER 1976 MEAN VALUES

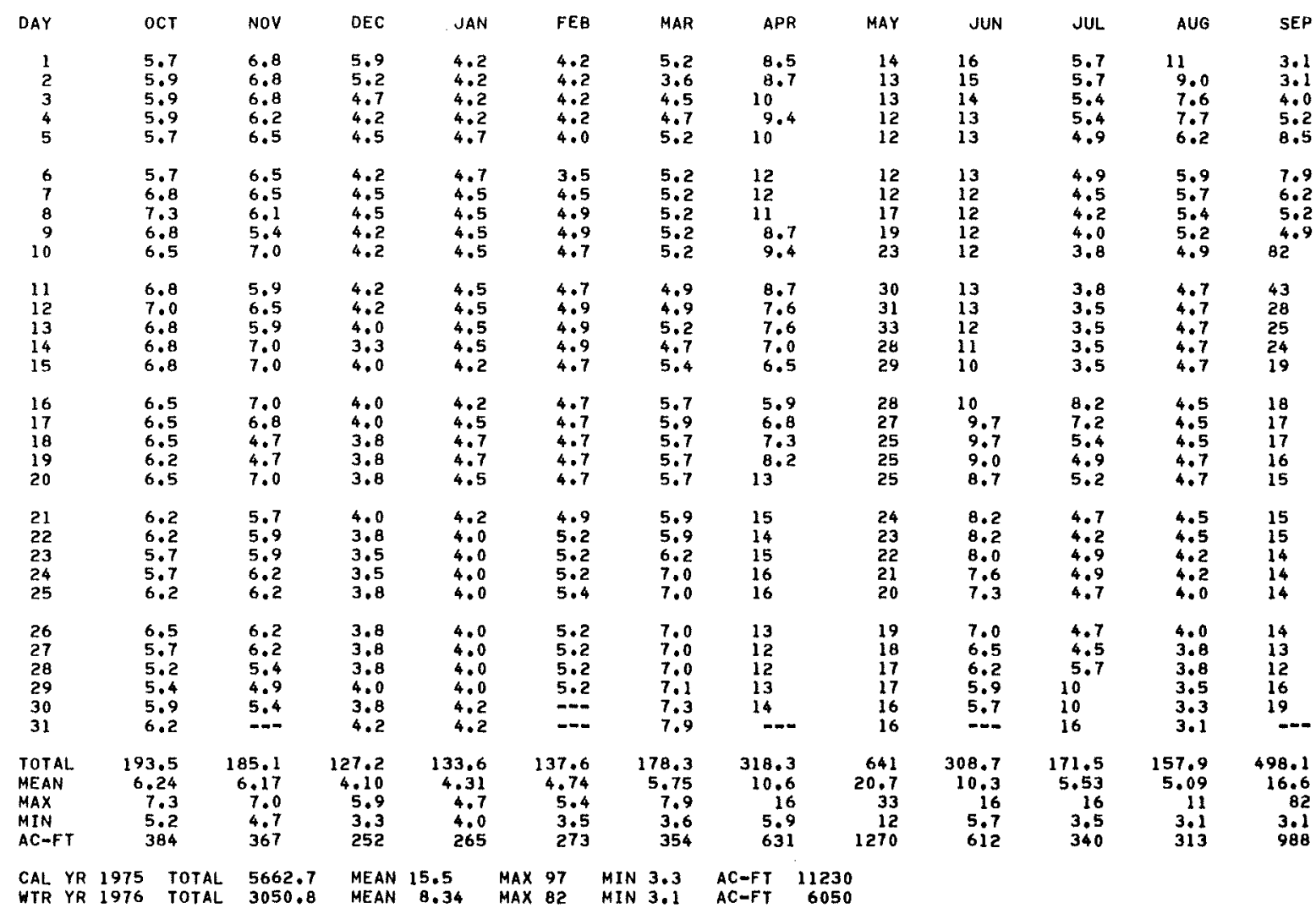


LOCATION.--Lat $37^{\circ} 58^{\prime} 46^{\prime \prime}$, long $119^{\circ} 08^{\prime} 11^{\prime \prime}$, in NW/ sec.5, T.2 N., R.26 E., Mono County, on west bank 1 mi (2 km) south of town of Mono Lake.

DRAINAGE AREA. $-785 \mathrm{mi}^{2}\left(2,033 \mathrm{~km}^{2}\right)$.

PERIOD OF RECORD.--June 1912 to current year. Records prior to September 1934, published in wSP 765.

GAGE,--Nonrecording gage or reference point read once a week. Gage heights prior to october 1944 are converted to elevations above mean sea level in WSP 1314. Gage readings have been reduced to elevations above mean sea level.

REMARKS.--Since 1941 water diverted to Owens Lake basin via Mono tunne1, capacity, $200 \mathrm{ft}^{3} / \mathrm{s}\left(5.66 \mathrm{~m}^{3} / \mathrm{s}\right.$ ). COOPERATION,--Records were furnished by city of Los Angeles, Department of Water and Power.

EXTREMES FOR PERIOD OF RECORD.--Maximum elevation observed, 6, 428.1 ft (1.959.28 m) Ju1y 18, 1919 , present datum; minimum observed, $6,377.75 \mathrm{ft}(1,943.938 \mathrm{~m})$ Sept. 30,1976 .

ELEVATION, IN FEET, WATER YEAR OCTOBER 1975 TO SEPTEMBER 1976

\begin{tabular}{|c|c|c|c|c|c|c|c|c|c|c|c|}
\hline \multicolumn{2}{|c|}{ Date } & \multirow{2}{*}{$\begin{array}{l}\text { Elevation } \\
6379.33\end{array}$} & \multicolumn{2}{|c|}{ Date } & \multirow{2}{*}{$\begin{array}{l}\text { Elevation } \\
6379.10\end{array}$} & \multicolumn{2}{|c|}{ Date } & \multirow{2}{*}{$\begin{array}{l}\text { Elevation } \\
6378.90\end{array}$} & \multicolumn{2}{|c|}{ Date } & \multirow{2}{*}{$\begin{array}{l}\text { Elevation } \\
6378.12\end{array}$} \\
\hline oct. & 9 & & Feb. & 10 & & June & 3 & & Aug. & 12 & \\
\hline & 31 & 6379.31 & Mar. & 8 & 6379.13 & & 17 & 6378.55 & & 19 & 6378.08 \\
\hline \multirow[t]{2}{*}{ Nov. } & 13 & 6379.26 & & 23 & 6379.11 & & 24 & 6378.52 & & 30 & 6377.92 \\
\hline & 25 & 6379.15 & & 6 & 6379.10 & & 8 & 6378.35 & & 13 & 6377.85 \\
\hline \multirow[t]{2}{*}{ Dec. } & 10 & 6379.10 & Apr. & 20 & 6379.07 & & 22 & 6378.24 & & 23 & 6377.81 \\
\hline & 22 & 6379.08 & & 28 & 6379.00 & & 29 & 6378.27 & & 30 & 6377.75 \\
\hline $\operatorname{Jan}$. & 9 & 6379.06 & May & 13 & 6378.96 & Aug. & 5 & 6378.20 & & & \\
\hline
\end{tabular}


10287070 MILL CREEK BELOW LUNDY LAKE, NEAR MONO LAKE, CA

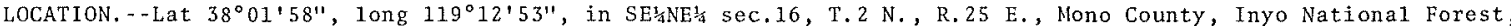
at road crossing $1,500 \mathrm{ft}(457 \mathrm{~m})$ downstream from Lundy Lake Dam, and $4.9 \mathrm{mi}$ ( $7.9 \mathrm{~km}) \mathrm{northwest}$ of Mono Lake Post office.

DRAINAGE AREA. --18.1 $\mathrm{mi}^{2}$ or $46.9 \mathrm{~km}^{2}$ (natural flow).

PERIOD OF RECORD.--October 1942 to current year. Monthly and yearly mean discharges prior to October 1969, pub1 ished in WSP 2127.

GAGE.--Water-stage recorder and Parshall flume on creek. Altitude of gage is $7,760 \mathrm{ft}(2,365 \mathrm{~m}$ ), from topographic map.

REMARKS. - Flow regulated for power development by Lundy Lake, capacity, 3,820 acre-ft (4.71 hm ${ }^{3}$ ). Records for "actual flow" include Mil1 Creek, Lundy powerplant tailrace, and Upper Conway ditch. Records for "natural flow" are computed as the "actual flow" plus change in contents and evaporation of Lundy lake.

COOPERATION. - - Records were furnished by Southern California Edison Co, and reviewed by the Geologica1 Survey, in connection with a Federal Power Commission Project.

AVERAGE DISCHARGE (Actual flow). -35 years, $28.3 \mathrm{ft}^{3} / \mathrm{s}\left(0.801 \mathrm{~m}^{3} / \mathrm{s}\right), 20,500 \mathrm{acre}-\mathrm{ft} / \mathrm{yr}(25.3 \mathrm{hm} / \mathrm{yr})$

(Natural flow). - -35 years, $30.1 \mathrm{ft}^{3} / \mathrm{s}\left(0.852 \mathrm{~m}^{3} / \mathrm{s}\right), 21,810 \mathrm{acre}-\mathrm{ft} / \mathrm{yr}\left(26.9 \mathrm{hm} / \mathrm{yr}^{3}\right)$

EXTREMES (ACTUAL FLOW) FOR PERIOD OF RECORD (SINCE 1970).--Maximum daily discharge, $117 \mathrm{ft}^{3} / \mathrm{s}^{2}\left(3.31 \mathrm{~m}^{3} / \mathrm{s}\right.$ ) June 14, 1973; no flow many days in 1971 and 1974 .

EXTREMES (ACTUAL FLOW) FOR CURRENT YEAR. - Maximum daily discharge, $33 \mathrm{ft}^{3} / \mathrm{s}\left(0.93 \mathrm{~m}^{3} / \mathrm{s}\right) \mathrm{June}^{4-8}$; minimum daily, $5.9 \mathrm{ft}^{3} / \mathrm{s}\left(0.17 \mathrm{~m}^{3} / \mathrm{s}\right) \mathrm{Apr} .13$.

DISCHARGE, IN CUBIC FEET PER SECOND, WATER YEAR OCTOBER 1975 TO SEPTEMBER 1976 MEAN VALUES

\begin{tabular}{|c|c|c|c|c|c|c|c|c|c|c|c|c|}
\hline DAY & OC耳 & NoV & DEC & JAN & FEB & MAR & APR & MAY & JUN & JUL & AUG & SEP \\
\hline $\begin{array}{l}1 \\
2 \\
3 \\
4 \\
5\end{array}$ & $\begin{array}{l}14 \\
14 \\
14 \\
14 \\
14\end{array}$ & $\begin{array}{l}14 \\
14 \\
14 \\
14 \\
14\end{array}$ & $\begin{array}{l}13 \\
13 \\
13 \\
12 \\
12\end{array}$ & $\begin{array}{l}7.7 \\
7.7 \\
7.7 \\
7.7 \\
7.7\end{array}$ & $\begin{array}{l}6.0 \\
6.0 \\
6.0 \\
6.0 \\
6.0\end{array}$ & $\begin{array}{l}6.2 \\
6.2 \\
6.2 \\
6.2 \\
6.2\end{array}$ & $\begin{array}{l}7.9 \\
7.9 \\
7.9 \\
7.9 \\
7.9\end{array}$ & $\begin{array}{l}8.5 \\
8.3 \\
8.3 \\
8.5 \\
9.2\end{array}$ & $\begin{array}{l}29 \\
29 \\
32 \\
33 \\
33\end{array}$ & $\begin{array}{l}27 \\
22 \\
18 \\
18 \\
17\end{array}$ & $\begin{array}{l}17 \\
17 \\
17 \\
17 \\
17\end{array}$ & $\begin{array}{l}14 \\
14 \\
14 \\
14 \\
14\end{array}$ \\
\hline $\begin{array}{r}6 \\
7 \\
8 \\
9 \\
10\end{array}$ & $\begin{array}{l}14 \\
14 \\
13 \\
13 \\
13\end{array}$ & $\begin{array}{l}14 \\
14 \\
13 \\
13 \\
13\end{array}$ & $\begin{array}{l}11 \\
11 \\
11 \\
11 \\
11\end{array}$ & $\begin{array}{l}7.7 \\
7.7 \\
7.7 \\
7.7 \\
7.5\end{array}$ & $\begin{array}{l}6.2 \\
6.2 \\
6.2 \\
6.2 \\
6.4\end{array}$ & $\begin{array}{l}6.2 \\
6.2 \\
6.2 \\
6.2 \\
6.2\end{array}$ & $\begin{array}{l}7.9 \\
7.9 \\
7.9 \\
7.9 \\
7.9\end{array}$ & $\begin{array}{l}9.5 \\
9.6 \\
9.6 \\
9.6 \\
9.5\end{array}$ & $\begin{array}{l}33 \\
33 \\
33 \\
32 \\
29\end{array}$ & $\begin{array}{l}17 \\
17 \\
17 \\
17 \\
17\end{array}$ & $\begin{array}{l}17 \\
16 \\
16 \\
16 \\
16\end{array}$ & $\begin{array}{l}14 \\
16 \\
14 \\
13 \\
12\end{array}$ \\
\hline $\begin{array}{l}11 \\
12 \\
13 \\
14 \\
15\end{array}$ & $\begin{array}{l}13 \\
13 \\
13 \\
13 \\
13\end{array}$ & $\begin{array}{l}13 \\
13 \\
13 \\
13 \\
12\end{array}$ & $\begin{array}{ll}11 \\
11 \\
11 \\
11 \\
11\end{array}$ & $\begin{array}{l}7.5 \\
7.5 \\
7.5 \\
7.5 \\
7.5\end{array}$ & $\begin{array}{l}6.4 \\
6.4 \\
6.4 \\
6.4 \\
6.4\end{array}$ & $\begin{array}{l}6.0 \\
6.0 \\
6.0 \\
6.0 \\
6.0\end{array}$ & $\begin{array}{l}7.9 \\
7.0 \\
5.9 \\
6.2 \\
6.4\end{array}$ & $\begin{array}{l}9.5 \\
9.5 \\
9.0 \\
8.6 \\
9.0\end{array}$ & $\begin{array}{l}28 \\
28 \\
27 \\
27 \\
27\end{array}$ & $\begin{array}{l}17 \\
17 \\
17 \\
17 \\
17\end{array}$ & $\begin{array}{l}16 \\
16 \\
16 \\
16 \\
17\end{array}$ & $\begin{array}{l}12 \\
12 \\
12 \\
12 \\
12\end{array}$ \\
\hline $\begin{array}{l}16 \\
17 \\
18 \\
19 \\
20\end{array}$ & $\begin{array}{l}13 \\
13 \\
14 \\
14 \\
14\end{array}$ & $\begin{array}{l}12 \\
12 \\
12 \\
13 \\
13\end{array}$ & $\begin{array}{l}11 \\
11 \\
11 \\
8.8 \\
7.7\end{array}$ & $\begin{array}{l}7.7 \\
7.7 \\
7.7 \\
7.7 \\
6.8\end{array}$ & $\begin{array}{l}6.4 \\
6.2 \\
6.2 \\
6.2 \\
6.2\end{array}$ & $\begin{array}{l}6.0 \\
6.2 \\
6.6 \\
6.4 \\
6.6\end{array}$ & $\begin{array}{l}6.4 \\
6.4 \\
6.4 \\
6.4 \\
6.5\end{array}$ & $\begin{array}{l}9.9 \\
14 \\
16 \\
17 \\
20\end{array}$ & $\begin{array}{l}27 \\
27 \\
27 \\
27 \\
27\end{array}$ & $\begin{array}{l}20 \\
21 \\
21 \\
19 \\
18\end{array}$ & $\begin{array}{l}16 \\
16 \\
15 \\
15 \\
15\end{array}$ & $\begin{array}{l}12 \\
14 \\
11 \\
12 \\
12\end{array}$ \\
\hline $\begin{array}{l}21 \\
22 \\
23 \\
24 \\
25\end{array}$ & $\begin{array}{l}14 \\
14 \\
14 \\
14 \\
14\end{array}$ & $\begin{array}{l}12 \\
12 \\
12 \\
12 \\
13\end{array}$ & $\begin{array}{l}7.7 \\
7.7 \\
7.7 \\
7.7 \\
7.7\end{array}$ & $\begin{array}{l}6.0 \\
6.0 \\
6.0 \\
6.0 \\
6.0\end{array}$ & $\begin{array}{l}6.2 \\
6.2 \\
6.2 \\
6.0 \\
6.0\end{array}$ & $\begin{array}{l}6.4 \\
7.3 \\
7.9 \\
7.7 \\
7.7\end{array}$ & $\begin{array}{l}6.5 \\
6.5 \\
6.5 \\
6.4 \\
6.4\end{array}$ & $\begin{array}{l}21 \\
21 \\
21 \\
21 \\
21\end{array}$ & $\begin{array}{l}27 \\
27 \\
27 \\
27 \\
27\end{array}$ & $\begin{array}{l}18 \\
17 \\
17 \\
17 \\
17\end{array}$ & $\begin{array}{l}15 \\
15 \\
15 \\
15 \\
15\end{array}$ & $\begin{array}{l}12 \\
11 \\
11 \\
11 \\
12\end{array}$ \\
\hline $\begin{array}{l}26 \\
27 \\
28 \\
29 \\
30 \\
31\end{array}$ & $\begin{array}{l}14 \\
14 \\
14 \\
14 \\
14 \\
14\end{array}$ & $\begin{array}{r}13 \\
13 \\
13 \\
13 \\
13 \\
--0\end{array}$ & $\begin{array}{l}7.7 \\
7.7 \\
7.7 \\
7.7 \\
7.7 \\
7.7\end{array}$ & $\begin{array}{l}6.0 \\
6.0 \\
6.0 \\
6.0 \\
6.0 \\
6.0\end{array}$ & $\begin{array}{l}6.0 \\
6.0 \\
6.0 \\
6.0 \\
\cdots-\end{array}$ & $\begin{array}{l}7.9 \\
7.9 \\
7.7 \\
7.9 \\
7.9 \\
8.1\end{array}$ & $\begin{array}{l}7.3 \\
7.3 \\
8.3 \\
8.8 \\
8.5 \\
-.-\end{array}$ & $\begin{array}{l}22 \\
25 \\
29 \\
28 \\
29 \\
29\end{array}$ & $\begin{array}{r}27 \\
27 \\
27 \\
27 \\
27 \\
-\end{array}$ & $\begin{array}{l}17 \\
17 \\
17 \\
17 \\
17 \\
17\end{array}$ & $\begin{array}{l}14 \\
14 \\
14 \\
14 \\
14 \\
14\end{array}$ & $\begin{array}{l}12 \\
10 \\
9.4 \\
9.4 \\
9.6 \\
=--\end{array}$ \\
\hline $\begin{array}{l}\text { TOTAL } \\
\text { MEAN } \\
\text { MAX } \\
\text { MIN } \\
\text { AC-FT }\end{array}$ & $\begin{array}{r}424 \\
13.7 \\
14 \\
13 \\
841\end{array}$ & $\begin{array}{r}389 \\
13.0 \\
14 \\
12 \\
772\end{array}$ & $\begin{array}{r}307.2 \\
9.91 \\
13 \\
7.7 \\
609\end{array}$ & $\begin{array}{r}217.9 \\
7.03 \\
7.7 \\
6.0 \\
432\end{array}$ & $\begin{array}{r}179.0 \\
6.17 \\
6.4 \\
6.0 \\
355\end{array}$ & $\begin{array}{r}208.2 \\
6.72 \\
8.1 \\
6.0 \\
413\end{array}$ & $\begin{array}{r}217.0 \\
7.23 \\
8.8 \\
5.9 \\
430\end{array}$ & $\begin{array}{r}480.1 \\
15.5 \\
29 \\
8.3 \\
952\end{array}$ & $\begin{array}{r}858 \\
28.6 \\
33 \\
27 \\
1700\end{array}$ & $\begin{array}{r}559 \\
18.0 \\
27 \\
17 \\
1110\end{array}$ & $\begin{array}{r}483 \\
15.6 \\
17 \\
14 \\
958\end{array}$ & $\begin{array}{r}367.4 \\
12.2 \\
16 \\
9.4 \\
729\end{array}$ \\
\hline$(\dagger)$ & 864 & 752 & 593 & 433 & 378 & 421 & 448 & 1770 & 1450 & 1070 & 780 & 659 \\
\hline
\end{tabular}

CAL YR 1975 TOTAL 10103.2 MEAN 27.7 MAX 84 MIN 6.7 AC-FT $20040 \quad \dagger 20500$

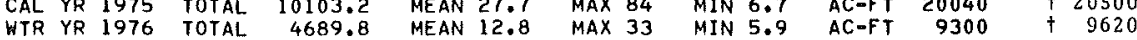

$\dagger$ Computed natura1 flow, in acre-feet. 


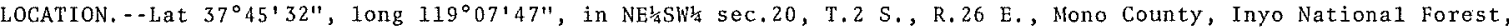
$500 \mathrm{ft}(152 \mathrm{~m})$ downstream from Agnew Lake Dam, and $3.4 \mathrm{mi}(5.5 \mathrm{~km})$ southwest of town of June Lake.

DRAINAGE AREA. $-23.3 \mathrm{mi}^{2}$ or $60.3 \mathrm{~km}^{2}$ (natural flow).

PERIOD OF RECORD.--October 1951 to current year. Monthly and yearly mean discharges prior to October 1969, published in WSP 2127 .

GAGE, - Water-stage recorder and Parshall flume on creek. Altitude of gage is $8,480 \mathrm{ft}(2,585 \mathrm{~m})$, from topographic map.

REMARKS, - -Flow regulated for power development by Waugh, Gem, and Agnew Lakes, combined capacity, 23,420 acre-ft $\left(28.9 \mathrm{hm}^{3}\right)$ and Rush Creek powerplant. "Actual flow" is total flow of Rush Creek below Agnew Lake and Rush Creek powerplant tailrace. "Natural flow" is the sum of "actual flow", change in contents and evaporation for Waugh, Gem, and Agnew Lakes.

COOPERATION,--Records furnished by Southern California Edison Co, and reviewed by the Geological Survey, in connection with a Federal Power Commission Project.

AVERAGE DISCHARGE (Actual flow). - -25 years, $54.8 \mathrm{ft}^{3} / \mathrm{s}\left(1.552 \mathrm{~m}^{3} / \mathrm{s}\right), 39,700 \mathrm{acre}-\mathrm{ft} / \mathrm{yr}^{\mathrm{r}}(49.0 \mathrm{hm} / \mathrm{yr})$.

(Natural flow). -25 years, $59.2 \mathrm{ft}^{3} / \mathrm{s}\left(1.677 \mathrm{~m}^{3} / \mathrm{s}\right), 42,890 \mathrm{acre}-\mathrm{ft} / \mathrm{yr}\left(52.9 \mathrm{hm} / \mathrm{yr}^{3}\right)$.

EXTREMES (ACTUAL FLOW) FOR PERIOD OF RECORD (SINCE 1970),--Maximum daily discharge, $398 \mathrm{ft}^{3} / \mathrm{s}\left(11.3 \mathrm{~m}^{3} / \mathrm{s}\right.$ ) Aug. 1,1974 ; minimum daily, $0.90 \mathrm{ft}^{3} / \mathrm{s}\left(0.025 \mathrm{~m}^{3} / \mathrm{s}\right)$ Aug. 31 to Sept. 2,1976 .

EXTREMES (ACTUAL FLOW) FOR CURRENT YEAR, --Maximum daily discharge, $66 \mathrm{ft}^{3} / \mathrm{s}\left(1.87 \mathrm{~m}^{3} / \mathrm{s}\right) \mathrm{Dec}$. 5 ; minimum daily, $0.90 \mathrm{ft}^{3} / \mathrm{s}\left(0.025 \mathrm{~m}^{3} / \mathrm{s}\right)$ Aug. 31 to Sept. 2 .

DISCHARGE, IN CUBIC FEET PER SECOND, WATER YEAR OCTOBER 1975 TO SEPTEMBER 1976 MEAN VALUES

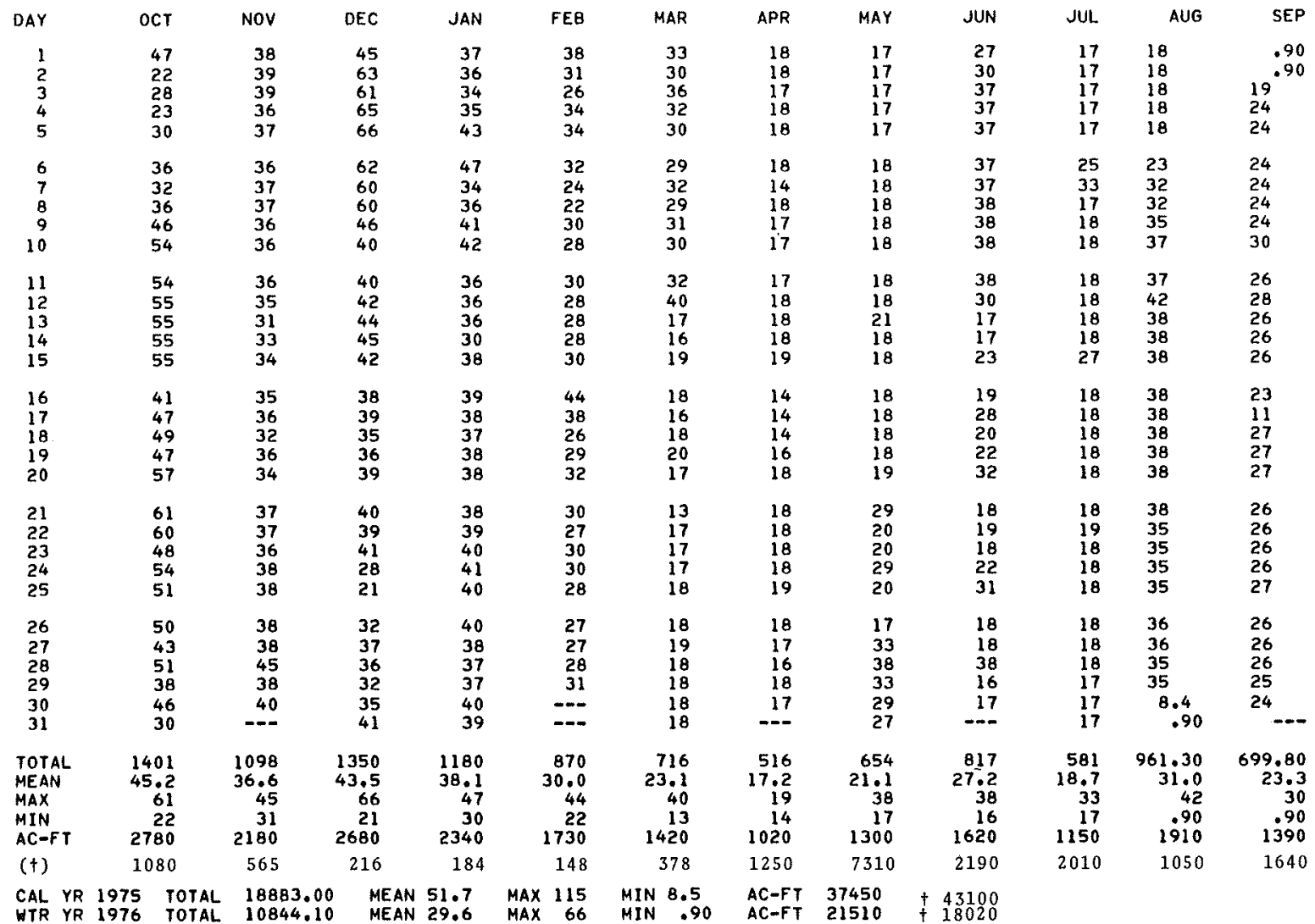

+ Computed natural flow, in acre-feet. 
10287400 RUSH CREEK ABOVE GRANT LAKE, NEAR JUNE LAKE, CA

LOCATION, - Lat $37^{\circ} 48^{\prime} 23^{\prime \prime}$, long $119^{\circ} 06^{\prime} 29^{\prime \prime}$, in NE's sec.4, T.2 S., R. 26 E, Mono County, on left bank in narrows, $0.6 \mathrm{mi}(1.0 \mathrm{~km})$ upstream from Grant Lake, and $2.7 \mathrm{mi}(4.3 \mathrm{~km})$ northwest of town of June Lake.

DRAINAGE AREA. $--51.3 \mathrm{mi}^{2}\left(132.9 \mathrm{~km}^{2}\right)$.

PERIOD OF RECORD.--December 1936 to current year. Prior to October 1959 monthly discharge only, pub1ished in WSP 1314 and 1734 .

GAGE. - Water-stage recorder and Parshall flume. Altitude of gage is 7,200 ft (2,195 m), from topographic map.

REMARKS, --Records poor. Flow regulated by Gem Lake, Lake Agnew, Waugh Lake, combined capacity, 23,400 acre-ft $\left(28.9 \mathrm{hm}^{3}\right)$ and by many natura1 lakes. No diversion above station.

COOPERATION,--Records were furnished by city of Los Angeles, Department of Water and Power.

AVERAGE DISCHARGE. - - 39 years (water years $1938-76), 81.2 \mathrm{ft}^{3} / \mathrm{s}\left(2.30 \mathrm{~m}^{3} / \mathrm{s}\right), 58,830 \mathrm{acre-ft} / \mathrm{yr}^{2}(72.5 \mathrm{hm} / \mathrm{yr})$

EXTREMES FOR PERIOD OF RECORD, - Maximum discharge, $1,070 \mathrm{ft}^{3} / \mathrm{s}\left(30.3 \mathrm{~m}^{3} / \mathrm{s}\right) \mathrm{July} 14$, 1967 , gage height, $6.20 \mathrm{ft}$

$(1.890 \mathrm{~m}) ;$ minimum daily, $5.5 \mathrm{ft}^{3} / \mathrm{s}(0.16 \mathrm{~m} / \mathrm{s})$ Sept. $6-8,14,1954$

OISCHARGE, IN CUBIC FEET PER SECOND, WATER YEAR OCTOBEA 1975 TO SEPTEMBER 1976 MEAN VALUES

\begin{tabular}{|c|c|c|c|c|c|c|c|c|c|c|c|c|}
\hline DAY & $O C T$ & NOV & DEC & JAN & FEB & MAR & APR & MAY & JUN & JUL & AUE & SEP \\
\hline $\begin{array}{l}1 \\
2 \\
3 \\
4 \\
5\end{array}$ & $\begin{array}{l}48 \\
44 \\
38 \\
35 \\
35\end{array}$ & $\begin{array}{l}\mathbf{5 5} \\
\mathbf{5 5} \\
\mathbf{5 6} \\
\mathbf{5 5} \\
\mathbf{5 2}\end{array}$ & $\begin{array}{l}55 \\
74 \\
77 \\
77 \\
76\end{array}$ & $\begin{array}{l}52 \\
48 \\
48 \\
46 \\
51\end{array}$ & $\begin{array}{l}48 \\
46 \\
42 \\
39 \\
43\end{array}$ & $\begin{array}{l}44 \\
42 \\
43 \\
45 \\
42\end{array}$ & $\begin{array}{l}31 \\
31 \\
31 \\
31 \\
31\end{array}$ & $\begin{array}{l}38 \\
41 \\
43 \\
44 \\
45\end{array}$ & $\begin{array}{l}55 \\
55 \\
54 \\
54 \\
54\end{array}$ & $\begin{array}{l}30 \\
29 \\
28 \\
28 \\
28\end{array}$ & $\begin{array}{l}37 \\
37 \\
35 \\
33 \\
33\end{array}$ & $\begin{array}{l}23 \\
19 \\
16 \\
17 \\
24\end{array}$ \\
\hline $\begin{array}{r}6 \\
7 \\
8 \\
9 \\
10\end{array}$ & $\begin{array}{l}39 \\
47 \\
47 \\
53 \\
70\end{array}$ & $\begin{array}{l}52 \\
52 \\
52 \\
52 \\
52\end{array}$ & $\begin{array}{l}74 \\
74 \\
74 \\
69 \\
53\end{array}$ & $\begin{array}{l}52 \\
52 \\
47 \\
49 \\
55\end{array}$ & $\begin{array}{l}46 \\
44 \\
39 \\
39 \\
42\end{array}$ & $\begin{array}{l}41 \\
41 \\
43 \\
42 \\
41\end{array}$ & $\begin{array}{l}31 \\
31 \\
30 \\
30 \\
30\end{array}$ & $\begin{array}{l}43 \\
43 \\
42 \\
42 \\
43\end{array}$ & $\begin{array}{l}\mathbf{5 4} \\
\mathbf{5 5} \\
\mathbf{5 7} \\
\mathbf{5 7} \\
\mathbf{5 7}\end{array}$ & $\begin{array}{l}30 \\
37 \\
11 \\
35 \\
32\end{array}$ & $\begin{array}{l}31 \\
37 \\
41 \\
43 \\
45\end{array}$ & $\begin{array}{l}31 \\
32 \\
33 \\
33 \\
37\end{array}$ \\
\hline $\begin{array}{l}11 \\
12 \\
13 \\
14 \\
15\end{array}$ & $\begin{array}{l}86 \\
77 \\
74 \\
72 \\
73\end{array}$ & $\begin{array}{l}51 \\
51 \\
52 \\
49 \\
49\end{array}$ & $\begin{array}{l}54 \\
55 \\
55 \\
57 \\
57\end{array}$ & $\begin{array}{l}52 \\
47 \\
47 \\
45 \\
45\end{array}$ & $\begin{array}{l}41 \\
41 \\
41 \\
41 \\
41\end{array}$ & $\begin{array}{l}42 \\
42 \\
32 \\
31 \\
31\end{array}$ & $\begin{array}{l}30 \\
31 \\
32 \\
33 \\
33\end{array}$ & $\begin{array}{l}46 \\
50 \\
54 \\
62 \\
61\end{array}$ & $\begin{array}{l}57 \\
57 \\
47 \\
38 \\
37\end{array}$ & $\begin{array}{l}31 \\
31 \\
31 \\
31 \\
31\end{array}$ & $\begin{array}{l}45 \\
46 \\
49 \\
46 \\
49\end{array}$ & $\begin{array}{l}40 \\
39 \\
39 \\
39 \\
39\end{array}$ \\
\hline $\begin{array}{l}16 \\
17 \\
18 \\
19 \\
20\end{array}$ & $\begin{array}{l}65 \\
58 \\
63 \\
65 \\
69\end{array}$ & $\begin{array}{l}49 \\
52 \\
50 \\
50 \\
49\end{array}$ & $\begin{array}{l}52 \\
51 \\
49 \\
47 \\
48\end{array}$ & $\begin{array}{l}48 \\
49 \\
49 \\
47 \\
47\end{array}$ & $\begin{array}{l}49 \\
52 \\
43 \\
41 \\
39\end{array}$ & $\begin{array}{l}32 \\
33 \\
33 \\
31 \\
31\end{array}$ & $\begin{array}{l}31 \\
29 \\
28 \\
30 \\
32\end{array}$ & $\begin{array}{l}62 \\
61 \\
59 \\
55 \\
52\end{array}$ & $\begin{array}{l}37 \\
37 \\
38 \\
39 \\
40\end{array}$ & $\begin{array}{l}32 \\
33 \\
32 \\
31 \\
29\end{array}$ & $\begin{array}{l}47 \\
48 \\
48 \\
48 \\
49\end{array}$ & $\begin{array}{l}\mathbf{3 9} \\
\mathbf{3 3} \\
\mathbf{3 3} \\
\mathbf{3 7} \\
\mathbf{3 8}\end{array}$ \\
\hline $\begin{array}{l}21 \\
22 \\
23 \\
24 \\
25\end{array}$ & $\begin{array}{l}75 \\
75 \\
70 \\
70 \\
69\end{array}$ & $\begin{array}{l}52 \\
52 \\
52 \\
51 \\
52\end{array}$ & $\begin{array}{l}51 \\
51 \\
51 \\
49 \\
39\end{array}$ & $\begin{array}{l}47 \\
47 \\
49 \\
50 \\
51\end{array}$ & $\begin{array}{l}40 \\
41 \\
39 \\
39 \\
39\end{array}$ & $\begin{array}{l}31 \\
20 \\
31 \\
31 \\
31\end{array}$ & $\begin{array}{l}34 \\
35 \\
35 \\
36 \\
38\end{array}$ & $\begin{array}{l}53 \\
58 \\
51 \\
50 \\
56\end{array}$ & $\begin{array}{l}42 \\
41 \\
36 \\
37 \\
37\end{array}$ & $\begin{array}{l}29 \\
29 \\
29 \\
29 \\
30\end{array}$ & $\begin{array}{l}49 \\
48 \\
46 \\
46 \\
46\end{array}$ & $\begin{array}{l}37 \\
37 \\
37 \\
37 \\
36\end{array}$ \\
\hline $\begin{array}{l}26 \\
27 \\
28 \\
29 \\
30 \\
31\end{array}$ & $\begin{array}{l}69 \\
70 \\
64 \\
64 \\
61 \\
56\end{array}$ & $\begin{array}{r}48 \\
49 \\
52 \\
54 \\
55 \\
-\end{array}$ & $\begin{array}{l}38 \\
45 \\
47 \\
45 \\
45 \\
50\end{array}$ & $\begin{array}{l}51 \\
50 \\
48 \\
47 \\
49 \\
49\end{array}$ & $\begin{array}{r}39 \\
39 \\
39 \\
41 \\
--\infty\end{array}$ & $\begin{array}{l}31 \\
31 \\
31 \\
31 \\
31 \\
31\end{array}$ & $\begin{array}{r}38 \\
37 \\
34 \\
35 \\
35 \\
-\end{array}$ & $\begin{array}{l}51 \\
52 \\
67 \\
66 \\
64 \\
59\end{array}$ & $\begin{array}{r}37 \\
36 \\
39 \\
40 \\
31 \\
-\infty\end{array}$ & $\begin{array}{l}30 \\
29 \\
31 \\
35 \\
32 \\
34\end{array}$ & $\begin{array}{l}46 \\
41 \\
40 \\
41 \\
39 \\
34\end{array}$ & $\begin{array}{r}37 \\
36 \\
36 \\
37 \\
38 \\
- \\
-\end{array}$ \\
\hline $\begin{array}{l}\text { TOTAL } \\
\text { MEAN } \\
\text { MAX } \\
\text { MIN } \\
\text { AC-FT }\end{array}$ & $\begin{array}{r}1901 \\
61,3 \\
86 \\
35 \\
3770\end{array}$ & $\begin{array}{r}1552 \\
51.7 \\
56 \\
48 \\
3000\end{array}$ & $\begin{array}{r}17.39 \\
56.1 \\
77 \\
38 \\
3450\end{array}$ & $\begin{array}{r}1514 \\
68,8 \\
55 \\
45 \\
3000\end{array}$ & $\begin{array}{r}1213 \\
41.6 \\
52 \\
39 \\
2410\end{array}$ & $\begin{array}{r}1100 \\
35.5 \\
45 \\
28 \\
2180\end{array}$ & $\begin{array}{r}973 \\
32.4 \\
38 \\
28 \\
1930\end{array}$ & $\begin{array}{r}1613 \\
52.0 \\
67 \\
38 \\
3200\end{array}$ & $\begin{array}{r}1357 \\
45,2 \\
57 \\
31 \\
2690\end{array}$ & $\begin{array}{r}967 \\
31.2 \\
41 \\
28 \\
2920\end{array}$ & $\begin{array}{r}1323 \\
42.7 \\
49 \\
31 \\
2620\end{array}$ & $\begin{array}{r}1009 \\
33.6 \\
40 \\
16 \\
2000\end{array}$ \\
\hline
\end{tabular}

CAL YR 1975 TOTAL 28722 MEAN 78.7 MAX 255 MIN 25 AC-FT 56970

WTR YR 1976 TOTAL 16261 MEAN 4.4 MAX 86 MIN 16 ACMF 32250 


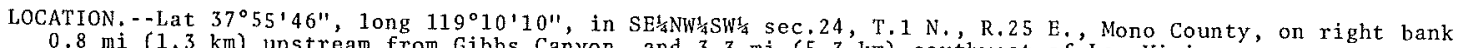
$0.8 \mathrm{mi}(1.3 \mathrm{~km})$ upstream from Gibbs Canyon, and $3.3 \mathrm{mi}(5.3 \mathrm{~km})$ southwest of Lee Vining.

DRAINAGE AREA, $--34.9 \mathrm{mi}^{2}\left(90.4 \mathrm{~km}^{2}\right)$.

PERIOD OF RECORD, - April 1934 to current year. Prior to October 1959 month1y discharge only, published in WSP 1314 and 1734 .

GAGE. - Water-stage recorder and partial concrete control. Altitude of gage is $7,400 \mathrm{ft}(2,256 \mathrm{~m})$, from topographic map. See WSP 1734 for history of changes prior to Aug. 6, 1944 .

REMARKS. - Records poor. Flow regulated for power development by Ellery, Saddlebag, and Tioga Lakes, combined capacity, 13,269 acre-ft $\left(16.4 \mathrm{hm}^{3}\right)$ and by severa1 sma11 natural lakes. No diversion above station.

COOPERATION. - -Records were furnished by city of Los Angeles, Department of Water and Power.

AVERAGE DISCHARGE. -42 years, $66.5 \mathrm{ft}^{3} / \mathrm{s}\left(1.88 \mathrm{~m}^{3} / \mathrm{s}\right), 48,180 \mathrm{acre}-\mathrm{ft} / \mathrm{yr}(59.4 \mathrm{hm} / \mathrm{yr})$,

EXTREMES FOR PERIOD OF RECORD, - Maximum discharge, $590 \mathrm{ft}^{3} / \mathrm{s}\left(16.7 \mathrm{~m}^{3} / \mathrm{s}\right)$ July 4,1967 , gage height, $4.42 \mathrm{ft}$
$(1.347 \mathrm{~m}) ;$ no flow Nov. 29, 1935 .

EXTREMES FOR CURRENT YEAR, - -Maximum daily discharge, $153 \mathrm{ft}^{3} / \mathrm{s}\left(4.33 \mathrm{~m}^{3} / \mathrm{s}\right) \mathrm{May} 14 ; \mathrm{minimum} \mathrm{daily,} 13 \mathrm{ft} 3 / \mathrm{s}$
$\left(0.37 \mathrm{~m}^{3} / \mathrm{s}\right)$ June 13, Sept. 20.

DISCHARGE, IN CUBIC FEET PER SECOND, HATER YEAR OCTOGER 1975 TO SEPTEMBER 1976 MEAN VALUES

\begin{tabular}{|c|c|c|c|c|c|c|c|c|c|c|c|c|}
\hline DAY & $\mathrm{OCT}$ & NoV & DEC & JAN & FEB & MAR & APR & MAY & JUN & JUL & AUG & SEP \\
\hline $\begin{array}{l}1 \\
2 \\
3 \\
4 \\
5\end{array}$ & $\begin{array}{l}27 \\
28 \\
27 \\
37 \\
27\end{array}$ & $\begin{array}{l}27 \\
25 \\
28 \\
28 \\
28\end{array}$ & $\begin{array}{l}24 \\
23 \\
23 \\
18 \\
19\end{array}$ & $\begin{array}{l}54 \\
56 \\
53 \\
54 \\
53\end{array}$ & $\begin{array}{l}35 \\
52 \\
30 \\
25 \\
36\end{array}$ & $\begin{array}{l}19 \\
25 \\
34 \\
27 \\
25\end{array}$ & $\begin{array}{l}18 \\
18 \\
18 \\
21 \\
23\end{array}$ & $\begin{array}{l}60 \\
63 \\
81 \\
64 \\
82\end{array}$ & $\begin{array}{l}57 \\
68 \\
72 \\
63 \\
40\end{array}$ & $\begin{array}{l}40 \\
44 \\
36 \\
33 \\
33\end{array}$ & $\begin{array}{l}69 \\
41 \\
35 \\
37 \\
47\end{array}$ & $\begin{array}{l}26 \\
22 \\
22 \\
22 \\
42\end{array}$ \\
\hline $\begin{array}{r}6 \\
7 \\
8 \\
9 \\
10\end{array}$ & $\begin{array}{l}30 \\
36 \\
32 \\
32 \\
32\end{array}$ & $\begin{array}{l}26 \\
26 \\
25 \\
25 \\
25\end{array}$ & $\begin{array}{l}19 \\
19 \\
19 \\
21 \\
26\end{array}$ & $\begin{array}{l}39 \\
37 \\
41 \\
40 \\
42\end{array}$ & $\begin{array}{l}46 \\
29 \\
24 \\
24 \\
24\end{array}$ & $\begin{array}{l}30 \\
35 \\
22 \\
17 \\
15\end{array}$ & $\begin{array}{l}20 \\
28 \\
23 \\
25 \\
25\end{array}$ & $\begin{array}{l}61 \\
64 \\
63 \\
77 \\
77\end{array}$ & $\begin{array}{l}21 \\
55 \\
40 \\
40 \\
37\end{array}$ & $\begin{array}{l}44 \\
40 \\
33 \\
34 \\
40\end{array}$ & $\begin{array}{l}41 \\
31 \\
30 \\
28 \\
33\end{array}$ & $\begin{array}{l}43 \\
32 \\
32 \\
32 \\
37\end{array}$ \\
\hline $\begin{array}{l}11 \\
12 \\
13 \\
14 \\
15\end{array}$ & $\begin{array}{l}32 \\
32 \\
35 \\
34 \\
34\end{array}$ & $\begin{array}{l}14 \\
21 \\
33 \\
31 \\
28\end{array}$ & $\begin{array}{l}22 \\
22 \\
19 \\
18 \\
18\end{array}$ & $\begin{array}{l}46 \\
33 \\
28 \\
38 \\
54\end{array}$ & $\begin{array}{l}26 \\
26 \\
19 \\
24 \\
28\end{array}$ & $\begin{array}{l}16 \\
20 \\
19 \\
18 \\
20\end{array}$ & $\begin{array}{l}22 \\
21 \\
23 \\
21 \\
24\end{array}$ & $\begin{array}{r}91 \\
109 \\
117 \\
153 \\
151\end{array}$ & $\begin{array}{l}30 \\
16 \\
13 \\
25 \\
45\end{array}$ & $\begin{array}{l}40 \\
40 \\
39 \\
44 \\
47\end{array}$ & $\begin{array}{l}29 \\
36 \\
26 \\
26 \\
26\end{array}$ & $\begin{array}{l}54 \\
53 \\
27 \\
48 \\
39\end{array}$ \\
\hline $\begin{array}{l}16 \\
17 \\
18 \\
19 \\
20\end{array}$ & $\begin{array}{l}35 \\
35 \\
34 \\
30 \\
29\end{array}$ & $\begin{array}{l}25 \\
24 \\
30 \\
30 \\
23\end{array}$ & $\begin{array}{l}18 \\
18 \\
18 \\
20 \\
21\end{array}$ & $\begin{array}{l}34 \\
38 \\
36 \\
36 \\
40\end{array}$ & $\begin{array}{l}38 \\
29 \\
17 \\
23 \\
22\end{array}$ & $\begin{array}{l}20 \\
19 \\
25 \\
25 \\
19\end{array}$ & $\begin{array}{l}19 \\
18 \\
16 \\
31 \\
20\end{array}$ & $\begin{array}{r}132 \\
134 \\
123 \\
86 \\
85\end{array}$ & $\begin{array}{l}55 \\
68 \\
72 \\
71 \\
76\end{array}$ & $\begin{array}{l}61 \\
54 \\
45 \\
42 \\
45\end{array}$ & $\begin{array}{l}26 \\
26 \\
26 \\
26 \\
25\end{array}$ & $\begin{array}{l}26 \\
25 \\
22 \\
19 \\
13\end{array}$ \\
\hline $\begin{array}{l}21 \\
24 \\
23 \\
24 \\
25\end{array}$ & $\begin{array}{l}31 \\
31 \\
33 \\
35 \\
34\end{array}$ & $\begin{array}{l}22 \\
24 \\
24 \\
24 \\
24\end{array}$ & $\begin{array}{l}21 \\
19 \\
20 \\
19 \\
19\end{array}$ & $\begin{array}{l}37 \\
44 \\
33 \\
32 \\
39\end{array}$ & $\begin{array}{l}21 \\
25 \\
25 \\
.29 \\
20\end{array}$ & $\begin{array}{l}18 \\
18 \\
19 \\
24 \\
20\end{array}$ & $\begin{array}{l}24 \\
25 \\
32 \\
27 \\
30\end{array}$ & $\begin{array}{l}92 \\
82 \\
76 \\
73 \\
91\end{array}$ & $\begin{array}{l}48 \\
42 \\
26 \\
15 \\
42\end{array}$ & $\begin{array}{l}\mathbf{3 7} \\
\mathbf{3 6} \\
\mathbf{3 7} \\
\mathbf{3 7} \\
\mathbf{3 7}\end{array}$ & $\begin{array}{l}25 \\
24 \\
24 \\
23 \\
22\end{array}$ & $\begin{array}{l}15 \\
19 \\
20 \\
19 \\
19\end{array}$ \\
\hline $\begin{array}{l}26 \\
27 \\
28 \\
29 \\
30 \\
31\end{array}$ & $\begin{array}{l}30 \\
25 \\
22 \\
22 \\
25 \\
30\end{array}$ & $\begin{array}{r}24 \\
24 \\
24 \\
24 \\
24 \\
-\end{array}$ & $\begin{array}{l}19 \\
18 \\
18 \\
18 \\
18 \\
18\end{array}$ & $\begin{array}{l}36 \\
35 \\
35 \\
35 \\
39 \\
35\end{array}$ & $\begin{array}{r}19 \\
29 \\
36 \\
19 \\
-\infty \\
-\infty\end{array}$ & $\begin{array}{l}22 \\
21 \\
19 \\
21 \\
25 \\
18\end{array}$ & $\begin{array}{r}31 \\
45 \\
20 \\
22 \\
40 \\
--\end{array}$ & $\begin{array}{l}87 \\
97 \\
91 \\
75 \\
66 \\
78\end{array}$ & $\begin{array}{r}33 \\
26 \\
50 \\
22 \\
16 \\
-\end{array}$ & $\begin{array}{l}37 \\
40 \\
47 \\
68 \\
52 \\
55\end{array}$ & $\begin{array}{l}23 \\
24 \\
24 \\
24 \\
22 \\
23\end{array}$ & $\begin{array}{r}19 \\
19 \\
19 \\
21 \\
29 \\
-\infty\end{array}$ \\
\hline $\begin{array}{l}\text { TOTAL } \\
\text { MEAN } \\
\text { MAX } \\
\text { MIN } \\
\text { AC } \triangle F T\end{array}$ & $\begin{array}{r}956 \\
30.8 \\
37 \\
22 \\
1900\end{array}$ & $\begin{array}{r}760 \\
25.3 \\
33 \\
14 \\
1510\end{array}$ & $\begin{array}{r}612 \\
19.7 \\
26 \\
18 \\
1210\end{array}$ & $\begin{array}{r}1252 \\
40.4 \\
56 \\
28 \\
2480\end{array}$ & $\begin{array}{r}798 \\
27.5 \\
52 \\
17 \\
1580\end{array}$ & $\begin{array}{r}675 \\
21.8 \\
35 \\
15 \\
1340\end{array}$ & $\begin{array}{r}730 \\
24.3 \\
45 \\
16 \\
1450\end{array}$ & $\begin{array}{r}2781 \\
89.7 \\
1.53 \\
60 \\
5520\end{array}$ & $\begin{array}{r}1284 \\
42.8 \\
76 \\
13 \\
2550\end{array}$ & $\begin{array}{r}1317 \\
42.5 \\
68 \\
33 \\
2610\end{array}$ & $\begin{array}{r}922 \\
29.7 \\
69 \\
22 \\
1830\end{array}$ & $\begin{array}{r}835 \\
27.8 \\
54 \\
13 \\
1660\end{array}$ \\
\hline
\end{tabular}

CAL YR 1975 TOTAL 24572 MEAN 67.3 MAX 327 MIN 13 AC-FT 48740

WTR YR 1976 TOTAL 12922 MEAN 35.3 MAX 153 MIN 13 AC-FT 25630 
11012000 COTTONWOOD CREEK ABOVE TECATE CREEK, NEAR DULZURA, CA

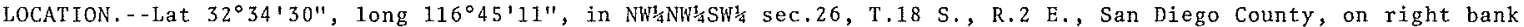
$0.8 \mathrm{mi}(1.3 \mathrm{~km})$ upstream from confluence with Tecate Creek, and $5.1 \mathrm{mi}$ ( 8.2 km) south of Dulzura.

DRAINAGE AREA, $--310 \mathrm{mi}^{2}\left(803 \mathrm{~km}^{2}\right)$.

PERIOD OF RECORD, - -October 1936 to current year.

GAGE. - Water-stage recorder. Control is a rock outcropping $75 \mathrm{ft}$ (23 m) downstream from gage, Datum of gage is $569.40 \mathrm{ft}(173.55 \mathrm{~m})$ above mean sea level (levels by International Boundary and Water Commission).

REMARKS. - Records good. Flow regulated by Morena Reservoir, capacity, 50,120 acre-ft (61.9 hm ${ }^{3}$ ) and Barrett

Reservoir, capacity, 44,760 acre-ft $\left(55.2 \mathrm{hm}^{3}\right)$. Water released from Barrett Reservoir through Dulzura conduit is diverted to Lower Otay Reservoir.

AVERAGE DISCHARGE, -40 years, $5.85 \mathrm{ft}^{3} / \mathrm{s}\left(0.166 \mathrm{~m}^{3} / \mathrm{s}\right), 4,240 \mathrm{acre}-\mathrm{ft} / \mathrm{yr}\left(5.23 \mathrm{hm}^{3} / \mathrm{yr}^{2}\right)$

EXTREMES FOR PERIOD OF RECORD. - Maximum discharge, $4,340 \mathrm{ft}^{3} / \mathrm{s}\left(123 \mathrm{~m}^{3} / \mathrm{s}\right)$ Feb, 7 , 1937, gage height, $9.65 \mathrm{ft}$ $(2.941 \mathrm{~m})$ from rating curve extended above $1,500 \mathrm{ft}^{3} / \mathrm{s}\left(42.5 \mathrm{~m}^{3} / \mathrm{s}\right)$; no flow for part of each year.

EXTREMES FOR CURRENT YEAR. - Maximum discharge, $61 \mathrm{ft}^{3} / \mathrm{s}\left(1.73 \mathrm{~m}^{3} / \mathrm{s}\right)$ Feb. 9 , gage height, 3.03 ft $(0.924 \mathrm{~m})$; no flow most of year.

DISCHARGE, IN CUBIC FEET PER SECOND, HATER YEAR OCTOBER 1975 TO SEPTEMBER 1976 MEAN VALUES

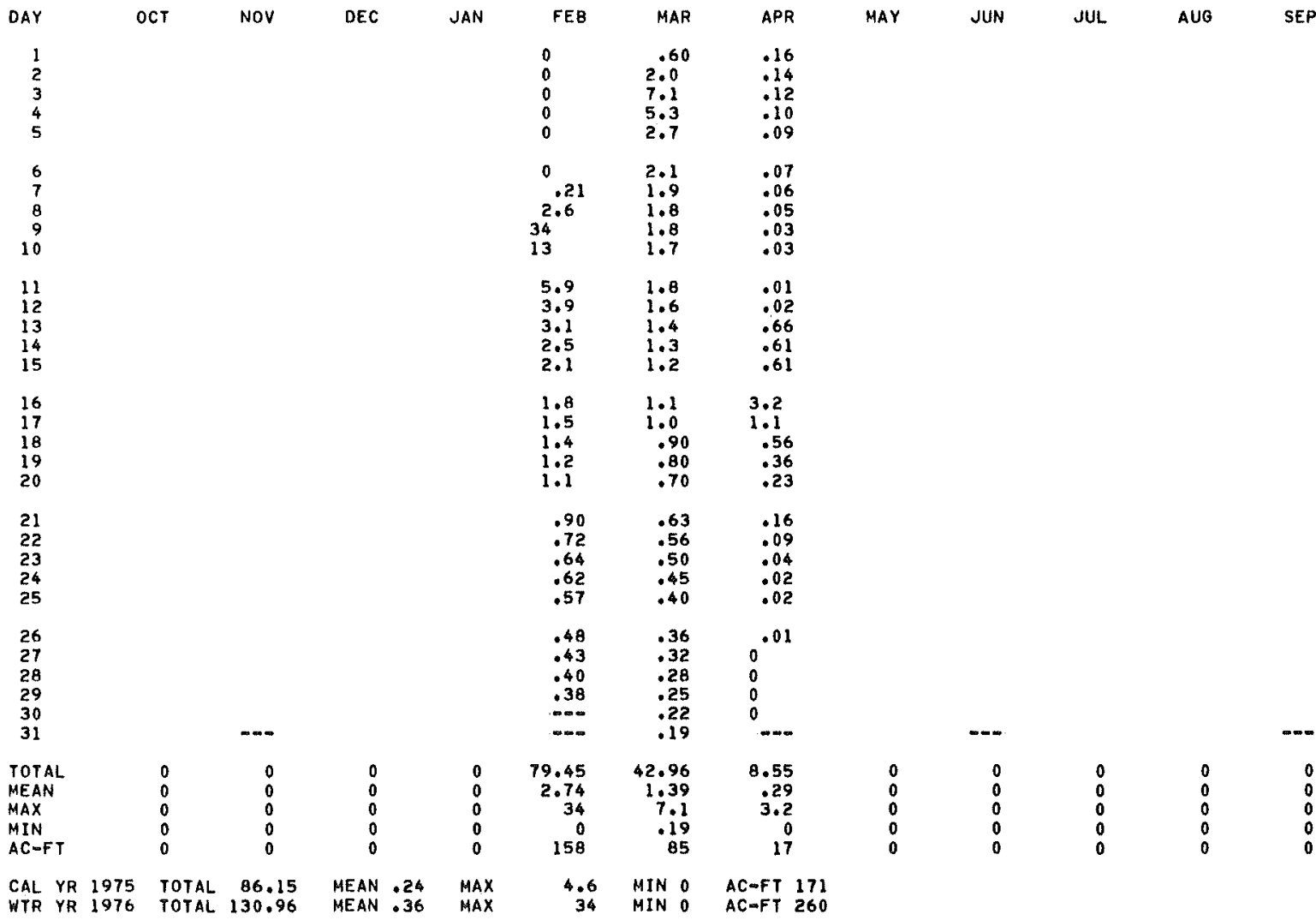




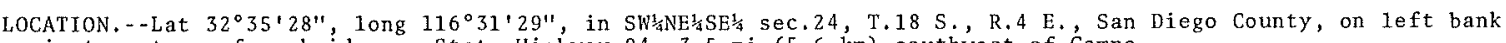
just upstream from bridge on State Highway $94,3.5$ mi $(5.6 \mathrm{~km})$ southwest of Campo.

DRAINAGE AREA, $-85.0 \mathrm{mi}^{2}\left(220.2 \mathrm{~km}^{2}\right)$, of which $3 \mathrm{mi}^{2}\left(8 \mathrm{~km}^{2}\right)$ are in Mexico.

PERIOD OF RECORD, - October 1936 to current year.

GAGE. - Water-stage recorder and broad-crested weir. Datum of gage is $2,178.92 \mathrm{ft}(664.135 \mathrm{~m})$ above mean sea level. Prior to Dec. 1, 1954, at datum $1 \mathrm{ft}(0.3 \mathrm{~m})$ higher.

REMARKS. --Records fair. Flow partly regulated by smal1 conservation reservoir since August 1956 . No diversion above station.

AVERAGE DISCHARGE. - -40 years, $1.59 \mathrm{ft}^{3} / \mathrm{s}\left(0.045 \mathrm{~m}^{3} / \mathrm{s}\right), 1,150 \mathrm{acre}-\mathrm{ft} / \mathrm{yr}(1.42 \mathrm{hm} / \mathrm{yr})$.

EXTREMES FOR PERIOD OF RECORD. - Maximum discharge, $880 \mathrm{ft}^{3} / \mathrm{s}\left(24.9 \mathrm{~m}^{3} / \mathrm{s}\right)$ Feb. 6 , 1937, gage height, $4.80 \mathrm{ft}$ $(1.463 \mathrm{~m})$, present datum, from rating curve extended above $110 \mathrm{ft}^{3} / \mathrm{s}\left(3.12 \mathrm{~m}^{3} / \mathrm{s}\right)$ on basis of velocity meandepth relation and cross-sectional area at control; no flow for part of most years.

EXTREMES FOR CURRENT YEAR.--Maximum discharge, $7.4 \mathrm{ft}^{3} / \mathrm{s}\left(0.21 \mathrm{~m}^{3} / \mathrm{s}\right) \mathrm{Sept}$. 10 , gage height, $1.71 \mathrm{ft}(0.521 \mathrm{~m})$, no peak above base of $20.0 \mathrm{ft}^{3} / \mathrm{s}(0.57 \mathrm{~m} / \mathrm{s})$; no flow for part of year.

DISCHARGE, IN CUBIC FEET PER SECOND, WATER YEAR OCTOBER 1975 TO SEPTEMBER 1976

\begin{tabular}{|c|c|c|c|c|c|c|c|c|c|c|c|c|}
\hline DAY & OCT & NOV & DEC & JAN & FEB & MAR & APR & MAY & JUN & JUL & AUG & SEP \\
\hline $\begin{array}{l}1 \\
2 \\
3 \\
4 \\
5\end{array}$ & & $\begin{array}{l}0 \\
0 \\
0 \\
0 \\
0\end{array}$ & $\begin{array}{l}0 \\
0 \\
0 \\
0 \\
0\end{array}$ & & $\begin{array}{l}0 \\
0 \\
.01 \\
.02\end{array}$ & $\begin{array}{l}.05 \\
.03 \\
.20 \\
.08 \\
.07\end{array}$ & $\begin{array}{l}.03 \\
.03 \\
.04 \\
.07 \\
.05\end{array}$ & $\begin{array}{l}.02 \\
.02 \\
.02 \\
.02 \\
.02\end{array}$ & $\begin{array}{l}.01 \\
.01 \\
.01 \\
.01 \\
.01\end{array}$ & & & $\begin{array}{l}0 \\
0 \\
0 \\
0 \\
0\end{array}$ \\
\hline $\begin{array}{r}6 \\
7 \\
8 \\
9 \\
10\end{array}$ & & $\begin{array}{l}0 \\
0 \\
0 \\
0 \\
0\end{array}$ & $\begin{array}{l}0 \\
0 \\
0 \\
0 \\
0\end{array}$ & & $\begin{array}{r}.04 \\
.06 \\
.11 \\
.02\end{array}$ & $\begin{array}{l}.06 \\
.05 \\
.05 \\
.05 \\
.05\end{array}$ & $\begin{array}{l}.06 \\
.06 \\
.06 \\
.06 \\
.06\end{array}$ & $\begin{array}{l}.03 \\
.03 \\
.02 \\
.02 \\
.02\end{array}$ & $\begin{array}{l}.01 \\
.01 \\
0 \begin{array}{l}.01 \\
0 \\
.01\end{array}\end{array}$ & & & $\begin{array}{l}0 \\
0 \\
0 \\
0 \\
\quad 19\end{array}$ \\
\hline $\begin{array}{l}11 \\
12 \\
13 \\
14 \\
15\end{array}$ & & $\begin{array}{l}0 \\
0 \\
0 \\
0 \\
0\end{array}$ & $\begin{array}{l}0 \\
0 \\
0 \\
0\end{array}$ & & $\begin{array}{l}.02 \\
.01 \\
0 \\
0 \\
0\end{array}$ & $\begin{array}{r}.02 \\
.02 \\
.02 \\
.02\end{array}$ & $\begin{array}{r}.06 \\
.07 \\
.10 \\
.08 \\
.12\end{array}$ & $\begin{array}{l}.01 \\
.01 \\
.01 \\
.01 \\
.01\end{array}$ & $\begin{array}{l}.01 \\
.01 \\
.01 \\
0 \\
0\end{array}$ & & & $\begin{array}{l}.23 \\
.02 \\
.01 \\
0 \\
0\end{array}$ \\
\hline $\begin{array}{l}16 \\
17 \\
18 \\
19 \\
20\end{array}$ & & $\begin{array}{l}0 \\
0 \\
0 \\
0 \\
0\end{array}$ & $\begin{array}{l}0 \\
0 \\
0 \\
0 \\
0\end{array}$ & & $\begin{array}{l}0 \\
0 \\
0 \\
0 \\
0\end{array}$ & $\begin{array}{l}.03 \\
.05 \\
.05 \\
.05 \\
.04\end{array}$ & $\begin{array}{l}.14 \\
.02 \\
.02 \\
.01 \\
.01\end{array}$ & $\begin{array}{l}.01 \\
.01 \\
.01 \\
.01 \\
.01\end{array}$ & $\begin{array}{l}0 \\
0 \\
0 \\
0 \\
0\end{array}$ & & & $\begin{array}{l}0^{.01} \\
0 \\
0 \\
0\end{array}$ \\
\hline $\begin{array}{l}21 \\
22 \\
23 \\
24 \\
25\end{array}$ & & $\begin{array}{l}0 \\
0 \\
0 \\
0 \\
0\end{array}$ & $\begin{array}{l}0 \\
0 \\
0 \\
0 \\
0\end{array}$ & & $\begin{array}{l}0 \\
0 \\
0 \\
0 \\
0\end{array}$ & $\begin{array}{l}.05 \\
.05 \\
.04 \\
.03 \\
.03\end{array}$ & $\begin{array}{l}.01 \\
.02 \\
.02 \\
.02 \\
.02\end{array}$ & $\begin{array}{l}.01 \\
.01 \\
.02 \\
.01 \\
.01\end{array}$ & $\begin{array}{l}0 \\
0 \\
0 \\
0 \\
0\end{array}$ & & & $\begin{array}{l}0 \\
0 \\
0 \\
.01 \\
.01\end{array}$ \\
\hline $\begin{array}{l}26 \\
27 \\
28 \\
29 \\
30 \\
31\end{array}$ & & $\begin{array}{l}0 \\
.01 \\
.14 \\
.07 \\
0\end{array}$ & $\begin{array}{l}0 \\
0 \\
0 \\
0 \\
0 \\
0\end{array}$ & & $\begin{array}{l}0 \\
0 \\
0 \\
0 \\
\\
\end{array}$ & $\begin{array}{l}.03 \\
.03 \\
.03 \\
.03 \\
.03 \\
.03\end{array}$ & $\begin{array}{l}.02 \\
.02 \\
.02 \\
.02 \\
.02 \\
.0\end{array}$ & $\begin{array}{l}.01 \\
.01 \\
.01 \\
.02 \\
.02 \\
.02 \\
.02\end{array}$ & $\begin{array}{l}0 \\
0 \\
0 \\
0 \\
0 \\
-\end{array}$ & & & $\begin{array}{r}.01 \\
.01 \\
.01 \\
.01 \\
.-0\end{array}$ \\
\hline $\begin{array}{l}\text { TOTAL } \\
\text { MEAN } \\
\text { MAX } \\
\text { MIN } \\
\text { AC-FT }\end{array}$ & $\begin{array}{l}0 \\
0 \\
0 \\
0 \\
0\end{array}$ & $\begin{array}{r}.22 \\
.007 \\
.14 \\
0 \\
.4\end{array}$ & $\begin{array}{r}.01 \\
.0003 \\
.01 \\
0 \\
.02\end{array}$ & $\begin{array}{l}0 \\
0 \\
0 \\
0 \\
0\end{array}$ & $\begin{array}{r}.29 \\
.010 \\
.11 \\
0 \\
.6\end{array}$ & $\begin{array}{r}1.37 \\
.044 \\
.20 \\
0 \\
2.7\end{array}$ & $\begin{array}{r}1.34 \\
.045 \\
.14 \\
.01 \\
2.7\end{array}$ & $\begin{array}{r}.47 \\
.015 \\
.03 \\
.01 \\
.9\end{array}$ & $\begin{array}{r}.11 \\
.004 \\
.01 \\
0 \\
.2\end{array}$ & $\begin{array}{l}0 \\
0 \\
0 \\
0 \\
0\end{array}$ & $\begin{array}{l}0 \\
0 \\
0 \\
0 \\
0\end{array}$ & $\begin{array}{r}.52 \\
.017 \\
.23 \\
0 \\
1.0\end{array}$ \\
\hline
\end{tabular}


11013000 TIJUANA RIVER NEAR DULZURA, CA

LOCATION. - Lat $32^{\circ} 33^{\prime} 56^{\prime \prime}$, long $116^{\circ} 46^{\prime} 27^{\prime \prime}$, in E $\frac{1 / 2}{2}$ sec. 33 , T.18 S., R. 2 E., San Diego County, on 1 eft bank 0.5 mi $(0.8 \mathrm{~km})$ downstream from confluence of'Cottonwood and Tecate Creeks, and $5.5 \mathrm{mi}$ (8.8 km) south of Dulzura. DRAINAGE AREA, $-481 \mathrm{mi}^{2}\left(1,246 \mathrm{~km}^{2}\right)$, of which $70 \mathrm{mi}^{2}\left(181 \mathrm{~km}^{2}\right)$ are in Mexico.

PERIOD OF RECORD.--October 1936 to current year.

GAGE. - Water-stage recorder. Datum of gage is $542.42 \mathrm{ft}(165.330 \mathrm{~m})$ above mean sea level (1evels by International Boundary and Water Commission). Prior to Sept. 19, 1939, at datum $2.00 \mathrm{ft}(0.610 \mathrm{~m}) \mathrm{higher}$.

REMARKS.--Records fair. Flow regulated by Morena Reservoir, capacity, 50,210 acre-ft ( $61.9 \mathrm{hm}^{3}$ ) and Barrett Reservoir, capacity, 44,760 acre-ft $\left(55.2 \mathrm{hm}^{3}\right)$. Water diverted from Cottonwood Creek at Barrett Dam by Dulzura conduit to Jamu1 Creek.

AVERAGE DISCHARgE. -40 years, $9.42 \mathrm{ft}^{3} / \mathrm{s}\left(0.267 \mathrm{~m}^{3} / \mathrm{s}\right), 6,820 \mathrm{acre}-\mathrm{ft} / \mathrm{yr}\left(8.41 \mathrm{hm}^{3} / \mathrm{yr}^{2}\right)$.

EXTREMES FOR PERIOD OF RECORD.--Maximum discharge, $4,700 \mathrm{ft}^{3} / \mathrm{s}\left(133 \mathrm{~m}^{3} / \mathrm{s}\right)$ Feb. 7 , 1937 , gage height, $8.50 \mathrm{ft}$ $(2.591 \mathrm{~m})$ present datum, from rating curve extended above $300 \mathrm{ft}^{3} / \mathrm{s}\left(8.50 \mathrm{~m}^{3} / \mathrm{s}\right)$ on basis of velocity, meandepth, and area studies; no flow for part of most years.

EXTREMES FOR CURRENT YEAR, --Maximum discharge, $86 \mathrm{ft}^{3} / \mathrm{s}\left(2.44 \mathrm{~m}^{3} / \mathrm{s}\right)$ Feb. 9 , gage height, $3.55 \mathrm{ft}(1.082 \mathrm{~m})$; minimum daily, $0.03 \mathrm{ft}^{3} / \mathrm{s}\left(0.001 \mathrm{~m}^{3} / \mathrm{s}\right)$ Aug. 24 to Sept. 2 .

DISCHARGE, IN CUBIC FEET PER SECOND, HATER YEAR OCTOBER 1975 TO SEPTEMBER 1976 MEAN VALUES

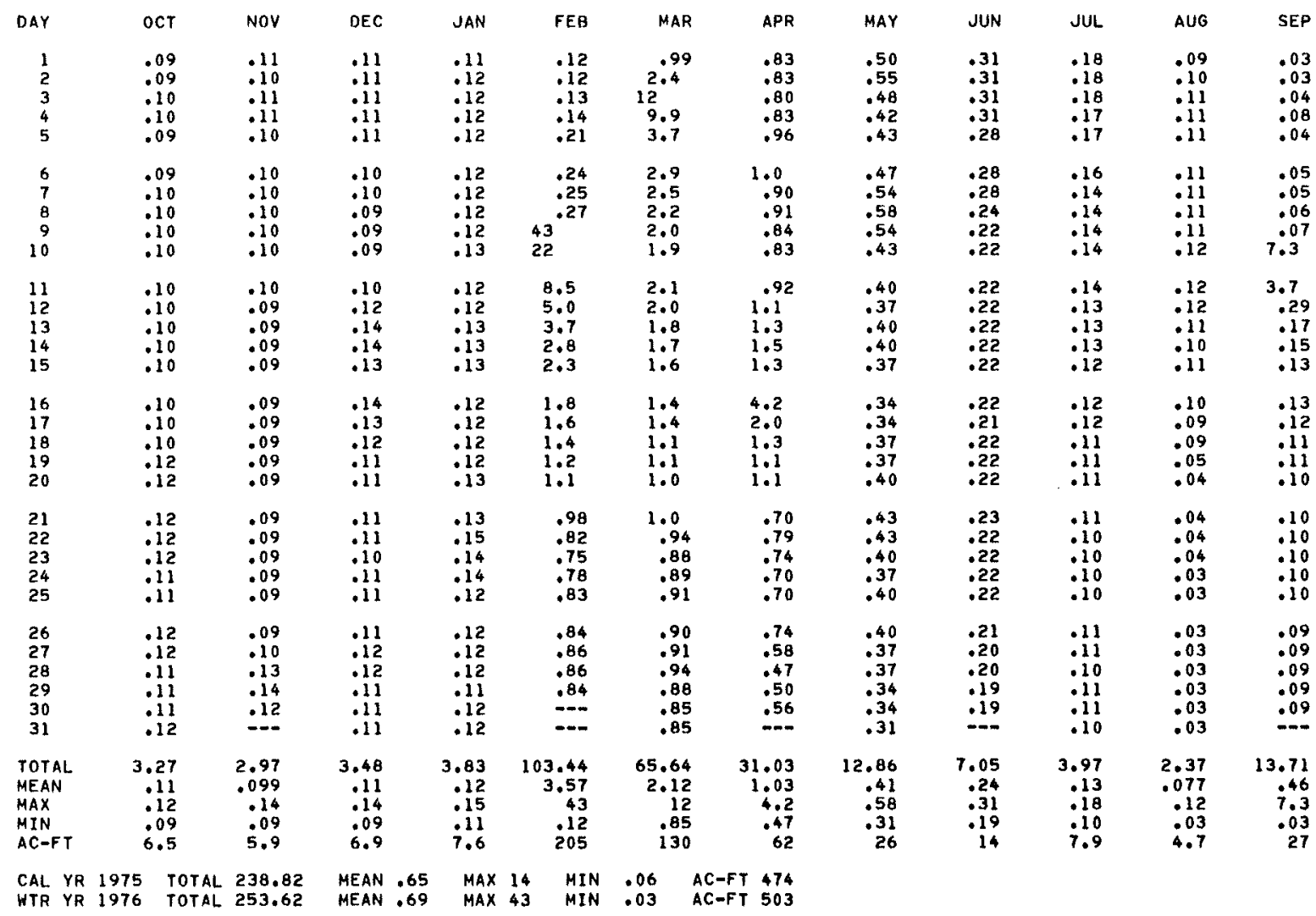


11013200 RODRIGUEZ RESERVOIR AT RODRIGUEZ DAM, BAJA CALIFORNIA, MEXICO

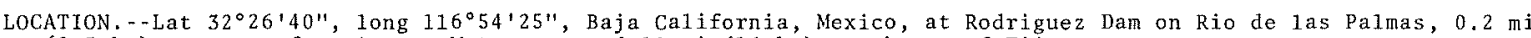
$(0.3 \mathrm{~km})$ upstream from Arroyo Matanuco, and $10 \mathrm{mi}(16 \mathrm{~km})$ southeast of Tijuana.

DRAINAGE AREA. $-977 \mathrm{mi}^{2}\left(2,530 \mathrm{~km}^{2}\right)$, of which $10 \mathrm{mi}^{2}\left(26 \mathrm{~km}^{2}\right)$ are in the United states.

PERIOD OF RECORD.--April 1937 to current year. Published with record for Tijuana River near Nestor, Calif. October 1953 to September 1957. Monthend contents for Apri1 1937 to September 1950 published in WSP $1315-B$ and for October 1950 to September 1960 in WSP 1735

GAGE. - Nonrecording gage read once a day. Datum of gage is at mean sea leve1 (1eve1s by National Irrigation Commission, Mexico).

REMARKS. - Reservoir is formed by thin-shell concrete-arch dam completed in 1936; storage began in 1937. Capacity table is based on surveys made in 1927 ; Maximum storage at crest of spi11way gates, elevation, $410.10 \mathrm{ft}$ $(124.998 \mathrm{~m})$, 111,070 acre-ft $\left(137 \mathrm{hm}^{3}\right)$; at spillway lip, elevation, $380.08 \mathrm{ft}(115.848 \mathrm{~m}), 74,580$ acre- ft
$\left(92.0 \mathrm{hm}^{3}\right)$; dead storage below outlet, elevation, $267.39 \mathrm{ft}(81.500 \mathrm{~m}), 1,650$ acre-ft (2.03 hm $\left.{ }^{3}\right)$ included in contents. Reservoir stores water for irrigation of 3,000 acres (12.1 kn ${ }^{2}$ ) on both banks 0.5 to $5.5 \mathrm{mi}$ $(0.8$ to $8.8 \mathrm{~km})$ downstream and municipal supp1y for city of Tijuana. Since August 1972 Colorado River water diverted through otay aqueduct into the reservoir for Tijuana emergency use; this year 245 acre-ft ( $302,000 \mathrm{~m}^{3}$ ) was imported.

COOPERATION. - Records furnished by Ministry of Hydraulic Resources, Government of Mexico, through International Boundary and Water Commission, United States section.

EXTREMES FOR PERIOD OF RECORD.--Reservoir spilled during March 1938, September 1940, February to May 1941 , March 1942, and February, March 1944; reservoir dry Apr. 2, 1964, to Apr. 9, 1965, Aug. 21 to Nov. 22 , 1965.

EXTREMES FOR CURRENT YEAR.--Maximum contents, 3,720 acre-ft $\left(4,59 \mathrm{hm}^{3}\right)$ Apr, $17-21 ; \mathrm{minimum}, 2,010$ acre-ft $\left(2.48 \mathrm{hm}^{3}\right)$ Feb. 3,4

MONTHEND CONTENTS, WATER YEAR OCTOBER 1975 TO SEPTEMBER 1976

Date

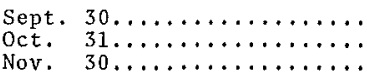

Nov. $\quad 30 \ldots \ldots \ldots \ldots \ldots \ldots$

$31 \ldots \ldots \ldots \ldots, \ldots$

CAL YR 1975

Jan. $31 \ldots \ldots \ldots \ldots \ldots \ldots$

Feb. $\quad 29 \ldots \ldots \ldots \ldots \ldots \ldots \ldots$

Mar $\quad 31 \ldots \ldots \ldots \ldots \ldots \ldots \ldots \ldots$

Apr. $\quad 30 \ldots \ldots \ldots \ldots \ldots \ldots \ldots \ldots$

May $\quad 31 \ldots \ldots \ldots \ldots \ldots \ldots \ldots \ldots$

June $30 \ldots \ldots \ldots \ldots \ldots \ldots \ldots$

Ju1y $31 \ldots \ldots \ldots \ldots \ldots \ldots \ldots$

Aug. $\quad 31 \ldots \ldots \ldots \ldots \ldots \ldots \ldots$

Sept. $30 \ldots \ldots \ldots \ldots \ldots \ldots \ldots$

WTR YR $1976 \ldots \ldots \ldots \ldots$

$\begin{array}{cc}\begin{array}{c}\text { Contents } \\ \text { (acre- } \\ \text { feet) }\end{array} & \begin{array}{c}\text { Change in } \\ \text { contents } \\ \text { (acre- } \\ \text { feet) }\end{array} \\ 2760 & -- \\ 2580 & -180 \\ 2370 & -210 \\ 2180 & -190 \\ -- & -1630 \\ & \\ 2020 & -160 \\ 3620 & +1600 \\ 3680 & +60 \\ 3690 & +10 \\ 3530 & -160 \\ 3300 & -230 \\ 3090 & -210 \\ 2820 & -270 \\ 2910 & +90 \\ -- & +150\end{array}$


11013500 TIJUANA RIVER NEAR NESTOR, CA

LOCATION. - Lat $32^{\circ} 33^{\prime} 06^{\prime \prime}$, long $117^{\circ} 05^{\prime} 00^{\prime \prime}$, on line between secs.3 and 4, T.19 S., R. 2 W., San Diego County, on downstrean side of Hoilister Street bridge (revised), $1.7 \mathrm{mi}(2.7 \mathrm{~km})$ south of Nestor, and 2.9 mi (4.7 km) upstream from mouth at Pacific Ocean.

DRAINAGE AREA. - -1,695 $\mathrm{mi}^{2}\left(4,390 \mathrm{~km}^{2}\right)$, of which $1,236 \mathrm{mi}^{2}\left(3,201 \mathrm{~km}^{2}\right)$ are in Mexico.

WATER-DISCHARGE RECORDS

PERIOD OF RECORD, - October 1914 to September 1915, October 1936 to current year.

GAGE. - Water-stage recorder. Datum of gage is $15.14 \mathrm{ft}(4.615 \mathrm{~m})$ above mean sea 1 evel. See WSP 1735 for history of changes prior to Aug. 5, 1958.

REMARKS, - Records fair, Flow regulated by Morena Reservoir, capacity, 50,210 acre-ft (61.9 hm ${ }^{3}$ ) and Barrett Reservoir, capacity, 44,760 acre-ft $\left(55.2 \mathrm{hm}^{3}\right)$ in the United States, and Rodriguez Reservoir (station

110132003 in Mexico. Water diverted from Cottonwood Creek at Barrett Dan by Dulzura conduit to Jamul Creek. AVERAGE DISCHARGE represents fiow to the ocean regardless of upstream development.

COOPERATION. - One discharge measurement was furnished by U. S. International Boundary and Water Comission.

AVERAGE DISCHARGE. - -41 years, $27.4 \mathrm{ft}^{3} / \mathrm{s}\left(0.776 \mathrm{~m}^{3} / \mathrm{s}\right), 19,850 \mathrm{acre}-\mathrm{ft} / \mathrm{yr}\left(24.5 \mathrm{hm}^{3} / \mathrm{yr}^{2}\right)$.

EXTREMES FOR PERIOD OF RECORD (SINCE 1936).--Maximum discharge, 17,700 $\mathrm{ft}^{3} / \mathrm{s}\left(501 \mathrm{~m}^{3} / \mathrm{s}\right.$ ) Feb. 7 , 1937, gage height, $8.20 \mathrm{ft}(2.499 \mathrm{~m})$, datum then in use, fron rating curve extended above $2,000 \mathrm{ft}^{3} / \mathrm{s}\left(56.6 \mathrm{~m}^{3} / \mathrm{s}\right)$ on basis of velocity-depth relation and cross section after peak; no flow parts of each year.

EXTREMES FOR CURRENT YEAR. - Maximum discharge, $168 \mathrm{ft}^{3} / \mathrm{s}\left(4.76 \mathrm{~m}^{3} / \mathrm{s}\right)$ Feb. 9 , gage height, 3.84 ft (1.170 m); no flow most of year.

DISCHARGE, IN CUBIC FEET PER SECOND, WATER YEAR OCTOBER 1975 TO SEPTEMBER 1976 MEAN VALUES

\begin{tabular}{|c|c|c|c|c|c|c|c|c|c|c|c|c|}
\hline DAY & OCT & NOV & DEC & JAN & FEB & MAR & APR & MAY & JUN & JUL & AUG & SEP \\
\hline $\begin{array}{l}1 \\
2 \\
3 \\
4 \\
5\end{array}$ & & & & & $\begin{array}{l}0 \\
0 \\
0 \\
0 \\
0\end{array}$ & $\begin{array}{l}1.30 \\
1.5 \\
5.3 \\
0.48\end{array}$ & $\begin{array}{l}0 \\
0 \\
0 \\
0 \\
0\end{array}$ & & & & & $\begin{array}{l}0 \\
0 \\
0 \\
0 \\
0\end{array}$ \\
\hline $\begin{array}{r}6 \\
7 \\
8 \\
9 \\
10\end{array}$ & & & & & $\begin{array}{r}11 \\
14 \\
14 \\
93 \\
117\end{array}$ & $\begin{array}{l}0 \\
0 \\
0 \\
0 \\
0\end{array}$ & $\begin{array}{l}0 \\
0 \\
0 \\
0 \\
0\end{array}$ & & & & & $\begin{array}{l}0 \\
0 \\
0 \\
0 \\
0\end{array}$ \\
\hline $\begin{array}{l}11 \\
12 \\
13 \\
14 \\
15\end{array}$ & & & & & $\begin{array}{l}67 \\
9.0 \\
.50 \\
0 \\
0\end{array}$ & $\begin{array}{l}0 \\
0 \\
0 \\
0 \\
0\end{array}$ & $\begin{array}{l}0 \\
0 \\
.62 \\
.14\end{array}$ & & & & & $\begin{array}{l}0^{-38} \\
0 \\
0 \\
0\end{array}$ \\
\hline $\begin{array}{l}16 \\
17 \\
18 \\
19 \\
20\end{array}$ & & & & & $\begin{array}{l}0 \\
0 \\
0 \\
0 \\
0\end{array}$ & $\begin{array}{l}0 \\
0 \\
0 \\
0 \\
0\end{array}$ & $\begin{array}{l}.15 \\
0 \\
0 \\
0\end{array}$ & & & & & $\begin{array}{l}0 \\
0 \\
0 \\
0 \\
0\end{array}$ \\
\hline $\begin{array}{l}21 \\
22 \\
23 \\
24 \\
25\end{array}$ & & & & & $\begin{array}{l}0 \\
0 \\
0 \\
0 \\
0\end{array}$ & $\begin{array}{l}0 \\
0 \\
0 \\
0 \\
0\end{array}$ & $\begin{array}{l}0 \\
0 \\
0 \\
0 \\
0\end{array}$ & & & & & $\begin{array}{l}0 \\
0 \\
0 \\
0 \\
0\end{array}$ \\
\hline $\begin{array}{l}26 \\
27 \\
28 \\
29 \\
30 \\
31\end{array}$ & & $-\infty$ & & & $\begin{array}{l}0 \\
0 \\
0 \\
0 \\
\\
\\
-\infty\end{array}$ & $\begin{array}{l}0 \\
0 \\
0 \\
0 \\
0 \\
0\end{array}$ & $\begin{array}{l}0 \\
0 \\
0 \\
0 \\
0 \\
-\infty\end{array}$ & & $\infty$ & & & $\begin{array}{l}0 \\
0 \\
0 \\
0 \\
0 \\
-\infty\end{array}$ \\
\hline $\begin{array}{l}\text { TOTAL } \\
\text { MEAN } \\
\text { MAX } \\
\text { MIN } \\
\text { AC } \sim F T\end{array}$ & $\begin{array}{l}0 \\
0 \\
0 \\
0 \\
0\end{array}$ & $\begin{array}{l}0 \\
0 \\
0 \\
0 \\
0\end{array}$ & $\begin{array}{l}0 \\
0 \\
0 \\
0 \\
0\end{array}$ & $\begin{array}{l}0 \\
0 \\
0 \\
0 \\
0\end{array}$ & $\begin{array}{r}325.50 \\
11.2 \\
117 \\
0 \\
646\end{array}$ & $\begin{array}{r}7.58 \\
.24 \\
5.3 \\
0 \\
15\end{array}$ & $\begin{array}{r}1.03 \\
.034 \\
.62 \\
0 \\
2.0\end{array}$ & $\begin{array}{l}0 \\
0 \\
0 \\
0 \\
0\end{array}$ & $\begin{array}{l}0 \\
0 \\
0 \\
0 \\
0\end{array}$ & $\begin{array}{l}0 \\
0 \\
0 \\
0 \\
0\end{array}$ & $\begin{array}{l}0 \\
0 \\
0 \\
0 \\
0\end{array}$ & $\begin{array}{r}.38 \\
.013 \\
.38 \\
0 \\
.8\end{array}$ \\
\hline
\end{tabular}

CAL YA 1975 TOTAL 25.14 MEAN .069 MAX 12 MIN 0 AC-FT 50

WTR YR 1976 TOTAL 334.49 MEAN .91 MAX 117 MIN O ACAFT 663


PERIOD OF DAILY RECORD, - -

WATER TEMPERATURES: October 1969 to September 1972

SEDIMENT RECORDS: October 1969 to current year.

REMARKS, - -Sediment table omitted for no flow periods october to December and July to September.

EXTREMES FOR PERIOD OF DAILY RECORD.- -

SEDIMENT CONCENTRATIONS: Maximum daily mean, 4,190 mg/1 Dec, 21, 1970; minimum daily mean, no flow for

many days each year.

SEDIMENT DISCHARGE: Maximum dai1y, 414 tons ( 376 tonnes) Feb, 9, 1976; minimum dai1y, 0 tons on many days each year,

EXTREMES FOR CURRENT YEAR, - -

SEDIMENT CONCENTRATIONS: Maximum daily mean, 2,380 mg/1 Feb. 6; minimum daily mean, no flow for many days,

SEDIMENT DISCHARGE: Maximum dai1y, 414 tons ( 376 tonnes) Feb. 9; minimum daily, 0 tons on many days.

SUSPENDED-SEOIMENT DISCHARGE (TONS/DAY), HATER YEAR OCTOBER 1975 TO SEPTEMBER 1976

\begin{tabular}{|c|c|c|c|c|c|c|c|c|c|}
\hline & & JANUARY & & & FEBRUARY & & & MARCH & \\
\hline DAY & $\begin{array}{l}\text { MEAN } \\
\text { DISCHARGE } \\
\text { (CFS) }\end{array}$ & $\begin{array}{l}\text { MEAN } \\
\text { CONCEN- } \\
\text { TRATION } \\
\text { (MG/L) }\end{array}$ & $\begin{array}{l}\text { SEOIMENT } \\
\text { DISCHARGE } \\
\text { (TONS/OAY) }\end{array}$ & $\begin{array}{l}\text { MEAN } \\
\text { DISCHARGE } \\
\text { (CFS) }\end{array}$ & $\begin{array}{l}\text { MEAN } \\
\text { CENCEN- } \\
\text { TRATION } \\
\text { (MGLL) }\end{array}$ & $\begin{array}{l}\text { SEDIMENT } \\
\text { DISCHARGE } \\
\text { (TONS/OAY) }\end{array}$ & $\begin{array}{l}\text { MEAN } \\
\text { DISCHARGE } \\
\text { (CFS) }\end{array}$ & $\begin{array}{l}\text { MEAN } \\
\text { CONCEN- } \\
\text { TRATION } \\
\text { (MG/L) }\end{array}$ & $\begin{array}{l}\text { SEDIMENT } \\
\text { DISCHARGE } \\
\text { (TONS/DAY) }\end{array}$ \\
\hline $\begin{array}{l}1 \\
2 \\
3 \\
4 \\
5\end{array}$ & & & & $\begin{array}{l}0 \\
0 \\
0 \\
0 \\
0\end{array}$ & $\begin{array}{l}0 \\
0 \\
0 \\
0 \\
0\end{array}$ & $\begin{array}{l}0 \\
0 \\
0 \\
0 \\
0\end{array}$ & $\begin{array}{l}1.30 \\
1.5 \\
5.3 \\
0.48\end{array}$ & $\begin{array}{r}750 \\
1000 \\
1880 \\
0 \\
0\end{array}$ & $\begin{array}{c}2: 61 \\
27 \\
0 \\
0\end{array}$ \\
\hline $\begin{array}{r}6 \\
7 \\
8 \\
9 \\
10\end{array}$ & & & & $\begin{array}{r}11 \\
14 \\
14 \\
93 \\
117\end{array}$ & $\begin{array}{l}2380 \\
1610 \\
1090 \\
1650 \\
1250\end{array}$ & $\begin{array}{r}71 \\
61 \\
41 \\
414 \\
395\end{array}$ & $\begin{array}{l}0 \\
0 \\
0 \\
0 \\
0\end{array}$ & $\begin{array}{l}0 \\
0 \\
0 \\
0 \\
0\end{array}$ & $\begin{array}{l}0 \\
0 \\
0 \\
0 \\
0\end{array}$ \\
\hline $\begin{array}{l}11 \\
12 \\
13 \\
14 \\
15\end{array}$ & & & & $\begin{array}{l}67 \\
9.0 \\
0 \\
0 \\
0\end{array}$ & $\begin{array}{r}361 \\
250 \\
200 \\
0 \\
0\end{array}$ & $\begin{array}{l}65 \\
6.1 \\
0 \\
0\end{array}$ & $\begin{array}{l}0 \\
0 \\
0 \\
0 \\
0\end{array}$ & $\begin{array}{l}0 \\
0 \\
0 \\
0 \\
0\end{array}$ & $\begin{array}{l}0 \\
0 \\
0 \\
0 \\
0\end{array}$ \\
\hline $\begin{array}{l}16 \\
17 \\
18 \\
19 \\
20\end{array}$ & & & & $\begin{array}{l}0 \\
0 \\
0 \\
0 \\
0\end{array}$ & $\begin{array}{l}0 \\
0 \\
0 \\
0 \\
0\end{array}$ & $\begin{array}{l}0 \\
0 \\
0 \\
0 \\
0\end{array}$ & $\begin{array}{l}0 \\
0 \\
0 \\
0 \\
0\end{array}$ & $\begin{array}{l}0 \\
0 \\
0 \\
0 \\
0\end{array}$ & $\begin{array}{l}0 \\
0 \\
0 \\
0 \\
0\end{array}$ \\
\hline $\begin{array}{l}21 \\
22 \\
23 \\
24 \\
25\end{array}$ & & & & $\begin{array}{l}0 \\
0 \\
0 \\
0 \\
0\end{array}$ & $\begin{array}{l}0 \\
0 \\
0 \\
0 \\
0\end{array}$ & $\begin{array}{l}0 \\
0 \\
0 \\
0 \\
0\end{array}$ & $\begin{array}{l}0 \\
0 \\
0 \\
0 \\
0\end{array}$ & $\begin{array}{l}0 \\
0 \\
0 \\
0 \\
0\end{array}$ & $\begin{array}{l}0 \\
0 \\
0 \\
0 \\
0\end{array}$ \\
\hline $\begin{array}{l}26 \\
27 \\
28 \\
29 \\
30 \\
31\end{array}$ & & & & $\begin{array}{l}0 \\
0 \\
0 \\
0 \\
---\end{array}$ & $\begin{array}{r}0 \\
0 \\
0 \\
0 \\
-- \\
--\end{array}$ & $\begin{array}{l}0 \\
0 \\
0 \\
0 \\
-.-\end{array}$ & $\begin{array}{l}0 \\
0 \\
0 \\
0 \\
0 \\
0\end{array}$ & $\begin{array}{l}0 \\
0 \\
0 \\
0 \\
0 \\
0\end{array}$ & $\begin{array}{l}0 \\
0 \\
0 \\
0 \\
0 \\
0\end{array}$ \\
\hline & 0 & 0 & 0 & 325.50 & --- & 1053.37 & 7.58 & $\ldots$ & 29.61 \\
\hline
\end{tabular}


11013500 TIJUANA RIVER NEAR NESTOR, CA--Continued

SUSPENDED-SEDIMENT DISCHARGE (TONS/DAY), HATER YEAR OCTOBER 1975 TO SEPTEMBER 1976

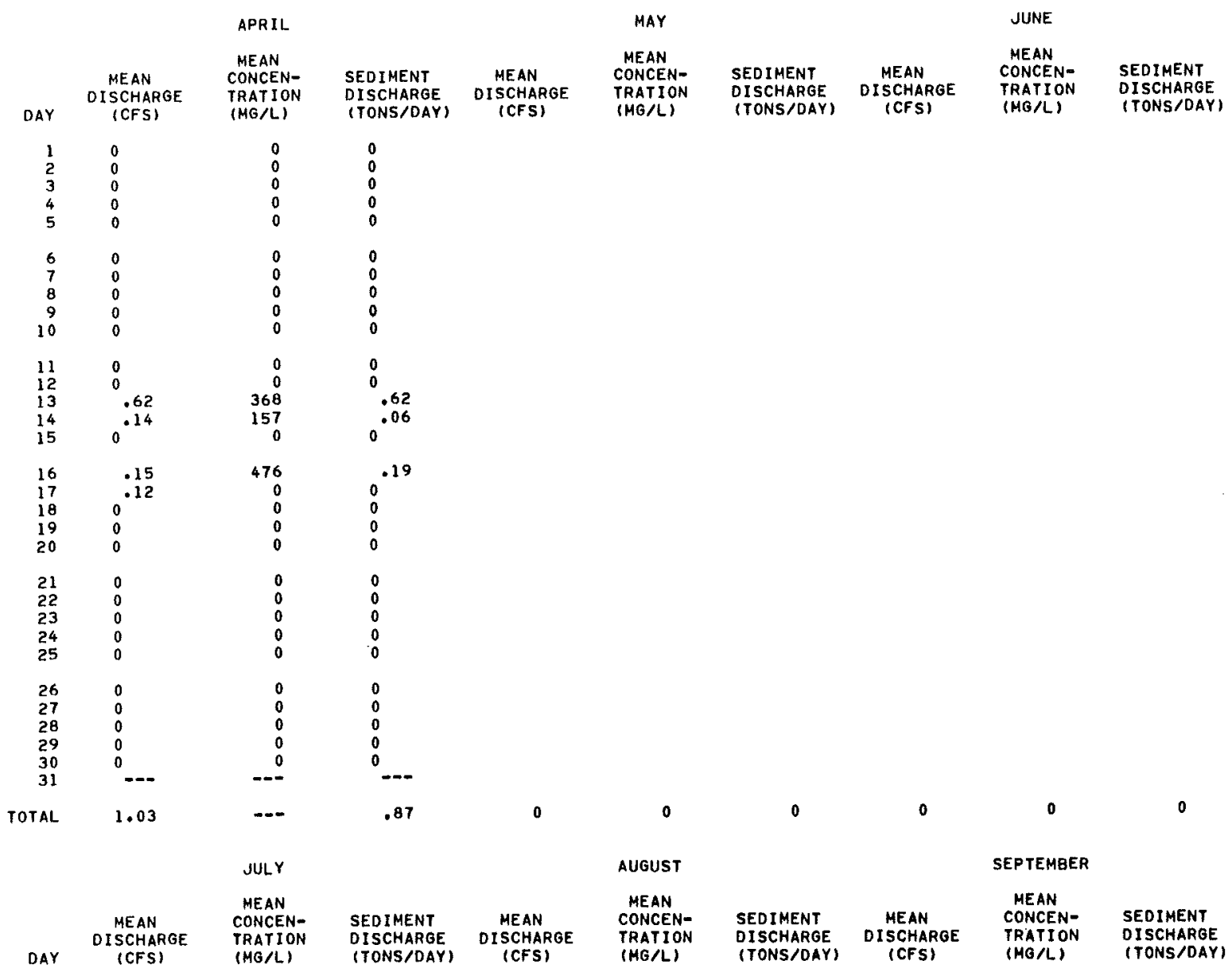


11013500 TIJUANA RIVER NEAR NESTOR, CA--Continued

PARTICLE-SIZE DISTRIBUTION OF SUSPENDED SEDIMENT, WATER YEAR OCTOBER 1975 TO SEPTEMEER 1976

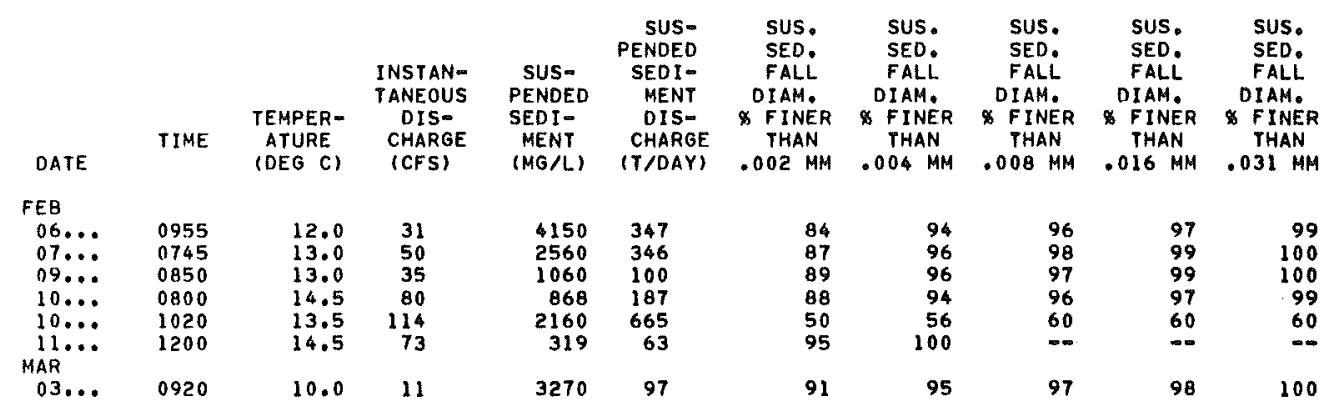

\begin{tabular}{|c|c|c|c|c|c|c|c|c|c|}
\hline & $\begin{array}{l}\text { SUS. } \\
\text { SED. } \\
\text { FALL } \\
\text { DIAM. } \\
\text { \$INER } \\
\text { THAN } \\
062 \text { MM }\end{array}$ & $\begin{array}{l}\text { SUS. } \\
\text { SED } \\
\text { SIEVE } \\
\text { OIAM. } \\
\text { W FINER } \\
\text { THAN } \\
\text { OG? MM }\end{array}$ & $\begin{array}{c}\text { SUS. } \\
\text { SED } \\
\text { FALL } \\
\text { DIAM. } \\
\text { \& FINER } \\
\text { THAN } \\
125 \text { MM }\end{array}$ & $\begin{array}{l}\text { SUS. } \\
\text { SED. } \\
\text { SIEVE } \\
\text { DIAM. } \\
\text { FINER } \\
\text { THAN } \\
125 \text { MM }\end{array}$ & $\begin{array}{c}\text { SUS. } \\
\text { SED } \\
\text { FALL } \\
\text { DIAM. } \\
\text { \% FINER } \\
\text { THAN } \\
250 \text { MM }\end{array}$ & $\begin{array}{l}\text { SUS. } \\
\text { SED } \\
\text { SIEVE } \\
\text { DIAH. } \\
\text { \$ FINER } \\
\text { THAN } \\
250 \text { MH }\end{array}$ & $\begin{array}{c}\text { SUS. } \\
\text { SEO, } \\
\text { FALL } \\
\text { DIAM, } \\
\text { \$ FINER } \\
\text { THAN } \\
500 \text { MM }\end{array}$ & $\begin{array}{c}\text { SUS. } \\
\text { SED, } \\
\text { FALL } \\
\text { DIAM. } \\
\text { * FINER } \\
\text { THAN } \\
\text { THO MM }\end{array}$ & $\begin{array}{l}\text { SUS. } \\
\text { SED: } \\
\text { FALi } \\
\text { OIAM. } \\
\text { OIANER } \\
\text { THAN } \\
2.00 \text { MH }\end{array}$ \\
\hline & $.062 \mathrm{MM}$ & $.062 \mathrm{MM}$ & $.125 \mathrm{MH}$ & $.125 \mathrm{MM}$ & $.250 \mathrm{MM}$ & $.250 \mathrm{MH}$ & $.500 \mathrm{MH}$ & $1.00 \mathrm{MH}$ & 2.00 \\
\hline
\end{tabular}

\begin{tabular}{|c|c|c|c|c|c|c|c|c|c|}
\hline \multicolumn{10}{|l|}{ FEB } \\
\hline $06 \ldots$ & $\because$ & 100 & $=$ & $\because$ & $=$ & $=$ & $=$ & $=$ & 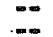 \\
\hline $\begin{array}{l}07 \ldots . . \\
09 . .\end{array}$ & $=$ & $=$ & $=$ & $\because$ & $=$ & $=$ & $=$ & $=$ & $=$ \\
\hline $10 . .$. & $\ldots$ & 99 & $=$ & 99 & $\ldots$ & 100 & $=$ & $=$ & $\ldots$ \\
\hline $10 \ldots$ & 63 & $=-$ & 64 & $\cdots$ & 76 & $=$ & 94 & 99 & 100 \\
\hline $11 \ldots$ & $-\infty$ & $\infty$ & - & $\infty$ & - & $-\infty$ & $-\infty$ & - & $=$ \\
\hline $\begin{array}{l}\text { MAR } \\
03 . . .\end{array}$ & $\infty$ & $=$ & $-\infty$ & $\infty$ & $=$ & $-\infty$ & $=$ & $=$ & 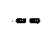 \\
\hline
\end{tabular}


11014000 JAMUL CREEK NEAR JAMUL, CA

LOCATION.--Lat $32^{\circ} 38^{\prime} 15^{\prime \prime}$, long $116^{\circ} 53^{\prime} 00^{\prime \prime}$, in NE⿺辶 sec.4, T.18 S., R. 1 E., San Diego County, on right bank 300 ft $(91 \mathrm{~m})$ upstream from otay Road crossing (revised) at upper end of Lower Otay Reservoir, $1.4 \mathrm{mi}$ (2.3 $\mathrm{km}$ ) downstream from Dulzura Creek, and $5.5 \mathrm{mi}(8.8 \mathrm{~km})$ south of Jamul.

DRAINAGE AREA. $-70.2 \mathrm{mi}^{2}\left(181.8 \mathrm{~km}^{2}\right)$.

PERIOD OF RECORD. - April 1940 to current year.

GAGE. - Water-stage recorder and broad-crested weir control with low-water venturi-type f1ume. Datum of gage is $511.64 \mathrm{ft}$ (155.948 $\mathrm{m})$ above mean sea level, Prior to 0ct, 1, 1951, at datum $1.00 \mathrm{ft}$ (0.305 m) higher.

REMARXS.--Records poor, No regulation above station. Water diverted from Cottonwood Creek (station 11012000 ) by Dulzura conduit discharges into Jamul Creek via Dulzura Creek and is included in discharge for this station.

EXTREMES FOR PERIOD OF RECORD.--Maximum discharge, 4,000 $\mathrm{ft}^{3} / \mathrm{s}\left(113 \mathrm{~m}^{3} / \mathrm{s}\right)$ Dec. 1 , $1947, \mathrm{gage}$ height, $6.42 \mathrm{ft}$ $(1.957 \mathrm{~m})$, present datum, from rating curve extended above $1,200 \mathrm{ft}^{3} / \mathrm{s}(34.0 \mathrm{~m} / \mathrm{s}) ; \mathrm{no}$ flow at times in some years.

EXTREMES FOR CURRENT YEAR, --Maximum discharge, $263 \mathrm{ft} / \mathrm{s}\left(7.45 \mathrm{~m}^{3} / \mathrm{s}\right)$ Feb. 9 (0300 hrs), gage height, $3.42 \mathrm{ft}$ $(1.042 \mathrm{~m})$, no other peak above base of $100 \mathrm{ft}^{3} / \mathrm{s}\left(2.83 \mathrm{~m}^{3} / \mathrm{s}\right)$; no flow for many months.

DISCHARGE, IN CUBIC FEET PER SECOND, HATER YEAR OCTOBER 1975 TO SEPTEMBER 1976

\begin{tabular}{|c|c|c|c|c|c|c|c|c|c|c|c|c|}
\hline DAY & OCT & NOV & $\mathrm{DEC}$ & JAN & FEB & MAR & APR & MAY & JUN & JUL & AUG & SEP \\
\hline $\begin{array}{l}1 \\
2 \\
3 \\
4 \\
5\end{array}$ & & & & & $\begin{array}{l}0 \\
0 \\
0 \\
0 \\
.17\end{array}$ & $\begin{array}{l}.71 \\
16 \\
34 \\
10\end{array}$ & $\begin{array}{l}16 \\
13 \\
13 \\
11 \\
7.6\end{array}$ & $\begin{array}{r}1.1 \\
.95 \\
.84 \\
.61 \\
.50\end{array}$ & & $\begin{array}{l}0 \\
0 \\
0 \\
0 \\
0\end{array}$ & $\begin{array}{l}.18 \\
.10 \\
.05 \\
0 \\
0\end{array}$ & $\begin{array}{l}0 \\
0 \\
0 \\
0 \\
0\end{array}$ \\
\hline $\begin{array}{r}6 \\
7 \\
8 \\
9 \\
10\end{array}$ & & & & & $\begin{array}{l}.70 \\
15 \\
.90 \\
74 \\
11\end{array}$ & $\begin{array}{l}5.2 \\
4.8 \\
4.4 \\
4.2 \\
4.0\end{array}$ & $\begin{array}{l}6.7 \\
13 \\
13 \\
5.5 \\
3.4\end{array}$ & $\begin{array}{l}.35 \\
.25 \\
.15 \\
.10 \\
.06\end{array}$ & & $\begin{array}{l}0 \\
0 \\
0 \\
0 \\
0\end{array}$ & $\begin{array}{l}0 \\
0 \\
0 \\
0 \\
0\end{array}$ & $\begin{array}{l}0 \\
0 \\
0 \\
0 \\
\quad .18\end{array}$ \\
\hline $\begin{array}{l}11 \\
12 \\
13 \\
14 \\
15\end{array}$ & & & & & $\begin{array}{l}8.6 \\
7.2 \\
6.1 \\
5.5 \\
4.5\end{array}$ & $\begin{array}{l}3.4 \\
2.8 \\
2.2 \\
2.0 \\
2.0\end{array}$ & $\begin{array}{l}4.1 \\
4.5 \\
6.8 \\
5.7 \\
5.0\end{array}$ & $\begin{array}{l}.04 \\
.03 \\
.02 \\
.01 \\
0\end{array}$ & & $\begin{array}{l}0 \\
0 \\
0 \\
0 \\
0\end{array}$ & $\begin{array}{l}0 \\
0 \\
0 \\
0 \\
0\end{array}$ & $\begin{array}{l}.95 \\
0.23 \\
0 \\
0\end{array}$ \\
\hline $\begin{array}{l}16 \\
17 \\
18 \\
19 \\
20\end{array}$ & & & & & $\begin{array}{l}3.6 \\
3.1 \\
2.5 \\
2.4 \\
3.4\end{array}$ & $\begin{array}{r}4.9 \\
2.6 \\
8.0 \\
9.9 \\
12\end{array}$ & $\begin{array}{l}4.4 \\
3.7 \\
7.8 \\
7.2 \\
6.2\end{array}$ & $\begin{array}{l}0 \\
0 \\
0 \\
0 \\
0\end{array}$ & & $\begin{array}{l}0 \\
0 \\
0 \\
0 \\
0\end{array}$ & $\begin{array}{l}0 \\
0 \\
0 \\
0 \\
0\end{array}$ & $\begin{array}{l}0 \\
0 \\
0 \\
0 \\
0\end{array}$ \\
\hline $\begin{array}{l}21 \\
22 \\
23 \\
24 \\
25\end{array}$ & & & & & $\begin{array}{l}2.6 \\
2.0 \\
1.7 \\
1.3 \\
1.2\end{array}$ & $\begin{array}{l}17 \\
17 \\
17 \\
17 \\
17\end{array}$ & $\begin{array}{l}5.3 \\
3.1 \\
2.3 \\
2.6 \\
3.1\end{array}$ & $\begin{array}{l}0 \\
0 \\
0 \\
0 \\
0\end{array}$ & & $\begin{array}{l}0 \\
0 \\
0 \\
0 \\
0\end{array}$ & $\begin{array}{l}0 \\
0 \\
0 \\
0 \\
0\end{array}$ & $\begin{array}{l}0 \\
0 \\
0 \\
0 \\
0\end{array}$ \\
\hline $\begin{array}{l}26 \\
27 \\
28 \\
29 \\
30 \\
31\end{array}$ & & $-\infty$ & & & $\begin{array}{l}1.1 \\
.93 \\
.82 \\
.71 \\
-.-0 \\
.-=\end{array}$ & $\begin{array}{l}17 \\
16 \\
16 \\
16 \\
16 \\
16\end{array}$ & $\begin{array}{l}2.8 \\
2.3 \\
1.8 \\
1.7 \\
1.4 \\
0.0\end{array}$ & $\begin{array}{l}0 \\
0 \\
0 \\
0 \\
0 \\
0\end{array}$ & $-\infty$ & $\begin{array}{l}1.3 \\
.48 \\
.36 \\
.32 \\
.24 \\
.24\end{array}$ & $\begin{array}{l}0 \\
0 \\
0 \\
0 \\
0 \\
0\end{array}$ & $\begin{array}{l}0 \\
0 \\
0 \\
0 \\
0\end{array}$ \\
\hline $\begin{array}{l}\text { TOTAL } \\
\text { MEAN } \\
\text { MAX } \\
\text { MIN } \\
\text { AC }-F T\end{array}$ & $\begin{array}{l}0 \\
0 \\
0 \\
0 \\
0\end{array}$ & $\begin{array}{l}0 \\
0 \\
0 \\
0 \\
0\end{array}$ & $\begin{array}{l}0 \\
0 \\
0 \\
0 \\
0\end{array}$ & $\begin{array}{l}0 \\
0 \\
0 \\
0 \\
0\end{array}$ & $\begin{array}{r}161.03 \\
5.55 \\
74 \\
0 \\
319\end{array}$ & $\begin{array}{r}315.90 \\
10.2 \\
34 \\
.71 \\
627\end{array}$ & $\begin{array}{r}183.8 \\
6.13 \\
16 \\
1.4 \\
365\end{array}$ & $\begin{array}{r}5.01 \\
016 \\
1.1 \\
0 \\
9.9\end{array}$ & $\begin{array}{l}0 \\
0 \\
0 \\
0 \\
0\end{array}$ & $\begin{array}{r}2.94 \\
.095 \\
1.3 \\
50 \\
5.8\end{array}$ & $\begin{array}{r}.33 \\
.011 \\
.18 \\
0 \\
.7\end{array}$ & $\begin{array}{r}1.36 \\
.045 \\
.95 \\
0 \\
2.7\end{array}$ \\
\hline
\end{tabular}

CAL YR 1975 TOTAL 255.65 MEAN .70 MAX 13 MIN 0 AC-FT 507 WTR YR 1976 TOTAL 670.37 MEAN 1.83 MAX 74 MIN 0 AC-FT 1330 
LOCATION.--Lat $32^{\circ} 36^{\prime} 35^{\prime \prime}$, long $116^{\circ} 55^{\prime} 35^{\prime \prime}$, in NWta NWt sec.18, T.18 S, R. 1 E., San Diego County, on upstream face $200 \mathrm{ft}(61 \mathrm{~m})$ from right end of Savage Dam on otay River, and $9 \mathrm{mi}(14 \mathrm{~km})$ east of Chula Vista.

DRAINAGE AREA, $--99.0 \mathrm{mi}^{2}\left(256.4 \mathrm{~km}^{2}\right)$.

PERIOD OF RECORD, - - October 1945 to September 1959 published with Otay River at Savage Dam (station 11014500 ). october 1972 to current year. Records of monthend gage heights october 1936 to September 1945 , in files of San Diego County Department of Sanitation and Flood Control.

GAGE.--Water-stage recorder. Datum of gage is $397.20 \mathrm{ft}(121.067 \mathrm{~m})$ above mean sea 1 eve1; gage readings have been reduced to elevations above mean sea level. Prior to oct. 1, 1972, nonrecording gage at different site at datum $50.00 \mathrm{ft}(15.240 \mathrm{~m})$ lower.

REMARKS.--Reservoir is formed by gravity section cyclopean concrete and masonary dam, built in 1919 . Capacity from Geological Survey table dated Apx. 3, 1956. Maximum capacity at top of spiliway gates, 56,520 acre-ft $\left(69.7 \mathrm{hm}^{3}\right)$, elevation, $490.70 \mathrm{ft}(149.565 \mathrm{~m})$. Capacity at permanent spi11way 1eve1, 49,510 acre-ft $\left(61.0 \mathrm{hm}{ }^{3}\right)$, elevation, $484.70 \mathrm{ft}(147.737 \mathrm{~m})$. Dead storage below lowest out $1 \mathrm{et}, 1,150, \mathrm{acre}-\mathrm{ft}\left(1.42 \mathrm{hm} \mathrm{f}^{3}\right)$, elevation, $395.05 \mathrm{ft}(120.411 \mathrm{~m})$. Dulzura conduit carries water from Barrett Reservoir on Cottonwood Creek to Dulzura Creek, where water is carried to the reservoir by Jamul Creek (11014000). Reservoir storage includes supplemental Colorado River water. Small diversions for local use near reservoir. Water used for municipal supply by city of San Diego.

COOPERATION.--Gage heights were furnished by San Diego County Department of Sanitation and Flood Control.

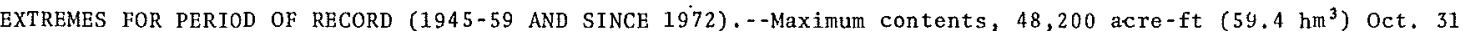
1945 , elevation, $493.87 \mathrm{ft}(150.532 \mathrm{~m})$; minimum 3,160 acre-ft $\left(3.90 \mathrm{hm}^{3}\right)$ Dec. 31 , 1951, elevation, 407.56 ft $(124.224 \mathrm{~m})$.

EXTREMES FOR CURRENT YEAR.--Maximum contents observed, 9,970 acre-ft $\left(12.3 \mathrm{hm}^{3}\right) \mathrm{May}^{1}$, elevation, $429.68 \mathrm{ft}$ $(130.965 \mathrm{~m})$; minimum, 4,920 acre-ft $\left(6.06 \mathrm{hm}^{3}\right)$ Jan. 6, elevation, 414.92 ft (126.468 m).

MONTHEND ELEVATION AND CONTENTS, AT 0800, WATER YEAR OCTOBER 1975 TO SEPTEMBER 1976

Date

Sept. $30 \ldots \ldots \ldots \ldots \ldots \ldots \ldots \ldots$

Oct. $31 \ldots \ldots \ldots \ldots \ldots \ldots \ldots$

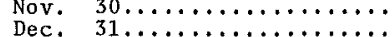

CAL YR 1975

Jan. $31 \ldots \ldots \ldots \ldots \ldots \ldots \ldots$

Feb. $\quad 29 \ldots \ldots \ldots \ldots \ldots \ldots \ldots$

Mar. $\quad 31 \ldots \ldots \ldots \ldots \ldots \ldots \ldots$

Apr $\quad 30 \ldots \ldots \ldots \ldots \ldots \ldots$

May $\quad 31 \ldots \ldots \ldots \ldots \ldots \ldots \ldots \ldots \ldots$

June $30 \ldots \ldots \ldots \ldots \ldots \ldots \ldots$.

Ju1y $\quad 31 \ldots \ldots \ldots \ldots \ldots \ldots \ldots$

$31 \ldots \ldots \ldots \ldots \ldots \ldots \ldots$

ept. $30 \ldots \ldots \ldots \ldots \ldots \ldots \ldots$

WTR YR 1976
Blevation
(feet) $\quad \begin{gathered}\text { Contents } \\ \text { acre-feet })\end{gathered}$

416.05

415.61

415.22

414.98

\section{0 \\ 5110}

5000

4940

-

418.05

427.45

427.45
428.77

428.77
429.68

429.68
429.53

429.53
429.21

429.21

428.14

423.70

420.11
Change in contents (acre-feet)

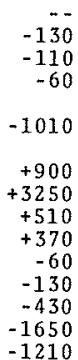

$-1210$

$-1250$ 
11015000 SWEETWATER RIVER NEAR DESCANSO, CA

LOCATION, - Lat $32^{\circ} 50^{\prime} 05^{\prime \prime}$, long $116^{\circ} 37^{\prime} 20^{\prime \prime}$, in NW/sE $\frac{1}{4}$ sec. 25 , T.15 S., R. 3 E., San Diego County, on right bank at Japatul Valley Road bridge (revised), $0.7 \mathrm{mi}(1.1 \mathrm{~km})$ downstream from unnamed tributary, and $1.3 \mathrm{mi}$ (2.1 $\mathrm{km}$ ) south of Descanso.

DRAINAGE AREA. $-45.4 \mathrm{mi}^{2}\left(117.6 \mathrm{~km}^{2}\right)$.

PERIOD OF RECORD,--October 1905 to September 1927 , October 1956 to current year. Monthly discharge only for October to December 1905, January to February 1916, February, March, June to September 1927, pub1ished in WSP 1315-B. Combined records of river and diversion, October 1956 to current year.

GAGE. - Water-stage recorder on river; water-stage recorder on concrete diversion. Datum of river gage is $3,269.24 \mathrm{ft}(996.464 \mathrm{~m})$ above mean sea level. Prior to June 25,1927 , nonrecording gages at several sites within $0.1 \mathrm{mi}(0.2 \mathrm{~km})$ upstream at various datums. Diversion gage at different datum.

REMARKS,--Records fair. No regulation above station. Sweetwater River diversion diverts $0.3 \mathrm{mi}$ (0.5 km) above station for irrigation below. For records of combined discharge of river and diversion, see following page.

AVERAGE DISCHARGE, - -Creek on $1 \mathrm{y}: 42$ years, $9.84 \mathrm{ft}^{3} / \mathrm{s}\left(0.279 \mathrm{~m}^{3} / \mathrm{s}\right), 7,130 \mathrm{acre}-\mathrm{ft} / \mathrm{yr}(8.79 \mathrm{hm} / \mathrm{yr})$ Combined creek and diversion: 20 years, $3.58 \mathrm{ft}^{3} / \mathrm{s}\left(0.101 \mathrm{~m}^{3} / \mathrm{s}\right), 2,590 \mathrm{acre}-\mathrm{ft} / \mathrm{yr}(3.19 \mathrm{hm} / \mathrm{yr})$.

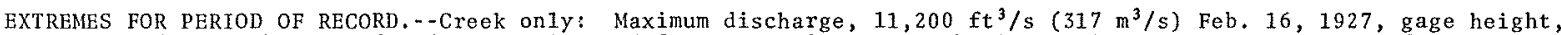
$13.2 \mathrm{ft}(4.023 \mathrm{~m})$, from floodmarks, site and datum then in use, on basis of slope-area measurement of maximum flow; no flow many days in most years.

Combined creek and diversion: Maximum discharge, $3,890 \mathrm{ft}^{3} / \mathrm{s}\left(110 \mathrm{~m}^{3} / \mathrm{s}\right)$ Dec, 6, 1966; no f1ow many days in each year.

EXTREMES FOR CURRENT YEAR. - Creek only: Maximum discharge, $128 \mathrm{ft}^{3} / \mathrm{s}\left(3.63 \mathrm{~m}^{3} / \mathrm{s}\right) \mathrm{Feb}$. 9 (0100 hrs), gage height, $4.72 \mathrm{ft}(1.439 \mathrm{~m})$, no other peak above base of $100 \mathrm{ft}^{3} / \mathrm{s}\left(2.83 \mathrm{~m}^{3} / \mathrm{s}\right)$; no flow many days . Combined creek and diversion: Maximum discharge, $129 \mathrm{ft}^{3} / \mathrm{s}\left(3.65 \mathrm{~m}^{3} / \mathrm{s}\right)$ Feb. 9 (0100 hrs); no flow many days.

DISCHARGE, IN CUBIC FEET PER SECOND, WATER YEAR OCTOBER 1975 TO SEPTEMBER 1976 MEAN VALUES

\begin{tabular}{|c|c|c|c|c|c|c|c|c|c|c|c|c|}
\hline DAY & $\mathrm{OCT}$ & NOV & DEC & JAN & FEQ & MAR & APR & MAY & JUN & JUL & AUG & SEP \\
\hline $\begin{array}{l}1 \\
2 \\
3 \\
4 \\
5\end{array}$ & & $\begin{array}{l}0 \\
0 \\
0 \\
0 \\
0\end{array}$ & $\begin{array}{l}.09 \\
.05 \\
.03 \\
.03 \\
.02\end{array}$ & $\begin{array}{l}.09 \\
.09 \\
.05 \\
.05 \\
.05\end{array}$ & $\begin{array}{r}.06 \\
.08 \\
.09 \\
.23 \\
2.2\end{array}$ & $\begin{array}{l}3.5 \\
3.5 \\
3.4 \\
3.4 \\
4.2\end{array}$ & $\begin{array}{l}1.1 \\
1.0 \\
.95 \\
1.5 \\
4.5\end{array}$ & $\begin{array}{l}1.2 \\
1.1 \\
1.0 \\
1.1 \\
.95\end{array}$ & $\begin{array}{l}.05 \\
.05 \\
.05 \\
.05 \\
.05\end{array}$ & $\begin{array}{l}0 \\
0 \\
0 \\
0 \\
0\end{array}$ & $\begin{array}{l}.09 \\
.08 \\
.08 \\
.05 \\
.03\end{array}$ & $\begin{array}{l}0 \\
0 \\
0 \\
0 \\
0\end{array}$ \\
\hline $\begin{array}{r}6 \\
7 \\
8 \\
9 \\
10\end{array}$ & & $\begin{array}{l}0 \\
0 \\
0 \\
0 \\
0\end{array}$ & $\begin{array}{l}.02 \\
.01 \\
.01 \\
.01 \\
.02\end{array}$ & $\begin{array}{l}.05 \\
.05 \\
.05 \\
.05 \\
.05\end{array}$ & $\begin{array}{r}4.0 \\
1.9 \\
4.2 \\
36 \\
8.3\end{array}$ & $\begin{array}{l}4.2 \\
4.2 \\
4.2 \\
4.2 \\
4.4\end{array}$ & $\begin{array}{l}3.0 \\
2.3 \\
1.9 \\
1.6 \\
1.5\end{array}$ & $\begin{array}{l}1.1 \\
1.2 \\
1.1 \\
.95 \\
.87\end{array}$ & $\begin{array}{r}.05 \\
.04 \\
.04 \\
.03 \\
.04\end{array}$ & $\begin{array}{l}0 \\
0 \\
0 \\
0 \\
0\end{array}$ & $\begin{array}{l}.02 \\
.01 \\
0 \\
0 \\
0\end{array}$ & $\begin{array}{l}0 \\
0 \\
0 \\
0 \\
3.6\end{array}$ \\
\hline $\begin{array}{l}11 \\
12 \\
13 \\
14 \\
15\end{array}$ & & $\begin{array}{l}0 \\
0 \\
0 \\
0 \\
0\end{array}$ & $\begin{array}{l}.02 \\
.22 \\
.29 \\
.16 \\
.09\end{array}$ & $\begin{array}{l}.05 \\
.05 \\
.05 \\
.05 \\
.05\end{array}$ & $\begin{array}{l}4.0 \\
2.3 \\
1.7 \\
1.3 \\
1.2\end{array}$ & $\begin{array}{l}4.9 \\
4.4 \\
3.8 \\
3.6 \\
3.2\end{array}$ & $\begin{array}{l}1.3 \\
1.2 \\
1.1 \\
3.0 \\
5.6\end{array}$ & $\begin{array}{l}.79 \\
.65 \\
.58 \\
.47 \\
.47\end{array}$ & $\begin{array}{l}.05 \\
.04 \\
.03 \\
.03 \\
.02\end{array}$ & $\begin{array}{l}0 \\
0 \\
0 \\
0 \\
0\end{array}$ & $\begin{array}{l}0 \\
0 \\
0 \\
0 \\
0\end{array}$ & $\begin{array}{r}1.1 \\
.29 \\
.16 \\
.09 \\
.08\end{array}$ \\
\hline $\begin{array}{l}16 \\
17 \\
18 \\
19 \\
20\end{array}$ & . & $\begin{array}{l}0 \\
0 \\
0 \\
0 \\
0\end{array}$ & $\begin{array}{l}.06 \\
.06 \\
.06 \\
.06 \\
.08\end{array}$ & $\begin{array}{l}.05 \\
.05 \\
.06 \\
.06 \\
.06\end{array}$ & $\begin{array}{l}1.1 \\
1.1 \\
1.0 \\
.95 \\
.87\end{array}$ & $\begin{array}{l}3.0 \\
2.8 \\
2.8 \\
2.6 \\
2.5\end{array}$ & $\begin{array}{r}11 \\
5.9 \\
4.0 \\
3.4 \\
2.8\end{array}$ & $\begin{array}{r}.37 \\
.37 \\
.33 \\
.33 \\
.29\end{array}$ & $\begin{array}{l}.02 \\
.02 \\
.02 \\
.02 \\
.01\end{array}$ & $\begin{array}{l}0 \\
0 \\
0 \\
0 \\
0\end{array}$ & $\begin{array}{l}.01 \\
.01 \\
.01 \\
.01 \\
0\end{array}$ & $\begin{array}{l}.06 \\
.05 \\
.04 \\
.04 \\
.05\end{array}$ \\
\hline $\begin{array}{l}21 \\
22 \\
23 \\
24 \\
25\end{array}$ & & $\begin{array}{l}0 \\
0 \\
0 \\
0 \\
0\end{array}$ & $\begin{array}{l}.08 \\
.08 \\
.08 \\
.08 \\
.08\end{array}$ & $\begin{array}{l}.06 \\
.08 \\
.08 \\
.08 \\
.06\end{array}$ & $\begin{array}{l}.87 \\
.79 \\
.87 \\
.87 \\
.95\end{array}$ & $\begin{array}{l}2.3 \\
2.3 \\
2.2 \\
3.9 \\
2.0\end{array}$ & $\begin{array}{l}2.6 \\
2.5 \\
2.2 \\
1.9 \\
1.9\end{array}$ & $\begin{array}{l}.25 \\
.22 \\
.22 \\
.16 \\
.14\end{array}$ & $\begin{array}{l}.01 \\
.01 \\
.01 \\
0 \\
0\end{array}$ & $\begin{array}{l}0 \\
0 \\
0 \\
0 \\
0\end{array}$ & $\begin{array}{l}0 \\
0 \\
0 \\
0 \\
0\end{array}$ & $\begin{array}{l}.05 \\
.03 \\
.06 \\
.08 \\
.14\end{array}$ \\
\hline $\begin{array}{l}26 \\
27 \\
28 \\
29 \\
30 \\
31\end{array}$ & & $\begin{array}{l}0 \\
0 \\
1.3 \\
.42 \\
.19 \\
-.-\end{array}$ & $\begin{array}{l}.06 \\
.06 \\
.05 \\
.05 \\
.06 \\
.11\end{array}$ & $\begin{array}{l}.06 \\
.06 \\
.06 \\
.06 \\
.06 \\
.06\end{array}$ & $\begin{array}{c}2.3 \\
3.5 \\
5.0 \\
3.6 \\
-\ldots\end{array}$ & $\begin{array}{l}1.8 \\
1.7 \\
1.6 \\
1.4 \\
1.3 \\
1.2\end{array}$ & $\begin{array}{l}1.9 \\
1.7 \\
1.5 \\
1.5 \\
1.3 \\
0-0\end{array}$ & $\begin{array}{l}.11 \\
.11 \\
.09 \\
.09 \\
.08 \\
.08\end{array}$ & $\begin{array}{l}0 \\
0 \\
0 \\
0 \\
0 \\
\end{array}$ & $\begin{array}{r}4.3 \\
.79 \\
.47 \\
.37 \\
.19 \\
.14\end{array}$ & $\begin{array}{l}0 \\
0 \\
0 \\
0 \\
0 \\
0\end{array}$ & $\begin{array}{l}.14 \\
.11 \\
.09 \\
.08 \\
.08 \\
0.0\end{array}$ \\
\hline $\begin{array}{l}\text { TOTAL } \\
\text { MEAN } \\
\text { MAX } \\
\text { MIN } \\
\text { AC-FT }\end{array}$ & $\begin{array}{l}0 \\
0 \\
0 \\
0 \\
0\end{array}$ & $\begin{array}{r}1.91 \\
.064 \\
1.3 \\
0 \\
3.8\end{array}$ & $\begin{array}{r}2.18 \\
.070 \\
.29 \\
.01 \\
4.3\end{array}$ & $\begin{array}{r}1.83 \\
.059 \\
.09 \\
.05 \\
3.6\end{array}$ & $\begin{array}{r}91.33 \\
3.15 \\
36 \\
.06 \\
181\end{array}$ & $\begin{array}{r}94.5 \\
3.05 \\
4.9 \\
1.2 \\
187\end{array}$ & $\begin{array}{r}77.65 \\
2.59 \\
11 \\
.95 \\
154\end{array}$ & $\begin{array}{r}16.77 \\
.54 \\
1.2 \\
.08 \\
33\end{array}$ & $\begin{array}{r}.74 \\
.025 \\
.05 \\
0 \\
1.5\end{array}$ & $\begin{array}{r}6.26 \\
.20 \\
4.3 \\
0 \\
12\end{array}$ & $\begin{array}{r}.40 \\
.013 \\
.09 \\
0 \\
.8\end{array}$ & $\begin{array}{r}6.42 \\
.21 \\
3.6 \\
0 \\
13\end{array}$ \\
\hline
\end{tabular}

CAL YR 1975 TOTAL 452.87 MEAN 1.24 MAX 13 MIN 0 AC WTR YR 1976 TOTAL 299.99 MEAN 92 MAX 36 MIN 0 AC-FT 595 
11015000 SWEETWATER RIVER NEAR DESCANSO, CA--Continued

COMBINED DISCHARGE, IN CUBIC FEET PER SECOND, OF SWEETWATER RIVER AND

SWEETWATER DIVERSION NEAR DESCANSO, CA, WATER YEAR OCTOBER 1975 TO SEPTEMBER 1976

DISCHARGE, IN CUBIC FEET PER SECOND, WATER YEAR OCTOBER 1975 TO SEPTEMBER 1976 MEAN VALUES

\begin{tabular}{|c|c|c|c|c|c|c|c|c|c|c|c|c|}
\hline DAY & OCT & NOV & DEC & JAN & FEB & MAR & APR & HAY & JUN & JUL & AUG & SEP \\
\hline $\begin{array}{l}1 \\
2 \\
3 \\
4 \\
5\end{array}$ & $\begin{array}{l}0 \\
0 \\
0 \\
0 \\
0\end{array}$ & $\begin{array}{l}.04 \\
.04 \\
.04 \\
.04 \\
.05\end{array}$ & $\begin{array}{l}.45 \\
.36 \\
.31 \\
.28 \\
.25\end{array}$ & $\begin{array}{r}.39 \\
.35 \\
.31 \\
.31 \\
.31\end{array}$ & $\begin{array}{r}.22 \\
.26 \\
.33 \\
.65 \\
2.9\end{array}$ & $\begin{array}{l}3.8 \\
3.9 \\
3.9 \\
3.9 \\
4.7\end{array}$ & $\begin{array}{l}1.4 \\
1.3 \\
1.3 \\
1.9 \\
5.0\end{array}$ & $\begin{array}{l}1.6 \\
1.5 \\
1.5 \\
1.5 \\
1.4\end{array}$ & $\begin{array}{l}.17 \\
.16 \\
.15 \\
.14 \\
.14\end{array}$ & $\begin{array}{l}0 \\
0 \\
0 \\
0 \\
0\end{array}$ & $\begin{array}{l}.09 \\
.08 \\
.08 \\
.05 \\
.03\end{array}$ & $\begin{array}{l}0 \\
0 \\
0 \\
0 \\
0\end{array}$ \\
\hline $\begin{array}{r}6 \\
7 \\
8 \\
9 \\
10\end{array}$ & $\begin{array}{l}0 \\
0 \\
0 \\
0 \\
0\end{array}$ & $\begin{array}{l}.05 \\
.06 \\
.06 \\
.08 \\
.09\end{array}$ & $\begin{array}{l}.23 \\
.21 \\
.19 \\
.19 \\
.20\end{array}$ & $\begin{array}{r}.29 \\
.29 \\
.29 \\
.29 \\
.29\end{array}$ & $\begin{array}{r}4.7 \\
2.5 \\
4.8 \\
36 \\
8.8\end{array}$ & $\begin{array}{l}4.7 \\
4.7 \\
4.7 \\
4.7 \\
4.9\end{array}$ & $\begin{array}{l}3.5 \\
2.7 \\
2.3 \\
2.0 \\
1.9\end{array}$ & $\begin{array}{l}1.5 \\
1.6 \\
1.5 \\
1.3 \\
1.2\end{array}$ & $\begin{array}{l}.14 \\
.13 \\
.11 \\
.10 \\
.15\end{array}$ & $\begin{array}{l}0 \\
0 \\
0 \\
0 \\
0\end{array}$ & $\begin{array}{l}.02 \\
0 \\
0 \\
0 \\
0\end{array}$ & $\begin{array}{l}0 \\
0 \\
0 \\
0 \\
4.1\end{array}$ \\
\hline $\begin{array}{l}11 \\
12 \\
13 \\
14 \\
15\end{array}$ & $\begin{array}{l}0 \\
0 \\
0 \\
0 \\
0\end{array}$ & $\begin{array}{l}.11 \\
.09 \\
.08 \\
.09 \\
.09\end{array}$ & $\begin{array}{l}.20 \\
.58 \\
.74 \\
.59 \\
.45\end{array}$ & $\begin{array}{r}.29 \\
.29 \\
.29 \\
.29 \\
.29\end{array}$ & $\begin{array}{l}4.4 \\
2.6 \\
2.0 \\
1.5 \\
1.4\end{array}$ & $\begin{array}{l}5.5 \\
5.0 \\
4.3 \\
4.1 \\
3.7\end{array}$ & $\begin{array}{l}1.6 \\
1.6 \\
1.7 \\
3.6 \\
6.3\end{array}$ & $\begin{array}{l}1.1 \\
.95 \\
.86 \\
.75 \\
.72\end{array}$ & $\begin{array}{r}.19 \\
.15 \\
.09 \\
.06 \\
.04\end{array}$ & $\begin{array}{l}0 \\
0 \\
0 \\
0 \\
0\end{array}$ & $\begin{array}{l}0 \\
0 \\
0 \\
0 \\
0\end{array}$ & $\begin{array}{l}1.8 \\
.70 \\
.46 \\
.32 \\
.29\end{array}$ \\
\hline $\begin{array}{l}16 \\
17 \\
18 \\
19 \\
20\end{array}$ & $\begin{array}{l}0 \\
0 \\
0 \\
0 \\
0\end{array}$ & $\begin{array}{r}.11 \\
.12 \\
.15 \\
.14 \\
.11\end{array}$ & $\begin{array}{r}.39 \\
.37 \\
.36 \\
.34 \\
.38\end{array}$ & $\begin{array}{r}.29 \\
.27 \\
.30 \\
.28 \\
.28\end{array}$ & $\begin{array}{l}1.3 \\
1.3 \\
1.2 \\
1.1 \\
1.1\end{array}$ & $\begin{array}{l}3.5 \\
3.3 \\
3.2 \\
3.0 \\
2.9\end{array}$ & $\begin{array}{l}12 \\
6.6 \\
4.7 \\
4.0 \\
3.4\end{array}$ & $\begin{array}{r}.60 \\
.60 \\
.54 \\
.54 \\
.49\end{array}$ & $\begin{array}{l}.04 \\
.04 \\
.03 \\
.03 \\
.02\end{array}$ & $\begin{array}{l}0 \\
0 \\
0 \\
0 \\
0\end{array}$ & $\begin{array}{l}.01 \\
.01 \\
.01 \\
.01\end{array}$ & $\begin{array}{l}.26 \\
.23 \\
.19 \\
.19 \\
.20\end{array}$ \\
\hline $\begin{array}{l}21 \\
22 \\
23 \\
24 \\
25\end{array}$ & $\begin{array}{l}0 \\
0 \\
0 \\
0 \\
0\end{array}$ & $\begin{array}{l}.11 \\
.09 \\
.09 \\
.09 \\
.11\end{array}$ & $\begin{array}{l}.38 \\
.38 \\
.38 \\
.36 \\
.36\end{array}$ & $\begin{array}{r}.28 \\
.32 \\
.34 \\
.34 \\
.28\end{array}$ & $\begin{array}{l}1.0 \\
.94 \\
1.0 \\
1.0 \\
1.1\end{array}$ & $\begin{array}{l}2.7 \\
2.7 \\
2.6 \\
4.4 \\
2.4\end{array}$ & $\begin{array}{l}3.2 \\
3.1 \\
2.8 \\
2.4 \\
2.4\end{array}$ & $\begin{array}{l}.43 \\
.40 \\
.40 \\
.32 \\
.30\end{array}$ & $\begin{array}{l}.01 \\
.01 \\
.01 \\
0 \\
0\end{array}$ & $\begin{array}{l}0 \\
0 \\
0 \\
0 \\
0\end{array}$ & $\begin{array}{l}0 \\
0 \\
0 \\
0 \\
0\end{array}$ & $\begin{array}{r}.20 \\
.17 \\
.18 \\
.19 \\
.25\end{array}$ \\
\hline $\begin{array}{l}26 \\
27 \\
28 \\
29 \\
30 \\
31\end{array}$ & $\begin{array}{l}0 \\
0 \\
0 \\
0 \\
0 \\
.02\end{array}$ & $\begin{array}{r}.11 \\
.20 \\
1.9 \\
.92 \\
.62 \\
.0-\end{array}$ & $\begin{array}{l}.31 \\
.31 \\
.30 \\
.28 \\
.32 \\
.47\end{array}$ & $\begin{array}{r}.28 \\
.26 \\
.24 \\
.24 \\
.24 \\
.24\end{array}$ & $\begin{array}{c}2.5 \\
3.7 \\
5.2 \\
3.8 \\
- \\
-\infty\end{array}$ & $\begin{array}{l}2.2 \\
2.1 \\
2.0 \\
1.7 \\
1.6 \\
1.5\end{array}$ & $\begin{array}{l}2.4 \\
2.2 \\
2.0 \\
2.0 \\
1.0 \\
-\infty\end{array}$ & $\begin{array}{l}.26 \\
.25 \\
.23 \\
.24 \\
.23 \\
.20\end{array}$ & $\begin{array}{l}0 \\
0 \\
0 \\
0 \\
0 \\
\end{array}$ & $\begin{array}{l}4.6 \\
.81 \\
.47 \\
.37 \\
.19 \\
.14\end{array}$ & $\begin{array}{l}0 \\
0 \\
0 \\
0 \\
0 \\
0\end{array}$ & $\begin{array}{r}.25 \\
.22 \\
.19 \\
.17 \\
.15\end{array}$ \\
\hline $\begin{array}{l}\text { TOTAL } \\
\text { MEAN } \\
\text { MAX } \\
\text { MIN } \\
\text { AC-FT }\end{array}$ & $\begin{array}{r}.02 \\
.0006 \\
.02 \\
0 \\
.04\end{array}$ & $\begin{array}{r}5.88 \\
.20 \\
1.9 \\
.04 \\
12\end{array}$ & $\begin{array}{r}10.92 \\
.35 \\
.74 \\
.19 \\
22\end{array}$ & $\begin{array}{r}9.05 \\
.29 \\
.39 \\
.24 \\
18\end{array}$ & $\begin{array}{r}99.30 \\
3.42 \\
36 \\
.22 \\
197\end{array}$ & $\begin{array}{r}108.3 \\
3.49 \\
5.5 \\
1.5 \\
215\end{array}$ & $\begin{array}{r}93.1 \\
3,10 \\
12 \\
1.3 \\
185\end{array}$ & $\begin{array}{r}25.01 \\
.81 \\
1.6 \\
.20 \\
50\end{array}$ & $\begin{array}{r}2.11 \\
.070 \\
.19 \\
0 \\
4.2\end{array}$ & $\begin{array}{r}6.58 \\
.21 \\
4.6 \\
0 \\
13\end{array}$ & $\begin{array}{r}.40 \\
.013 \\
.09 \\
0 \\
.0\end{array}$ & $\begin{array}{r}10.71 \\
.36 \\
4.1 \\
0 \\
21\end{array}$ \\
\hline
\end{tabular}

CAL YR 1975 TOTAL 465.60 MEAN 1.28 MAX 13 HIN 0 AC-FT 924 $\begin{array}{lllllll}\text { CAL YR } 1975 & \text { TOTAL } 465.60 & \text { MEAN } 1.28 & \text { MAX } 13 & \text { HIN } 0 & \text { ACWFT } 924 \\ \text { WTR } 1976 & \text { TOTAL } 371.38 & \text { MEAN } 1.01 & \text { MAX } 36 & \text { MIN } 0 & \text { ACWFT } 737\end{array}$ 
11016550 SWEETWATER RESERVOIR NEAR NAT IONAL CITY, CA

LOCATION,--Lat $32^{\circ} 41^{\prime} 20^{\prime \prime}$, Long $117^{\circ} 00^{\prime} 35^{\prime \prime}$, San Diego County, in La Nacion Grant, at Sweetwater Dam on Sweetwater River, $6 \mathrm{mi}(10 \mathrm{~km})$ east of National City, and $8 \mathrm{mi}$ (13 km) upstream from mouth.

DRAINAGE AREA. $-182 \mathrm{mi}^{2}\left(471 \mathrm{~km}^{2}\right)$.

PERIOD OF RECORD. - October 1943 to September 1966 published with Sweetwater River at Sweetwater Dam

(station 11016500). October 1972 to current year. Records of monthend gage heights October 1891 to

September 1943, in files of san Diego County Department of Sanitation and Fiood Control.

GAGE.--Nonrecording gage. Datum of gage is $149.28 \mathrm{ft}(45.501 \mathrm{~m})$ above mean sea leve1 (1evels by San Diego County); gage readings have been reduced to elevations above mean sea 1eve1, 0ct. 1, 1972, to Mar. 6 , 1975, water-stage recorder at same site and datum. Prior to oct. 1, 1972, nonrecording gage at same site at datum $0.16 \mathrm{ft}(0.049 \mathrm{~m})$ lower.

REMARKS, - Reservoir is formed by concrete-gravity dam. Dam completed Apr. 7, 1888, to elevation 223.82 ft $(68.220 \mathrm{~m})$, raised to elevation $228.82 \mathrm{ft}(69.744 \mathrm{~m})$ in 1895 , and raised to elevation $243.82 \mathrm{ft}$ ( $74.316 \mathrm{~m})$ in 1911. In 1939 the spillway was completed at its present elevation. Capacity table dated December ig47. Capacity of reservoir at spiliway level, 27,690 acre-ft (34.1 hin ${ }^{3}$ ), elevation, $238.82 \mathrm{ft}(72.792 \mathrm{~m})$. Dead storage below lowest outlet, 4.0 acre-ft $\left(4,930 \mathrm{~m}^{3}\right)$, elevation, $168.82 \mathrm{ft}$ (51.456 m). Diversions for irrigation. Regulation at Loveland Reservoir. Water is released by California-American Water Co. as required for irrigation and domestic use in Chula Vista, National City, and contiguous areas.

COOPERATION.--Gage heights were furnished by Sweetwater Authority.

EXTREMES FOR PERIOD OF RECORD (1943-66 AND SINCE 1972).--Maximum contents observed, 20,900 acre-ft (25.8 hm ${ }^{3}$ ) oct. 31,1943 , elevation, $231.24 \mathrm{ft}(70.482 \mathrm{~m}) ;$ minimum observed, 1,740 acre-ft (2.15 hm $\left.{ }^{3}\right) \mathrm{Nov}$. 1 , 1949 , elevation, $188.48 \mathrm{ft}(57.449 \mathrm{~m})$.

EXTREMES FOR CURRENT YEAR,--Maxinum contents observed, 7,280 acre-ft $\left(8,98 \mathrm{hm}^{3}\right) \mathrm{Sept}$. 28 , 29, 30 , elevation, $207.38 \mathrm{ft}(63.209 \mathrm{~m})$; minimum observed, 2,350 acre-ft $\left(2.90 \mathrm{hm}^{3}\right)$ Nov. 26 , e1evation, ig1.45 ft (58.354 $\left.\mathrm{m}\right)$.

MONTHEND ELEVATION AND CONTENTS, AT 0800, WATER YEAR OCTOBER 1975 TO SEPTEMBER 1976

Date

Sept. $30 \ldots \ldots \ldots \ldots \ldots \ldots \ldots$

oct. $31, \ldots \ldots \ldots \ldots \ldots \ldots \ldots \ldots$

Nov. $30 \ldots \ldots \ldots \ldots \ldots \ldots \ldots$

Dec. $\quad 31 \ldots \ldots \ldots \ldots \ldots \ldots \ldots$

CAL YR 1975

Jan. $\quad 31 \ldots \ldots \ldots \ldots \ldots \ldots \ldots$

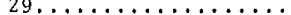

Mar. $\quad 31 \ldots \ldots \ldots \ldots \ldots \ldots \ldots$

Apr. $\quad 30 \ldots \ldots \ldots \ldots \ldots \ldots \ldots$

May $\quad 31 \ldots \ldots \ldots \ldots \ldots \ldots \ldots$

$30 \ldots \ldots \ldots \ldots \ldots \ldots \ldots$

July $31 \ldots \ldots \ldots \ldots \ldots \ldots$

Aug. $\quad 31, \ldots \ldots \ldots \ldots \ldots \ldots \ldots$

Sept. $30 \ldots \ldots \ldots \ldots \ldots$

WTR YR $1976 \ldots \ldots \ldots \ldots \ldots$
Elevation

(feet)

193.26

192.20

191.87

193.37

$-$

192.97
195.92

198.50

198.50
203.06

203.06

205.51

206.08

205.67

205.98

207.38
Contents

(acre-feet)

2780

2520

2440

2800

-

2710

2710
3460

4180

5650

6540

6760

6600

6720

-
Change in contents

(acre-feet)

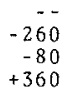

-80
+360

$+260$

$-90$

$+750$

$+720$

$+1470$

+890
+220

$-160$

$+120$

$+560$

$+4500$ 


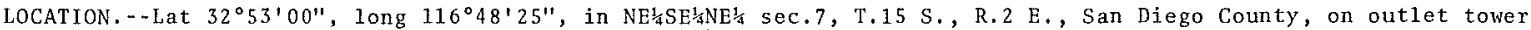
of 11 Capitan Dam on San Diego River, $7 \mathrm{mi}$ (11 km) east of Lakeside.'

DRAINAGE AREA, $-188 \mathrm{mi}^{2}\left(487 \mathrm{~km}^{2}\right)$.

PERIOD OF RECORD. --October 1945 to September 1966 pub1ished with San Diego River at El Capitan Dam (station 11020500), October 1972 to current year, October 1936 to September 1945 not equivalent owing to exclusion of greater part of flow released from Cuyamaca Reservoir.

GAGE.- Water-stage recorder. Datum of gage is $663.0 \mathrm{ft}(202.08 \mathrm{~m})$ above mean sea level; gage readings have been converted to elevations above mean sea level. Prior to oct. 1, 1972, nonrecording gage at same site at datum $110.0 \mathrm{ft}(33.53 \mathrm{~m})$ lower.

REMARKS. --Reservoir is formed by hydraulic fill-rock embankment, completed in 1935. Capacity table dated Mar, 29, 1956. Capacity of reservoir at spil1way leve1, 112,810 acre-ft (139 $\left.\mathrm{hm}^{3}\right)$, elevation, $750.00 \mathrm{ft}(228.600 \mathrm{~m})$. Dead storage below lowest outlet, 59.2 acre-ft $\left(73,000 \mathrm{~m}^{3}\right)$, elevation, $574.00 \mathrm{ft}(174.955 \mathrm{~m})$. Reservoir storage includes supplemental Colorado River water. No significant diversion above reservoir. Flow partly regulated by Cuyamaca Reservoir. Water is released as required for municipal use and irrigation.

COOPERATION, - Records were furnished by San Diego County, Department of Sanitation and Flood Control.

EXTREMES FOR PERIOD OF RECORD (1945-66 AND SINCE 1972).--Maximum contents, 62,400 acre-ft (76.9 hm $\left.{ }^{3}\right)$ OCt. 1 1945 , elevation, $708.75 \mathrm{ft}(216.027 \mathrm{~m})$; minimum, 2,252 acre-ft $\left(2.78 \mathrm{hm}^{3}\right)$ May 1 , 1957, e1evation, $606.28 \mathrm{ft}$ $(184.794 \mathrm{~m})$.

EXTREMES FOR CURRENT YEAR, - Maximum contents observed, $16,340 \mathrm{acre}^{\mathrm{ft}}\left(20.1 \mathrm{hm}^{3}\right)$ oct. 1 , e1evation, 651.66 ft $(198.626 \mathrm{~m})$; minimum, 8,870 acre-ft $\left(10.9 \mathrm{hm}^{3}\right)$ Jan. 27, elevation, 633.15 $\mathrm{ft}(192.984 \mathrm{~m})$.

MONTHEND ELEVATION AND CONTENTS, AT 0800, WATER YEAR OCTOBER 1975 TO SEPTEMBER 1976

\section{Date}

Sept. $30 \ldots \ldots \ldots \ldots \ldots \ldots \ldots \ldots$

oct. $31 \ldots \ldots \ldots \ldots \ldots \ldots \ldots \ldots \ldots$

Nov. $30 \ldots \ldots \ldots \ldots \ldots \ldots \ldots$

Dec. $\quad 31 \ldots \ldots \ldots \ldots \ldots \ldots \ldots$

CAL YR $1975 \ldots \ldots \ldots \ldots \ldots$

Jan. $31 \ldots \ldots \ldots \ldots \ldots \ldots \ldots$

Feb. $\quad 29 \ldots \ldots \ldots \ldots \ldots \ldots \ldots$

Mar. $\quad 31 \ldots \ldots \ldots \ldots \ldots \ldots \ldots$

Apr. $\quad 30 \ldots \ldots \ldots \ldots \ldots \ldots \ldots$

May $\quad 31 \ldots \ldots \ldots \ldots \ldots \ldots$

June $\quad 30 \ldots \ldots \ldots \ldots \ldots \ldots \ldots$

Ju1y $\quad 31 \ldots \ldots \ldots \ldots \ldots \ldots \ldots \ldots$

Sept. $30 \ldots \ldots \ldots \ldots \ldots \ldots \ldots \ldots$

WTR YR 1976 .
Blevation

(feet)

651.72

650.00

647.30

638.40

$$
\text { -. }
$$

633.16

616.66

640.04

641.56

643.18

642.70

642.18

636.48

634.06

$--$
Contents

(acre-feet)

16530

15530

14300

10710

-

8850

11320

11910

12550

12360

12150

10010

9160

-.
Change in contents (acre-feet)

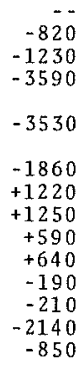

500

3530

$-1860$

+1220
+1250

$+590$

$-190$

$-2140$

$-7190$ 
11022100 SAN VICENTE RESERVOIR NEAR LAKESIDE, CA

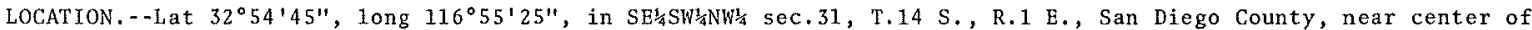
upstream face of San Vicente Dam on San Vicente Creek, $3.6 \mathrm{mi}(5.8 \mathrm{~km})$ north of Lakeside.

DRAINAGE AREA. $-74.2 \mathrm{mi}^{2}\left(192.2 \mathrm{~km}^{2}\right)$.

PERIOD OF RECORD.--October 1946 to September 1961 published with San Vicente Creek at San Vicente Dam, at Foster (station 11022000). October 1972 to current year.

GAGE.--Water-stage recorder. Datum of gage is $560.0 \mathrm{ft}(170.69 \mathrm{~m})$ above mean sea level; gage readings have been converted to elevations above mean sea leve1. October 1946 to September 1961, nonrecording gage at same site at datum $100 \mathrm{ft}(30.5 \mathrm{~m})$ lower.

REMARKS. - -Reservoir is formed by concrete-gravity dam, constructed in $1941-43$ by city of San Diego; storage began during construction period. Capacity table is dated Feb. 18, 1944. Capacity of reservoir at spillway 1evel, 90,230 acre-ft $\left(111 \mathrm{hm}^{3}\right)$, elevation, $650 \mathrm{ft}(198.1 \mathrm{~m})$. Dead storage below lowest outlet, 350 acre-ft $\left(432,000 \mathrm{~m}^{3}\right)$, elevation, $493.0 \mathrm{ft}(150.27 \mathrm{~m})$. Reservoir storage includes supplemental water from the San Diego River, Santa Ysabel Creek, and Colorado River basins. No diversion above reservoir. Water is released as required for municipal use.

COOPERATION, - Gage heights were furnished by San Diego County, Department of Sanitation and Flood Control.

EXTREMES FOR PERIOD OF RECORD (1946-61 AND SINCE 1972).--Maximum contents, 83,980 acre-ft (104 hm ${ }^{3}$ ) Ju1y 31 , 1973 , elevation, $664.07 \mathrm{ft}(202.409 \mathrm{~m})$; minimum, 12,390 acre-ft $\left(15.3 \mathrm{hm}^{3}\right)$ Nov. 1, 1947, elevation, $549.22 \mathrm{ft}(167.402 \mathrm{~m})$.

EXTREMES FOR CURRENT YEAR. - Maximum contents observed, 75,770 acte-ft $\left(93,4 \mathrm{hm}^{3}\right) \mathrm{June}^{7}$, elevation, 636.00 ft (193.853 m); minimum, 57,940 acre-ft (71.4 $\mathrm{hm}^{3}$ ) Sept. 30, elevation, $617.02 \mathrm{ft}$ (188.068 m).

MONTHEND ELEVATION AND CONTENTS, AT 0800, WATER YEAR OCTOBER 1975 TO SEPTEMBER 1976

Date

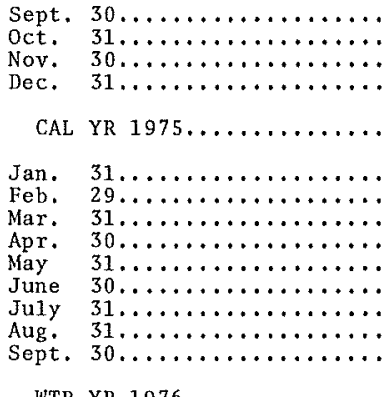

$\begin{array}{cc}\begin{array}{c}\text { Elevation } \\ \text { (feet) }\end{array} & \begin{array}{c}\text { Contents } \\ \text { (acre-feet) }\end{array} \\ 624.61 & 64830 \\ 619.74 & 60380 \\ 618.14 & 58940 \\ 623.60 & 63900 \\ & \\ . . & -- \\ 621.76 & 62210 \\ 624.25 & 64500 \\ 627.60 & 67630 \\ 633.73 & 73530 \\ 635.93 & 75700 \\ 634.10 & 73900 \\ 628.75 & 68720 \\ 622.75 & 63120 \\ 617.02 & 57940 \\ & \\ .- & \ldots\end{array}$

Change in contents
(acre-feet)

$-4450$

-1440
+4960

$-4180$

$-1690$

$+2290$

$+3130$

$+5900$

$+2170$

$-1800$

$-5180$

-5600
-5180

$-6890$ 
LOCATION, - Lat $32^{\circ} 49^{\prime} 29^{\prime \prime}$, long $117^{\circ} 03^{\prime} 17^{\prime \prime}$, in Ex Mission San Diego Grant, San Diego County, on right bank in Mission Gorge, $0.2 \mathrm{mi}(0.3 \mathrm{~km})$ upstream from left tributary, $6 \mathrm{mi}(10 \mathrm{~km})$ west of Santee, and $18 \mathrm{mi}(29 \mathrm{~km})$ downstream from E1 Capitan Reservoir.

DRAINAGE AREA. $-377 \mathrm{mi}^{2}\left(976 \mathrm{~km}^{2}\right)$.

WATER-DISCHARGE RECORDS

PERIOD OF RECORD. - May 1912 to December 1915, March 1916 to current year. Monthly discharge only for some periods and yearly estimates on $1 y$ for 1924-25, published in WSP 1315-B.

GAGE. - Water-stage recorder. Altitude of gage is $180 \mathrm{ft}(54.9 \mathrm{~m})$, from topographic map. Prior to Nov. 10 , 1920 , nonrecording gage at site $1.5 \mathrm{mi}(2.4 \mathrm{~km})$ upstrean at different datum. Nov. 10, 1920 , to Dec. 1 , 1954 , waterstage recorder at present site at datum $1.0 \mathrm{ft}(0.30 \mathrm{~m})$ higher.

REMARKS, - Record's fair. Flow regulated by Cuyamaca Reservoir, capacity, 11,540 acre-ft (46.7 hm ${ }^{3}$ ), El Capitan Reservoir (station 11020500), and San Vicente Reservoir (station 11022000), Diversions by city of San Diego for municipal supply and by Helix Irrigation District. AVERAGE DISCHARGE represents flow to ocean during period of record, regardless of upstream development.

AVERAGE DISCHARGE. - -63 years (water years $1913-1915,1917-1976), 21.9 \mathrm{ft}^{3} / \mathrm{s}\left(0.620 \mathrm{~m}^{3} / \mathrm{s}\right), 15,870 \mathrm{acre}-\mathrm{ft} / \mathrm{yr}$ $\left(19.6 \mathrm{hm}^{3} / \mathrm{yr}\right)$.

EXTREMES FOR PERIOD OF RECORD.--Maximum discharge, $70,200 \mathrm{ft}^{3} / \mathrm{s}\left(1,990 \mathrm{~m}^{3} / \mathrm{s}\right) \mathrm{Jan}$, 27 , 1916 , based on slopeconveyance computation of peak flow, gage height, $25.1 \mathrm{ft}(7.651 \mathrm{~m})$, from floodmarks, site and datum then in use; no flow at times in some years.

EXTREMES FOR CURRENT YEAR,--Maximum discharge $1,210 \mathrm{ft}^{3} / \mathrm{s}\left(34.3 \mathrm{~m}^{3} / \mathrm{s}\right) \mathrm{Feb}, 8, \mathrm{gage} \mathrm{height,} 7.72 \mathrm{ft}(2.353 \mathrm{~m})$, on basis of slope-area computation of $1,280 \mathrm{ft}^{3} / \mathrm{s}\left(36.2 \mathrm{~m}^{3} / \mathrm{s}\right)$; no flow Juiy $15-22$, Aug. $10-20$.

DISCHARGE, IN CUBIC FEET PER SECOND, WATER YEAR OCTOBER 1975 TO SEPTEMEER 1976 MEAN VALUES

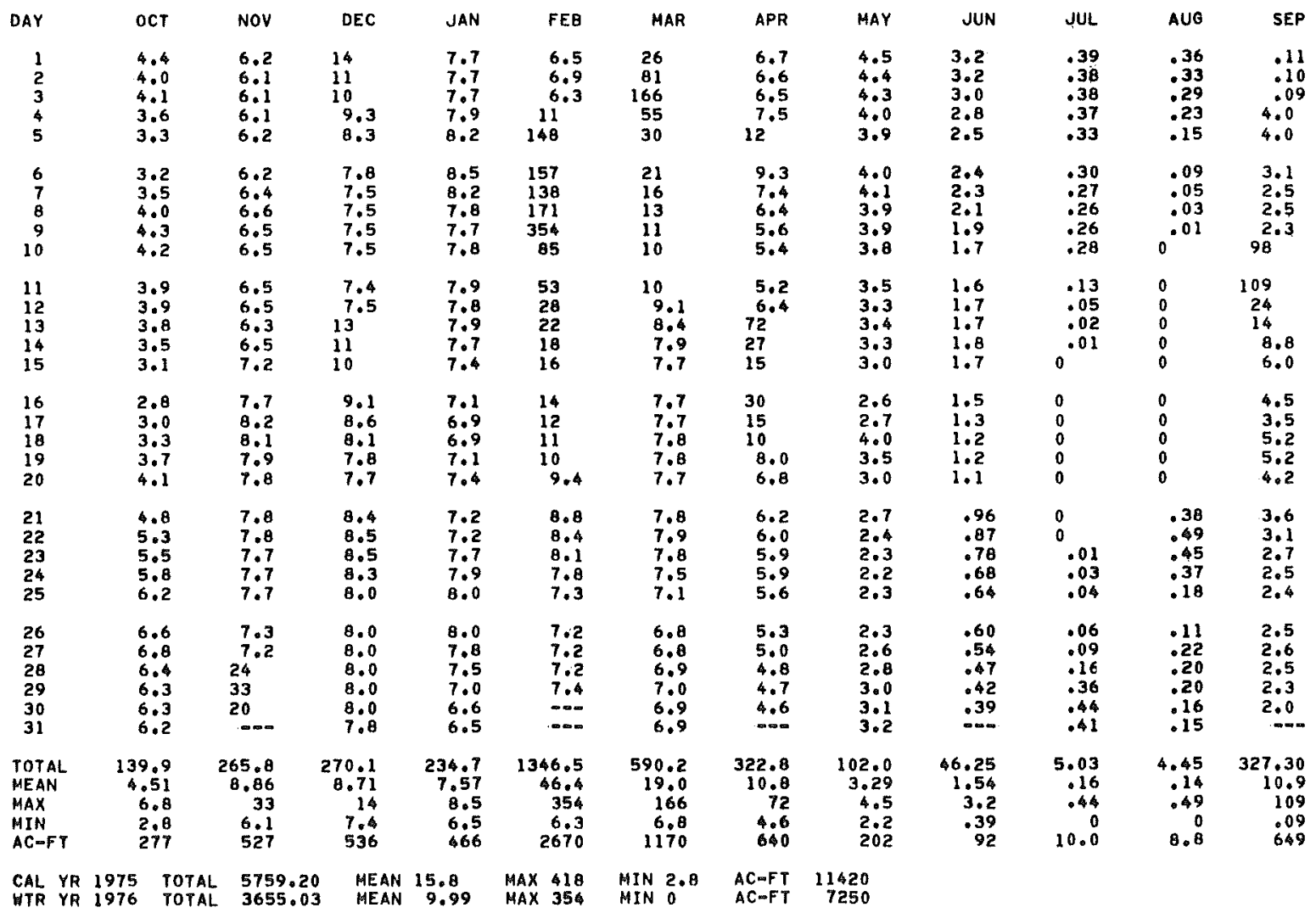


11022500 SAN DIEGO RIVER NEAR SANTEE, CA--Continued

WATER-QUALITY RECORDS

PERIOD OF DAILY RECORD - -

WATER TEMPERATURES: October 1970 to current year.

SEDIMENT RECORDS: October 1969 to current year.

EXTREMES FOR PERIOD OF DAILY RECORD. - -

SEDIMENT CONCENTRATIONS: Maximum daily mean, $512 \mathrm{mg} / 1 \mathrm{Mar}, 1,1970$; minimum daily mean, 0 mg/1 on many days

in July and August 1976 .

SEDIMENT DISCHARGE: Maximum daily, 656 tons (595 tonnes) Dec. 4, 1974; minimum daily, 0 tons on many days in 1969,1970 and 1976 .

EXTREMES FOR CURRENT YEAR, -

SEDIMENT CONCENTRATIONS: Maximum daily mean, $355 \mathrm{mg} / 1 \mathrm{Feb}$. 9; minimum daily mean, $0 \mathrm{mg} / 1$ on many days during July and August.

SEDIMENT DISCHARGE: Maximum dai1y, 478 tons (334 tonnes) Feb. 9; minimum daily, 0 tons many days during July and August.

TEMPERATURE (DEG. C) OF WATER, HATER YEAR OCTOBER 1975 TO SEPTEMBER 1976 ONCE-DAILY

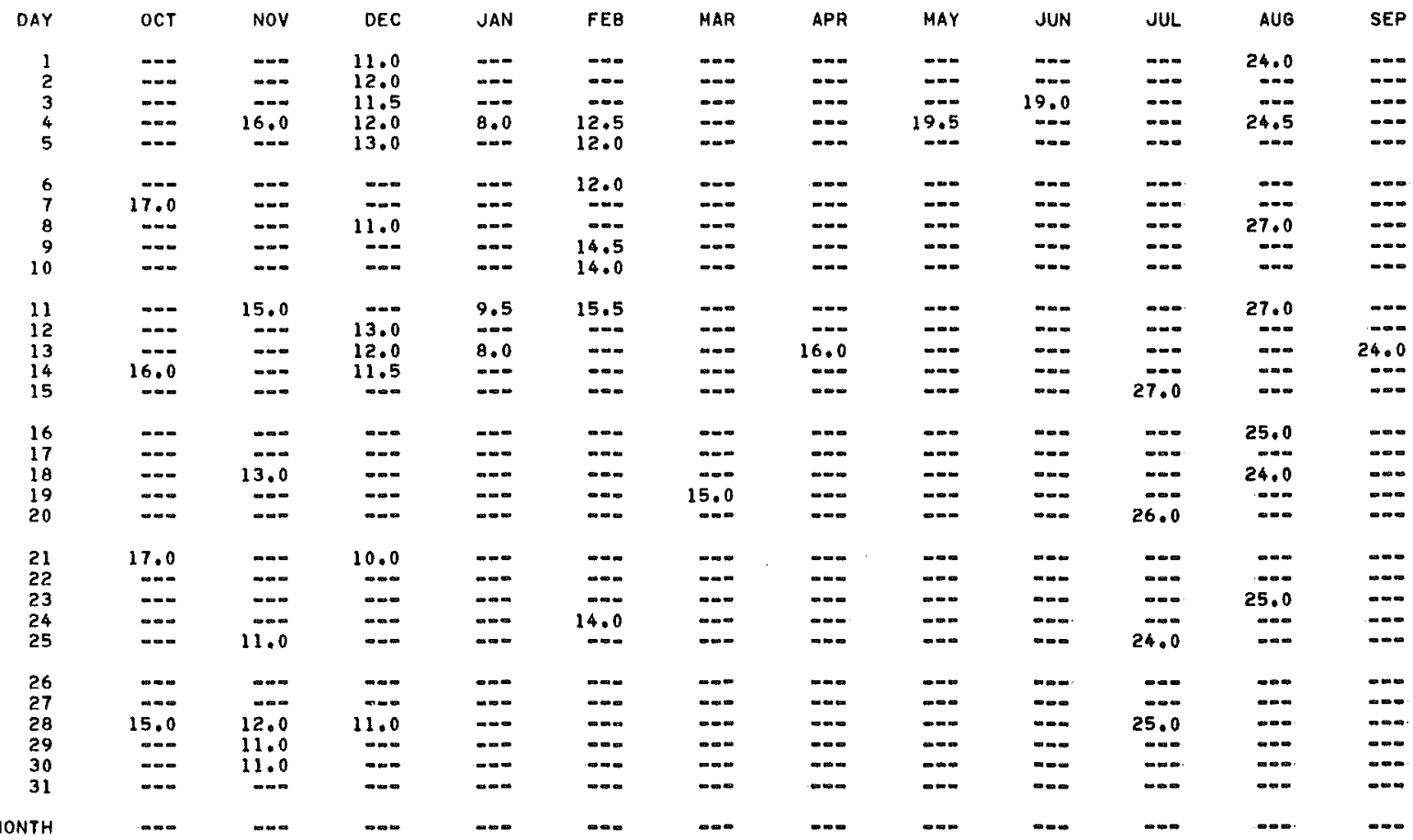




\begin{tabular}{|c|c|c|c|c|c|c|c|c|c|}
\hline & & OCTOBER & & & NOVEMBER & & & DEGEMBER & \\
\hline DAY & $\begin{array}{l}\text { MEAN } \\
\text { DISCHARGE } \\
\text { (CFS) }\end{array}$ & $\begin{array}{l}\text { MEAN } \\
\text { CONCEN- } \\
\text { TRATION } \\
\text { (MG/L) }\end{array}$ & $\begin{array}{l}\text { SEDIMENT } \\
\text { DISCHARGE } \\
\text { (TONS/DAYY) }\end{array}$ & $\begin{array}{l}\text { MEAN } \\
\text { DISCARGE } \\
\text { (CFS) }\end{array}$ & $\begin{array}{l}\text { MEAN } \\
\text { CONCEN- } \\
\text { TRAION } \\
\text { (MG/L) }\end{array}$ & $\begin{array}{l}\text { SEDIMENT } \\
\text { OISCHARGE } \\
\text { (TONS/DAY) }\end{array}$ & $\begin{array}{l}\text { MEAN } \\
\text { DISCARGE } \\
\text { (CFS) }\end{array}$ & $\begin{array}{l}\text { MEAN } \\
\text { CONCEN- } \\
\text { TRATION } \\
\text { (MO/L) }\end{array}$ & $\begin{array}{l}\text { SEDIMENT } \\
\text { DISCHARGE } \\
\text { (TONS/OAY) }\end{array}$ \\
\hline $\begin{array}{l}1 \\
2 \\
3 \\
4 \\
5\end{array}$ & $\begin{array}{l}4.4 \\
4.0 \\
4.1 \\
3.0 \\
3.3\end{array}$ & $\begin{array}{l}24 \\
23 \\
22 \\
21 \\
23\end{array}$ & $\begin{array}{l}.29 \\
: 25 \\
: 24 \\
: 20 \\
: 20\end{array}$ & $\begin{array}{l}6.2 \\
6.1 \\
6.1 \\
6.1 \\
6.2\end{array}$ & $\begin{array}{l}35 \\
33 \\
30 \\
28 \\
27\end{array}$ & $\begin{array}{l}.59 \\
.54 \\
.49 \\
.46 \\
.45\end{array}$ & $\begin{array}{l}14 \\
11 \\
10 \\
9.3 \\
8.3\end{array}$ & $\begin{array}{l}31 \\
27 \\
27 \\
25 \\
27\end{array}$ & $\begin{array}{c}1.2 \\
.80 \\
.73 \\
.63 \\
.61\end{array}$ \\
\hline $\begin{array}{r}6 \\
7 \\
8 \\
9 \\
10\end{array}$ & $\begin{array}{l}3.2 \\
3.5 \\
4.0 \\
4.3 \\
4.2\end{array}$ & $\begin{array}{l}27 \\
30 \\
36 \\
37 \\
34\end{array}$ & $\begin{array}{l}.23 \\
.28 \\
.39 \\
.43 \\
.39\end{array}$ & $\begin{array}{l}6.2 \\
6.4 \\
6.6 \\
6.5 \\
6.5\end{array}$ & $\begin{array}{l}26 \\
25 \\
25 \\
25 \\
24\end{array}$ & $\begin{array}{l}.44 \\
.43 \\
.45 \\
.44 \\
.42\end{array}$ & $\begin{array}{l}7.8 \\
7.5 \\
7.5 \\
7.5 \\
7.5\end{array}$ & $\begin{array}{l}24 \\
20 \\
19 \\
19 \\
18\end{array}$ & $\begin{array}{l}.51 \\
.41 \\
.38 \\
.38 \\
.36\end{array}$ \\
\hline $\begin{array}{l}11 \\
12 \\
13 \\
14 \\
15\end{array}$ & $\begin{array}{l}3.9 \\
3.9 \\
3.8 \\
3.5 \\
3.1\end{array}$ & $\begin{array}{l}32 \\
30 \\
28 \\
27 \\
24\end{array}$ & $\begin{array}{l}.34 \\
.32 \\
.29 \\
.26 \\
.20\end{array}$ & $\begin{array}{l}6.5 \\
6.5 \\
6.3 \\
6.5 \\
7.2\end{array}$ & $\begin{array}{l}24 \\
25 \\
25 \\
26 \\
27\end{array}$ & $\begin{array}{l}.42 \\
.44 \\
.43 \\
.46 \\
.52\end{array}$ & $\begin{array}{l}7.4 \\
7.5 \\
13 \\
11 \\
10\end{array}$ & $\begin{array}{l}18 \\
18 \\
32 \\
22 \\
19\end{array}$ & $\begin{array}{r}.36 \\
: 36 \\
1.1 \\
.65 \\
.51\end{array}$ \\
\hline $\begin{array}{l}16 \\
17 \\
18 \\
19 \\
20\end{array}$ & $\begin{array}{l}2.8 \\
3.0 \\
3.3 \\
3.7 \\
4.1\end{array}$ & $\begin{array}{l}22 \\
20 \\
22 \\
24 \\
28\end{array}$ & $\begin{array}{l}.17 \\
.16 \\
.20 \\
.24 \\
.31\end{array}$ & $\begin{array}{l}7.7 \\
8.2 \\
8.1 \\
7.9 \\
7.8\end{array}$ & $\begin{array}{l}29 \\
30 \\
29 \\
28 \\
27\end{array}$ & $\begin{array}{l}.60 \\
.66 \\
.63 \\
.60 \\
.57\end{array}$ & $\begin{array}{l}9.1 \\
8.6 \\
8.1 \\
7.8 \\
7.7\end{array}$ & $\begin{array}{l}18 \\
17 \\
16 \\
15 \\
15\end{array}$ & $\begin{array}{r}.44 \\
: 39 \\
: 35 \\
: 32 \\
.31\end{array}$ \\
\hline $\begin{array}{l}21 \\
22 \\
23 \\
24 \\
25\end{array}$ & $\begin{array}{l}4.8 \\
5.3 \\
5.5 \\
5.8 \\
6.2\end{array}$ & $\begin{array}{l}30 \\
33 \\
36 \\
41 \\
44\end{array}$ & $\begin{array}{l}.39 \\
.47 \\
.53 \\
.64 \\
.74\end{array}$ & $\begin{array}{l}7.8 \\
7: 8 \\
7: 7 \\
7: 7\end{array}$ & $\begin{array}{l}26 \\
25 \\
24 \\
23 \\
22\end{array}$ & $\begin{array}{l}.55 \\
.53 \\
.50 \\
.48 \\
.46\end{array}$ & $\begin{array}{l}8.4 \\
8.5 \\
8.5 \\
8.3 \\
8.0\end{array}$ & $\begin{array}{l}16 \\
16 \\
16 \\
16 \\
16\end{array}$ & $\begin{array}{l}: 36 \\
: 37 \\
: 37 \\
: 36 \\
: 35\end{array}$ \\
\hline $\begin{array}{l}26 \\
27 \\
28 \\
29 \\
30 \\
31\end{array}$ & $\begin{array}{l}6.6 \\
6.8 \\
6.4 \\
6.3 \\
6.3 \\
6.2\end{array}$ & $\begin{array}{l}48 \\
50 \\
47 \\
44 \\
40 \\
37\end{array}$ & $\begin{array}{r}.86 \\
11.92 \\
.75 \\
.68 \\
.62\end{array}$ & $\begin{array}{c}7.3 \\
7.2 \\
24 \\
33 \\
20 \\
\cdots\end{array}$ & $\begin{array}{r}21 \\
21 \\
136 \\
130 \\
53 \\
--\end{array}$ & $\begin{array}{l}.41 \\
11^{.41} \\
12 \\
2.9 \\
-\ldots .\end{array}$ & $\begin{array}{l}8.0 \\
8.0 \\
8.0 \\
8.0 \\
8.0 \\
7.8\end{array}$ & $\begin{array}{l}16 \\
15 \\
15 \\
15 \\
14 \\
14\end{array}$ & $\begin{array}{r}: 35 \\
: 32 \\
: 32 \\
: 32 \\
: 30 \\
: 29\end{array}$ \\
\hline TOTAL & 139.9 & -- & 22.99 & 265.8 & $\cdots$ & 39.28 & 270.1 & $\cdots$ & 14.51 \\
\hline & & JANUARY & & & FEBRUARY & & & MARCH & \\
\hline DAY & $\begin{array}{l}\text { MEAN } \\
\text { DISCARGE } \\
\text { (CFS) }\end{array}$ & $\begin{array}{l}\text { MEAN } \\
\text { CONCEN- } \\
\text { TRATION } \\
\text { (MG/L) }\end{array}$ & $\begin{array}{l}\text { SEDIMENT } \\
\text { DISCARGE } \\
\text { (TONS/DAY) }\end{array}$ & $\begin{array}{l}\text { MEAN } \\
\text { DISCAAGGE } \\
\text { (CFS) }\end{array}$ & $\begin{array}{l}\text { MEAN } \\
\text { CONCEN- } \\
\text { TRATON } \\
\text { (MG/L) }\end{array}$ & $\begin{array}{l}\text { SEDIMENT } \\
\text { DIISCHARGE } \\
\text { (TONS/DAYY }\end{array}$ & $\begin{array}{l}\text { MEAN } \\
\text { DISCHAREE } \\
\text { (CFS) }\end{array}$ & $\begin{array}{l}\text { MEAN } \\
\text { CONCEN- } \\
\text { TRATION } \\
\text { (MG/L) }\end{array}$ & $\begin{array}{l}\text { SEDIMENT } \\
\text { DISCHARGE } \\
\text { (TOHS/DAYY) }\end{array}$ \\
\hline $\begin{array}{l}1 \\
2 \\
3 \\
4 \\
5\end{array}$ & $\begin{array}{l}7.7 \\
7: 7 \\
7: 7 \\
7: 9 \\
8.2\end{array}$ & $\begin{array}{l}14 \\
14 \\
14 \\
14 \\
15\end{array}$ & $\begin{array}{l}.29 \\
: 29 \\
: 29 \\
: 30 \\
.33\end{array}$ & $\begin{array}{r}6.5 \\
6.9 \\
6.3 \\
11 \\
148\end{array}$ & $\begin{array}{r}10 \\
10 \\
10 \\
40 \\
239\end{array}$ & $\begin{array}{r}: 18 \\
: 19 \\
130 \\
1.37\end{array}$ & $\begin{array}{r}26 \\
81 \\
166 \\
55 \\
30\end{array}$ & $\begin{array}{r}95 \\
108 \\
124 \\
40 \\
25\end{array}$ & $\begin{array}{l}21 \\
39 \\
68 \\
5.9 \\
2.0\end{array}$ \\
\hline $\begin{array}{r}6 \\
7 \\
8 \\
9 \\
10\end{array}$ & $\begin{array}{l}8.5 \\
8.2 \\
7.8 \\
7.7 \\
7.8\end{array}$ & $\begin{array}{l}15 \\
15 \\
15 \\
14 \\
13\end{array}$ & $\begin{array}{l}.34 \\
.33 \\
.32 \\
.29 \\
.27\end{array}$ & $\begin{array}{r}157 \\
138 \\
171 \\
354 \\
85\end{array}$ & $\begin{array}{l}247 \\
214 \\
206 \\
355 \\
115\end{array}$ & $\begin{array}{r}133 \\
116 \\
300 \\
478 \\
28\end{array}$ & $\begin{array}{l}21 \\
16 \\
13 \\
11 \\
10\end{array}$ & $\begin{array}{l}20 \\
20 \\
18 \\
18 \\
18\end{array}$ & $\begin{array}{c}2.1 \\
.86 \\
.63 \\
.53 \\
.49\end{array}$ \\
\hline $\begin{array}{l}11 \\
12 \\
13 \\
14 \\
15\end{array}$ & $\begin{array}{l}7.9 \\
7.8 \\
7.9 \\
7.7 \\
7.4\end{array}$ & $\begin{array}{l}12 \\
12 \\
13 \\
13 \\
12\end{array}$ & $\begin{array}{l}.26 \\
.25 \\
.28 \\
.27 \\
.24\end{array}$ & $\begin{array}{l}53 \\
28 \\
22 \\
18 \\
16\end{array}$ & $\begin{array}{l}80 \\
53 \\
48 \\
44 \\
42\end{array}$ & $\begin{array}{l}11 \\
4.0 \\
2.9 \\
2.1 \\
1.8\end{array}$ & $\begin{array}{c}10 \\
9.1 \\
8.4 \\
7.9 \\
7.7\end{array}$ & $\begin{array}{l}18 \\
16 \\
16 \\
16 \\
16\end{array}$ & $\begin{array}{l}.49 \\
.39 \\
.36 \\
.34 \\
.33\end{array}$ \\
\hline $\begin{array}{l}16 \\
17 \\
18 \\
19 \\
20\end{array}$ & $\begin{array}{l}7.1 \\
6.9 \\
6.9 \\
7.1 \\
7.4\end{array}$ & $\begin{array}{l}12 \\
11 \\
11 \\
11 \\
11\end{array}$ & $\begin{array}{l}.23 \\
.20 \\
.20 \\
.21 \\
.22\end{array}$ & $\begin{array}{l}14 \\
12 \\
11 \\
10 \\
9.4\end{array}$ & $\begin{array}{l}41 \\
40 \\
40 \\
40 \\
39\end{array}$ & $\begin{array}{l}1.5 \\
1.3 \\
1.2 \\
1.1 \\
.99\end{array}$ & $\begin{array}{l}7.7 \\
7: 7 \\
7: 8 \\
7.8 \\
7.7\end{array}$ & $\begin{array}{l}15 \\
15 \\
14 \\
14 \\
14\end{array}$ & $\begin{array}{l}.31 \\
.31 \\
.29 \\
.29 \\
.29\end{array}$ \\
\hline $\begin{array}{l}21 \\
22 \\
23 \\
24 \\
25\end{array}$ & $\begin{array}{l}7.2 \\
7.2 \\
7.7 \\
7: 9 \\
8.0\end{array}$ & $\begin{array}{l}11 \\
11 \\
11 \\
12 \\
12\end{array}$ & $\begin{array}{l}.21 \\
.21 \\
.23 \\
.26 \\
.26\end{array}$ & $\begin{array}{l}8.8 \\
8.4 \\
8.1 \\
7.8 \\
7.3\end{array}$ & $\begin{array}{l}39 \\
39 \\
38 \\
38 \\
38\end{array}$ & $\begin{array}{l}.93 \\
.88 \\
.83 \\
.80 \\
.85\end{array}$ & $\begin{array}{l}7.8 \\
7: 9 \\
7: 8 \\
7: 5 \\
7: 1\end{array}$ & $\begin{array}{l}14 \\
14 \\
14 \\
14 \\
14\end{array}$ & $\begin{array}{l}.29 \\
: 30 \\
: 29 \\
.28 \\
.27\end{array}$ \\
\hline $\begin{array}{l}26 \\
27 \\
28 \\
29 \\
30 \\
31\end{array}$ & $\begin{array}{l}8.0 \\
7.8 \\
7.5 \\
7.0 \\
6.6 \\
6.5\end{array}$ & $\begin{array}{l}12 \\
12 \\
11 \\
11 \\
11 \\
10\end{array}$ & $\begin{array}{l}.26 \\
.25 \\
.22 \\
.21 \\
.20 \\
.18\end{array}$ & \begin{tabular}{l}
7.2 \\
7.2 \\
7.2 \\
7.4 \\
\hdashline..
\end{tabular} & $\begin{array}{r}36 \\
36 \\
36 \\
36 \\
\hdashline-0\end{array}$ & \begin{tabular}{l}
.70 \\
.70 \\
770 \\
$-\because-$ \\
\hdashline \\
$-\infty$
\end{tabular} & $\begin{array}{l}6.8 \\
6.8 \\
6.9 \\
7.0 \\
6.9 \\
6.9\end{array}$ & $\begin{array}{l}14 \\
14 \\
14 \\
14 \\
14 \\
14\end{array}$ & $\begin{array}{l}.26 \\
.26 \\
.26 \\
.26 \\
.26 \\
.26\end{array}$ \\
\hline TOTAL & 234.7 & $\cdots$ & 7.90 & 1346.5 & $\infty$ & 1221.02 & 590.2 & $\cdots$ & 145.90 \\
\hline
\end{tabular}




\begin{tabular}{|c|c|c|c|c|c|c|c|c|c|}
\hline \multirow[b]{2}{*}{ DAY } & \multicolumn{3}{|c|}{ APRIL } & \multicolumn{3}{|c|}{ MAY } & \multicolumn{3}{|c|}{ JUNE } \\
\hline & $\begin{array}{l}\text { MEAN } \\
\text { DISCHARGE } \\
\text { (CFS) }\end{array}$ & $\begin{array}{l}\text { MEAN } \\
\text { CONCEN- } \\
\text { TRAION } \\
\text { (MGIL) }\end{array}$ & $\begin{array}{l}\text { SEDIMENT } \\
\text { OISCHARGE } \\
\text { (TONS/OAY) }\end{array}$ & $\begin{array}{l}\text { MEAN } \\
\text { DISCAARGE } \\
\text { (CFS) }\end{array}$ & $\begin{array}{l}\text { MEAN } \\
\text { CONCEN- } \\
\text { TRAION } \\
\text { (MG/L) }\end{array}$ & $\begin{array}{l}\text { SEDIMENT } \\
\text { DISCAARGE } \\
\text { (TONS/DAY) }\end{array}$ & $\begin{array}{l}\text { MEAN } \\
\text { OISCAARGE } \\
\text { (CFS) }\end{array}$ & $\begin{array}{l}\text { MEAN } \\
\text { CONCEN- } \\
\text { TRATION } \\
\text { TMB/L) }\end{array}$ & $\begin{array}{l}\text { SEDIMENT } \\
\text { DISCHARGE } \\
\text { (TONS/DAY) }\end{array}$ \\
\hline $\begin{array}{l}1 \\
2 \\
3 \\
4 \\
5\end{array}$ & $\begin{array}{r}6.7 \\
6.0 \\
6.5 \\
7.5 \\
12\end{array}$ & $\begin{array}{l}14 \\
14 \\
14 \\
20 \\
32\end{array}$ & $\begin{array}{r}.25 \\
.25 \\
.25 \\
.41 \\
1.0\end{array}$ & $\begin{array}{l}4.5 \\
4.4 \\
4.3 \\
4.0 \\
3.9\end{array}$ & $\begin{array}{l}18 \\
18 \\
18 \\
18 \\
18\end{array}$ & $\begin{array}{l}.22 \\
.21 \\
.21 \\
.19 \\
.19\end{array}$ & $\begin{array}{l}3.2 \\
3.2 \\
3.0 \\
2.0 \\
2.5\end{array}$ & $\begin{array}{l}15 \\
15 \\
15 \\
14 \\
14\end{array}$ & $\begin{array}{l}.13 \\
: 13 \\
: 12 \\
: 11 \\
09\end{array}$ \\
\hline $\begin{array}{r}6 \\
7 \\
8 \\
9 \\
10\end{array}$ & $\begin{array}{l}9.3 \\
7.4 \\
6.4 \\
5.6 \\
5.4\end{array}$ & $\begin{array}{l}26 \\
20 \\
20 \\
15 \\
15\end{array}$ & $\begin{array}{l}.65 \\
.40 \\
.35 \\
.23 \\
.22\end{array}$ & $\begin{array}{l}4.0 \\
4.1 \\
3.9 \\
3.9 \\
3.8\end{array}$ & $\begin{array}{l}18 \\
18 \\
18 \\
18 \\
18\end{array}$ & $\begin{array}{r}19 \\
: 20 \\
.19 \\
119 \\
118\end{array}$ & $\begin{array}{l}2.4 \\
2.3 \\
2.1 \\
1: 9 \\
1.7\end{array}$ & $\begin{array}{l}14 \\
14 \\
13 \\
13 \\
13\end{array}$ & $\begin{array}{l}.09 \\
.09 \\
.07 \\
.07 \\
.06\end{array}$ \\
\hline $\begin{array}{l}11 \\
12 \\
13 \\
14 \\
15\end{array}$ & $\begin{array}{l}5.2 \\
6.4 \\
72 \\
27 \\
15\end{array}$ & $\begin{array}{r}15 \\
15 \\
121 \\
44 \\
28\end{array}$ & $\begin{array}{r}.21 \\
47.26 \\
3.2 \\
1.3\end{array}$ & $\begin{array}{l}3.5 \\
3.3 \\
3.4 \\
3.3 \\
3.0\end{array}$ & $\begin{array}{l}18 \\
18 \\
17 \\
17 \\
16\end{array}$ & $\begin{array}{l}.17 \\
: 16 \\
: 16 \\
: 15 \\
113\end{array}$ & $\begin{array}{l}1.6 \\
1.7 \\
1: 7 \\
1.8 \\
1.7\end{array}$ & $\begin{array}{l}13 \\
12 \\
12 \\
12 \\
12\end{array}$ & $\begin{array}{l}.06 \\
.06 \\
.06 \\
06 \\
.06\end{array}$ \\
\hline $\begin{array}{l}16 \\
17 \\
18 \\
19 \\
20\end{array}$ & $\begin{array}{l}30 \\
15 \\
10 \\
8.0 \\
6.8\end{array}$ & $\begin{array}{l}73 \\
28 \\
24 \\
22 \\
22\end{array}$ & $\begin{array}{l}6.8 \\
1.1 \\
.65 \\
.48 \\
.40\end{array}$ & $\begin{array}{l}2.6 \\
2.7 \\
4.0 \\
3.5 \\
3.0\end{array}$ & $\begin{array}{l}15 \\
20 \\
25 \\
21 \\
18\end{array}$ & $\begin{array}{l}.11 \\
: 15 \\
.27 \\
: 20 \\
.15\end{array}$ & $\begin{array}{l}1.5 \\
1.3 \\
1.2 \\
1.2 \\
1.1\end{array}$ & $\begin{array}{l}12 \\
12 \\
12 \\
12 \\
12\end{array}$ & $\begin{array}{l}.05 \\
.04 \\
.04 \\
.04 \\
.04\end{array}$ \\
\hline $\begin{array}{l}21 \\
22 \\
23 \\
24 \\
25\end{array}$ & $\begin{array}{l}6.2 \\
6.0 \\
5.9 \\
5.9 \\
5.6\end{array}$ & $\begin{array}{l}22 \\
22 \\
20 \\
20 \\
20\end{array}$ & $\begin{array}{r}.37 \\
.36 \\
.32 \\
.32 \\
.30\end{array}$ & $\begin{array}{l}2.7 \\
2.4 \\
2.3 \\
2.2 \\
2.3\end{array}$ & $\begin{array}{l}17 \\
15 \\
14 \\
13 \\
13\end{array}$ & $\begin{array}{l}.12 \\
.10 \\
09 \\
.08 \\
.08\end{array}$ & $\begin{array}{l}.96 \\
.87 \\
.78 \\
.68 \\
.64\end{array}$ & $\begin{array}{l}12 \\
12 \\
12 \\
12 \\
12\end{array}$ & $\begin{array}{l}.03 \\
.03 \\
.03 \\
.02 \\
.02\end{array}$ \\
\hline $\begin{array}{l}26 \\
27 \\
28 \\
29 \\
30 \\
31\end{array}$ & $\begin{array}{l}5.3 \\
5.0 \\
4.8 \\
4.7 \\
4.6 \\
-.-\end{array}$ & $\begin{array}{r}20 \\
20 \\
20 \\
20 \\
20 \\
--\end{array}$ & $\begin{array}{l}.29 \\
.27 \\
.26 \\
.25 \\
.25 \\
-.0\end{array}$ & $\begin{array}{l}2.3 \\
2.6 \\
2.8 \\
3.0 \\
3.1 \\
3.2\end{array}$ & $\begin{array}{r}14 \\
14 \\
15 \\
15 \\
15 \\
---\end{array}$ & \begin{tabular}{l}
.09 \\
$: 10$ \\
$: 11$ \\
$: 12$ \\
$: 13$ \\
\hdashline-
\end{tabular} & $\begin{array}{l}.60 \\
.54 \\
.47 \\
.42 \\
.39 \\
----\end{array}$ & $\begin{array}{r}12 \\
12 \\
12 \\
12 \\
12 \\
-\cdots\end{array}$ & $\begin{array}{l}.02 \\
.02 \\
002 \\
001 \\
001 \\
01 \\
-0\end{array}$ \\
\hline TOTAL & 322.8 & $\cdots$ & 68.40 & 102.0 & $\cdots$ & 4.64 & 46.25 & -- & 1.68 \\
\hline & & JULY & & & AUGUST & & & SEP TEMBER & \\
\hline DAY & $\begin{array}{l}\text { MEAN } \\
\text { DISCAARGE } \\
\text { (CFS) }\end{array}$ & $\begin{array}{l}\text { MEAN } \\
\text { CONCEN- } \\
\text { TRATION } \\
\text { (MG/L) }\end{array}$ & $\begin{array}{l}\text { SEDIMENT } \\
\text { DISCHARGE } \\
\text { (TONS/OAY) }\end{array}$ & $\begin{array}{l}\text { MEAN } \\
\text { DISCAARGE } \\
\text { (CFS) }\end{array}$ & $\begin{array}{l}\text { MEAN } \\
\text { CONEEN- } \\
\text { TRAION } \\
\text { (MG/L) }\end{array}$ & $\begin{array}{l}\text { SEDIMENT } \\
\text { OISCHARGE } \\
\text { (TONS/DAY) }\end{array}$ & $\begin{array}{l}\text { MEAN } \\
\text { DISCARGE } \\
\text { (CFS) }\end{array}$ & $\begin{array}{l}\text { MEAN } \\
\text { CONCEN- } \\
\text { TRATION } \\
\text { MAOL) }\end{array}$ & $\begin{array}{l}\text { SEDIMENT } \\
\text { DISCARGE } \\
\text { (TOHS/DAY) }\end{array}$ \\
\hline $\begin{array}{l}1 \\
2 \\
3 \\
4 \\
5\end{array}$ & $\begin{array}{l}.39 \\
: 38 \\
: 38 \\
.37 \\
.33\end{array}$ & $\begin{array}{l}11 \\
11 \\
11 \\
11 \\
11\end{array}$ & $\begin{array}{l}.01 \\
.01 \\
.01 \\
.01 \\
.01\end{array}$ & $\begin{array}{l}.36 \\
: 33 \\
: 29 \\
.23 \\
.15\end{array}$ & $\begin{array}{l}20 \\
20 \\
15 \\
12 \\
12\end{array}$ & $\begin{array}{l}.02 \\
.02 \\
.01 \\
.01 \\
0\end{array}$ & $\begin{array}{c}: 11 \\
: 10 \\
: 09 \\
4: 0 \\
4.0\end{array}$ & $\begin{array}{l}15 \\
15 \\
15 \\
35 \\
34\end{array}$ & $\begin{array}{l}0 \\
0 \\
0 \\
.38 \\
.37\end{array}$ \\
\hline $\begin{array}{r}6 \\
7 \\
8 \\
9 \\
10\end{array}$ & $\begin{array}{l}.30 \\
: 27 \\
.26 \\
.26 \\
.28\end{array}$ & $\begin{array}{l}11 \\
11 \\
11 \\
11 \\
10\end{array}$ & $\begin{array}{l}.01 \\
.01 \\
.01 \\
.01 \\
.01\end{array}$ & $\begin{array}{l}.09 \\
.05 \\
.03 \\
.01\end{array}$ & $\begin{array}{l}11 \\
11 \\
11 \\
10 \\
0\end{array}$ & $\begin{array}{l}0 \\
0 \\
0 \\
0 \\
0\end{array}$ & $\begin{array}{r}3.1 \\
2.5 \\
2.5 \\
2.3 \\
98\end{array}$ & $\begin{array}{l}35 \\
35 \\
35 \\
35 \\
97\end{array}$ & $\begin{array}{r}: 29 \\
: 24 \\
: 24 \\
51^{.22}\end{array}$ \\
\hline $\begin{array}{l}11 \\
12 \\
13 \\
14 \\
15\end{array}$ & $\begin{array}{l}.13 \\
.05 \\
.02 \\
.01\end{array}$ & $\begin{array}{r}10 \\
10 \\
8 \\
5 \\
0\end{array}$ & $\begin{array}{l}0 \\
0 \\
0 \\
0 \\
0\end{array}$ & $\begin{array}{l}0 \\
0 \\
0 \\
0 \\
0 \\
0\end{array}$ & $\begin{array}{l}0 \\
0 \\
0 \\
0 \\
0\end{array}$ & $\begin{array}{l}0 \\
0 \\
0 \\
0 \\
0\end{array}$ & $\begin{array}{r}109 \\
24 \\
14 \\
8.8 \\
6.0\end{array}$ & $\begin{array}{l}75 \\
42 \\
27 \\
20 \\
16\end{array}$ & $\begin{array}{c}26 \\
2.7 \\
1.0 \\
.48 \\
.26\end{array}$ \\
\hline $\begin{array}{l}16 \\
17 \\
18 \\
19 \\
20\end{array}$ & $\begin{array}{l}0 \\
0 \\
0 \\
0 \\
0\end{array}$ & $\begin{array}{l}0 \\
0 \\
0 \\
0 \\
0\end{array}$ & $\begin{array}{l}0 \\
0 \\
0 \\
0 \\
0\end{array}$ & $\begin{array}{l}0 \\
0 \\
0 \\
0 \\
0\end{array}$ & $\begin{array}{l}0 \\
0 \\
0 \\
0 \\
0\end{array}$ & $\begin{array}{l}0 \\
0 \\
0 \\
0 \\
0\end{array}$ & $\begin{array}{l}4.5 \\
3.5 \\
5.2 \\
5.2 \\
4.2\end{array}$ & $\begin{array}{l}14 \\
13 \\
14 \\
14 \\
13\end{array}$ & $\begin{array}{l}.17 \\
.12 \\
.20 \\
.20 \\
.15\end{array}$ \\
\hline $\begin{array}{l}21 \\
22 \\
23 \\
24 \\
25\end{array}$ & $\begin{array}{l}0 \\
0 \\
.01 \\
: 03 \\
.04\end{array}$ & $\begin{array}{l}0 \\
0 \\
5 \\
8 \\
8\end{array}$ & $\begin{array}{l}0 \\
0 \\
0 \\
0 \\
0\end{array}$ & $\begin{array}{l}.38 \\
.49 \\
.45 \\
.37 \\
.18\end{array}$ & $\begin{array}{l}20 \\
30 \\
34 \\
25 \\
12\end{array}$ & $\begin{array}{l}.02 \\
.04 \\
.04 \\
.02 \\
.01\end{array}$ & $\begin{array}{l}3.6 \\
3.1 \\
2.7 \\
2.5 \\
2.4\end{array}$ & $\begin{array}{c}12 \\
11 \\
10 \\
9 \\
9\end{array}$ & $\begin{array}{l}.12 \\
.09 \\
.07 \\
.06 \\
.06\end{array}$ \\
\hline $\begin{array}{l}26 \\
27 \\
28 \\
29 \\
30 \\
31\end{array}$ & $\begin{array}{l}.06 \\
.09 \\
.16 \\
.36 \\
.44 \\
.41\end{array}$ & $\begin{array}{r}8 \\
8 \\
8 \\
10 \\
15 \\
20\end{array}$ & $\begin{array}{l}0 \\
0 \\
0 \\
.01 \\
.02 \\
.02\end{array}$ & $\begin{array}{l}.11 \\
.22 \\
.20 \\
.20 \\
.16 \\
.15\end{array}$ & $\begin{array}{l}10 \\
11 \\
15 \\
20 \\
30 \\
20\end{array}$ & $\begin{array}{l}0 \\
.01 \\
.01 \\
.01 \\
.01 \\
.01\end{array}$ & $\begin{array}{l}2.5 \\
2.6 \\
2.5 \\
2.3 \\
2.0 \\
0.0\end{array}$ & $\begin{array}{r}9 \\
9 \\
9 \\
9 \\
9 \\
-0-\end{array}$ & $\begin{array}{l}.06 \\
.06 \\
.06 \\
.06 \\
.05 \\
.00\end{array}$ \\
\hline TOTAL & 5.03 & -- & .15 & 4.45 & $\cdots$ & .24 & 327.30 & $=-$ & 84.71 \\
\hline YEAR & 3655.03 & & 1611.42 & & & & & & \\
\hline
\end{tabular}


PARTICLE-SIZE DISTRIBUTION OF SUSPENDED SEDIMENT, HATER YEAR OCTOBER 1975 TO SEPTEMBER 1976

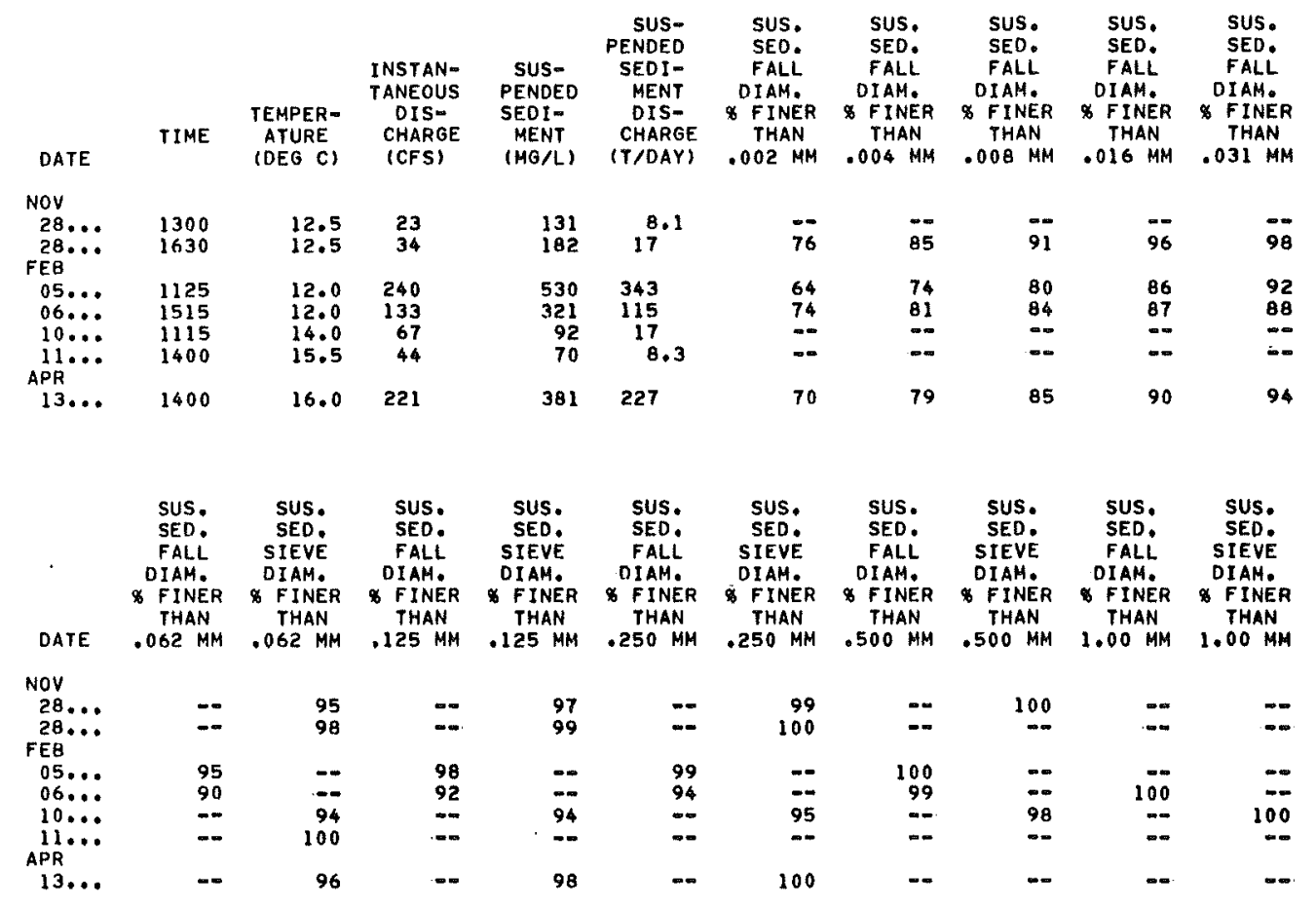


11023330 LOS PENASQUITOS CREEK BELOW POWAY CREEK, NEAR POWAY, CA

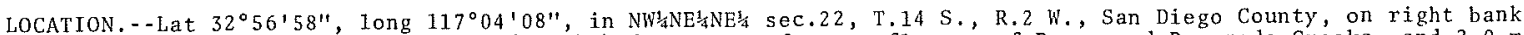
at Cobble $(3.2 \mathrm{~km})$ southwest of Poway.

DRAINAGE AREA. - - -31.2 $\mathrm{mi}^{2}\left(80.8 \mathrm{~km}^{2}\right)$.

PERIOD OF RECORD, --October 1970 to current year.

GAGE. - Water-stage recorder and rain-gage attachment. A1titude of gage is $415 \mathrm{ft}$ ( $126 \mathrm{~m}$ ), from topographic map. REMARKS.--Records fair. Flow partly regulated by small conservation reservoirs.

AVERAGE DISCHARGE, - -6 years, $1.67 \mathrm{ft}^{3} / \mathrm{s}\left(0.047 \mathrm{~m}^{3} / \mathrm{s}\right), 1,210 \mathrm{acre}-\mathrm{ft} / \mathrm{yr}^{2}\left(1.49 \mathrm{hm}^{3} / \mathrm{yr}^{\mathrm{r}}\right)$.

EXTREMES FOR PERIOD OF RECORD.--Maximum discharge, $651 \mathrm{ft}^{3} / \mathrm{s}\left(18.4 \mathrm{~m}^{3} / \mathrm{s}\right)$ Apr. 8,1975 , gage height, $7.50 \mathrm{ft}$

$(2.286 \mathrm{~m})$; no flow for parts of some years.

EXTREMES FOR CURRENT YEAR.--Maximum discharge, $453 \mathrm{ft}^{3} / \mathrm{s}\left(12.8 \mathrm{~m}^{3} / \mathrm{s}\right)$ Feb, 8 , gage height, $7.23 \mathrm{ft}(2.204 \mathrm{~m})$; maximum gage height, $7.25 \mathrm{ft}(2.210 \mathrm{~m})$ Feb. 6, due to backwater from Beeler Creek (station 11023325$)$;

minimum daily, $0.02 \mathrm{ft} / \mathrm{s}\left(0.00 \mathrm{i}^{3} / \mathrm{s}\right)$ Oct. 1 to Nov. 12 .

DISCHARGE, IN CUBIC FEET PER SECOND, WATER YEAR OCTOBER 1975 TO SEPTEMBER 1976 MEAN VALUES

\begin{tabular}{|c|c|c|c|c|c|c|c|c|c|c|c|c|}
\hline DAY & OCT & NOV & DEC & JAN & $F E B$ & MAR & APR & MAY & JUN & JUL & AUG & SEP \\
\hline $\begin{array}{l}1 \\
2 \\
3 \\
4 \\
5\end{array}$ & $\begin{array}{l}.02 \\
.02 \\
.02 \\
.02 \\
.02\end{array}$ & $\begin{array}{l}.02 \\
.02 \\
.02 \\
.02 \\
.02\end{array}$ & $\begin{array}{l}.17 \\
.15 \\
.17 \\
.13 \\
.13\end{array}$ & $\begin{array}{l}.32 \\
.24 \\
.24 \\
.24 \\
.24\end{array}$ & $\begin{array}{r}.13 \\
.13 \\
.33 \\
7.3 \\
24\end{array}$ & $\begin{array}{c}30 \\
7.9 \\
107 \\
19 \\
10\end{array}$ & $\begin{array}{l}.69 \\
.69 \\
.70 \\
6.9 \\
2.5\end{array}$ & $\begin{array}{r}.41 \\
.40 \\
.37 \\
.39 \\
.33\end{array}$ & $\begin{array}{r}.14 \\
.13 \\
.13 \\
.10 \\
.09\end{array}$ & $\begin{array}{l}.03 \\
.03 \\
.03 \\
.04 \\
.04\end{array}$ & $\begin{array}{l}.03 \\
.03 \\
.03 \\
.03 \\
.03\end{array}$ & $\begin{array}{r}.03 \\
.03 \\
1.4 \\
.87 \\
.04\end{array}$ \\
\hline $\begin{array}{r}6 \\
7 \\
8 \\
9 \\
10\end{array}$ & $\begin{array}{l}.02 \\
.02 \\
.02 \\
.02 \\
.02\end{array}$ & $\begin{array}{l}.02 \\
.02 \\
.02 \\
.02 \\
.02\end{array}$ & $\begin{array}{l}.13 \\
.13 \\
.13 \\
.24 \\
.16\end{array}$ & $\begin{array}{l}.24 \\
.24 \\
.26 \\
.26 \\
.26\end{array}$ & $\begin{array}{r}53 \\
21 \\
115 \\
82 \\
24\end{array}$ & $\begin{array}{l}7.0 \\
5.0 \\
3.5 \\
3.0 \\
2.5\end{array}$ & $\begin{array}{l}.98 \\
.76 \\
1.1 \\
2.0 \\
3.0\end{array}$ & $\begin{array}{r}.66 \\
.57 \\
.32 \\
.30 \\
.28\end{array}$ & $\begin{array}{l}.09 \\
.10 \\
.19 \\
.16 \\
.13\end{array}$ & $\begin{array}{l}.03 \\
.03 \\
.03 \\
.03 \\
.03\end{array}$ & $\begin{array}{l}.03 \\
.03 \\
.03 \\
.03 \\
.03\end{array}$ & $\begin{array}{r}.04 \\
.10 \\
.05 \\
18\end{array}$ \\
\hline $\begin{array}{l}11 \\
12 \\
13 \\
14 \\
15\end{array}$ & $\begin{array}{l}.02 \\
.02 \\
.02 \\
.02 \\
.02\end{array}$ & $\begin{array}{l}.02 \\
.02 \\
.05 \\
.04 \\
.03\end{array}$ & $\begin{array}{l}.17 \\
4.8 \\
2.0 \\
.60 \\
.32\end{array}$ & $\begin{array}{l}.24 \\
.24 \\
.24 \\
.23 \\
.23\end{array}$ & $\begin{array}{l}10 \\
5.7 \\
3.5 \\
2.4 \\
2.0\end{array}$ & $\begin{array}{l}2.0 \\
1.8 \\
1.5 \\
1.4 \\
1.3\end{array}$ & $\begin{array}{l}3.0 \\
3.5 \\
45 \\
4.9 \\
12\end{array}$ & $\begin{array}{l}.24 \\
.21 \\
.22 \\
.18 \\
.20\end{array}$ & $\begin{array}{l}.11 \\
.08 \\
.08 \\
.09 \\
.06\end{array}$ & $\begin{array}{l}.03 \\
.03 \\
.03 \\
.03 \\
.03\end{array}$ & $\begin{array}{r}.03 \\
.03 \\
.03 \\
.03 \\
.03\end{array}$ & $\begin{array}{r}9.4 \\
.39 \\
.28 \\
.21 \\
.18\end{array}$ \\
\hline $\begin{array}{l}16 \\
17 \\
18 \\
19 \\
20\end{array}$ & $\begin{array}{l}.02 \\
.02 \\
.02 \\
.02 \\
.02\end{array}$ & $\begin{array}{l}.03 \\
.03 \\
.03 \\
.03 \\
.03\end{array}$ & $\begin{array}{r}.32 \\
.30 \\
.34 \\
.30 \\
.55\end{array}$ & $\begin{array}{l}.23 \\
.21 \\
.21 \\
.21 \\
.21\end{array}$ & $\begin{array}{l}1.7 \\
1.5 \\
1.4 \\
1.3 \\
1.2\end{array}$ & $\begin{array}{l}1.3 \\
1.2 \\
1.1 \\
.97 \\
.93\end{array}$ & $\begin{array}{l}6.4 \\
1.6 \\
1.3 \\
1.3 \\
2.0\end{array}$ & $\begin{array}{r}.17 \\
.17 \\
.21 \\
.18 \\
.17\end{array}$ & $\begin{array}{l}.06 \\
.06 \\
.05 \\
.04 \\
.05\end{array}$ & $\begin{array}{l}.04 \\
.03 \\
.04 \\
.03 \\
.03\end{array}$ & $\begin{array}{r}.03 \\
.03 \\
.03 \\
.03 \\
.03\end{array}$ & $\begin{array}{l}.12 \\
.10 \\
.07 \\
.06 \\
.05\end{array}$ \\
\hline $\begin{array}{l}21 \\
22 \\
23 \\
24 \\
25\end{array}$ & $\begin{array}{l}.02 \\
.02 \\
.02 \\
.02 \\
.02\end{array}$ & $\begin{array}{l}.05 \\
.03 \\
.03 \\
.03 \\
.03\end{array}$ & $\begin{array}{l}.44 \\
.28 \\
.44 \\
.34 \\
.32\end{array}$ & $\begin{array}{r}.18 \\
.18 \\
.18 \\
.28 \\
.23\end{array}$ & $\begin{array}{l}.96 \\
.82 \\
.82 \\
.79 \\
.79\end{array}$ & $\begin{array}{l}.90 \\
.84 \\
.77 \\
.95 \\
.74\end{array}$ & $\begin{array}{l}2.0 \\
2.4 \\
3.3 \\
3.0 \\
2.9\end{array}$ & $\begin{array}{l}.15 \\
.15 \\
.15 \\
.15 \\
.15\end{array}$ & $\begin{array}{r}.04 \\
.96 \\
.04 \\
.03 \\
.03\end{array}$ & $\begin{array}{l}.03 \\
.03 \\
.03 \\
.03 \\
.03\end{array}$ & $\begin{array}{l}.03 \\
.03 \\
.03 \\
.03 \\
.03\end{array}$ & $\begin{array}{l}.04 \\
.04 \\
.04 \\
.04 \\
.04\end{array}$ \\
\hline $\begin{array}{l}26 \\
27 \\
28 \\
29 \\
30 \\
31\end{array}$ & $\begin{array}{l}.02 \\
.02 \\
.02 \\
.02 \\
.02 \\
.02\end{array}$ & $\begin{array}{c}.03 \\
6.6 \\
14 \\
3.6 \\
.27 \\
-.-0\end{array}$ & $\begin{array}{l}.30 \\
.28 \\
.28 \\
.26 \\
.24 \\
.58\end{array}$ & $\begin{array}{l}.17 \\
.16 \\
.16 \\
.14 \\
.13 \\
.13\end{array}$ & $\begin{array}{l}.80 \\
.74 \\
.74 \\
.80 \\
-.- \\
-.-\end{array}$ & $\begin{array}{l}.73 \\
.66 \\
.66 \\
.64 \\
.61 \\
.61\end{array}$ & $\begin{array}{l}2.2 \\
1.5 \\
1.5 \\
.46 \\
.47 \\
-.-\end{array}$ & $\begin{array}{l}.15 \\
.15 \\
.15 \\
.15 \\
.15 \\
.15\end{array}$ & $\begin{array}{l}.03 \\
.03 \\
.03 \\
.03 \\
.03 \\
0 .-\end{array}$ & $\begin{array}{l}.03 \\
.03 \\
.03 \\
.03 \\
.03 \\
.03\end{array}$ & $\begin{array}{l}.03 \\
.03 \\
.03 \\
.03 \\
.27 \\
.03\end{array}$ & $\begin{array}{r}.04 \\
.04 \\
.04 \\
.04 \\
.04 \\
.0 .\end{array}$ \\
\hline $\begin{array}{l}\text { TOTAL } \\
\text { MEAN } \\
\text { MAX } \\
\text { MIN } \\
\text { AC-FT }\end{array}$ & $\begin{array}{r}.62 \\
.020 \\
.02 \\
.02 \\
1.2\end{array}$ & $\begin{array}{r}25.18 \\
.84 \\
14 \\
.02 \\
50\end{array}$ & $\begin{array}{r}15.00 \\
.48 \\
4.8 \\
.13 \\
30\end{array}$ & $\begin{array}{r}6.73 \\
.22 \\
.32 \\
.13 \\
13\end{array}$ & $\begin{array}{r}364.85 \\
12.6 \\
115 \\
.13 \\
724\end{array}$ & $\begin{array}{r}216.51 \\
6.98 \\
107 \\
.61 \\
429\end{array}$ & $\begin{array}{r}120.05 \\
4.00 \\
45 \\
.46 \\
238\end{array}$ & $\begin{array}{r}7.63 \\
.25 \\
.66 \\
.15 \\
15\end{array}$ & $\begin{array}{r}3.19 \\
.11 \\
.96 \\
.03 \\
6.3\end{array}$ & $\begin{array}{r}.97 \\
.031 \\
.04 \\
.03 \\
1.9\end{array}$ & $\begin{array}{r}1.17 \\
.038 \\
.27 \\
.03 \\
2.3\end{array}$ & $\begin{array}{r}31.86 \\
1.06 \\
18 \\
.03 \\
63\end{array}$ \\
\hline (a) & .03 & 1.23 & .46 & .02 & 5.55 & 2.06 & 2.18 & .09 & 0 & .01 & 0 & 1.66 \\
\hline
\end{tabular}

CAL YR 1975 TOTAL 1057.83 MEAN 2.90 MAX 239 MIN .01 AC-FT 2100 WTR YR 1976 TOTAL 793.76 MEAN 2.17 MAX 115 MIN .02 AC-FT 1570

a Precipitation, in inches. 
LOCATION. - Lat $32^{\circ} 56^{\circ} 35^{\prime \prime}$, long $117^{\circ} 07^{\prime} 15^{\prime \prime}$, in Los Penasquitos Grant, San Diego County, on 1 eft bank 1.0 mi

$(1.6 \mathrm{~km})$ downstream from Cypress Creek, and $5.5 \mathrm{mi}(8.8 \mathrm{~km})$ southwest of Poway.

DRAINAGE AREA. $--42,1 \mathrm{mi}^{2}\left(109 \mathrm{~km}^{2}\right)$.

PERIOD OF RECORD. - -October 1964 to current year.

GAGE. - Water-stage recorder and crest-stage gage. A1titude of gage is $260 \mathrm{ft}$ (79.2 m), from topographic map.

REMARKS. -Records poor. No gage-height record Nov. 3 to Dec. 1 , Apr. 7 to July 9 , and Sept. 10-27. F1ow

partly regulated by several conservation reservoirs above station. Pumping from we1ls along stream for

irrigation. Flow augmented by reclaimed water from Poway area.

AVERAGE DISCHARGE. - -12 years, $3.67 \mathrm{ft}^{3} / \mathrm{s}\left(0.104 \mathrm{~m}^{3} / \mathrm{s}\right), 2,660$ acre- $\mathrm{ft} / \mathrm{yr}\left(3.28 \mathrm{~m}^{3} / \mathrm{yr}^{2}\right)$.

EXTREMES FOR PERIOD OF RECORD.--Maximum discharge, $2,100 \mathrm{ft}^{3} / \mathrm{s}\left(59.5 \mathrm{~m}^{3} / \mathrm{s}\right) \mathrm{Dec}$. 6, 1966 , gage height, $6.90 \mathrm{ft}$

$(2.103 \mathrm{~m})$ in gage wel1, $7.70 \mathrm{ft}(2.35 \mathrm{~m})$, from profile of floodmarks, from rating curve extended above

$400 \mathrm{ft}^{3} / \mathrm{s}\left(11.3 \mathrm{~m}^{3} / \mathrm{s}\right)$ on basis of slope-area measurement at gage height $6.23 \mathrm{ft}$ (1.90 m) in gage wel1.

$7.40 \mathrm{ft}(2.26 \mathrm{~m})$, from outside gage; no flow May 16, 17, 1968, July 1, 1972.

EXTREMES FOR CURRENT YEAR, --Peak discharges above base of $60 \mathrm{ft}^{3} / \mathrm{s}\left(1.70 \mathrm{~m}^{3} / \mathrm{s}\right)$ and maximum $\left({ }^{*}\right)$ :

\begin{tabular}{|c|c|c|c|c|c|c|c|c|c|}
\hline Date & Time & $\begin{array}{c}\text { Discharge } \\
\left(\mathrm{ft}^{3} / \mathrm{s}\right)\left(\mathrm{m}^{3} / \mathrm{s}\right)\end{array}$ & $\begin{array}{l}\text { Gage height } \\
\text { (ft) }\end{array}$ & Date & Time & $\begin{array}{r}D i s \\
\left(f t^{3} / s\right.\end{array}$ & $\left(\mathrm{m}^{3} / \mathrm{s}\right)$ & $\begin{array}{l}\text { Gage } \\
(\mathrm{ft})\end{array}$ & $\underset{\text { (m) }}{\operatorname{he}}$ \\
\hline $\begin{array}{l}\text { Feb. } 6 \\
\text { Feb. } 8\end{array}$ & $\begin{array}{l}\text { Unknown } \\
\text { Unknown }\end{array}$ & $\begin{array}{r}8.75 \\
16.3\end{array}$ & $\begin{array}{l}1.268 \\
1.545\end{array}$ & Mar. 3 & 0515 & 372 & 10.5 & 4.40 & 1.34 \\
\hline
\end{tabular}

Minimum daily discharge, $0.02 \mathrm{ft}^{3} / \mathrm{s}\left(0.001 \mathrm{~m}^{3} / \mathrm{s}\right)$ 0ct. $1-6$.

DISCHARGE, IN CUBIC FEET PER SECOND, WATER YEAR OCTOBER 1975 TO SEPTEMBER 1976 MEAN VALUES

\begin{tabular}{|c|c|c|c|c|c|c|c|c|c|c|c|c|}
\hline DAY & OCT & NoV & DEC & JAN & FEB & MAR & APR & MAY & JUN & JUL & AUG & SEP \\
\hline $\begin{array}{l}1 \\
2 \\
3 \\
4 \\
5\end{array}$ & $\begin{array}{l}.02 \\
.02 \\
.02 \\
.02 \\
.02\end{array}$ & $\begin{array}{l}.04 \\
.04 \\
.04 \\
.04 \\
.04\end{array}$ & $\begin{array}{l}.50 \\
.41 \\
.33 \\
.29 \\
.25\end{array}$ & $\begin{array}{l}.25 \\
.25 \\
.24 \\
.24 \\
.23\end{array}$ & $\begin{array}{c}.22 \\
.22 \\
.29 \\
2.1 \\
35\end{array}$ & $\begin{array}{r}18 \\
10 \\
110 \\
47 \\
21\end{array}$ & $\begin{array}{l}.76 \\
.76 \\
.63 \\
1.8 \\
4.1\end{array}$ & $\begin{array}{l}.50 \\
.50 \\
.45 \\
.45 \\
.45\end{array}$ & $\begin{array}{r}.20 \\
.20 \\
.20 \\
.20 \\
.20\end{array}$ & $\begin{array}{l}.07 \\
.07 \\
.06 \\
.06 \\
.05\end{array}$ & $\begin{array}{l}.03 \\
.03 \\
.03 \\
.04 \\
.04\end{array}$ & $\begin{array}{l}.04 \\
.04 \\
.05 \\
.05 \\
.05\end{array}$ \\
\hline $\begin{array}{r}6 \\
7 \\
8 \\
9 \\
10\end{array}$ & $\begin{array}{l}.02 \\
.03 \\
.03 \\
.03 \\
.03\end{array}$ & $\begin{array}{l}.04 \\
.04 \\
.04 \\
.04 \\
.04\end{array}$ & $\begin{array}{l}.23 \\
.22 \\
.21 \\
.20 \\
.22\end{array}$ & $\begin{array}{l}.23 \\
.23 \\
.23 \\
.23 \\
.23\end{array}$ & $\begin{array}{r}84 \\
30 \\
150 \\
95 \\
60\end{array}$ & $\begin{array}{r}11 \\
7.3 \\
5.5 \\
4.7 \\
4.3\end{array}$ & $\begin{array}{l}1.4 \\
1.7 \\
2.5 \\
3.5 \\
4.0\end{array}$ & $\begin{array}{l}.80 \\
.60 \\
.50 \\
.40 \\
.35\end{array}$ & $\begin{array}{l}.20 \\
.22 \\
.25 \\
.23 \\
.22\end{array}$ & $\begin{array}{r}.05 \\
.05 \\
.05 \\
.04 \\
.04\end{array}$ & $\begin{array}{r}.04 \\
.04 \\
.04 \\
.04 \\
.04\end{array}$ & $\begin{array}{r}.05 \\
.04 \\
.05 \\
.05\end{array}$ \\
\hline $\begin{array}{l}11 \\
12 \\
13 \\
14 \\
15\end{array}$ & $\begin{array}{l}.03 \\
.03 \\
.03 \\
.03 \\
.03\end{array}$ & $\begin{array}{l}.04 \\
.04 \\
.04 \\
.04 \\
.04\end{array}$ & $\begin{array}{l}.28 \\
1.0 \\
5.9 \\
1.7 \\
.86\end{array}$ & $\begin{array}{l}.23 \\
.23 \\
.23 \\
.23 \\
.23\end{array}$ & $\begin{array}{c}29 \\
14 \\
9.9 \\
7.8 \\
6.7\end{array}$ & $\begin{array}{l}3.6 \\
3.1 \\
2.6 \\
2.2 \\
1.9\end{array}$ & $\begin{array}{c}4.5 \\
5.0 \\
58 \\
6.6 \\
15\end{array}$ & $\begin{array}{r}.30 \\
.28 \\
.27 \\
.26 \\
.25\end{array}$ & $\begin{array}{l}.22 \\
.20 \\
.20 \\
.15 \\
.10\end{array}$ & $\begin{array}{l}.04 \\
.04 \\
.04 \\
.04 \\
.04\end{array}$ & $\begin{array}{l}.04 \\
.04 \\
.04 \\
.04 \\
.04\end{array}$ & $\begin{array}{l}13 \\
4.0 \\
1.0 \\
.50 \\
.45\end{array}$ \\
\hline $\begin{array}{l}16 \\
17 \\
18 \\
19 \\
20\end{array}$ & $\begin{array}{l}.03 \\
.03 \\
.03 \\
.03 \\
.03\end{array}$ & $\begin{array}{l}.04 \\
.04 \\
.04 \\
.04 \\
.04\end{array}$ & $\begin{array}{l}.50 \\
.29 \\
.26 \\
.24 \\
.22\end{array}$ & $\begin{array}{l}.23 \\
.23 \\
.22 \\
.22 \\
.20\end{array}$ & $\begin{array}{l}5.9 \\
4.9 \\
4.3 \\
4.3 \\
4.0\end{array}$ & $\begin{array}{l}1.6 \\
1.4 \\
1.2 \\
1.2 \\
1.2\end{array}$ & $\begin{array}{l}9.0 \\
3.0 \\
2.5 \\
2.5 \\
2.5\end{array}$ & $\begin{array}{l}.25 \\
.24 \\
.24 \\
.23 \\
.23\end{array}$ & $\begin{array}{r}.10 \\
.10 \\
.10 \\
.10 \\
.10\end{array}$ & $\begin{array}{l}.05 \\
.05 \\
.05 \\
.04 \\
.07\end{array}$ & $\begin{array}{l}.04 \\
.04 \\
.04 \\
.04 \\
.04\end{array}$ & $\begin{array}{l}.40 \\
.40 \\
.40 \\
.40 \\
.40\end{array}$ \\
\hline $\begin{array}{l}21 \\
22 \\
23 \\
24 \\
25\end{array}$ & $\begin{array}{l}.04 \\
.04 \\
.04 \\
.03 \\
.03\end{array}$ & $\begin{array}{l}.04 \\
.04 \\
.04 \\
.04 \\
.04\end{array}$ & $\begin{array}{r}.33 \\
.47 \\
.39 \\
.35 \\
.32\end{array}$ & $\begin{array}{l}.23 \\
.23 \\
.22 \\
.22 \\
.22\end{array}$ & $\begin{array}{l}3.9 \\
3.7 \\
3.5 \\
3.4 \\
2.7\end{array}$ & $\begin{array}{l}1.1 \\
1.0 \\
1.0 \\
1.1 \\
1.2\end{array}$ & $\begin{array}{l}3.0 \\
4.0 \\
5.0 \\
4.0 \\
3.5\end{array}$ & $\begin{array}{l}.22 \\
.22 \\
.21 \\
.21 \\
.21\end{array}$ & $\begin{array}{l}.09 \\
.09 \\
.08 \\
.08 \\
.08\end{array}$ & $\begin{array}{l}.04 \\
.05 \\
.05 \\
.04 \\
.04\end{array}$ & $\begin{array}{l}.04 \\
.04 \\
.04 \\
.04 \\
.05\end{array}$ & $\begin{array}{r}.40 \\
.40 \\
.40 \\
.40 \\
.35\end{array}$ \\
\hline $\begin{array}{l}26 \\
27 \\
28 \\
29 \\
30 \\
31\end{array}$ & $\begin{array}{l}.03 \\
.03 \\
.04 \\
.03 \\
.04 \\
.04\end{array}$ & $\begin{array}{c}9.04 \\
18 \\
6.0 \\
1.5 \\
=-\infty\end{array}$ & $\begin{array}{l}.31 \\
.30 \\
.28 \\
.27 \\
.26 \\
.26\end{array}$ & $\begin{array}{l}.22 \\
.22 \\
.22 \\
.22 \\
.22 \\
.22\end{array}$ & $\begin{array}{l}2.3 \\
2.3 \\
2.1 \\
2.0 \\
-0 . \\
-\infty\end{array}$ & $\begin{array}{l}.90 \\
.86 \\
.86 \\
.82 \\
.83 \\
.77\end{array}$ & $\begin{array}{l}2.5 \\
1.5 \\
1.0 \\
.60 \\
.55 \\
.-\infty\end{array}$ & $\begin{array}{l}.20 \\
.20 \\
.20 \\
.20 \\
.20 \\
.20\end{array}$ & $\begin{array}{l}.08 \\
.07 \\
.07 \\
.07 \\
.07 \\
.00\end{array}$ & $\begin{array}{l}.04 \\
.05 \\
.05 \\
.04 \\
.04 \\
.04\end{array}$ & $\begin{array}{l}.04 \\
.04 \\
.04 \\
.04 \\
.04 \\
.04\end{array}$ & $\begin{array}{r}.35 \\
.35 \\
.35 \\
.35 \\
.35 \\
-3-\end{array}$ \\
\hline $\begin{array}{l}\text { TOTAL } \\
\text { MEAN } \\
\text { MAX } \\
\text { MIN } \\
\text { AC-FT }\end{array}$ & $\begin{array}{r}.93 \\
.030 \\
.04 \\
.02 \\
1.8\end{array}$ & $\begin{array}{r}35.54 \\
1.18 \\
18 \\
.04 \\
70\end{array}$ & $\begin{array}{r}17.65 \\
.57 \\
5.9 \\
.20 \\
35\end{array}$ & $\begin{array}{r}7.05 \\
.23 \\
.25 \\
.20 \\
14\end{array}$ & $\begin{array}{r}573.53 \\
19.8 \\
150 \\
.22 \\
1140\end{array}$ & $\begin{array}{r}269.24 \\
8.69 \\
110 \\
.77 \\
534\end{array}$ & $\begin{array}{r}155.40 \\
5.18 \\
58 \\
.55 \\
308\end{array}$ & $\begin{array}{r}9.82 \\
.32 \\
.80 \\
.20 \\
19\end{array}$ & $\begin{array}{r}4.27 \\
.14 \\
.25 \\
.07 \\
8.5\end{array}$ & $\begin{array}{r}1.48 \\
.048 \\
.07 \\
.04 \\
2.9\end{array}$ & $\begin{array}{r}1.22 \\
.039 \\
.05 \\
.03 \\
2.4\end{array}$ & $\begin{array}{r}50.07 \\
1.67 \\
25 \\
.04 \\
99\end{array}$ \\
\hline
\end{tabular}

CAL YR 1975 TOTAL 1264.94 MEAN 3.47 MAX 300 MIN 02 AC-FT 2510 WTR YR 1976 TOTAL $1126.20 \quad$ HEAN 3.08 MAX 150 MIN $.02 \quad$ AC-FT 2230 
11025500 SANTA YSABEL CREEK NEAR RAMONA, CA

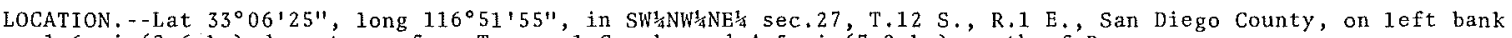
$1.6 \mathrm{mi}(2.6 \mathrm{~km})$ downstream from Temesca1 Creek, and $4.5 \mathrm{mi}(7.2 \mathrm{~km})$ north of Ramona.

DRAINAGE AREA. $-112 \mathrm{mi}^{2}\left(290 \mathrm{~km}^{2}\right)$.

PERIOD OF RECORD. - February 1912 to February 1923, October 1943 to current year. Month1y discharge on1y for February 1912, pub1ished in WSP $1315-B$.

GAGE, - Water-stage recorder and concrete cutoff wa11, repaired at times. Datum of gage is $847.88 \mathrm{ft}$ ( $258.434 \mathrm{~m}$ ) above mean sea level (levels by city of San Diego Water Departinent). See WSP 1315-A for history of changes prior to Feb. 3, 1923.

REMARKS.--Records fair. Flow regulated by Sutherland Reservoir (see sta 11024000) since July 1954. Some small diversions above station.

EXTREMES FOR PERIOD OF RECORD.--Maximum discharge, $28,400 \mathrm{ft}^{3} / \mathrm{s}\left(804 \mathrm{~m}^{3} / \mathrm{s}\right) \mathrm{Jan}, 27,1916$, gage height, $14.0 \mathrm{ft}$ $(4.27 \mathrm{~m})$ datum then in use, from rating curve extended above $1,500 \mathrm{ft}^{3} / \mathrm{s}\left(42.5 \mathrm{~m}^{3} / \mathrm{s}\right)$ on basis of $\mathrm{s}^{\circ}$ opeconveyance computation of maximum flow; no flow at times in some years.

EXTREMES FOR CURRENT YEAR, - Maximum discharge, $107 \mathrm{ft}^{3} / \mathrm{s}\left(3.03 \mathrm{~m}^{3} / \mathrm{s}\right)$ Feb. 9 , gage height, $3.33 \mathrm{ft}(1.015 \mathrm{~m})$; no flow for many days.

DISCHARGE, IN CUBIC FEET PER SECOND, WATER YEAR OCTOBER 1975 TO SEPTEMBER 1976

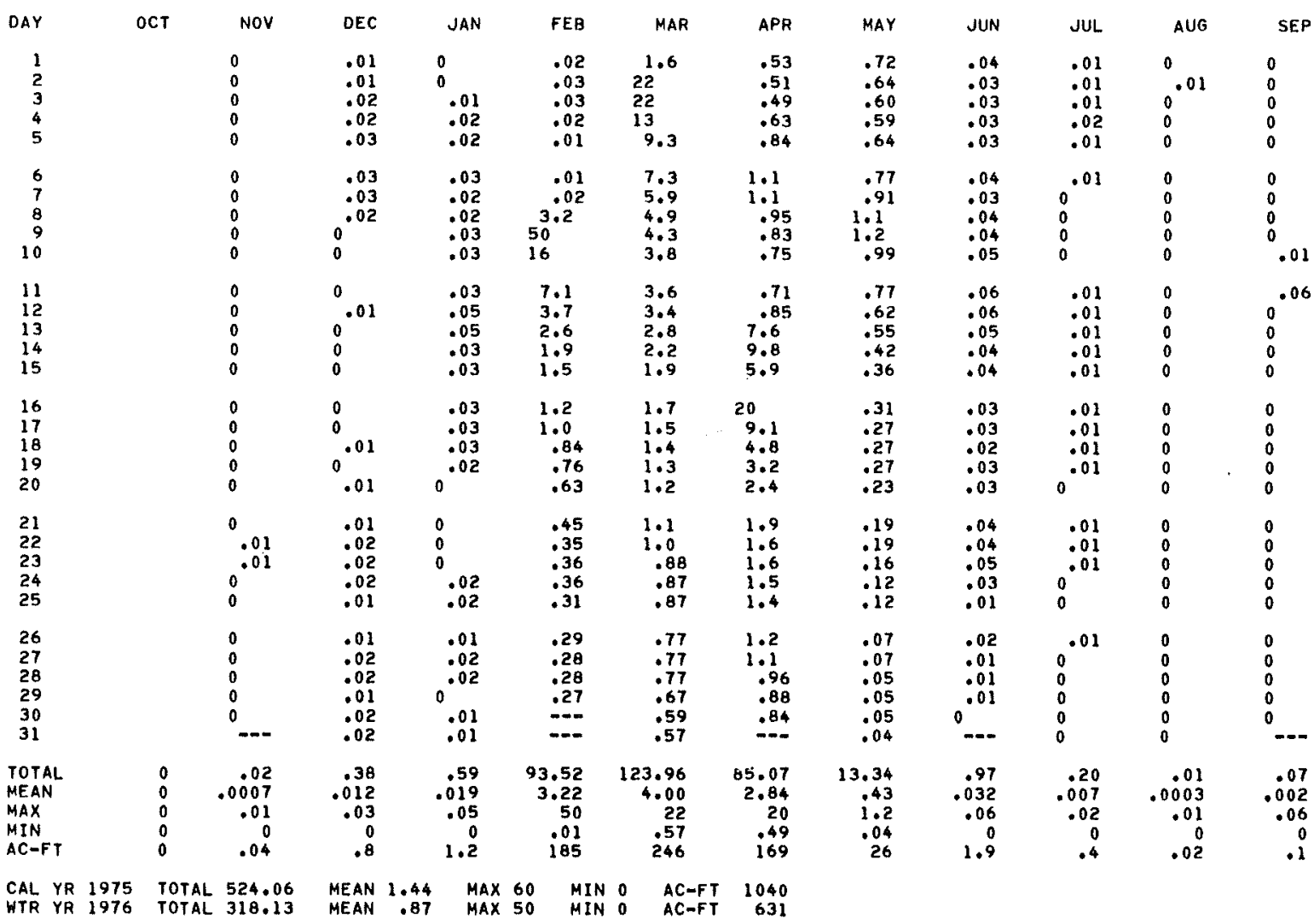


11026000 SANTA YSABEL CREEK NEAR SAN PASQUAL, CA

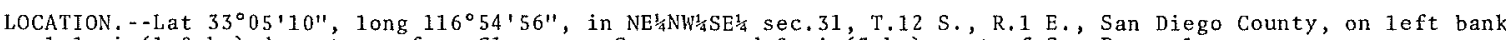
$1.1 \mathrm{mi}(1.8 \mathrm{~km})$ downstream from Clevenger Canyon, and $2 \mathrm{mi}$ ( $3 \mathrm{~km})$ east of San Pasqual.

DRAINAGE AREA. $--128 \mathrm{mi}^{2}\left(332 \mathrm{~km}^{2}\right)$.

PERIOD OF RECORD, - -December 1905 to September 1910 and May 1911 to September 1912 (published as "near Escondido") April 1947 to November 1955 (irrigation seasons only), Apri1 1956 to current year. Records for October to December 1910, published in WSP 447, have been found to be, in error and should not be used.

GAGE. - Water-stage recorder. Concrete control since April 1947. Altitude of gage is $510 \mathrm{ft}$ (155 m), from topo-

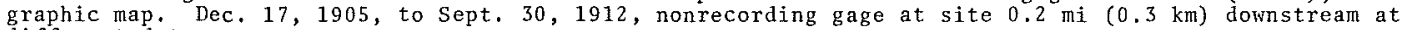
different datum.

REMARKS.--Records fair. Flow regulated by Sutherland Reservoir, $9.5 \mathrm{mi}$ (15.3 km) upstream, capacity, 29,680 acre-ft $\left(120 \mathrm{hm}^{3}\right)$ since Ju1y 1954 . Smal1 diversion above station.

EXTREMES FOR PERTOD OF RECORD.--Maximum discharge observed, $8,000 \mathrm{ft}^{3} / \mathrm{s}\left(227 \mathrm{~m}^{3} / \mathrm{s}\right) \mathrm{Mar}^{2} 24,1906$, gage height, $6.3 \mathrm{ft}(1.92 \mathrm{~m})$, site and datum then in use; no flow at times in most years.

EXTREMES FOR CURRENT YEAR. - Maximum discharge, $131 \mathrm{ft}^{3} / \mathrm{s}\left(3.71 \mathrm{~m}^{3} / \mathrm{s}\right) \mathrm{Feb} .9$, gage height, $2.71 \mathrm{ft}(0.826 \mathrm{~m}) ; \mathrm{no}$ flow Oct. 1 to Feb. 4, June 10 to Sept. 9, Sept. 16-30.

DISCHARGE, IN CUBIC FEET PER SECOND, WATER YEAR OCTOBER 1975 TO SEPTEMBER 1976 MEAN VALUES

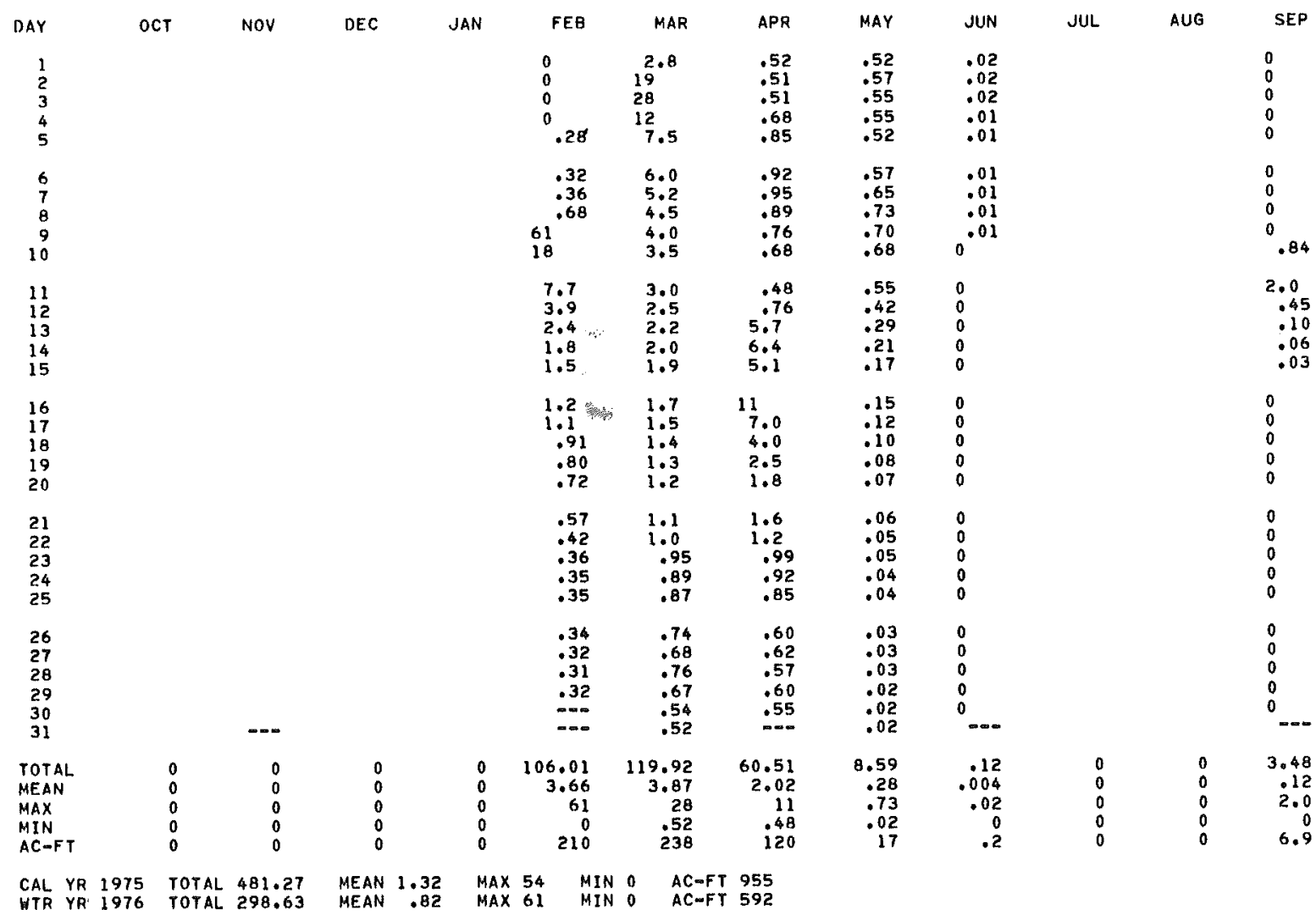


11027000 GUEJITO CREEK NEAR SAN PASQUAL, CA

LOCATION, - Lat $33^{\circ} 06^{\prime} 57^{\prime \prime}$, long $116^{\circ} 57^{\prime} 08^{\prime \prime}$, in NWhNW/sE $\frac{1}{4}$ sec. 23, T.12 S., R. 1 W. , San Diego County, on 1 eft bank $0.3 \mathrm{mi}(0.5 \mathrm{~km})$ upstream from Rockwood'Canyon Creek, and $1.8 \mathrm{mi}(2.9$ ' $\mathrm{km})$ north of $\mathrm{San}$ Pasqual.

DRAINAGE AREA. $-22.5 \mathrm{mi}^{2}\left(58.3 \mathrm{~km}^{2}\right)$.

PERIOD OF RECORD.--December 1946 to current year.

GAGE. - Water-stage recorder and Parshall flume. Altitude of gage is $560 \mathrm{ft}$ (171 m), from topographic map,

REMARKS. - Records fair. No regulation above station. Diversion for irrigation $0.2 \mathrm{mi}(0.3 \mathrm{~km}$ ) upstream.

AVERAGE DISCHARGE, - 29 years (water years $1948-76), 1.37 \mathrm{ft}^{3} / \mathrm{s}\left(0.039 \mathrm{~m}^{3} / \mathrm{s}\right), 993 \mathrm{acre}-\mathrm{ft} / \mathrm{yr}\left(1.22 \mathrm{hm}^{3} / \mathrm{yr}^{3}\right.$ )

EXTREMES FOR PERIOD OF RECORD. - Maximum discharge, $2,920 \mathrm{ft}^{3} / \mathrm{s}\left(82.7 \mathrm{~m}^{3} / \mathrm{s}\right)$ Dec. 6 , 1966 , gage height, $6.78 \mathrm{ft}$

$(2.067$ m) from rating curve extended above $440 \mathrm{ft} / \mathrm{s}(12.5 \mathrm{~m} / \mathrm{s})$ on basis of slope-area measurements at gage

heights $5.83 \mathrm{ft}(1.777 \mathrm{~m})$ and $6.30 \mathrm{ft}(1.920 \mathrm{~m}) ;$ no flow at times in most years.

EXTREMES FOR CURRENT YEAR. - Peak discharge above base of $30 \mathrm{ft} / \mathrm{s}\left(0.85 \mathrm{~m}^{3} / \mathrm{s}\right)$ and maximum $(*)$ :

\begin{tabular}{|c|c|c|c|}
\hline Date & Time & $\begin{array}{l}\text { Discharge } \\
\left(\mathrm{ft}^{3} / \mathrm{s}\right)\left(\mathrm{m}^{3} / \mathrm{s}\right)\end{array}$ & $\underset{(\mathrm{ft})}{\text { Gage height }}$ \\
\hline $\begin{array}{l}\text { Feb. } 9 \\
\text { Mar. } 3\end{array}$ & $\begin{array}{l}0230 \\
0530\end{array}$ & $\begin{array}{l}2.04 \\
1.08\end{array}$ & $\begin{array}{l}2.74 \\
2.45\end{array}$ \\
\hline
\end{tabular}

Minimum daily discharge, no flow many days.

DISCHARGE, IN CUBIC FEET PER SECOND, HATER YEAR OCTOBER 1975 TO SEPTEMBER 1976 MEAN VALUES

\begin{tabular}{|c|c|c|c|c|c|c|c|c|c|c|c|c|c|}
\hline DAY & $\mathrm{OCT}$ & NOV & DEC & & JAN & FEB & MAR & APR & MAY & JUN & JUL & AUG & SEP \\
\hline $\begin{array}{l}1 \\
2 \\
3 \\
4 \\
5\end{array}$ & $\begin{array}{l}0 \\
0 \\
.01 \\
.01 \\
0\end{array}$ & $\begin{array}{l}0 \\
0 \\
0 \\
0 \\
0\end{array}$ & $\begin{array}{l}.01 \\
.01 \\
.01 \\
.01 \\
.01\end{array}$ & & $\begin{array}{l}0 \\
0 \\
0 \\
0 \\
.01\end{array}$ & $\begin{array}{c}.01 \\
.01 \\
.01 \\
.02 \\
1.1\end{array}$ & $\begin{array}{c}5.5 \\
6.7 \\
14 \\
4.3 \\
2.4\end{array}$ & $\begin{array}{l}.14 \\
.13 \\
.14 \\
.20 \\
.41\end{array}$ & $\begin{array}{l}.13 \\
.12 \\
.11 \\
.12 \\
.12\end{array}$ & $\begin{array}{l}.07 \\
.05 \\
.04 \\
.04 \\
.04\end{array}$ & $\begin{array}{l}.01 \\
.01 \\
.01 \\
.01 \\
.01\end{array}$ & $\begin{array}{l}.01 \\
.01 \\
.01 \\
.01 \\
.01\end{array}$ & $\begin{array}{l}0 \\
0 \\
0 \\
0 \\
0\end{array}$ \\
\hline $\begin{array}{r}6 \\
7 \\
8 \\
9 \\
10\end{array}$ & $\begin{array}{l}0 \\
0 \\
0 \\
0 \\
0\end{array}$ & $\begin{array}{l}0 \\
0 \\
0 \\
.01 \\
.01\end{array}$ & $\begin{array}{l}.01 \\
.01 \\
.01 \\
.01 \\
.01\end{array}$ & & $\begin{array}{l}.01 \\
.01 \\
.01 \\
.01 \\
.01\end{array}$ & $\begin{array}{r}3.6 \\
3.0 \\
4.5 \\
27 \\
4.2\end{array}$ & $\begin{array}{l}1.4 \\
1.0 \\
.84 \\
.66 \\
.58\end{array}$ & $\begin{array}{r}.36 \\
.27 \\
.23 \\
.23 \\
.19\end{array}$ & $\begin{array}{l}.14 \\
.17 \\
.20 \\
.18 \\
.15\end{array}$ & $\begin{array}{l}.04 \\
.03 \\
.03 \\
.03 \\
.03\end{array}$ & $\begin{array}{l}.01 \\
.01 \\
.01 \\
.01 \\
.01\end{array}$ & $\begin{array}{l}.01 \\
.01 \\
.01 \\
.01 \\
.01\end{array}$ & $\begin{array}{l}0 \\
0 \\
0 \\
0 \\
.09\end{array}$ \\
\hline $\begin{array}{l}11 \\
12 \\
13 \\
14 \\
15\end{array}$ & $\begin{array}{l}0 \\
0 \\
0 \\
0 \\
0\end{array}$ & $\begin{array}{l}.01 \\
.01 \\
.01 \\
.01 \\
.01\end{array}$ & $\begin{array}{l}.01 \\
.01 \\
.01 \\
.01 \\
.01\end{array}$ & & $\begin{array}{l}.01 \\
0 \\
0 \\
.01 \\
.01\end{array}$ & $\begin{array}{r}1.7 \\
1.1 \\
.74 \\
.60 \\
.53\end{array}$ & $\begin{array}{r}.58 \\
.51 \\
.39 \\
.36 \\
.36\end{array}$ & $\begin{array}{l}18 \\
3.0 \\
3.6 \\
1.7\end{array}$ & $\begin{array}{l}.12 \\
.10 \\
.08 \\
.07 \\
.06\end{array}$ & $\begin{array}{l}.03 \\
.03 \\
.03 \\
.03 \\
.03\end{array}$ & $\begin{array}{l}.01 \\
.01 \\
.01 \\
.01 \\
.01\end{array}$ & $\begin{array}{l}.01 \\
.01 \\
.01 \\
.01 \\
.01\end{array}$ & $\begin{array}{l}4.5 \\
.27 \\
.08 \\
.03 \\
.02\end{array}$ \\
\hline $\begin{array}{l}16 \\
17 \\
18 \\
19 \\
20\end{array}$ & $\begin{array}{r}0 \\
0 \\
.01 \\
.01 \\
.01\end{array}$ & $\begin{array}{l}.01 \\
.01 \\
.01 \\
.01 \\
.01\end{array}$ & $\begin{array}{l}.01 \\
.01 \\
.01 \\
.01 \\
.01\end{array}$ & & $\begin{array}{l}.01 \\
.01 \\
.01 \\
.01 \\
.01\end{array}$ & $\begin{array}{r}.47 \\
.42 \\
.36 \\
.35 \\
.33\end{array}$ & $\begin{array}{r}.35 \\
.32 \\
.31 \\
.30 \\
.28\end{array}$ & $\begin{array}{l}4.8 \\
1.4 \\
.75 \\
.49 \\
.37\end{array}$ & $\begin{array}{l}.06 \\
.06 \\
.06 \\
.07 \\
.07\end{array}$ & $\begin{array}{l}.03 \\
.02 \\
.02 \\
.02 \\
.02\end{array}$ & $\begin{array}{r}.01 \\
.01 \\
.01 \\
.01 \\
.01\end{array}$ & $\begin{array}{l}.01 \\
0 \\
0 \\
0 \\
.01\end{array}$ & $\begin{array}{l}.02 \\
.02 \\
.02 \\
.01 \\
.02\end{array}$ \\
\hline $\begin{array}{l}21 \\
22 \\
23 \\
24 \\
25\end{array}$ & $\begin{array}{l}0 \\
0 \\
.01 \\
.01 \\
.01\end{array}$ & $\begin{array}{l}.01 \\
.01 \\
.01 \\
.01 \\
.01\end{array}$ & $\begin{array}{l}0 \\
0 \\
0 \\
0 \\
.01\end{array}$ & & $\begin{array}{l}.01 \\
.01 \\
.01 \\
.01 \\
.01\end{array}$ & $\begin{array}{l}.27 \\
.19 \\
.16 \\
.15 \\
.18\end{array}$ & $\begin{array}{r}.24 \\
.21 \\
.19 \\
.19 \\
.21\end{array}$ & $\begin{array}{r}.30 \\
.26 \\
.24 \\
.24 \\
.24\end{array}$ & $\begin{array}{l}.06 \\
.06 \\
.05 \\
.04 \\
.05\end{array}$ & $\begin{array}{l}.02 \\
.02 \\
.02 \\
.01 \\
.01\end{array}$ & $\begin{array}{l}.01 \\
.01 \\
.01 \\
.01 \\
.01\end{array}$ & $\begin{array}{l}.01 \\
.01 \\
.01 \\
0 \\
0\end{array}$ & $\begin{array}{l}.03 \\
.03 \\
.03 \\
.04 \\
.05\end{array}$ \\
\hline $\begin{array}{l}26 \\
27 \\
28 \\
29 \\
30 \\
31\end{array}$ & $\begin{array}{l}.01 \\
0 \\
0 \\
0 \\
0 \\
0\end{array}$ & $\begin{array}{l}.01 \\
.01 \\
.01 \\
.01 \\
.01 \\
0-2\end{array}$ & $\begin{array}{l}.01 \\
.01 \\
.01 \\
.01 \\
0 \\
.01\end{array}$ & & $\begin{array}{l}.01 \\
.01 \\
.01 \\
.01 \\
.01 \\
.01\end{array}$ & $\begin{array}{l}.20 \\
.21 \\
.21 \\
.21 \\
-2= \\
.2=\end{array}$ & $\begin{array}{l}.20 \\
.17 \\
.17 \\
.18 \\
.16 \\
.14\end{array}$ & $\begin{array}{l}.22 \\
.19 \\
.17 \\
.16 \\
.15 \\
.0-\end{array}$ & $\begin{array}{l}.06 \\
.06 \\
.06 \\
.08 \\
.10 \\
.10\end{array}$ & $\begin{array}{l}.01 \\
.01 \\
.01 \\
.01 \\
.01 \\
. .2\end{array}$ & $\begin{array}{l}.01 \\
.01 \\
.01 \\
.01 \\
.01 \\
.01\end{array}$ & $\begin{array}{l}0 \\
0 \\
0 \\
0 \\
0 \\
0\end{array}$ & $\begin{array}{l}.07 \\
.06 \\
.04 \\
.04 \\
.04 \\
.0 .\end{array}$ \\
\hline $\begin{array}{l}\text { TOTAL } \\
\text { MEAN } \\
\text { MAX } \\
\text { MIN } \\
\text { AC-FT }\end{array}$ & $\begin{array}{r}.10 \\
.003 \\
.01 \\
0 \\
.2\end{array}$ & $\begin{array}{r}.22 \\
.007 \\
.01 \\
0 \\
.4\end{array}$ & $\begin{array}{r}.26 \\
.008 \\
.01 \\
0 \\
.5\end{array}$ & & $\begin{array}{r}.25 \\
.008 \\
.01 \\
0 \\
.5\end{array}$ & $\begin{array}{r}51.83 \\
1.79 \\
27 \\
.01 \\
103\end{array}$ & $\begin{array}{r}42.90 \\
1.38 \\
14 \\
.14 \\
85\end{array}$ & $\begin{array}{r}18.95 \\
.63 \\
4.8 \\
.13 \\
38\end{array}$ & $\begin{array}{r}2.91 \\
.094 \\
.20 \\
.04 \\
5.8\end{array}$ & $\begin{array}{r}.79 \\
.026 \\
.07 \\
.01 \\
1.6\end{array}$ & $\begin{array}{r}.31 \\
.010 \\
.01 \\
.01 \\
.6\end{array}$ & $\begin{array}{r}.20 \\
.007 \\
.01 \\
0 \\
.4\end{array}$ & $\begin{array}{r}5.51 \\
.18 \\
.5 \\
0 \\
11\end{array}$ \\
\hline
\end{tabular}


LOCATION. - Lat $33^{\circ} 03^{\prime} 08^{\prime \prime}$, long $116^{\circ} 56^{\prime} 41^{\prime \prime}$, in SE⿺𠃊5E $\frac{1}{4} S E^{\frac{1}{4}}$ sec.11, T.13 S., R.1 W., San Diego County, on left bank $3.8 \mathrm{mi}(6.1 \mathrm{~km})$ northwest of Ramona, and $4.6 \mathrm{mi}(7.4 \mathrm{~km})$ upstream from mouth.

DRAINAGE AREA. $-57.6 \mathrm{mi}^{2}\left(149.2 \mathrm{~km}^{2}\right)$.

PERIOD OF RECORD. - November 1912 to September 1920 , October 1946 to current year.

GAGE, - Water-stage recorder. Concrete control since october 1946. Datum of gage is $1,294.44 \mathrm{ft}$ ( $394.545 \mathrm{~m}$ ) above mean sea leve1. Prior to oct. 1, 1946, at datum $1.78 \mathrm{ft}(0.543 \mathrm{~m}) 1$ lower.

REMARKS, - Records fair. No regulation above station.

AVERAGE DISCHARGE.--37 years (water years $1914-20,1947-76), 3.26 \mathrm{ft}^{3} / \mathrm{s}\left(0.092 \mathrm{~m}^{3} / \mathrm{s}\right), 2,360 \mathrm{acre}-\mathrm{ft} / \mathrm{yr}$ $\left(2.91 \mathrm{hm}^{3} / \gamma r\right)$.

EXTREMES FOR PERIOD OF RECORD. - Maximum discharge, $7,140 \mathrm{ft}^{3} / \mathrm{s}\left(202 \mathrm{~m}^{3} / \mathrm{s}\right) \mathrm{Jan}$. 27, 1916 , gage height, $14.1 \mathrm{ft}$

$(4.298 \mathrm{~m})$, from floodmarks, present datum, from rating curve extended above $600^{\prime} \mathrm{t}^{3} / \mathrm{s}^{\prime}\left(17.0 \mathrm{~m}^{3} / \mathrm{s}\right)$ on $\mathrm{bas} i \mathrm{~s}$ of slope-area measurement of maximum flow; no flow for several months in each year.

EXTREMES FOR CURRENT YEAR, --Peak discharges above base of $20 \mathrm{ft}^{3} / \mathrm{s}\left(0.57 \mathrm{~m}^{3} / \mathrm{s}\right)$ and maximum $(*)$ :

\begin{tabular}{cccccc} 
Date & Time & \multicolumn{2}{c}{ Discharge } & \multicolumn{2}{c}{ Gage height } \\
& & $\left(\mathrm{ft}^{3} / \mathrm{s}\right)$ & $\left(\mathrm{m}^{3} / \mathrm{s}\right)$ & $(\mathrm{ft})$ & (In) \\
Feb. 9 & 0300 & $* 190$ & 5.38 & 2.60 & 0.792 \\
Mar. 3 & 0600 & 169 & 4.79 & 2.52 & 0.768
\end{tabular}

Minimum daily discharge, no flow most of year.

DISCHARGE, IN CUBIC FEET PER SECOND, WATER YEAR OCTOBER 1975 TO SEPTEMBER 1976 MEAN VALUES

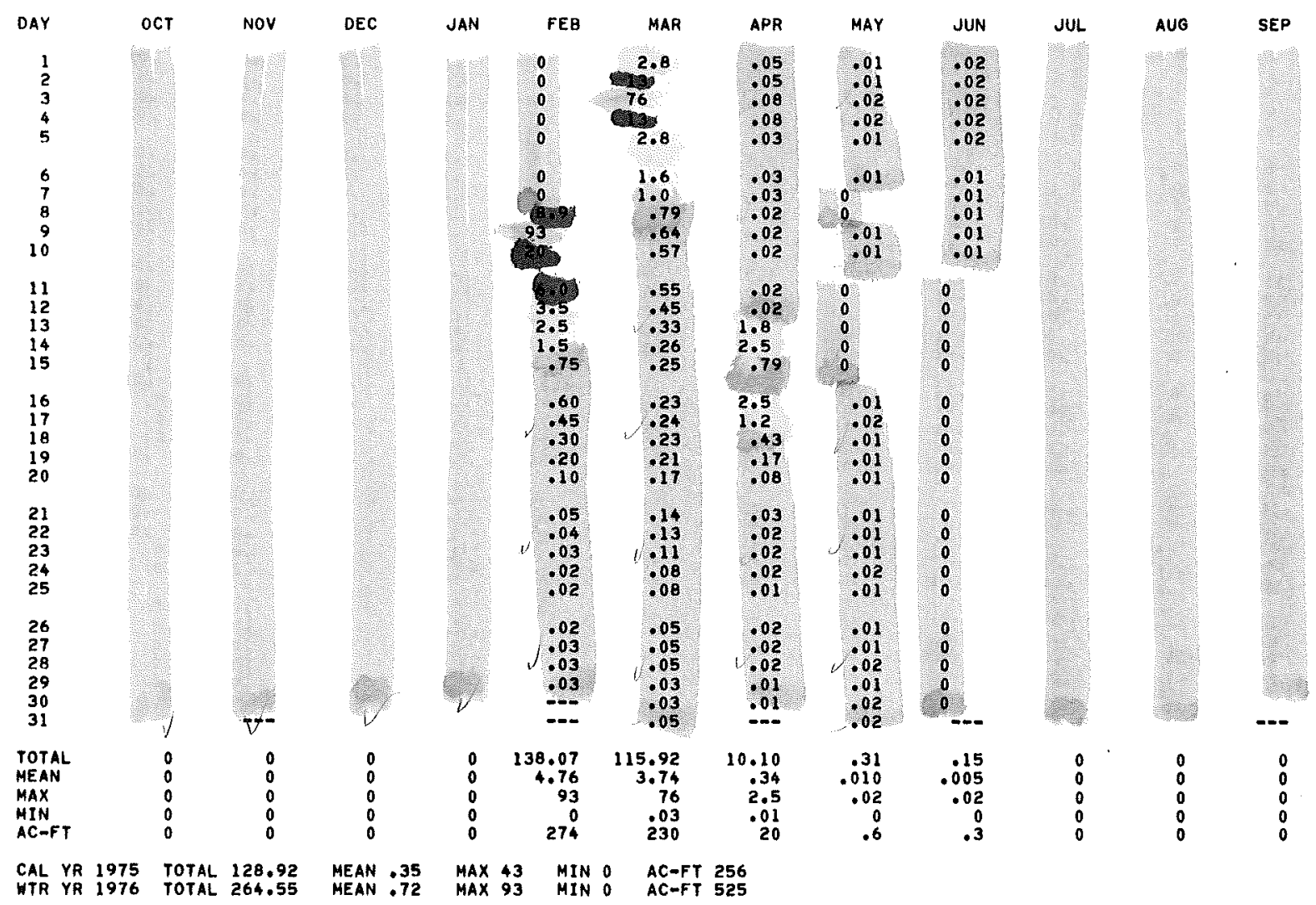


11030020 LAKE HODGES NEAR ESCONDIDO, CA

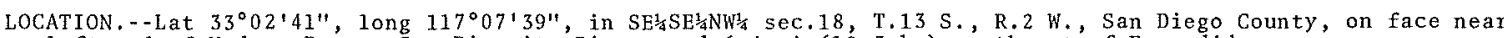
left end of Hodges Dam on San Dieguito River, and $6.4 \mathrm{mi}(10.3 \mathrm{~km})$ southwest of Escondido.

DRAINAGE AREA, $--303 \mathrm{mi}^{2}\left(785 \mathrm{~km}^{2}\right)$.

PERIOD OF RECORD, - -October 1945 to September 1968 published with San Dieguito River at Lake Hodges (station $11030000)$, October 1972 to current year. Records of monthend gage heights February 1919 to September 1945 , in files of San Diego County Department of Sanitation and Flood Control.

GAGE. - Water-stage recorder. Datum of gage is $200.0 \mathrm{ft}(60.96 \mathrm{~m})$ above mean sea 1 evel; gage readings have been reduced to elevations above mean sea leve1. Prior to oct. 1, 1972, nonrecording gage at site 800 ft (244 m) upstream on right bank at same datum.

REMARKS. - Reservoir is formed by multiple-arch reinforced concrete dam, constructed in 1917-19, Storage began in February 1919. Capacity table based on a 1948 survey; table dated Sept. 18, 1951. Capacity of reservoir at spillway leve1, 33,550 acre-ft $\left(41.4 \mathrm{hm}^{3}\right)$, elevation, $315.0 \mathrm{ft}(96.01 \mathrm{~m})$. Dead storage below lowest outlet, 1,160 acre-ft $\left(1.43 \mathrm{hm}^{3}\right)$, elevation, $254.0 \mathrm{ft}(77.42 \mathrm{~m})$ included in these records. Reservoir can be drawn down to 207 acre-ft $\left(255,000 \mathrm{~m}^{3}\right)$, elevation, $240.0 \mathrm{ft}(73.15 \mathrm{~m})$ by pumping. Water drawn from Lake Hodges passes through a conduit to $\mathrm{San}$ Dieguito re-regulating reservoir, from which it is released as required for municipal use. Flow regulated since July 1954 by Sutherland Reservoir (station 11024000). Diversions for irrigation above Lake Hodges.

COOPERATION. - Gage heights were furnished by San Diego County Department of Sanitation and Flood Control.

EXTREMES FOR PERIOD OF RECORD (1945-68 AND SINCE 1972).--Maximum contents, $37,930 \mathrm{acre}^{\mathrm{ft}}\left(46.8 \mathrm{hm}^{3}\right.$ )

Apr. 1, 1946, elevation, $315.30 \mathrm{ft}(96.103 \mathrm{~m})$; minimum, 114 acre-ft $\left(141,000 \mathrm{~m}^{3}\right)$ Oct. 31 , 1965, elevation, $235.80 \mathrm{ft}(71.872 \mathrm{~m})$.

EXTREMES FOR CURRENT YEAR,--Maximum contents observed, 4,660 acre-ft $\left(5.75 \mathrm{hm}^{3}\right) \mathrm{Apr}^{\mathrm{f}} 28$, elevation, $271.80 \mathrm{ft}$ $(82.845 \mathrm{~m})$; minimum, 2,240 acre-ft $\left(2.76 \mathrm{hm}^{3}\right)$ Nov. 26, elevation, $261.15 \mathrm{ft}$ (79.599 m).

MONTHEND ELEVATION AND CONTENTS, AT 0800, WATER YEAR OCTOBER 1975 TO SEPTEMBER 1976

Date

Sept. $30 \ldots \ldots \ldots \ldots \ldots \ldots \ldots$

Oct. $\quad 31 \ldots \ldots \ldots \ldots \ldots \ldots \ldots$

$30 \ldots \ldots \ldots \ldots \ldots$

Dec. $\quad 31 \ldots \ldots \ldots \ldots \ldots \ldots \ldots$

CAL YR 1975.

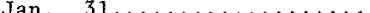

Feb. $\quad 29 \ldots \ldots \ldots \ldots \ldots \ldots \ldots$

Mar. $\quad 31 \ldots \ldots \ldots \ldots \ldots \ldots$

Apr $\quad 30 \ldots \ldots \ldots \ldots \ldots \ldots$

May $\quad 31 \ldots \ldots \ldots \ldots \ldots \ldots \ldots$

June $30 \ldots \ldots \ldots \ldots \ldots \ldots \ldots \ldots$

Ju1y $\quad 31 \ldots \ldots \ldots \ldots \ldots \ldots \ldots$

$\ldots \ldots \ldots \ldots \ldots$

WTR YR $1976 \ldots \ldots \ldots \ldots \ldots$

\section{E1evation}

(feet)

261.80

261.40
261.60

261.60
262.00

$--$

262.25

268.05

270.70

271.80

271.50

270.10

269.10

268.55

268.85

$-$
Contents

2370

2290

2330

2410

$-$

2450

3700

4360

4660

4850

4210

3960

3820

3890
Change in contents

(acre-feet)

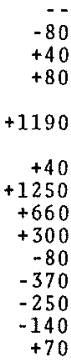

$+1520$ 
LOCATION, - Lat $33^{\circ} 10^{\prime} 00^{\prime \prime}$, long $117^{\circ} 00^{\prime} 14^{\prime \prime}$, in NW/4E $\frac{1}{4}$ sec.5, T.12 S., R.I W., San Diego County, on face of Lake Wohlford Dam, $330 \mathrm{ft}(101 \mathrm{~m})$ left of spillway, $3.9 \mathrm{mi}(6.3 \mathrm{~km})$ southeast of Valley Center Post office, and $5.7 \mathrm{mi}(9.2 \mathrm{~km})$ northeast of Escondido.

DRAINAGE AREA, $--7.96 \mathrm{mi}^{2}\left(20.62 \mathrm{~km}^{2}\right)$.

PERIOD OF RECORD,--October 1972 to current year, October 1933 to September 1972 in files of San Diego County Department of Sanitation and Flood Control.

GAGE.--Water-stage recorder. Datum of gage is $1,400.0 \mathrm{ft}$ ( $426.72 \mathrm{~m}$ ) above mean sea leve1 (1evels by city of Escondido Engineering Department); gage readings have been reduced to elevation above mean sea level. Prior to Oct. 1, 1972, nonrecording gage at same site at datum $15.0 \mathrm{ft}(4.57 \mathrm{~m}) 10$ wer.

REMARKS.--Reservoir is formed by earthfill dam riprapped upstream and downstream, with concrete spillway anchored to natural rock. Dam was completed in 1932. Capacity table dated March 1955. Capacity at spillway level, 6,940 acre-ft $\left(8.56 \mathrm{hm}^{3}\right)$, elevation, $1,480.0 \mathrm{ft}(451.10 \mathrm{~m})$. Dead storage below lowest out1et, 131 acre-ft $\left(162,000 \mathrm{~m}^{3}\right)$, elevation, $1,420.0 \mathrm{ft}(432.82 \mathrm{~m})$. Reservoir storage includes supplemental water diverted from the San Luis Rey River via Escondido Mutual Water Co.'s canal to Lake Wohl ford Reservoir. Stored water is released for municipal use by Vista Irrigation District and city of Escondido.

COOPERATION.--Gage heights were furnished by San Diego County Department of Sanitation and Flood Control.

EXTREMES FOR PERIOD OF RECORD.-Maximum contents, 6,940 acre-ft $\left(8.56 \mathrm{hm}^{3}\right)$ Apr. 30 to May 10 , 1952 , elevation, $1,480.0 \mathrm{ft}(451.10 \mathrm{~m})$; minimum, $809 \mathrm{acre}-\mathrm{ft}(997,000 \mathrm{~m}) \mathrm{bec} .1,1953$, elevation, $1,447.5 \mathrm{ft}(441.20 \mathrm{~m})$.

EXTREMES FOR CURRENT YEAR,--Maximum contents observed, 3,520 acre-ft $\left(4,33 \mathrm{hm}^{3}\right) \mathrm{June}^{8}$, elevation, $1,476.9$ ft $(450.16 \mathrm{~m})$; minimum, $1,180 \mathrm{acre}-\mathrm{ft}\left(1.46 \mathrm{hm}^{3}\right)$ Nov. 21 , elevation, $1,457.3 \mathrm{ft}(444.19 \mathrm{~m})$.

MONTHEND ELEVATION AND CONTENTS, AT 0800, WATER YEAR OCTOBER 1975 TO SEPTEMBER 1976

Date

Sept. $30 \ldots \ldots \ldots \ldots \ldots \ldots \ldots$

oct. $\quad 31 \ldots \ldots \ldots \ldots \ldots \ldots \ldots$

Nov. $\quad 30 \ldots \ldots \ldots \ldots \ldots \ldots \ldots$

Dec. $31 \ldots \ldots \ldots \ldots \ldots \ldots \ldots$

CAL YR 1975

Jan. $\quad 31 \ldots \ldots \ldots \ldots \ldots$

$29 \ldots \ldots \ldots \ldots \ldots \ldots$

$\operatorname{Mar}, \quad 31 \ldots \ldots \ldots \ldots \ldots \ldots \ldots$

May $\quad 30 \ldots \ldots \ldots \ldots \ldots \ldots \ldots \ldots \ldots$

June $30 \ldots \ldots \ldots \ldots \ldots \ldots \ldots$

July $31 \ldots \ldots \ldots \ldots \ldots \ldots \ldots$

Sept. $30, \ldots . . . \cdots$

WTR YR $1976 \ldots \ldots \ldots \ldots \ldots$
Elevation

(feet)

1450.0

1458.8

1464.9

1464.3

$-$

1462.4

1467.7

1473.1

1476.7

1476.6

1473.6

1474.5

1472.4

1475.5
Contents

1910

1300

1900

1830

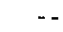

1630

2220

2940

3480

3470

3010

3140
2840

3290

--
Change in contents

(acre-feet)

$-10$

$-610$

+600
-70

$+590$

$-200$

-200
+590

$+720$

$+540$

-10
-460

-460
+130

$-300$

$+450$

$+1380$ 
11031500 AGUA CALIENTE CREEK NEAR WARNER SPRINGS, CA

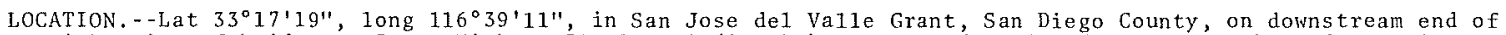
right pier of bridge on State Highway $79,1.2 \mathrm{mi}(1.9 \mathrm{~km})$ upstream from Canada Verde Creek, and $1.2 \mathrm{mi}$ $(1.9 \mathrm{~km})$ northwest of Warner Springs.

DRAINAGE AREA. $-19.0 \mathrm{mi}^{2}\left(49.2 \mathrm{~km}^{2}\right)$.

PERIOD OF RECORD, - -February 1961 to current year.

GAGE. - Water-stage recorder. Altitude of gage is $2,950 \mathrm{ft}(899 \mathrm{~m})$, from topographic map. Prior to Jan. 29 , 1966 , at site $120 \mathrm{ft}(37 \mathrm{~m})$ upstream at same datum, used as supplementary gage since Dec. 12 , 1968 .

REMARKS. - -Records fair. No regulation or diversion above station.

AVERAGE DISCHARGE, -15 years, $1.02 \mathrm{ft}^{3} / \mathrm{s}\left(0.029 \mathrm{~m}^{3} / \mathrm{s}\right), 739 \mathrm{acre}-\mathrm{ft} / \mathrm{yr}\left(911,000 \mathrm{~m}^{3} / \mathrm{yr}^{2}\right)$

EXTREMES FOR PERIOD OF RECORD, - Maximum discharge, $1,200 \mathrm{ft}^{3} / \mathrm{s}\left(34.0 \mathrm{~m}^{3} / \mathrm{s}\right)$ Dec, 6 , 1966 , gage height, $5.18 \mathrm{ft}$ $(1.579 \mathrm{~m})$, from rating curve extended above $240 \mathrm{ft} / \mathrm{s}\left(6.80 \mathrm{~m}^{3} / \mathrm{s}\right)$; no flow for much of each year.

EXTREMES FOR CURRENT YEAR, - Peak discharges above base of $50 \mathrm{ft}^{3} / \mathrm{s}\left(1.42 \mathrm{~m}^{3} / \mathrm{s}\right)$ and maximum (*), from $\mathrm{rating}$ curve extended above $20 \mathrm{ft}^{3} / \mathrm{s}\left(0.57 \mathrm{~m}^{3} / \mathrm{s}\right)$ on basis of slope-conveyance measurement:

\begin{tabular}{|c|c|c|c|c|c|}
\hline Date & Time & $\begin{array}{r}\text { Disc } \\
\left(\mathrm{ft} \mathrm{t}^{3} / \mathrm{s}\right.\end{array}$ & $\left(\mathrm{m}^{3} / \mathrm{s}\right)$ & $\begin{array}{l}\text { Gage } \\
\text { (ft) }\end{array}$ & $\begin{array}{r}\text { height } \\
\text { (m) }\end{array}$ \\
\hline eb. 9 & 0330 & $* 220$ & 6.23 & 3.52 & \\
\hline 10 & 1400 & 138 & 3.91 & 3.07 & \\
\hline
\end{tabular}

Minimum daily discharge, no flow for many months.

DISCHARGE, IN CUBIC FEET PER SECOND, WATER YEAR OCTOBER 1975 TO SEPTEMBER 1976 MEAN VALUES

\begin{tabular}{|c|c|c|c|c|c|c|c|c|c|c|c|c|}
\hline DAY & OCT & NoV & DEC & JAN & FEB & MAR & APR & MAY & JUN & JUL & AUG & SEP \\
\hline $\begin{array}{l}1 \\
2 \\
3 \\
4 \\
5\end{array}$ & & & & & $\begin{array}{l}0 \\
0 \\
0 \\
0 \\
0\end{array}$ & $\begin{array}{l}1.4 \\
5.9 \\
3.7 \\
3.3 \\
3.5\end{array}$ & $\begin{array}{l}0 \\
0 \\
0 \\
0 \\
0\end{array}$ & & & & & $\begin{array}{l}0 \\
0 \\
0 \\
0 \\
0\end{array}$ \\
\hline $\begin{array}{r}6 \\
7 \\
8 \\
9 \\
10\end{array}$ & & & & & $\begin{array}{l}7.7 \\
12 \\
5.6 \\
82 \\
21\end{array}$ & $\begin{array}{l}3.5 \\
3.5 \\
3.3 \\
2.6 \\
2.1\end{array}$ & $\begin{array}{l}0 \\
0 \\
0 \\
0 \\
0\end{array}$ & & & & & $\begin{array}{r}0 \\
0 \\
0 \\
0 \\
14\end{array}$ \\
\hline $\begin{array}{l}11 \\
12 \\
13 \\
14 \\
15\end{array}$ & & & & & $\begin{array}{l}6.6 \\
5.3 \\
3.1 \\
1.8 \\
1.2\end{array}$ & $\begin{array}{c}1.5 \\
1.2 \\
.76 \\
.60 \\
.33\end{array}$ & $\begin{array}{l}0 \\
0 \\
0 \\
0 \\
.55\end{array}$ & & & & & $\begin{array}{l}12 \\
0 \\
0 \\
0\end{array}$ \\
\hline $\begin{array}{l}16 \\
17 \\
18 \\
19 \\
20\end{array}$ & & & & & $\begin{array}{r}.72 \\
.50 \\
.35 \\
.25 \\
.18\end{array}$ & $\begin{array}{r}.22 \\
.18 \\
.14 \\
.10 \\
.07\end{array}$ & $\begin{array}{r}4.6 \\
2.6 \\
.85 \\
.27 \\
.04\end{array}$ & & & & & $\begin{array}{l}0 \\
0 \\
0 \\
0 \\
0\end{array}$ \\
\hline $\begin{array}{l}21 \\
22 \\
23 \\
24 \\
25\end{array}$ & & & & & $\begin{array}{l}.14 \\
0 \\
0 \\
0\end{array}$ & $\begin{array}{l}.06 \\
.04 \\
.02 \\
0 \\
0\end{array}$ & $\begin{array}{l}0 \\
0 \\
0 \\
0 \\
0\end{array}$ & & & & & $\begin{array}{l}0 \\
0 \\
0 \\
0 \\
0\end{array}$ \\
\hline $\begin{array}{l}26 \\
27 \\
28 \\
29 \\
30 \\
31\end{array}$ & & $-\infty$ & & & $\begin{array}{l}0 \\
0 \\
0 \\
0 \\
-\ldots- \\
-\infty\end{array}$ & $\begin{array}{l}0 \\
0 \\
0 \\
0 \\
0 \\
0\end{array}$ & $\begin{array}{l}0 \\
0 \\
0 \\
0 \\
0\end{array}$ & & $=\infty$ & & & $\begin{array}{l}0 \\
0 \\
0 \\
0 \\
0\end{array}$ \\
\hline $\begin{array}{l}\text { TOTAL } \\
\text { MEAN } \\
\text { MAX } \\
\text { MIN } \\
\text { AC }=F T\end{array}$ & $\begin{array}{l}0 \\
0 \\
0 \\
0 \\
0\end{array}$ & $\begin{array}{l}0 \\
0 \\
0 \\
0 \\
0\end{array}$ & $\begin{array}{l}0 \\
0 \\
0 \\
0 \\
0\end{array}$ & $\begin{array}{l}0 \\
0 \\
0 \\
0 \\
0\end{array}$ & $\begin{array}{r}150.75 \\
5.20 \\
82 \\
0 \\
299\end{array}$ & $\begin{array}{r}38.02 \\
1.23 \\
5.9 \\
0 \\
75\end{array}$ & $\begin{array}{r}8.91 \\
.30 \\
4.6 \\
0 \\
18\end{array}$ & $\begin{array}{l}0 \\
0 \\
0 \\
0 \\
0\end{array}$ & $\begin{array}{l}0 \\
0 \\
0 \\
0 \\
0\end{array}$ & $\begin{array}{l}0 \\
0 \\
0 \\
0 \\
0\end{array}$ & $\begin{array}{l}0 \\
0 \\
0 \\
0 \\
0\end{array}$ & $\begin{array}{r}26.68 \\
.89 \\
14 \\
0 \\
53\end{array}$ \\
\hline
\end{tabular}

$\begin{array}{llllllll}\text { CAL YR } 1975 & \text { TOTAL } 93.02 & \text { MEAN .25 } & \text { MAX } 21 & \text { MIN } 0 & \text { AC-FT } 185 \\ \text { WTR YR } 1976 & \text { TOTAL } 224.36 & \text { MEAN } & .61 & \text { MAX } 82 & \text { MIN } & \text { AC-FT } 445\end{array}$ 
LOCATION. - Lat $33^{\circ} 17^{\prime} 48^{\prime \prime}$, long $116^{\circ} 45^{\prime} 32^{\prime \prime}$, in San Jose de1 Valle Grant, San Diego County, on 1 eft bank 0.2 mi $(0.3 \mathrm{~km})$ upstream from Fink Road, $2.6 \mathrm{mi}(4.2 \mathrm{~km})$ upstream from mouth, and $7.5 \mathrm{mi}(12.1 \mathrm{~km})$ west of Warner
Springs.

DRAINAGE AREA. $-25.5 \mathrm{mi}^{2}\left(66.0 \mathrm{~km}^{2}\right)$.

PERIOD OF RECORD.--January 1913 to November 1915, october 1956 to current year. Low-flow recoras not equivalent prior to Nov. 5, 1971, due to undetermined amount of underflow between sites.

REVISED RECORDS. - -WDR CA-74: $1973(\mathrm{P})$.

GAGE, - Water-stage recorder. Altitude of gage is $2,800 \mathrm{ft}(853 \mathrm{~m})$, from topographic map. Prior to Oct. 1 , 1956 , at different datum. Prior to Nov. 5,1971 , at site 500 ft (152 m) downstream at same datum.

REMARKS.--Records fair. No regulation or diversion above station.

AVERAGE DISCHARGE. - -21 years (water years $1914-15,1957-76), 6.76 \mathrm{ft}^{3} / \mathrm{s}\left(0.191 \mathrm{~m}^{3} / \mathrm{s}\right), 4,900 \mathrm{acre}-\mathrm{ft}^{3} / \mathrm{yr}^{2}$ $\left(6.04 \mathrm{hm}^{3} / \mathrm{yr}\right)$.

EXTREMES FOR PERIOD OF RECORD. - Maximum discharge, 4,200 $\mathrm{ft}^{3} / \mathrm{s}\left(119 \mathrm{~m}^{3} / \mathrm{s}\right)$ Dec, $6,1966, \mathrm{gage}$ height, $11.87 \mathrm{ft}$ $(3.618 \mathrm{~m})$, from rating curve extended above $250 \mathrm{ft} / \mathrm{s}\left(7.08 \mathrm{~m}^{3} / \mathrm{s}\right)$ on basis of slope-area measurement of maximum flow; no flow at times in most years.

EXTREMES FOR CURRENT YEAR. --Peak discharges above base of $100 \mathrm{ft}^{3} / \mathrm{s}\left(2.83 \mathrm{~m}^{3} / \mathrm{s}\right)$ and maximum (*):

\begin{tabular}{|c|c|c|c|c|c|c|c|c|}
\hline Date & Time & $\begin{array}{c}\text { Discharge } \\
\left(\mathrm{ft}^{3} / \mathrm{s}\right)\left(\mathrm{m}^{3} / \mathrm{s}\right)\end{array}$ & 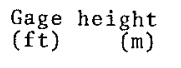 & Date & Time & $\begin{array}{c}\text { Discharge } \\
\left(\mathrm{ft}^{3} / \mathrm{s}\right)\left(\mathrm{m}^{3} / \mathrm{s}\right)\end{array}$ & $\begin{array}{l}\text { Gage } \\
(\mathrm{ft})\end{array}$ & $\begin{array}{r}\text { height } \\
\text { (m) }\end{array}$ \\
\hline $\begin{array}{l}\text { Feb. } 9 \\
\text { Mar. } 1\end{array}$ & $\begin{array}{l}\text { Unknown } \\
2045\end{array}$ & $\begin{array}{l}6.57 \\
8.21\end{array}$ & $\begin{array}{l}3.429 \\
3.475\end{array}$ & Apr. 15 & 2230 & 5,30 & 11.12 & 3.389 \\
\hline
\end{tabular}

Minimum daily discharge, no flow several months,

DISCHARGE, IN CUBIC FEET PER SECOND, HATER YEAR OCTOBER 1975 TO SEPTEMBER 1976

\begin{tabular}{|c|c|c|c|c|c|c|c|c|c|c|c|c|}
\hline DAY & OCT & NOV & DEC & JAN & FEB & MAR & APR & HAY & JUN & JUL & AUG & SEP \\
\hline $\begin{array}{l}1 \\
2 \\
3 \\
4 \\
5\end{array}$ & & $\begin{array}{l}0 \\
0 \\
0 \\
0 \\
0\end{array}$ & $\begin{array}{l}0^{.01} \\
0 \\
0 \\
0\end{array}$ & & $\begin{array}{l}0 \\
0 \\
0 \\
0 \\
7.0\end{array}$ & $\begin{array}{l}52 \\
42 \\
16 \\
13 \\
13\end{array}$ & $\begin{array}{l}.87 \\
.87 \\
.87 \\
1.2 \\
2.3\end{array}$ & $\begin{array}{l}1.7 \\
1.5 \\
1.6 \\
1.6 \\
1.7\end{array}$ & $\begin{array}{r}.37 \\
.32 \\
.30 \\
.22 \\
.22\end{array}$ & $\begin{array}{l}0^{.01} \\
0 \\
0 \\
0\end{array}$ & & \\
\hline $\begin{array}{r}6 \\
7 \\
8 \\
9 \\
10\end{array}$ & & $\begin{array}{l}0 \\
0 \\
0 \\
0 \\
0\end{array}$ & $\begin{array}{l}0 \\
0 \\
0 \\
0 \\
0\end{array}$ & & $\begin{array}{l}10 \\
6.5 \\
5.0 \\
70 \\
50\end{array}$ & $\begin{array}{l}13 \\
16 \\
15 \\
12 \\
9.9\end{array}$ & $\begin{array}{l}2.6 \\
2.6 \\
1.8 \\
1.2 \\
.90\end{array}$ & $\begin{array}{l}1.4 \\
1.8 \\
2.3 \\
1.9 \\
1.7\end{array}$ & $\begin{array}{l}.30 \\
.22 \\
.20 \\
.18 \\
.18\end{array}$ & $\begin{array}{l}0 \\
0 \\
0 \\
0 \\
0\end{array}$ & & \\
\hline $\begin{array}{l}11 \\
12 \\
13 \\
14 \\
15\end{array}$ & & $\begin{array}{l}0 \\
0 \\
0 \\
0 \\
0\end{array}$ & $\begin{array}{l}0 \\
0 \\
0 \\
0 \\
0\end{array}$ & & $\begin{array}{l}15 \\
7.7 \\
6.1 \\
5.2 \\
4.5\end{array}$ & $\begin{array}{l}9.0 \\
8.6 \\
7.8 \\
7.4 \\
7.2\end{array}$ & $\begin{array}{l}.74 \\
.90 \\
5.1 \\
5.9 \\
14\end{array}$ & $\begin{array}{l}1.5 \\
1.1 \\
.80 \\
.77 \\
.63\end{array}$ & $\begin{array}{l}.18 \\
.18 \\
.18 \\
.18 \\
.18\end{array}$ & $\begin{array}{l}0 \\
0 \\
0 \\
0 \\
0\end{array}$ & & \\
\hline $\begin{array}{l}16 \\
17 \\
18 \\
19 \\
20\end{array}$ & & $\begin{array}{l}0 \\
0 \\
0 \\
0 \\
0\end{array}$ & $\begin{array}{l}0 \\
0 \\
0 \\
0 \\
0\end{array}$ & & $\begin{array}{l}4.0 \\
3.6 \\
3.3 \\
3.1 \\
2.8\end{array}$ & $\begin{array}{l}6.9 \\
6.7 \\
6.0 \\
4.0 \\
2.6\end{array}$ & $\begin{array}{l}12 \\
9.0 \\
6.0 \\
4.5 \\
3.9\end{array}$ & $\begin{array}{l}.60 \\
.54 \\
.54 \\
.46 \\
.46\end{array}$ & $\begin{array}{r}.18 \\
.18 \\
.17 \\
.15 \\
.14\end{array}$ & $\begin{array}{l}0 \\
0 \\
0 \\
0 \\
0\end{array}$ & & \\
\hline $\begin{array}{l}21 \\
22 \\
23 \\
24 \\
25\end{array}$ & & $\begin{array}{l}0 \\
0 \\
0 \\
0 \\
0\end{array}$ & $\begin{array}{l}0 \\
0 \\
0 \\
0 \\
0\end{array}$ & & $\begin{array}{l}2.6 \\
2.5 \\
2.2 \\
2.0 \\
2.0\end{array}$ & $\begin{array}{l}1.9 \\
1.3 \\
1.0 \\
.90 \\
.78\end{array}$ & $\begin{array}{l}3.6 \\
3.6 \\
3.5 \\
3.3 \\
2.9\end{array}$ & $\begin{array}{r}.46 \\
.37 \\
.36 \\
.41 \\
.32\end{array}$ & $\begin{array}{l}.14 \\
.12 \\
.13 \\
.12 \\
.11\end{array}$ & $\begin{array}{l}0 \\
0 \\
0 \\
0 \\
0\end{array}$ & & \\
\hline $\begin{array}{l}26 \\
27 \\
28 \\
29 \\
30 \\
31\end{array}$ & & $\begin{array}{l}0 \\
0 \\
.02 \\
.01 \\
.01 \\
.01 \\
0.0\end{array}$ & $\begin{array}{l}0 \\
0 \\
0 \\
0 \\
0 \\
0\end{array}$ & & $\begin{array}{l}2.2 \\
2.3 \\
2.3 \\
2.0 \\
-. .-\end{array}$ & $\begin{array}{r}.76 \\
.74 \\
.74 \\
.74 \\
.87 \\
.74\end{array}$ & $\begin{array}{l}2.5 \\
2.6 \\
2.5 \\
2.3 \\
2.0 \\
.\end{array}$ & $\begin{array}{l}.30 \\
.25 \\
.18 \\
.22 \\
.32 \\
.43\end{array}$ & $\begin{array}{l}.10 \\
.07 \\
.05 \\
.04 \\
.02 \\
.02\end{array}$ & $\begin{array}{l}0 \\
0 \\
0 \\
0 \\
0 \\
0\end{array}$ & & $-\infty$ \\
\hline $\begin{array}{l}\text { TOTAL } \\
\text { MEAN } \\
\text { MAX } \\
\text { MIN } \\
\text { AC-FT }\end{array}$ & $\begin{array}{l}0 \\
0 \\
0 \\
0 \\
0\end{array}$ & $\begin{array}{r}.04 \\
.001 \\
.02 \\
0 \\
.08\end{array}$ & $\begin{array}{r}.01 \\
.0003 \\
.01 \\
0 \\
.02\end{array}$ & $\begin{array}{l}0 \\
0 \\
0 \\
0 \\
0\end{array}$ & $\begin{array}{r}223.9 \\
7.72 \\
70 \\
0 \\
444\end{array}$ & $\begin{array}{r}278.57 \\
0.99 \\
52 \\
.74 \\
553\end{array}$ & $\begin{array}{r}106.05 \\
3.54 \\
14 \\
.74 \\
210\end{array}$ & $\begin{array}{r}28.24 \\
.91 \\
2.3 \\
.18 \\
56\end{array}$ & $\begin{array}{r}5.13 \\
.17 \\
.37 \\
.02 \\
10\end{array}$ & $\begin{array}{r}.01 \\
.0003 \\
.01 \\
0 \\
.02\end{array}$ & $\begin{array}{l}0 \\
0 \\
0 \\
0 \\
0\end{array}$ & $\begin{array}{l}0 \\
0 \\
0 \\
0 \\
0\end{array}$ \\
\hline $\begin{array}{lll}\text { CAL YR } & 1975 \\
\text { HTR } & \text { YR } & 1976\end{array}$ & $\begin{array}{l}\text { TOTAL } \\
\text { TOTAL }\end{array}$ & $\begin{array}{r}1000.99 \\
641.95\end{array}$ & $\begin{array}{l}\text { MEAN } \\
\text { MEAN }\end{array}$ & $\begin{array}{l}2.74 \\
1.75\end{array}$ & $\begin{array}{ll}4 x & 55 \\
4 x & 70\end{array}$ & $\begin{array}{ll}M I N & 0 \\
M I N & 0\end{array}$ & $\begin{array}{l}1990 \\
1270\end{array}$ & & & & & \\
\hline
\end{tabular}


LOCATION. - Lat $33^{\circ} 20^{\prime} 10^{\prime \prime}$, long $116^{\circ} 58^{\prime} 25^{\prime \prime}$, in Pauma Grant, San Diego County, on right bank 0.3 mi (0.5 km) down * stream from unnamed tributary, and $2.2 \mathrm{mi}(3.5 \mathrm{~km})$ north of Pauma Valley.

DRAINAGE AREA. - - $11.0 \mathrm{mi}^{2}\left(28.5 \mathrm{~km}^{2}\right)$.

PERIOD OF RECORD. - - October 1964 to current year.

GAGE, - Water-stage recorder on creek; water-stage recorder and Parshal1 flume on diversion. Altitude of creek gage is $1,240 \mathrm{ft}(378 \mathrm{~m})$, from topographic map. Diversion gage is at different datum.

REMARKS. - Records fair. No regulation above station. Pauma Valley Water Co. diverts from a site 0.2 mi $(0.3 \mathrm{~km})$ upstream. For records of combined discharge of Pauma Creek and Pauma Valley Water Co.'s diversion, see following page.

AVERAGE DISCHARGE, - -Creek only: 12 years, $3.11 \mathrm{ft}^{3} / \mathrm{s}\left(0.088 \mathrm{~m}^{3} / \mathrm{s}\right), 2,250 \mathrm{acre}-\mathrm{ft} / \mathrm{yr}(2.77 \mathrm{hm} / \mathrm{yr})$ Combined creek and diversion: 12 years, $3.79 \mathrm{ft}^{3} / \mathrm{s}(0.107 \mathrm{~m} / \mathrm{s}), 2,750 \mathrm{acre}-\mathrm{ft} / \mathrm{yr}(3.39 \mathrm{hm} / \mathrm{yr})$

EXTREMES FOR PERIOD OF RECORD.--Creek only: Maximum discharge, $2,100 \mathrm{ft}^{3} / \mathrm{s}\left(59.9 \mathrm{~m}^{3} / \mathrm{s}\right) \mathrm{Dec} .6$, 1966 , gage height, $8.60 \mathrm{ft}(2.621 \mathrm{~m})$, from rating curve extended above $110 \mathrm{ft}^{3} / \mathrm{s}\left(3.12 \mathrm{~m}^{3} / \mathrm{s}\right)$ on basis of slope-area measurement of $1,360 \mathrm{ft}^{3} / \mathrm{s}\left(38.5 \mathrm{~m}^{3} / \mathrm{s}\right)$; no flow much of each year.

Combined creek and diversion: Maximum discharge, $2,100 \mathrm{ft}^{3} / \mathrm{s}\left(59.5 \mathrm{~m}^{3} / \mathrm{s}\right) \mathrm{Dec} .6,1966 ; \mathrm{minimum} \mathrm{daily,} 0.04 \mathrm{ft}{ }^{3} / \mathrm{s}$ $\left(0.001 \mathrm{~m}^{3} / \mathrm{s}\right)$ Ju1y 29 to Aug. 2, 1972.

EXTREMES FOR CURRENT YEAR. - - Creek on 1y: Maximum discharge, $33 \mathrm{ft}^{3} / \mathrm{s}\left(0.93 \mathrm{~m}^{3} / \mathrm{s}\right) \mathrm{Mar}$. 1, gage height, $3.40 \mathrm{ft}$ $(1.036 \mathrm{~m})$, no peak above base of $50 \mathrm{ft}^{3} / \mathrm{s}\left(15.2 \mathrm{~m}^{3} / \mathrm{s}\right)$; no flow many days.

Combined creek and diversion: Maximum discharge, $33 \mathrm{ft}^{3} / \mathrm{s}\left(0.93 \mathrm{~m}^{3} / \mathrm{s}\right) \mathrm{Mar}, 1 ; \mathrm{minimum} \mathrm{daily}, 0.05 \mathrm{ft} / \mathrm{s}$ $\left(0.001 \mathrm{~m}^{3} / \mathrm{s}\right)$ Aug, 31 .

DISCHARGE, IN CUBIC FEET PER SECOND, WATER YEAR OCTOBER 1975 TO SEPTEMBER 1976 MEAN VALUES

\begin{tabular}{|c|c|c|c|c|c|c|c|c|c|c|c|c|}
\hline DAY & $O C T$ & NOV & OEC & JAN & FEB & MAR & APR & MAY & JUN & JUL & AUG & SEP \\
\hline $\begin{array}{l}1 \\
2 \\
3 \\
4 \\
5\end{array}$ & $\begin{array}{l}0 \\
0 \\
0 \\
0 \\
0\end{array}$ & $\begin{array}{l}.01 \\
.01 \\
.01 \\
.05 \\
.05\end{array}$ & $\begin{array}{r}.80 \\
.62 \\
.56 \\
.62 \\
.62\end{array}$ & $\begin{array}{l}.62 \\
.62 \\
.62 \\
.62 \\
.56\end{array}$ & $\begin{array}{l}.19 \\
.15 \\
.15 \\
1.3 \\
10\end{array}$ & $\begin{array}{l}8.4 \\
11 \\
7.0 \\
5.5 \\
5.0\end{array}$ & $\begin{array}{l}1.4 \\
.62 \\
.56 \\
.93 \\
1.4\end{array}$ & $\begin{array}{r}.80 \\
.74 \\
.74 \\
.74 \\
.80\end{array}$ & $\begin{array}{l}.05 \\
.05 \\
.05 \\
.05 \\
.05\end{array}$ & & & $\begin{array}{l}0 \\
0 \\
0 \\
0 \\
0\end{array}$ \\
\hline $\begin{array}{r}6 \\
7 \\
8 \\
9 \\
10\end{array}$ & $\begin{array}{l}0 \\
0 \\
0 \\
0 \\
0\end{array}$ & $\begin{array}{l}.05 \\
.05 \\
.05 \\
.05 \\
.05\end{array}$ & $\begin{array}{l}.38 \\
.07 \\
.01 \\
0 \\
0\end{array}$ & $\begin{array}{l}.56 \\
.56 \\
.56 \\
.56 \\
.56\end{array}$ & $\begin{array}{l}11 \\
9.1 \\
10 \\
21 \\
12\end{array}$ & $\begin{array}{l}4.5 \\
4.0 \\
4.1 \\
4.3 \\
4.6\end{array}$ & $\begin{array}{l}1.6 \\
1.5 \\
.93 \\
.80 \\
.74\end{array}$ & $\begin{array}{l}.93 \\
1.4 \\
1.3 \\
1.0 \\
.80\end{array}$ & $\begin{array}{l}.03 \\
.03 \\
.03 \\
.01 \\
.01\end{array}$ & & & $\begin{array}{l}0 \\
0 \\
0 \\
0 \\
\quad .10\end{array}$ \\
\hline $\begin{array}{l}11 \\
12 \\
13 \\
14 \\
15\end{array}$ & $\begin{array}{l}.04 \\
.09 \\
.09 \\
.07 \\
.05\end{array}$ & $\begin{array}{l}.05 \\
.05 \\
.05 \\
.05 \\
.05\end{array}$ & $\begin{array}{l}0 \\
.13 \\
1.3 \\
.74 \\
.62\end{array}$ & $\begin{array}{l}.56 \\
.56 \\
.44 \\
.11 \\
.07\end{array}$ & $\begin{array}{l}7.7 \\
5.6 \\
4.6 \\
4.1 \\
3.5\end{array}$ & $\begin{array}{l}4.3 \\
3.9 \\
3.3 \\
3.1 \\
3.0\end{array}$ & $\begin{array}{r}.62 \\
.74 \\
2.9 \\
3.4 \\
6.3\end{array}$ & $\begin{array}{l}.62 \\
.44 \\
.32 \\
.15 \\
.11\end{array}$ & $\begin{array}{l}.01 \\
0 \\
0 \\
0 \\
0\end{array}$ & & & $\begin{array}{l}4.0 \\
1.0 \\
.70 \\
.39 \\
.03\end{array}$ \\
\hline $\begin{array}{l}16 \\
17 \\
18 \\
19 \\
20\end{array}$ & $\begin{array}{r}.03 \\
.03 \\
.03 \\
.03 \\
.03\end{array}$ & $\begin{array}{l}.05 \\
.05 \\
.05 \\
.07 \\
.11\end{array}$ & $\begin{array}{r}.38 \\
.32 \\
.19 \\
.15 \\
.11\end{array}$ & $\begin{array}{l}.09 \\
.09 \\
.09 \\
.09 \\
.11\end{array}$ & $\begin{array}{l}3.0 \\
2.8 \\
2.5 \\
2.4 \\
2.1\end{array}$ & $\begin{array}{l}2.8 \\
2.7 \\
2.6 \\
2.3 \\
2.2\end{array}$ & $\begin{array}{r}11 \\
6.8 \\
5.9 \\
4.4 \\
3.2\end{array}$ & $\begin{array}{l}.11 \\
.09 \\
.09 \\
.07 \\
.07\end{array}$ & $\begin{array}{l}0 \\
0 \\
0 \\
0 \\
0\end{array}$ & & & $\begin{array}{l}.03 \\
.03 \\
.01 \\
.01 \\
.01\end{array}$ \\
\hline $\begin{array}{l}21 \\
22 \\
23 \\
24 \\
25\end{array}$ & $\begin{array}{r}.03 \\
.03 \\
.01 \\
.01 \\
.01\end{array}$ & $\begin{array}{r}.19 \\
119 \\
119 \\
119 \\
.19\end{array}$ & $\begin{array}{l}.09 \\
.11 \\
.29 \\
.50 \\
.56\end{array}$ & $\begin{array}{r}.11 \\
.11 \\
.11 \\
.15 \\
.15\end{array}$ & $\begin{array}{l}1.6 \\
1.4 \\
1.4 \\
1.4 \\
1.4\end{array}$ & $\begin{array}{l}2.0 \\
1.8 \\
1.7 \\
1.9 \\
2.2\end{array}$ & $\begin{array}{l}3.0 \\
3.0 \\
2.9 \\
2.3 \\
1.8\end{array}$ & $\begin{array}{l}.05 \\
.05 \\
.05 \\
.05 \\
.05\end{array}$ & $\begin{array}{l}0 \\
0 \\
0 \\
0 \\
0\end{array}$ & & & $\begin{array}{r}.01 \\
.01 \\
.01 \\
.01 \\
.01\end{array}$ \\
\hline $\begin{array}{l}26 \\
27 \\
28 \\
29 \\
30 \\
31\end{array}$ & $\begin{array}{l}.01 \\
.01 \\
.01 \\
.01 \\
.01 \\
.01 \\
.01\end{array}$ & $\begin{array}{l}.19 \\
.28 \\
2.5 \\
1.9 \\
1.0 \\
-.--\end{array}$ & $\begin{array}{l}.56 \\
.44 \\
.23 \\
.23 \\
.32 \\
.56\end{array}$ & $\begin{array}{r}.15 \\
.15 \\
.15 \\
.15 \\
.15 \\
.19\end{array}$ & $\begin{array}{l}1.3 \\
1.3 \\
1.2 \\
1.2 \\
0-\infty \\
-=-\end{array}$ & $\begin{array}{l}2.1 \\
1.6 \\
.93 \\
.86 \\
.78 \\
1.7\end{array}$ & $\begin{array}{l}1.6 \\
1.5 \\
1.3 \\
1.2 \\
1.0 \\
-\end{array}$ & $\begin{array}{l}.05 \\
.05 \\
.03 \\
.03 \\
.03 \\
.05\end{array}$ & $\begin{array}{l}0 \\
0 \\
0 \\
0 \\
0 \\
\end{array}$ & & & $\begin{array}{l}.01 \\
.01 \\
.01 \\
.01 \\
.01 \\
.0\end{array}$ \\
\hline $\begin{array}{l}\text { TOTAL } \\
\text { MEAN } \\
\text { MAX } \\
\text { MIN } \\
\text { AC }=F T\end{array}$ & $\begin{array}{r}.64 \\
.021 \\
.09 \\
0 \\
1.3\end{array}$ & $\begin{array}{r}7.78 \\
.26 \\
2.5 \\
.01 \\
15\end{array}$ & $\begin{array}{r}11.51 \\
.37 \\
1.3 \\
0 \\
23\end{array}$ & $\begin{array}{r}9.62 \\
.31 \\
.62 \\
.07 \\
19\end{array}$ & $\begin{array}{r}125.39 \\
4.32 \\
21 \\
.15 \\
249\end{array}$ & $\begin{array}{r}106.17 \\
3.42 \\
11 \\
.78 \\
211\end{array}$ & $\begin{array}{r}75.34 \\
2.51 \\
11 \\
.56 \\
149\end{array}$ & $\begin{array}{r}11.81 \\
.38 \\
1.4 \\
.03 \\
23\end{array}$ & $\begin{array}{r}.37 \\
.012 \\
.05 \\
0 \\
.7\end{array}$ & $\begin{array}{l}0 \\
0 \\
0 \\
0 \\
0\end{array}$ & $\begin{array}{l}0 \\
0 \\
0 \\
0 \\
0\end{array}$ & $\begin{array}{r}6.41 \\
.21 \\
4.0 \\
0 \\
13\end{array}$ \\
\hline
\end{tabular}

CAL YR 1975 TOTAL 703.43 MEAN 1.93 MAX 31 MIN O AC-FT 1400 WTR YR 1976 TOTAL 355.04 MEAN 97 MAX 21 MIN O AC-FT 704 
COMBINED DISCHARGE, IN CUBIC FEET PER SECOND, OF PAUMA CREEK AND PAUMA VALLEY WATER CO.'S DIVERSION NEAR PAUMA VALLEY, CA, WATER YEAR OCTOBER 1975 TO SEPTEMBER 1976

DISCHARGE, IN CUBIC FEET PER SECOND, WATER YEAR OCTOBER 1975 TO SEPTEMBER 1976 MEAN VALUES

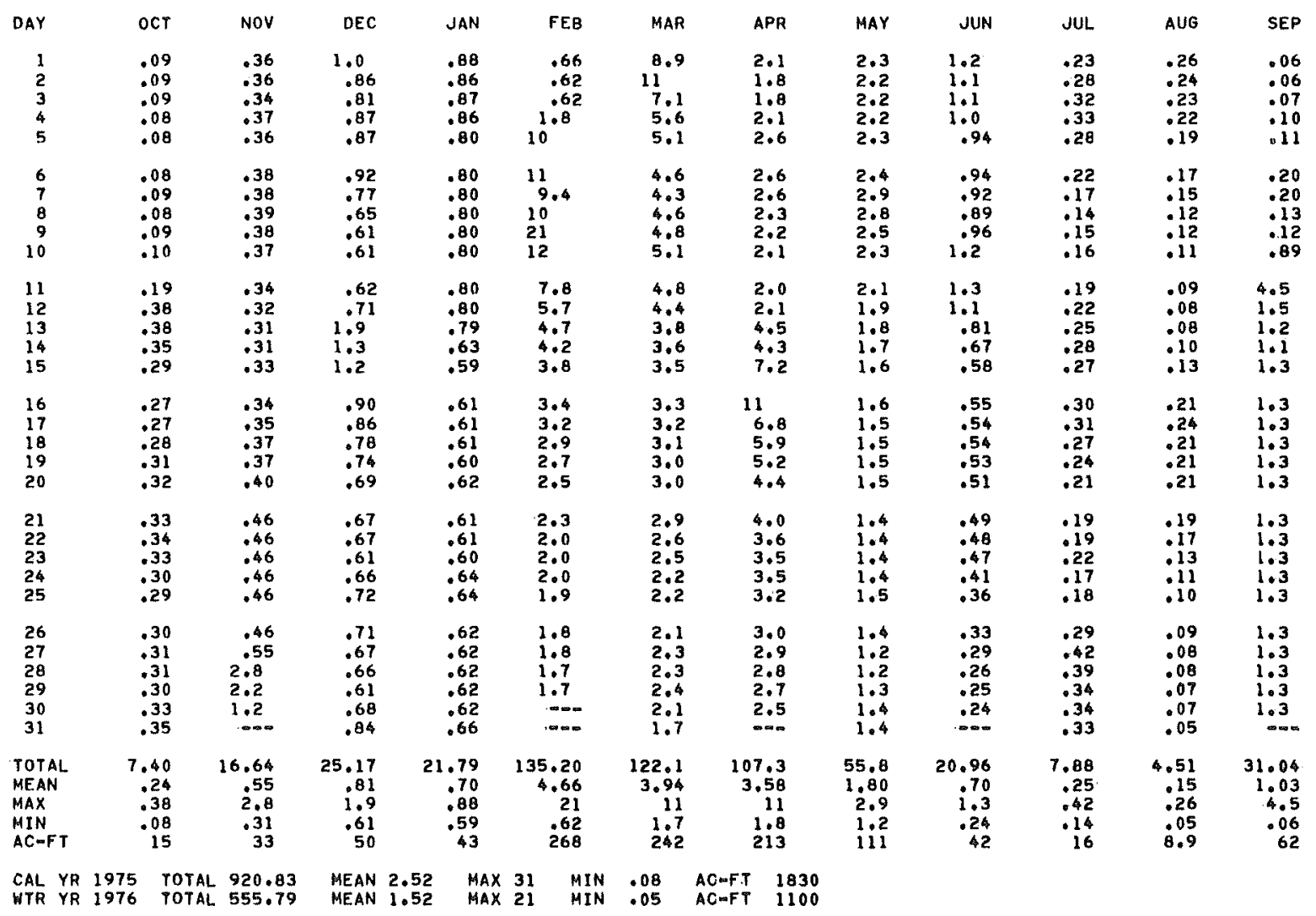


11040000 SAN LUIS REY RIVER AT MONSERATE NARROWS, NEAR PALA, CA

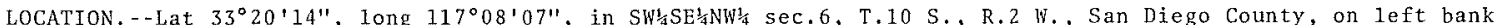
$4 \mathrm{mi}(6 \mathrm{~km})$ southwest of pala, $6 \mathrm{mi}(10 \mathrm{~km})$ northeast of Bonsall, and $27 \mathrm{mi}$ ( $43 \mathrm{~km})$ downstrean from Lake

Henshaw,
DRAINAGE AREA. $-373 \mathrm{mi}^{2}\left(966 \mathrm{~km}^{2}\right)$.

PERIOD OF RECORD,--December 1935 to March 1938 (fragmentary), April 1938 to November 1941 , October 1946 to current year.

GAGE - -Water-stage recorder, Datum of gage is $270.82 \mathrm{ft}(82.546 \mathrm{~m}$ ) above mean sea 1 evel (1evels by State of California). Prior to October 1946, at same site at different datum. 0ct, 22, 1946, to Nov. 30 , 1954, at datum $1.0 \mathrm{ft}(0.30 \mathrm{~m})$ higher.

REMARKS,--Records fair. Flow regulated by Lake Henshaw, capacity, 194,300 acre-ft (240 hm $\left.{ }^{3}\right)$. Several diversions above station.

AVERAGE DISCHARGE, - -33 years (water years $1939-41,1947-76), 6.19 \mathrm{ft}^{3} / \mathrm{s}\left(0.175 \mathrm{~m}^{3} / \mathrm{s}\right), 4,480 \mathrm{acre}-\mathrm{ft} / \mathrm{yr}$ $\left(5.52 \mathrm{hm}^{3} / \mathrm{yr}\right)$

EXTREMES FOR PERIOD OF RECORD. - Maximum discharge since $1946,7,000 \mathrm{ft}^{3} / \mathrm{s}\left(198 \mathrm{~m}^{3} / \mathrm{s}\right) \mathrm{Dec}$. 6 , 1966 , gage height, $6.70 \mathrm{ft}(2.042 \mathrm{~m})$; maximum gage height, $8.7 \mathrm{ft}(2.65 \mathrm{~m})$ Feb. 7,1937 , datum then in use, discharge not determined; no flow at times in most years.

EXTREMES FOR CURRENT YEAR.--Maximum discharge, $22 \mathrm{ft}^{3} / \mathrm{s}\left(0.62 \mathrm{~m}^{3} / \mathrm{s}\right)$ Mar. 1, gage height, $4.30 \mathrm{ft}(1.308 \mathrm{~m})$; no flow for several months.

DISCHARGE, IN CUBIC FEET PER SECOND, HATER YEAR OCTOEER 1975 TO SEPTEMBER 1976 MEAN VALUES

\begin{tabular}{|c|c|c|c|c|c|c|c|c|c|c|c|c|}
\hline DAY & OCT & NoV & DEC & JAN & FEB & MAR & APR & MAY & JUN & JUL & AUG & SEP \\
\hline $\begin{array}{l}1 \\
2 \\
3 \\
4 \\
5\end{array}$ & & $\begin{array}{l}0 \\
0 \\
0 \\
0 \\
0\end{array}$ & $\begin{array}{r}.11 \\
.19 \\
.13 \\
.13 \\
.16\end{array}$ & $\begin{array}{r}.30 \\
.19 \\
.19 \\
.19 \\
.19\end{array}$ & $\begin{array}{r}.30 \\
.19 \\
.22 \\
1.1 \\
2.4\end{array}$ & $\begin{array}{l}6.3 \\
4.2 \\
7.0 \\
3.8 \\
2.8\end{array}$ & $\begin{array}{l}1.0 \\
1.0 \\
1.0 \\
1.7 \\
1.6\end{array}$ & $\begin{array}{l}.71 \\
1.0 \\
1.0 \\
1.0 \\
1.0\end{array}$ & $\begin{array}{l}.92 \\
.53 \\
.43 \\
.53 \\
.43\end{array}$ & & & $\begin{array}{l}0 \\
0 \\
0 \\
0 \\
0\end{array}$ \\
\hline $\begin{array}{r}6 \\
7 \\
8 \\
9 \\
10\end{array}$ & & $\begin{array}{l}0 \\
0 \\
0 \\
0 \\
0\end{array}$ & $\begin{array}{r}.13 \\
.13 \\
.13 \\
.16 \\
.16\end{array}$ & $\begin{array}{r}.16 \\
.15 \\
.13 \\
.16 \\
.09\end{array}$ & $\begin{array}{c}3.3 \\
3.0 \\
10 \\
19 \\
4.7\end{array}$ & $\begin{array}{l}2.5 \\
2.4 \\
2.2 \\
2.2 \\
2.1\end{array}$ & $\begin{array}{l}1.4 \\
1.4 \\
1.3 \\
1.3 \\
1.3\end{array}$ & $\begin{array}{r}1.0 \\
1.2 \\
1.1 \\
.92 \\
.71\end{array}$ & $\begin{array}{r}.38 \\
.22 \\
.16 \\
.17 \\
.34\end{array}$ & & & $\begin{array}{l}0 \\
0 \\
0 \\
0 \\
\quad .14\end{array}$ \\
\hline $\begin{array}{l}11 \\
12 \\
13 \\
14 \\
15\end{array}$ & & $\begin{array}{l}0 \\
0 \\
0 \\
0 \\
0\end{array}$ & $\begin{array}{r}.38 \\
.54 \\
.92 \\
.58 \\
.38\end{array}$ & $\begin{array}{r}.07 \\
.19 \\
.22 \\
.26 \\
.22\end{array}$ & $\begin{array}{l}3.3 \\
2.8 \\
2.5 \\
2.2 \\
2.1\end{array}$ & $\begin{array}{l}1.9 \\
1.9 \\
1.7 \\
1.8 \\
1.7\end{array}$ & $\begin{array}{l}1.3 \\
1.7 \\
5.3 \\
2.8 \\
3.3\end{array}$ & $\begin{array}{r}.64 \\
.78 \\
.72 \\
.85 \\
.78\end{array}$ & $\begin{array}{l}.30 \\
.11 \\
.03 \\
.16 \\
.12\end{array}$ & & & $\begin{array}{r}4.1 \\
1.1 \\
.85 \\
.92 \\
.92\end{array}$ \\
\hline $\begin{array}{l}16 \\
17 \\
18 \\
19 \\
20\end{array}$ & & $\begin{array}{l}0 \\
0 \\
0 \\
0 \\
0\end{array}$ & $\begin{array}{r}.38 \\
.38 \\
.38 \\
.38 \\
.43\end{array}$ & $\begin{array}{r}.16 \\
.16 \\
.16 \\
.11 \\
.07\end{array}$ & $\begin{array}{l}2.1 \\
2.1 \\
2.0 \\
2.1 \\
2.0\end{array}$ & $\begin{array}{l}1.5 \\
1.5 \\
1.5 \\
1.5 \\
1.5\end{array}$ & $\begin{array}{l}3.6 \\
2.1 \\
1.8 \\
1.6 \\
1.5\end{array}$ & $\begin{array}{r}.71 \\
.64 \\
1.0 \\
.78 \\
.85\end{array}$ & $\begin{array}{l}.05 \\
0 \\
0 \\
0\end{array}$ & & & $\begin{array}{l}.85 \\
.71 \\
.64 \\
.78 \\
.78\end{array}$ \\
\hline $\begin{array}{l}21 \\
22 \\
23 \\
24 \\
25\end{array}$ & & $\begin{array}{l}0 \\
0 \\
0 \\
0 \\
0\end{array}$ & $\begin{array}{l}.48 \\
.48 \\
.43 \\
.38 \\
.43\end{array}$ & $\begin{array}{l}.06 \\
.06 \\
.05 \\
.04 \\
.04\end{array}$ & $\begin{array}{l}2.0 \\
2.0 \\
2.1 \\
2.1 \\
2.0\end{array}$ & $\begin{array}{l}1.4 \\
1.4 \\
1.2 \\
1.1 \\
1.2\end{array}$ & $\begin{array}{l}1.4 \\
1.2 \\
1.2 \\
1.1 \\
1.1\end{array}$ & $\begin{array}{r}.64 \\
.71 \\
.92 \\
.85 \\
.92\end{array}$ & $\begin{array}{l}0 \\
0 \\
0 \\
0 \\
0\end{array}$ & & & $\begin{array}{r}.85 \\
.78 \\
.64 \\
.58 \\
.58\end{array}$ \\
\hline $\begin{array}{l}26 \\
27 \\
28 \\
29 \\
30 \\
31\end{array}$ & & $\begin{array}{l}0 \\
0 \\
.46 \\
.58 \\
.16 \\
.16\end{array}$ & $\begin{array}{r}.38 \\
.34 \\
.34 \\
.26 \\
.26 \\
.30\end{array}$ & $\begin{array}{l}.04 \\
.04 \\
.06 \\
.07 \\
.26 \\
.43\end{array}$ & $\begin{array}{l}2.0 \\
2.0 \\
1.9 \\
1.9 \\
-\infty \\
=-\infty\end{array}$ & $\begin{array}{l}1.0 \\
1.1 \\
1.1 \\
1.0 \\
.92 \\
.92\end{array}$ & $\begin{array}{l}1.1 \\
1.0 \\
.92 \\
.78 \\
.85 \\
-\end{array}$ & $\begin{array}{l}1.1 \\
1.1 \\
1.5 \\
1.4 \\
1.0 \\
.85\end{array}$ & $\begin{array}{l}0 \\
0 \\
0 \\
0 \\
0 \\
\end{array}$ & & & $\begin{array}{r}.58 \\
.53 \\
.53 \\
.48 \\
.34 \\
.\end{array}$ \\
\hline $\begin{array}{l}\text { TOTAL } \\
\text { MEAN } \\
\text { MAX } \\
\text { MIN } \\
\text { AC }-F T\end{array}$ & $\begin{array}{l}0 \\
0 \\
0 \\
0 \\
0\end{array}$ & $\begin{array}{r}1.20 \\
.040 \\
.58 \\
0 \\
2.4\end{array}$ & $\begin{array}{r}10.26 \\
.33 \\
.92 \\
.11 \\
20\end{array}$ & $\begin{array}{r}4.52 \\
.15 \\
.43 \\
.04 \\
9.0\end{array}$ & $\begin{array}{r}85.41 \\
2.95 \\
19 \\
19 \\
169\end{array}$ & $\begin{array}{r}64.34 \\
2.08 \\
7.0 \\
.92 \\
128\end{array}$ & $\begin{array}{r}48.45 \\
1.62 \\
5.3 \\
.78 \\
96\end{array}$ & $\begin{array}{r}28.38 \\
.92 \\
1.5 \\
.64 \\
56\end{array}$ & $\begin{array}{r}4.88 \\
.16 \\
.92 \\
0 \\
9.7\end{array}$ & $\begin{array}{l}0 \\
0 \\
0 \\
0 \\
0\end{array}$ & $\begin{array}{l}0 \\
0 \\
0 \\
0 \\
0\end{array}$ & $\begin{array}{r}17.68 \\
.59 \\
4.1 \\
0 \\
35\end{array}$ \\
\hline
\end{tabular}

CAL YR 1975 TOTAL 78.54 MEAN .22 MAX $\quad 4.3$ MIN 0 AC 19 FT 156 


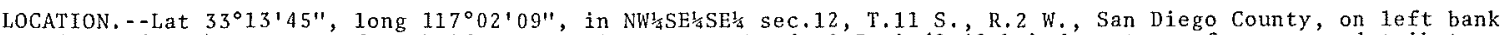
$140 \mathrm{ft}(43 \mathrm{~m})$ upstream from bridge on Valley Center Road, $0.3 \mathrm{mi}(0.48 \mathrm{~km})$ downstream from unnamed tributary, and $0.8 \mathrm{mi}(1.3 \mathrm{~km})$ north of val1ey Center.

DRAINAGE AREA. $-7.65 \mathrm{mi}^{2}\left(19.81 \mathrm{~km}^{2}\right)$.

PERIOD OF RECORD. - Apri1 1970 to current year.

GAGE. - Water-stage recorder. Datum of gage is $1,279.99 \mathrm{ft}(390.141 \mathrm{~m})$ above mean sea level (San Diego County Special District Services bench mark).

REMARKS. - Records good. No regulation above station. Some pumping for irrigation above station.

AVERAGE DISCHARGE. -6 years, $0.34 \mathrm{ft}^{3} / \mathrm{s}\left(0.010 \mathrm{~m}^{3} / \mathrm{s}\right), 246 \mathrm{acre}-\mathrm{ft} / \mathrm{yr}\left(303,000 \mathrm{~m}^{3} / \mathrm{yr}^{2}\right)$.

EXTREMES FOR PERIOD OF RECORD.--Maximum discharge, $304 \mathrm{ft}^{3} / \mathrm{s}\left(8.61 \mathrm{~m}^{3} / \mathrm{s}\right) \mathrm{Jan}$. 8 , 1974 , gage height, $3.86 \mathrm{ft}$ $(1.177 \mathrm{~m})$; no flow for part of each year.

EXTREMES OUTSIDE PERIOD OF RECORD.--Flood of Jan. $25,1969,990 \mathrm{ft}^{3} / \mathrm{s}\left(28 \mathrm{~m}^{3} / \mathrm{s}\right)$, by San Diego County Special District Services.

EXTREMES FOR CURRENT YEAR.--Peak discharges above base of $40 \mathrm{ft}^{3} / \mathrm{s}\left(1.13 \mathrm{~m}^{3} / \mathrm{s}\right)$ and maximum (*), based on slopeconveyance measurement of peak flow:

\begin{tabular}{cccccc} 
Date & Time & \multicolumn{2}{c}{ Discharge } & \multicolumn{2}{c}{ Gage height } \\
& & $\left.\mathrm{ft}^{3} / \mathrm{s}\right)$ & $\left(\mathrm{m}^{3} / \mathrm{s}\right)$ & $(\mathrm{ft})$ & $(\mathrm{m})$ \\
Feb.8 & 2230 & $* 165$ & 4.67 & 3.91 & 1.192 \\
Mar. 3 & 0145 & 67 & 1.90 & 3.60 & 1.097
\end{tabular}

Minimum daily discharge, no flow during parts of October, June to September.

DISCHARGE, IN CUBIC FEET PER SECOND, WATER YEAR OCTOBER 1975 TO SEPTEMBER 1976

\begin{tabular}{|c|c|c|c|c|c|c|c|c|c|c|c|c|}
\hline DAY & OCT & NOV & DEC & JAN & FEB & MAR & APR & MAY & JUN & JUL & AUG & SEP \\
\hline $\begin{array}{l}1 \\
2 \\
3 \\
4 \\
5\end{array}$ & $\begin{array}{l}0 \\
0 \\
0 \\
0 \\
0\end{array}$ & $\begin{array}{l}.03 \\
.02 \\
.02 \\
.02 \\
.02\end{array}$ & $\begin{array}{l}.05 \\
.05 \\
.05 \\
.06 \\
.06\end{array}$ & $\begin{array}{l}.04 \\
.04 \\
.05 \\
.05 \\
.05\end{array}$ & $\begin{array}{l}.04 \\
.05 \\
.05 \\
.13 \\
.97\end{array}$ & $\begin{array}{c}12 \\
1.7 \\
21 \\
1.3 \\
.67\end{array}$ & $\begin{array}{l}.06 \\
.07 \\
.17 \\
.10 \\
.09\end{array}$ & $\begin{array}{l}.04 \\
.04 \\
.02 \\
.01 \\
.04\end{array}$ & $\begin{array}{l}.07 \\
.06 \\
.05 \\
.05 \\
.05\end{array}$ & $\begin{array}{l}0 \\
0 \\
0 \\
0 \\
0\end{array}$ & & $\begin{array}{l}0 \\
0 \\
0 \\
0 \\
0\end{array}$ \\
\hline $\begin{array}{r}6 \\
7 \\
8 \\
9 \\
10\end{array}$ & $\begin{array}{l}0 \\
0 \\
0 \\
0 \\
0\end{array}$ & $\begin{array}{l}.02 \\
.02 \\
.02 \\
.02 \\
.01\end{array}$ & $\begin{array}{l}.05 \\
.05 \\
.05 \\
.05 \\
.05\end{array}$ & $\begin{array}{l}.05 \\
.05 \\
.05 \\
.04 \\
.04\end{array}$ & $\begin{array}{l}3.2 \\
1.6 \\
35 \\
31 \\
1.4\end{array}$ & $\begin{array}{r}.45 \\
.32 \\
.27 \\
.28 \\
.24\end{array}$ & $\begin{array}{l}.09 \\
.07 \\
.07 \\
.05 \\
.06\end{array}$ & $\begin{array}{l}.05 \\
.05 \\
.06 \\
.05 \\
.06\end{array}$ & $\begin{array}{l}.04 \\
.04 \\
.04 \\
.04 \\
.05\end{array}$ & $\begin{array}{l}0 \\
0 \\
0 \\
0.05\end{array}$ & & $\begin{array}{l}0 \\
0 \\
0 \\
0 \\
6.0\end{array}$ \\
\hline $\begin{array}{l}11 \\
12 \\
13 \\
14 \\
15\end{array}$ & $\begin{array}{l}0 \\
.01 \\
.01 \\
.01 \\
0\end{array}$ & $\begin{array}{l}.02 \\
.01 \\
.01 \\
.01 \\
.01\end{array}$ & $\begin{array}{l}.05 \\
.06 \\
.06 \\
.06 \\
.06\end{array}$ & $\begin{array}{l}.04 \\
.04 \\
.05 \\
.05 \\
.05\end{array}$ & $\begin{array}{l}.29 \\
.21 \\
.15 \\
.12 \\
.10\end{array}$ & $\begin{array}{l}.23 \\
.20 \\
.14 \\
.13 \\
.11\end{array}$ & $\begin{array}{l}.06 \\
.07 \\
2.2 \\
.46 \\
3.8\end{array}$ & $\begin{array}{l}.05 \\
.05 \\
.05 \\
.05 \\
.05\end{array}$ & $\begin{array}{l}.05 \\
.04 \\
.04 \\
.04 \\
.04\end{array}$ & $\begin{array}{l}0 \\
0 \\
0 \\
0 \\
0\end{array}$ & & $\begin{array}{l}.50 \\
.14 \\
.12 \\
.12 \\
.11\end{array}$ \\
\hline $\begin{array}{l}16 \\
17 \\
18 \\
19 \\
20\end{array}$ & $\begin{array}{l}0 \\
0 \\
0 \\
0 \\
.01\end{array}$ & $\begin{array}{l}.02 \\
.03 \\
.03 \\
.03 \\
.02\end{array}$ & $\begin{array}{l}.06 \\
.05 \\
.06 \\
.06 \\
.07\end{array}$ & $\begin{array}{l}.04 \\
.04 \\
.04 \\
.04 \\
.04\end{array}$ & $\begin{array}{l}.09 \\
.07 \\
.06 \\
.06 \\
.04\end{array}$ & $\begin{array}{l}.08 \\
.08 \\
.07 \\
.07 \\
.07\end{array}$ & $\begin{array}{l}2.0 \\
.30 \\
.17 \\
.10 \\
.08\end{array}$ & $\begin{array}{l}.04 \\
.05 \\
.07 \\
.06 \\
.05\end{array}$ & $\begin{array}{l}.03 \\
.02 \\
.02 \\
.01 \\
.02\end{array}$ & $\begin{array}{l}.01 \\
.01 \\
0 \\
0 \\
0\end{array}$ & & $\begin{array}{l}.09 \\
.08 \\
.08 \\
.11 \\
.07\end{array}$ \\
\hline $\begin{array}{l}21 \\
22 \\
23 \\
24 \\
25\end{array}$ & $\begin{array}{l}.01 \\
.01 \\
.01 \\
.01 \\
.01\end{array}$ & $\begin{array}{l}.02 \\
.02 \\
.03 \\
.02 \\
.02\end{array}$ & $\begin{array}{l}.05 \\
.05 \\
.05 \\
.05 \\
.06\end{array}$ & $\begin{array}{l}.05 \\
.04 \\
.05 \\
.05 \\
.05\end{array}$ & $\begin{array}{l}.04 \\
.03 \\
.03 \\
.02 \\
.02\end{array}$ & $\begin{array}{l}.07 \\
.07 \\
.07 \\
.07 \\
.07\end{array}$ & $\begin{array}{l}.08 \\
.07 \\
.07 \\
.06 \\
.07\end{array}$ & $\begin{array}{l}.05 \\
.04 \\
.05 \\
.05 \\
.06\end{array}$ & $\begin{array}{l}.02 \\
.01 \\
.01 \\
0 \\
0\end{array}$ & $\begin{array}{l}0 \\
0 \\
0 \\
0 \\
0\end{array}$ & & $\begin{array}{l}.06 \\
.04 \\
.04 \\
.04 \\
.04\end{array}$ \\
\hline $\begin{array}{l}26 \\
27 \\
28 \\
29 \\
30 \\
31\end{array}$ & $\begin{array}{l}.01 \\
.01 \\
.02 \\
.02 \\
.02 \\
.02\end{array}$ & $\begin{array}{l}.01 \\
.06 \\
.25 \\
.09 \\
.05 \\
.0\end{array}$ & $\begin{array}{l}.06 \\
.06 \\
.06 \\
.04 \\
.05 \\
.05\end{array}$ & $\begin{array}{l}.05 \\
.05 \\
.05 \\
.05 \\
.04 \\
.05\end{array}$ & \begin{tabular}{l}
.02 \\
.02 \\
.02 \\
.02 \\
\hdashline-0 \\
-0.
\end{tabular} & $\begin{array}{l}.08 \\
.08 \\
.08 \\
.07 \\
.06 \\
.06\end{array}$ & $\begin{array}{l}.06 \\
.06 \\
.05 \\
.05 \\
.04 \\
.0\end{array}$ & $\begin{array}{l}.09 \\
.06 \\
.06 \\
.06 \\
.06 \\
.07\end{array}$ & $\begin{array}{l}0 \\
0 \\
0 \\
0 \\
0 \\
-. .-\end{array}$ & $\begin{array}{l}0 \\
0 \\
0 \\
0 \\
0 \\
0\end{array}$ & & $\begin{array}{l}.03 \\
.02 \\
.01 \\
.01 \\
.01 \\
-0\end{array}$ \\
\hline $\begin{array}{l}\text { TOTAL } \\
\text { MEAN } \\
\text { MAX } \\
\text { MIN } \\
\text { AC-FT }\end{array}$ & $\begin{array}{r}.19 \\
.006 \\
.02 \\
0 \\
.4\end{array}$ & $\begin{array}{r}.96 \\
.032 \\
.25 \\
.01 \\
1.9\end{array}$ & $\begin{array}{r}1.69 \\
.055 \\
.07 \\
.04 \\
3.4\end{array}$ & $\begin{array}{r}1.42 \\
.046 \\
.05 \\
.04 \\
2.8\end{array}$ & $\begin{array}{r}74.85 \\
2.58 \\
35 \\
.02 \\
148\end{array}$ & $\begin{array}{r}40.19 \\
2.30 \\
21 \\
.06 \\
80\end{array}$ & $\begin{array}{r}10.68 \\
.36 \\
3.8 \\
.04 \\
21\end{array}$ & $\begin{array}{r}1.59 \\
.051 \\
.09 \\
.01 \\
3.2\end{array}$ & $\begin{array}{r}.84 \\
.028 \\
.07 \\
0 \\
1.7\end{array}$ & $\begin{array}{r}.07 \\
.002 \\
.05 \\
0 \\
.1\end{array}$ & $\begin{array}{l}0 \\
0 \\
0 \\
0 \\
0\end{array}$ & $\begin{array}{r}7.72 \\
.26 \\
6.0 \\
0 \\
15\end{array}$ \\
\hline
\end{tabular}

CAL YR 1975 TOTAL 116.75 MEAN .32 MAX 29 MIN D AC-FT 232

HTR YR 1976 TOTAL 140.20 MEAN:38 MAX 35 MIN O AC-FT 278 


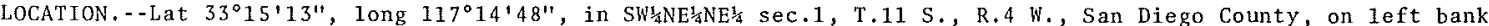
$0.7 \mathrm{mi}(1.1 \mathrm{~km})$ downstream from bridge on State Highway 76 , and 2.8 mi (4.5' km) southwest of Bonsa11.

DRAINAGE AREA, $--513 \mathrm{mi}^{2}\left(1,330 \mathrm{~km}^{2}\right)$.

PERIOD OF RECORD. - -July 1916 to September 1918 (gage heights and discharge measurements only), October 1929 to current year.

GAGE. - Water-stage recorder. Datum of gage is $108.10 \mathrm{ft}(32.949 \mathrm{~m})$ above mean sea 1 eve1, See WSP $1315-\mathrm{B}$, 1735 for history of changes prior to sept. 16, 1946.

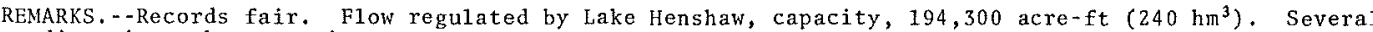
diversions above station.

AVERAGE DISCHARGE, - -47 years, $17.1 \mathrm{ft}^{3} / \mathrm{s}\left(0.484 \mathrm{~m}^{3} / \mathrm{s}\right), 12,390 \mathrm{acre}-\mathrm{ft} / \mathrm{yr}\left(15.3 \mathrm{hm} / \mathrm{yr}^{3}\right)$

EXTREMES FOR PERIOD OF RECORD.--Maximum discharge, $18,100 \mathrm{ft}^{3} / \mathrm{s}\left(513 \mathrm{~m}^{3} / \mathrm{s}\right) \mathrm{Mar}, 3,1938$, gage height, $16,04 \mathrm{ft}$ $(4.889 \mathrm{~m})$, present datum, from rating curve extended above $2,400 \mathrm{ft}^{3} / \mathrm{s}(68.0 \mathrm{~m} / \mathrm{s})$; no f1ow for part of most years.

EXTREMES FOR CURRENT YEAR, - Maximum discharge, $449 \mathrm{ft}^{3} / \mathrm{s}\left(12.7 \mathrm{~m}^{3} / \mathrm{s}\right) \mathrm{Feb} .9$, gage height, $9.02 \mathrm{ft}(2.749 \mathrm{~m})$; minimum daily, $0.32 \mathrm{ft} / \mathrm{s}\left(0.009 \mathrm{~m}^{3} / \mathrm{s}\right)$ Aug. $23-25$, Sept. 3 .

DISCHARGE, IN CUBIC FEET PER SECOND, HATER YEAR OCTOBER 1975 TO SEPTEMBER 1976 MEAN VALUES

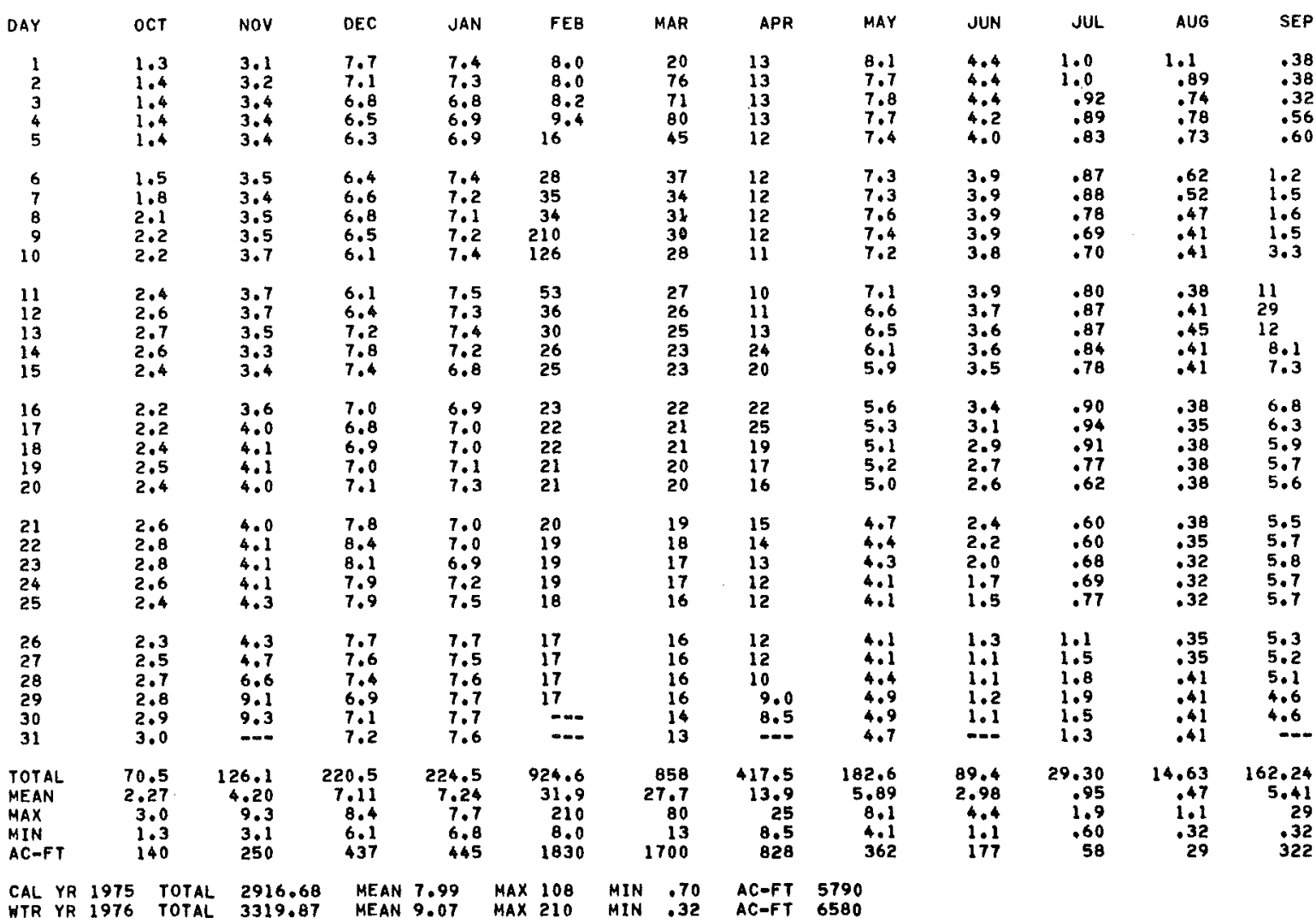


LOCATION, - -Lat $33^{\circ} 12^{\prime} 48^{\prime \prime}$, long $117^{\circ} 22^{\prime} 33^{\prime \prime}$, in SWtsE $\frac{1}{4} S W_{4}^{\prime}$ sec.14, T.11 S., R.5 W., San Diego County, on right bank $0.7 \mathrm{mi}(1.1 \mathrm{~km})$ upstream from bridge on Interstate Highway $5,1.1 \mathrm{mi}$ ( $1.8 \mathrm{~km})$ upstream from mouth, and 1.2 mi $(1.9 \mathrm{~km})$ north of Oceanside.

DRAINAGE AREA. $-558 \mathrm{mi}^{2}\left(1,450 \mathrm{~km}^{2}\right)$.

WATER-DISCHARGE RECORDS

PERIOD OF RECORD.--April 1912 to September 1914 (pub1ished as "near oceanside"), January 19l6, October 1929 to January 1942, october 1946 to current year.

GAGE. - Water-stage recorder. Altitude of gage is $20 \mathrm{ft}(6.1 \mathrm{~m})$, from topographic map. Apri1 1912 to September 1914, nonrecording gage at site $0.8 \mathrm{mi}(1.3 \mathrm{~km})$ upstream at different datum. January 1916 nonrecording gage $0.2 \mathrm{mi}(0.3 \mathrm{~km})$ downstream at different datum.

REMARKS.--Records fair. Flow regulated by Lake Henshaw, capacity, 194,300 acre-ft (240 hm ${ }^{3}$ ). Several diversions for irrigation and domestic use above station. AVERAGE DISCHARGE represents flow to ocean during period of record regardless of upstream development.

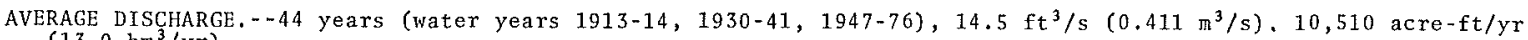
$\left(13.0 \mathrm{hm}^{3} / \mathrm{yr}^{2}\right)$.

EXTREMES FOR PERIOD OF RECORD.--Maximun discharge, 95,600 $\mathrm{ft}^{3} / \mathrm{s}\left(2,710 \mathrm{~m}^{3} / \mathrm{s}\right) \mathrm{Jan}, 27,1916$, from hydrograph based on discharge measurements; no flow for several months in some years.

EXTREMES FOR CURRENT YEAR,-MaXimum discharge, $154 \mathrm{ft}^{3} / \mathrm{s}\left(4.36 \mathrm{~m}^{3} / \mathrm{s}\right)$ Feb. 10 , gage height, $8.74 \mathrm{ft}(2.664 \mathrm{~m})$ minimum daily, $0.80 \mathrm{ft}^{3} / \mathrm{s}\left(0.023 \mathrm{~m}^{3} / \mathrm{s}\right)$ Aug: $22-24$.

DISCHARGE, IN CUBIC FEET PER SECOND, WATER YEAR OCTOBER 1975 TO SEPTEMBER 1976 MEAN VALUES

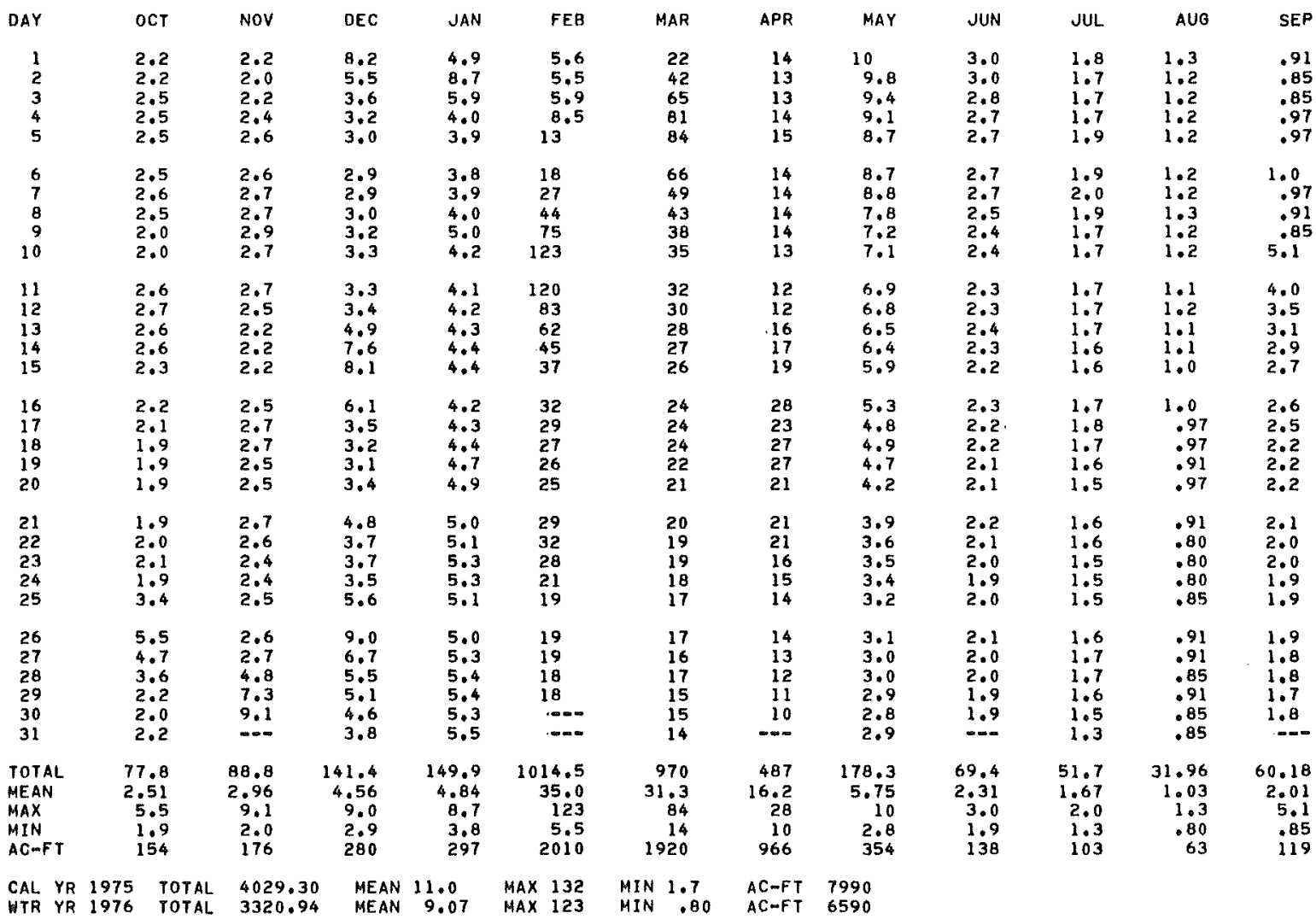


PERIOD OF RECORD.--Water year 1969 to current year.

WATER TEMPERATURES: Water year 1971 to current year.

SEDIMENT RECORDS: Water year 1969 to current year.

PERIOD OF DAILY RECORD

WATER TEMPERATURES: October 1970 to current year.

SEDINENT RECORDS: October 1969 to current year.

EXTREMES FOR PERIOD OF DAILY RECORD.--

SEDIMENT CONCENTRATIONS (Water year 1969 to current year): Maximum daily mean, $1,220 \mathrm{mg} / 1 \mathrm{Mar}$. 2 , 1970;

minimum daily, $2 \mathrm{mg} / 1$ on several days in 1972 .

SEDIMENT DISCHARGE (Water year 1969 to current year): Maximum daily, 943 tons ( 855 tonnes) Mar. 2 , 1970; minimum daily, 0.01 ton (0.01 tonne) Nov. 4, 1969 .

EXTREMES FOR CURRENT YEAR.--

SEDIMENT CONCENTRATIONS: Maximum daily mean, $72 \mathrm{mg} / 1$ March 5 ; minimum daily, $2 \mathrm{mg} / 1$ on several days during year.

SEDIMENT DISCHARGE: Maximum daily, 16 tons (14.5 tonnes) March 5; minimum daily, 0.02 ton (0.03 tonne) on several days in October, November and December.

TEMPERATURE (DEG, C) OF WATER, WATER YEAR OCTOBER 1975 TO SEPTEMBER 1976 ONCE-DAILY

\begin{tabular}{|c|c|c|c|c|c|c|c|c|c|c|c|c|}
\hline DAY & OCT & NOV & DEC & JAN & FEB & MAR & APR & MAY & JUN & JUL & AUG & SEP \\
\hline $\begin{array}{l}1 \\
2 \\
3 \\
4 \\
5\end{array}$ & 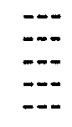 & $\begin{array}{r}--- \\
---5 \\
14.5\end{array}$ & $\begin{array}{l}=-\overline{0} \\
9.0 \\
=-0 \\
=--\end{array}$ & 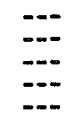 & $\begin{array}{r}- \\
11.0 \\
12.0 \\
13.0\end{array}$ & $\begin{array}{l}15.0 \\
12.5 \\
14.0 \\
14.0 \\
14.0\end{array}$ & $\begin{array}{r}=-.0 \\
14.0 \\
13.0\end{array}$ & $\begin{array}{r}13.0 \\
13.0 \\
17.0 \\
-\infty\end{array}$ & $\begin{array}{r}m-\infty \\
m-\infty \\
21.0 \\
\infty=-\infty\end{array}$ & $\begin{array}{r}19.0 \\
=-0 \\
=-0\end{array}$ & $\begin{array}{r}=- \\
22.0 \\
=-- \\
=--\end{array}$ & $\begin{array}{r}19.0 \\
18.0\end{array}$ \\
\hline $\begin{array}{r}6 \\
7 \\
8 \\
9 \\
10\end{array}$ & $\begin{array}{r}-=- \\
-0 \\
-0.0 \\
15.0\end{array}$ & $\begin{array}{r}14.5 \\
-.- \\
-=- \\
13.5\end{array}$ & $\begin{array}{l}=- \\
--5 \\
9.5 \\
---\end{array}$ & $\begin{array}{l}=-. \\
\overline{7.5} \\
7.5 \\
-.-0\end{array}$ & $\begin{array}{l}12.5 \\
14.0 \\
14.0 \\
14.0 \\
14.0\end{array}$ & 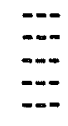 & $\begin{array}{r}15.0 \\
-0 \\
--0\end{array}$ & $\begin{array}{r}16.0 \\
16.0\end{array}$ & $\begin{array}{r}-0 . \\
21.0 \\
0.0 \\
16.5\end{array}$ & $\begin{array}{r}20- \\
23.0 \\
22.0 \\
2 .-\end{array}$ & $\begin{array}{r}21.0 \\
-0 \\
20.0 \\
-0\end{array}$ & $\begin{array}{r}19.0 \\
22.0 \\
21.0\end{array}$ \\
\hline $\begin{array}{l}11 \\
12 \\
13 \\
14 \\
15\end{array}$ & $\begin{array}{l}=- \\
=- \\
=-\end{array}$ & $\begin{array}{r}-0 \\
11.5 \\
---\end{array}$ & $\begin{array}{l}=- \\
=-- \\
=-- \\
=-\end{array}$ & $\begin{array}{l}--.5 \\
8.5 \\
--. \\
--.\end{array}$ & $\begin{array}{r}14.0 \\
14.0 \\
=-0 \\
=-\end{array}$ & $\begin{array}{r}14.5 \\
15.0 \\
=-\end{array}$ & $\begin{array}{r}10.0 \\
14.0 \\
13.0 \\
14.0\end{array}$ & $\begin{array}{r}17.0 \\
18.0 \\
0\end{array}$ & $\begin{array}{r}22.0 \\
0.0 \\
22.0 \\
0.0\end{array}$ & $\begin{array}{r}18.0 \\
=- \\
=-\end{array}$ & $\begin{array}{r}19.0 \\
22.0 \\
-\end{array}$ & $\begin{array}{r}22.0 \\
21.0 \\
-0\end{array}$ \\
\hline $\begin{array}{l}16 \\
17 \\
18 \\
19 \\
20\end{array}$ & $\begin{array}{l}=- \\
=-- \\
=-\end{array}$ & $\begin{array}{r}12.5 \\
-0 . \\
-0\end{array}$ & $\begin{array}{l}=- \\
=- \\
=- \\
=-\end{array}$ & $\begin{array}{r}11.0 \\
-0 . \\
13.0\end{array}$ & $\begin{array}{r}14.0 \\
=-0 \\
13.5\end{array}$ & $\begin{array}{r}14.0 \\
14.0\end{array}$ & 14.0 & $\begin{array}{r}17.0 \\
0 \\
\cdots\end{array}$ & $\begin{array}{r}-0 \\
23.0 \\
\therefore-0 \\
=-\infty\end{array}$ & $\begin{array}{r}21.0 \\
=00 \\
21.0\end{array}$ & $\begin{array}{r}24.0 \\
=0 \\
19.0 \\
=-0\end{array}$ & $\begin{array}{r}-.0 \\
21.0 \\
-\infty\end{array}$ \\
\hline $\begin{array}{l}21 \\
22 \\
23 \\
24 \\
25\end{array}$ & $\begin{array}{l}=-\infty \\
=-\infty \\
=-- \\
--\infty\end{array}$ & $\begin{array}{l}8.5 \\
=-5 \\
=-- \\
---\end{array}$ & $\begin{array}{l}=- \\
=-- \\
-\cdots- \\
---\end{array}$ & $\begin{array}{r}-\infty \\
12.0 \\
--\infty\end{array}$ & $\begin{array}{r}-.0 \\
14.0 \\
-0.0\end{array}$ & $\begin{array}{r}-\infty \\
17.0 \\
-\infty\end{array}$ & $\begin{array}{r}-\infty \\
18.0 \\
-\infty \\
-\infty\end{array}$ & $\begin{array}{r}19.0 \\
=-0 \\
20.0\end{array}$ & $\begin{array}{r}22.0 \\
-\ldots \\
-0 \\
21.0\end{array}$ & $\begin{array}{r}=-- \\
=-0 \\
23.0 \\
=-0\end{array}$ & $\begin{array}{r}-\infty \\
20.0 \\
=-\infty \\
=-\infty\end{array}$ & $\begin{array}{r}20.0 \\
--0 \\
20.0\end{array}$ \\
\hline $\begin{array}{l}26 \\
27 \\
28 \\
29 \\
30 \\
31\end{array}$ & 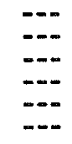 & $\begin{array}{r}9.5 \\
-0.5 \\
10.5 \\
=--\end{array}$ & $\begin{array}{l}=-5 \\
=-- \\
9.5 \\
=-5\end{array}$ & $\begin{array}{r}11.0 \\
=-0 \\
=-0 \\
11.0\end{array}$ & $\begin{array}{r}-0- \\
14.0 \\
-0-0 \\
=-0\end{array}$ & $\begin{array}{r}-0 \\
17.0 \\
=-0 \\
=-\infty\end{array}$ & $\begin{array}{l}m-\infty \\
m-\infty \\
=-\infty \\
=-\infty \\
=-\infty \\
=-\infty\end{array}$ & $\begin{array}{l}=-\infty \\
=-\infty \\
=-\infty \\
=-\infty\end{array}$ & $\begin{array}{r}-\infty \\
=0 \\
=-0 \\
=-0 \\
22.0 \\
=0\end{array}$ & $\begin{array}{r}20.0 \\
=-0 \\
=-0 \\
21.0 \\
=-\infty\end{array}$ & $\begin{array}{r}-0.0 \\
19.0 \\
=-0 \\
18.0 \\
=0\end{array}$ & 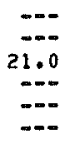 \\
\hline NTH & $m$ & $=--$ & --- & $\ldots-$ & $=-\infty$ & -- & $=\infty$ & $-\infty$ & 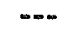 & $=\infty$ & $=-\infty$ & $=\infty$ \\
\hline
\end{tabular}

PARTICLE-SIZE DISTRIBUTION OF SUSPENDED SEDIMENT, WATER YEAR OCTOBER 1975 TO SEPTEMBER 1976

DATE

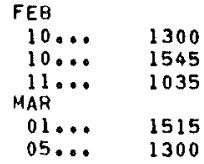

$\begin{array}{cc} & \text { INSTAN- } \\ \text { TANEOUS } \\ \text { TEMPER- } & \text { DIS- } \\ \text { ATURE } & \text { CHARGE }\end{array}$

$\begin{array}{ll}15.0 & 146 \\ 14.0 & 154 \\ 14.0 & 124 \\ 15.0 & 23 \\ 14.0 & 84\end{array}$
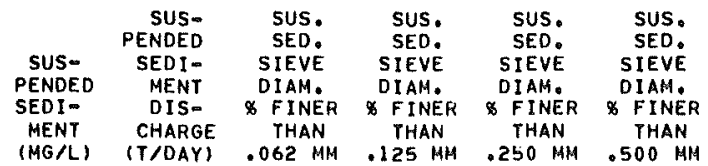

$\begin{array}{rc}44 & 17 \\ 37 & 15 \\ 22 & 7.4 \\ 33 & 2.0 \\ 248 & 56\end{array}$

56
67
98
99
24

$$
\begin{array}{r}
96 \\
97 \\
900
\end{array}
$$

$\begin{array}{rrr}96 & 100 & =0 \\ 97 & 100 & =0 \\ 99 & 100 & =0 \\ 100 & 00 & \\ 90 & 99 & 100\end{array}$


SAN LUIS REY RIVER BASIN

SUSPENDED-5EOIMENT DISCHARGE (TONS/DAY), WATER YEAR OCTOBER 1975 TO SEPTEMAER 1976

\begin{tabular}{|c|c|c|c|c|c|c|c|c|c|}
\hline \multirow[b]{2}{*}{ DAY } & \multicolumn{3}{|c|}{ OCTOBER } & \multicolumn{3}{|c|}{ NOVEMBER } & \multicolumn{3}{|c|}{ DECEMBER } \\
\hline & $\begin{array}{l}\text { MEAN } \\
\text { DISCHARGE. } \\
\text { (CFS) }\end{array}$ & $\begin{array}{l}\text { MEAN } \\
\text { CONCEN- } \\
\text { TRATION } \\
\text { (MG/L) }\end{array}$ & $\begin{array}{l}\text { SEDIMENT } \\
\text { OISCHARGE } \\
\text { (TONS/DAY) }\end{array}$ & $\begin{array}{c}\text { MEAN } \\
\text { OI SCHARGE } \\
\text { (CFS) }\end{array}$ & $\begin{array}{l}\text { MEAN } \\
\text { CONCEN- } \\
\text { TRATION } \\
\text { (MG/L) }\end{array}$ & $\begin{array}{l}\text { SEDIMENT } \\
\text { OISCHARGE } \\
\text { (TONS/OAY) }\end{array}$ & $\begin{array}{l}\text { MEAN } \\
\text { DISCHARGE } \\
\text { (CFS) }\end{array}$ & $\begin{array}{l}\text { MEAN } \\
\text { CONCEN- } \\
\text { TRATION } \\
\text { (MG/L) }\end{array}$ & $\begin{array}{l}\text { SEDIMENT } \\
\text { OISCHARGE } \\
\text { (TONS/OAY) }\end{array}$ \\
\hline $\begin{array}{l}1 \\
2 \\
3 \\
4 \\
5\end{array}$ & $\begin{array}{l}2.2 \\
2.2 \\
2.5 \\
2.5 \\
2.5\end{array}$ & $\begin{array}{r}9 \\
9 \\
10 \\
10 \\
10\end{array}$ & $\begin{array}{l}.05 \\
.05 \\
.07 \\
.07 \\
.07\end{array}$ & $\begin{array}{l}2.2 \\
2.0 \\
2.2 \\
2.4 \\
2.6\end{array}$ & $\begin{array}{l}4 \\
4 \\
4 \\
4 \\
4\end{array}$ & $\begin{array}{l}.02 \\
.02 \\
.02 \\
.03 \\
.03\end{array}$ & $\begin{array}{l}8.2 \\
5.5 \\
3.6 \\
3.2 \\
3.0\end{array}$ & $\begin{array}{r}10 \\
10 \\
8 \\
6 \\
4\end{array}$ & $\begin{array}{l}.22 \\
.15 \\
.08 \\
.05 \\
.03\end{array}$ \\
\hline $\begin{array}{r}6 \\
7 \\
8 \\
9 \\
10\end{array}$ & $\begin{array}{l}2.5 \\
2.6 \\
2.5 \\
2.0 \\
2.0\end{array}$ & $\begin{array}{r}10 \\
11 \\
10 \\
9 \\
9\end{array}$ & $\begin{array}{l}.07 \\
.08 \\
.07 \\
.05 \\
.05\end{array}$ & $\begin{array}{l}2.6 \\
2.7 \\
2.7 \\
2.9 \\
2.7\end{array}$ & $\begin{array}{l}4 \\
4 \\
4 \\
4 \\
3\end{array}$ & $\begin{array}{l}.03 \\
.03 \\
.03 \\
.03 \\
.02\end{array}$ & $\begin{array}{l}2.9 \\
2.9 \\
3.0 \\
3.2 \\
3.3\end{array}$ & $\begin{array}{l}3 \\
3 \\
3 \\
3 \\
4 \\
4\end{array}$ & $\begin{array}{l}.02 \\
.02 \\
.02 \\
.03 \\
.04\end{array}$ \\
\hline $\begin{array}{l}11 \\
12 \\
13 \\
14 \\
15\end{array}$ & $\begin{array}{l}2.6 \\
2.7 \\
2.6 \\
2.6 \\
2.3\end{array}$ & $\begin{array}{l}10 \\
10 \\
10 \\
10 \\
10\end{array}$ & $\begin{array}{l}.07 \\
.07 \\
.07 \\
.07 \\
.06\end{array}$ & $\begin{array}{l}2.7 \\
2.5 \\
2.2 \\
2.2 \\
2.2\end{array}$ & $\begin{array}{l}4 \\
6 \\
7 \\
7 \\
6\end{array}$ & $\begin{array}{l}.03 \\
.04 \\
.04 \\
.04 \\
.04\end{array}$ & $\begin{array}{l}3.3 \\
3.4 \\
4.9 \\
7.6 \\
8.1\end{array}$ & $\begin{array}{l}4 \\
4 \\
7 \\
8 \\
8\end{array}$ & $\begin{array}{l}.04 \\
.04 \\
.09 \\
.16 \\
.17\end{array}$ \\
\hline $\begin{array}{l}16 \\
17 \\
18 \\
19 \\
20\end{array}$ & $\begin{array}{l}2.2 \\
2.1 \\
1.9 \\
1.9 \\
1.9\end{array}$ & $\begin{array}{r}10 \\
10 \\
9 \\
9 \\
9\end{array}$ & $\begin{array}{l}.06 \\
.06 \\
.05 \\
.05 \\
.05\end{array}$ & $\begin{array}{l}2.5 \\
2.7 \\
2.7 \\
2.5 \\
2.5\end{array}$ & $\begin{array}{l}6 \\
5 \\
7 \\
6 \\
7\end{array}$ & $\begin{array}{l}.04 \\
.04 \\
.05 \\
.04 \\
.05\end{array}$ & $\begin{array}{l}6.1 \\
3.5 \\
3.2 \\
3.1 \\
3.4\end{array}$ & $\begin{array}{l}7 \\
5 \\
4 \\
4 \\
5\end{array}$ & $\begin{array}{l}.12 \\
.05 \\
.03 \\
.03 \\
.05\end{array}$ \\
\hline $\begin{array}{l}21 \\
22 \\
23 \\
24 \\
25\end{array}$ & $\begin{array}{l}1.9 \\
2.0 \\
2.1 \\
1.9 \\
3.4\end{array}$ & $\begin{array}{r}9 \\
9 \\
9 \\
9 \\
12\end{array}$ & $\begin{array}{l}.05 \\
.05 \\
.05 \\
.05 \\
.05\end{array}$ & $\begin{array}{l}2.7 \\
2.6 \\
2.4 \\
2.4 \\
2.5\end{array}$ & $\begin{array}{r}10 \\
8 \\
6 \\
4 \\
3\end{array}$ & $\begin{array}{l}.07 \\
.06 \\
.04 \\
.03 \\
.02\end{array}$ & $\begin{array}{l}4.8 \\
3.7 \\
3.7 \\
3.5 \\
5.6\end{array}$ & $\begin{array}{l}5 \\
4 \\
4 \\
4 \\
6\end{array}$ & $\begin{array}{l}.06 \\
.04 \\
.04 \\
.04 \\
.09\end{array}$ \\
\hline $\begin{array}{l}26 \\
27 \\
28 \\
29 \\
30 \\
31\end{array}$ & $\begin{array}{l}5.5 \\
4.7 \\
3.6 \\
2.2 \\
2.0 \\
2.2\end{array}$ & $\begin{array}{r}11 \\
10 \\
7 \\
5 \\
4 \\
4\end{array}$ & $\begin{array}{l}.16 \\
.13 \\
.07 \\
.03 \\
.02 \\
.02\end{array}$ & $\begin{array}{l}2.6 \\
2.7 \\
4.8 \\
7.3 \\
9.1 \\
-.-\end{array}$ & $\begin{array}{r}3 \\
4 \\
8 \\
11 \\
10 \\
-0\end{array}$ & $\begin{array}{l}.02 \\
.03 \\
.10 \\
.22 \\
.25 \\
.\end{array}$ & $\begin{array}{l}9.0 \\
6.7 \\
5.5 \\
5.1 \\
4.6 \\
3.8\end{array}$ & $\begin{array}{l}9 \\
6 \\
5 \\
5 \\
5 \\
5\end{array}$ & $\begin{array}{l}.22 \\
.11 \\
.07 \\
.07 \\
.06 \\
.05\end{array}$ \\
\hline TOTAL & 77.8 & --- & 1.98 & 88.8 & -- & 1.51 & 141.4 & -- & 2.29 \\
\hline
\end{tabular}

\begin{tabular}{|c|c|c|c|c|c|c|c|c|c|}
\hline \multirow[b]{2}{*}{ DAY } & \multicolumn{3}{|c|}{ JANUARY } & \multicolumn{3}{|c|}{ FEBRUARY } & \multicolumn{3}{|c|}{ MARCH } \\
\hline & $\begin{array}{l}\text { MEAN } \\
\text { DISCARGE } \\
\text { (CFS) }\end{array}$ & $\begin{array}{l}\text { MEAN } \\
\text { CONCEN- } \\
\text { TRATION } \\
\text { (MG/L) }\end{array}$ & $\begin{array}{l}\text { SEDIMENT } \\
\text { DISCARGE } \\
\text { (TONS/DAY) }\end{array}$ & $\begin{array}{l}\text { MEAN } \\
\text { OISCHARGE } \\
\text { (CFS) }\end{array}$ & $\begin{array}{l}\text { MEAN } \\
\text { CONCEN- } \\
\text { TRATION } \\
\text { (MG/L) }\end{array}$ & $\begin{array}{l}\text { SEDIMENT } \\
\text { DISCHARGE } \\
\text { (TONS/OAY) }\end{array}$ & $\begin{array}{l}\text { MEAN } \\
\text { DISCHARGE } \\
\text { (CFS) }\end{array}$ & $\begin{array}{l}\text { MEAN } \\
\text { CONCEN- } \\
\text { TRATION } \\
\text { (MG/L) }\end{array}$ & $\begin{array}{l}\text { SEDIMENT } \\
\text { DISCARGE } \\
\text { (TONS/DAY) }\end{array}$ \\
\hline $\begin{array}{l}1 \\
2 \\
3 \\
4 \\
5\end{array}$ & $\begin{array}{l}4.9 \\
8.7 \\
5.9 \\
4.0 \\
3.9\end{array}$ & $\begin{array}{l}7 \\
9 \\
7 \\
5 \\
4\end{array}$ & $\begin{array}{l}.09 \\
.21 \\
.11 \\
.05 \\
.04\end{array}$ & $\begin{array}{r}5.6 \\
5.5 \\
5.9 \\
8.5 \\
13\end{array}$ & $\begin{array}{l}2 \\
2 \\
2 \\
4 \\
4\end{array}$ & $\begin{array}{l}.03 \\
.03 \\
.03 \\
.09 \\
.14\end{array}$ & $\begin{array}{l}22 \\
42 \\
65 \\
81 \\
84\end{array}$ & $\begin{array}{r}14 \\
10 \\
8 \\
9 \\
72\end{array}$ & $\begin{array}{r}1.0 \\
1: 1 \\
1: 4 \\
1.99 \\
16\end{array}$ \\
\hline $\begin{array}{r}6 \\
7 \\
8 \\
9 \\
10\end{array}$ & $\begin{array}{l}3.8 \\
3.9 \\
4.0 \\
5.0 \\
4.2\end{array}$ & $\begin{array}{l}4 \\
3 \\
3 \\
3 \\
3\end{array}$ & $\begin{array}{l}.04 \\
.03 \\
.03 \\
.04 \\
.03\end{array}$ & $\begin{array}{r}18 \\
27 \\
44 \\
75 \\
123\end{array}$ & $\begin{array}{r}6 \\
5 \\
10 \\
12 \\
25\end{array}$ & $\begin{array}{c}.29 \\
.36 \\
1.44 \\
2.4 \\
9.4\end{array}$ & $\begin{array}{l}66 \\
49 \\
43 \\
38 \\
35\end{array}$ & $\begin{array}{r}16 \\
11 \\
7 \\
5 \\
3\end{array}$ & $\begin{array}{c}2.9 \\
1.5 \\
.81 \\
.51 \\
.28\end{array}$ \\
\hline $\begin{array}{l}11 \\
12 \\
13 \\
14 \\
15\end{array}$ & $\begin{array}{l}4: 1 \\
4: 2 \\
4: 3 \\
4: 4 \\
4: 4\end{array}$ & $\begin{array}{l}2 \\
2 \\
2 \\
3 \\
4\end{array}$ & $\begin{array}{l}.02 \\
.02 \\
.02 \\
.04 \\
.05\end{array}$ & $\begin{array}{r}120 \\
83 \\
62 \\
45 \\
37\end{array}$ & $\begin{array}{r}21 \\
8 \\
7 \\
6 \\
5\end{array}$ & $\begin{array}{l}7.0 \\
1.0 \\
1.2 \\
.73 \\
.50\end{array}$ & $\begin{array}{l}32 \\
30 \\
28 \\
27 \\
26\end{array}$ & $\begin{array}{l}3 \\
2 \\
2 \\
2 \\
3\end{array}$ & $\begin{array}{l}: 26 \\
: 16 \\
: 15 \\
: 15 \\
.21\end{array}$ \\
\hline $\begin{array}{l}16 \\
17 \\
18 \\
19 \\
20\end{array}$ & $\begin{array}{l}4.2 \\
4.3 \\
4.4 \\
4.7 \\
4.9\end{array}$ & $\begin{array}{l}4 \\
4 \\
4 \\
5 \\
5\end{array}$ & $\begin{array}{l}.05 \\
.05 \\
.05 \\
.06 \\
.07\end{array}$ & $\begin{array}{l}32 \\
29 \\
27 \\
26 \\
25\end{array}$ & $\begin{array}{l}4 \\
3 \\
3 \\
3 \\
3\end{array}$ & $\begin{array}{l}.35 \\
.23 \\
.22 \\
.21 \\
.20\end{array}$ & $\begin{array}{l}24 \\
24 \\
24 \\
22 \\
21\end{array}$ & $\begin{array}{l}3 \\
4 \\
4 \\
4 \\
4\end{array}$ & $\begin{array}{l}.19 \\
: 26 \\
.26 \\
.24 \\
.23\end{array}$ \\
\hline $\begin{array}{l}21 \\
22 \\
23 \\
24 \\
25\end{array}$ & $\begin{array}{l}5.0 \\
5.1 \\
5.3 \\
5.3 \\
5.1\end{array}$ & $\begin{array}{l}4 \\
3 \\
2 \\
2 \\
3\end{array}$ & $\begin{array}{l}.05 \\
.04 \\
.03 \\
.03 \\
.04\end{array}$ & $\begin{array}{l}29 \\
32 \\
28 \\
21 \\
19\end{array}$ & $\begin{array}{l}5 \\
6 \\
5 \\
4 \\
4\end{array}$ & $\begin{array}{l}.39 \\
.52 \\
.38 \\
.23 \\
.21\end{array}$ & $\begin{array}{l}20 \\
19 \\
19 \\
18 \\
17\end{array}$ & $\begin{array}{l}3 \\
3 \\
3 \\
3 \\
4\end{array}$ & $\begin{array}{l}.16 \\
: 15 \\
.15 \\
: 15 \\
: 18\end{array}$ \\
\hline $\begin{array}{l}26 \\
27 \\
28 \\
29 \\
30 \\
31\end{array}$ & $\begin{array}{l}5.0 \\
5.3 \\
5.4 \\
5.4 \\
5.3 \\
5.5\end{array}$ & $\begin{array}{l}3 \\
3 \\
3 \\
3 \\
2 \\
2\end{array}$ & $\begin{array}{l}.04 \\
.04 \\
.04 \\
.04 \\
.03 \\
.03\end{array}$ & $\begin{array}{c}19 \\
19 \\
18 \\
18 \\
\ldots-.\end{array}$ & $\begin{array}{r}\mathbf{4} \\
\mathbf{3} \\
\mathbf{3} \\
\mathbf{3} \\
\hdashline-. \\
\hdashline-.\end{array}$ & $\begin{array}{r}.21 \\
.15 \\
: 15 \\
.15 \\
-. . \\
-. .\end{array}$ & $\begin{array}{l}17 \\
16 \\
17 \\
15 \\
15 \\
14\end{array}$ & $\begin{array}{l}4 \\
4 \\
4 \\
4 \\
4\end{array}$ & $\begin{array}{l}: 18 \\
: 17 \\
: 18 \\
: 16 \\
: 16 \\
: 15\end{array}$ \\
\hline OTAL & 149.9 & $-\cdots$ & 1.51 & 1014.5 & $\cdots$ & 29.00 & 970 & $\cdots$ & 31.30 \\
\hline
\end{tabular}


11042000 SAN LUIS REY RIVER AT OCEANSIDE, CA- Continued

SUSPENDED-SEOIMENT DISCHARGE (TONS/OAY), HATER YEAR OCTOBER 1975 TO SEPTEMBER 1976

\begin{tabular}{|c|c|c|c|c|c|c|c|c|c|}
\hline & & APRIL & & & MAY & & & JUNE & \\
\hline DAY & $\begin{array}{l}\text { MEAN } \\
\text { DISCHARGE } \\
\text { (CFS) }\end{array}$ & $\begin{array}{l}\text { MEAN } \\
\text { CONCEN- } \\
\text { TRATION } \\
(H G / L)\end{array}$ & $\begin{array}{l}\text { SEDIMENT } \\
\text { DISCHARGE } \\
\text { (TONS/DAY) }\end{array}$ & $\begin{array}{l}\text { MEAN } \\
\text { OISCHARGE } \\
\text { (CFS) }\end{array}$ & $\begin{array}{l}\text { MEAN } \\
\text { CONCEN- } \\
\text { TRATION } \\
\text { (MG/L) }\end{array}$ & $\begin{array}{l}\text { SEDIMENT } \\
\text { DISCHARGE } \\
\text { (TONS/DAY) }\end{array}$ & $\begin{array}{l}\text { MEAN } \\
\text { DISCHARGE } \\
\text { (CFS) }\end{array}$ & $\begin{array}{l}\text { MEAN } \\
\text { CONCEN- } \\
\text { TRATION } \\
\text { (MG/L) }\end{array}$ & $\begin{array}{l}\text { SEDIMENT } \\
\text { OISCHARGE } \\
\text { (TONS/OAY) }\end{array}$ \\
\hline $\begin{array}{l}1 \\
2 \\
3 \\
4 \\
5\end{array}$ & $\begin{array}{l}14 \\
13 \\
13 \\
14 \\
15\end{array}$ & $\begin{array}{l}4 \\
4 \\
4 \\
4 \\
2\end{array}$ & $\begin{array}{l}.15 \\
.14 \\
.14 \\
.15 \\
.08\end{array}$ & $\begin{array}{l}10 \\
9.8 \\
9.4 \\
9.1 \\
8.7\end{array}$ & $\begin{array}{l}6 \\
6 \\
5 \\
5 \\
5\end{array}$ & $\begin{array}{l}.16 \\
.16 \\
.13 \\
.12 \\
.12\end{array}$ & $\begin{array}{l}3.0 \\
3.0 \\
2.8 \\
2.7 \\
2.7\end{array}$ & $\begin{array}{r}8 \\
8 \\
8 \\
8 \\
12\end{array}$ & $\begin{array}{l}.06 \\
.06 \\
.06 \\
.06 \\
.09\end{array}$ \\
\hline $\begin{array}{r}6 \\
7 \\
8 \\
9 \\
10\end{array}$ & $\begin{array}{l}14 \\
14 \\
14 \\
14 \\
13\end{array}$ & $\begin{array}{l}2 \\
4 \\
4 \\
4 \\
4\end{array}$ & $\begin{array}{l}.08 \\
.15 \\
.15 \\
.15 \\
.14\end{array}$ & $\begin{array}{l}8.7 \\
8.8 \\
7.8 \\
7.2 \\
7.1\end{array}$ & $\begin{array}{l}5 \\
6 \\
6 \\
7 \\
8\end{array}$ & $\begin{array}{l}.12 \\
.14 \\
.13 \\
.14 \\
.15\end{array}$ & $\begin{array}{l}2.7 \\
2.7 \\
2.5 \\
2.4 \\
2.4\end{array}$ & $\begin{array}{l}15 \\
19 \\
19 \\
19 \\
25\end{array}$ & $\begin{array}{l}11 \\
014 \\
13 \\
112 \\
116\end{array}$ \\
\hline $\begin{array}{l}11 \\
12 \\
13 \\
14 \\
15\end{array}$ & $\begin{array}{l}12 \\
12 \\
16 \\
17 \\
19\end{array}$ & $\begin{array}{r}4 \\
4 \\
12 \\
6 \\
4\end{array}$ & $\begin{array}{l}.13 \\
.13 \\
.51 \\
.28 \\
.24\end{array}$ & $\begin{array}{l}6.9 \\
6.8 \\
6.5 \\
6.4 \\
5.9\end{array}$ & $\begin{array}{l}4 \\
6 \\
8 \\
9 \\
9\end{array}$ & $\begin{array}{r}.07 \\
.11 \\
.14 \\
.16 \\
.14\end{array}$ & $\begin{array}{l}2.3 \\
2.3 \\
2.4 \\
2.3 \\
2.2\end{array}$ & $\begin{array}{l}24 \\
24 \\
24 \\
24 \\
22\end{array}$ & $\begin{array}{l}.15 \\
: 15 \\
.16 \\
.15 \\
.13\end{array}$ \\
\hline $\begin{array}{l}16 \\
17 \\
18 \\
19 \\
20\end{array}$ & $\begin{array}{l}28 \\
23 \\
27 \\
27 \\
21\end{array}$ & $\begin{array}{l}5 \\
4 \\
3 \\
3 \\
3\end{array}$ & $\begin{array}{l}.38 \\
.25 \\
.22 \\
.22 \\
.17\end{array}$ & $\begin{array}{l}5.3 \\
4.8 \\
4.9 \\
4.7 \\
4.2\end{array}$ & $\begin{array}{l}8 \\
8 \\
7 \\
7 \\
7\end{array}$ & $\begin{array}{l}.11 \\
.10 \\
.09 \\
.09 \\
.08\end{array}$ & $\begin{array}{l}2.3 \\
2.2 \\
2.2 \\
2.1 \\
2.1\end{array}$ & $\begin{array}{l}22 \\
20 \\
19 \\
22 \\
24\end{array}$ & $\begin{array}{l}.14 \\
.12 \\
.11 \\
.12 \\
.14\end{array}$ \\
\hline $\begin{array}{l}21 \\
22 \\
23 \\
24 \\
25\end{array}$ & $\begin{array}{l}21 \\
21 \\
16 \\
15 \\
14\end{array}$ & $\begin{array}{l}4 \\
4 \\
3 \\
3 \\
3\end{array}$ & $\begin{array}{l}.23 \\
.23 \\
.13 \\
.12 \\
.11\end{array}$ & $\begin{array}{l}3.9 \\
3.6 \\
3.5 \\
3.4 \\
3.2\end{array}$ & $\begin{array}{l}7 \\
7 \\
7 \\
7 \\
7\end{array}$ & $\begin{array}{l}.07 \\
.07 \\
.07 \\
.06 \\
.06\end{array}$ & $\begin{array}{l}2.2 \\
2.1 \\
2.0 \\
1.9 \\
2.0\end{array}$ & $\begin{array}{l}26 \\
26 \\
26 \\
28 \\
29\end{array}$ & $\begin{array}{l}.15 \\
.15 \\
.14 \\
.14 \\
16\end{array}$ \\
\hline $\begin{array}{l}26 \\
27 \\
28 \\
29 \\
30 \\
31\end{array}$ & $\begin{array}{r}14 \\
13 \\
12 \\
11 \\
10 \\
--.\end{array}$ & $\begin{array}{r}4 \\
4 \\
4 \\
5 \\
5 \\
---\end{array}$ & $\begin{array}{l}.15 \\
.14 \\
.13 \\
.15 \\
.14 \\
.14\end{array}$ & $\begin{array}{l}3.1 \\
3.0 \\
3.0 \\
2.9 \\
2.8 \\
2.9\end{array}$ & $\begin{array}{l}7 \\
7 \\
8 \\
8 \\
8 \\
8\end{array}$ & $\begin{array}{l}.06 \\
.06 \\
.06 \\
.06 \\
.06 \\
.06\end{array}$ & $\begin{array}{l}2.1 \\
2.0 \\
2.0 \\
1.9 \\
1.9 \\
-\ldots .\end{array}$ & $\begin{array}{r}29 \\
29 \\
29 \\
29 \\
30 \\
--\end{array}$ & $\begin{array}{l}.16 \\
.16 \\
: 16 \\
: 15 \\
: 15 \\
:-2\end{array}$ \\
\hline TOTAL & 487 & -- & 5.39 & 178.3 & --- & 3.15 & 69.4 & $\cdots$ & 3.88 \\
\hline DAY & $\begin{array}{l}\text { MEAN } \\
\text { OISCHARGE } \\
\text { (CFS) }\end{array}$ & $\begin{array}{l}\text { JULY } \\
\text { MEAN } \\
\text { CONCEN- } \\
\text { TRATION } \\
\text { (MG/L) }\end{array}$ & $\begin{array}{l}\text { SEDIMENT } \\
\text { DISCHARGE } \\
\text { (TONS/DAY) }\end{array}$ & $\begin{array}{l}\text { MEAN } \\
\text { OISCHARGE } \\
\text { (CFS) }\end{array}$ & $\begin{array}{l}\text { AUGUST } \\
\text { MEAN } \\
\text { CONCEN- } \\
\text { TRATION } \\
\text { (MG/L) }\end{array}$ & $\begin{array}{l}\text { SEDIMENT } \\
\text { DISCHARGE } \\
\text { (TONS/DAY) }\end{array}$ & $\begin{array}{l}\text { MEAN } \\
\text { DI SCHARGE } \\
\text { (CFS) }\end{array}$ & $\begin{array}{l}\text { SEPTEMEER } \\
\text { MEAN } \\
\text { CONCEN- } \\
\text { TRATION } \\
\text { (MG /L) }\end{array}$ & $\begin{array}{l}\text { SEDIMENT } \\
\text { DISCHARGE } \\
\text { (TONS /DAY) }\end{array}$ \\
\hline $\begin{array}{l}1 \\
2 \\
3 \\
4 \\
5\end{array}$ & $\begin{array}{l}1.8 \\
1.7 \\
1.7 \\
1.7 \\
1.9\end{array}$ & $\begin{array}{l}30 \\
30 \\
30 \\
30 \\
33\end{array}$ & $\begin{array}{l}.15 \\
.14 \\
.14 \\
.14 \\
.17\end{array}$ & $\begin{array}{l}1.3 \\
1.2 \\
1.2 \\
1.2 \\
1.2\end{array}$ & $\begin{array}{l}18 \\
25 \\
19 \\
19 \\
19\end{array}$ & $\begin{array}{l}.06 \\
.08 \\
.06 \\
.06 \\
.06\end{array}$ & $\begin{array}{l}.91 \\
.85 \\
.85 \\
.97 \\
.97\end{array}$ & $\begin{array}{r}17 \\
18 \\
18 \\
16 \\
8\end{array}$ & $\begin{array}{l}.04 \\
.04 \\
.04 \\
.04 \\
.02\end{array}$ \\
\hline $\begin{array}{r}6 \\
7 \\
8 \\
9 \\
10\end{array}$ & $\begin{array}{l}1.9 \\
2.0 \\
1.9 \\
1.7 \\
1.7\end{array}$ & $\begin{array}{l}33 \\
37 \\
33 \\
35 \\
30\end{array}$ & $\begin{array}{l}.17 \\
.20 \\
.17 \\
.16 \\
.14\end{array}$ & $\begin{array}{l}1.2 \\
1.2 \\
1.3 \\
1.2 \\
1.2\end{array}$ & $\begin{array}{l}25 \\
18 \\
17 \\
17 \\
17\end{array}$ & $\begin{array}{l}.08 \\
.06 \\
.06 \\
.06 \\
.06\end{array}$ & $\begin{array}{l}1.0 \\
.97 \\
.91 \\
.85 \\
5.1\end{array}$ & $\begin{array}{l}15 \\
15 \\
15 \\
18 \\
54\end{array}$ & $\begin{array}{l}.04 \\
.04 \\
.04 \\
.04 \\
.79\end{array}$ \\
\hline $\begin{array}{l}11 \\
12 \\
13 \\
14 \\
15\end{array}$ & $\begin{array}{l}1.7 \\
1.7 \\
1.7 \\
1.6 \\
1.6\end{array}$ & $\begin{array}{l}30 \\
30 \\
30 \\
28 \\
28\end{array}$ & $\begin{array}{l}.14 \\
.14 \\
.14 \\
.12 \\
.12\end{array}$ & $\begin{array}{l}1.1 \\
1.2 \\
1.1 \\
1.1 \\
1.0\end{array}$ & $\begin{array}{l}17 \\
20 \\
19 \\
20 \\
20\end{array}$ & $\begin{array}{l}.05 \\
.06 \\
.06 \\
.06 \\
.05\end{array}$ & $\begin{array}{l}4.0 \\
3.5 \\
3.1 \\
2.9 \\
2.7\end{array}$ & $\begin{array}{r}10 \\
8 \\
15 \\
5 \\
7\end{array}$ & $\begin{array}{l}.11 \\
.08 \\
.13 \\
.04 \\
.05\end{array}$ \\
\hline $\begin{array}{l}16 \\
17 \\
18 \\
19 \\
20\end{array}$ & $\begin{array}{l}1.7 \\
1.8 \\
1.7 \\
1.6 \\
1.5\end{array}$ & $\begin{array}{l}27 \\
26 \\
24 \\
23 \\
25\end{array}$ & $\begin{array}{l}.12 \\
.13 \\
.11 \\
110 \\
.10\end{array}$ & $\begin{array}{r}1.0 \\
.97 \\
.97 \\
.91 \\
.97\end{array}$ & $\begin{array}{l}23 \\
23 \\
23 \\
23 \\
20\end{array}$ & $\begin{array}{l}.06 \\
.06 \\
.06 \\
.06 \\
.05\end{array}$ & $\begin{array}{l}2.6 \\
2.5 \\
2.2 \\
2.2 \\
2.2\end{array}$ & $\begin{array}{r}9 \\
9 \\
10 \\
9 \\
9\end{array}$ & $\begin{array}{l}.06 \\
.06 \\
.06 \\
.05 \\
.05\end{array}$ \\
\hline $\begin{array}{l}21 \\
22 \\
23 \\
24 \\
25\end{array}$ & $\begin{array}{l}1.6 \\
1.6 \\
1.5 \\
1.5 \\
1.5\end{array}$ & $\begin{array}{l}21 \\
20 \\
19 \\
18 \\
18\end{array}$ & $\begin{array}{l}.09 \\
.09 \\
.08 \\
.07 \\
.07\end{array}$ & $\begin{array}{l}.91 \\
.80 \\
.80 \\
.80 \\
.85\end{array}$ & $\begin{array}{l}16 \\
14 \\
12 \\
12 \\
13\end{array}$ & $\begin{array}{l}.04 \\
.03 \\
.03 \\
.03 \\
.03\end{array}$ & $\begin{array}{l}2.1 \\
2.0 \\
2.0 \\
1.9 \\
1.9\end{array}$ & $\begin{array}{l}9 \\
8 \\
7 \\
7 \\
6\end{array}$ & $\begin{array}{l}.05 \\
.04 \\
.04 \\
.04 \\
.03\end{array}$ \\
\hline $\begin{array}{l}26 \\
27 \\
28 \\
29 \\
30 \\
31\end{array}$ & $\begin{array}{l}1.6 \\
1.7 \\
1.7 \\
1.6 \\
1.5 \\
1.3\end{array}$ & $\begin{array}{l}22 \\
18 \\
18 \\
18 \\
18 \\
18\end{array}$ & $\begin{array}{l}.10 \\
.08 \\
.08 \\
.08 \\
.07 \\
.06\end{array}$ & $\begin{array}{l}.91 \\
.91 \\
.85 \\
.91 \\
.85 \\
.85\end{array}$ & $\begin{array}{l}14 \\
14 \\
14 \\
15 \\
15 \\
15\end{array}$ & $\begin{array}{l}.03 \\
.03 \\
.03 \\
.04 \\
.03 \\
.03\end{array}$ & $\begin{array}{l}1.9 \\
1.8 \\
1.8 \\
1.7 \\
1.8 \\
\ldots . .0\end{array}$ & $\begin{array}{r}6 \\
7 \\
7 \\
7 \\
8 \\
-9\end{array}$ & $\begin{array}{l}.03 \\
.03 \\
.03 \\
.03 \\
.04 \\
-0.0\end{array}$ \\
\hline TOTAL & 51.7 & $\cdots$ & 3.67 & 31.96 & $-\infty$ & 1.56 & 60.18 & $\infty$ & 2.18 \\
\hline YEAR & 3320.94 & & 87.42 & & & & & & \\
\hline
\end{tabular}




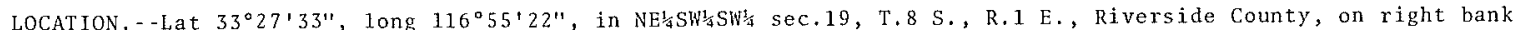
$1.6 \mathrm{mi}(2.6 \mathrm{~km})$ downstream from Long Canyon, and $3.5 \mathrm{mi}(5.6 \mathrm{~km})$ northwest of Aguanga.

DRAINAGE AREA. - -131 $\mathrm{mi}^{2}\left(339 \mathrm{~km}^{2}\right)$.

PERIOD OF RECORD. - August 1957 to current year.

GAGE, - Water-stage recorder. Altitude of gage is $1,590 \mathrm{ft}(485 \mathrm{~m})$, from topographic map.

REMARKS.--Records fair. No regulation above station. Pumping for irrigation above station.

AVERAGE DISCHARGE, - -19 years, $4.07 \mathrm{ft}^{3} / \mathrm{s}\left(0.115 \mathrm{~m}^{3} / \mathrm{s}\right), 2,950 \mathrm{acre}-\mathrm{ft} / \mathrm{yr}\left(3.64 \mathrm{hm} / \mathrm{yr}^{3}\right)$.

EXTREMES FOR PERIOD OF RECORD, - Maximum discharge, 3,540 $\mathrm{ft}^{3} / \mathrm{s}\left(100 \mathrm{~m}^{3} / \mathrm{s}\right)$ Apr. 3 , 1958 , gage height, $6.57 \mathrm{ft}$

$(2.003 \mathrm{~m})$, from rating curve extended above $1,200 \mathrm{ft} / \mathrm{s}\left(34 \mathrm{~m}^{3} / \mathrm{s}\right)$; no flow at times in each year.

EXTREMES FOR CURRENT YEAR. - - Peak discharges above base of $50 \mathrm{ft} / \mathrm{s}\left(1.42 \mathrm{~m}^{3} / \mathrm{s}\right)$ and maximum (\%):

\begin{tabular}{cccccc}
\multirow{2}{*}{ Date } & Time & \multicolumn{2}{c}{ Discharge } & \multicolumn{2}{c}{ Gage height: } \\
& $\left(\mathrm{ft}^{3} / \mathrm{s}\right)$ & $\left(\mathrm{m}^{3} / \mathrm{s}\right)$ & $(\mathrm{ft})$ & $(\mathrm{m})$ \\
Feb. 9 & 0315 & $\star 177$ & 5.01 & 2.90 & 0.884 \\
Mar. 1 & 2230 & 67 & 1.90 & 2.14 & 0.652
\end{tabular}

Minimum daily discharge, no flow Oct. 1-14, June 29 to Sept. 9.

DISCHARGE, IN CUBIC FEET PER SECOND, HATER YEAR OCTOBER 1975 TO SEPTEMBEA 1976 MEAN VALUES

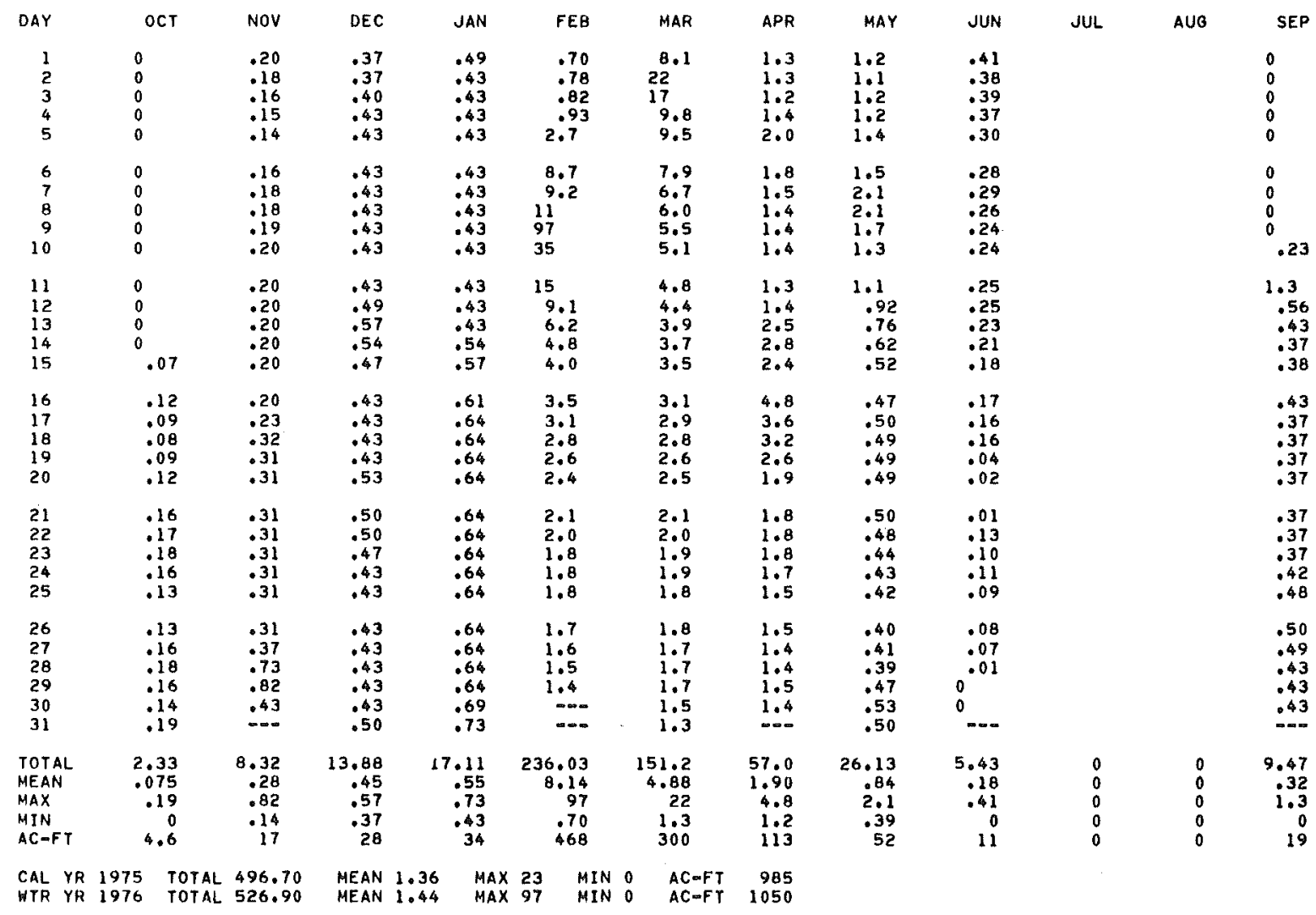




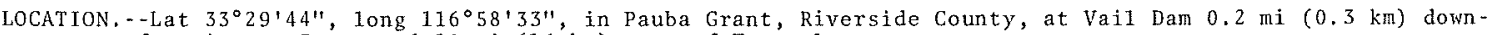
stream from Arroyo Seco, and $10 \mathrm{mi}(16 \mathrm{~km})$ east of Temecula.

DRAINAGE AREA, $--320 \mathrm{mi}^{2}\left(829 \mathrm{~km}^{2}\right)$.

PERIOD OF RECORD, - -October 1948 to current year. January 1923 to October 1930 at site $200 \mathrm{ft}$ (61 m) downstream and October 1930 to September 1948 at site $500 \mathrm{ft}$ (152 m) downstream published as "at Nigger Canyon, near Temecula"; records not equivalent owing to change in natural water loss resulting from creation of Vail Lake. October 1948 to September 1951 published as "at Nigger Canyon, near Temecula"; records are for draft and spil only from Vail Lake. October 1951 to September 1955 , published as "at Vail Dam, near Temecula,"

GAGE. - Two water-stage recorders. Main gage on lake. National weather Service type nonrecording rain gage $0.2 \mathrm{mi}(0.3 \mathrm{~km})$ upstream. Supplemental gage at site $500 \mathrm{ft}(152 \mathrm{~m})$ downstream measures release and spil1 at different datum. Datum of main gage is $1,350.0 \mathrm{ft}(411.48 \mathrm{~m}$ ) above mean sea leve1 (1evels by Bureau of Reclamation); gage readings have been reduced to elevations above mean sea leve1.

REMARKS. - -Records poor. Discharges represent all water reaching Vail Lake, including precipitation on 1ake surface. Discharge computed on basis of records of storage, release (draft), spili, and evaporation. Monthly evaporation from lake surface computed on basis of evaporation from a class A evaporation pan using coefficient of 0.77 , excepting the period June 1964 to September 1965 , when a 24-inch (0.61-m) diameter sunken screen pan with a coefficient of 0.98 was used. Area-capacity tables for lake are based on a survey made in 1947. Vail Dam completed in June 1949. Capacity of lake at spillway 1eve1, 49,370 acre-ft (60.9 hm ${ }^{3}$ ), elevation $1,470.00 \mathrm{ft}(448.056 \mathrm{~m})$. Dead storage, $2.4 \mathrm{acre}-\mathrm{ft}\left(2,960 \mathrm{~m}^{3}\right)$ below lowest outlet at elevation elevation, $1,470.00 \mathrm{ft}(448.056 \mathrm{~m})$. Dead storage, 2.4 acre-ft $\left(2,960 \mathrm{~m}^{3}\right)$ below lowest outlet at elevation
$1,352.5 \mathrm{ft}(412.24 \mathrm{~m})$ included in these records. There has been no spill since Nov, 13 , 1948 , date of $1,352.5$ ft $(412.24 \mathrm{~m}$ ) included in these records. There has been no spill since Nov, 13,1948, date of
closure. Water is released as required down Temecula Creek for diversion about $1 \mathrm{mi}$ (1.6 km) below dam. Month1y precipitation, in inches, from National weather Service type nonrecording rain gage is as follows October, $0.04(0.10 \mathrm{~cm})$; November, $1.42(3.61 \mathrm{~cm}) ;$ December, $0.24(0.61 \mathrm{~cm}) ;$ February, $4.26(10.82 \mathrm{~cm}) ;$ March, $1.80(4.57 \mathrm{~cm}) ;$ Apri1 1.01 (2.57 cm); May $0.48(1.22 \mathrm{~cm})$; September $2.41(6.12 \mathrm{~cm})$; the current year, $11.66(29.62 \mathrm{~cm})$

AVERAGE DISCHARGE. - - 25 years (water years $1924-48), 14.5 \mathrm{ft}^{3} / \mathrm{s}\left(0.411 \mathrm{~m}^{3} / \mathrm{s}\right), 10,500 \mathrm{acre}-\mathrm{ft} / \mathrm{yr}(12.9 \mathrm{hm} / \mathrm{yr})$ see PERIOD OF RECORD; 28 years (water years $1949-76), 5.27 \mathrm{ft}^{3} / \mathrm{s}\left(0.149 \mathrm{~m}^{3} / \mathrm{s}\right), 3,820 \mathrm{acre}-\mathrm{ft} / \mathrm{yr}^{2}\left(4.71 \mathrm{hm} / \mathrm{yr}^{3}\right)$ MONTHLY DISCHARGE, WATER YEAR OCTOBER 1975 TO SEPTEMBER 1976

Date

$\begin{array}{cc}\text { E1evation } & \text { Contents } \\ \text { at } 2400 & \text { (acre- } \\ \text { (feet) } & \text { feet) }\end{array}$

Vail Lake

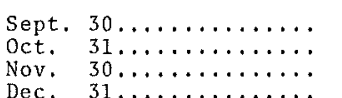

Dec. $31 \ldots \ldots \ldots \ldots \ldots$

CAL YR $1975 \ldots \ldots \ldots \ldots$

Jan. $\quad 31 \ldots \ldots \ldots \ldots \ldots \ldots$

Feb. $\quad 29 \ldots \ldots \ldots \ldots \ldots$

Mar. $\quad 31 \ldots \ldots \ldots \ldots \ldots \ldots$

May $31 \ldots \ldots \ldots \ldots \ldots$

June $30 \ldots \ldots \ldots \ldots$

July $31 \ldots \ldots \ldots \ldots \ldots$

Aug. $\quad 31 \ldots \ldots \ldots \ldots \ldots$

Sept. $30 \ldots \ldots \ldots \ldots \ldots$

WTR YR $1976 \ldots \ldots \ldots$

$\begin{array}{ll}a 1,434.04 & 18,820 \\ a 1,433.58 & 18,530 \\ a 1,433.42 & 18,430 \\ a 1,433.34 & 18,380\end{array}$

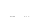

$a 1,433.26$

a1, 434.05

a1, 434,34

$a 1,434,25$

al, 433

$1,433.39$

$1,432.85$

$1,432.27$

$1,432.27$

\section{Change \\ in \\ (acre- \\ Draft
(acre-}

feet) feet) $\begin{array}{lc}\text { Evapo- } & \\ \text { ration } & \text { Discharge } \\ \text { (acre- } & \text { (acre- } \\ \text { feet) } & \text { feet) }\end{array}$

a Estimated.

$a$ Estimated. California.

NOTE. - For months when inflow to the lake was small and other quantities were large, discordant figures of discharge may appear. This arises primarily from the difficulty of computing discharge as a residual of several larger quantities, which are not susceptible to measurement with a precision necessary to produce a final answer within desirable limits of accuracy. 
LOCATION, - Lat $33^{\circ} 28^{\prime} 47^{\prime \prime}$, long $117^{\circ} 08^{\prime} 35^{\prime \prime}$, in Temecula Grant, Riverside County, on right bank 0.4 mi (0.6 km) upstream from mouth, and $1.0 \mathrm{mi}(1.6 \mathrm{~km})$ south of Temecula.

DRAINAGE AREA. $-222 \mathrm{mi}^{2}\left(575 \mathrm{~km}^{2}\right)$

PERIOD OF RECORD.--October 1924 to current year. Month1y discharge on 1 y October 1924 to September 1930 , published in WSP $1315-\mathrm{B}$.

GAGE. - Water-stage recorder. Altitude of gage is $970 \mathrm{ft}(296 \mathrm{~m})$, from topographic map. See WSP 1735 for history of changes prior to Dec. 16, 1938 .

REMARKS,--Records poor. No regulation above station. Pumping above station for irrigation of about 2 , 500 acres $\left(10.1 \mathrm{~km}^{2}\right)$.

AVERAGE DISCHARGE. - -52 years, $8.43 \mathrm{ft}^{3} / \mathrm{s}\left(0.239 \mathrm{~m}^{3} / \mathrm{s}\right), 6,110 \mathrm{acre}-\mathrm{ft} / \mathrm{yr}(7.53 \mathrm{hm} / \mathrm{yr})$.

EXTREMES FOR PERIOD OF RECORD.--Maximum discharge, 17,500 $\mathrm{ft}^{3} / \mathrm{s}\left(496 \mathrm{~m}^{3} / \mathrm{s}\right) \mathrm{Jan} .23,1943$, gage height, 13.82 $\mathrm{ft}$ $(4.212 \mathrm{~m})$; Minimum daily, $0.02 \mathrm{ft}^{3} / \mathrm{s}\left(0.001 \mathrm{~m}^{3} / \mathrm{s}\right)$ at times in 1969 .

EXTREMES FOR CURRENT YEAR.--Peak discharges above base of $55 \mathrm{ft}^{3} / \mathrm{s}\left(1.56 \mathrm{~m}^{3} / \mathrm{s}\right)$ and maximum $(*)$, based on $\mathrm{s} 1$ opearea measurement of maximum flow:

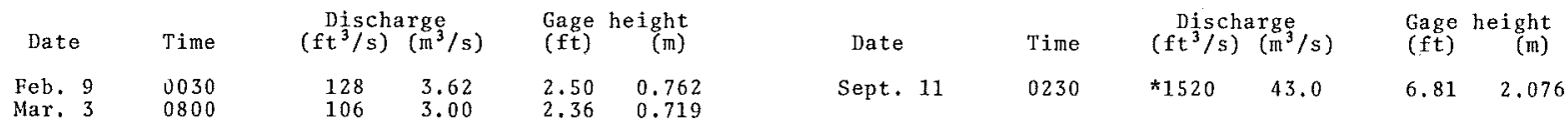

Minimum daily discharge, $0.28 \mathrm{ft}^{3} / \mathrm{s}\left(0.008 \mathrm{~m}^{3} / \mathrm{s}\right)$ Dec. 15 .

DISCHARGE, IN CUBIC FEET PER SECONO, WATER YEAR OCTOBER 1975 TO SEPTEMBER 1976 MEAN VALUES

\begin{tabular}{|c|c|c|c|c|c|c|c|c|c|c|c|c|}
\hline DAY & $O C T$ & NOV & DEC & JAN & FEB & MAR & APR & MAY & JUN & JUL & AUQ & SEP \\
\hline $\begin{array}{l}1 \\
2 \\
3 \\
4 \\
5\end{array}$ & $\begin{array}{l}.40 \\
.40 \\
.40 \\
.40 \\
.40\end{array}$ & $\begin{array}{l}.40 \\
.40 \\
.40 \\
.40 \\
.40\end{array}$ & $\begin{array}{l}.72 \\
.63 \\
.63 \\
.63 \\
.54\end{array}$ & $\begin{array}{r}.39 \\
.34 \\
.39 \\
.39 \\
.39\end{array}$ & $\begin{array}{r}.39 \\
.39 \\
.39 \\
2.1 \\
2.4\end{array}$ & $\begin{array}{c}14 \\
6.1 \\
44 \\
2.5 \\
1.6\end{array}$ & $\begin{array}{r}.52 \\
.52 \\
.52 \\
.60 \\
1.1\end{array}$ & $\begin{array}{l}.54 \\
.54 \\
.54 \\
.54 \\
.54\end{array}$ & $\begin{array}{l}.45 \\
.45 \\
.39 \\
.54 \\
.54\end{array}$ & $\begin{array}{l}.54 \\
.54 \\
.45 \\
.54 \\
.63\end{array}$ & $\begin{array}{r}.34 \\
.39 \\
.39 \\
.45 \\
.45\end{array}$ & $\begin{array}{l}.45 \\
.45 \\
.54 \\
.45 \\
.45\end{array}$ \\
\hline $\begin{array}{r}6 \\
7 \\
8 \\
9 \\
10\end{array}$ & $\begin{array}{l}.40 \\
.40 \\
.40 \\
.40 \\
.40\end{array}$ & $\begin{array}{r}.39 \\
.39 \\
.39 \\
.39 \\
.39\end{array}$ & $\begin{array}{r}.45 \\
.39 \\
.45 \\
.39 \\
.39\end{array}$ & $\begin{array}{r}.39 \\
.39 \\
.39 \\
.39 \\
.45\end{array}$ & $\begin{array}{l}7.1 \\
4.3 \\
23 \\
94 \\
18\end{array}$ & $\begin{array}{l}1.0 \\
.82 \\
.72 \\
.63 \\
.60\end{array}$ & $\begin{array}{r}1.1 \\
.98 \\
.87 \\
.87 \\
.87\end{array}$ & $\begin{array}{r}.54 \\
1.2 \\
.60 \\
.60 \\
.60\end{array}$ & $\begin{array}{l}.54 \\
.45 \\
.54 \\
.63 \\
.63\end{array}$ & $\begin{array}{l}.63 \\
.72 \\
.45 \\
.54 \\
.54\end{array}$ & $\begin{array}{l}.45 \\
.54 \\
.63 \\
.54 \\
.54\end{array}$ & $\begin{array}{r}.39 \\
.39 \\
.45 \\
.45 \\
9.5\end{array}$ \\
\hline $\begin{array}{l}11 \\
12 \\
13 \\
14 \\
15\end{array}$ & $\begin{array}{l}.40 \\
.40 \\
.40 \\
.40 \\
.40\end{array}$ & $\begin{array}{r}.33 \\
.33 \\
.33 \\
.33 \\
.39\end{array}$ & $\begin{array}{l}.39 \\
.54 \\
.63 \\
.34 \\
.28\end{array}$ & $\begin{array}{l}.45 \\
.45 \\
.45 \\
.39 \\
.39\end{array}$ & $\begin{array}{l}2.5 \\
1.4 \\
1.0 \\
.77 \\
.70\end{array}$ & $\begin{array}{l}.60 \\
.60 \\
.60 \\
.60 \\
.60\end{array}$ & $\begin{array}{l}.87 \\
.87 \\
1.7 \\
1.98\end{array}$ & $\begin{array}{l}.60 \\
.52 \\
.45 \\
.52 \\
.52\end{array}$ & $\begin{array}{l}.63 \\
.54 \\
.45 \\
.54 \\
.54\end{array}$ & $\begin{array}{l}.63 \\
.63 \\
.72 \\
.63 \\
.63\end{array}$ & $\begin{array}{l}.63 \\
.63 \\
.63 \\
.72 \\
.63\end{array}$ & $\begin{array}{r}274 \\
20 \\
2.0 \\
1.0 \\
.80\end{array}$ \\
\hline $\begin{array}{l}16 \\
17 \\
18 \\
19 \\
20\end{array}$ & $\begin{array}{l}.40 \\
.40 \\
.40 \\
.40 \\
.40\end{array}$ & $\begin{array}{r}.39 \\
.39 \\
.39 \\
.39 \\
.45\end{array}$ & $\begin{array}{r}.34 \\
.34 \\
.34 \\
.34 \\
.45\end{array}$ & $\begin{array}{r}.39 \\
.39 \\
.39 \\
.34 \\
.39\end{array}$ & $\begin{array}{l}.68 \\
.66 \\
.64 \\
.62 \\
.60\end{array}$ & $\begin{array}{l}.55 \\
.55 \\
.55 \\
.55 \\
.55\end{array}$ & $\begin{array}{l}1.6 \\
.91 \\
.72 \\
.72 \\
.82\end{array}$ & $\begin{array}{l}.45 \\
.45 \\
.52 \\
.52 \\
.39\end{array}$ & $\begin{array}{l}.54 \\
.45 \\
.45 \\
.63 \\
.72\end{array}$ & $\begin{array}{l}.72 \\
.72 \\
.63 \\
.54 \\
.54\end{array}$ & $\begin{array}{l}.63 \\
.63 \\
.54 \\
.54 \\
.45\end{array}$ & $\begin{array}{l}.70 \\
.65 \\
.60 \\
.55 \\
.50\end{array}$ \\
\hline $\begin{array}{l}21 \\
22 \\
23 \\
24 \\
25\end{array}$ & $\begin{array}{l}.40 \\
.40 \\
.40 \\
.40 \\
.40\end{array}$ & $\begin{array}{l}.45 \\
.39 \\
.39 \\
.39 \\
.45\end{array}$ & $\begin{array}{r}.45 \\
.39 \\
.34 \\
.39 \\
.34\end{array}$ & $\begin{array}{l}.39 \\
.39 \\
.45 \\
.45 \\
.39\end{array}$ & $\begin{array}{l}.56 \\
.52 \\
.52 \\
.52 \\
.52\end{array}$ & $\begin{array}{l}.50 \\
.50 \\
.50 \\
.50 \\
.50\end{array}$ & $\begin{array}{l}.72 \\
.72 \\
.72 \\
.82 \\
.82\end{array}$ & $\begin{array}{l}.39 \\
.45 \\
.39 \\
.34 \\
.39\end{array}$ & $\begin{array}{l}.72 \\
.72 \\
.63 \\
.72 \\
.63\end{array}$ & $\begin{array}{l}.45 \\
.45 \\
.45 \\
.39 \\
.39\end{array}$ & $\begin{array}{l}.45 \\
.45 \\
.39 \\
.45 \\
.45\end{array}$ & $\begin{array}{l}.50 \\
.45 \\
.45 \\
.45 \\
.40\end{array}$ \\
\hline $\begin{array}{l}26 \\
27 \\
28 \\
29 \\
30 \\
31\end{array}$ & $\begin{array}{l}.40 \\
.40 \\
.40 \\
.40 \\
40 \\
.40\end{array}$ & $\begin{array}{r}.45 \\
.72 \\
1.9 \\
1.2 \\
.68 \\
.0\end{array}$ & $\begin{array}{l}.34 \\
.34 \\
.34 \\
.34 \\
.34 \\
.34\end{array}$ & $\begin{array}{r}.39 \\
.39 \\
.34 \\
.34 \\
.39 \\
.39\end{array}$ & $\begin{array}{l}.52 \\
.50 \\
.50 \\
.50 \\
-\end{array}$ & $\begin{array}{l}.50 \\
.50 \\
.50 \\
.50 \\
.50 \\
.50\end{array}$ & $\begin{array}{l}.63 \\
.54 \\
.54 \\
.54 \\
.54 \\
.--.\end{array}$ & $\begin{array}{r}.39 \\
.39 \\
.45 \\
.39 \\
.39 \\
.39\end{array}$ & $\begin{array}{r}.54 \\
.54 \\
.45 \\
.54 \\
.54 \\
.-0 .\end{array}$ & $\begin{array}{r}.45 \\
.39 \\
.39 \\
.39 \\
.39 \\
.39\end{array}$ & $\begin{array}{r}.39 \\
.45 \\
.45 \\
.39 \\
.39 \\
.45\end{array}$ & $\begin{array}{l}.40 \\
.40 \\
.40 \\
.40 \\
.40 \\
.-.\end{array}$ \\
\hline $\begin{array}{l}\text { TOTAL } \\
\text { MEAN } \\
\text { MAX } \\
\text { MIN } \\
\text { AC-FT }\end{array}$ & $\begin{array}{r}12.40 \\
.40 \\
.40 \\
.40 \\
25\end{array}$ & $\begin{array}{r}14.69 \\
.49 \\
1.9 \\
.33 \\
29\end{array}$ & $\begin{array}{r}13.21 \\
.43 \\
.72 \\
.28 \\
26\end{array}$ & $\begin{array}{r}12.25 \\
.40 \\
.45 \\
.34 \\
24\end{array}$ & $\begin{array}{r}166.30 \\
5.73 \\
94 \\
.39 \\
330\end{array}$ & $\begin{array}{r}83.22 \\
2.68 \\
44 \\
.50 \\
165\end{array}$ & $\begin{array}{r}25.33 \\
.84 \\
1.7 \\
.52 \\
50\end{array}$ & $\begin{array}{r}15.54 \\
.50 \\
1.2 \\
.34 \\
31\end{array}$ & $\begin{array}{r}16.68 \\
.56 \\
.72 \\
.39 \\
33\end{array}$ & $\begin{array}{r}16.50 \\
.53 \\
.72 \\
.39 \\
33\end{array}$ & $\begin{array}{r}15.46 \\
.50 \\
.72 \\
.34 \\
31\end{array}$ & $\begin{array}{r}318.57 \\
10.6 \\
274 \\
.39 \\
632\end{array}$ \\
\hline
\end{tabular}


LOCATION, - Lat $33^{\circ} 28^{\prime} 26^{\prime \prime}$, long $117^{\circ} 08^{\prime} 29^{\prime \prime}$, in Temecula Grant, Riverside County, on 1 eft bank at upper end of Temecula Canyon, $0.1 \mathrm{mi}(0.2 \mathrm{~km})$ downstream from Murrieta Creek, $1.4 \mathrm{mi}(2.3 \mathrm{~km})$ south of Temecula, and $10 \mathrm{mi}(16 \mathrm{~km})$ downstream from Vail Lake.

DRAINAGE AREA, $--588 \mathrm{mi}^{2}\left(1,520 \mathrm{~km}^{2}\right)$.

PERIOD OF RECORD, - -January 1923 to current year. Prior to October 1952, published as Temecula Creek at Railroad Canyon, near Temecula.

GAGE, - Water-stage recorder and crest-stage gage. Altitude of gage is 950 ft (290 m), from topographic map. Prior to Nov, 3,1966 , at site $100 \mathrm{ft}(30.5 \mathrm{~m})$ downstream at same datum.

REMARKS. - - Records good below $60 \mathrm{ft}^{3} / \mathrm{s}\left(1.70 \mathrm{~m}^{3} / \mathrm{s}\right)$ and fair above. Flow partly regulated since November 1948 by Vail Lake (station 11042500). Pumping above station for irrigation.

AVERAGE DISCHARGE. -25 years (water years 1924-48), unregulated, $28.2 \mathrm{ft}^{3} / \mathrm{s}\left(0.799 \mathrm{~m}^{3} / \mathrm{s}\right), 20,420$ acre $-\mathrm{ft} / \mathrm{yr}$ $\left(25.2 \mathrm{hm}^{3} / \mathrm{yr}\right) ; 28$ years (water years $\left.1949-76\right), 9.58 \mathrm{ft} / \mathrm{s}\left(0.271 \mathrm{~m}^{3} / \mathrm{s}\right), 6,940 \mathrm{acre}-\mathrm{ft} / \mathrm{yr}\left(8.56 \mathrm{hm} / \mathrm{yr}^{3}\right)$.

EXTREMES FOR PERIOD OF RECORD, - Maximum discharge, $25,000 \mathrm{ft}^{3} / \mathrm{s}\left(708 \mathrm{~m}^{3} / \mathrm{s}\right) \mathrm{Feb}$. 16, 1927, gage height, $14.6 \mathrm{ft}$ $(4.45 \mathrm{~m})$, at site $100 \mathrm{ft}(30.5 \mathrm{~m})$ downstream, from rating curve extended above $10,000 \mathrm{ft}^{3} / \mathrm{s}^{2}\left(283 \mathrm{~m}^{3} / \mathrm{s}\right)$; minimum daily, $0.30 \mathrm{ft}^{3} / \mathrm{s}\left(0.009 \mathrm{~m}^{3} / \mathrm{s}\right)$ Aug. $18-22,1965$, regulation by construction work above station.

EXTREMES FOR CURRENT YEAR. - MaXimum discharge, $1,560 \mathrm{ft}^{3} / \mathrm{s}\left(44.2 \mathrm{~m}^{3} / \mathrm{s}\right) \mathrm{Sept}$. 11 , gage height, $7.97 \mathrm{ft}(2.429 \mathrm{~m})$, from rating curve extended above $60 \mathrm{ft}^{3} / \mathrm{s}\left(1.70 \mathrm{~m}^{3} / \mathrm{s}\right)$ on basis of estimate of maximum flow; minimum daily, $1.3 \mathrm{ft}^{3} / \mathrm{s}\left(0.037 \mathrm{~m}^{3} / \mathrm{s}\right)$ July 6 and 9 .

DISCHARGE, IN CUBIC FEET PER SECOND, HATER YEAR OCTOBER 1975 TO SEPTEMBER 1976 MEAN VALUES

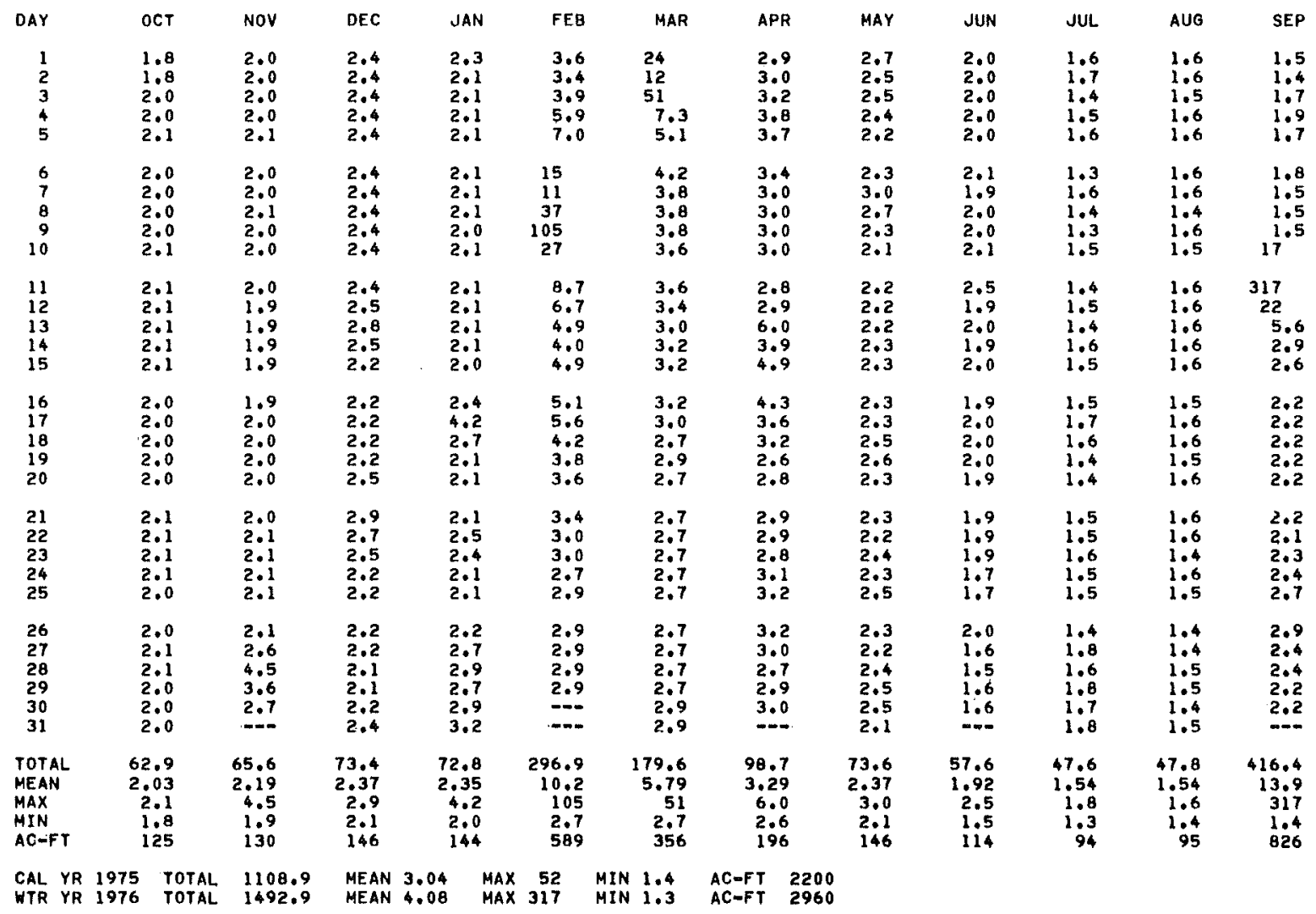


LOCATION.--Lat $33^{\circ} 23^{\prime} 54^{\prime \prime}$, long $117^{\circ} 15^{\prime} 44^{\prime \prime}$, in NE⿺辶E $\frac{1}{4} N^{1} \frac{1}{4}$ sec.14, T.9 S., R. 4 W., San Diego County, on right bank $180 \mathrm{ft}(55 \mathrm{~m})$ upstream from De tuz Road, $1.3 \mathrm{mi}(2.1 \mathrm{~km})$ northwest of Fal1brook, and $1.9 \mathrm{mi}(3.1 \mathrm{~km}) \mathrm{down}-$ stream from Sandia Canyon.

DRAINAGE AREA. $-644 \mathrm{mi}^{2}\left(1,668 \mathrm{~km}^{2}\right)$.

\section{WATER-DISCHARGE RECORDS}

PERIOD OF RECORD,--October 1924 to current year. Monthly discharge only for October and November 1924, published in WSP $1315-\mathrm{B}$

REVISED RECORDS, - WDR CA-72-1: 1971 .

GAGE. - Water-stage recorder. Concrete-road control since october 1955. Datum of gage is 267.96 ft ( $81.674 \mathrm{~m}$ ) above mean sea leve1 (levels by Bureau of Reclamation). Prior to Oct, 1, 1955, at site $1.7 \mathrm{mi}$ ( $2.7 \mathrm{~km}$ ) upstream at different datum. Records equivalent except for extreme low flows.

REMARKS. --Records good. Flow part1y regulated since November 1948 by Vail Lake (station 11042500 ). Several smali diversions above station for irrigation. The Fallbrook Public Utility District reports no water pumped during the current year from a we11 in the streambed $2.1 \mathrm{mi}(3.4 \mathrm{~km})$ upstream from the station.

AVERAGE DISCHARGE. -24 years (water years 1925-48), unregulated, $35.4, \mathrm{ft}^{3} / \mathrm{s}\left(1.003 \mathrm{~m}^{3} / \mathrm{s}\right.$ ), 25,630 acre-ft/yr $\left(31.6 \mathrm{hm}^{3} / \mathrm{yr}\right) ; 28$ years (water years $\left.1949-76\right), 11.8 \mathrm{ft}^{3} / \mathrm{s}\left(0.334 \mathrm{~m}^{3} / \mathrm{s}\right), 8,550 \mathrm{acre}-\mathrm{ft} / \mathrm{yr}(10.5 \mathrm{hm} / \mathrm{yr})$.

EXTREMES FOR PERIOD OF RECORD.--Maximum discharge, $33,100 \mathrm{ft}^{3} / \mathrm{s}\left(937 \mathrm{~m}^{3} / \mathrm{s}\right)$ Feb. 16,1927 , gage height, $15.6 \mathrm{ft}$ $(4.75 \mathrm{~m})$, site and datum then in use, from rating curve extended above $8,800 \mathrm{ft} / \mathrm{s}(249 \mathrm{~m} / \mathrm{s})$ on basis of slope-area measurement of maximum flow; no flow at times in recent years.

EXTREMES FOR CURRENT YEAR. - Maximum discharge, $213 \mathrm{ft}^{3} / \mathrm{s}\left(6.03 \mathrm{~m}^{3} / \mathrm{s}\right) \mathrm{Feb} .9$, gage height, $6.03 \mathrm{ft}(1.838 \mathrm{~m})$; no flow Oct. $1-8$, June 27 to July 15 , Aug. 5 to Sept. 7 .

DISCHARGE, IN CUBIC FEET PER SECOND, HATER YEAR OCTOBER 1975 TO SEPTENBER 1976 MEAN VALUES

\begin{tabular}{|c|c|c|c|c|c|c|c|c|c|c|c|c|}
\hline DAY & $\mathrm{OCT}$ & Nov & DEC & JAN & FEB & MAR & APR & MAY & JUN & JUL & AUG & SEP \\
\hline $\begin{array}{l}1 \\
2 \\
3 \\
4 \\
5\end{array}$ & $\begin{array}{l}0 \\
0 \\
0 \\
0 \\
0\end{array}$ & $\begin{array}{l}1.2 \\
1.2 \\
1.3 \\
1.3 \\
1.3\end{array}$ & $\begin{array}{l}3.0 \\
2.5 \\
2.4 \\
2.5 \\
2.5\end{array}$ & $\begin{array}{l}2.9 \\
2.8 \\
2.8 \\
2.9 \\
3.0\end{array}$ & $\begin{array}{l}3.6 \\
3.9 \\
4.1 \\
6.4 \\
9.5\end{array}$ & $\begin{array}{r}25 \\
55 \\
107 \\
31 \\
15\end{array}$ & $\begin{array}{l}4.3 \\
4.4 \\
4.4 \\
5.1 \\
6.0\end{array}$ & $\begin{array}{l}3.0 \\
3.1 \\
3.5 \\
3.3 \\
3.1\end{array}$ & $\begin{array}{l}2.0 \\
1.8 \\
1.8 \\
1.7 \\
1.5\end{array}$ & $\begin{array}{l}0 \\
0 \\
0 \\
0 \\
0\end{array}$ & $\begin{array}{l}.16 \\
.14 \\
.09 \\
0.08\end{array}$ & $\begin{array}{l}0 \\
0 \\
0 \\
0 \\
0\end{array}$ \\
\hline $\begin{array}{r}6 \\
7 \\
8 \\
9 \\
10\end{array}$ & $\begin{array}{l}0 \\
0 \\
0 \\
.01 \\
.21\end{array}$ & $\begin{array}{l}1.3 \\
1.3 \\
1.5 \\
1.5 \\
1.5\end{array}$ & $\begin{array}{l}2.5 \\
2.5 \\
2.3 \\
2.3 \\
2.4\end{array}$ & $\begin{array}{l}3.1 \\
3.0 \\
3.0 \\
3.0 \\
3.0\end{array}$ & $\begin{array}{r}18 \\
19 \\
21 \\
185 \\
101\end{array}$ & $\begin{array}{l}11 \\
9.4 \\
8.5 \\
8.0 \\
8.2\end{array}$ & $\begin{array}{l}5.8 \\
5.5 \\
4.9 \\
4.9 \\
4.6\end{array}$ & $\begin{array}{l}3.2 \\
3.7 \\
3.7 \\
3.3 \\
2.9\end{array}$ & $\begin{array}{l}1.4 \\
1.4 \\
1.3 \\
1.3 \\
2.0\end{array}$ & $\begin{array}{l}0 \\
0 \\
0 \\
0 \\
0\end{array}$ & $\begin{array}{l}0 \\
0 \\
0 \\
0 \\
0\end{array}$ & $\begin{array}{r}0 \\
0 \\
.06 \\
.10 \\
1.0\end{array}$ \\
\hline $\begin{array}{l}11 \\
12 \\
13 \\
14 \\
15\end{array}$ & $\begin{array}{l}.34 \\
.53 \\
.57 \\
.49 \\
.40\end{array}$ & $\begin{array}{l}1.5 \\
1.2 \\
1.0 \\
1.0 \\
1.1\end{array}$ & $\begin{array}{l}2.5 \\
2.8 \\
3.3 \\
3.1 \\
2.8\end{array}$ & $\begin{array}{l}3.0 \\
2.9 \\
2.9 \\
2.9 \\
2.8\end{array}$ & $\begin{array}{l}26 \\
15 \\
12 \\
9.4 \\
8.5\end{array}$ & $\begin{array}{l}7.6 \\
7.2 \\
6.7 \\
6.5 \\
6.4\end{array}$ & $\begin{array}{l}4.4 \\
4.4 \\
8.4 \\
8.1 \\
6.6\end{array}$ & $\begin{array}{l}2.6 \\
2.5 \\
2.3 \\
2.2 \\
2.2\end{array}$ & $\begin{array}{l}2.0 \\
1.6 \\
1.6 \\
1.1 \\
1.0\end{array}$ & $\begin{array}{l}0 \\
0 \\
0 \\
0 \\
0\end{array}$ & $\begin{array}{l}0 \\
0 \\
0 \\
0 \\
0\end{array}$ & $\begin{array}{r}321 \\
69 \\
9.4 \\
7.9 \\
6.4\end{array}$ \\
\hline $\begin{array}{l}16 \\
17 \\
18 \\
19 \\
20\end{array}$ & $\begin{array}{r}.38 \\
.40 \\
.57 \\
.84 \\
.92\end{array}$ & $\begin{array}{l}1.4 \\
1.5 \\
1.7 \\
1.7 \\
1.7\end{array}$ & $\begin{array}{l}2.7 \\
2.5 \\
2.7 \\
2.7 \\
3.0\end{array}$ & $\begin{array}{l}2.8 \\
3.0 \\
4.5 \\
3.8 \\
2.9\end{array}$ & $\begin{array}{c}0.6 \\
10 \\
8.9 \\
7.4 \\
6.7\end{array}$ & $\begin{array}{l}6.2 \\
6.0 \\
6.0 \\
5.8 \\
5.7\end{array}$ & $\begin{array}{l}8.4 \\
6.3 \\
5.3 \\
4.7 \\
4.5\end{array}$ & $\begin{array}{l}2.2 \\
2.1 \\
2.0 \\
2.0 \\
2.2\end{array}$ & $\begin{array}{l}.83 \\
.71 \\
.57 \\
.51 \\
.41\end{array}$ & $\begin{array}{r}.04 \\
.23 \\
.33 \\
.31 \\
.24\end{array}$ & $\begin{array}{l}0 \\
0 \\
0 \\
0 \\
0\end{array}$ & $\begin{array}{l}5.1 \\
4.0 \\
3.4 \\
3.2 \\
3.2\end{array}$ \\
\hline $\begin{array}{l}21 \\
22 \\
23 \\
24 \\
25\end{array}$ & $\begin{array}{l}.92 \\
1.0 \\
1.0 \\
1.0 \\
1.0\end{array}$ & $\begin{array}{l}1.6 \\
1.8 \\
1.7 \\
1.5 \\
1.5\end{array}$ & $\begin{array}{l}3.5 \\
3.3 \\
3.1 \\
3.1 \\
3.1\end{array}$ & $\begin{array}{l}2.4 \\
2.5 \\
2.9 \\
3.0 \\
2.9\end{array}$ & $\begin{array}{l}6.0 \\
5.7 \\
5.4 \\
5.4 \\
5.1\end{array}$ & $\begin{array}{l}5.4 \\
5.2 \\
5.0 \\
5.1 \\
5.1\end{array}$ & $\begin{array}{l}4.1 \\
4.0 \\
4.2 \\
4.1 \\
4.2\end{array}$ & $\begin{array}{l}2.1 \\
1.9 \\
1.9 \\
1.8 \\
1.7\end{array}$ & $\begin{array}{r}.41 \\
.38 \\
.30 \\
.22 \\
.11\end{array}$ & $\begin{array}{r}.16 \\
.13 \\
.18 \\
.13 \\
.11\end{array}$ & $\begin{array}{l}0 \\
0 \\
0 \\
0 \\
0\end{array}$ & $\begin{array}{l}3.1 \\
2.8 \\
2.7 \\
2.8 \\
3.1\end{array}$ \\
\hline $\begin{array}{l}26 \\
27 \\
28 \\
29 \\
30 \\
31\end{array}$ & $\begin{array}{l}1.0 \\
1.1 \\
1.1 \\
1.1 \\
1.2 \\
1.2\end{array}$ & $\begin{array}{l}1.6 \\
1.9 \\
3.2 \\
4.9 \\
4.0 \\
-\end{array}$ & $\begin{array}{l}3.0 \\
3.0 \\
2.9 \\
2.0 \\
2.8 \\
2.9\end{array}$ & $\begin{array}{l}2.8 \\
2.8 \\
3.0 \\
3.2 \\
3.2 \\
3.1\end{array}$ & $\begin{array}{l}5.1 \\
5.1 \\
5.1 \\
5.0 \\
-\infty \\
-\infty\end{array}$ & $\begin{array}{l}4.9 \\
4.8 \\
5.1 \\
4.9 \\
4.5 \\
4.3\end{array}$ & $\begin{array}{l}3.8 \\
3.7 \\
3.5 \\
3.4 \\
3.1 \\
0.2\end{array}$ & $\begin{array}{l}1.6 \\
1.8 \\
2.2 \\
2.5 \\
2.6 \\
2.2\end{array}$ & $\begin{array}{l}.04 \\
0 \\
0 \\
0 \\
0 \\
\ldots\end{array}$ & $\begin{array}{l}.12 \\
.41 \\
.26 \\
.16 \\
.22 \\
.25\end{array}$ & $\begin{array}{l}0 \\
0 \\
0 \\
0 \\
0 \\
0\end{array}$ & $\begin{array}{l}3.2 \\
2.8 \\
2.4 \\
2.1 \\
2.0 \\
--0\end{array}$ \\
\hline $\begin{array}{l}\text { POTAL } \\
\text { MEAN } \\
\text { MAX } \\
\text { MIN } \\
\text { AC }=F Y\end{array}$ & $\begin{array}{r}17.28 \\
.56 \\
1.2 \\
0 \\
34\end{array}$ & $\begin{array}{r}51.1 \\
1.70 \\
4.9 \\
1.0 \\
101\end{array}$ & $\begin{array}{r}86.5 \\
2.79 \\
3.5 \\
2.3 \\
172\end{array}$ & $\begin{array}{r}92.8 \\
2.99 \\
4.5 \\
2.4 \\
184\end{array}$ & $\begin{array}{r}531.9 \\
18.3 \\
185 \\
3.6 \\
1060\end{array}$ & $\begin{array}{r}396.5 \\
12.8 \\
107 \\
4.3 \\
786\end{array}$ & $\begin{array}{r}149.1 \\
4.97 \\
8.4 \\
3.1 \\
296\end{array}$ & $\begin{array}{r}77.4 \\
2.50 \\
3.7 \\
1.6 \\
154\end{array}$ & $\begin{array}{r}27.99 \\
.93 \\
2.0 \\
0 \\
56\end{array}$ & $\begin{array}{r}3.28 \\
.11 \\
.41 \\
0 \\
6.5\end{array}$ & $\begin{array}{r}.47 \\
.015 \\
.16 \\
0 \\
.9\end{array}$ & $\begin{array}{r}461.56 \\
15.4 \\
321 \\
0 \\
916\end{array}$ \\
\hline
\end{tabular}
$\begin{array}{lllllllll}\text { CAL YR } 1975 & \text { TOTAL } 1366.49 & \text { MEAN } 3.76 & \text { MAX } 93 & \text { MIN } 0 & \text { AC-FT } & 2710 \\ \text { WTR YA } 1976 & \text { TOTAL } & 1895.80 & \text { MEAN } 5.18 & \text { MAX } 321 & \text { MIN } 0 & \text { AC-FY } & 3760\end{array}$ 
PERIOD OF RECORD,--Chemica1 analyses: Water years 1967 to current year.

COOPERATION, - Chemica1-quality records were furnished by California Department of Water Resources.

CHEMICAL ANALYSES, WATER YEAR OCTOBER 1975 TO SEPTEMBER 1976

\begin{tabular}{|c|c|c|c|c|c|c|c|c|c|}
\hline DATE & TIME & $\begin{array}{l}\text { INSTAN- } \\
\text { TANEOUS } \\
\text { DIS- } \\
\text { CHARGE } \\
\text { (CFS) }\end{array}$ & $\begin{array}{l}\text { SPE- } \\
\text { CIFIC } \\
\text { CON- } \\
\text { DUCT- } \\
\text { ANCE } \\
\text { (MICRO- } \\
\text { MHOS) }\end{array}$ & $\begin{array}{c}\mathrm{PH} \\
\text { (UNITS) }\end{array}$ & $\begin{array}{l}\text { TEMPER- } \\
\text { ATURE } \\
\text { (DEG C) }\end{array}$ & $\begin{array}{l}\text { TUR- } \\
\text { BID- } \\
\text { ITY } \\
\text { (UTU) }\end{array}$ & $\begin{array}{l}\text { DIS- } \\
\text { SOLVEO } \\
\text { OXYGEN } \\
\text { (MG/L) }\end{array}$ & $\begin{array}{l}\text { HARD - } \\
\text { NESS } \\
(\mathrm{CA}, M G) \\
(M G / L)\end{array}$ & $\begin{array}{l}\text { NON- } \\
\text { CAR- } \\
\text { BONATE } \\
\text { HARD- } \\
\text { NESS } \\
(M G / L)\end{array}$ \\
\hline $\begin{array}{l}\text { DEC } \\
17 \ldots \\
\text { MAR }\end{array}$ & 1430 & 11 & 1250 & 8.0 & 6.5 & 3 & 11.2 & 468 & 170 \\
\hline $24 \ldots$ & 1130 & 5.3 & 1300 & 8.1 & 15.0 & 3 & 10.4 & 484 & 210 \\
\hline $23 \ldots$ & 0800 & .40 & 1580 & 7.8 & 19.0 & B & 6.2 & 520 & 200 \\
\hline
\end{tabular}

\begin{tabular}{|c|c|c|c|c|c|c|c|c|c|}
\hline DATE & $\begin{array}{l}\text { DIS- } \\
\text { SOLVED } \\
\text { CAL- } \\
\text { CIUM } \\
\text { (CA) } \\
\text { (MG/L) }\end{array}$ & $\begin{array}{l}\text { OIS- } \\
\text { SOLVED } \\
\text { MAG- } \\
\text { NE- } \\
\text { SIUM } \\
\text { (MG) } \\
\text { (MG/L) }\end{array}$ & $\begin{array}{l}\text { DIS- } \\
\text { SOLVED } \\
\text { SOOIUM } \\
\text { (NA) } \\
\text { (MG/L) }\end{array}$ & $\begin{array}{l}\text { PERCENT } \\
\text { SODIUM }\end{array}$ & $\begin{array}{l}\text { SODIUM } \\
\text { AD- } \\
\text { SORP- } \\
\text { TION } \\
\text { RATIO }\end{array}$ & $\begin{array}{l}\text { DIS- } \\
\text { SOLVED } \\
\text { PO= } \\
\text { TAS- } \\
\text { SIUH } \\
\text { (K) } \\
(M G / L)\end{array}$ & $\begin{array}{l}\text { BICAR- } \\
\text { BONATE } \\
\text { (HCO3) } \\
\text { (HG/L) }\end{array}$ & $\begin{array}{l}\text { CAR- } \\
\text { BONATE } \\
\text { (CO3) } \\
\text { (MG/L) }\end{array}$ & $\begin{array}{l}\text { ALKA- } \\
\text { LINITY } \\
\text { AS } \\
\text { CACO3 } \\
\text { (MG/L) }\end{array}$ \\
\hline $\begin{array}{l}\text { DEC } \\
17 \ldots \\
\text { MAR }\end{array}$ & 119 & 41 & 133 & 38 & 2.7 & 3.9 & 366 & 0 & 300 \\
\hline JUN & 121 & 44 & 131 & 37 & 2.6 & 3.9 & 329 & 0 & 323 \\
\hline DATE & $\begin{array}{l}\text { CARBON } \\
\text { DIOXIDE } \\
\text { (CO2) } \\
\text { (MG/L) }\end{array}$ & $\begin{array}{l}\text { DIS- } \\
\text { SOLVED } \\
\text { SULFATE } \\
\text { (SO4) } \\
(M G / L)\end{array}$ & $\begin{array}{l}\text { DIS= } \\
\text { SOLVEO } \\
\text { CHLO- } \\
\text { RIDE } \\
\text { (CL) } \\
\text { (HG/L) }\end{array}$ & $\begin{array}{l}\text { DIS- } \\
\text { SOLVED } \\
\text { FLUO- } \\
\text { RIDE } \\
\text { (F) } \\
\text { (MG/L) }\end{array}$ & $\begin{array}{l}\text { DIS- } \\
\text { SOLVED } \\
\text { SOLIDS } \\
\text { (RESI- } \\
\text { DUE AT } \\
180 \mathrm{C} \text { ) } \\
\text { (MG/L) }\end{array}$ & $\begin{array}{l}\text { DIS- } \\
\text { SOLVED } \\
\text { SOLIDS } \\
\text { (TONS } \\
\text { PER } \\
\text { AC-FT) }\end{array}$ & $\begin{array}{l}\text { DIS } \\
\text { SOLVED } \\
\text { SOLIDS } \\
\text { (TONS } \\
\text { PER } \\
\text { DAY) }\end{array}$ & $\begin{array}{c}\text { TOTAL } \\
\text { NITRATE } \\
\text { (N) } \\
(M G / L)\end{array}$ & $\begin{array}{c}\text { OIS- } \\
\text { SOLVED } \\
\text { BORON } \\
\text { (B) } \\
(U G / L)\end{array}$ \\
\hline $\begin{array}{l}\text { DEC } \\
17 \ldots \\
\text { MAR }\end{array}$ & 5.9 & 193 & 186 & .6 & 909 & 1.24 & 27.0 & .22 & 140 \\
\hline$\underset{\text { JUN }}{24} \cdots$ & 4.2 & 226 & 189 & .7 & 918 & 1.25 & 13.1 & .09 & 190 \\
\hline $23 \ldots$ & 10 & 204 & 222 & .7 & 1014 & 1.38 & 1.10 & .00 & 210 \\
\hline
\end{tabular}




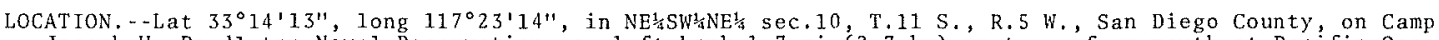
Joseph H. Pendleton Naval Reservation, 'on left bank $1.7 \mathrm{mi}(2.7 \mathrm{~km})$ upstream from mouth at Pacific ocean, and $2.0 \mathrm{mi}(3.2 \mathrm{~km})$ southwest of Ysidora.

DRAINAGE AREA. $-740 \mathrm{mi}^{2}\left(1,917 \mathrm{~km}^{2}\right)$.

\section{WATER-DISCHARGE RECORDS}

PERIOD OF RECORD, --February 1923 to current year.

GAGE. - Water-stage recorder. Datum of gage is $5.00 \mathrm{ft}(1.524 \mathrm{~m})$ below mean sea level (U.S. Navy reference mark). See WSP 1735 for history of changes prior to Nov. 27,1935 . Nov. 27,1935, to Feb. 25,1970, at site 0.8 mi $(1.3 \mathrm{~km})$ upstream at different datum.

REMARKS, - No flow since Apr, 15, 1974, Flow part1y regulated by Vail Lake since November 1948 (station 11042500 ). Diversions for irrigation on Rancho California (formerly Santa Margarita Ranch and Pauba Ranch)

Large conservation pools, starting $0.5 \mathrm{mi}(0.8 \mathrm{~km})$ upstrean can detain flow. AVERAGE DISCHARGE represents f1ow to ocean during period of record, regardiess of upstream development.

AVERAGE DISCHARgE, -53 years, $26.0 \mathrm{ft}^{3} / \mathrm{s}\left(0.736 \mathrm{~m}^{3} / \mathrm{s}\right), 18,840 \mathrm{acre}-\mathrm{ft} / \mathrm{yr}\left(23.2 \mathrm{hm}^{3} / \mathrm{yr}^{2}\right)$.

EXTREMES FOR PERIOD OF RECORD, - Maximum discharge, 33,600 $\mathrm{ft}^{3} / \mathrm{s}\left(952 \mathrm{~m}^{3} / \mathrm{s}\right)$ Feb. 16,1927 , gage height,

$18.00 \mathrm{ft}(5.486 \mathrm{~m})$, site and datum then in use, on basis of slope-area measurement of maximum flow;

no flow for all or part of most years.

EXTREMES FOR CURRENT YEAR. - No flow since April 15, 1974.

\section{WATER-QUALITY RECORDS}

PERIOD OF RECORD. - Water years 1969 to current year. WATER TEMPERATURES: Water years 1969 to current year. SEDIMENT RECORDS: Water years 1969 to current year.

PERIOD OF DAILY RECORD, - -

SEDIMENT RECORDS: . October 1968 to current year.

EXTREMES FOR PERIOD OF DAILY RECORD. - .

SEDIMENT CONCENTRATIONS: Maximum daily mean, 13,000 mg/l Feb. 24, 1969; minimum daily mean, no flow for many days each year.

SEDIMENT DISCHARGE: Maximum daily, 534,000 tons $(484,000$ tonnes) Feb. 24, 1969; minimum daily, 0 tons on many days each year.

EXTREMES FOR CURRENT YEAR, - -

SEDIMENT DISCHARGE: No flow since Apr. 15, 1974. 
11046100 LAS FLORES CREEK NEAR OCEANSIDE, CA

LOCATION.--Lat $33^{\circ} 17^{\prime} 32^{\prime \prime}$, Iong $117^{\circ} 27^{\prime} 21^{\prime \prime}$, in NWsSEt sec. 24 , T.10 S., R. 6 W. , San Diego County, Camp Joseph H, pendieton Naval Reservation, on upstream side and at center of bridge on Atchison, Topeka, and Santa Fe Railway, $0.5 \mathrm{mi}(0.8 \mathrm{~km})$ upstream from mouth, and $8.5 \mathrm{mi}(13.7 \mathrm{~km})$ northwest of oceanside.

DRATNAGE AREA. $--26.6 \mathrm{mi}^{2}\left(68.9 \mathrm{~km}^{2}\right)$.

PERIOD OF RECORD, - May 1951 to September 1967, october 1969 to current year.

REVISED RECORDS, - -WDR CA-72: 1971.

GAGE. - Water-stage recorder and multiple concrete culvert control. Altitude of gage is 35 ft (11 m), from topographic map.

REMARKS.--Records good to $0.1 \mathrm{ft}^{3} / \mathrm{s}\left(0.003 \mathrm{~m}^{3} / \mathrm{s}\right)$ and fair above. No regulation above station. Some pumping above station for irrigation.

AVERAGE DISCHARGE. -23 years, $0.53 \mathrm{ft}^{3} / \mathrm{s}\left(0.015 \mathrm{~m}^{3} / \mathrm{s}\right), 384$ acre-ft $/ \mathrm{yr}\left(473,000 \mathrm{~m}^{3} / \mathrm{yr}\right)$.

EXTREMES FOR PERIOD OF RECORD. - Maximum discharge, $960 \mathrm{ft}^{3} / \mathrm{s}\left(27.2 \mathrm{~m}^{3} / \mathrm{s}\right)$ Jan. 16, 1952, gage height, $4.75 \mathrm{ft}$ $(1.448 \mathrm{~m})$ based on critical-depth determination of maximum flow; no flow for long periods in most years.

EXTREMES OUTSIDE PERIOD OF RECORD,--Flood of Feb. 25, 1969, reached a stage of $7.25 \mathrm{ft}$ ( $2.210 \mathrm{~m}$ ), from f1oodmarks, discharge, 4,200 $\mathrm{ft}^{3} / \mathrm{s}\left(119 \mathrm{~m}^{3} / \mathrm{s}\right)$.

EXTREMES FOR CURRENT YEAR, - Maximum discharge, $0.65 \mathrm{ft}^{3} / \mathrm{s}\left(0.018 \mathrm{~m}^{3} / \mathrm{s}\right) \mathrm{Feb}, 6,10 ; \mathrm{gage}$ height, $0.27 \mathrm{ft}(0.082 \mathrm{~m})$, no peak above base of $100 \mathrm{ft} / \mathrm{s}\left(2.83 \mathrm{~m}^{3} / \mathrm{s}\right) ;$ no flow many days.

OISCHARGE, IN CUBIC FEET PER SECOND, WATER YEAR OCTOBER 1975 TO SEPTEMBER 1976 MEAN VALUES

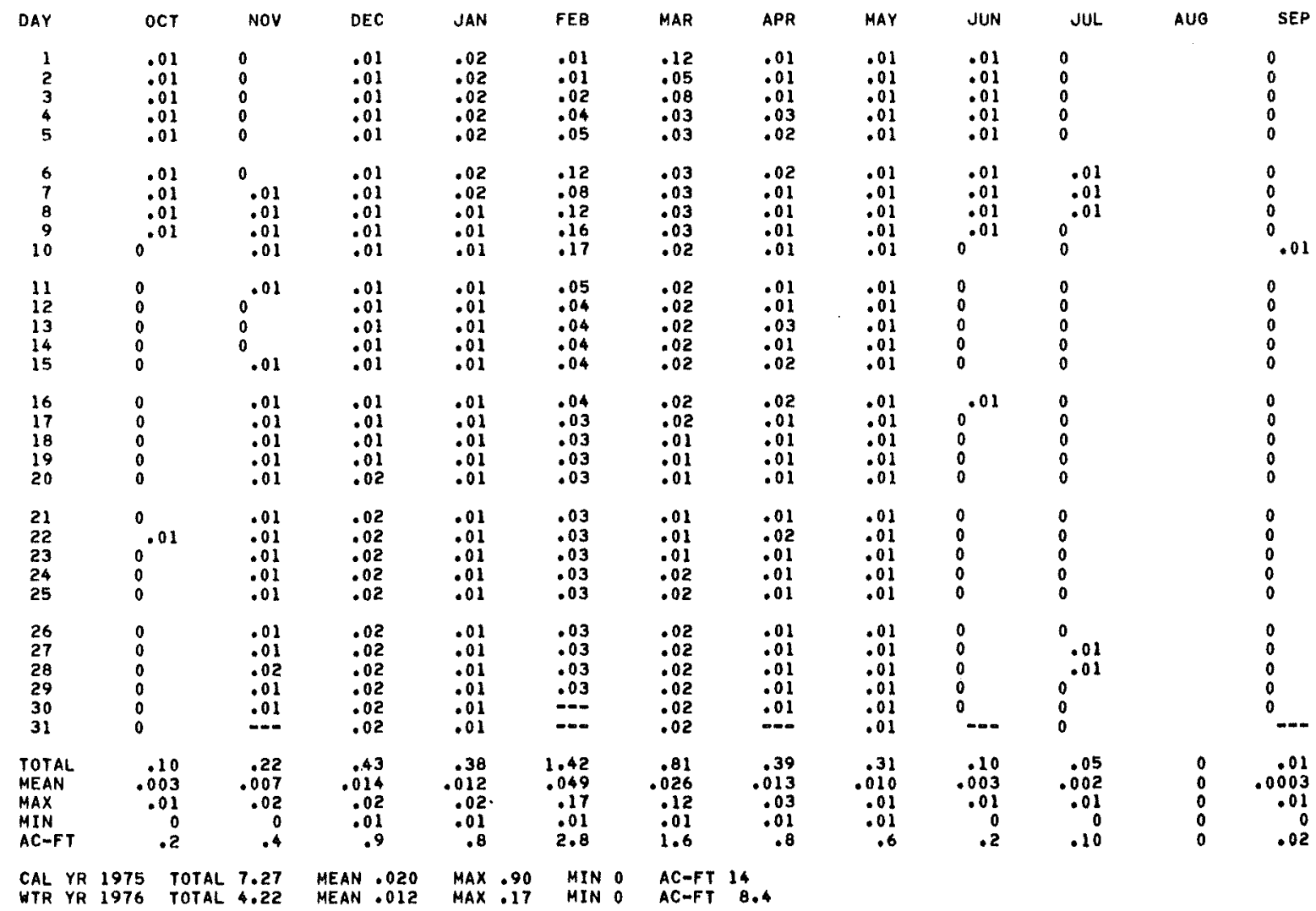




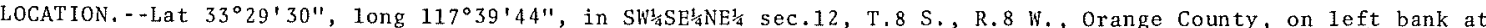
Camino Capistrano bridge, $0.2 \mathrm{mi}(0.3 \mathrm{~km}$ ) upstream from Arroyo Trabuco, and $0.6 \mathrm{mi}$ ( $1.0 \mathrm{~km}$ ) south of San Juan

DRAINAGE AREA. $-117 \mathrm{mi}^{2}\left(303 \mathrm{~km}^{2}\right)$.

WATER-DISCHARGE RECORDS

PERIOD OF RECORD. - October 1969 to current year.

GAGE. - Water-stage recorder. Altitude of gage is $67 \mathrm{ft}(20 \mathrm{~m})$.

REMARKS.--Records poor. No regulation above station. Capistrano Water Co. diverted 3.0 mi (4.8 km) upstream.

Various amounts of diverted water reach station as irrigation return flow and rising ground water. Data for

San Juan Creek near San Juan Capistrano (11046500) previously collected at site 2.8 mi (4.5 km) upstream was

published as creek only and combined.

COOPERATION.--Six discharge measurements were furnished by Orange County F1ood Contro1 District.

AVERAGE DISCHARGE. -7 years, $3.54 \mathrm{ft}^{3} / \mathrm{s}\left(0.100 \mathrm{~m}^{3} / \mathrm{s}\right), 2,560$ acre-ft/yr $\left(3.16 \mathrm{hm} / \mathrm{yr}^{3}\right)$.

EXTREMES FOR PERIOD OF RECORD.--Maximum discharge, $445 \mathrm{ft}^{3} / \mathrm{s}\left(12.6 \mathrm{~m}^{3} / \mathrm{s}\right) \mathrm{Feb} .11,1973$, gage height, $4.35 \mathrm{ft}$ $(1.326 \mathrm{~m})$; no flow at times in some years.

EXTREMES OUTSIDE PERIOD OF RECORD,--F1ood of Feb, $25,1969,22,400 \mathrm{ft}^{3} / \mathrm{s}\left(634 \mathrm{~m}^{3} / \mathrm{s}\right)$, at site $2.8 \mathrm{mi}(4.5 \mathrm{~km})$ upstream, as station 11046500.

EXTREMES FOR CURRENT YEAR.--Maximum discharge, $27 \mathrm{ft}^{3} / \mathrm{s}\left(0.76 \mathrm{~m}^{3} / \mathrm{s}\right)$ Feb. 9 , gage height, $1.70 \mathrm{ft}(0.518 \mathrm{~m})$, no peak above base of $200 \mathrm{ft}^{3} / \mathrm{s}\left(5.66 \mathrm{~m}^{3} / \mathrm{s}\right)$; minimum daily, $0.30 \mathrm{ft}^{3} / \mathrm{s}\left(0.008 \mathrm{~m}^{3} / \mathrm{s}\right)$ for several days.

DISCHARGE, IN CUBIC FEET PER SECOND, WATER YEAR OCTOBER 1975 TO SEPTEMBER 1976 MEAN VALUES

\begin{tabular}{|c|c|c|c|c|c|c|c|c|c|c|c|c|}
\hline DAY & OCT & NOV & $D E C$ & JAN & FEB & MAR & $A P R$ & MAY & JUN & JUL & AUG & SEP \\
\hline $\begin{array}{l}1 \\
2 \\
3 \\
4 \\
5\end{array}$ & $\begin{array}{l}.64 \\
.55 \\
.48 \\
.55 \\
.41\end{array}$ & $\begin{array}{l}1.0 \\
.64 \\
.41 \\
.35 \\
.55\end{array}$ & $\begin{array}{l}.48 \\
.48 \\
.48 \\
.48 \\
.41\end{array}$ & $\begin{array}{l}.48 \\
.75 \\
.64 \\
.64 \\
.55\end{array}$ & $\begin{array}{l}.75 \\
.75 \\
.75 \\
1.9 \\
2.5\end{array}$ & $\begin{array}{l}13 \\
12 \\
15 \\
7.7 \\
6.1\end{array}$ & $\begin{array}{l}1.7 \\
1.7 \\
2.1 \\
4.3 \\
2.9\end{array}$ & $\begin{array}{l}.75 \\
.64 \\
.75 \\
.56 \\
.64\end{array}$ & $\begin{array}{l}.75 \\
.75 \\
.75 \\
.75 \\
.75\end{array}$ & $\begin{array}{r}.55 \\
.41 \\
.86 \\
.64 \\
.55\end{array}$ & $\begin{array}{r}.55 \\
.50 \\
.50 \\
.50 \\
.50\end{array}$ & $\begin{array}{r}.86 \\
.75 \\
1.2 \\
.86 \\
.55\end{array}$ \\
\hline $\begin{array}{r}6 \\
7 \\
8 \\
9 \\
10\end{array}$ & $\begin{array}{r}.41 \\
.35 \\
.30 \\
.30 \\
.30\end{array}$ & $\begin{array}{r}.75 \\
.86 \\
.86 \\
.41 \\
.41\end{array}$ & $\begin{array}{l}.48 \\
.48 \\
.56 \\
.56 \\
.48\end{array}$ & $\begin{array}{l}.48 \\
.48 \\
.48 \\
.48 \\
.48\end{array}$ & $\begin{array}{r}5.1 \\
2.7 \\
5.2 \\
17 \\
12\end{array}$ & $\begin{array}{l}5.1 \\
5.1 \\
4.8 \\
4.4 \\
4.1\end{array}$ & $\begin{array}{l}2.3 \\
2.1 \\
2.3 \\
2.0 \\
1.7\end{array}$ & $\begin{array}{r}.64 \\
.75 \\
.87 \\
1.0 \\
.86\end{array}$ & $\begin{array}{r}.75 \\
.75 \\
.48 \\
.48 \\
1.2\end{array}$ & $\begin{array}{r}.55 \\
.48 \\
.75 \\
1.3 \\
1.3\end{array}$ & $\begin{array}{r}.48 \\
.48 \\
.48 \\
.41 \\
.41\end{array}$ & $\begin{array}{r}.48 \\
.41 \\
.35 \\
.30 \\
0.9\end{array}$ \\
\hline $\begin{array}{l}11 \\
12 \\
13 \\
14 \\
15\end{array}$ & $\begin{array}{r}.35 \\
.30 \\
.35 \\
.41 \\
.64\end{array}$ & $\begin{array}{r}.41 \\
.48 \\
.55 \\
.64 \\
.64\end{array}$ & $\begin{array}{r}.75 \\
.86 \\
1.0 \\
.48 \\
.35\end{array}$ & $\begin{array}{r}.55 \\
.55 \\
.64 \\
.86 \\
1.2\end{array}$ & $\begin{array}{l}6.4 \\
3.3 \\
3.3 \\
2.9 \\
2.9\end{array}$ & $\begin{array}{l}4.1 \\
4.0 \\
4.0 \\
3.9 \\
3.8\end{array}$ & $\begin{array}{l}1.3 \\
2.1 \\
6.0 \\
2.7 \\
3.8\end{array}$ & $\begin{array}{l}1.2 \\
.75 \\
1.2 \\
1.3 \\
.87\end{array}$ & $\begin{array}{l}.55 \\
.55 \\
.48 \\
.48 \\
.48\end{array}$ & $\begin{array}{r}.64 \\
.48 \\
.55 \\
.86 \\
.75\end{array}$ & $\begin{array}{r}.41 \\
.35 \\
.35 \\
.30 \\
.30\end{array}$ & $\begin{array}{c}3.3 \\
.75 \\
1.2 \\
1.3 \\
1.3\end{array}$ \\
\hline $\begin{array}{l}16 \\
17 \\
18 \\
19 \\
20\end{array}$ & $\begin{array}{l}.55 \\
.64 \\
1.0 \\
1.2 \\
1.3\end{array}$ & $\begin{array}{l}.55 \\
.55 \\
.55 \\
.64 \\
.64\end{array}$ & $\begin{array}{r}.41 \\
.48 \\
.55 \\
.55 \\
.86\end{array}$ & $\begin{array}{l}1.3 \\
1.0 \\
.64 \\
.75 \\
.86\end{array}$ & $\begin{array}{l}2.7 \\
2.7 \\
2.5 \\
2.3 \\
2.1\end{array}$ & $\begin{array}{l}3.8 \\
3.7 \\
3.6 \\
3.6 \\
3.5\end{array}$ & $\begin{array}{l}5.1 \\
3.6 \\
3.0 \\
2.5 \\
2.0\end{array}$ & $\begin{array}{r}.75 \\
.75 \\
.87 \\
1.2 \\
.90\end{array}$ & $\begin{array}{l}.48 \\
.41 \\
.41 \\
.48 \\
.41\end{array}$ & $\begin{array}{l}.64 \\
.64 \\
.55 \\
.64 \\
.64\end{array}$ & $\begin{array}{r}.30 \\
.30 \\
.30 \\
.35 \\
.35\end{array}$ & $\begin{array}{l}1.4 \\
1.4 \\
1.2 \\
1.0 \\
1.2\end{array}$ \\
\hline $\begin{array}{l}21 \\
22 \\
23 \\
24 \\
25\end{array}$ & $\begin{array}{r}1.3 \\
1.2 \\
.75 \\
.64 \\
.55\end{array}$ & $\begin{aligned} .86 \\
1.0 \\
.86 \\
1.0 \\
.86\end{aligned}$ & $\begin{array}{l}.75 \\
.75 \\
.75 \\
.75 \\
.64\end{array}$ & $\begin{array}{l}.86 \\
.86 \\
.86 \\
.86 \\
.75\end{array}$ & $\begin{array}{l}2.1 \\
2.1 \\
2.1 \\
2.1 \\
2.1\end{array}$ & $\begin{array}{l}3.4 \\
3.3 \\
3.1 \\
2.9 \\
2.7\end{array}$ & $\begin{array}{l}1.5 \\
1.2 \\
1.0 \\
.87 \\
.75\end{array}$ & $\begin{array}{l}.80 \\
.75 \\
.75 \\
.75 \\
.75\end{array}$ & $\begin{array}{l}.35 \\
.41 \\
.35 \\
.35 \\
.41\end{array}$ & $\begin{array}{r}.75 \\
.86 \\
1.0 \\
.75 \\
.86\end{array}$ & $\begin{array}{r}.30 \\
.35 \\
.35 \\
.35 \\
.41\end{array}$ & $\begin{array}{l}1.4 \\
1.6 \\
1.7 \\
1.7 \\
1.4\end{array}$ \\
\hline $\begin{array}{l}26 \\
27 \\
28 \\
29 \\
30 \\
31\end{array}$ & $\begin{array}{r}.55 \\
.64 \\
.55 \\
.55 \\
.64 \\
1.2\end{array}$ & $\begin{array}{r}.55 \\
.48 \\
.55 \\
.48 \\
.48 \\
.48\end{array}$ & $\begin{array}{l}.64 \\
.55 \\
.55 \\
.55 \\
.55 \\
.48\end{array}$ & $\begin{array}{r}.64 \\
.75 \\
.75 \\
1.0 \\
1.3 \\
.95\end{array}$ & $\begin{array}{c}2.1 \\
2.3 \\
2.3 \\
2.3 \\
=\infty \\
=\infty\end{array}$ & $\begin{array}{l}2.5 \\
2.3 \\
2.1 \\
2.0 \\
1.9 \\
1.8\end{array}$ & $\begin{array}{l}1.0 \\
1.0 \\
.87 \\
.75 \\
.75 \\
-\infty\end{array}$ & $\begin{array}{l}.75 \\
.75 \\
.75 \\
.75 \\
.75 \\
.75\end{array}$ & $\begin{array}{l}.48 \\
.41 \\
.35 \\
.64 \\
.86 \\
.80-\infty\end{array}$ & $\begin{array}{r}.75 \\
.64 \\
.64 \\
.41 \\
.41 \\
.35\end{array}$ & $\begin{array}{l}.48 \\
.55 \\
.55 \\
.41 \\
.48 \\
.64\end{array}$ & $\begin{array}{l}1.7 \\
1.3 \\
1.3 \\
1.3 \\
1.2 \\
-\infty=\infty\end{array}$ \\
\hline $\begin{array}{l}\text { TOTAL } \\
\text { MEAN } \\
\text { MAX } \\
\text { MIN } \\
\text { ACOFT }\end{array}$ & $\begin{array}{r}19.60 \\
.63 \\
1.3 \\
.30 \\
39\end{array}$ & $\begin{array}{r}19.01 \\
.63 \\
1.0 \\
.35 \\
38\end{array}$ & $\begin{array}{r}18.14 \\
059 \\
1.0 \\
.35 \\
36\end{array}$ & $\begin{array}{r}23.39 \\
.75 \\
1.3 \\
.48 \\
46\end{array}$ & $\begin{array}{r}99.25 \\
3.42 \\
17 \\
.75 \\
197\end{array}$ & $\begin{array}{r}143.3 \\
4.62 \\
15 \\
1.8 \\
284\end{array}$ & $\begin{array}{r}64.69 \\
2.16 \\
6.0 \\
.75 \\
129\end{array}$ & $\begin{array}{r}25.55 \\
.82 \\
1.3 \\
.56 \\
51\end{array}$ & $\begin{array}{r}16.75 \\
.56 \\
1.2 \\
.35 \\
33\end{array}$ & $\begin{array}{r}21.20 \\
.60 \\
1.3 \\
.35 \\
42\end{array}$ & $\begin{array}{r}12.99 \\
.42 \\
.64 \\
.30 \\
26\end{array}$ & $\begin{array}{r}43.31 \\
1.44 \\
0.9 \\
.30 \\
86\end{array}$ \\
\hline
\end{tabular}

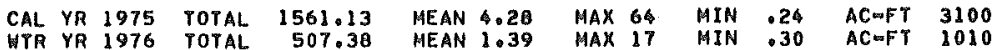


11046550 SAN JUAN CREEK AT SAN JUAN CAPISTRANO, CA--Continued

WATER-QUALITY RECORDS

PERIOD OF DAILY RECORD.--

WATER TEMPERATURES: October 1970 to current year.

SEDIMENT RECORDS: October 1970 to current year.

REMARKS,--Gravel mining created a large pit that acted as a sediment trap. Consequent1y, suspended sediment and bedload figures are substantially lower than previous years.

Particle-size distribution of bed material table was omitted in the 1975 water year and is published with 1976 water year records.

EXTREMES FOR PERIOD OF DAILY RECORD.-

SEDIMENT CONCENTRATIONS: Maximum daily mean, 4,600 mg/1 Feb. 28, 1973; minimum daily mean, no f1ow for many days in $1970-72$.

SEDIMENT DISCHARGE: Maximum dai1y, 1,990 tons $(1,810$ tonnes) Feb, 11, 1973 ; minimum dai1y, 0 tons on many days during most years.

EXTREMES FOR CURRENT YEAR. -

SEDIEMNT CONCENTRATIONS: Maximum daily mean, $478 \mathrm{mg} / 1 \mathrm{Mar}, 1$; minimum daily mean, $4 \mathrm{mg} / 1 \mathrm{Sept}, 25-30$.

SEDIMENT DISCHARGE: Maximum daily, 30 tons $(27$ tonnes) Mar. 1 ; minimum daily, 0.01 ton (0.01 tonne) Nov. 3 , 4 , and Sept. $27-30$

TEMPERATURE (DEG, C) OF WATER, WATER YEAR OCTOBER 1975 TO SEPTEMBER 1976 ONCE-DAILY

\begin{tabular}{|c|c|c|c|c|c|c|c|c|c|c|c|c|}
\hline DAY & $O C T$ & NOV & DEC & JAN & FEB & MAR & $A P R$ & MAY & JUN & JUL & AUG & SEP \\
\hline $\begin{array}{l}1 \\
2 \\
3 \\
4 \\
5\end{array}$ & $\begin{array}{r}18.0 \\
20.0 \\
-0 .\end{array}$ & 14.0 & $\begin{array}{r}-.-5 \\
12.5 \\
14.0\end{array}$ & $\begin{array}{r}--5 \\
6.5 \\
15.0 \\
--\end{array}$ & $\begin{array}{r}--0 \\
13.0 \\
13.0 \\
11.0\end{array}$ & $\begin{array}{r}14.0 \\
15.0 \\
8.0 \\
-0 . \\
--0\end{array}$ & $\begin{array}{r}20.5 \\
15.0 \\
13.0 \\
11.0\end{array}$ & $\begin{array}{r}24.0 \\
18.0 \\
\ldots .0\end{array}$ & $\begin{array}{r}19.0 \\
17.0\end{array}$ & 23.0 & $\begin{array}{r}20.0 \\
--0 \\
-\infty\end{array}$ & $\begin{array}{r}21.0 \\
20.0 \\
-\infty\end{array}$ \\
\hline $\begin{array}{r}6 \\
7 \\
8 \\
9 \\
10\end{array}$ & 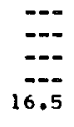 & $\begin{array}{r}14.0 \\
=-0 \\
=-\infty\end{array}$ & 15.0 & $\begin{array}{r}-.0 \\
9.0 \\
14.0\end{array}$ & $\begin{array}{l}11.0 \\
12.0 \\
14.0 \\
12.0 \\
14.0\end{array}$ & $\begin{array}{l}=-\infty \\
--\infty \\
-=- \\
=-\infty \\
=-\infty\end{array}$ & $\begin{array}{r}12.0 \\
0.0 \\
18.0 \\
18.0\end{array}$ & 15.0 & $\begin{array}{r}-0 \\
22.0 \\
-0- \\
=-0\end{array}$ & $\begin{array}{r}22.0 \\
20.0 \\
20.0\end{array}$ & $\begin{array}{r}15.0 \\
-0 \\
-0\end{array}$ & $\begin{array}{r}=0 \\
22.0 \\
=0\end{array}$ \\
\hline $\begin{array}{l}11 \\
12 \\
13 \\
14 \\
15\end{array}$ & $\begin{array}{l}=- \\
=-0 \\
=-0 \\
=-\end{array}$ & $\begin{array}{r}-0 \\
-0.0 \\
19.0 \\
-0\end{array}$ & $\begin{array}{r}13.0 \\
=-0 \\
--\infty\end{array}$ & $\begin{array}{l}--- \\
--0 \\
=-- \\
-\infty .0\end{array}$ & $\begin{array}{r}10.0 \\
11.0 \\
11.0 \\
-0.0\end{array}$ & $\begin{array}{r}-=-5 \\
10.5 \\
8.0 \\
- \\
-\end{array}$ & $\begin{array}{r}16.0 \\
16.0 \\
15.0\end{array}$ & $\begin{array}{r}21.0 \\
17.0\end{array}$ & $\begin{array}{r}--- \\
24.0 \\
-\ldots \\
=-\end{array}$ & $\begin{array}{r}-24.0 \\
-=0 \\
=-\infty\end{array}$ & $\begin{array}{r}21.0 \\
18.0 \\
-0.0\end{array}$ & $\begin{array}{r}20.0 \\
22.0 \\
\ldots-\end{array}$ \\
\hline $\begin{array}{l}16 \\
17 \\
18 \\
19 \\
20\end{array}$ & $\begin{array}{r}--5 \\
15.0 \\
=- \\
16.5\end{array}$ & $\begin{array}{l}-\infty \\
-\infty \\
=-\infty \\
--\infty \\
-\infty\end{array}$ & $\begin{array}{r}0- \\
9.0 \\
12.0\end{array}$ & $\begin{array}{r}18.0 \\
-\infty \\
-\infty\end{array}$ & $\begin{array}{r}=-0 \\
12.0 \\
=-\infty\end{array}$ & $\begin{array}{r}0 .- \\
16.5 \\
9.0\end{array}$ & $\begin{array}{l}---0 \\
9.0 \\
-0- \\
---\end{array}$ & $\begin{array}{l}=-\infty \\
=-\infty \\
=-\infty \\
-\infty\end{array}$ & $\begin{array}{r}18.0 \\
23.0 \\
-0.0\end{array}$ & $\begin{array}{r}20.0 \\
\ldots \\
\ldots\end{array}$ & $\begin{array}{l}-\infty \\
-\infty \\
-\infty-\infty \\
--\infty \\
-\infty-\infty\end{array}$ & $\begin{array}{r}-0 \\
16.0 \\
-\infty\end{array}$ \\
\hline $\begin{array}{l}21 \\
22 \\
23 \\
24 \\
25\end{array}$ & 18.0 & $\begin{array}{l}9.0 \\
=-- \\
=-\infty \\
=--\end{array}$ & $\begin{array}{l}=-0 \\
-=- \\
--\infty \\
-\infty-\infty \\
=-\infty\end{array}$ & $\begin{array}{r}-\infty- \\
10.0 \\
12.0 \\
-0\end{array}$ & $\begin{array}{r}12.0 \\
=-0 \\
=-0\end{array}$ & $\begin{array}{l}-\infty \\
=-\infty \\
=-- \\
-\infty \\
--\infty\end{array}$ & $\begin{array}{r}-0.5 \\
20.5 \\
19.0 \\
-0.0\end{array}$ & $\begin{array}{r}23.0 \\
23.0 \\
18.0 \\
-0\end{array}$ & 23.5 & $\begin{array}{r}21.0 \\
19.0 \\
-0\end{array}$ & $\begin{array}{r}19.0 \\
\ldots-0 \\
0-0\end{array}$ & 20.0 \\
\hline $\begin{array}{l}26 \\
27 \\
28 \\
29 \\
30 \\
31\end{array}$ & $\begin{array}{r}--0 \\
13.0 \\
15.0 \\
0-0\end{array}$ & $\begin{array}{r}10.5 \\
13.5 \\
\ldots-. \\
\ldots-\end{array}$ & $\begin{array}{r}12.0 \\
10.5 \\
-0\end{array}$ & $\begin{array}{l}0- \\
\cdots .5 \\
9.0 \\
9.0\end{array}$ & $\begin{array}{r}12.0 \\
10.0 \\
-0 \\
-\infty\end{array}$ & $\begin{array}{r}17.5 \\
10.0 \\
-\infty- \\
-\ldots \\
-\infty\end{array}$ & $\begin{array}{l}m \\
=-\infty \\
=-\infty \\
-\infty\end{array}$ & $\begin{array}{r}-0 \\
18.0 \\
-0\end{array}$ & $=$ & 25.0 & $\begin{array}{r}20.5 \\
16.0 \\
-\ldots \\
\cdots\end{array}$ & $\begin{array}{l}=-\infty \\
=-\infty \\
=-\infty \\
=-\infty\end{array}$ \\
\hline ONTH & $=-$ & $\cdots$ & $-\infty$ & $=-$ & $-\infty$ & 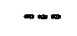 & -- & $-\infty$ & $m$ & $-\infty$ & $-\infty$ & $-\infty$ \\
\hline
\end{tabular}


11046550 SAN JUAN CREEK AT SAN JUAN CAPISTRANO, CA--Continued

SUSPENDED-SEDIMENT DISCHARGE (TONS/DAY), WATER YEAR OCTOBER 1975 TO SEPTEMBER 1976

\begin{tabular}{|c|c|c|c|c|c|c|c|c|c|}
\hline & & OCTOBER & & & NOVEMBER & & & DECEMBER & \\
\hline DAY & $\begin{array}{l}\text { MEAN } \\
\text { OISCHARGE } \\
\text { (CFS) }\end{array}$ & $\begin{array}{l}\text { MEAN } \\
\text { CONCEN- } \\
\text { TRATION } \\
\text { (MG/L) }\end{array}$ & $\begin{array}{l}\text { SEDIMENT } \\
\text { DISCHARGE } \\
\text { (TONS/DAY) }\end{array}$ & $\begin{array}{l}\text { MEAN } \\
\text { DISCHARGE } \\
\text { (CFS) }\end{array}$ & $\begin{array}{l}\text { MEAN } \\
\text { CONCEN- } \\
\text { TRATION } \\
\text { (MG/L) }\end{array}$ & $\begin{array}{l}\text { SEDIMENT } \\
\text { DISCHARGE } \\
\text { (TONS/DAY) }\end{array}$ & $\begin{array}{l}\text { MEAN } \\
\text { DISCHARGE } \\
\text { (CFS) }\end{array}$ & $\begin{array}{l}\text { MEAN } \\
\text { CONCEN- } \\
\text { TRATION } \\
\text { (MG/L) }\end{array}$ & $\begin{array}{l}\text { SEDIMENT } \\
\text { DISCHARGE } \\
\text { (TONS/DAY) }\end{array}$ \\
\hline $\begin{array}{l}1 \\
2 \\
3 \\
4 \\
5\end{array}$ & $\begin{array}{l}.64 \\
.55 \\
.48 \\
.55 \\
.41\end{array}$ & $\begin{array}{l}34 \\
40 \\
45 \\
50 \\
55\end{array}$ & $\begin{array}{l}.06 \\
.06 \\
.06 \\
.07 \\
.06\end{array}$ & $\begin{array}{l}1.0 \\
.64 \\
.41 \\
.35 \\
.55\end{array}$ & $\begin{array}{l}19 \\
16 \\
13 \\
11 \\
11\end{array}$ & $\begin{array}{r}.05 \\
.03 \\
.01 \\
.01 \\
.02\end{array}$ & $\begin{array}{r}.48 \\
.48 \\
.48 \\
.48 \\
.41\end{array}$ & $\begin{array}{l}73 \\
76 \\
80 \\
60 \\
41\end{array}$ & $\begin{array}{r}.09 \\
.10 \\
.10 \\
.08 \\
.05\end{array}$ \\
\hline $\begin{array}{r}6 \\
7 \\
8 \\
9 \\
10\end{array}$ & $\begin{array}{l}.41 \\
.35 \\
.30 \\
.30 \\
.30\end{array}$ & $\begin{array}{l}60 \\
65 \\
70 \\
75 \\
75\end{array}$ & $\begin{array}{l}.07 \\
.06 \\
.06 \\
.06 \\
.06\end{array}$ & $\begin{array}{l}.75 \\
.86 \\
.86 \\
.41 \\
.41\end{array}$ & $\begin{array}{l}10 \\
10 \\
17 \\
24 \\
31\end{array}$ & $\begin{array}{l}.02 \\
.02 \\
.04 \\
.03 \\
.03\end{array}$ & $\begin{array}{l}.48 \\
.48 \\
.56 \\
.56 \\
.48\end{array}$ & $\begin{array}{l}37 \\
32 \\
28 \\
24 \\
19\end{array}$ & $\begin{array}{l}.05 \\
.04 \\
.04 \\
.04 \\
.02\end{array}$ \\
\hline $\begin{array}{l}11 \\
12 \\
13 \\
14 \\
15\end{array}$ & $\begin{array}{l}.35 \\
.30 \\
.35 \\
.41 \\
.64\end{array}$ & $\begin{array}{l}70 \\
70 \\
65 \\
65 \\
60\end{array}$ & $\begin{array}{l}.07 \\
.06 \\
.06 \\
.07 \\
.10\end{array}$ & $\begin{array}{l}.41 \\
.48 \\
.55 \\
.64 \\
.64\end{array}$ & $\begin{array}{l}38 \\
45 \\
52 \\
56 \\
57\end{array}$ & $\begin{array}{l}.04 \\
.06 \\
.08 \\
.10 \\
.10\end{array}$ & $\begin{array}{l}.75 \\
.86 \\
1.0 \\
.48 \\
.35\end{array}$ & $\begin{array}{l}15 \\
31 \\
36 \\
41 \\
46\end{array}$ & $\begin{array}{l}.03 \\
.07 \\
.10 \\
.05 \\
.04\end{array}$ \\
\hline $\begin{array}{l}16 \\
17 \\
18 \\
19 \\
20\end{array}$ & $\begin{array}{l}.55 \\
.64 \\
1.0 \\
1.2 \\
1.3\end{array}$ & $\begin{array}{l}60 \\
55 \\
50 \\
40 \\
24\end{array}$ & $\begin{array}{l}.09 \\
.10 \\
.14 \\
.13 \\
.08\end{array}$ & $\begin{array}{l}.55 \\
.55 \\
.55 \\
.64 \\
.64\end{array}$ & $\begin{array}{l}58 \\
59 \\
60 \\
61 \\
62\end{array}$ & $\begin{array}{l}.09 \\
.09 \\
.09 \\
.11 \\
.11\end{array}$ & $\begin{array}{l}.41 \\
.48 \\
.55 \\
.55 \\
.86\end{array}$ & $\begin{array}{l}50 \\
55 \\
60 \\
64 \\
68\end{array}$ & $\begin{array}{l}.06 \\
.07 \\
.09 \\
.10 \\
.16\end{array}$ \\
\hline $\begin{array}{l}21 \\
22 \\
23 \\
24 \\
25\end{array}$ & $\begin{array}{l}1.3 \\
1.2 \\
.75 \\
.64 \\
.55\end{array}$ & $\begin{array}{l}26 \\
28 \\
30 \\
32 \\
32\end{array}$ & $\begin{array}{l}.09 \\
.09 \\
.06 \\
.06 \\
.05\end{array}$ & $\begin{array}{l}.86 \\
1.0 \\
.86 \\
1.0 \\
.86\end{array}$ & $\begin{array}{l}63 \\
60 \\
60 \\
60 \\
60\end{array}$ & $\begin{array}{l}.15 \\
.16 \\
114 \\
16 \\
14\end{array}$ & $\begin{array}{l}.75 \\
.75 \\
.75 \\
.75 \\
.64\end{array}$ & $\begin{array}{l}61 \\
55 \\
48 \\
42 \\
35\end{array}$ & $\begin{array}{r}.12 \\
.11 \\
.10 \\
.09 \\
.06\end{array}$ \\
\hline $\begin{array}{l}26 \\
27 \\
28 \\
29 \\
30 \\
31\end{array}$ & $\begin{array}{r}.55 \\
.64 \\
.55 \\
.55 \\
.64 \\
1.2\end{array}$ & $\begin{array}{l}33 \\
34 \\
35 \\
36 \\
37 \\
21\end{array}$ & $\begin{array}{l}.05 \\
.06 \\
.05 \\
.05 \\
.06 \\
.07\end{array}$ & $\begin{array}{r}.55 \\
.48 \\
.55 \\
.48 \\
.48 \\
.--.\end{array}$ & $\begin{array}{r}60 \\
60 \\
62 \\
66 \\
69 \\
-\end{array}$ & $\begin{array}{l}.09 \\
.08 \\
.09 \\
.09 \\
.09 \\
.0-\end{array}$ & $\begin{array}{r}.64 \\
.55 \\
.55 \\
.55 \\
.55 \\
.48\end{array}$ & $\begin{array}{l}29 \\
22 \\
20 \\
18 \\
16 \\
14\end{array}$ & $\begin{array}{l}.05 \\
.03 \\
.03 \\
.03 \\
.02 \\
.02\end{array}$ \\
\hline TOTAL. & 19.60 & $-\infty$ & 2.21 & 19.01 & $--\infty$ & 2.32 & $18 \cdot 14$ & $--\infty$ & 2.04 \\
\hline & & JANUARY & & & FEBRUARY & & & MARCH & \\
\hline DAY & $\begin{array}{l}\text { MEAN } \\
\text { OI SCHARGE } \\
\text { (CFS) }\end{array}$ & $\begin{array}{l}\text { MEAN } \\
\text { CONCEN- } \\
\text { TRATION } \\
\text { (MG/L) }\end{array}$ & $\begin{array}{l}\text { SEDIMENT } \\
\text { DISCHARGE } \\
\text { (TONS/DAY) }\end{array}$ & $\begin{array}{l}\text { MEAN } \\
\text { OISCHARGE } \\
\text { (CFS) }\end{array}$ & $\begin{array}{l}\text { MEAN } \\
\text { CONCEN- } \\
\text { TRATION } \\
\text { (MG/L) }\end{array}$ & $\begin{array}{l}\text { SEDIMENT } \\
\text { DISCHARGE } \\
\text { (TONS /DAY) }\end{array}$ & $\begin{array}{l}\text { MEAN } \\
\text { DISCHARGE } \\
\text { (CFS) }\end{array}$ & $\begin{array}{l}\text { MEAN } \\
\text { CONCEN- } \\
\text { TRATION } \\
\text { (MG/L) }\end{array}$ & $\begin{array}{l}\text { SEDIMENT } \\
\text { DISCHARGE } \\
\text { (TONS/DAY) }\end{array}$ \\
\hline $\begin{array}{l}1 \\
2 \\
3 \\
4 \\
5\end{array}$ & $\begin{array}{l}.48 \\
.75 \\
.64 \\
.64 \\
.55\end{array}$ & $\begin{array}{l}12 \\
11 \\
21 \\
21 \\
22\end{array}$ & $\begin{array}{l}.02 \\
.02 \\
.04 \\
.04 \\
.03\end{array}$ & $\begin{array}{r}.75 \\
.75 \\
.75 \\
1.9 \\
2.5\end{array}$ & $\begin{array}{r}129 \\
97 \\
65 \\
36 \\
42\end{array}$ & $\begin{array}{r}.26 \\
.20 \\
.13 \\
.22 \\
.38\end{array}$ & $\begin{array}{l}13 \\
12 \\
15 \\
7.7 \\
6.1\end{array}$ & $\begin{array}{l}478 \\
194 \\
351 \\
160 \\
140\end{array}$ & $\begin{array}{l}30 \\
11 \\
16 \\
3.3 \\
2.3\end{array}$ \\
\hline $\begin{array}{r}6 \\
7 \\
8 \\
9 \\
10\end{array}$ & $\begin{array}{l}.48 \\
.48 \\
.48 \\
.48 \\
.48\end{array}$ & $\begin{array}{l}22 \\
23 \\
23 \\
25 \\
28\end{array}$ & $\begin{array}{l}.03 \\
.03 \\
.03 \\
.03 \\
.04\end{array}$ & $\begin{array}{r}5.1 \\
2.7 \\
5.2 \\
17 \\
12\end{array}$ & $\begin{array}{r}117 \\
45 \\
54 \\
313 \\
80\end{array}$ & $\begin{array}{c}4.0 \\
.44 \\
.99 \\
18 \\
2.6\end{array}$ & $\begin{array}{l}5.1 \\
5.1 \\
4.8 \\
4.4 \\
4.1\end{array}$ & $\begin{array}{r}120 \\
100 \\
90 \\
75 \\
60\end{array}$ & $\begin{array}{l}1.7 \\
1.4 \\
1.2 \\
.89 \\
.66\end{array}$ \\
\hline $\begin{array}{l}11 \\
12 \\
13 \\
14 \\
15\end{array}$ & $\begin{array}{l}.55 \\
.55 \\
.64 \\
.86 \\
1.2\end{array}$ & $\begin{array}{l}27 \\
26 \\
25 \\
24 \\
22\end{array}$ & $\begin{array}{l}.04 \\
.04 \\
.04 \\
.06 \\
.07\end{array}$ & $\begin{array}{l}6.4 \\
3.3 \\
3.3 \\
2.9 \\
2.9\end{array}$ & $\begin{array}{l}44 \\
22 \\
19 \\
15 \\
23\end{array}$ & $\begin{array}{l}.76 \\
.20 \\
.17 \\
.12 \\
.18\end{array}$ & $\begin{array}{l}4.1 \\
4.0 \\
4.0 \\
3.9 \\
3.8\end{array}$ & $\begin{array}{l}49 \\
48 \\
48 \\
47 \\
46\end{array}$ & $\begin{array}{r}.54 \\
.52 \\
.52 \\
.49 \\
.47\end{array}$ \\
\hline $\begin{array}{l}16 \\
17 \\
18 \\
19 \\
20\end{array}$ & $\begin{array}{l}1.3 \\
1.0 \\
.64 \\
.75 \\
.86\end{array}$ & $\begin{array}{l}18 \\
14 \\
16 \\
18 \\
20\end{array}$ & $\begin{array}{l}.06 \\
.04 \\
.03 \\
.04 \\
.05\end{array}$ & $\begin{array}{l}2.7 \\
2.7 \\
2.5 \\
2.3 \\
2.1\end{array}$ & $\begin{array}{l}31 \\
39 \\
47 \\
44 \\
42\end{array}$ & $\begin{array}{l}.23 \\
.28 \\
.32 \\
.27 \\
.24\end{array}$ & $\begin{array}{l}3.8 \\
3.7 \\
3.6 \\
3.6 \\
3.5\end{array}$ & $\begin{array}{l}45 \\
44 \\
43 \\
42 \\
63\end{array}$ & $\begin{array}{r}.46 \\
.44 \\
.42 \\
.41 \\
.60\end{array}$ \\
\hline $\begin{array}{l}21 \\
22 \\
23 \\
24 \\
25\end{array}$ & $\begin{array}{l}.86 \\
.86 \\
.86 \\
.86 \\
.75\end{array}$ & $\begin{array}{r}22 \\
25 \\
29 \\
164 \\
152\end{array}$ & $\begin{array}{l}.05 \\
.06 \\
.07 \\
.38 \\
.31\end{array}$ & $\begin{array}{l}2.1 \\
2.1 \\
2.1 \\
2.1 \\
2.1\end{array}$ & $\begin{array}{l}39 \\
45 \\
51 \\
56 \\
62\end{array}$ & $\begin{array}{l}.22 \\
.26 \\
.29 \\
.32 \\
.35\end{array}$ & $\begin{array}{l}3.4 \\
3.3 \\
3.1 \\
2.9 \\
2.7\end{array}$ & $\begin{array}{l}57 \\
51 \\
44 \\
38 \\
32\end{array}$ & $\begin{array}{r}.52 \\
.45 \\
.37 \\
.30 \\
.23\end{array}$ \\
\hline $\begin{array}{l}26 \\
27 \\
28 \\
29 \\
30 \\
31\end{array}$ & $\begin{array}{l}.64 \\
.75 \\
.75 \\
1.0 \\
1.3 \\
.95\end{array}$ & $\begin{array}{l}141 \\
129 \\
117 \\
106 \\
94 \\
161\end{array}$ & $\begin{array}{l}.24 \\
.26 \\
.24 \\
.29 \\
.33 \\
.41\end{array}$ & $\begin{array}{l}2.1 \\
2.3 \\
2.3 \\
2.3 \\
-\ldots \\
\ldots-\infty\end{array}$ & $\begin{array}{r}68 \\
72 \\
56 \\
55 \\
-\infty- \\
--\infty\end{array}$ & $\begin{array}{r}.39 \\
.45 \\
.35 \\
.34 \\
-0- \\
---\end{array}$ & $\begin{array}{l}2.5 \\
2.3 \\
2.1 \\
2.0 \\
1.9 \\
1.8\end{array}$ & $\begin{array}{l}26 \\
31 \\
36 \\
42 \\
48 \\
53\end{array}$ & $\begin{array}{l}.18 \\
.19 \\
.20 \\
.23 \\
.25 \\
.26\end{array}$ \\
\hline
\end{tabular}


11046550 SAN JUAN CREEK AT SAN JUAN CAPISTRANO, CA--Continued

SUSPENDED-SEDIMENT DISCHARGE (TONS/DAY), WATER YEAR OCTOBER 1975 TO SEPTEMBER 1976

\begin{tabular}{|c|c|c|c|c|c|c|c|c|c|}
\hline & & APRIL & & & MAY & & & JUNE & \\
\hline DAY & $\begin{array}{l}\text { MEAN } \\
\text { DISCHARGE } \\
\text { (CFS) }\end{array}$ & $\begin{array}{l}\text { MEAN } \\
\text { CONCEN- } \\
\text { TRATION } \\
\text { (MG/L) }\end{array}$ & $\begin{array}{l}\text { SEDIMENT } \\
\text { DISCHARGE } \\
\text { (TONS/DAY) }\end{array}$ & $\begin{array}{l}\text { MEAN } \\
\text { DISCHARGE } \\
\text { (CFS) }\end{array}$ & $\begin{array}{l}\text { MEAN } \\
\text { CONCEN- } \\
\text { TRATION } \\
\text { (MG/L) }\end{array}$ & $\begin{array}{l}\text { SEDIMENT } \\
\text { DISCHARGE } \\
\text { (TONS/DAY) }\end{array}$ & $\begin{array}{l}\text { MEAN } \\
\text { DISCHARGE } \\
\text { (CFS) }\end{array}$ & $\begin{array}{l}\text { MEAN } \\
\text { CONCEN- } \\
\text { TRATION } \\
\text { (MG/L) }\end{array}$ & $\begin{array}{l}\text { SEDIMENT } \\
\text { DISCHAROE } \\
\text { (TONS/OAY) }\end{array}$ \\
\hline $\begin{array}{l}1 \\
2 \\
3 \\
4 \\
5\end{array}$ & $\begin{array}{l}1.7 \\
1.7 \\
2.1 \\
4.3 \\
2.9\end{array}$ & $\begin{array}{l}58 \\
64 \\
28 \\
56 \\
33\end{array}$ & $\begin{array}{r}.27 \\
.29 \\
.16 \\
.65 \\
.26\end{array}$ & $\begin{array}{r}.75 \\
.64 \\
.75 \\
.56 \\
.64\end{array}$ & $\begin{array}{l}88 \\
72 \\
57 \\
57 \\
57\end{array}$ & $\begin{array}{l}.18 \\
.12 \\
112 \\
.97 \\
.10\end{array}$ & $\begin{array}{r}.75 \\
.75 \\
.75 \\
.75 \\
.75\end{array}$ & $\begin{array}{l}112 \\
130 \\
110 \\
89 \\
69\end{array}$ & $\begin{array}{r}.23 \\
.26 \\
.22 \\
.18 \\
.14\end{array}$ \\
\hline $\begin{array}{r}6 \\
7 \\
8 \\
9 \\
10\end{array}$ & $\begin{array}{l}2.3 \\
2.1 \\
2.3 \\
2.0 \\
1.7\end{array}$ & $\begin{array}{l}13 \\
20 \\
27 \\
36 \\
24\end{array}$ & $\begin{array}{l}.08 \\
.11 \\
.17 \\
.19 \\
.11\end{array}$ & $\begin{array}{r}.64 \\
.75 \\
.87 \\
1.0 \\
.86\end{array}$ & $\begin{array}{l}56 \\
56 \\
56 \\
69 \\
82\end{array}$ & $\begin{array}{l}.10 \\
.11 \\
.13 \\
.19 \\
.19\end{array}$ & $\begin{array}{l}.75 \\
.75 \\
.48 \\
.48 \\
1.2\end{array}$ & $\begin{array}{l}71 \\
73 \\
66 \\
58 \\
68\end{array}$ & $\begin{array}{l}.14 \\
.15 \\
.09 \\
.08 \\
.28\end{array}$ \\
\hline $\begin{array}{l}11 \\
12 \\
13 \\
14 \\
15\end{array}$ & $\begin{array}{l}1.3 \\
2.1 \\
6.0 \\
2.7 \\
3.8\end{array}$ & $\begin{array}{l}20 \\
16 \\
11 \\
31 \\
41\end{array}$ & $\begin{array}{l}.07 \\
.09 \\
.18 \\
.23 \\
.42\end{array}$ & $\begin{array}{l}1.2 \\
.75 \\
1.2 \\
1.3 \\
.87\end{array}$ & $\begin{array}{r}96 \\
109 \\
90 \\
72 \\
53\end{array}$ & $\begin{array}{r}.31 \\
.22 \\
.29 \\
.25 \\
.12\end{array}$ & $\begin{array}{r}.55 \\
.55 \\
.48 \\
.48 \\
.48\end{array}$ & $\begin{array}{l}50 \\
40 \\
30 \\
45 \\
49\end{array}$ & $\begin{array}{r}.07 \\
.22 \\
1.2 \\
.06 \\
.51\end{array}$ \\
\hline $\begin{array}{l}16 \\
17 \\
18 \\
19 \\
20\end{array}$ & $\begin{array}{l}5.1 \\
3.6 \\
3.0 \\
2.5 \\
2.0\end{array}$ & $\begin{array}{r}25 \\
9 \\
9 \\
10 \\
11\end{array}$ & $\begin{array}{l}.34 \\
.09 \\
.07 \\
.07 \\
.06\end{array}$ & $\begin{array}{r}.75 \\
.75 \\
.87 \\
1.2 \\
.90\end{array}$ & $\begin{array}{l}50 \\
47 \\
44 \\
41 \\
38\end{array}$ & $\begin{array}{r}.10 \\
110 \\
.10 \\
113 \\
.09\end{array}$ & $\begin{array}{l}.48 \\
.41 \\
.41 \\
.48 \\
.41\end{array}$ & $\begin{array}{l}54 \\
49 \\
43 \\
37 \\
37\end{array}$ & $\begin{array}{l}.07 \\
.05 \\
.05 \\
.05 \\
.04\end{array}$ \\
\hline $\begin{array}{l}21 \\
22 \\
23 \\
24 \\
25\end{array}$ & $\begin{array}{l}1.5 \\
1.2 \\
1.0 \\
.87 \\
.75\end{array}$ & $\begin{array}{l}12 \\
12 \\
27 \\
52 \\
57\end{array}$ & $\begin{array}{l}.05 \\
.04 \\
.07 \\
.12 \\
.12\end{array}$ & $\begin{array}{r}.80 \\
.75 \\
.75 \\
.75 \\
.75\end{array}$ & $\begin{array}{r}35 \\
32 \\
75 \\
107 \\
97\end{array}$ & $\begin{array}{l}.08 \\
.06 \\
.15 \\
.22 \\
.20\end{array}$ & $\begin{array}{r}.35 \\
.41 \\
.35 \\
.35 \\
.41\end{array}$ & $\begin{array}{l}38 \\
39 \\
40 \\
41 \\
42\end{array}$ & $\begin{array}{l}.04 \\
.04 \\
.04 \\
.04 \\
.05\end{array}$ \\
\hline $\begin{array}{l}26 \\
27 \\
28 \\
29 \\
30 \\
31\end{array}$ & $\begin{array}{l}1.0 \\
1.0 \\
.87 \\
.75 \\
.75 \\
.-1\end{array}$ & $\begin{array}{r}62 \\
67 \\
72 \\
78 \\
83 \\
-\end{array}$ & $\begin{array}{l}.17 \\
.18 \\
117 \\
.16 \\
.17 \\
-10\end{array}$ & $\begin{array}{l}.75 \\
.75 \\
.75 \\
.75 \\
.75 \\
.75\end{array}$ & $\begin{array}{l}87 \\
76 \\
66 \\
56 \\
74 \\
93\end{array}$ & $\begin{array}{r}.18 \\
.15 \\
113 \\
.11 \\
.15 \\
.19\end{array}$ & $\begin{array}{r}.48 \\
.41 \\
.35 \\
.64 \\
.86 \\
-\infty\end{array}$ & $\begin{array}{r}39 \\
36 \\
32 \\
28 \\
24 \\
--0\end{array}$ & $\begin{array}{l}.05 \\
.04 \\
.03 \\
.05 \\
.06 \\
-\end{array}$ \\
\hline STAL & 64.89 & $-m$ & 5.16 & 25.55 & $-\infty$ & 5.54 & 16.75 & $-\infty$ & 4.53 \\
\hline
\end{tabular}

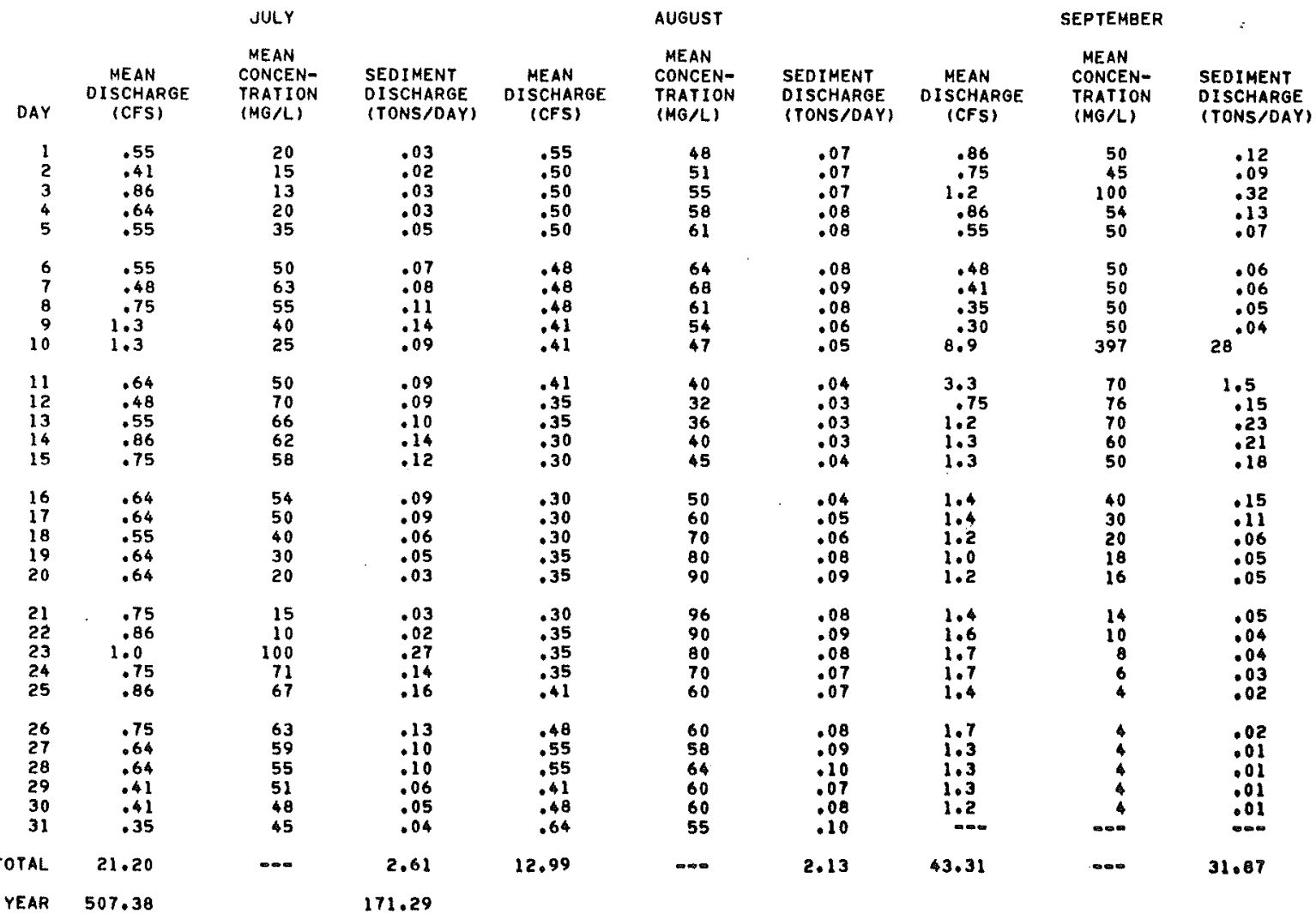


SUMMARY OF HATER AND SEOIMENT DISCHARGE, WATER YEAR OCTOBER 1975 TO SEPTEMBER 1976

\begin{tabular}{|c|c|c|c|c|}
\hline MONTH & $\begin{array}{c}\text { WATER } \\
\text { DISCHARGE } \\
\text { CFS-DAYS }\end{array}$ & $\begin{array}{l}\text { SUSPENDED } \\
\text { SEDIMENT } \\
\text { DISCHARGE } \\
\text { TONS }\end{array}$ & $\begin{array}{c}\text { BEDLOAD } \\
\text { DISCHARGE } \\
\text { TONS }\end{array}$ & $\begin{array}{l}\text { TOTAL } \\
\text { SEDIMENT } \\
\text { DISCHARGE } \\
\text { TONS }\end{array}$ \\
\hline OCTOBER 1975 & 19.60 & 2.21 & 0 & 2 \\
\hline NOVEMBER ... & 19.01 & 2.32 & 0 & 2 \\
\hline DECEMBER ... & 18.14 & 2.04 & 0 & 2 \\
\hline JANUARY 1976 & 23.39 & 3.42 & 0 & 3 \\
\hline FEBRUARY ... & 99.25 & 32.96 & 9 & 42 \\
\hline MARCH $\ldots . .$. & 143.30 & 76.50 & 15 & 91 \\
\hline APRIL $\ldots \ldots$ & 64.89 & 5.16 & 4 & 9 \\
\hline MAY $\ldots \ldots \ldots$ & 25.55 & 5.54 & 0 & 6 \\
\hline JUNE $\ldots . .$. & 16.75 & 4.53 & 0 & 5 \\
\hline JULY ........ & 21.20 & 2.61 & 0 & $\mathbf{3}$ \\
\hline AUGUST $\ldots . .$. & 12.99 & 2.13 & 0 & 2 \\
\hline SEPTEMBER .. & 43.31 & 31.87 & 2 & 34 \\
\hline TOTAL ...... & 507.38 & 171.29 & 30 & 201 \\
\hline
\end{tabular}

PARTICLE-SIZE OISTRIBUTION OF SUSPENDED SEDIMENT, WATER YEAR OCTOBER 1975 TO SEPTEMBER 1976

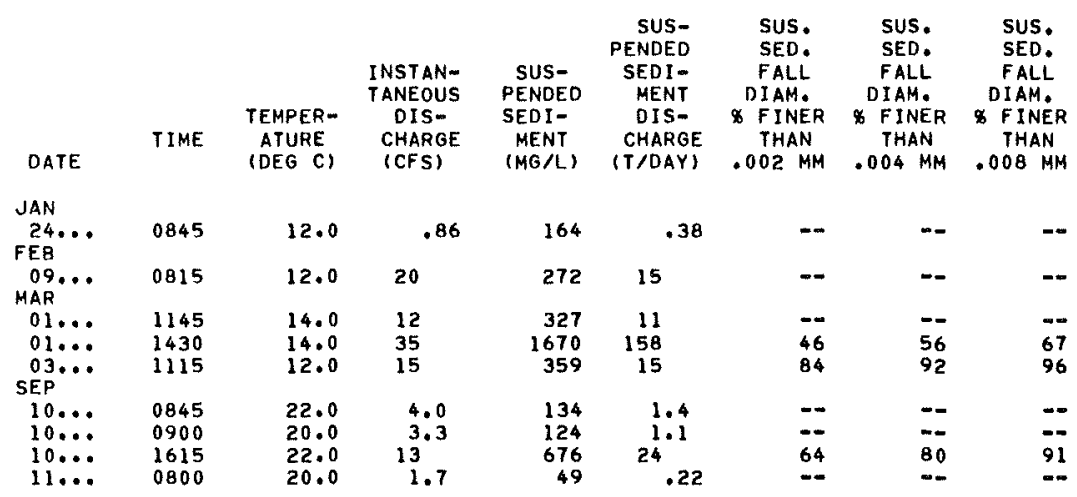

\begin{tabular}{|c|c|c|c|c|c|c|c|}
\hline & $\begin{array}{l}\text { SUS. } \\
\text { SED. } \\
\text { FALL } \\
\text { DIAM. } \\
\text { O FINER } \\
\text { THAN }\end{array}$ & $\begin{array}{l}\text { SUS. } \\
\text { SED. } \\
\text { FALL } \\
\text { DIAM. } \\
\text { \$ FINER } \\
\text { THAN }\end{array}$ & $\begin{array}{l}\text { SUS. } \\
\text { SED: } \\
\text { FALL } \\
\text { DIAM. } \\
\text { \& FINER } \\
\text { THAN }\end{array}$ & \multirow[t]{2}{*}{$\begin{array}{c}\text { SUS. } \\
\text { SED: } \\
\text { SIEVE } \\
\text { DIAM. } \\
\text { \$ FINER } \\
\text { THAN } \\
.062 \text { MM }\end{array}$} & \multirow[t]{2}{*}{$\begin{array}{l}\text { SUS. } \\
\text { SED. } \\
\text { FALL } \\
\text { DIAM. } \\
\text { O FINER } \\
\text { THAN } \\
\text { TI25 MM }\end{array}$} & $\begin{array}{l}\text { SUS. } \\
\text { SED: } \\
\text { SIEVE. } \\
\text { DIAM. } \\
\text { D FINER } \\
\text { THAN }\end{array}$ & \multirow[t]{2}{*}{$\begin{array}{l}\text { SUS. } \\
\text { SED. } \\
\text { SIEVE } \\
\text { DIAM. } \\
\text { FINER } \\
\text { THAN } \\
250 \text { MM }\end{array}$} \\
\hline & $.016 \mathrm{MM}$ & $.031 \mathrm{MM}$ & $.062 \mathrm{MM}$ & & & $.125 \mathrm{MM}$ & \\
\hline & & & & & & & \\
\hline $24 \cdot$. & -- & -- & -- & 99 & $\cdots$ & 100 & -- \\
\hline$\underset{\text { MAR }}{09 .}$ & -- & -- & $\cdots$ & 100 & -- & $\cdots$ & $\cdots$ \\
\hline $01 .$. & - & - & - & 100 & -- & 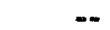 & $m$ \\
\hline 01. & 8 & 89 & & $\rightarrow$ & 100 & -- & \\
\hline 03. & 98 & 99 & 100 & $-\infty$ & - & 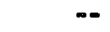 & -- \\
\hline & -- & -- & $-\infty$ & & -- & - & \\
\hline & & - & -- & & $\ldots$ & - & \\
\hline 10. & 99 & 100 & - & - & $=-$ & $\ldots$ & -- \\
\hline & - & -- & $=-$ & 96 & -- & 98 & 10 \\
\hline
\end{tabular}


11046550 SAN JUAN CREEK AT SAN JUAN CAPISTRANO, CA--Continued

PARTICLE-SIZE DISTRIBUTION OF SURFACE BEO MATERIAL, WATER YEAR OCTOBER 1974 TO SEPTEMBER 1975

\begin{tabular}{|c|c|c|c|c|c|c|c|}
\hline & TIME & $\begin{array}{c}\text { NUMBER } \\
\text { OF } \\
\text { SAM- } \\
\text { PL.ING } \\
\text { POINTS }\end{array}$ & $\begin{array}{l}\text { INSTAN- } \\
\text { TANEOUS } \\
\text { DIS- } \\
\text { CHARGE }\end{array}$ & $\begin{array}{l}\text { BED } \\
\text { MAT. } \\
\text { SIEVE } \\
\text { DIAM. } \\
\infty \text { FINER } \\
\text { THAN }\end{array}$ & $\begin{array}{c}\text { BED } \\
\text { MAT. } \\
\text { SIEVE } \\
\text { DIAM. } \\
\text { \$ FINER } \\
\text { THAN }\end{array}$ & $\begin{array}{c}\text { BED } \\
\text { MAT. } \\
\text { SIEVE } \\
\text { DIAM. } \\
\text { \$ FINER } \\
\text { THAN }\end{array}$ & $\begin{array}{l}\text { BEO } \\
\text { MAT. } \\
\text { SIEVE } \\
\text { DIAM. } \\
\text { FINER } \\
\text { THAN }\end{array}$ \\
\hline DATE & & & (CFS) & $.062 \mathrm{MM}$ & $.125 \mathrm{MM}$ & $.250 \mathrm{MM}$ & $.500 \mathrm{MM}$ \\
\hline $\begin{array}{l}\text { SEP } \\
29 . .\end{array}$ & 1400 & 3 & .70 & 2 & 4 & 9 & 26 \\
\hline
\end{tabular}

\begin{tabular}{|c|c|c|c|c|c|c|c|c|c|c|}
\hline \multirow[b]{3}{*}{ DATE } & \multirow{2}{*}{\multicolumn{2}{|c|}{$\begin{array}{l}\text { BED } \\
\text { MAT. } \\
\text { SIEVE } \\
\text { DIAM. } \\
\text { \% FINER }\end{array}$}} & \multicolumn{2}{|c|}{$\begin{array}{l}\text { BED } \\
\text { MAT. } \\
\text { SIEVE } \\
\text { DIAM. }\end{array}$} & \multicolumn{2}{|c|}{$\begin{array}{l}\text { BED } \\
\text { MAT } \\
\text { SIEVE } \\
\text { DIAM. }\end{array}$} & \multicolumn{2}{|c|}{$\begin{array}{l}\text { BED } \\
\text { MAT. } \\
\text { SIEVE } \\
\text { DIAM. }\end{array}$} & $\begin{array}{l}\text { GED } \\
\text { MAT. } \\
\text { SIEVE } \\
\text { DIAM. }\end{array}$ & $\begin{array}{l}\text { BED } \\
\text { MAT. } \\
\text { SIEVE } \\
\text { DIAM. }\end{array}$ \\
\hline & & $\begin{array}{l}\text { JER } \\
\text { AN }\end{array}$ & $\begin{array}{l}* \mathrm{FI} \\
\mathrm{TH}\end{array}$ & $\begin{array}{l}\text { NER } \\
A N\end{array}$ & $\begin{array}{l}\text { \$ F IN } \\
\text { THA }\end{array}$ & $\begin{array}{l}\text { NER } \\
A N\end{array}$ & $\begin{array}{l}\text { * FINE } \\
\text { THAN }\end{array}$ & & $\begin{array}{l}\text { * FINER } \\
\text { THAN }\end{array}$ & $\begin{array}{l}\text { * FINER } \\
\text { THAN }\end{array}$ \\
\hline & 1.00 & $M M$ & 2.00 & $M M$ & 4.00 & $M M$ & $8.00 \mathrm{M}$ & MM & $16.0 \mathrm{MM}$ & $32.0 \mathrm{HM}$ \\
\hline $29 \ldots$ & & 52 & & 69 & & 79 & & 89 & 99 & 100 \\
\hline
\end{tabular}


LOCATION, - Lat $33^{\circ} 33^{\prime} 29^{\prime \prime}$, long $117^{\circ} 40^{\prime} 33^{\prime \prime}$, in SEl sec.14, T.7 S., R. 8 w., Orange County, on right upstream side of Crown Valley Parkway bridge, $2.7 \mathrm{mi}(4.3 \mathrm{~km})$ south of Mission Viejo, and $4.0 \mathrm{mi}$ (6.4 $\mathrm{km}$ ) north of San Juan Capistrano.

DRAINAGE AREA, $--14.0 \mathrm{mi}^{2}\left(36.3 \mathrm{~km}^{2}\right)$.

FERIOD OF RECORD, - -December 1969 to current year.

GAGE. - Water-stage recorder. Altitude of gage is $250 \mathrm{ft}(76 \mathrm{~m})$, from topographic map.

REMARKS. - -Records poor, No regulation or diversion above station.

COOPERATION, - Records were furnished by Orange County Flood Control District.

AVERAGE DISCHARGE. - -6 years (water years $1971-76), 2.30 \mathrm{ft}^{3} / \mathrm{s}\left(0.065 \mathrm{~m}^{3} / \mathrm{s}\right), 1,670 \mathrm{acre} \cdot \mathrm{ft} / \mathrm{yr}(2.06 \mathrm{hm} / \mathrm{yr})$.

EXTREMES FOR PERIOD of RECORD, - Maximum discharge, $1,630 \mathrm{ft}^{3} / \mathrm{s}\left(46.2 \mathrm{~m}^{3} / \mathrm{s}\right) \mathrm{Feb} .11,1973$, gage height, $7.67 \mathrm{ft}$ $(2.338 \mathrm{~m})$; no flow at times in most years.

EXTREMES FOR CURRENT YEAR, - Maximum discharge, $440 \mathrm{ft}^{3} / \mathrm{s}\left(12.5 \mathrm{~m}^{3} / \mathrm{s}\right)$ Sept, 10, gage height, $9.90 \mathrm{ft}(3.018 \mathrm{~m})$;

minimum daily, $0.70 \mathrm{ft}^{3} / \mathrm{s}\left(0.020 \mathrm{~m}^{3} / \mathrm{s}\right)$ Oct. 1, Apr. $18-19$.

DISCHARGE, IN CUBIC FEET PER SECOND, HATER YEAR OCTOBER 1975 TO SEPTEMBER 1976 MEAN VALUES

\begin{tabular}{|c|c|c|c|c|c|c|c|c|c|c|c|c|}
\hline DAY & OCT & NOV & DEC & JAN & FEB & MAR & APR & MAY & JUN & JUL & AUG & SEP \\
\hline $\begin{array}{l}1 \\
2 \\
3 \\
4 \\
5\end{array}$ & $\begin{array}{l}.70 \\
.80 \\
.80 \\
.80 \\
.80\end{array}$ & $\begin{array}{l}1.2 \\
1.2 \\
1.4 \\
1.4 \\
1.5\end{array}$ & $\begin{array}{l}2.0 \\
1.7 \\
1.7 \\
2.0 \\
2.2\end{array}$ & $\begin{array}{l}2.4 \\
2.2 \\
2.2 \\
2.1 \\
2.1\end{array}$ & $\begin{array}{l}2.6 \\
2.8 \\
2.8 \\
11 \\
16\end{array}$ & $\begin{array}{l}50 \\
21 \\
39 \\
1.4 \\
.90\end{array}$ & $\begin{array}{c}.90 \\
.90 \\
1.2 \\
13 \\
3.3\end{array}$ & $\begin{array}{l}.80 \\
.90 \\
.90 \\
.80 \\
.80\end{array}$ & $\begin{array}{l}1.7 \\
1.7 \\
1.6 \\
1.6 \\
1.5\end{array}$ & $\begin{array}{l}1.1 \\
.90 \\
1.1 \\
1.2 \\
.80\end{array}$ & $\begin{array}{l}.90 \\
.90 \\
.90 \\
.90 \\
.90\end{array}$ & $\begin{array}{l}.90 \\
.90 \\
1.0 \\
1.0 \\
1.0\end{array}$ \\
\hline $\begin{array}{r}6 \\
7 \\
8 \\
9 \\
10\end{array}$ & $\begin{array}{l}.80 \\
.90 \\
1.2 \\
1.4 \\
1.2\end{array}$ & $\begin{array}{l}1.5 \\
1.5 \\
1.6 \\
1.6 \\
1.6\end{array}$ & $\begin{array}{l}2.2 \\
2.1 \\
2.1 \\
2.1 \\
2.1\end{array}$ & $\begin{array}{l}2.1 \\
2.1 \\
2.1 \\
2.1 \\
2.1\end{array}$ & $\begin{array}{l}53 \\
18 \\
40 \\
86 \\
17\end{array}$ & $\begin{array}{r}.90 \\
.90 \\
.90 \\
.90 \\
.90\end{array}$ & $\begin{array}{l}1.1 \\
1.0 \\
2.0 \\
1.5 \\
1.1\end{array}$ & $\begin{array}{r}.90 \\
.90 \\
.90 \\
1.1 \\
1.1\end{array}$ & $\begin{array}{r}1.5 \\
1.4 \\
1.2 \\
1.3 \\
28\end{array}$ & $\begin{array}{l}1.0 \\
.90 \\
1.0 \\
1.2 \\
1.1\end{array}$ & $\begin{array}{r}.90 \\
.90 \\
.90 \\
.90 \\
.90\end{array}$ & $\begin{array}{l}1.0 \\
1.0 \\
1.0 \\
1.0\end{array}$ \\
\hline $\begin{array}{l}11 \\
12 \\
13 \\
14 \\
15\end{array}$ & $\begin{array}{l}1.1 \\
1.1 \\
1.1 \\
1.1 \\
1.1\end{array}$ & $\begin{array}{l}1.6 \\
1.6 \\
1.6 \\
1.6 \\
1.6\end{array}$ & $\begin{array}{l}2.1 \\
3.7 \\
9.0 \\
3.8 \\
2.8\end{array}$ & $\begin{array}{l}2.1 \\
2.1 \\
2.1 \\
2.1 \\
2.1\end{array}$ & $\begin{array}{l}4.5 \\
4.2 \\
4.0 \\
3.8 \\
3.6\end{array}$ & $\begin{array}{l}.90 \\
.90 \\
.90 \\
.90 \\
.90\end{array}$ & $\begin{array}{r}1.2 \\
2.2 \\
24 \\
1.0 \\
3.2\end{array}$ & $\begin{array}{l}1.2 \\
1.4 \\
1.2 \\
1.2 \\
1.2\end{array}$ & $\begin{array}{l}2.6 \\
1.1 \\
1.2 \\
1.1 \\
1.1\end{array}$ & $\begin{array}{l}1.0 \\
.90 \\
1.0 \\
1.0 \\
1.0\end{array}$ & $\begin{array}{l}.90 \\
.90 \\
.90 \\
.90 \\
.90\end{array}$ & $\begin{array}{l}4.8 \\
1.1 \\
1.1 \\
1.1 \\
1.1\end{array}$ \\
\hline $\begin{array}{l}16 \\
17 \\
18 \\
19 \\
20\end{array}$ & $\begin{array}{l}1.1 \\
1.0 \\
1.0 \\
1.0 \\
1.0\end{array}$ & $\begin{array}{l}1.6 \\
1.6 \\
1.7 \\
1.7 \\
1.7\end{array}$ & $\begin{array}{l}2.2 \\
2.2 \\
2.1 \\
2.1 \\
3.8\end{array}$ & $\begin{array}{l}2.1 \\
2.1 \\
2.2 \\
2.4 \\
2.6\end{array}$ & $\begin{array}{l}3.4 \\
3.2 \\
3.0 \\
2.8 \\
2.4\end{array}$ & $\begin{array}{l}.90 \\
1.1 \\
1.1 \\
.90 \\
.90\end{array}$ & $\begin{array}{r}2.4 \\
.80 \\
.70 \\
.70 \\
.80\end{array}$ & $\begin{array}{l}1.0 \\
1.2 \\
1.4 \\
1.4 \\
1.2\end{array}$ & $\begin{array}{l}1.4 \\
1.0 \\
1.0 \\
1.1 \\
1.2\end{array}$ & $\begin{array}{l}1.0 \\
1.0 \\
1.4 \\
1.1 \\
1.0\end{array}$ & $\begin{array}{l}.90 \\
.90 \\
.90 \\
.90 \\
.90\end{array}$ & $\begin{array}{l}1.2 \\
1.2 \\
1.2 \\
1.2 \\
1.3\end{array}$ \\
\hline $\begin{array}{l}21 \\
22 \\
23 \\
24 \\
25\end{array}$ & $\begin{array}{l}1.0 \\
1.0 \\
1.0 \\
1.0 \\
1.0\end{array}$ & $\begin{array}{l}1.7 \\
1.7 \\
1.7 \\
1.7 \\
2.0\end{array}$ & $\begin{array}{l}8.9 \\
4.8 \\
3.4 \\
3.0 \\
3.0\end{array}$ & $\begin{array}{l}2.6 \\
2.4 \\
2.6 \\
2.6 \\
2.6\end{array}$ & $\begin{array}{l}2.1 \\
2.0 \\
1.7 \\
1.6 \\
1.4\end{array}$ & $\begin{array}{l}.90 \\
.90 \\
.90 \\
.90 \\
.90\end{array}$ & $\begin{array}{l}.90 \\
1.0 \\
1.1 \\
1.0 \\
2.1\end{array}$ & $\begin{array}{l}1 \cdot 2 \\
1 \cdot 2 \\
1 \cdot 2 \\
1 \cdot 2 \\
1 \cdot 2\end{array}$ & $\begin{array}{l}1.2 \\
1.1 \\
1.2 \\
1.1 \\
1.1\end{array}$ & $\begin{array}{l}1.0 \\
.90 \\
.90 \\
1.0 \\
1.2\end{array}$ & $\begin{array}{l}.90 \\
.90 \\
.90 \\
.90 \\
.90\end{array}$ & $\begin{array}{l}1.3 \\
1.4 \\
1.4 \\
1.4 \\
1.3\end{array}$ \\
\hline $\begin{array}{l}26 \\
27 \\
28 \\
29 \\
30 \\
31\end{array}$ & $\begin{array}{l}1.0 \\
1.0 \\
1.0 \\
1.0 \\
1.1 \\
1.1\end{array}$ & $\begin{array}{l}2.0 \\
2.0 \\
35 \\
20 \\
3.2 \\
-0-\end{array}$ & $\begin{array}{l}2.8 \\
2.8 \\
2.6 \\
2.4 \\
2.4 \\
2.4\end{array}$ & $\begin{array}{l}2.6 \\
2.4 \\
2.4 \\
2.6 \\
2.6 \\
2.6\end{array}$ & $\begin{array}{l}1.2 \\
1.0 \\
.90 \\
.90 \\
-0 . \\
-0 .\end{array}$ & $\begin{array}{l}.90 \\
.90 \\
.80 \\
.90 \\
.90 \\
.90\end{array}$ & $\begin{array}{l}1.6 \\
.80 \\
.80 \\
.80 \\
.80 \\
.-\infty\end{array}$ & $\begin{array}{l}1.2 \\
1.6 \\
1.6 \\
1.6 \\
1.6 \\
1.5\end{array}$ & $\begin{array}{l}1.4 \\
1.6 \\
3.4 \\
1.1 \\
1.2 \\
-.0\end{array}$ & $\begin{array}{l}1.6 \\
1.4 \\
.90 \\
.90 \\
.90 \\
.90\end{array}$ & $\begin{array}{l}.90 \\
.90 \\
.90 \\
.90 \\
.90 \\
.90\end{array}$ & $\begin{array}{l}1.3 \\
1.3 \\
1.3 \\
1.3 \\
1.3 \\
-\infty .\end{array}$ \\
\hline $\begin{array}{l}\text { TOTAL } \\
\text { MEAN } \\
\text { MAX } \\
\text { MIN } \\
\text { AC-FT }\end{array}$ & $\begin{array}{r}31.20 \\
1.01 \\
1.4 \\
.70 \\
62\end{array}$ & $\begin{array}{r}101.8 \\
3.39 \\
35 \\
1.2 \\
202\end{array}$ & $\begin{array}{r}92.5 \\
2.98 \\
9.0 \\
1.7 \\
183\end{array}$ & $\begin{array}{r}71.4 \\
2.30 \\
2.6 \\
2.1 \\
142\end{array}$ & $\begin{array}{r}296.90 \\
10.2 \\
86 \\
.90 \\
589\end{array}$ & $\begin{array}{r}136.00 \\
4.39 \\
50 \\
.80 \\
270\end{array}$ & $\begin{array}{r}73.90 \\
2.46 \\
24 \\
.70 \\
147\end{array}$ & $\begin{array}{r}36.50 \\
1.18 \\
1.6 \\
.80 \\
72\end{array}$ & $\begin{array}{r}68.7 \\
2.29 \\
28 \\
1.0 \\
136\end{array}$ & $\begin{array}{r}32.30 \\
1.04 \\
1.6 \\
.80 \\
64\end{array}$ & $\begin{array}{r}27.90 \\
.90 \\
.90 \\
.90 \\
55\end{array}$ & $\begin{array}{r}85.40 \\
2.85 \\
48 \\
.90 \\
169\end{array}$ \\
\hline $\begin{array}{l}\text { CAL YR } \\
\text { HTA YR }\end{array}$ & $\begin{array}{l}975 \\
976\end{array}$ & $\begin{array}{r}675.00 \\
1054.50\end{array}$ & $\begin{array}{l}\text { MEAN } \\
\text { MEAN }\end{array}$ & $\begin{array}{l}1.65 \\
2.88\end{array}$ & $\begin{array}{ll}\operatorname{MAX} & 35 \\
\text { MAX } & 86\end{array}$ & $\begin{array}{l}\text { MIN } \\
\text { MIN }\end{array}$ & $\begin{array}{l}A C=F T \\
A C=F T\end{array}$ & $\begin{array}{l}1340 \\
2090\end{array}$ & & & & \\
\hline
\end{tabular}


11047300 ARROYO TRABUCO AT SAN JUAN CAPISTRANO, CA

LOCATION,--Lat $33^{\circ} 29^{\prime} 54^{\prime \prime}$, long $117^{\circ} 39^{\prime} 54^{\prime \prime}$, on 1ine between secs.1 and $12, \mathrm{~T} .8 \mathrm{~S} ., \mathrm{R} .8$ W., Orange County, on downstream side of bridge on Del obispo Street in San Juan Capistrano.

DRAINAGE AREA. $-54.1 \mathrm{mi}^{2}\left(140 \mathrm{~km}^{2}\right)$.

WATER-DISCHARGE RECORDS

PERIOD OF RECORD.--October 1972 to current year.

GAGE.-Water-stage recorder. Datum of gage is $80 \mathrm{ft}(24.4 \mathrm{~m})$, from topograhic map.

REMARKS.--Records poor. No regulation or diversion above station.

COOPERATION. - Records were furnished by Orange County Flood Control District and reviewed by the Geological Survey. EXTREMES FOR PERIOD OF RECORD.--Maximum discharge, $1,380 \mathrm{ft}^{3} / \mathrm{s}\left(39.1 \mathrm{~m}^{3} / \mathrm{s}\right) \mathrm{Feb} .11,1973, \mathrm{gage}$ height, $2.50 \mathrm{ft}$ $(0.762 \mathrm{~m})$; no flow many days during most years. EXTREMES FOR CURRENT YEAR, - Maximum discharge, $236 \mathrm{ft}^{3} / \mathrm{s}\left(6.68 \mathrm{~m}^{3} / \mathrm{s}\right)$ Dec. 4, gage height, $2.49 \mathrm{ft}(0.759 \mathrm{~m})$;
minimum daily, $0.05 \mathrm{ft} / \mathrm{s}\left(0.001 \mathrm{~m}^{3} / \mathrm{s}\right)$ Dec. $2,3$.

DISCHARGE, IN CUBIC FEET PER SECOND, HATER YEAR OCTOBER 1975 TO SEPTEMBER 1976 MEAN VALUES

\begin{tabular}{|c|c|c|c|c|c|c|c|c|c|c|c|c|}
\hline DAY & $O C T$ & NOV & $D E C$ & JAN & FEB & MAR & APR & MAY & JUN & JUL & AUG & SEP \\
\hline $\begin{array}{l}1 \\
2 \\
3 \\
4 \\
5\end{array}$ & $\begin{array}{r}.50 \\
.50 \\
.50 \\
.50 \\
.50\end{array}$ & $\begin{array}{l}2.0 \\
2.0 \\
2.0 \\
2.0 \\
2.0\end{array}$ & $\begin{array}{l}1.5 \\
1.4 \\
1.4 \\
1.4 \\
1.4\end{array}$ & $\begin{array}{l}1.7 \\
1.2 \\
1.2 \\
1.4 \\
1.0\end{array}$ & $\begin{array}{l}3.3 \\
2.7 \\
4.0 \\
18 \\
27\end{array}$ & $\begin{array}{l}18 \\
6.0 \\
20 \\
10 \\
5.0\end{array}$ & $\begin{array}{l}2.0 \\
1.0 \\
1.0 \\
9.0 \\
6.0\end{array}$ & $\begin{array}{l}1.2 \\
1.2 \\
1.2 \\
1.4 \\
1.4\end{array}$ & $\begin{array}{l}.60 \\
.60 \\
.80 \\
.30 \\
.50\end{array}$ & $\begin{array}{r}.30 \\
.10 \\
.10 \\
.50\end{array}$ & $\begin{array}{l}0 \\
0 \\
0 \\
0 \\
0\end{array}$ & $\begin{array}{l}0 \\
0 \\
0.60 \\
.10\end{array}$ \\
\hline $\begin{array}{r}6 \\
7 \\
8 \\
9 \\
10\end{array}$ & $\begin{array}{r}.50 \\
.50 \\
.50 \\
.50 \\
.50\end{array}$ & $\begin{array}{l}2.0 \\
2.0 \\
2.0 \\
2.0 \\
2.0\end{array}$ & $\begin{array}{l}1.2 \\
1.5 \\
1.9 \\
1.5 \\
1.5\end{array}$ & $\begin{array}{l}.80 \\
.50 \\
.80 \\
1.0 \\
1.2\end{array}$ & $\begin{array}{r}96 \\
54 \\
81 \\
101 \\
40\end{array}$ & $\begin{array}{l}5.0 \\
5.0 \\
5.0 \\
5.0 \\
4.0\end{array}$ & $\begin{array}{l}3.0 \\
2.0 \\
2.0 \\
2.3 \\
1.2\end{array}$ & $\begin{array}{l}1.9 \\
1.9 \\
3.1 \\
4.2 \\
3.8\end{array}$ & $\begin{array}{l}.60 \\
.30 \\
.60 \\
.50 \\
6.1\end{array}$ & $\begin{array}{l}.80 \\
.10 \\
0 \\
0 \\
0\end{array}$ & $\begin{array}{l}0 \\
0 \\
0 \\
0 \\
0\end{array}$ & $\begin{array}{r}.10 \\
0 \\
0 \\
48\end{array}$ \\
\hline $\begin{array}{l}11 \\
12 \\
13 \\
14 \\
15\end{array}$ & $\begin{array}{l}.50 \\
.50 \\
1.0 \\
1.0 \\
1.0\end{array}$ & $\begin{array}{l}2.0 \\
2.0 \\
2.0 \\
2.0 \\
2.0\end{array}$ & $\begin{array}{l}1.2 \\
2.0 \\
4.7 \\
2.3 \\
1.9\end{array}$ & $\begin{array}{r}.80 \\
.50 \\
.10 \\
.10\end{array}$ & $\begin{array}{l}15 \\
8.0 \\
4.0 \\
4.0 \\
4.0\end{array}$ & $\begin{array}{l}4.0 \\
4.0 \\
4.0 \\
4.0 \\
4.0\end{array}$ & $\begin{array}{r}1.4 \\
2.0 \\
36 \\
5.9 \\
7.3\end{array}$ & $\begin{array}{l}3.1 \\
3.4 \\
2.3 \\
2.3 \\
1.9\end{array}$ & $\begin{array}{l}6.5 \\
1.9 \\
1.4 \\
1.2 \\
.80\end{array}$ & $\begin{array}{l}0 \\
0 \\
0 \\
0 \\
0\end{array}$ & $\begin{array}{l}0 \\
0 \\
0 \\
0 \\
0\end{array}$ & $\begin{array}{l}40 \\
4.6 \\
1.5 \\
0 \\
.30\end{array}$ \\
\hline $\begin{array}{l}16 \\
17 \\
18 \\
19 \\
20\end{array}$ & $\begin{array}{l}1.0 \\
1.0 \\
1.0 \\
1.0 \\
1.0\end{array}$ & $\begin{array}{l}2.0 \\
2.0 \\
2.0 \\
2.0 \\
2.0\end{array}$ & $\begin{array}{l}1.5 \\
1.4 \\
1.5 \\
1.9 \\
2.0\end{array}$ & $\begin{array}{l}0 \\
0 \\
0 \\
0 \\
0\end{array}$ & $\begin{array}{l}4.0 \\
4.0 \\
4.0 \\
4.0 \\
4.0\end{array}$ & $\begin{array}{l}4.0 \\
3.0 \\
3.0 \\
3.0 \\
3.0\end{array}$ & $\begin{array}{r}12 \\
3.1 \\
2.3 \\
1.9 \\
1.9\end{array}$ & $\begin{array}{l}1.5 \\
2.3 \\
1.9 \\
1.4 \\
.80\end{array}$ & $\begin{array}{r}.50 \\
.60 \\
.30 \\
. \\
.10\end{array}$ & $\begin{array}{l}0 \\
0 \\
0 \\
0 \\
0\end{array}$ & $\begin{array}{l}.10 \\
0 \\
.70 \\
1.9\end{array}$ & $\begin{array}{l}1.0 \\
.80 \\
1.4 \\
1.0 \\
.30\end{array}$ \\
\hline $\begin{array}{l}21 \\
22 \\
23 \\
24 \\
25\end{array}$ & $\begin{array}{l}1.0 \\
1.0 \\
1.0 \\
1.0 \\
1.0\end{array}$ & $\begin{array}{l}2.0 \\
2.0 \\
1.0 \\
1.0 \\
1.0\end{array}$ & $\begin{array}{l}5.5 \\
2.7 \\
2.7 \\
2.3 \\
2.3\end{array}$ & $\begin{array}{l}.50 \\
0 \\
0 \\
0 \\
1.0\end{array}$ & $\begin{array}{l}3.0 \\
3.0 \\
3.0 \\
3.0 \\
3.0\end{array}$ & $\begin{array}{l}3.0 \\
3.0 \\
3.0 \\
2.0 \\
2.0\end{array}$ & $\begin{array}{l}1.9 \\
2.1 \\
2.0 \\
1.9 \\
2.3\end{array}$ & $\begin{array}{l}.80 \\
.80 \\
1.0 \\
1.0 \\
.80\end{array}$ & $\begin{array}{r}.30 \\
.30 \\
.10 \\
1.0 \\
.80\end{array}$ & $\begin{array}{l}0 \\
0 \\
0 \\
0 \\
0\end{array}$ & $\begin{array}{l}1.0 \\
1.0 \\
1.0 \\
.50 \\
.10\end{array}$ & $\begin{array}{l}1.2 \\
1.0 \\
1.2 \\
1.0 \\
2.0\end{array}$ \\
\hline $\begin{array}{l}26 \\
27 \\
28 \\
29 \\
30 \\
31\end{array}$ & $\begin{array}{l}1.0 \\
1.0 \\
1.0 \\
1.0 \\
1.0 \\
1.0\end{array}$ & $\begin{array}{r}1.0 \\
1.5 \\
14 \\
9.1 \\
1.5 \\
-.-\end{array}$ & $\begin{array}{l}2.3 \\
2.3 \\
2.3 \\
1.9 \\
1.7 \\
1.7\end{array}$ & $\begin{array}{l}1.5 \\
1.5 \\
1.4 \\
2.3 \\
2.7 \\
3.1\end{array}$ & $\begin{array}{l}3.0 \\
3.0 \\
3.0 \\
3.0 \\
-\therefore- \\
---\end{array}$ & $\begin{array}{l}2.0 \\
2.0 \\
2.0 \\
2.0 \\
2.0 \\
2.0\end{array}$ & $\begin{array}{l}2.7 \\
1.4 \\
1.2 \\
1.2 \\
1.2 \\
-.--\end{array}$ & $\begin{array}{l}.60 \\
.60 \\
.10 \\
.30 \\
.10 \\
.50\end{array}$ & $\begin{array}{l}.50 \\
.30 \\
1.5 \\
.10 \\
0 \\
-.-.\end{array}$ & $\begin{array}{r}.80 \\
.30 \\
0 \\
.30 \\
.50 \\
.10\end{array}$ & $\begin{array}{l}.10 \\
0 \\
0 \\
0 \\
0.20\end{array}$ & $\begin{array}{l}1.4 \\
1.0 \\
.80 \\
1.0 \\
.80 \\
0--0\end{array}$ \\
\hline $\begin{array}{l}\text { TOTAL } \\
\text { MEAN } \\
\text { MAX } \\
\text { MIN } \\
\text { AC-FT }\end{array}$ & $\begin{array}{r}25.00 \\
.81 \\
1.0 \\
.50 \\
50\end{array}$ & $\begin{array}{r}74.1 \\
2.47 \\
14 \\
1.0 \\
147\end{array}$ & $\begin{array}{r}62.8 \\
2.03 \\
5.5 \\
1.2 \\
1.25\end{array}$ & $\begin{array}{r}26.30 \\
.85 \\
3.1 \\
0 \\
52\end{array}$ & $\begin{array}{r}509.0 \\
17.6 \\
101 \\
2.7 \\
1010\end{array}$ & $\begin{array}{r}144.0 \\
4.65 \\
20 \\
2.0 \\
286\end{array}$ & $\begin{array}{r}121.2 \\
4.04 \\
36 \\
1.0 \\
240\end{array}$ & $\begin{array}{r}48.80 \\
1.57 \\
4.2 \\
.10 \\
97\end{array}$ & $\begin{array}{r}29.10 \\
.97 \\
6.5 \\
0 \\
58\end{array}$ & $\begin{array}{r}3.90 \\
.13 \\
.80 \\
0 \\
7.7\end{array}$ & $\begin{array}{r}6.60 \\
.21 \\
1.9 \\
0 \\
13\end{array}$ & $\begin{array}{r}111.20 \\
3.71 \\
48 \\
0 \\
221\end{array}$ \\
\hline $\begin{array}{l}\text { CAL YR } \\
\text { WTR YR }\end{array}$ & $\begin{array}{ll}1975 & \text { TOTAL } \\
1976 & \text { TOTAL. }\end{array}$ & $\begin{array}{l}1286.20 \\
1162.00\end{array}$ & $\begin{array}{l}\text { MEAN } \\
\text { MEAN }\end{array}$ & $\begin{array}{l}3.52 \\
3.17\end{array}$ & $\begin{array}{ll}\operatorname{MAX} & 134 \\
\operatorname{MAX} & 101\end{array}$ & $\begin{array}{l}M I N \\
M I N\end{array} 0^{.20}$ & $\begin{array}{l}A C-F T \\
A C-F T\end{array}$ & $\begin{array}{l}2550 \\
2300\end{array}$ & & & & \\
\hline
\end{tabular}


PERIOD OF DAILY RECORD. - -

WATER TEMPERATURES: October 1970 to current year.

SEDIMENT RECORDS: October 1970 to current year.

REMARKS.--Records of discharge were furnished by Orange County Environmental Management Agency, Particle-size distribution of bed material table was omitted in the 1975 water year and is published with ig76 water year records.

EXTREMES FOR PERTOD OF DAILY RECORD. -

SEDIMENT CONCENTRATIONS: Maximum daily mean, 8,900 mg/1 Feb. 11, 1973; minimum daily mean, no filow for many days most years.

SEDIMENT DISCHARGE: Maximum daily, 7,820 tons ( 7,090 tonnes) Feb. 11, 1973; minimum daily, 0 tonș on many days each year.

EXTREMES FOR CURRENT YEAR. - -

SEDIMENT CONCENTRATIONS: Maximum daily mean, 2,990 mg/1 Feb. 9; minimum daily mean, no flow for many days. SEDIMENT DISCHARGE: Maximum daily, 848 tons ( 769 tonnes) Feb. 9; minimum daily, 0 tons on many days.

TEMPERATURE (DEG, C) OF WATER, WATER YEAR OCTOBER 1975 TO SEPTEMBER 1976

\begin{tabular}{|c|c|c|c|c|c|c|c|c|c|c|c|c|}
\hline DAY & OCT & Nov & $\mathrm{DEC}$ & JAN & FEB & MAR & APR & MAY & JUN & JUL. & AUG & SEP \\
\hline $\begin{array}{l}1 \\
2 \\
3 \\
4 \\
5\end{array}$ & $\begin{array}{r}20.0 \\
24.0 \\
-.0\end{array}$ & $\begin{array}{l}--\overline{-} \\
\overline{-} \\
-\overline{-} \\
-\overline{-}\end{array}$ & $\begin{array}{r}=- \\
15.0 \\
16.0\end{array}$ & $\begin{array}{r}---5 \\
9.5 \\
17.0 \\
---\end{array}$ & $\begin{array}{r}=-0 \\
12.0 \\
13.0 \\
12.0\end{array}$ & $\begin{array}{r}14.0 \\
11.0 \\
9.5 \\
-.-\end{array}$ & $\begin{array}{r}-10.5 \\
19.5 \\
17.0 \\
14.0 \\
12.0\end{array}$ & $\begin{array}{r}26.0 \\
19.5 \\
-. .-\end{array}$ & $\begin{array}{r}19.5 \\
-17.0 \\
17.0\end{array}$ & 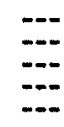 & & 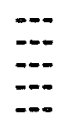 \\
\hline $\begin{array}{r}6 \\
7 \\
8 \\
9 \\
10\end{array}$ & $=$ & $\begin{array}{r}15.0 \\
--0 \\
-\cdots\end{array}$ & $=$ & $\begin{array}{r}=-0 \\
13.0 \\
17.0\end{array}$ & $\begin{array}{l}11.0 \\
12.0 \\
14.0 \\
13.0 \\
12.0\end{array}$ & \begin{tabular}{l}
9.0 \\
-0 \\
\hdashline- \\
-0
\end{tabular} & $\begin{array}{r}12.0 \\
-21.0 \\
21.0\end{array}$ & $\begin{array}{r}-- \\
15.0 \\
--\end{array}$ & $\begin{array}{l}=- \\
=- \\
=-\end{array}$ & $\begin{array}{r}27.0 \\
-0 \\
- \\
-\end{array}$ & & 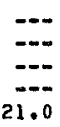 \\
\hline $\begin{array}{l}11 \\
12 \\
13 \\
14 \\
15\end{array}$ & 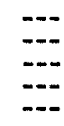 & 21.0 & $\begin{array}{r}18.0 \\
15.0 \\
=-0 \\
-0-\end{array}$ & $\overline{11.5}$ & $\begin{array}{r}0.0 \\
14.0 \\
13.0\end{array}$ & $\begin{array}{r}--0 \\
16.0 \\
10.0 \\
--\end{array}$ & $\begin{array}{l}-0 \\
16.0 \\
12.0 \\
16.0\end{array}$ & $\begin{array}{r}24.0 \\
m-0 \\
17.0\end{array}$ & $\begin{array}{r}26.0 \\
=-0 \\
---\end{array}$ & $\begin{array}{l}-m \\
-\infty \\
-\infty \\
-\infty\end{array}$ & & $\begin{array}{r}19.5 \\
22.0 \\
-. . \\
-.0\end{array}$ \\
\hline $\begin{array}{l}16 \\
17 \\
18 \\
19 \\
20\end{array}$ & $\begin{array}{r}20.0 \\
\cdots \\
\cdots\end{array}$ & $\begin{array}{l}-=- \\
=-\infty \\
-\infty \\
-\infty\end{array}$ & $\begin{array}{r}12.0 \\
14.0\end{array}$ & $\begin{array}{r}21.0 \\
\cdots \\
\cdots\end{array}$ & 15.0 & $\begin{array}{r}-\cdots \\
11.5 \\
11.0\end{array}$ & $\begin{array}{l}9.0 \\
9.0 \\
-.-\end{array}$ & $\begin{array}{l}--\infty \\
-\infty \\
-\infty \\
-\infty\end{array}$ & $\begin{array}{r}21.0 \\
=-0 \\
25.0 \\
=\end{array}$ & $=-$ & & 16.0 \\
\hline $\begin{array}{l}21 \\
22 \\
23 \\
24 \\
25\end{array}$ & $\begin{array}{r}22.0 \\
=- \\
=-\end{array}$ & $\begin{array}{r}16.0 \\
=-0 \\
- \\
-\end{array}$ & $=$ & $\begin{array}{r}13.0 \\
13.0 \\
-0.0\end{array}$ & $\begin{array}{r}16.0 \\
- \\
\cdots\end{array}$ & $\overline{-}$ & $\begin{array}{r}22.0 \\
20.0 \\
0.0\end{array}$ & $\begin{array}{r}23.0 \\
19.0 \\
\cdots\end{array}$ & $\begin{array}{r}=- \\
=- \\
28.0\end{array}$ & 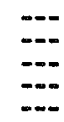 & & $\begin{array}{r}20.0 \\
-0 \\
20.0\end{array}$ \\
\hline $\begin{array}{l}26 \\
27 \\
28 \\
29 \\
30 \\
31\end{array}$ & $\begin{array}{l}=- \\
17.5 \\
16.0\end{array}$ & $\begin{array}{r}15.0 \\
11.0 \\
-0 \\
0.0\end{array}$ & $\begin{array}{r}14.0 \\
12.0 \\
-.0\end{array}$ & $\begin{array}{r}-12.5 \\
12.5 \\
9.0\end{array}$ & $\begin{array}{r}15.5 \\
11.0 \\
0.0 \\
\cdots\end{array}$ & $\begin{array}{r}12.0 \\
-\infty \\
--\end{array}$ & 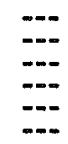 & 18.0 & $\begin{array}{r}17.0 \\
=-0 \\
=-0 \\
=-0 \\
=-0\end{array}$ & 28.0 & & $\begin{array}{r}24.0 \\
=0 \\
=-0 \\
=0\end{array}$ \\
\hline NTH & $=-$ & $m$ & $-\infty$ & $\ldots$ & $=-\infty$ & $m=-$ & $m$ & $-\infty$ & $m--$ & $m$ & & $-\infty$ \\
\hline
\end{tabular}


11047300 ARROYO TRABUCO AT SAN JUAN CAPISTRANO, CA--Continued

SUSPENDED-SEDIMENT DISCHARGE (TONS/OAY), WATER YEAR OCTOBER 1975 TO SEPTEMBER 1976

\begin{tabular}{|c|c|c|c|c|c|c|c|c|c|}
\hline & & OCTOBER & & & NOVEMBER & & & DECEMBER & \\
\hline DAY & $\begin{array}{l}\text { MEAN } \\
\text { DISCHARGE } \\
\text { (CFS) }\end{array}$ & $\begin{array}{l}\text { MEAN } \\
\text { CONCEN- } \\
\text { TRATION } \\
\text { (MG/L) }\end{array}$ & $\begin{array}{l}\text { SEOIMENT } \\
\text { DISCHARGE } \\
\text { (TONS/DAY) }\end{array}$ & $\begin{array}{l}\text { MEAN } \\
\text { OISCHARGE } \\
\text { (CFS) }\end{array}$ & $\begin{array}{l}\text { MEAN } \\
\text { CONCEN- } \\
\text { TRAT ION } \\
\text { (MG/L) }\end{array}$ & $\begin{array}{l}\text { SEDIMENT } \\
\text { DISCHARGE } \\
\text { (TONS/DAY) }\end{array}$ & $\begin{array}{l}\text { MEAN } \\
\text { DISCHARGE } \\
\text { (CFS) }\end{array}$ & $\begin{array}{l}\text { MEAN } \\
\text { CONCEN- } \\
\text { TRATION } \\
\text { (MG/L) }\end{array}$ & $\begin{array}{l}\text { SEDIHENT } \\
\text { DISCHARGE } \\
\text { (TONS/OAY) }\end{array}$ \\
\hline $\begin{array}{l}1 \\
2 \\
3 \\
4 \\
5\end{array}$ & $\begin{array}{l}.50 \\
.50 \\
.50 \\
.50 \\
.50\end{array}$ & $\begin{array}{l}10 \\
12 \\
14 \\
15 \\
17\end{array}$ & $\begin{array}{l}.01 \\
.02 \\
.02 \\
.02 \\
.02\end{array}$ & $\begin{array}{l}2.0 \\
2.0 \\
2.0 \\
2.0 \\
2.0\end{array}$ & $\begin{array}{l}5 \\
5 \\
4 \\
4 \\
3\end{array}$ & $\begin{array}{l}.03 \\
.03 \\
.02 \\
.02 \\
.02\end{array}$ & $\begin{array}{l}1.5 \\
1.4 \\
1.4 \\
1.4 \\
1.4\end{array}$ & $\begin{array}{l}2 \\
2 \\
2 \\
4 \\
6\end{array}$ & $\begin{array}{l}.01 \\
.01 \\
.01 \\
.02 \\
.02\end{array}$ \\
\hline $\begin{array}{r}6 \\
7 \\
8 \\
9 \\
10\end{array}$ & $\begin{array}{l}.50 \\
.50 \\
.50 \\
.50 \\
.50\end{array}$ & $\begin{array}{l}19 \\
21 \\
22 \\
23 \\
24\end{array}$ & $\begin{array}{l}.03 \\
.03 \\
.03 \\
.03 \\
.03\end{array}$ & $\begin{array}{l}2.0 \\
2.0 \\
2.0 \\
2.0 \\
2.0\end{array}$ & $\begin{array}{l}3 \\
3 \\
3 \\
3 \\
4\end{array}$ & $\begin{array}{l}.02 \\
.02 \\
.02 \\
.02 \\
.02\end{array}$ & $\begin{array}{l}1.2 \\
1.5 \\
1.9 \\
1.5 \\
1.5\end{array}$ & $\begin{array}{l}6 \\
7 \\
7 \\
7 \\
8\end{array}$ & $\begin{array}{l}.02 \\
.03 \\
.04 \\
.03 \\
.03\end{array}$ \\
\hline $\begin{array}{l}11 \\
12 \\
13 \\
14 \\
15\end{array}$ & $\begin{array}{l}.50 \\
.50 \\
1.0 \\
1.0 \\
1.0\end{array}$ & $\begin{array}{l}23 \\
21 \\
19 \\
17 \\
15\end{array}$ & $\begin{array}{l}.03 \\
.03 \\
.05 \\
.05 \\
.04\end{array}$ & $\begin{array}{l}2.0 \\
2.0 \\
2.0 \\
2.0 \\
2.0\end{array}$ & $\begin{array}{l}4 \\
4 \\
5 \\
5 \\
5\end{array}$ & $\begin{array}{l}.02 \\
.02 \\
.03 \\
.03 \\
.03\end{array}$ & $\begin{array}{l}1.2 \\
2.0 \\
4.7 \\
2.3 \\
1.9\end{array}$ & $\begin{array}{r}8 \\
30 \\
29 \\
30 \\
30\end{array}$ & $\begin{array}{r}.03 \\
.13 \\
.38 \\
.19 \\
.15\end{array}$ \\
\hline $\begin{array}{l}16 \\
17 \\
18 \\
19 \\
20\end{array}$ & $\begin{array}{l}1.0 \\
1.0 \\
1.0 \\
1.0 \\
1.0\end{array}$ & $\begin{array}{l}13 \\
11 \\
11 \\
11 \\
11\end{array}$ & $\begin{array}{l}.04 \\
.03 \\
.03 \\
.03 \\
.03\end{array}$ & $\begin{array}{l}2.0 \\
2.0 \\
2.0 \\
2.0 \\
2.0\end{array}$ & $\begin{array}{l}5 \\
5 \\
6 \\
6 \\
6\end{array}$ & $\begin{array}{l}.03 \\
.03 \\
.03 \\
.03 \\
.03\end{array}$ & $\begin{array}{l}1.5 \\
1.4 \\
1.5 \\
1.9 \\
2.0\end{array}$ & $\begin{array}{l}30 \\
30 \\
25 \\
25 \\
27\end{array}$ & $\begin{array}{l}.12 \\
111 \\
110 \\
113 \\
116\end{array}$ \\
\hline $\begin{array}{l}21 \\
22 \\
23 \\
24 \\
25\end{array}$ & $\begin{array}{l}1.0 \\
1.0 \\
1.0 \\
1.0 \\
1.0\end{array}$ & $\begin{array}{r}11 \\
11 \\
10 \\
9 \\
8\end{array}$ & $\begin{array}{l}.03 \\
.03 \\
.03 \\
.02 \\
.02\end{array}$ & $\begin{array}{l}2.0 \\
2.0 \\
1.0 \\
1.0 \\
1.0\end{array}$ & $\begin{array}{l}6 \\
6 \\
7 \\
7 \\
8\end{array}$ & $\begin{array}{l}.03 \\
.03 \\
.02 \\
.02 \\
.02\end{array}$ & $\begin{array}{l}5.5 \\
2.7 \\
2.7 \\
2.3 \\
2.3\end{array}$ & $\begin{array}{r}24 \\
9 \\
9 \\
9 \\
9\end{array}$ & $\begin{array}{l}.39 \\
.07 \\
.07 \\
.06 \\
.06\end{array}$ \\
\hline $\begin{array}{l}26 \\
27 \\
28 \\
29 \\
30 \\
31\end{array}$ & $\begin{array}{l}1.0 \\
1.0 \\
1.0 \\
1.0 \\
1.0 \\
1.0\end{array}$ & $\begin{array}{l}7 \\
6 \\
5 \\
4 \\
3 \\
5\end{array}$ & $\begin{array}{l}.02 \\
.02 \\
.01 \\
.01 \\
.01 \\
.01\end{array}$ & $\begin{array}{r}1.0 \\
1.5 \\
14 \\
9.1 \\
1.5 \\
.-.\end{array}$ & $\begin{array}{r}29 \\
21 \\
193 \\
128 \\
6 \\
- \\
--\end{array}$ & $\begin{array}{c}.02 \\
.13 \\
13 \\
3.9 \\
.02 \\
-.0\end{array}$ & $\begin{array}{l}2.3 \\
2.3 \\
2.3 \\
1.9 \\
1.7 \\
1.7\end{array}$ & $\begin{array}{r}9 \\
9 \\
17 \\
26 \\
23 \\
21\end{array}$ & $\begin{array}{l}.06 \\
.06 \\
.11 \\
.13 \\
.11 \\
.10\end{array}$ \\
\hline TOTAL & 25.00 & --- & .81 & 74.1 & --- & 17.69 & 62.8 & -- & 2.94 \\
\hline
\end{tabular}

\begin{tabular}{|c|c|c|c|c|c|c|c|c|c|}
\hline \multirow[b]{2}{*}{ DAY } & \multicolumn{3}{|c|}{ JANUARY } & \multicolumn{3}{|c|}{ FEBRUARY } & \multicolumn{3}{|c|}{ MARCH } \\
\hline & $\begin{array}{l}\text { MEAN } \\
\text { DISCARGE } \\
\text { (CFS) }\end{array}$ & $\begin{array}{l}\text { MEAN } \\
\text { CONCEN- } \\
\text { TRATION } \\
\text { (MG/L) }\end{array}$ & $\begin{array}{l}\text { SEDIMENT } \\
\text { DISCHARGE } \\
\text { (TONS/DAY) }\end{array}$ & $\begin{array}{l}\text { MEAN } \\
\text { DISCHARGE } \\
\text { (CFS) }\end{array}$ & $\begin{array}{l}\text { MEAN } \\
\text { CONCEN- } \\
\text { TRATION } \\
\text { (MGLL) }\end{array}$ & $\begin{array}{l}\text { SEDIMENT } \\
\text { DISCHARGE } \\
\text { ITONS/DAYY }\end{array}$ & $\begin{array}{l}\text { MEAN } \\
\text { DISCARGE } \\
\text { (CFS) }\end{array}$ & $\begin{array}{l}\text { MEAN } \\
\text { CONCEN- } \\
\text { TRATON } \\
\text { (MG/L) }\end{array}$ & $\begin{array}{l}\text { SEDIMENT } \\
\text { DISCHARGE } \\
\text { (TONS/DAY) }\end{array}$ \\
\hline $\begin{array}{l}1 \\
2 \\
3 \\
4 \\
5\end{array}$ & $\begin{array}{l}1.7 \\
1.2 \\
1.2 \\
1.4 \\
1.0\end{array}$ & $\begin{array}{r}19 \\
17 \\
8 \\
11 \\
14\end{array}$ & $\begin{array}{l}.09 \\
.06 \\
.03 \\
.04 \\
.04\end{array}$ & $\begin{array}{l}3.3 \\
2.7 \\
4.0 \\
18 \\
27\end{array}$ & $\begin{array}{r}16 \\
16 \\
9 \\
58 \\
77\end{array}$ & $\begin{array}{l}.14 \\
: 12 \\
: 13 \\
3.4 \\
5.9\end{array}$ & $\begin{array}{c}18 \\
6.0 \\
20 \\
10 . \\
5.0\end{array}$ & $\begin{array}{r}2230 \\
700 \\
1400 \\
180 \\
100\end{array}$ & $\begin{array}{r}155 \\
11 \\
76 \\
4.9 \\
1.4\end{array}$ \\
\hline $\begin{array}{r}6 \\
7 \\
8 \\
9 \\
10\end{array}$ & $\begin{array}{r}.80 \\
.50 \\
.80 \\
1.00 \\
1.2\end{array}$ & $\begin{array}{l}17 \\
21 \\
25 \\
17 \\
9\end{array}$ & $\begin{array}{l}.04 \\
: 03 \\
: 05 \\
: 05 \\
.03\end{array}$ & $\begin{array}{r}96 \\
54 \\
81 \\
101 \\
40\end{array}$ & $\begin{array}{r}1630 \\
407 \\
434 \\
2990 \\
700\end{array}$ & $\begin{array}{r}587 \\
53 \\
142 \\
848 \\
76\end{array}$ & $\begin{array}{l}5.0 \\
5: 0 \\
5: 0 \\
5: 0 \\
4: 0\end{array}$ & $\begin{array}{l}43 \\
39 \\
32 \\
25 \\
16\end{array}$ & $\begin{array}{l}: 58 \\
: 53 \\
: 43 \\
: 34 \\
: 17\end{array}$ \\
\hline $\begin{array}{l}11 \\
12 \\
13 \\
14 \\
15\end{array}$ & $\begin{array}{r}.80 \\
.50 \\
.10 \\
.10\end{array}$ & $\begin{array}{l}7 \\
6 \\
5 \\
4 \\
0\end{array}$ & $\begin{array}{l}.02 \\
.01 \\
0 \\
0\end{array}$ & $\begin{array}{c}15 \\
8.0 \\
4,0 \\
4.0 \\
4.0\end{array}$ & $\begin{array}{r}100 \\
48 \\
39 \\
31 \\
25\end{array}$ & $\begin{array}{c}4.1 \\
1.0 \\
.42 \\
.33 \\
.27\end{array}$ & $\begin{array}{l}4.0 \\
4.0 \\
4.0 \\
4.0 \\
4.0\end{array}$ & $\begin{array}{r}9 \\
2 \\
58 \\
56 \\
52\end{array}$ & $\begin{array}{l}.10 \\
.02 \\
.63 \\
.60 \\
.56\end{array}$ \\
\hline $\begin{array}{l}16 \\
17 \\
18 \\
19 \\
20\end{array}$ & $\begin{array}{l}0 \\
0 \\
0 \\
0 \\
0\end{array}$ & $\begin{array}{l}0 \\
0 \\
0 \\
0 \\
0\end{array}$ & $\begin{array}{l}0 \\
0 \\
0 \\
0 \\
0\end{array}$ & $\begin{array}{l}4: 0 \\
4: 0 \\
4: 0 \\
4: 0 \\
4: 0\end{array}$ & $\begin{array}{l}19 \\
13 \\
7 \\
32 \\
57\end{array}$ & $\begin{array}{l}.21 \\
.14 \\
.08 \\
.35 \\
.62\end{array}$ & $\begin{array}{l}4.0 \\
3.0 \\
3.0 \\
3.0 \\
3.0\end{array}$ & $\begin{array}{l}48 \\
44 \\
40 \\
36 \\
53\end{array}$ & $\begin{array}{l}: 52 \\
: 36 \\
: 32 \\
: 29 \\
: 43\end{array}$ \\
\hline $\begin{array}{l}21 \\
22 \\
23 \\
24 \\
25\end{array}$ & $\begin{array}{l}.50 \\
0^{0} \\
0 \\
1.0\end{array}$ & $\begin{array}{r}4 \\
0 \\
0 \\
0 \\
11\end{array}$ & $\begin{array}{l}.01 \\
0 \\
0 \\
0 \\
.03\end{array}$ & $\begin{array}{l}3.0 \\
3.0 \\
3.0 \\
3.0 \\
3.0\end{array}$ & $\begin{array}{l}81 \\
69 \\
58 \\
47 \\
36\end{array}$ & $\begin{array}{l}.66 \\
.56 \\
.47 \\
.38 \\
.29\end{array}$ & $\begin{array}{l}3.0 \\
3.0 \\
3.0 \\
2.0 \\
2.0\end{array}$ & $\begin{array}{l}47 \\
41 \\
34 \\
27 \\
20\end{array}$ & $\begin{array}{r}.38 \\
: 33 \\
: 28 \\
: 15 \\
: 11\end{array}$ \\
\hline $\begin{array}{l}26 \\
27 \\
28 \\
29 \\
30 \\
31\end{array}$ & $\begin{array}{l}1.5 \\
1.5 \\
1.4 \\
2.3 \\
2.7 \\
3.1\end{array}$ & $\begin{array}{l}15 \\
19 \\
23 \\
27 \\
30 \\
16\end{array}$ & $\begin{array}{l}.06 \\
.08 \\
.09 \\
.17 \\
.22 \\
.13\end{array}$ & $\begin{array}{l}3.0 \\
3.0 \\
3.0 \\
3.0 \\
\ldots .0 \\
\ldots .0\end{array}$ & $\begin{array}{r}25 \\
48 \\
72 \\
72 \\
\cdots \\
\cdots\end{array}$ & \begin{tabular}{r}
.20 \\
.39 \\
$: 58$ \\
.58 \\
\hdashline-0 \\
$-:-$
\end{tabular} & $\begin{array}{l}2.0 \\
2.0 \\
2.0 \\
2.0 \\
2.0 \\
2.0\end{array}$ & $\begin{array}{l}13 \\
6 \\
11 \\
16 \\
21 \\
26\end{array}$ & $\begin{array}{l}.07 \\
003 \\
006 \\
09 \\
011 \\
.14\end{array}$ \\
\hline TTAL & 26.30 & $\cdots$ & 1.28 & 509.0 & $\cdots$ & 1727.32 & 144.0 &.- & 255.93 \\
\hline
\end{tabular}


11047300 ARROYO TRABUCO AT SAN JUAN CAPISTRANO, CA--Continued

SUSPENDED-SEDIMENT DISCHARGE (TONS/DAY), WATER YEAR OCTOBER 1975 TO SEPTEMBER 1976

\begin{tabular}{|c|c|c|c|c|c|c|c|c|c|}
\hline & & APRIL & & & MAY & & & JUNE & \\
\hline DAY & $\begin{array}{c}\text { MEAN } \\
\text { DISCHARGE } \\
\text { (CFS) }\end{array}$ & $\begin{array}{l}\text { MEAN } \\
\text { CONCEN- } \\
\text { TRAT ION } \\
\text { (MG/L) }\end{array}$ & $\begin{array}{l}\text { SEDIMENT } \\
\text { DISCHARGE } \\
\text { (TONS/DAY) }\end{array}$ & $\begin{array}{c}\text { MEAN } \\
\text { DISCHARGE } \\
\text { (CFS) }\end{array}$ & $\begin{array}{l}\text { MEAN } \\
\text { CONCEN- } \\
\text { TRATION } \\
\text { (MG LL) }\end{array}$ & $\begin{array}{l}\text { SEDIMENT } \\
\text { DISCHAKGE } \\
\text { (TONS/DAY) }\end{array}$ & $\begin{array}{c}\text { MEAN } \\
\text { DISCHARGE } \\
\text { (CF } 5 \text { ) }\end{array}$ & $\begin{array}{l}\text { MEAN } \\
\text { CONCEN- } \\
\text { TRATION } \\
\text { (HG L ) }\end{array}$ & $\begin{array}{l}\text { SEDIMENT } \\
\text { DISCHARGE } \\
\text { (TONS/OAY) }\end{array}$ \\
\hline $\begin{array}{l}1 \\
2 \\
3 \\
4 \\
5\end{array}$ & $\begin{array}{l}2.0 \\
1.0 \\
1.0 \\
9.0 \\
6.0\end{array}$ & $\begin{array}{r}31 \\
34 \\
13 \\
250 \\
176\end{array}$ & $\begin{array}{r}.17 \\
.09 \\
.04 \\
6.1 \\
2.9\end{array}$ & $\begin{array}{l}1.2 \\
1.2 \\
1.2 \\
1.4 \\
1.4\end{array}$ & $\begin{array}{l}24 \\
26 \\
29 \\
35 \\
41\end{array}$ & $\begin{array}{l}.08 \\
.08 \\
.09 \\
.13 \\
.15\end{array}$ & $\begin{array}{l}.60 \\
.60 \\
.80 \\
.30 \\
.50\end{array}$ & $\begin{array}{l}26 \\
28 \\
29 \\
30 \\
32\end{array}$ & $\begin{array}{l}.04 \\
.05 \\
.06 \\
.02 \\
.04\end{array}$ \\
\hline $\begin{array}{r}6 \\
7 \\
8 \\
9 \\
10\end{array}$ & $\begin{array}{l}3.0 \\
2.0 \\
2.0 \\
2.3 \\
1.2\end{array}$ & $\begin{array}{r}3 \\
8 \\
13 \\
17 \\
8\end{array}$ & $\begin{array}{l}.02 \\
.04 \\
.07 \\
.11 \\
.03\end{array}$ & $\begin{array}{l}1.9 \\
1.9 \\
3.1 \\
4.2 \\
3.8\end{array}$ & $\begin{array}{l}47 \\
53 \\
60 \\
67 \\
74\end{array}$ & $\begin{array}{l}.24 \\
.27 \\
.50 \\
.76 \\
.76\end{array}$ & $\begin{array}{l}.60 \\
.30 \\
.60 \\
.50 \\
6.1\end{array}$ & $\begin{array}{r}32 \\
32 \\
32 \\
32 \\
219\end{array}$ & $\begin{array}{r}.05 \\
.03 \\
.05 \\
10\end{array}$ \\
\hline $\begin{array}{l}11 \\
12 \\
13 \\
14 \\
15\end{array}$ & $\begin{array}{r}1.4 \\
2.0 \\
36 \\
5.9 \\
7.3\end{array}$ & $\begin{array}{r}8 \\
12 \\
394 \\
12 \\
18\end{array}$ & $\begin{array}{r}.03 \\
58 \\
.10 \\
.19 \\
.79\end{array}$ & $\begin{array}{l}3.1 \\
3.4 \\
2.3 \\
2.3 \\
1.9\end{array}$ & $\begin{array}{l}81 \\
88 \\
65 \\
41 \\
17\end{array}$ & $\begin{array}{l}.68 \\
.81 \\
.40 \\
.25 \\
.09\end{array}$ & $\begin{array}{l}6.5 \\
1.9 \\
1.4 \\
1.2 \\
.80\end{array}$ & $\begin{array}{r}210 \\
35 \\
25 \\
20 \\
15\end{array}$ & $\begin{array}{l}3.7 \\
.18 \\
.09 \\
.07 \\
.03\end{array}$ \\
\hline $\begin{array}{l}16 \\
17 \\
18 \\
19 \\
20\end{array}$ & $\begin{array}{l}12 \\
3.1 \\
2.3 \\
1.9 \\
1.9\end{array}$ & $\begin{array}{r}24 \\
1 \\
3 \\
5 \\
7\end{array}$ & $\begin{array}{l}1.1 \\
.01 \\
.02 \\
.03 \\
.04\end{array}$ & $\begin{array}{l}1.5 \\
2.3 \\
1.9 \\
1.4 \\
.80\end{array}$ & $\begin{array}{l}19 \\
21 \\
23 \\
25 \\
27\end{array}$ & $\begin{array}{l}.08 \\
.13 \\
.12 \\
.09 \\
.06\end{array}$ & $\begin{array}{r}.50 \\
.60 \\
.30 \\
.10\end{array}$ & $\begin{array}{r}8 \\
11 \\
14 \\
0 \\
15\end{array}$ & $\begin{array}{l}.01 \\
.02 \\
.01 \\
0 \\
0\end{array}$ \\
\hline $\begin{array}{l}21 \\
22 \\
23 \\
24 \\
25\end{array}$ & $\begin{array}{l}1.9 \\
2.1 \\
2.0 \\
1.9 \\
2.3\end{array}$ & $\begin{array}{l}10 \\
13 \\
19 \\
26 \\
26\end{array}$ & $\begin{array}{l}.05 \\
.07 \\
.10 \\
.13 \\
.16\end{array}$ & $\begin{array}{l}.80 \\
.80 \\
1.0 \\
1.0 \\
.80\end{array}$ & $\begin{array}{l}29 \\
30 \\
29 \\
28 \\
25\end{array}$ & $\begin{array}{l}.06 \\
.06 \\
.08 \\
.08 \\
.05\end{array}$ & $\begin{array}{r}.30 \\
.30 \\
.10 \\
1.0 \\
.80\end{array}$ & $\begin{array}{r}13 \\
11 \\
9 \\
7 \\
5\end{array}$ & $\begin{array}{l}.01 \\
0.01 \\
0.02 \\
.01\end{array}$ \\
\hline $\begin{array}{l}26 \\
27 \\
28 \\
29 \\
30 \\
31\end{array}$ & $\begin{array}{l}2.7 \\
1.4 \\
1.2 \\
1.2 \\
1.2 \\
-.-\end{array}$ & $\begin{array}{r}26 \\
25 \\
25 \\
25 \\
24 \\
---\end{array}$ & $\begin{array}{l}.19 \\
.09 \\
.08 \\
.08 \\
.08 \\
-.-\end{array}$ & $\begin{array}{r}.60 \\
.60 \\
.10 \\
.30 \\
.10 \\
.50\end{array}$ & $\begin{array}{l}23 \\
21 \\
19 \\
17 \\
20 \\
23\end{array}$ & $\begin{array}{l}.04 \\
.03 \\
.01 \\
.01 \\
.01 \\
.03\end{array}$ & $\begin{array}{r}.50 \\
.30 \\
1.5 \\
.10 \\
0 .\end{array}$ & $\begin{array}{r}5 \\
5 \\
9 \\
5 \\
0 \\
--\end{array}$ & $\begin{array}{l}0^{.01} \\
0_{0}^{.04} \\
. . .\end{array}$ \\
\hline TAL & 121.2 & -- & 70.91 & 48.80 &.-- & 6.23 & 29.10 & --- & 14.59 \\
\hline
\end{tabular}

\begin{tabular}{|c|c|c|c|c|c|c|c|c|c|}
\hline \multirow[b]{2}{*}{ DAY } & \multicolumn{3}{|c|}{ JULY } & \multicolumn{3}{|c|}{ AUGUST } & \multicolumn{3}{|c|}{ SEPTEMGER } \\
\hline & $\begin{array}{l}\text { MEAN } \\
\text { DIISHARGE } \\
\text { (CFS) }\end{array}$ & $\begin{array}{l}\text { MEAN } \\
\text { CONCEN- } \\
\text { TRATION } \\
\text { (MG/L) }\end{array}$ & $\begin{array}{l}\text { SEDIMENT } \\
\text { DIISCHARGE } \\
\text { (TONS/OAY) }\end{array}$ & $\begin{array}{l}\text { MEAN } \\
\text { DIISCHARGE } \\
\text { (CFS) }\end{array}$ & $\begin{array}{l}\text { MEAN } \\
\text { CONCEN- } \\
\text { TRATION } \\
\text { (MG/L) }\end{array}$ & $\begin{array}{l}\text { SEOIMENT } \\
\text { DISCHARGE } \\
\text { (TONS/OAY) }\end{array}$ & $\begin{array}{l}\text { MEAN } \\
\text { DISCARGE } \\
\text { (CFS) }\end{array}$ & $\begin{array}{l}\text { MEAN } \\
\text { CONEEN- } \\
\text { TRAION } \\
\text { (MG } L \text { ) }\end{array}$ & $\begin{array}{l}\text { SEDIMENT } \\
\text { DISCHARGE } \\
\text { (TONS/OAY) }\end{array}$ \\
\hline $\begin{array}{l}1 \\
2 \\
3 \\
4 \\
5\end{array}$ & $\begin{array}{r}.30 \\
.10 \\
0.10 \\
.50\end{array}$ & $\begin{array}{l}15 \\
17 \\
0 \\
24 \\
28\end{array}$ & $\begin{array}{l}0^{.01} \\
0 \\
.01 \\
.04\end{array}$ & $\begin{array}{l}0 \\
0 \\
0 \\
0 \\
0\end{array}$ & $\begin{array}{l}0 \\
0 \\
0 \\
0 \\
0\end{array}$ & $\begin{array}{l}0 \\
0 \\
0 \\
0 \\
0\end{array}$ & $\begin{array}{l}0 \\
0 \\
0.60 \\
.10\end{array}$ & $\begin{array}{r}0 \\
0 \\
17 \\
0 \\
17\end{array}$ & $\begin{array}{l}0 \\
0 \\
0 \\
0\end{array}$ \\
\hline $\begin{array}{r}6 \\
7 \\
8 \\
9 \\
10\end{array}$ & $\begin{array}{l}: 80 \\
: 10 \\
0 \\
0 \\
0\end{array}$ & $\begin{array}{r}33 \\
38 \\
0 \\
0 \\
0\end{array}$ & $\begin{array}{l}.07 \\
.01 \\
0 \\
0 \\
0\end{array}$ & $\begin{array}{l}0 \\
0 \\
0 \\
0 \\
0\end{array}$ & $\begin{array}{l}0 \\
0 \\
0 \\
0 \\
0\end{array}$ & $\begin{array}{l}0 \\
0 \\
0 \\
0 \\
0\end{array}$ & $\begin{array}{l}.10 \\
0 \\
0 \\
48\end{array}$ & $\begin{array}{r}16 \\
14 \\
0 \\
0 \\
1590\end{array}$ & $\begin{array}{r}0 \\
0 \\
0 \\
0 \\
367\end{array}$ \\
\hline $\begin{array}{l}11 \\
12 \\
13 \\
14 \\
15\end{array}$ & $\begin{array}{l}0 \\
0 \\
0 \\
0 \\
0\end{array}$ & $\begin{array}{l}0 \\
0 \\
0 \\
0 \\
0\end{array}$ & $\begin{array}{l}0 \\
0 \\
0 \\
0 \\
0\end{array}$ & $\begin{array}{l}0 \\
0 \\
0 \\
0 \\
0\end{array}$ & $\begin{array}{l}0 \\
0 \\
0 \\
0 \\
0\end{array}$ & $\begin{array}{l}0 \\
0 \\
0 \\
0 \\
0\end{array}$ & $\begin{array}{c}40 \\
4.6 \\
1.5 \\
0 \\
.30\end{array}$ & $\begin{array}{r}1750 \\
80 \\
32 \\
0 \\
29\end{array}$ & $\begin{array}{r}372 \\
.99 \\
0.13 \\
.02\end{array}$ \\
\hline $\begin{array}{l}16 \\
17 \\
18 \\
19 \\
20\end{array}$ & $\begin{array}{l}0 \\
0 \\
0 \\
0 \\
0\end{array}$ & $\begin{array}{l}0 \\
0 \\
0 \\
0 \\
0\end{array}$ & $\begin{array}{l}0 \\
0 \\
0 \\
0 \\
0\end{array}$ & $\begin{array}{l}.10 \\
0 \\
0 \\
.70 \\
1.9\end{array}$ & $\begin{array}{l}9 \\
0 \\
0 \\
6 \\
5\end{array}$ & $\begin{array}{l}0 \\
0 \\
0 \\
.01 \\
.03\end{array}$ & $\begin{array}{l}1.0 \\
: 80 \\
1.4 \\
1.0 \\
.30\end{array}$ & $\begin{array}{l}26 \\
23 \\
20 \\
23 \\
25\end{array}$ & $\begin{array}{l}.07 \\
.05 \\
.08 \\
.06 \\
.02\end{array}$ \\
\hline $\begin{array}{l}21 \\
22 \\
23 \\
24 \\
25\end{array}$ & $\begin{array}{l}0 \\
0 \\
0 \\
0 \\
0\end{array}$ & $\begin{array}{l}0 \\
0 \\
0 \\
0 \\
0\end{array}$ & $\begin{array}{l}0 \\
0 \\
0 \\
0 \\
0\end{array}$ & $\begin{array}{r}1.0 \\
1.0 \\
1.0 \\
\times .50 \\
.10\end{array}$ & $\begin{array}{r}4 \\
9 \\
14 \\
19 \\
24\end{array}$ & $\begin{array}{l}.01 \\
.02 \\
.04 \\
.03 \\
.01\end{array}$ & $\begin{array}{l}1.2 \\
1: 0 \\
1: 2 \\
1: 0 \\
2: 0\end{array}$ & $\begin{array}{l}27 \\
29 \\
31 \\
33 \\
36\end{array}$ & $\begin{array}{l}.09 \\
.08 \\
.10 \\
.09 \\
.19\end{array}$ \\
\hline $\begin{array}{l}26 \\
27 \\
28 \\
29 \\
30 \\
31\end{array}$ & $\begin{array}{r}.80 \\
.30 \\
0.30 \\
.50 \\
.50\end{array}$ & $\begin{array}{l}6 \\
5 \\
0 \\
3 \\
2 \\
1\end{array}$ & $\begin{array}{l}0_{0}^{.01} \\
0 \\
0 \\
0 \\
0\end{array}$ & $\begin{array}{l}0^{.10} \\
0 \\
0 \\
0^{.20}\end{array}$ & $\begin{array}{r}21 \\
0 \\
0 \\
0 \\
28 \\
0\end{array}$ & $\begin{array}{l}0^{.01} \\
0 \\
0 \\
0^{.02}\end{array}$ & $\begin{array}{l}1.4 \\
1.0 \\
: 80 \\
1.0 \\
: 80 \\
-\ldots\end{array}$ & $\begin{array}{r}34 \\
32 \\
30 \\
28 \\
26 \\
-.-\end{array}$ & $\begin{array}{l}.13 \\
090 \\
06 \\
.08 \\
06 \\
0 .\end{array}$ \\
\hline & 3.90 & -- & .15 & 6.60 & $\cdots$ & .18 & 111.20 & $\cdots$ & 741.42 \\
\hline
\end{tabular}


11047300 ARROYO TRABUCO AT SAN JUAN CAPISTRANO, CA--Continued

SUMMARY OF WATER AND SEDIMENT DISCHARGE, WATER YEAR OCTOBER 1975 TO SEPTEMBER 1976

\begin{tabular}{|c|c|c|c|c|}
\hline MONTH & $\begin{array}{l}\text { WATER } \\
\text { DISCHARGE } \\
\text { CFS-DAYS }\end{array}$ & $\begin{array}{l}\text { SUSPENDEO } \\
\text { SEDIMENT } \\
\text { OISCHARGE } \\
\text { TONS }\end{array}$ & $\begin{array}{l}\text { BEDLOAD } \\
\text { DISCHARGE } \\
\text { TONS }\end{array}$ & $\begin{array}{l}\text { TOTAL } \\
\text { SEDIMENT } \\
\text { DISCHARGE } \\
\text { TONS }\end{array}$ \\
\hline OCTOBER 1975 & 25.00 & 0.81 & 3 & 4 \\
\hline NOVEMBER $\ldots$ & 74.10 & 17.69 & 45 & 63 \\
\hline DECEMBER $\cdots$ & 62.80 & 2.94 & 17 & 20 \\
\hline JANUARY 1976 & $26 \cdot 30$ & 1.28 & 5 & 6 \\
\hline FEBRUARY $\ldots$ & 509.00 & 1727.32 & 3260 & 4980 \\
\hline MARCH $\ldots \ldots$ & 144.00 & 255.93 & 143 & 399 \\
\hline APRIL $\ldots \ldots$ & 121.20 & 70.91 & 207 & 278 \\
\hline MAY $\ldots \ldots \ldots$ & 48.80 & 6.23 & 12 & 18 \\
\hline JUNE $\ldots \ldots \ldots$ & 29.10 & 14.59 & 12 & 27 \\
\hline JULY $\ldots \ldots \bullet$ & 3.90 & 0.15 & 0 & 0 \\
\hline AUGUST $\ldots \ldots$ & 6.60 & 0.18 & 1 & 1 \\
\hline SEPTEMBER & 111.20 & 741.42 & 458 & 1200 \\
\hline TOTAL $\ldots \ldots$ & 1162.00 & 2839.45 & 4163 & 6996 \\
\hline
\end{tabular}

PARTICLE-SIZE DISTRIBUTION OF SUSPENDED SEDIMENT, WATER YEAR OCTOBER 1975 TO SEPTEMBER 1976

\begin{tabular}{|c|c|c|c|c|c|c|c|c|c|}
\hline & TIME & $\begin{array}{l}\text { TEMPER- } \\
\text { ATURE }\end{array}$ & $\begin{array}{l}\text { OIS- } \\
\text { CHARGE }\end{array}$ & $\begin{array}{l}\text { INSTAN- } \\
\text { TANEOUS } \\
\text { DIS- } \\
\text { CHARGE }\end{array}$ & $\begin{array}{l}\text { SUS- } \\
\text { PENDED } \\
\text { SEDI- } \\
\text { MENT }\end{array}$ & $\begin{array}{c}\text { SUS- } \\
\text { PENDED } \\
\text { SEDI- } \\
\text { HENT } \\
\text { DIS- } \\
\text { CHARGE }\end{array}$ & $\begin{array}{l}\text { SUS, } \\
\text { SED } \\
\text { FALi } \\
\text { DIAM. } \\
\text { DIINER } \\
\text { THAN }\end{array}$ & $\begin{array}{l}\text { SUS. } \\
\text { SED } \\
\text { FALL } \\
\text { DIAM. } \\
\text { D FINER } \\
\text { THAN }\end{array}$ & $\begin{array}{l}\text { SUS. } \\
\text { SED: } \\
\text { FALL } \\
\text { DIAM. } \\
\text { \$ FINER } \\
\text { THAN }\end{array}$ \\
\hline DATE & & COEG Cl & (CFS) & $(\mathrm{CF} S)$ & (MG/L) & $(T / D A Y)$ & $.002 \mathrm{MM}$ & $.004 \mathrm{MM}$ & $.008 \mathrm{MM}$ \\
\hline \multicolumn{10}{|l|}{ FEB } \\
\hline $\begin{array}{l}05 \ldots . \\
06 \ldots \\
06 \ldots \\
06 \ldots \\
\text { MAR }\end{array}$ & $\begin{array}{l}0745 \\
0745 \\
0845 \\
1130\end{array}$ & $\begin{array}{l}12.0 \\
11.0 \\
10.5 \\
13.0\end{array}$ & $\begin{array}{l}m \\
=- \\
-=\end{array}$ & $\begin{array}{r}27 \\
213 \\
163 \\
77\end{array}$ & $\begin{array}{r}97 \\
3120 \\
2990 \\
2220\end{array}$ & $\begin{array}{c}7.1 \\
1790 \\
1320 \\
462\end{array}$ & $\begin{array}{l}-5 \\
61 \\
53 \\
59\end{array}$ & $\begin{array}{l}-- \\
64 \\
59 \\
67\end{array}$ & $\begin{array}{l}-5 \\
69 \\
67 \\
74\end{array}$ \\
\hline $\begin{array}{l}01 \ldots \\
03 \ldots \\
\text { SEP }\end{array}$ & $\begin{array}{l}1700 \\
1100\end{array}$ & $\begin{array}{l}14.0 \\
11.0\end{array}$ & $18 \ldots$ & $86^{--}$ & $\begin{array}{l}5190 \\
2840\end{array}$ & $\begin{array}{l}252 \\
659\end{array}$ & $\begin{array}{l}52 \\
51\end{array}$ & $\begin{array}{l}57 \\
56\end{array}$ & $\begin{array}{l}66 \\
60\end{array}$ \\
\hline $\begin{array}{l}10 \ldots \\
11 \ldots \\
11 \ldots\end{array}$ & $\begin{array}{l}1600 \\
0745 \\
0925\end{array}$ & $\begin{array}{l}21.0 \\
19.5 \\
21.5\end{array}$ & $\begin{array}{l}-- \\
--\end{array}$ & $\begin{array}{l}59 \\
40 \\
28\end{array}$ & $\begin{array}{l}1210 \\
1530 \\
2240\end{array}$ & $\begin{array}{l}193 \\
165 \\
169\end{array}$ & $\begin{array}{l}75 \\
68 \\
69\end{array}$ & $\begin{array}{l}79 \\
81 \\
84\end{array}$ & $\begin{array}{l}89 \\
89 \\
93\end{array}$ \\
\hline
\end{tabular}

\begin{tabular}{|c|c|c|c|c|c|c|c|c|}
\hline & $\begin{array}{l}\text { SUS. } \\
\text { SED. } \\
\text { FALL } \\
\text { DIAM. } \\
\text { FINER } \\
\text { THAN }\end{array}$ & $\begin{array}{l}\text { SUS. } \\
\text { SEO } \\
\text { FALL } \\
\text { DIAM. } \\
\text { \& FINER } \\
\text { THAN }\end{array}$ & $\begin{array}{l}\text { SUS. } \\
\text { SED } \\
\text { FALL } \\
\text { DIAM. } \\
\text { \$ FINER } \\
\text { THAN }\end{array}$ & $\begin{array}{l}\text { SUS. } \\
\text { SED: } \\
\text { SIEVE } \\
\text { DIAM. } \\
\text { \& FINER } \\
\text { THAN }\end{array}$ & $\begin{array}{l}\text { SUS. } \\
\text { SED. } \\
\text { FALL } \\
\text { DIAM. } \\
\text { * FINER } \\
\text { THAN }\end{array}$ & $\begin{array}{l}\text { SUS. } \\
\text { SED. } \\
\text { FALL } \\
\text { DIAM. } \\
\text { FINER } \\
\text { THAN }\end{array}$ & $\begin{array}{l}\text { SUS. } \\
\text { SED. } \\
\text { FALL } \\
\text { DIAM. } \\
\text { FINER } \\
\text { THAN }\end{array}$ & $\begin{array}{l}\text { SUS } \\
\text { SED } \\
\text { FALL } \\
\text { DIAM. } \\
\text { \& FINER } \\
\text { THAN }\end{array}$ \\
\hline DATE & $.016 \mathrm{MM}$ & $.031 \mathrm{MM}$ & $.062 \mathrm{MM}$ & $.062 \mathrm{MM}$ & $.125 \mathrm{MM}$ & $.250 \mathrm{MM}$ & $.500 \mathrm{MH}$ & $1.00 \mathrm{MM}$ \\
\hline $\begin{array}{l}=\text { EB } \\
05 \ldots . .\end{array}$ & & & & & & & & \\
\hline $05 . \ldots$ & 81 & 91 & $\begin{array}{l}99 \\
95\end{array}$ & $\because$ & $\begin{array}{r}100 \\
97\end{array}$ & 100 & $=$ & \\
\hline $\begin{array}{l}06 \ldots \\
06 \cdots \\
\text { MAR }\end{array}$ & $\begin{array}{l}74 \\
80\end{array}$ & $\begin{array}{l}82 \\
87\end{array}$ & $\begin{array}{l}86 \\
88\end{array}$ & $=$ & $\begin{array}{l}87 \\
69\end{array}$ & $\begin{array}{l}92 \\
93\end{array}$ & $\begin{array}{r}99 \\
100\end{array}$ & 100 \\
\hline $\begin{array}{r}01 \cdots \\
03 \cdots \\
\text { SEP }\end{array}$ & $\begin{array}{l}75 \\
69\end{array}$ & $\begin{array}{l}85 \\
77\end{array}$ & $\begin{array}{l}92 \\
85\end{array}$ & $=$ & $\begin{array}{l}96 \\
92\end{array}$ & $\begin{array}{l}97 \\
96\end{array}$ & $\begin{array}{r}99 \\
100\end{array}$ & $\begin{array}{r}100 \\
-\infty\end{array}$ \\
\hline $\begin{array}{l}10 \ldots \\
11 \ldots\end{array}$ & $\begin{array}{l}94 \\
93\end{array}$ & $\begin{array}{r}100 \\
97\end{array}$ & 98 & $=$ & 99 & 99 & $=9$ & $\ddot{0}$ \\
\hline $11 \ldots$ & 98 & 99 & - & 100 & $=0$ & $=0$ & $\begin{array}{l}49 \\
-0\end{array}$ & 100 \\
\hline
\end{tabular}


11047300 ARROYO TRABUGO AT SAN JUAN CAPISTRANO, CA--Continued

PARTICLE-SIZE DISTRIBUTION OF SURFACE BED MATERIAL, YATER YEAR OCTOBER 1974 TO SEPTEMBER 1975

\begin{tabular}{|c|c|c|c|c|c|c|c|c|c|c|}
\hline & TIME & $\begin{array}{c}\text { NUMBER } \\
\text { OF } \\
\text { SAM- } \\
\text { PLING } \\
\text { POINTS }\end{array}$ & $\begin{array}{c}\text { BED } \\
\text { MAT. } \\
\text { SIEVE } \\
\text { DIAM. } \\
* \text { FINER } \\
\text { THAN }\end{array}$ & $\begin{array}{l}\text { 8ED } \\
\text { MAT. } \\
\text { SIEVE } \\
\text { DIAH. } \\
\text { \$ FINER } \\
\text { THAN }\end{array}$ & $\begin{array}{l}\text { BED } \\
\text { MAT. } \\
\text { SIEVE } \\
\text { DIAM. } \\
\text { क FINER } \\
\text { THAN }\end{array}$ & $\begin{array}{l}\text { BED } \\
\text { MAT. } \\
\text { SIEVE } \\
\text { DIAM. } \\
\text { \& FINER } \\
\text { THAN }\end{array}$ & $\begin{array}{c}\text { BED } \\
\text { MAT. } \\
\text { SIEVE } \\
\text { DIAM. } \\
\text { * FINER } \\
\text { THAN }\end{array}$ & $\begin{array}{l}\text { BED } \\
\text { MAT } \\
\text { SIEVE } \\
\text { DIAM. } \\
\text { \% FINER } \\
\text { THAN }\end{array}$ & $\begin{array}{l}\text { BED } \\
\text { MAT. } \\
\text { SIEVE } \\
\text { OIAM. } \\
\text { X FINER } \\
\text { THAN }\end{array}$ & $\begin{array}{c}\text { BED } \\
\text { MAT. } \\
\text { SIEVE } \\
\text { OIAM. } \\
\text { \& FINER } \\
\text { THAN }\end{array}$ \\
\hline DATE & & & $.250 \mathrm{MM}$ & $.500 \mathrm{MM}$ & $1.00 \mathrm{MM}$ & $2.00 \mathrm{MM}$ & $4.00 \mathrm{MM}$ & $8.00 \mathrm{mM}$ & $16.0 \mathrm{MM}$ & $32.0 \mathrm{MM}$ \\
\hline P & 1415 & 3 & 1 & 6 & 17 & 27 & 39 & 54 & 75 & 100 \\
\hline
\end{tabular}


11047500 ALISO CREEK AT EL TORO, CA

LOCATTON - - Lat $33^{\circ} 37^{\prime} 33^{\prime \prime}$, Iong $117^{\circ} 41^{\prime} 08^{\prime \prime}$, in Canada de $10 \mathrm{~s}$ Alisos Grant, Orange County on right

bank $500 \mathrm{ft}(150 \mathrm{~m})$ downstream from Second Street Bridge at El Toro. Prior to Nov. 18, 1975 at site

$500 \mathrm{ft}(150 \mathrm{~m})$ upstream.

DRATNAGE AREA. $--7.91 \mathrm{mi}^{2}\left(20.5 \mathrm{~km}^{2}\right)$.

PERIOD OF RECORD, - October 1930 to current year.

GAGE, - Water-stage recorder. Altitude of gage is $425 \mathrm{ft}(130 \mathrm{~m})$, from topographic map. Prior to July 1962 , at different datum. July 1962 to Nov, 18, 1975, water-stage recorder at site $500 \mathrm{ft}$ (150 $\mathrm{m}$ ) upstream at different datum.

REMARKS.--Records poor. No regulation or diversion above station; some pumping from wells along stream. At times since 1964, Metropolitan Water District has wasted water to creek.

COOPERATION.--Records were furnished by Orange County Flood Control District.

AVERAGE DISCHARGE, -46 years, $0.71 \mathrm{ft}^{3} / \mathrm{s}\left(0.020 \mathrm{~m}^{3} / \mathrm{s}\right), 514 \mathrm{acre}-\mathrm{ft} / \mathrm{yr}\left(634,000 \mathrm{~m}^{3} / \mathrm{yr}^{2}\right)$.

EXTREMES FOR PERIOD OF RECORD.--Maximum discharge, 2,500 $\mathrm{ft}^{3} / \mathrm{s}\left(70.8 \mathrm{~m}^{3} / \mathrm{s}\right) \mathrm{Feb} .24$, 1969 , gage height, 11.00 ft $(3.353 \mathrm{~m})$ from floodmark, from rating curve extended above $220 \mathrm{ft}^{3} / \mathrm{s}\left(6.23 \mathrm{~m}^{3} / \mathrm{s}\right)$ on basis of slope-area measurement of maximum flow; no flow most of each year.

EXTREMES FOR CURRENT YEAR.--Maximun daily discharge, $12 \mathrm{ft}^{3} / \mathrm{s}\left(0.34 \mathrm{~m}^{3} / \mathrm{s}\right) \mathrm{Sept}$. 10 ; no flow many days.

DISCHARGE, IN CUBIC FEET PER SECOND, WATER YEAR OCTOBER 1975 TO SEPTEMBER 1976 MEAN VALUES

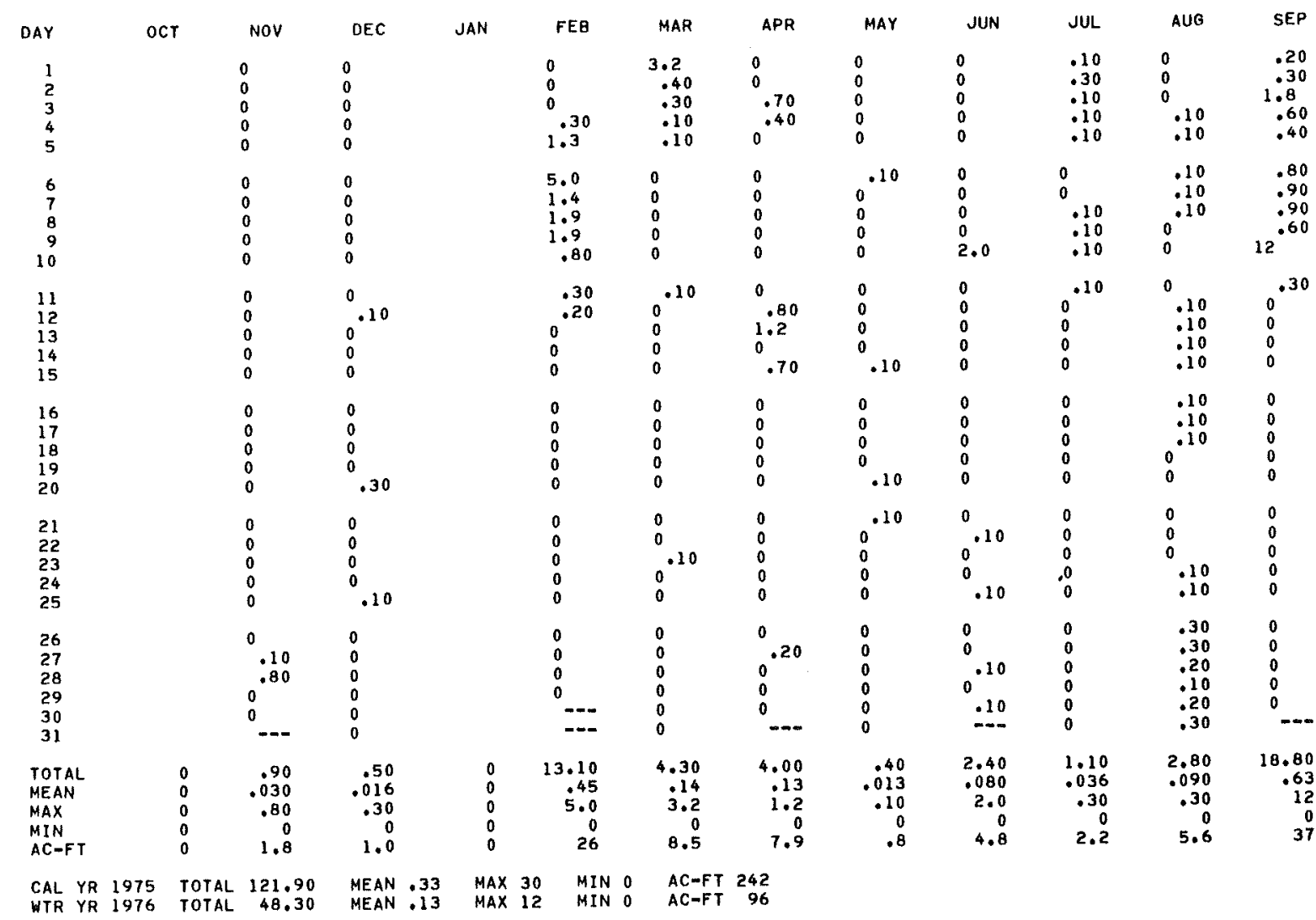


LOCATION, - Lat $33^{\circ} 40^{\prime} 20^{\prime \prime}$, 1ong $117^{\circ} 47^{\prime} 10^{\prime \prime}$, in San Joaquin Grant, Orange County, on 1 eft bank 200 ft (61 m) downstream from Jeffrey Road Bridge, and $1.5 \mathrm{mi}(2.4 \mathrm{~km})$ west of Irvine.

DRAINAGE AREA. $-40.3 \mathrm{mi}^{2}\left(104.4 \mathrm{~km}^{2}\right)$.

WATER-DISCHARGE RECORDS

PERIOD OF RECORD, -October 1949 to current year.

GAGE, - Water-stage recorder. Datum of gage is $102.86 \mathrm{ft}(31.352 \mathrm{~m})$ above mean sea level (1evels by 0range County Flood Control District).

REMARKS.--Records poor. Pumping from wells along stream causes low-flow fluctuation in discharge.

COOPERATION. --Five discharge measurements were furnished by Orange County F1ood Control District.

AVERAGE DISCHARGE. - -27 years, $3.56 \mathrm{ft}^{3} / \mathrm{s}\left(0.101 \mathrm{~m}^{3} / \mathrm{s}\right), 2,580 \mathrm{acre}-\mathrm{ft} / \mathrm{yr}\left(3.18 \mathrm{hm} / \mathrm{yr}^{3}\right)$

EXTREMES FOR PERIOD OF RECORD.--Maximum discharge, $6,700 \mathrm{ft}^{3} / \mathrm{s}\left(190 \mathrm{~m}^{3} / \mathrm{s}\right)$ Feb. 24 , 1969 , gage height, $11.46 \mathrm{ft}$

$(3.493 \mathrm{~m})$, from rating curve extended above $510 \mathrm{ft}^{3} / \mathrm{s}\left(14.4 \mathrm{~m}^{3} / \mathrm{s}\right)$ on basis of stope-area measurements at

gage heights $9.20 \mathrm{ft}(2.804 \mathrm{~m})$ and $11.46 \mathrm{ft}(3.493 \mathrm{~m})$; no flow for 1 ong periods in most years.

EXTREMES FOR CURRENT YEAR.--Peak discharges above base of $300 \mathrm{ft}^{3} / \mathrm{s}\left(8.50 \mathrm{~m}^{3} / \mathrm{s}\right)$ and maximum (*):

\begin{tabular}{|c|c|c|c|c|c|c|c|c|c|}
\hline Date & Time & $\begin{array}{c}\text { Discharge } \\
\left(\mathrm{ft}^{3} / \mathrm{s}\right)\left(\mathrm{m}^{3} / \mathrm{s}\right)\end{array}$ & $\begin{array}{l}\text { Gage height } \\
\text { (ft) (m) }\end{array}$ & Date & Time & $\begin{array}{r}\text { Disc } \\
\left(\mathrm{ft}^{3} / \mathrm{s}\right.\end{array}$ & $\left(\mathrm{m}^{3} / \mathrm{s}\right)$ & $\begin{array}{l}\text { Gage } \\
(\mathrm{ft})\end{array}$ & $\begin{array}{r}\text { height } \\
\text { (m) }\end{array}$ \\
\hline $\begin{array}{ll}\text { Feb. } & 9 \\
\text { Mar. } & 1\end{array}$ & $\begin{array}{l}0930 \\
1400\end{array}$ & $\begin{array}{r}* 1220 \\
841\end{array}$ & $\begin{array}{l}1.539 \\
1.375\end{array}$ & Mar. 3 & 0100 & 418 & 11.8 & 3.67 & 1.11 \\
\hline
\end{tabular}

Minimum daily discharge, no flow for several days in August and September.

DISCHARGE, IN CUBIC FEET PER SECOND, WATER YEAR OCTOBER 1975 TO SEPTEMBER 1976 MEAN VALUES

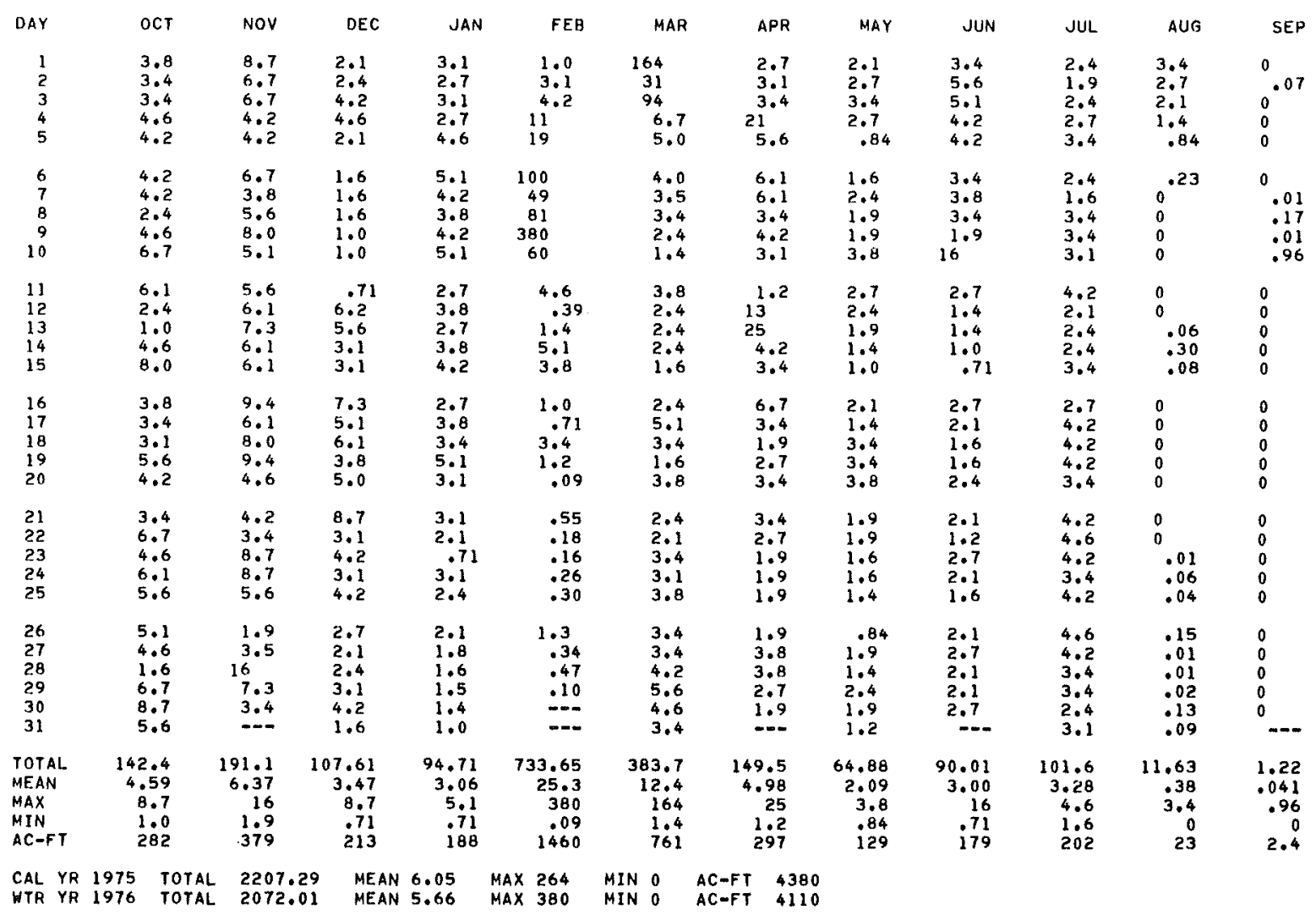


11048500 SAN DIEGO CREEK NEAR IRVINE, CA--Continued

WATER-QUALITY RECORDS

'ERIOD OF DAILY RECORD. --

WATER TEMPERATURES: June 1972 to current year.

SEDIMENT RECORDS: June 1972 to current year.

REMARKS.--Channel was altered to bypass this gaging station on Aug. 5 . It was moved 1 mi ( 2 km) upstream for water year 1977. Particle-size distribution of bed material table was omitted in the 1975 water year and published with 1976 water year records.

EXTREMES FOR PERIOD OF DAILY RECORD. -

SEDIMENT CONCENTRATIONS: Maximum daily mean, 9,400 mg/1 Feb. 11, 1973; minimum daily mean, no flow Dec. 25,1972 , Nov. 15-17, 1973, Jan, 13, 1975

SEDIMENT'DISCHARGE: Maximum daily, 22,300 tons $(20,200$ tonnes) Feb. 11, 1973; minimum daily, 0 tons on several days each year.

EXTREMES FOR CURRENT YEAR.--

SEDIMENT CONCENTRATIONS: Maximum daily mean, $7,620 \mathrm{mg} / 1 \mathrm{Feb}$. 9; minimum daily mean, no flow for many days during year.

SEDIMENT DISCHARGE: Maximum daily, 9,420 tons $(8,550$ tonnes) Feb. 9 ; mininum daily, 0 tons for many days

during year.

TEMPERATURE (DEG. C) OF HATER, WATER YEAR OCTOBER 1975 TO SEPTEMBER 1976

ONCE-DAILY

\begin{tabular}{|c|c|c|c|c|c|c|c|c|c|c|c|c|}
\hline DAY & OCT & NOV & DEC & JAN & FEB & MAR & APR & MAY & JUN & JUL & AUG & SEP \\
\hline $\begin{array}{l}1 \\
2 \\
3 \\
4 \\
5\end{array}$ & $\begin{array}{r}21.0 \\
24.0 \\
-0\end{array}$ & $\begin{array}{r}15.5 \\
=-.5 \\
19.0 \\
16.5 \\
=-0\end{array}$ & $\begin{array}{r}14.0 \\
13.0 \\
0.0\end{array}$ & $\begin{array}{r}7.0 \\
12.5 \\
-0 .\end{array}$ & $\begin{array}{l}8.5 \\
-0 . \\
-=- \\
-.0\end{array}$ & $\begin{array}{r}15.5 \\
13.5 \\
10.0 \\
11.5 \\
\end{array}$ & $\begin{array}{r}25.0 \\
15.5 \\
-\end{array}$ & 20.0 & $\begin{array}{r}21.0 \\
\cdots \\
0\end{array}$ & $\begin{array}{r}20.5 \\
=- \\
=-\end{array}$ & $\begin{array}{r}23.5 \\
16.5 \\
=-5\end{array}$ & 21.0 \\
\hline $\begin{array}{r}6 \\
7 \\
8 \\
9 \\
10\end{array}$ & $\begin{array}{r}-.-5 \\
22.5 \\
20.0\end{array}$ & $=-$ & $\begin{array}{l}9.5 \\
-.5 \\
8.5 \\
-.-\end{array}$ & 11.0 & $\begin{array}{r}12.0 \\
=0 \\
=-0\end{array}$ & $=-$ & $=$ & $\bar{m}$ & $\begin{array}{r}30.0 \\
\cdots \\
-\end{array}$ & $\begin{array}{r}21.5 \\
29.5 \\
=-5 \\
22.5\end{array}$ & $=$ & 22.0 \\
\hline $\begin{array}{l}11 \\
12 \\
13 \\
14 \\
15\end{array}$ & $\begin{array}{r}17.0 \\
17.0 \\
\hdashline-0\end{array}$ & $\begin{array}{l}=- \\
=- \\
=- \\
--\end{array}$ & $\begin{array}{r}12.5 \\
8.5 \\
-\end{array}$ & $\begin{array}{r}10.0 \\
=- \\
=-\end{array}$ & $\begin{array}{r}14.5 \\
--. \\
-\end{array}$ & $\begin{array}{r}16.0 \\
8.5 \\
-\end{array}$ & $\begin{array}{r}16.0 \\
19.5 \\
-.0 \\
--.\end{array}$ & $\begin{array}{r}29.0 \\
0-\end{array}$ & $\begin{array}{l}=-0 \\
=- \\
=- \\
=-\end{array}$ & $\begin{array}{r}30.5 \\
19.5 \\
21.0\end{array}$ & $\begin{array}{l}=- \\
=- \\
=-\infty\end{array}$ & $=-$ \\
\hline $\begin{array}{l}16 \\
17 \\
18 \\
19 \\
20\end{array}$ & 16.5 & $\ddot{-0}$ & $\begin{array}{r}-.- \\
10.5 \\
-\ldots\end{array}$ & $\begin{array}{r}12.5 \\
- \\
-\end{array}$ & 17.5 & 19.5 & $\begin{array}{l}=- \\
=- \\
=-\end{array}$ & 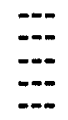 & $\begin{array}{l}=- \\
=-\infty \\
=-\infty\end{array}$ & 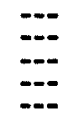 & 19.5 & $=-$ \\
\hline $\begin{array}{l}21 \\
22 \\
23 \\
24 \\
25\end{array}$ & $\begin{array}{r}18.5 \\
-.-5 \\
13.5 \\
-. .-\end{array}$ & $\begin{array}{r}13.0 \\
10.5 \\
-. .5 \\
0 .\end{array}$ & $\begin{array}{c}10.5 \\
=- \\
=-\end{array}$ & $\begin{array}{r}13.0 \\
0.5 \\
0.5\end{array}$ & $\bar{m}$ & $\begin{array}{l}=- \\
=- \\
=-\end{array}$ & $\begin{array}{r}20.5 \\
--. \\
--.\end{array}$ & 22.5 & $\begin{array}{r}29.5 \\
19.0\end{array}$ & $\begin{array}{r}23.5 \\
\hdashline 21.5 \\
\hdashline-5\end{array}$ & $\begin{array}{r}27.0 \\
=-0 \\
=-0\end{array}$ & $\begin{array}{l}=-0 \\
=-0 \\
=-0 \\
=-0\end{array}$ \\
\hline $\begin{array}{l}26 \\
27 \\
28 \\
29 \\
30 \\
31\end{array}$ & $\begin{array}{r}13.0 \\
-0 . \\
-0 . \\
17.5 \\
-0.5\end{array}$ & $\begin{array}{r}14.0 \\
8.5 \\
- \\
-\end{array}$ & $\begin{array}{r}-0 \\
11.5 \\
-0-\end{array}$ & 14.0 & $\begin{array}{r}17.5 \\
=-5 \\
=-0 \\
=-\end{array}$ & $\begin{array}{r}23.5 \\
=- \\
20.5 \\
- \\
=-\end{array}$ & $\begin{array}{r}22.5 \\
-1.5 \\
22.0 \\
-.0\end{array}$ & $=0$ & $\begin{array}{r}-.0 \\
21.0 \\
20.5 \\
-0.5\end{array}$ & $\begin{array}{r}=- \\
=-0 \\
=-0 \\
21.0\end{array}$ & $\begin{array}{r}-\infty \\
20.5 \\
-0.5 \\
-\infty\end{array}$ & $\begin{array}{l}=-\infty \\
=-\infty \\
=-\infty \\
=-\infty\end{array}$ \\
\hline ITH & --- & $m$ & $=-$ & $-\infty$ & $\cdots$ & $-\infty$ & - & $\ldots$ & $-\infty$ & & $-\infty$ & - \\
\hline
\end{tabular}


11048500 SAN DIEGO CREEK NEAR IRVINE, CA--Continued SUSPENDED-SEDIMENT DISCHARGE (TONS/DAY), WATER YEAR OCTOBER 1975 TO SEPTEMBER 1976

\begin{tabular}{|c|c|c|c|c|c|c|c|c|c|}
\hline \multirow[b]{2}{*}{ DAY } & \multicolumn{3}{|c|}{ OCTOBER } & \multicolumn{3}{|c|}{ NOVEMBER } & \multicolumn{3}{|c|}{ DECEMBER } \\
\hline & $\begin{array}{l}\text { MEAN } \\
\text { DISCHARGE } \\
\text { (CFS) }\end{array}$ & $\begin{array}{l}\text { MEAN } \\
\text { CONCEN- } \\
\text { TRATION } \\
(M G / L)\end{array}$ & $\begin{array}{l}\text { SEDIMENT } \\
\text { DISCHARGE } \\
\text { (TONS/DAY) }\end{array}$ & $\begin{array}{l}\text { MEAN } \\
\text { DISCHARGE } \\
\text { (CFS) }\end{array}$ & $\begin{array}{l}\text { MEAN } \\
\text { CONCEN- } \\
\text { TRATION } \\
\text { (MG LL) }\end{array}$ & $\begin{array}{l}\text { SEDIMENT } \\
\text { DISCHARGE } \\
\text { (TONS/DAY) }\end{array}$ & $\begin{array}{l}\text { MEAN } \\
\text { DISCHARGE } \\
\text { (CFS) }\end{array}$ & $\begin{array}{l}\text { MEAN } \\
\text { CONCEN- } \\
\text { TRATION } \\
\text { (MG } L)\end{array}$ & $\begin{array}{l}\text { SEOIMENT } \\
\text { DISCHARGE } \\
\text { ITONS } / D A Y\end{array}$ \\
\hline $\begin{array}{l}1 \\
2 \\
3 \\
4 \\
5\end{array}$ & $\begin{array}{l}3.8 \\
3.4 \\
3.4 \\
4.6 \\
4.2\end{array}$ & $\begin{array}{l}530 \\
450 \\
350 \\
330 \\
280\end{array}$ & $\begin{array}{l}5.4 \\
4.1 \\
3.2 \\
4.1 \\
3.2\end{array}$ & $\begin{array}{l}8.7 \\
6.7 \\
6.7 \\
4.2 \\
4.2\end{array}$ & $\begin{array}{l}300 \\
250 \\
200 \\
240 \\
200\end{array}$ & $\begin{array}{l}7.0 \\
4.5 \\
3.6 \\
2.7 \\
2.3\end{array}$ & $\begin{array}{l}2.1 \\
2.4 \\
4.2 \\
4.6 \\
2.1\end{array}$ & $\begin{array}{l}300 \\
320 \\
350 \\
300 \\
250\end{array}$ & $\begin{array}{l}1.7 \\
2.1 \\
4.0 \\
3.7 \\
1.4\end{array}$ \\
\hline $\begin{array}{r}6 \\
7 \\
8 \\
9 \\
10\end{array}$ & $\begin{array}{l}6^{4} .2 \\
4.2 \\
2.4 \\
4.6 \\
6.7\end{array}$ & $\begin{array}{l}230 \\
180 \\
140 \\
200 \\
360\end{array}$ & $\begin{array}{l}2.6 \\
2.0 \\
.91 \\
2.5 \\
6.5\end{array}$ & $\begin{array}{l}6.7 \\
3.8 \\
5.6 \\
8.0 \\
5.1\end{array}$ & $\begin{array}{r}300 \\
200 \\
500 \\
1000 \\
400\end{array}$ & $\begin{array}{r}5.4 \\
2.1 \\
7.6 \\
22 \\
5.5\end{array}$ & $\begin{array}{l}1.6 \\
1.6 \\
1.6 \\
1.0 \\
1.0\end{array}$ & $\begin{array}{r}200 \\
170 \\
120 \\
100 \\
80\end{array}$ & $\begin{array}{l}.86 \\
.73 \\
.52 \\
.27 \\
.22\end{array}$ \\
\hline $\begin{array}{l}11 \\
12 \\
13 \\
14 \\
15\end{array}$ & $\begin{array}{l}6.1 \\
2.4 \\
1.0 \\
4.6 \\
8.0\end{array}$ & $\begin{array}{l}650 \\
300 \\
100 \\
400 \\
530\end{array}$ & $\begin{array}{c}11 \\
1.9 \\
.27 \\
5.0 \\
11\end{array}$ & $\begin{array}{l}5.6 \\
6.1 \\
7.3 \\
6.1 \\
6.1\end{array}$ & $\begin{array}{r}500 \\
700 \\
1400 \\
1250 \\
800\end{array}$ & $\begin{array}{l}7.6 \\
12 \\
28 \\
21 \\
13\end{array}$ & $\begin{array}{l}.71 \\
6.2 \\
5.6 \\
3.1 \\
3.1\end{array}$ & $\begin{array}{r}50 \\
1180 \\
500 \\
220 \\
200\end{array}$ & $\begin{array}{c}25^{.10} \\
7.6 \\
1.8 \\
1.7\end{array}$ \\
\hline $\begin{array}{l}16 \\
17 \\
18 \\
19 \\
20\end{array}$ & $\begin{array}{l}3.8 \\
3.4 \\
3.1 \\
5.6 \\
4.2\end{array}$ & $\begin{array}{l}350 \\
250 \\
180 \\
200 \\
170\end{array}$ & $\begin{array}{l}3.6 \\
2.3 \\
1.5 \\
3.0 \\
1.9\end{array}$ & $\begin{array}{l}9.4 \\
6.1 \\
8.0 \\
9.4 \\
4.6\end{array}$ & $\begin{array}{r}1000 \\
200 \\
250 \\
300 \\
260\end{array}$ & $\begin{array}{l}25 \\
3.3 \\
5.4 \\
7.6 \\
3.2\end{array}$ & $\begin{array}{l}7.3 \\
5.1 \\
6.1 \\
3.8 \\
5.0\end{array}$ & $\begin{array}{l}900 \\
600 \\
400 \\
200 \\
722\end{array}$ & $\begin{array}{c}18 \\
8.3 \\
6.6 \\
2.1 \\
15\end{array}$ \\
\hline $\begin{array}{l}21 \\
22 \\
23 \\
24 \\
25\end{array}$ & $\begin{array}{l}3.4 \\
6.7 \\
4.6 \\
6.1 \\
5.6\end{array}$ & $\begin{array}{l}140 \\
300 \\
230 \\
350 \\
300\end{array}$ & $\begin{array}{l}1.3 \\
5.4 \\
2.9 \\
5.8 \\
4.5\end{array}$ & $\begin{array}{l}4.2 \\
3.4 \\
8.7 \\
8.7 \\
5.6\end{array}$ & $\begin{array}{l}210 \\
200 \\
500 \\
400 \\
200\end{array}$ & $\begin{array}{r}2.4 \\
1.8 \\
12 \\
9.4 \\
3.0\end{array}$ & $\begin{array}{l}8.7 \\
3.1 \\
4.2 \\
3.1 \\
4.2\end{array}$ & $\begin{array}{l}550 \\
350 \\
400 \\
200 \\
300\end{array}$ & $\begin{array}{l}13 \\
2.9 \\
4.5 \\
1.7 \\
3.4\end{array}$ \\
\hline $\begin{array}{l}26 \\
27 \\
28 \\
29 \\
30 \\
31\end{array}$ & $\begin{array}{l}5.1 \\
4.6 \\
1.6 \\
6.7 \\
8.7 \\
5.6\end{array}$ & $\begin{array}{l}270 \\
220 \\
180 \\
250 \\
360 \\
300\end{array}$ & $\begin{array}{l}3.7 \\
2.7 \\
.78 \\
4.5 \\
8.5 \\
4.5\end{array}$ & $\begin{array}{r}1.9 \\
3.5 \\
16 \\
7.3 \\
3.4 \\
-. .5\end{array}$ & $\begin{array}{r}100 \\
396 \\
2240 \\
900 \\
500 \\
---\end{array}$ & $\begin{array}{c}15^{.51} \\
168 \\
18 \\
4.6 \\
--.\end{array}$ & $\begin{array}{l}2.7 \\
2.1 \\
2.4 \\
3.1 \\
4.2 \\
1.6\end{array}$ & $\begin{array}{l}250 \\
200 \\
200 \\
200 \\
250 \\
150\end{array}$ & $\begin{array}{l}1.8 \\
1.1 \\
1.3 \\
1.7 \\
2.8 \\
.65\end{array}$ \\
\hline DTAL & 142.4 & $\cdots$ & 120.56 & 191.1 & --- & 423.51 & 107.61 & $\cdots$ & 136.55 \\
\hline
\end{tabular}

\begin{tabular}{|c|c|c|c|c|c|c|c|c|c|}
\hline DAY & $\begin{array}{l}\text { MEAN } \\
\text { DISCHARGE } \\
\text { (CFS) }\end{array}$ & $\begin{array}{l}\text { JANUARY } \\
\text { MEAN } \\
\text { CONCEN- } \\
\text { TRATION } \\
\text { (MG/L) }\end{array}$ & $\begin{array}{l}\text { SEDIMENT } \\
\text { DISCHARGE } \\
\text { (TONS/DAY) }\end{array}$ & $\begin{array}{l}\text { MEAN } \\
\text { DISCHARGE } \\
\text { (CFS) }\end{array}$ & $\begin{array}{l}\text { FEBRUARY } \\
\text { MEAN } \\
\text { CONCEN- } \\
\text { TRATION } \\
\text { (MG/L) }\end{array}$ & $\begin{array}{l}\text { SEDIMENT } \\
\text { DISCHARGE } \\
\text { (TONS/DAY) }\end{array}$ & $\begin{array}{l}\text { MEAN } \\
\text { DISCHARGE } \\
\text { (CFS) }\end{array}$ & $\begin{array}{l}\text { MARCH } \\
\text { MEAN } \\
\text { CONCEN- } \\
\text { TRATION } \\
\text { (MG/L) }\end{array}$ & $\begin{array}{l}\text { SEOIMENT } \\
\text { DISCHARGE } \\
\text { (TONS/DAY) }\end{array}$ \\
\hline $\begin{array}{l}1 \\
2 \\
3 \\
4 \\
5\end{array}$ & $\begin{array}{l}3.1 \\
2.7 \\
3.1 \\
2.7 \\
4.6\end{array}$ & $\begin{array}{l}300 \\
280 \\
300 \\
250 \\
350\end{array}$ & $\begin{array}{l}2.5 \\
2.0 \\
2.5 \\
1.8 \\
4.3\end{array}$ & $\begin{array}{l}1.0 \\
3.1 \\
4.2 \\
11 \\
19\end{array}$ & $\begin{array}{r}150 \\
300 \\
400 \\
1000 \\
1360\end{array}$ & $\begin{array}{l}.41 \\
2.5 \\
4.5 \\
30 \\
90\end{array}$ & $\begin{array}{l}164 \\
31 \\
94 \\
6.7 \\
5.0\end{array}$ & $\begin{array}{r}4170 \\
1830 \\
2760 \\
350 \\
300\end{array}$ & $\begin{array}{r}4330 \\
425 \\
1370 \\
6.3 \\
4.1\end{array}$ \\
\hline $\begin{array}{r}6 \\
7 \\
8 \\
9 \\
10\end{array}$ & $\begin{array}{l}5.1 \\
4.2 \\
3.8 \\
4.2 \\
5.1\end{array}$ & $\begin{array}{l}400 \\
300 \\
210 \\
260 \\
300\end{array}$ & $\begin{array}{l}5.5 \\
3.4 \\
2.2 \\
2.9 \\
4.1\end{array}$ & $\begin{array}{r}100 \\
49 \\
81 \\
380 \\
60\end{array}$ & $\begin{array}{l}3760 \\
2230 \\
3260 \\
7620 \\
3000\end{array}$ & $\begin{array}{r}1650 \\
436 \\
1350 \\
9420 \\
486\end{array}$ & $\begin{array}{l}4.0 \\
3.5 \\
3.4 \\
2.4 \\
1.4\end{array}$ & $\begin{array}{l}250 \\
220 \\
190 \\
150 \\
100\end{array}$ & $\begin{array}{l}2.7 \\
2.1 \\
1.7 \\
.97 \\
.38\end{array}$ \\
\hline $\begin{array}{l}11 \\
12 \\
13 \\
14 \\
15\end{array}$ & $\begin{array}{l}2.7 \\
3.8 \\
2.7 \\
3.8 \\
4.2\end{array}$ & $\begin{array}{r}70 \\
250 \\
200 \\
250 \\
280\end{array}$ & $\begin{array}{l}.51 \\
2.6 \\
1.5 \\
2.6 \\
3.2\end{array}$ & $\begin{array}{l}4.6 \\
.39 \\
1.4 \\
5.1 \\
3.8\end{array}$ & $\begin{array}{r}500 \\
40 \\
150 \\
350 \\
350\end{array}$ & $\begin{array}{l}6.2 \\
.04 \\
.57 \\
4.8 \\
3.6\end{array}$ & $\begin{array}{l}3.8 \\
2.4 \\
2.4 \\
2.4 \\
1.6\end{array}$ & $\begin{array}{l}50 \\
200 \\
200 \\
200 \\
150\end{array}$ & $\begin{array}{l}.51 \\
1.3 \\
1.3 \\
1.3 \\
.65\end{array}$ \\
\hline $\begin{array}{l}16 \\
17 \\
18 \\
19 \\
20\end{array}$ & $\begin{array}{l}2.7 \\
3.8 \\
3.4 \\
5.1 \\
3.1\end{array}$ & $\begin{array}{l}200 \\
400 \\
350 \\
500 \\
300\end{array}$ & $\begin{array}{l}1.5 \\
4.1 \\
3.2 \\
6.9 \\
2.5\end{array}$ & $\begin{array}{l}1.0 \\
.71 \\
3.4 \\
1.2 \\
.09\end{array}$ & $\begin{array}{r}100 \\
50 \\
350 \\
100 \\
20\end{array}$ & $\begin{array}{l}.27 \\
.10 \\
3.2 \\
.32 \\
0\end{array}$ & $\begin{array}{l}2.4 \\
5.1 \\
3.4 \\
1.6 \\
3.8\end{array}$ & $\begin{array}{l}200 \\
300 \\
200 \\
100 \\
150\end{array}$ & $\begin{array}{l}1.3 \\
4.1 \\
1.8 \\
.43 \\
1.5\end{array}$ \\
\hline $\begin{array}{l}21 \\
22 \\
23 \\
24 \\
25\end{array}$ & $\begin{array}{l}3.1 \\
2.1 \\
.71 \\
3.1 \\
2.4\end{array}$ & $\begin{array}{l}250 \\
200 \\
300 \\
300 \\
200\end{array}$ & $\begin{array}{l}2.1 \\
1.1 \\
.58 \\
2.5 \\
1.3\end{array}$ & $\begin{array}{l}.55 \\
.18 \\
.16 \\
.26 \\
.30\end{array}$ & $\begin{array}{l}50 \\
20 \\
20 \\
30 \\
30\end{array}$ & $\begin{array}{l}.07 \\
.01 \\
.01 \\
.02 \\
.02\end{array}$ & $\begin{array}{l}2.4 \\
2.1 \\
3.4 \\
3.1 \\
3.8\end{array}$ & $\begin{array}{r}100 \\
80 \\
100 \\
80 \\
100\end{array}$ & $\begin{array}{r}.65 \\
.45 \\
.92 \\
.67 \\
1.0\end{array}$ \\
\hline $\begin{array}{l}26 \\
27 \\
28 \\
29 \\
30 \\
31\end{array}$ & $\begin{array}{l}2.1 \\
1.8 \\
1.6 \\
1.5 \\
1.4 \\
1.0\end{array}$ & $\begin{array}{l}200 \\
190 \\
190 \\
180 \\
180 \\
180\end{array}$ & $\begin{array}{c}1.1 \\
.92 \\
.82 \\
.73 \\
.68 \\
.49\end{array}$ & $\begin{array}{r}1.3 \\
.34 \\
.47 \\
.10 \\
: .0 \\
.0 .\end{array}$ & $\begin{array}{r}400 \\
50 \\
50 \\
20 \\
20 \\
-\infty\end{array}$ & $\begin{array}{l}1.4 \\
.05 \\
.06 \\
.01 \\
.0 \\
.0 .\end{array}$ & $\begin{array}{l}3.4 \\
3.4 \\
4.2 \\
5.6 \\
4.6 \\
3.4\end{array}$ & $\begin{array}{l}130 \\
100 \\
150 \\
250 \\
200 \\
150\end{array}$ & $\begin{array}{l}1.2 \\
1.92 \\
1.7 \\
3.8 \\
2.5 \\
1.4\end{array}$ \\
\hline ALL & 94.71 & $\infty$ & 72.13 & 733.65 & $-\infty$ & 13490.16 & 383.7 & $\infty$ & 6172.65 \\
\hline
\end{tabular}


11048500 SAN DIEGO CREEK NEAR IRVINE, CA-Continued

SUSPENDED-SEDIMENT DISCHARGE (TONS/DAY), WATER YEAR OCTOBER 1975 TO SEPTEMBER 1976

\begin{tabular}{|c|c|c|c|c|c|c|c|c|c|}
\hline & & APRIL & & & MAY & & & JUNE & \\
\hline DAY & $\begin{array}{c}\text { MEAN } \\
\text { DISCHARGE } \\
\text { (CFS) }\end{array}$ & $\begin{array}{l}\text { MEAN } \\
\text { CONCEN- } \\
\text { TRATION } \\
\text { (HG/L) }\end{array}$ & $\begin{array}{l}\text { SEDIMENT } \\
\text { DISCHARGE } \\
\text { (TONS/DAY) }\end{array}$ & $\begin{array}{l}\text { MEAN } \\
\text { OISCHARGE } \\
\text { (CFS) }\end{array}$ & $\begin{array}{l}\text { MEAN } \\
\text { CONCEN- } \\
\text { TRATION } \\
\text { (MG/L) }\end{array}$ & $\begin{array}{l}\text { SEOIMENT } \\
\text { OISCHARGE } \\
\text { (TONS/OAY) }\end{array}$ & $\begin{array}{l}\text { MEAN } \\
\text { DISCHARGE } \\
\text { (CFS) }\end{array}$ & $\begin{array}{l}\text { MEAN } \\
\text { CONCEN- } \\
\text { TRATION } \\
\text { (MG/L) }\end{array}$ & $\begin{array}{l}\text { SEOI IMENT } \\
\text { DISCHARGE } \\
\text { (TONS/DAY }\end{array}$ \\
\hline $\begin{array}{l}1 \\
2 \\
3 \\
4 \\
5\end{array}$ & $\begin{array}{r}2.7 \\
3.1 \\
3.4 \\
21 \\
5.6\end{array}$ & $\begin{array}{l}200 \\
250 \\
300 \\
654 \\
500\end{array}$ & $\begin{array}{r}1.5 \\
2.1 \\
2.8 \\
43 \\
7.6\end{array}$ & $\begin{array}{r}2.1 \\
2.7 \\
3.4 \\
2.7 \\
.84\end{array}$ & $\begin{array}{l}150 \\
300 \\
350 \\
300 \\
150\end{array}$ & $\begin{array}{l}.85 \\
2.2 \\
3.2 \\
2.2 \\
.34\end{array}$ & $\begin{array}{l}3.4 \\
5.6 \\
5.1 \\
4.2 \\
4.2\end{array}$ & $\begin{array}{r}350 \\
1000 \\
1000 \\
800 \\
800\end{array}$ & $\begin{array}{l}3.2 \\
15 \\
14 \\
9.1 \\
9.1\end{array}$ \\
\hline $\begin{array}{r}6 \\
7 \\
8 \\
9 \\
10\end{array}$ & $\begin{array}{l}6.1 \\
6.1 \\
3.4 \\
4.2 \\
3.1\end{array}$ & $\begin{array}{l}500 \\
400 \\
300 \\
350 \\
250\end{array}$ & $\begin{array}{l}8.2 \\
6.6 \\
2.8 \\
4.0 \\
2.1\end{array}$ & $\begin{array}{l}1.6 \\
2.4 \\
1.9 \\
1.9 \\
3.8\end{array}$ & $\begin{array}{r}100 \\
150 \\
100 \\
80 \\
150\end{array}$ & $\begin{array}{r}.43 \\
.97 \\
.51 \\
.41 \\
1.5\end{array}$ & $\begin{array}{l}3.4 \\
3.8 \\
3.4 \\
1.9 \\
16\end{array}$ & $\begin{array}{r}600 \\
700 \\
600 \\
400 \\
1570\end{array}$ & $\begin{array}{r}5.5 \\
7.2 \\
5.5 \\
2.1 \\
118\end{array}$ \\
\hline $\begin{array}{l}11 \\
12 \\
13 \\
14 \\
15\end{array}$ & $\begin{array}{l}1.2 \\
13 \\
25 \\
4.2 \\
3.4\end{array}$ & $\begin{array}{r}50 \\
388 \\
840 \\
400 \\
200\end{array}$ & $\begin{array}{l}93^{.16} \\
95 \\
4.5 \\
1.8\end{array}$ & $\begin{array}{l}2.7 \\
2.4 \\
1.9 \\
1.4 \\
1.0\end{array}$ & $\begin{array}{r}100 \\
60 \\
40 \\
30 \\
20\end{array}$ & $\begin{array}{l}.73 \\
.39 \\
.21 \\
.11 \\
.05\end{array}$ & $\begin{array}{l}2.7 \\
1.4 \\
1.4 \\
1.0 \\
.71\end{array}$ & $\begin{array}{r}1200 \\
800 \\
700 \\
600 \\
400\end{array}$ & $\begin{array}{l}8.7 \\
3.0 \\
2.6 \\
1.6 \\
.77\end{array}$ \\
\hline $\begin{array}{l}16 \\
17 \\
18 \\
19 \\
20\end{array}$ & $\begin{array}{l}6.7 \\
3.4 \\
1.9 \\
2.7 \\
3.4\end{array}$ & $\begin{array}{r}300 \\
150 \\
50 \\
80 \\
100\end{array}$ & $\begin{array}{l}5.4 \\
1.4 \\
.26 \\
.58 \\
.92\end{array}$ & $\begin{array}{l}2.1 \\
1.4 \\
3.4 \\
3.4 \\
3.8\end{array}$ & $\begin{array}{r}50 \\
40 \\
100 \\
100 \\
200\end{array}$ & $\begin{array}{r}.28 \\
.15 \\
.92 \\
.92 \\
2.1\end{array}$ & $\begin{array}{l}2.7 \\
2.1 \\
1.6 \\
1.6 \\
2.4\end{array}$ & $\begin{array}{r}1000 \\
800 \\
600 \\
500 \\
800\end{array}$ & $\begin{array}{l}7.3 \\
4.5 \\
2.6 \\
2.2 \\
5.2\end{array}$ \\
\hline $\begin{array}{l}21 \\
22 \\
23 \\
24 \\
25\end{array}$ & $\begin{array}{l}3.4 \\
2.7 \\
1.9 \\
1.9 \\
1.9\end{array}$ & $\begin{array}{l}80 \\
60 \\
50 \\
40 \\
30\end{array}$ & $\begin{array}{l}.73 \\
.44 \\
.26 \\
.21 \\
.15\end{array}$ & $\begin{array}{l}1.9 \\
1.9 \\
1.6 \\
1.6 \\
1.4\end{array}$ & $\begin{array}{l}150 \\
100 \\
350 \\
500 \\
400\end{array}$ & $\begin{array}{l}.77 \\
.51 \\
1.5 \\
2.2 \\
1.5\end{array}$ & $\begin{array}{l}2.1 \\
1.2 \\
2.7 \\
2.1 \\
1.6\end{array}$ & $\begin{array}{r}700 \\
800 \\
700 \\
700 \\
2000\end{array}$ & $\begin{array}{l}4.0 \\
2.6 \\
5.1 \\
4.0 \\
4.3\end{array}$ \\
\hline $\begin{array}{l}26 \\
27 \\
28 \\
29 \\
30 \\
31\end{array}$ & $\begin{array}{l}1.9 \\
3.8 \\
3.8 \\
2.7 \\
1.9 \\
-.-\end{array}$ & $\begin{array}{l}20 \\
200 \\
200 \\
180 \\
150 \\
-\infty-\end{array}$ & $\begin{array}{l}.10 \\
2.1 \\
2.1 \\
1.3 \\
.77 \\
-.-\end{array}$ & $\begin{array}{l}.84 \\
1.9 \\
1.4 \\
2.4 \\
1.9 \\
1.2\end{array}$ & $\begin{array}{l}100 \\
200 \\
150 \\
250 \\
200 \\
150\end{array}$ & $\begin{array}{l}.23 \\
1.0 \\
.57 \\
1.6 \\
1.0 \\
.49\end{array}$ & $\begin{array}{l}2.1 \\
2.7 \\
2.1 \\
2.1 \\
2.7 \\
-.-\end{array}$ & $\begin{array}{l}1200 \\
1300 \\
1400 \\
1400 \\
1500 \\
-0-\infty\end{array}$ & $\begin{array}{r}6.8 \\
9.5 \\
7.9 \\
7.9 \\
11 .\end{array}$ \\
\hline TAL & 149.5 & $-\infty$ & 291.88 & 64.88 & $--\infty$ & 29.84 & 90.01 & -- & 290.27 \\
\hline
\end{tabular}

\begin{tabular}{|c|c|c|c|c|c|c|c|c|c|}
\hline & & JULY & & & AUGUST & & & SEPTEMBER & \\
\hline DAY & $\begin{array}{l}\text { MEAN } \\
\text { DISCHARGE } \\
\text { (CFS) }\end{array}$ & $\begin{array}{l}\text { MEAN } \\
\text { CONCEN- } \\
\text { TRATION } \\
(M G / L)\end{array}$ & $\begin{array}{l}\text { SEDIMENT } \\
\text { DISCHARGE } \\
\text { (TONS/DAY) }\end{array}$ & $\begin{array}{l}\text { MEAN } \\
\text { DISCHARGE } \\
\text { (CFS) }\end{array}$ & $\begin{array}{l}\text { MEAN } \\
\text { CONCEN- } \\
\text { TRATION } \\
\text { (MG/L) }\end{array}$ & $\begin{array}{l}\text { SEDIMENT } \\
\text { OISCHARGE } \\
\text { (TONS/DAY) }\end{array}$ & $\begin{array}{l}\text { MEAN } \\
\text { DISCHARGE } \\
\text { (CFS) }\end{array}$ & $\begin{array}{l}\text { MEAN } \\
\text { CONCEN- } \\
\text { TRATION } \\
\text { (MG/L) }\end{array}$ & $\begin{array}{l}\text { SEDIMENT } \\
\text { DISCHARGE } \\
\text { (TONS/DAY) }\end{array}$ \\
\hline $\begin{array}{l}1 \\
2 \\
3 \\
4 \\
5\end{array}$ & $\begin{array}{l}2.4 \\
1.9 \\
2.4 \\
2.7 \\
3.4\end{array}$ & $\begin{array}{l}2000 \\
3000 \\
2000 \\
3000 \\
3000\end{array}$ & $\begin{array}{l}13 \\
15 \\
13 \\
22 \\
28\end{array}$ & $\begin{array}{l}3.4 \\
2.7 \\
2.1 \\
1.4 \\
.84\end{array}$ & $\begin{array}{l}850 \\
650 \\
650 \\
650 \\
650\end{array}$ & $\begin{array}{l}7.8 \\
4.7 \\
3.7 \\
2.5 \\
1.5\end{array}$ & $\begin{array}{l}0 \\
0 \\
0 \\
0 \\
0\end{array}$ & $\begin{array}{r}50 \\
20 \\
0 \\
0 \\
0\end{array}$ & $\begin{array}{l}0 \\
0 \\
0 \\
0 \\
0\end{array}$ \\
\hline $\begin{array}{r}6 \\
7 \\
8 \\
9 \\
10\end{array}$ & $\begin{array}{l}2.4 \\
1.6 \\
3.4 \\
3.4 \\
3.1\end{array}$ & $\begin{array}{r}2000 \\
850 \\
3000 \\
3000 \\
3000\end{array}$ & $\begin{array}{l}13 \\
3.7 \\
28 \\
28 \\
25\end{array}$ & $\begin{array}{l}0^{.23} \\
0 \\
0 \\
0\end{array}$ & $\begin{array}{r}300 \\
0 \\
0 \\
0 \\
0\end{array}$ & $\begin{array}{l}0^{-19} \\
0 \\
0 \\
0\end{array}$ & $\begin{array}{l}0 \\
.01 \\
.17 \\
.01 \\
.96\end{array}$ & $\begin{array}{r}0 \\
0 \\
50 \\
100 \\
298\end{array}$ & $\begin{array}{l}0 \\
0 \\
0 \\
0.02 \\
2.8\end{array}$ \\
\hline $\begin{array}{l}11 \\
12 \\
13 \\
14 \\
15\end{array}$ & $\begin{array}{l}4.2 \\
2.1 \\
2.4 \\
2.4 \\
3.4\end{array}$ & $\begin{array}{l}3000 \\
3500 \\
2500 \\
2500 \\
2500\end{array}$ & $\begin{array}{l}34 \\
20 \\
16 \\
16 \\
23\end{array}$ & $\begin{array}{l}0 \\
0 \\
.06 \\
.30 \\
.08\end{array}$ & $\begin{array}{r}0 \\
0 \\
0 \\
50 \\
20\end{array}$ & $\begin{array}{l}0 \\
0 \\
0 \\
0\end{array}$ & $\begin{array}{l}0 \\
0 \\
0 \\
0 \\
0\end{array}$ & $\begin{array}{r}23 \\
0 \\
0 \\
0 \\
0\end{array}$ & $\begin{array}{l}0 \\
0 \\
0 \\
0 \\
0\end{array}$ \\
\hline $\begin{array}{l}16 \\
17 \\
18 \\
19 \\
20\end{array}$ & $\begin{array}{l}2.7 \\
4.2 \\
4.2 \\
4.2 \\
3.4\end{array}$ & $\begin{array}{l}2000 \\
1900 \\
1800 \\
1700 \\
1600\end{array}$ & $\begin{array}{l}15 \\
22 \\
20 \\
19 \\
15\end{array}$ & $\begin{array}{l}0 \\
0 \\
0 \\
0 \\
0\end{array}$ & $\begin{array}{r}0 \\
0 \\
0 \\
0 \\
20\end{array}$ & $\begin{array}{l}0 \\
0 \\
0 \\
0 \\
0\end{array}$ & $\begin{array}{l}0 \\
0 \\
0 \\
0 \\
0\end{array}$ & $\begin{array}{l}0 \\
0 \\
0 \\
0 \\
0\end{array}$ & $\begin{array}{l}0 \\
0 \\
0 \\
0 \\
0\end{array}$ \\
\hline $\begin{array}{l}21 \\
22 \\
23 \\
24 \\
25\end{array}$ & $\begin{array}{l}4.2 \\
4.6 \\
4.2 \\
3.4 \\
4.2\end{array}$ & $\begin{array}{l}1500 \\
1400 \\
1300 \\
1200 \\
1200\end{array}$ & $\begin{array}{l}17 \\
17 \\
15 \\
11 \\
14\end{array}$ & $\begin{array}{l}0 \\
0 \\
.01 \\
.06 \\
.04\end{array}$ & $\begin{array}{l}20 \\
20 \\
10 \\
60 \\
40\end{array}$ & $\begin{array}{l}0 \\
0 \\
0 \\
0^{.01}\end{array}$ & $\begin{array}{l}0 \\
0 \\
0 \\
0 \\
0\end{array}$ & $\begin{array}{l}0 \\
0 \\
0 \\
0 \\
0\end{array}$ & $\begin{array}{l}0 \\
0 \\
0 \\
0 \\
0\end{array}$ \\
\hline $\begin{array}{l}26 \\
27 \\
28 \\
29 \\
30 \\
31\end{array}$ & $\begin{array}{l}4.6 \\
4.2 \\
3.4 \\
3.4 \\
2.4 \\
3.1\end{array}$ & $\begin{array}{r}1300 \\
1200 \\
1100 \\
1100 \\
800 \\
1000\end{array}$ & $\begin{array}{l}16 \\
14 \\
10 \\
10 \\
5.2 \\
8.4\end{array}$ & $\begin{array}{l}.15 \\
.01 \\
.01 \\
.02 \\
.13 \\
.09\end{array}$ & $\begin{array}{l}80 \\
30 \\
30 \\
40 \\
70 \\
50\end{array}$ & $\begin{array}{l}.03 \\
0 \\
0 \\
0 \\
.02 \\
.01\end{array}$ & $\begin{array}{l}0 \\
0 \\
0 \\
0 \\
0 \\
\end{array}$ & $\begin{array}{r}0 \\
0 \\
0 \\
0 \\
0 \\
-\infty\end{array}$ & $\begin{array}{l}0 \\
0 \\
0 \\
0 \\
0\end{array}$ \\
\hline OTAL & 101.6 & $\infty$ & 526.3 & 11.63 & $\infty$ & 20.50 & 1.22 & $\rightarrow \infty$ & 2.82 \\
\hline YEAR & 2072.01 & & 21577.17 & & & & & & \\
\hline
\end{tabular}


11048500 SAN DIEGO CREEK NEAR IRVINE, CA--Continued

SUMMARY OF HATER AND SEDIMENT DISCHARGE, HATER YEAR OCTOBER 1975 TO SEPTEMBER 1976

\begin{tabular}{|c|c|c|c|c|}
\hline MONTH & $\begin{array}{l}\text { WATER } \\
\text { DISCHARGE } \\
\text { CFS-DAYS }\end{array}$ & $\begin{array}{l}\text { SUSPENDED } \\
\text { SEDIMENT } \\
\text { DISCHARGE } \\
\text { TONS }\end{array}$ & $\begin{array}{c}\text { BEDLOAD } \\
\text { DISCHARGE } \\
\text { TONS }\end{array}$ & $\begin{array}{l}\text { TOTAL } \\
\text { SEDIMENT } \\
\text { DI SCHARGE } \\
\text { TONS }\end{array}$ \\
\hline OCTOBER 1975 & 142.40 & 120.56 & 134 & 255 \\
\hline NOVEMBER $\ldots$ & $191 \cdot 10$ & 423.51 & 295 & 719 \\
\hline DECEMBER $\ldots$ & 107.61 & 136.55 & 82 & 219 \\
\hline JANUARY 1976 & 94.71 & $72 \cdot 13$ & 45 & 117 \\
\hline FEBRUARY $\cdots$ & 733.65 & 13490.16 & 6660 & 20200 \\
\hline MARCH $\ldots \ldots$ & 383.70 & 6172.65 & 3070 & 9240 \\
\hline APRIL $\cdots \cdots$ & 149.50 & 291.88 & 345 & 637 \\
\hline MAY ...... & $64 \cdot 88$ & 29.84 & 16 & 46 \\
\hline JIINE $\cdots \cdots \cdots$ & 90.01 & 290.27 & 91 & 381 \\
\hline JULY $\ldots \ldots$. & 101.60 & 526.30 & 47 & 573 \\
\hline AUGUST $\ldots \ldots$ & 11.63 & 20.50 & 3 & 23 \\
\hline SEPTEMBER . & 1.22 & 2.82 & 0 & 3 \\
\hline TOTAL ....... & 2072.01 & 21577.17 & 10788 & 32413 \\
\hline
\end{tabular}

PARTICLE-SIZE DISTRIBUTION OF SUSPENDED SEOIMENT, WATER YEAR OCTOBER 1975 TO SEPTEMBER 1976

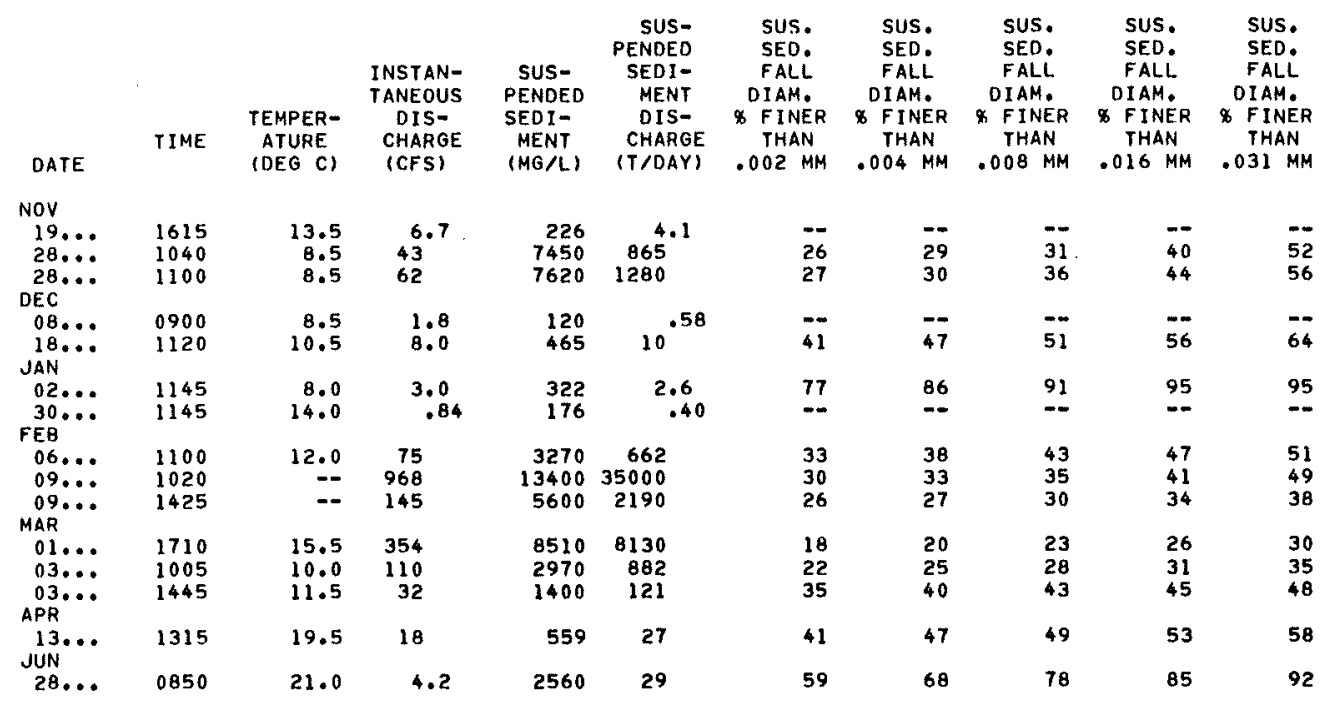


11048500 SAN DIEGO CREEK NEAR IRVINE, CA--Continued

PARTICLE-SIZE DISIRIBUTION OF SUSPENOED SEDIMENT, WATER YEAR OCTOBER 1975 TO SEPTEMBER 1976

\begin{tabular}{|c|c|c|c|c|c|c|c|c|c|c|}
\hline & $\begin{array}{l}\text { SUS. } \\
\text { SED. } \\
\text { FALL } \\
\text { DIAM. } \\
\text { क FINER } \\
\text { THAN }\end{array}$ & $\begin{array}{l}\text { SUS. } \\
\text { SED. } \\
\text { SIEVE } \\
\text { DIAM. } \\
\text { P FINER } \\
\text { THAN }\end{array}$ & $\begin{array}{l}\text { SUS. } \\
\text { SED. } \\
\text { FALL } \\
\text { DIAM. } \\
\text { \% FINER } \\
\text { THAN }\end{array}$ & $\begin{array}{l}\text { SUS. } \\
\text { SED. } \\
\text { SIEVE } \\
\text { DIAM. } \\
\text { \$ FINEA } \\
\text { THAN }\end{array}$ & $\begin{array}{l}\text { SUS. } \\
\text { SED. } \\
\text { FALL } \\
\text { DIAM. } \\
\text { \% FINER } \\
\text { THAN }\end{array}$ & $\begin{array}{l}\text { SUS. } \\
\text { SED. } \\
\text { SIEVE } \\
\text { DIAM. } \\
\text { Q FINER } \\
\text { THAN }\end{array}$ & $\begin{array}{l}\text { SUS. } \\
\text { SED } \\
\text { FALL } \\
\text { OIAH. } \\
\text { \% FINER } \\
\text { THAN }\end{array}$ & $\begin{array}{l}\text { SUS. } \\
\text { SED, } \\
\text { SIEVE } \\
\text { DIAM. } \\
\text { \& FINER } \\
\text { THAN }\end{array}$ & $\begin{array}{l}\text { SUS. } \\
\text { SED. } \\
\text { FALL } \\
\text { DIAM. } \\
\text { S FINER } \\
\text { THAN }\end{array}$ & $\begin{array}{l}\text { SUS } \\
\text { SED. } \\
\text { SIEVE } \\
\text { DIAM. } \\
\$ \text { FINER } \\
\text { THAN }\end{array}$ \\
\hline DATE & $.062 \mathrm{MM}$ & $.062 \mathrm{MM}$ & $.125 \mathrm{MM}$ & $.125 \mathrm{MM}$ & $.250 \mathrm{MH}$ & $.250 \mathrm{MM}$ & $.500 \mathrm{MM}$ & $.500 \mathrm{MM}$ & $1.00 \mathrm{MM}$ & $1.00 \mathrm{MM}$ \\
\hline
\end{tabular}

Nov

\begin{tabular}{|c|c|c|c|c|c|c|c|c|c|c|}
\hline $\begin{array}{l}\text { Nov } \\
19 \ldots . .\end{array}$ & -- & 83 & $-\infty$ & 93 & - & 99 & $=$ & 100 & $-=$ & - \\
\hline $28 \ldots$ & 62 & -- & 78 & - & 93 & $-\infty$ & 100 & $=$ & -- & $=\infty$ \\
\hline OEC & 67 & $=-$ & 87 & $-=$ & 94 & - & 100 & $m$ & -- & $=-$ \\
\hline $08 \ldots$ & $=-$ & 98 & $-\infty$ & 100 & -- & $-\pi$ & - & $-\infty$ & $-\infty$ & - \\
\hline$\underset{\text { JAN }}{18 \ldots}$ & -- & 75 & -- & 93 & -- & 100 & -- & -- & $-\infty$ & -- \\
\hline $02 \ldots$ & $-\overline{-}$ & 95 & -- & 98 & -- & 100 & $\infty$ & -- & $=$ & - \\
\hline $\begin{array}{r}30 \cdots \\
F E B\end{array}$ & -- & 95 & $=$ & 98 & -- & 100 & $m$ & -- & $-\infty$ & -- \\
\hline $06 \ldots$ & 63 & -- & 84 & -- & 98 & - & 100 & $-\infty$ & $\rightarrow$ & $-\infty$ \\
\hline $09 \ldots$ & 60 & -- & 78 & - & 92 & $=$ & 98 & $\cdots$ & 100 & $m-$ \\
\hline $09 \ldots$ & 45 & -- & 63 & -- & 88 & -- & 98 & $-\infty$ & 100 & -- \\
\hline MAR & & & & & & & & & & \\
\hline $01 \ldots$ & 36 & -- & 51 & -- & 75 & $-\infty$ & 93 & - & 100 & - \\
\hline $03 \ldots$ & 43 & $=-$ & 62 & $=$ & 92 & $=-$ & 100 & -- & $\infty$ & - \\
\hline $03 \ldots$ & -- & 53 & -- & 70 & $=-$ & 92 & - & 99 & -- & 100 \\
\hline APR & & & & & & & & & & \\
\hline $13 \ldots$ & -- & 66 & -- & 82 & -- & 96 & -- & 100 & -- & $-\infty$ \\
\hline JUN & & & & & & & & & & \\
\hline $28 \ldots$ & -- & 97 & - & 99 & -- & 100 & $\infty$ & $-\infty$ & -- & \\
\hline
\end{tabular}

PARTICLE-SIZE DISTRIBUTION OF SURFACE BED MATERIAL, WATER YEAR OCTOBER 1974 TO SEPTEMBER 1975

\begin{tabular}{|c|c|c|c|c|c|c|c|c|c|c|c|}
\hline & TIME & $\begin{array}{c}\text { NUMBER } \\
\text { OF } \\
\text { SAM- } \\
\text { PLING } \\
\text { POINTS }\end{array}$ & $\begin{array}{l}\text { INSTAN- } \\
\text { TANEOUS } \\
\text { OIS- } \\
\text { CHARGE }\end{array}$ & $\begin{array}{c}\text { BED } \\
\text { MAT } \\
\text { SIEVE } \\
\text { DIAM. } \\
\text { \& FINER } \\
\text { THAN }\end{array}$ & $\begin{array}{c}\text { BED } \\
\text { MAT, } \\
\text { SIEVE } \\
\text { DIAM. } \\
\text { क FINER } \\
\text { THAN }\end{array}$ & $\begin{array}{c}\text { BED } \\
\text { MAT. } \\
\text { SIEVE } \\
\text { DIAM. } \\
\text { \$ FINER } \\
\text { THAN }\end{array}$ & $\begin{array}{c}\text { BED } \\
\text { MAT. } \\
\text { SIEVE } \\
\text { DIAM. } \\
\text { \& FINER } \\
\text { THAN }\end{array}$ & $\begin{array}{c}\text { BED } \\
\text { MAT } \\
\text { SIEVE } \\
\text { DIAM. } \\
\$ \text { FINER } \\
\text { THAN }\end{array}$ & $\begin{array}{l}\text { BED } \\
\text { MAT. } \\
\text { SIEVE } \\
\text { DIAM. } \\
\$ \text { FINER } \\
\text { THAN }\end{array}$ & $\begin{array}{c}\text { BEO } \\
\text { MAT. } \\
\text { SIEVE } \\
\text { DIAM. } \\
\text { \$ FINER } \\
\text { THAN }\end{array}$ & $\begin{array}{l}\text { BED } \\
\text { MAT. } \\
\text { SIEVE } \\
\text { DIAM. } \\
\text { S FINER } \\
\text { THAN }\end{array}$ \\
\hline TE & & & (CFS) & $.062 \mathrm{MM}$ & $.125 \mathrm{MM}$ & $.250 \mathrm{MM}$ & $.500 \mathrm{MM}$ & $1.00 \mathrm{MM}$ & $2.00 \mathrm{MH}$ & $4.00 \mathrm{MM}$ & $8.00 \mathrm{mM}$ \\
\hline
\end{tabular}
SEP

29... 1045

3.00

1

3

15

53

84

97

99

100 
LOCATION.--Lat $33^{\circ} 42^{\prime} 49^{\prime \prime}$, long $117^{\circ} 48^{\prime} 01^{\prime \prime}$, in Lomas Santiago Grant, Orange County, on downstream side of county road bridge, $50 \mathrm{ft}(30 \mathrm{~m})$ west of intersection of Myford Road and Wa1nut Avenue, $0.5 \mathrm{mi}(0.8 \mathrm{~km})$ southwest of Interstate 5 .

PERIOD OF RECORD.--October 1974 to current year.

GAGE.--Water-stage recorder. Altitude of gage is $60 \mathrm{ft}(19 \mathrm{~m})$, from topographic map.

REMARKS, - -Records good.

COOPERATION.--Records of discharge were furnished by Orange County Flood Control District and reviewed by the Geological Survey.

EXTREMES FOR PERIOD OF RECORD.--Maximum discharge, $1,040 \mathrm{ft}^{3} / \mathrm{s}\left(29.5 \mathrm{~m}^{3} / \mathrm{s}\right) \mathrm{Dec}, 4,1974, \mathrm{gage} \mathrm{height}$, $8.40 \mathrm{ft}$ $(2.560 \mathrm{~m}) ;$ minimum daily, $0.20 \mathrm{ft}^{3} / \mathrm{s}\left(0.006 \mathrm{~m}^{3} / \mathrm{s}\right)$ for several days in 1975 and 1976 water years.

EXTREMES FOR CURRENT YEAR, - Maximum discharge, $388 \mathrm{ft}^{3} / \mathrm{s}\left(11.0 \mathrm{~m}^{3} / \mathrm{s}\right)$ Sept. 19, gage height, $4.75 \mathrm{ft}$ (1.448 $\left.\mathrm{m}\right)$; minimum daily, $0.20 \mathrm{ft}^{3} / \mathrm{s}\left(0.006 \mathrm{~m}^{3} / \mathrm{s}\right)$ several days in March and April.

DISCHARGE, IN CUBIC FEET PER SECONO, WATER YEAR OCTOBER 1975 TO SEPTEMBER 1976 MEAN VALUES

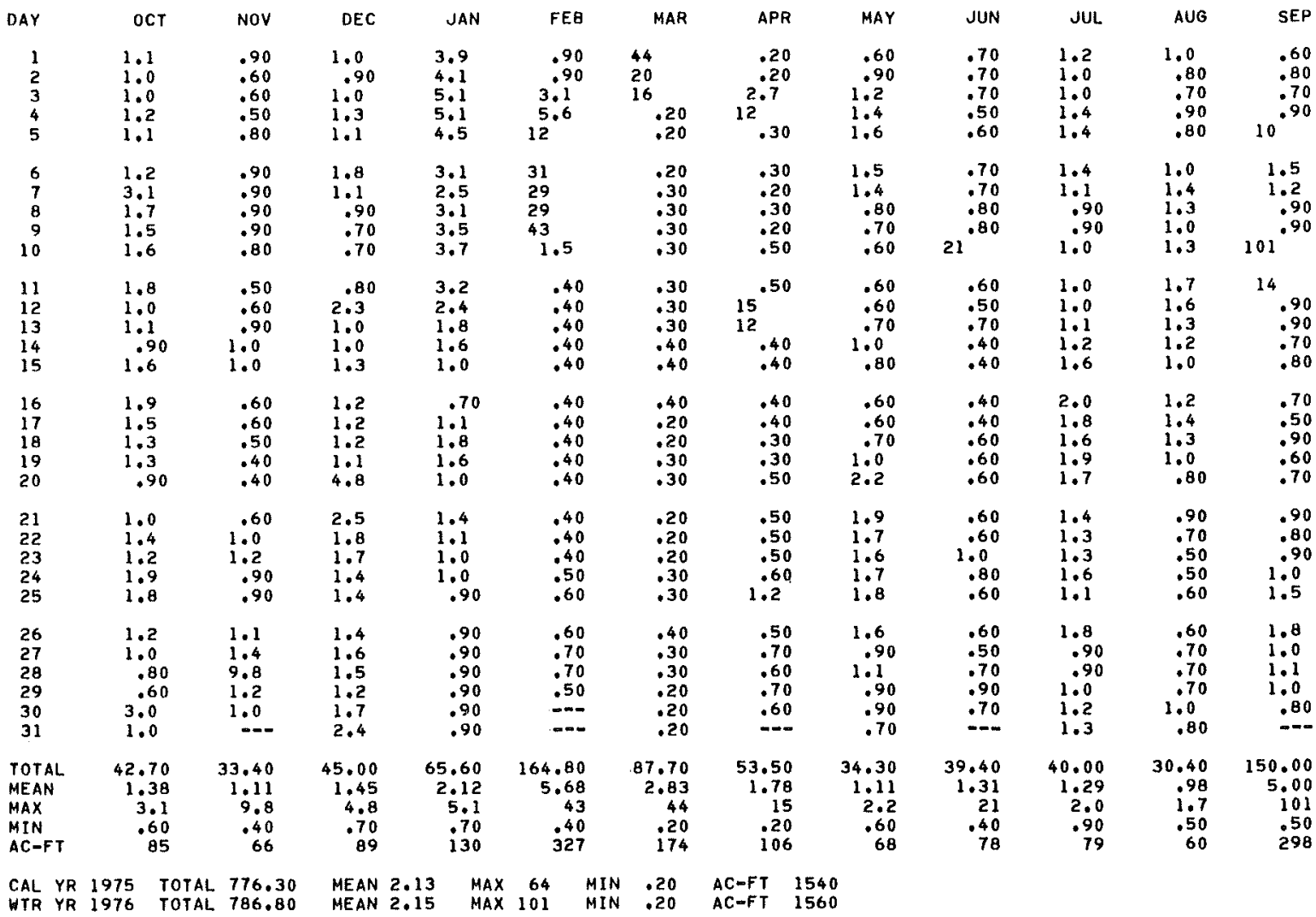


11048530 EL MODENA IRVINE CHANNEL NEAR IRVINE, CA--Continued WATER-QUALITY RECORDS

PERIOD OF DAILY RECORD, -

WATER TEMPERATURES: October 1974 to current year.

SEDIMENT RECORDS: October 1974 to current year.

REMARKS.--Records of discharge were furnished by Orange County Environmenta1 Management Agency,

EXTREMES FOR PERIOD OF DAILY RECORD. - -

SEDIMENT CONCENTRATTONS: Maximum daily mean, 3,230 mg/1 Dec, 4, 1974; minimum daily mean, $1 \mathrm{mg} / 1$ Feb. 18 , 1976.

SEDIMENT DISCHARGE: Maximum daily, 3,050 tons $(2,770$ tonnes) Dec. 4, 1974; minimum daily, 0 tons Feb. $12-18,1976$.

EXTREMES FOR CURRENT YEAR, -

SEDIMENT CONCENTRATIONS: Maximum daily mean, $1,930 \mathrm{mg} / 1 \mathrm{sept}$. 10; minimum daily mean, $1 \mathrm{mg} / 1 \mathrm{Feb}$, 18 .

SEDIMENT DISCHARGE: Maximum daily, 1,150 tons (1,040 tonnes) Sept. 10; minimun daily, 0 tons Feb. 12-18.

TEMPERATURE (DEG. C) OF WATER, WATER YEAR OCTOHER 1975 TO SEPTEMBER 1976 ONCE-DAILY

\begin{tabular}{|c|c|c|c|c|c|c|c|c|c|c|c|c|}
\hline DAY & $\mathrm{OCT}$ & NOV & DEC & JAN & FEB & MAR & APR & MAY & JUN & JUL & $A \cup G$ & SEP \\
\hline $\begin{array}{l}1 \\
2 \\
3 \\
4 \\
5\end{array}$ & $\begin{array}{r}25.5 \\
25.0 \\
19.5 \\
27.0 \\
-.-0\end{array}$ & $\begin{array}{r}16.0 \\
-0.0 \\
22.0 \\
=-0\end{array}$ & $\begin{array}{r}19.5 \\
-.5 \\
17.5 \\
=-.0\end{array}$ & $\begin{array}{l}-=- \\
9.0 \\
=- \\
--\end{array}$ & $\begin{array}{r}10.0 \\
18.0 \\
13.0 \\
14.5\end{array}$ & $\begin{array}{r}-.-5 \\
17.0 \\
17.0 \\
=-.5 \\
21.5\end{array}$ & $\begin{array}{r}18.0 \\
-.0 \\
17.0 \\
16.5\end{array}$ & $\begin{array}{r}--- \\
-0.5 \\
19.5 \\
---\end{array}$ & $\begin{array}{r}22.5 \\
-.- \\
=-\end{array}$ & $\begin{array}{r}23.0 \\
=-- \\
=--\end{array}$ & $\begin{array}{r}-.-5 \\
29.5 \\
17.5 \\
-.-5\end{array}$ & $\begin{array}{r}21.5 \\
29.5 \\
22.0 \\
21.5 \\
=-\end{array}$ \\
\hline $\begin{array}{r}6 \\
7 \\
8 \\
9 \\
10\end{array}$ & 22.5 & $=$ & $\begin{array}{r}13.5 \\
9.5 \\
=-.- \\
=--\end{array}$ & $\begin{array}{r}16.0 \\
13.0 \\
-0 .\end{array}$ & $\begin{array}{l}13.5 \\
12.5 \\
13.0 \\
15.5 \\
17.0\end{array}$ & $\begin{array}{r}17.5 \\
17.5 \\
-0.5\end{array}$ & 21.0 & 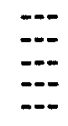 & $\begin{array}{r}29.0 \\
-0 \\
-0\end{array}$ & $\begin{array}{r}24.0 \\
32.0 \\
0.0 \\
21.5\end{array}$ & $\begin{array}{r}--5 \\
18.0 \\
22.5\end{array}$ & 22.5 \\
\hline $\begin{array}{l}11 \\
12 \\
13 \\
14 \\
15\end{array}$ & $\begin{array}{r}17.5 \\
0.5 \\
13.0\end{array}$ & $\begin{array}{r}-0- \\
19.5 \\
--0\end{array}$ & $\begin{array}{r}12.0 \\
9.0 \\
-0\end{array}$ & $\begin{array}{r}9.5 \\
7.5 \\
16.5\end{array}$ & $\begin{array}{r}19.5 \\
-\infty-5 \\
--5\end{array}$ & $\begin{array}{r}-.5 \\
19.5 \\
10.5 \\
-.5\end{array}$ & $\begin{array}{r}18.5 \\
16.0 \\
0 .\end{array}$ & $\begin{array}{r}29.0 \\
20.0 \\
-\cdots\end{array}$ & $\begin{array}{l}m-\infty \\
=-\infty \\
=-\infty \\
=-\infty\end{array}$ & $\begin{array}{r}30.0 \\
22.0 \\
21.5\end{array}$ & $\begin{array}{r}23.5 \\
28.5 \\
18.0 \\
22.0\end{array}$ & $\begin{array}{r}20.5 \\
28.5 \\
20.0 \\
-.-\end{array}$ \\
\hline $\begin{array}{l}16 \\
17 \\
18 \\
19 \\
20\end{array}$ & $\begin{array}{r}17.0 \\
25.0 \\
20\end{array}$ & $\begin{array}{r}\ldots . \\
15.5 \\
\ldots-0\end{array}$ & $\begin{array}{r}15.0 \\
=- \\
\cdots\end{array}$ & $\begin{array}{r}13.5 \\
19.0 \\
=0\end{array}$ & $\begin{array}{r}--. \\
20.5 \\
10.0\end{array}$ & $\begin{array}{r}-1 \\
21.0 \\
15.0\end{array}$ & $\begin{array}{r}-.0 \\
18.0 \\
-0 .\end{array}$ & $\overline{-}$ & $\begin{array}{r}28.5 \\
- \\
-\ldots \\
=- \\
=-\end{array}$ & $=$ & $\begin{array}{r}19.5 \\
20.0\end{array}$ & $\begin{array}{r}\ldots \\
21.0 \\
\cdots\end{array}$ \\
\hline $\begin{array}{l}21 \\
22 \\
23 \\
24 \\
25\end{array}$ & $\begin{array}{r}18.0 \\
12.5 \\
-. .\end{array}$ & $\begin{array}{r}15.5 \\
13.0 \\
\ldots \ldots \\
\ldots-0\end{array}$ & $\begin{array}{r}12.0 \\
=0 \\
\cdots \\
\cdots\end{array}$ & $\begin{array}{r}17.0 \\
9.5\end{array}$ & 12.0 & $=$ & $\begin{array}{r}24.0 \\
18.0\end{array}$ & $\begin{array}{r}24.0 \\
23.0 \\
-0 .\end{array}$ & $\begin{array}{r}31.0 \\
26.0 \\
20\end{array}$ & \begin{tabular}{r}
20.5 \\
\hdashline-5 \\
23.5
\end{tabular} & $\begin{array}{r}-0.0 \\
-0 \\
--\end{array}$ & 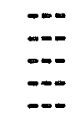 \\
\hline $\begin{array}{l}26 \\
27 \\
28 \\
29 \\
30 \\
31\end{array}$ & $\begin{array}{r}14.5 \\
\ldots \\
20.0 \\
0.0\end{array}$ & $\begin{array}{r}18.0 \\
11.0 \\
- \\
-\end{array}$ & $\begin{array}{r}-.- \\
-.-5 \\
14.5 \\
10.5 \\
=\ldots-\end{array}$ & $\begin{array}{r}-0.0 \\
8.0 \\
-0-0 \\
17.5 \\
--0\end{array}$ & $\begin{array}{r}20.5 \\
13.5 \\
- \\
-\end{array}$ & $\begin{array}{r}24.0 \\
15.0 \\
22.5 \\
-.0 \\
-0 .\end{array}$ & $\begin{array}{r}--5 \\
23.5 \\
--5 \\
22.5 \\
-\end{array}$ & $\begin{array}{l}m-0 \\
+-\infty \\
-\infty \\
-\infty \\
-\infty\end{array}$ & $\begin{array}{r}--- \\
23.5 \\
m-5 \\
22.0 \\
=-0\end{array}$ & $\begin{array}{l}\infty-\infty \\
m-\infty \\
-\infty \\
-\infty\end{array}$ & $\begin{array}{r}-\infty .0 \\
28.0 \\
21.5 \\
=- \\
-\infty\end{array}$ & $\begin{array}{r}19.5 \\
28.0 \\
-0 \\
-0\end{array}$ \\
\hline ONTH & -- & -- & $-\infty-$ & $m-$ & -- & $m$ & $-\infty$ & $m$ & $-\infty$ & $-\infty$ & $\cdots$ & $--\infty$ \\
\hline
\end{tabular}


11048530 EL MODENA IRVINE CHANNEL NEAR IRVINE, CA--Continued

SUSPENDED-SEDIMENT DISCHARGE (TONS/DAY), WATER YEAR OCTOBER 1975 TO SEPTEMBER 1976

\begin{tabular}{|c|c|c|c|c|c|c|c|c|c|}
\hline & & OCTOBER & & & NOVEMBER & & & DECEMBER & \\
\hline DAY & $\begin{array}{c}\text { MEAN } \\
\text { UISCHARGE } \\
\text { (CFS) }\end{array}$ & $\begin{array}{l}\text { MEAN } \\
\text { CONCEN- } \\
\text { TRATION } \\
(M G / L)\end{array}$ & $\begin{array}{l}\text { SEDIMENT } \\
\text { DISCHARGE } \\
\text { (TONS/DAY) }\end{array}$ & $\begin{array}{c}\text { MEAN } \\
\text { DISCHARGE } \\
\text { (CFS) }\end{array}$ & $\begin{array}{l}\text { MEAN } \\
\text { CONCEN- } \\
\text { TRATION } \\
\text { (MG/L) }\end{array}$ & $\begin{array}{l}\text { SEDIHENT } \\
\text { DISCHARGE } \\
\text { (TONS/DAY) }\end{array}$ & $\begin{array}{l}\text { MEAN } \\
\text { DI SCHARGE } \\
\text { (CFS) }\end{array}$ & $\begin{array}{l}\text { MEAN } \\
\text { CONCEN- } \\
\text { TRATION } \\
\text { (MG } / L)\end{array}$ & $\begin{array}{l}\text { SEDIMENT } \\
\text { DISCHARGE } \\
\text { (TONS/DAY) }\end{array}$ \\
\hline $\begin{array}{l}1 \\
2 \\
3 \\
4 \\
5\end{array}$ & $\begin{array}{l}1.1 \\
1.0 \\
1.0 \\
1.2 \\
1.1\end{array}$ & $\begin{array}{r}124 \\
95 \\
67 \\
39 \\
40\end{array}$ & $\begin{array}{r}.37 \\
.26 \\
.18 \\
.13 \\
.12\end{array}$ & $\begin{array}{l}.90 \\
.60 \\
.60 \\
.50 \\
.80\end{array}$ & $\begin{array}{l}89 \\
58 \\
25 \\
35 \\
45\end{array}$ & $\begin{array}{l}.22 \\
.09 \\
.04 \\
.05 \\
.10\end{array}$ & $\begin{array}{l}1.0 \\
: 90 \\
1.0 \\
1.3 \\
1.1\end{array}$ & $\begin{array}{l}13 \\
22 \\
51 \\
61 \\
71\end{array}$ & $\begin{array}{l}.04 \\
.05 \\
.14 \\
.21 \\
.21\end{array}$ \\
\hline $\begin{array}{r}6 \\
7 \\
8 \\
9 \\
10\end{array}$ & $\begin{array}{l}1.2 \\
3.1 \\
1.7 \\
1.5 \\
1.6\end{array}$ & $\begin{array}{r}40 \\
218 \\
108 \\
103 \\
98\end{array}$ & $\begin{array}{r}.13 \\
3.9 \\
.50 \\
.42 \\
.42\end{array}$ & $\begin{array}{r}.90 \\
.90 \\
.90 \\
.90 \\
.80\end{array}$ & $\begin{array}{l}55 \\
65 \\
75 \\
85 \\
95\end{array}$ & $\begin{array}{r}.13 \\
.16 \\
.18 \\
.21 \\
.21\end{array}$ & $\begin{array}{l}1.8 \\
1.1 \\
.90 \\
.70 \\
.70\end{array}$ & $\begin{array}{l}82 \\
90 \\
99 \\
92 \\
86\end{array}$ & $\begin{array}{r}.40 \\
.27 \\
.24 \\
.17 \\
.16\end{array}$ \\
\hline $\begin{array}{l}11 \\
12 \\
13 \\
14 \\
15\end{array}$ & $\begin{array}{l}1.8 \\
1.0 \\
1.1 \\
.90 \\
1.6\end{array}$ & $\begin{array}{l}149 \\
128 \\
163 \\
198 \\
234\end{array}$ & $\begin{array}{l}1.2 \\
.35 \\
.48 \\
.48 \\
1.0\end{array}$ & $\begin{array}{l}.50 \\
.60 \\
.90 \\
1.0 \\
1.0\end{array}$ & $\begin{array}{l}105 \\
115 \\
125 \\
135 \\
122\end{array}$ & $\begin{array}{r}.14 \\
.19 \\
.30 \\
.36 \\
.33\end{array}$ & $\begin{array}{l}.80 \\
2.3 \\
1.0 \\
1.0 \\
1.3\end{array}$ & $\begin{array}{r}80 \\
91 \\
150 \\
120 \\
96\end{array}$ & $\begin{array}{r}.17 \\
.88 \\
.41 \\
.32 \\
.34\end{array}$ \\
\hline $\begin{array}{l}16 \\
17 \\
18 \\
19 \\
20\end{array}$ & $\begin{array}{l}1.9 \\
1.5 \\
1.3 \\
1.3 \\
.90\end{array}$ & $\begin{array}{r}191 \\
148 \\
105 \\
86 \\
66\end{array}$ & $\begin{array}{l}.98 \\
.60 \\
.37 \\
.30 \\
.16\end{array}$ & $\begin{array}{l}.60 \\
.60 \\
.50 \\
.40 \\
.40\end{array}$ & $\begin{array}{r}111 \\
100 \\
89 \\
78 \\
95\end{array}$ & $\begin{array}{l}.18 \\
.16 \\
.12 \\
.08 \\
.10\end{array}$ & $\begin{array}{l}1.2 \\
1.2 \\
1.2 \\
1.1 \\
4.8\end{array}$ & $\begin{array}{l}73 \\
50 \\
26 \\
26 \\
96\end{array}$ & $\begin{array}{r}.24 \\
.16 \\
.08 \\
.08 \\
3.3\end{array}$ \\
\hline $\begin{array}{l}21 \\
22 \\
23 \\
24 \\
25\end{array}$ & $\begin{array}{l}1.0 \\
1.4 \\
1.2 \\
1.9 \\
1.8\end{array}$ & $\begin{array}{l}41 \\
59 \\
78 \\
72 \\
66\end{array}$ & $\begin{array}{l}.11 \\
.22 \\
.25 \\
.37 \\
.32\end{array}$ & $\begin{array}{l}.60 \\
1.0 \\
1.2 \\
.90 \\
.90\end{array}$ & $\begin{array}{r}112 \\
94 \\
84 \\
73 \\
62\end{array}$ & $\begin{array}{l}.18 \\
.25 \\
.27 \\
.18 \\
.15\end{array}$ & $\begin{array}{l}2.5 \\
1.8 \\
1.7 \\
1.4 \\
1.4\end{array}$ & $\begin{array}{l}53 \\
50 \\
47 \\
44 \\
41\end{array}$ & $\begin{array}{r}.36 \\
.24 \\
.22 \\
.17 \\
.15\end{array}$ \\
\hline $\begin{array}{l}26 \\
27 \\
28 \\
29 \\
30 \\
31\end{array}$ & $\begin{array}{r}1.2 \\
1.0 \\
.80 \\
.60 \\
3.0 \\
1.0\end{array}$ & $\begin{array}{r}60 \\
64 \\
67 \\
70 \\
252 \\
90\end{array}$ & $\begin{array}{r}.19 \\
.17 \\
.14 \\
10.11 \\
.24\end{array}$ & $\begin{array}{l}1.1 \\
1.4 \\
9.8 \\
1.2 \\
1.0 \\
-.--\end{array}$ & $\begin{array}{r}51 \\
51 \\
1530 \\
40 \\
26 \\
---\end{array}$ & $\begin{array}{r}.15 \\
128 \\
.19 \\
.13 \\
.07\end{array}$ & $\begin{array}{l}1.4 \\
1.6 \\
1.5 \\
1.2 \\
1.7 \\
2.4\end{array}$ & $\begin{array}{l}38 \\
35 \\
32 \\
29 \\
12 \\
24\end{array}$ & $\begin{array}{l}.14 \\
.15 \\
.13 \\
.09 \\
.06 \\
.16\end{array}$ \\
\hline THAL & 42.70 & $-\infty$ & 24.47 & 33.40 & -- & 132.92 & 45.00 & -- & 9.74 \\
\hline
\end{tabular}

\begin{tabular}{|c|c|c|c|c|c|c|c|c|c|}
\hline \multirow[b]{2}{*}{ DAY } & \multicolumn{3}{|c|}{ JANUARY } & \multicolumn{3}{|c|}{ FEBRUARY } & \multicolumn{3}{|c|}{ MARCH } \\
\hline & $\begin{array}{l}\text { MEAN } \\
\text { DISCHARGE } \\
\text { (CFS) }\end{array}$ & $\begin{array}{l}\text { MEAN } \\
\text { CONCEN- } \\
\text { TRAIION } \\
\text { (MG/L) }\end{array}$ & $\begin{array}{l}\text { SEDIMENT } \\
\text { OISCHARGE } \\
\text { (TONS/DAY) }\end{array}$ & $\begin{array}{l}\text { MEAN } \\
\text { DISCHARGE } \\
\text { (CFS) }\end{array}$ & $\begin{array}{l}\text { MEAN } \\
\text { CONCEN- } \\
\text { TRATION } \\
\text { (MG/L) }\end{array}$ & $\begin{array}{l}\text { SEDIMENT } \\
\text { DISCHARGE } \\
\text { (TONS/DAY) }\end{array}$ & $\begin{array}{l}\text { MEAN } \\
\text { DISCHARGE } \\
\text { (CFS) }\end{array}$ & $\begin{array}{l}\text { MEAN } \\
\text { CONCEN- } \\
\text { TRATION } \\
\text { (MG/L) }\end{array}$ & $\begin{array}{l}\text { SEDIMENT } \\
\text { DISCHARGE } \\
\text { (TONS/DAY }\end{array}$ \\
\hline $\begin{array}{l}1 \\
2 \\
3 \\
4 \\
5\end{array}$ & $\begin{array}{l}3.9 \\
4.1 \\
5.1 \\
5.1 \\
4.5\end{array}$ & $\begin{array}{l}36 \\
48 \\
45 \\
42 \\
39\end{array}$ & $\begin{array}{l}.38 \\
.53 \\
.62 \\
.58 \\
.47\end{array}$ & $\begin{array}{l}.90 \\
.90 \\
3.1 \\
5.6 \\
12\end{array}$ & $\begin{array}{r}29 \\
50 \\
138 \\
348 \\
472\end{array}$ & $\begin{array}{c}.07 \\
3.12 \\
3.6 \\
28\end{array}$ & $\begin{array}{l}44 \\
20 \\
16 \\
.20 \\
.20\end{array}$ & $\begin{array}{r}1230 \\
590 \\
1040 \\
49 \\
49\end{array}$ & $\begin{array}{l}414 \\
287 \\
110 \\
.03 \\
.03\end{array}$ \\
\hline $\begin{array}{r}6 \\
7 \\
8 \\
9 \\
10\end{array}$ & $\begin{array}{l}3.1 \\
2.5 \\
3.1 \\
3.5 \\
3.7\end{array}$ & $\begin{array}{r}36 \\
74 \\
113 \\
108 \\
103\end{array}$ & $\begin{aligned}: 30 \\
: 50 \\
: 95 \\
1: 0 \\
1: 0\end{aligned}$ & $\begin{array}{l}31 \\
29 \\
29 \\
43 \\
1.5\end{array}$ & $\begin{array}{r}775 \\
624 \\
707 \\
1050 \\
. \quad 39\end{array}$ & $\begin{array}{r}172 \\
94 \\
110 \\
245 \\
\quad .16\end{array}$ & $\begin{array}{l}.20 \\
: 30 \\
: 30 \\
: 30 \\
.30\end{array}$ & $\begin{array}{l}49 \\
36 \\
24 \\
12 \\
18\end{array}$ & $\begin{array}{l}.03 \\
.03 \\
.02 \\
.01 \\
.01\end{array}$ \\
\hline $\begin{array}{l}11 \\
12 \\
13 \\
14 \\
15\end{array}$ & $\begin{array}{l}3.2 \\
2.4 \\
1.8 \\
1.6 \\
1.0\end{array}$ & $\begin{array}{r}98 \\
110 \\
122 \\
135 \\
111\end{array}$ & $\begin{array}{l}.85 \\
.71 \\
.59 \\
.58 \\
.30\end{array}$ & $\begin{array}{l}.40 \\
.40 \\
.40 \\
.40 \\
.40\end{array}$ & $\begin{array}{r}21 \\
4 \\
4 \\
3 \\
3\end{array}$ & $\begin{array}{l}0_{0}^{.02} \\
0 \\
0 \\
0\end{array}$ & $\begin{array}{l}.30 \\
: 30 \\
: 30 \\
: 40 \\
.40\end{array}$ & $\begin{array}{l}24 \\
30 \\
50 \\
69 \\
60\end{array}$ & $\begin{array}{l}.02 \\
.02 \\
.04 \\
.07 \\
.06\end{array}$ \\
\hline $\begin{array}{l}16 \\
17 \\
18 \\
19 \\
20\end{array}$ & $\begin{array}{l}.70 \\
1.1 \\
1.8 \\
1.6 \\
1.0\end{array}$ & $\begin{array}{l}87 \\
63 \\
54 \\
44 \\
34\end{array}$ & $\begin{array}{l}: 16 \\
: 19 \\
: 26 \\
: 19 \\
.09\end{array}$ & $\begin{array}{l}.40 \\
.40 \\
.40 \\
.40 \\
.40\end{array}$ & $\begin{array}{r}2 \\
2 \\
1 \\
9 \\
17\end{array}$ & $\begin{array}{l}0 \\
0 \\
0 \\
.01 \\
.02\end{array}$ & $\begin{array}{l}.40 \\
: 20 \\
: 20 \\
.30 \\
.30\end{array}$ & $\begin{array}{l}51 \\
43 \\
35 \\
27 \\
62\end{array}$ & $\begin{array}{l}.06 \\
.02 \\
.02 \\
.02 \\
.05\end{array}$ \\
\hline $\begin{array}{l}21 \\
22 \\
23 \\
24 \\
25\end{array}$ & $\begin{array}{l}1.4 \\
1: 1 \\
1: 0 \\
1: 0 \\
.90\end{array}$ & $\begin{array}{r}138 \\
243 \\
102 \\
80 \\
48\end{array}$ & $\begin{array}{l}.52 \\
.72 \\
.28 \\
.22 \\
.12\end{array}$ & $\begin{array}{l}.40 \\
.40 \\
.40 \\
.50 \\
.60\end{array}$ & $\begin{array}{l}27 \\
37 \\
46 \\
41 \\
37\end{array}$ & $\begin{array}{l}.03 \\
.04 \\
.05 \\
.06 \\
.06\end{array}$ & $\begin{array}{l}.20 \\
.20 \\
.20 \\
.30 \\
.30\end{array}$ & $\begin{array}{l}60 \\
58 \\
56 \\
54 \\
52\end{array}$ & $\begin{array}{l}.03 \\
.03 \\
.03 \\
.04 \\
.04\end{array}$ \\
\hline $\begin{array}{l}26 \\
27 \\
28 \\
29 \\
30 \\
31\end{array}$ & $\begin{array}{l}.90 \\
.90 \\
.90 \\
.90 \\
.90 \\
.90\end{array}$ & $\begin{array}{l}64 \\
80 \\
85 \\
90 \\
96 \\
62\end{array}$ & $\begin{array}{l}.16 \\
.19 \\
.21 \\
.22 \\
.23 \\
.15\end{array}$ & $\begin{array}{l}.60 \\
.70 \\
.70 \\
.50 \\
-:- \\
-.-\end{array}$ & $\begin{array}{r}33 \\
26 \\
29 \\
32 \\
-- \\
--\end{array}$ & $\begin{array}{l}.05 \\
.05 \\
.05 \\
.04 \\
--.- \\
-. .\end{array}$ & $\begin{array}{l}.40 \\
.30 \\
.30 \\
.20 \\
.20 \\
.20\end{array}$ & $\begin{array}{r}50 \\
62 \\
54 \\
46 \\
41 \\
-0 .\end{array}$ & $\begin{array}{l}.05 \\
.05 \\
.04 \\
.02 \\
.02 \\
. . .0\end{array}$ \\
\hline & 65.60 & -- & 13.27 & 164.80 & $=--$ & 663.23 & 87.70 & -- & 811.89 \\
\hline
\end{tabular}


11048530 EL MODENA IRVINE CHANNEL NEAR IRVINE, CA--Continued

SUSPENDEO-SEDIMENT DISCHARGE (TONS/DAY), WATER YEAR OCTOBER 1975 TO SEPTEMBER 1976

\begin{tabular}{|c|c|c|c|c|c|c|c|c|c|}
\hline & & APRIL & & & MAY & & & JUNE & \\
\hline DAY & $\begin{array}{l}\text { MEAN } \\
\text { DISCHARGE } \\
\text { (CFS) }\end{array}$ & $\begin{array}{l}\text { MEAN } \\
\text { CONCEN- } \\
\text { TRATION } \\
\text { (MG/L) }\end{array}$ & $\begin{array}{l}\text { SEDIMENT } \\
\text { DISCHARGE } \\
\text { (TONS/DAY) }\end{array}$ & $\begin{array}{l}\text { MEAN } \\
\text { DISCHARGE } \\
\text { (CFS) }\end{array}$ & $\begin{array}{l}\text { MEAN } \\
\text { CONCEN- } \\
\text { TRATION } \\
\text { (MG/L) }\end{array}$ & $\begin{array}{l}\text { SEDIMENT } \\
\text { DISCHARGE } \\
\text { (TONS/DAY) }\end{array}$ & $\begin{array}{l}\text { MEAN } \\
\text { DISCHARGE } \\
\text { (CFS) }\end{array}$ & $\begin{array}{l}\text { MEAN } \\
\text { CONCEN- } \\
\text { TRATION } \\
\text { (MG/L) }\end{array}$ & $\begin{array}{l}\text { SEDIMENT } \\
\text { DISCHARGE } \\
\text { (TONS/DAY) }\end{array}$ \\
\hline $\begin{array}{l}1 \\
2 \\
3 \\
4 \\
5\end{array}$ & $\begin{array}{l}.20 \\
.20 \\
2.7 \\
12.30\end{array}$ & $\begin{array}{r}36 \\
36 \\
102 \\
453 \\
30\end{array}$ & $\begin{array}{rr}.02 \\
20.02 \\
61 & \\
& .02\end{array}$ & $\begin{array}{l}.60 \\
.90 \\
1.2 \\
1.4 \\
1.6\end{array}$ & $\begin{array}{r}57 \\
108 \\
159 \\
158 \\
157\end{array}$ & $\begin{array}{l}.09 \\
.26 \\
.52 \\
.60 \\
.68\end{array}$ & $\begin{array}{l}.70 \\
.70 \\
.70 \\
.50 \\
.60\end{array}$ & $\begin{array}{l}125 \\
132 \\
146 \\
160 \\
175\end{array}$ & $\begin{array}{l}.24 \\
.25 \\
.28 \\
.22 \\
.28\end{array}$ \\
\hline $\begin{array}{r}6 \\
7 \\
8 \\
9 \\
10\end{array}$ & $\begin{array}{l}.30 \\
.20 \\
.30 \\
.20 \\
.50\end{array}$ & $\begin{array}{l}41 \\
52 \\
63 \\
79 \\
95\end{array}$ & $\begin{array}{l}.03 \\
.03 \\
.05 \\
.04 \\
.13\end{array}$ & $\begin{array}{r}1.5 \\
1.4 \\
.80 \\
.70 \\
.60\end{array}$ & $\begin{array}{l}156 \\
155 \\
154 \\
153 \\
152\end{array}$ & $\begin{array}{l}.63 \\
.59 \\
.33 \\
.29 \\
.25\end{array}$ & $\begin{array}{r}.70 \\
.70 \\
.80 \\
.81\end{array}$ & $\begin{array}{l}190 \\
205 \\
200 \\
200 \\
654\end{array}$ & $\begin{array}{r}.36 \\
.39 \\
.43 \\
100^{.43}\end{array}$ \\
\hline $\begin{array}{l}11 \\
12 \\
13 \\
14 \\
15\end{array}$ & $\begin{array}{l}15^{.50} \\
12.40 \\
.40\end{array}$ & $\begin{array}{r}111 \\
414 \\
633 \\
57 \\
57\end{array}$ & $\begin{array}{r}108^{.15} \\
40 \\
.06 \\
.06\end{array}$ & $\begin{array}{r}.60 \\
.60 \\
.70 \\
1.0 \\
.80\end{array}$ & $\begin{array}{l}151 \\
150 \\
141 \\
134 \\
127\end{array}$ & $\begin{array}{l}.24 \\
.24 \\
.27 \\
.36 \\
.27\end{array}$ & $\begin{array}{l}.60 \\
.50 \\
.70 \\
.40 \\
.40\end{array}$ & $\begin{array}{l}30 \\
30 \\
30 \\
30 \\
30\end{array}$ & $\begin{array}{l}.05 \\
.04 \\
.06 \\
.03 \\
.03\end{array}$ \\
\hline $\begin{array}{l}16 \\
17 \\
18 \\
19 \\
20\end{array}$ & $\begin{array}{l}.40 \\
.40 \\
.30 \\
.30 \\
.50\end{array}$ & $\begin{array}{r}31 \\
6 \\
10 \\
27 \\
44\end{array}$ & $\begin{array}{l}.03 \\
.01 \\
.01 \\
.02 \\
.06\end{array}$ & $\begin{array}{r}.60 \\
.60 \\
.70 \\
1.0 \\
2.2\end{array}$ & $\begin{array}{r}120 \\
113 \\
106 \\
99 \\
92\end{array}$ & $\begin{array}{l}.19 \\
.18 \\
.20 \\
.27 \\
.55\end{array}$ & $\begin{array}{l}.40 \\
.40 \\
.60 \\
.60 \\
.60\end{array}$ & $\begin{array}{l}30 \\
30 \\
29 \\
29 \\
28\end{array}$ & $\begin{array}{l}.03 \\
.03 \\
.05 \\
.05 \\
.05\end{array}$ \\
\hline $\begin{array}{l}21 \\
22 \\
23 \\
24 \\
25\end{array}$ & $\begin{array}{r}.50 \\
.50 \\
.50 \\
.60 \\
1.2\end{array}$ & $\begin{array}{r}25 \\
6 \\
22 \\
38 \\
44\end{array}$ & $\begin{array}{l}.03 \\
.01 \\
.03 \\
.06 \\
.14\end{array}$ & $\begin{array}{l}1.9 \\
1.7 \\
1.6 \\
1.7 \\
1.8\end{array}$ & $\begin{array}{l}85 \\
78 \\
71 \\
64 \\
72\end{array}$ & $\begin{array}{l}.44 \\
.36 \\
.31 \\
.29 \\
.35\end{array}$ & $\begin{array}{r}.60 \\
.60 \\
1.0 \\
.80 \\
.60\end{array}$ & $\begin{array}{l}28 \\
28 \\
31 \\
34 \\
36\end{array}$ & $\begin{array}{l}.05 \\
.05 \\
.08 \\
.07 \\
.06\end{array}$ \\
\hline $\begin{array}{l}26 \\
27 \\
28 \\
29 \\
30 \\
31\end{array}$ & $\begin{array}{l}.50 \\
.70 \\
.60 \\
.70 \\
.60 \\
.-.\end{array}$ & $\begin{array}{r}27 \\
10 \\
8 \\
7 \\
6 \\
---\end{array}$ & $\begin{array}{l}.04 \\
.02 \\
.01 \\
.01 \\
.01 \\
.--\end{array}$ & $\begin{array}{c}1.6 \\
.90 \\
1.1 \\
.90 \\
.90 \\
.70\end{array}$ & $\begin{array}{r}80 \\
88 \\
97 \\
104 \\
111 \\
118\end{array}$ & $\begin{array}{l}.35 \\
.21 \\
.29 \\
.25 \\
.27 \\
.22\end{array}$ & $\begin{array}{l}.60 \\
.50 \\
.70 \\
.90 \\
.70 \\
.7-\end{array}$ & $\begin{array}{r}37 \\
38 \\
40 \\
93 \\
146 \\
- \\
-0-\end{array}$ & $\begin{array}{l}.06 \\
.05 \\
.08 \\
.23 \\
.28 \\
.---\end{array}$ \\
\hline TOTAL & 53.50 & --- & 230.10 & $34 \cdot 30$ & -- & 10.35 & 39.40 & -- & $104 \cdot 31$ \\
\hline & & JULYY & & & AUGUST & & & SEPTEMBER & \\
\hline DAY & $\begin{array}{l}\text { MEAN } \\
\text { DISCHARGE } \\
\text { (CFS) }\end{array}$ & $\begin{array}{l}\text { MEAN } \\
\text { CONCEN- } \\
\text { TRATION } \\
\text { (MG/L) }\end{array}$ & $\begin{array}{l}\text { SEDIMENT } \\
\text { DISCHARGE } \\
\text { (TONS/DAY) }\end{array}$ & $\begin{array}{l}\text { MEAN } \\
\text { DISCHARGE } \\
\text { (CFS) }\end{array}$ & $\begin{array}{l}\text { MEAN } \\
\text { CONCEN- } \\
\text { TRATION } \\
\text { (MG/L) }\end{array}$ & $\begin{array}{l}\text { SEDIMENT } \\
\text { DISCHARGE } \\
\text { (TONS/DAY) }\end{array}$ & $\begin{array}{l}\text { MEAN } \\
\text { DISCHARGE } \\
\text { (CFS) }\end{array}$ & $\begin{array}{l}\text { MEAN } \\
\text { CONCEN- } \\
\text { TRATION } \\
\text { (MG } / L)\end{array}$ & $\begin{array}{l}\text { SEDIHENT } \\
\text { DISCHARGE } \\
\text { (TONS/DAY) }\end{array}$ \\
\hline $\begin{array}{l}1 \\
2 \\
3 \\
4 \\
5\end{array}$ & $\begin{array}{l}1.2 \\
1.0 \\
1.0 \\
1.4 \\
1.4\end{array}$ & $\begin{array}{l}513 \\
870 \\
707 \\
544 \\
381\end{array}$ & $\begin{array}{l}1.7 \\
2.3 \\
1.9 \\
2.1 \\
1.4\end{array}$ & $\begin{array}{l}1.0 \\
.80 \\
.70 \\
.90 \\
.80\end{array}$ & $\begin{array}{r}250 \\
327 \\
204 \\
81 \\
121\end{array}$ & $\begin{array}{l}.68 \\
.71 \\
.39 \\
.20 \\
.26\end{array}$ & $\begin{array}{r}.60 \\
.80 \\
.70 \\
10\end{array}$ & $\begin{array}{r}120 \\
94 \\
69 \\
77 \\
342\end{array}$ & $\begin{array}{r}.19 \\
.20 \\
.13 \\
52^{.19}\end{array}$ \\
\hline $\begin{array}{r}6 \\
7 \\
8 \\
9 \\
10\end{array}$ & $\begin{array}{l}1.4 \\
1.1 \\
.90 \\
.90 \\
1.0\end{array}$ & $\begin{array}{l}218 \\
232 \\
201 \\
170 \\
140\end{array}$ & $\begin{array}{l}.82 \\
.69 \\
.49 \\
.41 \\
.38\end{array}$ & $\begin{array}{l}1.0 \\
1.4 \\
1.3 \\
1.0 \\
1.3\end{array}$ & $\begin{array}{l}161 \\
201 \\
240 \\
209 \\
178\end{array}$ & $\begin{array}{l}.43 \\
.76 \\
.84 \\
.56 \\
.62\end{array}$ & $\begin{array}{r}1.5 \\
1.2 \\
.90 \\
101\end{array}$ & $\begin{array}{r}212 \\
102 \\
108 \\
108 \\
1930\end{array}$ & $\begin{array}{r}2.1 \\
.33 \\
.26 \\
1150^{.26}\end{array}$ \\
\hline $\begin{array}{l}11 \\
12 \\
13 \\
14 \\
15\end{array}$ & $\begin{array}{l}1.0 \\
1.0 \\
1.1 \\
1.2 \\
1.6\end{array}$ & $\begin{array}{l}183 \\
226 \\
171 \\
117 \\
196\end{array}$ & $\begin{array}{r}.49 \\
.61 \\
.51 \\
.38 \\
.85\end{array}$ & $\begin{array}{l}1.7 \\
1.6 \\
1.3 \\
1.2 \\
1.0\end{array}$ & $\begin{array}{l}212 \\
251 \\
212 \\
172 \\
132\end{array}$ & $\begin{array}{r}.97 \\
1.1 \\
.74 \\
.56 \\
.36\end{array}$ & $\begin{array}{r}14 \\
.90 \\
.90 \\
.70 \\
.80\end{array}$ & $\begin{array}{r}335 \\
13 \\
13 \\
16 \\
19\end{array}$ & $\begin{array}{r}63 \\
.03 \\
.03 \\
.03 \\
.04\end{array}$ \\
\hline $\begin{array}{l}16 \\
17 \\
18 \\
19 \\
20\end{array}$ & $\begin{array}{l}2.0 \\
1.8 \\
1.6 \\
1.9 \\
1.7\end{array}$ & $\begin{array}{l}178 \\
161 \\
144 \\
127 \\
110\end{array}$ & $\begin{array}{l}.96 \\
.78 \\
.62 \\
.65 \\
.50\end{array}$ & $\begin{array}{l}1.2 \\
1.4 \\
1.3 \\
1.0 \\
.80\end{array}$ & $\begin{array}{l}145 \\
158 \\
171 \\
184 \\
198\end{array}$ & $\begin{array}{l}.47 \\
.60 \\
.60 \\
.50 \\
.43\end{array}$ & $\begin{array}{l}.70 \\
.50 \\
.90 \\
.60 \\
.70\end{array}$ & $\begin{array}{l}22 \\
25 \\
29 \\
34 \\
32\end{array}$ & $\begin{array}{l}.04 \\
.03 \\
.07 \\
.06 \\
.06\end{array}$ \\
\hline $\begin{array}{l}21 \\
22 \\
23 \\
24 \\
25\end{array}$ & $\begin{array}{l}1.4 \\
1.3 \\
1.3 \\
1.6 \\
1.1\end{array}$ & $\begin{array}{r}93 \\
76 \\
86 \\
96 \\
106\end{array}$ & $\begin{array}{r}.35 \\
.27 \\
.30 \\
.41 \\
.31\end{array}$ & $\begin{array}{l}.90 \\
.70 \\
.50 \\
.50 \\
.60\end{array}$ & $\begin{array}{l}135 \\
123 \\
120 \\
118 \\
116\end{array}$ & $\begin{array}{l}.33 \\
.23 \\
.16 \\
.16 \\
.19\end{array}$ & $\begin{array}{r}.90 \\
.80 \\
.90 \\
1.0 \\
1.5\end{array}$ & $\begin{array}{l}31 \\
30 \\
29 \\
27 \\
25\end{array}$ & $\begin{array}{l}.08 \\
.06 \\
.07 \\
.07 \\
.10\end{array}$ \\
\hline $\begin{array}{l}26 \\
27 \\
28 \\
29 \\
30 \\
31\end{array}$ & $\begin{array}{l}1.8 \\
.90 \\
.90 \\
1.0 \\
1.2 \\
1.3\end{array}$ & $\begin{array}{l}123 \\
140 \\
157 \\
175 \\
193 \\
200\end{array}$ & $\begin{array}{r}.60 \\
.34 \\
.38 \\
.47 \\
.63 \\
.70\end{array}$ & $\begin{array}{r}.60 \\
.70 \\
.70 \\
.70 \\
1.0 \\
.80\end{array}$ & $\begin{array}{r}114 \\
112 \\
62 \\
76 \\
91 \\
106\end{array}$ & $\begin{array}{l}.18 \\
.21 \\
.12 \\
.14 \\
.25 \\
.23\end{array}$ & $\begin{array}{l}1.8 \\
1.0 \\
1.1 \\
1.0 \\
.80 \\
=-\infty\end{array}$ & $\begin{array}{r}23 \\
25 \\
27 \\
29 \\
31 \\
- \\
-\end{array}$ & $\begin{array}{l}.11 \\
.07 \\
.08 \\
.08 \\
.07 \\
0-\infty\end{array}$ \\
\hline
\end{tabular}


SUMMARY OF WATER AND SEDIMENT DISCHARGE, HATER YEAR OCTOBER 1975 TO SEPTEMBER 1976

\begin{tabular}{|c|c|c|c|c|}
\hline MONTH & $\begin{array}{c}\text { WATER } \\
\text { DISCHARGE } \\
\text { CFS-DAYS }\end{array}$ & $\begin{array}{l}\text { SUSPENDED } \\
\text { SEDIMENT } \\
\text { DISCHARGE } \\
\text { TONS }\end{array}$ & $\begin{array}{l}\text { BEDLOAD } \\
\text { DISCHARGE }\end{array}$ & $\begin{array}{l}\text { TOTAL } \\
\text { SEDIMENT } \\
\text { DISCHARGE } \\
\text { TONS }\end{array}$ \\
\hline OCTOBER 1975 & 42.70 & 24.47 & 0 & 24 \\
\hline NOVEMBER $\ldots$ & 33.40 & 132.92 & 1 & 134 \\
\hline DECEMBER $\ldots$ & 45.00 & 9.74 & 0 & 10 \\
\hline JANUARY 1976 & 65.60 & 13.27 & 0 & 13 \\
\hline FEBRUARY $\ldots$ & 164.80 & 663.23 & 117 & 780 \\
\hline MARCH $\cdots \cdots$ & 87.70 & 811.89 & 66 & 878 \\
\hline APRIL $\ldots \ldots \cdots$ & 53.50 & $230 \cdot 10$ & 8 & 238 \\
\hline MAY $\ldots \ldots \ldots$ & 34.30 & 10.35 & 0 & 10 \\
\hline JUNE $\ldots \ldots \ldots$ & 39.40 & 104.31 & 9 & 113 \\
\hline JULY $\ldots \ldots$ & 40.00 & 23.30 & 0 & 23 \\
\hline AUGUST $\ldots \ldots$ & 30.40 & 13.98 & 0 & 14 \\
\hline SEPTEMBER . & 150.00 & 1269.84 & 313 & 1580 \\
\hline TOTAL $\ldots \ldots \ldots$ & 786.80 & 3307.40 & 514 & 3817 \\
\hline
\end{tabular}

PARTICLE-SIZE DISTRIBUTION OF SUSPENDED SEDIMENT, HATER YEAR OCTOBER 1975 TO SEPTEMBER 1976

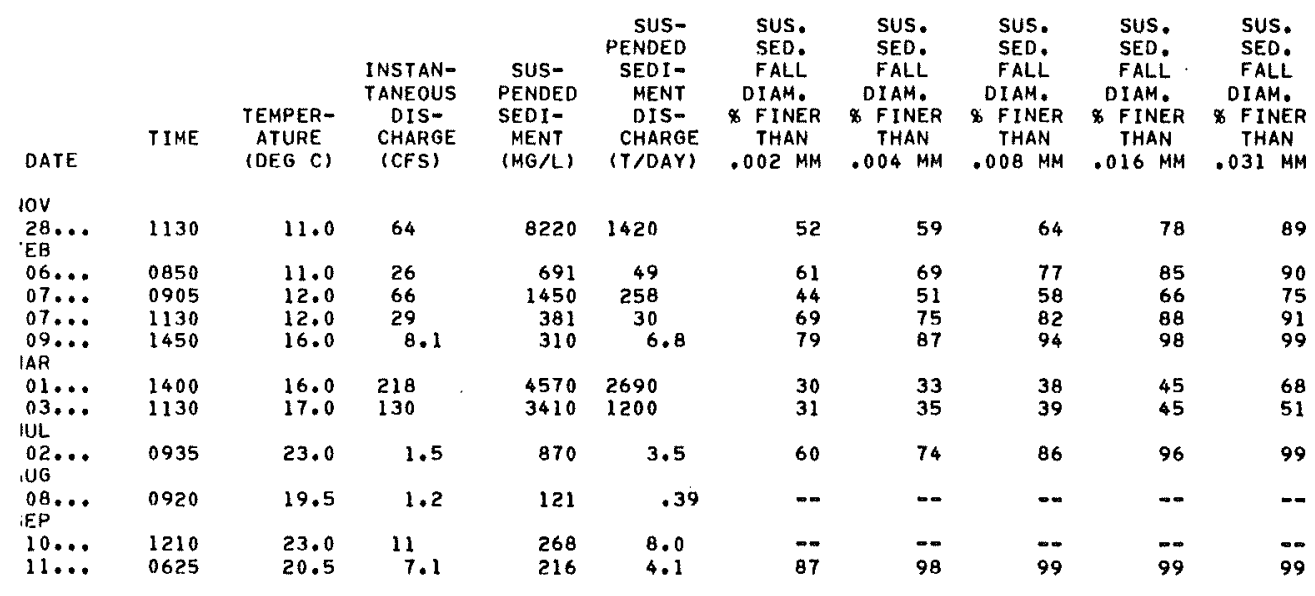

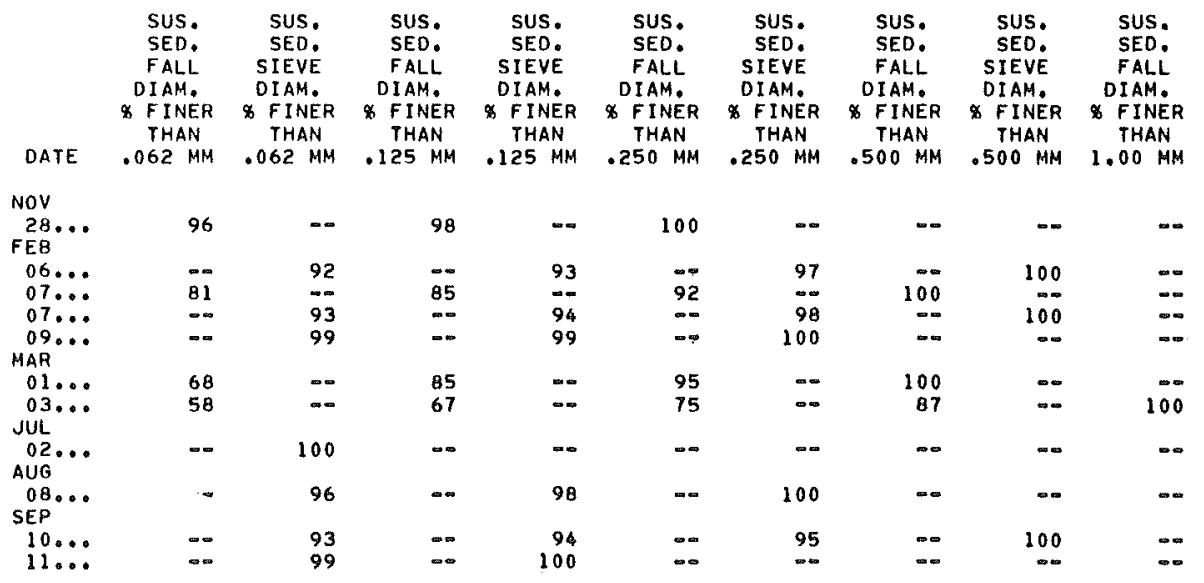


11048530 EL MODENA IRVINE CHANNEL NEAR IRVINE, CA--Continued PARTICLE-SIZE DISTRIBUTION OF SURFACE BED MATERIAL, HATER YEAR OCTOBER 1974 TO SEPTEMBER 1975

\begin{tabular}{|c|c|c|c|c|c|c|c|c|c|c|c|c|}
\hline & TIME & $\begin{array}{c}\text { NUMBER } \\
\text { OF } \\
\text { SAM- } \\
\text { PLING } \\
\text { POINTS }\end{array}$ & $\begin{array}{c}\text { INSTAN- } \\
\text { TANEOUS } \\
\text { OIS- } \\
\text { CHARGE }\end{array}$ & $\begin{array}{c}\text { BED } \\
\text { MAT. } \\
\text { SIEVE } \\
\text { DIAM. } \\
\text { \$ FINER } \\
\text { THAN }\end{array}$ & $\begin{array}{c}\text { BED } \\
\text { MAT. } \\
\text { SIEVE } \\
\text { DIAM. } \\
\text { \$ FINER } \\
\text { THAN }\end{array}$ & $\begin{array}{l}\text { BED } \\
\text { MAT. } \\
\text { SIEVE } \\
\text { DIAM. } \\
\text { \& FINER } \\
\text { THAN }\end{array}$ & $\begin{array}{l}\text { BED } \\
\text { HAT. } \\
\text { SIEVE } \\
\text { DIAM. } \\
\text { \$ FINER } \\
\text { THAN }\end{array}$ & $\begin{array}{l}\text { BED } \\
\text { MAT. } \\
\text { SIEVE } \\
\text { DIAM. } \\
\text { \& FINER } \\
\text { THAN }\end{array}$ & $\begin{array}{l}\text { BED } \\
\text { MAT. } \\
\text { SIEVE } \\
\text { DIAM. } \\
\text { \& FINER } \\
\text { THAN }\end{array}$ & $\begin{array}{l}\text { BED } \\
\text { MAT. } \\
\text { SIEVE } \\
\text { DIAM. } \\
\text { \$ FINER } \\
\text { THAN }\end{array}$ & $\begin{array}{l}\text { BED } \\
\text { MAT, } \\
\text { SIEVE } \\
\text { DIAM. } \\
\text { \& FINER } \\
\text { THAN }\end{array}$ & $\begin{array}{l}\text { BED } \\
\text { MAT. } \\
\text { SIEVE } \\
\text { DIAN. } \\
\text { \$ FINER } \\
\text { THAN }\end{array}$ \\
\hline DATE & & & (CFS) & $.125 \mathrm{MM}$ & $.250 \mathrm{MM}$ & $.500 \mathrm{MM}$ & $1.00 \mathrm{MM}$ & $2.00 \mathrm{MH}$ & $4.00 \mathrm{MM}$ & $8.00 \mathrm{MH}$ & $16.0 \mathrm{MM}$ & $32.0 \mathrm{MM}$ \\
\hline$P$ & 100 & 3 & 1,7 & 1 & 8 & 47 & 71 & 80 & 88 & 94 & 97 & 100 \\
\hline
\end{tabular}


11048550 SAN DIEGO CREEK AT LANE ROAD, NEAR IRVINE, CA

LOCATION, - Lat $33^{\circ} 40^{\prime} 18^{\prime \prime}$, long $117^{\circ} 50^{\prime} 06^{\prime \prime}$, in NW' sec.60, T.6 S., R. 8 W., in San Joaquin Grant, Orange County, on downstream side of abandoned county road bridge $800 \mathrm{ft}(200 \mathrm{~m})$ north of the San Diego Freeway

(Interstate 405$), 0.2 \mathrm{mi}(0.3 \mathrm{~km})$ downstream from Lane Road, and $1.7 \mathrm{mi}$ ( $2.7 \mathrm{~km})$ north of University of California at Irvine.

PERIOD OF RECORD. - October 1973 to current year. previous records published by orange County F1ood Contro1 District.

GAGE.- Water-stage recorder. Altitude of gage is $30 \mathrm{ft}(9.1 \mathrm{~m})$, from topographic map.

REMARKS. - Records poor because of undefined rating above $100 \mathrm{ft}^{3} / \mathrm{s}\left(2.83 \mathrm{~m}^{3} / \mathrm{s}\right)$. Low-f1ow discharge is affected by ground-water pumping and irrigation runoff.

COOPERATION.--Records were furnished by Orange County Flood Control District and reviewed by the Geologica1 Survey.

EXTREMES FOR PERIOD OF RECORD.--Maximum discharge, 4,000 $\mathrm{ft}^{3} / \mathrm{s}\left(113 \mathrm{~m}^{3} / \mathrm{s}\right)$ Dec, 4, 1974, gage height, $8,76 \mathrm{ft}$

$(2.760 \mathrm{~m})$, from rating curve extended above $100 \mathrm{ft}^{3} / \mathrm{s}(2.83 \mathrm{~m} / \mathrm{s}) ; \mathrm{minimum} \mathrm{dait}^{3} 1 \mathrm{y}^{3} 4.2 \mathrm{ft} / \mathrm{s}\left(0.12 \mathrm{~m}^{3} / \mathrm{s}\right)$

Dec. 31,1974 .

EXTREMES FOR CURRENT YEAR. - Maximum discharge, 1,035 $\mathrm{ft}^{3} / \mathrm{s}\left(29.3 \mathrm{~m}^{3} / \mathrm{s}\right)$ Feb. 9 , gage height, $5.05 \mathrm{ft}(1.539 \mathrm{~m})$, from rating curve extended above $100 \mathrm{ft}^{3} / \mathrm{s}\left(2.83 \mathrm{~m}^{3} / \mathrm{s}\right) ; \mathrm{minimum} \mathrm{daily}, 4.9 \mathrm{ft} / \mathrm{s}\left(0.14 \mathrm{~m}^{3} / \mathrm{s}\right) \mathrm{Feb}$. $24,28,29$.

DISCHARGE, IN CUBIC FEET PER SECOND, WATER YEAR OCTOBER 1975 TO SEPTEMBER 1976 MEAN VALUES

\begin{tabular}{|c|c|c|c|c|c|c|c|c|c|c|c|c|}
\hline DAY & OCT & NoV & DEC & JAN & FEB & MAR & $A P R$ & MAY & JUN & JUL & $A \cup O$ & SEP \\
\hline $\begin{array}{l}1 \\
2 \\
3 \\
4 \\
5\end{array}$ & $\begin{array}{l}16 \\
18 \\
18 \\
17 \\
18\end{array}$ & $\begin{array}{l}14 \\
14 \\
14 \\
13 \\
15\end{array}$ & $\begin{array}{l}6.8 \\
6.8 \\
7.3 \\
8.4 \\
7.3\end{array}$ & $\begin{array}{l}6.6 \\
7.6 \\
7.6 \\
7.6 \\
8.4\end{array}$ & $\begin{array}{l}7.1 \\
7.1 \\
13 \\
20 \\
26\end{array}$ & $\begin{array}{r}274 \\
108 \\
160 \\
14 \\
8.7\end{array}$ & $\begin{array}{l}9.9 \\
9.9 \\
11 \\
65 \\
19\end{array}$ & $\begin{array}{l}11 \\
12 \\
12 \\
11 \\
11\end{array}$ & $\begin{array}{l}15 \\
20 \\
18 \\
16 \\
16\end{array}$ & $\begin{array}{l}23 \\
19 \\
19 \\
19 \\
19\end{array}$ & $\begin{array}{l}13 \\
11 \\
15 \\
10 \\
27\end{array}$ & $\begin{array}{l}7.1 \\
9.0 \\
13 \\
13 \\
13\end{array}$ \\
\hline $\begin{array}{r}6 \\
7 \\
6 \\
9 \\
10\end{array}$ & $\begin{array}{l}16 \\
32 \\
14 \\
14 \\
21\end{array}$ & $\begin{array}{l}13 \\
12 \\
15 \\
15 \\
15\end{array}$ & $\begin{array}{l}7.3 \\
7.8 \\
7.3 \\
6.8 \\
6.6\end{array}$ & $\begin{array}{l}8.4 \\
7.1 \\
8.1 \\
8.7 \\
9.3\end{array}$ & $\begin{array}{r}195 \\
120 \\
148 \\
455 \\
33\end{array}$ & $\begin{array}{l}9.0 \\
9.6 \\
9.0 \\
9.3 \\
9.9\end{array}$ & $\begin{array}{l}14 \\
13 \\
11 \\
11 \\
9.6\end{array}$ & $\begin{array}{l}12 \\
14 \\
11 \\
11 \\
14\end{array}$ & $\begin{array}{r}15 \\
18 \\
18 \\
18 \\
144\end{array}$ & $\begin{array}{l}18 \\
19 \\
19 \\
21 \\
21\end{array}$ & $\begin{array}{l}13 \\
15 \\
8.7 \\
9.0 \\
7.8\end{array}$ & $\begin{array}{r}19 \\
15 \\
13 \\
10 \\
150\end{array}$ \\
\hline $\begin{array}{l}11 \\
12 \\
13 \\
14 \\
15\end{array}$ & $\begin{array}{l}23 \\
18 \\
13 \\
13 \\
18\end{array}$ & $\begin{array}{l}14 \\
12 \\
14 \\
15 \\
15\end{array}$ & $\begin{array}{l}6.6 \\
10 \\
9.8 \\
7.3 \\
7.6\end{array}$ & $\begin{array}{l}8.1 \\
7.8 \\
8.1 \\
8.7 \\
8.4\end{array}$ & $\begin{array}{l}10 \\
7.6 \\
7.6 \\
9.0 \\
7.8\end{array}$ & $\begin{array}{l}10 \\
9.9 \\
9.6 \\
9.3 \\
9.3\end{array}$ & $\begin{array}{c}8.7 \\
62 \\
158 \\
14 \\
14\end{array}$ & $\begin{array}{l}14 \\
13 \\
14 \\
15 \\
15\end{array}$ & $\begin{array}{l}20 \\
12 \\
12 \\
10 \\
11\end{array}$ & $\begin{array}{l}21 \\
20 \\
21 \\
22 \\
25\end{array}$ & $\begin{array}{l}12 \\
12 \\
10 \\
12 \\
12\end{array}$ & $\begin{array}{l}40 \\
20 \\
15 \\
10 \\
7.0\end{array}$ \\
\hline $\begin{array}{l}16 \\
17 \\
18 \\
19 \\
20\end{array}$ & $\begin{array}{l}19 \\
15 \\
14 \\
17 \\
15\end{array}$ & $\begin{array}{l}14 \\
14 \\
13 \\
13 \\
13\end{array}$ & $\begin{array}{r}9.0 \\
9.0 \\
9.0 \\
8.7 \\
22\end{array}$ & $\begin{array}{l}7.1 \\
7.6 \\
8.1 \\
8.1 \\
7.3\end{array}$ & $\begin{array}{l}6.6 \\
6.6 \\
8.1 \\
6.3 \\
5.1\end{array}$ & $\begin{array}{l}9.3 \\
10 \\
10 \\
8.7 \\
9.9\end{array}$ & $\begin{array}{l}16 \\
10 \\
9.3 \\
10 \\
11\end{array}$ & $\begin{array}{l}16 \\
15 \\
15 \\
17 \\
20\end{array}$ & $\begin{array}{l}13 \\
14 \\
13 \\
15 \\
15\end{array}$ & $\begin{array}{l}14 \\
26 \\
26 \\
22 \\
22\end{array}$ & $\begin{array}{l}27 \\
13 \\
15 \\
9.9 \\
8.7\end{array}$ & $\begin{array}{l}7.0 \\
7.0 \\
7.0 \\
7.0 \\
7.3\end{array}$ \\
\hline $\begin{array}{l}21 \\
22 \\
23 \\
24 \\
25\end{array}$ & $\begin{array}{l}14 \\
16 \\
15 \\
18 \\
19\end{array}$ & $\begin{array}{l}13 \\
12 \\
13 \\
13 \\
13\end{array}$ & $\begin{array}{r}12 \\
7.8 \\
7.6 \\
7.3 \\
6.8\end{array}$ & $\begin{array}{l}7.8 \\
7.3 \\
6.8 \\
7.8 \\
6.8\end{array}$ & $\begin{array}{l}5.3 \\
5.3 \\
5.8 \\
4.9 \\
5.3\end{array}$ & $\begin{array}{l}9.6 \\
9.0 \\
9.9 \\
9.0 \\
9.9\end{array}$ & $\begin{array}{l}12 \\
13 \\
11 \\
11 \\
11\end{array}$ & $\begin{array}{l}19 \\
18 \\
16 \\
16 \\
16\end{array}$ & $\begin{array}{l}16 \\
16 \\
17 \\
18 \\
18\end{array}$ & $\begin{array}{l}22 \\
22 \\
22 \\
22 \\
22\end{array}$ & $\begin{array}{l}14 \\
10 \\
9.3 \\
7.6 \\
11\end{array}$ & $\begin{array}{l}7.1 \\
7.0 \\
6.8 \\
9.3 \\
6.8\end{array}$ \\
\hline $\begin{array}{l}26 \\
27 \\
28 \\
29 \\
30 \\
31\end{array}$ & $\begin{array}{l}16 \\
15 \\
13 \\
13 \\
27 \\
17\end{array}$ & $\begin{array}{l}12 \\
12 \\
85 \\
11 \\
7.6 \\
-\end{array}$ & $\begin{array}{l}6.6 \\
6.8 \\
6.1 \\
6.6 \\
6.4 \\
7.1\end{array}$ & $\begin{array}{l}7.6 \\
9.0 \\
8.4 \\
8.4 \\
7.6 \\
7.6\end{array}$ & $\begin{array}{r}6.1 \\
5.3 \\
4.9 \\
4.9 \\
-.-0\end{array}$ & $\begin{array}{l}10 \\
9.6 \\
12 \\
10 \\
10 \\
9.9\end{array}$ & $\begin{array}{l}12 \\
12 \\
13 \\
12 \\
11 \\
-=-\end{array}$ & $\begin{array}{l}16 \\
15 \\
16 \\
15 \\
15 \\
14\end{array}$ & $\begin{array}{r}20 \\
19 \\
19 \\
19 \\
21 \\
-\end{array}$ & $\begin{array}{l}22 \\
30 \\
22 \\
31 \\
15 \\
16\end{array}$ & $\begin{array}{r}7.1 \\
9.3 \\
11 \\
7.8 \\
6.8 \\
6.7\end{array}$ & $\begin{array}{l}7.1 \\
6.6 \\
7.6 \\
8.1 \\
7.3 \\
-\end{array}$ \\
\hline $\begin{array}{l}\text { TOTAL } \\
\text { MEAN } \\
\text { MAX } \\
\text { MIN } \\
\text { AC-FT }\end{array}$ & $\begin{array}{r}532 \\
17.2 \\
32 \\
13 \\
1060\end{array}$ & $\begin{array}{r}468.6 \\
15.6 \\
85 \\
7.6 \\
929\end{array}$ & $\begin{array}{r}254.5 \\
8.21 \\
22 \\
6.1 \\
505\end{array}$ & $\begin{array}{r}243.8 \\
7.86 \\
9.3 \\
6.6 \\
484\end{array}$ & $\begin{array}{r}1146.7 \\
39.5 \\
455 \\
4.9 \\
2270\end{array}$ & $\begin{array}{r}816.4 \\
26.3 \\
274 \\
8.7 \\
1620\end{array}$ & $\begin{array}{r}624.4 \\
20.8 \\
158 \\
8.7 \\
1240\end{array}$ & $\begin{array}{r}449 \\
14.5 \\
20 \\
11 \\
891\end{array}$ & $\begin{array}{r}616 \\
20.5 \\
144 \\
10 \\
1220\end{array}$ & $\begin{array}{r}662 \\
21.4 \\
31 \\
14 \\
1310\end{array}$ & $\begin{array}{r}363.7 \\
11.7 \\
27 \\
6.8 \\
721\end{array}$ & $\begin{array}{r}463.1 \\
15.4 \\
150 \\
6.6 \\
919\end{array}$ \\
\hline
\end{tabular}

CAL YR 1975 TOTAL 5679.3 MEAN 15.6 MAX 325 MIN 4.6 AC-FT 11260

WTR YR 1976 TOTAL 6640.2 MEAN 18.1 MAX 455 MIN 4.9 AC-FT 13170 
11048550 SAN DIEGO CREEK AT LANE ROAD, NEAR IRVINE, CA--Continued

WATER-QUALITY RECORDS

PERIOD OF DAILY RECORD.--

WATER TEMPERATURES: February 1972 to September 1976 (discontinued).

SEDIMENT RECORDS: Apri1 1972 to September 1976 (discontinued).

REMARKS.--Particle-size distribution of bed material table was omitted in the 1975 water year and is published with 1976 water year records.

EXTREMES FOR PERIOD OF DAILY RECORD. -

SEDIMENT CONCENTRATIONS: Maximum daily mean, 10,000 $\mathrm{mg} / 1$ May 4, 1972; minimum daily mean, $20 \mathrm{mg} / 1 \mathrm{Apr}$, 22 , 23, May 5,1975 .

SEDIMENT DISCHARGE: Maximum daily, 22,900 tons $(20,800$ tonnes) Dec. 4, 1974; minimum dai1y, 0.26 tons (0.24 tonnes) May 5,1975 .

EXTREMES FOR CURRENT YEAR.--

SEDIMENT CONCENTRATIONS: Maximum daily mean, $5,020 \mathrm{mg} / 1 \mathrm{Feb}, 9$; minimum daily mean, $37 \mathrm{mg} / 1 \mathrm{Apr}$. 18

SEDIMENT DISCHARGE: Maximun daily, 8,770 tons $(7,960$ tonnes) Feb. 9; minimum daily, 0.93 ton (0.84 tonne) April 18

TEMPERATURE (DEG, C) OF WATER, WATER YEAR OCTOBER 1975 TO SEPTEMBER 1976 ONCE-DAILY

\begin{tabular}{|c|c|c|c|c|c|c|c|c|c|c|c|c|}
\hline DAY & OCT & Nov & DEC & JAN & FEB & MAR & APR & MAY & JUN & JUL. & AUG & SEP \\
\hline $\begin{array}{l}1 \\
2 \\
3 \\
4 \\
5\end{array}$ & $\begin{array}{r}24.0 \\
25.0 \\
-0.0\end{array}$ & $\begin{array}{r}16.5 \\
20.0 \\
- \\
-.-\end{array}$ & $\begin{array}{r}18.0 \\
18.5 \\
-.0\end{array}$ & $\begin{array}{r}11.5 \\
--5 \\
--.\end{array}$ & $\begin{array}{r}11.5 \\
16.0 \\
13.0 \\
14.5\end{array}$ & $\begin{array}{r}16.0 \\
11.0 \\
-\end{array}$ & $\begin{array}{r}15.0 \\
17.0 \\
16.0\end{array}$ & 21.0 & 21.0 & $\begin{array}{r}22.5 \\
--5\end{array}$ & $\begin{array}{r}25.0 \\
17.5 \\
-. .5\end{array}$ & $\begin{array}{r}22.0 \\
23.5 \\
-\end{array}$ \\
\hline $\begin{array}{r}6 \\
7 \\
8 \\
9 \\
10\end{array}$ & $\begin{array}{r}-- \\
22.5 \\
22.0\end{array}$ & $\begin{array}{l}m- \\
m- \\
m- \\
-\overline{-}\end{array}$ & $\begin{array}{r}13.0 \\
10.0 \\
-.0\end{array}$ & $\begin{array}{r}13.5 \\
14.0 \\
-.0\end{array}$ & $\begin{array}{r}11.0 \\
12.0 \\
13.0 \\
15.5\end{array}$ & $\begin{array}{r}8.0 \\
=-0 \\
=-5\end{array}$ & 19.0 & $\overline{=-}$ & $\begin{array}{r}30.0 \\
- \\
-\end{array}$ & $\begin{array}{r}25.0 \\
32.5 \\
-21.5 \\
21.5\end{array}$ & 20.0 & 23.5 \\
\hline $\begin{array}{l}11 \\
12 \\
13 \\
14 \\
15\end{array}$ & $\begin{array}{r}17.5 \\
=-0 \\
13.0\end{array}$ & 19.0 & $\begin{array}{r}12.5 \\
10.0 \\
-\end{array}$ & $\begin{array}{r}12.0 \\
28.0 \\
15.0\end{array}$ & $\begin{array}{r}18.0 \\
-0\end{array}$ & $\begin{array}{r}-.0 \\
16.5 \\
0.5 \\
--.\end{array}$ & $\begin{array}{r}18.0 \\
20.0 \\
16.0\end{array}$ & $\begin{array}{r}30.5 \\
=- \\
=-\end{array}$ & $\begin{array}{l}=- \\
=-0 \\
=-\infty\end{array}$ & $\begin{array}{r}=-0 \\
31.0 \\
20.5 \\
21.0\end{array}$ & $\begin{array}{r}25.0 \\
28.5 \\
21.5 \\
2.0\end{array}$ & $\begin{array}{r}21.0 \\
19.5 \\
\end{array}$ \\
\hline $\begin{array}{l}16 \\
17 \\
18 \\
19 \\
20\end{array}$ & $\begin{array}{r}17.5 \\
--- \\
--\end{array}$ & $\begin{array}{r}=- \\
--0 \\
--0 \\
14.5 \\
=-0\end{array}$ & $\begin{array}{l}-\infty \\
-\infty \\
-m \\
-\infty\end{array}$ & $\begin{array}{r}14.0 \\
19.0 \\
-0.0\end{array}$ & $\begin{array}{r}20.5 \\
8.5\end{array}$ & $\begin{array}{r}=- \\
21.0 \\
14.0\end{array}$ & $\begin{array}{r}17.0 \\
-\infty\end{array}$ & $\begin{array}{l}m-m \\
-m \\
-m\end{array}$ & $\begin{array}{r}29.5 \\
=- \\
=-- \\
--\end{array}$ & $\begin{array}{l}=- \\
-=0 \\
-0 \\
-\infty\end{array}$ & $\begin{array}{r}19.5 \\
21.0\end{array}$ & $\begin{array}{r}=- \\
=-0 \\
21.0 \\
=-\infty\end{array}$ \\
\hline $\begin{array}{l}21 \\
22 \\
23 \\
24 \\
25\end{array}$ & $\begin{array}{r}17.5 \\
13.0 \\
-\end{array}$ & $\begin{array}{r}15.0 \\
11.0 \\
- \\
=-0\end{array}$ & $\begin{array}{r}11.5 \\
=-0 \\
=-\infty\end{array}$ & 17.0 & $\begin{array}{r}-\infty .5 \\
11.5 \\
-\infty\end{array}$ & $\begin{array}{l}=-\infty \\
=-\infty \\
=-\infty \\
=-\infty\end{array}$ & $\begin{array}{r}24.0 \\
=-0 \\
17.5\end{array}$ & $\begin{array}{r}--0 \\
=-0 \\
24.5 \\
--\infty\end{array}$ & $\begin{array}{r}31.5 \\
=-5 \\
27.5\end{array}$ & $\begin{array}{r}=-5 \\
20.5 \\
m-=0 \\
23.5\end{array}$ & $\begin{array}{r}20.5 \\
=-0 \\
=-\infty\end{array}$ & $\begin{array}{l}=-\infty \\
=-\infty \\
=-\infty \\
=-\infty\end{array}$ \\
\hline $\begin{array}{l}26 \\
27 \\
28 \\
29 \\
30 \\
31\end{array}$ & $\begin{array}{r}14.0 \\
0.00 \\
19.0\end{array}$ & $\begin{array}{r}16.0 \\
12.0 \\
\ldots \\
\ldots\end{array}$ & $\begin{array}{r}13.0 \\
12.0\end{array}$ & $\begin{array}{r}6.5 \\
6.5 \\
17.5\end{array}$ & $\begin{array}{r}19.5 \\
11.0 \\
0-0 \\
-0 \\
-\end{array}$ & $\begin{array}{r}26.0 \\
15.0 \\
20.5 \\
-\end{array}$ & $\begin{array}{r}23.5 \\
23.5 \\
-.0\end{array}$ & $\begin{array}{l}=- \\
=- \\
=- \\
-0\end{array}$ & $\begin{array}{r}24.5 \\
22.5 \\
-1.5\end{array}$ & 23.0 & $\begin{array}{r}26.5 \\
21.0 \\
= \\
=-\end{array}$ & $\begin{array}{r}20.5 \\
27.0 \\
- \\
=-0\end{array}$ \\
\hline ONTH & $-\infty$ & 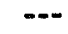 & $-\infty$ & - & $=$ & $-\infty$ & $-\infty$ & $-\infty$ & $=-0$ & $=-\infty$ & $--\infty$ & $=-\infty$ \\
\hline
\end{tabular}


11048550 SAN DIEGO CREEK AT LANE ROAD, NEAR'IRVINE, CA--Continued

SUSPENDED-SEDIMENT DISCHARGE (TONS/DAY), WATER YEAR OCTOBER 1975 TO SEPTEMBER 1976

\begin{tabular}{|c|c|c|c|c|c|c|c|c|c|}
\hline \multirow[b]{2}{*}{ DAY } & \multicolumn{3}{|c|}{ OCTOBER } & \multicolumn{3}{|c|}{ NOVEMBER } & \multicolumn{3}{|c|}{ DECEMBER } \\
\hline & $\begin{array}{l}\text { MEAN } \\
\text { DISCHARGE } \\
\text { (CFS) }\end{array}$ & $\begin{array}{l}\text { MEAN } \\
\text { CONCEN- } \\
\text { TRATION } \\
\text { (MG/L) }\end{array}$ & $\begin{array}{l}\text { SEDIMENT } \\
\text { DISCHARGE } \\
\text { (TONS/DAY) }\end{array}$ & $\begin{array}{l}\text { MEAN } \\
\text { DISCHARGE } \\
\text { (CFS) }\end{array}$ & $\begin{array}{l}\text { MEAN } \\
\text { CONCEN- } \\
\text { TRAION } \\
\text { (MG/L) }\end{array}$ & $\begin{array}{l}\text { SEDIMENT } \\
\text { DISCHARGE } \\
\text { (TONS/OAY) }\end{array}$ & $\begin{array}{l}\text { MEAN } \\
\text { DISCARGE } \\
\text { (CFS) }\end{array}$ & $\begin{array}{l}\text { MEAN } \\
\text { CONCEN- } \\
\text { TRATION } \\
\text { (MG/L) }\end{array}$ & $\begin{array}{l}\text { SEDIMENT } \\
\text { DISCARGE } \\
\text { ITONS/DAY }\end{array}$ \\
\hline $\begin{array}{l}1 \\
2 \\
3 \\
4 \\
5\end{array}$ & $\begin{array}{l}16 \\
18 \\
18 \\
17 \\
18\end{array}$ & $\begin{array}{l}443 \\
400 \\
365 \\
332 \\
325\end{array}$ & $\begin{array}{l}19 \\
19 \\
18 \\
15 \\
16\end{array}$ & $\begin{array}{l}14 \\
14 \\
14 \\
13 \\
15\end{array}$ & $\begin{array}{l}160 \\
190 \\
229 \\
236 \\
244\end{array}$ & $\begin{array}{l}6.0 \\
7.2 \\
8.7 \\
8.3 \\
9.9\end{array}$ & $\begin{array}{l}6.8 \\
6.8 \\
7.3 \\
8.4 \\
7.3\end{array}$ & $\begin{array}{l}118 \\
140 \\
162 \\
162 \\
161\end{array}$ & $\begin{array}{l}2.2 \\
2.6 \\
3.2 \\
3.7 \\
3,2\end{array}$ \\
\hline $\begin{array}{r}6 \\
7 \\
8 \\
9 \\
10\end{array}$ & $\begin{array}{l}16 \\
32 \\
14 \\
14 \\
21\end{array}$ & $\begin{array}{r}315 \\
715 \\
496 \\
300 \\
1000\end{array}$ & $\begin{array}{l}14 \\
62 \\
19 \\
11 \\
57\end{array}$ & $\begin{array}{l}13 \\
12 \\
15 \\
15 \\
15\end{array}$ & $\begin{array}{l}251 \\
259 \\
266 \\
274 \\
281\end{array}$ & $\begin{array}{c}\mathbf{8 . 8} \\
8.4 \\
11 \\
11 \\
11\end{array}$ & $\begin{array}{l}7.3 \\
7.8 \\
7.3 \\
6.8 \\
6.6\end{array}$ & $\begin{array}{l}161 \\
140 \\
121 \\
110 \\
105\end{array}$ & $\begin{array}{l}3.2 \\
2.9 \\
2.4 \\
2.0 \\
1.9\end{array}$ \\
\hline $\begin{array}{l}11 \\
12 \\
13 \\
14 \\
15\end{array}$ & $\begin{array}{l}23 \\
18 \\
13 \\
13 \\
18\end{array}$ & $\begin{array}{l}740 \\
580 \\
480 \\
380 \\
382\end{array}$ & $\begin{array}{l}46 \\
28 \\
17 \\
13 \\
19\end{array}$ & $\begin{array}{l}14 \\
12 \\
14 \\
15 \\
15\end{array}$ & $\begin{array}{l}289 \\
296 \\
304 \\
312 \\
290\end{array}$ & $\begin{array}{l}11 \\
9.6 \\
11 \\
13 \\
12\end{array}$ & $\begin{array}{r}6.6 \\
10 \\
9.8 \\
7.3 \\
7.6\end{array}$ & $\begin{array}{l}100 \\
470 \\
289 \\
179 \\
170\end{array}$ & $\begin{array}{r}1.8 \\
13 \\
7.6 \\
3.5 \\
3.5\end{array}$ \\
\hline $\begin{array}{l}16 \\
17 \\
18 \\
19 \\
20\end{array}$ & $\begin{array}{l}19 \\
15 \\
14 \\
17 \\
15\end{array}$ & $\begin{array}{l}440 \\
480 \\
239 \\
480 \\
440\end{array}$ & $\begin{array}{l}23 \\
19 \\
9.0 \\
22 \\
10\end{array}$ & $\begin{array}{l}14 \\
14 \\
13 \\
13 \\
13\end{array}$ & $\begin{array}{l}270 \\
250 \\
230 \\
210 \\
190\end{array}$ & $\begin{array}{l}10 \\
9.5 \\
8.1 \\
7.4 \\
6.7\end{array}$ & $\begin{array}{r}9.0 \\
9: 0 \\
9.0 \\
8.7 \\
22\end{array}$ & $\begin{array}{l}160 \\
150 \\
140 \\
130 \\
470\end{array}$ & $\begin{array}{r}3.9 \\
3.6 \\
3.4 \\
3.1 \\
47\end{array}$ \\
\hline $\begin{array}{l}21 \\
22 \\
23 \\
24 \\
25\end{array}$ & $\begin{array}{l}14 \\
16 \\
15 \\
18 \\
19\end{array}$ & $\begin{array}{l}400 \\
360 \\
322 \\
270 \\
255\end{array}$ & $\begin{array}{l}15 \\
16 \\
13 \\
13 \\
13\end{array}$ & $\begin{array}{l}13 \\
12 \\
13 \\
13 \\
13\end{array}$ & $\begin{array}{l}186 \\
434 \\
410 \\
380 \\
350\end{array}$ & $\begin{array}{l}6.5 \\
14 \\
14 \\
13 \\
12\end{array}$ & $\begin{array}{r}12 \\
7.8 \\
7.6 \\
7.3 \\
6.8\end{array}$ & $\begin{array}{l}325 \\
150 \\
130 \\
120 \\
115\end{array}$ & $\begin{array}{r}11 \\
3.2 \\
2.7 \\
2.4 \\
2.1\end{array}$ \\
\hline $\begin{array}{l}26 \\
27 \\
28 \\
29 \\
30 \\
31\end{array}$ & $\begin{array}{l}16 \\
15 \\
13 \\
13 \\
27 \\
17\end{array}$ & $\begin{array}{l}243 \\
250 \\
265 \\
280 \\
602 \\
200\end{array}$ & $\begin{array}{c}10 \\
10 \\
9.3 \\
9.8 \\
44.2 \\
9.2\end{array}$ & $\begin{array}{c}12 \\
12 \\
85 \\
11 \\
7.6 \\
-.-\end{array}$ & $\begin{array}{r}348 \\
436 \\
1410 \\
750 \\
250 \\
--.\end{array}$ & $\begin{array}{c}11 \\
14 \\
324 \\
22 \\
5.1 \\
-\cdots\end{array}$ & $\begin{array}{l}6.6 \\
6.8 \\
6.1 \\
6.6 \\
8.4 \\
7.1\end{array}$ & $\begin{array}{r}110 \\
105 \\
102 \\
99 \\
198 \\
150\end{array}$ & $\begin{array}{l}2.0 \\
1.9 \\
1.7 \\
1.8 \\
4.5 \\
2.9\end{array}$ \\
\hline TAL & 532 & -..- & 626.3 & 468.6 & -- & 624.2 & 254.5 & $\cdots$ & 153.9 \\
\hline
\end{tabular}

\begin{tabular}{|c|c|c|c|c|c|c|c|c|c|}
\hline \multirow[b]{2}{*}{ DAY } & \multicolumn{3}{|c|}{ JANUARY } & \multicolumn{3}{|c|}{ FEBRUARY } & \multicolumn{3}{|c|}{ MARCH } \\
\hline & $\begin{array}{l}\text { MEAN } \\
\text { DISCAARGE } \\
\text { (CFS) }\end{array}$ & $\begin{array}{l}\text { MEAN } \\
\text { CONCEN- } \\
\text { TRATION } \\
\text { (MG/L) }\end{array}$ & $\begin{array}{l}\text { SEDIMENT } \\
\text { DISCARGE } \\
\text { (TONS/DAY) }\end{array}$ & $\begin{array}{l}\text { MEAN } \\
\text { DISCARGE } \\
\text { (CFS) }\end{array}$ & $\begin{array}{l}\text { MEAN } \\
\text { CONCEN- } \\
\text { TRATON } \\
\text { (MG/L) }\end{array}$ & $\begin{array}{l}\text { SEDIMENT } \\
\text { OISCHARGE } \\
\text { (TONS/DAY) }\end{array}$ & $\begin{array}{l}\text { MEAN } \\
\text { DISCHARE } \\
\text { (CFS) }\end{array}$ & $\begin{array}{l}\text { MEAN } \\
\text { CONCEN- } \\
\text { TRATION } \\
\text { (MG/L) }\end{array}$ & $\begin{array}{l}\text { SEDIMENT } \\
\text { DISCARGE } \\
\text { (TONS/DAY) }\end{array}$ \\
\hline $\begin{array}{l}1 \\
2 \\
3 \\
4 \\
5\end{array}$ & $\begin{array}{l}6.6 \\
7.6 \\
7.6 \\
7.6 \\
8.4\end{array}$ & $\begin{array}{l}130 \\
156 \\
130 \\
120 \\
150\end{array}$ & $\begin{array}{l}2.3 \\
3.2 \\
2.7 \\
2.5 \\
3.4\end{array}$ & $\begin{array}{l}7.1 \\
7.1 \\
13 \\
20 \\
26\end{array}$ & $\begin{array}{r}496 \\
450 \\
1840 \\
1460 \\
865\end{array}$ & $\begin{array}{c}9.5 \\
8.6 \\
85 \\
103 \\
73\end{array}$ & $\begin{array}{c}274 \\
108 \\
160 \\
14 \\
8,7\end{array}$ & $\begin{array}{r}3090 \\
2370 \\
2310 \\
1500 \\
430\end{array}$ & $\begin{array}{r}4240 \\
691 \\
998 \\
57 \\
10\end{array}$ \\
\hline $\begin{array}{r}6 \\
7 \\
8 \\
9 \\
10\end{array}$ & $\begin{array}{l}8.4 \\
7.1 \\
8.1 \\
8.7 \\
9.3\end{array}$ & $\begin{array}{l}140 \\
130 \\
180 \\
220 \\
240\end{array}$ & $\begin{array}{l}3.2 \\
2.5 \\
3.9 \\
5.2 \\
6.0\end{array}$ & $\begin{array}{r}195 \\
120 \\
148 \\
455 \\
33\end{array}$ & $\begin{array}{l}2950 \\
1340 \\
1990 \\
5020 \\
2040\end{array}$ & $\begin{array}{r}2750 \\
617 \\
1270 \\
8770 \\
182\end{array}$ & $\begin{array}{l}9.0 \\
9.6 \\
9.0 \\
9.3 \\
9.9\end{array}$ & $\begin{array}{l}178 \\
200 \\
220 \\
244 \\
215\end{array}$ & $\begin{array}{l}4.3 \\
5.2 \\
5.3 \\
6.1 \\
5.7\end{array}$ \\
\hline $\begin{array}{l}11 \\
12 \\
13 \\
14 \\
15\end{array}$ & $\begin{array}{l}8.1 \\
7.8 \\
8.1 \\
8.7 \\
8.4\end{array}$ & $\begin{array}{l}182 \\
170 \\
250 \\
367 \\
228\end{array}$ & $\begin{array}{l}4.0 \\
3.6 \\
5.5 \\
8.6 \\
5.2\end{array}$ & $\begin{array}{r}10 \\
7.6 \\
7.6 \\
9.0 \\
7.8\end{array}$ & $\begin{array}{r}700 \\
79 \\
110 \\
140 \\
180\end{array}$ & $\begin{array}{r}19 \\
1.6 \\
2.3 \\
3.4 \\
3.8\end{array}$ & $\begin{array}{c}10 \\
9.9 \\
9.6 \\
9.3 \\
9.3\end{array}$ & $\begin{array}{r}200 \\
180 \\
110 \\
74 \\
92\end{array}$ & $\begin{array}{l}5.4 \\
4.8 \\
2.9 \\
1.9 \\
2.3\end{array}$ \\
\hline $\begin{array}{l}16 \\
17 \\
18 \\
19 \\
20\end{array}$ & $\begin{array}{l}7.1 \\
7.6 \\
8.1 \\
8.1 \\
7.3\end{array}$ & $\begin{array}{l}300 \\
381 \\
330 \\
280 \\
246\end{array}$ & $\begin{array}{l}5.8 \\
7.8 \\
7.2 \\
6.1 \\
4.8\end{array}$ & $\begin{array}{l}6.6 \\
6.6 \\
8.1 \\
6.3 \\
5.1\end{array}$ & $\begin{array}{l}230 \\
310 \\
406 \\
350 \\
296\end{array}$ & $\begin{array}{l}4.1 \\
5.5 \\
8.9 \\
6.0 \\
4.1\end{array}$ & $\begin{array}{c}9.3 \\
10 \\
10 \\
8.7 \\
9.9\end{array}$ & $\begin{array}{l}103 \\
122 \\
147 \\
177 \\
114\end{array}$ & $\begin{array}{l}2.6 \\
3.3 \\
4.0 \\
4.2 \\
3.0\end{array}$ \\
\hline $\begin{array}{l}21 \\
22 \\
23 \\
24 \\
25\end{array}$ & $\begin{array}{l}7.8 \\
7.3 \\
6.8 \\
7.8 \\
6.8\end{array}$ & $\begin{array}{l}250 \\
290 \\
330 \\
320 \\
276\end{array}$ & $\begin{array}{l}5.3 \\
5.7 \\
6.1 \\
6.7 \\
5.1\end{array}$ & $\begin{array}{l}5.3 \\
5.3 \\
5.8 \\
4.9 \\
5.3\end{array}$ & $\begin{array}{l}280 \\
250 \\
235 \\
220 \\
195\end{array}$ & $\begin{array}{l}4.0 \\
3.6 \\
3.7 \\
2.9 \\
2.8\end{array}$ & $\begin{array}{l}9.6 \\
9: 0 \\
9: 9 \\
9.0 \\
9.9\end{array}$ & $\begin{array}{l}102 \\
105 \\
109 \\
115 \\
122\end{array}$ & $\begin{array}{l}2.6 \\
2.6 \\
2.9 \\
2.8 \\
3.3\end{array}$ \\
\hline $\begin{array}{l}26 \\
27 \\
28 \\
29 \\
30 \\
31\end{array}$ & $\begin{array}{l}7.6 \\
9.0 \\
8.4 \\
8.4 \\
7.6 \\
7.6\end{array}$ & $\begin{array}{l}360 \\
590 \\
600 \\
640 \\
668 \\
600\end{array}$ & $\begin{array}{l}7.4 \\
14 \\
14 \\
15 \\
14 \\
12\end{array}$ & $\begin{array}{l}6.1 \\
5.3 \\
4.9 \\
4.9 \\
-. . \\
-. .\end{array}$ & $\begin{array}{l}152 \\
286 \\
305 \\
300 \\
-\ldots- \\
-\infty\end{array}$ & $\begin{array}{l}2.5 \\
4: 1 \\
4.0 \\
4.0 \\
-:-\end{array}$ & $\begin{array}{l}10 \\
9.6 \\
12 \\
10 \\
10 \\
9.9\end{array}$ & $\begin{array}{r}227 \\
86 \\
97 \\
116 \\
150 \\
180\end{array}$ & $\begin{array}{l}6.1 \\
2.2 \\
3.1 \\
3.1 \\
4.1 \\
4.8\end{array}$ \\
\hline & 4.8 & $\ldots$ & 198.8 & 1146.7 & $=-\infty$ & 13958.4 & 816.4 & $\ldots$ & 6094.6 \\
\hline
\end{tabular}


11048550 SAN DIEGO CREEK AT LANE ROAD, NEAR IRVINE, CA--Continued

SUSPENDED-SEDIMENT DISCHARGE (TONS/DAY), WATER YEAR OCTOBER 1975 TO SEPTEMBER 1976

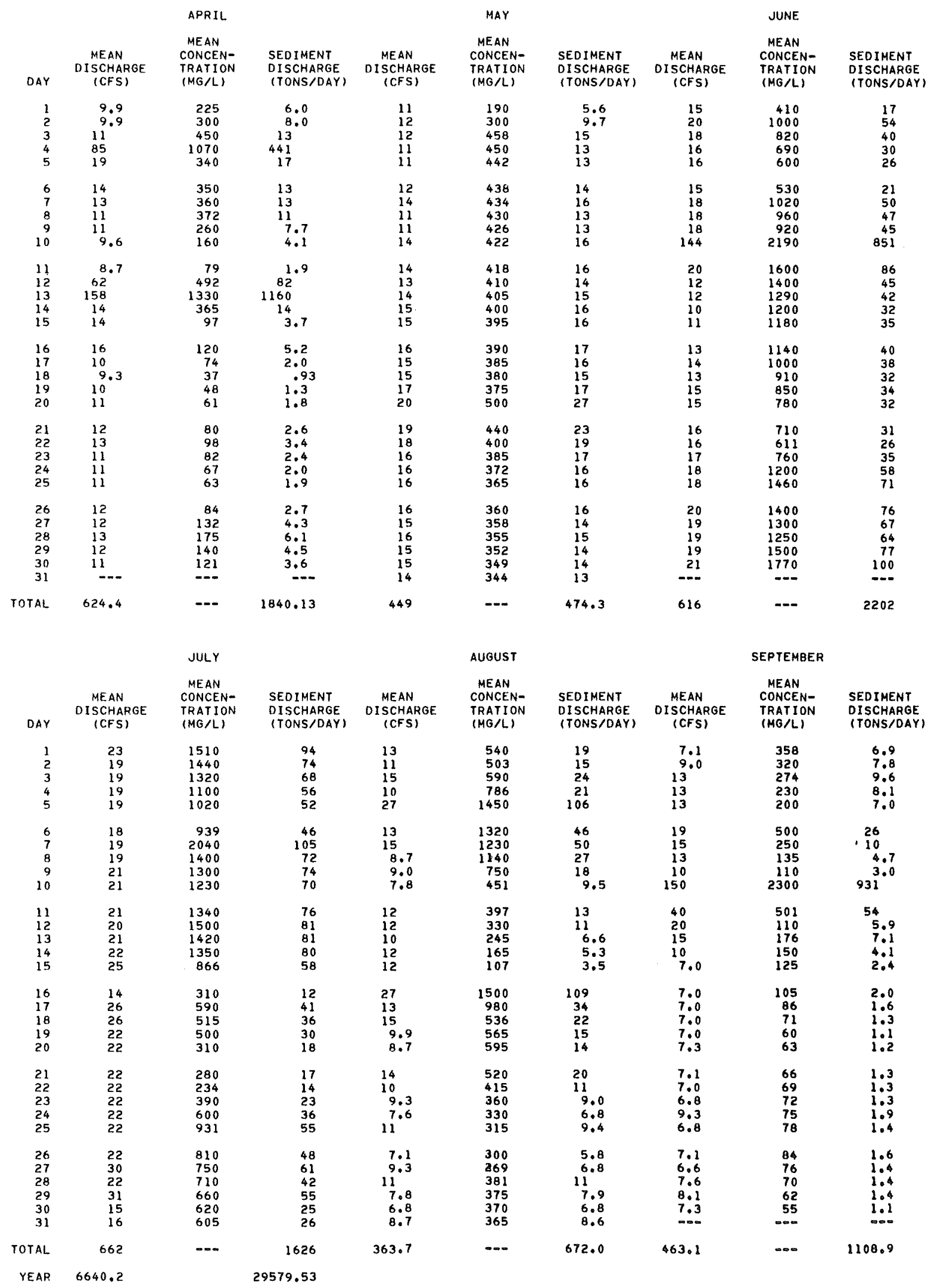


11048550 SAN DIEGO CREEK AT LANE ROAD, NEAR IRVINE, CA--Continued

SUMMARY OF WATER AND SEDIMENT DISCHARGE, WATER YEAR OCTOBER 1975 TO SEPTEMBER 1976

\begin{tabular}{|c|c|c|c|c|}
\hline MONTH & $\begin{array}{l}\text { WATER } \\
\text { DISCHARGE } \\
\text { CFS-DAYS }\end{array}$ & $\begin{array}{l}\text { SUSPENDED } \\
\text { SEDIMENT } \\
\text { DI SCHARGE } \\
\text { TONS }\end{array}$ & $\begin{array}{c}\text { BEDLOAD } \\
\text { DISCHARGE } \\
\text { TONS }\end{array}$ & $\begin{array}{l}\text { TOTAL } \\
\text { SEOIMENT } \\
\text { DISCHARGE } \\
\text { TONS }\end{array}$ \\
\hline OCTOBER 1975 & 532.00 & 626.30 & 367 & 993 \\
\hline NOVEMBER $\ldots$ & 468.60 & 624.20 & 334 & 958 \\
\hline DECEMBER .. & 254.50 & 153.90 & 130 & 284 \\
\hline JANUARY 1976 & 243.80 & 198.80 & 119 & 318 \\
\hline FEBRUARY $\ldots$ & 1146.70 & 13958,40 & 1420 & 15400 \\
\hline MARCH $\ldots \ldots$ & 816.40 & 6094.60 & 879 & 6970 \\
\hline APRIL $\ldots \ldots$ & 624.40 & 1840.13 & 560 & 2400 \\
\hline MAY ....... & 449.00 & 474.30 & 288 & 762 \\
\hline JUNE $\ldots \ldots \ldots$ & 616.00 & 2202.00 & 502 & 2700 \\
\hline JULY .... & 662.00 & 1626.00 & 495 & 2120 \\
\hline AUGUST $\ldots \ldots$ & 363.70 & 672.00 & 220 & 892 \\
\hline SEPTEMRER & 463.10 & 1108.90 & 385 & 1490 \\
\hline TOTAL ...... & 6640.20 & 29579.53 & 5699 & 35287 \\
\hline
\end{tabular}

PARTICLEMIZE DISTRIQUTION OF SUSPENDED SEDIMENT, WATER YEAR OCTOBER 1975 TO SEPTEMBER 1976

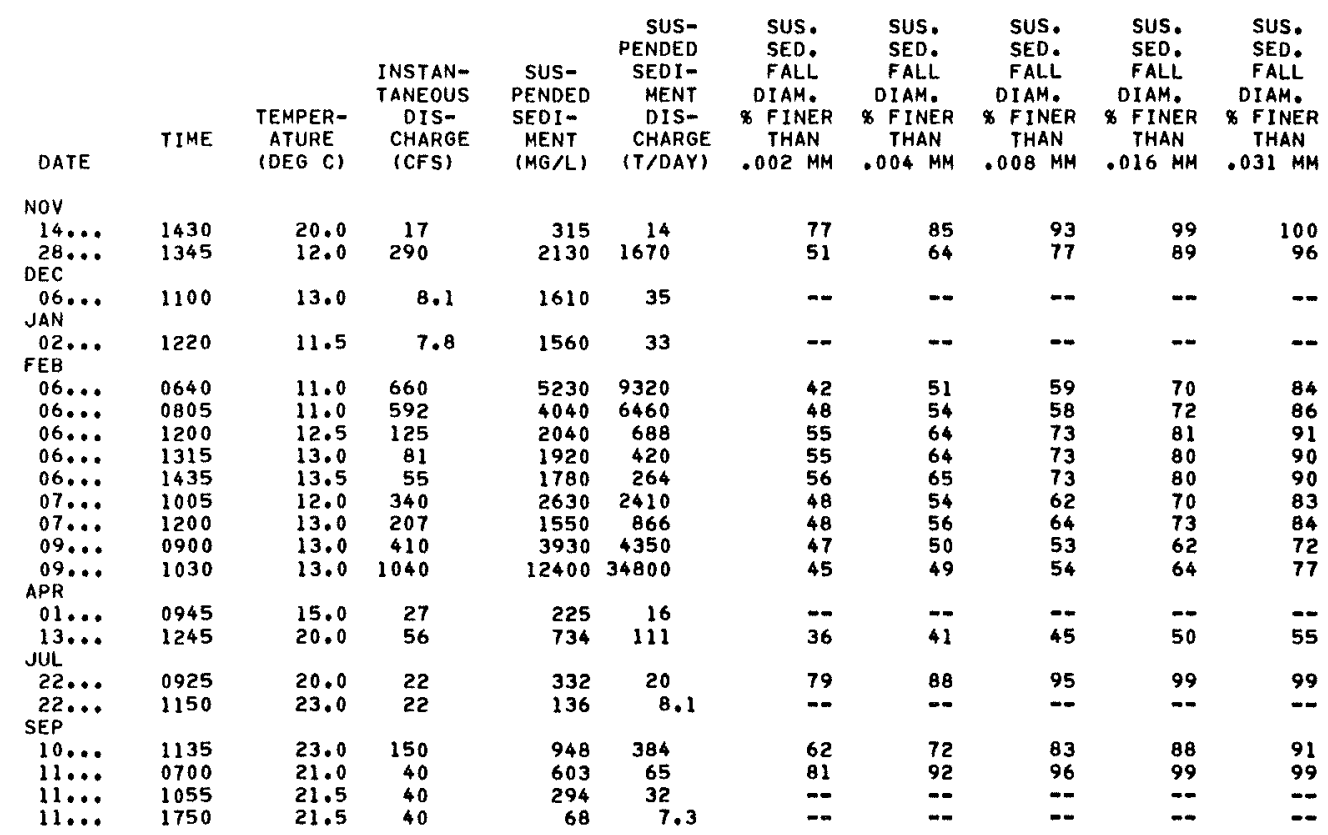


11048550 SAN DIEGO CREEK AT LANE ROAD, NEAR IRVINE, CA--Continued

PARTICLE-SIZE DISTRIBUTION OF SUSPENDED SEDIMENT, WATER YEAR OCTOBER 1975 TO SEPTEMBER 1976

\begin{tabular}{|c|c|c|c|c|c|c|c|c|}
\hline $\begin{array}{l}\text { SUS. } \\
\text { SED. } \\
\text { FALL } \\
\text { DIAM. } \\
\text { FINER } \\
\text { THAN } \\
\text { O62 MM }\end{array}$ & $\begin{array}{l}\text { SUS. } \\
\text { SEO } \\
\text { SIEVE } \\
\text { DIAM. } \\
\text { \$ FINER } \\
\text { THAN } \\
\text { OGZ MM }\end{array}$ & $\begin{array}{l}\text { SUS. } \\
\text { SEO } \\
\text { FALL } \\
\text { DIAM. } \\
\text { \% FINER } \\
\text { THAN } \\
125 \text { MM }\end{array}$ & $\begin{array}{c}\text { SUS. } \\
\text { SED. } \\
\text { SIEVE } \\
\text { DIAM. } \\
\times \text { FINER } \\
\text { THAN } \\
125 \text { MM }\end{array}$ & $\begin{array}{l}\text { SUS. } \\
\text { SED } \\
\text { FALL. } \\
\text { DIAM. } \\
\text { Q FINER } \\
\text { THAN } \\
.250 \text { MH }\end{array}$ & $\begin{array}{l}\text { SUS } \\
\text { SED } \\
\text { SIEVE } \\
\text { DIAM. } \\
\text { FINER } \\
\text { THAN }\end{array}$ & $\begin{array}{l}\text { SUS. } \\
\text { SEO. } \\
\text { FALL } \\
\text { DIAM. } \\
\text { \$ FINER } \\
\text { THAN } \\
500 \text { MM }\end{array}$ & $\begin{array}{l}\text { SUS. } \\
\text { SED. } \\
\text { SIEVE } \\
\text { DIAH. } \\
\text { * FINE } \\
\text { THAN }\end{array}$ & $\begin{array}{l}\text { SUS, } \\
\text { SED, } \\
\text { SIEVE } \\
\text { DIAM, } \\
\text { × FINER } \\
\text { THAN } \\
1.00 \mathrm{HM}\end{array}$ \\
\hline
\end{tabular}

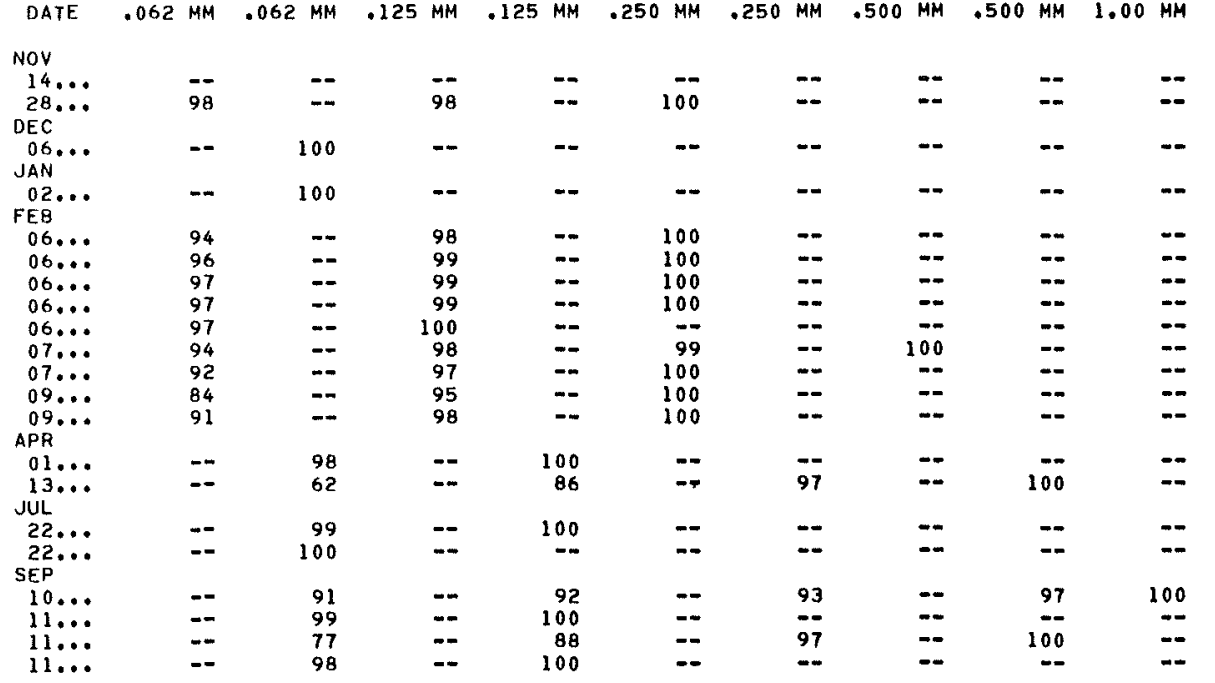

PARTICLE-SIZE DISTRIBUTION OF SURFACE BED MATERIAL, WATER YEAR OCTOBER 1974 TO SEPTEMBER 1975 SEP

BED

BED

BED BED

MAT. MAT.

SIEVE

SIEVE

SIEVE

DIAMER

\& FINER

DIAM. DIAM.

\$ FINER

FINER
THAN FINER
THAN THANER \$ FINER THINER F FINER THAN FINER

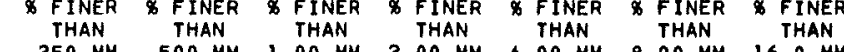

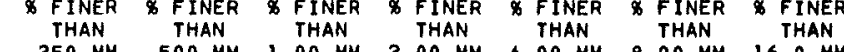

\& FINER \& FINER \$ FINER \$ FINER \& FINER \& FINER \& FINER
THAN THAN

BEO BED BED

MAT. MAT. MAT.
SIEVE SIEVE SIEVE

DIAN.

FINER DIAM.

DIAM.

THAN THAN THAN

29... 1115

6.7

14

38

65

77

84

92

98

100 


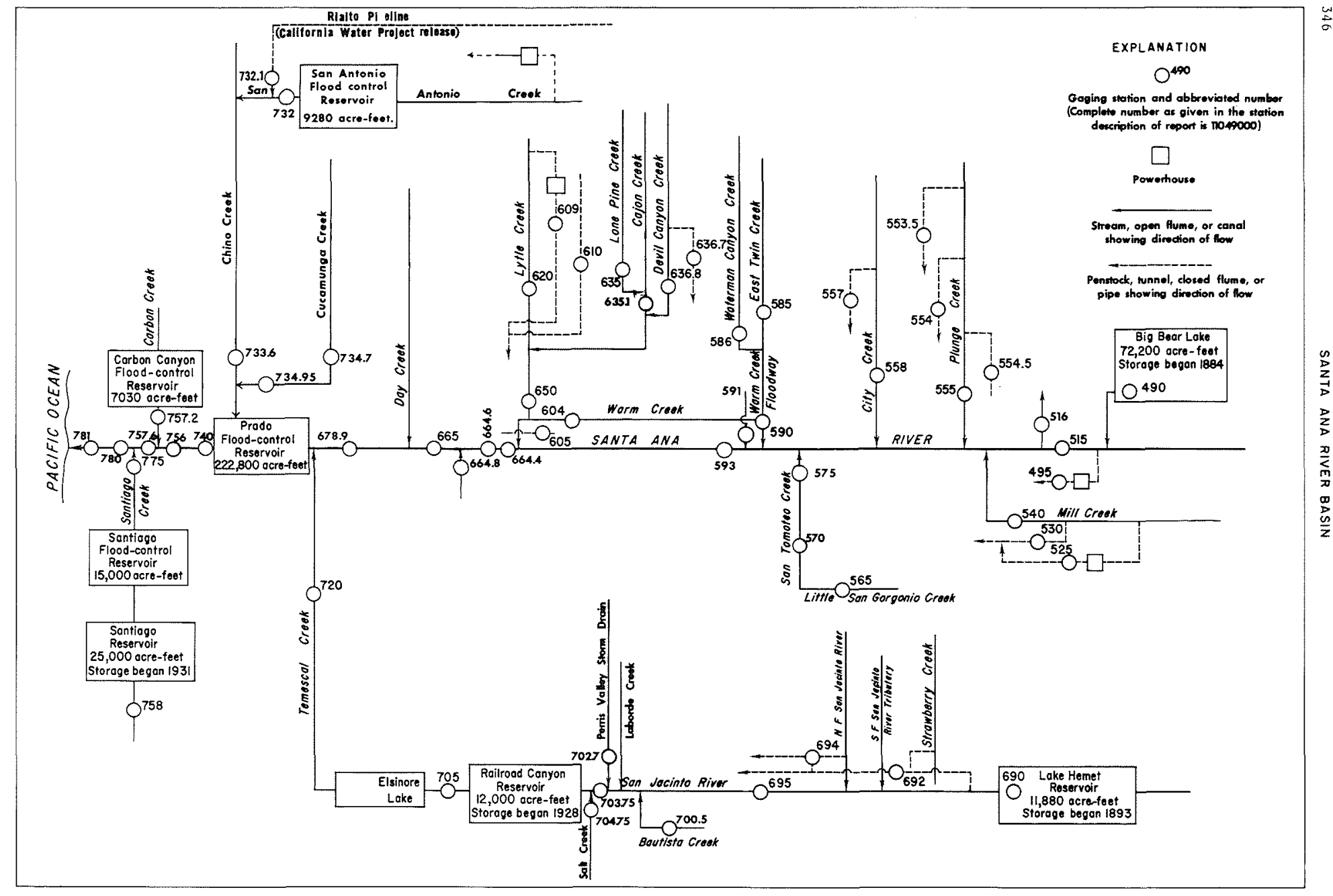

Figure 5-- Schemotic diagram showing diversions and storage in Santa Ano River basin. 
11049000 BIG BEAR LAKE NEAR BIG BEAR LAKE, CA

LOCATION, - Lat $34^{\circ} 14^{\prime} 33^{\prime \prime}$, long $116^{\circ} 58^{\prime} 33^{\prime \prime}$, in SW/4 sec.22, T.2 N., R. 1 W., San Bernardino County, at Big Bear Lake Dam on Bear Creek, $4 \mathrm{mi}(6 \mathrm{~km})$ west of town of Big Bear Lake, and 7.5 mi (12.I km) upstream from mouth.

DRAINAGE AREA. $-72.2 \mathrm{mi}^{2}\left(187.0 \mathrm{~km}^{2}\right)$, revised, including Baldwin Lake drainage.

PERIOD OF RECORD. - October 1950 to current year in reports of Geological Survey. February 1884 to September 1950 in files of Bear Valley Mutual Water Co.

GAGE. - Nonrecording gage. Datum of gage is $6,670.9 \mathrm{ft}(2,033,290 \mathrm{~m}$ ) above mean sea 1 evel (levels by Bear Val1ey Mutual Water Co.). Prior to 1912 at old dam $200 \mathrm{ft}(61 \mathrm{~m})$ upstrean at same datum; spillway at gage height $52.4 \mathrm{ft}(16.0 \mathrm{~m})$.

REMARKS. - Lake is formed by multiple-arch concrete dam, completed in 1912, replacing existing lower dam built in 1884; storage began in spring of 1884. Capacity, 72,200 acre-ft $\left(89.0 \mathrm{hm}{ }^{3}\right.$ ) at elevation $6,743.2$ ft

$(2,055.327 \mathrm{~m})$, top of dam. Capacity table based on survey made in 1883 . No dead storage. Water used for

irrigation only. See schematic diagram of Santa Ana River basin.

COOPERATION. - Record of contents furnished by Bear Valley Mutual Water Co.

EXTREMES FOR PERIOD OF RECORD.--Maximum contents unknown, lake spil1ed in 1916, 1917, 1922, 1923, 1938,

1939 , 1969, 1970; 1ake dry October, November 1898, August to November 1899, October, November 1904.

EXTREMES FOR CURRENT YEAR. - Maximum contents observed, 46,450 acre-ft (57.3 hm ${ }^{3}$ ) Oct. 1; minimum contents observed, 37,160 acre-ft $\left(45.8 \mathrm{hm}^{3}\right)$ Aug. 31 .

MONTHEND CONTENTS, WATER YEAR OCTOBER 1975 TO SEPTEMBER 1976

\section{Date}

Sept. $30 \ldots \ldots \ldots \ldots \ldots \ldots \ldots \ldots$

oct. $\quad 31 \ldots \ldots \ldots \ldots \ldots \ldots \ldots \ldots$

Nov. $30 \ldots \ldots \ldots \ldots \ldots \ldots \ldots \ldots \ldots$

Dec. $\quad 31 \ldots \ldots \ldots \ldots \ldots \ldots \ldots \ldots$

CAL YR $1975 \ldots \ldots \ldots \ldots \ldots$

Jan. $\quad 31 \ldots \ldots \ldots \ldots \ldots \ldots \ldots \ldots$

Feb. $\quad 28 \ldots \ldots \ldots \ldots \ldots \ldots \ldots \ldots$

Mar. $\quad 31 \ldots \ldots \ldots \ldots \ldots \ldots \ldots \ldots$

Apr. $\quad 30 \ldots \ldots \ldots \ldots \ldots \ldots \ldots$

May $\quad 31 \ldots \ldots \ldots \ldots \ldots \ldots \ldots \ldots \ldots \ldots$

June $\quad 30 \ldots \ldots \ldots \ldots \ldots \ldots \ldots \ldots \ldots \ldots$

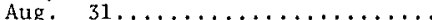

Sept. $30 \ldots \ldots \ldots \ldots \ldots \ldots \ldots \ldots \ldots$

WTR YR $1976 \ldots \ldots \ldots \ldots \ldots \ldots \ldots$

Contents
(acre-feet)

46450
44660
43660
43660

42270

42870

45260

45460

44260

41870

39610

37160

37690
Change in contents

(acre-feet)

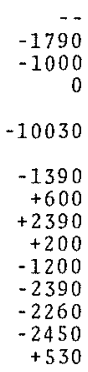

$-8760$ 


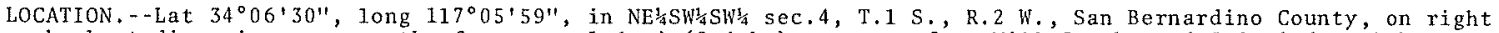
bank at diversion near mouth of canyon, $1.6 \mathrm{mi}(2.6 \mathrm{~km})$ upstream from Mi.11 Creek, and $3.2 \mathrm{mi}(5.1 \mathrm{~km}) \mathrm{north}$ east of Mentone.

DRAINAGE AREA. $-210 \mathrm{mi}^{2}\left(544 \mathrm{~km}^{2}\right)$, revised, including area tributary to Baldwin Lake at head of Bear Valley.

PERIOD OF RECORD. - July 1896 to current year. Prior to october 1914, observed records not equivalent owing to Greenspot pipeline diversion between sites and exclusion of discharge Erom Warm Springs Canyon. Monthly discharge only for January 1910, January and February 1916 published in WSP $1315-B$.

GAGE.-Three water-stage recorders. Main gage on right bank of river, canal gage on powerhouse diversion, and since 1970 supplementary gage on left bank of river, Altitude of main and supplementary gages is 1 , 950 ft $(594 \mathrm{~m})$, from topographic map. Prior to Sept. 2, 1917, nonrecording gages at several sites within 1.5 mi $(2.4 \mathrm{~km})$ upstream at various datums. Sept. 3, 1917, to May 27, 1969, water-stage recorder at site 0.2 mi $(0.3 \mathrm{~km})$ upstream at different datum. Canal gage at different datum.

REMARKS.--Records fair. Flow partly regulated by Big Bear Lake (station 11049000). For records of combined discharge of Santa Ana River and Southern California Edison Co.'s canal below powerplant No. 2 , which diverts above station, see following page. Bear valley Mutual Water Co. pumped 328 acre-ft (404, $400 \mathrm{~m}^{3}$ ) into canal below canal gage. Prior to oct. 1, 1952, and after Apr. 26, 1976, pumped water entered canal above gage, See schematic diagram of Santa Ana River basin.

COOPERATION, - Three discharge measurements on Southern California Edison Co.'s canal below powerplant No. 2 were furnished by that agency, in connection with a Federal Power Conmission project.

AVERAGE DISCHARGE. - -River on 1 y: 62 years (water years $1915-76), 32.2 \mathrm{ft}^{3} / \mathrm{s}(0.912 \mathrm{~m} / \mathrm{s}), 23,330 \mathrm{acre}-\mathrm{ft} / \mathrm{yr}$ $\left(28.7 \mathrm{hm}^{3} / \mathrm{yr}\right)$.

Combined river and canal: 80 years, $80.2 \mathrm{ft}^{3} / \mathrm{s}\left(2.27 \mathrm{~m}^{3} / \mathrm{s}\right), 58,100 \mathrm{acre}-\mathrm{ft} / \mathrm{yr}(71.6 \mathrm{hm} / \mathrm{yr})$

EXTREMES FOR PERIOD OF RECORD. - -River on 1y: Maximum discharge, $52,300 \mathrm{ft}^{3} / \mathrm{s}(1,480 \mathrm{~m} / \mathrm{s}) \mathrm{Mar}$. 2 , 1938 , gage height, $14.3 \mathrm{ft}(4.359 \mathrm{~m})$, site and datum then in use, on basis of slope-area measurement of maximum flow; no flow at times in some years.

Combined river and canal: Maximum discharge, $52,300 \mathrm{ft}^{3} / \mathrm{s}\left(1,480 \mathrm{~m}^{3} / \mathrm{s}\right) \mathrm{Mar} .2,1938 ; \mathrm{minimum} \mathrm{dail}^{\mathrm{y}}$, $7.4 \mathrm{ft} / \mathrm{s}$ $\left(0.21 \mathrm{~m}^{3} / \mathrm{s}\right)$ Sept. 21,1971 .

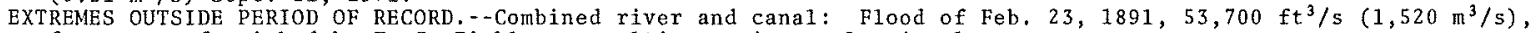
from notes furnished by $\mathrm{F}$. C. Finkle, consulting engineer, Los Angeles.

EXTREMES FOR CURRENT YEAR. - - Peak discharges above base of $150 \mathrm{ft}^{3} / \mathrm{s}\left(4.25 \mathrm{~m}^{3} / \mathrm{s}\right)$ and maximum (*), on basis of slope-area measurement of peak flow:

\begin{tabular}{|c|c|c|c|c|c|c|c|}
\hline Date & Time & $\begin{array}{r}\mathrm{Ri} \\
\mathrm{Disc} \\
\left(\mathrm{ft}^{3} / \mathrm{s}\right.\end{array}$ & $\begin{array}{l}r \\
\mathrm{rge} \\
\left(\mathrm{m}^{3} / \mathrm{s}\right)\end{array}$ & $\begin{array}{l}\text { Gage } \\
(\mathrm{ft})\end{array}$ & $\underset{\text { (III) }}{\operatorname{eight}}$ & $\begin{array}{r}\text { Combined River } \\
\text { Disc } \\
\left(\mathrm{ft}^{3} / \mathrm{s}\right.\end{array}$ & $\begin{array}{l}\text { nd D } \\
\mathrm{rge} \\
\left(\mathrm{m}^{3} / \mathrm{s}\right.\end{array}$ \\
\hline $\begin{array}{lr}\text { Feb. } & 9 \\
\text { Mar. } & 1 \\
\text { Sept. } & 11\end{array}$ & $\begin{array}{l}0100 \\
1600 \\
0500\end{array}$ & $\begin{array}{r}785 \\
544 \\
* 1380\end{array}$ & $\begin{array}{l}22.2 \\
15.4 \\
39.1\end{array}$ & $\begin{array}{l}4.44 \\
3.86 \\
6.15\end{array}$ & $\begin{array}{l}1.353 \\
1.177 \\
1.875\end{array}$ & $\begin{array}{r}889 \\
547 \\
* 1380\end{array}$ & $\begin{array}{l}25 . \\
15 . \\
39 .\end{array}$ \\
\hline
\end{tabular}

Combined river and diversion: Minimum daily discharge, no flow many days.

DISCHARGE, IN CUBIC FEET PER SECOND, WATER YEAR OCTOBER 1975 TO SEPTEMBER 1976 MEAN VALUES

\begin{tabular}{|c|c|c|c|c|c|c|c|c|c|c|c|c|}
\hline DAY & OCT & NOV & DEC & JAN & FEB & MAR & APR & MAY & JUN & JUL & AUB & SEP \\
\hline $\begin{array}{l}1 \\
2 \\
3 \\
4 \\
5\end{array}$ & $\begin{array}{l}0 \\
0 \\
0 \\
0 \\
0\end{array}$ & $\begin{array}{l}0 \\
0 \\
0 \\
0 \\
0\end{array}$ & $\begin{array}{l}13 \\
0 \\
0 \\
0\end{array}$ & & $\begin{array}{l}0 \\
0 \\
0 \\
0 \\
4.3\end{array}$ & $\begin{array}{r}144 \\
141 \\
92 \\
20 \\
17\end{array}$ & $\begin{array}{l}2.6 \\
2.4 \\
2.4 \\
3.1 \\
3.6\end{array}$ & $\begin{array}{l}2.1 \\
2.0 \\
2.6 \\
. .49\end{array}$ & $\begin{array}{l}.08 \\
.07 \\
.08 \\
.08 \\
.08\end{array}$ & & & $\begin{array}{l}0 \\
0 \\
0 \\
0 \\
0\end{array}$ \\
\hline $\begin{array}{r}6 \\
7 \\
8 \\
9 \\
10\end{array}$ & $\begin{array}{l}0 \\
0 \\
1.4 \\
0 \\
0\end{array}$ & $\begin{array}{l}0 \\
0 \\
0 \\
0 \\
0\end{array}$ & $\begin{array}{l}0 \\
0 \\
0 \\
0 \\
0\end{array}$ & & $\begin{array}{r}12 \\
25 \\
91 \\
355 \\
103\end{array}$ & $\begin{array}{l}14 \\
12 \\
14 \\
14 \\
14\end{array}$ & $\begin{array}{l}2.9 \\
2.6 \\
2.9 \\
2.9 \\
2.6\end{array}$ & $\begin{array}{l}0 \\
.58 \\
.02 \\
.09 \\
.03\end{array}$ & $\begin{array}{l}.13 \\
.26 \\
.07 \\
.05 \\
.08\end{array}$ & & & $\begin{array}{r}0 \\
16 \\
72 \\
88 \\
308\end{array}$ \\
\hline $\begin{array}{l}11 \\
12 \\
13 \\
14 \\
15\end{array}$ & $\begin{array}{l}0 \\
0 \\
0 \\
0 \\
0\end{array}$ & $\begin{array}{l}0 \\
0 \\
0 \\
0 \\
0\end{array}$ & $\begin{array}{r}0 \\
0 \\
14 \\
17 \\
20\end{array}$ & & $\begin{array}{l}59 \\
48 \\
32 \\
7.1 \\
5.9\end{array}$ & $\begin{array}{l}14 \\
12 \\
15 \\
12 \\
11\end{array}$ & $\begin{array}{l}2.3 \\
2.6 \\
4.0 \\
3.8 \\
5.8\end{array}$ & $\begin{array}{l}.03 \\
.03 \\
.06 \\
.12 \\
.12\end{array}$ & $\begin{array}{l}.07 \\
.04 \\
.03 \\
.02 \\
.02\end{array}$ & & & $\begin{array}{r}646 \\
122 \\
59 \\
40 \\
29\end{array}$ \\
\hline $\begin{array}{l}16 \\
17 \\
18 \\
19 \\
20\end{array}$ & $\begin{array}{l}0 \\
0 \\
0 \\
0 \\
0\end{array}$ & $\begin{array}{l}0 \\
0 \\
0 \\
0 \\
0\end{array}$ & $\begin{array}{c}21 \\
16 \\
6.6 \\
9.3 \\
.43\end{array}$ & & $\begin{array}{l}5.0 \\
4.0 \\
3.8 \\
3.8 \\
3.8\end{array}$ & $\begin{array}{l}8.5 \\
7.9 \\
7.9 \\
7.6 \\
6.6\end{array}$ & $\begin{array}{l}5.6 \\
4.0 \\
2.6 \\
2.3 \\
2.2\end{array}$ & $\begin{array}{r}.12 \\
.12 \\
.10 \\
.10 \\
.10\end{array}$ & $\begin{array}{l}0 \\
0 \\
0 \\
0 \\
0\end{array}$ & & & $\begin{array}{l}24 \\
22 \\
18 \\
16 \\
13\end{array}$ \\
\hline $\begin{array}{l}21 \\
22 \\
23 \\
24 \\
25\end{array}$ & $\begin{array}{l}0 \\
0 \\
0 \\
0 \\
0\end{array}$ & $\begin{array}{l}0 \\
0 \\
0 \\
0 \\
0\end{array}$ & $\begin{array}{l}0 \\
0 \\
0 \\
0 \\
0\end{array}$ & & $\begin{array}{l}3.4 \\
3.2 \\
2.9 \\
2.6 \\
2.2\end{array}$ & $\begin{array}{l}5.4 \\
5.2 \\
5.6 \\
5.0 \\
4.2\end{array}$ & $\begin{array}{l}5.9 \\
2.8 \\
2.6 \\
2.4 \\
2.5\end{array}$ & $\begin{array}{l}.10 \\
.10 \\
.10 \\
.08 \\
.08\end{array}$ & $\begin{array}{l}0 \\
0 \\
0 \\
0 \\
0\end{array}$ & & & $\begin{array}{l}6.8 \\
6.6 \\
6.3 \\
44 \\
35\end{array}$ \\
\hline $\begin{array}{l}26 \\
27 \\
28 \\
29 \\
30 \\
31\end{array}$ & $\begin{array}{l}0 \\
0 \\
0 \\
0 \\
0 \\
2.5\end{array}$ & $\begin{array}{l}0 \\
0 \\
0 \\
0 \\
7.2 \\
-2\end{array}$ & $\begin{array}{l}0 \\
0 \\
0 \\
0 \\
0 \\
0\end{array}$ & & $\begin{array}{l}2.2 \\
2.0 \\
2.0 \\
2.0 \\
-\end{array}$ & $\begin{array}{l}4.0 \\
2.9 \\
2.8 \\
2.6 \\
2.6 \\
2.6\end{array}$ & $\begin{array}{l}2.5 \\
2.5 \\
2.5 \\
2.5 \\
2.5 \\
-.-\end{array}$ & $\begin{array}{l}.08 \\
.08 \\
.08 \\
.06 \\
.06 \\
.06\end{array}$ & $\begin{array}{l}0 \\
0 \\
0 \\
0 \\
0 \\
-\end{array}$ & & & $\begin{array}{r}11 \\
9.3 \\
7.9 \\
5.0 \\
4.8 \\
-\end{array}$ \\
\hline $\begin{array}{l}\text { TOTAL } \\
\text { MEAN } \\
\text { MAX } \\
\text { MIN } \\
\text { AC-FT }\end{array}$ & $\begin{array}{r}3.9 \\
.13 \\
2.5 \\
0 \\
7.7\end{array}$ & $\begin{array}{r}7.2 \\
.24 \\
7.2 \\
0 \\
14\end{array}$ & $\begin{array}{r}117.60 \\
3.79 \\
21 \\
0 \\
233\end{array}$ & $\begin{array}{l}0 \\
0 \\
0 \\
0 \\
0\end{array}$ & $\begin{array}{r}785.2 \\
27.1 \\
355 \\
0 \\
1560\end{array}$ & $\begin{array}{r}627.4 \\
20.2 \\
144 \\
2.6 \\
1240\end{array}$ & $\begin{array}{r}91.9 \\
3.06 \\
5.9 \\
2.2 \\
182\end{array}$ & $\begin{array}{r}9.69 \\
.31 \\
2.6 \\
0 \\
19\end{array}$ & $\begin{array}{r}1.16 \\
.039 \\
.26 \\
0 \\
2.3\end{array}$ & $\begin{array}{l}0 \\
0 \\
0 \\
0 \\
0\end{array}$ & $\begin{array}{l}0 \\
0 \\
0 \\
0 \\
0\end{array}$ & $\begin{array}{r}1609.7 \\
53.7 \\
646 \\
0 \\
3190\end{array}$ \\
\hline
\end{tabular}

$\begin{array}{lllllllll}\text { CAL YR } 1975 & \text { TOTAL } 1890.63 & \text { MEAN } 5.18 & \text { MAX } 153 & \text { MIN } 0 & \text { AC-FT } & 3750 \\ \text { WTF YR } 1976 & \text { TOTAL } & 3253.75 & \text { MEAN } 8.89 & \text { MAX } 646 & \text { MIN } 0 & \text { AC-FT } & 6450\end{array}$ 
11051500 SANTA ANA RIVER NEAR MENTONE, CA--Continued

COMBINED DISCHARGE, IN CUBIC FEET PER SECOND, OF SANTA ANA RIVER AND SOUTHERN CALIFORNIA EDISON CO.' S CANAL NEAR MENTONE, CA, WATER YEAR OCTOBER 1975 TO SEPTEMBER 1976

DISCHARGE, IN CUBIC FEET PER SECOND, WATER YEAR OCTOBER 1975 TO SEPTEMBER 1976 MEAN VALUES

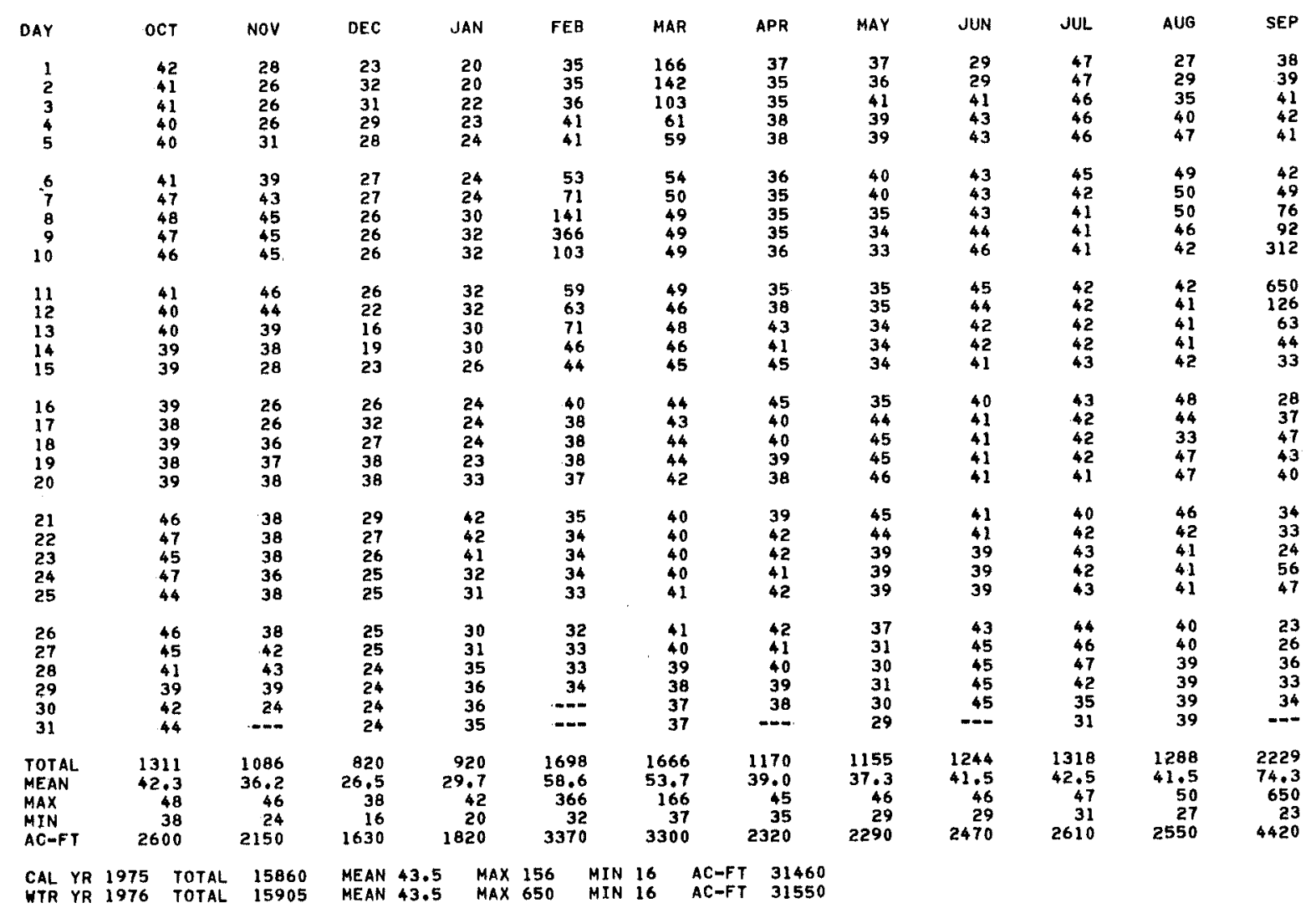


11051600 SANTA ANA RIVER SPREADING DIVERSION NEAR MENTONE, CA

LOCATION, - Lat $34^{\circ} 06^{\prime} 12^{\prime \prime}$, long $117^{\circ} 06^{\prime} 37^{\prime \prime}$, in SW/ $W^{\frac{1}{4}} \mathrm{NE}^{\frac{1}{4}}$ sec.8, T.1 S., R. 2 W., San Bernardino County, on

diversion channel 0.8 'mi $(1.3 \mathrm{~km})$ down'stream from Southern'California Edison Co. 's powerhouse No.' 3 , and $2.4 \mathrm{mi}(3.9 \mathrm{~km})$ northeast of Mentone.

PERIOD OF RECORD, - - October 1951 to current year,

GAGE, - Water-stage recorder and Parsha11 flume control. Altitude of gage is $1,840 \mathrm{ft}$ (561 $\mathrm{m}$ ), from topographic map.

REMARKS.--Records good. Water is diverted from Santa Ana River at diversion dam $0.8 \mathrm{mi}$ (1.3 km) upstream, for spreading on debris cone downstream from mouth of Santa Ana River Canyon. Diversion began prior to 1951 .

EXTREMES FOR PERIOD OF RECORD,--Maximum daily discharge, $141 \mathrm{ft}^{3} / \mathrm{s}\left(3.99 \mathrm{~m}^{3} / \mathrm{s}\right) \mathrm{Mar}$. 16 , 1973 ; no flow for $10 \mathrm{fg}$ periods in each year.

DISCHARGE, IN CUBIC FEET PER SECOND, WATER YEAR OCTOBER 1975 TO SEPTEMBER 1976 MEAN VALUES

\begin{tabular}{|c|c|c|c|c|c|c|c|c|c|c|c|c|}
\hline DAY & OCT & NOV & DEC & JAN & FEB & MAR & APR & MAY & JUN & JUL & AUG & SEP \\
\hline $\begin{array}{l}1 \\
2 \\
3 \\
4 \\
5\end{array}$ & & $\begin{array}{l}0 \\
0 \\
0 \\
0 \\
0\end{array}$ & $\begin{array}{l}0 \\
0 \\
2.8 \\
4.7 \\
4.7\end{array}$ & & $\begin{array}{l}0 \\
0 \\
0 \\
3.7 \\
9.7\end{array}$ & $\begin{array}{l}50 \\
63 \\
59 \\
53 \\
50\end{array}$ & $\begin{array}{l}11 \\
7.0 \\
7.1 \\
7.9 \\
8.1\end{array}$ & $\begin{array}{l}0 \\
0 \\
0 \\
0 \\
0\end{array}$ & & & & $\begin{array}{l}0 \\
0 \\
0 \\
0 \\
0\end{array}$ \\
\hline $\begin{array}{r}6 \\
7 \\
8 \\
9 \\
10\end{array}$ & & $\begin{array}{l}0 \\
0 \\
0 \\
0 \\
0\end{array}$ & $\begin{array}{l}2,2 \\
0 \\
0 \\
0 \\
0\end{array}$ & & $\begin{array}{l}29 \\
45 \\
40 \\
79 \\
83\end{array}$ & $\begin{array}{l}40 \\
35 \\
34 \\
33 \\
32\end{array}$ & $\begin{array}{c}7.4 \\
7.3 \\
3.5 \\
.30 \\
.30\end{array}$ & $\begin{array}{l}0 \\
0 \\
0 \\
0 \\
0\end{array}$ & & & & $\begin{array}{l}0 \\
0 \\
3.8 \\
3.4 \\
.92\end{array}$ \\
\hline $\begin{array}{l}11 \\
12 \\
13 \\
14 \\
15\end{array}$ & & $\begin{array}{l}0 \\
0 \\
0 \\
0 \\
0\end{array}$ & $\begin{array}{l}0 \\
0 \\
0 \\
0 \\
0\end{array}$ & & $\begin{array}{l}44 \\
31 \\
24 \\
18 \\
16\end{array}$ & $\begin{array}{l}32 \\
31 \\
30 \\
30 \\
29\end{array}$ & $\begin{array}{l}.26 \\
3.6 \\
8.7 \\
8.0 \\
9.5\end{array}$ & $\begin{array}{l}0 \\
0 \\
0 \\
0 \\
2.4\end{array}$ & & & & $\begin{array}{r}0 \\
49 \\
46 \\
30 \\
24\end{array}$ \\
\hline $\begin{array}{l}16 \\
17 \\
18 \\
19 \\
20\end{array}$ & & $\begin{array}{l}0 \\
0 \\
0 \\
0 \\
0\end{array}$ & $\begin{array}{l}0 \\
0 \\
0 \\
0\end{array}$ & & $\begin{array}{l}18 \\
21 \\
21 \\
21 \\
20\end{array}$ & $\begin{array}{l}29 \\
28 \\
27 \\
26 \\
25\end{array}$ & $\begin{array}{l}18 \\
19 \\
16 \\
16 \\
18\end{array}$ & $\begin{array}{l}2.5 \\
0 \\
0 \\
0 \\
0\end{array}$ & & & & $\begin{array}{l}22 \\
13 \\
20 \\
23 \\
7.6\end{array}$ \\
\hline $\begin{array}{l}21 \\
22 \\
23 \\
24 \\
25\end{array}$ & & $\begin{array}{l}0 \\
0 \\
0 \\
0 \\
0\end{array}$ & $\begin{array}{l}0 \\
0 \\
0 \\
0 \\
0\end{array}$ & & $\begin{array}{l}19 \\
18 \\
18 \\
17 \\
17\end{array}$ & $\begin{array}{l}24 \\
23 \\
22 \\
21 \\
20\end{array}$ & $\begin{array}{l}19 \\
18 \\
13 \\
9.2 \\
8.7\end{array}$ & $\begin{array}{l}0 \\
0 \\
0 \\
0 \\
0\end{array}$ & & & & $\begin{array}{l}5.2 \\
11 \\
13 \\
24 \\
16\end{array}$ \\
\hline $\begin{array}{l}26 \\
27 \\
28 \\
29 \\
30 \\
31\end{array}$ & & $\begin{array}{l}0 \\
0 \\
4.6 \\
12 \\
3.5 \\
-.--\end{array}$ & $\begin{array}{l}0 \\
0 \\
0 \\
0 \\
0 \\
0\end{array}$ & & $\begin{array}{l}19 \\
22 \\
22 \\
23 \\
- \\
--\end{array}$ & $\begin{array}{l}20 \\
19 \\
19 \\
19 \\
18 \\
17\end{array}$ & $\begin{array}{l}8.4 \\
8.4 \\
8.3 \\
3.5 \\
.18 \\
.0-\end{array}$ & $\begin{array}{l}0 \\
0 \\
0 \\
0 \\
0 \\
0\end{array}$ & $\ldots$ & & & $\begin{array}{c}8.5 \\
8.9 \\
12 \\
16 \\
9.2 \\
----\end{array}$ \\
\hline $\begin{array}{l}\text { TOTAL } \\
\text { MEAN } \\
\text { MAX } \\
\text { MIN } \\
\text { AC-FT }\end{array}$ & $\begin{array}{l}0 \\
0 \\
0 \\
0 \\
0\end{array}$ & $\begin{array}{r}20.1 \\
.67 \\
12 \\
0 \\
40\end{array}$ & $\begin{array}{r}14.71 \\
.47 \\
4.7 \\
0 \\
29\end{array}$ & $\begin{array}{l}0 \\
0 \\
0 \\
0 \\
0\end{array}$ & $\begin{array}{r}698.4 \\
24.1 \\
83 \\
0 \\
1390\end{array}$ & $\begin{array}{r}958 \\
30.9 \\
63 \\
17 \\
1900\end{array}$ & $\begin{array}{r}273.64 \\
9.12 \\
19 \\
.18 \\
543\end{array}$ & $\begin{array}{r}4.9 \\
116 \\
2.5 \\
0 \\
9.7\end{array}$ & $\begin{array}{l}0 \\
0 \\
0 \\
0 \\
0\end{array}$ & $\begin{array}{l}0 \\
0 \\
0 \\
0 \\
0\end{array}$ & $\begin{array}{l}0 \\
0 \\
0 \\
0 \\
0\end{array}$ & $\begin{array}{r}366.52 \\
12.2 \\
49 \\
0 \\
727\end{array}$ \\
\hline
\end{tabular}

$\begin{array}{lllllllll}\text { CAL YR } 1975 & \text { TOTAL } & 3698.70 & \text { MEAN } 10.1 & \text { MAX } 71 & \text { MIN } 0 & \text { AC-FT } 7340 \\ \text { WTR YR } 1976 & \text { TOTAL } & 2336.27 & \text { MEAN } 6.38 & \text { MAX } 83 & \text { MIN } 0 & \text { AC-FT } 4630\end{array}$ 
11054000 MILL CREEK NEAR YUCAIPA, CA

LOCATION. --Lat $34^{\circ} 05^{\prime} 27^{\prime \prime}$, long $117^{\circ} 02^{\prime} 12^{\prime \prime}$, in NWhEs $\mathrm{NE}_{4}$ sec.13, T.1 S., R. 2 W., San Bernardino County, on 1 eft bank $50 \mathrm{ft}(15 \mathrm{~m})$ downstream from bridge on State Highway 38 (revised), $3 . \dot{9}^{\prime} \mathrm{mi}$ ( $6.3 \mathrm{~km}$ ) north of Yucaipa, and $5.3 \mathrm{mi}(8.5 \mathrm{~km})$ upstream from mouth.

DRAINAGE AREA. $-42.4 \mathrm{mi}^{2}\left(110 \mathrm{~km}^{2}\right)$.

PERIOD OF RECORD, - January 1919 to September 1938 , October 1947 to current year. Month1y figures only for April and May 1923, published in WSP 1315-B. prior to October 1954, published as "near Craftonvilie,"

GAGE.-Water-stage recorder on creek; water-stage recorder and sharp-crested weir on power canal No. 1 ; waterstage recorder and Parshall flume on power canals Nos, 2 and 3 . Datum of creek gage is $2,916.36 \mathrm{ft}$ ( $888.907 \mathrm{~m}$ ) above mean sea level (Southern California Edison Co. bench mark). Canals are all at different datums. See WSP 1735 for history of changes prior to Mar. 2, 1938

REMARKS. - Records poor. No regulation above station. Mil1 Creek power canals Nos. 1 , 2 , and 3 divert from points $100 \mathrm{ft}(30 \mathrm{~m}), 3 \mathrm{mi}(5 \mathrm{~km})$, and $6 \mathrm{mi}(10 \mathrm{~km})$ above station, respectively. Combined flow of Mili Creek and Mill Creek power canals Nos. 1, 2, and 3 is given on following page. See schematic diagram of Santa Ana River basin.

COOPERATION. - Water-stage recorder graph and three discharge measurements for Mill Creek power canals Nos. 2 and 3 furnished by Southern California Edison Co, in connection with a Federa1 Power Commission project.

AVERAGE DISCHARGE.--Creek only: 48 years (water years 1920-38, 1948-76), 12.8 $\mathrm{ft}^{3} / \mathrm{s}^{2}\left(0.362 \mathrm{~m} / \mathrm{s}^{3}\right), 9,270 \mathrm{acre}-\mathrm{ft} / \mathrm{yr}$ $\left(11.4 \mathrm{hm}^{3} / \mathrm{yr}\right)$

Combined creek and canals: 48 years, $33.5 \mathrm{ft}^{3} / \mathrm{s}\left(0.949 \mathrm{~m}^{3} / \mathrm{s}\right), 24,270 \mathrm{acre}-\mathrm{ft} / \mathrm{yr}\left(29.9 \mathrm{hm} / \mathrm{yr}^{3}\right)$

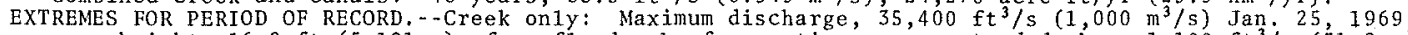
gage height, $16.8 \mathrm{ft}(5.12 \mathrm{~m})$, from floodmark, from rating curve extended above $1,100 \mathrm{ft}{ }^{3} / \mathrm{s}(31.2 \mathrm{~m} / \mathrm{s})$ on basis of two field estimates at gage height $14.5 \mathrm{ft}(4.420 \mathrm{~m})$ and slope-area measurement of maximum flow; no flow at times in some years.

Combined creek and cana1s: Maximum discharge, $35,400 \mathrm{ft}^{3} / \mathrm{s}\left(1,000 \mathrm{~m}^{3} / \mathrm{s}\right) \mathrm{Jan} .25,1969 ; \mathrm{minimum} \mathrm{daily,}$ $2.7 \mathrm{ft}^{3} / \mathrm{s}\left(0.077 \mathrm{~m}^{3} / \mathrm{s}\right) \mathrm{Feb}, 23,1949$

EXTREMES FOR CURRENT YEAR. - Peak discharge above base of $100 \mathrm{ft}^{3} / \mathrm{s}\left(2.83 \mathrm{~m}^{3} / \mathrm{s}\right)$ and maximum $(*)$ :

\begin{tabular}{|c|c|c|c|c|}
\hline Date & Tine & $\begin{array}{c}\text { Creek } \\
\text { Discharge } \\
\left(\mathrm{ft}^{3} / \mathrm{s}\right)\left(\mathrm{m}^{3} / \mathrm{s}\right)\end{array}$ & $\begin{array}{rr}\text { Gage height } \\
(\mathrm{ft}) & (\mathrm{m})\end{array}$ & $\begin{array}{c}\text { Combined Creek and Canals } \\
\text { Discharge } \\
\left(\mathrm{ft}^{3} / \mathrm{s}\right)\left(\mathrm{m}^{3} / \mathrm{s}\right)\end{array}$ \\
\hline $\begin{array}{lr}\text { Feb. } & 8 \\
\text { Mar. } & 1 \\
\text { Sept. } & 11\end{array}$ & $\begin{array}{l}2200 \\
1700 \\
0600\end{array}$ & $\begin{array}{c}10.1 \\
4.42 \\
142.0\end{array}$ & $\begin{array}{r}8.91 \\
8.46 \\
10.95\end{array}$ & $\begin{aligned} 10.1 \\
4.45 \\
142.0\end{aligned}$ \\
\hline
\end{tabular}

Creek only: Minimum daily discharge, no flow oct. 8-19.

Combined creek and canals: Minimum daily discharge; $7.3 \mathrm{ft}^{3} / \mathrm{s}\left(0.21 \mathrm{~m}^{3} / \mathrm{s}\right) \mathrm{Sept} .26$.

DISCHARGE, IN CUBIC FEET PER SECOND, HATER YEAR OCTOBER 1975 TO SEPTEMBER 1976 MEAN VALUES

\begin{tabular}{|c|c|c|c|c|c|c|c|c|c|c|c|c|}
\hline DAY & OCT & Nov & DEC & JAN & FEB & MAR & APR & MAY & JUN & JUL & AUG & SEP \\
\hline $\begin{array}{l}1 \\
2 \\
3 \\
4 \\
5\end{array}$ & $\begin{array}{l}.05 \\
.05 \\
.10 \\
.10 \\
.10\end{array}$ & $\begin{array}{l}.04 \\
.04 \\
.04 \\
.04 \\
.01\end{array}$ & $\begin{array}{l}.47 \\
.34 \\
.29 \\
.29 \\
.29\end{array}$ & $\begin{array}{l}.17 \\
.17 \\
.17 \\
.20 \\
.20\end{array}$ & $\begin{array}{r}.40 \\
.47 \\
.40 \\
.74 \\
1.3\end{array}$ & $\begin{array}{l}28 \\
15 \\
12 \\
6.2 \\
4.2\end{array}$ & $\begin{array}{r}.33 \\
.33 \\
.37 \\
.33 \\
.30\end{array}$ & $\begin{array}{l}.07 \\
.07 \\
.07 \\
.07 \\
.07\end{array}$ & $\begin{array}{l}.09 \\
.09 \\
.09 \\
.08 \\
.08\end{array}$ & $\begin{array}{r}.08 \\
.08 \\
.08 \\
.08 \\
.08\end{array}$ & $\begin{array}{r}.10 \\
110 \\
110 \\
110 \\
110\end{array}$ & $\begin{array}{l}.13 \\
.13 \\
.13 \\
.13 \\
.13\end{array}$ \\
\hline $\begin{array}{r}6 \\
7 \\
8 \\
9 \\
10\end{array}$ & $\begin{array}{l}.10 \\
.05 \\
0 \\
0 \\
0\end{array}$ & $\begin{array}{l}.01 \\
.02 \\
.04 \\
.05 \\
.05\end{array}$ & $\begin{array}{r}.29 \\
.29 \\
.62 \\
.74 \\
1.2\end{array}$ & $\begin{array}{l}.20 \\
.17 \\
.17 \\
.17 \\
.14\end{array}$ & $\begin{array}{l}1.7 \\
2.5 \\
92 \\
68 \\
9.8\end{array}$ & $\begin{array}{l}4.2 \\
4.4 \\
4.2 \\
4.2 \\
4.4\end{array}$ & $\begin{array}{l}.39 \\
.27 \\
.30 \\
.15 \\
.08\end{array}$ & $\begin{array}{l}.08 \\
.08 \\
.08 \\
.08 \\
.08\end{array}$ & $\begin{array}{l}.09 \\
.10 \\
.10 \\
10 \\
11\end{array}$ & $\begin{array}{l}.08 \\
.08 \\
.08 \\
.08 \\
.08\end{array}$ & $\begin{array}{l}.10 \\
.10 \\
.10 \\
110 \\
.10 \\
.10\end{array}$ & ${ }_{461}^{13^{.17}}$ \\
\hline $\begin{array}{l}11 \\
12 \\
13 \\
14 \\
15\end{array}$ & $\begin{array}{l}0 \\
0 \\
0 \\
0 \\
0\end{array}$ & $\begin{array}{l}.09 \\
.09 \\
.11 \\
.11 \\
.14\end{array}$ & $\begin{array}{l}2.6 \\
1.4 \\
.36 \\
.07 \\
.07\end{array}$ & $\begin{array}{l}.14 \\
.14 \\
.14 \\
.14 \\
.11\end{array}$ & $\begin{array}{l}1.8 \\
.20 \\
.20 \\
.20 \\
1.5\end{array}$ & $\begin{array}{l}4.4 \\
3.9 \\
3.7 \\
3.7 \\
3.7\end{array}$ & $\begin{array}{l}.10 \\
.11 \\
.10 \\
.08 \\
.09\end{array}$ & $\begin{array}{l}.08 \\
.07 \\
.07 \\
.07 \\
.07\end{array}$ & $\begin{array}{r}11 \\
110 \\
110 \\
110 \\
110\end{array}$ & $\begin{array}{r}.08 \\
.08 \\
.08 \\
.07 \\
.07\end{array}$ & 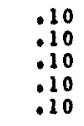 & $\begin{array}{r}793 \\
9.5 \\
7.6 \\
6.4 \\
6.0\end{array}$ \\
\hline $\begin{array}{l}16 \\
17 \\
18 \\
19 \\
20\end{array}$ & $\begin{array}{l}0 \\
0 \\
0 \\
0 \\
.01\end{array}$ & $\begin{array}{r}.14 \\
.17 \\
.17 \\
.20 \\
.24\end{array}$ & $\begin{array}{l}.07 \\
.07 \\
.05 \\
.05 \\
.07\end{array}$ & $\begin{array}{l}.11 \\
.14 \\
.17 \\
.17 \\
.20\end{array}$ & $\begin{array}{l}2.5 \\
2.7 \\
1.9 \\
1.9 \\
.98\end{array}$ & $\begin{array}{r}3.4 \\
2.5 \\
1.8 \\
1.6 \\
.98\end{array}$ & $\begin{array}{l}.08 \\
.08 \\
.08 \\
.08 \\
.08\end{array}$ & $\begin{array}{l}.08 \\
.08 \\
.08 \\
.09 \\
.09\end{array}$ & $\begin{array}{r}.10 \\
.09 \\
.08 \\
.08 \\
.07\end{array}$ & $\begin{array}{r}.07 \\
.07 \\
.06 \\
.06 \\
.06\end{array}$ & $\begin{array}{l}.10 \\
6.1 \\
4.2 \\
1.6 \\
.90\end{array}$ & $\begin{array}{l}5.7 \\
4.2 \\
3.9 \\
3.9 \\
3.9\end{array}$ \\
\hline $\begin{array}{l}21 \\
22 \\
23 \\
24 \\
25\end{array}$ & $\begin{array}{l}.01 \\
.02 \\
.02 \\
.03 \\
.03\end{array}$ & $\begin{array}{l}.24 \\
.24 \\
.24 \\
.24 \\
.29\end{array}$ & $\begin{array}{l}.09 \\
.09 \\
.09 \\
.09 \\
.09\end{array}$ & $\begin{array}{l}.24 \\
.24 \\
.24 \\
.26 \\
.24\end{array}$ & $\begin{array}{l}.20 \\
.20 \\
.20 \\
.20 \\
.20\end{array}$ & $\begin{array}{l}.84 \\
.70 \\
.50 \\
.30 \\
.30\end{array}$ & $\begin{array}{l}.07 \\
.07 \\
.07 \\
.07 \\
.07\end{array}$ & $\begin{array}{l}.09 \\
.09 \\
.09 \\
.09 \\
.09\end{array}$ & $\begin{array}{l}.07 \\
.07 \\
.07 \\
.07 \\
.07\end{array}$ & $\begin{array}{l}.06 \\
.06 \\
.06 \\
.06 \\
.06\end{array}$ & $\begin{array}{l}.50 \\
.20 \\
.10 \\
.10 \\
.10\end{array}$ & $\begin{array}{l}3.7 \\
3.0 \\
3.0 \\
3.2 \\
3.2\end{array}$ \\
\hline $\begin{array}{l}26 \\
27 \\
28 \\
29 \\
30 \\
31\end{array}$ & $\begin{array}{l}.04 \\
.05 \\
.06 \\
.08 \\
.75 \\
.43\end{array}$ & $\begin{array}{l}.14 \\
.24 \\
1.9 \\
.99 \\
.47 \\
.0-0\end{array}$ & $\begin{array}{l}.09 \\
.09 \\
.11 \\
.14 \\
.14 \\
.17\end{array}$ & $\begin{array}{r}.24 \\
.24 \\
.24 \\
.24 \\
.29 \\
.34\end{array}$ & $\begin{array}{r}.62 \\
1.5 \\
.85 \\
.20 \\
.0- \\
.--\infty\end{array}$ & $\begin{array}{r}.30 \\
.30 \\
.30 \\
.30 \\
.33 \\
.33\end{array}$ & $\begin{array}{l}.07 \\
.07 \\
.07 \\
.07 \\
.07 \\
0.0\end{array}$ & $\begin{array}{l}.09 \\
.09 \\
.09 \\
.10 \\
.10 \\
.10\end{array}$ & $\begin{array}{l}.07 \\
.07 \\
.08 \\
.08 \\
.08 \\
.0-\infty\end{array}$ & $\begin{array}{r}2.0 \\
9.8 \\
7.5 \\
3.5 \\
.10 \\
.10\end{array}$ & $\begin{array}{l}.10 \\
3.6 \\
2.2 \\
1.0 \\
.50 \\
.13\end{array}$ & $\begin{array}{l}3.0 \\
3.0 \\
2.8 \\
2.6 \\
2.4 \\
-0 .\end{array}$ \\
\hline $\begin{array}{l}\text { TOTAL } \\
\text { MEAN } \\
\text { MAX } \\
\text { MIN } \\
\text { AC } \rightarrow F T\end{array}$ & $\begin{array}{r}2.08 \\
.067 \\
.75 \\
0 \\
4.1\end{array}$ & $\begin{array}{r}6.79 \\
.23 \\
1.9 \\
.01 \\
13\end{array}$ & $\begin{array}{r}10.82 \\
.35 \\
2.6 \\
.05 \\
21\end{array}$ & $\begin{array}{r}0.01 \\
.19 \\
.34 \\
.11 \\
12\end{array}$ & $\begin{array}{r}195.36 \\
6.74 \\
92 \\
.20 \\
387\end{array}$ & $\begin{array}{r}120.78 \\
3.90 \\
28 \\
.30 \\
240\end{array}$ & $\begin{array}{r}4.43 \\
.15 \\
.39 \\
.07 \\
8.8\end{array}$ & $\begin{array}{r}2.55 \\
.082 \\
.10 \\
.07 \\
5.1\end{array}$ & $\begin{array}{r}2.59 \\
.006 \\
.11 \\
.07 \\
5.1\end{array}$ & $\begin{array}{r}24.80 \\
.80 \\
9.8 \\
.06 \\
49\end{array}$ & $\begin{array}{r}22.93 \\
.74 \\
6.1 \\
.10 \\
45\end{array}$ & $\begin{array}{r}1361.15 \\
45.4 \\
793 \\
2700\end{array}$ \\
\hline
\end{tabular}

CAL YR 1975 TOTAL 248.95 MEAN .68 MAX 24 MIN O AC=FT 494 HTR YA 1976 TOTAL 1760.29 MEAN 4.81 MAX 793 MIN 0 AOMF 3490 
11054000 MILL CREEK NEAR YUCAIPA, CA--Continued

COMBINED DISCHARGE, IN CUBIC FEET PER SECOND, OF MILL CREEK AND MILL CREEK POWER

CANALS NOS. 1, 2, AND 3 NEAR YUCAIPA, CA, WATER YEAR OCTOBER 1975 TO SEPTEMBER 1976

DISCHARGE, IN CUBIC FEET PER SECOND, HATER YEAR OCTOBER 1975 TO SEPTEMBER 1976 MEAN VALUES

\begin{tabular}{|c|c|c|c|c|c|c|c|c|c|c|c|c|}
\hline DAY & OCT & NOV & DEC & JAN & FEB & MAR & APR & MAY & JUN & JUL & AUG & SEP \\
\hline $\begin{array}{l}1 \\
2 \\
3 \\
4 \\
5\end{array}$ & $\begin{array}{l}16 \\
16 \\
16 \\
16 \\
16\end{array}$ & $\begin{array}{l}12 \\
13 \\
13 \\
14 \\
14\end{array}$ & $\begin{array}{l}15 \\
17 \\
15 \\
12 \\
12\end{array}$ & $\begin{array}{l}14 \\
14 \\
14 \\
14 \\
14\end{array}$ & $\begin{array}{l}15 \\
15 \\
15 \\
17 \\
15\end{array}$ & $\begin{array}{l}38 \\
24 \\
22 \\
18 \\
18\end{array}$ & $\begin{array}{l}18 \\
18 \\
18 \\
18 \\
18\end{array}$ & $\begin{array}{l}21 \\
21 \\
21 \\
20 \\
20\end{array}$ & $\begin{array}{l}20 \\
19 \\
19 \\
19 \\
19\end{array}$ & $\begin{array}{l}17 \\
18 \\
18 \\
17 \\
17\end{array}$ & $\begin{array}{l}16 \\
16 \\
16 \\
16 \\
16\end{array}$ & $\begin{array}{l}15 \\
15 \\
15 \\
15 \\
15\end{array}$ \\
\hline $\begin{array}{r}6 \\
7 \\
8 \\
9 \\
10\end{array}$ & $\begin{array}{l}16 \\
16 \\
16 \\
16 \\
16\end{array}$ & $\begin{array}{l}14 \\
14 \\
14 \\
15 \\
14\end{array}$ & $\begin{array}{l}11 \\
11 \\
13 \\
13 \\
13\end{array}$ & $\begin{array}{l}14 \\
13 \\
13 \\
13 \\
13\end{array}$ & $\begin{array}{r}14 \\
16 \\
101 \\
68 \\
15\end{array}$ & $\begin{array}{l}16 \\
15 \\
16 \\
15 \\
14\end{array}$ & $\begin{array}{l}17 \\
17 \\
18 \\
17 \\
17\end{array}$ & $\begin{array}{l}20 \\
21 \\
19 \\
19 \\
20\end{array}$ & $\begin{array}{l}21 \\
20 \\
21 \\
21 \\
22\end{array}$ & $\begin{array}{l}17 \\
17 \\
16 \\
16 \\
16\end{array}$ & $\begin{array}{l}15 \\
15 \\
15 \\
15 \\
14\end{array}$ & $\begin{array}{r}15 \\
25 \\
22 \\
15 \\
474\end{array}$ \\
\hline $\begin{array}{l}11 \\
12 \\
13 \\
14 \\
15\end{array}$ & $\begin{array}{l}17 \\
17 \\
17 \\
17 \\
16\end{array}$ & $\begin{array}{l}15 \\
14 \\
14 \\
14 \\
14\end{array}$ & $\begin{array}{l}16 \\
14 \\
13 \\
14 \\
13\end{array}$ & $\begin{array}{l}14 \\
14 \\
14 \\
14 \\
14\end{array}$ & $\begin{array}{l}16 \\
15 \\
14 \\
13 \\
15\end{array}$ & $\begin{array}{l}15 \\
15 \\
16 \\
17 \\
20\end{array}$ & $\begin{array}{l}17 \\
18 \\
19 \\
18 \\
19\end{array}$ & $\begin{array}{l}21 \\
22 \\
23 \\
25 \\
25\end{array}$ & $\begin{array}{l}21 \\
20 \\
20 \\
20 \\
20\end{array}$ & $\begin{array}{l}16 \\
16 \\
17 \\
16 \\
16\end{array}$ & $\begin{array}{l}14 \\
14 \\
14 \\
15 \\
15\end{array}$ & $\begin{array}{r}797 \\
14 \\
12 \\
11 \\
10\end{array}$ \\
\hline $\begin{array}{l}16 \\
17 \\
18 \\
19 \\
20\end{array}$ & $\begin{array}{l}16 \\
16 \\
16 \\
16 \\
16\end{array}$ & $\begin{array}{l}14 \\
14 \\
14 \\
13 \\
14\end{array}$ & $\begin{array}{l}13 \\
13 \\
12 \\
13 \\
14\end{array}$ & $\begin{array}{l}14 \\
14 \\
14 \\
14 \\
14\end{array}$ & $\begin{array}{l}15 \\
15 \\
15 \\
16 \\
15\end{array}$ & $\begin{array}{l}19 \\
21 \\
22 \\
20 \\
20\end{array}$ & $\begin{array}{l}19 \\
18 \\
18 \\
18 \\
19\end{array}$ & $\begin{array}{l}24 \\
24 \\
23 \\
23 \\
23\end{array}$ & $\begin{array}{l}19 \\
17 \\
19 \\
19 \\
19\end{array}$ & $\begin{array}{l}17 \\
16 \\
16 \\
16 \\
15\end{array}$ & $\begin{array}{l}15 \\
21 \\
19 \\
17 \\
16\end{array}$ & $\begin{array}{l}10 \\
12 \\
16 \\
17 \\
17\end{array}$ \\
\hline $\begin{array}{l}21 \\
22 \\
23 \\
24 \\
25\end{array}$ & $\begin{array}{l}16 \\
15 \\
15 \\
14 \\
14\end{array}$ & $\begin{array}{l}14 \\
14 \\
13 \\
13 \\
13\end{array}$ & $\begin{array}{l}14 \\
14 \\
12 \\
12 \\
12\end{array}$ & $\begin{array}{l}14 \\
14 \\
13 \\
13 \\
13\end{array}$ & $\begin{array}{l}15 \\
15 \\
15 \\
15 \\
14\end{array}$ & $\begin{array}{l}19 \\
19 \\
18 \\
16 \\
17\end{array}$ & $\begin{array}{l}20 \\
22 \\
21 \\
20 \\
21\end{array}$ & $\begin{array}{l}23 \\
23 \\
22 \\
22 \\
22\end{array}$ & $\begin{array}{l}19 \\
19 \\
19 \\
19 \\
18\end{array}$ & $\begin{array}{l}15 \\
16 \\
16 \\
16 \\
16\end{array}$ & $\begin{array}{l}17 \\
15 \\
15 \\
15 \\
15\end{array}$ & $\begin{array}{l}17 \\
18 \\
17 \\
15 \\
7.6\end{array}$ \\
\hline $\begin{array}{l}26 \\
27 \\
28 \\
29 \\
30 \\
31\end{array}$ & $\begin{array}{l}14 \\
14 \\
14 \\
14 \\
16 \\
12\end{array}$ & $\begin{array}{l}14 \\
15 \\
15 \\
14 \\
15 \\
-\end{array}$ & $\begin{array}{l}12 \\
12 \\
12 \\
12 \\
13 \\
14\end{array}$ & $\begin{array}{l}14 \\
13 \\
13 \\
13 \\
14 \\
15\end{array}$ & $\begin{array}{r}14 \\
14 \\
15 \\
14 \\
-0- \\
-\end{array}$ & $\begin{array}{l}18 \\
17 \\
17 \\
16 \\
17 \\
18\end{array}$ & $\begin{array}{l}21 \\
21 \\
19 \\
21 \\
20 \\
-\end{array}$ & $\begin{array}{l}21 \\
21 \\
21 \\
21 \\
21 \\
20\end{array}$ & $\begin{array}{r}18 \\
15 \\
15 \\
16 \\
17 \\
--0\end{array}$ & $\begin{array}{l}17 \\
18 \\
15 \\
16 \\
17 \\
17\end{array}$ & $\begin{array}{l}15 \\
18 \\
16 \\
16 \\
16 \\
15\end{array}$ & $\begin{array}{l}7.3 \\
13 \\
19 \\
18 \\
21 \\
-\infty\end{array}$ \\
\hline $\begin{array}{l}\text { TOTAL } \\
\text { MEAN } \\
\text { MAX } \\
\text { MIN } \\
\text { ACMFT }\end{array}$ & $\begin{array}{r}482 \\
15,5 \\
17 \\
12 \\
956\end{array}$ & $\begin{array}{r}417 \\
13.9 \\
15 \\
12 \\
827\end{array}$ & $\begin{array}{r}406 \\
13.1 \\
17 \\
11 \\
805\end{array}$ & $\begin{array}{r}425 \\
13.7 \\
15 \\
13 \\
843\end{array}$ & $\begin{array}{r}571 \\
19.7 \\
101 \\
13 \\
1130\end{array}$ & $\begin{array}{r}573 \\
18.5 \\
38 \\
14 \\
1140\end{array}$ & $\begin{array}{r}565 \\
18.8 \\
22 \\
17 \\
1120\end{array}$ & $\begin{array}{r}672 \\
21.7 \\
25 \\
19 \\
1330\end{array}$ & $\begin{array}{r}570 \\
19.0 \\
22 \\
15 \\
1130\end{array}$ & $\begin{array}{r}509 \\
16.4 \\
18 \\
15 \\
1010\end{array}$ & $\begin{array}{r}487 \\
15.7 \\
21 \\
14 \\
966\end{array}$ & $\begin{array}{r}1694.9 \\
56.5 \\
797 \\
7.3 \\
3360\end{array}$ \\
\hline
\end{tabular}

$\begin{array}{llllllllll}\text { CAL YR } 1975 & \text { TOTAL } 7024.0 & \text { MEAN } 19.2 & \text { MAX } 42 & \text { MIN } & 11 & \text { AC-FT } & 13930 \\ \text { WTR YR } 1976 & \text { TOTAL } & 7371.9 & \text { MEAN } 20.1 & \text { MAX } 797 & \text { MIN } & 7.3 & \text { AC-FT } & 14620\end{array}$ 
11055500 PLUNGE CREEK NEAR EAST HIGHLANDS, CA

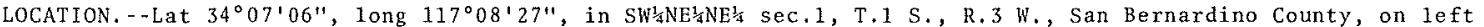
bank at mouth of canyon at crossing of North Fork ditch siphon, $1.8 \mathrm{mi}$ (2.9 kn) northeast of East Highlands. DRAINAGE AREA. $-16.9 \mathrm{mi}^{2}\left(43.8 \mathrm{~km}^{2}\right)$.

PERIOD OF RECORD.--January 1919 to current year; combined records of creek and diversions, March 1951 to current year.

GAGE.--Water-stage recorder on creek. Since March 1951 water-stage recorder and weir on upper diversion, waterstage recorder and concrete-lined canal on middle diversion, crest-stage gage and sharp-crested weir on lower diversion. Altitude of creek gage is $1,590 \mathrm{ft}(485 \mathrm{~m})$, from topographic map. Prior to oct. 1 , 1969 , creek gage at datum $4.00 \mathrm{ft}(1.219 \mathrm{~m})$ higher. Diversions are a 11 at different datums.

REMARKS.--Records good. No regulation above station. Diversion from Alder Creek to Upper Plunge Greek area was active 1904-67. Diversions for irrigation are made at sites $0.5 \mathrm{mi}(0.8 \mathrm{~km}), 1.0 \mathrm{mi}(1.6 \mathrm{~km})$, and $2.5 \mathrm{mi}$ $(4.0 \mathrm{~km})$ above station. Water has been diverted above station for irrigation during entire period of record. Combined discharge of Plunge Creek and upper, middle, and lower diversions is given on following page. No flow in lower diversion since May 29, 1966. See schematic diagram of Santa Ana River basin.

AVERAGE DISCHARGE. - Creek only: 57 years, $6.06 \mathrm{ft}^{3} / \mathrm{s}\left(0.172 \mathrm{~m}^{3} / \mathrm{s}\right), 4,390 \mathrm{acre}-\mathrm{ft} / \mathrm{yr}\left(5.41 \mathrm{hm} / \mathrm{yr}^{3}\right)$ Combined creek and diversions: 25 years, $7.42 \mathrm{ft}^{3} / \mathrm{s}\left(0.210 \mathrm{~m}^{3} / \mathrm{s}\right), 5,380 \mathrm{acre}-\mathrm{ft} / \mathrm{yr}^{2}\left(6.63 \mathrm{hm} / \mathrm{yr}^{3}\right)$.

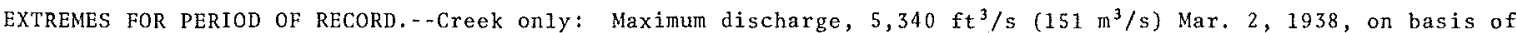
slope-area measurement of maximum flow; no flow for part of most years.

Combined creek and diversions: Maximum discharge, 4,770 $\mathrm{ft}^{3} / \mathrm{s}\left(135 \mathrm{~m}^{3} / \mathrm{s}\right)$ Dec. 6, 1966; no flow Nov. 12, 1964 , Sept. $29,1965$.

EXTREMES FOR CURRENT YEAR. - Peak discharge above base of $130 \mathrm{ft} / \mathrm{s}\left(3.68 \mathrm{~m}^{3} / \mathrm{s}\right)$ and maximum(*):

\begin{tabular}{|c|c|c|c|c|c|c|}
\hline Date & Time & $\begin{array}{c}\text { Creek } \\
\text { Discharge } \\
\left(\mathrm{ft}^{3} / \mathrm{s}\right)\left(\mathrm{m}^{3} / \mathrm{s}\right)\end{array}$ & $\begin{array}{r}\text { Gage height } \\
\text { (ft) }\end{array}$ & Combined & $\begin{array}{c}\text { Creek } \\
\text { Disch } \\
\left(\mathrm{ft}^{3} / \mathrm{s}\right)\end{array}$ & $\begin{array}{l}\text { and Di } \\
\operatorname{arge} \\
\left(\mathrm{m}^{3} / \mathrm{s}\right.\end{array}$ \\
\hline 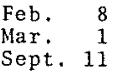 & $\begin{array}{l}2400 \\
1700 \\
0400\end{array}$ & $\begin{array}{c}6.46 \\
11.2 \\
7.31\end{array}$ & $\begin{array}{l}1.052 \\
1.234 \\
1.088\end{array}$ & & $\begin{array}{l}228 \\
395 \\
258\end{array}$ & $\begin{array}{r}6.46 \\
11.2 \\
7.31\end{array}$ \\
\hline
\end{tabular}

Creek only: Minimum daily discharge, no flow many days.

Combined creek and diversions: Minimum daily discharge, $0.46 \mathrm{ft}^{3} / \mathrm{s}\left(0.013 \mathrm{~m}^{3} / \mathrm{s}\right) \mathrm{Aug}$. 31 .

DISCHARGE, IN CUBIC FEET PER SECOND, WATER YEAR OCTOBER 1975 TO SEPTEMBER 1976 MEAN VALUES

\begin{tabular}{|c|c|c|c|c|c|c|c|c|c|c|c|c|}
\hline DAY & $\mathrm{OCT}$ & NOV & DEC & JAN & FEB & MAR & APR & MAY & JUN & JUL & AUG & SEP \\
\hline $\begin{array}{l}1 \\
2 \\
3 \\
4 \\
5\end{array}$ & $\begin{array}{l}.06 \\
0 \\
0 \\
0 \\
0\end{array}$ & $\begin{array}{r}.62 \\
.47 \\
.39 \\
.24 \\
.21\end{array}$ & $\begin{array}{l}1.2 \\
1.9 \\
1.9 \\
1.9 \\
1.9\end{array}$ & $\begin{array}{l}2.0 \\
2.0 \\
1.7 \\
1.4 \\
1.4\end{array}$ & $\begin{array}{r}.88 \\
.88 \\
.88 \\
2.2 \\
5.3\end{array}$ & $\begin{array}{l}74 \\
30 \\
24 \\
17 \\
16\end{array}$ & $\begin{array}{l}2.9 \\
2.5 \\
2.8 \\
4.0 \\
3.7\end{array}$ & $\begin{array}{l}1.3 \\
1.3 \\
1.3 \\
1.8 \\
1.6\end{array}$ & $\begin{array}{l}.01 \\
.01 \\
.01 \\
.01 \\
.01\end{array}$ & $\begin{array}{l}0 \\
0 \\
0 \\
0 \\
0\end{array}$ & $\begin{array}{l}0 \\
0 \\
.01 \\
.02 \\
.03\end{array}$ & $\begin{array}{l}0 \\
0 \\
0 \\
0 \\
0\end{array}$ \\
\hline $\begin{array}{r}6 \\
7 \\
8 \\
9 \\
10\end{array}$ & $\begin{array}{l}0 \\
.30 \\
.47 \\
.35 \\
.39\end{array}$ & $\begin{array}{l}.21 \\
.24 \\
.24 \\
.31 \\
.31\end{array}$ & $\begin{array}{l}1.9 \\
1.8 \\
1.8 \\
1.8 \\
1.7\end{array}$ & $\begin{array}{l}1.4 \\
1.2 \\
1.2 \\
1.2 \\
1.2\end{array}$ & $\begin{array}{l}7.0 \\
19 \\
43 \\
115 \\
35\end{array}$ & $\begin{array}{l}14 \\
13 \\
12 \\
9.8 \\
10\end{array}$ & $\begin{array}{l}2.8 \\
3.4 \\
3.4 \\
3.7 \\
3.4\end{array}$ & $\begin{array}{l}1.7 \\
2.1 \\
1.7 \\
1.4 \\
1.4\end{array}$ & $\begin{array}{l}.01 \\
.04 \\
.18 \\
.18 \\
.24\end{array}$ & $\begin{array}{l}0 \\
0 \\
0 \\
0 \\
0\end{array}$ & $\begin{array}{r}.03 \\
.03 \\
.03 \\
.03 \\
.03\end{array}$ & $\begin{array}{r}0 \\
0 \\
0 \\
0 \\
28\end{array}$ \\
\hline $\begin{array}{l}11 \\
12 \\
13 \\
14 \\
15\end{array}$ & $\begin{array}{l}.35 \\
.30 \\
.28 \\
.26 \\
.24\end{array}$ & $\begin{array}{r}.35 \\
.35 \\
.27 \\
.24 \\
.24\end{array}$ & $\begin{array}{l}1.7 \\
2.6 \\
2.8 \\
2.1 \\
1.8\end{array}$ & $\begin{array}{l}1.1 \\
1.0 \\
1.0 \\
1.0 \\
1.0\end{array}$ & $\begin{array}{r}14 \\
9.8 \\
7.7 \\
5.7 \\
4.9\end{array}$ & $\begin{array}{l}9.8 \\
8.3 \\
7.4 \\
6.9 \\
6.9\end{array}$ & $\begin{array}{l}3.2 \\
3.9 \\
6.0 \\
1.1\end{array}$ & $\begin{array}{l}1.3 \\
1.1 \\
.47 \\
.24 \\
.08\end{array}$ & $\begin{array}{l}.12 \\
.05 \\
.04 \\
.03 \\
.02\end{array}$ & $\begin{array}{l}0 \\
0 \\
0 \\
0 \\
0\end{array}$ & $\begin{array}{l}.21 \\
0.29 \\
0 \\
0\end{array}$ & $\begin{array}{l}74 \\
4.5 \\
2.4 \\
1.7 \\
1.7\end{array}$ \\
\hline $\begin{array}{l}16 \\
17 \\
18 \\
19 \\
20\end{array}$ & $\begin{array}{l}.22 \\
.21 \\
.24 \\
.39 \\
.39\end{array}$ & $\begin{array}{l}.24 \\
.27 \\
.35 \\
.43 \\
.47\end{array}$ & $\begin{array}{l}1.5 \\
1.1 \\
1.1 \\
1.0 \\
1.0\end{array}$ & $\begin{array}{l}1.0 \\
1.0 \\
1.0 \\
1.0 \\
.95\end{array}$ & $\begin{array}{l}4.1 \\
3.9 \\
4.1 \\
4.1 \\
3.4\end{array}$ & $\begin{array}{l}6.9 \\
6.4 \\
6.4 \\
6.7 \\
6.2\end{array}$ & $\begin{array}{l}9.0 \\
7.5 \\
7.0 \\
6.6 \\
6.5\end{array}$ & $\begin{array}{l}.03 \\
.03 \\
.02 \\
.02 \\
.03\end{array}$ & $\begin{array}{l}.02 \\
.02 \\
.02 \\
.02 \\
.02\end{array}$ & $\begin{array}{l}0 \\
0 \\
0 \\
0 \\
0\end{array}$ & $\begin{array}{l}.03 \\
.03 \\
.02 \\
.02 \\
.02\end{array}$ & $\begin{array}{l}1.6 \\
1.5 \\
1.4 \\
1.5 \\
1.6\end{array}$ \\
\hline $\begin{array}{l}21 \\
22 \\
23 \\
24 \\
25\end{array}$ & $\begin{array}{l}.39 \\
.43 \\
.47 \\
.39 \\
.39\end{array}$ & $\begin{array}{l}.47 \\
.47 \\
.47 \\
.52 \\
.52\end{array}$ & $\begin{array}{l}1.0 \\
1.0 \\
1.4 \\
2.1 \\
2.1\end{array}$ & $\begin{array}{l}.95 \\
.95 \\
.95 \\
.95 \\
.95\end{array}$ & $\begin{array}{l}2.9 \\
2.8 \\
2.6 \\
2.4 \\
2.4\end{array}$ & $\begin{array}{l}5.7 \\
5.7 \\
5.3 \\
5.3 \\
5.3\end{array}$ & $\begin{array}{l}6.4 \\
6.2 \\
6.2 \\
6.0 \\
5.3\end{array}$ & $\begin{array}{l}.02 \\
.02 \\
.01 \\
.02 \\
.02\end{array}$ & $\begin{array}{l}.01 \\
0 \\
0 \\
0 \\
0\end{array}$ & $\begin{array}{l}0 \\
0 \\
0 \\
0 \\
0\end{array}$ & $\begin{array}{l}.02 \\
.01 \\
.01 \\
.01 \\
.01\end{array}$ & $\begin{array}{l}1.6 \\
1.7 \\
2.5 \\
4.3 \\
2.0\end{array}$ \\
\hline $\begin{array}{l}26 \\
27 \\
28 \\
29 \\
30 \\
31\end{array}$ & $\begin{array}{r}.39 \\
.39 \\
.52 \\
.81 \\
.81 \\
1.7\end{array}$ & $\begin{array}{l}.35 \\
.68 \\
2.0 \\
1.6 \\
1.1 \\
-. . .\end{array}$ & $\begin{array}{l}2.1 \\
2.1 \\
2.0 \\
2.0 \\
2.0 \\
2.0\end{array}$ & $\begin{array}{l}.95 \\
.95 \\
.88 \\
.88 \\
.88 \\
.88\end{array}$ & $\begin{array}{l}2.2 \\
2.1 \\
2.1 \\
2.1 \\
-1 .-\end{array}$ & $\begin{array}{l}5.7 \\
5.7 \\
5.1 \\
2.9 \\
2.2 \\
3.2\end{array}$ & $\begin{array}{l}5.7 \\
4.9 \\
3.7 \\
3.4 \\
1.0 \\
-\end{array}$ & $\begin{array}{l}.02 \\
.01 \\
.02 \\
.01 \\
.02 \\
.02\end{array}$ & $\begin{array}{l}0 \\
0 \\
0 \\
0 \\
0 \\
\ldots\end{array}$ & $\begin{array}{l}0 \\
0 \\
0 \\
0 \\
0 \\
.01\end{array}$ & $\begin{array}{l}0 \\
0 \\
0 \\
0 \\
0 \\
0\end{array}$ & $\begin{array}{l}1.5 \\
1.4 \\
1.3 \\
1.3 \\
1.3 \\
-. .\end{array}$ \\
\hline $\begin{array}{l}\text { TOTAL } \\
\text { MEAN } \\
\text { MAX } \\
\text { MIN } \\
\text { AC-FT }\end{array}$ & $\begin{array}{r}11.16 \\
.36 \\
1.7 \\
0 \\
22\end{array}$ & $\begin{array}{r}14.63 \\
.49 \\
2.0 \\
.21 \\
29\end{array}$ & $\begin{array}{r}54.3 \\
1.75 \\
2.8 \\
1.0 \\
108\end{array}$ & $\begin{array}{r}34.92 \\
1.13 \\
2.0 \\
.88 \\
69\end{array}$ & $\begin{array}{r}312,44 \\
10,8 \\
115 \\
.88 \\
620\end{array}$ & $\begin{array}{r}343.8 \\
11.1 \\
74 \\
2.2 \\
682\end{array}$ & $\begin{array}{r}145.2 \\
4.84 \\
10 \\
1.0 \\
288\end{array}$ & $\begin{array}{r}19.30 \\
.62 \\
2.1 \\
.01 \\
38\end{array}$ & $\begin{array}{r}1.07 \\
.036 \\
.24 \\
0 \\
2.1\end{array}$ & $\begin{array}{r}.01 \\
.0003 \\
.01 \\
0 \\
.02\end{array}$ & $\begin{array}{r}.89 \\
.029 \\
.29 \\
0 \\
1.8\end{array}$ & $\begin{array}{r}138.8 \\
4.63 \\
74 \\
0 \\
275\end{array}$ \\
\hline
\end{tabular}

CAL YR 1975 TOTAL 1105.43 MEAN 3.03 MAX 76 MIN O AC-FT 2190 
11055500 PLUNGE CREEK NEAR EAST HIGHLANDS, CA--Continued

COMBINED DTSCHARGE, IN CUBIC FEET PER SECOND, OF PLUNGE CREEK AND

DIVERSIONS NEAR EAST HIGHLANDS, CA, WATER YEAR OCTOBER 1975 TO SEPTEMBER 1976

\begin{tabular}{|c|c|c|c|c|c|c|c|c|c|c|c|c|}
\hline DAY & OCT & Nov & DEC & JAN & FEB & MAR & APR & MAY & JUN & JUL & AUG & SEP \\
\hline $\begin{array}{l}1 \\
2 \\
3 \\
4 \\
5\end{array}$ & $\begin{array}{l}.73 \\
.66 \\
.62 \\
.62 \\
.62\end{array}$ & $\begin{array}{l}1.3 \\
1.2 \\
1.1 \\
1.0 \\
1.0\end{array}$ & $\begin{array}{l}1.6 \\
1.9 \\
1.9 \\
1.9 \\
1.9\end{array}$ & $\begin{array}{l}2.7 \\
2.8 \\
2.5 \\
2.3 \\
2.1\end{array}$ & $\begin{array}{l}1.6 \\
1.6 \\
1.6 \\
3.1 \\
5.4\end{array}$ & $\begin{array}{l}74 \\
30 \\
24 \\
17 \\
16\end{array}$ & $\begin{array}{l}5.7 \\
5.2 \\
5.5 \\
6.7 \\
6.4\end{array}$ & $\begin{array}{l}4.3 \\
4.2 \\
4.3 \\
4.4 \\
4.3\end{array}$ & $\begin{array}{l}1.9 \\
1.9 \\
1.9 \\
1.7 \\
1.7\end{array}$ & $\begin{array}{r}.75 \\
.83 \\
.86 \\
.78 \\
.72\end{array}$ & $\begin{array}{l}.63 \\
.65 \\
.65 \\
.63 \\
.60\end{array}$ & $\begin{array}{l}.47 \\
.50 \\
.63 \\
.61 \\
.58\end{array}$ \\
\hline $\begin{array}{r}6 \\
7 \\
8 \\
9 \\
10\end{array}$ & $\begin{array}{l}.66 \\
1.0 \\
1.2 \\
1.0 \\
1.1\end{array}$ & $\begin{array}{l}1.1 \\
1.1 \\
1.1 \\
1.1 \\
1.1\end{array}$ & $\begin{array}{l}1.9 \\
1.8 \\
1.8 \\
1.8 \\
1.7\end{array}$ & $\begin{array}{l}2.2 \\
2.0 \\
2.0 \\
2.0 \\
1.9\end{array}$ & $\begin{array}{c}7.0 \\
19 \\
43 \\
115 \\
35\end{array}$ & $\begin{array}{l}14 \\
13 \\
12 \\
9.8 \\
10\end{array}$ & $\begin{array}{l}5.7 \\
6.2 \\
6.0 \\
6.3 \\
6.0\end{array}$ & $\begin{array}{l}4.0 \\
4.4 \\
3.6 \\
3.0 \\
3.0\end{array}$ & $\begin{array}{l}1.7 \\
1.5 \\
1.6 \\
1.7 \\
2.0\end{array}$ & $\begin{array}{l}.67 \\
.65 \\
.62 \\
.65 \\
.65\end{array}$ & $\begin{array}{r}.57 \\
.54 \\
.53 \\
.50 \\
.53\end{array}$ & $\begin{array}{r}.61 \\
.64 \\
.58 \\
.69\end{array}$ \\
\hline $\begin{array}{l}11 \\
12 \\
13 \\
14 \\
15\end{array}$ & $\begin{array}{l}1.0 \\
1.0 \\
.98 \\
.95 \\
.91\end{array}$ & $\begin{array}{l}1.2 \\
1.2 \\
1.1 \\
1.1 \\
1.1\end{array}$ & $\begin{array}{l}1.7 \\
2.6 \\
3.0 \\
2.4 \\
2.1\end{array}$ & $\begin{array}{l}1.9 \\
1.8 \\
1.8 \\
1.8 \\
1.8\end{array}$ & $\begin{array}{r}14 \\
9.8 \\
7.7 \\
5.7 \\
4.9\end{array}$ & $\begin{array}{l}9.8 \\
8.3 \\
7.4 \\
6.9 \\
6.9\end{array}$ & $\begin{array}{c}5.8 \\
6.8 \\
9.1 \\
6.9 \\
13\end{array}$ & $\begin{array}{l}3.2 \\
2.7 \\
2.6 \\
2.7 \\
2.5\end{array}$ & $\begin{array}{l}2.1 \\
1.9 \\
1.7 \\
1.5 \\
1.4\end{array}$ & $\begin{array}{r}.70 \\
.72 \\
.75 \\
.72 \\
.81\end{array}$ & $\begin{array}{l}.77 \\
.84 \\
.57 \\
.63 \\
.69\end{array}$ & $\begin{array}{l}74 \\
4.5 \\
2.4 \\
1.7 \\
1.7\end{array}$ \\
\hline $\begin{array}{l}16 \\
17 \\
18 \\
19 \\
20\end{array}$ & $\begin{array}{l}.88 \\
.86 \\
.89 \\
1.0 \\
1.0\end{array}$ & $\begin{array}{l}1.1 \\
1.1 \\
1.2 \\
1.2 \\
1.3\end{array}$ & $\begin{array}{l}2.2 \\
2.0 \\
2.0 \\
1.8 \\
1.8\end{array}$ & $\begin{array}{l}1.8 \\
1.8 \\
1.8 \\
1.8 \\
1.8\end{array}$ & $\begin{array}{l}4.1 \\
3.9 \\
4.1 \\
4.1 \\
3.4\end{array}$ & $\begin{array}{l}6.9 \\
6.4 \\
6.4 \\
6.7 \\
6.2\end{array}$ & $\begin{array}{l}9.2 \\
7.5 \\
7.0 \\
6.6 \\
6.5\end{array}$ & $\begin{array}{l}2 \cdot 4 \\
2 \cdot 3 \\
2 \cdot 2 \\
2 \cdot 3 \\
2 \cdot 3\end{array}$ & $\begin{array}{l}1.3 \\
1.1 \\
.99 \\
.88 \\
.83\end{array}$ & $\begin{array}{l}.83 \\
.75 \\
.72 \\
.67 \\
.65\end{array}$ & $\begin{array}{l}.69 \\
.67 \\
.64 \\
.66 \\
.71\end{array}$ & $\begin{array}{l}1.6 \\
1.5 \\
1.4 \\
1.5 \\
1.6\end{array}$ \\
\hline $\begin{array}{l}21 \\
22 \\
23 \\
24 \\
25\end{array}$ & $\begin{array}{l}1.0 \\
1.1 \\
1.1 \\
1.1 \\
1.1\end{array}$ & $\begin{array}{l}1.2 \\
1.2 \\
1.2 \\
1.2 \\
1.2\end{array}$ & $\begin{array}{l}1.9 \\
1.9 \\
2.2 \\
2.8 \\
2.9\end{array}$ & $\begin{array}{l}1.8 \\
1.8 \\
1.8 \\
1.8 \\
1.7\end{array}$ & $\begin{array}{l}2.9 \\
2.8 \\
2.6 \\
2.4 \\
2.4\end{array}$ & $\begin{array}{l}5.7 \\
5.7 \\
5.3 \\
5.3 \\
5.3\end{array}$ & $\begin{array}{l}6.4 \\
6.2 \\
6.2 \\
6.0 \\
5.3\end{array}$ & $\begin{array}{l}2.3 \\
2.3 \\
2.2 \\
2.3 \\
2.4\end{array}$ & $\begin{array}{l}.78 \\
.78 \\
.77 \\
.76 \\
.71\end{array}$ & $\begin{array}{l}.62 \\
.72 \\
.67 \\
.62 \\
.69\end{array}$ & $\begin{array}{l}.68 \\
.64 \\
.60 \\
.60 \\
.62\end{array}$ & $\begin{array}{l}1.6 \\
1.7 \\
2.5 \\
4.3 \\
2.0\end{array}$ \\
\hline $\begin{array}{l}26 \\
27 \\
28 \\
29 \\
30 \\
31\end{array}$ & $\begin{array}{l}1.1 \\
1.1 \\
1.7 \\
3.5 \\
2.3 \\
2.4\end{array}$ & $\begin{array}{l}1.1 \\
1.5 \\
2.8 \\
2.4 \\
1.9 \\
-.-\end{array}$ & $\begin{array}{l}2.9 \\
2.9 \\
2.7 \\
2.7 \\
2.7 \\
2.7\end{array}$ & $\begin{array}{l}1.7 \\
1.7 \\
1.7 \\
1.7 \\
1.6 \\
1.6\end{array}$ & $\begin{array}{l}2.2 \\
2.1 \\
2.1 \\
2.1 \\
=.2\end{array}$ & $\begin{array}{l}6.3 \\
8.0 \\
8.5 \\
6.1 \\
5.4 \\
6.2\end{array}$ & $\begin{array}{l}5.7 \\
4.9 \\
4.3 \\
5.7 \\
4.2 \\
-.2\end{array}$ & $\begin{array}{l}2.2 \\
2.0 \\
2.0 \\
2.3 \\
2.3 \\
2.2\end{array}$ & $\begin{array}{l}.75 \\
.76 \\
.75 \\
.75 \\
.72 \\
.--.\end{array}$ & $\begin{array}{l}.75 \\
.72 \\
.73 \\
.68 \\
.71 \\
.67\end{array}$ & $\begin{array}{l}.62 \\
.52 \\
.50 \\
.49 \\
.47 \\
.46\end{array}$ & $\begin{array}{l}1.5 \\
1.4 \\
1.6 \\
1.7 \\
1.6 \\
=-0\end{array}$ \\
\hline $\begin{array}{l}\text { TOTAL } \\
\text { MEAN } \\
\text { MAX } \\
\text { MIN } \\
\text { AC-FT }\end{array}$ & $\begin{array}{r}35.18 \\
1.13 \\
3.5 \\
.62 \\
70\end{array}$ & $\begin{array}{r}38.4 \\
1.28 \\
2.8 \\
1.0 \\
76\end{array}$ & $\begin{array}{r}68.1 \\
2.20 \\
3.0 \\
1.6 \\
135\end{array}$ & $\begin{array}{r}59.5 \\
1.92 \\
2.8 \\
1.6 \\
118\end{array}$ & $\begin{array}{r}315.6 \\
10.9 \\
115 \\
1.6 \\
626\end{array}$ & $\begin{array}{r}359.5 \\
11.6 \\
74 \\
5.3 \\
713\end{array}$ & $\begin{array}{r}193.0 \\
6.43 \\
13 \\
4.2 \\
383\end{array}$ & $\begin{array}{r}89.2 \\
2.88 \\
4.4 \\
2.0 \\
177\end{array}$ & $\begin{array}{r}38.03 \\
1.29 \\
2.1 \\
.71 \\
77\end{array}$ & $\begin{array}{r}22.08 \\
.71 \\
.86 \\
.62 \\
44\end{array}$ & $\begin{array}{r}18.90 \\
.61 \\
.84 \\
.46 \\
37\end{array}$ & $\begin{array}{r}146.07 \\
4.87 \\
74 \\
.47 \\
290\end{array}$ \\
\hline $\begin{array}{ll}\text { CAL } & Y R \\
\text { HTR } & Y R\end{array}$ & $\begin{array}{l}\text { TOTAL } \\
\text { TOTAL }\end{array}$ & $\begin{array}{l}1446.60 \\
1384.36\end{array}$ & $\begin{array}{l}\text { MEAN } \\
\text { MEAN }\end{array}$ & $\begin{array}{l}3.96 \\
3.78\end{array}$ & $\begin{array}{l}\operatorname{MAX} \quad 76 \\
\operatorname{MAX} 115\end{array}$ & $\begin{array}{ll}\text { MIN } & .62 \\
\text { MIN } & .46\end{array}$ & $\begin{array}{l}A C-F T \\
A C-F T\end{array}$ & $\begin{array}{l}2870 \\
2750\end{array}$ & & & & \\
\hline
\end{tabular}


11055800 CITY CREEK NEAR HIGHLAND, CA

LOCATION. - Lat $34^{\circ} 08^{\prime} 38^{\prime \prime}$, long $117^{\circ} 11^{\prime} 16^{\prime \prime}$, in SEtaSWLNWta sec.27, T.1 N., R. 3 W., San Bernardino County, on right bank $0.6 \mathrm{mi}(1.0 \mathrm{~km})$ upstream from Highland Avenue, and $1.5 \mathrm{mi}(2.4 \mathrm{~km})$ northeast of Highland.

DRAINAGE AREA. $--19.6 \mathrm{mi}^{2} ; 50.8 \mathrm{~km}^{2}$ ).

PERIOD OF RECORD, - October 1919 to current year; combined records of creek and cana1, June 1924 to current year.

GAGE. - Water-stage recorder on creek; water-stage recorder on canal. Altitude of creek gage is 1,580 ft (482 $\mathrm{m}$ ), from topographic map. Prior to Mar. 1, 1939, at site $0.2 \mathrm{mi}(0.3 \mathrm{~km})$ downstream at different datum. Canal gage at different datum.

REMARKS. - -Records fair. No regulation above station. City Creek Water Co.'s canal has diverted from point 0.5 mi $(0.8 \mathrm{~km})$ above station for irrigation throughout period of record. See schematic diagram of Santa Ana River basin. Combined discharge of city Creek and canal is given on following page.

AVERAGE DISCHARGE, --Creek on $1 \mathrm{y}: 57 \mathrm{years,} 8.56 \mathrm{ft}^{3} / \mathrm{s}\left(0.242 \mathrm{~m}^{3} / \mathrm{s}\right), 6,200 \mathrm{acre}-\mathrm{ft} / \mathrm{yr}(7.64 \mathrm{hm} / \mathrm{yr})$. Combined creek and canal: 52 years, $10.2 \mathrm{ft}^{3} / \mathrm{s}\left(0.289 \mathrm{~m}^{3} / \mathrm{s}\right), 7,390$ acre- $\mathrm{ft}_{\mathrm{tyr}}(9.11 \mathrm{hm} / \mathrm{yr})$.

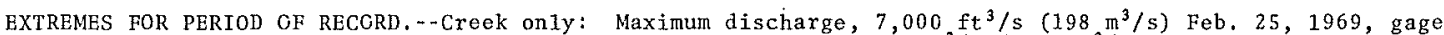
height, $9.39 \mathrm{ft}(2.862 \mathrm{~m})$, from rating curve extended above $580 \mathrm{ft} / \mathrm{s}\left(16.4 \mathrm{~m}^{3} / \mathrm{s}\right)$ on basis of $\mathrm{siope-area}$ measurement at gage height $8.83 \mathrm{ft}(2.691 \mathrm{~m})$; no flow for several months in some years.

Combined creek and cana1: Maximum discharge, $7,000 \mathrm{ft}^{3} / \mathrm{s}\left(198 \mathrm{~m}^{3} / \mathrm{s}\right) \mathrm{Feb}$, 25, 1969; no flow at times in some years.

EXTREMES FOR CURRENT YEAR.--Creek only: Maximum discharge, $326 \mathrm{ft}^{3} / \mathrm{s}\left(9.23 \mathrm{~m}^{3} / \mathrm{s}\right) \mathrm{Sept}$. 11 (0330 hrs), gage height, $5.64 \mathrm{ft}(1.719 \mathrm{~m})$, on basis of slope-axea measurement of peak flow, no other peak above base of $150 \mathrm{ft} / \mathrm{s}$ $\left(4.25 \mathrm{~m}^{3} / \mathrm{s}\right)$; minimum daily, $0.06 \mathrm{ft}^{3} / \mathrm{s}\left(0.002 \mathrm{~m}^{3} / \mathrm{s}\right)$ Aug. 29 to Sept. 2, Sept. 4, 5 . Combined creek and canal: Maximum discharge, $326 \mathrm{ft}^{3} / \mathrm{s}\left(9.23 \mathrm{~m}^{3} / \mathrm{s}\right)$ Sept. 11 (0330 hrs), no other peak above base of $150 \mathrm{ft}^{3} / \mathrm{s}\left(4.25 \mathrm{~m}^{3} / \mathrm{s}\right)$; minimum daily, $0.11 \mathrm{ft}^{3} / \mathrm{s}(0.003 \mathrm{~m} / \mathrm{s})$ Juiy 9 .

DISCHARGE, IN CUBIC FEET PER SECOND, HATER YEAR OCTOQER 1975 TO SEPTEMBER 1976 MEAN VALUES

\begin{tabular}{|c|c|c|c|c|c|c|c|c|c|c|c|c|}
\hline DAY & OCT & NOV & DEC & JAN & FEB & MAR & APR & MAY & JUN & JUL & AUO & SEF \\
\hline $\begin{array}{l}1 \\
2 \\
3 \\
4 \\
5\end{array}$ & $\begin{array}{l}.13 \\
.12 \\
11 \\
.10 \\
.08\end{array}$ & $\begin{array}{l}1.3 \\
1.2 \\
.75 \\
.34 \\
.30\end{array}$ & $\begin{array}{l}.38 \\
.92 \\
.77 \\
.54 \\
.43\end{array}$ & $\begin{array}{l}2.4 \\
2.5 \\
3.0 \\
3.6 \\
3.1\end{array}$ & $\begin{array}{l}.40 \\
.40 \\
.40 \\
1.0 \\
2.8\end{array}$ & $\begin{array}{l}33 \\
18 \\
18 \\
11 \\
10\end{array}$ & $\begin{array}{l}2.6 \\
1.9 \\
.89 \\
1.5 \\
1.3\end{array}$ & $\begin{array}{l}1.8 \\
1.8 \\
1.8 \\
1.8 \\
1.8\end{array}$ & $\begin{array}{l}1.1 \\
.95 \\
1.0 \\
1.2 \\
1.2\end{array}$ & $\begin{array}{l}.08 \\
.12 \\
.17 \\
.15 \\
.12\end{array}$ & $\begin{array}{l}.14 \\
.13 \\
.14 \\
.15 \\
.12\end{array}$ & $\begin{array}{l}.06 \\
.06 \\
.08 \\
.06 \\
.06\end{array}$ \\
\hline $\begin{array}{r}6 \\
7 \\
8 \\
9 \\
10\end{array}$ & $\begin{array}{l}.09 \\
.37 \\
.72 \\
.67 \\
.41\end{array}$ & $\begin{array}{r}.32 \\
.31 \\
.33 \\
.30 \\
.29\end{array}$ & $\begin{array}{l}.38 \\
.34 \\
.32 \\
.34 \\
.36\end{array}$ & $\begin{array}{l}1.0 \\
.49 \\
.47 \\
.48 \\
.49\end{array}$ & $\begin{array}{l}16 \\
22 \\
22 \\
38 \\
29\end{array}$ & $\begin{array}{l}9.6 \\
9.2 \\
8.9 \\
8.5 \\
8.2\end{array}$ & $\begin{array}{l}2.3 \\
2.7 \\
2.8 \\
1.6 \\
.75\end{array}$ & $\begin{array}{l}1.8 \\
2.2 \\
1.8 \\
1.6 \\
1.5\end{array}$ & $\begin{array}{l}1.2 \\
1.4 \\
1.2 \\
1.3 \\
1.9\end{array}$ & $\begin{array}{l}.10 \\
.08 \\
.08 \\
.07 \\
.09\end{array}$ & $\begin{array}{r}.11 \\
.10 \\
.09 \\
.08 \\
.08\end{array}$ & $\begin{array}{r}.07 \\
.06 \\
.11 \\
14\end{array}$ \\
\hline $\begin{array}{l}11 \\
12 \\
13 \\
14 \\
15\end{array}$ & $\begin{array}{l}.26 \\
.25 \\
.21 \\
.16 \\
.14\end{array}$ & $\begin{array}{l}.27 \\
.24 \\
.22 \\
.20 \\
.20\end{array}$ & $\begin{array}{l}.37 \\
3.1 \\
4.3 \\
3.2 \\
2.5\end{array}$ & $\begin{array}{l}.49 \\
.50 \\
.52 \\
.46 \\
.72\end{array}$ & $\begin{array}{l}19 \\
14 \\
11 \\
9.4 \\
8.1\end{array}$ & $\begin{array}{l}8.5 \\
8.2 \\
7.5 \\
6.9 \\
6.7\end{array}$ & $\begin{array}{l}.76 \\
1.0 \\
7.2 \\
6.1 \\
14\end{array}$ & $\begin{array}{l}1.4 \\
1.3 \\
1 \cdot 2 \\
1.2 \\
1.3\end{array}$ & $\begin{array}{l}1.8 \\
1.5 \\
1.2 \\
1.0 \\
.84\end{array}$ & $\begin{array}{r}.09 \\
.11 \\
112 \\
111 \\
113\end{array}$ & $\begin{array}{l}.09 \\
.09 \\
.09 \\
.09 \\
.11\end{array}$ & $\begin{array}{l}91 \\
9.2 \\
4.9 \\
3.6 \\
3.4\end{array}$ \\
\hline $\begin{array}{l}16 \\
17 \\
18 \\
19 \\
20\end{array}$ & $\begin{array}{l}.11 \\
.11 \\
.13 \\
.15 \\
.15\end{array}$ & $\begin{array}{l}.21 \\
.26 \\
.29 \\
.28 \\
.27\end{array}$ & $\begin{array}{l}2.3 \\
2 \cdot 2 \\
2 \cdot 2 \\
2 \cdot 1 \\
2.3\end{array}$ & $\begin{array}{l}.24 \\
.21 \\
.22 \\
.21 \\
.20\end{array}$ & $\begin{array}{l}7.3 \\
6.6 \\
6.0 \\
5.8 \\
5.6\end{array}$ & $\begin{array}{l}6.5 \\
6.3 \\
6.0 \\
6.0 \\
5.4\end{array}$ & $\begin{array}{r}14 \\
9.4 \\
7.8 \\
7.3 \\
6.3\end{array}$ & $\begin{array}{l}1.3 \\
1.3 \\
1.3 \\
1.3 \\
1.4\end{array}$ & $\begin{array}{r}.79 \\
.84 \\
.63 \\
.27 \\
.22\end{array}$ & $\begin{array}{r}.19 \\
.19 \\
.15 \\
.13 \\
.11\end{array}$ & $\begin{array}{r}.16 \\
.12 \\
.11 \\
.11 \\
.11\end{array}$ & $\begin{array}{l}3.1 \\
2.6 \\
2.5 \\
2.6 \\
2.5\end{array}$ \\
\hline $\begin{array}{l}21 \\
22 \\
23 \\
24 \\
25\end{array}$ & $\begin{array}{l}.18 \\
.24 \\
.22 \\
.16 \\
.16\end{array}$ & $\begin{array}{l}.26 \\
.25 \\
.23 \\
.24 \\
.26\end{array}$ & $\begin{array}{l}2.6 \\
2.3 \\
2.4 \\
2.4 \\
2.3\end{array}$ & $\begin{array}{l}.21 \\
.21 \\
.21 \\
.23 \\
.23\end{array}$ & $\begin{array}{l}5.2 \\
4.0 \\
4.4 \\
4.3 \\
4.3\end{array}$ & $\begin{array}{l}5.4 \\
5.5 \\
5.3 \\
5.3 \\
5.4\end{array}$ & $\begin{array}{l}6.3 \\
6.8 \\
6.8 \\
4.7 \\
2.8\end{array}$ & $\begin{array}{l}1.3 \\
1.3 \\
1.3 \\
1.4 \\
1.6\end{array}$ & $\begin{array}{r}.20 \\
.19 \\
.15 \\
.11 \\
.09\end{array}$ & $\begin{array}{r}.09 \\
.11 \\
.16 \\
.11 \\
.12\end{array}$ & $\begin{array}{r}.10 \\
.09 \\
.09 \\
.08 \\
.08\end{array}$ & $\begin{array}{l}2.5 \\
2.3 \\
2.6 \\
3.3 \\
4.0\end{array}$ \\
\hline $\begin{array}{l}26 \\
27 \\
28 \\
29 \\
30 \\
31\end{array}$ & $\begin{array}{l}.16 \\
.20 \\
.24 \\
.22 \\
1.0 \\
2.3\end{array}$ & $\begin{array}{r}.28 \\
.63 \\
2.3 \\
.84 \\
.49 \\
-0 .-\end{array}$ & $\begin{array}{l}2.2 \\
2.2 \\
2.2 \\
2.2 \\
2.2 \\
2.3\end{array}$ & $\begin{array}{r}.61 \\
1.1 \\
.23 \\
.58 \\
.12 \\
.14\end{array}$ & $\begin{array}{l}4.2 \\
4.0 \\
3.8 \\
3.8 \\
.0- \\
-0 .\end{array}$ & $\begin{array}{l}5.0 \\
3.7 \\
3.0 \\
2.9 \\
2.7 \\
2.6\end{array}$ & $\begin{array}{l}2.8 \\
2.2 \\
1.8 \\
1.8 \\
1.6 \\
\ldots-2\end{array}$ & $\begin{array}{l}1.5 \\
1.3 \\
1.5 \\
1.4 \\
1.4 \\
1.3\end{array}$ & $\begin{array}{l}.09 \\
.08 \\
.07 \\
.07 \\
.08 \\
-\infty\end{array}$ & $\begin{array}{l}.18 \\
.17 \\
.15 \\
.15 \\
.14 \\
.16\end{array}$ & $\begin{array}{l}.07 \\
.07 \\
.07 \\
.06 \\
.06 \\
.06\end{array}$ & $\begin{array}{l}3.6 \\
3.2 \\
3.0 \\
3.1 \\
3.2\end{array}$ \\
\hline $\begin{array}{l}\text { TOTAL } \\
\text { MEAN } \\
\text { MAX } \\
\text { MIN } \\
\text { AC-FT }\end{array}$ & $\begin{array}{r}9.55 \\
.31 \\
2.3 \\
.08 \\
19\end{array}$ & $\begin{array}{r}13.66 \\
.46 \\
2.3 \\
.20 \\
27\end{array}$ & $\begin{array}{r}54.65 \\
1.76 \\
4.3 \\
.32 \\
108\end{array}$ & $\begin{array}{r}25.17 \\
.81 \\
3.6 \\
.12 \\
50\end{array}$ & $\begin{array}{r}263.60 \\
9.09 \\
38 \\
.40 \\
523\end{array}$ & $\begin{array}{r}249.2 \\
8.04 \\
33 \\
2.6 \\
494\end{array}$ & $\begin{array}{r}129.80 \\
4.33 \\
14 \\
.75 \\
257\end{array}$ & $\begin{array}{r}46.2 \\
1.49 \\
2.2 \\
1.2 \\
92\end{array}$ & $\begin{array}{r}22.67 \\
.76 \\
1.9 \\
.07 \\
45\end{array}$ & $\begin{array}{r}3.93 \\
.13 \\
.19 \\
.07 \\
7.8\end{array}$ & $\begin{array}{l}3.05 \\
.098 \\
.16 \\
.06 \\
6.0\end{array}$ & $\begin{array}{r}170.93 \\
5.70 \\
91 \\
.06 \\
339\end{array}$ \\
\hline
\end{tabular}

CAL YR 1975 TOTAL 1234.28 MEAN 3.38 MAX 43 MIN .03 AC-FT 2450 HTR YR 1976 TOTAL 992.41 MEAN 2.71 MAX 91 MIN .06 AC-FT 1970 
COMBINED DISCHARGE, IN CUBIC FEET PER SECOND, OF CITY CREEK AND CITY CREEK WATER CO.'S CANAL NEAR HIGHLAND, CA, WATER YEAR OCTOBER 1975 TO SEPTEMBER 1976

DISCHARGE, IN CUBIC FEET PER SECOND, HATER YEAR OCTOBER 1975 TO SEPTEMBER 1976 MEAN VALUES

\begin{tabular}{|c|c|c|c|c|c|c|c|c|c|c|c|c|}
\hline DAY & $\mathrm{OCT}$ & NoV & DEC & JAN & FEB & MAR & APR & MAY & JUN & JUL & AUO & SEP \\
\hline $\begin{array}{l}1 \\
2 \\
3 \\
4 \\
5\end{array}$ & $\begin{array}{r}.52 \\
.43 \\
.37 \\
.31 \\
.28\end{array}$ & $\begin{array}{l}1.3 \\
1.2 \\
1.1 \\
.99 \\
.99\end{array}$ & $\begin{array}{l}3.1 \\
3.8 \\
3.6 \\
3.2 \\
3.1\end{array}$ & $\begin{array}{l}2.4 \\
2.5 \\
3.0 \\
3.6 \\
3.5\end{array}$ & $\begin{array}{l}1.6 \\
1.6 \\
1.6 \\
1.6 \\
2.8\end{array}$ & $\begin{array}{l}33 \\
18 \\
18 \\
11 \\
10\end{array}$ & $\begin{array}{l}2.6 \\
2.5 \\
2.5 \\
4.5 \\
3.9\end{array}$ & $\begin{array}{l}3.1 \\
3.0 \\
3.1 \\
3.2 \\
3.3\end{array}$ & $\begin{array}{l}1.9 \\
1.6 \\
1.7 \\
1.6 \\
1.9\end{array}$ & $\begin{array}{r}.20 \\
.34 \\
.46 \\
.39 \\
.26\end{array}$ & $\begin{array}{r}.37 \\
.37 \\
.41 \\
.46 \\
.35\end{array}$ & $\begin{array}{l}.14 \\
.14 \\
.25 \\
.25 \\
.23\end{array}$ \\
\hline $\begin{array}{r}6 \\
7 \\
8 \\
9 \\
10\end{array}$ & $\begin{array}{l}.36 \\
.84 \\
1.0 \\
.90 \\
1.0\end{array}$ & $\begin{array}{l}1.1 \\
1.1 \\
1.2 \\
1.2 \\
1.2\end{array}$ & $\begin{array}{l}2.9 \\
2.6 \\
2.4 \\
2.4 \\
2.5\end{array}$ & $\begin{array}{l}2.5 \\
2.3 \\
2.2 \\
2.2 \\
2.2\end{array}$ & $\begin{array}{l}16 \\
22 \\
22 \\
38 \\
29\end{array}$ & $\begin{array}{l}9.6 \\
9.2 \\
8.9 \\
8.5 \\
8.2\end{array}$ & $\begin{array}{l}3.1 \\
2.7 \\
2.8 \\
2.3 \\
1.9\end{array}$ & $\begin{array}{l}3.4 \\
4.3 \\
3.4 \\
2.9 \\
2.7\end{array}$ & $\begin{array}{l}1.8 \\
1.0 \\
1.7 \\
2.0 \\
3.0\end{array}$ & $\begin{array}{r}.18 \\
.14 \\
.13 \\
.11 \\
.14\end{array}$ & $\begin{array}{r}.31 \\
.25 \\
.21 \\
.19 \\
.17\end{array}$ & $\begin{array}{r}.26 \\
.30 \\
.33 \\
1.41\end{array}$ \\
\hline $\begin{array}{l}11 \\
12 \\
13 \\
14 \\
15\end{array}$ & $\begin{array}{l}1.5 \\
1.6 \\
1.4 \\
1.2 \\
.94\end{array}$ & $\begin{array}{l}1.2 \\
1.1 \\
1.1 \\
1.1 \\
1.1\end{array}$ & $\begin{array}{l}2.6 \\
4.5 \\
4.3 \\
3.2 \\
2.5\end{array}$ & $\begin{array}{l}2 \cdot 2 \\
2 \cdot 2 \\
2 \cdot 2 \\
2 \cdot 2 \\
2 \cdot 2\end{array}$ & $\begin{array}{l}19 \\
14 \\
11 \\
9.4 \\
0.1\end{array}$ & $\begin{array}{l}8.5 \\
8.2 \\
7.5 \\
6.9 \\
6.7\end{array}$ & $\begin{array}{l}1.9 \\
2.5 \\
8.1 \\
6.1 \\
14\end{array}$ & $\begin{array}{l}2.4 \\
2.2 \\
2.0 \\
2.0 \\
2.1\end{array}$ & $\begin{array}{l}2.9 \\
2.4 \\
1.9 \\
1.5 \\
1.3\end{array}$ & $\begin{array}{r}.17 \\
.23 \\
.29 \\
.33 \\
.39\end{array}$ & $\begin{array}{l}.17 \\
.16 \\
.16 \\
.21 \\
.31\end{array}$ & $\begin{array}{l}91 \\
9.2 \\
4.9 \\
3.6 \\
3.4\end{array}$ \\
\hline $\begin{array}{l}16 \\
17 \\
18 \\
19 \\
20\end{array}$ & $\begin{array}{r}.85 \\
.80 \\
.88 \\
1.0 \\
.99\end{array}$ & $\begin{array}{l}1.2 \\
1.3 \\
1.5 \\
1.5 \\
1.5\end{array}$ & $\begin{array}{l}2.3 \\
2.2 \\
2.2 \\
2.1 \\
2.3\end{array}$ & $\begin{array}{l}1.9 \\
1.9 \\
1.9 \\
1.8 \\
1.8\end{array}$ & $\begin{array}{l}7.3 \\
6.6 \\
6.0 \\
5.8 \\
5.6\end{array}$ & $\begin{array}{l}6.5 \\
6.3 \\
6.0 \\
6.0 \\
5.4\end{array}$ & $\begin{array}{r}14 \\
9.4 \\
7.8 \\
7.3 \\
6.3\end{array}$ & $\begin{array}{l}2.1 \\
2.1 \\
2.0 \\
2.1 \\
2.2\end{array}$ & $\begin{array}{l}1.2 \\
1.2 \\
1.2 \\
.92 \\
.85\end{array}$ & $\begin{array}{r}.53 \\
.53 \\
.41 \\
.37 \\
.30\end{array}$ & $\begin{array}{l}.44 \\
.36 \\
.35 \\
.36 \\
.37\end{array}$ & $\begin{array}{l}3.1 \\
2.6 \\
2.5 \\
2.6 \\
2.5\end{array}$ \\
\hline $\begin{array}{l}21 \\
22 \\
23 \\
24 \\
25\end{array}$ & $\begin{array}{l}1.2 \\
1.3 \\
1.2 \\
1.0 \\
1.0\end{array}$ & $\begin{array}{l}1.5 \\
1.5 \\
1.3 \\
1.2 \\
1.4\end{array}$ & $\begin{array}{l}2.6 \\
2.3 \\
2.4 \\
2.4 \\
2.3\end{array}$ & $\begin{array}{l}1.8 \\
1.8 \\
1.8 \\
1.9 \\
1.9\end{array}$ & $\begin{array}{l}5.2 \\
4.8 \\
4.4 \\
4.3 \\
4.3\end{array}$ & $\begin{array}{l}5.4 \\
5.5 \\
5.3 \\
5.3 \\
5.4\end{array}$ & $\begin{array}{l}6.3 \\
6.8 \\
6.8 \\
5.4 \\
4.7\end{array}$ & $\begin{array}{l}2.1 \\
2.2 \\
2.1 \\
2.3 \\
2.5\end{array}$ & $\begin{array}{r}.80 \\
.77 \\
.64 \\
.45 \\
.38\end{array}$ & $\begin{array}{r}.23 \\
.30 \\
.42 \\
.28 \\
.30\end{array}$ & $\begin{array}{l}.34 \\
.29 \\
.26 \\
.23 \\
.21\end{array}$ & $\begin{array}{l}2.5 \\
2.3 \\
2.6 \\
3.3 \\
4.0\end{array}$ \\
\hline $\begin{array}{l}26 \\
27 \\
28 \\
29 \\
30 \\
31\end{array}$ & $\begin{array}{l}1.0 \\
1.1 \\
1.2 \\
1.2 \\
1.6 \\
2.3\end{array}$ & $\begin{array}{l}1.4 \\
2.3 \\
4.5 \\
3.7 \\
3.1 \\
.=-\end{array}$ & $\begin{array}{l}2.2 \\
2.2 \\
2.2 \\
2.2 \\
2.2 \\
2.2\end{array}$ & $\begin{array}{l}1.8 \\
1.9 \\
1.6 \\
1.8 \\
1.7 \\
1.6\end{array}$ & $\begin{array}{l}4.2 \\
4.0 \\
3.8 \\
3.8 \\
-.-2 \\
-.0\end{array}$ & $\begin{array}{l}5.0 \\
3.7 \\
3.0 \\
2.9 \\
2.7 \\
2.6\end{array}$ & $\begin{array}{l}4.4 \\
3.9 \\
3.5 \\
3.4 \\
3.0 \\
-.-\end{array}$ & $\begin{array}{l}2.3 \\
2.0 \\
2.3 \\
2.4 \\
2.5 \\
2.2\end{array}$ & $\begin{array}{r}.35 \\
.27 \\
.21 \\
.17 \\
.18 \\
.+2\end{array}$ & $\begin{array}{l}.49 \\
.51 \\
.46 \\
.46 \\
.42 \\
.47\end{array}$ & $\begin{array}{l}.19 \\
.19 \\
.17 \\
.14 \\
.12 \\
.13\end{array}$ & $\begin{array}{l}3.6 \\
3.2 \\
3.0 \\
3.1 \\
3.2 \\
-\end{array}$ \\
\hline $\begin{array}{l}\text { TOTAL } \\
\text { MEAN } \\
\text { MAX } \\
\text { MIN } \\
\text { AC-FT }\end{array}$ & $\begin{array}{r}31.17 \\
1.01 \\
2.3 \\
.28 \\
62\end{array}$ & $\begin{array}{r}45.88 \\
1.53 \\
4.5 \\
.99 \\
91\end{array}$ & $\begin{array}{r}83.1 \\
2.68 \\
4.5 \\
2.1 \\
165\end{array}$ & $\begin{array}{r}66.3 \\
2.14 \\
3.6 \\
1.6 \\
132\end{array}$ & $\begin{array}{r}267.8 \\
9.23 \\
38 \\
1.6 \\
531\end{array}$ & $\begin{array}{r}249.2 \\
8.04 \\
33 \\
2.6 \\
494\end{array}$ & $\begin{array}{r}154.4 \\
5.15 \\
14 \\
1.9 \\
306\end{array}$ & $\begin{array}{r}78.5 \\
2.53 \\
4.3 \\
2.0 \\
156\end{array}$ & $\begin{array}{r}38.79 \\
1.29 \\
3.0 \\
.17 \\
77\end{array}$ & $\begin{array}{r}10.24 \\
.33 \\
.53 \\
.11 \\
20\end{array}$ & $\begin{array}{r}8.25 \\
.27 \\
.46 \\
.12 \\
16\end{array}$ & $\begin{array}{r}172.51 \\
5.75 \\
91 \\
.14 \\
342\end{array}$ \\
\hline
\end{tabular}


11056500 LITTLE SAN GORGONIO CREEK NEAR BEAUMONT, CA

LOCATION. - Lat $34^{\circ} 01^{\prime} 45^{\prime \prime}$, long $116^{\circ} 56^{\prime} 43^{\prime \prime}$, in NW/ SWtaNW/4 sec.1, T.2 S., R. 1 W., San Bernardino County, on right bank at upstream side of bridge on Oak'Glen Road, $3.0 \mathrm{mi}(4.8 \mathrm{~km})$ upstream from Wallace Creek, and $7 \mathrm{mi}$ (11 km) north of Beaumont.

DRAINAGE AREA. $-1.74 \mathrm{mi}^{2}\left(4.51 \mathrm{~km}^{2}\right)$, revised.

PERIOD OF RECORD, - -October 1948 to current year.

GAGE. - Water-stage recorder and concrete control. Altitude of gage is $4,320 \mathrm{ft}$ ( $1,317 \mathrm{~m}$ ), from topographic map. Prior to July 30,1970 , at site $42 \mathrm{ft}(13 \mathrm{~m})$ downstream on left bank at same datum.

REMARKS.--Records poor. No regulation above station. Several small diversions above station for irrigation. See schematic diagram of Santa Ana River basin.

AVERAGE DISCHARGE. - -28 years, $0.44 \mathrm{ft}^{3} / \mathrm{s}\left(0.013 \mathrm{~m}^{3} / \mathrm{s}\right), 319 \mathrm{acre}-\mathrm{ft} / \mathrm{yr}\left(393,000 \mathrm{~m}^{3} / \mathrm{yr}^{\mathrm{r}}\right)$.

EXTREMES FOR PERIOD OF RECORD.--Maximum discharge, 11,000 $\mathrm{ft}^{3} / \mathrm{s}\left(312 \mathrm{~m}^{3} / \mathrm{s}\right)$ Feb. 25 , 1969, gage height, $8.50 \mathrm{ft}$ . $(2.591 \mathrm{~m})$, from floodmarks, from rating curve extended above $32 \mathrm{ft}^{3} / \mathrm{s}\left(0.91 \mathrm{~m}^{3} / \mathrm{s}\right)$ on basis of $\mathrm{s} 1 \mathrm{ope}-\mathrm{area}$ measurements at gage heights $2.18 \mathrm{ft}(0.655 \mathrm{~m}), 3.45 \mathrm{ft}(1.052 \mathrm{~m})$, and $8.50 \mathrm{ft}(2.591 \mathrm{~m})$; no flow for several months in most years.

EXTREMES FOR CURRENT YEAR. --Peak discharges above base of $10 \mathrm{ft}^{3} / \mathrm{s}\left(0.28 \mathrm{~m}^{3} / \mathrm{s}\right)$ and maximun (*), on basis of slope-area measurement made at peak flow:

\begin{tabular}{|c|c|c|c|c|c|c|c|c|c|}
\hline Date & Time & $\begin{array}{c}\text { Discharge } \\
\left(\mathrm{ft}^{3} / \mathrm{s}\right)\left(\mathrm{m}^{3} / \mathrm{s}\right)\end{array}$ & $\begin{array}{l}\text { Gage height } \\
\text { (ft) (m) }\end{array}$ & Date & Time & $\begin{array}{r}\text { Disc } \\
\left(\mathrm{ft}^{3} / \mathrm{s}\right.\end{array}$ & $\left(\mathrm{m}^{3} / \mathrm{s}\right)$ & $\begin{array}{l}\text { Gage } \\
(\mathrm{ft})\end{array}$ & $\begin{array}{r}\text { height } \\
(\mathrm{m})\end{array}$ \\
\hline $\begin{array}{l}\text { Feb. } 9 \\
\text { Mar. } 1\end{array}$ & $\begin{array}{l}1400 \\
1600\end{array}$ & $\begin{array}{l}1.25 \\
0.57\end{array}$ & $\begin{array}{l}1.241 \\
1.180\end{array}$ & Sept. 10 & 2330 & $* 427$ & 12.1 & 5.30 & 1.615 \\
\hline
\end{tabular}

Minimum daily discharge, no flow several months.

DISCHARGE, IN CUBIC FEET PER SECOND, WATER YEAR OCTOBER 1975 TO SEPTEMBER 1976

\begin{tabular}{|c|c|c|c|c|c|c|c|c|c|c|c|c|}
\hline DAY & $\mathrm{OCr}$ & NOV & DEC & JAN & FEB & MAR & APR & MAY & JUN & JUL & AUG & SEP \\
\hline $\begin{array}{l}1 \\
2 \\
3 \\
4 \\
5\end{array}$ & & & & & $\begin{array}{l}0 \\
0 \\
0 \\
0 \\
.01\end{array}$ & $\begin{array}{l}2.9 \\
.58 \\
.32 \\
.34 \\
.10\end{array}$ & $\begin{array}{l}.01 \\
.01 \\
.01 \\
.01 \\
.01\end{array}$ & $\begin{array}{l}.01 \\
.01 \\
.01 \\
.02 \\
.03\end{array}$ & $\begin{array}{l}0 \\
0 \\
0 \\
.01\end{array}$ & & & $\begin{array}{l}0 \\
0 \\
0 \\
0 \\
0\end{array}$ \\
\hline $\begin{array}{r}6 \\
7 \\
8 \\
9 \\
10\end{array}$ & & & & & $\begin{array}{r}.64 \\
5.93 \\
21.2 \\
.64\end{array}$ & $\begin{array}{l}.06 \\
.06 \\
.06 \\
.06 \\
.06\end{array}$ & $\begin{array}{l}.01 \\
.01 \\
.01 \\
.01 \\
.01\end{array}$ & $\begin{array}{l}.03 \\
.06 \\
.03 \\
.02 \\
.02\end{array}$ & $\begin{array}{l}0 \\
0 \\
0 \\
0 \\
.01\end{array}$ & & & $\begin{array}{r}0 \\
0 \\
0 \\
0 \\
23\end{array}$ \\
\hline $\begin{array}{l}11 \\
12 \\
13 \\
14 \\
15\end{array}$ & & & & & $\begin{array}{l}0^{.04} \\
0 \\
0 \\
0\end{array}$ & $\begin{array}{l}.04 \\
.04 \\
.02 \\
.02 \\
.01\end{array}$ & $\begin{array}{l}.01 \\
.04 \\
.04 \\
.20 \\
.40\end{array}$ & $\begin{array}{l}.01 \\
.01 \\
.01 \\
0 \\
0\end{array}$ & $\begin{array}{l}0^{.01} \\
0 \\
0 \\
0\end{array}$ & & & $\begin{array}{r}13 \\
1.7 \\
.08 \\
.04 \\
.02\end{array}$ \\
\hline $\begin{array}{l}16 \\
17 \\
18 \\
19 \\
20\end{array}$ & & & & & $\begin{array}{l}0 \\
0 \\
0 \\
0\end{array}$ & $\begin{array}{l}.01 \\
.01 \\
.01 \\
.01 \\
.01\end{array}$ & $\begin{array}{l}.10 \\
.06 \\
.03 \\
.02 \\
.02\end{array}$ & $\begin{array}{l}.01 \\
.01 \\
0 \\
0 \\
.01\end{array}$ & $\begin{array}{l}0 \\
0 \\
0 \\
0 \\
0\end{array}$ & & & $\begin{array}{l}.03 \\
.02 \\
.02 \\
.01 \\
.01\end{array}$ \\
\hline $\begin{array}{l}21 \\
22 \\
23 \\
24 \\
25\end{array}$ & & & & & $\begin{array}{l}0 \\
.01 \\
.03 \\
.05 \\
.04\end{array}$ & $\begin{array}{l}.01 \\
.01 \\
.01 \\
.01 \\
.01 \\
.01\end{array}$ & $\begin{array}{l}.02 \\
.02 \\
.01 \\
.01 \\
.01\end{array}$ & $\begin{array}{l}.01 \\
.01 \\
.01 \\
.01 \\
0\end{array}$ & $\begin{array}{l}0 \\
0 \\
0 \\
0 \\
0\end{array}$ & & & $\begin{array}{l}.01 \\
.01 \\
.01 \\
.03 \\
.04\end{array}$ \\
\hline $\begin{array}{l}26 \\
27 \\
28 \\
29 \\
30 \\
31\end{array}$ & & $-\infty$ & & & $\begin{array}{l}.02 \\
.01 \\
.02 \\
.01 \\
.0- \\
.-\end{array}$ & $\begin{array}{l}.01 \\
.01 \\
.01 \\
.01 \\
.01 \\
.01 \\
.01\end{array}$ & $\begin{array}{l}.01 \\
.01 \\
.01 \\
.01 \\
.01 \\
.01\end{array}$ & $\begin{array}{l}0 \\
0 \\
0 \\
.01 \\
.01\end{array}$ & $\begin{array}{l}0 \\
0 \\
0 \\
0 \\
0 \\
-\cdots\end{array}$ & & & $\begin{array}{l}.03 \\
.03 \\
.02 \\
.02 \\
.02 \\
0 .-\end{array}$ \\
\hline $\begin{array}{l}\text { TOTAL } \\
\text { MEAN } \\
\text { MAX } \\
\text { MIN } \\
\text { AC-FT }\end{array}$ & $\begin{array}{l}0 \\
0 \\
0 \\
0 \\
0\end{array}$ & $\begin{array}{l}0 \\
0 \\
0 \\
0 \\
0\end{array}$ & $\begin{array}{l}0 \\
0 \\
0 \\
0 \\
0\end{array}$ & $\begin{array}{l}0 \\
0 \\
0 \\
0 \\
0\end{array}$ & $\begin{array}{r}28.67 \\
.99 \\
21 \\
0 \\
.57\end{array}$ & $\begin{array}{r}4.83 \\
.16 \\
2.9 \\
.01 \\
9.6\end{array}$ & $\begin{array}{r}1.14 \\
.038 \\
.40 \\
.01 \\
2.3\end{array}$ & $\begin{array}{r}.36 \\
.012 \\
.06 \\
0 \\
.7\end{array}$ & $\begin{array}{r}.03 \\
.001 \\
.01 \\
0 \\
.06\end{array}$ & $\begin{array}{l}0 \\
0 \\
0 \\
0 \\
0\end{array}$ & $\begin{array}{l}0 \\
0 \\
0 \\
0 \\
0\end{array}$ & $\begin{array}{r}38.15 \\
1.27 \\
23 \\
0 \\
76\end{array}$ \\
\hline
\end{tabular}

$\begin{array}{lllllllll}\text { CAL YR } & 1975 & \text { TOTAL } 21.76 & \text { MEAN } .060 & \text { MAX } & .61 & \text { HIN } 0 & \text { AC-FT } 43 \\ \text { HTR YR } 1976 & \text { TOTAL } 73.18 & \text { MEAN } 020 & \text { MAX } & 23 & \text { MIN } 0 & \text { AC-FT } 145\end{array}$ 
11057000 SAN TIMOTEO CREEK NEAR REDLANDS, CA

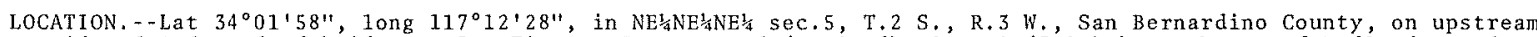
side of left end of bridge on San Timoteo Canyon Road (revised), 2.0 mi ( 3 .'2 km) southwest of Rediands, and $3.4 \mathrm{mi}(5.5 \mathrm{~km})$ downstream from Yucaipa Creek.

DRAINAGE AREA. $--118 \mathrm{mi}^{2}\left(306 \mathrm{~km}^{2}\right)$, revised.

PERIOD OF RECORD,--October 1926 to September 1968 , October 1973 to current year.

GAGE, - Water-stage recorder. Altitude of gage is $1,280 \mathrm{ft}(390 \mathrm{~m})$, from topographic map. Prior to Oct. 30 , 1934 , at site $2 \mathrm{mi}(3 \mathrm{~km})$ upstream at different datum.

REMARKS.--Records poor. No regulation above station. Pumping above station for irrigation. See schematic diagram of Santa Ana River basin.

AVERAGE DISCHARGE, - -45 years (water years $1927-68,1974-76), 1.32 \mathrm{ft}^{3} / \mathrm{s}\left(0.037 \mathrm{~m}^{3} / \mathrm{s}\right), 957 \mathrm{acre}-\mathrm{ft} / \mathrm{yr}\left(1.18 \mathrm{hm}{ }^{3} / \mathrm{yr}\right)$. EXTREMES FOR PERIOD OF RECORD.--Maximum discharge, $7,460 \mathrm{ft}^{3} / \mathrm{s}\left(211 \mathrm{~m}^{3} / \mathrm{s}\right) \mathrm{Mar} .2$, 1938, result of slope-area measurement of maximum flow; no flow for many months in each year.

EXTREMES FOR CURRENT YEAR.--Peak discharge above base of $150 \mathrm{ft}^{3} / \mathrm{s}\left(4.25 \mathrm{~m}^{3} / \mathrm{s}\right)$ and maximum $(*)$ :

\begin{tabular}{|c|c|c|c|c|c|c|c|c|c|}
\hline Date & Time & $\begin{array}{c}\text { Discharge } \\
\left(\mathrm{ft}^{3} / \mathrm{s}\right)\left(\mathrm{m}^{3} / \mathrm{s}\right)\end{array}$ & $\begin{array}{l}\text { Gage height } \\
(\mathrm{ft}) \quad(\mathrm{m})\end{array}$ & Date & Tine & $\begin{array}{r}\text { Disch } \\
\left(\mathrm{ft}^{3} / \mathrm{s}\right)\end{array}$ & $\stackrel{\mathrm{rge}}{\left(\mathrm{m}^{3} / \mathrm{s}\right)}$ & $\begin{array}{l}\text { Gage } \\
(\mathrm{ft})\end{array}$ & $\begin{array}{r}\text { height } \\
\text { (II) }\end{array}$ \\
\hline $\begin{array}{l}\text { Feb. } \quad 9 \\
\text { Sept, } 119\end{array}$ & $\begin{array}{l}2300 \\
0230\end{array}$ & $\begin{array}{r}9.54 \\
27.8\end{array}$ & $\begin{array}{l}1.213 \\
1.332\end{array}$ & Sept. 24 & Unknown & ${ }^{*} 1330$ & 37.7 & 4.50 & 1.372 \\
\hline
\end{tabular}

Minimum daily discharge, no flow most of year.

DISCHARGE, IN CUBIC FEET PER SECOND, WATER YEAR OCTOBER 1975 TO SEPTEMBER 1976 MEAN VALUES

\begin{tabular}{|c|c|c|c|c|c|c|c|c|c|c|c|c|}
\hline DAY & $\mathrm{OCT}$ & NOV & DEC & JAN & FEB & MAR & APR & MAY & JUN & JUL & AUG & SEP \\
\hline $\begin{array}{l}1 \\
2 \\
3 \\
4 \\
5\end{array}$ & & $\begin{array}{l}0 \\
0 \\
0 \\
0 \\
0\end{array}$ & & & $\begin{array}{l}0 \\
0 \\
0 \\
0 \\
0\end{array}$ & $\begin{array}{l}9.7 \\
4.9 \\
9.6 \\
0 \\
0\end{array}$ & $\begin{array}{l}0 \\
0 \\
0 \\
0 \\
0\end{array}$ & $\begin{array}{l}0 \\
0 \\
0 \\
0 \\
0\end{array}$ & $\begin{array}{l}0 \\
0 \\
0 \\
0 \\
0\end{array}$ & & & $\begin{array}{l}0 \\
0 \\
0 \\
0 \\
0\end{array}$ \\
\hline $\begin{array}{r}6 \\
7 \\
8 \\
9 \\
10\end{array}$ & & $\begin{array}{l}0 \\
0 \\
0 \\
0 \\
0\end{array}$ & & & $0_{0}^{.21}$ & $\begin{array}{l}0 \\
0 \\
0 \\
0 \\
0\end{array}$ & $\begin{array}{l}0 \\
0 \\
0 \\
0 \\
0\end{array}$ & $\begin{array}{l}0 \\
0 \\
0 \\
0\end{array}$ & $\begin{array}{l}0 \\
0 \\
0 \\
0 \\
.20\end{array}$ & & & $\begin{array}{r}0 \\
0 \\
0 \\
0 \\
35\end{array}$ \\
\hline $\begin{array}{l}11 \\
12 \\
13 \\
14 \\
15\end{array}$ & & $\begin{array}{l}0 \\
0 \\
0 \\
0 \\
0\end{array}$ & & & $\begin{array}{l}0 \\
0 \\
0 \\
0 \\
0\end{array}$ & $\begin{array}{l}0 \\
0 \\
0 \\
0 \\
0\end{array}$ & $\begin{array}{l}0 \\
0 \\
0 \\
1.2 \\
1.7\end{array}$ & $\begin{array}{l}0 \\
0 \\
0 \\
0 \\
0\end{array}$ & $\begin{array}{l}0 \\
0 \\
0 \\
0 \\
0\end{array}$ & & & $\begin{array}{r}77 \\
0 \\
0 \\
0 \\
0\end{array}$ \\
\hline $\begin{array}{l}16 \\
17 \\
18 \\
19 \\
20\end{array}$ & & $\begin{array}{l}0 \\
0 \\
0 \\
0 \\
0\end{array}$ & & & $\begin{array}{l}0 \\
0 \\
0 \\
0 \\
0\end{array}$ & $\begin{array}{l}0 \\
0 \\
0 \\
0 \\
0\end{array}$ & $\begin{array}{l}.03 \\
0 \\
0 \\
0\end{array}$ & $\begin{array}{l}0 \\
0 \\
0 \\
0 \\
0\end{array}$ & $\begin{array}{l}0 \\
0 \\
0 \\
0 \\
0\end{array}$ & & & $\begin{array}{l}0 \\
0 \\
0 \\
0 \\
0\end{array}$ \\
\hline $\begin{array}{l}21 \\
22 \\
23 \\
24 \\
25\end{array}$ & & $\begin{array}{l}0 \\
0 \\
0 \\
0 \\
0\end{array}$ & & & $\begin{array}{l}0 \\
0 \\
0 \\
0 \\
0\end{array}$ & $\begin{array}{l}0 \\
0 \\
0 \\
0 \\
0\end{array}$ & $\begin{array}{l}0 \\
0 \\
0 \\
0 \\
0\end{array}$ & $\begin{array}{l}0 \\
0 \\
0 \\
0 \\
0\end{array}$ & $\begin{array}{l}0 \\
0 \\
0 \\
0 \\
0\end{array}$ & & & $\begin{array}{r}0 \\
0 \\
0 \\
60 \\
0\end{array}$ \\
\hline $\begin{array}{l}26 \\
27 \\
28 \\
29 \\
30 \\
31\end{array}$ & & $\begin{array}{l}0 \\
0 \\
1.0 \\
0 \\
0 \\
-\end{array}$ & & & $\begin{array}{l}0 \\
0 \\
0 \\
0 \\
- \\
- \\
-\end{array}$ & $\begin{array}{l}0 \\
0 \\
0 \\
0 \\
0 \\
0\end{array}$ & $\begin{array}{l}0 \\
0 \\
0 \\
0 \\
0 \\
=-\infty\end{array}$ & $\begin{array}{l}0 \\
0 \\
0 \\
0 \\
0 \\
0\end{array}$ & $\begin{array}{l}0 \\
0 \\
0 \\
0 \\
0 \\
\end{array}$ & & & $\begin{array}{r}0 \\
0 \\
0 \\
0 \\
0 \\
-\end{array}$ \\
\hline $\begin{array}{l}\text { TOTAL } \\
\text { MEAN } \\
\text { MAX } \\
\text { MIN } \\
\text { AC-FT }\end{array}$ & $\begin{array}{l}0 \\
0 \\
0 \\
0 \\
0\end{array}$ & $\begin{array}{r}1.0 \\
.033 \\
1.0 \\
0 \\
2.0\end{array}$ & $\begin{array}{l}0 \\
0 \\
0 \\
0 \\
0\end{array}$ & $\begin{array}{l}0 \\
0 \\
0 \\
0 \\
0\end{array}$ & $\begin{array}{r}14.06 \\
.48 \\
13 \\
0 \\
28\end{array}$ & $\begin{array}{r}24.2 \\
.78 \\
9.7 \\
0 \\
48\end{array}$ & $\begin{array}{r}2.93 \\
.098 \\
1.7 \\
0 \\
5.8\end{array}$ & $\begin{array}{r}.24 \\
.008 \\
.24 \\
0 \\
.5\end{array}$ & $\begin{array}{r}.20 \\
.007 \\
.20 \\
0 \\
.4\end{array}$ & $\begin{array}{l}0 \\
0 \\
0 \\
0 \\
0\end{array}$ & $\begin{array}{l}0 \\
0 \\
0 \\
0 \\
0\end{array}$ & $\begin{array}{r}172 \\
5.73 \\
77 \\
0 \\
341\end{array}$ \\
\hline
\end{tabular}

CAL YR 1975 TOTAL 146.84 MEAN .40 MAX 67 MIN 0 AC-FT 291 HTR YR 1976 TOTAL 214.63 MEAN .59 MAX 77 MIN O AC-FT 426 
11058500 EAST TWIN CREEK NEAR ARROWHEAD SPRINGS, CA

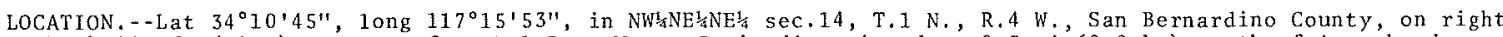
bank $100 \mathrm{ft}(30 \mathrm{~m})$ upstream from Del Rosa Water Co.'s diversion dam, $0.5 \mathrm{mi}(0.8 \mathrm{~km}) \mathrm{south}$ of Arrowhead

Springs, and $1.0 \mathrm{mi}(1.6 \mathrm{~km})$ downstream from Strawberry Creek.

DRAINAGE AREA. $--8.80 \mathrm{mi}^{2}\left(22.79 \mathrm{~km}^{2}\right)$.

PERTOD OF RECORD.--December 1919 to current year. Prior to October 1952, pub1ished as Strawberry Creek near Arrowhead Springs.

GAGE. - Water-stage recorder. Broad-crested weir since September 1938. Altitude of gage is 1,590 ft (485 m), from topographic map.

REMARKS. - Records fair. No regulation above station. One small diversion for domestic use above station. See schematic diagram of Santa Ana River basin.

AVERAGE DISCHARGE. - -56 years (water years $1921-76), 4.37 \mathrm{ft}^{3} / \mathrm{s}\left(0.124 \mathrm{~m}^{3} / \mathrm{s}\right), 3,170 \mathrm{acre}-\mathrm{ft} / \mathrm{yr}\left(3.91 \mathrm{hm} / \mathrm{yr}^{3}\right)$.

EXTREMES FOR PERIOD OF RECORD,-Maximum discharge, 3,360 $\mathrm{ft}^{3} / \mathrm{s}\left(95.2 \mathrm{~m}^{3} / \mathrm{s}\right) \mathrm{Mar}$. 2, 1938, based on rainfa11-runoff studies; no flow at times in $1929,1931-35$.

EXTREMES FOR CURRENT YEAR. -- Peak discharges above base of $40 \mathrm{ft}^{3} / \mathrm{s}\left(1.13 \mathrm{~m}^{3} / \mathrm{s}\right)$ and maximum $(*)$ :

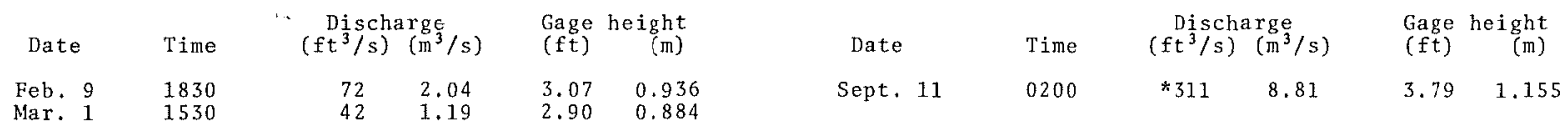

Minimum daily discharge, $0.34 \mathrm{ft}^{3} / \mathrm{s}\left(0.010 \mathrm{~m}^{3} / \mathrm{s}\right)$ Oct. 2, 3, Aug. 11 .

DISCHARGE, IN CUBIC FEET PER SECOND, WATER YEAR OCTOBER 1975 TO SEPTEMBER 1976 MEAN VALUES

\begin{tabular}{|c|c|c|c|c|c|c|c|c|c|c|c|c|}
\hline DAY & OCT & Nov & DEC & JAN & FEB & MAR & APR & MAY & JUN & JUL & AUG & SEP \\
\hline $\begin{array}{l}1 \\
2 \\
3 \\
4 \\
5\end{array}$ & $\begin{array}{r}.36 \\
.34 \\
.34 \\
.37 \\
.37\end{array}$ & $\begin{array}{l}.55 \\
.71 \\
.60 \\
.60 \\
.64\end{array}$ & $\begin{array}{l}1.3 \\
1.1 \\
1.1 \\
1.1 \\
1.2\end{array}$ & $\begin{array}{l}.97 \\
1.0 \\
1.2 \\
1.2 \\
1.0\end{array}$ & $\begin{array}{r}.88 \\
.76 \\
.87 \\
2.5 \\
5.2\end{array}$ & $\begin{array}{r}11 \\
9.7 \\
7.4 \\
4.7 \\
3.8\end{array}$ & $\begin{array}{r}.82 \\
.79 \\
.76 \\
1.5 \\
1.2\end{array}$ & $\begin{array}{l}1.3 \\
1.2 \\
1.4 \\
1.4 \\
1.7\end{array}$ & $\begin{array}{l}.88 \\
.78 \\
.80 \\
.80 \\
.84\end{array}$ & $\begin{array}{r}.48 \\
.51 \\
.51 \\
.53 \\
.58\end{array}$ & $\begin{array}{r}.40 \\
.39 \\
.37 \\
.37 \\
.38\end{array}$ & $\begin{array}{r}.37 \\
.37 \\
.42 \\
.40 \\
.40\end{array}$ \\
\hline $\begin{array}{r}6 \\
7 \\
8 \\
9 \\
10\end{array}$ & $\begin{array}{l}.40 \\
.45 \\
.41 \\
.41 \\
.41\end{array}$ & $\begin{array}{l}.60 \\
.46 \\
.50 \\
.53 \\
.53\end{array}$ & $\begin{array}{l}1.0 \\
.89 \\
.89 \\
.83 \\
.89\end{array}$ & $\begin{array}{l}1.1 \\
1.1 \\
.88 \\
.80 \\
.89\end{array}$ & $\begin{array}{l}6.0 \\
10 \\
16 \\
27 \\
11\end{array}$ & $\begin{array}{l}3.4 \\
3.5 \\
3.2 \\
3.0 \\
2.7\end{array}$ & $\begin{array}{l}1.0 \\
.92 \\
.99 \\
.91 \\
.80\end{array}$ & $\begin{array}{l}1.7 \\
2.1 \\
1.5 \\
1.3 \\
1.1\end{array}$ & $\begin{array}{r}.87 \\
.81 \\
.74 \\
.78 \\
1.1\end{array}$ & $\begin{array}{r}.49 \\
.48 \\
.48 \\
.48 \\
.45\end{array}$ & $\begin{array}{r}.36 \\
.37 \\
.36 \\
.36 \\
.35\end{array}$ & $\begin{array}{r}.41 \\
.41 \\
.43 \\
.43 \\
5.5\end{array}$ \\
\hline $\begin{array}{l}11 \\
12 \\
13 \\
14 \\
15\end{array}$ & $\begin{array}{l}.61 \\
.60 \\
.55 \\
.45 \\
.45\end{array}$ & $\begin{array}{l}.49 \\
.45 \\
.42 \\
.42 \\
.42\end{array}$ & $\begin{array}{l}.96 \\
1.7 \\
1.6 \\
1.2 \\
1.2\end{array}$ & $\begin{array}{l}1.1 \\
1.0 \\
.95 \\
.94 \\
.86\end{array}$ & $\begin{array}{l}5.8 \\
3.9 \\
3.0 \\
2.6 \\
2.4\end{array}$ & $\begin{array}{l}2.9 \\
2.6 \\
2.5 \\
2.4 \\
2.3\end{array}$ & $\begin{array}{r}.73 \\
.95 \\
4.7 \\
2.9 \\
4.4\end{array}$ & $\begin{array}{r}1.0 \\
.87 \\
.85 \\
.76 \\
.79\end{array}$ & $\begin{array}{r}1.1 \\
.85 \\
.72 \\
.60 \\
.46\end{array}$ & $\begin{array}{l}.45 \\
.46 \\
.47 \\
.49 \\
.50\end{array}$ & $\begin{array}{r}.34 \\
.35 \\
.36 \\
.35 \\
.37\end{array}$ & $\begin{array}{r}55 \\
4.5 \\
3.5 \\
3.0 \\
2.2\end{array}$ \\
\hline $\begin{array}{l}16 \\
17 \\
18 \\
19 \\
20\end{array}$ & $\begin{array}{l}.47 \\
.50 \\
.55 \\
.60 \\
.65\end{array}$ & $\begin{array}{l}.46 \\
.53 \\
.60 \\
.59 \\
.60\end{array}$ & $\begin{array}{l}1.1 \\
1.1 \\
1.1 \\
1.1 \\
1.1\end{array}$ & $\begin{array}{r}.77 \\
.81 \\
.96 \\
.94 \\
.84\end{array}$ & $\begin{array}{l}2.1 \\
1.9 \\
1.8 \\
1.8 \\
1.7\end{array}$ & $\begin{array}{l}2.2 \\
2.2 \\
2.0 \\
1.9 \\
1.8\end{array}$ & $\begin{array}{l}3.5 \\
3.0 \\
2.6 \\
2.4 \\
2.2\end{array}$ & $\begin{array}{r}.98 \\
.91 \\
.85 \\
.96 \\
.93\end{array}$ & $\begin{array}{l}.45 \\
.51 \\
.65 \\
.60 \\
.60\end{array}$ & $\begin{array}{r}.51 \\
.51 \\
.52 \\
.50 \\
.50\end{array}$ & $\begin{array}{r}.39 \\
.38 \\
.38 \\
.40 \\
.38\end{array}$ & $\begin{array}{l}2.1 \\
1.9 \\
1.8 \\
1.6 \\
1.5\end{array}$ \\
\hline $\begin{array}{l}21 \\
22 \\
23 \\
24 \\
25\end{array}$ & $\begin{array}{l}.60 \\
.65 \\
.60 \\
.55 \\
.60\end{array}$ & $\begin{array}{l}.53 \\
.55 \\
.59 \\
.52 \\
.50\end{array}$ & $\begin{array}{l}1.2 \\
1.2 \\
1.1 \\
1.1 \\
1.0\end{array}$ & $\begin{array}{l}.85 \\
.75 \\
.82 \\
1.0 \\
1.0\end{array}$ & $\begin{array}{l}1.6 \\
1.5 \\
1.3 \\
1.4 \\
1.3\end{array}$ & $\begin{array}{r}1.5 \\
1.0 \\
.94 \\
.96 \\
.92\end{array}$ & $\begin{array}{l}2.1 \\
2.1 \\
2.0 \\
1.8 \\
1.6\end{array}$ & $\begin{array}{r}.91 \\
.93 \\
.98 \\
1.1 \\
.97\end{array}$ & $\begin{array}{l}.58 \\
.60 \\
.52 \\
.47 \\
.46\end{array}$ & $\begin{array}{l}.43 \\
.46 \\
.43 \\
.41 \\
.44\end{array}$ & $\begin{array}{r}.40 \\
.42 \\
.40 \\
.39 \\
.38\end{array}$ & $\begin{array}{l}1.4 \\
1.3 \\
1.2 \\
1.4 \\
1.2\end{array}$ \\
\hline $\begin{array}{l}26 \\
27 \\
28 \\
29 \\
30 \\
31\end{array}$ & $\begin{array}{l}.65 \\
.77 \\
.65 \\
.55 \\
.55 \\
.55\end{array}$ & $\begin{array}{l}.51 \\
.96 \\
1.8 \\
1.6 \\
1.3 \\
. .+\end{array}$ & $\begin{array}{l}1.0 \\
1.0 \\
1.1 \\
1.0 \\
1.1 \\
.94\end{array}$ & $\begin{array}{l}.91 \\
.84 \\
.85 \\
.81 \\
.76 \\
.82\end{array}$ & $\begin{array}{l}1.2 \\
.98 \\
1.0 \\
1.1 \\
-. .0\end{array}$ & $\begin{array}{l}.93 \\
.86 \\
.95 \\
.91 \\
.83 \\
.83\end{array}$ & $\begin{array}{l}1.4 \\
1.6 \\
1.5 \\
1.5 \\
1.3 \\
-0-\end{array}$ & $\begin{array}{l}.94 \\
.95 \\
.98 \\
1.0 \\
1.2 \\
1.2\end{array}$ & $\begin{array}{l}.45 \\
.45 \\
.47 \\
.46 \\
.51 \\
.0 .\end{array}$ & $\begin{array}{l}.44 \\
.43 \\
.44 \\
.42 \\
.42 \\
.40\end{array}$ & $\begin{array}{r}.37 \\
.37 \\
.36 \\
.36 \\
.36 \\
.36\end{array}$ & $\begin{array}{l}1.1 \\
1.1 \\
1.0 \\
.95 \\
.92 \\
=-0\end{array}$ \\
\hline $\begin{array}{l}\text { TOTAL } \\
\text { MEAN } \\
\text { MAX } \\
\text { MIN } \\
\text { AC-FT }\end{array}$ & $\begin{array}{r}16.01 \\
.52 \\
.77 \\
.34 \\
32\end{array}$ & $\begin{array}{r}19.56 \\
.65 \\
1.8 \\
.42 \\
39\end{array}$ & $\begin{array}{r}34.20 \\
1.10 \\
1.7 \\
.83 \\
68\end{array}$ & $\begin{array}{r}28.72 \\
.93 \\
1.2 \\
.75 \\
57\end{array}$ & $\begin{array}{r}118.49 \\
4.09 \\
27 \\
.76 \\
235\end{array}$ & $\begin{array}{r}85.83 \\
2.77 \\
11 \\
.83 \\
170\end{array}$ & $\begin{array}{r}53.97 \\
1.80 \\
4.7 \\
173 \\
107\end{array}$ & $\begin{array}{r}34.76 \\
1.12 \\
2.11 \\
.76 \\
69\end{array}$ & $\begin{array}{r}19.91 \\
.66 \\
1.1 \\
.45 \\
39\end{array}$ & $\begin{array}{r}14.62 \\
.47 \\
.58 \\
.40 \\
29\end{array}$ & $\begin{array}{r}11.58 \\
.37 \\
.42 \\
.34 \\
23\end{array}$ & $\begin{array}{r}97.81 \\
3.26 \\
55 \\
* 37 \\
194\end{array}$ \\
\hline
\end{tabular}
$\begin{array}{llllllllll}\text { CAL YR } 1975 & \text { TOTAL } 740.32 & \text { MEAN } 2.03 & \text { MAX 14 } & \text { MIN } & .34 & \text { AC=FT } & 1470 \\ \text { WTR YR } 1976 & \text { TOTAL } 535.46 & \text { MEAN } 1.46 & \text { MAX } 55 & \text { MIN } & .34 & \text { AOFT } & 1060\end{array}$ 


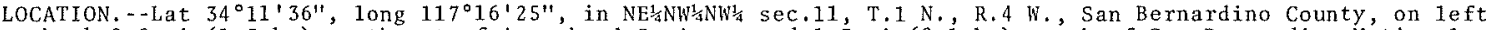
bank $0.8 \mathrm{mi}(1.3 \mathrm{~km})$ northwest of Arrowhead Springs, and $1.3 \mathrm{mi}(2.1 \mathrm{~km})$ north of San Bernardino National Forest boundary.

DRAINAGE AREA, $--4.65 \mathrm{mi}^{2}\left(12.04 \mathrm{~km}^{2}\right)$.

PERIOD OF RECORD, - November 1911 to October 1914 (published as "near San Bernardino"), December 1919 to current year.

GAGE. - Water-stage recorder. Broad-crested weir since September 1938. Datum of gage is $2,045.46 \mathrm{ft}$ (623.456 m) above mean sea level. Prior to December 1919, nonrecording gage at site $300 \mathrm{ft}$ ( $91 \mathrm{~m}$ ) downstream at different datum.

REMARKS. - Records good. Periods of no gage-height record Jan. 19 to Feb. 19, fair. No regulation above station. One small diversion for domestic use above station. See schematic diagram of Santa Ana River basin.

AVERAGE DISCHARGE, - -58 years, (water years $1913-14,1921-76), 2.53 \mathrm{ft}^{3} / \mathrm{s}\left(0.072 \mathrm{~m}^{3} / \mathrm{s}\right), 1,830 \mathrm{acre}-\mathrm{ft} / \mathrm{yr}$ (2. $\left.26 \mathrm{hm}^{3} / \mathrm{yr}\right)$.

EXTREMES FOR PERTOD OF RECORD (SINCE 1920), - -Maximum discharge, $2,350 \mathrm{ft}^{3} / \mathrm{s}\left(66.6 \mathrm{~m}^{3} / \mathrm{s}\right) \mathrm{Mar}$. 2 , 1938 , based on rainfall-runoff studies; no flow at times in some years.

EXTREMES FOR CURRENT YEAR, - Peak discharges above base of $35 \mathrm{ft}^{3} / \mathrm{s}\left(0.99 \mathrm{~m}^{3} / \mathrm{s}\right)$ and maximum $(*)$ :

\begin{tabular}{|c|c|c|c|c|c|}
\hline Date & Time & $\begin{array}{r}\text { Disc } \\
\left(\mathrm{ft}^{\frac{3}{3}} / \mathrm{s}\right.\end{array}$ & $\left.\mathrm{m}^{3} / \mathrm{s}\right)$ & $\begin{array}{l}\text { Gage } \\
\text { (ft) }\end{array}$ & $\begin{array}{r}\text { height } \\
\text { (m) }\end{array}$ \\
\hline $\begin{array}{ll}\text { ar. } & 1 \\
\text { ept. } & 11\end{array}$ & $\begin{array}{l}1400 \\
0130\end{array}$ & $\begin{array}{r}46 \\
* 554\end{array}$ & $\begin{array}{r}1.30 \\
15.7\end{array}$ & $\begin{array}{l}2.66 \\
4.32\end{array}$ & \\
\hline
\end{tabular}

Minimum daily discharge, $0.02 \mathrm{ft}^{3} / \mathrm{s}\left(0.001 \mathrm{~m}^{3} / \mathrm{s}\right)$ Aug. 31, Sept. 1 .

DISCHARGE, IN CUBIC FEET PER SECOND, HATER YEAR OCTOBER 1975 TO SEPTEMBER 1976 MEAN VALUES

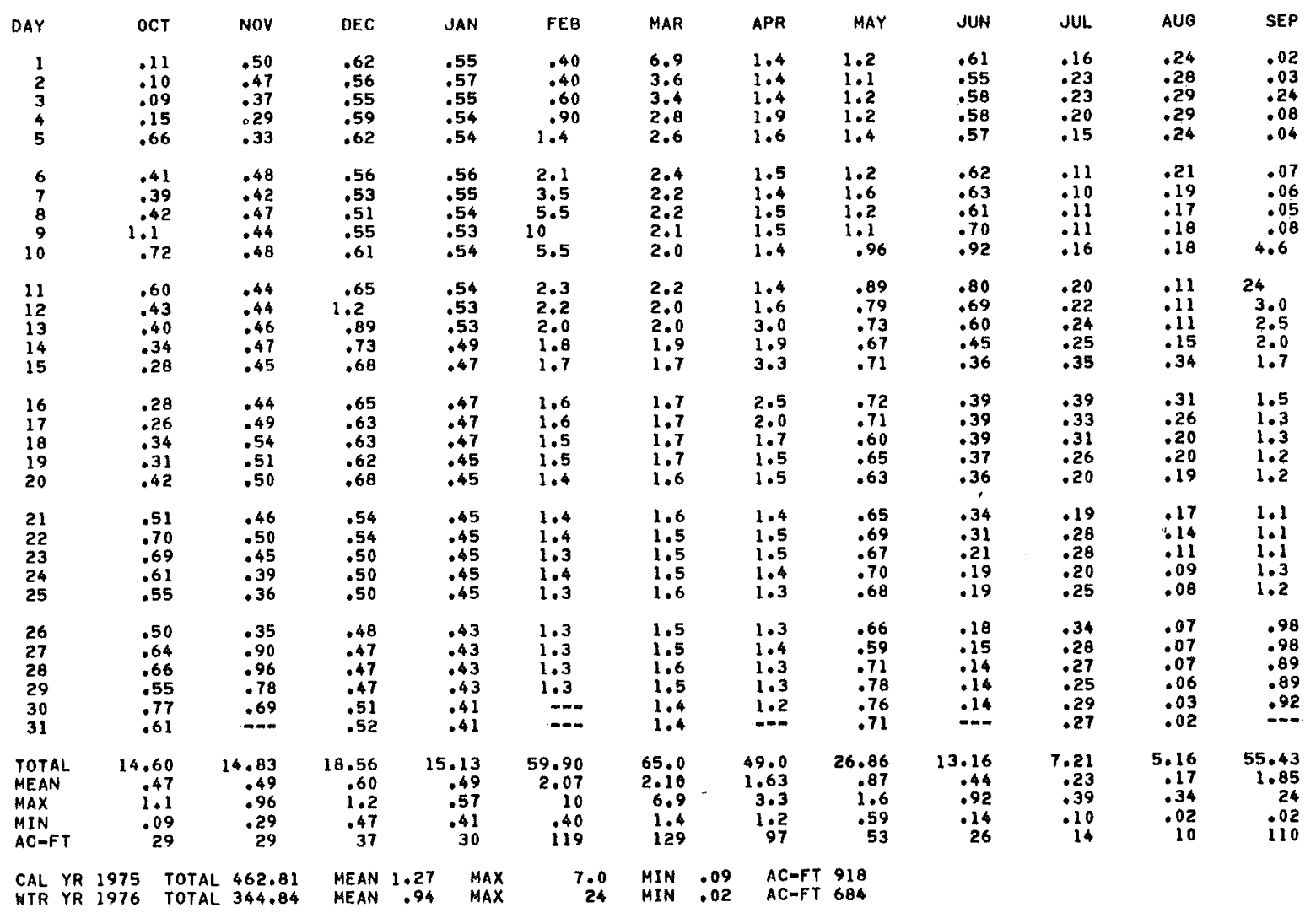


11059000 WARM CREEK FLOODWAY AT SAN BERNARDINO, CA

LOCATION.--Lat $34^{\circ} 05^{\prime} 45^{\prime \prime}$, long $117^{\circ} 16^{\prime} 30^{\prime \prime}$, in San Bernardino Grant, San Bernardino County, on left bank 0.4 mi $(0.6 \mathrm{~km})$ upstream from Mili street, and $1.8 \mathrm{mi}(2.9 \mathrm{~km})$ upstream from mouth.

DRAINAGE AREA. $-47.8 \mathrm{mi}^{2}\left(123.8 \mathrm{~km}^{2}\right)$.

PERIOD OF RECORD, - -January 1961 to current year. Prior to October 1965, published as "near San Bernardino."

GAGE. - Water-stage recorder. A1titude of gage is $1,000 \mathrm{ft}(305 \mathrm{~m})$, from topographic map. prior to Dec. 21 , 1967 , at site $0.4 \mathrm{mi}(0.6 \mathrm{~km})$ downstream at different datum.

REMARKS. - -Records poor. Flow partly regulated by percolation basins above Marshall Boulevard. Del Rosa Water Co. diverts from East Twin Creek for domestic use and irrigation. See schematic diagram of Santa Ana River basin.

EXTREMES FOR PERIOD OF RECORD.--Maximum discharge, $9,600 \mathrm{ft}^{3} / \mathrm{s}\left(272 \mathrm{~m}^{3} / \mathrm{s}\right) \mathrm{Feb} .25,1969, \mathrm{gage} \mathrm{height}$, $6.75 \mathrm{ft}$ $(2.057 \mathrm{~m})$, from rating curve extended above $3,000 \mathrm{ft}^{3} / \mathrm{s}\left(85.0 \mathrm{~m}^{3} / \mathrm{s}\right)$; no flow most of each year.

EXTREMES FOR CURRENT YEAR.--Maximum discharge, $1,500 \mathrm{ft}^{3} / \mathrm{s}\left(42.5 \mathrm{~m}^{3} / \mathrm{s}\right)$, estimated, Sept. 11, gage height, unknown, no flow several days.

OISCHARGE, IN CUBIC FEET PER SECOND, WATER YEAR OCTOBER 1975 TO SEPTEMBER 1976 MEAN VALUES

\begin{tabular}{|c|c|c|c|c|c|c|c|c|c|c|c|c|}
\hline DAY & $O C T$ & NOV & DEC & JAN & FEB & MAR & APR & MAY & JUN & JUL & AUG & SEP \\
\hline $\begin{array}{l}1 \\
2 \\
3 \\
4 \\
5\end{array}$ & $\begin{array}{l}0 \\
0 \\
0 \\
0 \\
0\end{array}$ & $\begin{array}{l}0 \\
0 \\
0 \\
0 \\
0\end{array}$ & $\begin{array}{l}.61 \\
.44 \\
.22 \\
.44 \\
.46\end{array}$ & $\begin{array}{l}.33 \\
.65 \\
.81 \\
.47 \\
.34\end{array}$ & $\begin{array}{l}1.6 \\
1.2 \\
2.1 \\
22 \\
18\end{array}$ & $\begin{array}{l}93 \\
34 \\
67 \\
8.7 \\
3.9\end{array}$ & $\begin{array}{r}.57 \\
.08 \\
17.46 \\
2.0\end{array}$ & $\begin{array}{r}.30 \\
.30 \\
.30 \\
.30 \\
.30\end{array}$ & $\begin{array}{l}.14 \\
.03 \\
.13 \\
.12 \\
.19\end{array}$ & $\begin{array}{r}.04 \\
.25 \\
.11 \\
.07 \\
.30\end{array}$ & $\begin{array}{l}.14 \\
.25 \\
.37 \\
.21 \\
.63\end{array}$ & $\begin{array}{r}.64 \\
23.74 \\
2.0 \\
.50\end{array}$ \\
\hline $\begin{array}{r}6 \\
7 \\
8 \\
9 \\
10\end{array}$ & $\begin{array}{l}0 \\
0^{.60} \\
0 \\
0\end{array}$ & $\begin{array}{l}.06 \\
.09 \\
.10 \\
.06 \\
.10\end{array}$ & $\begin{array}{l}.56 \\
.49 \\
.63 \\
.64 \\
.47\end{array}$ & $\begin{array}{l}.62 \\
.22 \\
.44 \\
.73 \\
.79\end{array}$ & $\begin{array}{r}30 \\
126 \\
217 \\
189 \\
37\end{array}$ & $\begin{array}{l}8.0 \\
5.6 \\
2.0 \\
1.9 \\
1.8\end{array}$ & $\begin{array}{l}1.1 \\
1.2 \\
.67 \\
1.4 \\
1.0\end{array}$ & $\begin{array}{r}15.30 \\
.30 \\
.30 \\
.30\end{array}$ & $\begin{array}{l}.03 \\
.19 \\
.53 \\
1.5 \\
2.1\end{array}$ & $\begin{array}{l}.43 \\
.13 \\
.06 \\
.18 \\
.31\end{array}$ & $\begin{array}{l}1.7 \\
1.8 \\
1.3 \\
1.4 \\
1.3\end{array}$ & $\begin{array}{r}.30 \\
.30 \\
.30 \\
.30 \\
.30\end{array}$ \\
\hline $\begin{array}{l}11 \\
12 \\
13 \\
14 \\
15\end{array}$ & $\begin{array}{c}15^{.77} \\
0 \\
0 \\
0\end{array}$ & $\begin{array}{l}.11 \\
.06 \\
.07 \\
.12 \\
.09\end{array}$ & $\begin{array}{c}13^{.39} \\
1.3 \\
.51 \\
.44\end{array}$ & $\begin{array}{l}.81 \\
.90 \\
.61 \\
.58 \\
.71\end{array}$ & $\begin{array}{l}1.0 \\
.74 \\
.30 \\
.28 \\
.28\end{array}$ & $\begin{array}{l}2.4 \\
.57 \\
0 \\
0 \\
0\end{array}$ & $\begin{array}{l}0 \\
1.6 \\
32 \\
17 \\
13\end{array}$ & $\begin{array}{r}.30 \\
.30 \\
.30 \\
.30 \\
.30\end{array}$ & $\begin{array}{l}1.4 \\
1.6 \\
.86 \\
1.4 \\
.98\end{array}$ & $\begin{array}{r}.26 \\
.31 \\
.30 \\
.30 \\
.27\end{array}$ & $\begin{array}{l}2.1 \\
.94 \\
1.9 \\
2.4 \\
2.2\end{array}$ & $\begin{aligned} & 340 \\
& 1.0 \\
& .30 \\
& .15 \\
& .10\end{aligned}$ \\
\hline $\begin{array}{l}16 \\
17 \\
18 \\
19 \\
20\end{array}$ & $\begin{array}{l}0 \\
0 \\
0 \\
0 \\
.19\end{array}$ & $\begin{array}{l}.08 \\
.11 \\
.06 \\
.03 \\
.09\end{array}$ & $\begin{array}{r}.35 \\
.35 \\
.42 \\
2.0 \\
7.0\end{array}$ & $\begin{array}{l}.77 \\
1.1 \\
1.1 \\
.74 \\
.99\end{array}$ & $\begin{array}{l}.17 \\
.21 \\
.17 \\
.33 \\
.59\end{array}$ & $\begin{array}{r}.47 \\
.53 \\
.41 \\
.44 \\
.13\end{array}$ & $\begin{array}{r}14 \\
3.7 \\
1.9 \\
.08 \\
.29\end{array}$ & $\begin{array}{r}.30 \\
.30 \\
.30 \\
.30 \\
.30\end{array}$ & $\begin{array}{l}.42 \\
.56 \\
1.2 \\
1.8 \\
2.2\end{array}$ & $\begin{array}{r}.38 \\
.31 \\
.32 \\
.28 \\
.35\end{array}$ & $\begin{array}{l}1.9 \\
1.8 \\
1.0 \\
.21 \\
.47\end{array}$ & $\begin{array}{l}0.05 \\
0 \\
0 \\
0\end{array}$ \\
\hline $\begin{array}{l}21 \\
22 \\
23 \\
24 \\
25\end{array}$ & $\begin{array}{l}0 \\
0 \\
0 \\
0 \\
0\end{array}$ & $\begin{array}{l}.13 \\
.32 \\
.48 \\
.41 \\
.42\end{array}$ & $\begin{array}{l}1.3 \\
.42 \\
.21 \\
.74 \\
.47\end{array}$ & $\begin{array}{l}.88 \\
1.1 \\
1.5 \\
1.6 \\
1.6\end{array}$ & $\begin{array}{l}.60 \\
.01 \\
0 \\
. .23 \\
2.0\end{array}$ & $\begin{array}{l}0 \\
.01 \\
.10 \\
.26 \\
.26\end{array}$ & $\begin{array}{l}2.6 \\
.30 \\
.30 \\
.30 \\
.30\end{array}$ & $\begin{array}{r}.30 \\
.30 \\
.30 \\
.30 \\
.30\end{array}$ & $\begin{array}{l}1.5 \\
2.6 \\
1.9 \\
1.2 \\
2.8\end{array}$ & $\begin{array}{l}.33 \\
.36 \\
.24 \\
.16 \\
.36\end{array}$ & $\begin{array}{r}.75 \\
.74 \\
1.2 \\
.93 \\
.73\end{array}$ & $\begin{array}{l}0 \\
0 \\
0 \\
9.7 \\
2.0\end{array}$ \\
\hline $\begin{array}{l}26 \\
27 \\
28 \\
29 \\
30 \\
31\end{array}$ & $\begin{array}{c}0 \\
0 \\
0 \\
0 \\
13 \\
1.0\end{array}$ & $\begin{array}{c}3.24 \\
14.5 \\
6.1 \\
.78 \\
=.-\end{array}$ & $\begin{array}{r}.62 \\
.54 \\
.43 \\
.53 \\
.67 \\
1.2\end{array}$ & $\begin{array}{l}1.3 \\
.88 \\
.66 \\
2.0 \\
2.0 \\
2.2\end{array}$ & $\begin{array}{l}1.1 \\
.78 \\
.93 \\
.59 \\
. .-\end{array}$ & $\begin{array}{r}.16 \\
.06 \\
0.11 \\
.57 \\
.87\end{array}$ & $\begin{array}{l}.30 \\
.30 \\
.30 \\
.30 \\
.30 \\
-.-\end{array}$ & $\begin{array}{r}.02 \\
.25 \\
.20 \\
.19 \\
.13\end{array}$ & $\begin{array}{l}3.1 \\
1.2 \\
.05 \\
.60 \\
.04 \\
.0\end{array}$ & $\begin{array}{l}.47 \\
.12 \\
.31 \\
.88 \\
.42 \\
.37\end{array}$ & $\begin{array}{r}.85 \\
.96 \\
.92 \\
.33 \\
.54 \\
.62\end{array}$ & $\begin{array}{l}0 \\
0 \\
0 \\
0 \\
0 \\
0\end{array}$ \\
\hline $\begin{array}{l}\text { TOTAL } \\
\text { MEAN } \\
\text { MAX } \\
\text { MIN } \\
\text { AC-FY }\end{array}$ & $\begin{array}{r}31.36 \\
1.01 \\
15 \\
0 \\
62\end{array}$ & $\begin{array}{r}27.61 \\
.92 \\
14 \\
0 \\
55\end{array}$ & $\begin{array}{r}38.65 \\
1.25 \\
13 \\
.21 \\
77\end{array}$ & $\begin{array}{r}29.43 \\
.95 \\
2.2 \\
.22 \\
58\end{array}$ & $\begin{array}{r}654.21 \\
22.6 \\
217 \\
0 \\
1300\end{array}$ & $\begin{array}{r}233.25 \\
7.52 \\
93 \\
0 \\
463\end{array}$ & $\begin{array}{r}114.35 \\
3.81 \\
32 \\
0 \\
227\end{array}$ & $\begin{array}{r}22.99 \\
.74 \\
15 \\
0 \\
46\end{array}$ & $\begin{array}{r}32.37 \\
1.08 \\
3.1 \\
.03 \\
64\end{array}$ & $\begin{array}{r}8.98 \\
.29 \\
.88 \\
.04 \\
18\end{array}$ & $\begin{array}{r}32.59 \\
1.05 \\
2.4 \\
.14 \\
65\end{array}$ & $\begin{array}{r}401.38 \\
13.4 \\
340 \\
0 \\
796\end{array}$ \\
\hline
\end{tabular}

CAL YR 1975 TOTAL 906.58 MEAN 2.48 MAX 151 MIN 0 AC-FT 1800 $\begin{array}{llllllll}\text { HTR YR } 1976 & \text { TOTAL } & 906.58 & \text { MEAN } 2.48 & \text { MAX } 151 & \text { HIN } 0 & \text { AC-FT } & 1800 \\ \text { MEAN } 4.45 & \text { MAX } 340 & \text { MIN } 0 & \text { AC-FT } 3230\end{array}$ 
11059100 SAN BERNARDINO WATER QUALITY CONTROL PLANT AT SAN BERNARDINO, CA

LOCATION, - Lat $34^{\circ} 04^{\prime} 16^{\prime \prime}$, Iong $11^{\circ} 17^{\prime} 16^{\prime \prime}$, in San Bernardino Grant, San Bernardino County, at effluent end of

chlorine contact chamber, $0.5 \mathrm{mi}(0.8 \mathrm{~km})$ upstream from Santa Ana River at E Street bridge, in San Bernardino.

WATER-DISCHARGE RECORDS

PERIOD OF RECORD. --October 1972 to current year.

GAGE. - Water-stage recorder and concrete control. Datum of gage is $979.50 \mathrm{ft}$ (298.552 $\mathrm{m}$ ) above mean sea level (levels by city of San Bernardino).

REMARKS. - -Records good.

EXTREMES FOR PERIOD OF RECORD. - Maximum daily discharge, $30 \mathrm{ft}^{3} / \mathrm{s}\left(0.85 \mathrm{~m}^{3} / \mathrm{s}\right) \mathrm{Jan} .7$, 1974, Sept. 10 , 11 , 1976; minimum daily, $12 \mathrm{ft}^{3} / \mathrm{s}\left(0.34 \mathrm{~m}^{3} / \mathrm{s}\right)$ Oct. 25 , Nov. $4,5,7-9,1972$.

DISCHARGE, IN CURIC FEET PER SECOND, WATER YEAR OCTOBER 1975 TO SEPTEMBER 1976

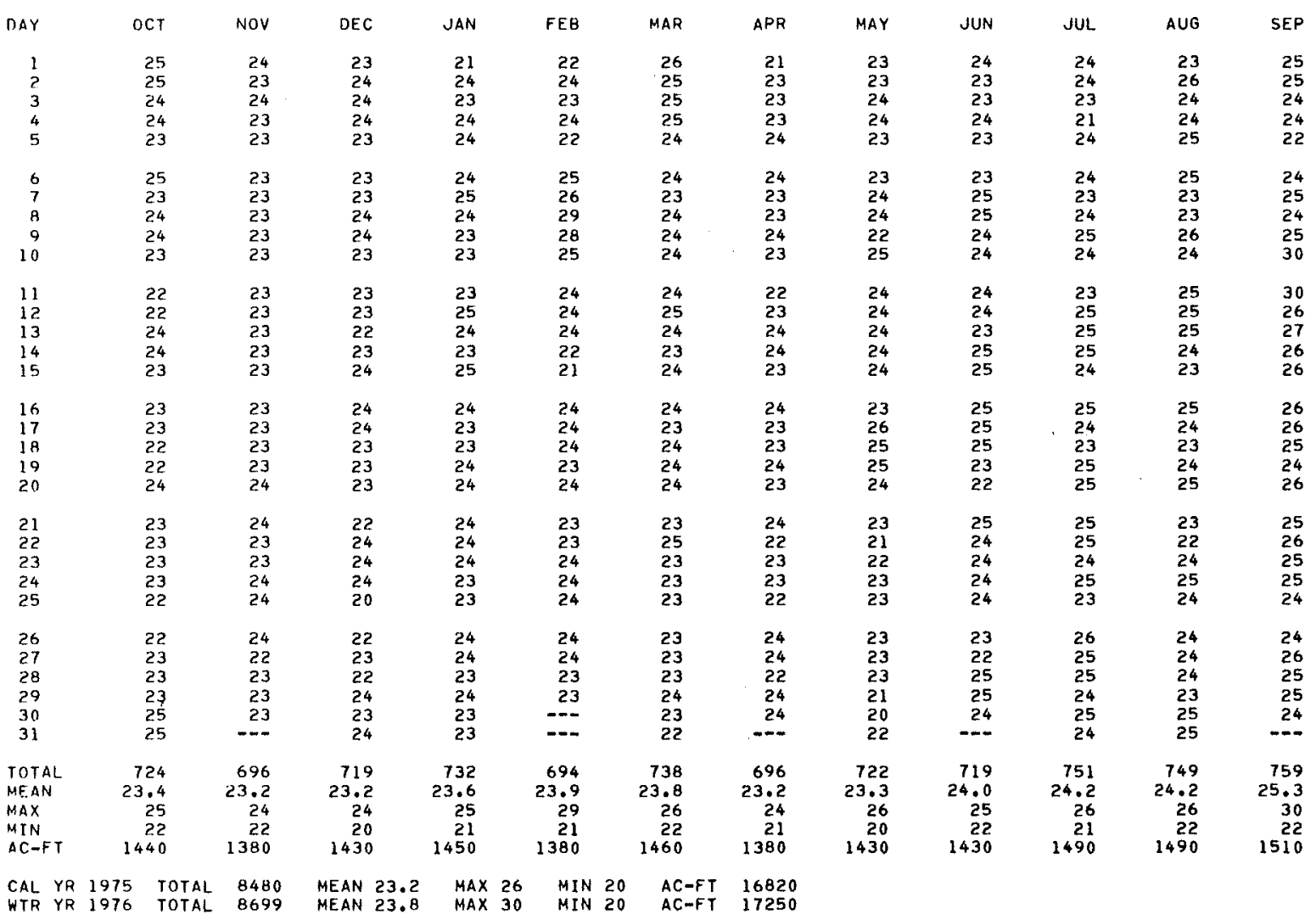


11059100 SAN BERNARDINO WATER QUALITY CONTROL PLANT AT SAN BERNARDINO, CA- Continued

PERIOD OF RECORD. - Water years 1973 to current year.

CHEMICAL ANALYSES: Water years 1973 to current year.

PERTOD OF DAILY RECORD.--

SPECIFIC CONDUCTANCE: October 1972 to current year.

INSTRUMENTATION. --Specific conductance recorder since October 1972 .

EXTREMES FOR PERIOD OF RECORD. - -

SPECIFIC CONDUCTANCE: Maximum recorded, 1,260 micromhos May 23, 1975; minimum, 725 micromhos Sept. $11,1976$.

EXTREMES FOR CURRENT YEAR.--

SPECIFIC CONDUCTANCE: Maximum, 1,180 micromhos Sept. 20; minimum, 725 micromhos Sept. 11.

CHEMICAL ANALYSES, WATER YEAR OCTOBER 1975 TO SEPTEMBER 1976

\begin{tabular}{|c|c|c|c|c|c|c|c|}
\hline DATE & TIME & $\begin{array}{l}\text { INSTAN- } \\
\text { TANEOUS } \\
\text { DIS- } \\
\text { CHARGE } \\
\text { (CFS) }\end{array}$ & $\begin{array}{l}\text { SPE- } \\
\text { CIFIC } \\
\text { CON- } \\
\text { DUCT- } \\
\text { ANCE } \\
\text { (MICRO- } \\
\text { MHOS) }\end{array}$ & $\begin{array}{l}\text { TEMPER- } \\
\text { ATURE } \\
\text { (DEG C) }\end{array}$ & $\begin{array}{l}\text { DIS- } \\
\text { SOLVED } \\
\text { SOLIDS } \\
\text { (RESI } \\
\text { DUE AT } \\
180 \mathrm{C}) \\
\text { (MG LL) }\end{array}$ & $\begin{array}{l}\text { DIS- } \\
\text { SOLVED } \\
\text { SOLIDS } \\
\text { (TONS } \\
\text { PER } \\
\text { AC-FT) }\end{array}$ & $\begin{array}{l}\text { DIS- } \\
\text { SOLVED } \\
\text { SOLIDS } \\
\text { (TONS } \\
\text { PER } \\
\text { DAY) }\end{array}$ \\
\hline OCT & & & & & & & \\
\hline $\begin{array}{l}02 \ldots \\
16 \ldots \\
\text { NOY }\end{array}$ & $\begin{array}{l}0910 \\
1415\end{array}$ & $\begin{array}{l}30 \\
30\end{array}$ & $\begin{array}{l}974 \\
947\end{array}$ & $\begin{array}{l}27.0 \\
27.0\end{array}$ & $\begin{array}{l}528 \\
509\end{array}$ & $\begin{array}{l}.72 \\
.69\end{array}$ & $\begin{array}{l}42.8 \\
41.2\end{array}$ \\
\hline $\begin{array}{l}\text { NOV } \\
04 \ldots \ldots \\
17 \ldots \ldots \\
\text { DEC }\end{array}$ & $\begin{array}{l}1150 \\
1200\end{array}$ & $\begin{array}{l}34 \\
16\end{array}$ & $\begin{array}{r}1010 \\
918\end{array}$ & $\begin{array}{l}26.6 \\
23.8\end{array}$ & $\begin{array}{l}522 \\
486\end{array}$ & .71 & $\begin{array}{l}47.9 \\
21.0\end{array}$ \\
\hline $\begin{array}{l}01 \cdots \\
17 \cdots \\
29 \cdots \\
\text { JAN }\end{array}$ & $\begin{array}{l}1400 \\
1400 \\
1400\end{array}$ & $\begin{array}{l}31 \\
30 \\
37\end{array}$ & $\begin{array}{l}918 \\
943 \\
889\end{array}$ & $\begin{array}{l}22.5 \\
22.5 \\
21.0\end{array}$ & $\begin{array}{l}481 \\
520 \\
526\end{array}$ & $\begin{array}{l}.65 \\
.71 \\
.72\end{array}$ & $\begin{array}{l}40.3 \\
42.1 \\
52.5\end{array}$ \\
\hline $\begin{array}{l}07 \ldots \\
20 \ldots \\
F E B\end{array}$ & $\begin{array}{l}1115 \\
1000\end{array}$ & $\begin{array}{l}34 \\
33\end{array}$ & $\begin{array}{r}941 \\
1050\end{array}$ & $\begin{array}{l}21.5 \\
21.3\end{array}$ & $\begin{array}{l}530 \\
542\end{array}$ & $\begin{array}{l}.72 \\
.74\end{array}$ & $\begin{array}{l}48.7 \\
48.3\end{array}$ \\
\hline $\begin{array}{l}03 \ldots \\
18 \ldots \\
\text { HAR }\end{array}$ & $\begin{array}{l}0900 \\
0900\end{array}$ & $\begin{array}{l}26 \\
30\end{array}$ & $\begin{array}{l}1010 \\
1010\end{array}$ & $\begin{array}{l}20.8 \\
20.5\end{array}$ & $\begin{array}{l}550 \\
530\end{array}$ & $\begin{array}{l}.75 \\
.72\end{array}$ & $\begin{array}{l}38.6 \\
42.9\end{array}$ \\
\hline $\begin{array}{l}01 \ldots \\
25 \ldots \\
\text { APR }\end{array}$ & $\begin{array}{l}1000 \\
1230\end{array}$ & $\begin{array}{l}36 \\
31\end{array}$ & $\begin{array}{l}997 \\
944\end{array}$ & $\begin{array}{l}21.5 \\
23.3\end{array}$ & $\begin{array}{l}546 \\
522\end{array}$ & $\begin{array}{r}.74 \\
.71\end{array}$ & $\begin{array}{l}53.1 \\
43.7\end{array}$ \\
\hline $\begin{array}{l}01 \ldots \\
14 \ldots \\
\text { MAY }\end{array}$ & $\begin{array}{l}1100 \\
1000\end{array}$ & $\begin{array}{l}38 \\
33\end{array}$ & $\begin{array}{l}982 \\
977\end{array}$ & $\begin{array}{l}23.2 \\
22.3\end{array}$ & $\begin{array}{l}529 \\
519\end{array}$ & $\begin{array}{l}.72 \\
.71\end{array}$ & $\begin{array}{l}54.3 \\
46.2\end{array}$ \\
\hline $\begin{array}{l}04 \ldots \\
21 \ldots\end{array}$ & $\begin{array}{l}1400 \\
1000\end{array}$ & $\begin{array}{l}\mathbf{3 0} \\
\mathbf{3 3}\end{array}$ & $\begin{array}{r}997 \\
1000\end{array}$ & $\begin{array}{l}25.2 \\
23.0\end{array}$ & $\begin{array}{l}537 \\
522\end{array}$ & $\begin{array}{r}.73 \\
.71\end{array}$ & $\begin{array}{l}43.5 \\
46.5\end{array}$ \\
\hline $\begin{array}{l}02 \ldots \\
15 \ldots \ldots \\
J U L\end{array}$ & $\begin{array}{l}1400 \\
1200\end{array}$ & $\begin{array}{l}30 \\
34\end{array}$ & $\begin{array}{l}970 \\
961\end{array}$ & $\begin{array}{l}26.8 \\
27.3\end{array}$ & $\begin{array}{l}510 \\
562\end{array}$ & $\begin{array}{r}.69 \\
.76\end{array}$ & $\begin{array}{l}41.3 \\
51.6\end{array}$ \\
\hline $\begin{array}{l}02 \ldots \\
13 \ldots \\
\text { AUG }\end{array}$ & $\begin{array}{l}1100 \\
0820\end{array}$ & $\begin{array}{l}33 \\
18\end{array}$ & $\begin{array}{r}952 \\
1010\end{array}$ & $\begin{array}{l}27.8 \\
27.4\end{array}$ & $\begin{array}{l}544 \\
536\end{array}$ & $\begin{array}{l}.74 \\
.73\end{array}$ & $\begin{array}{l}48.5 \\
26.0\end{array}$ \\
\hline $\begin{array}{l}03 . . . \\
16 . . \\
\text { SEP }\end{array}$ & $\begin{array}{l}0900 \\
0950\end{array}$ & $\begin{array}{l}23 \\
30\end{array}$ & $\begin{array}{r}1020 \\
927\end{array}$ & $\begin{array}{l}27.5 \\
27.7\end{array}$ & $\begin{array}{l}559 \\
503\end{array}$ & $\begin{array}{l}.76 \\
.68\end{array}$ & $\begin{array}{l}34.7 \\
40.7\end{array}$ \\
\hline $01 \ldots$ & $\begin{array}{l}1100 \\
1000\end{array}$ & $\begin{array}{l}31 \\
33\end{array}$ & $\begin{array}{l}980 \\
978\end{array}$ & $\begin{array}{l}28.6 \\
27.1\end{array}$ & $\begin{array}{l}552 \\
524\end{array}$ & $\begin{array}{l}.75 \\
.71\end{array}$ & $\begin{array}{l}46.7 \\
46.7\end{array}$ \\
\hline
\end{tabular}


11059100 SAN BERNARDINO WATER QUALITY CONTROL PLANT AT SAN BERNARDINO, CA--Continued SPECIFIC CONDUCTANCE (MICROMHOS/CM AT 25 DEG, C), WATER YEAR OCTOBER 1975 TO SEPTEMBER 1976

\begin{tabular}{|c|c|c|c|c|c|c|c|c|c|c|c|c|}
\hline \multirow[b]{2}{*}{ DAY } & \multicolumn{3}{|c|}{ OCTOBER } & \multicolumn{3}{|c|}{ NOVEMBER } & \multicolumn{3}{|c|}{ DECEMBER } & \multicolumn{3}{|c|}{ JANUARY } \\
\hline & $\operatorname{MAX}$ & MIN & MEAN & $\operatorname{MAX}$ & MIN & MEAN & $\operatorname{mAX}$ & MIN & MEAN & $\operatorname{MAX}$ & MIN & MEAN \\
\hline $\begin{array}{l}1 \\
2 \\
3 \\
4 \\
5\end{array}$ & $\begin{array}{r}1050 \\
1070 \\
1050 \\
1020 \\
969\end{array}$ & $\begin{array}{l}942 \\
942 \\
949 \\
914 \\
865\end{array}$ & $\begin{array}{r}1010 \\
1010 \\
1010 \\
965 \\
921\end{array}$ & $\begin{array}{l}1080 \\
1060 \\
1110 \\
1110 \\
1100\end{array}$ & $\begin{array}{r}1000 \\
971 \\
956 \\
994 \\
964\end{array}$ & $\begin{array}{l}1040 \\
1020 \\
1010 \\
1060 \\
1030\end{array}$ & $\begin{array}{l}1030 \\
1040 \\
1070 \\
1070 \\
1070\end{array}$ & $\begin{array}{l}914 \\
939 \\
957 \\
980 \\
989\end{array}$ & $\begin{array}{r}969 \\
995 \\
1020 \\
1030 \\
1020\end{array}$ & $\begin{array}{r}1040 \\
992 \\
993 \\
983 \\
1000\end{array}$ & $\begin{array}{l}920 \\
860 \\
905 \\
875 \\
862\end{array}$ & $\begin{array}{l}974 \\
923 \\
962 \\
936 \\
937\end{array}$ \\
\hline $\begin{array}{r}6 \\
7 \\
8 \\
9 \\
10\end{array}$ & $\begin{array}{l}1050 \\
1080 \\
1090 \\
1060 \\
1060\end{array}$ & $\begin{array}{l}872 \\
951 \\
972 \\
964 \\
959\end{array}$ & $\begin{array}{r}947 \\
1000 \\
1030 \\
1020 \\
1020\end{array}$ & $\begin{array}{l}1100 \\
1100 \\
1080 \\
1070 \\
1130\end{array}$ & $\begin{array}{r}1000 \\
990 \\
972 \\
952 \\
938\end{array}$ & $\begin{array}{l}1060 \\
1040 \\
1040 \\
1020 \\
1020\end{array}$ & $\begin{array}{l}1030 \\
1000 \\
1050 \\
1090 \\
1070\end{array}$ & $\begin{array}{r}939 \\
914 \\
916 \\
1000 \\
988\end{array}$ & $\begin{array}{r}990 \\
964 \\
976 \\
1050 \\
1030\end{array}$ & $\begin{array}{l}1020 \\
1020 \\
1020 \\
1000 \\
1030\end{array}$ & $\begin{array}{l}906 \\
911 \\
903 \\
923 \\
921\end{array}$ & $\begin{array}{l}975 \\
979 \\
973 \\
974 \\
981\end{array}$ \\
\hline $\begin{array}{l}11 \\
12 \\
13 \\
14 \\
15\end{array}$ & $\begin{array}{l}1070 \\
1050 \\
1080 \\
1120 \\
1070\end{array}$ & $\begin{array}{l}978 \\
963 \\
912 \\
955 \\
962\end{array}$ & $\begin{array}{r}1020 \\
1000 \\
995 \\
1030 \\
1020\end{array}$ & $\begin{array}{l}1170 \\
1080 \\
1050 \\
1030 \\
1040\end{array}$ & $\begin{array}{r}974 \\
952 \\
1020 \\
894 \\
936\end{array}$ & $\begin{array}{r}1070 \\
1040 \\
1040 \\
988 \\
996\end{array}$ & $\begin{array}{l}1040 \\
1060 \\
1060 \\
1050 \\
1060\end{array}$ & $\begin{array}{l}950 \\
967 \\
970 \\
944 \\
925\end{array}$ & $\begin{array}{r}1000 \\
1020 \\
1020 \\
1000 \\
990\end{array}$ & $\begin{array}{l}1060 \\
1040 \\
1040 \\
1060 \\
1070\end{array}$ & $\begin{array}{l}931 \\
919 \\
915 \\
971 \\
961\end{array}$ & $\begin{array}{r}1010 \\
982 \\
994 \\
1030 \\
1030\end{array}$ \\
\hline $\begin{array}{l}16 \\
17 \\
18 \\
19 \\
20\end{array}$ & $\begin{array}{l}1050 \\
1050 \\
1040 \\
1020 \\
1090\end{array}$ & $\begin{array}{l}927 \\
943 \\
940 \\
914 \\
932\end{array}$ & $\begin{array}{r}991 \\
1000 \\
1010 \\
976 \\
997\end{array}$ & $\begin{array}{l}1090 \\
1060 \\
1070 \\
1060 \\
1060\end{array}$ & $\begin{array}{r}1000 \\
918 \\
948 \\
976 \\
982\end{array}$ & $\begin{array}{r}1020 \\
981 \\
1020 \\
1030 \\
1030\end{array}$ & $\begin{array}{l}1060 \\
1080 \\
1080 \\
1060 \\
1050\end{array}$ & $\begin{array}{l}955 \\
943 \\
962 \\
956 \\
940\end{array}$ & $\begin{array}{l}1010 \\
1020 \\
1030 \\
1020 \\
1000\end{array}$ & $\begin{array}{l}1060 \\
1050 \\
1040 \\
1080 \\
1110\end{array}$ & $\begin{array}{r}953 \\
935 \\
969 \\
977 \\
1010\end{array}$ & $\begin{array}{l}1010 \\
1010 \\
1010 \\
1020 \\
1070\end{array}$ \\
\hline $\begin{array}{l}21 \\
22 \\
23 \\
24 \\
25\end{array}$ & $\begin{array}{l}1090 \\
1060 \\
1080 \\
1060 \\
1050\end{array}$ & $\begin{array}{l}946 \\
955 \\
979 \\
977 \\
943\end{array}$ & $\begin{array}{l}1030 \\
1010 \\
1040 \\
1030 \\
1000\end{array}$ & $\begin{array}{l}1050 \\
1070 \\
1050 \\
1060 \\
1060\end{array}$ & $\begin{array}{l}976 \\
984 \\
942 \\
940 \\
984\end{array}$ & $\begin{array}{l}1020 \\
1040 \\
1000 \\
1000 \\
1040\end{array}$ & $\begin{array}{l}1010 \\
1060 \\
1080 \\
1090 \\
1090\end{array}$ & $\begin{array}{l}890 \\
902 \\
968 \\
948 \\
934\end{array}$ & $\begin{array}{r}960 \\
979 \\
1030 \\
1030 \\
1000\end{array}$ & $\begin{array}{l}1110 \\
1130 \\
1140 \\
1080 \\
1070\end{array}$ & $\begin{array}{l}1010 \\
1000 \\
1050 \\
1010 \\
1010\end{array}$ & $\begin{array}{l}1070 \\
1060 \\
1090 \\
1050 \\
1050\end{array}$ \\
\hline $\begin{array}{l}26 \\
27 \\
28 \\
29 \\
30 \\
31\end{array}$ & $\begin{array}{l}1020 \\
1080 \\
1060 \\
1080 \\
1100 \\
1110\end{array}$ & $\begin{array}{r}932 \\
904 \\
988 \\
996 \\
981 \\
1010\end{array}$ & $\begin{array}{r}981 \\
989 \\
1030 \\
1050 \\
1040 \\
1060\end{array}$ & $\begin{array}{r}1060 \\
1060 \\
1000 \\
1000 \\
994 \\
-\infty\end{array}$ & $\begin{array}{l}980 \\
968 \\
904 \\
942 \\
912 \\
-\end{array}$ & $\begin{array}{r}1030 \\
1010 \\
945 \\
984 \\
962 \\
---\end{array}$ & $\begin{array}{r}998 \\
1010 \\
1010 \\
1050 \\
1050 \\
1050\end{array}$ & $\begin{array}{l}862 \\
932 \\
894 \\
890 \\
937 \\
949\end{array}$ & $\begin{array}{r}920 \\
977 \\
955 \\
959 \\
1010 \\
1010\end{array}$ & $\begin{array}{l}1120 \\
1110 \\
1090 \\
1080 \\
1080 \\
1040\end{array}$ & $\begin{array}{r}985 \\
998 \\
990 \\
987 \\
1000 \\
957\end{array}$ & $\begin{array}{l}1050 \\
1060 \\
1050 \\
1040 \\
1060 \\
1010\end{array}$ \\
\hline ONTH & 1120 & 865 & 1010 & 1170 & 894 & 1020 & 1090 & 862 & 999 & 1140 & 860 & 1010 \\
\hline
\end{tabular}

\begin{tabular}{|c|c|c|c|c|c|c|c|c|c|c|c|c|}
\hline \multirow[b]{2}{*}{ DAY } & \multicolumn{3}{|c|}{ FEBRUARY } & \multicolumn{3}{|c|}{ MARCH } & \multicolumn{3}{|c|}{ APRIL } & \multicolumn{3}{|c|}{ MAY } \\
\hline & $\operatorname{MAX}$ & MIN & MEAN & MAX & MIN & MEAN & MAX & MIN & MEAN & $\operatorname{MAX}$ & MIN & MEAN \\
\hline $\begin{array}{l}1 \\
2 \\
3 \\
4 \\
5\end{array}$ & $\begin{array}{l}1010 \\
1080 \\
1050 \\
1050 \\
1050\end{array}$ & $\begin{array}{r}934 \\
947 \\
988 \\
1000 \\
967\end{array}$ & $\begin{array}{r}975 \\
997 \\
1040 \\
1040 \\
1010\end{array}$ & $\begin{array}{l}1060 \\
1070 \\
1060 \\
1100 \\
1090\end{array}$ & $\begin{array}{l}993 \\
967 \\
944 \\
990 \\
996\end{array}$ & $\begin{array}{l}1020 \\
1010 \\
1010 \\
1040 \\
1050\end{array}$ & $\begin{array}{l}1090 \\
1080 \\
1050 \\
1040 \\
1090\end{array}$ & $\begin{array}{l}976 \\
960 \\
948 \\
964 \\
958\end{array}$ & $\begin{array}{l}1040 \\
1020 \\
1000 \\
1010 \\
1020\end{array}$ & $\begin{array}{l}1060 \\
1010 \\
1050 \\
1050 \\
1050\end{array}$ & $\begin{array}{l}977 \\
937 \\
940 \\
992 \\
988\end{array}$ & $\begin{array}{r}1020 \\
978 \\
990 \\
1030 \\
1030\end{array}$ \\
\hline $\begin{array}{r}6 \\
7 \\
8 \\
9 \\
10\end{array}$ & $\begin{array}{r}1040 \\
1030 \\
995 \\
1040 \\
1060\end{array}$ & $\begin{array}{l}960 \\
917 \\
909 \\
818 \\
957\end{array}$ & $\begin{array}{r}1010 \\
971 \\
963 \\
918 \\
1000\end{array}$ & $\begin{array}{l}1060 \\
1040 \\
1090 \\
1080 \\
1040\end{array}$ & $\begin{array}{l}983 \\
967 \\
961 \\
990 \\
952\end{array}$ & $\begin{array}{l}1030 \\
1010 \\
1020 \\
1050 \\
1010\end{array}$ & $\begin{array}{l}1100 \\
1080 \\
1090 \\
1090 \\
1060\end{array}$ & $\begin{array}{r}1000 \\
978 \\
978 \\
1010 \\
980\end{array}$ & $\begin{array}{l}1060 \\
1040 \\
1040 \\
1060 \\
1030\end{array}$ & $\begin{array}{l}1050 \\
1050 \\
1040 \\
1020 \\
1060\end{array}$ & $\begin{array}{l}976 \\
984 \\
988 \\
968 \\
960\end{array}$ & $\begin{array}{l}1020 \\
1020 \\
1020 \\
1000 \\
1010\end{array}$ \\
\hline $\begin{array}{l}11 \\
12 \\
13 \\
14 \\
15\end{array}$ & $\begin{array}{l}1080 \\
1090 \\
1090 \\
1100 \\
1090\end{array}$ & $\begin{array}{l}979 \\
988 \\
983 \\
973 \\
980\end{array}$ & $\begin{array}{l}1040 \\
1050 \\
1050 \\
1040 \\
1030\end{array}$ & $\begin{array}{l}1090 \\
1090 \\
1070 \\
1020 \\
1040\end{array}$ & $\begin{array}{l}976 \\
987 \\
961 \\
939 \\
928\end{array}$ & $\begin{array}{r}1030 \\
1050 \\
1020 \\
990 \\
989\end{array}$ & $\begin{array}{l}1040 \\
1060 \\
1050 \\
1070 \\
1120\end{array}$ & $\begin{array}{l}964 \\
966 \\
986 \\
968 \\
979\end{array}$ & $\begin{array}{l}1010 \\
1020 \\
1030 \\
1020 \\
1050\end{array}$ & $\begin{array}{r}1050 \\
1030 \\
0-0 \\
1000\end{array}$ & $\begin{array}{l}988 \\
946 \\
-2- \\
946\end{array}$ & $\begin{array}{r}1020 \\
988 \\
-20 \\
975\end{array}$ \\
\hline $\begin{array}{l}16 \\
17 \\
18 \\
19 \\
20\end{array}$ & $\begin{array}{l}1080 \\
1070 \\
1070 \\
1100 \\
1100\end{array}$ & $\begin{array}{r}963 \\
953 \\
958 \\
1000 \\
1000\end{array}$ & $\begin{array}{l}1020 \\
1020 \\
1020 \\
1050 \\
1050\end{array}$ & $\begin{array}{l}1050 \\
1050 \\
1090 \\
1090 \\
1050\end{array}$ & $\begin{array}{l}952 \\
947 \\
951 \\
988 \\
984\end{array}$ & $\begin{array}{l}1010 \\
1010 \\
1030 \\
1060 \\
1020\end{array}$ & $\begin{array}{l}1090 \\
1060 \\
1020 \\
1070 \\
1100\end{array}$ & $\begin{array}{r}1010 \\
972 \\
948 \\
945 \\
1000\end{array}$ & $\begin{array}{r}1060 \\
1020 \\
991 \\
1010 \\
1050\end{array}$ & $\begin{array}{l}1000 \\
1030 \\
1030 \\
1050 \\
1070\end{array}$ & $\begin{array}{l}934 \\
944 \\
982 \\
964 \\
988\end{array}$ & $\begin{array}{r}963 \\
984 \\
1010 \\
1010 \\
1030\end{array}$ \\
\hline $\begin{array}{l}21 \\
22 \\
23 \\
24 \\
25\end{array}$ & $\begin{array}{l}1040 \\
1020 \\
1080 \\
1080 \\
1060\end{array}$ & $\begin{array}{l}959 \\
936 \\
938 \\
972 \\
977\end{array}$ & $\begin{array}{r}1000 \\
989 \\
1010 \\
1040 \\
1030\end{array}$ & $\begin{array}{l}1020 \\
1070 \\
1060 \\
1060 \\
1050\end{array}$ & $\begin{array}{l}939 \\
931 \\
962 \\
968 \\
944\end{array}$ & $\begin{array}{r}988 \\
1000 \\
1020 \\
1030 \\
1000\end{array}$ & $\begin{array}{l}1090 \\
1060 \\
1060 \\
1050 \\
1030\end{array}$ & $\begin{array}{l}980 \\
968 \\
969 \\
991 \\
956\end{array}$ & $\begin{array}{r}1040 \\
1020 \\
1020 \\
1030 \\
996\end{array}$ & $\begin{array}{l}1050 \\
1050 \\
1020 \\
1040 \\
1060\end{array}$ & $\begin{array}{l}980 \\
985 \\
973 \\
960 \\
989\end{array}$ & $\begin{array}{r}1010 \\
1010 \\
999 \\
998 \\
1020\end{array}$ \\
\hline $\begin{array}{l}26 \\
27 \\
28 \\
29 \\
30 \\
31\end{array}$ & $\begin{array}{r}1090 \\
1090 \\
1070 \\
1050 \\
-0- \\
-\ldots\end{array}$ & $\begin{array}{l}977 \\
984 \\
986 \\
971 \\
---\end{array}$ & $\begin{array}{r}1030 \\
1050 \\
1030 \\
1020 \\
-\ldots \\
---\end{array}$ & $\begin{array}{l}1050 \\
1050 \\
1040 \\
1080 \\
1070 \\
1070\end{array}$ & $\begin{array}{l}962 \\
980 \\
961 \\
962 \\
981 \\
969\end{array}$ & $\begin{array}{l}1020 \\
1030 \\
1000 \\
1020 \\
1040 \\
1030\end{array}$ & $\begin{array}{c}1060 \\
1080 \\
1080 \\
1100 \\
1080 \\
-\end{array}$ & $\begin{array}{l}952 \\
987 \\
995 \\
994 \\
982 \\
0-\end{array}$ & $\begin{array}{l}1000 \\
1040 \\
1040 \\
1050 \\
1040 \\
=0\end{array}$ & $\begin{array}{l}1060 \\
1050 \\
1080 \\
1070 \\
1040 \\
1040\end{array}$ & $\begin{array}{r}1010 \\
966 \\
975 \\
1000 \\
903 \\
973\end{array}$ & $\begin{array}{l}1040 \\
1000 \\
1020 \\
1030 \\
1000 \\
1000\end{array}$ \\
\hline MONTH & 1100 & 818 & 1020 & 1100 & 928 & 1020 & 1120 & 945 & 1030 & 1080 & 934 & 1010 \\
\hline
\end{tabular}


11059100 SAN BERNARDINO WATER QUALITY CONTROL PLANT AT SAN BERNARDINO, CA--Continued SPECIFIC CONDUCTANCE (MICROMHOS/CM AT 25 DEG, C), WATER YEAR OCTOBER 1975 TO SEPTEMBER 1976

\begin{tabular}{|c|c|c|c|c|c|c|c|c|c|c|c|c|}
\hline \multirow[b]{2}{*}{ DAY } & \multicolumn{3}{|c|}{ JUNE } & \multicolumn{3}{|c|}{ JULY } & \multicolumn{3}{|c|}{ AUGUST } & \multicolumn{3}{|c|}{ SEPTEMBER } \\
\hline & $\operatorname{MAX}$ & MIN & MEAN & MAX & MIN & MEAN & $\operatorname{MAX}$ & MIN & MEAN & MAX & MIN & MEAN \\
\hline $\begin{array}{l}1 \\
2 \\
3 \\
4 \\
5\end{array}$ & $\begin{array}{l}1060 \\
1060 \\
1030 \\
1030 \\
1010\end{array}$ & $\begin{array}{l}984 \\
970 \\
985 \\
972 \\
942\end{array}$ & $\begin{array}{r}1020 \\
1020 \\
1010 \\
1000 \\
978\end{array}$ & $\begin{array}{r}1130 \\
1050 \\
1030 \\
984 \\
983\end{array}$ & $\begin{array}{l}946 \\
938 \\
951 \\
904 \\
889\end{array}$ & $\begin{array}{l}996 \\
998 \\
990 \\
956 \\
941\end{array}$ & $\begin{array}{r}991 \\
1030 \\
1040 \\
1040 \\
1010\end{array}$ & $\begin{array}{l}923 \\
930 \\
968 \\
932 \\
946\end{array}$ & $\begin{array}{r}962 \\
969 \\
1010 \\
989 \\
985\end{array}$ & $\begin{array}{l}1050 \\
1040 \\
1060 \\
1020 \\
1040\end{array}$ & $\begin{array}{l}950 \\
931 \\
977 \\
932 \\
962\end{array}$ & $\begin{array}{r}1000 \\
994 \\
1020 \\
971 \\
993\end{array}$ \\
\hline $\begin{array}{r}5 \\
7 \\
8 \\
9 . \\
10\end{array}$ & $\begin{array}{r}989 \\
1020 \\
1020 \\
1020 \\
1020\end{array}$ & $\begin{array}{l}923 \\
897 \\
953 \\
932 \\
954\end{array}$ & $\begin{array}{l}957 \\
950 \\
996 \\
979 \\
993\end{array}$ & $\begin{array}{l}1020 \\
1020 \\
1000 \\
1020 \\
1010\end{array}$ & $\begin{array}{l}854 \\
931 \\
871 \\
852 \\
927\end{array}$ & $\begin{array}{l}937 \\
977 \\
964 \\
962 \\
964\end{array}$ & $\begin{array}{r}1020 \\
1000 \\
978 \\
1060 \\
1050\end{array}$ & $\begin{array}{l}944 \\
916 \\
910 \\
932 \\
964\end{array}$ & $\begin{array}{r}994 \\
961 \\
945 \\
1020 \\
1020\end{array}$ & $\begin{array}{l}1020 \\
1150 \\
1130 \\
1090 \\
1040\end{array}$ & $\begin{array}{r}923 \\
985 \\
1000 \\
987 \\
918\end{array}$ & $\begin{array}{r}972 \\
1050 \\
1070 \\
1050 \\
977\end{array}$ \\
\hline $\begin{array}{l}11 \\
12 \\
13 \\
14 \\
15\end{array}$ & $\begin{array}{r}1020 \\
1020 \\
959 \\
1030 \\
1030\end{array}$ & $\begin{array}{l}946 \\
927 \\
903 \\
894 \\
958\end{array}$ & $\begin{array}{r}990 \\
969 \\
933 \\
951 \\
1000\end{array}$ & $\begin{array}{r}960 \\
1040 \\
1040 \\
996 \\
979\end{array}$ & $\begin{array}{l}894 \\
919 \\
998 \\
912 \\
929\end{array}$ & $\begin{array}{r}930 \\
963 \\
1010 \\
960 \\
958\end{array}$ & $\begin{array}{r}1070 \\
1010 \\
1010 \\
1000 \\
968\end{array}$ & $\begin{array}{l}960 \\
934 \\
912 \\
940 \\
908\end{array}$ & $\begin{array}{r}1020 \\
981 \\
969 \\
969 \\
.942\end{array}$ & $\begin{array}{r}949 \\
992 \\
981 \\
981 \\
1020\end{array}$ & $\begin{array}{l}725 \\
912 \\
899 \\
921 \\
934\end{array}$ & $\begin{array}{l}841 \\
952 \\
957 \\
965 \\
978\end{array}$ \\
\hline $\begin{array}{l}16 \\
17 \\
18 \\
19 \\
20\end{array}$ & $\begin{array}{r}976 \\
1010 \\
1020 \\
990 \\
980\end{array}$ & $\begin{array}{l}912 \\
906 \\
922 \\
918 \\
920\end{array}$ & $\begin{array}{l}952 \\
961 \\
975 \\
956 \\
952\end{array}$ & $\begin{array}{r}997 \\
982 \\
974 \\
1050 \\
1040\end{array}$ & $\begin{array}{l}939 \\
926 \\
916 \\
921 \\
959\end{array}$ & $\begin{array}{r}973 \\
960 \\
949 \\
978 \\
1000\end{array}$ & $\begin{array}{l}1040 \\
1030 \\
1020 \\
1080 \\
1060\end{array}$ & $\begin{array}{l}904 \\
906 \\
948 \\
932 \\
960\end{array}$ & $\begin{array}{r}978 \\
994 \\
989 \\
997 \\
1020\end{array}$ & $\begin{array}{r}981 \\
1050 \\
1040 \\
1050 \\
1180\end{array}$ & $\begin{array}{l}933 \\
946 \\
949 \\
942 \\
957\end{array}$ & $\begin{array}{r}969 \\
1000 \\
990 \\
981 \\
1040\end{array}$ \\
\hline $\begin{array}{l}21 \\
22 \\
23 \\
24 \\
25\end{array}$ & $\begin{array}{l}1020 \\
1040 \\
1040 \\
1000 \\
1060\end{array}$ & $\begin{array}{l}926 \\
950 \\
976 \\
926 \\
928\end{array}$ & $\begin{array}{r}968 \\
996 \\
1010 \\
966 \\
984\end{array}$ & $\begin{array}{r}1010 \\
994 \\
1040 \\
987 \\
964\end{array}$ & $\begin{array}{l}926 \\
932 \\
981 \\
915 \\
902\end{array}$ & $\begin{array}{r}983 \\
973 \\
1010 \\
953 \\
935\end{array}$ & $\begin{array}{l}1040 \\
1010 \\
1160 \\
1150 \\
1110\end{array}$ & $\begin{array}{l}942 \\
932 \\
900 \\
978 \\
956\end{array}$ & $\begin{array}{r}998 \\
965 \\
1020 \\
1070 \\
1040\end{array}$ & $\begin{array}{l}1150 \\
1080 \\
1040 \\
1060 \\
1040\end{array}$ & $\begin{array}{l}986 \\
941 \\
940 \\
985 \\
951\end{array}$ & $\begin{array}{r}1070 \\
1010 \\
989 \\
1030 \\
995\end{array}$ \\
\hline $\begin{array}{l}26 \\
27 \\
28 \\
29 \\
30 \\
31\end{array}$ & $\begin{array}{r}1040 \\
980 \\
1000 \\
1030 \\
1010 \\
-\end{array}$ & $\begin{array}{l}940 \\
908 \\
908 \\
938 \\
950 \\
---\end{array}$ & $\begin{array}{l}983 \\
948 \\
954 \\
980 \\
984 \\
---\end{array}$ & $\begin{array}{l}1050 \\
1040 \\
1010 \\
1030 \\
1030 \\
1030\end{array}$ & $\begin{array}{l}936 \\
963 \\
949 \\
946 \\
966 \\
963\end{array}$ & $\begin{array}{l}978 \\
998 \\
989 \\
988 \\
996 \\
998\end{array}$ & $\begin{array}{r}1060 \\
1140 \\
1140 \\
998 \\
1030 \\
1050\end{array}$ & $\begin{array}{l}968 \\
958 \\
994 \\
902 \\
898 \\
936\end{array}$ & $\begin{array}{r}1020 \\
1020 \\
1050 \\
943 \\
951 \\
985\end{array}$ & $\begin{array}{r}1020 \\
975 \\
1030 \\
1040 \\
1060 \\
0-0\end{array}$ & $\begin{array}{l}902 \\
881 \\
934 \\
933 \\
958 \\
---\end{array}$ & $\begin{array}{r}974 \\
953 \\
976 \\
988 \\
1010 \\
-0\end{array}$ \\
\hline MONTH & 1060 & 894 & 977 & 1130 & 852 & 973 & 1160 & 898 & 993 & 1180 & 725 & 992 \\
\hline YEAR & 1180 & 725 & 1000 & & & & & & & & & \\
\hline
\end{tabular}


LOCATION. - Lat $34^{\circ} 04^{\prime} 05^{\prime \prime}$, long $117^{\circ} 17^{\prime} 36^{\prime \prime}$, in San Bernardino Grant, San Bernardino County, on downstream side of E Street bridge, $0.8 \mathrm{mi}(1.3 \mathrm{~km})$ downstream from San Timoteo Creek, $1 \mathrm{mi}$ (2 km) upstream from Warm Creek, and $3 \mathrm{mi}(5 \mathrm{~km})$ south of San Bernardino.

DRAINAGE AREA, $-532 \mathrm{mi}^{2}\left(1,378 \mathrm{~km}^{2}\right)$.

PERIOD OF RECORD.--March 1939 to September 1954, October 1966 to current year.

GAGE. - Water-stage recorder. Datum of gage is $954.50 \mathrm{ft}(290.932 \mathrm{~m})$ above mean sea $1 \mathrm{evel}$. Prior to Nov. 10 , 1950, water-stage recorder on right bank at datum $10.00 \mathrm{ft}$ (3.048 m) higher. Nov. 11 , 1950 , to Sept. 30 , 1954, water-stage recorders on both banks at datum $10.00 \mathrm{ft}$ ( $3.048 \mathrm{~m}) \mathrm{higher}$.

REMARKS, - -Records poor. Major construction work in river channel throughout entire water year precluded collection of gage-height data and definition of stage-discharge relation; therefore, flow was estimated on basis of records and upstream stations. Flow partly regulated by Big Bear lake (station 11049000). Natural flow of stream affected by ground-water withdrawals and diversions for domestic use and irrigation above station. Effluent from sewage reclamation plant causes sustained flow since station was last operated. See schematic diagram of Santa Ana River basin.

AVERAGE DISCHARGE. - - 15 years (water years $1940-54), 12.5 \mathrm{ft}^{3} / \mathrm{s}\left(0.354 \mathrm{~m}^{3} / \mathrm{s}\right), 9,050 \mathrm{acre}-\mathrm{ft} / \mathrm{yr}\left(11.2 \mathrm{hm} / \mathrm{yr}^{3}\right)$; 10 years (water years $1967-76), 61.0 \mathrm{ft} / \mathrm{s}\left(1.728 \mathrm{~m}^{3} / \mathrm{s}\right), 44,190 \mathrm{acre}-\mathrm{ft} / \mathrm{yr}^{3}\left(54.5 \mathrm{hm} / \mathrm{yr}^{3}\right.$. The figure published in the 1975 report was in error; the correct figure is 9 years (water years $1967-75), 64.3 \mathrm{ft}{ }^{3} / \mathrm{s}(1.821 \mathrm{~m} / \mathrm{s}$ ), 46,590 acre-ft/yr $\left(57.4 \mathrm{hm}^{3} / \mathrm{yr}\right)$.

EXTREMES FOR PERIOD OF RECORD. - -Maximum discharge, $28,000 \mathrm{ft}^{3} / \mathrm{s}\left(793 \mathrm{mb}^{3} / \mathrm{s}\right)$ Feb. 25,$1969 ;$ maximum gage height $16.50 \mathrm{ft}(5.029 \mathrm{~m})$, present datum, Jan. 23 , 1943 , discharge uncertain but was probably 1 ess than 8 , 000 ft $3 / \mathrm{s}$ $(227 \mathrm{~m} / \mathrm{s})$; no flow many days priór to 1967 .

DISCHARGE, IN CUBIC FEET PER SECOND, WATER YEAR OCTOBER 1975 TO SEPTEMBER 1976 MEAN VALUES

\begin{tabular}{|c|c|c|c|c|c|c|c|c|c|c|c|c|}
\hline DAY & OCT & Nov & DEC & JAN & FEB & MAR & APR & MAY & JUN & JUL & AUG & SEP \\
\hline $\begin{array}{l}1 \\
2 \\
3 \\
4 \\
5\end{array}$ & $\begin{array}{l}26 \\
26 \\
25 \\
25 \\
24\end{array}$ & $\begin{array}{l}25 \\
24 \\
25 \\
24 \\
24\end{array}$ & $\begin{array}{l}25 \\
25 \\
25 \\
25 \\
24\end{array}$ & $\begin{array}{l}22 \\
26 \\
25 \\
25 \\
25\end{array}$ & $\begin{array}{l}25 \\
26 \\
26 \\
47 \\
41\end{array}$ & $\begin{array}{r}140 \\
70 \\
100 \\
35 \\
29\end{array}$ & $\begin{array}{l}23 \\
24 \\
24 \\
50 \\
27\end{array}$ & $\begin{array}{l}24 \\
24 \\
25 \\
25 \\
24\end{array}$ & $\begin{array}{l}25 \\
24 \\
24 \\
25 \\
24\end{array}$ & $\begin{array}{l}25 \\
25 \\
24 \\
22 \\
25\end{array}$ & $\begin{array}{l}24 \\
27 \\
25 \\
25 \\
27\end{array}$ & $\begin{array}{l}27 \\
27 \\
70 \\
27 \\
24\end{array}$ \\
\hline $\begin{array}{r}6 \\
7 \\
8 \\
9 \\
10\end{array}$ & $\begin{array}{l}26 \\
25 \\
25 \\
25 \\
24\end{array}$ & $\begin{array}{l}24 \\
24 \\
24 \\
24 \\
24\end{array}$ & $\begin{array}{l}25 \\
24 \\
26 \\
26 \\
24\end{array}$ & $\begin{array}{l}26 \\
26 \\
25 \\
25 \\
25\end{array}$ & $\begin{array}{r}54 \\
190 \\
325 \\
284 \\
100\end{array}$ & $\begin{array}{l}33 \\
30 \\
27 \\
27 \\
27\end{array}$ & $\begin{array}{l}28 \\
25 \\
25 \\
26 \\
25\end{array}$ & $\begin{array}{l}24 \\
50 \\
25 \\
23 \\
26\end{array}$ & $\begin{array}{l}24 \\
26 \\
27 \\
27 \\
27\end{array}$ & $\begin{array}{l}25 \\
24 \\
25 \\
26 \\
25\end{array}$ & $\begin{array}{l}28 \\
26 \\
25 \\
28 \\
26\end{array}$ & $\begin{array}{l}25 \\
26 \\
25 \\
25 \\
26\end{array}$ \\
\hline $\begin{array}{l}11 \\
12 \\
13 \\
14 \\
15\end{array}$ & $\begin{array}{l}24 \\
45 \\
25 \\
25 \\
24\end{array}$ & $\begin{array}{l}24 \\
24 \\
24 \\
24 \\
24\end{array}$ & $\begin{array}{l}24 \\
42 \\
24 \\
25 \\
25\end{array}$ & $\begin{array}{l}25 \\
27 \\
26 \\
25 \\
27\end{array}$ & $\begin{array}{l}26 \\
26 \\
25 \\
23 \\
22\end{array}$ & $\begin{array}{l}27 \\
27 \\
25 \\
24 \\
25\end{array}$ & $\begin{array}{l}23 \\
26 \\
70 \\
50 \\
40\end{array}$ & $\begin{array}{l}25 \\
25 \\
25 \\
25 \\
25\end{array}$ & $\begin{array}{l}26 \\
27 \\
25 \\
27 \\
27\end{array}$ & $\begin{array}{l}24 \\
26 \\
26 \\
26 \\
25\end{array}$ & $\begin{array}{l}28 \\
27 \\
28 \\
27 \\
26\end{array}$ & $\begin{array}{r}800 \\
28 \\
28 \\
27 \\
27\end{array}$ \\
\hline $\begin{array}{l}16 \\
17 \\
18 \\
19 \\
20\end{array}$ & $\begin{array}{l}24 \\
24 \\
23 \\
23 \\
25\end{array}$ & $\begin{array}{l}24 \\
24 \\
24 \\
24 \\
25\end{array}$ & $\begin{array}{l}25 \\
25 \\
24 \\
26 \\
32\end{array}$ & $\begin{array}{l}26 \\
25 \\
25 \\
26 \\
26\end{array}$ & $\begin{array}{l}25 \\
25 \\
25 \\
25 \\
27\end{array}$ & $\begin{array}{l}25 \\
25 \\
25 \\
25 \\
25\end{array}$ & $\begin{array}{l}43 \\
32 \\
26 \\
25 \\
24\end{array}$ & $\begin{array}{l}24 \\
27 \\
26 \\
26 \\
25\end{array}$ & $\begin{array}{l}26 \\
27 \\
27 \\
25 \\
25\end{array}$ & $\begin{array}{l}26 \\
25 \\
24 \\
26 \\
26\end{array}$ & $\begin{array}{l}28 \\
27 \\
25 \\
25 \\
26\end{array}$ & $\begin{array}{l}27 \\
27 \\
26 \\
25 \\
27\end{array}$ \\
\hline $\begin{array}{l}21 \\
22 \\
23 \\
24 \\
25\end{array}$ & $\begin{array}{l}24 \\
24 \\
24 \\
24 \\
23\end{array}$ & $\begin{array}{l}25 \\
24 \\
24 \\
25 \\
25\end{array}$ & $\begin{array}{l}24 \\
25 \\
25 \\
26 \\
21\end{array}$ & $\begin{array}{l}26 \\
26 \\
27 \\
26 \\
26\end{array}$ & $\begin{array}{l}25 \\
24 \\
25 \\
25 \\
27\end{array}$ & $\begin{array}{l}24 \\
26 \\
24 \\
24 \\
24\end{array}$ & $\begin{array}{l}28 \\
23 \\
24 \\
24 \\
23\end{array}$ & $\begin{array}{l}24 \\
22 \\
23 \\
24 \\
24\end{array}$ & $\begin{array}{l}28 \\
28 \\
27 \\
26 \\
28\end{array}$ & $\begin{array}{l}26 \\
26 \\
25 \\
26 \\
24\end{array}$ & $\begin{array}{l}25 \\
24 \\
26 \\
27 \\
26\end{array}$ & $\begin{array}{l}26 \\
27 \\
26 \\
45 \\
27\end{array}$ \\
\hline $\begin{array}{l}26 \\
27 \\
28 \\
29 \\
30 \\
31\end{array}$ & $\begin{array}{l}23 \\
24 \\
24 \\
24 \\
45 \\
28\end{array}$ & $\begin{array}{r}25 \\
27 \\
50 \\
30 \\
25 \\
-\end{array}$ & $\begin{array}{l}24 \\
25 \\
23 \\
26 \\
25 \\
26\end{array}$ & $\begin{array}{l}26 \\
26 \\
25 \\
27 \\
26 \\
26\end{array}$ & $\begin{array}{r}26 \\
26 \\
25 \\
25 \\
--- \\
---\end{array}$ & $\begin{array}{l}24 \\
24 \\
24 \\
25 \\
25 \\
24\end{array}$ & $\begin{array}{r}25 \\
25 \\
23 \\
25 \\
25 \\
---0\end{array}$ & $\begin{array}{l}24 \\
24 \\
24 \\
22 \\
21 \\
23\end{array}$ & $\begin{array}{r}27 \\
24 \\
26 \\
27 \\
25 \\
-\end{array}$ & $\begin{array}{l}27 \\
26 \\
26 \\
26 \\
26 \\
25\end{array}$ & $\begin{array}{l}26 \\
26 \\
26 \\
24 \\
27 \\
27\end{array}$ & $\begin{array}{r}25 \\
27 \\
26 \\
26 \\
25 \\
-\end{array}$ \\
\hline $\begin{array}{l}\text { TOTAL } \\
\text { MEAN } \\
\text { MAX } \\
\text { MIN } \\
\text { AC-FT }\end{array}$ & $\begin{array}{r}800 \\
25.8 \\
45 \\
23 \\
1590\end{array}$ & $\begin{array}{r}763 \\
25.4 \\
50 \\
24 \\
1510\end{array}$ & $\begin{array}{r}791 \\
25.5 \\
42 \\
21 \\
1570\end{array}$ & $\begin{array}{r}795 \\
25.6 \\
27 \\
22 \\
1580\end{array}$ & $\begin{array}{r}1595 \\
55.0 \\
325 \\
22 \\
3160\end{array}$ & $\begin{array}{r}1039 \\
33.5 \\
140 \\
24 \\
2060\end{array}$ & $\begin{array}{r}881 \\
29.4 \\
70 \\
23 \\
1750\end{array}$ & $\begin{array}{r}778 \\
25.1 \\
50 \\
21 \\
1540\end{array}$ & $\begin{array}{r}781 \\
26.0 \\
28 \\
24 \\
1550\end{array}$ & $\begin{array}{r}783 \\
25.3 \\
27 \\
22 \\
1550\end{array}$ & $\begin{array}{r}812 \\
26.2 \\
28 \\
24 \\
1610\end{array}$ & $\begin{array}{r}1624 \\
54.1 \\
800 \\
24 \\
3220\end{array}$ \\
\hline
\end{tabular}

$\begin{array}{llllllllll}\text { CAL YR } 1975 & \text { TOTAL } & 9785 & \text { MEAN } 26.8 & \text { MAX } 270 & \text { MIN } 20 & \text { AC-FT } & 19410 \\ \text { WTR YR } 1976 & \text { TOTAL } 11442 & \text { MEAN } 31.3 & \text { MAX BO0 } & \text { MIN 21 } & \text { AC-FT } & 22700\end{array}$ 
11060400 WARM CREEK NEAR SAN BERNARDINO, CA

LOCATION, - Lat $34^{\circ} 04^{\prime} 42^{\prime \prime}$, 1ong $117^{\circ} 17^{\prime} 58^{\prime \prime}$, in San Bernardino Grant, San Bernardino County, on 1eft bank 0.2 mi

$(0.3 \mathrm{~km})$ downstream from State Highway' $395 \mathrm{bridge,} \mathrm{and} 2.0 \mathrm{mi}(3.2 \mathrm{~km})$ southeast of San Bernardino.

DRAINAGE AREA. $-15.0 \mathrm{mi}^{2}\left(38.9 \mathrm{~km}^{2}\right)$.

PERIOD OF RECORD, - February 1964 to September 1972, October 1974 to current year.

GAGE.--Water-stage recorder. Altitude of gage is $960 \mathrm{ft}(293 \mathrm{~m})$, from topographic map. Prior to 0ct. 1 , 1974 , at site $0.1 \mathrm{mi}(0.2 \mathrm{~km})$ upstream at different datum.

REMARKS.--Records fair, except those for period of no gage-height record, Aug. 25 to Sept. 13, which are poor. Natural channe1 prior to September 1972 ; concrete-1ined channe1 October 1974 to current year. No regulation or diversion above station. See schematic diagram of Santa Ana River basin.

AVERAGE DISCHARGE, - -8 years (water years $1965-72), 1.61 \mathrm{ft}^{3} / \mathrm{s}\left(0.046 \mathrm{~m}^{3} / \mathrm{s}\right), 1,170 \mathrm{acre}-\mathrm{ft} / \mathrm{yr}(1.44 \mathrm{hm} / \mathrm{yr})$.

EXTREMES FOR PERIOD OF RECORD, - Maximum discharge, $2,200 \mathrm{ft}^{3} / \mathrm{s}\left(62.3 \mathrm{~m}^{3} / \mathrm{s}\right) \mathrm{Jan} .25,1969$, gage height, $5.55 \mathrm{ft}$

$(1.692 \mathrm{~m})$, at site and datum then in use; no flow many days in each year.

EXTREMES FOR CURRENT YEAR. - Maximum discharge, $1,930 \mathrm{ft}^{3} / \mathrm{s}\left(54.7 \mathrm{~m}^{3} / \mathrm{s}\right)$ Sept. 11 , gage height, $3.01 \mathrm{ft}(0.917 \mathrm{~m})$; no flow for several days.

DISCHARGE, IN CUBIC FEET PER SECOND, WATER YEAR OCTOBER 1975 TO SEPTEMBER 1976 MEAN VALUES

\begin{tabular}{|c|c|c|c|c|c|c|c|c|c|c|c|c|}
\hline DAY & OCT & NOV & DEC & JAN & FEB & MAR & $A P R$ & MAY & JUN & JUL & AUG & SEP \\
\hline $\begin{array}{l}1 \\
2 \\
3 \\
4 \\
5\end{array}$ & $\begin{array}{l}.73 \\
.42 \\
.43 \\
.31 \\
.32\end{array}$ & $\begin{array}{l}.05 \\
.18 \\
.21 \\
.23 \\
.06\end{array}$ & $\begin{array}{l}.07 \\
.28 \\
.04 \\
.14 \\
.12\end{array}$ & $\begin{array}{l}0 \\
0 \\
0 \\
.01 \\
.07\end{array}$ & $\begin{array}{l}.21 \\
.06 \\
22.23 \\
13\end{array}$ & $\begin{aligned} & 53 \\
& 28 \\
& 11 \\
& .04 \\
& .07\end{aligned}$ & $\begin{array}{r}.33 \\
.28 \\
.26 \\
6.7 \\
.27\end{array}$ & $\begin{array}{l}.07 \\
.10 \\
.18 \\
.19 \\
.26\end{array}$ & $\begin{array}{l}.34 \\
.13 \\
.45 \\
.42 \\
.24\end{array}$ & $\begin{array}{l}1.0 \\
1.3 \\
.82 \\
.75 \\
.78\end{array}$ & $\begin{array}{l}.16 \\
.13 \\
.41 \\
.37 \\
.15\end{array}$ & $\begin{array}{r}.30 \\
13.30 \\
.30 \\
.30\end{array}$ \\
\hline $\begin{array}{r}6 \\
7 \\
6 \\
9 \\
10\end{array}$ & $\begin{array}{l}.56 \\
.88 \\
.19 \\
.13 \\
.11\end{array}$ & $\begin{array}{r}.07 \\
.18 \\
.03 \\
0.10\end{array}$ & $\begin{array}{l}.03 \\
.16 \\
.43 \\
.13 \\
.44\end{array}$ & $\begin{array}{l}.20 \\
.08 \\
.12 \\
.19 \\
.02\end{array}$ & $\begin{array}{c}21 \\
67 \\
128 \\
46 \\
1.6\end{array}$ & $\begin{array}{l}0 \\
0 \\
0.05 \\
.19\end{array}$ & $\begin{array}{l}.25 \\
.50 \\
.14 \\
.07 \\
.03\end{array}$ & $\begin{array}{r}.21 \\
0.6 \\
.15 \\
.08 \\
.51\end{array}$ & $\begin{array}{r}.20 \\
.35 \\
.15 \\
.11 \\
3.5\end{array}$ & $\begin{array}{l}1.0 \\
.86 \\
.86 \\
.97 \\
.61\end{array}$ & $\begin{array}{l}.58 \\
.26 \\
.23 \\
.44 \\
.47\end{array}$ & $\begin{array}{r}.30 \\
.30 \\
.30 \\
.30 \\
56\end{array}$ \\
\hline $\begin{array}{l}11 \\
12 \\
13 \\
14 \\
15\end{array}$ & $\begin{array}{r}2.8 \\
12 \\
.38 \\
.12 \\
.15\end{array}$ & $\begin{array}{l}.03 \\
.14 \\
.12 \\
.07 \\
.16\end{array}$ & $\begin{array}{l}.18 \\
5.3 \\
.24 \\
.02 \\
.03\end{array}$ & $\begin{array}{l}.04 \\
.02 \\
.09 \\
.02 \\
.08\end{array}$ & $\begin{array}{r}.04 \\
.04 \\
.13 \\
.30 \\
.44\end{array}$ & $\begin{array}{l}.34 \\
.01 \\
.09 \\
.12 \\
.28\end{array}$ & $\begin{array}{l}0 \\
2.0 \\
19 \\
1.6 \\
3.3\end{array}$ & $\begin{array}{l}.59 \\
.14 \\
.27 \\
.08 \\
.10\end{array}$ & $\begin{array}{l}.39 \\
.12 \\
.19 \\
.20 \\
.28\end{array}$ & $\begin{array}{l}1.1 \\
.60 \\
.69 \\
.84 \\
.82\end{array}$ & $\begin{array}{l}.25 \\
.13 \\
.27 \\
.21 \\
.23\end{array}$ & $\begin{array}{r}205 \\
.30 \\
.30 \\
.29 \\
.32\end{array}$ \\
\hline $\begin{array}{l}16 \\
17 \\
18 \\
19 \\
20\end{array}$ & $\begin{array}{l}.13 \\
.12 \\
.05 \\
.05 \\
.24\end{array}$ & $\begin{array}{l}.04 \\
.07 \\
.26 \\
.12 \\
.14\end{array}$ & $\begin{array}{r}.15 \\
.14 \\
.49 \\
.23 \\
9.1\end{array}$ & $\begin{array}{l}.13 \\
.25 \\
.21 \\
.18 \\
.25\end{array}$ & $\begin{array}{l}.20 \\
.03 \\
.02 \\
.01\end{array}$ & $\begin{array}{l}.28 \\
.32 \\
.56 \\
.38 \\
.25\end{array}$ & $\begin{array}{r}.29 \\
.01 \\
0 \\
.02 \\
.10\end{array}$ & $\begin{array}{l}.07 \\
.29 \\
.24 \\
.25 \\
.68\end{array}$ & $\begin{array}{l}.16 \\
1.4 \\
.26 \\
.78 \\
.18\end{array}$ & $\begin{array}{l}.90 \\
.41 \\
.39 \\
.59 \\
.50\end{array}$ & $\begin{array}{r}.24 \\
.37 \\
.35 \\
.37 \\
.42\end{array}$ & $\begin{array}{l}.10 \\
.04 \\
.42 \\
.26 \\
.09\end{array}$ \\
\hline $\begin{array}{l}21 \\
22 \\
23 \\
24 \\
25\end{array}$ & $\begin{array}{l}.17 \\
.12 \\
.05 \\
.01 \\
.13\end{array}$ & $\begin{array}{r}.24 \\
.01 \\
.11 \\
.13\end{array}$ & $\begin{array}{l}.23 \\
.12 \\
.04 \\
.09 \\
.02\end{array}$ & $\begin{array}{l}.12 \\
.21 \\
.20 \\
.08 \\
.03\end{array}$ & $\begin{array}{l}0 \\
0 \\
0 \\
.01 \\
.03\end{array}$ & $\begin{array}{l}.47 \\
.34 \\
.51 \\
.29 \\
.52\end{array}$ & $\begin{array}{l}.17 \\
.14 \\
.13 \\
.04 \\
.01\end{array}$ & $\begin{array}{l}.60 \\
.08 \\
.02 \\
.10 \\
.31\end{array}$ & $\begin{array}{l}.36 \\
.29 \\
.22 \\
.29 \\
.47\end{array}$ & $\begin{array}{l}.56 \\
.50 \\
.83 \\
.60 \\
.33\end{array}$ & $\begin{array}{l}.25 \\
.13 \\
.37 \\
.22 \\
.30\end{array}$ & $\begin{array}{r}.19 \\
.27 \\
.30 \\
4.0 \\
.57\end{array}$ \\
\hline $\begin{array}{l}26 \\
27 \\
28 \\
29 \\
30 \\
31\end{array}$ & $\begin{array}{r}.67 \\
.42 \\
.09 \\
.04 \\
15 \\
.63\end{array}$ & $\begin{array}{r}7.27 \\
10.5 \\
.59 \\
.21 \\
-.-4\end{array}$ & $\begin{array}{l}.16 \\
.04 \\
.03 \\
.19 \\
.14 \\
.03\end{array}$ & $\begin{array}{l}0 \\
.15 \\
.22 \\
.09 \\
.16 \\
.10\end{array}$ & $\begin{array}{l}.05 \\
.01 \\
.07 \\
.06 \\
.0- \\
. .-\end{array}$ & $\begin{array}{l}.32 \\
.43 \\
.10 \\
.06 \\
.09 \\
.10\end{array}$ & $\begin{array}{l}.03 \\
.16 \\
.09 \\
.07 \\
.09 \\
.0\end{array}$ & $\begin{array}{r}.15 \\
.15 \\
.19 \\
.20 \\
.07 \\
.18\end{array}$ & $\begin{array}{r}.50 \\
.51 \\
.94 \\
1.1 \\
.76 \\
.0-\end{array}$ & $\begin{array}{l}1.3 \\
.56 \\
.48 \\
.39 \\
.58 \\
.34\end{array}$ & $\begin{array}{l}.30 \\
.30 \\
.30 \\
.30 \\
.30 \\
.30\end{array}$ & $\begin{array}{r}.19 \\
.62 \\
1.6 \\
2.4 \\
1.9 \\
.--\end{array}$ \\
\hline $\begin{array}{l}\text { TOTAL } \\
\text { MEAN } \\
\text { MAX } \\
\text { MIN } \\
\text { AC-FT }\end{array}$ & $\begin{array}{r}37.45 \\
1.21 \\
15 \\
.01 \\
74\end{array}$ & $\begin{array}{r}21.32 \\
.71 \\
10 \\
0 \\
42\end{array}$ & $\begin{array}{r}18.81 \\
.61 \\
9.1 \\
.02 \\
37\end{array}$ & $\begin{array}{r}3.32 \\
.11 \\
.25 \\
0 \\
6.6\end{array}$ & $\begin{array}{r}300.54 \\
10.4 \\
128 \\
0 \\
596\end{array}$ & $\begin{array}{r}98.21 \\
3.17 \\
53 \\
0 \\
195\end{array}$ & $\begin{array}{r}36.08 \\
1.20 \\
19 \\
0 \\
72\end{array}$ & $\begin{array}{r}15.11 \\
.49 \\
8.6 \\
.02 \\
30\end{array}$ & $\begin{array}{r}15.29 \\
.51 \\
3.5 \\
.11 \\
30\end{array}$ & $\begin{array}{r}22.26 \\
.72 \\
1.3 \\
.33 \\
44\end{array}$ & $\begin{array}{r}9.11 \\
.29 \\
.58 \\
.13 \\
18\end{array}$ & $\begin{array}{r}290.56 \\
9.69 \\
205 \\
.04 \\
576\end{array}$ \\
\hline
\end{tabular}

CAL YR 1975 TOTAL 668.38 MEAN 1.83 MAX 81 MIN O AC-FT 1330 UTR YR 1976 TOTAL B68.06 MEAN 2.37 MAX 205 MIN 0 AC-FT 1720 
11060500 MEEKS AND DALEY CANAL NEAR COLTON, CA

LOCATION, - Lat $34^{\circ} 04^{\prime} 47^{\prime \prime}$, long $117^{\circ} 18^{\prime} 00^{\prime \prime}$, in San Bernardino Grant, San Bernardino County, 1.5 mi (2.4 km) northeast of Colton.

PERIOD OF RECORD.--September 1920 to current year. Published with station Warm Creek near Colton, October 1950 to September 1961 .

GAGE. - Water-stage recorder. Altitude of gage is $965 \mathrm{ft}(294 \mathrm{~m})$, from topographic map.

REMARKS.--Records good. All flow passing station is pumped from ground-water basin for irrigation in vicinity of Colton, Riverside, and Corona. See schematic diagram of Santa Ana River basin.

EXTREMES FOR PERIOD OF RECORD. -Maximum daily discharge, $25 \mathrm{ft}^{3} / \mathrm{s}\left(0.71 \mathrm{~m}^{3} / \mathrm{s}\right) \mathrm{Mar}$. 2 , 1938 ; no flow at times in most years.

DISCHARGE, IN CUBIC FEET PER SECOND, HATER YEAR OCTOBER 1975 TO SEPTEMBER 1976

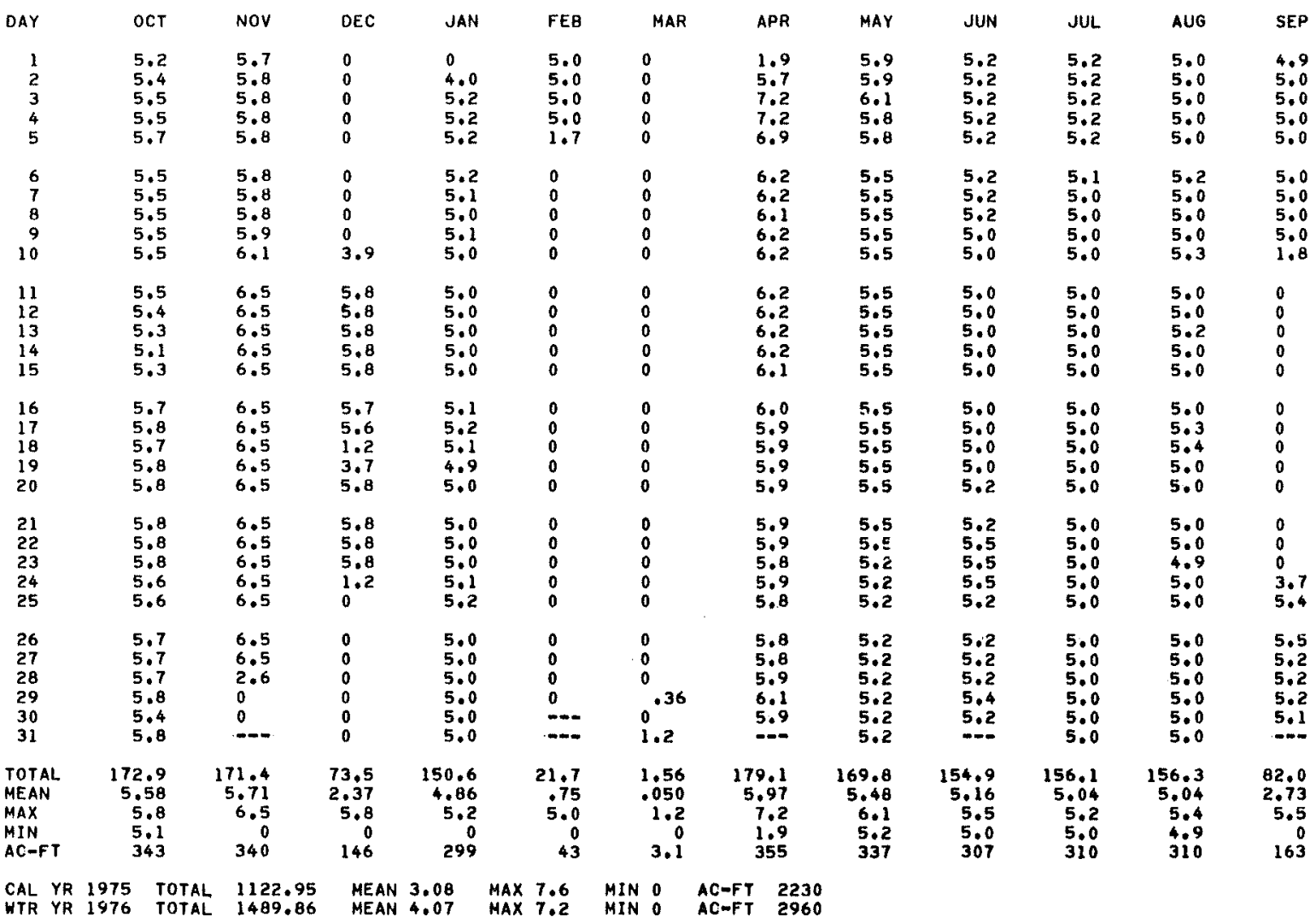


11062000 LYTLE CREEK NEAR FONTANA, CA

LOCATION. - Lat $34^{\circ} 12^{\prime} 44^{\prime \prime}$, long $117^{\circ} 27^{\prime} 26^{\prime \prime}$, in SElNWtsE $\frac{1}{4}$ sec.36, T.2 N., R. 6 W., San Bernardino County, on right bank $75 \mathrm{ft}$ (23 $\mathrm{mll})$ upstream from highway bridge, $0.7 \mathrm{mi}(1.1 \mathrm{~km})$ upstream from right tributary, $2.3 \mathrm{mi}$ (3.7 $\mathrm{km})$ downstream from Lyt1e Creek conduit, and $8 \mathrm{mi}(13 \mathrm{~km})$ north of Fontana.

DRAINAGE AREA. $-46.3 \mathrm{mi}^{2}\left(119.9 \mathrm{~km}^{2}\right)$.

PERIOD OF RECORD,--October 1918 to current year. Combined records of Lytle Creek and diversions, October 1898 to December 1899, October 1904 to current year (pub1ished as "at mouth of canyon near Rialto" $1898-99$, as "near San Bernardino" 1904-18, and as Lytle Creek and Fontana pipeline near Fontana 1919-31). Monthly discharge on1y for some periods published in WSP 1315-B.

GAGE. - Water-stage recorder on creek. Dual arch-culvert control since 1964 . Water-stage recorders and sharpcrested weirs on conduit since June 3, 1949, and infiltration line since oct. 1, 1971. A1titude of creek gage is $2,380 \mathrm{ft}(725 \mathrm{~m})$, from topographic map. October 1918 to Mar. 21,1938 , at site $1 \mathrm{mi}$ (1.6 km) downstrean at different datum. Mar. 22, 1938, to Nov. 20, 1963, at site $75 \mathrm{ft}$ ( $23 \mathrm{~m}$ ) downstream at datum $4.58 \mathrm{ft}$ (1.396 m). Sharp-crested weirs at different datum.

REMARKS, - -Records, creek only, poor; combined creek and diversion, fair. No regulation above station. Southern California Edison Co.'s Lytle Creek conduit diverts $2.3 \mathrm{mi}$ ( $3.7 \mathrm{~km}$ ) upstream for power development, and Fontana Union Water Co. collects water from an infiltration line upstream for irrigation. See schematic diagram of Santa Ana River basin. For records of combined discharge of Lytle Creek and diversions, see following page.

AVERAGE DISCHARGE.--Creek only: 58 years, $13.5 \mathrm{ft}^{3} / \mathrm{s}\left(0.382 \mathrm{~m}^{3} / \mathrm{s}\right), 9,780 \mathrm{acre}-\mathrm{ft} / \mathrm{yr}(12.1 \mathrm{hm} / \mathrm{yr})$. Combined creek and diversions: 73 years (water years $1899,1905-76), 41.9 \mathrm{ft}^{3} / \mathrm{s}\left(1.187 \mathrm{~m}^{3} / \mathrm{s}\right)$, 30,360 acre-ft/yr $\left(37.4 \mathrm{hm}^{3} / \mathrm{yr}\right)$

EXTREMES FOR PERIOD OF RECORD, - -Creek only: Maximum discharge, $35,900 \mathrm{ft}^{3} / \mathrm{s}\left(1,020 \mathrm{~m}^{3} / \mathrm{s}\right) \mathrm{Jan}$. 25 , 1969 , gage height, $15.0 \mathrm{ft}(4.57 \mathrm{~m})$, from floodmark, from rating extended above $570 \mathrm{ft} / \mathrm{s}$ (16.1 $\left.\mathrm{m}^{3} / \mathrm{s}\right)$ on basis of $\mathrm{s} 10 \mathrm{pe}$ area measurements at gage heights $10.78 \mathrm{ft}(3.286 \mathrm{~m})$ and $15.0 \mathrm{ft}(4.57 \mathrm{~m})$; no flow at times each year. Combined creek and diversions : Maximum discharge, 35,900 $\mathrm{ft}^{3} / \mathrm{s}\left(1,020 \mathrm{~m}^{3} / \mathrm{s}\right) \mathrm{Jan}$. 25 , 1969; minimum daily discharge, $0.12 \mathrm{ft}^{3} / \mathrm{s}\left(0.34 \mathrm{~m}^{3} / \mathrm{s}\right)$ June $21,22,1976$.

EXTREMES FOR CURRENT YEAR, - -Peak discharges above base of $200 \mathrm{ft}^{3} / \mathrm{s}\left(5.66 \mathrm{~m}^{3} / \mathrm{s}\right)$ and maximum $(*)$;

\begin{tabular}{|c|c|c|c|c|c|c|c|}
\hline Date & & Time & $\begin{array}{r}\text { Cre } \\
\mathrm{Disch} \\
\left(\mathrm{ft}^{3} / \mathrm{s}\right)\end{array}$ & $\begin{array}{l}\mathrm{k} \\
\left(\mathrm{m}^{3} / \mathrm{s}\right)\end{array}$ & $\begin{array}{l}\text { Gage } \\
\text { (ft) }\end{array}$ & $\begin{array}{l}\text { eight } \\
\text { (m) }\end{array}$ & $\begin{array}{c}\text { Combined Creek and Di } \\
\text { Discharge } \\
\left(\mathrm{ft}^{3} / \mathrm{s}\right)\left(\mathrm{m}^{3} / \mathrm{s}\right)\end{array}$ \\
\hline Feb. & 6 & Unknown & 386 & 10.9 & 5.18 & 1.579 & Unknown \\
\hline Mar. & 1 & 1300 & 350 & 9.91 & 5.10 & 1.554 & $360 \quad 10$ \\
\hline & 10 & 2200 & *395 & 11.2 & 5.20 & 1.585 & * 403 \\
\hline
\end{tabular}

Creek only: Minimum daily discharge, no flow for many months.

Combined creek and diversions: Minimum daily discharge, $12 \mathrm{ft}^{3} / \mathrm{s}\left(0.34 \mathrm{~m}^{3} / \mathrm{s}\right) \mathrm{June} 21,22$.

DISCHARGE, IN CUBIC FEET PER SECOND, WATER YEAR OCTOBER 1975 TO SEPTEMBER 1976 MEAN VALUES

\begin{tabular}{|c|c|c|c|c|c|c|c|c|c|c|c|c|}
\hline DAY & OCT & NoV & DEC & JAN & FEB & MAR & APR & MAY & JUN & JUL & AUG & SEP \\
\hline $\begin{array}{l}1 \\
2 \\
3 \\
4 \\
5\end{array}$ & & & & & $\begin{array}{l}0 \\
0 \\
0 \\
0 \\
5.0\end{array}$ & $\begin{array}{l}57 \\
30 \\
9.7 \\
3.0 \\
2.5\end{array}$ & $\begin{array}{l}0 \\
0 \\
0 \\
0 \\
0\end{array}$ & & & & & $\begin{array}{l}0 \\
0 \\
0 \\
0 \\
0\end{array}$ \\
\hline $\begin{array}{r}6 \\
7 \\
8 \\
9 \\
10\end{array}$ & & & & & $\begin{array}{l}16 \\
31 \\
48 \\
84 \\
64\end{array}$ & $\begin{array}{l}2.0 \\
1.5 \\
1.2 \\
1.0 \\
.80\end{array}$ & $\begin{array}{l}0 \\
0 \\
0 \\
0 \\
0\end{array}$ & & & & & $\begin{array}{r}0 \\
0 \\
0 \\
0 \\
42\end{array}$ \\
\hline $\begin{array}{l}11 \\
12 \\
13 \\
14 \\
15\end{array}$ & & & & & $\begin{array}{r}38 \\
0 \\
0 \\
0 \\
0\end{array}$ & $\begin{array}{l}.60 \\
.30 \\
.20 \\
.10 \\
.05\end{array}$ & $\begin{array}{l}0 \\
0 \\
0 \\
0 \\
.03\end{array}$ & & & & & $\begin{array}{l}85 \\
28 \\
21 \\
17 \\
16\end{array}$ \\
\hline $\begin{array}{l}16 \\
17 \\
18 \\
19 \\
20\end{array}$ & & & & & $\begin{array}{l}0 \\
0 \\
0 \\
0^{.22}\end{array}$ & $\begin{array}{l}0 \\
0 \\
0 \\
0 \\
0\end{array}$ & $\begin{array}{l}0.02 \\
0 \\
0 \\
0\end{array}$ & & & & & $\begin{array}{l}21 \\
19 \\
19 \\
11 \\
3.0\end{array}$ \\
\hline $\begin{array}{l}21 \\
22 \\
23 \\
24 \\
25\end{array}$ & & & & & $\begin{array}{l}0 \\
0 \\
0 \\
0 \\
0\end{array}$ & $\begin{array}{l}0 \\
0 \\
0 \\
0 \\
0\end{array}$ & $\begin{array}{l}0 \\
0 \\
0 \\
0 \\
0\end{array}$ & & & & & $\begin{array}{l}3.0 \\
3.0 \\
3.0 \\
18 \\
28\end{array}$ \\
\hline $\begin{array}{l}26 \\
27 \\
28 \\
29 \\
30 \\
31\end{array}$ & & - & & & $\begin{array}{l}0 \\
0 \\
.07 \\
.18 \\
-1 . \\
-\end{array}$ & $\begin{array}{l}0 \\
0 \\
0 \\
0 \\
0 \\
0\end{array}$ & $\begin{array}{l}0 \\
0 \\
0 \\
0 \\
0 \\
\end{array}$ & & $-\infty$ & & & $\begin{array}{l}26 \\
25 \\
24 \\
20 \\
21 \\
--\infty\end{array}$ \\
\hline $\begin{array}{l}\text { TOTAL } \\
\text { MEAN } \\
\text { MAX } \\
\text { MIN } \\
\text { AC-FT }\end{array}$ & $\begin{array}{l}0 \\
0 \\
0 \\
0 \\
0\end{array}$ & $\begin{array}{l}0 \\
0 \\
0 \\
0 \\
0\end{array}$ & $\begin{array}{l}0 \\
0 \\
0 \\
0 \\
0\end{array}$ & $\begin{array}{l}0 \\
0 \\
0 \\
0 \\
0\end{array}$ & $\begin{array}{r}286.47 \\
9.88 \\
84 \\
0 \\
568\end{array}$ & $\begin{array}{r}109.95 \\
3.55 \\
57 \\
0 \\
218\end{array}$ & $\begin{array}{r}.05 \\
.002 \\
.03 \\
0 \\
.10\end{array}$ & $\begin{array}{l}0 \\
0 \\
0 \\
0 \\
0\end{array}$ & $\begin{array}{l}0 \\
0 \\
0 \\
0 \\
0\end{array}$ & $\begin{array}{l}0 \\
0 \\
0 \\
0 \\
0\end{array}$ & $\begin{array}{l}0 \\
0 \\
0 \\
0 \\
0\end{array}$ & $\begin{array}{r}453.0 \\
15.1 \\
85 \\
0 \\
899\end{array}$ \\
\hline
\end{tabular}


11062000 LYTLE CREEK NEAR FONTANA, CA--Continued

COMBINED DISCHARGE, IN CUBIC FEET PER SECOND, OF LYTLE CREEK,

SOUTHERN CALIFORNIA EDISON CO.'S LYTLE CONDUIT, AND FONTANA UNTON WATER

CO.'S INFILTRATION LINE, NEAR FONTANA, CA, WATER YEAR' OCTOBER 1975 TO SEPTEMBER 1976

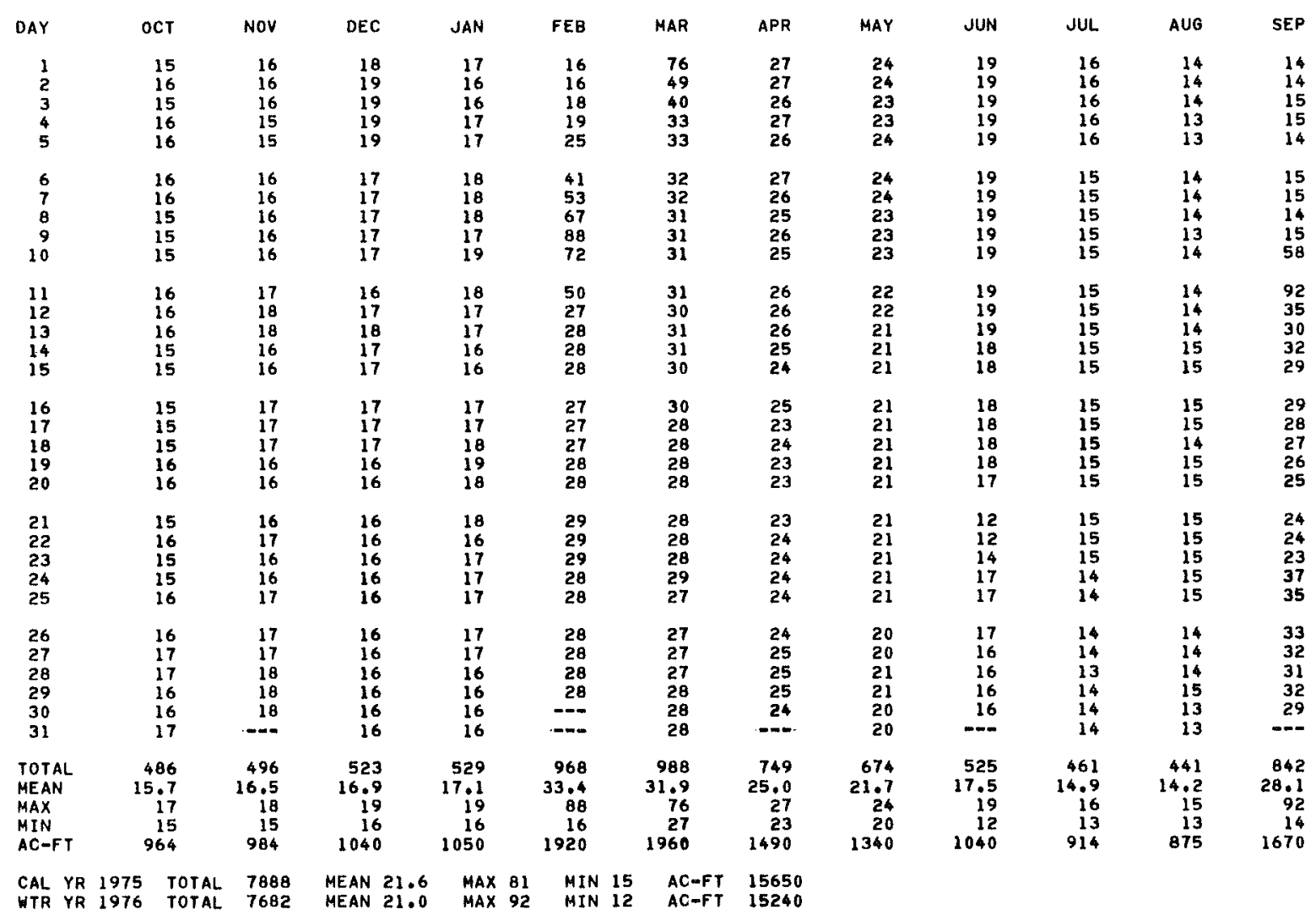


11063500 LONE PINE CREEK NEAR KEENBROOK, CA

LOCATION. - Lat $34^{\circ} 15^{\prime} 59^{\prime \prime}$, long $117^{\circ} 27^{\prime} 4^{\prime \prime \prime}$, in SE $\frac{1}{4} S E^{\frac{1}{4} S W^{\frac{1}{4}}}$ sec.12, T.2 N., R. 6 W. San Bernardino County, on right bank $50 \mathrm{ft}(15 \mathrm{~m})$ upstream from the Atchison, Topeka, and Santa Fe Railway Co. bridge, 150 ft (46 m) upstream from mouth, and $1.1 \mathrm{mi}(1.8 \mathrm{~km})$ north of Keenbrook.

DRAINAGE AREA. $--15.1 \mathrm{mi}^{2}\left(39.1 \mathrm{~km}^{2}\right)$.

PERIOD OF RECORD, --December 1919 to September 1938, June 1949 to current year.

GAGE.- Water-stage recorder and concrete control. Datum of gage is $2,605.92 \mathrm{ft}$ ( $794.284 \mathrm{~m}$ ) above mean sea 1 eve1. Prior to Mar. 2, 1938, water-stage recorder (destroyed by flood) and Mar. 2 to Sept. 30,1938 , nonrecording gage at same site at datum $0.98 \mathrm{ft}(0.299 \mathrm{~m})$ higher.

REMARKS,--Records good except those for periods of no gage-height record, Dec. 13 to Jan. 22 , Feb, 6-17, and

May is to June 29, which are poor. No regulation or diversion above station. See schematic diagram of

Santa Ana River basin.

AVERAGE DISCHARGE, -45 years (water years $192 \mathrm{I}-38,1950-76), 1.41 \mathrm{ft} / \mathrm{s}\left(0.040 \mathrm{~m}^{3} / \mathrm{s}\right), 1,020$ acre-ft/yr $\left(1.26 \mathrm{hm}^{3} / \mathrm{yr}^{2}\right)$.

EXTREMES FOR PERIOD OF RECORD.--Maximum discharge, $6,180 \mathrm{ft}^{3} / \mathrm{s}\left(175 \mathrm{~m}^{3} / \mathrm{s}\right)$ Mar. 2 , 1938 , on basis of $\mathrm{s} 10 \mathrm{pe}-\mathrm{area}$ measurement of maximun flow; no flow Aug. 6-8, Sept. 29, 30, 1965 .

EXTREMES FOR CURRENT YEAR, --Peak discharges above base of $80 \mathrm{ft}^{3} / \mathrm{s}\left(2.27 \mathrm{~m}^{3} / \mathrm{s}\right)$ and maximum (*):

\begin{tabular}{|c|c|c|c|c|}
\hline Date & Time & $\begin{array}{r}D i s c \\
\left(f t^{3} / s\right.\end{array}$ & $\left.\mathrm{rge}^{\mathrm{rge}} / \mathrm{s}\right)$ & $\begin{array}{l}\text { Gage } \\
\text { (ft) }\end{array}$ \\
\hline $\begin{array}{l}\text { Feb, } \\
\text { Sept. } 10\end{array}$ & $\begin{array}{l}\text { Unknown } \\
2200\end{array}$ & $\begin{array}{r}147 \\
* 274\end{array}$ & $\begin{array}{l}4.16 \\
7.76\end{array}$ & $\begin{array}{l}3.22 \\
4.07\end{array}$ \\
\hline
\end{tabular}

Minimum daily discharge, $0.11 \mathrm{ft}^{3} / \mathrm{s}\left(0.003 \mathrm{~m}^{3} / \mathrm{s}\right)$ Aug, 30, 31, Sept. 1 .

DISCHARGE, IN CUBIC FEET PER SECOND, WATER YEAR OCTOBER 1975 TO SEPTEMBER 1976 MEAN VALUES

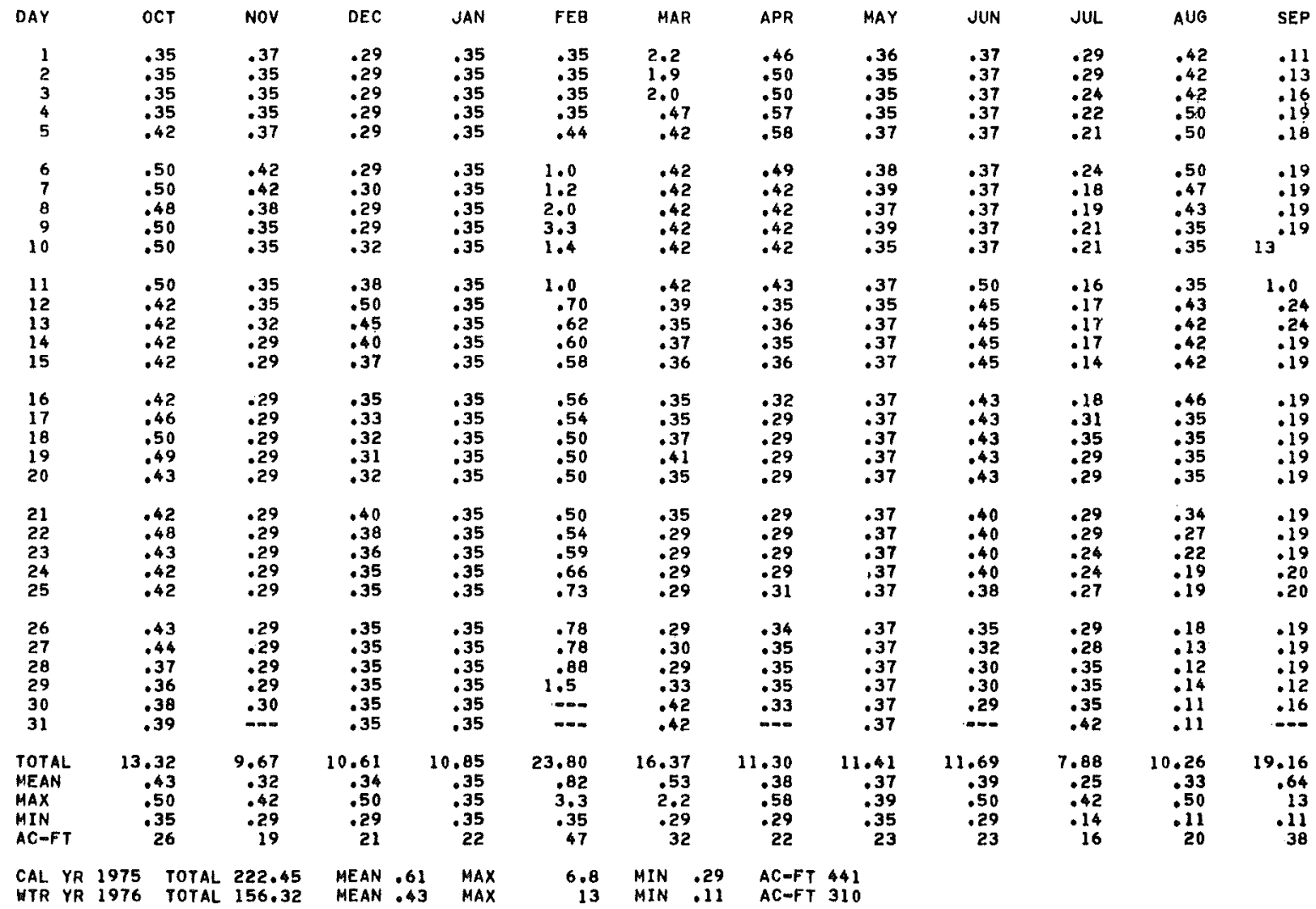


LOCATION. - Lat $34^{\circ} 15^{\prime} 58^{\prime \prime}$, long $117^{\circ} 27^{\prime} 47^{\prime \prime}$, in NE $\frac{1}{4} N^{\prime} / 4$ sec.13, T. 2 N., R. 6 W. , San Bernardino County, on right bank $25 \mathrm{ft}(8 \mathrm{~m})$ downstream from confluence with Lone Pine Creek, $1.1 \mathrm{mi}$ (1.8 km) north of Keenbrook.

DRAINAGE AREA. $--55.8 \mathrm{mi}^{2}\left(144.5 \mathrm{~km}^{2}\right)$.

PERIOD OF RECORD,--October 1971 to current year.

GAGE, - Water-stage recorder. Altitude of gage is $2,600 \mathrm{ft}(792 \mathrm{~m})$, from topographic map.

REMARKS.--Records poor. No gage-height record oct, 23 to Feb. 18, May 12 to June 30 , Sept. 10-14. No regulation or diversion above station. See schematic diagram of Santa Ana River basin.

AVERAGE DISCHARGE, -5 years, $7.94 \mathrm{ft}^{3} / \mathrm{s}\left(0.225 \mathrm{~m}^{3} / \mathrm{s}\right), 5,750 \mathrm{acre}-\mathrm{ft} / \mathrm{yr}\left(7.09 \mathrm{hm}^{3} / \mathrm{yr}^{3}\right)$.

EXTREMES FOR PERIOD OF RECORD. - Maximum discharge, 1,780 $\mathrm{ft}^{3} / \mathrm{s}\left(50.4 \mathrm{~m}^{3} / \mathrm{s}\right)$ Feb. 11 , I973, gage height, $13.50 \mathrm{ft}$

$(4.115 \mathrm{~m})$; minimum daily, 2.2 $\mathrm{ft}^{3} / \mathrm{s}\left(0.062 \mathrm{~m}^{3} / \mathrm{s}\right)$ Bec. 16,1975 .

EXTREMES FOR CURRENT YEAR.--Peak discharges above base of $150 \mathrm{ft} / \mathrm{s}\left(4.25 \mathrm{~m}^{3} / \mathrm{s}\right)$ and maximum (*), from rating extended above $10 \mathrm{ft}^{3} / \mathrm{s}\left(0.28 \mathrm{~m}^{3} / \mathrm{s}\right)$ on basis of slope-area measurement of peak flow:

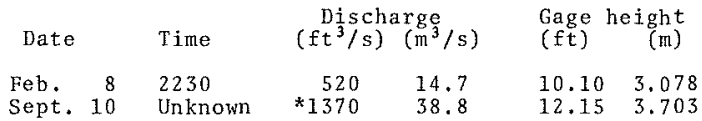

Minimum daily discharge, $2.2 \mathrm{ft}^{3} / \mathrm{s}\left(0.062 \mathrm{~m}^{3} / \mathrm{s}\right)$ Dec. 16.

DISCHARGE, IN CUBIC FEET PER SECOND, WATER YEAR OCTOBER 1975 TO SEPTEMBER 1976 MEAN VALUES

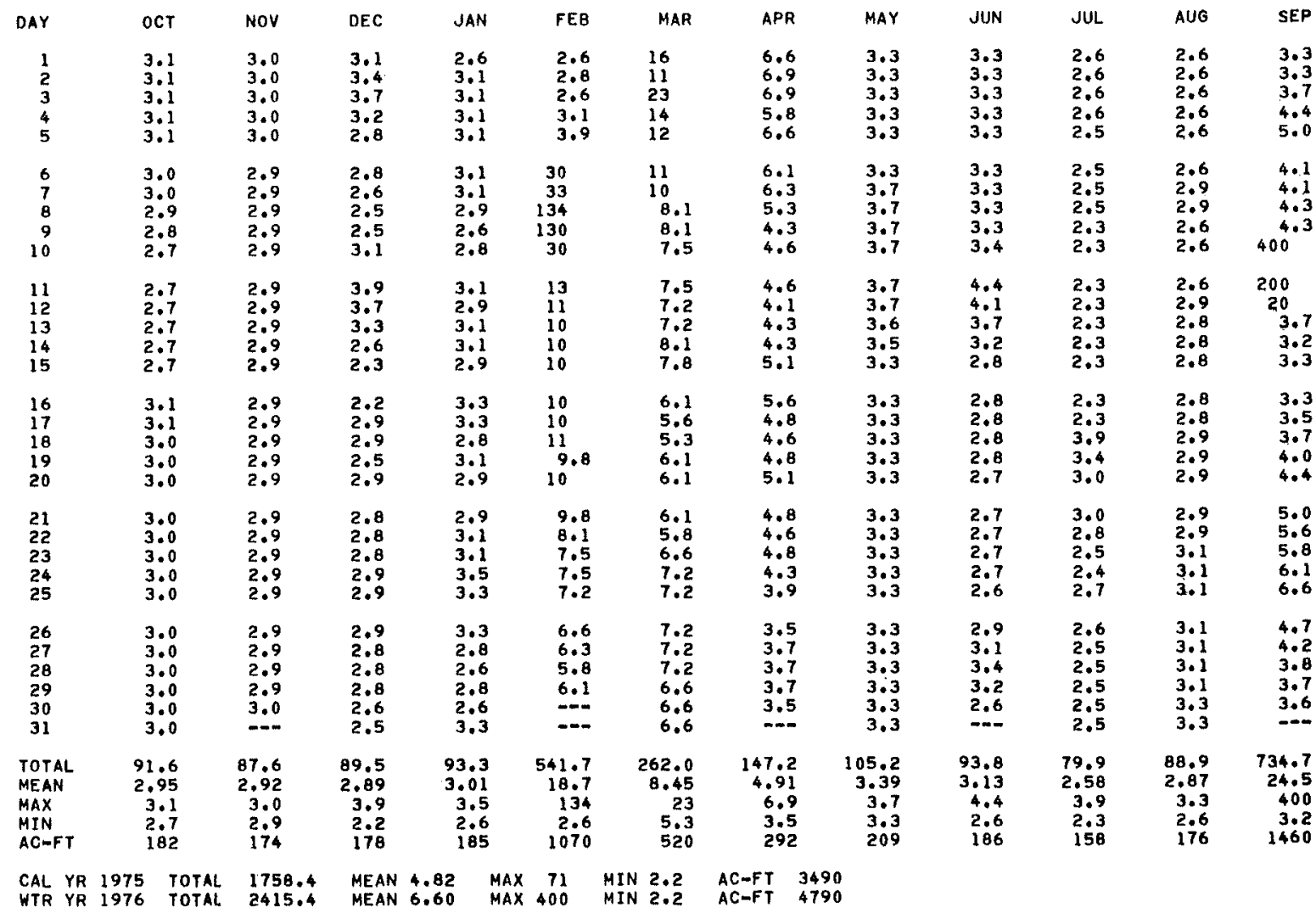


11063680 DEVIL CANYON CREEK NEAR SAN BERNARDINO, CA

LOCATION, - - Lat $34^{\circ} 12^{\prime} 30^{\prime \prime}$, Iong $117^{\circ} 19^{\prime} 50^{\prime \prime}$, in Muscupiabe Grant, San Bernardino County, on left bank 0.6 mi

$(1.0 \mathrm{~km})$ downstream from confluence of East and West Forks, and $7.5 \mathrm{mi}$ (12.1 km) northwest of San Bernardino.

DRAINAGE AREA, $-5.49 \mathrm{mi}^{2}\left(14.22 \mathrm{~km}^{2}\right)$.

PERIOD OF RECORD. - November 1911 to September 1912 , October 1913 to September 1914 , December 1919 to current year. Monthly figures only for January 1914 , published in WSP $1315-B$.

GAGE, - Water-stage recorder on creek; flowmeter on diversion. Altitude of gage is $2,080 \mathrm{ft}(634 \mathrm{~m})$, from topographic map. Prior to December 1919, nonrecording gage at site $0.5 \mathrm{mi}(0.8 \mathrm{~km})$ downstream at different datum. December 1919 to Ju1y 1969 , at site $0.4 \mathrm{mi}(0.6 \mathrm{~km})$ downstream at different datum. July 1969 to September 1972, present gage used as supplementary gage. Oct. 1, 1973, to Feb. 25, 1974, supplementary gage at site $0.5 \mathrm{mi}(0.8 \mathrm{~km})$ downstream at different datum.

REMARKS. - Records fair. No regulation above station. City of San Bernardino diverts above station for municipal supply. See schematic diagram of Santa Ana River basin.

COOPERATION. - -Records of diversion were furnished by city of San Bernardino.

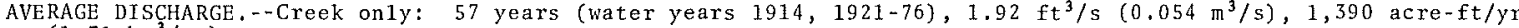

Combined creek and diversion. -43 years (water years $1914,1935-76), 3.57 \mathrm{ft}^{3} / \mathrm{s}\left(0.10 \mathrm{~m}^{3} / \mathrm{s}\right), 2,590 \mathrm{acre}-\mathrm{ft} / \mathrm{yr}^{3}$ $\left(3,19 \mathrm{hm}^{3} / \mathrm{yr}^{\mathrm{r}}\right)$.

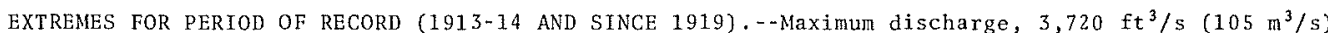

Jan. 25,1969 , gage height, $5.40 \mathrm{ft}(1.646 \mathrm{~m})$, site and datum then in use, on basis of slope-area measurement of maximum flow: no flow at times in some years.

EXTREMES FOR CURRENT YEAR, - -Peak discharges above base of $25 \mathrm{ft}^{3} / \mathrm{s}\left(0.71 \mathrm{~m}^{3} / \mathrm{s}\right)$ and maximum (*) based on extension of rating curve above $30 \mathrm{ft}^{3} / \mathrm{s}\left(0.85 \mathrm{~m}^{3} / \mathrm{s}\right)$ and indirect measurement made at peak flow:

\begin{tabular}{|c|c|c|c|c|c|c|c|c|c|c|}
\hline Date & Time & $\begin{array}{c}\text { Discharge } \\
\left(\mathrm{ft}^{3} / \mathrm{s}\right)\left(\mathrm{m}^{3} / \mathrm{s}\right)\end{array}$ & $\begin{array}{l}\text { Gage } \\
\text { (ft) }\end{array}$ & $\begin{array}{l}\text { height } \\
\text { (m) }\end{array}$ & Date & Time & $\begin{array}{r}\text { Disc } \\
\left(\mathrm{ft}^{3} / \mathrm{s}\right.\end{array}$ & $\begin{array}{l}r g e \\
\left(m^{3} / s\right)\end{array}$ & $\begin{array}{l}\text { Gage } \\
(f t)\end{array}$ & $\begin{array}{r}\text { height } \\
\text { (m) }\end{array}$ \\
\hline $\begin{array}{l}\text { Feb. } 8 \\
\text { Mar. } 1\end{array}$ & $\begin{array}{l}2330 \\
\text { Unknown }\end{array}$ & $\begin{array}{l}1.44 \\
1.10\end{array}$ & $\begin{array}{l}3.63 \\
3.50\end{array}$ & $\begin{array}{l}1.106 \\
1.067\end{array}$ & Sept. 11 & 0445 & $* 334$ & 9.46 & 4.92 & 1.500 \\
\hline
\end{tabular}

Minimum daily discharge, $0.50 \mathrm{ft}^{3} / \mathrm{s}\left(0.014 \mathrm{~m}^{3} / \mathrm{s}\right)$ Aug, 30 to Sept. 1 .

DISCHARGE, IN CURIC FEET PER SECOND, WATER YEAR OCTOGER 1975 TO SEPIEMBER 1976 MEAN VALUES

\begin{tabular}{|c|c|c|c|c|c|c|c|c|c|c|c|c|}
\hline DAY & OCT & NOV & DEC & JAN & FEB & MAR & $A P R$ & MAY & JUN & JUL & AUG & SEP \\
\hline $\begin{array}{l}1 \\
2 \\
3 \\
4 \\
5\end{array}$ & $\begin{array}{r}.90 \\
.90 \\
.90 \\
.90 \\
.90\end{array}$ & $\begin{array}{r}.99 \\
.97 \\
.92 \\
.89 \\
.78\end{array}$ & $\begin{array}{l}2.5 \\
2.4 \\
2.5 \\
2.5 \\
2.5\end{array}$ & $\begin{array}{l}1.8 \\
1.8 \\
1.8 \\
1.8 \\
1.8\end{array}$ & $\begin{array}{l}2.1 \\
2.1 \\
2.1 \\
2.9 \\
3.5\end{array}$ & $\begin{array}{r}17 \\
9.0 \\
5.6 \\
5.3 \\
5.3\end{array}$ & $\begin{array}{l}4.2 \\
4.5 \\
4.2 \\
4.6 \\
4.5\end{array}$ & $\begin{array}{l}2.6 \\
2.6 \\
2.6 \\
2.6 \\
2.6\end{array}$ & $\begin{array}{l}1.2 \\
1.1 \\
1.1 \\
1.1 \\
1.1\end{array}$ & $\begin{array}{r}.81 \\
.95 \\
.95 \\
.93 \\
.90\end{array}$ & $\begin{array}{r}.82 \\
.84 \\
.84 \\
.82 \\
.81\end{array}$ & $\begin{array}{r}.50 \\
.51 \\
.59 \\
.56 \\
.53\end{array}$ \\
\hline $\begin{array}{r}6 \\
7 \\
8 \\
9 \\
10\end{array}$ & $\begin{array}{r}.90 \\
.90 \\
.90 \\
.90 \\
1.1\end{array}$ & $\begin{array}{r}.83 \\
.92 \\
.92 \\
.85 \\
.89\end{array}$ & $\begin{array}{l}2.5 \\
2.5 \\
2.5 \\
2.5 \\
2.5\end{array}$ & $\begin{array}{l}1.0 \\
2.0 \\
2.0 \\
2.0 \\
2.0\end{array}$ & $\begin{array}{c}6.9 \\
8.3 \\
14 \\
23 \\
9.6\end{array}$ & $\begin{array}{l}5.5 \\
5.3 \\
5.3 \\
5.3 \\
5.1\end{array}$ & $\begin{array}{l}4.5 \\
4.5 \\
4.3 \\
4.1 \\
4.0\end{array}$ & $\begin{array}{l}2.6 \\
3.2 \\
2.8 \\
2.5 \\
2.5\end{array}$ & $\begin{array}{l}1.0 \\
1.0 \\
1.0 \\
1.1 \\
1.3\end{array}$ & $\begin{array}{l}.87 \\
.82 \\
.82 \\
.82 \\
.86\end{array}$ & $\begin{array}{r}.80 \\
.72 \\
.71 \\
.69 \\
.66\end{array}$ & $\begin{array}{r}.56 \\
.54 \\
.53 \\
.58 \\
9.5\end{array}$ \\
\hline $\begin{array}{l}11 \\
12 \\
13 \\
14 \\
15\end{array}$ & $\begin{array}{l}1.0 \\
.90 \\
.90 \\
.90 \\
.74\end{array}$ & $\begin{array}{r}.88 \\
.85 \\
.90 \\
.86 \\
.87\end{array}$ & $\begin{array}{l}2.6 \\
2.5 \\
1.7 \\
1.7 \\
1.6\end{array}$ & $\begin{array}{l}2.1 \\
2.1 \\
2.1 \\
2.1 \\
2.2\end{array}$ & $\begin{array}{l}5.9 \\
4.5 \\
4.2 \\
4.1 \\
3.9\end{array}$ & $\begin{array}{l}5.1 \\
4.5 \\
4.3 \\
4.1 \\
3.9\end{array}$ & $\begin{array}{l}4.0 \\
3.9 \\
5.3 \\
4.3 \\
5.6\end{array}$ & $\begin{array}{l}2.2 \\
2.0 \\
1.9 \\
1.8 \\
1.7\end{array}$ & $\begin{array}{l}1.2 \\
1.1 \\
1.0 \\
.97 \\
.93\end{array}$ & $\begin{array}{r}.88 \\
.90 \\
.93 \\
.94 \\
.99\end{array}$ & $\begin{array}{l}.63 \\
.62 \\
.62 \\
.62 \\
.74\end{array}$ & $\begin{array}{r}45 \\
5.7 \\
3.9 \\
2.8 \\
2.9\end{array}$ \\
\hline $\begin{array}{l}16 \\
17 \\
18 \\
19 \\
20\end{array}$ & $\begin{array}{l}.90 \\
.98 \\
1.0 \\
1.1 \\
1.2\end{array}$ & $\begin{array}{l}.87 \\
.85 \\
.80 \\
.79 \\
.83\end{array}$ & $\begin{array}{l}1.5 \\
1.4 \\
1.4 \\
1.4 \\
1.5\end{array}$ & $\begin{array}{l}2.1 \\
2.1 \\
2.1 \\
2.0 \\
2.2\end{array}$ & $\begin{array}{l}3.8 \\
3.6 \\
3.4 \\
3.4 \\
3.4\end{array}$ & $\begin{array}{l}3.8 \\
3.7 \\
3.7 \\
3.7 \\
3.7\end{array}$ & $\begin{array}{l}5.7 \\
5.3 \\
5.3 \\
5.1 \\
4.6\end{array}$ & $\begin{array}{l}1.7 \\
1.7 \\
1.6 \\
1.6 \\
1.5\end{array}$ & $\begin{array}{r}.97 \\
.97 \\
.96 \\
.96 \\
.90\end{array}$ & $\begin{array}{l}1.0 \\
.99 \\
1.0 \\
1.0 \\
1.0\end{array}$ & $\begin{array}{l}.73 \\
.70 \\
.71 \\
.70 \\
.69\end{array}$ & $\begin{array}{l}2.4 \\
2.0 \\
1.8 \\
2.2 \\
1.9\end{array}$ \\
\hline $\begin{array}{l}21 \\
22 \\
23 \\
24 \\
25\end{array}$ & $\begin{array}{l}1.2 \\
1.2 \\
1.3 \\
1.3 \\
1.2\end{array}$ & $\begin{array}{l}.94 \\
1.2 \\
1.2 \\
1.1 \\
1.2\end{array}$ & $\begin{array}{l}1.6 \\
1.5 \\
1.5 \\
1.6 \\
1.6\end{array}$ & $\begin{array}{l}2 \cdot 1 \\
2 \cdot 1 \\
2 \cdot 1 \\
2 \cdot 2 \\
2 \cdot 2\end{array}$ & $\begin{array}{l}3.3 \\
3.3 \\
3.1 \\
3.1 \\
3.0\end{array}$ & $\begin{array}{l}3.7 \\
3.6 \\
3.4 \\
3.4 \\
3.3\end{array}$ & $\begin{array}{l}4.0 \\
3.5 \\
2.9 \\
2.7 \\
2.7\end{array}$ & $\begin{array}{l}1.5 \\
1.5 \\
1.4 \\
1.4 \\
1.4\end{array}$ & $\begin{array}{r}.89 \\
.90 \\
.82 \\
.79 \\
.78\end{array}$ & $\begin{array}{l}.99 \\
1.0 \\
1.0 \\
.99 \\
1.0\end{array}$ & $\begin{array}{l}.68 \\
.66 \\
.63 \\
.61 \\
.60\end{array}$ & $\begin{array}{l}1.6 \\
1.5 \\
1.4 \\
1.7 \\
2.0\end{array}$ \\
\hline $\begin{array}{l}26 \\
27 \\
28 \\
29 \\
30 \\
31\end{array}$ & $\begin{array}{l}1.2 \\
1.1 \\
1.1 \\
1.1 \\
1.1 \\
.99\end{array}$ & $\begin{array}{l}1.2 \\
2.2 \\
2.8 \\
2.6 \\
2.5 \\
-.-\end{array}$ & $\begin{array}{l}1.6 \\
1.6 \\
1.6 \\
1.6 \\
1.6 \\
1.6\end{array}$ & $\begin{array}{l}2.2 \\
2.1 \\
2.1 \\
2.1 \\
2.1 \\
2.1\end{array}$ & $\begin{array}{l}3.1 \\
3.0 \\
3.0 \\
3.0 \\
-\ldots- \\
-\ldots\end{array}$ & $\begin{array}{l}3.3 \\
3.3 \\
3.3 \\
3.2 \\
3.2 \\
3.2\end{array}$ & $\begin{array}{l}3.1 \\
3.2 \\
3.1 \\
3.2 \\
3.0 \\
-.-\end{array}$ & $\begin{array}{l}1.3 \\
1.3 \\
1.4 \\
1.5 \\
1.4 \\
1.3\end{array}$ & $\begin{array}{l}.78 \\
.77 \\
.75 \\
.76 \\
.78 \\
-.0\end{array}$ & $\begin{array}{l}1.0 \\
.90 \\
.88 \\
.87 \\
.83 \\
.83\end{array}$ & $\begin{array}{l}.59 \\
.59 \\
.56 \\
.56 \\
.50 \\
.50\end{array}$ & $\begin{array}{l}1.7 \\
1.8 \\
1.5 \\
1.1 \\
.65 \\
.--0\end{array}$ \\
\hline $\begin{array}{l}\text { TOTAL } \\
\text { MEAN } \\
\text { MAX } \\
\text { MIN } \\
\text { AC }-F T\end{array}$ & $\begin{array}{r}31.61 \\
1.02 \\
1.3 \\
.74 \\
63\end{array}$ & $\begin{array}{r}34.40 \\
1.15 \\
2.8 \\
.78 \\
68\end{array}$ & $\begin{array}{r}59.6 \\
1.92 \\
2.6 \\
1.4 \\
118\end{array}$ & $\begin{array}{r}63.3 \\
2.04 \\
2.2 \\
1.8 \\
126\end{array}$ & $\begin{array}{r}142.6 \\
4.92 \\
23 \\
2.1 \\
283\end{array}$ & $\begin{array}{r}146.1 \\
4.71 \\
17 \\
3.2 \\
290\end{array}$ & $\begin{array}{r}123.9 \\
4.13 \\
5.7 \\
2.7 \\
246\end{array}$ & $\begin{array}{r}59.7 \\
1.93 \\
3.2 \\
1.3 \\
118\end{array}$ & $\begin{array}{r}28.98 \\
.97 \\
1.3 \\
.75 \\
57\end{array}$ & $\begin{array}{r}28.65 \\
.92 \\
1.0 \\
.81 \\
57\end{array}$ & $\begin{array}{r}20.95 \\
.68 \\
.84 \\
.50 \\
.42\end{array}$ & $\begin{array}{r}99.95 \\
3.33 \\
45 \\
.50 \\
198\end{array}$ \\
\hline (a) & 120 & 148 & 225 & 267 & 360 & 396 & 357 & 211 & 131 & 127 & 99 & 223 \\
\hline
\end{tabular}

$\begin{array}{llllllllllll}\text { CAL YR } 1975 & \text { TOTAL 838.89 } & \text { MEAN } 2.30 & \text { MAX } 10 & \text { MIN } & .74 & \text { AC-FT } & 1660 & \text { AC-FT a } 2,820 \\ \text { WTR YR } 1976 & \text { TOTAL 839.74 } & \text { MEAN 2.29 } & \text { MAX 45 } & \text { MIN } & .50 & \text { AC-FT } & 1670 & \text { AC-FT a } & 2,660\end{array}$

a Combined discharge, in acre-feet, of Devil Canyon Creek and city of San Bernardino diversion. 
LOCATION, - - Lat $34^{\circ} 04^{\prime} 44^{\prime \prime}$, long $117^{\circ} 18^{\prime} 17^{\prime \prime}$, in San Bernardino Grant, San Bernardino County, on right bank 400 ft

$(122 \mathrm{~m})$ downstream from Colton Avenue, $1,930 \mathrm{ft}(588 \mathrm{~m})$ upstream from outlet end of channel, and $1.3 \mathrm{mi}$

$(2.1 \mathrm{~km})$ northeast of Colton.

DRAINAGE AREA. $-172 \mathrm{mi}^{2}\left(445 \mathrm{~km}^{2}\right)$.

PERIOD OF RECORD. - October 1957 to current year.

GAGE. - Water-stage recorder. Datum of gage is $974.67 \mathrm{ft}(297.079 \mathrm{~m})$ above mean sea 1 eve1 (Corps of Engineers bench mark).

REMARKS. --Records poor. Flow partly regulated by Lytle Creek spreading grounds $3.2 \mathrm{mi}$ ( $5.1 \mathrm{~km}$ ) upstream.

Diversions above station for irrigation, power development, domestic use, and ground-water replenishment.

See schematic diagram of Santa Ana River basin.

EXTREMES FOR PERIOD OF RECORD. - Maximum discharge, $16,800 \mathrm{ft}^{3} / \mathrm{s}\left(476 \mathrm{~m}^{3} / \mathrm{s}\right) \mathrm{Jan} .25$, 1969 , gage height, $13.6 \mathrm{ft}$ $(4.15 \mathrm{~m})$, from floodmarks, from rating curve extended above $4,200 \mathrm{ft}^{3} / \mathrm{s}$ (119 $\mathrm{m}^{3} / \mathrm{s}$ ) on basis of discharge for design flood at gage height $21.4 \mathrm{ft}(6.52 \mathrm{~m})$; no flow most of each year.

EXTREMES FOR CURRENT YEAR. - Maximum discharge, $1,170 \mathrm{ft}^{3} / \mathrm{s}\left(33.1 \mathrm{~m}^{3} / \mathrm{s}\right) \mathrm{Sept}$. 11, gage height, $3.20 \mathrm{ft}(0.975 \mathrm{~m})$; no flow most of year.

DISCHARGE, IN CUBIC FEET PER SECOND, WATER YEAR OCTOBER 1975 TO SEPTEMBER 1976 MEAN VALUES

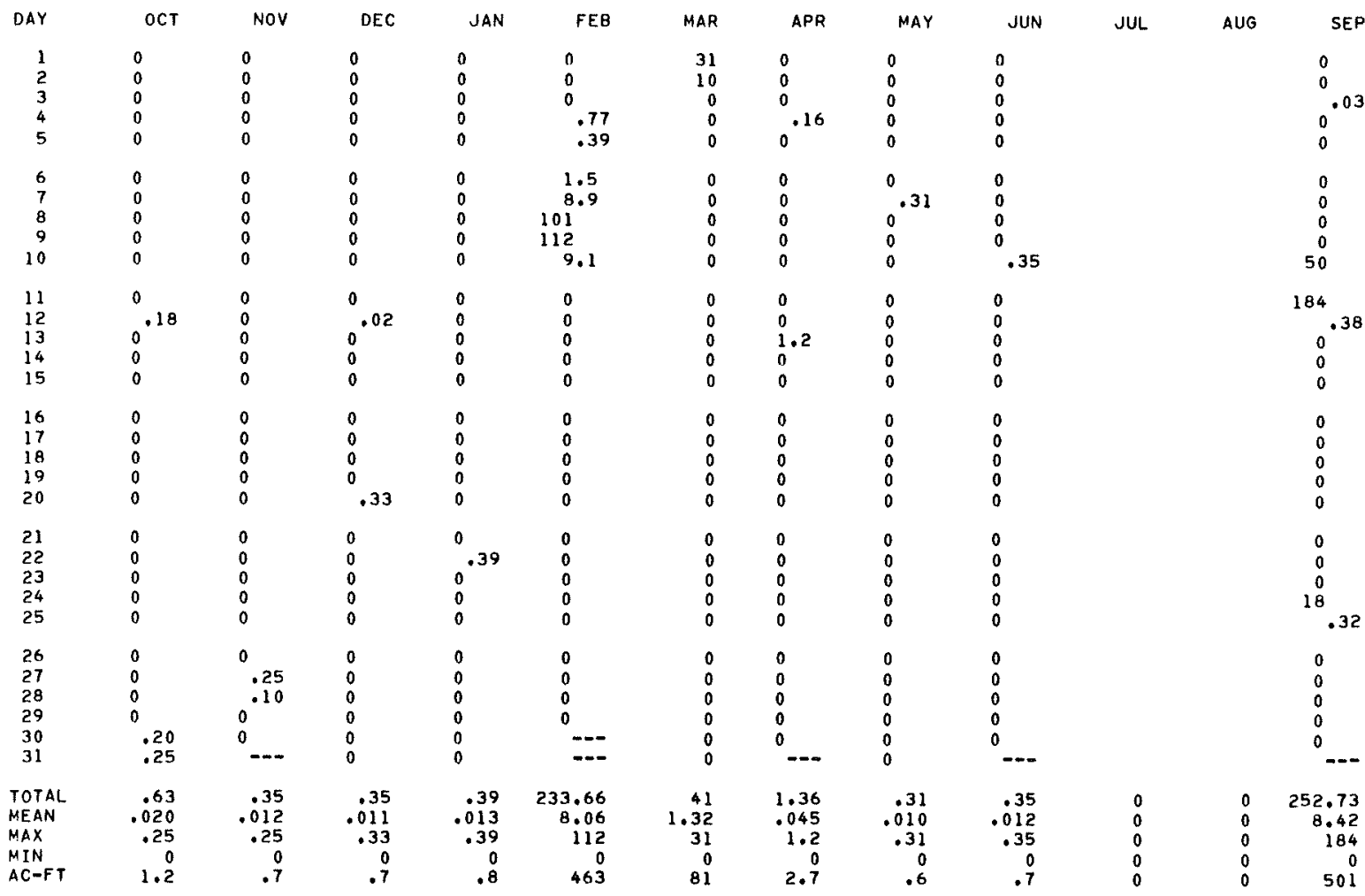


LOCATION, - Lat $33^{\circ} 59^{\prime} 28^{\prime \prime}$, Iong $117^{\circ} 23^{\prime} 36^{\prime \prime}$, in Jurupa Grant, Riverside County, near right bank on downstream end

of pier of Mission Boulevard Bridge between Rubidoux and Riverside.

DRAINAGE AREA. $--810 \mathrm{mi}^{2}\left(2,098 \mathrm{~km}^{2}\right)$.

PERIOD OF RECORD, --February 1971 to current year.

GAGE. - Water-stage recorder. Datum of gage is $758.52 \mathrm{ft}(231.197 \mathrm{~m})$ above mean sea level.

REMARKS.--Records poor. This is a project station the purpose of which is to record surface flow entering

Riverside narrows from upper Santa Ana River drainage. See schenatic diagram of Santa Ana River basin.

AVERAGE DISCHARGE. -5 years, $8.17 \mathrm{ft}^{3} / \mathrm{s}\left(0.231 \mathrm{~m}^{3} / \mathrm{s}\right), 5,920 \mathrm{acre}-\mathrm{ft} / \mathrm{yr}\left(7.30 \mathrm{hm}^{3} / \mathrm{yr}^{2}\right)$.

EXTREMES FOR PERIOD OF RECORD.--Maximum discharge $12,000 \mathrm{ft}^{3} / \mathrm{s}\left(340 \mathrm{~m}^{3} / \mathrm{s}\right)$ Sept. 11 , 1976 , gage height, $12.60 \mathrm{ft}$

$(3.840 \mathrm{~m})$, on basis of slope-conveyance measurement of maximum flow; no flow most of each year.

EXTREMES FOR CURRENT YEAR. - -Peak discharges above base of $500 \mathrm{ft}^{3} / \mathrm{s}\left(14.2 \mathrm{~m}^{3} / \mathrm{s}\right)$ and maximum (*), on basis of slope-conveyance measurement of maximum flow.

\begin{tabular}{|c|c|c|c|c|c|c|c|c|c|}
\hline Date & Time & $\begin{array}{c}\text { Discharge } \\
\left(\mathrm{ft}^{3} / \mathrm{s}\right)\left(\mathrm{m}^{3} / \mathrm{s}\right)\end{array}$ & $\begin{array}{l}\text { Gage height } \\
\text { (ft) }\end{array}$ & Date & Time & $\begin{array}{r}\text { Disch } \\
\left(\mathrm{ft}^{3} / \mathrm{s}\right)\end{array}$ & $\underset{\left(m^{3} / s\right)}{\operatorname{arge}}$ & $\begin{array}{l}\text { Gage } \\
(f t)\end{array}$ & $\begin{array}{r}\text { height } \\
\text { (m) }\end{array}$ \\
\hline $\begin{array}{ll}\text { Feb. } & 8 \\
\text { Mar: } & 1 \\
\text { Mar: } & 3\end{array}$ & $\begin{array}{l}2400 \\
1900 \\
0430\end{array}$ & $\begin{array}{ll}750 & 21.2 \\
520 & 14.7 \\
595 & 16.9\end{array}$ & $\begin{array}{r}10.80 \\
9.32 \\
9.50\end{array}$ & $\begin{array}{l}\text { Sept. } 11 \\
\text { Sept. } 24\end{array}$ & $\begin{array}{l}0230 \\
2000\end{array}$ & $\begin{array}{r}* 12000 \\
950\end{array}$ & $\begin{array}{l}340 \\
26.9\end{array}$ & $\begin{array}{l}12.60 \\
10.00\end{array}$ & $\begin{array}{l}3.840 \\
3.048\end{array}$ \\
\hline
\end{tabular}

Minimum daily discharge, no flow most of year.

DISCHARGE, IN CUBIC FEET PER SECOND, WATER YEAR OCTOBER 1975 TO SEPTEMBER 1976 MEAN VALUES

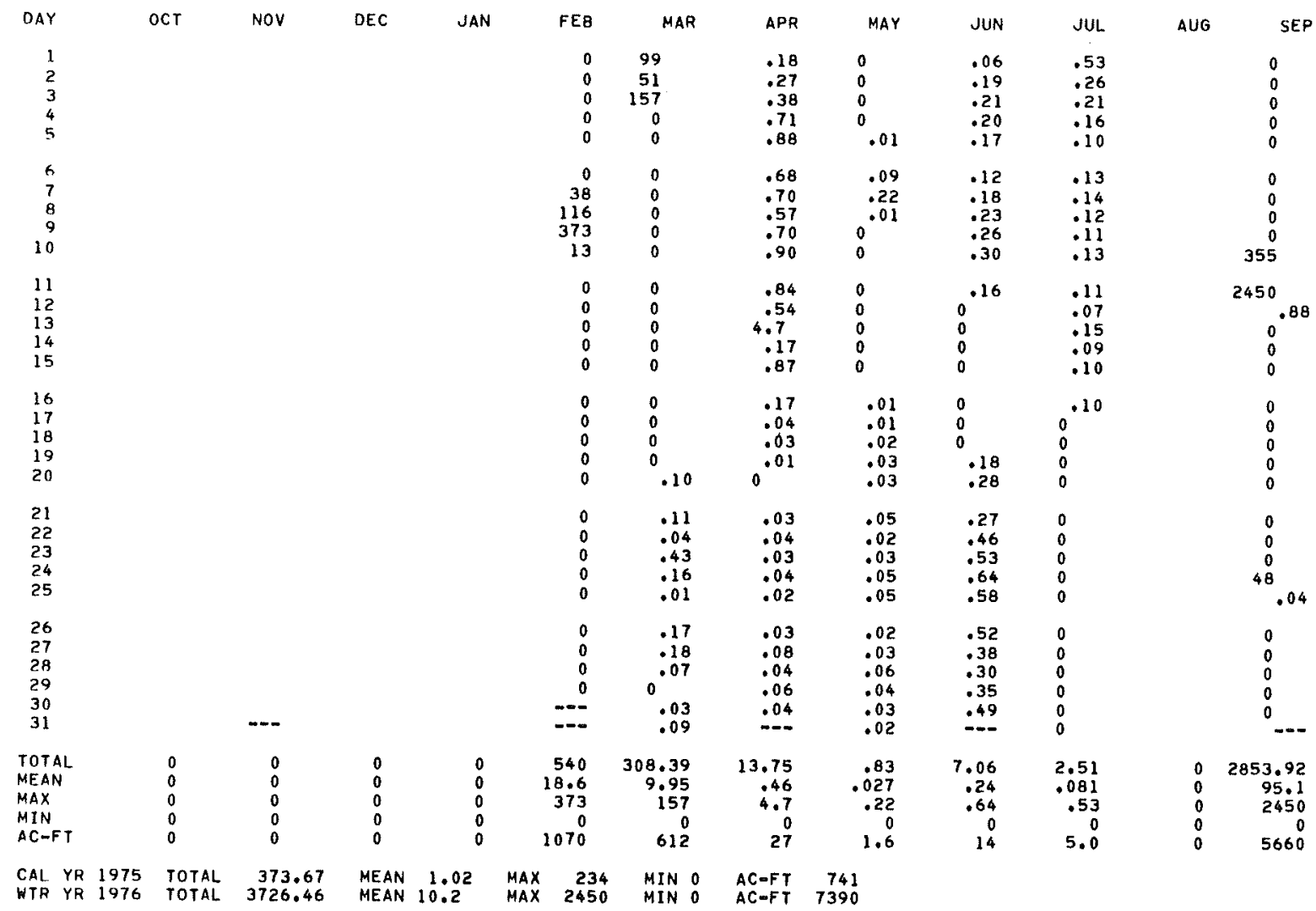




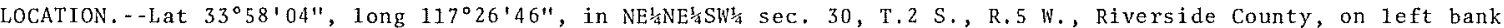
$300 \mathrm{ft}(91 \mathrm{~m})$ upstream from MWD crossing, $0.7 \mathrm{mi}(1.1 \mathrm{~km})$ downstream from Union Pacific Railroad bridge, $1.2 \mathrm{mi}(1.9 \mathrm{~km})$ upstream from bridge on Van Buren Boulevard, and $3.3 \mathrm{mi}$ ( $5.3 \mathrm{~km})$ north of Arlington. DRAINAGE AREA. $-854 \mathrm{mi}^{2}\left(2,112 \mathrm{~km}^{2}\right)$.

PERIOD OF RECORD, - March 1970 to current year.

GAGE. - Water-stage recorder and concrete low-flow control. Altitude of gage is $685 \mathrm{ft}$ ( $209 \mathrm{~m}$ ), $\mathrm{from}$ topographic map.

REMARKS. - Records good below $100 \mathrm{ft}^{3} / \mathrm{s}\left(2.83 \mathrm{~m}^{3} / \mathrm{s}\right)$ and poor above. Flow partly regulated by Big Bear Lake (station 11049000). Natural streamflow affected by ground-water withdrawals, diversions for irrigation, and return flows from irrigated areas. The records at this station are equivalent to those collected at 11066500 Santa Ana River at Riverside Narrows, near Arlington minus the flow at 11066480 Riverside Water Quality Control P1ant at Riverside Narrows, near Arlington. See schematic diagram of Santa Ana River basin. AVERAGE DISCHARGE . -6 years, $35.5 \mathrm{ft}^{3} / \mathrm{s}\left(1.005 \mathrm{~m}^{3} / \mathrm{s}\right), 25,720$ acre-ft $/ \mathrm{yr}^{2}\left(31.7 \mathrm{hm}^{3} / \mathrm{yr}^{\mathrm{r}}\right)$.

EXTREMES FOR PERIOD OF RECORD,--Maximum discharge, $9,520 \mathrm{ft}^{3} / \mathrm{s}\left(270 \mathrm{~m}^{3} / \mathrm{s}\right)$ Sept. 11 , 1976 , gage height, $12.92 \mathrm{ft}$ $(3.938 \mathrm{~m})$, from rating extended above $3600 \mathrm{ft} / \mathrm{s}\left(102 \mathrm{~m}^{3} / \mathrm{s}\right)$ on basis of slope-area measurement of maximum flow; minimum daily, $16 \mathrm{ft}^{3} / \mathrm{s}\left(0.45 \mathrm{~m}^{3} / \mathrm{s}\right)$ Aug, $18,19,1973$.

EXTREMES OUTSIDE PERIOD OF RECORD.--Maximum discharge since at least $1927,100,000 \mathrm{ft}^{3} / \mathrm{s}\left(2,830 \mathrm{~m}^{3} / \mathrm{s}\right)$

Mar. 2, 1938, on basis of slope-area measurement at site $1.2 \mathrm{mi}(1.9 \mathrm{~km})$ downstream.

Flood of Jan. 22, 1862, 320,000 ft $3 / \mathrm{s}\left(9,060 \mathrm{~m}^{3} / \mathrm{s}\right)$, by slope-conveyance measurement at site $8.1 \mathrm{mi}$ $13.0 \mathrm{~km})$ upstream. Stage at that site was $5 \mathrm{ft}(2 \mathrm{~m})$ higher than Mar, 2,1938

EXTREMES FOR CURRENT YEAR. - Peak discharge above base of $500 \mathrm{ft}^{3} / \mathrm{s}\left(14.2 \mathrm{~m}^{3} / \mathrm{s}\right)$ and maximum (*), from rating curve extended above $3,600 \mathrm{ft}^{3} / \mathrm{s}\left(102 \mathrm{~m}^{3} / \mathrm{s}\right)$ on basis of slope-area measurement of maximum flow:

\begin{tabular}{lrrrrr} 
& & \multicolumn{2}{c}{ Discharge } & \multicolumn{2}{c}{ Gage height } \\
Date & Time & $\left(\mathrm{ft}^{3} / \mathrm{s}\right)$ & $\left(\mathrm{m}^{3} / \mathrm{s}\right)$ & (ft) & (m) \\
Feb. 9 & 0315 & 1120 & 31.7 & 10.45 & 3.185 \\
Sept. 11 & 0430 & $* 9520$ & 270 & 12.92 & 3.938
\end{tabular}

Minimun daily discharge, $19 \mathrm{ft}^{3} / \mathrm{s}\left(0.54 \mathrm{~m}^{3} / \mathrm{s}\right)$ July 24,31 , Aug. 1, 4, 6, 13, $15,22,30$.

OISCHARGE, IN CUBIC FEET PER SECONO, WATER YEAR OCTOBER 1975 TO SEPTEMBER 1976 MEAN VALUES

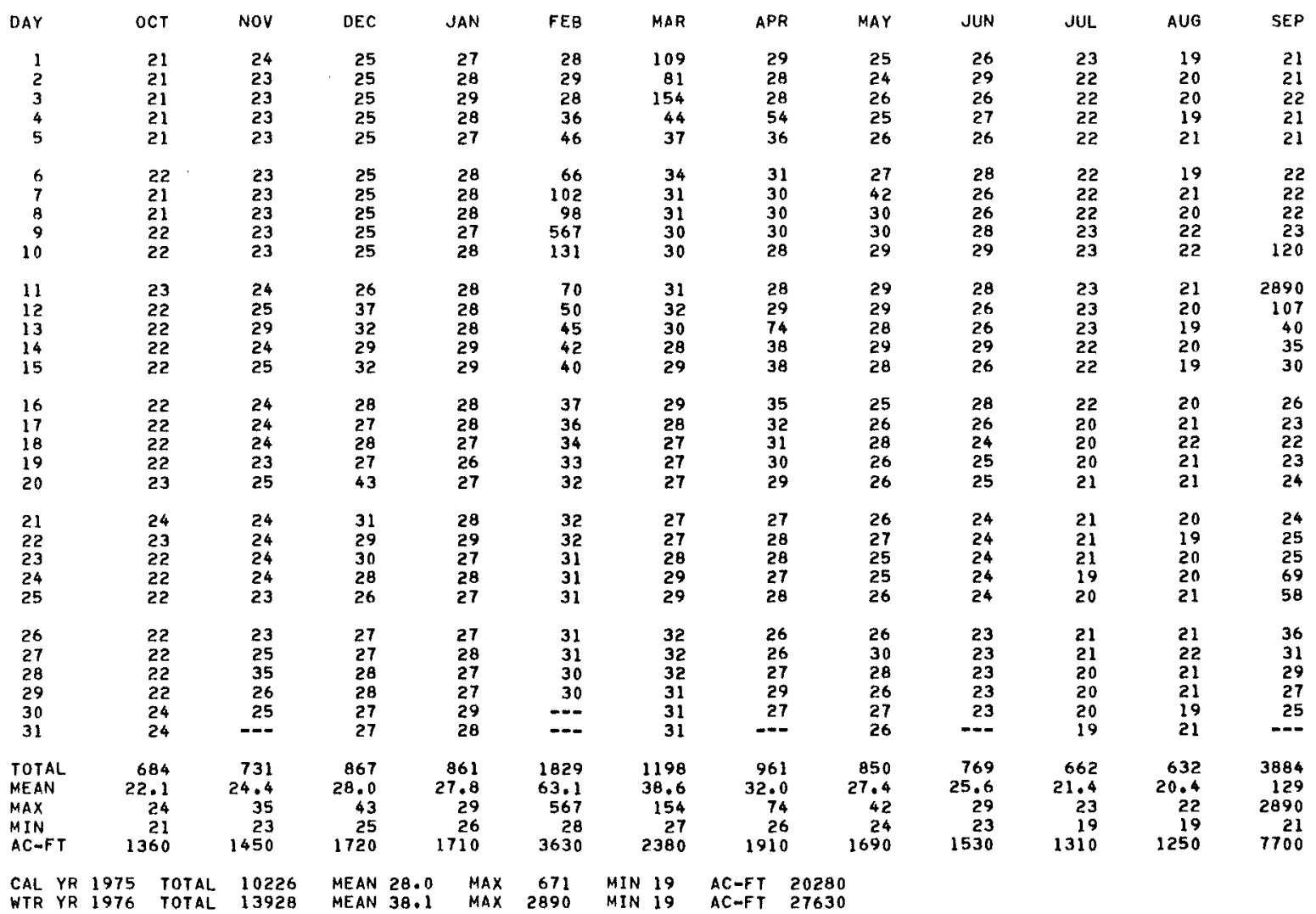


11066460 SANTA ANA RIVER AT MWD CROSSING, NEAR ARLINGTON, CA--Continued

WATER-QUALITY RECORDS

PERIOD OF RECORD. - Water years 1970 to current year.

CHEMICAL ANALYSES: Water years 1970 to current year.

PERIOD OF DAILY RECORD.--

SPECIFIC CONDUCTANCE: October 1969 to current year.

INSTRUMENTATION. --Specific conductance recorder since October 1969 .

REMARKS. - -Periods of missing specific conductance record due to poor flow communication at probe or recorder malfunction.

EXTREMES FOR PERIOD OF RECORD.--

SPECIFIC CONDUCTANCE: Naximum recorded, 1,320 micromhos Nov, 4, 1969; minimum, 95 micromhos Nov. 27 , 1970.

EXTREMES FOR CURRENT YEAR, - -

SPECIFIC CONDUCTANCE: Maximum recorded, 1,190 micromhos Nov, 13; minimum recorded, 186 micromhos Mar, 1.

CHEMICAL ANALYSES, WATER YEAR OCTOBER 1975 TO SEPTEMBER 1976

\begin{tabular}{|c|c|c|c|c|c|c|c|}
\hline DATE & TIME & $\begin{array}{l}\text { INSTAN- } \\
\text { TANEOUS } \\
\text { DIS- } \\
\text { CHARGE } \\
\text { (CFS) }\end{array}$ & $\begin{array}{l}\text { SPE- } \\
\text { CIFIC } \\
\text { CON- } \\
\text { OUCT- } \\
\text { ANCE } \\
\text { (MICRO- } \\
\text { MHOS) }\end{array}$ & $\begin{array}{l}\text { TEMPER- } \\
\text { ATURE } \\
\text { (DEG C) }\end{array}$ & $\begin{array}{l}\text { DIS- } \\
\text { SOLVED } \\
\text { SOLIDS } \\
\text { (RESI- } \\
\text { DUE AT } \\
180 \mathrm{C}) \\
(M G / L)\end{array}$ & $\begin{array}{l}\text { DIS- } \\
\text { SOLVED } \\
\text { SOLIDS } \\
\text { (TONS } \\
\text { PER } \\
\text { AC-FT) }\end{array}$ & $\begin{array}{l}\text { DIS- } \\
\text { SOLVED } \\
\text { SOLIDS } \\
\text { (TONS } \\
\text { PER } \\
\text { DAY) }\end{array}$ \\
\hline \multicolumn{8}{|l|}{ OCT } \\
\hline nov & $\begin{array}{l}0900 \\
1340\end{array}$ & $\begin{array}{l}21 \\
22\end{array}$ & $\begin{array}{l}1100 \\
1120\end{array}$ & $\begin{array}{l}18.5 \\
23.0\end{array}$ & $\begin{array}{l}708 \\
702\end{array}$ & $\begin{array}{r}.96 \\
.95\end{array}$ & $\begin{array}{l}40.1 \\
41.7\end{array}$ \\
\hline $\begin{array}{l}04 \ldots \\
17 \ldots \\
\text { DEC }\end{array}$ & $\begin{array}{l}1350 \\
0900\end{array}$ & $\begin{array}{l}24 \\
25\end{array}$ & $\begin{array}{l}1110 \\
1080\end{array}$ & $\begin{array}{l}22.0 \\
16.5\end{array}$ & $\begin{array}{l}692 \\
669\end{array}$ & $\begin{array}{r}.94 \\
.91\end{array}$ & $\begin{array}{l}44.8 \\
45.2\end{array}$ \\
\hline $\begin{array}{l}01 \ldots \\
17 \ldots \\
30 \cdots \\
\text { JAN }\end{array}$ & $\begin{array}{l}1000 \\
1100 \\
0900\end{array}$ & $\begin{array}{l}24 \\
27 \\
27\end{array}$ & $\begin{array}{l}1110 \\
1090 \\
1110\end{array}$ & $\begin{array}{l}15.8 \\
16.2 \\
14.8\end{array}$ & $\begin{array}{l}689 \\
686 \\
705\end{array}$ & $\begin{array}{l}.94 \\
.93 \\
.96\end{array}$ & $\begin{array}{l}44.6 \\
50.0 \\
51.4\end{array}$ \\
\hline $\begin{array}{l}07 \ldots \\
20 \ldots \\
F E B\end{array}$ & $\begin{array}{l}0900 \\
1115\end{array}$ & $\begin{array}{l}27 \\
29\end{array}$ & $\begin{array}{l}1100 \\
1110\end{array}$ & $\begin{array}{l}14.0 \\
17.8\end{array}$ & $\begin{array}{l}707 \\
702\end{array}$ & $\begin{array}{r}.96 \\
.95\end{array}$ & $\begin{array}{l}51.5 \\
55.0\end{array}$ \\
\hline $\begin{array}{l}02 \ldots \\
10 \ldots \\
12 \ldots \\
20 \ldots \\
\text { MAR }\end{array}$ & $\begin{array}{l}0950 \\
1515 \\
1330 \\
1100\end{array}$ & $\begin{array}{l}29 \\
76 \\
47 \\
32\end{array}$ & $\begin{array}{r}1090 \\
845 \\
1020 \\
1130\end{array}$ & $\begin{array}{r}15.2 \\
-0 \\
19.0 \\
17.0\end{array}$ & $\begin{array}{l}697 \\
459 \\
622 \\
699\end{array}$ & $\begin{array}{l}.95 \\
.62 \\
.85 \\
.95\end{array}$ & $\begin{array}{l}54.6 \\
94.2 \\
78.9 \\
60.4\end{array}$ \\
\hline $\begin{array}{l}02 \ldots \\
16 \ldots \\
25 \ldots \\
31 \ldots\end{array}$ & $\begin{array}{l}0930 \\
0925 \\
1005 \\
1115\end{array}$ & $\begin{array}{l}47 \\
28 \\
29 \\
32\end{array}$ & $\begin{array}{l}886 \\
1100 \\
1110 \\
1080\end{array}$ & $\begin{array}{l}15.2 \\
17.8 \\
17.9 \\
22.0\end{array}$ & $\begin{array}{l}561 \\
694 \\
705 \\
694\end{array}$ & $\begin{array}{r}.76 \\
.94 \\
.96 \\
.94\end{array}$ & $\begin{array}{l}71.2 \\
52.5 \\
55.2 \\
60.0\end{array}$ \\
\hline $\begin{array}{l}14 \ldots \\
01 \ldots\end{array}$ & $\begin{array}{l}0845 \\
0830\end{array}$ & $\begin{array}{l}29 \\
35\end{array}$ & $\begin{array}{l}1070 \\
1050\end{array}$ & $\begin{array}{l}17.2 \\
16.6\end{array}$ & $\begin{array}{l}675 \\
656\end{array}$ & $\begin{array}{l}.92 \\
.89\end{array}$ & $\begin{array}{l}52.9 \\
62.0\end{array}$ \\
\hline $\begin{array}{l}05 \ldots \\
07 \ldots \\
11 \ldots \\
20 \ldots\end{array}$ & $\begin{array}{l}0955 \\
1000 \\
1000 \\
0830\end{array}$ & $\begin{array}{l}27 \\
60 \\
30 \\
26\end{array}$ & $\begin{array}{r}1100 \\
766 \\
1060 \\
1070\end{array}$ & $\begin{array}{r}17.8 \\
17.2 \\
17.0\end{array}$ & $\begin{array}{l}703 \\
482 \\
670 \\
712\end{array}$ & $\begin{array}{l}.96 \\
.66 \\
.91 \\
.97\end{array}$ & $\begin{array}{l}51.2 \\
78.1 \\
54.3 \\
50.0\end{array}$ \\
\hline JUN & & & & & & & \\
\hline $\begin{array}{l}02 \ldots \ldots \\
17 \ldots \ldots \\
\text { JUL }\end{array}$ & $\begin{array}{l}1000 \\
0900\end{array}$ & $\begin{array}{l}31 \\
27\end{array}$ & $\begin{array}{l}1060 \\
1060\end{array}$ & $\begin{array}{l}20.7 \\
19.7\end{array}$ & $\begin{array}{l}652 \\
700\end{array}$ & $\begin{array}{r}.89 \\
.95\end{array}$ & $\begin{array}{l}54.6 \\
51.0\end{array}$ \\
\hline $\begin{array}{l}01 \\
13 \ldots\end{array}$ & $\begin{array}{l}0830 \\
0900\end{array}$ & $\begin{array}{l}23 \\
24\end{array}$ & $\begin{array}{l}1080 \\
1060\end{array}$ & $\begin{array}{l}20.0 \\
20.6\end{array}$ & $\begin{array}{l}736 \\
664\end{array}$ & $\begin{array}{r}1.00 \\
.90\end{array}$ & $\begin{array}{l}45.7 \\
43.0\end{array}$ \\
\hline AUG & & & & & & & \\
\hline $\begin{array}{l}02 \ldots \\
16 \ldots \\
\text { SEP }\end{array}$ & $\begin{array}{l}1100 \\
1030\end{array}$ & $\begin{array}{l}21 \\
20\end{array}$ & $\begin{array}{l}1110 \\
1100\end{array}$ & $\begin{array}{l}22.0 \\
20.5\end{array}$ & $\begin{array}{l}705 \\
705\end{array}$ & $\begin{array}{r}.96 \\
.96\end{array}$ & $\begin{array}{l}40.2 \\
38.1\end{array}$ \\
\hline $01 \ldots$ & 1230 & 20 & 1100 & 25.0 & 710 & .97 & 38.3 \\
\hline
\end{tabular}


11066460 SANTA ANA RIVER AT MWD CROSSING, NEAR ARLINGTON, CA--Continued SPECIFIC CONDUCTANCE (MICROMHOS/CM AT 25 DEG, C), WATER YEAR OCTOBER 1975 TO SEPTEMBER 1976

\begin{tabular}{|c|c|c|c|c|c|c|c|c|c|c|c|c|}
\hline \multirow[b]{2}{*}{ DAY } & \multicolumn{3}{|c|}{ OCTOBER } & \multicolumn{3}{|c|}{ NOVEMAER } & \multicolumn{3}{|c|}{ DECEMBER } & \multicolumn{3}{|c|}{ JANUARY } \\
\hline & MAX & MIN & MEAN & $\operatorname{MAX}$ & MIN & MEAN & MAX & MIN & MEAN & $\operatorname{MAX}$ & MIN & MEAN \\
\hline $\begin{array}{l}1 \\
2 \\
3 \\
4 \\
5\end{array}$ & $\begin{array}{l}1110 \\
1110 \\
1100 \\
1110 \\
1110\end{array}$ & $\begin{array}{l}1090 \\
1090 \\
1090 \\
1090 \\
1090\end{array}$ & $\begin{array}{l}1100 \\
1100 \\
1100 \\
1100 \\
1100\end{array}$ & $\begin{array}{l}1120 \\
1120 \\
1130 \\
1120 \\
1130\end{array}$ & $\begin{array}{l}1110 \\
1110 \\
1110 \\
1110 \\
1110\end{array}$ & $\begin{array}{l}1120 \\
1120 \\
1120 \\
1120 \\
1120\end{array}$ & 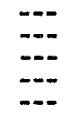 & $\overline{-u}$ & ב- & $\begin{array}{l}11100 \\
1100 \\
1100 \\
11100 \\
11100\end{array}$ & $\begin{array}{l}1100 \\
1080 \\
1070 \\
1080 \\
1090\end{array}$ & $\begin{array}{l}1100 \\
1090 \\
1080 \\
1090 \\
1100\end{array}$ \\
\hline $\begin{array}{r}6 \\
7 \\
8 \\
9 \\
10\end{array}$ & $\begin{array}{l}11110 \\
111 \\
1130 \\
11130 \\
11120\end{array}$ & $\begin{array}{l}1090 \\
1100 \\
1100 \\
1100 \\
1110\end{array}$ & $\begin{array}{llll}1 & 1 & 0 & 0 \\
1 & 1 & 1 & 0 \\
1 & 1 & 1 & 0 \\
1 & 1 & 1 & 0 \\
1 & 1 & 1 & 0\end{array}$ & $\begin{array}{l}1130 \\
1140 \\
1130 \\
1130 \\
1130\end{array}$ & $\begin{array}{l}1110 \\
1120 \\
1120 \\
1120 \\
1120\end{array}$ & $\begin{array}{l}1120 \\
1130 \\
1130 \\
1120 \\
1120\end{array}$ & $\begin{array}{l}--\overline{-} \\
-\overline{-} \\
--\end{array}$ & $\overline{-}$ & 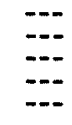 & $\begin{array}{l}1110 \\
1110 \\
1110 \\
1110 \\
1100\end{array}$ & $\begin{array}{l}1090 \\
1090 \\
1090 \\
1100 \\
1090\end{array}$ & $\begin{array}{l}1100 \\
1100 \\
1100 \\
1100 \\
1100\end{array}$ \\
\hline $\begin{array}{l}11 \\
12 \\
13 \\
14 \\
15\end{array}$ & $\begin{array}{l}1120 \\
1120 \\
1120 \\
1120 \\
1120\end{array}$ & $\begin{array}{l}1090 \\
1100 \\
1110 \\
1100 \\
1110\end{array}$ & $\begin{array}{l}1110 \\
1110 \\
1110 \\
1120 \\
1110\end{array}$ & $\begin{array}{l}1130 \\
1120 \\
1190 \\
1130 \\
1120\end{array}$ & $\begin{array}{l}1100 \\
1030 \\
1030 \\
1110 \\
1070\end{array}$ & $\begin{array}{l}1120 \\
1090 \\
1120 \\
1120 \\
1090\end{array}$ & $\begin{array}{l}=- \\
=- \\
=-\end{array}$ & $\overline{-}$ & 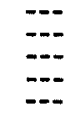 & $\begin{array}{l}1110 \\
1090 \\
1090 \\
1080 \\
1090\end{array}$ & $\begin{array}{l}1090 \\
1040 \\
1040 \\
1040 \\
1060\end{array}$ & $\begin{array}{l}1100 \\
1070 \\
1050 \\
1060 \\
1080\end{array}$ \\
\hline $\begin{array}{l}16 \\
17 \\
18 \\
19 \\
20\end{array}$ & $\begin{array}{l}1120 \\
1120 \\
1120 \\
1120 \\
1120\end{array}$ & $\begin{array}{l}11100 \\
11110 \\
1110 \\
1100 \\
1110\end{array}$ & $\begin{array}{l}1120 \\
11110 \\
1110 \\
1110 \\
1110\end{array}$ & $\begin{array}{l}1120 \\
1120 \\
1130 \\
1120 \\
1110\end{array}$ & $\begin{array}{l}1100 \\
1080 \\
1100 \\
1070 \\
1050\end{array}$ & $\begin{array}{l}1110 \\
1110 \\
1110 \\
1100 \\
1080\end{array}$ & $\begin{array}{l}1100 \\
1100 \\
1090 \\
1080\end{array}$ & $\begin{array}{r}1080 \\
1080 \\
1060 \\
482\end{array}$ & $\begin{array}{r}1090 \\
1090 \\
1080 \\
960\end{array}$ & $\begin{array}{l}1080 \\
1100 \\
1110 \\
1130 \\
1120\end{array}$ & $\begin{array}{l}1070 \\
1060 \\
1090 \\
1110 \\
1110\end{array}$ & $\begin{array}{l}1080 \\
1080 \\
1100 \\
1120 \\
1110\end{array}$ \\
\hline $\begin{array}{l}21 \\
22 \\
23 \\
24 \\
25\end{array}$ & $\begin{array}{l}--- \\
1120 \\
1120 \\
1120\end{array}$ & $\begin{array}{l}1100 \\
1110 \\
1120\end{array}$ & $\begin{array}{l}1110 \\
1120 \\
1120\end{array}$ & $\begin{array}{l}1080 \\
1130 \\
1130 \\
1130 \\
1130\end{array}$ & $\begin{array}{l}1060 \\
1060 \\
1070 \\
1060 \\
1110\end{array}$ & $\begin{array}{l}1070 \\
1090 \\
1110 \\
1110 \\
1120\end{array}$ & $\begin{array}{l}1080 \\
1090 \\
1100 \\
1110 \\
1120\end{array}$ & $\begin{array}{l}1020 \\
1070 \\
1080 \\
1080 \\
1100\end{array}$ & $\begin{array}{l}1060 \\
1080 \\
1100 \\
1100 \\
1100\end{array}$ & $\begin{array}{l}1100 \\
1110 \\
1100 \\
1110 \\
1120\end{array}$ & $\begin{array}{l}1090 \\
1050 \\
1080 \\
1090 \\
1100\end{array}$ & $\begin{array}{l}1100 \\
1090 \\
1100 \\
1100 \\
1110\end{array}$ \\
\hline $\begin{array}{l}26 \\
27 \\
28 \\
29 \\
30 \\
31\end{array}$ & $\begin{array}{l}1130 \\
1130 \\
1130 \\
1120 \\
1120 \\
1120\end{array}$ & $\begin{array}{l}1120 \\
1110 \\
1120 \\
1100 \\
1020 \\
1100\end{array}$ & $\begin{array}{l}1120 \\
1120 \\
1120 \\
1110 \\
11100 \\
11100\end{array}$ & $\begin{array}{r}1120 \\
1120 \\
1100 \\
1120 \\
=--\end{array}$ & $\begin{array}{r}1110 \\
1020 \\
772 \\
993 \\
---\end{array}$ & $\begin{array}{r}1120 \\
1100 \\
974 \\
1090 \\
\ldots-\end{array}$ & $\begin{array}{lll}1 & 1 & 00 \\
1 & 120 \\
1 & 110 \\
1 & 1 & 10 \\
1 & 120 \\
1 & 1 & 20\end{array}$ & $\begin{array}{l}1090 \\
1100 \\
1100 \\
1090 \\
1110 \\
1110\end{array}$ & 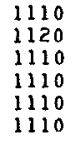 & $\begin{array}{l}11100 \\
1110 \\
11110 \\
1120 \\
11110 \\
11100\end{array}$ & $\begin{array}{l}1100 \\
1090 \\
1090 \\
1100 \\
1060 \\
1090\end{array}$ & $\begin{array}{l}1110 \\
1100 \\
1100 \\
1110 \\
1100 \\
1100\end{array}$ \\
\hline ONTH & 1130 & 1020 & 1110 & 1190 & 772 & 1110 & -- & -- & -- & 1130 & 1040 & 1090 \\
\hline
\end{tabular}

\begin{tabular}{|c|c|c|c|c|c|c|c|c|c|c|c|c|}
\hline \multirow[b]{2}{*}{ DAY } & \multicolumn{3}{|c|}{ FEBRUARY } & \multicolumn{3}{|c|}{ MARCH } & \multicolumn{3}{|c|}{ APRIL } & \multicolumn{3}{|c|}{ MAY } \\
\hline & MAX & $M I N$ & MEAN & MAX & MIN & MEAN & $\operatorname{MAX}$ & MIN & MEAN & $\operatorname{MAX}$ & MIN & MEAN \\
\hline $\begin{array}{l}1 \\
2 \\
3 \\
4 \\
5\end{array}$ & $\begin{array}{r}1100 \\
1110 \\
=- \\
=-\end{array}$ & $\begin{array}{r}1080 \\
1090 \\
--- \\
-0-\end{array}$ & $\begin{array}{r}1090 \\
1100 \\
0 \\
-0\end{array}$ & $\begin{array}{r}1110 \\
1030 \\
630 \\
942 \\
1010\end{array}$ & $\begin{array}{l}186 \\
238 \\
238 \\
646 \\
942\end{array}$ & $\begin{array}{l}693 \\
811 \\
477 \\
821 \\
961\end{array}$ & $\begin{array}{l}1100 \\
1120 \\
1090 \\
1040 \\
1060\end{array}$ & $\begin{array}{r}1070 \\
1040 \\
1040 \\
374 \\
788\end{array}$ & $\begin{array}{r}1090 \\
1080 \\
1060 \\
830 \\
997\end{array}$ & $\begin{array}{l}1130 \\
1140 \\
1130 \\
1120 \\
1120\end{array}$ & $\begin{array}{l}1080 \\
1100 \\
1100 \\
1090 \\
1100\end{array}$ & $\begin{array}{l}11110 \\
1110 \\
1110 \\
1110 \\
11110\end{array}$ \\
\hline $\begin{array}{r}6 \\
7 \\
8 \\
9 \\
10\end{array}$ & $\begin{array}{l}=- \\
=- \\
=- \\
--\end{array}$ & $\begin{array}{l}=- \\
=- \\
=- \\
=-\end{array}$ & $\begin{array}{l}--\overline{-} \\
=-\overline{-} \\
=-\end{array}$ & $\begin{array}{r}1040 \\
-- \\
-\end{array}$ & $\begin{array}{r}1020 \\
-0 \\
-0 \\
-0\end{array}$ & $\begin{array}{r}10.30 \\
=- \\
=-\end{array}$ & $\begin{array}{l}1080 \\
1090 \\
1070 \\
1090 \\
1100\end{array}$ & $\begin{array}{r}936 \\
1040 \\
1040 \\
1040 \\
1060\end{array}$ & $\begin{array}{l}1060 \\
1060 \\
1060 \\
1060 \\
1070\end{array}$ & $\begin{array}{l}1120 \\
1050 \\
1110 \\
1120 \\
1100\end{array}$ & $\begin{array}{r}1040 \\
341 \\
1040 \\
1060 \\
1070\end{array}$ & $\begin{array}{r}1090 \\
885 \\
1080 \\
1090 \\
1090\end{array}$ \\
\hline $\begin{array}{l}11 \\
12 \\
13 \\
14 \\
15\end{array}$ & $\begin{array}{l}=-5 \\
=-0 \\
1130\end{array}$ & $\begin{array}{l}=-- \\
--0 \\
-1110\end{array}$ & 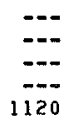 & $\begin{array}{l}=- \\
--\overline{-} \\
-\overline{-} \\
-\overline{-}\end{array}$ & $\begin{array}{l}=- \\
=-\overline{-} \\
=-\overline{-}\end{array}$ & $\bar{m}=$ & $\begin{array}{r}1080 \\
1070 \\
977 \\
1050 \\
1040\end{array}$ & $\begin{array}{r}1050 \\
1010 \\
379 \\
892 \\
888\end{array}$ & $\begin{array}{r}1070 \\
1050 \\
717 \\
1020 \\
1000\end{array}$ & $\begin{array}{l}1080 \\
1100 \\
1100 \\
1120 \\
1130\end{array}$ & $\begin{array}{l}1060 \\
1060 \\
1060 \\
1070 \\
1100\end{array}$ & $\begin{array}{l}1070 \\
1080 \\
1080 \\
1090 \\
1120\end{array}$ \\
\hline $\begin{array}{l}16 \\
17 \\
18 \\
19 \\
20\end{array}$ & $\begin{array}{l}1140 \\
1130 \\
1130 \\
1130 \\
1130\end{array}$ & $\begin{array}{l}1120 \\
1120 \\
1120 \\
1110 \\
1120\end{array}$ & $\begin{array}{l}1130 \\
1130 \\
1120 \\
1120 \\
1120\end{array}$ & $\begin{array}{l}-0- \\
1100 \\
1090\end{array}$ & \begin{tabular}{l}
-0 \\
\hdashline-0 \\
1080 \\
1070
\end{tabular} & $\begin{array}{r}-\ldots- \\
\cdots=- \\
1090 \\
1080\end{array}$ & $\begin{array}{l}1060 \\
1090 \\
1080 \\
1100 \\
1120\end{array}$ & $\begin{array}{l}1010 \\
1040 \\
1050 \\
1050 \\
1070\end{array}$ & $\begin{array}{l}1040 \\
1060 \\
1060 \\
1080 \\
1100\end{array}$ & $\begin{array}{l}1130 \\
1130 \\
1170 \\
1140 \\
1100\end{array}$ & $\begin{array}{l}1100 \\
1100 \\
1080 \\
1080 \\
1060\end{array}$ & $\begin{array}{l}1110 \\
1120 \\
1110 \\
1100 \\
1090\end{array}$ \\
\hline $\begin{array}{l}21 \\
22 \\
23 \\
24 \\
25\end{array}$ & $\begin{array}{l}1120 \\
1120 \\
1120 \\
1120 \\
1110\end{array}$ & $\begin{array}{llll}1 & 1 & 1 & 0 \\
1 & 1 & 1 & 0 \\
1 & 1 & 1 & 0 \\
1 & 1 & 0 & 0 \\
1 & 1 & 0 & 0\end{array}$ & $\begin{array}{l}1120 \\
1120 \\
1110 \\
1110 \\
1110\end{array}$ & $\begin{array}{l}1100 \\
1110 \\
1100 \\
1080 \\
1110\end{array}$ & $\begin{array}{l}1060 \\
1070 \\
1080 \\
1060 \\
1080\end{array}$ & $\begin{array}{l}1080 \\
1090 \\
1090 \\
1080 \\
1070\end{array}$ & $\begin{array}{l}1090 \\
1090 \\
1110 \\
1130 \\
1130\end{array}$ & $\begin{array}{l}1070 \\
1030 \\
1070 \\
1080 \\
1080\end{array}$ & $\begin{array}{l}1080 \\
1070 \\
1090 \\
1100 \\
1100\end{array}$ & $\begin{array}{l}1100 \\
1110 \\
1110 \\
1100 \\
1110\end{array}$ & $\begin{array}{l}1060 \\
1040 \\
1070 \\
1080 \\
1070\end{array}$ & $\begin{array}{l}1080 \\
1080 \\
1090 \\
1090 \\
1090\end{array}$ \\
\hline $\begin{array}{l}26 \\
27 \\
28 \\
29 \\
30 \\
31\end{array}$ & $\begin{array}{llll}1 & 1 & 1 & 0 \\
1 & 1 & 1 & 0 \\
1 & 1 & 1 & 0 \\
1 & 1 & 1 & 0 \\
-0 & -0 \\
& \cdots\end{array}$ & $\begin{array}{l}1100 \\
1100 \\
1100 \\
1090 \\
-0- \\
---\end{array}$ & $\begin{array}{l}11110 \\
11110 \\
1110 \\
11110 \\
-0-0 \\
-\infty\end{array}$ & $\begin{array}{r}1120 \\
1130 \\
1150 \\
1150 \\
1120 \\
-\ldots\end{array}$ & $\begin{array}{c}1080 \\
1090 \\
1100 \\
1090 \\
1070 \\
-\end{array}$ & $\begin{array}{l}1100 \\
1100 \\
1120 \\
1120 \\
1100 \\
-=-\infty\end{array}$ & 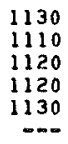 & $\begin{array}{l}1090 \\
1080 \\
1100 \\
1080 \\
1070 \\
\ldots\end{array}$ & $\begin{array}{l}1100 \\
1100 \\
1110 \\
1100 \\
1100 \\
=00\end{array}$ & $\begin{array}{l}1090 \\
1090 \\
1090 \\
1100 \\
1090 \\
1110\end{array}$ & $\begin{array}{l}1050 \\
1050 \\
1070 \\
1070 \\
1070 \\
1080\end{array}$ & $\begin{array}{l}1070 \\
1070 \\
1080 \\
1080 \\
1080 \\
1090\end{array}$ \\
\hline ONTH & $--m$ & --- & $-\infty$ & $-\infty$ & $-\infty$ & $-\infty$ & 1130 & 374 & 1050 & 1170 & 341 & 1090 \\
\hline
\end{tabular}


11066460 SANTA ANA RIVER AT MWD CROSSING, NEAR ARLINGTON, CA--Continued

SPECIFIC CONDUCTANCE (MICROMHOS/CM AT 25 DEG, C), WATER YEAR OCTOBER 1975 TO SEPTEMAER 1976

\begin{tabular}{|c|c|c|c|c|c|c|c|c|c|c|c|c|}
\hline \multirow[b]{2}{*}{ DAY } & \multicolumn{3}{|c|}{ JIJNE } & \multicolumn{3}{|c|}{ JULY } & \multicolumn{3}{|c|}{ AUGUST } & \multicolumn{3}{|c|}{ SEPTEMBER } \\
\hline & $\operatorname{MAX}$ & MIN & MEAN & $\operatorname{MAX}$ & MIN & MEAN & HAX & MIN & MEAN & MAX & MIN & MEAN \\
\hline $\begin{array}{l}1 \\
2 \\
3 \\
4 \\
5\end{array}$ & $\begin{array}{l}1100 \\
1090 \\
1100 \\
1090 \\
1120\end{array}$ & $\begin{array}{l}1070 \\
1040 \\
1080 \\
1040 \\
1080\end{array}$ & $\begin{array}{l}1080 \\
1070 \\
1090 \\
1070 \\
1100\end{array}$ & $\begin{array}{l}1090 \\
1090 \\
1060 \\
1060 \\
1060\end{array}$ & $\begin{array}{l}1060 \\
1050 \\
1040 \\
1040 \\
1050\end{array}$ & $\begin{array}{l}1080 \\
1080 \\
1050 \\
1050 \\
1060\end{array}$ & $\begin{array}{l}1120 \\
1120 \\
1110 \\
1110 \\
1130\end{array}$ & $\begin{array}{l}-110 \\
1110 \\
1080 \\
1070 \\
1050\end{array}$ & $\begin{array}{l}1120 \\
1090 \\
1090 \\
1080\end{array}$ & $\begin{array}{l}1120 \\
1120 \\
1120 \\
1110 \\
1110\end{array}$ & $\begin{array}{l}1090 \\
1090 \\
1080 \\
1080 \\
1080\end{array}$ & $\begin{array}{llll}1 & 1 & 1 & 0 \\
1 & 1 & 1 & 0 \\
1 & 10 & 0 \\
1 & 1 & 0 & 0 \\
1 & 1 & 0 & 0\end{array}$ \\
\hline $\begin{array}{r}6 \\
7 \\
8 \\
9 \\
10\end{array}$ & $\begin{array}{l}1120 \\
1120 \\
1100 \\
1100 \\
1100\end{array}$ & $\begin{array}{r}1090 \\
1090 \\
1080 \\
1060 \\
938\end{array}$ & $\begin{array}{l}1100 \\
1100 \\
1090 \\
1070 \\
1040\end{array}$ & $\begin{array}{l}1080 \\
1080 \\
1090 \\
1090 \\
1100\end{array}$ & $\begin{array}{l}1060 \\
1070 \\
1050 \\
1050 \\
1070\end{array}$ & $\begin{array}{l}1070 \\
1080 \\
1070 \\
1070 \\
1080\end{array}$ & $\begin{array}{l}1120 \\
1130 \\
1130 \\
1130 \\
1140\end{array}$ & $\begin{array}{l}1110 \\
1110 \\
1120 \\
1110 \\
1110\end{array}$ & $\begin{array}{l}1120 \\
1120 \\
1120 \\
1120 \\
1120\end{array}$ & $\begin{array}{l}1140 \\
1120 \\
1110 \\
1100 \\
1080\end{array}$ & $\begin{array}{r}1100 \\
1090 \\
1080 \\
1060 \\
284\end{array}$ & $\begin{array}{r}1110 \\
1110 \\
1090 \\
1080 \\
610\end{array}$ \\
\hline $\begin{array}{l}11 \\
12 \\
13 \\
14 \\
15\end{array}$ & $\begin{array}{l}1080 \\
11110 \\
11110 \\
1150 \\
11800\end{array}$ & $\begin{array}{l}1040 \\
1050 \\
1100 \\
1100 \\
1050\end{array}$ & $\begin{array}{l}1050 \\
1080 \\
11110 \\
11110 \\
1100\end{array}$ & $\begin{array}{r}1090 \\
1090 \\
1080 \\
- \\
-\end{array}$ & $\begin{array}{r}1070 \\
1070 \\
1060 \\
- \\
-\end{array}$ & $\begin{array}{r}1080 \\
1080 \\
1070 \\
- \\
-\end{array}$ & $\begin{array}{l}1130 \\
1120 \\
1120 \\
1120 \\
1120\end{array}$ & $\begin{array}{l}1100 \\
1090 \\
1100 \\
1090 \\
1100\end{array}$ & $\begin{array}{l}1110 \\
1100 \\
1110 \\
1100 \\
1110\end{array}$ & $\begin{array}{r}448 \\
936 \\
1090 \\
1100 \\
1100\end{array}$ & $\begin{array}{r}230 \\
472 \\
920 \\
1060 \\
1080\end{array}$ & $\begin{array}{r}299 \\
804 \\
990 \\
1090 \\
1090\end{array}$ \\
\hline $\begin{array}{l}16 \\
17 \\
18 \\
19 \\
20\end{array}$ & $\begin{array}{l}1100 \\
1090 \\
1110 \\
11100 \\
11000\end{array}$ & $\begin{array}{l}1050 \\
1060 \\
1080 \\
1080 \\
1080\end{array}$ & $\begin{array}{l}1090 \\
1080 \\
1090 \\
1090 \\
1090\end{array}$ & $\begin{array}{l}m- \\
m-m \\
=-m\end{array}$ & $\begin{array}{l}m- \\
m-m \\
m-\end{array}$ & 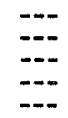 & $\begin{array}{l}1120 \\
1110 \\
1110 \\
1110 \\
1120\end{array}$ & $\begin{array}{l}1100 \\
1100 \\
1090 \\
1080 \\
1090\end{array}$ & 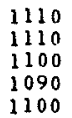 & $\begin{array}{l}11100 \\
11100 \\
11100 \\
11100 \\
11100\end{array}$ & $\begin{array}{l}1080 \\
1080 \\
1080 \\
1080 \\
1080\end{array}$ & $\begin{array}{l}1090 \\
1090 \\
1090 \\
1090 \\
1090\end{array}$ \\
\hline $\begin{array}{l}21 \\
22 \\
23 \\
24 \\
25\end{array}$ & $\begin{array}{l}1090 \\
1070 \\
1090 \\
1080 \\
1060\end{array}$ & $\begin{array}{l}1030 \\
1010 \\
1040 \\
1040 \\
1020\end{array}$ & $\begin{array}{l}1070 \\
1050 \\
1070 \\
1060 \\
1050\end{array}$ & $=-$ & 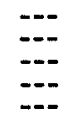 & 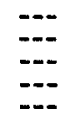 & $\begin{array}{l}1110 \\
1110 \\
1110 \\
1100 \\
1100\end{array}$ & $\begin{array}{l}1100 \\
1100 \\
1100 \\
1080 \\
1090\end{array}$ & $\begin{array}{l}11110 \\
11110 \\
11110 \\
1090 \\
1090\end{array}$ & $\begin{array}{l}1110 \\
1110 \\
1110 \\
-20\end{array}$ & $\begin{array}{c}1080 \\
1090 \\
1090 \\
-\end{array}$ & $\begin{array}{l}1090 \\
1100 \\
1100 \\
-\end{array}$ \\
\hline $\begin{array}{l}26 \\
27 \\
28 \\
29 \\
30 \\
31\end{array}$ & $\begin{array}{l}1060 \\
1050 \\
1100 \\
1100 \\
1100 \\
-1-0\end{array}$ & $\begin{array}{l}1000 \\
1030 \\
1040 \\
1050 \\
1080 \\
=-0\end{array}$ & $\begin{array}{l}1040 \\
1040 \\
1060 \\
1090 \\
1090 \\
\end{array}$ & $\begin{array}{l}--- \\
--- \\
---\end{array}$ & 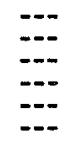 & $\begin{array}{l}=- \\
=- \\
=- \\
=-\end{array}$ & $\begin{array}{lll}1 & 1 & 00 \\
1 & 1 & 20 \\
1 & 120 \\
1 & 120 \\
1 & 1 & 30 \\
1 & 120\end{array}$ & $\begin{array}{l}1070 \\
1060 \\
1090 \\
1080 \\
1080 \\
1090\end{array}$ & $\begin{array}{l}1080 \\
1090 \\
1100 \\
1100 \\
1110 \\
1110\end{array}$ & 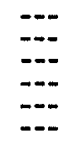 & $\begin{array}{l}=- \\
=- \\
=- \\
=- \\
=-\end{array}$ & $\begin{array}{l}=- \\
-- \\
=- \\
-- \\
--\end{array}$ \\
\hline DNTH & 1180 & 938 & 1080 & --- & $=-m$ & --- & 1140 & 1050 & 1100 & $-\infty$ & $-\infty$ & -- \\
\hline
\end{tabular}


11066480 RIVERSIDE WATER QUALITY CONTROL PLANT AT RIVERSIDE NARROWS, NEAR ARLINGTON, CA

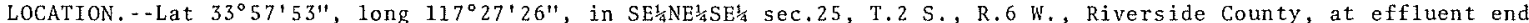
of chlorine contact chambers, $0.4 \mathrm{mi}(0.6 \mathrm{~km})$ upstream from van Buren Boulevard, and $3.1 \mathrm{mi}$ ( $5.0 \mathrm{~km}) \mathrm{northwe} 5 \mathrm{t}$ of Arlington.

WATER-DISCHARGE RECORDS

PERIOD OF RECORD.--October 1947 to current year. Prior to May 25, 1967, pub1ished as "Sheehan ditch."

GAGE. - Water-stage recorders and concrete controls for plants Nos. 1 and 2 . A1titude of gages are 690 ft (210 m), from topographic map.

REMARKS. - Records good. Discharge reported is total effluent from city of Riverside's Water Quality Control Plants Nos. 1 and 2 , released to river $1.0 \mathrm{mi}(1.6 \mathrm{~km})$ downstream from Santa Ana River at MWD crossing (station 11065460$)$,

EXTREMES FOR PERIOD OF RECORD, - Maximum daily discharge, $32 \mathrm{ft}^{3} / \mathrm{s}\left(0.91 \mathrm{~m}^{3} / \mathrm{s}\right) \mathrm{Apr}$. 6, 1969, Ju1y 2 , 1976; minimum daily, $17 \mathrm{ft}^{3} / \mathrm{s}\left(0.48 \mathrm{~m}^{3} / \mathrm{s}\right)$ May 11 , June 8,1969 .

DISCHARGE, IN CUBIC FEET PER SECOND, WATER YEAR OCTOBER 1975 TO SEPTEMBER 1976 MEAN VALUES

\begin{tabular}{|c|c|c|c|c|c|c|c|c|c|c|c|}
\hline DAY & $O C T$ & NOV & DEC & JAN & FEB & MAR & APR & MAY & JUN & JUL & AUG \\
\hline $\begin{array}{l}1 \\
2 \\
3 \\
4 \\
5\end{array}$ & $\begin{array}{l}26 \\
27 \\
27 \\
25 \\
24\end{array}$ & $\begin{array}{l}25 \\
24 \\
26 \\
27 \\
27\end{array}$ & $\begin{array}{l}27 \\
27 \\
27 \\
27 \\
27\end{array}$ & $\begin{array}{l}21 \\
23 \\
25 \\
25 \\
27\end{array}$ & $\begin{array}{l}24 \\
27 \\
27 \\
27 \\
27\end{array}$ & $\begin{array}{l}29 \\
29 \\
29 \\
28 \\
28\end{array}$ & $\begin{array}{l}28 \\
28 \\
26 \\
25 \\
28\end{array}$ & $\begin{array}{l}26 \\
25 \\
29 \\
29 \\
28\end{array}$ & $\begin{array}{l}28 \\
29 \\
28 \\
30 \\
29\end{array}$ & $\begin{array}{l}30 \\
32 \\
26 \\
24 \\
30\end{array}$ & $\begin{array}{l}24 \\
28 \\
27 \\
28 \\
28\end{array}$ \\
\hline $\begin{array}{r}6 \\
7 \\
8 \\
9 \\
10\end{array}$ & $\begin{array}{l}27 \\
27 \\
27 \\
27 \\
27\end{array}$ & $\begin{array}{l}27 \\
27 \\
24 \\
23 \\
27\end{array}$ & $\begin{array}{l}25 \\
25 \\
27 \\
26 \\
27\end{array}$ & $\begin{array}{l}27 \\
27 \\
27 \\
26 \\
25\end{array}$ & $\begin{array}{l}28 \\
27 \\
28 \\
31 \\
29\end{array}$ & $\begin{array}{l}27 \\
26 \\
28 \\
29 \\
29\end{array}$ & $\begin{array}{l}28 \\
28 \\
28 \\
28 \\
24\end{array}$ & $\begin{array}{l}29 \\
30 \\
28 \\
25 \\
29\end{array}$ & $\begin{array}{l}28 \\
31 \\
31 \\
31 \\
30\end{array}$ & $\begin{array}{l}29 \\
28 \\
28 \\
27 \\
26\end{array}$ & $\begin{array}{l}27 \\
24 \\
24 \\
28 \\
27\end{array}$ \\
\hline $\begin{array}{l}11 \\
12 \\
13 \\
14 \\
15\end{array}$ & $\begin{array}{l}25 \\
23 \\
28 \\
28 \\
27\end{array}$ & $\begin{array}{l}27 \\
27 \\
28 \\
26 \\
25\end{array}$ & $\begin{array}{l}26 \\
28 \\
25 \\
24 \\
27\end{array}$ & $\begin{array}{l}24 \\
27 \\
27 \\
28 \\
27\end{array}$ & $\begin{array}{l}30 \\
30 \\
29 \\
26 \\
24\end{array}$ & $\begin{array}{l}28 \\
28 \\
28 \\
24 \\
29\end{array}$ & $\begin{array}{l}25 \\
28 \\
29 \\
29 \\
28\end{array}$ & $\begin{array}{l}29 \\
29 \\
29 \\
28 \\
26\end{array}$ & $\begin{array}{l}31 \\
29 \\
27 \\
31 \\
30\end{array}$ & $\begin{array}{l}27 \\
30 \\
31 \\
31 \\
31\end{array}$ & $\begin{array}{l}27 \\
27 \\
27 \\
24 \\
24\end{array}$ \\
\hline $\begin{array}{l}16 \\
17 \\
18 \\
19 \\
20\end{array}$ & $\begin{array}{l}27 \\
26 \\
24 \\
24 \\
27\end{array}$ & $\begin{array}{l}24 \\
26 \\
27 \\
27 \\
26\end{array}$ & $\begin{array}{l}26 \\
28 \\
26 \\
26 \\
25\end{array}$ & $\begin{array}{l}27 \\
25 \\
25 \\
28 \\
27\end{array}$ & $\begin{array}{l}29 \\
28 \\
28 \\
28 \\
28\end{array}$ & $\begin{array}{l}28 \\
28 \\
28 \\
27 \\
27\end{array}$ & $\begin{array}{l}28 \\
26 \\
25 \\
29 \\
29\end{array}$ & $\begin{array}{l}26 \\
28 \\
28 \\
29 \\
28\end{array}$ & $\begin{array}{l}30 \\
29 \\
28 \\
27 \\
25\end{array}$ & $\begin{array}{l}29 \\
26 \\
25 \\
29 \\
29\end{array}$ & $\begin{array}{l}27 \\
27 \\
27 \\
27 \\
28\end{array}$ \\
\hline $\begin{array}{l}21 \\
22 \\
23 \\
24 \\
25\end{array}$ & $\begin{array}{l}28 \\
27 \\
27 \\
26 \\
24\end{array}$ & $\begin{array}{l}28 \\
24 \\
24 \\
28 \\
28\end{array}$ & $\begin{array}{l}23 \\
26 \\
26 \\
25 \\
21\end{array}$ & $\begin{array}{l}27 \\
27 \\
27 \\
25 \\
25\end{array}$ & $\begin{array}{l}25 \\
25 \\
28 \\
28 \\
28\end{array}$ & $\begin{array}{l}25 \\
28 \\
28 \\
28 \\
28\end{array}$ & $\begin{array}{l}28 \\
27 \\
28 \\
25 \\
25\end{array}$ & $\begin{array}{l}28 \\
26 \\
25 \\
28 \\
28\end{array}$ & $\begin{array}{l}28 \\
28 \\
29 \\
29 \\
27\end{array}$ & $\begin{array}{l}29 \\
29 \\
29 \\
26 \\
24\end{array}$ & $\begin{array}{l}25 \\
24 \\
27 \\
27 \\
28\end{array}$ \\
\hline $\begin{array}{l}26 \\
27 \\
28 \\
29 \\
30 \\
31\end{array}$ & $\begin{array}{l}24 \\
27 \\
27 \\
27 \\
27 \\
27\end{array}$ & $\begin{array}{r}27 \\
24 \\
23 \\
23 \\
25 \\
---\end{array}$ & $\begin{array}{l}23 \\
23 \\
23 \\
25 \\
24 \\
25\end{array}$ & $\begin{array}{l}28 \\
27 \\
27 \\
27 \\
27 \\
25\end{array}$ & $\begin{array}{r}28 \\
28 \\
25 \\
25 \\
--- \\
--\end{array}$ & $\begin{array}{l}28 \\
25 \\
25 \\
28 \\
28 \\
28\end{array}$ & $\begin{array}{r}28 \\
28 \\
28 \\
28 \\
28 \\
---\end{array}$ & $\begin{array}{l}26 \\
25 \\
26 \\
22 \\
21 \\
25\end{array}$ & $\begin{array}{r}28 \\
26 \\
30 \\
30 \\
31 \\
- \\
-\end{array}$ & $\begin{array}{l}29 \\
29 \\
28 \\
28 \\
28 \\
25\end{array}$ & $\begin{array}{l}28 \\
27 \\
25 \\
24 \\
28 \\
28\end{array}$ \\
\hline $\begin{array}{l}\text { TOTAL } \\
\text { MEAN } \\
\text { MAX } \\
\text { MIN } \\
\text { AC-FT }\end{array}$ & $\begin{array}{r}814 \\
26.3 \\
28 \\
23 \\
1610\end{array}$ & $\begin{array}{r}774 \\
25.8 \\
28 \\
23 \\
1540\end{array}$ & $\begin{array}{r}790 \\
25.5 \\
28 \\
21 \\
1570\end{array}$ & $\begin{array}{r}810 \\
26.1 \\
28 \\
21 \\
1610\end{array}$ & $\begin{array}{r}795 \\
27.4 \\
31 \\
24 \\
1580\end{array}$ & $\begin{array}{r}856 \\
27.6 \\
29 \\
24 \\
1700\end{array}$ & $\begin{array}{r}820 \\
27.3 \\
29 \\
24 \\
1630\end{array}$ & $\begin{array}{r}838 \\
27.0 \\
30 \\
21 \\
1660\end{array}$ & $\begin{array}{r}868 \\
28.9 \\
31 \\
25 \\
1720\end{array}$ & $\begin{array}{r}872 \\
28.1 \\
32 \\
24 \\
1730\end{array}$ & $\begin{array}{r}821 \\
26.5 \\
28 \\
24 \\
1630\end{array}$ \\
\hline
\end{tabular}

CAL YR 1975 TOTAL 9650 MEAN 26.4 MAX 31 MIN 21 AC-FT 19140

$\begin{array}{lllllllll}\text { CAL YR } 1975 & \text { TOTAL } 9650 & \text { MEAN } 26.4 & \text { MAX } 31 & \text { MIN } 21 & \text { AC-FT } & 19140 \\ \text { WTR YR } 1976 & \text { TOTAL } & 9871 & \text { MEAN } 27.0 & \text { MAX } 32 & \text { MIN } 21 & \text { AC-FT } & 19580\end{array}$ 
11066480 RIVERSTE WATER QUALITY CONTROL PLANT AT RIVERSIDE NARROWS, NEAR ARLINGTON, CA--ContIIUUed WATER-QUALITY RECORDS

PERIOD OF RECORD. - Water year 1970 to current year.

CHEMICAL ANALYSES: Water year 1970 to current year.

PERIOD OF DATLY RECORD - -

SPECIFIC CONDUCTANCE: October 1969 to current year.

INSTRUMENTATION.--Specific conductance recorder since October 1969.

EXTREMES FOR PERIOD OF RECORD.--

SPECIFIC CONDUCTANCE: Maximum, 1, 740 micromhos Oct. 29, 1971; minimum, 672 micromhos May 5 , 1971.

EXTREMES FOR CURRENT YEAR.--

SPECIFIC CONDUC'TANCE: Maximum, 1,230 micromhos Aug, 13; minimum, 774 micromhos Feb. 9.

CHEMICAL ANALYSES, HATER YEAR OCTOBER 1975 TO SEPTEMBER 1976

\begin{tabular}{|c|c|c|c|c|c|c|c|}
\hline DATE & TIME & $\begin{array}{l}\text { INSTAN- } \\
\text { TANEOUS } \\
\text { DIS- } \\
\text { CHARGE } \\
\text { (CFS) }\end{array}$ & $\begin{array}{l}\text { SPE- } \\
\text { CIFIC } \\
\text { CON- } \\
\text { DUCT- } \\
\text { ANCE } \\
\text { (MICRO- } \\
\text { MHOS) }\end{array}$ & $\begin{array}{l}\text { TEMPER- } \\
\text { ATURE } \\
\text { (DEG C) }\end{array}$ & $\begin{array}{l}\text { DIS- } \\
\text { SOLVED } \\
\text { SOLIDS } \\
\text { (RESI - } \\
\text { DUE AT } \\
180 \text { C) } \\
\text { (MG L ) }\end{array}$ & $\begin{array}{l}\text { DIS- } \\
\text { SOLVED } \\
\text { SOL IOS } \\
\text { (TONS } \\
\text { PER } \\
\text { AC-FT) }\end{array}$ & $\begin{array}{l}\text { DIS- } \\
\text { SOLVED } \\
\text { SOLIDS } \\
\text { (TONS } \\
\text { PER } \\
\text { DAYे) }\end{array}$ \\
\hline $\mathrm{OCT}$ & & & & & & & \\
\hline $\begin{array}{l}01 \ldots \\
16 \ldots \\
\text { NOY }\end{array}$ & $\begin{array}{l}1020 \\
1320\end{array}$ & $\begin{array}{l}35 \\
33\end{array}$ & $\begin{array}{l}1060 \\
1050\end{array}$ & $\begin{array}{l}26.5 \\
27.0\end{array}$ & $\begin{array}{l}645 \\
627\end{array}$ & $\begin{array}{l}.88 \\
.85\end{array}$ & $\begin{array}{l}61.0 \\
55.9\end{array}$ \\
\hline $\begin{array}{l}04 \ldots \\
17 \ldots \\
\text { DEC }\end{array}$ & $\begin{array}{l}1320 \\
1000\end{array}$ & $\begin{array}{l}34 \\
36\end{array}$ & $\begin{array}{l}1050 \\
1020\end{array}$ & $\begin{array}{l}25.0 \\
22.5\end{array}$ & $\begin{array}{l}611 \\
597\end{array}$ & $\begin{array}{r}.83 \\
.81\end{array}$ & $\begin{array}{l}56.1 \\
58.0\end{array}$ \\
\hline $\begin{array}{l}01 \ldots \\
17 \ldots \\
29 \ldots \\
\text { JAN }\end{array}$ & $\begin{array}{l}1200 \\
1140 \\
1545\end{array}$ & $\begin{array}{l}39 \\
36 \\
33\end{array}$ & $\begin{array}{r}929 \\
1010 \\
1030\end{array}$ & $\begin{array}{l}21.0 \\
20.8 \\
20.0\end{array}$ & $\begin{array}{l}561 \\
616 \\
609\end{array}$ & $\begin{array}{l}.76 \\
.84 \\
.83\end{array}$ & $\begin{array}{l}59.1 \\
59.9 \\
54.3\end{array}$ \\
\hline $\begin{array}{l}07 \ldots \\
20 . \ldots \\
F E 8\end{array}$ & $\begin{array}{l}0900 \\
1045\end{array}$ & $\begin{array}{l}29 \\
36\end{array}$ & $\begin{array}{r}1040 \\
963\end{array}$ & $\begin{array}{l}18.0 \\
19.8\end{array}$ & $\begin{array}{l}634 \\
585\end{array}$ & $\begin{array}{r}.86 \\
.80\end{array}$ & $\begin{array}{l}49.6 \\
56.9\end{array}$ \\
\hline $\begin{array}{l}03 \ldots \\
18 \ldots \\
M A R\end{array}$ & $\begin{array}{l}1100 \\
1100\end{array}$ & $\begin{array}{l}38 \\
43\end{array}$ & $\begin{array}{l}957 \\
961\end{array}$ & $\begin{array}{l}20.8 \\
21.8\end{array}$ & $\begin{array}{l}579 \\
555\end{array}$ & $\begin{array}{r}.79 \\
.75\end{array}$ & $\begin{array}{l}59.4 \\
64.4\end{array}$ \\
\hline $\begin{array}{l}01 \ldots \\
16 \ldots \\
A P R\end{array}$ & $\begin{array}{l}1100 \\
1000\end{array}$ & $\begin{array}{l}39 \\
38\end{array}$ & $\begin{array}{l}936 \\
970\end{array}$ & $\begin{array}{l}20.8 \\
21.8\end{array}$ & $\begin{array}{l}559 \\
574\end{array}$ & $\begin{array}{r}.76 \\
.78\end{array}$ & $\begin{array}{l}58.9 \\
58.9\end{array}$ \\
\hline $\begin{array}{l}01 \ldots \\
14 \ldots \\
\text { MAY }\end{array}$ & $\begin{array}{l}0800 \\
0900\end{array}$ & $\begin{array}{l}22 \\
35\end{array}$ & $\begin{array}{l}1110 \\
1020\end{array}$ & $\begin{array}{l}21.5 \\
21.8\end{array}$ & $\begin{array}{l}669 \\
600\end{array}$ & $\begin{array}{r}.91 \\
.82\end{array}$ & $\begin{array}{l}39.7 \\
56.7\end{array}$ \\
\hline $\begin{array}{r}04 \ldots \\
20 \ldots \\
\text { JUN }\end{array}$ & $\begin{array}{l}1200 \\
1000\end{array}$ & $\begin{array}{l}38 \\
24\end{array}$ & $\begin{array}{l}1040 \\
1020\end{array}$ & $\begin{array}{l}24.2 \\
22.8\end{array}$ & $\begin{array}{l}625 \\
632\end{array}$ & $\begin{array}{l}.85 \\
.86\end{array}$ & $\begin{array}{l}64.1 \\
41.0\end{array}$ \\
\hline $\begin{array}{l}02 \ldots \\
22 \ldots \\
\text { JUL }\end{array}$ & $\begin{array}{l}1115 \\
1145\end{array}$ & $\begin{array}{l}37 \\
38\end{array}$ & $\begin{array}{l}1020 \\
1020\end{array}$ & $\begin{array}{l}25.8 \\
25.8\end{array}$ & $\begin{array}{l}582 \\
626\end{array}$ & $\begin{array}{r}.79 \\
.85\end{array}$ & $\begin{array}{l}58.1 \\
64.2\end{array}$ \\
\hline $\begin{array}{l}02 \ldots \\
13 \ldots \\
\text { AUG }\end{array}$ & $\begin{array}{l}0920 \\
1100\end{array}$ & $\begin{array}{l}34 \\
36\end{array}$ & $\begin{array}{l}1090 \\
1040\end{array}$ & $\begin{array}{l}26.0 \\
27.5\end{array}$ & $\begin{array}{l}658 \\
618\end{array}$ & $\begin{array}{r}.89 \\
.84\end{array}$ & $\begin{array}{l}60.4 \\
60.1\end{array}$ \\
\hline $\begin{array}{l}02 \ldots \\
16 \ldots \\
\text { SEP }\end{array}$ & $\begin{array}{l}1150 \\
1040\end{array}$ & $\begin{array}{l}40 \\
34\end{array}$ & $\begin{array}{r}1020 \\
953\end{array}$ & $\begin{array}{l}27.5 \\
27.0\end{array}$ & $\begin{array}{l}608 \\
593\end{array}$ & $\begin{array}{r}.83 \\
.81\end{array}$ & $\begin{array}{l}65.7 \\
54.9\end{array}$ \\
\hline $01 \ldots$ & 1340 & 41 & 1110 & 28.8 & 677 & .92 & 74.9 \\
\hline
\end{tabular}


11066480 RIVERSIDE WATER QUALITY CONTROL PLANT AT RIVERSIDE NARROWS, NEAR ARLINGTON, CA--Continued SPECIFIC CONDUCTANCE (MICROMHOS/CM AT 25 DEG. C), HATER YEAR OCTOBER 1975 TO SEPTEHEER 1976

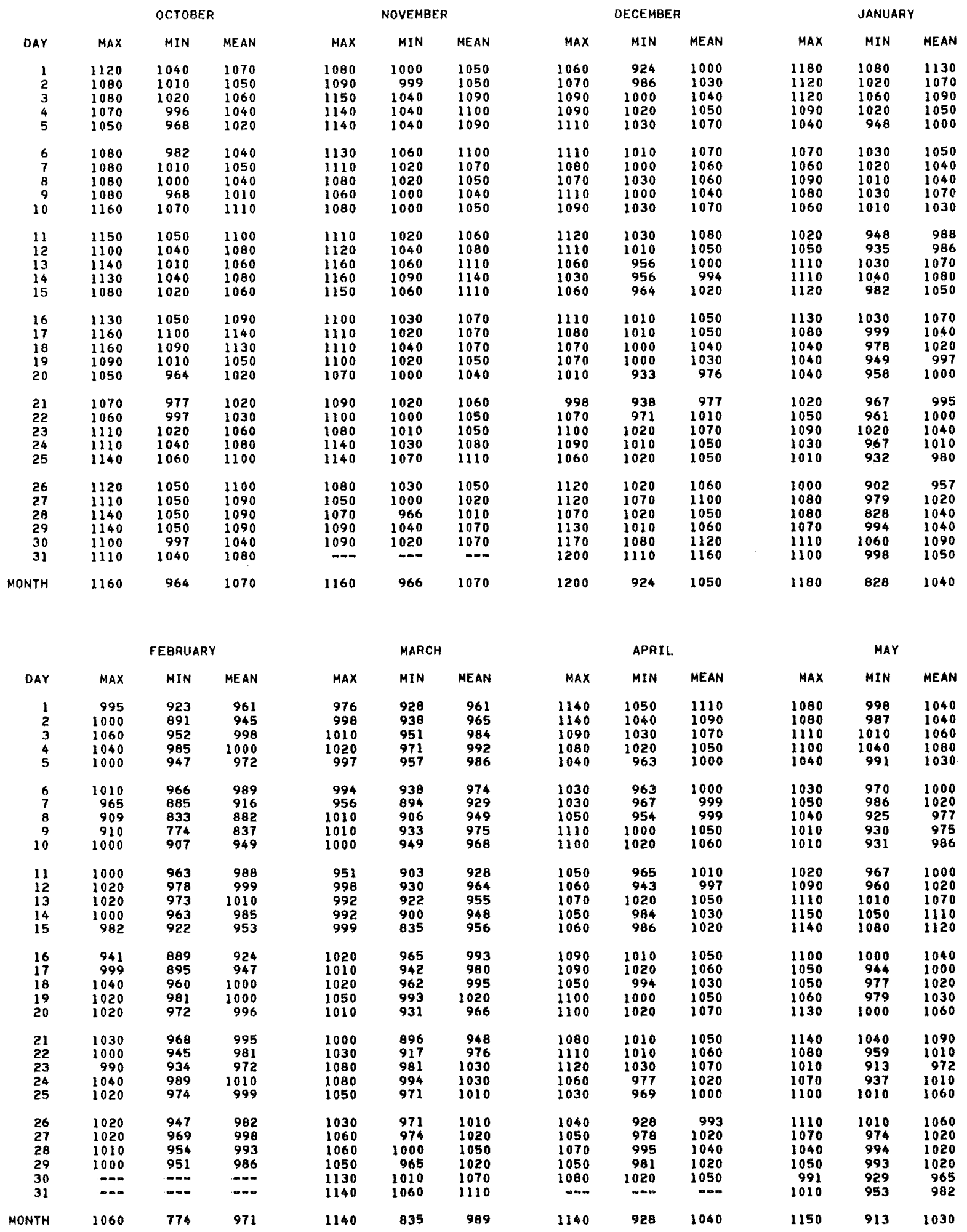


SANTA ANA RIVER BASIN

11066480 RIVERSIDE WATER QUALITY CONTROL PLANT AT RIVERSIDE NARROWS, NEAR ARLINGTON, CA -CONTINUEd

SPECIFIC CONDUCTANCE (MICRONHOS/CM AT 25 DEG, C), HATER YEAR OCTOBER 1975 TO SEPTEMBER 1976

\begin{tabular}{|c|c|c|c|c|c|c|c|c|c|c|c|c|}
\hline \multirow[b]{2}{*}{ DAY } & \multicolumn{3}{|c|}{ JUNE } & \multicolumn{3}{|c|}{ JULY } & \multicolumn{3}{|c|}{ AUGUST } & \multicolumn{3}{|c|}{ SEPTEMBER } \\
\hline & MAX & MIN & MEAN & $\operatorname{MAX}$ & MIN & MEAN & MAX & MIN & MEAN & $\operatorname{MAX}$ & MIN & MEAN \\
\hline $\begin{array}{l}1 \\
2 \\
3 \\
4 \\
5\end{array}$ & $\begin{array}{l}1090 \\
1110 \\
1120 \\
1150 \\
1090\end{array}$ & $\begin{array}{r}940 \\
1020 \\
1070 \\
1060 \\
1010\end{array}$ & $\begin{array}{l}1010 \\
1060 \\
1090 \\
1100 \\
1050\end{array}$ & $\begin{array}{l}1220 \\
1170 \\
1160 \\
1100 \\
1030\end{array}$ & $\begin{array}{r}1090 \\
1060 \\
1060 \\
1020 \\
971\end{array}$ & $\begin{array}{l}1150 \\
1120 \\
1100 \\
1050 \\
1010\end{array}$ & $\begin{array}{l}1040 \\
1100 \\
1090 \\
1070 \\
1110\end{array}$ & $\begin{array}{r}975 \\
997 \\
1010 \\
968 \\
1060\end{array}$ & $\begin{array}{l}1020 \\
1040 \\
1050 \\
1030 \\
1080\end{array}$ & $\begin{array}{l}1170 \\
1150 \\
1090 \\
1070 \\
1010\end{array}$ & $\begin{array}{l}1090 \\
1090 \\
1010 \\
991 \\
905\end{array}$ & $\begin{array}{r}1130 \\
1120 \\
1060 \\
1030 \\
967\end{array}$ \\
\hline $\begin{array}{r}6 \\
7 \\
8 \\
9 \\
10\end{array}$ & $\begin{array}{l}1070 \\
1070 \\
1090 \\
1090 \\
1100\end{array}$ & $\begin{array}{r}992 \\
976 \\
980 \\
1020 \\
1020\end{array}$ & $\begin{array}{l}1030 \\
1030 \\
1040 \\
1060 \\
1060\end{array}$ & $\begin{array}{l}1050 \\
1170 \\
1170 \\
1160 \\
1160\end{array}$ & $\begin{array}{r}934 \\
1030 \\
1080 \\
1090 \\
1080\end{array}$ & $\begin{array}{r}994 \\
1080 \\
1130 \\
1130 \\
1120\end{array}$ & $\begin{array}{l}1180 \\
1190 \\
1120 \\
1180 \\
1100\end{array}$ & $\begin{array}{l}1070 \\
1030 \\
1020 \\
1010 \\
1030\end{array}$ & $\begin{array}{l}1130 \\
1100 \\
1090 \\
1070 \\
1080\end{array}$ & $\begin{array}{r}1000 \\
983 \\
1060 \\
1100 \\
1100\end{array}$ & $\begin{array}{r}905 \\
919 \\
963 \\
1050 \\
976\end{array}$ & $\begin{array}{r}954 \\
961 \\
1020 \\
1080 \\
1040\end{array}$ \\
\hline $\begin{array}{l}11 \\
12 \\
13 \\
14 \\
15\end{array}$ & $\begin{array}{r}1120 \\
1070 \\
984 \\
1120 \\
1200\end{array}$ & $\begin{array}{r}1030 \\
968 \\
914 \\
950 \\
1040\end{array}$ & $\begin{array}{r}1070 \\
1010 \\
960 \\
1020 \\
1100\end{array}$ & $\begin{array}{l}1150 \\
1100 \\
1090 \\
1110 \\
1090\end{array}$ & $\begin{array}{l}1040 \\
1010 \\
1030 \\
1030 \\
1040\end{array}$ & $\begin{array}{l}1090 \\
1070 \\
1060 \\
1080 \\
1070\end{array}$ & $\begin{array}{l}1110 \\
1130 \\
1230 \\
1190 \\
1090\end{array}$ & $\begin{array}{r}1030 \\
1030 \\
1090 \\
1090 \\
954\end{array}$ & $\begin{array}{l}1080 \\
1100 \\
1140 \\
1140 \\
1050\end{array}$ & $\begin{array}{r}966 \\
1030 \\
1080 \\
1070 \\
1060\end{array}$ & $\begin{array}{r}864 \\
924 \\
958 \\
1010 \\
1020\end{array}$ & $\begin{array}{r}936 \\
970 \\
1010 \\
1040 \\
1040\end{array}$ \\
\hline $\begin{array}{l}16 \\
17 \\
18 \\
19 \\
20\end{array}$ & $\begin{array}{l}1190 \\
1190 \\
1180 \\
1100 \\
1080\end{array}$ & $\begin{array}{l}1110 \\
1120 \\
1090 \\
1050 \\
1000\end{array}$ & $\begin{array}{l}1150 \\
1170 \\
1120 \\
1080 \\
1050\end{array}$ & $\begin{array}{r}1080 \\
1040 \\
992 \\
1010 \\
1110\end{array}$ & $\begin{array}{r}1030 \\
985 \\
932 \\
918 \\
999\end{array}$ & $\begin{array}{r}1050 \\
1010 \\
968 \\
962 \\
1040\end{array}$ & $\begin{array}{l}1070 \\
1140 \\
1170 \\
1200 \\
1130\end{array}$ & $\begin{array}{r}952 \\
1030 \\
1040 \\
1070 \\
1070\end{array}$ & $\begin{array}{l}1010 \\
1070 \\
1100 \\
1120 \\
1110\end{array}$ & $\begin{array}{r}1040 \\
1030 \\
1030 \\
995 \\
1000\end{array}$ & $\begin{array}{l}981 \\
943 \\
971 \\
943 \\
931\end{array}$ & $\begin{array}{r}1020 \\
993 \\
1000 \\
976 \\
973\end{array}$ \\
\hline $\begin{array}{l}21 \\
22 \\
23 \\
24 \\
25\end{array}$ & $\begin{array}{l}1090 \\
1140 \\
1140 \\
1160 \\
1170\end{array}$ & $\begin{array}{l}1000 \\
1020 \\
1050 \\
1070 \\
1090\end{array}$ & $\begin{array}{l}1050 \\
1080 \\
1100 \\
1110 \\
1150\end{array}$ & $\begin{array}{r}1060 \\
1070 \\
1020 \\
1030 \\
989\end{array}$ & $\begin{array}{l}983 \\
988 \\
962 \\
948 \\
917\end{array}$ & $\begin{array}{l}1010 \\
1030 \\
1000 \\
994 \\
957\end{array}$ & $\begin{array}{l}1120 \\
1090 \\
1100 \\
1120 \\
1150\end{array}$ & $\begin{array}{r}1020 \\
996 \\
980 \\
992 \\
1060\end{array}$ & $\begin{array}{l}1070 \\
1040 \\
1050 \\
1060 \\
1100\end{array}$ & $\begin{array}{l}1040 \\
1040 \\
1050 \\
1070 \\
1020\end{array}$ & $\begin{array}{l}981 \\
952 \\
972 \\
946 \\
960\end{array}$ & $\begin{array}{r}1010 \\
995 \\
1010 \\
996 \\
992\end{array}$ \\
\hline $\begin{array}{l}26 \\
27 \\
28 \\
29 \\
30 \\
31\end{array}$ & $\begin{array}{l}1160 \\
1140 \\
1130 \\
1160 \\
1220 \\
\end{array}$ & $\begin{array}{l}1090 \\
1050 \\
1050 \\
1070 \\
1120 \\
-\end{array}$ & $\begin{array}{l}1130 \\
1110 \\
1100 \\
1120 \\
1180\end{array}$ & $\begin{array}{l}1040 \\
1030 \\
1030 \\
1100 \\
1120 \\
1090\end{array}$ & $\begin{array}{r}935 \\
955 \\
921 \\
1000 \\
1070 \\
1010\end{array}$ & $\begin{array}{r}988 \\
980 \\
975 \\
1050 \\
1090 \\
1060\end{array}$ & $\begin{array}{l}1150 \\
1120 \\
1170 \\
1120 \\
1130 \\
1220\end{array}$ & $\begin{array}{l}1070 \\
1040 \\
1050 \\
1020 \\
1020 \\
1110\end{array}$ & $\begin{array}{l}1110 \\
1080 \\
1110 \\
1080 \\
1080 \\
1160\end{array}$ & $\begin{array}{r}980 \\
1010 \\
1070 \\
1080 \\
1090 \\
-\end{array}$ & $\begin{array}{r}918 \\
908 \\
977 \\
957 \\
1010 \\
-0\end{array}$ & $\begin{array}{r}955 \\
965 \\
1010 \\
1020 \\
1050 \\
-\end{array}$ \\
\hline MONTH & 1220 & 914 & 1080 & 1220 & 917 & 1050 & 1230 & 952 & 1080 & 1170 & 864 & 1010 \\
\hline YEAR & 1230 & 774 & 1040 & & & & & & & & & \\
\hline
\end{tabular}


LOCATION. - Lat $33^{\circ} 55^{\prime} 42^{\prime \prime}$, long $117^{\circ} 35^{\prime} 44^{\prime \prime}$, in Jurupa Grant, Riverside County, in Prado Park on right bank 0.4 mi $(0.6 \mathrm{~km})$ upstream from Auburndale Bridge, and $4.1 \mathrm{mi}(6.6 \mathrm{~km})$ northwest of Corona.

DRAINAGE AREA. $-1,010 \mathrm{mi}^{2}\left(2,616 \mathrm{~km}^{2}\right)$.

\section{WATER-DISCHARGE RECORDS}

PERIOD OF RECORD. - March 1971 to current year. Records May 1930 to November 1966 (irrigation seasons only), October 1966 to September 1968 at site $0.4 \mathrm{mi}(0.6 \mathrm{~km})$ downstream (at Auburndale Bridge, station 11068000$)$, equivalent if diversion to Durkee ditch added.

GAGE. - Water-stage recorder. Altitude of gage is $560 \mathrm{ft}(171 \mathrm{~m})$, from topographic map.

REMARKS. --Records good below $100 \mathrm{ft}^{3} / \mathrm{s}\left(2.83 \mathrm{~m}^{3} / \mathrm{s}\right)$ and poor above. Flow partly regulated by Big Bear Lake

(station 11049000). Natural streamflow affected by ground-water withdrawals, diversions for irrigation, and return flows from irrigated areas. See schematic diagram of Santa Ana River basin.

AVERAGE DISCHARGE. -5 years, $55,0 \mathrm{ft}^{3} / \mathrm{s}\left(1.558 \mathrm{~m}^{3} / \mathrm{s}\right), 39,850 \mathrm{acre}-\mathrm{ft} / \mathrm{yr}\left(49.1 \mathrm{hm} / \mathrm{yr}^{3}\right)$.

EXTREMES FOR PERIOD OF RECORD,--Maximum discharge, about $5,400 \mathrm{ft}^{3} / \mathrm{s}\left(153 \mathrm{~m}^{3} / \mathrm{s}\right) \mathrm{Feb}$. 11 , 1973 , by flood routing; minimum daily, $10 \mathrm{ft}^{3} / \mathrm{s}\left(0.28 \mathrm{~m}^{3} / \mathrm{s}\right)$ Aug. 7, Sept. 23,1971 .

EXTREMES FOR CURRENT YEAR, - - Peak discharges above base of $500 \mathrm{ft}^{3} / \mathrm{s}\left(14.2 \mathrm{~m}^{3} / \mathrm{s}\right)$ and maximum $\left({ }^{*}\right)$ :

\begin{tabular}{|c|c|c|c|c|c|c|c|c|c|c|}
\hline Date & Time & $\begin{array}{r}\text { Disch } \\
\left(\mathrm{ft}^{3} / \mathrm{s}\right)\end{array}$ & $\left(\mathrm{m}^{3} / \mathrm{s}\right)$ & $\begin{array}{l}\text { Gage height } \\
\text { (ft) }\end{array}$ & Date & Time & $\begin{array}{r}\text { Disch } \\
\left(\mathrm{ft}^{3} / \mathrm{s}\right)\end{array}$ & $\underset{\left(\mathrm{m}^{3} / \mathrm{s}\right)}{\mathrm{rge}}$ & $\begin{array}{l}\text { Gage } \\
\text { (ft) }\end{array}$ & $\begin{array}{r}\text { leight } \\
\text { (m) }\end{array}$ \\
\hline $\begin{array}{l}\text { Feb. } 9 \\
\text { Mar. } 1 \\
\text { Mar. } 3\end{array}$ & $\begin{array}{l}0815 \\
1745 \\
0345\end{array}$ & $\begin{array}{r}1530 \\
656 \\
636\end{array}$ & $\begin{array}{l}43.3 \\
18.6 \\
18.0\end{array}$ & $\begin{array}{l}1.676 \\
1.320 \\
1.311\end{array}$ & $\begin{array}{l}\text { Sept. } 11 \\
\text { Sept. } 25\end{array}$ & $\begin{array}{l}1500 \\
0145\end{array}$ & $\begin{array}{r}* 3390 \\
609\end{array}$ & $\begin{array}{l}96.0 \\
17.2\end{array}$ & $\begin{array}{l}6.80 \\
4.15\end{array}$ & $\begin{array}{l}2.073 \\
1.265\end{array}$ \\
\hline
\end{tabular}

Minimum daily discharge, $16 \mathrm{ft}^{3} / \mathrm{s}\left(0.45 \mathrm{~m}^{3} / \mathrm{s}\right)$ Altg. 5 .

DISCHARGE, IN CUBIC FEET PER SECONO, WATER YEAR OCTOBER 1975 TO SEPTEMBER 1976 MEAN VALUES

\begin{tabular}{|c|c|c|c|c|c|c|c|c|c|c|c|c|}
\hline DAY & $O C T$ & NOV & DEC & JAN & FEB & MAR & APR & MAY & JUN & JUL & AUG & SEP \\
\hline $\begin{array}{l}1 \\
2 \\
3 \\
4 \\
5\end{array}$ & $\begin{array}{l}33 \\
35 \\
32 \\
29 \\
33\end{array}$ & $\begin{array}{l}33 \\
31 \\
31 \\
35 \\
34\end{array}$ & $\begin{array}{l}41 \\
43 \\
42 \\
44 \\
43\end{array}$ & $\begin{array}{l}41 \\
42 \\
47 \\
46 \\
46\end{array}$ & $\begin{array}{l}44 \\
46 \\
50 \\
55 \\
73\end{array}$ & $\begin{array}{r}194 \\
138 \\
234 \\
73 \\
63\end{array}$ & $\begin{array}{l}44 \\
36 \\
36 \\
52 \\
69\end{array}$ & $\begin{array}{l}43 \\
41 \\
42 \\
42 \\
43\end{array}$ & $\begin{array}{l}42 \\
42 \\
43 \\
41 \\
40\end{array}$ & $\begin{array}{l}21 \\
18 \\
17 \\
21 \\
22\end{array}$ & $\begin{array}{l}25 \\
25 \\
26 \\
23 \\
16\end{array}$ & $\begin{array}{l}19 \\
21 \\
21 \\
21 \\
25\end{array}$ \\
\hline $\begin{array}{r}6 \\
7 \\
8 \\
9 \\
10\end{array}$ & $\begin{array}{l}35 \\
37 \\
30 \\
29 \\
31\end{array}$ & $\begin{array}{l}37 \\
35 \\
33 \\
38 \\
35\end{array}$ & $\begin{array}{l}41 \\
40 \\
40 \\
41 \\
40\end{array}$ & $\begin{array}{l}44 \\
43 \\
43 \\
42 \\
41\end{array}$ & $\begin{array}{l}109 \\
214 \\
217 \\
913 \\
245\end{array}$ & $\begin{array}{l}55 \\
49 \\
50 \\
52 \\
58\end{array}$ & $\begin{array}{l}37 \\
35 \\
38 \\
35 \\
36\end{array}$ & $\begin{array}{l}45 \\
77 \\
56 \\
48 \\
47\end{array}$ & $\begin{array}{l}39 \\
45 \\
42 \\
41 \\
46\end{array}$ & $\begin{array}{l}26 \\
26 \\
25 \\
23 \\
19\end{array}$ & $\begin{array}{l}17 \\
19 \\
17 \\
21 \\
33\end{array}$ & $\begin{array}{r}26 \\
28 \\
25 \\
20 \\
142\end{array}$ \\
\hline $\begin{array}{l}11 \\
12 \\
13 \\
14 \\
15\end{array}$ & $\begin{array}{l}27 \\
30 \\
31 \\
28 \\
26\end{array}$ & $\begin{array}{l}36 \\
39 \\
40 \\
35 \\
32\end{array}$ & $\begin{array}{l}42 \\
45 \\
80 \\
67 \\
61\end{array}$ & $\begin{array}{l}44 \\
47 \\
46 \\
46 \\
47\end{array}$ & $\begin{array}{r}110 \\
99 \\
95 \\
86 \\
78\end{array}$ & $\begin{array}{l}61 \\
61 \\
52 \\
50 \\
56\end{array}$ & $\begin{array}{l}36 \\
36 \\
94 \\
66 \\
52\end{array}$ & $\begin{array}{l}45 \\
44 \\
44 \\
42 \\
40\end{array}$ & $\begin{array}{l}47 \\
43 \\
38 \\
43 \\
38\end{array}$ & $\begin{array}{l}21 \\
19 \\
20 \\
22 \\
23\end{array}$ & $\begin{array}{l}29 \\
25 \\
25 \\
30 \\
29\end{array}$ & $\begin{array}{r}1530 \\
370 \\
113 \\
89 \\
81\end{array}$ \\
\hline $\begin{array}{l}16 \\
17 \\
18 \\
19 \\
20\end{array}$ & $\begin{array}{l}34 \\
29 \\
31 \\
35 \\
27\end{array}$ & $\begin{array}{l}36 \\
35 \\
35 \\
38 \\
43\end{array}$ & $\begin{array}{l}53 \\
5 ? \\
50 \\
47 \\
49\end{array}$ & $\begin{array}{l}48 \\
48 \\
48 \\
48 \\
49\end{array}$ & $\begin{array}{l}85 \\
88 \\
78 \\
76 \\
76\end{array}$ & $\begin{array}{l}52 \\
53 \\
53 \\
53 \\
63\end{array}$ & $\begin{array}{l}49 \\
48 \\
47 \\
47 \\
46\end{array}$ & $\begin{array}{l}35 \\
36 \\
35 \\
34 \\
35\end{array}$ & $\begin{array}{l}38 \\
37 \\
37 \\
34 \\
27\end{array}$ & $\begin{array}{l}24 \\
22 \\
22 \\
29 \\
26\end{array}$ & $\begin{array}{l}28 \\
27 \\
29 \\
30 \\
46\end{array}$ & $\begin{array}{l}81 \\
77 \\
75 \\
77 \\
73\end{array}$ \\
\hline $\begin{array}{l}21 \\
22 \\
23 \\
24 \\
25\end{array}$ & $\begin{array}{l}32 \\
31 \\
34 \\
36 \\
27\end{array}$ & $\begin{array}{l}44 \\
41 \\
39 \\
38 \\
51\end{array}$ & $\begin{array}{l}82 \\
59 \\
57 \\
55 \\
53\end{array}$ & $\begin{array}{l}48 \\
50 \\
49 \\
48 \\
47\end{array}$ & $\begin{array}{l}71 \\
66 \\
71 \\
75 \\
71\end{array}$ & $\begin{array}{l}53 \\
50 \\
52 \\
58 \\
55\end{array}$ & $\begin{array}{l}46 \\
44 \\
44 \\
39 \\
42\end{array}$ & $\begin{array}{l}35 \\
34 \\
40 \\
49 \\
60\end{array}$ & $\begin{array}{l}26 \\
28 \\
26 \\
24 \\
25\end{array}$ & $\begin{array}{l}26 \\
25 \\
27 \\
23 \\
19\end{array}$ & $\begin{array}{l}39 \\
30 \\
31 \\
27 \\
23\end{array}$ & $\begin{array}{r}77 \\
79 \\
83 \\
93 \\
145\end{array}$ \\
\hline $\begin{array}{l}26 \\
27 \\
28 \\
29 \\
30 \\
31\end{array}$ & $\begin{array}{l}32 \\
32 \\
34 \\
36 \\
31 \\
35\end{array}$ & $\begin{array}{r}37 \\
38 \\
63 \\
58 \\
42 \\
--\end{array}$ & $\begin{array}{l}52 \\
52 \\
50 \\
44 \\
43 \\
44\end{array}$ & $\begin{array}{l}48 \\
48 \\
49 \\
49 \\
49 \\
47\end{array}$ & $\begin{array}{r}75 \\
71 \\
71 \\
71 \\
- \\
---\end{array}$ & $\begin{array}{l}53 \\
51 \\
49 \\
54 \\
58 \\
52\end{array}$ & $\begin{array}{r}43 \\
43 \\
48 \\
44 \\
47 \\
---\end{array}$ & $\begin{array}{l}48 \\
35 \\
36 \\
34 \\
29 \\
28\end{array}$ & $\begin{array}{r}22 \\
22 \\
21 \\
18 \\
22 \\
---\end{array}$ & $\begin{array}{l}24 \\
25 \\
22 \\
21 \\
22 \\
24\end{array}$ & $\begin{array}{l}23 \\
22 \\
18 \\
21 \\
19 \\
18\end{array}$ & $\begin{array}{r}63 \\
58 \\
50 \\
53 \\
58 \\
---\end{array}$ \\
\hline $\begin{array}{l}\text { TOTAL } \\
\text { MEAN } \\
\text { MAX } \\
\text { MIN } \\
\text { AC-FT }\end{array}$ & $\begin{array}{r}982 \\
31.7 \\
37 \\
26 \\
1950\end{array}$ & $\begin{array}{r}1162 \\
38.7 \\
63 \\
31 \\
2300\end{array}$ & $\begin{array}{r}1552 \\
50.1 \\
82 \\
40 \\
3080\end{array}$ & $\begin{array}{r}1438 \\
46.4 \\
50 \\
41 \\
2850\end{array}$ & $\begin{array}{r}3479 \\
120 \\
913 \\
44 \\
6900\end{array}$ & $\begin{array}{r}2105 \\
67.9 \\
234 \\
49 \\
4180\end{array}$ & $\begin{array}{r}1379 \\
46.0 \\
94 \\
35 \\
2740\end{array}$ & $\begin{array}{r}1302 \\
42.0 \\
77 \\
28 \\
2580\end{array}$ & $\begin{array}{r}1037 \\
34.6 \\
47 \\
18 \\
2060\end{array}$ & $\begin{array}{r}704 \\
22.7 \\
29 \\
17 \\
1400\end{array}$ & $\begin{array}{r}791 \\
25.5 \\
46 \\
16 \\
1570\end{array}$ & $\begin{array}{r}3673 \\
122 \\
1530 \\
19 \\
7290\end{array}$ \\
\hline
\end{tabular}

CAL YR 1975 TOTAL 17063 MEAN 46.7 MAX 380 MIN 22 AC-FT 33840 WTR YR 1976 TOTAL 19604 MEAN 53.6 MAX 1530 MIN 16 AC $=F$ F 38880 
11067890 SANTA ANA RIVER AT PRADO PARK NEAR CORONA, CA--Continued

WATER-QUALITY RECORDS

PERIOD OF DAILY RECORD. - -

WATER TEMPERATURES: October 1975 to current year.

SEDIMENT RECORDS: February 1976 to September 1976.

REMARKS.- - Partial record for suspended sediment with insufficient data for total load computations in 1976 water year.

EXTREMES FOR PERIOD OF DAILY RECORD. -

SEDIMENT CONCENTRATION: Maximum daily mean, $8,820 \mathrm{mg} / 1$ sept. 11, 1976; minimum daily mean, $20 \mathrm{mg} / 1$

July $15,1976$.

SEDIMENT DISCHARGE: Maximum daily, 46,800 tons (42,500 tonnes) Sept. 11, 1976; minimum daily, 1.2 tons

(1.1 tonnes) July 15,1976

EXTREMES FOR CURRENT YEAR.-.

SEDINENT CONCENTRATIONS: Maximum daily mean, $8,820 \mathrm{mg} / 1 \mathrm{Sept}$. 11; minimum daily mean, $20 \mathrm{mg} / 1 \mathrm{Ju} 1 \mathrm{y} 15$. SEDINENT CONCENTRATIONS: Maximum daily mean, 8,820 mg 1 SISCHARGE: Maximum daily, 46,800 tons $(42,500$ tonnes $)$ Sept. 11; minimum daily, 1.2 tons ( 1.1 tonnes) July 15 .

TEMPERATURE (DEG. C) OF WATER, WATER YEAR OCTOBER 1975 TO SEPTEMBER 1976 ONCE-DAILY

\begin{tabular}{|c|c|c|c|c|c|c|c|c|c|c|c|c|}
\hline OAY & OCT & NOV & DEC & JAN & FEB & MAR & $A P R$ & MAY & JUN & JUL & AUG & SEP \\
\hline 1 & 18.5 & $=-$ & 15.5 & $m$ & $=-$ & $m$ & -- & $m$ & 23.0 & 19.5 & $m--$ & $\cdots$ \\
\hline 2 & $=-$ & $=-$ & $=$ & $-\infty$ & 14.0 & 14.0 & $=-$ & $m$ & $=$ & $=-$ & 28.0 & 22.0 \\
\hline 3 & -- & 20.5 & $-\infty$ & $-\infty$ & -- & $-\infty$ & -- & $m$ & $-\infty$ & $m$ & $=-$ & -- \\
\hline 4 & $=-$ & $m$ & -- & -- & $-n$ & $=-$ & $=-$ & -- & -- & $-\ldots$ & 26.5 & -- \\
\hline 5 & $=-$ & --- & -- & $=\cdots$ & 14.0 & $=--$ & $--=$ & 19.0 & 27.0 & --- & -- & -+ \\
\hline 6 & $\rightarrow$ & --- & $-\cdots$ & -- & 14.0 & - & -- & $-\infty$ & $=$ & $=-$ & 28.0 & $--=$ \\
\hline 7 & --- & -- & -- & 14.0 & $=-$ & $-\infty$ & -- & $-\infty$ & $-\infty$ & $22 \cdot 5$ & $=-$ & --- \\
\hline 8 & $m-$ & $-m$ & -- & $-\infty$ & --- & $--m$ & $m-$ & $=--$ & $-\cdots$ & $-\infty$ & -- & $\cdots$ \\
\hline 9 & $=-$ & $=-$ & $-\infty$ & $m$ & 12.0 & $-\infty$ & $-\infty$ & $=-$ & 26.0 & 32.0 & $=-\infty$ & $-\infty$ \\
\hline 10 & -- & -- & -- & $-\infty$ & 12.5 & $m-\infty$ & $m-$ & -- & $-m-$ & $\rightarrow-\infty$ & 28,0 & $-\infty$ \\
\hline 11 & $-\infty$ & $-\cdots$ & $=-$ & $m-$ & $-\infty$ & $-\infty$ & $=-$ & $\ldots$ & 26.5 & $=-$ & $-\infty$ & 20.5 \\
\hline 12 & $-\infty$ & $--\infty$ & $=-$ & -- & $--=$ & $-\infty$ & - & -- & $=-$ & $-\infty$ & $=-$ & 20.5 \\
\hline 13 & -- & -- & $-\cdots$ & $\cdots$ & $-m$ & $\cdots$ & 16.0 & -- & $m$ & 25.0 & $-\infty$ & 24.5 \\
\hline 14 & $=-$ & -- & $-m$ & $-\infty$ & $-\infty$ & $=-$ & $-\infty$ & $=-\infty$ & -- & $=-$ & $-\infty$ & $--\infty$ \\
\hline 15 & -- & -- & -- & -- & $-\infty$ & 21.0 & $-\infty$ & $\cdots$ & 20.0 & 22.5 & $-m$ & -- \\
\hline 16 & 18.5 & $=-\infty$ & $-\infty$ & $-\cdots$ & $-\infty$ & $-m$ & $=-$ & -- & - & $-\infty$ & $-m$ & --- \\
\hline 17 & $=-$ & 17.0 & $=-$ & -- & $m-$ & $=-$ & $-\infty$ & $m$ & $=-$ & 19.5 & 19.5 & $m$ \\
\hline 18 & -. & $-\infty$ & 8.5 & -- & 18.5 & $-\infty$ & $-m$ & $-\infty$ & $=-$ & $m$ & - & $=-$ \\
\hline 19 & $-\infty$ & -- & $m$ & $-\infty$ & - & $m$ & $m-$ & $=-$ & -- & $=-$ & --- & $m$ \\
\hline 20 & $=-$ & $--=$ & -- & 15.5 & -- & -- & -- & 28.0 & $m$ & $=-$ & 27.5 & -- \\
\hline 21 & $-\infty$ & $-\infty$ & $=-$ & $-\infty$ & $-m$ & -- & $=-$ & $m$ & $=-$ & 24.5 & $-\infty$ & $=$ \\
\hline 22 & -- & $\cdots$ & $-\infty$ & 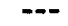 & $m$ & $--n$ & 19.0 & -- & $m-\infty$ & $m$ & $m$ & -- \\
\hline 23 & $=-$ & $-\infty$ & $m$ & $=-$ & $-\pi$ & --- & $=-$ & -- & $=-$ & 26.0 & 28.5 & -- \\
\hline 24 & $m$ & $\rightarrow-\infty$ & $-\cdots$ & -- & $-m$ & $\ldots$ & $-m$ & $m-$ & $=-$ & $\because$ & $\ldots$ & $-\infty$ \\
\hline 25 & --- & -- & -- & --- & -- & $=--$ & -- & $-\infty$ & $=-$ & $-\infty$ & $=-$ & -- \\
\hline 26 & $m-m$ & $=-\infty$ & $-\infty$ & $--\infty$ & $--\infty$ & --0 & $-\infty$ & $-\infty$ & $--\infty$ & -- & $-\infty$ & -- \\
\hline 27 & $-\infty$ & $m$ & $-\infty$ & $-m-$ & --- & $-\infty$ & $-\infty$ & 19.5 & $-\infty$ & $m-$ & $\approx$ & $m-=$ \\
\hline 28 & --- & $--\infty$ & $=$ & $--\infty$ & 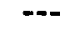 & --- & $=-$ & $=$ & -- & 30.5 & $m$ & 20.0 \\
\hline 29 & -- & -- & 13.5 & $--m$ & 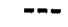 & $-\infty$ & $m-$ & $-\infty$ & $m$ & -- & -- & $-\infty$ \\
\hline 30 & --- & --- & $--=$ & -- & $-\infty=$ & -- & $-\infty$ & -- & $-\infty$ & $-m$ & $--\infty$ & 20.0 \\
\hline 31 & -- & -- & - & -- & $m$ & 23.5 & -- & $-\infty$ & $m-\infty$ & 29.5 & $=-$ & $m$ \\
\hline NTH & -- & $m$ & -- & $-\ldots$ & -- & $-\infty$ & $m$ & -- & $=-$ & $m$ & $-\infty$ & --- \\
\hline
\end{tabular}




\begin{tabular}{|c|c|c|c|c|c|c|c|c|c|}
\hline & & JANUARY & & & FEBRUARY & & & MARCH & \\
\hline DAY & $\begin{array}{l}\text { MEAN } \\
\text { DISCHARGE } \\
\text { (CFS) }\end{array}$ & $\begin{array}{l}\text { MEAN } \\
\text { CONCEN- } \\
\text { TRATION } \\
\text { (MG/L) }\end{array}$ & $\begin{array}{l}\text { SEDIMENT } \\
\text { OISCHARGE } \\
\text { (TONS/DAY) }\end{array}$ & $\begin{array}{l}\text { MEAN } \\
\text { DISCHARGE } \\
\text { (CFS) }\end{array}$ & $\begin{array}{l}\text { MEAN } \\
\text { CONCEN- } \\
\text { TRATION } \\
\text { (MGL) }\end{array}$ & $\begin{array}{l}\text { SEDIMENT } \\
\text { DISCHARGE } \\
\text { (TONS/DAY) }\end{array}$ & $\begin{array}{l}\text { MEAN } \\
\text { DISCHARGE } \\
\text { (CFS) }\end{array}$ & $\begin{array}{l}\text { MEAN } \\
\text { CONCEN- } \\
\text { TRATION } \\
\text { (MG/L) }\end{array}$ & $\begin{array}{l}\text { SEDIMENT } \\
\text { DISCHARGE } \\
\text { (TONS/DAY) }\end{array}$ \\
\hline $\begin{array}{l}1 \\
2 \\
3 \\
4 \\
5\end{array}$ & & & & $\begin{array}{l}44 \\
46 \\
50 \\
55 \\
73\end{array}$ & $\begin{array}{l}100 \\
115 \\
125 \\
135 \\
150\end{array}$ & $\begin{array}{l}12 \\
14 \\
17 \\
20 \\
30\end{array}$ & $\begin{array}{r}194 \\
138 \\
234 \\
73 \\
63\end{array}$ & $\begin{array}{r}1270 \\
1410 \\
2080 \\
900 \\
500\end{array}$ & $\begin{array}{r}1470 \\
740 \\
1840 \\
177 \\
85\end{array}$ \\
\hline $\begin{array}{r}6 \\
7 \\
8 \\
9 \\
10\end{array}$ & & & & $\begin{array}{l}109 \\
214 \\
217 \\
913 \\
245\end{array}$ & $\begin{array}{r}397 \\
1450 \\
800 \\
6120 \\
2320\end{array}$ & $\begin{array}{r}125 \\
1080 \\
717 \\
17200 \\
1790\end{array}$ & $\begin{array}{l}55 \\
49 \\
50 \\
52 \\
58\end{array}$ & $\begin{array}{l}250 \\
250 \\
250 \\
250 \\
250\end{array}$ & $\begin{array}{l}37 \\
33 \\
34 \\
35 \\
39\end{array}$ \\
\hline $\begin{array}{l}11 \\
12 \\
13 \\
14 \\
15\end{array}$ & & & & $\begin{array}{r}110 \\
99 \\
95 \\
86 \\
78\end{array}$ & $\begin{array}{l}114 \\
130 \\
150 \\
170 \\
190\end{array}$ & $\begin{array}{r}135 \\
35 \\
38 \\
39 \\
40\end{array}$ & $\begin{array}{l}61 \\
61 \\
52 \\
50 \\
56\end{array}$ & $\begin{array}{l}250 \\
250 \\
250 \\
250 \\
249\end{array}$ & $\begin{array}{l}41 \\
41 \\
35 \\
34 \\
38\end{array}$ \\
\hline $\begin{array}{l}16 \\
17 \\
18 \\
19 \\
20\end{array}$ & & & & $\begin{array}{l}85 \\
88 \\
78 \\
76 \\
76\end{array}$ & $\begin{array}{l}220 \\
250 \\
278 \\
260 \\
240\end{array}$ & $\begin{array}{l}50 \\
59 \\
59 \\
53 \\
49\end{array}$ & $\begin{array}{l}52 \\
53 \\
53 \\
53 \\
63\end{array}$ & $\begin{array}{l}245 \\
240 \\
236 \\
232 \\
227\end{array}$ & $\begin{array}{l}34 \\
34 \\
34 \\
33 \\
39\end{array}$ \\
\hline $\begin{array}{l}21 \\
22 \\
23 \\
24 \\
25\end{array}$ & & & & $\begin{array}{l}71 \\
66 \\
71 \\
75 \\
71\end{array}$ & $\begin{array}{l}230 \\
220 \\
210 \\
200 \\
190\end{array}$ & $\begin{array}{l}44 \\
39 \\
40 \\
40 \\
36\end{array}$ & $\begin{array}{l}53 \\
50 \\
52 \\
58 \\
55\end{array}$ & $\begin{array}{l}223 \\
219 \\
215 \\
211 \\
206\end{array}$ & $\begin{array}{l}32 \\
30 \\
30 \\
33 \\
31\end{array}$ \\
\hline $\begin{array}{l}26 \\
27 \\
28 \\
29 \\
30 \\
31\end{array}$ & & & & $\begin{array}{r}75 \\
71 \\
71 \\
71 \\
--0\end{array}$ & $\begin{array}{l}180 \\
170 \\
160 \\
150 \\
--0\end{array}$ & $\begin{array}{r}36 \\
33 \\
31 \\
29 \\
--- \\
---\end{array}$ & $\begin{array}{l}53 \\
51 \\
49 \\
54 \\
58 \\
52\end{array}$ & $\begin{array}{l}202 \\
198 \\
194 \\
190 \\
185 \\
181\end{array}$ & $\begin{array}{l}29 \\
27 \\
26 \\
28 \\
29 \\
25\end{array}$ \\
\hline TOTAL & & & & 3479 & --- & 21890 & 2105 & -- & 5173 \\
\hline & & APRIL & & & MAY & & & JUNE & \\
\hline DAY & $\begin{array}{l}\text { MEAN } \\
\text { DISCHARGE } \\
\text { (CFS) }\end{array}$ & $\begin{array}{l}\text { MEAN } \\
\text { CONCEN- } \\
\text { TRATION } \\
\text { (MG/L) }\end{array}$ & $\begin{array}{l}\text { SEDIMENT } \\
\text { OISCHARGE } \\
\text { (TONS/DAY) }\end{array}$ & $\begin{array}{l}\text { MEAN } \\
\text { DISCHARGE } \\
\text { (CFS) }\end{array}$ & $\begin{array}{l}\text { MEAN } \\
\text { CONCEN- } \\
\text { TRATION } \\
\text { (MG/L) }\end{array}$ & $\begin{array}{l}\text { SEDIMENT } \\
\text { OISCHARGE } \\
\text { (TONS/DAY) }\end{array}$ & $\begin{array}{l}\text { MEAN } \\
\text { DISCHARGE } \\
\text { (CFS) }\end{array}$ & $\begin{array}{l}\text { MEAN } \\
\text { CONCEN- } \\
\text { TRATION } \\
\text { (MG/L) }\end{array}$ & $\begin{array}{l}\text { SEDIMENT } \\
\text { OISCHARGE } \\
\text { (TONS/DAY) }\end{array}$ \\
\hline $\begin{array}{l}1 \\
2 \\
3 \\
4 \\
5\end{array}$ & $\begin{array}{l}44 \\
36 \\
36 \\
52 \\
69\end{array}$ & $\begin{array}{l}175 \\
170 \\
165 \\
347 \\
778\end{array}$ & $\begin{array}{r}21 \\
17 \\
16 \\
86 \\
152\end{array}$ & $\begin{array}{l}43 \\
41 \\
42 \\
42 \\
43\end{array}$ & $\begin{array}{l}311 \\
308 \\
306 \\
303 \\
301\end{array}$ & $\begin{array}{l}36 \\
34 \\
35 \\
34 \\
35\end{array}$ & $\begin{array}{l}42 \\
42 \\
43 \\
41 \\
40\end{array}$ & $\begin{array}{r}145 \\
131 \\
117 \\
103 \\
89\end{array}$ & $\begin{array}{l}16 \\
15 \\
14 \\
11 \\
9.6\end{array}$ \\
\hline $\begin{array}{r}6 \\
7 \\
8 \\
9 \\
10\end{array}$ & $\begin{array}{l}37 \\
35 \\
38 \\
35 \\
36\end{array}$ & $\begin{array}{l}450 \\
350 \\
300 \\
200 \\
150\end{array}$ & $\begin{array}{l}45 \\
33 \\
31 \\
19 \\
15\end{array}$ & $\begin{array}{l}45 \\
77 \\
56 \\
48 \\
47\end{array}$ & $\begin{array}{l}300 \\
879 \\
600 \\
400 \\
300\end{array}$ & $\begin{array}{r}36 \\
237 \\
91 \\
52 \\
38\end{array}$ & $\begin{array}{l}39 \\
45 \\
42 \\
41 \\
46\end{array}$ & $\begin{array}{r}92 \\
95 \\
99 \\
102 \\
75\end{array}$ & $\begin{array}{l}9.7 \\
12 \\
11 \\
11 \\
9.3\end{array}$ \\
\hline $\begin{array}{l}11 \\
12 \\
13 \\
14 \\
15\end{array}$ & $\begin{array}{l}36 \\
36 \\
94 \\
66 \\
52\end{array}$ & $\begin{array}{r}130 \\
120 \\
1100 \\
625 \\
600\end{array}$ & $\begin{array}{r}13 \\
12 \\
323 \\
111 \\
84\end{array}$ & $\begin{array}{l}45 \\
44 \\
44 \\
42 \\
40\end{array}$ & $\begin{array}{l}200 \\
177 \\
166 \\
155 \\
144\end{array}$ & $\begin{array}{l}24 \\
21 \\
20 \\
18 \\
16\end{array}$ & $\begin{array}{l}47 \\
43 \\
38 \\
43 \\
38\end{array}$ & $\begin{array}{r}50 \\
65 \\
80 \\
95 \\
110\end{array}$ & $\begin{array}{r}6.3 \\
7.5 \\
8.2 \\
11 \\
11\end{array}$ \\
\hline $\begin{array}{l}16 \\
17 \\
18 \\
19 \\
20\end{array}$ & $\begin{array}{l}49 \\
48 \\
47 \\
47 \\
46\end{array}$ & $\begin{array}{l}400 \\
350 \\
343 \\
340 \\
338\end{array}$ & $\begin{array}{l}53 \\
45 \\
44 \\
43 \\
42\end{array}$ & $\begin{array}{l}35 \\
36 \\
35 \\
34 \\
35\end{array}$ & $\begin{array}{r}133 \\
122 \\
110 \\
99 \\
88\end{array}$ & $\begin{array}{l}13 \\
12 \\
10 \\
9.1 \\
8.3\end{array}$ & $\begin{array}{l}38 \\
37 \\
37 \\
34 \\
27\end{array}$ & $\begin{array}{l}69 \\
69 \\
68 \\
68 \\
67\end{array}$ & $\begin{array}{l}7.1 \\
6.9 \\
6.8 \\
6.2 \\
4.9\end{array}$ \\
\hline $\begin{array}{l}21 \\
22 \\
23 \\
24 \\
25\end{array}$ & $\begin{array}{l}46 \\
44 \\
44 \\
39 \\
42\end{array}$ & $\begin{array}{l}335 \\
333 \\
330 \\
328 \\
326\end{array}$ & $\begin{array}{l}42 \\
40 \\
39 \\
35 \\
37\end{array}$ & $\begin{array}{l}35 \\
34 \\
40 \\
49 \\
60\end{array}$ & $\begin{array}{r}86 \\
84 \\
82 \\
80 \\
350\end{array}$ & $\begin{array}{l}8.1 \\
7.7 \\
8.9 \\
11 \\
57\end{array}$ & $\begin{array}{l}26 \\
28 \\
26 \\
24 \\
25\end{array}$ & $\begin{array}{l}67 \\
40 \\
21 \\
28 \\
36\end{array}$ & $\begin{array}{l}4.7 \\
3.0 \\
1.5 \\
1.8 \\
2.4\end{array}$ \\
\hline $\begin{array}{l}26 \\
27 \\
28 \\
29 \\
30 \\
31\end{array}$ & $\begin{array}{r}43 \\
43 \\
48 \\
44 \\
47 \\
-\ldots\end{array}$ & $\begin{array}{l}323 \\
321 \\
318 \\
316 \\
313 \\
-\ldots-\end{array}$ & $\begin{array}{r}38 \\
37 \\
41 \\
38 \\
40 \\
-\end{array}$ & $\begin{array}{l}48 \\
35 \\
36 \\
34 \\
29 \\
28\end{array}$ & $\begin{array}{r}280 \\
185 \\
130 \\
100 \\
80 \\
70\end{array}$ & $\begin{array}{l}36 \\
17 \\
13 \\
9.2 \\
6.3 \\
5.3\end{array}$ & $\begin{array}{r}22 \\
22 \\
21 \\
18 \\
22 \\
-\infty\end{array}$ & $\begin{array}{r}45 \\
55 \\
65 \\
70 \\
68 \\
-.-\end{array}$ & $\begin{array}{l}2.7 \\
3.3 \\
3.7 \\
3.4 \\
4.0 \\
0 .-0\end{array}$ \\
\hline TOTAL & 1379 & $\infty$ & 1592 & 1302 & $m$ & 950.9 & 1037 & $\infty$ & 225.0 \\
\hline
\end{tabular}


SANTA ANA RIVER BASIN

11067890 SANTA ANA RIVER AT PRADO PARK NEAR CORONA, CA-Continued

SUSPENDED-SEDIMENT DISCHARGE (TONS/DAY), WATER YEAR OCTOBER 1975 TO SEPTEMBER 1976

\begin{tabular}{|c|c|c|c|c|c|c|c|c|c|}
\hline & & JULY & & & AUGUST & & & SEPTEMBER & \\
\hline DAY & $\begin{array}{l}\text { MEAN } \\
\text { DISCHARGE } \\
\text { (CFS) }\end{array}$ & $\begin{array}{l}\text { MEAN } \\
\text { CONCEN- } \\
\text { TRAT ION } \\
\text { (MG/L) }\end{array}$ & $\begin{array}{l}\text { SEDIMENT } \\
\text { DISCHARGE } \\
\text { (TONS/DAY) }\end{array}$ & $\begin{array}{l}\text { MEAN } \\
\text { DISCHARGE } \\
\text { (CFS) }\end{array}$ & $\begin{array}{l}\text { MEAN } \\
\text { CONCEN- } \\
\text { TRATION } \\
\text { (MG/L) }\end{array}$ & $\begin{array}{l}\text { SED IMENT } \\
\text { DISCHARGE } \\
\text { (TONS/DAY) }\end{array}$ & $\begin{array}{c}\text { MEAN } \\
\text { DISCHARGE } \\
\text { (CFS) }\end{array}$ & $\begin{array}{l}\text { MEAN } \\
\text { CONCEN- } \\
\text { TRATION } \\
\text { (MG/L) }\end{array}$ & $\begin{array}{l}\text { SEDIMENT } \\
\text { DI SCHARGE } \\
\text { (TONS/OAY) }\end{array}$ \\
\hline $\begin{array}{l}1 \\
2 \\
3 \\
4 \\
5\end{array}$ & $\begin{array}{l}21 \\
18 \\
17 \\
21 \\
22\end{array}$ & $\begin{array}{r}64 \\
52 \\
40 \\
87 \\
133\end{array}$ & $\begin{array}{l}3.6 \\
2.5 \\
1.8 \\
4.9 \\
7.9\end{array}$ & $\begin{array}{l}25 \\
25 \\
26 \\
23 \\
16\end{array}$ & $\begin{array}{l}52 \\
40 \\
35 \\
29 \\
31\end{array}$ & $\begin{array}{l}3.5 \\
2.7 \\
2.5 \\
1.8 \\
1.3\end{array}$ & $\begin{array}{l}19 \\
21 \\
21 \\
21 \\
25\end{array}$ & $\begin{array}{l}55 \\
60 \\
55 \\
50 \\
60\end{array}$ & $\begin{array}{l}2.8 \\
3.4 \\
3.1 \\
2.8 \\
4.1\end{array}$ \\
\hline $\begin{array}{r}6 \\
7 \\
8 \\
9 \\
10\end{array}$ & $\begin{array}{l}26 \\
26 \\
25 \\
23 \\
19\end{array}$ & $\begin{array}{r}180 \\
227 \\
133 \\
39 \\
36\end{array}$ & $\begin{array}{l}13 \\
16 \\
9.0 \\
2.4 \\
1.8\end{array}$ & $\begin{array}{l}17 \\
19 \\
17 \\
21 \\
33\end{array}$ & $\begin{array}{l}34 \\
39 \\
44 \\
49 \\
54\end{array}$ & $\begin{array}{l}1.6 \\
2.0 \\
2.0 \\
2.8 \\
4.8\end{array}$ & $\begin{array}{r}26 \\
28 \\
25 \\
20 \\
142\end{array}$ & $\begin{array}{r}50 \\
45 \\
43 \\
40 \\
2290\end{array}$ & $\begin{array}{r}3.5 \\
3.4 \\
2.9 \\
2.2 \\
2140\end{array}$ \\
\hline $\begin{array}{l}11 \\
12 \\
13 \\
14 \\
15\end{array}$ & $\begin{array}{l}21 \\
19 \\
20 \\
22 \\
23\end{array}$ & $\begin{array}{l}34 \\
31 \\
28 \\
24 \\
20\end{array}$ & $\begin{array}{l}1.9 \\
1.6 \\
1.5 \\
1.4 \\
1.2\end{array}$ & $\begin{array}{l}29 \\
25 \\
25 \\
30 \\
29\end{array}$ & $\begin{array}{l}55 \\
56 \\
57 \\
51 \\
45\end{array}$ & $\begin{array}{l}4.3 \\
3.8 \\
3.8 \\
4.1 \\
3.5\end{array}$ & $\begin{array}{r}1530 \\
370 \\
113 \\
89 \\
81\end{array}$ & $\begin{array}{r}8820 \\
3880 \\
396 \\
353 \\
310\end{array}$ & $\begin{array}{r}46800 \\
5540 \\
121 \\
85 \\
68\end{array}$ \\
\hline $\begin{array}{l}16 \\
17 \\
18 \\
19 \\
20\end{array}$ & $\begin{array}{l}24 \\
22 \\
22 \\
29 \\
26\end{array}$ & $\begin{array}{l}50 \\
73 \\
82 \\
90 \\
99\end{array}$ & $\begin{array}{l}3.2 \\
4.3 \\
4.9 \\
7.0 \\
6.9\end{array}$ & $\begin{array}{l}28 \\
27 \\
29 \\
30 \\
46\end{array}$ & $\begin{array}{l}40 \\
45 \\
50 \\
56 \\
62\end{array}$ & $\begin{array}{l}3.0 \\
3.3 \\
3.9 \\
4.5 \\
7.7\end{array}$ & $\begin{array}{l}81 \\
77 \\
75 \\
77 \\
73\end{array}$ & $\begin{array}{l}267 \\
224 \\
181 \\
138 \\
251\end{array}$ & $\begin{array}{l}58 \\
47 \\
37 \\
29 \\
49\end{array}$ \\
\hline $\begin{array}{l}21 \\
22 \\
23 \\
24 \\
25\end{array}$ & $\begin{array}{l}26 \\
25 \\
27 \\
23 \\
19\end{array}$ & $\begin{array}{r}108 \\
98 \\
88 \\
77 \\
67\end{array}$ & $\begin{array}{l}7.6 \\
6.6 \\
6.4 \\
4.8 \\
3.4\end{array}$ & $\begin{array}{l}39 \\
30 \\
31 \\
27 \\
23\end{array}$ & $\begin{array}{l}60 \\
59 \\
57 \\
55 \\
50\end{array}$ & $\begin{array}{l}6.3 \\
4.8 \\
4.8 \\
4.0 \\
3.1\end{array}$ & $\begin{array}{r}77 \\
79 \\
83 \\
93 \\
145\end{array}$ & $\begin{array}{r}274 \\
298 \\
322 \\
346 \\
2140\end{array}$ & $\begin{array}{r}57 \\
64 \\
72 \\
87 \\
1670\end{array}$ \\
\hline $\begin{array}{l}26 \\
27 \\
28 \\
29 \\
30 \\
31\end{array}$ & $\begin{array}{l}24 \\
25 \\
22 \\
21 \\
22 \\
24\end{array}$ & $\begin{array}{l}56 \\
46 \\
35 \\
45 \\
55 \\
63\end{array}$ & $\begin{array}{l}3.6 \\
3.1 \\
2.1 \\
2.6 \\
3.3 \\
4.1\end{array}$ & $\begin{array}{l}23 \\
22 \\
18 \\
21 \\
19 \\
18\end{array}$ & $\begin{array}{l}45 \\
50 \\
55 \\
55 \\
56 \\
50\end{array}$ & $\begin{array}{l}2.8 \\
3.0 \\
2.7 \\
3.1 \\
2.9 \\
2.4\end{array}$ & $\begin{array}{r}63 \\
58 \\
50 \\
53 \\
58 \\
---\end{array}$ & $\begin{array}{l}900 \\
800 \\
699 \\
620 \\
561 \\
-\cdots\end{array}$ & $\begin{array}{r}153 \\
125 \\
94 \\
89 \\
88 \\
-\end{array}$ \\
\hline TOTAL & 704 & --- & 144.4 & 791 & $-\infty$ & 106.8 & 3673 & $-m$ & 57501.2 \\
\hline
\end{tabular}

PARTICLE-SIZE DISTRIBUTION OF SUSPENDED SEOIMENT, WATER YEAR OCTOBER 1975 TO SEPTEMAER I976

\begin{tabular}{|c|c|c|c|c|c|c|c|c|c|c|}
\hline DATE & TIME & $\begin{array}{l}\text { TEMPER- } \\
\text { ATURE } \\
\text { (DEG C) }\end{array}$ & $\begin{array}{l}\text { INSTAN- } \\
\text { TANEOUS } \\
\text { DIS- } \\
\text { CHARGE } \\
\text { (CFS) }\end{array}$ & $\begin{array}{l}\text { SUS- } \\
\text { PENDED } \\
\text { SEDI- } \\
\text { MENT } \\
\text { (MG/L) }\end{array}$ & $\begin{array}{c}\text { SUS- } \\
\text { PENDED } \\
\text { SEDI- } \\
\text { MENT } \\
\text { OIS- } \\
\text { CHARGE } \\
\text { (T/DAY) }\end{array}$ & $\begin{array}{l}\text { SUS. } \\
\text { SED: } \\
\text { FALL } \\
\text { DIAM. } \\
\text { क FINER } \\
\text { THAN } \\
.002 \text { MM }\end{array}$ & $\begin{array}{l}\text { SUS. } \\
\text { SED: } \\
\text { FALL } \\
\text { DIAM. } \\
\text { क FINER } \\
\text { THAN } \\
.004 \text { MM }\end{array}$ & $\begin{array}{l}\text { SUS. } \\
\text { SED: } \\
\text { FALL } \\
\text { DIAH. } \\
\text { क FINER } \\
\text { THAN } \\
.008 \mathrm{MM}\end{array}$ & $\begin{array}{l}\text { SUS. } \\
\text { SED, } \\
\text { FALL } \\
\text { OIAM. } \\
\text { \$ FINER } \\
\text { THAN } \\
.016 \mathrm{MM}\end{array}$ & $\begin{array}{c}\text { SUS. } \\
\text { SED: } \\
\text { FALL } \\
\text { DIAM. } \\
\text { \% FINER } \\
\text { THAN } \\
.031 \text { MM }\end{array}$ \\
\hline \multicolumn{11}{|l|}{ FEB } \\
\hline $\begin{array}{l}06 \ldots \\
09 \cdots \\
10 \cdots \\
\text { SEP }\end{array}$ & $\begin{array}{l}1145 \\
1130 \\
0945\end{array}$ & $\begin{array}{l}14.0 \\
12.0 \\
12.5\end{array}$ & $\begin{array}{r}155 \\
1010 \\
210\end{array}$ & $\begin{array}{r}620 \\
7610 \\
2350\end{array}$ & $\begin{array}{r}259 \\
20800 \\
1330\end{array}$ & $\begin{array}{l}30 \\
41 \\
34\end{array}$ & $\begin{array}{l}39 \\
58 \\
51\end{array}$ & $\begin{array}{l}45 \\
76 \\
66\end{array}$ & $\begin{array}{l}48 \\
87 \\
76\end{array}$ & $\begin{array}{l}49 \\
90 \\
81\end{array}$ \\
\hline $\begin{array}{l}11 \ldots \\
11 \ldots \\
11 \ldots \\
12 \ldots \\
13 \ldots \\
28 \ldots\end{array}$ & $\begin{array}{l}0900 \\
1330 \\
1545 \\
1200 \\
1415 \\
1045\end{array}$ & $\begin{array}{l}20.5 \\
19.5 \\
19.5 \\
20.5 \\
24.5 \\
20.0\end{array}$ & $\begin{array}{r}742 \\
1672 \\
2689 \\
209 \\
113 \\
37\end{array}$ & $\begin{array}{r}9320 \\
13400 \\
15900 \\
2940 \\
396 \\
699\end{array}$ & $\begin{array}{r}18700 \\
60500 \\
115000 \\
1660 \\
121 \\
70\end{array}$ & $\begin{array}{l}39 \\
49 \\
49 \\
35 \\
37 \\
34\end{array}$ & $\begin{array}{l}55 \\
64 \\
64 \\
54 \\
46 \\
47\end{array}$ & $\begin{array}{l}74 \\
86 \\
85 \\
71 \\
58 \\
58\end{array}$ & $\begin{array}{l}87 \\
93 \\
94 \\
83 \\
70 \\
70\end{array}$ & $\begin{array}{l}90 \\
97 \\
96 \\
86 \\
77 \\
77\end{array}$ \\
\hline
\end{tabular}

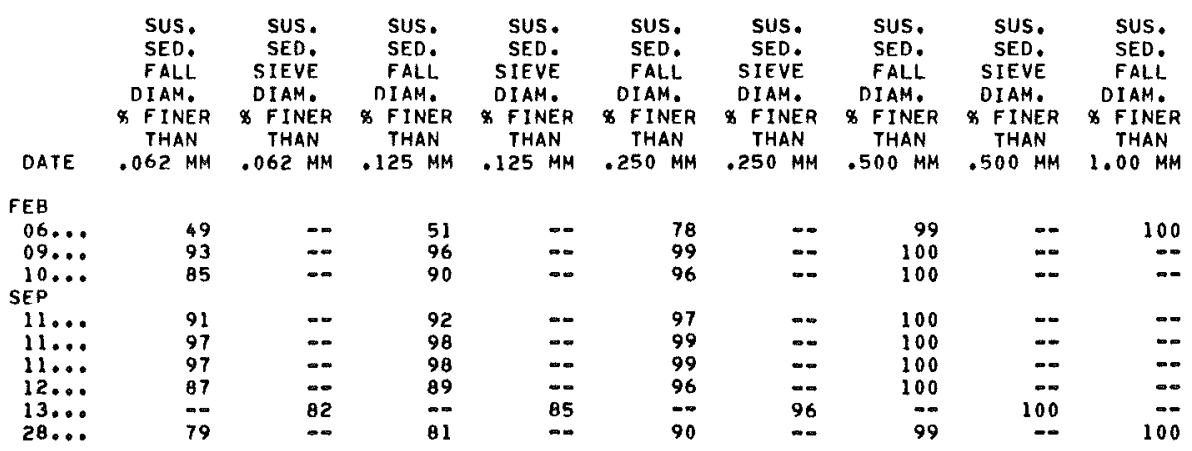




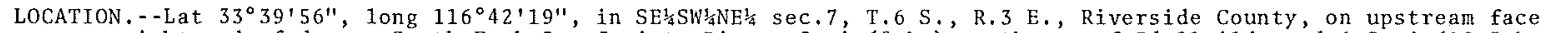
near right end of dam on South Fork San Jacinto River, $5 \mathrm{mi}$ ( $8 \mathrm{~km})$ southeast of Idy11wild, and $6.5 \mathrm{mi}$ (10.5 km) upstream from mouth.

DRAINAGE AREA. $--65.6 \mathrm{mi}^{2}\left(169.9 \mathrm{~km}^{2}\right)$.

PERIOD OF RECORD. - -October 1961 to current year.

GAGE.--Nonrecording gage read once daily. Datum of gage is $4,201.5 \mathrm{ft}(1,280.617 \mathrm{~m})$ above mean sea 1 evel (levels by Lake Hemet Municipal Water District).

REMARKS. - Lake is formed by single-arch dam. Dam was completed to a height of $110 \mathrm{ft}$ ( $33.5 \mathrm{~m}$ ) in 1893 ; raised to $122.5 \mathrm{ft}(37.34 \mathrm{~m})$ in 1895 , and to $135 \mathrm{ft}(41.1 \mathrm{ml}$ ) in 1923 . Capacity table is dated February 1932 (furnished by Lake Hemet Municipal Water District). Lowest sluice gate silted, elevation, 4,222.6 ft (1,287.05 m). Capacity below spillway level, elevation, $4,333.0 \mathrm{ft}(1,320.70 \mathrm{~m}), 11,882 \mathrm{acre}^{-\mathrm{ft}}(14.7 \mathrm{hm})^{3}$. Water is released from 1ake to South Fork San Jacinto River for domestic use and irrigation in the Hemet-San Jacinto Valley. See schematic diagram of Santa Ana River basin.

COOPERATION.--Elevations were furnished by Lake Hemet Municipal Water District.

EXTREMES FOR PERIOD OF RECORD.--Maximum contents observed, 13,880 acre-ft (17.1 hm ${ }^{3}$ ) Feb. 25, 1969 , elevation, $4,337.58 \mathrm{ft}(1,322.094 \mathrm{~m})$; minimum observed, 264 acre-ft $\left(326 \mathrm{~m}^{3}\right)$ Nov. 19, 1962, Nov. 19, 1963, elevation, $4,266.9$ ft $(1,300.55 \mathrm{~m})$.

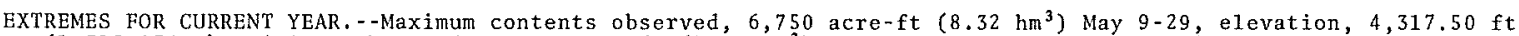
$(1.315 .974 \mathrm{~m})$; minimum observed, 5,700 acre-ft $\left(7.03 \mathrm{hm}^{3}\right)$ Sept. 1, 14-16, e1evation, 4,313.33 ft (1,314.703 $\left.\mathrm{m}\right)$

MONTHEND ELEVATION AND CONTENTS, AT 0800, WATER YEAR OCTOBER 1975 TO SEPTEMBER 1976

\begin{tabular}{|c|c|c|c|c|}
\hline & Date & $\begin{array}{c}\text { Elevation } \\
\text { (feet) }\end{array}$ & $\begin{array}{l}\text { Contents } \\
(\text { acre-feet })\end{array}$ & $\begin{array}{c}\text { Change in contents } \\
\text { (acre-feet) }\end{array}$ \\
\hline $\begin{array}{l}\text { Sept. } \\
\text { Oct. } \\
\text { Nov. } \\
\text { Dec. }\end{array}$ & $\begin{array}{l}30 \ldots \ldots \ldots \ldots \ldots \ldots \ldots \ldots \\
31 \ldots \ldots \ldots \ldots \ldots \ldots \\
30 \ldots \ldots \ldots \ldots \ldots\end{array}$ & $\begin{array}{l}4314.92 \\
4313.50 \\
4312.67 \\
4313.08\end{array}$ & $\begin{array}{l}6080 \\
5740 \\
5550 \\
5640\end{array}$ & $\begin{array}{r}-340 \\
-190 \\
+90\end{array}$ \\
\hline CAL & YR $1975 \ldots \ldots \ldots \ldots \ldots$ & -- & -- & -720 \\
\hline $\begin{array}{l}\text { Jan. } \\
\text { Feb. } \\
\text { Mar. } \\
\text { Apr. } \\
\text { May } \\
\text { June } \\
\text { July } \\
\text { Aug. } \\
\text { Sept. }\end{array}$ & 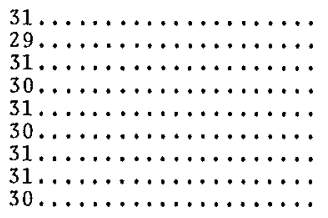 & $\begin{array}{l}4313.42 \\
4316.33 \\
4316.67 \\
4317.17 \\
4317.42 \\
4316.33 \\
4315.08 \\
4317.42 \\
4313.08\end{array}$ & $\begin{array}{l}5720 \\
6440 \\
6530 \\
6660 \\
6730 \\
6440 \\
6130 \\
6730 \\
5640\end{array}$ & $\begin{array}{r}+80 \\
+720 \\
+90 \\
+130 \\
+70 \\
-290 \\
-310 \\
+600 \\
-1090\end{array}$ \\
\hline WTR & YR $1976 \ldots \ldots \ldots \ldots \ldots$ & -- & -- & -440 \\
\hline
\end{tabular}


11069500 SAN JACINTO RIVER NEAR SAN JACINTO, CA

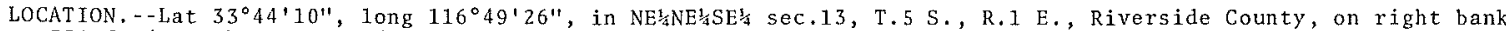
$350 \mathrm{ft}(107 \mathrm{~m})$ upstream from bridge on State Highway $74,1 \mathrm{mi}$ ( $2 \mathrm{~km})$ downstream from North Fork, $8.3 \mathrm{mi}$ $(13.4 \mathrm{~km})$ southeast of San Jacinto, and $9 \mathrm{mi}(14 \mathrm{~km})$ downstream from Lake Hemet.

DRAINAGE AREA. $-141 \mathrm{mi}^{2}\left(365 \mathrm{~km}^{2}\right)$

PERIOD OF RECORD.--October 1920 to February 1927, March 1927 to current year. Records since oct. 1 , 1969, equivalent to prior records if lower diversion is deducted from flow past station. Combined records of river and diversion, october 1948 to current year. Monthly discharge only for october ig20 and July to September 1926 , published in WSP $1315-B$.

GAGE - Water-stage recorder on river; water-stage recorder on upper canal. Datum of river gage is $1,982.75$ ft (604.342 m) above mean sea level (Corps of Engineers bench mark). See wsp 1735 for history of changes prior to Jan. 23, 1948. Prior to Oct. 1, 1969, at site $350 \mathrm{ft}$ (107 m) downstream at same datum. Canal gage at different datum.

REMARKS. - Records poor. Flow partly regulated by Lake Hemet (station 11069000). Lake Henet Municipal Water District's upper canal diverts $4.0 \mathrm{mi}(6.4 \mathrm{~km})$ above station. Fairview Land and Water Co. diverted 6 acre-ft $\left(7,400 \mathrm{~m}^{3}\right)$ above station for domestic use during current year. Diversion above station began prior to 1920. Since relocation of station above lower diversion on oct. 1 , 1969, the records of lower diversion are available at Lake Hemet Municipal Water District. See schematic diagram of Santa Ana River basin.

Combined records are equivalent for period of record. For records of combined daily discharge of San Jacinto River and diversion, see following page.

AVERAGE DISCHARGE.--River only: 48 years (water years $1921-26,1928-69), 18.0 \mathrm{ft}^{3} / \mathrm{s}\left(0.510 \mathrm{~m}^{3} / \mathrm{s}\right)$

13,040 acre-ft/yr $\left(16.1 \mathrm{hm}^{3} / \mathrm{yr}\right) ; 7$ years (water years $\left.1970-76\right), 4.94 \mathrm{ft}^{3} / \mathrm{s}^{2}\left(0.140 \mathrm{~m}^{3} / \mathrm{s}\right), 3,580$ acre-ft/yr $\left(4.41 \mathrm{hm}^{3} / \mathrm{yr}\right)$

Combined river and diversion: 28 years (water years $1949-76), 17.5 \mathrm{ft}^{3} / \mathrm{s}\left(0.496 \mathrm{~m}^{3} / \mathrm{s}\right), 12,680$ acre-ft/yr $\left(15.6 \mathrm{hm}^{3} / \mathrm{yr}\right)$.

EXTREMES FOR PERIOD OF RECORD.--River only: Maximum discharge, 45,000 $\mathrm{ft}^{3} / \mathrm{s}\left(1,270 \mathrm{~m}^{3} / \mathrm{s}\right) \mathrm{Feb}$. 16,1927, on basis of slope-area measurement of maximum flow; no flow for several months in each year.

Combined river and diversion: Maximum discharge, $7,420 \mathrm{ft}^{3} / \mathrm{s}\left(210 \mathrm{~m}^{3} / \mathrm{s}\right) \mathrm{Jan}$, 25, $1969 ;$ no flow at times in $1951,1952,1957,1976$

EXTREMES FOR CURRENT YEAR. - Peak discharges above base of $100 \mathrm{ft}^{3} / \mathrm{s}\left(2.83 \mathrm{~m}^{3} / \mathrm{s}\right)$ and maximum (*):

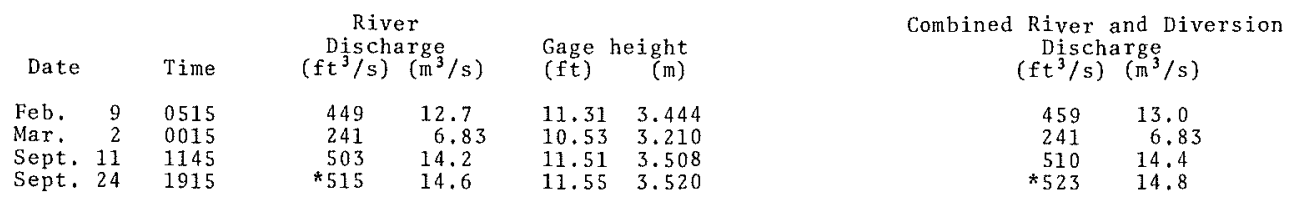

River only: Minimum daily discharge, no flow several months

Combined river and diversion: Minimum daily discharge, no fiow Jan. 16-19.

DISCHARGE, IN CUBIC FEET PER SECOND, VATER YEAR OCTOBER 1975 TO SEPTEMBER 1976 MEAN VALUES

\begin{tabular}{|c|c|c|c|c|c|c|c|c|c|c|c|c|}
\hline DAY & OCT & NOV & DEC & JAN & FEB & MAR & APR & MAY & JUN & JUL & AUG & SEP \\
\hline $\begin{array}{l}1 \\
2 \\
3 \\
4 \\
5\end{array}$ & & & & & $\begin{array}{l}0 \\
0 \\
0 \\
0 \\
8.3\end{array}$ & $\begin{array}{l}30 \\
55 \\
24 \\
16 \\
14\end{array}$ & $\begin{array}{l}5.6 \\
4.5 \\
3.1 \\
4.0 \\
5.8\end{array}$ & $\begin{array}{l}.04 \\
.04 \\
.06 \\
.08 \\
.12\end{array}$ & $\begin{array}{l}.06 \\
.05 \\
.08 \\
.10 \\
.34\end{array}$ & $\begin{array}{l}.06 \\
.06 \\
.06 \\
.06 \\
.05\end{array}$ & & $\begin{array}{l}0 \\
0 \\
0 \\
0 \\
0\end{array}$ \\
\hline $\begin{array}{r}6 \\
7 \\
8 \\
9 \\
10\end{array}$ & & & & & $\begin{array}{c}4.6 \\
10 \\
13 \\
260 \\
75\end{array}$ & $\begin{array}{l}14 \\
14 \\
14 \\
13 \\
13\end{array}$ & $\begin{array}{l}5.4 \\
2.2 \\
1.5 \\
.26 \\
.07\end{array}$ & $\begin{array}{l}31^{.16} \\
15 \\
6.0 \\
4.5\end{array}$ & $\begin{array}{l}1.4 \\
2.1 \\
3.1 \\
4.0 \\
3.3\end{array}$ & $\begin{array}{l}.05 \\
.05 \\
.05 \\
.04 \\
.04\end{array}$ & & $\begin{array}{r}0 \\
0 \\
0 \\
0 \\
78\end{array}$ \\
\hline $\begin{array}{l}11 \\
12 \\
13 \\
14 \\
15\end{array}$ & & & & & $\begin{array}{l}34 \\
18 \\
13 \\
10 \\
7.0\end{array}$ & $\begin{array}{l}13 \\
12 \\
12 \\
13 \\
14\end{array}$ & $\begin{array}{l}.09 \\
.12 \\
.27 \\
.16 \\
.18\end{array}$ & $\begin{array}{l}4.5 \\
4.1 \\
3.0 \\
2.3 \\
1.7\end{array}$ & $\begin{array}{l}1.3 \\
1.3 \\
2.2 \\
.79 \\
.63\end{array}$ & $\begin{array}{l}.04 \\
.04 \\
.04 \\
.03 \\
.03\end{array}$ & & $\begin{array}{c}270 \\
49 \\
17 \\
7.6 \\
2.4\end{array}$ \\
\hline $\begin{array}{l}16 \\
17 \\
18 \\
19 \\
20\end{array}$ & & & & & $\begin{array}{l}4.1 \\
2.6 \\
2.4 \\
2.4 \\
2.1\end{array}$ & $\begin{array}{l}14 \\
14 \\
15 \\
14 \\
12\end{array}$ & $\begin{array}{l}2.7 \\
.30 \\
.22 \\
.30 \\
.76\end{array}$ & $\begin{array}{l}1.2 \\
.63 \\
.16 \\
.10 \\
.04\end{array}$ & $\begin{array}{l}.48 \\
.37 \\
.31 \\
.27 \\
.24\end{array}$ & $\begin{array}{l}.02 \\
0.01 \\
0 \\
0\end{array}$ & & $\begin{array}{l}.12 \\
.10 \\
.13 \\
.18 \\
.23\end{array}$ \\
\hline $\begin{array}{l}21 \\
22 \\
23 \\
24 \\
25\end{array}$ & & & & & $\begin{array}{l}1.6 \\
1.6 \\
1.4 \\
1.3 \\
1.1\end{array}$ & $\begin{array}{l}9.8 \\
7.9 \\
6.5 \\
6.2 \\
7.0\end{array}$ & $\begin{array}{l}1.2 \\
1.5 \\
1.3 \\
1.0 \\
1.2\end{array}$ & $\begin{array}{l}.04 \\
.06 \\
.02 \\
.02 \\
.02\end{array}$ & $\begin{array}{r}.22 \\
.20 \\
.17 \\
.15 \\
.13\end{array}$ & $\begin{array}{l}0 \\
0 \\
0 \\
0 \\
0\end{array}$ & & $\begin{array}{r}.24 \\
.22 \\
45 \\
9.19 \\
9.9\end{array}$ \\
\hline $\begin{array}{l}26 \\
27 \\
28 \\
29 \\
30 \\
31\end{array}$ & & -- & & & $\begin{array}{l}1.3 \\
1.1 \\
1.1 \\
1.1 \\
-1 . \\
2.2\end{array}$ & $\begin{array}{l}7.1 \\
5.9 \\
5.8 \\
5.0 \\
4.4 \\
4.7\end{array}$ & $\begin{array}{l}.86 \\
.10 \\
.06 \\
.06 \\
.04 \\
.0\end{array}$ & $\begin{array}{l}.02 \\
.02 \\
.03 \\
.04 \\
.08 \\
.09\end{array}$ & $\begin{array}{l}.11 \\
.10 \\
.09 \\
.08 \\
.07 \\
.0\end{array}$ & $\begin{array}{l}0 \\
0 \\
0 \\
0 \\
0 \\
0\end{array}$ & & $\begin{array}{r}1.2 \\
.76 \\
.68 \\
.57 \\
.38 \\
.\end{array}$ \\
\hline $\begin{array}{l}\text { TOTAL } \\
\text { MEAN } \\
\text { MAX } \\
\text { MIN } \\
\text { AC-FT }\end{array}$ & $\begin{array}{l}0 \\
0 \\
0 \\
0 \\
0\end{array}$ & $\begin{array}{l}0 \\
0 \\
0 \\
0 \\
0\end{array}$ & $\begin{array}{l}0 \\
0 \\
0 \\
0 \\
0\end{array}$ & $\begin{array}{l}0 \\
0 \\
0 \\
0 \\
0\end{array}$ & $\begin{array}{r}478.1 \\
16.5 \\
260 \\
0 \\
948\end{array}$ & $\begin{array}{r}410.3 \\
13.2 \\
55 \\
4.4 \\
814\end{array}$ & $\begin{array}{r}44.85 \\
1.50 \\
5.8 \\
.04 \\
89\end{array}$ & $\begin{array}{r}75.17 \\
2.42 \\
31 \\
.02 \\
149\end{array}$ & $\begin{array}{r}23.74 \\
.79 \\
4.0 \\
.05 \\
47\end{array}$ & $\begin{array}{r}.73 \\
.024 \\
.06 \\
0 \\
1.4\end{array}$ & $\begin{array}{l}0 \\
0 \\
0 \\
0 \\
0\end{array}$ & $\begin{array}{r}483.90 \\
16.1 \\
270 \\
0 \\
960\end{array}$ \\
\hline
\end{tabular}

CAL YR 1975 TOTAL 1425.77 MEAN 3.91 MAX 160 MIN 0 AC-FT 2830 
11069500 SAN JACINTO RIVER NEAR SAN JACINTO, CA--Continued

COMBINED DISCHARGE, IN CUBIC FEET PER SECOND, OF SAN JACINTO RIVER AND LAKE HEMET WATER CO.'S UPPER CANAL, NEAR SAN JACINTO, CA, WATER YEAR OCTOBER 1975 TO SEPTEMBER 1976

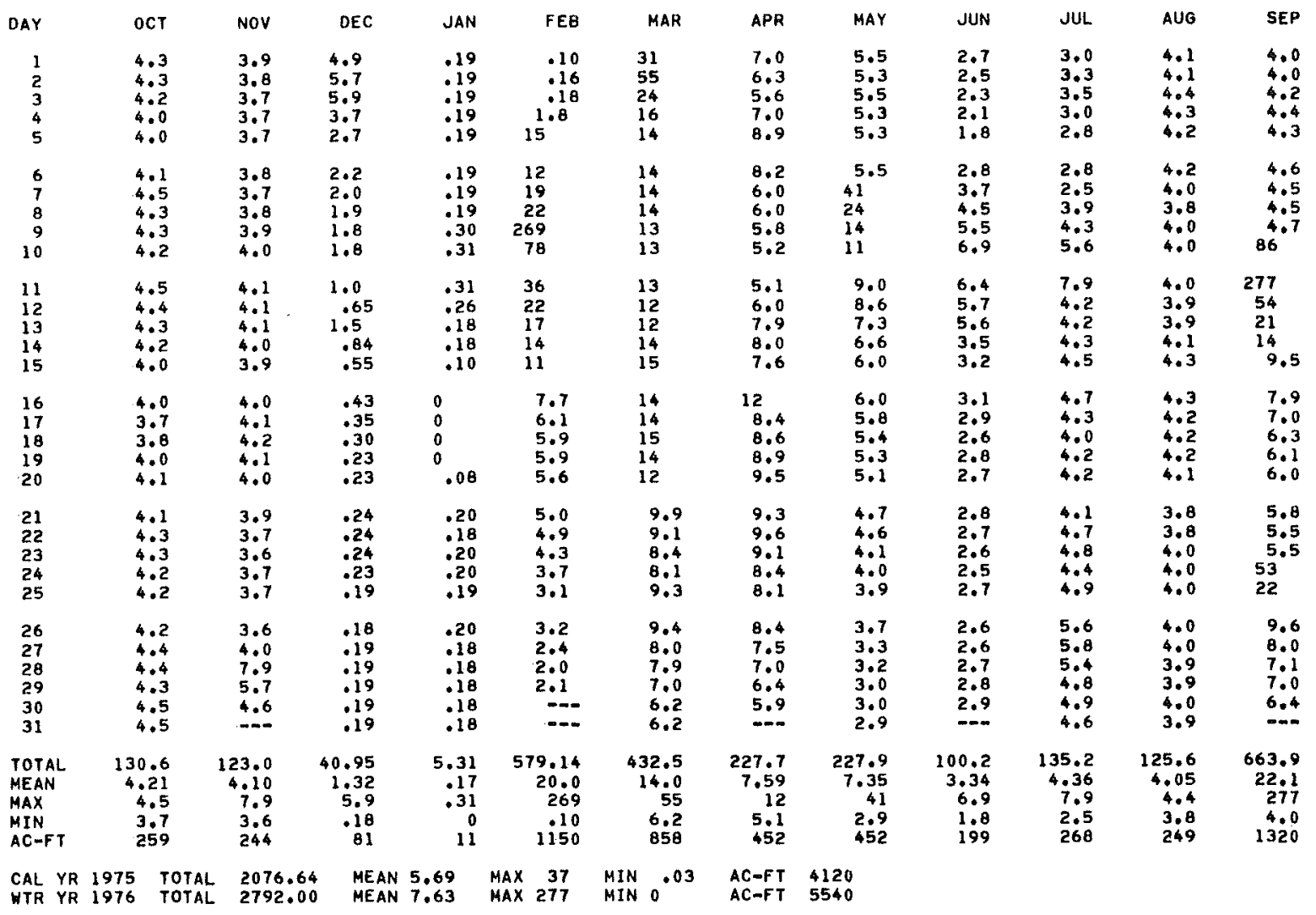




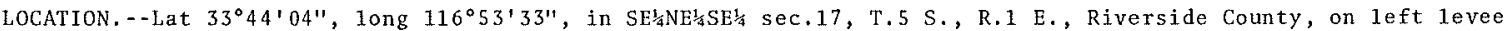
of flood channel, $1.0 \mathrm{mi}(1.6 \mathrm{~km})$ south of Valle Vista.

DRAINAGE AREA. $-47.2 \mathrm{mi}^{2}\left(122.2 \mathrm{~km}^{2}\right)$.

PERIOD OF RECORD.--October 1969 to current year,

GAGE.- Water-stage recorder. Altitude of gage is $1,835 \mathrm{ft}(559 \mathrm{~m})$, from topographic map.

REMARKS,--Records poor. No regulation above station. Diversion above station for irrigation of about 15 acres $\left(61,000 \mathrm{~m}^{2}\right)$. Some infiltration by detention dam, $1.5 \mathrm{mi}(2.4 \mathrm{~km})$ upstream.

AVERAGE DISCHARGE. -7 years, $0.43 \mathrm{ft}^{3} / \mathrm{s}\left(0.012 \mathrm{~m}^{3} / \mathrm{s}\right), 312$ acre-ft/yr $\left(385,000 \mathrm{~m}^{3} / \mathrm{yr}^{2}\right)$.

EXTREMES FOR PERIOD OF RECORD. - Maximum discharge, $750 \mathrm{ft}^{3} / \mathrm{s}\left(21.2 \mathrm{~m}^{3} / \mathrm{s}\right)$ Ju1y 23 , 1974 , gage height, $2.60 \mathrm{ft}$ $(0.792 \mathrm{~m})$, from floodmark, from rating curve extended above $80 \mathrm{ft}^{3} / \mathrm{s}\left(2.27 \mathrm{~m}^{3} / \mathrm{s}\right)$ on basis of computation of flow in concrete-1ined channel at gage heights $1.50 \mathrm{ft}(0.457 \mathrm{~m}), 2.00 \mathrm{ft}(0.610 \mathrm{~m})$, and $3.00 \mathrm{ft}(0.914 \mathrm{~m})$; no flow for many days in each year.

EXTREMES FOR CURRENT YEAR.--Maximum discharge, $73 \mathrm{ft}^{3} / \mathrm{s}\left(2.07 \mathrm{~m}^{3} / \mathrm{s}\right)$ Sept. 10 , gage height, $1.41 \mathrm{ft}(0.430 \mathrm{~m})$, from rating curve extended as explained above, no peak above base of $100 \mathrm{ft}^{3} / \mathrm{s}(2.82 \mathrm{~m} / \mathrm{s}) ; \mathrm{no}$ fiow for many days.

DISCHARGE, IN CUBIC FEET PER SECOND, WATER YEAR OCTOBER 1975 TO SEPTEMBER 1976 MEAN VALUES

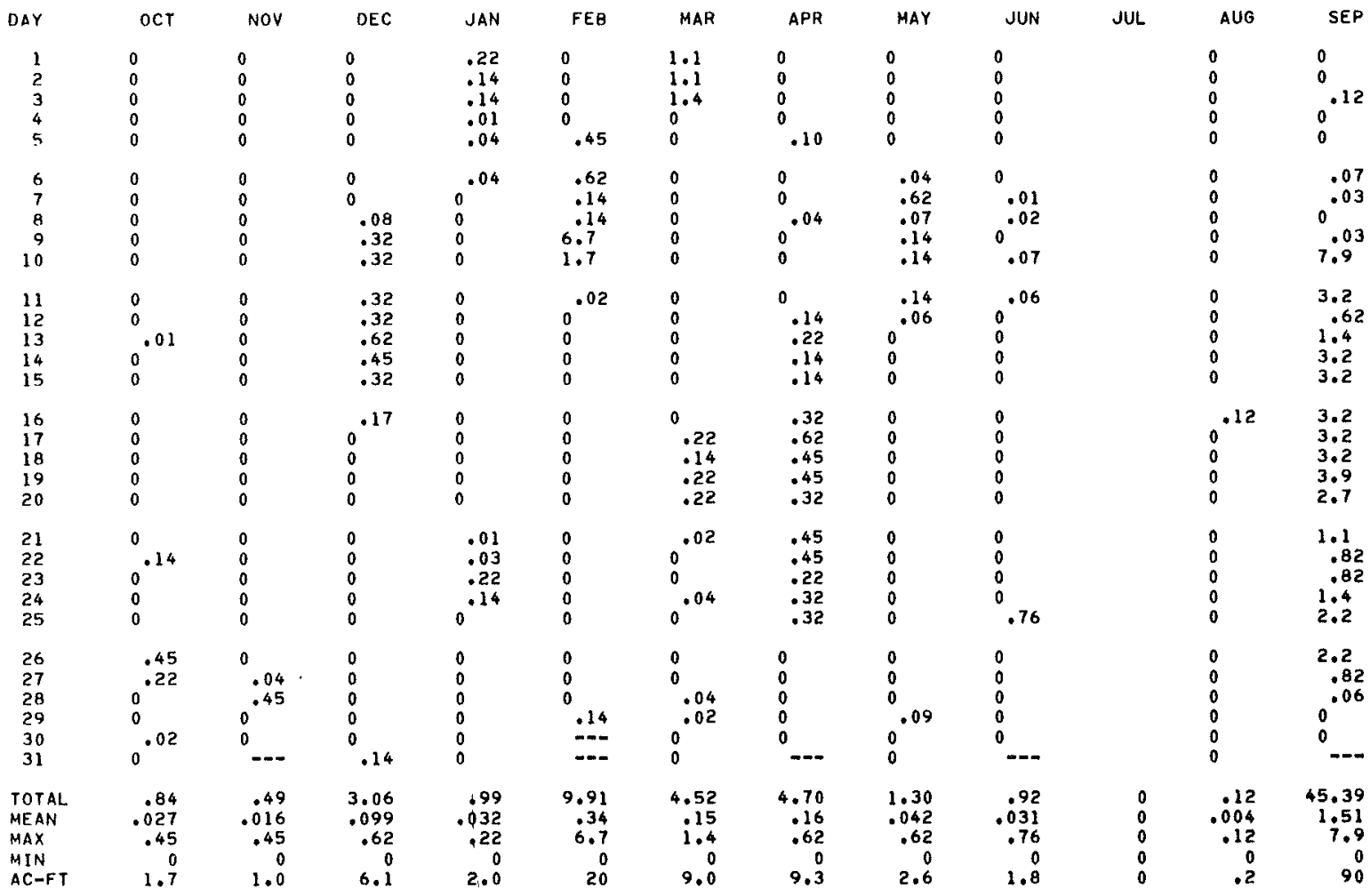

$\begin{array}{llllllllll}\text { CAL YR } 1975 & \text { TOTAL } 143.93 & \text { MEAN } & .39 & \text { MAX } & 17 & \text { MIN } & 0 & \text { AC-FT } 285 \\ \text { WTR YR } 1976 & \text { TOTAL } & 72.24 & \text { MEAN } & .20 & \text { MAX } & 7.9 & \text { MIN } & 0 & \text { AC-FT } 143\end{array}$ 


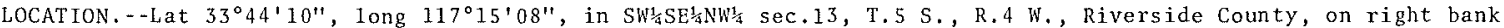

$4.3 \mathrm{mi}(6.9 \mathrm{~km})$ northeast of Railroad Canyon Dam, and $5.8 \mathrm{mi}(9.3 \mathrm{~km})$ northeast of Elsinore.

DRAINAGE AREA. $-562 \mathrm{mi}^{2}\left(1,456 \mathrm{~km}^{2}\right)$.

PERIOD OF RECORD.--October 1951 to current year. Month1y discharge only prior to October 1971 . Daily discharge available in district files.

GAGE, - Water-stage recorder. Altitude of gage is $1,400 \mathrm{ft}(427 \mathrm{~m})$, from topographic map. Prior to Sept. 28 , 1960 , at site $0.8 \mathrm{mi}(1.3 \mathrm{~km})$ upstrean at different datum.

REMARKS. - Flow partially regulated by Lake Hemet (station 11069000). Diversions for irrigation and domestic use above station. At times imported Colorado River water is discharged into channel above station by Temescal Water Co. or Elsinore Valley Municipal Water District.

COOPERATION. - Records were published as furnished by Riverside County Flood Control and Water Conservation District. AVERAGE DISCHARGE.--River on $1 \mathrm{y}: 25$ years, $5.55 \mathrm{ft}^{3} / \mathrm{s}\left(0.157 \mathrm{~m}^{3} / \mathrm{s}\right), 4,020 \mathrm{acre}-\mathrm{ft} / \mathrm{yr}\left(4.96 \mathrm{hm} / \mathrm{yr}^{3}\right)$.

EXTREMES FOR PERIOD OF RECORD. - Maximum discharge, $5,330 \mathrm{ft}^{3} / \mathrm{s}\left(151 \mathrm{~m}^{3} / \mathrm{s}\right)$ Feb. 25 , 1969 , results of runoff study by Riverside County Flood Control and Water Conservation District; no flow for long periods in each year.

EXTREMES FOR CURRENT YEAR. - Maximum discharge, $495 \mathrm{ft}^{3} / \mathrm{s}\left(14.0 \mathrm{~m}^{3} / \mathrm{s}\right)$ Sept. 11, gage height, $2.80 \mathrm{ft}(0.853 \mathrm{~m})$; no flow most of year.

OISCHARGE, IN CUBIC FEET PER SECOND, WATER YEAR OCTOBER 1975 TO SEPTEMBER 1976 MEAN VALUES

\begin{tabular}{|c|c|c|c|c|c|c|c|c|c|c|c|c|}
\hline OAY & $O C T$ & NoV & DEC & JAN & FEB & MAA & APR & MAY & JUN & JUL & AUG & SEP \\
\hline $\begin{array}{l}1 \\
2 \\
3 \\
4 \\
5\end{array}$ & & & & & $\begin{array}{l}0 \\
0 \\
0 \\
0 \\
0\end{array}$ & $\begin{array}{c}17 \\
31 \\
52 \\
6.4 \\
.84\end{array}$ & $\begin{array}{l}0 \\
0 \\
0 \\
0 \\
0\end{array}$ & $\begin{array}{l}0 \\
0 \\
0 \\
0 \\
0\end{array}$ & & & & $\begin{array}{l}0 \\
0 \\
0 \\
0 \\
0\end{array}$ \\
\hline $\begin{array}{r}6 \\
7 \\
8 \\
9 \\
10\end{array}$ & & & & & $\begin{array}{r}18 \\
22 \\
13 \\
194 \\
19\end{array}$ & $\begin{array}{l}0 \\
0 \\
0 \\
0 \\
0\end{array}$ & $\begin{array}{l}0 \\
0 \\
0 \\
0 \\
0\end{array}$ & $\begin{array}{c}0 \\
12 \\
6.1 \\
1.4 \\
.44\end{array}$ & & & & $\begin{array}{r}0 \\
0 \\
0 \\
0 \\
63\end{array}$ \\
\hline $\begin{array}{l}11 \\
12 \\
13 \\
14 \\
15\end{array}$ & & & & & $\begin{array}{l}2.5 \\
1.2 \\
.72 \\
.45 \\
.36\end{array}$ & $\begin{array}{l}0 \\
0 \\
0 \\
0 \\
0\end{array}$ & $\begin{array}{l}0 \\
0 \\
0 \\
1.1 \\
2.6\end{array}$ & $\begin{array}{l}0 \\
0 \\
0 \\
0 \\
0\end{array}$ & & & & $\begin{array}{c}204 \\
24 \\
18 \\
7.9 \\
0\end{array}$ \\
\hline $\begin{array}{l}16 \\
17 \\
18 \\
19 \\
20\end{array}$ & & & & & $\begin{array}{l}.36 \\
: 18 \\
0 \\
0\end{array}$ & $\begin{array}{l}0 \\
0 \\
0 \\
0 \\
0\end{array}$ & $\begin{array}{l}0^{.37} \\
0 \\
0 \\
0\end{array}$ & $\begin{array}{l}0 \\
0 \\
0 \\
0 \\
0\end{array}$ & & & & $\begin{array}{l}0 \\
0 \\
0 \\
0 \\
0\end{array}$ \\
\hline $\begin{array}{l}21 \\
22 \\
23 \\
24 \\
25\end{array}$ & & & & & $\begin{array}{l}0 \\
0 \\
0 \\
0 \\
0\end{array}$ & $\begin{array}{l}0 \\
0 \\
0 \\
0 \\
0\end{array}$ & $\begin{array}{l}0 \\
0 \\
0 \\
0 \\
0\end{array}$ & $\begin{array}{l}0 \\
0 \\
0 \\
0 \\
0\end{array}$ & & & & $\begin{array}{c}0 \\
0 \\
0 \\
15^{.02}\end{array}$ \\
\hline $\begin{array}{l}26 \\
27 \\
28 \\
29 \\
30 \\
31\end{array}$ & & -- & & & $\begin{array}{l}0 \\
0 \\
0 \\
0 \\
-\end{array}$ & $\begin{array}{l}0 \\
0 \\
0 \\
0 \\
0 \\
0\end{array}$ & $\begin{array}{l}0 \\
0 \\
0 \\
0 \\
0\end{array}$ & $\begin{array}{l}0 \\
0 \\
0 \\
0 \\
0 \\
0\end{array}$ & - & & & $\begin{array}{l}0 \\
0 \\
0 \\
0 \\
0\end{array}$ \\
\hline $\begin{array}{l}\text { TOTAL } \\
\text { MEAN } \\
\text { MAX } \\
\text { MIN } \\
\text { AC }-F T\end{array}$ & $\begin{array}{l}0 \\
0 \\
0 \\
0 \\
0\end{array}$ & $\begin{array}{l}0 \\
0 \\
0 \\
0 \\
0\end{array}$ & $\begin{array}{l}0 \\
0 \\
0 \\
0 \\
0\end{array}$ & $\begin{array}{l}0 \\
0 \\
0 \\
0 \\
0\end{array}$ & $\begin{array}{r}271.77 \\
9.37 \\
194 \\
0 \\
539\end{array}$ & $\begin{array}{r}107.24 \\
3.46 \\
52 \\
0 \\
213\end{array}$ & $\begin{array}{r}4.07 \\
.14 \\
2.6 \\
0 \\
8.1\end{array}$ & $\begin{array}{r}19.94 \\
.64 \\
12 \\
0 \\
40\end{array}$ & $\begin{array}{l}0 \\
0 \\
0 \\
0 \\
0\end{array}$ & $\begin{array}{l}0 \\
0 \\
0 \\
0 \\
0\end{array}$ & $\begin{array}{l}0 \\
0 \\
0 \\
0 \\
0\end{array}$ & $\begin{array}{r}331.92 \\
11.1 \\
204 \\
0 \\
658\end{array}$ \\
\hline (a) & 1790 & 0 & 0 & 0 & 0 & 0 & 0 & 260 & 0 & 0 & 2070 & 601 \\
\hline
\end{tabular}

CAL YR 1975 TOTAL 384.17 MEAN 1.05 MAX 119 MIN O AC-FT. 762 WTR YR 1976 TOTAL 734.94 MEAN 2.01 MAX 204 MIN O AC-FT 1460

a Imported Colorado River water, in acre-feet 
I1070475 SALT CREEK AT RAILROAD CANYON RESERVOIR, NEAR ELSINORE, CA

LOCATION. - Lat $33^{\circ} 40^{\prime} 42^{\prime \prime}$, long $117^{\circ} 14^{\prime} 03^{\prime \prime}$, in SW/4E $\frac{1}{4} W^{1} \frac{1}{4}$ sec.6, T.6 S., R. 3 W., Riverside County, on left bank at Railroad Canyon Road, $5.1 \mathrm{mi}(8.2 \mathrm{~km})$ northeast of Elsinore.

DRAINAGE AREA, $-122 \mathrm{mi}^{2}\left(316 \mathrm{~km}^{2}\right)$, largely noncontributing except during extreme floods.

PERIOD OF RECORD, - -October 1969 to current year.

GAGE. - Water-stage recorder. Datum of gage is $1,382.0 \mathrm{ft}(421.23 \mathrm{~m})$ above mean sea level (1evels by Riverside County Flood Control and Water Conservation District).

REMARKS. - No regulation or diversion above station.

COOPERATION, - -Records were published as furnished by Riverside County Flood Control and Water Conservation District.

AVERAGE DISCHARGE. - - 7 years, $0.32 \mathrm{ft}^{3} / \mathrm{s}\left(0.009 \mathrm{~m}^{3} / \mathrm{s}\right), 232 \mathrm{acre}-\mathrm{ft} / \mathrm{yr}\left(286,000 \mathrm{~m}^{3} / \mathrm{yr}^{2}\right)$.

EXTREMES FOR PERIOD OF RECORD,--Maximum discharge, $169 \mathrm{ft}^{3} / \mathrm{s}\left(4.79 \mathrm{~m}^{3} / \mathrm{s}\right) \mathrm{Jan}, 8$, 1974 , gage height not furnished; no flow most of each year.

EXTREMES OUTSIDE PERIOD OF RECORD,--Flood of Feb. $25,1969,2,010 \mathrm{ft}^{3} / \mathrm{s}\left(56.9 \mathrm{~m}^{3} / \mathrm{s}\right)$, at $\mathrm{site} 1 \mathrm{mi}(1.6 \mathrm{~km})$ upstream, from records of Riverside County Flood Control and Water Conservation District.

EXTREMES FOR CURRENT YEAR.--Maximum đischarge, $104 \mathrm{ft}^{3} / \mathrm{s}\left(2.95 \mathrm{~m}^{3} / \mathrm{s}\right) \mathrm{Feb} .9$, gage height, $2.51 \mathrm{ft}(0.765 \mathrm{~m})$; no flow most of year.

DISCHARGE, IN CUBIC FEET PER SECOND, HATER YEAR OCTOBER 1975 TO SEPTEMEER 1976 MEAN VALUES

\begin{tabular}{|c|c|c|c|c|c|c|c|c|c|c|c|c|c|}
\hline DAY & OCT & NOV & DEC & & JAN & FEB & MAR & APR & MAY & JUN & JUL & AU6 & SEP \\
\hline $\begin{array}{l}1 \\
2 \\
3 \\
4 \\
5\end{array}$ & & & & & & $\begin{array}{l}0 \\
0 \\
0 \\
0 \\
0\end{array}$ & $\begin{array}{l}0 \\
0 \\
5.0 \\
0^{.67}\end{array}$ & & & & & & $\begin{array}{l}0 \\
0 \\
0 \\
0 \\
0\end{array}$ \\
\hline $\begin{array}{r}6 \\
7 \\
8 \\
9 \\
10\end{array}$ & & & & & & $\begin{array}{l}0 \\
4.0 \\
7.5 \\
44 \\
10\end{array}$ & $\begin{array}{l}0 \\
0 \\
0 \\
0 \\
0\end{array}$ & & & & & & $\begin{array}{l}0 \\
0.02 \\
0 \\
1.2\end{array}$ \\
\hline $\begin{array}{l}11 \\
12 \\
13 \\
14 \\
15\end{array}$ & & & & & & $\begin{array}{l}.91 \\
0 \\
0 \\
0\end{array}$ & $\begin{array}{l}0 \\
0 \\
0 \\
0 \\
0\end{array}$ & & & & & & $\begin{array}{l}12 \\
1.5 \\
2.2 \\
.68 \\
0\end{array}$ \\
\hline $\begin{array}{l}16 \\
17 \\
18 \\
19 \\
20\end{array}$ & & & & & & $\begin{array}{l}0 \\
0 \\
0 \\
0 \\
0\end{array}$ & $\begin{array}{l}0 \\
0 \\
0 \\
0 \\
0\end{array}$ & & & & & & $\begin{array}{l}0 \\
0 \\
0 \\
0 \\
0\end{array}$ \\
\hline $\begin{array}{l}21 \\
22 \\
23 \\
24 \\
25\end{array}$ & & & & & & $\begin{array}{l}0 \\
0 \\
0 \\
0 \\
0\end{array}$ & $\begin{array}{l}0 \\
0 \\
0 \\
0 \\
0\end{array}$ & & & & & & $\begin{array}{l}0 \\
0 \\
0 \\
0 \\
0\end{array}$ \\
\hline $\begin{array}{l}26 \\
27 \\
28 \\
29 \\
30 \\
31\end{array}$ & & $\ldots$ & & & & $\begin{array}{l}0 \\
0 \\
0 \\
0\end{array}$ & $\begin{array}{l}0 \\
0 \\
0 \\
0 \\
0 \\
0\end{array}$ & $-\infty$ & & $-\infty$ & & & $\begin{array}{l}0 \\
0 \\
0 \\
0 \\
0 \\
-\end{array}$ \\
\hline $\begin{array}{l}\text { TOTAL } \\
\text { MEAN } \\
\text { MAX } \\
\text { MIN } \\
\text { AC-FT }\end{array}$ & $\begin{array}{l}0 \\
0 \\
0 \\
0 \\
0\end{array}$ & $\begin{array}{l}0 \\
0 \\
0 \\
0 \\
0\end{array}$ & $\begin{array}{l}0 \\
0 \\
0 \\
0 \\
0\end{array}$ & & $\begin{array}{l}0 \\
0 \\
0 \\
0 \\
0\end{array}$ & $\begin{array}{r}66.41 \\
2.29 \\
44 \\
0 \\
132\end{array}$ & $\begin{array}{r}5.67 \\
.18 \\
5.0 \\
0 \\
11\end{array}$ & $\begin{array}{l}0 \\
0 \\
0 \\
0 \\
0\end{array}$ & $\begin{array}{l}0 \\
0 \\
0 \\
0 \\
0\end{array}$ & $\begin{array}{l}0 \\
0 \\
0 \\
0 \\
0\end{array}$ & $\begin{array}{l}0 \\
0 \\
0 \\
0 \\
0\end{array}$ & $\begin{array}{l}0 \\
0 \\
0 \\
0 \\
0\end{array}$ & $\begin{array}{r}17.60 \\
.59 \\
12 \\
0 \\
35\end{array}$ \\
\hline $\begin{array}{lll}\text { CAL YR } & 1975 \\
\text { WTR YR } & 1976\end{array}$ & $\begin{array}{l}\text { TOTAL } \\
\text { TOTAL }\end{array}$ & $\begin{array}{r}125.78 \\
89.68\end{array}$ & $\begin{array}{l}\text { MEAN } \\
\text { MEAN }\end{array}$ & $\begin{array}{r}.34 \\
.25\end{array}$ & $\begin{array}{l}\text { MAX } \\
\text { MAX }\end{array}$ & $\begin{array}{l}\text { MIN } \\
\text { MIN }\end{array}$ & $\begin{array}{l}A C-F T \\
A C-F T\end{array}$ & $\begin{array}{l}249 \\
178\end{array}$ & & & & & \\
\hline
\end{tabular}


LOCATION, - Lat $33^{\circ} 39^{\prime} 51^{\prime \prime}$, long $117^{\circ} 17^{\prime} 35^{\prime \prime}$, in SE/4E $\frac{1}{4} N_{\frac{1}{4}}$ sec.9, T.6 S., R. 4 W., Riverside County, on right bank $2 \mathrm{mi}(3 \mathrm{~km})$ east of Eisinore, and $2.1 \mathrm{mi}(3.4 \mathrm{~km})$ downstream from Railroad Canyon Dam.

DRAINAGE AREA. $-723 \mathrm{mi}^{2}\left(1,873 \mathrm{~km}^{2}\right)$.

PERIOD OF RECORD.--January 1916 to current year. Month1y figures 1927-50, adjusted for diversion, published in WSP $1315-B$.

GAGE.--Water-stage recorder. Altitude of gage is $1,270 \mathrm{ft}$ ( $387 \mathrm{~m})$, from topographic map. Prior to Feb. 13, 1916 , nonrecording gage at site $0.7 \mathrm{mi}(1.1 \mathrm{~km})$ downstream at different datum. Feb. 13, 1916 , to 0ct. 27, 1921 , nonrecording gage at present site at different datum.

REMARKS. - Records fair. Flow part1y regulated by Lake Hemet (station 11069000) and regulated since 1928 by Railroad Canyon Reservoir, Capacity, 12,000 acre-ft (14.8 $\mathrm{hm}^{3}$ ), $2.1 \mathrm{mi}$ ( $3.4 \mathrm{~km}$ ) above station. Diversion for irrigation and domestic use above Railroad Canyon Reservoir. Temescal Water Co. diverted 1450 acre-ft ( $1.79 \mathrm{hm}^{3} / \mathrm{yr}$ ) during current year from Railroad Canyon Reservoir for irrigation below station in vicinity of Corona. See schematic diagran of Santa Ana River basin.

EXTREMES FOR PERIOD OF RECORD. - Maximum discharge, $16,000 \mathrm{ft}^{3} / \mathrm{s}\left(453 \mathrm{~m}^{3} / \mathrm{s}\right)$ Feb. 17, 1927 , gage height, 11.8 ft $(3.60 \mathrm{~m})$, from rating curve extended above $2,000 \mathrm{ft}^{3} / \mathrm{s}(56.6 \mathrm{~m} / \mathrm{s})$ on basis of s1ope-area measurement of maximum flow; no flow for several months in most years.

EXTREMES FOR CURRENT YEAR, - Maximum discharge, $18 \mathrm{ft}^{3} / \mathrm{s}\left(0.51 \mathrm{~m}^{3} / \mathrm{s}\right)$ Feb. 9 , gage height, $3.17 \mathrm{ft}(0.966 \mathrm{~m})$ extended above $3.0 \mathrm{ft}^{3} / \mathrm{s}\left(0.09 \mathrm{~m}^{3} / \mathrm{s}\right) ;$ minimum daily, no flow for several months.

DISCHARGE, IN CUBIC FEET PER SECOND, WATER YEAR OCTOBER 1975 TO SEPTEMBER I976 MEAN VALUES

\begin{tabular}{|c|c|c|c|c|c|c|c|c|c|c|c|c|}
\hline DAY & OCT & NOV & DEC & JAN & FEB & MAR & APR & MAY & JUN & JUL & AUS & SEP \\
\hline $\begin{array}{l}1 \\
2 \\
3 \\
4 \\
5\end{array}$ & & $\begin{array}{l}0 \\
0 \\
0 \\
0 \\
0\end{array}$ & $\begin{array}{l}.11 \\
.11 \\
.11 \\
.11 \\
.11 \\
.11\end{array}$ & $\begin{array}{r}.15 \\
.15 \\
.16 \\
.17 \\
.18\end{array}$ & $\begin{array}{l}.43 \\
.44 \\
.45 \\
.58 \\
.66\end{array}$ & $\begin{array}{l}.49 \\
.74 \\
1.0 \\
2.0 \\
2.7\end{array}$ & $\begin{array}{l}3.0 \\
2.7 \\
2.5 \\
2.4 \\
2.4\end{array}$ & $\begin{array}{r}.16 \\
.14 \\
.13 \\
.15 \\
.16\end{array}$ & & $\begin{array}{l}.29 \\
.06 \\
.04 \\
.03 \\
.01\end{array}$ & & $\begin{array}{l}0 \\
0 \\
0 \\
0 \\
0\end{array}$ \\
\hline $\begin{array}{r}6 \\
7 \\
8 \\
9 \\
10\end{array}$ & & $\begin{array}{l}0 \\
0 \\
0 \\
0 \\
0\end{array}$ & $\begin{array}{r}.11 \\
.11 \\
.10 \\
.10 \\
.11\end{array}$ & $\begin{array}{r}.18 \\
119 \\
.19 \\
.19 \\
.19\end{array}$ & $\begin{array}{l}1.4 \\
1.5 \\
2.3 \\
7.6 \\
2.1\end{array}$ & $\begin{array}{l}2.7 \\
2.7 \\
2.7 \\
2.7 \\
2.7\end{array}$ & $\begin{array}{l}2.5 \\
2.5 \\
2.4 \\
1.2 \\
.36\end{array}$ & $\begin{array}{r}.19 \\
.22 \\
.22 \\
.18 \\
.15\end{array}$ & & $\begin{array}{l}0 \\
0 \\
0 \\
0 \\
0\end{array}$ & & $\begin{array}{l}0 \\
0 \\
0 \\
0 \\
.45\end{array}$ \\
\hline $\begin{array}{l}11 \\
12 \\
13 \\
14 \\
15\end{array}$ & & $\begin{array}{l}0 \\
0 \\
0 \\
0 \\
.01\end{array}$ & $\begin{array}{r}.11 \\
.13 \\
.18 \\
.13 \\
.12\end{array}$ & $\begin{array}{l}.19 \\
.20 \\
.21 \\
.21 \\
.22\end{array}$ & $\begin{array}{l}1.5 \\
.95 \\
.64 \\
.52 \\
.47\end{array}$ & $\begin{array}{l}2.7 \\
2.6 \\
2.7 \\
2.7 \\
2.5\end{array}$ & $\begin{array}{r}.33 \\
.30 \\
.47 \\
.44 \\
.42\end{array}$ & $\begin{array}{l}.12 \\
.10 \\
.08 \\
.06 \\
.05\end{array}$ & & $\begin{array}{l}0 \\
0 \\
0 \\
0 \\
0\end{array}$ & & $\begin{array}{r}1.3 \\
.23 \\
.15 \\
.13 \\
.13\end{array}$ \\
\hline $\begin{array}{l}16 \\
17 \\
18 \\
19 \\
20\end{array}$ & & $\begin{array}{l}.03 \\
.05 \\
.06 \\
.07 \\
.07\end{array}$ & $\begin{array}{r}.12 \\
.12 \\
.12 \\
.12 \\
.16\end{array}$ & $\begin{array}{r}.22 \\
.23 \\
.25 \\
.26 \\
.26\end{array}$ & $\begin{array}{r}.44 \\
.42 \\
.41 \\
.38 \\
.37\end{array}$ & $\begin{array}{l}2.4 \\
2.6 \\
2.9 \\
3.0 \\
3.0\end{array}$ & $\begin{array}{r}.37 \\
.31 \\
.28 \\
.25 \\
.23\end{array}$ & $\begin{array}{l}.03 \\
0.01 \\
0 \\
0\end{array}$ & & $\begin{array}{l}0 \\
0 \\
0 \\
0 \\
0\end{array}$ & & $\begin{array}{l}.12 \\
111 \\
110 \\
11 \\
114\end{array}$ \\
\hline $\begin{array}{l}21 \\
22 \\
23 \\
24 \\
25\end{array}$ & & $\begin{array}{l}.08 \\
.08 \\
.08 \\
.08 \\
.08\end{array}$ & $\begin{array}{r}.23 \\
.16 \\
.15 \\
.14 \\
.15\end{array}$ & $\begin{array}{r}.27 \\
.30 \\
.32 \\
.33 \\
.34\end{array}$ & $\begin{array}{r}.35 \\
.35 \\
.35 \\
.35 \\
.35\end{array}$ & $\begin{array}{l}3.0 \\
3.0 \\
3.0 \\
3.0 \\
3.0\end{array}$ & $\begin{array}{l}.21 \\
.21 \\
.21 \\
.22 \\
.22\end{array}$ & $\begin{array}{l}0 \\
0 \\
0 \\
0 \\
0\end{array}$ & & $\begin{array}{l}0 \\
0 \\
0 \\
0 \\
0\end{array}$ & & $\begin{array}{r}.15 \\
.14 \\
.15 \\
.16 \\
.122\end{array}$ \\
\hline $\begin{array}{l}26 \\
27 \\
28 \\
29 \\
30 \\
31\end{array}$ & & $\begin{array}{l}.08 \\
.10 \\
.16 \\
.17 \\
.11 \\
-\end{array}$ & $\begin{array}{r}.15 \\
.15 \\
.15 \\
.14 \\
.15 \\
.16\end{array}$ & $\begin{array}{r}.34 \\
.35 \\
.37 \\
.38 \\
.41 \\
.42\end{array}$ & $\begin{array}{r}.34 \\
.37 \\
+39 \\
.34 \\
-30 \\
-\infty\end{array}$ & $\begin{array}{l}3.0 \\
3.0 \\
2.9 \\
3.0 \\
3.0 \\
3.0\end{array}$ & $\begin{array}{r}.21 \\
.20 \\
.20 \\
.19 \\
.18 \\
-\infty\end{array}$ & $\begin{array}{l}0 \\
0 \\
0 \\
0 \\
0 \\
0\end{array}$ & $=\infty$ & $\begin{array}{l}0 \\
0 \\
0 \\
0 \\
0 \\
0\end{array}$ & & $\begin{array}{r}.22 \\
119 \\
116 \\
.15 \\
115 \\
-00\end{array}$ \\
\hline $\begin{array}{l}\text { TOTAL } \\
\text { MEAN } \\
\text { MAX } \\
\text { MIN } \\
\text { AC }=F T\end{array}$ & $\begin{array}{l}0 \\
0 \\
0 \\
0 \\
0\end{array}$ & $\begin{array}{r}1.31 \\
.044 \\
.17 \\
0 \\
2.6\end{array}$ & $\begin{array}{r}4.12 \\
.13 \\
.23 \\
.10 \\
0.2\end{array}$ & $\begin{array}{r}7.83 \\
.25 \\
.42 \\
.15 \\
16\end{array}$ & $\begin{array}{r}26.75 \\
.92 \\
7.6 \\
.34 \\
53\end{array}$ & $\begin{array}{r}80.43 \\
2.59 \\
3.0 \\
.49 \\
160\end{array}$ & $\begin{array}{r}27.41 \\
.91 \\
3.0 \\
.18 \\
54\end{array}$ & $\begin{array}{r}2.15 \\
.069 \\
.22 \\
0 \\
4.3\end{array}$ & $\begin{array}{l}0 \\
0 \\
0 \\
0 \\
0\end{array}$ & $\begin{array}{r}.43 \\
.014 \\
.29 \\
0 \\
.9\end{array}$ & $\begin{array}{l}0 \\
0 \\
0 \\
0 \\
0\end{array}$ & $\begin{array}{r}4.66 \\
.16 \\
1.3 \\
0 \\
9.2\end{array}$ \\
\hline
\end{tabular}

CAL YR 1975 TOTAL 227.51 MEAN .62 MAX 8.8 MIN 0 AC-FT 451 HTR YR 1976 TOTAL 155.09 MEAN .42 MAX 7.6 MIN 0 ACFFT 308 
11072000 TEMESCAL CREEK NEAR CORONA, CA

LOCATION, - Lat $33^{\circ} 50^{\prime} 29^{\prime \prime}$, long $117^{\circ} 30^{\prime} 37^{\prime \prime}$, in El Sobrante de San Jacinto Grant, Riverside County, on left bank $0.2 \mathrm{mi}(0.3 \mathrm{~km})$ downstrean from unnamed tributary, and $3.8 \mathrm{mi}(6.1 \mathrm{~km})$ southeast of Corona.

DRAINAGE AREA. - -164 $\mathrm{mi}^{2}\left(425 \mathrm{~km}^{2}\right)$, excludes $768 \mathrm{mi}^{2}\left(1,989 \mathrm{~km}^{2}\right)$ above Lake E1sinore.

PERIOD OF RECORD.--October 1927 to current year. Monthly discharge only for the period October 1928 to January 1929, published in WSP $1315-B$.

GAGE. - Water-stage recorder. Concrete control since June 12, 1970. A1titude of gage is 730 ft ( $223 \mathrm{~m}$ ), from topographic map. Prior to Feb. 11, 1943, at datum $6.00 \mathrm{ft}(1.829 \mathrm{~m})$ higher.

REMARKS,--Records poor, Flow regulated by several storage reservoirs. Many diversions above station for irrigation. See schematic diagram of Santa Ana River basin.

AVERAGE DISCHARGE. -49 years, $3.26 \mathrm{ft}^{3} / \mathrm{s}\left(0.092 \mathrm{~m}^{3} / \mathrm{s}\right), 2,360 \mathrm{acre}-\mathrm{ft} / \mathrm{yr}(2.91 \mathrm{hm} / \mathrm{yr})$.

EXTREMES FOR PERIOD OF RECORD. - Maximum discharge, 14,900 $\mathrm{ft}^{3} / \mathrm{s}\left(422 \mathrm{~m}^{3} / \mathrm{s}\right)$ Mar. 2 , 1938 , on basis of slope-area measurement of maximum flow; no flow at times in most years.

EXTREMES FOR CURRENT YEAR. - Maximum discharge, $630 \mathrm{ft}^{3} / \mathrm{s}\left(17.8 \mathrm{~m}^{3} / \mathrm{s}\right)$ Sept. 7 , gage height, $10.32 \mathrm{ft}$ ( $\left.3.146 \mathrm{~m}\right)$; no flow many days.

DISCHARGE, IN CUBIC FEET PER SECOND, WATER YEAR OCTOBER 1975 TO SEPTEMBER 1976 MEAN VALUES

\begin{tabular}{|c|c|c|c|c|c|c|c|c|c|c|c|c|}
\hline DAY & $\mathrm{OCT}$ & NOV & DEC & JAN & FEB & MAR & APR & MAY & JUN & JUL & AUG & SEP \\
\hline $\begin{array}{l}1 \\
2 \\
3 \\
4 \\
5\end{array}$ & & & & $\begin{array}{l}0 \\
0 \\
0 \\
0 \\
0\end{array}$ & $\begin{array}{l}.01 \\
0 \\
0 \\
0\end{array}$ & $\begin{array}{l}.04 \\
.58 \\
1.1 \\
.04 \\
.03\end{array}$ & & $\begin{array}{l}0 \\
0 \\
0 \\
0 \\
0\end{array}$ & & & & $\begin{array}{l}0 \\
0 \\
0 \\
0 \\
0\end{array}$ \\
\hline $\begin{array}{r}6 \\
7 \\
8 \\
9 \\
10\end{array}$ & & & & $\begin{array}{l}0 \\
0 \\
0 \\
0 \\
0\end{array}$ & $\begin{array}{l}0 \\
0 \\
.40 \\
.53 \\
0.5\end{array}$ & $\begin{array}{l}.06 \\
.02 \\
0.01\end{array}$ & & $\begin{array}{l}0 \\
0 \\
0 \\
0 \\
0\end{array}$ & & & & ${ }^{37} 0^{.25}$ \\
\hline $\begin{array}{l}11 \\
12 \\
13 \\
14 \\
15\end{array}$ & & & & $\begin{array}{l}0 \\
0 \\
0 \\
0 \\
.01\end{array}$ & $\begin{array}{l}0 \\
0 \\
0 \\
0 \\
0\end{array}$ & $\begin{array}{l}0 \\
0 \\
0 \\
.01\end{array}$ & & $\begin{array}{l}0 \\
0 \\
0 \\
0 \\
0\end{array}$ & & & & $\begin{array}{l}1 \cdot 2 \\
0 \\
0 \\
0 \\
0\end{array}$ \\
\hline $\begin{array}{l}16 \\
17 \\
18 \\
19 \\
20\end{array}$ & & & & $\begin{array}{l}.02 \\
.02 \\
.01 \\
.01 \\
.02\end{array}$ & $\begin{array}{l}.02 \\
.08 \\
.08 \\
.06 \\
.06\end{array}$ & $\begin{array}{l}0 \\
0 \\
0 \\
0 \\
0\end{array}$ & & $\begin{array}{l}0 \\
0 \\
0 \\
0 \\
0\end{array}$ & & & & $\begin{array}{l}0 \\
0 \\
0 \\
0 \\
0\end{array}$ \\
\hline $\begin{array}{l}21 \\
22 \\
23 \\
24 \\
25\end{array}$ & & & & $\begin{array}{l}.01 \\
.02 \\
0 \\
0.01\end{array}$ & $\begin{array}{l}.08 \\
.06 \\
.05 \\
.03 \\
0\end{array}$ & $\begin{array}{l}0 \\
0 \\
0 \\
0 \\
0\end{array}$ & & $\begin{array}{l}0 \\
0 \\
0 \\
0 \\
0\end{array}$ & & & & $\begin{array}{l}0 \\
0 \\
0 \\
0 \\
0\end{array}$ \\
\hline $\begin{array}{l}26 \\
27 \\
28 \\
29 \\
30 \\
31\end{array}$ & & $-\infty$ & & $\begin{array}{l}.03 \\
.01 \\
.02 \\
.02 \\
.01 \\
.01\end{array}$ & $\begin{array}{l}0 \\
0 \\
0 \\
0 \\
-\infty \\
-\infty\end{array}$ & $\begin{array}{l}0 \\
0 \\
0 \\
0 \\
0 \\
0\end{array}$ & $\rightarrow-$ & $\begin{array}{l}0 \\
0 \\
0 \\
0 \\
0 \\
0\end{array}$ & $-\infty$ & & & $\begin{array}{l}0 \\
0 \\
0 \\
0 \\
0\end{array}$ \\
\hline $\begin{array}{l}\text { TOTAL } \\
\text { MEAN } \\
\text { MAX } \\
\text { MIN } \\
\text { AC } \triangle F \text { F }\end{array}$ & $\begin{array}{l}0 \\
0 \\
0 \\
0 \\
0\end{array}$ & $\begin{array}{l}0 \\
0 \\
0 \\
0 \\
0\end{array}$ & $\begin{array}{l}0 \\
0 \\
0 \\
0 \\
0\end{array}$ & $\begin{array}{r}.23 \\
.007 \\
.03 \\
0 \\
.5\end{array}$ & $\begin{array}{r}1.46 \\
.050 \\
.53 \\
0 \\
2.9\end{array}$ & $\begin{array}{r}1.89 \\
.061 \\
1.1 \\
0.7\end{array}$ & $\begin{array}{l}0 \\
0 \\
0 \\
0 \\
0\end{array}$ & $\begin{array}{r}.04 \\
.001 \\
.04 \\
0 \\
.08\end{array}$ & $\begin{array}{l}0 \\
0 \\
0 \\
0 \\
0\end{array}$ & $\begin{array}{l}0 \\
0 \\
0 \\
0 \\
0\end{array}$ & $\begin{array}{l}0 \\
0 \\
0 \\
0 \\
0\end{array}$ & $\begin{array}{r}48.45 \\
1.62 \\
37 \\
0 \\
96\end{array}$ \\
\hline
\end{tabular}

$\begin{array}{llllllll}\text { CAL YR } 1975 & \text { TOTAL } 46.96 & \text { MEAN } 13 & \text { MAX } 11 & \text { MIN } 0 & \text { AC-FT } 93 \\ \text { HTR YR } 1976 & \text { TOTAL } 52.07 & \text { MEAN } 14 & \text { MAX } 37 & \text { MIN } 0 & \text { AC-FT 103 }\end{array}$ 
11073200 SAN ANTONIO CREEK BELOW SAN ANTONIO DAM, CA

LOCATION, - Lat $34^{\circ} 09^{\prime} 26^{\prime \prime}$, Iong $117^{\circ} 40^{\prime} 50^{\prime \prime}$, in NE $\frac{1}{4} \mathrm{NE}_{4}^{1} \mathrm{SE}^{\frac{1}{4}}$ sec. 23 , T. I N., R. 8 W., Los Ange1es-San Bernardino County line, on left wall of'outlet channel at toe of San Antonio Dam, and 4.7 mi ( $7.6 \mathrm{~km}$ ) northeast of Claremont.

DRAINAGE AREA. $--26.9 \mathrm{mi}^{2}\left(69.7 \mathrm{~km}^{2}\right)$.

PERIOD OF RECORD.--October 1962 to current year.

GAGE. - Water-stage recorder. Datum of gage is $2,093.94 \mathrm{ft}(638.233 \mathrm{~m})$ above mean sea level (Corps of Engineers berch mark).

REMARKS,--Records fair. Flow regulated by San Antonio flood-control reservoir, capacity, 7,620 acre-ft

$\left(9.40 \mathrm{hm}^{3}\right)$. Water diverted out of basin for power, domestic use, and irrigation. See schematic diagram of Santa Ana River basin.

EXTREMES FOR PERIOD OF RECORD. - -Maximum discharge, $8,420 \mathrm{ft}^{3} / \mathrm{s}\left(238 \mathrm{~m}^{3} / \mathrm{s}\right) \mathrm{Jan}, 25,1969$, gage height, $11.22 \mathrm{ft}$ $(3.420 \mathrm{~m})$, from rating curve extended above $400 \mathrm{ft} / \mathrm{s}\left(11.3 \mathrm{~m}^{3} / \mathrm{s}\right)$ on basis of gate openings at dam; no flow most of each year.

EXTREMES FOR CURRENT YEAR.--Maximum discharge, $763 \mathrm{ft}^{3} / \mathrm{s}\left(21.6 \mathrm{~m}^{3} / \mathrm{s}\right)$ Sept, 10, gage height, $2.99 \mathrm{ft}(0.911 \mathrm{~m})$; no flow most of year.

DISCHARGE, IN CUBIC FEET PER SECOND, WATER YEAR OCTOBER 1975 TOO SEPTEMBER 1976 MEAN VALUES

\begin{tabular}{|c|c|c|c|c|c|c|c|c|c|c|c|c|}
\hline DAY & OCT & NoV & DEC & JAN & FEB & MAR & APR & MAY & JUN & JUL & AUG & SEP \\
\hline $\begin{array}{l}1 \\
2 \\
3 \\
4 \\
5\end{array}$ & & & & & & $\begin{array}{l}0 \\
0 \\
0 \\
0 \\
0\end{array}$ & $\begin{array}{l}.10 \\
110 \\
110 \\
.10 \\
18\end{array}$ & $\begin{array}{l}.05 \\
.05 \\
.05 \\
.05 \\
.05\end{array}$ & & & & $\begin{array}{c}0 \\
0 \\
47 \\
0\end{array}$ \\
\hline $\begin{array}{r}6 \\
7 \\
8 \\
9 \\
10\end{array}$ & & & & & & $\begin{array}{l}0 \\
0 \\
0 \\
0 \\
0\end{array}$ & $\begin{array}{l}.16 \\
.16 \\
.12 \\
.10 \\
.10\end{array}$ & $\begin{array}{l}.05 \\
.05 \\
.05 \\
.05 \\
.05\end{array}$ & & & & $0_{203}^{0}$ \\
\hline $\begin{array}{l}11 \\
12 \\
13 \\
14 \\
15\end{array}$ & & & & & & $\begin{array}{l}0 \\
0 \\
0 \\
0 \\
0\end{array}$ & $\begin{array}{l}.10 \\
110 \\
.10 \\
.10 \\
.10\end{array}$ & $\begin{array}{l}0_{0}^{.05} \\
0 \\
0 \\
0\end{array}$ & & & & $\begin{array}{l}0.10 \\
0 \\
0 \\
0\end{array}$ \\
\hline $\begin{array}{l}16 \\
17 \\
18 \\
19 \\
20\end{array}$ & & & & & & $\begin{array}{l}0 \\
0 \\
0 \\
0 \\
0\end{array}$ & $\begin{array}{l}.10 \\
.10 \\
.10 \\
.10 \\
.10\end{array}$ & $\begin{array}{l}0 \\
0 \\
0 \\
0 \\
.04\end{array}$ & & & & $\begin{array}{r}39 \\
342 \\
417 \\
334 \\
392\end{array}$ \\
\hline $\begin{array}{l}21 \\
22 \\
23 \\
24 \\
25\end{array}$ & & & & & & $\begin{array}{l}0 \\
0 \\
0 \\
0 \\
.15\end{array}$ & $\begin{array}{r}.10 \\
2.9 \\
.20 \\
.10 \\
.10\end{array}$ & $\begin{array}{l}0 \\
0 \\
0 \\
0 \\
0\end{array}$ & & & & $\begin{array}{l}418 \\
402 \\
344 \\
208 \\
74\end{array}$ \\
\hline $\begin{array}{l}26 \\
27 \\
28 \\
29 \\
30 \\
31\end{array}$ & & $--\infty$ & & & $=$ & $\begin{array}{l}1.7 \\
.24 \\
.24 \\
.16 \\
.10 \\
.10\end{array}$ & $\begin{array}{l}.08 \\
.05 \\
.05 \\
.05 \\
.05 \\
.--\end{array}$ & $\begin{array}{l}.02 \\
.05 \\
.01 \\
0 \\
0 \\
0\end{array}$ & -- & & & $\begin{array}{l}19 \\
110 \\
110 \\
110 \\
110 \\
-1\end{array}$ \\
\hline $\begin{array}{l}\text { TOTAL } \\
\text { MEAN } \\
\text { MAX } \\
\text { MIN } \\
\text { AC }=F T\end{array}$ & $\begin{array}{l}0 \\
0 \\
0 \\
0 \\
0\end{array}$ & $\begin{array}{l}0 \\
0 \\
0 \\
0 \\
0\end{array}$ & $\begin{array}{l}0 \\
0 \\
0 \\
0 \\
0\end{array}$ & $\begin{array}{l}0 \\
0 \\
0 \\
0 \\
0\end{array}$ & $\begin{array}{l}0 \\
0 \\
0 \\
0 \\
0\end{array}$ & $\begin{array}{r}2.69 \\
.087 \\
1.7 \\
0 \\
5.3\end{array}$ & $\begin{array}{r}5.90 \\
.20 \\
2.9 \\
.05 \\
12\end{array}$ & $\begin{array}{r}.67 \\
.022 \\
.05 \\
0 \\
1.3\end{array}$ & $\begin{array}{l}0 \\
0 \\
0 \\
0 \\
0\end{array}$ & $\begin{array}{l}0 \\
0 \\
0 \\
0 \\
0\end{array}$ & $\begin{array}{l}0 \\
0 \\
0 \\
0 \\
0\end{array}$ & $\begin{array}{r}3305.69 \\
110 \\
418 \\
0 \\
6560\end{array}$ \\
\hline
\end{tabular}

CAL YR 1975 TOTAL 
11073210 RIALTO PIPELINE BELOW SAN ANTONIO DAM, NEAR CLAREMONT, CA

LOCATION.--Lat $34^{\circ} 07^{\prime} 43^{\prime \prime}$, long $117^{\circ} 41^{\prime} 29^{\prime \prime}$, in NW/4Et/sWt sec. 35, T. 1 N., R. 8 W., Los Angeles County, 0.5 mi $(0.8 \mathrm{~km})$ north of Baseije Road, and $2.1 \mathrm{mi}(3.4 \mathrm{~km})$ downstream from San Antonio Dam.

PERIOD OF RECORD. - -

CHEMICAL ANALYSES: March 1974 to current year.

REMARKS.--Discharge values are from Chino Creek at Schaefer Avenue, near Chino (station 11073360).

CHËMICAL ANALYSES, WATER YEAR OCTOBER 1975 TO SEPTEMBER 1976

\begin{tabular}{|c|c|c|c|c|c|c|c|c|c|}
\hline DATE & TIME & $\begin{array}{l}\text { INSTAN- } \\
\text { TANEOUS } \\
\text { DIS- } \\
\text { CHARGE } \\
\text { (CFS) }\end{array}$ & $\begin{array}{l}\text { SPE- } \\
\text { CIFIC } \\
\text { CON- } \\
\text { DUCT- } \\
\text { ANCE } \\
\text { (MICRO- } \\
\text { MHOS) }\end{array}$ & $\begin{array}{c}\mathrm{PH} \\
\text { (UNITS) }\end{array}$ & $\begin{array}{l}\text { TEMPER- } \\
\text { ATURE } \\
\text { (DEG C) }\end{array}$ & $\begin{array}{l}\text { HARD- } \\
\text { NESS } \\
\text { (CA,MG) } \\
\text { (MG/L) }\end{array}$ & $\begin{array}{l}\text { NON- } \\
\text { CAR- } \\
\text { BONATE } \\
\text { HARD- } \\
\text { NESS } \\
(M G / L)\end{array}$ & $\begin{array}{l}\text { DIS- } \\
\text { SOLVED } \\
\text { CAL- } \\
\text { CIUH } \\
\text { (CA) } \\
\text { (MG/L) }\end{array}$ & $\begin{array}{l}\text { DIS- } \\
\text { SOLVEO } \\
\text { MAG- } \\
\text { NE- } \\
\text { SIUM } \\
\text { (MG) } \\
\text { (MG/L) }\end{array}$ \\
\hline Nov & & & & & & & & & \\
\hline $\operatorname{DEC}_{11} \cdots$ & 1000 & 100 & 348 & 8.2 & 15.0 & 93 & 11 & 21 & 9.9 \\
\hline JAN $_{11}$ & 1100 & 97 & 330 & 8.2 & 10.4 & 86 & 8 & 19 & 9.4 \\
\hline $30 \ldots$ & 1400 & 180 & 310 & 7.9 & 9.4 & 79 & 9 & 18 & 0.3 \\
\hline
\end{tabular}

\begin{tabular}{|c|c|c|c|c|c|c|c|c|c|}
\hline OATE & $\begin{array}{l}\text { DIS- } \\
\text { SOLVED } \\
\text { CHLO- } \\
\text { RIDE } \\
\text { (CL) } \\
(M G / L)\end{array}$ & $\begin{array}{l}\text { OIS- } \\
\text { SOLVEO } \\
\text { FLUO- } \\
\text { RIDE } \\
\text { (F) } \\
\text { (MG/L) }\end{array}$ & $\begin{array}{l}\text { DIS- } \\
\text { SOLVEO } \\
\text { SILICA } \\
\text { (SIOZ) } \\
\text { (MG/L) }\end{array}$ & $\begin{array}{l}\text { DIS- } \\
\text { SOLVED } \\
\text { SOLIDS } \\
\text { (SUM OF } \\
\text { CONSTI- } \\
\text { TUENTS) } \\
\text { (MG/L) }\end{array}$ & $\begin{array}{l}\text { DIS- } \\
\text { SOLVED } \\
\text { SOLIDS } \\
\text { (TONS } \\
\text { PER } \\
\text { AC }-F T \text { ) }\end{array}$ & $\begin{array}{l}\text { DIS- } \\
\text { SOLVED } \\
\text { SOLIDS } \\
\text { (TONS } \\
\text { PER } \\
\text { DAY) }\end{array}$ & $\begin{array}{l}\text { OIS- } \\
\text { SOLVED } \\
\text { NI TRITE } \\
\text { PLUS } \\
\text { NI TRATE } \\
\text { (N) } \\
\text { (HG/L) }\end{array}$ & $\begin{array}{c}\text { DIS- } \\
\text { SOLVED } \\
\text { BORON } \\
\text { (B) } \\
\text { (UG/L) }\end{array}$ & $\begin{array}{l}\text { DIS- } \\
\text { SOLVED } \\
\text { IRON } \\
\text { (FE) } \\
\text { (UG/L) }\end{array}$ \\
\hline \multicolumn{10}{|l|}{ NOV } \\
\hline DEC & 42 & .1 & 9.8 & 198 & .27 & 53.5 & .15 & 150 & 10 \\
\hline${ }_{\text {JAN }} 11 \cdots$ & 38 & .1 & 10 & 190 & .26 & 49.8 & .67 & 130 & 20 \\
\hline $30 \ldots$ & 36 & .1 & 12 & 179 & .25 & 87.0 & .54 & 150 & 20 \\
\hline
\end{tabular}

\begin{tabular}{|c|c|c|c|c|c|c|c|c|c|}
\hline DATE & $\begin{array}{l}\text { DIS- } \\
\text { SOLVED } \\
\text { SODIUM } \\
\text { (NA) } \\
(M Q / L)\end{array}$ & $\begin{array}{l}\text { PERCENT } \\
\text { SODIUM }\end{array}$ & $\begin{array}{l}\text { SODIUM } \\
\text { AD- } \\
\text { SORP- } \\
\text { TION } \\
\text { RATIO }\end{array}$ & $\begin{array}{l}\text { DIS- } \\
\text { SOLVED } \\
\text { PO- } \\
\text { YAS- } \\
\text { SIUM } \\
\text { (K) } \\
(M G / L)\end{array}$ & $\begin{array}{l}\text { BICAR- } \\
\text { BONATE } \\
\text { (HCO3) } \\
\text { (HG/L) }\end{array}$ & $\begin{array}{l}\text { CAR- } \\
\text { BONATE } \\
\text { (CO3) } \\
\text { (MG/L) }\end{array}$ & $\begin{array}{l}\text { ALKA- } \\
\text { LINITY } \\
\text { AS } \\
\text { CACO3 } \\
(M G / L)\end{array}$ & $\begin{array}{l}\text { CARBON } \\
\text { OIOXIDE } \\
\text { (CO2) } \\
\text { (MO/L) }\end{array}$ & $\begin{array}{l}\text { DIS- } \\
\text { SOLVEO } \\
\text { SULFATE } \\
\text { (SO4) } \\
\text { (MG/L) }\end{array}$ \\
\hline
\end{tabular}

\begin{tabular}{|c|c|c|c|c|c|c|c|c|c|}
\hline $\begin{array}{l}\text { NOV } \\
11 \ldots . . \\
\text { DEC }\end{array}$ & 34 & 44 & 1.5 & 1.8 & 100 & 0 & 82 & 1.0 & 29 \\
\hline${ }_{\text {JAN }} 11 \cdots$ & 33 & 45 & 1.5 & 2.4 & 95 & 0 & 78 & 1.0 & 28 \\
\hline $30 \ldots$ & 30 & 44 & 1.5 & 2.5 & 85 & 0 & 70 & 1.7 & 28 \\
\hline
\end{tabular}


11073360 CHINO CREEK AT SCHAEFER AVENUE, NEAR CHINO, CA

LOCATION. - Lat $34^{\circ} 00^{\prime} 14^{\prime \prime}$, long $117^{\circ} 43^{\prime} 34^{\prime \prime}$, in Santa Ana del Chino Grant, San Bernardino County, on right bank

$300 \mathrm{ft}(91 \mathrm{~m})$ downstream from Schaefer'Avenue, $0.8 \mathrm{mi}(1.3 \mathrm{~km}$ ) downstream from San Antonio Creek, and $1.5 \mathrm{mi}$

$(2.4 \mathrm{~km})$ southwest of Chino.

DRAINAGE AREA. $--48.9 \mathrm{ni}^{2}\left(126.7 \mathrm{~km}^{2}\right)$.

WATER-DISCHARGE RECORDS

PERIOD OF RECORD.--October 1969 to current year.

GAGE. - Water-stage recorder. Altitude of gage is 685 ft (209 m), from topographic map.

REMARKS, - -Records good. Flow partly regulated by San Antonio flood-control reservoir, capacity, 7,620 acre-ft

$\left(9.40 \mathrm{hm}^{3}\right)$. Natural streamflow affected by extensive ground-water withdrawals, diversions for power, domestic

use irrigation, and return flow from irrigated areas. California Water project reported releases of

61,770 acre-ft $\left(76.2 \mathrm{hml}^{3}\right.$ ) to basin at San Antonio Creek at Rialto pipeline below San Antonio Dam (station

$11073210)$ at a point $10 \mathrm{mi}(16 \mathrm{~km})$ upstream. See schematic diagram of Santa Ana River basin.

EXTREMES FOR PERIOD OF RECORD. - Maximum discharge, $2,920 \mathrm{ft}^{3} / \mathrm{s}\left(82.7 \mathrm{~m}^{3} / \mathrm{s}\right)$ Dec. 4, 1974, gage height, 6.61 ft $(2.015 \mathrm{~m})$, from floodnarks, from rating curve extended above $620 \mathrm{ft} 3 / \mathrm{s}\left(17.6 \mathrm{~m}^{3} / \mathrm{s}\right)$ on basis of computation of flow in concrete-lined chamnel at $1,600 \mathrm{ft}^{3} / \mathrm{s}\left(45.3 \mathrm{~m}^{3} / \mathrm{s}\right)$ and a contracted opening measurement at 9.23 ft

$(2.813 \mathrm{~m}) ; \mathrm{minimum}$ daily, $0.03 \mathrm{ft}^{3} / \mathrm{s}\left(0.001 \mathrm{~m}^{3} / \mathrm{s}\right)$ May $24,1976$.

EXTREMES OUTSIDE PERIOD OF RECORD. - Flood of Jan. $25,1969,9,200 \mathrm{ft}^{3} / \mathrm{s}\left(261 \mathrm{~m}^{3} / \mathrm{s}\right)$, gage height, $9.23 \mathrm{ft}$

$(2.813 \mathrm{~m})$, present datum, by contracted-opening measurement at site $6.1 \mathrm{mi}(9.8 \mathrm{~km}) \mathrm{downstream}$.

EXTREMES FOR CURRENT YEAR. - Peak discharge above base of $600 \mathrm{ft}^{3} / \mathrm{s}\left(17.0 \mathrm{~m}^{3} / \mathrm{s}\right)$ and maximum (*), extended above $300 \mathrm{ft}^{3} / \mathrm{s}\left(8.50 \mathrm{~m}^{3} / \mathrm{s}\right)$ on basis of contracted-opening measurement of $9.23 \mathrm{ft}(2.813 \mathrm{~m})$ :

\begin{tabular}{|c|c|c|c|c|c|c|c|c|c|c|c|}
\hline Date & Time & $\begin{array}{r}D_{j}^{j} \mathrm{sc} \\
\left(\mathrm{ft}^{3} / \mathrm{s}\right.\end{array}$ & $\stackrel{\mathrm{rge}}{\left(\mathrm{m}^{3} / \mathrm{s}\right)}$ & $\begin{array}{l}\text { Gage } \\
(f t)\end{array}$ & $\begin{array}{l}\text { ight } \\
\text { (m) }\end{array}$ & Date & Time & $\begin{array}{r}\text { Discl } \\
\left(\mathrm{ft}^{3} / \mathrm{s}\right)\end{array}$ & $\begin{array}{l}r g e \\
\left(m^{3} / s\right)\end{array}$ & $\begin{array}{l}\text { Gage } \\
\text { (ft) }\end{array}$ & $\begin{array}{r}\text { height } \\
\text { (m) }\end{array}$ \\
\hline Feb. 6 & 0600 & $\begin{array}{l}635 \\
720\end{array}$ & 18.0 & 6.15 & 1.875 & Sept. 7 & 1700 & $\begin{array}{r}852 \\
\times 1410\end{array}$ & 24.1 & 6.36 & $\begin{array}{l}1.939 \\
2.063\end{array}$ \\
\hline Mar. 1 & 1130 & 720 & $\begin{array}{l}20.4 \\
20.4\end{array}$ & $\begin{array}{l}0.24 \\
6.24\end{array}$ & $\begin{array}{l}1.902 \\
1.902\end{array}$ & & & & & & \\
\hline
\end{tabular}

Minimum daily discharge, $0.03 \mathrm{ft}^{3} / \mathrm{s}\left(0.001 \mathrm{~m}^{3} / \mathrm{s}\right)$ May 24 .

DISCHARGE, IN CUBIC FEET PER SECOND, HATER YEAR OCTOBER 1975 TO SEPTEMBER 1976

\begin{tabular}{|c|c|c|c|c|}
\hline DAY & OCT & NOV & DEC & JAN \\
\hline $\begin{array}{l}1 \\
2 \\
3 \\
4 \\
5\end{array}$ & $\begin{array}{l}47 \\
50 \\
47 \\
44 \\
44\end{array}$ & $\begin{array}{r}.33 \\
.33 \\
.39 \\
.33 \\
.39\end{array}$ & $\begin{array}{l}237 \\
242 \\
235 \\
205 \\
255\end{array}$ & $\begin{array}{l}171 \\
174 \\
174 \\
169 \\
201\end{array}$ \\
\hline $\begin{array}{r}6 \\
7 \\
8 \\
9 \\
10\end{array}$ & $\begin{array}{l}21 \\
1.1 \\
1.26 \\
1.1\end{array}$ & $\begin{array}{r}.33 \\
.33 \\
.33 \\
.29 \\
52\end{array}$ & $\begin{array}{l}273 \\
278 \\
190 \\
110 \\
105\end{array}$ & $\begin{array}{l}216 \\
216 \\
228 \\
189 \\
233\end{array}$ \\
\hline $\begin{array}{l}11 \\
12 \\
13 \\
14 \\
15\end{array}$ & $\begin{array}{l}2.3 \\
1.4 \\
1.1 \\
.52 \\
.29\end{array}$ & $\begin{array}{l}95 \\
96 \\
96 \\
96 \\
96\end{array}$ & $\begin{array}{r}99 \\
125 \\
100 \\
96 \\
96\end{array}$ & $\begin{array}{l}216 \\
224 \\
224 \\
216 \\
216\end{array}$ \\
\hline $\begin{array}{l}16 \\
17 \\
18 \\
19 \\
20\end{array}$ & $\begin{array}{l}27 \\
51 \\
50 \\
47\end{array}$ & $\begin{array}{r}96 \\
96 \\
152 \\
190 \\
190\end{array}$ & $\begin{array}{l}181 \\
233 \\
241 \\
237 \\
237\end{array}$ & $\begin{array}{l}212 \\
228 \\
209 \\
193 \\
169\end{array}$ \\
\hline $\begin{array}{l}21 \\
22 \\
23 \\
24 \\
25\end{array}$ & $\begin{array}{l}46 \\
46 \\
46 \\
47 \\
47\end{array}$ & $\begin{array}{l}190 \\
190 \\
195 \\
198 \\
200\end{array}$ & $\begin{array}{l}233 \\
212 \\
186 \\
190 \\
190\end{array}$ & $\begin{array}{r}171 \\
74 \\
82 \\
177 \\
169\end{array}$ \\
\hline $\begin{array}{l}26 \\
27 \\
28 \\
29 \\
30 \\
31\end{array}$ & $\begin{array}{r}47 \\
72 \\
93 \\
95 \\
80 \\
.52\end{array}$ & $\begin{array}{l}210 \\
230 \\
241 \\
237 \\
233\end{array}$ & $\begin{array}{l}186 \\
182 \\
182 \\
182 \\
177 \\
171\end{array}$ & $\begin{array}{l}169 \\
171 \\
174 \\
166 \\
169 \\
160\end{array}$ \\
\hline $\begin{array}{l}\text { TOTAL. } \\
\text { MEAN } \\
\text { MAX } \\
\text { MIN } \\
\text { AC }-F T\end{array}$ & $\begin{array}{r}1057.02 \\
34.1 \\
95 \\
.26 \\
2100\end{array}$ & $\begin{array}{r}3382,05 \\
113 \\
241 \\
.29 \\
6710\end{array}$ & $\begin{array}{r}5866 \\
189 \\
278 \\
96 \\
11640\end{array}$ & $\begin{array}{r}5760 \\
186 \\
233 \\
74 \\
11420\end{array}$ \\
\hline
\end{tabular}

$\begin{array}{cc}\text { FEB } & \text { MAR } \\ 151 & 124 \\ 196 & 35 \\ 197 & 7.8 \\ 132 & .66 \\ 43 & .25 \\ 108 & .12 \\ 44 & .07 \\ 137 & .14 \\ 148 & .29 \\ 1.8 & 120\end{array}$

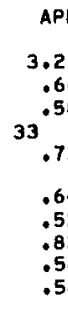

$\begin{array}{rr}.92 & 158 \\ .92 & 175 \\ 1.0 & 182 \\ .92 & 171\end{array}$

.64

$.58 \quad 169$

$.64 \quad 185$

$.64 \quad 196$

$.64 \quad 140$

$.73 \quad 123$

$\begin{array}{rr}.73 & 123 \\ .58 & 125 \\ .52 & 125 \\ .45 & 127 \\ 117^{4} & 127\end{array}$

117

$179 \quad 129$

$177 \quad 132$

171
140

140

m- $\quad 141$

$1951.56 \quad 3382.33$

67.3

67.3
197

.45
3070

3382.33
109
196
6707
6710

109
196
6710

IN .05 $\begin{array}{lllllllllll}\text { CAL YR } 1975 & \text { TOTAL } & 20288,58 & \text { MEAN } 55.6 & \text { MAX } 278 & \text { MIN } & .05 & \text { AC } & \text { MFT } & 40240 \\ \text { GTR YR } 1976 & \text { TOTAL } & 29883.17 & \text { HEAN } 81.6 & \text { MAX } 292 & \text { MIN } & .03 & \text { AC } & \text { MFT } & 59270\end{array}$
APR MAY

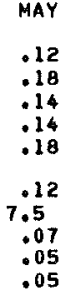

6.5

32.2

$14^{.45}$

.05
.07
.09
.09
.14

.52

.39

.29

.21

.29
.25
.25
.29

.25
.29
.21

98.45

96.45
3.28

33
122
195

$A C=F T$
.14
.18
.18
.12
.33
.0

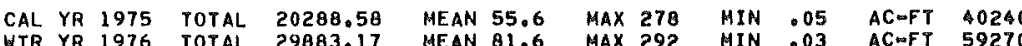

$\begin{array}{cccc}\text { JUN } & \text { JUL } & \text { AUG } & \text { SEP } \\ 179 & 151 & .12 & .21 \\ 182 & 163 & .12 & .21 \\ 179 & 163 & .12 & .21 \\ 179 & 163 & .18 & .21 \\ 179 & 108 & .21 & .09 \\ 177 & 68 & .18 & .09 \\ 177 & 73 & .18 & 27 \\ 174 & 116 & .09 & 1.4 \\ 177 & 71 & .09 & .92 \\ 237 & 72 & .18 & 292 \\ 283 & 72 & .14 & 44 \\ 289 & 72 & .14 & .52 \\ 289 & 72 & .21 & .21 \\ 220 & 73 & .18 & .14 \\ 179 & 33 & .21 & .21 \\ 186 & .33 & .18 & .25 \\ 186 & .25 & .14 & .18 \\ 179 & .29 & .14 & .21 \\ 182 & .29 & .14 & .33 \\ 179 & .21 & .14 & .21 \\ 179 & .21 & .21 & .21 \\ 179 & .21 & .12 & .21 \\ 190 & .14 & .07 & .33 \\ 182 & .18 & .07 & 1.6 \\ 136 & .14 & .09 & .33 \\ 117 & .21 & .07 & .21 \\ 118 & .29 & .12 & .21 \\ 132 & .25 & .09 & .21 \\ 142 & : 14 & .09 & .21 \\ 138 & : 14 & .09 & 53 \\ 009 & .14 & .12 & .0 . \\ 5525 & 1473.42 & 4.23 & 425.12 \\ 184 & 47.5 & .14 & 14.2 \\ 289 & 163 & .21 & 292 \\ 117 & .14 & .07 & .09 \\ 10960 & 2920 & .04 & 843\end{array}$


11073360 CHINO CREEK AT SCHAEFER AVENUE, NEAR CHINO, CA--Continued

WATER-QUALITY RECORDS

PERTOD OF RECORD, - -

CHEMICAL ANALYSES: March 1974 to current year.

CHEMICAL ANALYSES, WATER YEAR OCTOBER 1975 TO SEPTEMBER 1976

\begin{tabular}{|c|c|c|c|c|c|c|c|c|c|c|}
\hline DATE & TIME & $\begin{array}{l}\text { INSTAN- } \\
\text { TANEOUS } \\
\text { DIS- } \\
\text { CHARGE } \\
\text { (CFS) }\end{array}$ & $\begin{array}{l}\text { SPE- } \\
\text { CIFIC } \\
\text { CON- } \\
\text { DUCT- } \\
\text { ANCE } \\
\text { (MICRO- } \\
\text { MHOS) }\end{array}$ & $\begin{array}{r}\text { PH } \\
\text { (UNITS) }\end{array}$ & $\begin{array}{l}\text { TEMPER - } \\
\text { ATURE } \\
\text { (DEG C) }\end{array}$ & $\begin{array}{l}\text { HARD- } \\
\text { NESS } \\
\text { (CA,MG) } \\
(M G / L)\end{array}$ & $\begin{array}{l}\text { NON- } \\
\text { CAR- } \\
\text { BONATE } \\
\text { HARD- } \\
\text { NESS } \\
(M G / L)\end{array}$ & $\begin{array}{l}\text { DIS- } \\
\text { SOLVED } \\
\text { CAL- } \\
\text { CIUM } \\
\text { (CA) } \\
(M G / L)\end{array}$ & $\begin{array}{l}\text { OIS- } \\
\text { SOLVEO } \\
\text { MAG- } \\
\text { NE- } \\
\text { SIUM } \\
\text { (MG) } \\
\text { (MG/L) }\end{array}$ & $\begin{array}{l}\text { DIS- } \\
\text { SOLVED } \\
\text { SODIUM } \\
\text { (NA) } \\
(M G / L)\end{array}$ \\
\hline \multicolumn{11}{|l|}{ NOV } \\
\hline$\underset{D E C}{11} \cdots$ & 1215 & 101 & 350 & 9.1 & 17.0 & 93 & 9 & 21 & 9.9 & 34 \\
\hline$\underset{\text { JAN }}{11} \cdots$ & 0930 & 96 & 330 & 8.5 & 10.5 & 85 & 9 & 19 & 9.0 & 33 \\
\hline $30 \ldots$ & 1300 & 180 & 310 & 8.9 & 11.0 & 76 & 7 & 17 & 8.1 & 30 \\
\hline
\end{tabular}

\begin{tabular}{|c|c|c|c|c|c|c|c|c|c|}
\hline DATE & $\begin{array}{l}\text { DIS- } \\
\text { SOLVED } \\
\text { FLUO- } \\
\text { RIDE } \\
\text { (F) } \\
\text { (MG/L) }\end{array}$ & $\begin{array}{l}\text { DIS- } \\
\text { SOLVED } \\
\text { SILICA } \\
\text { (SIOZ) } \\
\text { (MG/L) }\end{array}$ & $\begin{array}{l}\text { DIS- } \\
\text { SOLVED } \\
\text { SOLIDS } \\
\text { (REST- } \\
\text { OUE AT } \\
180 \mathrm{C}) \\
\text { (MG/L) }\end{array}$ & $\begin{array}{l}\text { DIS- } \\
\text { SOLVED } \\
\text { SOLIDS } \\
\text { (SUM OF } \\
\text { CONSTI- } \\
\text { TUENTS) } \\
\text { (MG/L) }\end{array}$ & $\begin{array}{l}\text { OIS- } \\
\text { SOLVED } \\
\text { SOLIDS } \\
\text { (TONS } \\
\text { PER } \\
\text { AC-FT) }\end{array}$ & $\begin{array}{l}\text { DIS- } \\
\text { SOLVED } \\
\text { SOLIDS } \\
\text { (TONS } \\
\text { PER } \\
\text { DAY) }\end{array}$ & $\begin{array}{l}\text { DIS- } \\
\text { SOLVED } \\
\text { NITRITE } \\
\text { PLUS } \\
\text { NI TRATE } \\
\text { (N) } \\
\text { (MG LL) }\end{array}$ & $\begin{array}{c}\text { DIS- } \\
\text { SOLVED } \\
\text { BORON } \\
\text { (B) } \\
\text { (UG/L) }\end{array}$ & $\begin{array}{l}\text { DIS- } \\
\text { SOLVEO } \\
\text { IRON } \\
\text { (FE) } \\
\text { (UG/L) }\end{array}$ \\
\hline $\begin{array}{l}\text { NOV } \\
11 . . . \\
\text { DEC }\end{array}$ & .1 & 9.8 & 198 & 201 & .27 & 54,0 & .10 & 150 & 0 \\
\hline $\begin{array}{l}11 \ldots \\
\text { JAN } \\
30 \ldots\end{array}$ & .1 & 10 & 187 & 186 & .25 & 48.8 & .24 & 120 & 30 \\
\hline
\end{tabular}

\begin{tabular}{|c|c|c|c|c|c|c|c|c|c|}
\hline DATE & $\begin{array}{l}\text { PERCENT } \\
\text { SODIUM }\end{array}$ & $\begin{array}{c}\text { SODIUM } \\
\text { AD- } \\
\text { SORP- } \\
\text { TION } \\
\text { RATIO }\end{array}$ & $\begin{array}{l}\text { DIS- } \\
\text { SOLVED } \\
\text { PO- } \\
\text { TAS- } \\
\text { SIUM } \\
\text { (K) } \\
\text { (MG/L) }\end{array}$ & $\begin{array}{l}\text { BICAR- } \\
\text { BONATE } \\
\text { (HCO3) } \\
\text { (MG/L) }\end{array}$ & $\begin{array}{l}\text { CAR }= \\
\text { BONATE } \\
\text { (CO3) } \\
\text { (HG/L) }\end{array}$ & $\begin{array}{l}\text { ALKA- } \\
\text { LINITY } \\
\text { AS } \\
\text { CACO3 } \\
\text { (MG/L) }\end{array}$ & $\begin{array}{l}\text { CARBON } \\
\text { OIOXIDE } \\
\text { (COL) } \\
\text { (HG/L) }\end{array}$ & $\begin{array}{c}\text { DIS- } \\
\text { SOLVED } \\
\text { SULFATE } \\
\text { (SO\&) } \\
\text { (MO/L) }\end{array}$ & $\begin{array}{l}\text { DIS- } \\
\text { SOLVED } \\
\text { CHLO- } \\
\text { RIOE } \\
\text { (CL) } \\
(M G / L)\end{array}$ \\
\hline
\end{tabular}

\begin{tabular}{|c|c|c|c|c|c|c|c|c|c|}
\hline NOV & & & & & & & & & \\
\hline${ }_{D E C}^{11} \cdots$ & 44 & 1.5 & 1.7 & 80 & 11 & 84 & .1 & 31 & 42 \\
\hline${ }_{\text {JAN }} 11 \cdots$ & 45 & 1.6 & 2.5 & 92 & 0 & 75 & .5 & 28 & 38 \\
\hline $30 \ldots$ & 45 & 1.5 & 2.2 & 58 & 13 & 69 & .2 & 28 & 36 \\
\hline
\end{tabular}




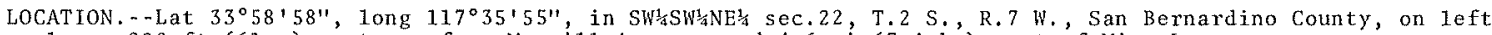

levee $200 \mathrm{ft}(61 \mathrm{~m})$ upstream from Merri11 Avenue, and $4.6 \mathrm{mi}(7.4 \mathrm{~km})$ west of Mira Loma.

DRAINAGE AREA. $\rightarrow-75.8 \mathrm{mi}^{2}\left(196.3 \mathrm{~km}^{2}\right)$.

PERIOD OF RECORD, - -January 1968 to current year.

GAGE. - Water-stage recorder. Datum of gage is $655.3 \mathrm{ft}(199.74 \mathrm{~m})$ above mean sea 1 eve 1.

REMARKS.--Records poor. Extensive ground-water withdrawals for municipal supply and irrigation. See schematic diagran of Santa Ana River basin.

AVERAGE DISCHARGE, -8 years, $2.74 \mathrm{ft}^{3} / \mathrm{s}\left(0.078 \mathrm{~m}^{3} / \mathrm{s}\right), 1,990 \mathrm{acre}-\mathrm{ft} / \mathrm{yr}\left(2.45 \mathrm{hm}^{3} / \mathrm{yr}^{2}\right)$.

EXTREMES FOR PERIOD OF RECORD. - Maximum discharge, $9,100 \mathrm{ft}^{3} / \mathrm{s}\left(258 \mathrm{~m}^{3} / \mathrm{s}\right) \mathrm{Jan}$. 25, 1969 , gage height, $7.08 \mathrm{ft}$

$(2.158 \mathrm{~m})$, from floodmark, on basis of slope-area measurement of maximum fiow; no flow most of each year.

EXTREMES FOR CURRENT YEAR. - Maximum discharge, $356 \mathrm{ft}^{3} / \mathrm{s}\left(10.1 \mathrm{~m}^{3} / \mathrm{s}\right)$ Sept. 11 (0030 hrs), gage height, $1.88 \mathrm{ft}$

$(0.573 \mathrm{~m})$, no other peak above base of $300 \mathrm{ft}^{3} / \mathrm{s}\left(8.50 \mathrm{~m}^{3} / \mathrm{s}\right)$; no flow most of year.

DISCHARGE, IN CUBIC FEET PER SECOND, HATER YEAR OCTOBER 1975 TO SEPTEMBER 1976 MEAN VALUES

\begin{tabular}{|c|c|c|c|c|c|c|c|c|c|c|c|c|}
\hline DAY & $O C T$ & NOV & DEC & JAN & FEB & MAR & APR & MAY & JUN & JUL & AUG & SEP \\
\hline $\begin{array}{l}1 \\
2 \\
3 \\
4 \\
5\end{array}$ & & & & & $\begin{array}{l}0 \\
0 \\
0 \\
0 \\
0\end{array}$ & $\begin{array}{r}0 \\
0 \\
0 \\
0 \\
11\end{array}$ & & & & & & $\begin{array}{l}0 \\
0 \\
0 \\
0 \\
0\end{array}$ \\
\hline $\begin{array}{r}6 \\
7 \\
8 \\
9 \\
10\end{array}$ & & & & & $\begin{array}{l}2.3 \\
1.3 \\
3.4 \\
1.5 \\
0\end{array}$ & $\begin{array}{l}0 \\
7,6 \\
0 \\
0 \\
0\end{array}$ & & & & & & $\begin{array}{r}0 \\
0 \\
0 \\
0 \\
14\end{array}$ \\
\hline $\begin{array}{l}11 \\
12 \\
13 \\
14 \\
15\end{array}$ & & & & & $\begin{array}{l}0 \\
0 \\
0 \\
0 \\
0\end{array}$ & $\begin{array}{l}0 \\
0 \\
0 \\
0 \\
0\end{array}$ & & & & & & $\begin{array}{r}17 \\
0 \\
0 \\
0 \\
0\end{array}$ \\
\hline $\begin{array}{l}16 \\
17 \\
18 \\
19 \\
20\end{array}$ & & & & & $\begin{array}{l}0 \\
0 \\
0 \\
0 \\
0\end{array}$ & $\begin{array}{l}0 \\
0 \\
0 \\
0 \\
0\end{array}$ & & & & & & $\begin{array}{l}0 \\
0 \\
0 \\
0 \\
0\end{array}$ \\
\hline $\begin{array}{l}21 \\
22 \\
23 \\
24 \\
25\end{array}$ & & & & & $\begin{array}{l}0 \\
0 \\
0 \\
0 \\
0\end{array}$ & $\begin{array}{l}0 \\
0 \\
0 \\
0 \\
0\end{array}$ & & & & & & $\begin{array}{l}0 \\
0 \\
0 \\
0 \\
0\end{array}$ \\
\hline $\begin{array}{l}26 \\
27 \\
28 \\
29 \\
30 \\
31\end{array}$ & & 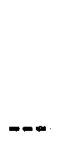 & & & $\begin{array}{l}0 \\
0 \\
0 \\
0 \\
- \\
-\end{array}$ & $\begin{array}{l}0 \\
0 \\
0 \\
0 \\
0 \\
0\end{array}$ & $\ldots$ & & $=-\infty$ & & & $\begin{array}{r}0 \\
0 \\
0 \\
0 \\
0 \\
-\end{array}$ \\
\hline $\begin{array}{l}\text { TOTAL } \\
\text { MEAN } \\
\text { MAX } \\
\text { MIN } \\
\text { ACMFT }\end{array}$ & $\begin{array}{l}0 \\
0 \\
0 \\
0 \\
0\end{array}$ & $\begin{array}{l}0 \\
0 \\
0 \\
0 \\
0\end{array}$ & $\begin{array}{l}0 \\
0 \\
0 \\
0 \\
0\end{array}$ & $\begin{array}{l}0 \\
0 \\
0 \\
0 \\
0\end{array}$ & $\begin{array}{r}8.5 \\
.29 \\
3.4 \\
0 \\
17\end{array}$ & $\begin{array}{r}18,6 \\
.60 \\
11 \\
0 \\
37\end{array}$ & $\begin{array}{l}0 \\
0 \\
0 \\
0 \\
0\end{array}$ & $\begin{array}{l}0 \\
0 \\
0 \\
0 \\
0\end{array}$ & $\begin{array}{l}0 \\
0 \\
0 \\
0 \\
0\end{array}$ & $\begin{array}{l}0 \\
0 \\
0 \\
0 \\
0\end{array}$ & $\begin{array}{l}0 \\
0 \\
0 \\
0 \\
0\end{array}$ & $\begin{array}{r}31 \\
1.03 \\
17 \\
0 \\
61\end{array}$ \\
\hline
\end{tabular}

CAL YR 1975 TOTAL 30.31 MEAN .083 MAX 19 MIN O AC-FT 60 HTR YR 1976 TOTAL 58.10 MEAN:16 MAX I7 MIN 0 AC-FT 115 
11074000 SANTA ANA RIVER BELOW PRADO DAM, CA

(National strean-quality accounting network station)

LOCATION. - Lat $33^{\circ} 53^{\prime} 00^{\prime \prime}$, Iong $117^{\circ} 38^{\prime} 40^{\prime \prime}$, in La Sierra Grant, Riverside County, on left bank of out1et channel, $2,500 \mathrm{ft}(762 \mathrm{~m})$ downstream from axis of Prado Dam, and $4.5 \mathrm{mi}(7.2 \mathrm{~km})$ west of Corona.

DRAINAGE AREA. - - 1,490 $\mathrm{mi}^{2}\left(3,859 \mathrm{~km}^{2}\right)$, excludes $768 \mathrm{mi}^{2}\left(1,989 \mathrm{~km}^{2}\right)$ above Lake Elsinore.

WATER-DISCHARGE RECORDS

PERIOD OF RECORD. - May 1930 to November 1939 (irrigation seasons only), March 1940 to current year. Published as "at Santa Fe Railroad Bridge, near Prado" May 1930 to November 1931, as "at Atchison, Topeka, and Santa Fe Railroad Bridge, near Prado" May 1932 to November 1939, and as "below Prado Dam, near Prado"'March 1940 to September 1950

GAGE. - Water-stage recorder and concrete control since August 1944. Datum of gage is approximately 449 ft (136.9 m) above mean sea level (Corps of Engineers Survey). Prior to Mar. 18, 1940, at about same site at various datums.

REMARKS.--Records good. Flow regulated since 1941 by Prado Reservoir, capacity, 201,200 acre-ft (248 hm ${ }^{3}$ ) and Big Bear Lake (station 11049000). Natural streamflow affected by extensive ground-water withdrawals, diversion for irrigation, and return flow from irrigated areas. California Water Project released 61, 770 acre-ft $\left(76.2 \mathrm{hm}^{3}\right.$ ) to basin (station 11073360). See schematic diagram of Santa Ana River basin.

EXTREMES FOR PERIOD OF RECORD, - -Maximum discharge, $5,800 \mathrm{ft}^{3} / \mathrm{s}\left(164 \mathrm{~m}^{3} / \mathrm{s}\right) \mathrm{Jan}$. 26, 1969 , gage height, $5.75 \mathrm{ft}^{3}$ $(1.753 \mathrm{~m})$; minimum daily $3.0 \mathrm{ft}^{3} / \mathrm{s}\left(0.085 \mathrm{~m}^{3} / \mathrm{s}\right)$ Sept. $24-30,1973$. F1ood of Mar. 2, $1938,100,000 \mathrm{ft} 3 / \mathrm{s}$ $\left(2,830 \mathrm{~m}^{3} / \mathrm{s}\right)$, by slope-area measurement at site $2.5 \mathrm{mi}(4.0 \mathrm{~km})$ downstream.

EXTREMES FOR CURRENT YEAR. - Maximum discharge, $599 \mathrm{ft}^{3} / \mathrm{s}\left(17.0 \mathrm{~m}^{3} / \mathrm{s}\right)$ Sept. 11, gage height, $3.86 \mathrm{ft}(1.177 \mathrm{~m})$; minimum daily, $33 \mathrm{ft}^{3} / \mathrm{s}\left(0.93 \mathrm{~m}^{3} / \mathrm{s}\right)$ Aug. 6, 30, Sept. 1 .

DISCHARGE, IN CUBIC FEET PER SECOND, WATER YEAR OCTOBER 1975 TO SEPTEMBER 1976 ME AN VALUES

\begin{tabular}{|c|c|c|c|c|c|c|c|c|c|c|c|c|}
\hline DAY & OCT & NOV & DEC & JAN & FEB & MAR & APR & MAY & JUN & JUL & AUG & SEP \\
\hline $\begin{array}{l}1 \\
2 \\
3 \\
4 \\
5\end{array}$ & $\begin{array}{l}98 \\
99 \\
97 \\
89 \\
84\end{array}$ & $\begin{array}{l}66 \\
66 \\
66 \\
66 \\
66\end{array}$ & $\begin{array}{l}318 \\
323 \\
345 \\
280 \\
327\end{array}$ & $\begin{array}{l}265 \\
262 \\
266 \\
264 \\
281\end{array}$ & $\begin{array}{l}255 \\
292 \\
334 \\
286 \\
197\end{array}$ & $\begin{array}{l}216 \\
217 \\
265 \\
286 \\
270\end{array}$ & $\begin{array}{r}158 \\
79 \\
73 \\
107 \\
128\end{array}$ & $\begin{array}{l}63 \\
60 \\
62 \\
66 \\
77\end{array}$ & $\begin{array}{l}258 \\
248 \\
254 \\
255 \\
255\end{array}$ & $\begin{array}{l}180 \\
203 \\
200 \\
203 \\
178\end{array}$ & $\begin{array}{l}42 \\
41 \\
45 \\
46 \\
41\end{array}$ & $\begin{array}{l}33 \\
34 \\
36 \\
40 \\
44\end{array}$ \\
\hline $\begin{array}{r}6 \\
7 \\
8 \\
9 \\
10\end{array}$ & $\begin{array}{l}88 \\
54 \\
49 \\
48 \\
48\end{array}$ & $\begin{array}{l}66 \\
66 \\
66 \\
66 \\
71\end{array}$ & $\begin{array}{l}362 \\
366 \\
339 \\
180 \\
175\end{array}$ & $\begin{array}{l}329 \\
328 \\
338 \\
340 \\
339\end{array}$ & $\begin{array}{l}270 \\
279 \\
307 \\
321 \\
296\end{array}$ & $\begin{array}{r}203 \\
102 \\
97 \\
97 \\
139\end{array}$ & $\begin{array}{l}77 \\
70 \\
72 \\
70 \\
68\end{array}$ & $\begin{array}{r}76 \\
108 \\
90 \\
74 \\
71\end{array}$ & $\begin{array}{l}255 \\
257 \\
255 \\
257 \\
311\end{array}$ & $\begin{array}{l}110 \\
107 \\
167 \\
109 \\
107\end{array}$ & $\begin{array}{l}33 \\
36 \\
35 \\
34 \\
38\end{array}$ & $\begin{array}{r}47 \\
46 \\
64 \\
49 \\
149\end{array}$ \\
\hline $\begin{array}{l}11 \\
12 \\
13 \\
14 \\
15\end{array}$ & $\begin{array}{l}51 \\
51 \\
48 \\
49 \\
50\end{array}$ & $\begin{array}{l}149 \\
149 \\
152 \\
155 \\
155\end{array}$ & $\begin{array}{l}168 \\
178 \\
203 \\
181 \\
174\end{array}$ & $\begin{array}{l}334 \\
329 \\
339 \\
338 \\
332\end{array}$ & $\begin{array}{l}279 \\
266 \\
215 \\
180 \\
180\end{array}$ & $\begin{array}{l}247 \\
250 \\
256 \\
260 \\
263\end{array}$ & $\begin{array}{r}66 \\
73 \\
158 \\
130 \\
92\end{array}$ & $\begin{array}{l}69 \\
66 \\
59 \\
60 \\
60\end{array}$ & $\begin{array}{l}382 \\
370 \\
362 \\
326 \\
244\end{array}$ & $\begin{array}{l}107 \\
107 \\
105 \\
107 \\
105\end{array}$ & $\begin{array}{l}42 \\
37 \\
38 \\
41 \\
41\end{array}$ & $\begin{array}{l}423 \\
410 \\
398 \\
378 \\
329\end{array}$ \\
\hline $\begin{array}{l}16 \\
17 \\
18 \\
19 \\
20\end{array}$ & $\begin{array}{r}52 \\
52 \\
96 \\
100 \\
100\end{array}$ & $\begin{array}{l}154 \\
153 \\
176 \\
258 \\
260\end{array}$ & $\begin{array}{l}194 \\
331 \\
333 \\
330 \\
330\end{array}$ & $\begin{array}{l}328 \\
337 \\
334 \\
316 \\
270\end{array}$ & $\begin{array}{l}178 \\
177 \\
206 \\
254 \\
264\end{array}$ & $\begin{array}{l}280 \\
290 \\
290 \\
294 \\
284\end{array}$ & $\begin{array}{r}105 \\
81 \\
79 \\
75 \\
77\end{array}$ & $\begin{array}{l}57 \\
56 \\
58 \\
56 \\
58\end{array}$ & $\begin{array}{l}248 \\
245 \\
237 \\
237 \\
238\end{array}$ & $\begin{array}{l}53 \\
43 \\
45 \\
49 \\
47\end{array}$ & $\begin{array}{l}38 \\
36 \\
37 \\
43 \\
49\end{array}$ & $\begin{array}{r}114 \\
100 \\
86 \\
87 \\
86\end{array}$ \\
\hline $\begin{array}{l}21 \\
22 \\
23 \\
24 \\
25\end{array}$ & $\begin{array}{l}100 \\
100 \\
100 \\
100 \\
100\end{array}$ & $\begin{array}{l}256 \\
254 \\
258 \\
251 \\
264\end{array}$ & $\begin{array}{l}354 \\
335 \\
287 \\
286 \\
286\end{array}$ & $\begin{array}{r}269 \\
235 \\
95 \\
287 \\
286\end{array}$ & $\begin{array}{l}256 \\
237 \\
162 \\
107 \\
132\end{array}$ & $\begin{array}{l}277 \\
263 \\
246 \\
237 \\
234\end{array}$ & $\begin{array}{l}77 \\
76 \\
79 \\
72 \\
73\end{array}$ & $\begin{array}{l}56 \\
56 \\
61 \\
71 \\
75\end{array}$ & $\begin{array}{l}234 \\
229 \\
231 \\
229 \\
198\end{array}$ & $\begin{array}{l}47 \\
50 \\
49 \\
45 \\
42\end{array}$ & $\begin{array}{l}53 \\
43 \\
40 \\
36 \\
36\end{array}$ & $\begin{array}{r}85 \\
86 \\
87 \\
86 \\
137\end{array}$ \\
\hline $\begin{array}{l}26 \\
27 \\
28 \\
29 \\
30 \\
31\end{array}$ & $\begin{array}{r}100 \\
120 \\
150 \\
150 \\
160 \\
95\end{array}$ & $\begin{array}{l}269 \\
317 \\
329 \\
339 \\
321 \\
-\end{array}$ & $\begin{array}{l}281 \\
276 \\
271 \\
270 \\
268 \\
269\end{array}$ & $\begin{array}{l}273 \\
281 \\
283 \\
274 \\
274 \\
271\end{array}$ & $\begin{array}{l}252 \\
263 \\
267 \\
270 \\
-0 . \\
-. .\end{array}$ & $\begin{array}{l}230 \\
230 \\
230 \\
227 \\
234 \\
234\end{array}$ & $\begin{array}{r}73 \\
72 \\
72 \\
68 \\
67 \\
---\end{array}$ & $\begin{array}{r}75 \\
216 \\
252 \\
247 \\
253 \\
252\end{array}$ & $\begin{array}{l}153 \\
152 \\
152 \\
170 \\
170 \\
--1\end{array}$ & $\begin{array}{l}46 \\
47 \\
47 \\
46 \\
45 \\
45\end{array}$ & $\begin{array}{l}35 \\
41 \\
37 \\
36 \\
33 \\
34\end{array}$ & $\begin{array}{r}98 \\
90 \\
87 \\
86 \\
98 \\
--\end{array}$ \\
\hline $\begin{array}{l}\text { TOTAL } \\
\text { MEAN } \\
\text { MAX } \\
\text { MIN } \\
\text { AC }-F T\end{array}$ & $\begin{array}{r}2678 \\
86.4 \\
160 \\
48 \\
5310\end{array}$ & $\begin{array}{r}5284 \\
176 \\
339 \\
66 \\
10480\end{array}$ & $\begin{array}{r}8620 \\
278 \\
366 \\
168 \\
17100\end{array}$ & $\begin{array}{r}9097 \\
293 \\
340 \\
95 \\
18040\end{array}$ & $\begin{array}{r}6982 \\
241 \\
334 \\
107 \\
13850\end{array}$ & $\begin{array}{r}7248 \\
234 \\
294 \\
97 \\
14380\end{array}$ & $\begin{array}{r}2567 \\
85.6 \\
158 \\
66 \\
5090\end{array}$ & $\begin{array}{r}2960 \\
95.5 \\
253 \\
56 \\
5870\end{array}$ & $\begin{array}{r}7412 \\
247 \\
382 \\
152 \\
14700\end{array}$ & $\begin{array}{r}2841 \\
91.6 \\
203 \\
42 \\
5640\end{array}$ & $\begin{array}{r}1217 \\
39.3 \\
53 \\
33 \\
2410\end{array}$ & $\begin{array}{r}3893 \\
130 \\
423 \\
33 \\
7720\end{array}$ \\
\hline
\end{tabular}
$\begin{array}{llllllllll}\text { CAL YR } 1975 & \text { TOTAL } & 49588 & \text { MEAN } 136 & \text { MAX } & 366 & \text { MIN } 45 & \text { AC-FT } & 98360 \\ \text { HTR YR } 1976 & \text { TOTAL } & 60799 & \text { MEAN } 166 & \text { MAX } & 423 & \text { MIN } 33 & \text { AC-FT } & 120600\end{array}$ 
PERIOD OF RECORD, - Water year 1967 to current year.

CHEMICAL ANALYSES: Water year 1967 to current year.

WATER TEMPERATURES: Water year 1970 to current year.

SEDIMENT RECORDS: Water year 1974 to current year.

PERIOD OF DAILY RECORD. -

CHLORIDE: October 1970 to September 1971 .

SPECIFIC CONDUCTANCE: October 1969 to current year.

WATER TEMPERATURES: October 1969 to current year.

SEDIMENT RECORDS.--October 1973 to current year.

INSTRUMENTATION. - -Water-quality monitor October 1970 to September 1971. Specific conductance recorder since October 1969. Temperature recorder since october 1969.

REMARKS.-Periods of missing temperature record due to recorder malfunction. Particle-size distribution of bed material table was omitted in the 1975 water year and is published with the 1976 water year records.

COOPERATION. - The letter "A" following a date indicates chemical-quality data furnished by California

Department of Water Resources.

EXTREMES FOR PERIOD OF DAILY RECORD. -

SPECIFIC CONDUCTANCE: Maximum, I, 830 micromhos Apr. 30, 1971 ; minimum, 316 micromhos Dec. 4, 1974. WATER TEMPTERATURES: Maximum, $36.0 \mathrm{C}^{\circ} \mathrm{C}$ Sept. 4,$1972 ; \mathrm{minimum}, 2.5^{\circ} \mathrm{C}$ Dec. 30,1969 ,

SEDIMENT CONCENTRATIONS: Maximum daily mean, $1,300 \mathrm{mg} / 1 \mathrm{Jan} .8$, 1974 ; minimum daily mean, $15 \mathrm{mg} / 1$ on several days in 1975 .

SEDIMENT DISCHARGE: Maximum daily, 5,050 tons $(4,580$ tonnes) Jan. 8, 1974; minimum daily, 5.0 tons

(4.5 tonnes) Feb. 13, 1975 .

EXTREMES FOR CURRENT YEAR - -

SPECIFIC CONDUCTANCE: Maximum, 1,390 micromhos Feb, 23; minimum, 482 micromhos Feb. 6.

WATER TEMPERATURES: Maximum, $27.0^{\circ} \mathrm{C}$ May 12 , July 27 , Sept. $4 ;$ minimum, $4.0^{\circ} \mathrm{C} J a n .2$.

SEDIMENT CONCENTRATIONS: Maximum daily mean, 1,010 mg/1 Feb. 23; minimum daily mean, $17 \mathrm{mg} / 1 \mathrm{Mar}$. 19.

SEDIMENT DISCHARGE: Maximum daily, 458 tons (415 tonnes) Sept. I0; minimum daily, 8.7 tons (7.9 tonnes)

Apr, 17.

CHEMICAL ANALYSES, WATER YEAR OCTOBER 1975 TO SEPTEMBER 1976

\begin{tabular}{|c|c|c|c|c|c|c|c|c|c|c|}
\hline DATE & TIHE & $\begin{array}{l}\text { INSTAN- } \\
\text { TANEOUS } \\
\text { DIS- } \\
\text { CHARGE } \\
\text { (CFS) }\end{array}$ & $\begin{array}{l}\text { SPE- } \\
\text { CIFIC } \\
\text { CON- } \\
\text { DUCT- } \\
\text { ANCE } \\
\text { (MICRO- } \\
\text { MHOS) }\end{array}$ & $\begin{array}{c}P H \\
\text { (UNITS) }\end{array}$ & $\begin{array}{l}\text { TEMPER - } \\
\text { ATURE } \\
\text { (DEG C) }\end{array}$ & $\begin{array}{l}\text { DIS- } \\
\text { SOLVED } \\
\text { SOLIDS } \\
\text { (RESI - } \\
\text { DUE AT } \\
\text { IBO C) } \\
\text { (NG/L) }\end{array}$ & $\begin{array}{l}\text { DIS- } \\
\text { SOLVED } \\
\text { SOLIDS } \\
\text { (SUH OF } \\
\text { CONSTI - } \\
\text { TUENTS) } \\
\text { (MG/L) }\end{array}$ & $\begin{array}{l}\text { OIS- } \\
\text { SOLVEO } \\
\text { SOLIDS } \\
\text { (TONS } \\
\text { PER } \\
\text { AC } \rightarrow F T \text { ) }\end{array}$ & $\begin{array}{l}\text { DIS- } \\
\text { SOLVED } \\
\text { SOLIOS } \\
\text { (TONS } \\
\text { PER } \\
\text { DAY) }\end{array}$ & $\begin{array}{l}\text { TOTAL } \\
\text { NON- } \\
\text { FILT- } \\
\text { RABLE } \\
\text { RESIDUE } \\
\text { (MG/L) }\end{array}$ \\
\hline $\begin{array}{l}\text { Oct } \\
01 \ldots . . \\
16 \ldots \\
28 \ldots . \\
30 \ldots A\end{array}$ & $\begin{array}{l}1600 \\
0930 \\
1445 \\
1315\end{array}$ & $\begin{array}{r}98 \\
56 \\
150 \\
160\end{array}$ & $\begin{array}{r}790 \\
1110 \\
780 \\
760\end{array}$ & $\begin{array}{r}-5 \\
7.8 \\
7.9\end{array}$ & $\begin{array}{l}21.1 \\
13.0 \\
16.0 \\
14.0\end{array}$ & $\begin{array}{l}471 \\
684 \\
437 \\
423\end{array}$ & $=$ & $\begin{array}{l}.64 \\
.93 \\
.59 \\
.58\end{array}$ & $\begin{array}{l}125 \\
103 \\
177 \\
183\end{array}$ & $\begin{array}{r}=- \\
159 \\
=-\end{array}$ \\
\hline $\begin{array}{l}\text { NOV } \\
03 \ldots . \\
17 \ldots \\
19 \ldots \\
20 \ldots \text { A } \\
25 \ldots \text { A } \\
\text { DEC }\end{array}$ & $\begin{array}{l}1205 \\
1500 \\
1200 \\
1330 \\
1310\end{array}$ & $\begin{array}{r}70 \\
162 \\
257 \\
265 \\
270\end{array}$ & $\begin{array}{r}1140 \\
705 \\
607 \\
650 \\
611\end{array}$ & $\begin{array}{r}=- \\
=- \\
7.7 \\
7.9\end{array}$ & $\begin{array}{l}14.5 \\
13.5 \\
10.2 \\
11.0 \\
11.9\end{array}$ & $\begin{array}{l}680 \\
411 \\
349 \\
407 \\
372\end{array}$ & $\begin{array}{l}-1 \\
-\infty \\
358\end{array}$ & $\begin{array}{l}.92 \\
.56 \\
.47 \\
.55 \\
.51\end{array}$ & $\begin{array}{l}129 \\
180 \\
242 \\
291 \\
271\end{array}$ & $\begin{array}{l}= \\
=- \\
68\end{array}$ \\
\hline $\begin{array}{l}02 \ldots \ldots \\
18 \ldots \ldots \text { A } \\
18 \ldots \ldots \\
29 \ldots \ldots \\
31 \ldots . \\
\text { JAN }\end{array}$ & $\begin{array}{l}1100 \\
1100 \\
1430 \\
1300 \\
1145\end{array}$ & $\begin{array}{l}322 \\
333 \\
336 \\
270 \\
270\end{array}$ & $\begin{array}{l}576 \\
583 \\
500 \\
605 \\
665\end{array}$ & $\begin{array}{r}-5 \\
7.6 \\
7.9\end{array}$ & $\begin{array}{r}9.7 \\
7.2 \\
10.0 \\
11.1 \\
11.2\end{array}$ & $\begin{array}{l}320 \\
338 \\
401 \\
359 \\
372\end{array}$ & $\begin{array}{l}-- \\
361\end{array}$ & $\begin{array}{l}.44 \\
.46 \\
.55 \\
.49 \\
.51\end{array}$ & $\begin{array}{l}278 \\
304 \\
364 \\
262 \\
271\end{array}$ & $\begin{array}{l}=- \\
53 \\
=-\end{array}$ \\
\hline $\begin{array}{l}07 \ldots \ldots \\
16 \ldots \ldots \\
20 \ldots \ldots \\
30 \ldots \text { A } \\
\text { FEB }\end{array}$ & $\begin{array}{l}1400 \\
0930 \\
1430 \\
1420\end{array}$ & $\begin{array}{l}327 \\
339 \\
270 \\
266\end{array}$ & $\begin{array}{l}564 \\
515 \\
624 \\
550\end{array}$ & $\begin{array}{r}-.0 \\
8.0 \\
7.9\end{array}$ & $\begin{array}{r}9.2 \\
8.0 \\
12.4 \\
12.0\end{array}$ & $\begin{array}{l}342 \\
328 \\
363 \\
363\end{array}$ & $\begin{array}{r}336 \\
-\infty\end{array}$ & $\begin{array}{l}.47 \\
.45 \\
.49 \\
.49\end{array}$ & $\begin{array}{l}302 \\
300 \\
265 \\
261\end{array}$ & $=-$ \\
\hline $\begin{array}{l}02 \ldots \ldots \\
09 \ldots \ldots \\
20 \ldots \ldots \\
23 \ldots \ldots \\
26 \ldots \ldots \text { A }\end{array}$ & $\begin{array}{l}1400 \\
0930 \\
1300 \\
1115 \\
1300\end{array}$ & $\begin{array}{l}287 \\
273 \\
260 \\
200 \\
253\end{array}$ & $\begin{array}{r}580 \\
750 \\
1110 \\
1320 \\
570\end{array}$ & $\begin{array}{l}7.8 \\
7.8 \\
7.8 \\
7.6\end{array}$ & $\begin{array}{l}11.8 \\
13.1 \\
13.5 \\
11.2 \\
11.0\end{array}$ & $\begin{array}{l}342 \\
507 \\
652 \\
836 \\
388\end{array}$ & $\begin{array}{r}442 \\
038 \\
0-\end{array}$ & $\begin{array}{r}.47 \\
.69 \\
.89 \\
1.14 \\
.53\end{array}$ & $\begin{array}{l}265 \\
374 \\
658 \\
451 \\
265\end{array}$ & $\begin{array}{l}=- \\
=- \\
128\end{array}$ \\
\hline $\begin{array}{l}01 \ldots \\
03 \ldots \\
15 \ldots \\
30 \ldots \\
30 \ldots \text { A } \\
\text { APR }\end{array}$ & $\begin{array}{l}1300 \\
1000 \\
1000 \\
1000 \\
1350\end{array}$ & $\begin{array}{l}167 \\
234 \\
266 \\
234 \\
230\end{array}$ & $\begin{array}{l}873 \\
716 \\
607 \\
700 \\
620\end{array}$ & $\begin{array}{r}-.5 \\
7.5 \\
7.8 \\
7.7\end{array}$ & $\begin{array}{l}13.9 \\
10.7 \\
13.3 \\
11.8 \\
15.5\end{array}$ & $\begin{array}{l}530 \\
430 \\
353 \\
394 \\
377\end{array}$ & $\begin{array}{r}-\infty \\
427 \\
396 \\
-\infty\end{array}$ & $\begin{array}{l}.72 \\
.56 \\
.48 \\
.54 \\
.51\end{array}$ & $\begin{array}{l}239 \\
272 \\
254 \\
249 \\
234\end{array}$ & $\begin{array}{l}=- \\
=- \\
93\end{array}$ \\
\hline $\begin{array}{l}01 \ldots \ldots \\
13 \ldots \ldots \\
22 \ldots \ldots \text { A } \\
30 \ldots \ldots\end{array}$ & $\begin{array}{l}1400 \\
1200 \\
1310 \\
1250\end{array}$ & $\begin{array}{r}103 \\
200 \\
78 \\
69\end{array}$ & $\begin{array}{r}1050 \\
620 \\
1120 \\
1190\end{array}$ & $\begin{array}{l}.0 \\
7.7 \\
7.9\end{array}$ & $\begin{array}{l}18.8 \\
13.5 \\
19.5 \\
19.2\end{array}$ & $\begin{array}{l}631 \\
377 \\
674 \\
702\end{array}$ & $\begin{array}{l}= \\
= \\
=\end{array}$ & $\begin{array}{r}.86 \\
.51 \\
.92 \\
.95\end{array}$ & $\begin{array}{l}175 \\
204 \\
142 \\
131\end{array}$ & $\begin{array}{r}-\infty \\
107\end{array}$ \\
\hline $04 \ldots$ & 0900 & 70 & 1120 & $\infty$ & 16.7 & 693 & $-\infty$ & .94 & 131 & $=$ \\
\hline
\end{tabular}


11074000 SANTA ANA RIVER BELOW PRADO DAM, CA--Continued

CHEMICAL ANALYSES, HATER YEAR OCTOBER 1975 TO SEPTEMBER 1976

\begin{tabular}{|c|c|c|c|c|c|c|c|c|c|c|}
\hline DATE & TIME & $\begin{array}{c}\text { INSTAN- } \\
\text { TANEOUS } \\
\text { OIS- } \\
\text { CHARGE } \\
\text { (CFS) }\end{array}$ & $\begin{array}{l}\text { SPE- } \\
\text { CIFIC } \\
\text { CON- } \\
\text { DUCT- } \\
\text { ANCE } \\
\text { (MICRO- } \\
\text { MHOS) }\end{array}$ & $\begin{array}{c}\text { PH } \\
\text { (UNITS) }\end{array}$ & $\begin{array}{l}\text { TEMPER- } \\
\text { ATURE } \\
\text { (DEG C) }\end{array}$ & $\begin{array}{l}\text { DIS- } \\
\text { SOLVED } \\
\text { SOLIDS } \\
\text { (RESI- } \\
\text { DUE AT } \\
180 \text { C) } \\
\text { (MG/L) }\end{array}$ & $\begin{array}{l}\text { DIS- } \\
\text { SOLVEO } \\
\text { SOLIDS } \\
\text { (SUM OF } \\
\text { CONSTI- } \\
\text { TUENTS) } \\
\text { (MG/L) }\end{array}$ & $\begin{array}{l}\text { DIS- } \\
\text { SOLVED } \\
\text { SOLIDS } \\
\text { (TONS } \\
\text { PER } \\
\text { AC-FT) }\end{array}$ & $\begin{array}{l}\text { DIS- } \\
\text { SOLVED } \\
\text { SOLIDS } \\
\text { (TONS } \\
\text { PER } \\
\text { DAY) }\end{array}$ & $\begin{array}{l}\text { TOTAL } \\
\text { NON- } \\
\text { FILT- } \\
\text { RABLE } \\
\text { RESIDUE } \\
\text { (MG/L) }\end{array}$ \\
\hline MAY & & & & & & & & & & \\
\hline $\begin{array}{l}20 \ldots A \\
20 \ldots \ldots \\
24 \ldots \ldots\end{array}$ & $\begin{array}{l}1315 \\
1400 \\
1200\end{array}$ & $\begin{array}{l}63 \\
61 \\
82\end{array}$ & $\begin{array}{l}1080 \\
1100 \\
1100\end{array}$ & $\begin{array}{r}7.8 \\
7.9\end{array}$ & $\begin{array}{l}21.0 \\
22.1 \\
17.5\end{array}$ & $\begin{array}{l}671 \\
696 \\
708\end{array}$ & -0 & $\begin{array}{l}.91 \\
.95 \\
.96\end{array}$ & $\begin{array}{l}114 \\
115 \\
157\end{array}$ & $\begin{array}{l}= \\
=-\end{array}$ \\
\hline $\begin{array}{l}\text { JUN } \\
01 \ldots . . \\
15 \ldots \ldots \\
25 \ldots \ldots \text { A } \\
30 \ldots \ldots \\
\text { JUL }\end{array}$ & $\begin{array}{l}1200 \\
1300 \\
1200 \\
1115\end{array}$ & $\begin{array}{l}270 \\
247 \\
209 \\
180\end{array}$ & $\begin{array}{l}650 \\
575 \\
570 \\
580\end{array}$ & $\begin{array}{l}-- \\
7.6 \\
7.6\end{array}$ & $\begin{array}{l}17.1 \\
19.4 \\
21.0 \\
24.5\end{array}$ & $\begin{array}{r}372 \\
360 \\
331 \\
-\end{array}$ & $\begin{array}{l}-- \\
-- \\
--\end{array}$ & $\begin{array}{r}.51 \\
.49 \\
.45 \\
.-\end{array}$ & $\begin{array}{l}271 \\
240 \\
187\end{array}$ & $\begin{array}{l}-= \\
-= \\
=-\end{array}$ \\
\hline $\begin{array}{l}01 \ldots \\
13 \ldots \ldots \\
29 \ldots \\
29 \ldots \\
30 \ldots \text { A } \\
\text { AUG }\end{array}$ & $\begin{array}{l}1145 \\
1220 \\
1100 \\
1225 \\
0925\end{array}$ & $\begin{array}{r}178 \\
111 \\
51 \\
50 \\
49\end{array}$ & $\begin{array}{r}592 \\
705 \\
1000 \\
1050 \\
1000\end{array}$ & $\begin{array}{l}-= \\
7.8 \\
7.7\end{array}$ & $\begin{array}{l}19.4 \\
21.8 \\
22.5 \\
21.9 \\
21.0\end{array}$ & $\begin{array}{l}352 \\
396 \\
657 \\
646 \\
594\end{array}$ & $\begin{array}{l}m- \\
677 \\
=- \\
--\end{array}$ & $\begin{array}{l}.48 \\
.54 \\
.89 \\
.88 \\
.81\end{array}$ & $\begin{array}{r}169 \\
119 \\
90.5 \\
88.6 \\
78.6\end{array}$ & $=$ \\
\hline $\begin{array}{l}16 \ldots \\
24 \ldots \\
\text { SEP }\end{array}$ & $\begin{array}{l}1215 \\
1130\end{array}$ & $\begin{array}{l}45 \\
40\end{array}$ & $\begin{array}{l}1090 \\
1050\end{array}$ & $8 . \overline{1}$ & $\begin{array}{l}20.8 \\
19.5\end{array}$ & $\begin{array}{l}669 \\
674\end{array}$ & $6 \overline{91}$ & .91 & $\begin{array}{l}81.3 \\
72.8\end{array}$ & $=$ \\
\hline $\begin{array}{l}02 \ldots \\
03 \ldots \ldots A \\
24 \ldots\end{array}$ & $\begin{array}{l}1100 \\
0935 \\
1050\end{array}$ & $\begin{array}{l}38 \\
32 \\
90\end{array}$ & $\begin{array}{l}1120 \\
1050 \\
1100\end{array}$ & $\begin{array}{l}7.5 \\
7.8\end{array}$ & $\begin{array}{l}20.4 \\
23.0 \\
21.5\end{array}$ & $\begin{array}{l}688 \\
696 \\
712\end{array}$ & $\ddot{725}$ & $\begin{array}{l}.94 \\
.95 \\
.97\end{array}$ & $\begin{array}{l}70.6 \\
60.1 \\
173\end{array}$ & 100 \\
\hline
\end{tabular}

\begin{tabular}{|c|c|c|c|c|c|c|c|c|c|c|}
\hline DATE & TIME & $\begin{array}{l}\text { INSTAN- } \\
\text { TANEOUS } \\
\text { DIS- } \\
\text { CHARGE } \\
\text { (CFS) }\end{array}$ & $\begin{array}{l}\text { TUR- } \\
\text { BID- } \\
\text { ITY } \\
\text { (JTU) }\end{array}$ & $\begin{array}{l}\text { DIS- } \\
\text { SOLVED } \\
\text { OXYGEN } \\
\text { (MG/L) }\end{array}$ & $\begin{array}{l}\text { CHEM- } \\
\text { ICAL } \\
\text { OXYGEN } \\
\text { DEMAND } \\
\text { (HIGH } \\
\text { LEVEL) } \\
\text { (MG/L.) }\end{array}$ & $\begin{array}{l}\text { FECAL } \\
\text { COLI- } \\
\text { FORM } \\
\text { (COL. } \\
\text { PER } \\
100 \mathrm{ML} \text { ) }\end{array}$ & $\begin{array}{l}\text { STREP- } \\
\text { TOCOCCI } \\
\text { ICOL- } \\
\text { ONIES } \\
\text { PER } \\
100 \text { ML.) }\end{array}$ & $\begin{array}{l}\text { HARD- } \\
\text { NESS } \\
(C A, M G) \\
(M G / L)\end{array}$ & $\begin{array}{l}\text { NON- } \\
\text { CAR- } \\
\text { BONATE } \\
\text { HARD- } \\
\text { NESS } \\
\text { (MG/L) }\end{array}$ & $\begin{array}{l}\text { DIS- } \\
\text { SOLVED } \\
\text { CAL- } \\
\text { CIUM } \\
\text { (CA) } \\
\text { (MG/L) }\end{array}$ \\
\hline $\begin{array}{l}\mathrm{OCT} \\
28 \ldots \mathrm{A} \\
30 \ldots .\end{array}$ & $\begin{array}{l}1445 \\
1315\end{array}$ & $\begin{array}{l}150 \\
160\end{array}$ & $\begin{array}{l}48 \\
30\end{array}$ & $\begin{array}{r}8.4 \\
-2\end{array}$ & $\overrightarrow{23}$ & 235 & 460 & $\begin{array}{l}206 \\
190\end{array}$ & $\begin{array}{l}63 \\
37\end{array}$ & $\begin{array}{l}57 \\
53\end{array}$ \\
\hline $\begin{array}{l}\text { NOV } \\
20 \ldots . . A \\
25 \ldots . \\
\text { DEC }\end{array}$ & $\begin{array}{l}1330 \\
1310\end{array}$ & $\begin{array}{l}265 \\
270\end{array}$ & $\begin{array}{l}26 \\
15\end{array}$ & 10.3 & 18 & 150 & 740 & $\begin{array}{l}169 \\
170\end{array}$ & $\begin{array}{l}45 \\
40\end{array}$ & $\begin{array}{l}45 \\
45\end{array}$ \\
\hline $\begin{array}{l}18 \ldots A \\
31 \ldots \ldots \\
\text { JAN }\end{array}$ & $\begin{array}{l}1430 \\
1145\end{array}$ & $\begin{array}{l}336 \\
270\end{array}$ & $\begin{array}{l}17 \\
20\end{array}$ & $\begin{array}{r}10.5 \\
. .-\end{array}$ & 10 & 820 & $28 \overline{0}$ & $\begin{array}{l}163 \\
180\end{array}$ & $\begin{array}{l}41 \\
43\end{array}$ & $\begin{array}{l}43 \\
48\end{array}$ \\
\hline $\begin{array}{c}16 \ldots \ldots \\
30 \ldots A\end{array}$ & $\begin{array}{l}0930 \\
1420\end{array}$ & $\begin{array}{l}339 \\
266\end{array}$ & $\begin{array}{l}20 \\
20\end{array}$ & $10 . \overline{8}$ & 21 & $\begin{array}{l}88 \\
--\end{array}$ & 190 & $\begin{array}{l}170 \\
173\end{array}$ & $\begin{array}{l}49 \\
47\end{array}$ & $\begin{array}{l}46 \\
47\end{array}$ \\
\hline $\begin{array}{l}09 \ldots \ldots \\
23 \ldots \ldots \\
26 \ldots \ldots A \\
M A R\end{array}$ & $\begin{array}{l}0930 \\
1115 \\
1300\end{array}$ & $\begin{array}{l}273 \\
200 \\
253\end{array}$ & $\begin{array}{r}110 \\
700 \\
47\end{array}$ & $10 . \overline{3}$ & $\begin{array}{r}54 \\
270 \\
-\end{array}$ & $\begin{array}{r}=- \\
8300 \\
=-\end{array}$ & $\begin{array}{l}-- \\
B 0\end{array}$ & $\begin{array}{l}180 \\
420 \\
187\end{array}$ & $\begin{array}{r}54 \\
130 \\
56\end{array}$ & $\begin{array}{r}48 \\
120 \\
52\end{array}$ \\
\hline $\begin{array}{l}03 \ldots \\
30 \ldots \\
30 \ldots \text { A } \\
A P R\end{array}$ & $\begin{array}{l}1000 \\
1000 \\
1350\end{array}$ & $\begin{array}{l}234 \\
234 \\
230\end{array}$ & $\begin{array}{r}130 \\
30 \\
16\end{array}$ & 9.9 & $\begin{array}{l}16 \\
18 \\
--\end{array}$ & $\begin{array}{r}-5 \\
154 \\
--\end{array}$ & $\begin{array}{r}-- \\
270 \\
=-\end{array}$ & $\begin{array}{l}200 \\
180 \\
189\end{array}$ & $\begin{array}{l}47 \\
45 \\
57\end{array}$ & $\begin{array}{l}56 \\
49 \\
51\end{array}$ \\
\hline $\begin{array}{l}22 \ldots \ldots \text { A } \\
30 \ldots\end{array}$ & $\begin{array}{l}1310 \\
1250\end{array}$ & $\begin{array}{l}78 \\
69\end{array}$ & $\begin{array}{l}37 \\
30\end{array}$ & $\begin{array}{r}7.5 \\
-.\end{array}$ & 39 & 91000 & 8640 & $\begin{array}{l}320 \\
330\end{array}$ & $\begin{array}{r}110 \\
80\end{array}$ & $\begin{array}{l}93 \\
95\end{array}$ \\
\hline$\underset{J I J N}{20 \ldots \ldots A}$ & $\begin{array}{l}1315 \\
1200\end{array}$ & $\begin{array}{l}63 \\
82\end{array}$ & $\begin{array}{l}31 \\
35\end{array}$ & $\begin{array}{r}7.8 \\
--\end{array}$ & $\overline{34}$ & $B 830$ & $10 \overline{10}$ & $\begin{array}{l}315 \\
320\end{array}$ & $\begin{array}{l}110 \\
120\end{array}$ & $\begin{array}{l}88 \\
93\end{array}$ \\
\hline $\begin{array}{l}25 \ldots \ldots A \\
30 \ldots \ldots\end{array}$ & $\begin{array}{l}1200 \\
1115\end{array}$ & $\begin{array}{l}209 \\
180\end{array}$ & $\begin{array}{l}50 \\
30\end{array}$ & $\begin{array}{r}7.9 \\
-.-\end{array}$ & $=$ & $=$ & $=$ & $\begin{array}{l}160 \\
150\end{array}$ & $\begin{array}{l}45 \\
--\end{array}$ & $\begin{array}{l}41 \\
40\end{array}$ \\
\hline $\begin{array}{r}29 \\
30 \ldots A\end{array}$ & $\begin{array}{l}1100 \\
0925\end{array}$ & $\begin{array}{l}51 \\
49\end{array}$ & $\begin{array}{l}45 \\
53\end{array}$ & 6.2 & $\begin{array}{l}48 \\
--\end{array}$ & $\begin{array}{r}2600 \\
--\end{array}$ & $\begin{array}{r}B 448 \\
--\end{array}$ & $\begin{array}{l}310 \\
297\end{array}$ & $\begin{array}{l}95 \\
61\end{array}$ & $\begin{array}{l}88 \\
83\end{array}$ \\
\hline$\underset{S F P}{24} \cdots$ & 1130 & 40 & 50 & $=-$ & 63 & 320 & 300 & 330 & 110 & 97 \\
\hline $\begin{array}{l}03 \ldots A \\
24 \ldots\end{array}$ & $\begin{array}{l}0935 \\
1050\end{array}$ & $\begin{array}{l}32 \\
90\end{array}$ & $\begin{array}{r}30 \\
130\end{array}$ & 5.4 & $=$ & $B 1350$ & 480 & $\begin{array}{l}308 \\
330\end{array}$ & $\begin{array}{r}67 \\
110\end{array}$ & $\begin{array}{l}82 \\
94\end{array}$ \\
\hline
\end{tabular}

B Results based on colony count outside the acceptable range (non-ideal colony count). 
SANTA ANA RIVER BASIN

11074000 SANTA ANA RIVER BELOW PRADO DAM, CA--Continued

CHEMICAL ANALYSES, WATER YEAR OCTOBER 1975 TO SEPTEMBER 1976

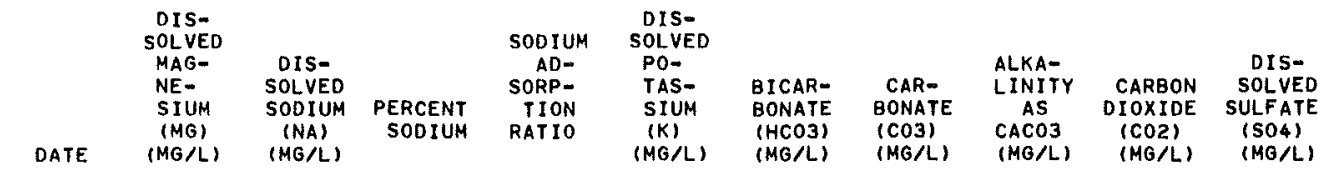

\begin{tabular}{|c|c|c|c|c|c|c|c|c|c|c|}
\hline $\begin{array}{l}\mathrm{OCT} \\
28 \ldots \ldots \mathrm{A} \\
30 \ldots \ldots\end{array}$ & $\begin{array}{l}15 \\
14\end{array}$ & $\begin{array}{l}65 \\
69\end{array}$ & $\begin{array}{l}40 \\
43\end{array}$ & $\begin{array}{l}2.0 \\
2.2\end{array}$ & $\begin{array}{l}5.9 \\
6.2\end{array}$ & $\begin{array}{l}174 \\
186\end{array}$ & $\begin{array}{l}0 \\
0\end{array}$ & $\begin{array}{l}143 \\
153\end{array}$ & $\begin{array}{l}4.4 \\
3.7\end{array}$ & $\begin{array}{l}84 \\
71\end{array}$ \\
\hline NOV & & & & & & & & & & \\
\hline$\underset{D E C}{25 \cdots \cdots A}$ & $\begin{array}{l}14 \\
14\end{array}$ & $\begin{array}{l}54 \\
59\end{array}$ & $\begin{array}{l}40 \\
42\end{array}$ & $\begin{array}{l}1.8 \\
2.0\end{array}$ & $\begin{array}{l}4.7 \\
5.7\end{array}$ & $\begin{array}{l}151 \\
158\end{array}$ & $\begin{array}{l}0 \\
0\end{array}$ & $\begin{array}{l}124 \\
130\end{array}$ & $\begin{array}{l}4.8 \\
3.2\end{array}$ & $\begin{array}{l}64 \\
64\end{array}$ \\
\hline $\begin{array}{l}18 \ldots \ldots \\
31 \ldots \ldots \\
\text { JAN }\end{array}$ & $\begin{array}{l}13 \\
14\end{array}$ & $\begin{array}{l}52 \\
57\end{array}$ & $\begin{array}{l}40 \\
40\end{array}$ & $\begin{array}{l}1.8 \\
1.9\end{array}$ & $\begin{array}{l}4.3 \\
5.0\end{array}$ & $\begin{array}{l}149 \\
164\end{array}$ & $\begin{array}{l}0 \\
0\end{array}$ & $\begin{array}{l}122 \\
135\end{array}$ & $\begin{array}{l}6.0 \\
3.3\end{array}$ & $\begin{array}{l}60 \\
61\end{array}$ \\
\hline $\begin{array}{l}16 \ldots \ldots \\
30 \ldots \ldots \text { A } \\
F E B\end{array}$ & $\begin{array}{l}13 \\
13\end{array}$ & $\begin{array}{l}52 \\
54\end{array}$ & $\begin{array}{l}40 \\
40\end{array}$ & $\begin{array}{l}1.7 \\
1.8\end{array}$ & $\begin{array}{l}3.9 \\
3.9\end{array}$ & $\begin{array}{l}145 \\
154\end{array}$ & $\begin{array}{l}0 \\
0\end{array}$ & $\begin{array}{l}119 \\
126\end{array}$ & $\begin{array}{l}2.3 \\
3.1\end{array}$ & $\begin{array}{l}62 \\
66\end{array}$ \\
\hline $\begin{array}{l}09 \ldots \\
23 \ldots \ldots \\
26 \ldots A \\
M A R\end{array}$ & $\begin{array}{l}15 \\
29 \\
14\end{array}$ & $\begin{array}{r}74 \\
120 \\
54\end{array}$ & $\begin{array}{l}45 \\
38 \\
38\end{array}$ & $\begin{array}{l}2.4 \\
2.6 \\
1.7\end{array}$ & $\begin{array}{l}13 \\
10 \\
5.1\end{array}$ & $\begin{array}{l}156 \\
353 \\
160\end{array}$ & $\begin{array}{l}0 \\
0 \\
0\end{array}$ & $\begin{array}{l}128 \\
290 \\
131\end{array}$ & $\begin{array}{l}4.0 \\
9.0 \\
6.4\end{array}$ & $\begin{array}{r}100 \\
160 \\
70\end{array}$ \\
\hline $\begin{array}{l}03 \ldots \ldots \\
30 \ldots \ldots \\
30 \ldots \ldots \\
A P R\end{array}$ & $\begin{array}{l}15 \\
15 \\
15\end{array}$ & $\begin{array}{l}66 \\
58 \\
59\end{array}$ & $\begin{array}{l}40 \\
40 \\
40\end{array}$ & $\begin{array}{l}2.0 \\
1.9 \\
1.9\end{array}$ & $\begin{array}{l}7.7 \\
5.1 \\
4.3\end{array}$ & $\begin{array}{l}189 \\
170 \\
161\end{array}$ & $\begin{array}{l}0 \\
0 \\
0\end{array}$ & $\begin{array}{l}155 \\
139 \\
132\end{array}$ & $\begin{array}{l}9.6 \\
4.3 \\
5.1\end{array}$ & $\begin{array}{l}81 \\
69 \\
73\end{array}$ \\
\hline $\begin{array}{l}22 \ldots \text { A } \\
30 \ldots \ldots \\
\text { MAY }\end{array}$ & $\begin{array}{l}22 \\
23\end{array}$ & $\begin{array}{l}103 \\
110\end{array}$ & $\begin{array}{l}40 \\
41\end{array}$ & $\begin{array}{l}2.5 \\
2.6\end{array}$ & $\begin{array}{l}9.0 \\
8.7\end{array}$ & $\begin{array}{l}260 \\
307\end{array}$ & $\begin{array}{l}0 \\
0\end{array}$ & $\begin{array}{l}213 \\
252\end{array}$ & $\begin{array}{l}8.3 \\
6.2\end{array}$ & $\begin{array}{l}135 \\
130\end{array}$ \\
\hline $\begin{array}{l}20 \ldots A \\
24 \ldots A\end{array}$ & $\begin{array}{l}23 \\
22\end{array}$ & $\begin{array}{l}112 \\
110\end{array}$ & $\begin{array}{l}43 \\
42\end{array}$ & $\begin{array}{l}2.7 \\
2.7\end{array}$ & $\begin{array}{l}9.0 \\
8.0\end{array}$ & $\begin{array}{l}250 \\
247\end{array}$ & $\begin{array}{l}0 \\
0\end{array}$ & $\begin{array}{l}205 \\
203\end{array}$ & $\begin{array}{l}6.3 \\
5.0\end{array}$ & $\begin{array}{l}138 \\
130\end{array}$ \\
\hline$\underset{J U L}{25 \ldots \ldots A}$ & $\begin{array}{l}14 \\
13\end{array}$ & $\begin{array}{l}56 \\
55\end{array}$ & $\begin{array}{l}42 \\
43\end{array}$ & 1.9 & $\begin{array}{l}3.9 \\
4.3\end{array}$ & 140 & $\begin{array}{r}0 \\
--\end{array}$ & 115 & 5.6 & $\begin{array}{l}65 \\
54\end{array}$ \\
\hline $\begin{array}{l}29 \ldots \ldots \\
30 \ldots A\end{array}$ & $\begin{array}{l}22 \\
22\end{array}$ & $\begin{array}{l}110 \\
102\end{array}$ & $\begin{array}{l}43 \\
42\end{array}$ & $\begin{array}{l}2.7 \\
2.6\end{array}$ & $\begin{array}{l}9.0 \\
7.8\end{array}$ & $\begin{array}{l}262 \\
288\end{array}$ & $\begin{array}{l}0 \\
0\end{array}$ & $\begin{array}{l}215 \\
236\end{array}$ & $\begin{array}{l}6.6 \\
9.2\end{array}$ & $\begin{array}{l}110 \\
112\end{array}$ \\
\hline$\underset{\text { SEP }}{24 \ldots}$ & 21 & 100 & 39 & 2.4 & 9.3 & 263 & 0 & 216 & 3.3 & 120 \\
\hline $\begin{array}{l}03 \ldots A \\
24 \ldots A\end{array}$ & $\begin{array}{l}25 \\
22\end{array}$ & $\begin{array}{l}110 \\
110\end{array}$ & $\begin{array}{l}43 \\
42\end{array}$ & $\begin{array}{l}2.7 \\
2.7\end{array}$ & $\begin{array}{l}10 \\
9.6\end{array}$ & $\begin{array}{l}294 \\
268\end{array}$ & $\begin{array}{l}0 \\
0\end{array}$ & $\begin{array}{l}241 \\
220\end{array}$ & $\begin{array}{l}7.5 \\
6.8\end{array}$ & $\begin{array}{l}121 \\
140\end{array}$ \\
\hline DATE & $\begin{array}{l}\text { DIS- } \\
\text { SOLVED } \\
\text { CHLO- } \\
\text { RIOE } \\
\text { (CL) } \\
(M G / L)\end{array}$ & $\begin{array}{l}\text { DIS- } \\
\text { SOLVED } \\
\text { FLUO- } \\
\text { RIDE } \\
(F) \\
(M G / L)\end{array}$ & $\begin{array}{l}\text { DIS- } \\
\text { SOLVED } \\
\text { SILICA } \\
\text { (SIOZ) } \\
\text { (MG/L) }\end{array}$ & $\begin{array}{l}\text { TOTAL } \\
\text { NI TRATE } \\
\text { (N) } \\
\text { (MG/L.) }\end{array}$ & $\begin{array}{c}\text { TOTAL } \\
\text { NITRITE } \\
\text { PLUS } \\
\text { NITRATE } \\
\text { (N) } \\
\text { (MG/L) }\end{array}$ & $\begin{array}{c}\text { DIS- } \\
\text { SOLVED } \\
\text { NITRITE } \\
\text { PLUS } \\
\text { NITRATE } \\
\text { (N) } \\
\text { (MG/L) }\end{array}$ & $\begin{array}{l}\text { TOTAL } \\
\text { AMMONIA } \\
\text { NITRO- } \\
\text { GEN } \\
\text { (N) } \\
(M G / L)\end{array}$ & $\begin{array}{c}\text { TOTAL } \\
\text { ORGANIC } \\
\text { NITRO- } \\
\text { GEN } \\
\text { (N) } \\
\text { (MG/L) }\end{array}$ & $\begin{array}{l}\text { TOTAL } \\
\text { KJEL- } \\
\text { OAHL } \\
\text { NITRO- } \\
\text { GEN } \\
\text { (N) } \\
\text { (HG/L) }\end{array}$ & $\begin{array}{l}\text { DIS- } \\
\text { SOLVE } \\
\text { KJEL. } \\
\text { NITRO } \\
\text { GEN } \\
\text { (N) } \\
\text { (MG/L }\end{array}$ \\
\hline
\end{tabular}

$O C$

\begin{tabular}{|c|c|c|c|c|c|c|c|c|c|c|}
\hline $\begin{array}{l}28 \ldots \text { A } \\
30 \ldots \ldots \\
\text { NOV }\end{array}$ & $\begin{array}{l}75 \\
77\end{array}$ & .5 & $17^{--}$ & $\begin{array}{c}4 \cdot 3 \\
--\end{array}$ & $2.8^{--}$ & $2 . \overline{7}$ & 1.9 & $1.9^{-\infty}$ & $3 . \overline{8}$ & $3 . \overline{8}$ \\
\hline $\begin{array}{l}20 \ldots A \\
25 \ldots \ldots \\
D E C\end{array}$ & $\begin{array}{l}62 \\
64\end{array}$ & $\begin{array}{l}.3 \\
.2\end{array}$ & $16^{--}$ & 3.4 & $2.1^{--}$ & $2 . \overline{1}$ & $1.3^{--}$ & 1.7 & $3.0^{-\infty}$ & $=$ \\
\hline $\begin{array}{l}18 \ldots \ldots \\
31 \ldots \ldots \\
\text { JAN }\end{array}$ & $\begin{array}{l}60 \\
70\end{array}$ & .2 & $14^{-\infty}$ & $\begin{array}{r}2.9 \\
-=\end{array}$ & 1.8 & $1.8^{--}$ & $1.6^{--}$ & 2.0 & 3.6 & $=$ \\
\hline $\begin{array}{l}16 \ldots \ldots \\
30 \ldots A \\
F E B\end{array}$ & $\begin{array}{l}62 \\
64\end{array}$ & .3 & $13=$ & 3.6 & 2.0 & 1.9 & 1.1 & 1.3 & 2,4 & 3.2 \\
\hline $\begin{array}{l}09 \ldots \\
23 \ldots \ldots \\
26 \ldots \text { A } \\
M A R\end{array}$ & $\begin{array}{r}92 \\
150 \\
65\end{array}$ & $\begin{array}{l}.5 \\
.8 \\
.5\end{array}$ & $\begin{array}{r}8.6 \\
25 \\
--\end{array}$ & 4.7 & $\begin{array}{r}2.8 \\
5.6 \\
-.-\end{array}$ & $\begin{array}{r}2.7 \\
9.8 \\
--\end{array}$ & $\begin{array}{c}.66 \\
3.1 \\
--\end{array}$ & $\begin{array}{r}2.7 \\
9.9 \\
-.\end{array}$ & $13^{3.4}=$ & $\begin{array}{r}3.4 \\
-. \\
--\end{array}$ \\
\hline $\begin{array}{l}03 \ldots \\
30 \cdots \\
30 \ldots \text { A } \\
\text { APR }\end{array}$ & $\begin{array}{l}77 \\
71 \\
69\end{array}$ & $\begin{array}{l}.5 \\
.3 \\
.5\end{array}$ & $\begin{array}{l}14 \\
16 \\
-\infty\end{array}$ & $4 . \overline{--}$ & $\begin{array}{r}3.2 \\
4.9 \\
-.\end{array}$ & $\begin{array}{l}3.0 \\
5.7 \\
--\end{array}$ & $\begin{array}{r}1.9 \\
.93 \\
--\end{array}$ & $\begin{array}{r}2.4 \\
.37 \\
-.-\end{array}$ & $\begin{array}{c}4.3 \\
1.3 \\
--\end{array}$ & $\begin{array}{r}4.5 \\
=- \\
=-\end{array}$ \\
\hline $\begin{array}{l}22 \ldots \ldots A \\
30 \ldots \ldots \\
\text { MAY }\end{array}$ & $\begin{array}{l}117 \\
120\end{array}$ & .9 & $24^{--}$ & 9.9 & 5.9 & $5.8^{--}$ & 4.9 & 1.0 & $5.9^{--}$ & $\overline{--}$ \\
\hline $\begin{array}{l}20 \cdots \cdots A \\
24 \cdots \cdots \\
\text { JUN }\end{array}$ & $\begin{array}{l}121 \\
120\end{array}$ & .9 & $28^{-\infty}$ & 9.7 & 6.8 & $6 . \overline{3}$ & $4 . \overline{0}$ & .90 & $4.9^{--}$ & $=$ \\
\hline $\begin{array}{l}25 \ldots \text { A } \\
30 \ldots \text { A } \\
\text { JUL }\end{array}$ & $\begin{array}{l}67 \\
66\end{array}$ & $\begin{array}{l}.4 \\
.4\end{array}$ & $12^{-m}$ & 1.8 & 1.5 & $=$ & 1.0 & 1.0 & $2 . \overline{0}$ & $\overline{--}$ \\
\hline $\begin{array}{l}29 \\
30 \cdots A\end{array}$ & $\begin{array}{l}120 \\
118\end{array}$ & $\begin{array}{r}.7 \\
1.0\end{array}$ & 27 & $7 . \overline{7}$ & $11=$ & 11 & 6.0 & .00 & $\begin{array}{c}3.3 \\
--\end{array}$ & $=$ \\
\hline $\begin{array}{l}24 \cdots \cdots \\
\text { SEP }\end{array}$ & 120 & .6 & 28 & $=-$ & 11 & 12 & .27 & 6.2 & 6.5 & $-\infty$ \\
\hline $\begin{array}{l}03 \ldots \ldots \mathrm{A} \\
24 \ldots \mathrm{A}\end{array}$ & $\begin{array}{l}123 \\
130\end{array}$ & $\begin{array}{r}1.2 \\
.7\end{array}$ & $27^{--}$ & 4.1 & $11^{--}$ & 11 & 4.8 &.$\overline{00}$ & $3 . \overline{0}$ & $=$ \\
\hline
\end{tabular}


SANTA ANA RIVER BASIN

11074000 SANTA ANA RIVER BELOW PRADO DAM, CA--Continued

CHEMICAL ANALYSES, WATER YEAR OCTOBER 1975 TO SEPTEMBER 1976

\begin{tabular}{|c|c|c|c|c|c|c|c|c|c|c|}
\hline DATE & $\begin{array}{l}\text { TOTAL } \\
\text { NITRO- } \\
\text { GEN } \\
\text { (N) } \\
\text { (MG/L) }\end{array}$ & $\begin{array}{l}\text { TOTAL } \\
\text { NITRO- } \\
\text { GEN } \\
\text { (NO3) } \\
\text { (MG/L) }\end{array}$ & $\begin{array}{l}\text { TOTAL } \\
\text { PHOS- } \\
\text { PHORUS } \\
\text { (P) } \\
\text { (MG/L) }\end{array}$ & $\begin{array}{l}\text { DIS- } \\
\text { SOLVEO } \\
\text { ORTHO. } \\
\text { PHOS- } \\
\text { PHORUS } \\
\text { (P) } \\
\text { (MG/L) }\end{array}$ & $\begin{array}{l}\text { DIS- } \\
\text { SOLVEO } \\
\text { ORTHO } \\
\text { PHOS- } \\
\text { PHATE } \\
(\text { PO } 4) \\
\text { (MG/L) }\end{array}$ & $\begin{array}{c}\text { DIS- } \\
\text { SOLVEO } \\
\text { BORON } \\
\text { (B) } \\
\text { (UG/L) }\end{array}$ & $\begin{array}{l}\text { TOTAL } \\
\text { IRON } \\
\text { (FE) } \\
\text { (UG/L) }\end{array}$ & $\begin{array}{l}\text { DIS- } \\
\text { SOL VED } \\
\text { IRON } \\
\text { (FE) } \\
\text { (UG/L) }\end{array}$ & $\begin{array}{l}\text { TOTAL } \\
\text { ORGANIC } \\
\text { CARBON } \\
\text { (C) } \\
\text { (MG/L) }\end{array}$ & $\begin{array}{l}\text { TOTAL } \\
\text { PHYTO- } \\
\text { PLANK- } \\
\text { TON } \\
\text { (CELLS } \\
\text { PER } \\
\text { ML) }\end{array}$ \\
\hline $\begin{array}{l}\mathrm{OCT} \\
28 \ldots \mathrm{A}\end{array}$ & -- & $\Rightarrow$ & - & 1.1 & 3.4 & 220 & $=$ & $-\infty$ & $-\infty$ & $-\infty$ \\
\hline NOV & 6.6 & 29 & 1.4 & .99 & 3.0 & 280 & 3900 & 20 & $=-$ & 2300 \\
\hline $\begin{array}{l}20 \ldots A \\
25 \ldots \ldots \\
D E C\end{array}$ & $5 . \overline{1}$ & $23^{--}$ &.$\overline{88}$ & .66 & $\begin{array}{l}2.0 \\
2.2\end{array}$ & $\begin{array}{l}260 \\
300\end{array}$ & $=$ & 520 & 7.5 & 750 \\
\hline $\begin{array}{l}18 \ldots \text { A } \\
31 \ldots \ldots \\
\text { JAN }\end{array}$ & $5 . \overline{4}$ & $24^{--}$ &.$\overline{91}$ & $\begin{array}{l}.55 \\
.72\end{array}$ & $\begin{array}{l}1.7 \\
2.2\end{array}$ & $\begin{array}{l}160 \\
240\end{array}$ & $\approx$ & $\overline{30}$ & $14^{-\infty}$ & 1300 \\
\hline $\begin{array}{l}16 \ldots \text { A } \\
30 \cdots A \text { A }\end{array}$ & $\begin{array}{c}4.4 \\
-.\end{array}$ & 19 & $\begin{array}{r}.78 \\
--\end{array}$ & $\begin{array}{l}.61 \\
.80\end{array}$ & $\begin{array}{l}1.9 \\
2.5\end{array}$ & $\begin{array}{l}210 \\
250\end{array}$ & $\begin{array}{r}2400 \\
--\end{array}$ & $\begin{array}{r}1700 \\
--\end{array}$ & $\begin{array}{r}5.8 \\
-.-\end{array}$ & $\begin{array}{r}2100 \\
--\end{array}$ \\
\hline $\begin{array}{l}09 \ldots \\
23 \ldots \\
26 \ldots A \\
M A R\end{array}$ & $\begin{array}{l}6.2 \\
19 \\
=-\end{array}$ & $\begin{array}{l}27 \\
82 \\
\end{array}$ & $\begin{array}{r}1.0 \\
5.1 \\
-=\end{array}$ & $\begin{aligned} .58 \\
1.7 \\
.81\end{aligned}$ & $\begin{array}{l}1.8 \\
5.2 \\
2.5\end{array}$ & $\begin{array}{l}310 \\
420 \\
180\end{array}$ & $=$ & $\begin{array}{r}180 \\
100 \\
-0\end{array}$ & $\begin{array}{l}22 \\
69 \\
--\end{array}$ & 9700 \\
\hline $\begin{array}{l}03 \ldots \text { A } \\
30 \ldots \text { A } \\
30 \ldots \\
A P R\end{array}$ & $\begin{array}{r}7.5 \\
6.2 \\
--.\end{array}$ & $\begin{array}{l}33 \\
27\end{array}$ & $\begin{array}{r}1.4 \\
1.4 \\
--\end{array}$ & $\begin{array}{r}.94 \\
.94 \\
.98\end{array}$ & $\begin{array}{l}2.9 \\
2.9 \\
3.0\end{array}$ & $\begin{array}{l}270 \\
380 \\
300\end{array}$ & $=$ & $\begin{array}{l}70 \\
10 \\
--\end{array}$ & $\begin{array}{r}16 \\
7.0 \\
=-\end{array}$ & 3900 \\
\hline $\begin{array}{l}22 \ldots A \\
30 \ldots \\
\text { MAY }\end{array}$ & $12^{--}$ & $52^{--}$ & $2 . \overline{7}$ & $\begin{array}{l}2.2 \\
2.1\end{array}$ & $\begin{array}{l}6.7 \\
6.4\end{array}$ & $\begin{array}{l}630 \\
500\end{array}$ & 4300 & 40 & 9.8 & 2900 \\
\hline $\begin{array}{c}20 \ldots A \\
24 \ldots \\
J U N\end{array}$ & $12^{--}$ & $52^{--}$ & $=$ & $\begin{array}{l}2.1 \\
2.3\end{array}$ & $\begin{array}{l}6.4 \\
7.1\end{array}$ & $\begin{array}{l}520 \\
700\end{array}$ & $=$ & 70 & $=$ & 2200 \\
\hline $\begin{array}{l}25 \ldots A \\
30 \ldots A \\
\text { JUL. }\end{array}$ & $3 . \overline{5}$ & $15^{-\infty}$ & 1.0 & $\begin{array}{l}.58 \\
.87\end{array}$ & $\begin{array}{l}1.8 \\
2.7\end{array}$ & $\begin{array}{l}250 \\
143\end{array}$ & $=$ & 290 & $=$ & 1900 \\
\hline $\begin{array}{l}29 \cdots \ldots \\
30 \cdots A \\
A \cup G\end{array}$ & $14 \ldots$ & $63 \ldots$ & 4.5 & $\begin{array}{r}3.5 \\
--\end{array}$ & 11 & $\begin{array}{l}530 \\
500\end{array}$ & $\begin{array}{r}6100 \\
--\end{array}$ & $\begin{array}{r}140 \\
--\end{array}$ & 16 & $\begin{array}{r}230 \\
--\end{array}$ \\
\hline$\underset{\text { SFP }}{24 \cdots}$ & 18 & 77 & 4.7 & 3.9 & 12 & 540 & -- & 80 & 12 & 550000 \\
\hline $\begin{array}{l}03 \ldots A \\
24 \ldots A\end{array}$ & $14^{-\infty}$ & $62^{-\infty}$ & 4.5 & $\begin{array}{l}4.5 \\
3.2\end{array}$ & $\begin{array}{l}14 \\
9.8\end{array}$ & $\begin{array}{l}280 \\
610\end{array}$ & $m$ & 20 & $33^{--}$ & $=$ \\
\hline
\end{tabular}


CHEMICAL ANALYSES, WATER YEAR OCTOBER 1975 TO SEPTEMBER 1976

\begin{tabular}{|c|c|c|c|c|c|c|c|c|c|c|c|c|}
\hline DATE & TIME & $\begin{array}{l}\text { TOTAL } \\
\text { ARSENIC } \\
\text { (AS) } \\
\text { (UG/L) }\end{array}$ & $\begin{array}{c}\text { SUS- } \\
\text { PENDEO } \\
\text { ARSENIC } \\
\text { (AS) } \\
(U G / L)\end{array}$ & $\begin{array}{c}\text { DIS- } \\
\text { SOLVED } \\
\text { ARSENIC } \\
\text { (AS) } \\
\text { (UG/L) }\end{array}$ & $\begin{array}{l}\text { TOTAL } \\
\text { BARIUM } \\
\text { (BA) } \\
\text { (UG/L) }\end{array}$ & $\begin{array}{l}\text { TOTAL } \\
\text { CAD- } \\
\text { MIUM } \\
(C D) \\
(U G / L)\end{array}$ & $\begin{array}{l}\text { SUS- } \\
\text { PENDED } \\
\text { CAD- } \\
\text { MIUM } \\
\text { (CD) } \\
\text { (UO/L) }\end{array}$ & $\begin{array}{l}\text { DIS- } \\
\text { SOLVED } \\
\text { CAD- } \\
\text { MIUM } \\
\text { (CD) } \\
\text { (UG/L) }\end{array}$ & $\begin{array}{l}\text { TOTAL } \\
\text { CHRO- } \\
\text { MIUM } \\
\text { (CR) } \\
(U G / L)\end{array}$ & $\begin{array}{l}\text { SUS- } \\
\text { PENDEO } \\
\text { CHRO- } \\
\text { MIUM } \\
\text { (CR) } \\
\text { (UG/L) }\end{array}$ & $\begin{array}{l}\text { DIS- } \\
\text { SOLVED } \\
\text { CHRO- } \\
\text { MIUM } \\
\text { (CR) } \\
\text { (UG/L) }\end{array}$ & $\begin{array}{l}\text { TOTAL } \\
\text { COBALT } \\
(\mathrm{CO}) \\
(U G / L)\end{array}$ \\
\hline $\begin{array}{l}\text { OCT } \\
30 \ldots . .\end{array}$ & 1315 & 4 & 1 & 3 & 100 & 0 & 0 & 1 & 4 & 2 & 2 & $<50$ \\
\hline $\begin{array}{l}\text { JAN } \\
16 \ldots\end{array}$ & 0930 & 2 & 0 & 2 & 0 & $<10$ & $<9$ & 1 & 10 & 10 & 0 & $<50$ \\
\hline $09 .$. & 0930 & 12 & -- & -- & 0 & $<10$ & -- & $\cdots$ & 10 & -- & -- & $<50$ \\
\hline${ }_{A P R}^{03} \cdots$ & 1000 & 9 & $-\infty$ & -- & 100 & $<10$ & -- & - & 20 & - & -- & $<50$ \\
\hline${ }_{\text {JUL }}^{30} \cdot \cdots$ & 1250 & 4 & 0 & 4 & -- & $<10$ & $<7$ & 3 & 10 & 10 & 0 & $<50$ \\
\hline $29 . \ldots$ & 1100 & 3 & 0 & 3 & - & 10 & 0 & 30 & 10 & 0 & 10 & $<50$ \\
\hline
\end{tabular}

\begin{tabular}{|c|c|c|c|c|c|c|c|c|c|c|c|c|}
\hline DATE & $\begin{array}{l}\text { SUS- } \\
\text { PENDED } \\
\text { COBALT } \\
(C O) \\
(U G / L)\end{array}$ & $\begin{array}{l}\text { DIS- } \\
\text { SOLVED } \\
\text { COBALT } \\
\text { (CO) } \\
(U G / L)\end{array}$ & $\begin{array}{l}\text { TOTAL } \\
\text { COPPER } \\
\text { (CU) } \\
\text { (UG/L) }\end{array}$ & $\begin{array}{l}\text { SUS- } \\
\text { PENDED } \\
\text { COPPER } \\
\text { (CU) } \\
\text { (UG/L) }\end{array}$ & $\begin{array}{l}\text { DIS- } \\
\text { SOLVED } \\
\text { COPPER } \\
\text { (CU) } \\
(U G / L)\end{array}$ & $\begin{array}{l}\text { TOTAL } \\
\text { LEAD } \\
\text { (PB) } \\
\text { (UG/L) }\end{array}$ & $\begin{array}{l}\text { SUS- } \\
\text { PENDED } \\
\text { LEAD } \\
\text { (PB) } \\
\text { (UG/L) }\end{array}$ & $\begin{array}{l}\text { DIS- } \\
\text { SOLVED } \\
\text { LEAD } \\
\text { (PB) } \\
\text { (UG/L) }\end{array}$ & $\begin{array}{l}\text { TOTAL } \\
\text { MAN- } \\
\text { GANESE } \\
\text { (MN) } \\
\text { (UG/L) }\end{array}$ & $\begin{array}{l}\text { SUS- } \\
\text { PENDED } \\
\text { MAN- } \\
\text { GANESE } \\
\text { (MN) } \\
(U G / L)\end{array}$ & $\begin{array}{l}\text { DIS- } \\
\text { SOLVED } \\
\text { MAN- } \\
\text { GANESE } \\
\text { (MN) } \\
\text { (UG/L) }\end{array}$ & $\begin{array}{c}\text { TOTAL } \\
\text { MERCURY } \\
\text { (HG) } \\
\text { (UGAL) }\end{array}$ \\
\hline $\begin{array}{l}\text { OCT } \\
30 \ldots\end{array}$ & $<49$ & 1 & 20 & 14 & 6 & 0 & 0 & 3 & 150 & 70 & 80 & .0 \\
\hline $\begin{array}{l}\text { JAN } \\
16 \ldots \\
F E Q\end{array}$ & $<48$ & 2 & $<10$ & $<2$ & 8 & $<100$ & $<97$ & 3 & 140 & 80 & 60 & .0 \\
\hline $09 .$. & -- & -- & 30 & $-m$ & -- & $<100$ & $-\infty$ & -- & 250 & $=-$ & $-\infty$ & .0 \\
\hline${ }_{A P R}^{03} \cdots$ & -- & -- & 20 & - & -- & 100 & -- & -- & 450 & -- & -- & .1 \\
\hline JUL $30 . \cdots$ & $<48$ & 2 & 30 & 25 & 5 & $<100$ & $<90$ & 10 & 270 & 120 & 150 & .0 \\
\hline & $<48$ & 2 & 30 & 23 & 7 & $<100$ & $<97$ & 3 & 310 & 130 & 180 & .1 \\
\hline
\end{tabular}

\begin{tabular}{|c|c|c|c|c|c|c|c|c|c|c|c|}
\hline DATE & $\begin{array}{c}\text { SUS- } \\
\text { PENDED } \\
\text { MERCURY } \\
\text { (HG) } \\
\text { (UG/L) }\end{array}$ & $\begin{array}{c}\text { DIS- } \\
\text { SOLVED } \\
\text { MERCURY } \\
\text { (HG) } \\
\text { (UG/L) }\end{array}$ & $\begin{array}{l}\text { TOTAL } \\
\text { SELE- } \\
\text { NIUM } \\
\text { (SE) } \\
\text { (UG/L) }\end{array}$ & $\begin{array}{l}\text { SUS- } \\
\text { PENDED } \\
\text { SELE- } \\
\text { NIUM } \\
\text { (SE) } \\
\text { (UG/L) }\end{array}$ & $\begin{array}{l}\text { DIS- } \\
\text { SOLVED } \\
\text { SELE- } \\
\text { NIUM } \\
\text { (SE) } \\
\text { (UG } / \text { ) }\end{array}$ & $\begin{array}{l}\text { TOTAL } \\
\text { SILVER } \\
\text { (AG) } \\
(U G / L)\end{array}$ & $\begin{array}{l}\text { TOTAL } \\
\text { ZINC } \\
\text { (ZN) } \\
(U G / L)\end{array}$ & $\begin{array}{l}\text { SUS- } \\
\text { PENDED } \\
\text { ZINC } \\
\text { (ZN) } \\
(U G / L)\end{array}$ & $\begin{array}{l}\text { DIS- } \\
\text { SOLVED } \\
\text { ZINC } \\
(Z N) \\
(U G / L)\end{array}$ & $\begin{array}{c}\text { CYANIDE } \\
\text { (CN) } \\
\text { (MG/L) }\end{array}$ & $\begin{array}{l}\text { METHY- } \\
\text { LENE } \\
\text { BLUE } \\
\text { ACTIVE } \\
\text { SUB- } \\
\text { STANCE } \\
\text { (MG/L) }\end{array}$ \\
\hline $\begin{array}{l}0 \mathrm{OCT} \\
30 \ldots . . .\end{array}$ & .0 & .0 & 0 & 0 & 0 & 0 & 70 & 0 & 70 & .00 & .10 \\
\hline $16 \ldots$ & .0 & .0 & 0 & 0 & 0 & $<10$ & 70 & 10 & 60 & .00 & .00 \\
\hline$\underset{\text { MAR }}{09 .}$ & -- & -- & -- & -- & $\cdots$ & $<10$ & 80 & $-\infty$ & -- & .01 & .10 \\
\hline${ }_{A P R}^{03 . . .}$ & -- & - & - & -- & - & $<10$ & 50 & - & -- & .02 & .10 \\
\hline $30 \ldots$ & .0 & .0 & 1 & 0 & 1 & 10 & 160 & 130 & 30 & .02 & .30 \\
\hline $\begin{array}{l}J U L \\
29 . \ldots\end{array}$ & .0 & .1 & 1 & 0 & 1 & 30 & 80 & 50 & 30 & .15 & .00 \\
\hline
\end{tabular}


CHEMICAL ANALYSES, WATER YEAR OCTOBER 1975 TO SEPTEMBER 1976

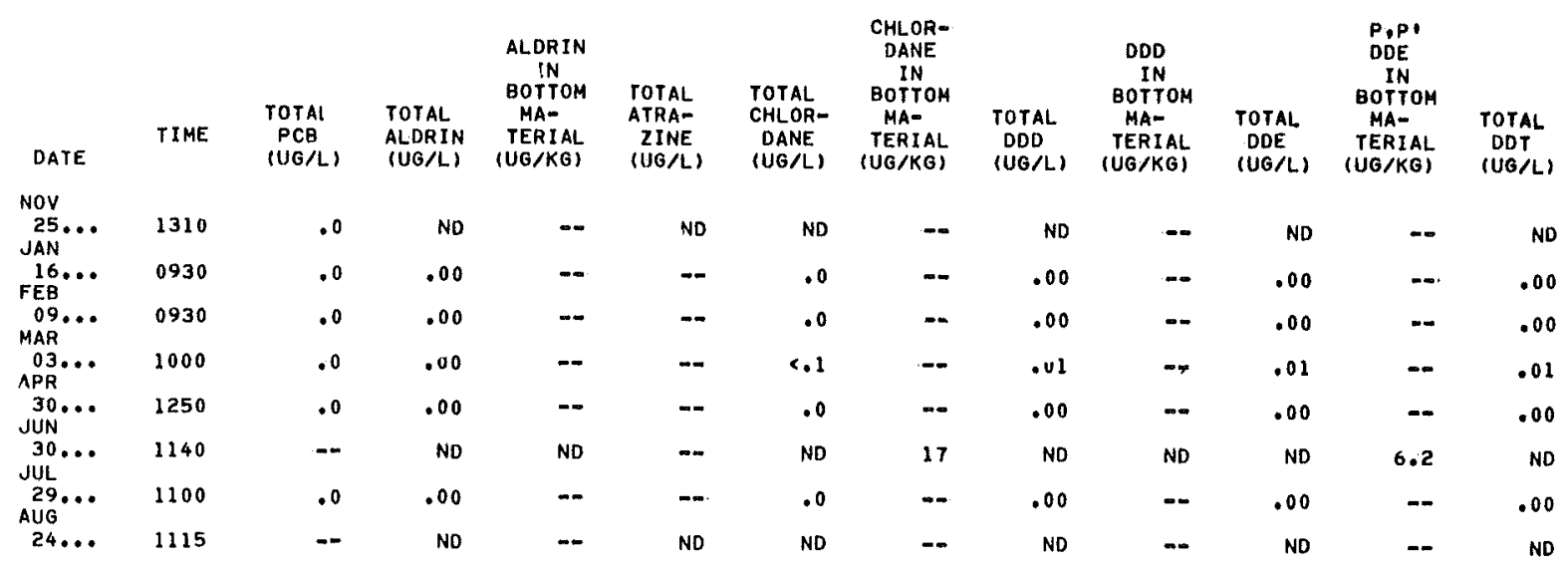

\begin{tabular}{|c|c|c|c|c|c|c|c|c|c|c|c|c|}
\hline DATE & $\begin{array}{c}\text { P,P' } \\
\text { DOT } \\
\text { IN } \\
\text { BOTTOM } \\
\text { MA- } \\
\text { TERIAL } \\
\text { (UG/KG) }\end{array}$ & $\begin{array}{l}\text { TOTAL } \\
\text { DI- } \\
\text { AZINON } \\
\text { (UG/L) }\end{array}$ & $\begin{array}{c}\text { DI- } \\
\text { AZINON } \\
\text { IN } \\
\text { BOTTOM } \\
\text { MA- } \\
\text { TERIAL } \\
\text { (UO/KG) }\end{array}$ & $\begin{array}{l}\text { TOTAL } \\
\text { DI- } \\
\text { ELDRIN } \\
\text { (UG/L) }\end{array}$ & $\begin{array}{c}\text { DI- } \\
\text { ELDRIN } \\
\text { IN } \\
\text { BOTTOM } \\
\text { MA- } \\
\text { TERIAL } \\
\text { (UO/KG) }\end{array}$ & $\begin{array}{l}\text { TOTAL } \\
\text { ENDRIN } \\
\text { (UG/L) }\end{array}$ & $\begin{array}{l}\text { ENDRIN } \\
\text { IN } \\
\text { BOTTOH } \\
\text { HA- } \\
\text { TERIAL } \\
\text { (UO/KG) }\end{array}$ & $\begin{array}{l}\text { TOTAL } \\
\text { ETHION } \\
\text { (UG/L) }\end{array}$ & $\begin{array}{l}\text { ETHION } \\
\text { IN } \\
\text { BOTTOH } \\
\text { MA- } \\
\text { TERIAL } \\
\text { (UG/KG) }\end{array}$ & $\begin{array}{l}\text { TOTAL } \\
\text { HEPTA- } \\
\text { CHLOR } \\
\text { (UG/L) }\end{array}$ & $\begin{array}{c}\text { HEPTA- } \\
\text { CHLOR } \\
\text { IN } \\
\text { BOTTOM } \\
\text { HA- } \\
\text { TERIAL } \\
\text { (UG/KG) }\end{array}$ & $\begin{array}{l}\text { TOTAL } \\
\text { HEPTA- } \\
\text { CHLOR } \\
\text { EPOXIOE } \\
\text { (UG/L) }\end{array}$ \\
\hline
\end{tabular}

\begin{tabular}{|c|c|c|c|c|c|c|c|c|c|c|c|}
\hline NOV & & & & & & & & & & & \\
\hline$\underset{\text { JAN }}{25} \cdots$ & - & ND & -- & ND & $-\infty$ & NO & $m$ & ND & -- & ND & $-\infty$ \\
\hline FEB & -- & .01 & -- & .00 & $\omega$ & .00 & -- & .00 & -- & .00 & $m$ \\
\hline$\stackrel{09}{M A R} \cdots$ & $\cdots$ & .03 & $m$ & .00 & -- & .00 & $m$ & .00 & $-\infty$ & .00 & $-m$ \\
\hline$\underset{A P R}{03 \cdots \cdots}$ & -- & .06 & $-\infty$ & .00 & $-\infty$ & .00 & $=$ & .00 & $-\infty$ & .00 & $-\infty$ \\
\hline$\underset{\text { JUN }}{30 \ldots}$ & -- & .02 & - & .00 & $m$ & .00 & $\infty$ & .00 & -- & .00 & $\cdots$ \\
\hline & 2.2 & ND & ND & ND & 1.7 & ND & ND & ND & ND & ND & ND \\
\hline$\underset{A \cup G}{29} \ldots$ & $-\infty$ & .06 & - & .00 & -- & .00 & $-\infty$ & .00 & -- & .00 & -- \\
\hline $24 \ldots$ & -- & ND & $m$ & ND & -- & NO & -- & No & $-\infty$ & ND & $\cdots$ \\
\hline DATE & $\begin{array}{l}\text { HEPTA- } \\
\text { CHLOR } \\
\text { EPOXIDE } \\
\text { IN BOT- } \\
\text { TOM MA- } \\
\text { TERIAL } \\
\text { (UG/KG) }\end{array}$ & $\begin{array}{l}\text { TOTAL } \\
\text { LINDANE } \\
\text { (UG/L) }\end{array}$ & $\begin{array}{l}\text { LINOANE } \\
\text { IN } \\
\text { BOTTOM } \\
\text { MA- } \\
\text { TERIAL } \\
\text { (UG/KG) }\end{array}$ & $\begin{array}{l}\text { TOTAL } \\
\text { MALA- } \\
\text { THION } \\
\text { (UG/L) }\end{array}$ & $\begin{array}{l}\text { MALA- } \\
\text { THION } \\
\text { IN } \\
\text { BOTTOM } \\
\text { MA- } \\
\text { TERIAL } \\
\text { (UG/KG) }\end{array}$ & $\begin{array}{l}\text { TOTAL. } \\
\text { METH- } \\
\text { OXY- } \\
\text { CHLOR } \\
\text { (UG/L) }\end{array}$ & $\begin{array}{l}\text { METHOX- } \\
\text { YCHLOR } \\
\text { IN BOT- } \\
\text { TOM MA- } \\
\text { TERIAL } \\
\text { (UG/KG) }\end{array}$ & $\begin{array}{l}\text { TOTAL } \\
\text { METHYL } \\
\text { PARA- } \\
\text { THION } \\
\text { (UG/L) }\end{array}$ & $\begin{array}{l}\text { METHYL } \\
\text { PARA- } \\
\text { THION } \\
\text { IN BOT- } \\
\text { TOM MA- } \\
\text { TERIAL } \\
\text { (UG/KG) }\end{array}$ & $\begin{array}{l}\text { TOTAL } \\
\text { METHYL } \\
\text { TRI- } \\
\text { THION } \\
\text { (UG/L) }\end{array}$ & $\begin{array}{l}\text { METHYL } \\
\text { TRI- } \\
\text { THION } \\
\text { IN BOT- } \\
\text { TOM HA- } \\
\text { TERIAL } \\
\text { (UG/KG) }\end{array}$ \\
\hline
\end{tabular}

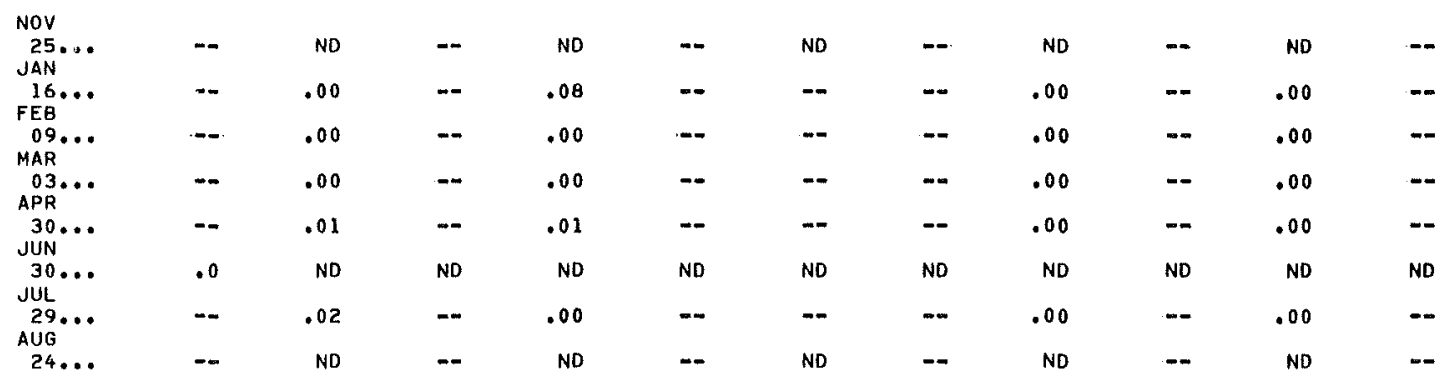


11074000 SANTA ANA RIVER BELOW PRADO DAM, CA--Continued

QUALITATIVE AND ASSOCIATED QUANTITATIVE ANALYSES OF BIOLOGICAL DATA, WATER YEAR OCTOBER 1975 TO SEPTEMBER 1976

PHYTOPLANKTON

\begin{tabular}{|c|c|c|}
\hline DATE & TIME & $\begin{array}{l}\text { PHYLUM } \\
\text {.CLASS } \\
\ldots \text { ORDER } \\
\ldots \text { FAMILY } \\
\ldots \ldots \text { GENUS } \\
\ldots \text {. . SPECIES }\end{array}$ \\
\hline \multirow[t]{3}{*}{$\begin{array}{r}\text { OCT } \\
30\end{array}$} & 1315 & $\begin{array}{l}\text { CHLOROPHYTA } \\
\text { CHLOROPHYCEAE } \\
\text { CCHLOROCOCCALES } \\
\ldots \text { SCENEDESMACEAE } \\
\ldots \text { SCENEDESMUS } \\
\ldots \text { VOL VOCALES } \\
\ldots \text {. CHLAMYDOMONADACEAE } \\
\ldots \text {. CHLAMYDOMONAS }\end{array}$ \\
\hline & & 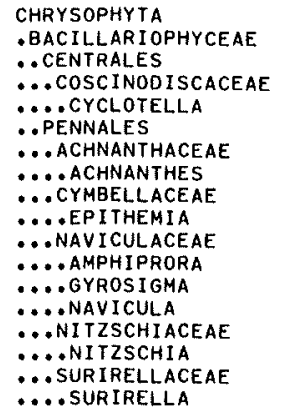 \\
\hline & & TOTAL PHYTOPLANKTON \\
\hline
\end{tabular}

\begin{tabular}{|c|c|c|}
\hline $\begin{array}{r}\text { Nov } \\
25\end{array}$ & 1310 & $\begin{array}{l}\text { CHLOROPHYTA } \\
. \text { CHLOROPHYCEAE } \\
\ldots \text { CHLOROCOCCALES } \\
\ldots \text { OOCYSTACEAE } \\
\ldots \text {. ANKISTRODESMUS } \\
\ldots \text { SCENEDESMACEAE } \\
\text {... SCENEOESMUS }\end{array}$ \\
\hline
\end{tabular}

CHRYSOPHYTA - BACILLARI OPHYCEAE .. CENTRALES

$\because$ COSCINODISCACEAE

\# ... CYCLOTELLA

... MEL OSIRA

. PENNALES

... CYMBELLACEAE

* .... CYMBELLa

....EPI THEMI A

...fRagilar iaceae

\#... osYNedRa

... Naviculaceae

....AMPHIPRORA

.... NAVICUl a

... NITZSCHIACEAE

* ... DENTI CULA

* . . nItzSchia

.... Surirella

CYANOPHYTA

- MYXOPHYCEAE

. OSCILLATORI ALES

... OSC ILLA TOR I ACEAE

.... SP irul ina

TOTAL PHYTOPLANKTON

$\begin{array}{ccc}\text { COMMON } & \text { COUNT } & \text { PERCENT } \\ \text { NAME } & \text { (CELLS/ML) } & \text { OF TOTAL }\end{array}$

GREEN ALGAE

160

DIATOMS

CENTRIC

PENNATE

NAVICULOID

1,200

2,300

GREEN ALGAE

DIATOMS

CENTRIC

PENNATE

NAVICULOID

BLUE-GREEN ALGAE

FILAMENTOUS
81

320

81
160

$\begin{array}{ll}81 & 3 \\ 81 & 3 \\ 81 & 3\end{array}$

81

20

3

0

$\begin{array}{rr}180 & 24 \\ 41 & 5\end{array}$

180

100

200

0
27

3

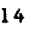

7

3
3
3

52

3

24
5

0

24

0

0

20

750

See footnotes at end of table. 
11074000 SANTA ANA RIVER BELOW PRADO DAM, CA--Continued

QUALITATIVE AND ASSOCIATED QUANTITATIVE ANALYSES OF BIOLOGICAL DATA, WATER YEAR OCTOBER 1975 TO SEPTEMBER 1976

PHYTOPLANKTON

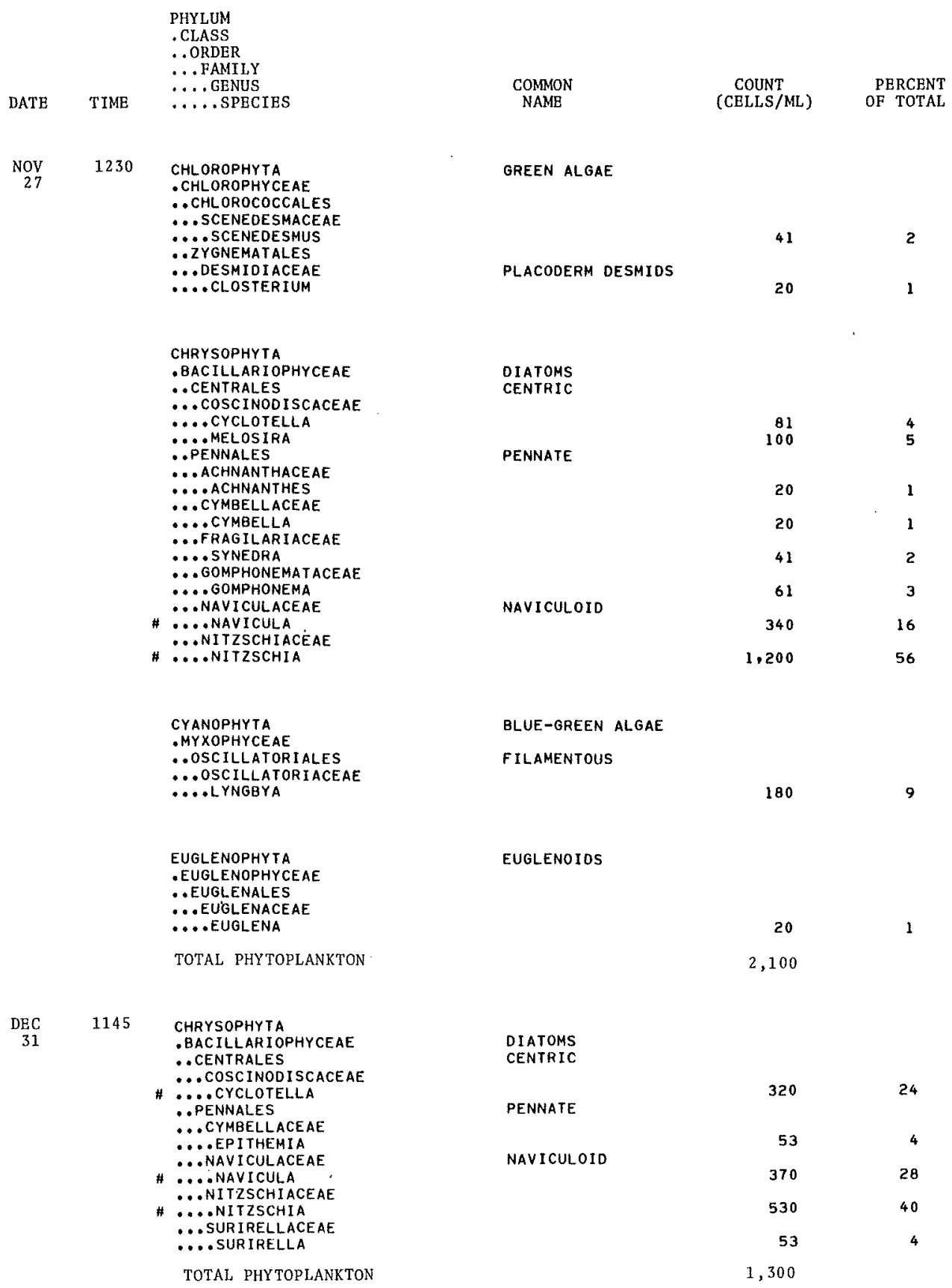


11074000 SANTA ANA RIVER BELOW PRADO DAM, CA--Continued

QUALITATIVE AND ASSOCIATED QUANTITATIVE ANALYSES OF BIOLOGICAL DATA, WATER YEAR OCTOBER 1975 TO SEPTEMBER 1976 PHYTOPLANKTON

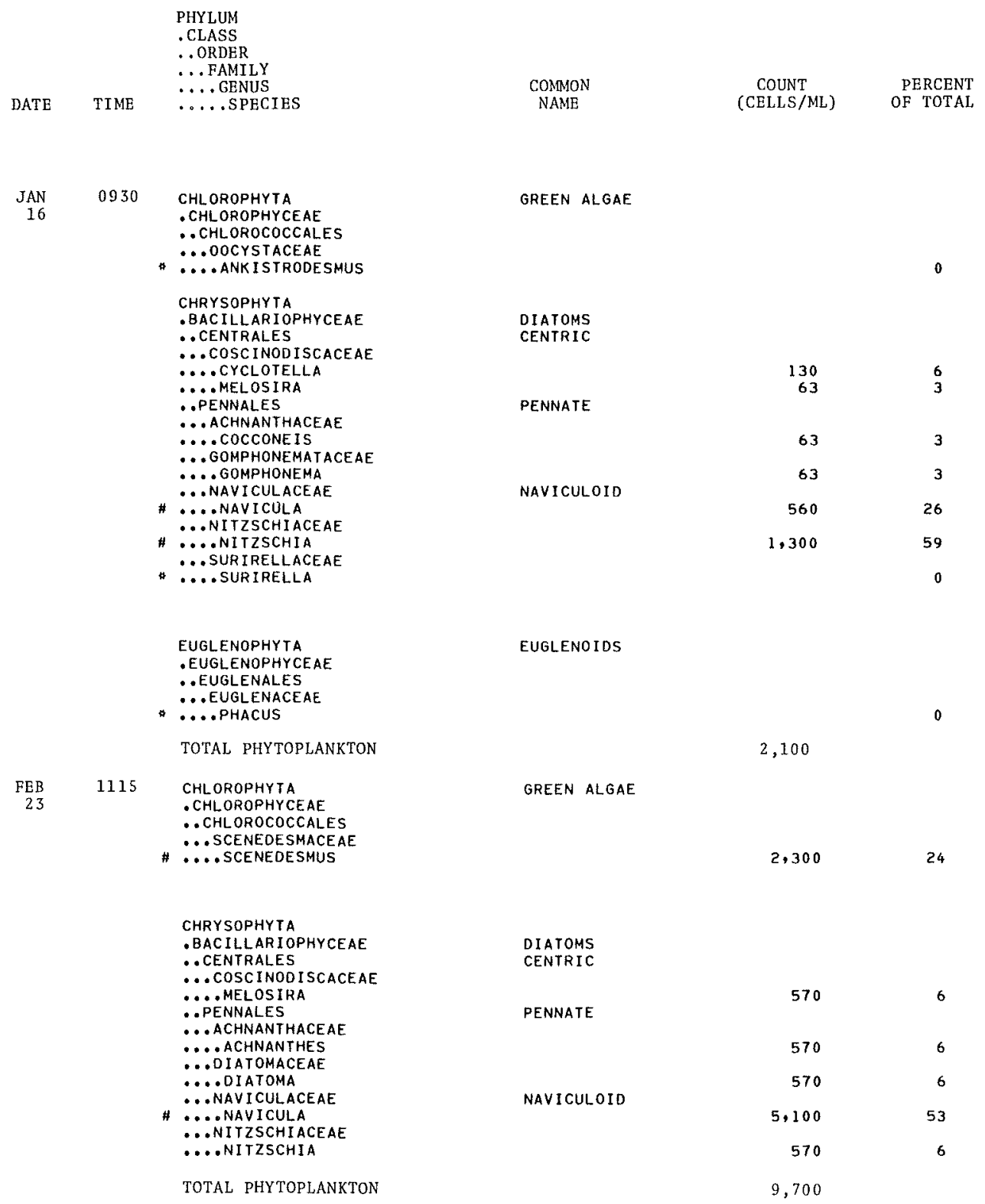


11074000 SANTA ANA RIVER BELOW PRADO DAM, CA--Continued

QUALITATIVE AND ASSOCIATED QUANTITATIVE ANALYSES OF BIOLOGICAL DATA, WATER YEAR OCTOBER 1975 TO SEPTEMBER 1976 PHYTOPLANKTON

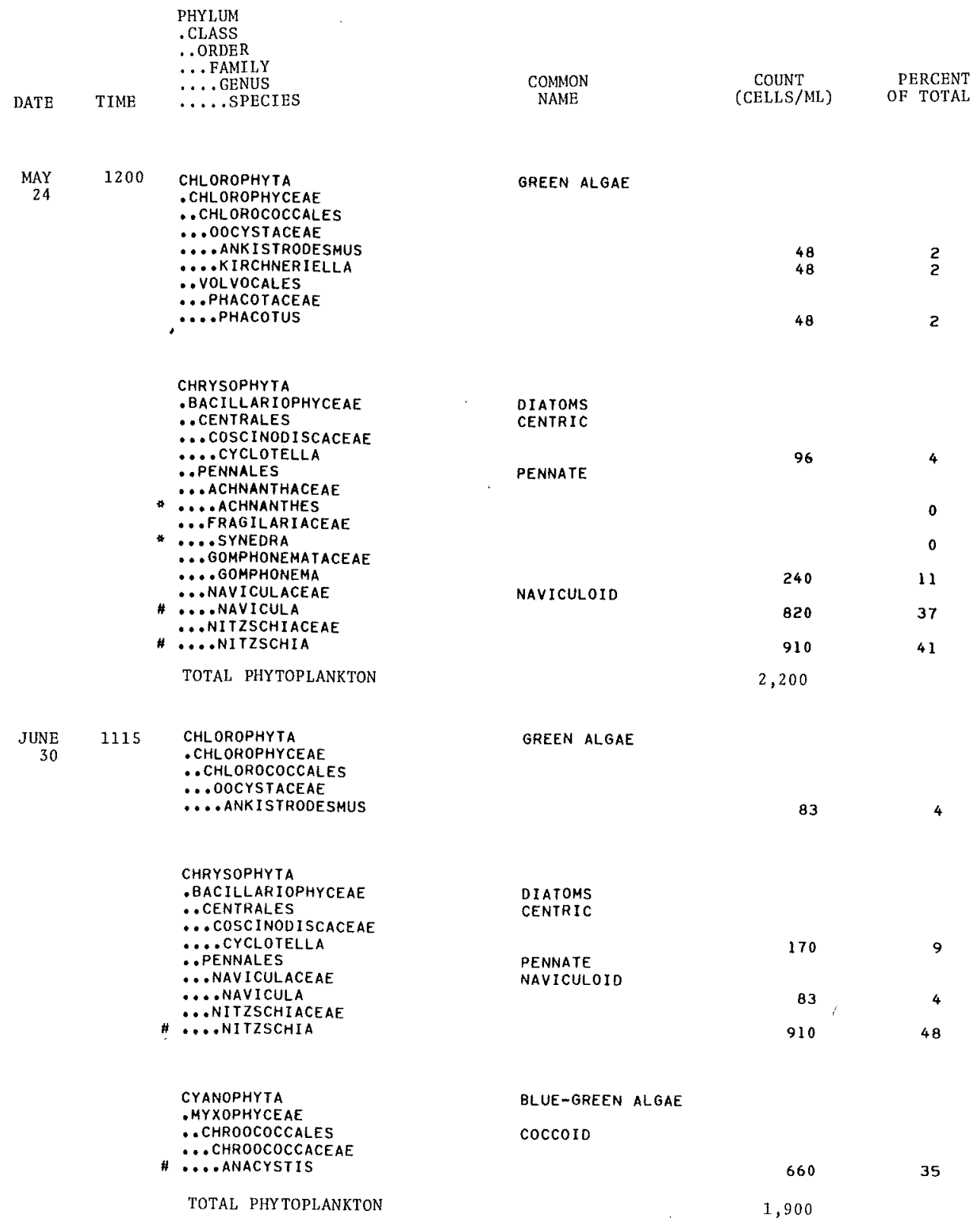

See footnotes at end of table. 
SANTA ANA RIVER BASIN

11074000 SANTA ANA RIVER BELOW PRADO DAM, CA--Continued

QUALITATIVE AND ASSOCIATED QUANTITATIVE ANALYSES OF BIOLOGICAL DATA, WATER YEAR OCTOBER 1975 TO SEPTEMBER 1976 PHYTOPLANKTON

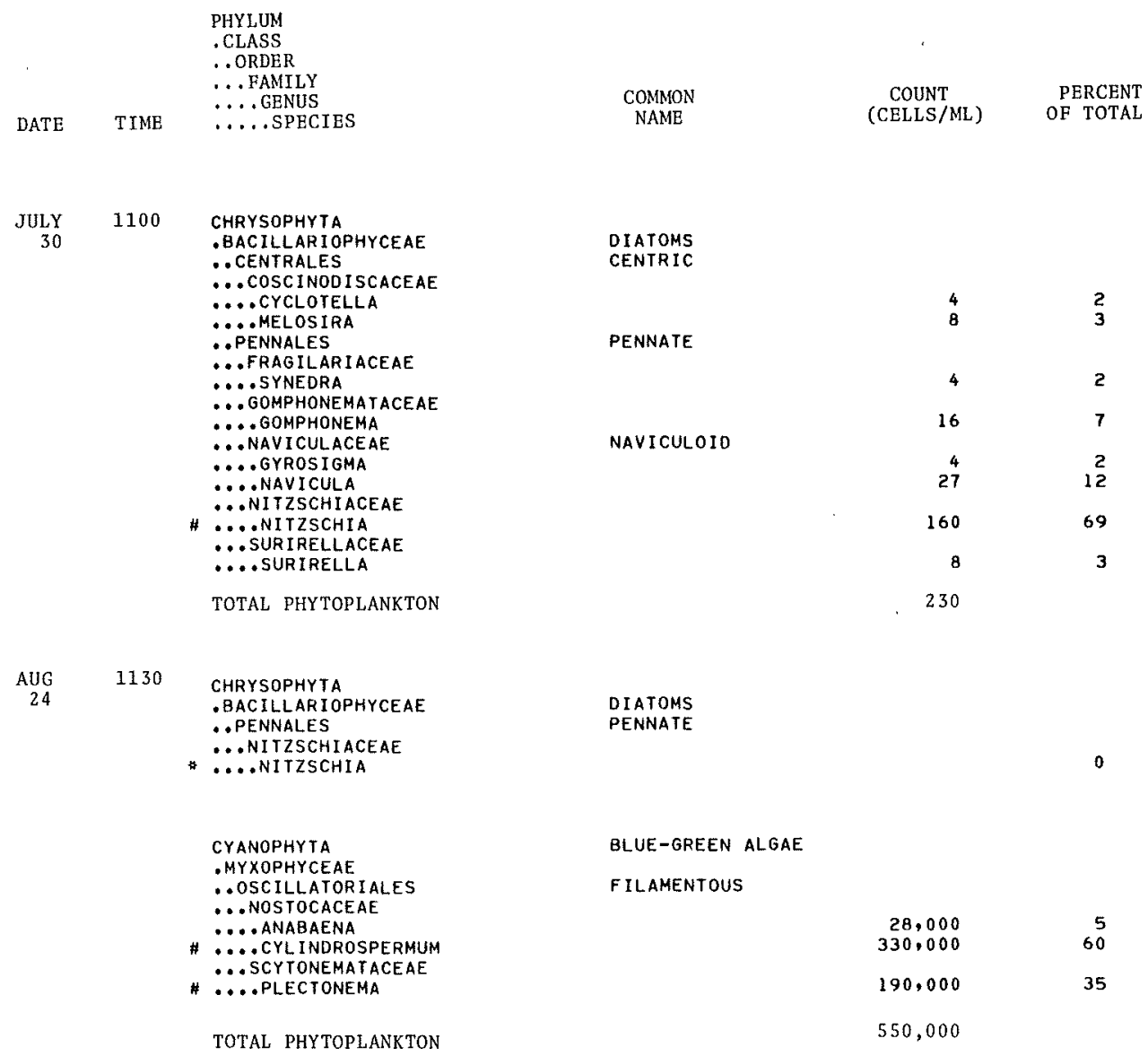

NOTE: \# - DOMINANT ORGANISM; GREATER OR EQUAL TO $15 \%$

* - LESS THEN $1 \%$; MAY NOT HAVE BEEN ACTUALLY COUNTEO

QUALITATIVE AND ASSOCIATED QUANTTTATIVE ANALYSES OF BIOLOGICAL DATA, WATER YEAR OCTOBER 1975 TO SEPTEMBER 1976

\section{PERIPHYTON}

$$
\text { Date Length of exposure }
$$

Feb. 29
31

\begin{tabular}{|c|c|c|c|}
\hline \multicolumn{3}{|c|}{ Biomass $\left(\mathrm{g} / \mathrm{m}^{2}\right)$} & Ch1orophy 11 \\
\hline Dry & weight & Ash weight & $\left(m g / m^{2}\right)$ \\
\hline & 9.6 & 7.5 & 5.2 \\
\hline
\end{tabular}
Ch1orophy11

$\left(\mathrm{mg} / \mathrm{m}^{2}\right)$
0.7

Biomass
pigment
ratio

410

$$
\begin{gathered}
\text { Sampling } \\
\text { method }
\end{gathered}
$$

polyethylene 
11074000 SANTA ANA RIVER BELOW PRADO DAM, CA--Continued

SPECIFIC CONOUCTANCE (MICROMHOS/CM AT 25 DEG. C), HATER YEAR OCTOBER 1975 TO SEPTEMBER 1976

\begin{tabular}{|c|c|c|c|c|c|c|c|c|c|c|c|c|}
\hline \multirow[b]{2}{*}{ DAY } & \multicolumn{3}{|c|}{ OCTOBER } & \multicolumn{3}{|c|}{ NOVEMBER } & \multicolumn{3}{|c|}{ DECEMGER } & \multicolumn{3}{|c|}{ JANUARY } \\
\hline & $\operatorname{MAX}$ & MIN & MEAN & MAX & MIN & MEAN & $\operatorname{MAX}$ & MIN & MEAN & $\operatorname{MAX}$ & MIN & MEAN \\
\hline $\begin{array}{l}1 \\
2 \\
3 \\
4 \\
5\end{array}$ & $\begin{array}{l}806 \\
796 \\
790 \\
782 \\
768\end{array}$ & $\begin{array}{l}756 \\
750 \\
738 \\
730 \\
722\end{array}$ & $\begin{array}{l}782 \\
772 \\
766 \\
755 \\
742\end{array}$ & $\begin{array}{l}-1-0 \\
1140 \\
1140 \\
1150\end{array}$ & $\begin{array}{l}-0 \\
1110 \\
1110 \\
1130\end{array}$ & $\begin{array}{l}1120 \\
1120 \\
1140\end{array}$ & $\begin{array}{l}578 \\
576 \\
574 \\
630 \\
580\end{array}$ & $\begin{array}{l}550 \\
544 \\
550 \\
562 \\
540\end{array}$ & $\begin{array}{l}563 \\
562 \\
560 \\
615 \\
565\end{array}$ & $\begin{array}{l}637 \\
627 \\
635 \\
641 \\
639\end{array}$ & $\begin{array}{l}613 \\
603 \\
609 \\
611 \\
561\end{array}$ & $\begin{array}{l}625 \\
616 \\
623 \\
625 \\
607\end{array}$ \\
\hline $\begin{array}{r}6 \\
7 \\
8 \\
9 \\
10\end{array}$ & $\begin{array}{r}874 \\
1080 \\
1090 \\
1100 \\
1100\end{array}$ & $\begin{array}{r}716 \\
894 \\
1050 \\
1060 \\
1080\end{array}$ & $\begin{array}{l}767 \\
1020 \\
1070 \\
1080 \\
1090\end{array}$ & $\begin{array}{l}1150 \\
1150 \\
1140 \\
1140 \\
1150\end{array}$ & $\begin{array}{r}1120 \\
1120 \\
1130 \\
1120 \\
849\end{array}$ & $\begin{array}{l}1140 \\
1140 \\
1130 \\
1130 \\
1110\end{array}$ & $\begin{array}{l}566 \\
560 \\
678 \\
724 \\
724\end{array}$ & $\begin{array}{l}542 \\
530 \\
524 \\
692 \\
704\end{array}$ & $\begin{array}{l}552 \\
545 \\
559 \\
706 \\
718\end{array}$ & $\begin{array}{l}587 \\
587 \\
590 \\
624 \\
576\end{array}$ & $\begin{array}{l}563 \\
554 \\
554 \\
558 \\
554\end{array}$ & $\begin{array}{l}575 \\
572 \\
571 \\
579 \\
565\end{array}$ \\
\hline $\begin{array}{l}11 \\
12 \\
13 \\
14 \\
15\end{array}$ & $\begin{array}{l}1120 \\
1120 \\
1110 \\
1120 \\
-10-\end{array}$ & $\begin{array}{l}1080 \\
1090 \\
1080 \\
1080 \\
--\infty\end{array}$ & $\begin{array}{c}1100 \\
1110 \\
1100 \\
1090 \\
-\end{array}$ & $\begin{array}{l}812 \\
720 \\
712 \\
714 \\
714\end{array}$ & $\begin{array}{l}702 \\
662 \\
686 \\
674 \\
672\end{array}$ & $\begin{array}{l}752 \\
697 \\
697 \\
700 \\
695\end{array}$ & $\begin{array}{l}756 \\
776 \\
794 \\
780 \\
780\end{array}$ & $\begin{array}{l}720 \\
580 \\
682 \\
762 \\
760\end{array}$ & $\begin{array}{l}740 \\
727 \\
765 \\
773 \\
768\end{array}$ & $\begin{array}{l}586 \\
596 \\
582 \\
582 \\
586\end{array}$ & $\begin{array}{l}564 \\
552 \\
554 \\
562 \\
558\end{array}$ & $\begin{array}{l}573 \\
577 \\
570 \\
572 \\
570\end{array}$ \\
\hline $\begin{array}{l}16 \\
17 \\
18 \\
19 \\
20\end{array}$ & $\begin{array}{r}1110 \\
1100 \\
1010 \\
834 \\
825\end{array}$ & $\begin{array}{r}1070 \\
1050 \\
814 \\
786 \\
776\end{array}$ & $\begin{array}{r}1080 \\
1090 \\
863 \\
815 \\
795\end{array}$ & $\begin{array}{l}716 \\
716 \\
715 \\
646 \\
614\end{array}$ & $\begin{array}{l}668 \\
688 \\
636 \\
590 \\
590\end{array}$ & $\begin{array}{l}694 \\
703 \\
693 \\
612 \\
602\end{array}$ & $\begin{array}{l}764 \\
630 \\
590 \\
579 \\
581\end{array}$ & $\begin{array}{l}552 \\
560 \\
566 \\
561 \\
557\end{array}$ & $\begin{array}{l}701 \\
583 \\
577 \\
569 \\
570\end{array}$ & $\begin{array}{l}580 \\
580 \\
590 \\
604 \\
636\end{array}$ & $\begin{array}{l}552 \\
546 \\
558 \\
568 \\
600\end{array}$ & $\begin{array}{l}566 \\
559 \\
572 \\
584 \\
614\end{array}$ \\
\hline $\begin{array}{l}21 \\
22 \\
23 \\
24 \\
25\end{array}$ & $\begin{array}{l}816 \\
840 \\
836 \\
812 \\
804\end{array}$ & $\begin{array}{l}776 \\
808 \\
782 \\
764 \\
762\end{array}$ & $\begin{array}{l}802 \\
826 \\
815 \\
794 \\
783\end{array}$ & $\begin{array}{l}616 \\
606 \\
602 \\
574 \\
611\end{array}$ & $\begin{array}{l}586 \\
578 \\
564 \\
554 \\
562\end{array}$ & $\begin{array}{l}601 \\
594 \\
582 \\
565 \\
593\end{array}$ & $\begin{array}{l}612 \\
619 \\
641 \\
638 \\
636\end{array}$ & $\begin{array}{l}572 \\
573 \\
613 \\
612 \\
608\end{array}$ & $\begin{array}{l}588 \\
590 \\
626 \\
625 \\
621\end{array}$ & $\begin{array}{r}632 \\
928 \\
1140 \\
716 \\
612\end{array}$ & $\begin{array}{l}598 \\
596 \\
930 \\
564 \\
574\end{array}$ & $\begin{array}{r}610 \\
665 \\
1090 \\
606 \\
592\end{array}$ \\
\hline $\begin{array}{l}26 \\
27 \\
28 \\
29 \\
30 \\
31\end{array}$ & $\begin{array}{l}812 \\
808 \\
722 \\
706 \\
716 \\
--\end{array}$ & $\begin{array}{l}762 \\
712 \\
672 \\
656 \\
656 \\
-\end{array}$ & $\begin{array}{l}789 \\
777 \\
704 \\
683 \\
693 \\
---\end{array}$ & $\begin{array}{l}586 \\
584 \\
644 \\
650 \\
600 \\
--\end{array}$ & $\begin{array}{l}544 \\
548 \\
572 \\
590 \\
560 \\
--\infty\end{array}$ & $\begin{array}{l}568 \\
569 \\
611 \\
620 \\
580 \\
-\infty\end{array}$ & $\begin{array}{l}627 \\
630 \\
634 \\
617 \\
631 \\
641\end{array}$ & $\begin{array}{l}597 \\
606 \\
596 \\
589 \\
603 \\
617\end{array}$ & $\begin{array}{l}612 \\
619 \\
616 \\
603 \\
618 \\
629\end{array}$ & $\begin{array}{l}606 \\
600 \\
602 \\
634 \\
632 \\
640\end{array}$ & $\begin{array}{l}572 \\
576 \\
574 \\
576 \\
574 \\
592\end{array}$ & $\begin{array}{l}589 \\
587 \\
589 \\
600 \\
601 \\
609\end{array}$ \\
\hline NTH & 1120 & 656 & 881 & 1150 & 544 & 777 & 794 & 524 & 628 & 1140 & 546 & 608 \\
\hline
\end{tabular}

FEBRUARY

MARCH

APRIL

MAY

DAY

MIN MEAN

MAX

$\begin{array}{rr}\text { MIN } & \text { MEAN } \\ \mathbf{5 8 0} & \mathbf{7 3 8}\end{array}$

$\begin{array}{lll}966 & 580 & 738 \\ 744 & 558 & 669 \\ 838 & 680 & 771\end{array}$

802
1130

682
786

771
736
973

1120

$\begin{array}{ll}510 & 624 \\ 560 & 582 \\ 492 & 579 \\ 730 & 614\end{array}$

614
867

1380

$482 \quad 811$

1030
1180

1150
836

$\begin{array}{ll}784 & 999 \\ 592 & 917\end{array}$

1380
1220

1150
1190

$\begin{array}{ll}1190 & 1200 \\ 1160 & 1170\end{array}$

$\begin{array}{rrr}1180 & 1160 & 1170 \\ 1190 & 1150 & 1170 \\ 1200 & 624 & 1010\end{array}$

$\begin{array}{lll}656 & 604 & 620 \\ 772 & 606 & 644\end{array}$

$772 \quad 606$

$626 \quad 586$

$586 \quad 622$

622
606
635

$642 \quad 58$
$642 \quad 58$

$\begin{array}{ll}586 & 613 \\ 588 & 618\end{array}$

613
618
609

$\begin{array}{ll}580 & 609 \\ 590 & 608\end{array}$

608
664

$\begin{array}{ll}668 & 682 \\ 668 & 687\end{array}$

$\begin{array}{ll}668 & 687 \\ 674 & 694 \\ 672 & 692 \\ 664 & 686\end{array}$

1180
1190
1270

1190
1090

MI

656938

$1130 \quad 1160$

$1170 \quad 1180$

$\begin{array}{rr}830 & 1040 \\ 918 & 1010\end{array}$

$\begin{array}{lll}1180 & 1110 & 1150 \\ 1190 & 1180 & 1180 \\ 1180 & 1160 & 1170 \\ 1160 & 1140 & 1150 \\ 1150 & 1130 & 1140\end{array}$

1150

1120

1150

1070

1120
1100

$1100 \quad 1110$

$\begin{array}{rr}604 & 869 \\ 922 & 1010\end{array}$

$\begin{array}{rr}922 & 1010 \\ 1050 & 1090\end{array}$

1080
1120

1120
1110

$\begin{array}{rr}856 & 1000 \\ 1080 & 1100 \\ 1090 & 1100\end{array}$

$1120 \quad 1080 \quad 1100$

$1120 \quad 1100 \quad 1110$

$\begin{array}{lll}1120 & 1100 & 1110 \\ 1090 & 1080 & 1090 \\ 1120 & 1090 & 1110\end{array}$

$\begin{array}{lll}1120 & 1090 & 1110 \\ 1120 & 1100 & 1110\end{array}$

$\begin{array}{lll}1120 & 1100 & 1110 \\ 1110 & 1090 & 1100\end{array}$

$648 \quad 677$

$636 \quad 670$

$\begin{array}{ll}638 & 668 \\ 620 & 655 \\ 619 & 647\end{array}$

$\begin{array}{ll}619 & 647 \\ 628 & 666\end{array}$

1110

$1110 \quad 1100 \quad 1100$

$1120 \quad 1100 \quad 1110$

$1130 \quad 1120 \quad 1130$

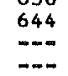

$\begin{array}{ll}629 & 692 \\ 623 & 680\end{array}$

663
732

558

753

1270

$604 \quad 1090$

\begin{tabular}{|c|c|c|}
\hline MAX & MIN & MEAN \\
\hline $\begin{array}{l}1160 \\
1160 \\
1160 \\
1150 \\
1140\end{array}$ & $\begin{array}{l}1140 \\
1140 \\
1130 \\
1120 \\
1100\end{array}$ & $\begin{array}{l}1150 \\
1150 \\
1140 \\
1140 \\
1120\end{array}$ \\
\hline $\begin{array}{l}1140 \\
1160\end{array}$ & $\begin{array}{r}1110 \\
862\end{array}$ & $\begin{array}{l}1130 \\
1040\end{array}$ \\
\hline $\begin{array}{l}1040 \\
1030 \\
1020\end{array}$ & $\begin{array}{r}904 \\
1010 \\
988\end{array}$ & $\begin{array}{l}1010 \\
1020 \\
1000\end{array}$ \\
\hline $\begin{array}{l}1120 \\
1090 \\
1100 \\
1110 \\
1090\end{array}$ & $\begin{array}{r}976 \\
1080 \\
1050 \\
1070 \\
1070\end{array}$ & $\begin{array}{l}1050 \\
1090 \\
1070 \\
1090 \\
1080\end{array}$ \\
\hline $\begin{array}{l}1080 \\
1060 \\
1110 \\
1160 \\
1150\end{array}$ & $\begin{array}{l}1050 \\
1050 \\
1080 \\
1100 \\
1090\end{array}$ & $\begin{array}{l}1070 \\
1050 \\
1100 \\
1120 \\
1110\end{array}$ \\
\hline $\begin{array}{l}1130 \\
1100 \\
1090 \\
1110 \\
1090\end{array}$ & $\begin{array}{l}1090 \\
1080 \\
1080 \\
1070 \\
1070\end{array}$ & $\begin{array}{l}1100 \\
1090 \\
1080 \\
1090 \\
1080\end{array}$ \\
\hline $\begin{array}{r}1120 \\
1070 \\
605 \\
708 \\
609 \\
600\end{array}$ & $\begin{array}{r}1080 \\
588 \\
571 \\
578 \\
567 \\
554\end{array}$ & $\begin{array}{r}1100 \\
695 \\
592 \\
615 \\
592 \\
581\end{array}$ \\
\hline
\end{tabular}


11074000 SANTA ANA RIVER BELON PRADO DAM, CA--Continued

SPECIFIC CONDUCTANCE (MICROMHOS/CM AT 25 DEG. C), HATER YEAR OCTOBER 1975 TO SEPTEMEER 1976

\begin{tabular}{|c|c|c|c|c|c|c|c|c|c|c|c|c|}
\hline \multirow[b]{2}{*}{ DAY } & \multicolumn{3}{|c|}{ JUNE } & \multicolumn{3}{|c|}{ JULY } & \multicolumn{3}{|c|}{ AUGUST } & \multicolumn{3}{|c|}{ SEPTEMBER } \\
\hline & MAX & MIN & MEAN & $\operatorname{MAX}$ & MIN & MEAN & MAX & MIN & MEAN & $\operatorname{MAX}$ & MIN & MEAN \\
\hline $\begin{array}{l}1 \\
2 \\
3 \\
4 \\
5\end{array}$ & $\begin{array}{l}651 \\
595 \\
593 \\
587 \\
580\end{array}$ & $\begin{array}{l}559 \\
565 \\
569 \\
557 \\
544\end{array}$ & $\begin{array}{l}598 \\
582 \\
583 \\
576 \\
565\end{array}$ & $\begin{array}{l}595 \\
569 \\
560 \\
575 \\
633\end{array}$ & $\begin{array}{l}541 \\
519 \\
520 \\
525 \\
543\end{array}$ & $\begin{array}{l}575 \\
555 \\
545 \\
556 \\
579\end{array}$ & $\begin{array}{l}1140 \\
1120 \\
1080 \\
1090 \\
1080\end{array}$ & $\begin{array}{l}1050 \\
1050 \\
1040 \\
1060 \\
1030\end{array}$ & $\begin{array}{l}1090 \\
1080 \\
1070 \\
1080 \\
1070\end{array}$ & $\begin{array}{l}1130 \\
1130 \\
1160 \\
1110 \\
1110\end{array}$ & $\begin{array}{l}1070 \\
1090 \\
1080 \\
1090 \\
1080\end{array}$ & $\begin{array}{l}1090 \\
1120 \\
1110 \\
1100 \\
1090\end{array}$ \\
\hline $\begin{array}{r}6 \\
7 \\
8 \\
9 \\
10\end{array}$ & $\begin{array}{l}580 \\
588 \\
578 \\
583 \\
660\end{array}$ & $\begin{array}{l}544 \\
546 \\
546 \\
555 \\
562\end{array}$ & $\begin{array}{l}563 \\
566 \\
562 \\
569 \\
586\end{array}$ & $\begin{array}{l}718 \\
707 \\
680 \\
707 \\
696\end{array}$ & $\begin{array}{l}630 \\
651 \\
562 \\
637 \\
634\end{array}$ & $\begin{array}{l}684 \\
683 \\
609 \\
680 \\
671\end{array}$ & $\begin{array}{l}1060 \\
1080 \\
1080 \\
1080 \\
1140\end{array}$ & $\begin{array}{l}1030 \\
1050 \\
1060 \\
1060 \\
1050\end{array}$ & $\begin{array}{l}1040 \\
1070 \\
1070 \\
1070 \\
1070\end{array}$ & $\begin{array}{l}1090 \\
1220 \\
1210 \\
1160 \\
1180\end{array}$ & $\begin{array}{r}1060 \\
1060 \\
1060 \\
1080 \\
693\end{array}$ & $\begin{array}{l}1070 \\
1090 \\
1120 \\
1130 \\
1030\end{array}$ \\
\hline $\begin{array}{l}11 \\
12 \\
13 \\
14 \\
15\end{array}$ & $\begin{array}{l}583 \\
553 \\
542 \\
549 \\
584\end{array}$ & $\begin{array}{l}519 \\
507 \\
492 \\
505 \\
531\end{array}$ & $\begin{array}{l}553 \\
534 \\
520 \\
524 \\
562\end{array}$ & $\begin{array}{l}696 \\
709 \\
706 \\
708 \\
836\end{array}$ & $\begin{array}{l}638 \\
645 \\
644 \\
644 \\
652\end{array}$ & $\begin{array}{l}672 \\
682 \\
680 \\
681 \\
715\end{array}$ & $\begin{array}{l}1130 \\
1090 \\
1080 \\
1090 \\
1090\end{array}$ & $\begin{array}{l}1090 \\
1070 \\
1070 \\
1070 \\
1080\end{array}$ & $\begin{array}{l}1110 \\
1080 \\
1080 \\
1080 \\
1080\end{array}$ & $\begin{array}{r}918 \\
631 \\
788 \\
1060 \\
1300\end{array}$ & $\begin{array}{r}576 \\
563 \\
620 \\
803 \\
1070\end{array}$ & $\begin{array}{r}788 \\
595 \\
689 \\
944 \\
1160\end{array}$ \\
\hline $\begin{array}{l}16 \\
17 \\
18 \\
19 \\
20\end{array}$ & $\begin{array}{l}584 \\
582 \\
575 \\
563 \\
562\end{array}$ & $\begin{array}{l}550 \\
550 \\
511 \\
509 \\
516\end{array}$ & $\begin{array}{l}570 \\
568 \\
551 \\
542 \\
540\end{array}$ & $\begin{array}{l}1060 \\
1130 \\
1120 \\
1080 \\
1080\end{array}$ & $\begin{array}{r}836 \\
1030 \\
1070 \\
1050 \\
1040\end{array}$ & $\begin{array}{l}1000 \\
1080 \\
1090 \\
1070 \\
1070\end{array}$ & $\begin{array}{l}1100 \\
11110 \\
11100 \\
11100 \\
1100\end{array}$ & $\begin{array}{l}1090 \\
1090 \\
1100 \\
1080 \\
1080\end{array}$ & $\begin{array}{l}1090 \\
1100 \\
1110 \\
1090 \\
1090\end{array}$ & $\begin{array}{l}1230 \\
1180 \\
1190 \\
1180 \\
1170\end{array}$ & $\begin{array}{l}1180 \\
1160 \\
1160 \\
1150 \\
1140\end{array}$ & $\begin{array}{l}1200 \\
1170 \\
1170 \\
1160 \\
1150\end{array}$ \\
\hline $\begin{array}{l}21 \\
22 \\
23 \\
24 \\
25\end{array}$ & $\begin{array}{l}562 \\
551 \\
559 \\
545 \\
577\end{array}$ & $\begin{array}{l}510 \\
501 \\
505 \\
501 \\
519\end{array}$ & $\begin{array}{l}537 \\
530 \\
532 \\
526 \\
558\end{array}$ & $\begin{array}{l}1140 \\
1110 \\
1110 \\
1100 \\
1120\end{array}$ & $\begin{array}{l}1050 \\
1080 \\
1070 \\
1070 \\
1060\end{array}$ & $\begin{array}{l}1090 \\
1090 \\
1090 \\
1080 \\
1070\end{array}$ & $\begin{array}{l}1090 \\
1090 \\
1090 \\
1070 \\
1080\end{array}$ & $\begin{array}{l}1070 \\
1070 \\
1050 \\
1050 \\
1060\end{array}$ & $\begin{array}{l}1080 \\
1080 \\
1060 \\
1060 \\
1070\end{array}$ & $\begin{array}{l}1150 \\
1140 \\
1110 \\
1110 \\
1100\end{array}$ & $\begin{array}{r}1120 \\
1100 \\
1090 \\
1100 \\
864\end{array}$ & $\begin{array}{r}1140 \\
1130 \\
1100 \\
1110 \\
973\end{array}$ \\
\hline $\begin{array}{l}26 \\
27 \\
28 \\
29 \\
30 \\
31\end{array}$ & $\begin{array}{l}619 \\
619 \\
615 \\
577 \\
581 \\
-\end{array}$ & $\begin{array}{l}569 \\
565 \\
539 \\
531 \\
523 \\
---\end{array}$ & $\begin{array}{l}600 \\
596 \\
588 \\
556 \\
558 \\
-\end{array}$ & $\begin{array}{l}1070 \\
1110 \\
1080 \\
1080 \\
1080 \\
1080\end{array}$ & $\begin{array}{l}1050 \\
1030 \\
1030 \\
1030 \\
1040 \\
1040\end{array}$ & $\begin{array}{l}1060 \\
1070 \\
1060 \\
1050 \\
1060 \\
1060\end{array}$ & $\begin{array}{l}1100 \\
1100 \\
1080 \\
1090 \\
1080 \\
1080\end{array}$ & $\begin{array}{l}1080 \\
1070 \\
1070 \\
1080 \\
1070 \\
1060\end{array}$ & $\begin{array}{l}1080 \\
1080 \\
1080 \\
1080 \\
1070 \\
1070\end{array}$ & $\begin{array}{l}1110 \\
1120 \\
1110 \\
1100 \\
1100 \\
\end{array}$ & $\begin{array}{r}1040 \\
1070 \\
1060 \\
1070 \\
974 \\
-\end{array}$ & $\begin{array}{c}1090 \\
1090 \\
1080 \\
1080 \\
1080 \\
-\end{array}$ \\
\hline MONTH & 660 & 492 & 560 & 1140 & 519 & 860 & 1140 & 1030 & 1080 & 1300 & 563 & 1060 \\
\hline YEAR & 1390 & 482 & 847 & & & & & & & & & \\
\hline
\end{tabular}

TEMPERATURE (DEG, C) OF WATER, WATER YEAR OCTOBER 1975 TO SEPTEMBER 1976

\begin{tabular}{|c|c|c|c|c|c|c|c|c|c|c|c|c|}
\hline \multirow[b]{2}{*}{ DAY } & \multicolumn{3}{|c|}{ OCTOBER } & \multicolumn{3}{|c|}{ NOVEMBER } & \multicolumn{3}{|c|}{ DECEMBER } & \multicolumn{3}{|c|}{ JANUARY } \\
\hline & $\max$ & MIN & MEAN & $\max$ & MIN & MEAN & $\max$ & MIN & MEAN & $\max$ & MIN & MEAN \\
\hline $\begin{array}{l}1 \\
2 \\
3 \\
4 \\
5\end{array}$ & $\begin{array}{l}21.5 \\
22.0 \\
22.5 \\
22.5 \\
21.5\end{array}$ & $\begin{array}{l}18.0 \\
17.5 \\
18.5 \\
18.00 \\
17.0\end{array}$ & $\begin{array}{l}20.0 \\
20.0 \\
20.5 \\
20.5 \\
20.0\end{array}$ & \begin{tabular}{l}
.-- \\
\hdashline.- \\
17.5 \\
16.5
\end{tabular} & \begin{tabular}{l}
$-=-$ \\
\hdashline-- \\
12.0 \\
13.0
\end{tabular} & \begin{tabular}{l}
-- \\
\hdashline- \\
15.0 \\
15.0
\end{tabular} & $\begin{array}{l}13.0 \\
13.5 \\
13.0 \\
12.0 \\
12.5\end{array}$ & $\begin{array}{r}8.0 \\
9.0 \\
9.5 \\
10.5 \\
11.0\end{array}$ & $\begin{array}{l}10.0 \\
11.0 \\
11.0 \\
11.5 \\
11.5\end{array}$ & $\begin{array}{r}8.5 \\
9.0 \\
7.0 \\
5.5 \\
10.5\end{array}$ & $\begin{array}{l}5.0 \\
4.00 \\
4.5 \\
5.0 \\
5.5\end{array}$ & $\begin{array}{l}7.0 \\
6.5 \\
5.0 \\
5.0 \\
8.0\end{array}$ \\
\hline $\begin{array}{r}6 \\
7 \\
8 \\
9 \\
10\end{array}$ & $\begin{array}{l}21.0 \\
20.5 \\
19.0 \\
19.0 \\
18.5\end{array}$ & $\begin{array}{l}18.0 \\
18.0 \\
14.5 \\
15.0 \\
16.0\end{array}$ & $\begin{array}{l}19.5 \\
19.0 \\
17.0 \\
17.0 \\
17.0\end{array}$ & $\begin{array}{l}17.0 \\
16.5 \\
16.0 \\
16.0 \\
16.0\end{array}$ & $\begin{array}{l}14.5 \\
12.5 \\
14.0 \\
13.0 \\
12.0\end{array}$ & $\begin{array}{l}15.5 \\
14.5 \\
15.0 \\
14.5 \\
14.0\end{array}$ & $\begin{array}{l}13.0 \\
13.0 \\
14.0 \\
14.0 \\
13.0\end{array}$ & $\begin{array}{l}9.0 \\
8.5 \\
9.0 \\
9.5 \\
9.5\end{array}$ & $\begin{array}{l}11.0 \\
11.0 \\
11.5 \\
12.0 \\
11.5\end{array}$ & $\begin{array}{l}10.5 \\
11: 0 \\
11.0 \\
11.5 \\
11.5\end{array}$ & $\begin{array}{l}6.0 \\
6.0 \\
6.0 \\
6.5 \\
8.0\end{array}$ & $\begin{array}{l}8.0 \\
8.5 \\
8.5 \\
9.0 \\
9.5\end{array}$ \\
\hline $\begin{array}{l}11 \\
12 \\
13 \\
14 \\
15\end{array}$ & $\begin{array}{l}19.5 \\
19.0 \\
18.0 \\
19.0\end{array}$ & $\begin{array}{r}17.5 \\
15.5 \\
13.5 \\
13.0 \\
--.-\end{array}$ & $\begin{array}{l}18.0 \\
17.0 \\
16.0 \\
16.0\end{array}$ & $\begin{array}{l}15.0 \\
15.0 \\
16.0 \\
15.0 \\
14.5\end{array}$ & $\begin{array}{r}11.5 \\
12.0 \\
12.5 \\
10.0 \\
9.5\end{array}$ & $\begin{array}{l}13.5 \\
13.5 \\
14.0 \\
13.0 \\
12.5\end{array}$ & $\begin{array}{l}13.5 \\
12.5 \\
12.0 \\
10.5 \\
10.0\end{array}$ & $\begin{array}{r}12.0 \\
11.0 \\
10.5 \\
8.5 \\
6.0\end{array}$ & $\begin{array}{r}12.5 \\
12.0 \\
11.0 \\
9.5 \\
8.5\end{array}$ & $\begin{array}{l}11.5 \\
11.0 \\
12.0 \\
12.5 \\
13.0\end{array}$ & $\begin{array}{l}6.5 \\
6.0 \\
6.0 \\
6.5 \\
7.0\end{array}$ & $\begin{array}{r}9.0 \\
8.5 \\
9.0 \\
9.5 \\
10.0\end{array}$ \\
\hline $\begin{array}{l}16 \\
17 \\
18 \\
19 \\
20\end{array}$ & \begin{tabular}{l}
$-\cdots$ \\
\hdashline- \\
\hdashline- \\
\hdashline-
\end{tabular} & $\begin{array}{l}\because- \\
\because-: \\
\because-:\end{array}$ & \begin{tabular}{l}
-- \\
$\because-$ \\
\hdashline- \\
\hdashline-
\end{tabular} & $\begin{array}{l}14.0 \\
14.0 \\
13.5 \\
13.5 \\
13.0\end{array}$ & $\begin{array}{r}10: 0 \\
11: 0 \\
11: 5 \\
9: 0 \\
8: 0\end{array}$ & $\begin{array}{l}12.0 \\
13.0 \\
12.5 \\
11.0 \\
10.5\end{array}$ & $\begin{array}{l}11: 0 \\
11: 0 \\
11: 5 \\
11: 0 \\
11: 0\end{array}$ & $\begin{array}{l}6.5 \\
6.5 \\
6.5 \\
7: 0 \\
7.0\end{array}$ & $\begin{array}{l}8.5 \\
9.0 \\
9.0 \\
9.0 \\
9.0\end{array}$ & $\begin{array}{l}14.0 \\
14: 0 \\
13.0 \\
13.0 \\
13.5\end{array}$ & $\begin{array}{l}8.5 \\
8.5 \\
8.5 \\
9.0 \\
9.5\end{array}$ & $\begin{array}{l}11.0 \\
11.5 \\
11.0 \\
11.0 \\
11.5\end{array}$ \\
\hline $\begin{array}{l}21 \\
22 \\
23 \\
24 \\
25\end{array}$ & \begin{tabular}{l}
$-\because$ \\
\hdashline- \\
\hdashline- \\
\hdashline- \\
-
\end{tabular} & $\begin{array}{l}\because- \\
\because- \\
\because- \\
\because-\end{array}$ & \begin{tabular}{l}
--- \\
$\because-$ \\
\hdashline- \\
\hdashline-
\end{tabular} & $\begin{array}{l}13.0 \\
13.5 \\
14.0 \\
15.0 \\
14.5\end{array}$ & $\begin{array}{r}9.0 \\
10.0 \\
8.5 \\
12.0 \\
9.5\end{array}$ & $\begin{array}{l}11.0 \\
11.5 \\
11.5 \\
13.0 \\
12.0\end{array}$ & $\begin{array}{l}12.0 \\
11.5 \\
12.0 \\
12.0 \\
12.0\end{array}$ & $\begin{array}{l}9.0 \\
9.0 \\
7.5 \\
7.5 \\
7.5\end{array}$ & $\begin{array}{r}10.5 \\
10.0 \\
10.0 \\
10.0 \\
9.5\end{array}$ & $\begin{array}{l}13.0 \\
14.0 \\
15.5 \\
13.0 \\
12.5\end{array}$ & $\begin{array}{r}9.0 \\
9.0 \\
10.0 \\
8.5 \\
7.5\end{array}$ & $\begin{array}{l}11.0 \\
11.5 \\
12.5 \\
10.5 \\
10.0\end{array}$ \\
\hline $\begin{array}{l}26 \\
27 \\
28 \\
29 \\
30 \\
31\end{array}$ & \begin{tabular}{l}
--- \\
\hdashline- \\
\hdashline- \\
$\cdots-$
\end{tabular} & 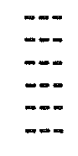 & $\begin{array}{l}=- \\
\because- \\
\cdots \\
\cdots- \\
-\cdots\end{array}$ & $\begin{array}{l}14.0 \\
13.0 \\
12.0 \\
11.0 \\
11.5 \\
\cdots \cdots\end{array}$ & $\begin{array}{r}11.0 \\
11: 0 \\
10.0 \\
8.0 \\
7.5 \\
\cdots\end{array}$ & $\begin{array}{r}13.0 \\
12.0 \\
11.0 \\
10.0 \\
9.5 \\
-0 .\end{array}$ & $\begin{array}{l}12.5 \\
11.0 \\
13.0 \\
13.0 \\
12.0 \\
11.0\end{array}$ & $\begin{array}{l}7.0 \\
8.0 \\
8.5 \\
9.5 \\
7.5 \\
8.0\end{array}$ & $\begin{array}{r}9.5 \\
9.5 \\
11.0 \\
11.0 \\
10.0 \\
9.5\end{array}$ & $\begin{array}{l}13.0 \\
13.5 \\
14.0 \\
14.0 \\
14.0 \\
15.0\end{array}$ & $\begin{array}{l}8.0 \\
6.5 \\
7.5 \\
8.0 \\
7.5 \\
8.0\end{array}$ & $\begin{array}{l}10.5 \\
10.0 \\
11.0 \\
11.0 \\
10.5 \\
11.5\end{array}$ \\
\hline IONTH & -- & -- & $\cdots$ & 17.5 & 7.5 & 12.5 & 14.0 & 6.0 & 10.5 & 15.5 & 4.0 & 9.5 \\
\hline
\end{tabular}


11074000 SANTA ANA RIVER BELOW PRADO DAM, CA--Continued

TEMPERATURE (DEG, C) OF HATER, HATER YEAR OCTOBER 1975 TO SEPIEMBER 1976

\begin{tabular}{|c|c|c|c|c|c|c|c|c|c|c|c|c|}
\hline \multirow[b]{2}{*}{ DAY } & \multicolumn{3}{|c|}{ FEBRUARY } & \multicolumn{3}{|c|}{ MARCH } & \multicolumn{3}{|c|}{ APRIL } & \multicolumn{3}{|c|}{ MAY } \\
\hline & $\max$ & MIN & MEAN & MAK & MIN & MEAN & $\operatorname{MAX}$ & MIN & MEAN & $\operatorname{MAX}$ & MIN & MEAN \\
\hline $\begin{array}{l}1 \\
2 \\
3 \\
4 \\
5\end{array}$ & $\begin{array}{l}15.0 \\
14.0 \\
12.5 \\
11.5 \\
13.0\end{array}$ & $\begin{array}{r}8.0 \\
8.0 \\
8.0 \\
10.5 \\
11.0\end{array}$ & $\begin{array}{l}11: 5 \\
11: 0 \\
10: 5 \\
11: 0 \\
12.0\end{array}$ & \begin{tabular}{l}
$\square$ \\
\hdashline \\
\hdashline
\end{tabular} & 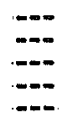 & $\begin{array}{l}= \\
=- \\
=-\end{array}$ & $\begin{array}{l}21.0 \\
17.5 \\
14.5 \\
16.5\end{array}$ & $\begin{array}{l}12.5 \\
14.5 \\
11.0 \\
12.5\end{array}$ & $\begin{array}{l}17.5 \\
15.5 \\
13.5 \\
14.5\end{array}$ & $\begin{array}{l}24.5 \\
23.5 \\
21.5 \\
23.0 \\
20.0\end{array}$ & $\begin{array}{l}15.5 \\
16.0 \\
17.5 \\
16.5 \\
16.5\end{array}$ & $\begin{array}{l}20.0 \\
19.5 \\
19.0 \\
19.5 \\
18.0\end{array}$ \\
\hline $\begin{array}{r}6 \\
7 \\
8 \\
9 \\
10\end{array}$ & $\begin{array}{l}12.5 \\
13.5 \\
13.5 \\
13.5 \\
13.0\end{array}$ & $\begin{array}{l}10.5 \\
12.0 \\
12.5 \\
13.0 \\
13.0\end{array}$ & $\begin{array}{l}12.0 \\
12.5 \\
13.0 \\
13.0 \\
13.0\end{array}$ & \begin{tabular}{r}
$-=$ \\
\hdashline$-:$ \\
16.5 \\
16.5
\end{tabular} & \begin{tabular}{l}
$-:$ \\
\hdashline 11.0 \\
12.0
\end{tabular} & \begin{tabular}{c}
$\cdots$ \\
\hdashline- \\
13.5 \\
13.5
\end{tabular} & $\begin{array}{l}19.0 \\
20.5 \\
18.0 \\
21.0 \\
20.0\end{array}$ & $\begin{array}{l}13.5 \\
12.5 \\
14.0 \\
12.5 \\
12.5\end{array}$ & $\begin{array}{l}15.5 \\
16.5 \\
16.0 \\
16.5 \\
16.5\end{array}$ & $\begin{array}{l}17.5 \\
20.5 \\
23.5 \\
24.0 \\
24.5\end{array}$ & $\begin{array}{l}15.5 \\
15.5 \\
15.5 \\
16.5 \\
17.5\end{array}$ & $\begin{array}{l}16.5 \\
17.5 \\
19.0 \\
20.0 \\
20.5\end{array}$ \\
\hline $\begin{array}{l}11 \\
12 \\
13 \\
14 \\
15\end{array}$ & $\begin{array}{l}14.0 \\
13.0 \\
13.0 \\
13.0 \\
13.5\end{array}$ & $\begin{array}{l}13.0 \\
12.5 \\
12.5 \\
13.0 \\
13.0\end{array}$ & $\begin{array}{l}13.0 \\
13.0 \\
13.0 \\
13.0 \\
13.0\end{array}$ & $\begin{array}{l}13.0 \\
15.0 \\
15.5 \\
15.5 \\
16.0\end{array}$ & $\begin{array}{l}11.0 \\
10: 0 \\
10.0 \\
11.0 \\
12.5\end{array}$ & $\begin{array}{l}12.0 \\
12.5 \\
12.0 \\
12.5 \\
14.0\end{array}$ & $\begin{array}{l}20.5 \\
18.0 \\
15.5 \\
19.5 \\
16.0\end{array}$ & $\begin{array}{l}12.5 \\
13.5 \\
13.0 \\
11.5 \\
12.5\end{array}$ & $\begin{array}{l}16.5 \\
15.5 \\
14.0 \\
15.5 \\
15.0\end{array}$ & $\begin{array}{l}25.5 \\
27.0 \\
26.5 \\
26.0 \\
25.0\end{array}$ & $\begin{array}{l}17.5 \\
18.0 \\
17.5 \\
18.0 \\
18.0\end{array}$ & $\begin{array}{l}21.5 \\
22.0 \\
22.0 \\
22.0 \\
21.0\end{array}$ \\
\hline $\begin{array}{l}16 \\
17 \\
18 \\
19 \\
20\end{array}$ & $\begin{array}{l}13.5 \\
13.5 \\
14.0 \\
13.5 \\
14.0\end{array}$ & $\begin{array}{l}13.0 \\
13.5 \\
13.5 \\
13.5 \\
13.0\end{array}$ & $\begin{array}{l}13.5 \\
13.5 \\
13.5 \\
13.5 \\
13.5\end{array}$ & \begin{tabular}{c}
16.5 \\
\hdashline- \\
\hdashline
\end{tabular} & $\begin{array}{r}13.0 \\
\hdashline- \\
\hdashline\end{array}$ & \begin{tabular}{r}
14.5 \\
\hdashline$-:$ \\
\hdashline- \\
$-\square$
\end{tabular} & $\begin{array}{l}18.0 \\
19.5 \\
20.5 \\
22.5 \\
23.5\end{array}$ & $\begin{array}{l}10.5 \\
10.5 \\
111.5 \\
12.5 \\
13.5\end{array}$ & $\begin{array}{l}14.0 \\
15: 0 \\
15.5 \\
17.0 \\
18.5\end{array}$ & $\begin{array}{l}24.5 \\
24.5 \\
25.0 \\
23.5 \\
24.0\end{array}$ & $\begin{array}{l}18.0 \\
17.0 \\
16.0 \\
16.5 \\
17.0\end{array}$ & $\begin{array}{l}20.5 \\
20.0 \\
20.0 \\
19.5 \\
20.0\end{array}$ \\
\hline $\begin{array}{l}21 \\
22 \\
23 \\
24 \\
25\end{array}$ & $\begin{array}{l}13.5 \\
14.5 \\
17.0 \\
18.5 \\
18.5\end{array}$ & $\begin{array}{l}12.0 \\
12.0 \\
10.5 \\
11.5 \\
11.5\end{array}$ & $\begin{array}{l}12.5 \\
12.5 \\
13.5 \\
14.5 \\
14.5\end{array}$ & $\begin{array}{l}= \\
=- \\
-\end{array}$ & ":- & $\begin{array}{l}=- \\
=- \\
=-\end{array}$ & $\begin{array}{l}23.5 \\
20.5 \\
21.5 \\
22.5 \\
22.5\end{array}$ & $\begin{array}{l}14.5 \\
16.5 \\
16.0 \\
14.5 \\
16.5\end{array}$ & $\begin{array}{l}19.0 \\
18.5 \\
18.5 \\
18.5 \\
18.5\end{array}$ & $\begin{array}{l}23.5 \\
23.5 \\
24.0 \\
22.5 \\
23.0\end{array}$ & $\begin{array}{l}16.5 \\
16.5 \\
15.5 \\
16.5 \\
17.5\end{array}$ & $\begin{array}{l}19.5 \\
19.5 \\
19.5 \\
19.5 \\
19.5\end{array}$ \\
\hline $\begin{array}{l}26 \\
27 \\
28 \\
29 \\
30 \\
31\end{array}$ & \begin{tabular}{r}
16.0 \\
15.5 \\
15.5 \\
15.5 \\
\hdashline.- \\
-
\end{tabular} & $\begin{array}{r}9.5 \\
10.5 \\
11.0 \\
11.5 \\
\hdashline-. .\end{array}$ & $\begin{array}{r}12.5 \\
13.0 \\
13.0 \\
13.0 \\
-\ldots .0\end{array}$ & \begin{tabular}{l}
$=-$ \\
\hdashline- \\
\hdashline \\
\hdashline
\end{tabular} & \begin{tabular}{l}
$\square$ \\
$\because \because$ \\
\hdashline- \\
\hdashline-
\end{tabular} & $\begin{array}{l}=- \\
=- \\
=- \\
=\end{array}$ & $\begin{array}{r}22.5 \\
22.5 \\
22.5 \\
22.5 \\
24.5 \\
-. .\end{array}$ & $\begin{array}{l}14.0 \\
15.0 \\
15.0 \\
14.0 \\
14.5 \\
\therefore . .\end{array}$ & $\begin{array}{r}18.0 \\
18.0 \\
18.0 \\
18.0 \\
19.5 \\
\cdots \cdots\end{array}$ & $\begin{array}{l}24.5 \\
21.5 \\
19.5 \\
17.5 \\
19.5 \\
21.5\end{array}$ & $\begin{array}{l}16.5 \\
16.0 \\
16.5 \\
15.5 \\
15.0 \\
15.0\end{array}$ & $\begin{array}{l}20.5 \\
18.5 \\
17.5 \\
16.5 \\
17.0 \\
18.5\end{array}$ \\
\hline MONTH & 18.5 & 8.0 & 13.0 & -- & $\cdots$ & --- & 24.5 & 10.5 & 16.5 & 27.0 & 15,0 & 19.5 \\
\hline
\end{tabular}

\begin{tabular}{|c|c|c|c|c|c|c|c|c|c|c|c|c|}
\hline \multirow[b]{2}{*}{ DAY } & \multicolumn{3}{|c|}{ JUNE } & \multicolumn{3}{|c|}{ JULY } & \multicolumn{3}{|c|}{ AUGUST } & \multicolumn{3}{|c|}{ SEPTEMBER } \\
\hline & $\operatorname{MAX}$ & MIN & MEAN & $\operatorname{MAX}$ & MIN & MEAN & $\operatorname{mAX}$ & MIN & MEAN & MAX & MIN & MEAN \\
\hline $\begin{array}{l}1 \\
2 \\
3 \\
4 \\
5\end{array}$ & $\begin{array}{l}23.0 \\
21.0 \\
20.5 \\
21.0 \\
21.0\end{array}$ & $\begin{array}{l}16.0 \\
16.5 \\
17.0 \\
16.0 \\
15.0\end{array}$ & $\begin{array}{l}19.5 \\
19.0 \\
19.0 \\
18.5 \\
18.5\end{array}$ & $\begin{array}{l}24.0 \\
23.5 \\
24.0 \\
24.5 \\
24.5\end{array}$ & $\begin{array}{l}18.0 \\
18.0 \\
18.0 \\
18.0 \\
18.5\end{array}$ & $\begin{array}{l}21.5 \\
21.0 \\
21.5 \\
21.5 \\
22.0\end{array}$ & $\begin{array}{l}24.5 \\
23.5 \\
24.5 \\
24.5 \\
25.0\end{array}$ & $\begin{array}{l}19.0 \\
18.0 \\
19.0 \\
18.0 \\
18.0\end{array}$ & $\begin{array}{l}21.5 \\
21.0 \\
21.5 \\
21.5 \\
21.5\end{array}$ & $\begin{array}{l}25.5 \\
25.0 \\
25.5 \\
27.0 \\
25.0\end{array}$ & $\begin{array}{l}20.5 \\
19.5 \\
21.5 \\
21.0 \\
20.5\end{array}$ & $\begin{array}{l}23.0 \\
22.5 \\
23.5 \\
24.0 \\
23.0\end{array}$ \\
\hline $\begin{array}{r}6 \\
7 \\
8 \\
9 \\
10\end{array}$ & $\begin{array}{l}21.0 \\
21.0 \\
20.0 \\
19.5 \\
18.0\end{array}$ & $\begin{array}{l}15.0 \\
15.5 \\
14.5 \\
15.5 \\
15.0\end{array}$ & $\begin{array}{l}18.5 \\
18.5 \\
17.5 \\
17.5 \\
16.5\end{array}$ & $\begin{array}{l}25.5 \\
25.5 \\
25.5 \\
25.0 \\
25.0\end{array}$ & $\begin{array}{l}19.5 \\
20.0 \\
19.5 \\
20.0 \\
20.5\end{array}$ & $\begin{array}{l}23.0 \\
23.0 \\
23.0 \\
23.0 \\
23.0\end{array}$ & $\begin{array}{l}24.5 \\
24.5 \\
24.5 \\
24.5 \\
24.5\end{array}$ & $\begin{array}{l}19.0 \\
17.5 \\
18.0 \\
18.0 \\
18.5\end{array}$ & $\begin{array}{l}21.5 \\
21.0 \\
21.0 \\
21.0 \\
21.5\end{array}$ & $\begin{array}{l}25.5 \\
25.5 \\
26.0 \\
23.5 \\
23.0\end{array}$ & $\begin{array}{l}21.0 \\
20.0 \\
20.5 \\
21.5 \\
22.0\end{array}$ & $\begin{array}{l}23.0 \\
22.5 \\
23.0 \\
22.5 \\
22.5\end{array}$ \\
\hline $\begin{array}{l}11 \\
12 \\
13 \\
14 \\
15\end{array}$ & $\begin{array}{l}20.5 \\
21.5 \\
22.0 \\
23.5 \\
23.5\end{array}$ & $\begin{array}{l}15.0 \\
15.0 \\
15.5 \\
16.0 \\
17.0\end{array}$ & $\begin{array}{l}17.5 \\
18.5 \\
19.0 \\
20.0 \\
20.5\end{array}$ & $\begin{array}{l}24.5 \\
25.0 \\
24.5 \\
24.5 \\
23.0\end{array}$ & $\begin{array}{l}20.5 \\
21.0 \\
21.0 \\
20.0 \\
21.0\end{array}$ & $\begin{array}{l}22.5 \\
23.0 \\
22.5 \\
22.5 \\
22.0\end{array}$ & $\begin{array}{l}24.5 \\
24.5 \\
24.5 \\
24.0 \\
21.5\end{array}$ & $\begin{array}{l}17.5 \\
17.5 \\
18.0 \\
19.5 \\
19.0\end{array}$ & $\begin{array}{l}21.5 \\
21.0 \\
21.0 \\
21.0 \\
20.0\end{array}$ & $\begin{array}{l}22.0 \\
20.5 \\
21.0 \\
21.5 \\
21.5\end{array}$ & $\begin{array}{l}20.5 \\
20.0 \\
20.0 \\
20.5 \\
20.5\end{array}$ & $\begin{array}{l}21.5 \\
20.5 \\
20.5 \\
21.0 \\
21.5\end{array}$ \\
\hline $\begin{array}{l}16 \\
17 \\
18 \\
19 \\
20\end{array}$ & $\begin{array}{l}23.0 \\
23.0 \\
23.5 \\
23.5 \\
24.0\end{array}$ & $\begin{array}{l}17.0 \\
16.5 \\
17.0 \\
16.5 \\
17.5\end{array}$ & $\begin{array}{l}20.0 \\
20.0 \\
20.0 \\
20.5 \\
21.0\end{array}$ & $\begin{array}{l}24.5 \\
24.0 \\
24.5 \\
25.0 \\
25.5\end{array}$ & $\begin{array}{l}20.0 \\
19.5 \\
19.0 \\
19.0 \\
19.5\end{array}$ & $\begin{array}{l}22.0 \\
21.5 \\
21.5 \\
22.0 \\
22.5\end{array}$ & $\begin{array}{l}23.5 \\
23.5 \\
23.5 \\
24.0 \\
25.0\end{array}$ & $\begin{array}{l}19.0 \\
18.0 \\
17.5 \\
17.0 \\
19.0\end{array}$ & $\begin{array}{l}21.0 \\
20.5 \\
20.5 \\
20.5 \\
22.0\end{array}$ & $\begin{array}{l}23.0 \\
23.0 \\
23.0 \\
20.5 \\
22.0\end{array}$ & $\begin{array}{l}19.5 \\
19.0 \\
18.0 \\
19.0 \\
19.5\end{array}$ & $\begin{array}{l}21.0 \\
21.0 \\
20.5 \\
20.0 \\
20.5\end{array}$ \\
\hline $\begin{array}{l}21 \\
22 \\
23 \\
24 \\
25\end{array}$ & $\begin{array}{l}23.5 \\
23.0 \\
24.5 \\
24.5 \\
24.5\end{array}$ & $\begin{array}{l}17.0 \\
16.5 \\
17.0 \\
17.5 \\
18.0\end{array}$ & $\begin{array}{l}20.5 \\
20.0 \\
21.0 \\
21.5 \\
21.5\end{array}$ & $\begin{array}{l}25.5 \\
22.5 \\
26.0 \\
25.5 \\
22.5\end{array}$ & $\begin{array}{l}20.0 \\
20.0 \\
19.5 \\
19.5 \\
20.0\end{array}$ & $\begin{array}{l}22.5 \\
21.5 \\
22.5 \\
22.5 \\
21.5\end{array}$ & $\begin{array}{l}25.5 \\
24.5 \\
25.0 \\
25.0 \\
25.0\end{array}$ & $\begin{array}{l}19.0 \\
18.5 \\
17.5 \\
18.5 \\
18.5\end{array}$ & $\begin{array}{l}22.0 \\
21.5 \\
21.5 \\
21.5 \\
21.5\end{array}$ & $\begin{array}{l}23.5 \\
23.0 \\
24.0 \\
22.5 \\
21.0\end{array}$ & $\begin{array}{l}20.0 \\
19.0 \\
20.5 \\
21.0 \\
20.0\end{array}$ & $\begin{array}{l}21.5 \\
21.0 \\
22.0 \\
21.5 \\
20.5\end{array}$ \\
\hline $\begin{array}{l}26 \\
27 \\
28 \\
29 \\
30 \\
31\end{array}$ & $\begin{array}{l}25.0 \\
25.5 \\
25.0 \\
24.5 \\
24.0 \\
-.-\end{array}$ & $\begin{array}{r}18.0 \\
18.5 \\
19.0 \\
19.0 \\
18.5 \\
-.-\end{array}$ & $\begin{array}{l}22.0 \\
22.5 \\
22.5 \\
22.5 \\
22.0 \\
-. .\end{array}$ & $\begin{array}{l}23.5 \\
27.0 \\
26.0 \\
25.5 \\
25.0 \\
25.5\end{array}$ & $\begin{array}{l}20.5 \\
20.5 \\
21.0 \\
20.0 \\
20.0 \\
20.5\end{array}$ & $\begin{array}{l}22.0 \\
23.5 \\
23.5 \\
22.5 \\
22.5 \\
22.5\end{array}$ & $\begin{array}{l}24.5 \\
25.0 \\
26.0 \\
26.5 \\
26.5 \\
26.0\end{array}$ & $\begin{array}{l}18.0 \\
18.0 \\
19.0 \\
19.5 \\
19.5 \\
20.0\end{array}$ & $\begin{array}{l}21.5 \\
21.5 \\
22.5 \\
23.0 \\
23.0 \\
23.0\end{array}$ & $\begin{array}{r}21.0 \\
23.5 \\
22.5 \\
23.0 \\
24.0 \\
-.0\end{array}$ & $\begin{array}{r}18.5 \\
19.0 \\
18.0 \\
19.5 \\
20.0 \\
-. .\end{array}$ & $\begin{array}{l}20.0 \\
21.0 \\
20.5 \\
21.0 \\
21.5 \\
-. .\end{array}$ \\
\hline MONTH & 25.5 & 14.5 & 20.0 & 27.0 & 18.0 & 22.5 & 26.5 & 17.0 & 21.5 & 27.0 & 18.0 & 21.5 \\
\hline YEAR & 27.0 & 4.0 & 16.5 & & & & & & & & & \\
\hline
\end{tabular}


11074000 SANTA ANA RIVER BELOW PRADO DAM, CA--Continued

SUSPENDED-SEDIMENT DISCHARGE (TONS/DAY), HATER YEAR OCTOBER 1975 TO SEPTEMBER 1976

\begin{tabular}{|c|c|c|c|c|c|c|c|c|c|}
\hline & & OCTOBER & & & NOVEMBER & & & DECEMBER & \\
\hline DAY & $\begin{array}{l}\text { MEAN } \\
\text { DISCHARGE } \\
\text { (CFS) }\end{array}$ & $\begin{array}{l}\text { MEAN } \\
\text { CONCEN- } \\
\text { TRATION } \\
\text { (MG/L) }\end{array}$ & $\begin{array}{l}\text { SEDIMENT } \\
\text { DISCHARGE } \\
\text { (TONS/DAY) }\end{array}$ & $\begin{array}{l}\text { HEAN } \\
\text { DISCHARGE } \\
\text { (CFS) }\end{array}$ & $\begin{array}{l}\text { MEAN } \\
\text { CONCEN- } \\
\text { TRATION } \\
\text { (MG/L) }\end{array}$ & $\begin{array}{l}\text { SEDIMENT } \\
\text { DISCHARGE } \\
\text { (TONS/DAY) }\end{array}$ & $\begin{array}{l}\text { MEAN } \\
\text { DISCHARGE } \\
\text { (CFS) }\end{array}$ & $\begin{array}{l}\text { MEAN } \\
\text { CONCEN- } \\
\text { TRATION } \\
\text { (MG/L) }\end{array}$ & $\begin{array}{l}\text { SEDIMENT } \\
\text { OISCHARGE } \\
\text { (TONS/DAY) }\end{array}$ \\
\hline $\begin{array}{l}2 \\
2 \\
3 \\
4 \\
5\end{array}$ & $\begin{array}{l}98 \\
99 \\
97 \\
89 \\
84\end{array}$ & $\begin{array}{l}192 \\
167 \\
144 \\
132 \\
123\end{array}$ & $\begin{array}{l}51 \\
45 \\
38 \\
32 \\
28\end{array}$ & $\begin{array}{l}66 \\
66 \\
66 \\
66 \\
66\end{array}$ & $\begin{array}{l}141 \\
140 \\
140 \\
140 \\
141\end{array}$ & $\begin{array}{l}25 \\
25 \\
25 \\
25 \\
25\end{array}$ & $\begin{array}{l}318 \\
323 \\
345 \\
280 \\
327\end{array}$ & $\begin{array}{l}59 \\
58 \\
57 \\
59 \\
60\end{array}$ & $\begin{array}{l}51 \\
51 \\
53 \\
45 \\
53\end{array}$ \\
\hline $\begin{array}{r}6 \\
7 \\
8 \\
9 \\
10\end{array}$ & $\begin{array}{l}88 \\
54 \\
49 \\
48 \\
48\end{array}$ & $\begin{array}{l}121 \\
111 \\
103 \\
103 \\
104\end{array}$ & $\begin{array}{l}29 \\
16 \\
14 \\
13 \\
13\end{array}$ & $\begin{array}{l}66 \\
66 \\
66 \\
66 \\
71\end{array}$ & $\begin{array}{l}141 \\
142 \\
143 \\
143 \\
152\end{array}$ & $\begin{array}{l}25 \\
25 \\
25 \\
25 \\
29\end{array}$ & $\begin{array}{l}362 \\
366 \\
339 \\
180 \\
175\end{array}$ & $\begin{array}{r}61 \\
62 \\
305 \\
220 \\
80\end{array}$ & $\begin{array}{r}60 \\
61 \\
219 \\
108 \\
38\end{array}$ \\
\hline $\begin{array}{l}11 \\
12 \\
13 \\
14 \\
15\end{array}$ & $\begin{array}{l}51 \\
51 \\
48 \\
49 \\
50\end{array}$ & $\begin{array}{l}104 \\
105 \\
105 \\
106 \\
106\end{array}$ & $\begin{array}{l}14 \\
14 \\
14 \\
14 \\
14\end{array}$ & $\begin{array}{l}149 \\
149 \\
152 \\
155 \\
155\end{array}$ & $\begin{array}{r}157 \\
58 \\
56 \\
55 \\
55\end{array}$ & $\begin{array}{l}63 \\
23 \\
23 \\
23 \\
23\end{array}$ & $\begin{array}{l}168 \\
178 \\
203 \\
181 \\
174\end{array}$ & $\begin{array}{r}75 \\
138 \\
114 \\
73 \\
69\end{array}$ & $\begin{array}{l}34 \\
76 \\
64 \\
36 \\
32\end{array}$ \\
\hline $\begin{array}{l}16 \\
17 \\
18 \\
19 \\
20\end{array}$ & $\begin{array}{r}52 \\
52 \\
96 \\
100 \\
100\end{array}$ & $\begin{array}{l}107 \\
107 \\
108 \\
109 \\
111\end{array}$ & $\begin{array}{l}15 \\
15 \\
28 \\
29 \\
30\end{array}$ & $\begin{array}{l}154 \\
153 \\
176 \\
258 \\
260\end{array}$ & $\begin{array}{r}53 \\
51 \\
105 \\
231 \\
130\end{array}$ & $\begin{array}{r}22 \\
21 \\
62 \\
159 \\
91\end{array}$ & $\begin{array}{l}194 \\
331 \\
333 \\
330 \\
330\end{array}$ & $\begin{array}{r}187 \\
400 \\
65 \\
57 \\
57\end{array}$ & $\begin{array}{r}121 \\
370 \\
58 \\
51 \\
51\end{array}$ \\
\hline $\begin{array}{l}21 \\
22 \\
23 \\
24 \\
25\end{array}$ & $\begin{array}{l}100 \\
100 \\
100 \\
100 \\
100\end{array}$ & $\begin{array}{l}114 \\
116 \\
118 \\
123 \\
125\end{array}$ & $\begin{array}{l}31 \\
31 \\
32 \\
33 \\
34\end{array}$ & $\begin{array}{l}256 \\
254 \\
258 \\
251 \\
264\end{array}$ & $\begin{array}{l}98 \\
95 \\
93 \\
91 \\
89\end{array}$ & $\begin{array}{l}68 \\
65 \\
65 \\
62 \\
63\end{array}$ & $\begin{array}{l}354 \\
335 \\
287 \\
286 \\
286\end{array}$ & $\begin{array}{l}57 \\
58 \\
58 \\
56 \\
54\end{array}$ & $\begin{array}{l}54 \\
52 \\
45 \\
43 \\
42\end{array}$ \\
\hline $\begin{array}{l}26 \\
27 \\
28 \\
29 \\
30 \\
31\end{array}$ & $\begin{array}{r}100 \\
120 \\
150 \\
150 \\
160 \\
95\end{array}$ & $\begin{array}{l}128 \\
130 \\
138 \\
145 \\
144 \\
142\end{array}$ & $\begin{array}{l}35 \\
42 \\
56 \\
59 \\
62 \\
36\end{array}$ & $\begin{array}{l}269 \\
317 \\
329 \\
339 \\
321 \\
---\end{array}$ & $\begin{array}{r}64 \\
64 \\
62 \\
61 \\
60 \\
--\end{array}$ & $\begin{array}{r}46 \\
\mathbf{5 5} \\
\mathbf{5 5} \\
\mathbf{5 6} \\
\mathbf{5 2} \\
---\end{array}$ & $\begin{array}{l}281 \\
276 \\
271 \\
270 \\
268 \\
269\end{array}$ & $\begin{array}{r}52 \\
50 \\
50 \\
49 \\
50 \\
-=0\end{array}$ & $\begin{array}{r}39 \\
37 \\
37 \\
36 \\
36 \\
--\infty\end{array}$ \\
\hline TAL & 2678 & -- & 917 & 5284 & $-\infty$ & 1351 & 8620 & $m-m$ & 2053 \\
\hline
\end{tabular}

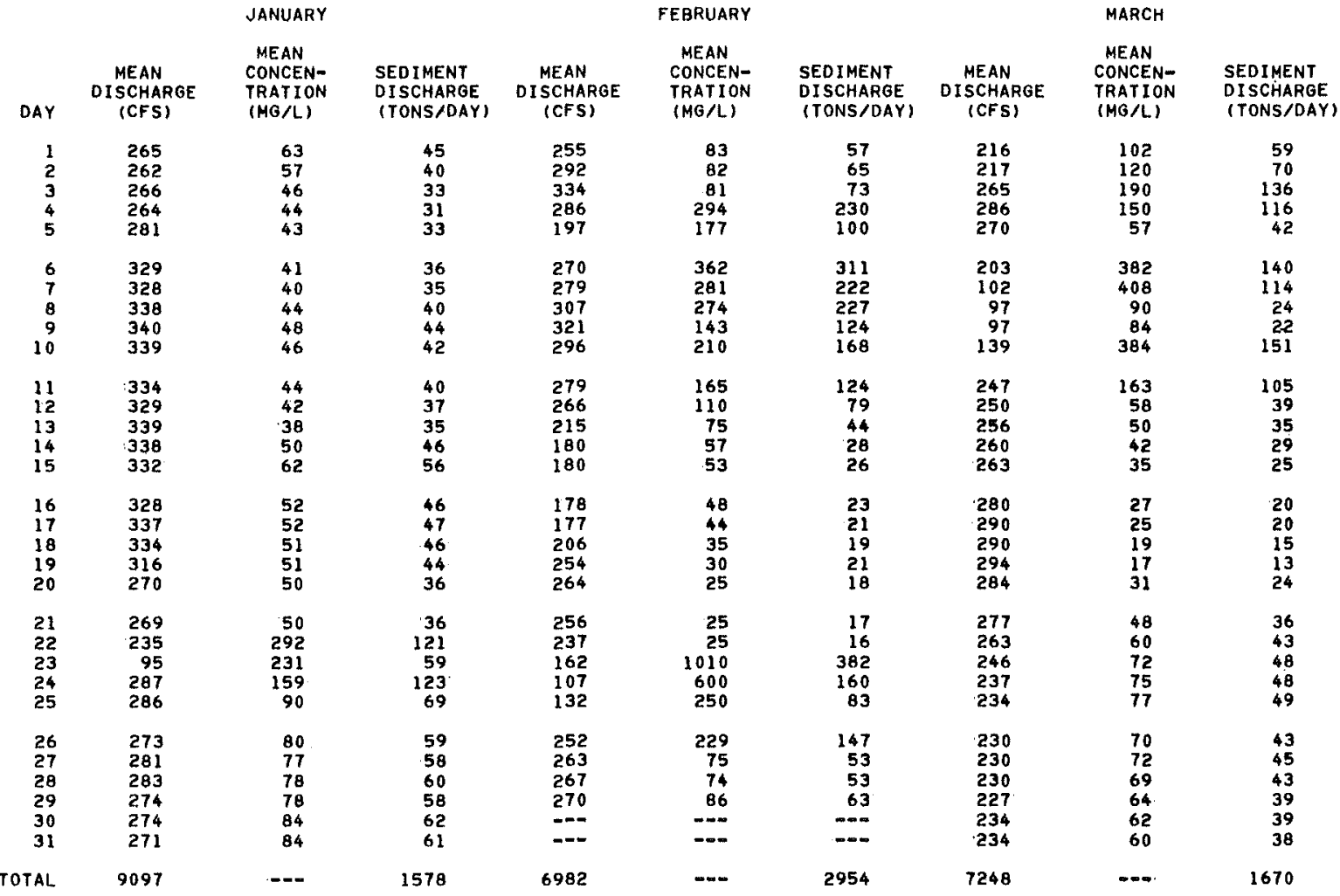




\begin{tabular}{|c|c|c|c|c|c|c|c|c|c|}
\hline \multirow[b]{2}{*}{ DAY } & \multicolumn{3}{|c|}{ APRIL } & \multicolumn{3}{|c|}{ MAY } & \multicolumn{3}{|c|}{ JUNE } \\
\hline & $\begin{array}{l}\text { MEAN } \\
\text { OISCARGE } \\
\text { (CFS) }\end{array}$ & $\begin{array}{l}\text { MEAN } \\
\text { CONCEN- } \\
\text { TRATION } \\
\text { (MG LL) }\end{array}$ & $\begin{array}{l}\text { SEDIMENT } \\
\text { OISCHARGE } \\
\text { (TONS/OAY) }\end{array}$ & $\begin{array}{l}\text { MEAN } \\
\text { DISCHARGE } \\
\text { (CFS) }\end{array}$ & $\begin{array}{l}\text { MEAN } \\
\text { CONCEN- } \\
\text { TRATION } \\
\text { (MGG }\end{array}$ & $\begin{array}{l}\text { SEDIMENT } \\
\text { DISCHARGE } \\
\text { (IONS/DAY) }\end{array}$ & $\begin{array}{l}\text { Mr.AN } \\
\text { DISCARGE } \\
\text { (CFS) }\end{array}$ & $\begin{array}{l}\text { MEAN } \\
\text { CENCEN- } \\
\text { TRAION } \\
\text { (MGIL) }\end{array}$ & $\begin{array}{l}\text { SEDIMENT } \\
\text { DISCHARGE } \\
\text { ITONS/DAY }\end{array}$ \\
\hline $\begin{array}{l}1 \\
2 \\
3 \\
4 \\
5\end{array}$ & $\begin{array}{r}158 \\
79 \\
73 \\
107 \\
128\end{array}$ & $\begin{array}{l}244 \\
170 \\
165 \\
122 \\
157\end{array}$ & $\begin{array}{l}85 \\
36 \\
33 \\
36 \\
56\end{array}$ & $\begin{array}{l}63 \\
60 \\
62 \\
66 \\
77\end{array}$ & $\begin{array}{l}148 \\
140 \\
137 \\
130 \\
123\end{array}$ & $\begin{array}{l}25 \\
23 \\
23 \\
23 \\
26\end{array}$ & $\begin{array}{l}258 \\
248 \\
254 \\
255 \\
255\end{array}$ & $\begin{array}{l}80 \\
75 \\
68 \\
60 \\
53\end{array}$ & $\begin{array}{l}56 \\
50 \\
47 \\
41 \\
36\end{array}$ \\
\hline $\begin{array}{r}6 \\
7 \\
8 \\
9 \\
10\end{array}$ & $\begin{array}{l}77 \\
70 \\
72 \\
70 \\
68\end{array}$ & $\begin{array}{l}147 \\
162 \\
167 \\
178 \\
177\end{array}$ & $\begin{array}{l}31 \\
31 \\
32 \\
34 \\
32\end{array}$ & $\begin{array}{r}76 \\
108 \\
90 \\
74 \\
71\end{array}$ & $\begin{array}{r}115 \\
141 \\
71 \\
62 \\
75\end{array}$ & $\begin{array}{l}24 \\
45 \\
19 \\
12 \\
14\end{array}$ & $\begin{array}{l}255 \\
257 \\
255 \\
257 \\
311\end{array}$ & $\begin{array}{r}50 \\
45 \\
43 \\
44 \\
394\end{array}$ & $\begin{array}{r}34 \\
31 \\
30 \\
31 \\
38 B\end{array}$ \\
\hline $\begin{array}{l}11 \\
12 \\
13 \\
14 \\
15\end{array}$ & $\begin{array}{r}66 \\
73 \\
158 \\
130 \\
92\end{array}$ & $\begin{array}{l}176 \\
175 \\
186 \\
56 \\
56\end{array}$ & $\begin{array}{l}31 \\
34 \\
80 \\
20 \\
14\end{array}$ & $\begin{array}{l}69 \\
66 \\
59 \\
60 \\
60\end{array}$ & $\begin{array}{r}95 \\
113 \\
110 \\
110 \\
108\end{array}$ & $\begin{array}{l}18 \\
20 \\
18 \\
18 \\
17\end{array}$ & $\begin{array}{l}382 \\
370 \\
362 \\
326 \\
244\end{array}$ & $\begin{array}{r}353 \\
47 \\
48 \\
418 \\
270\end{array}$ & $\begin{array}{r}368 \\
47 \\
47 \\
325 \\
181\end{array}$ \\
\hline $\begin{array}{l}16 \\
17 \\
18 \\
19 \\
20\end{array}$ & $\begin{array}{r}105 \\
81 \\
79 \\
75 \\
77\end{array}$ & $\begin{array}{r}84 \\
40 \\
115 \\
173 \\
216\end{array}$ & $\begin{array}{l}28 \\
8.7 \\
25 \\
35 \\
45\end{array}$ & $\begin{array}{l}57 \\
56 \\
58 \\
56 \\
58\end{array}$ & $\begin{array}{r}105 \\
102 \\
100 \\
98 \\
95\end{array}$ & $\begin{array}{l}16 \\
15 \\
16 \\
15 \\
15\end{array}$ & $\begin{array}{l}248 \\
245 \\
237 \\
237 \\
238\end{array}$ & $\begin{array}{l}175 \\
160 \\
145 \\
126 \\
117\end{array}$ & $\begin{array}{r}117 \\
106 \\
93 \\
81 \\
75\end{array}$ \\
\hline $\begin{array}{l}21 \\
22 \\
23 \\
24 \\
25\end{array}$ & $\begin{array}{l}77 \\
76 \\
79 \\
72 \\
73\end{array}$ & $\begin{array}{l}200 \\
156 \\
110 \\
110 \\
112\end{array}$ & $\begin{array}{l}42 \\
32 \\
23 \\
21 \\
22\end{array}$ & $\begin{array}{l}56 \\
56 \\
61 \\
71 \\
75\end{array}$ & $\begin{array}{l}100 \\
108 \\
112 \\
115 \\
118\end{array}$ & $\begin{array}{l}15 \\
16 \\
18 \\
22 \\
24\end{array}$ & $\begin{array}{l}234 \\
229 \\
231 \\
229 \\
198\end{array}$ & $\begin{array}{l}110 \\
107 \\
109 \\
114 \\
119\end{array}$ & $\begin{array}{l}69 \\
66 \\
68 \\
70 \\
64\end{array}$ \\
\hline $\begin{array}{l}26 \\
27 \\
28 \\
29 \\
30 \\
31\end{array}$ & $\begin{array}{r}73 \\
72 \\
72 \\
68 \\
67 \\
6 \\
--.\end{array}$ & $\begin{array}{l}114 \\
115 \\
125 \\
135 \\
150 \\
--\end{array}$ & $\begin{array}{l}22 \\
22 \\
24 \\
25 \\
27 \\
---\end{array}$ & $\begin{array}{r}75 \\
216 \\
252 \\
247 \\
253 \\
252\end{array}$ & $\begin{array}{r}120 \\
324 \\
85 \\
82 \\
83 \\
84 \\
84\end{array}$ & $\begin{array}{r}24 \\
198 \\
58 \\
55 \\
57 \\
57\end{array}$ & $\begin{array}{l}153 \\
152 \\
152 \\
170 \\
170 \\
-.-\end{array}$ & $\begin{array}{l}123 \\
130 \\
135 \\
144 \\
163 \\
-\end{array}$ & $\begin{array}{r}51 \\
53 \\
55 \\
66 \\
75 \\
7 .-\end{array}$ \\
\hline TAL & 2567 & -- & 986.7 & 2960 & $\cdots$ & 946 & 7412 & -- & 2821 \\
\hline
\end{tabular}

\begin{tabular}{|c|c|c|c|c|c|c|c|c|c|}
\hline \multirow[b]{2}{*}{ DAY } & \multicolumn{3}{|c|}{ JULY } & \multicolumn{3}{|c|}{ AUGUST } & \multicolumn{3}{|c|}{ SEPTEMBER } \\
\hline & $\begin{array}{l}\text { MEAN } \\
\text { DISCHARGE } \\
\text { (CFS) }\end{array}$ & $\begin{array}{l}\text { MEAN } \\
\text { CENCEN- } \\
\text { TRAION } \\
\text { (MGIL) }\end{array}$ & $\begin{array}{l}\text { SEDIMENT } \\
\text { DISCHARGE } \\
\text { (TONS/DAY) }\end{array}$ & $\begin{array}{l}\text { MEAN } \\
\text { DISCHARGE } \\
\text { (CFS) }\end{array}$ & $\begin{array}{l}\text { MEAN } \\
\text { CONCEN- } \\
\text { TRAION } \\
\text { RAGIL) }\end{array}$ & $\begin{array}{l}\text { SEDIMENT } \\
\text { OISCHARGE } \\
\text { (TONS/DAY) }\end{array}$ & $\begin{array}{l}\text { MEAN } \\
\text { DISCHARGE } \\
\text { (CFS) }\end{array}$ & $\begin{array}{l}\text { MEAN } \\
\text { CONCEN- } \\
\text { TRATON } \\
\text { (MG L L) }\end{array}$ & $\begin{array}{l}\text { SEDIMENT } \\
\text { DISCHARGE } \\
\text { (TONS/DAY) }\end{array}$ \\
\hline $\begin{array}{l}1 \\
2 \\
3 \\
4 \\
5\end{array}$ & $\begin{array}{l}180 \\
203 \\
200 \\
203 \\
178\end{array}$ & $\begin{array}{l}152 \\
138 \\
137 \\
135 \\
288\end{array}$ & $\begin{array}{r}74 \\
76 \\
74 \\
74 \\
108\end{array}$ & $\begin{array}{l}42 \\
41 \\
45 \\
46 \\
41\end{array}$ & $\begin{array}{l}152 \\
150 \\
148 \\
144 \\
140\end{array}$ & $\begin{array}{l}17 \\
17 \\
18 \\
18 \\
15\end{array}$ & $\begin{array}{l}33 \\
34 \\
36 \\
40 \\
44\end{array}$ & $\begin{array}{l}133 \\
132 \\
132 \\
131 \\
131\end{array}$ & $\begin{array}{l}12 \\
12 \\
13 \\
14 \\
16\end{array}$ \\
\hline $\begin{array}{r}6 \\
7 \\
8 \\
9 \\
10\end{array}$ & $\begin{array}{l}110 \\
107 \\
167 \\
109 \\
107\end{array}$ & $\begin{array}{l}248 \\
175 \\
280 \\
175 \\
176\end{array}$ & $\begin{array}{r}73 \\
51 \\
135 \\
52 \\
51\end{array}$ & $\begin{array}{l}33 \\
36 \\
35 \\
34 \\
38\end{array}$ & $\begin{array}{l}135 \\
142 \\
149 \\
151 \\
149\end{array}$ & $\begin{array}{l}12 \\
14 \\
14 \\
14 \\
15\end{array}$ & $\begin{array}{r}47 \\
46 \\
64 \\
49 \\
149\end{array}$ & $\begin{array}{l}130 \\
130 \\
130 \\
130 \\
631\end{array}$ & $\begin{array}{r}16 \\
16 \\
22 \\
17 \\
458\end{array}$ \\
\hline $\begin{array}{l}11 \\
12 \\
13 \\
14 \\
15\end{array}$ & $\begin{array}{l}107 \\
107 \\
105 \\
107 \\
105\end{array}$ & $\begin{array}{l}177 \\
179 \\
180 \\
180 \\
180\end{array}$ & $\begin{array}{l}51 \\
52 \\
51 \\
52 \\
51\end{array}$ & $\begin{array}{l}42 \\
37 \\
38 \\
41 \\
41\end{array}$ & $\begin{array}{l}143 \\
138 \\
132 \\
130 \\
125\end{array}$ & $\begin{array}{l}16 \\
14 \\
14 \\
14 \\
14\end{array}$ & $\begin{array}{l}423 \\
410 \\
398 \\
378 \\
329\end{array}$ & $\begin{array}{l}344 \\
118 \\
105 \\
93 \\
176\end{array}$ & $\begin{array}{r}449 \\
131 \\
113 \\
95 \\
149\end{array}$ \\
\hline $\begin{array}{l}16 \\
17 \\
18 \\
19 \\
20\end{array}$ & $\begin{array}{l}53 \\
43 \\
45 \\
49 \\
47\end{array}$ & $\begin{array}{l}160 \\
160 \\
160 \\
160 \\
160\end{array}$ & $\begin{array}{l}23 \\
19 \\
19 \\
21 \\
20\end{array}$ & $\begin{array}{l}38 \\
36 \\
37 \\
43 \\
49\end{array}$ & $\begin{array}{l}123 \\
121 \\
155 \\
189 \\
213\end{array}$ & $\begin{array}{l}13 \\
12 \\
15 \\
22 \\
28\end{array}$ & $\begin{array}{r}114 \\
100 \\
86 \\
87 \\
86\end{array}$ & $\begin{array}{l}921 \\
630 \\
590 \\
545 \\
500\end{array}$ & $\begin{array}{l}284 \\
170 \\
137 \\
128 \\
116\end{array}$ \\
\hline $\begin{array}{l}21 \\
22 \\
23 \\
24 \\
25\end{array}$ & $\begin{array}{l}47 \\
50 \\
49 \\
45 \\
42\end{array}$ & $\begin{array}{l}155 \\
150 \\
145 \\
152 \\
158\end{array}$ & $\begin{array}{l}20 \\
20 \\
19 \\
18 \\
18\end{array}$ & $\begin{array}{l}53 \\
43 \\
40 \\
36 \\
36\end{array}$ & $\begin{array}{l}200 \\
180 \\
161 \\
145 \\
140\end{array}$ & $\begin{array}{l}29 \\
21 \\
17 \\
14 \\
14\end{array}$ & $\begin{array}{r}85 \\
86 \\
87 \\
86 \\
137\end{array}$ & $\begin{array}{l}450 \\
440 \\
430 \\
420 \\
277\end{array}$ & $\begin{array}{c}103 \\
102 \\
101 \\
98 \\
111\end{array}$ \\
\hline $\begin{array}{l}26 \\
27 \\
28 \\
29 \\
30 \\
31\end{array}$ & $\begin{array}{l}46 \\
47 \\
47 \\
46 \\
45 \\
45\end{array}$ & $\begin{array}{l}164 \\
170 \\
173 \\
170 \\
158 \\
155\end{array}$ & $\begin{array}{l}20 \\
22 \\
22 \\
21 \\
19 \\
19\end{array}$ & $\begin{array}{l}35 \\
41 \\
37 \\
36 \\
33 \\
34\end{array}$ & $\begin{array}{l}138 \\
135 \\
135 \\
134 \\
134 \\
133\end{array}$ & $\begin{array}{l}13 \\
15 \\
13 \\
13 \\
12 \\
12\end{array}$ & $\begin{array}{l}98 \\
90 \\
87 \\
86 \\
98 \\
-\infty\end{array}$ & $\begin{array}{l}145 \\
160 \\
175 \\
180 \\
200 \\
\end{array}$ & $\begin{array}{r}38 \\
39 \\
41 \\
42 \\
53 \\
-5-\end{array}$ \\
\hline OTAL & 2841 &.-- & 1345 & 1217 & $-\infty$ & 489 & 3893 & $\ldots$ & 3096 \\
\hline YEAR & 60799.0 & & 20206.7 & & & & & & \\
\hline
\end{tabular}


SANTA ANA RIVER BASIN

11074000 SANTA ANA RIVER BELOW PRADO DAM, CA--Continued

CHEMICAL ANALYSES, WATER YEAR OCTOBER 1975 TO SEPTEMBER 1976

\begin{tabular}{|c|c|c|c|c|c|c|c|c|c|c|c|}
\hline DATE & $\begin{array}{l}\text { TOTAL } \\
\text { PARA- } \\
\text { THION } \\
\text { (UG/L) }\end{array}$ & $\begin{array}{l}\text { PARA- } \\
\text { THION } \\
\text { IN } \\
\text { BOTTOM } \\
\text { MA- } \\
\text { TERIAL } \\
\text { (UG/KG) }\end{array}$ & $\begin{array}{l}\text { POLY- } \\
\text { CHLO- } \\
\text { RINATED } \\
\text { NAPH- } \\
\text { THA- } \\
\text { LENES } \\
\text { (UG/L) }\end{array}$ & $\begin{array}{l}\text { SIMA- } \\
\text { ZINE } \\
\text { TOTAL }, \\
\text { (UG/L) }\end{array}$ & $\begin{array}{l}\text { TOTAL } \\
\text { TOX- } \\
\text { APHENE } \\
\text { (UG/L) }\end{array}$ & $\begin{array}{c}\text { TOX- } \\
\text { APHENE } \\
\text { IN } \\
\text { BOTTOM } \\
\text { MA- } \\
\text { TERIAL } \\
\text { (UG/KG) }\end{array}$ & $\begin{array}{l}\text { TOTAL } \\
\text { TRI- } \\
\text { THION } \\
\text { (UO/L) }\end{array}$ & $\begin{array}{l}\text { TRI- } \\
\text { THION } \\
\text { IN } \\
\text { BOTTOM } \\
\text { HA- } \\
\text { TERIAL } \\
\text { (UG/KG) }\end{array}$ & $\begin{array}{l}\text { TOTAL } \\
2,4=0 \\
\text { (UG/L) }\end{array}$ & $\begin{array}{l}\text { TOTAL } \\
2,4,5-T \\
\text { (UG/L) }\end{array}$ & $\begin{array}{l}\text { TOTAL } \\
\text { SILVEX } \\
\text { (UG/L) }\end{array}$ \\
\hline $\begin{array}{l}\text { NOV } \\
25 . . .\end{array}$ & ND & $-\infty$ & -- & $=$ & No & -- & ND & $-\infty$ & ND & ND & ND \\
\hline $\begin{array}{l}\text { JAN } \\
16 \cdots \cdots \\
\text { FEB }\end{array}$ & .00 & $-\infty$ & .00 & $m$ & 0 & $-\infty$ & .00 & $=$ & .11 & .00 & .01 \\
\hline $\begin{array}{l}09 \ldots \\
\text { MAR }\end{array}$ & .00 & $=$ & .00 & -+ & 0 & $-\infty$ & .00 & $=$ & .07 & .00 & .00 \\
\hline $\begin{array}{l}03 \cdots \\
\mathrm{APR}\end{array}$ & .00 & -- & .00 & $-\infty$ & 0 & $-\infty$ & .00 & - & .00 & .00 & .00 \\
\hline$\underset{\text { JUN }}{30 . . .}$ & .00 & $\infty$ & .00 & $-\infty$ & 0 & $-\infty$ & .00 & -- & .00 & .00 & .00 \\
\hline $\begin{array}{l}30 \ldots . . \\
\text { JUL }\end{array}$ & ND & NO & $\rightarrow$ & -- & ND & ND & ND & ND & ND & ND & ND \\
\hline$\underset{\text { AUG }}{29 . . .}$ & .00 & -- & .00 & $-\infty$ & 0 & - & .00 & -- & .06 & .00 & .00 \\
\hline $24 \ldots$ & ND & $m-$ & $\Rightarrow$ & ND & ND & $=$ & ND & -- & ND & ND & ND \\
\hline
\end{tabular}

ND Material specifically analyzed for but not detected.

PARTICLE-SIZE DISTRIBUTION OF SUSPENDED SEDIMENT, HATER YEAR OCTOBER 1975 TO SEPTEMBER 1976

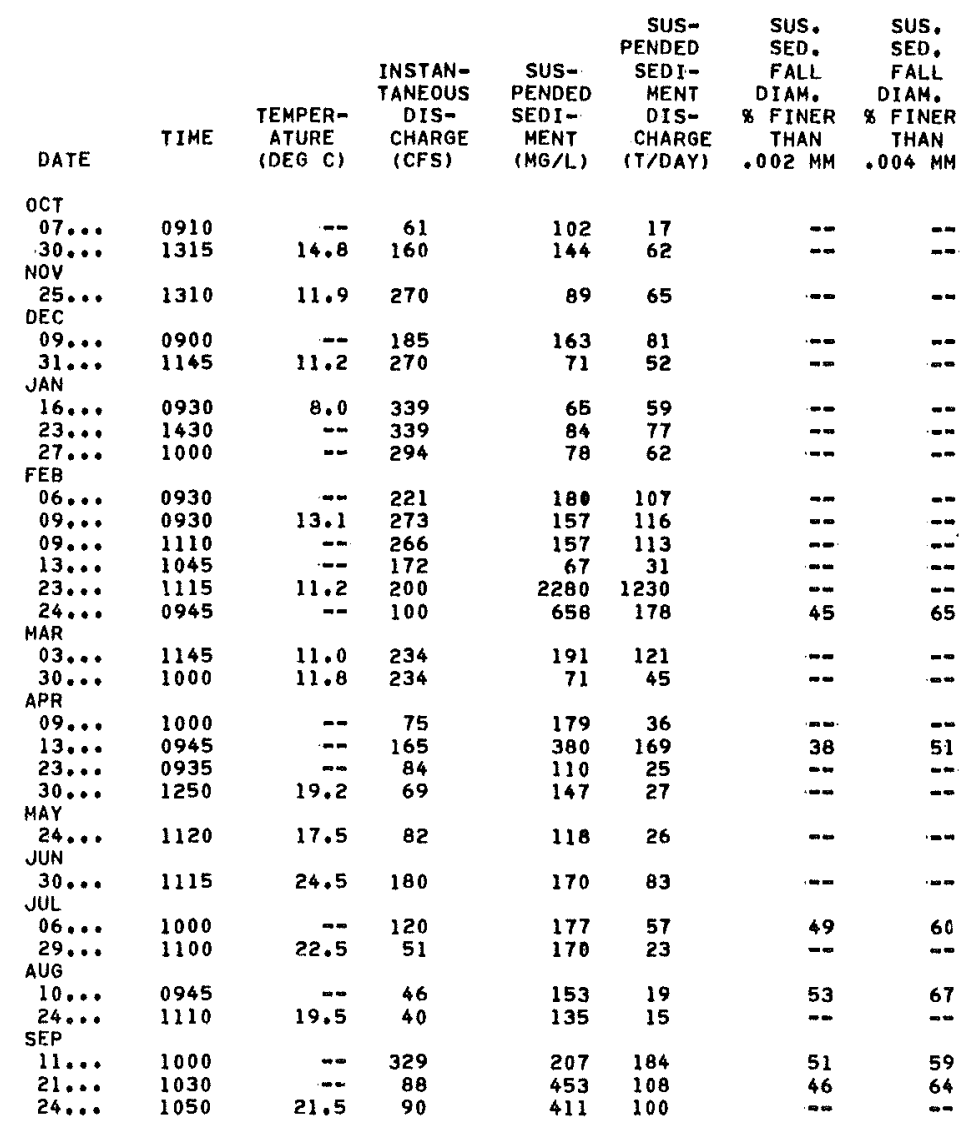


PARTICLE-SIZE DISTRIBUTION OF SUSPENDED SEDIMENT, HATER YEAR OCTOBER 1975 TO SEPTEMBER 1976

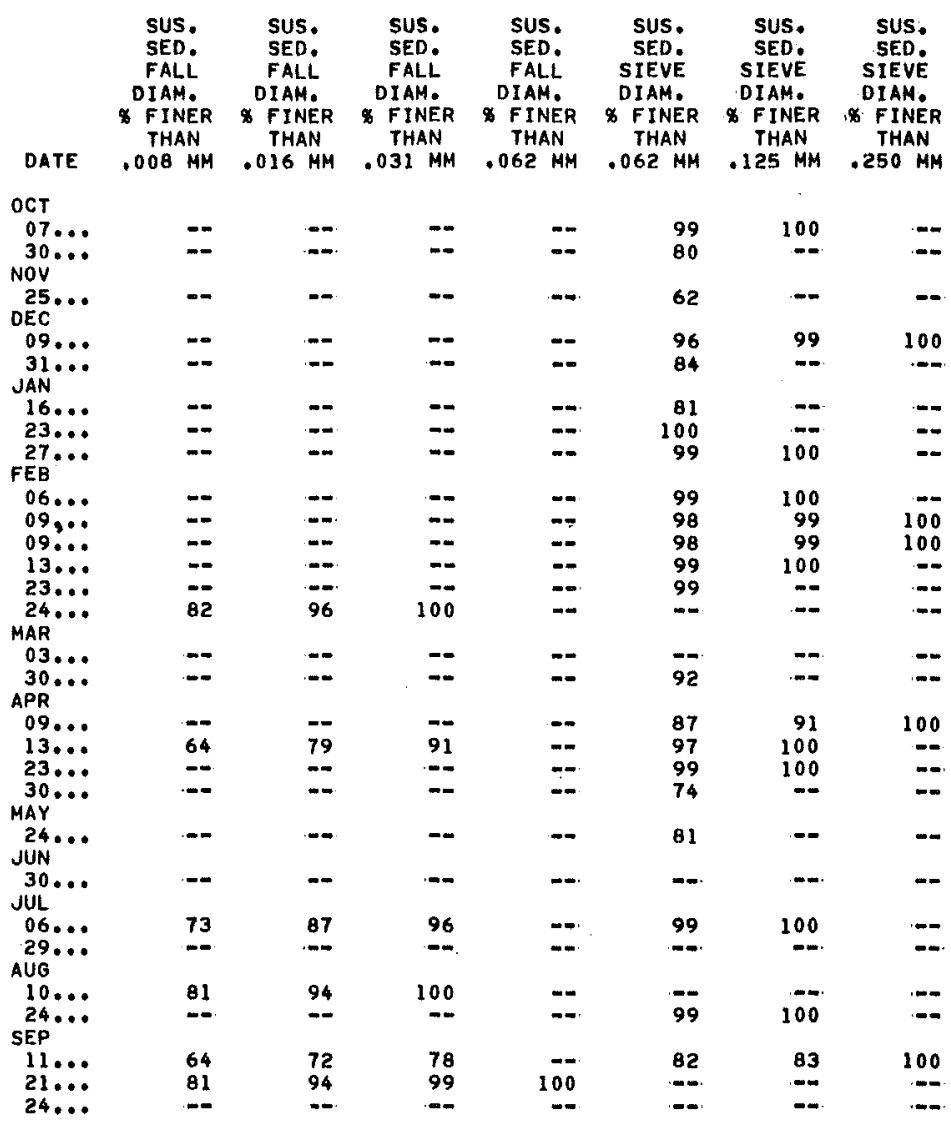

PARTICLE-SIZE DISTRIBUTION OF SUSPENDED SEDIMENT, WATER YEAR OCTOBER 1974 TO SEPTEMBER 1975

\begin{tabular}{|c|c|c|c|c|c|c|}
\hline DATE & TIME & $\begin{array}{l}\text { INSTAN- } \\
\text { TANEOUS } \\
\text { DIS-- } \\
\text { CHARGE } \\
\text { (CFS) }\end{array}$ & $\begin{array}{l}\text { TEMPER - } \\
\text { ATURE } \\
\text { (DEG C) }\end{array}$ & $\begin{array}{l}\text { SUS- } \\
\text { PENDED } \\
\text { SEDI- } \\
\text { MENT } \\
\text { (MG/L) }\end{array}$ & $\begin{array}{c}\text { SUS- } \\
\text { PENDED } \\
\text { SEDI- } \\
\text { MENT } \\
\text { DIS- } \\
\text { CHARGE } \\
\text { (T/OAY) }\end{array}$ & $\begin{array}{l}\text { SUS. } \\
\text { SEO: } \\
\text { SIEVE } \\
\text { DIAM. } \\
\text { D FINEA } \\
\text { THAN } \\
.062 \mathrm{MH}\end{array}$ \\
\hline $\begin{array}{l}\text { AUG } \\
26 \ldots \\
\text { SEP }\end{array}$ & 1000 & 84 & 17.5 & 207 & 47 & 98 \\
\hline $30 \ldots$ & 1300 & 84 & 19.5 & 206 & 47 & 54 \\
\hline
\end{tabular}


11075600 SANTA ANA RIVER AT IMPERIAL HIGHWAY, NEAR ANAHEIM, CA

LOCATION,--Lat $33^{\circ} 51^{\prime} 23^{\prime \prime}$, long $117^{\circ} 47^{\prime} 23^{\prime \prime}$, in Canon De Santa Ana, Orange County, on right bank 500 ft (152 m) upstream from State Highway 91 , and $0.4 \mathrm{mi}(0.6 \mathrm{~km})$ south of orangethorpe Avenue.

DRAINAGE AREA. - - 1,544 $\mathrm{mi}^{2}\left(3,999 \mathrm{~km}^{2}\right)$, excludes $768 \mathrm{mi}^{2}\left(1,989 \mathrm{~km}^{2}\right)$ above Lake E1sinore.

WATER-DISCHARGE RECORDS

PERIOD OF RECORD. - October 1973 to current year.

GAGE, - Water-stage recorder, Altitude of gage is $282 \mathrm{ft}(86 \mathrm{~m})$, from topographic map. Prior to June 4 , 1975 , at datum $3.00 \mathrm{ft}(0.914 \mathrm{~m})$ higher.

REMARKS. --Records good. Natural flow affected by ground-water withdrawa1s, diversions, importation from Metropolitan Water District and California Aqueduct, municipal use, return fiow from irrigation, prado floodcontrol reservoir, capacity, 201,200 acre-ft $\left(248 \mathrm{hm}^{3}\right)$ since 1940 , and Big Bear Lake (station 11049000$)$. See schematic diagram of Santa Ana River basin.

COOPERATION. - Fifteen discharge measurements were furnished by Orange County Flood Control District.

EXTREMES FOR PERIOD OF RECORD. - Maximum discharge, $2,170 \mathrm{ft}^{3} / \mathrm{s}\left(61,5 \mathrm{~m}^{3} / \mathrm{s}\right)$ Jan. 8,1974 , gage height, $3.02 \mathrm{ft}$ $(0.920 \mathrm{~m})$; maximum gage height, $5.22 \mathrm{ft}(1.591 \mathrm{~m})$ Dec. 4,$1974 ; \mathrm{minimum}$ daily discharge, $24 \mathrm{ft} / \mathrm{s}(0.68 \mathrm{~m} / \mathrm{s})$ Aug. $18,1976$.

EXTREMES FOR CURRENT YEAR, - Maximum discharge, $875 \mathrm{ft}^{3} / \mathrm{s}\left(24.8 \mathrm{~m}^{3} / \mathrm{s}\right)$ Dec. 16, gage height, $5.60 \mathrm{ft}$ (1.707 m); minimun daily, $24 \mathrm{ft}^{3} / \mathrm{s}\left(0.68 \mathrm{~m}^{3} / \mathrm{s}\right)$ Aug. 18

DISCHARGE, IN CURIC FEET PER SECOND, HATER YEAR OCTOBER 1975 TO SEPTEMBER 1976 MEAN VALUES

\begin{tabular}{|c|c|c|c|c|c|c|c|c|c|c|c|c|}
\hline DAY & OCT & NoV & DEC & JAN & FEB & MAR & APR & MAY & JUN & JUL & AUG & SEP \\
\hline $\begin{array}{l}1 \\
2 \\
3 \\
4 \\
5\end{array}$ & $\begin{array}{l}90 \\
87 \\
83 \\
74 \\
71\end{array}$ & $\begin{array}{l}56 \\
62 \\
64 \\
64 \\
66\end{array}$ & $\begin{array}{l}292 \\
296 \\
304 \\
284 \\
296\end{array}$ & $\begin{array}{l}253 \\
246 \\
246 \\
239 \\
246\end{array}$ & $\begin{array}{l}249 \\
264 \\
320 \\
297 \\
224\end{array}$ & $\begin{array}{l}272 \\
255 \\
336 \\
352 \\
308\end{array}$ & $\begin{array}{r}183 \\
180 \\
80 \\
105 \\
130\end{array}$ & $\begin{array}{l}64 \\
59 \\
59 \\
62 \\
74\end{array}$ & $\begin{array}{l}232 \\
222 \\
232 \\
246 \\
253\end{array}$ & $\begin{array}{l}165 \\
185 \\
187 \\
187 \\
178\end{array}$ & $\begin{array}{l}48 \\
45 \\
50 \\
53 \\
48\end{array}$ & $\begin{array}{l}33 \\
30 \\
41 \\
38 \\
42\end{array}$ \\
\hline $\begin{array}{r}6 \\
7 \\
6 \\
9 \\
10\end{array}$ & $\begin{array}{l}77 \\
52 \\
44 \\
38 \\
41\end{array}$ & $\begin{array}{l}67 \\
71 \\
71 \\
72 \\
74\end{array}$ & $\begin{array}{l}312 \\
324 \\
324 \\
206 \\
185\end{array}$ & $\begin{array}{l}268 \\
272 \\
280 \\
296 \\
292\end{array}$ & $\begin{array}{l}274 \\
316 \\
376 \\
409 \\
320\end{array}$ & $\begin{array}{l}248 \\
142 \\
135 \\
132 \\
143\end{array}$ & $\begin{array}{l}90 \\
78 \\
75 \\
75 \\
70\end{array}$ & $\begin{array}{l}78 \\
96 \\
96 \\
76 \\
71\end{array}$ & $\begin{array}{l}260 \\
280 \\
296 \\
312 \\
344\end{array}$ & $\begin{array}{l}125 \\
118 \\
148 \\
126 \\
116\end{array}$ & $\begin{array}{l}38 \\
38 \\
37 \\
36 \\
45\end{array}$ & $\begin{array}{r}61 \\
49 \\
122\end{array}$ \\
\hline $\begin{array}{l}11 \\
12 \\
13 \\
14 \\
15\end{array}$ & $\begin{array}{l}47 \\
47 \\
28 \\
50 \\
41\end{array}$ & $\begin{array}{l}127 \\
140 \\
150 \\
152 \\
152\end{array}$ & $\begin{array}{l}172 \\
167 \\
185 \\
167 \\
170\end{array}$ & $\begin{array}{l}292 \\
280 \\
292 \\
288 \\
280\end{array}$ & $\begin{array}{l}312 \\
308 \\
302 \\
256 \\
216\end{array}$ & $\begin{array}{l}228 \\
239 \\
249 \\
253 \\
253\end{array}$ & $\begin{array}{r}65 \\
70 \\
142 \\
142 \\
96\end{array}$ & $\begin{array}{l}74 \\
71 \\
62 \\
57 \\
57\end{array}$ & $\begin{array}{l}425 \\
430 \\
415 \\
360 \\
256\end{array}$ & $\begin{array}{l}116 \\
116 \\
116 \\
114 \\
118\end{array}$ & $\begin{array}{l}41 \\
37 \\
38 \\
37 \\
37\end{array}$ & $\begin{array}{l}318 \\
356 \\
365 \\
356 \\
336\end{array}$ \\
\hline $\begin{array}{l}16 \\
17 \\
18 \\
19 \\
20\end{array}$ & $\begin{array}{l}57 \\
59 \\
82 \\
90 \\
94\end{array}$ & $\begin{array}{l}157 \\
172 \\
180 \\
235 \\
249\end{array}$ & $\begin{array}{l}200 \\
354 \\
320 \\
320 \\
324\end{array}$ & $\begin{array}{l}268 \\
272 \\
272 \\
260 \\
242\end{array}$ & $\begin{array}{l}201 \\
190 \\
198 \\
222 \\
232\end{array}$ & $\begin{array}{l}268 \\
284 \\
284 \\
288 \\
288\end{array}$ & $\begin{array}{r}108 \\
85 \\
83 \\
81 \\
81\end{array}$ & $\begin{array}{l}54 \\
51 \\
51 \\
53 \\
53\end{array}$ & $\begin{array}{l}235 \\
232 \\
216 \\
213 \\
213\end{array}$ & $\begin{array}{l}65 \\
50 \\
45 \\
48 \\
50\end{array}$ & $\begin{array}{l}34 \\
31 \\
24 \\
31 \\
37\end{array}$ & $\begin{array}{r}150 \\
109 \\
100 \\
93 \\
93\end{array}$ \\
\hline $\begin{array}{l}21 \\
22 \\
23 \\
24 \\
25\end{array}$ & $\begin{array}{r}96 \\
100 \\
104 \\
102 \\
106\end{array}$ & $\begin{array}{l}260 \\
260 \\
264 \\
264 \\
260\end{array}$ & $\begin{array}{l}336 \\
344 \\
304 \\
296 \\
296\end{array}$ & $\begin{array}{l}232 \\
220 \\
132 \\
253 \\
280\end{array}$ & $\begin{array}{r}219 \\
195 \\
148 \\
89 \\
94\end{array}$ & $\begin{array}{l}276 \\
268 \\
260 \\
239 \\
232\end{array}$ & $\begin{array}{l}81 \\
78 \\
79 \\
76 \\
74\end{array}$ & $\begin{array}{l}56 \\
56 \\
59 \\
72 \\
79\end{array}$ & $\begin{array}{l}210 \\
213 \\
213 \\
210 \\
192\end{array}$ & $\begin{array}{l}53 \\
54 \\
57 \\
53 \\
47\end{array}$ & $\begin{array}{l}43 \\
40 \\
35 \\
34 \\
34\end{array}$ & $\begin{array}{r}91 \\
93 \\
93 \\
91 \\
133\end{array}$ \\
\hline $\begin{array}{l}26 \\
27 \\
28 \\
29 \\
30 \\
31\end{array}$ & $\begin{array}{l}106 \\
108 \\
134 \\
142 \\
152 \\
106\end{array}$ & $\begin{array}{l}260 \\
280 \\
280 \\
292 \\
296 \\
-=0\end{array}$ & $\begin{array}{l}296 \\
288 \\
276 \\
272 \\
268 \\
256\end{array}$ & $\begin{array}{l}272 \\
268 \\
272 \\
268 \\
272 \\
268\end{array}$ & $\begin{array}{l}232 \\
242 \\
249 \\
253 \\
--- \\
---\end{array}$ & $\begin{array}{l}232 \\
228 \\
232 \\
225 \\
232 \\
235\end{array}$ & $\begin{array}{r}72 \\
71 \\
71 \\
67 \\
64 \\
-\end{array}$ & $\begin{array}{r}85 \\
162 \\
225 \\
204 \\
210 \\
216\end{array}$ & $\begin{array}{l}150 \\
147 \\
150 \\
165 \\
167 \\
-\cdots\end{array}$ & $\begin{array}{l}53 \\
56 \\
56 \\
51 \\
47 \\
53\end{array}$ & $\begin{array}{l}34 \\
35 \\
36 \\
35 \\
33 \\
33\end{array}$ & $\begin{array}{r}109 \\
98 \\
92 \\
88 \\
88 \\
-\end{array}$ \\
\hline $\begin{array}{l}\text { TOTAL } \\
\text { MEAN } \\
\text { MAX } \\
\text { MIN } \\
\text { AC-FT }\end{array}$ & $\begin{array}{r}2508 \\
80.9 \\
152 \\
28 \\
4970\end{array}$ & $\begin{array}{r}5097 \\
170 \\
296 \\
56 \\
10110\end{array}$ & $\begin{array}{r}8434 \\
272 \\
354 \\
167 \\
16730\end{array}$ & $\begin{array}{r}8121 \\
262 \\
296 \\
132 \\
16110\end{array}$ & $\begin{array}{r}7207 \\
249 \\
409 \\
89 \\
14300\end{array}$ & $\begin{array}{r}7616 \\
246 \\
352 \\
132 \\
15110\end{array}$ & $\begin{array}{r}2752 \\
91.7 \\
183 \\
64 \\
5460\end{array}$ & $\begin{array}{r}2742 \\
88.5 \\
225 \\
51 \\
5440\end{array}$ & $\begin{array}{r}7489 \\
250 \\
430 \\
147 \\
14850\end{array}$ & $\begin{array}{r}2953 \\
95.3 \\
187 \\
45 \\
5860\end{array}$ & $\begin{array}{r}1177 \\
38.0 \\
53 \\
24 \\
2330\end{array}$ & $\begin{array}{r}3759 \\
125 \\
365 \\
30 \\
7460\end{array}$ \\
\hline
\end{tabular}

CAL YR 1975 TOTAL 47747 MEAN 131 MAX 354 MIN 28 AC-FT 94710 WTR YR 1976 TOTAL 59855 MEAN 164 MAX 430 MIN 24 AC-FT 118700 
PERIOD OF DAILY RECORD, -

WATER TEMPERATURES: October 1972 to current year.

SEDIMENT RECORDS: October 1972 to current year.

REMARKS,--Particle-size distribution of bed material table was omitted in 1975 water year and is published with 1976 water year records.

EXTREMES FOR PERIOD OF DAILY RECORD, .

SEDIMENT CONCENTRATIONS: Maximum daily mean, 6,870 mg/1 Feb. 11, 1973; minimum daily mean, $20 \mathrm{mg} / 1$ on several days in 1973 .

SEDIMENT DISCHARGE: Maximum daily, 22,400 tons (20,300 tonnes) Jan. 8, 1974; minimum daily, 0.01 tons

$(0.01$ tonnes) on several days in 1973 .

EXTREMES FOR CURRENT YEAR, - -

SEDIMENT CONCENTRATIONS: Maximum daily mean, 3,870 mg/1 sept. 25; minimum daily mean, $30 \mathrm{mg} / 1$ Feb. 17.

SEDIMENT DISCHARGE: Maximum daily, 1,730 tons (1,570 tonnes) Sept. 25 ; minimum daily, 3.2 tons (2.90 tonnes)

Sept. 2 .

TEMPERATURE (DEG, C) OF HATER, WATER YEAR OCTOQER 1975 TO SEPTEMBER 1976 ONCE-DAILY

\begin{tabular}{|c|c|c|c|c|c|c|c|c|c|c|c|c|}
\hline DAY & OCT & NOV & DEC & JAN & FEB & MAR & APR & MAY & JUN & JUL & AUG & SEP \\
\hline $\begin{array}{l}1 \\
2 \\
3 \\
4 \\
5\end{array}$ & $\begin{array}{r}20.5 \\
=- \\
=-\end{array}$ & $=$ & $\begin{array}{r}9.5 \\
10.5 \\
0.0 \\
12.0\end{array}$ & - & 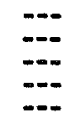 & $\begin{array}{r}14.5 \\
14.0 \\
12.0 \\
\ldots \\
=-\end{array}$ & $\begin{array}{r}15.5 \\
0.0 \\
-0 \\
14.0\end{array}$ & $\begin{array}{r}22.0 \\
18.5 \\
-.5\end{array}$ & $\begin{array}{r}19.0 \\
-0- \\
-0 \\
-0-\end{array}$ & $\begin{array}{r}22.5 \\
- \\
-\end{array}$ & $\begin{array}{r}--0 \\
23.5 \\
=-0\end{array}$ & $\begin{array}{r}21.5 \\
24.0 \\
\hdashline-0\end{array}$ \\
\hline $\begin{array}{r}6 \\
7 \\
8 \\
9 \\
10\end{array}$ & 21.0 & $\begin{array}{r}14.5 \\
14.0 \\
. .0 \\
-.0\end{array}$ & 12.0 & $\begin{array}{r}=-\infty \\
12.5 \\
=--\end{array}$ & $\begin{array}{r}12.0 \\
-0 \\
-0\end{array}$ & $\begin{array}{r}--- \\
15.5 \\
---\end{array}$ & 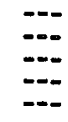 & 22.0 & $\begin{array}{r}20.0 \\
18.0 \\
16.0\end{array}$ & $\begin{array}{r}25.0 \\
25.0 \\
=-0\end{array}$ & $\begin{array}{r}-.-5 \\
26.5 \\
26.5\end{array}$ & $\begin{array}{r}26.0 \\
25.5 \\
22.5\end{array}$ \\
\hline $\begin{array}{l}11 \\
12 \\
13 \\
14 \\
15\end{array}$ & $\begin{array}{r}-- \\
20.0 \\
\cdots-\end{array}$ & $\begin{array}{r}12.0 \\
\cdots \\
\cdots\end{array}$ & $\begin{array}{r}11.5 \\
-0.0\end{array}$ & 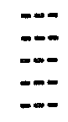 & 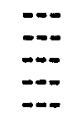 & $\begin{array}{r}12.5 \\
13.5 \\
= \\
17.0\end{array}$ & $\begin{array}{r}--. \\
16.5 \\
--5\end{array}$ & $\begin{array}{r}24.5 \\
25.0 \\
-\ldots . \\
-. .-\end{array}$ & $\begin{array}{l}m \\
=-\infty \\
\ddot{m-}\end{array}$ & $\begin{array}{r}23.0 \\
--0 \\
---\end{array}$ & 23.0 & $\begin{array}{r}21.5 \\
21.5 \\
21.5\end{array}$ \\
\hline $\begin{array}{l}16 \\
17 \\
18 \\
19 \\
20\end{array}$ & $\begin{array}{r}16.0 \\
-0 \\
--0\end{array}$ & $\begin{array}{r}11.5 \\
-.0 \\
10.0\end{array}$ & $\begin{array}{l}=-- \\
8.0 \\
--\end{array}$ & $\begin{array}{l}--- \\
--- \\
--- \\
-\infty- \\
-\infty-\end{array}$ & $\begin{array}{r}-. . \\
14.5 \\
-\infty\end{array}$ & $\begin{array}{r}-=- \\
17.0 \\
16.5 \\
-.\end{array}$ & $\begin{array}{r}\ldots \\
15.0 \\
-\infty\end{array}$ & $\begin{array}{r}20.0 \\
\ldots \\
\ldots-.0 \\
20.0\end{array}$ & $\begin{array}{r}19.5 \\
-0.5 \\
21.0\end{array}$ & 25.0 & $\begin{array}{r}22.5 \\
23.0 \\
- \\
23.0\end{array}$ & $=-$ \\
\hline $\begin{array}{l}21 \\
22 \\
23 \\
24 \\
25\end{array}$ & 16.5 & $\begin{array}{r}0 \\
14.0 \\
-0\end{array}$ & $\begin{array}{r}11.0 \\
=0 \\
=0.5\end{array}$ & $\begin{array}{r}-m- \\
13.0 \\
---0 \\
---\end{array}$ & $\begin{array}{r}12.0 \\
15.5 \\
0.0\end{array}$ & $\begin{array}{r}--0 \\
15.0 \\
---\end{array}$ & $\begin{array}{r}20.0 \\
21.5\end{array}$ & 22.0 & $\begin{array}{r}=- \\
=-0 \\
21.0\end{array}$ & $\begin{array}{r}25.0 \\
25.0 \\
22.5\end{array}$ & 24.5 & $\begin{array}{r}-1 . \\
22.0 \\
20.5\end{array}$ \\
\hline $\begin{array}{l}26 \\
27 \\
28 \\
29 \\
30 \\
31\end{array}$ & $\begin{array}{r}=-5 \\
15.0 \\
=-5.5 \\
14.5\end{array}$ & $\begin{array}{r}12.5 \\
12.5 \\
10.5 \\
-=- \\
--\end{array}$ & $\begin{array}{l}m \\
m-0 \\
m-0\end{array}$ & $\begin{array}{l}=- \\
=-0 \\
11.0 \\
=-0\end{array}$ & $\begin{array}{r}13.5 \\
=0 \\
14.0 \\
=0\end{array}$ & $\begin{array}{r}--0 \\
14.0 \\
15.0 \\
-\end{array}$ & $\begin{array}{r}18.5 \\
--5 \\
-\infty \\
-\infty\end{array}$ & $\begin{array}{r}-19.0 \\
18.0 \\
19.0 \\
-\end{array}$ & $\begin{array}{r}23.0 \\
-.0 \\
22.5 \\
-.0 \\
\end{array}$ & $\begin{array}{l}=-\infty \\
=-\infty \\
=-- \\
26.5 \\
25.5\end{array}$ & $\begin{array}{r}-5.5 \\
25.5 \\
=-0 \\
-5 . \overline{0}\end{array}$ & $\begin{array}{r}-\infty \\
23.0 \\
-\end{array}$ \\
\hline NTH & $m$ & $-m$ & $=-$ & $-\infty$ & $m$ & $m$ & $-\infty$ & $-\infty$ & $m-=$ & $-\infty$ & $\cdots$ & -- \\
\hline
\end{tabular}


11075600 SANTA ANA RIVER AT IMPERTAL HIGHWAY, NEAR ANAHEIM, CA--Continued

SUSPENOED-SEDIMENT OISCHARGE (TONS/OAY), WATER YEAR OCTOBER 1975 TO SEPTEMBER 1976

\begin{tabular}{|c|c|c|c|c|c|c|c|c|c|}
\hline & & OCTOBER & & & NOVEMBER & & & DECEMBER & \\
\hline DAY & $\begin{array}{l}\text { MEAN } \\
\text { DISCHARGE } \\
\text { (CFS) }\end{array}$ & $\begin{array}{l}\text { MEAN } \\
\text { CONCEN- } \\
\text { TRATION } \\
(M G / L)\end{array}$ & $\begin{array}{l}\text { SEDIMENT } \\
\text { DISCHARGE } \\
\text { (TONS/DAY) }\end{array}$ & $\begin{array}{l}\text { MEAN } \\
\text { DISCHARGE } \\
\text { (CFS) }\end{array}$ & $\begin{array}{l}\text { MEAN } \\
\text { CONCEN- } \\
\text { TRATION } \\
\text { (MG/L) }\end{array}$ & $\begin{array}{l}\text { SEDIMENT } \\
\text { DISCHARGE } \\
\text { (TONS/DAY) }\end{array}$ & $\begin{array}{l}\text { MEAN } \\
\text { DISCHARGE } \\
\text { (CFS) }\end{array}$ & $\begin{array}{l}\text { MEAN } \\
\text { CONCEN- } \\
\text { TRATION } \\
\text { (MG/L) }\end{array}$ & $\begin{array}{l}\text { SEOIMENT } \\
\text { OISCHARGE } \\
\text { (TONS/DAY) }\end{array}$ \\
\hline $\begin{array}{l}1 \\
2 \\
3 \\
4 \\
5\end{array}$ & $\begin{array}{l}90 \\
87 \\
83 \\
74 \\
71\end{array}$ & $\begin{array}{r}100 \\
90 \\
90 \\
85 \\
85\end{array}$ & $\begin{array}{l}24 \\
21 \\
20 \\
17 \\
16\end{array}$ & $\begin{array}{l}56 \\
62 \\
64 \\
64 \\
66\end{array}$ & $\begin{array}{l}140 \\
140 \\
130 \\
120 \\
110\end{array}$ & $\begin{array}{l}21 \\
23 \\
22 \\
21 \\
20\end{array}$ & $\begin{array}{l}292 \\
296 \\
304 \\
284 \\
296\end{array}$ & $\begin{array}{l}210 \\
340 \\
330 \\
280 \\
270\end{array}$ & $\begin{array}{l}166 \\
272 \\
271 \\
215 \\
216\end{array}$ \\
\hline $\begin{array}{r}6 \\
7 \\
8 \\
9 \\
10\end{array}$ & $\begin{array}{l}77 \\
52 \\
44 \\
38 \\
41\end{array}$ & $\begin{array}{l}800 \\
700 \\
250 \\
200 \\
800\end{array}$ & $\begin{array}{r}166 \\
98 \\
30 \\
21 \\
89\end{array}$ & $\begin{array}{l}67 \\
71 \\
71 \\
72 \\
74\end{array}$ & $\begin{array}{r}100 \\
90 \\
90 \\
90 \\
90\end{array}$ & $\begin{array}{l}18 \\
17 \\
17 \\
17 \\
18\end{array}$ & $\begin{array}{l}312 \\
324 \\
324 \\
206 \\
185\end{array}$ & $\begin{array}{l}320 \\
370 \\
410 \\
233 \\
160\end{array}$ & $\begin{array}{r}270 \\
324 \\
359 \\
136 \\
80\end{array}$ \\
\hline $\begin{array}{l}11 \\
12 \\
13 \\
14 \\
15\end{array}$ & $\begin{array}{l}47 \\
47 \\
28 \\
50 \\
41\end{array}$ & $\begin{array}{l}600 \\
400 \\
600 \\
250 \\
200\end{array}$ & $\begin{array}{l}76 \\
51 \\
45 \\
34 \\
22\end{array}$ & $\begin{array}{l}127 \\
140 \\
150 \\
152 \\
152\end{array}$ & $\begin{array}{l}327 \\
235 \\
220 \\
220 \\
200\end{array}$ & $\begin{array}{r}114 \\
89 \\
89 \\
90 \\
82\end{array}$ & $\begin{array}{l}172 \\
167 \\
185 \\
167 \\
170\end{array}$ & $\begin{array}{r}120 \\
90 \\
90 \\
80 \\
70\end{array}$ & $\begin{array}{l}56 \\
41 \\
45 \\
36 \\
32\end{array}$ \\
\hline $\begin{array}{l}16 \\
17 \\
18 \\
19 \\
20\end{array}$ & $\begin{array}{l}57 \\
59 \\
62 \\
90 \\
94\end{array}$ & $\begin{array}{l}250 \\
250 \\
420 \\
250 \\
200\end{array}$ & $\begin{array}{l}38 \\
40 \\
93 \\
61 \\
51\end{array}$ & $\begin{array}{l}157 \\
172 \\
180 \\
235 \\
249\end{array}$ & $\begin{array}{l}180 \\
200 \\
268 \\
970 \\
980\end{array}$ & $\begin{array}{r}76 \\
93 \\
132 \\
615 \\
659\end{array}$ & $\begin{array}{l}200 \\
354 \\
320 \\
320 \\
324\end{array}$ & $\begin{array}{l}800 \\
300 \\
135 \\
120 \\
110\end{array}$ & $\begin{array}{l}432 \\
287 \\
117 \\
104 \\
96\end{array}$ \\
\hline $\begin{array}{l}21 \\
22 \\
23 \\
24 \\
25\end{array}$ & $\begin{array}{l}96 \\
100 \\
104 \\
102 \\
106\end{array}$ & $\begin{array}{l}200 \\
200 \\
200 \\
150 \\
150\end{array}$ & $\begin{array}{l}52 \\
54 \\
56 \\
41 \\
43\end{array}$ & $\begin{array}{l}260 \\
260 \\
264 \\
264 \\
260\end{array}$ & $\begin{array}{l}890 \\
660 \\
410 \\
260 \\
160\end{array}$ & $\begin{array}{l}625 \\
463 \\
292 \\
185 \\
112\end{array}$ & $\begin{array}{l}336 \\
344 \\
304 \\
296 \\
296\end{array}$ & $\begin{array}{r}110 \\
105 \\
90 \\
85 \\
85\end{array}$ & $\begin{array}{r}100 \\
98 \\
74 \\
68 \\
68\end{array}$ \\
\hline $\begin{array}{l}26 \\
27 \\
28 \\
29 \\
30 \\
31\end{array}$ & $\begin{array}{l}106 \\
108 \\
134 \\
142 \\
152 \\
106\end{array}$ & $\begin{array}{l}160 \\
180 \\
300 \\
200 \\
230 \\
180\end{array}$ & $\begin{array}{r}46 \\
52 \\
109 \\
77 \\
94 \\
52\end{array}$ & $\begin{array}{l}260 \\
280 \\
280 \\
292 \\
296 \\
---\end{array}$ & $\begin{array}{l}150 \\
190 \\
200 \\
180 \\
170 \\
-.-\end{array}$ & $\begin{array}{l}105 \\
144 \\
151 \\
142 \\
136 \\
-\end{array}$ & $\begin{array}{l}296 \\
288 \\
276 \\
272 \\
268 \\
256\end{array}$ & $\begin{array}{l}85 \\
85 \\
85 \\
90 \\
80 \\
70\end{array}$ & $\begin{array}{l}68 \\
66 \\
63 \\
66 \\
58 \\
48\end{array}$ \\
\hline TOTAL & 2508 & -- & 1689 & 5097 & -- & 4588 & 8434 & $\cdots$ & 4332 \\
\hline & & JANUARY & & & FEBRUARY & & & MARCH & \\
\hline DAY & $\begin{array}{l}\text { MEAN } \\
\text { DISCHARGE } \\
\text { (CFS) }\end{array}$ & $\begin{array}{l}\text { MEAN } \\
\text { CONCEN- } \\
\text { TRATION } \\
\text { (MG/L) }\end{array}$ & $\begin{array}{l}\text { SEDIMENT } \\
\text { OISCHARGE } \\
\text { (TONS/OAY) }\end{array}$ & $\begin{array}{l}\text { MEAN } \\
\text { DISCHARGE } \\
\text { (CFS) }\end{array}$ & $\begin{array}{l}\text { MEAN } \\
\text { CONCEN- } \\
\text { TRATION } \\
\text { (MG/L) }\end{array}$ & $\begin{array}{l}\text { SEDIMENT } \\
\text { DISCHARGE } \\
\text { (TONS/DAY) }\end{array}$ & $\begin{array}{l}\text { MEAN } \\
\text { DISCHARGE } \\
\text { (CFS) }\end{array}$ & $\begin{array}{l}\text { MEAN } \\
\text { CONCEN- } \\
\text { TRATION } \\
\text { (MG/L) }\end{array}$ & $\begin{array}{l}\text { SEDIMENT } \\
\text { DISCHARGE } \\
\text { (TONS/DAY) }\end{array}$ \\
\hline $\begin{array}{l}1 \\
2 \\
3 \\
4 \\
5\end{array}$ & $\begin{array}{l}253 \\
246 \\
246 \\
239 \\
246\end{array}$ & $\begin{array}{l}70 \\
65 \\
65 \\
60 \\
65\end{array}$ & $\begin{array}{l}48 \\
43 \\
43 \\
39 \\
43\end{array}$ & $\begin{array}{l}249 \\
264 \\
320 \\
297 \\
224\end{array}$ & $\begin{array}{l}150 \\
170 \\
185 \\
191 \\
168\end{array}$ & $\begin{array}{l}101 \\
121 \\
160 \\
156 \\
102\end{array}$ & $\begin{array}{l}272 \\
255 \\
336 \\
352 \\
308\end{array}$ & $\begin{array}{l}545 \\
404 \\
471 \\
280 \\
230\end{array}$ & $\begin{array}{l}468 \\
383 \\
408 \\
266 \\
191\end{array}$ \\
\hline $\begin{array}{r}6 \\
7 \\
8 \\
9 \\
10\end{array}$ & $\begin{array}{l}268 \\
272 \\
280 \\
296 \\
292\end{array}$ & $\begin{array}{l}80 \\
75 \\
75 \\
85 \\
75\end{array}$ & $\begin{array}{l}58 \\
55 \\
57 \\
68 \\
59\end{array}$ & $\begin{array}{l}274 \\
316 \\
376 \\
409 \\
320\end{array}$ & $\begin{array}{l}390 \\
284 \\
368 \\
584 \\
345\end{array}$ & $\begin{array}{l}294 \\
244 \\
381 \\
678 \\
298\end{array}$ & $\begin{array}{l}248 \\
142 \\
135 \\
132 \\
143\end{array}$ & $\begin{array}{l}175 \\
100 \\
100 \\
100 \\
124\end{array}$ & $\begin{array}{r}117 \\
38 \\
36 \\
36 \\
51\end{array}$ \\
\hline $\begin{array}{l}11 \\
12 \\
13 \\
14 \\
15\end{array}$ & $\begin{array}{l}292 \\
280 \\
292 \\
288 \\
280\end{array}$ & $\begin{array}{l}80 \\
75 \\
80 \\
80 \\
85\end{array}$ & $\begin{array}{l}63 \\
57 \\
63 \\
62 \\
64\end{array}$ & $\begin{array}{l}312 \\
308 \\
302 \\
256 \\
216\end{array}$ & $\begin{array}{r}265 \\
195 \\
115 \\
55 \\
41\end{array}$ & $\begin{array}{r}223 \\
162 \\
94 \\
38 \\
24\end{array}$ & $\begin{array}{l}228 \\
239 \\
249 \\
253 \\
253\end{array}$ & $\begin{array}{r}195 \\
124 \\
85 \\
75 \\
66\end{array}$ & $\begin{array}{r}120 \\
80 \\
57 \\
51 \\
45\end{array}$ \\
\hline $\begin{array}{l}16 \\
17 \\
18 \\
19 \\
20\end{array}$ & $\begin{array}{l}268 \\
272 \\
272 \\
260 \\
242\end{array}$ & $\begin{array}{r}90 \\
93 \\
95 \\
95 \\
100\end{array}$ & $\begin{array}{l}65 \\
68 \\
70 \\
67 \\
65\end{array}$ & $\begin{array}{l}201 \\
190 \\
198 \\
222 \\
232\end{array}$ & $\begin{array}{l}35 \\
30 \\
45 \\
65 \\
80\end{array}$ & $\begin{array}{l}19 \\
15 \\
24 \\
39 \\
50\end{array}$ & $\begin{array}{l}268 \\
284 \\
284 \\
288 \\
288\end{array}$ & $\begin{array}{l}60 \\
55 \\
55 \\
65 \\
60\end{array}$ & $\begin{array}{l}43 \\
42 \\
42 \\
51 \\
47\end{array}$ \\
\hline $\begin{array}{l}21 \\
22 \\
23 \\
24 \\
25\end{array}$ & $\begin{array}{l}232 \\
220 \\
132 \\
253 \\
280\end{array}$ & $\begin{array}{l}120 \\
130 \\
135 \\
335 \\
120\end{array}$ & $\begin{array}{r}75 \\
77 \\
48 \\
221 \\
91\end{array}$ & $\begin{array}{r}219 \\
195 \\
148 \\
89 \\
94\end{array}$ & $\begin{array}{l}80 \\
78 \\
70 \\
60 \\
94\end{array}$ & $\begin{array}{l}47 \\
41 \\
28 \\
14 \\
29\end{array}$ & $\begin{array}{l}276 \\
268 \\
260 \\
239 \\
232\end{array}$ & $\begin{array}{l}60 \\
60 \\
60 \\
65 \\
65\end{array}$ & $\begin{array}{l}45 \\
43 \\
42 \\
42 \\
41\end{array}$ \\
\hline $\begin{array}{l}26 \\
27 \\
28 \\
29 \\
30 \\
31\end{array}$ & $\begin{array}{l}272 \\
268 \\
272 \\
268 \\
272 \\
268\end{array}$ & $\begin{array}{l}110 \\
100 \\
90 \\
120 \\
200 \\
150\end{array}$ & $\begin{array}{r}81 \\
72 \\
66 \\
87 \\
147 \\
109\end{array}$ & $\begin{array}{l}232 \\
242 \\
249 \\
253 \\
-\cdots \\
--\end{array}$ & $\begin{array}{r}280 \\
135 \\
90 \\
77 \\
-9- \\
-\cdots-\end{array}$ & $\begin{array}{r}175 \\
88 \\
61 \\
53 \\
--\infty \\
---\end{array}$ & $\begin{array}{l}232 \\
228 \\
232 \\
225 \\
232 \\
235\end{array}$ & $\begin{array}{r}70 \\
70 \\
74 \\
70 \\
70 \\
100\end{array}$ & $\begin{array}{l}44 \\
43 \\
46 \\
43 \\
44 \\
63\end{array}$ \\
\hline TOTAL & 8121 & $=-\infty$ & 2231 & 7207 & $-\infty$ & 3759 & 7616 & $\cdots$ & 3068 \\
\hline
\end{tabular}


11075600 SANTA ANA RIVER AT IMPERIAL HIGHWAY, NEAR ANAHEIM, CA--Continued

SUSPENDEO-SEDIMENT OISCHARGE (TONS/DAY), WATER YEAR OCTOBER 1975 TO SEPTEMBER 1976

\begin{tabular}{|c|c|c|c|c|c|c|c|c|c|}
\hline & & APRIL & & & MAY & & & JUNE & \\
\hline DAY & $\begin{array}{c}\text { MEAN } \\
\text { DISCHARGE } \\
\text { (CFS) }\end{array}$ & $\begin{array}{l}\text { MEAN } \\
\text { CONCEN- } \\
\text { TRATION } \\
\text { (MG/L) }\end{array}$ & $\begin{array}{l}\text { SEDIMENT } \\
\text { DISCHARGE } \\
\text { (TONS/DAY) }\end{array}$ & $\begin{array}{l}\text { MEAN } \\
\text { DISCHARGE } \\
\text { (CFS) }\end{array}$ & $\begin{array}{l}\text { MEAN } \\
\text { CONCEN- } \\
\text { TRATION } \\
\text { (MG/L) }\end{array}$ & $\begin{array}{l}\text { SEDIMENT } \\
\text { DISCHARGE } \\
\text { (TONS/OAY) }\end{array}$ & $\begin{array}{l}\text { MEAN } \\
\text { DISCHARGE } \\
\text { (CFS) }\end{array}$ & $\begin{array}{l}\text { MEAN } \\
\text { CONCEN- } \\
\text { TRATION } \\
\text { (MGL) }\end{array}$ & $\begin{array}{l}\text { SEDIMENT } \\
\text { DISCHARGE } \\
\text { (TONS/DAY) }\end{array}$ \\
\hline $\begin{array}{l}1 \\
2 \\
3 \\
4 \\
5\end{array}$ & $\begin{array}{r}183 \\
180 \\
80 \\
105 \\
130\end{array}$ & $\begin{array}{r}120 \\
120 \\
70 \\
85 \\
200\end{array}$ & $\begin{array}{l}59 \\
58 \\
15 \\
24 \\
70\end{array}$ & $\begin{array}{l}64 \\
59 \\
59 \\
62 \\
74\end{array}$ & $\begin{array}{l}60 \\
66 \\
65 \\
80 \\
85\end{array}$ & $\begin{array}{l}10 \\
11 \\
10 \\
13 \\
17\end{array}$ & $\begin{array}{l}232 \\
222 \\
232 \\
246 \\
253\end{array}$ & $\begin{array}{l}240 \\
220 \\
205 \\
180 \\
150\end{array}$ & $\begin{array}{l}150 \\
132 \\
128 \\
120 \\
102\end{array}$ \\
\hline $\begin{array}{r}6 \\
7 \\
8 \\
9 \\
10\end{array}$ & $\begin{array}{l}90 \\
78 \\
75 \\
75 \\
70\end{array}$ & $\begin{array}{r}100 \\
75 \\
70 \\
70 \\
70\end{array}$ & $\begin{array}{l}24 \\
16 \\
16 \\
14 \\
13\end{array}$ & $\begin{array}{l}78 \\
96 \\
96 \\
76 \\
71\end{array}$ & $\begin{array}{r}90 \\
130 \\
120 \\
125 \\
125\end{array}$ & $\begin{array}{l}19 \\
34 \\
31 \\
26 \\
24\end{array}$ & $\begin{array}{l}260 \\
280 \\
296 \\
312 \\
344\end{array}$ & $\begin{array}{l}130 \\
110 \\
100 \\
110 \\
104\end{array}$ & $\begin{array}{r}91 \\
83 \\
80 \\
93 \\
100\end{array}$ \\
\hline $\begin{array}{l}11 \\
12 \\
13 \\
14 \\
15\end{array}$ & $\begin{array}{r}65 \\
70 \\
142 \\
142 \\
96\end{array}$ & $\begin{array}{r}70 \\
70 \\
328 \\
180 \\
115\end{array}$ & $\begin{array}{r}12 \\
13 \\
155 \\
69 \\
30\end{array}$ & $\begin{array}{l}74 \\
71 \\
62 \\
57 \\
57\end{array}$ & $\begin{array}{l}179 \\
240 \\
225 \\
175 \\
135\end{array}$ & $\begin{array}{l}39 \\
46 \\
38 \\
27 \\
21\end{array}$ & $\begin{array}{l}425 \\
430 \\
415 \\
360 \\
256\end{array}$ & $\begin{array}{l}260 \\
230 \\
190 \\
175 \\
145\end{array}$ & $\begin{array}{l}298 \\
267 \\
213 \\
170 \\
100\end{array}$ \\
\hline $\begin{array}{l}16 \\
17 \\
18 \\
19 \\
20\end{array}$ & $\begin{array}{r}108 \\
85 \\
83 \\
81 \\
81\end{array}$ & $\begin{array}{r}134 \\
85 \\
80 \\
90 \\
100\end{array}$ & $\begin{array}{l}42 \\
20 \\
18 \\
20 \\
22\end{array}$ & $\begin{array}{l}54 \\
51 \\
51 \\
53 \\
53\end{array}$ & $\begin{array}{l}90 \\
85 \\
80 \\
70 \\
70\end{array}$ & $\begin{array}{l}13 \\
12 \\
11 \\
10 \\
10\end{array}$ & $\begin{array}{l}235 \\
232 \\
216 \\
213 \\
213\end{array}$ & $\begin{array}{l}120 \\
100 \\
100 \\
100 \\
100\end{array}$ & $\begin{array}{l}76 \\
63 \\
58 \\
58 \\
58\end{array}$ \\
\hline $\begin{array}{l}21 \\
22 \\
23 \\
24 \\
25\end{array}$ & $\begin{array}{l}81 \\
78 \\
79 \\
76 \\
74\end{array}$ & $\begin{array}{r}115 \\
110 \\
100 \\
85 \\
82\end{array}$ & $\begin{array}{l}25 \\
23 \\
21 \\
17 \\
16\end{array}$ & $\begin{array}{l}56 \\
56 \\
59 \\
72 \\
79\end{array}$ & $\begin{array}{l}65 \\
60 \\
50 \\
65 \\
80\end{array}$ & $\begin{array}{l}9.8 \\
9.1 \\
8.0 \\
13 \\
17\end{array}$ & $\begin{array}{l}210 \\
213 \\
213 \\
210 \\
192\end{array}$ & $\begin{array}{l}130 \\
110 \\
100 \\
105 \\
110\end{array}$ & $\begin{array}{l}74 \\
63 \\
58 \\
60 \\
57\end{array}$ \\
\hline $\begin{array}{l}26 \\
27 \\
28 \\
29 \\
30 \\
31\end{array}$ & $\begin{array}{r}72 \\
71 \\
71 \\
67 \\
64 \\
---\end{array}$ & $\begin{array}{r}70 \\
70 \\
69 \\
70 \\
70 \\
-7\end{array}$ & $\begin{array}{r}14 \\
13 \\
13 \\
13 \\
12 \\
---\end{array}$ & $\begin{array}{r}85 \\
162 \\
225 \\
204 \\
210 \\
216\end{array}$ & $\begin{array}{l}75 \\
440 \\
280 \\
260 \\
260 \\
250\end{array}$ & $\begin{array}{l}17 \\
210 \\
170 \\
143 \\
147 \\
146\end{array}$ & $\begin{array}{l}150 \\
147 \\
150 \\
165 \\
167 \\
--\end{array}$ & $\begin{array}{l}110 \\
110 \\
110 \\
128 \\
130 \\
--1\end{array}$ & $\begin{array}{r}45 \\
44 \\
45 \\
57 \\
59 \\
-9-\end{array}$ \\
\hline TOTAL & 2752 & -- & 875 & 2742 & --- & 1311.9 & 7489 & $\begin{array}{l}-- \\
\text { SEPTEMAER }\end{array}$ & 3002 \\
\hline DAY & $\begin{array}{l}\text { MEAN } \\
\text { DISCHARGE } \\
\text { (CFS) }\end{array}$ & $\begin{array}{l}\text { MEAN } \\
\text { CONCEN- } \\
\text { TRATION } \\
\text { (MG/L) }\end{array}$ & $\begin{array}{l}\text { SEDIMENT } \\
\text { DISCHARGE } \\
\text { (TONS/DAY) }\end{array}$ & $\begin{array}{l}\text { MEAN } \\
\text { DISCHARGE } \\
\text { (CFS) }\end{array}$ & $\begin{array}{l}\text { MEAN } \\
\text { CONCEN- } \\
\text { TRATION } \\
\text { (MG/L) }\end{array}$ & $\begin{array}{l}\text { SEDIMENT } \\
\text { DISCHARGE } \\
\text { (TONS/OAY) }\end{array}$ & $\begin{array}{c}\text { MEAN } \\
\text { DISCHARGE } \\
\text { (CFS) }\end{array}$ & $\begin{array}{l}\text { MEAN } \\
\text { CONCEN- } \\
\text { TRATION } \\
\text { (MG/L) }\end{array}$ & $\begin{array}{l}\text { SEDIMENT } \\
\text { DISCMARGE } \\
\text { (TONS/DAY) }\end{array}$ \\
\hline $\begin{array}{l}1 \\
2 \\
3 \\
4 \\
5\end{array}$ & $\begin{array}{l}165 \\
185 \\
187 \\
187 \\
178\end{array}$ & $\begin{array}{l}170 \\
250 \\
240 \\
215 \\
200\end{array}$ & $\begin{array}{r}76 \\
125 \\
121 \\
109 \\
96\end{array}$ & $\begin{array}{l}48 \\
45 \\
50 \\
53 \\
48\end{array}$ & $\begin{array}{l}90 \\
90 \\
85 \\
85 \\
80\end{array}$ & $\begin{array}{l}12 \\
11 \\
11 \\
12 \\
10\end{array}$ & $\begin{array}{l}33 \\
30 \\
41 \\
38 \\
42\end{array}$ & $\begin{array}{r}60 \\
40 \\
60 \\
110 \\
120\end{array}$ & $\begin{array}{l}5.3 \\
3.2 \\
6.6 \\
11 \\
14\end{array}$ \\
\hline $\begin{array}{r}6 \\
7 \\
8 \\
9 \\
10\end{array}$ & $\begin{array}{l}125 \\
118 \\
148 \\
126 \\
116\end{array}$ & $\begin{array}{l}170 \\
160 \\
234 \\
165 \\
120\end{array}$ & $\begin{array}{l}57 \\
51 \\
98 \\
56 \\
38\end{array}$ & $\begin{array}{l}38 \\
38 \\
37 \\
36 \\
45\end{array}$ & $\begin{array}{r}80 \\
80 \\
80 \\
80 \\
120\end{array}$ & $\begin{array}{l}8.2 \\
8.2 \\
8.0 \\
7.8 \\
15\end{array}$ & $\begin{array}{r}48 \\
43 \\
61 \\
49 \\
122\end{array}$ & $\begin{array}{l}110 \\
123 \\
270 \\
180 \\
597\end{array}$ & $\begin{array}{r}14 \\
15 \\
48 \\
24 \\
293\end{array}$ \\
\hline $\begin{array}{l}11 \\
12 \\
13 \\
14 \\
15\end{array}$ & $\begin{array}{l}116 \\
116 \\
116 \\
114 \\
118\end{array}$ & $\begin{array}{l}115 \\
125 \\
125 \\
120 \\
125\end{array}$ & $\begin{array}{l}36 \\
39 \\
39 \\
37 \\
40\end{array}$ & $\begin{array}{l}41 \\
37 \\
38 \\
37 \\
37\end{array}$ & $\begin{array}{l}205 \\
215 \\
190 \\
165 \\
175\end{array}$ & $\begin{array}{l}23 \\
21 \\
19 \\
16 \\
17\end{array}$ & $\begin{array}{l}318 \\
356 \\
365 \\
356 \\
336\end{array}$ & $\begin{array}{l}551 \\
310 \\
340 \\
240 \\
110\end{array}$ & $\begin{array}{l}470 \\
298 \\
335 \\
231 \\
100\end{array}$ \\
\hline $\begin{array}{l}16 \\
17 \\
18 \\
19 \\
20\end{array}$ & $\begin{array}{l}65 \\
50 \\
45 \\
48 \\
50\end{array}$ & $\begin{array}{l}110 \\
100 \\
100 \\
115 \\
115\end{array}$ & $\begin{array}{l}19 \\
13 \\
12 \\
15 \\
16\end{array}$ & $\begin{array}{l}34 \\
31 \\
24 \\
31 \\
37\end{array}$ & $\begin{array}{r}170 \\
150 \\
130 \\
110 \\
85\end{array}$ & $\begin{array}{l}16 \\
13 \\
8.4 \\
9.2 \\
8.5\end{array}$ & $\begin{array}{r}150 \\
109 \\
100 \\
93 \\
93\end{array}$ & $\begin{array}{l}125 \\
160 \\
190 \\
220 \\
240\end{array}$ & $\begin{array}{l}51 \\
47 \\
51 \\
55 \\
60\end{array}$ \\
\hline $\begin{array}{l}21 \\
22 \\
23 \\
24 \\
25\end{array}$ & $\begin{array}{l}53 \\
54 \\
57 \\
53 \\
47\end{array}$ & $\begin{array}{l}115 \\
110 \\
110 \\
105 \\
90\end{array}$ & $\begin{array}{l}16 \\
16 \\
17 \\
15 \\
11\end{array}$ & $\begin{array}{l}43 \\
40 \\
35 \\
34 \\
34\end{array}$ & $\begin{array}{r}80 \\
90 \\
100 \\
100 \\
100\end{array}$ & $\begin{array}{l}9.3 \\
9.7 \\
9.5 \\
9.2 \\
9.2\end{array}$ & $\begin{array}{r}91 \\
93 \\
93 \\
91 \\
133\end{array}$ & $\begin{array}{r}270 \\
295 \\
320 \\
350 \\
3870\end{array}$ & $\begin{array}{r}66 \\
74 \\
80 \\
86 \\
1730\end{array}$ \\
\hline $\begin{array}{l}26 \\
27 \\
28 \\
29 \\
30 \\
31\end{array}$ & $\begin{array}{l}53 \\
56 \\
56 \\
51 \\
47 \\
53\end{array}$ & $\begin{array}{r}95 \\
100 \\
100 \\
95 \\
95 \\
90\end{array}$ & $\begin{array}{l}14 \\
15 \\
15 \\
13 \\
12 \\
13\end{array}$ & $\begin{array}{l}34 \\
35 \\
36 \\
35 \\
33 \\
33\end{array}$ & $\begin{array}{r}100 \\
95 \\
90 \\
85 \\
80 \\
75\end{array}$ & $\begin{array}{l}9.2 \\
9.0 \\
8.7 \\
8.0 \\
7.1 \\
6.7\end{array}$ & $\begin{array}{r}109 \\
98 \\
92 \\
88 \\
88 \\
-8\end{array}$ & $\begin{array}{l}840 \\
600 \\
600 \\
600 \\
600 \\
--.\end{array}$ & $\begin{array}{c}247 \\
159 \\
149 \\
143 \\
143 \\
-\ldots\end{array}$ \\
\hline TOTAL & 2953 & $-\cdots$ & 1250 & 1177 & $-\infty$ & 349.9 & 3759 & -- & 5009.1 \\
\hline YEAR & 59855.0 & & 31464.9 & & & & & & \\
\hline
\end{tabular}


11075600 SANTA aNa RIVER A Imperial highway, NEAR ANAHEIM, CA--Continued

SUMMARY OF HATER AND SEOIMENT DISCHARGE, HATER YEAR OCTOBER 1975 TO SEPTEMBER 1976

\begin{tabular}{|c|c|c|c|c|}
\hline MONTH & $\begin{array}{l}\text { WATER } \\
\text { DISCHARGE } \\
\text { CFS-DAYS }\end{array}$ & $\begin{array}{l}\text { SUSPENDED } \\
\text { SED I MENT } \\
\text { DI SCHARGE } \\
\text { TONS }\end{array}$ & $\begin{array}{l}\text { BEDLOAD } \\
\text { DISCHARGE } \\
\text { TONS }\end{array}$ & $\begin{array}{l}\text { TOTAL } \\
\text { SEDIMENT } \\
\text { DISCHARGE } \\
\text { TONS }\end{array}$ \\
\hline OCTOBER 1975 & 2508.00 & 1689.00 & 984 & 2670 \\
\hline NOVEMBER $\ldots$ & 5097.00 & 4588.00 & 4760 & 9350 \\
\hline DECEMBER $\ldots$ & 8434.00 & 4332.00 & 10400 & 14700 \\
\hline JANUARY 1976 & 8121.00 & 2231.00 & 9410 & 11600 \\
\hline FEBRUARY $\cdots$ & 7207.00 & 3759.00 & 8410 & 12200 \\
\hline MARCH $\ldots \ldots$ & 7616.00 & 3068.00 & 8530 & 11600 \\
\hline APRIL $\cdots \cdots$ & 2752.00 & 675.00 & 1210 & 2080 \\
\hline MAY \#..... & 2742.00 & 1311.90 & 1400 & 2720 \\
\hline JUNE $\cdots \cdots \cdots$ & 7489.00 & 3002.00 & 8860 & 11900 \\
\hline JULY $\cdots \cdots \cdots$ & 2953.00 & 1250.00 & 1530 & 2780 \\
\hline AUGUST $\ldots \ldots$ & 1177.00 & 349.90 & 156 & 506 \\
\hline SEPTEMBER — & 3759.00 & $5009 \cdot 10$ & 3360 & 8370 \\
\hline TOTAL $\cdots \ldots$. & 59855.00 & 31464.90 & 59010 & 90476 \\
\hline
\end{tabular}

PARTICLE-SIZE DISTRIBUTION OF SUSPENDED SEDIMENT, WATER YEAR OCTOBER 1975 TO SEPTEMBER 1976

\begin{tabular}{|c|c|c|c|c|c|c|c|c|c|c|}
\hline DATE & TIME & $\begin{array}{l}\text { TEMPER- } \\
\text { ATURE } \\
\text { (DEG C) }\end{array}$ & $\begin{array}{l}\text { INSTAN- } \\
\text { TANEOUS } \\
\text { DIS- } \\
\text { CHARGE } \\
\text { (CFS) }\end{array}$ & $\begin{array}{l}\text { SUS- } \\
\text { PENDED } \\
\text { SEDI- } \\
\text { MENT } \\
\text { (MG/L) }\end{array}$ & $\begin{array}{c}\text { SUS- } \\
\text { PENDED } \\
\text { SEDI- } \\
\text { MENT } \\
\text { DIS- } \\
\text { CHARGE } \\
\text { (T/DAY) }\end{array}$ & $\begin{array}{c}\text { SUS } \\
\text { SED. } \\
\text { FALL } \\
\text { DIAM. } \\
\text { X FINER } \\
\text { THAN } \\
.002 \text { MH }\end{array}$ & $\begin{array}{l}\text { SUS } \\
\text { SED. } \\
\text { FALL } \\
\text { DIAM. } \\
\text { \% FINER } \\
\text { THAN } \\
.004 \mathrm{MM}\end{array}$ & $\begin{array}{c}\text { SUS. } \\
\text { SED: } \\
\text { FALL } \\
\text { DIAM. } \\
\text { \$ FINER } \\
\text { THAN } \\
.008 \mathrm{MH}\end{array}$ & $\begin{array}{l}\text { SUS, } \\
\text { SED, } \\
\text { FALL } \\
\text { DIAM, } \\
\text { \$ FINER } \\
\text { THAN } \\
\text { OIG MM }\end{array}$ & $\begin{array}{l}\text { SUS. } \\
\text { SED. } \\
\text { FALL } \\
\text { DIAM. } \\
\text { \& FINER } \\
\text { THAN } \\
.031 \mathrm{MM}\end{array}$ \\
\hline OCT & & & & & & & & & & \\
\hline $\begin{array}{l}10 \ldots \\
13 \ldots \\
17 \ldots \\
28 \ldots \\
30 \ldots \\
\text { Nov }\end{array}$ & $\begin{array}{l}1410 \\
1305 \\
1735 \\
1510 \\
1215\end{array}$ & $\begin{array}{c}21.0 \\
20.0 \\
16.0 \\
15.0 \\
-.0\end{array}$ & $\begin{array}{r}47 \\
44 \\
66 \\
142 \\
155\end{array}$ & $\begin{array}{r}1370 \\
1550 \\
288 \\
366 \\
298\end{array}$ & $\begin{array}{r}174 \\
184 \\
51 \\
140 \\
125\end{array}$ & $\begin{array}{l}25 \\
24 \\
24 \\
24 \\
--\end{array}$ & $\begin{array}{l}37 \\
36 \\
33 \\
32 \\
--\end{array}$ & $\begin{array}{l}48 \\
50 \\
42 \\
41 \\
--\end{array}$ & $\begin{array}{l}70 \\
67 \\
51 \\
52 \\
--\end{array}$ & $\begin{array}{l}84 \\
79 \\
62 \\
60 \\
-\end{array}$ \\
\hline${ }_{\text {DEC }}^{27} \cdots$ & 1315 & 12.5 & 280 & 198 & 150 & -- & -- & $=$ & $-\infty$ & - \\
\hline JAN & 1300 & 12.0 & 328 & 418 & 370 & 19 & 27 & 33 & 42 & 55 \\
\hline $\begin{array}{l}08 \ldots \\
12 \ldots \\
23 \ldots \\
28 \ldots \\
F E B\end{array}$ & $\begin{array}{l}1315 \\
1330 \\
1300 \\
1515\end{array}$ & $\begin{array}{r}12.5 \\
13.0 \\
=-\end{array}$ & $\begin{array}{l}284 \\
284 \\
125 \\
268\end{array}$ & $\begin{array}{r}76 \\
71 \\
137 \\
85\end{array}$ & $\begin{array}{l}58 \\
54 \\
46 \\
62\end{array}$ & $=$ & $\begin{array}{l}= \\
= \\
=\end{array}$ & $i$ & $\begin{array}{l}= \\
= \\
=\end{array}$ & $\begin{array}{l}=- \\
=- \\
=-\end{array}$ \\
\hline $\begin{array}{l}06 \ldots \\
09 \ldots \\
\text { MAR }\end{array}$ & $\begin{array}{l}0915 \\
0835\end{array}$ & 12,0 & $\begin{array}{l}217 \\
492\end{array}$ & $\begin{array}{l}445 \\
914\end{array}$ & $\begin{array}{r}261 \\
1210\end{array}$ & $\begin{array}{l}32 \\
39\end{array}$ & $\begin{array}{l}42 \\
48\end{array}$ & $\begin{array}{l}51 \\
54\end{array}$ & $\begin{array}{l}61 \\
62\end{array}$ & $\begin{array}{l}67 \\
69\end{array}$ \\
\hline$\underset{A P R}{12 \ldots}$ & 1130 & 13.5 & 231 & 124 & 77 & $-\infty$ & -- & - & -- & -- \\
\hline$\underset{\text { MAY }}{13 \ldots}$ & $\begin{array}{l}1315 \\
1420\end{array}$ & $\begin{array}{l}16.5 \\
18.5\end{array}$ & $\begin{array}{r}141 \\
78\end{array}$ & $\begin{array}{r}570 \\
69\end{array}$ & $\begin{array}{r}217 \\
15\end{array}$ & $\begin{array}{l}32 \\
--\end{array}$ & $\begin{array}{l}42 \\
--\end{array}$ & $\begin{array}{l}55 \\
--\end{array}$ & $\begin{array}{l}72 \\
--\end{array}$ & 86 \\
\hline $\begin{array}{l}02 \ldots \\
18 \ldots \ldots \\
25 \ldots \ldots \\
27 \ldots \\
\text { SEP }\end{array}$ & $\begin{array}{l}1510 \\
0930 \\
1400 \\
0930\end{array}$ & $\begin{array}{l}22.0 \\
20.0 \\
19.5 \\
19.0\end{array}$ & $\begin{array}{r}67 \\
60 \\
92 \\
167\end{array}$ & $\begin{array}{r}66 \\
84 \\
89 \\
846\end{array}$ & $\begin{array}{r}12 \\
14 \\
22 \\
381\end{array}$ & $=-$ & $=$ & $\begin{array}{l}-= \\
=- \\
60\end{array}$ & $\begin{array}{l}-= \\
-- \\
=- \\
77\end{array}$ & $\begin{array}{l}-- \\
94\end{array}$ \\
\hline $\begin{array}{l}10 \ldots \\
11 \ldots \\
25 \ldots \\
25 \ldots\end{array}$ & $\begin{array}{l}1030 \\
1715 \\
1300 \\
1745\end{array}$ & $\begin{array}{l}22.5 \\
21.0 \\
20.5 \\
20.5\end{array}$ & $\begin{array}{l}58 \\
305 \\
201 \\
150\end{array}$ & $\begin{array}{r}182 \\
253 \\
7000 \\
8490\end{array}$ & $\begin{array}{r}29 \\
208 \\
3800 \\
3440\end{array}$ & $\begin{array}{l}-5 \\
48 \\
50 \\
54\end{array}$ & $\begin{array}{l}25 \\
56 \\
69 \\
73\end{array}$ & $\begin{array}{l}-2 \\
63 \\
90 \\
92\end{array}$ & $\begin{array}{l}-- \\
69 \\
97 \\
98\end{array}$ & $\begin{array}{r}-77 \\
99 \\
100\end{array}$ \\
\hline
\end{tabular}


11075600 SANTA ANA RIVER AT IMPERIAL HIGHWAY, NEAR ANAHEIM, CA--Continued

PARTICLE $=5$ IZE DISTRIBUTION OF SUSPENDED SEDIMENT, HATER YEAR OCTOBER 1975 TO SEPTEMBER 1976

\begin{tabular}{|c|c|c|c|c|c|c|c|c|c|}
\hline & $\begin{array}{l}\text { SUS, } \\
\text { SED, } \\
\text { FALL } \\
\text { DIAM, } \\
\text { FINER } \\
\text { THAN }\end{array}$ & $\begin{array}{l}\text { SUS. } \\
\text { SED. } \\
\text { SIEVE } \\
\text { DIAM. } \\
\text { F FINER } \\
\text { THAN }\end{array}$ & $\begin{array}{l}\text { SUS. } \\
\text { SED. } \\
\text { FALL } \\
\text { DIAM. } \\
\text { FINER } \\
\text { THAN }\end{array}$ & $\begin{array}{l}\text { SUS. } \\
\text { SED: } \\
\text { SIEVE } \\
\text { DIAH. } \\
\text { FINER } \\
\text { THAN }\end{array}$ & $\begin{array}{l}\text { SUS. } \\
\text { SED. } \\
\text { FALL } \\
\text { DIAM. } \\
\text { × FINER } \\
\text { THAN }\end{array}$ & $\begin{array}{l}\text { SUS. } \\
\text { SED } \\
\text { SIEVE } \\
\text { DIAM. } \\
\text { × FINER } \\
\text { THAN }\end{array}$ & $\begin{array}{l}\text { SUS } \\
\text { SED. } \\
\text { SIEVE } \\
\text { DIAM. } \\
\text { \& FINER } \\
\text { THAN }\end{array}$ & $\begin{array}{l}\text { SUS. } \\
\text { SED } \\
\text { SIEVE } \\
\text { DIAH. } \\
\text { \& FINER } \\
\text { THAN }\end{array}$ & $\begin{array}{l}\text { SUS. } \\
\text { SED. } \\
\text { SIEVE } \\
\text { DIAM. } \\
\text { \$ FINER } \\
\text { THAN }\end{array}$ \\
\hline DATE & $.062 \mathrm{MH}$ & $.062 \mathrm{MH}$ & $.125 \mathrm{MH}$ & $.125 \mathrm{MM}$ & $.250 \mathrm{MM}$ & $.250 \mathrm{MH}$ & $.500 \mathrm{MH}$ & $1.00 \mathrm{MM}$ & $2.00 \mathrm{MM}$ \\
\hline \multicolumn{10}{|l|}{ OCT } \\
\hline $\begin{array}{l}10 \ldots \\
13 \ldots\end{array}$ & 93 & 83 & $\begin{array}{l}97 \\
-=\end{array}$ & 85 & $\begin{array}{r}100 \\
-7\end{array}$ & 86 & 88 & 93 & 97 \\
\hline $17 \ldots$ & -- & 78 & $-\infty$ & 94 & $-m$ & 98 & 100 & - & $\therefore$ \\
\hline $28 \ldots$ & $-\infty$ & 67 & -- & 78 & $-\infty$ & 92 & 100 & $=$ & $-\infty$ \\
\hline $\begin{array}{l}30 \cdots \\
\text { NOV }\end{array}$ & $-\infty$ & 60 & - & 76 & $-\infty$ & 89 & 99 & 100 & $-\infty$ \\
\hline OEC $27 \ldots$ & - & 60 & -- & 66 & - & 74 & 91 & 100 & $m$ \\
\hline JAN & - & 68 & - & 85 & $\Rightarrow$ & 92 & 97 & 100 & - \\
\hline $\begin{array}{l}08 \ldots \\
12 \ldots\end{array}$ & $=$ & $\begin{array}{l}79 \\
77\end{array}$ & $=$ & $\begin{array}{l}85 \\
82\end{array}$ & $\Rightarrow$ & $\begin{array}{l}92 \\
87\end{array}$ & $\begin{array}{l}98 \\
98\end{array}$ & $\begin{array}{l}100 \\
100\end{array}$ & $=$ \\
\hline $23 \ldots$ & $-\infty$ & 99 & -- & 100 & $-\infty$ & $-\infty$ & - & - & - \\
\hline $\begin{array}{l}28 \ldots \\
\text { FEB }\end{array}$ & $m$ & 90 & - & 93 & -- & 96 & 100 & - & $-\infty$ \\
\hline $06 \ldots$ & -- & 72 & - & 78 & - & 94 & 99 & 99 & 100 \\
\hline$\underset{\text { MAR }}{09 . . .}$ & - & 78 & - & 89 & $-\infty$ & 96 & 99 & 100 & $-\infty$ \\
\hline$\underset{A P R}{12} \cdots$ & -- & 86 & - & 92 & $m$ & 96 & 100 & -- & 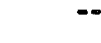 \\
\hline $13 \ldots$ & - & 93 & $\cdots$ & 97 & -- & 99 & 100 & - & -- \\
\hline MAY $27 \cdots$ & $=-$ & 98 & -- & 99 & -- & 100 & -- & -- & -- \\
\hline $02 \ldots$ & -- & 98 & $\rightarrow$ & 100 & $=-$ & - & -- & $=$ & $-\infty$ \\
\hline $18 \ldots$ & $\sim$ & 99 & $-\infty$ & 100 & - & -- & $\cdots$ & $-\infty$ & -- \\
\hline $25 \ldots$ & -- & 98 & - & 100 & $-\infty$ & -- & - & - & $=-$ \\
\hline$\underset{S E P}{27} \cdot$. & $\cdots$ & 99 & $=$ & 100 & -- & -- & -- & -- & -- \\
\hline SEP $10 .$. & $m$ & 86 & $-m$ & 98 & $m$ & 100 & - & "w- & $=-$ \\
\hline $11 \ldots$ & 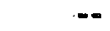 & 80 & -- & 84 & $=$ & 92 & 98 & 100 & $=$ \\
\hline 25. & - & 100 & - & $-\infty$ & $-\infty$ & -- & $-\infty$ & -- & $=-$ \\
\hline & - & $-\infty$ & $-m$ & $-\infty$ & $-=$ & -- & $=-$ & $=-$ & -- \\
\hline
\end{tabular}

PARTICLE-SIZE DISTRIBUTION OF SURFACE BED MATERIAL, HATER YEAR OCTOBER 1974 TO SEPTEMBER 1975
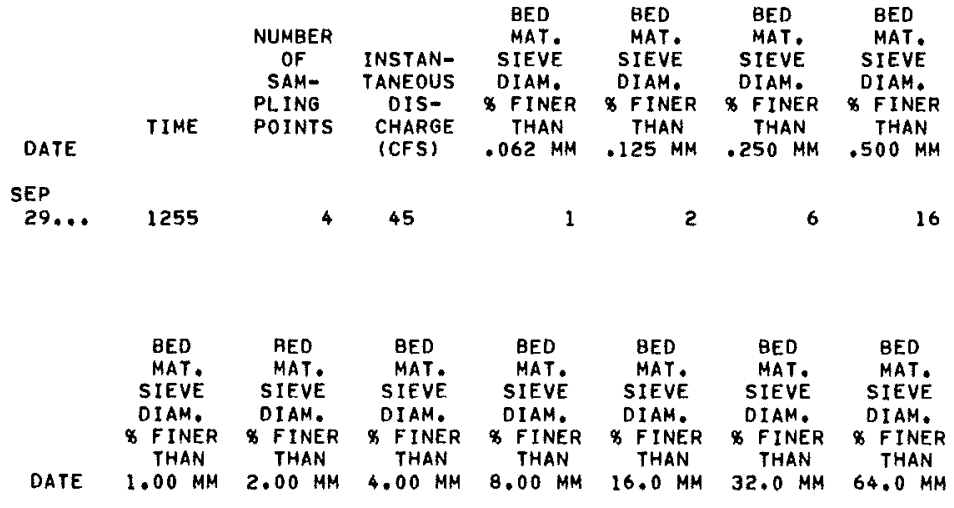
SEP

$\begin{array}{llllllll}29 \ldots & 45 & 77 & 92 & 98 & 99 & 100 & 100\end{array}$


11075620 SANTA ANA RIVER SPREADING DIVERSION BELOW IMPERIAL HIGHWAY NEAR ANAHEIM, CA

LOCATION.--Lat $33^{\circ} 57^{\prime} 23^{\prime \prime}$, long $117^{\circ} 48^{\prime} 00^{\prime \prime}$, in Canon De Santa Ana, Orange County, on diversion channel, 100 ft $(30 \mathrm{~m})$ downstream from diversion point, $0.1 \mathrm{mi}(0.2 \mathrm{~km})$ south of La Palma Avenue, and $0.6 \mathrm{mi}(1.0 \mathrm{~km})$ west of Imperial Highway.

\section{WATER-DISCHARGE RECORDS}

PERIOD OF RECORD.--July 1974 to current year. Records from July 1974 to September 1975 pub1ished in WDR CA-76-1. GAGE.-Water-stage recorder and Parshall flume control. Altitude of gage is $262 \mathrm{ft}$ ( $80 \mathrm{~m}$ ), from topographic map.

REMARKS.--Records good. Water is diverted from Santa Ana River at diversion point 100 ft (30 m) upstream, for recharging to spreading basin.

EXTREMES FOR PERIOD OF RECORD. - Maximum daily discharge, $250 \mathrm{ft}^{3} / \mathrm{s}\left(7.08 \mathrm{~m}^{3} / \mathrm{s}\right)$ Dec. 7,' 8 , 1975; no flow for some periods in each year.

DISCHARGE, IN CUBIC FEET PER SECOND, HATER YEAR OCTOBER 1973 TO SEPTEMBER 1974 MEAN VALUES

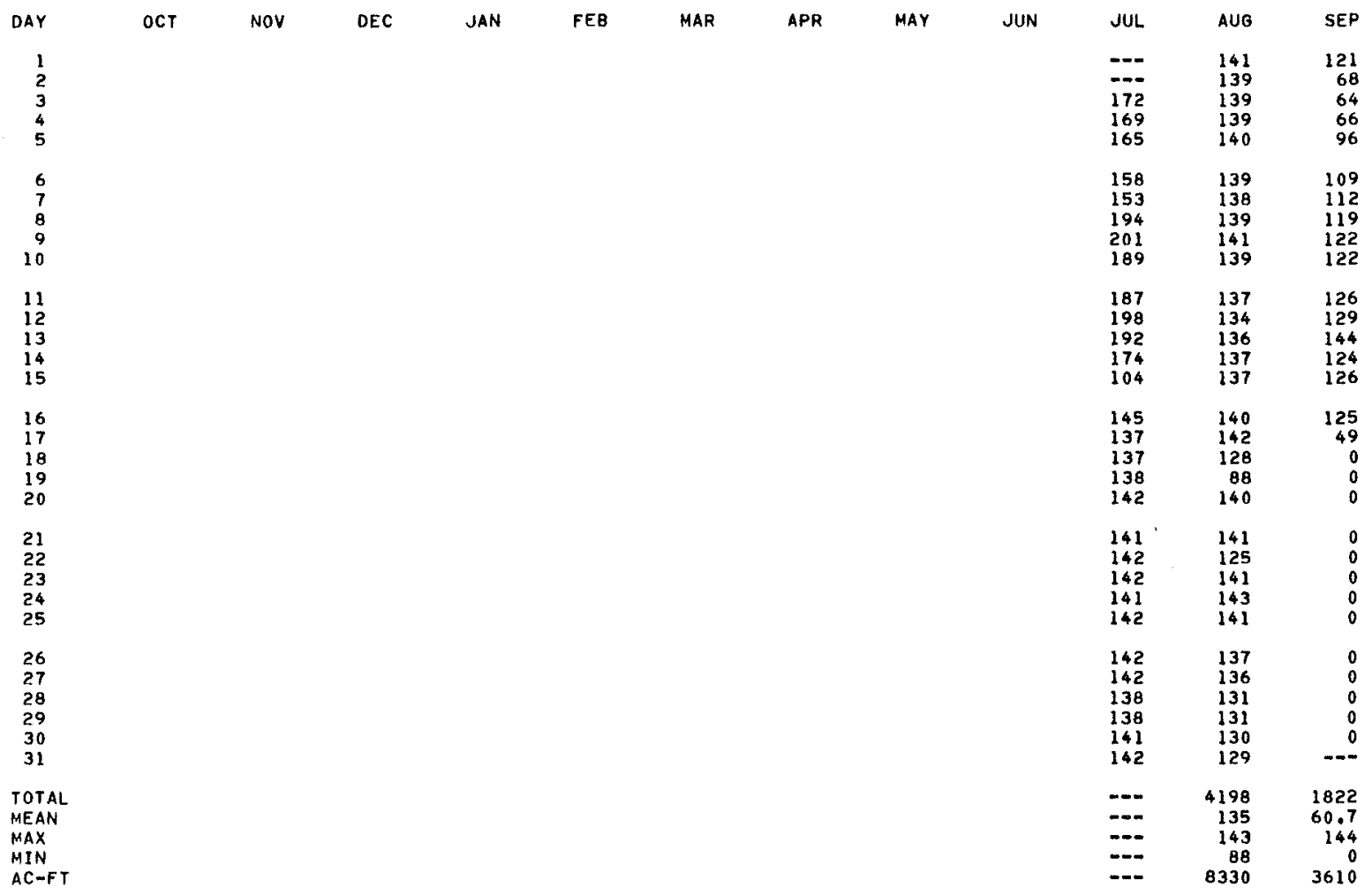


11075620 SANTA ANA RIVER SPREADING DIVERSION BELOW IMPERIAL HIGHWAY NEAR ANAHETM, CA--CONEIIUUEd DISCHARGE, IN CUBIC FEET PER SECOND, WATER YEAR OCTOBER 1974 TO SEPTEMBER 1975 MEAN VALUES

\begin{tabular}{|c|c|c|c|c|c|c|c|c|c|c|c|c|}
\hline DAY & OCT & Nov & DEC & JAN & FEB & MAR & APR & MAY & JUN & JUL & AUG & SEP \\
\hline $\begin{array}{l}1 \\
2 \\
3 \\
4 \\
5\end{array}$ & $\begin{array}{l}0 \\
0 \\
0 \\
0 \\
0\end{array}$ & $\begin{array}{l}71 \\
58 \\
56 \\
57 \\
48\end{array}$ & $\begin{array}{r}125 \\
129 \\
87 \\
39 . \\
58\end{array}$ & $\begin{array}{r}.73 \\
.47 \\
.42 \\
2.3 \\
4.5\end{array}$ & $\begin{array}{l}1.1 \\
1.1 \\
7.6 \\
2.9 \\
4.0\end{array}$ & $\begin{array}{l}4.9 \\
4.9 \\
5.2 \\
3.0 \\
.62\end{array}$ & $\begin{array}{l}4.4 \\
4.3 \\
4.6 \\
4.9 \\
6.2\end{array}$ & $\begin{array}{l}73 \\
69 \\
65 \\
69 \\
69\end{array}$ & $\begin{array}{l}32 \\
38 \\
41 \\
52 \\
54\end{array}$ & $\begin{array}{r}0 \\
0 \\
77 \\
130 \\
128\end{array}$ & $\begin{array}{l}70 \\
71 \\
69 \\
68 \\
71\end{array}$ & $\begin{array}{l}49 \\
49 \\
51 \\
51 \\
51\end{array}$ \\
\hline $\begin{array}{r}6 \\
7 \\
8 \\
9 \\
10\end{array}$ & $\begin{array}{l}0 \\
0 \\
0 \\
0 \\
0\end{array}$ & $\begin{array}{r}12 \\
.86 \\
.68 \\
.60 \\
.60\end{array}$ & $\begin{array}{l}85 \\
96 \\
54 \\
55 \\
72\end{array}$ & $\begin{array}{l}4.5 \\
4.2 \\
4.4 \\
2.7 \\
1.6\end{array}$ & $\begin{array}{l}9.0 \\
12 \\
15 \\
20 \\
19\end{array}$ & $\begin{array}{l}.47 \\
.44 \\
.39 \\
.34 \\
.34\end{array}$ & $\begin{array}{l}9.9 \\
10 \\
9.6 \\
13 \\
10\end{array}$ & $\begin{array}{l}70 \\
59 \\
59 \\
58 \\
55\end{array}$ & $\begin{array}{l}58 \\
42 \\
38 \\
48 \\
45\end{array}$ & $\begin{array}{l}125 \\
147 \\
158 \\
163 \\
125\end{array}$ & $\begin{array}{l}73 \\
73 \\
70 \\
72 \\
76\end{array}$ & $\begin{array}{l}52 \\
51 \\
52 \\
55 \\
57\end{array}$ \\
\hline $\begin{array}{l}11 \\
12 \\
13 \\
14 \\
15\end{array}$ & $\begin{array}{l}0 \\
0 \\
0 \\
0 \\
0\end{array}$ & $\begin{array}{l}.60 \\
.60 \\
.54 \\
.47 \\
.46\end{array}$ & $\begin{array}{l}50 \\
2.4 \\
3.6 \\
3.6 \\
3.6\end{array}$ & $\begin{array}{l}2.3 \\
3.4 \\
3.2 \\
3.7 \\
3.6\end{array}$ & $\begin{array}{r}17 \\
8.6 \\
8.3 \\
9.6 \\
15\end{array}$ & $\begin{array}{r}.34 \\
.27 \\
.31 \\
.34 \\
.34\end{array}$ & $\begin{array}{l}6.0 \\
3.5 \\
3.1 \\
2.9 \\
2.7\end{array}$ & $\begin{array}{l}53 \\
50 \\
50 \\
48 \\
50\end{array}$ & $\begin{array}{l}64 \\
68 \\
66 \\
51 \\
51\end{array}$ & $\begin{array}{l}141 \\
124 \\
127 \\
128 \\
167\end{array}$ & $\begin{array}{l}76 \\
64 \\
59 \\
63 \\
65\end{array}$ & $\begin{array}{l}50 \\
58 \\
59 \\
59 \\
58\end{array}$ \\
\hline $\begin{array}{l}16 \\
17 \\
18 \\
19 \\
20\end{array}$ & $\begin{array}{r}43 \\
101 \\
99 \\
102 \\
104\end{array}$ & $\begin{array}{l}.46 \\
.46 \\
.46 \\
.61 \\
.76\end{array}$ & $\begin{array}{l}2.0 \\
1.1 \\
1.1 \\
1.1 \\
.95\end{array}$ & $\begin{array}{l}3.5 \\
3.0 \\
2.9 \\
2.0 \\
2.0\end{array}$ & $\begin{array}{l}16 \\
9.5 \\
8.3 \\
7.2 \\
6.9\end{array}$ & $\begin{array}{r}.34 \\
.34 \\
.34 \\
.34 \\
.25\end{array}$ & $\begin{array}{c}2.6 \\
2.8 \\
.93 \\
9.0 \\
13\end{array}$ & $\begin{array}{l}52 \\
50 \\
45 \\
45 \\
49\end{array}$ & $\begin{array}{r}67 \\
19 \\
.12 \\
.07 \\
.03\end{array}$ & $\begin{array}{l}166 \\
167 \\
166 \\
167 \\
166\end{array}$ & $\begin{array}{l}65 \\
66 \\
66 \\
66 \\
67\end{array}$ & $\begin{array}{l}57 \\
58 \\
59 \\
65 \\
64\end{array}$ \\
\hline $\begin{array}{l}21 \\
22 \\
23 \\
24 \\
25\end{array}$ & $\begin{array}{l}105 \\
124 \\
124 \\
124 \\
123\end{array}$ & $\begin{array}{l}.76 \\
.76 \\
.75 \\
.61 \\
.60\end{array}$ & $\begin{array}{r}.94 \\
.94 \\
.87 \\
.80 \\
2.6\end{array}$ & $\begin{array}{l}2.0 \\
1.8 \\
1.8 \\
1.8 \\
1.3\end{array}$ & $\begin{array}{l}7.0 \\
6.9 \\
6.5 \\
6.3 \\
5.4\end{array}$ & $\begin{array}{l}2.3 \\
8.7 \\
10 \\
10 \\
11\end{array}$ & $\begin{array}{l}13 \\
3.4 \\
68 \\
94 \\
99\end{array}$ & $\begin{array}{l}48 \\
41 \\
39 \\
38 \\
37\end{array}$ & $\begin{array}{l}0 \\
0 \\
0 \\
0 \\
0\end{array}$ & $\begin{array}{r}164 \\
158 \\
19 \\
48 \\
93\end{array}$ & $\begin{array}{l}66 \\
68 \\
70 \\
69 \\
63\end{array}$ & $\begin{array}{l}65 \\
64 \\
64 \\
64 \\
65\end{array}$ \\
\hline $\begin{array}{l}26 \\
27 \\
28 \\
29 \\
30 \\
31\end{array}$ & $\begin{array}{l}123 \\
124 \\
134 \\
165 \\
148 \\
142\end{array}$ & $\begin{array}{r}60 \\
130 \\
132 \\
129 \\
124\end{array}$ & $\begin{array}{r}4.9 \\
2.5 \\
1.4 \\
1.4 \\
1.2 \\
.99\end{array}$ & $\begin{array}{l}.84 \\
1.0 \\
1.1 \\
1.0 \\
.86 \\
.84\end{array}$ & $\begin{array}{l}5.0 \\
4.8 \\
5.0 \\
-. .2 \\
-. .0 \\
-.-0\end{array}$ & $\begin{array}{l}13 \\
15 \\
15 \\
15 \\
9.3 \\
4.8\end{array}$ & $\begin{array}{l}92 \\
82 \\
82 \\
82 \\
72\end{array}$ & $\begin{array}{l}39 \\
42 \\
47 \\
44 \\
43 \\
31\end{array}$ & $\begin{array}{l}0 \\
0 \\
0 \\
0 \\
0 \\
\end{array}$ & $\begin{array}{l}94 \\
94 \\
94 \\
95 \\
88 \\
72\end{array}$ & $\begin{array}{l}48 \\
47 \\
35 \\
29 \\
46 \\
49\end{array}$ & $\begin{array}{r}64 \\
62 \\
47 \\
44 \\
50 \\
-\end{array}$ \\
\hline $\begin{array}{l}\text { TOTAL } \\
\text { MEAN } \\
\text { MAX } \\
\text { MIN } \\
\text { AC-FT }\end{array}$ & $\begin{array}{r}1885 \\
60.8 \\
165 \\
0 \\
3740\end{array}$ & $\begin{array}{r}888.64 \\
29.6 \\
132 \\
.46 \\
1760\end{array}$ & $\begin{array}{r}887.99 \\
28.6 \\
129 \\
.80 \\
1760\end{array}$ & $\begin{array}{r}71.46 \\
2.31 \\
4.5 \\
.42 \\
142\end{array}$ & $\begin{array}{r}245.0 \\
8.75 \\
20 \\
1.1 \\
486\end{array}$ & $\begin{array}{r}137.91 \\
4.45 \\
15 \\
.25 \\
274\end{array}$ & $\begin{array}{r}810.83 \\
27.0 \\
99 \\
.93 \\
1610\end{array}$ & $\begin{array}{r}1587 \\
51.2 \\
73 \\
31 \\
3150\end{array}$ & $\begin{array}{r}834.22 \\
27.8 \\
68 \\
0 \\
1650\end{array}$ & $\begin{array}{r}3591 \\
116 \\
167 \\
0 \\
7120\end{array}$ & $\begin{array}{r}1960 \\
63.2 \\
76 \\
29 \\
3890\end{array}$ & $\begin{array}{r}1694 \\
56.5 \\
65 \\
44 \\
3360\end{array}$ \\
\hline
\end{tabular}


11075620 SANTA ANA RIVER SPREADING DIVERSION BELOW IMPERIAL HIGHWY NEAR ANAHEIM, CA--Continued

DISCHARGE, IN CUBIC FEET PER SECOND, HATER YEAR OCTOBER 1975 TO SEPTEMBEA 1976 MEAN VALUES

\begin{tabular}{|c|c|c|c|c|c|c|c|c|c|c|c|c|}
\hline DAY & OCT & Nov & DEC & JAN & FEB & MAR & APR & MAY & JUN & JUL & AUG & SEP \\
\hline $\begin{array}{l}1 \\
2 \\
3 \\
4 \\
5\end{array}$ & $\begin{array}{l}52 \\
52 \\
50 \\
47 \\
52\end{array}$ & $\begin{array}{r}44 \\
51 \\
14 \\
.16 \\
.08\end{array}$ & $\begin{array}{l}216 \\
224 \\
236 \\
213 \\
219\end{array}$ & $\begin{array}{r}97 \\
101 \\
96 \\
89 \\
95\end{array}$ & $\begin{array}{r}92 \\
101 \\
115 \\
107 \\
87\end{array}$ & $\begin{array}{l}171 \\
154 \\
148 \\
214 \\
210\end{array}$ & $\begin{array}{r}126 \\
80 \\
80 \\
106 \\
128\end{array}$ & $\begin{array}{l}41 \\
36 \\
38 \\
42 \\
20\end{array}$ & $\begin{array}{l}166 \\
160 \\
169 \\
180 \\
180\end{array}$ & $\begin{array}{l}120 \\
133 \\
129 \\
131 \\
129\end{array}$ & $\begin{array}{l}49 \\
44 \\
48 \\
48 \\
44\end{array}$ & $\begin{array}{l}33 \\
30 \\
35 \\
36 \\
39\end{array}$ \\
\hline $\begin{array}{r}6 \\
7 \\
8 \\
9 \\
10\end{array}$ & $\begin{array}{l}55 \\
38 \\
30 \\
26 \\
30\end{array}$ & $\begin{array}{l}.04 \\
.04 \\
.08 \\
.08 \\
.04\end{array}$ & $\begin{array}{l}242 \\
250 \\
250 \\
154 \\
130\end{array}$ & $\begin{array}{l}112 \\
117 \\
116 \\
118 \\
113\end{array}$ & $\begin{array}{r}87 \\
96 \\
68 \\
105 \\
94\end{array}$ & $\begin{array}{r}174 \\
92 \\
90 \\
91 \\
102\end{array}$ & $\begin{array}{l}91 \\
77 \\
75 \\
74 \\
71\end{array}$ & $\begin{array}{l}1.4 \\
.55 \\
.28 \\
.16 \\
.12\end{array}$ & $\begin{array}{l}182 \\
183 \\
184 \\
185 \\
200\end{array}$ & $\begin{array}{r}88 \\
88 \\
110 \\
104 \\
102\end{array}$ & $\begin{array}{l}31 \\
35 \\
34 \\
32 \\
37\end{array}$ & $\begin{array}{r}43 \\
41 \\
52 \\
47 \\
104\end{array}$ \\
\hline $\begin{array}{l}11 \\
12 \\
13 \\
14 \\
15\end{array}$ & $\begin{array}{l}36 \\
39 \\
40 \\
40 \\
39\end{array}$ & $\begin{array}{l}0 \\
0 \\
0 \\
0 \\
0\end{array}$ & $\begin{array}{l}123 \\
121 \\
170 \\
161 \\
152\end{array}$ & $\begin{array}{l}109 \\
104 \\
112 \\
116 \\
121\end{array}$ & $\begin{array}{l}91 \\
139 \\
188 \\
148 \\
144\end{array}$ & $\begin{array}{l}169 \\
178 \\
177 \\
177 \\
174\end{array}$ & $\begin{array}{r}67 \\
30 \\
63 \\
101 \\
73\end{array}$ & $\begin{array}{l}.12 \\
.08 \\
.08 \\
.08 \\
.08\end{array}$ & $\begin{array}{l}240 \\
244 \\
241 \\
239 \\
190\end{array}$ & $\begin{array}{l}102 \\
102 \\
103 \\
103 \\
108\end{array}$ & $\begin{array}{l}38 \\
32 \\
33 \\
34 \\
36\end{array}$ & $\begin{array}{l}182 \\
223 \\
243 \\
248 \\
235\end{array}$ \\
\hline $\begin{array}{l}16 \\
17 \\
18 \\
19 \\
20\end{array}$ & $\begin{array}{l}47 \\
46 \\
68 \\
85 \\
88\end{array}$ & $\begin{array}{r}0 \\
0 \\
36 \\
137 \\
142\end{array}$ & $\begin{array}{r}136 \\
143 \\
131 \\
105 \\
99\end{array}$ & $\begin{array}{l}122 \\
126 \\
127 \\
124 \\
113\end{array}$ & $\begin{array}{l}148 \\
168 \\
159 \\
183 \\
196\end{array}$ & $\begin{array}{l}199 \\
196 \\
199 \\
199 \\
200\end{array}$ & $\begin{array}{l}81 \\
62 \\
60 \\
58 \\
56\end{array}$ & $\begin{array}{l}27^{.08} \\
44 \\
49 \\
47\end{array}$ & $\begin{array}{l}168 \\
157 \\
153 \\
152 \\
152\end{array}$ & $\begin{array}{l}66 \\
55 \\
49 \\
54 \\
54\end{array}$ & $\begin{array}{l}35 \\
31 \\
24 \\
31 \\
37\end{array}$ & $\begin{array}{r}122 \\
99 \\
95 \\
90 \\
91\end{array}$ \\
\hline $\begin{array}{l}21 \\
22 \\
23 \\
24 \\
25\end{array}$ & $\begin{array}{l}85 \\
89 \\
90 \\
88 \\
88\end{array}$ & $\begin{array}{l}140 \\
140 \\
142 \\
142 \\
142\end{array}$ & $\begin{array}{l}98 \\
97 \\
92 \\
94 \\
95\end{array}$ & $\begin{array}{r}112 \\
107 \\
56 \\
99 \\
109\end{array}$ & $\begin{array}{r}193 \\
102 \\
141 \\
88 \\
88\end{array}$ & $\begin{array}{l}192 \\
185 \\
175 \\
162 \\
159\end{array}$ & $\begin{array}{l}58 \\
52 \\
54 \\
52 \\
51\end{array}$ & $\begin{array}{l}48 \\
44 \\
46 \\
56 \\
59\end{array}$ & $\begin{array}{l}151 \\
149 \\
147 \\
142 \\
135\end{array}$ & $\begin{array}{l}55 \\
53 \\
56 \\
52 \\
45\end{array}$ & $\begin{array}{l}43 \\
40 \\
35 \\
34 \\
34\end{array}$ & $\begin{array}{r}88 \\
89 \\
89 \\
85 \\
110\end{array}$ \\
\hline $\begin{array}{l}26 \\
27 \\
28 \\
29 \\
30 \\
31\end{array}$ & $\begin{array}{r}87 \\
90 \\
116 \\
106 \\
97 \\
74\end{array}$ & $\begin{array}{l}166 \\
191 \\
204 \\
213 \\
208\end{array}$ & $\begin{array}{l}94 \\
92 \\
92 \\
90 \\
91 \\
95\end{array}$ & $\begin{array}{l}105 \\
105 \\
105 \\
97 \\
94 \\
94\end{array}$ & $\begin{array}{l}173 \\
192 \\
197 \\
209 \\
-\infty- \\
-0-\end{array}$ & $\begin{array}{l}153 \\
146 \\
144 \\
165 \\
165 \\
154\end{array}$ & $\begin{array}{r}42 \\
45 \\
47 \\
41 \\
42 \\
---\end{array}$ & $\begin{array}{r}64 \\
108 \\
161 \\
158 \\
160 \\
163\end{array}$ & $\begin{array}{l}112 \\
111 \\
112 \\
117 \\
119 \\
-0\end{array}$ & $\begin{array}{l}49 \\
52 \\
53 \\
50 \\
47 \\
49\end{array}$ & $\begin{array}{l}34 \\
35 \\
36 \\
35 \\
33 \\
33\end{array}$ & $\begin{array}{r}92 \\
87 \\
82 \\
80 \\
81 \\
-=-\end{array}$ \\
\hline $\begin{array}{l}\text { TOTAL } \\
\text { MEAN } \\
\text { MAX } \\
\text { MIN } \\
\text { AC-FT }\end{array}$ & $\begin{array}{r}1972 \\
63.6 \\
116 \\
26 \\
3910\end{array}$ & $\begin{array}{r}2112.52 \\
70.4 \\
213 \\
0 \\
4190\end{array}$ & $\begin{array}{r}4505 \\
145 \\
250 \\
90 \\
8940\end{array}$ & $\begin{array}{r}3311 \\
107 \\
127 \\
56 \\
6570\end{array}$ & $\begin{array}{r}3959 \\
137 \\
209 \\
68 \\
7850\end{array}$ & $\begin{array}{r}5114 \\
165 \\
214 \\
90 \\
10140\end{array}$ & $\begin{array}{r}2043 \\
68.1 \\
128 \\
30 \\
4050\end{array}$ & $\begin{array}{r}1414,03 \\
45.6 \\
163 \\
.08 \\
2800\end{array}$ & $\begin{array}{r}5020 \\
167 \\
244 \\
111 \\
9960\end{array}$ & $\begin{array}{r}2491 \\
80.4 \\
133 \\
45 \\
4940\end{array}$ & $\begin{array}{r}1125 \\
36.3 \\
49 \\
24 \\
2230\end{array}$ & $\begin{array}{r}2971 \\
99.0 \\
248 \\
30 \\
5890\end{array}$ \\
\hline
\end{tabular}

CAL YR 1975 TOTAL 19520.94 MEAN 53.5 MAX 250 MIN 0 AC-FT 38720 HTR YR 2976 TOTAL 36037.55 MEAN 98.5 MAX 250 MIN 0 AC-FT 71480 
PERIOD OF RECORD, - - Water year 1975 to current year.

CHEMICAL ANALYSES: November 1974 to current year.

PERIOD OF DAILY RECORD, - -

SPBCIFIC CONDUCTANCE: July 1974 to current year.

INSTRUMENTATION, --Specific conductance recorder since July 1974.

REMARKS.--Periods of missing specific conductance data due to fouling of probe or no flow.

EXTREMES FOR PERIOD OF DAILY RECORD.--

SPECIFIC CONDUCTANCE: Maximum, 1,380 micromhos May 10, 1975; minimum, 238 micromhos Dec. $4,1974$.

EXTREMES FOR CURRENT YEAR. - -

SPECIFIC CONDUCTANCE: Maximum, 1,350 micromhos Mar. 6; minimum, 505 micromhos Mar. 1 ,

CHEMICAL ANALYSES, WATER YEAR OCTOBER 1975 TO SEPTEMBER 1976

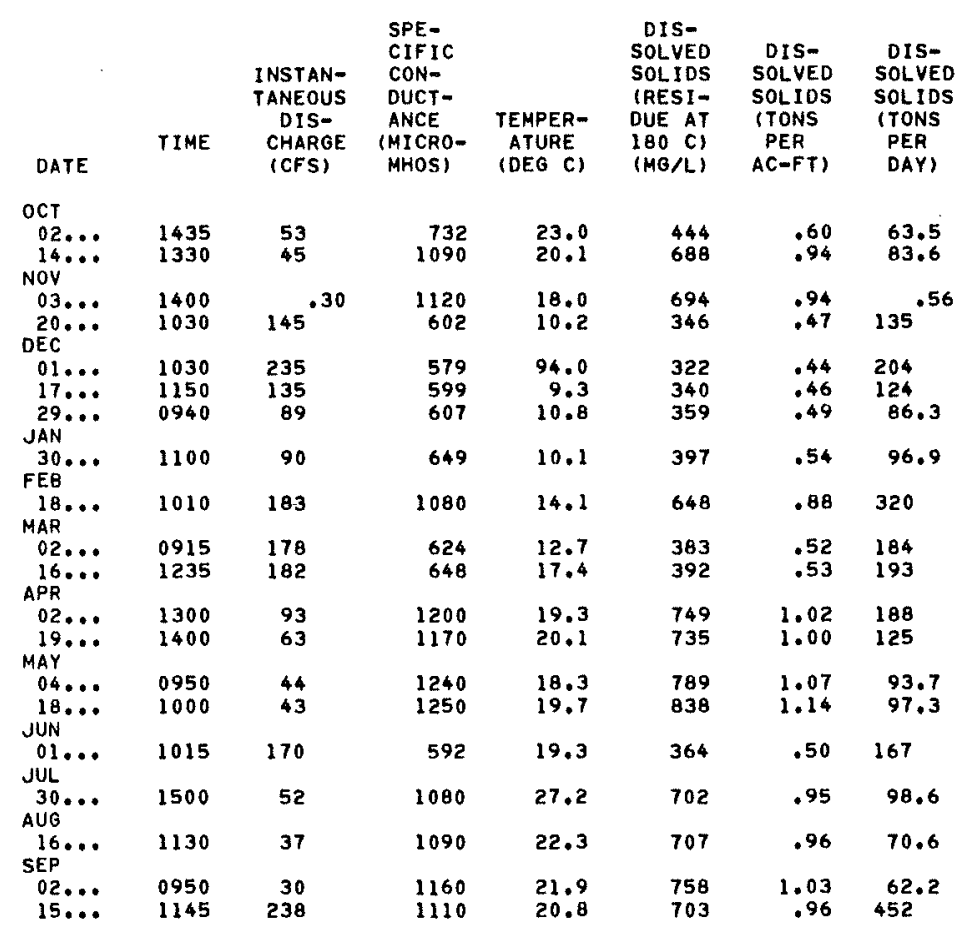


SANTA ANA RIVER BASIN

11075620 SANTA ANA RIVER SPREADING DIVERSION BELOW IMPERIAL HIGHWAY, NEAR ANAHEIM, CA---Continued

SPECIFIC CONOUCTANCE (MICROMHOS/CM AT 25 DEG. C), WATER YEAR OCTOBER 1975 TO SEPTEMBER 1976

\begin{tabular}{|c|c|c|c|c|c|c|c|c|c|c|c|c|}
\hline \multirow[b]{2}{*}{ DAY } & \multicolumn{3}{|c|}{ OCTOBER } & \multicolumn{3}{|c|}{ NOVEMEER } & \multicolumn{3}{|c|}{ DECEMBER } & \multicolumn{3}{|c|}{ JANUARY } \\
\hline & MAX & MIN & MEAN & $\operatorname{MAX}$ & MIN & MEAN & $\max$ & MIN & MEAN & $\max$ & MIN & MEAN \\
\hline $\begin{array}{l}1 \\
2 \\
3 \\
4 \\
5\end{array}$ & $\begin{array}{l}782 \\
760 \\
749 \\
749 \\
747\end{array}$ & $\begin{array}{l}726 \\
724 \\
715 \\
705 \\
695\end{array}$ & $\begin{array}{l}755 \\
744 \\
734 \\
731 \\
721\end{array}$ & $\begin{array}{r}1200 \\
1170 \\
1120 \\
\hdashline--\end{array}$ & $\begin{array}{r}1070 \\
1120 \\
1110 \\
---\end{array}$ & $\begin{array}{r}1150 \\
1130 \\
1110 \\
-\because-\end{array}$ & $\begin{array}{l}598 \\
583 \\
573 \\
640 \\
634\end{array}$ & $\begin{array}{l}562 \\
545 \\
531 \\
552 \\
550\end{array}$ & $\begin{array}{l}582 \\
575 \\
558 \\
609 \\
583\end{array}$ & \begin{tabular}{c}
647 \\
$\square-$ \\
\hdashline- \\
\hdashline
\end{tabular} & \begin{tabular}{c}
615 \\
\hdashline- \\
\hdashline- \\
--
\end{tabular} & \begin{tabular}{l}
628 \\
$\because-$ \\
\hdashline \\
\hdashline
\end{tabular} \\
\hline $\begin{array}{r}6 \\
7 \\
8 \\
9 \\
10\end{array}$ & $\begin{array}{r}743 \\
1060 \\
1100 \\
1110 \\
1100\end{array}$ & $\begin{array}{r}689 \\
729 \\
1060 \\
1070 \\
1080\end{array}$ & $\begin{array}{r}717 \\
890 \\
1080 \\
1090 \\
1090\end{array}$ & \begin{tabular}{l}
-- \\
\hdashline- \\
\hdashline- \\
\hdashline-
\end{tabular} & \begin{tabular}{l}
$=-$ \\
\hdashline- \\
\hdashline- \\
\hdashline-
\end{tabular} & \begin{tabular}{l}
$=-$ \\
\hdashline- \\
\hdashline- \\
$-\because$
\end{tabular} & $\begin{array}{l}573 \\
573 \\
570 \\
744 \\
735\end{array}$ & $\begin{array}{l}537 \\
541 \\
542 \\
590 \\
669\end{array}$ & $\begin{array}{l}561 \\
560 \\
560 \\
713 \\
697\end{array}$ & \begin{tabular}{l}
$\because-$ \\
$\because \because$ \\
$\because \because$ \\
\hdashline-
\end{tabular} & $\begin{array}{l}-- \\
\because \because \\
\because-:\end{array}$ & $\begin{array}{l}\because- \\
\because \because \\
\because \because \\
\because-\end{array}$ \\
\hline $\begin{array}{l}11 \\
12 \\
13 \\
14 \\
15\end{array}$ & $\begin{array}{l}1110 \\
1120 \\
1120 \\
1120 \\
1130\end{array}$ & $\begin{array}{l}1080 \\
1100 \\
1100 \\
1090 \\
1100\end{array}$ & $\begin{array}{l}1090 \\
1110 \\
1110 \\
1110 \\
1110\end{array}$ & $\begin{array}{l}=- \\
=- \\
=- \\
=-\end{array}$ & \begin{tabular}{l}
$\because=$ \\
$\because \because$ \\
$\because=$ \\
\hdashline-
\end{tabular} & $\begin{array}{l}=- \\
\because= \\
\because=\end{array}$ & $\begin{array}{l}741 \\
794 \\
820 \\
823 \\
821 \\
821\end{array}$ & $\begin{array}{l}653 \\
744 \\
622 \\
783 \\
787\end{array}$ & $\begin{array}{l}692 \\
771 \\
754 \\
806 \\
810\end{array}$ & $\begin{array}{l}=- \\
\because= \\
\because \because \\
\because-\end{array}$ & 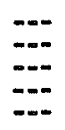 & $\begin{array}{l}\because \\
\because \because \\
\because \because \\
\because-\end{array}$ \\
\hline $\begin{array}{l}16 \\
17 \\
18 \\
19 \\
20\end{array}$ & $\begin{array}{r}1120 \\
1110 \\
1110 \\
868 \\
856\end{array}$ & $\begin{array}{r}1080 \\
1090 \\
870 \\
844 \\
824\end{array}$ & $\begin{array}{r}1110 \\
1100 \\
991 \\
859 \\
840\end{array}$ & $\begin{array}{l}3-- \\
726 \\
694 \\
614\end{array}$ & $\begin{array}{l}-- \\
704 \\
616 \\
578\end{array}$ & $\begin{array}{l}-- \\
-- \\
720 \\
644 \\
606\end{array}$ & $\begin{array}{l}816 \\
6550 \\
620 \\
604 \\
612\end{array}$ & $\begin{array}{l}692 \\
584 \\
576 \\
574 \\
572\end{array}$ & $\begin{array}{l}796 \\
607 \\
603 \\
592 \\
591\end{array}$ & \begin{tabular}{l}
$\because-$ \\
$\because \because$ \\
$\because \because$ \\
\hdashline-
\end{tabular} & $\begin{array}{l}=- \\
=: \\
=-:\end{array}$ & $\begin{array}{l}\because \\
\because \because \\
\because-\end{array}$ \\
\hline $\begin{array}{l}21 \\
22 \\
23 \\
24 \\
25\end{array}$ & $\begin{array}{l}854 \\
872 \\
864 \\
852 \\
842\end{array}$ & $\begin{array}{l}818 \\
836 \\
848 \\
822 \\
806\end{array}$ & $\begin{array}{l}837 \\
855 \\
858 \\
838 \\
825\end{array}$ & $\begin{array}{l}619 \\
622 \\
619 \\
612 \\
641\end{array}$ & $\begin{array}{l}579 \\
600 \\
575 \\
598 \\
605\end{array}$ & $\begin{array}{l}607 \\
615 \\
608 \\
605 \\
622\end{array}$ & \begin{tabular}{l}
632 \\
618 \\
654 \\
654 \\
\hdashline-
\end{tabular} & \begin{tabular}{l}
580 \\
578 \\
594 \\
\hdashline-0
\end{tabular} & \begin{tabular}{l}
606 \\
604 \\
636 \\
\hdashline-
\end{tabular} & $\begin{array}{l}\because= \\
\because \because \\
\because \because \\
-\because\end{array}$ & $\begin{array}{l}\because \\
\because \because \\
\because \because \\
\because\end{array}$ & "-" \\
\hline $\begin{array}{l}26 \\
27 \\
28 \\
29 \\
30 \\
31\end{array}$ & $\begin{array}{r}846 \\
840 \\
830 \\
738 \\
748 \\
1060\end{array}$ & $\begin{array}{l}804 \\
804 \\
742 \\
712 \\
700 \\
734\end{array}$ & $\begin{array}{l}826 \\
826 \\
763 \\
728 \\
723 \\
864\end{array}$ & $\begin{array}{l}649 \\
596 \\
625 \\
630 \\
605 \\
--\end{array}$ & $\begin{array}{l}593 \\
550 \\
569 \\
582 \\
571 \\
---\end{array}$ & $\begin{array}{l}623 \\
580 \\
593 \\
616 \\
593 \\
\cdots\end{array}$ & \begin{tabular}{l}
- \\
\hdashline- \\
649 \\
647 \\
657
\end{tabular} & \begin{tabular}{l}
.- \\
\hdashline- \\
607 \\
609 \\
607
\end{tabular} & \begin{tabular}{l}
$7 .-$ \\
\hdashline- \\
635 \\
627 \\
639
\end{tabular} & \begin{tabular}{l}
$-\cdots$ \\
\hdashline 719 \\
79. \\
693
\end{tabular} & \begin{tabular}{l}
$=-$ \\
\hdashline-- \\
649 \\
671
\end{tabular} & \begin{tabular}{l}
$\cdots$ \\
$\because-$ \\
\hdashline- \\
687 \\
682
\end{tabular} \\
\hline NTH & 1130 & 689 & 901 & $\cdots$ &.- & --- & 823 & 531 & 645 & $\cdots$ & -- & $\cdots$ \\
\hline
\end{tabular}

\begin{tabular}{|c|c|c|c|c|c|c|c|c|c|c|c|c|}
\hline \multirow[b]{2}{*}{ DAY } & \multicolumn{3}{|c|}{ FEBRUARY } & \multicolumn{3}{|c|}{ MARCH } & \multicolumn{3}{|c|}{ APRIL } & \multicolumn{3}{|c|}{ MAY } \\
\hline & $\operatorname{MAX}$ & MIN & MEAN & $\max$ & MIN & MEAN & $\max$ & MIN & MEAN & $\max$ & MIN & MEAN \\
\hline $\begin{array}{l}1 \\
2 \\
3 \\
4 \\
5\end{array}$ & $\begin{array}{l}726 \\
712 \\
668 \\
733 \\
965\end{array}$ & $\begin{array}{l}688 \\
608 \\
598 \\
565 \\
709\end{array}$ & $\begin{array}{l}707 \\
668 \\
630 \\
629 \\
858\end{array}$ & $\begin{array}{r}977 \\
867 \\
840 \\
806 \\
806 \\
1050\end{array}$ & $\begin{array}{l}505 \\
528 \\
552 \\
696 \\
756\end{array}$ & $\begin{array}{l}702 \\
673 \\
742 \\
746 \\
899\end{array}$ & $\begin{array}{l}1140 \\
1240 \\
1270 \\
1200 \\
1120\end{array}$ & $\begin{array}{r}638 \\
1150 \\
946 \\
774 \\
960\end{array}$ & $\begin{array}{r}835 \\
1190 \\
1230 \\
1060 \\
1040\end{array}$ & $\begin{array}{l}1270 \\
1280 \\
1270 \\
1280 \\
1290\end{array}$ & $\begin{array}{r}1200 \\
1230 \\
1230 \\
1220 \\
746\end{array}$ & $\begin{array}{l}1220 \\
1250 \\
1260 \\
1240 \\
1110\end{array}$ \\
\hline $\begin{array}{r}6 \\
7 \\
8 \\
9 \\
10\end{array}$ & $\begin{array}{r}1030 \\
1150 \\
1060 \\
989 \\
815\end{array}$ & $\begin{array}{l}554 \\
840 \\
792 \\
575 \\
711\end{array}$ & $\begin{array}{r}802 \\
1010 \\
909 \\
767 \\
762\end{array}$ & $\begin{array}{l}1350 \\
1260 \\
1210 \\
1200 \\
1190\end{array}$ & $\begin{array}{r}1070 \\
1180 \\
1170 \\
1070 \\
784\end{array}$ & $\begin{array}{l}1190 \\
1210 \\
1190 \\
1170 \\
1140\end{array}$ & $\begin{array}{l}1240 \\
1270 \\
1280 \\
1260 \\
1260\end{array}$ & $\begin{array}{l}1090 \\
1230 \\
1170 \\
1220 \\
1210\end{array}$ & $\begin{array}{l}1150 \\
1250 \\
1250 \\
1240 \\
1240\end{array}$ & $\begin{array}{l}=- \\
\because \because \\
\because \because\end{array}$ & $\begin{array}{l}=- \\
\because \because \\
\because= \\
=-\end{array}$ & \begin{tabular}{l}
$=-$ \\
\hdashline- \\
\hdashline-
\end{tabular} \\
\hline $\begin{array}{l}11 \\
12 \\
13 \\
14 \\
15\end{array}$ & $\begin{array}{l}727 \\
702 \\
874 \\
863 \\
971\end{array}$ & $\begin{array}{l}623 \\
594 \\
634 \\
793 \\
877\end{array}$ & $\begin{array}{l}677 \\
652 \\
724 \\
820 \\
912\end{array}$ & $\begin{array}{l}684 \\
770 \\
676 \\
652 \\
724\end{array}$ & $\begin{array}{l}598 \\
600 \\
598 \\
596 \\
596\end{array}$ & $\begin{array}{l}632 \\
655 \\
650 \\
631 \\
638\end{array}$ & $\begin{array}{l}1260 \\
1240 \\
1140 \\
1150 \\
1210\end{array}$ & $\begin{array}{r}1220 \\
1210 \\
700 \\
822 \\
1120\end{array}$ & $\begin{array}{r}1230 \\
1220 \\
834 \\
1010 \\
1180\end{array}$ & $\begin{array}{l}\because-8 \\
\because \because \\
\because-\end{array}$ & $\begin{array}{l}\square \\
\because- \\
\because-\end{array}$ & $\begin{array}{l}=- \\
=-1 \\
=-1\end{array}$ \\
\hline $\begin{array}{l}16 \\
17 \\
18 \\
19 \\
20\end{array}$ & $\begin{array}{l}1060 \\
1090 \\
1130 \\
1130 \\
1130\end{array}$ & $\begin{array}{r}937 \\
1010 \\
1060 \\
1070 \\
1080\end{array}$ & $\begin{array}{r}972 \\
1150 \\
1100 \\
1100 \\
1110\end{array}$ & $\begin{array}{l}722 \\
666 \\
662 \\
652 \\
722\end{array}$ & $\begin{array}{l}604 \\
620 \\
610 \\
590 \\
620\end{array}$ & $\begin{array}{l}656 \\
645 \\
636 \\
627 \\
674\end{array}$ & $\begin{array}{l}1180 \\
1200 \\
1210 \\
1200 \\
1220\end{array}$ & $\begin{array}{r}926 \\
1150 \\
1170 \\
1170 \\
1160\end{array}$ & $\begin{array}{l}1070 \\
1160 \\
1190 \\
1180 \\
1190\end{array}$ & $\begin{array}{l}1280 \\
1300 \\
1270 \\
1290\end{array}$ & $\begin{array}{l}1200 \\
1190 \\
1190 \\
1210\end{array}$ & $\begin{array}{l}1240 \\
1240 \\
1230 \\
1240\end{array}$ \\
\hline $\begin{array}{l}21 \\
22 \\
23 \\
24 \\
25\end{array}$ & $\begin{array}{l}1180 \\
1240 \\
1340 \\
1250 \\
1220\end{array}$ & $\begin{array}{l}1110 \\
1160 \\
1260 \\
1200 \\
1170\end{array}$ & $\begin{array}{l}1140 \\
1190 \\
1300 \\
1220 \\
1200\end{array}$ & $\begin{array}{l}714 \\
762 \\
752 \\
744 \\
746\end{array}$ & $\begin{array}{l}684 \\
690 \\
710 \\
704 \\
722\end{array}$ & $\begin{array}{l}703 \\
718 \\
736 \\
730 \\
734\end{array}$ & $\begin{array}{l}1250 \\
1250 \\
1210 \\
1220 \\
1210\end{array}$ & $\begin{array}{l}1180 \\
1160 \\
1170 \\
1180 \\
1170\end{array}$ & $\begin{array}{l}1200 \\
1180 \\
1190 \\
1200 \\
1190\end{array}$ & $\begin{array}{l}1270 \\
1270 \\
1210 \\
1200 \\
1230\end{array}$ & $\begin{array}{l}1180 \\
1150 \\
1150 \\
1160 \\
1160\end{array}$ & $\begin{array}{l}1230 \\
1210 \\
1180 \\
1180 \\
1190\end{array}$ \\
\hline $\begin{array}{l}26 \\
27 \\
28 \\
29 \\
30 \\
31\end{array}$ & $\begin{array}{l}903 \\
669 \\
688 \\
670 \\
- \\
--\end{array}$ & $\begin{array}{l}611 \\
585 \\
596 \\
652 \\
--. \\
---\end{array}$ & \begin{tabular}{l}
663 \\
637 \\
644 \\
661 \\
\hdashline--
\end{tabular} & $\begin{array}{l}744 \\
742 \\
746 \\
736 \\
716 \\
766\end{array}$ & $\begin{array}{l}706 \\
702 \\
710 \\
702 \\
676 \\
668\end{array}$ & $\begin{array}{l}731 \\
726 \\
730 \\
723 \\
703 \\
701\end{array}$ & $\begin{array}{l}1200 \\
1200 \\
1190 \\
1210 \\
1210 \\
-1 .\end{array}$ & $\begin{array}{l}1160 \\
1170 \\
1170 \\
1170 \\
1190 \\
-\end{array}$ & $\begin{array}{l}1180 \\
1180 \\
1180 \\
1190 \\
1200 \\
-0 .\end{array}$ & $\begin{array}{r}1210 \\
1260 \\
700 \\
765 \\
6990 \\
650\end{array}$ & $\begin{array}{r}1170 \\
706 \\
665 \\
651 \\
642 \\
610\end{array}$ & $\begin{array}{r}1190 \\
958 \\
684 \\
677 \\
654 \\
643\end{array}$ \\
\hline MONTH & 1340 & 554 & 880 & 1350 & 505 & 776 & 1280 & 638 & 1150 & -- & --- & $\cdots$ \\
\hline
\end{tabular}


11075620 SANTA ANA RIVER SPREADING DIVERSION BELOW IMPERIAL HIGHWAY, NEAR ANAHEIM, CA--Continued SPECIFIC CONDUCTANCE (MICROMHOS/CM AT 25 DEG. C), WATER YEAR OCTOBER 1975 TO SEPTEMBER 1976

\begin{tabular}{|c|c|c|c|c|c|c|c|c|c|c|c|c|}
\hline \multirow[b]{2}{*}{ DAY } & \multicolumn{3}{|c|}{ JUNE } & \multicolumn{3}{|c|}{ JULLY } & \multicolumn{3}{|c|}{ AUGUST } & \multicolumn{3}{|c|}{ SEPTEMBER } \\
\hline & MAX & MIN & MEAN & MAX & MIN & MEAN & $\operatorname{MAX}$ & MIN & MEAN & $\operatorname{mAX}$ & MIN & MEAN \\
\hline $\begin{array}{l}1 \\
2 \\
3 \\
4 \\
5\end{array}$ & $\begin{array}{l}691 \\
644 \\
644 \\
643 \\
638\end{array}$ & $\begin{array}{l}591 \\
598 \\
604 \\
613 \\
590\end{array}$ & $\begin{array}{l}643 \\
636 \\
632 \\
632 \\
619\end{array}$ & $\begin{array}{l}670 \\
634 \\
622 \\
632 \\
668\end{array}$ & $\begin{array}{l}604 \\
614 \\
594 \\
590 \\
604\end{array}$ & $\begin{array}{l}637 \\
625 \\
613 \\
616 \\
623\end{array}$ & $\begin{array}{l}1130 \\
1180 \\
1150 \\
1130 \\
1120\end{array}$ & $\begin{array}{l}1090 \\
1110 \\
1080 \\
1080 \\
1050\end{array}$ & $\begin{array}{l}1110 \\
1150 \\
1110 \\
1110 \\
1090\end{array}$ & $\begin{array}{l}1120 \\
1170 \\
1120 \\
1130 \\
1080\end{array}$ & $\begin{array}{l}1070 \\
1100 \\
1040 \\
1070 \\
1040\end{array}$ & $\begin{array}{l}1110 \\
1140 \\
1090 \\
1090 \\
1060\end{array}$ \\
\hline $\begin{array}{r}6 \\
7 \\
8 \\
9 \\
10\end{array}$ & $\begin{array}{l}630 \\
651 \\
644 \\
652 \\
659\end{array}$ & $\begin{array}{l}578 \\
577 \\
584 \\
590 \\
573\end{array}$ & $\begin{array}{l}619 \\
625 \\
625 \\
632 \\
629\end{array}$ & $\begin{array}{l}804 \\
794 \\
776 \\
800 \\
796\end{array}$ & $\begin{array}{l}684 \\
754 \\
632 \\
632 \\
724\end{array}$ & $\begin{array}{l}760 \\
779 \\
706 \\
741 \\
760\end{array}$ & $\begin{array}{l}1090 \\
1070 \\
1080 \\
1100 \\
1080\end{array}$ & $\begin{array}{l}1030 \\
1020 \\
1040 \\
1040 \\
1020\end{array}$ & $\begin{array}{l}1060 \\
1050 \\
1070 \\
1070 \\
1060\end{array}$ & $\begin{array}{l}1070 \\
1070 \\
1190 \\
1130 \\
1110\end{array}$ & $\begin{array}{r}1020 \\
1020 \\
1040 \\
1080 \\
550\end{array}$ & $\begin{array}{r}1040 \\
1050 \\
1100 \\
1100 \\
855\end{array}$ \\
\hline $\begin{array}{l}11 \\
12 \\
13 \\
14 \\
15\end{array}$ & $\begin{array}{l}602 \\
582 \\
579 \\
596 \\
628\end{array}$ & $\begin{array}{l}566 \\
540 \\
555 \\
530 \\
598\end{array}$ & $\begin{array}{l}591 \\
568 \\
569 \\
562 \\
613\end{array}$ & $\begin{array}{l}776 \\
776 \\
774 \\
772 \\
778\end{array}$ & $\begin{array}{l}726 \\
746 \\
728 \\
722 \\
722\end{array}$ & $\begin{array}{l}754 \\
760 \\
756 \\
756 \\
753\end{array}$ & $\begin{array}{l}1140 \\
1130 \\
1080 \\
1090 \\
1100\end{array}$ & $\begin{array}{l}1070 \\
1060 \\
1060 \\
1040 \\
1060\end{array}$ & $\begin{array}{l}1100 \\
1090 \\
1070 \\
1070 \\
1080\end{array}$ & $\begin{array}{r}908 \\
722 \\
720 \\
1040 \\
1220\end{array}$ & $\begin{array}{r}714 \\
558 \\
588 \\
724 \\
1050\end{array}$ & $\begin{array}{r}825 \\
597 \\
641 \\
865 \\
1110\end{array}$ \\
\hline $\begin{array}{l}16 \\
17 \\
18 \\
19 \\
20\end{array}$ & $\begin{array}{l}623 \\
623 \\
628 \\
612 \\
601\end{array}$ & $\begin{array}{l}593 \\
591 \\
592 \\
574 \\
573\end{array}$ & $\begin{array}{l}609 \\
608 \\
609 \\
598 \\
591\end{array}$ & $\begin{array}{l}1100 \\
1130 \\
1160 \\
1140 \\
1140\end{array}$ & $\begin{array}{r}784 \\
1090 \\
1110 \\
1040 \\
1100\end{array}$ & $\begin{array}{r}955 \\
1110 \\
1140 \\
1110 \\
1110\end{array}$ & $\begin{array}{l}1110 \\
1110 \\
1160 \\
1140 \\
1130\end{array}$ & $\begin{array}{l}1080 \\
1080 \\
1090 \\
1070 \\
1070\end{array}$ & $\begin{array}{l}1090 \\
1100 \\
1120 \\
1100 \\
1100\end{array}$ & $\begin{array}{l}1300 \\
1220 \\
1190 \\
1210 \\
1200\end{array}$ & $\begin{array}{l}1210 \\
1180 \\
1170 \\
1170 \\
1160\end{array}$ & $\begin{array}{l}1240 \\
1200 \\
1180 \\
1190 \\
1180\end{array}$ \\
\hline $\begin{array}{l}21 \\
22 \\
23 \\
24 \\
25\end{array}$ & $\begin{array}{l}661 \\
607 \\
614 \\
616 \\
642\end{array}$ & $\begin{array}{l}571 \\
569 \\
574 \\
584 \\
570\end{array}$ & $\begin{array}{l}592 \\
587 \\
599 \\
603 \\
617\end{array}$ & $\begin{array}{l}1140 \\
1180 \\
1140 \\
1150 \\
1160\end{array}$ & $\begin{array}{l}1100 \\
1090 \\
1110 \\
1110 \\
1080\end{array}$ & $\begin{array}{l}1120 \\
1140 \\
1120 \\
1130 \\
1130\end{array}$ & $\begin{array}{l}1110 \\
1090 \\
1160 \\
1080 \\
1110\end{array}$ & $\begin{array}{l}1070 \\
1070 \\
1060 \\
1060 \\
1080\end{array}$ & $\begin{array}{l}1080 \\
1080 \\
1100 \\
1070 \\
1090\end{array}$ & $\begin{array}{l}1180 \\
1180 \\
1170 \\
1140 \\
1140\end{array}$ & $\begin{array}{r}1150 \\
1140 \\
1090 \\
1100 \\
880\end{array}$ & $\begin{array}{l}1170 \\
1150 \\
1130 \\
1120 \\
1030\end{array}$ \\
\hline $\begin{array}{l}26 \\
27 \\
28 \\
29 \\
30 \\
31\end{array}$ & $\begin{array}{l}699 \\
699 \\
720 \\
670 \\
652 \\
--1\end{array}$ & $\begin{array}{l}641 \\
661 \\
660 \\
626 \\
608 \\
-\end{array}$ & $\begin{array}{l}681 \\
683 \\
686 \\
643 \\
629 \\
---\end{array}$ & $\begin{array}{l}1130 \\
1140 \\
1120 \\
1120 \\
1120 \\
1130\end{array}$ & $\begin{array}{l}1070 \\
1110 \\
1080 \\
1070 \\
1080 \\
1080\end{array}$ & $\begin{array}{l}1110 \\
1120 \\
1100 \\
1100 \\
1100 \\
1110\end{array}$ & $\begin{array}{l}1120 \\
1140 \\
1110 \\
1120 \\
1130 \\
1110\end{array}$ & $\begin{array}{l}1080 \\
1080 \\
1080 \\
1090 \\
1080 \\
1050\end{array}$ & $\begin{array}{l}1100 \\
1110 \\
1100 \\
1100 \\
1110 \\
1090\end{array}$ & $\begin{array}{r}1130 \\
1140 \\
1150 \\
1120 \\
1100 \\
-\end{array}$ & $\begin{array}{r}944 \\
1090 \\
1090 \\
1080 \\
1070 \\
-\ldots\end{array}$ & $\begin{array}{l}1060 \\
1120 \\
1110 \\
1100 \\
1090 \\
-\end{array}$ \\
\hline MONTH & 720 & 530 & 618 & 1180 & 590 & 914 & 1180 & 1020 & 1090 & 1300 & 550 & 1060 \\
\hline
\end{tabular}


11075720 CARBON CREBK BELOW CARBON CANYON DAM, CA

LOCATION, - -Lat $33^{\circ} 54^{\prime} 40^{\prime \prime}$, long $117^{\circ} 50^{\prime} 29^{\prime \prime}$, in SWt $\frac{1}{4} \mathrm{~L}_{4}$ sec.17, T.3 S., R.9 W., Orange County, on right wa11 of outlet channel $250 \mathrm{ft}(76 \mathrm{~m})$ downstream from toe of Carbon Canyon Dam, and $2.4 \mathrm{mi}$ (3.9 $\mathrm{km}$ ) northwest of Yorba Linda.

DRAINAGE AREA. $--19.5 \mathrm{mi}^{2}\left(50.5 \mathrm{~km}^{2}\right)$.

PERIOD OF RECORD.--October 1961 to current year.

GAGE.--Water-stage recorder, Datum of gage is $396.29 \mathrm{ft}(120.789 \mathrm{~m})$ above mean sea 1 eve1 (Corps of Engineers bench mark). Prior to Dec. 3, 1971, at datum $2.00 \mathrm{ft}(0.610 \mathrm{~m})$ higher.

REMARKS, - Records fair. Flow regulated by Carbon Canyon flood-control reservoir, capacity, 6,610 acre-ft $\left(8.15 \mathrm{hm}^{3}\right)$. No diversion above station. See schematic diagram of Santa Ana River basin.

AVERAGE DISCHARGE. - - 15 years, $0.46 \mathrm{ft}^{3} / \mathrm{s}\left(0.013 \mathrm{~m}^{3} / \mathrm{s}\right), 333 \mathrm{acre}-\mathrm{f} t / \mathrm{yr}\left(411,000 \mathrm{~m}^{3} / \mathrm{yr}^{\mathrm{r}}\right)$.

EXTREMES FOR PERIOD OF RECORD,--Maximum discharge, $446 \mathrm{ft}^{3} / \mathrm{s}\left(12.6 \mathrm{~m}^{3} / \mathrm{s}\right) \mathrm{Feb}, 25,1969, \mathrm{gage} \mathrm{height}, 4.64 \mathrm{ft}$ $(1.414 \mathrm{~m})$, present datum, from rating curve extended above $110 \mathrm{ft}^{3} / \mathrm{s}\left(3.12 \mathrm{~m}^{3} / \mathrm{s}\right)$ on basis of computation of flow in concrete-lined channel at gage height $6.18 \mathrm{ft}(1.884 \mathrm{~m})$; no flow most of each year.

EXTREMES FOR CURRENT YEAR.--Maximum discharge, $23 \mathrm{ft}^{3} / \mathrm{s}\left(0.65 \mathrm{~m}^{3} / \mathrm{s}\right)$ Mar. 17, gage height, $2.53 \mathrm{ft}(0.771 \mathrm{~m})$; no flow most of year.

DISCHARGE, IN CUBIC FEET PER SECOND, WATER YEAR OCTOBER 1975 TO SEPTEMBER 1976 MEAN VALUES

\begin{tabular}{|c|c|c|c|c|c|c|c|c|c|c|c|c|}
\hline DAY & OCT & NoV & DEC & JAN & FEB & MAR & APR & MAY & JUN & JUL & AUO & SEP \\
\hline $\begin{array}{l}1 \\
2 \\
3 \\
4 \\
5\end{array}$ & & & & & & $\begin{array}{l}0 \\
0 \\
0 \\
0 \\
0\end{array}$ & & $\begin{array}{l}0 \\
0 \\
0 \\
0 \\
0\end{array}$ & $\begin{array}{l}0 \\
0 \\
0 \\
0 \\
0\end{array}$ & $\begin{array}{l}.01 \\
.03 \\
0 \\
0 \\
0\end{array}$ & & $\begin{array}{l}0 \\
0 \\
0 \\
0 \\
0\end{array}$ \\
\hline $\begin{array}{r}6 \\
7 \\
8 \\
9 \\
10\end{array}$ & & & & & & $\begin{array}{l}0 \\
0 \\
0 \\
0 \\
0\end{array}$ & & $\begin{array}{l}0 \\
0 \\
0 \\
0 \\
.04\end{array}$ & $\begin{array}{l}0 \\
0 \\
0 \\
0 \\
0\end{array}$ & $\begin{array}{l}0 \\
0 \\
0 \\
0 \\
0\end{array}$ & . & $\begin{array}{l}0 \\
0 \\
0 \\
0 \\
1.6\end{array}$ \\
\hline $\begin{array}{l}11 \\
12 \\
13 \\
14 \\
15\end{array}$ & & & & & & $\begin{array}{l}0 \\
0 \\
0 \\
0 \\
0\end{array}$ & & $\begin{array}{l}0 \\
0 \\
0 \\
0 \\
0\end{array}$ & $\begin{array}{l}0^{.02} \\
0 \\
0 \\
0\end{array}$ & $\begin{array}{l}0 \\
0 \\
. .31 \\
.50\end{array}$ & & $\begin{array}{l}4.9 \\
0 \\
0 \\
0 \\
0\end{array}$ \\
\hline $\begin{array}{l}16 \\
17 \\
18 \\
19 \\
20\end{array}$ & & & & & & $\begin{array}{l}0 \\
1.4 \\
0 \\
0 \\
0\end{array}$ & & $\begin{array}{l}0 \\
0 \\
0 \\
0 \\
0\end{array}$ & $\begin{array}{l}0 \\
0 \\
0 \\
0 \\
0\end{array}$ & $\begin{array}{l}0 \\
0 \\
0 \\
0 \\
7.7\end{array}$ & & $\begin{array}{l}0 \\
0 \\
0 \\
0 \\
0\end{array}$ \\
\hline $\begin{array}{l}21 \\
22 \\
23 \\
24 \\
25\end{array}$ & & & & & & $\begin{array}{l}0 \\
0 \\
0 \\
0 \\
0\end{array}$ & & $\begin{array}{l}0 \\
0 \\
0 \\
0 \\
0\end{array}$ & $\begin{array}{l}0 \\
0 \\
0 \\
0 \\
0\end{array}$ & $\begin{array}{l}1.1 \\
.75 \\
.14 \\
0 \\
0\end{array}$ & & $\begin{array}{l}0 \\
0 \\
0 \\
0 \\
0\end{array}$ \\
\hline $\begin{array}{l}26 \\
27 \\
28 \\
29 \\
30 \\
31\end{array}$ & & $\ldots$ & & & $-\infty$ & $\begin{array}{l}0 \\
0 \\
0 \\
0 \\
0 \\
0\end{array}$ & $-\infty$ & $\begin{array}{l}0 \\
0 \\
0 \\
0 \\
0 \\
0\end{array}$ & $\begin{array}{l}0 \\
0 \\
0 \\
0 \\
0 \\
-\ldots\end{array}$ & $\begin{array}{l}0 \\
0 \\
0 \\
0 \\
0 \\
0\end{array}$ & & $\begin{array}{l}0 \\
0 \\
0 \\
0 \\
0 \\
--\end{array}$ \\
\hline $\begin{array}{l}\text { TOTAL } \\
\text { MEAN } \\
\text { MAX } \\
\text { MIN } \\
\text { AC } \rightarrow F T\end{array}$ & $\begin{array}{l}0 \\
0 \\
0 \\
0 \\
0\end{array}$ & $\begin{array}{l}0 \\
0 \\
0 \\
0 \\
0\end{array}$ & $\begin{array}{l}0 \\
0 \\
0 \\
0 \\
0\end{array}$ & $\begin{array}{l}0 \\
0 \\
0 \\
0 \\
0\end{array}$ & $\begin{array}{l}0 \\
0 \\
0 \\
0 \\
0\end{array}$ & $\begin{array}{r}1.4 \\
.045 \\
1.4 \\
0 \\
2.8\end{array}$ & $\begin{array}{l}0 \\
0 \\
0 \\
0 \\
0\end{array}$ & $\begin{array}{r}.15 \\
.005 \\
.11 \\
0 \\
.3\end{array}$ & $\begin{array}{r}.09 \\
.003 \\
.07 \\
0 \\
.2\end{array}$ & $\begin{array}{r}10.54 \\
.34 \\
7.7 \\
0 \\
21\end{array}$ & $\begin{array}{l}0 \\
0 \\
0 \\
0 \\
0\end{array}$ & $\begin{array}{r}6.5 \\
.22 \\
4.9 \\
0 \\
13\end{array}$ \\
\hline
\end{tabular}

CAL YR 1975 TOTAL 15.52 MEAN .043 MAX 9.5 MIN O AC-FT 31 WTR YR 1976 TOTAL 18.68 MEAN .051 MAX 7.7 MIN 0 AC-FT 37 
LOCATION, - Lat $33^{\circ} 48^{\prime} 08^{\prime \prime}$, long $117^{\circ} 52^{\prime} 39^{\prime \prime}$, sec.25, T.4 S., R. 10 W., Orange County, on right bank, 0.2 mi $(0.3 \mathrm{~km})$ south of Katella Avenue, and $0.6 \mathrm{mi}(1.0 \mathrm{~km})$ east of Śtate College Boulevard near Anaheim Stadium, at Orange.

DRAINAGE AREA. $-1,593 \mathrm{mi}^{2}\left(4,126 \mathrm{~km}^{2}\right)$, excludes $768 \mathrm{mi}^{2}\left(1,990 \mathrm{~km}^{2}\right)$ above Lake E1sinore. WATER-DISCHARGE RECORDS

PERIOD OF RECORD. - -December 1973 to september 1976 (discontinued).

GAGE, - Water-stage recorder, Altitude of gage is $145 \mathrm{ft}(44 \mathrm{~m})$, from topographic map.

REMARKS.--Records poor. Natural flow affected by ground-water withdrawals, diversions, importation by Metropolitan Water District, municipal use, and return flow from irrigation. Prado flood control reservoir, capacity, 201,200 acre-ft $\left(248 \mathrm{hm}^{3}\right)$ since 1940 , three smal1 flood-control reservoirs, combined capacity, 31,900 acre-ft $\left(39.3 \mathrm{hm}^{3}\right)$, and Big Bear Lake (station 11049000$)$. Discharge up to $100 \mathrm{ft} / \mathrm{s}(2.83 \mathrm{~m} / \mathrm{s})$ can be diverted from Carbon Creek to Coyote Creek, $1.5 \mathrm{mi}(2.4 \mathrm{~km})$ upstream from mouth of Carbon Creek, See schematic diagram of Santa Ana River basin. Daily discharges for Sept. 10 and 11 storm were estimated on the basis of comparison with the downstream stations Santa Ana River at Santa Ana (station 11078000) and Santiago Creek at Santa Ana (station 11077500).

EXTREMES FOR PERIOD OF RECORD.--Maximum discharge, 5,400 $\mathrm{ft}^{3} / \mathrm{s}\left(153 \mathrm{~m}^{3} / \mathrm{s}\right) \mathrm{Dec}, 4,1976, \mathrm{gage} \mathrm{height}, 6.53 \mathrm{ft}$ $(1.990 \mathrm{~m})$, from rating curve extended above $2,900 \mathrm{ft}^{3} / \mathrm{s}\left(82.1 \mathrm{~m}^{3} / \mathrm{s}\right)$ for gage height $6.53 \mathrm{ft}(1.990 \mathrm{~m})$, based on indirect computation; no flow for long periods in most years.

EXTREMES FOR CURRENT YEAR.--Maximum discharge, unknown, Sept, 10, gage height, unknown; no flow most of year.

DISCHARGE, IN CUBIC FEET PER SECOND, WATER YEAR OCTOBER 1975 TO SEPTEMBER 1976 MEAN YALUES

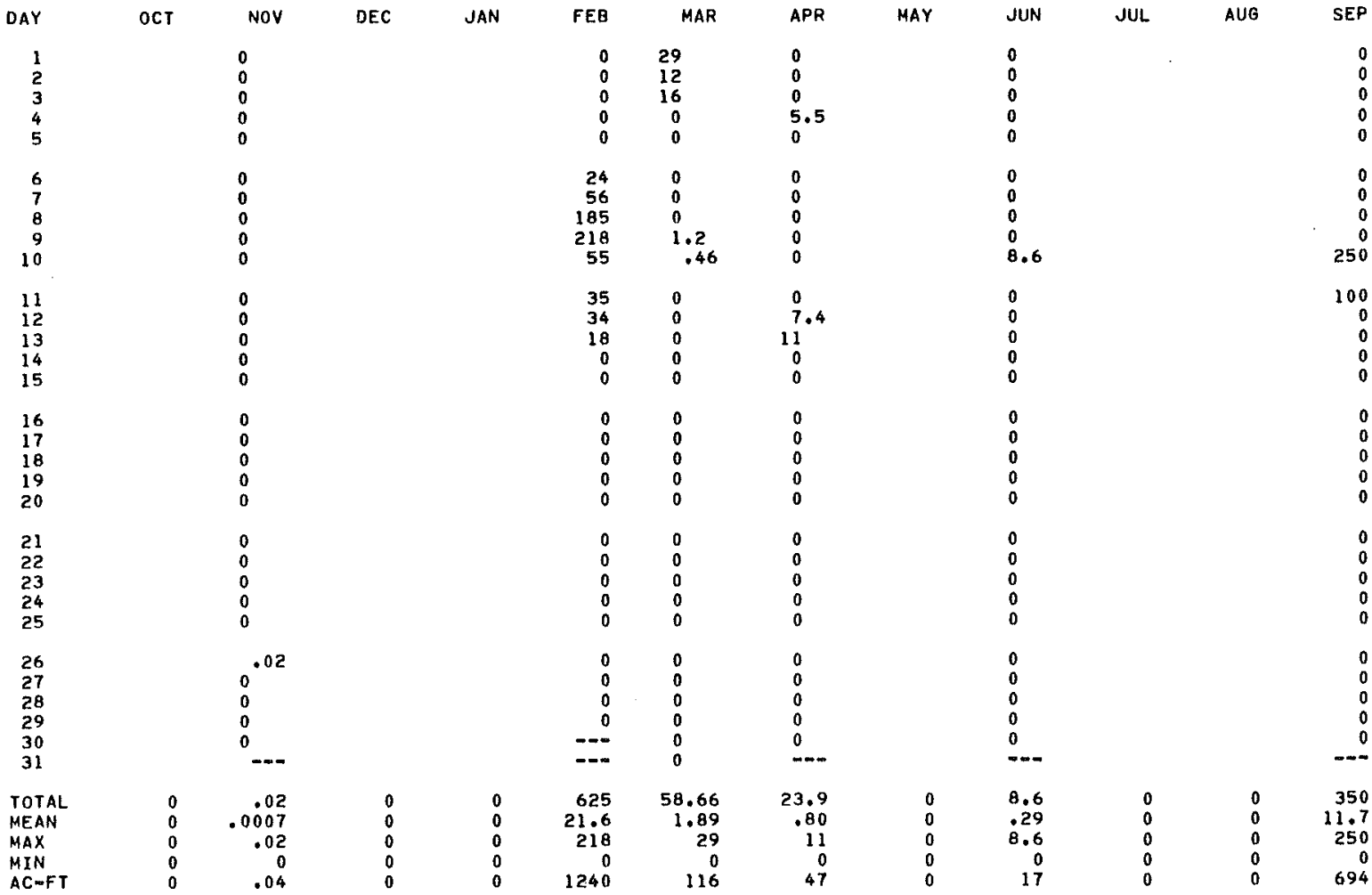

$\begin{array}{llllllllll}\text { CAL YR } 1975 & \text { TOTAL } & 1007.02 & \text { MEAN } 2.76 & \text { HAX } 161 & \text { MIN } 0 & \text { AC-FT } & 2000 \\ \text { WTR YR } 1976 & \text { TOTAL } & 1066.18 & \text { MEAN } 2.91 & \text { MAX } 250 & \text { MIN } 0 & \text { AC-FT } & 2110\end{array}$ 
11075760 SANTA ANA RIVER NEAR KATELLA AVENUE, AT ORANGE, CA--Continued

WATER-QUALITY RECORDS

PERIOD OF DAILY RECORD.- -

WATER TEMPERATURES: January 1974 to September 1976 (discontinued)

SEDIMENT RECORDS: January 1974 to September 1976 (discontinued).

REMARKS.--Particle-size distribution of bed material table was omitted in the 1975 water year and is pub1ished with the 1976 water year records.

EXTREMES FOR PERIOD OF DAILY RECORD. -

SEDIMENT CONCENTRATIONS: Maximum daily mean, 8,840 mg/1 Jan. 8, 1974; minimum daily mean, no flow for many days each year.

SEDIMENT DISCHARGE: Maximum daily, 30,900 tons $(28,000$ tonnes) Jan, 8,1974 ; minimum daily, 0 tons on many days each year.

EXTREMES FOR CURRENT YEAR. -

SEDIMENT CONCENTRATIONS: Maximum daily mean, $4,590 \mathrm{mg} / 1$ sept. 10; minimum daily mean, no flow for many days. SEDIMENT DISCHARGE: Maximum daily, 3,100 tons $(2,790$ tomes) Sept. 10; minimum daily, 0 tons on many days.

TEMPERATURE (DEG. C) OF HATER, WATER YEAR OCTOBER 1975 TO SEPTEMBER 1976 ONCE-DAILY

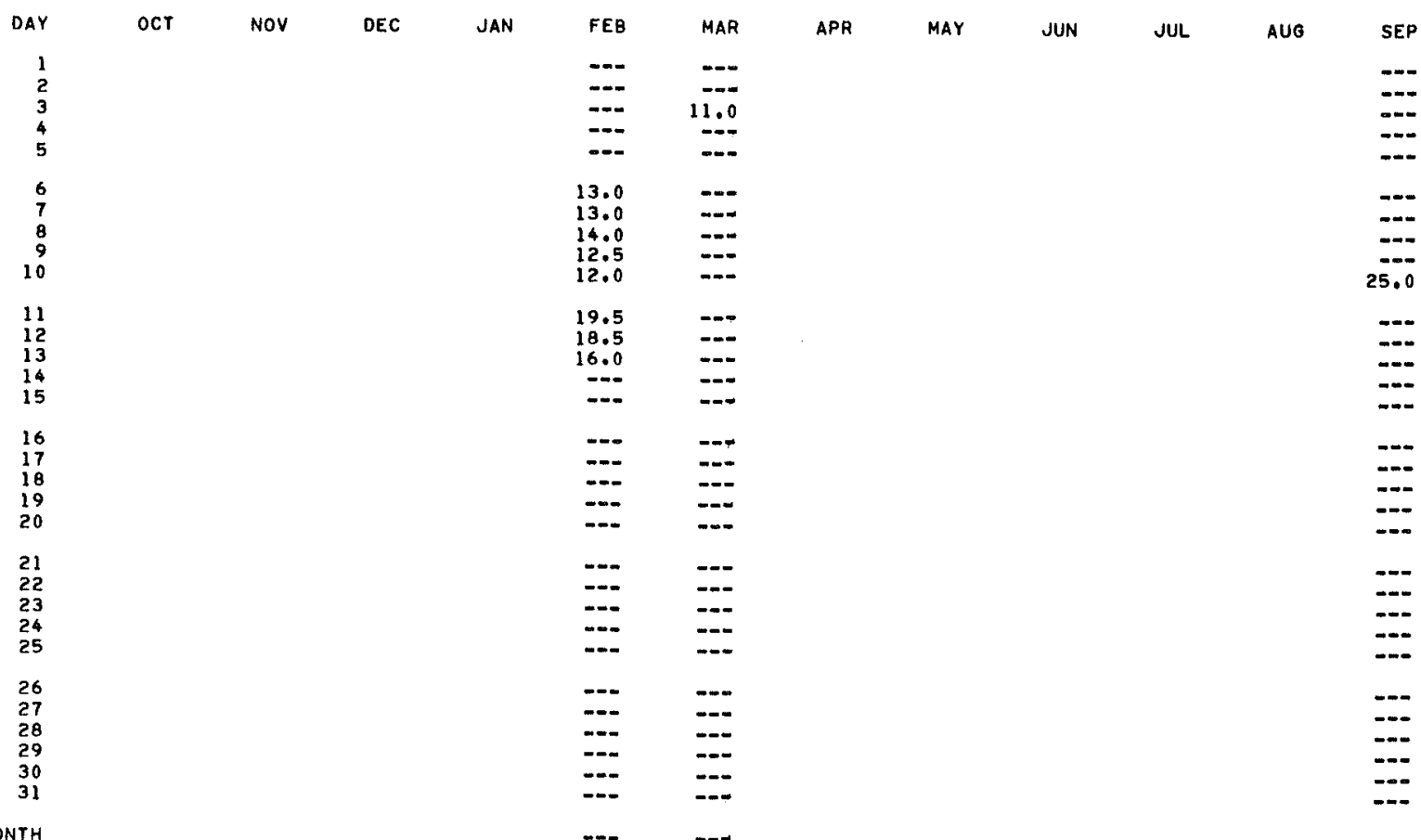

MONTH 
SUSPENDED-SEOIMENT DISCHARGE (TONS/DAY), WATER YEAR OCTOBER 1975 TO SEPTEMBER 1976

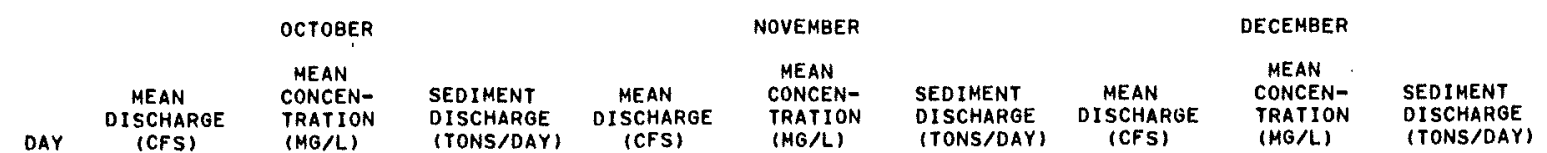

JANUARY

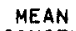
CONCENTRATION (MG/L)
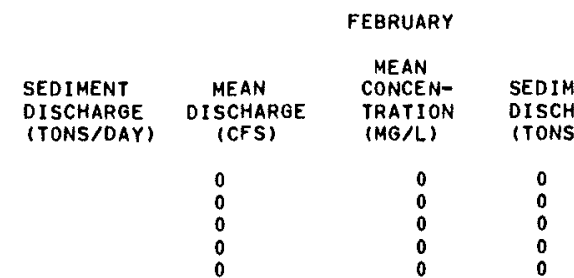

0

0

0

DAY ISCHARGE (TONS/OAY) (CFS)

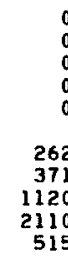

0
0
0
0
0

262
71
20
10
15

TMENT ISCHARGE

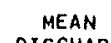
OISCHARGE (CFS)

29
12
16
0
0

65
85
2650
1760

385 $\begin{array}{rr}35 & 385 \\ 34 & 260 \\ 18 & 160 \\ 0 & 0 \\ 0 & 0\end{array}$ $\begin{array}{rr}35 & 385 \\ 34 & 260 \\ 18 & 160 \\ 0 & 0 \\ 0 & 0\end{array}$

0

$$
\begin{aligned}
& 0 \\
& 0 \\
& 0 \\
& 0 \\
& 0
\end{aligned}
$$$$
\begin{aligned}
& 0 \\
& 0 \\
& 0 \\
& 0 \\
& 0
\end{aligned}
$$$$
\begin{aligned}
& 0 \\
& 0 \\
& 0 \\
& 0 \\
& 0
\end{aligned}
$$

\section{0
0
0}

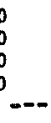

0

625.00

\section{MARCH}

\section{MEAN} CONCENTRATION

SEDIMENT (TONS/DAY)

$\begin{array}{rc}178 & 67 \\ 84 & 30 \\ 91 & 11 \\ 0 & 0 \\ 0 & 0 \\ 0 & 0 \\ 0 & 0 \\ 0 & 0 \\ 16 & .91 \\ 7 & .20\end{array}$$$
20
$$

$$
\begin{array}{ll}
0 & 0 \\
0 & 0 \\
0 & 0 \\
0 & 0 \\
0 & 0
\end{array}
$$

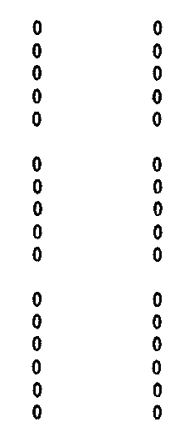


11075760 SANTA ANA RIVER NEAR KATELlA AVENUE, AT ORANGE, CA--Continued

SUSPENDEO-SEDIMENT DISCHARGE (TONS/OAY), WATER YEAR OCTOBER 1975 TO SEPTEMBER 1976

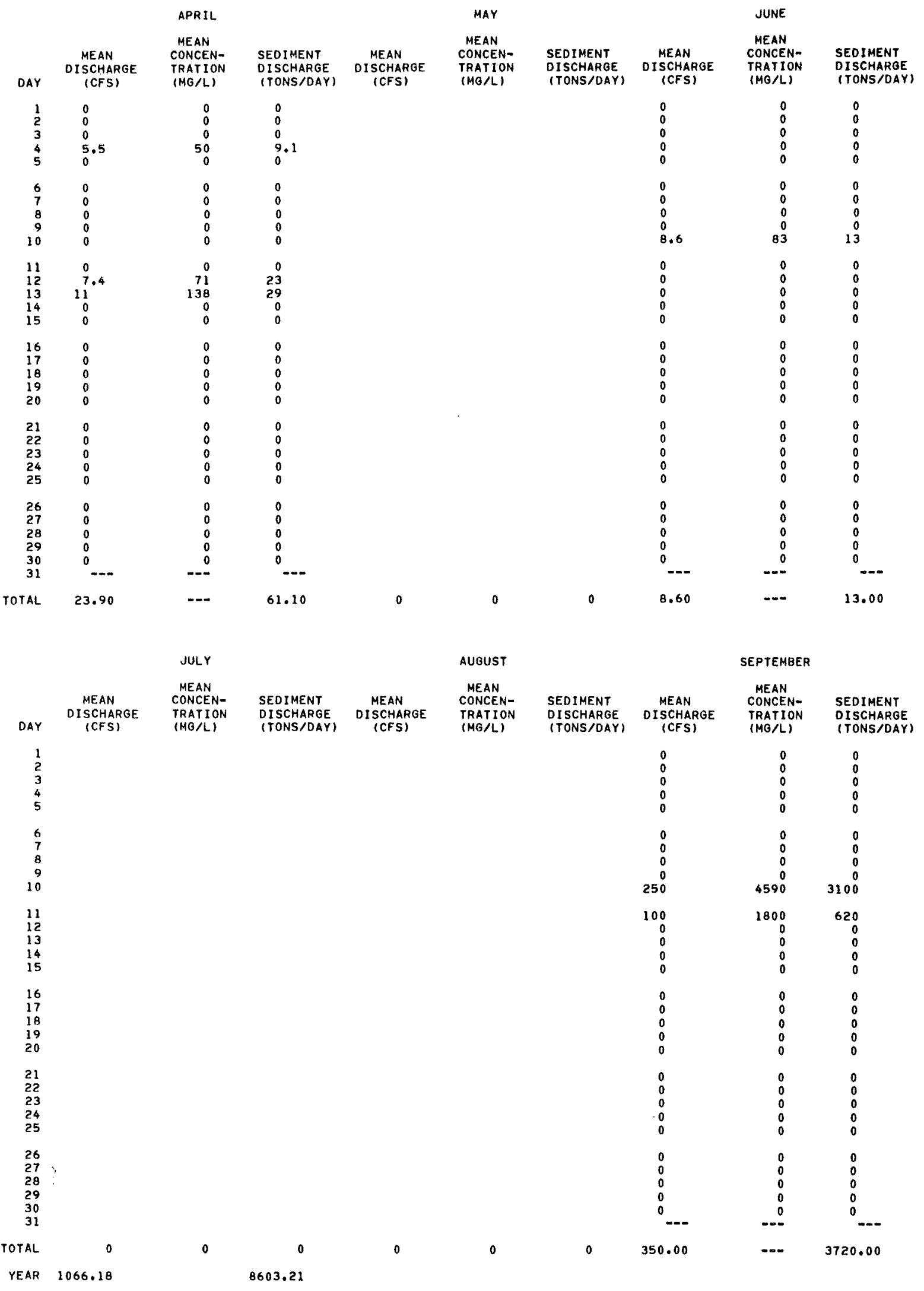


11075760 SANTA ANA RIVER NEAR KATELLA AVENUE, AT ORANGE, CA--Continued

SUMMARY OF HATER AND SEOIHENT DISCHARGE, HATER YEAR OCTOBER 1975 TO SEPTEMBER 1976

$\begin{array}{ccccc}\text { HATER } & \text { SUSPENDEO } & \text { BEDLOAD } & \text { TOTAL } \\ \text { MONTH } & \text { DISCHARGE } & \text { SEDIMENT } & \text { DISCHARGE } & \text { SEDIMENT } \\ & \text { DISCHARGE } & \text { DISCHARGE } \\ & \text { CFS-DAYS } & \text { TONS } & \text { TONS } & \text { TONS }\end{array}$

\begin{tabular}{|c|c|c|c|c|}
\hline OCTOBER 1975 & 0.0 & 0.0 & 0 & 0 \\
\hline NOVEMBER $\ldots$ & 0.02 & 0.0 & 0 & 0 \\
\hline DECEMBER $\ldots$ & 0.0 & 0.0 & 0 & 0 \\
\hline JANUARY 1976 & 0.0 & 0.0 & 0 & 0 \\
\hline FEBRUARY $\ldots$ & 625.00 & 4700.00 & 463 & 5160 \\
\hline MARCH $\cdots \cdots$ & 58.66 & 109.11 & 11 & 120 \\
\hline APRIL $\cdots \cdots$ & 23.90 & 61.10 & 3 & 64 \\
\hline MAY $\ldots \ldots \ldots$ & 0.0 & 0.0 & 0 & 0 \\
\hline JUNE $\ldots \ldots \cdots$ & 8.60 & 13.00 & 1 & 14 \\
\hline JULY ..... & 0.0 & 0.0 & 0 & 0 \\
\hline AUGUST $\ldots \ldots$ & 0.0 & 0.0 & 0 & 0 \\
\hline SEPTEMBER —. & 350.00 & 3720.00 & 345 & 4060 \\
\hline TOTAL ...... & 1066.18 & 8603.21 & 823 & 9418 \\
\hline
\end{tabular}

PARTICLE-SIZE DISTRIBUTION OF SUSPENDED SEDIMENT, WATER YEAR OCTOBER 1975 TO SEPTEMBER 1976

\begin{tabular}{|c|c|c|c|c|c|c|c|c|c|c|}
\hline & TIME & $\begin{array}{l}\text { TEMPER- } \\
\text { ATURE }\end{array}$ & $\begin{array}{c}\text { INSTAN- } \\
\text { TANEOUS } \\
\text { DIS- } \\
\text { CHARGE }\end{array}$ & $\begin{array}{l}\text { SUS - } \\
\text { PENDED } \\
\text { SEDI- } \\
\text { MENT }\end{array}$ & $\begin{array}{c}\text { SUS- } \\
\text { PENDED } \\
\text { SEDI- } \\
\text { MENT } \\
\text { DIS- } \\
\text { CHARGE }\end{array}$ & $\begin{array}{l}\text { SUS } \\
\text { SED } \\
\text { FALL } \\
\text { DIAM. } \\
\text { \& FINER } \\
\text { THAN }\end{array}$ & $\begin{array}{l}\text { SUS } \\
\text { SED } \\
\text { FAL } \\
\text { DIAM } \\
\text { D FIN } \\
\text { THA }\end{array}$ & ín & $\begin{array}{r}\text { SUS } \\
\text { SED } \\
\text { FAL } \\
\text { DIAM } \\
\times \text { FIA } \\
\text { THA }\end{array}$ & \\
\hline DATE & & (DEG C) & (CFS) & (MG/L) & (T/DAY) & $.002 \mathrm{MM}$ & .004 & $M M$ & .008 & MM \\
\hline \multicolumn{11}{|l|}{ FEB } \\
\hline $09 \ldots$ & $\begin{array}{l}0930 \\
1300\end{array}$ & $\begin{array}{l}12.5 \\
19.5\end{array}$ & $\begin{array}{r}351 \\
9.9\end{array}$ & $\begin{array}{r}7030 \\
197\end{array}$ & $\begin{array}{r}6660 \\
5.3\end{array}$ & $\begin{array}{r}5 \\
--\end{array}$ & & $\begin{array}{r}7 \\
--\end{array}$ & & $\begin{array}{r}8 \\
--\end{array}$ \\
\hline$\underset{M A R}{13} \cdots$ & 1450 & 16.0 & 16 & 156 & 6.7 & -- & & $=-$ & & -- \\
\hline $\begin{array}{l}01 \ldots . \\
03 \ldots\end{array}$ & $\begin{array}{l}1600 \\
1050\end{array}$ & 13.0 & $\begin{array}{l}36 \\
68\end{array}$ & $\begin{array}{l}152 \\
382\end{array}$ & $\begin{array}{l}15 \\
70\end{array}$ & $\overline{47}$ & & 56 & & $-\infty$ \\
\hline
\end{tabular}


11075760 SANTA ANA RIVER NEAR KATELLA AVFNUE, AT ORANGE, CA--Continued

PARTICLE-SIZE DISTRIBUTION OF SUSPENDED SEDIMENT, WATER YEAR OCTOBER 1975 TO SEPTEMBER 1976

\begin{tabular}{|c|c|c|c|c|c|c|c|c|}
\hline & $\begin{array}{l}\text { SUS, } \\
\text { SED. } \\
\text { FALL } \\
\text { OIAM. } \\
\text { O FINER } \\
\text { THAN }\end{array}$ & $\begin{array}{l}\text { SUS. } \\
\text { SED. } \\
\text { FALL } \\
\text { DIAM. } \\
\text { \& FINER } \\
\text { THAN }\end{array}$ & $\begin{array}{l}\text { SUS. } \\
\text { SED. } \\
\text { SIEVE } \\
\text { DIAM. } \\
\text { \& FINER } \\
\text { THAN }\end{array}$ & $\begin{array}{l}\text { SUS. } \\
\text { SED } \\
\text { SIEVE } \\
\text { DIAM. } \\
\text { \$ FINER } \\
\text { THAN }\end{array}$ & $\begin{array}{l}\text { SUS, } \\
\text { SED, } \\
\text { SIEVE } \\
\text { DIAM. } \\
\text { \& FINER } \\
\text { THAN }\end{array}$ & $\begin{array}{l}\text { SUS. } \\
\text { SED } \\
\text { SIEVE } \\
\text { DIAM. } \\
\text { FINER } \\
\text { THAN }\end{array}$ & $\begin{array}{l}\text { SUS. } \\
\text { SED } \\
\text { SIEVE } \\
\text { DIAM. } \\
\text { \& FINER } \\
\text { THAN }\end{array}$ & $\begin{array}{l}\text { SUS, } \\
\text { SED } \\
\text { SIEVE } \\
\text { DIAM. } \\
\text { F FINER } \\
\text { THAN }\end{array}$ \\
\hline DATE & $.016 \mathrm{MM}$ & $.031 \mathrm{NM}$ & $.062 \mathrm{MM}$ & $.125 \mathrm{MM}$ & $.250 \mathrm{MM}$ & $.500 \mathrm{MM}$ & $1.00 \mathrm{HM}$ & $2.00 \mathrm{MM}$ \\
\hline \multicolumn{9}{|l|}{ FEB } \\
\hline $09 \ldots$ & 9 & 10 & 12 & 14 & 23 & 56 & 93 & 100 \\
\hline $11 \ldots$ & $=$ & - & 97 & 98 & 99 & 100 & -- & -- \\
\hline$\underset{M A R}{13 \cdots}$ & $m$ & $-\infty$ & 98 & 98 & 100 & $-\infty$ & - & -- \\
\hline $01 \ldots$ & $=$ & $-\pi$ & 93 & 96 & 98 & 100 & $-\infty$ & -- \\
\hline & 70 & 79 & 86 & 93 & 98 & 100 & $=$ & $=-$ \\
\hline
\end{tabular}

PARTICLE-SIZE DISTRIBUTION OF SURFACE BED MATERIAL, WATER YEAR OCTOBER 1974 TO SEPTEMBER 1975

\begin{tabular}{|c|c|c|c|c|c|c|c|c|c|c|c|}
\hline & & $\begin{array}{c}\text { NUMBER } \\
\text { OF } \\
\text { SAM- }\end{array}$ & $\begin{array}{l}\text { INSTAN- } \\
\text { TANEOUS }\end{array}$ & $\begin{array}{l}\text { BED } \\
\text { MAT. } \\
\text { SIEVE } \\
\text { DIAM. }\end{array}$ & $\begin{array}{l}\text { BED } \\
\text { MAT. } \\
\text { SIEVE } \\
\text { DIAM. }\end{array}$ & $\begin{array}{l}\text { BED } \\
\text { MAT. } \\
\text { SIEVE } \\
\text { DIAM. }\end{array}$ & $\begin{array}{l}\text { BED } \\
\text { MAT. } \\
\text { SIEVE } \\
\text { DIAM. }\end{array}$ & $\begin{array}{l}\text { BED } \\
\text { MAT. } \\
\text { SIEVE } \\
\text { DIAM. }\end{array}$ & $\begin{array}{l}\text { BED } \\
\text { MAT. } \\
\text { SIEVE } \\
\text { DIAM. }\end{array}$ & $\begin{array}{l}\text { BED } \\
\text { MAT. } \\
\text { SIEVE } \\
\text { DIAM. }\end{array}$ & $\begin{array}{l}\text { BED } \\
\text { MAT } \\
\text { SIEVE } \\
\text { DIAM. }\end{array}$ \\
\hline & IME & $\begin{array}{l}\text { PLING } \\
\text { POINTS }\end{array}$ & $\begin{array}{c}\text { DIS- } \\
\text { CHARGE }\end{array}$ & $\begin{array}{c}* \text { F INER } \\
\text { THAN }\end{array}$ & $\begin{array}{l}\text { \% FINER } \\
\text { THAN }\end{array}$ & $\begin{array}{l}\text { \% FINER } \\
\text { THAN }\end{array}$ & $\begin{array}{l}\text { F INER } \\
\text { THAN }\end{array}$ & $\begin{array}{l}\text { F FNER } \\
\text { THAN }\end{array}$ & $\begin{array}{l}\text { * F INER } \\
\text { THAN }\end{array}$ & $\begin{array}{c}\text { F INER } \\
\text { THAN }\end{array}$ & $\begin{array}{c}\text { \% FINER } \\
\text { THAN }\end{array}$ \\
\hline ATE & & & (CFS) & $.062 \mathrm{MM}$ & $.125 \mathrm{MM}$ & $.250 \mathrm{MM}$ & $.500 \mathrm{MM}$ & $1.00 \mathrm{MM}$ & $2.00 \mathrm{M}$ & $4.00 \mathrm{MM}$ & $8.00 \mathrm{MN}$ \\
\hline
\end{tabular}

3.00

1

7

16

51

88

97

99

100 


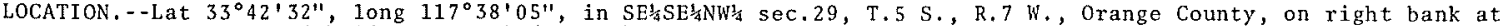
Santiago Canyon road bridge, $0.3 \mathrm{mi}(0.5 \mathrm{~km})$ west of Modjeska, and $0.4 \mathrm{mi}(0.6 \mathrm{~km})$ downstream from Harding Creek.

DRAINAGE AREA, $--12.5 \mathrm{mi}^{2}\left(32.4 \mathrm{~km}^{2}\right)$.

PERIOD OF RECORD, - -October 1961 to current year.

GAGE. - Water-stage recorder and crest-stage gage. Datum of gage is $1,254.35 \mathrm{ft}$ (382.326 m) above mean sea 1 eve1. Prior to Sept. 10, 1969 , at datum $4.42 \mathrm{ft}(1.347 \mathrm{~m})$ higher.

REMARKS,--Records poor. Slight regulation by Modjeska Reservoir on Harding Creek. No diversion above station. See schematic diagram of Santa Ana River basin.

AVERAGE DISCHARGE, - - 15 years, $6.30 \mathrm{ft}^{3} / \mathrm{s}\left(0.178 \mathrm{~m}^{3} / \mathrm{s}\right), 4,560 \mathrm{acre}-\mathrm{ft} / \mathrm{yr}\left(5.62 \mathrm{hm} / \mathrm{yr}^{3}\right)$.

EXTREMES FOR PERIOD OF RECORD,--Maximum discharge, 6,520 ft $\mathrm{t}^{3} / \mathrm{s}\left(185 \mathrm{~m}^{3} / \mathrm{s}\right)$ Feb. 25,1969, gage height, $10.50 \mathrm{ft}$ $(3.200 \mathrm{~m})$, present datum, from rating curve extended above $840 \mathrm{ft} / \mathrm{s}\left(23.8 \mathrm{~m}^{3} / \mathrm{s}\right)$ on basis of siope-area measurement of maximum flow; no flow at times in each year.

EXTREMES FOR CURRENT YEAR, --Maximum discharge, $440 \mathrm{ft}^{3} / \mathrm{s}\left(12.5 \mathrm{~m}^{3} / \mathrm{s}\right)$ Mar. 1 (1715 hrs), gage height, $4.80 \mathrm{ft}$ $(1.463 \mathrm{~m})$, no other pegk above base of $100 \mathrm{ft}^{3} / \mathrm{s}\left(12.5 \mathrm{~m}^{3} / \mathrm{s}\right)$; no flow many days.

DISCHARGE, IN CUAIC FEET PER SECOND, WATER YEAR OCTOBER 1975 TO SEPTEMBER 1976 MEAN VALUES

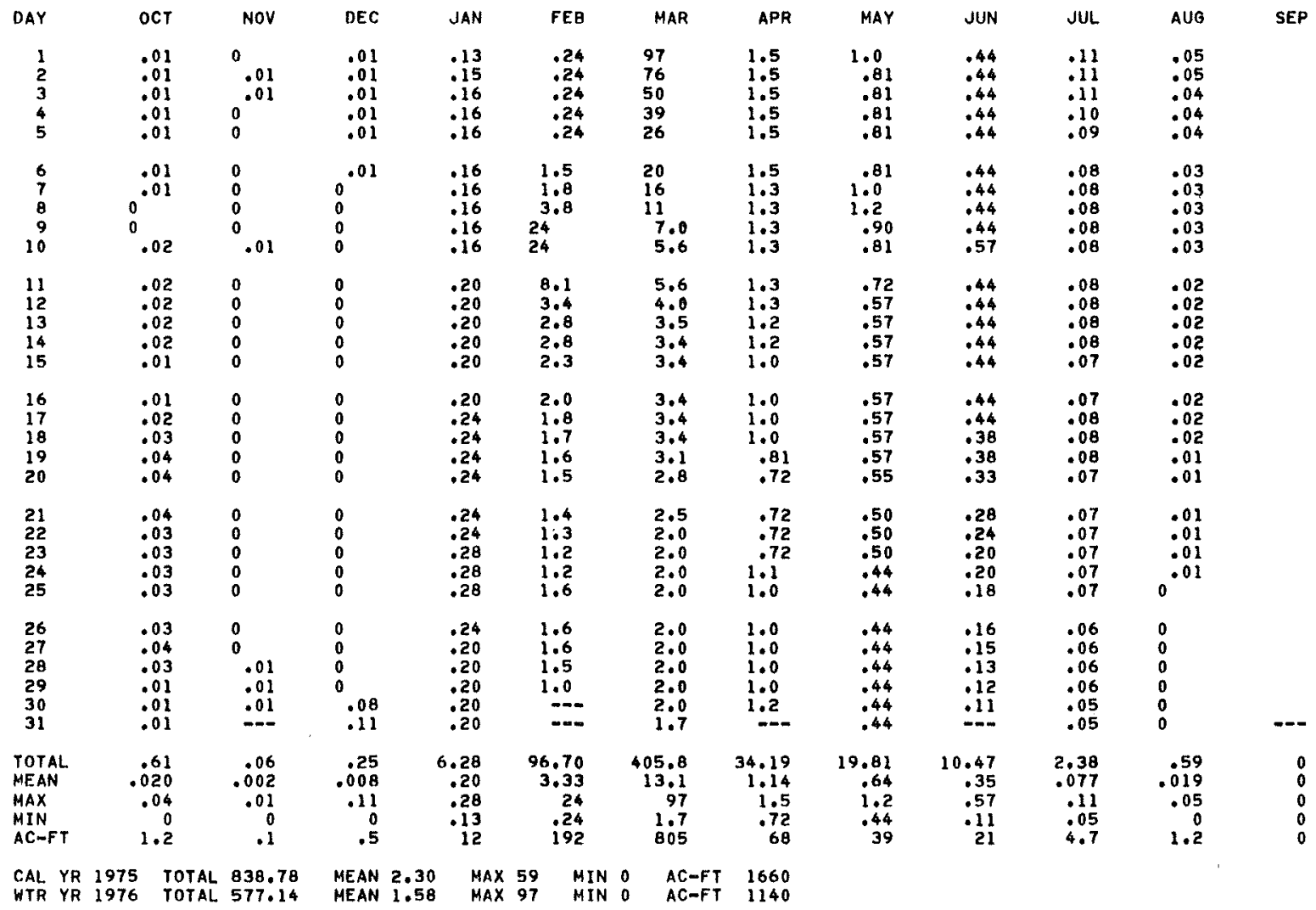


11077500 SANTIAGO CREEK AT SANTA ANA, CA

LOCATION (REVISED).--Lat $33^{\circ} 46^{\prime} 13^{\prime \prime}$, long $117^{\circ} 53^{\prime} 01^{\prime \prime}$, in NW'SWhNW/4 sec.1, T.5 S, R. 10 W., Orange County, on left bank $127 \mathrm{ft}(39 \mathrm{~m})$ upstream from Bristol Street bridge at Santa Ana, and 1,700 ft (518 m) upstream from mouth at Santa Ana River.

WATER-DISCHARGE RECORDS

DRAINAGE AREA. $-98,6 \mathrm{mi}^{2}\left(255 \mathrm{~km}^{2}\right)$.

PERIOD OF RECORD.--October 1928 to current year. Month1y discharge only october to December 1928 , published in WSP $1315-\mathrm{B}$.

GAGE. - Water-stage recorder and crest-stage gage. Datum of gage is $105.00 \mathrm{ft}(32.004 \mathrm{~m})$ above mean sea level (Orange County Flood Control District bench mark). Prior to Sept. 8, 1969, at site $0.1 \mathrm{mi}(0.2 \mathrm{~km})$ upstream at different datum. Prior to July 21 , 1976 , at site $127 \mathrm{ft}(38.7 \mathrm{~m})$ downstream at datum $2.66 \mathrm{ft}(0.811 \mathrm{ft})$ lower.

REMARKS. --Records poor. Flow regulated by Santiago Reservoir, capacity, 25,000 acre-ft (30.8 hm ${ }^{3}$ ), since January 1963 by Vilia Park flood-control reservoir, capacity, 15,500 acre-ft (19.1 hms), and affected by intervening gravel pits. Diversions above station by Irvine co. and Serrano and Carpenter Irrigation Districts. See schematic diagram of Santa Ana River basin.

AVERAGE DISCHARGE. -48 years, $4.93 \mathrm{ft}^{3} / \mathrm{s}\left(0.140 \mathrm{~m}^{3} / \mathrm{s}\right), 3,570$ acre-ft/yr $\left(4.40 \mathrm{hm}^{3} / \mathrm{yr}^{2}\right)$.

EXTREMES FOR PERIOD OF RECORD, - -Maximum discharge, 6,600 $\mathrm{ft}^{3} / \mathrm{s}\left(187 \mathrm{~m}^{3} / \mathrm{s}\right)$ Feb. 25 , 1969 , gage height, 9.10 ft $(2.774 \mathrm{~m})$, site and datum then in use; maximum gage height, $9.85 \mathrm{ft}(3.002 \mathrm{~m}) \mathrm{Jan}$. 16 , $1952 ;$ no fiow for several months in each year.

EXTREMES FOR CURRENT YEAR.--Maximum discharge, $326 \mathrm{ft}^{3} / \mathrm{s}\left(9.23 \mathrm{~m}^{3} / \mathrm{s}\right) \mathrm{Feb} .9$, gage height, $5.38 \mathrm{ft}(1.640 \mathrm{~m})$; no flow for several months.

DISCHARGE, IN CUBIC FEET PER SECOND, WATER YEAR OCTOBER 1975 TO SEPTEMBER 1976 MEAN VALUES

\begin{tabular}{|c|c|c|c|c|c|c|c|c|c|c|c|c|}
\hline DAY & OCT & NOV & DEC & JAN & FEB & MAR & $A P R$ & MAY & JUN & JUL & AUG & SEP \\
\hline $\begin{array}{l}1 \\
2 \\
3 \\
4 \\
5\end{array}$ & $\begin{array}{l}0 \\
0 \\
0 \\
.01 \\
.01\end{array}$ & $\begin{array}{l}0 \\
0 \\
0 \\
0 \\
0\end{array}$ & $\begin{array}{l}0 \\
0 \\
0 \\
.01 \\
.02 \\
.02\end{array}$ & $\begin{array}{l}.01 \\
.01 \\
0 \\
0 \\
.01\end{array}$ & $\begin{array}{l}0 \\
0 \\
.21 \\
.20 \\
.41\end{array}$ & $\begin{array}{l}22 \\
12 \\
6.7 \\
0 \\
0.06\end{array}$ & $\begin{array}{r}0 \\
.09 \\
.36 \\
1.7 \\
.18\end{array}$ & & $\begin{array}{l}0 \\
0 \\
0 \\
0 \\
0\end{array}$ & & $\begin{array}{l}0 \\
0 \\
0 \\
0 \\
0\end{array}$ & $\begin{array}{l}0 \\
0 \\
0 \\
0 \\
1.2\end{array}$ \\
\hline $\begin{array}{r}6 \\
7 \\
8 \\
9 \\
10\end{array}$ & $\begin{array}{l}.13 \\
.07 \\
.01 \\
0 \\
0\end{array}$ & $\begin{array}{l}0 \\
0 \\
0 \\
.04\end{array}$ & $\begin{array}{l}0 \\
.01 \\
.02 \\
.18 \\
0\end{array}$ & $\begin{array}{l}0 \\
0 \\
0 \\
0 \\
0\end{array}$ & $\begin{array}{l}16 \\
10 \\
16 \\
57 \\
.38\end{array}$ & $\begin{array}{l}0 \\
0 \\
.16 \\
.09 \\
.08\end{array}$ & $\begin{array}{l}.01 \\
.05 \\
.01 \\
.04\end{array}$ & & $\begin{array}{l}0 \\
0 \\
0 \\
0 \\
2.0\end{array}$ & . & $\begin{array}{l}0 \\
0 \\
0 \\
0 \\
0\end{array}$ & $\begin{array}{l}0 \\
0 \\
0 \\
43\end{array}$ \\
\hline $\begin{array}{l}11 \\
12 \\
13 \\
14 \\
15\end{array}$ & $\begin{array}{l}0_{0}^{.08} \\
0 \\
0 \\
0\end{array}$ & $\begin{array}{l}0 \\
0 \\
.01 \\
0.01\end{array}$ & $\begin{array}{l}0 \\
0 \\
0 \\
0.07\end{array}$ & $\begin{array}{l}0 \\
0 \\
0 \\
0 \\
.01\end{array}$ & $\begin{array}{l}0^{.04} \\
0 \\
0 \\
0\end{array}$ & $\begin{array}{l}0 \\
0 \\
.01 \\
0.03\end{array}$ & $\begin{array}{l}.02 \\
5.9 \\
3.4 \\
.10 \\
.75\end{array}$ & & $\begin{array}{l}0 \\
0 \\
0 \\
0 \\
0\end{array}$ & & $\begin{array}{l}0 \\
0 \\
0 \\
0 \\
0\end{array}$ & $\begin{array}{r}3.4 \\
.04 \\
.04 \\
0.04 \\
.04\end{array}$ \\
\hline $\begin{array}{l}16 \\
17 \\
18 \\
19 \\
20\end{array}$ & $\begin{array}{l}0 \\
0 \\
0 \\
0 \\
0\end{array}$ & $\begin{array}{l}.01 \\
0 \\
.01\end{array}$ & $\begin{array}{l}0 \\
0 \\
.01 \\
.02 \\
.01\end{array}$ & $\begin{array}{l}.01 \\
.01 \\
.07 \\
0\end{array}$ & $0_{0}^{.02}$ & $\begin{array}{l}.14 \\
0 \\
0 \\
.01 \\
.04\end{array}$ & $\begin{array}{l}0^{.25} \\
0 \\
0 \\
0\end{array}$ & & $\begin{array}{l}0 \\
0 \\
0 \\
0 \\
0\end{array}$ & & $\begin{array}{l}0 \\
0 \\
0 \\
0 \\
0\end{array}$ & $\begin{array}{l}0.04 \\
0 \\
0 \\
0\end{array}$ \\
\hline $\begin{array}{l}21 \\
22 \\
23 \\
24 \\
25\end{array}$ & $\begin{array}{l}0 \\
0 \\
0 \\
.01\end{array}$ & $\begin{array}{l}0 \\
.02 \\
.02 \\
.03 \\
.02\end{array}$ & $\begin{array}{l}.02 \\
0.01 \\
0 \\
0\end{array}$ & $\begin{array}{l}0 \\
0 \\
0 \\
0 \\
0\end{array}$ & $\begin{array}{l}.01 \\
.03 \\
.01 \\
.01 \\
.02\end{array}$ & $\begin{array}{l}.06 \\
.08 \\
.08 \\
.07 \\
.14\end{array}$ & $\begin{array}{l}0 \\
0 \\
0 \\
0 \\
0\end{array}$ & & $\begin{array}{l}0 \\
0 \\
0 \\
0 \\
0\end{array}$ & & $\begin{array}{l}0 \\
0 \\
0 \\
0 \\
0\end{array}$ & $\begin{array}{l}0^{.04} \\
0 \\
0 \\
0\end{array}$ \\
\hline $\begin{array}{l}26 \\
27 \\
28 \\
29 \\
30 \\
31\end{array}$ & $\begin{array}{l}0 \\
0 \\
0 \\
0 \\
0 \\
0\end{array}$ & $\begin{array}{l}.02 \\
.01 \\
.66 \\
.07 \\
.01 \\
. .-\end{array}$ & $\begin{array}{l}0 \\
0 \\
0 \\
.01 \\
.02 \\
.01\end{array}$ & $\begin{array}{l}0^{.02} \\
0 \\
0 \\
0 \\
0\end{array}$ & $\begin{array}{l}0 \\
.18 \\
0.03 \\
0 \\
-. .\end{array}$ & $\begin{array}{r}.11 \\
.77 \\
.36 \\
.15 \\
.09 \\
.09\end{array}$ & $\begin{array}{l}0 \\
0 \\
0 \\
0 \\
0\end{array}$ & & $\begin{array}{l}0 \\
0 \\
0 \\
0 \\
0 \\
-\end{array}$ & & $\begin{array}{l}0 \\
0 \\
0 \\
0 \\
0^{.01}\end{array}$ & $\begin{array}{l}0 \\
0 \\
0 \\
0 \\
0\end{array}$ \\
\hline $\begin{array}{l}\text { TOTAL } \\
\text { MEAN } \\
\text { MAX } \\
\text { MIN } \\
\text { AC } \rightarrow F T\end{array}$ & $\begin{array}{r}.42 \\
.014 \\
.13 \\
0 \\
.8\end{array}$ & $\begin{array}{r}.94 \\
.031 \\
.66 \\
0 \\
1.9\end{array}$ & $\begin{array}{r}.42 \\
.014 \\
.18 \\
0 \\
.8\end{array}$ & $\begin{array}{r}.16 \\
.005 \\
.07 \\
0 \\
.3\end{array}$ & $\begin{array}{r}100.59 \\
3.47 \\
57 \\
0 \\
200\end{array}$ & $\begin{array}{r}43.32 \\
1.40 \\
22 \\
0 \\
86\end{array}$ & $\begin{array}{r}12.86 \\
.43 \\
5.9 \\
0 \\
26\end{array}$ & $\begin{array}{l}0 \\
0 \\
0 \\
0 \\
0\end{array}$ & $\begin{array}{r}2.0 \\
.067 \\
2.0 \\
0 \\
4.0\end{array}$ & $\begin{array}{l}0 \\
0 \\
0 \\
0 \\
0\end{array}$ & $\begin{array}{r}.01 \\
.0003 \\
.01 \\
0 \\
.02\end{array}$ & $\begin{array}{r}47.84 \\
1.59 \\
43 \\
0 \\
95\end{array}$ \\
\hline
\end{tabular}

CAL YR 1975 TOTAL 262.59 MEAN .72 MAX 61 MIN 0 AC-FT 521 $\begin{array}{lllllll}\text { WTR YR } 1976 & \text { TOTAL } 208.56 & \text { MEAN } & .57 & \text { MAX } 61 & \text { MIN } 0 & \text { AC-FT } 521 \\ & & & \end{array}$ 
PERIOD OF RECORD. -

SEDIMENT RECORDS: Water year 1974 to current year (partial-record station).

PARTICLE-SIZE DISTRIBUTION OF SUSPENDED SEOIMENT, WATER YEAR OCTOBER 1975 TO SEPTEMBER 1976

SUS- SUS. SUS. SUS. SUS.

PENDED SED. SED. SEO, SED.

INSTAN- SUS- SEDI- SIEVE SIEVE

TANEOUS PENDED MENT DIAM. DIAM. DIAM. DIAM.

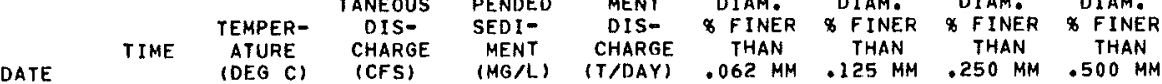

NOV (DEG C)

\begin{tabular}{|c|c|c|c|c|c|c|c|c|c|}
\hline $\begin{array}{l}\text { NOV } \\
28, \ldots \\
\text { FEB }\end{array}$ & 0945 & 11.0 & .88 & 176 & .42 & 99 & 100 & -- & $m$ \\
\hline $\begin{array}{l}08 \ldots \\
08 \ldots\end{array}$ & $\begin{array}{l}1455 \\
1540\end{array}$ & 15.0 & $\begin{array}{l}51 \\
69\end{array}$ & $\begin{array}{l}175 \\
388\end{array}$ & $\begin{array}{l}24 \\
72\end{array}$ & $\begin{array}{l}98 \\
96\end{array}$ & $\begin{array}{l}99 \\
98\end{array}$ & $\begin{array}{l}100 \\
100\end{array}$ & $=$ \\
\hline $10 \ldots$ & 1420 & 24.5 & 36 & 68 & 6.6 & 97 & 97 & 97 & 100 \\
\hline
\end{tabular}




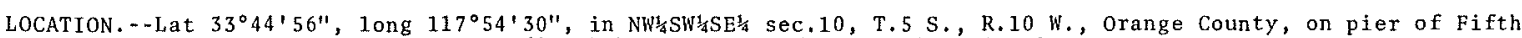
Street Bridge in Santa Ana, $1.8 \mathrm{mi}(2.9 \mathrm{~km})$ downstream from Santiago Creek.

DRAINAGE AREA. $\cdots 1,700 \mathrm{mi}^{2}\left(4,403 \mathrm{~km}^{2}\right)$, excludes $768 \mathrm{mi}^{2}\left(1,989 \mathrm{~km}^{2}\right)$ above Lake E1sinore.

WATER-DISCHARGE RECORDS

PERIOD OF RECORD..--January 1923 to current year.

REVISED RECORDS. - -WDR CA-74-1: Drainage area.

GAGE.--Water-stage recorder. Datum of gage is $71.20 \mathrm{ft}(21.702 \mathrm{~m})$ above mean sea level (Orange County bench mark). Jan. 3, 1923 , to Jan. 24, 1929 , at same site at different datum. Jan. 25,1929, to June 20 , 1948 , at site $450^{\circ} \mathrm{ft}(137 \mathrm{~m})$ upstream at different datum. June 21,1948 , to May 2, 1960 , at same site at different at site $450 \mathrm{ft}(137 \mathrm{~m})$ upstream at different datum. June 21,1948 , to May 2,1960 , at
datum. Feb. 28,1961 , to Oct. 1, 1961, at same site at datum $2.00 \mathrm{ft}(0.610 \mathrm{~m}) \mathrm{higher}$

REMARKS.--Records fair. Natural flow affected by ground-water withdrawals, diversions, inportation by Metropolitan Water District, municipal use, return flow from irrigation, Prado flood-control reservoir, capacity, 201,200 acre-ft $\left(248 \mathrm{hm}^{3}\right)$ since 1940 , three small flood-control reservoirs, combined capacity, 31,900 acre-ft $\left(39.3 \mathrm{hm}^{3}\right.$ ), Big Bear Lake (station 11049000), and Santiago Reservoir, capacity, 25,000 acre-ft (30, $8 \mathrm{hm}^{3}$ ). Discharge up to. $100 \mathrm{ft}^{3} / \mathrm{s}\left(2.83 \mathrm{~m}^{3} / \mathrm{s}\right)$ can be diverted from Carbon Creek to Coyote Creek $1.5 \mathrm{mi}$ (2. $4 \mathrm{~km}$ ) upstream from mouth of Carbon Creek. See schematic diagram of Santa Ana River basin.

COOPERATION.--Three discharge measurements were furnished by Orange County Environmenta1 Management Agency.

EXTREMES FOR PERIOD OF RECORD.--Maximun discharge (excludes flow which bypassed gage from break in levee below Imperial Highway), 46,300 $\mathrm{ft}^{3} / \mathrm{s}\left(1,310 \mathrm{~m}^{3} / \mathrm{s}\right)$ Mar, 3, 1938, gage height, $10.20 \mathrm{ft}$ (3.109 m), site and datum then in use, on basis of slope-area measurement of maximum flow; no flow for several months in each year.

EXTREMES FOR CURRENT YEAR, - Maximum discharge, $1,670 \mathrm{ft}^{3} / \mathrm{s}\left(47.3 \mathrm{~m}^{3} / \mathrm{s}\right)$ Sept, 10 , gage height, $3.87 \mathrm{ft}$ $(1.180 \mathrm{~m})$; no flow most of year.

DISCHARGE. IN CUBIC FEET PER SECOND, HATER YEAR OCTOBER 1975 TO SEPTEMBER 1976 MEAN VALUES

\begin{tabular}{|c|c|c|c|c|c|c|c|c|c|c|c|c|}
\hline DAY & OCT & NOV & DEC & JAN & FEB & MAR & APR & MAY & JUN & JUL. & AUG & SEP \\
\hline $\begin{array}{l}1 \\
1 \\
3 \\
3 \\
4 \\
5\end{array}$ & & & & & $\begin{array}{l}0 \\
0 \\
0 \\
0 \\
\\
.98\end{array}$ & $\begin{array}{c}103 \\
33 \\
59 \\
11 \\
1.1\end{array}$ & $\begin{array}{l}0 \\
0 \\
0 \\
8.1 \\
1.8\end{array}$ & $\begin{array}{l}.10 \\
110 \\
110 \\
.10 \\
110\end{array}$ & $\begin{array}{l}.10 \\
110 \\
.10 \\
110 \\
.10\end{array}$ & $\begin{array}{l}.10 \\
.10 \\
.10 \\
110 \\
.10\end{array}$ & $\begin{array}{l}.10 \\
.05 \\
0 \\
0 \\
0\end{array}$ & $\begin{array}{l}0 \\
0 \\
0 \\
0 \\
0\end{array}$ \\
\hline $\begin{array}{r}6 \\
7 \\
8 \\
9 \\
10\end{array}$ & & & & & $\begin{array}{r}56 \\
63 \\
129 \\
245 \\
70\end{array}$ & $\begin{array}{l}0.06 \\
0 \\
0 \\
2.5\end{array}$ & $\begin{array}{l}0 \\
0 \\
0 \\
0 \\
0\end{array}$ & $\begin{array}{l}.10 \\
.10 \\
.10 \\
.10 \\
.10\end{array}$ & $\begin{array}{l}.10 \\
110 \\
110 \\
110 \\
110\end{array}$ & $\begin{array}{l}.10 \\
110 \\
110 \\
110 \\
.10\end{array}$ & $\begin{array}{l}0 \\
0 \\
0 \\
0 \\
0\end{array}$ & $\begin{array}{r}0 \\
0 \\
0 \\
0 \\
359\end{array}$ \\
\hline $\begin{array}{l}11 \\
12 \\
13 \\
14 \\
15\end{array}$ & & & & & $\begin{array}{l}22 \\
22 \\
17 \\
3.7 \\
0\end{array}$ & $\begin{array}{l}0 \\
0 \\
0 \\
0 \\
0\end{array}$ & $\begin{array}{r}0 \\
16 \\
77 \\
0 \\
0\end{array}$ & $\begin{array}{l}.110 \\
.10 \\
110 \\
.10 \\
.10\end{array}$ & $\begin{array}{l}.10 \\
.10 \\
.10 \\
.10 \\
.10\end{array}$ & $\begin{array}{r}10 \\
110 \\
110 \\
110 \\
110\end{array}$ & $\begin{array}{l}0 \\
0 \\
0 \\
0 \\
0\end{array}$ & $\begin{array}{r}138 \\
0 \\
0 \\
0 \\
0\end{array}$ \\
\hline $\begin{array}{l}16 \\
17 \\
18 \\
19 \\
20\end{array}$ & & & & & $\begin{array}{l}0 \\
0 \\
0 \\
0 \\
0\end{array}$ & $\begin{array}{l}0 \\
0 \\
0 \\
0 \\
0\end{array}$ & $\begin{array}{l}0 \\
0 \\
0 \\
0 \\
\quad .10\end{array}$ & $\begin{array}{r}+10 \\
110 \\
110 \\
.10 \\
110\end{array}$ & $\begin{array}{l}.10 \\
.10 \\
.10 \\
.10 \\
.10\end{array}$ & $\begin{array}{l}.10 \\
.10 \\
.10 \\
.10 \\
.10\end{array}$ & $\begin{array}{l}0 \\
0 \\
0 \\
0 \\
0\end{array}$ & $\begin{array}{l}0 \\
0 \\
0 \\
0 \\
0\end{array}$ \\
\hline $\begin{array}{l}21 \\
22 \\
23 \\
24 \\
25\end{array}$ & & & & & $\begin{array}{l}0 \\
0 \\
0 \\
0 \\
0\end{array}$ & $\begin{array}{l}0 \\
0 \\
0 \\
0 \\
0\end{array}$ & $\begin{array}{r}.10 \\
.10 \\
.10 \\
.10 \\
.10\end{array}$ & $\begin{array}{l}.10 \\
.10 \\
.10 \\
.10 \\
.10\end{array}$ & $\begin{array}{l}.10 \\
110 \\
.10 \\
.10 \\
.10\end{array}$ & $\begin{array}{l}.10 \\
.10 \\
.10 \\
.10 \\
.10\end{array}$ & $\begin{array}{l}0 \\
0 \\
0 \\
0 \\
0\end{array}$ & $\begin{array}{l}0 \\
0 \\
0 \\
0 \\
0\end{array}$ \\
\hline $\begin{array}{l}26 \\
27 \\
28 \\
29 \\
30 \\
31\end{array}$ & & --- & & & $\begin{array}{l}0 \\
0 \\
0 \\
0 \\
-\end{array}$ & $\begin{array}{l}0 \\
0 \\
0 \\
0 \\
0 \\
0\end{array}$ & $\begin{array}{l}.10 \\
.10 \\
.10 \\
.10 \\
.10 \\
2=-\end{array}$ & $\begin{array}{l}.10 \\
110 \\
110 \\
110 \\
110 \\
.10\end{array}$ & $\begin{array}{r}.10 \\
110 \\
110 \\
110 \\
110 \\
-2=\end{array}$ & $\begin{array}{l}.10 \\
.10 \\
.10 \\
.10 \\
.10 \\
.10\end{array}$ & $\begin{array}{l}0 \\
0 \\
0 \\
0 \\
0 \\
0\end{array}$ & $\begin{array}{l}0 \\
0 \\
0 \\
0 \\
0 \\
-\end{array}$ \\
\hline $\begin{array}{l}\text { TOTAL } \\
\text { MEAN } \\
\text { MAX } \\
\text { MIN } \\
\text { AC }-F T\end{array}$ & $\begin{array}{l}0 \\
0 \\
0 \\
0 \\
0\end{array}$ & $\begin{array}{l}0 \\
0 \\
0 \\
0 \\
0\end{array}$ & $\begin{array}{l}0 \\
0 \\
0 \\
0 \\
0\end{array}$ & $\begin{array}{l}0 \\
0 \\
0 \\
0 \\
0\end{array}$ & $\begin{array}{r}628.68 \\
21.7 \\
245 \\
0 \\
1250\end{array}$ & $\begin{array}{r}209.66 \\
6.76 \\
103 \\
0 \\
416\end{array}$ & $\begin{array}{r}104.00 \\
3.47 \\
77 \\
0 \\
206\end{array}$ & $\begin{array}{r}3.10 \\
.10 \\
.10 \\
.10 \\
6.1\end{array}$ & $\begin{array}{r}3.00 \\
.10 \\
.10 \\
.10 \\
6.0\end{array}$ & $\begin{array}{r}3.10 \\
.10 \\
.10 \\
.10 \\
6.1\end{array}$ & $\begin{array}{r}.15 \\
.005 \\
.10 \\
0 \\
.3\end{array}$ & $\begin{array}{r}497 \\
16.6 \\
359 \\
0 \\
986\end{array}$ \\
\hline
\end{tabular}

CAL YR 1975 TOTAL 1609.89 MEAN 4.41 MAX 254 MIN 0 AC-FT 3190 WTR YR 1976 TOTAL 1448.69 MEAN 3.96 MAX 359 MIN 0 AC-FT 2870 
PERIOD OF DAILY RECORD. - -

WATER TEMPERATURES: October 1967 to September 1969, October 1970 to September 1971 , October 1972 to current year.

SEDIMENT RECORDS: October 1967 to September 1971, October 1972 to current year.

REMARKS.--Particle-size distribution of bed material table was omitted in the 1975 water year and is published with 1976 water year records.

EXTREMES FOR PERIOD OF DAILY RECORD..-

SEDINENT CONCENTRATTONS: Maximum daily mean, 78,000 mg/1 Feb. 25, 1969; minimum daily mean, no flow for many days each year.

SEDIMENT DISCHARGE: Maximum daily, 2,670,000 tons $(2,420,000$ tonnes $\}$ Feb, 25, 1969; minimum daily, 0 tons

on many days each year.

EXTREMES FOR CURRENT YEAR, -

SEDIMENT CONCENTRATIONS: Maximum daily mean, 1,640 mg/l Sept. 10; minimum daily mean, no flow for many days. SEDIMENT DISCHARGE: Maximum daily, 4,170 tons $(3,780$ tonnes) Sept. 10 ; minimum daily, 0 tons on many days.

TEMPERATURE (DEG. C) OF HATER, WATER YEAR OCTOBER 1975 TO SEPTEMBER 1976

\begin{tabular}{|c|c|c|c|c|c|c|c|c|c|c|c|c|}
\hline \\
\hline DAY & OCT & NoV & DEC & JAN & FEB & MAR & $A P R$ & MAY & JUN & JUL & AUG & SEP \\
\hline $\begin{array}{l}1 \\
2 \\
3 \\
4 \\
5\end{array}$ & & & & & 15.0 & $\begin{array}{r}16.0 \\
17.0 \\
11.5 \\
16.5 \\
-.--\end{array}$ & & $\begin{array}{r}-=- \\
20.5 \\
---\end{array}$ & & $\begin{array}{l}-=- \\
=-\infty \\
--\infty \\
--\infty \\
--\infty\end{array}$ & & $=$ \\
\hline $\begin{array}{r}6 \\
7 \\
8 \\
9 \\
10\end{array}$ & & & & & $\begin{array}{l}12.0 \\
12.0 \\
14.5 \\
14.0 \\
15.5\end{array}$ & $\begin{array}{l}=-\infty \\
=-\infty \\
=-\infty \\
=-\infty\end{array}$ & & $\begin{array}{l}=-\infty \\
-=- \\
-=0 \\
=-\infty\end{array}$ & & $\begin{array}{r}--0 \\
29.0 \\
=---\end{array}$ & & 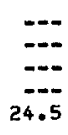 \\
\hline $\begin{array}{l}11 \\
12 \\
13 \\
14 \\
15\end{array}$ & & & & & $\begin{array}{r}21.0 \\
20.0 \\
15.5 \\
\ldots-.-\end{array}$ & $\begin{array}{l}=- \\
=-- \\
-\infty- \\
--\infty\end{array}$ & & $\begin{array}{l}=-0 \\
=-0 \\
=-- \\
=-\infty\end{array}$ & & $\begin{array}{l}=-0 \\
=-\infty \\
=-\infty \\
-=-\end{array}$ & & $\begin{array}{r}21.5 \\
=- \\
=- \\
=-\end{array}$ \\
\hline $\begin{array}{l}16 \\
17 \\
18 \\
19 \\
20\end{array}$ & & & & & $\begin{array}{l}--\infty \\
=-- \\
=- \\
-\infty\end{array}$ & $\begin{array}{l}--- \\
--\infty \\
-m- \\
---\end{array}$ & & $\begin{array}{l}=- \\
=-0 \\
=-0 \\
=-0 \\
=-\end{array}$ & & $\begin{array}{l}=- \\
=-- \\
=-- \\
=--\end{array}$ & & $\begin{array}{l}=- \\
=- \\
=-\infty\end{array}$ \\
\hline $\begin{array}{l}21 \\
22 \\
23 \\
24 \\
25\end{array}$ & & & & & $\begin{array}{l}=-\infty \\
=-\infty \\
=-\infty \\
=-\infty\end{array}$ & $\begin{array}{l}m-- \\
=-- \\
=-- \\
=-\infty \\
=-\infty\end{array}$ & & $\begin{array}{l}m-m \\
-m- \\
m-- \\
--\infty\end{array}$ & & $\begin{array}{l}-=- \\
--\infty \\
=-\infty \\
-=- \\
--\infty\end{array}$ & & 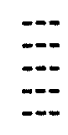 \\
\hline $\begin{array}{l}26 \\
27 \\
28 \\
29 \\
30 \\
31\end{array}$ & & & & & $\begin{array}{l}=- \\
=- \\
m- \\
m- \\
m-\end{array}$ & 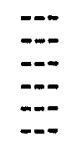 & & $\begin{array}{l}=- \\
=- \\
=- \\
--\infty \\
-\infty\end{array}$ & & $\begin{array}{l}=- \\
=- \\
=- \\
=-\end{array}$ & & $=0$ \\
\hline NTH & & & & & -- & -- & & $m$ & & $m$ & & 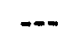 \\
\hline
\end{tabular}


11078000 SANTA ANA RIVER AT SANTA ANA, CA--Continued

SUSPENDED-SEDIMENT DISCHARGE (TONS/DAY), WATER YEAR OCTOBER 1975 TO SEPTEMBER 1976

\begin{tabular}{|c|c|c|c|c|c|c|c|c|c|}
\hline & & JANUARY & & & FEBRUARY & & & MARCH & \\
\hline DAY & $\begin{array}{l}\text { MEAN } \\
\text { DISCHARGE } \\
\text { (CFS) }\end{array}$ & $\begin{array}{l}\text { MEAN } \\
\text { CONCEN- } \\
\text { TRATION } \\
\text { (MG/L) }\end{array}$ & $\begin{array}{l}\text { SEDIMENT } \\
\text { DISCHARGE } \\
\text { (TONS/DAY) }\end{array}$ & $\begin{array}{l}\text { MEAN } \\
\text { DISCHARGE } \\
\text { (CFS) }\end{array}$ & $\begin{array}{l}\text { MEAN } \\
\text { CONCEN- } \\
\text { TRATION } \\
\text { (MG/L) }\end{array}$ & $\begin{array}{l}\text { SEDIMENT } \\
\text { DISCHARGE } \\
\text { (TONS/DAY) }\end{array}$ & $\begin{array}{l}\text { MEAN } \\
\text { DISCHARGE } \\
\text { (CFS) }\end{array}$ & $\begin{array}{l}\text { MEAN } \\
\text { CONCEN- } \\
\text { TRATION } \\
\text { (MG/L) }\end{array}$ & $\begin{array}{l}\text { SEDIMENT } \\
\text { DISCHARGE } \\
\text { (TONS/OAY) }\end{array}$ \\
\hline $\begin{array}{l}1 \\
2 \\
3 \\
4 \\
5\end{array}$ & & & & $\begin{array}{l}0 \\
0 \\
0 \\
0 \\
.98\end{array}$ & $\begin{array}{r}0 \\
0 \\
0 \\
0 \\
46\end{array}$ & $\begin{array}{l}0 \\
0 \\
0 \\
0 \\
.24\end{array}$ & $\begin{array}{c}103 \\
33 \\
59 \\
11 \\
1.1\end{array}$ & $\begin{array}{r}293 \\
203 \\
296 \\
35 \\
20\end{array}$ & $\begin{array}{l}247 \\
103 \\
96 \\
1.0 \\
.06\end{array}$ \\
\hline $\begin{array}{r}6 \\
7 \\
8 \\
9 \\
10\end{array}$ & & & & $\begin{array}{r}56 \\
63 \\
129 \\
245 \\
70\end{array}$ & $\begin{array}{l}314 \\
288 \\
534 \\
923 \\
300\end{array}$ & $\begin{array}{r}144 \\
68 \\
283 \\
817 \\
57\end{array}$ & $\begin{array}{l}0^{.06} \\
0 \\
0 \\
2.5\end{array}$ & $\begin{array}{r}5 \\
0 \\
0 \\
0 \\
46\end{array}$ & $\begin{array}{l}0 \\
0 \\
0 \\
0 \\
.65\end{array}$ \\
\hline $\begin{array}{l}11 \\
12 \\
13 \\
14 \\
15\end{array}$ & & & & $\begin{array}{l}22 \\
22 \\
17 \\
3.7 \\
0\end{array}$ & $\begin{array}{r}225 \\
215 \\
200 \\
110 \\
0\end{array}$ & $\begin{array}{l}13 \\
13 \\
9.2 \\
1.1 \\
0\end{array}$ & $\begin{array}{l}0 \\
0 \\
0 \\
0 \\
0\end{array}$ & $\begin{array}{l}0 \\
0 \\
0 \\
0 \\
0\end{array}$ & $\begin{array}{l}0 \\
0 \\
0 \\
0 \\
0\end{array}$ \\
\hline $\begin{array}{l}16 \\
17 \\
18 \\
19 \\
20\end{array}$ & & & & $\begin{array}{l}0 \\
0 \\
0 \\
0 \\
0\end{array}$ & $\begin{array}{l}0 \\
0 \\
0 \\
0 \\
0\end{array}$ & $\begin{array}{l}0 \\
0 \\
0 \\
0 \\
0\end{array}$ & $\begin{array}{l}0 \\
0 \\
0 \\
0 \\
0\end{array}$ & $\begin{array}{l}0 \\
0 \\
0 \\
0 \\
0\end{array}$ & $\begin{array}{l}0 \\
0 \\
0 \\
0 \\
0\end{array}$ \\
\hline $\begin{array}{l}21 \\
22 \\
23 \\
24 \\
25\end{array}$ & & & & $\begin{array}{l}0 \\
0 \\
0 \\
0 \\
0\end{array}$ & $\begin{array}{l}0 \\
0 \\
0 \\
0 \\
0\end{array}$ & $\begin{array}{l}0 \\
0 \\
0 \\
0 \\
0\end{array}$ & $\begin{array}{l}0 \\
0 \\
0 \\
0 \\
0\end{array}$ & $\begin{array}{l}0 \\
0 \\
0 \\
0 \\
0\end{array}$ & $\begin{array}{l}0 \\
0 \\
0 \\
0 \\
0\end{array}$ \\
\hline $\begin{array}{l}26 \\
27 \\
28 \\
29 \\
30 \\
31\end{array}$ & & & & $\begin{array}{l}0 \\
0 \\
0 \\
0 \\
-\ldots\end{array}$ & $\begin{array}{r}0 \\
0 \\
0 \\
0 \\
-- \\
--\end{array}$ & $\begin{array}{l}0 \\
0 \\
0 \\
0 \\
- \\
- \\
--\end{array}$ & $\begin{array}{l}0 \\
0 \\
0 \\
0 \\
0 \\
0\end{array}$ & $\begin{array}{l}0 \\
0 \\
0 \\
0 \\
0 \\
0\end{array}$ & $\begin{array}{l}0 \\
0 \\
0 \\
0 \\
0 \\
0\end{array}$ \\
\hline TOTAL & 0 & 0 & 0 & 628.68 & - & 1405.54 & 209.66 & $\cdots$ & 447.71 \\
\hline DAY & $\begin{array}{l}\text { MEAN } \\
\text { DISCHARGE } \\
\text { (CFS) }\end{array}$ & $\begin{array}{l}\text { APRIL } \\
\text { MEAN } \\
\text { CONCEN- } \\
\text { TRATION } \\
\text { (MG/L) }\end{array}$ & $\begin{array}{l}\text { SEDIMENT } \\
\text { DISCHARGE } \\
\text { (TONS/DAY) }\end{array}$ & $\begin{array}{l}\text { MEAN } \\
\text { DISCHARGE } \\
\text { (CFS) }\end{array}$ & $\begin{array}{l}\text { MAY } \\
\text { MEAN } \\
\text { CONCEN- } \\
\text { TRATION } \\
\text { (MG/L) }\end{array}$ & $\begin{array}{l}\text { SEOIMENT } \\
\text { DISCHARGE } \\
\text { (TONS/DAY) }\end{array}$ & $\begin{array}{l}\text { MEAN } \\
\text { OISCHARGE } \\
\text { (CFS) }\end{array}$ & $\begin{array}{l}\text { JUNE } \\
\text { MEAN } \\
\text { CONCEN- } \\
\text { TRATION } \\
\text { (MG/L) }\end{array}$ & $\begin{array}{l}\text { SEOIMENT } \\
\text { DISCHARGE } \\
\text { (TONS/DAY) }\end{array}$ \\
\hline $\begin{array}{l}1 \\
2 \\
3 \\
4 \\
5\end{array}$ & $\begin{array}{l}0 \\
0 \\
0 \\
8.1 \\
1.8\end{array}$ & $\begin{array}{r}0 \\
0 \\
0 \\
85 \\
25\end{array}$ & $\begin{array}{l}0 \\
0 \\
0 \\
3.2 \\
.22\end{array}$ & $\begin{array}{l}.10 \\
.10 \\
110 \\
.10 \\
10\end{array}$ & $\begin{array}{l}10 \\
10 \\
10 \\
10 \\
10\end{array}$ & & $\begin{array}{l}.10 \\
: 10 \\
110 \\
110 \\
110\end{array}$ & $\begin{array}{l}10 \\
10 \\
10 \\
10 \\
10\end{array}$ & $\begin{array}{l}0 \\
0 \\
0 \\
0 \\
0\end{array}$ \\
\hline $\begin{array}{r}6 \\
7 \\
8 \\
9 \\
10\end{array}$ & $\begin{array}{l}0 \\
0 \\
0 \\
0 \\
0\end{array}$ & $\begin{array}{l}0 \\
0 \\
0 \\
0 \\
0\end{array}$ & $\begin{array}{l}0 \\
0 \\
0 \\
0 \\
0\end{array}$ & $\begin{array}{l}10 \\
110 \\
110 \\
10 \\
10\end{array}$ & $\begin{array}{l}10 \\
10 \\
10 \\
10 \\
10\end{array}$ & & $\begin{array}{r}10 \\
110 \\
: 10 \\
.10 \\
.10\end{array}$ & $\begin{array}{r}10 \\
10 \\
10 \\
10 \\
135\end{array}$ & $\begin{array}{l}0 \\
0 \\
0 \\
0 \\
.04\end{array}$ \\
\hline $\begin{array}{l}11 \\
12 \\
13 \\
14 \\
15\end{array}$ & $\begin{array}{r}0 \\
16 \\
77 \\
0 \\
0\end{array}$ & $\begin{array}{r}0 \\
55 \\
256 \\
0 \\
0\end{array}$ & $\begin{array}{r}0 \\
81 \\
255 \\
0 \\
0\end{array}$ & $\begin{array}{l}.10 \\
: 10 \\
.10 \\
110 \\
.10\end{array}$ & $\begin{array}{l}10 \\
10 \\
10 \\
10 \\
10\end{array}$ & & $\begin{array}{l}.10 \\
: 10 \\
: 10 \\
10 \\
110\end{array}$ & $\begin{array}{l}10 \\
10 \\
10 \\
10 \\
10\end{array}$ & $\begin{array}{l}0 \\
0 \\
0 \\
0 \\
0\end{array}$ \\
\hline $\begin{array}{l}16 \\
17 \\
18 \\
19 \\
20\end{array}$ & $\begin{array}{l}0 \\
0 \\
0 \\
0 \\
.110\end{array}$ & $\begin{array}{r}0 \\
0 \\
0 \\
0 \\
10\end{array}$ & $\begin{array}{l}0 \\
0 \\
0 \\
0 \\
0\end{array}$ & $\begin{array}{l}.10 \\
.10 \\
.10 \\
.10 \\
.10\end{array}$ & $\begin{array}{l}10 \\
10 \\
10 \\
10 \\
10\end{array}$ & & $\begin{array}{l}.10 \\
.10 \\
110 \\
.10 \\
.10\end{array}$ & $\begin{array}{l}10 \\
10 \\
10 \\
10 \\
10\end{array}$ & $\begin{array}{l}0 \\
0 \\
0 \\
0 \\
0\end{array}$ \\
\hline $\begin{array}{l}21 \\
22 \\
23 \\
24 \\
25\end{array}$ & $\begin{array}{l}.10 \\
.10 \\
: 10 \\
.10 \\
.10\end{array}$ & $\begin{array}{l}10 \\
10 \\
10 \\
10 \\
10\end{array}$ & $\begin{array}{l}0 \\
0 \\
0 \\
0 \\
0\end{array}$ & $\begin{array}{l}.10 \\
.10 \\
.10 \\
.10 \\
10\end{array}$ & $\begin{array}{l}10 \\
10 \\
10 \\
10 \\
10\end{array}$ & & $\begin{array}{l}.10 \\
.10 \\
.10 \\
.10 \\
.10\end{array}$ & $\begin{array}{l}10 \\
10 \\
10 \\
10 \\
10\end{array}$ & $\begin{array}{l}0 \\
0 \\
0 \\
0 \\
0\end{array}$ \\
\hline $\begin{array}{l}26 \\
27 \\
28 \\
29 \\
30 \\
31\end{array}$ & $\begin{array}{l}.10 \\
.10 \\
.10 \\
.10 \\
: 10 \\
-.-\end{array}$ & $\begin{array}{r}10 \\
10 \\
10 \\
10 \\
10 \\
-10\end{array}$ & $\begin{array}{l}0 \\
0 \\
0 \\
0 \\
0\end{array}$ & $\begin{array}{l}.10 \\
.10 \\
110 \\
.10 \\
.10 \\
.10\end{array}$ & $\begin{array}{l}10 \\
10 \\
10 \\
10 \\
10 \\
10\end{array}$ & & $\begin{array}{r}10 \\
: 10 \\
110 \\
: 10 \\
: 10 \\
-:-\end{array}$ & $\begin{array}{r}10 \\
10 \\
10 \\
10 \\
10 \\
---\end{array}$ & $\begin{array}{l}0 \\
0 \\
0 \\
0 \\
0 \\
\ldots\end{array}$ \\
\hline TOTAL & 104.00 & --- & 339.42 & 3.10 &.-- & 0 & 3.00 &.-- & .04 \\
\hline
\end{tabular}


SUSPENDED-SEDIMENT DISCHARGE (TONS/DAY), HATER YEAR OCTOBER 1975 TO SEPTEMBER 1976

\begin{tabular}{|c|c|c|c|c|c|c|c|c|c|}
\hline \multirow[b]{2}{*}{ DAY } & \multicolumn{3}{|c|}{ JULY } & \multicolumn{3}{|c|}{ AUGUST } & \multicolumn{3}{|c|}{ SEPTEMAER } \\
\hline & $\begin{array}{l}\text { MEAN } \\
\text { DISCHARGE } \\
\text { (CFS) }\end{array}$ & $\begin{array}{l}\text { MEAN } \\
\text { CONCEN- } \\
\text { TRATION } \\
(M G / L)\end{array}$ & $\begin{array}{l}\text { SEDIMENT } \\
\text { DISCHARGE } \\
\text { (TONS/DAY) }\end{array}$ & $\begin{array}{l}\text { MEAN } \\
\text { DISCHARGE } \\
\text { (CFS) }\end{array}$ & $\begin{array}{l}\text { MEAN } \\
\text { CONCEN- } \\
\text { TRATI ON } \\
\text { (MG/L) }\end{array}$ & $\begin{array}{l}\text { SEDIMENT } \\
\text { DISCHARGE } \\
\text { (TONS/DAY) }\end{array}$ & $\begin{array}{l}\text { MEAN } \\
\text { DISCHARGE } \\
\text { (CFS) }\end{array}$ & $\begin{array}{l}\text { MEAN } \\
\text { CONCEN- } \\
\text { TRATION } \\
\text { (MGLI) }\end{array}$ & $\begin{array}{l}\text { SEDIMENT } \\
\text { DISCHARGE } \\
\text { (TONS/OAY) }\end{array}$ \\
\hline $\begin{array}{l}1 \\
2 \\
3 \\
4 \\
5\end{array}$ & $\begin{array}{l}: 10 \\
: 10 \\
: 10 \\
: 10 \\
110\end{array}$ & $\begin{array}{l}10 \\
10 \\
10 \\
10 \\
10\end{array}$ & & $\begin{array}{l}.10 \\
0 \\
0 \\
0 \\
0\end{array}$ & $\begin{array}{r}10 \\
5 \\
0 \\
0 \\
0\end{array}$ & & $\begin{array}{l}0 \\
0 \\
0 \\
0 \\
0\end{array}$ & $\begin{array}{l}0 \\
0 \\
0 \\
0 \\
0\end{array}$ & $\begin{array}{l}0 \\
0 \\
0 \\
0 \\
0\end{array}$ \\
\hline $\begin{array}{r}6 \\
7 \\
8 \\
9 \\
10\end{array}$ & $\begin{array}{l}10 \\
110 \\
110 \\
: 10 \\
110\end{array}$ & $\begin{array}{l}10 \\
10 \\
10 \\
10 \\
10\end{array}$ & & $\begin{array}{l}0 \\
0 \\
0 \\
0 \\
0\end{array}$ & $\begin{array}{l}0 \\
0 \\
0 \\
0 \\
0\end{array}$ & & $\begin{array}{r}0 \\
0 \\
0 \\
0 \\
359\end{array}$ & $\begin{array}{r}0 \\
0 \\
0 \\
0 \\
1640\end{array}$ & $\begin{array}{r}0 \\
0 \\
0 \\
0 \\
4170\end{array}$ \\
\hline $\begin{array}{l}11 \\
12 \\
13 \\
14 \\
15\end{array}$ & $\begin{array}{l}.10 \\
.10 \\
.10 \\
.10 \\
.10\end{array}$ & $\begin{array}{l}10 \\
10 \\
10 \\
10 \\
10\end{array}$ & & $\begin{array}{l}0 \\
0 \\
0 \\
0 \\
0\end{array}$ & $\begin{array}{l}0 \\
0 \\
0 \\
0 \\
0\end{array}$ & & $\begin{array}{r}138 \\
0 \\
0 \\
0 \\
0\end{array}$ & $\begin{array}{r}413 \\
0 \\
0 \\
0 \\
0\end{array}$ & $\begin{array}{r}572 \\
0 \\
0 \\
0 \\
0\end{array}$ \\
\hline $\begin{array}{l}16 \\
17 \\
18 \\
19 \\
20\end{array}$ & $\begin{array}{l}.10 \\
: 10 \\
: 10 \\
.10 \\
110\end{array}$ & $\begin{array}{l}10 \\
10 \\
10 \\
10 \\
10\end{array}$ & & $\begin{array}{l}0 \\
0 \\
0 \\
0 \\
0\end{array}$ & $\begin{array}{l}0 \\
0 \\
0 \\
0 \\
0\end{array}$ & & $\begin{array}{l}0 \\
0 \\
0 \\
0 \\
0\end{array}$ & $\begin{array}{l}0 \\
0 \\
0 \\
0 \\
0\end{array}$ & $\begin{array}{l}0 \\
0 \\
0 \\
0 \\
0\end{array}$ \\
\hline $\begin{array}{l}21 \\
22 \\
23 \\
24 \\
25\end{array}$ & $\begin{array}{l}.10 \\
.10 \\
.10 \\
10 \\
.10\end{array}$ & $\begin{array}{l}10 \\
10 \\
10 \\
10 \\
10\end{array}$ & & $\begin{array}{l}0 \\
0 \\
0 \\
0 \\
0\end{array}$ & $\begin{array}{l}0 \\
0 \\
0 \\
0 \\
0\end{array}$ & & $\begin{array}{l}0 \\
0 \\
0 \\
0 \\
0\end{array}$ & $\begin{array}{l}0 \\
0 \\
0 \\
0 \\
0\end{array}$ & $\begin{array}{l}0 \\
0 \\
0 \\
0 \\
0\end{array}$ \\
\hline $\begin{array}{l}26 \\
27 \\
28 \\
29 \\
30 \\
31\end{array}$ & $\begin{array}{l}.10 \\
: 10 \\
.10 \\
.10 \\
.10 \\
.10\end{array}$ & $\begin{array}{l}10 \\
10 \\
10 \\
10 \\
10 \\
10\end{array}$ & & $\begin{array}{l}0 \\
0 \\
0 \\
0 \\
0 \\
0\end{array}$ & $\begin{array}{l}0 \\
0 \\
0 \\
0 \\
0 \\
0\end{array}$ & & $\begin{array}{l}0 \\
0 \\
0 \\
0 \\
0 \\
- \\
--.\end{array}$ & $\begin{array}{r}0 \\
0 \\
0 \\
0 \\
0 \\
--\end{array}$ & $\begin{array}{l}0 \\
0 \\
0 \\
0 \\
0 \\
--.-\end{array}$ \\
\hline TOTAL & 3.10 & $\cdots$ & 0 & .15 & $\cdots$ & 0 & 497.00 & --- & $47,42.00$ \\
\hline YEAR & 1448.69 & & 6934.71 & & & & & & \\
\hline
\end{tabular}

SUMMARY OF WATER AND SEDIMENT OISCHARGE, WATER YEAR OCTOBER 1975 TO SEPTEMBER 1976

\begin{tabular}{|c|c|c|c|c|}
\hline MONTH & $\begin{array}{c}\text { HATER } \\
\text { DISCHARGE } \\
\text { CFS-DAYS }\end{array}$ & $\begin{array}{l}\text { SUSPENDED } \\
\text { SEDIMENT } \\
\text { OISCHARGE } \\
\text { TONS }\end{array}$ & $\begin{array}{c}\text { BEDLOAD } \\
\text { DISCHARGE } \\
\text { TONS }\end{array}$ & $\begin{array}{l}\text { TOTAL } \\
\text { SEDIMENT } \\
\text { DISCHARGE } \\
\text { TONS }\end{array}$ \\
\hline OCTOBER 1975 & 0.0 & 0.0 & 0 & 0 \\
\hline NOVEMBER ... & 0.0 & 0.0 & 0 & 0 \\
\hline DECEMBER ... & 0.0 & 0.0 & 0 & 0 \\
\hline JANUARY 1976 & 0.0 & 0.0 & 0 & o \\
\hline FEBRUARY $\ldots$ & 628.68 & 1405.54 & 688 & 2090 \\
\hline MARCH $\ldots \ldots$ & 209.66 & 447.71 & 169 & 617 \\
\hline APRIL $\ldots \ldots$ & 104.00 & 339.42 & 75 & 414 \\
\hline MAY $\ldots \ldots \ldots$ & 3.10 & 0.0 & 0 & 0 \\
\hline JUNE $\ldots \ldots \cdots$ & 3.00 & 0.04 & 0 & 0 \\
\hline JULY $\ldots \ldots .$. & 3.10 & 0.0 & 0 & 0 \\
\hline AUGUST $\ldots .$. & 0.15 & 0.0 & 0 & 0 \\
\hline SEPTEMBER & 497.00 & 4742.00 & 796 & 5540 \\
\hline TOTAL ...... & 1448.69 & 6934.71 & 1728 & 8661 \\
\hline
\end{tabular}


11078000 SANTA ANA RIVER AT SANTA ANA, CA--Continued

PARTICLE-SIZE DISTRIBUTION OF SUSPENOEO SEDIMENT, WATER YEAR OCTOBER 1975 TO SEPTEMBER 1976

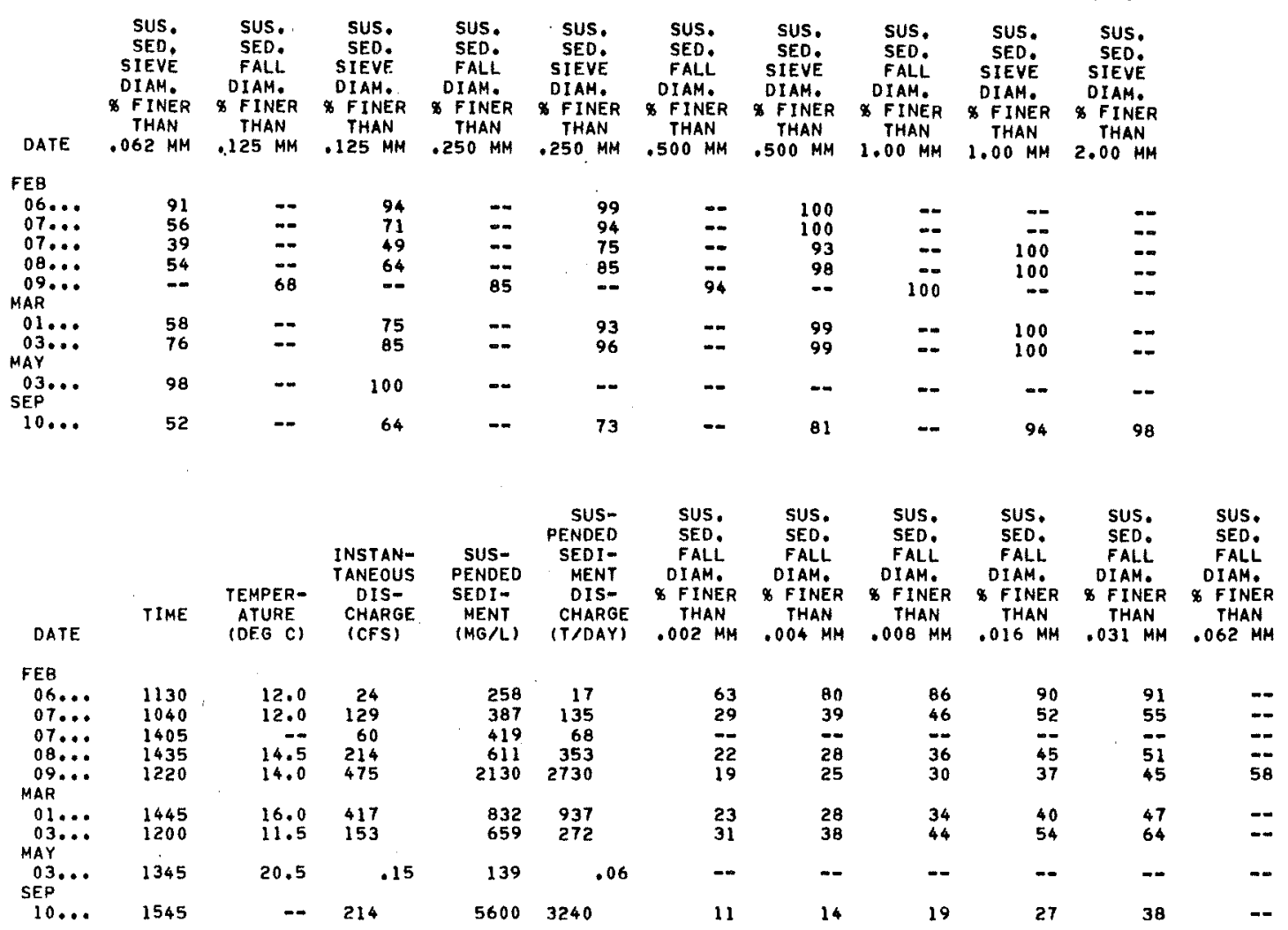

PARTICLE-SIZE DISTRIBUTION OF SURFACE BED MATERIAL. WATER YEAR OCTOBER 1974 TO SEPTEMBER 1975

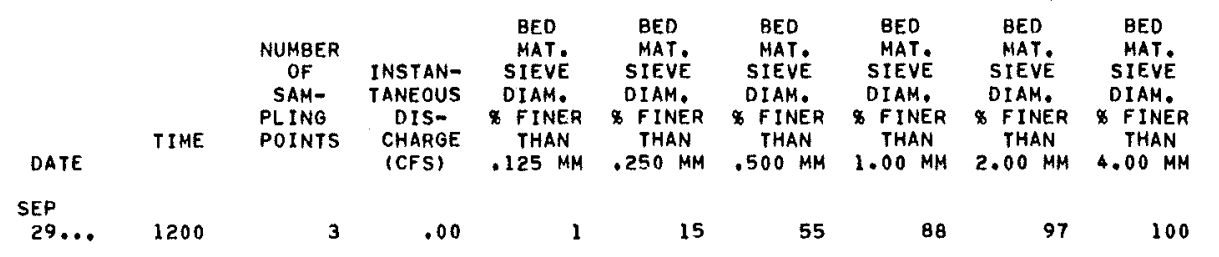


LOCATION, - Lat $33^{\circ} 40^{\prime} 19^{\prime \prime}$, long $117^{\circ} 56^{\prime} 42^{\prime \prime}$, on line between secs.5 and 8, T.6 S., R. 10 W., Orange County, 0.5 mi $(0.8 \mathrm{~km})$ east of Brookhurst Street, $1.3 \mathrm{mi}(2.1 \mathrm{~km})$ northwest of Fairview State Hospital and $2.5 \mathrm{mi}$ ( $4.0 \mathrm{~km})$ northwest of Costa Mesa.

DRAINAGE AREA. $\cdots-1,700 \mathrm{mi}^{2}\left(4,403 \mathrm{~km}^{2}\right)$, excludes $768 \mathrm{mi}^{2}\left(1,989 \mathrm{~km}^{2}\right)$ above Lake E1sinore

WATER-DISCHARGE RECORDS

PERIOD OF RECORD.--October 1974 to current year.

GAGE. - Nonrecording gage. Altitude of gage is $12 \mathrm{ft}(3.7 \mathrm{~m})$, from topographic map.

REMARKS. - Records poor. Discharge is computed from nonrecording gage readings made during periods of flow.

EXTREMES FOR PERIOD OF RECORD.--Maximum discharge, $5,100 \mathrm{ft}^{3} / \mathrm{s}\left(144 \mathrm{~m}^{3} / \mathrm{s}\right)$ Dec, 4, 1974 , gage height, $8.30 \mathrm{ft}$

$(2.530 \mathrm{ml})$; no flow most of each year.

EXTREMES FOR CURRENT YEAR,--Maximum discharge, $1,000 \mathrm{ft}^{3} / \mathrm{s}\left(28.3 \mathrm{~m}^{3} / \mathrm{s}\right) \mathrm{Feb} .9, \mathrm{gage}$ height, $5.46 \mathrm{ft}(1.664 \mathrm{~m})$;

no flow most of year.

DISCHARGE, IN CUBIC FEET PER SECONO, WATER YEAR OCTOBER 1975 TO SEPTEMBER 1976 MEAN VALUES

\begin{tabular}{|c|c|c|c|c|c|c|c|c|c|c|c|c|}
\hline DAY & $O C T$ & Nov & DEC & JAN & FEB & MAR & APR & MAY & JUN & JUL & AUG & SEP \\
\hline $\begin{array}{l}1 \\
2 \\
3 \\
4 \\
5\end{array}$ & & & & & $\begin{array}{l}0 \\
0 \\
0 \\
0 \\
0\end{array}$ & $\begin{array}{c}90 \\
16 \\
120 \\
6.5 \\
0\end{array}$ & $\begin{array}{l}0 \\
0 \\
0 \\
0 \\
0\end{array}$ & & & & & $\begin{array}{l}0 \\
0 \\
0 \\
0 \\
0\end{array}$ \\
\hline $\begin{array}{r}6 \\
7 \\
8 \\
9 \\
10\end{array}$ & & & & & $\begin{array}{r}31 \\
38 \\
78 \\
350 \\
70\end{array}$ & $\begin{array}{l}0 \\
0 \\
0 \\
0 \\
0\end{array}$ & $\begin{array}{l}0 \\
0 \\
0 \\
0 \\
0\end{array}$ & & & & & $\begin{array}{r}0 \\
0 \\
0 \\
0 \\
230\end{array}$ \\
\hline $\begin{array}{l}11 \\
12 \\
13 \\
14 \\
15\end{array}$ & & & & & $\begin{array}{l}32 \\
17 \\
7.0 \\
0 \\
0\end{array}$ & $\begin{array}{l}0 \\
0 \\
0 \\
0 \\
0\end{array}$ & $\begin{array}{l}0 \\
0 \\
52 \\
2.2 \\
0\end{array}$ & & & & & $\begin{array}{c}185 \\
0 \\
0 \\
0 \\
0\end{array}$ \\
\hline $\begin{array}{l}16 \\
17 \\
18 \\
19 \\
20\end{array}$ & & & & & $\begin{array}{l}0 \\
0 \\
0 \\
0 \\
0\end{array}$ & $\begin{array}{l}0 \\
0 \\
0 \\
0 \\
0\end{array}$ & $\begin{array}{l}0 \\
0 \\
0 \\
0 \\
0\end{array}$ & & & & & $\begin{array}{l}0 \\
0 \\
0 \\
0 \\
0\end{array}$ \\
\hline $\begin{array}{l}21 \\
22 \\
23 \\
24 \\
25\end{array}$ & & & & & $\begin{array}{l}0 \\
0 \\
0 \\
0 \\
0\end{array}$ & $\begin{array}{l}0 \\
0 \\
0 \\
0 \\
0\end{array}$ & $\begin{array}{l}0 \\
0 \\
0 \\
0 \\
0\end{array}$ & & & & & $\begin{array}{l}0 \\
0 \\
0 \\
0 \\
0\end{array}$ \\
\hline $\begin{array}{l}26 \\
27 \\
28 \\
29 \\
30 \\
31\end{array}$ & & $--m$ & & & $\begin{array}{l}0 \\
0 \\
0 \\
0 \\
-\cdots \\
-\cdots\end{array}$ & $\begin{array}{l}0 \\
0 \\
0 \\
0 \\
0 \\
0\end{array}$ & $\begin{array}{l}0 \\
0 \\
0 \\
0 \\
0 \\
---\end{array}$ & & $\cdots$ & & & $\begin{array}{l}0 \\
0 \\
0 \\
0 \\
0 \\
\end{array}$ \\
\hline $\begin{array}{l}\text { TOTAL } \\
\text { MEAN } \\
\text { MAX } \\
\text { MIN } \\
\text { AC-FT }\end{array}$ & $\begin{array}{l}0 \\
0 \\
0 \\
0 \\
0\end{array}$ & $\begin{array}{l}0 \\
0 \\
0 \\
0 \\
0\end{array}$ & $\begin{array}{l}0 \\
0 \\
0 \\
0 \\
0\end{array}$ & $\begin{array}{l}0 \\
0 \\
0 \\
0 \\
0\end{array}$ & $\begin{array}{r}623.0 \\
21.5 \\
350 \\
0 \\
1240\end{array}$ & $\begin{array}{r}232.5 \\
7.50 \\
120 \\
0 \\
461\end{array}$ & $\begin{array}{r}54.2 \\
1.81 \\
52 \\
0 \\
108\end{array}$ & $\begin{array}{l}0 \\
0 \\
0 \\
0 \\
0\end{array}$ & $\begin{array}{l}0 \\
0 \\
0 \\
0 \\
0\end{array}$ & $\begin{array}{l}0 \\
0 \\
0 \\
0 \\
0\end{array}$ & $\begin{array}{l}0 \\
0 \\
0 \\
0 \\
0\end{array}$ & $\begin{array}{r}415.83 \\
13.9 \\
230 \\
0 \\
825\end{array}$ \\
\hline
\end{tabular}

CAL YR 1975 TOTAL 1473.00 MEAN 4.04 MAX 228 MIN O AC-FT 2920

WTR YR 1976 TOTAL 1325.53 MEAN 3.62 MAX 350 MIN 0 AC-FT 2630 
11078100 SANTA ANA RIVER AT ADAMS AVENUE, NEAR COSTA MESA, CA- Continued

WATER-QUALITY RECORDS

PERIOD OF DAILY RECORD. - -

WATER TEMPERATURES: October 1973 to current year.

SEDIMENT RECORDS: October 1973 to current year.

REMARKS.--Sediment table omitted for period of no flow during october to December. Particle-size distribution of bed material table was omitted in the 1975 water year and is published with 1976 water year records.

EXTREMES FOR PERIOD OF DAILY RECORD. - -

SEDIMENT CONCENTRATIONS: Maximum daily mean, 10,200 $\mathrm{mg} / 1 \mathrm{Jan}$. 9, 1974; minimum daily mean, no f1ow for many days each year.

SEDIMENT DISCHARGE: Maximum daily, 27,800 tons $(25,200$ tonnes) Jan. 9, 1974 ; minimum daily, 0 tons on many days each year.

EXTREMES FOR CURRENT YEAR.--

SEDIMENT CONCENTRATIONS: Maximum daily mean, 2,760 mg/1 Sept. 10; minimum daily mean, no flow for many days. SEDIMENT DISCHARGE: Maximum daily, 3,930 tons ( 3,560 tonnes) sept, 10 ; minimum daily, 0 tons on many days.

TEMPERATURE (OEG, C) OF WATER, WATER YEAR OCTOBER 1975 TO SEPTEMBER 1976 ONCE-DAILY

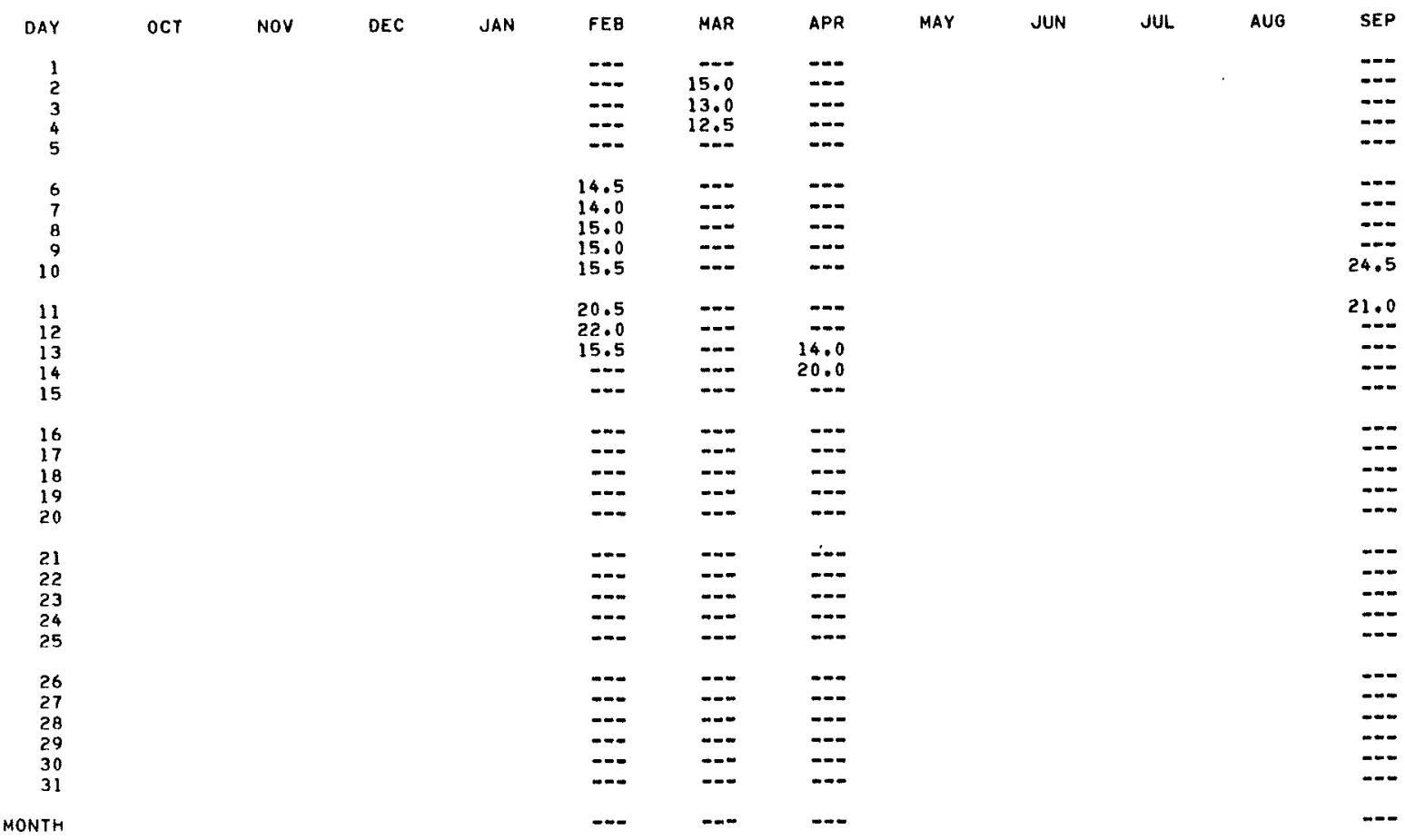


11078100 SANTA ANA RIVER AT ADAMS AVENUE, NEAR COSTA MESA, CA--Continued

SUSPENDED-SEDIMENT DISCHARGE (TONS/DAY), HATER YEAR OCTOBER 1975 TO SEPTEMBER 1976

\begin{tabular}{|c|c|c|c|c|c|c|c|c|c|}
\hline & & JANUARY & & & FEBRUARY & & & MARCH & \\
\hline DAY & $\begin{array}{l}\text { MEAN } \\
\text { DISCHARGE } \\
\text { (CFS) }\end{array}$ & $\begin{array}{l}\text { MEAN } \\
\text { CONCEN- } \\
\text { TRATION } \\
\text { (MG/L) }\end{array}$ & $\begin{array}{l}\text { SEDIMENT } \\
\text { DISCHARGE } \\
\text { (TONS/OAY) }\end{array}$ & $\begin{array}{l}\text { MEAN } \\
\text { DISCHARGE } \\
\text { (CFS) }\end{array}$ & $\begin{array}{l}\text { MEAN } \\
\text { CONCEN- } \\
\text { TRATION } \\
\text { (MG/L) }\end{array}$ & $\begin{array}{l}\text { SEDIMENT } \\
\text { DISCHARGE } \\
\text { (TONS/DAY) }\end{array}$ & $\begin{array}{l}\text { MFAN } \\
\text { DISCHARGE } \\
\text { (CFS) }\end{array}$ & $\begin{array}{l}\text { MEAN } \\
\text { CONCEN- } \\
\text { TRATION } \\
\text { (MG/L) }\end{array}$ & $\begin{array}{l}\text { SEOIMENT } \\
\text { DI SCHARGE } \\
\text { (TONS /OAY) }\end{array}$ \\
\hline $\begin{array}{l}1 \\
2 \\
3 \\
4 \\
5\end{array}$ & & & & $\begin{array}{l}0 \\
0 \\
0 \\
0 \\
0\end{array}$ & $\begin{array}{l}0 \\
0 \\
0 \\
0 \\
0\end{array}$ & $\begin{array}{l}0 \\
0 \\
0 \\
0 \\
0\end{array}$ & $\begin{array}{c}90 \\
16 \\
120 \\
6.5 \\
0\end{array}$ & $\begin{array}{r}290 \\
72 \\
470 \\
48 \\
0\end{array}$ & $\begin{array}{c}290 \\
6.6 \\
287 \\
1.3 \\
0\end{array}$ \\
\hline $\begin{array}{r}6 \\
7 \\
8 \\
9 \\
10\end{array}$ & & & & $\begin{array}{r}31 \\
38 \\
78 \\
350 \\
70\end{array}$ & $\begin{array}{r}379 \\
453 \\
644 \\
1630 \\
460\end{array}$ & $\begin{array}{r}92 \\
96 \\
151 \\
1930 \\
97\end{array}$ & $\begin{array}{l}0 \\
0 \\
0 \\
0 \\
0\end{array}$ & $\begin{array}{l}0 \\
0 \\
0 \\
0 \\
0\end{array}$ & $\begin{array}{l}0 \\
0 \\
0 \\
0 \\
0\end{array}$ \\
\hline $\begin{array}{l}11 \\
12 \\
13 \\
14 \\
15\end{array}$ & & & - & $\begin{array}{l}32 \\
17 \\
7.0 \\
0 \\
0\end{array}$ & $\begin{array}{r}390 \\
260 \\
150 \\
52 \\
0\end{array}$ & $\begin{array}{l}34 \\
12 \\
2.8 \\
0 \\
0\end{array}$ & $\begin{array}{l}0 \\
0 \\
0 \\
0 \\
0\end{array}$ & $\begin{array}{l}0 \\
0 \\
0 \\
0 \\
0\end{array}$ & $\begin{array}{l}0 \\
0 \\
0 \\
0 \\
0\end{array}$ \\
\hline $\begin{array}{l}16 \\
17 \\
18 \\
19 \\
20\end{array}$ & & & & $\begin{array}{l}0 \\
0 \\
0 \\
0 \\
0\end{array}$ & $\begin{array}{l}0 \\
0 \\
0 \\
0 \\
0\end{array}$ & $\begin{array}{l}0 \\
0 \\
0 \\
0 \\
0\end{array}$ & $\begin{array}{l}0 \\
0 \\
0 \\
0 \\
0\end{array}$ & $\begin{array}{l}0 \\
0 \\
0 \\
0 \\
0\end{array}$ & $\begin{array}{l}0 \\
0 \\
0 \\
0 \\
0\end{array}$ \\
\hline $\begin{array}{l}21 \\
22 \\
23 \\
24 \\
25\end{array}$ & & & & $\begin{array}{l}0 \\
0 \\
0 \\
0 \\
0\end{array}$ & $\begin{array}{l}0 \\
0 \\
0 \\
0 \\
0\end{array}$ & $\begin{array}{l}0 \\
0 \\
0 \\
0 \\
0\end{array}$ & $\begin{array}{l}0 \\
0 \\
0 \\
0 \\
0\end{array}$ & $\begin{array}{l}0 \\
0 \\
0 \\
0 \\
0\end{array}$ & $\begin{array}{l}0 \\
0 \\
0 \\
0 \\
0\end{array}$ \\
\hline $\begin{array}{l}26 \\
27 \\
28 \\
29 \\
30 \\
31\end{array}$ & & & & $\begin{array}{l}0 \\
0 \\
0 \\
0 \\
-\ldots \\
\ldots\end{array}$ & $\begin{array}{r}0 \\
0 \\
0 \\
0 \\
--- \\
---\end{array}$ & $\begin{array}{l}0 \\
0 \\
0 \\
0 \\
-=- \\
=-\end{array}$ & $\begin{array}{l}0 \\
0 \\
0 \\
0 \\
0 \\
0\end{array}$ & $\begin{array}{l}0 \\
0 \\
0 \\
0 \\
0 \\
0\end{array}$ & $\begin{array}{l}0 \\
0 \\
0 \\
0 \\
0 \\
0\end{array}$ \\
\hline \multirow[t]{3}{*}{ TOTAL } & 0 & 0 & 0 & 623.00 & $m$ & 2414.80 & 232.50 & --- & 584.90 \\
\hline & & APRIL & & & MAY & & & JUNE & \\
\hline & $\begin{array}{l}\text { MEAN } \\
\text { DISCHARGE } \\
\text { (CFS) }\end{array}$ & $\begin{array}{l}\text { MEAN } \\
\text { CONCEN- } \\
\text { TRAT I ON } \\
\text { (MG/L) }\end{array}$ & $\begin{array}{l}\text { SEOIMENT } \\
\text { DISCHARGE } \\
\text { (TONS/OAY) }\end{array}$ & $\begin{array}{l}\text { MEAN } \\
\text { DISCHARGE } \\
\text { (CFS) }\end{array}$ & $\begin{array}{l}\text { MEAN } \\
\text { CONCEN- } \\
\text { TRATION } \\
\text { (MG/L) }\end{array}$ & $\begin{array}{l}\text { SEDIMENT } \\
\text { OISCHARGE } \\
\text { (TONS/DAY) }\end{array}$ & $\begin{array}{l}\text { MEAN } \\
\text { DISCHARGE } \\
\text { (CFS) }\end{array}$ & $\begin{array}{l}\text { MEAN } \\
\text { CONCEN- } \\
\text { TRATI ON } \\
\text { (MG/L) }\end{array}$ & $\begin{array}{l}\text { SEOIMENT } \\
\text { OISCHARGE } \\
\text { (TONS/DAY) }\end{array}$ \\
\hline
\end{tabular}


11078100 SANTA ANA RIVER AT ADAMS AVENUE, NEAR COSTA MESA, CA--Continued

SUSPENDEO-SEOIMENT OISCHARGE (TONS/DAY), WATER YEAR OCTOBER 1975 TO SEPTEMBER 1976

AY

\begin{tabular}{|c|c|c|c|c|}
\hline & JULY & & & AUGUST \\
\hline $\begin{array}{l}\text { MEAN } \\
\text { DISCHARGE } \\
\text { (CFS) }\end{array}$ & $\begin{array}{l}\text { HEAN } \\
\text { CONCEN- } \\
\text { TRATION } \\
\text { (MG/L) }\end{array}$ & $\begin{array}{l}\text { SEDIMENT } \\
\text { OISCHARGE } \\
\text { (TONS/DAY) }\end{array}$ & $\begin{array}{l}\text { MEAN } \\
\text { DISCHARGE } \\
\text { (CFS) }\end{array}$ & $\begin{array}{l}\text { MEAN } \\
\text { CONCEN- } \\
\text { TRATION } \\
\text { (MG/L) }\end{array}$ \\
\hline
\end{tabular}

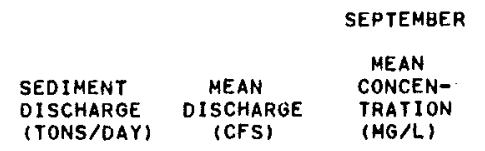

SEDIMENT

DISCHARGE

(TONS/DAY)

1
2
3
4
5

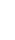

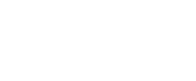

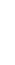

9987.90

SUMMARY OF WATER AND SEOIMENT DISCHARGE, WATER YEAR OCTOBER 1975 TO SEPTEMBER I'976

\begin{tabular}{|c|c|c|c|c|}
\hline MONTH & $\begin{array}{l}\text { WATER } \\
\text { OISCHARGE } \\
\text { CFS-DAYS }\end{array}$ & $\begin{array}{l}\text { SUSPENDED } \\
\text { SEDIMENT } \\
\text { DISCHARGE } \\
\text { TONS }\end{array}$ & $\begin{array}{c}\text { BEDLOAD } \\
\text { DISCHARGE } \\
\text { TONS }\end{array}$ & $\begin{array}{l}\text { TOTAL. } \\
\text { SEDIMENT } \\
\text { DI SCHARGE } \\
\text { TONS }\end{array}$ \\
\hline OCTOBER 1975 & 0.0 & 0.0 & 0 & 0 \\
\hline NOVEMBER «. & 0.0 & 0.0 & 0 & 0 \\
\hline DECEMBER $\ldots$ & 0.0 & 0.0 & D & 0 \\
\hline JANUARY 1976 & 0.0 & 0.0 & 0 & 0 \\
\hline FEBRUARY ... & 623.00 & 2414.80 & 1040 & 3450 \\
\hline MARCH $\ldots \ldots$ & 232.50 & 584.90 & 257 & 842 \\
\hline APRIL $\ldots \ldots$ & $54 \cdot 20$ & 108.15 & 37 & 145 \\
\hline MAY $\ldots \ldots \ldots$ & 0.0 & 0.0 & 0 & 0 \\
\hline JUNE $\ldots \ldots$ & 0.0 & 0.0 & 0 & 0 \\
\hline JULY $\ldots \ldots$ & 0.0 & 0.0 & 0 & 0 \\
\hline AUGUST $\ldots \ldots$ & 0.0 & 0.0 & 0 & 0 \\
\hline SEPTEMBER .. & 415.83 & 6880.05 & 768 & 7650 \\
\hline TOTAL ...... & 1325.53 & 9987.90 & 2102 & 12087 \\
\hline
\end{tabular}


PARTICLE-SIZE DISTRIBUTION OF SUSPENDED SEDIMENT, WATER YEAR OCTOBER 1975 TO SEPTEMEER 1976

\begin{tabular}{|c|c|c|c|c|c|c|c|c|c|}
\hline DATE & TIME & $\begin{array}{l}\text { TEMPER- } \\
\text { ATURE } \\
\text { (DEG C) }\end{array}$ & $\begin{array}{l}\text { INSTAN- } \\
\text { TANEOUS } \\
\text { DIS- } \\
\text { CHARGE } \\
\text { (CFS) }\end{array}$ & $\begin{array}{l}\text { SUS- } \\
\text { PENDED } \\
\text { SEDI - } \\
\text { MENT } \\
\text { (MG } / L)\end{array}$ & $\begin{array}{c}\text { SUS- } \\
\text { PENDED } \\
\text { SEDI- } \\
\text { MENT } \\
\text { DIS- } \\
\text { CHARGE } \\
\text { (T/DAY) }\end{array}$ & $\begin{array}{l}\text { SUS. } \\
\text { SED, } \\
\text { FALL } \\
\text { OIAM. } \\
\text { O FINER } \\
\text { THAN } \\
\text { OOO MM }\end{array}$ & $\begin{array}{l}\text { SUS. } \\
\text { SED, } \\
\text { FALL } \\
\text { DIAM, } \\
\text { D FINER } \\
\text { THAN } \\
.004 \text { MH }\end{array}$ & $\begin{array}{l}\text { SUS. } \\
\text { SED. } \\
\text { FALL } \\
\text { DIAM. } \\
\text { D FINER } \\
\text { THAN } \\
\text { OOOB MM }\end{array}$ & $\begin{array}{l}\text { SUS. } \\
\text { SED. } \\
\text { FALL } \\
\text { DIAM. } \\
\text { \$ FINER } \\
\text { THAN } \\
\text { OIS MH }\end{array}$ \\
\hline \multicolumn{10}{|l|}{ FEB } \\
\hline $\begin{array}{l}06 \ldots \\
07 \ldots \\
09 \ldots \\
09 \ldots \\
\text { SEP }\end{array}$ & $\begin{array}{l}1315 \\
1430 \\
1230 \\
1305\end{array}$ & $\begin{array}{l}14.5 \\
14.0 \\
15.0 \\
15.0\end{array}$ & $\begin{array}{r}41 \\
90 \\
280 \\
360\end{array}$ & $\begin{array}{l}1210 \\
1190 \\
1920 \\
2720\end{array}$ & $\begin{array}{r}134 \\
289 \\
1450 \\
2640\end{array}$ & $\begin{array}{l}44 \\
31 \\
33 \\
24\end{array}$ & $\begin{array}{l}60 \\
43 \\
42 \\
30\end{array}$ & $\begin{array}{l}75 \\
56 \\
55 \\
39\end{array}$ & $\begin{array}{l}87 \\
68 \\
68 \\
47\end{array}$ \\
\hline $\begin{array}{l}10 \ldots \\
10 \ldots \\
10 \ldots \\
11 \ldots\end{array}$ & $\begin{array}{l}1715 \\
1755 \\
1800 \\
1440\end{array}$ & $\begin{array}{r}24.5 \\
24.0 \\
24.0 \\
.-\end{array}$ & $\begin{array}{r}51 \\
400 \\
620 \\
5.0\end{array}$ & $\begin{array}{r}2840 \\
9600 \\
8980 \\
253\end{array}$ & $\begin{array}{r}391 \\
10400 \\
15000 \\
3.4\end{array}$ & $\begin{array}{l}38 \\
34 \\
37 \\
--\end{array}$ & $\begin{array}{l}54 \\
41 \\
45 \\
-0\end{array}$ & $\begin{array}{l}71 \\
60 \\
64 \\
-0\end{array}$ & $\begin{array}{l}86 \\
80 \\
84 \\
--\end{array}$ \\
\hline
\end{tabular}

\begin{tabular}{|c|c|c|c|c|c|c|c|c|}
\hline & $\begin{array}{l}\text { SUS. } \\
\text { SED. } \\
\text { FALL } \\
\text { DIAH. } \\
\text { \& FINER } \\
\text { THAN }\end{array}$ & $\begin{array}{l}\text { SUS. } \\
\text { SED } \\
\text { FALL } \\
\text { DIAM. } \\
\text { \$ FINER } \\
\text { THAN }\end{array}$ & $\begin{array}{l}\text { SUS. } \\
\text { SED. } \\
\text { SIEVE } \\
\text { DIAM. } \\
\text { FINER } \\
\text { THAN }\end{array}$ & $\begin{array}{l}\text { SUS. } \\
\text { SED } \\
\text { FALL } \\
\text { DIAM. } \\
\text { FINER } \\
\text { THAN }\end{array}$ & $\begin{array}{l}\text { SUS. } \\
\text { SED. } \\
\text { SIEVE } \\
\text { DIAM. } \\
\text { FINER } \\
\text { THAN }\end{array}$ & $\begin{array}{l}\text { SUS. } \\
\text { SED. } \\
\text { FALL } \\
\text { DIAH. } \\
\text { \& FINER } \\
\text { THAN }\end{array}$ & $\begin{array}{l}\text { SUS. } \\
\text { SED } \\
\text { SIEVE } \\
\text { DIAH. } \\
\text { D FINER } \\
\text { THAN }\end{array}$ & $\begin{array}{l}\text { SUS. } \\
\text { SED. } \\
\text { FALL } \\
\text { OIAM. } \\
\text { \$ FINER } \\
\text { THAN }\end{array}$ \\
\hline ITE & $.031 \mathrm{MM}$ & $.062 \mathrm{MM}$ & $.062 \mathrm{MM}$ & $.125 \mathrm{MM}$ & $.125 \mathrm{MM}$ & $.250 \mathrm{MM}$ & $.250 \mathrm{MM}$ & $.500 \mathrm{MH}$ \\
\hline
\end{tabular}

\begin{tabular}{|c|c|c|c|c|c|c|c|c|}
\hline \multicolumn{9}{|l|}{ FEB } \\
\hline $06 \ldots$ & 94 & 96 & $=-$ & 97 & -- & 100 & -- & $\ldots$ \\
\hline $07 \ldots$ & 79 & 86 & -- & 93 & $-\infty$ & 100 & $=$ & $=$ \\
\hline $09 \ldots$ & 80 & 93 & -- & 100 & -- & $=$ & -- & - \\
\hline 09. & 58 & 74 & -- & 91 & - & 99 & - & 100 \\
\hline SEP & & & & & & & & \\
\hline $10 \ldots$ & 95 & $=$ & 98 & $m$ & 99 & - & 100 & - \\
\hline & 96 & $=$ & 99 & - & 100 & - & - & $\ldots$ \\
\hline $10 \ldots$ & 97 & $m$ & 99 & $-m$ & 99 & - & 100 & $\ldots$ \\
\hline $11 \ldots$ & -- & $-\infty$ & 98 & -- & 99 & -- & 100 & $-\infty$ \\
\hline
\end{tabular}

PARTICLE-SIZE DISTRIBUTION OF SURFACE BED MATERIAL. WATER YEAR OCTOBER 1974 TO SEPTEMBER 1975

\begin{tabular}{|c|c|c|c|c|c|c|c|c|c|c|c|c|}
\hline & TIME & $\begin{array}{c}\text { NUMBER } \\
\text { OF } \\
\text { SAM- } \\
\text { PLING } \\
\text { POINTS }\end{array}$ & $\begin{array}{l}\text { INSTAN- } \\
\text { TANEOUS } \\
\text { DIS- } \\
\text { CHARGE }\end{array}$ & $\begin{array}{l}\text { BED } \\
\text { MAT. } \\
\text { SIEVE } \\
\text { DIAM. } \\
\text { Q FINER } \\
\text { THAN }\end{array}$ & $\begin{array}{l}\text { BED } \\
\text { MAT. } \\
\text { SIEVE } \\
\text { DIAM. } \\
\text { D FINER } \\
\text { THAN }\end{array}$ & $\begin{array}{l}\text { BED } \\
\text { MAT. } \\
\text { SIEVE } \\
\text { DIAM, } \\
\text { D FINER } \\
\text { THAN }\end{array}$ & $\begin{array}{l}\text { BED } \\
\text { MAT. } \\
\text { SIEVE } \\
\text { DIAM. } \\
\text { Q FINER } \\
\text { THAN }\end{array}$ & $\begin{array}{l}\text { BED } \\
\text { MAT. } \\
\text { SIEVE } \\
\text { DIAM. } \\
\text { \$ FINER } \\
\text { THAN }\end{array}$ & $\begin{array}{l}\text { BED } \\
\text { MAT. } \\
\text { SIEVE } \\
\text { DIAM. } \\
\text { \$ FINER } \\
\text { THAN }\end{array}$ & $\begin{array}{l}\text { BED } \\
\text { MAT. } \\
\text { SIEVE } \\
\text { OIAM. } \\
\text { F FINER } \\
\text { THAN }\end{array}$ & $\begin{array}{l}\text { BED } \\
\text { MAT. } \\
\text { SIEVE } \\
\text { OIAM. } \\
\text { X FINER } \\
\text { THAN }\end{array}$ & $\begin{array}{l}\text { BED } \\
\text { MAT. } \\
\text { SIEVE } \\
\text { DIAM. } \\
\text { \$ FINER } \\
\text { THAN }\end{array}$ \\
\hline TIE & & & (CFS) & $.062 \mathrm{MH}$ & $.125 \mathrm{MM}$ & $.250 \mathrm{MM}$ & $.500 \mathrm{MH}$ & $1.00 \mathrm{MH}$ & $2.00 \mathrm{MM}$ & $4.00 \mathrm{MA}$ & $8.00 \mathrm{MM}$ & $16.0 \mathrm{MH}$ \\
\hline $\begin{array}{l}E P \\
29 . \ldots\end{array}$ & 1145 & 3 & .00 & 11 & 34 & 62 & 89 & 96 & 98 & 98 & 99 & 100 \\
\hline
\end{tabular}




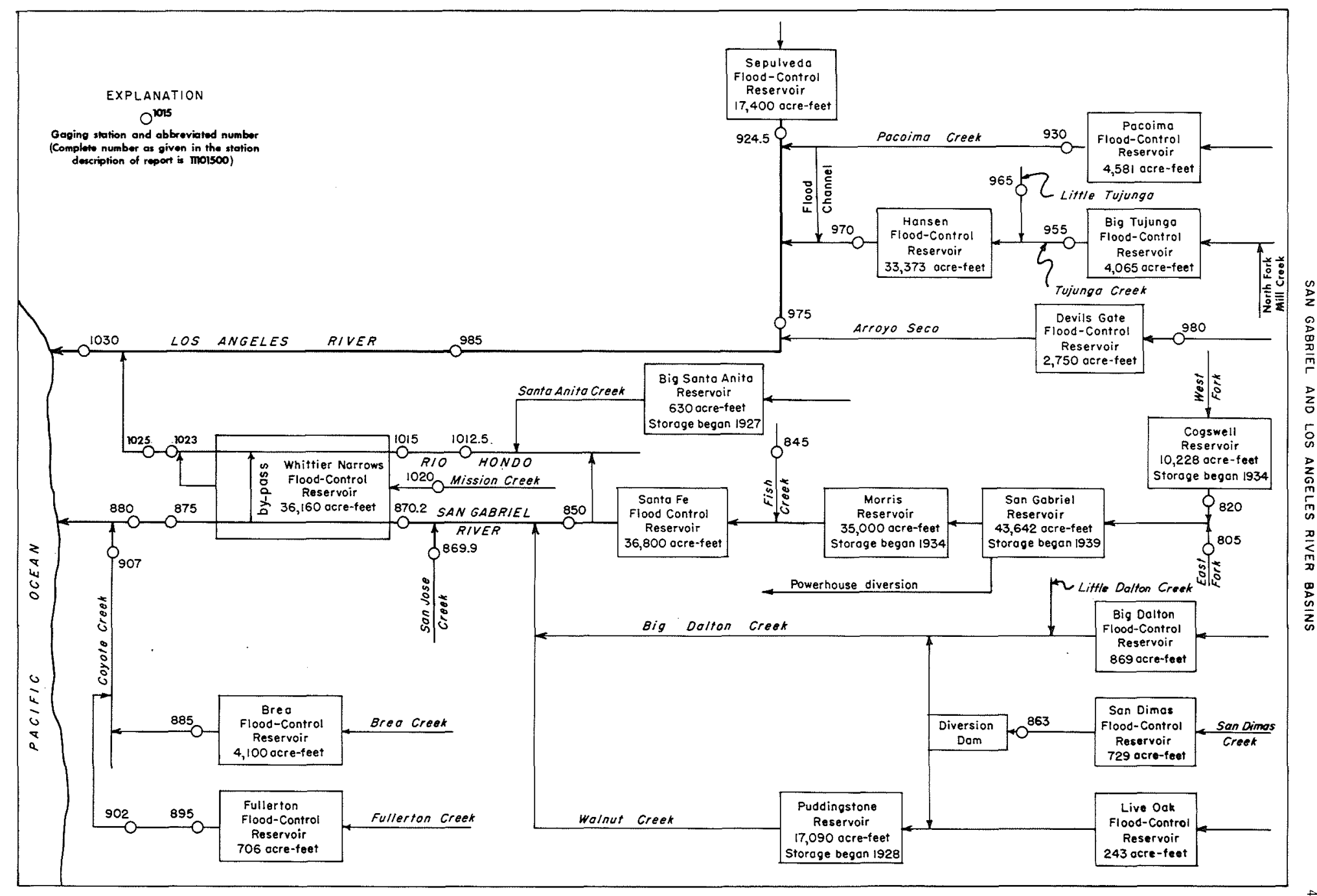

Figure 6.--Schematic diogrom showing diversions and storage in San Gabriel and Los Angeles River basins. 


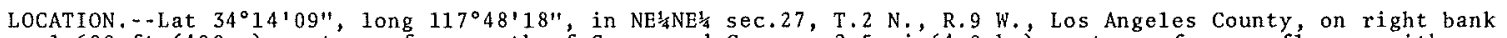
$1,600 \mathrm{ft}(400 \mathrm{~m})$ upstream from mouth of Graveyard Canyon, $2.5 \mathrm{mi}(4.0 \mathrm{~km})$ upstream from confiuence with West Fork, and $2.5 \mathrm{mi}(4.0 \mathrm{~km})$ west of Camp Bonita.

DRAINAGE AREA, $--84.6 \mathrm{mi}^{2}\left(219.1 \mathrm{~km}^{2}\right)$.

PERIOD OF RECORD.--December 1932 to current year. Prior to 1940 , pub1ished as San Gabrie1 River near Camp Bonita.

GAGE.--Water-stage recorder. Datum of gage is $1,567.04 \mathrm{ft}(477.634 \mathrm{~m})$ above mean sea 1 eve 1 (1eve1s by Los Angeles County F1ood Contro1 District), Prior to Dec, 10 , 1938 , at site $0.6 \mathrm{mi}$ (1.0 km) downstream at different datum.

REMARKS.--Records fair. No regulation or diversion above station. See schematic diagram of San Gabriel and Los Angeles River basins.

COOPERATION.--Records were furnished by Los Angeles County Flood Control District.

AVERAGE DISCHARGE, -43 years (water years $1934-76), 67.6 \mathrm{ft}^{3} / \mathrm{s}\left(1.914 \mathrm{~m}^{3} / \mathrm{s}\right), 48,980 \mathrm{acre}-\mathrm{ft} / \mathrm{yr}\left(60.4 \mathrm{hm}{ }^{3} / \mathrm{yr}^{2}\right)$.

EXTREMES FOR PERIOD OF RECORD. - Maximum discharge, $46,000 \mathrm{ft}^{3} / \mathrm{s}\left(1,300 \mathrm{~m}^{3} / \mathrm{s}\right) \mathrm{Mar}$. 2 , 1938 , from rating

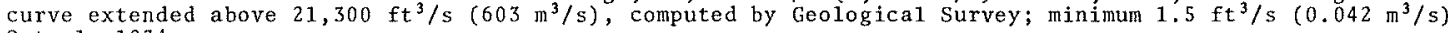
oct. 1,1934

EXTREMES FOR CURRENT YEAR.--MaXimum discharge $5,120 \mathrm{ft}^{3} / \mathrm{s}\left(145 \mathrm{~m}^{3} / \mathrm{s}\right)$ Sept, 10, gage height, 12.22 ft (3.725 m); minimum daily, $8.7 \mathrm{ft}^{3} / \mathrm{s}\left(0.25 \mathrm{~m}^{3} / \mathrm{s}\right)$ Aug. 30,31 and Sept. 5 .

DISCHARGE, IN CUBIC FEET PER SECONO, WATER YEAR OCTOBER 1975 TO SEPTEMBER 1976 MEAN VALUES

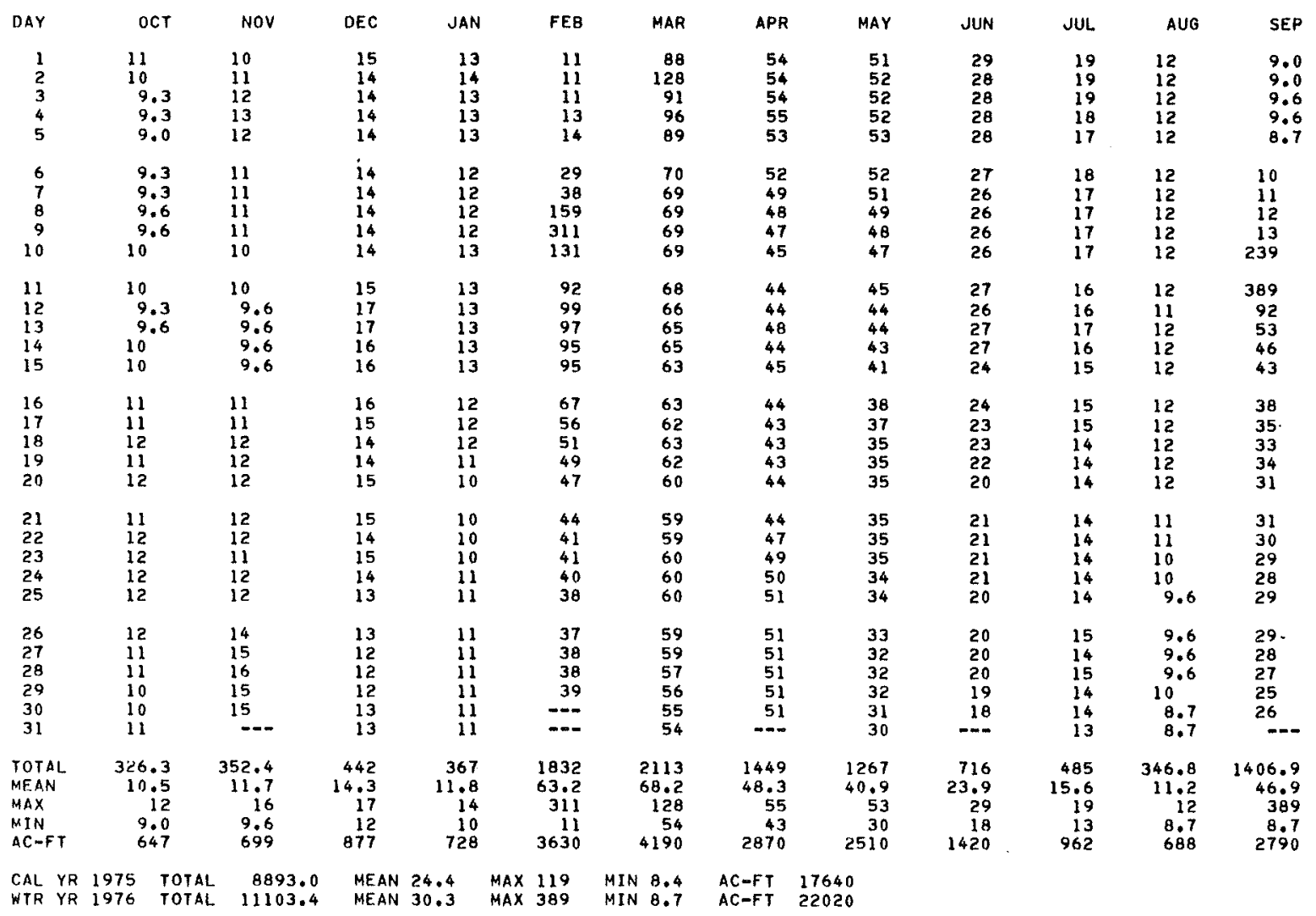


11082000 WEST FORK SAN GABRIEL RIVER AT CAMP RINCON, CA

LOCATION, - - Lat $34^{\circ} 14^{\prime} 28^{\prime \prime}$, Long $117^{\circ} 51^{\prime} 45^{\prime \prime}$, Los Angeles County, in Angeles National Forest, on right bank 0.2 mi $(0.3 \mathrm{~km})$ upstream from Camp Rincon, $0.5 \mathrm{mi}(0.8 \mathrm{~km})$ downstream from North Fork, and $6 \mathrm{mi}$ (10 km) downstream from Cogswe11 Dam.

DRAINAGE AREA, $-104 \mathrm{mi}^{2}\left(269 \mathrm{~km}^{2}\right)$.

PERIOD OF RECORD. - - October 1927 to current year.

GAGE. - Water-stage recorder. Datum of gage is $1,474.94 \mathrm{ft}(449.562 \mathrm{~m})$ above mean sea 1 evel (leve1s by Los Angeles County Flood Control District). See WSP 1735 for history of changes prior to July 3 , 1941 .

REMARKS - - Records good, Flow partly regulated by Cogswe11 flood-control reservoir since 1934 , capacity, 9,339 acre-ft $\left(11.5 \mathrm{hm}^{3}\right)$. No diversion above station. See schematic diagram of San Gabriel and Los Angeles River basins.

COOPERATION.--Records were furnished by Los Angeles County Flood Control District.

AVERAGE DISCHARGE. - -49 years, $66.2 \mathrm{ft}^{3} / \mathrm{s}\left(1.875 \mathrm{~m}^{3} / \mathrm{s}\right), 47,960 \mathrm{acre}-\mathrm{ft} / \mathrm{yr}\left(59.1 \mathrm{hm}^{3} / \mathrm{yr}\right)$.

EXTREMES FOR PERIOD OF RECORD, - Maximum discharge, $34,000 \mathrm{ft}^{3} / \mathrm{s}\left(963 \mathrm{~m}^{3} / \mathrm{s}\right)$, estimated, Mar. 2 , 1938 ; no flow at times in $1928-29$

EXTREMES FOR CURRENT YEAR. --Maximum discharge, $757 \mathrm{ft}^{3} / \mathrm{s}\left(21.4 \mathrm{~m}^{3} / \mathrm{s}\right)$ Feb. 9 , gage height, 15.83 ft (4.825 $\left.\mathrm{m}\right)$; minimum daily, $7.7 \mathrm{ft}^{3} / \mathrm{s}\left(0.22 \mathrm{~m}^{3} / \mathrm{s}\right)$ Ju1y 21 .

DISCHARGE, IN CUBIC FEET PER SECOND, WATER YEAR OCTOBER 1975 TO SEPTEMBER 1976 HEAN VALUES

\begin{tabular}{|c|c|c|c|c|c|c|c|c|c|c|c|c|}
\hline DAY & OCT & Nov & $D E C$ & JAN & FEB & MAR & APR & MAY & JUN & JUL & AUG & SEP \\
\hline $\begin{array}{l}1 \\
2 \\
3 \\
4 \\
5\end{array}$ & $\begin{array}{l}33 \\
33 \\
33 \\
33 \\
33\end{array}$ & $\begin{array}{l}10 \\
10 \\
9.7 \\
9.7 \\
9.7\end{array}$ & $\begin{array}{l}10 \\
10 \\
10 \\
10 \\
11\end{array}$ & $\begin{array}{l}13 \\
13 \\
12 \\
12 \\
12\end{array}$ & $\begin{array}{l}10 \\
11 \\
11 \\
14 \\
22\end{array}$ & $\begin{array}{l}99 \\
81 \\
80 \\
67 \\
62\end{array}$ & $\begin{array}{l}28 \\
27 \\
27 \\
29 \\
27\end{array}$ & $\begin{array}{l}21 \\
21 \\
20 \\
20 \\
20\end{array}$ & $\begin{array}{l}13 \\
13 \\
13 \\
14 \\
15\end{array}$ & $\begin{array}{l}9.2 \\
9.2 \\
9.2 \\
9.2 \\
9.2\end{array}$ & $\begin{array}{l}16 \\
16 \\
16 \\
15 \\
15\end{array}$ & $\begin{array}{l}14 \\
14 \\
15 \\
16 \\
15\end{array}$ \\
\hline $\begin{array}{r}6 \\
7 \\
8 \\
9 \\
10\end{array}$ & $\begin{array}{l}32 \\
33 \\
33 \\
33 \\
33\end{array}$ & $\begin{array}{r}9.7 \\
9.7 \\
9.7 \\
9.7 \\
10\end{array}$ & $\begin{array}{l}11 \\
11 \\
11 \\
10 \\
10\end{array}$ & $\begin{array}{l}13 \\
12 \\
11 \\
11 \\
11\end{array}$ & $\begin{array}{r}64 \\
76 \\
228 \\
506 \\
228\end{array}$ & $\begin{array}{l}57 \\
54 \\
51 \\
49 \\
47\end{array}$ & $\begin{array}{l}25 \\
25 \\
26 \\
26 \\
25\end{array}$ & $\begin{array}{l}21 \\
20 \\
19 \\
18 \\
18\end{array}$ & $\begin{array}{l}15 \\
14 \\
15 \\
15 \\
15\end{array}$ & $\begin{array}{l}8.4 \\
8.1 \\
8.1 \\
8.4 \\
8.8\end{array}$ & $\begin{array}{l}14 \\
14 \\
13 \\
13 \\
14\end{array}$ & $\begin{array}{l}15 \\
16 \\
15 \\
15 \\
57\end{array}$ \\
\hline $\begin{array}{l}11 \\
12 \\
13 \\
14 \\
15\end{array}$ & $\begin{array}{l}36 \\
35 \\
35 \\
33 \\
32\end{array}$ & $\begin{array}{l}10 \\
10 \\
9.7 \\
9.4 \\
9.4\end{array}$ & $\begin{array}{l}10 \\
11 \\
12 \\
11 \\
11\end{array}$ & $\begin{array}{l}10 \\
10 \\
10 \\
9.6 \\
9.6\end{array}$ & $\begin{array}{l}96 \\
70 \\
59 \\
55 \\
51\end{array}$ & $\begin{array}{l}45 \\
43 \\
42 \\
40 \\
38\end{array}$ & $\begin{array}{l}26 \\
28 \\
37 \\
29 \\
29\end{array}$ & $\begin{array}{l}17 \\
16 \\
16 \\
16 \\
16\end{array}$ & $\begin{array}{l}15 \\
14 \\
13 \\
13 \\
12\end{array}$ & $\begin{array}{l}8.8 \\
8.8 \\
9.6 \\
9.6 \\
9.6\end{array}$ & $\begin{array}{l}13 \\
13 \\
13 \\
14 \\
15\end{array}$ & $\begin{array}{r}239 \\
51 \\
34 \\
29 \\
30\end{array}$ \\
\hline $\begin{array}{l}16 \\
17 \\
18 \\
19 \\
20\end{array}$ & $\begin{array}{l}32 \\
30 \\
29 \\
29 \\
29\end{array}$ & $\begin{array}{l}9.1 \\
9.1 \\
9.7 \\
9.7 \\
9.7\end{array}$ & $\begin{array}{l}11 \\
11 \\
11 \\
11 \\
11\end{array}$ & $\begin{array}{l}9.2 \\
9.2 \\
8.8 \\
8.8 \\
8.8\end{array}$ & $\begin{array}{l}46 \\
43 \\
43 \\
43 \\
41\end{array}$ & $\begin{array}{l}37 \\
37 \\
37 \\
37 \\
36\end{array}$ & $\begin{array}{l}29 \\
27 \\
27 \\
26 \\
26\end{array}$ & $\begin{array}{l}15 \\
15 \\
14 \\
14 \\
15\end{array}$ & $\begin{array}{l}12 \\
12 \\
11 \\
11 \\
11\end{array}$ & $\begin{array}{l}9.6 \\
9.2 \\
8.8 \\
8.4 \\
8.1\end{array}$ & $\begin{array}{l}15 \\
15 \\
15 \\
15 \\
16\end{array}$ & $\begin{array}{l}46 \\
45 \\
45 \\
43 \\
42\end{array}$ \\
\hline $\begin{array}{l}21 \\
22 \\
23 \\
24 \\
25\end{array}$ & $\begin{array}{l}29 \\
23 \\
11 \\
10 \\
10\end{array}$ & $\begin{array}{l}9.7 \\
9.7 \\
9.7 \\
9.1 \\
9.1\end{array}$ & $\begin{array}{l}11 \\
11 \\
12 \\
12 \\
12\end{array}$ & $\begin{array}{l}8.8 \\
8.4 \\
8.4 \\
8.8 \\
8.8\end{array}$ & $\begin{array}{l}39 \\
37 \\
36 \\
34 \\
33\end{array}$ & $\begin{array}{l}33 \\
33 \\
32 \\
32 \\
32\end{array}$ & $\begin{array}{l}25 \\
26 \\
26 \\
25 \\
23\end{array}$ & $\begin{array}{l}15 \\
15 \\
15 \\
15 \\
15\end{array}$ & $\begin{array}{l}10 \\
10 \\
9.6 \\
9.6 \\
9.6\end{array}$ & $\begin{array}{l}7.7 \\
9.2 \\
16 \\
15 \\
15\end{array}$ & $\begin{array}{l}15 \\
15 \\
15 \\
15 \\
15\end{array}$ & $\begin{array}{l}42 \\
42 \\
41 \\
42 \\
42\end{array}$ \\
\hline $\begin{array}{l}26 \\
27 \\
28 \\
29 \\
30 \\
31\end{array}$ & $\begin{array}{l}10 \\
9.7 \\
10 \\
10 \\
10 \\
10\end{array}$ & $\begin{array}{l}9.7 \\
10 \\
12 \\
11 \\
11 \\
--0\end{array}$ & $\begin{array}{l}11 \\
11 \\
11 \\
11 \\
11 \\
12\end{array}$ & $\begin{array}{c}8.4 \\
8.4 \\
8.4 \\
8.8 \\
9.6 \\
10\end{array}$ & $\begin{array}{r}32 \\
32 \\
31 \\
31 \\
-\ldots-\end{array}$ & $\begin{array}{l}31 \\
30 \\
30 \\
30 \\
29 \\
30\end{array}$ & $\begin{array}{r}23 \\
24 \\
24 \\
23 \\
22 \\
-\end{array}$ & $\begin{array}{l}15 \\
14 \\
15 \\
15 \\
15 \\
14\end{array}$ & $\begin{array}{l}9.6 \\
9.2 \\
9.2 \\
9.2 \\
8.8 \\
-.-\end{array}$ & $\begin{array}{l}15 \\
15 \\
15 \\
15 \\
16 \\
16\end{array}$ & $\begin{array}{l}15 \\
15 \\
14 \\
14 \\
13 \\
13\end{array}$ & $\begin{array}{r}41 \\
40 \\
40 \\
40 \\
40 \\
-\end{array}$ \\
\hline $\begin{array}{l}\text { TOTAL } \\
\text { MEAN } \\
\text { MAX } \\
\text { MIN } \\
\text { AC-FT }\end{array}$ & $\begin{array}{r}791.7 \\
25.5 \\
36 \\
9.7 \\
1570\end{array}$ & $\begin{array}{r}294.7 \\
9.82 \\
12 \\
9.1 \\
585\end{array}$ & $\begin{array}{r}339 \\
10.9 \\
12 \\
10 \\
672\end{array}$ & $\begin{array}{r}310.8 \\
10.0 \\
13 \\
8.4 \\
616\end{array}$ & $\begin{array}{r}2022 \\
69.7 \\
506 \\
10 \\
4010\end{array}$ & $\begin{array}{r}1381 \\
44.5 \\
99 \\
29 \\
2740\end{array}$ & $\begin{array}{r}790 \\
26.3 \\
37 \\
22 \\
1570\end{array}$ & $\begin{array}{r}515 \\
16.6 \\
21 \\
14 \\
1020\end{array}$ & $\begin{array}{r}360.8 \\
12.0 \\
15 \\
8.8 \\
716\end{array}$ & $\begin{array}{r}333.2 \\
10.7 \\
16 \\
7.7 \\
661\end{array}$ & $\begin{array}{r}449 \\
14.5 \\
16 \\
13 \\
891\end{array}$ & $\begin{array}{r}1206 \\
40.2 \\
239 \\
14 \\
2390\end{array}$ \\
\hline
\end{tabular}

CAL YR 1975 TOTAL 9984.4 MEAN 27.4 MAX 175 MIN 9.1 AC-FT 19800 WTR YR 1976 TOTAL 8793.2 MEAN 24.0 MAX 506 MIN 7.7 AC-FT 17440 
11082800 SAN GABRIEL RIVER AT AZUSA POWERHOUSE, AT AZUSA, CA

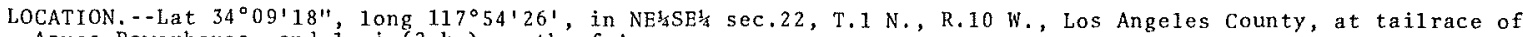
Azusa Powerhouse, and $1 \mathrm{mi}(2 \mathrm{~km})$ north'of Azusa.

PERIOD OF RECORD.--Chemica1 analyses: December 1907 to December 1908 , water year 1967 to current year.

REMARKS.--Records of discharge were furnished by Los Angeles County Flood Control District.

COOPERATION. - Chemical-quality records were furnished by California Department of Water Resources.

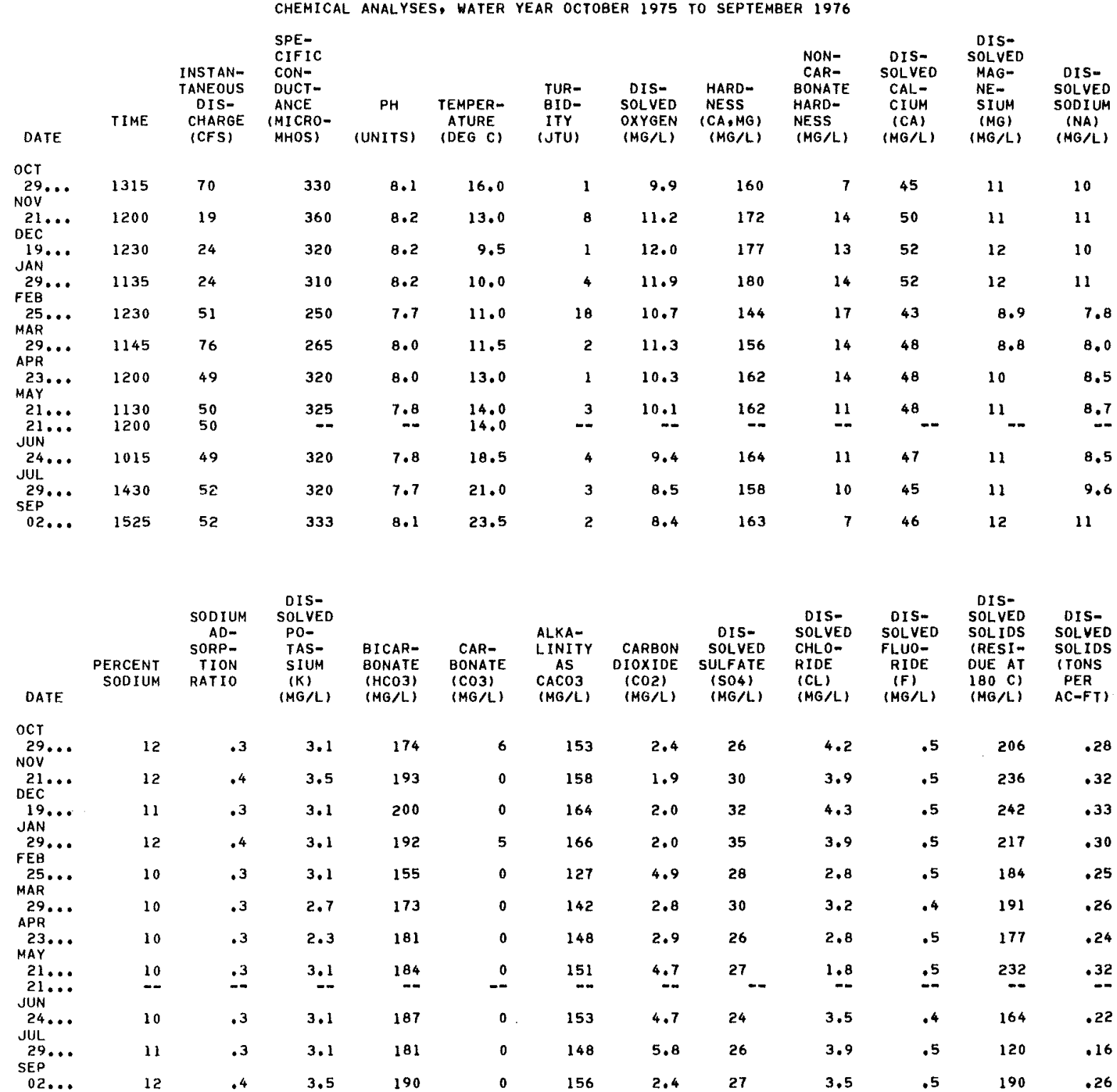


11082800 SAN GABRIEL RIVER AT AZUSA POWERHOUSE, AT AZUSA, CA--Continued

CHEHICAL ANALYSES, WATER YEAR OCTOBER 1975 TO SEPTEMBER 1976

\begin{tabular}{|c|c|c|c|c|c|c|c|c|c|c|c|c|}
\hline DATE & $\begin{array}{l}\text { DIS- } \\
\text { SOLVED } \\
\text { SOLIDS } \\
\text { (TONS } \\
\text { PER } \\
\text { DAY) }\end{array}$ & $\begin{array}{l}\text { TOTAL } \\
\text { NITRATE } \\
\text { (N) } \\
\text { (MG/L) }\end{array}$ & $\begin{array}{l}\text { DIS- } \\
\text { SOLVED } \\
\text { ARSENIC } \\
\text { (AS) } \\
\text { (UG/L) }\end{array}$ & $\begin{array}{l}\text { DIS- } \\
\text { SOLVED } \\
\text { BORON } \\
\text { (B) } \\
(U G / L)\end{array}$ & $\begin{array}{l}\text { DIS- } \\
\text { SOLVED } \\
\text { CAD- } \\
\text { MIUM } \\
\text { (CD) } \\
\text { (UG/L) }\end{array}$ & $\begin{array}{l}\text { DIS- } \\
\text { SOLVED } \\
\text { CHRO- } \\
\text { MIUH } \\
\text { (CR) } \\
\text { (UO/L) }\end{array}$ & $\begin{array}{c}\text { HEXA- } \\
\text { VALENT } \\
\text { CHRO- } \\
\text { MIUM } \\
\text { (CR6) } \\
\text { (UG/L) }\end{array}$ & $\begin{array}{l}\text { DIS- } \\
\text { SOLVEO } \\
\text { COPPER } \\
\text { (CU) } \\
(U G / L)\end{array}$ & $\begin{array}{l}\text { DIS- } \\
\text { SOLVED } \\
\text { IRON } \\
\text { (FE) } \\
\text { (UG/L) }\end{array}$ & $\begin{array}{l}\text { OIS- } \\
\text { SOLVED } \\
\text { LEAD } \\
\text { (PB) } \\
(U G / L)\end{array}$ & $\begin{array}{l}\text { OIS- } \\
\text { SOLVED } \\
\text { MAN- } \\
\text { GANESE } \\
\text { (UN) } \\
\text { (UG/L) }\end{array}$ & $\begin{array}{l}\text { DIS- } \\
\text { SOLVED } \\
\text { ZINC } \\
\text { (ZN) } \\
(U G / L)\end{array}$ \\
\hline $\begin{array}{l}\mathrm{OCT} \\
29 . . .\end{array}$ & 38.9 & .00 & -- & 80 & -- & - & -- & -- & -- & - & -- & - \\
\hline $\begin{array}{l}\text { NOV } \\
21 . . . \\
D E C\end{array}$ & 12.1 & .04 & -- & 50 & 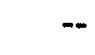 & -- & -- & - & -- & $\cdots$ & $-\infty$ & -- \\
\hline JAN $19 .$. & 15.7 & .02 & $-\cdots$ & 20 & -- & - & - & -- & - & -- & - & -- \\
\hline $29 \ldots$ & 14.1 & .00 & -- & 60 & $=$ & - & - & - & - & - & -- & -- \\
\hline MAR & 25.3 & 1.2 & -- & 150 & -- & $-\infty$ & -- & -- & - & -- & -- & -- \\
\hline${ }_{A P R}^{29} .$. & 39.2 & .90 & -- & 120 & -- & $\cdots$ & - & - & -- & -- & -- & $\cdots$ \\
\hline$\underset{M A Y}{23} \cdots$ & 23.4 & .47 & $\cdots$ & 80 & -- & $-\infty$ & - & $\cdots$ & -- & -- & -- & - \\
\hline $\begin{array}{l}21 \ldots \\
21 \ldots\end{array}$ & 31.3 & .61 & $-\overline{0}$ & $\begin{array}{l}50 \\
--\end{array}$ & $-\overrightarrow{0}$ & $-\overline{0}$ & 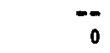 & $=$ & 20 & $\overline{0}$ & $\overline{0}$ & $\overline{0}$ \\
\hline $\begin{array}{l}\text { JUN } \\
24 \ldots\end{array}$ & 21.7 & .18 & -- & 40 & -- & - & -- & - & - & - & - & -- \\
\hline $\begin{array}{l}\text { JUL } \\
29 . . .\end{array}$ & 16.8 & .16 & -- & 100 & -- & -- & -- & $\cdots$ & $=-$ & -- & -- & -- \\
\hline $02 . .$. & 26.7 & .11 & -- & 130 & - & - & -- & - & -- & -- & -- & - \\
\hline
\end{tabular}


LOCATION. - Lat $34^{\circ} 09^{\prime} 57^{\prime \prime}$, long $117^{\circ} 55^{\prime} 24^{\prime \prime}$, in SW'SW!SWl sec.15, T.1 N., R.10 W., Los Angeles County, on 1eft bank $0.8 \mathrm{mi}(1.3 \mathrm{~km})$ upstream from mouth of canyon, and $3.2 \mathrm{mi}(5.1 \mathrm{~km})$ northeast of Duarte.

DRAINAGE AREA, $-6.36 \mathrm{mi}^{2}\left(16.47 \mathrm{~km}^{2}\right)$.

PERIOD OF RECORD. --July to September 1916, Ju1y 1917 to current year.

GAGE. - Water-stage recorder. Broad-crested weir since July 1917, restored in December 1938. Datum of gage is $905.9 \mathrm{ft}(276.12 \mathrm{~m})$ above mean sea level. See WSP 1315-B for history of changes prior to Dec. 7 , 1938 .

Dec. 7,1938 , to Oct. 3, 1951, at datum $1.00 \mathrm{ft}(0.305 \mathrm{~m})$ higher.

REMARKS.--Records fair. No regulation or diversion above station. See schematic diagram of San Gabriel and Los Angeles River basins.

COOPERATION.--Records were furnished by Los Angeles County Flood Control District.

AVERAGE DISCHARGE . - -59 years (water years $1918-76), 4.51 \mathrm{ft}^{3} / \mathrm{s}\left(0.128 \mathrm{~m}^{3} / \mathrm{s}\right), 3,270 \mathrm{acre}-\mathrm{ft} / \mathrm{yr}(4.03 \mathrm{hm} / \mathrm{yr})$.

EXTREMES FOR PERIOD OF RECORD,--Maximum discharge, $13,000 \mathrm{ft}^{3} / \mathrm{s}\left(368 \mathrm{~m}^{3} / \mathrm{s}\right) \mathrm{Jan}$. 25,1969 , gage height, $11.98 \mathrm{ft}$ $(3.652 \mathrm{~m})$, from inside gage, from rating curve extended above $1,100 \mathrm{ft}^{3} / \mathrm{s}\left(31.2 \mathrm{~m}^{3} / \mathrm{s}\right)$ on basis of $\mathrm{s}^{\circ} \mathrm{ope}-$

area measurement of maximum flow; maximum gage height, about $14.5 \mathrm{ft}(4.42 \mathrm{~m}$ ) Feb. 11 , 16 , 1959 (from debris wave); no flow at times in some years.

EXTREMES FOR CURRENT YEAR, -Maximum discharge $145 \mathrm{ft}^{3} / \mathrm{s}\left(4.11 \mathrm{~m}^{3} / \mathrm{s}\right)$ Mar. 1 , gage height, $3.25 \mathrm{ft}(0.991 \mathrm{~m})$ minimum daily, $0.10 \mathrm{ft}^{3} / \mathrm{s}\left(0.003 \mathrm{~m}^{3} / \mathrm{s}\right)$ June 24 to July 10 ; Aug. $12-15$, Aug. 31 to Sept. 9.

DISCHARGE, IN CUBIC FEET PER SECOND, WATER YEAR OCTOBER 1975 TO SEPTEMBER 1976 MEAN VALUES

\begin{tabular}{|c|c|c|c|c|c|c|c|c|c|c|c|c|}
\hline DAY & OCT & NOV & DEC & JAN & FEB & MAR & APR & MAY & JUN & JUL & AUG & SEP \\
\hline $\begin{array}{l}1 \\
2 \\
3 \\
4 \\
5\end{array}$ & $\begin{array}{l}.50 \\
.40 \\
.40 \\
.30 \\
.30\end{array}$ & $\begin{array}{l}.70 \\
.70 \\
.70 \\
.70 \\
.70\end{array}$ & $\begin{array}{l}.90 \\
.80 \\
.80 \\
.80 \\
.90\end{array}$ & $\begin{array}{l}1.0 \\
1.0 \\
1.0 \\
1.0 \\
1.0\end{array}$ & $\begin{array}{l}1.2 \\
1.4 \\
1.4 \\
6.5 \\
15\end{array}$ & $\begin{array}{l}37 \\
19 \\
22 \\
12 \\
7.8\end{array}$ & $\begin{array}{l}1.2 \\
1.2 \\
1.3 \\
1.8 \\
1.4\end{array}$ & $\begin{array}{l}.80 \\
1.1 \\
1.3 \\
1.3 \\
1.5\end{array}$ & $\begin{array}{l}.40 \\
.40 \\
.40 \\
.50 \\
.50\end{array}$ & $\begin{array}{l}.10 \\
110 \\
110 \\
110 \\
110\end{array}$ & $\begin{array}{l}.20 \\
.20 \\
.20 \\
.20 \\
.20\end{array}$ & $\begin{array}{l}.10 \\
110 \\
110 \\
110 \\
.10\end{array}$ \\
\hline $\begin{array}{r}6 \\
7 \\
8 \\
9 \\
10\end{array}$ & $\begin{array}{r}.30 \\
.50 \\
.50 \\
.50 \\
.50\end{array}$ & $\begin{array}{r}.70 \\
.80 \\
.80 \\
.90 \\
.90\end{array}$ & $\begin{array}{l}.90 \\
.70 \\
.70 \\
.80 \\
.80\end{array}$ & $\begin{array}{l}1.1 \\
1.0 \\
.90 \\
.80 \\
.90\end{array}$ & $\begin{array}{c}17 \\
8.7 \\
14 \\
41 \\
16\end{array}$ & $\begin{array}{l}5.4 \\
4.4 \\
4.0 \\
3.4 \\
3.0\end{array}$ & $\begin{array}{l}1.3 \\
1.3 \\
1.3 \\
1.3 \\
1.2\end{array}$ & $\begin{array}{l}1.6 \\
1.7 \\
1.4 \\
1.3 \\
1.0\end{array}$ & $\begin{array}{l}.40 \\
.30 \\
.30 \\
.40 \\
.50\end{array}$ & $\begin{array}{l}.10 \\
110 \\
110 \\
.10 \\
.10\end{array}$ & $\begin{array}{r}.20 \\
.20 \\
.20 \\
.20 \\
.20\end{array}$ & $\begin{array}{r}.10 \\
.10 \\
.10 \\
.10 \\
6.1\end{array}$ \\
\hline $\begin{array}{l}11 \\
12 \\
13 \\
14 \\
15\end{array}$ & $\begin{array}{l}1.0 \\
.70 \\
.60 \\
.60 \\
.50\end{array}$ & $\begin{array}{l}.90 \\
.80 \\
.70 \\
.70 \\
.70\end{array}$ & $\begin{array}{l}.90 \\
1.3 \\
1.1 \\
1.0 \\
.90\end{array}$ & $\begin{array}{r}.90 \\
.90 \\
.90 \\
.90 \\
.90\end{array}$ & $\begin{array}{l}4.8 \\
2.0 \\
1.7 \\
1.6 \\
1.4\end{array}$ & $\begin{array}{l}2.8 \\
2.5 \\
2.1 \\
2.0 \\
1.8\end{array}$ & $\begin{array}{l}1.1 \\
1.2 \\
2.2 \\
1.4 \\
1.7\end{array}$ & $\begin{array}{r}.90 \\
.80 \\
.60 \\
.50 \\
.50\end{array}$ & $\begin{array}{l}.40 \\
.50 \\
.70 \\
.90 \\
.50\end{array}$ & $\begin{array}{l}.20 \\
.20 \\
.20 \\
.20 \\
.20\end{array}$ & $\begin{array}{r}.20 \\
.10 \\
.10 \\
.10 \\
.10\end{array}$ & $\begin{array}{r}18 \\
2.0 \\
1.6 \\
1.1 \\
1.2\end{array}$ \\
\hline $\begin{array}{l}16 \\
17 \\
18 \\
19 \\
20\end{array}$ & $\begin{array}{l}.40 \\
.40 \\
.50 \\
.60 \\
.60\end{array}$ & $\begin{array}{r}.70 \\
.90 \\
.90 \\
.90 \\
.80\end{array}$ & $\begin{array}{r}.90 \\
.90 \\
.90 \\
.90 \\
.80\end{array}$ & $\begin{array}{r}.90 \\
.90 \\
.90 \\
.80 \\
.80\end{array}$ & $\begin{array}{l}1.4 \\
1.5 \\
1.6 \\
1.6 \\
1.7\end{array}$ & $\begin{array}{l}1.7 \\
1.6 \\
1.6 \\
1.6 \\
1.6\end{array}$ & $\begin{array}{l}1.5 \\
1.3 \\
1.3 \\
1.4 \\
1.3\end{array}$ & $\begin{array}{l}.50 \\
.50 \\
.50 \\
.40 \\
.40\end{array}$ & $\begin{array}{r}.40 \\
.40 \\
.50 \\
.40 \\
.30\end{array}$ & $\begin{array}{l}.40 \\
.40 \\
.40 \\
.30 \\
.30\end{array}$ & $\begin{array}{r}.20 \\
.20 \\
.20 \\
.20 \\
.20\end{array}$ & $\begin{array}{r}1.0 \\
.90 \\
.80 \\
.80 \\
.70\end{array}$ \\
\hline $\begin{array}{l}21 \\
22 \\
23 \\
24 \\
25\end{array}$ & $\begin{array}{l}.70 \\
.70 \\
.60 \\
.60 \\
.60\end{array}$ & $\begin{array}{l}.90 \\
.80 \\
.80 \\
.70 \\
.70\end{array}$ & $\begin{array}{r}.80 \\
.80 \\
.90 \\
.90 \\
.90\end{array}$ & $\begin{array}{r}.80 \\
.90 \\
.90 \\
1.0 \\
1.1\end{array}$ & $\begin{array}{l}1.6 \\
1.5 \\
1.5 \\
1.5 \\
1.6\end{array}$ & $\begin{array}{l}1.5 \\
1.4 \\
1.3 \\
1.4 \\
1.5\end{array}$ & $\begin{array}{r}1.3 \\
1.3 \\
1.2 \\
.90 \\
.80\end{array}$ & $\begin{array}{r}.50 \\
.50 \\
.40 \\
.40 \\
.50\end{array}$ & $\begin{array}{r}.20 \\
.20 \\
+20 \\
.10 \\
110\end{array}$ & $\begin{array}{r}.20 \\
.30 \\
.30 \\
.20 \\
.20\end{array}$ & $\begin{array}{l}.20 \\
.20 \\
.20 \\
.20 \\
.20\end{array}$ & $\begin{array}{r}.70 \\
.70 \\
.60 \\
.60 \\
.70\end{array}$ \\
\hline $\begin{array}{l}26 \\
27 \\
28 \\
29 \\
30 \\
31\end{array}$ & $\begin{array}{l}.60 \\
.60 \\
.70 \\
.60 \\
.70 \\
.90\end{array}$ & $\begin{array}{l}.70 \\
1.1 \\
1.3 \\
1.3 \\
1.3 \\
---\end{array}$ & $\begin{array}{r}.90 \\
.80 \\
.90 \\
1.0 \\
1.0 \\
1.0\end{array}$ & $\begin{array}{l}1.0 \\
1.0 \\
.90 \\
1.1 \\
1.2 \\
1.2\end{array}$ & $\begin{array}{l}1.6 \\
1.6 \\
1.6 \\
1.6 \\
0 .-\end{array}$ & $\begin{array}{l}1.3 \\
1.3 \\
1.3 \\
1.3 \\
1.2 \\
1.2\end{array}$ & $\begin{array}{l}.70 \\
.70 \\
.80 \\
.80 \\
.70 \\
-.0\end{array}$ & $\begin{array}{r}.50 \\
.30 \\
.50 \\
.60 \\
.60 \\
.50\end{array}$ & $\begin{array}{l}.10 \\
110 \\
110 \\
110 \\
110 \\
-\end{array}$ & $\begin{array}{l}.20 \\
.20 \\
.20 \\
.20 \\
.20 \\
.20\end{array}$ & $\begin{array}{r}.20 \\
.20 \\
.20 \\
.20 \\
.20 \\
.10\end{array}$ & $\begin{array}{l}.60 \\
.60 \\
.60 \\
.60 \\
.50 \\
.\end{array}$ \\
\hline $\begin{array}{l}\text { TOTAL } \\
\text { MEAN } \\
\text { MAX } \\
\text { MIN } \\
\text { AC-FT }\end{array}$ & $\begin{array}{r}17.40 \\
.56 \\
1.0 \\
.30 \\
35\end{array}$ & $\begin{array}{r}25.20 \\
.84 \\
1.3 \\
.70 \\
50\end{array}$ & $\begin{array}{r}27.60 \\
.89 \\
1.3 \\
.70 \\
55\end{array}$ & $\begin{array}{r}29.60 \\
.95 \\
1.2 \\
.80 \\
59\end{array}$ & $\begin{array}{r}155.6 \\
5.37 \\
41 \\
1.2 \\
309\end{array}$ & $\begin{array}{r}152.0 \\
4.90 \\
37 \\
1.2 \\
301\end{array}$ & $\begin{array}{r}36.90 \\
1.23 \\
2.2 \\
.70 \\
73\end{array}$ & $\begin{array}{r}23.90 \\
.77 \\
1.7 \\
.30 \\
47\end{array}$ & $\begin{array}{r}10.40 \\
.35 \\
.90 \\
.10 \\
21\end{array}$ & $\begin{array}{r}6.20 \\
.20 \\
.40 \\
.10 \\
12\end{array}$ & $\begin{array}{r}5.70 \\
.18 \\
.20 \\
.10 \\
11\end{array}$ & $\begin{array}{r}41.30 \\
1.38 \\
18 \\
.10 \\
82\end{array}$ \\
\hline
\end{tabular}

CAL YR 1975 TOTAL 838.00 MEAN 2.30 MAX $30 \quad$ MIN $.20 \quad$ AC-FT 1660 WTR YR 1976 TOTAL 531.80 MEAN 1.45 MAX 41 MIN 10 AC=FT 1050 
11085000 SAN GABRIEL RIVER BELOW SANTA FE DAM, NEAR BALDWIN PARK, CA

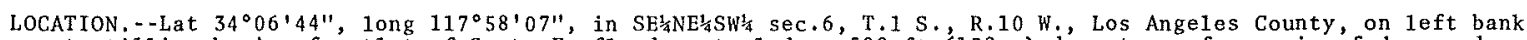
at stilling basin of outlet of Santa Fe flood-control dam, $500 \mathrm{ft}$ ( $152 \mathrm{~m})$ downstream from axis of dam, and

$1.7 \mathrm{mi}(2.7 \mathrm{~km})$ north of Baldwin Park.

DRAINAGE AREA. $--236 \mathrm{mi}^{2}\left(611 \mathrm{~km}^{2}\right)$.

PERIOD OF RECORD.--October 1942 to current year.

GAGE, - Water-stage recorder. Datum of gage is $400.00 \mathrm{ft}(121.920 \mathrm{~m}$ ) above mean sea level (1evels by Corps of Engineers).

REMARKS.- -Records fair. Flow regulated by Cogswell and San Gabriel flood-control reservoirs, combined capacity, 53,870 acre-ft $\left(66.4 \mathrm{hm}^{3}\right)$, Morris Reservoir, capacity, 35,000 acre-ft $\left(43.2 \mathrm{hm}^{3}\right)$, and Santa Fe f1ood-control reservoir, capacity, 32,640 acre-ft $\left(40.2 \mathrm{hm}^{3}\right)$. Diversions above station for irrigation, power development, and ground-water replenishment. At times water diverted from side of stilling basin to headwaters of Rio Hondo; no flow was diverted during current year. See schematic diagram of San Gabriel and Los Angeles River basins.

COOPERATION, - Records of diversion to Rio Hondo were furnished by Los Angeles County Flood Control District.

EXTREMES FOR PERIOD OF RECORD.--Maximum discharge, $30,900 \mathrm{ft}^{3} / \mathrm{s}\left(875 \mathrm{~m}^{3} / \mathrm{s}\right) \mathrm{Jan} .26,1969$, gage height, $22.20 \mathrm{ft}$ $(6.767 \mathrm{~m})$; no flow for several months in each year.

EXTREMES FOR CURRENT YEAR.--Maximum discharge, $2.8 \mathrm{ft}^{3} / \mathrm{s}\left(0.079 \mathrm{~m}^{3} / \mathrm{s}\right)$ Mar. 2 , gage height, $10.20 \mathrm{ft}$ $(3.110 \mathrm{~m})$; no flow most of year.

DISCHARGE, IN CUBIC FEET PER SECONO, WATER YEAR OCTOBER 1975 TO SEPTEMBER 1976 MEAN VALUES

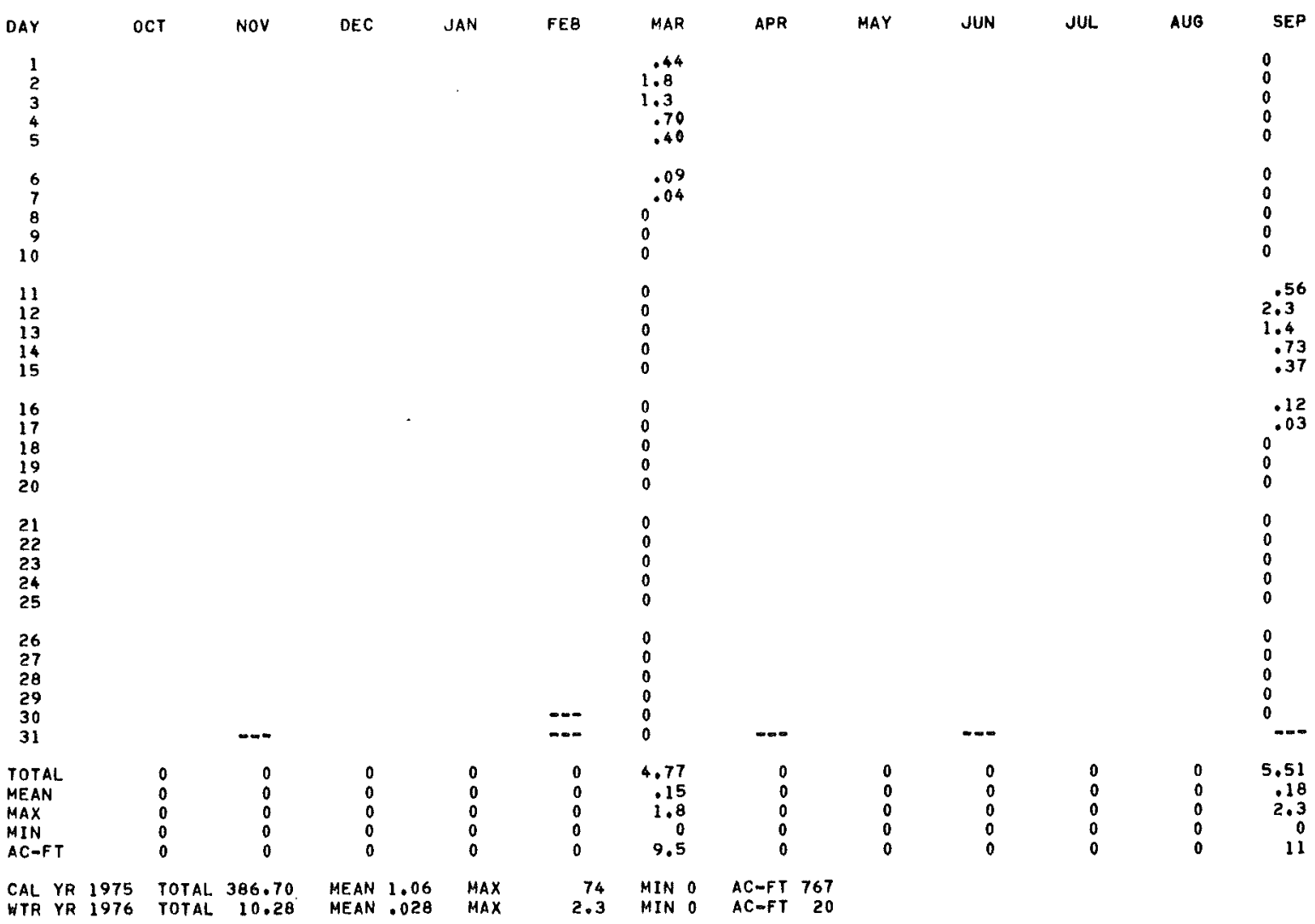


LOCATION. - Lat $34^{\circ} 09^{\prime} 10^{\prime \prime}$, long $117^{\circ} 46^{\prime} 18^{\prime \prime}$, in SWhSE 4 sec. 24 , T.1 N., R. 9 W., Los Angeles County, on left bank $1,000 \mathrm{ft}(305 \mathrm{~m})$ downstream from San Dimas Dam, and $3.7 \mathrm{mi}(6.0 \mathrm{~km})$ northeast of San Dimas.

DRAINAGE AREA. $--16.3 \mathrm{mi}^{2}\left(42.2 \mathrm{~km}^{2}\right)$.

PERIOD OF RECORD.--October 1951 to current year. prior to october 1956 monthly discharge only, published in WSP 1735 .

GAGE. - Water-stage recorder and low-flow concrete control. Datum of gage is $1,325.0 \mathrm{ft}(403.86 \mathrm{~m})$ above mean sea level (levels by Los Angeles County Flood Control District).

REMARKS.--Records fair. Flow regulated by San Dimas flood-control reservoir, capacity, 756 acre-ft ( $932,000 \mathrm{~m}^{3}$ ) and at times by o1d water tunnel $150 \mathrm{ft}(45 \mathrm{~m})$ upstream. No diversion above station. See schematic diagram of San Gabrie1 and Los Angeles River basins.

COOPERATION, - -Records were furnished by Los Angeles County Flood Control District.

EXTREMES FOR PERIOD OF RECORD.--Maximun discharge, 4,280 $\mathrm{ft}^{3} / \mathrm{s}\left(121 \mathrm{~m}^{3} / \mathrm{s}\right) \mathrm{Jan}, 25,1969, \mathrm{gage} \mathrm{height,} 6.98 \mathrm{ft}$ $(2.128 \mathrm{~m})$, from rating curve extended above $600 \mathrm{ft}^{3} / \mathrm{s}(17.0 \mathrm{~m} / \mathrm{s})$ on basis of computation of maximum flow over dam; no flow at times in most years.

EXTREMES FOR CURRENT YEAR. - Maximum daily discharge, $9.3 \mathrm{ft}^{3} / \mathrm{s}\left(0.26 \mathrm{~m}^{3} / \mathrm{s}\right) \mathrm{Mar} .6-12 ; \mathrm{minimum}$ daily, $0.04 \mathrm{ft} / \mathrm{s}$ $\left(0.001 \mathrm{~m}^{3} / \mathrm{s}\right)$ Apr, $15-21$.

DISCHARGE, IN CUBIC FEET PER SECOND, HATER YEAR OCTOBER 1975 TO SEPTEMBER 1976 HEAN VALUES

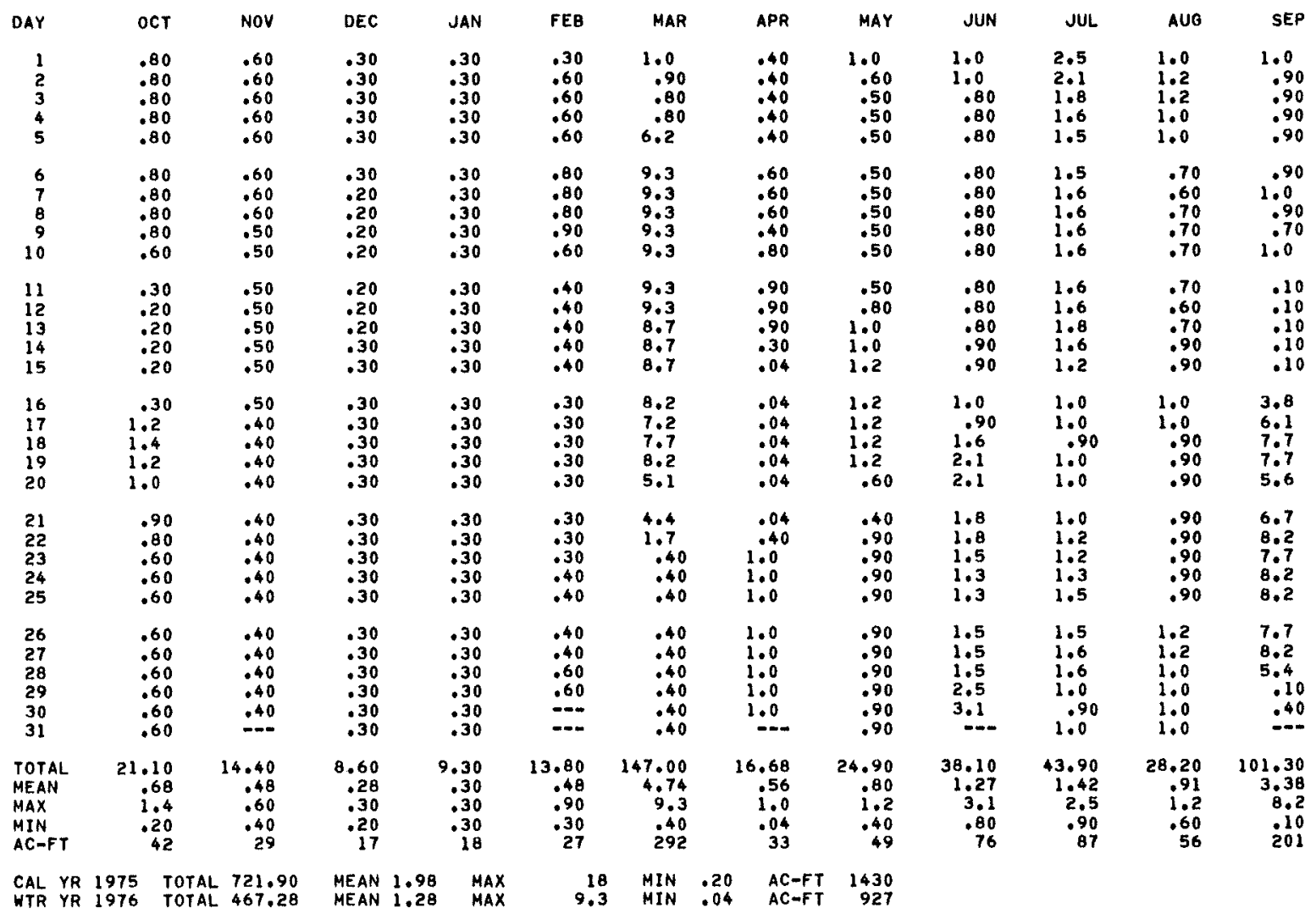


11086990 SAN JOSE CREEK NEAR EL MONTE, CA

LOCATION.--Lat $34^{\circ} 01^{\prime} 55^{\prime \prime}$, long $118^{\circ} 00^{\prime} 40^{\prime \prime}$, in E1 Monte Grant, Los Angeles County, on right bank of San Jose

flood channe1, $1,650 \mathrm{ft}(503 \mathrm{~m})$ upstream from Workman Mi11 Road, and $2.7 \mathrm{mi}$ (4.3 km) southeast of E1 Monte.

DRAINAGE AREA. $--87.8 \mathrm{mi}^{2}\left(227 \mathrm{~km}^{2}\right)$.

PERIOD OF RECORD. - October 1964 to current year.

GAGE. - Water-stage recorder. Datum of gage is $248.52 \mathrm{ft}(75.749 \mathrm{~m})$ above mean sea level (1evels by Los Angeles County Flood Control District).

REMARKS.--Records poor. No regulation above station. One small diversion for ground-water recharge. At times effluent from city of Pomona's sewage reclamation plant is released to creek above Spadra and at Lemon Street. Bypass to the original San Jose Creek channel has been closed since Oct. 1, 1964. See schematic diagram of San Gabriel and Los Angeles River basins.

COOPERATION.--Records were furnished by Los Angeles County Flood Control District.

AVERAGE DISCHARGE, -12 years, $33.3 \mathrm{ft}^{3} / \mathrm{s}\left(0.943 \mathrm{~m}^{3} / \mathrm{s}\right), 24,130 \mathrm{acre}-\mathrm{ft} / \mathrm{yr}\left(29.8 \mathrm{hm} / \mathrm{yr}^{3}\right)$.

EXTREMES FOR PERIOD OF RECORD.--Maximum discharge, $10,200 \mathrm{ft}^{3} / \mathrm{s}\left(289 \mathrm{~m}^{3} / \mathrm{s}\right) \mathrm{Jan} .24,1967, \mathrm{gage}$ height, $6.80 \mathrm{ft}$ $(2.073 \mathrm{~m})$, fron outside gage; no flow at times in some years.

EXTREMES FOR CURRENT YEAR.--Maximum discharge, $5,000 \mathrm{ft}^{3} / \mathrm{s}\left(142 \mathrm{~m}^{3} / \mathrm{s}\right)$ Sept, 10, gage height, $5.72 \mathrm{ft}(1.743 \mathrm{~m})$; minimum daily, $5.0 \mathrm{ft}^{3} / \mathrm{s}\left(0.14 \mathrm{~m}^{3} / \mathrm{s}\right)$ Dec. $2,3, J a n .20,21,24,30$.

DISCHARGE, IN CUBIC FEET PER SECOND, WATER YEAR OCTOBER 1975 TO SEPTEMBER 1976 HEAN VALUES

\begin{tabular}{|c|c|c|c|c|c|c|c|c|c|c|c|c|c|}
\hline DAY & $O C$ & & NoV & DEC & JAN & FEB & MAR & APR & MAY & JUN & JUL & AUG & SEP \\
\hline $\begin{array}{l}1 \\
2 \\
3 \\
4 \\
5\end{array}$ & $\begin{array}{l}13 \\
21 \\
21 \\
21 \\
21\end{array}$ & & $\begin{array}{l}18 \\
18 \\
17 \\
7.0 \\
7.0\end{array}$ & $\begin{array}{l}9.0 \\
5.0 \\
5.0 \\
10 \\
10\end{array}$ & $\begin{array}{l}9.0 \\
9.0 \\
9.0 \\
9.0 \\
9.0\end{array}$ & $\begin{array}{l}10 \\
10 \\
10 \\
198 \\
290\end{array}$ & $\begin{array}{r}377 \\
106 \\
103 \\
25 \\
15\end{array}$ & $\begin{array}{r}10 \\
11 \\
15 \\
303 \\
30\end{array}$ & $\begin{array}{l}11 \\
11 \\
11 \\
11 \\
11\end{array}$ & $\begin{array}{l}10 \\
10 \\
10 \\
10 \\
10\end{array}$ & $\begin{array}{l}13 \\
13 \\
13 \\
13 \\
13\end{array}$ & $\begin{array}{l}11 \\
11 \\
11 \\
9.0 \\
9.0\end{array}$ & $\begin{array}{l}10 \\
12 \\
75 \\
30 \\
50\end{array}$ \\
\hline $\begin{array}{r}6 \\
7 \\
8 \\
9 \\
10\end{array}$ & $\begin{array}{l}21 \\
18 \\
15 \\
14 \\
14\end{array}$ & & $\begin{array}{l}6.0 \\
8.0 \\
11 \\
13 \\
10\end{array}$ & $\begin{array}{l}13 \\
13 \\
8.0 \\
6.0 \\
6.0\end{array}$ & $\begin{array}{l}8.0 \\
8.0 \\
8.0 \\
8.0 \\
8.0\end{array}$ & $\begin{array}{r}470 \\
212 \\
425 \\
680 \\
12\end{array}$ & $\begin{array}{l}14 \\
14 \\
13 \\
13 \\
13\end{array}$ & $\begin{array}{l}15 \\
12 \\
46 \\
25 \\
15\end{array}$ & $\begin{array}{l}15 \\
50 \\
20 \\
15 \\
14\end{array}$ & $\begin{array}{l}11 \\
11 \\
11 \\
11 \\
11\end{array}$ & $\begin{array}{l}13 \\
11 \\
14 \\
13 \\
11\end{array}$ & $\begin{array}{l}11 \\
11 \\
10 \\
9.0 \\
11\end{array}$ & $\begin{array}{r}25 \\
60 \\
30 \\
15 \\
1200\end{array}$ \\
\hline $\begin{array}{l}11 \\
12 \\
13 \\
14 \\
15\end{array}$ & $\begin{array}{c}18 \\
11 \\
8 . \\
8 . \\
8 .\end{array}$ & $\begin{array}{l}0 \\
0 \\
0 \\
0\end{array}$ & $\begin{array}{c}10 \\
9.0 \\
10 \\
7.0 \\
8.0\end{array}$ & $\begin{array}{l}6.0 \\
9.0 \\
13 \\
13 \\
11\end{array}$ & $\begin{array}{l}8.0 \\
8.0 \\
7.0 \\
7.0 \\
6.0\end{array}$ & $\begin{array}{l}11 \\
11 \\
11 \\
11 \\
11\end{array}$ & $\begin{array}{l}12 \\
12 \\
12 \\
12 \\
12\end{array}$ & $\begin{array}{r}10 \\
52 \\
419 \\
25 \\
30\end{array}$ & $\begin{array}{l}14 \\
13 \\
13 \\
12 \\
12\end{array}$ & $\begin{array}{l}12 \\
12 \\
12 \\
12 \\
12\end{array}$ & $\begin{array}{l}11 \\
10 \\
10 \\
11 \\
14\end{array}$ & $\begin{array}{ll}13 \\
11 \\
11 \\
11 \\
17\end{array}$ & $\begin{array}{r}181 \\
30 \\
15 \\
15 \\
15\end{array}$ \\
\hline $\begin{array}{l}16 \\
17 \\
18 \\
19 \\
20\end{array}$ & $\begin{array}{l}9 . \\
9 . \\
9 . \\
9 . \\
9 .\end{array}$ & & $\begin{array}{l}7.0 \\
7.0 \\
7.0 \\
7.0 \\
6.0\end{array}$ & $\begin{array}{l}11 \\
10 \\
10 \\
10 \\
10\end{array}$ & $\begin{array}{l}6.0 \\
6.0 \\
6.0 \\
6.0 \\
5.0\end{array}$ & $\begin{array}{l}10 \\
9.0 \\
8.0 \\
8.0 \\
8.0\end{array}$ & $\begin{array}{l}11 \\
11 \\
11 \\
11 \\
11\end{array}$ & $\begin{array}{l}15 \\
13 \\
12 \\
12 \\
12\end{array}$ & $\begin{array}{l}12 \\
11 \\
11 \\
11 \\
11\end{array}$ & $\begin{array}{l}13 \\
13 \\
13 \\
13 \\
13\end{array}$ & $\begin{array}{l}14 \\
15 \\
14 \\
14 \\
15\end{array}$ & $\begin{array}{ll}13 \\
11 \\
11 \\
10 \\
13\end{array}$ & $\begin{array}{l}13 \\
13 \\
13 \\
12 \\
12\end{array}$ \\
\hline $\begin{array}{l}21 \\
22 \\
23 \\
24 \\
25\end{array}$ & $\begin{array}{l}8 . \\
8 . \\
8 . \\
8 . \\
9 .\end{array}$ & & $\begin{array}{l}8.0 \\
9.0 \\
9.0 \\
8.0 \\
8.0\end{array}$ & $\begin{array}{l}10 \\
10 \\
10 \\
10 \\
10\end{array}$ & $\begin{array}{l}5.0 \\
6.0 \\
6.0 \\
5.0 \\
9.0\end{array}$ & $\begin{array}{l}10 \\
10 \\
11 \\
11 \\
12\end{array}$ & $\begin{array}{l}10 \\
10 \\
10 \\
10 \\
10\end{array}$ & $\begin{array}{l}12 \\
11 \\
11 \\
11 \\
11\end{array}$ & $\begin{array}{l}10 \\
10 \\
10 \\
10 \\
10\end{array}$ & $\begin{array}{l}12 \\
12 \\
12 \\
12 \\
12\end{array}$ & $\begin{array}{l}15 \\
17 \\
15 \\
15 \\
15\end{array}$ & $\begin{array}{l}13 \\
13 \\
13 \\
11 \\
8.0\end{array}$ & $\begin{array}{l}11 \\
11 \\
11 \\
10 \\
9.0\end{array}$ \\
\hline $\begin{array}{l}26 \\
27 \\
28 \\
29 \\
30 \\
31\end{array}$ & $\begin{array}{l}9 . \\
9 . \\
9 . \\
8 . \\
14 \\
21\end{array}$ & & $\begin{array}{l}8.0 \\
19 \\
10 \\
10 \\
9.0 \\
-0 .\end{array}$ & $\begin{array}{l}10 \\
10 \\
9.0 \\
9.0 \\
9.0 \\
9.0\end{array}$ & $\begin{array}{l}9.0 \\
8.0 \\
11 \\
11 \\
5.0 \\
10\end{array}$ & $\begin{array}{l}12 \\
11 \\
11 \\
10 \\
--\infty\end{array}$ & $\begin{array}{l}9.0 \\
9.0 \\
9.0 \\
9.0 \\
9.0 \\
9.0\end{array}$ & $\begin{array}{r}10 \\
10 \\
10 \\
10 \\
10 \\
-\end{array}$ & $\begin{array}{l}9.0 \\
9.0 \\
9.0 \\
9.0 \\
9.0 \\
9.0\end{array}$ & $\begin{array}{r}11 \\
11 \\
11 \\
10 \\
10 \\
--\end{array}$ & $\begin{array}{l}13 \\
10 \\
9.0 \\
10 \\
10 \\
11\end{array}$ & $\begin{array}{l}9.0 \\
11 \\
13 \\
11 \\
9.0 \\
9.0\end{array}$ & $\begin{array}{l}10 \\
10 \\
11 \\
11 \\
11\end{array}$ \\
\hline $\begin{array}{l}\text { TOTAL } \\
\text { MEAN } \\
\text { MAX } \\
\text { MIN } \\
\text { AC-FT }\end{array}$ & $\begin{array}{r}388 . \\
12 . \\
2 \\
8 . \\
77\end{array}$ & & $\begin{array}{r}291.0 \\
9.70 \\
19 \\
6.0 \\
577\end{array}$ & $\begin{array}{r}294.0 \\
9.48 \\
13 \\
5.0 \\
583\end{array}$ & $\begin{array}{r}235.0 \\
7.58 \\
11 \\
5.0 \\
466\end{array}$ & $\begin{array}{r}2513.0 \\
86.7 \\
680 \\
8.0 \\
4980\end{array}$ & $\begin{array}{r}912.0 \\
29.4 \\
377 \\
9.0 \\
1810\end{array}$ & $\begin{array}{r}1180 \\
39.6 \\
419 \\
10 \\
2360\end{array}$ & $\begin{array}{r}393.0 \\
12.7 \\
50 \\
9.0 \\
780\end{array}$ & $\begin{array}{r}343 \\
11.4 \\
13 \\
10 \\
680\end{array}$ & $\begin{array}{r}395.0 \\
12.7 \\
17 \\
9.0 \\
783\end{array}$ & $\begin{array}{r}344.0 \\
11.1 \\
17 \\
8.0 \\
682\end{array}$ & $\begin{array}{r}1931.0 \\
64.4 \\
1200 \\
9.0 \\
3830\end{array}$ \\
\hline
\end{tabular}


11087020 SAN GABRIEL RIVER ABOVE WHITTIER NARROWS DAM, CA

LOCATION. - Lat $34^{\circ} 02^{\prime} 00^{\prime \prime}$, long $118^{\circ} 02^{\prime} 14^{\prime \prime}$, in La Puente Grant, Los Angeles County, on downstream side of bridge near center on Peck Road, $0.8 \mathrm{mi}(1.3 \mathrm{~km})$ downstream from San Jose flood channe1, $1.2 \mathrm{mi}$ (1.9 km) upstream from axis of Whittier Narrows Dam, and $1.8 \mathrm{mi}(2.9 \mathrm{~km})$ south of E1 Monte.

DRAINAGE AREA. $-353 \mathrm{mi}^{2}\left(914 \mathrm{~km}^{2}\right)$.

PERIOD OF RECORD.--October 1955 to September 1957 , October 1963 to current year.

GAGE.--Water-stage recorder. Altitude of gage is $220 \mathrm{ft}(67 \mathrm{~m})$, from topographic map.

REMARKS. --Records good. Flow regulated by San Gabrie1, Cogswell, and Santa Fe flood-control reservoirs,

combined capacity, 90,670 acre-ft $\left(112 \mathrm{hm}^{3}\right)$, several small flood-control reservoirs, combined capacity,

19,100 acre-ft $\left(23.6 \mathrm{hm}^{3}\right)$, and Morris Reservoir, capacity, 35,000 acre-ft (43.2 hm ${ }^{3}$. Many diversions

above station for irrigation, power development, and ground-water replenishment. Colorado River water

released to the San Gabriel River at a site $14.9 \mathrm{mi}(24.0 \mathrm{~km})$ upstream from gage, at Metropolitan Water

District aqueduct crossing on San Dimas Creek for ground-water replenishment. No water was diverted by

Los Angeles County Flood Control District from San Gabriel River below Santa Fe Dan to Rio Hondo during

current year. See schematic diagram of San Gabriel and Los Angeles River basins.

COOPERATION. - Records of diversion to Rio Hondo were furnished by Los Angeles County Flood Control District.

EXTREMES FOR PERIOD OF RECORD. - Maximum discharge, $46,600 \mathrm{ft}^{3} / \mathrm{s}\left(1,320 \mathrm{~m}^{3} / \mathrm{s}\right) \mathrm{Jan}$. 25 , 1969 , gage height, 10.90 ft

$(3.322 \mathrm{~m})$; no flow for part of most years.

EXTREMES FOR CURRENT YEAR.--Maximum discharge, 4,880 $\mathrm{ft}^{3} / \mathrm{s}\left(138 \mathrm{~m}^{3} / \mathrm{s}\right)$ Sept. 10 , gage height, $6.20 \mathrm{ft}(1.890 \mathrm{~m})$;

minimum daily, $2.6 \mathrm{ft}^{3} / \mathrm{s}\left(0.074 \mathrm{~m}^{3} / \mathrm{s}\right)$ Aug. 26 .

DISCHARGE, IN CUBIC FEET PER SECOND, WATER YEAR OCTOBER 1975 TO SEPTEMBER 1976 MEAN VALUES

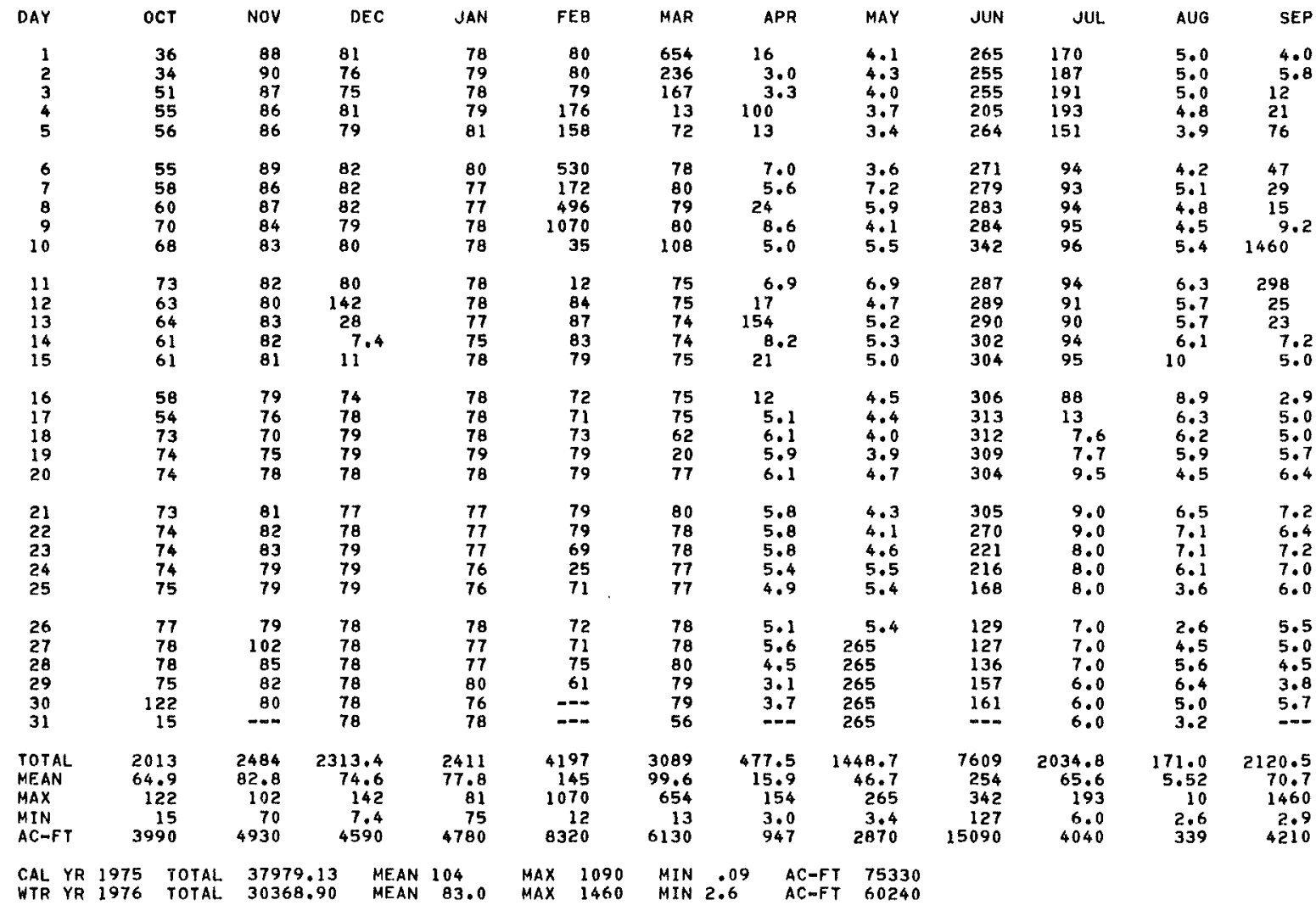


11087040 SAN GABRIEL RIVER AT WHITTIER NARROWS, CA

LOCATION,--Lat $34^{\circ} 01^{\prime} 25^{\prime \prime}$, long $118^{\circ} 03^{\prime} 11^{\prime \prime}$, in sec.5, T.2 S., R.11 W., Los Angeles County, 200 ft (60 m) from end of San Gabriel Boulevard (Siphon Road), upstream from Whittier Narrows Dam, and $2.5 \mathrm{mi}$ ( $4.0 \mathrm{~km}$ ) northeast of Mont ebe110.

PERIOD OF RECORD.--Chemical analyses: Water year 1967 to current year.

REMARKS.--Records of discharge are given for San Gabrie1 River above Whittier Narrows Dam (station 11087020 ).

COOPERATION,--Chemica1-quality records were furnished by California Department of Water Resources.

CHEMICAL ANALYSES, HATER YEAR OCTOBER 1975 TO SEPTEMBER 1976

\begin{tabular}{|c|c|c|c|c|c|c|c|}
\hline DATE & TIME & $\begin{array}{l}\text { INSTAN- } \\
\text { TANEOUS } \\
\text { DIS- } \\
\text { CHARGE } \\
\text { (CF S) }\end{array}$ & $\begin{array}{l}\text { SPE- } \\
\text { CIFIC } \\
\text { CON- } \\
\text { OUCT- } \\
\text { ANCE } \\
\text { (MICRO- } \\
\text { MHOS) }\end{array}$ & $\begin{array}{c}\text { PH } \\
\text { (UNITS) }\end{array}$ & $\begin{array}{l}\text { TEMPER- } \\
\text { ATURE } \\
\text { (DEG C) }\end{array}$ & $\begin{array}{l}\text { TUR- } \\
\text { BID- } \\
\text { ITY } \\
\text { (JTU) }\end{array}$ & $\begin{array}{l}\text { DIS- } \\
\text { SOLVED } \\
\text { OXYGEN } \\
\text { (NG/L) }\end{array}$ \\
\hline OCT & & & & & & & \\
\hline $\begin{array}{l}29 \\
\text { NOV }\end{array}$ & 1130 & 79 & 520 & 8.5 & 18.5 & 2 & 17.7 \\
\hline${ }_{\mathrm{DEC}}^{21} \cdots$ & 1045 & 79 & 510 & 8.1 & 11.0 & 5 & 11.6 \\
\hline $\begin{array}{l}19 \ldots \\
\text { JAN }\end{array}$ & 1015 & 79 & 430 & 8.0 & 9.0 & 4 & 11.9 \\
\hline$\underset{\text { FEB }}{29 \ldots}$ & 1010 & 83 & 480 & 8.1 & 9.5 & 3 & 12.1 \\
\hline$\underset{\text { MAR }}{25}$ & 1020 & 71 & 420 & 7.8 & 11.0 & 4 & 11.4 \\
\hline$\underset{A P R}{29 . . .}$ & 1000 & 83 & 440 & 8.5 & 14.0 & 2 & 13.8 \\
\hline$\underset{\text { MAY }}{23} \cdot \cdots$ & 1010 & 8.1 & 1200 & 8.4 & 17.0 & 2 & 8.6 \\
\hline$\underset{J U N}{21} \cdots$ & 0900 & 5.0 & 1400 & 8.4 & 19.0 & 4 & 6.0 \\
\hline $24 \ldots$ & 0900 & 223 & 420 & 8.4 & 21.0 & 2 & 11.6 \\
\hline
\end{tabular}

\begin{tabular}{|c|c|c|c|c|c|c|}
\hline DATE & $\begin{array}{l}\text { HARO- } \\
\text { NESS } \\
(C A, M G) \\
(M G / L)\end{array}$ & $\begin{array}{l}\text { DIS- } \\
\text { SOLVED } \\
\text { SULFATE } \\
\text { (SOL) } \\
\text { (MG/L) }\end{array}$ & $\begin{array}{l}\text { DIS- } \\
\text { SOLVED } \\
\text { CHLO- } \\
\text { RIOE } \\
\text { (CL) } \\
(M G / L)\end{array}$ & $\begin{array}{l}\text { DIS- } \\
\text { SOLVED } \\
\text { SOLIDS } \\
\text { (RESI } \\
\text { OUE AT } \\
180 \text { C) } \\
(M G / L)\end{array}$ & $\begin{array}{l}\text { DIS- } \\
\text { SOLVED } \\
\text { SOLIDS } \\
\text { (TONS } \\
\text { PER } \\
\text { AC-FT) }\end{array}$ & $\begin{array}{l}\text { DIS- } \\
\text { SOLVED } \\
\text { SOLIDS } \\
\text { (TONS } \\
\text { PER } \\
\text { DAY) }\end{array}$ \\
\hline $\begin{array}{l}\text { OCT } \\
29 . . . \\
\text { NOV }\end{array}$ & 133 & 47 & 55 & 283 & .38 & 60.4 \\
\hline$\underset{D E C}{21} \ldots$ & 133 & 50 & 48 & 265 & .36 & 56.5 \\
\hline JAN $19 . \cdots$ & 127 & 49 & 48 & 261 & .35 & 55.7 \\
\hline FEB & 138 & 55 & 51 & 297 & .40 & 66.6 \\
\hline MAR & 130 & 54 & 46 & 251 & .34 & 48.1 \\
\hline$\underset{A P R}{29} \cdots$ & 139 & 61 & 49 & 287 & .39 & 64.3 \\
\hline$\underset{\text { MAY }}{23} \cdots$ & 335 & 177 & 123 & 754 & 1.03 & 16.5 \\
\hline $21 \ldots$ & 355 & 223 & 182 & 874 & 1.19 & 11.8 \\
\hline $24 \ldots$ & 113 & 48 & 52 & 223 & .30 & 134 \\
\hline
\end{tabular}


LOCATION. - - Lat $34^{\circ} 00^{\prime} 47^{\prime \prime}$, long $118^{\circ} 03^{\prime} 48^{\prime \prime}$, in Paso de Bartolo Grant, Los Angeles County, on right levee 460 ft $(140 \mathrm{~m})$ downstream from San Gabriel River Parkway, $4,200 \mathrm{ft}(1,280 \mathrm{~m})$ downstream from axis of Whittier Narrows Dam, and $1.4 \mathrm{mi}(2.3 \mathrm{~km})$ northeast of Pico Rivera.

DRAINAGE AREA. - -447 $\mathrm{mi}^{2}\left(1,158 \mathrm{~km}^{2}\right)$.

PERIOD OF RECORD, - - October 1928 to current year. Since 1954 Colorado River water released to San Gabrie1 River above station. Since 1954 records not equivalent.

GAGE.- -Water-stage recorder. Datum of gage is $181.55 \mathrm{ft}(55.336 \mathrm{~m})$ above mean sea 1 evel. See WSP 1735 for history of changes prior to Mar. 6, 1952, Mar. 6, 1952, to Aug. 9, 1968, at bridge $0.5 \mathrm{mi}(0.8 \mathrm{~km})$ downstream at datum $9.05 \mathrm{ft}(2.758 \mathrm{~m})$ lower.

REMARKS.--Records poor. Flow regulated by Cogswel1 Reservoir since 1934 and San Gabriel flood-control reservoir since 1939, combined capacity, 46,087 acre-ft $\left(56.8 \mathrm{hm}^{3}\right)$, Morris Reservoir since 1934 , capacity, 35,000 acre-ft $\left(43.2 \mathrm{hm}^{3}\right)$, Santa Fe flood-control reservoir since october 1942 , capacity, 36,800 acre-ft $\left(45.4 \mathrm{hm}^{3}\right)$, Whittier Narrows flood-control reservoir since January 1956 , capacity, 36,160 acre-ft (44.6 hm ${ }^{3}$ ), and several small flood-control reservoirs, combined capacity, 19,100 acre-ft ( $23.6 \mathrm{hm}^{3}$ ). Diversions for irrigation, power development, and ground-water replenishment, For Colorado River water released to San Gabriel River for ground-water replenishment see station 11087020. During the current year, no water

was diverted from the San Gabriel River below Santa Fe Dam to Rio Hondo. See schematic diagram of San

Gabriel and Los Angeles River basins.

COOPERATION. - -Records were furnished by Los Angeles County Flood Control District.

EXTREMES FOR PERIOD OF RECORD. - Maximum discharge, $22,700 \mathrm{ft}^{3} / \mathrm{s}\left(643 \mathrm{~m}^{3} / \mathrm{s}\right)$ Mar. 2 , 1938 ; no flow for periods in most years.

EXTREMES FOR CURRENT YEAR. - Maximum discharge, unknown; no flow many days.

DISCHARGE, IN CUBIC FEET PER SECOND, WATER YEAR OCTOBER 1975 TO SEPTEMBER 1976 MEAN VALUES

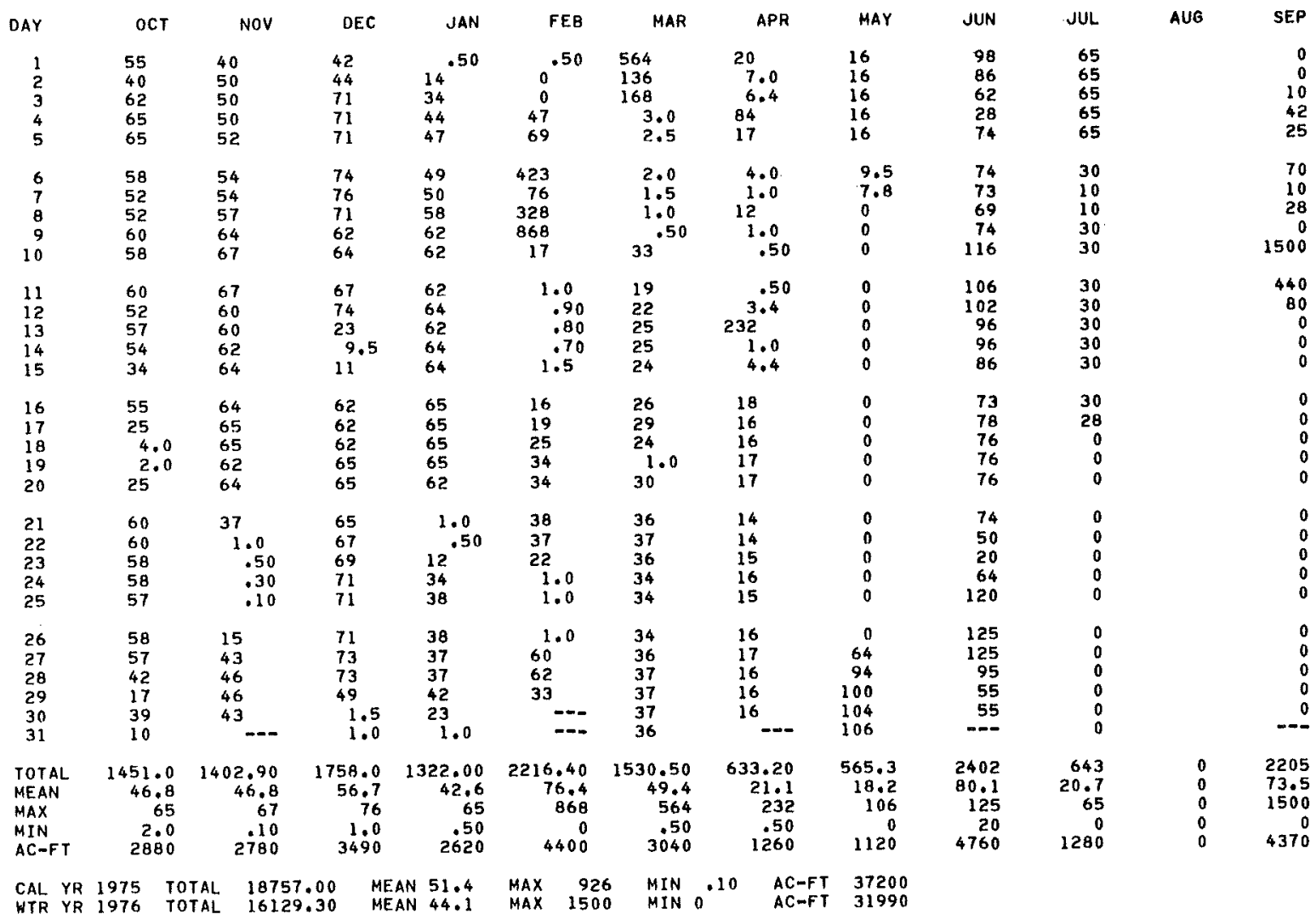


11088000 SAN GABRIEL RIVER AT SPRING STREET, NEAR LOS ALAMTTCS, CA

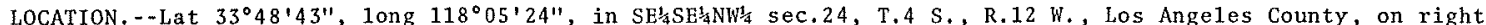
levee $455 \mathrm{ft}(139 \mathrm{~m})$ upstream from Spring street bridge, $1.3 \mathrm{mi}$ (2.1 km) upstream from Coyote Creek, and $1.3 \mathrm{mi}$ $(2.1 \mathrm{~km})$ northwest of Los Alamitos.

DRAINAGE AREA, $-472 \mathrm{mi}^{2}\left(1,222 \mathrm{~km}^{2}\right)$.

PERIOD GF RECORD.--October 1927 to September 1951 , october 1952 to current year. Month1y discharge on1y for october 1927 to September 1936 , published in WSP $1315 * \mathrm{~B}$

GAGE. - Water-stage recorder. Datum of gage is $11.87 \mathrm{ft}(3.618 \mathrm{~m}$ ) above mean sea level (levels by Los Angeles County Flood Control District). Prior to October 1952 , at datum $4.82 \mathrm{ft}(1.469 \mathrm{~m}) \mathrm{higher}$ and from October 1952 to Nov. 17, 1964 , at datum $0.38 \mathrm{ft}(0.116 \mathrm{~m})$ higher.

REMARKS.--Records poor. Regulation and diversions same as station 11087500. Additional diversion to percolation basin near Washington Boulevard and percolation basins in streambed. AVERAGE DISCHARGE represents flow to ocean during period of record regardless of upstream development. See schematic diagram of San Gabriel and Los Angeles River basins.

COOPERATION, --Records were furnished by Los Angeles County Flood Control District.

AVERAGE DISCHARGE. -48 years $31.2 \mathrm{ft}^{3} / \mathrm{s}\left(0.884 \mathrm{~m}^{3} / \mathrm{s}\right), 22,600 \mathrm{acre}-\mathrm{ft} / \mathrm{yr}\left(27.9 \mathrm{hm}^{3} / \mathrm{yr}^{2} \mathrm{.}\right.$

EXTREMES FOR PERIOD OF RECORD,--Maximum discharge, $27,000 \mathrm{ft}^{3} / \mathrm{s}\left(765 \mathrm{~m}^{3} / \mathrm{s}\right)$, estimated, Mar. 2, 1938 ; no flow at times in some years.

EXTREMES FOR CURRENT YEAR.--Maximum discharge, $3,890 \mathrm{ft}^{3} / \mathrm{s}\left(110 \mathrm{~m}^{3} / \mathrm{s}\right)$ Sept. 10 , gage height, $6.00 \mathrm{ft}(1.829 \mathrm{~m})$; minimum daily, $12 \mathrm{ft}^{3} / \mathrm{s}\left(0.34 \mathrm{~m}^{3} / \mathrm{s}\right)$ Dec. 8 .

DISCHARGE, IN CUBIC FEET PER SECOND, WATER YEAR OCTOBER 1975 TO SEPTEMBER 1976 MEAN VALUES

\begin{tabular}{|c|c|c|c|c|c|c|c|c|c|c|c|c|}
\hline DAY & OCT & Nov & DEC & JAN & FEB & MAR & APR & MAY & JUN & JUL & AUG & SEP \\
\hline $\begin{array}{l}1 \\
2 \\
3 \\
4 \\
5\end{array}$ & $\begin{array}{l}40 \\
42 \\
45 \\
44 \\
24\end{array}$ & $\begin{array}{l}41 \\
31 \\
22 \\
31 \\
30\end{array}$ & $\begin{array}{l}17 \\
18 \\
19 \\
40 \\
34\end{array}$ & $\begin{array}{l}22 \\
22 \\
19 \\
19 \\
22\end{array}$ & $\begin{array}{l}13 \\
27 \\
46 \\
35 \\
44\end{array}$ & $\begin{array}{r}363 \\
105 \\
188 \\
67 \\
65\end{array}$ & $\begin{array}{r}60 \\
62 \\
64 \\
107 \\
63\end{array}$ & $\begin{array}{l}69 \\
65 \\
70 \\
70 \\
69\end{array}$ & $\begin{array}{l}40 \\
34 \\
36 \\
53 \\
56\end{array}$ & $\begin{array}{l}70 \\
56 \\
58 \\
39 \\
28\end{array}$ & $\begin{array}{l}55 \\
55 \\
56 \\
64 \\
70\end{array}$ & $\begin{array}{l}61 \\
62 \\
58 \\
62 \\
87\end{array}$ \\
\hline $\begin{array}{r}6 \\
7 \\
8 \\
9 \\
10\end{array}$ & $\begin{array}{l}21 \\
23 \\
44 \\
44 \\
40\end{array}$ & $\begin{array}{l}44 \\
46 \\
45 \\
29 \\
19\end{array}$ & $\begin{array}{l}27 \\
16 \\
12 \\
18 \\
29\end{array}$ & $\begin{array}{l}21 \\
21 \\
21 \\
21 \\
21\end{array}$ & $\begin{array}{r}260 \\
34 \\
160 \\
240 \\
46\end{array}$ & $\begin{array}{l}48 \\
45 \\
48 \\
47 \\
40\end{array}$ & $\begin{array}{l}66 \\
58 \\
69 \\
66 \\
64\end{array}$ & $\begin{array}{l}68 \\
58 \\
64 \\
62 \\
66\end{array}$ & $\begin{array}{l}31 \\
27 \\
36 \\
59 \\
98\end{array}$ & $\begin{array}{l}33 \\
32 \\
62 \\
61 \\
50\end{array}$ & $\begin{array}{l}64 \\
65 \\
62 \\
63 \\
59\end{array}$ & $\begin{array}{r}61 \\
61 \\
64 \\
64 \\
660\end{array}$ \\
\hline $\begin{array}{l}11 \\
12 \\
13 \\
14 \\
15\end{array}$ & $\begin{array}{l}42 \\
21 \\
21 \\
20 \\
36\end{array}$ & $\begin{array}{l}19 \\
34 \\
34 \\
44 \\
47\end{array}$ & $\begin{array}{l}25 \\
34 \\
28 \\
25 \\
17\end{array}$ & $\begin{array}{l}21 \\
21 \\
21 \\
21 \\
28\end{array}$ & $\begin{array}{l}32 \\
32 \\
32 \\
32 \\
32\end{array}$ & $\begin{array}{l}47 \\
48 \\
47 \\
31 \\
14\end{array}$ & $\begin{array}{l}62 \\
75 \\
88 \\
61 \\
64\end{array}$ & $\begin{array}{l}70 \\
70 \\
68 \\
72 \\
67\end{array}$ & $\begin{array}{l}46 \\
62 \\
41 \\
32 \\
63\end{array}$ & $\begin{array}{l}41 \\
31 \\
31 \\
54 \\
66\end{array}$ & $\begin{array}{l}62 \\
66 \\
65 \\
63 \\
61\end{array}$ & $\begin{array}{r}506 \\
59 \\
53 \\
68 \\
64\end{array}$ \\
\hline $\begin{array}{l}16 \\
17 \\
18 \\
19 \\
20\end{array}$ & $\begin{array}{l}37 \\
45 \\
33 \\
18 \\
17\end{array}$ & $\begin{array}{l}31 \\
19 \\
1.5 \\
19 \\
20\end{array}$ & $\begin{array}{l}17 \\
22 \\
21 \\
24 \\
24\end{array}$ & $\begin{array}{l}28 \\
27 \\
29 \\
31 \\
26\end{array}$ & $\begin{array}{l}32 \\
32 \\
32 \\
32 \\
32\end{array}$ & $\begin{array}{l}20 \\
61 \\
61 \\
61 \\
60\end{array}$ & $\begin{array}{l}59 \\
62 \\
59 \\
57 \\
59\end{array}$ & $\begin{array}{l}66 \\
65 \\
59 \\
64 \\
64\end{array}$ & $\begin{array}{l}62 \\
64 \\
64 \\
57 \\
50\end{array}$ & $\begin{array}{l}68 \\
63 \\
59 \\
59 \\
59\end{array}$ & $\begin{array}{l}64 \\
66 \\
65 \\
66 \\
64\end{array}$ & $\begin{array}{l}62 \\
58 \\
57 \\
34 \\
39\end{array}$ \\
\hline $\begin{array}{l}21 \\
22 \\
23 \\
24 \\
25\end{array}$ & $\begin{array}{l}14 \\
31 \\
27 \\
38 \\
33\end{array}$ & $\begin{array}{l}19 \\
17 \\
20 \\
19 \\
19\end{array}$ & $\begin{array}{l}24 \\
24 \\
24 \\
33 \\
34\end{array}$ & $\begin{array}{l}19 \\
23 \\
21 \\
17 \\
16\end{array}$ & $\begin{array}{l}29 \\
33 \\
35 \\
40 \\
27\end{array}$ & $\begin{array}{l}39 \\
27 \\
29 \\
62 \\
66\end{array}$ & $\begin{array}{l}62 \\
67 \\
70 \\
68 \\
66\end{array}$ & $\begin{array}{l}66 \\
66 \\
63 \\
64 \\
66\end{array}$ & $\begin{array}{l}31 \\
57 \\
64 \\
59 \\
68\end{array}$ & $\begin{array}{l}59 \\
59 \\
59 \\
59 \\
59\end{array}$ & $\begin{array}{l}65 \\
61 \\
64 \\
65 \\
62\end{array}$ & $\begin{array}{l}50 \\
40 \\
41 \\
42 \\
29\end{array}$ \\
\hline $\begin{array}{l}26 \\
27 \\
28 \\
29 \\
30 \\
31\end{array}$ & $\begin{array}{l}18 \\
20 \\
17 \\
18 \\
36 \\
19\end{array}$ & $\begin{array}{r}19 \\
18 \\
33 \\
17 \\
16 \\
-\end{array}$ & $\begin{array}{l}37 \\
38 \\
37 \\
35 \\
33 \\
27\end{array}$ & $\begin{array}{l}21 \\
41 \\
34 \\
18 \\
14 \\
13\end{array}$ & $\begin{array}{r}29 \\
31 \\
29 \\
33 \\
---\end{array}$ & $\begin{array}{l}61 \\
50 \\
27 \\
28 \\
29 \\
31\end{array}$ & $\begin{array}{r}68 \\
68 \\
67 \\
67 \\
68 \\
--0\end{array}$ & $\begin{array}{l}66 \\
64 \\
63 \\
59 \\
57 \\
62\end{array}$ & $\begin{array}{r}46 \\
29 \\
27 \\
71 \\
64 \\
-\end{array}$ & $\begin{array}{l}59 \\
59 \\
57 \\
56 \\
57 \\
54\end{array}$ & $\begin{array}{l}63 \\
64 \\
63 \\
61 \\
61 \\
63\end{array}$ & $\begin{array}{r}40 \\
40 \\
40 \\
40 \\
40 \\
-\end{array}$ \\
\hline $\begin{array}{l}\text { TOTAL } \\
\text { MEAN } \\
\text { MAX } \\
\text { MIN } \\
\text { AC }-F T\end{array}$ & $\begin{array}{r}928 \\
29.9 \\
45 \\
14 \\
1840\end{array}$ & $\begin{array}{r}817 \\
27.2 \\
47 \\
15 \\
1620\end{array}$ & $\begin{array}{r}813 \\
26.2 \\
40 \\
12 \\
1610\end{array}$ & $\begin{array}{r}699 \\
22.5 \\
41 \\
13 \\
1390\end{array}$ & $\begin{array}{r}1511 \\
52.1 \\
260 \\
13 \\
3000\end{array}$ & $\begin{array}{r}1915 \\
61.8 \\
363 \\
14 \\
3800\end{array}$ & $\begin{array}{r}1996 \\
66.5 \\
107 \\
57 \\
3960\end{array}$ & $\begin{array}{r}2022 \\
65.2 \\
72 \\
57 \\
4010\end{array}$ & $\begin{array}{r}1527 \\
50.9 \\
98 \\
27 \\
3030\end{array}$ & $\begin{array}{r}1657 \\
53.5 \\
70 \\
28 \\
3290\end{array}$ & $\begin{array}{r}1947 \\
62.8 \\
70 \\
55 \\
3860\end{array}$ & $\begin{array}{r}2642 \\
88.1 \\
660 \\
29 \\
5240\end{array}$ \\
\hline
\end{tabular}

$\begin{array}{llllllllll}\text { CAL YR } 1975 & \text { TOTAL } & 14256.8 & \text { MEAN } 39.1 & \text { MAX } & 1060 & \text { MIN } & 9.8 & \text { AC-FT } & 28280 \\ \text { WYR YR } 1976 & \text { TOTAL } & 18474.0 & \text { MEAN } 50.5 & \text { MAX } & 660 & \text { MIN } & 12 & \text { AC-FT } & 36640\end{array}$ 


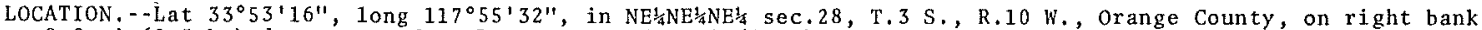

$0.2 \mathrm{mi}(0.3 \cdot \mathrm{km})$ downstream from Brea Dam, and $1 \mathrm{mi}(2 \mathrm{~km})$ north of Fullerton.

DRAINAGE AREA, $\cdots 21.6 \mathrm{mi}^{2}\left(55.9 \mathrm{~km}^{2}\right)$.

PERIOD OF RECORD. - January 1942 to current year.

GAGE. - Water-stage recorder. V-notch sharp-crested weir since October 1946. Datum of gage is $196.67 \mathrm{ft}$

$(59.945 \mathrm{~m})$ above mean sea level (levels by Corps of Engineers). Prior to Dec. 4 , 1964, at datum $1.03 \mathrm{ft}$

$(0.314 \mathrm{~m})$ higher.

REMARKS. - -Records fair. Flow regulated by Brea flood-control reservoir, capacity, 4,100 acre-ft (506 hm ${ }^{3}$ )

No diversion above station. Since August 1966 low flow mostly the result of irrigation waste water from golf course $0.8 \mathrm{mi}(1.3 \mathrm{~km})$ upstream. See schematic diagram of San Gabriel and Los Angeles River basins.

AVERAGE DISCHARGE. - -34 years, $1.24 \mathrm{ft}^{3} / \mathrm{s}\left(0.035 \mathrm{~m}^{3} / \mathrm{s}\right), 898 \mathrm{acre}-\mathrm{ft} / \mathrm{yr}\left(1.11 \mathrm{hm}^{3} / \mathrm{yr}^{2}\right)$.

EXTREMES FOR PERIOD OF RECORD.--Maximum discharge, $970 \mathrm{ft}^{3} / \mathrm{s}\left(27.5 \mathrm{~m}^{3} / \mathrm{s}\right) \mathrm{Feb}, 25,1969$, gage height, $6.30 \mathrm{ft}$

$(1.920 \mathrm{~m})$, from rating curve extended above $340 \mathrm{ft}^{3} / \mathrm{s}\left(9.63 \mathrm{~m}^{3} / \mathrm{s}\right)$; no flow for parts of some years.

EXTREMES FOR CURRENT YEAR. - Maximum discharge, $339 \mathrm{ft}^{3} / \mathrm{s}\left(9.60 \mathrm{~m}^{3} / \mathrm{s}\right)$ Sept. 10, gage height, $4.54 \mathrm{ft}(1.384 \mathrm{~m})$,

on basis of slope-area measurement of maximum flow; minimum daily, $0.08 \mathrm{ft}^{3} / \mathrm{s}^{2}(0.002 \mathrm{~m} / \mathrm{s}) \mathrm{May} 17$ and 20 .

DISCHARGE, IN CUBIC FEET PER SECOND, WATER YEAR OCTOBER 1975 TO SEPTEMBER 1976 MEAN VALUES

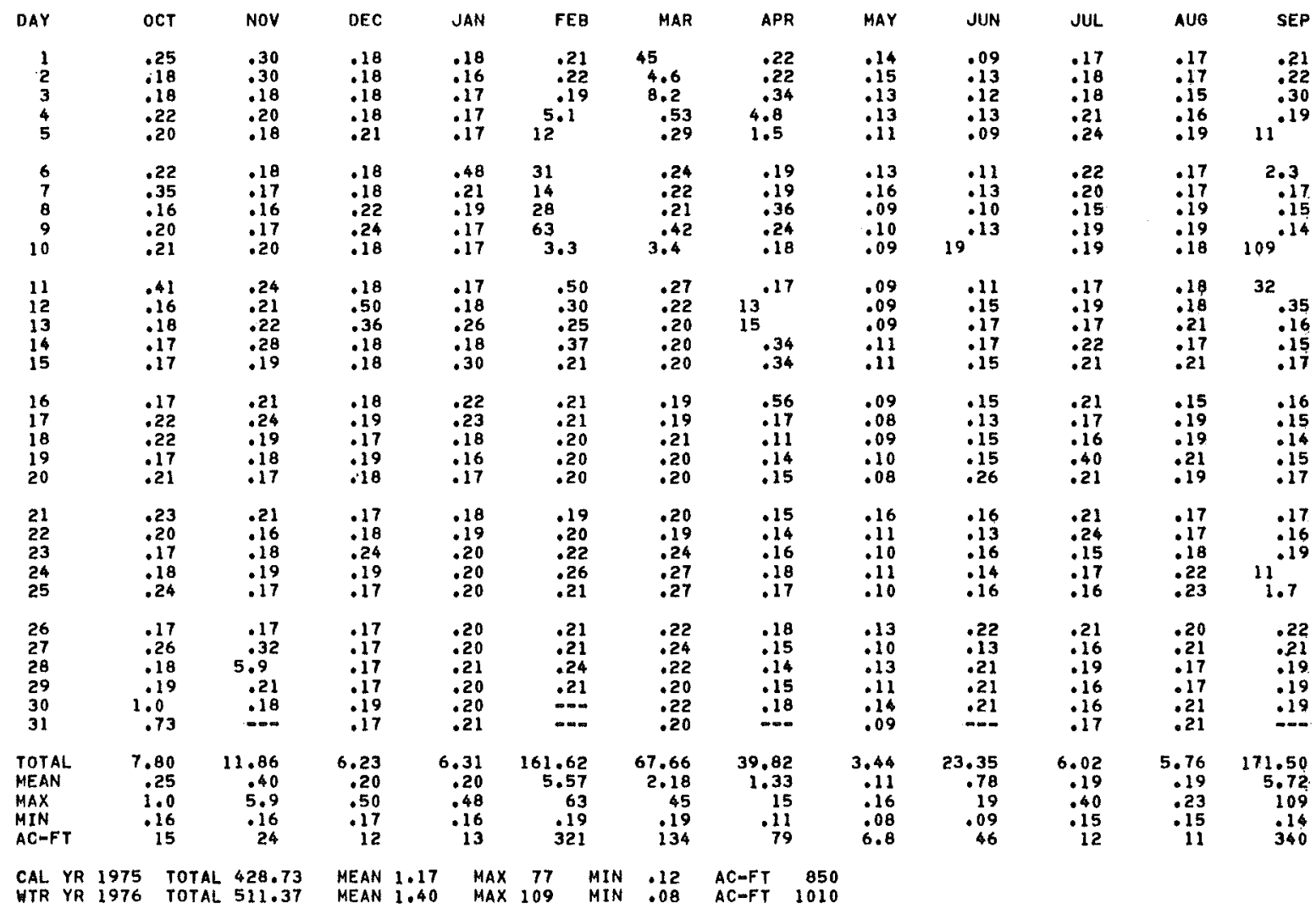


11089500 FULLERTON CREEK BELOW FULLERTON DAM, NEAR BREA, CA

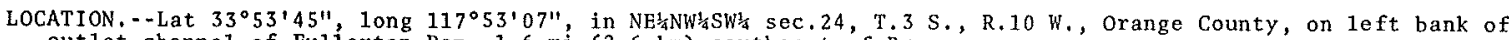
outlet channel of Fulierton Dan, $1.6 \mathrm{mi}(2.6 \mathrm{~km})$ southeast of Brea.

DRAINAGE AREA. $-4,94 \mathrm{mi}^{2}\left(12,79 \mathrm{~km}^{2}\right)$.

PERIOD OF RECORD.--October 1941 to current year.

GAGE. - Water-stage recorder. Altitude of gage is $250 \mathrm{ft}(76 \mathrm{~m})$, from topographic map. V-notch sharp-crested weir used Oct. 25, 1946, to Feb. 2, 1956. Prior to Dec. 3, i971, at datum $3.00 \mathrm{ft}(0.914 \mathrm{~m}) \mathrm{higher}$.

REMARKS, - Records fair. Flow regulated by Fullerton flood-control reservoir, capacity, 706 acre-ft ( 870,000 m ${ }^{3}$ ). Smali tributary formerly entering below station diverted into reservoir since December 1954 . See schematic diagram of San Gabriel and Los Angeles River basins.

AVERAGE DISCHARGE, - -13 years (water years 1942-54), $0.19 \mathrm{ft}^{3} / \mathrm{s}\left(0.005 \mathrm{~m}^{3} / \mathrm{s}\right), 135 \mathrm{acre}-\mathrm{ft} / \mathrm{yr}\left(166,000 \mathrm{~m}^{3} / \mathrm{yr}\right.$ ); 22 years (water years $1955-76), 0.55 \mathrm{ft}^{3} / \mathrm{s}\left(0.016 \mathrm{~m}^{3} / \mathrm{s}\right), 398$ acre-ft/yr $\left(491,000 \mathrm{~m}^{3} / \mathrm{yr}^{2}\right)$.

EXTREMES FOR PERIOD OF RECORD.--Maximum discharge, $313 \mathrm{ft}^{3} / \mathrm{s}\left(8.86 \mathrm{~m}^{3} / \mathrm{s}\right) \mathrm{Jan} .25,1969, \mathrm{gage}$ height, $7.32 \mathrm{ft}$ $(2.231 \mathrm{~m})$, present datum; no flow at times in each year.

EXTREMES FOR CURRENT YEAR.--Maximum discharge, $48 \mathrm{ft}^{3} / \mathrm{s}\left(1.36 \mathrm{~m}^{3} / \mathrm{s}\right)$ Sept. 12, gage height, $4.34 \mathrm{ft}(1.323 \mathrm{~m})$; no flow some days.

DISCHARGE, IN CUBIC FEET PER SECOND, WATER YEAR OCTOBER 1975 TO SEPIEMBER 1976 MEAN VALUES

\begin{tabular}{|c|c|c|c|c|c|c|c|c|c|c|c|c|}
\hline DAY & OCT & Nov & DEC & JAN & FEB & MAR & APR & MAY & JUN & JUL & AUG & SEP \\
\hline $\begin{array}{l}1 \\
2 \\
3 \\
4 \\
5\end{array}$ & $\begin{array}{r}.03 \\
.09 \\
.08 \\
0.05\end{array}$ & $\begin{array}{l}0 \\
0 \\
.01 \\
.46 \\
1.5\end{array}$ & $\begin{array}{l}.33 \\
.23 \\
.07 \\
.08 \\
.05\end{array}$ & $\begin{array}{l}0^{.04} \\
.14 \\
0.17\end{array}$ & $\begin{array}{l}1.1 \\
.61 \\
.20 \\
.40 \\
3.9\end{array}$ & $\begin{array}{l}7.1 \\
9.4 \\
7.0 \\
1.2 \\
.20\end{array}$ & $\begin{array}{l}.87 \\
.56 \\
.08 \\
.68 \\
.13\end{array}$ & $\begin{array}{l}.03 \\
.03 \\
.03 \\
.03 \\
.03\end{array}$ & $\begin{array}{l}.04 \\
.04 \\
.03 \\
.03 \\
.03\end{array}$ & $\begin{array}{r}.30 \\
.30 \\
.30 \\
.24 \\
.24\end{array}$ & $\begin{array}{l}.12 \\
11 \\
.09 \\
.09 \\
.09\end{array}$ & $\begin{array}{r}.07 \\
.07 \\
.07 \\
.08 \\
1.5\end{array}$ \\
\hline $\begin{array}{r}6 \\
7 \\
8 \\
9 \\
10\end{array}$ & $\begin{array}{l}.10 \\
.14 \\
.21 \\
.07 \\
.05\end{array}$ & $\begin{array}{r}1.4 \\
.62 \\
.30 \\
.18 \\
.24\end{array}$ & $\begin{array}{l}.12 \\
.17 \\
.11 \\
.12 \\
.14\end{array}$ & $\begin{array}{l}0 \\
0 \\
0 \\
0 \\
0\end{array}$ & $\begin{array}{r}3.7 \\
2.2 \\
9.0 \\
11 \\
9.7\end{array}$ & $\begin{array}{l}.15 \\
.13 \\
.12 \\
.26 \\
1.2\end{array}$ & $\begin{array}{l}.06 \\
.05 \\
.04 \\
.04 \\
.04\end{array}$ & $\begin{array}{l}.03 \\
.03 \\
.03 \\
.03 \\
.03\end{array}$ & $\begin{array}{r}.03 \\
.03 \\
.03 \\
.03 \\
1.9\end{array}$ & $\begin{array}{l}.24 \\
.24 \\
.24 \\
.24 \\
.24\end{array}$ & $\begin{array}{l}.09 \\
.09 \\
.09 \\
.09 \\
.09\end{array}$ & $\begin{array}{r}7.4 \\
: 16 \\
: 15 \\
13\end{array}$ \\
\hline $\begin{array}{l}11 \\
12 \\
13 \\
14 \\
15\end{array}$ & $\begin{array}{l}0 \\
0 \\
0 \\
0 \\
0\end{array}$ & $\begin{array}{l}.01 \\
.11 \\
.14 \\
0.11\end{array}$ & $\begin{array}{l}.12 \\
.13 \\
.28 \\
.19 \\
.05\end{array}$ & $\begin{array}{l}0 \\
0 \\
0 \\
0 \\
0\end{array}$ & $\begin{array}{r}12 \\
14 \\
.30 \\
.19 \\
.15\end{array}$ & $\begin{array}{l}.70 \\
.46 \\
.32 \\
.18 \\
.12\end{array}$ & $\begin{aligned} .03 \\
10 \\
2.62 \\
.0 \\
.09\end{aligned}$ & $\begin{array}{l}.03 \\
.03 \\
.03 \\
.03 \\
.04\end{array}$ & $\begin{array}{r}.57 \\
.38 \\
.36 \\
.30 \\
.30\end{array}$ & $\begin{array}{l}.24 \\
.24 \\
.24 \\
.24 \\
.24\end{array}$ & $\begin{array}{l}.09 \\
.09 \\
.09 \\
.09 \\
.09\end{array}$ & $\begin{array}{l}20 \\
19 \\
.12 \\
.13 \\
.07\end{array}$ \\
\hline $\begin{array}{l}16 \\
17 \\
18 \\
19 \\
20\end{array}$ & $\begin{array}{l}0 \\
0 \\
0 \\
0 \\
0\end{array}$ & $\begin{array}{l}.11 \\
.23 \\
.14 \\
.07 \\
.14\end{array}$ & $\begin{array}{r}.14 \\
.08 \\
.05 \\
0.18\end{array}$ & $\begin{array}{l}0 \\
0 \\
0 \\
0 \\
0\end{array}$ & $\begin{array}{l}.12 \\
.12 \\
.12 \\
.12 \\
.12\end{array}$ & $\begin{array}{l}.09 \\
.08 \\
.07 \\
.05 \\
.05\end{array}$ & $\begin{array}{l}.09 \\
.09 \\
.05 \\
.04 \\
.04\end{array}$ & $\begin{array}{l}.04 \\
.04 \\
.04 \\
.04 \\
.04\end{array}$ & $\begin{array}{r}.28 \\
.30 \\
.30 \\
.30 \\
.30\end{array}$ & $\begin{array}{r}.19 \\
.19 \\
.18 \\
.15 \\
.15\end{array}$ & $\begin{array}{l}.09 \\
.09 \\
.09 \\
.09 \\
.09\end{array}$ & $\begin{array}{l}.06 \\
.04 \\
.03 \\
.02 \\
.01\end{array}$ \\
\hline $\begin{array}{l}21 \\
22 \\
23 \\
24 \\
25\end{array}$ & $\begin{array}{l}0 \\
0 \\
0 \\
0 \\
0\end{array}$ & $\begin{array}{l}.12 \\
.11 \\
.10 \\
.13 \\
.17\end{array}$ & $\begin{array}{l}.08 \\
.13 \\
.12 \\
.02 \\
0\end{array}$ & $\begin{array}{l}0 \\
0.01 \\
.02 \\
.03\end{array}$ & $\begin{array}{l}.07 \\
.05 \\
.05 \\
.05 \\
.07\end{array}$ & $\begin{array}{l}.04 \\
.04 \\
.04 \\
.04 \\
.04\end{array}$ & $\begin{array}{l}.04 \\
.04 \\
.04 \\
.04 \\
.04\end{array}$ & $\begin{array}{r}.04 \\
.04 \\
.04 \\
.04 \\
.04\end{array}$ & $\begin{array}{r}.30 \\
.30 \\
.24 \\
.24 \\
.24\end{array}$ & $\begin{array}{r}.15 \\
.15 \\
.15 \\
.15 \\
.15\end{array}$ & $\begin{array}{l}.09 \\
.07 \\
.07 \\
.07 \\
.07\end{array}$ & $\begin{array}{l}.01 \\
.02 \\
.02 \\
.02 \\
.03\end{array}$ \\
\hline $\begin{array}{l}26 \\
27 \\
28 \\
29 \\
30 \\
31\end{array}$ & $\begin{array}{l}0 \\
0 \\
.03 \\
.01 \\
.01 \\
0\end{array}$ & $\begin{array}{l}.11 \\
.13 \\
.63 \\
.73 \\
.22 \\
-.-5\end{array}$ & $\begin{array}{l}0 \\
.12 \\
.21 \\
.14 \\
.12 \\
.14\end{array}$ & $\begin{array}{l}.03 \\
.02 \\
.02 \\
.03 \\
.03 \\
.05\end{array}$ & $\begin{array}{l}.09 \\
.09 \\
.09 \\
.09 \\
-0 .\end{array}$ & $\begin{array}{l}.04 \\
.03 \\
.03 \\
.08 \\
.44 \\
.08\end{array}$ & $\begin{array}{l}.04 \\
.04 \\
.04 \\
.03 \\
.03 \\
.0\end{array}$ & $\begin{array}{l}.04 \\
.04 \\
.04 \\
.04 \\
.04 \\
.04\end{array}$ & $\begin{array}{r}.24 \\
.24 \\
.24 \\
.24 \\
.29 \\
-.0\end{array}$ & $\begin{array}{l}.12 \\
.12 \\
.09 \\
.09 \\
.10 \\
.12\end{array}$ & $\begin{array}{l}.07 \\
.07 \\
.07 \\
.07 \\
.07 \\
.07\end{array}$ & $\begin{array}{l}.03 \\
.03 \\
.02 \\
.02 \\
.01 \\
0 .\end{array}$ \\
\hline $\begin{array}{l}\text { TOTAL } \\
\text { MEAN } \\
\text { MAX } \\
\text { MIN } \\
\text { AC }-F T\end{array}$ & $\begin{array}{r}.87 \\
.028 \\
.21 \\
0 \\
1.7\end{array}$ & $\begin{array}{r}8.22 \\
.27 \\
1.5 \\
0 \\
16\end{array}$ & $\begin{array}{r}3.72 \\
.12 \\
.33 \\
0 \\
7.4\end{array}$ & $\begin{array}{r}.59 \\
.019 \\
.17 \\
0 \\
1.2\end{array}$ & $\begin{array}{r}69.70 \\
2.40 \\
14 \\
.05 \\
138\end{array}$ & $\begin{array}{r}30.38 \\
.98 \\
9.4 \\
.03 \\
60\end{array}$ & $\begin{array}{r}15.98 \\
.53 \\
10 \\
.03 \\
32\end{array}$ & $\begin{array}{l}2.10 \\
.036 \\
.04 \\
.03 \\
2.2\end{array}$ & $\begin{array}{r}8.15 \\
.27 \\
1.9 \\
.03 \\
16\end{array}$ & $\begin{array}{r}6.03 \\
.19 \\
.30 \\
.09 \\
12\end{array}$ & $\begin{array}{r}2.64 \\
.085 \\
.12 \\
.07 \\
5.2\end{array}$ & $\begin{array}{r}62.36 \\
2.08 \\
20 \\
.01 \\
124\end{array}$ \\
\hline
\end{tabular}

CAL YR 1975 TOTAL 208.68 MEAN .57 MAX 34 MIN 0 AC-FT 414 WTR YR 1976 TOTAL 209.74 MEAN .57 MAX 20 HIN 0 AC-FT 416 


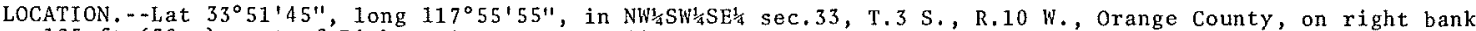

$125 \mathrm{ft}(38 \mathrm{~m})$ east of Richman Avenue, at Fullerton.

DRAINAGE AREA, $--12.1 \mathrm{mi}^{2}\left(31.3 \mathrm{~km}^{2}\right)$.

PERIOD OF RECORD, - -October 1959 to current year.

GAGE. - Water-stage recorder. Datum of gage is $126.4 \mathrm{ft}(38.53 \mathrm{~m})$ above mean sea 1 eve 1 (1evels by orange County Flood Control District).

REMARKS.- Flow regulated by Fullerton flood-control reservoir, capacity, 706 acre-ft ( $870,000 \mathrm{~m}^{3}$ ). No diversion above station. See schematic diagram of San Gabriel and Los Angeles River basins.

COOPERATION. - Records were pub1ished as furnished by Orange County Flood Contro1 District.

AVERAGE DISCHARGE. - -17 years, $2.03 \mathrm{ft}^{3} / \mathrm{s}\left(0.058 \mathrm{~m}^{3} / \mathrm{s}\right), 1,470 \mathrm{acre}-\mathrm{ft} / \mathrm{yr}\left(1.81 \mathrm{hm} / \mathrm{yr}^{3}\right)$.

EXTREMES FOR PERIOD OF RECORD. - -Maximum discharge, $1,100 \mathrm{ft}^{3} / \mathrm{s}\left(31.2 \mathrm{~m}^{3} / \mathrm{s}\right) \mathrm{Jan}$. 25 , 1969 , gage height, $4.78 \mathrm{ft}$

$(1.457 \mathrm{~m})$; no flow many days in each year.

EXTREMES FOR CURRENT YEAR. - Maximum discharge, $782 \mathrm{ft}^{3} / \mathrm{s}\left(22.1 \mathrm{~m}^{3} / \mathrm{s}\right) \mathrm{Apr}$. 12 , gage height, $4.04 \mathrm{ft}(1.231 \mathrm{~m})$; no flow Aug. 3-20, 25-31, Sept. $2,13-30$.

DISCHARGE, IN CUBIC FEET PER SECOND, WATER YEAR OCTOBER 1975 TO SEPTEMEER 1976

\begin{tabular}{|c|c|c|c|c|c|c|c|c|c|c|c|c|c|}
\hline DAY & OCT & NOV & DEC & & JAN & FEB & MAR & APR & MAY & JUN & JUL & AUO & SEP \\
\hline $\begin{array}{l}1 \\
2 \\
3 \\
4 \\
5\end{array}$ & $\begin{array}{l}1.0 \\
1.0 \\
1.4 \\
1.3 \\
1.0\end{array}$ & $\begin{array}{l}.20 \\
110 \\
110 \\
110 \\
1.3\end{array}$ & $\begin{array}{r}.20 \\
1.0 \\
.50 \\
.20 \\
.20\end{array}$ & & $\begin{array}{l}.10 \\
.10 \\
.10 \\
.10 \\
.20\end{array}$ & $\begin{array}{r}.60 \\
12^{.60} \\
19\end{array}$ & $\begin{array}{l}97 \\
33 \\
17 \\
3.3 \\
.50\end{array}$ & $\begin{array}{c}2.6 \\
2.1 \\
12.70 \\
.50\end{array}$ & $\begin{array}{l}.40 \\
.50 \\
.30 \\
.20 \\
.20\end{array}$ & $\begin{array}{l}.30 \\
.30 \\
.30 \\
.40 \\
.50\end{array}$ & $\begin{array}{l}.10 \\
110 \\
110 \\
110 \\
.10\end{array}$ & $\begin{array}{l}.30 \\
.20 \\
0 \\
0\end{array}$ & $\begin{array}{r}.10 \\
.10 \\
16\end{array}$ \\
\hline $\begin{array}{r}6 \\
7 \\
8 \\
9 \\
10\end{array}$ & $\begin{array}{l}1.0 \\
1.7 \\
1.5 \\
1.4 \\
.70\end{array}$ & $\begin{array}{l}1.8 \\
1.0 \\
.50 \\
.60 \\
.40\end{array}$ & $\begin{array}{r}.20 \\
.30 \\
.40 \\
.40 \\
.50\end{array}$ & & $\begin{array}{l}.40 \\
.40 \\
.20 \\
.20 \\
.20\end{array}$ & $\begin{array}{l}58 \\
36 \\
50 \\
93 \\
16\end{array}$ & $\begin{array}{l}.20 \\
.10 \\
.10 \\
4.5 \\
3.8\end{array}$ & $\begin{array}{r}.10 \\
.10 \\
.50 \\
.30 \\
.40\end{array}$ & $\begin{array}{r}.10 \\
1.7 \\
.30 \\
.40 \\
.60\end{array}$ & $\begin{array}{r}.50 \\
.30 \\
.30 \\
.40\end{array}$ & $\begin{array}{l}.10 \\
.10 \\
.10 \\
.10 \\
.10\end{array}$ & $\begin{array}{l}0 \\
0 \\
0 \\
0 \\
0\end{array}$ & $\begin{array}{r}14 \\
.60 \\
.40 \\
132\end{array}$ \\
\hline $\begin{array}{l}11 \\
12 \\
13 \\
14 \\
15\end{array}$ & $\begin{array}{l}1.8 \\
.70 \\
.60 \\
.70 \\
.80\end{array}$ & $\begin{array}{l}.40 \\
.40 \\
.20 \\
.30 \\
.30\end{array}$ & 12.50 & & $\begin{array}{l}.20 \\
.20 \\
.20 \\
.20 \\
.20\end{array}$ & $\begin{array}{r}13 \\
14 \\
.70 \\
.20 \\
.10\end{array}$ & $\begin{array}{l}1.0 \\
.50 \\
.50 \\
.50 \\
.50\end{array}$ & $\begin{array}{l}60^{.30} \\
19 \\
2.6 \\
2.1\end{array}$ & $\begin{array}{l}.70 \\
1.0 \\
.50 \\
.60 \\
.60\end{array}$ & $\begin{array}{l}1.3 \\
.20 \\
.10 \\
.10 \\
.10\end{array}$ & $\begin{array}{r}.10 \\
110 \\
.10 \\
.10 \\
.10\end{array}$ & $\begin{array}{l}0 \\
0 \\
0 \\
0 \\
0\end{array}$ & $\begin{array}{l}1.7 \\
0 \\
0 \\
0 \\
0\end{array}$ \\
\hline $\begin{array}{l}16 \\
17 \\
18 \\
19 \\
20\end{array}$ & $\begin{array}{l}.80 \\
.70 \\
.80 \\
.60 \\
.60\end{array}$ & $\begin{array}{l}.20 \\
.50 \\
.40 \\
.30 \\
.20\end{array}$ & $\begin{array}{r}.30 \\
.30 \\
.20 \\
.20 \\
.10\end{array}$ & & $\begin{array}{l}.20 \\
.30 \\
.10 \\
.10 \\
.30\end{array}$ & $\begin{array}{l}.10 \\
110 \\
110 \\
110 \\
.20\end{array}$ & $\begin{array}{l}.40 \\
.30 \\
.30 \\
.30 \\
.40\end{array}$ & $\begin{array}{l}.50 \\
.30 \\
.20 \\
.60 \\
.50\end{array}$ & $\begin{array}{l}.70 \\
.60 \\
.50 \\
.60 \\
.60\end{array}$ & $\begin{array}{r}.10 \\
.10 \\
.10 \\
.10 \\
.10\end{array}$ & $\begin{array}{r}10 \\
110 \\
110 \\
110 \\
.10\end{array}$ & $\begin{array}{l}0 \\
0 \\
0 \\
0 \\
0\end{array}$ & $\begin{array}{l}0 \\
0 \\
0 \\
0 \\
0\end{array}$ \\
\hline $\begin{array}{l}21 \\
22 \\
23 \\
24 \\
25\end{array}$ & $\begin{array}{l}.60 \\
.60 \\
.60 \\
.50 \\
.50\end{array}$ & $\begin{array}{r}.30 \\
.30 \\
.20 \\
.30 \\
.30\end{array}$ & $\begin{array}{l}.40 \\
.20 \\
.30 \\
.40 \\
.20\end{array}$ & & $\begin{array}{l}.20 \\
.10 \\
.10 \\
.10 \\
.10\end{array}$ & $\begin{array}{l}.20 \\
.10 \\
.10 \\
.20 \\
.20\end{array}$ & $\begin{array}{l}.50 \\
.50 \\
.30 \\
.20 \\
.20\end{array}$ & $\begin{array}{l}.40 \\
.10 \\
.10 \\
.30 \\
.50\end{array}$ & $\begin{array}{l}.80 \\
1.0 \\
1.0 \\
.60 \\
.50\end{array}$ & $\begin{array}{r}.10 \\
.10 \\
110 \\
.10 \\
.10\end{array}$ & $\begin{array}{l}.10 \\
110 \\
110 \\
110 \\
110\end{array}$ & $\begin{array}{r}.10 \\
.10 \\
.10 \\
.10\end{array}$ & $\begin{array}{l}0 \\
0 \\
0 \\
0 \\
0\end{array}$ \\
\hline $\begin{array}{l}26 \\
27 \\
28 \\
29 \\
30 \\
31\end{array}$ & $\begin{array}{r}.50 \\
.60 \\
.70 \\
.80 \\
4.3 \\
.50\end{array}$ & $\begin{array}{r}.40 \\
.70 \\
7.0 \\
.80 \\
.50 \\
.0-\end{array}$ & $\begin{array}{l}.20 \\
.20 \\
.30 \\
.20 \\
.10 \\
.30\end{array}$ & & $\begin{array}{l}.10 \\
.20 \\
.20 \\
.10 \\
.10 \\
.10\end{array}$ & $\begin{array}{l}.20 \\
.20 \\
.20 \\
.10 \\
.+- \\
-2\end{array}$ & $\begin{array}{r}.10 \\
.20 \\
.30 \\
.20 \\
.50 \\
1.5\end{array}$ & $\begin{array}{l}.10 \\
.50 \\
.50 \\
.60 \\
.60 \\
-. .\end{array}$ & $\begin{array}{l}.50 \\
.60 \\
1.0 \\
.50 \\
.40 \\
.40\end{array}$ & $\begin{array}{l}.10 \\
110 \\
110 \\
.10 \\
110 \\
-10\end{array}$ & $\begin{array}{l}.10 \\
.10 \\
.10 \\
.10 \\
.20 \\
.30\end{array}$ & $\begin{array}{l}0 \\
0 \\
0 \\
0 \\
0 \\
0\end{array}$ & $\begin{array}{l}0 \\
0 \\
0 \\
0 \\
0 \\
-\end{array}$ \\
\hline $\begin{array}{l}\text { TOTAL } \\
\text { MEAN } \\
\text { MAX } \\
\text { MIN } \\
\text { AC-FT }\end{array}$ & $\begin{array}{r}30.30 \\
.98 \\
4.3 \\
.50 \\
60\end{array}$ & $\begin{array}{r}20.10 \\
.67 \\
7.0 \\
.10 \\
40\end{array}$ & $\begin{array}{r}21.60 \\
.70 \\
12 \\
.10 \\
43\end{array}$ & s & $\begin{array}{r}5.40 \\
.17 \\
.40 \\
.10 \\
11\end{array}$ & $\begin{array}{r}315.70 \\
10.9 \\
93 \\
.10 \\
626\end{array}$ & $\begin{array}{r}168.70 \\
5.44 \\
97 \\
.10 \\
335\end{array}$ & $\begin{array}{r}117.10 \\
3.90 \\
68 \\
.10 \\
232\end{array}$ & $\begin{array}{r}10.40 \\
.59 \\
1.7 \\
.10 \\
36\end{array}$ & $\begin{array}{r}30.60 \\
1.02 \\
24 \\
.10 \\
61\end{array}$ & $\begin{array}{r}3.40 \\
.11 \\
.30 \\
.10 \\
6.7\end{array}$ & $\begin{array}{r}.90 \\
.029 \\
.30 \\
0 \\
1.8\end{array}$ & $\begin{array}{r}165.20 \\
5.51 \\
132 \\
0 \\
328\end{array}$ \\
\hline
\end{tabular}


11090700 COYOTE CREEK AT LOS ALAMITOS, CA

LOCATION. - Lat $33^{\circ} 48^{\prime} 38^{\prime \prime}$, long $118^{\circ} 04^{\prime} 28^{\prime \prime}$, in NWhElswi sec.19, T.4 S., R.11 W., Orange County, on right bank about $250 \mathrm{ft}(76 \mathrm{~m})$ downstream from Spring Street, $0.5 \mathrm{mi}(0.8 \mathrm{~km})$ northwest of Los Alamitos.

DRAINAGE AREA. $--150 \mathrm{mi}^{2}\left(388 \mathrm{~km}^{2}\right)$.

PERIOD OF RECORD. --October 1963 to current year.

REVISED RECORDS, - -WDR CA-74-1: Drainage area,

GAGE. - Water-stage recorder. Datum of gage is $7.37 \mathrm{ft}(2.246 \mathrm{~m})$ above mean sea leve1 (1eve1s by Los Angeles County Flood Control District).

REMARKS. -Records poor. Flows up to $100 \mathrm{ft}^{3} / \mathrm{s}\left(2.83 \mathrm{~m}^{3} / \mathrm{s}\right)$ can be diverted from present Carbon Creek channel to Coyote Creek through the original Carbon Creek channe1. Flow partially regulated by Carbon Canyon, Brea and Fullerton flood-contro1 reservoirs, combined capacity, 11,840 acre-ft (14.6 hm ${ }^{3}$ ). AVERAGE DISCHARGE represents flow to ocean during period of record, regardless of upstream development. See schematic diagram of San Gabriel and Los Angeles River basins.

COOPERATION. - Records were furnished by Los Angeles County Flood Control District.

AVERAGE DISCHARGE.--13 years, $34.9 \mathrm{ft}^{3} / \mathrm{s}\left(0.988 \mathrm{~m}^{3} / \mathrm{s}\right), 25,290 \mathrm{acre}-\mathrm{ft} / \mathrm{yr}(31.2 \mathrm{hm} / \mathrm{yr})$.

EXTREMES FOR PERIOD OF RECORD. - Maximum discharge, $14,300 \mathrm{ft}^{3} / \mathrm{s}\left(405 \mathrm{~m}^{3} / \mathrm{s}\right)$ Dec, 4, 1974, gage height, $7.25 \mathrm{ft}$ $(2.210 \mathrm{~m})$, from outside'gage; no flow Jan. $25, \mathrm{Feb} .15-17,1964$.

EXTREMES FOR CURRENT YEAR, - Maximum discharge, $5,430 \mathrm{ft}^{3} / \mathrm{s}\left(154 \mathrm{~m}^{3} / \mathrm{s}\right)$ Feb. 6 , gage height, $4.50 \mathrm{ft}(1.372 \mathrm{~m})$, from floodmark; minimum daily, $2.3 \mathrm{ft}^{3} / \mathrm{s}\left(0.065 \mathrm{~m}^{3} / \mathrm{s}\right) \mathrm{Feb} .16-18$.

DISCHARGE, IN CUBIC FEET PER SECOND, WATER YEAR OCTOBER. 1975 TO SEPTEMBER 1976

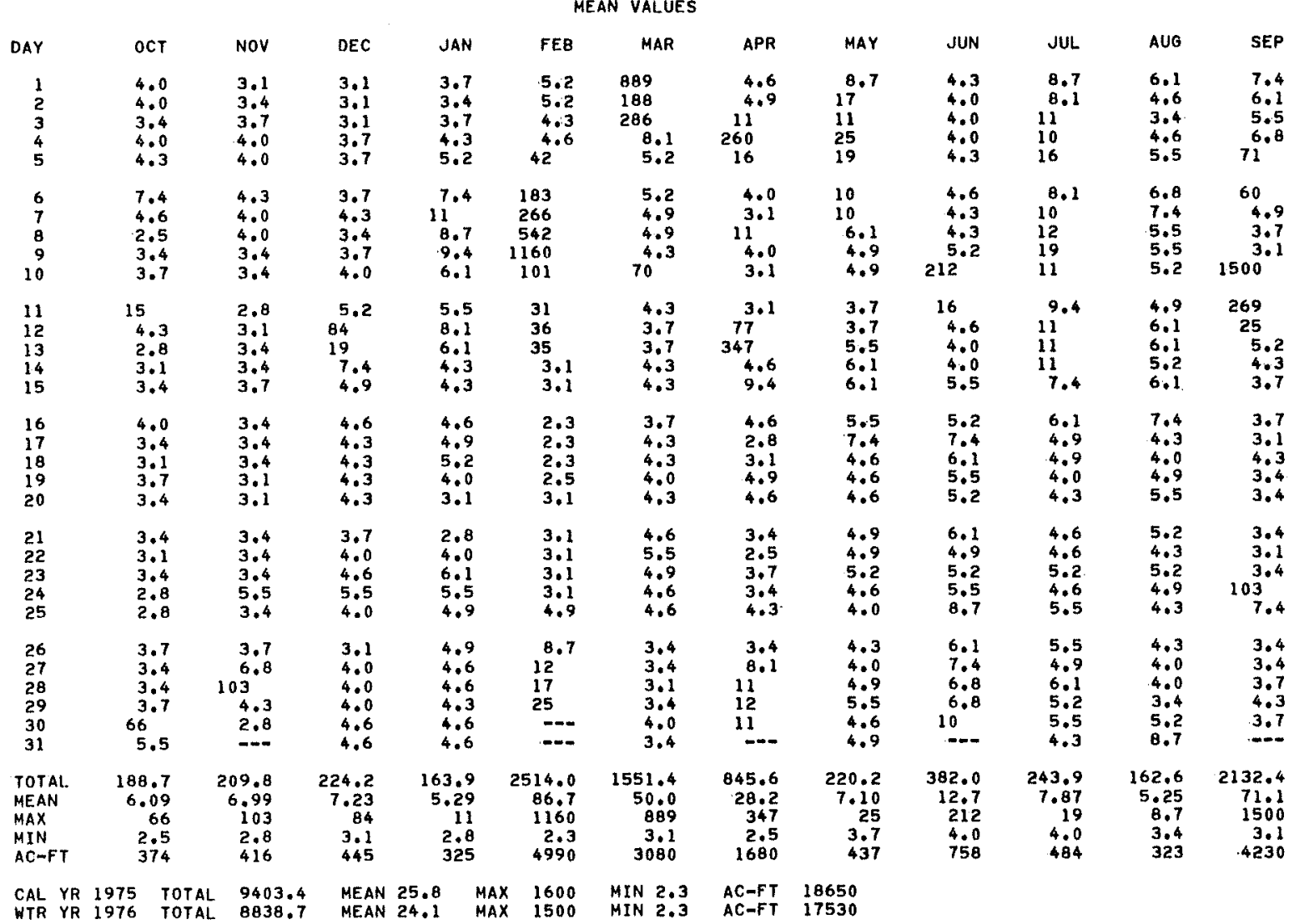




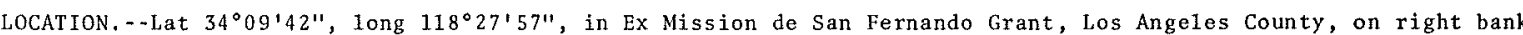
of outlet channel of Sepulveda Dam, $200 \mathrm{ft}(61 \mathrm{~m})$ upstream from Sepulveda Boulevard in city of Los Angeles, and $1.8 \mathrm{mi}(2.9 \mathrm{~km})$ southwest of Van Nuys.

DRAINAGE AREA. - - $158 \mathrm{mi}^{2}\left(409 \mathrm{~km}^{2}\right)$.

PERIOD OF RECORD.--January 1929 to February 1938, May 1938 to current year. See WSP $1315-\mathrm{B}$, 1735 for history of records prior to September 1950.

GAGE, - Water-stage recorder. Datum of gage is $652.7 \mathrm{ft}(198.94 \mathrm{~m})$ above mean sea 1 evel. See WSP 1735 for history of changes prior to Aug. $29,1953$.

REMARKS,--Records fair, Flow regulated since December 1941 by Sepulveda flood-control reservoir, capacity, 17,400 acre-ft $\left(21,5 \mathrm{hm}^{3}\right)$. Some diversion above station. At times, city of Los Angeles discharges imported Owens River water into Los Angeles River from upstrean distributing reservoirs. During current year, no imported water was reported. See schematic diagram of San Gabriel and Los Angeles River basins.

COOPERATION,--Records of released water from reservoirs were furnished by city of Los Angeles.

AVERAGE DISCHARGE. - -46 years (water years $1930-37,1939-76), 30.8 \mathrm{ft}^{3} / \mathrm{s}\left(0.872 \mathrm{~m}^{3} / \mathrm{s}\right), 22,310$ acre-ft/yr $\left(27.5 \mathrm{hm}^{3} / \mathrm{yr}^{\prime}\right)$.

EXTREMES FOR PERIOD OF RECORD. - Maximum discharge, 13,800 $\mathrm{ft}^{3} / \mathrm{s}\left(391 \mathrm{~m}^{3} / \mathrm{s}\right) \mathrm{Jan}, 25,1969, \mathrm{gage} \mathrm{height,} 11.42 \mathrm{ft}$ $(3.481 \mathrm{~m})$; no f1ow Sept. $19,20,1930$.

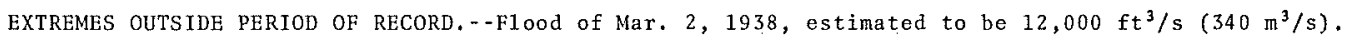

EXTREMES FOR CURRENT YEAR.--Maximum discharge, $5,740 \mathrm{ft}^{3} / \mathrm{s}\left(163 \mathrm{~m}^{3} / \mathrm{s}\right) \mathrm{Feb} .9$, gage height, $6.27 \mathrm{ft}(1.911 \mathrm{~m})$; minimum daily, $1.3 \mathrm{ft}^{3} / \mathrm{s}\left(0.037 \mathrm{~m}^{3} / \mathrm{s}\right) \mathrm{Mar} .6$.

DISCHARGE, IN CUBIC FEET PER SECOW, WATER YEAR OCTOBER 1975 TO SEPTEMBER 1976

\begin{tabular}{|c|c|c|c|c|c|c|c|c|c|c|c|c|}
\hline DAY & OCT & NOV & DEC & JAN & FEB & MAR & APR & MAY & JUN & JUL & AUG & SEP \\
\hline $\begin{array}{l}1 \\
2 \\
3 \\
4 \\
5\end{array}$ & $\begin{array}{l}5.0 \\
5.7 \\
5.4 \\
4.6 \\
5.4\end{array}$ & $\begin{array}{l}5.1 \\
9.0 \\
9.0 \\
8.3 \\
9.2\end{array}$ & $\begin{array}{r}5.2 \\
5.8 \\
6.6 \\
11 \\
6.0\end{array}$ & $\begin{array}{l}2.1 \\
2.1 \\
3.4 \\
3.5 \\
4.0\end{array}$ & $\begin{array}{r}5.4 \\
5.5 \\
4.7 \\
7.3 \\
15\end{array}$ & $\begin{array}{r}260 \\
276 \\
41 \\
2.3 \\
1.7\end{array}$ & $\begin{array}{c}5.9 \\
6.2 \\
26 \\
88 \\
7.2\end{array}$ & $\begin{array}{l}10 \\
12 \\
11 \\
9.3 \\
9.8\end{array}$ & $\begin{array}{l}6.9 \\
6.6 \\
6.5 \\
6.3 \\
6.6\end{array}$ & $\begin{array}{l}6.4 \\
7.7 \\
6.3 \\
7.2 \\
6.8\end{array}$ & $\begin{array}{l}6.7 \\
7.5 \\
6.8 \\
6.2 \\
6.1\end{array}$ & $\begin{array}{r}7.0 \\
6.5 \\
9.6 \\
8.0 \\
108\end{array}$ \\
\hline $\begin{array}{r}6 \\
7 \\
8 \\
9 \\
10\end{array}$ & $\begin{array}{l}5.1 \\
4.2 \\
3.1 \\
3.4 \\
3.4\end{array}$ & $\begin{array}{l}8.3 \\
8.4 \\
7.9 \\
6.7 \\
0.6\end{array}$ & $\begin{array}{l}6.5 \\
6.5 \\
6.5 \\
7.0 \\
8.0\end{array}$ & $\begin{array}{l}3.6 \\
3.6 \\
3.6 \\
4.0 \\
5.7\end{array}$ & $\begin{array}{r}508 \\
423 \\
517 \\
1500 \\
174\end{array}$ & $\begin{array}{l}1.3 \\
1.6 \\
2.1 \\
1.8 \\
8.7\end{array}$ & $\begin{array}{c}3.5 \\
3.6 \\
30 \\
4.8 \\
4.0\end{array}$ & $\begin{array}{c}8.1 \\
19 \\
8.1 \\
8.8 \\
8.3\end{array}$ & $\begin{array}{r}7.2 \\
6.4 \\
6.2 \\
6.0 \\
66\end{array}$ & $\begin{array}{l}8.5 \\
8.7 \\
7.9 \\
9.1 \\
8.8\end{array}$ & $\begin{array}{l}6.5 \\
6.2 \\
5.8 \\
5.5 \\
5.5\end{array}$ & $\begin{array}{r}101 \\
5.5 \\
5.5 \\
7.0 \\
1090\end{array}$ \\
\hline $\begin{array}{l}11 \\
12 \\
13 \\
14 \\
15\end{array}$ & $\begin{array}{l}37 \\
3.1 \\
2.7 \\
2.7 \\
3.1\end{array}$ & $\begin{array}{l}6.5 \\
5.5 \\
5.7 \\
6.8 \\
6.8\end{array}$ & $\begin{array}{l}8.0 \\
49 \\
20 \\
7.5 \\
6.5\end{array}$ & $\begin{array}{l}5.7 \\
5.3 \\
5.3 \\
7.8 \\
4.8\end{array}$ & $\begin{array}{l}8.0 \\
4.6 \\
3.7 \\
2.7 \\
2.4\end{array}$ & $\begin{array}{l}2.3 \\
2.0 \\
3.3 \\
4.1 \\
4.7\end{array}$ & $\begin{array}{l}4.2 \\
14 \\
67 \\
8.4 \\
5.2\end{array}$ & $\begin{array}{l}8.5 \\
8.8 \\
9.2 \\
9.4 \\
9.2\end{array}$ & $\begin{array}{l}6.6 \\
4.0 \\
4.7 \\
5.5 \\
7.5\end{array}$ & $\begin{array}{l}8.5 \\
8.0 \\
8.3 \\
8.9 \\
7.4\end{array}$ & $\begin{array}{l}6.1 \\
6.1 \\
5.9 \\
6.1 \\
53\end{array}$ & $\begin{array}{c}180 \\
10 \\
5.1 \\
5.1 \\
3.8\end{array}$ \\
\hline $\begin{array}{l}16 \\
17 \\
18 \\
19 \\
20\end{array}$ & $\begin{array}{l}3.8 \\
4.2 \\
4.2 \\
4.2 \\
4.6\end{array}$ & $\begin{array}{l}6.8 \\
6.2 \\
5.3 \\
5.8 \\
5.9\end{array}$ & $\begin{array}{c}8.0 \\
13 \\
6.0 \\
6.0 \\
6.0\end{array}$ & $\begin{array}{l}4.6 \\
6.0 \\
5.9 \\
4.8 \\
3.8\end{array}$ & $\begin{array}{l}2.6 \\
2.9 \\
3.2 \\
3.2 \\
2.6\end{array}$ & $\begin{array}{l}5.0 \\
5.0 \\
5.2 \\
4.7 \\
4.4\end{array}$ & $\begin{array}{l}3.5 \\
3.7 \\
4.7 \\
5.2 \\
6.3\end{array}$ & $\begin{array}{l}9.2 \\
9.3 \\
11 \\
11 \\
9.5\end{array}$ & $\begin{array}{l}8.2 \\
8.6 \\
9.5 \\
8.2 \\
7.4\end{array}$ & $\begin{array}{l}6.7 \\
5.9 \\
6.6 \\
6.6 \\
7.4\end{array}$ & $\begin{array}{l}7.2 \\
4.9 \\
5.3 \\
5.0 \\
5.6\end{array}$ & $\begin{array}{l}3.8 \\
3.4 \\
5.1 \\
5.5 \\
5.5\end{array}$ \\
\hline $\begin{array}{l}21 \\
22 \\
23 \\
24 \\
25\end{array}$ & $\begin{array}{l}4.6 \\
4.2 \\
3.4 \\
3.1 \\
3.4\end{array}$ & $\begin{array}{l}6.0 \\
5.3 \\
5.9 \\
6.9 \\
7.7\end{array}$ & $\begin{array}{l}6.0 \\
5.5 \\
4.6 \\
4.6 \\
5.1\end{array}$ & $\begin{array}{l}3.9 \\
4.9 \\
5.9 \\
5.9 \\
4.8\end{array}$ & $\begin{array}{l}2.6 \\
3.5 \\
3.5 \\
4.0 \\
4.3\end{array}$ & $\begin{array}{r}5.4 \\
11 \\
3.0 \\
3.1 \\
2.7\end{array}$ & $\begin{array}{l}6.9 \\
6.8 \\
6.8 \\
9.8 \\
7.7\end{array}$ & $\begin{array}{l}9.6 \\
9.5 \\
9.1 \\
0.5 \\
7.8\end{array}$ & $\begin{array}{r}6.7 \\
8.3 \\
9.6 \\
9.6 \\
11\end{array}$ & $\begin{array}{l}5.6 \\
5.4 \\
4.4 \\
4.6 \\
4.7\end{array}$ & $\begin{array}{l}6.1 \\
6.4 \\
5.6 \\
6.4 \\
6.4\end{array}$ & $\begin{array}{l}5.5 \\
5.1 \\
6.0 \\
5.5 \\
6.2\end{array}$ \\
\hline $\begin{array}{l}26 \\
27 \\
28 \\
29 \\
30 \\
31\end{array}$ & $\begin{array}{l}5.0 \\
5.1 \\
4.8 \\
4.4 \\
30 \\
4.8\end{array}$ & $\begin{array}{l}6.7 \\
6.3 \\
5.7 \\
4.7 \\
5.5 \\
-.2\end{array}$ & $\begin{array}{l}4.2 \\
4.6 \\
3.8 \\
4.2 \\
3.8 \\
2.8\end{array}$ & $\begin{array}{l}4.6 \\
4.5 \\
4.8 \\
4.8 \\
5.9 \\
5.6\end{array}$ & $\begin{array}{l}5.0 \\
4.7 \\
5.3 \\
5.1 \\
-.0 \\
-.\end{array}$ & $\begin{array}{l}3.2 \\
3.8 \\
5.2 \\
5.6 \\
6.5 \\
6.1\end{array}$ & $\begin{array}{c}7.3 \\
8.1 \\
8.1 \\
8.3 \\
10 \\
-\end{array}$ & $\begin{array}{l}8.2 \\
6.9 \\
8.0 \\
7.4 \\
6.8 \\
6.7\end{array}$ & $\begin{array}{l}10 \\
10 \\
9.1 \\
8.0 \\
6.4 \\
-.--\end{array}$ & $\begin{array}{l}4.9 \\
4.3 \\
4.3 \\
4.5 \\
5.1 \\
6.1\end{array}$ & $\begin{array}{l}7.0 \\
7.1 \\
7.2 \\
7.6 \\
7.6 \\
7.5\end{array}$ & $\begin{array}{r}5.1 \\
5.8 \\
6.4 \\
26 \\
5.5 \\
-\end{array}$ \\
\hline $\begin{array}{l}\text { TOTAL } \\
\text { MEAN } \\
\text { MAX } \\
\text { MIN } \\
\text { AC-FT }\end{array}$ & $\begin{array}{r}187.7 \\
6.05 \\
37 \\
2.7 \\
372\end{array}$ & $\begin{array}{r}202.5 \\
6.75 \\
9.2 \\
4.7 \\
402\end{array}$ & $\begin{array}{r}250.3 \\
8.07 \\
49 \\
2.8 \\
496\end{array}$ & $\begin{array}{r}144.3 \\
4.65 \\
7.8 \\
2.1 \\
286\end{array}$ & $\begin{array}{r}3233.8 \\
112 \\
1500 \\
2.4 \\
6410\end{array}$ & $\begin{array}{r}692.8 \\
22.3 \\
276 \\
1.3 \\
1370\end{array}$ & $\begin{array}{r}381.2 \\
12.7 \\
88 \\
3.5 \\
756\end{array}$ & $\begin{array}{r}290.0 \\
9.35 \\
19 \\
6.7 \\
575\end{array}$ & $\begin{array}{r}283.6 \\
9.45 \\
66 \\
4.0 \\
563\end{array}$ & $\begin{array}{r}205.6 \\
6.63 \\
9.1 \\
4.3 \\
408\end{array}$ & $\begin{array}{r}242.9 \\
7.84 \\
53 \\
4.9 \\
482\end{array}$ & $\begin{array}{r}1652.5 \\
55.1 \\
1090 \\
3.4 \\
3280\end{array}$ \\
\hline
\end{tabular}

CAL YR 1975 TOTAL 11448.0 MEAN 31.4 MAX 1470 MIN 1.8 AC-FT 22710 
11093000 PACOIMA CREEK NEAR SAN FERNANDO, CA

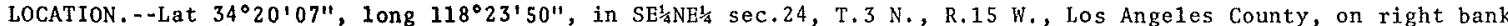
$500 \mathrm{ft}(152 \mathrm{~m})$ downstream from Pacoima Dam, $0.3 \mathrm{mi}(0.5 \mathrm{~km})$ upstream from mouth of canyon, and $4 \mathrm{mi}(6 \mathrm{~km})$ northeast of San Fernando.

DRAINAGE AREA. $--28.3 \mathrm{mi}^{2}\left(73.3 \mathrm{~km}^{2}\right)$.

PERIOD OF RECORD,--March to July 1916 (fragmentary), December 1916 to current year.

GAGE, - Water-stage recorder. Flume or weir control since June 1937. Altitude of gage is 1,650 ft (503 m), from topographic map. See WSP 1735 for history of changes prior to Feb. 1, 1935.

REMARKS. - -Records poor. Flow regulated by Pacoima flood-control reservoir since February 1929, capacity,

3,841 acre-ft $\left(4.74 \mathrm{hm}^{3}\right)$. Flow passing over pacoima Dam spillway enters creek below station. No diversion above station. See schematic diagram of San Gabriel and Los Angeles River basins.

COOPERATION.--Records were furnished by Los Angeles County Flood Control District.

AVERAGE DISCHARGE. - -59 years (water years 1918-76), $9.24 \mathrm{ft}^{3} / \mathrm{s}\left(0.262 \mathrm{~m}^{3} / \mathrm{s}\right), 6,690 \mathrm{acre}-\mathrm{ft} / \mathrm{yr}\left(8.25 \mathrm{hm}^{3} / \mathrm{yr}\right)$. EXTREMES FOR PERIOD OF RECORD.--Maximum discharge, 2,440 $\mathrm{ft}^{3} / \mathrm{s}\left(69.1 \mathrm{~m}^{3} / \mathrm{s}\right)$ Mar. 3, 1938; no f1ow at times in most years.

EXTREMES FOR CURRENT YEAR, -Maximum discharge, $66 \mathrm{ft}^{3} / \mathrm{s}\left(1.87 \mathrm{~m}^{3} / \mathrm{s}\right)$ June 15, gage height, $0.84 \mathrm{ft}(0.256 \mathrm{~m})$; minimum daily, 0.10 $\mathrm{ft}^{3} / \mathrm{s}(0.003 \mathrm{~m} / \mathrm{s})$ many days in November, December and January.

DISCHARGE, IN CUBIC FEET PER SECOND, WATER YEAR OCTOBER 1975 TO SEPTEMBER 1976 MEAN VALUES

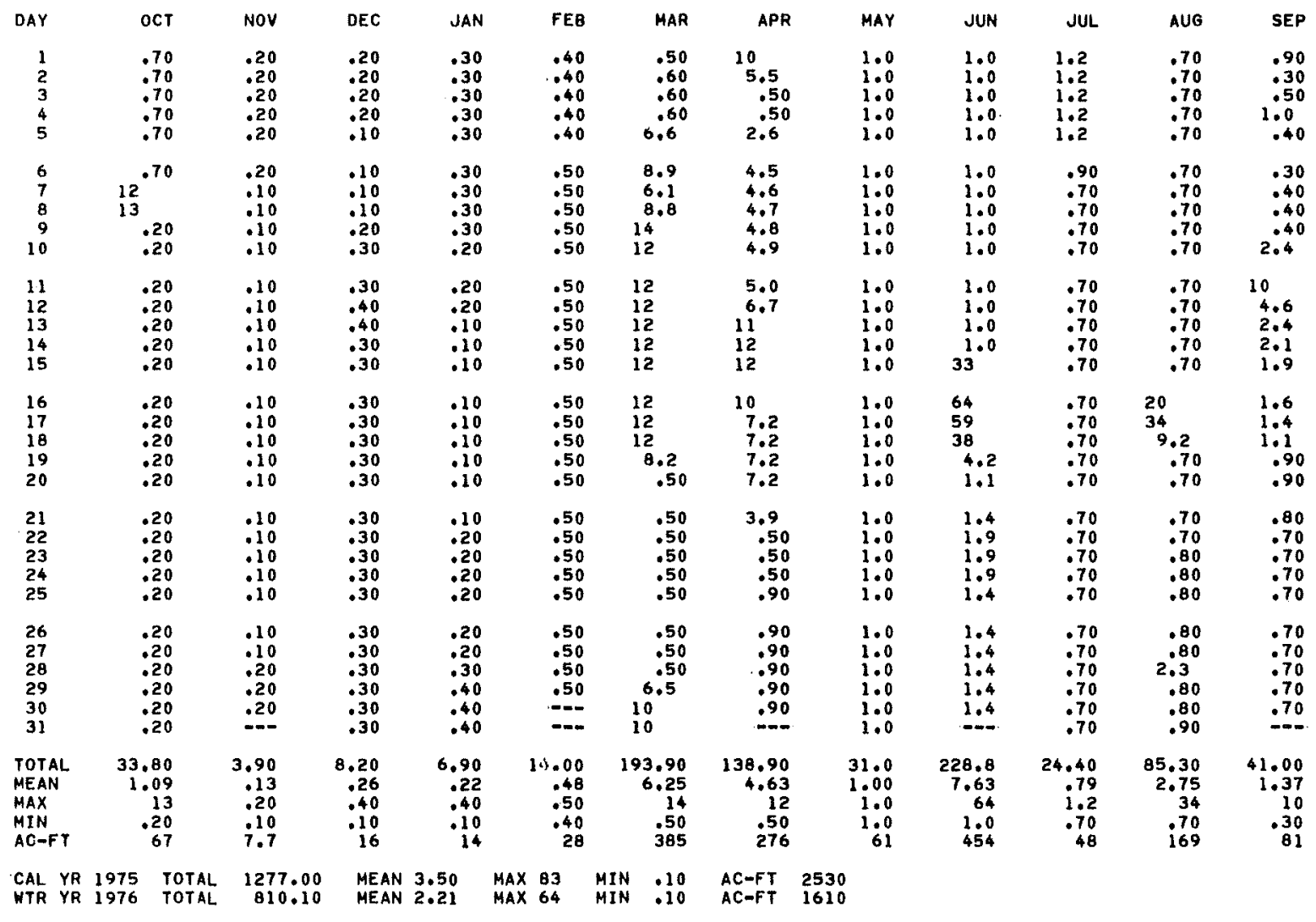


LOCATION, - -Lat $34^{\circ} 18^{\prime} 02^{\prime \prime}$, long $118^{\circ} 16^{\prime} 04^{\prime \prime}$, in SW' $W_{4}^{\prime} W_{4}^{1} S W^{1} / 4$ sec.32, T.3 N., R.13 W., Los Angeles County, on 1eft bank $1,000 \mathrm{ft}(305 \mathrm{~m})$ upstream from Gold Canyon, $2 \mathrm{mi}(3 \mathrm{~km})$ upstream from mouth of canyon, and $4 \mathrm{mi}$ (6 $\mathrm{km})$ northeast of Sunland.

DRAINAGE AREA. $--106 \mathrm{mi}^{2}\left(275 \mathrm{~km}^{2}\right)$.

PERIOD OF RECORD,--October 1916 to current year. Prior to October 1974, published as Tujunga Creek near Sun1and.

GAGE. - Water-stage recorder. Datum of gage is $1,571.80 \mathrm{ft}(479.085 \mathrm{~m})$ above mean sea level (1evels by Los Angeles County Flood Control District). Prior to Oct. 1, 1932, at site 1,000 ft (305 m) upstream at different datum.

REMARKS,--Records poor. Flow regulated since Ju1y 1931 by Big Tujunga flood-contro1 reservoir, capacity

3,819 acre-ft $\left(4.71 \mathrm{hm}^{3}\right)$. Several smal1 diversions above station for irrigation. See schematic diagram of San Gabriel and Los Angeles River basins.

COOPERATION. - -Records were furnished by Los Angeles County Flood Control District.

AVERAGE DISCHARGE. - -59 years (water years $1918-76), 28.3 \mathrm{ft}^{3} / \mathrm{s}\left(0.801 \mathrm{~m}^{3} / \mathrm{s}\right), 20,500 \mathrm{acre}-\mathrm{ft} / \mathrm{yr}(25.3 \mathrm{hrn} / \mathrm{yr})$.

EXTREMES FOR PERIOD OF RECORD, - Maximum discharge, $50,000 \mathrm{ft}^{3} / \mathrm{s}\left(1,420 \mathrm{~m}^{3} / \mathrm{s}\right)$, estimated, Mar. 2 , $1938 ;$ minimum, $0.10 \mathrm{ft}^{3} / \mathrm{s}\left(0.003 \mathrm{~m}^{3} / \mathrm{s}\right)$ at times in some years.

EXTREMES FOR CURRENT YEAR,--Maximum discharge, $378 \mathrm{ft}^{3} / \mathrm{s}\left(10.7 \mathrm{~m}^{3} / \mathrm{s}\right) \mathrm{Feb}, 9$, gage height, $8.52 \mathrm{ft}(2.597 \mathrm{~m})$; minimum daily, $0.90 \mathrm{ft}^{3} / \mathrm{s}\left(0.025 \mathrm{~m}^{3} / \mathrm{s}\right)$ Dec. 30 to Jan. 5, Jan. $8-18,26,27$.

DISCHARGE, IN CUBIC FEET PER SECOND, WATER YEAR OCTOBER 1975 TO SEPTEMBER 1976 MEAN VALUES

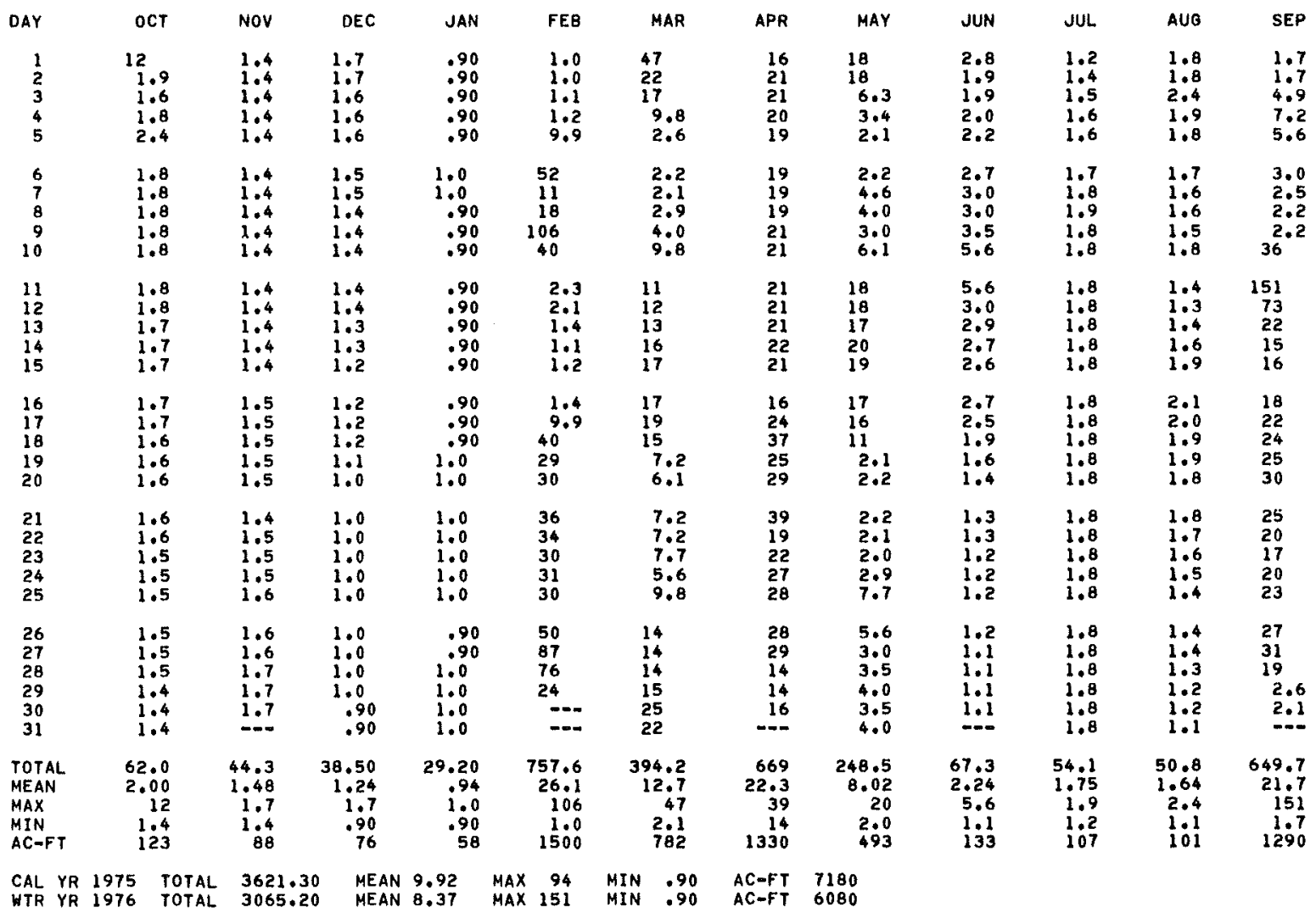


11097000 BIG TUJUNGA CREEK BELOW HANSEN DAM, CA

(Formerly published as Tujunga Creek below Hansen Dam)

LOCATION.--Lat $34^{\circ} 15^{\prime} 13^{\prime \prime}$, long $118^{\circ} 23^{\prime} 17^{\prime \prime}$, in Ex Mission San Fernando Grant, Los Angeles County, in city of Los Angeles, on left bank of outlet channei of Hansen Dam, $0.1 \mathrm{mi}(0.2 \mathrm{~km})$ upstream from Glen Oaks Boulevard, and $3 \mathrm{mi}(5 \mathrm{~km})$ southeast of San Fernando.

DRAINAGE AREA. $--153 \mathrm{mi}^{2}\left(396 \mathrm{~km}^{2}\right)$.

PERIOD OF RECORD, - May 1932 to February 1938, August 1940 to current year. Monthly discharge on1y for some periods, published in WSP $1315-B$.

GAGE. - Water-stage recorder. Datum of gage is $943.32 \mathrm{ft}(287.524 \mathrm{~m})$ above mean sea leve1 (Corps of Engineers bench mark). See WSP 1735 for history of changes prior to Oct. 1, 1953.

REMARKS. - Records poor. Flow regulated since Ju1y 1931 by Big Tujunga flood-contro1 reservoir, capacity, 4,240 acre-ft $\left(5.23 \mathrm{hm}^{3}\right)$ and since September 1940 by Hansen flood-contro1 reservoir, capacity, 29,700 acre-ft $\left(36.6 \mathrm{hm}^{3}\right)$. Several small diversions for domestic use and irrigation. Water reported herein is that which passed Hansen Dam. Los Angeles County Flood Control District diverts $0.3 \mathrm{mi}(0.5 \mathrm{~km})$ upstream from gage to spreading grounds. See schematic diagram of San Gabriel and Los Angeles River basins.

COOPERATION.--Records of diversion were furnished by Los Angeles County F1ood Control District.

EXTREMES FOR PERIOD OF RECORD.--Maximum discharge, 11,700 $\mathrm{ft}^{3} / \mathrm{s}\left(331 \mathrm{~m}^{3} / \mathrm{s}\right) \mathrm{Feb} .25,1969, \mathrm{gage} \mathrm{height,} 7.36 \mathrm{ft}$ $(2.243 \mathrm{~m})$, from rating curve extended above $5,000 \mathrm{ft} / \mathrm{s}\left(142 \mathrm{~m}^{3} / \mathrm{s}\right)$ on basis of gate openings at dam; no flow for all or parts of each year.

EXTREMES OUTSIDE PERIOD OF RECORD.--Maximum discharge, 54,000 $\mathrm{ft}^{3} / \mathrm{s}\left(1,530 \mathrm{~m}^{3} / \mathrm{s}\right)$, estimated, Mar. 2 , 1938 . EXTREMES FOR CURRENT YEAR.--Maximum discharge, $31 \mathrm{ft}^{3} / \mathrm{s}\left(0.88 \mathrm{~m}^{3} / \mathrm{s}\right)$ Mar. 11, gage height, $1.15 \mathrm{ft}(0.351 \mathrm{~m})$; no flow most of year.

DISCHARGE, IN CUBIC FEET PER SECOND, WATER YEAR OCTOBER 1975 TO SEPTEMBER 1976 MEAN VALUES

\begin{tabular}{|c|c|c|c|c|c|c|c|c|c|c|c|c|}
\hline DAY & OCT & NOV & DEC & JAN & FEB & MAR & APR & MAY & JUN & JUL & AUG & SEP \\
\hline 1 & 0 & & 0 & & 0 & .67 & 0 & & & & & 0 \\
\hline 2 & 0 & & 0 & & 0 & .67 & 0 & & & & & 0 \\
\hline 3 & 0 & & 0 & & 0 & 0 & .06 & & & & & 0 \\
\hline 4 & 0 & & 0 & & 0 & 0 & .05 & & & & & 0 \\
\hline 5 & 0 & & 0 & & 0 & 0 & 0 & & & & & .07 \\
\hline 6 & 0 & & 0 & & .38 & 0 & 0 & & & & & 0 \\
\hline 7 & 0 & & 0 & & .50 & 0 & 0 & & & & & 0 \\
\hline 8 & 0 & & 0 & & 1.1 & .16 & .02 & & & & & 0 \\
\hline 9 & 0 & & 0 & & 1.9 & 0 & 0 & & & & & 0 \\
\hline 10 & 0 & & 0 & & .06 & 0 & 0 & & & & & 1.1 \\
\hline 11 & .11 & & 0 & & 0 & .53 & 0 & & & & & .52 \\
\hline 12 & 0 & & .35 & & 0 & 0 & .11 & & & & & 0 \\
\hline 13 & 0 & & 0 & & 0 & 0 & .16 & & & & & 0 \\
\hline 14 & 0 & & 0 & & 0 & 0 & 0 & & & & & 0 \\
\hline 15 & 0 & & 0 & & 0 & 0 & 0 & & & & & 0 \\
\hline 16 & 0 & & 0 & & 0 & 0 & 0 & & & & & 0 \\
\hline 17 & 0 & & 0 & & 0 & 0 & 0 & & & & & 0 \\
\hline 18 & 0 & & 0 & & 0 & 0 & 0 & & & & & 0 \\
\hline 19 & 0 & & 0 & & .89 & 0 & 0 & & & & & 0 \\
\hline 20 & 0 & & 0 & & .92 & 0 & 0 & & & & & 0 \\
\hline 21 & 0 & & 0 & & .35 & 0 & 0 & & & & & 0 \\
\hline 22 & 0 & & 0 & & .10 & 0 & 0 & & & & & 0 \\
\hline 23 & 0 & & 0 & & .51 & 0 & 0 & & & & & 0 \\
\hline 24 & 0 & & 0 & & 0 & 0 & 0 & & & & & 0 \\
\hline 25 & 0 & & 0 & & 0 & 0 & 0 & & & & & 0 \\
\hline 26 & 0 & & 0 & & 0 & 0 & 0 & & & & & 0 \\
\hline 27 & 0 & & 0 & & 0 & 0 & .02 & & & & & 0 \\
\hline 28 & 0 & & 0 & & 0 & 0 & 0 & & & & & 0 \\
\hline 29 & 0 & & 0 & & 0 & 0 & .30 & & & & & 0 \\
\hline 30 & .04 & & 0 & & -- & 0 & 0 & & & & & 0 \\
\hline 31 & 0 & $-\infty$ & 0 & & -- & 0 & $=-$ & & --- & & & \\
\hline TOTAL & .15 & 0 & .35 & 0 & 6.71 & 2.03 & .72 & 0 & 0 & 0 & 0 & 1.69 \\
\hline MEAN & .005 & 0 & .011 & 0 & .23 & .066 & .024 & 0 & 0 & 0 & 0 & .056 \\
\hline $\operatorname{MAX}$ & .11 & 0 & .35 & 0 & 1.9 & .67 & .30 & 0 & 0 & 0 & 0 & 1.1 \\
\hline MIN & 0 & 0 & 0 & 0 & 0 & 0 & 0 & 0 & 0 & 0 & 0 & \\
\hline$A C-F T$ & .3 & 0 & .7 & 0 & 13 & 4.0 & 1.4 & 0 & 0 & 0 & 0 & 3.4 \\
\hline (a) & 1,360 & 1,470 & 1,800 & 878 & 13 & 4.0 & 1.4 & 0 & 0 & 0 & 0 & 3.4 \\
\hline
\end{tabular}

CAL YR 1975 TOTAL 13.30 MEAN .036 MAX 2.5 MIN 0 AC-FT 26 AC-FT a 8,360

WTR YR 1976 TOTAL 11.65 MEAN .032 MAX 1.9 MIN O AC-FT 23 AC-FT a 5,530

a Combined discharge, in acre-feet, of creek and diversion. 
11097490 LOS ANGELES RIVER AT FELIZ BOULEVARD, AT LOS ANGELES, CA

-LOCATION. - Lat $34^{\circ} 07^{\prime} 18^{\prime \prime}$, long $118^{\circ} 16^{\prime} 10^{\prime \prime}$, Los Angeles County, on bridge at Feliz Boulevard in Los Angeles. PERIOD OF RECORD. - Chemical analyses: November 1973 to current year,

COOPERATION. - -Records were furnished by California Department of Water Resources.

CHEMICAL ANALYSES, WATER YEAR OCTOBER 1975 TO SEPTEMRER 1976

\begin{tabular}{|c|c|c|c|c|c|c|c|c|c|c|}
\hline DATE & TIME & $\begin{array}{l}\text { SPE- } \\
\text { CIFIC } \\
\text { CON- } \\
\text { DUCT- } \\
\text { ANCE } \\
\text { (HICRO- } \\
\text { MHOS) }\end{array}$ & $\begin{array}{l}\text { TEMPER- } \\
\text { ATURE } \\
\text { (DEG C) }\end{array}$ & $\begin{array}{l}\text { DIS- } \\
\text { SOLVED } \\
\text { OXYGEN } \\
(M G / L)\end{array}$ & $\begin{array}{l}\text { CHEM- } \\
\text { ICAL } \\
\text { OXYGEN } \\
\text { DEMAND } \\
\text { (HIGH } \\
\text { LEVEL) } \\
\text { (MG/L) }\end{array}$ & $\begin{array}{l}\text { BIO- } \\
\text { CHEM- } \\
\text { ICAL } \\
\text { OXYGEN } \\
\text { DEMANO } \\
5 \text { DAY } \\
\text { (MG } / \text { L) }\end{array}$ & $\begin{array}{c}\text { IMME- } \\
\text { DIATE } \\
\text { COLI- } \\
\text { FORM } \\
\text { (COL. } \\
\text { PER } \\
100 \mathrm{ML})\end{array}$ & $\begin{array}{l}\text { FECAL } \\
\text { COLI- } \\
\text { FORM } \\
\text { (COL. } \\
\text { PER } \\
100 \mathrm{ML} \text { ) }\end{array}$ & $\begin{array}{c}\text { STREP- } \\
\text { TOCOCC I } \\
\text { (COL- } \\
\text { ONIES } \\
\text { PER } \\
100 \mathrm{ML} \text { ) }\end{array}$ & $\begin{array}{l}\text { HARO- } \\
\text { NESS } \\
\text { (CA,MG) } \\
(M G / L)\end{array}$ \\
\hline $\begin{array}{l}\text { OCT } \\
\text { O6.... } \\
\text { NoV }\end{array}$ & 0635 & 1160 & 19,0 & 1.9 & 40 & 3.0 & 1000 & 230 & 300 & 350 \\
\hline DEC & 0530 & 1010 & 16.0 & 3.6 & 56 & 21 & $-\infty$ & 115 & 700 & 270 \\
\hline JAN $05 \cdots$ & 0520 & 1180 & 13.0 & 3.3 & 24 & 9.0 & 9000 & 460 & 1300 & 389 \\
\hline FEB & 0540 & 1340 & 6.0 & B. 0 & 32 & 4.0 & 34000 & 240 & 1200 & 413 \\
\hline $\begin{array}{l}03 \ldots . . \\
05 \ldots \\
06 \ldots . . \\
08 \ldots \\
\text { MAR }\end{array}$ & $\begin{array}{l}0530 \\
0730 \\
1000 \\
1000\end{array}$ & $\begin{array}{r}1000 \\
158 \\
187 \\
108\end{array}$ & $\begin{array}{l}10.0 \\
11.0 \\
11.0 \\
11.0\end{array}$ & $\begin{array}{r}5.9 \\
=- \\
=\end{array}$ & $\begin{array}{l}33 \\
=- \\
=- \\
=-\end{array}$ & $\begin{array}{l}6.0 \\
25 \\
14 \\
10\end{array}$ & $\begin{array}{r}1200 \\
15800 \\
=- \\
-=\end{array}$ & $\begin{array}{r}80 \\
3200 \\
=-\end{array}$ & $\begin{array}{r}800 \\
163000 \\
-\end{array}$ & $\begin{array}{r}243 \\
=- \\
=-\end{array}$ \\
\hline $\begin{array}{l}01 \cdots \\
02 \cdots \\
A P R\end{array}$ & $\begin{array}{l}1230 \\
0740\end{array}$ & $\begin{array}{l}193 \\
604\end{array}$ & $\begin{array}{r}14.0 \\
7.0\end{array}$ & $=$ & $=$ & $\begin{array}{l}15 \\
6.0\end{array}$ & $=$ & 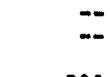 & $=$ & $=$ \\
\hline $\begin{array}{l}01 \ldots \\
05 \ldots \\
\text { MAY }\end{array}$ & $\begin{array}{l}0440 \\
0630\end{array}$ & $\begin{array}{l}965 \\
586\end{array}$ & $\begin{array}{l}13.0 \\
14.5\end{array}$ & $\begin{array}{r}6.0 \\
--\end{array}$ & 57 & $20^{8.0}$ & $\begin{array}{r}14000 \\
-\cdots\end{array}$ & 900 & $\begin{array}{r}3500 \\
-\end{array}$ & 251 \\
\hline$\underset{\text { JUN }}{07 \ldots}$ & 0540 & 681 & 15.5 & 6.0 & 175 & 39 & 14400 & 4200 & $<50800$ & 184 \\
\hline $\begin{array}{l}07 \ldots \\
\text { JUL }\end{array}$ & 0545 & 965 & 15.5 & 4.7 & 38 & 5.0 & 3600 & 420 & 700 & 244 \\
\hline $\begin{array}{l}07 \ldots \\
\text { AUG }\end{array}$ & 0809 & 1020 & 19.5 & 2.9 & 54 & 7.0 & 3000 & 330 & 1500 & 260 \\
\hline$\underset{\text { SEP }}{05 \cdots}$ & 0530 & 949 & 20.0 & 1.2 & 36 & 4.0 & 4500 & 20 & 400 & 283 \\
\hline $03 \ldots$ & 0550 & 1040 & 21.5 & 1.6 & 62 & 4.0 & 3800 & 170 & 300 & 301 \\
\hline DATE & $\begin{array}{l}\text { NON- } \\
\text { CAR- } \\
\text { BONATE } \\
\text { HARD- } \\
\text { NESS } \\
\text { (MG/L) }\end{array}$ & $\begin{array}{l}\text { DIS- } \\
\text { SOLVED } \\
\text { CAL- } \\
\text { CIUM } \\
\text { (CA) } \\
\text { (HG LL) }\end{array}$ & $\begin{array}{l}\text { OIS- } \\
\text { SOLVED } \\
\text { MAG- } \\
\text { NE- } \\
\text { SIUM } \\
\text { (MG) } \\
\text { (MG/L) }\end{array}$ & $\begin{array}{l}\text { DIS- } \\
\text { SOLVED } \\
\text { SODIUM } \\
\text { (NA) } \\
\text { (MG/L) }\end{array}$ & $\begin{array}{r}\text { PERCENT } \\
\text { SODIUM }\end{array}$ & $\begin{array}{c}\text { SOOIUM } \\
\text { AD- } \\
\text { SORP- } \\
\text { TION } \\
\text { RATIO }\end{array}$ & $\begin{array}{l}\text { DIS- } \\
\text { SOLVED } \\
\text { PO- } \\
\text { TAS- } \\
\text { SIUM } \\
\text { (K) } \\
\text { (MG/L) }\end{array}$ & $\begin{array}{l}\text { BICAR- } \\
\text { BONATE } \\
\text { (HCO3) } \\
\text { (HG/L) }\end{array}$ & $\begin{array}{l}\text { CAR- } \\
\text { BONATE } \\
\text { (CO3) } \\
\text { (MG/L) }\end{array}$ & $\begin{array}{l}\text { ALKA- } \\
\text { LINITY } \\
\text { AS } \\
\text { CACO3 } \\
\text { (MG } / L)\end{array}$ \\
\hline
\end{tabular}

\begin{tabular}{|c|c|c|c|c|c|c|c|c|c|c|}
\hline OCT & & & & & & & & & & \\
\hline $\begin{array}{l}06 \ldots . . \\
\text { NOV }\end{array}$ & 190 & $8 \theta$ & 32 & 103 & 38 & 2.4 & 10 & 193 & 0 & 158 \\
\hline $\begin{array}{l}06 \cdots \\
\text { DEC }\end{array}$ & 170 & 76 & 20 & 107 & 45 & 2.8 & 10 & 121 & 0 & 99 \\
\hline $\begin{array}{l}05 \ldots \\
\text { JAN }\end{array}$ & 210 & 106 & 30 & 106 & 36 & $2 \cdot 3$ & 11 & 214 & 0 & 176 \\
\hline FEB & 270 & 114 & 32 & 120 & 38 & 2.6 & 8.3 & 174 & 0 & 143 \\
\hline $03 \ldots$ & 99 & 71 & 16 & 96 & 44 & 2.7 & 17 & 175 & 0 & 144 \\
\hline $05 \ldots$ & $-\infty$ & - & - & -- & -- & - & - & $=$ & $-\infty$ & $=$ \\
\hline $06 \ldots$ & $=$ & - & $=$ & -- & $=$ & $=$ & $=$ & $=-$ & - & 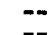 \\
\hline$\underset{M A R}{08 \ldots}$ & - & -- & - & - & -- & -- & - & $-\infty$ & $-\infty$ & -- \\
\hline $01 \ldots$ & $-\infty$ & -- & $-\infty$ & -- & -- & $-\infty$ & -- & -- & $=-$ & $=-$ \\
\hline$\underset{A P R}{02 \cdots}$ & $-\infty$ & -- & - & $-\infty$ & $-\infty$ & $\cdots$ & $-\infty$ & -- & -- & $-\infty$ \\
\hline $01 \ldots$ & 91 & 76 & 15 & 94 & 44 & 2.6 & 11 & 195 & 0 & 160 \\
\hline $\begin{array}{l}05 \cdots \\
\text { MAY }\end{array}$ & $m-$ & $\infty$ & $\infty$ & $=$ & $\cdots$ & -- & - & -- & $-\infty$ & -- \\
\hline$\underset{\text { JUN }}{07 \ldots}$ & 100 & 53 & 12 & 58 & 40 & 2.9 & 7.9 & 101 & 0 & 83 \\
\hline$\underset{\text { JUL. }}{07 \ldots}$ & 51 & 80 & 11 & 94 & 44 & 2.6 & 11 & 235 & 0 & 193 \\
\hline $\begin{array}{l}07 \ldots \\
\text { AUG }\end{array}$ & 51 & 71 & 20 & 93 & 43 & 2.5 & 11 & 255 & 0 & 209 \\
\hline $\begin{array}{l}05 \ldots \\
\text { SEP }\end{array}$ & 120 & 73 & 24 & 84 & 38 & 2.2 & 10 & 205 & 0 & 168 \\
\hline $03 \ldots$ & 89 & 76 & 27 & 94 & 39 & 2.4 & 11 & 258 & 0 & 212 \\
\hline
\end{tabular}


$11097490^{\circ}$ LOS ANGELES RIVER AT FELIZ BOULEVARD, AT LOS ANGELES, CA--Continued

CHEMICAL ANALYSES, HATER YEAR OCTOBER 1975 TO SEPTEMBER 1976

\begin{tabular}{|c|c|c|c|c|c|c|c|c|c|}
\hline DATE & $\begin{array}{l}\text { DIS- } \\
\text { SOLVED } \\
\text { SULFATE } \\
\text { (SO4) } \\
(M G / L)\end{array}$ & $\begin{array}{l}\text { DIS- } \\
\text { SOLVED } \\
\text { CHLO- } \\
\text { RIDE } \\
\text { (CL) } \\
\text { (MG/L) }\end{array}$ & $\begin{array}{c}\text { TOTAL } \\
\text { NON- } \\
\text { FILTE } \\
\text { RABLE } \\
\text { RESIDUE } \\
\text { (HG/L) }\end{array}$ & $\begin{array}{c}\text { VOL. } \\
\text { NON- } \\
\text { FILTE } \\
\text { RABLE } \\
\text { RESIDUE } \\
\text { (MG/L) }\end{array}$ & $\begin{array}{c}\text { TOTAL } \\
\text { NITRATE } \\
\text { (N) } \\
\text { (MG/L) }\end{array}$ & $\begin{array}{l}\text { TOTAL } \\
\text { AMMONIA } \\
\text { NITRO- } \\
\text { GEN } \\
\text { (N) } \\
\text { (MG/L) }\end{array}$ & $\begin{array}{l}\text { TOTAL } \\
\text { ORTHO } \\
\text { PHOS- } \\
\text { PHORUS } \\
\text { (P) } \\
\text { (MG/L) }\end{array}$ & $\begin{array}{c}\text { CYANIDE } \\
\text { (CN) } \\
\text { (MG/L) }\end{array}$ & $\begin{array}{l}\text { OIL } \\
\text { AND } \\
\text { OREASE } \\
\text { (HQ/L) }\end{array}$ \\
\hline $\begin{array}{l}\text { OCT } \\
\text { O6... } \\
\text { NOV }\end{array}$ & 269 & 96 & -- & $=$ & 5.5 & .42 & 4.0 & - & - \\
\hline${ }_{\operatorname{DEC}}^{06} \cdots$ & 237 & 104 & -- & - & 2.8 & .92 & .95 & - & -- \\
\hline JAN 05 & 254 & 103 & $=$ & -- & 7.9 & .53 & 3.2 & - & - \\
\hline$\underset{\text { FEB }}{06 . \cdots !}$ & 320 & 136 & - & -- & 4.6 & .21 & 2.2 & - & -- \\
\hline $03 \ldots$ & 141 & 92 & 530 & $\overline{110}$ & $11 \ldots$ & .00 & 6.5 & .00 & - \\
\hline $06 \ldots$ & -- & $=$ & 424 & 76 & - & -- & -- & .00 & - \\
\hline MAR & $=$ & -4 & 106 & 18 & -- & $-\infty$ & -- & .00 & $\cdots$ \\
\hline $\begin{array}{l}01 \ldots \\
02 \ldots \\
\operatorname{APR}\end{array}$ & $=$ & $\overline{-}$ & $\begin{array}{l}656 \\
122\end{array}$ & $\begin{array}{r}116 \\
30\end{array}$ & 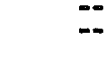 & $\overline{--}$ & $\overline{-}$ & $\begin{array}{l}.00 \\
.00\end{array}$ & -2 \\
\hline $\begin{array}{l}01 \ldots \\
05 . . .\end{array}$ & 143 & 106 & $=$ & $\ddot{8}$ & $10 \ldots$ & 1.4 & 6.0 &.$\overline{00}$ & $=$ \\
\hline & & & & & & & & & $=-$ \\
\hline JUN.." & 107 & 68 & $=$ & -- & 2.9 & 1.6 & .82 & - & -- \\
\hline${ }_{\text {JUL }}^{07 . . .}$ & 137 & 108 & - & -- & 4.4 & 6.5 & 5.7 & -- & - \\
\hline${ }_{A \cup G}^{07} \cdots$ & 158 & 100 & -- & -- & 6.2 & 6.4 & 6.0 & -- & - \\
\hline SEP. & 170 & 99 & -- & - & 4.8 & .34 & 3.3 & $\cdots$ & -- \\
\hline $03 \ldots$ & 187 & 92 & -- & $-\infty$ & .82 & .00 & 3.8 & - & -- \\
\hline
\end{tabular}


LOCATION, - Lat $34^{\circ} 04^{\prime} 52^{\prime \prime}$, long $118^{\circ} 13^{\prime} 36^{\prime \prime}$, landline location not available, Los Angeles County, on right bank near Figueroa Street, Los Angeles, and $800 \mathrm{ft}(244 \mathrm{~m})$ upstream from Arroyo Seco.

DRAINAGE AREA. $-514 \mathrm{mi}^{2}\left(1,331 \mathrm{~km}^{2}\right)$.

PERIOD OF RECORD.--October 1929 to current year.

GAGE. - Water-stage recorder. Datum of gage is $292.58 \mathrm{ft}(89.178 \mathrm{~m}$ ) above mean sea leve1 (1eve1s by Los Ange1es County Flood Control District). See WSP 1315-B for history of changes prior to Dec. 8 , 1939.

REMARKS. - -Records fair. Flow regulated since September 1940 by Hansen f1ood-contro1 reservoir and since December

1941 by Sepulveda fiood-control reservoir, combined capacity, 49,400 acre-ft (60.9 ha 3 ) and severa1 small

flood-control reservoirs. At times city of Los Angeles discharges imported owens River water into Los Angeles River from upstream distributing reservoirs, Excess treated sewage effluent from Los Angeles Bureau of Sani-

tation is released to channel about $8 \mathrm{mi}(13 \mathrm{~km})$ upstream. Many diversions above station for domestic use and

irrigation. See schematic diagram of San Gabriel and Los Angeles River basins.

COOPERATION, - -Records furnished by Los Angeles County Flood Control District.

AVERAGE DISCHARgE. -47 years, $73.7 \mathrm{ft}^{3} / \mathrm{s}\left(2.087 \mathrm{~m}^{3} / \mathrm{s}\right), 53,400 \mathrm{acre}-\mathrm{ft} / \mathrm{yr}\left(65.8 \mathrm{hm} / \mathrm{yr}^{3}\right)$.

EXTREMES FOR PERIOD OF RECORD, - Maximum discharge, $67,000 \mathrm{ft}^{3} / \mathrm{s}\left(1,900 \mathrm{~m}^{3} / \mathrm{s}\right) \mathrm{Mar}$. 2 , 1938 ; no $\mathrm{flow}$ at $\mathrm{times}$ in some years.

EXTREMES FOR CURRENT YEAR,--Maximum discharge, $13,900 \mathrm{ft}^{3} / \mathrm{s}\left(394 \mathrm{~m}^{3} / \mathrm{s}\right)$ Feb, 9 , gage height, $5.89 \mathrm{ft}$ (1.795 $\left.\mathrm{m}\right)$; minimum daily, $2.7 \mathrm{ft}^{3} / \mathrm{s}\left(0.076 \mathrm{~m}^{3} / \mathrm{s}\right)$ June 13

DISCHARGE, IN CUBIC FEET PER SECOND, WATER YEAR OCTOBER 1975 TO SEPTEMBER 1976 MEAN VALUES

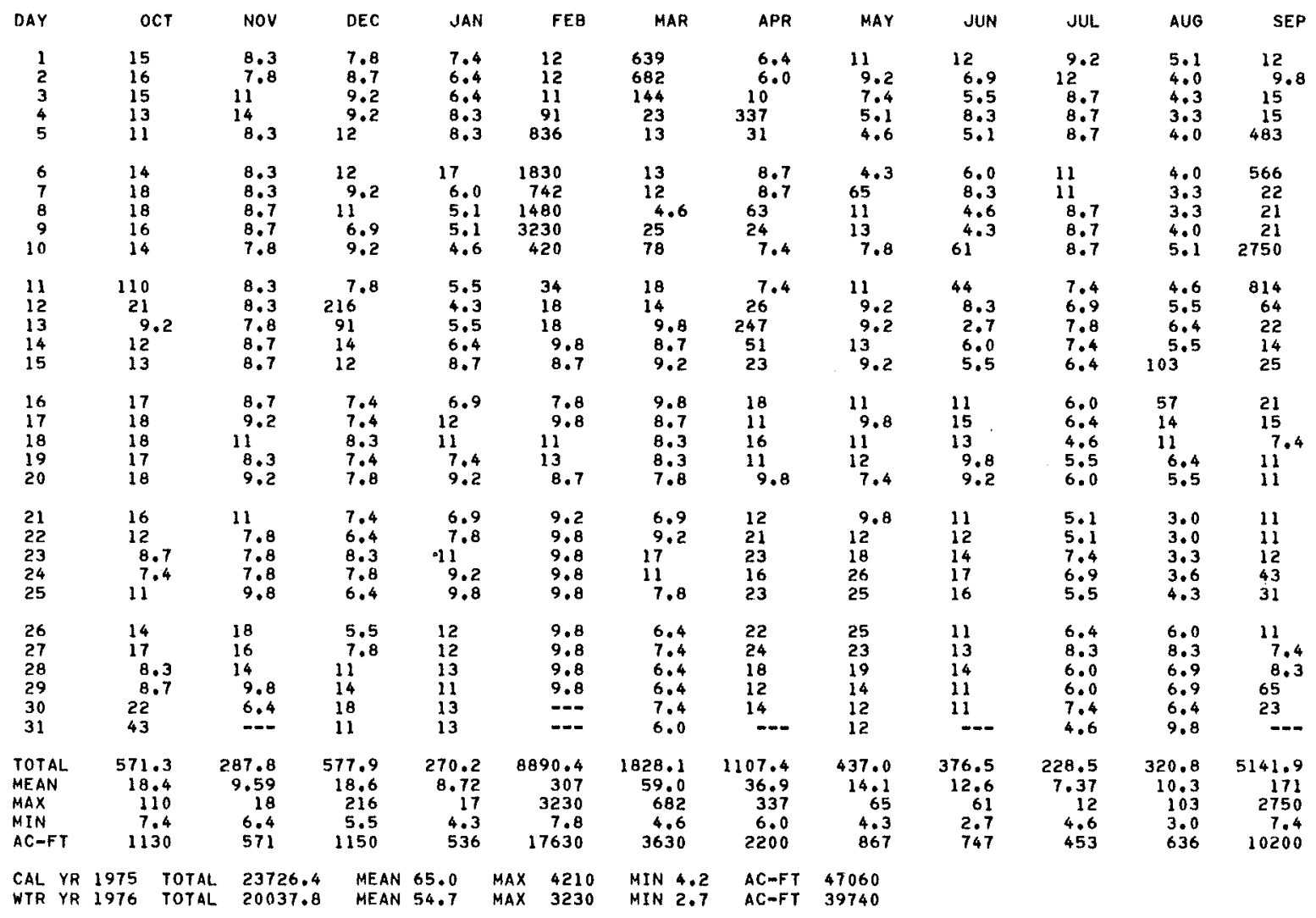


11098000 ARROYO SECO NEAR PASADENA, CA

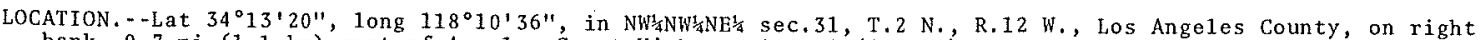

bank, $0.7 \mathrm{mi}(1.1 \mathrm{~km})$ 'east of Angeles Crest Highway, $1.5 \mathrm{mi}(2.4 \mathrm{~km})$ upstream from Millard Canyon, and

$5.5 \mathrm{mi}(8.8 \mathrm{~km})$ northwest of Pasadena.

DRAINAGE AREA. $--16.0 \mathrm{mi}^{2}\left(41.4 \mathrm{~km}^{2}\right)$.

PERIOD OF RECORD. --December 1910 to current year.

GAGE. - Water-stage recorder. Broad-crested weir since November 1938. Datum of gage is $1,397.88$ ft (426.074 m)

above mean sea level. prior to Oct. 1, 1916, nonrecording gage at different datum. oct. 1 , 1916 , to Oct. 19, 1945, water-stage recorder at datum $4.00 \mathrm{ft}(1.219 \mathrm{~m})$ lower

REMARKS, - Records good. Minor regulation by debris dam $1.5 \mathrm{mi}(2.4 \mathrm{~km})$ upstream. No diversion above station.

See schenatic diagram of San Gabriel and Los Angeles River basins. AVERAGE DISCHARGE. - -62 years (water years $1914-15,1917-76), 9.24 \mathrm{ft}^{3} / \mathrm{s}\left(0.262 \mathrm{~m}^{3} / \mathrm{s}\right), 6,690 \mathrm{acre}-\mathrm{ft}^{3} / \mathrm{yr}^{3}$
$\left(8.25 \mathrm{hm}^{3} / \mathrm{yr}\right)$.

EXTREMES FOR PERIOD OF RECORD.--Maximum discharge, $8,620 \mathrm{ft}^{3} / \mathrm{s}\left(244 \mathrm{~m}^{3} / \mathrm{s}\right) \mathrm{Mar}, 2,1938, \mathrm{gage}$ height, $9.42 \mathrm{ft}$

$(2.871 \mathrm{~m})$, present datum, on basis of slope-area measurement of maximum flow; no flow at times in some years. EXTREMES FOR CURRENT YEAR. --Peak discharges above base of $150 \mathrm{ft}^{3} / \mathrm{s}\left(4.25 \mathrm{~m}^{3} / \mathrm{s}\right)$ and maximum (*):

\begin{tabular}{|c|c|c|c|c|c|c|c|c|}
\hline Date & Time & $\begin{array}{c}\text { Discharge } \\
\left(\mathrm{ft}^{3} / \mathrm{s}\right)\left(\mathrm{m}^{3} / \mathrm{s}\right)\end{array}$ & $\begin{array}{l}\text { Gage height } \\
\text { (ft) (m) }\end{array}$ & Date & Time & $\begin{array}{c}\text { Discharge } \\
\left(\mathrm{ft}^{3} / \mathrm{s}\right)\left(\mathrm{m}^{3} / \mathrm{s}\right)\end{array}$ & $\begin{array}{l}\text { Gage } \\
(f t)\end{array}$ & $\begin{array}{r}\text { height } \\
\text { (m) }\end{array}$ \\
\hline $\begin{array}{l}\text { eb. } 9 \\
\text { lar. } 1\end{array}$ & $\begin{array}{l}0530 \\
0915\end{array}$ & $\begin{array}{r}16.7 \\
6.54\end{array}$ & $\begin{array}{l}1.109 \\
0.881\end{array}$ & Sept. 10 & 2145 & 14.7 & 3.51 & 1.070 \\
\hline
\end{tabular}

Minimum daily discharge, $0.17 \mathrm{ft}^{3} / \mathrm{s}\left(0.005 \mathrm{~m}^{3} / \mathrm{s}\right)$ Aug. 30 .

DISCHARGE, IN CUBIC FEET PER SECOND, WATER YEAR OCTOBER 1975 TO SEPTEMBER 1976 MEAN VALUES

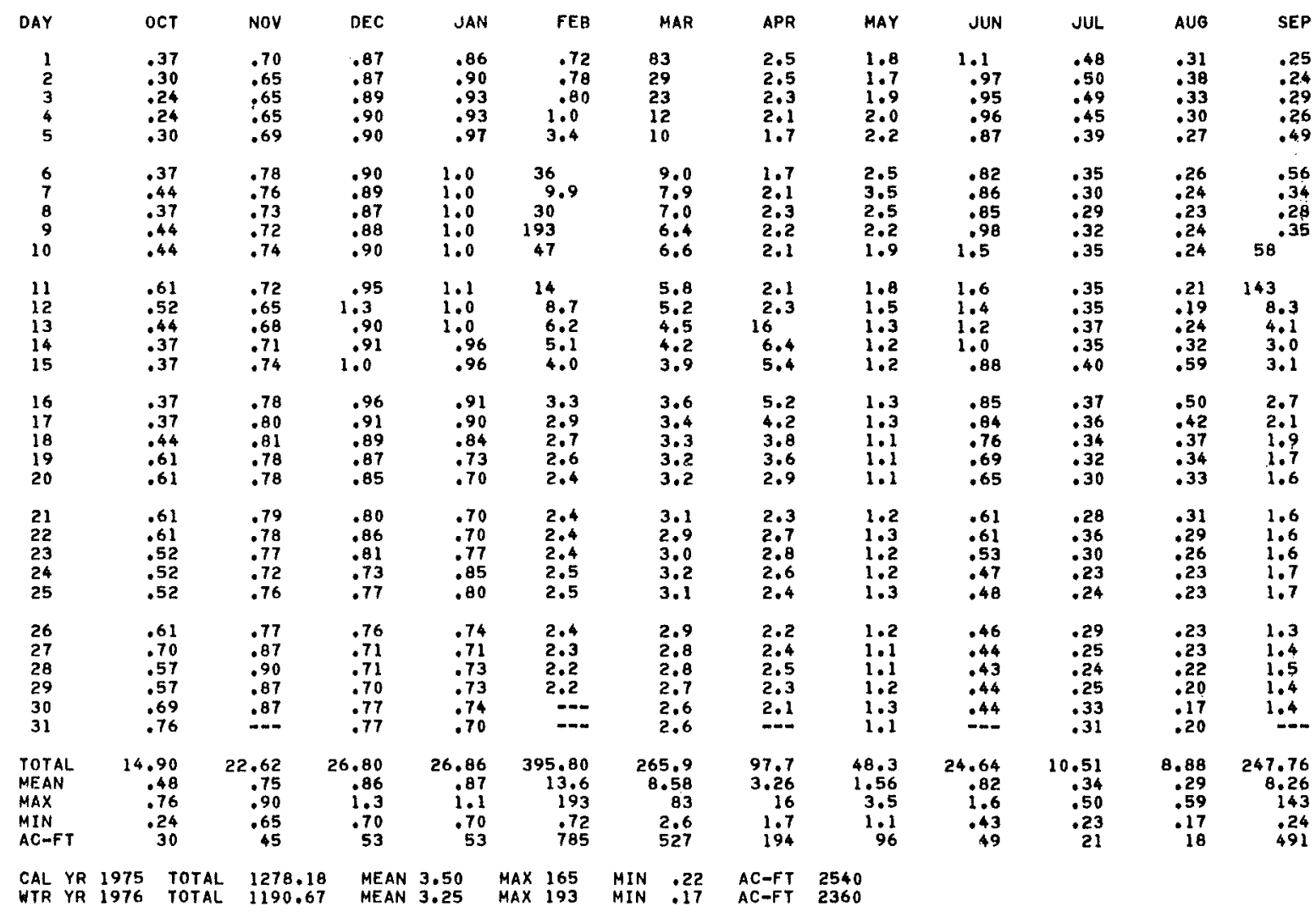


LOCATION.--Lat $33^{\circ} 56^{\prime} 58^{\prime \prime}$, long $18^{\circ} 10^{\prime} 23^{\prime \prime}$, in San Antonio Grant, Los Angeles County, on right bank 400 ft (122 m) downstream from Firestone Boulevard bridge, $1 \mathrm{mi}(2 \mathrm{~km})$ upstream from Rio Hondo, $2.5 \mathrm{mi}(4,0 \mathrm{~km})$ west of Downey and $33 \mathrm{mi}(53 \mathrm{~km})$ downstream from Hansen flood-control reservoir.

DRAINAGE AREA. - -599 $\mathrm{mi}^{2}\left(1,551 \mathrm{~km}^{2}\right)$.

PERIOD OF RECORD. - March 1928 to current year.

GAGE. - Water-stage recorder. Datum of gage is $96.12 \mathrm{ft}(29.297 \mathrm{~m})$ above mean sea level (1evels by Los Angeles County Flood Control District). See WSP 1735 for history of changes prior to Dec. 11 , 1956.

REMARKS.--Records poor. Flow regulated since September 1940 by Hansen flood-control reservoir, since December 1941 by Sepulveda flood-control reservoir, combined capacity, 49,400 acre-ft (60.9 hm $\left.{ }^{3} / y r\right)$, and several small flood-control reservoirs. City of Los Angeles stores imported owens River water in San Fernando and Chatsworth Reservoirs and at times discharges imported water into Los Angeles River. Many diversions for domestic use and irrigation above station. See schematic diagram of San Gabriel and Los Angeles River basins. COOPERATION. - Records were furnished by Los Angeles County Flood Control District.

AVERAGE DISCHARGE, --48 years (water years $1929-76), 111 \mathrm{ft}^{3} / \mathrm{s}\left(3.144 \mathrm{~m}^{3} / \mathrm{s}\right), 80,420 \mathrm{acre}-\mathrm{ft} / \mathrm{yr}(99.2 \mathrm{hm} / \mathrm{yr})$. EXTREMES FOR PERIOD OF RECORD, - Maximum discharge, $79,700 \mathrm{ft}^{3} / \mathrm{s}\left(2,260 \mathrm{~m}^{3} / \mathrm{s}\right)$ Mar, 2 , 1938 , on basis of slope-

area measurement; no flow at times in some years.

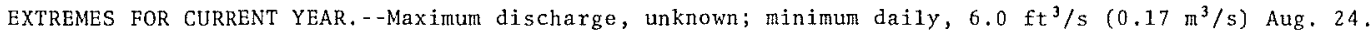

DISCHARGE, IN CUBIC FEET PER SECOND, WATER YEAR OCTOBER 1975 TO SEPTEMBER 1976 MEAN VALUES

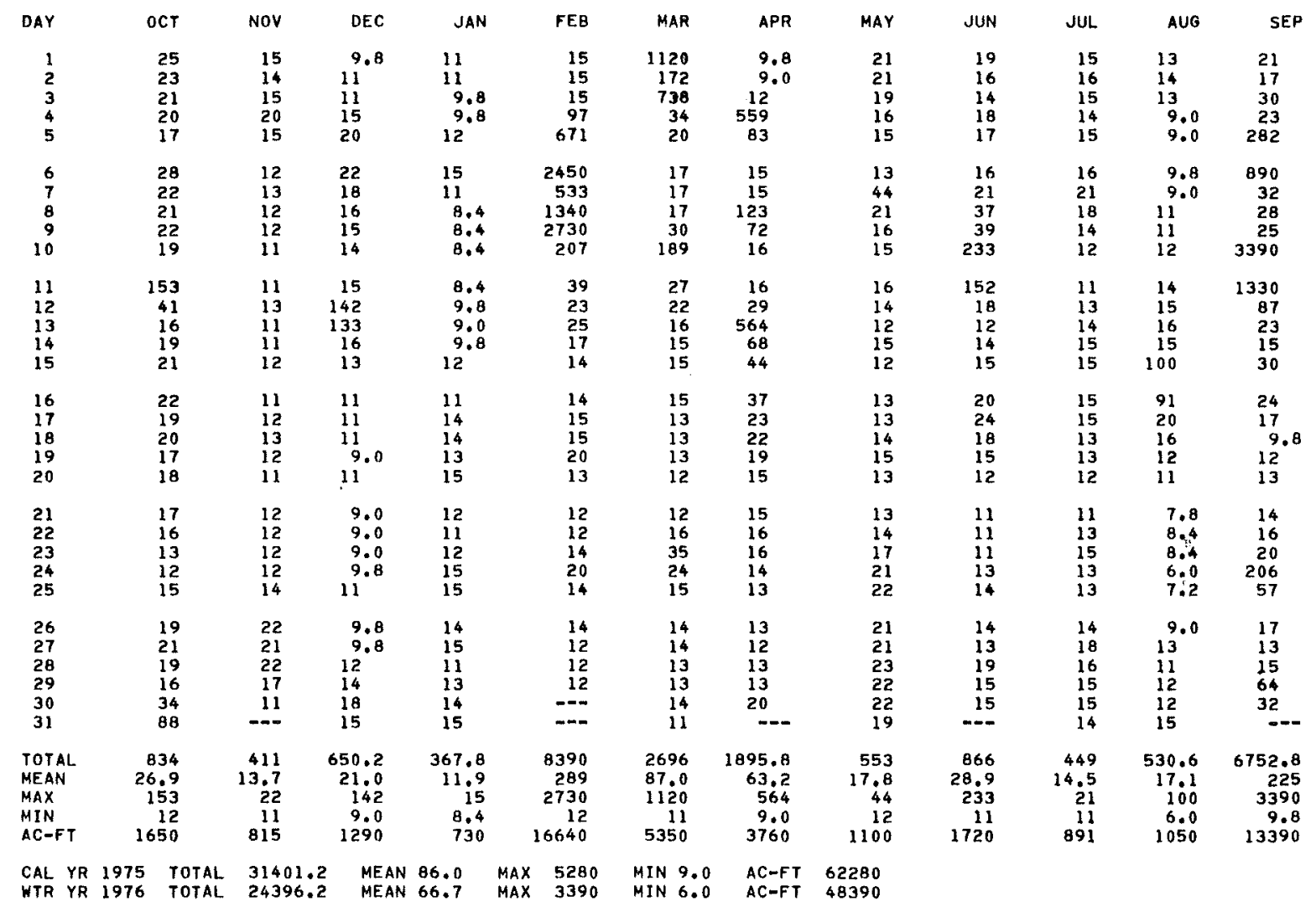


11101250 RIO HONDO ABOVE WHITTIER NARROWS DAM, CA

LOCATION,--Lat $34^{\circ} 03^{\prime} 32^{\prime \prime}$, long $118^{\circ} 04^{\prime} 1^{\prime \prime}$, in Potrero Grande Grant, Los Angeles County, on right bank 0.3 mi $(0.5 \mathrm{~km})$ downstream from Garvey Avenue, $0.4 \mathrm{mi}(0.6 \mathrm{~km})$ downstream from Rubio Wash, and $2.2 \mathrm{mi}(3.5 \mathrm{~km})$ west of E1 Monte.

DRAINAGE AREA. $\cdots 91.2 \mathrm{mi}^{2}\left(236.2 \mathrm{~km}^{2}\right)$.

PERIOD OF RECORD.--February 1956 to current year.

GAGE,--Water-stage recorder, Datum of gage is $217.8 \mathrm{ft}(66.39 \mathrm{~m})$ above mean sea 1 evel.

REMARKS. - Records fair. Flow regulated by Big Santa Anita, Sawpit, and Eaton flood-control reservoirs, combined capacity, 1,700 acre-ft $\left(2.01 \mathrm{hm}^{3}\right)$ and Sierra Madre, Las F1ores, and Rubio debris basins. Many diversions

above station for domestic use and irrigation. No water diverted by Los Angeles County Flood Control District

from San Gabriel River below Santa Fe Dam to Rio Hondo during current year. See schematic diagram of San

Gabrie1 and Los Angeles River basins.

COOPERATION, --Records of diversion were furnished by the Los Angeles County Flood Control District.

AVERAGE DISCHARGE, -20 years, $30.3 \mathrm{ft}^{3} / \mathrm{s}\left(0.858 \mathrm{~m}^{3} / \mathrm{s}\right), 21,950 \mathrm{acre}-\mathrm{ft} / \mathrm{yr}^{\mathrm{r}}\left(27.1 \mathrm{hm} / \mathrm{yr}^{3}\right)$.

EXTREMES FOR PERIOD OF RECORD. --Maximum discharge, 17,700 $\mathrm{ft}^{3} / \mathrm{s}\left(501 \mathrm{~m}^{3} / \mathrm{s}\right) \mathrm{Jan} .25,1969, \mathrm{gage} \mathrm{height,} 7.23 \mathrm{ft}$

$(2.204 \mathrm{~m})$; no flow in some years.

EXTREMES FOR CURRENT YEAR.--Peak discharges above base of $3,000 \mathrm{ft}^{3} / \mathrm{s}\left(85.0 \mathrm{~m}^{3} / \mathrm{s}\right)$ and maximum $(*):$

\begin{tabular}{|c|c|c|c|c|c|c|c|c|c|c|c|}
\hline Date & Time & $\begin{array}{r}\text { Disc } \\
\left(\mathrm{ft}^{3} / \mathrm{s}\right.\end{array}$ & $\left(\mathrm{m}^{3} / \mathrm{s}\right)$ & $\begin{array}{l}\text { Gage } \\
\text { (ft) }\end{array}$ & $\begin{array}{l}\text { eight } \\
(\mathrm{m})\end{array}$ & Date & Time & $\begin{array}{r}\text { Disc } \\
\left(f t^{3} / s\right.\end{array}$ & $\left(\mathrm{m}^{3} / \mathrm{s}\right)$ & $\begin{array}{l}\text { Gage } \\
(\mathrm{ft})\end{array}$ & $\begin{array}{r}\text { height } \\
\text { (II) }\end{array}$ \\
\hline $\begin{array}{l}\text { Feb. } 5 \\
\text { Feb. } 9\end{array}$ & $\begin{array}{l}2400 \\
0245\end{array}$ & $\begin{array}{l}3820 \\
3310\end{array}$ & $\begin{array}{l}108 \\
93.7\end{array}$ & $\begin{array}{l}3.75 \\
3.60\end{array}$ & $\begin{array}{l}1.143 \\
1.097\end{array}$ & $\begin{array}{l}\text { Mar. } 2 \\
\text { Sept. } 11\end{array}$ & $\begin{array}{l}1945 \\
0250\end{array}$ & $\begin{array}{r}3220 \\
* 8500\end{array}$ & $\begin{array}{l}91.2 \\
241\end{array}$ & $\begin{array}{l}3.57 \\
4.93\end{array}$ & $\begin{array}{l}1.088 \\
1.503\end{array}$ \\
\hline
\end{tabular}

Minimum daily discharge, $0.14 \mathrm{ft}^{3} / \mathrm{s}\left(0.004 \mathrm{~m}^{3} / \mathrm{s}\right)$ Apr. 17.

DISCHARGE, IN CUBIC FEET PER SECOND, WATER YEAR OCTOBER 1975 TO SEPTEMBER 1976 MEAN VALUES

\begin{tabular}{|c|c|c|c|c|c|c|c|c|c|c|c|c|}
\hline DAY & $\mathrm{OCT}$ & NOV & DEC & JAN & FEB & MAR & APR & MAY & JUN & JUL & AUG & SEP \\
\hline $\begin{array}{l}1 \\
2 \\
3 \\
4 \\
5\end{array}$ & $\begin{array}{l}2.9 \\
2.2 \\
1.8 \\
2.4 \\
2.3\end{array}$ & $\begin{array}{l}.56 \\
.80 \\
1.0 \\
1.1 \\
.88\end{array}$ & $\begin{array}{r}.75 \\
.72 \\
1.1 \\
.97 \\
.92\end{array}$ & $\begin{array}{r}.29 \\
.38 \\
.50 \\
.54 \\
1.1\end{array}$ & $\begin{array}{r}1.0 \\
1.3 \\
1.0 \\
67 \\
192\end{array}$ & $\begin{array}{r}446 \\
285 \\
9.2 \\
1.7 \\
1.1\end{array}$ & $\begin{array}{c}.90 \\
1.6 \\
7.9 \\
92 \\
2.8\end{array}$ & $\begin{array}{l}.50 \\
.72 \\
.45 \\
.28 \\
1.6\end{array}$ & $\begin{array}{l}.45 \\
.57 \\
.58 \\
.65 \\
.62\end{array}$ & $\begin{array}{l}1.7 \\
1.6 \\
1.3 \\
1.4 \\
1.1\end{array}$ & $\begin{array}{l}.97 \\
3.1 \\
.82 \\
1.4 \\
2.8\end{array}$ & $\begin{array}{l}1.6 \\
2.1 \\
4.2 \\
1.8 \\
80\end{array}$ \\
\hline $\begin{array}{r}6 \\
7 \\
8 \\
9 \\
10\end{array}$ & $\begin{array}{l}10 \\
7.4 \\
1.4 \\
1.4 \\
1.6\end{array}$ & $\begin{array}{r}.81 \\
.72 \\
.76 \\
.71 \\
.90\end{array}$ & $\begin{array}{l}1.2 \\
.97 \\
1.8 \\
1.0 \\
.86\end{array}$ & $\begin{array}{l}1.2 \\
.84 \\
1.1 \\
1.1 \\
1.1\end{array}$ & $\begin{array}{r}396 \\
46 \\
305 \\
440 \\
6.8\end{array}$ & $\begin{array}{c}.62 \\
.53 \\
1.7 \\
2.9 \\
11\end{array}$ & $\begin{array}{r}.68 \\
.75 \\
.80 \\
.67\end{array}$ & $\begin{array}{r}12.38 \\
.19 \\
.31 \\
.45\end{array}$ & $\begin{array}{r}.53 \\
.62 \\
.72 \\
19.96\end{array}$ & $\begin{array}{l}2.7 \\
2.7 \\
2.7 \\
2.9 \\
.96\end{array}$ & $\begin{array}{l}2.3 \\
1.1 \\
1.3 \\
2.3 \\
2.7\end{array}$ & $\begin{array}{r}16 \\
4.3 \\
2.1 \\
1.4 \\
1010\end{array}$ \\
\hline $\begin{array}{l}11 \\
12 \\
13 \\
14 \\
15\end{array}$ & $\begin{array}{r}37 \\
3.9 \\
1.0 \\
.55 \\
.86\end{array}$ & $\begin{array}{l}.80 \\
.80 \\
.64 \\
.73 \\
.81\end{array}$ & $\begin{array}{c}86 \\
1.84 \\
.63 \\
.71\end{array}$ & $\begin{array}{l}.85 \\
.91 \\
1.2 \\
1.6 \\
1.1\end{array}$ & $\begin{array}{l}1.0 \\
.96 \\
.79 \\
.59 \\
.54\end{array}$ & $\begin{array}{l}4.3 \\
3.6 \\
.84 \\
.84 \\
3.1\end{array}$ & $\begin{array}{c}3.2 \\
51 \\
132 \\
5.38 \\
5.9\end{array}$ & $\begin{array}{r}.38 \\
.53 \\
.53 \\
.84 \\
1.7\end{array}$ & $\begin{array}{l}.72 \\
.53 \\
.62 \\
.84 \\
.84\end{array}$ & $\begin{array}{l}.96 \\
4.8 \\
7.1 \\
4.8 \\
6.5\end{array}$ & $\begin{array}{l}2.0 \\
2.1 \\
2.9 \\
2.0 \\
8.2\end{array}$ & $\begin{array}{r}691 \\
1.6 \\
1.1 \\
1.2 \\
8.7\end{array}$ \\
\hline $\begin{array}{l}16 \\
17 \\
18 \\
19 \\
20\end{array}$ & $\begin{array}{l}.93 \\
1.0 \\
.72 \\
2.0 \\
1.3\end{array}$ & $\begin{array}{l}.77 \\
.82 \\
.53 \\
.71 \\
.68\end{array}$ & $\begin{array}{l}.41 \\
.50 \\
.51 \\
.61 \\
.67\end{array}$ & $\begin{array}{l}1.1 \\
1.1 \\
.99 \\
1.1 \\
.77\end{array}$ & $\begin{array}{l}.67 \\
.80 \\
.70 \\
.79 \\
.66\end{array}$ & $\begin{array}{l}4.8 \\
2.9 \\
3.6 \\
3.8 \\
1.4\end{array}$ & $\begin{array}{r}.38 \\
.14 \\
.25 \\
.38 \\
.53\end{array}$ & $\begin{array}{l}.83 \\
.48 \\
.51 \\
.51 \\
.42\end{array}$ & $\begin{array}{r}.96 \\
.72 \\
3.1 \\
.96 \\
.71\end{array}$ & $\begin{array}{l}4.1 \\
4.3 \\
2.7 \\
1.9 \\
2.1\end{array}$ & $\begin{array}{l}1.4 \\
.86 \\
.65 \\
.81 \\
1.4\end{array}$ & $\begin{array}{l}.72 \\
.45 \\
.72 \\
.72 \\
.96\end{array}$ \\
\hline $\begin{array}{l}21 \\
22 \\
23 \\
24 \\
25\end{array}$ & $\begin{array}{l}.84 \\
.69 \\
.76 \\
.77 \\
.74\end{array}$ & $\begin{array}{r}.77 \\
.60 \\
.81 \\
1.1 \\
.89\end{array}$ & $\begin{array}{l}.66 \\
.77 \\
.92 \\
.64 \\
.47\end{array}$ & $\begin{array}{r}.92 \\
.90 \\
1.0 \\
.88 \\
.74\end{array}$ & $\begin{array}{l}.68 \\
.53 \\
1.3 \\
1.3 \\
.73\end{array}$ & $\begin{array}{l}1.7 \\
4.8 \\
4.6 \\
4.1 \\
4.1\end{array}$ & $\begin{array}{l}.53 \\
.38 \\
.45 \\
.45 \\
.62\end{array}$ & $\begin{array}{l}.37 \\
.45 \\
.59 \\
.58 \\
.37\end{array}$ & $\begin{array}{l}.88 \\
1.1 \\
.89 \\
1.6 \\
2.0\end{array}$ & $\begin{array}{l}4.6 \\
3.8 \\
3.3 \\
2.5 \\
2.0\end{array}$ & $\begin{array}{l}.64 \\
.51 \\
1.5 \\
1.5 \\
1.1\end{array}$ & $\begin{array}{r}.84 \\
.84 \\
.72 \\
6.6 \\
3.5\end{array}$ \\
\hline $\begin{array}{l}26 \\
27 \\
28 \\
29 \\
30 \\
31\end{array}$ & $\begin{array}{r}.78 \\
.78 \\
.83 \\
1.2 \\
9.6 \\
.79\end{array}$ & $\begin{array}{l}.75 \\
7.3 \\
2.2 \\
1.3 \\
.44 \\
-.-\end{array}$ & $\begin{array}{r}.58 \\
.58 \\
.61 \\
1.0 \\
.77 \\
.53\end{array}$ & $\begin{array}{l}1.3 \\
.79 \\
.86 \\
.88 \\
1.1 \\
1.1\end{array}$ & $\begin{array}{l}.80 \\
.75 \\
.66 \\
.73 \\
.7 . \\
. .-\end{array}$ & $\begin{array}{l}3.4 \\
3.4 \\
2.3 \\
2.5 \\
1.3 \\
.94\end{array}$ & $\begin{array}{l}.72 \\
.46 \\
.34 \\
.30 \\
.39 \\
-.-\end{array}$ & $\begin{array}{l}.63 \\
.55 \\
.63 \\
.58 \\
.57 \\
.51\end{array}$ & $\begin{array}{c}2.2 \\
1.6 \\
3.0 \\
2.7 \\
1.7 \\
-. .-\end{array}$ & $\begin{array}{l}2.8 \\
3.4 \\
3.0 \\
1.2 \\
1.3 \\
.96\end{array}$ & $\begin{array}{l}2.0 \\
2.3 \\
1.1 \\
.88 \\
2.5 \\
2.8\end{array}$ & $\begin{array}{l}.58 \\
.60 \\
.67 \\
.83 \\
.93 \\
.9-\end{array}$ \\
\hline $\begin{array}{l}\text { TOTAL } \\
\text { MEAN } \\
\text { MAX } \\
\text { MIN } \\
\text { AC-FT }\end{array}$ & $\begin{array}{r}100.44 \\
3.24 \\
37 \\
.55 \\
199\end{array}$ & $\begin{array}{r}31.69 \\
1.06 \\
7.3 \\
.44 \\
63\end{array}$ & $\begin{array}{r}110.60 \\
3.57 \\
86 \\
.41 \\
219\end{array}$ & $\begin{array}{r}29.34 \\
.95 \\
1.6 \\
.29 \\
58\end{array}$ & $\begin{array}{r}1471.08 \\
50.7 \\
440 \\
.53 \\
2920\end{array}$ & $\begin{array}{r}822.07 \\
26.5 \\
446 \\
.53 \\
1630\end{array}$ & $\begin{array}{r}320.90 \\
10.7 \\
132 \\
.14 \\
637\end{array}$ & $\begin{array}{r}29.44 \\
.95 \\
12 \\
.19 \\
58\end{array}$ & $\begin{array}{r}52.37 \\
1.75 \\
19 \\
.45 \\
104\end{array}$ & $\begin{array}{r}87.18 \\
2.81 \\
7.1 \\
.96 \\
173\end{array}$ & $\begin{array}{r}57.94 \\
1.87 \\
8.2 \\
.51 \\
115\end{array}$ & $\begin{array}{r}1846.78 \\
61.6 \\
1010 \\
365 \\
3660\end{array}$ \\
\hline $\begin{array}{l}\text { CAL YR } \\
\text { WTR YR }\end{array}$ & $\begin{array}{l}1975 \\
1976\end{array}$ & $\begin{array}{l}367 \\
495\end{array}$ & $\begin{array}{l}\text { MEAN } \\
\text { MEAN }\end{array}$ & $\begin{array}{l}10.1 \\
13.6\end{array}$ & $\begin{array}{lr}\text { MAX } & 545 \\
\text { HAX } & 1010\end{array}$ & $\begin{array}{l}\text { MIN } \\
\text { MIN }\end{array}$ & $\begin{array}{l}A C-F T \\
A C-F T\end{array}$ & $\begin{array}{l}7300 \\
9840\end{array}$ & & & & \\
\hline
\end{tabular}


LOCATION - - Lat $34^{\circ} 03^{\prime} 22^{\prime \prime}$, long $118^{\circ} 05^{\prime} 12^{\prime \prime}$, in Potrero Grande Grant, Los Angeles County, on left bank 250 ft $(76 \mathrm{~m})$ north of K1ingerman Street and $0.1 \mathrm{mi}(0.2 \mathrm{~km})$ south of Garvey Avenue in South San Gabrie1.

DRAINAGE AREA. - - $15.2 \mathrm{mi}^{2}\left(39.4 \mathrm{~km}^{2}\right)$, by Los Angeles County Flood Control District.

PERIOD OF RECORD.-October 1975 to September 1976. September 1936 to September 1975 in the files of Los Angeles County Flood Control District.

GAGE. - Water-stage recorder. Altitude of gage is $240 \mathrm{ft}(73 \mathrm{~m})$ from topographic map.

REMARKS. --Records poor. No regulation or diversion above station.

COOPERATION.--Records were furnished by Los Angeles County Flood Control District.

EXTREMES OUTSIDE PERIOD OF RECORD.--Maximum discharge, $5,010 \mathrm{ft}^{3} / \mathrm{s}\left(142 \mathrm{~m}^{3} / \mathrm{s}\right) \mathrm{Mar}$. 2 , 1938, gage height unknown, from information by Los Angeles County Flood Control District.

EXTREMES FOR CURRENT YEAR,--Maximum discharge, 1,820 $\mathrm{ft}^{3} / \mathrm{s}\left(51.5 \mathrm{~m}^{3} / \mathrm{s}\right) \mathrm{Feb}$. 5, gage height, $3.12 \mathrm{ft}(0.951 \mathrm{~m})$;

minimum daily, $0.30 \mathrm{ft}^{3} / \mathrm{s}\left(0.008 \mathrm{~m}^{3} / \mathrm{s}\right)$ June $5-7$.

DISCHARGE, IN CUBIC FEET PER SECOND, WATER YEAR OCTOBER 1975 TO SEPTEMBER 1976 MEAN VALUES

\begin{tabular}{|c|c|c|c|c|c|c|c|c|c|c|c|c|}
\hline DAY & OCT & Nov & DEC & JAN & FEB & MAR & APR & MAY & JUN & JUL & AUG & SEP \\
\hline $\begin{array}{l}1 \\
2 \\
3 \\
4 \\
5\end{array}$ & $\begin{array}{l}.90 \\
.60 \\
.60 \\
.60 \\
.60\end{array}$ & $\begin{array}{l}.40 \\
.40 \\
.60 \\
.90 \\
.90\end{array}$ & $\begin{array}{l}1.8 \\
2.3 \\
1.8 \\
1.6 \\
1.4\end{array}$ & $\begin{array}{l}.90 \\
.60 \\
.90 \\
.90 \\
.90\end{array}$ & $\begin{array}{r}.90 \\
.90 \\
26 \\
.90 \\
104\end{array}$ & $\begin{aligned} & 131 \\
& 85 \\
& 6.8 \\
& .60 \\
& .60\end{aligned}$ & $\begin{array}{l}1.1 \\
1.1 \\
14 \\
12.90\end{array}$ & $\begin{array}{l}.90 \\
.90 \\
.90 \\
.60 \\
.40\end{array}$ & $\begin{array}{l}.60 \\
.90 \\
.60 \\
.60 \\
.30\end{array}$ & $\begin{array}{l}.90 \\
1.4 \\
1.1 \\
1.4 \\
1.4\end{array}$ & $\begin{array}{l}1.4 \\
1.6 \\
1.6 \\
2.1 \\
2.3\end{array}$ & $\begin{array}{l}1.6 \\
1.8 \\
13 \\
1.8 \\
37^{\circ}\end{array}$ \\
\hline $\begin{array}{r}6 \\
7 \\
8 \\
9 \\
10\end{array}$ & $\begin{array}{l}7.9 \\
1.1 \\
.90 \\
.60 \\
.40\end{array}$ & $\begin{array}{l}1.1 \\
.40 \\
.40 \\
.40 \\
.60\end{array}$ & $\begin{array}{l}1.4 \\
.90 \\
1.1 \\
1.1 \\
.90\end{array}$ & $\begin{array}{r}.90 \\
.90 \\
.90 \\
.90 \\
.90\end{array}$ & $\begin{array}{r}137 \\
32 \\
144 \\
188 \\
2.1\end{array}$ & $\begin{array}{l}.60 \\
.60 \\
.60 \\
5.9 \\
4.1\end{array}$ & $\begin{array}{l}.60 \\
14.60 \\
1.1 \\
1.1\end{array}$ & $\begin{array}{l}3.5 \\
4.1 \\
.90 \\
.90 \\
.90\end{array}$ & $\begin{array}{r}.30 \\
.30 \\
.40 \\
.40 \\
3.9\end{array}$ & $\begin{array}{l}1.6 \\
1.6 \\
1.6 \\
1.6 \\
1.8\end{array}$ & $\begin{array}{l}1.8 \\
1.8 \\
1.8 \\
1.8 \\
1.8\end{array}$ & $\begin{array}{r}4.0 \\
2.3 \\
2.6 \\
2.3 \\
274\end{array}$ \\
\hline $\begin{array}{l}11 \\
12 \\
13 \\
14 \\
15\end{array}$ & $\begin{array}{l}15 \\
1.6 \\
1.8 \\
1.6 \\
1.8\end{array}$ & $\begin{array}{l}.60 \\
.60 \\
.60 \\
.60 \\
.60\end{array}$ & $\begin{array}{l}1.1 \\
50 \\
1.4 \\
1.1 \\
1.4\end{array}$ & $\begin{array}{l}.90 \\
.90 \\
1.1 \\
1.1 \\
.90\end{array}$ & $\begin{array}{l}.90 \\
.90 \\
.60 \\
.60 \\
.60\end{array}$ & $\begin{array}{l}.60 \\
.60 \\
.60 \\
.60 \\
.60\end{array}$ & $\begin{array}{l}1.1 \\
36 \\
22 \\
.60 \\
.90\end{array}$ & $\begin{array}{l}.90 \\
.90 \\
1.1 \\
1.1 \\
1.1\end{array}$ & $\begin{array}{l}1.1 \\
1.1 \\
1.4 \\
1.4 \\
1.4\end{array}$ & $\begin{array}{l}1.6 \\
1.6 \\
1.6 \\
1.4 \\
1.4\end{array}$ & $\begin{array}{l}1.4 \\
1.4 \\
1.4 \\
1.4 \\
16\end{array}$ & $\begin{array}{r}139 \\
2.1 \\
1.8 \\
1.6 \\
2.1\end{array}$ \\
\hline $\begin{array}{l}16 \\
17 \\
18 \\
19 \\
20\end{array}$ & $\begin{array}{l}1.8 \\
2.1 \\
1.8 \\
1.8 \\
1.6\end{array}$ & $\begin{array}{l}.40 \\
.40 \\
.60 \\
.60 \\
.90\end{array}$ & $\begin{array}{l}1.4 \\
1.1 \\
1.1 \\
1.1 \\
.90\end{array}$ & $\begin{array}{l}.90 \\
1.1 \\
1.1 \\
1.4 \\
1.1\end{array}$ & $\begin{array}{l}.60 \\
.60 \\
.60 \\
.90 \\
.60\end{array}$ & $\begin{array}{l}.60 \\
.60 \\
.90 \\
.90 \\
.90\end{array}$ & $\begin{array}{l}.40 \\
.60 \\
.40 \\
.90 \\
.90\end{array}$ & $\begin{array}{r}.90 \\
.90 \\
.90 \\
1.1 \\
.90\end{array}$ & $\begin{array}{l}1.4 \\
1.4 \\
1.4 \\
1.4 \\
1.1\end{array}$ & $\begin{array}{l}1.4 \\
1.4 \\
1.1 \\
1.1 \\
.90\end{array}$ & $\begin{array}{l}1.6 \\
1.6 \\
1.4 \\
1.6 \\
1.6\end{array}$ & $\begin{array}{l}1.6 \\
1.6 \\
1.4 \\
1.6 \\
1.6\end{array}$ \\
\hline $\begin{array}{l}21 \\
22 \\
23 \\
24 \\
25\end{array}$ & $\begin{array}{l}1.6 \\
1.6 \\
1.8 \\
1.1 \\
1.1\end{array}$ & $\begin{array}{l}.60 \\
.60 \\
.60 \\
.90 \\
1.4\end{array}$ & $\begin{array}{l}.90 \\
.90 \\
.90 \\
.90 \\
.90\end{array}$ & $\begin{array}{l}1.1 \\
1.1 \\
.90 \\
.60 \\
.60\end{array}$ & $\begin{array}{l}.60 \\
.90 \\
.90 \\
.90 \\
.60\end{array}$ & $\begin{array}{l}.90 \\
.90 \\
.90 \\
.90 \\
.90\end{array}$ & $\begin{array}{l}.90 \\
.60 \\
.90 \\
.90 \\
.90\end{array}$ & $\begin{array}{l}1.1 \\
.60 \\
.40 \\
.90 \\
1.1\end{array}$ & $\begin{array}{r}.90 \\
.90 \\
.90 \\
.90 \\
1.1\end{array}$ & $\begin{array}{l}1.4 \\
1.6 \\
1.6 \\
1.6 \\
1.6\end{array}$ & $\begin{array}{l}1.4 \\
1.6 \\
1.8 \\
1.8 \\
1.6\end{array}$ & $\begin{array}{l}1.6 \\
1.6 \\
1.6 \\
4.1 \\
1.8\end{array}$ \\
\hline $\begin{array}{l}26 \\
27 \\
28 \\
29 \\
30 \\
31\end{array}$ & $\begin{array}{l}1.1 \\
1.1 \\
1.1 \\
1.1 \\
8.5 \\
.60\end{array}$ & $\begin{array}{c}1.1 \\
1.1 \\
.90 \\
.90 \\
1.4 \\
0 .-\end{array}$ & $\begin{array}{l}.90 \\
.90 \\
.90 \\
.90 \\
.90 \\
.90\end{array}$ & $\begin{array}{l}.60 \\
.90 \\
.90 \\
.90 \\
.90 \\
.90\end{array}$ & $\begin{array}{l}.60 \\
.60 \\
.90 \\
.60 \\
. \\
.0\end{array}$ & $\begin{array}{r}1.1 \\
.90 \\
.90 \\
1.1 \\
.90 \\
.90\end{array}$ & $\begin{array}{l}1.1 \\
.90 \\
.60 \\
.90 \\
.90 \\
.0 .\end{array}$ & $\begin{array}{l}1.1 \\
1.1 \\
.90 \\
.40 \\
.40 \\
.40\end{array}$ & $\begin{array}{l}1.1 \\
1.1 \\
1.4 \\
1.4 \\
1.1 \\
.0 .0\end{array}$ & $\begin{array}{l}1.6 \\
1.8 \\
1.6 \\
1.8 \\
1.8 \\
1.6\end{array}$ & $\begin{array}{l}1.6 \\
1.8 \\
1.6 \\
1.6 \\
1.8 \\
1.8\end{array}$ & $\begin{array}{l}1.6 \\
1.6 \\
1.8 \\
1.4 \\
1.8 \\
-\end{array}$ \\
\hline $\begin{array}{l}\text { TOTAL } \\
\text { MEAN } \\
\text { MAX } \\
\text { MIN } \\
\text { AC-FT }\end{array}$ & $\begin{array}{r}65.80 \\
2.12 \\
15 \\
.40 \\
131\end{array}$ & $\begin{array}{r}21.50 \\
.72 \\
1.4 \\
.40 \\
43\end{array}$ & $\begin{array}{r}84.80 \\
2.74 \\
50 \\
.90 \\
168\end{array}$ & $\begin{array}{r}28.60 \\
.92 \\
1.4 \\
.60 \\
57\end{array}$ & $\begin{array}{r}649.30 \\
22.4 \\
188 \\
160 \\
1290\end{array}$ & $\begin{array}{r}253.00 \\
8.16 \\
131 \\
.60 \\
502\end{array}$ & $\begin{array}{r}110.90 \\
3.96 \\
36 \\
.40 \\
236\end{array}$ & $\begin{array}{r}32.20 \\
1.04 \\
4.1 \\
.40 \\
64\end{array}$ & $\begin{array}{r}32.20 \\
1.07 \\
3.9 \\
.30 \\
64\end{array}$ & $\begin{array}{r}45.90 \\
1.48 \\
1.6 \\
.90 \\
91\end{array}$ & $\begin{array}{r}65.8 \\
2.12 \\
16 \\
1.4 \\
131\end{array}$ & $\begin{array}{r}513.3 \\
17.1 \\
274 \\
1.4 \\
1020\end{array}$ \\
\hline
\end{tabular}

WTR YR 1976 TOTAL 1911.30 MEAN 5.22 MAX 274 MIN .30 AC-FT 3790 
11101500 RIO HONDO NEAR MONTEBELLO, CA

LOCATION, - Lat $34^{\circ} 02^{\prime} 00^{\prime \prime}$, long $118^{\circ} 04^{\prime} 22^{\prime \prime}$, in Potrero Grande Grant, Los Angeles County, on right bank 900 ft $(274 \mathrm{~m})$ upstream from Mission bridge, and $2 \mathrm{mi}(3 \mathrm{~km})$ northeast of Montebello.

DRAINAGE AREA.--116 $\mathrm{mi}^{2}\left(300 \mathrm{~km}^{2}\right)$, excludes area above Santa Fe Dam.

PERIOD OF RECORD, - -October 1928 to current year.

GAGE, - Water-stage recorder. Datum of gage is $190.77 \mathrm{ft}$ ( $58.147 \mathrm{~m}$ ) above mean sea level (1evels by Los Angeles County Flood Control District). See WSP 1735 for history of changes prior to september 1962.

REMARKS, - Records poor. Flow regulated by Big Santa Anita, Sawpit, and Eaton flood-control reservoirs, combined capacity, 1,700 acre-ft $\left(2.10 \mathrm{hm}^{3}\right)$ and Sierra Madre, Las Flores, and Rubio debris basins. Many diversions above station for domestic use and irrigation. At times flow is diverted from San Gabriel River below Santa Fe Dam to Rio Hondo above station. Since 1957, with the exception of 1972, imported Colorado River water has been released to Rio Hondo $1.6 \mathrm{mi}(2.6 \mathrm{~km})$ above station for ground-water recharge. See schematic diagram of San Gabriel and Los Angeles River basins.

COOPERATION, - -Records were furnished by Los Angeles County Flood Control District.

AVERAGE DISCHARGE. - -29 years (water years 1929-57), $51.5 \mathrm{ft}^{3} / \mathrm{s}\left(1.458 \mathrm{~m}^{3} / \mathrm{s}\right), 37,280 \mathrm{acre}-\mathrm{ft} / \mathrm{\gamma r}\left(46.0 \mathrm{hm} / \mathrm{yr}^{3}\right)$.

EXTREMES FOR PERIOD OF RECORD.--Maximum discharge, $28,000 \mathrm{ft}^{3} / \mathrm{s}$ (793 $\left.\mathrm{m}^{3} / \mathrm{s}\right) \mathrm{Mar}, 2$, 1938 , gage height, $16.69 \mathrm{ft}$ $(5.087 \mathrm{~m})$, present datum; from rating curve extended above $9,000 \mathrm{ft}^{3} / \mathrm{s}\left(255 \mathrm{~m}^{3} / \mathrm{s}\right)$ on basis of $\mathrm{s} 10 \mathrm{ope}-\mathrm{area}$ measurement and runoff from contributing stream; no flow for some days in $1964-65$.

EXTREMES FOR CURRENT YEAR,--Maximum discharge, $9,660 \mathrm{ft}^{3} / \mathrm{s}\left(274 \mathrm{~m}^{3} / \mathrm{s}\right)$ Sept, 11 , gage height, $9.81 \mathrm{ft}(2.990 \mathrm{~m})$; minimum daily, $0.20 \mathrm{ft}^{3} / \mathrm{s}\left(0.006 \mathrm{~m}^{3} / \mathrm{s}\right)$ for several days.

DISCHARGE, IN CUBIC FEET PER SECOND, WATER YEAR OCTOBER 1975 TO SEPTEMBER 1976 MEAN VALUES

\begin{tabular}{|c|c|c|c|c|c|c|c|c|c|c|c|c|}
\hline DAY & OCT & NOV & DEC & JAN & $F E B$ & MAR & APR & MAY & JUN & JUL & AUG & SEP \\
\hline $\begin{array}{l}1 \\
2 \\
3 \\
4 \\
5\end{array}$ & $\begin{array}{l}1.9 \\
2.1 \\
1.9 \\
1.9 \\
2.1\end{array}$ & $\begin{array}{l}2.5 \\
2.3 \\
2.3 \\
2.5 \\
2.5\end{array}$ & $\begin{array}{l}1.4 \\
2.1 \\
1.5 \\
1.4 \\
1.4\end{array}$ & $\begin{array}{l}1.5 \\
1.5 \\
1.5 \\
1.5 \\
1.4\end{array}$ & $\begin{array}{r}.40 \\
.50 \\
.56 \\
167\end{array}$ & $\begin{array}{r}493 \\
386 \\
35 \\
6.3 \\
5.4\end{array}$ & $\begin{array}{c}1.5 \\
2.1 \\
4.0 \\
99 \\
5.6\end{array}$ & $\begin{array}{l}1.0 \\
1.0 \\
1.0 \\
1.0 \\
1.0\end{array}$ & $\begin{array}{l}1.8 \\
1.8 \\
1.8 \\
2.0 \\
1.7\end{array}$ & $\begin{array}{l}.80 \\
.70 \\
.70 \\
.50 \\
.30\end{array}$ & $\begin{array}{l}.20 \\
1.0 \\
.50 \\
1.9 \\
2.8\end{array}$ & $\begin{array}{c}2.1 \\
1.5 \\
33 \\
6.4 \\
158\end{array}$ \\
\hline $\begin{array}{r}6 \\
7 \\
8 \\
9 \\
10\end{array}$ & $\begin{array}{r}14 \\
9.5 \\
3.2 \\
2.8 \\
2.8\end{array}$ & $\begin{array}{l}2.6 \\
2.3 \\
2.3 \\
2.3 \\
2.1\end{array}$ & $\begin{array}{l}1.5 \\
1.4 \\
1.5 \\
1.5 \\
1.4\end{array}$ & $\begin{array}{l}1.4 \\
1.4 \\
1.4 \\
1.3 \\
1.3\end{array}$ & $\begin{array}{r}650 \\
75 \\
345 \\
592 \\
18\end{array}$ & $\begin{array}{l}4.7 \\
3.4 \\
3.4 \\
7.8 \\
2.2\end{array}$ & $\begin{array}{r}1.0 \\
1.0 \\
20 \\
2.0 \\
1.0\end{array}$ & $\begin{array}{l}1.0 \\
13 \\
1.0 \\
1.0 \\
1.0\end{array}$ & $\begin{array}{l}1.5 \\
1.5 \\
1.7 \\
1.9 \\
32\end{array}$ & $\begin{array}{l}1.2 \\
1.2 \\
1.5 \\
1.9 \\
1.5\end{array}$ & $\begin{array}{r}.70 \\
.50 \\
.40 \\
.40 \\
.20\end{array}$ & $\begin{array}{c}32 \\
4.9 \\
3.0 \\
2.5 \\
1400\end{array}$ \\
\hline $\begin{array}{l}11 \\
12 \\
13 \\
14 \\
15\end{array}$ & $\begin{array}{l}41 \\
4.7 \\
4.0 \\
3.0 \\
2.0\end{array}$ & $\begin{array}{l}1.9 \\
1.9 \\
2.1 \\
1.7 \\
1.0\end{array}$ & $\begin{array}{l}1.2 \\
314 \\
10 \\
2.0 \\
1.9\end{array}$ & $\begin{array}{l}1.3 \\
1.2 \\
1.2 \\
1.2 \\
1.2\end{array}$ & $\begin{array}{l}3.0 \\
2.9 \\
2.8 \\
2.7 \\
2.6\end{array}$ & $\begin{array}{l}7.2 \\
5.8 \\
4.8 \\
3.7 \\
2.6\end{array}$ & $\begin{array}{c}1.0 \\
45 \\
165 \\
3.8 \\
8.3\end{array}$ & $\begin{array}{l}1.0 \\
1.0 \\
1.0 \\
1.0 \\
1.0\end{array}$ & $\begin{array}{l}1.9 \\
1.7 \\
1.7 \\
1.9 \\
1.4\end{array}$ & $\begin{array}{l}.80 \\
1.5 \\
1.2 \\
1.0 \\
3.6\end{array}$ & $\begin{array}{r}.30 \\
.20 \\
.20 \\
.20\end{array}$ & $\begin{array}{r}1090 \\
6.9 \\
3.4 \\
2.5 \\
17\end{array}$ \\
\hline $\begin{array}{l}16 \\
17 \\
18 \\
19 \\
20\end{array}$ & $\begin{array}{l}1.5 \\
1.8 \\
2.1 \\
2.4 \\
2.7\end{array}$ & $\begin{array}{l}1.0 \\
1.0 \\
1.1 \\
1.1 \\
1.1\end{array}$ & $\begin{array}{l}1.9 \\
1.8 \\
1.8 \\
1.8 \\
1.8\end{array}$ & $\begin{array}{l}1.2 \\
1.3 \\
1.4 \\
1.4 \\
1.5\end{array}$ & $\begin{array}{l}2.5 \\
2.5 \\
2.5 \\
2.5 \\
2.5\end{array}$ & $\begin{array}{l}3.2 \\
3.0 \\
3.2 \\
3.0 \\
1.9\end{array}$ & $\begin{array}{l}3.0 \\
2.5 \\
2.0 \\
1.5 \\
1.2\end{array}$ & $\begin{array}{l}1.2 \\
1.2 \\
1.2 \\
1.2 \\
1.2\end{array}$ & $\begin{array}{l}1.9 \\
.80 \\
2.3 \\
2.3 \\
1.9\end{array}$ & $\begin{array}{l}1.9 \\
1.5 \\
1.0 \\
.70 \\
.50\end{array}$ & $\begin{array}{l}5.4 \\
1.2 \\
.20 \\
.20 \\
1.7\end{array}$ & $\begin{array}{l}1.0 \\
1.0 \\
.80 \\
.80 \\
.60\end{array}$ \\
\hline $\begin{array}{l}21 \\
22 \\
23 \\
24 \\
25\end{array}$ & $\begin{array}{l}3.0 \\
3.3 \\
3.6 \\
3.4 \\
3.2\end{array}$ & $\begin{array}{l}1.2 \\
1.2 \\
1.2 \\
1.2 \\
1.2\end{array}$ & $\begin{array}{l}1.8 \\
1.7 \\
1.7 \\
1.7 \\
1.7\end{array}$ & $\begin{array}{l}1.4 \\
1.5 \\
1.7 \\
1.5 \\
1.2\end{array}$ & $\begin{array}{l}2.4 \\
2.4 \\
2.3 \\
2.3 \\
2.2\end{array}$ & $\begin{array}{l}1.9 \\
3.0 \\
3.0 \\
3.4 \\
3.2\end{array}$ & $\begin{array}{l}1.0 \\
.90 \\
.90 \\
.90 \\
.90\end{array}$ & $\begin{array}{l}1.4 \\
1.4 \\
1.4 \\
1.4 \\
1.4\end{array}$ & $\begin{array}{c}2.5 \\
2.3 \\
3.8 \\
11 \\
1.4\end{array}$ & $\begin{array}{l}1.4 \\
2.3 \\
2.1 \\
1.7 \\
.80\end{array}$ & $\begin{array}{r}.70 \\
.30 \\
.30 \\
2.5 \\
2.6\end{array}$ & $\begin{array}{r}.60 \\
.50 \\
22 \\
9.50 \\
9.2\end{array}$ \\
\hline $\begin{array}{l}26 \\
27 \\
28 \\
29 \\
30 \\
31\end{array}$ & $\begin{array}{c}3.0 \\
2.8 \\
2.6 \\
2.4 \\
17 \\
6.9\end{array}$ & $\begin{array}{l}2.3 \\
0.7 \\
2.1 \\
3.0 \\
1.2 \\
-.-\end{array}$ & $\begin{array}{l}1.7 \\
1.6 \\
1.6 \\
1.6 \\
1.6 \\
1.6\end{array}$ & $\begin{array}{l}1.5 \\
.70 \\
1.0 \\
.80 \\
1.0 \\
.30\end{array}$ & $\begin{array}{l}2.2 \\
2.1 \\
2.0 \\
2.0 \\
-.- \\
---\end{array}$ & $\begin{array}{l}3.0 \\
3.0 \\
2.1 \\
2.3 \\
1.5 \\
1.5\end{array}$ & $\begin{array}{r}.90 \\
.90 \\
.90 \\
1.5 \\
1.0 \\
---\end{array}$ & $\begin{array}{l}1.6 \\
1.6 \\
1.6 \\
1.6 \\
1.6 \\
1.6\end{array}$ & $\begin{array}{l}.80 \\
.80 \\
1.2 \\
1.9 \\
1.0 \\
-.-\end{array}$ & $\begin{array}{l}1.5 \\
3.2 \\
2.1 \\
1.0 \\
.80 \\
.20\end{array}$ & $\begin{array}{l}2.6 \\
2.8 \\
2.1 \\
.30 \\
3.2 \\
4.5\end{array}$ & $\begin{array}{l}3.6 \\
2.6 \\
2.3 \\
2.6 \\
4.0 \\
-.--\end{array}$ \\
\hline $\begin{array}{l}\text { TOTAL } \\
\text { MEAN } \\
\text { MAX } \\
\text { MIN } \\
\text { AC }-F T\end{array}$ & $\begin{array}{r}158.6 \\
5.12 \\
41 \\
1.5 \\
315\end{array}$ & $\begin{array}{r}60.9 \\
2.03 \\
8.7 \\
1.0 \\
121\end{array}$ & $\begin{array}{r}371.6 \\
12.0 \\
314 \\
1.2 \\
737\end{array}$ & $\begin{array}{r}39.70 \\
1.28 \\
1.7 \\
.30 \\
79\end{array}$ & $\begin{array}{r}1950.80 \\
67.3 \\
650 \\
6.40 \\
3870\end{array}$ & $\begin{array}{r}1013.5 \\
32.7 \\
493 \\
1.5 \\
2010\end{array}$ & $\begin{array}{r}380.30 \\
12.7 \\
165 \\
.90 \\
754\end{array}$ & $\begin{array}{r}49.6 \\
1.60 \\
13 \\
1.0 \\
98\end{array}$ & $\begin{array}{r}92.20 \\
3.07 \\
32 \\
.80 \\
183\end{array}$ & $\begin{array}{r}41.10 \\
1.33 \\
3.6 \\
.20 \\
82\end{array}$ & $\begin{array}{r}89.10 \\
2.87 \\
49 \\
.20 \\
177\end{array}$ & $\begin{array}{r}2815.30 \\
93.8 \\
1400 \\
.50 \\
5580\end{array}$ \\
\hline
\end{tabular}


LOCATION. - Lat $34^{\circ} 01^{\prime} 45^{\prime \prime}$, long $118^{\circ} 04^{\prime} 07^{\prime \prime}$, in La Merced Grant, Los Angeles County, on upstream side of right abutment of San Gabriél Boulevard bridge, $2 \mathrm{mi}(3 \mathrm{~km})$ northeast of Montebello.

DRAINAGE AREA, $-4.16 \mathrm{mi}^{2}\left(10.77 \mathrm{~km}^{2}\right)$.

PERIOD OF RECORD.--October 1929 to current year. Yearly estimate for 1938, published in wSP 1315-B. Prior to October 1944, published as Rio Hondo Slough near Montebello.

GAGE. - Water-stage recorder. Datum of gage is $188.2 \mathrm{ft}(57.36 \mathrm{~m})$ above mean sea 1 eve1. Prior to Nov. 3 , 1938 , at datum $6.30 \mathrm{ft}(1.920 \mathrm{~m})$ higher.

REMARKS.--Records poor. Flow is almost entirely from ground-water seepage. Flow partially regulated above station by Legg Lake. No diversion above station. See schematic diagran of San Gabrie1 and Los Angeles River basins.

COOPERATION. --Records furnished by Los Angeles County Flood Control District.

AVERAGE DISCHARGE, -47 years, $10.2 \mathrm{ft}^{3} / \mathrm{s}\left(0.289 \mathrm{~m}^{3} / \mathrm{s}\right), 7,390 \mathrm{acre}-\mathrm{ft} / \mathrm{yr}\left(9.11 \mathrm{hm}^{3} / \mathrm{yr}^{2}\right)$.

EXTREMES FOR PERIOD OF RECORD. - MaXimum discharge not determined, occurred Mar. 2, 1938; no flow at times in some years.

EXTREMES FOR CURRENT YEAR. - Maximum daily discharge, $1.6 \mathrm{ft}^{3} / \mathrm{s}\left(0.045 \mathrm{~m}^{3} / \mathrm{s}\right)$ Sept. 11; no flow most of year.

DISCHARGE, IN CUBIC FEET PER SECOND, WATER YEAR OCTOBER 1975 TO SEPTEMBER 1976 MEAN VALUES

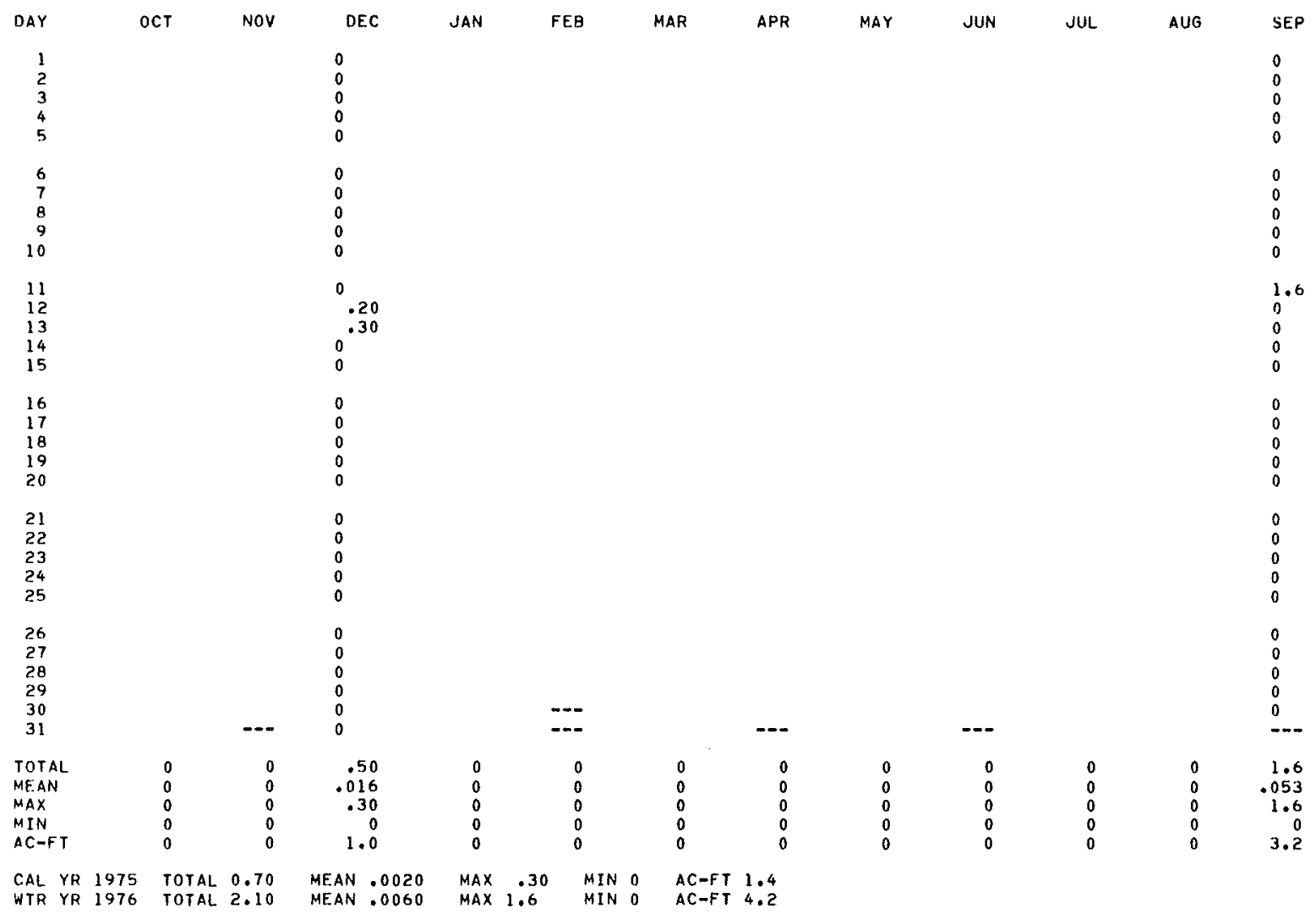


11102300 RIO HONDO BELOW WHITTIER NARROWS DAM, CA

LOCATION, - Lat $34^{\circ} 01^{\prime} 00^{\prime \prime}$, long $118^{\circ} 05^{\prime} 15^{\prime \prime}$, in Paso de Bartolo Grant, Los Angeles County, on right 1 evee 0.2 mi

$(0.3 \mathrm{~km})$ upstream from Beverly Boulevard, $0.4 \mathrm{mi}(0.6 \mathrm{~km})$ downstream from axis of Whittier Narrows Dam, and $1.0 \mathrm{mi}(1.6 \mathrm{~km})$ northeast of Montebe1lo.

DRAINAGE AREA. $--124 \mathrm{mi}^{2}\left(321 \mathrm{~km}^{2}\right)$.

PERIOD OF RECORD, --October 1966 to current year.

GAGE. - Water-stage recorder, Altitude of gage is $175 \mathrm{ft}(53 \mathrm{~m})$, from topographic map.

REMARKS, - Records poor. Flow regulated by Whittier Narrows flood-control reservoir, capacity, 36,160 acre-ft $\left(44.6 \mathrm{hm}^{3}\right)$. There are several small flood-control reservoirs, combined capacities, 1,700 acre-ft (2.10 hm $\left.{ }^{3}\right)$ and several small debris basins above Whittier Narrows Dam. Many diversions for domestic use and irrigation. At times flow is diverted from San Gabriel River to Rio Hondo from sites below Santa Fe Dam and above Whittier Narrows Dam. See schematic diagram of San Gabriel and Los Angeles River basins.

EXTREMES FOR PERIOD OF RECORD,--Maximum discharge, $38,800 \mathrm{ft}^{3} / \mathrm{s}\left(1,100 \mathrm{~m}^{3} / \mathrm{s}\right) \mathrm{Jan}$. 25, 1969 , gage height, $13.82 \mathrm{ft}$ $(4.212 \mathrm{~m})$, from rating curve extended above $15,000 \mathrm{ft} / \mathrm{s}(425 \mathrm{~m} / \mathrm{s})$ on basis of gate openings at dam at gage heights $12.32 \mathrm{ft}(3.755 \mathrm{~m})$ and $13.82 \mathrm{ft}(4.212 \mathrm{~m})$; no flow at times in each year.

EXTREMES FOR CURRENT YEAR.--Maximum discharge, $12,430 \mathrm{ft}^{3} / \mathrm{s}\left(352 \mathrm{~m}^{3} / \mathrm{s}\right)$ Sept, 11 , gage height, $7.33 \mathrm{ft}$ $(2.234 \mathrm{~m})$; no flow for severa1 days.

DISCHARGE, IN CUBIC FEET PER SECOND, HATER YEAR OCTOBER 1975 TO SEPTEMBER 1976 MEAN VALUES

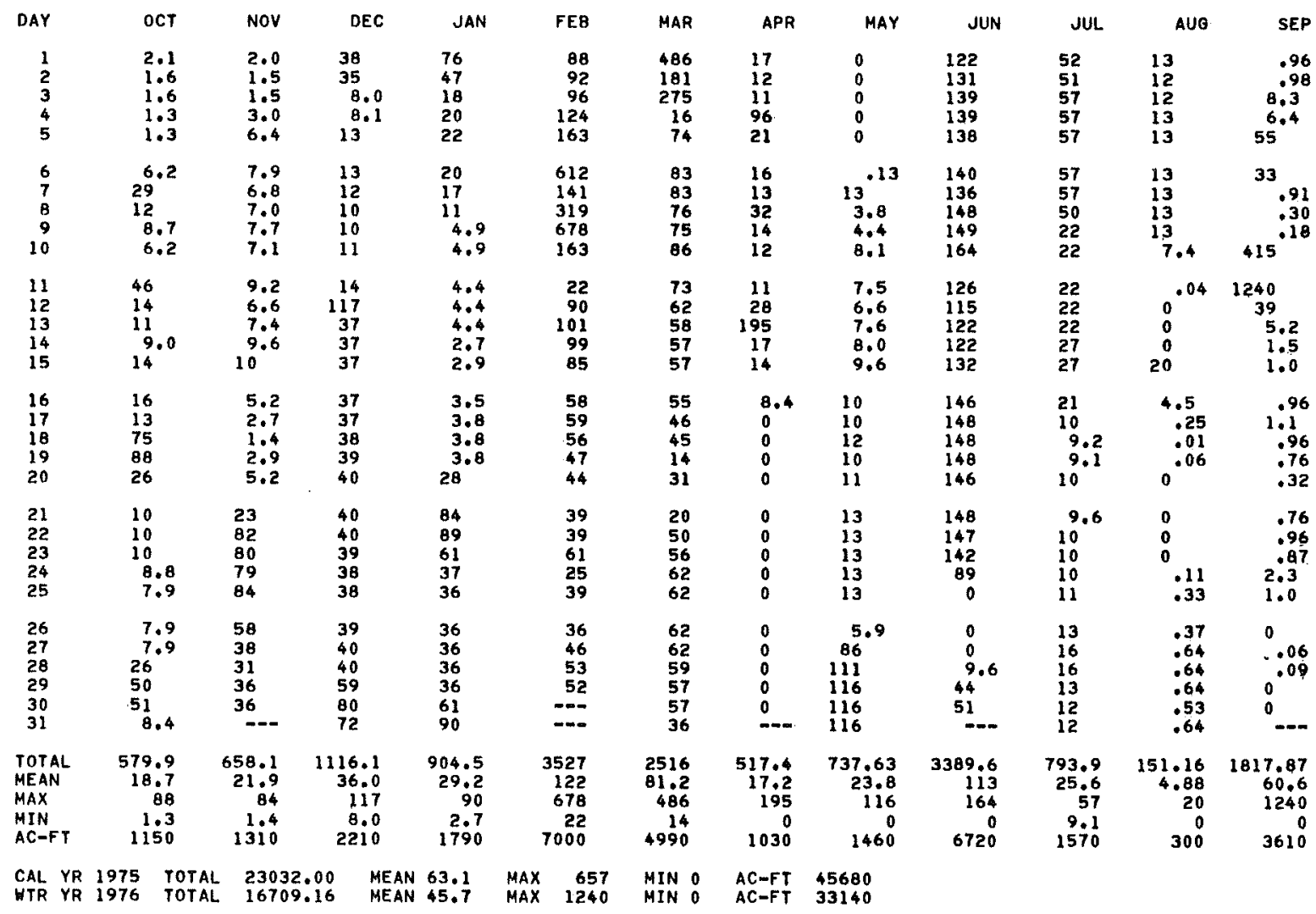


LOCATION, - Lat $33^{\circ} 56^{\circ} 48^{\prime \prime}$, long $118^{\circ} 09^{\prime} 43^{\prime \prime}$, in San Antonio Grant, Los Angeles County, on 1 eft bank 700 ft. $(213$ m) upstream from Stewart and Gray Road bridge, $1.0 \mathrm{mi}(1.6 \mathrm{~km})$ upstream from mouth, and $1.5 \mathrm{mi}$ (2.4 km) west of Downey.

DRAINAGE AREA. $-143 \mathrm{mi}^{2}\left(370 \mathrm{~km}^{2}\right)$, excludes area above Santa Fe Dam.

PERIOD OF RECORD. - March 1928 to current year.

GAGE, - Water-stage recorder. Datum of gage is $91.4 \mathrm{ft}(27.86 \mathrm{~m})$ above mean sea 1 evel (1evels by Los Angeles County Flood Control District). Prior to Oct. 31, 1951, at site $700 \mathrm{ft}$ (213 m) downstream at datum 1.5 ft $(0.46 \mathrm{~m})$ lower.

REMARKS, - -Records poor. Flow regulated since January 1956 by Whittier Narrows flood-control reservoir, capacity, 36,160 acre-ft $\left(44.6 \mathrm{hm}^{3}\right)$. There are several small flood-control reservoirs, combined capacity, 1 , 700 acre-ft $\left(2.10 \mathrm{hm}^{3}\right)$ and several debris basins above Whittier Narrows Dam. Many diversions above station for domestic use and irrigation. At times flow is diverted from San Gabriel River below Santa Fe Dam and above Whittier

Narrows Dam to Rio Hondo above station. Since 1937 much of the flow in Rio Hondo has been diverted to perco-

lation basin from a site $5.5 \mathrm{mi}(8.8 \mathrm{~km})$ upstream. See schematic diagram of San Gabriel and Los Angeles River basins.

COOPERATION. --Records furnished by Los Angeles County Flood Control District.

EXTREMES FOR PERIOD OF RECORD. --Maximum discharge, 46,900 $\mathrm{ft}^{3} / \mathrm{s}\left(1,330 \mathrm{~m}^{3} / \mathrm{s}\right) \mathrm{Jan}$. 25, 1969 , gage height, $15.15 \mathrm{ft}$ $(4.618 \mathrm{~m})$; no flow at times in most years.

EXTREMES FOR CURRENT YEAR.--Maximum discharge, $9,820 \mathrm{ft}^{3} / \mathrm{s}\left(278 \mathrm{~m}^{3} / \mathrm{s}\right)$ Sept. 11, gage height, $6.35 \mathrm{ft}(1.935 \mathrm{~m})$ no flow many days.

DISCHARGE, IN CUBIC FEET PER SECOND, WATER YEAR OCTOBER 1975 TO SEPTEMBER 1976 MEAN VALUES

\begin{tabular}{|c|c|c|c|c|c|c|c|c|c|c|c|c|}
\hline DAY & $O C T$ & NOV & DEC & JAN & FEB & MAR & $A P R$ & MAY & JUN & JUL & AUG & SEP \\
\hline $\begin{array}{l}1 \\
2 \\
3 \\
4 \\
5\end{array}$ & $\begin{array}{l}.60 \\
.60 \\
.30 \\
.10 \\
.30\end{array}$ & $\begin{array}{l}.10 \\
.10 \\
110 \\
.10 \\
.10\end{array}$ & $\begin{array}{l}.10 \\
.10 \\
.10 \\
.10 \\
.10\end{array}$ & $\begin{array}{l}0 \\
0 \\
0 \\
0 \\
0\end{array}$ & $\begin{array}{r}.10 \\
.10 \\
.10 \\
5.7 \\
50\end{array}$ & $\begin{array}{r}112 \\
385 \\
69 \\
.10 \\
.10\end{array}$ & $\begin{array}{c}.10 \\
7.10 \\
19 \\
.10\end{array}$ & $\begin{array}{r}.10 \\
.10 \\
.10 \\
.10\end{array}$ & $\begin{array}{l}.10 \\
.10 \\
.10 \\
.10 \\
.10\end{array}$ & $\begin{array}{l}.10 \\
.10 \\
.10 \\
.10 \\
.10\end{array}$ & $\begin{array}{l}.10 \\
.10 \\
.10 \\
.10 \\
.10\end{array}$ & $\begin{array}{r}.10 \\
.10 \\
.10 \\
4.6 \\
25\end{array}$ \\
\hline $\begin{array}{r}6 \\
7 \\
8 \\
9 \\
10\end{array}$ & $\begin{array}{l}3.9 \\
0 \\
0 \\
0\end{array}$ & $\begin{array}{l}.10 \\
.10 \\
.10 \\
.10 \\
.10\end{array}$ & $\begin{array}{l}.10 \\
.10 \\
.10 \\
.10 \\
.10\end{array}$ & $\begin{array}{r}.10 \\
.10 \\
.10 \\
.10 \\
.10\end{array}$ & $\begin{array}{c}143 \\
5.7 \\
40 \\
920 \\
554\end{array}$ & $\begin{array}{l}.10 \\
.10 \\
410 \\
4.1\end{array}$ & $\begin{array}{l}0 \\
0 \\
1.2 \\
.10\end{array}$ & $\begin{array}{r}.10 \\
.10 \\
.10 \\
.10 \\
.10\end{array}$ & $\begin{array}{l}.10 \\
.10 \\
.30 \\
.10 \\
5.1\end{array}$ & $\begin{array}{r}.10 \\
.10 \\
.10 \\
.10 \\
.10\end{array}$ & $\begin{array}{l}.10 \\
.10 \\
.10 \\
.10 \\
.10\end{array}$ & $\begin{array}{r}2.0 \\
.50 \\
.10 \\
.10\end{array}$ \\
\hline $\begin{array}{l}11 \\
12 \\
13 \\
14 \\
15\end{array}$ & $\begin{array}{l}15 \\
0 \\
0 \\
0 \\
\quad .10\end{array}$ & $\begin{array}{l}.10 \\
.10 \\
110 \\
.10 \\
.10\end{array}$ & $\begin{array}{l}: 10 \\
8: 10 \\
0 \\
0\end{array}$ & $\begin{array}{r}.10 \\
.10 \\
.10 \\
.10 \\
.10\end{array}$ & $\begin{array}{r}12 \\
.10 \\
.10 \\
.10 \\
.10\end{array}$ & $\begin{array}{l}.10 \\
0 \\
0 \\
0\end{array}$ & $\begin{array}{l}23 \\
16 \\
0 \\
.30\end{array}$ & $\begin{array}{l}.10 \\
.10 \\
.10 \\
.10 \\
.10\end{array}$ & $\begin{array}{l}.10 \\
.10 \\
.10 \\
.10 \\
.10\end{array}$ & $\begin{array}{l}.10 \\
.10 \\
.30 \\
.10 \\
.10\end{array}$ & $\begin{array}{r}.10 \\
.10 \\
.10 \\
.10 \\
.90\end{array}$ & $\begin{array}{r}574 \\
.10 \\
.10 \\
.10 \\
.10\end{array}$ \\
\hline $\begin{array}{l}16 \\
17 \\
18 \\
19 \\
20\end{array}$ & $\begin{array}{l}.10 \\
.10 \\
.10 \\
.10 \\
.10\end{array}$ & $\begin{array}{r}.10 \\
.10 \\
.10 \\
.10 \\
.10\end{array}$ & $\begin{array}{l}0 \\
.10 \\
0 \\
.10 \\
.10\end{array}$ & $\begin{array}{l}.10 \\
.10 \\
.10 \\
.10 \\
.10\end{array}$ & $\begin{array}{l}.10 \\
.10 \\
.10 \\
.10 \\
.10\end{array}$ & $\begin{array}{l}.10 \\
.10 \\
.10 \\
0 \\
0\end{array}$ & $\begin{array}{l}0^{-10} \\
0 \\
0 \\
0\end{array}$ & $\begin{array}{r}.10 \\
.10 \\
.10 \\
.10 \\
.10\end{array}$ & $\begin{array}{l}.10 \\
.10 \\
10 \\
.10 \\
.10\end{array}$ & $\begin{array}{l}.10 \\
.10 \\
.10 \\
.10 \\
.10\end{array}$ & $\begin{array}{r}.10 \\
.10 \\
.10 \\
.10 \\
.10\end{array}$ & $\begin{array}{l}.10 \\
.10 \\
.10 \\
.10 \\
10\end{array}$ \\
\hline $\begin{array}{l}21 \\
22 \\
23 \\
24 \\
25\end{array}$ & $\begin{array}{l}.10 \\
.10 \\
0 \\
0 \\
0\end{array}$ & $\begin{array}{l}.10 \\
110 \\
10 \\
10 \\
110\end{array}$ & $\begin{array}{l}.10 \\
.10 \\
.10 \\
.10 \\
.10\end{array}$ & $\begin{array}{l}.10 \\
.10 \\
.10 \\
.10 \\
.10\end{array}$ & $\begin{array}{l}.10 \\
.10 \\
.10 \\
.10 \\
.10\end{array}$ & $\begin{array}{l}.10 \\
0 \\
.10 \\
.10 \\
.10\end{array}$ & $\begin{array}{l}.10 \\
.10 \\
.10 \\
.10 \\
.10\end{array}$ & $\begin{array}{l}.10 \\
.10 \\
.10 \\
.10 \\
.10\end{array}$ & $\begin{array}{r}.10 \\
.30 \\
.30 \\
.30 \\
.50\end{array}$ & $\begin{array}{l}.10 \\
.10 \\
.10 \\
.10 \\
.10\end{array}$ & $\begin{array}{l}.10 \\
.10 \\
.10 \\
.10 \\
.10\end{array}$ & $\begin{array}{r}.10 \\
.10 \\
69 \\
.10 \\
.70\end{array}$ \\
\hline $\begin{array}{l}26 \\
27 \\
28 \\
29 \\
30 \\
31\end{array}$ & $\begin{array}{l}0 \\
0 \\
0 \\
.10 \\
4.5 \\
.10\end{array}$ & $\begin{array}{r}.10 \\
.10 \\
.10 \\
0 \\
.10 \\
.1-\end{array}$ & $\begin{array}{l}.10 \\
.10 \\
110 \\
.10 \\
.10 \\
110\end{array}$ & $\begin{array}{l}.10 \\
110 \\
110 \\
.10 \\
.10 \\
.10\end{array}$ & $\begin{array}{l}.10 \\
.10 \\
110 \\
.10 \\
=-- \\
-+-\end{array}$ & $\begin{array}{r}.10 \\
.10 \\
.10 \\
.10 \\
.10\end{array}$ & $\begin{array}{l}.10 \\
0 \\
0 \\
.10 \\
-.-\end{array}$ & $\begin{array}{l}.10 \\
.10 \\
110 \\
.10 \\
.10 \\
.10\end{array}$ & $\begin{array}{l}.10 \\
.10 \\
.30 \\
.50 \\
.30 \\
.+-\end{array}$ & $\begin{array}{l}.50 \\
.10 \\
.10 \\
.10 \\
.10 \\
.10\end{array}$ & $\begin{array}{l}.10 \\
.10 \\
.10 \\
.10 \\
.10 \\
.10\end{array}$ & $\begin{array}{l}.10 \\
.10 \\
110 \\
.10 \\
110 \\
-1 .\end{array}$ \\
\hline $\begin{array}{l}\text { TOTAL } \\
\text { MEAN } \\
\text { MAX } \\
\text { MIN } \\
\text { AC-FT }\end{array}$ & $\begin{array}{r}27.10 \\
.87 \\
15 \\
0 \\
54\end{array}$ & $\begin{array}{r}2.90 \\
.097 \\
.10 \\
0 \\
5.8\end{array}$ & $\begin{array}{r}10.70 \\
.35 \\
8.1 \\
0 \\
21\end{array}$ & $\begin{array}{r}2.60 \\
.084 \\
.10 \\
0 \\
5.2\end{array}$ & $\begin{array}{r}1732.50 \\
59.7 \\
920 \\
310 \\
3440\end{array}$ & $\begin{array}{r}585.00 \\
18.9 \\
385 \\
0 \\
1160\end{array}$ & $\begin{array}{r}68.10 \\
2.27 \\
23 \\
0 \\
135\end{array}$ & $\begin{array}{r}3.00 \\
.097 \\
.10 \\
0 \\
6.0\end{array}$ & $\begin{array}{r}10.00 \\
.33 \\
5.1 \\
.10 \\
20\end{array}$ & $\begin{array}{r}3.70 \\
.12 \\
.50 \\
.10 \\
7.3\end{array}$ & $\begin{array}{r}3.90 \\
.13 \\
.90 \\
.10 \\
7.7\end{array}$ & $\begin{array}{r}907.00 \\
30.2 \\
574 \\
110 \\
1800\end{array}$ \\
\hline
\end{tabular}

$\begin{array}{llllllllll}\text { CAL YR } 1975 & \text { TOTAL } & 1361.50 & \text { MEAN } 3.73 & \text { MAX } 303 & \text { MIN } 0 & \text { AC-FT } & 2700 \\ \text { WTR YR } & 1976 & \text { TOTAL } & 3356.50 & \text { MEAN } 9.17 & \text { MAX } 920 & \text { MIN } 0 & \text { AC-FT } & 6660\end{array}$ 
11103000 LOS ANGELES RIVER AT LONG BEACH, CA

LOCATION. - Lat $33^{\circ} 49^{\prime} 02^{\prime \prime}$, Iong $118^{\circ} 12^{\prime} 20^{\prime \prime}$, in Los Cerritos Grant, Los Angeles County, on right bank 5,000 ft

$(1,524 \mathrm{~m})$ upstream from Willow Street, $3.4 \mathrm{mi}(5.5 \mathrm{~km})$ north of Long Beach, and $3.7 \mathrm{mi}$ ( (6.0 km) upstream

from mouth.

DRAINAGE AREA. $--827 \mathrm{mi}^{2}\left(2,140 \mathrm{~km}^{2}\right)$.

PERIOD OF RECORD. - -December 1928 to current year.

GAGE. - Water-stage recorder. Datum of gage is $11.91 \mathrm{ft}(3.630 \mathrm{~m})$ above mean sea 1 eve1 (1evels by Los Angeles County Flood Control District). See WSP 1735 for history of changes prior to Jan. 19 , 1956 .

REMARKS.--Records fair. Flow regulated since September 1940 by Hansen flood-control reservoir, since

December 1941 by Sepulveda flood-control reservoir, combined capacity, 49,400 acre-ft (60.9 hm ${ }^{3}$ ), and several

smal1 flood-control reservoirs. City of Los Angeles stores imported Owens River water in San Fernando and

Chatsworth reservoirs and at times discharges imported water into Los Angeles River above station. Many

diversions above station for domestic use and irrigation. AVERAGE DISCHARGE represents f1ow to the ocean,

regardless of upstream development. See schematic diagram of San Gabrie1 and Los Ange1es River basins.

COOPERATION. - Records were furnished by Los Angeles County Flood Control District.

AVERAGE DISCHARGE, - -47 years (watex years 1930-76), $166 \mathrm{ft}^{3} / \mathrm{s}\left(4.701 \mathrm{~m}^{3} / \mathrm{s}\right), 120,300 \mathrm{acre}-\mathrm{ft} / \mathrm{yr}(148 \mathrm{hm} / \mathrm{yr}$ )

EXTREMES FOR PERIOD OF RECORD. - Maximum discharge, $102,000 \mathrm{ft}^{3} / \mathrm{s}\left(2,890 \mathrm{~m}^{3} / \mathrm{s}\right) \mathrm{Jan}$. 25, 1969, gage height, 16.00 ft $(4.877 \mathrm{~m})$; no flow at times in $1929-30,1934$.

EXTREMES FOR CURRENT YEAR.--Maximum discharge, $16,000 \mathrm{ft}^{3} / \mathrm{s}\left(453 \mathrm{~m}^{3} / \mathrm{s}\right)$ Feb. 9 , gage height, $5.85 \mathrm{ft}(1.783 \mathrm{~m})$; minimum daily, $12 \mathrm{ft}^{3} / \mathrm{s}\left(0.34 \mathrm{~m}^{3} / \mathrm{s}\right)$ Jan. 2 .

DISCHARGE, IN CUBIC FEET PER SECOND, WATER YEAR OCTOBER 1975 TO SEPTEMBER 1976 MEAN VALUES

\begin{tabular}{|c|c|c|c|c|c|c|c|c|c|c|c|c|}
\hline DAY & OCT & Nov & DEC & JAN & FEB & MAR & APR & MAY & JUN & JUL & AUG & SEP \\
\hline $\begin{array}{l}1 \\
2 \\
3 \\
4 \\
5\end{array}$ & $\begin{array}{l}36 \\
31 \\
32 \\
33 \\
30\end{array}$ & $\begin{array}{l}30 \\
24 \\
23 \\
29 \\
23\end{array}$ & $\begin{array}{l}19 \\
19 \\
21 \\
22 \\
26\end{array}$ & $\begin{array}{l}15 \\
12 \\
13 \\
14 \\
17\end{array}$ & $\begin{array}{r}19 \\
19 \\
20 \\
139 \\
969\end{array}$ & $\begin{array}{r}1640 \\
620 \\
1080 \\
50 \\
22\end{array}$ & $\begin{array}{r}20 \\
19 \\
22 \\
785 \\
114\end{array}$ & $\begin{array}{l}36 \\
36 \\
32 \\
34 \\
26\end{array}$ & $\begin{array}{l}26 \\
22 \\
20 \\
20 \\
20\end{array}$ & $\begin{array}{l}26 \\
25 \\
23 \\
19 \\
19\end{array}$ & $\begin{array}{l}16 \\
18 \\
16 \\
16 \\
16\end{array}$ & $\begin{array}{l}33 \\
27 \\
27 \\
52 \\
61\end{array}$ \\
\hline $\begin{array}{r}6 \\
7 \\
8 \\
9 \\
10\end{array}$ & $\begin{array}{l}51 \\
62 \\
34 \\
35 \\
30\end{array}$ & $\begin{array}{l}19 \\
19 \\
19 \\
18 \\
18\end{array}$ & $\begin{array}{l}27 \\
23 \\
20 \\
21 \\
19\end{array}$ & $\begin{array}{l}21 \\
20 \\
15 \\
16 \\
15\end{array}$ & $\begin{array}{r}3500 \\
736 \\
1870 \\
4660 \\
838\end{array}$ & $\begin{array}{r}19 \\
18 \\
16 \\
26 \\
272\end{array}$ & $\begin{array}{r}29 \\
28 \\
170 \\
98 \\
21\end{array}$ & $\begin{array}{l}23 \\
98 \\
42 \\
29 \\
29\end{array}$ & $\begin{array}{r}18 \\
19 \\
41 \\
34 \\
324\end{array}$ & $\begin{array}{l}20 \\
25 \\
24 \\
24 \\
25\end{array}$ & $\begin{array}{l}17 \\
17 \\
15 \\
15 \\
18\end{array}$ & $\begin{array}{r}1200 \\
46 \\
36 \\
32 \\
3830\end{array}$ \\
\hline $\begin{array}{l}11 \\
12 \\
13 \\
14 \\
15\end{array}$ & $\begin{array}{r}242 \\
94 \\
25 \\
28 \\
30\end{array}$ & $\begin{array}{l}19 \\
22 \\
19 \\
17 \\
19\end{array}$ & $\begin{array}{r}22 \\
222 \\
303 \\
32 \\
21\end{array}$ & $\begin{array}{l}15 \\
17 \\
15 \\
16 \\
19\end{array}$ & $\begin{array}{l}73 \\
34 \\
32 \\
19 \\
15\end{array}$ & $\begin{array}{l}37 \\
24 \\
18 \\
17 \\
19\end{array}$ & $\begin{array}{r}24 \\
65 \\
788 \\
99 \\
57\end{array}$ & $\begin{array}{l}26 \\
24 \\
23 \\
26 \\
23\end{array}$ & $\begin{array}{r}208 \\
19 \\
15 \\
13 \\
14\end{array}$ & $\begin{array}{l}22 \\
24 \\
24 \\
26 \\
24\end{array}$ & $\begin{array}{l}18 \\
19 \\
19 \\
19 \\
64\end{array}$ & $\begin{array}{r}2650 \\
183 \\
51 \\
35 \\
46\end{array}$ \\
\hline $\begin{array}{l}16 \\
17 \\
18 \\
19 \\
20\end{array}$ & $\begin{array}{l}30 \\
29 \\
32 \\
28 \\
24\end{array}$ & $\begin{array}{l}19 \\
18 \\
20 \\
19 \\
19\end{array}$ & $\begin{array}{l}20 \\
19 \\
20 \\
19 \\
19\end{array}$ & $\begin{array}{l}19 \\
24 \\
23 \\
22 \\
25\end{array}$ & $\begin{array}{l}16 \\
19 \\
19 \\
27 \\
20\end{array}$ & $\begin{array}{l}23 \\
23 \\
23 \\
22 \\
20\end{array}$ & $\begin{array}{l}47 \\
21 \\
23 \\
21 \\
19\end{array}$ & $\begin{array}{l}21 \\
21 \\
22 \\
25 \\
22\end{array}$ & $\begin{array}{l}23 \\
37 \\
30 \\
27 \\
20\end{array}$ & $\begin{array}{l}23 \\
19 \\
19 \\
19 \\
20\end{array}$ & $\begin{array}{r}143 \\
28 \\
22 \\
19 \\
17\end{array}$ & $\begin{array}{l}31 \\
28 \\
20 \\
18 \\
20\end{array}$ \\
\hline $\begin{array}{l}21 \\
22 \\
23 \\
24 \\
25\end{array}$ & $\begin{array}{l}26 \\
24 \\
21 \\
19 \\
20\end{array}$ & $\begin{array}{l}21 \\
20 \\
19 \\
18 \\
19\end{array}$ & $\begin{array}{l}17 \\
19 \\
20 \\
19 \\
20\end{array}$ & $\begin{array}{l}21 \\
20 \\
19 \\
21 \\
19\end{array}$ & $\begin{array}{l}19 \\
15 \\
15 \\
28 \\
20\end{array}$ & $\begin{array}{l}19 \\
18 \\
42 \\
37 \\
24\end{array}$ & $\begin{array}{l}21 \\
23 \\
28 \\
22 \\
20\end{array}$ & $\begin{array}{l}23 \\
23 \\
26 \\
28 \\
32\end{array}$ & $\begin{array}{l}21 \\
23 \\
22 \\
23 \\
25\end{array}$ & $\begin{array}{l}19 \\
19 \\
22 \\
19 \\
19\end{array}$ & $\begin{array}{l}13 \\
15 \\
17 \\
15 \\
16\end{array}$ & $\begin{array}{r}20 \\
22 \\
24 \\
379 \\
140\end{array}$ \\
\hline $\begin{array}{l}26 \\
27 \\
28 \\
29 \\
30 \\
31\end{array}$ & $\begin{array}{r}24 \\
26 \\
29 \\
23 \\
79 \\
126\end{array}$ & $\begin{array}{r}32 \\
34 \\
40 \\
24 \\
19 \\
-\end{array}$ & $\begin{array}{l}16 \\
19 \\
19 \\
22 \\
30 \\
26\end{array}$ & $\begin{array}{l}18 \\
19 \\
18 \\
21 \\
23 \\
21\end{array}$ & $\begin{array}{r}19 \\
19 \\
19 \\
19 \\
-0-\end{array}$ & $\begin{array}{l}23 \\
22 \\
21 \\
21 \\
25 \\
21\end{array}$ & $\begin{array}{r}23 \\
26 \\
29 \\
23 \\
32 \\
---\end{array}$ & $\begin{array}{l}30 \\
29 \\
29 \\
25 \\
26 \\
25\end{array}$ & $\begin{array}{r}24 \\
23 \\
34 \\
29 \\
28 \\
-\end{array}$ & $\begin{array}{l}20 \\
22 \\
23 \\
19 \\
19 \\
19\end{array}$ & $\begin{array}{l}19 \\
22 \\
20 \\
19 \\
19 \\
23\end{array}$ & $\begin{array}{r}45 \\
25 \\
19 \\
35 \\
83 \\
--\end{array}$ \\
\hline $\begin{array}{l}\text { TOTAL } \\
\text { MEAN } \\
M A X \\
M I N \\
\text { MC } \sim F T\end{array}$ & $\begin{array}{r}1353 \\
43.6 \\
242 \\
19 \\
2680\end{array}$ & $\begin{array}{r}659 \\
22.0 \\
40 \\
17 \\
1310\end{array}$ & $\begin{array}{r}1141 \\
36.8 \\
303 \\
16 \\
2260\end{array}$ & $\begin{array}{r}573 \\
18.5 \\
25 \\
12 \\
1140\end{array}$ & $\begin{array}{r}13217 \\
456 \\
4660 \\
15 \\
26220\end{array}$ & $\begin{array}{r}4262 \\
137 \\
1640 \\
16 \\
8450\end{array}$ & $\begin{array}{r}2717 \\
90.6 \\
788 \\
19 \\
5390\end{array}$ & $\begin{array}{r}914 \\
29.5 \\
98 \\
21 \\
1810\end{array}$ & $\begin{array}{r}1202 \\
40.1 \\
324 \\
13 \\
2380\end{array}$ & $\begin{array}{r}670 \\
21.6 \\
26 \\
19 \\
1330\end{array}$ & $\begin{array}{r}730 \\
23.5 \\
143 \\
13 \\
1450\end{array}$ & $\begin{array}{r}9218 \\
307 \\
3830 \\
18 \\
18280\end{array}$ \\
\hline
\end{tabular}

$\begin{array}{lllllllllll}\text { CAL YR } & 1975 & \text { TOTAL } & 41721 & \text { MEAN } 114 & \text { MAX } & 5410 & \text { MIN } 15 & \text { AC-FT } & \text { B2750 } \\ \text { WTR YR } 1976 & \text { TOTAL } & 36656 & \text { MEAN } 100 & \text { MAX } & 4660 & \text { MIN } 12 & \text { AC-FT } & 72710\end{array}$ 
LOCATION. - Lat $33^{\circ} 48^{\prime} 16^{\prime \prime}$, long $118^{\circ} 12^{\prime} 15^{\prime \prime}$, in Los Cerritos Grant, Los Angeles County, on the Willow Street Bridge, $2.8 \mathrm{mi}(4.5 \mathrm{~km})$ upstream from mouth in Long Beach.

DRAINAGE AREA. $--831 \mathrm{mi}^{2}\left(2,152 \mathrm{~km}^{2}\right)$.

PERIOD OF RECORD.--February 1973 to current year.

CHEMICAL ANALYSES: February 1973 to current year.

SPECIFIC CONDUCTANCE: October 1973 to current year.

WATER TEMPERATURES: October 1973 to current year.

SEDIMENT RECORDS: Water year 1975 to current year (partial-record station).

PERIOD OF DAILY RECORD.--

SPECIFIC CONDUCTANCE: October 1973 to September 1975

WATER TEMPERATURES: October 1973 to September 1975 .

INSTRUMENTATION. --Specific-conductance recorder October 1973 to September 1975. Temperature recorder October 1973 to September 1975 .

REMARKS. - Discharge va1ues from Los Angeles River at Long Beach (station 11103000).

EXTREMES FOR PERIOD OF RECORD. - -

SPECIFIC CONDUCTANCE: Maximum recorded, 2,010 micromhos June 30, 1975; minimum recorded, 117 micromhos Mar. 6, 1975 .

WATER TEMPERATURES: Maximum recorded, $34.5^{\circ} \mathrm{C}$, Aug. 7, $1975 ;$ minimum recorded, $2.0^{\circ} \mathrm{C} J a n .31,1975$.

CHEMICAL ANALYSES, HATER YEAR OCTOBER 1975 TO SEPTEMBER 1976

\begin{tabular}{|c|c|c|c|c|c|c|c|c|c|c|c|}
\hline DATE & TIME & $\begin{array}{c}\text { INSIAN- } \\
\text { TANEOUS } \\
\text { DIS- } \\
\text { CHARGE } \\
\text { (CFS) }\end{array}$ & $\begin{array}{c}\text { PH } \\
\text { (UNITS) }\end{array}$ & $\begin{array}{l}\text { TUR- } \\
\text { BID- } \\
\text { ITY } \\
\text { (JTU) }\end{array}$ & $\begin{array}{l}\text { FECAL } \\
\text { COLI - } \\
\text { FORM } \\
\text { (COL. } \\
\text { PER } \\
100 \mathrm{ML} \text { ) }\end{array}$ & $\begin{array}{l}\text { STREP- } \\
\text { TOCOCCI } \\
\text { (COL - } \\
\text { ONIES } \\
\text { PER } \\
100 \mathrm{ML} \text { ) }\end{array}$ & $\begin{array}{l}\text { HARD- } \\
\text { NESS } \\
\text { (CA,MG) } \\
\text { (MG/L) }\end{array}$ & $\begin{array}{l}\text { NON- } \\
\text { CAR- } \\
\text { BONATE } \\
\text { HARD- } \\
\text { NESS } \\
\text { (MG/L) }\end{array}$ & $\begin{array}{l}\text { DIS- } \\
\text { SOLVED } \\
\text { CAL- } \\
\text { CIUH } \\
\text { (CA) } \\
(M G / L)\end{array}$ & $\begin{array}{l}\text { OIS- } \\
\text { SOLVEO } \\
\text { MAG- } \\
\text { NE- } \\
\text { SIUM } \\
\text { (MG) } \\
\text { (MG/L) }\end{array}$ & $\begin{array}{l}\text { DIS- } \\
\text { SOLVED } \\
\text { SODIUM } \\
\text { (NA) } \\
\text { (MG/L) }\end{array}$ \\
\hline $\begin{array}{l}\text { OCT } \\
20 \ldots \\
\text { VOV }\end{array}$ & -- & 26 & 9.1 & 4 & 660 & 255 & 350 & 140 & 91 & 29 & 150 \\
\hline DEC & 1040 & 17 & 9.1 & B & B50 & B15 & 390 & 160 & 97 & 35 & 140 \\
\hline JAN & 1200 & 21 & 9.2 & 5 & 84700 & 680 & 340 & 64 & 88 & 29 & 130 \\
\hline$=27 \cdots$ & 1115 & 19 & 9.1 & 15 & 2100 & 570 & 390 & 150 & 100 & 33 & 110 \\
\hline $12 \ldots$ & 1000 & 24 & 8.0 & 6 & 2800 & 2000 & 370 & 180 & 100 & 28 & 100 \\
\hline $\begin{array}{l}23 \\
A P R\end{array}$ & 1055 & 60 & 9.1 & 6 & 170 & 170 & 310 & 150 & 81 & 26 & 89 \\
\hline MAY & 1110 & 19 & 8.3 & 3 & 8100 & 470 & 340 & 140 & 78 & 35 & 100 \\
\hline JUN & 1145 & 23 & 9.1 & 20 & 400 & 40 & 360 & 180 & 63 & 38 & 120 \\
\hline JuL $^{17 \ldots}$ & 1015 & 31 & 9.2 & 2 & 920 & -- & 360 & $=$ & 87 & 34 & 120 \\
\hline $\begin{array}{l}07 \ldots . . \\
\text { Aug }\end{array}$ & 1020 & 30 & 9.3 & B & 500 & 320 & 350 & 130 & 83 & 35 & 120 \\
\hline$\underset{\text { OEP }}{04} \cdots$ & 1130 & 14 & 9.1 & 35 & 1720 & 960 & 420 & 200 & 100 & 41 & 130 \\
\hline $02 \ldots$ & 1030 & 29 & 8.9 & 6 & 410 & 300 & 360 & 160 & 91 & 33 & 110 \\
\hline DATE & $\begin{array}{r}\text { PERCENT } \\
\text { SODIUM }\end{array}$ & $\begin{array}{l}\text { SODIUM } \\
\text { AD- } \\
\text { SORP- } \\
\text { TION } \\
\text { RATIO }\end{array}$ & $\begin{array}{l}\text { DIS- } \\
\text { SOLVEO } \\
\text { PO- } \\
\text { TAS- } \\
\text { SIUM } \\
\text { (K) } \\
\text { (MG/L) }\end{array}$ & $\begin{array}{l}\text { BICAR- } \\
\text { BONATE } \\
\text { (HCO3) } \\
\text { (MG/L) }\end{array}$ & $\begin{array}{l}\text { CAR- } \\
\text { BONATE } \\
\text { (CO3) } \\
\text { (MG/L) }\end{array}$ & $\begin{array}{l}\text { ALKA- } \\
\text { LINITY } \\
\text { AS } \\
\text { CACO3 } \\
\text { (MG/L) }\end{array}$ & $\begin{array}{c}\text { CARBON } \\
\text { DIOXIDE } \\
\text { (CO2) } \\
\text { (MG/L) }\end{array}$ & $\begin{array}{l}\text { OIS- } \\
\text { SOLVED } \\
\text { SULFATE } \\
\text { (SO4) } \\
\text { (MG/L) }\end{array}$ & $\begin{array}{l}\text { DIS- } \\
\text { SOLVED } \\
\text { CHLO- } \\
\text { RIDE } \\
\text { (CLL) } \\
\text { (MG/L) }\end{array}$ & $\begin{array}{l}\text { DIS- } \\
\text { SOLVED } \\
\text { FLUO- } \\
\text { RIDE } \\
\text { (F) } \\
(\mathrm{MG} / L)\end{array}$ & $\begin{array}{l}\text { DIS- } \\
\text { SOLVED } \\
\text { SILICA } \\
\text { (SIOL) } \\
\text { (MG/L) }\end{array}$ \\
\hline
\end{tabular}

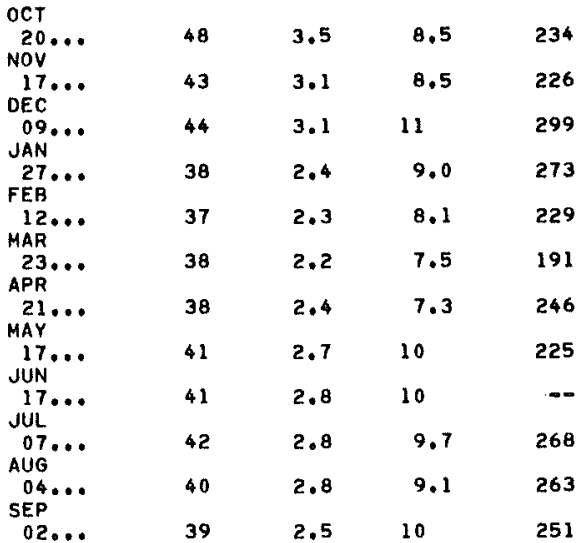

$\begin{array}{rrrrrrr}8 & 205 & .3 & 210 & 170 & .6 & 17 \\ 25 & 227 & .4 & 240 & 140 & .6 & 7.2 \\ 18 & 275 & .3 & 240 & 110 & .4 & 11 \\ 6 & 234 & .4 & 230 & 120 & .6 & 7.3 \\ 0 & 188 & 3.7 & 230 & 120 & .7 & 23 \\ 0 & 157 & .2 & 190 & 87 & .5 & 12 \\ 0 & 202 & 2.0 & 200 & 110 & .6 & 18 \\ 0 & 185 & .3 & 210 & 130 & 14 & 19 \\ -. & .0 & . . & 260 & 120 & .8 & 24 \\ 0 & 220 & .2 & 220 & 120 & .5 & 24 \\ 0 & 216 & .3 & 270 & 160 & .6 & 25 \\ 0 & 206 & .5 & 220 & 140 & .6 & 21\end{array}$


CHEMICAL ANALYSES, WATER YEAR OCTOBER 1975 TO SEPTEMBER 1976

\begin{tabular}{|c|c|c|c|c|c|c|c|c|c|c|}
\hline DATE & $\begin{array}{l}\text { DIS- } \\
\text { SOLVED } \\
\text { SOLIDS } \\
\text { (RESI- } \\
\text { DUE AT } \\
\text { IBO C) } \\
\text { (MG/L) }\end{array}$ & $\begin{array}{l}\text { DIS- } \\
\text { SOLVED } \\
\text { SOLIDS } \\
\text { (SUM OF } \\
\text { CONSTI- } \\
\text { TUENTS) } \\
\text { (MG/L) }\end{array}$ & $\begin{array}{l}\text { DIS- } \\
\text { SOLVED } \\
\text { SOLIDS } \\
\text { (TONS } \\
\text { PER } \\
\text { AC-FT) }\end{array}$ & $\begin{array}{l}\text { DIS- } \\
\text { SOLVED } \\
\text { SOLIDS } \\
\text { (TONS } \\
\text { PER } \\
\text { DAY) }\end{array}$ & $\begin{array}{c}\text { TOTAL } \\
\text { NITRITE } \\
\text { PLUS } \\
\text { NITRATE } \\
\text { (N) } \\
\text { (MG/L) }\end{array}$ & $\begin{array}{l}\text { TOTAL } \\
\text { KJEL- } \\
\text { OAHL } \\
\text { NITRO- } \\
\text { GEN } \\
\text { (N) } \\
\text { (MG/L) }\end{array}$ & $\begin{array}{l}\text { TOTAL } \\
\text { NITRO- } \\
\text { GEN } \\
\text { (N) } \\
\text { (HG/L) }\end{array}$ & $\begin{array}{l}\text { TOTAL } \\
\text { NITRO- } \\
\text { GEN } \\
\text { (NO3) } \\
\text { (MG/L) }\end{array}$ & $\begin{array}{l}\text { TOTAL } \\
\text { PHOS- } \\
\text { PHORUS } \\
\text { (P) } \\
\text { (MG/L) }\end{array}$ & $\begin{array}{l}\text { TOTAL } \\
\text { PHYTO- } \\
\text { PLANK- } \\
\text { TON } \\
\text { (CELLLS } \\
\text { PER } \\
\text { ML) }\end{array}$ \\
\hline $\begin{array}{l}\mathrm{OCT} \\
20 \ldots . . \\
\text { NOV }\end{array}$ & 857 & 800 & 1.17 & 60.2 & 1.6 & 2.4 & 4.0 & 18 & 1.2 & 15000 \\
\hline OEC & 834 & 805 & 1.13 & 38,3 & 1.2 & 1.9 & 3.1 & 14 & 2.2 & 47000 \\
\hline JAN $09 . \cdots$ & 762 & 785 & 1.04 & 43.2 & 3.5 & 5.0 & 8.5 & 38 & 2.1 & 25000 \\
\hline $\begin{array}{l}27 \ldots \\
\text { FEB }\end{array}$ & 798 & 751 & 1.09 & 40.9 & 1.6 & 4.2 & 5.8 & 26 & 3.4 & 35000 \\
\hline $12 \cdots$ & 764 & 723 & 1.04 & 49.5 & 2.8 & 3.3 & 6.1 & 27 & 1.0 & 440 \\
\hline$\stackrel{23 \cdots \cdots}{A P R}$ & 633 & 587 & .86 & 103 & 2.0 & 2.5 & 4.5 & 20 & .41 & 20000 \\
\hline $21 \cdots$ & 713 & 670 & .97 & 36.6 & 2.2 & 2.5 & 4.7 & 21 & .66 & 65000 \\
\hline JUN & 746 & 735 & 1.01 & 46.3 & .14 & 1.4 & 1.5 & 6.8 & .63 & 11000 \\
\hline $\begin{array}{l}17 \ldots \\
\text { JUL }\end{array}$ & $-m$ & - & -- & -- & .80 & 2.0 & 2.8 & 12 & 1.4 & 53000 \\
\hline $\begin{array}{l}07 \ldots \\
\text { AUG }\end{array}$ & 773 & 744 & 1.05 & 62.6 & .02 & 4.6 & 4.6 & 20 & 1.9 & 130000 \\
\hline $\begin{array}{l}04 \cdots \cdots \\
\text { SEP }\end{array}$ & 885 & 865 & 1.20 & 3.3 .5 & .02 & 7.4 & 7.4 & 33 & 2.0 & 190000 \\
\hline & 792 & 749 & 1,08 & 62.0 & .08 & 1.4 & 1.5 & 6.6 & 1.5 & 20000 \\
\hline
\end{tabular}

CHEMICAL ANALYSES, HATER YEAR OCTOBER 1975 TO SEPTEMBER 1976

\begin{tabular}{|c|c|c|c|c|c|c|c|c|c|c|c|c|}
\hline DATE & TIME & $\begin{array}{c}\text { TOTAL } \\
\text { ARSENIC } \\
\text { (AS) } \\
\text { (UG/L) }\end{array}$ & $\begin{array}{c}\text { SUS- } \\
\text { PENDED } \\
\text { ARSENIC } \\
\text { (AS) } \\
\text { (UG/L) }\end{array}$ & $\begin{array}{l}\text { DIS- } \\
\text { SOLVED } \\
\text { ARSENIC } \\
\text { (AS) } \\
\text { (UG/L) }\end{array}$ & $\begin{array}{l}\text { TOTAL } \\
\text { CAD- } \\
\text { MIUH } \\
\text { (CD) } \\
\text { (UG/L) }\end{array}$ & $\begin{array}{l}\text { SUS- } \\
\text { PENDED } \\
\text { CAD- } \\
\text { MIUM } \\
\text { (CD) } \\
(U G / L)\end{array}$ & $\begin{array}{l}\text { DIS- } \\
\text { SOLVED } \\
\text { CAD- } \\
\text { MIUM } \\
\text { (CD) } \\
\text { (UG/L) }\end{array}$ & $\begin{array}{l}\text { TOTAL, } \\
\text { CHRO- } \\
\text { MIUM } \\
\text { (CR) } \\
\text { (UG/L) }\end{array}$ & $\begin{array}{l}\text { SUS- } \\
\text { PENDED } \\
\text { CHRO- } \\
\text { MIUM } \\
\text { (CR) } \\
\text { (UG/L) }\end{array}$ & $\begin{array}{l}\text { DIS- } \\
\text { SOLVED } \\
\text { CHRO- } \\
\text { MIUM } \\
\text { (CR) } \\
\text { (UG/L) }\end{array}$ & $\begin{array}{l}\text { TOTAL } \\
\text { COBALT } \\
\text { (CO) } \\
\text { (UG/L) }\end{array}$ & $\begin{array}{l}\text { SUS- } \\
\text { PENDED } \\
\text { COBALT } \\
\text { (CO) } \\
\text { (UG/L) }\end{array}$ \\
\hline \multicolumn{13}{|l|}{ OCT } \\
\hline $20 \cdots$ & - & 6 & 1 & 5 & $<10$ & $<9$ & 1 & 50 & 44 & 6 & $<50$ & $<49$ \\
\hline$\underset{A P R}{27} \cdots$ & 1115 & 8 & 4 & 4 & $-\infty$ & -- & 2 & $=-$ & $-\infty$ & 30 & $<50$ & $<48$ \\
\hline$\underset{J U L}{21} \cdots$ & 1110 & 12 & 0 & 12 & 60 & 38 & 22 & 40 & 10 & 30 & $<50$ & $<50$ \\
\hline $07 \ldots$ & 1020 & 3 & 0 & 4 & $<10$ & $<9$ & 1 & 10 & 0 & 10 & $<50$ & $<48$ \\
\hline
\end{tabular}

\begin{tabular}{|c|c|c|c|c|c|c|c|c|c|c|c|}
\hline DATE & $\begin{array}{l}\text { DIS- } \\
\text { SOLVED } \\
\text { COBALT } \\
\text { (CO) } \\
\text { (UG/L) }\end{array}$ & $\begin{array}{l}\text { TOTAL } \\
\text { COPPER } \\
\text { (CU) } \\
\text { (UG/L) }\end{array}$ & $\begin{array}{l}\text { SUS- } \\
\text { PENDED } \\
\text { COPPER } \\
\text { (CU) } \\
\text { (UG/L) }\end{array}$ & $\begin{array}{l}\text { DIS- } \\
\text { SOLVED } \\
\text { COPPER } \\
\text { (CU) } \\
\text { (UG/L) }\end{array}$ & $\begin{array}{l}\text { TOTAL } \\
\text { IRON } \\
\text { (FE) } \\
\text { (UG/L) }\end{array}$ & $\begin{array}{l}\text { DIS- } \\
\text { SOLVED } \\
\text { IRON } \\
\text { (FE) } \\
\text { (UG/L) }\end{array}$ & $\begin{array}{c}\text { TOTAL } \\
\text { LEAO } \\
\text { (PB) } \\
\text { (UG/L) }\end{array}$ & $\begin{array}{l}\text { SUS- } \\
\text { PENDED } \\
\text { LEAD } \\
\text { (PB) } \\
\text { (UG/L) }\end{array}$ & $\begin{array}{l}\text { DIS- } \\
\text { SOLVED } \\
\text { LEAD } \\
\text { (PB) } \\
\text { (UG/L) }\end{array}$ & $\begin{array}{l}\text { TOTAL } \\
\text { MAN- } \\
\text { GANESE } \\
\text { (MN) } \\
\text { (UG/L) }\end{array}$ & $\begin{array}{l}\text { SUS- } \\
\text { PENDED } \\
\text { MAN- } \\
\text { GANESE } \\
\text { (MN) } \\
\text { (UG/L) }\end{array}$ \\
\hline $\begin{array}{l}\text { OCT } \\
20 \ldots \\
\text { JAN }\end{array}$ & 1 & 20 & 15 & 5 & 290 & 50 & 100 & 92 & 8 & 60 & 20 \\
\hline$\underset{A P R}{27} \cdots$ & 2 & 30 & 18 & 12 & 620 & 40 & - & $-\infty$ & 10 & -- & $-\infty$ \\
\hline$\underset{\text { JUL }}{21} \cdots$ & 0 & 90 & 57 & 33 & 240 & 80 & $<100$ & $<97$ & 3 & 30 & 20 \\
\hline $07 \ldots$ & 2 & 40 & 27 & 13 & 370 & 40 & 100 & 92 & 8 & 60 & 50 \\
\hline
\end{tabular}


CHEMICAL ANALYSES, WATER YEAR OCTOBER 1975 TO SEPTEMBER 1976

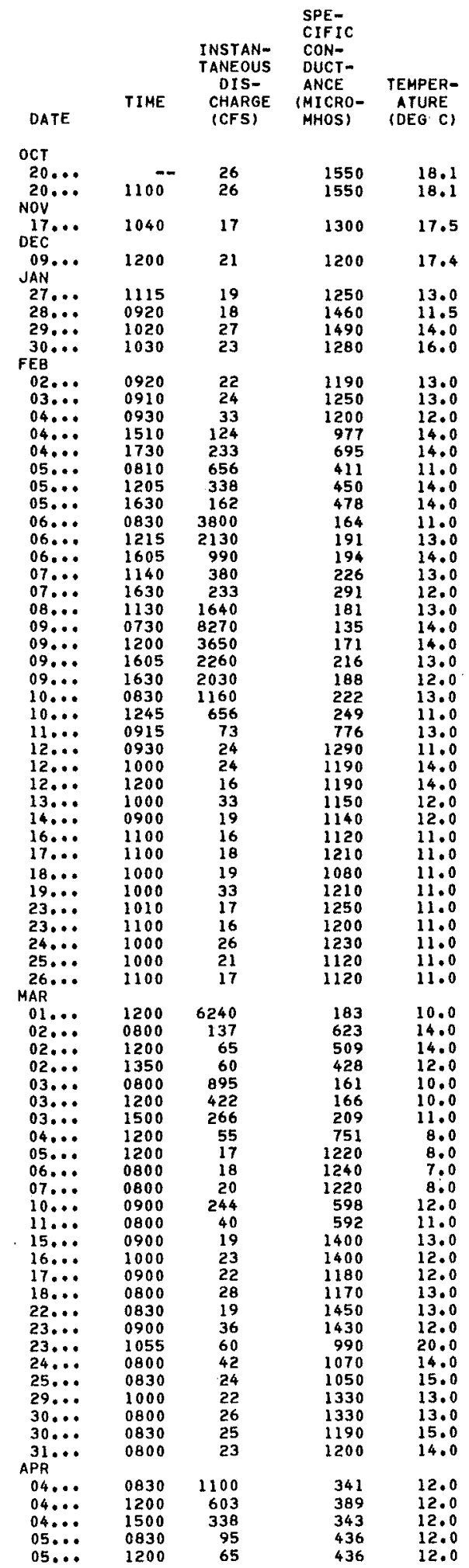


11103010 LOS ANGELES RIVER AT WILLOW STREET BRIDGE, AT LONG BEACH, CA - Continued

CHEMICAL ANALYSES, HATER YEAR OCTOBER 1975 TO SEPTEMBER 1976

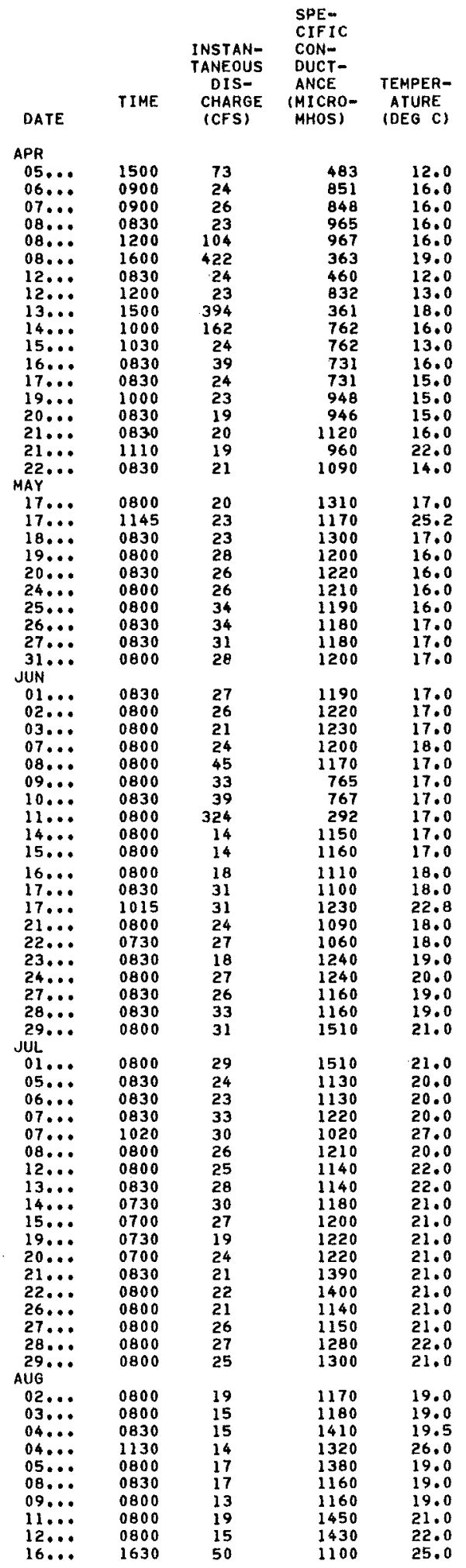


11103010 LOS ANGELES RIVER AT WILLOW STREET BRIDGE, AT LONG BEACH, CA--Continued

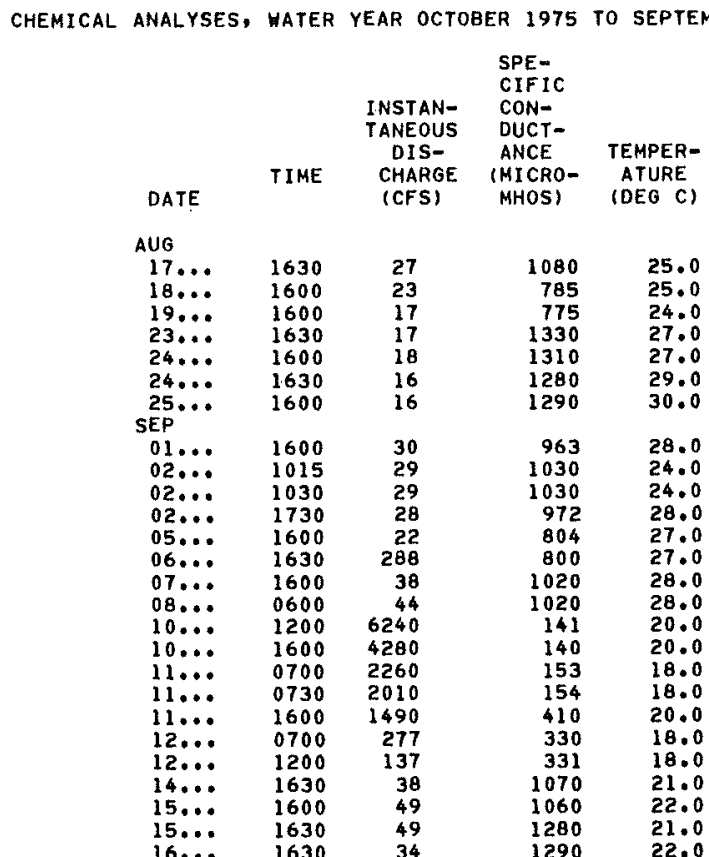


11103010 LOS ANGELES RIVER AT WILlOW STREET BRIDGE, AT LONG BEACH, CA--Continued

QUALITATIVE AND ASSOCIATED QUANTITATIVE ANALYSES OF BIOLOGICAL DATA, WATER YEAR OCTOBER 1975 TO SEPTEMBER 1976 PHYTOPLANKTON

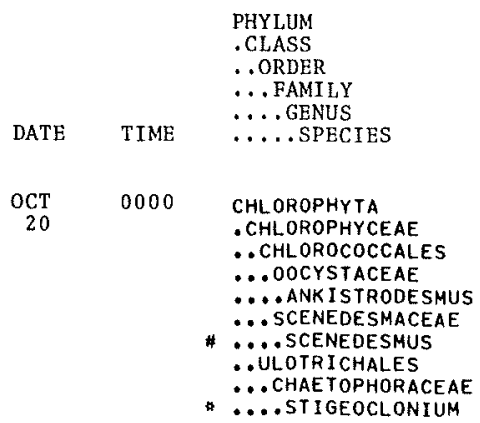

$\begin{array}{lrr}\text { COMMON } & \text { COUNT } & \text { PERCENT } \\ \text { NAME } & \text { (CEELS/ML) } & \text { OF TOTAL }\end{array}$

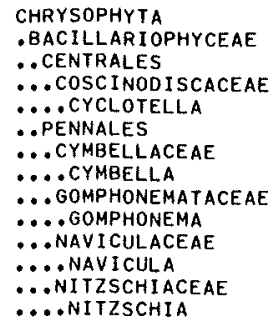

TOTAL PHYTOPLANKTON
GREEN ALGAE

$\begin{array}{rr}170 & 1 \\ 5,700 & 38\end{array}$

DIATOMS

CENTRIC

PENNATE

NAVICULOID

NAVICULOID

DI ATOMS

CENTRIC

PENNATE

BLUE-GREEN ALGAE

F ILAMENTOUS

EUGLENOIDS

EUGLENOPHYTA - CRYPTOPHYCEAE

- CRYPTOMONIDALES

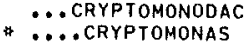

CRYPTOMONADS
0

2,200

14

13,000

29

11,000

23

$\begin{array}{rr}4.100 & 9 \\ 240 & 1 \\ 240 & 1 \\ 720 & 2 \\ 17,000 & 37\end{array}$

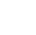

15,000

17,000

37
- EUGLENOPHYCEAE

. Euglenales

$\because$ EUGLENACEAE

*... Euguglena

TOTAL PHYTOPLANKTON 
11103010 LOS ANGELES RIVER AT WILLOW STREET BRIDGE, AT LONG BEACH, CA--Continued QUALITATIVE AND ASSOCIATED QUANTITATIVE ANALYSES OF BIOLOGICAL DATA, WATER YEAR OCTOBER 1975 TO SEPTEMBER 1976 PHYTOPLANKTON

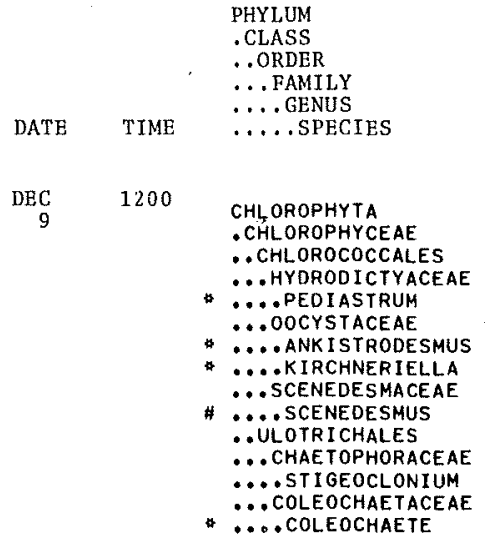

CHRYSOPHYTA - BAC ILLARI OPHYCEAE . CENTRALES

... COSCINOd I SCACEAE

* ... cyclotella

. PENNALES

... CYMBELLACEAE

... FRAG ILAR I ACEAE

.... SYNEDRA

... GOMPHONEMATACEAE

... gomphonema

.. . NAVI CULACEAE

.... Navicula

...NITZSCHIACEAE

... SUR IRELLaceaE

....surirella

CYANOPHYTA

- MYXOPHYCEAE

- CHROOCOCCALES

. CHROOCOCCACEAE

.... ANACYSTIS

TOTAL PHYTOPLANKTON

\begin{tabular}{|c|c|c|}
\hline $\begin{array}{r}\text { JAN } \\
27\end{array}$ & 1115 & 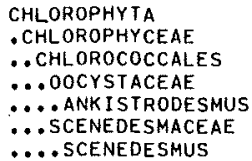 \\
\hline
\end{tabular}

CHRYSOPHYTA

- BACILLARI OPHYCEAE

. CENTRALES

. coscinod ISCACEAE

\# ... Cyclotella

..PEnNales

@.. CYMBELLACEAE

.... AMPHORA

@... CYMBELLA

. gOMPHONEMATACEAE

.... GOMPHONEMA

... NAVI CULACEAE

.... NAVICULa

\#. NITZSCHIACEaE

\#.... NITZSCHIa

TOTAL PHYTOPLANKTON

$\begin{array}{lcr}\text { COMMON } & \text { COUNT } & \text { PERCENT } \\ \text { NAME } & \text { (CELLS/ML) } & \text { OF TOTAL }\end{array}$

GREEN ALGAE

$\begin{array}{rr} & 0 \\ 4,000 & 0 \\ 2,700 & 16 \\ & 11 \\ & 0\end{array}$

DIATOMS

CENTRIC

PENNATE

9,300

37

NAVICULOIO

$\begin{array}{rr}330 & 1 \\ 330 & 1 \\ 330 & 1 \\ 2,700 & 11 \\ 3,300 & 13 \\ 1,000 & 4\end{array}$

BLUE-GREEN ALGAE

COCCOID

1,000

25,000

GREEN ALGAE

$\begin{array}{rr}350 & 1 \\ 3,100 & 9\end{array}$

DIATOMS

CENTRIC

PENNATE

5,600

16

1,000
4.900

3
14

700

2

NAVICULOID

2,800

8

16,000

46 
11103010 LOS ANGELES RIVER AT WILLOW STREET BRIDGE, AT LONG BEACH, CA--Continued

QUALITATIVE AND ASSOCIATED QUANTITATIVE ANALYSES OF BIOLOGICAL DATA, WATER YEAR OCTOBER 1975 TO SEPTEMBER 1976 PHYTOPLANKTON

\begin{tabular}{|c|c|c|}
\hline DATE & TIME & $\begin{array}{l}\text { PHYLUM } \\
\text {. CLASS } \\
\ldots \text { ORDER } \\
\ldots \text { FAMILY } \\
\ldots \text { GENUS }\end{array}$ \\
\hline $\begin{array}{r}\text { FEB } \\
12\end{array}$ & 1000 & $\begin{array}{l}\text { CHL OROPHYTA } \\
\text {-CHLOROPHYCEAE } \\
\text {. CHLOROCOCCALES } \\
\ldots \text { OOCYSTACEAE } \\
\because \ldots \text { ANKI ISTRODESMUS } \\
\because \ldots \text { TETRAEDRON } \\
\ldots \text { SCENEDESMACEAE }\end{array}$ \\
\hline
\end{tabular}

*.... SCENEDESMUUS

CHRYSOPHYTA

-8ACILLARIOPHYCEAE

. CEnTRALES

.. coscinod Iscaceae

* ... cyclotella

$\because$ PENNALES

.. NAVICULACEAE

... NAVI CULA

... NITZSCHIACEAE

.... NITZSCHIA

CYANOPHYTA

- MYXOPHYCEAE

- chroococcales

... CHROOCOCCACEAE

... ANACYSTIS

. OSCILLATOR I ALES

\#NOSTOCACEAE

... ANABAEna

. Oscillatoriaceae

\# . . oscillatoria

TOTAL PHYTOPLANKTON

$7 \%$

MAR

1055

CHLOROPHYCEA

- CHL orococcale

. OOCYSTACEAE

... ANKISTRODESMUS

... 00cYstIS

... TETRAEDRON

... SCENEDESHACEAE

....SCENEDESMUS

CHRYSOPHYTA

- BaCILlariophyceae

. CENTRALES

.. COSCINOdISCACEAE

... CYClotella

. PENNALES

... CYMBELLACEAE

... AMPHORA

* ... cYMBelLa

. gOMPHONEMATACEAE

... gOMPHONEMA

... Naviculacea

... Navicula

..NITZSCHIACEAE

\# .....nitzSchia

TOTAL PHYTOPLANKTON

$\begin{array}{lcr}\text { COMMON } & \text { COUNT } & \text { PERCENT } \\ \text { NAME } & \text { (CELLS/ML) } & \text { OF TOTAL }\end{array}$

GREEN ALGAE

$\begin{array}{ll}26 & 6 \\ 16 & 4\end{array}$

DIATOMS

CENTRIC

PENNATE.

84

19

NAVICULOID

$\begin{array}{ll}31 & 7 \\ 37 & 8\end{array}$

BLUE-GREEN ALGAE

COCCOID

F ILAMENTOUS

$\begin{array}{lr}21 & 5 \\ 42 & 9 \\ 89 & 20\end{array}$

440

GREEN ALGAE

250

250

1,000

5

DIATOMS

CENTRIC

PENNATE

1,000

$\begin{array}{rrr}750 & 4 \\ 3,000 & 15 \\ \text { NAVICULOID } & 500 & 3 \\ 1,700 & 9 \\ 11,000 & 58 \\ 20,000 & \end{array}$

See footnotes at end of table. 
11103010 LOS ANGELES RIVER AT WILLOW STREET BRIDGE, AT LONG BEACH, CA--Continued

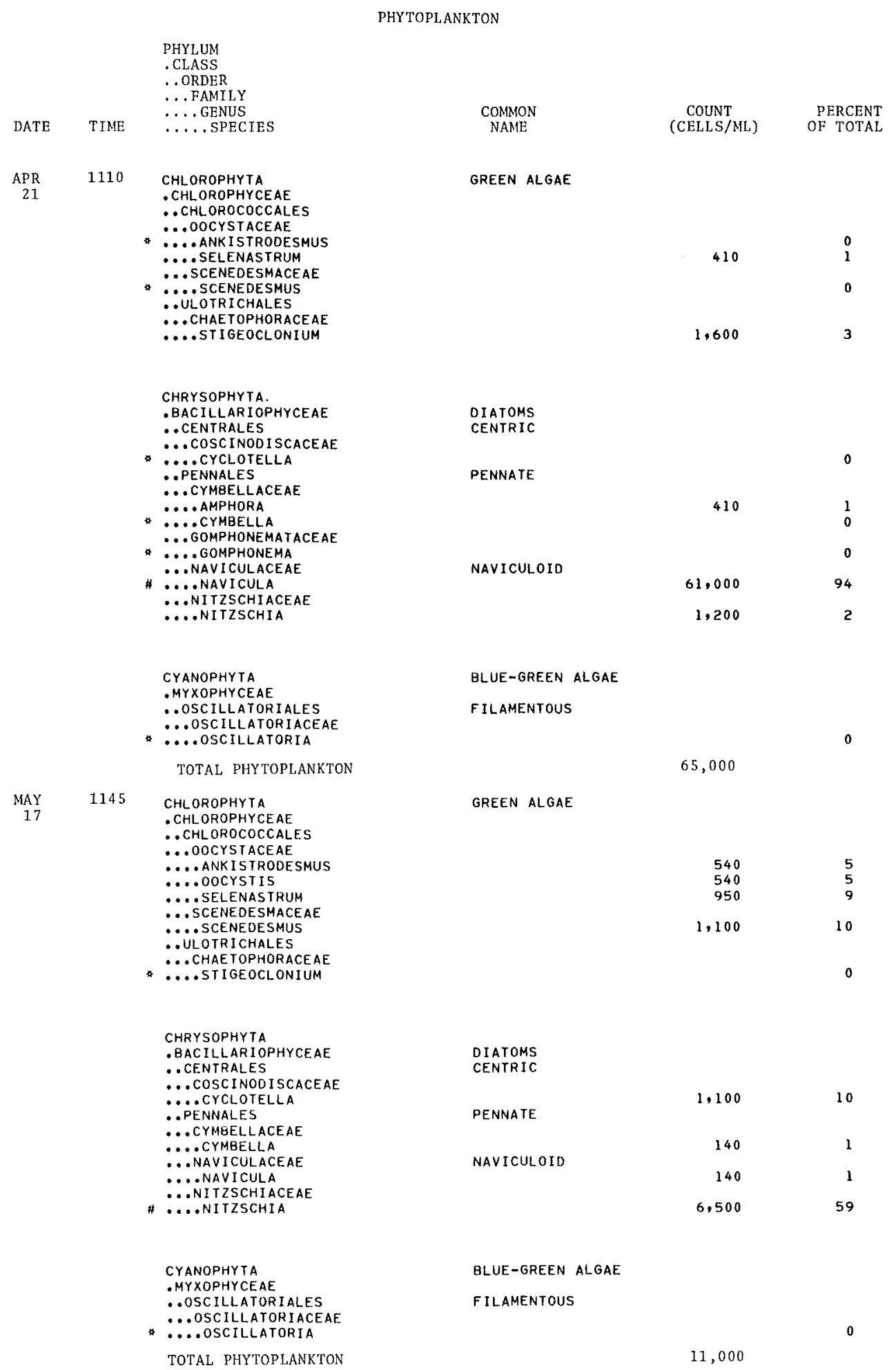

See footnotes at end of table. 
11103010 LOS ANGELES RIVER AT WILLOW STREET BRIDGE, AT LONG BEACH, CA--Continued

QUALITATIVE AND ASSOCIATED QUANTITATIVE ANALYSES OF BIOLOGICAL DATA, WATER YEAR OCTOBER 1975 TO SEPTEMBER 1976

PHYTOPLANKTON

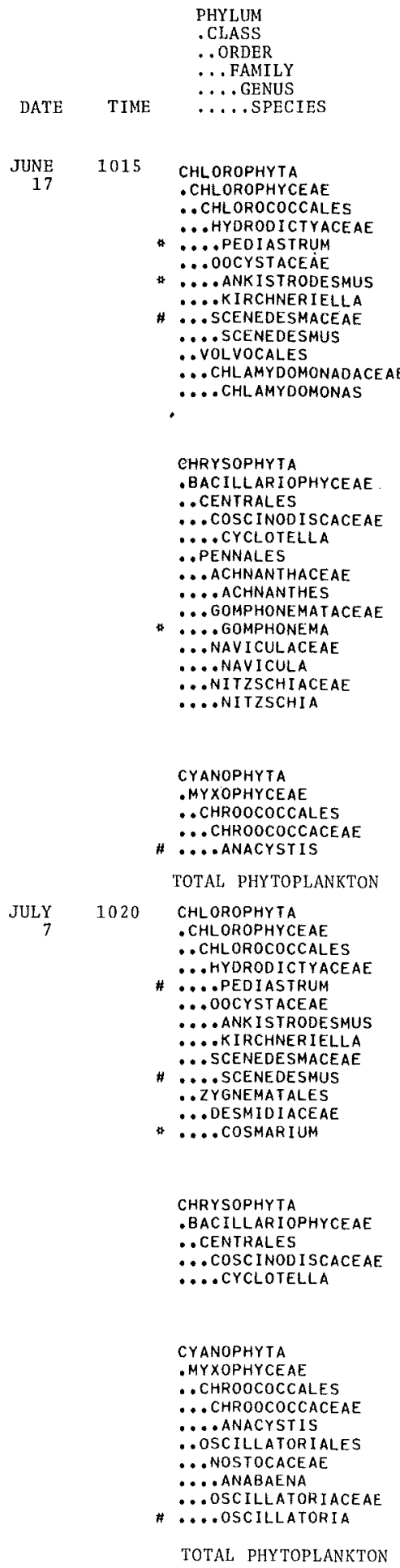

\begin{tabular}{|c|c|}
\hline $\begin{array}{l}\text { COMMON } \\
\text { NAME }\end{array}$ & $\begin{array}{c}\text { COUNT } \\
\text { (CELLS/ML) }\end{array}$ \\
\hline
\end{tabular}

GREEN ALGAE

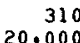

20,000

2,100

920

0
1
37
4

DIATOMS

CENTRIC

PENNATE

310

310

NAVICULOID

920

310

2

1

BLUE-GREEN ALGAE

COCCOID

28,000

53

53,000

GREEN ALGAE

$\begin{array}{rr}33,000 & 25 \\ 1,200 & 1 \\ 5,700 & 4 \\ 57,000 & 43\end{array}$

PLACODERM DESMIDS

DI ATOMS

CENTRIC

1,400

1

BLUE-GREEN ALGAE

COCCOID

FILAMENTOUS

$\begin{array}{rr}810 & 1 \\ 2,000 & 2 \\ 32,000 & 24\end{array}$

130,000 
11103010 LOS ANGELES RIVER AT WILLOW STREET BRIDGE, AT LONG BEACH, CA--Continued

QUALITATIVE AND ASSOCIATED QUANTITATIVE ANALYSES OF BIOLOGICAL DATA, WATER YEAR OCTOBER 1975 TO SEPTEMBER 1976

PHYTOPLANKTON

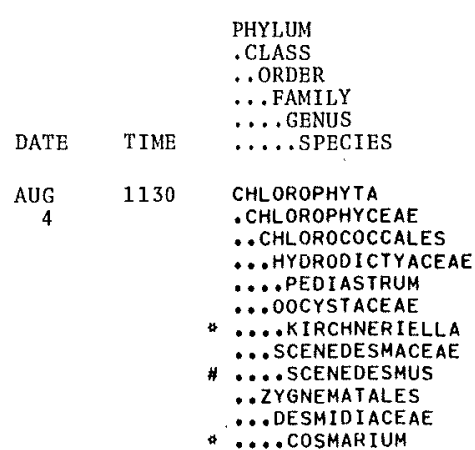

...DESMIDIACEA

CHRYSOPHYTA

- BACILLAR I OPHYCEAE

. CENTRALES

... COSC INODISCACEAE

.... CYClotella

PENNALES

.. CYMBELlaceae

*... crmbella

CYANOPHYTA

-MYXOPHYCEAE

-. Chroococcales

.. CHROOCOCCACEAE

.... Agmenellum

$\because$ OSC ILLATORI ALES

.. NOSTOCACEAE

.... CYLINOROSPERMUM

.. OSCILLATORI ACEAE

\# .... oscillatoria

TOTAL PHYTOPLANKTON

$\begin{array}{rll}\text { SEP } & 1030 & \text { CHLOROPHYTA } \\ 2 & & \text {. CHLOROPHYCEAE }\end{array}$

- CHLOROCOCCALES

... HYDRODI I TYACEAE

....PEOIASTRUM

... MI I RACTINIACEAE

... GOLENKINIA

\#. SCENEDESMACEAE

... SCENEDESMUS

. TETRASPORALES

...PAlmellaceae

* ...

. Ulotrichales

... CHAE TOPHORACEAE

@... ST I gEOCLONIUM

... MI crosporaceae

....MICROROSPORA

$\because$ VOLIVOCALES

. VOLVOCALES

$\because$... CHL CHLAMYODOMOMONAS

... PHacotaceae

*...phacotus

...volvocaceaE

*...evudorina

-. zYgnematales

... DESMIDIACEAE

- ... cosmarium

See footnotes at end of table.

$\begin{array}{lcr}\text { COMMON } & \text { COUNT } & \text { PERCENT } \\ \text { NAME } & \text { (CELLS/ML) } & \text { OF TOTAL }\end{array}$

GREEN ALGAE

$\begin{array}{rr}5,500 & 3 \\ 47,000 & 0 \\ & 25\end{array}$

PLACOOERM DESMIDS

DIATOMS

CENTRIC

PENNATE

1,000

BLUE-GREEN ALGAE

Coccoso

FILAMENTOUS

$\begin{array}{rr}2,100 & 1 \\ 17,000 & 9 \\ 110,000 & 60\end{array}$

190,000

GREEN ALGAE

$\begin{array}{rr}1,900 & 9 \\ 980 & 5 \\ 1,600 & 8 \\ 1,700 & 0 \\ 640 & 3\end{array}$

0

0

0

PLACODERM DESMIOS 
11103010 LOS ANGELES RIVER AT WILLOW STREET BRIDGE, AT LONG BEACH, CA-Continued

PHYTOPLANKTON

\begin{tabular}{|c|c|c|c|}
\hline DATE & TIME & & $\begin{array}{l}\text { PHYLUM } \\
\text { CLASS } \\
\ldots \text { ORDER } \\
\ldots \text { FAMILY } \\
\ldots \text { GENUS } \\
\ldots . \text {. SPECIES }\end{array}$ \\
\hline \multirow[t]{4}{*}{$\begin{array}{r}\text { SEP } \\
2\end{array}$} & CONT. & & $\begin{array}{l}\text { CHRY SOPHYTA } \\
\text { BACILLARIOPHYCEAE } \\
\ldots \text { CENTRALES } \\
\ldots \text { COSCINODISCACEAE } \\
\ldots \text { CYCLOTELLA } \\
\ldots \text { PENNALES } \\
\ldots \text { ACHNANTHACEAE } \\
\ldots \text { ACHNANTHES } \\
\ldots \text { FRAGILARIACEAE } \\
\ldots \text {. SYNEDRA } \\
\ldots \text { GOMPHONEMATACEAE } \\
\ldots \text { GOMPHONEMA } \\
\ldots \text { NITZSCHIACEAE } \\
\ldots \text { NITZSCHIA }\end{array}$ \\
\hline & & & $\begin{array}{l}\text { CYANOPHYTA } \\
\text { - MYXOPHYCEAE }\end{array}$ \\
\hline & & $\#$ & $\begin{array}{l}\text {. CHROOCOCCALES } \\
\ldots \text { CHROOCOCCACEAE } \\
\ldots \text { ANACYSTIS } \\
\text { OOSCILLATORIALES } \\
\ldots \text { NOSIOCACEAE } \\
\ldots \text {. ANABAENA } \\
\text {. OSCILLATORI ACEAE } \\
\text {. OOSCILLATORIA }\end{array}$ \\
\hline & & & TOTAL PHYTOPLANKTON \\
\hline
\end{tabular}

COUNT $\quad$ PERCENT

$\begin{array}{lrr}\text { COMMON } & \text { COUNT } & \text { PERCENT } \\ \text { NAME } & (\text { CELLS/ML }) & \text { OF TOTAL }\end{array}$

DIATOMS

CENTRIC

PENNATE

290

1

$200 \quad 1$

$200 \quad 1$

2501

$340 \quad 2$

BLUE-GREEN ALGAE

COCCOID

F ILAMENTOUS

$\begin{array}{rr}3,400 & 17 \\ 8,700 & 43 \\ 20,000 & \end{array}$

NOTE: \# - DOMINANT ORGANISM; GREATER OR EQUAL TO $15 \%$

* - LESS tHEN 1\%; may not have beEn actually Counted 
11103010 LOS ANGELES RIVER AT WILLOW STREET BRIDGE, AT LONG BEACH, CA--Continued

PARTICLE-SIZE DISTRIBUTION OF SUSPENDED SEDIMENT, WATER YEAR OCTOBER 1975 TO SEPTEMBER 1976

\begin{tabular}{|c|c|c|c|c|c|c|}
\hline DATE & TIME & $\begin{array}{l}\text { INSTAN- } \\
\text { TANEOUS } \\
\text { OIS- } \\
\text { CHARGE } \\
\text { (CFS) }\end{array}$ & $\begin{array}{l}\text { TEMPER- } \\
\text { ATURE } \\
\text { (DEG C) }\end{array}$ & $\begin{array}{l}\text { SUS- } \\
\text { PENDED } \\
\text { SEDI- } \\
\text { MENT } \\
(M G / L)\end{array}$ & $\begin{array}{c}\text { SUS- } \\
\text { PENDED } \\
\text { SEDI- } \\
\text { MENT } \\
\text { DIS- } \\
\text { CHARGE } \\
\text { (T/DAY) }\end{array}$ & $\begin{array}{c}\text { SUS. } \\
\text { SED. } \\
\text { SIEVE } \\
\text { DIAM. } \\
\text { \$ FINER } \\
\text { THAN } \\
.062 \text { MM }\end{array}$ \\
\hline $\begin{array}{l}\text { OCT } \\
20 . . . \\
\text { NOV }\end{array}$ & 1100 & 26 & 18.1 & 23 & 1.6 & 55 \\
\hline${ }_{\mathrm{OEC}}^{17} \cdots$ & 1040 & 17 & 17.5 & 24 & 1.1 & 54 \\
\hline JAN $09 .$. & 1200 & 21 & 17.4 & 25 & 1.4 & 75 \\
\hline$\underset{\text { FEB }}{27 . .}$ & 1115 & 19 & 13.0 & 28 & 1.4 & 72 \\
\hline $12 \ldots$ & 1200 & 16 & 14.0 & 5 & .22 & 64 \\
\hline$\underset{A P R}{23} \cdot \cdots$ & 1055 & 60 & 20.0 & 36 & 5.8 & 70 \\
\hline$\underset{\text { MAY }}{21} \cdot \cdots$ & 1110 & 19 & 22.0 & 83 & 4.3 & 29 \\
\hline JUN & 1145 & 23 & 25.2 & 25 & 1.6 & 74 \\
\hline${ }_{\text {JuL }}^{17} \cdots$ & 1015 & 31 & 22.8 & 20 & 1.7 & $m$ \\
\hline AUG $07 .$. & 1020 & 30 & 27.0 & 30 & 2.4 & $=$ \\
\hline $\operatorname{SEP}_{\text {SEP }}^{04} \cdots$ & 1130 & 14 & 26.0 & 94 & 3.6 & 91 \\
\hline $02 \ldots$ & 1015 & 29 & 24.0 & 18 & 1.4 & - \\
\hline
\end{tabular}


11103500 BALLONA CREEK NEAR CULVER CITY, CA

LOCATION,--Lat $33^{\circ} 59^{\prime} 54^{\prime \prime}$, long $118^{\circ} 24^{\prime} 05^{\prime \prime}$, in La Ballona Grant, Los Angeles County, 500 ft (152 m) upstream from Sawtelle Boulevard bridge, $1.7 \mathrm{mi}\left(2.7^{\prime} \mathrm{km}\right)$ south of Culver City, and $4.1 \mathrm{mi}(6.6 \mathrm{~km})$ upstream from mouth.

DRAINAGE AREA. $-89.5 \mathrm{mi}^{2}\left(231.8 \mathrm{~km}^{2}\right)$, exc1udes that of Sepulveda Creek. Prior to January 1951 , $111 \mathrm{mi}{ }^{2}$ $\left(287 \mathrm{~km}^{2}\right)$, change due to tributary channel realignment.

PERIOD OF RECORD.--February 1928 to current year (after December 1950, flow of Sepulveda Creek excluded).

GAGE. - Water-stage recorder. Datum of gage is $11.98 \mathrm{ft}(3.652 \mathrm{~m}$ ) above mean sea level (levels by Los Angeles County Flood Control District). Prior to May 14 , 1936 , at site 1 mi (2 km) downstream at different datum. May 14, 1936, to Oct. 3, 1961 , at datum $0.72 \mathrm{ft}(0.219 \mathrm{~m})$ lower and oct. 24, 1961, to Aug. 10, 1967 , at datum $0.92 \mathrm{ft}(0.280 \mathrm{~m}) 1$ ower at site $500 \mathrm{ft}(152 \mathrm{~m})$ downstream.

REMARKS, - No regulation above station. At times city of Los Angeles discharges imported owens River water from several distribution reservoirs into the creek above station. Some small pumping diversions above station for lawn and park use.

COOPERATION. - Records were furnished by Los Angeles County Flood Control District.

AVERAGE DISCHARGE.--22 years (water years $1929-50), 35.2 \mathrm{ft}^{3} / \mathrm{s}\left(0.997 \mathrm{~m}^{3} / \mathrm{s}\right), 25,480 \mathrm{acre}-\mathrm{ft} / \mathrm{yr}(31.4 \mathrm{hm} / \mathrm{yr}) ;$ 26 years (water years $1951-76), 44.2 \mathrm{ft}^{3} / \mathrm{s}\left(1.252 \mathrm{~m}^{3} / \mathrm{s}\right), 32,020$ acre-ft/yr $\left(39.5 \mathrm{hm}^{3} / \mathrm{yr}^{3}\right.$.

EXTREMES FOR PERIOD OF RECORD, - Maximum discharge, $32,500 \mathrm{ft}^{3} / \mathrm{s}\left(920 \mathrm{~m}^{3} / \mathrm{s}\right) \mathrm{Nov}$. 21, 1967, gage height, 14.89 ft $(4.538 \mathrm{~m})$; no flow at times in some years.

EXTREMES FOR CURRENT YEAR.--Maximum discharge, $12,940 \mathrm{ft}^{3} / \mathrm{s}\left(366 \mathrm{~m}^{3} / \mathrm{s}\right) \mathrm{sept} .10, \mathrm{gage} \mathrm{height,} 9.50 \mathrm{ft}$ (2.896 m); minimum daily, $6.2 \mathrm{ft}^{3} / \mathrm{s}\left(0.18 \mathrm{~m}^{3} / \mathrm{s}\right)$ Dec. 13 .

OISCHARGE, IN CUBIC FEET PER SECOND, WATER YEAR OCTOBER 1975 TO SEPTEMBER 1976 MEAN VALUES

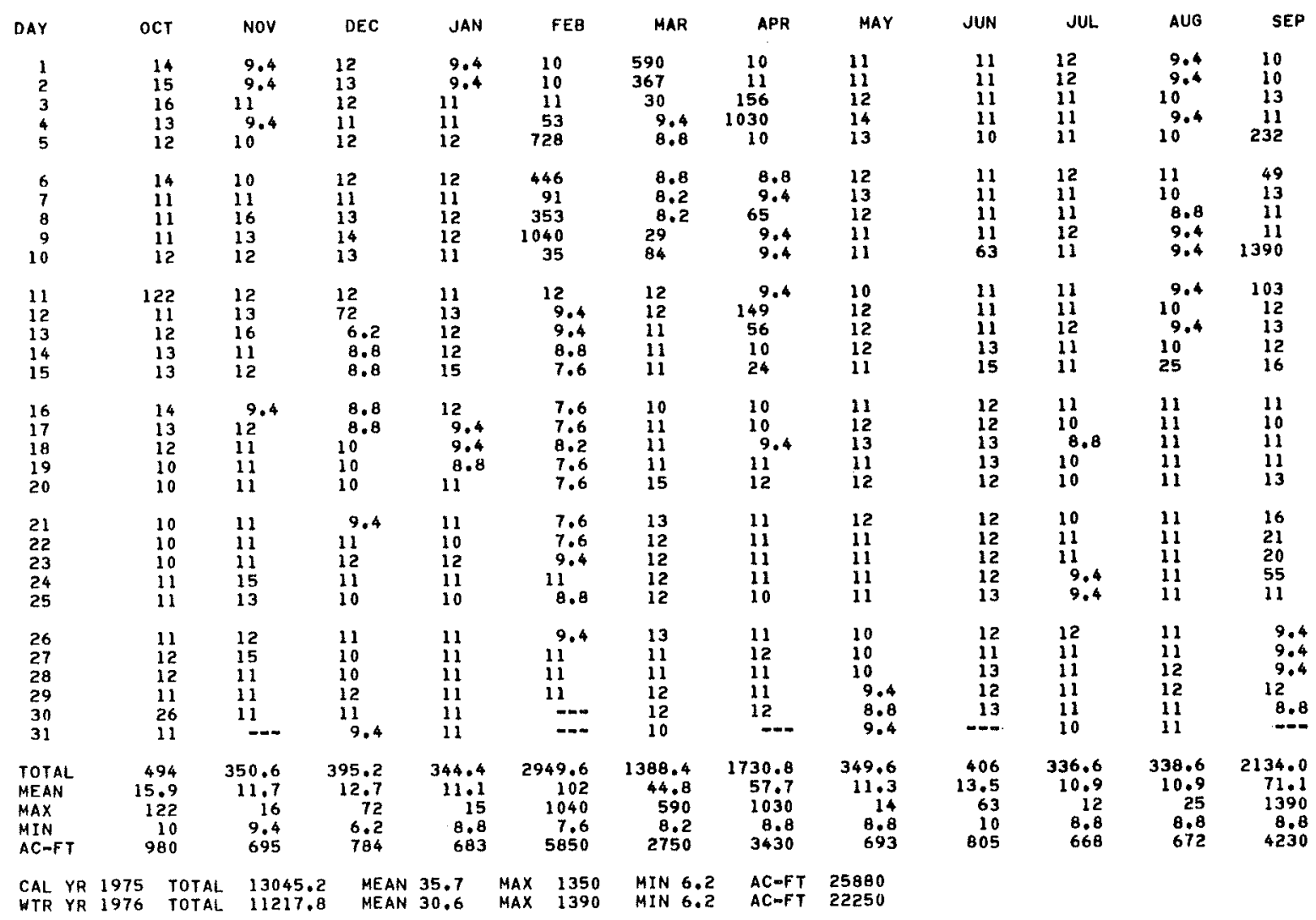


LOCATION, - Lat $34^{\circ} 03^{\prime} 52^{\prime \prime}$, long $118^{\circ} 35^{\prime} 10^{\prime \prime}$, in Boca de Santa Monica Grant, Los Angeles County, on right downstream side of bridge abutment on State Highway $27,1.7 \mathrm{mi}(2.7 \mathrm{~km})$ north of Topanga Beach.

DRAINAGE AREA, $-18.0 \mathrm{mi}^{2}\left(46.6 \mathrm{~km}^{2}\right)$.

PERIOD OF RECORD,--January 1930 to September 1938, october 1939 to current year.

GAGE, - Water-stage recorder. Datum of gage is $265.60 \mathrm{ft}(80.955 \mathrm{~m})$ above mean sea $1 \mathrm{evel}$ (1evels by Los Angeles County Flood Control District). Prior to June 5, 1940, at different datum. June 5, 1940, to Dec, 9, 1941 ,

at site $400 \mathrm{ft}(122 \mathrm{~m})$ upstream at different datum.

REMARKS.--Records poor. No regulation or diversion above station.

COOPERATION. - -Records were furnished by Los Angeles County Flood Control District.

AVERAGE DISCHARGE. -45 years (water years $1931-38,1940-76), 5.51 \mathrm{ft}^{3} / \mathrm{s}\left(0.156 \mathrm{~m}^{3} / \mathrm{s}\right), 3,990 \mathrm{acre}-\mathrm{ft} / \mathrm{yr}^{2}\left(4.92 \mathrm{hm}{ }^{3} / \mathrm{yr}^{2}\right)$.

EXTREMES FOR PERIOD OF RECORD. - Maximum discharge, $12,200 \mathrm{ft}^{3} / \mathrm{s}\left(346 \mathrm{~m}^{3} / \mathrm{s}\right) \mathrm{Jan}, 25$, 1969, gage height, 13,36 ft $(4.072 \mathrm{~m})$ from rating curve extended above $610 \mathrm{ft}^{3} / \mathrm{s}\left(17.3 \mathrm{~m}^{3} / \mathrm{s}\right)$ on basis of slope-area measurement of maximum flow; no flow at times in some years.

EXTREMES FOR CURRENT YEAR,--Maximum discharge, $72 \mathrm{ft}^{3} / \mathrm{s}\left(2.04 \mathrm{~m}^{3} / \mathrm{s}\right)$, Feb. 9 , gage height, $5.33 \mathrm{ft}(1.625 \mathrm{~m})$; minimum daily, $0.04 \mathrm{ft}^{3} / \mathrm{s}(0.001 \mathrm{~m} / \mathrm{s})$ Aug. $19-21,24,25$.

DISCHARGE, IN CUBIC FEET PER SECOND, WATER YEAR OCTOBER 1975 TO SEPTEMBER 1976 MEAN VALUES

\begin{tabular}{|c|c|c|c|c|c|c|c|c|c|c|c|c|}
\hline DAY & OCT & Nov & DEC & JAN & FEB & MAR & APR & MAY & JUN & JUL & AUG & SEP \\
\hline $\begin{array}{l}1 \\
2 \\
3 \\
4 \\
5\end{array}$ & $\begin{array}{l}.20 \\
.20 \\
.20 \\
.10 \\
.10\end{array}$ & $\begin{array}{l}.30 \\
.20 \\
.20 \\
.20 \\
.20\end{array}$ & $\begin{array}{l}.20 \\
.20 \\
.20 \\
.20 \\
.20\end{array}$ & $\begin{array}{l}.20 \\
.20 \\
.20 \\
.20 \\
.20\end{array}$ & $\begin{array}{l}.20 \\
.20 \\
.20 \\
.40 \\
.50\end{array}$ & $\begin{array}{l}3.2 \\
1.9 \\
2.9 \\
.70 \\
.70\end{array}$ & $\begin{array}{l}.20 \\
.20 \\
.20 \\
.40 \\
.40\end{array}$ & $\begin{array}{l}.20 \\
.20 \\
.20 \\
.20 \\
.20\end{array}$ & $\begin{array}{l}.10 \\
.10 \\
.10 \\
.10 \\
.10\end{array}$ & $\begin{array}{l}.05 \\
.05 \\
.10 \\
.10 \\
.10\end{array}$ & $\begin{array}{l}.10 \\
.10 \\
.05 \\
.05 \\
.05\end{array}$ & $\begin{array}{l}.05 \\
.05 \\
.10 \\
.10 \\
.10\end{array}$ \\
\hline $\begin{array}{r}6 \\
7 \\
8 \\
9 \\
10\end{array}$ & $\begin{array}{r}.10 \\
110 \\
.10 \\
10 \\
110\end{array}$ & $\begin{array}{l}.20 \\
.20 \\
.20 \\
.20 \\
.20\end{array}$ & $\begin{array}{l}.20 \\
.20 \\
.20 \\
.20 \\
.20\end{array}$ & $\begin{array}{l}.20 \\
.20 \\
.20 \\
.20 \\
.20\end{array}$ & $\begin{array}{c}1.4 \\
.90 \\
1.9 \\
24 \\
5.4\end{array}$ & $\begin{array}{l}.40 \\
.40 \\
.40 \\
.30 \\
.30\end{array}$ & $\begin{array}{l}.20 \\
.20 \\
.20 \\
.20 \\
.20\end{array}$ & $\begin{array}{l}.20 \\
.20 \\
.20 \\
.20 \\
.20\end{array}$ & $\begin{array}{l}.10 \\
.10 \\
.10 \\
.10 \\
.10\end{array}$ & $\begin{array}{l}.05 \\
.05 \\
.05 \\
.05 \\
.10\end{array}$ & $\begin{array}{l}.05 \\
.05 \\
.10 \\
.10 \\
.10\end{array}$ & $\begin{array}{r}.10 \\
.10 \\
.10 \\
.10 \\
2.7\end{array}$ \\
\hline $\begin{array}{l}11 \\
12 \\
13 \\
14 \\
15\end{array}$ & $\begin{array}{r}.50 \\
.30 \\
.30 \\
.30 \\
.20\end{array}$ & $\begin{array}{l}.20 \\
.20 \\
.20 \\
.20 \\
.20\end{array}$ & $\begin{array}{l}.20 \\
.20 \\
.20 \\
.20 \\
.20\end{array}$ & $\begin{array}{l}.20 \\
.20 \\
.20 \\
.20 \\
.20\end{array}$ & $\begin{array}{l}.70 \\
.50 \\
.40 \\
.40 \\
.40\end{array}$ & $\begin{array}{l}.40 \\
.30 \\
.30 \\
.40 \\
.40\end{array}$ & $\begin{array}{l}.20 \\
.20 \\
.40 \\
.20 \\
.20\end{array}$ & $\begin{array}{r}.20 \\
.20 \\
.10 \\
.10 \\
.10\end{array}$ & $\begin{array}{l}.10 \\
.10 \\
.10 \\
.10 \\
.10\end{array}$ & $\begin{array}{l}.10 \\
110 \\
110 \\
.10 \\
.10\end{array}$ & $\begin{array}{l}.10 \\
.10 \\
.10 \\
.10 \\
.05\end{array}$ & $\begin{array}{l}1.5 \\
.40 \\
.10 \\
.10 \\
.20\end{array}$ \\
\hline $\begin{array}{l}16 \\
17 \\
18 \\
19 \\
20\end{array}$ & $\begin{array}{r}.20 \\
.20 \\
.20 \\
.20 \\
.20\end{array}$ & $\begin{array}{l}.20 \\
.20 \\
.20 \\
.10 \\
.10\end{array}$ & $\begin{array}{r}.20 \\
.20 \\
.20 \\
.20 \\
.20\end{array}$ & $\begin{array}{r}.20 \\
.20 \\
.20 \\
.20 \\
.20\end{array}$ & $\begin{array}{r}.30 \\
.30 \\
.20 \\
.20 \\
.20\end{array}$ & $\begin{array}{l}.40 \\
.40 \\
.40 \\
.40 \\
.40\end{array}$ & $\begin{array}{r}.20 \\
.30 \\
.20 \\
.20 \\
.20\end{array}$ & $\begin{array}{r}.10 \\
110 \\
110 \\
.10 \\
.10\end{array}$ & $\begin{array}{r}.10 \\
.10 \\
.10 \\
.05 \\
.05\end{array}$ & $\begin{array}{r}.10 \\
110 \\
110 \\
110 \\
110\end{array}$ & $\begin{array}{l}.05 \\
.05 \\
.05 \\
.04 \\
.04\end{array}$ & $\begin{array}{r}.10 \\
.10 \\
.10 \\
.20 \\
.20\end{array}$ \\
\hline $\begin{array}{l}21 \\
22 \\
23 \\
24 \\
25\end{array}$ & $\begin{array}{r}.20 \\
.20 \\
.20 \\
.10 \\
.10\end{array}$ & $\begin{array}{r}.10 \\
.10 \\
.20 \\
.20 \\
.20\end{array}$ & $\begin{array}{l}.20 \\
.20 \\
.20 \\
.20 \\
.20\end{array}$ & $\begin{array}{r}.20 \\
.20 \\
.20 \\
.20 \\
.20\end{array}$ & $\begin{array}{r}.20 \\
.20 \\
.30 \\
.30 \\
.30\end{array}$ & $\begin{array}{r}.40 \\
.30 \\
.30 \\
.30 \\
.40\end{array}$ & $\begin{array}{r}.20 \\
.20 \\
.20 \\
.20 \\
.20\end{array}$ & $\begin{array}{r}.10 \\
.10 \\
.10 \\
.10 \\
110\end{array}$ & $\begin{array}{l}.05 \\
.05 \\
.05 \\
.05 \\
.05\end{array}$ & $\begin{array}{r}.10 \\
110 \\
.10 \\
110 \\
.10\end{array}$ & $\begin{array}{l}.04 \\
.05 \\
.05 \\
.04 \\
.04\end{array}$ & $\begin{array}{r}.20 \\
.20 \\
.20 \\
.20 \\
.20\end{array}$ \\
\hline $\begin{array}{l}26 \\
27 \\
28 \\
29 \\
30 \\
31\end{array}$ & $\begin{array}{r}.10 \\
.20 \\
.20 \\
.20 \\
.20 \\
.20\end{array}$ & $\begin{array}{l}.20 \\
.20 \\
.20 \\
.20 \\
.20 \\
-.-0\end{array}$ & $\begin{array}{l}.20 \\
.20 \\
.20 \\
.20 \\
.20 \\
.20\end{array}$ & $\begin{array}{r}.20 \\
.20 \\
.20 \\
.20 \\
.20 \\
.20\end{array}$ & $\begin{array}{r}.30 \\
.30 \\
.30 \\
.30 \\
- \\
-\end{array}$ & $\begin{array}{r}.30 \\
.30 \\
.20 \\
.30 \\
.20 \\
.20\end{array}$ & $\begin{array}{l}.20 \\
.20 \\
+20 \\
.20 \\
.20 \\
-2-0\end{array}$ & $\begin{array}{r}.10 \\
.10 \\
.20 \\
.10 \\
.10 \\
.10\end{array}$ & $\begin{array}{l}.05 \\
.05 \\
.05 \\
.05 \\
.05 \\
.0-\end{array}$ & $\begin{array}{r}10 \\
110 \\
110 \\
110 \\
110 \\
110\end{array}$ & $\begin{array}{l}.05 \\
.05 \\
.05 \\
.05 \\
.05 \\
.05\end{array}$ & $\begin{array}{r}.20 \\
.10 \\
.10 \\
.20 \\
.20 \\
-2-\end{array}$ \\
\hline $\begin{array}{l}\text { TOTAL } \\
\text { MEAN } \\
\text { MAX } \\
\text { MIN } \\
\text { AC }-F T\end{array}$ & $\begin{array}{r}5.80 \\
.19 \\
.50 \\
.10 \\
12\end{array}$ & $\begin{array}{r}5.70 \\
.19 \\
.30 \\
.10 \\
11\end{array}$ & $\begin{array}{r}6.20 \\
.20 \\
.20 \\
.20 \\
12\end{array}$ & $\begin{array}{r}6.20 \\
.20 \\
.20 \\
.20 \\
12\end{array}$ & $\begin{array}{r}41.20 \\
1.42 \\
24 \\
.20 \\
82\end{array}$ & $\begin{array}{r}18.20 \\
.59 \\
3.2 \\
.20 \\
36\end{array}$ & $\begin{array}{r}6.70 \\
.22 \\
.40 \\
.20 \\
13\end{array}$ & $\begin{array}{r}4.40 \\
.14 \\
.20 \\
.10 \\
8.7\end{array}$ & $\begin{array}{r}2.40 \\
.080 \\
.10 \\
.05 \\
4.8\end{array}$ & $\begin{array}{r}2.80 \\
.090 \\
.10 \\
.05 \\
5.6\end{array}$ & $\begin{array}{r}1.95 \\
.063 \\
.10 \\
.04 \\
3.9\end{array}$ & $\begin{array}{r}8.30 \\
.28 \\
2.7 \\
.05 \\
16\end{array}$ \\
\hline
\end{tabular}

CAL YR 1975 TOTAL 970.70 MEAN 2.66 MAX 286 MIN 10 AC-FT 1930 WTR YR 1976 TOTAL 109.85 MEAN .30 MAX 24 MIN .04 AC-FT 218 
11105500 MALIBU CREEK AT CRATER CAMP, NEAR CALABASAS, CA

LOCATION, - Lat $34^{\circ} 04^{\prime} 40^{\prime \prime}$, long $118^{\circ} 42^{\prime} 03^{\prime \prime}$, in SW/4 sec.18, T.1 S, R, 17 W. , Los Angeles County, on right bank $700 \mathrm{ft}(213 \mathrm{~m})$ downstream from Cold Creek, $0.2 \mathrm{mi}(0.3 \mathrm{~km})$ downstream from Crater Camp, and $6 \mathrm{mi}(10 \mathrm{~km})$ southwest of Calabasas.

DRAINAGE AREA, $--105 \mathrm{mi}^{2}\left(272 \mathrm{~km}^{2}\right)$.

PERIOD OF RECORD.--January 1931 to current year.

GAGE, - Water-stage recorder. Datum of gage is $432.82 \mathrm{ft}(131.924 \mathrm{~m})$ above mean sea leve1 (levels by Los Angeles County Flood Control District). Prior to Nov, 16, 1954, at datum 2.31 ft (0.704 m) 10wer

REMARKS.--Records fair. Flow partly regulated by many small recreational reservoirs. Small diversions above station for domestic use.

COOPERATION. - - Records were furnished by Los Angeles County Flood Control District.

AVERAGE DISCHARGE. -45 years, $21.3 \mathrm{ft}^{3} / \mathrm{s}\left(0.603 \mathrm{~m}^{3} / \mathrm{s}\right), 15,430 \mathrm{acre}-\mathrm{ft} / \mathrm{yr}\left(19.0 \mathrm{hm} / \mathrm{yr}^{3}\right)$.

EXTREMES FOR PERIOD OF RECORD,--Maximum discharge, 33,800 $\mathrm{ft}^{3} / \mathrm{s}\left(957 \mathrm{~m}^{3} / \mathrm{s}\right) \mathrm{Jan}$, 25,1969 , gage height, $21.43 \mathrm{ft}$ $(6.532 \mathrm{~m})$, from rating curve extended above $6,000 \mathrm{ft}^{3} / \mathrm{s}\left(170 \mathrm{~m}^{3} / \mathrm{s}\right)$ on basis of slope-area measurements at gage heights $17.27 \mathrm{ft}(5.264 \mathrm{~m})$ and $21.43 \mathrm{ft}(6.532 \mathrm{~m})$; no flow at times in some years prior to 1961 .

EXTREMES FOR CURRENT YEAR.--Maximum discharge, $339 \mathrm{ft}^{3} / \mathrm{s}\left(9.60 \mathrm{~m}^{3} / \mathrm{s}\right)$ Feb. 9 , gage height, $3.78 \mathrm{ft}(1.152 \mathrm{~m})$; minimum daily, $1.1 \mathrm{ft}^{3} / \mathrm{s}\left(0.031 \mathrm{~m}^{3} / \mathrm{s}\right)$ July 12 , Aug. $8-11$, Sept. 1 .

DISCHARGE, IN CUBIC FEET PER SECOND, HATER YEAR OCTOBER 1975 TO SEPTEMBER 1976

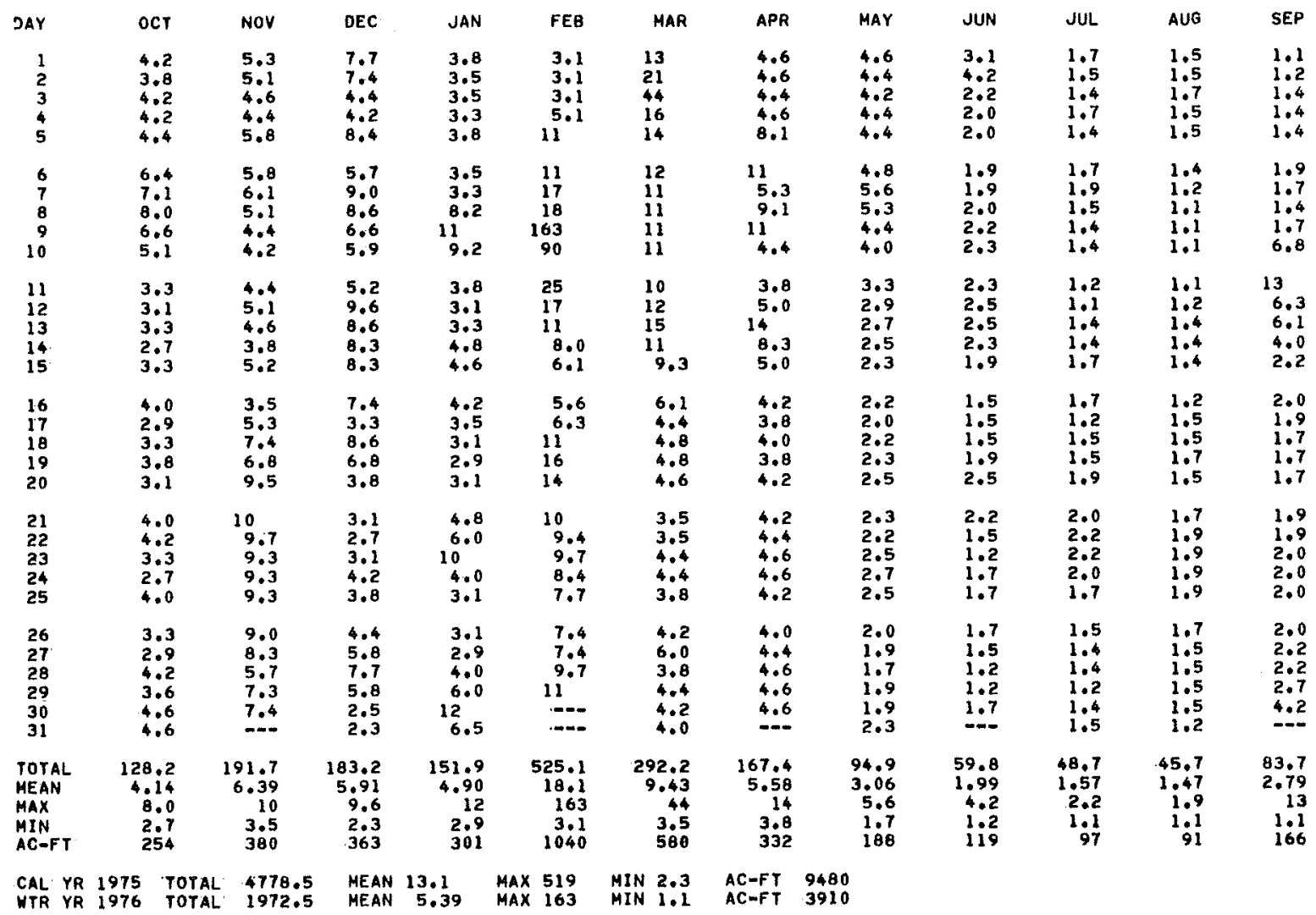


LOCATION.--Lat $34^{\circ} 16^{\prime} 41^{\prime \prime}$, long $118^{\circ} 47^{\prime} 43^{\prime \prime}$, on line between secs.7 and 8 , T.2 N., R.18 W., Ventura County, on downstream side of bridge on Los Angeles Avenue, in town of Simi Va11ey, $0.5 \mathrm{mi}$ (0.8 km) upstrearn from Brea Canyon, and $1.1 \mathrm{mi}(1.8 \mathrm{~km})$ northwest of Simi.

DRAINAGE AREA. $--70.6 \mathrm{mi}^{2}\left(182.9 \mathrm{~km}^{2}\right)$.

WATER-DISCHARGE RECORDS

PERIOD OF RECORD.--October 1933 to September 1951 , October 1952 to current year. Month1y discharge, in acre-ft only, for October 1933 to September 1951, October 1952 to October 1968, published in WSP 2128 .

GAGE. - Water-stage recorder. Datum of gage is $700.59 \mathrm{ft}(213.540 \mathrm{~m})$ above mean sea level (1evels by Ventura County Flood Control District).

REMARKS. - No gage-height record May 19 to September 30 . No regulation above station. Pumping from we11s for irrigation. City of Simi Valley intermittently discharged ground water into channel from extraction wells this year.

COOPERATION.--Records were furnished by Ventura County Flood Control District and reviewed by Geological Survey. AVERAGE DISCHARGE, -8 years (watex years $1969-76), 6.79 \mathrm{ft}^{3} / \mathrm{s}\left(0.192 \mathrm{~m}^{3} / \mathrm{s}\right), 4,920 \mathrm{acre}-\mathrm{ft} / \mathrm{yr}\left(6.07 \mathrm{hm} / \mathrm{yr}^{3}\right)$. EXTREMES FOR PERIOD OF RECORD,--Maximum discharge, $6,330 \mathrm{ft}^{3} / \mathrm{s}\left(179 \mathrm{~m}^{3} / \mathrm{s}\right) \mathrm{Feb}, 25$, 1969 , gage height, $5.7 \mathrm{ft}$ $(1.74 \mathrm{~m})$, from floodmark; no flow at times in some years.

EXTREMES FOR CURRENT YEAR. - Peak discharges above base of $500 \mathrm{ft}^{3} / \mathrm{s}\left(14.2 \mathrm{~m}^{3} / \mathrm{s}\right)$ and maximum $(*)$ :

\begin{tabular}{crlcccc} 
& \multicolumn{3}{c}{} & \multicolumn{2}{c}{ Discharge } & \multicolumn{2}{c}{ Gage height } \\
Date & Time & $\left(\mathrm{ft}^{3} / \mathrm{s}\right)\left(\mathrm{m}^{3} / \mathrm{s}\right)$ & $(\mathrm{ft})$ & $(\mathrm{m})$ \\
Feb. 9 & 0300 & $* 670$ & 19.0 & 2.32 & 0.707 \\
Sept. 10 & Unknown & 578 & 16.4 & Unknown
\end{tabular}

No flow Nov. 22,23 , Jan. 31, Feb. 1 .

DISCHARGE, IN CUBIC FEET PER SECONO, WATER YEAR OCTOBER 1975 TO SEPTEMBER 1976 MEAN VALUES

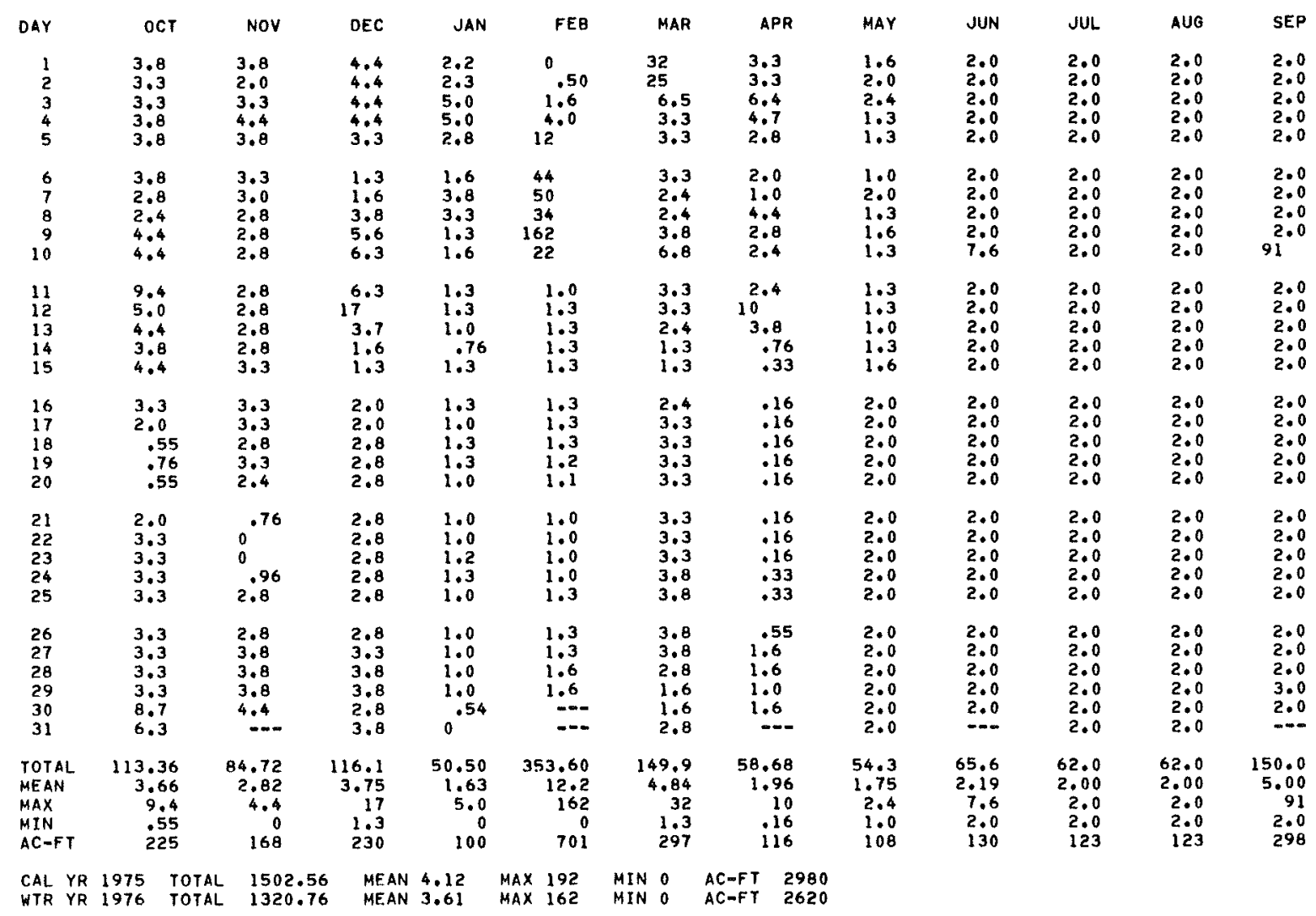


11105850 ARROYO SIMI NEAR SIMI, CA--Continued

WATER-QUALITY RECORDS

PERIOD OF DAILY RECORD. - -

WATER TEMPERATURES: October 1970 to September 1971 , October 1973 to current year.

SEDIMENT RECORDS: October 1968 to September 1971, october 1972 to current year.

COOPERATION.--Records of discharge were furnished by Ventura County Flood Control District.

REMARKS. - Some sediment-discharge values were estinated from a sediment-transport curve. Monthly totals for sediment discharge along with particle-size and temperature tables for 1975-76 water years are published in this report.

EXTREMES FOR PERTOD OF DAILY RECORD.--

SEDIMENT CONCENTRATIONS: Maximum daily mean, 29,000 mg/1 Nov. 29, 1970; minimum daily mean, no flow for many days during some years.

SEDIMENT DISCHARGE: Maximum daily, 169,000 tons (153,000 tonnes) Feb. 25, 1969; minimum daily, 0 tons on many days during some years.

MONTHLY AND ANNUAL SUMMARY OF SUSPENDED-SEDIMENT DISCHARGE, 1975 AND 1976 WATER YEARS

MONTH

DISCHARGE

(CFS)

SUSPENDED - SEDTMENT

OCTOBER $1974 \ldots$

NOVEMBER. . . . .

DECEMBER. . . . .

65

JANUARY $1975 \ldots$

FEBRUARY . . . . .

MARCH. . . . . . .

APRIL .........

MAY ..........

JUNE. . . . . . .

JULY..........

AUGUST ........

SEPTEMBER.....

TOTAL FOR 1975 WATER YEAR ...

35
422

(TONS)

OCTOBER 1975...

NOVEMBER . .........

DECEMBER ........

34
177

177
410

149

76

JANUARY $1976 \ldots$

FEBRUARY. . . .

MARCH . . . . . . . .

APRIL ........

MAY . . . . . . .

JUNE. . . . . .

JULY . . . . . . .

AUGUST .......

SEPTEMBER.....

TOTAL FOR 1976 WATER YEAR...

1710

29533

113

85
116

157

220

50
354

150

59

66

62

62
150

1321

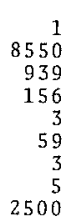

12596

PARTICLE-SIZE DISTRIBUTION OF SUSPENDED SEDIMENT, WATER YEAR OCTOBER 1974 TO SEPTEMBER 1975

\begin{tabular}{|c|c|c|c|c|c|c|c|c|c|c|}
\hline DATE & TIME & $\begin{array}{l}\text { TEMPER- } \\
\text { ATURE } \\
\text { (DEG C) }\end{array}$ & $\begin{array}{l}\text { INSTAN- } \\
\text { TANEOUS } \\
\text { DIS- } \\
\text { CHARGE } \\
\text { (CFS) }\end{array}$ & $\begin{array}{l}\text { SUS- } \\
\text { PENDED } \\
\text { SEDI- } \\
\text { MENT } \\
(M G / L)\end{array}$ & $\begin{array}{c}\text { SUS- } \\
\text { PENDED } \\
\text { SEDI- } \\
\text { MENT } \\
\text { DIS- } \\
\text { CHARGE } \\
\text { (T/DAY) }\end{array}$ & $\begin{array}{l}\text { SUS. } \\
\text { SED. } \\
\text { SIEVE } \\
\text { DIAM. } \\
\text { \$ FINER } \\
\text { THAN } \\
\text { O062 MM }\end{array}$ & $\begin{array}{l}\text { SUS. } \\
\text { SED. } \\
\text { SIEVE } \\
\text { DIAM. } \\
\text { \% FINER } \\
\text { THAN } \\
\text {.125 MM }\end{array}$ & $\begin{array}{l}\text { SUS. } \\
\text { SED. } \\
\text { SIEVE } \\
\text { DIAM. } \\
\text { FINER } \\
\text { THAN } \\
250 \mathrm{MM}\end{array}$ & $\begin{array}{l}\text { SUS. } \\
\text { SED. } \\
\text { SIEVE } \\
\text { DIAM. } \\
\text { \& FINER } \\
\text { THAN } \\
.500 \mathrm{MM}\end{array}$ & $\begin{array}{l}\text { SUS } \\
\text { SED, } \\
\text { SIEVE } \\
\text { DIAM. } \\
\approx \text { FINER } \\
\text { THAN } \\
1.00 \text { MH }\end{array}$ \\
\hline $\begin{array}{l}\text { DEC } \\
28 \ldots .\end{array}$ & 1200 & 20.0 & 16 & 3200 & 138 & 74 & B1 & 91 & 99 & 100 \\
\hline
\end{tabular}


TEMPERATURE (DEG, C) OF HATER, HATER YEAR OCTOBER 1974 TO SEPTEMBER 1975

\begin{tabular}{|c|c|c|c|c|c|c|c|c|c|c|c|c|}
\hline DAY & OCT & NOV & DEC & JAN & FEB & MAR & $A P R$ & MAY & JUN & JUL & AUG & SEP \\
\hline $\begin{array}{l}1 \\
2 \\
3 \\
4 \\
5\end{array}$ & $\begin{array}{r}24.0 \\
24.0 \\
=-.\end{array}$ & 20.0 & 12.0 & $\begin{array}{r}14.0 \\
18.0 \\
0.0\end{array}$ & $\begin{array}{l}10.0 \\
11.0 \\
14.0\end{array}$ & $=0$ & $\begin{array}{r}19.0 \\
-0 . \\
20.0 \\
15.0\end{array}$ & $=0$ & $\begin{array}{r}22.0 \\
21.0\end{array}$ & $\begin{array}{r}26.0 \\
26.0 \\
0.0\end{array}$ & 26.0 & 20.0 \\
\hline $\begin{array}{r}6 \\
7 \\
8 \\
9 \\
10\end{array}$ & $\begin{array}{r}21.0 \\
-\infty \\
-0\end{array}$ & $\begin{array}{r}19.0 \\
--0 \\
-0\end{array}$ & $\begin{array}{r}15.0 \\
15.0 \\
0.0\end{array}$ & $\begin{array}{r}13.0 \\
18.0\end{array}$ & $\begin{array}{l}0.0 \\
14.0 \\
14.0\end{array}$ & $\begin{array}{r}14.0 \\
15.0 \\
15.0 \\
10.0\end{array}$ & $\begin{array}{r}11.0 \\
15.0 \\
18.0 \\
0.0\end{array}$ & 24.0 & 21.0 & $\begin{array}{r}28.0 \\
28.0 \\
-0\end{array}$ & $\begin{array}{r}24.0 \\
-\infty\end{array}$ & 21.0 \\
\hline $\begin{array}{l}11 \\
12 \\
13 \\
14 \\
15\end{array}$ & $\begin{array}{r}21.0 \\
=-0 \\
17.0\end{array}$ & $\begin{array}{r}18.0 \\
17.0 \\
=0\end{array}$ & $\begin{array}{r}15.0 \\
0- \\
0-\end{array}$ & 18.0 & $\begin{array}{r}0.0 \\
18.0 \\
\ldots\end{array}$ & $\begin{array}{l}-0 \\
-0 . \\
=-0 \\
=-\end{array}$ & 18.0 & $\begin{array}{r}\ldots-0 \\
25.0 \\
\ldots\end{array}$ & $\begin{array}{r}\ldots-0 \\
22.0 \\
\cdots\end{array}$ & 19.0 & $\begin{array}{r}26.0 \\
26.0\end{array}$ & 21.0 \\
\hline $\begin{array}{l}16 \\
17 \\
18 \\
19 \\
20\end{array}$ & $\begin{array}{r}18.0 \\
-\end{array}$ & 19.0 & $\begin{array}{c}19.0 \\
=-0 \\
=-0\end{array}$ & 18.0 & $\begin{array}{r}18.0 \\
18.0\end{array}$ & $\begin{array}{r}12.0 \\
15.0 \\
0.0 \\
\end{array}$ & $=0$ & $\begin{array}{r}24.0 \\
22.0 \\
=-0\end{array}$ & $\begin{array}{r}22.0 \\
22.0 \\
=0\end{array}$ & $\begin{array}{r}20.0 \\
=-\end{array}$ & $\begin{array}{r}-\infty \\
27.0 \\
=-0\end{array}$ & 21.0 \\
\hline $\begin{array}{l}21 \\
22 \\
23 \\
24 \\
25\end{array}$ & $\begin{array}{r}23.0 \\
24.0 \\
-.0\end{array}$ & $\begin{array}{r}19.0 \\
16.0\end{array}$ & $\begin{array}{r}19.0 \\
=-0 \\
=-\end{array}$ & $=$ & 17.0 & $\begin{array}{r}15.0 \\
15.0 \\
=-0\end{array}$ & 22.0 & $\begin{array}{r}22.0 \\
-0 \\
-\end{array}$ & 22.0 & $\begin{array}{r}20.0 \\
=-0 \\
22.0\end{array}$ & 27.0 & 21.0 \\
\hline $\begin{array}{l}26 \\
27 \\
28 \\
29 \\
30 \\
31\end{array}$ & $\begin{array}{r}16.0 \\
22.0 \\
--0\end{array}$ & $\begin{array}{r}12.0 \\
=- \\
=-\end{array}$ & $\begin{array}{r}20.0 \\
--0 \\
-\infty\end{array}$ & $\begin{array}{r}15.0 \\
14.0 \\
- \\
-\end{array}$ & $\begin{array}{r}18.0 \\
--0 \\
=-\end{array}$ & $\begin{array}{l}=0 \\
19.0 \\
=-0\end{array}$ & $\begin{array}{r}25.0 \\
25.0 \\
25\end{array}$ & $\begin{array}{r}24.0 \\
24.0 \\
-0.0\end{array}$ & $\begin{array}{r}26.0 \\
=-\infty \\
=-\infty\end{array}$ & $\begin{array}{r}20.0 \\
19.0 \\
0.0\end{array}$ & $\begin{array}{r}27.0 \\
26.0 \\
-0\end{array}$ & 26.0 \\
\hline MEAN & 21.0 & 17.5 & 16.5 & 14.5 & 15.0 & 14.5 & 19.0 & 23.5 & 22.5 & 23.0 & 26.0 & 21.5 \\
\hline WTR & & & & MAX & 28.0 & & & & & & & \\
\hline
\end{tabular}

TEMPERATURE (DEG, C) OF WATER, WATER YEAR OCTOBER 1975 TO SEPTEMBER 1976 ONCE-DAILY

\begin{tabular}{|c|c|c|c|c|c|c|c|c|c|c|c|c|}
\hline DAY & OCT & NOV & DEC & JAN & FEB & MAR & APR & MAY & JUN & JUL & AUG & SEP \\
\hline $\begin{array}{l}1 \\
2 \\
3 \\
4 \\
5\end{array}$ & 23.0 & 20.0 & $\begin{array}{r}18.0 \\
-\infty\end{array}$ & $\begin{array}{r}15.5 \\
-0 \\
--0\end{array}$ & $\begin{array}{r}15.0 \\
-0.0 \\
12.0 \\
12.0\end{array}$ & $\begin{array}{r}15.0 \\
12.0 \\
17.0 \\
\ldots \\
\ldots-\end{array}$ & $\begin{array}{r}-0 \\
-0 \\
13.0 \\
-\infty\end{array}$ & 15.0 & $\begin{array}{r}16.0 \\
- \\
=-\end{array}$ & & $=$ & $=$ \\
\hline $\begin{array}{r}6 \\
7 \\
8 \\
9 \\
10\end{array}$ & $\begin{array}{r}23.0 \\
m-0 \\
-\infty\end{array}$ & $\begin{array}{r}16.0 \\
-19.0 \\
0.0\end{array}$ & 15.0 & $\begin{array}{r}16.0 \\
16.0\end{array}$ & $\begin{array}{l}11.0 \\
13.0 \\
12.0 \\
14.0 \\
19.0\end{array}$ & 18.0 & 16.0 & 15.0 & $\begin{array}{r}15.0 \\
0 \\
0\end{array}$ & & $=$ & $\begin{array}{l}=- \\
-=- \\
-=-\end{array}$ \\
\hline $\begin{array}{l}11 \\
12 \\
13 \\
14 \\
15\end{array}$ & $\begin{array}{r}21.0 \\
25.0 \\
-\end{array}$ & 20.0 & $\begin{array}{r}-0 \\
15.0 \\
=-0\end{array}$ & $\begin{array}{r}12.5 \\
22.0 \\
- \\
--\end{array}$ & 20.0 & $\begin{array}{c}0 \\
15.0 \\
0\end{array}$ & $\begin{array}{r}15.0 \\
16.0 \\
0\end{array}$ & 15.0 & $=$ & & 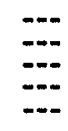 & 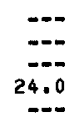 \\
\hline $\begin{array}{l}16 \\
17 \\
18 \\
19 \\
20\end{array}$ & $\begin{array}{r}26.0 \\
25.0 \\
250\end{array}$ & 20.0 & $\begin{array}{r}19.0 \\
16.0 \\
0.0\end{array}$ & $\begin{array}{r}19.0 \\
18.0\end{array}$ & 19.0 & $\begin{array}{l}=0 \\
=-0 \\
15.0\end{array}$ & $\begin{array}{r}-150 \\
15.0 \\
=-0\end{array}$ & $\begin{array}{r}15.0 \\
- \\
--\end{array}$ & $\begin{array}{l}=-\infty \\
=-\infty \\
-\infty\end{array}$ & & $=$ & 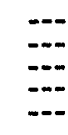 \\
\hline $\begin{array}{l}21 \\
22 \\
23 \\
24 \\
25\end{array}$ & $\begin{array}{r}=-0 \\
25.0 \\
-\infty\end{array}$ & $\begin{array}{r}17.0 \\
19.0\end{array}$ & $\begin{array}{r}15.0 \\
-0 \\
-\end{array}$ & $=$ & $\begin{array}{r}0- \\
19.0 \\
-0-\end{array}$ & 15.0 & $\begin{array}{r}15.0 \\
-0 \\
-0\end{array}$ & $\begin{array}{r}15.0 \\
=0 \\
15.0\end{array}$ & $\begin{array}{r}-.0 \\
--1 \\
--0 \\
28.5\end{array}$ & & $\begin{array}{r}=0 \\
24.0 \\
=-0\end{array}$ & 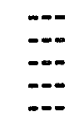 \\
\hline $\begin{array}{l}26 \\
27 \\
28 \\
29 \\
30 \\
31\end{array}$ & $\begin{array}{r}24.0 \\
16.0 \\
22.0\end{array}$ & $\begin{array}{r}19.0 \\
0 \\
0\end{array}$ & $\begin{array}{r}15.0 \\
16.0 \\
=-0\end{array}$ & 16.0 & $\begin{array}{l}=- \\
=- \\
=- \\
=-\end{array}$ & $\begin{array}{r}15.0 \\
-0 \\
0-0 \\
15.0\end{array}$ & $\begin{array}{r}15.0 \\
15.0 \\
0.0\end{array}$ & 15.0 & $=$ & & 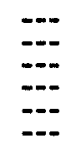 & 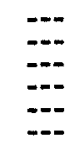 \\
\hline MEAN & 23.0 & 19.0 & 16.0 & 16.5 & 15.0 & 15.0 & 15.0 & 15.0 & 20.0 & & $\ldots$ & $-\cdots$ \\
\hline
\end{tabular}


11106400 CONEJO CREEK ABOVE HIGHWAY 101, NEAR CAMARILLO, CA

LOCATION, - Lat $34^{\circ} 14^{\prime} 12^{\prime \prime}$, long $118^{\circ} 57^{\circ} 50^{\prime \prime}$, T.2 N., R. 20 W., Ventura County, on 1 eft bank 2.6 mi (4.2 km) upstream from U.S. Highway 101, and $4.4 \mathrm{mi}(7.1$ ' $\mathrm{km})$ northeast of Camarillo.

DRAINAGE AREA. $--64.2 \mathrm{mi}^{2}\left(166.3 \mathrm{~km}^{2}\right)$.

PERIOD OF RECORD. - October 1972 to current year.

GAGE. - Water-stage recorder. A1titude of gage is $180 \mathrm{ft}(55 \mathrm{~m})$, from topographic map.

REMARKS. - -No regulation or diversion above station.

COOpERATION. --Records were furnished by Ventura County Flood control District; two discharge measurements were made and records were reviewed by Geological Survey.

EXTREMES FOR PERIOD OF RECORD,--Maximum discharge, $5,740 \mathrm{ft}^{3} / \mathrm{s}\left(163 \mathrm{~m}^{3} / \mathrm{s}\right) \mathrm{Feb}, 11,1973, \mathrm{gage}$ height, $7.3 \mathrm{~s} \mathrm{ft}$ $(2.240 \mathrm{~m})$; minimum daily, $0.13 \mathrm{ft}^{3} / \mathrm{s}\left(0.004 \mathrm{~m}^{3} / \mathrm{s}\right)$ May 31,1973 .

EXTREMES FOR CURRENT YEAR. - Peak discharges above base of $400 \mathrm{ft}^{3} / \mathrm{s}\left(11.3 \mathrm{~m}^{3} / \mathrm{s}\right)$ and $\mathrm{maximum}\left({ }^{*}\right)$ :

\begin{tabular}{|c|c|c|c|c|c|c|c|c|c|c|}
\hline Date & Time & $\begin{array}{c}\text { Discharge } \\
\left(\mathrm{ft}^{3} / \mathrm{s}\right)\left(\mathrm{m}^{3} / \mathrm{s}\right)\end{array}$ & $\begin{array}{l}\text { Gage } \\
\text { (ft) }\end{array}$ & $\begin{array}{r}\text { ight } \\
\text { (m) }\end{array}$ & Date & Time & $\begin{array}{r}\text { Disc } \\
\left(\mathrm{ft}^{3} / \mathrm{s}\right.\end{array}$ & $\left(m^{3} / s\right)$ & $\begin{array}{l}\text { Gage } \\
(\mathrm{ft})\end{array}$ & $\begin{array}{c}\text { height } \\
\text { (m) }\end{array}$ \\
\hline $\begin{array}{l}\text { Feb. } \\
\text { Sept. } \quad 10\end{array}$ & $\begin{array}{l}0900 \\
1300\end{array}$ & $\begin{array}{l}13.3 \\
15.9\end{array}$ & $\begin{array}{l}2.83 \\
3.33\end{array}$ & $\begin{array}{l}0.863 \\
1.015\end{array}$ & Sept. 29 & 0600 & ${ }^{*} 1290$ & 36.5 & 4.51 & 1.375 \\
\hline
\end{tabular}

Minimum daily discharge, $6.1 \mathrm{ft}^{3} / \mathrm{s}\left(0.17 \mathrm{~m}^{3} / \mathrm{s}\right)$ July 30 .

DISCHARGE, IN CUBIC FEET PER SECOND, WATER YEAR OCTOBER 1975 TO SEPTEMBER 1976 MEAN VALUES

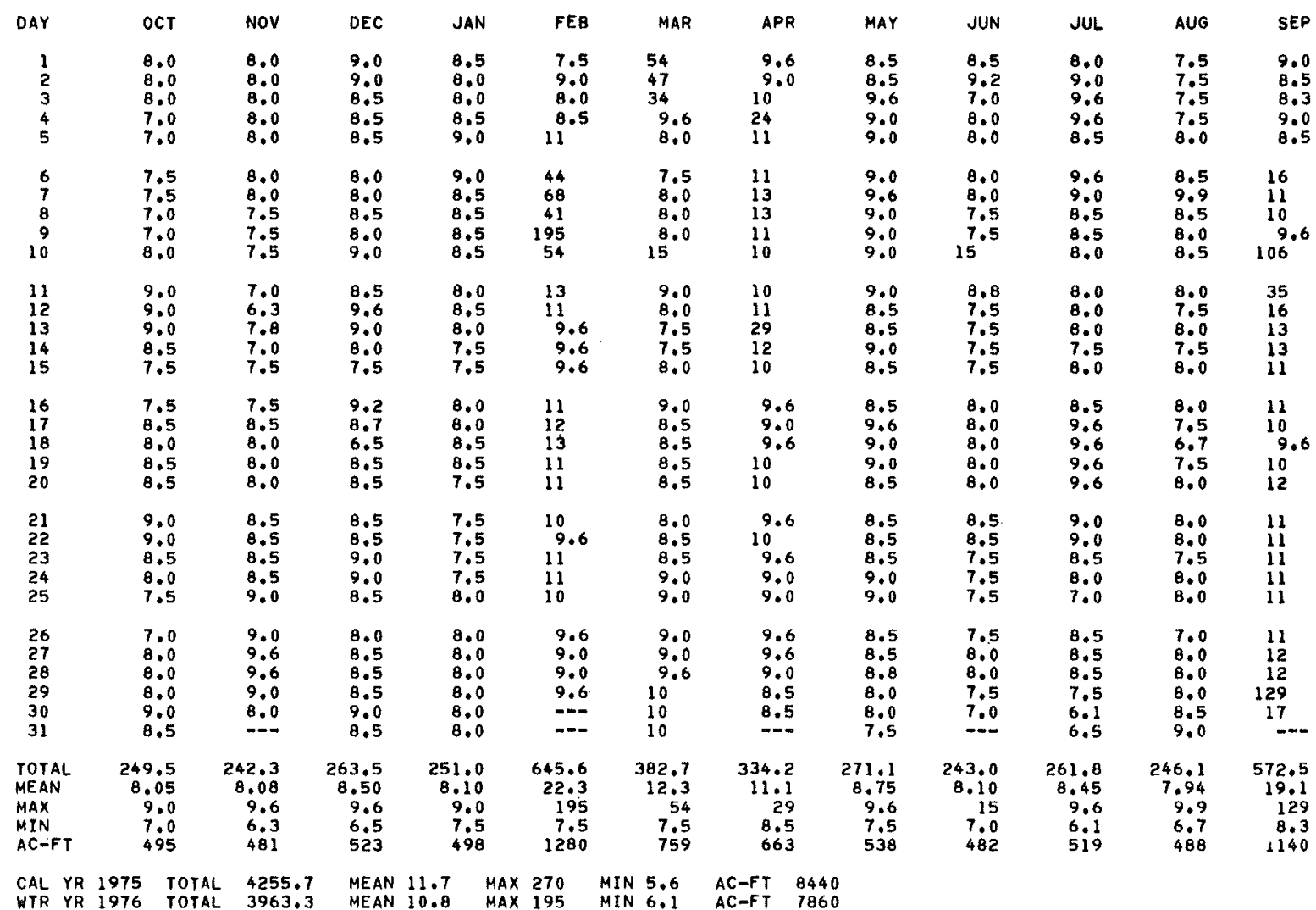


LOCATION. - - Lat $34^{\circ} 10^{\prime} 46^{\prime \prime}$, long $119^{\circ} 02^{\prime} 20^{\prime \prime}$, in Guadalasca Grant, Ventura County, on downstream side of county road bridge, $1.0 \mathrm{mi}(1.6 \mathrm{~km})$ northeast of Camarillo State Hospital, and $1.4 \mathrm{mi}(2.3 \mathrm{~km}) \mathrm{downstream}$ from Conejo Creek.

DRAINAGE AREA. $-248 \mathrm{mi}^{2}\left(642 \mathrm{~km}^{2}\right)$.

WATER-DISCHARGE RECORDS

PERIOD OF RECORD, - -October 1968 to current year.

GAGE. - Water-stage recorder. Datum of gage is $58.42 \mathrm{ft}(17.806 \mathrm{~m})$ above mean sea level (levels by Ventura County Flood Control District).

REMARKS. - No regulation above station. Pumping for irrigation in valley $1.0 \mathrm{mi}$ (1.6 km) above stat/fon.

Sustained flow from city of Thousand oaks reclamation plant.

COOPERATION.--Records were furnished by Ventura County Flood Control District and reviewed by the Geologicat survey. AVERAGE DISCHARGE. - -8 years, $23.2 \mathrm{ft}^{3} / \mathrm{s}\left(0.657 \mathrm{~m}^{3} / \mathrm{s}\right), 16,810 \mathrm{acre}-\mathrm{ft} / \mathrm{yr}\left(20.7 \mathrm{hm} / \mathrm{yr}^{3}\right)$.

EXTREMES FOR PERIOD OF RECORD. - Maximum discharge, $16,300 \mathrm{ft}^{3} / \mathrm{s}\left(462 \mathrm{~m}^{3} / \mathrm{s}\right) \mathrm{Feb} .25,1969$, gage height, $8.50 \mathrm{ft}$ $(2.591 \mathrm{~m})$; no flow at times in some years.

EXTREMES FOR CURRENT YEAR, - - Peak discharges above revised base of $500 \mathrm{ft}^{3} / \mathrm{s}\left(14.2 \mathrm{~m}^{2} / \mathrm{s}\right)$ and $\mathrm{maximum}^{*}$ ):

\begin{tabular}{|c|c|c|c|c|c|}
\hline Date & Time & $\begin{array}{r}\text { Disc } \\
\left(\mathrm{ft}^{3} / \mathrm{s}\right.\end{array}$ & $\begin{array}{l}\mathrm{rge} \\
\left(\mathrm{m}^{3} / \mathrm{s}\right)\end{array}$ & $\begin{array}{l}\text { Gage } \\
(\mathbf{f} t)\end{array}$ & height \\
\hline $\begin{array}{lr}\text { eb. } & 9 \\
\text { ept. } & 29\end{array}$ & $\begin{array}{l}0930 \\
1000\end{array}$ & $\begin{array}{r}* 893 \\
550\end{array}$ & $\begin{array}{l}25.3 \\
15.6\end{array}$ & $\begin{array}{l}2.71 \\
2.61\end{array}$ & $\begin{array}{l}0.826 \\
0.796\end{array}$ \\
\hline
\end{tabular}

Minimum daily discharge, $0.40 \mathrm{ft}^{3} / \mathrm{s}\left(0.011 \mathrm{~m}^{3} / \mathrm{s}\right) \mathrm{Ju} 1 \mathrm{y} 1$.

DISCHARGE, IN CUBIC FEET PER SECONO, WATER YEAR OCTOBEA 1975 TO SEPTEMBER 1976 MEAN VALUES

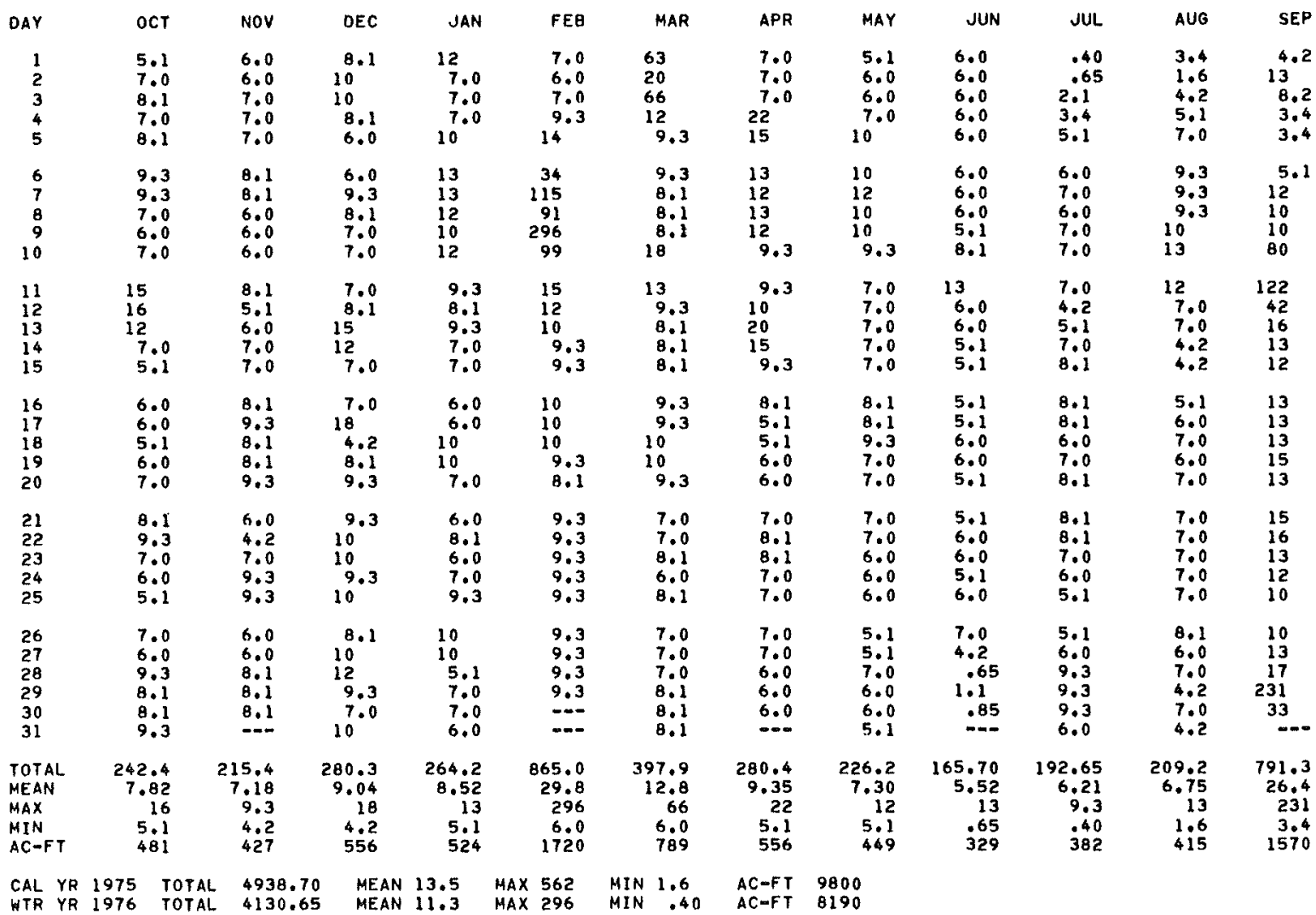


PERIOD OF DAILY RECORD, - -

WATER TEMPERATURES: October 1970 to current year.

SEDIMENT RECORDS: October 1968 to current year.

EXTREMES FOR PERIOD OF DAILY RECORD, - -

SEDIMENT CONCENTRATIONS: Maximum daily mean, 62,900 $\mathrm{mg} / \mathrm{l} \mathrm{Jan}$. 25, 1969; minimum daily mean, no flow for many days.

SEDIMENT DISCHARGE: Maximum daily, 1,700,000 tons $(1,540,000$ tonnes) Jan. 25, 1969; minimum daily, 0 tons

on many days during most years.

EXTREMES FOR CURRENT YEAR, - -

SEDIMENT CONCENTRATIONS: Maximum daily mean, $6,490 \mathrm{mg} / 1$ Feb. 9 ; minimum daily mean, $3 \mathrm{mg} / 1$ Sept. $6-9$. SEDIMENT DISCHARGE: Maximum dai1y, 9,660 tons $(8,760$ tonnes) Feb. 9; minimum daily, 0.04 tons (0.04 tonnes) Sept. 6.

TEMPERATURE (DEG. C) OF WATER, WATER YEAR OCTOBER 1975 TO SEPTEMBER 1976 ONCE-DAILY

\begin{tabular}{|c|c|c|c|c|c|c|c|c|c|c|c|c|}
\hline DAY & OCT & NOV & DEC & JAN & FEB & MAR & APR & MAY & JUN & JUL & AUG & SEP \\
\hline $\begin{array}{l}1 \\
2 \\
3 \\
4 \\
5\end{array}$ & $\begin{array}{r}22.0 \\
- \\
-\end{array}$ & & $\begin{array}{r}14.5 \\
-.5 \\
=-0\end{array}$ & $\begin{array}{l}--= \\
--0 \\
=-0 \\
5.5\end{array}$ & 13.0 & $\begin{array}{c}15.0 \\
=- \\
=- \\
=-\end{array}$ & $\begin{array}{l}=0 \\
=-0 \\
17.0\end{array}$ & $\begin{array}{r}20.5 \\
--- \\
---\end{array}$ & $\begin{array}{r}=- \\
26.5 \\
=-0\end{array}$ & $\begin{array}{r}31.5 \\
=-0 \\
---\end{array}$ & $\begin{array}{r}27.0 \\
0-0 \\
- \\
-0\end{array}$ & $\begin{array}{r}25.0 \\
20.5 \\
20.0\end{array}$ \\
\hline $\begin{array}{r}6 \\
7 \\
8 \\
9 \\
10\end{array}$ & $\begin{array}{l}=-0 \\
=-\infty \\
=-\infty \\
-\infty\end{array}$ & & $\begin{array}{r}-10- \\
14.5 \\
=-0 \\
=-0\end{array}$ & $=$ & $\begin{array}{l}10.0 \\
11.0 \\
14.0 \\
13.0 \\
11.5\end{array}$ & $\begin{array}{l}11.0 \\
-\ldots- \\
-0\end{array}$ & $=$ & $\begin{array}{r}20.5 \\
--- \\
--\end{array}$ & $\begin{array}{l}-.- \\
26.0 \\
20.5 \\
16.5\end{array}$ & $\begin{array}{r}30.0 \\
-\infty \\
-\infty\end{array}$ & $\begin{array}{r}28.0 \\
-.0 \\
-.-\end{array}$ & $\begin{array}{r}22.0 \\
--0 \\
--0 \\
24.5 \\
24.0\end{array}$ \\
\hline $\begin{array}{l}11 \\
12 \\
13 \\
14 \\
15\end{array}$ & $\begin{array}{l}=- \\
=- \\
=- \\
=-\end{array}$ & & $\begin{array}{r}14.5 \\
=-- \\
=-- \\
=--\end{array}$ & $=$ & $\begin{array}{r}10.0 \\
=- \\
=-\end{array}$ & $\begin{array}{r}15.5 \\
--0 \\
--0 \\
-.-0\end{array}$ & $\begin{array}{r}=-0 \\
16.0 \\
=-\end{array}$ & $\begin{array}{r}28.0 \\
-\infty \\
-\infty\end{array}$ & $\begin{array}{r}--5 \\
17.5 \\
=-\infty\end{array}$ & $\begin{array}{r}27.5 \\
--5 \\
22.5\end{array}$ & $\begin{array}{r}27.5 \\
-0.5 \\
-.5\end{array}$ & $\begin{array}{r}21.0 \\
=- \\
24.0\end{array}$ \\
\hline $\begin{array}{l}16 \\
17 \\
18 \\
19 \\
20\end{array}$ & 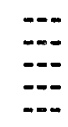 & & $\begin{array}{r}10.5 \\
-.5 \\
14.5\end{array}$ & 10.0 & $\begin{array}{r}-0 \\
11.0 \\
--0 \\
---\end{array}$ & $\begin{array}{r}14.5 \\
-\ldots \\
-\infty\end{array}$ & $\begin{array}{r}14.0 \\
=- \\
-\end{array}$ & $\begin{array}{r}18.0 \\
20.5 \\
-.-\end{array}$ & $\begin{array}{r}--- \\
22.5 \\
---\end{array}$ & $\begin{array}{r}-0 \\
20.0 \\
=-\end{array}$ & $\begin{array}{r}26.5 \\
\ldots-. \\
-\end{array}$ & 22.0 \\
\hline $\begin{array}{l}21 \\
22 \\
23 \\
24 \\
25\end{array}$ & $=$ & & $\begin{array}{l}=- \\
=- \\
-= \\
--\end{array}$ & $\begin{array}{l}-0 . \\
=-- \\
14.5\end{array}$ & $\begin{array}{r}13.5 \\
0.5 \\
-0 \\
-0\end{array}$ & $\begin{array}{r}17.0 \\
- \\
- \\
-\infty \\
=-\infty\end{array}$ & $\begin{array}{r}19.0 \\
0-0 \\
=-0\end{array}$ & $\begin{array}{r}22.5 \\
=-.0 \\
15.0\end{array}$ & $\begin{array}{r}=- \\
31.0 \\
32.0\end{array}$ & $\begin{array}{r}24.0 \\
-0 \\
-\end{array}$ & $\begin{array}{r}20.5 \\
=-. \\
=- \\
=-\end{array}$ & $\begin{array}{r}=- \\
=-0 \\
22.0\end{array}$ \\
\hline $\begin{array}{l}26 \\
27 \\
28 \\
29 \\
30 \\
31\end{array}$ & $\begin{array}{r}=-0 \\
17.5 \\
13.5\end{array}$ & & $\begin{array}{r}12.5 \\
=-5 \\
=-0 \\
9.0\end{array}$ & 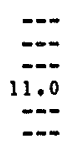 & $\begin{array}{r}11.0 \\
-\infty \\
-\infty \\
-\infty\end{array}$ & 18.0 & $\begin{array}{r}17.0 \\
=-0 \\
=-\end{array}$ & $\begin{array}{r}20.0 \\
18.5 \\
=-.5 \\
-.-5\end{array}$ & $\begin{array}{r}32.0 \\
\cdots \\
\cdots\end{array}$ & $\begin{array}{r}29.5 \\
28.0 \\
- \\
- \\
-\end{array}$ & $\begin{array}{r}19.5 \\
22.0 \\
0 .- \\
-0.5 \\
28.5\end{array}$ & $\begin{array}{r}19.0 \\
23.0 \\
\cdots\end{array}$ \\
\hline NTH & -- & & -- & $-n$ & $m$ & $-\pi$ & $-m$ & -- & $-\cdots$ & $m$ & -- & -- \\
\hline
\end{tabular}


11106550 CALLEGUAS CREEK AT CAMARILLO STATE HOSPITAL, CA--Continued

SUSPENDED-SEOIMENT DISCHARGE (TONS/DAY), WATER YEAR OCTOBER 1975 TO SEPTEMBER 1976

\begin{tabular}{|c|c|c|c|c|c|c|c|c|c|}
\hline \multirow[b]{2}{*}{ DAY } & \multicolumn{3}{|c|}{ OCTOBER } & \multicolumn{3}{|c|}{ NOVEMBER } & \multicolumn{3}{|c|}{ DECEMBER } \\
\hline & $\begin{array}{l}\text { MEAN } \\
\text { OISCHARGE } \\
\text { (CFS) }\end{array}$ & $\begin{array}{l}\text { MEAN } \\
\text { CONCEN- } \\
\text { TRATION } \\
\text { (MATL) }\end{array}$ & $\begin{array}{l}\text { SEDIMENT } \\
\text { DISCHARGE } \\
\text { (TONS/DAY) }\end{array}$ & $\begin{array}{l}\text { MEAN } \\
\text { DISCHARGE } \\
\text { (CFS) }\end{array}$ & $\begin{array}{l}\text { MEAN } \\
\text { CONCEN- } \\
\text { TRAION } \\
\text { (MG/L) }\end{array}$ & $\begin{array}{l}\text { SEOIMENT } \\
\text { OISCHARGE } \\
\text { (TONS/OAY) }\end{array}$ & $\begin{array}{l}\text { MEAN } \\
\text { DISCHARGE } \\
\text { (CFS) }\end{array}$ & $\begin{array}{l}\text { MEAN } \\
\text { CONCEN- } \\
\text { TRATION } \\
\text { (MG/L) }\end{array}$ & $\begin{array}{l}\text { SEOIMENT } \\
\text { DISCHARGE } \\
\text { ITONS/DAY }\end{array}$ \\
\hline $\begin{array}{l}1 \\
2 \\
3 \\
4 \\
5\end{array}$ & $\begin{array}{l}5.1 \\
7: 0 \\
8.1 \\
7.0 \\
8.1\end{array}$ & $\begin{array}{l}5 \\
6 \\
6 \\
6 \\
6\end{array}$ & $\begin{array}{l}.07 \\
011 \\
113 \\
111 \\
.11\end{array}$ & $\begin{array}{l}6.0 \\
6: 0 \\
7: 0 \\
7: 0 \\
7.0\end{array}$ & $\begin{array}{l}20 \\
20 \\
20 \\
20 \\
20\end{array}$ & $\begin{array}{l}: 32 \\
: 32 \\
: 38 \\
: 38 \\
: 38\end{array}$ & $\begin{array}{c}8.1 \\
10 \\
10 \\
8.1 \\
6.0\end{array}$ & $\begin{array}{l}30 \\
64 \\
64 \\
50 \\
40\end{array}$ & $\begin{array}{l}.66 \\
1: 7 \\
1: 7 \\
1: 1 \\
.65\end{array}$ \\
\hline $\begin{array}{r}6 \\
7 \\
8 \\
9 \\
10\end{array}$ & $\begin{array}{l}9.3 \\
9: 3 \\
7: 0 \\
6: 0 \\
7: 0\end{array}$ & $\begin{array}{l}10 \\
10 \\
10 \\
10 \\
10\end{array}$ & $\begin{array}{l}.25 \\
: 15 \\
: 19 \\
: 16 \\
: 19\end{array}$ & $\begin{array}{l}8.1 \\
8.1 \\
6.0 \\
6.0 \\
6.0\end{array}$ & $\begin{array}{l}25 \\
25 \\
20 \\
20 \\
20\end{array}$ & $\begin{array}{l}.55 \\
.55 \\
.32 \\
.32 \\
.32\end{array}$ & $\begin{array}{l}6: 0 \\
9: 3 \\
8: 1 \\
7: 0 \\
7: 0\end{array}$ & $\begin{array}{l}40 \\
39 \\
39 \\
39 \\
40\end{array}$ & $\begin{array}{l}.65 \\
.98 \\
.95 \\
.74 \\
.76\end{array}$ \\
\hline $\begin{array}{l}11 \\
12 \\
13 \\
14 \\
15\end{array}$ & $\begin{array}{c}15 \\
16 \\
12 \\
7.0 \\
5.1\end{array}$ & $\begin{array}{r}120 \\
120 \\
120 \\
60 \\
57\end{array}$ & $\begin{array}{l}4.9 \\
5.2 \\
3.9 \\
1.1 \\
.78\end{array}$ & $\begin{array}{l}8.1 \\
5: 1 \\
6.0 \\
7: 0 \\
7.0\end{array}$ & $\begin{array}{l}25 \\
20 \\
20 \\
20 \\
20\end{array}$ & $\begin{array}{l}.55 \\
.28 \\
.32 \\
.38 \\
.38\end{array}$ & $\begin{array}{c}7.0 \\
8.1 \\
15 \\
12 \\
7.0\end{array}$ & $\begin{array}{r}40 \\
40 \\
100 \\
75 \\
40\end{array}$ & $\begin{array}{l}.76 \\
: 87 \\
4: 1 \\
2: 4 \\
: 76\end{array}$ \\
\hline $\begin{array}{l}16 \\
17 \\
18 \\
19 \\
20\end{array}$ & $\begin{array}{l}6.0 \\
6.0 \\
5.1 \\
6.0 \\
7.0\end{array}$ & $\begin{array}{l}55 \\
50 \\
40 \\
35 \\
30\end{array}$ & $\begin{array}{l}.89 \\
.81 \\
.55 \\
.57 \\
.57\end{array}$ & $\begin{array}{l}8.1 \\
9.3 \\
8.1 \\
8.1 \\
9.3\end{array}$ & $\begin{array}{l}25 \\
30 \\
25 \\
25 \\
30\end{array}$ & $\begin{array}{l}.55 \\
.75 \\
.55 \\
.55 \\
.75\end{array}$ & $\begin{array}{c}7.0 \\
18 \\
4.2 \\
8.1 \\
9.3\end{array}$ & $\begin{array}{l}40 \\
52 \\
39 \\
39 \\
39\end{array}$ & $\begin{array}{c}.76 \\
2.5 \\
.44 \\
.85 \\
.98\end{array}$ \\
\hline $\begin{array}{l}21 \\
22 \\
23 \\
24 \\
25\end{array}$ & $\begin{array}{l}8.1 \\
9.3 \\
9.0 \\
6.0 \\
5.1\end{array}$ & $\begin{array}{l}25 \\
25 \\
25 \\
23 \\
23\end{array}$ & $\begin{array}{l}.55 \\
.63 \\
.47 \\
.37 \\
.32\end{array}$ & $\begin{array}{l}6.0 \\
4.2 \\
7.0 \\
9.3 \\
9.3\end{array}$ & $\begin{array}{l}20 \\
20 \\
20 \\
30 \\
30\end{array}$ & $\begin{array}{l}.32 \\
.23 \\
.38 \\
.75 \\
.75\end{array}$ & $\begin{array}{c}9.3 \\
10^{\circ} \\
10 \\
9.3 \\
10\end{array}$ & $\begin{array}{l}36 \\
33 \\
30 \\
27 \\
24\end{array}$ & $\begin{array}{l}.90 \\
.89 \\
.81 \\
.68 \\
.65\end{array}$ \\
\hline $\begin{array}{l}26 \\
27 \\
28 \\
29 \\
30 \\
31\end{array}$ & $\begin{array}{l}7.0 \\
6.0 \\
9.3 \\
8.1 \\
8: 1 \\
9.3\end{array}$ & $\begin{array}{l}22 \\
22 \\
21 \\
21 \\
20 \\
20\end{array}$ & $\begin{array}{l}.42 \\
.36 \\
.53 \\
.46 \\
.44 \\
.50\end{array}$ & $\begin{array}{l}6.0 \\
6.0 \\
8.1 \\
8.1 \\
8.1 \\
-.-\end{array}$ & $\begin{array}{r}20 \\
20 \\
30 \\
30 \\
30 \\
---\end{array}$ & \begin{tabular}{l}
.32 \\
.32 \\
.66 \\
.66 \\
.66 \\
\hdashline--
\end{tabular} & $\begin{array}{c}8.1 \\
10^{12} \\
9.3 \\
7.0 \\
10^{\circ}\end{array}$ & $\begin{array}{r}22 \\
30 \\
45 \\
45 \\
45 \\
108\end{array}$ & $\begin{array}{l}.48 \\
: 81 \\
1.5 \\
1.1 \\
: 85 \\
2.9\end{array}$ \\
\hline & 242.4 & -- & 25.91 & 215.4 & --- & 13.95 & 280.3 & --- & 5.78 \\
\hline
\end{tabular}

\begin{tabular}{|c|c|c|c|c|c|c|c|c|c|}
\hline \multirow[b]{2}{*}{ DAY } & \multicolumn{3}{|c|}{ JANUARY } & \multicolumn{3}{|c|}{ FEBRUARY } & \multicolumn{3}{|c|}{ MARCH } \\
\hline & $\begin{array}{l}\text { MEAN } \\
\text { DISCHARGE } \\
\text { (CFS) }\end{array}$ & $\begin{array}{l}\text { MEAN } \\
\text { CONCEN- } \\
\text { TRATION } \\
\text { (MG/L) }\end{array}$ & $\begin{array}{l}\text { SEDIMENT } \\
\text { DISCHARGE } \\
\text { (TONS/DAY) }\end{array}$ & $\begin{array}{l}\text { MEAN } \\
\text { OISCHARGE } \\
\text { (CFS) }\end{array}$ & $\begin{array}{l}\text { MEAN } \\
\text { CONCEN- } \\
\text { TRAI ON } \\
\text { (MG/L) }\end{array}$ & $\begin{array}{l}\text { SEDIMENT } \\
\text { DISCHARGE } \\
\text { (rONS/DAY) }\end{array}$ & $\begin{array}{l}\text { MEAN } \\
\text { OISCHARGE } \\
\text { (CFS) }\end{array}$ & $\begin{array}{l}\text { MEAN } \\
\text { CONCEN- } \\
\text { TRAIION } \\
\text { (MG/L) }\end{array}$ & $\begin{array}{l}\text { SEDIMENT } \\
\text { OISCARARG } \\
\text { (TONS/OAY) }\end{array}$ \\
\hline $\begin{array}{l}1 \\
2 \\
3 \\
4 \\
5\end{array}$ & $\begin{array}{r}12 \\
7.0 \\
7: 0 \\
70 \\
10\end{array}$ & $\begin{array}{l}99 \\
90 \\
81 \\
72 \\
64\end{array}$ & $\begin{array}{l}3.2 \\
1.7 \\
1.5 \\
1.4 \\
1.7\end{array}$ & $\begin{array}{r}7.0 \\
6.0 \\
7.0 \\
9.3 \\
14\end{array}$ & $\begin{array}{r}45 \\
42 \\
38 \\
40 \\
116\end{array}$ & $\begin{array}{r}: 85 \\
: 68 \\
: 72 \\
1: 0 \\
7: 3\end{array}$ & $\begin{array}{c}63 \\
20 \\
66 \\
12 \\
9.3\end{array}$ & $\begin{array}{r}838 \\
580 \\
706 \\
75 \\
50\end{array}$ & $\begin{array}{r}276 \\
33 \\
261 \\
2.4 \\
1.3\end{array}$ \\
\hline $\begin{array}{r}6 \\
7 \\
8 \\
9 \\
10\end{array}$ & $\begin{array}{l}13 \\
13 \\
12 \\
10 \\
12\end{array}$ & $\begin{array}{l}56 \\
48 \\
40 \\
32 \\
23\end{array}$ & $\begin{array}{l}2.0 \\
1.7 \\
1.3 \\
.86 \\
.75\end{array}$ & $\begin{array}{r}34 \\
115 \\
91 \\
296 \\
99\end{array}$ & $\begin{array}{r}1030 \\
3130 \\
783 \\
6490 \\
1090\end{array}$ & $\begin{array}{r}123 \\
1850 \\
316 \\
9660 \\
495\end{array}$ & $\begin{array}{c}9.3 \\
8.1 \\
8.1 \\
8.1 \\
18\end{array}$ & $\begin{array}{l}42 \\
45 \\
45 \\
50 \\
55\end{array}$ & $\begin{array}{l}1.1 \\
.98 \\
.98 \\
1.1 \\
2.7\end{array}$ \\
\hline $\begin{array}{l}11 \\
12 \\
13 \\
14 \\
15\end{array}$ & $\begin{array}{l}9.3 \\
8: 1 \\
9: 3 \\
7: 0 \\
7: 0\end{array}$ & $\begin{array}{l}23 \\
24 \\
25 \\
25 \\
26\end{array}$ & $\begin{array}{l}.58 \\
.52 \\
.63 \\
.47 \\
.49\end{array}$ & $\begin{array}{l}15 \\
12 \\
10 \\
9.3 \\
9.3\end{array}$ & $\begin{array}{l}75 \\
54 \\
54 \\
50 \\
45\end{array}$ & $\begin{array}{l}3.0 \\
1.7 \\
1.5 \\
1.3 \\
1.1\end{array}$ & $\begin{array}{c}13 \\
9.3 \\
8.1 \\
8.1 \\
8.1\end{array}$ & $\begin{array}{l}60 \\
65 \\
70 \\
75 \\
80\end{array}$ & $\begin{array}{l}2.1 \\
1.6 \\
1.5 \\
1.6 \\
1.7\end{array}$ \\
\hline $\begin{array}{l}16 \\
17 \\
18 \\
19 \\
20\end{array}$ & $\begin{array}{c}6.0 \\
6.0 \\
10^{\circ} \\
10 \\
7.0\end{array}$ & $\begin{array}{l}30 \\
34 \\
38 \\
40 \\
44\end{array}$ & $\begin{array}{l}.49 \\
: 55 \\
1: 0 \\
1.1 \\
.83\end{array}$ & $\begin{array}{c}10 \\
10 \\
10 \\
9.3 \\
8.1\end{array}$ & $\begin{array}{l}45 \\
40 \\
40 \\
45 \\
45\end{array}$ & $\begin{array}{l}1.2 \\
1.1 \\
1.1 \\
1.1 \\
.98\end{array}$ & $\begin{array}{c}9.3 \\
9.3 \\
10 \\
10 \\
9.3\end{array}$ & $\begin{array}{l}100 \\
128 \\
118 \\
118 \\
115\end{array}$ & $\begin{array}{l}2.5 \\
3.2 \\
3.2 \\
3.2 \\
2.9\end{array}$ \\
\hline $\begin{array}{l}21 \\
22 \\
23 \\
24 \\
25\end{array}$ & $\begin{array}{l}6.0 \\
8.1 \\
6.0 \\
7: 0 \\
9.3\end{array}$ & $\begin{array}{l}44 \\
45 \\
46 \\
48 \\
50\end{array}$ & $\begin{array}{r}.71 \\
: 98 \\
: 75 \\
: 91 \\
1.3\end{array}$ & $\begin{array}{l}9.3 \\
9.3 \\
9.3 \\
9.3 \\
9.3\end{array}$ & $\begin{array}{l}49 \\
49 \\
49 \\
45 \\
40\end{array}$ & $\begin{array}{l}1.2 \\
1.2 \\
1.2 \\
1.1 \\
1.0\end{array}$ & $\begin{array}{l}7.0 \\
7.0 \\
8.1 \\
6.0 \\
8.1\end{array}$ & $\begin{array}{l}115 \\
110 \\
110 \\
110 \\
105\end{array}$ & $\begin{array}{l}2.2 \\
2.1 \\
2.4 \\
1.8 \\
2.3\end{array}$ \\
\hline $\begin{array}{l}26 \\
27 \\
28 \\
29 \\
30 \\
31\end{array}$ & $\begin{array}{c}10 \\
10 \\
5.1 \\
7: 0 \\
7: 0 \\
6.0\end{array}$ & $\begin{array}{l}50 \\
52 \\
52 \\
54 \\
51 \\
48\end{array}$ & $\begin{array}{r}1.4 \\
1.4 \\
.72 \\
1.0 \\
.96 \\
.78\end{array}$ & $\begin{array}{l}9.3 \\
9.3 \\
9.3 \\
9.3 \\
--- \\
-.-\end{array}$ & $\begin{array}{r}40 \\
37 \\
35 \\
35 \\
-\because- \\
--.\end{array}$ & $\begin{array}{r}1.0 \\
.93 \\
: 88 \\
.88 \\
\hdashline-.\end{array}$ & $\begin{array}{l}7.0 \\
7.0 \\
7.0 \\
8.1 \\
8.1 \\
8.1\end{array}$ & $\begin{array}{l}105 \\
105 \\
101 \\
101 \\
101 \\
101\end{array}$ & $\begin{array}{l}2.0 \\
2.0 \\
1.9 \\
2.2 \\
2.2 \\
2.2\end{array}$ \\
\hline OTAL & 264,2 & --- & 33.68 & 865,0 & --- & 12478.02 & 397.9 & -- & 627.36 \\
\hline
\end{tabular}


CALLEGUAS CREEK BASIN

11106550 CALLEGUAS CREEK AT CAMARILlo STATE hOSPITAL, CA--Continued

SUSPENOED-SEDIMENT DISCHARGE (TONS/DAY), HATER YEAR OCTOBER 1975 TO SEPTEMBER 1976

DAY

MEAN
DISCHARGE
(CFS)
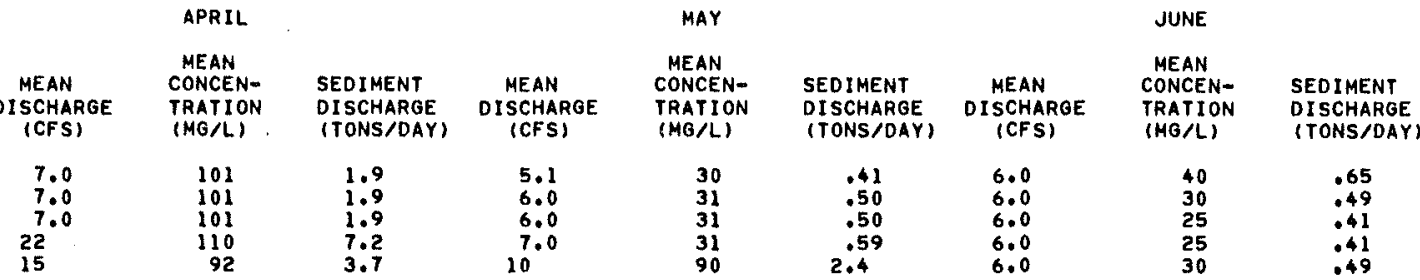

13
12
13
12
9.3

3.2
2.6
2.5
1.9
1.3
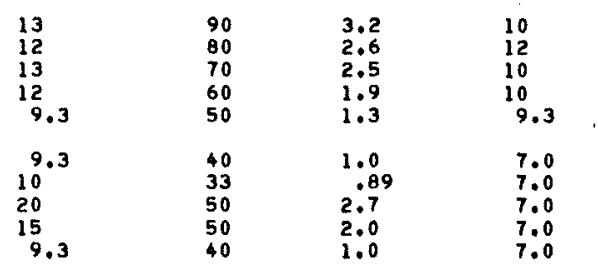

8.1

5.1

6.0

7.0
8.1
8.1
7.0

8.1
7.0
7.0

7.0

7.0
6.0

6.0

6.0

280.4

AY
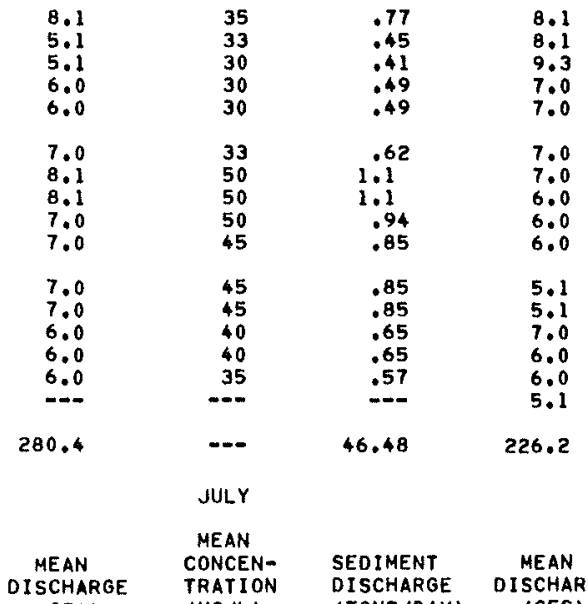

.62
1.1
1.1
.94

.94
.85

7.0
7.0

6.0

6.0

$.85 \quad 5.1$

.85
.85

.65
.65

.57

5.1
5.1

5.1
7.0
6.0

6.0

46.48

226.2

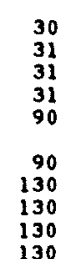

.41
.50
.50
.59

6.0
6.0
6.0
6.0

2.4

2.4
4.2
3.5
3.5
3.3

6.0
6.0
6.0
5.1
8.1

2.5
3.2
2.6
2.3
1.9

13

130

169

140
120

120
100

88
88
44
42
40
38
40
42
45
48
60
98
75
69
65
50

---

1.9
1.9
1.1
.79
.76

6.0
6.0
5.1
5.1

5.1
5.1
6.0
6.0

.72
.76
.68
.73

.73
.78

1.03

1.3

1.1

1.19

$50.34 \quad 165.70$

5.1

5.1
6.0
6.0
5.1
6.0

6.0

7.0
4.2

. .65

1.185

165.70

40
30
25
25
30

30
35
40
33
54

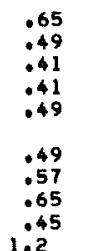

1.45

1.6

.65
.55
.47
.41

.34

.21

.24
.28 (CFS)

(MG/L)
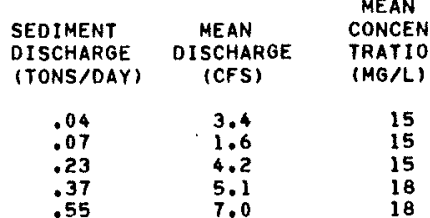

6.0

7.0
6.0

7.0
7.0

7.0

5.2

5.1
7.0
8.1

8.1

8.1

6.0

8.1

8.1

8.1

7.0
6.0

5.1

5.1

6.0

9.3

9.3

6.0

TOTAL

192.65

4130.65
9.3
9.3

.65

.65

$\begin{array}{lll}.04 & 3.4 & 15 \\ .07 & 1.6 & 15 \\ .23 & 4.2 & 15 \\ .37 & 5.1 & 18 \\ .55 & 7.0 & 18\end{array}$

9.3
9.3

10
13

\section{.57}

.57
.34
.41

.66
.85

12.0

7.0

4.2
4.2

.98
1.2

.81

.85
.87

.77

.66
.57

.41
.28

.21

.16
.25

.25

16.36

17145.73

18

20

25
30

40

45
40
35

40
35
30

5.1

6.0

7.0
6.0

7.0

7.0
7.0

7.0

B. 1

6.0

7.0

4.2
7.0

209.2

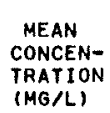

TRATION
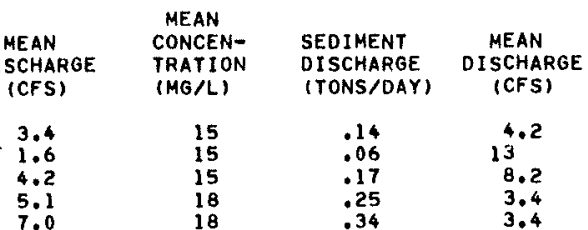

.14
.06
.17
.25
.34

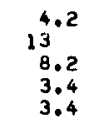

.45
.50
.63

1.81

1.5
.76
.66
.34
.29
.43
.41
.47
.32
.28

.19

19
.19
.19

.19

.22

.09

.06
.11
.08

5
12
10
10
80

122

42
16
13
12

12

13
13
13
15

13

11.78

15
16
13
12
10

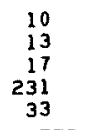

MEAN
CONCEN

TRATION SEDIMENT

(MG/L) (TONS/DAY)

6
5
6



37
30
8
5
25
1
1
1
1
1
14

$\begin{array}{ll}6 & .07 \\ 5 & .18 \\ 4 & .09 \\ 6 & .06 \\ 7 & .06\end{array}$

$\begin{array}{rr}3 & .04 \\ 3 & .10 \\ 3 & .08 \\ 3 & .08 \\ 776 & 935\end{array}$

$\begin{array}{cc}300 & 99 \\ 80 & 9.1 \\ 50 & 2.2 \\ 25 & .88 \\ 12 & .39 \\ 12 & .42 \\ 12 & .42 \\ 14 & .49 \\ 14 & .57 \\ 14 & .49\end{array}$

10

$\begin{array}{ll}10 & .43 \\ 10 & .35\end{array}$

.35
.26

$8 \quad .22$

$\begin{array}{r}8 \\ 8 \\ 15 \\ 2660 \\ 100 \\ \hline\end{array}$

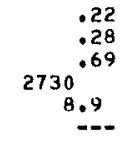

$791 \cdot 3$

$--$

3791.48 
11106550 CALLEGUAS CREEK AT CAMARILLO STATE HOSPITAL, CA--Continued

PARTICLE-SIZE DISTRIBUTION OF SUSPENDEO SEOIMENT, WATER YEAR OCTOBER 1975 TO SEPTEMBER 1976

\begin{tabular}{|c|c|c|c|c|c|c|c|c|c|c|}
\hline DATE & TIME & $\begin{array}{l}\text { TEMPER- } \\
\text { ATURE } \\
\text { (DEG C) }\end{array}$ & $\begin{array}{l}\text { INSTAN- } \\
\text { TANEOUS } \\
\text { DIS- } \\
\text { CHARGE } \\
\text { (CFS) }\end{array}$ & $\begin{array}{l}\text { SUS- } \\
\text { PENDEO } \\
\text { SEDI- } \\
\text { MENT } \\
\text { (MG/L) }\end{array}$ & $\begin{array}{c}\text { SUS- } \\
\text { PENDED } \\
\text { SEDI - } \\
\text { MENT } \\
\text { DIS- } \\
\text { CHARGE } \\
(T / D A Y)\end{array}$ & $\begin{array}{l}\text { SUS. } \\
\text { SED: } \\
\text { FALL } \\
\text { OIAM. } \\
\text { F FINER } \\
\text { THAN } \\
\text { O02 MM }\end{array}$ & $\begin{array}{l}\text { SUS. } \\
\text { SED } \\
\text { FALL } \\
\text { OIAM. } \\
\text { O FINER } \\
\text { THAN } \\
\text { OOOA MM }\end{array}$ & $\begin{array}{c}\text { SUS. } \\
\text { SED } \\
\text { FALL } \\
\text { DIAM. } \\
\text { FINER } \\
\text { THAN } \\
\text { OOOB MM }\end{array}$ & $\begin{array}{l}\text { SUS, } \\
\text { SED: } \\
\text { FALL } \\
\text { DIAM. } \\
\text { D FINER } \\
\text { THAN } \\
\text { OIG MM }\end{array}$ & $\begin{array}{r}\text { SUS. } \\
\text { SED } \\
\text { FALL } \\
\text { OIAH. } \\
\text { FINER } \\
\text { THAN } \\
\text { O31 HM }\end{array}$ \\
\hline \multicolumn{11}{|l|}{$F E B$} \\
\hline $\begin{array}{r}06 \ldots \\
07 \ldots \\
\text { SEP }\end{array}$ & $\begin{array}{l}0900 \\
2140\end{array}$ & $\begin{array}{l}10.0 \\
11.5\end{array}$ & $\begin{array}{l}19 \\
55\end{array}$ & $\begin{array}{r}188 \\
1410\end{array}$ & $209^{9.6}$ & -7 & 42 & -5 & 50 & $-\infty$ \\
\hline $\begin{array}{l}29 \ldots \\
29 \ldots\end{array}$ & $\begin{array}{l}1030 \\
1655\end{array}$ & $\begin{array}{l}18.5 \\
20.0\end{array}$ & $\begin{array}{l}510 \\
200\end{array}$ & $\begin{array}{r}7000 \\
881\end{array}$ & $\begin{array}{r}9640 \\
476\end{array}$ & $\begin{array}{l}48 \\
67\end{array}$ & $\begin{array}{l}56 \\
83\end{array}$ & $\begin{array}{l}65 \\
92\end{array}$ & $\begin{array}{l}72 \\
96\end{array}$ & $\begin{array}{l}78 \\
99\end{array}$ \\
\hline
\end{tabular}

\begin{tabular}{|c|c|c|c|c|c|c|c|c|c|c|c|c|c|c|c|c|}
\hline \multirow[b]{2}{*}{ DATE } & $\begin{array}{l}\text { SUS. } \\
\text { SED: } \\
\text { FALL } \\
\text { DIAM. } \\
\text { FINER } \\
\text { THAN }\end{array}$ & $\begin{array}{l}\text { SUS. } \\
\text { SED } \\
\text { SIEVE } \\
\text { DIAM. } \\
\text { \$ FINER } \\
\text { THAN }\end{array}$ & \multicolumn{2}{|c|}{$\begin{array}{l}\text { SUS. } \\
\text { SED: } \\
\text { FALL } \\
\text { DIAM. } \\
\text { O FINER } \\
\text { THAN }\end{array}$} & \multicolumn{2}{|c|}{$\begin{array}{l}\text { SUS. } \\
\text { SED: } \\
\text { SIEVE } \\
\text { DIAM. } \\
\text { \& FINER } \\
\text { THAN }\end{array}$} & \multicolumn{2}{|c|}{$\begin{array}{l}\text { SUS. } \\
\text { SED } \\
\text { FALL } \\
\text { DIAH. } \\
\text { FINER } \\
\text { THAN }\end{array}$} & \multicolumn{2}{|c|}{$\begin{array}{l}\text { SUS. } \\
\text { SEO } \\
\text { SIEVE } \\
\text { OIAM. } \\
\text { \$ FINER } \\
\text { THAN }\end{array}$} & \multicolumn{2}{|c|}{$\begin{array}{l}\text { SUS. } \\
\text { SED: } \\
\text { FALL } \\
\text { DIAM. } \\
\text { FINER } \\
\text { THAN }\end{array}$} & \multicolumn{2}{|c|}{$\begin{array}{l}\text { SUS. } \\
\text { SED. } \\
\text { SIEVE } \\
\text { DIAM. } \\
\text { \$ FINER } \\
\text { THAN }\end{array}$} & $\begin{array}{l}\text { SUS. } \\
\text { SED } \\
\text { FALL } \\
\text { DIAM. } \\
\text { FINER } \\
\text { THAN }\end{array}$ & \multirow[t]{2}{*}{$\begin{array}{l}\text { SUS. } \\
\text { SED. } \\
\text { SIEVE } \\
\text { DIAM. } \\
\text { \$ FINER } \\
\text { THAN } \\
1.00 \text { MM }\end{array}$} \\
\hline & $.062 \mathrm{MM}$ & $.062 \mathrm{MM}$ & .125 & MM & .125 & MH & .250 & MM & .250 & MM & .500 & $M M$ & .500 & MM & $1.00 \mathrm{MH}$ & \\
\hline \multicolumn{17}{|l|}{ FEB } \\
\hline $06 \ldots$ & - & 38 & & $=$ & & 45 & & $m$ & & 76 & & $=$ & & 98 & - & 100 \\
\hline SFP & 54 & - & & 56 & & -- & & 69 & & $=$ & & 94 & & -- & 100 & $-\infty$ \\
\hline $29 \ldots$ & 80 & -- & & 80 & & - & & 84 & & -- & & 97 & & - & 100 & -- \\
\hline $29 . \ldots$ & $-\infty$ & 100 & & -- & & -- & & - & & $=-$ & & $=-$ & & - & -- & -- \\
\hline
\end{tabular}


11107745 SANTA CLARA RIVER ABOVE RAILROAD STATION, NEAR LANG, CA

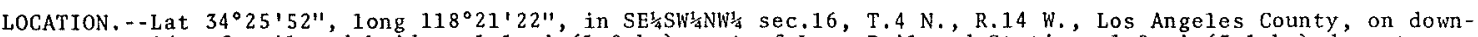
stream side of railroad bridge, $1.1 \mathrm{mi}(1.8 \mathrm{~km})$ east of Lang Railroad Station, $1.9 \mathrm{mi}$ (3.1 $\mathrm{km})$ downstream from Agua Dulce Canyon, and $5.2 \mathrm{mi}(8.4 \mathrm{~km})$ northeast of Solemint.

DRAINAGE AREA. $--157 \mathrm{mi}^{2}\left(407 \mathrm{~km}^{2}\right)$.

PERIOD OF RECORD, - October 1949 to September 1968, October 1969 to current year. Monthly discharge only for 1950-70 published in WDR CA-71-1. Daily discharge available in historical computer files.

GAGE.- Water-stage recorder. Altitude of gage is $1,750 \mathrm{ft}$ (533 $\mathrm{m})$, from topographic map. Prior to Apr. 3 , 1970 , at site $0.4 \mathrm{mi}(0.6 \mathrm{~km})$ downstream at different datum.

REMARKS.--Records poor. No regulation above station. Small diversions for irrigation and recreation.

COOPERATION, - - Records were furnished by Los Angeles County Flood Control District.

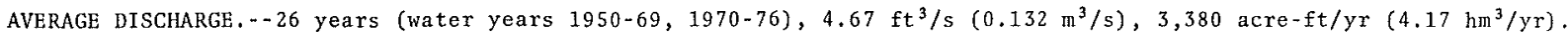
EXTREMES FOR PERIOD OF RECORD.--Maximum discharge, 5,910 $\mathrm{ft}^{3} / \mathrm{s}\left(167 \mathrm{~m}^{3} / \mathrm{s}\right)$, estimated, Feb. 25,$1969 ;$ no f1ow at times in some years.

EXTREMES FOR CURRENT YEAR.--Maximum discharge, $24 \mathrm{ft}^{3} / \mathrm{s}\left(0.68 \mathrm{~m}^{3} / \mathrm{s}\right)$ Feb. 9 , gage height, $2.42 \mathrm{ft}(0.738 \mathrm{~m})$ no flow many days.

DISCHARGE, IN CUBIC FEET PER SECOND, WATER YEAR OCTOBER 1975 TO SEPTEMBER 1976 MEAN VALUES

\begin{tabular}{|c|c|c|c|c|c|c|c|c|c|c|c|c|}
\hline DAY & $\mathrm{OCT}$ & NoV & DEC & JAN & FEg & MAR & APR & MAY & JUN & JUL. & AUG & SEP \\
\hline $\begin{array}{l}1 \\
2 \\
3 \\
4 \\
5\end{array}$ & & & & & $\begin{array}{l}0 \\
0 \\
0 \\
0 \\
0\end{array}$ & $\begin{array}{l}2.3 \\
2.5 \\
3.3 \\
2.3 \\
1.4\end{array}$ & $\begin{array}{l}.60 \\
.40 \\
.40 \\
1.0 \\
.80\end{array}$ & $\begin{array}{l}.70 \\
.60 \\
.70 \\
.70 \\
.70\end{array}$ & $\begin{array}{l}.50 \\
.40 \\
.40 \\
.30 \\
.30\end{array}$ & $\begin{array}{l}.01 \\
.01 \\
.01 \\
.01 \\
0\end{array}$ & & $\begin{array}{l}0 \\
0 \\
0 \\
0 \\
0\end{array}$ \\
\hline $\begin{array}{r}6 \\
7 \\
8 \\
9 \\
10\end{array}$ & & & & & $\begin{array}{c}2.9 \\
1.8 \\
2.6 \\
11 \\
4.8\end{array}$ & $\begin{array}{l}1.3 \\
1.2 \\
1.0 \\
.80 \\
1.0\end{array}$ & $\begin{array}{l}.60 \\
.60 \\
.70 \\
.70 \\
.70\end{array}$ & $\begin{array}{r}.70 \\
.70 \\
.50 \\
.50 \\
.60\end{array}$ & $\begin{array}{l}.20 \\
.20 \\
.30 \\
.40 \\
.40\end{array}$ & $\begin{array}{l}0 \\
0 \\
0 \\
0 \\
0\end{array}$ & & $\begin{array}{l}0 \\
0 \\
0 \\
0 \\
0\end{array}$ \\
\hline $\begin{array}{l}11 \\
12 \\
13 \\
14 \\
15\end{array}$ & & & & & $\begin{array}{l}4.4 \\
4.0 \\
3.6 \\
3.2 \\
2.8\end{array}$ & $\begin{array}{r}.80 \\
.70 \\
.80 \\
1.1 \\
.90\end{array}$ & $\begin{array}{r}.70 \\
.70 \\
1.5 \\
.70 \\
.50\end{array}$ & $\begin{array}{l}.60 \\
.60 \\
.60 \\
.60 \\
.60\end{array}$ & $\begin{array}{l}.30 \\
.20 \\
.20 \\
.20 \\
.20\end{array}$ & $\begin{array}{l}0 \\
0 \\
0 \\
0 \\
0\end{array}$ & & $\begin{array}{l}0 \\
0 \\
0 \\
0 \\
0\end{array}$ \\
\hline $\begin{array}{l}16 \\
17 \\
18 \\
19 \\
20\end{array}$ & & & & & $\begin{array}{l}2.5 \\
2.1 \\
1.7 \\
1.3 \\
.90\end{array}$ & $\begin{array}{l}.60 \\
.60 \\
.60 \\
.60 \\
.90\end{array}$ & $\begin{array}{l}.40 \\
.40 \\
.60 \\
.60 \\
.50\end{array}$ & $\begin{array}{r}.50 \\
.40 \\
.40 \\
.30 \\
.30\end{array}$ & $\begin{array}{l}.20 \\
.20 \\
.10 \\
.10 \\
.10\end{array}$ & $\begin{array}{l}0 \\
0 \\
0 \\
0 \\
0\end{array}$ & & $\begin{array}{l}0 \\
0 \\
0 \\
0 \\
0\end{array}$ \\
\hline $\begin{array}{l}21 \\
22 \\
23 \\
24 \\
25\end{array}$ & & & & & $\begin{array}{l}.90 \\
1.1 \\
1.0 \\
.70 \\
.50\end{array}$ & $\begin{array}{r}.90 \\
.70 \\
.60 \\
.50 \\
.50\end{array}$ & $\begin{array}{l}.50 \\
.50 \\
.50 \\
.60 \\
.80\end{array}$ & $\begin{array}{r}.30 \\
.40 \\
.40 \\
.60 \\
.60\end{array}$ & $\begin{array}{l}.10 \\
.10 \\
.10 \\
.10 \\
.10\end{array}$ & $\begin{array}{l}0 \\
0 \\
0 \\
0 \\
0\end{array}$ & & $\begin{array}{l}0 \\
0 \\
0 \\
0 \\
0.60\end{array}$ \\
\hline $\begin{array}{l}26 \\
27 \\
28 \\
29 \\
30 \\
31\end{array}$ & & -- & & & $\begin{array}{l}.50 \\
.50 \\
.50 \\
.60 \\
.-- \\
. .-\end{array}$ & $\begin{array}{l}.50 \\
.50 \\
.80 \\
.70 \\
.60 \\
.60\end{array}$ & $\begin{array}{l}.80 \\
.80 \\
.80 \\
.70 \\
.70 \\
.0-\end{array}$ & $\begin{array}{l}.60 \\
.50 \\
.50 \\
.50 \\
.40 \\
.50\end{array}$ & $\begin{array}{r}.10 \\
110 \\
110 \\
110 \\
110 \\
-1 .\end{array}$ & $\begin{array}{l}0 \\
0 \\
0 \\
0 \\
0 \\
0\end{array}$ & & $\begin{array}{l}0 \\
0 \\
0 \\
0 \\
0 \\
-\end{array}$ \\
\hline $\begin{array}{l}\text { TOTAL } \\
\text { MEAN } \\
\text { MAX } \\
\text { MIN } \\
\text { AC-FT }\end{array}$ & $\begin{array}{l}0 \\
0 \\
0 \\
0 \\
0\end{array}$ & $\begin{array}{l}0 \\
0 \\
0 \\
0 \\
0\end{array}$ & $\begin{array}{l}0 \\
0 \\
0 \\
0 \\
0\end{array}$ & $\begin{array}{l}0 \\
0 \\
0 \\
0 \\
0\end{array}$ & $\begin{array}{r}55.90 \\
1.93 \\
11 \\
0 \\
111\end{array}$ & $\begin{array}{r}31.60 \\
1.02 \\
3.3 \\
.50 \\
63\end{array}$ & $\begin{array}{r}19.80 \\
.66 \\
1.5 \\
.40 \\
39\end{array}$ & $\begin{array}{r}16.60 \\
.54 \\
.70 \\
.30 \\
33\end{array}$ & $\begin{array}{r}6.20 \\
.21 \\
.50 \\
.10 \\
12\end{array}$ & $\begin{array}{r}.04 \\
.001 \\
.01 \\
0 \\
.08\end{array}$ & $\begin{array}{l}0 \\
0 \\
0 \\
0 \\
0\end{array}$ & $\begin{array}{r}.60 \\
.020 \\
.60 \\
0 \\
1.2\end{array}$ \\
\hline
\end{tabular}


11107922 SOUTH FORK SANTA CLARA RIVER AT SAUGUS, CA

LOCATION. - -Lat $34^{\circ} 24^{\prime} 55^{\prime \prime}$, long $118^{\circ} 32^{\prime} 34^{\prime \prime}$, in San Francisco Grant, Los Angeles County, on upstream side of Magic Mountain Parkway, $800 \mathrm{ft}(244 \mathrm{~m})$ ' west of San Fernando Road in Saugus.

DRAINAGE AREA. $--43,4 \mathrm{mi}^{2}\left(112,4 \mathrm{~km}^{2}\right)$.

PERIOD OF RECORD.--OCtober 1975 to September 1976. September 1947 to September 1975 in files of Los Angeles County Flood Control District.

GAGE. - Water-stage recorder. A1titude of gage is $1150 \mathrm{ft}$ ( $351 \mathrm{~m})$ from topographic map.

REMARKS. - Records fair. No regulation or diversion above station.

COOPERATION.--Records were furnished by Los Angeles County Flood Control District.

EXTREMES OUTSIDE PERIOD OF RECORD,--Maximum discharge, 6,800 $\mathrm{ft}^{3} / \mathrm{s}$ (193 $\left.\mathrm{m}^{3} / \mathrm{s}\right) \mathrm{Jan} .15$, 1952, gage height unknown, from information by Los Angeles County Flood Control District.

EXTREMES FOR CURRENT YEAR.--Maximum discharge, $586 \mathrm{ft}^{3} / \mathrm{s}\left(16.6 \mathrm{~m}^{3} / \mathrm{s}\right)$ Feb. 9 , gage height, $4.89 \mathrm{ft}(1.490 \mathrm{~m})$; no flow most of year.

DISCHARGE, IN CUBIC FEET PER SECOND, WATER YEAR OCTOBER 1975 TO SEPTEMBER 1976

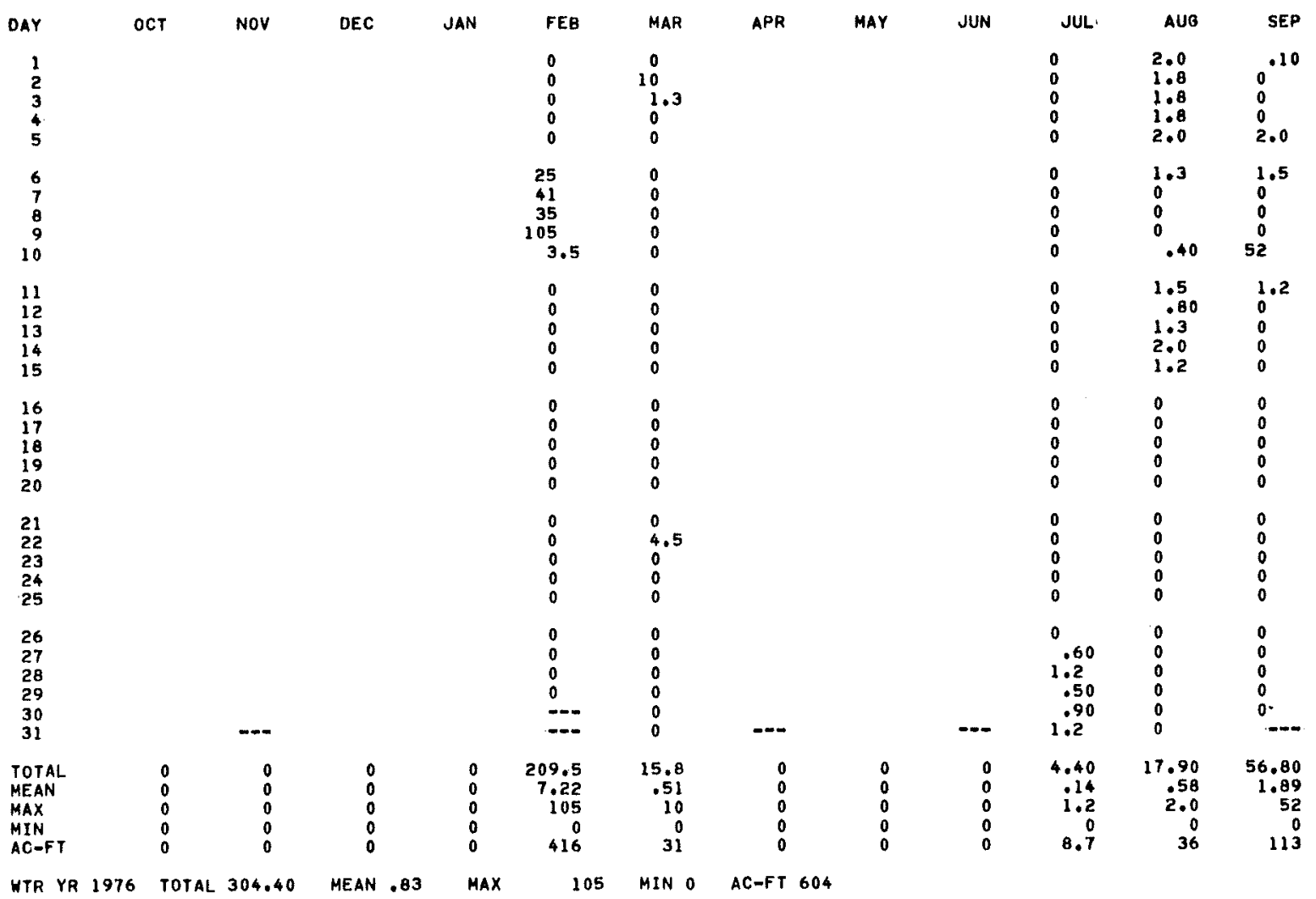


11108145 CASTAIC CREEK NEAR SAUGUS, CA

LOCATION, - Lat $34^{\circ} 25^{\prime} 42^{\prime \prime}$, long $118^{\circ} 37^{\prime} 40^{\prime \prime}$, in San Francisco Grant, Los Angeles County, on downstream side of bridge on State Highway $126,0.6 \mathrm{mi}(1.0 \mathrm{~km})$ upstream from mouth, $4.6 \mathrm{mi}$ (7.4 km) southwest of Castaic, $5.1 \mathrm{mi}(8.2 \mathrm{~km})$ northwest of Saugus, and $7 \mathrm{mi}(11.3 \mathrm{~km})$ upstream from Castaic Reservoir.

DRAINAGE AREA, $--202 \mathrm{mi}^{2}\left(523 \mathrm{~km}^{2}\right)$.

PERIOD OF RECORD,--December 1945 to current year. Month1y discharge on1y for 1947-70 pub1ished in WDR CA-71. Daily discharge available in historical computer files.

GAGE. - Water-stage recorder. Datun of gage is $952.05 \mathrm{ft}(290.185 \mathrm{~m})$ above mean sea leve1 (1evels by Los Angeles County F1ood Contro1 District).

REMARKS. - -Records fair. Flow regulated beginning in 1972 by Castaic Reservoir, capacity, 350,000 acre-ft $\left(432 \mathrm{hm}^{3}\right)$. Imported water from California Water project stored and released at Castaic Dam.

COOPERATION.--Records were furnished by Los Angeles County Flood Control District.

AVERAGE DISCHARGE. - -25 years (water years 1947-71), before regulation by Castaic Reservoir, 12.2 ft ${ }^{3} / \mathrm{s}^{2}$ (0.346 ${ }^{3} / \mathrm{s}$ ), 8,840 acre-ft/yr $\left(10.9 \mathrm{hm}^{3} / \mathrm{yr}\right)$.

5 years (water years $1972-76), 7.81 \mathrm{ft}^{3} / \mathrm{s}\left(0.221 \mathrm{~m}^{3} / \mathrm{s}\right), 5,660 \mathrm{acre}-\mathrm{ft} / \mathrm{yr}\left(6.98 \mathrm{hm}^{3} / \mathrm{yr}^{2}\right)$

EXTREMES FOR PERIOD OF RECORD.--Maximum discharge, $19,300 \mathrm{ft}^{3} / \mathrm{s}\left(547 \mathrm{~m}^{3} / \mathrm{s}\right)$ Feb. 25 , 1969 , result of s1ope-area measurement of maximum flow; no flow for all or long periods in each year.

EXTREMES FOR CURRENT YEAR.--Maximum discharge, $40 \mathrm{ft}^{3} / \mathrm{s}\left(1.13 \mathrm{~m}^{3} / \mathrm{s}\right)$ Feb. 9 , gage height, $2.07 \mathrm{ft}(0.631 \mathrm{~m})$; no flow many days.

DISCHARGE, IN CUBIC FEET PER SECOND, WATER YEAR OCTOBER 1975 TO SEPTEMBER 1976

\begin{tabular}{|c|c|c|c|c|c|c|c|c|c|c|c|c|}
\hline \multicolumn{13}{|c|}{ MEAN VALUES } \\
\hline DAY & $\mathrm{OCT}$ & NOV & DEC & JAN & FE,B & MAR & APR & MAY & JUN & JUL & AUG & SEP \\
\hline $\begin{array}{l}1 \\
2 \\
3 \\
4 \\
5\end{array}$ & $\begin{array}{l}0 \\
0 \\
0 \\
0 \\
0\end{array}$ & $\begin{array}{l}.40 \\
.30 \\
.30 \\
.40 \\
.30\end{array}$ & $\begin{array}{l}.10 \\
.10 \\
110 \\
.10 \\
110\end{array}$ & $\begin{array}{l}.30 \\
.30 \\
.40 \\
.40 \\
.40\end{array}$ & $\begin{array}{l}0 \\
0 \\
0 \\
0 \\
.03\end{array}$ & $\begin{array}{l}.60 \\
.60 \\
.80 \\
.60 \\
.60\end{array}$ & $\begin{array}{r}.60 \\
.50 \\
.60 \\
.60 \\
.50\end{array}$ & $\begin{array}{l}.01 \\
.01 \\
.01 \\
.01 \\
0^{.01}\end{array}$ & & & & $\begin{array}{l}0 \\
0 \\
0 \\
0 \\
0\end{array}$ \\
\hline $\begin{array}{r}6 \\
7 \\
8 \\
9 \\
10\end{array}$ & $\begin{array}{l}.10 \\
.10 \\
0 \\
0\end{array}$ & $\begin{array}{r}.30 \\
.30 \\
.30 \\
.30 \\
.30\end{array}$ & $\begin{array}{l}.10 \\
.10 \\
.10 \\
.20 \\
.20\end{array}$ & $\begin{array}{l}.40 \\
.50 \\
.40 \\
.40 \\
.30\end{array}$ & $\begin{array}{c}.30 \\
2.80 \\
2.3 \\
15 \\
7.7\end{array}$ & $\begin{array}{l}.60 \\
.60 \\
.60 \\
.60 \\
.60\end{array}$ & $\begin{array}{r}.40 \\
.50 \\
.50 \\
.40 \\
.30\end{array}$ & $\begin{array}{l}0 \\
0 \\
0 \\
0 \\
0\end{array}$ & & & & $\begin{array}{l}0 \\
0 \\
0 \\
0 \\
.10\end{array}$ \\
\hline $\begin{array}{l}11 \\
12 \\
13 \\
14 \\
15\end{array}$ & $\begin{array}{l}0 \\
0 \\
0 \\
0\end{array}$ & $\begin{array}{r}.30 \\
.30 \\
.30 \\
.30 \\
.30\end{array}$ & $\begin{array}{l}.20 \\
.10 \\
110 \\
.10 \\
.10\end{array}$ & $\begin{array}{l}.30 \\
.30 \\
.30 \\
.20 \\
.20\end{array}$ & $\begin{array}{r}1.3 \\
.80 \\
.70 \\
.60 \\
.60\end{array}$ & $\begin{array}{l}.60 \\
.60 \\
.60 \\
.60 \\
.70\end{array}$ & $\begin{array}{r}.30 \\
.30 \\
.30 \\
.30 \\
.30\end{array}$ & $\begin{array}{l}0 \\
0 \\
0 \\
0 \\
0\end{array}$ & & & & $\begin{array}{l}1.8 \\
.10 \\
0 \\
0 \\
0\end{array}$ \\
\hline $\begin{array}{l}16 \\
17 \\
18 \\
19 \\
20\end{array}$ & $\begin{array}{l}0 \\
0 \\
.02 \\
.10\end{array}$ & $\begin{array}{l}.30 \\
.30 \\
.30 \\
.20 \\
.20\end{array}$ & $\begin{array}{l}.20 \\
.20 \\
.20 \\
.20 \\
.20\end{array}$ & $\begin{array}{l}.20 \\
.20 \\
.20 \\
.10 \\
.10\end{array}$ & $\begin{array}{l}.60 \\
.50 \\
.50 \\
.50 \\
.50\end{array}$ & $\begin{array}{l}.70 \\
.70 \\
.80 \\
.80 \\
.70\end{array}$ & $\begin{array}{r}.30 \\
.30 \\
.30 \\
.20 \\
.10\end{array}$ & $\begin{array}{l}0 \\
0 \\
0 \\
0 \\
0\end{array}$ & & & & $\begin{array}{l}0 \\
0 \\
0 \\
0 \\
0\end{array}$ \\
\hline $\begin{array}{l}21 \\
22 \\
23 \\
24 \\
25\end{array}$ & $\begin{array}{l}0 \\
0 \\
0 \\
0 \\
0\end{array}$ & $\begin{array}{l}.10 \\
.10 \\
.10 \\
.20 \\
.40\end{array}$ & $\begin{array}{r}.20 \\
.30 \\
.30 \\
.40 \\
.30\end{array}$ & $\begin{array}{l}.10 \\
.10 \\
.10 \\
.03 \\
.02\end{array}$ & $\begin{array}{l}.50 \\
.50 \\
.60 \\
.60 \\
.50\end{array}$ & $\begin{array}{l}.70 \\
.70 \\
.80 \\
.80 \\
.70\end{array}$ & $\begin{array}{l}.02 \\
.03 \\
.01 \\
.01 \\
.04\end{array}$ & $\begin{array}{l}0 \\
0 \\
0 \\
0 \\
0\end{array}$ & & & & $\begin{array}{l}0 \\
0 \\
0 \\
0 \\
0\end{array}$ \\
\hline $\begin{array}{l}26 \\
27 \\
28 \\
29 \\
30 \\
31\end{array}$ & $\begin{array}{l}0 \\
0 \\
.10 \\
.20 \\
.30 \\
.40\end{array}$ & $\begin{array}{l}.10 \\
110 \\
110 \\
110 \\
110\end{array}$ & $\begin{array}{r}.30 \\
.30 \\
.30 \\
.30 \\
.30 \\
.30\end{array}$ & $\begin{array}{l}0 \\
.01 \\
0 \\
0 \\
0 \\
.03\end{array}$ & $\begin{array}{r}.60 \\
.50 \\
.50 \\
.50 \\
-.- \\
-.-\end{array}$ & $\begin{array}{l}.60 \\
.60 \\
.70 \\
.70 \\
.80 \\
.70\end{array}$ & $\begin{array}{r}.01 \\
.10 \\
.10 \\
.10 \\
.01 \\
.\end{array}$ & $\begin{array}{l}0 \\
0 \\
0 \\
0 \\
0 \\
0\end{array}$ & $-n$ & & & $\begin{array}{l}0 \\
0 \\
0 \\
0 \\
0\end{array}$ \\
\hline $\begin{array}{l}\text { TOTAL } \\
\text { MEAN } \\
\text { MAX } \\
\text { MIN } \\
\text { AC }-F T\end{array}$ & $\begin{array}{r}1.33 \\
.043 \\
.40 \\
0 \\
2.6\end{array}$ & $\begin{array}{r}7.40 \\
.25 \\
.40 \\
.10 \\
15\end{array}$ & $\begin{array}{r}6.10 \\
.20 \\
.40 \\
.10 \\
12\end{array}$ & $\begin{array}{r}6.29 \\
.20 \\
.50 \\
0 \\
12\end{array}$ & $\begin{array}{r}37.53 \\
1.29 \\
15 \\
0 \\
74\end{array}$ & $\begin{array}{r}20.80 \\
.67 \\
.80 \\
.60 \\
41\end{array}$ & $\begin{array}{r}8.03 \\
.27 \\
.60 \\
.01 \\
16\end{array}$ & $\begin{array}{r}.04 \\
.001 \\
.01 \\
0 \\
.08\end{array}$ & $\begin{array}{l}0 \\
0 \\
0 \\
0 \\
0\end{array}$ & $\begin{array}{l}0 \\
0 \\
0 \\
0 \\
0\end{array}$ & $\begin{array}{l}0 \\
0 \\
0 \\
0 \\
0\end{array}$ & $\begin{array}{r}2.00 \\
.067 \\
1.8 \\
0 \\
4.0\end{array}$ \\
\hline
\end{tabular}

CAL YR 1975 TOTAL 1021.83 MEAN 2.80 MAX 88 MIN O AC-FT 2030 WTR YR 1976 TOTAL 89.52 MEAN .24 MAX 15 MIN D AC $-F T$ ITE 
LOCATION, - Lat $34^{\circ} 23^{\prime} 59^{\prime \prime}$, long $118^{\circ} 42^{\prime} 14^{\prime \prime}$, in San Francisco Grant, Ventura County, on downstream end of old diversion weir on right bank, on private road $0.2 \mathrm{mi}(0.3 \mathrm{~km})$ south of Highway $126,0.8 \mathrm{mi}(1,3 \mathrm{~km})$ west of Los Angeles-Ventura County line, and $6.4 \mathrm{mi}(10.3 \mathrm{~km})$ west of intersection of Highway 126 and Interstate 5 .

DRAINAGE AREA. $-644 \mathrm{mi}^{2}\left(1,668 \mathrm{~km}^{2}\right)$.

WATER-DISCHARGE RECORDS

PERIOD OF RECORD. - -October 1952 to current year.

GAGE.-Water-stage recorder. Datum of gage is $794.93 \mathrm{ft}(242.295 \mathrm{~m})$ above mean sea level.

REMARKS.--Records fair. Base flow affected by pumping from wells along stream for irrigation. Flow partly regulated since January 1972 by Castaic Reservoir, capacity, 324,000 acre-ft (399 hm ${ }^{3}$ ). Imported water from California Water Project stored and released at Castaic Dam.

AVERAGE DISCHARGE, - -24 years, $35.7 \mathrm{ft}^{3} / \mathrm{s}\left(1.011 \mathrm{~m}^{3} / \mathrm{s}\right), 25,860 \mathrm{acre}-\mathrm{ft} / \mathrm{yr}(31.9 \mathrm{hm} / \mathrm{yr})$.

EXTREMES FOR PERIOD OF RECORD.--Maximum discharge, $68,800 \mathrm{ft}^{3} / \mathrm{s}\left(1,950 \mathrm{~m}^{3} / \mathrm{s}\right) \mathrm{Jan}, 25$, 1969, gage height, $19.01 \mathrm{ft}(5.794 \mathrm{~m})$, from rating curve extended above $9,200 \mathrm{ft} / \mathrm{s}\left(261 \mathrm{~m}^{3} / \mathrm{s}\right)$ on basis of field estinate of maximum flow; no flow at times in some years.

EXTREMES FOR CURRENT YEAR.--Maximum discharge, $1,700 \mathrm{ft}^{3} / \mathrm{s}\left(48.1 \mathrm{~m}^{3} / \mathrm{s}\right.$ ) Feb, 9 (1400 hrs), gage height, $5.43 \mathrm{ft}$ $(1.655 \mathrm{~m})$, no other peak above base of $750 \mathrm{ft} / \mathrm{s}(21.2 \mathrm{~m} / \mathrm{s})$; minimum daily, $1.9 \mathrm{ft}^{3} / \mathrm{s}\left(0.054 \mathrm{~m}^{3} / \mathrm{s}\right) \mathrm{Aug}$. 30 to Sept. 1 .

DISCHARGE, IN CUBIC FEET PER SECOND, WATER YEAR OCTOBER 1975 TO SEPTEMBER 1976 MEAN VALUES

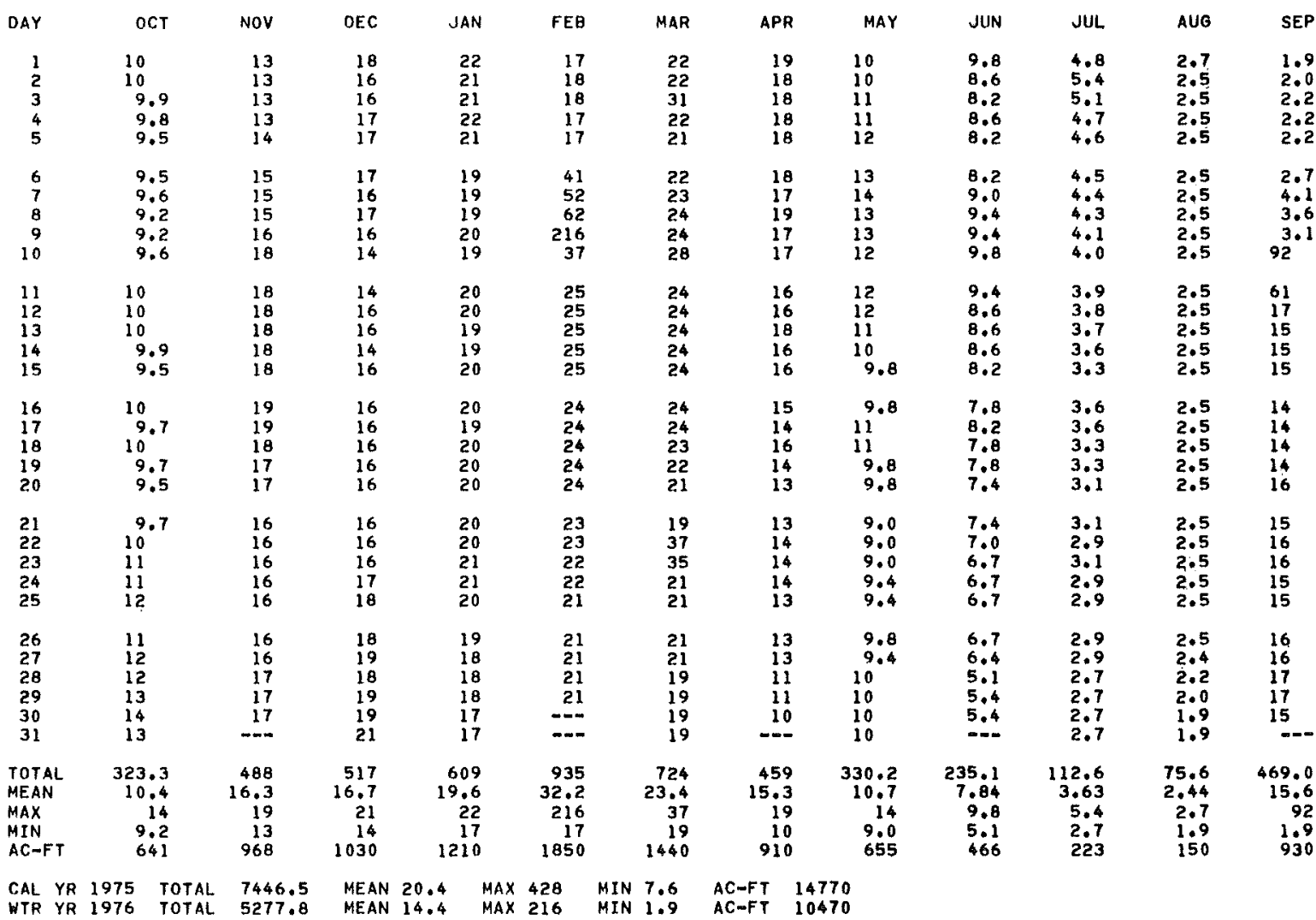


11108500 SANTA CLARA RIVER AT LOS ANGELES-VENTURA COUNTY LINE, CA--Continued

WATER-QUALITY RECORDS

PERIOD OF RECORD. - -Water years 1969 to current year.

CHEMICAL ANALYSIS: Water years 1969,1972 to current year.

WATER TEMPERATURES: Water years 1969 to current year.

SEDIMENT RECORDS: Water years 1969 to current year.

PERIOD OF DAILY RECORD. - -

SPECIFIC CONDUCTANCE: June 1969, to current year.

$\mathrm{pH}$ : June to September 1969.

CHLORIDE: June to September 1969

WATER TEMPERATURES: October 1968 to current year.

SEDIMENT RECORDS: October 1968 to current year.

INSTRUNENTATION,--Watex-quality monitor from June to September 1969. Specific conductance recorder since June 1969 .

REMARKS.-- The letter "A" following a date indicates chemical-quality data furnished by California Department of Water Resources. Missing specific conductance data due to probe or recorder malfunction.

EXTREMES FOR PERIOD OF DAILY RECORD, -

SPECIFIC CONDUCTANCE: Maximum, 3,600 micromhos Mar. 31, 1971; minimum recorded, 665 micromhos Jan. 18 , 1973.

SEDINENT CONCENTRATIONS: Maximum daily mean, 27,400 mg/1 Nov, 29, 1970; minimum daily mean, 4 mg/1

Sept. 9,1976

SEDIMENT DISCHARGE: Maximum daily, 3,300,000 tons (2,990,000 tonnes), estimated, Feb. 25, 1969; minimum daily, 0.03 ton (0.03 tonne) Sept. 9, 1976 .

EXTREMES FOR CURRENT YEAR. - -

SPECIFIC CONDUCTANCE: Maximum recorded, 2,490 micromhos Aug, 30; minimum recorded, 788 micromhos Sept. 10. SEDIMENT CONCENTRATIONS: Maximum daily mean, 4,020 mg/1 Sept. 1i; minimum daily mean, $4 \mathrm{mg} / 1 \mathrm{Sept} 9$.

SEDIMENT DISCHARGE: Maximum daily, 3,970 tons ( 3,600 tonnes) Feb. 9 ; minimum daily, 0.03 ton (0.03 tonnes) Sept. 9 .

CHEMICAL ANALYSES, WATER YEAR OCTOBER 1975 TO SEPTEMBER 1976

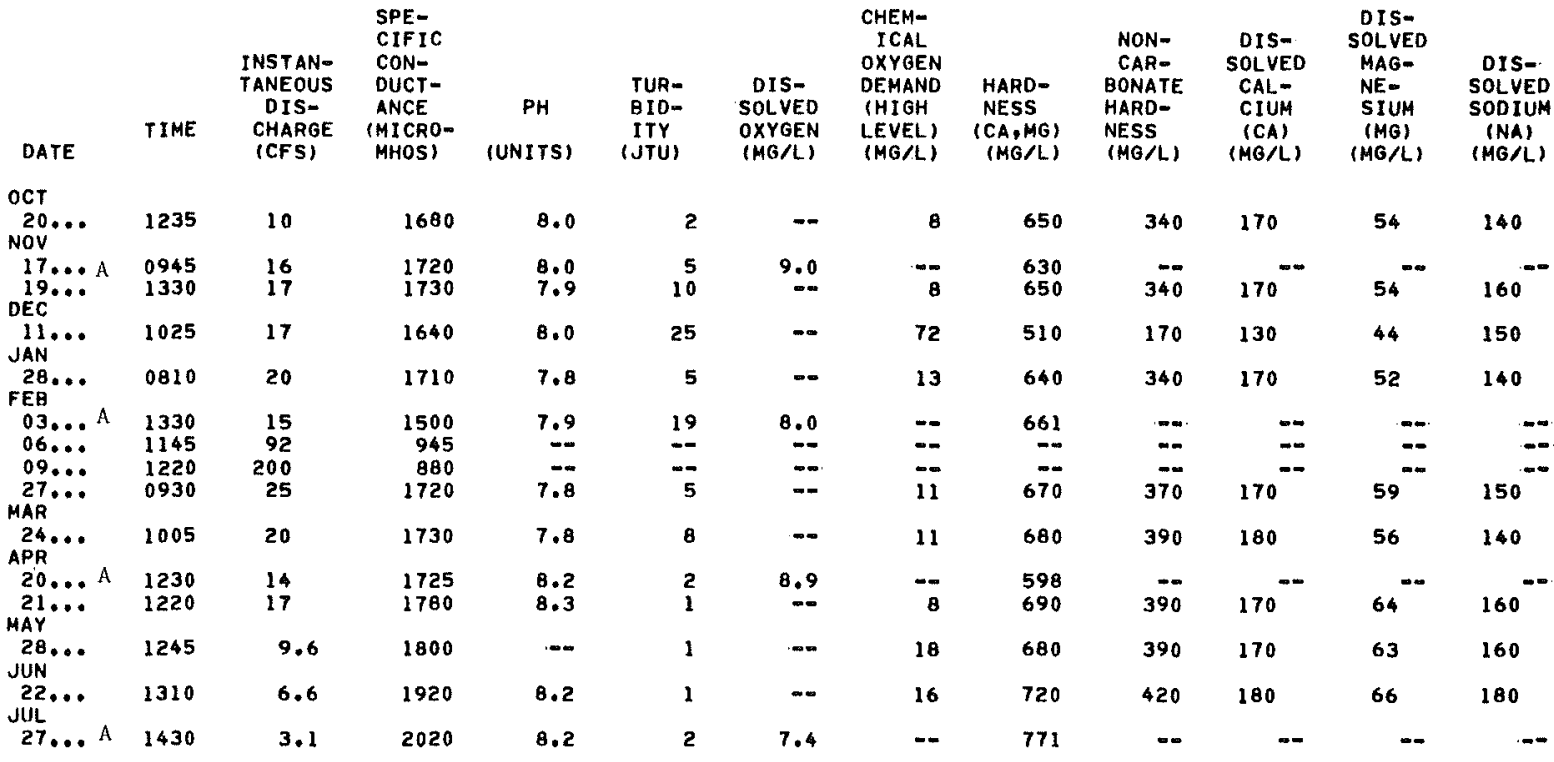


CHEMICAL ANALYSES, WATER YEAR OCTOBER 1975 TO SEPTEMBER 1976

\begin{tabular}{|c|c|c|c|c|c|c|c|c|c|c|c|}
\hline DATE & $\begin{array}{l}\text { DIS- } \\
\text { SOLVED } \\
\text { SOLIDS } \\
\text { (TONS } \\
\text { PER } \\
\text { DAYI }\end{array}$ & $\begin{array}{c}\text { TOTAL } \\
\text { NITRITE } \\
\text { PLUS } \\
\text { NITRATE } \\
\text { (N) } \\
\text { (NG/L) }\end{array}$ & $\begin{array}{l}\text { TOTAL } \\
\text { AMMONIA } \\
\text { NITRO- } \\
\text { GEN } \\
\text { (N) } \\
\text { (HG/L) }\end{array}$ & $\begin{array}{l}\text { TOTAL } \\
\text { ORGANIC } \\
\text { NITRO- } \\
\text { GEN } \\
\text { (N) } \\
\text { (NG/L) }\end{array}$ & $\begin{array}{l}\text { TOTAL } \\
\text { KJEL- } \\
\text { DAHL } \\
\text { NITRO- } \\
\text { GEN } \\
\text { (N) } \\
\text { (HG/L) }\end{array}$ & $\begin{array}{l}\text { TOTAL } \\
\text { NITRO- } \\
\text { GEN } \\
\text { (N) } \\
\text { (MG/L) }\end{array}$ & $\begin{array}{l}\text { TOTAL } \\
\text { NITRO- } \\
\text { GEN } \\
\text { (NO3) } \\
\text { (MG/L) }\end{array}$ & $\begin{array}{l}\text { TOTAL } \\
\text { PHOS- } \\
\text { PHORUS } \\
\text { (P) } \\
\text { (MG/L) }\end{array}$ & $\begin{array}{c}\text { DIS- } \\
\text { SOLVED } \\
\text { BORON } \\
\text { (B) } \\
\text { (UG/L) }\end{array}$ & $\begin{array}{c}\text { TOTAL } \\
\text { ORGANIC } \\
\text { CARBON } \\
\text { (C) } \\
\text { (MG/L) }\end{array}$ & $\begin{array}{l}\text { METHY- } \\
\text { LENE } \\
\text { BLUE } \\
\text { ACTIVE } \\
\text { SUB- } \\
\text { STANCE } \\
\text { (MG/L) }\end{array}$ \\
\hline OCT & & & & & & & & & & & \\
\hline$\underset{\mathrm{NOV}}{20} \ldots$ & 34.0 & 2.9 & .07 & .84 & .91 & 3.8 & 17 & 1.2 & 580 & 5.7 & .40 \\
\hline $\begin{array}{l}17 \ldots A \\
19 \ldots \ldots\end{array}$ & $\begin{array}{l}52.4 \\
58.3\end{array}$ & 3.0 & .04 & 2.0 & $2.0^{-\infty}$ & $5.0^{-\infty}$ & $22^{--}$ & .97 & 770 & 6.9 & $=$ \\
\hline $\operatorname{JAN}_{11} \cdots$ & 49.1 & 6.8 & 1.3 & 7.1 & 0.4 & 15 & 67 & 5.9 & 1500 & 23 & 8.0 \\
\hline FEB & 67.0 & 4.0 & .41 & 1.6 & 2.0 & 6.0 & 27 & 1.7 & 830 & 5.9 & .10 \\
\hline $\begin{array}{l}03 \ldots A \mathrm{~A} \\
06 \ldots \ldots\end{array}$ & $\begin{array}{l}51 \cdot 2 \\
164\end{array}$ & $\ddot{-\infty}$ & $\ddot{-a}$ & $=$ & $=$ & $=$ & $=$ & $=-$ & $=$ & $=$ & $=$ \\
\hline $\begin{array}{l}09 \ldots \\
27 \ldots \\
\text { MAR }\end{array}$ & $\begin{array}{r}334 \\
87.8\end{array}$ & 2.9 &.$\overline{.02}$ & .46 & .48 & $3.4^{--}$ & $15^{--}$ & .75 & 680 & 8.5 & .00 \\
\hline$\underset{A P R}{24} \cdots$ & 68.0 & 2.4 & .04 & .45 & .49 & 2.9 & 13 & .60 & 660 & 4.4 & .00 \\
\hline$\underset{M A Y}{20 \ldots A}$ & $\begin{array}{l}51.3 \\
63.8\end{array}$ & 1.0 & .02 & .00 & $N . \overline{0}$ & $1 . B^{-\infty}$ & $8 . \overline{0}$ & .45 & 750 & 3.0 & .00 \\
\hline$\underset{\text { JUN }}{28} \cdots$ & 35.8 & 1.3 & .05 & .19 & .24 & 1.5 & 6,8 & .42 & 770 & 1.9 & .00 \\
\hline $\begin{array}{l}22 \ldots \\
\text { JUL }\end{array}$ & 25.8 & 1.2 & .04 & .11 & .15 & 1.4 & 6.0 & .30 & 580 & 2.2 & .00 \\
\hline $27 \ldots A$ & 13.8 & -- & -- & -- & -- & - & $-\infty$ & -- & $-\infty$ & -- & - \\
\hline
\end{tabular}

CHEMICAL ANALYSES, WATER YEAR OCTOBER 1975 TO SEPTEMBER 1976

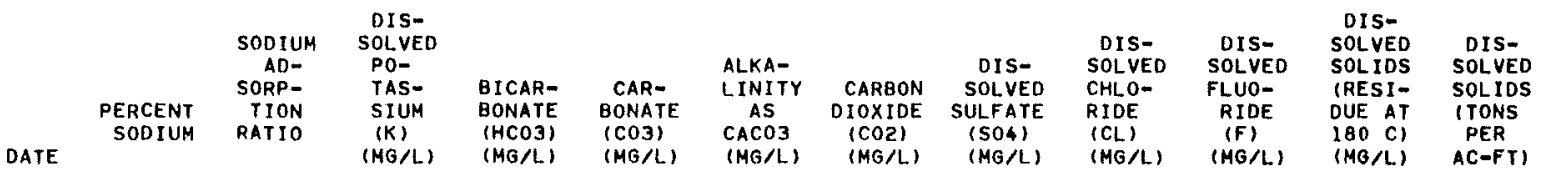

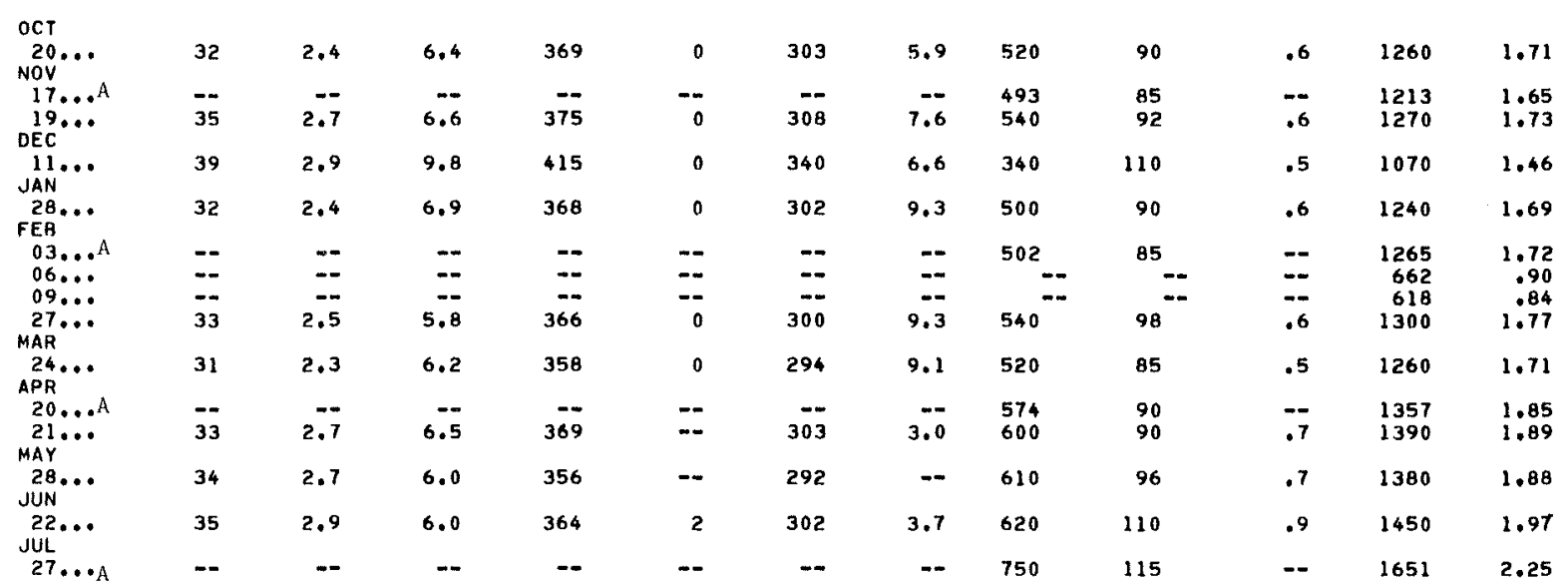


11108500 SANTA CLARA RIVER AT LOS ANGELES-VENTURA COUNTY LINE, CA--Continued CHEMICAL ANALYSES, WATER YEAR OCTOBER 1975 TO SEPTEMBER 1976

\begin{tabular}{|c|c|c|c|c|c|c|c|c|c|c|c|c|}
\hline DATE & TIME & $\begin{array}{l}\text { TOTAL } \\
\text { PCB } \\
\text { (UG/L) }\end{array}$ & $\begin{array}{l}\text { TOTAL } \\
\text { ALORIN } \\
\text { (UG/L) }\end{array}$ & $\begin{array}{l}\text { TOTAL } \\
\text { CHLOR- } \\
\text { DANE } \\
\text { (UG/L) }\end{array}$ & $\begin{array}{l}\text { TOTAL } \\
\text { DDD } \\
\text { (UG/L) }\end{array}$ & $\begin{array}{l}\text { TOTAL } \\
\text { DDE } \\
\text { (UG/L) }\end{array}$ & $\begin{array}{l}\text { TOTAL } \\
\text { ODT } \\
\text { (UOAL) }\end{array}$ & $\begin{array}{l}\text { TOTAL } \\
\text { DI- } \\
\text { AZINON } \\
\text { (UG/L) }\end{array}$ & $\begin{array}{l}\text { TOTAL } \\
\text { OI- } \\
\text { ELDRIN } \\
\text { (UG/L) }\end{array}$ & $\begin{array}{l}\text { TOTAL } \\
\text { ENDRIN } \\
\text { (UG/L) }\end{array}$ & $\begin{array}{l}\text { TOTAL } \\
\text { ETHION } \\
\text { (UG/L) }\end{array}$ & $\begin{array}{l}\text { TOTAL } \\
\text { HEPTA- } \\
\text { CHLOR } \\
\text { (UG/L) }\end{array}$ \\
\hline $\begin{array}{l}\text { JUN } \\
22 \ldots . .\end{array}$ & 1310 & .0 & .00 & .0 & .00 & .00 & .00 & .00 & .00 & .00 & .00 & .00 \\
\hline JUN & .00 & .00 & .00 & .00 & .00 & .00 & .00 & 0 & .00 & .00 & .00 & .00 \\
\hline
\end{tabular}

\begin{tabular}{|c|c|c|c|c|c|c|c|c|c|}
\hline DATE & TIME & $\begin{array}{c}\text { TOTAL } \\
\text { ARSENIC } \\
\text { (USS) } \\
\text { (UG/L) }\end{array}$ & $\begin{array}{c}\text { DIS- } \\
\text { SOLVED } \\
\text { ARSENIC } \\
\text { (AS) } \\
\text { (UG/L) }\end{array}$ & $\begin{array}{c}\text { TOTAL } \\
\text { CAD } \\
\text { MIUM } \\
\text { (CD) } \\
\text { (UG/L) }\end{array}$ & $\begin{array}{l}\text { DIS- } \\
\text { SOLVED } \\
\text { CAD- } \\
\text { MIUM } \\
\text { (CD) } \\
\text { (UG/L) }\end{array}$ & $\begin{array}{l}\text { TOTAL } \\
\text { CHRO- } \\
\text { MIUM } \\
\text { (CR) } \\
\text { (UG/L) }\end{array}$ & $\begin{array}{c}\text { HEXA- } \\
\text { VALENT } \\
\text { CHRO- } \\
\text { MIUM } \\
\text { (CRG) } \\
\text { (UG/L) }\end{array}$ & $\begin{array}{l}\text { OIS- } \\
\text { SOLVED } \\
\text { CHRO- } \\
\text { MIUH } \\
\text { (CR) } \\
\text { (UG/L) }\end{array}$ & $\begin{array}{l}\text { DIS- } \\
\text { SOLVED } \\
\text { COPPER } \\
\text { (CU) } \\
\text { (UG/L) }\end{array}$ \\
\hline $\begin{array}{l}\text { OCT } \\
20 . . .\end{array}$ & 1235 & 2 & -- & 0 & -- & 70 & $\cdots$ & - & -- \\
\hline $19 . .$. & 1330 & 2 & -- & 20 & -- & 10 & -- & -- & $\cdots$ \\
\hline JAN & 1025 & 2 & -- & $<10$ & $=$ & 0 & -- & -- & $\cdots$ \\
\hline $28 \ldots$ & 0810 & 2 & -- & $<10$ & -- & 0 & -- & - & - \\
\hline$\underset{M A R}{27} \ldots$ & 0930 & 2 & -- & $<10$ & -- & 0 & -- & -- & -- \\
\hline $24 \ldots$ & 1005 & 2 & -- & $<10$ & -- & 0 & -- & - & $\cdots$ \\
\hline $21 . .$. & 1220 & 1 & -- & $<10$ & -- & 10 & -- & -- & - \\
\hline $25 \ldots A$ & 1130 & -- & 0 & -- & 0 & $-\bar{c}$ & 0 & 0 & 0 \\
\hline & 1245 & & & & -- & 10 & - & -- & - \\
\hline 22. & 1310 & 2 & -- & 0 & -- & 20 & -- & $\cdots$ & -- \\
\hline
\end{tabular}

\begin{tabular}{|c|c|c|c|c|c|c|c|c|c|}
\hline DATE & $\begin{array}{l}\text { TOTAL } \\
\text { IRON } \\
\text { (FE) } \\
(U G / L)\end{array}$ & $\begin{array}{l}\text { DIS- } \\
\text { SOLED } \\
\text { IRON } \\
\text { (FE) } \\
\text { (UGL) }\end{array}$ & $\begin{array}{c}\text { TOTAL } \\
\text { LEAD } \\
\text { (PBD) } \\
(U G / L)\end{array}$ & $\begin{array}{l}\text { DIS- } \\
\text { SOLVED } \\
\text { LEAD } \\
\text { (PB) } \\
\text { (UG/L) }\end{array}$ & $\begin{array}{l}\text { TOTAL } \\
\text { MAN- } \\
\text { GANESE } \\
\text { (MN) } \\
\text { (UOAL) }\end{array}$ & $\begin{array}{l}\text { DIS- } \\
\text { SOLVED } \\
\text { MAN- } \\
\text { GANESE } \\
\text { (MN) } \\
\text { (UG/L) }\end{array}$ & $\begin{array}{c}\text { TOTAL } \\
\text { MERCURY } \\
\text { (HG) } \\
\text { (UGL) }\end{array}$ & $\begin{array}{l}\text { DIS- } \\
\text { SOLVED } \\
\text { ZINC } \\
\text { IZN } \\
(U G / L)\end{array}$ & $\begin{array}{c}\text { TOTAL } \\
\text { SELE- } \\
\text { NIUM } \\
\text { (SE) } \\
(U G / L)\end{array}$ \\
\hline $\begin{array}{l}\text { OCT } \\
20 \ldots\end{array}$ & 280 & -- & 100 & -- & 70 & -- & .0 & -- & 2 \\
\hline $19 .$. & 2600 & $\cdots$ & $<100$ & -- & 100 & -- & .0 & - & 3 \\
\hline & 970 & -- & $<100$ & - & 180 & - & .4 & -- & 5 \\
\hline & 1600 & $\cdots$ & $<100$ & -- & 210 & -- & .0 & -- & 3 \\
\hline & 630 & -- & $<100$ & -- & 150 & -- & .2 & -- & 4 \\
\hline $24 \ldots$ & 2400 & -- & $<100$ & -- & 130 & -- & .0 & -- & 2 \\
\hline $211 \ldots$ & 240 & -- & $<200$ & $=$ & 90 & -- & .0 & -- & 3 \\
\hline$\ldots A$ & -- & 10 & $\overline{-}$ & 0 & 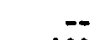 & 0 & $-\square$ & 0 & - \\
\hline & 1400 & -- & 0 & $\cdots$ & 100 & -- & .7 & -- & -- \\
\hline & 960 & -- & 10 & - & 70 & -- & .1 & -- & 3 \\
\hline
\end{tabular}


11108500 SANTA CLARA RIVBR AT LOS ANGELES-VENTURA COUNTY LINE, CA--Continued

SPECIFIC CONDUCTANCE (HICROMHOS/CM AT 25 DEG, C), HATER YEAR OCTOBER 1975 TO SEPTEMBER 1976

\begin{tabular}{|c|c|c|c|c|c|c|c|c|c|c|c|c|}
\hline DAY & \multicolumn{2}{|c|}{ OCTOBER } & MEAN & $\operatorname{HAX}$ & $\begin{array}{c}\text { MIN } \\
\text { NOVEMBE }\end{array}$ & MEAN & $\operatorname{MAX}$ & $\begin{array}{c}\text { MIN } \\
\text { DECEMBE }\end{array}$ & MEAN & MAX & $\begin{array}{c}\text { MIN } \\
\text { JANUAR }\end{array}$ & MEAN \\
\hline $\begin{array}{l}1 \\
2 \\
3 \\
4 \\
5\end{array}$ & $\begin{array}{l}m-- \\
-\infty- \\
=-- \\
--\infty \\
--\infty\end{array}$ & $\begin{array}{l}--- \\
--\infty \\
=-- \\
--- \\
--\infty\end{array}$ & $\begin{array}{l}--\infty \\
-\infty- \\
--\infty \\
-\infty- \\
--\infty\end{array}$ & $\begin{array}{l}1750 \\
1730 \\
1730 \\
1730 \\
1730\end{array}$ & $\begin{array}{l}1600 \\
1580 \\
1580 \\
1550 \\
1600\end{array}$ & $\begin{array}{l}1710 \\
1700 \\
1680 \\
1690 \\
1690\end{array}$ & $\begin{array}{l}1720 \\
1730 \\
1750 \\
1760 \\
1770\end{array}$ & $\begin{array}{l}1660 \\
1630 \\
1620 \\
1710 \\
1710\end{array}$ & $\begin{array}{l}1700 \\
1690 \\
1710 \\
1740 \\
1740\end{array}$ & $\begin{array}{l}1740 \\
1740 \\
1740 \\
1710 \\
1700\end{array}$ & $\begin{array}{l}1650 \\
1620 \\
1620 \\
1600 \\
1610\end{array}$ & $\begin{array}{l}1720 \\
1710 \\
1710 \\
1680 \\
1670\end{array}$ \\
\hline $\begin{array}{r}6 \\
7 \\
8 \\
9 \\
10\end{array}$ & $\begin{array}{l}=0 \\
0-0 \\
1700\end{array}$ & $=0$ & 20 & $\begin{array}{l}1720 \\
1730 \\
1720 \\
1740 \\
1720\end{array}$ & $\begin{array}{l}1650 \\
1580 \\
1610 \\
1590 \\
1650\end{array}$ & $\begin{array}{l}1690 \\
1700 \\
1700 \\
1710 \\
1700\end{array}$ & $\begin{array}{l}1780 \\
1760 \\
1750 \\
1750 \\
1720\end{array}$ & $\begin{array}{l}1690 \\
1670 \\
1650 \\
1610 \\
1590\end{array}$ & $\begin{array}{l}1750 \\
1720 \\
1710 \\
1680 \\
1660\end{array}$ & $\begin{array}{l}1700 \\
1700 \\
1720 \\
1710 \\
1720\end{array}$ & $\begin{array}{l}1580 \\
1580 \\
1600 \\
1610 \\
1610\end{array}$ & $\begin{array}{l}1670 \\
1670 \\
1670 \\
1670 \\
1690\end{array}$ \\
\hline $\begin{array}{l}11 \\
12 \\
13 \\
14 \\
15\end{array}$ & $\begin{array}{l}1660 \\
1680 \\
1660 \\
1670 \\
1670\end{array}$ & $\begin{array}{l}1610 \\
1580 \\
1610 \\
1610 \\
1590\end{array}$ & $\begin{array}{l}1630 \\
1640 \\
1630 \\
1650 \\
1650\end{array}$ & $\begin{array}{l}1720 \\
1710 \\
1720 \\
1720 \\
1720\end{array}$ & $\begin{array}{l}1610 \\
1610 \\
1610 \\
1680 \\
1680\end{array}$ & $\begin{array}{l}1700 \\
1690 \\
1700 \\
1710 \\
1710\end{array}$ & $\begin{array}{l}1720 \\
1740 \\
1740 \\
1760 \\
1780\end{array}$ & $\begin{array}{l}1640 \\
1670 \\
1640 \\
1680 \\
1670\end{array}$ & $\begin{array}{l}1690 \\
1700 \\
1720 \\
1740 \\
1740\end{array}$ & $\begin{array}{l}1740 \\
1710 \\
1700 \\
1690 \\
1680\end{array}$ & $\begin{array}{l}1620 \\
1600 \\
1570 \\
1580 \\
1570\end{array}$ & $\begin{array}{l}1690 \\
1670 \\
1650 \\
1650 \\
1640\end{array}$ \\
\hline $\begin{array}{l}16 \\
17 \\
18 \\
19 \\
20\end{array}$ & $\begin{array}{l}1670 \\
1670 \\
1680 \\
1700 \\
1690\end{array}$ & $\begin{array}{l}1560 \\
1580 \\
1630 \\
1600 \\
1610\end{array}$ & $\begin{array}{l}1640 \\
1650 \\
1670 \\
1670 \\
1670\end{array}$ & $\begin{array}{l}1710 \\
1690 \\
1730 \\
1740 \\
1740\end{array}$ & $\begin{array}{l}1670 \\
1650 \\
1650 \\
1660 \\
1660\end{array}$ & $\begin{array}{l}1690 \\
1680 \\
1700 \\
1730 \\
1720\end{array}$ & $\begin{array}{l}1770 \\
1780 \\
1790 \\
1800 \\
1800\end{array}$ & $\begin{array}{l}1640 \\
1630 \\
1610 \\
1650 \\
1680\end{array}$ & $\begin{array}{l}1740 \\
1750 \\
1760 \\
1770 \\
1760\end{array}$ & $\begin{array}{l}1680 \\
1710 \\
1720 \\
1720 \\
1740\end{array}$ & $\begin{array}{l}1590 \\
1580 \\
1620 \\
1630 \\
1610\end{array}$ & $\begin{array}{l}1650 \\
1660 \\
1690 \\
1680 \\
1680\end{array}$ \\
\hline $\begin{array}{l}21 \\
22 \\
23 \\
24 \\
25\end{array}$ & $\begin{array}{l}1710 \\
1710 \\
1700 \\
1700 \\
1700\end{array}$ & $\begin{array}{l}1630 \\
1640 \\
1600 \\
1590 \\
1540\end{array}$ & $\begin{array}{l}1680 \\
1680 \\
1680 \\
1680 \\
1670\end{array}$ & $\begin{array}{l}1740 \\
1750 \\
1730 \\
1720 \\
1720\end{array}$ & $\begin{array}{l}1690 \\
1670 \\
1650 \\
1640 \\
1650\end{array}$ & $\begin{array}{l}1720 \\
1720 \\
1700 \\
1690 \\
1700\end{array}$ & $\begin{array}{l}1770 \\
1760 \\
1800 \\
1820 \\
1810\end{array}$ & $\begin{array}{l}1650 \\
1650 \\
1630 \\
1650 \\
1640\end{array}$ & $\begin{array}{l}1740 \\
1730 \\
1750 \\
1780 \\
1760\end{array}$ & $\begin{array}{l}1740 \\
1780 \\
1730 \\
1740 \\
1750\end{array}$ & $\begin{array}{l}1600 \\
1630 \\
1630 \\
1630 \\
1620\end{array}$ & $\begin{array}{l}1710 \\
1710 \\
1700 \\
1700 \\
1710\end{array}$ \\
\hline $\begin{array}{l}26 \\
27 \\
28 \\
29 \\
30 \\
31\end{array}$ & $\begin{array}{l}1710 \\
1680 \\
1690 \\
1720 \\
1730 \\
1760\end{array}$ & $\begin{array}{l}1560 \\
1550 \\
1540 \\
1560 \\
1650 \\
1590\end{array}$ & $\begin{array}{l}1670 \\
1640 \\
1660 \\
1670 \\
1700 \\
1720\end{array}$ & $\begin{array}{r}1730 \\
1730 \\
1740 \\
1750 \\
1750 \\
-\end{array}$ & $\begin{array}{r}1640 \\
1650 \\
1680 \\
1680 \\
1680 \\
-0-0\end{array}$ & $\begin{array}{r}1690 \\
1700 \\
1720 \\
1730 \\
1730 \\
-\end{array}$ & $\begin{array}{l}1800 \\
1800 \\
1770 \\
1790 \\
1780 \\
1740\end{array}$ & $\begin{array}{l}1660 \\
1660 \\
1650 \\
1650 \\
1660 \\
1650\end{array}$ & $\begin{array}{l}1760 \\
1750 \\
1730 \\
1750 \\
1720 \\
1720\end{array}$ & $\begin{array}{l}1760 \\
1750 \\
1770 \\
1790 \\
1780 \\
1800\end{array}$ & $\begin{array}{l}1590 \\
1570 \\
1600 \\
1610 \\
1610 \\
1540\end{array}$ & $\begin{array}{l}1700 \\
1690 \\
1710 \\
1740 \\
1720 \\
1690\end{array}$ \\
\hline MONTH & 1760 & 1540 & 1660 & 1750 & 1550 & 1700 & 1820 & 1590 & 1730 & 1800 & 1540 & 1690 \\
\hline \multirow[t]{2}{*}{ DAY } & MAX & MIN & MEAN & $\operatorname{MAX}$ & MIN & MEAN & $\operatorname{MAX}$ & MIN & MEAN & MAX & MIN & MEAN \\
\hline & \multicolumn{3}{|c|}{ FEBRUARY } & \multicolumn{3}{|c|}{ MARCH } & \multicolumn{3}{|c|}{ APRIL } & \multicolumn{3}{|c|}{ MAY } \\
\hline $\begin{array}{l}1 \\
2 \\
3 \\
4 \\
5\end{array}$ & $\begin{array}{l}1790 \\
1690 \\
1690 \\
1600 \\
1710\end{array}$ & $\begin{array}{l}1470 \\
1510 \\
1300 \\
1410 \\
1580\end{array}$ & $\begin{array}{l}1610 \\
1630 \\
1440 \\
1480 \\
1660\end{array}$ & $\begin{array}{r}1810 \\
1830 \\
\ldots-0 \\
\ldots-0\end{array}$ & $\begin{array}{r}1620 \\
1450 \\
- \\
-0 .\end{array}$ & $\begin{array}{r}1750 \\
1700 \\
-0- \\
-\cdots\end{array}$ & $\begin{array}{l}1680 \\
1690 \\
1710 \\
1710 \\
1760\end{array}$ & $\begin{array}{l}1650 \\
1660 \\
1630 \\
1630 \\
1710\end{array}$ & $\begin{array}{l}1670 \\
1670 \\
1680 \\
1680 \\
1730\end{array}$ & $\begin{array}{l}1760 \\
1770 \\
1750 \\
1790 \\
1780\end{array}$ & $\begin{array}{l}1700 \\
1710 \\
1710 \\
1740 \\
1730\end{array}$ & $\begin{array}{l}1730 \\
1740 \\
1740 \\
1760 \\
1750\end{array}$ \\
\hline $\begin{array}{r}6 \\
7 \\
8 \\
9 \\
10\end{array}$ & $\begin{array}{l}m-- \\
=-\infty \\
=-\infty\end{array}$ & $\begin{array}{l}--\infty \\
--\infty \\
-\infty \\
-\infty \\
-\infty\end{array}$ & $\begin{array}{l}=-\infty \\
-\infty \\
-\infty \\
-\infty \\
-\infty\end{array}$ & $\begin{array}{r}-\infty \\
=0 \\
=0 \\
1690\end{array}$ & $=0$ & $\begin{array}{r}-10 \\
-00 \\
1640\end{array}$ & $\begin{array}{l}1770 \\
1780 \\
1770 \\
1780 \\
1790\end{array}$ & $\begin{array}{l}1710 \\
1740 \\
1730 \\
1740 \\
1740\end{array}$ & $\begin{array}{l}1750 \\
1760 \\
1750 \\
1760 \\
1770\end{array}$ & $\begin{array}{l}1760 \\
1740 \\
1770 \\
1770 \\
1770\end{array}$ & $\begin{array}{l}1700 \\
1650 \\
1730 \\
1700 \\
1720\end{array}$ & $\begin{array}{l}1740 \\
1710 \\
1750 \\
1740 \\
1750\end{array}$ \\
\hline $\begin{array}{l}11 \\
12 \\
13 \\
14 \\
15\end{array}$ & $=-$ & $\begin{array}{l}--m \\
--\infty \\
--\infty \\
--\infty \\
--\infty\end{array}$ & $\begin{array}{l}--\infty \\
--- \\
--- \\
=-\infty \\
=-\infty\end{array}$ & $\begin{array}{l}1710 \\
1710 \\
1700 \\
1700 \\
1710\end{array}$ & $\begin{array}{l}1680 \\
1680 \\
1680 \\
1680 \\
1680\end{array}$ & $\begin{array}{l}1690 \\
1690 \\
1690 \\
1690 \\
1690\end{array}$ & $\begin{array}{l}1790 \\
1820 \\
1780 \\
1850 \\
1850\end{array}$ & $\begin{array}{l}1770 \\
1690 \\
1670 \\
1690 \\
1720\end{array}$ & $\begin{array}{l}1780 \\
1770 \\
1740 \\
1790 \\
1780\end{array}$ & $\begin{array}{r}1790 \\
1860 \\
2010 \\
-0 \\
-0\end{array}$ & $\begin{array}{r}1740 \\
1750 \\
1840 \\
=-- \\
--\infty\end{array}$ & $\begin{array}{r}1760 \\
1800 \\
1910 \\
=-\end{array}$ \\
\hline $\begin{array}{l}16 \\
17 \\
18 \\
19 \\
20\end{array}$ & $\begin{array}{l}=-\infty \\
-\infty- \\
=-- \\
=-\infty \\
-=-\end{array}$ & $\begin{array}{l}=-\infty \\
--\infty \\
-\infty \\
-\infty- \\
-\infty\end{array}$ & $\begin{array}{l}-\infty \\
-\infty \\
--\infty \\
-\infty \\
-\infty\end{array}$ & $\begin{array}{l}1710 \\
1700 \\
1700 \\
1700 \\
1730\end{array}$ & $\begin{array}{l}1670 \\
1670 \\
1660 \\
1670 \\
1630\end{array}$ & $\begin{array}{l}1690 \\
1680 \\
1680 \\
1690 \\
1700\end{array}$ & $\begin{array}{l}1930 \\
1930 \\
1850 \\
1860 \\
1830\end{array}$ & $\begin{array}{l}1630 \\
1610 \\
1620 \\
1540 \\
1670\end{array}$ & $\begin{array}{l}1800 \\
1790 \\
1750 \\
1740 \\
1760\end{array}$ & $\begin{array}{l}1990 \\
1890 \\
1900 \\
1950 \\
1950\end{array}$ & $\begin{array}{l}1900 \\
1790 \\
1790 \\
1800 \\
1870\end{array}$ & $\begin{array}{l}1930 \\
1840 \\
1840 \\
1890 \\
1910\end{array}$ \\
\hline $\begin{array}{l}21 \\
22 \\
23 \\
24 \\
25\end{array}$ & 1840 & $=0$ & $\begin{array}{r}=-0 \\
20-0 \\
1810\end{array}$ & $\begin{array}{r}1750 \\
=0 \\
=-\infty \\
=-\infty\end{array}$ & $\begin{array}{r}1550 \\
-- \\
---\end{array}$ & $\begin{array}{r}1690 \\
-0 \\
-0-\end{array}$ & $\begin{array}{l}1800 \\
1730 \\
1770 \\
1780 \\
1890\end{array}$ & $\begin{array}{l}1630 \\
1690 \\
1680 \\
1670 \\
1750\end{array}$ & $\begin{array}{l}1720 \\
1710 \\
1720 \\
1740 \\
1810\end{array}$ & $\begin{array}{l}1940 \\
1930 \\
1900 \\
1850 \\
1890\end{array}$ & $\begin{array}{l}1880 \\
1870 \\
1820 \\
1790 \\
1800\end{array}$ & $\begin{array}{l}1910 \\
1900 \\
1860 \\
1830 \\
1840\end{array}$ \\
\hline $\begin{array}{l}26 \\
27 \\
28 \\
29 \\
30 \\
31\end{array}$ & $\begin{array}{r}1810 \\
1820 \\
1820 \\
1810 \\
-0- \\
-\infty\end{array}$ & $\begin{array}{r}1670 \\
1740 \\
1690 \\
1650 \\
\ldots 0 \\
\ldots-0\end{array}$ & $\begin{array}{r}1770 \\
1780 \\
1770 \\
1750 \\
-\infty \\
-\infty\end{array}$ & $\begin{array}{l}=-\infty \\
=-\infty \\
=-\infty \\
=-\infty \\
=-\infty\end{array}$ & $=-$ & $\begin{array}{l}=- \\
=\infty \\
=-\infty \\
=-\infty \\
=-\infty \\
=\infty\end{array}$ & $\begin{array}{r}-0 . \\
1760 \\
1740 \\
1750 \\
-0\end{array}$ & $\begin{array}{r}-00 \\
1660 \\
1690 \\
1700 \\
-\end{array}$ & $\begin{array}{r}0-0 \\
1690 \\
1710 \\
1730 \\
\end{array}$ & $\begin{array}{l}1920 \\
1880 \\
1840 \\
1860 \\
1820 \\
1820\end{array}$ & $\begin{array}{l}1790 \\
1820 \\
1780 \\
1790 \\
1770 \\
1760\end{array}$ & $\begin{array}{l}1840 \\
1850 \\
1810 \\
1820 \\
1800 \\
1790\end{array}$ \\
\hline MONTH & 1840 & 1300 & 1670 & 1830 & 1450 & 1690 & 1930 & 1540 & 1740 & 2010 & 1650 & 1810 \\
\hline
\end{tabular}


SANTA CLARA RIVER BASIN

11108500 SANTA CLARA RIVER AT LOS ANGELES-VENTURA COUNTY LINE, CA--Continued

SPECIFIC CONDUCTANCE (MICROHHOS/CM AT 25 DEG. C), HATER YEAR OCTOBER 1975 TO SEPTEMBER 1976

\begin{tabular}{|c|c|c|c|c|c|c|c|c|c|c|c|c|}
\hline \multirow{2}{*}{ DAY } & \multirow[t]{2}{*}{$\max$} & MIN & \multirow[t]{2}{*}{ MEAN } & \multirow[t]{2}{*}{$\max$} & MIN & MEAN & $\operatorname{MAX}$ & MIN & MEAN & MAX & MIN & MEAN \\
\hline & & JUNE & & & \multicolumn{2}{|c|}{ JULY } & \multicolumn{3}{|c|}{ AUGUST } & \multicolumn{3}{|c|}{ SEPTEMBER } \\
\hline $\begin{array}{l}1 \\
2 \\
3 \\
4 \\
5\end{array}$ & $\begin{array}{l}1860 \\
1900 \\
1880 \\
1860 \\
1890\end{array}$ & $\begin{array}{l}1720 \\
1770 \\
1810 \\
1750 \\
1680\end{array}$ & $\begin{array}{l}1800 \\
1820 \\
1850 \\
1810 \\
1830\end{array}$ & 20 & 1850 & \begin{tabular}{l}
$=-$ \\
\hdashline 1910
\end{tabular} & $\begin{array}{l}2430 \\
2350 \\
2290 \\
2290 \\
2290\end{array}$ & $\begin{array}{l}2070 \\
2080 \\
2000 \\
2020 \\
1970\end{array}$ & $\begin{array}{l}2230 \\
2240 \\
2170 \\
2170 \\
2150\end{array}$ & $\begin{array}{l}2430 \\
2410 \\
2350 \\
2410 \\
2370\end{array}$ & $\begin{array}{l}2220 \\
2220 \\
2210 \\
2200 \\
2220\end{array}$ & $\begin{array}{l}2330 \\
2320 \\
2290 \\
2290 \\
2280\end{array}$ \\
\hline $\begin{array}{r}6 \\
7 \\
8 \\
9 \\
10\end{array}$ & $\begin{array}{l}1930 \\
1860 \\
1830 \\
1840 \\
1840\end{array}$ & $\begin{array}{l}1700 \\
1730 \\
1750 \\
1740 \\
1560\end{array}$ & $\begin{array}{l}1830 \\
1770 \\
1790 \\
1800 \\
1760\end{array}$ & 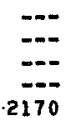 & 20 & 2120 & $\begin{array}{l}2280 \\
2330 \\
2300 \\
2250 \\
2260\end{array}$ & $\begin{array}{l}1960 \\
1970 \\
2020 \\
2030 \\
2030\end{array}$ & $\begin{array}{l}2140 \\
2140 \\
2180 \\
2140 \\
2180\end{array}$ & $\begin{array}{l}2270 \\
2190 \\
2240 \\
2210 \\
2180\end{array}$ & $\begin{array}{l}2050 \\
1910 \\
2030 \\
2100 \\
788\end{array}$ & $\begin{array}{l}2200 \\
2040 \\
2150 \\
2150 \\
1670\end{array}$ \\
\hline $\begin{array}{l}11 \\
12 \\
13 \\
14 \\
15\end{array}$ & $\begin{array}{r}1910 \\
1980 \\
2000 \\
-0 \\
-\because-\end{array}$ & $\begin{array}{r}1710 \\
1810 \\
1760 \\
-\end{array}$ & $\begin{array}{r}1810 \\
1910 \\
1890 \\
-0-\end{array}$ & $\begin{array}{l}2160 \\
2120 \\
2130 \\
2120 \\
2080\end{array}$ & $\begin{array}{l}2050 \\
2020 \\
2040 \\
2000 \\
2000\end{array}$ & $\begin{array}{l}2110 \\
2100 \\
2090 \\
2090 \\
2050\end{array}$ & $\begin{array}{l}2270 \\
2310 \\
2310 \\
2260 \\
2200\end{array}$ & $\begin{array}{l}2100 \\
2100 \\
2110 \\
2110 \\
1900\end{array}$ & $\begin{array}{l}2210 \\
2230 \\
2230 \\
2200 \\
2140\end{array}$ & $\begin{array}{l}1860 \\
1930 \\
1940 \\
1940 \\
1920\end{array}$ & $\begin{array}{r}810 \\
1740 \\
1870 \\
1880 \\
1850\end{array}$ & $\begin{array}{l}1350 \\
1860 \\
1910 \\
1920 \\
1910\end{array}$ \\
\hline $\begin{array}{l}16 \\
17 \\
18 \\
19 \\
20\end{array}$ & $\begin{array}{r}--- \\
2050 \\
\hdashline-\end{array}$ & $\begin{array}{r}1790 \\
\hdashline- \\
\hdashline-\end{array}$ & \begin{tabular}{r}
1940 \\
\hdashline- \\
--
\end{tabular} & $\begin{array}{l}2100 \\
2090 \\
2080 \\
2080 \\
2090\end{array}$ & $\begin{array}{l}2000 \\
1980 \\
1980 \\
1960 \\
1960\end{array}$ & $\begin{array}{l}2050 \\
2060 \\
2050 \\
2050 \\
2050\end{array}$ & $\begin{array}{l}2180 \\
2190 \\
2210 \\
2230 \\
2240\end{array}$ & $\begin{array}{l}2040 \\
2060 \\
2080 \\
2070 \\
2090\end{array}$ & $\begin{array}{l}2140 \\
2150 \\
2160 \\
2180 \\
2190\end{array}$ & $\begin{array}{l}1960 \\
1950 \\
1900 \\
1890 \\
1860\end{array}$ & $\begin{array}{l}1870 \\
1810 \\
1770 \\
1840 \\
1780\end{array}$ & $\begin{array}{l}1910 \\
1900 \\
1870 \\
1870 \\
1830\end{array}$ \\
\hline $\begin{array}{l}21 \\
22 \\
23 \\
24 \\
25\end{array}$ & \begin{tabular}{l}
$\square-$ \\
\hdashline- \\
\hdashline- \\
\hdashline-
\end{tabular} & \begin{tabular}{l}
$-\cdots$ \\
\hdashline- \\
\hdashline- \\
\hdashline-
\end{tabular} & \begin{tabular}{l}
-- \\
\hdashline- \\
\hdashline- \\
$-\cdots$
\end{tabular} & $\begin{array}{l}2110 \\
2090 \\
2150 \\
2210 \\
2260\end{array}$ & $\begin{array}{l}1970 \\
1970 \\
1960 \\
1960 \\
1980\end{array}$ & $\begin{array}{l}2060 \\
2040 \\
2060 \\
2100 \\
2120\end{array}$ & $\begin{array}{l}2270 \\
2290 \\
2310 \\
2310 \\
2340\end{array}$ & $\begin{array}{l}2100 \\
2110 \\
2130 \\
2110 \\
2110\end{array}$ & $\begin{array}{l}2210 \\
2230 \\
2260 \\
2230 \\
2240\end{array}$ & $\begin{array}{l}1860 \\
1850 \\
1810 \\
1800 \\
1790\end{array}$ & $\begin{array}{l}1790 \\
1770 \\
1730 \\
1730 \\
1730\end{array}$ & $\begin{array}{l}1830 \\
1820 \\
1790 \\
1790 \\
1770\end{array}$ \\
\hline $\begin{array}{l}26 \\
27 \\
28 \\
29 \\
30 \\
31\end{array}$ & \begin{tabular}{l}
$-\cdots$ \\
\hdashline- \\
\hdashline- \\
\hdashline-
\end{tabular} & \begin{tabular}{l}
-- \\
\hdashline- \\
\hdashline- \\
\hdashline- \\
--
\end{tabular} & \begin{tabular}{l}
--- \\
\hdashline- \\
\hdashline- \\
\hdashline-
\end{tabular} & $\begin{array}{l}2260 \\
2350 \\
2340 \\
2360 \\
2320 \\
2410\end{array}$ & $\begin{array}{l}1970 \\
1990 \\
2030 \\
2070 \\
2050 \\
2050\end{array}$ & $\begin{array}{l}2120 \\
2160 \\
2190 \\
2210 \\
2200 \\
2210\end{array}$ & $\begin{array}{l}2370 \\
2400 \\
2420 \\
2460 \\
2490 \\
2480\end{array}$ & $\begin{array}{l}2140 \\
2160 \\
2180 \\
2170 \\
2210 \\
2220\end{array}$ & $\begin{array}{l}2260 \\
2290 \\
2300 \\
2320 \\
2340 \\
2350\end{array}$ & $\begin{array}{r}1790 \\
1780 \\
1770 \\
1770 \\
1780 \\
-\end{array}$ & $\begin{array}{r}1730 \\
1720 \\
1700 \\
1690 \\
1700 \\
-\end{array}$ & $\begin{array}{r}1770 \\
1760 \\
1750 \\
1740 \\
1760 \\
-\end{array}$ \\
\hline MONTH & 2050 & 1560 & 1830 & 2410 & 1850 & 2100 & 2490 & 1900 & 2210 & 2430 & 788 & 1930 \\
\hline YEAR & 2490 & 788 & 1830 & & & & & & & & & \\
\hline
\end{tabular}

TEMPERATURE (DEG. C) OF WATER, WATER YEAR OCTOBER 1975 TO SEPTEMBER 1976 ONCE-DAILY

\begin{tabular}{|c|c|c|c|c|c|c|c|c|c|c|c|c|}
\hline DAY & OCT & Nov & DEC & JAN & FEB & MAR & APR & MAY & JUN & JUL & AUG & SEP \\
\hline 1 & -- & $\rightarrow$ & $=-$ & $m$ & -- & 14.0 & $-\cdots$ & $\cdots$ & -- & -- & $\cdots$ & -- \\
\hline 2 & -- & $\cdots$ & 17.0 & -- & -- & $=$ & --- & -- & 26.0 & -- & $-\cdots$ & - \\
\hline 3 & 26.0 & $\cdots$ & - & 14.0 & 17.0 & -- & 15.0 & $\cdots$ & $\cdots$ & $\cdots$ & 28.0 & \\
\hline 4 & -- & 20.0 & $-\cdots$ & $\cdots$ & $-\infty$ & -- & -- & $m$ & -- & $\cdots$ & 23.0 & 25.5 \\
\hline 5 & $\cdots$ & -- & 16.0 & $-\cdots$ & $=-$ & 14.0 & $\cdots$ & $\cdots$ & 16.0 & $\cdots$ & $\cdots$ & $\cdots$ \\
\hline 6 & $-\infty$ & -- & -..- & 14.0 & 10.0 & $-\cdots$ & -- & - & $-\cdots$ & -- & 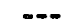 & -- \\
\hline 7 & 23.0 & --- & --- & - & 13.0 & --- & 23.0 & $-\cdots$ & 22.5 & 31.0 & $=-$ & -- \\
\hline 8 & -- & 14.5 & $=-$ & -- & 14.0 & $-=$ & -- & 24.0 & 25.0 & $\cdots$ & -- & - \\
\hline 9 & -- & m. & 18.0 & 14.5 & 14.0 & 17.5 & $\ldots$ & $\cdots$ & $\cdots$ & -- & -- & 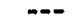 \\
\hline 10 & 22.0 & $\cdots$ & -. & $\cdots$ & 16.0 & -- & 21.0 & $\cdots$ & $=$ & 21.0 & -- & $\cdots$ \\
\hline 11 & $-\infty$ & $\cdots$ & $-\infty$ & $=-$ & $\cdots$ & -- & --- & $\cdots$ & 26.0 & $\cdots$ & -- & $-\cdots$ \\
\hline 12 & $-\infty$ & 16.0 & $m$ & -- & 18.0 & --- & -- & 28.0 & $=$ & $\cdots$ & -.- & \\
\hline 13 & - & $\ldots$ & 9.0 & 14.5 & $\cdots$ & 21.0 & $=-$ & -- & -- & -- & 27.0 & 26.0 \\
\hline 14 & 21.0 & $-\infty$ & -- & -n. & $\cdots$ & $-\cdots$ & --- & $\cdots$ & $\cdots$ & $\cdots$ & -- & \\
\hline 15 & -- & 15.0 & $m$ & $\cdots$ & -.. & $-\infty$ & $\cdots$ & $-\infty$ & $-\infty$ & $-\cdots$ & -- & 20.0 \\
\hline 16 & -- & -- & $-\cdots$ & 18.0 & - & 22,0 & -- & - & 21.0 & $-\infty$ & 26.0 & 24.0 \\
\hline 17 & 21.0 & $\cdots$ & 11.5 & -- & 18.0 & $-\infty$ & -- & $\cdots$ & $=-$ & 26.5 & -.- & \\
\hline 18 & -- & 14.5 & $\cdots$ & -- & -- &.-- & $-\cdots$ & 20.5 & $-\cdots$ & --- & $-\infty$ & $\cdots$ \\
\hline 19 & $-\infty$ & --- & $\cdots$ & $\cdots$ & $-\infty$ & $\ldots$ & -- & -.- & 21.0 & $\cdots$ & $\rightarrow-$ & - \\
\hline 20 & $\cdots$ & $\cdots$ & 11.0 & --- & - & 20.0 & 24.5 & $\cdots$ & $\cdots$ & $\cdots$ & 20.0 & $\cdots$ \\
\hline 21 & 21.5 & 15,0 & $=-\infty$ & -- & -- & $m$ & $\cdots$ & 25.0 & $=--$ & 25.0 & $-\cdots$ & 25.0 \\
\hline 22 & & & $\ldots$ & $\cdots$ & $-\infty$ & $-\cdots$ & $-\infty$ & -- & -- & $\cdots$ & $\cdots$ & \\
\hline 23 & $\cdots$ & $-\infty$ & $-\infty$ & $\cdots$ & $\cdots$ & 21.5 & $-\infty$ & $=-$ & 20.0 & $-\infty$ & 26.0 & -- \\
\hline 24 & 17.5 & $-\infty$ & 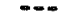 & 16.0 & 16.0 & $\ldots$ & $\cdots$ & $=m$ & $\cdots$ & 22.0 & $\cdots$ & 24.5 \\
\hline 25 & - & $\cdots$ & $\infty$ & $\ldots$ & $\ldots$ & $=--$ & $\ldots$ & 25.0 & $\cdots$ &.- & $\infty$ & $\cdots$ \\
\hline 26 & $\cdots$ & 17.0 & $-\infty$ & $\infty$ & $=$ & $=\infty$ & $-\infty$ & $-\infty$ & $=\infty$ & $-\infty$ & $\ldots$ & $\cdots$ \\
\hline 27 & $\cdots$ & $\cdots$ & 16.0 & 12.0 & 21.0 & 13.0 & 23.0 & $\ldots-$ & $m$ & 29.0 & 28.0 & $\cdots$ \\
\hline 28 & 19.0 & $\cdots$ & $-\infty=$ & $-\infty$ & $\infty$ & $=\infty$ & $\ldots$ & $\rightarrow \infty$ & $\infty$ & $\infty$ & $-\infty$ & $-\infty$ \\
\hline 29 & $\ldots$ & 14,0 & $=-\infty$ & $-\infty$ & $=-$ & $-\infty$ & 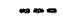 & 18.0 & $=-$ & $\cdots$ & $-\infty$ & $=\infty$ \\
\hline 30 & $\cdots-$ & $=0$ & $\cdots$ & $\infty$ & $=\infty$ & $=-$ & $=-\infty$ & $-m$ & 29.0 & 23.0 & $=\infty$ & $\infty$ \\
\hline 31 & 19.5 & --- & 12.0 & 17.5 & $\cdots$ & 15.0 & $-\infty$ & $\cdots$ & $\cdots$ & $\cdots$ & 21.5 & $\cdots$ \\
\hline NTH & $\ldots$ & $\rightarrow-$ & $m$ & $\ldots$ & $\cdots$ & $-\infty$ & $-\infty$ & $-\infty$ & $-\infty$ & $m$ & $-\infty$ & $-m \infty$ \\
\hline
\end{tabular}




\begin{tabular}{|c|c|c|c|c|c|c|c|c|c|}
\hline \multirow[b]{2}{*}{ DAY } & \multicolumn{3}{|c|}{ OCTOBER } & \multicolumn{3}{|c|}{ NOVEMBER } & \multicolumn{3}{|c|}{ DECEMBER } \\
\hline & $\begin{array}{l}\text { MEAN } \\
\text { DI SCHARGE } \\
\text { (CFS) }\end{array}$ & $\begin{array}{l}\text { MEAN } \\
\text { CONCEN- } \\
\text { TRAIDN } \\
\text { (MG/L) }\end{array}$ & $\begin{array}{l}\text { SEDIMENT } \\
\text { DISCHARGE } \\
\text { (TONS/DAY) }\end{array}$ & $\begin{array}{l}\text { MEAN } \\
\text { DISCHARGE } \\
\text { (CFS) }\end{array}$ & $\begin{array}{l}\text { MEAN } \\
\text { CONCEN- } \\
\text { TRAIION } \\
\text { IMG/L) }\end{array}$ & $\begin{array}{l}\text { SEDIMENT } \\
\text { DISCHARGE } \\
\text { (TONS/DAY) }\end{array}$ & $\begin{array}{l}\text { MEAN } \\
\text { DISCHARGE } \\
\text { (CFS) }\end{array}$ & $\begin{array}{l}\text { MEAN } \\
\text { CONCEN- } \\
\text { TAAION } \\
\text { IMG/L) }\end{array}$ & $\begin{array}{l}\text { SEDIMENT } \\
\text { DISCHARGE } \\
\text { ITONS/DAY }\end{array}$ \\
\hline $\begin{array}{l}1 \\
2 \\
3 \\
4 \\
5\end{array}$ & $\begin{array}{l}10 \\
10 \\
9.9 \\
9.8 \\
9.5\end{array}$ & $\begin{array}{l}50 \\
35 \\
26 \\
26 \\
27\end{array}$ & $\begin{array}{l}1.4 \\
.94 \\
.69 \\
.69 \\
.69\end{array}$ & $\begin{array}{l}13 \\
13 \\
13 \\
13 \\
14\end{array}$ & $\begin{array}{l}55 \\
46 \\
37 \\
28 \\
32\end{array}$ & $\begin{array}{l}1.9 \\
1: 6 \\
1.3 \\
: 98 \\
1.2\end{array}$ & $\begin{array}{l}18 \\
16 \\
16 \\
17 \\
17\end{array}$ & $\begin{array}{l}53 \\
53 \\
54 \\
55 \\
56\end{array}$ & $\begin{array}{l}2.6 \\
2.3 \\
2.3 \\
2.5 \\
2.6\end{array}$ \\
\hline $\begin{array}{r}6 \\
7 \\
8 \\
9 \\
10\end{array}$ & $\begin{array}{l}9.5 \\
9.6 \\
9.2 \\
9.2 \\
9.6\end{array}$ & $\begin{array}{l}27 \\
28 \\
29 \\
30 \\
33\end{array}$ & $\begin{array}{l}.69 \\
.73 \\
.72 \\
.75 \\
.86\end{array}$ & $\begin{array}{l}15 \\
15 \\
15 \\
16 \\
18\end{array}$ & $\begin{array}{l}53 \\
76 \\
78 \\
71 \\
50\end{array}$ & $\begin{array}{l}2.1 \\
3.1 \\
3.2 \\
3.1 \\
2.4 \\
2.4\end{array}$ & $\begin{array}{l}17 \\
16 \\
17 \\
16 \\
14\end{array}$ & $\begin{array}{l}56 \\
56 \\
56 \\
56 \\
57\end{array}$ & $\begin{array}{l}2.6 \\
2.04 \\
2.6 \\
2.64 \\
2.2\end{array}$ \\
\hline $\begin{array}{l}11 \\
12 \\
13 \\
14 \\
15\end{array}$ & $\begin{array}{l}10 \\
10 \\
10 \\
9.9 \\
9.5\end{array}$ & $\begin{array}{l}32 \\
31 \\
29 \\
28 \\
25\end{array}$ & $\begin{array}{l}.86 \\
.84 \\
.78 \\
.75 \\
.64\end{array}$ & $\begin{array}{l}18 \\
18 \\
18 \\
18 \\
18\end{array}$ & $\begin{array}{l}37 \\
37 \\
53 \\
68 \\
73\end{array}$ & $\begin{array}{l}1.8 \\
1.8 \\
2.6 \\
3.3 \\
3.5\end{array}$ & $\begin{array}{l}14 \\
16 \\
16 \\
14 \\
16\end{array}$ & $\begin{array}{l}59 \\
71 \\
84 \\
81 \\
78\end{array}$ & $\begin{array}{l}2.2 \\
3.1 \\
3.6 \\
3.1 \\
3.4\end{array}$ \\
\hline $\begin{array}{l}16 \\
17 \\
18 \\
19 \\
20\end{array}$ & $\begin{array}{c}10 \\
9.7 \\
10 \\
9.7 \\
9.5\end{array}$ & $\begin{array}{l}22 \\
20 \\
18 \\
16 \\
15\end{array}$ & $\begin{array}{l}.59 \\
.52 \\
.49 \\
.42 \\
.38\end{array}$ & $\begin{array}{l}19 \\
19 \\
18 \\
17 \\
17\end{array}$ & $\begin{array}{l}79 \\
85 \\
90 \\
80 \\
70\end{array}$ & $\begin{array}{l}4.1 \\
4.4 \\
4.4 \\
3.7 \\
3.2\end{array}$ & $\begin{array}{l}16 \\
16 \\
16 \\
16 \\
16\end{array}$ & $\begin{array}{l}75 \\
73 \\
66 \\
59 \\
53\end{array}$ & $\begin{array}{l}3.2 \\
3.2 \\
2.9 \\
2.5 \\
2.3\end{array}$ \\
\hline $\begin{array}{l}21 \\
22 \\
23 \\
24 \\
25\end{array}$ & $\begin{array}{l}9.7 \\
10^{\circ} \\
11 \\
11 \\
12\end{array}$ & $\begin{array}{l}14 \\
14 \\
20 \\
30 \\
44\end{array}$ & $\begin{array}{r}.37 \\
: 38 \\
.59 \\
.89 \\
1.44\end{array}$ & $\begin{array}{l}16 \\
16 \\
16 \\
16 \\
16\end{array}$ & $\begin{array}{l}59 \\
59 \\
58 \\
58 \\
57\end{array}$ & $\begin{array}{l}2.5 \\
2.5 \\
2.5 \\
2.5 \\
2.5\end{array}$ & $\begin{array}{l}16 \\
16 \\
16 \\
17 \\
18\end{array}$ & $\begin{array}{l}55 \\
53 \\
69 \\
74 \\
67\end{array}$ & $\begin{array}{l}2.4 \\
2.3 \\
3.0 \\
3.4 \\
3.3\end{array}$ \\
\hline $\begin{array}{l}26 \\
27 \\
28 \\
29 \\
30 \\
31\end{array}$ & $\begin{array}{l}11 \\
12 \\
12 \\
13 \\
14 \\
13\end{array}$ & $\begin{array}{l}58 \\
72 \\
84 \\
67 \\
50 \\
64\end{array}$ & $\begin{array}{l}1.7 \\
2.3 \\
2.7 \\
2.4 \\
1.9 \\
2.2\end{array}$ & $\begin{array}{l}16 \\
16 \\
17 \\
17 \\
17 \\
-2\end{array}$ & $\begin{array}{r}56 \\
55 \\
50 \\
45 \\
49 \\
---\end{array}$ & $\begin{array}{l}2.4 \\
2.4 \\
2.3 \\
2.1 \\
2.2 \\
-. .\end{array}$ & $\begin{array}{l}18 \\
19 \\
18 \\
19 \\
19 \\
21\end{array}$ & $\begin{array}{l}55 \\
49 \\
49 \\
49 \\
49 \\
57\end{array}$ & $\begin{array}{l}2.7 \\
2.5 \\
2.4 \\
2.5 \\
2.5 \\
3.2\end{array}$ \\
\hline TOTAL & 323.3 & --- & 31.26 & 488 & $=-$ & 77.58 & 517 & -- & 84.2 \\
\hline DAY & $\begin{array}{l}\text { MEAN } \\
\text { DISCHARGE } \\
\text { (CFS) }\end{array}$ & $\begin{array}{l}\text { JANUARY } \\
\text { MEAN } \\
\text { CONCEN- } \\
\text { TRATION } \\
\text { (MG/L) }\end{array}$ & $\begin{array}{l}\text { SEDIMENT } \\
\text { OISCHARGE } \\
\text { (TONS/DAY) }\end{array}$ & $\begin{array}{l}\text { MEAN } \\
\text { OISCARGE } \\
\text { (CFS) }\end{array}$ & $\begin{array}{l}\text { FEBRUARY } \\
\text { MEAN } \\
\text { CONEEN- } \\
\text { TRATION } \\
\text { (MG/L) }\end{array}$ & $\begin{array}{l}\text { SEDIMENT } \\
\text { DISCHAREE } \\
\text { (TONS/OAY) }\end{array}$ & $\begin{array}{l}\text { MEAN } \\
\text { DISSCARGE } \\
\text { (CFS) }\end{array}$ & $\begin{array}{l}\text { MARCH } \\
\text { MEAN } \\
\text { CONCEN- } \\
\text { TRATION } \\
\text { (MG/L) }\end{array}$ & $\begin{array}{l}\text { SEDIMENT } \\
\text { DISCARGE } \\
\text { ITONS/DAY }\end{array}$ \\
\hline $\begin{array}{l}1 \\
2 \\
3 \\
4 \\
5\end{array}$ & $\begin{array}{l}22 \\
21 \\
21 \\
22 \\
21\end{array}$ & $\begin{array}{l}57 \\
56 \\
55 \\
55 \\
54\end{array}$ & $\begin{array}{l}3.4 \\
3.2 \\
3.2 \\
3.1 \\
3.3 \\
3.1\end{array}$ & $\begin{array}{l}17 \\
18 \\
18 \\
17 \\
17\end{array}$ & $\begin{array}{l}132 \\
134 \\
136 \\
136 \\
136\end{array}$ & $\begin{array}{l}6.1 \\
6.5 \\
6.6 \\
6.2 \\
6.2\end{array}$ & $\begin{array}{l}22 \\
22 \\
31 \\
22 \\
21\end{array}$ & $\begin{array}{l}402 \\
402 \\
662 \\
180 \\
129\end{array}$ & $\begin{array}{l}24 \\
24 \\
91 \\
11 \\
7.3\end{array}$ \\
\hline $\begin{array}{r}6 \\
7 \\
8 \\
9 \\
10\end{array}$ & $\begin{array}{l}19 \\
19 \\
19 \\
20 \\
19\end{array}$ & $\begin{array}{l}54 \\
60 \\
66 \\
73 \\
79\end{array}$ & $\begin{array}{l}2.8 \\
3.1 \\
3.4 \\
3.9 \\
4.1\end{array}$ & $\begin{array}{r}41 \\
52 \\
62 \\
216 \\
37 \\
37\end{array}$ & $\begin{array}{r}2420 \\
1410 \\
1360 \\
3020 \\
689\end{array}$ & $\begin{array}{r}431 \\
576 \\
432 \\
3970 \\
86\end{array}$ & $\begin{array}{l}22 \\
23 \\
24 \\
24 \\
28\end{array}$ & $\begin{array}{l}152 \\
175 \\
198 \\
220 \\
250\end{array}$ & $\begin{array}{l}9.0 \\
11 \\
13 \\
14 \\
19\end{array}$ \\
\hline $\begin{array}{l}11 \\
12 \\
13 \\
14 \\
15\end{array}$ & $\begin{array}{l}20 \\
20 \\
19 \\
19 \\
20\end{array}$ & $\begin{array}{l}85 \\
91 \\
97 \\
87 \\
77\end{array}$ & $\begin{array}{l}4.6 \\
4.9 \\
5.0 \\
4.5 \\
4.2\end{array}$ & $\begin{array}{l}25 \\
25 \\
25 \\
25 \\
25\end{array}$ & $\begin{array}{l}430 \\
353 \\
310 \\
299 \\
272\end{array}$ & $\begin{array}{l}29 \\
24 \\
21 \\
20 \\
18\end{array}$ & $\begin{array}{l}24 \\
24 \\
24 \\
24 \\
24\end{array}$ & $\begin{array}{l}180 \\
145 \\
125 \\
120 \\
105\end{array}$ & $\begin{array}{c}12 \\
9.4 \\
8.1 \\
7.8 \\
6.8\end{array}$ \\
\hline $\begin{array}{l}16 \\
17 \\
18 \\
19 \\
20\end{array}$ & $\begin{array}{l}20 \\
19 \\
20 \\
20 \\
20\end{array}$ & $\begin{array}{r}67 \\
71 \\
75 \\
79 \\
83\end{array}$ & $\begin{array}{l}3.6 \\
3.6 \\
4.1 \\
4.3 \\
4.5\end{array}$ & $\begin{array}{l}24 \\
24 \\
24 \\
24 \\
24\end{array}$ & $\begin{array}{l}247 \\
219 \\
205 \\
200 \\
233\end{array}$ & $\begin{array}{l}16 \\
14 \\
13 \\
13 \\
15\end{array}$ & $\begin{array}{l}24 \\
24 \\
23 \\
22 \\
21\end{array}$ & $\begin{array}{l}94 \\
90 \\
81 \\
65 \\
35\end{array}$ & $\begin{array}{l}6.1 \\
5.8 \\
5.0 \\
3.9 \\
2.0\end{array}$ \\
\hline $\begin{array}{l}21 \\
22 \\
23 \\
24 \\
25\end{array}$ & $\begin{array}{l}20 \\
20 \\
21 \\
21 \\
20\end{array}$ & $\begin{array}{r}87 \\
91 \\
100 \\
162 \\
189\end{array}$ & $\begin{array}{r}4.7 \\
4.9 \\
5.7 \\
9.2 \\
10\end{array}$ & $\begin{array}{l}23 \\
23 \\
22 \\
22 \\
21\end{array}$ & $\begin{array}{l}289 \\
284 \\
272 \\
247 \\
208\end{array}$ & $\begin{array}{l}18 \\
18 \\
16 \\
15 \\
12\end{array}$ & $\begin{array}{l}19 \\
37 \\
35 \\
21 \\
21\end{array}$ & $\begin{array}{r}35 \\
682 \\
779 \\
263 \\
249\end{array}$ & $\begin{array}{c}1.8 \\
162 \\
126 \\
15 \\
14\end{array}$ \\
\hline $\begin{array}{l}26 \\
27 \\
28 \\
29 \\
30 \\
31\end{array}$ & $\begin{array}{l}19 \\
18 \\
18 \\
18 \\
17 \\
17\end{array}$ & $\begin{array}{l}216 \\
242 \\
215 \\
187 \\
160 \\
132\end{array}$ & $\begin{array}{l}11 \\
12 \\
10 \\
9.1 \\
7.3 \\
6.1\end{array}$ & \begin{tabular}{r}
21 \\
21 \\
21 \\
21 \\
\hdashline- \\
--
\end{tabular} & $\begin{array}{l}175 \\
152 \\
212 \\
291 \\
-\square \\
---\end{array}$ & \begin{tabular}{c}
9.9 \\
8.6 \\
12 \\
16 \\
\hdashline- \\
$-\cdots$
\end{tabular} & $\begin{array}{l}21 \\
21 \\
19 \\
19 \\
19 \\
19\end{array}$ & $\begin{array}{l}230 \\
214 \\
197 \\
181 \\
165 \\
150\end{array}$ & $\begin{array}{l}13 \\
12 \\
10 \\
9.3 \\
8.5 \\
7.7\end{array}$ \\
\hline TOTAL & 609 & --- & 166.7 & 935 & $--\cdot$ & 5835.1 & 724 & $\cdots$ & 669.5 \\
\hline
\end{tabular}


11108500 SANTA CLARA RIVER AT LOS ANGELES-VENTURA COUNTY LINE, CA--Continued

SUSPENDED-SEDIMENT DISCHARGE (TONS/DAY), WATER YEAR OCTOBER 1975 TO SEPTEMBER 1976

\begin{tabular}{|c|c|c|c|c|c|c|c|c|c|}
\hline DAY & $\begin{array}{l}\text { MEAN } \\
\text { DISCHARGE } \\
\text { (CFS) }\end{array}$ & $\begin{array}{l}\text { APRIL } \\
\text { MEAN } \\
\text { CONCEN- } \\
\text { TRATION } \\
\text { (MG/L) }\end{array}$ & $\begin{array}{l}\text { SEDIMENT } \\
\text { DISCHARGE } \\
\text { (TONS/DAY) }\end{array}$ & $\begin{array}{l}\text { MEAN } \\
\text { DISCHARGE } \\
\text { (CFS) }\end{array}$ & $\begin{array}{l}\text { MAY } \\
\text { MEAN } \\
\text { CONCEN- } \\
\text { TRATION } \\
\text { (MG/L) }\end{array}$ & $\begin{array}{l}\text { SEDIMENT } \\
\text { OISCHARGE } \\
\text { (TONS/OAY) }\end{array}$ & $\begin{array}{l}\text { MEAN } \\
\text { DISCARGE } \\
\text { (CFS) }\end{array}$ & $\begin{array}{l}\text { JUNE } \\
\text { MEAN } \\
\text { CONCEN- } \\
\text { TRAION } \\
\text { (MG/L) }\end{array}$ & $\begin{array}{l}\text { SEDIMENT } \\
\text { OISCARGE } \\
\text { (TONS/DAY) }\end{array}$ \\
\hline $\begin{array}{l}1 \\
2 \\
3 \\
4 \\
5\end{array}$ & $\begin{array}{l}19 \\
18 \\
18 \\
18 \\
18\end{array}$ & $\begin{array}{r}128 \\
112 \\
95 \\
93 \\
78\end{array}$ & $\begin{array}{l}6.6 \\
5.4 \\
4.6 \\
4.5 \\
3.8\end{array}$ & $\begin{array}{l}10 \\
10 \\
11 \\
11 \\
12\end{array}$ & $\begin{array}{l}15 \\
24 \\
32 \\
38 \\
45\end{array}$ & $\begin{array}{r}: 41 \\
: 65 \\
: 95 \\
1: 1 \\
1.5\end{array}$ & $\begin{array}{l}9.8 \\
8.6 \\
8.2 \\
8.6 \\
8.2\end{array}$ & $\begin{array}{l}42 \\
45 \\
45 \\
48 \\
50\end{array}$ & $\begin{array}{l}1: 1 \\
1: 0 \\
1: 0 \\
1: 1 \\
1.1\end{array}$ \\
\hline $\begin{array}{r}6 \\
7 \\
8 \\
9 \\
10\end{array}$ & $\begin{array}{l}18 \\
17 \\
19 \\
17 \\
17\end{array}$ & $\begin{array}{l}65 \\
50 \\
53 \\
65 \\
76\end{array}$ & $\begin{array}{l}3.2 \\
2.3 \\
2.7 \\
3.0 \\
3.0\end{array}$ & $\begin{array}{l}13 \\
13 \\
13 \\
13 \\
12\end{array}$ & $\begin{array}{l}43 \\
41 \\
39 \\
39 \\
36\end{array}$ & $\begin{array}{l}1.5 \\
1.5 \\
11.4 \\
1.4 \\
1.2\end{array}$ & $\begin{array}{l}8.2 \\
9.0 \\
9.4 \\
9.4 \\
9.8\end{array}$ & $\begin{array}{l}48 \\
46 \\
44 \\
38 \\
38\end{array}$ & $\begin{array}{l}1.1 \\
1: 1 \\
1.1 \\
1096\end{array}$ \\
\hline $\begin{array}{l}11 \\
12 \\
13 \\
14 \\
15\end{array}$ & $\begin{array}{l}16 \\
16 \\
18 \\
16 \\
16\end{array}$ & $\begin{array}{r}92 \\
115 \\
124 \\
117 \\
111\end{array}$ & $\begin{array}{l}4.0 \\
5.0 \\
6.0 \\
5.1 \\
4.8\end{array}$ & $\begin{array}{l}12 \\
12 \\
11 \\
10 \\
9.8\end{array}$ & $\begin{array}{l}33 \\
30 \\
29 \\
28 \\
28\end{array}$ & $\begin{array}{r}1.1 \\
.97 \\
.86 \\
.76 \\
.74\end{array}$ & $\begin{array}{l}9.4 \\
8.6 \\
8.6 \\
8.6 \\
8.2\end{array}$ & $\begin{array}{l}38 \\
38 \\
38 \\
38 \\
45\end{array}$ & $\begin{array}{r}.96 \\
.88 \\
.88 \\
1.08\end{array}$ \\
\hline $\begin{array}{l}16 \\
17 \\
19 \\
19 \\
20\end{array}$ & $\begin{array}{l}15 \\
14 \\
16 \\
14 \\
13\end{array}$ & $\begin{array}{r}100 \\
82 \\
59 \\
40 \\
28\end{array}$ & $\begin{array}{l}4.1 \\
3.1 \\
2.5 \\
1.5 \\
.98\end{array}$ & $\begin{array}{c}9.8 \\
11 \\
11 \\
9.8 \\
9.8\end{array}$ & $\begin{array}{l}26 \\
25 \\
23 \\
28 \\
35\end{array}$ & $\begin{array}{l}.69 \\
.74 \\
.68 \\
.74 \\
.93\end{array}$ & $\begin{array}{l}7.8 \\
8.8 \\
7.8 \\
7.8 \\
7.4\end{array}$ & $\begin{array}{l}45 \\
47 \\
47 \\
48 \\
58\end{array}$ & $\begin{array}{l}195 \\
1: 0 \\
: 99 \\
1: 0 \\
1.2\end{array}$ \\
\hline $\begin{array}{l}21 \\
22 \\
23 \\
24 \\
25\end{array}$ & $\begin{array}{l}13 \\
14 \\
14 \\
14 \\
13\end{array}$ & $\begin{array}{l}27 \\
25 \\
23 \\
21 \\
26\end{array}$ & $\begin{array}{l}.95 \\
: 94 \\
.87 \\
.79 \\
.91\end{array}$ & $\begin{array}{l}9.0 \\
9: 0 \\
9.0 \\
9.4 \\
9.4\end{array}$ & $\begin{array}{l}40 \\
39 \\
39 \\
38 \\
\mathbf{3 8}\end{array}$ & $\begin{array}{l}.97 \\
.95 \\
.95 \\
.96 \\
.96\end{array}$ & $\begin{array}{l}7.4 \\
7.0 \\
6.7 \\
6.7 \\
6.7\end{array}$ & $\begin{array}{r}71 \\
81 \\
84 \\
105 \\
132\end{array}$ & $\begin{array}{l}1.4 \\
1.5 \\
1.5 \\
1.9 \\
2.4\end{array}$ \\
\hline $\begin{array}{l}26 \\
27 \\
28 \\
29 \\
30 \\
31\end{array}$ & $\begin{array}{l}13 \\
13 \\
11 \\
11 \\
10 \\
---\end{array}$ & $\begin{array}{l}29 \\
34 \\
30 \\
25 \\
20 \\
---\end{array}$ & $\begin{array}{l}1.0 \\
1.2 \\
.89 \\
.74 \\
.54 \\
---\end{array}$ & $\begin{array}{l}9.8 \\
9.4 \\
10^{-4} \\
10 \\
10 \\
10\end{array}$ & $\begin{array}{l}37 \\
35 \\
32 \\
29 \\
34 \\
37\end{array}$ & $\begin{array}{r}.98 \\
.89 \\
.86 \\
.78 \\
.92 \\
1.0\end{array}$ & $\begin{array}{l}6.7 \\
6.4 \\
5.1 \\
5.4 \\
5.4 \\
-. .\end{array}$ & $\begin{array}{r}152 \\
135 \\
113 \\
92 \\
68 \\
-\cdots\end{array}$ & $\begin{array}{c}2.7 \\
2.3 \\
1.6 \\
1.3 \\
: 99 \\
-. .\end{array}$ \\
\hline & 459 & $\cdots$ & 85.51 & 330.2 & $\cdots$ & 30.04 & 235.1 & $\cdots$ & 37.89 \\
\hline
\end{tabular}

\begin{tabular}{|c|c|c|c|c|c|c|c|c|c|}
\hline \multirow[b]{2}{*}{ DAY } & \multicolumn{3}{|c|}{ JULY } & \multicolumn{3}{|c|}{ AUGUST } & \multicolumn{3}{|c|}{ SEPTEMBER } \\
\hline & $\begin{array}{l}\text { MEAN } \\
\text { DISCHARGE } \\
\text { (CFS) }\end{array}$ & $\begin{array}{l}\text { MEAN } \\
\text { CONCEN- } \\
\text { TRATION } \\
\text { (MG/L) }\end{array}$ & $\begin{array}{l}\text { SEDIMENT } \\
\text { DISCHARGE } \\
\text { (TONS/DAY) }\end{array}$ & $\begin{array}{l}\text { MEAN } \\
\text { DISCHARGE } \\
\text { (CFS) }\end{array}$ & $\begin{array}{l}\text { MEAN } \\
\text { CONCEN- } \\
\text { TRAION } \\
\text { (MGLL) }\end{array}$ & $\begin{array}{l}\text { SEDIMENT } \\
\text { OIISCHARGE } \\
\text { (TONS/OAYY) }\end{array}$ & $\begin{array}{l}\text { MEAN } \\
\text { DISCHARGE } \\
\text { (CFS) }\end{array}$ & $\begin{array}{l}\text { MEAN } \\
\text { CONCEN- } \\
\text { TRAIION } \\
\text { (MOLL) }\end{array}$ & $\begin{array}{l}\text { SEDIMENT } \\
\text { DISCARGE } \\
\text { (TONS/OAY) }\end{array}$ \\
\hline $\begin{array}{l}1 \\
2 \\
3 \\
4 \\
5\end{array}$ & $\begin{array}{l}4.8 \\
5.4 \\
5.1 \\
4.7 \\
4.6\end{array}$ & $\begin{array}{l}67 \\
66 \\
65 \\
63 \\
55\end{array}$ & $\begin{array}{l}.87 \\
.96 \\
.90 \\
.80 \\
.68\end{array}$ & $\begin{array}{l}2.7 \\
2.5 \\
2.5 \\
2.5 \\
2.5\end{array}$ & $\begin{array}{l}11 \\
11 \\
15 \\
14 \\
13\end{array}$ & $\begin{array}{l}.08 \\
.07 \\
.10 \\
.09 \\
.09\end{array}$ & $\begin{array}{l}1.9 \\
2.0 \\
2.2 \\
2.2 \\
2.2\end{array}$ & $\begin{array}{l}12 \\
17 \\
20 \\
22 \\
19\end{array}$ & $\begin{array}{l}: 06 \\
: 09 \\
: 12 \\
: 13 \\
: 11\end{array}$ \\
\hline $\begin{array}{r}6 \\
7 \\
8 \\
9 \\
10\end{array}$ & $\begin{array}{l}4.5 \\
4.4 \\
4: 3 \\
4.1 \\
4.0\end{array}$ & $\begin{array}{l}49 \\
44 \\
52 \\
56 \\
61\end{array}$ & $\begin{array}{l}.60 \\
.52 \\
.60 \\
.62 \\
.66\end{array}$ & $\begin{array}{l}2.5 \\
2.5 \\
2.5 \\
2.5 \\
2.5\end{array}$ & $\begin{array}{l}13 \\
13 \\
13 \\
17 \\
30\end{array}$ & $\begin{array}{l}.09 \\
099 \\
: 09 \\
: 11 \\
: 20\end{array}$ & $\begin{array}{r}2.7 \\
4.1 \\
3.6 \\
3.1 \\
92\end{array}$ & $\begin{array}{r}13 \\
8 \\
6 \\
4 \\
3180\end{array}$ & $\begin{array}{r}.09 \\
.09 \\
.06 \\
2090^{.03}\end{array}$ \\
\hline $\begin{array}{l}11 \\
12 \\
13 \\
14 \\
15\end{array}$ & $\begin{array}{l}3.9 \\
3.8 \\
3.7 \\
3.6 \\
3.3\end{array}$ & $\begin{array}{l}61 \\
68 \\
68 \\
68 \\
64\end{array}$ & $\begin{array}{l}.64 \\
.70 \\
.68 \\
.66 \\
.57\end{array}$ & $\begin{array}{l}2.5 \\
2.5 \\
2.5 \\
2.5 \\
2.5\end{array}$ & $\begin{array}{l}35 \\
37 \\
41 \\
33 \\
25\end{array}$ & $\begin{array}{l}.24 \\
.25 \\
.28 \\
.22 \\
.27\end{array}$ & $\begin{array}{l}61 \\
17 \\
15 \\
15 \\
15\end{array}$ & $\begin{array}{r}4020 \\
230 \\
33 \\
27 \\
19\end{array}$ & $\begin{array}{c}922 \\
11 \\
1.3 \\
1: 1 \\
.77\end{array}$ \\
\hline $\begin{array}{l}16 \\
17 \\
18 \\
19 \\
20\end{array}$ & $\begin{array}{l}3.6 \\
3.6 \\
3.3 \\
3.3 \\
3.1\end{array}$ & $\begin{array}{l}60 \\
53 \\
43 \\
40 \\
38\end{array}$ & $\begin{array}{l}.58 \\
.52 \\
.38 \\
.36 \\
.32\end{array}$ & $\begin{array}{l}2.5 \\
2.5 \\
2.5 \\
2.5 \\
2.5\end{array}$ & $\begin{array}{l}16 \\
17 \\
18 \\
18 \\
18\end{array}$ & $\begin{array}{l}.11 \\
.11 \\
.12 \\
112 \\
.12\end{array}$ & $\begin{array}{l}14 \\
14 \\
14 \\
14 \\
16\end{array}$ & $\begin{array}{r}130 \\
80 \\
60 \\
40 \\
25\end{array}$ & $\begin{array}{l}4.9 \\
3.0 \\
2.3 \\
1.5 \\
1.1\end{array}$ \\
\hline $\begin{array}{l}21 \\
22 \\
23 \\
24 \\
25\end{array}$ & $\begin{array}{l}3.1 \\
2.9 \\
3.1 \\
2.9 \\
2.9\end{array}$ & $\begin{array}{l}37 \\
32 \\
26 \\
19 \\
18\end{array}$ & $\begin{array}{l}.31 \\
.25 \\
.22 \\
.15 \\
.14\end{array}$ & $\begin{array}{l}2.5 \\
2.5 \\
2.5 \\
2.5 \\
2.5\end{array}$ & $\begin{array}{l}21 \\
24 \\
28 \\
26 \\
20\end{array}$ & $\begin{array}{l}: 14 \\
116 \\
119 \\
119 \\
114\end{array}$ & $\begin{array}{l}15 \\
16 \\
16 \\
15 \\
15\end{array}$ & $\begin{array}{l}14 \\
13 \\
12 \\
12 \\
12\end{array}$ & $\begin{array}{l}.57 \\
.56 \\
.52 \\
.49 \\
.49\end{array}$ \\
\hline $\begin{array}{l}26 \\
27 \\
28 \\
29 \\
30 \\
31\end{array}$ & $\begin{array}{l}2.9 \\
2.9 \\
2.7 \\
2.7 \\
2.7 \\
2.7\end{array}$ & $\begin{array}{l}17 \\
16 \\
15 \\
13 \\
11 \\
11\end{array}$ & $\begin{array}{l}.13 \\
.13 \\
111 \\
.09 \\
.08 \\
.08\end{array}$ & $\begin{array}{l}2.5 \\
2.4 \\
2.2 \\
2.0 \\
1.9 \\
1.9\end{array}$ & $\begin{array}{r}13 \\
9 \\
9 \\
9 \\
9 \\
11\end{array}$ & $\begin{array}{l}.09 \\
.06 \\
.05 \\
.05 \\
.05 \\
.06\end{array}$ & $\begin{array}{l}16 \\
16 \\
17 \\
17 \\
15 \\
-\ldots\end{array}$ & $\begin{array}{l}12 \\
11 \\
11 \\
11 \\
11 \\
\ldots\end{array}$ & $\begin{array}{l}.52 \\
.48 \\
.50 \\
.50 \\
.45 \\
. . .\end{array}$ \\
\hline & 112.6 & -- & 14.31 & 75.6 & --- & 3.92 & 469.0 & --- & 3044.83 \\
\hline
\end{tabular}


11108500 SANTA CLARA RIVER AT LOS ANGELES-VENTURA COUNTY LINE, CA--Continued

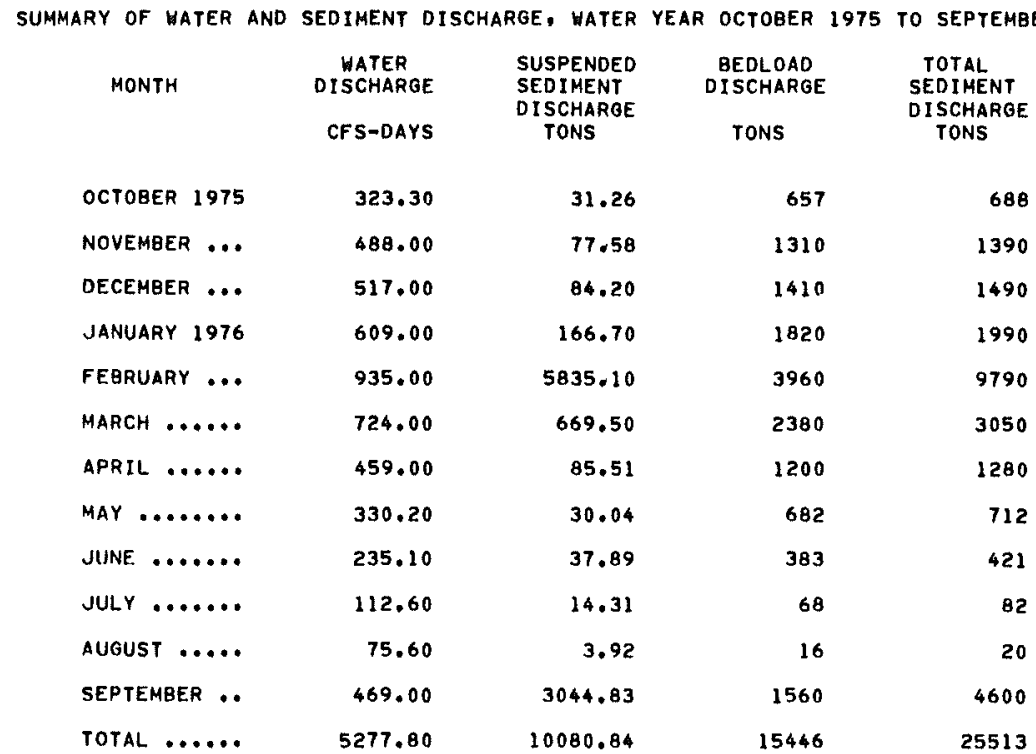

PARTICLE-SIZE DISTRIBUTION OF SUSPENDED SEDIMENT, WATER YEAR OCTOBER 1975 TO SEPTEMBER 1976

\begin{tabular}{|c|c|c|c|c|c|c|c|c|c|c|}
\hline DATE & TIME & $\begin{array}{l}\text { TEMPER- } \\
\text { ATURE } \\
\text { (DEG C) }\end{array}$ & $\begin{array}{l}\text { INSTAN- } \\
\text { TANEOUS } \\
\text { DIS- } \\
\text { CHARGE } \\
\text { (CFS) }\end{array}$ & $\begin{array}{l}\text { SUS- } \\
\text { PENDED } \\
\text { SEDI- } \\
\text { MENT } \\
\text { (MG } / L)\end{array}$ & $\begin{array}{c}\text { SUS- } \\
\text { PENDED } \\
\text { SEDI- } \\
\text { MENT } \\
\text { DIS- } \\
\text { CHARGE } \\
(T / D A Y)\end{array}$ & $\begin{array}{c}\text { SUS. } \\
\text { SED. } \\
\text { FALL } \\
\text { DIAH. } \\
\text { FINER } \\
\text { THAN } \\
.002 \mathrm{MH}\end{array}$ & $\begin{array}{l}\text { SUS. } \\
\text { SED: } \\
\text { FALL } \\
\text { DIAM. } \\
\text { O FINER } \\
\text { THAN } \\
\text { OOA MH }\end{array}$ & $\begin{array}{l}\text { SUS. } \\
\text { SED: } \\
\text { FALL } \\
\text { DIAM. } \\
\text { \$ FINER } \\
\text { THAN } \\
.000 \text { MH }\end{array}$ & $\begin{array}{l}\text { SUS. } \\
\text { SED, } \\
\text { FALL } \\
\text { DIAM. } \\
\text { \% FINER } \\
\text { THAN } \\
\text { OIG MM }\end{array}$ & $\begin{array}{l}\text { SUS. } \\
\text { SED. } \\
\text { FALL } \\
\text { OIAH. } \\
\text { OINER } \\
\text { THAN } \\
\text { O3I MM }\end{array}$ \\
\hline \multicolumn{11}{|l|}{ FEB } \\
\hline $\begin{array}{l}06 \ldots \\
06 \ldots \ldots \\
08 \ldots \cdots \\
09 \cdots \\
09 \cdots \\
5 E P\end{array}$ & $\begin{array}{l}0820 \\
1330 \\
1155 \\
0740 \\
1130\end{array}$ & $\begin{array}{r}8.0 \\
10.0 \\
14.0 \\
11.0 \\
11.5\end{array}$ & $\begin{array}{r}88 \\
44 \\
27 \\
1510 \\
225\end{array}$ & $\begin{array}{r}6240 \\
1820 \\
377 \\
9690 \\
5270\end{array}$ & $\begin{array}{r}1480 \\
216 \\
27 \\
39500 \\
3200\end{array}$ & $\begin{array}{l}41 \\
32 \\
31 \\
40 \\
39\end{array}$ & $\begin{array}{l}58 \\
50 \\
35 \\
53 \\
51\end{array}$ & $\begin{array}{l}76 \\
66 \\
42 \\
69 \\
70\end{array}$ & $\begin{array}{l}88 \\
76 \\
49 \\
83 \\
85\end{array}$ & $\begin{array}{l}93 \\
79 \\
54 \\
90 \\
93\end{array}$ \\
\hline $\begin{array}{l}11 \ldots \\
11 \ldots \\
16 \ldots\end{array}$ & $\begin{array}{l}1015 \\
1635 \\
1540\end{array}$ & $\begin{array}{l}19.0 \\
19.5 \\
24.0\end{array}$ & $\begin{array}{l}32 \\
72 \\
12\end{array}$ & $\begin{array}{r}2100 \\
4380 \\
250\end{array}$ & $\begin{array}{r}181 \\
851 \\
8.1\end{array}$ & $\begin{array}{l}53 \\
54 \\
59\end{array}$ & $\begin{array}{l}75 \\
72 \\
73\end{array}$ & $\begin{array}{l}87 \\
91 \\
88\end{array}$ & $\begin{array}{l}96 \\
98 \\
98\end{array}$ & $\begin{array}{r}97 \\
100 \\
99\end{array}$ \\
\hline
\end{tabular}

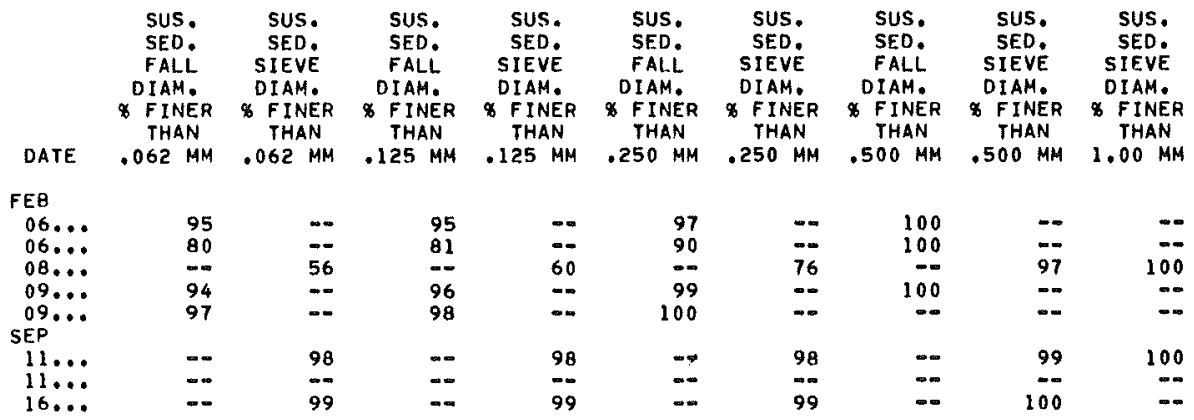


11109100 PIRU CREEK BELOW THORN MEADOWS, NEAR STAUFFER, CA

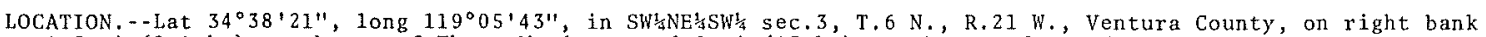
$1.3 \mathrm{mi}(2.1 \mathrm{~km})$ northeast of Thorn Meadows, and $8 \mathrm{mi}$ (13 km) southwest of Stauffer.

DRAINAGE AREA. $-22.5 \mathrm{mi}^{2}\left(58,3 \mathrm{~km}^{2}\right)$.

PERIOD OF RECORD,-OCtober 1971 to current year.

GAGE. - Water-stage recorder. Altitude of gage is 4,280 ft $(1,305 \mathrm{~m})$, from topographic map.

REMARKS,--Records fair. No regulation or diversion above station.

COOPERATION, - Fourteen discharge measurements furnished by Ventura County Flood Control District.

AVERAGE DISCHARGE, - -5 years, $5.35 \mathrm{ft}^{3} / \mathrm{s}\left(0.152 \mathrm{~m}^{3} / \mathrm{s}\right), 3,880 \mathrm{acre}-\mathrm{ft} / \mathrm{yr}\left(4.78 \mathrm{hm}^{3} / \mathrm{yr}^{\mathrm{r}}\right)$

EXTREMES FOR PERIOD OF RECORD.--Maximum discharge, $1,660 \mathrm{ft}^{3} / \mathrm{s}\left(47.0 \mathrm{~m}^{3} / \mathrm{s}\right)$ Feb. 11 , 1973 , gage height, $5.37 \mathrm{ft}$

$(1.637 \mathrm{~m})$, from floodmarks, from rating curve extended above $60 \mathrm{ft}^{3} / \mathrm{s}$ (1.70 $\left.\mathrm{m}^{3} / \mathrm{s}\right)$ on basis of $\mathrm{s} 10 \mathrm{pe}-\mathrm{area}$ measurement of maximum flow; no flow many days in most years.

EXTREMES FOR CURRENT YEAR. - - peak discharge above base of $50 \mathrm{ft}^{3} / \mathrm{s}\left(1.42 \mathrm{~m}^{3} / \mathrm{s}\right)$ and maximum (*):

\begin{tabular}{|c|c|c|c|c|c|c|c|c|}
\hline Date & Time & $\begin{array}{c}\text { Discharge } \\
\left(\mathrm{ft}^{3} / \mathrm{s}\right)\left(\mathrm{m}^{3} / \mathrm{s}\right)\end{array}$ & $\begin{array}{l}\text { Gage height } \\
\text { (ft) }\end{array}$ & Date & Time & $\begin{array}{r}\mathrm{Dis} \\
\left(\mathrm{ft} \mathrm{t}^{3}\right)\end{array}$ & $\left.\mathrm{m}^{3} / \mathrm{s}\right)$ & $\begin{array}{l}\text { Gage } \\
\text { (ft) }\end{array}$ \\
\hline $\begin{array}{l}\text { Feb. } \\
\text { Sept. } 10\end{array}$ & $\begin{array}{l}0430 \\
2400\end{array}$ & $\begin{array}{r}14.3 \\
4.08\end{array}$ & $\begin{array}{l}1.131 \\
0.808\end{array}$ & Sept. 29 & 0900 & 85 & 2.41 & 2.35 \\
\hline
\end{tabular}

Minimum daily discharge, no flow Sept. 7-9.

DISCHARGE, IN CUBIC FEET PER SECOND, WATER YEAR OCTOBER 1975 TO SEPTEMBER 1976 MEAN VALUES

\begin{tabular}{|c|c|c|c|c|c|c|c|c|c|c|c|c|}
\hline DAY & OCT & NOV & DEC & JAN & FEB & MAR & $A P R$ & MAY & JUN & JUL & AUG & $S E$ \\
\hline $\begin{array}{l}1 \\
2 \\
3 \\
4 \\
5\end{array}$ & $\begin{array}{l}.01 \\
.01 \\
.01 \\
.01 \\
.01\end{array}$ & $\begin{array}{l}.02 \\
.02 \\
.02 \\
.02 \\
.02\end{array}$ & $\begin{array}{l}.04 \\
.04 \\
.05 \\
.05 \\
.05\end{array}$ & $\begin{array}{l}.05 \\
.04 \\
.05 \\
.05 \\
.05\end{array}$ & $\begin{array}{l}.07 \\
.07 \\
.07 \\
.07 \\
.19\end{array}$ & $\begin{array}{l}20 \\
11 \\
8.4 \\
6.2 \\
5.4\end{array}$ & $\begin{array}{l}3.3 \\
3.3 \\
3.3 \\
4.2 \\
4.3\end{array}$ & $\begin{array}{l}2.2 \\
1.9 \\
1.8 \\
1.8 \\
1.8\end{array}$ & $\begin{array}{l}.36 \\
.32 \\
.32 \\
.30 \\
.25\end{array}$ & $\begin{array}{l}.07 \\
.07 \\
.07 \\
.07 \\
.07\end{array}$ & $\begin{array}{l}.01 \\
.01 \\
.01 \\
.01 \\
.01 \\
.01\end{array}$ & $\begin{array}{l}.02 \\
.01 \\
.01 \\
.01 \\
.01\end{array}$ \\
\hline $\begin{array}{r}6 \\
7 \\
8 \\
9 \\
10\end{array}$ & $\begin{array}{l}.01 \\
.01 \\
.01 \\
.01 \\
.01\end{array}$ & $\begin{array}{l}.02 \\
.02 \\
.02 \\
.02 \\
.03\end{array}$ & $\begin{array}{l}.05 \\
.05 \\
.05 \\
.05 \\
.05\end{array}$ & $\begin{array}{l}.05 \\
.05 \\
.06 \\
.06 \\
.06\end{array}$ & $\begin{array}{r}.30 \\
64^{.26} \\
173 \\
41\end{array}$ & $\begin{array}{l}5.4 \\
5.4 \\
5.0 \\
5.0 \\
5.4\end{array}$ & $\begin{array}{l}3.9 \\
3.3 \\
3.8 \\
3.7 \\
3.3\end{array}$ & $\begin{array}{l}1.9 \\
2.2 \\
1.8 \\
1.7 \\
1.6\end{array}$ & $\begin{array}{l}.25 \\
.25 \\
.25 \\
.25 \\
.41\end{array}$ & $\begin{array}{l}.07 \\
.07 \\
.06 \\
.06 \\
.06\end{array}$ & $\begin{array}{l}.01 \\
.01 \\
.01 \\
.01 \\
.01 \\
.01\end{array}$ & $\begin{array}{l}0 \\
0 \\
0 \\
13\end{array}$ \\
\hline $\begin{array}{l}11 \\
12 \\
13 \\
14 \\
15\end{array}$ & $\begin{array}{l}.01 \\
.01 \\
.01 \\
.01 \\
.01\end{array}$ & $\begin{array}{l}.03 \\
.03 \\
.03 \\
.04 \\
.04\end{array}$ & $\begin{array}{l}.06 \\
.06 \\
.06 \\
.05 \\
.05\end{array}$ & $\begin{array}{l}.05 \\
.05 \\
.06 \\
.06 \\
.06\end{array}$ & $\begin{array}{l}21 \\
17 \\
13 \\
13 \\
12\end{array}$ & $\begin{array}{l}5.7 \\
5.5 \\
5.3 \\
5.4 \\
5.4\end{array}$ & $\begin{array}{l}3.2 \\
3.4 \\
4.5 \\
3.8 \\
3.4\end{array}$ & $\begin{array}{l}1.4 \\
1.3 \\
1.1 \\
1.0 \\
1.1\end{array}$ & $\begin{array}{l}.41 \\
.29 \\
.23 \\
.17 \\
.14\end{array}$ & $\begin{array}{l}.05 \\
.06 \\
.05 \\
.03 \\
.04\end{array}$ & $\begin{array}{l}.01 \\
.01 \\
.01 \\
.01 \\
.01\end{array}$ & $\begin{array}{r}25 \\
1.1 \\
.09 \\
.05 \\
.05\end{array}$ \\
\hline $\begin{array}{l}16 \\
17 \\
18 \\
19 \\
20\end{array}$ & $\begin{array}{l}.01 \\
.01 \\
.01 \\
.01 \\
.01\end{array}$ & $\begin{array}{l}.04 \\
.04 \\
.04 \\
.03 \\
.04\end{array}$ & $\begin{array}{l}.05 \\
.05 \\
.05 \\
.05 \\
.05\end{array}$ & $\begin{array}{l}.07 \\
.07 \\
.07 \\
.07 \\
.07\end{array}$ & $\begin{array}{l}6.7 \\
6.2 \\
6.2 \\
6.6 \\
5.4\end{array}$ & $\begin{array}{l}5.4 \\
7.0 \\
9.5 \\
8.6 \\
6.6\end{array}$ & $\begin{array}{l}4.1 \\
3.6 \\
3.3 \\
3.3 \\
3.5\end{array}$ & $\begin{array}{l}.98 \\
.89 \\
.98 \\
.95 \\
.92\end{array}$ & $\begin{array}{l}.13 \\
.10 \\
.10 \\
.10 \\
.10\end{array}$ & $\begin{array}{l}.04 \\
.03 \\
.04 \\
.03 \\
.02\end{array}$ & $\begin{array}{l}.01 \\
.01 \\
.01 \\
.02 \\
.01\end{array}$ & $\begin{array}{l}.05 \\
.04 \\
.04 \\
.04 \\
.04\end{array}$ \\
\hline $\begin{array}{l}21 \\
22 \\
23 \\
24 \\
25\end{array}$ & $\begin{array}{l}.01 \\
.01 \\
.01 \\
.01 \\
.01\end{array}$ & $\begin{array}{l}.04 \\
.04 \\
.04 \\
.04 \\
.04\end{array}$ & $\begin{array}{l}.05 \\
.05 \\
.05 \\
.05 \\
.05\end{array}$ & $\begin{array}{l}.07 \\
.07 \\
.07 \\
.07 \\
.07\end{array}$ & $\begin{array}{l}4.4 \\
3.9 \\
3.7 \\
3.7 \\
3.4\end{array}$ & $\begin{array}{l}5.7 \\
5.3 \\
5.2 \\
5.2 \\
5.6\end{array}$ & $\begin{array}{l}3.6 \\
3.7 \\
3.6 \\
3.1 \\
3.0\end{array}$ & $\begin{array}{l}.83 \\
.77 \\
.72 \\
.66 \\
.61\end{array}$ & $\begin{array}{l}.09 \\
.07 \\
.07 \\
.07 \\
.07\end{array}$ & $\begin{array}{l}.02 \\
.02 \\
.02 \\
.02 \\
.02\end{array}$ & $\begin{array}{l}.01 \\
.01 \\
.01 \\
.01 \\
.01\end{array}$ & $\begin{array}{l}.04 \\
.04 \\
.04 \\
.04 \\
.04\end{array}$ \\
\hline $\begin{array}{l}26 \\
27 \\
28 \\
29 \\
30 \\
31\end{array}$ & $\begin{array}{l}.01 \\
.01 \\
.01 \\
.01 \\
.01 \\
.01\end{array}$ & $\begin{array}{l}.04 \\
.04 \\
.04 \\
.04 \\
.04 \\
-.-\end{array}$ & $\begin{array}{l}.05 \\
.05 \\
.05 \\
.05 \\
.05 \\
.05\end{array}$ & $\begin{array}{l}.07 \\
.07 \\
.07 \\
.07 \\
.07 \\
.07\end{array}$ & $\begin{array}{l}3.4 \\
3.4 \\
3.7 \\
4.7 \\
-. .- \\
-.-.\end{array}$ & $\begin{array}{l}5.0 \\
4.6 \\
4.2 \\
3.9 \\
3.6 \\
3.5\end{array}$ & $\begin{array}{l}2.8 \\
2.7 \\
2.7 \\
2.4 \\
2.3 \\
--.\end{array}$ & $\begin{array}{r}.57 \\
.53 \\
.49 \\
.46 \\
.42 \\
.39\end{array}$ & $\begin{array}{l}.10 \\
.10 \\
.10 \\
.09 \\
.07 \\
.--0\end{array}$ & $\begin{array}{l}.02 \\
.02 \\
.02 \\
.02 \\
.02 \\
.02\end{array}$ & $\begin{array}{l}.01 \\
.01 \\
.02 \\
.02 \\
.03 \\
.03\end{array}$ & $\begin{array}{r}.04 \\
.04 \\
.04 \\
11 \\
1.6 \\
-.-0\end{array}$ \\
\hline $\begin{array}{l}\text { TOTAL } \\
\text { MFAN } \\
\text { MAX } \\
\text { MIN } \\
A C-F Y\end{array}$ & $\begin{array}{r}.31 \\
.010 \\
.01 \\
.01 \\
.6\end{array}$ & $\begin{array}{r}.97 \\
.032 \\
.04 \\
.02 \\
1.9\end{array}$ & $\begin{array}{r}1.36 \\
.050 \\
.06 \\
.04 \\
3.1\end{array}$ & $\begin{array}{r}1.92 \\
.062 \\
.07 \\
.04 \\
3.8\end{array}$ & $\begin{array}{r}420.43 \\
14.5 \\
173 \\
.07 \\
834\end{array}$ & $\begin{array}{r}193.4 \\
6.24 \\
20 \\
3.5 \\
384\end{array}$ & $\begin{array}{r}102.4 \\
3.41 \\
4.5 \\
2.3 \\
203\end{array}$ & $\begin{array}{r}35.77 \\
1.15 \\
2.2 \\
.39 \\
71\end{array}$ & $\begin{array}{r}5.56 \\
.19 \\
.41 \\
.07 \\
11\end{array}$ & $\begin{array}{r}1.28 \\
.041 \\
.07 \\
.02 \\
2.5\end{array}$ & $\begin{array}{r}.38 \\
.012 \\
.03 \\
.01 \\
.8\end{array}$ & $\begin{array}{r}52.49 \\
1.75 \\
25\end{array}$ \\
\hline
\end{tabular}

CAL YR 1975 TOTAL 2019.53 MEAN 5.53 MAX 344 MIN 0 AC-FT 4010

WTR YR 1976 TOTAL 816.47 MEAN 2.23 MAX $173 \quad$ MIN 0 AC-FT 1620 
LOCATION.-Lat $34^{\circ} 45^{\prime} 56^{\prime \prime}$, long $119^{\circ} 07^{\prime} 12^{\prime \prime}$, in SWhNE ${ }_{4}^{\prime} S E^{\prime}$ sec. 20, T.8 N., R. 21 W., Ventura County, on right bank

$3.3 \mathrm{mi}$ (5.3 km) upstream from Lockwood'Creek, and $3.3 \mathrm{mi}(5.3 \mathrm{~km})$ northwest of Stauffer.

DRAINAGE AREA. $--5.50 \mathrm{mi}^{2},\left(14.24 \mathrm{~km}^{2}\right)$.

PERIOD OF RECORD, - - October 1971 to current year.

GAGE. - Water-stage recorder. Altitude of gage is $5,530 \mathrm{ft}(1,686 \mathrm{~m})$, from topographic map.

REMARKS, --Records fair except those for February and september, which are poor. No regulation or diversion above

station.

COOPERATION. --Eighteen discharge measurements were furnished by Ventura County f1ood Contro1 District.

AVERAGE DISCHARGE, - - 5 years, $0.55 \mathrm{ft}^{3} / \mathrm{s}\left(0.016 \mathrm{mt}^{3} / \mathrm{s}\right), 398 \mathrm{acre}-\mathrm{ft} / \mathrm{yr}\left(491,000 \mathrm{~m}^{3} / \mathrm{yr}^{2}\right)$.

EXTREMES FOR PERIOD OF RECORD,--Maximum discharge, $697 \mathrm{ft}^{3} / \mathrm{s}\left(19.7 \mathrm{~m}^{3} / \mathrm{s}\right)$ Sept. 6,1976 , gage height, $4.80 \mathrm{ft}$

$(1.463 \mathrm{~m})$, from rating curve extended above $2.9 \mathrm{ft}^{3} / \mathrm{s}\left(0.082 \mathrm{~m}^{3} / \mathrm{s}\right)$ on basis of slope-area measurement of maximum flow; no flow for some days in each year.

EXTREMES FOR CURRENT YEAR. - Maximum discharge, $697 \mathrm{ft}^{3} / \mathrm{s}\left(19.7 \mathrm{~m}^{3} / \mathrm{s}\right)$ Sept. 6 (1415 hrs), gage height, $4.80 \mathrm{ft}$

$(1.463 \mathrm{~m})$

flow; no other peaks above base of $100 \mathrm{ft}^{3} / \mathrm{s}(2.83 \mathrm{~m} / \mathrm{s})$; no flow July 18 to Sept. 5, Sept. $7-9$, $18-28$.

flow; no other peaks above base of $100 \mathrm{ft} / \mathrm{s}(2.83 \mathrm{~m} / \mathrm{s})$; no flow July 18 to Sept. 5 , Sept. $7-9$, $18-28$.

DISCHARGE, IN CUBIC FEET PER SECOND, WATER YEAR OCTOBER 1975 TO SEPTEMBER 1976 MEAN VALUES

\begin{tabular}{|c|c|c|c|c|c|c|c|c|c|c|c|c|}
\hline DAY & OCT & NOV & DEC & JAN & FEB & MAR & APR & MAY & JUN & JUL & AUB & SEP \\
\hline $\begin{array}{l}1 \\
2 \\
3 \\
4 \\
5\end{array}$ & $\begin{array}{l}.05 \\
.05 \\
.05 \\
.05 \\
.05\end{array}$ & $\begin{array}{l}.12 \\
.08 \\
.07 \\
.07 \\
.08\end{array}$ & $\begin{array}{r}.19 \\
.17 \\
.15 \\
.13 \\
.13\end{array}$ & $\begin{array}{l}.08 \\
.08 \\
.11 \\
.12 \\
.15\end{array}$ & $\begin{array}{l}.17 \\
.16 \\
.16 \\
.16 \\
.19\end{array}$ & $\begin{array}{l}.70 \\
.85 \\
.86 \\
.75 \\
.60\end{array}$ & $\begin{array}{r}.30 \\
.27 \\
.27 \\
1.9 \\
1.4\end{array}$ & $\begin{array}{l}.41 \\
.33 \\
.33 \\
.25 \\
.25\end{array}$ & $\begin{array}{l}.17 \\
.14 \\
.14 \\
.14 \\
.14\end{array}$ & $\begin{array}{l}.03 \\
.03 \\
.03 \\
.02 \\
.02\end{array}$ & & $\begin{array}{l}0 \\
0 \\
0 \\
0 \\
0\end{array}$ \\
\hline $\begin{array}{r}6 \\
7 \\
8 \\
9 \\
10\end{array}$ & $\begin{array}{l}.05 \\
.05 \\
.05 \\
.05 \\
.05\end{array}$ & $\begin{array}{l}.08 \\
.06 \\
.06 \\
.06 \\
.07\end{array}$ & $\begin{array}{r}.13 \\
.12 \\
.13 \\
.11 \\
.11\end{array}$ & $\begin{array}{l}.14 \\
.15 \\
.14 \\
.14 \\
.13\end{array}$ & $\begin{array}{c}.22 \\
12.28 \\
13 \\
2.6\end{array}$ & $\begin{array}{l}.60 \\
.60 \\
.50 \\
.50 \\
.50\end{array}$ & $\begin{array}{l}.82 \\
.61 \\
.60 \\
.50 \\
.50\end{array}$ & $\begin{array}{l}.27 \\
.25 \\
.21 \\
.21 \\
.21\end{array}$ & $\begin{array}{r}.13 \\
.14 \\
.14 \\
.14 \\
.19\end{array}$ & $\begin{array}{l}.02 \\
.02 \\
.01 \\
.01 \\
.01\end{array}$ & & $\begin{array}{l}9.7 \\
0 \\
0 \\
0 \\
3.1\end{array}$ \\
\hline $\begin{array}{l}11 \\
12 \\
13 \\
14 \\
15\end{array}$ & $\begin{array}{l}.08 \\
.08 \\
.08 \\
.08 \\
.07\end{array}$ & $\begin{array}{l}.06 \\
.05 \\
.06 \\
.06 \\
.06\end{array}$ & $\begin{array}{l}.13 \\
.12 \\
.12 \\
.06 \\
.10\end{array}$ & $\begin{array}{l}.14 \\
.14 \\
112 \\
.12 \\
.11\end{array}$ & $\begin{array}{l}1.9 \\
1.9 \\
1.9 \\
1.9 \\
1.2\end{array}$ & $\begin{array}{l}.52 \\
.51 \\
.66 \\
.82 \\
.93\end{array}$ & $\begin{array}{l}.50 \\
.50 \\
.50 \\
.41 \\
.41\end{array}$ & $\begin{array}{l}.20 \\
.24 \\
.23 \\
.21 \\
.23\end{array}$ & $\begin{array}{l}.15 \\
.11 \\
.10 \\
.09 \\
.09\end{array}$ & $\begin{array}{l}.01 \\
.01 \\
.01 \\
.01 \\
.01 \\
.01\end{array}$ & & $\begin{array}{r}1.5 \\
.02 \\
.01 \\
.01 \\
.01\end{array}$ \\
\hline $\begin{array}{l}16 \\
17 \\
18 \\
19 \\
20\end{array}$ & $\begin{array}{l}.05 \\
.05 \\
.05 \\
.06 \\
.06\end{array}$ & $\begin{array}{l}.04 \\
.04 \\
.04 \\
.05 \\
.05\end{array}$ & $\begin{array}{l}.10 \\
.10 \\
.09 \\
.09 \\
.10\end{array}$ & $\begin{array}{l}.11 \\
.10 \\
.10 \\
.10 \\
.11\end{array}$ & $\begin{array}{l}1.0 \\
1.2 \\
1.6 \\
1.3 \\
.80\end{array}$ & $\begin{array}{l}1.4 \\
2.6 \\
2.2 \\
1.5 \\
1.1\end{array}$ & $\begin{array}{l}1.1 \\
.74 \\
.50 \\
.50 \\
.60\end{array}$ & $\begin{array}{l}.20 \\
.20 \\
.20 \\
.20 \\
.20\end{array}$ & $\begin{array}{l}.08 \\
.07 \\
.07 \\
.07 \\
.07\end{array}$ & $\begin{array}{l}.01 \\
.01 \\
0 \\
0 \\
0\end{array}$ & & $\begin{array}{l}.01 \\
.01 \\
0 \\
0 \\
0\end{array}$ \\
\hline $\begin{array}{l}21 \\
22 \\
23 \\
24 \\
25\end{array}$ & $\begin{array}{l}.06 \\
.06 \\
.07 \\
.07 \\
.06\end{array}$ & $\begin{array}{l}.05 \\
.05 \\
.05 \\
.05 \\
.05\end{array}$ & $\begin{array}{l}.09 \\
.09 \\
.11 \\
11 \\
.10\end{array}$ & $\begin{array}{l}.12 \\
.12 \\
.12 \\
.15 \\
.14\end{array}$ & $\begin{array}{l}.66 \\
.60 \\
.60 \\
.60 \\
.60\end{array}$ & $\begin{array}{l}.92 \\
.95 \\
.90 \\
.99 \\
.89\end{array}$ & $\begin{array}{l}.55 \\
.55 \\
.61 \\
.57 \\
.66\end{array}$ & $\begin{array}{r}.19 \\
.19 \\
.18 \\
.18 \\
.18\end{array}$ & $\begin{array}{l}.06 \\
.06 \\
.06 \\
.04 \\
.03\end{array}$ & $\begin{array}{l}0 \\
0 \\
0 \\
0 \\
0\end{array}$ & & $\begin{array}{l}0 \\
0 \\
0 \\
0 \\
0\end{array}$ \\
\hline $\begin{array}{l}26 \\
27 \\
28 \\
29 \\
30 \\
31\end{array}$ & $\begin{array}{l}.07 \\
.10 \\
.10 \\
.09 \\
.12 \\
.13\end{array}$ & $\begin{array}{l}.06 \\
.05 \\
.05 \\
.54 \\
.11 \\
-.0\end{array}$ & $\begin{array}{l}.10 \\
.10 \\
.13 \\
.13 \\
.13 \\
.06\end{array}$ & $\begin{array}{l}.15 \\
.17 \\
.17 \\
.17 \\
.17 \\
.17\end{array}$ & $\begin{array}{l}.60 \\
.60 \\
.60 \\
.60 \\
. .0 \\
. .-\end{array}$ & $\begin{array}{r}.65 \\
.47 \\
.38 \\
.35 \\
.32 \\
.32\end{array}$ & $\begin{array}{l}.57 \\
.67 \\
.61 \\
.45 \\
.41 \\
.0 .\end{array}$ & $\begin{array}{l}.21 \\
.20 \\
119 \\
119 \\
.19 \\
.18\end{array}$ & $\begin{array}{l}.03 \\
.03 \\
.02 \\
.03 \\
.03 \\
-0 .-\end{array}$ & $\begin{array}{l}0 \\
0 \\
0 \\
0 \\
0 \\
0\end{array}$ & & $\begin{array}{l}0 \\
0 \\
0 \\
.22 \\
.03 \\
:-\end{array}$ \\
\hline $\begin{array}{l}\text { TOTAL } \\
\text { MEAN } \\
\text { MAX } \\
\text { MIN } \\
\text { AC-FT }\end{array}$ & $\begin{array}{r}2.09 \\
.067 \\
.13 \\
.05 \\
4.1\end{array}$ & $\begin{array}{r}2.32 \\
.077 \\
.54 \\
.04 \\
4.6\end{array}$ & $\begin{array}{r}3.53 \\
.11 \\
.19 \\
.06 \\
7.0\end{array}$ & $\begin{array}{r}4.04 \\
.13 \\
.17 \\
.08 \\
8.0\end{array}$ & $\begin{array}{r}49.10 \\
1.69 \\
13 \\
.16 \\
97\end{array}$ & $\begin{array}{r}25.84 \\
.83 \\
2.6 \\
.32 \\
51\end{array}$ & $\begin{array}{r}18.58 \\
.62 \\
1.9 \\
.27 \\
37\end{array}$ & $\begin{array}{r}6.91 \\
.22 \\
.41 \\
.18 \\
14\end{array}$ & $\begin{array}{r}2.76 \\
.092 \\
.19 \\
.02 \\
5.5\end{array}$ & $\begin{array}{r}.27 \\
.009 \\
.03 \\
0 \\
.5\end{array}$ & $\begin{array}{l}0 \\
0 \\
0 \\
0 \\
0\end{array}$ & $\begin{array}{r}14.62 \\
.49 \\
9.7 \\
0 \\
29\end{array}$ \\
\hline
\end{tabular}

$\begin{array}{lllllllll}\text { CAL YR } 1975 & \text { TOTAL } 160.64 & \text { MEAN } .44 & \text { MAX } & 4.0 & \text { MIN } 0 & \text { AC-FT } 319 \\ \text { WTR YR } 1976 & \text { TOTAL } 130.06 & \text { MEAN } .36 & \text { MAX } & 13 & \text { MIN } 0 & \text { AC-FT } 258\end{array}$ 
11109250 LOCKWOOD CREEK AT GORGE, NEAR STAUFFER, CA

LOCATION, - Lat $34^{\circ} 43^{\prime} 57^{\prime \prime}$, long $119^{\circ} 02^{\prime} 14^{\prime \prime}$, in SEt SW ${ }^{\frac{1}{4} S S^{\frac{1}{4}}}$ sec.31, T.8 N., R. 20 W., Ventura County, on right bank

$2.1 \mathrm{mi}(3.4 \mathrm{~km})$ southeast of Stauffer, and $3.8 \mathrm{mi}(6.1 \mathrm{~km})$ upstream from Piru Creek.

DRAINAGE AREA. $-58.7 \mathrm{mi}^{2}\left(152.0 \mathrm{~km}^{2}\right)$.

PERIOD OF RECORD. - October 1971 to current year.

REVISED RECORDS. - -WDR CA-74-1: 1973 (M)

GAGE.--Water-stage recorder. Altitude of gage is $4,790 \mathrm{ft}(1,460 \mathrm{~m})$, from topographic map.

REMARKS, --Records good except those above $20 \mathrm{ft}^{3} / \mathrm{s}\left(0.57 \mathrm{~m}^{3} / \mathrm{s}\right)$ and for months of December and January, which are fair.

COOPERATION. - Nineteen discharge measurements furnished by Ventura County Flood Control District.

AVERAgE Discharge, -5 years, $4.83 \mathrm{ft}^{3} / \mathrm{s}\left(0.137 \mathrm{~m}^{3} / \mathrm{s}\right), 3,500 \mathrm{acre}-\mathrm{ft} / \mathrm{yr}(4.32 \mathrm{hm} / \mathrm{yr})$.

EXTREMES FOR PERIOD OF RECORD, - Maximum discharge, $906 \mathrm{ft} \mathrm{t}^{3} / \mathrm{s}\left(25.7 \mathrm{~m}^{3} / \mathrm{s}\right)$ Aug. 2,1974 , gage height, $4.92 \mathrm{ft}$

$(1.500 \mathrm{~m})$, from rating curve extended above $34 \mathrm{ft}^{3} / \mathrm{s}\left(0.96 \mathrm{~m}^{3} / \mathrm{s}\right)$ on basis of slope-area measurement at gage height $4.92 \mathrm{ft}(1.500 \mathrm{~m})$; minimum dail $1.0 \mathrm{ft} / \mathrm{s}\left(0.028 \mathrm{~m}^{3} / \mathrm{s}\right)$ Aug. 15, 16, 18-20, $22,23,1974$.

EXTREMES FOR CURRENT YEAR.--Peak discharge above base of $100 \mathrm{ft}^{3} / \mathrm{s}\left(2.83 \mathrm{~m}^{3} / \mathrm{s}\right)$ and maximum (*):

\begin{tabular}{|c|c|c|c|c|c|}
\hline Date & Time & $\begin{array}{r}D i \\
\left(\mathrm{ft}^{3}\right)\end{array}$ & $\underset{\left(\mathrm{m}^{3} / \mathrm{s}\right)}{\mathrm{rge}}$ & $\begin{array}{l}\text { Gage } \\
(\mathrm{ft})\end{array}$ & $\begin{array}{r}\text { height } \\
\text { (m) }\end{array}$ \\
\hline $\begin{array}{ll}\text { eb. } & 9 \\
\text { ept. } & 6\end{array}$ & $\begin{array}{l}0430 \\
1530\end{array}$ & $\begin{array}{r}* 149 \\
145\end{array}$ & $\begin{array}{l}4.22 \\
4.11\end{array}$ & $\begin{array}{l}3.53 \\
3.50\end{array}$ & $\begin{array}{l}1.076 \\
1.067\end{array}$ \\
\hline
\end{tabular}

Minimum daily discharge, $1.2 \mathrm{ft}^{3} / \mathrm{s}\left(0.033 \mathrm{~m}^{3} / \mathrm{s}\right)$ Ju1y 16,17 , Sept. 1 .

DISCHARGE, IN CUBIC FEET PER SECOND, WATER YEAR OCTOBER 1975 TO SEPTEMBER 1976 MEAN VALUES

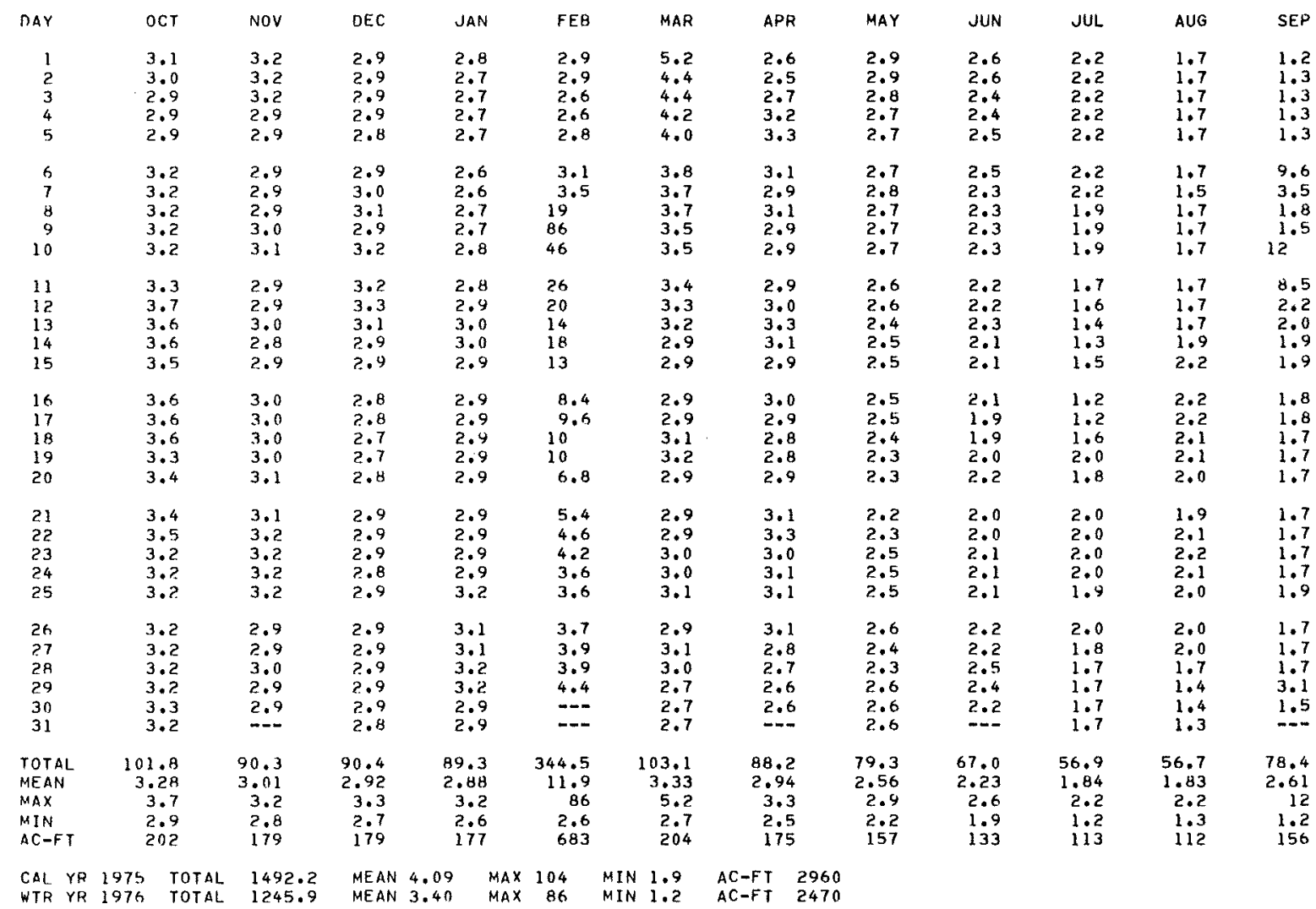




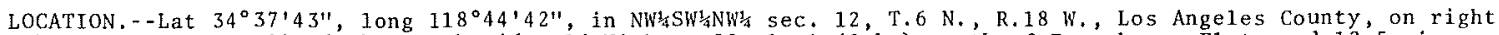
bank of concrete-1ined'channel beside oid Highway 99,1 mi (2 km) north of Frenchmans Flat, and 12 , 5 mi $(20.1 \mathrm{~km})$ north of Castaic.

PERIOD OF DAILY RECORD. - -

SPECIFIC CONDUCTANCE: March 1972 to current year.

INSTRUMENTATION. - Specific conductance recorder since March 1972.

REMARKS,--Gaging station $700 \mathrm{ft}(213 \mathrm{~m})$ upstream operated by Ca1ifornia Department of Water Resources.

EXTREMES FOR PERIOD OF DAILY RECORD, - -

SPECIFIC CONDUCTANCE: Maximum recorded, 2,540 micromhos Dec. 29, 1973; minimum recorded, 338 micromhos Nov, $30,1972, \mathrm{Feb}, 13,1976$

EXTREMES FOR CURRENT YEAR.-

SPECIFIC CONDUCTANCE: Maximum, 1,400 micromhos sept. 10; minimum, 338 micromhos Feb. 13.

SPECIFIC CONDUCTANCE (MICROMHOS/CM AT 25 DEG, C), HATER YEAR OCTOBER 1975 TO SEPTEMBER 1976

\begin{tabular}{|c|c|c|c|c|c|c|c|c|c|c|c|c|}
\hline \multirow[b]{2}{*}{ DAY } & \multicolumn{3}{|c|}{ OCTOAER } & \multicolumn{3}{|c|}{ NOVEMAER } & \multicolumn{3}{|c|}{ DECEMBER } & \multicolumn{3}{|c|}{ JANUARY } \\
\hline & $\operatorname{MAX}$ & MIN & MEAN & MAX & MIN & MEAN & $\operatorname{MAX}$ & MIN & MEAN & MAX & MIN & MEAN \\
\hline $\begin{array}{l}1 \\
2 \\
3 \\
4 \\
5\end{array}$ & $\begin{array}{l}586 \\
588 \\
590 \\
592 \\
586\end{array}$ & $\begin{array}{l}568 \\
572 \\
568 \\
572 \\
570\end{array}$ & $\begin{array}{l}578 \\
580 \\
580 \\
580 \\
581\end{array}$ & $\begin{array}{l}614 \\
610 \\
608 \\
608 \\
608\end{array}$ & $\begin{array}{l}592 \\
588 \\
588 \\
574 \\
580\end{array}$ & $\begin{array}{l}606 \\
602 \\
598 \\
593 \\
595\end{array}$ & $\begin{array}{l}606 \\
804 \\
588 \\
714 \\
596\end{array}$ & $\begin{array}{l}582 \\
574 \\
554 \\
548 \\
554\end{array}$ & $\begin{array}{l}596 \\
620 \\
572 \\
602 \\
578\end{array}$ & $\begin{array}{l}580 \\
578 \\
578 \\
576 \\
578\end{array}$ & $\begin{array}{l}\mathbf{5 5 4} \\
\mathbf{5 6 0} \\
\mathbf{5 5 4} \\
\mathbf{5 5 2} \\
\mathbf{5 5 2}\end{array}$ & $\begin{array}{l}567 \\
569 \\
565 \\
568 \\
567\end{array}$ \\
\hline $\begin{array}{r}6 \\
7 \\
8 \\
9 \\
10\end{array}$ & $\begin{array}{l}690 \\
690 \\
682 \\
654 \\
632\end{array}$ & $\begin{array}{l}572 \\
668 \\
636 \\
604 \\
610\end{array}$ & $\begin{array}{l}622 \\
682 \\
659 \\
628 \\
623\end{array}$ & $\begin{array}{l}604 \\
604 \\
606 \\
604 \\
604\end{array}$ & $\begin{array}{l}580 \\
584 \\
582 \\
586 \\
586\end{array}$ & $\begin{array}{l}\mathbf{5 9 6} \\
\mathbf{5 9 6} \\
\mathbf{5 9 7} \\
\mathbf{5 9 6} \\
\mathbf{5 9 3}\end{array}$ & $\begin{array}{r}1050 \\
716 \\
600 \\
594 \\
594\end{array}$ & $\begin{array}{l}582 \\
574 \\
564 \\
564 \\
568\end{array}$ & $\begin{array}{l}713 \\
601 \\
585 \\
585 \\
586\end{array}$ & $\begin{array}{l}582 \\
570 \\
576 \\
578 \\
568\end{array}$ & $\begin{array}{l}548 \\
542 \\
548 \\
548 \\
542\end{array}$ & $\begin{array}{l}563 \\
560 \\
562 \\
565 \\
559\end{array}$ \\
\hline $\begin{array}{l}11 \\
12 \\
13 \\
14 \\
15\end{array}$ & $\begin{array}{l}646 \\
636 \\
636 \\
626 \\
632\end{array}$ & $\begin{array}{l}592 \\
620 \\
612 \\
612 \\
594\end{array}$ & $\begin{array}{l}624 \\
629 \\
623 \\
622 \\
618\end{array}$ & $\begin{array}{l}602 \\
600 \\
598 \\
602 \\
598\end{array}$ & $\begin{array}{l}578 \\
576 \\
574 \\
576 \\
576\end{array}$ & $\begin{array}{l}591 \\
590 \\
591 \\
588 \\
585\end{array}$ & $\begin{array}{l}594 \\
604 \\
602 \\
590 \\
586\end{array}$ & $\begin{array}{l}572 \\
580 \\
580 \\
564 \\
560\end{array}$ & $\begin{array}{l}587 \\
590 \\
591 \\
582 \\
578\end{array}$ & $\begin{array}{l}568 \\
568 \\
566 \\
564 \\
560\end{array}$ & $\begin{array}{l}\mathbf{5 3 4} \\
546 \\
\mathbf{5 4 0} \\
542 \\
544\end{array}$ & $\begin{array}{l}\mathbf{5 5 6} \\
\mathbf{5 5 7} \\
\mathbf{5 5 5} \\
\mathbf{5 5 5} \\
\mathbf{5 5 4}\end{array}$ \\
\hline $\begin{array}{l}16 \\
17 \\
18 \\
19 \\
20\end{array}$ & $\begin{array}{l}626 \\
624 \\
624 \\
622 \\
620\end{array}$ & $\begin{array}{l}606 \\
602 \\
604 \\
578 \\
578\end{array}$ & $\begin{array}{l}618 \\
615 \\
617 \\
606 \\
605\end{array}$ & $\begin{array}{l}602 \\
596 \\
592 \\
594 \\
600\end{array}$ & $\begin{array}{l}568 \\
564 \\
574 \\
568 \\
574\end{array}$ & $\begin{array}{l}586 \\
586 \\
583 \\
584 \\
586\end{array}$ & $\begin{array}{l}590 \\
588 \\
586 \\
582 \\
586\end{array}$ & $\begin{array}{l}574 \\
570 \\
570 \\
566 \\
566\end{array}$ & $\begin{array}{l}582 \\
580 \\
577 \\
575 \\
576\end{array}$ & $\begin{array}{l}560 \\
560 \\
558 \\
556 \\
556\end{array}$ & $\begin{array}{l}540 \\
542 \\
542 \\
538 \\
538\end{array}$ & $\begin{array}{l}\mathbf{5 5 3} \\
\mathbf{5 5 0} \\
\mathbf{5 5 1} \\
548 \\
\mathbf{5 4 6}\end{array}$ \\
\hline $\begin{array}{l}21 \\
22 \\
23 \\
24 \\
25\end{array}$ & $\begin{array}{l}620 \\
620 \\
628 \\
624 \\
620\end{array}$ & $\begin{array}{l}582 \\
604 \\
604 \\
604 \\
600\end{array}$ & $\begin{array}{l}607 \\
613 \\
615 \\
613 \\
609\end{array}$ & $\begin{array}{l}592 \\
596 \\
586 \\
594 \\
618\end{array}$ & $\begin{array}{l}570 \\
564 \\
566 \\
560 \\
562\end{array}$ & $\begin{array}{l}583 \\
581 \\
578 \\
577 \\
583\end{array}$ & $\begin{array}{l}582 \\
584 \\
582 \\
578 \\
582\end{array}$ & $\begin{array}{l}564 \\
558 \\
550 \\
550 \\
546\end{array}$ & $\begin{array}{l}575 \\
574 \\
569 \\
568 \\
568\end{array}$ & $\begin{array}{l}554 \\
556 \\
562 \\
560 \\
554\end{array}$ & $\begin{array}{l}\mathbf{5 3 8} \\
\mathbf{5 3 6} \\
\mathbf{5 3 6} \\
\mathbf{5 3 4} \\
\mathbf{5 3 6}\end{array}$ & $\begin{array}{l}545 \\
547 \\
551 \\
548 \\
548\end{array}$ \\
\hline $\begin{array}{l}26 \\
27 \\
28 \\
29 \\
30 \\
31\end{array}$ & $\begin{array}{l}616 \\
612 \\
608 \\
610 \\
622 \\
624\end{array}$ & $\begin{array}{l}596 \\
588 \\
590 \\
588 \\
590 \\
596\end{array}$ & $\begin{array}{l}607 \\
605 \\
601 \\
600 \\
602 \\
610\end{array}$ & $\begin{array}{l}658 \\
606 \\
614 \\
612 \\
604 \\
--10\end{array}$ & $\begin{array}{l}576 \\
572 \\
572 \\
576 \\
574 \\
-\end{array}$ & $\begin{array}{l}600 \\
589 \\
599 \\
597 \\
592 \\
-\infty\end{array}$ & $\begin{array}{l}576 \\
580 \\
580 \\
572 \\
576 \\
582\end{array}$ & $\begin{array}{l}554 \\
546 \\
562 \\
546 \\
546 \\
552\end{array}$ & $\begin{array}{l}568 \\
567 \\
570 \\
560 \\
562 \\
571\end{array}$ & $\begin{array}{l}558 \\
556 \\
552 \\
576 \\
550 \\
544\end{array}$ & $\begin{array}{l}\mathbf{5 3 4} \\
\mathbf{5 3 6} \\
\mathbf{5 3 6} \\
\mathbf{5 3 2} \\
\mathbf{5 2 6} \\
\mathbf{5 3 0}\end{array}$ & $\begin{array}{l}547 \\
546 \\
544 \\
548 \\
540 \\
538\end{array}$ \\
\hline NTH & 690 & 568 & 612 & 658 & 560 & 591 & 1050 & 546 & 584 & 582 & 526 & 554 \\
\hline
\end{tabular}


11109550 PIRU CREEK ABOVE FRENCHMANS FLAT, CA--Continued

SPECIFIC CONOUCTANCE (MICROHHOS/CM AT 25 DEG, C), WATER YEAR OCTOBER 1975 TO SEPTEMBER 1976

\begin{tabular}{|c|c|c|c|c|c|c|c|c|c|c|c|c|}
\hline \multirow[b]{2}{*}{ DAY } & \multicolumn{3}{|c|}{ FEBRLIARY } & \multicolumn{3}{|c|}{ MARCH } & \multicolumn{3}{|c|}{ APRIL } & \multicolumn{3}{|c|}{ MAY } \\
\hline & MAX & MIN & MEAN & $\operatorname{MAX}$ & MIN & MEAN & $\operatorname{MAX}$ & MIN & MEAN & $\operatorname{MAX}$ & MIN & MEAN \\
\hline $\begin{array}{l}1 \\
2 \\
3 \\
4 \\
5\end{array}$ & $\begin{array}{r}550 \\
558 \\
564 \\
600 \\
1260\end{array}$ & $\begin{array}{l}530 \\
536 \\
536 \\
542 \\
556\end{array}$ & $\begin{array}{l}543 \\
548 \\
551 \\
562 \\
813\end{array}$ & $\begin{array}{l}814 \\
925 \\
958 \\
813 \\
774\end{array}$ & $\begin{array}{l}680 \\
599 \\
786 \\
749 \\
732\end{array}$ & $\begin{array}{l}738 \\
728 \\
853 \\
778 \\
751\end{array}$ & $\begin{array}{l}656 \\
664 \\
658 \\
668 \\
660\end{array}$ & $\begin{array}{l}612 \\
610 \\
618 \\
608 \\
614\end{array}$ & $\begin{array}{l}636 \\
638 \\
642 \\
644 \\
638\end{array}$ & $\begin{array}{l}633 \\
625 \\
631 \\
631 \\
631\end{array}$ & $\begin{array}{l}585 \\
587 \\
587 \\
589 \\
599\end{array}$ & $\begin{array}{l}612 \\
608 \\
611 \\
611 \\
618\end{array}$ \\
\hline $\begin{array}{r}6 \\
7 \\
8 \\
9 \\
10\end{array}$ & $\begin{array}{r}1280 \\
1140 \\
1260 \\
1390 \\
538\end{array}$ & $\begin{array}{r}904 \\
860 \\
1080 \\
530 \\
348\end{array}$ & $\begin{array}{r}1140 \\
1010 \\
1190 \\
1030 \\
446\end{array}$ & $\begin{array}{l}757 \\
747 \\
740 \\
735 \\
721\end{array}$ & $\begin{array}{l}717 \\
703 \\
694 \\
675 \\
673\end{array}$ & $\begin{array}{l}737 \\
726 \\
717 \\
708 \\
696\end{array}$ & $\begin{array}{l}654 \\
651 \\
704 \\
696 \\
667\end{array}$ & $\begin{array}{l}604 \\
603 \\
602 \\
622 \\
613\end{array}$ & $\begin{array}{l}629 \\
626 \\
639 \\
651 \\
637\end{array}$ & $\begin{array}{r}633 \\
649 \\
--- \\
---\end{array}$ & $\begin{array}{l}609 \\
601 \\
--- \\
---\end{array}$ & $\begin{array}{l}622 \\
616 \\
--0 \\
---\end{array}$ \\
\hline $\begin{array}{l}11 \\
12 \\
13 \\
14 \\
15\end{array}$ & $\begin{array}{l}372 \\
378 \\
912 \\
910 \\
874\end{array}$ & $\begin{array}{l}352 \\
356 \\
338 \\
874 \\
830\end{array}$ & $\begin{array}{l}364 \\
370 \\
530 \\
892 \\
850\end{array}$ & $\begin{array}{l}708 \\
700 \\
691 \\
685 \\
678\end{array}$ & $\begin{array}{l}662 \\
660 \\
651 \\
647 \\
640\end{array}$ & $\begin{array}{l}685 \\
681 \\
672 \\
668 \\
662\end{array}$ & $\begin{array}{l}662 \\
659 \\
815 \\
716 \\
677\end{array}$ & $\begin{array}{l}618 \\
593 \\
623 \\
640 \\
631\end{array}$ & $\begin{array}{l}640 \\
626 \\
700 \\
670 \\
654\end{array}$ & $\begin{array}{l}=- \\
=-5 \\
633\end{array}$ & $\begin{array}{l}-\infty \\
--\infty \\
-\infty \\
593\end{array}$ & 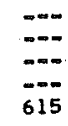 \\
\hline $\begin{array}{l}16 \\
17 \\
18 \\
19 \\
20\end{array}$ & $\begin{array}{l}834 \\
800 \\
774 \\
768 \\
760\end{array}$ & $\begin{array}{l}800 \\
766 \\
760 \\
746 \\
736\end{array}$ & $\begin{array}{l}813 \\
786 \\
766 \\
755 \\
749\end{array}$ & $\begin{array}{l}678 \\
669 \\
669 \\
672 \\
662\end{array}$ & $\begin{array}{l}636 \\
631 \\
633 \\
634 \\
628\end{array}$ & $\begin{array}{l}658 \\
654 \\
653 \\
655 \\
646\end{array}$ & $\begin{array}{l}670 \\
664 \\
667 \\
656 \\
671\end{array}$ & $\begin{array}{l}636 \\
620 \\
617 \\
614 \\
611\end{array}$ & $\begin{array}{l}653 \\
646 \\
645 \\
637 \\
639\end{array}$ & $\begin{array}{l}644 \\
628 \\
627 \\
626 \\
623\end{array}$ & $\begin{array}{l}600 \\
594 \\
597 \\
594 \\
593\end{array}$ & $\begin{array}{l}622 \\
612 \\
611 \\
610 \\
609\end{array}$ \\
\hline $\begin{array}{l}21 \\
22 \\
23 \\
24 \\
25\end{array}$ & $\begin{array}{l}757 \\
750 \\
749 \\
741 \\
734\end{array}$ & $\begin{array}{l}743 \\
736 \\
733 \\
725 \\
720\end{array}$ & $\begin{array}{l}749 \\
742 \\
739 \\
732 \\
725\end{array}$ & $\begin{array}{l}657 \\
655 \\
664 \\
668 \\
670\end{array}$ & $\begin{array}{l}621 \\
615 \\
618 \\
630 \\
636\end{array}$ & $\begin{array}{l}642 \\
637 \\
644 \\
651 \\
653\end{array}$ & $\begin{array}{l}641 \\
636 \\
635 \\
639 \\
635\end{array}$ & $\begin{array}{l}601 \\
598 \\
605 \\
605 \\
597\end{array}$ & $\begin{array}{l}622 \\
620 \\
622 \\
624 \\
620\end{array}$ & $\begin{array}{l}623 \\
658 \\
635 \\
620 \\
622\end{array}$ & $\begin{array}{l}593 \\
592 \\
589 \\
590 \\
590\end{array}$ & $\begin{array}{l}608 \\
617 \\
608 \\
607 \\
607\end{array}$ \\
\hline $\begin{array}{l}26 \\
27 \\
28 \\
29 \\
30 \\
31\end{array}$ & $\begin{array}{l}729 \\
720 \\
713 \\
720 \\
=--\end{array}$ & $\begin{array}{l}715 \\
710 \\
703 \\
686 \\
-\end{array}$ & $\begin{array}{l}719 \\
715 \\
707 \\
702 \\
-\infty \\
-\infty\end{array}$ & $\begin{array}{l}664 \\
666 \\
668 \\
660 \\
662 \\
662\end{array}$ & $\begin{array}{l}624 \\
626 \\
626 \\
616 \\
612 \\
612\end{array}$ & $\begin{array}{l}646 \\
649 \\
648 \\
639 \\
638 \\
637\end{array}$ & $\begin{array}{l}641 \\
645 \\
633 \\
633 \\
623 \\
-2 .\end{array}$ & $\begin{array}{l}603 \\
587 \\
595 \\
591 \\
583 \\
-\end{array}$ & $\begin{array}{l}625 \\
618 \\
615 \\
615 \\
608 \\
--\end{array}$ & $\begin{array}{l}617 \\
620 \\
635 \\
611 \\
612 \\
611\end{array}$ & $\begin{array}{l}583 \\
592 \\
583 \\
583 \\
590 \\
581\end{array}$ & $\begin{array}{l}602 \\
604 \\
607 \\
599 \\
600 \\
599\end{array}$ \\
\hline \multirow[t]{2}{*}{ MONTH } & 1390 & 338 & 732 & 958 & 599 & 682 & 815 & 583 & 636 & $-\infty$ & $m-$ & $-\infty$ \\
\hline & \multicolumn{3}{|c|}{ JUNE } & \multicolumn{3}{|c|}{ JULY } & \multicolumn{3}{|c|}{ AUGUST } & \multicolumn{3}{|c|}{ SEPTEMBER } \\
\hline DAY & MAX & MIN & MEAN & MAX & MIN & MEAN & MAX & MIN & MEAN & $\operatorname{MAX}$ & MIN & MEAN \\
\hline $\begin{array}{l}1 \\
2 \\
3 \\
4 \\
5\end{array}$ & $\begin{array}{l}606 \\
606 \\
605 \\
632 \\
635\end{array}$ & $\begin{array}{l}584 \\
572 \\
577 \\
578 \\
575\end{array}$ & $\begin{array}{l}597 \\
592 \\
593 \\
594 \\
602\end{array}$ & $\begin{array}{l}626 \\
534 \\
542 \\
530 \\
526\end{array}$ & $\begin{array}{l}524 \\
498 \\
500 \\
506 \\
502\end{array}$ & $\begin{array}{l}583 \\
517 \\
522 \\
520 \\
514\end{array}$ & $\begin{array}{l}503 \\
506 \\
506 \\
501 \\
498\end{array}$ & $\begin{array}{l}477 \\
476 \\
472 \\
479 \\
474\end{array}$ & $\begin{array}{l}492 \\
491 \\
490 \\
491 \\
488\end{array}$ & $\begin{array}{l}513 \\
513 \\
513 \\
517 \\
524\end{array}$ & $\begin{array}{l}473 \\
499 \\
501 \\
493 \\
502\end{array}$ & $\begin{array}{l}492 \\
508 \\
508 \\
506 \\
512\end{array}$ \\
\hline $\begin{array}{r}6 \\
7 \\
8 \\
9 \\
10\end{array}$ & $\begin{array}{l}627 \\
624 \\
644 \\
646 \\
640\end{array}$ & $\begin{array}{l}577 \\
588 \\
610 \\
610 \\
620\end{array}$ & $\begin{array}{l}595 \\
610 \\
625 \\
628 \\
632\end{array}$ & $\begin{array}{l}526 \\
550 \\
546 \\
540 \\
540\end{array}$ & $\begin{array}{l}506 \\
508 \\
518 \\
512 \\
514\end{array}$ & $\begin{array}{l}\mathbf{5 1 7} \\
\mathbf{5 2 2} \\
\mathbf{5 3 2} \\
\mathbf{5 2 7} \\
\mathbf{5 2 8}\end{array}$ & $\begin{array}{l}505 \\
502 \\
493 \\
500 \\
495\end{array}$ & $\begin{array}{l}475 \\
476 \\
471 \\
468 \\
473\end{array}$ & $\begin{array}{l}489 \\
493 \\
486 \\
483 \\
484\end{array}$ & $\begin{array}{r}792 \\
530 \\
525 \\
521 \\
1400\end{array}$ & $\begin{array}{l}524 \\
514 \\
511 \\
513 \\
501\end{array}$ & $\begin{array}{l}568 \\
523 \\
519 \\
518 \\
931\end{array}$ \\
\hline $\begin{array}{l}11 \\
12 \\
13 \\
14 \\
15\end{array}$ & $\begin{array}{l}636 \\
634 \\
632 \\
620 \\
620\end{array}$ & $\begin{array}{l}614 \\
614 \\
608 \\
606 \\
602\end{array}$ & $\begin{array}{l}628 \\
624 \\
620 \\
614 \\
613\end{array}$ & $\begin{array}{l}536 \\
536 \\
496 \\
494 \\
496\end{array}$ & $\begin{array}{l}514 \\
486 \\
476 \\
476 \\
480\end{array}$ & $\begin{array}{l}528 \\
513 \\
485 \\
486 \\
488\end{array}$ & $\begin{array}{l}492 \\
491 \\
488 \\
488 \\
488\end{array}$ & $\begin{array}{l}468 \\
469 \\
468 \\
472 \\
472\end{array}$ & $\begin{array}{l}483 \\
483 \\
479 \\
483 \\
482\end{array}$ & $\begin{array}{r}1330 \\
1040 \\
850 \\
790 \\
781\end{array}$ & $\begin{array}{r}1050 \\
858 \\
790 \\
732 \\
745\end{array}$ & $\begin{array}{r}1200 \\
930 \\
813 \\
772 \\
758\end{array}$ \\
\hline $\begin{array}{l}16 \\
17 \\
18 \\
19 \\
20\end{array}$ & $\begin{array}{l}626 \\
626 \\
624 \\
620 \\
618\end{array}$ & $\begin{array}{l}608 \\
608 \\
604 \\
602 \\
604\end{array}$ & $\begin{array}{l}616 \\
616 \\
614 \\
612 \\
611\end{array}$ & $\begin{array}{l}498 \\
502 \\
502 \\
506 \\
502\end{array}$ & $\begin{array}{l}476 \\
482 \\
482 \\
482 \\
482\end{array}$ & $\begin{array}{l}489 \\
491 \\
493 \\
495 \\
494\end{array}$ & $\begin{array}{l}488 \\
488 \\
490 \\
492 \\
488\end{array}$ & $\begin{array}{l}474 \\
476 \\
472 \\
462 \\
474\end{array}$ & $\begin{array}{l}482 \\
483 \\
483 \\
479 \\
486\end{array}$ & $\begin{array}{l}743 \\
737 \\
718 \\
710 \\
696\end{array}$ & $\begin{array}{l}691 \\
705 \\
700 \\
690 \\
682\end{array}$ & $\begin{array}{l}729 \\
721 \\
708 \\
700 \\
691\end{array}$ \\
\hline $\begin{array}{l}21 \\
22 \\
23 \\
24 \\
25\end{array}$ & $\begin{array}{l}624 \\
626 \\
626 \\
630 \\
634\end{array}$ & $\begin{array}{l}606 \\
612 \\
604 \\
606 \\
614\end{array}$ & $\begin{array}{l}614 \\
619 \\
616 \\
620 \\
623\end{array}$ & $\begin{array}{l}506 \\
514 \\
510 \\
505 \\
504\end{array}$ & $\begin{array}{l}488 \\
488 \\
486 \\
487 \\
480\end{array}$ & $\begin{array}{l}499 \\
501 \\
500 \\
497 \\
\$ 95\end{array}$ & $\begin{array}{l}490 \\
486 \\
488 \\
490 \\
498\end{array}$ & $\begin{array}{l}468 \\
468 \\
472 \\
472 \\
474\end{array}$ & $\begin{array}{l}482 \\
462 \\
483 \\
484 \\
487\end{array}$ & $\begin{array}{l}694 \\
687 \\
687 \\
681 \\
654\end{array}$ & $\begin{array}{l}680 \\
653 \\
629 \\
653 \\
637\end{array}$ & $\begin{array}{l}687 \\
673 \\
652 \\
662 \\
647\end{array}$ \\
\hline $\begin{array}{l}26 \\
27 \\
28 \\
29 \\
30 \\
31\end{array}$ & $\begin{array}{l}630 \\
624 \\
622 \\
626 \\
626 \\
=00\end{array}$ & $\begin{array}{l}608 \\
600 \\
604 \\
606 \\
604 \\
-\infty\end{array}$ & $\begin{array}{l}620 \\
614 \\
612 \\
614 \\
614 \\
0-\infty\end{array}$ & $\begin{array}{l}509 \\
506 \\
505 \\
506 \\
511 \\
508\end{array}$ & $\begin{array}{l}485 \\
482 \\
479 \\
482 \\
481 \\
478\end{array}$ & $\begin{array}{l}497 \\
497 \\
495 \\
497 \\
\$ 97 \\
494\end{array}$ & $\begin{array}{l}490 \\
486 \\
496 \\
494 \\
494 \\
486\end{array}$ & $\begin{array}{l}472 \\
468 \\
474 \\
478 \\
472 \\
470\end{array}$ & $\begin{array}{l}484 \\
480 \\
486 \\
489 \\
482 \\
481\end{array}$ & $\begin{array}{l}658 \\
658 \\
656 \\
655 \\
649 \\
\end{array}$ & $\begin{array}{l}624 \\
640 \\
622 \\
641 \\
639 \\
60\end{array}$ & $\begin{array}{l}652 \\
649 \\
638 \\
649 \\
646 \\
-60\end{array}$ \\
\hline MONTH & 646 & 572 & 613 & 626 & 476 & 507 & 506 & 462 & 485 & 1400 & 473 & 672 \\
\hline
\end{tabular}

YEAR $\quad 1400 \quad 338 \quad 606$ 
LOCATION,--Lat $34^{\circ} 31^{\prime} 23^{\prime \prime}$, long $118^{\circ} 45^{\prime} 22^{\prime \prime}$, in SW/4E $\frac{1}{4} N W_{4}$ sec. 15, T.5 N., R. 18 W., Ventura County, on 1 eft bank near Blue Point, $1.3 \mathrm{mi}(2.1 \mathrm{~km})$ downstream from Agua Blanca Creek, $4.3 \mathrm{mi}$ (6.9 km) upstream from Santa
Felicia Dam, and $8.0 \mathrm{mi}(12.9 \mathrm{~km})$ northeast of Piru.

DRAINAGE AREA. $--372 \mathrm{mi}^{2}\left(963 \mathrm{~km}^{2}\right)$.

WATER-DISCHARGE RECORDS

PERIOD OF RECORD. - - October 1955 to current year.

GAGE, - Water-stage recorder. Datum of gage is $1,058.55 \mathrm{ft}(322.646 \mathrm{~m})$ above mean sea 1 eve 1 (levels by U.S. Forest Service). Prior to Dec. 15, 1972, at site $0.3 \mathrm{mi}(0.5 \mathrm{~km})$ upstream at different datum.

REMARKS, - -Records fair. Flow regulated beginning December 1971 by Pyramid Dam, capacity, 173,500 acre-ft $\left(214 \mathrm{hm}^{3}\right) 15 \mathrm{mi}(24 \mathrm{~km})$ upstream. Imported water from the California Water Project stored and released
from Pyramid Dan. No diversion above station.

AVERAGE DISCHARGE. - - 16 years (water years $1956-71), 55.1 \mathrm{ft}^{3} / \mathrm{s}\left(1.560 \mathrm{~m}^{3} / \mathrm{s}\right), 39,920 \mathrm{acre}-\mathrm{ft} / \mathrm{yr}(49.2 \mathrm{hm} / \mathrm{yr})$.

EXTREMES FOR PERIOD OF RECORD. - Maximum discharge, 31, $200 \mathrm{ft}^{3} / \mathrm{s}\left(884 \mathrm{~m}^{3} / \mathrm{s}\right)$ Feb. 25 , 1969 , gage height, $18.6 \mathrm{ft}$ $(5.669 \mathrm{~m})$, site and datum then in use, from floodmark, from rating curve extended above $4,000 \mathrm{ft} / \mathrm{s}(113 \mathrm{~m} / \mathrm{s})$ no flow in some years. EXTREMES OUTSIDE PERIOD OF RECORD.--Flood of Mar. 2, 1938, 35,000 $\mathrm{ft}^{3} / \mathrm{s}\left(991 \mathrm{~m}^{3} / \mathrm{s}\right)$, is the greatest since that
date.

EXTREMES FOR CURRENT YEAR,--Maximum discharge, $706 \mathrm{ft}^{3} / \mathrm{s}\left(20.0 \mathrm{~m}^{3} / \mathrm{s}\right)$ Feb. 9 , gage height, $5.56 \mathrm{ft}(1.695 \mathrm{~m})$; minimum daily, $1.7 \mathrm{ft}^{3} / \mathrm{s}\left(0.048 \mathrm{~m}^{3} / \mathrm{s}\right)$ June 27,28 .

DISCHARGE, IN CUBIC FEET PER SECOND, WATER YEAR OCTOBER 1975 TO SEPTEMBER 1976 MEAN VALUES

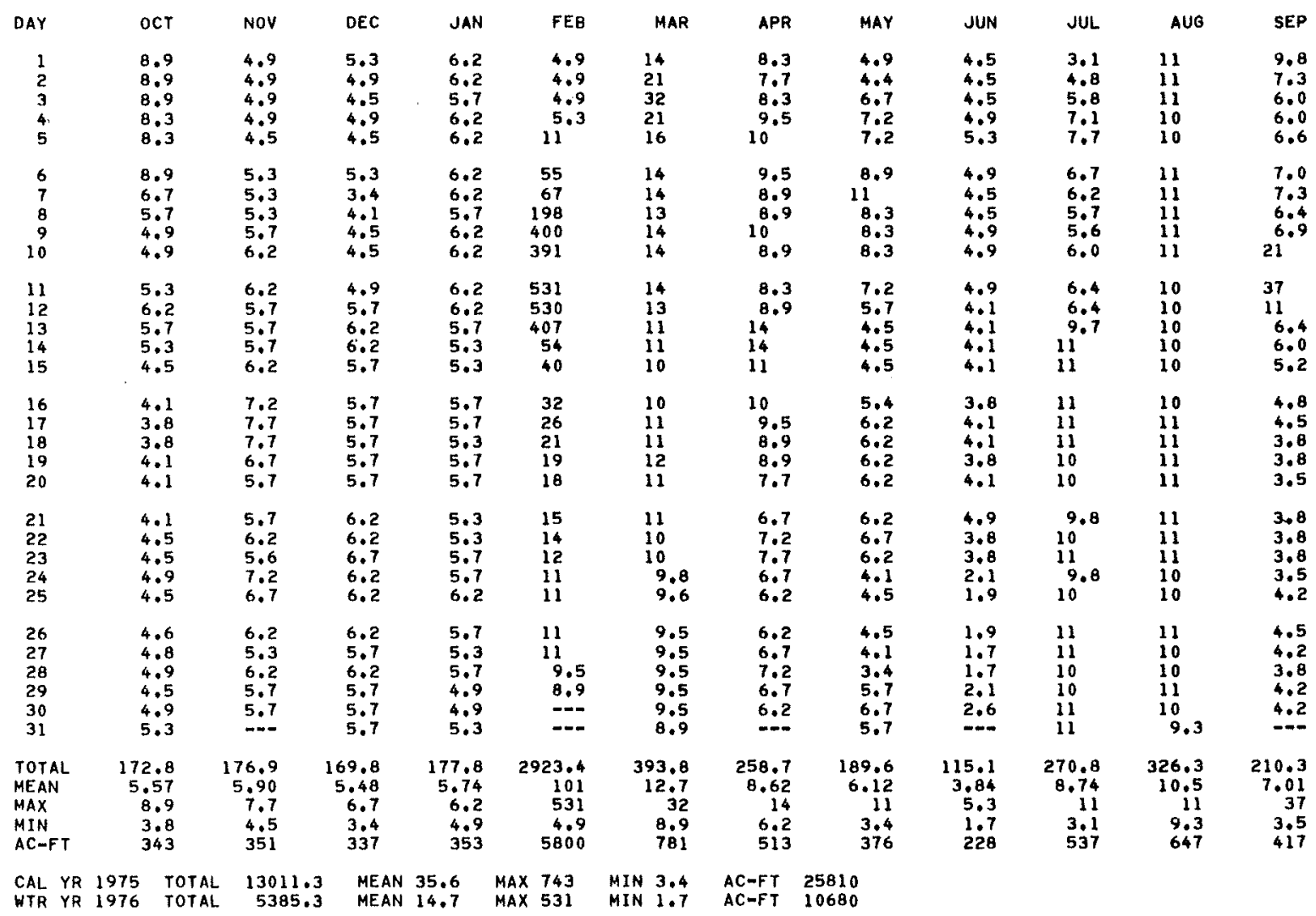


11109600 PIRU CREEK ABOVE LAKE PIRU, CA--Continued

WATER-QUALITY RECORDS

PERIOD OF DAILY RECORD.--

SPECIFIC CONDUCTANCE: March 1971 to current year.

INSTRUMENTATION, - -Specific conductance recorder since March 1971.

REMARKS.--Periods of missing specific conductance data due to recorder malfunction and vandalism.

EXTREMES FOR PERIOD OF DAILY RECORD..-

SPECIFIC CONDUCTANCE: Maximum recorded, 1,980 micromhos June 3, 1973; minimum recorded, 464 micromhos Apr. $22,1973$.

EXTREMES FOR CURRENT YEAR.--

SPECIFIC CONDUCTANCE: Maximum recorded, 1,180 micromhos Feb. 7; minimum recorded, 485 micromhos Feb, 9.

SPECIFIC CONDUCTANCE (MICROMMOS/CM AT 25 DEG, C), WATER YEAR OCTOEER 1975 TO SEPTEMBER 1976

\begin{tabular}{|c|c|c|c|c|c|c|c|c|c|c|c|c|}
\hline \multirow[b]{2}{*}{ DAY } & \multicolumn{3}{|c|}{ OCTOBER } & \multicolumn{3}{|c|}{ NOVEMBER } & \multicolumn{3}{|c|}{ DECEMBER } & \multicolumn{3}{|c|}{ JANUARYY } \\
\hline & $\operatorname{MAX}$ & MIN & MEAN & MAX & MIN & MEAN & $\operatorname{Max}$ & MIN & MEAN & $\max$ & MIN & MEAN \\
\hline $\begin{array}{l}1 \\
2 \\
3 \\
4 \\
5\end{array}$ & $\begin{array}{l}816 \\
818 \\
809 \\
811 \\
816\end{array}$ & $\begin{array}{l}748 \\
732 \\
737 \\
743 \\
750\end{array}$ & $\begin{array}{l}782 \\
777 \\
772 \\
778 \\
782\end{array}$ & $\begin{array}{l}896 \\
900 \\
882 \\
890 \\
892\end{array}$ & $\begin{array}{l}832 \\
832 \\
818 \\
820 \\
832\end{array}$ & $\begin{array}{l}869 \\
867 \\
858 \\
863 \\
865\end{array}$ & $\begin{array}{l}908 \\
889 \\
894 \\
896 \\
888\end{array}$ & $\begin{array}{l}853 \\
847 \\
864 \\
854 \\
856\end{array}$ & $\begin{array}{l}882 \\
874 \\
882 \\
879 \\
874\end{array}$ & $\begin{array}{l}884 \\
881 \\
883 \\
882 \\
886\end{array}$ & $\begin{array}{l}860 \\
855 \\
841 \\
850 \\
854\end{array}$ & $\begin{array}{l}875 \\
873 \\
868 \\
871 \\
875\end{array}$ \\
\hline $\begin{array}{r}6 \\
7 \\
8 \\
9 \\
10\end{array}$ & $\begin{array}{l}819 \\
834 \\
871 \\
896 \\
903\end{array}$ & $\begin{array}{l}765 \\
798 \\
821 \\
842 \\
847\end{array}$ & $\begin{array}{l}792 \\
815 \\
848 \\
869 \\
875\end{array}$ & $\begin{array}{l}894 \\
882 \\
898 \\
904 \\
902\end{array}$ & $\begin{array}{l}836 \\
832 \\
842 \\
846 \\
850\end{array}$ & $\begin{array}{l}871 \\
872 \\
874 \\
879 \\
881\end{array}$ & $\begin{array}{l}888 \\
921 \\
899 \\
928 \\
887\end{array}$ & $\begin{array}{l}844 \\
865 \\
845 \\
846 \\
845\end{array}$ & $\begin{array}{l}872 \\
888 \\
879 \\
887 \\
870\end{array}$ & $\begin{array}{l}883 \\
880 \\
886 \\
879 \\
878\end{array}$ & $\begin{array}{l}855 \\
852 \\
848 \\
847 \\
846\end{array}$ & $\begin{array}{l}873 \\
870 \\
871 \\
868 \\
867\end{array}$ \\
\hline $\begin{array}{l}11 \\
12 \\
13 \\
14 \\
15\end{array}$ & $\begin{array}{l}890 \\
891 \\
902 \\
903 \\
908\end{array}$ & $\begin{array}{l}840 \\
845 \\
848 \\
849 \\
850\end{array}$ & $\begin{array}{l}865 \\
868 \\
875 \\
881 \\
885\end{array}$ & $\begin{array}{l}910 \\
908 \\
914 \\
906 \\
906\end{array}$ & $\begin{array}{l}858 \\
856 \\
850 \\
848 \\
852\end{array}$ & $\begin{array}{l}885 \\
887 \\
887 \\
881 \\
882\end{array}$ & $\begin{array}{l}882 \\
876 \\
878 \\
878 \\
881\end{array}$ & $\begin{array}{l}840 \\
822 \\
852 \\
850 \\
851\end{array}$ & $\begin{array}{l}866 \\
862 \\
867 \\
869 \\
871\end{array}$ & $\begin{array}{l}879 \\
877 \\
880 \\
881 \\
880\end{array}$ & $\begin{array}{l}847 \\
841 \\
844 \\
841 \\
840\end{array}$ & $\begin{array}{l}867 \\
862 \\
867 \\
867 \\
866\end{array}$ \\
\hline $\begin{array}{l}16 \\
17 \\
18 \\
19 \\
20\end{array}$ & $\begin{array}{l}913 \\
917 \\
918 \\
909 \\
912\end{array}$ & $\begin{array}{l}847 \\
855 \\
868 \\
855 \\
856\end{array}$ & $\begin{array}{l}886 \\
887 \\
890 \\
885 \\
885\end{array}$ & $\begin{array}{l}908 \\
902 \\
910 \\
908 \\
906\end{array}$ & $\begin{array}{l}854 \\
856 \\
864 \\
856 \\
844\end{array}$ & $\begin{array}{l}883 \\
885 \\
887 \\
885 \\
882\end{array}$ & $\begin{array}{l}883 \\
879 \\
874 \\
873 \\
872\end{array}$ & $\begin{array}{l}847 \\
843 \\
842 \\
827 \\
834\end{array}$ & $\begin{array}{l}868 \\
866 \\
861 \\
859 \\
858\end{array}$ & $\begin{array}{l}877 \\
875 \\
880 \\
869 \\
875\end{array}$ & $\begin{array}{l}837 \\
827 \\
838 \\
839 \\
835\end{array}$ & $\begin{array}{l}864 \\
860 \\
862 \\
860 \\
860\end{array}$ \\
\hline $\begin{array}{l}21 \\
22 \\
23 \\
24 \\
25\end{array}$ & $\begin{array}{l}912 \\
905 \\
916 \\
924 \\
921\end{array}$ & $\begin{array}{l}854 \\
849 \\
866 \\
866 \\
861\end{array}$ & $\begin{array}{l}883 \\
880 \\
892 \\
897 \\
893\end{array}$ & $\begin{array}{l}898 \\
902 \\
904 \\
902 \\
908\end{array}$ & $\begin{array}{l}844 \\
844 \\
852 \\
844 \\
850\end{array}$ & $\begin{array}{l}880 \\
882 \\
882 \\
881 \\
881\end{array}$ & $\begin{array}{l}867 \\
866 \\
866 \\
871 \\
871\end{array}$ & $\begin{array}{l}831 \\
832 \\
832 \\
831 \\
833\end{array}$ & $\begin{array}{l}854 \\
854 \\
853 \\
857 \\
858\end{array}$ & $\begin{array}{l}884 \\
884 \\
883 \\
881 \\
882\end{array}$ & $\begin{array}{l}846 \\
834 \\
843 \\
843 \\
844\end{array}$ & $\begin{array}{l}871 \\
866 \\
868 \\
866 \\
868\end{array}$ \\
\hline $\begin{array}{l}26 \\
27 \\
28 \\
29 \\
30 \\
31\end{array}$ & $\begin{array}{l}916 \\
911 \\
917 \\
910 \\
904 \\
894\end{array}$ & $\begin{array}{l}860 \\
855 \\
855 \\
848 \\
848 \\
834\end{array}$ & $\begin{array}{l}892 \\
886 \\
889 \\
886 \\
878 \\
870\end{array}$ & $\begin{array}{l}900 \\
896 \\
904 \\
906 \\
916 \\
-\end{array}$ & $\begin{array}{l}854 \\
876 \\
868 \\
862 \\
856 \\
-\end{array}$ & $\begin{array}{l}881 \\
888 \\
888 \\
887 \\
884 \\
---\end{array}$ & $\begin{array}{l}870 \\
872 \\
873 \\
879 \\
881 \\
886\end{array}$ & $\begin{array}{l}834 \\
846 \\
841 \\
837 \\
845 \\
858\end{array}$ & $\begin{array}{l}856 \\
862 \\
864 \\
866 \\
867 \\
875\end{array}$ & $\begin{array}{l}882 \\
883 \\
883 \\
885 \\
882 \\
874\end{array}$ & $\begin{array}{l}842 \\
843 \\
843 \\
837 \\
832 \\
830\end{array}$ & $\begin{array}{l}868 \\
868 \\
870 \\
867 \\
862 \\
861\end{array}$ \\
\hline ONTH & 924 & 732 & 859 & 916 & 818 & 879 & 928 & 822 & 868 & 886 & 827 & 867 \\
\hline
\end{tabular}


11109600 PIRU CREEK ABOVE LAKE PIRU, CA--Continued

SPECIFIC CONOUCTANCE (MICROMHOS/CM AT 25 OEG, C), HATER YEAR OCTOBER 1975 TO SEPTEHBER 1976

\begin{tabular}{|c|c|c|c|c|c|c|c|c|c|c|c|c|}
\hline \multirow[b]{2}{*}{ DAY } & \multicolumn{3}{|c|}{ FEBRUARY } & \multicolumn{3}{|c|}{ MARCH } & \multicolumn{3}{|c|}{ APRIL } & \multicolumn{3}{|c|}{ MAY } \\
\hline & MAX & MIN & HEAN & $\operatorname{MAX}$ & MIN & MEAN & HAX & MIN & MEAN & MAX & MIN & MEAN \\
\hline $\begin{array}{l}1 \\
2 \\
3 \\
4 \\
5\end{array}$ & $\begin{array}{l}875 \\
877 \\
878 \\
872 \\
946\end{array}$ & $\begin{array}{l}829 \\
829 \\
802 \\
850 \\
844\end{array}$ & $\begin{array}{l}858 \\
858 \\
857 \\
862 \\
886\end{array}$ & $\begin{array}{l}988 \\
988 \\
988 \\
924 \\
--9\end{array}$ & $\begin{array}{l}-0 . \\
724 \\
868 \\
844 \\
--\infty\end{array}$ & $\begin{array}{l}-2.5 \\
943 \\
923 \\
891 \\
-0 .\end{array}$ & $\begin{array}{l}964 \\
967 \\
967 \\
963 \\
942\end{array}$ & $\begin{array}{l}940 \\
941 \\
951 \\
905 \\
930\end{array}$ & $\begin{array}{l}953 \\
954 \\
960 \\
947 \\
936\end{array}$ & $\begin{array}{l}936 \\
934 \\
936 \\
934 \\
930\end{array}$ & $\begin{array}{l}848 \\
848 \\
868 \\
860 \\
910\end{array}$ & $\begin{array}{l}999 \\
900 \\
907 \\
902 \\
919\end{array}$ \\
\hline $\begin{array}{r}6 \\
7 \\
8 \\
9 \\
10\end{array}$ & $\begin{array}{r}1180 \\
761 \\
-\infty 0-0\end{array}$ & $\begin{array}{l}567 \\
-85 \\
-85\end{array}$ & $\begin{array}{r}1080 \\
603 \\
-\infty\end{array}$ & $\begin{array}{l}=-\infty \\
=-\infty \\
=-\infty\end{array}$ & $=-\infty$ & $\begin{array}{l}=- \\
=-\infty \\
=-\infty\end{array}$ & $\begin{array}{l}944 \\
948 \\
947 \\
937 \\
947\end{array}$ & $\begin{array}{l}926 \\
910 \\
921 \\
909 \\
921\end{array}$ & $\begin{array}{l}937 \\
933 \\
933 \\
923 \\
935\end{array}$ & $\begin{array}{l}936 \\
922 \\
924 \\
924 \\
922\end{array}$ & $\begin{array}{l}900 \\
868 \\
838 \\
844 \\
858\end{array}$ & $\begin{array}{l}922 \\
698 \\
892 \\
892 \\
894\end{array}$ \\
\hline $\begin{array}{l}11 \\
12 \\
13 \\
14 \\
15\end{array}$ & $\begin{array}{r}581 \\
789 \\
931 \\
-00\end{array}$ & $\begin{array}{l}563 \\
--2 \\
537 \\
811 \\
-\end{array}$ & $\begin{array}{l}571 \\
-601 \\
857 \\
--2\end{array}$ & $\begin{array}{l}=-\infty \\
=-\infty \\
=-\infty \\
=-\infty\end{array}$ & $\begin{array}{l}=-\infty \\
=-\infty \\
=-\infty\end{array}$ & $\begin{array}{l}=-\infty \\
=-\infty \\
=-\infty\end{array}$ & $\begin{array}{l}948 \\
944 \\
912 \\
--2 \\
--.\end{array}$ & $\begin{array}{l}920 \\
904 \\
818 \\
-\infty \\
--0\end{array}$ & $\begin{array}{l}936 \\
930 \\
864 \\
-0- \\
---\end{array}$ & $\begin{array}{l}922 \\
942 \\
942 \\
938 \\
938\end{array}$ & $\begin{array}{l}862 \\
870 \\
878 \\
874 \\
862\end{array}$ & $\begin{array}{l}900 \\
911 \\
909 \\
911 \\
913\end{array}$ \\
\hline $\begin{array}{l}16 \\
17 \\
18 \\
19 \\
20\end{array}$ & $\begin{array}{r}982 \\
1000 \\
-\end{array}$ & $\begin{array}{l}937 \\
-=0 \\
970 \\
--- \\
---\end{array}$ & $\begin{array}{l}972 \\
990 \\
=-\end{array}$ & $\begin{array}{l}940 \\
944 \\
940 \\
948\end{array}$ & $\begin{array}{l}92- \\
926 \\
920 \\
926 \\
914\end{array}$ & $\begin{array}{l}200 \\
935 \\
930 \\
934 \\
933\end{array}$ & $\begin{array}{l}=-\infty \\
=-\infty \\
=-\infty\end{array}$ & $=$ & $\begin{array}{l}-\infty \\
-\infty \\
-\infty \\
-\infty \\
-\infty\end{array}$ & $\begin{array}{l}936 \\
940 \\
940 \\
940 \\
934\end{array}$ & $\begin{array}{l}886 \\
880 \\
872 \\
876 \\
872\end{array}$ & $\begin{array}{l}918 \\
917 \\
917 \\
919 \\
915\end{array}$ \\
\hline $\begin{array}{l}21 \\
22 \\
23 \\
24 \\
25\end{array}$ & $\begin{array}{l}m-\infty \\
=-\infty \\
=-\end{array}$ & $\begin{array}{l}-\infty \\
-\infty \\
m-\infty \\
m-\infty \\
m-\infty\end{array}$ & $\begin{array}{l}=-\infty \\
=-\infty \\
=-\infty\end{array}$ & $=$ & $=$ & $=0$ & $\begin{array}{l}=- \\
=- \\
=-\infty \\
=-\infty\end{array}$ & $\begin{array}{l}m-\infty \\
=-\infty \\
=\infty \\
-\infty\end{array}$ & $\begin{array}{l}=-0 \\
=-\infty \\
=-\infty \\
=-\infty \\
=-\infty\end{array}$ & $\begin{array}{l}932 \\
930 \\
932 \\
934 \\
928\end{array}$ & $\begin{array}{l}868 \\
874 \\
860 \\
876 \\
854\end{array}$ & $\begin{array}{l}914 \\
913 \\
911 \\
914 \\
908\end{array}$ \\
\hline $\begin{array}{l}26 \\
27 \\
28 \\
29 \\
30 \\
31\end{array}$ & $\begin{array}{l}=- \\
=-\infty \\
=-\infty \\
=-\infty\end{array}$ & $\begin{array}{l}=-\infty \\
-\infty \\
-\infty \\
-\infty \\
-\infty \\
-\infty\end{array}$ & $\begin{array}{l}=-\infty \\
=-\infty \\
-\infty \\
-\infty\end{array}$ & $\begin{array}{l}962 \\
960 \\
968 \\
958 \\
960 \\
962\end{array}$ & $\begin{array}{l}924 \\
900 \\
940 \\
930 \\
936 \\
940\end{array}$ & $\begin{array}{l}949 \\
950 \\
953 \\
945 \\
947 \\
951\end{array}$ & $=0$ & 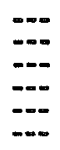 & $\begin{array}{l}m-\infty \\
=-\infty \\
=-\infty \\
=-\infty\end{array}$ & $\begin{array}{l}930 \\
932 \\
930 \\
930 \\
932 \\
930\end{array}$ & $\begin{array}{l}862 \\
858 \\
866 \\
868 \\
864 \\
870\end{array}$ & $\begin{array}{l}908 \\
905 \\
913 \\
914 \\
913 \\
909\end{array}$ \\
\hline NTH & $-\infty$ & $-\infty$ & $\Rightarrow$ & $-\infty-$ & $-\infty$ & --- & $\infty$ & $-\infty$ & $-\infty$ & 942 & 638 & 909 \\
\hline
\end{tabular}

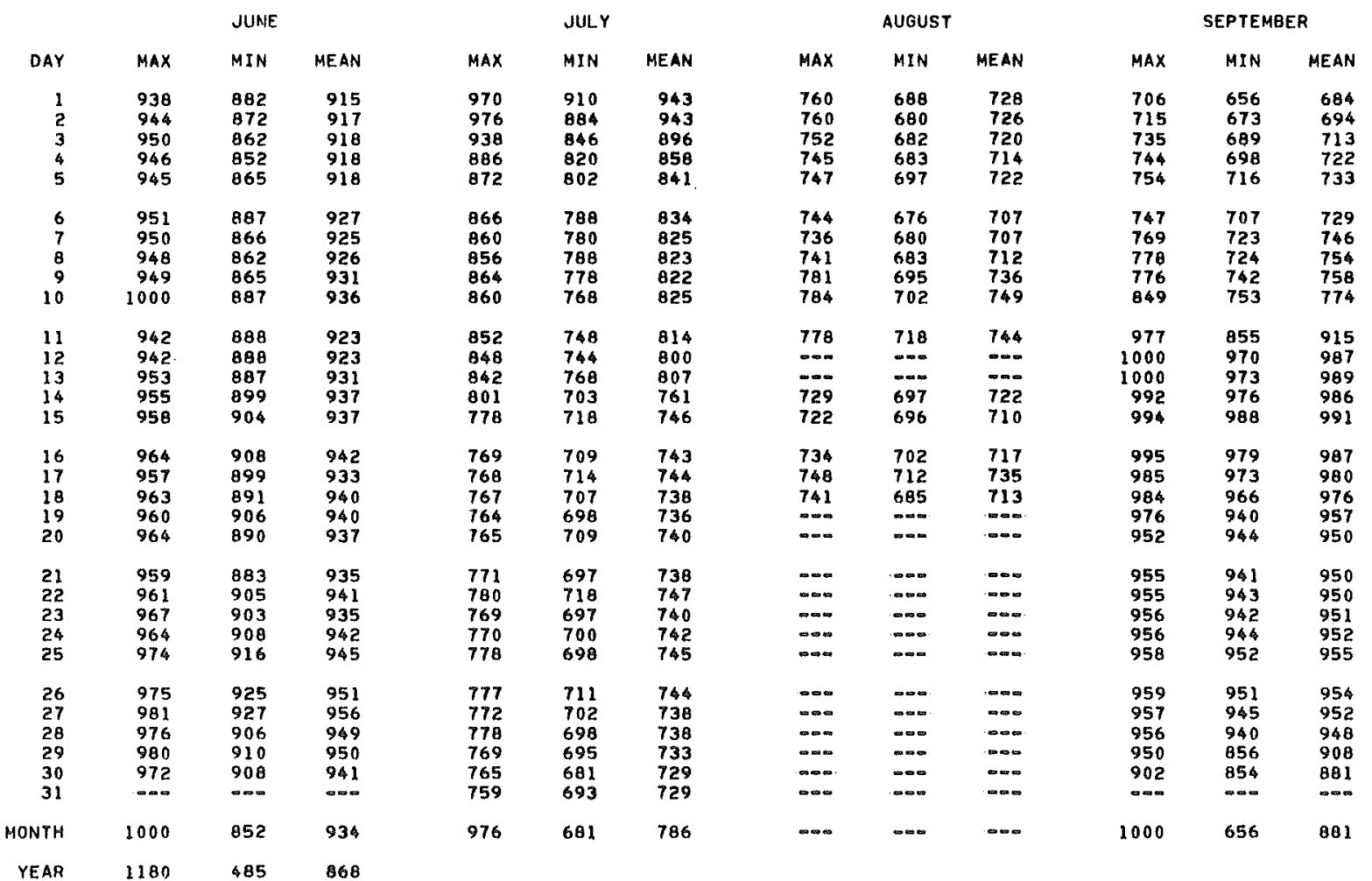


11109700 LAKE PIRU NEAR PIRU, CA

LOCATION.--Lat $34^{\circ} 27^{\prime} 52^{\prime \prime}$, long $118^{\circ} 44^{\prime} 57^{\prime \prime}$, in Temescal Grant, Ventura County, at Santa Felicia Dam on Piru Creek, on left bank $1,000 \mathrm{ft}(305 \mathrm{~m})$ upstream 'from left end of dam, $0.5 \mathrm{mi}(0.8 \mathrm{~km})$ downstream from Santa Felicia Canyon, and $4.2 \mathrm{mi}(6.8 \mathrm{~km})$ northeast of piru.

DRAINAGE AREA. $-425 \mathrm{mi}^{2}\left(1,101 \mathrm{~km}^{2}\right)$.

PERIOD OF RECORD. - May 1955 to current year.

GAGE.-Nonrecording gage. Datum of gage is at mean sea leve1 (levels by United Water Conservation Bistrict). prior to Jan. 27, 1956 , reference point at intake tower at same datum.

REMARKS. --Lake is formed by earthfil1 dam. Storage began May 20, 1955. Capacity table is based on a survey made in 1975. Capacity below spillway level at elevation $1,055.0 \mathrm{ft}(321.564 \mathrm{~m}), 91,010 \mathrm{acre}-\mathrm{ft}\left(112 \mathrm{hm}{ }^{3}\right)$ Flow regulated since December 1971 by pyramid Dam, capacity, 173,500 acre-ft (214 hm). Imported water from the California Water Project stored behind and released from Pyramid Dam. Water is released from outlet to Piru Creek for ground-water recharge, domestic use, and irrigation on the oxnard plain.

COOPERATION.--Elevations furnished by United Water Conservation District.

EXTREMES FOR PERIOD OF RECORD. - Maximum contents observed, 109,400 acre-ft (135 hm ${ }^{3}$ ) Feb. 25,1969 , elevation, $1,061.45 \mathrm{ft}(323.530 \mathrm{~m}) ; 1$ lake dry Oct. 25 to Nov. 20, 1961.

EXTREMES FOR CURRENT YEAR. - Maximum contents, 16,170 acre-ft (19.9 $\left.\mathrm{hm}^{3}\right)$ Mar. 23, 24, elevation, 971.30 ft $(296.052 \mathrm{~m})$; minimum, $10,340 \mathrm{acre}-\mathrm{ft}\left(12.7 \mathrm{hm}^{3}\right)$ Jan. 29 to Feb. 5, elevation, $958.00 \mathrm{ft}$ (291.998 $\left.\mathrm{m}\right)$.

MONTHEND ELEVATION AND CONTENTS, AT 0800 , WATER YEAR OCTOBER 1975 TO SEPTEMBER 1976

\begin{tabular}{|c|c|c|c|c|}
\hline \multicolumn{2}{|c|}{ Date } & $\begin{array}{l}\text { Elevation } \\
\text { (feet) }\end{array}$ & $\begin{array}{l}\text { Contents } \\
(\text { acre-feet })\end{array}$ & $\begin{array}{c}\text { Change in contents } \\
\text { (acre-feet) }\end{array}$ \\
\hline $\begin{array}{l}\text { Sept. } \\
\text { Oct. } \\
\text { Nov. } \\
\text { Dec. }\end{array}$ & $\begin{array}{l}30 \ldots \ldots \ldots \ldots \ldots \\
31 \ldots \ldots \ldots \ldots \\
30 \ldots \ldots \ldots \ldots \\
31 \ldots \ldots \ldots \ldots\end{array}$ & $\begin{array}{l}960.00 \\
959.00 \\
958.35 \\
958.10\end{array}$ & $\begin{array}{l}11060 \\
10700 \\
10470 \\
10380\end{array}$ & $\begin{array}{r}- \\
-360 \\
-230 \\
-90\end{array}$ \\
\hline CAL & YR $1975 \ldots \ldots \ldots$ & -- & - & +3030 \\
\hline $\begin{array}{l}\text { Jan. } \\
\text { Feb. } \\
\text { Mar. } \\
\text { Apr. } \\
\text { May } \\
\text { June } \\
\text { Ju1y } \\
\text { Aug. } \\
\text { Sept. }\end{array}$ & 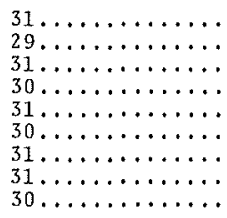 & $\begin{array}{l}958.00 \\
970.05 \\
971.20 \\
971.15 \\
967.15 \\
962.65 \\
962.15 \\
962.20 \\
962.30\end{array}$ & $\begin{array}{l}10340 \\
15520 \\
16110 \\
16090 \\
14090 \\
12100 \\
11890 \\
11920 \\
11960\end{array}$ & $\begin{array}{r}-40 \\
+5180 \\
+590 \\
-20 \\
-2000 \\
-1990 \\
-210 \\
+30 \\
+40\end{array}$ \\
\hline WTR & YR $1976 \ldots \ldots \ldots$ & -- & -- & +900 \\
\hline
\end{tabular}


LOCATION, - Lat $34^{\circ} 27^{\prime} 37^{\prime \prime}$, long $118^{\circ} 45^{\prime} 04^{\prime \prime}$, in Temescal Grant, Ventura County, on right bank 750 ft (229 m) downstream from Santa Felicia Dam, $1 \mathrm{mi}(2 \mathrm{~km})$ upstream from Lime Canyon, and 4 mi (6 km) northeast of piru.

DRAINAGE AREA. $-425 \mathrm{mi}^{2}\left(1,100 \mathrm{~km}^{2}\right)$.

WATER-DISCHARGE RECORDS

PERIOD OF RECORD.--October 1955 to September 1968, October 1973 to current year.

GAGE, - Water-stage recorder and concrete control. Datum of gage is $858.8 \mathrm{ft}$ (261.76 m) above mean sea 1 eve 1 (levels by United Water Conservation District).

REMARKS.--Records good. Flow regulated since December 1971 by Pyramid Dam, capacity, 173,500 acre-ft (214 hm $\left.{ }^{3}\right)$. Imported water from the California Water Project stored behind and released from Pyramid Dam. Flow also regulated by Lake Piru (station 11109700). No diversion above station.

EXTREMES FOR PERIOD OF RECORD.--Maximum discharge, $544 \mathrm{ft}^{3} / \mathrm{s}\left(15.4 \mathrm{~m}^{3} / \mathrm{s}\right)$ Aug. 18, 1958 , gage height, $3.66 \mathrm{ft}$ $(1.116 \mathrm{~m})$; no flow at times in some years.

EXTREMES FOR CURRENT YEAR, - Maximum daily discharge, $39 \mathrm{ft}^{3} / \mathrm{s}\left(1.10 \mathrm{~m}^{3} / \mathrm{s}\right) \mathrm{June} 24-27$; no flow Feb. $10 \mathrm{to}$ Mar. 17 , Mar. $19-20$.

DISCHARGE, IN CUBIC FEET PER SECOND, WATER YEAR OCTOBER 1975 TO SEPTEMBER 1976 MEAN VALUES

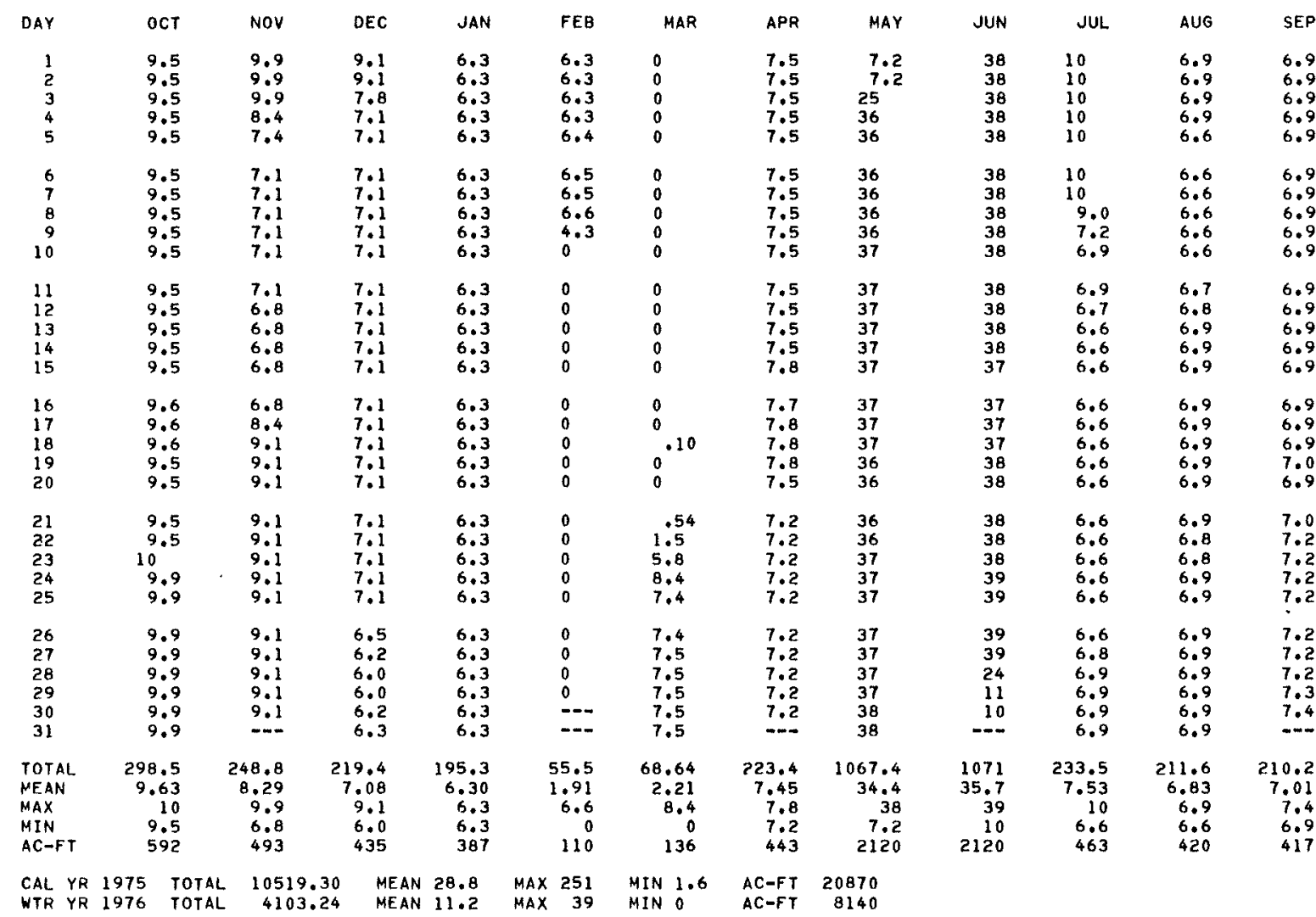


11109800 PIRU CREEK BELOW SANTA FELICIA DAM, CA--Continued

\section{WATER-QUALITY RECORDS}

PERIOD OF DAILY RECORD, -

SPECIFIC CONDUCTANCE: "February 1974 to current year.

INSTRUMENTATION, --Specific conductance recorder since February 1974.

REMARKS.--Periods of missing specific conductance data due to recorder malfunction except Feb. 9 to Mar. 21 which was a period of no flow.

EXTREMES FOR PERIOD OF DAILY RECORD.-

SPECIFIC CONDUCTANCE: Maximum, 1,320 micromhos June 13, 1975; minimum, 801 micromhos June 23 , 1975 .

EXTREMES FOR CURRENT YEAR.--

SPECIFIC CONDUCTANCE: Maximum, 1,160 micromhos Dec. 17; minimum, 916 micromhos Apri1 30.

SPECIFIC CONDUCTANCE (MICROMHOS/CM AT 25 DEQ, C), WATER YEAR OCTOBER 1975 TO SEPTEMBER I976

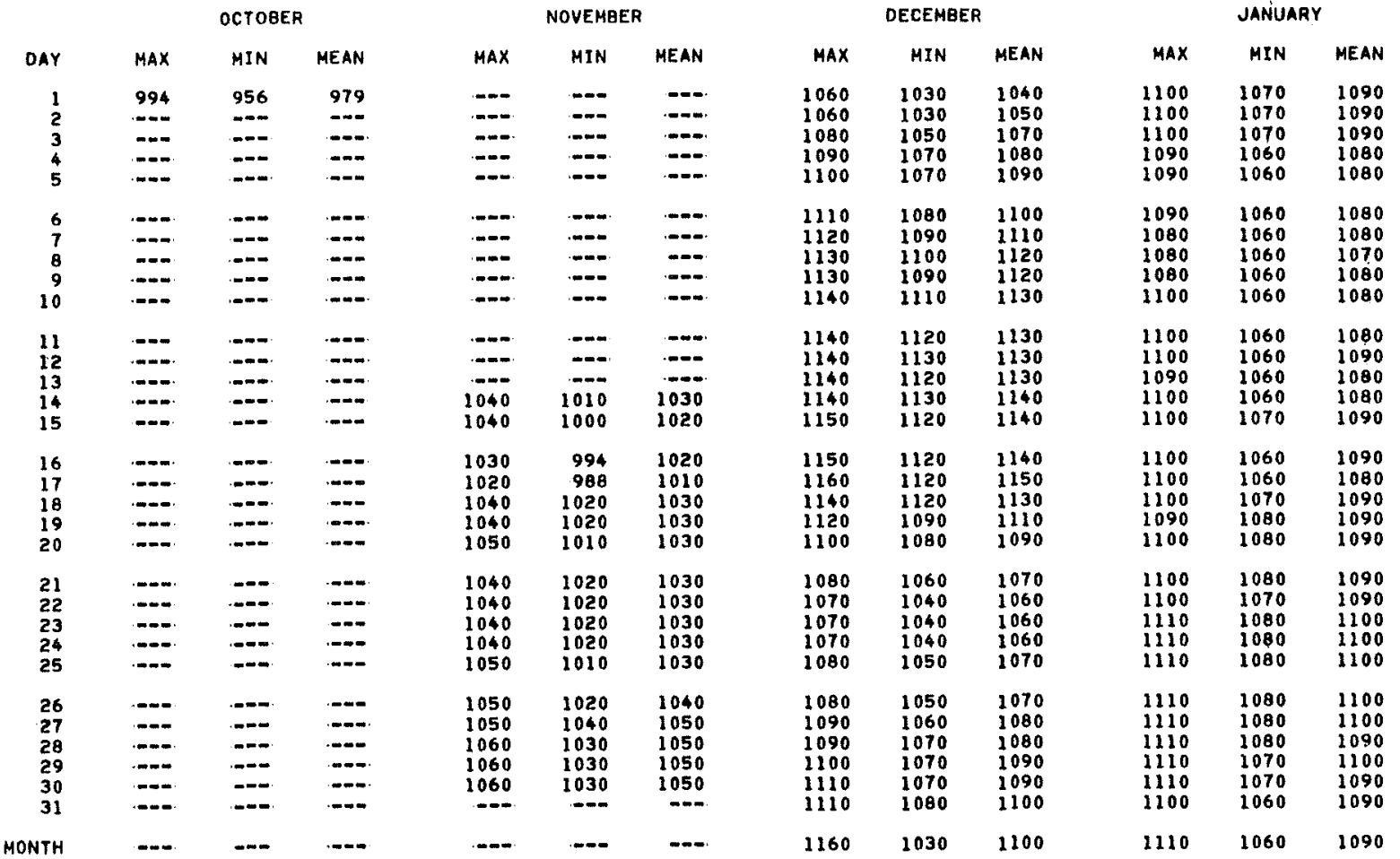


11109800 PIRU CREEK BELOW SANTA FELICTA DAM, CA--Continued

SPECIFIC CONOUCTANCE IMICROMHOS/CM AT 25 DEQ. C), WATER YEAR OCTOBER 1975 TO SEPTEMBER 1976

\begin{tabular}{|c|c|c|c|c|c|c|c|c|c|c|c|c|}
\hline \multirow[b]{2}{*}{ DAY } & \multicolumn{3}{|c|}{ FEBRUARY } & \multicolumn{3}{|c|}{ MARCH } & \multicolumn{3}{|c|}{ APRIL } & \multicolumn{3}{|c|}{ HAY } \\
\hline & $\operatorname{MAX}$ & MIN & MEAN & $\operatorname{MAX}$ & MIN & MEAN & $\max$ & MIN & MEAN & $\operatorname{MAX}$ & MIN & MEAN \\
\hline $\begin{array}{l}1 \\
2 \\
3 \\
4 \\
5\end{array}$ & $\begin{array}{l}1100 \\
1100 \\
1100 \\
1090 \\
1090\end{array}$ & $\begin{array}{l}1070 \\
1070 \\
1070 \\
1070 \\
1060\end{array}$ & $\begin{array}{l}1090 \\
1090 \\
1090 \\
1080 \\
1080\end{array}$ & $\begin{array}{l}\because \\
\because \because \\
\because-\end{array}$ & $\begin{array}{l}=- \\
=- \\
=-\end{array}$ & \begin{tabular}{l}
$=$ \\
$\because-$ \\
\hdashline \\
\hdashline
\end{tabular} & $\begin{array}{l}952 \\
949 \\
947 \\
948 \\
945\end{array}$ & $\begin{array}{l}924 \\
921 \\
935 \\
932 \\
933\end{array}$ & $\begin{array}{l}939 \\
937 \\
943 \\
942 \\
941\end{array}$ & $\begin{array}{l}949 \\
953 \\
958 \\
955 \\
955\end{array}$ & $\begin{array}{l}917 \\
925 \\
942 \\
939 \\
949\end{array}$ & $\begin{array}{l}936 \\
941 \\
949 \\
948 \\
953\end{array}$ \\
\hline $\begin{array}{r}6 \\
7 \\
8 \\
9 \\
10\end{array}$ & $\begin{array}{r}1090 \\
1080 \\
1080 \\
\hdashline- \\
\hdashline-\end{array}$ & $\begin{array}{r}1070 \\
1060 \\
1060 \\
- \\
-\end{array}$ & \begin{tabular}{r}
1080 \\
1070 \\
1070 \\
\hdashline \\
\end{tabular} & $\begin{array}{l}=- \\
\because \because \\
\because- \\
\because-\end{array}$ & $\begin{array}{l}= \\
= \\
\cdots \\
\cdots\end{array}$ & \begin{tabular}{l}
- \\
\hdashline \\
\hdashline
\end{tabular} & $\begin{array}{l}946 \\
945 \\
942 \\
944 \\
945\end{array}$ & $\begin{array}{l}920 \\
921 \\
920 \\
918 \\
919\end{array}$ & $\begin{array}{l}936 \\
934 \\
935 \\
934 \\
934 \\
933\end{array}$ & $\begin{array}{l}962 \\
962 \\
965 \\
964 \\
966\end{array}$ & $\begin{array}{l}952 \\
9950 \\
947 \\
944 \\
948\end{array}$ & $\begin{array}{l}957 \\
956 \\
956 \\
956 \\
958\end{array}$ \\
\hline $\begin{array}{l}11 \\
12 \\
13 \\
14 \\
15\end{array}$ & $=$ & $=$ & \begin{tabular}{l}
$\because$ \\
\hdashline$-\because$ \\
\hdashline
\end{tabular} & $\begin{array}{l}\because= \\
\because \because \\
\because \because\end{array}$ & $\begin{array}{l}=- \\
=- \\
=- \\
=-\end{array}$ & $\begin{array}{l}z \\
\because z \\
z\end{array}$ & $\begin{array}{l}942 \\
941 \\
942 \\
943 \\
944\end{array}$ & $\begin{array}{l}918 \\
921 \\
920 \\
921 \\
924\end{array}$ & $\begin{array}{l}933 \\
934 \\
935 \\
9334 \\
937\end{array}$ & $\begin{array}{l}965 \\
966 \\
968 \\
969 \\
968\end{array}$ & $\begin{array}{l}945 \\
940 \\
942 \\
949 \\
950\end{array}$ & $\begin{array}{l}956 \\
956 \\
958 \\
961 \\
960\end{array}$ \\
\hline $\begin{array}{l}16 \\
17 \\
18 \\
19 \\
20\end{array}$ & $=$ & $\cdots$ & \begin{tabular}{l}
$=$ \\
$=-$ \\
\hdashline- \\
$-\cdots$
\end{tabular} & \begin{tabular}{l}
$=-$ \\
\hdashline- \\
\hdashline- \\
-
\end{tabular} & \begin{tabular}{l}
$=-$ \\
$=-$ \\
\hdashline- \\
-
\end{tabular} & \begin{tabular}{c}
$-\cdots$ \\
\hdashline- \\
\hdashline- \\
\hdashline
\end{tabular} & $\begin{array}{l}946 \\
951 \\
950 \\
949 \\
950\end{array}$ & $\begin{array}{l}928 \\
927 \\
924 \\
919 \\
918\end{array}$ & $\begin{array}{l}939 \\
940 \\
939 \\
937 \\
937\end{array}$ & $\begin{array}{l}965 \\
967 \\
962 \\
963 \\
963\end{array}$ & $\begin{array}{l}947 \\
945 \\
940 \\
939 \\
943\end{array}$ & $\begin{array}{l}958 \\
956 \\
952 \\
953 \\
953\end{array}$ \\
\hline $\begin{array}{l}21 \\
22 \\
23 \\
24 \\
25\end{array}$ & \begin{tabular}{l}
$=$ \\
$=:$ \\
\hdashline-
\end{tabular} & $\begin{array}{l}= \\
=- \\
=-\end{array}$ & ": & $\begin{array}{l}952 \\
947 \\
942 \\
944\end{array}$ & $\begin{array}{l}930 \\
930 \\
926 \\
926 \\
930\end{array}$ & $\begin{array}{l}9-5 \\
942 \\
939 \\
937 \\
938\end{array}$ & $\begin{array}{l}951 \\
952 \\
953 \\
955 \\
954\end{array}$ & $\begin{array}{l}921 \\
928 \\
9227 \\
9227 \\
924\end{array}$ & $\begin{array}{l}938 \\
942 \\
942 \\
942 \\
943\end{array}$ & $\begin{array}{l}962 \\
961 \\
963 \\
960 \\
962\end{array}$ & $\begin{array}{l}942 \\
943 \\
941 \\
942 \\
942\end{array}$ & $\begin{array}{l}953 \\
953 \\
952 \\
953 \\
952\end{array}$ \\
\hline $\begin{array}{l}26 \\
27 \\
28 \\
29 \\
30 \\
31\end{array}$ & \begin{tabular}{l}
$=$ \\
$=$ \\
\hdashline- \\
$-\square$ \\
-
\end{tabular} & \begin{tabular}{c}
$=$ \\
$=-$ \\
$=-$ \\
\hdashline-
\end{tabular} & $\begin{array}{l}a \\
\square \\
\square\end{array}$ & $\begin{array}{l}943 \\
945 \\
944 \\
944 \\
943 \\
947\end{array}$ & $\begin{array}{l}921 \\
927 \\
926 \\
924 \\
919 \\
925\end{array}$ & $\begin{array}{l}934 \\
938 \\
937 \\
936 \\
934 \\
938\end{array}$ & $\begin{array}{l}953 \\
956 \\
947 \\
951 \\
950 \\
-.-\end{array}$ & $\begin{array}{l}927 \\
924 \\
923 \\
923 \\
916 \\
---\end{array}$ & $\begin{array}{r}943 \\
944 \\
937 \\
939 \\
935 \\
---\end{array}$ & $\begin{array}{l}961 \\
961 \\
959 \\
964 \\
962 \\
962\end{array}$ & $\begin{array}{l}939 \\
941 \\
943 \\
946 \\
944 \\
942\end{array}$ & $\begin{array}{l}952 \\
952 \\
954 \\
955 \\
955 \\
953\end{array}$ \\
\hline MONTH & -- & -- & $-\cdot$ & -- & $\cdots$ & $\cdots$ & 956 & 916 & 938 & 969 & 917 & 953 \\
\hline
\end{tabular}

JUNE

JULY

AUGUST

SEPTEMBER

\begin{tabular}{|c|c|c|c|c|c|c|c|c|c|c|c|c|}
\hline DAY & MAX & MIN & MEAN & MAX & MIN & MEAN & MAX & MIN & MEAN & MAX & MIN & MEAN \\
\hline $\begin{array}{l}1 \\
2 \\
3 \\
4 \\
5\end{array}$ & $\begin{array}{l}963 \\
965 \\
960 \\
964 \\
967\end{array}$ & $\begin{array}{l}939 \\
935 \\
942 \\
946 \\
949\end{array}$ & $\begin{array}{l}952 \\
951 \\
953 \\
956 \\
959\end{array}$ & $\begin{array}{l}1030 \\
1030 \\
1020 \\
1020 \\
1020\end{array}$ & $\begin{array}{r}1000 \\
1000 \\
995 \\
996 \\
993\end{array}$ & $\begin{array}{l}1010 \\
1020 \\
1010 \\
1010 \\
1010\end{array}$ & $\begin{array}{l}1060 \\
1060 \\
1050 \\
1040 \\
1030\end{array}$ & $\begin{array}{r}1020 \\
1020 \\
1010 \\
996 \\
981\end{array}$ & $\begin{array}{l}1040 \\
1040 \\
1030 \\
1020 \\
1010\end{array}$ & $\begin{array}{l}1060 \\
1060 \\
1060 \\
1060 \\
1060\end{array}$ & $\begin{array}{l}1030 \\
1030 \\
1030 \\
1030 \\
1030\end{array}$ & $\begin{array}{l}1050 \\
1050 \\
1050 \\
1050 \\
1050\end{array}$ \\
\hline $\begin{array}{r}6 \\
7 \\
8 \\
9 \\
10\end{array}$ & $\begin{array}{l}971 \\
974 \\
978 \\
979 \\
983\end{array}$ & $\begin{array}{l}949 \\
954 \\
958 \\
961 \\
967\end{array}$ & $\begin{array}{l}962 \\
966 \\
969 \\
972 \\
977\end{array}$ & $\begin{array}{l}1020 \\
1010 \\
1010 \\
1010 \\
1010\end{array}$ & $\begin{array}{l}986 \\
984 \\
981 \\
980 \\
979\end{array}$ & $\begin{array}{r}1000 \\
999 \\
999 \\
998 \\
997\end{array}$ & $\begin{array}{l}1020 \\
1020 \\
1020 \\
1030 \\
1030\end{array}$ & $\begin{array}{l}972 \\
974 \\
975 \\
973 \\
975\end{array}$ & $\begin{array}{r}999 \\
999 \\
1000 \\
1000 \\
1010\end{array}$ & $\begin{array}{l}1060 \\
1060 \\
1060 \\
1060 \\
1060\end{array}$ & $\begin{array}{l}1040 \\
1030 \\
1030 \\
1050 \\
1040\end{array}$ & $\begin{array}{l}1050 \\
1050 \\
1050 \\
1060 \\
1050\end{array}$ \\
\hline $\begin{array}{l}11 \\
12 \\
13 \\
14 \\
15\end{array}$ & $\begin{array}{l}986 \\
990 \\
995 \\
999 \\
998\end{array}$ & $\begin{array}{l}966 \\
968 \\
973 \\
971 \\
968\end{array}$ & $\begin{array}{l}977 \\
980 \\
985 \\
986 \\
983\end{array}$ & $\begin{array}{l}1010 \\
1010 \\
1000 \\
1000 \\
1010\end{array}$ & $\begin{array}{l}974 \\
978 \\
977 \\
974 \\
986\end{array}$ & $\begin{array}{r}994 \\
994 \\
991 \\
990 \\
1000\end{array}$ & $\begin{array}{l}1030 \\
1030 \\
1030 \\
1030 \\
1030\end{array}$ & $\begin{array}{r}976 \\
974 \\
980 \\
993 \\
1000\end{array}$ & $\begin{array}{l}1010 \\
1000 \\
1010 \\
1010 \\
1020\end{array}$ & $\begin{array}{l}1070 \\
1070 \\
1080 \\
1070 \\
1070\end{array}$ & $\begin{array}{l}1050 \\
1050 \\
1050 \\
1040 \\
1050\end{array}$ & $\begin{array}{l}1060 \\
1060 \\
1060 \\
1060 \\
1060\end{array}$ \\
\hline $\begin{array}{l}16 \\
17 \\
18 \\
19 \\
20\end{array}$ & $\begin{array}{r}990 \\
999 \\
1000 \\
1000 \\
1000\end{array}$ & $\begin{array}{l}976 \\
973 \\
974 \\
977 \\
978\end{array}$ & $\begin{array}{l}989 \\
987 \\
990 \\
990 \\
990\end{array}$ & $\begin{array}{l}1020 \\
1020 \\
1030 \\
1040 \\
1050\end{array}$ & $\begin{array}{r}992 \\
1000 \\
1010 \\
1010 \\
1020\end{array}$ & $\begin{array}{l}1010 \\
1010 \\
1020 \\
1030 \\
1040\end{array}$ & $\begin{array}{l}1040 \\
1040 \\
1040 \\
1070 \\
1080\end{array}$ & $\begin{array}{r}990 \\
982 \\
990 \\
985 \\
1030\end{array}$ & $\begin{array}{l}1020 \\
1020 \\
1020 \\
1030 \\
1060\end{array}$ & $\begin{array}{l}1070 \\
1070 \\
1070 \\
1070 \\
1070\end{array}$ & $\begin{array}{l}1030 \\
1040 \\
1040 \\
1040 \\
1040\end{array}$ & $\begin{array}{l}1060 \\
1060 \\
1060 \\
1060 \\
1060\end{array}$ \\
\hline $\begin{array}{l}21 \\
22 \\
23 \\
24 \\
25\end{array}$ & $\begin{array}{l}1010 \\
1010 \\
1010 \\
1010 \\
1010\end{array}$ & $\begin{array}{l}979 \\
982 \\
974 \\
973 \\
978\end{array}$ & $\begin{array}{l}992 \\
994 \\
992 \\
992 \\
996\end{array}$ & $\begin{array}{l}1050 \\
1060 \\
1060 \\
1070 \\
1080\end{array}$ & $\begin{array}{l}1020 \\
1030 \\
1040 \\
1040 \\
1040\end{array}$ & $\begin{array}{l}1040 \\
1050 \\
1050 \\
1060 \\
1070\end{array}$ & $\begin{array}{l}1080 \\
1080 \\
1080 \\
1080 \\
1080\end{array}$ & $\begin{array}{l}1030 \\
1040 \\
1030 \\
1030 \\
1030\end{array}$ & $\begin{array}{l}1060 \\
1060 \\
1060 \\
1060 \\
1060\end{array}$ & $\begin{array}{l}1070 \\
2080 \\
1070 \\
1070 \\
1070\end{array}$ & $\begin{array}{l}1040 \\
1050 \\
1020 \\
1020 \\
1040\end{array}$ & $\begin{array}{l}1060 \\
1060 \\
1060 \\
1050 \\
1060\end{array}$ \\
\hline $\begin{array}{l}26 \\
27 \\
28 \\
29 \\
30 \\
31\end{array}$ & $\begin{array}{l}1010 \\
1010 \\
1020 \\
1030 \\
1030 \\
-\end{array}$ & $\begin{array}{l}983 \\
984 \\
983 \\
992 \\
999 \\
-0 .\end{array}$ & $\begin{array}{r}998 \\
999 \\
1000 \\
1010 \\
1020 \\
-0-\end{array}$ & $\begin{array}{l}1080 \\
1090 \\
1080 \\
1080 \\
1070 \\
1060\end{array}$ & $\begin{array}{l}1050 \\
1050 \\
1050 \\
1040 \\
1030 \\
1030\end{array}$ & $\begin{array}{l}1070 \\
1070 \\
1070 \\
1060 \\
1060 \\
1050\end{array}$ & $\begin{array}{l}1080 \\
1080 \\
1080 \\
1080 \\
1070 \\
1050\end{array}$ & $\begin{array}{l}1030 \\
1030 \\
1020 \\
1020 \\
1020 \\
1020\end{array}$ & $\begin{array}{l}1060 \\
1060 \\
1050 \\
1050 \\
1050 \\
1040\end{array}$ & $\begin{array}{c}1070 \\
1080 \\
1080 \\
1080 \\
1080 \\
m\end{array}$ & $\begin{array}{l}1050 \\
1030 \\
1030 \\
1030 \\
1030 \\
\end{array}$ & $\begin{array}{c}1060 \\
1060 \\
1060 \\
1070 \\
1060 \\
=-\end{array}$ \\
\hline ONTH & 1030 & 935 & 982 & 1090 & 974 & 1030 & 1080 & 972 & 1030 & 1080 & 1020 & 1060 \\
\hline
\end{tabular}

$\begin{array}{llll}\text { YEAR } & 1160 \quad 916 & 1020\end{array}$ 
11110500 HOPPER CREEK NEAR PIRU, CA

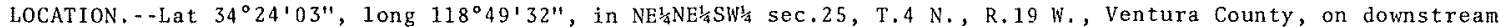
end of center pier of bridge on State Highway $126,1 \mathrm{mi}(2 \mathrm{~km})$ upstream from mouth, and $2.1 \mathrm{mi}$ ( $3.4 \mathrm{~km})$ southwest of Piru.

DRAINAGE AREA. $--23.6 \mathrm{mi}^{2}\left(61.1 \mathrm{~km}^{2}\right)$.

PERIOD OF RECORD. - October 1930 to September 1932, October 1933 to September 1936, October 1937 to current year.

GAGE. - Water-stage recorder. Altitude of gage is $590 \mathrm{ft}(180 \mathrm{~m})$, from topographic map.

REMARKS, - No regulation above station. Some pumping along stream for irrigation.

COOPERATION, - -Records were furnished by Ventura County Flood Control District and reviewed by Geological survey.

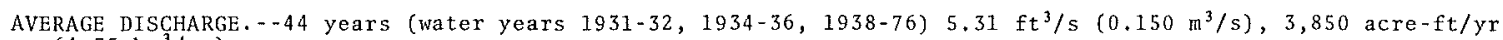
$\left(4.75 \mathrm{hm}^{3} / \mathrm{yr}\right)$.

EXTREMES FOR PERIOD OF RECORD. - Maximum discharge, $8,400 \mathrm{ft}^{3} / \mathrm{s}\left(238 \mathrm{~m}^{3} / \mathrm{s}\right) \mathrm{Jan} .25,1969$, gage height, $12.72 \mathrm{ft}$ $(3.877 \mathrm{~m})$, from floodmarks, from rating curve extended above $850 \mathrm{ft} / \mathrm{s}(24.1 \mathrm{~m} / \mathrm{s})$ on basis of slope-area neasurement of maximum flow; no flow for several months in most years.

EXTREMES FOR CURRENT YEAR. - Maximum discharge, $266 \mathrm{ft}^{3} / \mathrm{s}\left(7.53 \mathrm{~m}^{3} / \mathrm{s}\right)$ Feb. 9 (1030 hrs); maximum gage height, $5.67 \mathrm{ft}$ $(1.728 \mathrm{~m}) \mathrm{Feb} .7$ (2300 hrs), no other peaks above base of $150 \mathrm{ft}^{3} / \mathrm{s}\left(4.25 \mathrm{~m}^{3} / \mathrm{s}\right) ;$ no flow most of year.

DISCHARGE, IN CUBIC FEET PER SECOND, WATER YEAR OCTOBER 1975 TO SEPTEMBER 1976 MEAN VALUES

\begin{tabular}{|c|c|c|c|c|c|c|c|c|c|c|c|c|}
\hline DAY & $O C T$ & NOV & DEC & JAN & FEB & MAR & $A P R$ & MAY & JUN & JUL & AUG & SEP \\
\hline $\begin{array}{l}1 \\
2 \\
3 \\
4 \\
5\end{array}$ & & & & & $\begin{array}{l}0 \\
0 \\
0 \\
0 \\
.01\end{array}$ & $\begin{array}{l}4.8 \\
2.5 \\
5.3 \\
2.6 \\
.74\end{array}$ & $\begin{array}{l}0 \\
0 \\
0 \\
0 \\
0\end{array}$ & & & & & $\begin{array}{l}0 \\
0 \\
0 \\
0 \\
0\end{array}$ \\
\hline $\begin{array}{r}6 \\
7 \\
8 \\
9 \\
10\end{array}$ & & & & & $\begin{array}{l}4.7 \\
7.2 \\
23 \\
92 \\
39\end{array}$ & $\begin{array}{l}.37 \\
.18 \\
.02 \\
.10 \\
.62\end{array}$ & $\begin{array}{l}0 \\
0 \\
0 \\
0 \\
0\end{array}$ & & & & & $\begin{array}{l}0 \\
0 \\
0 \\
0 \\
0\end{array}$ \\
\hline $\begin{array}{l}11 \\
12 \\
13 \\
14 \\
15\end{array}$ & & & & & $\begin{array}{l}2.8 \\
.52 \\
.01 \\
0 \\
0\end{array}$ & $\begin{array}{l}0 \\
0 \\
0 \\
0 \\
0\end{array}$ & $\begin{array}{l}0 \\
.01 \\
.27 \\
0 \\
0\end{array}$ & & & & & $\begin{array}{l}21 \\
1.3 \\
0 \\
0 \\
0\end{array}$ \\
\hline $\begin{array}{l}16 \\
17 \\
18 \\
19 \\
20\end{array}$ & & & & & $\begin{array}{l}0 \\
0 \\
0 \\
0 \\
0\end{array}$ & $\begin{array}{l}0 \\
0 \\
0 \\
0 \\
0\end{array}$ & $\begin{array}{l}0 \\
0 \\
0 \\
0 \\
0\end{array}$ & & & & & $\begin{array}{l}0 \\
0 \\
0 \\
0 \\
0\end{array}$ \\
\hline $\begin{array}{l}21 \\
22 \\
23 \\
24 \\
25\end{array}$ & & & & & $\begin{array}{l}0 \\
0 \\
0 \\
0 \\
0\end{array}$ & $\begin{array}{l}0 \\
0 \\
0 \\
0 \\
0\end{array}$ & $\begin{array}{l}0 \\
0 \\
0 \\
0 \\
0\end{array}$ & & & & & $\begin{array}{l}0 \\
0 \\
0 \\
0 \\
0\end{array}$ \\
\hline $\begin{array}{l}26 \\
27 \\
28 \\
29 \\
30 \\
31\end{array}$ & & -- & & & $\begin{array}{l}0 \\
0 \\
0 \\
0 \\
- \\
--\end{array}$ & $\begin{array}{l}0 \\
0 \\
0 \\
0 \\
0 \\
0\end{array}$ & $\begin{array}{l}0 \\
0 \\
0 \\
0 \\
0\end{array}$ & & -- & & & $\begin{array}{l}0 \\
0 \\
0 \\
0 \\
0 \\
----\end{array}$ \\
\hline $\begin{array}{l}\text { IOTAL } \\
\text { MEAN } \\
\text { MAX } \\
\text { MIN } \\
\text { AC-FT }\end{array}$ & $\begin{array}{l}0 \\
0 \\
0 \\
0 \\
0\end{array}$ & $\begin{array}{l}0 \\
0 \\
0 \\
0 \\
0\end{array}$ & $\begin{array}{l}0 \\
0 \\
0 \\
0 \\
0\end{array}$ & $\begin{array}{l}0 \\
0 \\
0 \\
0 \\
0\end{array}$ & $\begin{array}{r}169.24 \\
5.84 \\
92 \\
0 \\
336\end{array}$ & $\begin{array}{r}17.23 \\
.56 \\
5.3 \\
0 \\
34\end{array}$ & $\begin{array}{r}.28 \\
.009 \\
.27 \\
0 \\
.6\end{array}$ & $\begin{array}{l}0 \\
0 \\
0 \\
0 \\
0\end{array}$ & $\begin{array}{l}0 \\
0 \\
0 \\
0 \\
0\end{array}$ & $\begin{array}{l}0 \\
0 \\
0 \\
0 \\
0\end{array}$ & $\begin{array}{l}0 \\
0 \\
0 \\
0 \\
0\end{array}$ & $\begin{array}{r}22.3 \\
.74 \\
21 \\
0 \\
44\end{array}$ \\
\hline
\end{tabular}

CAL YR 1975 TOTAL 836.34 MEAN 2.29 MAX 207 MIN 0 AC-FT 1660

WTR YR 1976 TOTAL 209.05 MEAN .57 MAX 92 MIN O AC-FT 415 


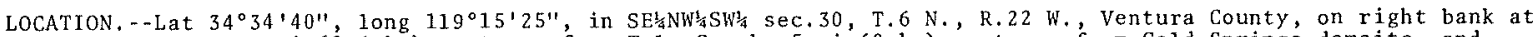

Sespe Gorge, $1.6 \mathrm{mi}(2.6 \mathrm{~km})$ upstream from Tule Creek, $5 \mathrm{mi}(8 \mathrm{~km})$ upstream from Cold Springs damsite, and

$5 \mathrm{mi}(8 \mathrm{~km})$ northeast of Wheeler Springs.

DRAINAGE AREA. $-49.5 \mathrm{Hi}^{2}\left(128.2 \mathrm{~km}^{2}\right)$.

WATER-DISCHARGE RECORDS

PERIOD OF RECORD. - October 1947 to current year. Daily discharge for period October 1947 to July 1948 estinated on basis of weather records and records for North Fork Matilija Creek.

GAGE, - Water-stage recorder. Datum of gage is $3,500.65 \mathrm{ft}(1,066.998 \mathrm{~m})$ above mean sea level (1evels by Ventura County F1ood Control District).

REMARKS. - Records fair. No regulation or diversion above station.

AVERAGE DISCHARGE. - -29 years, $10.2 \mathrm{ft}^{3} / \mathrm{s}\left(0.289 \mathrm{~m}^{3} / \mathrm{s}\right), 7,390 \mathrm{acre}-\mathrm{ft} / \mathrm{yr}\left(9.11 \mathrm{hm} / \mathrm{yr}^{3}\right)$.

EXTREMES FOR PERIOD OF RECORD, - -Maximum discharge, $9,700 \mathrm{ft}^{3} / \mathrm{s}\left(275 \mathrm{~m}^{3} / \mathrm{s}\right) \mathrm{Jan}$. 25 , 1969 , gage height $13.60 \mathrm{ft}$

$(4.145 \mathrm{~m})$, from rating curve extended above $3,000 \mathrm{ft}^{3} / \mathrm{s}\left(85.0 \mathrm{~m}^{3} / \mathrm{s}\right)$ on basis of slope-area measurement of

maximum flow; no flow many days in some years.

EXTREMES FOR CURRENT YEAR. - Peak discharges above base of $50 \mathrm{ft}^{3} / \mathrm{s}\left(1.42 \mathrm{~m}^{3} / \mathrm{s}\right)$ and maximum $(*)$ :

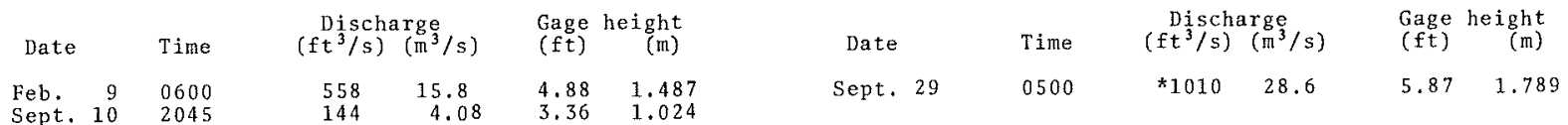

Minimum daily discharge, $0.08 \mathrm{ft}^{3} / \mathrm{s}\left(0.002 \mathrm{~m}^{3} / \mathrm{s}\right)$ Aug. 25 .

DISCHARGE, IN CUBIC FEET PER SECOND, WATER YEAR OCTOBER 1975 TO SEPTEMBER 1976 MEAN VALUES

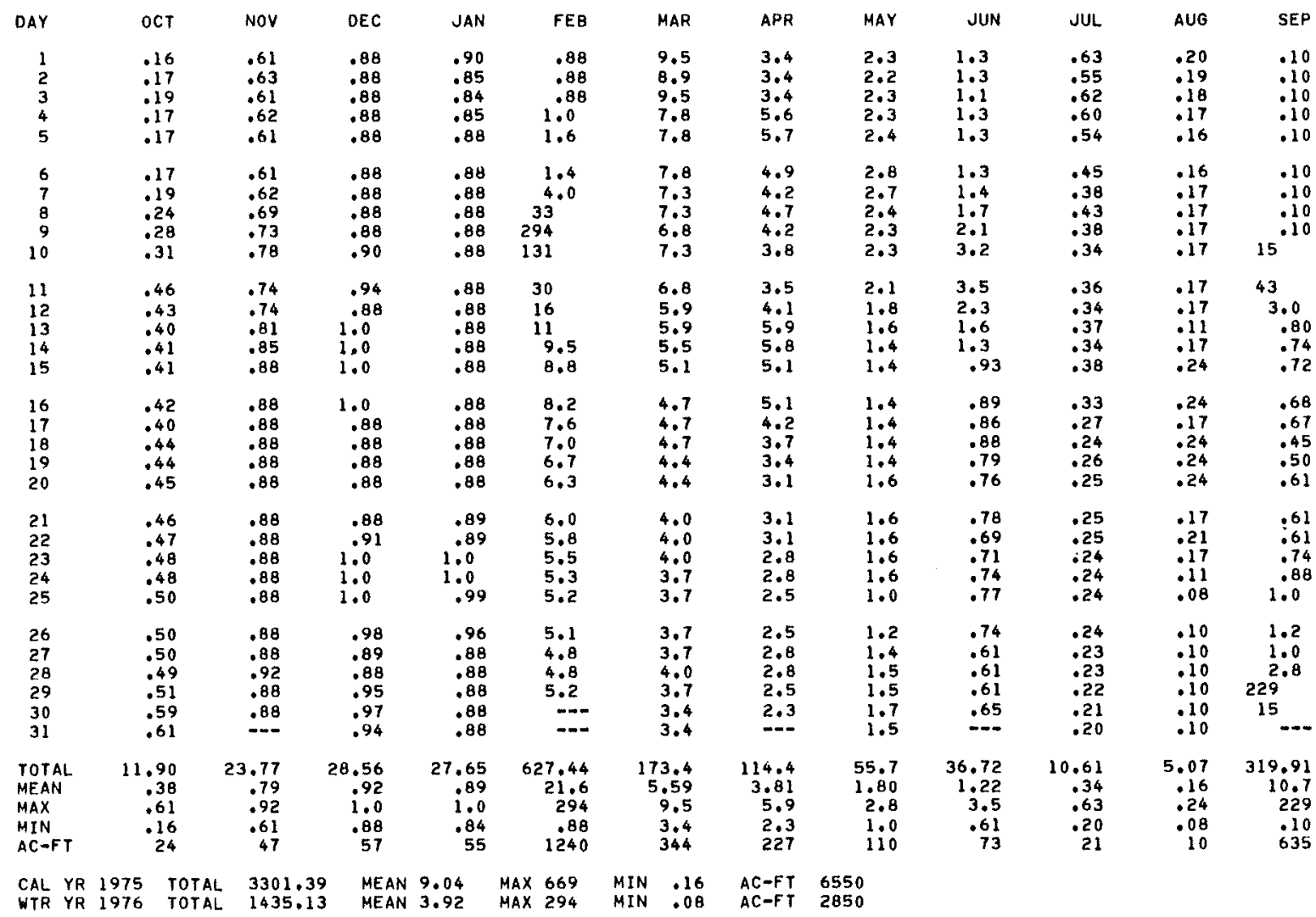


11111500 SESPE CREEK NEAR WHEELER SPRINGS, CA--Continued

WATER-QUALITY RECORDS

PERIOD OF RECORD, - Water year 1956 (partial record station), February 1962 to current year. SEDIMENT RECORDS: Water year 1956 (partial record station).

PERIOD OF DATLY RECORD, - -

WATER TEMPERATURES: February 1962 to current year.

INSTRUMENTATION. - - Temperature recorder since February 1962.

REMARKS, - Periods of missing record due to equipment malfunction or probe out of water.

EXTREMES FOR PERIOD OF DAILY RECORD.--

WATER TEMPERATURES: Maximum, $29.0^{\circ} \mathrm{C}$ Aug, 11,1964 ; minimum, $0.0^{\circ} \mathrm{C}$ on severa 1 days in 1970 , 1971 , and 1976.

EXTREMES FOR CURRENT YEAR.--

WATER TEMPERATURES: Maximum recorded, $27.0^{\circ} \mathrm{C} \mathrm{July} 20$; minimum, $0.0^{\circ} \mathrm{C} \mathrm{Feb.6.}$

TEMPERATURE (DEG, C) OF WATER, WATER YEAR OCTOBER 1975 TO SEPTEMBER 1976

\begin{tabular}{|c|c|c|c|c|c|c|c|c|c|c|c|c|}
\hline \multirow[b]{2}{*}{ DAY } & \multicolumn{3}{|c|}{ OCTOBER } & \multicolumn{3}{|c|}{ NOVEMBER } & \multicolumn{3}{|c|}{ DECEHBER } & \multicolumn{3}{|c|}{ JANUARY } \\
\hline & MAX & MIN & MEAN & $\operatorname{MAX}$ & MIN & MEAN & MAX & MIN & MEAN & MAX & MIN & MEAN \\
\hline $\begin{array}{l}1 \\
2 \\
3 \\
4 \\
5\end{array}$ & $\begin{array}{l}19.0 \\
19.0 \\
19.5 \\
19.5 \\
19.5\end{array}$ & $\begin{array}{l}13.0 \\
13.0 \\
13.5 \\
13.5 \\
13.5\end{array}$ & $\begin{array}{l}15.5 \\
16.0 \\
16.0 \\
16.5 \\
16.0\end{array}$ & $\begin{array}{l}11.5 \\
11.5 \\
12.0 \\
12.0 \\
11.0\end{array}$ & $\begin{array}{l}7.0 \\
7.0 \\
7.0 \\
7.0 \\
7.0\end{array}$ & $\begin{array}{r}9.5 \\
9.5 \\
10.0 \\
9.5 \\
9.0\end{array}$ & $\begin{array}{r}9.5 \\
10.5 \\
10.0 \\
9.5 \\
9.0\end{array}$ & $\begin{array}{l}5.0 \\
7.5 \\
6.5 \\
6.5 \\
5.0\end{array}$ & $\begin{array}{l}7.5 \\
9.0 \\
8.5 \\
8.0 \\
7.0\end{array}$ & $\begin{array}{l}3.5 \\
4.5 \\
6.0 \\
6.5 \\
8.0\end{array}$ & $\begin{array}{l}1.0 \\
1.0 \\
1.0 \\
3.0 \\
3.5\end{array}$ & $\begin{array}{l}2.5 \\
2.5 \\
3.5 \\
4.5 \\
5.5\end{array}$ \\
\hline $\begin{array}{r}6 \\
7 \\
8 \\
9 \\
10\end{array}$ & $\begin{array}{l}17.0 \\
15.5 \\
15.0 \\
14.5 \\
15.0\end{array}$ & $\begin{array}{r}11.5 \\
11.0 \\
9.0 \\
9.0 \\
8.5\end{array}$ & $\begin{array}{l}14.5 \\
13.5 \\
12.0 \\
12.0 \\
12.5\end{array}$ & $\begin{array}{l}11.5 \\
13.0 \\
12.5 \\
10.0 \\
11.0\end{array}$ & $\begin{array}{l}7.5 \\
8.5 \\
9.0 \\
7.0 \\
7.0\end{array}$ & $\begin{array}{r}9.5 \\
10.5 \\
11.0 \\
8.5 \\
8.5\end{array}$ & $\begin{array}{r}8.0 \\
7.5 \\
8.5 \\
8.5 \\
10.0\end{array}$ & $\begin{array}{l}4.0 \\
4.0 \\
4.0 \\
4.5 \\
5.5\end{array}$ & $\begin{array}{l}6.0 \\
6.0 \\
6.0 \\
6.5 \\
8.0\end{array}$ & $\begin{array}{l}7.0 \\
7.5 \\
8.5 \\
8.0 \\
7.5\end{array}$ & $\begin{array}{l}4.5 \\
3.0 \\
4.0 \\
4.5 \\
4.5\end{array}$ & $\begin{array}{l}5.5 \\
5.5 \\
6.0 \\
6.5 \\
6.0\end{array}$ \\
\hline $\begin{array}{l}11 \\
12 \\
13 \\
14 \\
15\end{array}$ & $\begin{array}{c}15.0 \\
\cdots \\
\cdots\end{array}$ & $\begin{array}{r}13.0 \\
\cdots \\
0.0 \\
=0\end{array}$ & $\begin{array}{r}13.5 \\
-0 . \\
-0 .\end{array}$ & $\begin{array}{r}9.0 \\
9.0 \\
9.5 \\
9.5 \\
10.0\end{array}$ & $\begin{array}{l}5.5 \\
5.0 \\
5.0 \\
6.0 \\
6.0\end{array}$ & $\begin{array}{l}7.5 \\
7.5 \\
7.5 \\
8.0 \\
8.0\end{array}$ & $\begin{array}{l}9.5 \\
8.5 \\
7.5 \\
6.0 \\
6.5\end{array}$ & $\begin{array}{l}6.0 \\
6.0 \\
4.5 \\
3.5 \\
2.5\end{array}$ & $\begin{array}{l}7.5 \\
7.0 \\
6.0 \\
4.5 \\
4.5\end{array}$ & $\begin{array}{l}7.0 \\
7.5 \\
8.5 \\
8.0 \\
8.5\end{array}$ & $\begin{array}{l}3.0 \\
4.5 \\
5.0 \\
4.0 \\
4.5\end{array}$ & $\begin{array}{l}5.0 \\
6.0 \\
6.5 \\
6.0 \\
6.5\end{array}$ \\
\hline $\begin{array}{l}16 \\
17 \\
18 \\
19 \\
20\end{array}$ & $\begin{array}{l}m- \\
=- \\
--\end{array}$ & $\begin{array}{l}--- \\
=-- \\
-\cdots\end{array}$ & $\begin{array}{l}-=- \\
--- \\
=-- \\
--- \\
---\end{array}$ & $\begin{array}{r}10.5 \\
8.5 \\
6.5 \\
6.5 \\
7.5\end{array}$ & $\begin{array}{l}6.5 \\
4.5 \\
3.5 \\
2.5 \\
3.5\end{array}$ & $\begin{array}{l}8.5 \\
7.0 \\
5.0 \\
4.5 \\
5.5\end{array}$ & $\begin{array}{l}6.5 \\
6.5 \\
6.5 \\
6.5 \\
7.5\end{array}$ & $\begin{array}{l}2.5 \\
2.5 \\
2.5 \\
2.5 \\
3.0\end{array}$ & $\begin{array}{l}4.5 \\
4.5 \\
4.5 \\
4.5 \\
5.5\end{array}$ & $\begin{array}{r}10.0 \\
10.0 \\
10.5 \\
10.0 \\
9.0\end{array}$ & $\begin{array}{l}5.5 \\
5.5 \\
5.5 \\
7.5 \\
5.0\end{array}$ & $\begin{array}{l}7.5 \\
8.0 \\
8.0 \\
8.5 \\
7.0\end{array}$ \\
\hline $\begin{array}{l}21 \\
22 \\
23 \\
24 \\
25\end{array}$ & $\begin{array}{l}-.- \\
-\infty \\
11.5\end{array}$ & $\begin{array}{l}=- \\
--. \\
-0\end{array}$ & $\begin{array}{l}-- \\
--- \\
--0 \\
9.0\end{array}$ & $\begin{array}{r}8.0 \\
8.0 \\
9.0 \\
9.5 \\
10.0\end{array}$ & $\begin{array}{l}4.5 \\
3.5 \\
5.0 \\
5.0 \\
6.5\end{array}$ & $\begin{array}{l}6.0 \\
5.5 \\
7.0 \\
7.5 \\
8.5\end{array}$ & $\begin{array}{l}8.0 \\
7.5 \\
7.5 \\
8.5 \\
9.5\end{array}$ & $\begin{array}{l}4.0 \\
5.0 \\
4.5 \\
5.0 \\
6.5\end{array}$ & $\begin{array}{l}6.0 \\
6.0 \\
6.0 \\
6.5 \\
7.5\end{array}$ & $\begin{array}{l}8.0 \\
9.0 \\
9.0 \\
9.0 \\
8.5\end{array}$ & $\begin{array}{l}4.5 \\
4.5 \\
5.0 \\
5.0 \\
4.5\end{array}$ & $\begin{array}{l}6.5 \\
7.0 \\
7.0 \\
7.0 \\
6.5\end{array}$ \\
\hline $\begin{array}{l}26 \\
27 \\
28 \\
29 \\
30 \\
31\end{array}$ & $\begin{array}{l}13.0 \\
13.0 \\
11.0 \\
11.0 \\
11.0 \\
12.0\end{array}$ & $\begin{array}{l}8.0 \\
9.0 \\
6.5 \\
6.0 \\
7.5 \\
7.5\end{array}$ & $\begin{array}{r}11.0 \\
11.5 \\
9.0 \\
9.0 \\
9.0 \\
9.5\end{array}$ & $\begin{array}{l}8.5 \\
8.5 \\
7.5 \\
6.0 \\
7.0 \\
.-.\end{array}$ & $\begin{array}{l}5.5 \\
7.0 \\
4.5 \\
3.5 \\
3.5 \\
-.-\end{array}$ & $\begin{array}{l}7.0 \\
7.5 \\
6.5 \\
5.0 \\
5.5 \\
-.-\end{array}$ & $\begin{array}{r}9.0 \\
9.0 \\
10.0 \\
9.0 \\
8.5 \\
6.0\end{array}$ & $\begin{array}{l}5.0 \\
7.5 \\
7.0 \\
5.5 \\
6.0 \\
3.0\end{array}$ & $\begin{array}{l}7.0 \\
8.0 \\
8.5 \\
7.5 \\
7.5 \\
4.5\end{array}$ & $\begin{array}{r}8.0 \\
8.5 \\
9.0 \\
9.5 \\
10.5 \\
10.0\end{array}$ & $\begin{array}{l}3.0 \\
3.0 \\
4.0 \\
4.5 \\
5.5 \\
6.0\end{array}$ & $\begin{array}{l}5.5 \\
6.0 \\
7.0 \\
7.0 \\
8.0 \\
8.0\end{array}$ \\
\hline ONTH & --- & $=-$ & $m$ & 13.0 & 2.5 & 7.5 & 10.5 & 2.5 & 6.5 & 10.5 & 1.0 & 6.0 \\
\hline
\end{tabular}


11111500 SESPE CREEK NEAR WHEELER SPRINGS, CA--Continued TEMPERATURE IDEG, C) OF WATER, WATER YEAR OCTOBER 1975 TO SEPTEMBER 1976

\begin{tabular}{|c|c|c|c|c|c|c|c|c|c|c|c|c|}
\hline \multirow[b]{2}{*}{ DAY } & \multicolumn{3}{|c|}{ FEARUARY } & \multicolumn{3}{|c|}{ MARCH } & \multicolumn{3}{|c|}{ APR IL } & \multicolumn{3}{|c|}{ MAY } \\
\hline & MAX & MIN & MEAN & MAX & MIN & MEAN & $\operatorname{MAX}$ & MIN & MEAN & $\operatorname{MAX}$ & MIN & MEAN \\
\hline $\begin{array}{l}1 \\
2 \\
3 \\
4 \\
5\end{array}$ & $\begin{array}{l}9.5 \\
9.5 \\
9.5 \\
7.0 \\
6.5\end{array}$ & $\begin{array}{l}4.5 \\
4.0 \\
4.5 \\
5.0 \\
0.5\end{array}$ & $\begin{array}{l}7.0 \\
7.0 \\
7.0 \\
6.0 \\
3.5\end{array}$ & $\begin{array}{r}12.5 \\
7.0 \\
6.5 \\
8.0 \\
10.0\end{array}$ & $\begin{array}{l}7.0 \\
1.5 \\
2.0 \\
2.5 \\
5.5\end{array}$ & $\begin{array}{r}10.0 \\
4.5 \\
4.0 \\
5.5 \\
7.5\end{array}$ & $\begin{array}{r}15.0 \\
15.0 \\
9.0 \\
9.0 \\
8.5\end{array}$ & $\begin{array}{l}6.5 \\
6.5 \\
6.5 \\
6.0 \\
5.0\end{array}$ & $\begin{array}{r}11.0 \\
11.0 \\
8.0 \\
7.0 \\
7.0\end{array}$ & $\begin{array}{l}19.0 \\
19.5 \\
19.5 \\
20.0 \\
14.0\end{array}$ & $\begin{array}{l}10.5 \\
11.5 \\
11.5 \\
12.0 \\
12.0\end{array}$ & $\begin{array}{l}15.0 \\
15.5 \\
15.5 \\
16.0 \\
12.5\end{array}$ \\
\hline $\begin{array}{r}6 \\
7 \\
8 \\
9 \\
10\end{array}$ & $\begin{array}{l}4.0 \\
6.0 \\
5.0 \\
4.0 \\
8.5\end{array}$ & $\begin{array}{l}0.0 \\
2.5 \\
2.0 \\
1.0 \\
3.5\end{array}$ & $\begin{array}{l}2.0 \\
4.5 \\
3.5 \\
2.5 \\
5.5\end{array}$ & $\begin{array}{l}10.0 \\
10.5 \\
10.0 \\
11.0 \\
12.0\end{array}$ & $\begin{array}{l}4.5 \\
4.5 \\
5.5 \\
6.0 \\
7.5\end{array}$ & $\begin{array}{l}7.0 \\
7.5 \\
7.5 \\
8.5 \\
9.5\end{array}$ & $\begin{array}{l}14.0 \\
15.5 \\
12.5 \\
15.5 \\
14.0\end{array}$ & $\begin{array}{l}6.0 \\
7.5 \\
8.0 \\
6.5 \\
7.0\end{array}$ & $\begin{array}{l}10.5 \\
11.5 \\
10.0 \\
11.0 \\
11.0\end{array}$ & $\begin{array}{l}14.0 \\
16.5 \\
19.0 \\
20.0 \\
18.5\end{array}$ & $\begin{array}{r}9.5 \\
9.5 \\
11.0 \\
11.5 \\
12.5\end{array}$ & $\begin{array}{l}11.5 \\
13.0 \\
15.0 \\
15.5 \\
15.5\end{array}$ \\
\hline $\begin{array}{l}11 \\
12 \\
13 \\
14 \\
15\end{array}$ & $\begin{array}{l}8.0 \\
8.0 \\
9.0 \\
9.5 \\
9.5\end{array}$ & $\begin{array}{l}3.5 \\
3.5 \\
4.0 \\
6.5 \\
5.0\end{array}$ & $\begin{array}{l}5.5 \\
6.0 \\
6.5 \\
8.0 \\
7.0\end{array}$ & $\begin{array}{l}13.0 \\
12.0 \\
12.0 \\
13.5 \\
14.0\end{array}$ & $\begin{array}{l}8.0 \\
6.5 \\
5.0 \\
7.0 \\
7.0\end{array}$ & $\begin{array}{r}10.0 \\
9.5 \\
9.0 \\
10.0 \\
10.5\end{array}$ & $\begin{array}{l}13.0 \\
10.5 \\
11.0 \\
12.0 \\
11.5\end{array}$ & $\begin{array}{l}8.0 \\
6.5 \\
6.5 \\
7.0 \\
6.5\end{array}$ & $\begin{array}{r}10.5 \\
8.5 \\
8.0 \\
9.5 \\
9.0\end{array}$ & $\begin{array}{l}21.0 \\
22.0 \\
22.0 \\
23.0 \\
22.0\end{array}$ & $\begin{array}{l}12.5 \\
12.5 \\
12.5 \\
14.0 \\
13.0\end{array}$ & $\begin{array}{l}17.0 \\
17.5 \\
17.5 \\
18.5 \\
17.5\end{array}$ \\
\hline $\begin{array}{l}16 \\
17 \\
18 \\
19 \\
20\end{array}$ & $\begin{array}{r}9.0 \\
9.5 \\
10.5 \\
10.0 \\
9.0\end{array}$ & $\begin{array}{l}4.5 \\
6.5 \\
5.5 \\
5.5 \\
4.0\end{array}$ & $\begin{array}{l}7.0 \\
8.0 \\
8.0 \\
7.0 \\
6.5\end{array}$ & $\begin{array}{l}14.0 \\
15.5 \\
15.0 \\
13.0 \\
12.5\end{array}$ & $\begin{array}{l}8.5 \\
9.5 \\
8.5 \\
7.5 \\
5.5\end{array}$ & $\begin{array}{r}11.0 \\
12.0 \\
11.5 \\
10.0 \\
9.0\end{array}$ & $\begin{array}{l}11.0 \\
14.0 \\
16.0 \\
17.0 \\
18.5\end{array}$ & $\begin{array}{l}5.0 \\
5.5 \\
7.5 \\
8.0 \\
9.0\end{array}$ & $\begin{array}{r}8.0 \\
10.0 \\
11.5 \\
12.5 \\
13.5\end{array}$ & $\begin{array}{l}21.5 \\
21.5 \\
21.0 \\
20.0 \\
19.5\end{array}$ & $\begin{array}{l}12.5 \\
12.5 \\
11.5 \\
11.0 \\
12.0\end{array}$ & $\begin{array}{l}17.0 \\
17.0 \\
16.0 \\
15.5 \\
15.5\end{array}$ \\
\hline $\begin{array}{l}21 \\
22 \\
23 \\
24 \\
25\end{array}$ & $\begin{array}{r}9.0 \\
9.5 \\
9.0 \\
11.0 \\
11.0\end{array}$ & $\begin{array}{l}3.0 \\
3.5 \\
4.0 \\
6.0 \\
5.0\end{array}$ & $\begin{array}{l}6.0 \\
6.5 \\
6.0 \\
8.0 \\
8.0\end{array}$ & $\begin{array}{l}14.0 \\
14.5 \\
15.0 \\
15.5 \\
14.5\end{array}$ & $\begin{array}{r}6.0 \\
6.5 \\
8.5 \\
8.5 \\
.7 .5\end{array}$ & $\begin{array}{l}10.0 \\
10.5 \\
11.5 \\
11.5 \\
10.5\end{array}$ & $\begin{array}{l}18.0 \\
18.0 \\
19.0 \\
18.5 \\
18.5\end{array}$ & $\begin{array}{r}9.5 \\
10.5 \\
10.5 \\
10.5 \\
11.5\end{array}$ & $\begin{array}{l}14.0 \\
14.0 \\
14.5 \\
14.5 \\
14.5\end{array}$ & $\begin{array}{l}19.5 \\
20.5 \\
20.5 \\
20.5 \\
21.0\end{array}$ & $\begin{array}{l}11.0 \\
11.5 \\
12.0 \\
12.0 \\
12.0\end{array}$ & $\begin{array}{l}15.5 \\
16.0 \\
16.5 \\
16.0 \\
16.5\end{array}$ \\
\hline $\begin{array}{l}26 \\
27 \\
28 \\
29 \\
30 \\
31\end{array}$ & $\begin{array}{r}11.0 \\
12.0 \\
12.5 \\
12.5 \\
-. .- \\
-.-\end{array}$ & $\begin{array}{l}b .5 \\
0.5 \\
7.5 \\
8.0 \\
-. .- \\
-. .-\end{array}$ & $\begin{array}{r}8.5 \\
9.0 \\
10.0 \\
10.0 \\
- \\
-.-\end{array}$ & $\begin{array}{l}13.5 \\
13.5 \\
12.0 \\
14.5 \\
15.0 \\
14.5\end{array}$ & $\begin{array}{l}6.0 \\
7.0 \\
5.5 \\
6.5 \\
6.5 \\
7.0\end{array}$ & $\begin{array}{r}10.0 \\
10.0 \\
8.5 \\
10.5 \\
10.5 \\
11.0\end{array}$ & $\begin{array}{r}17.0 \\
16.5 \\
18.0 \\
19.0 \\
19.5 \\
=-.\end{array}$ & $\begin{array}{r}8.5 \\
8.0 \\
11.0 \\
9.5 \\
10.0 \\
-\end{array}$ & $\begin{array}{r}13.0 \\
12.5 \\
14.5 \\
14.0 \\
15.0 \\
\ldots\end{array}$ & $\begin{array}{l}21.5 \\
21.5 \\
22.0 \\
21.0 \\
21.0 \\
21.5\end{array}$ & $\begin{array}{l}12.5 \\
12.5 \\
13.5 \\
12.0 \\
12.0 \\
13.0\end{array}$ & $\begin{array}{l}17.0 \\
17.0 \\
17.0 \\
16.0 \\
16.5 \\
17.0\end{array}$ \\
\hline MONTH & 12.5 & 0.0 & 6.5 & 15.5 & 1.5 & 9.5 & 19.5 & 5.0 & 11.5 & 23.0 & 9.5 & 16.0 \\
\hline
\end{tabular}

\begin{tabular}{|c|c|c|c|c|c|c|c|c|c|c|c|c|}
\hline \multirow[b]{2}{*}{ DAY } & \multicolumn{3}{|c|}{ JUNE } & \multicolumn{3}{|c|}{ JULY } & \multicolumn{3}{|c|}{ AUGUST } & \multicolumn{3}{|c|}{ SEPTEMBEH } \\
\hline & $\operatorname{MAX}$ & MIN & MEAN & $\max$ & $M I N$ & MEAN & $\operatorname{MAX}$ & MIN & MEAN & $\operatorname{MAX}$ & MIN & MEAN \\
\hline $\begin{array}{l}1 \\
2 \\
3 \\
4 \\
5\end{array}$ & $\begin{array}{l}21.0 \\
21.0 \\
21.0 \\
20.5 \\
21.0\end{array}$ & $\begin{array}{l}12.5 \\
12.5 \\
12.5 \\
12.0 \\
12.0\end{array}$ & $\begin{array}{l}16.5 \\
17.0 \\
17.0 \\
16.5 \\
16.5\end{array}$ & $\begin{array}{l}21.5 \\
22.0 \\
22.5 \\
24.0 \\
24.5\end{array}$ & $\begin{array}{l}13.5 \\
14.0 \\
14.0 \\
16.0 \\
16.0\end{array}$ & $\begin{array}{l}18.0 \\
18.0 \\
18.5 \\
20.0 \\
20.0\end{array}$ & $=-\overline{-}$ & 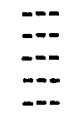 & $=$ & $\begin{array}{l}25.0 \\
24.5 \\
22.0 \\
25.0 \\
22.5\end{array}$ & $\begin{array}{l}15.5 \\
14.0 \\
17.0 \\
17.5 \\
16.5\end{array}$ & $\begin{array}{l}19.5 \\
19.0 \\
19.5 \\
20.0 \\
19.5\end{array}$ \\
\hline $\begin{array}{r}6 \\
7 \\
8 \\
9 \\
10\end{array}$ & $\begin{array}{l}20.5 \\
19.5 \\
19.5 \\
18.5 \\
17.0\end{array}$ & $\begin{array}{l}12.0 \\
12.0 \\
11.0 \\
13.0 \\
12.5\end{array}$ & $\begin{array}{l}16.5 \\
16.0 \\
15.5 \\
15.5 \\
14.5\end{array}$ & $\begin{array}{l}24.5 \\
26.0 \\
25.5 \\
26.0 \\
25.5\end{array}$ & $\begin{array}{l}16.5 \\
17.0 \\
16.5 \\
17.0 \\
17.0\end{array}$ & $\begin{array}{l}20.5 \\
20.5 \\
20.5 \\
21.0 \\
21.0\end{array}$ & $\begin{array}{l}---5 \\
24.5 \\
23.5 \\
23.5 \\
23.0\end{array}$ & $\begin{array}{l}-0 \\
15.0 \\
15.0 \\
15.0 \\
14.0\end{array}$ & $\begin{array}{l}19.0 \\
19.0 \\
19.0 \\
18.5 \\
18.5\end{array}$ & $\begin{array}{l}24.5 \\
24.0 \\
23.5 \\
22.0 \\
19.0\end{array}$ & $\begin{array}{l}17.0 \\
15.5 \\
15.5 \\
17.0 \\
16.0\end{array}$ & $\begin{array}{l}20.0 \\
19.0 \\
19.0 \\
19.0 \\
18.0\end{array}$ \\
\hline $\begin{array}{l}11 \\
12 \\
13 \\
14 \\
15\end{array}$ & $\begin{array}{l}21.0 \\
22.0 \\
22.0 \\
22.5 \\
21.5\end{array}$ & $\begin{array}{l}12.0 \\
12.0 \\
13.5 \\
13.5 \\
12.0\end{array}$ & $\begin{array}{l}16.0 \\
18.0 \\
17.5 \\
17.5 \\
17.0\end{array}$ & $\begin{array}{l}25.5 \\
26.0 \\
25.5 \\
25.5 \\
21.5\end{array}$ & $\begin{array}{l}17.5 \\
18.0 \\
16.5 \\
16.5 \\
17.5\end{array}$ & $\begin{array}{l}21.0 \\
21.0 \\
20.0 \\
20.0 \\
19.5\end{array}$ & $\begin{array}{l}24.0 \\
24.0 \\
24.5 \\
21.0 \\
19.5\end{array}$ & $\begin{array}{l}15.0 \\
15.5 \\
16.0 \\
16.0 \\
16.0\end{array}$ & $\begin{array}{l}19.0 \\
19.5 \\
19.5 \\
18.5 \\
17.5\end{array}$ & $\begin{array}{r}16.5 \\
18.0 \\
=-- \\
=-.\end{array}$ & $\begin{array}{r}16.0 \\
15.0 \\
-0 \\
-\end{array}$ & $\begin{array}{r}16.5 \\
16.5 \\
\\
\end{array}$ \\
\hline $\begin{array}{l}16 \\
17 \\
18 \\
19 \\
20\end{array}$ & $\begin{array}{l}23.5 \\
24.0 \\
23.0 \\
22.5 \\
26.0\end{array}$ & $\begin{array}{l}14.5 \\
14.5 \\
13.0 \\
13.5 \\
13.5\end{array}$ & $\begin{array}{l}19.0 \\
18.5 \\
17.5 \\
17.0 \\
17.5\end{array}$ & $\begin{array}{l}25.0 \\
25.0 \\
25.0 \\
26.0 \\
27.0\end{array}$ & $\begin{array}{l}15.5 \\
15.5 \\
17.0 \\
17.0 \\
17.0\end{array}$ & $\begin{array}{l}19.5 \\
19.5 \\
20.0 \\
20.5 \\
20.5\end{array}$ & $\begin{array}{l}22.0 \\
22.0 \\
21.0 \\
21.5 \\
22.5\end{array}$ & $\begin{array}{l}13.0 \\
14.5 \\
13.5 \\
14.0 \\
14.0\end{array}$ & $\begin{array}{l}17.0 \\
17.5 \\
16.5 \\
17.5 \\
18.0\end{array}$ & $\begin{array}{l}-1.0 \\
21.5 \\
22.0 \\
18.0\end{array}$ & $\begin{array}{l}-0- \\
11.5 \\
12.0 \\
13.0\end{array}$ & $\begin{array}{l}15.5 \\
16.0 \\
15.5\end{array}$ \\
\hline $\begin{array}{l}21 \\
22 \\
23 \\
24 \\
25\end{array}$ & $\begin{array}{l}m-- \\
--- \\
--- \\
---\end{array}$ & $\begin{array}{l}-- \\
--\infty \\
--- \\
--\infty \\
---\end{array}$ & $\begin{array}{l}--- \\
--- \\
--- \\
-m- \\
--\infty\end{array}$ & $\begin{array}{l}26.0 \\
23.0 \\
25.5 \\
26.5 \\
26.5\end{array}$ & $\begin{array}{l}16.5 \\
14.0 \\
15.5 \\
16.5 \\
17.0\end{array}$ & $\begin{array}{l}19.5 \\
18.5 \\
18.5 \\
19.5 \\
20.5\end{array}$ & $\begin{array}{r}22.5 \\
=- \\
=- \\
=-\end{array}$ & $\begin{array}{r}13.5 \\
-0- \\
---\end{array}$ & $\begin{array}{r}17.0 \\
=- \\
=-\end{array}$ & $\begin{array}{l}21.5 \\
20.5 \\
21.5 \\
19.5 \\
17.0\end{array}$ & $\begin{array}{l}12.0 \\
12.5 \\
11.5 \\
13.5 \\
15.0\end{array}$ & $\begin{array}{l}16.5 \\
16.0 \\
16.0 \\
16.5 \\
16.0\end{array}$ \\
\hline $\begin{array}{l}26 \\
27 \\
28 \\
29 \\
30 \\
31\end{array}$ & $\begin{array}{l}=- \\
=- \\
m- \\
=- \\
=-\end{array}$ & $\begin{array}{l}\cdots \\
-\cdots \\
-\cdots \\
--\infty\end{array}$ & $\begin{array}{l}=- \\
=- \\
=- \\
-- \\
-- \\
-\infty\end{array}$ & $\begin{array}{l}23.0 \\
26.0 \\
26.0 \\
26.0 \\
25.5 \\
25.0\end{array}$ & $\begin{array}{l}17.0 \\
18.5 \\
18.0 \\
18.5 \\
18.0 \\
17.0\end{array}$ & $\begin{array}{l}20.5 \\
21.5 \\
21.5 \\
21.5 \\
21.0 \\
20.0\end{array}$ & $\begin{array}{l}25.0 \\
23.5 \\
23.5 \\
24.0 \\
25.5 \\
25.5\end{array}$ & $\begin{array}{l}16.0 \\
14.0 \\
14.0 \\
14.5 \\
15.5 \\
16.5\end{array}$ & $\begin{array}{l}19.5 \\
18.0 \\
18.5 \\
18.5 \\
19.5 \\
19.5\end{array}$ & $\begin{array}{r}18.5 \\
21.0 \\
16.0 \\
14.0 \\
16.0 \\
=0\end{array}$ & $\begin{array}{r}13.0 \\
13.5 \\
11.5 \\
11.5 \\
13.5 \\
-.0\end{array}$ & $\begin{array}{r}15.0 \\
16.5 \\
14.0 \\
12.5 \\
14.5 \\
=0\end{array}$ \\
\hline NTH & $-\infty$ & $m-\infty$ & $-\infty$ & 27.0 & 13.5 & 20.0 & $-\infty$ & $-\infty$ & $-\infty$ & 25.0 & 11.5 & \\
\hline
\end{tabular}

YEAR $\quad 27.0 \quad 0.0 \quad 12.0$ 
SANTA CLARA RIVER BASIN

11113000 SESPE CREEK NEAR FILLMORE, CA

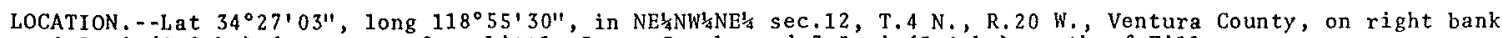
$0.1 \mathrm{mi}(0.2 \mathrm{~km})$ downstream from Little Sespe Creek, and $3.5 \mathrm{mi}(5.6 \mathrm{~km})$ north of Fillmore.

DRAINAGE AREA. $-251 \mathrm{mi}^{2}\left(650 \mathrm{~km}^{2}\right)$.

\section{WATER-DISCHARGE RECORDS}

PERIOD OF RECORD, - -September 1911 to September 1913 , October 1927 to current year; combined records of creek and cana1, October 1927 to current year. Prior to 1935 , published as "at Sespe."

GAGE. - Water-stage recorder on creek; water-stage recorder and Parshall flume on canal. A1titude of creek gage is $580 \mathrm{ft}(177 \mathrm{~m})$, from topographic map. Canal gage is at different datum. See wSp $1315-\mathrm{B}$ for history of changes prior to Jan. $17,1946$.

REMARKS. - - Records fair. No regulation above station. Filimore Irrigation Co. has diverted water 1 mi (2 km) upstream since September 1911. For records of combined discharge of Sespe Creek and Fillmore irrigation Co.'s canal, see following page.

AVERAGE DISCHARGE.--Creek on $1 \mathrm{y}: 51$ years, $103 \mathrm{ft}^{3} / \mathrm{s}\left(2.917 \mathrm{~m}^{3} / \mathrm{s}\right), 74,620 \mathrm{acre}-\mathrm{ft} / \mathrm{yr}(92.0 \mathrm{hm} / \mathrm{yr})$.

Combined creek and canal: 49 years, $109 \mathrm{ft}^{3} / \mathrm{s}\left(3.087 \mathrm{~m}^{3} / \mathrm{s}\right) .78,970 \mathrm{acre}-\mathrm{ft} / \mathrm{yr}^{(97.4 \mathrm{hm} / \mathrm{yr})}$.

EXTREMES FOR PERIOD OF RECORD.--Creek only: Maximum discharge, $60,000 \mathrm{ft}^{3} / \mathrm{s}\left(1,700 \mathrm{~m}^{3} / \mathrm{s}\right) \mathrm{Jan}, 25,1969, \mathrm{gage} \mathrm{height}$ $20.80 \mathrm{ft}(6.340 \mathrm{~m})$, from rating curve extended above $22,000 \mathrm{ft}^{3} / \mathrm{s}\left(623 \mathrm{~m}^{3} / \mathrm{s}\right)$ on basis of s1ope-area measurement at gage height $19.0 \mathrm{ft}(5.79 \mathrm{~m})$; maximum gage height, $24.95 \mathrm{ft}(7.605 \mathrm{~m})$ Feb. 25 , 1969 , from debris wave; no flow at times in some years.

Combined creek and cantl: Maximum discharge, $60,000 \mathrm{ft}^{3} / \mathrm{s}\left(1,700 \mathrm{~m}^{3} / \mathrm{s}\right) \mathrm{Jan} .25,1969 ; \mathrm{minimum} \mathrm{dail}^{\mathrm{y}}, 1.1 \mathrm{ft} / \mathrm{s}$ $\left(0.031 \mathrm{~m}^{3} / \mathrm{s}\right)$ Ju1y 31 , Aug. 2, 1951 .

EXTREMES FOR CURRENT YEAR. - Creek only: Maximum discharge, $3,650 \mathrm{ft}^{3} / \mathrm{s}\left(103 \mathrm{~m}^{3} / \mathrm{s}\right) \mathrm{Feb}$. 9 (1115 hrs), gage height, $14.39 \mathrm{ft}(4.386 \mathrm{~m})$, no other peak above base of $1,300 \mathrm{ft}^{3} / \mathrm{s}\left(36.8 \mathrm{~m}^{3} / \mathrm{s}\right) ; \mathrm{minimum} \mathrm{daily,} 0.21 \mathrm{ft} / \mathrm{s}(0.006 \mathrm{~m} / \mathrm{s})$ Aug. $29-31$.

Combined creek and canal: Maximum discharge, $3,650 \mathrm{ft}^{3} / \mathrm{s}\left(103 \mathrm{~m}^{3} / \mathrm{s}\right) \mathrm{Feb}, 9 ; \mathrm{minimum} \mathrm{daily,} 3.4 \mathrm{ft} \mathrm{d}^{3} / \mathrm{s}(0.096 \mathrm{~m} / \mathrm{s})$ Sept. 1 .

DISCHARGE, IN CUBIC FEET PER SECOND, HATER YEAR OCTOBER 1975 TO SEPTEMBER 1976 MEAN VALUES

\begin{tabular}{|c|c|c|c|c|c|c|c|c|c|c|c|c|}
\hline DAY & OCT & NOV & $\mathrm{OEC}$ & JAN & FEB & MAR & $A P R$ & MAY & JiN & JUL & AUG & SEP \\
\hline $\begin{array}{l}1 \\
2 \\
3 \\
4 \\
5\end{array}$ & $\begin{array}{l}.56 \\
.87 \\
.70 \\
.56 \\
.49\end{array}$ & $\begin{array}{r}.43 \\
.43 \\
.43 \\
.43 \\
.43\end{array}$ & $\begin{array}{l}5.1 \\
1.3 \\
1.4 \\
1.5 \\
1.6\end{array}$ & $\begin{array}{l}2.6 \\
2.6 \\
2.6 \\
2.5 \\
2.6\end{array}$ & $\begin{array}{r}2.8 \\
2.8 \\
2.8 \\
5.4 \\
18\end{array}$ & $\begin{array}{r}70 \\
125 \\
114 \\
83 \\
71\end{array}$ & $\begin{array}{l}34 \\
32 \\
30 \\
33 \\
33\end{array}$ & $\begin{array}{l}14 \\
13 \\
13 \\
13 \\
13\end{array}$ & $\begin{array}{l}4.1 \\
3.9 \\
2.9 \\
2.7 \\
2.4\end{array}$ & $\begin{array}{r}.42 \\
.40 \\
.39 \\
.38 \\
.37\end{array}$ & $\begin{array}{r}.32 \\
.31 \\
.31 \\
.29 \\
.30\end{array}$ & $\begin{array}{r}.22 \\
.29 \\
.36 \\
.56 \\
.40\end{array}$ \\
\hline $\begin{array}{r}6 \\
7 \\
8 \\
9 \\
10\end{array}$ & $\begin{array}{r}.49 \\
.49 \\
.43 \\
.43 \\
.43\end{array}$ & $\begin{array}{r}.43 \\
.43 \\
.43 \\
.43 \\
.43\end{array}$ & $\begin{array}{l}1.6 \\
1.5 \\
1.4 \\
1.5 \\
1.5\end{array}$ & $\begin{array}{l}3.2 \\
3.0 \\
2.9 \\
2.7 \\
2.9\end{array}$ & $\begin{array}{r}71 \\
188 \\
758 \\
2670 \\
1550\end{array}$ & $\begin{array}{l}66 \\
64 \\
62 \\
61 \\
63\end{array}$ & $\begin{array}{l}32 \\
30 \\
32 \\
30 \\
29\end{array}$ & $\begin{array}{l}14 \\
15 \\
14 \\
12 \\
11\end{array}$ & $\begin{array}{l}1.7 \\
1.4 \\
1.3 \\
1.2 \\
.85\end{array}$ & $\begin{array}{r}.36 \\
.34 \\
.32 \\
.31 \\
.31\end{array}$ & $\begin{array}{r}.26 \\
.25 \\
.25 \\
.23 \\
.26\end{array}$ & $\begin{array}{r}.44 \\
.62 \\
.38 \\
50^{.39}\end{array}$ \\
\hline $\begin{array}{l}11 \\
12 \\
13 \\
14 \\
15\end{array}$ & $\begin{array}{l}.49 \\
.56 \\
.53 \\
.48 \\
.46\end{array}$ & $\begin{array}{r}.40 \\
.38 \\
.41 \\
.50 \\
.77\end{array}$ & $\begin{array}{l}1.6 \\
2.1 \\
2.4 \\
2.2 \\
1.8\end{array}$ & $\begin{array}{l}2.9 \\
2.9 \\
2.8 \\
3.1 \\
3.3\end{array}$ & $\begin{array}{l}426 \\
240 \\
171 \\
137 \\
121\end{array}$ & $\begin{array}{l}63 \\
59 \\
57 \\
54 \\
52\end{array}$ & $\begin{array}{l}26 \\
26 \\
33 \\
33 \\
30\end{array}$ & $\begin{array}{l}9.8 \\
8.7 \\
7.9 \\
7.8 \\
7.4\end{array}$ & $\begin{array}{l}1.1 \\
1.2 \\
2.0 \\
.96 \\
.79\end{array}$ & $\begin{array}{l}.31 \\
.31 \\
.33 \\
.37 \\
.44\end{array}$ & $\begin{array}{r}.32 \\
.32 \\
.31 \\
.28 \\
.28\end{array}$ & $\begin{array}{r}152 \\
29 \\
24 \\
15 \\
12\end{array}$ \\
\hline $\begin{array}{l}16 \\
17 \\
18 \\
19 \\
20\end{array}$ & $\begin{array}{l}.43 \\
.43 \\
.48 \\
.47 \\
.46\end{array}$ & $\begin{array}{r}1.8 \\
1.1 \\
.81 \\
.82 \\
.87\end{array}$ & $\begin{array}{l}1.8 \\
1.8 \\
1.8 \\
1.9 \\
2.0\end{array}$ & $\begin{array}{l}3.2 \\
3.3 \\
3.5 \\
3.0 \\
2.6\end{array}$ & $\begin{array}{r}104 \\
89 \\
79 \\
76 \\
73\end{array}$ & $\begin{array}{l}49 \\
49 \\
52 \\
53 \\
49\end{array}$ & $\begin{array}{l}29 \\
27 \\
26 \\
26 \\
28\end{array}$ & $\begin{array}{l}7.1 \\
6.8 \\
6.6 \\
6.5 \\
6.4\end{array}$ & $\begin{array}{r}.73 \\
.71 \\
.65 \\
1.9 \\
.73\end{array}$ & $\begin{array}{l}.50 \\
.58 \\
.63 \\
.69 \\
.75\end{array}$ & $\begin{array}{r}.31 \\
.32 \\
.28 \\
.31 \\
.34\end{array}$ & $\begin{array}{l}10 \\
8.6 \\
8.2 \\
7.7 \\
7.4\end{array}$ \\
\hline $\begin{array}{l}21 \\
22 \\
23 \\
24 \\
25\end{array}$ & $\begin{array}{l}.43 \\
.43 \\
.43 \\
.43 \\
.43\end{array}$ & $\begin{array}{l}.95 \\
.99 \\
1.1 \\
3.6 \\
5.4\end{array}$ & $\begin{array}{l}2.4 \\
2.6 \\
2.6 \\
2.7 \\
2.6\end{array}$ & $\begin{array}{l}2.5 \\
2.5 \\
2.5 \\
2.6 \\
2.6\end{array}$ & $\begin{array}{l}66 \\
61 \\
57 \\
55 \\
51\end{array}$ & $\begin{array}{l}45 \\
42 \\
42 \\
42 \\
41\end{array}$ & $\begin{array}{l}28 \\
25 \\
25 \\
23 \\
20\end{array}$ & $\begin{array}{l}6.4 \\
7.3 \\
7.5 \\
5.8 \\
6.1\end{array}$ & $\begin{array}{l}.64 \\
.61 \\
.56 \\
.51 \\
.56\end{array}$ & $\begin{array}{r}.79 \\
.68 \\
.50 \\
.43 \\
.37\end{array}$ & $\begin{array}{r}.31 \\
.26 \\
.23 \\
.28 \\
.30\end{array}$ & $\begin{array}{l}7.3 \\
7.2 \\
7.0 \\
7.0 \\
7.1\end{array}$ \\
\hline $\begin{array}{l}26 \\
27 \\
28 \\
29 \\
30 \\
31\end{array}$ & $\begin{array}{l}.43 \\
.46 \\
.48 \\
.49 \\
.49 \\
.46\end{array}$ & $\begin{array}{l}2.7 \\
1.4 \\
2.4 \\
3.1 \\
7.7 \\
. .-0\end{array}$ & $\begin{array}{l}2.4 \\
2.7 \\
3.1 \\
3.1 \\
2.6 \\
2.6\end{array}$ & $\begin{array}{l}2.6 \\
2.7 \\
2.8 \\
2.8 \\
2.8 \\
2.8\end{array}$ & $\begin{array}{l}50 \\
49 \\
48 \\
50 \\
-0 . \\
=0-\end{array}$ & $\begin{array}{l}42 \\
40 \\
38 \\
38 \\
35 \\
34\end{array}$ & $\begin{array}{l}19 \\
18 \\
18 \\
18 \\
17 \\
--\infty\end{array}$ & $\begin{array}{l}6.7 \\
6.6 \\
5.6 \\
4.5 \\
4.4 \\
4.3\end{array}$ & $\begin{array}{l}.56 \\
.51 \\
.49 \\
.47 \\
.42 \\
.0-\end{array}$ & $\begin{array}{r}.36 \\
.34 \\
.34 \\
.32 \\
.33 \\
.33\end{array}$ & $\begin{array}{l}.29 \\
.28 \\
.24 \\
.21 \\
.21 \\
.21\end{array}$ & $\begin{array}{r}7.4 \\
7.3 \\
7.3 \\
96 \\
143 \\
\ldots\end{array}$ \\
\hline $\begin{array}{l}\text { TOTAL } \\
\text { MEAN } \\
\text { MAX } \\
\text { MIN } \\
\text { AC-FT }\end{array}$ & $\begin{array}{r}15.20 \\
.49 \\
.87 \\
.43 \\
30\end{array}$ & $\begin{array}{r}41.50 \\
1.38 \\
7.7 \\
.38 \\
82\end{array}$ & $\begin{array}{r}67.2 \\
2.17 \\
5.1 \\
1.3 \\
133\end{array}$ & $\begin{array}{r}87.4 \\
2.82 \\
3.5 \\
2.5 \\
173\end{array}$ & $\begin{array}{r}7271.8 \\
251 \\
2670 \\
2.8 \\
14420\end{array}$ & $\begin{array}{r}1755 \\
56.6 \\
125 \\
34 \\
3480\end{array}$ & $\begin{array}{r}810 \\
27.0 \\
34 \\
17 \\
1610\end{array}$ & $\begin{array}{r}272.2 \\
8.78 \\
15 \\
4.3 \\
540\end{array}$ & $\begin{array}{r}38.55 \\
1.29 \\
4.1 \\
.42 \\
76\end{array}$ & $\begin{array}{r}13.30 \\
.43 \\
.79 \\
.31 \\
26\end{array}$ & $\begin{array}{r}8.67 \\
.28 \\
.34 \\
.21 \\
17\end{array}$ & $\begin{array}{r}624.16 \\
20.8 \\
152 \\
.22 \\
1240\end{array}$ \\
\hline
\end{tabular}

CAL YR 1975 TOTAL 28009.88 MEAN 76.7 MAX 5110 MIN .38 AC-FT 55560 WTR YR 1976 TOTAL 11004.98 MEAN 30.1 MAX 2670 MIN .21 AC-FT 21830 
DISCHARGE, IN CUBIC FEET PER SECOND, WATER YEAR OCTOBER 1975 TO SEPTEMBER 1976 MEAN VALUES

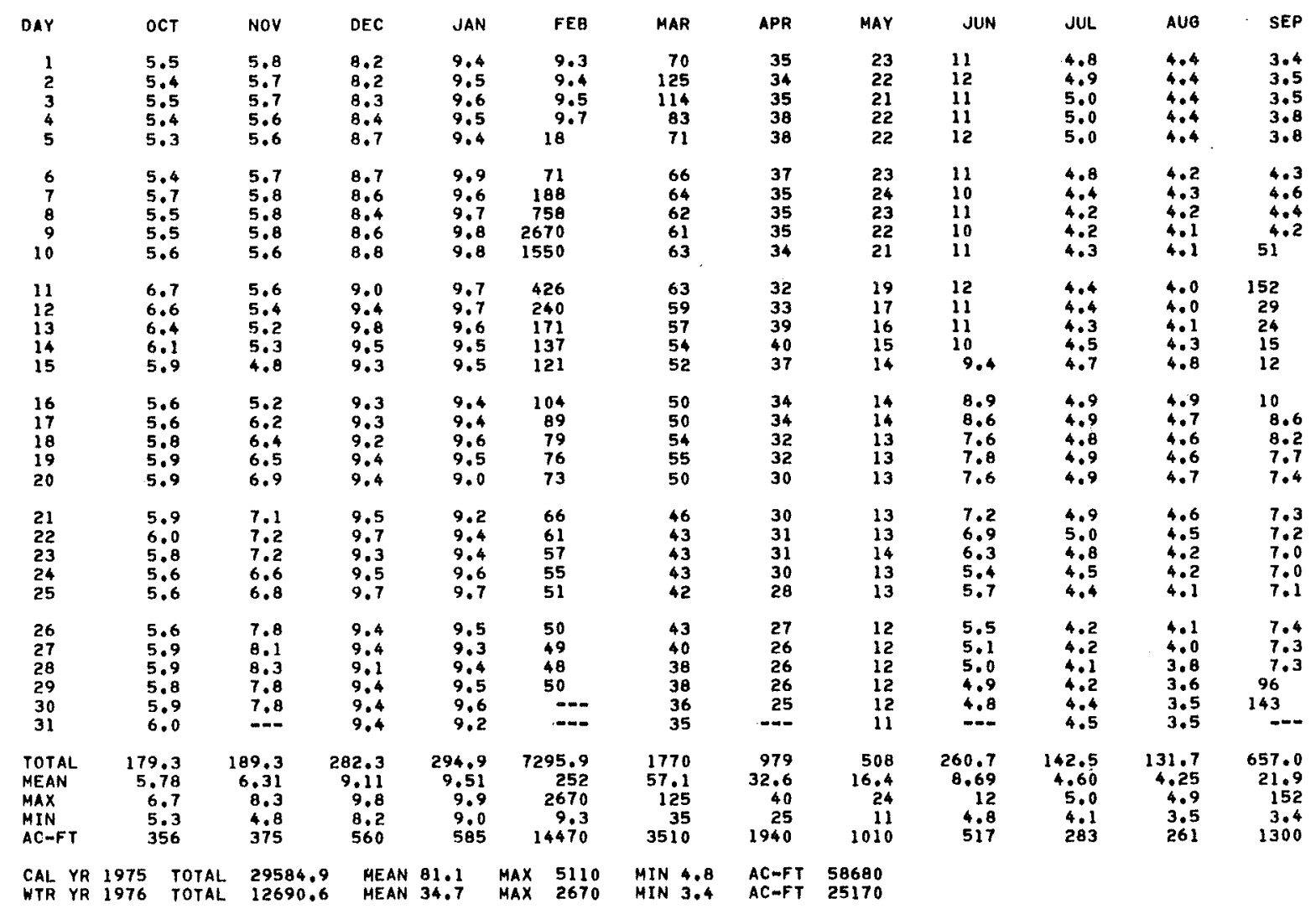


11113000 SESPE CREEK NEAR FILLMORE, CA--Continued

WATER-QUALITY RECORDS

PERIOD OF RECORD, - -Water years 1956-62, 1967 to current year

CHEMICAL ANALYSES: Water years 1967 to current year.

WATER TEMPERATURES: Water years 1967 to current year.

SEDIMENT RECORDS: Water years 1956-62, 1967 to current year.

PERIOD OF DATLY RECORD. -

SPECIFIC CONDUCTANCE: October 1969 to current year.

SEDIMENT RECORDS: October 1966 to current year.

INSTRUMENTATION.--Specific conductance recorder since October 1969 .

REMARKS.--Periods of missing specific conductance data due to probe silted or not in contact with water.

COOPERATION.--Chemical-quality records were furnished by California Department of Water Resources.

EXTREMES FOR PERIOD OF DAILY RECORD. -

SPECIFIC CONDUCTANCE: Maximum, 1,360 micromhos July 27, 1970; minimum, 185 micromhos Dec, 25, 1971.

WATER TEMPERATURES: (Water year 1970): Maximum $29.5^{\circ} \mathrm{C}$ July 4, 18, 20, $1970 ;$ minimum, 4, ${ }^{\circ} \mathrm{C}$ Jan. 4 , 1970.

SEDIMENT CONCENTRATIONS: Maximum daily mean, $31,800 \mathrm{mg} / 1 \mathrm{Jan} .25,1969 ; \mathrm{minimum}$ daily, $1 \mathrm{mg} / 1$ on many

days in $1966-69$ and 1976 .

SEDIMENT DISCHARGE: Maximum daily, 2,950,000 tons (2,680,000 tonnes) Jan, 25, 1969; minimum daily, 0 tons on many days in most years.

EXTREMES FOR CURRENT YEAR. -

SPECIFIC CONDUCTANCE: Maximum recorded, 1,230 micromhos Sept, 29; minimum recorded, 309 micromhos Feb. 9.

SEDIMENT CONCENTRATIONS: Maximum daily mean, 1,560 $\mathrm{mg} / 1 \mathrm{Feb} .9$; minimum daily, 1 mg/1 on many days.

SEDIMENT DISCHARGE: Maximum daily, 11,200 tons $(10,200$ tonnes) Feb. 9 ; minimum daily, 0 tons on many days.

CHEMICAL ANALYSES, MATER YEAR OCTOBER 1975 TO SEPTEMBER 1976

\begin{tabular}{|c|c|c|c|c|c|c|c|c|c|c|c|}
\hline DATE & TIME & $\begin{array}{l}\text { INSTAN- } \\
\text { TANEOUS } \\
\text { OIS- } \\
\text { CHARGE } \\
\text { (CFS) }\end{array}$ & $\begin{array}{l}\text { SPE- } \\
\text { CIFIC } \\
\text { CON- } \\
\text { DUCT- } \\
\text { ANCE } \\
\text { (MICRO- } \\
\text { MHOS) }\end{array}$ & $\begin{array}{c}\text { PH } \\
\text { (UNITS) }\end{array}$ & $\begin{array}{l}\text { TEMPER- } \\
\text { ATURE } \\
\text { (DEG C) }\end{array}$ & $\begin{array}{l}\text { TUR- } \\
\text { BID- } \\
\text { ITY } \\
\text { (JTU) }\end{array}$ & $\begin{array}{l}\text { DIS- } \\
\text { SOLVED } \\
\text { OXYGEN } \\
\text { (MG/L) }\end{array}$ & $\begin{array}{l}\text { HARD- } \\
\text { NESS } \\
(C A, M G) \\
(M G / L)\end{array}$ & $\begin{array}{l}\text { DIS- } \\
\text { SOLVEO } \\
\text { SULFATE } \\
\text { (SO4) } \\
\text { (MG/L) }\end{array}$ & $\begin{array}{l}\text { DIS- } \\
\text { SOLVEO } \\
\text { CHLO- } \\
\text { RIDE } \\
\text { (CL) } \\
\text { (MG/L) }\end{array}$ & $\begin{array}{l}\text { DIS- } \\
\text { SOLVED } \\
\text { SOLIDS } \\
\text { (RESI- } \\
\text { DUE AT } \\
\text { 180 C) } \\
\text { (MG/L) }\end{array}$ \\
\hline $\begin{array}{l}\text { NOV } \\
17 \ldots . .\end{array}$ & 1145 & 1.2 & 1060 & 8.1 & 16.5 & 2 & 11.0 & 371 & 234 & 88 & 667 \\
\hline $\begin{array}{l}03 \ldots . . \\
06 \ldots \\
08 \ldots \\
10 . . .\end{array}$ & $\begin{array}{l}1145 \\
0910 \\
1250 \\
1100\end{array}$ & $\begin{array}{r}2.8 \\
67 \\
550 \\
1480\end{array}$ & $\begin{array}{r}1000 \\
1035 \\
735 \\
370\end{array}$ & $\begin{array}{r}8.3 \\
-- \\
--\end{array}$ & $\begin{array}{r}14.0 \\
=.0 \\
9.0\end{array}$ & $\begin{array}{l}1 \\
-- \\
--\end{array}$ & $\begin{array}{r}12.0 \\
=- \\
=\end{array}$ & $\begin{array}{r}378 \\
=- \\
=-\end{array}$ & $\begin{array}{r}285 \\
=- \\
=-\end{array}$ & 84 & $\begin{array}{l}765 \\
702 \\
527 \\
260\end{array}$ \\
\hline $\begin{array}{l}\text { APR } \\
20 . . . \\
\text { MAY }\end{array}$ & 1045 & 29 & 830 & 8.4 & 16.5 & 0 & 10.5 & 335 & 247 & 32 & 600 \\
\hline $\begin{array}{c}25 \ldots \\
\text { JUL } \\
27 \ldots\end{array}$ & 1230 & 5.8 & 900 & 8.3 & 19.0 & $\cdots$ & 12.1 & 347 & 266 & 15 & 645 \\
\hline
\end{tabular}

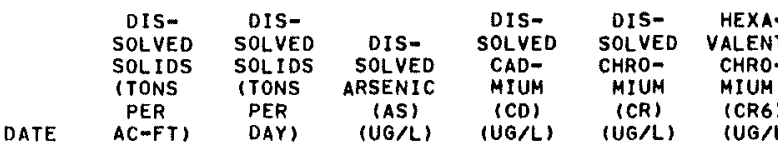

$\begin{array}{rrr}\text { NOV } & & \\ 17 \ldots & .91 & 2.16 \\ \text { FEB } & & \\ 03 \ldots & 1.04 & 5.78 \\ 06 \ldots . . & .95 & 127 \\ 08 \ldots & .72 & 783 \\ 10 \ldots . & .35 & 1040 \\ \text { APR } & & \\ 20 \ldots & .82 & 47.0 \\ \text { MAY } & & \\ 25 \ldots & .- & .- \\ \text { JUL } & & \\ 27 \ldots & .88 & .59\end{array}$ 
11113000 SESPE CREEK NEAR FILLMORE, CA--Continued

SPECIFIC CONDUCTANCE (MICROMHOS/CH AT 25 DEG. C), HATER YEAR OCTOBER 1975 TO SEPTEMBER 1976

\begin{tabular}{|c|c|c|c|c|c|c|c|c|c|c|c|c|}
\hline \multirow[b]{2}{*}{ DAY } & \multicolumn{3}{|c|}{ OCTOBER } & \multicolumn{3}{|c|}{ NOVEMBER } & \multicolumn{3}{|c|}{ DECEMBER } & \multicolumn{3}{|c|}{ JANUARY } \\
\hline & $\operatorname{MAX}$ & MIN & MEAN & $\operatorname{MAX}$ & MIN & ME.AN & $\operatorname{MAX}$ & MIN & MEAN & $\operatorname{MAX}$ & MIN & MEAN \\
\hline $\begin{array}{l}1 \\
2 \\
3 \\
4 \\
5\end{array}$ & $\begin{array}{l}970 \\
975 \\
969 \\
964 \\
972\end{array}$ & $\begin{array}{l}942 \\
943 \\
921 \\
928 \\
936\end{array}$ & $\begin{array}{l}955 \\
957 \\
944 \\
943 \\
951\end{array}$ & $\begin{array}{l}1120 \\
1130 \\
1130 \\
1130 \\
1150\end{array}$ & $\begin{array}{l}1060 \\
1060 \\
1050 \\
1050 \\
1090\end{array}$ & $\begin{array}{l}1090 \\
1100 \\
1090 \\
1090 \\
1120\end{array}$ & $\begin{array}{l}1100 \\
1080 \\
1090 \\
1090 \\
1100\end{array}$ & $\begin{array}{l}1060 \\
1040 \\
1040 \\
1060 \\
1060\end{array}$ & $\begin{array}{l}1090 \\
1060 \\
1070 \\
1080 \\
1090\end{array}$ & $\begin{array}{l}1100 \\
1100 \\
1100 \\
1090 \\
1080\end{array}$ & $\begin{array}{l}1070 \\
1070 \\
1070 \\
1060 \\
1060\end{array}$ & $\begin{array}{l}1090 \\
1080 \\
1080 \\
1080 \\
1070\end{array}$ \\
\hline $\begin{array}{r}6 \\
7 \\
8 \\
9 \\
10\end{array}$ & $\begin{array}{r}983 \\
987 \\
1010 \\
1010 \\
1010\end{array}$ & $\begin{array}{l}955 \\
963 \\
962 \\
960 \\
966\end{array}$ & $\begin{array}{l}966 \\
973 \\
979 \\
982 \\
985\end{array}$ & $\begin{array}{l}1140 \\
1140 \\
1120 \\
1110 \\
1090\end{array}$ & $\begin{array}{l}1090 \\
1070 \\
1060 \\
1040 \\
1040\end{array}$ & $\begin{array}{l}1120 \\
1100 \\
1090 \\
1080 \\
1070\end{array}$ & $\begin{array}{l}1100 \\
1110 \\
1100 \\
1110 \\
1110\end{array}$ & $\begin{array}{l}1060 \\
1070 \\
1060 \\
1060 \\
1080\end{array}$ & $\begin{array}{l}1090 \\
1090 \\
1090 \\
1090 \\
1100\end{array}$ & $\begin{array}{l}1090 \\
1080 \\
1090 \\
1100 \\
1090\end{array}$ & $\begin{array}{l}1060 \\
1060 \\
1060 \\
1070 \\
1070\end{array}$ & $\begin{array}{l}1080 \\
1070 \\
1080 \\
1080 \\
1080\end{array}$ \\
\hline $\begin{array}{l}11 \\
12 \\
13 \\
14 \\
15\end{array}$ & $\begin{array}{l}1060 \\
1020 \\
1030 \\
1010 \\
1020\end{array}$ & $\begin{array}{l}986 \\
972 \\
968 \\
954 \\
962\end{array}$ & $\begin{array}{r}1020 \\
995 \\
991 \\
982 \\
988\end{array}$ & $\begin{array}{l}1080 \\
1040 \\
1040 \\
1040 \\
1030\end{array}$ & $\begin{array}{r}1020 \\
981 \\
952 \\
988 \\
995\end{array}$ & $\begin{array}{l}1050 \\
1020 \\
1010 \\
1010 \\
1010\end{array}$ & $\begin{array}{l}1110 \\
1110 \\
1110 \\
1120 \\
1120\end{array}$ & $\begin{array}{l}1090 \\
1100 \\
1090 \\
1090 \\
1090\end{array}$ & $\begin{array}{l}1100 \\
1100 \\
1100 \\
1110 \\
1110\end{array}$ & $\begin{array}{l}1100 \\
1110 \\
1100 \\
1100 \\
1080\end{array}$ & $\begin{array}{l}1070 \\
1070 \\
1070 \\
1060 \\
1060\end{array}$ & $\begin{array}{l}1080 \\
1080 \\
1080 \\
1080 \\
1070\end{array}$ \\
\hline $\begin{array}{l}16 \\
17 \\
18 \\
19 \\
20\end{array}$ & $\begin{array}{l}1030 \\
1030 \\
1050 \\
1060 \\
1050\end{array}$ & $\begin{array}{r}970 \\
983 \\
1000 \\
1010 \\
1000\end{array}$ & $\begin{array}{r}995 \\
1000 \\
1020 \\
1030 \\
1020\end{array}$ & $\begin{array}{l}1030 \\
1010 \\
1030 \\
1040 \\
1040\end{array}$ & $\begin{array}{r}963 \\
980 \\
1000 \\
999 \\
1000\end{array}$ & $\begin{array}{r}998 \\
997 \\
1020 \\
1020 \\
1020\end{array}$ & $\begin{array}{l}1110 \\
1110 \\
1110 \\
1110 \\
1110\end{array}$ & $\begin{array}{l}1080 \\
1070 \\
1070 \\
1080 \\
1090\end{array}$ & $\begin{array}{l}1100 \\
1100 \\
1100 \\
1100 \\
1100\end{array}$ & $\begin{array}{l}1080 \\
1080 \\
1080 \\
1090 \\
1090\end{array}$ & $\begin{array}{l}1050 \\
1050 \\
1060 \\
1060 \\
1060\end{array}$ & $\begin{array}{l}1070 \\
1070 \\
1070 \\
1080 \\
1070\end{array}$ \\
\hline $\begin{array}{l}21 \\
22 \\
23 \\
24 \\
25\end{array}$ & $\begin{array}{l}1060 \\
1080 \\
1100 \\
1100 \\
1110\end{array}$ & $\begin{array}{l}1010 \\
1030 \\
1020 \\
1030 \\
1040\end{array}$ & $\begin{array}{l}1040 \\
1050 \\
1060 \\
1060 \\
1070\end{array}$ & $\begin{array}{l}1030 \\
1020 \\
1030 \\
1060 \\
1070\end{array}$ & $\begin{array}{r}1000 \\
993 \\
1000 \\
1020 \\
1050\end{array}$ & $\begin{array}{l}1020 \\
1010 \\
1020 \\
1040 \\
1070\end{array}$ & $\begin{array}{l}1110 \\
1110 \\
1090 \\
1090 \\
1100\end{array}$ & $\begin{array}{l}1080 \\
1070 \\
1060 \\
1060 \\
1050\end{array}$ & $\begin{array}{l}1100 \\
1090 \\
1080 \\
1080 \\
1080\end{array}$ & $\begin{array}{l}1090 \\
1090 \\
1090 \\
1090 \\
1090\end{array}$ & $\begin{array}{l}1060 \\
1060 \\
1070 \\
1070 \\
1070\end{array}$ & $\begin{array}{l}1080 \\
1080 \\
1080 \\
1080 \\
1080\end{array}$ \\
\hline $\begin{array}{l}26 \\
27 \\
28 \\
29 \\
30 \\
31\end{array}$ & $\begin{array}{l}1110 \\
1100 \\
1120 \\
1100 \\
1100 \\
1130\end{array}$ & $\begin{array}{l}1030 \\
1040 \\
1040 \\
1030 \\
1060 \\
1050\end{array}$ & $\begin{array}{l}1070 \\
1070 \\
1070 \\
1070 \\
1080 \\
1080\end{array}$ & $\begin{array}{l}1080 \\
1060 \\
1090 \\
1090 \\
1100 \\
-\end{array}$ & $\begin{array}{l}1050 \\
1050 \\
1050 \\
1050 \\
1070 \\
-\end{array}$ & $\begin{array}{l}1060 \\
1050 \\
1070 \\
1080 \\
1090 \\
\end{array}$ & $\begin{array}{l}1080 \\
1090 \\
1080 \\
1080 \\
1090 \\
1100\end{array}$ & $\begin{array}{l}1050 \\
1050 \\
1050 \\
1050 \\
1050 \\
1070\end{array}$ & $\begin{array}{l}1070 \\
1070 \\
1070 \\
1070 \\
1080 \\
1090\end{array}$ & $\begin{array}{l}1090 \\
1090 \\
1090 \\
1080 \\
1080 \\
1080\end{array}$ & $\begin{array}{l}1060 \\
1060 \\
1040 \\
1040 \\
1050 \\
1050\end{array}$ & $\begin{array}{l}1080 \\
1080 \\
1070 \\
1070 \\
1070 \\
1070\end{array}$ \\
\hline MONTH & 1130 & 921 & 1010 & 1150 & 952 & 1050 & 1120 & 1040 & 1090 & 1110 & 1040 & 1080 \\
\hline
\end{tabular}

\begin{tabular}{|c|c|c|c|c|c|c|c|c|c|c|c|c|}
\hline \multirow[b]{2}{*}{ DAY } & \multicolumn{3}{|c|}{ FEBRUARY } & \multicolumn{3}{|c|}{ MARCH } & \multicolumn{3}{|c|}{ APRIL } & \multicolumn{3}{|c|}{ MAY } \\
\hline & $\max$ & MIN & MEAN & $\max$ & MIN & MEAN & MAX & MIN & MEAN & $\max$ & MIN & MEAN \\
\hline $\begin{array}{l}1 \\
2 \\
3 \\
4 \\
5\end{array}$ & $\begin{array}{l}1080 \\
1090 \\
1090 \\
1120 \\
1090\end{array}$ & $\begin{array}{r}1050 \\
1050 \\
1060 \\
1070 \\
973\end{array}$ & $\begin{array}{l}1070 \\
1070 \\
1070 \\
1090 \\
1060\end{array}$ & $\begin{array}{l}866 \\
828 \\
726 \\
7770 \\
799\end{array}$ & $\begin{array}{l}738 \\
566 \\
644 \\
6996 \\
773\end{array}$ & $\begin{array}{l}818 \\
764 \\
680 \\
741 \\
791\end{array}$ & $\begin{array}{l}806 \\
809 \\
812 \\
813 \\
814\end{array}$ & $\begin{array}{l}798 \\
801 \\
806 \\
8005 \\
808\end{array}$ & $\begin{array}{l}802 \\
805 \\
809 \\
809 \\
812\end{array}$ & $\begin{array}{l}817 \\
840 \\
822 \\
831 \\
834\end{array}$ & $\begin{array}{l}737 \\
742 \\
800 \\
771 \\
810\end{array}$ & $\begin{array}{l}779 \\
794 \\
812 \\
808 \\
823\end{array}$ \\
\hline $\begin{array}{r}6 \\
7 \\
8 \\
9 \\
10\end{array}$ & $\begin{array}{r}1080 \\
801 \\
739 \\
501 \\
446\end{array}$ & $\begin{array}{l}782 \\
5563 \\
379 \\
309 \\
352\end{array}$ & $\begin{array}{r}1000 \\
730 \\
576 \\
364 \\
393\end{array}$ & $\begin{array}{l}808 \\
811 \\
823 \\
824 \\
819\end{array}$ & $\begin{array}{l}800 \\
810 \\
815 \\
814 \\
815\end{array}$ & $\begin{array}{l}803 \\
814 \\
819 \\
818 \\
816\end{array}$ & $\begin{array}{l}813 \\
812 \\
814 \\
820 \\
819\end{array}$ & $\begin{array}{l}803 \\
800 \\
790 \\
8006 \\
805\end{array}$ & $\begin{array}{l}809 \\
8006 \\
805 \\
813 \\
813\end{array}$ & $\begin{array}{l}843 \\
834 \\
856 \\
854 \\
884\end{array}$ & $\begin{array}{l}805 \\
776 \\
774 \\
780 \\
780\end{array}$ & $\begin{array}{l}827 \\
808 \\
816 \\
820 \\
820\end{array}$ \\
\hline $\begin{array}{l}11 \\
12 \\
13 \\
14 \\
15\end{array}$ & $\begin{array}{l}558 \\
624 \\
662 \\
680 \\
728\end{array}$ & $\begin{array}{l}434 \\
560 \\
626 \\
6644 \\
632\end{array}$ & $\begin{array}{l}506 \\
595 \\
6443 \\
670 \\
683\end{array}$ & $\begin{array}{l}816 \\
817 \\
820 \\
811 \\
819\end{array}$ & $\begin{array}{l}812 \\
813 \\
814 \\
812 \\
811\end{array}$ & $\begin{array}{l}814 \\
815 \\
816 \\
815 \\
814\end{array}$ & $\begin{array}{l}819 \\
823 \\
824 \\
823 \\
819\end{array}$ & $\begin{array}{l}807 \\
799 \\
800 \\
811 \\
807\end{array}$ & $\begin{array}{l}814 \\
813 \\
814 \\
8118 \\
815\end{array}$ & \begin{tabular}{l}
$\because-$ \\
$\because \because$ \\
$\because-$ \\
\hdashline-
\end{tabular} & 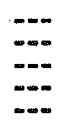 & $\begin{array}{l}\because- \\
\because= \\
\because=\end{array}$ \\
\hline $\begin{array}{l}16 \\
17 \\
18 \\
19 \\
20\end{array}$ & \begin{tabular}{l}
754 \\
\hdashline-1 \\
844 \\
849
\end{tabular} & \begin{tabular}{l}
484 \\
\hdashline-8 \\
836 \\
843
\end{tabular} & \begin{tabular}{l}
604 \\
\hdashline- \\
841 \\
847
\end{tabular} & $\begin{array}{l}818 \\
815 \\
813 \\
806 \\
793\end{array}$ & $\begin{array}{l}812 \\
805 \\
803 \\
790 \\
777\end{array}$ & $\begin{array}{l}815 \\
811 \\
808 \\
799 \\
785\end{array}$ & $\begin{array}{l}820 \\
821 \\
822 \\
821 \\
815\end{array}$ & $\begin{array}{l}806 \\
8005 \\
802 \\
797 \\
791\end{array}$ & $\begin{array}{l}815 \\
815 \\
813 \\
809 \\
803\end{array}$ & $\begin{array}{l}\because- \\
\because \because \\
\because- \\
-\because\end{array}$ & $\begin{array}{l}\cdots \\
\cdots \\
\cdots \\
\cdots\end{array}$ & \begin{tabular}{l}
-- \\
\hdashline- \\
\hdashline- \\
\hdashline-
\end{tabular} \\
\hline $\begin{array}{l}21 \\
22 \\
23 \\
24 \\
25\end{array}$ & $\begin{array}{l}847 \\
850 \\
860 \\
865 \\
873\end{array}$ & $\begin{array}{l}839 \\
846 \\
852 \\
859 \\
867\end{array}$ & $\begin{array}{l}842 \\
847 \\
857 \\
864 \\
870\end{array}$ & $\begin{array}{l}782 \\
784 \\
793 \\
798 \\
800\end{array}$ & $\begin{array}{l}774 \\
776 \\
783 \\
792 \\
792\end{array}$ & $\begin{array}{l}777 \\
779 \\
787 \\
794 \\
796\end{array}$ & $\begin{array}{l}810 \\
809 \\
806 \\
800 \\
800\end{array}$ & $\begin{array}{l}786 \\
7865 \\
772 \\
776 \\
763\end{array}$ & $\begin{array}{l}799 \\
799 \\
791 \\
787 \\
787\end{array}$ & $\begin{array}{l}-- \\
\because- \\
861\end{array}$ & 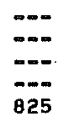 & $\begin{array}{l}m- \\
\cdots \\
345\end{array}$ \\
\hline $\begin{array}{l}26 \\
27 \\
28 \\
29 \\
30 \\
31\end{array}$ & \begin{tabular}{l}
880 \\
884 \\
876 \\
864 \\
-6 \\
\hdashline-
\end{tabular} & $\begin{array}{l}874 \\
878 \\
868 \\
850 \\
-\end{array}$ & $\begin{array}{l}876 \\
881 \\
872 \\
861 \\
- \\
-\end{array}$ & $\begin{array}{l}799 \\
794 \\
794 \\
795 \\
802 \\
805\end{array}$ & $\begin{array}{l}791 \\
778 \\
782 \\
785 \\
794 \\
795\end{array}$ & $\begin{array}{l}795 \\
791 \\
787 \\
789 \\
797 \\
800\end{array}$ & $\begin{array}{l}807 \\
814 \\
810 \\
821 \\
820 \\
\cdots\end{array}$ & $\begin{array}{l}771 \\
7714 \\
776 \\
765 \\
752 \\
-\end{array}$ & $\begin{array}{l}789 \\
795 \\
796 \\
796 \\
787 \\
-9-\end{array}$ & $\begin{array}{l}857 \\
8554 \\
853 \\
867 \\
866 \\
864\end{array}$ & $\begin{array}{l}823 \\
818 \\
831 \\
815 \\
816 \\
806\end{array}$ & $\begin{array}{l}841 \\
837 \\
846 \\
844 \\
843 \\
839\end{array}$ \\
\hline & 1120 & 309 & 799 & 866 & 566 & 795 & 824 & 752 & 805 & $m$ & -- & $-\infty$ \\
\hline
\end{tabular}


11113000 SESPE CREEK NEAR FILLMORE, CA--Continued

SPECIFIC CONDUCTANCE (MICROHHOS/CM AT 25 DEG. C), HATER YEAR OCTOBER 1975 TO SEPTEMBER 1976

\begin{tabular}{|c|c|c|c|c|c|c|c|c|c|c|c|c|}
\hline \multirow[b]{2}{*}{ DAY } & \multicolumn{3}{|c|}{ JUNE } & \multicolumn{3}{|c|}{ JULY } & \multicolumn{3}{|c|}{ AUGUST } & \multicolumn{3}{|c|}{ SEPTEMEER } \\
\hline & $\operatorname{MAX}$ & MIN & MEAN & $\operatorname{MAX}$ & MIN & MEAN & MAX & MIN & MEAN & $\operatorname{MAX}$ & MIN & MEAN \\
\hline $\begin{array}{l}1 \\
2 \\
3 \\
4 \\
5\end{array}$ & $\begin{array}{l}867 \\
876 \\
948 \\
--5 \\
960\end{array}$ & $\begin{array}{l}801 \\
816 \\
836 \\
0 \\
844\end{array}$ & $\begin{array}{l}836 \\
848 \\
876 \\
-89 \\
890\end{array}$ & $\begin{array}{l}985 \\
995 \\
992 \\
992 \\
990\end{array}$ & $\begin{array}{l}941 \\
949 \\
944 \\
942 \\
936\end{array}$ & $\begin{array}{l}968 \\
974 \\
972 \\
970 \\
966\end{array}$ & $\begin{array}{l}1020 \\
1020 \\
1030 \\
1020 \\
1010\end{array}$ & $\begin{array}{l}986 \\
985 \\
982 \\
975 \\
975\end{array}$ & $\begin{array}{l}1000 \\
1000 \\
1000 \\
996 \\
995\end{array}$ & $\begin{array}{l}1020 \\
1020 \\
1020 \\
1030 \\
1040\end{array}$ & $\begin{array}{r}984 \\
990 \\
997 \\
993 \\
1000\end{array}$ & $\begin{array}{l}1000 \\
1010 \\
1010 \\
1010 \\
1020\end{array}$ \\
\hline $\begin{array}{r}6 \\
7 \\
8 \\
9 \\
10\end{array}$ & $\begin{array}{l}-1= \\
957 \\
987 \\
958 \\
937\end{array}$ & $\begin{array}{l}--2 \\
883 \\
875 \\
852 \\
899\end{array}$ & $\begin{array}{l}925 \\
934 \\
898 \\
914\end{array}$ & $\begin{array}{l}984 \\
980 \\
976 \\
986 \\
991\end{array}$ & $\begin{array}{l}920 \\
916 \\
920 \\
944 \\
945\end{array}$ & $\begin{array}{l}959 \\
952 \\
954 \\
966 \\
973\end{array}$ & $\begin{array}{l}1010 \\
1000 \\
1000 \\
1000 \\
1000\end{array}$ & $\begin{array}{l}954 \\
959 \\
948 \\
940 \\
941\end{array}$ & $\begin{array}{l}987 \\
982 \\
978 \\
978 \\
974\end{array}$ & $\begin{array}{l}1040 \\
1040 \\
1040 \\
1040 \\
1040\end{array}$ & $\begin{array}{r}1010 \\
1010 \\
1010 \\
1020 \\
619\end{array}$ & $\begin{array}{r}1020 \\
1020 \\
1020 \\
1030 \\
958\end{array}$ \\
\hline $\begin{array}{l}11 \\
12 \\
13 \\
14 \\
15\end{array}$ & $\begin{array}{l}935 \\
942 \\
905 \\
942 \\
952\end{array}$ & $\begin{array}{l}873 \\
876 \\
849 \\
886 \\
902\end{array}$ & $\begin{array}{l}907 \\
908 \\
888 \\
915 \\
926\end{array}$ & $\begin{array}{l}990 \\
984 \\
977 \\
976 \\
980\end{array}$ & $\begin{array}{l}944 \\
944 \\
943 \\
946 \\
954\end{array}$ & $\begin{array}{l}972 \\
970 \\
964 \\
963 \\
969\end{array}$ & $\begin{array}{l}981 \\
982 \\
984 \\
987 \\
991\end{array}$ & $\begin{array}{l}945 \\
944 \\
952 \\
961 \\
965\end{array}$ & $\begin{array}{l}967 \\
968 \\
973 \\
977 \\
981\end{array}$ & $\begin{array}{r}601 \\
1200 \\
1240\end{array}$ & $\begin{array}{r}567 \\
120 \\
1150 \\
1100\end{array}$ & $\begin{array}{r}578 \\
1180 \\
1120\end{array}$ \\
\hline $\begin{array}{l}16 \\
17 \\
18 \\
19 \\
20\end{array}$ & $\begin{array}{l}961 \\
968 \\
970 \\
962 \\
966\end{array}$ & $\begin{array}{l}919 \\
928 \\
936 \\
910 \\
920\end{array}$ & $\begin{array}{l}938 \\
948 \\
952 \\
930 \\
949\end{array}$ & $\begin{array}{l}983 \\
987 \\
990 \\
992 \\
997\end{array}$ & $\begin{array}{l}949 \\
959 \\
956 \\
962 \\
963\end{array}$ & $\begin{array}{l}969 \\
975 \\
976 \\
979 \\
984\end{array}$ & $\begin{array}{r}990 \\
996 \\
999 \\
1000 \\
996\end{array}$ & $\begin{array}{l}964 \\
968 \\
973 \\
973 \\
974\end{array}$ & $\begin{array}{l}981 \\
987 \\
990 \\
990 \\
989\end{array}$ & $\begin{array}{l}1100 \\
1060 \\
1070 \\
1070 \\
1060\end{array}$ & $\begin{array}{l}1070 \\
1060 \\
1040 \\
1040 \\
1040\end{array}$ & $\begin{array}{l}1090 \\
1070 \\
1060 \\
1050 \\
1050\end{array}$ \\
\hline $\begin{array}{l}21 \\
22 \\
23 \\
24 \\
25\end{array}$ & $\begin{array}{l}974 \\
979 \\
979 \\
969 \\
981\end{array}$ & $\begin{array}{l}938 \\
939 \\
927 \\
919 \\
902\end{array}$ & $\begin{array}{l}958 \\
960 \\
954 \\
950 \\
943\end{array}$ & $\begin{array}{l}1000 \\
1010 \\
1010 \\
1030 \\
1030\end{array}$ & $\begin{array}{l}979 \\
986 \\
982 \\
983 \\
987\end{array}$ & $\begin{array}{r}991 \\
997 \\
1000 \\
1010 \\
1010\end{array}$ & $\begin{array}{l}1000 \\
1010 \\
1010 \\
1010 \\
1010\end{array}$ & $\begin{array}{l}974 \\
979 \\
981 \\
976 \\
976\end{array}$ & $\begin{array}{l}992 \\
995 \\
997 \\
994 \\
994\end{array}$ & $\begin{array}{l}1050 \\
1050 \\
1050 \\
1050 \\
1050\end{array}$ & $\begin{array}{l}1030 \\
1030 \\
1020 \\
1030 \\
1040\end{array}$ & $\begin{array}{l}1040 \\
1040 \\
1030 \\
1040 \\
1050\end{array}$ \\
\hline $\begin{array}{l}26 \\
27 \\
28 \\
29 \\
30 \\
31\end{array}$ & $\begin{array}{l}968 \\
957 \\
967 \\
980 \\
988 \\
---\end{array}$ & $\begin{array}{l}916 \\
917 \\
923 \\
924 \\
934 \\
-2-\end{array}$ & $\begin{array}{l}941 \\
942 \\
948 \\
956 \\
962 \\
---\end{array}$ & $\begin{array}{l}1020 \\
1020 \\
1020 \\
1020 \\
1020 \\
1020\end{array}$ & $\begin{array}{l}982 \\
977 \\
976 \\
980 \\
983 \\
978\end{array}$ & $\begin{array}{l}1010 \\
1000 \\
1000 \\
1000 \\
1000 \\
1000\end{array}$ & $\begin{array}{l}1010 \\
1010 \\
1010 \\
1010 \\
1010 \\
1010\end{array}$ & $\begin{array}{l}978 \\
978 \\
978 \\
974 \\
978 \\
980\end{array}$ & $\begin{array}{l}995 \\
995 \\
998 \\
997 \\
998 \\
999\end{array}$ & $\begin{array}{r}1050 \\
1050 \\
1060 \\
1230 \\
783 \\
-\ldots\end{array}$ & $\begin{array}{r}1030 \\
1020 \\
1020 \\
758 \\
745 \\
---\end{array}$ & $\begin{array}{l}1040 \\
1040 \\
1040 \\
1020 \\
759 \\
-\end{array}$ \\
\hline MONTH & 988 & 801 & 925 & 1030 & 916 & 980 & 1030 & 940 & 989 & 1230 & 567 & 1010 \\
\hline YEAR & 1230 & 309 & 953 & & & & & & & & & \\
\hline
\end{tabular}

TEMPERATURE (DEG. C) OF HATER, HATER YEAR OCTOBER 1975 TO SEPTEMBER 1976 ONCE $\rightarrow$ DA ILY

\begin{tabular}{|c|c|c|c|c|c|c|c|c|c|c|c|c|}
\hline DAY & OCT & NOV & DEC & JAN & FEB & NAR & APR & MAY & JUN & JUL & AUG & SEP \\
\hline $\begin{array}{l}1 \\
2 \\
3 \\
4 \\
5\end{array}$ & $=$ & $\begin{array}{r}--0 \\
-00 \\
19.0 \\
-0.0\end{array}$ & $\begin{array}{r}16.5 \\
-- \\
--\end{array}$ & $\begin{array}{r}-\infty \\
11.5 \\
--\infty\end{array}$ & $\begin{array}{r}--0 \\
14.5 \\
10.0\end{array}$ & $\begin{array}{r}13.0 \\
10.5 \\
11.0 \\
=-\end{array}$ & $\begin{array}{l}-\infty \\
=-0 \\
0-0 \\
11.5\end{array}$ & 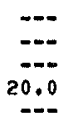 & $\begin{array}{r}=-0 \\
25.0 \\
=-0 \\
22.0\end{array}$ & $\begin{array}{r}--0 \\
22.0 \\
-\infty \\
=-\infty\end{array}$ & $=-$ & $\begin{array}{l}=-- \\
=- \\
=- \\
=-\end{array}$ \\
\hline $\begin{array}{r}6 \\
7 \\
8 \\
9 \\
10\end{array}$ & $\begin{array}{r}21.0 \\
=- \\
=-\end{array}$ & 18.0 & $\begin{array}{r}16.0 \\
=-0 \\
17.0 \\
=-0\end{array}$ & 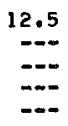 & $\begin{array}{r}9.5 \\
9.5 \\
10.0 \\
9.0 \\
10.5\end{array}$ & $\begin{array}{r}-- \\
12.0 \\
-\end{array}$ & $\begin{array}{r}-\infty \\
15.0 \\
-\infty\end{array}$ & $\begin{array}{r}m-- \\
20.0 \\
--- \\
--\end{array}$ & $\begin{array}{r}=-0 \\
=-0 \\
22.0 \\
20.0\end{array}$ & $\begin{array}{l}=- \\
=-\infty \\
=-\infty\end{array}$ & $\begin{array}{l}=- \\
=-\infty \\
=-\end{array}$ & $\begin{array}{r}m-5 \\
25.5 \\
--0 \\
22.0\end{array}$ \\
\hline $\begin{array}{l}11 \\
12 \\
13 \\
14 \\
15\end{array}$ & $\begin{array}{r}19.0 \\
0 \\
0 \\
20.0\end{array}$ & $\begin{array}{r}15.0 \\
-0 \\
\cdots\end{array}$ & $\begin{array}{r}=-\infty \\
13.0 \\
=--\end{array}$ & $\begin{array}{r}13.0 \\
-.-5 \\
14.5 \\
-.-5\end{array}$ & 11.5 & $\begin{array}{r}12.0 \\
16.0 \\
-0.0\end{array}$ & $\begin{array}{c}-.0 \\
13.0 \\
-\infty\end{array}$ & $\begin{array}{r}24.0 \\
-0 . \\
25.0 \\
-\end{array}$ & $\begin{array}{l}=- \\
=- \\
=-1 \\
22.0\end{array}$ & $\begin{array}{r}=-0 \\
23.0 \\
=-\infty \\
=-\infty\end{array}$ & $=$ & $\begin{array}{r}19.5 \\
22.0 \\
=-5 \\
23.5\end{array}$ \\
\hline $\begin{array}{l}16 \\
17 \\
18 \\
19 \\
20\end{array}$ & $\begin{array}{r}=- \\
19.5 \\
=--\end{array}$ & $\begin{array}{c}16.0 \\
0- \\
\cdots\end{array}$ & $\begin{array}{r}14.0 \\
=0 \\
=0 \\
13.0\end{array}$ & $\begin{array}{r}16.0 \\
14.5 \\
\hdashline-5\end{array}$ & 11.5 & 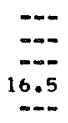 & $\begin{array}{r}-0.0 \\
16.0 \\
-0.5\end{array}$ & 20.0 & $\begin{array}{r}-0 \\
22.5 \\
=-\end{array}$ & $\begin{array}{l}=- \\
-\ldots \\
-\infty \\
-\infty\end{array}$ & $\begin{array}{l}=- \\
=- \\
=-\end{array}$ & 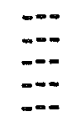 \\
\hline $\begin{array}{l}21 \\
22 \\
23 \\
24 \\
25\end{array}$ & $\begin{array}{r}=-5 \\
19.5 \\
=-5 \\
=-0\end{array}$ & $\begin{array}{r}15.0 \\
=0 \\
=0 \\
15.0\end{array}$ & $\begin{array}{r}12.5 \\
14.0 \\
=- \\
=-\end{array}$ & $\begin{array}{r}-0 \\
14.5 \\
-2-\end{array}$ & $\begin{array}{r}-0 \\
10.5 \\
=-5\end{array}$ & 17.0 & 21.0 & $\begin{array}{r}23.0 \\
20.0 \\
0.0\end{array}$ & $\begin{array}{r}22.0 \\
=-0 \\
=-\infty\end{array}$ & $\begin{array}{r}-0 \\
26.0 \\
\ldots-\end{array}$ & 26.0 & $\begin{array}{r}23.5 \\
-\infty \\
-\infty\end{array}$ \\
\hline $\begin{array}{l}26 \\
27 \\
28 \\
29 \\
30 \\
31\end{array}$ & $\begin{array}{r}-.0 \\
18.0 \\
16.0 \\
18.0\end{array}$ & $\begin{array}{r}2 .- \\
12.0 \\
12.0\end{array}$ & $\begin{array}{r}14.0 \\
14.0 \\
-0\end{array}$ & $\begin{array}{r}15.0 \\
-0 . \\
16.5 \\
-.0\end{array}$ & $\begin{array}{r}14.0 \\
-0= \\
12.0 \\
=-0\end{array}$ & $\begin{array}{r}17.5 \\
-5.5 \\
17.5 \\
-.-5\end{array}$ & 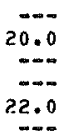 & $\begin{array}{r}24.0 \\
-0.0 \\
22.0 \\
-0.0 \\
-0 .\end{array}$ & $\begin{array}{r}=\ldots \\
=-\infty \\
22.0 \\
=-\infty \\
=-\infty\end{array}$ & $\begin{array}{l}-\infty \\
=-\infty \\
=-\infty \\
=-\infty\end{array}$ & $\begin{array}{l}m-\infty \\
=-\infty \\
=-\infty \\
=-\infty\end{array}$ & $\begin{array}{r}-\infty \\
23.5 \\
23.5 \\
=-\infty \\
-\infty\end{array}$ \\
\hline
\end{tabular}


11113000 SESPE CREEK NEAR FILLMORE, CA--Continued

SUSPENDEO-SEDIHENT DISCHARGE (TONS/OAY), WATER YEAR OCTOBER 1975 TO SEPTEMBER 1976

\begin{tabular}{|c|c|c|c|c|c|c|c|c|c|}
\hline \multirow[b]{2}{*}{ DAY } & \multicolumn{3}{|c|}{ OCTOBEA } & \multicolumn{3}{|c|}{ NOVEMBER } & \multicolumn{3}{|c|}{ DECEMBER } \\
\hline & $\begin{array}{l}\text { MEAN } \\
\text { DISCARGE } \\
\text { (CFS) }\end{array}$ & $\begin{array}{l}\text { MEAN } \\
\text { CONCEN- } \\
\text { TRATION } \\
\text { (MG/L) }\end{array}$ & $\begin{array}{l}\text { SEDIMENT } \\
\text { DISCHARGE } \\
\text { (TONS/DAY) }\end{array}$ & $\begin{array}{l}\text { MEAN } \\
\text { DISHARGE } \\
\text { (CFS) }\end{array}$ & $\begin{array}{l}\text { MEAN } \\
\text { CONCEN- } \\
\text { TRATION } \\
\text { (MG/L) }\end{array}$ & $\begin{array}{l}\text { SEDIMENT } \\
\text { DISCHARGE } \\
\text { (TONS/OAY) }\end{array}$ & $\begin{array}{l}\text { MEAN } \\
\text { DISCHARGE } \\
\text { (CFS) }\end{array}$ & $\begin{array}{l}\text { MEAN } \\
\text { CONCEN- } \\
\text { TRAIION } \\
\text { (MG/L) }\end{array}$ & $\begin{array}{l}\text { SEDIMENT } \\
\text { DISCHAGEE } \\
\text { (TONS DAAY }\end{array}$ \\
\hline $\begin{array}{l}1 \\
2 \\
3 \\
4 \\
5\end{array}$ & $\begin{array}{l}.56 \\
.87 \\
.70 \\
.56 \\
.49\end{array}$ & $\begin{array}{l}5 \\
5 \\
5 \\
5 \\
5\end{array}$ & $\begin{array}{l}.01 \\
.01 \\
.01 \\
.01 \\
.01\end{array}$ & $\begin{array}{l}.43 \\
.43 \\
.43 \\
.43 \\
.43\end{array}$ & $\begin{array}{l}5 \\
6 \\
7 \\
7 \\
7\end{array}$ & $\begin{array}{l}.01 \\
.01 \\
.01 \\
.01 \\
.01\end{array}$ & $\begin{array}{l}5.1 \\
1.3 \\
1.4 \\
1.5 \\
1.6\end{array}$ & $\begin{array}{l}4 \\
5 \\
5 \\
4 \\
3\end{array}$ & $\begin{array}{l}: 06 \\
.02 \\
.02 \\
.02 \\
.01\end{array}$ \\
\hline $\begin{array}{r}6 \\
7 \\
8 \\
9 \\
10\end{array}$ & $\begin{array}{l}.49 \\
.49 \\
.43 \\
.43 \\
.43\end{array}$ & $\begin{array}{l}6 \\
6 \\
6 \\
6 \\
6\end{array}$ & $\begin{array}{l}.01 \\
.01 \\
.01 \\
.01 \\
.01\end{array}$ & $\begin{array}{l}.43 \\
.43 \\
.43 \\
.43 \\
.43\end{array}$ & $\begin{array}{l}7 \\
7 \\
7 \\
7 \\
7\end{array}$ & $\begin{array}{l}.01 \\
.01 \\
.01 \\
.01 \\
.01\end{array}$ & $\begin{array}{l}1.6 \\
1.5 \\
1.4 \\
1.5 \\
1.5\end{array}$ & $\begin{array}{l}3 \\
3 \\
2 \\
2 \\
2\end{array}$ & $\begin{array}{l}.02 \\
.01 \\
.01 \\
0.01 \\
.01\end{array}$ \\
\hline $\begin{array}{l}11 \\
12 \\
13 \\
14 \\
15\end{array}$ & $\begin{array}{l}.49 \\
.56 \\
.53 \\
.48 \\
.46\end{array}$ & $\begin{array}{l}6 \\
5 \\
4 \\
3 \\
3\end{array}$ & $\begin{array}{l}.01 \\
.01 \\
.01 \\
0\end{array}$ & $\begin{array}{l}.40 \\
: 38 \\
.41 \\
.50 \\
.77\end{array}$ & $\begin{array}{l}7 \\
7 \\
7 \\
7 \\
7\end{array}$ & $\begin{array}{l}.01 \\
.01 \\
.01 \\
.01 \\
.01\end{array}$ & $\begin{array}{l}1.6 \\
2.1 \\
2.4 \\
2.2 \\
1.8\end{array}$ & $\begin{array}{l}3 \\
4 \\
5 \\
4 \\
3\end{array}$ & $\begin{array}{l}.01 \\
: 02 \\
.03 \\
: 02 \\
.01\end{array}$ \\
\hline $\begin{array}{l}16 \\
17 \\
18 \\
19 \\
20\end{array}$ & $\begin{array}{l}.43 \\
.43 \\
.48 \\
.47 \\
.46\end{array}$ & $\begin{array}{l}3 \\
4 \\
5 \\
5 \\
4\end{array}$ & $\begin{array}{l}0 \\
0 \\
.01 \\
.01\end{array}$ & $\begin{array}{c}1.8 \\
1.1 \\
.81 \\
.82 \\
.87\end{array}$ & $\begin{array}{l}20 \\
20 \\
19 \\
18 \\
17\end{array}$ & $\begin{array}{l}.10 \\
.06 \\
.04 \\
.04 \\
.04\end{array}$ & $\begin{array}{l}1.8 \\
1.8 \\
1.8 \\
1.9 \\
2.0\end{array}$ & $\begin{array}{l}2 \\
2 \\
2 \\
3 \\
3\end{array}$ & $\begin{array}{l}.01 \\
.01 \\
.01 \\
.02 \\
.02\end{array}$ \\
\hline $\begin{array}{l}21 \\
22 \\
23 \\
24 \\
25\end{array}$ & $\begin{array}{l}.43 \\
.43 \\
.43 \\
.43 \\
.43\end{array}$ & $\begin{array}{l}3 \\
2 \\
2 \\
2 \\
2\end{array}$ & $\begin{array}{l}0 \\
0 \\
0 \\
0 \\
0\end{array}$ & $\begin{array}{l}.95 \\
: 99 \\
1.1 \\
3.6 \\
5.4\end{array}$ & $\begin{array}{l}17 \\
15 \\
13 \\
20 \\
12\end{array}$ & $\begin{array}{l}.04 \\
.04 \\
.04 \\
.19 \\
.17\end{array}$ & $\begin{array}{l}2.4 \\
2.6 \\
2.6 \\
2.7 \\
2.6\end{array}$ & $\begin{array}{l}5 \\
7 \\
3 \\
3 \\
4\end{array}$ & $\begin{array}{l}.03 \\
.05 \\
.02 \\
.02 \\
.03\end{array}$ \\
\hline $\begin{array}{l}26 \\
27 \\
28 \\
29 \\
30 \\
31\end{array}$ & $\begin{array}{l}.43 \\
.46 \\
.48 \\
.49 \\
.49 \\
.46\end{array}$ & $\begin{array}{l}2 \\
2 \\
2 \\
3 \\
5 \\
4\end{array}$ & $\begin{array}{l}0 \\
0 \\
0 \\
0 \\
.01 \\
0^{.01}\end{array}$ & $\begin{array}{l}2.7 \\
1.4 \\
2.4 \\
3.1 \\
7.7 \\
\cdots\end{array}$ & $\begin{array}{r}10 \\
5 \\
2 \\
3 \\
10 \\
-\end{array}$ & $\begin{array}{l}.07 \\
.02 \\
.01 \\
.03 \\
.21 \\
0 .-\end{array}$ & $\begin{array}{l}2.4 \\
2.7 \\
3.1 \\
3.1 \\
2.6 \\
2.6\end{array}$ & $\begin{array}{l}5 \\
5 \\
5 \\
4 \\
4 \\
3\end{array}$ & $\begin{array}{l}.03 \\
.04 \\
.04 \\
.03 \\
.03 \\
.02\end{array}$ \\
\hline TOTAL & 15.20 & $\cdots$ & .16 & 41.50 & $\cdots$ & 1.25 & 67.2 & -- & .68 \\
\hline
\end{tabular}

\begin{tabular}{|c|c|c|c|c|c|c|c|c|c|}
\hline \multirow[b]{2}{*}{ DAY } & \multicolumn{3}{|c|}{ JANUARY } & \multicolumn{3}{|c|}{ FEBRUARY } & \multicolumn{3}{|c|}{ MARCH } \\
\hline & $\begin{array}{l}\text { MEAN } \\
\text { DISCAARGE } \\
\text { (CFS) }\end{array}$ & $\begin{array}{l}\text { MEAN } \\
\text { CONCEN- } \\
\text { TRATION } \\
\text { (MG/L) }\end{array}$ & $\begin{array}{l}\text { SEOIMENT } \\
\text { OIISCHARGE } \\
\text { (TONS/OAYY) }\end{array}$ & $\begin{array}{l}\text { MEAN } \\
\text { DISCHARGE } \\
\text { (CFS) }\end{array}$ & $\begin{array}{l}\text { MEAN } \\
\text { CONCEN- } \\
\text { RAAION } \\
\text { (MG/L) }\end{array}$ & $\begin{array}{l}\text { SEDIMENT } \\
\text { DISCHARGE } \\
\text { (TONS/DAY) }\end{array}$ & $\begin{array}{l}\text { MEAN } \\
\text { DISCHARGE } \\
\text { (CFS) }\end{array}$ & $\begin{array}{l}\text { MEAN } \\
\text { CONCEN- } \\
\text { TRATION } \\
\text { (MG/L) }\end{array}$ & $\begin{array}{l}\text { SEDIMENT } \\
\text { OISCHARGE } \\
\text { (TONS/DAY) }\end{array}$ \\
\hline $\begin{array}{l}1 \\
2 \\
3 \\
4 \\
5\end{array}$ & $\begin{array}{l}2.6 \\
2.6 \\
2.6 \\
2.5 \\
2.6\end{array}$ & $\begin{array}{l}2 \\
2 \\
2 \\
2 \\
2\end{array}$ & $\begin{array}{l}.01 \\
001 \\
.01 \\
.01 \\
.01 \\
.01\end{array}$ & $\begin{array}{r}2.8 \\
2.8 \\
2.8 \\
5.4 \\
18\end{array}$ & $\begin{array}{r}2 \\
3 \\
3 \\
4 \\
18\end{array}$ & $\begin{array}{l}.02 \\
.02 \\
.02 \\
.06\end{array}$ & $\begin{array}{r}70 \\
125 \\
114 \\
83 \\
71\end{array}$ & $\begin{array}{r}61 \\
138 \\
62 \\
11 \\
8\end{array}$ & $\begin{array}{l}12 \\
47 \\
19 \\
2.5 \\
1.5\end{array}$ \\
\hline $\begin{array}{r}6 \\
7 \\
8 \\
9 \\
10\end{array}$ & $\begin{array}{l}3.2 \\
3.0 \\
2.9 \\
2.7 \\
2.9\end{array}$ & $\begin{array}{l}4 \\
3 \\
3 \\
3 \\
3 \\
3\end{array}$ & $\begin{array}{l}.03 \\
.02 \\
.02 \\
.02 \\
.02\end{array}$ & $\begin{array}{r}71 \\
188 \\
758 \\
2670 \\
1550\end{array}$ & $\begin{array}{r}79 \\
195 \\
783 \\
1560 \\
726\end{array}$ & $\begin{array}{r}15 \\
99 \\
1600 \\
11200 \\
3040\end{array}$ & $\begin{array}{l}66 \\
64 \\
62 \\
61 \\
63\end{array}$ & $\begin{array}{l}5 \\
3 \\
2 \\
2 \\
3\end{array}$ & $\begin{array}{l}.89 \\
.52 \\
.53 \\
.33 \\
.51\end{array}$ \\
\hline $\begin{array}{l}11 \\
12 \\
13 \\
14 \\
15\end{array}$ & $\begin{array}{l}2.9 \\
2.9 \\
2.8 \\
3.1 \\
3.3\end{array}$ & $\begin{array}{l}3 \\
3 \\
4 \\
5 \\
4\end{array}$ & $\begin{array}{l}.02 \\
.02 \\
.03 \\
.04 \\
.04\end{array}$ & $\begin{array}{l}426 \\
240 \\
171 \\
137 \\
121\end{array}$ & $\begin{array}{r}160 \\
50 \\
30 \\
20 \\
15\end{array}$ & $\begin{array}{c}184 \\
32 \\
14 \\
7.4 \\
4.9\end{array}$ & $\begin{array}{l}63 \\
59 \\
57 \\
54 \\
52\end{array}$ & $\begin{array}{l}\mathbf{3} \\
\mathbf{3} \\
\mathbf{3} \\
\mathbf{3} \\
\mathbf{3}\end{array}$ & $\begin{array}{l}.51 \\
.48 \\
.46 \\
.44 \\
.42\end{array}$ \\
\hline $\begin{array}{l}16 \\
17 \\
18 \\
19 \\
20\end{array}$ & $\begin{array}{l}3.2 \\
3.3 \\
3.5 \\
3.0 \\
2.6\end{array}$ & $\begin{array}{l}3 \\
3 \\
3 \\
2 \\
2\end{array}$ & $\begin{array}{l}.03 \\
.03 \\
.03 \\
.02 \\
.01\end{array}$ & $\begin{array}{r}104 \\
89 \\
79 \\
76 \\
73\end{array}$ & $\begin{array}{r}10 \\
5 \\
3 \\
2 \\
2\end{array}$ & $\begin{array}{c}2.8 \\
1.2 \\
.64 \\
.41 \\
.39\end{array}$ & $\begin{array}{l}49 \\
49 \\
52 \\
53 \\
49\end{array}$ & $\begin{array}{l}3 \\
3 \\
2 \\
2 \\
2 \\
2\end{array}$ & $\begin{array}{l}.40 \\
.40 \\
.28 \\
.29 \\
.26\end{array}$ \\
\hline $\begin{array}{l}21 \\
22 \\
23 \\
24 \\
25\end{array}$ & $\begin{array}{l}2.5 \\
2.5 \\
2.5 \\
2.6 \\
2.6\end{array}$ & $\begin{array}{l}2 \\
2 \\
2 \\
2 \\
2 \\
2\end{array}$ & $\begin{array}{l}.01 \\
.01 \\
.01 \\
.01 \\
.01\end{array}$ & $\begin{array}{l}66 \\
61 \\
57 \\
55 \\
51\end{array}$ & $\begin{array}{l}2 \\
1 \\
1 \\
1 \\
1\end{array}$ & $\begin{array}{l}.36 \\
.16 \\
.15 \\
.15 \\
.14\end{array}$ & $\begin{array}{l}45 \\
42 \\
42 \\
42 \\
41\end{array}$ & $\begin{array}{l}2 \\
2 \\
2 \\
4 \\
5\end{array}$ & $\begin{array}{l}.24 \\
.23 \\
.23 \\
.45 \\
.55\end{array}$ \\
\hline $\begin{array}{l}26 \\
27 \\
28 \\
29 \\
30 \\
31\end{array}$ & $\begin{array}{l}2.6 \\
2.7 \\
2.8 \\
2.8 \\
2.8 \\
2.8\end{array}$ & $\begin{array}{l}2 \\
3 \\
2 \\
2 \\
2 \\
2\end{array}$ & $\begin{array}{l}.01 \\
.02 \\
.02 \\
.02 \\
.02 \\
.02\end{array}$ & $\begin{array}{r}50 \\
49 \\
48 \\
50 \\
--- \\
--\end{array}$ & $\begin{array}{r}1 \\
1 \\
1 \\
1 \\
-- \\
---\end{array}$ & 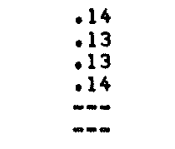 & $\begin{array}{l}42 \\
40 \\
38 \\
38 \\
35 \\
34\end{array}$ & $\begin{array}{r}5 \\
10 \\
15 \\
15 \\
18 \\
10\end{array}$ & $\begin{array}{l}.57 \\
101 \\
1.5 \\
1.5 \\
1.7 \\
.92\end{array}$ \\
\hline TAL & 87.4 & --- & .59 & 7271.8 & --- & 16204.23 & 1755 & $-\infty$ & 97.51 \\
\hline
\end{tabular}


11113000 SESPE CREEK NEAR FILLMORE, CA--Continued

SUSPENDED-SEDIMENT DISCHARGE (TONS/DAY), HATER YEAR OCTOBER 1975 TO SEPTEMBER 1976

\begin{tabular}{|c|c|c|c|c|c|c|c|c|c|}
\hline DAY & $\begin{array}{l}\text { MEAN } \\
\text { DISCHARGE } \\
\text { (CFS) }\end{array}$ & $\begin{array}{l}\text { APRIL } \\
\text { MEAN } \\
\text { CONCEN- } \\
\text { TRAT ION } \\
\text { (MG/L) }\end{array}$ & $\begin{array}{l}\text { SEDIMENT } \\
\text { DISCHARGE } \\
\text { (TONS/DAY) }\end{array}$ & $\begin{array}{l}\text { MEAN } \\
\text { DISCHARGE } \\
\text { (CFS) }\end{array}$ & $\begin{array}{l}\text { MAY } \\
\text { MEAN } \\
\text { CONCEN- } \\
\text { TRATI I } \\
\text { (MG/L) }\end{array}$ & $\begin{array}{l}\text { SEDIMENT } \\
\text { DI SCHARGE } \\
\text { (TONS/DAY) }\end{array}$ & $\begin{array}{l}\text { MEAN } \\
\text { OISCHARGE } \\
\text { (CFS) }\end{array}$ & $\begin{array}{l}\text { JUNE } \\
\text { MEAN } \\
\text { CONCEN- } \\
\text { TRATION } \\
\text { (MG/L) }\end{array}$ & $\begin{array}{l}\text { SEDIMENT } \\
\text { DISCHARGE } \\
\text { (TONS/DAY) }\end{array}$ \\
\hline $\begin{array}{l}1 \\
2 \\
3 \\
4 \\
5\end{array}$ & $\begin{array}{l}34 \\
32 \\
30 \\
33 \\
33\end{array}$ & $\begin{array}{l}8 \\
6 \\
4 \\
3 \\
3\end{array}$ & $\begin{array}{r}.73 \\
.52 \\
.32 \\
.27 \\
.27\end{array}$ & $\begin{array}{l}14 \\
13 \\
13 \\
13 \\
13\end{array}$ & $\begin{array}{l}4 \\
4 \\
5 \\
6 \\
5\end{array}$ & $\begin{array}{r}.15 \\
.14 \\
.18 \\
.21 \\
.18\end{array}$ & $\begin{array}{l}4.1 \\
3.9 \\
2.9 \\
2.7 \\
2.4\end{array}$ & $\begin{array}{l}2 \\
2 \\
1 \\
1 \\
1\end{array}$ & $\begin{array}{l}.02 \\
.02 \\
.01 \\
.01 \\
.01\end{array}$ \\
\hline $\begin{array}{r}6 \\
7 \\
8 \\
9 \\
10\end{array}$ & $\begin{array}{l}32 \\
30 \\
32 \\
30 \\
29\end{array}$ & $\begin{array}{r}3 \\
3 \\
10 \\
10 \\
7\end{array}$ & $\begin{array}{l}.26 \\
.24 \\
.86 \\
.81 \\
.55\end{array}$ & $\begin{array}{l}14 \\
15 \\
14 \\
12 \\
11\end{array}$ & $\begin{array}{l}5 \\
5 \\
4 \\
3 \\
3\end{array}$ & $\begin{array}{r}.19 \\
.20 \\
.15 \\
.10 \\
.09\end{array}$ & $\begin{array}{l}1.7 \\
1.4 \\
1.3 \\
1.2 \\
.85\end{array}$ & $\begin{array}{l}1 \\
1 \\
1 \\
1 \\
1\end{array}$ & $\begin{array}{l}0 \\
0 \\
0 \\
0 \\
0\end{array}$ \\
\hline $\begin{array}{l}11 \\
12 \\
13 \\
14 \\
15\end{array}$ & $\begin{array}{l}26 \\
26 \\
33 \\
33 \\
30\end{array}$ & $\begin{array}{l}7 \\
7 \\
7 \\
7 \\
6\end{array}$ & $\begin{array}{r}.49 \\
.49 \\
.62 \\
.62 \\
.49\end{array}$ & $\begin{array}{l}9.8 \\
8.7 \\
7.9 \\
7.8 \\
7.4\end{array}$ & $\begin{array}{l}3 \\
3 \\
3 \\
5 \\
3\end{array}$ & $\begin{array}{l}.08 \\
.07 \\
.06 \\
.11 \\
.06\end{array}$ & $\begin{array}{l}1.1 \\
1.2 \\
2.0 \\
.96 \\
.79\end{array}$ & $\begin{array}{l}2 \\
2 \\
5 \\
6 \\
7\end{array}$ & $\begin{array}{l}.01 \\
.01 \\
.03 \\
.02 \\
.01\end{array}$ \\
\hline $\begin{array}{l}16 \\
17 \\
18 \\
19 \\
20\end{array}$ & $\begin{array}{l}29 \\
27 \\
26 \\
26 \\
28\end{array}$ & $\begin{array}{r}6 \\
6 \\
6 \\
10 \\
20\end{array}$ & $\begin{array}{l}.47 \\
.44 \\
.42 \\
.70 \\
1.5\end{array}$ & $\begin{array}{l}7.1 \\
6.8 \\
6.6 \\
6.5 \\
6.4\end{array}$ & $\begin{array}{l}2 \\
2 \\
2 \\
2 \\
2\end{array}$ & $\begin{array}{l}.04 \\
.04 \\
.04 \\
.04 \\
.03\end{array}$ & $\begin{array}{r}.73 \\
.71 \\
.65 \\
1.9 \\
.73\end{array}$ & $\begin{array}{r}7 \\
7 \\
11 \\
15 \\
15\end{array}$ & $\begin{array}{l}.01 \\
.01 \\
.02 \\
.08 \\
.03\end{array}$ \\
\hline $\begin{array}{l}21 \\
22 \\
23 \\
24 \\
25\end{array}$ & $\begin{array}{l}28 \\
25 \\
25 \\
23 \\
20\end{array}$ & $\begin{array}{r}20 \\
10 \\
5 \\
3 \\
3\end{array}$ & $\begin{array}{r}1.5 \\
.68 \\
.34 \\
.19 \\
.16\end{array}$ & $\begin{array}{l}6.4 \\
7.3 \\
7.5 \\
5.8 \\
6.1\end{array}$ & $\begin{array}{l}2 \\
3 \\
3 \\
3 \\
3\end{array}$ & $\begin{array}{l}.03 \\
.06 \\
.06 \\
.05 \\
.05\end{array}$ & $\begin{array}{l}.64 \\
.61 \\
.56 \\
.51 \\
.56\end{array}$ & $\begin{array}{r}14 \\
13 \\
10 \\
8 \\
6\end{array}$ & $\begin{array}{l}.02 \\
.02 \\
.02 \\
.01 \\
.01\end{array}$ \\
\hline $\begin{array}{l}26 \\
27 \\
28 \\
29 \\
30 \\
31\end{array}$ & $\begin{array}{r}19 \\
18 \\
18 \\
18 \\
17 \\
--\end{array}$ & $\begin{array}{r}3 \\
3 \\
3 \\
3 \\
4 \\
---\end{array}$ & $\begin{array}{l}.15 \\
.15 \\
.15 \\
.15 \\
.18 \\
.--\infty\end{array}$ & $\begin{array}{l}6.7 \\
6.6 \\
5.6 \\
4.5 \\
4.4 \\
4.3\end{array}$ & $\begin{array}{l}3 \\
3 \\
2 \\
2 \\
2 \\
2\end{array}$ & $\begin{array}{l}.05 \\
.05 \\
.03 \\
.02 \\
.02 \\
.02\end{array}$ & $\begin{array}{l}.56 \\
.51 \\
.49 \\
.47 \\
.42 \\
.0-\end{array}$ & $\begin{array}{r}6 \\
8 \\
10 \\
10 \\
7 \\
- \\
--\end{array}$ & $\begin{array}{l}.01 \\
.01 \\
01 \\
.01 \\
.01 \\
.01 \\
0 .-\end{array}$ \\
\hline TAL & 810 & $-\infty$ & 14.72 & 272.2 & $-\infty$ & 2.60 & 38.55 & $-\infty$ & .43 \\
\hline
\end{tabular}

\begin{tabular}{|c|c|c|c|c|c|c|c|c|c|}
\hline & & JULY & & & AUGUST & & & SEPTEMBER & \\
\hline DAY & $\begin{array}{l}\text { MEAN } \\
\text { DISCHARGE } \\
\text { (CFS) }\end{array}$ & $\begin{array}{l}\text { MEAN } \\
\text { CONCEN- } \\
\text { TRATION } \\
\text { (MG/L) }\end{array}$ & $\begin{array}{l}\text { SEDIMENT } \\
\text { DI SCHARGE } \\
\text { (TONS/DAY) }\end{array}$ & $\begin{array}{l}\text { MEAN } \\
\text { DISCHARGE } \\
\text { (CFS) }\end{array}$ & $\begin{array}{l}\text { MEAN } \\
\text { CONCEN- } \\
\text { TRATION } \\
\text { (MG/L) }\end{array}$ & $\begin{array}{l}\text { SEDIMENT } \\
\text { DISCHARGE } \\
\text { (TONS/DAY) }\end{array}$ & $\begin{array}{c}\text { MEAN } \\
\text { DISCHARGE } \\
\text { (CFS) }\end{array}$ & $\begin{array}{l}\text { MEAN } \\
\text { CONCEN- } \\
\text { TRATION } \\
\text { (MG } / L)\end{array}$ & $\begin{array}{l}\text { SEDIMENT } \\
\text { DISCHARGE } \\
\text { (TONS/DAY) }\end{array}$ \\
\hline $\begin{array}{l}1 \\
2 \\
3 \\
4 \\
5\end{array}$ & $\begin{array}{l}.42 \\
.40 \\
.39 \\
.38 \\
.37\end{array}$ & $\begin{array}{l}3 \\
3 \\
3 \\
3 \\
3\end{array}$ & $\begin{array}{l}0 \\
0 \\
0 \\
0 \\
0\end{array}$ & $\begin{array}{r}.32 \\
.31 \\
.31 \\
.29 \\
.30\end{array}$ & $\begin{array}{l}2 \\
2 \\
2 \\
2 \\
2\end{array}$ & & $\begin{array}{l}.22 \\
.29 \\
.36 \\
.56 \\
.40\end{array}$ & $\begin{array}{l}2 \\
2 \\
2 \\
2 \\
2\end{array}$ & $\begin{array}{l}0 \\
0 \\
0 \\
0 \\
0\end{array}$ \\
\hline $\begin{array}{r}6 \\
7 \\
8 \\
9 \\
10\end{array}$ & $\begin{array}{r}.36 \\
.34 \\
.32 \\
.31 \\
.31\end{array}$ & $\begin{array}{l}3 \\
3 \\
3 \\
3 \\
3\end{array}$ & $\begin{array}{l}0 \\
0 \\
0 \\
0 \\
0\end{array}$ & $\begin{array}{l}.26 \\
.25 \\
.25 \\
.23 \\
.26\end{array}$ & $\begin{array}{l}2 \\
2 \\
2 \\
2 \\
2\end{array}$ & & $\begin{array}{r}.44 \\
.62 \\
.38 \\
.39 \\
50^{.39}\end{array}$ & $\begin{array}{r}2 \\
2 \\
3 \\
5 \\
102\end{array}$ & $\begin{array}{c}0 \\
0 \\
0 \\
14.01\end{array}$ \\
\hline $\begin{array}{l}11 \\
12 \\
13 \\
14 \\
15\end{array}$ & $\begin{array}{r}.31 \\
.31 \\
.33 \\
.37 \\
.44\end{array}$ & $\begin{array}{l}5 \\
8 \\
5 \\
3 \\
3\end{array}$ & $\begin{array}{l}0 \\
0 \\
0 \\
0 \\
0\end{array}$ & $\begin{array}{l}.32 \\
.32 \\
.31 \\
.28 \\
.28\end{array}$ & $\begin{array}{l}2 \\
2 \\
2 \\
2 \\
2\end{array}$ & & $\begin{array}{r}152 \\
29 \\
24 \\
15 \\
12\end{array}$ & $\begin{array}{r}331 \\
63 \\
20 \\
10 \\
5\end{array}$ & $\begin{array}{r}136 \\
4.9 \\
1.3 \\
.41 \\
.16\end{array}$ \\
\hline $\begin{array}{l}16 \\
17 \\
18 \\
19 \\
20\end{array}$ & $\begin{array}{l}.50 \\
.58 \\
.63 \\
.69 \\
.75\end{array}$ & $\begin{array}{l}3 \\
3 \\
3 \\
3 \\
3\end{array}$ & $\begin{array}{l}0 \\
0 \\
.01 \\
.01 \\
.01\end{array}$ & $\begin{array}{l}.31 \\
.32 \\
.28 \\
.31 \\
.34\end{array}$ & $\begin{array}{l}2 \\
2 \\
2 \\
2 \\
3\end{array}$ & & $\begin{array}{l}10 \\
8.6 \\
8.2 \\
7.7 \\
7.4\end{array}$ & $\begin{array}{l}4 \\
4 \\
3 \\
3 \\
2\end{array}$ & $\begin{array}{l}.11 \\
.09 \\
.07 \\
.06 \\
.04\end{array}$ \\
\hline $\begin{array}{l}21 \\
22 \\
23 \\
24 \\
25\end{array}$ & $\begin{array}{l}.79 \\
.68 \\
.50 \\
.43 \\
.37\end{array}$ & $\begin{array}{l}3 \\
3 \\
3 \\
3 \\
3\end{array}$ & $\begin{array}{l}.01 \\
.01 \\
0 \\
0 \\
0\end{array}$ & $\begin{array}{l}.31 \\
.26 \\
.23 \\
.28 \\
.30\end{array}$ & $\begin{array}{l}3 \\
3 \\
3 \\
3 \\
3\end{array}$ & & $\begin{array}{l}7.3 \\
7 \cdot 2 \\
7.0 \\
7.0 \\
7.1\end{array}$ & $\begin{array}{l}2 \\
2 \\
1 \\
1 \\
1\end{array}$ & $\begin{array}{l}.04 \\
.04 \\
.02 \\
.02 \\
.02\end{array}$ \\
\hline $\begin{array}{l}26 \\
27 \\
28 \\
29 \\
30 \\
31\end{array}$ & $\begin{array}{r}.36 \\
.34 \\
.34 \\
.32 \\
.33 \\
.33\end{array}$ & $\begin{array}{l}3 \\
3 \\
3 \\
3 \\
3 \\
3\end{array}$ & $\begin{array}{l}0 \\
0 \\
0 \\
0 \\
0 \\
0\end{array}$ & $\begin{array}{l}.29 \\
.28 \\
.24 \\
.21 \\
.21 \\
.21\end{array}$ & $\begin{array}{l}3 \\
3 \\
3 \\
3 \\
3 \\
3\end{array}$ & & $\begin{array}{r}7.4 \\
7.3 \\
7.3 \\
96 \\
143 \\
\ldots\end{array}$ & $\begin{array}{r}1 \\
1 \\
1 \\
527 \\
1410 \\
-00\end{array}$ & $\begin{array}{r}.02 \\
.02 \\
137^{.02} \\
544 \\
\end{array}$ \\
\hline OTAL & 13.30 & --- & .06 & 0.67 & $-\infty$ & 0 & 624.16 & --- & 838.35 \\
\hline YEAR & 11004.98 & & 17160.58 & & & & & & \\
\hline
\end{tabular}


11113000 SESPE CREEK NEAR FILLMORE, CA--Continued

PARTICLE-SIZE DISTRIBUTION OF SUSPENDED SEDIMENT, HATER YEAR OCTOBER 1975 TO SEPTEMBER 1976

\begin{tabular}{|c|c|c|c|c|c|c|c|c|c|}
\hline DATE & TIME & $\begin{array}{l}\text { TEMPER- } \\
\text { ATURE } \\
\text { (DEG C) }\end{array}$ & $\begin{array}{l}\text { INSTAN- } \\
\text { TANEOUS } \\
\text { DIS- } \\
\text { CHARGE } \\
\text { (CFS) }\end{array}$ & $\begin{array}{l}\text { SUS- } \\
\text { PENDEO } \\
\text { SEDI - } \\
\text { MENT } \\
\text { (MG/L) }\end{array}$ & $\begin{array}{c}\text { SUS- } \\
\text { PENDED } \\
\text { SEDI- } \\
\text { MENT } \\
\text { DIS- } \\
\text { CHARGE } \\
\text { (T/DAY) }\end{array}$ & $\begin{array}{l}\text { SUS. } \\
\text { SED. } \\
\text { FALL } \\
\text { OIAM. } \\
\text { X FINER } \\
\text { THAN } \\
.002 \text { MM }\end{array}$ & $\begin{array}{l}\text { SUS. } \\
\text { SED. } \\
\text { FALL } \\
\text { DIAM. } \\
\text { \$ FINER } \\
\text { THAN } \\
.004 \text { MM }\end{array}$ & $\begin{array}{c}\text { SUS. } \\
\text { SED } \\
\text { FALL } \\
\text { DIAM. } \\
\text { \$ FINER } \\
\text { THAN } \\
\text {.00B HM }\end{array}$ & $\begin{array}{l}\text { SUS, } \\
\text { SED, } \\
\text { FALL } \\
\text { DIAM, } \\
\text { क FINER } \\
\text { THAN } \\
.016 \text { MH }\end{array}$ \\
\hline \multicolumn{10}{|l|}{ FEB } \\
\hline $06 \ldots$ & 1000 & 9.0 & 64 & 72 & 12 & -- & $=$ & $=-$ & $=$ \\
\hline $\begin{array}{l}07 \ldots \\
08 \ldots \\
09 \ldots \\
10 \ldots \\
\text { MAR }\end{array}$ & $\begin{array}{l}1530 \\
1040 \\
1410 \\
1345\end{array}$ & $\begin{array}{r}9.5 \\
10.0 \\
9.0 \\
10.0\end{array}$ & $\begin{array}{r}108 \\
557 \\
2930 \\
1120\end{array}$ & $\begin{array}{r}297 \\
362 \\
1650 \\
493\end{array}$ & $\begin{array}{r}87 \\
544 \\
13100 \\
1490\end{array}$ & $\begin{array}{l}48 \\
43 \\
21 \\
35\end{array}$ & $\begin{array}{l}64 \\
58 \\
30 \\
48\end{array}$ & $\begin{array}{l}80 \\
71 \\
45 \\
62\end{array}$ & $\begin{array}{l}93 \\
81 \\
60 \\
75\end{array}$ \\
\hline $\begin{array}{l}03 \ldots \\
\text { SEP }\end{array}$ & 1540 & 10.5 & 97 & 32 & 8.4 & -- & $=$ & -- & - \\
\hline $11 \ldots$ & 1520 & 19.5 & 97 & 241 & 63 & 37 & 47 & 60 & 76 \\
\hline
\end{tabular}

PARTICLE-SIZE DISTRIBUTION OF SUSPENDED SEDIMENT, WATER YEAR OCTOBER 1975 TO SEPTEMBER 1976

\begin{tabular}{|c|c|c|c|c|c|c|c|c|c|}
\hline & $\begin{array}{l}\text { SUS. } \\
\text { SED. } \\
\text { FALL } \\
\text { DIAM. } \\
\text { \$ FINER } \\
\text { THAN }\end{array}$ & $\begin{array}{l}\text { SUS. } \\
\text { SED. } \\
\text { FALL } \\
\text { DIAM. } \\
\text { D FINER } \\
\text { THAN }\end{array}$ & $\begin{array}{l}\text { SUS. } \\
\text { SED. } \\
\text { SIEVE } \\
\text { DIAM. } \\
\text { \& FINER } \\
\text { THAN }\end{array}$ & $\begin{array}{l}\text { SUS. } \\
\text { SED. } \\
\text { FALL } \\
\text { DIAH. } \\
\text { \$ FINER } \\
\text { THAN }\end{array}$ & $\begin{array}{l}\text { SUS. } \\
\text { SEO. } \\
\text { SIEVE } \\
\text { DIAM. } \\
\text { \& FINER } \\
\text { THAN }\end{array}$ & $\begin{array}{l}\text { SUS. } \\
\text { SED } \\
\text { FALL. } \\
\text { DIAM. } \\
\text { \% FINER } \\
\text { THAN }\end{array}$ & $\begin{array}{l}\text { SUS. } \\
\text { SED. } \\
\text { SIEVE } \\
\text { DIAN. } \\
\text { \& FINER } \\
\text { THAN }\end{array}$ & $\begin{array}{l}\text { SUS. } \\
\text { SED: } \\
\text { FALL } \\
\text { DIAM. } \\
\text { \& FINER } \\
\text { THAN }\end{array}$ & $\begin{array}{l}\text { SUS. } \\
\text { SED. } \\
\text { SIEVE } \\
\text { DIAM. } \\
\text { \& FINER } \\
\text { THAN }\end{array}$ \\
\hline IATE & $.031 \mathrm{MM}$ & $.062 \mathrm{MM}$ & $.062 \mathrm{MM}$ & $.125 \mathrm{MM}$ & $.125 \mathrm{MM}$ & $.250 \mathrm{MM}$ & $.250 \mathrm{MM}$ & $.500 \mathrm{MM}$ & $.500 \mathrm{MM}$ \\
\hline
\end{tabular}

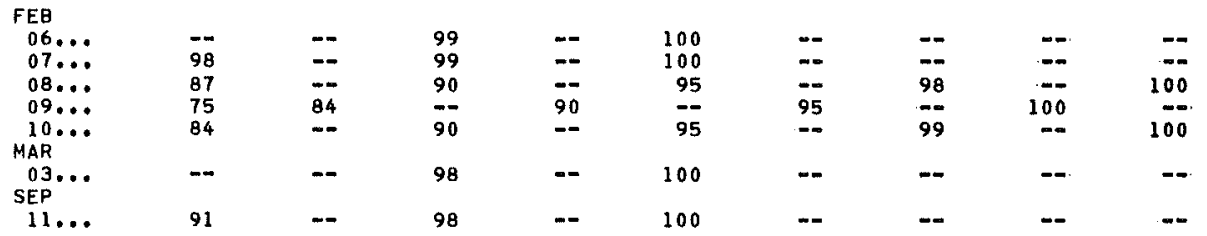


11113300 SANTA CLARA RIVER NEAR SANTA PAULA, CA

LOCATION. - Lat $34^{\circ} 21^{\prime} 14^{\prime \prime}$, long $119^{\circ} 01^{\prime} 38^{\prime \prime}$, in sec.12, T.3 N., R. 21 W., Ventura County .

PERIOD OF RECORD.--Chemical analyses: Water year 1967 to July 1971, water years 1972 to current year (partialrecord station).

COOPERATION.--Records were furnished by California Department of Water Resources.

CHEMICAL ANALYSES, HATER YEAR OCTOBER 1975 TO SEPTEMBER 1976

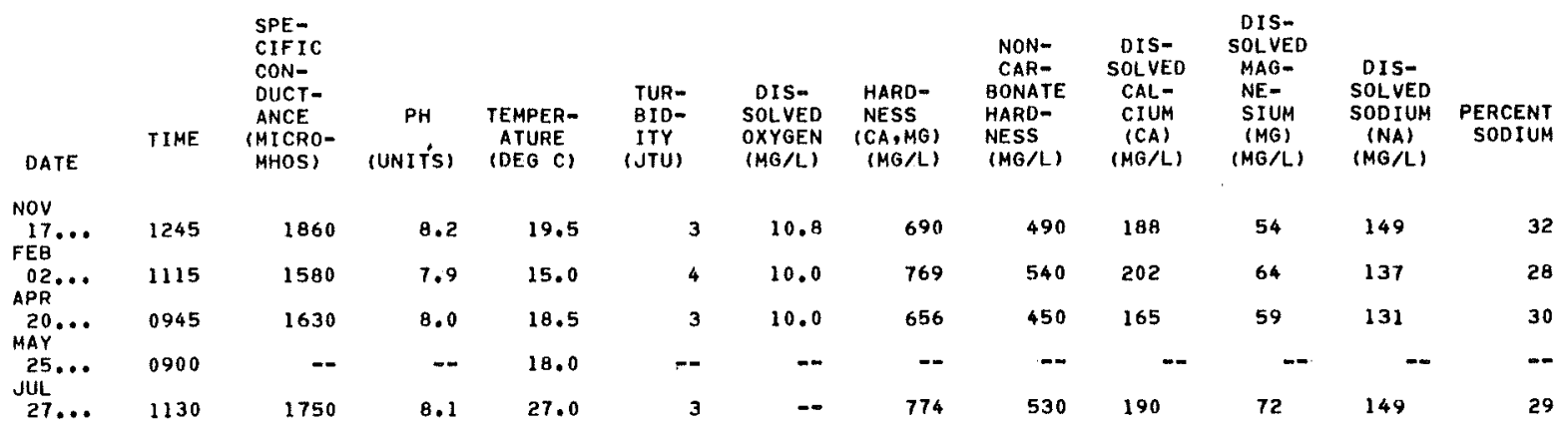

DATE

$\begin{array}{cc} & \text { DIS- } \\ \text { SODIUM } & \text { SOLVED } \\ \text { AD- } & \text { PO- } \\ \text { SORP- } & \text { TAS- } \\ \text { TION } & \text { SIUM } \\ \text { RATIO } & (K) \\ & (M G / L)\end{array}$
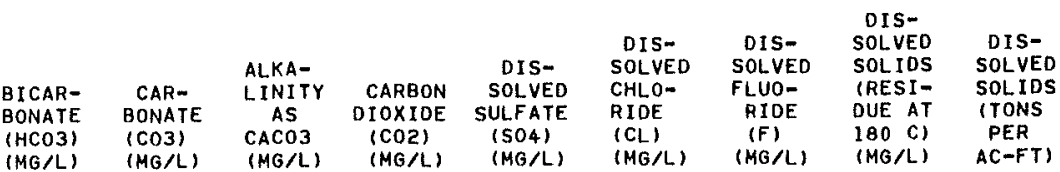

NOV
$17 \ldots$
FEB
$02 \ldots$
APR
$20 \ldots$
MAY
$25 \ldots$
JUL

$\begin{array}{rrrr}2.5 & 6.2 & 248 \\ 2.2 & 5.9 & 284 \\ 2.2 & 5.5 & 256 \\ -- & -- & -- \\ 2.3 & 5.9 & 292\end{array}$

0
0
0
0

$\begin{array}{rrr}203 & 2.5 & 670 \\ 233 & 5.7 & 694 \\ 210 & 4.1 & 610 \\ =- & -- & -- \\ 239 & 3.7 & 734\end{array}$

\section{7}

1.0

1464

1.99

59

1.0

1489

2.03

55

1.1

1318

1.79

62

$1.5 \quad 1441$

1.96

\begin{tabular}{|c|c|c|c|c|c|c|c|c|c|c|c|}
\hline DATE & $\begin{array}{l}\text { TOTAL } \\
\text { NITRATE } \\
\text { (N) } \\
\text { (MG/L) }\end{array}$ & $\begin{array}{c}\text { DIS- } \\
\text { SOLVED } \\
\text { ARSENIC } \\
\text { (AS) } \\
(U G / L)\end{array}$ & $\begin{array}{c}\text { DIS- } \\
\text { SOLVED } \\
\text { BORON } \\
\text { (B) } \\
(U G / L)\end{array}$ & $\begin{array}{l}\text { OIS- } \\
\text { SOLVED } \\
\text { CAD- } \\
\text { MIUM } \\
\text { (CD) } \\
\text { (UQ/L) }\end{array}$ & $\begin{array}{l}\text { DIS- } \\
\text { SOLVED } \\
\text { CHRO= } \\
\text { MIUM } \\
\text { (CR) } \\
(U G / L)\end{array}$ & $\begin{array}{l}\text { HEXA- } \\
\text { VALENT } \\
\text { CHRO- } \\
\text { MIUM } \\
\text { (CRG) } \\
\text { (UG/L) }\end{array}$ & $\begin{array}{l}\text { DIS- } \\
\text { SOLVED } \\
\text { COPPER } \\
\text { (CU) } \\
\text { (UG/L) }\end{array}$ & $\begin{array}{l}\text { DIS- } \\
\text { SOLVEO } \\
\text { IRON } \\
\text { (FE) } \\
\text { (UG/L) }\end{array}$ & $\begin{array}{l}\text { DIS- } \\
\text { SOLVED } \\
\text { LEAD } \\
\text { (PB) } \\
(U G / L)\end{array}$ & $\begin{array}{l}\text { OIS- } \\
\text { SOLVED } \\
\text { MAN- } \\
\text { GANESE } \\
\text { (MN) } \\
\text { (UG/L) }\end{array}$ & $\begin{array}{l}\text { DIS- } \\
\text { SOLVED } \\
\text { ZINC } \\
\text { (ZN) } \\
(U G / L)\end{array}$ \\
\hline NOV & & & & & & & & & & & \\
\hline $\begin{array}{l}17 \ldots \\
F E B\end{array}$ & 4.7 & $m=$ & 970 & -- & -- & $=$ & - & -- & $-\infty$ & -- & -- \\
\hline${ }_{A P R}^{02} \cdots$ & 5.2 & $=-$ & 810 & -- & -- & $-\infty$ & $-\infty$ & -- & $-\infty$ & $m$ & $-\infty$ \\
\hline $20 \ldots$ & 4.1 & -- & 750 & -- & - & $-\infty$ & - & $-\infty$ & $=-$ & -- & $-\infty$ \\
\hline$\underset{\text { JUL }}{25 \ldots}$ & $-\infty$ & 0 & -- & 0 & 0 & 0 & 0 & 10 & 0 & 0 & 10 \\
\hline $27 \ldots$ & 4.5 & -- & 870 & $-\infty$ & - & $-\infty$ & $=-$ & -- & -- & $-\infty$ & -- \\
\hline
\end{tabular}


LOCATION. - Lat $34^{\circ} 23^{\prime} 44^{\prime \prime}$, long $119^{\circ} 04^{\prime} 32^{\prime \prime}$, in NW/4WtsWta sec. 27 , T.4 N., R. 21 W., Ventura County, on right bank $15 \mathrm{ft}(5 \mathrm{~m})$ upstream from Santa Paula Water Works diversion dam, $200 \mathrm{ft}$ (61 m) upstreal from Mud Creek, and $3 \mathrm{mi}(5 \mathrm{~km})$ north of Santa Paula.

DRATNAGE AREA, $-40.0 \mathrm{mi}^{2}\left(103.6 \mathrm{~km}^{2}\right)$.

WATER-DISCHARGE RECORDS

PERIOD OF RECORD,--October 1927 to current year. March 1912 to September 1913, at site $2.5 \mathrm{mi}$ (4.0 km) upstream; records not equivalent.

GAGE. - Water-stage recorder and concrete diversion dam control. Datum of gage is $619.43 \mathrm{ft}(188.802 \mathrm{~m})$ above mean sea level (Corps of Engineers bench mark). Oct. 1, 1927, to Feb. 19, 1931, at site 500 ft (152 m) downstream at different datum. Feb. 20, 1931, to Dec, 5, 1963, and July 30, 1965, to May 5 , 1969, at datum $3.00 \mathrm{ft}(0.914 \mathrm{~m})$ higher. Dec. 6 , 1963 , to July 29 , 1965 , at site $50 \mathrm{ft}$ (15 m) upstream at datum $3.00 \mathrm{ft}$ $(0.914 \mathrm{~m})$ higher. Datum published prior to 1976 water year as $638.59 \mathrm{ft}$ (194.642 $\mathrm{m}$ ) is in error.

REMARKS.--Records good. No regulation above station. Diversion above station for irrigation of 60 acres $\left(243,000 \mathrm{~m}^{2}\right)$ by Santa Paula Water Works began prior to October $1927 ; 449$ acre-ft (554,000 $\mathrm{m}{ }^{3}$ ) was diverted during current year.

COOPERATION.--Records of diversion were furnished by santa Paula Water Works.

AVERAge Discharge. -49 years, $21.3 \mathrm{ft}^{3} / \mathrm{s}\left(0.603 \mathrm{~m}^{3} / \mathrm{s}\right), 15,430 \mathrm{acre}-\mathrm{ft} / \mathrm{yr}\left(19.0 \mathrm{hm} / \mathrm{yr}^{3}\right)$.

EXTREMES FOR PERIOD OF RECORD. - -Maximum discharge, $21,000 \mathrm{ft}^{3} / \mathrm{s}\left(595 \mathrm{~m}^{3} / \mathrm{s}\right)$ Feb, 25,1969, gage height, $18,18 \mathrm{ft}$

$(5.541 \mathrm{~m})$, from floodmark, present datum, from rating curve extended above $2,30 \mathrm{ft}^{3} / \mathrm{s}(65.1 \mathrm{~m} / \mathrm{s})$ on basis of critical-depth measurement at gage height $15.2 \mathrm{ft}(4.63 \mathrm{~m})$; no flow at times in 1949 , $1951-52$, 1965 .

EXTREMES FOR CURRENT YEAR.--Maximum discharge, $458 \mathrm{ft} 3 / \mathrm{s}\left(13.0 \mathrm{~m}^{3} / \mathrm{s}\right)$ Feb. 9 (0715 hrs), gage height $7.96 \mathrm{ft}$

$(2.426 \mathrm{~m})$, no other peak above base of $200 \mathrm{ft}^{3} / \mathrm{s}\left(5.66 \mathrm{~m}^{3} / \mathrm{s}\right) ; \mathrm{minimum}$ daily, $0.16 \mathrm{ft} / \mathrm{s}(0.005 \mathrm{~m} / \mathrm{s}) \mathrm{Alug}$. 30 .

DISCHARGE, IN CUBIC FEET PER SECOND, WATER YEAR OCTOBER 1975 TO SEPTEMBER 1976

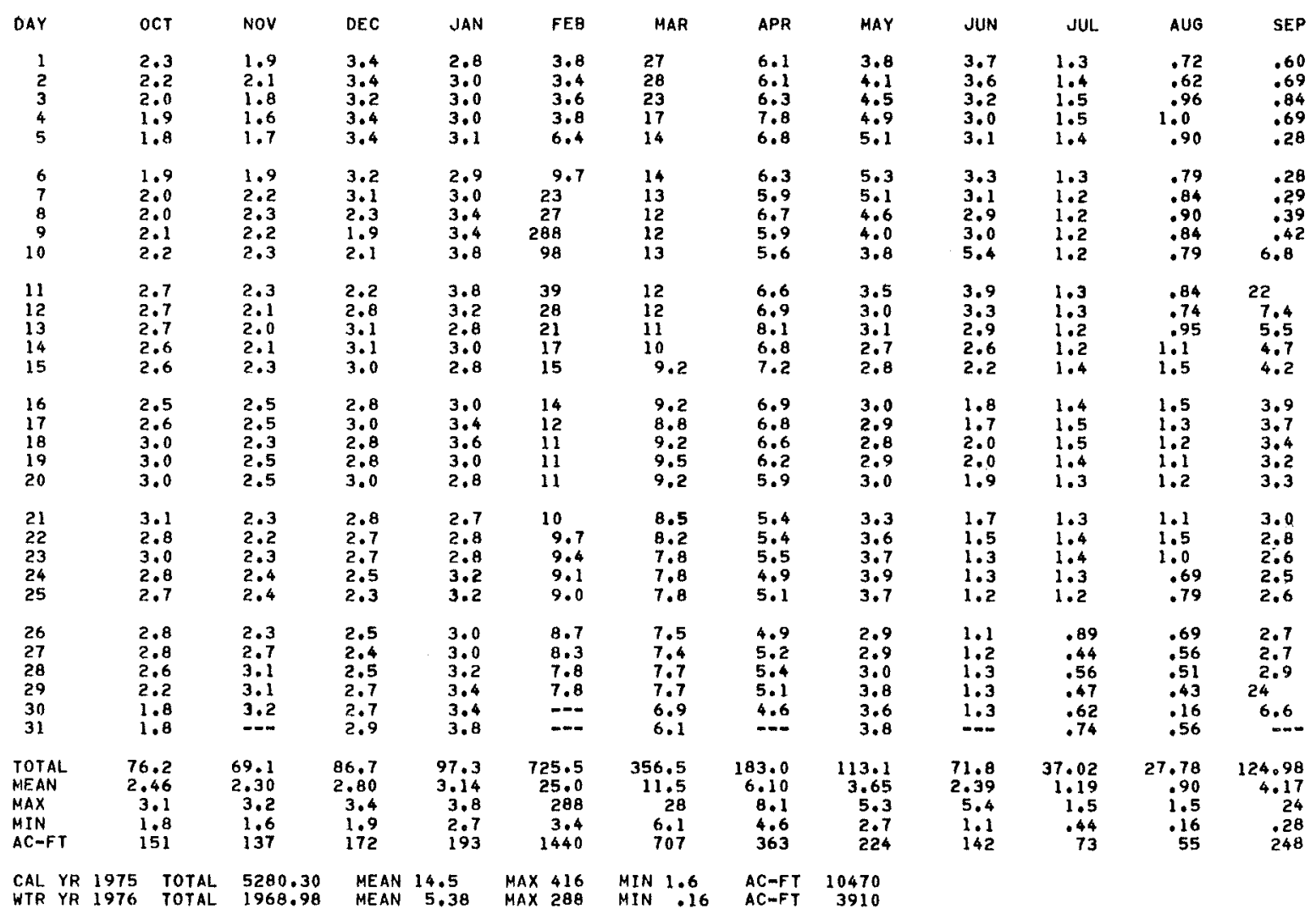


11113500 SANTA PAULA CREEK NEAR SANTA PAULA, CA--Continued

WATER-QUALITY RECORDS

PERIOD OF RECORD, --Water years 1967 to current year.

CHEMICAL ANALYSES: Water years 1967 to current year.

PERIOD OF DAILY RECORD, - -

SPECIFIC CONDUCTANCE: Apri1 1969 to current year.

WATER TEMPERATURES: Apri1 1969 to September 1970.

INSTRUMENTATION,--Specific-conductance recorder since Apri1 1969 . Water temperature recorder April 1969 to September 1970 .

REMARKS.--Missing specific-conductance data due to equipment malfunction.

COOPERATION. - Chemical-quality data was furnished by California Department of Water Resources.

EXTREMES FOR PERIOD OF DAILY RECORD. - -

SPECIFIC CONDUCTANCE: Maximum recorded, 1,450 micromhos Feb. 7, 1976; minimum recorded, 191 micromhos Mar, 8, 1975.

EXTREMES FOR CURRENT YEAR.--

SPECIFIC CONDUCTANCE: Maximum, 1,450 micromhos Feb. 7; minimum, 191 micromhos Feb. 9.

\begin{tabular}{|c|c|c|c|c|c|c|c|c|c|c|c|}
\hline DATE & TIME & $\begin{array}{l}\text { INSTAN- } \\
\text { TANEOUS } \\
\text { DIS- } \\
\text { CHARGE } \\
\text { (CFS) }\end{array}$ & $\begin{array}{l}\text { SPE- } \\
\text { CIFIC } \\
\text { CON- } \\
\text { DUCT- } \\
\text { ANCE } \\
\text { (MICRO- } \\
\text { MHOS) }\end{array}$ & $\begin{array}{c}\mathrm{PH} \\
\text { (UNITS) }\end{array}$ & $\begin{array}{l}\text { TEMPER- } \\
\text { ATURE } \\
\text { (OEG C) }\end{array}$ & $\begin{array}{l}\text { TUR- } \\
\text { BIO- } \\
\text { ITY } \\
\text { (JTU) }\end{array}$ & $\begin{array}{l}\text { DIS- } \\
\text { SOLVED } \\
\text { OXYGEN } \\
\text { (MG/L) }\end{array}$ & $\begin{array}{l}\text { HARD- } \\
\text { NESS } \\
(\mathrm{CA}, M G) \\
(M G / L)\end{array}$ & $\begin{array}{l}\text { DIS- } \\
\text { SOLVED } \\
\text { SULFATE } \\
\text { (SO4) } \\
(M G / L)\end{array}$ & $\begin{array}{l}\text { DIS- } \\
\text { SOLVED } \\
\text { CHLO- } \\
\text { RIDE } \\
\text { (CL) } \\
\text { (HG/L) }\end{array}$ & $\begin{array}{l}\text { DIS- } \\
\text { SOLVED } \\
\text { SOLIDS } \\
\text { (RESI - } \\
\text { DUE AT } \\
\text { IBO C) } \\
(M G / L)\end{array}$ \\
\hline NOV & & & & & & & & & & & \\
\hline FEB & 1315 & 2.5 & 940 & 8.3 & 16.0 & 0 & 11.6 & 298 & 215 & 40 & 569 \\
\hline $\begin{array}{l}03 \ldots \\
A P R\end{array}$ & 1015 & 3.6 & 890 & 8.4 & 11.0 & 1 & 13.6 & 363 & 234 & 47 & 672 \\
\hline $\begin{array}{l}20 . \cdots \\
\text { MAY }\end{array}$ & 0845 & 6.3 & 770 & 8.2 & 14.0 & 0 & 10.5 & 318 & 189 & 27 & 520 \\
\hline$\underset{\text { JUL. }}{25 \ldots}$ & 0800 & 3.9 & -- & $-\infty$ & 15.5 & -- & $m-$ & -- & -- & -- & -- \\
\hline $27 \ldots$ & 1000 & .69 & 850 & 8.3 & 24.0 & 1 & 10.0 & 324 & 196 & 46 & 588 \\
\hline
\end{tabular}

\begin{tabular}{|c|c|c|c|c|c|c|c|c|c|c|c|}
\hline DATE & $\begin{array}{l}\text { DIS- } \\
\text { SOLVED } \\
\text { SOLIDS } \\
\text { (TONS } \\
\text { PER } \\
\text { AC-FT) }\end{array}$ & $\begin{array}{l}\text { DIS- } \\
\text { SOLVED } \\
\text { SOLIDS } \\
\text { (TONS } \\
\text { PER } \\
\text { DAY) }\end{array}$ & $\begin{array}{c}\text { OIS- } \\
\text { SOLVED } \\
\text { ARSENIC } \\
\text { (AS) } \\
\text { (UG/L) }\end{array}$ & $\begin{array}{l}\text { DIS- } \\
\text { SOLVED } \\
\text { CAD- } \\
\text { MIUM } \\
\text { (CD) } \\
\text { (UG/L) }\end{array}$ & $\begin{array}{l}\text { OIS- } \\
\text { SOLVED } \\
\text { CHRO- } \\
\text { MIUM } \\
\text { (CR) } \\
\text { (UG/L) }\end{array}$ & $\begin{array}{l}\text { HEXA- } \\
\text { VALENT } \\
\text { CHRO- } \\
\text { MIUM } \\
\text { (CR6) } \\
\text { (UG/L) }\end{array}$ & $\begin{array}{l}\text { DIS- } \\
\text { SOLVED } \\
\text { COPPER } \\
\text { (CU) } \\
\text { (UG/L) }\end{array}$ & $\begin{array}{l}\text { DIS- } \\
\text { SOLVED } \\
\text { IRON } \\
\text { (FE) } \\
\text { (UG/L) }\end{array}$ & $\begin{array}{l}\text { DIS- } \\
\text { SOLVEO } \\
\text { LEAD } \\
\text { (PB) } \\
\text { (UG/L) }\end{array}$ & $\begin{array}{l}\text { DIS- } \\
\text { SOLVED } \\
\text { MAN- } \\
\text { GANESE } \\
\text { (MN) } \\
\text { (UG/L) }\end{array}$ & $\begin{array}{l}\text { DIS- } \\
\text { SOLVED } \\
\text { ZINC } \\
\text { (ZN) } \\
\text { (UG/L) }\end{array}$ \\
\hline \multicolumn{12}{|l|}{ NoV } \\
\hline$\underset{F E B}{17} \cdots$ & .77 & 3.84 & $m-$ & $-m$ & $m$ & -- & $=-$ & -- & - & -- & -- \\
\hline$\underset{A P R}{03} \cdots$ & .91 & 6.53 & -- & -- & - & -- & -- & -- & - & -- & -- \\
\hline$\underset{M A Y}{20} \cdots$ & .71 & 8.85 & -- & -- & -- & -- & -- & -- & - & -- & -- \\
\hline $\begin{array}{l}25 \ldots L \\
\text { JUL }\end{array}$ & -- & $-\infty$ & 0 & 0 & 0 & 0 & 0 & 10 & 0 & 0 & 10 \\
\hline $27 \ldots$ & .80 & 1.10 & $\rightarrow-$ & -- & -- & -- & -- & $\rightarrow$ & -- & -- & $-\infty$ \\
\hline
\end{tabular}


SPECIFIC CONDUCTANCE (MICROMHOS/CM AT 25 DEG, C), WATER YEAR OCTOBER 1975 TO SEPTEMBER 1976

\begin{tabular}{|c|c|c|c|c|c|c|c|c|c|c|c|c|}
\hline \multirow[b]{2}{*}{ DAY } & \multicolumn{3}{|c|}{ OCTOBER } & \multicolumn{3}{|c|}{ NOVEMBER } & \multicolumn{3}{|c|}{ DECEMBER } & \multicolumn{3}{|c|}{ JANUARY } \\
\hline & $\operatorname{MAX}$ & MIN & MEAN & $\operatorname{MAX}$ & MIN & MEAN & $\max$ & MIN & MEAN & MAX & MIN & MEAN \\
\hline $\begin{array}{l}1 \\
2 \\
3 \\
4 \\
5\end{array}$ & $\begin{array}{l}856 \\
867 \\
853 \\
844 \\
842\end{array}$ & $\begin{array}{l}720 \\
715 \\
711 \\
706 \\
710\end{array}$ & $\begin{array}{l}811 \\
810 \\
803 \\
798 \\
799\end{array}$ & $\begin{array}{l}868 \\
866 \\
861 \\
861 \\
864\end{array}$ & $\begin{array}{l}752 \\
756 \\
755 \\
751 \\
756\end{array}$ & $\begin{array}{l}833 \\
830 \\
826 \\
824 \\
829\end{array}$ & $\begin{array}{l}892 \\
888 \\
892 \\
894 \\
886\end{array}$ & $\begin{array}{l}784 \\
780 \\
788 \\
804 \\
790\end{array}$ & $\begin{array}{l}855 \\
853 \\
859 \\
862 \\
855\end{array}$ & $\begin{array}{l}905 \\
899 \\
897 \\
899 \\
918\end{array}$ & $\begin{array}{l}841 \\
831 \\
821 \\
829 \\
845\end{array}$ & $\begin{array}{l}878 \\
872 \\
868 \\
869 \\
886\end{array}$ \\
\hline $\begin{array}{r}6 \\
7 \\
8 \\
9 \\
10\end{array}$ & $\begin{array}{l}841 \\
833 \\
834 \\
833 \\
837\end{array}$ & $\begin{array}{l}717 \\
713 \\
716 \\
707 \\
715\end{array}$ & $\begin{array}{l}800 \\
793 \\
794 \\
792 \\
796\end{array}$ & $\begin{array}{l}872 \\
879 \\
889 \\
893 \\
889\end{array}$ & $\begin{array}{l}752 \\
763 \\
776 \\
775 \\
779\end{array}$ & $\begin{array}{l}834 \\
843 \\
858 \\
852 \\
850\end{array}$ & $\begin{array}{l}886 \\
882 \\
882 \\
888 \\
888\end{array}$ & $\begin{array}{l}792 \\
786 \\
790 \\
778 \\
794\end{array}$ & $\begin{array}{l}854 \\
850 \\
848 \\
853 \\
853\end{array}$ & $\begin{array}{l}930 \\
934 \\
942 \\
942 \\
966\end{array}$ & $\begin{array}{l}836 \\
842 \\
844 \\
844 \\
864\end{array}$ & $\begin{array}{l}900 \\
900 \\
906 \\
908 \\
928\end{array}$ \\
\hline $\begin{array}{l}11 \\
12 \\
13 \\
14 \\
15\end{array}$ & $\begin{array}{l}850 \\
834 \\
825 \\
821 \\
824\end{array}$ & $\begin{array}{l}722 \\
726 \\
707 \\
713 \\
712\end{array}$ & $\begin{array}{l}797 \\
794 \\
785 \\
784 \\
787\end{array}$ & $\begin{array}{l}890 \\
886 \\
881 \\
888 \\
901\end{array}$ & $\begin{array}{l}778 \\
780 \\
771 \\
762 \\
795\end{array}$ & $\begin{array}{l}853 \\
851 \\
847 \\
843 \\
866\end{array}$ & $\begin{array}{l}884 \\
890 \\
897 \\
927 \\
935\end{array}$ & $\begin{array}{l}822 \\
844 \\
825 \\
855 \\
865\end{array}$ & $\begin{array}{l}862 \\
877 \\
872 \\
898 \\
911\end{array}$ & $\begin{array}{l}980 \\
982 \\
978 \\
986 \\
976\end{array}$ & $\begin{array}{l}894 \\
886 \\
880 \\
880 \\
874\end{array}$ & $\begin{array}{l}949 \\
947 \\
945 \\
947 \\
939\end{array}$ \\
\hline $\begin{array}{l}16 \\
17 \\
18 \\
19 \\
20\end{array}$ & $\begin{array}{l}829 \\
835 \\
854 \\
870 \\
871\end{array}$ & $\begin{array}{l}717 \\
725 \\
766 \\
756 \\
757\end{array}$ & $\begin{array}{l}793 \\
798 \\
826 \\
832 \\
835\end{array}$ & $\begin{array}{l}906 \\
911 \\
914 \\
914 \\
916\end{array}$ & $\begin{array}{l}802 \\
811 \\
820 \\
806 \\
802\end{array}$ & $\begin{array}{l}875 \\
880 \\
878 \\
876 \\
873\end{array}$ & $\begin{array}{l}931 \\
931 \\
937 \\
937 \\
933\end{array}$ & $\begin{array}{l}857 \\
849 \\
847 \\
851 \\
847\end{array}$ & $\begin{array}{l}906 \\
904 \\
911 \\
907 \\
905\end{array}$ & $\begin{array}{l}976 \\
976 \\
974 \\
968 \\
974\end{array}$ & $\begin{array}{l}858 \\
868 \\
866 \\
862 \\
868\end{array}$ & $\begin{array}{l}936 \\
935 \\
930 \\
931 \\
934\end{array}$ \\
\hline $\begin{array}{l}21 \\
22 \\
23 \\
24 \\
25\end{array}$ & $\begin{array}{l}871 \\
872 \\
877 \\
879 \\
878\end{array}$ & $\begin{array}{l}751 \\
758 \\
769 \\
771 \\
760\end{array}$ & $\begin{array}{l}834 \\
840 \\
843 \\
844 \\
840\end{array}$ & $\begin{array}{l}908 \\
904 \\
900 \\
898 \\
906\end{array}$ & $\begin{array}{l}794 \\
798 \\
790 \\
792 \\
790\end{array}$ & $\begin{array}{l}872 \\
869 \\
865 \\
860 \\
860\end{array}$ & $\begin{array}{l}931 \\
925 \\
923 \\
919 \\
915\end{array}$ & $\begin{array}{l}841 \\
841 \\
829 \\
833 \\
833\end{array}$ & $\begin{array}{l}901 \\
898 \\
891 \\
887 \\
885\end{array}$ & $\begin{array}{l}974 \\
972 \\
974 \\
970 \\
962\end{array}$ & $\begin{array}{l}862 \\
868 \\
858 \\
852 \\
852\end{array}$ & $\begin{array}{l}936 \\
934 \\
933 \\
924 \\
923\end{array}$ \\
\hline $\begin{array}{l}26 \\
27 \\
28 \\
29 \\
30 \\
31\end{array}$ & $\begin{array}{l}872 \\
875 \\
867 \\
866 \\
867 \\
865\end{array}$ & $\begin{array}{l}754 \\
743 \\
747 \\
746 \\
799 \\
753\end{array}$ & $\begin{array}{l}835 \\
831 \\
829 \\
829 \\
845 \\
831\end{array}$ & $\begin{array}{l}900 \\
920 \\
904 \\
900 \\
892 \\
---\end{array}$ & $\begin{array}{l}788 \\
812 \\
794 \\
798 \\
800 \\
---\end{array}$ & $\begin{array}{l}859 \\
872 \\
864 \\
862 \\
860 \\
---\end{array}$ & $\begin{array}{l}911 \\
909 \\
905 \\
905 \\
909 \\
909\end{array}$ & $\begin{array}{l}817 \\
817 \\
821 \\
809 \\
819 \\
833\end{array}$ & $\begin{array}{l}875 \\
873 \\
873 \\
872 \\
874 \\
879\end{array}$ & $\begin{array}{l}964 \\
962 \\
956 \\
970 \\
960 \\
990\end{array}$ & $\begin{array}{l}858 \\
848 \\
836 \\
832 \\
854 \\
892\end{array}$ & $\begin{array}{l}922 \\
919 \\
915 \\
919 \\
923 \\
957\end{array}$ \\
\hline MONTH & 879 & 706 & 814 & 920 & 751 & 855 & 937 & 778 & 878 & 990 & 821 & 920 \\
\hline
\end{tabular}

\begin{tabular}{|c|c|c|c|c|c|c|c|c|c|c|c|c|}
\hline \multirow[b]{2}{*}{ DAY } & \multicolumn{3}{|c|}{ FEBRUARY } & \multicolumn{3}{|c|}{ MARCH } & \multicolumn{3}{|c|}{ APRIL } & \multicolumn{3}{|c|}{ MAY } \\
\hline & MAX & MIN & MEAN & $\operatorname{MAX}$ & MIN & MEAN & $\operatorname{MAX}$ & MIN & MEAN & $\operatorname{MAX}$ & MIN & MEAN \\
\hline $\begin{array}{l}1 \\
2 \\
3 \\
4 \\
5\end{array}$ & $\begin{array}{l}1020 \\
1020 \\
1020 \\
1020 \\
1060\end{array}$ & $\begin{array}{l}904 \\
914 \\
916 \\
982 \\
802\end{array}$ & $\begin{array}{r}981 \\
980 \\
982 \\
1010 \\
973\end{array}$ & $\begin{array}{l}835 \\
686 \\
725 \\
729 \\
724\end{array}$ & $\begin{array}{l}635 \\
580 \\
653 \\
701 \\
714\end{array}$ & $\begin{array}{l}717 \\
655 \\
703 \\
714 \\
718\end{array}$ & $\begin{array}{l}=-0 \\
=-\infty \\
=-0 \\
-\infty \\
=-\infty\end{array}$ & $=$ & $\begin{array}{l}=-- \\
=-\infty \\
=-\infty \\
m=- \\
=-\infty\end{array}$ & $\begin{array}{l}790 \\
792 \\
790 \\
788 \\
812\end{array}$ & $\begin{array}{l}704 \\
708 \\
772 \\
724 \\
768\end{array}$ & $\begin{array}{l}757 \\
760 \\
783 \\
765 \\
781\end{array}$ \\
\hline $\begin{array}{r}6 \\
7 \\
8 \\
9 \\
10\end{array}$ & $\begin{array}{r}1030 \\
1450 \\
951 \\
495 \\
540\end{array}$ & $\begin{array}{l}808 \\
578 \\
543 \\
191 \\
310\end{array}$ & $\begin{array}{r}1040 \\
931 \\
787 \\
370 \\
453\end{array}$ & $\begin{array}{l}707 \\
712 \\
709 \\
708 \\
782\end{array}$ & $\begin{array}{l}693 \\
696 \\
697 \\
694 \\
688\end{array}$ & $\begin{array}{l}703 \\
704 \\
705 \\
704 \\
710\end{array}$ & $\begin{array}{l}770 \\
775 \\
772 \\
775\end{array}$ & $\begin{array}{l}-7 . \\
676 \\
705 \\
678 \\
683\end{array}$ & $\begin{array}{l}7-5 \\
741 \\
749 \\
743 \\
745\end{array}$ & $\begin{array}{l}792 \\
788 \\
822 \\
834 \\
834\end{array}$ & $\begin{array}{l}734 \\
698 \\
730 \\
742 \\
744\end{array}$ & $\begin{array}{l}772 \\
757 \\
782 \\
803 \\
806\end{array}$ \\
\hline $\begin{array}{l}11 \\
12 \\
13 \\
14 \\
15\end{array}$ & $\begin{array}{l}550 \\
505 \\
539 \\
574 \\
643\end{array}$ & $\begin{array}{l}472 \\
465 \\
505 \\
536 \\
563\end{array}$ & $\begin{array}{l}513 \\
482 \\
521 \\
561 \\
576\end{array}$ & $\begin{array}{l}711 \\
694 \\
700 \\
708 \\
712\end{array}$ & $\begin{array}{l}687 \\
680 \\
684 \\
692 \\
694\end{array}$ & $\begin{array}{l}692 \\
688 \\
694 \\
701 \\
704\end{array}$ & $\begin{array}{l}775 \\
776 \\
791 \\
786 \\
789\end{array}$ & $\begin{array}{l}689 \\
710 \\
723 \\
710 \\
729\end{array}$ & $\begin{array}{l}743 \\
747 \\
755 \\
762 \\
768\end{array}$ & $\begin{array}{l}838 \\
843 \\
845 \\
850 \\
850\end{array}$ & $\begin{array}{l}742 \\
739 \\
743 \\
748 \\
748\end{array}$ & $\begin{array}{l}803 \\
805 \\
809 \\
811 \\
810\end{array}$ \\
\hline $\begin{array}{l}16 \\
17 \\
18 \\
19 \\
20\end{array}$ & $\begin{array}{l}655 \\
696 \\
726 \\
731 \\
740\end{array}$ & $\begin{array}{l}633 \\
668 \\
684 \\
701 \\
704\end{array}$ & $\begin{array}{l}646 \\
683 \\
705 \\
717 \\
724\end{array}$ & $\begin{array}{l}716 \\
712 \\
710 \\
700 \\
698\end{array}$ & $\begin{array}{l}692 \\
686 \\
678 \\
670 \\
672\end{array}$ & $\begin{array}{l}705 \\
701 \\
696 \\
688 \\
688\end{array}$ & $\begin{array}{l}788 \\
781 \\
780 \\
778 \\
779\end{array}$ & $\begin{array}{l}694 \\
687 \\
686 \\
680 \\
681\end{array}$ & $\begin{array}{l}755 \\
750 \\
749 \\
745 \\
745\end{array}$ & $\begin{array}{l}842 \\
841 \\
839 \\
840 \\
836\end{array}$ & $\begin{array}{l}754 \\
757 \\
761 \\
760 \\
758\end{array}$ & $\begin{array}{lll}8 & 1 & 2 \\
8 & 1 & 1 \\
8 & 1 & 1 \\
8 & 1 & 0 \\
8 & 0 & 7\end{array}$ \\
\hline $\begin{array}{l}21 \\
22 \\
23 \\
24 \\
25\end{array}$ & $\begin{array}{l}754 \\
777 \\
805 \\
846 \\
855\end{array}$ & $\begin{array}{l}736 \\
745 \\
775 \\
796 \\
835\end{array}$ & $\begin{array}{l}746 \\
764 \\
787 \\
825 \\
845\end{array}$ & 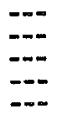 & $\begin{array}{l}-=0 \\
--= \\
--\infty \\
--0\end{array}$ & $\begin{array}{l}--- \\
=-- \\
--- \\
--\infty \\
--\infty\end{array}$ & $\begin{array}{l}782 \\
785 \\
782 \\
788 \\
784\end{array}$ & $\begin{array}{l}684 \\
707 \\
684 \\
692 \\
698\end{array}$ & $\begin{array}{l}747 \\
757 \\
746 \\
754 \\
754\end{array}$ & $\begin{array}{l}836 \\
833 \\
833 \\
826 \\
842\end{array}$ & $\begin{array}{l}766 \\
767 \\
773 \\
780 \\
764\end{array}$ & $\begin{array}{l}810 \\
808 \\
806 \\
801 \\
807\end{array}$ \\
\hline $\begin{array}{l}26 \\
27 \\
28 \\
29 \\
30 \\
31\end{array}$ & $\begin{array}{l}856 \\
854 \\
847 \\
844 \\
=-- \\
---\end{array}$ & $\begin{array}{l}840 \\
836 \\
825 \\
820 \\
-\ldots \\
=--\end{array}$ & $\begin{array}{l}850 \\
847 \\
839 \\
836 \\
--- \\
=-\infty\end{array}$ & $\begin{array}{l}=-\infty \\
=-\infty \\
=-\infty \\
=-\infty \\
=-\infty\end{array}$ & $\begin{array}{l}-\infty \\
-\infty \\
=-\infty \\
=-\infty \\
=-\infty\end{array}$ & $\begin{array}{l}-\infty- \\
--\infty \\
-\infty- \\
--\infty \\
=-\infty \\
-\infty-\end{array}$ & $\begin{array}{l}788 \\
790 \\
782 \\
782 \\
786 \\
---\end{array}$ & $\begin{array}{l}706 \\
728 \\
712 \\
698 \\
698 \\
---\end{array}$ & $\begin{array}{l}759 \\
767 \\
757 \\
753 \\
755 \\
-\infty\end{array}$ & $\begin{array}{l}858 \\
863 \\
865 \\
836 \\
840 \\
844\end{array}$ & $\begin{array}{l}788 \\
795 \\
831 \\
804 \\
804 \\
812\end{array}$ & $\begin{array}{l}829 \\
834 \\
850 \\
824 \\
827 \\
833\end{array}$ \\
\hline ONTH & 1450 & 191 & 758 & $-\infty$ & $-\infty$ & $-\infty$ & 791 & 676 & 752 & 865 & 698 & 803 \\
\hline
\end{tabular}


11113900 SATICOY DIVERSION NEAR SATICOY, CA

LOCATION, - - Lat 34 $4^{\circ} 17^{\prime} 06^{\prime \prime}$, long $119^{\circ} 07^{\prime} 14^{\prime \prime}$, in Santa Paula Y Saticoy Grant, Ventura County, on diversion ditch $0.7 \mathrm{mi}(1.1 \mathrm{~km})$ downstream from Santa Clara River, and $1.5 \mathrm{mi}(2.4 \mathrm{~km})$ east of Saticoy.

WATER-DISCHARGE RECORDS

PERIOD OF RECORD.--April 1969 to current year. October 1928 to April 1969 in files of United Water Conservation District.

GAGE. - Water-stage recorder. A1titude of gage is $160 \mathrm{ft}(49 \mathrm{~m})$, from topographic map.

REMARKS, - Water is diverted from left bank of Santa Clara River to percolation basin near Los Angeles Avenue (State Highway 118) and for irrigation in Pleasant Valley. See station 11110000, Piru Creek near Piru, for report of controlled releases from Lake Piru. Imported water from the California Water project released to the basin at Castaic Dan and Pyramid Dam since 1972.

COOPERATION.--Records were furnished by United Water Conservation District; one discharge measurement was made by Geological Survey.

EXTREMES FOR PERIOD OF RECORD.--Maximum daily discharge, $411 \mathrm{ft}^{3} / \mathrm{s}\left(11.6 \mathrm{~m}^{3} / \mathrm{s}\right) \mathrm{Mar}$. 15, 1975 ; no flow at times in most years.

OISCHARGE, IN CUBIC FEET PER SECOND, WATER YEAR OCTOBER 1975 TO SEPTEMBER 1976 HEAN VALUES

\begin{tabular}{|c|c|c|c|c|c|c|c|c|c|c|c|c|}
\hline DAY & OCT & Nov & DEC & JAN & FEB & MAR & APR & MAY & JUN & JUL & $A \cup G$ & SEP \\
\hline $\begin{array}{l}1 \\
2 \\
3 \\
4 \\
5\end{array}$ & $\begin{array}{l}17 \\
16 \\
16 \\
16 \\
16\end{array}$ & $\begin{array}{l}18 \\
16 \\
16 \\
17 \\
18\end{array}$ & $\begin{array}{l}16 \\
16 \\
16 \\
16 \\
16\end{array}$ & $\begin{array}{l}23 \\
22 \\
22 \\
23 \\
24\end{array}$ & $\begin{array}{l}15 \\
16 \\
16 \\
17 \\
26\end{array}$ & $\begin{array}{r}89 \\
104 \\
200 \\
115 \\
97\end{array}$ & $\begin{array}{l}55 \\
57 \\
57 \\
62 \\
60\end{array}$ & $\begin{array}{l}34 \\
35 \\
35 \\
32 \\
33\end{array}$ & $\begin{array}{l}25 \\
22 \\
22 \\
22 \\
22\end{array}$ & $\begin{array}{l}11 \\
14 \\
9.9 \\
11 \\
11\end{array}$ & $\begin{array}{l}5.6 \\
5.1 \\
4.9 \\
4.4 \\
4.0\end{array}$ & $\begin{array}{l}2.0 \\
2.2 \\
2.7 \\
2.9 \\
3.4\end{array}$ \\
\hline $\begin{array}{r}6 \\
7 \\
8 \\
9 \\
10\end{array}$ & $\begin{array}{l}16 \\
16 \\
16 \\
16 \\
16\end{array}$ & $\begin{array}{l}18 \\
18 \\
18 \\
18 \\
18\end{array}$ & $\begin{array}{l}16 \\
16 \\
16 \\
17 \\
18\end{array}$ & $\begin{array}{l}23 \\
23 \\
23 \\
24 \\
23\end{array}$ & $\begin{array}{l}37 \\
0 \\
0 \\
0 \\
7.2\end{array}$ & $\begin{array}{l}88 \\
84 \\
82 \\
81 \\
97\end{array}$ & $\begin{array}{l}56 \\
56 \\
61 \\
63 \\
63\end{array}$ & $\begin{array}{l}32 \\
31 \\
32 \\
31 \\
32\end{array}$ & $\begin{array}{l}21 \\
22 \\
22 \\
21 \\
17\end{array}$ & $\begin{array}{r}11 \\
9.3 \\
8.4 \\
7.2 \\
7.5\end{array}$ & $\begin{array}{l}3.4 \\
3.6 \\
4.0 \\
3.4 \\
4.6\end{array}$ & $\begin{array}{r}4.4 \\
6.7 \\
6.0 \\
7.0 \\
12\end{array}$ \\
\hline $\begin{array}{l}11 \\
12 \\
13 \\
14 \\
15\end{array}$ & $\begin{array}{l}16 \\
16 \\
17 \\
18 \\
17\end{array}$ & $\begin{array}{l}19 \\
20 \\
17 \\
16 \\
16\end{array}$ & $\begin{array}{l}18 \\
19 \\
19 \\
20 \\
20\end{array}$ & $\begin{array}{l}23 \\
23 \\
23 \\
23 \\
23\end{array}$ & $\begin{array}{l}190 \\
330 \\
229 \\
181 \\
157\end{array}$ & $\begin{array}{l}86 \\
82 \\
77 \\
75 \\
73\end{array}$ & $\begin{array}{l}61 \\
60 \\
63 \\
61 \\
60\end{array}$ & $\begin{array}{l}31 \\
31 \\
30 \\
30 \\
29\end{array}$ & $\begin{array}{l}19 \\
19 \\
19 \\
18 \\
20\end{array}$ & $\begin{array}{l}8.7 \\
11 \\
12 \\
13 \\
11\end{array}$ & $\begin{array}{l}5.1 \\
4.2 \\
4.0 \\
5.3 \\
6.5\end{array}$ & $\begin{array}{l}42 \\
53 \\
32 \\
24 \\
21\end{array}$ \\
\hline $\begin{array}{l}16 \\
17 \\
18 \\
19 \\
20\end{array}$ & $\begin{array}{l}17 \\
16 \\
15 \\
15 \\
17\end{array}$ & $\begin{array}{l}15 \\
16 \\
16 \\
16 \\
16\end{array}$ & $\begin{array}{l}20 \\
20 \\
21 \\
21 \\
20\end{array}$ & $\begin{array}{l}14 \\
13 \\
13 \\
14 \\
16\end{array}$ & $\begin{array}{r}138 \\
107 \\
93 \\
86 \\
84\end{array}$ & $\begin{array}{l}71 \\
69 \\
70 \\
73 \\
71\end{array}$ & $\begin{array}{l}56 \\
50 \\
50 \\
50 \\
47\end{array}$ & $\begin{array}{l}30 \\
29 \\
26 \\
26 \\
26\end{array}$ & $\begin{array}{l}18 \\
18 \\
18 \\
19 \\
18\end{array}$ & $\begin{array}{l}7.8 \\
7.5 \\
9.0 \\
9.9 \\
9.3\end{array}$ & $\begin{array}{l}7.5 \\
8.3 \\
6.7 \\
6.0 \\
5.6\end{array}$ & $\begin{array}{l}23 \\
20 \\
20 \\
20 \\
20\end{array}$ \\
\hline $\begin{array}{l}21 \\
22 \\
23 \\
24 \\
25\end{array}$ & $\begin{array}{l}18 \\
18 \\
19 \\
21 \\
18\end{array}$ & $\begin{array}{l}17 \\
17 \\
16 \\
18 \\
21\end{array}$ & $\begin{array}{l}20 \\
20 \\
21 \\
21 \\
20\end{array}$ & $\begin{array}{l}16 \\
16 \\
16 \\
16 \\
16\end{array}$ & $\begin{array}{l}79 \\
72 \\
68 \\
64 \\
57\end{array}$ & $\begin{array}{l}69 \\
66 \\
64 \\
63 \\
64\end{array}$ & $\begin{array}{l}43 \\
39 \\
38 \\
37 \\
39\end{array}$ & $\begin{array}{l}26 \\
26 \\
26 \\
26 \\
24\end{array}$ & $\begin{array}{l}19 \\
18 \\
17 \\
16 \\
15\end{array}$ & $\begin{array}{l}8.7 \\
7.8 \\
8.7 \\
8.1 \\
8.7\end{array}$ & $\begin{array}{l}5.6 \\
5.6 \\
5.8 \\
7.0 \\
4.4\end{array}$ & $\begin{array}{l}21 \\
21 \\
21 \\
20 \\
22\end{array}$ \\
\hline $\begin{array}{l}26 \\
27 \\
28 \\
29 \\
30 \\
31\end{array}$ & $\begin{array}{l}17 \\
19 \\
20 \\
20 \\
20 \\
21\end{array}$ & $\begin{array}{r}21 \\
18 \\
17 \\
16 \\
16 \\
-\end{array}$ & $\begin{array}{l}23 \\
23 \\
24 \\
24 \\
23 \\
23\end{array}$ & $\begin{array}{l}16 \\
15 \\
15 \\
15 \\
15 \\
14\end{array}$ & $\begin{array}{l}57 \\
57 \\
56 \\
55 \\
- \\
-\end{array}$ & $\begin{array}{l}63 \\
63 \\
64 \\
63 \\
61 \\
58\end{array}$ & $\begin{array}{r}39 \\
39 \\
32 \\
26 \\
29 \\
-\end{array}$ & $\begin{array}{l}25 \\
23 \\
23 \\
24 \\
24 \\
24\end{array}$ & $\begin{array}{c}13 \\
8.2 \\
8.2 \\
10 \\
9.1 \\
-.--\end{array}$ & $\begin{array}{l}9.0 \\
7.8 \\
8.4 \\
9.3 \\
7.8 \\
7.2\end{array}$ & $\begin{array}{l}3.8 \\
2.9 \\
2.5 \\
2.7 \\
3.4 \\
3.3\end{array}$ & $\begin{array}{r}24 \\
23 \\
24 \\
48 \\
125 \\
-\end{array}$ \\
\hline $\begin{array}{l}\text { TOTAL } \\
\text { MEAN } \\
\text { MAX } \\
\text { MIN } \\
\text { AC-FT }\end{array}$ & $\begin{array}{r}536 \\
17.3 \\
21 \\
15 \\
1060\end{array}$ & $\begin{array}{r}519 \\
17.3 \\
21 \\
15 \\
1030\end{array}$ & $\begin{array}{r}603 \\
19.5 \\
24 \\
16 \\
1200\end{array}$ & $\begin{array}{r}585 \\
18.9 \\
24 \\
13 \\
1160\end{array}$ & $\begin{array}{r}2294.2 \\
79.1 \\
330 \\
0 \\
4550\end{array}$ & $\begin{array}{r}2482 \\
80.1 \\
200 \\
58 \\
4920\end{array}$ & $\begin{array}{r}1509 \\
50.3 \\
63 \\
26 \\
2990\end{array}$ & $\begin{array}{r}886 \\
28.6 \\
35 \\
23 \\
1760\end{array}$ & $\begin{array}{r}535.5 \\
17.9 \\
25 \\
8.2 \\
1060\end{array}$ & $\begin{array}{r}291.0 \\
9.39 \\
14 \\
7.2 \\
577\end{array}$ & $\begin{array}{r}149.2 \\
4.81 \\
8.3 \\
2.5 \\
296\end{array}$ & $\begin{array}{r}673.3 \\
22.4 \\
125 \\
2.0 \\
1340\end{array}$ \\
\hline
\end{tabular}

CAL YR 1975 TOTAL 27541.00 MEAN 75.5 MAX 411 MIN 0 AC-FT 54630

WTR YR 1976 TOTAL 11063.20 MEAN 30.2 MAX 330 MIN 0 AC-FT 21940 
PERIOD OF DAILY RECORD, - -

SPECIFIC CONDUCTANCE: April 1969 to current year.

WATER TEMPERATURES: . Apri1 1969 to September 1970.

INSTRUMENTATION.--Specific conductance recorder since Apri1 1969.

REMARKS. - No flow Feb. 7-10. Interruptions in record were due to malfunctions of the instrument.

EXTREMES FOR PERIOD OF DAILY RECORD. - .

SPECIFIC CONDUCTANCE: Maximum 2,320 micromhos Oct. 21, 1972; minimum, 755 micromhos Apr. 5, 1975.

EXTREMES FOR CURRENT YEAR, - -

SPECIFIC CONDUCTANCE: Maximum recorded, 2,170 micromhos sept. 29; minimum recorded, 902 micromhos Sept. 11.

SPECIFIC CONDUCTANCE (MICROMHOS/CM AT 25 DEG. C), WATER YEAR OCTOBER 1975 TO SEPTENBER 1976

\begin{tabular}{|c|c|c|c|c|c|c|c|c|c|c|c|c|}
\hline \multirow[b]{2}{*}{ DAY } & \multicolumn{3}{|c|}{ OCTOBER } & \multicolumn{3}{|c|}{ NOVEABER } & \multicolumn{3}{|c|}{ DECEMBER } & \multicolumn{3}{|c|}{ JANUARY } \\
\hline & MAX & MIN & MEAN & $\max$ & MIN & MEAN & MAX & MIN & MEAN & MAX & MIN & MEAN \\
\hline $\begin{array}{l}1 \\
2 \\
3 \\
4 \\
5\end{array}$ & $\begin{array}{l}1770 \\
1750 \\
1750 \\
1810 \\
1790\end{array}$ & $\begin{array}{l}1730 \\
1710 \\
1710 \\
1740 \\
1780\end{array}$ & $\begin{array}{l}1750 \\
1730 \\
1730 \\
1790 \\
1790\end{array}$ & $=$ & $=$ & $\begin{array}{l}=-1 \\
=-\infty \\
=-\infty \\
=-\infty \\
=-\infty\end{array}$ & $\begin{array}{l}1760 \\
1770 \\
1770 \\
1780 \\
1780\end{array}$ & $\begin{array}{l}1730 \\
1740 \\
1750 \\
1760 \\
1750\end{array}$ & $\begin{array}{l}1750 \\
1760 \\
1770 \\
1770 \\
1770\end{array}$ & $=$ & $=$ & $=$ \\
\hline $\begin{array}{r}6 \\
7 \\
8 \\
9 \\
10\end{array}$ & $\begin{array}{r}1800 \\
0 \\
0 \\
-\end{array}$ & $\begin{array}{r}1780 \\
- \\
=-\infty\end{array}$ & $\begin{array}{r}1780 \\
=- \\
=-\end{array}$ & $=$ & $=$ & $=$ & $\begin{array}{l}1780 \\
1780 \\
1760 \\
1780 \\
1760\end{array}$ & $\begin{array}{l}1770 \\
1750 \\
1740 \\
1750 \\
1750\end{array}$ & $\begin{array}{l}1770 \\
1760 \\
1750 \\
1760 \\
1750\end{array}$ & $\begin{array}{l}=-- \\
=-0 \\
=-\infty\end{array}$ & $\begin{array}{l}=-\infty \\
=-\infty \\
=-\infty \\
=-\infty\end{array}$ & $\begin{array}{l}=- \\
=- \\
=-\end{array}$ \\
\hline $\begin{array}{l}11 \\
12 \\
13 \\
14 \\
15\end{array}$ & $=$ & $=$ & $=$ & $=$ & $\begin{array}{l}=- \\
=-\end{array}$ & $=$ & $\begin{array}{l}1750 \\
1760 \\
1780 \\
1780 \\
1780\end{array}$ & $\begin{array}{l}1740 \\
1710 \\
1740 \\
1760 \\
1750\end{array}$ & $\begin{array}{l}1750 \\
1740 \\
1770 \\
1770 \\
1760\end{array}$ & 1980 & 1790 & 1860 \\
\hline $\begin{array}{l}16 \\
17 \\
18 \\
19 \\
20\end{array}$ & $=$ & $\begin{array}{l}=- \\
=-- \\
=-0\end{array}$ & $=$ & $\begin{array}{l}=-\infty \\
=- \\
=-\end{array}$ & $\begin{array}{l}=- \\
=- \\
=-\end{array}$ & $\begin{array}{l}=-\infty \\
=-\infty \\
=-\infty\end{array}$ & $\begin{array}{l}1790 \\
1800 \\
1820 \\
\end{array}$ & $\begin{array}{r}1770 \\
1770 \\
1800 \\
- \\
-\end{array}$ & $\begin{array}{r}1780 \\
1790 \\
1810 \\
- \\
-\end{array}$ & $\begin{array}{l}1980 \\
1870 \\
1870 \\
1870 \\
1890\end{array}$ & $\begin{array}{l}1860 \\
1830 \\
1820 \\
1860 \\
1850\end{array}$ & $\begin{array}{l}1900 \\
1850 \\
1860 \\
1860 \\
1880\end{array}$ \\
\hline $\begin{array}{l}21 \\
22 \\
23 \\
24 \\
25\end{array}$ & $=$ & $\begin{array}{l}=-0 \\
=-\infty \\
=-\infty\end{array}$ & $=$ & $\begin{array}{l}1790 \\
1810 \\
1810\end{array}$ & $\begin{array}{l}1770 \\
1800 \\
1770\end{array}$ & $\begin{array}{l}1780 \\
1800 \\
1790\end{array}$ & $\begin{array}{l}=-\infty \\
=-\infty \\
=-\infty \\
=-\infty\end{array}$ & $\begin{array}{l}=-\infty \\
=-\infty \\
=-\infty\end{array}$ & $\begin{array}{l}=0 \\
-\infty \\
-\infty\end{array}$ & $\begin{array}{l}1860 \\
1870 \\
1860 \\
1850 \\
1820\end{array}$ & $\begin{array}{l}1820 \\
1840 \\
1820 \\
1800 \\
1730\end{array}$ & $\begin{array}{l}1850 \\
1850 \\
1840 \\
1830 \\
1790\end{array}$ \\
\hline $\begin{array}{l}26 \\
27 \\
28 \\
29 \\
30 \\
31\end{array}$ & $\begin{array}{l}=- \\
=- \\
=- \\
-\end{array}$ & $=$ & $\begin{array}{l}=- \\
=- \\
=-\end{array}$ & $\begin{array}{r}1810 \\
1780 \\
1780 \\
1780 \\
1780 \\
\end{array}$ & $\begin{array}{l}1760 \\
1760 \\
1760 \\
1760 \\
1760 \\
\end{array}$ & $\begin{array}{r}1780 \\
1770 \\
1770 \\
1770 \\
1770 \\
-\end{array}$ & $\begin{array}{l}=-\infty \\
=-\infty \\
=-\infty \\
=-\infty \\
=-\infty\end{array}$ & $\begin{array}{l}=-\infty \\
=-\infty \\
=-\infty \\
=-\infty\end{array}$ & $\begin{array}{l}=-\infty \\
=-\infty \\
=-\infty \\
=-\infty\end{array}$ & $\begin{array}{l}1830 \\
1860 \\
1850 \\
1850 \\
1840 \\
1860\end{array}$ & $\begin{array}{l}1750 \\
1830 \\
1830 \\
1810 \\
1810 \\
1830\end{array}$ & $\begin{array}{l}1800 \\
1840 \\
1840 \\
1830 \\
1830 \\
1850\end{array}$ \\
\hline DNTH & $-\infty$ & $-\infty$ & $-\infty$ & $-m$ & $-\infty$ & $-\infty$ & $-\infty$ & $-\infty$ & $=m$ & $=\infty$ & $=-\infty$ & $m-\infty$ \\
\hline
\end{tabular}


11113900 SATICOY DIVERSION NEAR SATICOY, CA--Continued SPECIFIC CONDUCTANCE (MICROMHOS/CM AT 25 DEO, C), HATER YEAR OCTOBER 1975 TO SEPTEMBER 1976

\begin{tabular}{|c|c|c|c|c|c|c|c|c|c|c|c|c|}
\hline \multirow[b]{2}{*}{ DAY } & \multicolumn{3}{|c|}{ FEBRUARY } & \multicolumn{3}{|c|}{ MARCH } & \multicolumn{3}{|c|}{ APRIL } & \multicolumn{3}{|c|}{ MAY } \\
\hline & MAX & HIN & MEAN & MAX & MIN & MEAN & MAX & MIN & MEAN & HAX & MIN & MEAN \\
\hline $\begin{array}{l}1 \\
2 \\
3 \\
4 \\
5\end{array}$ & $\begin{array}{l}1860 \\
1850 \\
1840 \\
1830 \\
1780\end{array}$ & $\begin{array}{l}1820 \\
1810 \\
1780 \\
1770 \\
1410\end{array}$ & $\begin{array}{l}1850 \\
1830 \\
1820 \\
1810 \\
1660\end{array}$ & $\begin{array}{l}1670 \\
1420 \\
1260 \\
1330 \\
1410\end{array}$ & $\begin{array}{l}1240 \\
1130 \\
1140 \\
1270 \\
1340\end{array}$ & $\begin{array}{l}1500 \\
1360 \\
1200 \\
1300 \\
1380\end{array}$ & $\begin{array}{l}1540 \\
1550 \\
1550 \\
1550 \\
1540\end{array}$ & $\begin{array}{l}1500 \\
1520 \\
1530 \\
1460 \\
1510\end{array}$ & $\begin{array}{l}1520 \\
1530 \\
1540 \\
1530 \\
1530\end{array}$ & $\begin{array}{l}1740 \\
1750 \\
1750 \\
1770 \\
1750\end{array}$ & $\begin{array}{l}1620 \\
1640 \\
1690 \\
1650 \\
1690\end{array}$ & $\begin{array}{l}1690 \\
1710 \\
1730 \\
1720 \\
1730\end{array}$ \\
\hline $\begin{array}{r}6 \\
8 \\
9 \\
10\end{array}$ & $\begin{array}{l}1810 \\
-0.0 \\
=0\end{array}$ & $\begin{array}{r}1310 \\
-\infty \\
-\infty\end{array}$ & $\begin{array}{r}1650 \\
-10 \\
0\end{array}$ & $\begin{array}{l}1420 \\
1430 \\
1450 \\
1450 \\
1430\end{array}$ & $\begin{array}{l}1400 \\
1420 \\
1430 \\
1430 \\
1180\end{array}$ & $\begin{array}{l}1410 \\
1430 \\
1440 \\
1440 \\
1370\end{array}$ & $\begin{array}{l}1560 \\
1580 \\
1600 \\
1550 \\
1560\end{array}$ & $\begin{array}{l}1520 \\
1540 \\
1430 \\
1500 \\
1520\end{array}$ & $\begin{array}{l}1540 \\
1560 \\
1540 \\
1530 \\
1540\end{array}$ & $\begin{array}{l}1780 \\
1760 \\
1740 \\
1740 \\
1750\end{array}$ & $\begin{array}{l}1660 \\
1630 \\
1590 \\
1550 \\
1540\end{array}$ & $\begin{array}{l}1730 \\
1700 \\
1680 \\
1680 \\
1660\end{array}$ \\
\hline $\begin{array}{l}11 \\
12 \\
13 \\
14 \\
15\end{array}$ & $\begin{array}{l}=-\infty \\
=-\infty \\
=-\infty \\
=-\infty\end{array}$ & $=$ & $\begin{array}{l}=-\infty \\
=-\infty \\
=-\infty \\
-\infty \\
=-\infty\end{array}$ & $\begin{array}{l}1450 \\
1450 \\
1470 \\
1470 \\
1490\end{array}$ & $\begin{array}{l}1420 \\
1430 \\
14 \$ 0 \\
1430 \\
1470\end{array}$ & $\begin{array}{l}1440 \\
1440 \\
1450 \\
1460 \\
1480\end{array}$ & $\begin{array}{l}1570 \\
1590 \\
1570 \\
1570 \\
1560\end{array}$ & $\begin{array}{l}1530 \\
1540 \\
1440 \\
1500 \\
1520\end{array}$ & $\begin{array}{l}1550 \\
1560 \\
1530 \\
1530 \\
1540\end{array}$ & $\begin{array}{l}1750 \\
1760 \\
1740 \\
1760 \\
1760\end{array}$ & $\begin{array}{l}1570 \\
1540 \\
1520 \\
1590 \\
1590\end{array}$ & $\begin{array}{l}1670 \\
1660 \\
1640 \\
1680 \\
1700\end{array}$ \\
\hline $\begin{array}{l}16 \\
17 \\
18 \\
19 \\
20\end{array}$ & $\begin{array}{l}=-\infty \\
=-\infty \\
=-\infty \\
=-\infty \\
=-\infty\end{array}$ & $=$ & $\begin{array}{l}-\infty \\
--\infty \\
=-\infty \\
--\infty\end{array}$ & $\begin{array}{l}1500 \\
1530 \\
1510 \\
1500 \\
1490\end{array}$ & $\begin{array}{l}1480 \\
1470 \\
1480 \\
1440 \\
1450\end{array}$ & $\begin{array}{l}1490 \\
1500 \\
1490 \\
1470 \\
1470\end{array}$ & $\begin{array}{l}1570 \\
1570 \\
1570 \\
1570 \\
1580\end{array}$ & $\begin{array}{l}1510 \\
1480 \\
1490 \\
1490 \\
1490\end{array}$ & $\begin{array}{l}1550 \\
1540 \\
1540 \\
1540 \\
1540\end{array}$ & $\begin{array}{l}1760 \\
1740 \\
1750 \\
1760 \\
1770\end{array}$ & $\begin{array}{l}1620 \\
1590 \\
1630 \\
1630 \\
1610\end{array}$ & $\begin{array}{l}1700 \\
1680 \\
1700 \\
1700 \\
1710\end{array}$ \\
\hline $\begin{array}{l}21 \\
22 \\
23 \\
24 \\
25\end{array}$ & $\begin{array}{l}=-0 \\
=0 \\
=0 \\
=0\end{array}$ & $\begin{array}{l}=- \\
=-\infty \\
=-\infty\end{array}$ & $\begin{array}{l}=- \\
m-\infty \\
m-\infty\end{array}$ & $\begin{array}{l}1500 \\
1510 \\
1500 \\
1500 \\
1490\end{array}$ & $\begin{array}{l}1460 \\
1470 \\
1460 \\
1450 \\
1450\end{array}$ & $\begin{array}{l}1480 \\
1490 \\
1490 \\
1480 \\
1480\end{array}$ & $\begin{array}{l}1580 \\
1600 \\
1590 \\
1620 \\
1630\end{array}$ & $\begin{array}{l}1480 \\
1530 \\
1470 \\
1510 \\
1520\end{array}$ & $\begin{array}{l}1540 \\
1570 \\
1540 \\
1580 \\
1590\end{array}$ & $\begin{array}{l}1780 \\
1780 \\
1780 \\
1760 \\
1750\end{array}$ & $\begin{array}{l}1680 \\
1620 \\
1640 \\
1630 \\
1550\end{array}$ & $\begin{array}{l}1740 \\
1730 \\
1710 \\
1710 \\
1670\end{array}$ \\
\hline $\begin{array}{l}26 \\
27 \\
28 \\
29 \\
30 \\
31\end{array}$ & $\begin{array}{r}1620 \\
1620 \\
1630 \\
1640 \\
-\end{array}$ & $\begin{array}{r}1590 \\
1610 \\
1610 \\
1610 \\
\ldots\end{array}$ & $\begin{array}{r}1610 \\
1620 \\
1620 \\
1620 \\
-\end{array}$ & $\begin{array}{l}1510 \\
1490 \\
1510 \\
1510 \\
1510 \\
1520\end{array}$ & $\begin{array}{l}1470 \\
1450 \\
1450 \\
1470 \\
1480 \\
1490\end{array}$ & $\begin{array}{l}1490 \\
1470 \\
1480 \\
1490 \\
1500 \\
1500\end{array}$ & $\begin{array}{l}1660 \\
1700 \\
1720 \\
1720 \\
1730 \\
=\end{array}$ & $\begin{array}{l}1540 \\
1590 \\
1590 \\
1570 \\
1600 \\
\end{array}$ & $\begin{array}{l}1600 \\
1650 \\
1660 \\
1660 \\
1680 \\
\ldots\end{array}$ & $\begin{array}{l}1740 \\
1750 \\
1750 \\
1760 \\
1750 \\
1740\end{array}$ & $\begin{array}{l}1420 \\
1610 \\
1660 \\
1510 \\
1470 \\
1430\end{array}$ & $\begin{array}{l}1650 \\
1700 \\
1710 \\
1670 \\
1640 \\
1620\end{array}$ \\
\hline NTH & $=-\infty$ & $-m-\infty$ & - - & 1670 & 1130 & 1450 & 1730 & 1430 & 1560 & 1780 & 1420 & 1690 \\
\hline
\end{tabular}

\begin{tabular}{|c|c|c|c|c|c|c|c|c|c|c|c|c|}
\hline \multirow[b]{2}{*}{ DAY } & \multicolumn{3}{|c|}{ JUNE } & \multicolumn{3}{|c|}{ JULY } & \multicolumn{3}{|c|}{ AUGUST } & \multicolumn{3}{|c|}{ SEPTEMBER } \\
\hline & MAX & MIN & MEAN & $\operatorname{MAX}$ & MIN & MEAN & MAX & MIN & MEAN & MAX & MIN & MEAN \\
\hline $\begin{array}{l}1 \\
2 \\
3 \\
4 \\
5\end{array}$ & $\begin{array}{l}1730 \\
1750 \\
1760 \\
1760 \\
1760\end{array}$ & $\begin{array}{l}1470 \\
1550 \\
1640 \\
1580 \\
1610\end{array}$ & $\begin{array}{l}1630 \\
1660 \\
1710 \\
1690 \\
1700\end{array}$ & $\begin{array}{l}1830 \\
1830 \\
1840 \\
1840 \\
1820\end{array}$ & $\begin{array}{l}1760 \\
1770 \\
1780 \\
1770 \\
1760\end{array}$ & $\begin{array}{l}1800 \\
1800 \\
1810 \\
1810 \\
1800\end{array}$ & $\begin{array}{l}1910 \\
1900 \\
1890 \\
1890 \\
1870\end{array}$ & $\begin{array}{l}1880 \\
1860 \\
1860 \\
1840 \\
1850\end{array}$ & $\begin{array}{l}1900 \\
1890 \\
1880 \\
1870 \\
1860\end{array}$ & $\begin{array}{l}1980 \\
2020 \\
2030 \\
1990 \\
1980\end{array}$ & $\begin{array}{l}1960 \\
1980 \\
1970 \\
1960 \\
1950\end{array}$ & $\begin{array}{l}1970 \\
2000 \\
2000 \\
1980 \\
1970\end{array}$ \\
\hline $\begin{array}{r}6 \\
7 \\
8 \\
9 \\
10\end{array}$ & $\begin{array}{l}-\infty \\
=-\infty \\
=-\infty \\
=-\infty\end{array}$ & $\begin{array}{l}=-\infty \\
=-\infty \\
=-\infty\end{array}$ & $\begin{array}{l}=-\infty \\
=-\infty \\
=-\infty\end{array}$ & $\begin{array}{l}1820 \\
1810 \\
1830 \\
1850 \\
1860\end{array}$ & $\begin{array}{l}1760 \\
1760 \\
1780 \\
1780 \\
1760\end{array}$ & $\begin{array}{l}1800 \\
1790 \\
1810 \\
1820 \\
1820\end{array}$ & $\begin{array}{l}1890 \\
1880 \\
1870 \\
1880 \\
1900\end{array}$ & $\begin{array}{l}1850 \\
1850 \\
1840 \\
1840 \\
1850\end{array}$ & $\begin{array}{l}1880 \\
1870 \\
1860 \\
1860 \\
1880\end{array}$ & $\begin{array}{l}1960 \\
1940 \\
1940 \\
1940 \\
1920\end{array}$ & $\begin{array}{l}1940 \\
1910 \\
1910 \\
1920 \\
1390\end{array}$ & $\begin{array}{l}1950 \\
1930 \\
1920 \\
1930 \\
1790\end{array}$ \\
\hline $\begin{array}{l}11 \\
12 \\
13 \\
14 \\
15\end{array}$ & $\begin{array}{l}1780 \\
1790 \\
1780 \\
1780\end{array}$ & $\begin{array}{l}1690 \\
1700 \\
1700 \\
1690\end{array}$ & $\begin{array}{l}1740 \\
1750 \\
1750 \\
1740\end{array}$ & $\begin{array}{l}1870 \\
1850 \\
1880 \\
1860 \\
1850\end{array}$ & $\begin{array}{l}1780 \\
1790 \\
1800 \\
1800 \\
1800\end{array}$ & $\begin{array}{l}1840 \\
1830 \\
1830 \\
1830 \\
1830\end{array}$ & $\begin{array}{l}1910 \\
1900 \\
1910 \\
1900 \\
1900\end{array}$ & $\begin{array}{l}1870 \\
1880 \\
1870 \\
1850 \\
1860\end{array}$ & $\begin{array}{l}1890 \\
1900 \\
1890 \\
1880 \\
1890\end{array}$ & $\begin{array}{l}2160 \\
1600 \\
1740 \\
1810 \\
1800\end{array}$ & $\begin{array}{r}902 \\
1040 \\
1610 \\
1720 \\
1770\end{array}$ & $\begin{array}{l}1460 \\
1350 \\
1700 \\
1770 \\
1790\end{array}$ \\
\hline $\begin{array}{l}16 \\
17 \\
18 \\
19 \\
20\end{array}$ & $\begin{array}{l}1780 \\
1790 \\
1790 \\
1780 \\
1760\end{array}$ & $\begin{array}{l}1700 \\
1710 \\
1710 \\
1700 \\
1710\end{array}$ & $\begin{array}{l}1740 \\
1750 \\
1760 \\
1750 \\
1740\end{array}$ & $\begin{array}{l}1850 \\
1860 \\
1870 \\
1860 \\
1860\end{array}$ & $\begin{array}{l}1800 \\
1830 \\
1830 \\
1790 \\
1810\end{array}$ & $\begin{array}{l}1840 \\
1850 \\
1860 \\
1840 \\
1840\end{array}$ & $\begin{array}{l}1880 \\
1880 \\
1900 \\
1910 \\
1920\end{array}$ & $\begin{array}{l}1840 \\
1850 \\
1860 \\
1870 \\
1880\end{array}$ & $\begin{array}{l}1860 \\
1870 \\
1890 \\
1900 \\
1910\end{array}$ & $\begin{array}{l}1800 \\
1810 \\
1820 \\
1800 \\
1800\end{array}$ & $\begin{array}{l}1760 \\
1780 \\
1790 \\
1790 \\
1780\end{array}$ & $\begin{array}{l}1770 \\
1800 \\
1800 \\
1790 \\
1790\end{array}$ \\
\hline $\begin{array}{l}21 \\
22 \\
23 \\
24 \\
25\end{array}$ & $\begin{array}{l}1770 \\
1760 \\
1770 \\
1780 \\
1810\end{array}$ & $\begin{array}{l}1700 \\
1690 \\
1710 \\
1730 \\
1740\end{array}$ & $\begin{array}{l}1740 \\
1730 \\
1740 \\
1760 \\
1780\end{array}$ & $\begin{array}{l}1860 \\
1860 \\
1860 \\
1870 \\
1870\end{array}$ & $\begin{array}{l}1820 \\
1820 \\
1830 \\
1830 \\
1820\end{array}$ & $\begin{array}{l}1850 \\
1850 \\
1850 \\
1850 \\
1860\end{array}$ & $\begin{array}{l}1930 \\
1920 \\
1930 \\
1930 \\
1940\end{array}$ & $\begin{array}{l}1880 \\
1880 \\
1880 \\
1890 \\
1890\end{array}$ & $\begin{array}{l}1910 \\
1900 \\
1910 \\
1910 \\
1920\end{array}$ & $\begin{array}{l}1820 \\
1810 \\
1810 \\
1830 \\
1860\end{array}$ & $\begin{array}{l}1780 \\
1780 \\
1770 \\
1780 \\
1800\end{array}$ & $\begin{array}{l}1800 \\
1800 \\
1790 \\
1810 \\
1830\end{array}$ \\
\hline $\begin{array}{l}26 \\
27 \\
28 \\
29 \\
30 \\
31\end{array}$ & $\begin{array}{l}1800 \\
1830 \\
1820 \\
1820 \\
1830 \\
-\end{array}$ & $\begin{array}{l}1730 \\
1760 \\
1750 \\
1760 \\
1770 \\
-\end{array}$ & $\begin{array}{r}1770 \\
1790 \\
1790 \\
1790 \\
1800 \\
-00\end{array}$ & $\begin{array}{l}1950 \\
1870 \\
1880 \\
1880 \\
1890 \\
1910\end{array}$ & $\begin{array}{l}1810 \\
1820 \\
1830 \\
1850 \\
1860 \\
1880\end{array}$ & $\begin{array}{l}1860 \\
1850 \\
1860 \\
1870 \\
1880 \\
1900\end{array}$ & $\begin{array}{l}1960 \\
1970 \\
2000 \\
1990 \\
1980 \\
1980\end{array}$ & $\begin{array}{l}1910 \\
1910 \\
1930 \\
1930 \\
1930 \\
1920\end{array}$ & $\begin{array}{l}1930 \\
1940 \\
1960 \\
1970 \\
1960 \\
1950\end{array}$ & $\begin{array}{r}1820 \\
1810 \\
1850 \\
2170 \\
1610 \\
-\end{array}$ & $\begin{array}{r}1770 \\
1710 \\
1700 \\
1140 \\
1090 \\
\end{array}$ & $\begin{array}{r}1800 \\
1780 \\
1790 \\
1540 \\
1350 \\
---\end{array}$ \\
\hline 10NTH & 1830 & 1470 & 1740 & 1950 & 1760 & 1840 & 2000 & 1840 & 1900 & 2170 & 902 & 1790 \\
\hline
\end{tabular}


LOCATION, - Lat $34^{\circ} 14^{\prime} 31^{\prime \prime}$, long $19^{\circ} 11^{\prime} 21^{\prime \prime}$, in San Miguel Grant, Ventura County, on downstrean end of center pier southbound bridge on U.S. Highway $101,0.9 \mathrm{mi}(1.4 \mathrm{~km})$ southeast of Montalvo.

DRAINAGE AREA. - -1,612 $\mathrm{mi}^{2}\left(4,175 \mathrm{~km}^{2}\right)$.

WATER-DISCHARGE RECORDS

PERIOD OF RECORD. - - October 1927 to September 1932 , October 1949 to current year. Month1y discharge only for 1950-67, published in WRD 1968 report. October 1949 to September 1969, published as "at Saticoy."

GAGE, - Water-stage recorder. Datum of gage is $51.88 \mathrm{ft}(15.813 \mathrm{~m}$ ) above mean sea level (1evels by Ventura County Flood Control District). Oct. 1, 1927, to Sept. 30, 1932, and oct. 1, 1949, to Sept. 30, 1967, at same site at different datums. Oct, 1, 1967, to Feb. 2, 1970, at site $3.9 \mathrm{mi}$ ( $6.3 \mathrm{~km}$ ) upstream at different datum.

REMARKS.--Records good. Flow part1y regulated since May 1955 by Lake Piru (station 11109700 ), since December 1971 by Pyramid Dam, capacity, 173,500 acre-ft $\left(214 \mathrm{hm}^{3}\right)$, and since January 1972 by Castaic Reservoir, capacity, 324,000 acre-ft $\left(399 \mathrm{hm}^{3}\right)$. Natural flow affected by ground-water withdrawals, diversions, municipal use, and ground-water replenishment. Imported water from the California Water Project released to the basin at Castaic Dam and Pyramid Dam. Diversion to spreading grounds and for irrigation in Pleasant Valley, at site $6.0 \mathrm{mi}(9.7 \mathrm{~km})$ upstream (station 11113900). AVERAGE DISCHARGE represents flow to the ocean regardless of upstream development.

COOPERATION.--Four discharge measurements were furnished by Ventura County flood Control District.

AVERAGE DISCHARGE. - - 32 years, $112 \mathrm{ft}^{3} / \mathrm{s}(3,172 \mathrm{~m} / \mathrm{s}), 81,140 \mathrm{acre}-\mathrm{ft} / \mathrm{yr}\left(100 \mathrm{hm} / \mathrm{yr}^{3}\right)$.

EXTREMES FOR PERIOD OF RECORD.--Maximum discharge, $165,000 \mathrm{ft}^{3} / \mathrm{s}\left(4,670 \mathrm{~m}^{3} / \mathrm{s}\right) \mathrm{Jan}, 25,1969, \mathrm{gage}$ height, $17.41 \mathrm{ft}$ $(5.307 \mathrm{~m})$, present datum; no flow for long periods in most years.

EXTREMES OUTSIDE PERIOD OF RECORD.--F1ood of Mar. 2, 1938, $120,000 \mathrm{ft}^{3} / \mathrm{s}\left(3,400 \mathrm{~m}^{3} / \mathrm{s}\right)$, estimated by Ventura County F1ood Control District.

EXTREMES FOR CURRENT YEAR.--Maximum discharge, $5,420 \mathrm{ft}^{3} / \mathrm{s}\left(153 \mathrm{~m}^{3} / \mathrm{s}\right) \mathrm{Feb} .9$, gage height, $5.58 \mathrm{ft}(1.701 \mathrm{~m})$; no flow many months.

DISCHARGE, IN CUBIC FEET PER SECOND, HATER YEAR OCTOBER 1975 TO SEPTEMBER 1976 MEAN VALUES

\begin{tabular}{|c|c|c|c|c|c|c|c|c|c|c|c|c|}
\hline DAY & $\mathrm{OCT}$ & NOV & DEC & JAN & FEB & MAR & APR & MAY & JUN & JUL & $A \cup G$ & SEP \\
\hline $\begin{array}{l}1 \\
2 \\
3 \\
4 \\
5\end{array}$ & & & & & $\begin{array}{l}0 \\
0 \\
0 \\
0 \\
0\end{array}$ & $\begin{array}{l}.01 \\
.01 \\
.02 \\
.02 \\
.08\end{array}$ & $\begin{array}{l}0 \\
0 \\
0 \\
.01 \\
.01\end{array}$ & & & & & $\begin{array}{l}0 \\
0 \\
0 \\
0 \\
0\end{array}$ \\
\hline $\begin{array}{r}6 \\
7 \\
8 \\
9 \\
10\end{array}$ & & & & & $\begin{array}{c}0 \\
2.9 \\
297 \\
2800 \\
2600\end{array}$ & $\begin{array}{r}.01 \\
.08 \\
.04 \\
.02 \\
.04\end{array}$ & $\begin{array}{l}0 \\
0 \\
0 \\
0 \\
0\end{array}$ & & & & & $\begin{array}{l}0 \\
0 \\
0 \\
0 \\
0\end{array}$ \\
\hline $\begin{array}{l}11 \\
12 \\
13 \\
14 \\
15\end{array}$ & & & & & $\begin{array}{r}504 \\
15 \\
1.3 \\
.56 \\
.33\end{array}$ & $\begin{array}{l}.02 \\
.02 \\
.02 \\
.09 \\
.07\end{array}$ & $\begin{array}{l}0 \\
.01 \\
.06 \\
.07 \\
.07\end{array}$ & & & & & $\begin{array}{l}0 \\
0 \\
0 \\
0 \\
0\end{array}$ \\
\hline $\begin{array}{l}16 \\
17 \\
18 \\
19 \\
20\end{array}$ & & & & & $\begin{array}{l}.20 \\
.15 \\
.13 \\
.12 \\
.10\end{array}$ & $\begin{array}{l}.04 \\
.06 \\
.04 \\
.04 \\
.04\end{array}$ & $\begin{array}{l}.04 \\
.02 \\
0 \\
0 \\
0\end{array}$ & & & & & $\begin{array}{l}0 \\
0 \\
0 \\
0 \\
0\end{array}$ \\
\hline $\begin{array}{l}21 \\
22 \\
23 \\
24 \\
25\end{array}$ & & & & & $\begin{array}{l}.08 \\
.07 \\
.05 \\
.06 \\
.04\end{array}$ & $\begin{array}{l}.02 \\
.02 \\
.01 \\
.02 \\
.04\end{array}$ & $\begin{array}{l}0 \\
0 \\
0 \\
0 \\
0\end{array}$ & & & & & $\begin{array}{l}0 \\
0 \\
0 \\
0 \\
0\end{array}$ \\
\hline $\begin{array}{l}26 \\
27 \\
28 \\
29 \\
30 \\
31\end{array}$ & & $-\infty$ & & & $\begin{array}{l}.04 \\
.02 \\
.02 \\
.02 \\
.+\infty \\
.-\infty\end{array}$ & $\begin{array}{l}.04 \\
.08 \\
.01 \\
.01 \\
0 \\
0\end{array}$ & $\begin{array}{l}0 \\
0 \\
0 \\
0 \\
0\end{array}$ & & $-\infty$ & & & $\begin{array}{r}0 \\
0 \\
0 \\
189 \\
.61 \\
-\end{array}$ \\
\hline $\begin{array}{l}\text { TOTAL } \\
\text { MEAN } \\
\text { MAX } \\
\text { MIN } \\
\text { AC-FY }\end{array}$ & $\begin{array}{l}0 \\
0 \\
0 \\
0 \\
0\end{array}$ & $\begin{array}{l}0 \\
0 \\
0 \\
0 \\
0\end{array}$ & $\begin{array}{l}0 \\
0 \\
0 \\
0 \\
0\end{array}$ & $\begin{array}{l}0 \\
0 \\
0 \\
0 \\
0\end{array}$ & $\begin{array}{r}6222.19 \\
215 \\
2800 \\
0 \\
12340\end{array}$ & $\begin{array}{r}.03 \\
.027 \\
.09 \\
0 \\
1.6\end{array}$ & $\begin{array}{r}.29 \\
.010 \\
.07 \\
0 \\
.6\end{array}$ & $\begin{array}{l}0 \\
0 \\
0 \\
0 \\
0\end{array}$ & $\begin{array}{l}0 \\
0 \\
0 \\
0 \\
0\end{array}$ & $\begin{array}{l}0 \\
0 \\
0 \\
0 \\
0\end{array}$ & $\begin{array}{l}0 \\
0 \\
0 \\
0 \\
0\end{array}$ & $\begin{array}{r}189.61 \\
6.32 \\
189 \\
0 \\
376\end{array}$ \\
\hline $\begin{array}{lll}\text { CAL YR } 1975 \\
\text { WTR YR } 1976\end{array}$ & $\begin{array}{l}\text { TOTAL } \\
\text { TOTAL }\end{array}$ & $\begin{array}{r}21699.08 \\
6412.92\end{array}$ & $\begin{array}{l}\text { MEAN } \\
\text { MEAN }\end{array}$ & $\begin{array}{l}59.4 \\
17.5\end{array}$ & $\begin{array}{ll}\text { MAX } & 7110 \\
\text { MAX } & 2800\end{array}$ & $\begin{array}{ll}\text { MIN } & 0 \\
\text { MIN } & 0\end{array}$ & $\begin{array}{l}A C=F T \\
A C=F T\end{array}$ & $\begin{array}{l}43040 \\
12720\end{array}$ & & & & \\
\hline
\end{tabular}


11114000 SANTA CLARA RIVER AT MONTALVO, CA--Continued

WATER-QUALITY RECORDS

PERIOD OF DAILY RECORD, ..-

WATER TEMPERATURES: October 1967 to September 1969, October 1970 to current year.

SEDIMENT RECORDS: October 1967 to current year.

Prior to October 1969, pubilished as "at Saticoy" (station 11113920).

REMARKS. - Sediment table omitted for period of no flow during october to December.

EXTREMES FOR PERIOD OF DAILY RECORD. -

SEDIMENT CONCENTRATIONS:--Maximum daily mean, 69,200 mg/1 Feb, 25, 1969; minimum daily mean, no flow for many days each year.

SEDIMENT DISCHARGE: Maximum dai1y, 20,400,000 tons (18,500,000 tonnes) Feb, 25, 1969; minimum daily, 0 tons on many days each year.

EXTREMES FOR CURRENT YEAR.--

SEDIMENT CONCENTRATIONS: Maximum daily mean, 4,410 mg/1 Feb. 9; minimum dajly mean, no flow for many days. SEDTMENT DISCHARGE: Maximum daily, 44,400 tons $(40,300$ tonnes) Feb. 9 ; minimum daily 0 tons on many days

REVISIONS. - The bedioad curve used for water year 1975 was in error. The 1975 total $10 a d$ computations were rerun and are published with 1976 water year records.

TEMPERATURE (DEG. C) OF WATER, WATER YEAR OCTOBER 1975 TO SEPTEMBER 1976 ONCE-DAILY

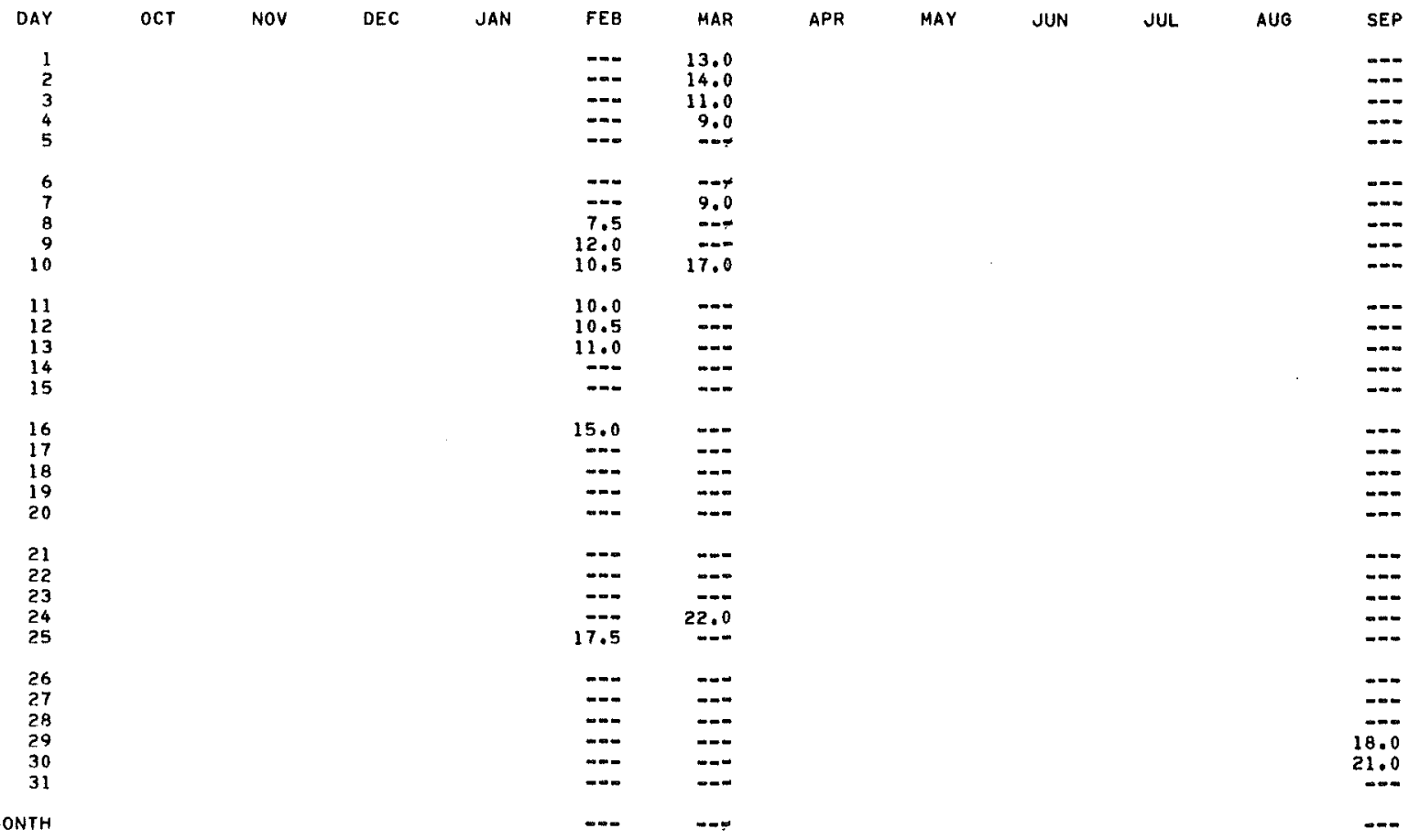


SUSPENDED-SEDIMENT DISCHARGE (TONS/DAY), WATER YEAR OCTOBER 1975 TO SEPTEMBER 1976

\begin{tabular}{|c|c|c|c|c|c|c|c|c|c|}
\hline & & JANUARY & & & FEBRUARY & & & MARCH & \\
\hline DAY & $\begin{array}{l}\text { MEAN } \\
\text { DISCHARGE } \\
\text { (CFS) }\end{array}$ & $\begin{array}{l}\text { MEAN } \\
\text { CONCEN- } \\
\text { TRATION } \\
\text { (MG/L) }\end{array}$ & $\begin{array}{l}\text { SEDIMENT } \\
\text { DISCHARGE } \\
\text { (TONS/DAY) }\end{array}$ & $\begin{array}{l}\text { MEAN } \\
\text { DISCHARGE } \\
\text { (CFS) }\end{array}$ & $\begin{array}{l}\text { MEAN } \\
\text { CONCEN- } \\
\text { TRATION } \\
\text { (MG/L) }\end{array}$ & $\begin{array}{l}\text { SEDIMENT } \\
\text { DISCHARGE } \\
\text { (TONS/OAY) }\end{array}$ & $\begin{array}{l}\text { MEAN } \\
\text { DISCHARGE } \\
\text { (CFS) }\end{array}$ & $\begin{array}{l}\text { MEAN } \\
\text { CONCEN- } \\
\text { TRATION } \\
\text { (HG/L) }\end{array}$ & $\begin{array}{l}\text { SEDIHENT } \\
\text { DISCHARGE } \\
\text { (TONS/DAY) }\end{array}$ \\
\hline $\begin{array}{l}1 \\
2 \\
3 \\
4 \\
5\end{array}$ & & & & $\begin{array}{l}0 \\
0 \\
0 \\
0 \\
0\end{array}$ & $\begin{array}{l}0 \\
0 \\
0 \\
0 \\
0\end{array}$ & $\begin{array}{l}0 \\
0 \\
0 \\
0 \\
0\end{array}$ & $\begin{array}{l}.01 \\
.01 \\
.02 \\
.02 \\
.02\end{array}$ & $\begin{array}{l}50 \\
57 \\
43 \\
41 \\
49\end{array}$ & $\begin{array}{l}0 \\
0 \\
0 \\
0 \\
0\end{array}$ \\
\hline $\begin{array}{r}6 \\
7 \\
8 \\
9 \\
10\end{array}$ & & & & $\begin{array}{c}0 \\
2.9 \\
297 \\
2800 \\
2600\end{array}$ & $\begin{array}{r}0 \\
21 \\
586 \\
4410 \\
2260\end{array}$ & $\begin{array}{c}0 \\
3.1 \\
565 \\
44400 \\
19000\end{array}$ & $\begin{array}{l}.01 \\
.02 \\
.04 \\
.02 \\
.04\end{array}$ & $\begin{array}{l}55 \\
63 \\
60 \\
55 \\
50\end{array}$ & $\begin{array}{l}0 \\
0 \\
0.01 \\
.01\end{array}$ \\
\hline $\begin{array}{l}11 \\
12 \\
13 \\
14 \\
15\end{array}$ & & & & $\begin{array}{c}504 \\
15 \\
1.3 \\
.56 \\
.33\end{array}$ & $\begin{array}{r}302 \\
29 \\
7 \\
5 \\
18\end{array}$ & $\begin{aligned} & 581 \\
& 2.0 \\
& .02 \\
& .01 \\
& .02\end{aligned}$ & $\begin{array}{l}.02 \\
.02 \\
.02 \\
.09 \\
.07\end{array}$ & $\begin{array}{l}50 \\
45 \\
45 \\
40 \\
35\end{array}$ & $\begin{array}{l}0 \\
0 \\
0 \\
.01 \\
.01\end{array}$ \\
\hline $\begin{array}{l}16 \\
17 \\
18 \\
19 \\
20\end{array}$ & & & & $\begin{array}{l}.20 \\
.15 \\
.13 \\
.12 \\
.10\end{array}$ & $\begin{array}{l}36 \\
30 \\
25 \\
25 \\
30\end{array}$ & $\begin{array}{l}.02 \\
.01 \\
.01 \\
.01 \\
.01\end{array}$ & $\begin{array}{l}.04 \\
.06 \\
.04 \\
.04 \\
.04\end{array}$ & $\begin{array}{l}30 \\
25 \\
20 \\
15 \\
10\end{array}$ & $\begin{array}{l}0 \\
0 \\
0 \\
0 \\
0\end{array}$ \\
\hline $\begin{array}{l}21 \\
22 \\
23 \\
24 \\
25\end{array}$ & & & & $\begin{array}{l}.08 \\
.07 \\
.05 \\
.06 \\
.04\end{array}$ & $\begin{array}{l}30 \\
30 \\
35 \\
35 \\
35\end{array}$ & $0^{.01}$ & $\begin{array}{l}.02 \\
.02 \\
.01 \\
.01 \\
.04\end{array}$ & $\begin{array}{l}5 \\
5 \\
5 \\
5 \\
5\end{array}$ & $\begin{array}{l}0 \\
0 \\
0 \\
0 \\
0\end{array}$ \\
\hline $\begin{array}{l}26 \\
27 \\
28 \\
29 \\
30 \\
31\end{array}$ & & & & $\begin{array}{l}.04 \\
.02 \\
.02 \\
.02 \\
-.- \\
.--\end{array}$ & $\begin{array}{r}40 \\
40 \\
45 \\
45 \\
--- \\
---\end{array}$ & $\begin{array}{l}0 \\
0 \\
0 \\
0 \\
\cdots\end{array}$ & $\begin{array}{l}.04 \\
.02 \\
.01 \\
.01 \\
0 \\
0\end{array}$ & $\begin{array}{l}5 \\
5 \\
5 \\
5 \\
0 \\
0\end{array}$ & $\begin{array}{l}0 \\
0 \\
0 \\
0 \\
0 \\
0\end{array}$ \\
\hline \multirow[t]{3}{*}{ TOTAL } & 0 & 0 & 0 & $6222 \cdot 19$ & $-m-$ & 64551.24 & .83 & $-\infty$ & .04 \\
\hline & & APRIL & & & MAY & & & JUNE & \\
\hline & $\begin{array}{c}\text { MEAN } \\
\text { DISCHARGE } \\
\text { (CFS) }\end{array}$ & $\begin{array}{l}\text { MEAN } \\
\text { CONCEN- } \\
\text { TRATION } \\
\text { (MG/L) }\end{array}$ & $\begin{array}{l}\text { SEDIMENT } \\
\text { DISCHARGE } \\
\text { (TONS/DAY) }\end{array}$ & $\begin{array}{l}\text { MEAN } \\
\text { DISCHARGE } \\
\text { (CFS) }\end{array}$ & $\begin{array}{l}\text { MEAN } \\
\text { CONCEN- } \\
\text { TRATION } \\
\text { (MG/L) }\end{array}$ & $\begin{array}{l}\text { SEDIMENT } \\
\text { DISCHARGE } \\
\text { (TONS/DAY) }\end{array}$ & $\begin{array}{l}\text { MEAN } \\
\text { DISCHARGE } \\
\text { (CFS) }\end{array}$ & $\begin{array}{l}\text { MEAN } \\
\text { CONCEN- } \\
\text { TRATION } \\
\text { (MG/L) }\end{array}$ & $\begin{array}{l}\text { SEDIMENT } \\
\text { DISCHARGE } \\
\text { (TONS/DAY) }\end{array}$ \\
\hline
\end{tabular}

$\begin{array}{lll}1 & 0 & 0 \\ 2 & 0 & 0 \\ 3 & 0 & 0 \\ 4 & 0.01 & 5 \\ 5 & .01 & 5\end{array}$

0

0

0
0
0
5
5

0.01

.01

.07

.07

ISCHARGE (CFS) 
11114000 SANTA CLARA RIVER AT MONTALVO, CA--Continued

SUSPENDED-SEDIMENT DISCHARGE (TONS/DAY), HATER YEAR OCTOBER 1975 TO SEPTEMBER 1976

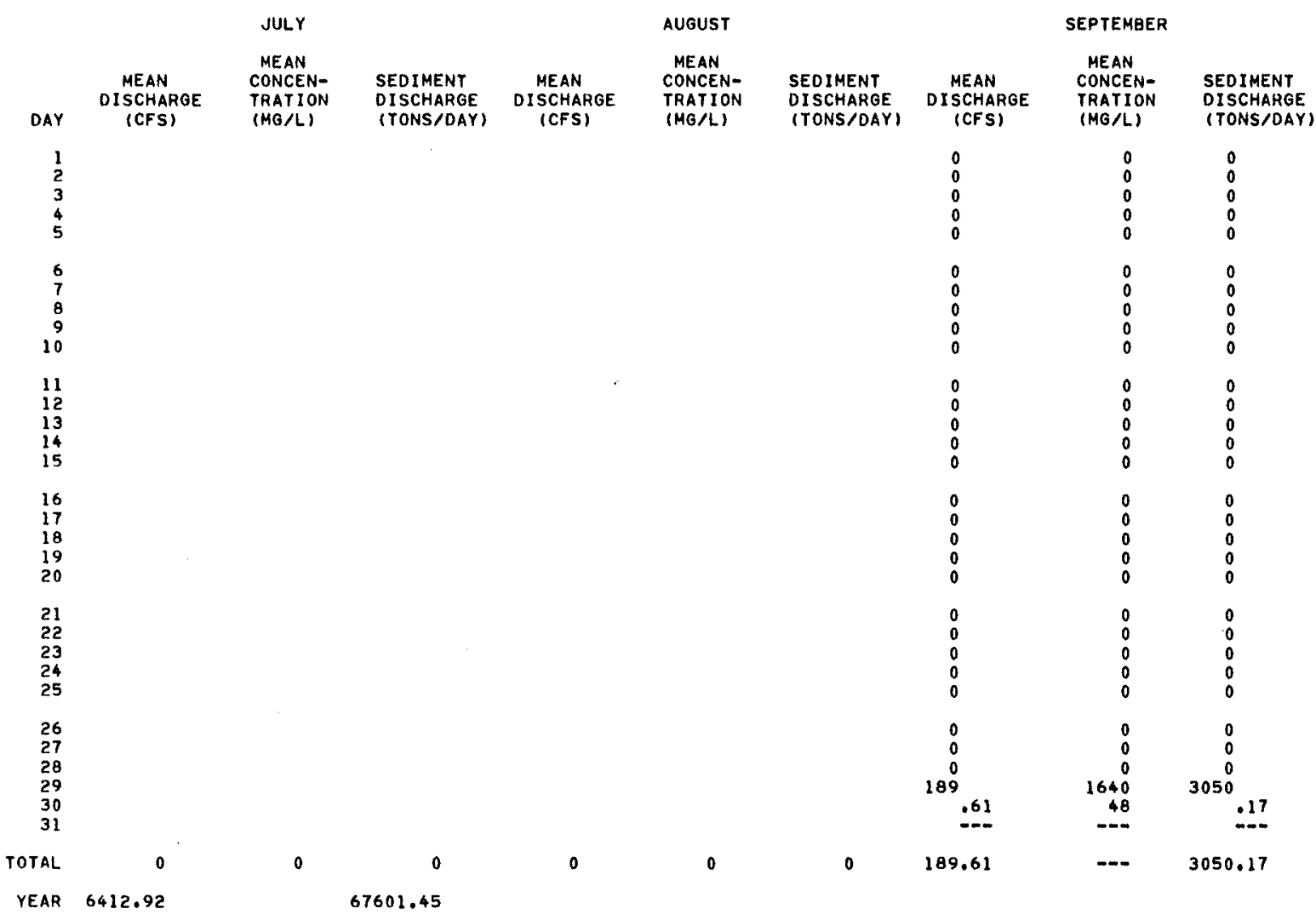

SUMMARY OF WATER AND SEDIMENT DISCHARGE, HATER YEAR OCTOBER 1974 TO SEPTEMBER 1975

MONTH

OCTOBER 1974

NOVEMBER ...

DECEMBER ...

JANUARY 1975

FEBRUARY ...

MARCH ......

APRIL .....

MAY ........

JUNE —....

JULY ......

AUGUST .....

SEPTEMBER -

TOTAL .....

$\begin{array}{cc}\text { HATER } & \text { SUSPENDED } \\ \text { DISCHARGE } & \text { SEDIMENT } \\ \text { CFS-DAYS } & \text { DISCHARGE } \\ \text { TONS }\end{array}$

$$
0.0
$$

0.0

0.0

4666.88

1.67

3030.72

17931.46

734.42

0.81

0.0

0.0

0.0

0.0

26365.96
BEDLOAD

DISCHARGE

TONS

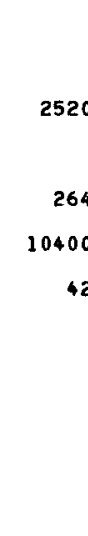

TOTAL

SEDINENT

DISCHARGE

TONS

0
0
157000
0
4920
502000
4600
0
0
0
0
0
668520


SUMMARY OF WATER AND SEOIMENT DISCHARGE, WATER YEAR OCTOBER 1975 TO SEPTEMBEA 1976

\begin{tabular}{|c|c|c|c|c|}
\hline MONTH & $\begin{array}{c}\text { HATER } \\
\text { DI SCHARGE } \\
\text { CFS-DAYS }\end{array}$ & $\begin{array}{l}\text { SUSPENDED } \\
\text { SEDIMENT } \\
\text { DISCHARGE } \\
\text { TONS }\end{array}$ & $\begin{array}{l}\text { BEDLOAD } \\
\text { DISCHARGE } \\
\text { TONS }\end{array}$ & $\begin{array}{l}\text { TOTAL } \\
\text { SEDIMENT } \\
\text { DISCHARGE } \\
\text { TONS }\end{array}$ \\
\hline OCTOBER 1975 & 0.0 & 0.0 & 0 & 0 \\
\hline NOVEMBER ... & 0.0 & 0.0 & 0 & 0 \\
\hline DECEMBER ... & 0.0 & 0.0 & 0 & 0 \\
\hline JANUARY 1976 & 0.0 & 0.0 & 0 & 0 \\
\hline FEBRUARY $\ldots$ & 6222.19 & 64551.24 & 33000 & 97600 \\
\hline MARCH ..... & 0.83 & 0.04 & 0 & 0 \\
\hline APRIL $\ldots \ldots$ & 0.29 & 0.0 & 0 & 0 \\
\hline MAY ...... & 0.0 & 0.0 & 0 & 0 \\
\hline JUNE $\ldots \ldots$ & 0.0 & 0.0 & 0 & 0 \\
\hline JULY ....... & 0.0 & 0.0 & 0 & 0 \\
\hline AUGUST ..... & 0.0 & 0.0 & 0 & 0 \\
\hline SEPTEMBER .. & 189.61 & 3050.17 & 91 & 3140 \\
\hline TOTAL ...... & 6412,92 & 67601.45 & 33091 & 100740 \\
\hline
\end{tabular}

PARTICLE-SIZE DISTRIBUTION OF SUSPENDED SEDIMENT, HATER YEAR OCTOBER 1975 TO SEPTEMBER 1976

\begin{tabular}{|c|c|c|c|c|c|c|c|c|c|c|}
\hline DATE & TIME & $\begin{array}{l}\text { TEMPER- } \\
\text { ATURE } \\
\text { (DEG C) }\end{array}$ & $\begin{array}{l}\text { INSTAN- } \\
\text { TANEOUS } \\
\text { DIS- } \\
\text { CHARGE } \\
\text { (CFS) }\end{array}$ & $\begin{array}{l}\text { SUS- } \\
\text { PENDE.D } \\
\text { SEDI - } \\
\text { MENT } \\
\text { (MG/L) }\end{array}$ & $\begin{array}{c}\text { SUS- } \\
\text { PENDED } \\
\text { SEDI - } \\
\text { MENT } \\
\text { DIS- } \\
\text { CHARGE } \\
\text { (T/DAY) }\end{array}$ & $\begin{array}{c}\text { SUS. } \\
\text { SED } \\
\text { FALL } \\
\text { DIAM. } \\
\text { FINER } \\
\text { THAN } \\
.002 \mathrm{MM}\end{array}$ & $\begin{array}{c}\text { SUS. } \\
\text { SED: } \\
\text { FALL } \\
\text { OIAH. } \\
\text { O FINER } \\
\text { THAN } \\
.004 \text { MM }\end{array}$ & $\begin{array}{l}\text { SUS, } \\
\text { SED, } \\
\text { FALL } \\
\text { DIAM, } \\
\text { \$ FINER } \\
\text { THAN } \\
\text { TOOB MM }\end{array}$ & $\begin{array}{c}\text { SUS. } \\
\text { SED, } \\
\text { FALL } \\
\text { DIAH, } \\
\text { * FINER } \\
\text { THAN } \\
.016 \text { MM }\end{array}$ & $\begin{array}{l}\text { SUS. } \\
\text { SED. } \\
\text { FALL } \\
\text { DIAM. } \\
\text { OFINER } \\
\text { THAN } \\
.031 \text { MH }\end{array}$ \\
\hline \multicolumn{11}{|l|}{ FEB } \\
\hline $\begin{array}{l}08 \ldots \\
09 \ldots \\
10 \ldots \\
11 \ldots \\
\text { SEP }\end{array}$ & $\begin{array}{l}1045 \\
1400 \\
1015 \\
1030\end{array}$ & $\begin{array}{l}12.0 \\
11.0 \\
.0\end{array}$ & $\begin{array}{r}181 \\
3640 \\
3160 \\
702\end{array}$ & $\begin{array}{r}286 \\
4860 \\
2160 \\
327\end{array}$ & $\begin{array}{r}140 \\
47800 \\
18400 \\
620\end{array}$ & $\begin{array}{l}53 \\
33 \\
23 \\
44\end{array}$ & $\begin{array}{l}65 \\
46 \\
32 \\
56\end{array}$ & $\begin{array}{l}74 \\
63 \\
41 \\
69\end{array}$ & $\begin{array}{l}84 \\
78 \\
56 \\
81\end{array}$ & $\begin{array}{l}92 \\
88 \\
68 \\
88\end{array}$ \\
\hline $\begin{array}{l}29 \ldots \\
29 \ldots\end{array}$ & $\begin{array}{l}1045 \\
1400\end{array}$ & $\begin{array}{l}18.0 \\
18.0\end{array}$ & $\begin{array}{l}716 \\
209\end{array}$ & $\begin{array}{l}8360 \\
1090\end{array}$ & $\begin{array}{r}16200 \\
615\end{array}$ & $\begin{array}{l}47 \\
58\end{array}$ & $\begin{array}{l}59 \\
73\end{array}$ & $\begin{array}{l}77 \\
86\end{array}$ & $\begin{array}{l}92 \\
94\end{array}$ & $\begin{array}{l}99 \\
98\end{array}$ \\
\hline
\end{tabular}

\begin{tabular}{|c|c|c|c|c|c|c|c|c|c|c|}
\hline & $\begin{array}{l}\text { SUS. } \\
\text { SED. } \\
\text { FALL } \\
\text { DIAM. } \\
\text { FINER } \\
\text { THAN }\end{array}$ & $\begin{array}{l}\text { SUS. } \\
\text { SED, } \\
\text { SIEVE } \\
\text { DIAM. } \\
\text { \& FINER } \\
\text { THAN }\end{array}$ & $\begin{array}{l}\text { SUS. } \\
\text { SED. } \\
\text { FALL } \\
\text { DIAM. } \\
\text { \$ FINER } \\
\text { THAN }\end{array}$ & $\begin{array}{l}\text { SUS. } \\
\text { SED, } \\
\text { SIEVE } \\
\text { DIAM. } \\
\text { \& FINER } \\
\text { THAN }\end{array}$ & $\begin{array}{l}\text { SUS. } \\
\text { SED. } \\
\text { FALL } \\
\text { OIAM. } \\
\text { FINER } \\
\text { THAN }\end{array}$ & $\begin{array}{l}\text { SUS. } \\
\text { SED } \\
\text { SIEVE } \\
\text { DIAM. } \\
\text { \& FINER } \\
\text { THAN }\end{array}$ & $\begin{array}{l}\text { SUS } \\
\text { SED } \\
\text { FALL } \\
\text { DIAM. } \\
\text { DINER } \\
\text { THAN }\end{array}$ & $\begin{array}{l}\text { SUS. } \\
\text { SED, } \\
\text { SIEVE } \\
\text { DIAM. } \\
\text { D FINER } \\
\text { THAN }\end{array}$ & $\begin{array}{l}\text { SUS. } \\
\text { SED. } \\
\text { FALL } \\
\text { DIAM. } \\
\text { X FINER } \\
\text { THAN }\end{array}$ & $\begin{array}{l}\text { SUS. } \\
\text { SED. } \\
\text { SIEVE } \\
\text { DIAH. } \\
\text { WINER } \\
\text { THAN }\end{array}$ \\
\hline ITE & $.062 \mathrm{MM}$ & $.062 \mathrm{MM}$ & $.125 \mathrm{MM}$ & $.125 \mathrm{MM}$ & $.250 \mathrm{MM}$ & $.250 \mathrm{MM}$ & $.500 \mathrm{MM}$ & $.500 \mathrm{MM}$ & $1.00 \mathrm{MM}$ & $1.00 \mathrm{MM}$ \\
\hline
\end{tabular}

\begin{tabular}{|c|c|c|c|c|c|c|c|c|c|c|}
\hline FEB & -- & & -- & & & & & & & \\
\hline $09 \ldots$ & 94 & 94 & 97 & 95 & 99 & $\begin{array}{l}91 \\
0=\end{array}$ & 100 & 99 & $=$ & 100 \\
\hline $10 \ldots$ & 74 & - & 78 & -- & 86 & $-\infty$ & 99 & - & 100 & $-\infty$ \\
\hline $11 \ldots$ & $=-$ & 90 & $=$ & 91 & $-\infty$ & 93 & -- & 99 & - & 100 \\
\hline $29 \ldots$ & $-\infty$ & 100 & 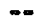 & -- & $-\infty$ & $-\infty$ & $=-$ & $=$ & $-\infty$ & $-\infty$ \\
\hline $29 \ldots$ & $=-$ & 100 & $m$ & $-=$ & $=$ & -- & $-\infty$ & $\infty$ & - & \\
\hline
\end{tabular}


11115000 MATILIJA RESERVOIR AT MATILIJA HOT SPRINGS, CA

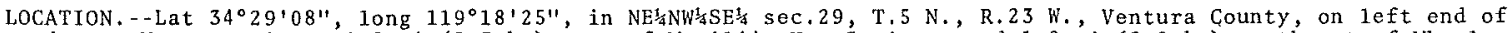
dam on Ventura River, $0.2 \mathrm{mi}(0.3 \mathrm{~km})$ east of Matilija Hot Springs, and $1.8 \mathrm{mi}(2.9 \mathrm{~km})$ southwest of Wheeler Springs.

DRAINAGE AREA, $--54.4 \mathrm{mi}^{2}\left(140.9 \mathrm{~km}^{2}\right)$.

PERIOD OF RECORD, - March 1948 to September 1965, October 1970 to current year. Prior to October 1953, pub1ished as "at Matilija."

GAGE. - Water-stage recorder. Datun of gage is at mean sea level (Ventura County Department of Public Works bench mark). Prior to Nov. 12, 1970, at site near right end of dan at same datum.

REMARKS. - Reservoir is formed by concrete-arch dam. Dam was completed in 1948. Storage began Mar. 14 , 1948. Capacity table is dated October 1970 (furnished by Ventura County Flood Control District). Lowest sluice gate

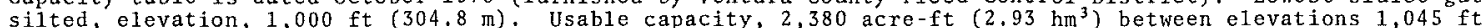
$(318.5 \mathrm{~m})$ lowest usable outlet and $1,095 \mathrm{ft}(333.8 \mathrm{~m})$, crest of spillway. Dead storage below lowest usable outlet, 93 acre-ft $\left(115,000 \mathrm{~m}^{3}\right)$. Capacity below spiliway, 2,473 acre-ft (3.05 hm ${ }^{3}$. Water is released from reservoir to natural stream for recharge of ground-water basin in Ventura River Valley and at times releases up to $500 \mathrm{ft}^{3} / \mathrm{s}(14.2 \mathrm{~m} / \mathrm{s})$, diverted since May 1959 at Robles diversion dam to Lake Casitas on Coyote Creek.

EXTREMES FOR PERIOD OF RECORD. - Maximum contents, 7,399 acre-ft $\left(9.12 \mathrm{hm}^{3}\right)$ Apr, 3 , 1958, elevation, 1,128,10 ft $(343.845 \mathrm{~m})$; minimum, 5.90 acre-ft $\left(7,270 \mathrm{~m}^{3}\right)$ oct. 31, 1970, elevation, 1,038.31 ft (316.477 m).

EXTREMES OUFSIDE PERIOD OF RECORD. - Maximum contents from October 1965 to September $1970,3,128$ acre-ft $\left(3.86 \mathrm{hm}^{3}\right)$ Jan. 25,1969 , elevation, $1,103.6 \mathrm{ft}(336.377 \mathrm{~m})$.

EXTREMES FOR CURRENT YEAR.--Maximum contents, 1,853 acre-ft $\left(2.28 \mathrm{hm}^{3}\right.$ ) Feb. 10, e1evation, $1,085.97 \mathrm{ft}(331.004 \mathrm{~m})$; minimum, 521 acre-ft $\left(642,000 \mathrm{~m}^{3}\right)$ Dec. 3, elevation, $1,059.67 \mathrm{ft}(322.987 \mathrm{~m})$.

MONTHEND ELEVATION AND CONTENTS, AT 2400, WATER YEAR OCTOBER 1975 TO SEPTEMBER 1976

\begin{tabular}{|c|c|c|c|c|}
\hline & Date & $\begin{array}{l}\text { Elevation } \\
\text { (feet) }\end{array}$ & $\begin{array}{l}\text { Contents } \\
(\text { acre-feet })\end{array}$ & $\begin{array}{l}\text { Change in contents } \\
\text { (acre-feet) }\end{array}$ \\
\hline $\begin{array}{l}\text { Sept. } \\
\text { Oct. } \\
\text { Nov. } \\
\text { Dec. }\end{array}$ & $\begin{array}{l}30 \ldots \ldots \ldots \ldots \ldots \ldots \ldots \\
31 \ldots \ldots \ldots \ldots \ldots \ldots \\
30 \ldots \ldots \ldots \ldots \ldots\end{array}$ & $\begin{array}{l}1073.19 \\
1073.63 \\
1060.12 \\
1060.13\end{array}$ & $\begin{array}{r}1104 \\
1128 \\
538 \\
538\end{array}$ & $\begin{array}{r}-- \\
+24 \\
-590 \\
0\end{array}$ \\
\hline CAL & YR $1975 \ldots \ldots \ldots \ldots$ & -- & -- & -232 \\
\hline $\begin{array}{l}\text { Jan. } \\
\text { Feb. } \\
\text { Mar. } \\
\text { Apr. } \\
\text { May } \\
\text { June } \\
\text { July } \\
\text { Aug. } \\
\text { Sept. }\end{array}$ & 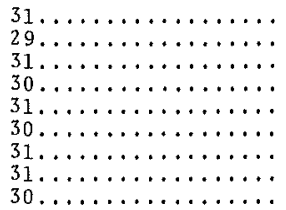 & $\begin{array}{l}1060.23 \\
1060.79 \\
1060.98 \\
1060.59 \\
1060.17 \\
1059.90 \\
1059.99 \\
1060.05 \\
1062.15\end{array}$ & $\begin{array}{l}541 \\
561 \\
568 \\
554 \\
540 \\
530 \\
533 \\
535 \\
611\end{array}$ & $\begin{array}{r}+3 \\
+20 \\
+7 \\
-14 \\
-14 \\
-10 \\
+3 \\
+2 \\
+76\end{array}$ \\
\hline WTR & $\mathrm{YR} 1976 \ldots \ldots \ldots \ldots$ & -- & -- & -493 \\
\hline
\end{tabular}


LOCATION, - - Lat $34^{\circ} 28^{\prime} 58^{\prime \prime}$, long $119^{\circ} 18^{\prime} 03^{\prime \prime}$, in SWhN' $\frac{1}{4}$ SW $s$ sec. 28, T. 5 N., R. 23 W. Ventura County, on right bank $0.2 \mathrm{mi}(0.3 \mathrm{~km})$ east of Matilija Hot Springs, $0.2 \mathrm{mi}(0.3 \mathrm{~km})$ upstream from North Fork, and $0.4 \mathrm{mi}(0.6 \mathrm{~km})$ downstream from Matilija Dam.

DRAINAGE AREA. $-54.6 \mathrm{mi}^{2} ;\left(141.4 \mathrm{~km}^{2}\right)$

WATER-DISCHARGE RECORDS

PERIOD OF RECORD. - October 1927 to current year. Combined month1y records for creek and diversion, May 1951 to September 1969 . Prior to October 1953, published as "at Matilija."

GAGE. - Water-stage recorder. Concrete control since September 1969. Altitude of gage is 900 ft (274 m), from topographic map. Prior to Feb. 11, 1939, at site $0.6 \mathrm{mi}(1.0 \mathrm{~km})$ upstream at different datum.

REMARKS. - Records good. Flow regulated by Matilija Reservoir March 1948 to March 1964, capacity, 7,020 acre-ft $\left(8.66 \mathrm{hm}^{3}\right)$ and partly regulated since March 1964 , capacity, 2,470 acre-ft $\left(3.05 \mathrm{hm}^{3}\right)$. Water diverted at dam by Matilija conduit to Ventura River basin and ojai Valley for irrigation from May 1951 to January 1969.

EXTREMES FOR PERIOD OF RECORD.--Maximum discharge, $20,000 \mathrm{ft}^{3} / \mathrm{s}\left(566 \mathrm{~m}^{3} / \mathrm{s}\right) \mathrm{Jan} .25,1969, \mathrm{gage} \mathrm{height}$, $16.5 \mathrm{ft}$ $(5,03 \mathrm{~m})$, from rating curve extended above $4,200 \mathrm{ft} / \mathrm{s}(119 \mathrm{~m} / \mathrm{s})$ on basis of computation of maximum fiow over dam; minimum daily, $0.10 \mathrm{ft}^{3} / \mathrm{s}(0.003 \mathrm{~m} / \mathrm{s})$ for several days in some years of regulated flow.

EXTREMES FOR CURRENT YEAR, -Maximum discharge, $529 \mathrm{ft}^{3} / \mathrm{s}\left(15.0 \mathrm{~m}^{3} / \mathrm{s}\right) \mathrm{Feb}$. 10, gage height, $4.32 \mathrm{ft}(1.317 \mathrm{~m})$; minimum daily, $0.89 \mathrm{ft}^{3} / \mathrm{s}\left(0.025 \mathrm{~m}^{3} / \mathrm{s}\right)$ Aug. 14 .

DISCHARGE, IN CUBIC FEET PER SECOND, WATER YEAR OCTOBER 1975 TO SEPTEMBER 1976 MEAN VALUES

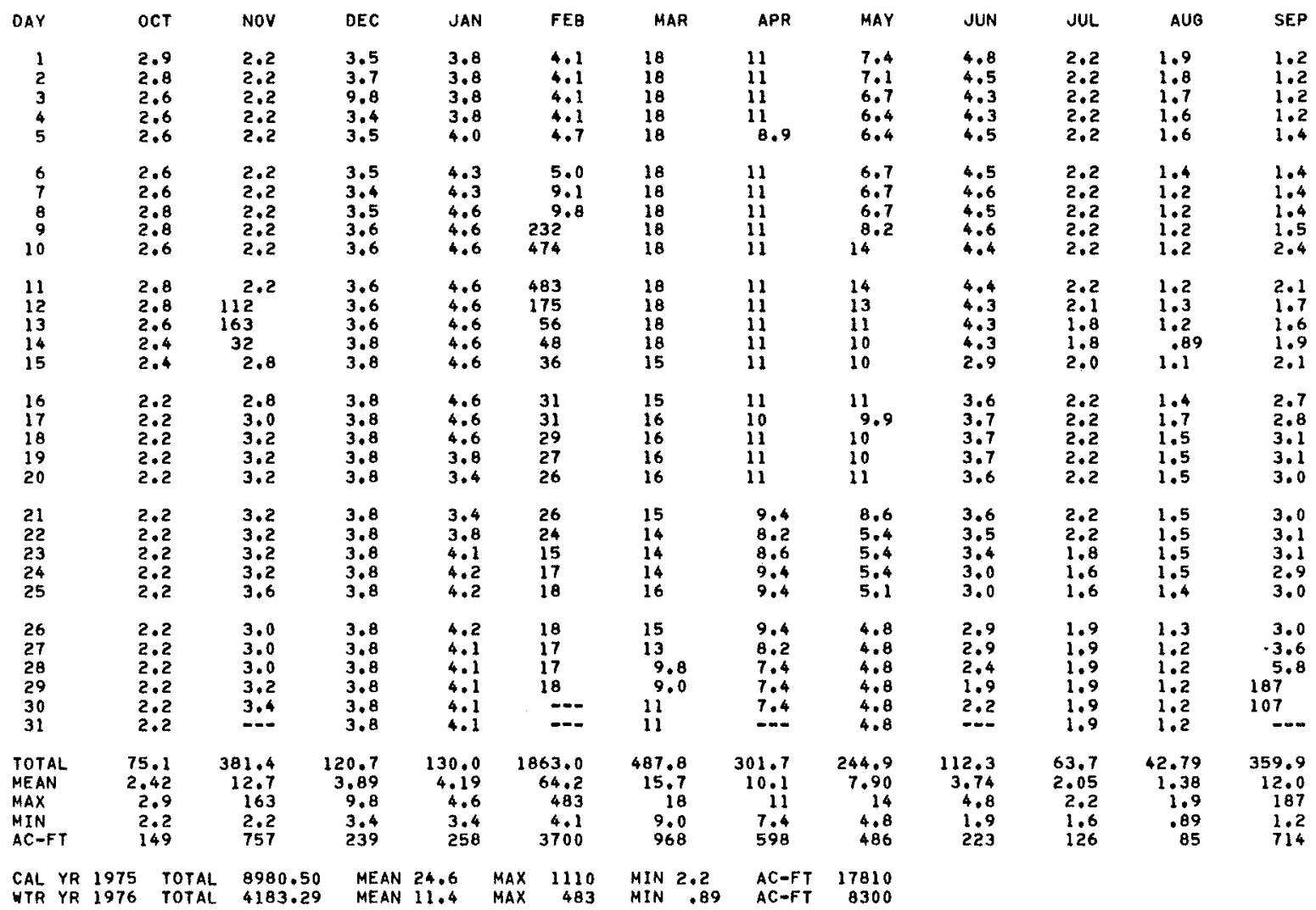


11115500 MATILIJA CREEK AT MATILIJA HOT SPRINGS, CA--Continued

WATER-QUALITY RECORDS

PERIOD OF RECORD, - -Chemica1 analyses: Water years 1972 to current year (partial-record station). COOPERATION.--Chemica1-qua1ity records were furnished by California Department of Water Resources.

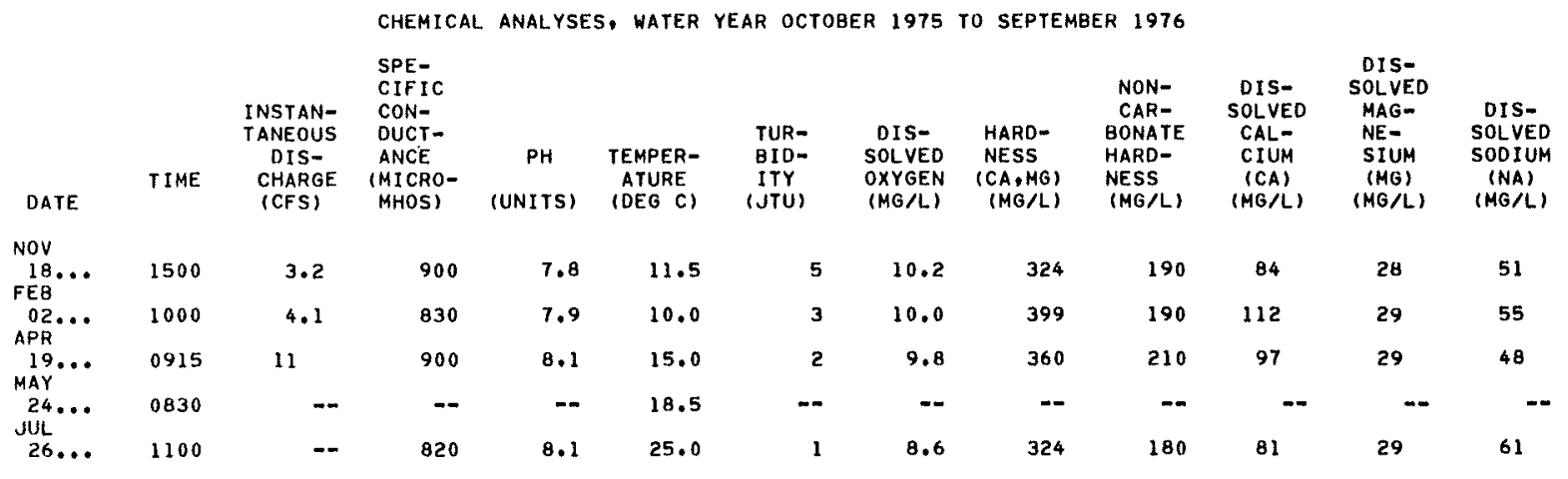

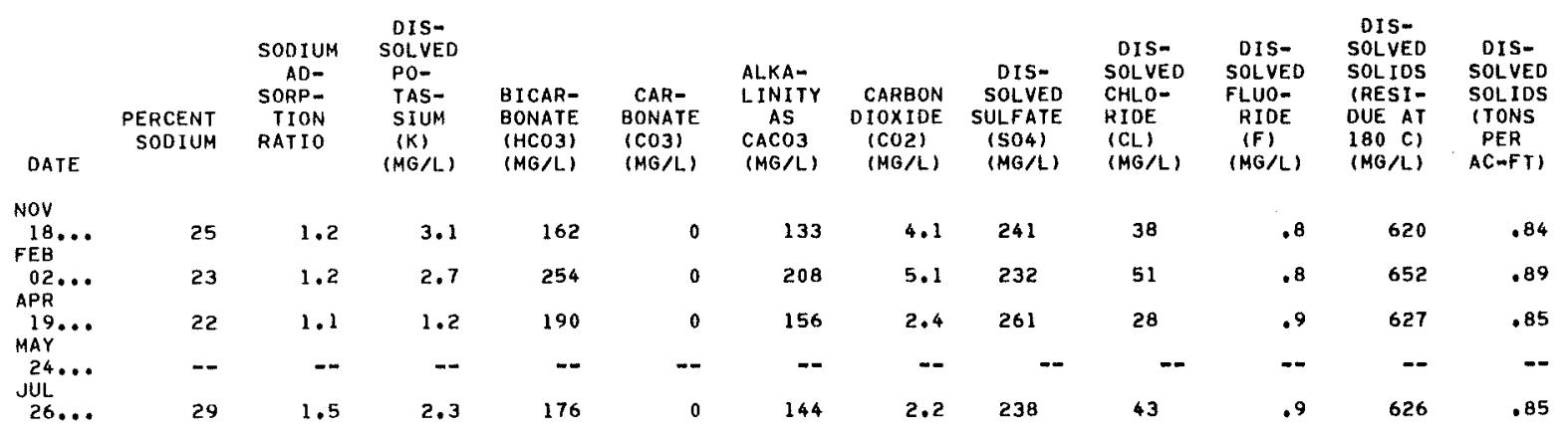

\begin{tabular}{|c|c|c|c|c|c|c|c|c|c|c|c|c|}
\hline DATE & $\begin{array}{l}\text { DIS- } \\
\text { SOLVED } \\
\text { SOLIDS } \\
\text { (TONS } \\
\text { PER } \\
\text { DAY) }\end{array}$ & $\begin{array}{l}\text { TOTAL } \\
\text { NITRATE } \\
\text { (N) } \\
\text { (MG/L) }\end{array}$ & $\begin{array}{c}\text { DIS- } \\
\text { SOLVED } \\
\text { ARSENIC } \\
\text { (AS) } \\
\text { (UG/L) }\end{array}$ & $\begin{array}{l}\text { DIS- } \\
\text { SOLVED } \\
\text { BORON } \\
\text { (B) } \\
\text { (UG/L) }\end{array}$ & $\begin{array}{l}\text { OIS- } \\
\text { SOLVED } \\
\text { CAO- } \\
\text { MIUM } \\
\text { (CD) } \\
\text { (UG/L) }\end{array}$ & $\begin{array}{l}\text { DIS- } \\
\text { SOLVED } \\
\text { CHRO- } \\
\text { MIUM } \\
\text { (CR) } \\
\text { (UG/L) }\end{array}$ & $\begin{array}{l}\text { HEXA- } \\
\text { VALENT } \\
\text { CHRO- } \\
\text { MIUM } \\
\text { (CR6) } \\
\text { (UG/L) }\end{array}$ & $\begin{array}{l}\text { DIS- } \\
\text { SOLVED } \\
\text { COPPER } \\
\text { (CU) } \\
\text { (UG/L) }\end{array}$ & $\begin{array}{l}\text { DIS- } \\
\text { SOLVED } \\
\text { IRON } \\
\text { (FE) } \\
\text { (UG/L) }\end{array}$ & $\begin{array}{l}\text { OIS- } \\
\text { SOLVED } \\
\text { LEAD } \\
\text { (PB) } \\
\text { (UG/L) }\end{array}$ & $\begin{array}{l}\text { DIS- } \\
\text { SOLVED } \\
\text { MAN- } \\
\text { GANESE } \\
\text { (MN) } \\
(U G / L)\end{array}$ & $\begin{array}{l}\text { DIS- } \\
\text { SOLVEO } \\
\text { ZINC } \\
\text { (ZN) } \\
(U G / L)\end{array}$ \\
\hline $\begin{array}{l}\text { NOV } \\
18 \ldots \\
\text { FEB }\end{array}$ & 5.36 & .00 & -- & 1700 & -- & $m$ & -- & $-\infty$ & -- & $-\infty$ & -- & -- \\
\hline$\underset{A P R}{02} \cdots$ & 7.22 & .00 & -- & 1010 & -- & $-m$ & -- & $-\cdots$ & -- & - & -+ & -- \\
\hline MAY $19 .$. & 18.6 & .00 & -- & 680 & -- & -- & $=-$ & -- & -- & -- & -- & -- \\
\hline$\underset{j U L}{24 \ldots}$ & - & $=-$ & 0 & -- & 0 & 0 & 0 & 0 & 10 & 0 & 0 & 0 \\
\hline $26 \ldots$ & -- & .11 & $-\infty$ & 920 & $m$ & -- & -- & -- & -- & $m$ & - & $\cdots$ \\
\hline
\end{tabular}


11116000 NORTH FORK MATILIJA CREEK AT MATILIJA HOT SPRINGS, CA

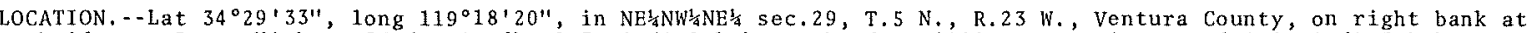
bridge on State Highway 33 (revised), $0.7 \mathrm{mi}(1.1 \mathrm{~km}$ ) north of Matilija Hot Springs, and $0.8 \mathrm{mi}$ (1.3 $\mathrm{km}$ ) upstream from mouth.

DRAINAGE AREA. $-15.6 \mathrm{mi}^{2}\left(40.4 \mathrm{~km}^{2}\right)$.

PERIOD OF RECORD.--October 1928 to September 1932, October 1933 to current year. Prior to October 1953, published as "at Matilija."

GAGE. - Water-stage recorder. Concrete contro1 since September 1966. Datum of gage is $1,141.62 \mathrm{ft}$ ( $347.966 \mathrm{~m}$ ), above mean sea level (levels by Ventura County Flood Control District). Prior to Nov. 12, 1948, at site $0.3 \mathrm{mi}(0.5 \mathrm{~km})$ downstream at different datum.

REMARKS . - No regulation or diversion above station.

COOPERATION. - Records were furnished by Ventura County Flood Control District and reviewed by Geological Survey.

AVERAGE DISCHARGE , - -47 years, $10.1 \mathrm{ft}^{3} / \mathrm{s}\left(0.286 \mathrm{~m}^{3} / \mathrm{s}\right), 7,320 \mathrm{acre}-\mathrm{ft} / \mathrm{yr}\left(9.03 \mathrm{hm} / \mathrm{yr}^{3}\right)$.

EXTREMES FOR PERIOD OF RECORD, - Maximum discharge, $9,440 \mathrm{ft}^{3} / \mathrm{s}\left(267 \mathrm{~m}^{3} / \mathrm{s}\right)$ Feb. 24,1969 , gage height, $11.0 \mathrm{ft}$ $(3.35 \mathrm{~m})$, from floodmark, from rating curve extended above $1,700 \mathrm{ft}^{3} / \mathrm{s}\left(48.1 \mathrm{~m}^{3} / \mathrm{s}\right)$ on basis of slope-area measurement at gage height $10.0 \mathrm{ft}(3.05 \mathrm{~m})$; minimum daily, $0.10 \mathrm{ft} / \mathrm{s}\left(0.003 \mathrm{~m}^{3} / \mathrm{s}\right) \mathrm{for}$ several days in some years.

EXTREMES FOR CURRENT YEAR. - Maximum discharge, $375 \mathrm{ft}^{3} / \mathrm{s}\left(10.6 \mathrm{~m}^{3} / \mathrm{s}\right)$ Sept. 29, gage height, $3.55 \mathrm{ft}(1.082 \mathrm{~m})$, no peak above base of $400 \mathrm{ft} / \mathrm{s}\left(11.3 \mathrm{~m}^{3} / \mathrm{s}\right)$; minimum daily, $0.42 \mathrm{ft} / \mathrm{s}(0.012 \mathrm{~m} / \mathrm{s})$ Aug. 26 to Sept. 2 .

DISCHARGE, IN CUBIC FEET PER SECOND, WATER YEAR OCTOBER 1975 TO SEPTEMBER 1976 MEAN VALUES

\begin{tabular}{|c|c|c|c|c|c|c|c|c|c|c|c|c|}
\hline DAY & OCT & NOV & DEC & JAN & FEB & MAR & APR & MAY & JUN & JUL & AUG & SEP \\
\hline $\begin{array}{l}1 \\
2 \\
3 \\
4 \\
5\end{array}$ & $\begin{array}{l}1.1 \\
1.1 \\
.98 \\
.98 \\
.98\end{array}$ & $\begin{array}{l}1.1 \\
1.1 \\
1.1 \\
1.1 \\
1.1\end{array}$ & $\begin{array}{l}1.3 \\
1.3 \\
1.3 \\
1.3 \\
1.3\end{array}$ & $\begin{array}{l}1.4 \\
1.4 \\
1.4 \\
1.4 \\
1.4\end{array}$ & $\begin{array}{l}1.4 \\
1.3 \\
1.3 \\
1.4 \\
3.5\end{array}$ & $\begin{array}{l}3.5 \\
4.7 \\
4.4 \\
4.1 \\
4.1\end{array}$ & $\begin{array}{l}2.5 \\
2.5 \\
2.5 \\
2.7 \\
2.7\end{array}$ & $\begin{array}{l}1.6 \\
1.6 \\
1.6 \\
1.8 \\
1.8\end{array}$ & $\begin{array}{l}1.3 \\
1.2 \\
1 \cdot 2 \\
1.2 \\
1.2\end{array}$ & $\begin{array}{l}.68 \\
.68 \\
.68 \\
.68 \\
.68\end{array}$ & $\begin{array}{l}.61 \\
.61 \\
.61 \\
.61 \\
.61\end{array}$ & $\begin{array}{l}.42 \\
.42 \\
.48 \\
.48 \\
.48\end{array}$ \\
\hline $\begin{array}{r}6 \\
7 \\
8 \\
9 \\
10\end{array}$ & $\begin{array}{l}.98 \\
1.1 \\
1.1 \\
1.1 \\
1.2\end{array}$ & $\begin{array}{l}1.1 \\
1.1 \\
1.1 \\
1.1 \\
1.2\end{array}$ & $\begin{array}{l}1.3 \\
1.3 \\
1.3 \\
1.2 \\
1.2\end{array}$ & $\begin{array}{l}1.4 \\
1.4 \\
1.4 \\
1.4 \\
1.4\end{array}$ & $\begin{array}{l}6.0 \\
5.2 \\
7.5 \\
94 \\
52\end{array}$ & $\begin{array}{l}3.8 \\
3.8 \\
3.8 \\
3.5 \\
3.5\end{array}$ & $\begin{array}{l}2.5 \\
2.5 \\
2.7 \\
2.5 \\
2.5\end{array}$ & $\begin{array}{l}1.8 \\
1.8 \\
1.8 \\
1.6 \\
1.6\end{array}$ & $\begin{array}{l}1.2 \\
1.2 \\
1.1 \\
1.2 \\
1.2\end{array}$ & $\begin{array}{l}.61 \\
.54 \\
.54 \\
.54 \\
.61\end{array}$ & $\begin{array}{l}.61 \\
.54 \\
.54 \\
.54 \\
.48\end{array}$ & $\begin{array}{r}.48 \\
.48 \\
.48 \\
.48 \\
4.2\end{array}$ \\
\hline $\begin{array}{l}11 \\
12 \\
13 \\
14 \\
15\end{array}$ & $\begin{array}{l}1.4 \\
1.4 \\
1.3 \\
1.2 \\
1.2\end{array}$ & $\begin{array}{l}1.2 \\
1.2 \\
1.2 \\
1.2 \\
1.2\end{array}$ & $\begin{array}{l}1.3 \\
1.4 \\
1.5 \\
1.5 \\
1.5\end{array}$ & $\begin{array}{l}1.4 \\
1.4 \\
1.4 \\
1.4 \\
1.4\end{array}$ & $\begin{array}{l}13 \\
8.2 \\
6.0 \\
5.6 \\
5.2\end{array}$ & $\begin{array}{l}3.5 \\
3.2 \\
3.2 \\
3.0 \\
2.7\end{array}$ & $\begin{array}{l}2.2 \\
2.5 \\
2.7 \\
2.5 \\
2.3\end{array}$ & $\begin{array}{l}1.5 \\
1.5 \\
1.4 \\
1.4 \\
1.5\end{array}$ & $\begin{array}{l}1.2 \\
1.2 \\
1.1 \\
1.1 \\
.98\end{array}$ & $\begin{array}{l}.61 \\
.61 \\
.61 \\
.61 \\
.68\end{array}$ & $\begin{array}{l}.48 \\
.48 \\
.54 \\
.61 \\
.68\end{array}$ & $\begin{array}{l}5.2 \\
1.8 \\
1.5 \\
1.3 \\
1.3\end{array}$ \\
\hline $\begin{array}{l}16 \\
17 \\
18 \\
19 \\
20\end{array}$ & $\begin{array}{l}1.2 \\
1.1 \\
1.2 \\
1.2 \\
1.2\end{array}$ & $\begin{array}{l}1.2 \\
1.2 \\
1.2 \\
1.2 \\
1.2\end{array}$ & $\begin{array}{l}1.5 \\
1.4 \\
1.4 \\
1.4 \\
1.4\end{array}$ & $\begin{array}{l}1.4 \\
1.4 \\
1.4 \\
1.4 \\
1.4\end{array}$ & $\begin{array}{l}4.8 \\
4.1 \\
4.1 \\
3.8 \\
3.8\end{array}$ & $\begin{array}{l}2.7 \\
2.7 \\
2.7 \\
2.7 \\
2.5\end{array}$ & $\begin{array}{l}2.0 \\
2.0 \\
2.0 \\
1.8 \\
1.8\end{array}$ & $\begin{array}{l}1.5 \\
1.4 \\
1.4 \\
1.4 \\
1.4\end{array}$ & $\begin{array}{r}.98 \\
.98 \\
.90 \\
.90 \\
.90\end{array}$ & $\begin{array}{l}.68 \\
.68 \\
.68 \\
.68 \\
.68\end{array}$ & $\begin{array}{l}.68 \\
.68 \\
.68 \\
.68 \\
.61\end{array}$ & $\begin{array}{l}1.3 \\
1.3 \\
1.3 \\
1.3 \\
1.3\end{array}$ \\
\hline $\begin{array}{l}21 \\
22 \\
23 \\
24 \\
25\end{array}$ & $\begin{array}{l}1.2 \\
1.2 \\
1.2 \\
1.2 \\
1.2\end{array}$ & $\begin{array}{l}1.2 \\
1.2 \\
1.1 \\
1.1 \\
1.1\end{array}$ & $\begin{array}{l}1.4 \\
1.4 \\
1.4 \\
1.4 \\
1.4\end{array}$ & $\begin{array}{l}1.4 \\
1.4 \\
1.4 \\
1.4 \\
1.4\end{array}$ & $\begin{array}{l}3.5 \\
3.2 \\
3.2 \\
3.2 \\
3.0\end{array}$ & $\begin{array}{l}2.5 \\
2.5 \\
2.5 \\
2.5 \\
2.5\end{array}$ & $\begin{array}{l}1.8 \\
1.8 \\
1.8 \\
1.8 \\
1.8\end{array}$ & $\begin{array}{l}1.4 \\
1.4 \\
1.4 \\
1.4 \\
1.4\end{array}$ & $\begin{array}{r}.90 \\
.82 \\
.82 \\
.75 \\
.75\end{array}$ & $\begin{array}{l}.68 \\
.68 \\
.68 \\
.61 \\
.61\end{array}$ & $\begin{array}{l}.54 \\
.54 \\
.54 \\
.48 \\
.48\end{array}$ & $\begin{array}{l}1.2 \\
1.2 \\
1.2 \\
1.2 \\
1.2\end{array}$ \\
\hline $\begin{array}{l}26 \\
27 \\
28 \\
29 \\
30 \\
31\end{array}$ & $\begin{array}{l}1.2 \\
1.2 \\
1.2 \\
1.1 \\
1.1 \\
1.1\end{array}$ & $\begin{array}{l}1.1 \\
1.2 \\
1.3 \\
1.3 \\
1.3 \\
-.-2\end{array}$ & $\begin{array}{l}1.4 \\
1.4 \\
1.4 \\
1.4 \\
1.4 \\
1.4\end{array}$ & $\begin{array}{l}1.4 \\
1.4 \\
1.4 \\
1.4 \\
1.4 \\
1.4\end{array}$ & $\begin{array}{l}2.7 \\
2.7 \\
2.5 \\
2.7 \\
-. . \\
-.-\end{array}$ & $\begin{array}{l}2.5 \\
2.5 \\
2.5 \\
2.5 \\
2.5 \\
2.5\end{array}$ & $\begin{array}{l}1.8 \\
1.8 \\
1.8 \\
1.8 \\
1.8 \\
-0 .\end{array}$ & $\begin{array}{l}1.3 \\
1.3 \\
1.3 \\
1.3 \\
1.3 \\
1.3\end{array}$ & $\begin{array}{l}.75 \\
.68 \\
.68 \\
.68 \\
.68 \\
.0-\end{array}$ & $\begin{array}{l}.61 \\
.54 \\
.54 \\
.54 \\
.61 \\
.61\end{array}$ & $\begin{array}{l}.42 \\
.42 \\
.42 \\
.42 \\
.42 \\
.42\end{array}$ & $\begin{array}{r}1.2 \\
1.2 \\
1.4 \\
87 \\
6.2 \\
0 .--\end{array}$ \\
\hline $\begin{array}{l}\text { TOTAL } \\
\text { MEAN } \\
\text { MAX } \\
\text { MIN } \\
\text { AC-FT }\end{array}$ & $\begin{array}{r}35.92 \\
1.16 \\
1.4 \\
.98 \\
71\end{array}$ & $\begin{array}{r}35.0 \\
1.17 \\
1.3 \\
1.1 \\
69\end{array}$ & $\begin{array}{r}42.5 \\
1.37 \\
1.5 \\
1.2 \\
84\end{array}$ & $\begin{array}{r}43.4 \\
1.40 \\
1.4 \\
1.4 \\
86\end{array}$ & $\begin{array}{r}258.9 \\
0.93 \\
94 \\
1.3 \\
514\end{array}$ & $\begin{array}{r}95.6 \\
3.08 \\
4.7 \\
2.5 \\
190\end{array}$ & $\begin{array}{r}65.4 \\
2.18 \\
2.7 \\
1.8 \\
130\end{array}$ & $\begin{array}{r}46.2 \\
1.49 \\
1.8 \\
1.3 \\
92\end{array}$ & $\begin{array}{r}29.75 \\
.99 \\
1.3 \\
.68 \\
59\end{array}$ & $\begin{array}{r}19.47 \\
.63 \\
.68 \\
.54 \\
39\end{array}$ & $\begin{array}{r}16.98 \\
.55 \\
.68 \\
.42 \\
34\end{array}$ & $\begin{array}{r}129.00 \\
4.30 \\
87 \\
.42 \\
256\end{array}$ \\
\hline
\end{tabular}


11116550 VENTURA RIVER NEAR MEINERS OAKS, CA

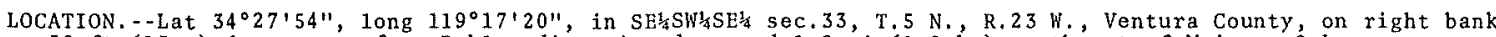
$50 \mathrm{ft}(15 \mathrm{~m})$ downstream from Robles diversion dam, and $1.2 \mathrm{mi}(1.9 \mathrm{~km})$ northwest of Meiners Óaks.

DRAINAGE AREA. $--76.4 \mathrm{mi}^{2}\left(197.9 \mathrm{~km}^{2}\right)$.

PERIOD OF RECORD.--May 1959 to current year.

GAGE. - Water-stage recorder. Datum of gage is $750.00 \mathrm{ft}(228.600 \mathrm{~m})$ above mean sea leve1 (Bureau of Reclamation bench mark). Prior to oct. 30,1969 , at site $500 \mathrm{ft}$ (152 m) downstream at datum $5.40 \mathrm{ft}$ (1.646 m) 10 wer.

REMARKS, - Records good except those above $40 \mathrm{ft}^{3} / \mathrm{s}\left(1.13 \mathrm{~m}^{3} / \mathrm{s}\right)$, which are poor. Flow regulated by Matilija Reservoir, capacity, 3,800 acre-ft $\left(4.69 \mathrm{hm}^{3}\right)$. Flow up to $500 \mathrm{ft} / \mathrm{s}\left(14.2 \mathrm{~m}^{3} / \mathrm{s}\right)$ diverted since May 1959 at Robles diversion dam to Lake Casitas on Coyote Creek. Flow reported herein is that released through gates in Robles diversion dam.

EXTREMES FOR PERIOD OF RECORD.--Maximum discharge, 28,000 $\mathrm{ft}^{3} / \mathrm{s}\left(793 \mathrm{~m}^{3} / \mathrm{s}\right)$, estimated, Jan. 25 , 1969, (gage height, unknown); no flow for several. months in most years.

EXTREMES FOR CURRENT YEAR, --Maximum discharge, $312 \mathrm{ft}^{3} / \mathrm{s}\left(8.84 \mathrm{~m}^{3} / \mathrm{s}\right)$, Sept. 29 , gage height, $3.81 \mathrm{ft}(1.161 \mathrm{~m})$; no flow for several months.

DISCHARGE, IN CUBIC FEET PER SECOND, WATER YEAR OCTOBER 1975 TO SEPTEMBER 1976 MEAN VALUES

\begin{tabular}{|c|c|c|c|c|c|c|c|c|c|c|c|c|}
\hline DAY & $O C T$ & Nov & DEC & JAN & FEB & MAR & APR & MAY & JUN & JUL & AUG & SEP \\
\hline $\begin{array}{l}1 \\
2 \\
3 \\
4 \\
5\end{array}$ & & $\begin{array}{l}0 \\
0 \\
0 \\
0 \\
0\end{array}$ & $\begin{array}{l}0 \\
0 \\
2.1 \\
.10 \\
.05\end{array}$ & $\begin{array}{l}.18 \\
.17 \\
.07 \\
.03 \\
.02\end{array}$ & $\begin{array}{l}0 \\
0.03 \\
.10 \\
3.4\end{array}$ & $\begin{array}{l}20 \\
22 \\
21 \\
18 \\
18\end{array}$ & $\begin{array}{l}5.0 \\
4.8 \\
4.9 \\
5.9 \\
4.5\end{array}$ & $\begin{array}{l}1.1 \\
1.1 \\
1.2 \\
1.0 \\
.75\end{array}$ & & & & $\begin{array}{l}0 \\
0 \\
0 \\
0 \\
0\end{array}$ \\
\hline $\begin{array}{r}6 \\
7 \\
8 \\
9 \\
10\end{array}$ & & $\begin{array}{l}0 \\
0 \\
0 \\
0 \\
0\end{array}$ & $\begin{array}{l}.01 \\
0 \\
0 \\
0\end{array}$ & $\begin{array}{l}.08 \\
.25 \\
.17 \\
.02 \\
0\end{array}$ & $\begin{array}{l}7.3 \\
9.8 \\
13 \\
14 \\
24\end{array}$ & $\begin{array}{l}17 \\
16 \\
16 \\
16 \\
16\end{array}$ & $\begin{array}{l}5.8 \\
5.9 \\
6.1 \\
6.0 \\
6.3\end{array}$ & $\begin{array}{l}1.0 \\
1.3 \\
1.3 \\
1.5 \\
1.4\end{array}$ & & & & $\begin{array}{l}0 \\
0 \\
0 \\
0 \\
0\end{array}$ \\
\hline $\begin{array}{l}11 \\
12 \\
13 \\
14 \\
15\end{array}$ & & $\begin{array}{r}0 \\
.31 \\
.31 \\
.84\end{array}$ & $\begin{array}{l}0 \\
0 \\
0 \\
0 \\
0\end{array}$ & $\begin{array}{l}.12 \\
.04 \\
0 \\
0 \\
0\end{array}$ & $\begin{array}{l}37 \\
35 \\
33 \\
31 \\
32\end{array}$ & $\begin{array}{l}15 \\
15 \\
14 \\
13 \\
11\end{array}$ & $\begin{array}{l}6.1 \\
6.5 \\
7.5 \\
6.7 \\
6.4\end{array}$ & $\begin{array}{r}.84 \\
.76 \\
.33 \\
.32 \\
.11\end{array}$ & & & & $\begin{array}{l}0 \\
0 \\
0 \\
0 \\
0\end{array}$ \\
\hline $\begin{array}{l}16 \\
17 \\
18 \\
19 \\
20\end{array}$ & & $\begin{array}{l}1.8 \\
.38 \\
.04 \\
0 \\
0\end{array}$ & $\begin{array}{l}0 \\
0 \\
0 \\
0 \\
0\end{array}$ & $\begin{array}{l}0.10 \\
.14 \\
.03 \\
0\end{array}$ & $\begin{array}{l}31 \\
34 \\
32 \\
27 \\
26\end{array}$ & $\begin{array}{l}7.4 \\
9.7 \\
9.1 \\
8.8 \\
8.6\end{array}$ & $\begin{array}{l}6.0 \\
5.4 \\
4.3 \\
4.0 \\
3.8\end{array}$ & $\begin{array}{l}0_{0}^{.15} \\
0 \\
0 \\
0\end{array}$ & & & & $\begin{array}{l}.07 \\
.09 \\
.26 \\
.48 \\
.43\end{array}$ \\
\hline $\begin{array}{l}21 \\
22 \\
23 \\
24 \\
25\end{array}$ & & $\begin{array}{l}0 \\
0 \\
0 \\
0 \\
0\end{array}$ & $\begin{array}{l}0 \\
0 \\
0 \\
0 \\
0\end{array}$ & $\begin{array}{l}0 \\
0 \\
0 \\
0 \\
.07\end{array}$ & $\begin{array}{l}25 \\
24 \\
14 \\
15 \\
16\end{array}$ & $\begin{array}{r}8.0 \\
8.0 \\
8.0 \\
9.0 \\
10\end{array}$ & $\begin{array}{l}3.2 \\
2.9 \\
2.7 \\
3.2 \\
2.7\end{array}$ & $\begin{array}{l}0 \\
0.02 \\
0 \\
.03 \\
.02\end{array}$ & & & & $\begin{array}{l}.48 \\
.48 \\
.52 \\
.43 \\
.33\end{array}$ \\
\hline $\begin{array}{l}25 \\
27 \\
28 \\
29 \\
30 \\
31\end{array}$ & & $\begin{array}{l}0 \\
0 \\
0 \\
0 \\
0 \\
-\ldots-\end{array}$ & $\begin{array}{r}.10 \\
.10 \\
.10 \\
.10 \\
0 \quad .05\end{array}$ & $\begin{array}{l}.12 \\
.06 \\
.01 \\
0 \\
0 \\
0\end{array}$ & $\begin{array}{l}16 \\
15 \\
15 \\
15 \\
\end{array}$ & $\begin{array}{l}8.9 \\
6.4 \\
5.6 \\
4.0 \\
5.7 \\
5.8\end{array}$ & $\begin{array}{l}2.4 \\
1.7 \\
1.7 \\
1.6 \\
1.3 \\
-.-1\end{array}$ & $\begin{array}{l}.03 \\
0 \\
0 \\
.06 \\
.53 \\
.36\end{array}$ & $-\cdots$ & & & $\begin{array}{r}.66 \\
.89 \\
1.3 \\
37 \\
14 \\
. .--\end{array}$ \\
\hline $\begin{array}{l}\text { TOTAL } \\
\text { MEAN } \\
\text { MAX }\end{array}$ & $\begin{array}{l}0 \\
0 \\
0\end{array}$ & $\begin{array}{r}14.67 \\
.49 \\
11\end{array}$ & $\begin{array}{r}2.71 \\
.087 \\
2.1\end{array}$ & $\begin{array}{r}1.68 \\
.054 \\
.25\end{array}$ & $\begin{array}{r}544.63 \\
18.8 \\
37\end{array}$ & $\begin{array}{r}371.0 \\
12.0 \\
22\end{array}$ & $\begin{array}{r}135.3 \\
4.51 \\
7.5\end{array}$ & $\begin{array}{r}15.21 \\
: 49 \\
1.5\end{array}$ & $\begin{array}{l}0 \\
0 \\
0\end{array}$ & $\begin{array}{l}0 \\
0 \\
0\end{array}$ & $\begin{array}{l}0 \\
0 \\
0\end{array}$ & $\begin{array}{r}57.42 \\
1.91 \\
37\end{array}$ \\
\hline $\begin{array}{l}M I N \\
A C-F T\end{array}$ & $\begin{array}{l}0 \\
0\end{array}$ & $\begin{array}{r}0 \\
29\end{array}$ & $\begin{array}{r}0 \\
5.4\end{array}$ & $\begin{array}{r}0 \\
3.3\end{array}$ & $\begin{array}{r}0 \\
1080\end{array}$ & $\begin{array}{l}4.0 \\
736\end{array}$ & $\begin{array}{l}1,3 \\
268\end{array}$ & $\begin{array}{r}0 \\
30\end{array}$ & $\begin{array}{l}0 \\
0\end{array}$ & $\begin{array}{l}0 \\
0\end{array}$ & $\begin{array}{l}0 \\
0\end{array}$ & $\begin{array}{r}0 \\
114\end{array}$ \\
\hline
\end{tabular}

CAL YR 1975 TOTAL 2987.59 MEAN 8.19 MAX 790 MIN 0 AC-FT 5930 WTR YR 1976 TOTAL 1142.62 MEAN 3.12 MAX 37 MIN 0 AC-FT 2270 
LOCATION (REVISED) .--Lat $34^{\circ} 22^{\prime} 49^{\prime \prime}$, long $119^{\circ} 18^{\prime} 13^{\prime \prime}$, in Santa Ana Grant, Ventura County, on left bank downstream side of bridge on State Highway $33,0.2 \mathrm{mi}(0.3 \mathrm{~km})$ upstream from mouth, and 0.9 mi (1.4 km) north of Casitas Springs. DRAINAGE AREA, $--51.2 \mathrm{mi}^{2}\left(132.6 \mathrm{~km}^{2}\right)$.

PERIOD OF RECORD, - -October 1949 to current year.

GAGE, - Water-stage recorder. Datum of gage is $306.72 \mathrm{ft}(93.488 \mathrm{~m})$ above mean sea 1 evel (1eve1s by Ventura County Flood Control District). Prior to Jan. 30,1962 , at datum $0.83 \mathrm{ft}(0.253 \mathrm{~m})$ higher.

REMARKS.--No regulation above station; pumping from we11s $100 \mathrm{ft}$ (30 m) upstream for irrigation during summer months. COOPERATION.-- Records were furnished by Ventura County Flood Control District; one discharge measurement was made and records were reviewed by Geological Survey.

AVERAGE DISCHARGE. --27 years, $11.0 \mathrm{ft}^{3} / \mathrm{s}\left(0.312 \mathrm{~m}^{3} / \mathrm{s}\right), 7,970 \mathrm{acre}-\mathrm{ft} / \mathrm{yr}\left(9.83 \mathrm{hm} / \mathrm{yr}^{3}\right)$.

EXTREMES FOR PERIOD OF RECORD.--Maximum discharge, $16,200 \mathrm{ft}^{3} / \mathrm{s}\left(459 \mathrm{~m}^{3} / \mathrm{s}\right) \mathrm{Jan}$. 25, $1969, \mathrm{gage} \mathrm{height}$, $14.30 \mathrm{ft}$ $(4.359 \mathrm{~m})$, from inside gage, from rating curve extended above $2,000 \mathrm{ft}^{3} / \mathrm{s}\left(56.6 \mathrm{~m}^{3} / \mathrm{s}\right)$ on basis of $\mathrm{s} 10 \mathrm{pe}-\mathrm{area}$ measurement of maximum flow; no flow for several months in most years.

EXTREMES FOR CURRENT YEAR. - -Peak discharges above base of $200 \mathrm{ft}^{3} / \mathrm{s}\left(5.66 \mathrm{~m}^{3} / \mathrm{s}\right)$ and maximum (*):

\begin{tabular}{|c|c|c|c|c|c|}
\hline Date & Time & $\begin{array}{r}D i s c h \\
\left(\mathrm{ft}^{3} / \mathrm{s}\right)\end{array}$ & $\underset{\left(\mathrm{m}^{3} / \mathrm{s}\right)}{\operatorname{arge}}$ & $\begin{array}{l}\text { Gage } \\
\text { (ft) }\end{array}$ & $\begin{array}{r}\text { height } \\
\text { (m) }\end{array}$ \\
\hline eb. 9 & $\begin{array}{l}0700 \\
0600\end{array}$ & $\begin{array}{r}300 \\
* 1040\end{array}$ & $\begin{array}{r}8.50 \\
29.5\end{array}$ & $\begin{array}{l}7.12 \\
8.30\end{array}$ & $\begin{array}{l}2.170 \\
2.530\end{array}$ \\
\hline
\end{tabular}

Minimum daily discharge, no flow July 14, 15, July 17 to Sept. 9, Sept. 13-19.

DISCHARGE, IN CUBIC FEET PER SECONO, WATER YEAR OCTOBER 1975 TO SEPTEMBER 1976 MEAN VALUES

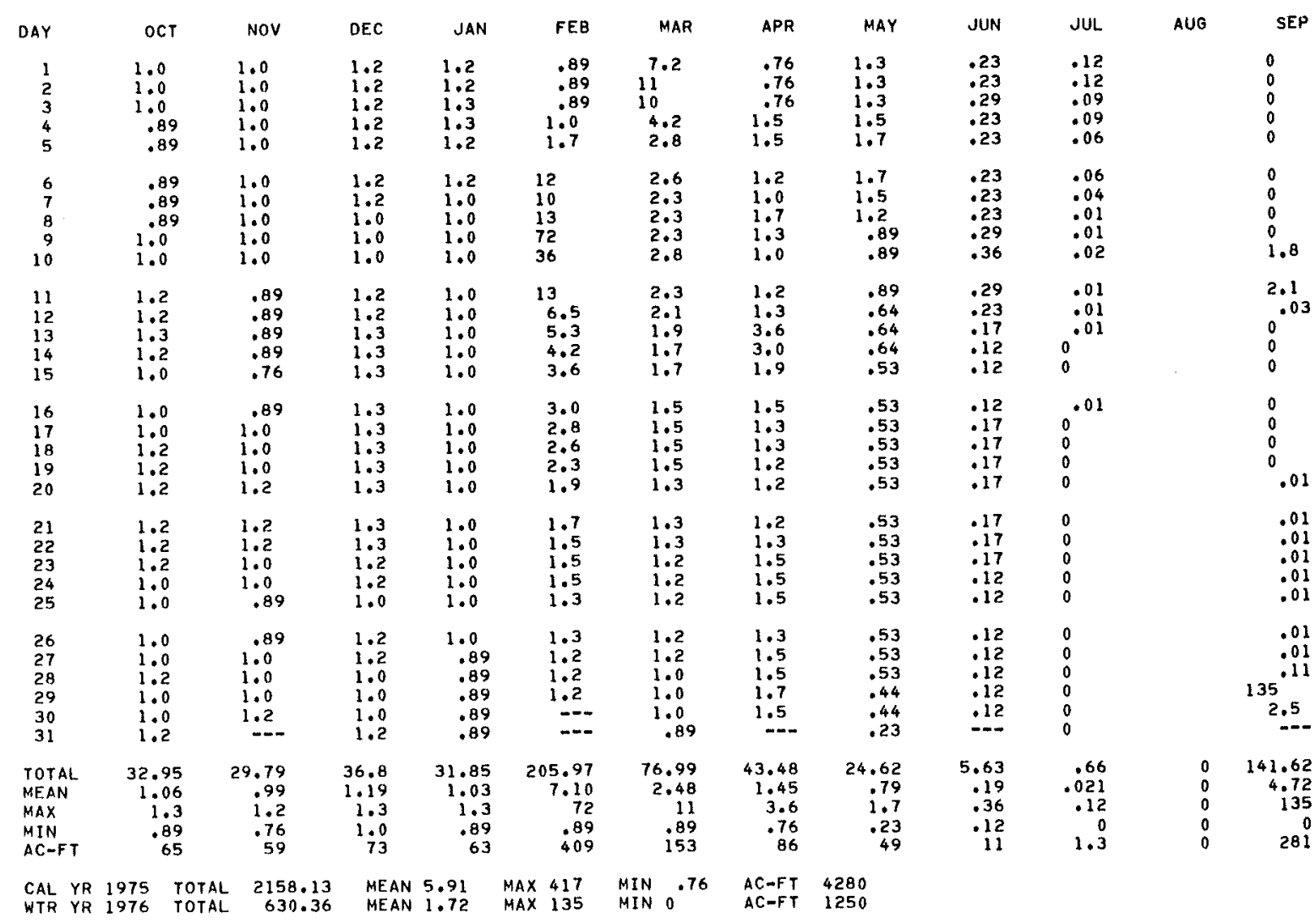


11117600 COYOTE CREEK NEAR OAK VIEW, CA

LOCATION.--Lat $34^{\circ} 25^{\prime} 02^{\prime \prime}$, long $119^{\circ} 22^{\prime} 01^{\prime \prime}$, in Santa Ana Grant, Ventura County, on right bank 1,000 ft (305 m) downstream from Los Padres National Forest boundary, $0.6 \mathrm{mi}(1.0 \mathrm{~km})$ upstream from poplin Creek, and $4.2 \mathrm{mi}$ $(6.8 \mathrm{~km})$ northwest of oak view.

DRAINAGE AREA. $--13.2 \mathrm{mi}^{2}\left(34.2 \mathrm{~km}^{2}\right)$.

PERIOD OF RECORD. - - October 1958 to current year.

GAGE. - Water-stage recorder. Datum of gage is $560.47 \mathrm{ft}(17.0 .831 \mathrm{~m}$ ) above mean sea level (Bureau of Reclamation bench mark).

REMARKS. - -Records good. No regulation or diversion above station.

AVERAGE DISCHARGE. - -18 years, $6.36 \mathrm{ft}^{3} / \mathrm{s}\left(0.180 \mathrm{~m}^{3} / \mathrm{s}\right), 4,610 \mathrm{acre}-\mathrm{ft} / \mathrm{yr}\left(5.68 \mathrm{hm} / \mathrm{yr}^{3}\right)$.

EXTREMES FOR PERIOD OF RECORD, --Maximum discharge, $8,000 \mathrm{ft}^{3} / \mathrm{s}\left(227 \mathrm{~m}^{3} / \mathrm{s}\right) \mathrm{Jan}$. 25 , 1969 , gage height,

$12.00 \mathrm{ft}(3.658 \mathrm{~m})$, from floodmarks, from rating curve extended above $2,100 \mathrm{ft} / \mathrm{s}(59.5 \mathrm{~m} / \mathrm{s}) \mathrm{on}^{3}$

basis of slope-area measurements at gage heights $9.10 \mathrm{ft}(2.774 \mathrm{~m})$ and $12.00 \mathrm{ft}(3.658 \mathrm{~m}) ; \mathrm{no} \mathrm{flow}$ at

times in some years.

EXTREMES FOR CURRENT YEAR. - Peak discharges above base of $150 \mathrm{ft}^{3} / \mathrm{s}\left(4.25 \mathrm{~m}^{3} / \mathrm{s}\right)$ and maximum (*)

\begin{tabular}{lrrrrr} 
& & \multicolumn{2}{c}{ Discharge } & \multicolumn{2}{c}{ Gage Height } \\
Date & Time & $\left(\mathrm{ft}^{3} / \mathrm{s}\right)$ & $\left(\mathrm{m}^{3} / \mathrm{s}\right)$ & $(\mathrm{ft})$ & $(\mathrm{m})$ \\
& & & & & \\
Feb. 9 & 2400 & 690 & 19.5 & 7.11 & 2.167 \\
Sept. 29 & 0430 & 304 & 8.61 & 6.23 & 1.899
\end{tabular}

Minimum daily discharge, $0.04 \mathrm{ft}^{3} / \mathrm{s}\left(0.001 \mathrm{~m}^{3} / \mathrm{s}\right)$ Aug. $26,27,30,31$.

DISCHARGE, IN CUBIC FEET PER SECOND, WATER YEAR OCTOBER 1975 TO SEPTEMBER 1976 MEAN VALUES

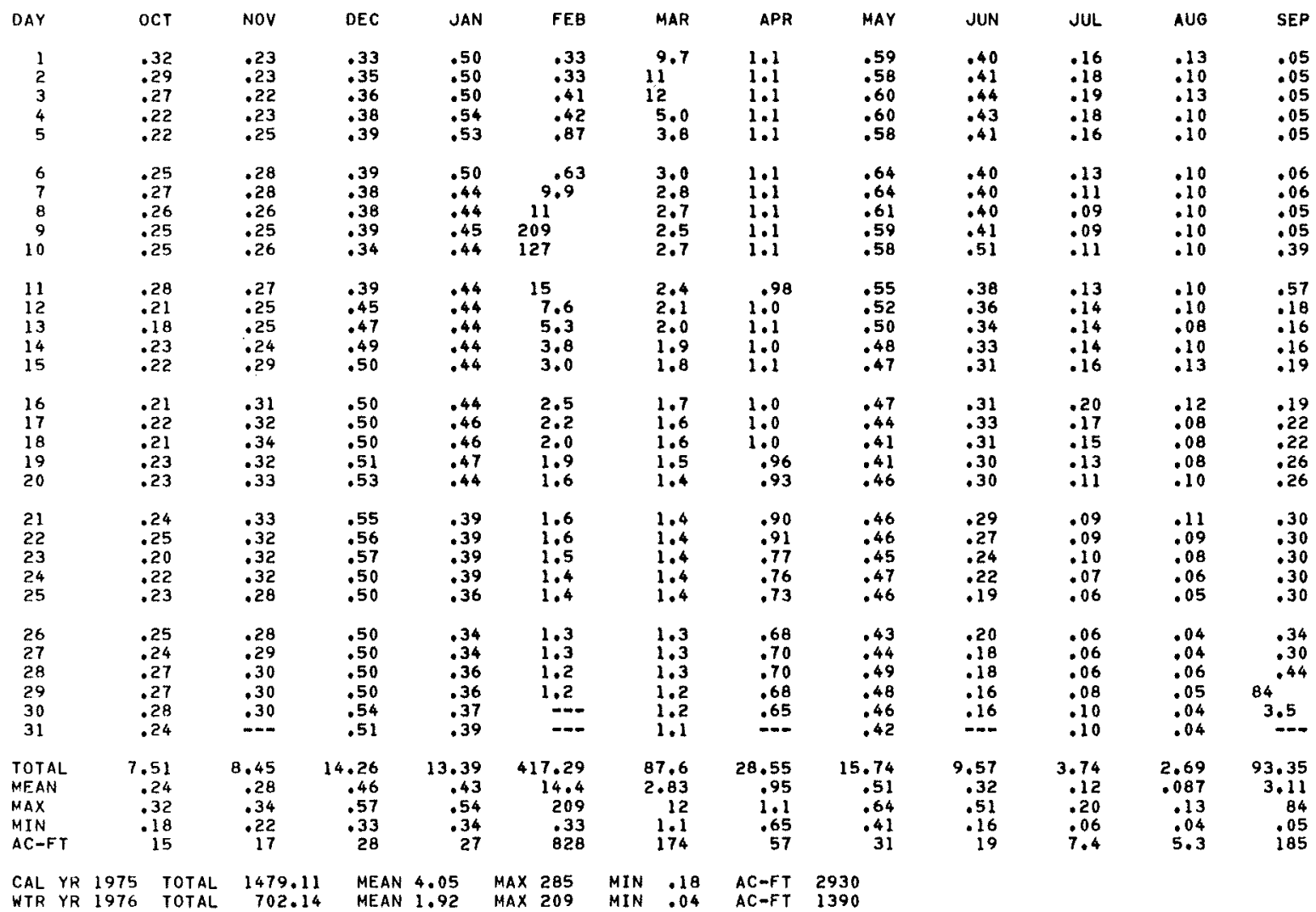


LOCATION. - Lat $34^{\circ} 25^{\prime} 25^{\prime \prime}$, long $119^{\circ} 20^{\prime} 25^{\prime \prime}$, in Santa Ana Grant, Ventura County, on upstream end of right abutment of bridge on Santa Ana Road (revised), $400 \mathrm{ft}(122 \mathrm{~m})$ upstream from unnamed tributary, and $3.0 \mathrm{mi}$ ( $4.8 \mathrm{~km})$ northwest of oak View.

DRAINAGE AREA. $--9.11 \mathrm{mi}^{2}\left(23.6 \mathrm{~km}^{2}\right)$.

PERIOD OF RECORD. - October 1958 to current year.

GAGE. - Water-stage recorder. Datum of gage is $612.43 \mathrm{ft}(186.669 \mathrm{~m}$ ) above mean sea leve1 (Bureau of Reclamation bench mark). Prior to Aug. 17, 1970, on downstream end of right abutment at same datum.

REMARKS. - - Records fair. No regulation or diversion above station.

COOPERATION,--One discharge measurement was furnished by Casitas Municipal Water District.

AVERAGE DISCHARGE, -18 years, $5.19 \mathrm{ft}^{3} / \mathrm{s}\left(0.147 \mathrm{~m}^{3} / \mathrm{s}\right), 3,760 \mathrm{acre}-\mathrm{ft} / \mathrm{yr}\left(4.64 \mathrm{hm}^{3} / \mathrm{yr}^{2}\right)$.

EXTREMES FOR PERIOD OF RECORD,--Maximum discharge, $4,730 \mathrm{ft}^{3} / \mathrm{s}\left(134 \mathrm{~m}^{3} / \mathrm{s}\right) \mathrm{Jan}, 25,1969$, gage height, $10.70 \mathrm{ft}$

$(3.261 \mathrm{~m})$; no flow at times in each year.

EXTREMES OUTSIDE PERIOD OF RECORD.--Maximum discharge, 3,780 $\mathrm{ft}^{3} / \mathrm{s}\left(107 \mathrm{~m}^{3} / \mathrm{s}\right) \mathrm{Mar}$. 2, 1938 , by slope-area measurement at site $2.0 \mathrm{mi}(3.2 \mathrm{~km})$ downstream.

EXTREMES FOR CURRENT YEAR. - - Peak discharges above base of $150 \mathrm{ft}^{3} / \mathrm{s}\left(4.25 \mathrm{~m}^{3} / \mathrm{s}\right)$ and maximum (*):

\begin{tabular}{|c|c|c|c|c|c|}
\hline Date & Time & $\begin{array}{r}\text { Disc } \\
\left(\mathrm{ft}^{3} / \mathrm{s}\right.\end{array}$ & $\underset{\left(\mathrm{m}^{3} / \mathrm{s}\right)}{\mathrm{rge}}$ & $\begin{array}{l}\text { Gage } \\
\text { (ft) }\end{array}$ & $\begin{array}{r}\text { height } \\
(\pi I)\end{array}$ \\
\hline $\begin{array}{lr}\text { eb. } & 9 \\
\text { ept. } & 29\end{array}$ & $\begin{array}{l}2300 \\
0330\end{array}$ & $\begin{array}{r}445 \\
\star 767\end{array}$ & $\begin{array}{l}12.6 \\
21.7\end{array}$ & $\begin{array}{l}5.30 \\
5.86\end{array}$ & $\begin{array}{l}1.615 \\
1.786\end{array}$ \\
\hline
\end{tabular}

Minimum daily discharge, no flow many months.

DISCHAREE, IN CUAIC FEET PER SECONB, WATER YEAR OCTOBER 1975 TO SEPTEMBER 1976 MEAN VALUES

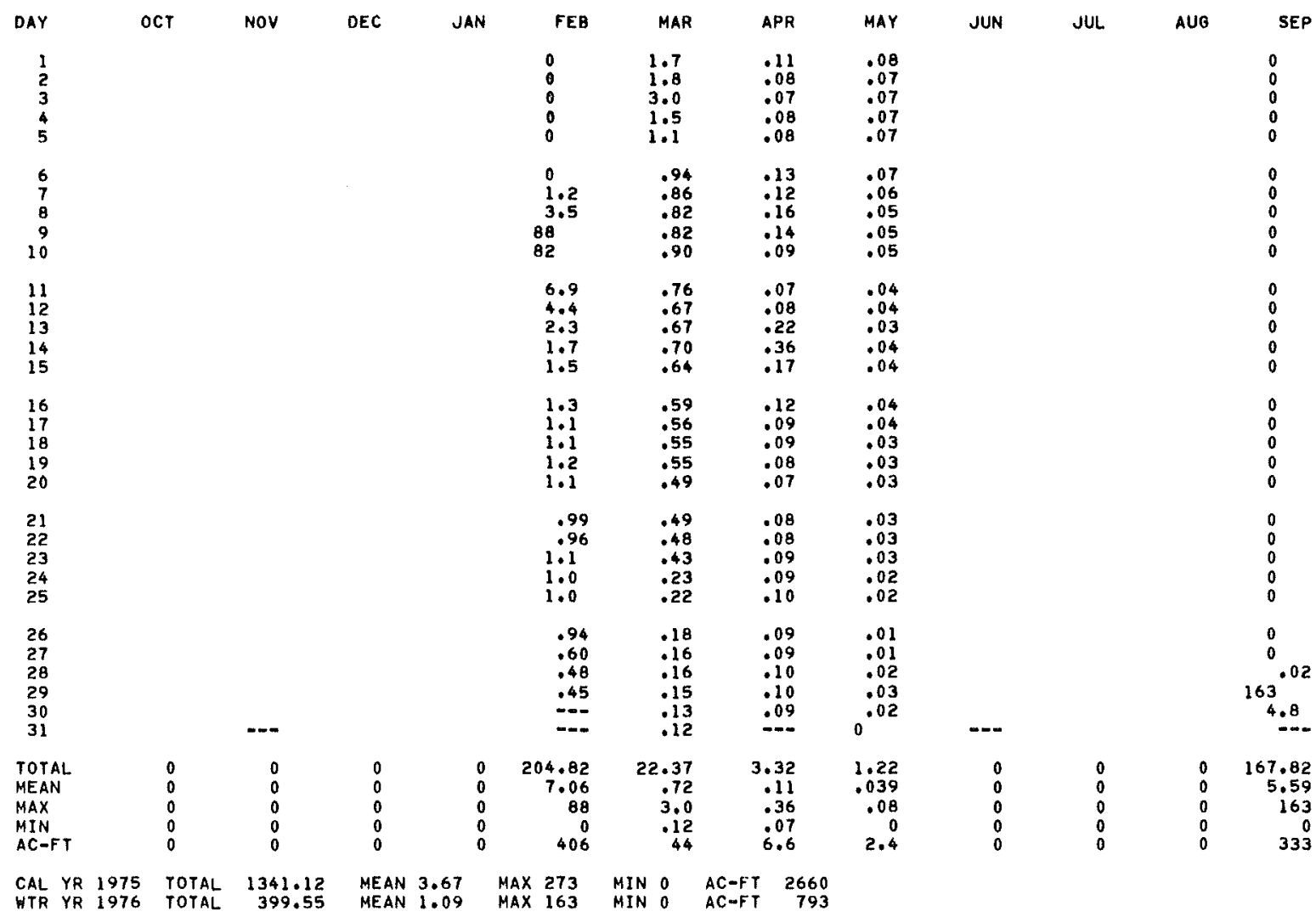


11118000 COYOTE CREEK NEAR VENTURA, CA

LOCATION, - Lat $34^{\circ} 21^{\prime} 26^{\prime \prime}$, long $119^{\circ} 18^{\prime} 46^{\prime \prime}$, near southeast corner of Santa Ana Grant, Ventura County, on right bank $200 \mathrm{ft}(61 \mathrm{~m})$ downstream from bridge on Santa Ana Road, $0.3 \mathrm{mi}(0.5 \mathrm{~km})$ upstream from mouth, and

$5.5 \mathrm{mi}(8.8 \mathrm{~km})$ northwest of Ventura.

DRAINAGE AREA. $--41.2 \mathrm{mi}^{2}\left(106.7 \mathrm{~km}^{2}\right)$.

PERIOD OF RECORD, - -October 1927 to September 1932, October 1933 to September 1958, October 1969 to current year.

GAGE.--Water-stage recorder. Datum of gage is $224.95 \mathrm{ft}(68.565 \mathrm{~m})$ above mean sea leve 1 (Ventura County Flood Control bench mark). See WSP 1735 for history of changes prior to Oct. 1, 1969.

REMARKS. - -Records good. Flow mostly, regulated by Casitas Reservoir since October 1959, capacity, 267,000 acre-ft $\left(329 \mathrm{hm}^{3}\right)$.

AVERAGE DISCHARGE, - -30 years (water years $1928-32,1934-58), 13.2 \mathrm{ft}^{3} / \mathrm{s}\left(0.374 \mathrm{~m}^{3} / \mathrm{s}\right), 9.560 \mathrm{acre}-\mathrm{ft} / \mathrm{yr}\left(11.8 \mathrm{hm} / \mathrm{yr}^{3}\right)$. EXTREMES FOR PERIOD OF RECORD. - Maximum discharge, $11,500 \mathrm{ft}^{3} / \mathrm{s}\left(326 \mathrm{~m}^{3} / \mathrm{s}\right)$ Mar. 2 , 1938 , on basis of $\mathrm{s} l$ ope-area measurement of maximum flow; no flow at times in some years.

EXTREMES FOR CURRENT YEAR, - Maximum discharge, $43 \mathrm{ft}^{3} / \mathrm{s}\left(1.22 \mathrm{~m}^{3} / \mathrm{s}\right)$ Sept. 29 , gage height, $7.36 \mathrm{ft}$ (2.243 m); no flow several months.

DISCHARGE, IN CUBIC FEET PER SECOND, HATER YEAR OCTOBER 1975 TO SEPTEMBER 1976 MEAN VALUES

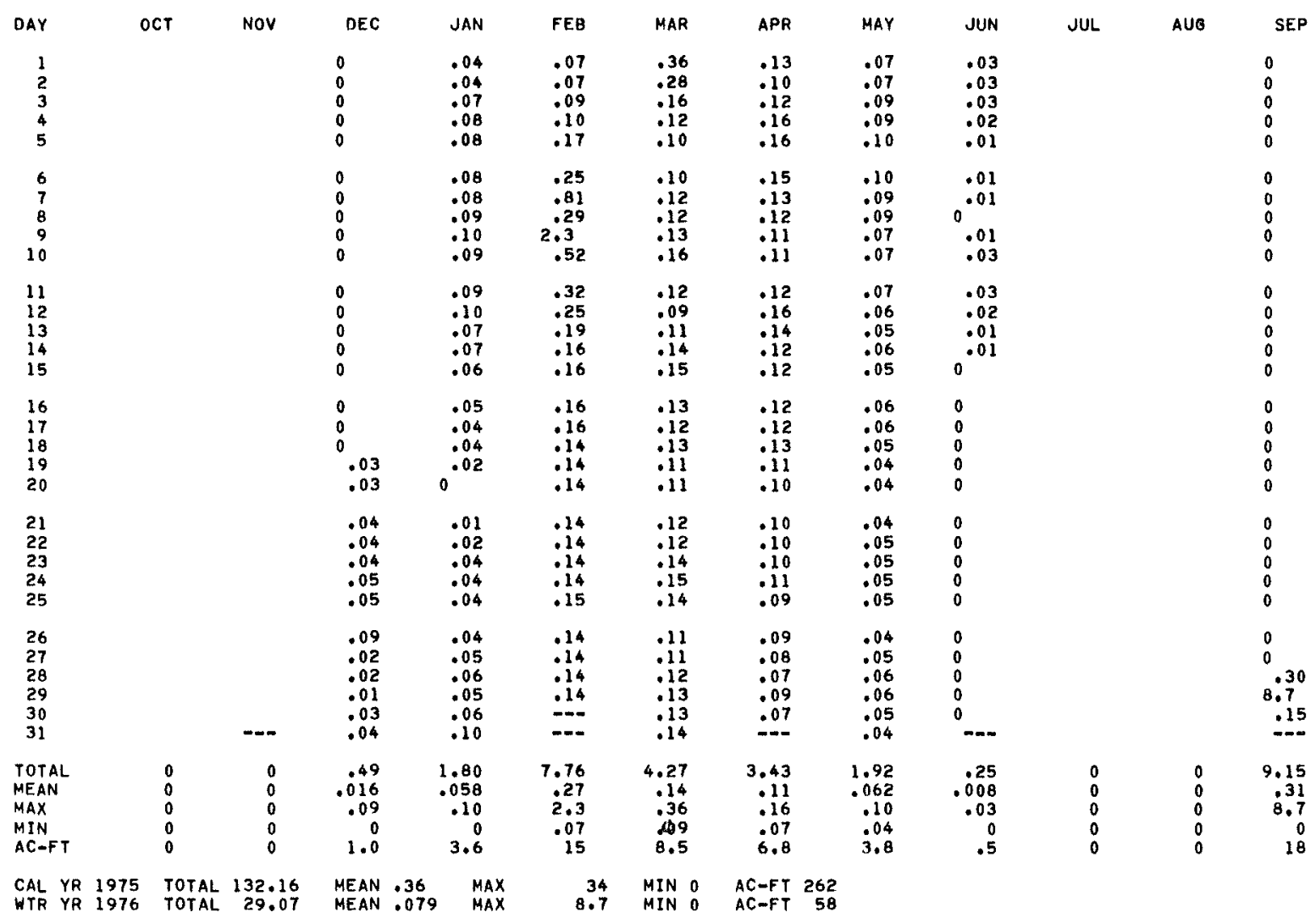


LOCATION.--Lat $34^{\circ} 21^{\prime} 08^{\prime \prime}$, long $119^{\circ} 18^{\prime} 27^{\prime \prime}$, in southeast corner of Santa Ana Grant, Ventura County, on right bank $50 \mathrm{ft}(15 \mathrm{~m})$ downstream from bridge on Casitas pass Road (revised) at Foster Memorial Park, $0.2 \mathrm{mi}(0.3 \mathrm{~km})$ downstream from Coyote Creek, and $5 \mathrm{mi}(8 \mathrm{~km})$ north of Ventura.

DRAINAGE AREA.--188 $\mathrm{mi}^{2}\left(487 \mathrm{~km}^{2}\right)$.

WATER-DISCHARGE RECORDS

PERIOD OF RECORD,--September 1911 to January 1914, October 1929 to current year; combined records of river and diversion, October 1932 to current year.

GAGE. - Water-stage recorder on river; water-stage recorder and parsha11 flume on diversion. Datum of gage is $205.23 \mathrm{ft}(62.554 \mathrm{~m})$ above mean sea level (Ventura County Flood Control bench mark). See wSP $1315-\mathrm{B}$ for history of changes prior to Nov. 2, 1949. Nov. 2, 1949, to June 12, 1969, at site 450 ft (137 m) downstream at datum $4.00 \mathrm{ft}(1.219 \mathrm{~m})$ lower.

REMARKS.--Records fair. F1ow partly regulated since March 1948 by Matilija Reservoir, capacity, 3,800 acre-ft $\left(4.69 \mathrm{hm}^{3}\right)$ and since October 1959 by Casitas Reservoir, capacity, 267,000 acre-ft (329 hm $\left.{ }^{3}\right)$. Water diverted to Casitas Reservoir on Coyote Creek since January 1959. Diversion by city of Ventura for municipal supply began prior to 1911. AVERAGE DISCHARGE (River only) represents flow to ocean regardless of upstream development. For records of combined discharge of river and Ventura City diversion, see following page.

AVERAGE DISCHARGE.--River on $1 \mathrm{y}: 49$ years (water years $1912-13,1930-76), 53.9 \mathrm{ft} / \mathrm{s}\left(1.526 \mathrm{~m}^{3} / \mathrm{s}\right), 39,050 \mathrm{acre-ft} / \mathrm{yr}$ $\left(48.1 \mathrm{hm}^{3} / \mathrm{yr}\right)$.

Combined river and diversion: 44 years, $62.9 \mathrm{ft}^{3} / \mathrm{s}\left(1.781 \mathrm{~m}^{3} / \mathrm{s}\right), 45,570 \mathrm{acre}-\mathrm{ft} / \mathrm{yr}(56.2 \mathrm{hm} / \mathrm{yr})$.

EXTREMES FOR PERIOD OF RECORD.--River on 1y: Maximum discharge, 58,000 $\mathrm{ft}^{3} / \mathrm{s}\left(1,640 \mathrm{~m}^{3} / \mathrm{s}\right) \mathrm{Jan}$. $25,1969, \mathrm{gage}$ height, $24.3 \mathrm{ft}(7.41 \mathrm{~m})$, present datum, from floodmarks, from rating curve extended above $19,600 \mathrm{ft} / \mathrm{s}$ $\left(555 \mathrm{~m}^{3} / \mathrm{s}\right)$ on basis of contracted-opening measurement of maximum flow; no flow at times in many years. Combined river and diversion: Maximum discharge, $58,000 \mathrm{ft}^{3} / \mathrm{s}\left(1,640 \mathrm{~m}^{3} / \mathrm{s}\right) \mathrm{Jan}$. 25, $1969 ; \mathrm{minimum} \mathrm{daily,}$ $0.10 \mathrm{ft}^{3} / \mathrm{s}\left(0.003 \mathrm{~m}^{3} / \mathrm{s}\right)$ Sept. $3,4,13,1961$

EXTREMES FOR CURRENT YEAR.--River only: Maximum discharge, 1,990 ft $\mathrm{f}^{3} / \mathrm{s}\left(56.4 \mathrm{~m}^{3} / \mathrm{s}\right) \mathrm{Sept}$. 29 , gage height, 8.58 ft $(2.615 \mathrm{~m})$; no flow for several months.

Combined river and diversion: Maximum discharge, 2,000 $\mathrm{ft}^{3} / \mathrm{s}\left(56.6 \mathrm{~m}^{3} / \mathrm{s}\right) \mathrm{Sept}$. 29; minimum dai1y, $4.1 \mathrm{ft} / \mathrm{s}$ $\left(0.12 \mathrm{~m}^{3} / \mathrm{s}\right)$ Feb. 16

DISCHARGE, IN CUBIC FEET PER SECOND, WATER YEAR OCTOBER 1975 TO SEPTEMBER 1976 MEAN VALUES

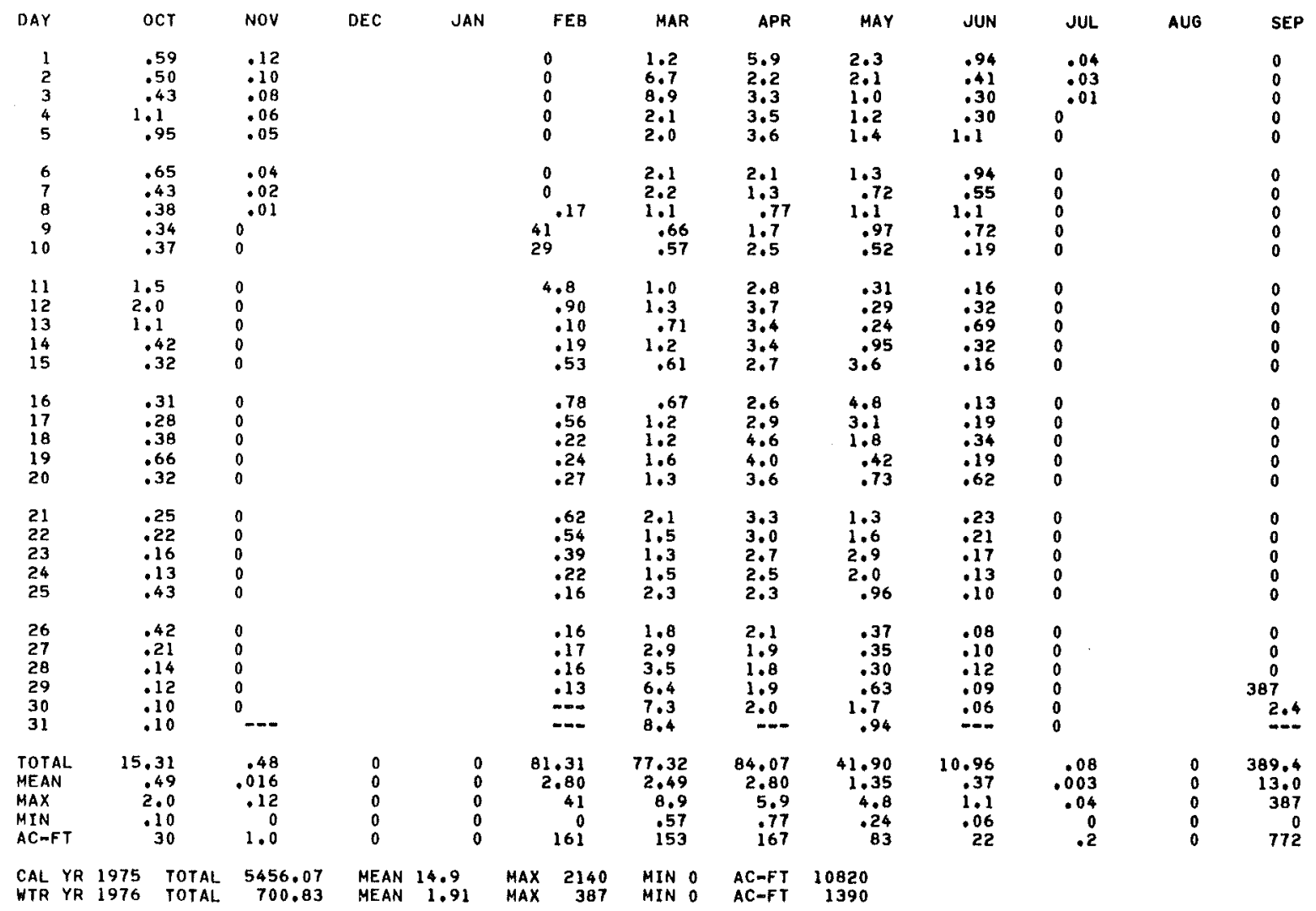


11118500 VENTURA RIVER NEAR VENTURA, CA--Continued

COMBINED DISCHARGE, IN CUBIC FEET PER SECOND, OF VENTURA RIVER AND VENTURA

CITY DIVERSION NEAR VENTURA, CA, WATER YEAR OCTOBER 1975 TO SEPTEMBER 1976

DISCHARGE, IN CUBIC FEET PER SECOND, WATER YEAR OCTOBER 1975 TO SEPTEMBER 1976 MEAN VALUES

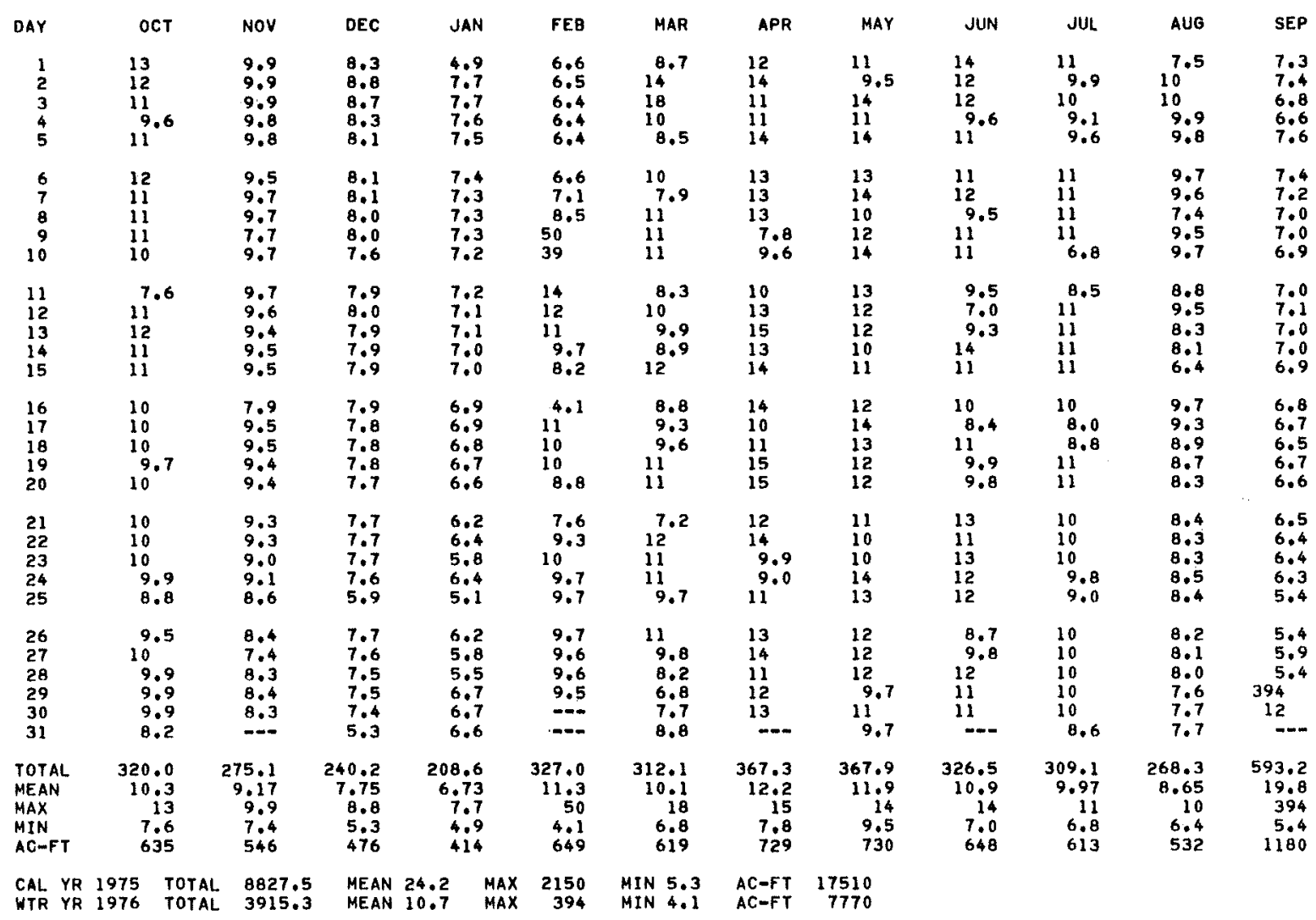


PERIOD OF RECORD,--December 1907 to December 1908 , water years 1967 to current year. CHEMICAL ANALYSES: December 1907 to December 1908, water years 1967 to current year. WATER TEMPERATURES: Water years $1969,1971-73,1975$ to current year.

SEDIMENT RECORDS: Water years $1969-73,1975$ to current year.

PERIOD OF DAILY RECORD, --

SEDIMENT RECORDS: October 1968 to September 1973 , October 1974 to current year.

WATER TEMPERATURES: October 1968 to September 1969, October 1970 to September 1973, October 1975 to current year.

COOPERATION. - - Chemical-quality data were furnished by California Department of Water Resources .

EXTREMES FOR PERIOD OF DAILY RECORD. -

SEDIMENT CONCENTRATIONS: Maximum daily mean, 32,000 mg/1 (estimated) Jan. 25, 1969; minimum daily mean, no f1ow for many days most years.

SEDIMENT DISCHARGE: Maximum dai1y, 2,220,000 tons (2,014,000 tonnes), estimated Jan. 25, 1969; minimum daily, 0 tons on many days most years.

EXTREMES FOR CURRENT YEAR.--

SEDIMENT CONCENTRATIONS: Maximum daily mean, $706 \mathrm{mg} / 1$ Sept. 29; minimum daily mean, no flow for many days

SEDIMENT DISCHARGE: Maximum dai1y, 1,540 tons ( 1,400 tonnes) Sept. 29 ; minimum daily, 0 tons on many days most years.

CHEMICAL ANALYSES, HATER YEAR OCTOBER 1975 TO SEPTEMBER 1976

\begin{tabular}{|c|c|c|c|c|c|c|c|}
\hline DATE & TIME & $\begin{array}{l}\text { INSTAN- } \\
\text { TANEOUS } \\
\text { DIS- } \\
\text { CHARGE } \\
\text { (CFS) }\end{array}$ & $\begin{array}{l}\text { SPE- } \\
\text { CIFIC } \\
\text { CON- } \\
\text { DUCT- } \\
\text { ANCE } \\
\text { (MICRO- } \\
\text { MHOS) }\end{array}$ & $\begin{array}{c}\text { PH } \\
\text { (UNITS) }\end{array}$ & $\begin{array}{l}\text { TEMPER- } \\
\text { ATURE } \\
\text { (DEG C) }\end{array}$ & $\begin{array}{l}\text { TUR- } \\
\text { BID- } \\
\text { ITY } \\
\text { (JTU) }\end{array}$ & $\begin{array}{l}\text { DIS- } \\
\text { SOLVEO } \\
\text { OXYGEN } \\
\text { (MG/L) }\end{array}$ \\
\hline $\begin{array}{l}\text { APR } \\
19 . .\end{array}$ & 0830 & 4.5 & 1000 & 7.6 & 14.5 & 0 & 8.2 \\
\hline DATE & $\begin{array}{l}\text { HARD- } \\
\text { NESS } \\
\text { (CA,MG) } \\
(M G / L)\end{array}$ & $\begin{array}{c}\text { DIS- } \\
\text { SOLVED } \\
\text { SULFATE } \\
\text { (SOA) } \\
\text { (MG/L) }\end{array}$ & $\begin{array}{l}\text { DIS- } \\
\text { SOLVED } \\
\text { CHLO } \\
\text { RIDE } \\
(C L) \\
(M G / L)\end{array}$ & $\begin{array}{l}\text { DIS- } \\
\text { SOLVED } \\
\text { SOLIDS } \\
\text { (RESI - } \\
\text { DUE AT } \\
\text { IBO C) } \\
\text { (MG/L) }\end{array}$ & $\begin{array}{l}\text { DIS- } \\
\text { SOLVED } \\
\text { SOL IDS } \\
\text { (TONS } \\
\text { PER } \\
\text { AC-FT) }\end{array}$ & $\begin{array}{l}\text { DIS- } \\
\text { SOLVED } \\
\text { SOLIDS } \\
\text { (TONS } \\
\text { PER } \\
\text { DAY) }\end{array}$ & \\
\hline $\begin{array}{l}\text { APR } \\
19 . . .\end{array}$ & 450 & 258 & 46 & 747 & 1.02 & 9.08 & \\
\hline
\end{tabular}

TEMPERATURE (DEG, C) OF WATER, HATER YEAR OCTOBER 1975 TO SEPTEMEER 1976

\begin{tabular}{|c|c|c|c|c|c|c|c|c|c|c|c|c|}
\hline DAY & OCT & NOV & DEC & JAN & FEB & MAR & APR & MAY & JUN & JUL & AUG & SEP \\
\hline $\begin{array}{l}1 \\
2 \\
3 \\
4 \\
5\end{array}$ & 20.0 & $\begin{array}{r}-\infty \\
15.0 \\
=-\infty\end{array}$ & & & $\begin{array}{l}=-\infty \\
=-\infty \\
=-\infty \\
=-\infty\end{array}$ & $\begin{array}{r}14.0 \\
13.0 \\
9.0 \\
10.0 \\
\end{array}$ & - & $\begin{array}{r}21.0 \\
- \\
-\end{array}$ & $\begin{array}{r}22.0 \\
=- \\
=- \\
=-\end{array}$ & $\begin{array}{r}22.0 \\
\cdots \\
\cdots\end{array}$ & & $=$ \\
\hline $\begin{array}{r}6 \\
7 \\
8 \\
9 \\
10\end{array}$ & $\begin{array}{l}=- \\
=-\overline{-} \\
=-\end{array}$ & $\begin{array}{r}-0 \\
15.0 \\
-0\end{array}$ & & & $\begin{array}{l} \\
14.0 \\
13.0 \\
12.0\end{array}$ & $\begin{array}{l}=0 \\
15.0 \\
14.0\end{array}$ & $\begin{array}{l}-0 \\
18.0 \\
-0\end{array}$ & $\begin{array}{r}17.0 \\
- \\
-\end{array}$ & $\begin{array}{r}20.0 \\
=- \\
=-\end{array}$ & $=$ & & $\begin{array}{l}=-0 \\
=-0 \\
=-- \\
=--\end{array}$ \\
\hline $\begin{array}{l}11 \\
12 \\
13 \\
14 \\
15\end{array}$ & $\begin{array}{r}19.0 \\
-0- \\
-\end{array}$ & $=$ & & & $\begin{array}{r}11.0 \\
- \\
--\end{array}$ & 17.0 & $\begin{array}{r}-\infty- \\
--- \\
=-- \\
17.0\end{array}$ & $\begin{array}{r}21.0 \\
- \\
-\end{array}$ & $\begin{array}{r}19.0 \\
=- \\
=-\infty \\
=-\infty\end{array}$ & $\begin{array}{l}=- \\
=- \\
=-\end{array}$ & & $\begin{array}{l}=-- \\
=-- \\
=-- \\
=--\end{array}$ \\
\hline $\begin{array}{l}16 \\
17 \\
18 \\
19 \\
20\end{array}$ & $\begin{array}{r}18.0 \\
- \\
-\end{array}$ & $\begin{array}{l}=-0 \\
=-0 \\
=-0\end{array}$ & & & $\begin{array}{r}15.0 \\
=- \\
=-\end{array}$ & 17.0 & $\begin{array}{l}-\infty \\
=-\infty \\
=-- \\
=-- \\
-\infty-\end{array}$ & $\begin{array}{r}20.0 \\
-\infty \\
-\infty\end{array}$ & $\begin{array}{r}19.0 \\
=- \\
=-0\end{array}$ & $\begin{array}{l}=-0 \\
=-0 \\
=-\infty \\
--\end{array}$ & & $=$ \\
\hline $\begin{array}{l}21 \\
22 \\
23 \\
24 \\
25\end{array}$ & $\begin{array}{r}-=- \\
17.0 \\
-\infty\end{array}$ & $=$ & & & $\begin{array}{r}16.0 \\
=-0 \\
=-0 \\
=-\end{array}$ & $=$ & $\begin{array}{r}19.0 \\
- \\
-\end{array}$ & $\begin{array}{r}-\infty \\
21.0 \\
-\infty\end{array}$ & $\begin{array}{r}22.0 \\
20 \\
20.5\end{array}$ & $\begin{array}{l}--\infty \\
=-\infty \\
=-\infty\end{array}$ & & $\begin{array}{l}=-- \\
-\infty- \\
-\infty-\end{array}$ \\
\hline $\begin{array}{l}26 \\
27 \\
28 \\
29 \\
30 \\
31\end{array}$ & $\begin{array}{r}-\infty \\
16.0 \\
-\infty\end{array}$ & $\begin{array}{l}=- \\
=-\infty \\
=-- \\
=-\infty \\
=-\infty\end{array}$ & & & $\begin{array}{r}16.0 \\
=-\infty \\
-\infty \\
-\infty \\
-\infty\end{array}$ & $\begin{array}{r}17.0 \\
-0 \\
=-0 \\
17.0\end{array}$ & $\begin{array}{r}20.0 \\
- \\
- \\
-\infty\end{array}$ & $\begin{array}{r}20.0 \\
20.0 \\
=-0 \\
=-\infty\end{array}$ & $\begin{array}{r}-\infty \\
22.0 \\
\ldots- \\
\ldots \\
\ldots\end{array}$ & $=$ & & $\begin{array}{r}-\infty \\
19.0 \\
21.0 \\
-\infty\end{array}$ \\
\hline MONTH & $=-\infty$ & $=-$ & & & $-\infty$ & - & $-\infty$ & $-\infty$ & $=-$ & $=-\infty$ & & $-\infty$ \\
\hline
\end{tabular}


11118500 VENTURA RIVER NEAR VENTURA, CA--Continued

SUSPENDEDASEDIMENT DISCHARGE (TONS/OAY), HATER YEAR OCTOBER 1975 TO SEPTEMBER 1976

\begin{tabular}{|c|c|c|c|c|c|c|c|c|c|}
\hline & & OCTOBER & & & NOVEMBER & & & OE CEMBER & \\
\hline DAY & $\begin{array}{l}\text { MEAN } \\
\text { DISCHARGE } \\
\text { (CFS) }\end{array}$ & $\begin{array}{l}\text { MEAN } \\
\text { CONCEN- } \\
\text { TRAT ION } \\
\text { (MG/L) }\end{array}$ & $\begin{array}{l}\text { SEDINENT } \\
\text { DISCHARGE } \\
\text { (TONS/DAY) }\end{array}$ & $\begin{array}{l}\text { MEAN } \\
\text { OISCHARGE } \\
\text { (CFS) }\end{array}$ & $\begin{array}{l}\text { MEAN } \\
\text { CONCEN- } \\
\text { TRATION } \\
(M G / L)\end{array}$ & $\begin{array}{l}\text { SEDIMENT } \\
\text { DISCHARGE } \\
\text { (TONS/DAY) }\end{array}$ & $\begin{array}{l}\text { MEAN } \\
\text { DISCHARGE } \\
\text { (CFS) }\end{array}$ & $\begin{array}{l}\text { MEAN } \\
\text { CONCEN- } \\
\text { TRATION } \\
\text { (MG/L) }\end{array}$ & $\begin{array}{l}\text { SED IMENT } \\
\text { DISCHARGE } \\
\text { (TONS/DAY) }\end{array}$ \\
\hline
\end{tabular}

.59

.01
.01
.01
.01
.01
.01
$0_{0}^{.01}$
0
0

.12

.50
$1: 1$
$: 95$

.95

8
6
5
4
4

.65
.43

.38
.34

.37

1.5
2.0

1.1
.42

.42
.32

.31

.28

.38
.66

.32

0

.10
.08
.06

9

.05

10
10

.25
.22
.16
.13
.43

.02
.02
.01
.01
.01

$0^{.04} .02$

10

.42

.21
.14

.12

.10

TOTAL

15.31

.01
.01
.01
.01
.01

0
0
0
0
0
0
0
0

.01

.01

0
0
0

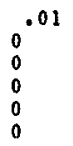

0
0
0
0

.23

.48

JANUARY
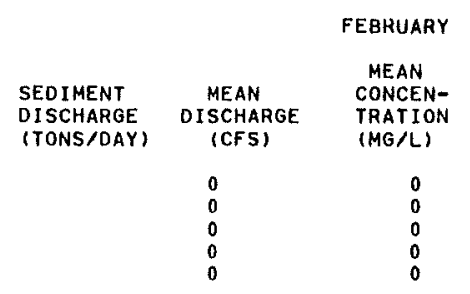

SED

SEDIMENT
DISCHARGE
(TONS/DAY)

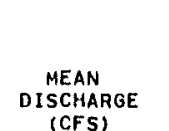

MARCH

MENAN

TRATION

DISCHARGE

(MG/L)

(MG/L)

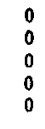

1.2

6.7
8.9
2.1
2.0

0

${ }_{41}^{.17}$

o

29

$48^{.01}$

2.1
2.2

0
0
8
235
73

1.1

4.8

.90
.10

.10
.19
.53

.26
0.04
0.01

1.0

20
15

15
10
8
6

.71
1.2
.61

.78
.56

.22
.24
.27

.01
0
0
0

.67
1.2
1.2

1.6
1.3

.62

.54
.39

.39
.22

.01

.01
.01
0.01

2.1

2.1
1.5

1.5
1.3
1.5

.16
.17
.16
13

11
-13

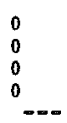

1.8
2.9
3.5

$$
\begin{aligned}
& 3.5 \\
& 3.5 \\
& 6.4 \\
& 7.3
\end{aligned}
$$

TOTAL

0

0

81.31

56.37

77.32

MEAN

CONCEN- SEDIMENT

TRATION DISCHARGE (MG/L) (TONS/DAY)

6
6
4
1

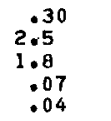

.03

03

.01

.01

.01

.02

.01

.01

.02

.02

.02

.02

$---$

.06
.08
.08
.10
.08
.09
5.57


SUSPENDED-SEDIMENT DISCHARGE (TONS/DAY), HATER YEAR OCTOBER 1975 TO SEPTEMBER 1976

\begin{tabular}{|c|c|c|c|c|c|c|c|c|c|}
\hline \multirow[b]{2}{*}{ DAY } & \multicolumn{3}{|c|}{ APRIL } & \multicolumn{3}{|c|}{ MAY } & \multicolumn{3}{|c|}{ JUNE } \\
\hline & $\begin{array}{l}\text { MEAN } \\
\text { DISCARGE } \\
\text { (CFS) }\end{array}$ & $\begin{array}{l}\text { MEAN } \\
\text { CONCEN- } \\
\text { TRATION } \\
\text { (MG/L) }\end{array}$ & $\begin{array}{l}\text { SEDIMENT } \\
\text { DISCHARGE } \\
\text { (TONS/DAY) }\end{array}$ & $\begin{array}{c}\text { MEAN } \\
\text { DISCHARGE } \\
\text { (CFS) }\end{array}$ & $\begin{array}{l}\text { MEAN } \\
\text { CONCEN- } \\
\text { TRAION } \\
\text { (MG/L) }\end{array}$ & $\begin{array}{l}\text { SEDIMENT } \\
\text { DISCHARGE } \\
\text { (TONS/OAY) }\end{array}$ & $\begin{array}{l}\text { MEAN } \\
\text { OISCARGE } \\
\text { (CFS) }\end{array}$ & $\begin{array}{l}\text { MEAN } \\
\text { CONCEN- } \\
\text { TRATION } \\
\text { (MG/L) }\end{array}$ & $\begin{array}{l}\text { SEDIMENT } \\
\text { OISCHARGE } \\
\text { (TONS/OAY) }\end{array}$ \\
\hline $\begin{array}{l}1 \\
2 \\
3 \\
4 \\
5\end{array}$ & $\begin{array}{l}5.9 \\
2.2 \\
3.3 \\
3.5 \\
3.6\end{array}$ & $\begin{array}{l}4 \\
4 \\
4 \\
4 \\
5\end{array}$ & $\begin{array}{l}.06 \\
.02 \\
.04 \\
.04 \\
.05\end{array}$ & $\begin{array}{l}2.3 \\
2.1 \\
1.0 \\
1.2 \\
1.4\end{array}$ & $\begin{array}{r}15 \\
10 \\
8 \\
6 \\
5\end{array}$ & $\begin{array}{l}.09 \\
.06 \\
.02 \\
.02 \\
.02\end{array}$ & $\begin{array}{c}.94 \\
: 41 \\
.30 \\
: 30 \\
1.1\end{array}$ & $\begin{array}{l}5 \\
4 \\
4 \\
4 \\
9\end{array}$ & $\begin{array}{l}.01 \\
0 \\
0 \\
0 \\
.03\end{array}$ \\
\hline $\begin{array}{r}6 \\
7 \\
8 \\
9 \\
10\end{array}$ & $\begin{array}{l}2.1 \\
1.3 \\
.77 \\
1.7 \\
2.5\end{array}$ & $\begin{array}{l}5 \\
5 \\
5 \\
6 \\
7\end{array}$ & $\begin{array}{l}.03 \\
.02 \\
.01 \\
.03 \\
.05\end{array}$ & $\begin{array}{l}1.3 \\
.72 \\
1.1 \\
.97 \\
.52\end{array}$ & $\begin{array}{l}4 \\
4 \\
4 \\
5 \\
6\end{array}$ & $\begin{array}{l}.01 \\
.01 \\
.01 \\
.01 \\
.01\end{array}$ & $\begin{array}{r}.94 \\
.55 \\
1.1 \\
.72 \\
.19\end{array}$ & $\begin{array}{r}9 \\
10 \\
12 \\
12 \\
14\end{array}$ & $\begin{array}{l}.02 \\
.01 \\
.04 \\
.02 \\
.01\end{array}$ \\
\hline $\begin{array}{l}11 \\
12 \\
13 \\
14 \\
15\end{array}$ & $\begin{array}{l}2.8 \\
3.7 \\
3.4 \\
3.4 \\
2.7\end{array}$ & $\begin{array}{l}7 \\
6 \\
6 \\
6 \\
6\end{array}$ & $\begin{array}{l}.05 \\
.06 \\
.06 \\
.06 \\
.04\end{array}$ & $\begin{array}{l}.31 \\
.29 \\
.24 \\
.95 \\
3.6\end{array}$ & $\begin{array}{r}7 \\
7 \\
7 \\
7 \\
10\end{array}$ & $\begin{array}{l}.01 \\
.01 \\
0.02 \\
.10\end{array}$ & $\begin{array}{l}.16 \\
: 32 \\
: 69 \\
: 32 \\
.16\end{array}$ & $\begin{array}{l}15 \\
15 \\
15 \\
15 \\
15\end{array}$ & $\begin{array}{l}.01 \\
.01 \\
.03 \\
.01 \\
.01\end{array}$ \\
\hline $\begin{array}{l}16 \\
17 \\
18 \\
19 \\
20\end{array}$ & $\begin{array}{l}2.6 \\
2.9 \\
4.6 \\
4.0 \\
3.6\end{array}$ & $\begin{array}{l}6 \\
6 \\
6 \\
6 \\
6\end{array}$ & $\begin{array}{l}.04 \\
.05 \\
.07 \\
.06 \\
.06\end{array}$ & $\begin{array}{l}4.8 \\
3.1 \\
1.8 \\
.42 \\
.73\end{array}$ & $\begin{array}{l}12 \\
11 \\
11 \\
11 \\
11\end{array}$ & $\begin{array}{l}.16 \\
.09 \\
.05 \\
.01 \\
.02\end{array}$ & $\begin{array}{l}.13 \\
: 19 \\
.34 \\
.19 \\
.62\end{array}$ & $\begin{array}{l}15 \\
16 \\
20 \\
20 \\
20\end{array}$ & $\begin{array}{l}.01 \\
.01 \\
.02 \\
.01 \\
.03\end{array}$ \\
\hline $\begin{array}{l}21 \\
22 \\
23 \\
24 \\
25\end{array}$ & $\begin{array}{l}3.3 \\
3.0 \\
2.7 \\
2.5 \\
2.3\end{array}$ & $\begin{array}{l}6 \\
6 \\
6 \\
6 \\
7\end{array}$ & $\begin{array}{l}.05 \\
.05 \\
.04 \\
.04 \\
.04\end{array}$ & $\begin{array}{l}1.3 \\
1.6 \\
2.9 \\
2.0 \\
.96\end{array}$ & $\begin{array}{l}14 \\
14 \\
15 \\
20 \\
20\end{array}$ & $\begin{array}{l}.05 \\
: 06 \\
.12 \\
.11 \\
.05\end{array}$ & $\begin{array}{l}.23 \\
: 21 \\
: 17 \\
: 13 \\
.10\end{array}$ & $\begin{array}{l}20 \\
24 \\
30 \\
50 \\
71\end{array}$ & $\begin{array}{l}.01 \\
.01 \\
.01 \\
.02 \\
.02\end{array}$ \\
\hline $\begin{array}{l}26 \\
27 \\
28 \\
29 \\
30 \\
31\end{array}$ & $\begin{array}{l}2.1 \\
1.9 \\
1.8 \\
1.9 \\
2.0 \\
-.-\end{array}$ & $\begin{array}{r}7 \\
7 \\
7 \\
7 \\
7 \\
--\end{array}$ & $\begin{array}{l}.04 \\
.04 \\
.03 \\
.04 \\
.04 \\
-. .\end{array}$ & $\begin{array}{r}.37 \\
: 35 \\
: 30 \\
: 63 \\
1: 7 \\
: 94\end{array}$ & $\begin{array}{r}24 \\
20 \\
15 \\
10 \\
8 \\
5\end{array}$ & $\begin{array}{l}.02 \\
.02 \\
.01 \\
.02 \\
.04 \\
.01\end{array}$ & \begin{tabular}{l}
.08 \\
$: 10$ \\
$: 12$ \\
.09 \\
06 \\
\hdashline.
\end{tabular} & $\begin{array}{r}30 \\
15 \\
15 \\
15 \\
15 \\
- \\
-.\end{array}$ & $\begin{array}{l}.01 \\
0 \\
0 \\
0 \\
0 \\
-.-\end{array}$ \\
\hline TOTAL & 84.07 & $\cdots$ & 1.31 & 41.90 & -- & 1.24 & 10.96 & -- & .37 \\
\hline & & JULY & & & AUGUST & & & SEPTEMBER & \\
\hline DAY & $\begin{array}{l}\text { MEAN } \\
\text { DISCHARGE } \\
\text { (CFS) }\end{array}$ & $\begin{array}{l}\text { MEAN } \\
\text { CONCEN- } \\
\text { TRAION } \\
\text { (MG/L) }\end{array}$ & $\begin{array}{l}\text { SEOIMENT } \\
\text { OISCHARGE } \\
\text { (TONS/DAY) }\end{array}$ & $\begin{array}{l}\text { MEAN } \\
\text { DISCHARGE } \\
\text { (CFS) }\end{array}$ & $\begin{array}{l}\text { MEAN } \\
\text { CONCEN- } \\
\text { RATION } \\
\text { (MG/L) }\end{array}$ & $\begin{array}{l}\text { SEDIMENT } \\
\text { DISCHARGE } \\
\text { (TONS/DAY) }\end{array}$ & $\begin{array}{l}\text { MEAN } \\
\text { DISCHARGE } \\
\text { (CFS) }\end{array}$ & $\begin{array}{l}\text { MEAN } \\
\text { CONCEN- } \\
\text { TRAION } \\
\text { (MG/L) }\end{array}$ & $\begin{array}{l}\text { SEDIMENT } \\
\text { DISCHARGE } \\
\text { (TONS/DAY) }\end{array}$ \\
\hline $\begin{array}{l}1 \\
2 \\
3 \\
4 \\
5\end{array}$ & $\begin{array}{l}.04 \\
.03 \\
0.01 \\
0\end{array}$ & $\begin{array}{r}30 \\
45 \\
15 \\
0 \\
0\end{array}$ & & & & & $\begin{array}{l}0 \\
0 \\
0 \\
0 \\
0\end{array}$ & $\begin{array}{l}0 \\
0 \\
0 \\
0 \\
0\end{array}$ & $\begin{array}{l}0 \\
0 \\
0 \\
0 \\
0\end{array}$ \\
\hline $\begin{array}{r}6 \\
7 \\
8 \\
9 \\
10\end{array}$ & $\begin{array}{l}0 \\
0 \\
0 \\
0 \\
0\end{array}$ & $\begin{array}{l}0 \\
0 \\
0 \\
0 \\
0\end{array}$ & & & & & $\begin{array}{l}0 \\
0 \\
0 \\
0 \\
0\end{array}$ & $\begin{array}{l}0 \\
0 \\
0 \\
0 \\
0\end{array}$ & $\begin{array}{l}0 \\
0 \\
0 \\
0 \\
0\end{array}$ \\
\hline $\begin{array}{l}11 \\
12 \\
13 \\
14 \\
15\end{array}$ & $\begin{array}{l}0 \\
0 \\
0 \\
0 \\
0\end{array}$ & $\begin{array}{l}0 \\
0 \\
0 \\
0 \\
0\end{array}$ & & & & & $\begin{array}{l}0 \\
0 \\
0 \\
0 \\
0\end{array}$ & $\begin{array}{l}0 \\
0 \\
0 \\
0 \\
0\end{array}$ & $\begin{array}{l}0 \\
0 \\
0 \\
0 \\
0\end{array}$ \\
\hline $\begin{array}{l}16 \\
17 \\
18 \\
19 \\
20\end{array}$ & $\begin{array}{l}0 \\
0 \\
0 \\
0 \\
0\end{array}$ & $\begin{array}{l}0 \\
0 \\
0 \\
0 \\
0\end{array}$ & & & & & $\begin{array}{l}0 \\
0 \\
0 \\
0 \\
0\end{array}$ & $\begin{array}{l}0 \\
0 \\
0 \\
0 \\
0\end{array}$ & $\begin{array}{l}0 \\
0 \\
0 \\
0 \\
0\end{array}$ \\
\hline $\begin{array}{l}21 \\
22 \\
23 \\
24 \\
25\end{array}$ & $\begin{array}{l}0 \\
0 \\
0 \\
0 \\
0\end{array}$ & $\begin{array}{l}0 \\
0 \\
0 \\
0 \\
0\end{array}$ & & & & & $\begin{array}{l}0 \\
0 \\
0 \\
0 \\
0\end{array}$ & $\begin{array}{l}0 \\
0 \\
0 \\
0 \\
0\end{array}$ & $\begin{array}{l}0 \\
0 \\
0 \\
0 \\
0\end{array}$ \\
\hline $\begin{array}{l}26 \\
27 \\
28 \\
29 \\
30 \\
31\end{array}$ & $\begin{array}{l}0 \\
0 \\
0 \\
0 \\
0 \\
0\end{array}$ & $\begin{array}{l}0 \\
0 \\
0 \\
0 \\
0 \\
0\end{array}$ & & & & & $\begin{array}{r}0 \\
0 \\
0 \\
387 \\
2.4 \\
-. .\end{array}$ & $\begin{array}{r}0 \\
0 \\
0 \\
706 \\
30 \\
-\ldots\end{array}$ & $\begin{array}{r}0 \\
0 \\
0 \\
1540 \\
\quad .19\end{array}$ \\
\hline TOTAL & .08 & $\cdots$ & 0 & 0 & 0 & 0 & 389.40 & -- & 1540.19 \\
\hline YEAR & 700.83 & & & & & & & & \\
\hline
\end{tabular}


11118500 VENTURA RIVER NEAR VENTURA, CA--Continued

PARTICLE-SIZE DISTRIBUTION OF SUSPENDED SEDIMENT, WATER YEAR OCTOBER 1975 TO SEPTEMBER 1976

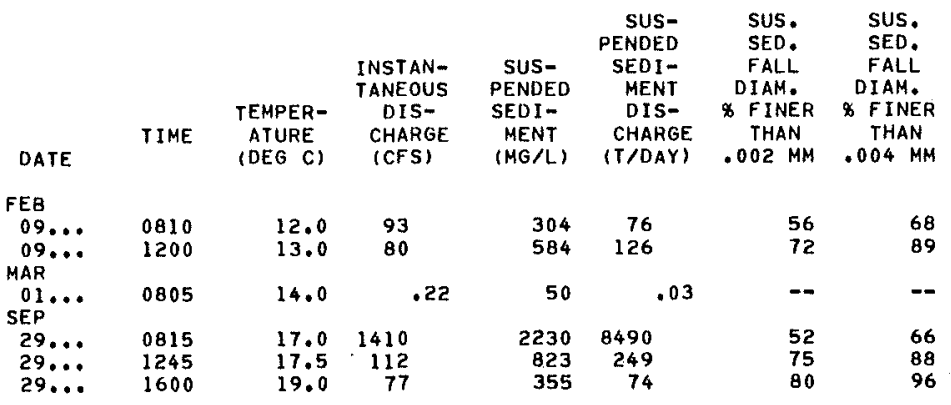

\begin{tabular}{|c|c|c|c|c|c|c|}
\hline & $\begin{array}{l}\text { SUS. } \\
\text { SED: } \\
\text { FALL } \\
\text { DIAM. } \\
\text { X FINER } \\
\text { THAN }\end{array}$ & $\begin{array}{l}\text { SUS. } \\
\text { SED, } \\
\text { FALL } \\
\text { DIAH. } \\
\text { × FINER } \\
\text { THAN }\end{array}$ & $\begin{array}{l}\text { SUS. } \\
\text { SED. } \\
\text { FALL } \\
\text { DIAM. } \\
\text { \& FINER } \\
\text { THAN }\end{array}$ & $\begin{array}{l}\text { SUS. } \\
\text { SED. } \\
\text { SIEVE } \\
\text { DIAM. } \\
\text { \& FINER } \\
\text { THAN }\end{array}$ & $\begin{array}{l}\text { SUS. } \\
\text { SED. } \\
\text { SIEVE } \\
\text { DIAH. } \\
\text { \% FINER } \\
\text { THAN }\end{array}$ & $\begin{array}{l}\text { SUS. } \\
\text { SED. } \\
\text { SIEVE } \\
\text { DIAM. } \\
\text { \& FINER } \\
\text { THAN }\end{array}$ \\
\hline DATE & $.008 \mathrm{MM}$ & $.016 \mathrm{MM}$ & $.031 \mathrm{MH}$ & $.062 \mathrm{MH}$ & $.125 \mathrm{MM}$ & $.250 \mathrm{MM}$ \\
\hline \multicolumn{7}{|l|}{ FEB } \\
\hline $\begin{array}{l}09 . . \\
09 . \cdots \\
\text { MAR }\end{array}$ & $\begin{array}{l}75 \\
96\end{array}$ & $\begin{array}{r}82 \\
100\end{array}$ & 89 & 95 & 98 & 100 \\
\hline$\underset{\text { SEP }}{01 \ldots}$ & -- & - & - & 97 & 98 & 100 \\
\hline $\begin{array}{l}29 \ldots \\
29 \ldots \\
29 \ldots\end{array}$ & $\begin{array}{l}80 \\
95 \\
98\end{array}$ & $\begin{array}{r}93 \\
97 \\
100\end{array}$ & $\begin{array}{l}98 \\
99 \\
--\end{array}$ & $\begin{array}{r}99 \\
100 \\
-0\end{array}$ & $\begin{array}{r}100 \\
= \\
=\end{array}$ & $=$ \\
\hline
\end{tabular}


SPECIFIC CONDUCTANCE (MICROMHOS/CM AT 25 DEG, C), WATER YEAR OCTOBER 1975 TO SEPTEMBER 1976

\begin{tabular}{|c|c|c|c|c|c|c|c|c|c|c|c|c|}
\hline \multirow[b]{2}{*}{ DAY } & \multicolumn{3}{|c|}{ JUNE } & \multicolumn{3}{|c|}{ JULY } & \multicolumn{3}{|c|}{ AUGUST } & \multicolumn{3}{|c|}{ SEPTEMBER } \\
\hline & MAX & MIN & MEAN & $\operatorname{MAX}$ & MIN & MEAN & MAX & MIN & MEAN & $\operatorname{MAX}$ & MIN & MEAN \\
\hline $\begin{array}{l}1 \\
2 \\
3 \\
4 \\
5\end{array}$ & $\begin{array}{l}845 \\
847 \\
862 \\
870 \\
852\end{array}$ & $\begin{array}{l}813 \\
791 \\
816 \\
814 \\
838\end{array}$ & $\begin{array}{l}834 \\
828 \\
837 \\
846 \\
845\end{array}$ & $\begin{array}{l}868 \\
886 \\
906 \\
918 \\
916\end{array}$ & $\begin{array}{l}770 \\
782 \\
810 \\
804 \\
804\end{array}$ & $\begin{array}{l}832 \\
844 \\
869 \\
872 \\
878\end{array}$ & $\begin{array}{r}979 \\
990 \\
986 \\
1000 \\
1020\end{array}$ & $\begin{array}{l}867 \\
880 \\
866 \\
873 \\
872\end{array}$ & $\begin{array}{l}941 \\
956 \\
948 \\
961 \\
979\end{array}$ & $\begin{array}{r}943 \\
959 \\
958 \\
996 \\
1010\end{array}$ & $\begin{array}{l}907 \\
919 \\
940 \\
942 \\
939\end{array}$ & $\begin{array}{l}927 \\
944 \\
948 \\
965 \\
984\end{array}$ \\
\hline $\begin{array}{r}6 \\
7 \\
8 \\
9 \\
10\end{array}$ & $\begin{array}{l}881 \\
885 \\
894 \\
882 \\
889\end{array}$ & $\begin{array}{l}849 \\
867 \\
868 \\
844 \\
687\end{array}$ & $\begin{array}{l}864 \\
876 \\
880 \\
869 \\
833\end{array}$ & $\begin{array}{l}928 \\
944 \\
958 \\
934 \\
932\end{array}$ & $\begin{array}{l}808 \\
808 \\
802 \\
794 \\
786\end{array}$ & $\begin{array}{l}885 \\
898 \\
899 \\
881 \\
874\end{array}$ & $\begin{array}{r}1010 \\
1000 \\
982 \\
981 \\
978\end{array}$ & $\begin{array}{l}876 \\
869 \\
872 \\
863 \\
858\end{array}$ & $\begin{array}{l}973 \\
955 \\
945 \\
948 \\
940\end{array}$ & $\begin{array}{r}999 \\
960 \\
1060 \\
1050 \\
1090\end{array}$ & $\begin{array}{l}927 \\
930 \\
934 \\
966 \\
670\end{array}$ & $\begin{array}{r}966 \\
949 \\
967 \\
1020 \\
956\end{array}$ \\
\hline $\begin{array}{l}11 \\
12 \\
13 \\
14 \\
15\end{array}$ & $\begin{array}{l}899 \\
898 \\
884 \\
885 \\
897\end{array}$ & $\begin{array}{l}837 \\
854 \\
844 \\
807 \\
815\end{array}$ & $\begin{array}{l}875 \\
874 \\
864 \\
856 \\
862\end{array}$ & $\begin{array}{l}920 \\
914 \\
912 \\
906 \\
905\end{array}$ & $\begin{array}{l}786 \\
796 \\
790 \\
784 \\
829\end{array}$ & $\begin{array}{l}868 \\
870 \\
864 \\
887 \\
878\end{array}$ & $\begin{array}{r}976 \\
1030 \\
974 \\
960 \\
949\end{array}$ & $\begin{array}{l}852 \\
855 \\
852 \\
870 \\
873\end{array}$ & $\begin{array}{l}939 \\
953 \\
952 \\
920 \\
910\end{array}$ & $\begin{array}{r}1140 \\
864 \\
892 \\
890 \\
858\end{array}$ & $\begin{array}{l}628 \\
824 \\
020 \\
834 \\
792\end{array}$ & $\begin{array}{l}816 \\
847 \\
865 \\
864 \\
823\end{array}$ \\
\hline $\begin{array}{l}16 \\
17 \\
18 \\
19 \\
20\end{array}$ & $\begin{array}{l}902 \\
904 \\
899 \\
894 \\
884\end{array}$ & $\begin{array}{l}828 \\
834 \\
831 \\
814 \\
808\end{array}$ & $\begin{array}{l}870 \\
878 \\
869 \\
859 \\
853\end{array}$ & $\begin{array}{l}905 \\
910 \\
911 \\
915 \\
932\end{array}$ & $\begin{array}{l}791 \\
798 \\
799 \\
809 \\
818\end{array}$ & $\begin{array}{l}864 \\
868 \\
868 \\
875 \\
887\end{array}$ & $\begin{array}{l}917 \\
918 \\
922 \\
927 \\
955\end{array}$ & $\begin{array}{l}821 \\
816 \\
822 \\
819 \\
839\end{array}$ & $\begin{array}{l}880 \\
878 \\
882 \\
890 \\
906\end{array}$ & $\begin{array}{l}=- \\
=- \\
=-\end{array}$ & $\begin{array}{l}=- \\
=- \\
=- \\
=-\end{array}$ & $=$ \\
\hline $\begin{array}{l}21 \\
22 \\
23 \\
24 \\
25\end{array}$ & $\begin{array}{l}877 \\
877 \\
880 \\
886 \\
893\end{array}$ & $\begin{array}{l}807 \\
801 \\
796 \\
796 \\
789\end{array}$ & $\begin{array}{l}851 \\
847 \\
847 \\
853 \\
848\end{array}$ & $\begin{array}{l}930 \\
923 \\
915 \\
925 \\
923\end{array}$ & $\begin{array}{l}814 \\
823 \\
803 \\
811 \\
805\end{array}$ & $\begin{array}{l}884 \\
885 \\
875 \\
881 \\
876\end{array}$ & $\begin{array}{r}986 \\
1000 \\
1010 \\
1020 \\
1040\end{array}$ & $\begin{array}{l}874 \\
892 \\
889 \\
891 \\
902\end{array}$ & $\begin{array}{l}944 \\
960 \\
972 \\
971 \\
972\end{array}$ & $\begin{array}{l}=- \\
=-- \\
--- \\
--\end{array}$ & $\begin{array}{l}=- \\
=- \\
=- \\
=-\end{array}$ & $\begin{array}{l}--- \\
=-- \\
--- \\
---\end{array}$ \\
\hline $\begin{array}{l}26 \\
27 \\
28 \\
29 \\
30 \\
31\end{array}$ & $\begin{array}{l}885 \\
890 \\
880 \\
894 \\
872 \\
-\end{array}$ & $\begin{array}{l}787 \\
782 \\
778 \\
772 \\
762 \\
-\cdots\end{array}$ & $\begin{array}{l}848 \\
848 \\
838 \\
834 \\
831 \\
--\end{array}$ & $\begin{array}{r}972 \\
1010 \\
994 \\
963 \\
949 \\
973\end{array}$ & $\begin{array}{l}810 \\
842 \\
840 \\
845 \\
847 \\
869\end{array}$ & $\begin{array}{l}896 \\
942 \\
923 \\
927 \\
916 \\
939\end{array}$ & $\begin{array}{r}972 \\
954 \\
973 \\
943 \\
1020 \\
1040\end{array}$ & $\begin{array}{l}898 \\
894 \\
883 \\
885 \\
932 \\
884\end{array}$ & $\begin{array}{l}936 \\
927 \\
928 \\
915 \\
973 \\
964\end{array}$ & $\begin{array}{r}-- \\
-0 \\
1090 \\
-0\end{array}$ & $\begin{array}{r}-- \\
=- \\
=- \\
1030 \\
-\infty\end{array}$ & $\begin{array}{c}0- \\
1060 \\
=-\end{array}$ \\
\hline MONTH & 904 & 687 & 854 & 1010 & 770 & 884 & 1040 & 816 & 939 & --- & --- & $m-$ \\
\hline YEAR & 1450 & 191 & 843 & & & & & & & & & \\
\hline
\end{tabular}


LOCATION, - Lat $34^{\circ} 24^{\prime} 05^{\prime \prime}$, long $119^{\circ} 29^{\prime} 10^{\prime \prime}$, in E1 Rincon Grant, Santa Barbara County, on right bank at downstream side of bridge on State Highway $192,235 \mathrm{ft}(72 \mathrm{~m})$ downstream from Gobernador Creek, and $1.8 \mathrm{mi}$ (2.9 $\mathrm{km}$ ) northeast of Carpinteria.

DRAINAGE AREA, $--13.1 \mathrm{mi}^{2}\left(33.9 \mathrm{~km}^{2}\right)$.

PERIOD OF RECORD.--January 1941 to current year.

GAGE. - Water-stage recorder. Altitude of gage is $130 \mathrm{ft}(40 \mathrm{~m})$, from topographic map. Prior to July 1 , 1958 , at datum $6.00 \mathrm{ft}(1.829 \mathrm{~m})$ higher. Ju1y 2,1958 , to Aug, 27,1970 , at site $35 \mathrm{ft}$ (11 m) upstream at datum $4.00 \mathrm{ft}(1.219 \mathrm{~m}) \mathrm{higher}$.

REMARKS. - Records good. No regulation above station. Gobernador Land and Water Co. diverts from Gobernador Creek $1.8 \mathrm{mi}(2.9 \mathrm{~km})$ above station. Smal1 lake $0.8 \mathrm{mi}(1.3 \mathrm{~km})$ southeast of station and outside the drainage area stores storm runoff and surplus water diverted by Gobernador Land and Water Co. from Gobernador Creek. At times this lake is drained by pumping water back into Gobernador Creek $1,000 \mathrm{ft}$ ( $305 \mathrm{~m}$ ) above station.

AVERAGE DISCHARGE. - - -35 years, $2.94 \mathrm{ft}^{3} / \mathrm{s}\left(0.083 \mathrm{~m}^{3} / \mathrm{s}\right), 2,130 \mathrm{acre}-\mathrm{ft} / \mathrm{yr}\left(2.63 \mathrm{hm}^{3} / \mathrm{yr}^{2}\right)$.

EXTREMES FOR PERIOD OF RECORD.--Maximum discharge, $8,880 \mathrm{ft}^{3} / \mathrm{s}\left(251 \mathrm{~m}^{3} / \mathrm{s}\right)$ Dec, 27,1971 , gage height, $14.10 \mathrm{ft}$ $(4.298 \mathrm{~m})$, from floodmark, from rating curve extended above $130 \mathrm{ft} / \mathrm{s}\left(3.68 \mathrm{~m}^{3} / \mathrm{s}\right)$ on basis of slope-area measurement of maximum flow; no flow at times in each year.

EXTREMES FOR CURRENT YEAR. --Maximum discharge, $227 \mathrm{ft}^{3} / \mathrm{s}\left(6.43 \mathrm{~m}^{3} / \mathrm{s}\right)$ Feb. 9 (0615 hrs), gage height $2.47 \mathrm{ft}$ $(0.753 \mathrm{mt})$, no other peaks above base of $125 \mathrm{ft} / \mathrm{s}\left(3.54 \mathrm{~m}^{3} / \mathrm{s}\right)$; no flow many months.

DISCHARGE, IN CUBIC FEET PER SECOND, WATER YEAR OCTOBER 1975 TO SEPTEMBER 1976 MEAN VALUES

\begin{tabular}{|c|c|c|c|c|c|c|c|c|c|c|c|c|}
\hline DAY & OCT & NOV & DEC & JAN & FE日 & MAR & APR & MAY & JUN & JUL & AUG & SEP \\
\hline $\begin{array}{l}1 \\
2 \\
3 \\
4 \\
5\end{array}$ & & & & & $\begin{array}{l}0 \\
0 \\
0 \\
.02 \\
2.0\end{array}$ & $\begin{array}{l}16 \\
8.7 \\
6.7 \\
2.3 \\
1.5\end{array}$ & $\begin{array}{l}0 \\
0 \\
0 \\
.08 \\
.07\end{array}$ & & & & & $\begin{array}{l}0 \\
0 \\
0 \\
0 \\
0\end{array}$ \\
\hline $\begin{array}{r}6 \\
7 \\
8 \\
9 \\
10\end{array}$ & & & & & $\begin{array}{l}2.8 \\
6.8 \\
4.8 \\
85 \\
48\end{array}$ & $\begin{array}{l}1.2 \\
1.0 \\
.85 \\
.89 \\
.82\end{array}$ & $\begin{array}{l}0 \\
0 \\
.18 \\
.03 \\
0^{.03}\end{array}$ & & & & & $\begin{array}{l}0 \\
0 \\
0 \\
0 \\
.57\end{array}$ \\
\hline $\begin{array}{l}11 \\
12 \\
13 \\
14 \\
15\end{array}$ & & & & & $\begin{array}{r}5.3 \\
1.4 \\
.49 \\
.61 \\
.49\end{array}$ & $\begin{array}{l}.61 \\
.42 \\
.26 \\
.13 \\
.08\end{array}$ & $\begin{array}{l}0 \\
.04 \\
.24 \\
.04 \\
0\end{array}$ & & & & & $\begin{array}{l}4.0 \\
0 \\
0 \\
0 \\
0\end{array}$ \\
\hline $\begin{array}{l}16 \\
17 \\
18 \\
19 \\
20\end{array}$ & & & & & $\begin{array}{l}.32 \\
1.3 \\
.99 \\
.17 \\
.06\end{array}$ & $\begin{array}{l}.04 \\
.02 \\
.02 \\
.02 \\
.01\end{array}$ & $\begin{array}{l}0 \\
0 \\
0 \\
0 \\
0\end{array}$ & & & & & $\begin{array}{l}0 \\
0 \\
0 \\
0 \\
0\end{array}$ \\
\hline $\begin{array}{l}21 \\
22 \\
23 \\
24 \\
25\end{array}$ & & & & & $\begin{array}{l}.03 \\
.01 \\
0 \\
0 \\
0\end{array}$ & $\begin{array}{l}0 \\
0 \\
0 \\
0 \\
0\end{array}$ & $\begin{array}{l}0 \\
0 \\
0 \\
0 \\
0\end{array}$ & & & & & $\begin{array}{l}0 \\
0 \\
0 \\
0 \\
0\end{array}$ \\
\hline $\begin{array}{l}26 \\
27 \\
28 \\
29 \\
30 \\
31\end{array}$ & & $-\infty$ & & & $\begin{array}{l}0 \\
0 \\
0 \\
0 \\
- \\
-\end{array}$ & $\begin{array}{l}0 \\
0 \\
0 \\
0 \\
0 \\
0\end{array}$ & $\begin{array}{l}0 \\
0 \\
0 \\
0 \\
0 \\
\end{array}$ & & -- & & & $\begin{array}{c}0 \\
0 \\
1.2 \\
23 \\
.97 \\
-\square-\end{array}$ \\
\hline $\begin{array}{l}\text { TOTAL } \\
\text { MEAN } \\
\text { MAX } \\
\text { MIN } \\
\text { AC-FT }\end{array}$ & $\begin{array}{l}0 \\
0 \\
0 \\
0 \\
0\end{array}$ & $\begin{array}{l}0 \\
0 \\
0 \\
0 \\
0\end{array}$ & $\begin{array}{l}0 \\
0 \\
0 \\
0 \\
0\end{array}$ & $\begin{array}{l}0 \\
0 \\
0 \\
0 \\
0\end{array}$ & $\begin{array}{r}160.59 \\
5.54 \\
85 \\
0 \\
319\end{array}$ & $\begin{array}{r}41.57 \\
1.34 \\
16 \\
0 \\
82\end{array}$ & $\begin{array}{r}.68 \\
.023 \\
.24 \\
0 \\
1.3\end{array}$ & $\begin{array}{l}0 \\
0 \\
0 \\
0 \\
0\end{array}$ & $\begin{array}{l}0 \\
0 \\
0 \\
0 \\
0\end{array}$ & $\begin{array}{l}0 \\
0 \\
0 \\
0 \\
0\end{array}$ & $\begin{array}{l}0 \\
0 \\
0 \\
0 \\
0\end{array}$ & $\begin{array}{r}29.74 \\
.99 \\
23 \\
0 \\
59\end{array}$ \\
\hline
\end{tabular}

$\begin{array}{lrrrrrrrrr}\text { CAL YR } 1975 & \text { TOTAL } 711.63 & \text { MEAN } 1.95 & \text { MAX } 113 & \text { MIN } 0 & \text { AC-FT } & 1410 \\ \text { WTR YR } 1976 & \text { TOTAL } 232.58 & \text { MEAN } & .64 & \text { MAX } & 85 & \text { MIN } & 0 & \text { AC-FT } & 461\end{array}$

WTR YR 1976 TOTAL 232.58 
LOCATION.--Lat $34^{\circ} 24^{\prime} 15^{\prime \prime}$, long $119^{\circ} 31^{\prime} 05^{\prime \prime}$, in Pueblo Lands of Santa Barbara, Santa Barbara County, on right bank $300 \mathrm{ft}(91 \mathrm{~m})$ downstream from Malibu Drive bridge, $0.5 \mathrm{mi}(0.8 \mathrm{~km})$ north of Carpinteria, and $0.9 \mathrm{mi}$ ( $1.4 \mathrm{~km})$

upstream from mouth.

DRATNAGE AREA. $--1.81 \mathrm{mi}^{2}\left(4.69 \mathrm{~km}^{2}\right)$.

PERTOD OF RECORD.-October 1970 to current year.

GAGE.- Water-stage recorder and concrete channel. Altitude of gage is $30 \mathrm{ft}$ ( $9 \mathrm{~m}$ ), from topographic map.

REMARKS. - Records fair. No regulation or diversion above station.

AVERAGE DISCHARGE. -6 years, $0.75 \mathrm{ft} / \mathrm{s}\left(0.021 \mathrm{~m}^{3} / \mathrm{s}\right), 543 \mathrm{acre}-\mathrm{ft} / \mathrm{yr}\left(670,000 \mathrm{~m}^{3} / \mathrm{yr}^{3}\right)$.

EXTREMES FOR PERIOD OF RECORD, - Maximum discharge, $1,600 \mathrm{ft}^{3} / \mathrm{s}\left(45.3 \mathrm{~m}^{3} / \mathrm{s}\right)$ Dec, 27 , 1971 , gage height, $6.1 \mathrm{ft}$

$(1.86 \mathrm{~m})$, from floodmark, from rating curve extended above $25 \mathrm{ft} / \mathrm{s}\left(0.71 \mathrm{~m}^{3} / \mathrm{s}\right)$ on basis of conputation

of flow in concrete channel; minimum daily, $0.01 \mathrm{ft}^{3} / \mathrm{s}\left(<0.001 \mathrm{~m}^{3} / \mathrm{s}\right)$ Oct. $1 \mathrm{to}$ Nov. 24,1970 .

EXTREMES FOR CURRENT YEAR. --Peak discharge above base of $50 \mathrm{ft} / \mathrm{s}\left(1.42 \mathrm{~m}^{3} / \mathrm{s}\right)$ and $\mathrm{maximum}^{*}$ ), from rating

curve extended above $16 \mathrm{ft}^{3} / \mathrm{s}\left(0.45 \mathrm{~m}^{3} / \mathrm{s}\right)$, on basis of computation of flow in concrete channel:

\begin{tabular}{|c|c|c|c|c|c|c|c|}
\hline Date & Time & $\begin{array}{c}\text { Discharge } \\
\left(\mathrm{ft}^{3} / \mathrm{s}\right)\left(\mathrm{m}^{3} / \mathrm{s}\right)\end{array}$ & $\begin{array}{l}\text { Gage height } \\
\text { (ft) (m) }\end{array}$ & Date & Time & $\begin{array}{c}\text { Discharge } \\
\left(\mathrm{ft}^{3} / \mathrm{s}\right)\left(\mathrm{m}^{3} / \mathrm{s}\right)\end{array}$ & $\begin{array}{l}\text { Gage } \\
(\mathrm{ft})\end{array}$ \\
\hline $\begin{array}{l}\text { Feb. } 9 \\
\text { Mar. } 1\end{array}$ & $\begin{array}{l}0145 \\
0315\end{array}$ & $\begin{array}{r}11.0 \\
4.53\end{array}$ & $\begin{array}{ll}3.47 & 1.057 \\
2.73 & 0.832\end{array}$ & Sept. 28 & 2300 & 16.2 & 3.91 \\
\hline
\end{tabular}

Minimum daily discharge, $0.11 \mathrm{ft}^{3} / \mathrm{s}\left(0.003 \mathrm{~m}^{3} / \mathrm{s}\right)$ Oct. 1, 17-21, May 17.

DISCHARGE, IN CUBIC FEET PER SECOND, WATER YEAR OCTOBER 1975 TO SEPTEMBER 1976 MEAN VALUES

\begin{tabular}{|c|c|c|c|c|c|c|c|c|c|c|c|c|}
\hline DAY & OCT & NOV & DEC & JAN & FEB & MAR & $A P R$ & MAY & JUN & JUL & AUG & SEP \\
\hline $\begin{array}{l}1 \\
2 \\
3 \\
4 \\
5\end{array}$ & $\begin{array}{l}.11 \\
.12 \\
.12 \\
.14 \\
.14\end{array}$ & $\begin{array}{l}.22 \\
.21 \\
.21 \\
.21 \\
.21 \\
.21\end{array}$ & $\begin{array}{l}.18 \\
.20 \\
.28 \\
.37 \\
.36\end{array}$ & $\begin{array}{l}.17 \\
.17 \\
.19 \\
.18 \\
.18\end{array}$ & $\begin{array}{r}.14 \\
.19 \\
.22 \\
.24 \\
3.0\end{array}$ & $\begin{array}{r}13 \\
8.2 \\
.88 \\
.43 \\
.35\end{array}$ & $\begin{array}{r}.23 \\
.23 \\
.37 \\
.23 \\
.22\end{array}$ & $\begin{array}{l}.33 \\
.26 \\
.33 \\
.21 \\
.28\end{array}$ & $\begin{array}{r}.50 \\
.28 \\
.28 \\
.28 \\
.35\end{array}$ & $\begin{array}{r}.14 \\
.18 \\
.18 \\
.18 \\
.18\end{array}$ & $\begin{array}{r}.23 \\
.26 \\
.41 \\
.47 \\
.52\end{array}$ & $\begin{array}{r}.17 \\
.21 \\
.17 \\
.17 \\
.21\end{array}$ \\
\hline $\begin{array}{r}6 \\
7 \\
8 \\
9 \\
10\end{array}$ & $\begin{array}{l}.14 \\
.16 \\
.12 \\
.12 \\
.20\end{array}$ & $\begin{array}{r}.21 \\
.22 \\
.19 \\
.18 \\
.18\end{array}$ & $\begin{array}{r}.18 \\
.17 \\
.15 \\
.17 \\
.18\end{array}$ & $\begin{array}{l}.18 \\
.18 \\
.18 \\
.18 \\
.18\end{array}$ & $\begin{array}{c}2.1 \\
8.8 \\
4.8 \\
53 \\
4.6\end{array}$ & $\begin{array}{l}.36 \\
.36 \\
.36 \\
.36 \\
.44\end{array}$ & $\begin{array}{l}.21 \\
.24 \\
.69 \\
.23 \\
.23\end{array}$ & $\begin{array}{l}.43 \\
.24 \\
.20 \\
.26 \\
.29\end{array}$ & $\begin{array}{l}.35 \\
.35 \\
.35 \\
.42 \\
.35\end{array}$ & $\begin{array}{r}.18 \\
.18 \\
.18 \\
.18 \\
.18\end{array}$ & $\begin{array}{r}.49 \\
.53 \\
.53 \\
.30 \\
.33\end{array}$ & $\begin{array}{r}.34 \\
.26 \\
.23 \\
.20 \\
2.8\end{array}$ \\
\hline $\begin{array}{l}11 \\
12 \\
13 \\
14 \\
15\end{array}$ & $\begin{array}{l}.16 \\
.15 \\
.14 \\
.13 \\
.12\end{array}$ & $\begin{array}{l}.22 \\
.17 \\
.16 \\
.16 \\
.16\end{array}$ & $\begin{array}{l}.16 \\
.34 \\
.18 \\
.16 \\
.16\end{array}$ & $\begin{array}{r}.18 \\
.18 \\
.22 \\
.18 \\
.18\end{array}$ & $\begin{array}{r}.71 \\
.61 \\
.47 \\
.42 \\
.38\end{array}$ & $\begin{array}{r}.28 \\
.29 \\
.28 \\
.23 \\
.22\end{array}$ & $\begin{array}{l}.27 \\
.57 \\
.25 \\
.22 \\
.22\end{array}$ & $\begin{array}{l}.20 \\
.13 \\
.14 \\
.14 \\
.24\end{array}$ & $\begin{array}{l}.22 \\
.22 \\
.22 \\
.22 \\
.22\end{array}$ & $\begin{array}{r}.18 \\
.18 \\
.18 \\
.19 \\
.19\end{array}$ & $\begin{array}{r}.34 \\
.20 \\
.24 \\
.19 \\
.17\end{array}$ & $\begin{array}{r}2.8 \\
.31 \\
.27 \\
.24 \\
.27\end{array}$ \\
\hline $\begin{array}{l}16 \\
17 \\
18 \\
19 \\
20\end{array}$ & $\begin{array}{l}.12 \\
.11 \\
.11 \\
.11 \\
.11\end{array}$ & $\begin{array}{r}.15 \\
.16 \\
.18 \\
.16 \\
.15\end{array}$ & $\begin{array}{l}.19 \\
.14 \\
.17 \\
.17 \\
.18\end{array}$ & $\begin{array}{l}.18 \\
.18 \\
.28 \\
.18 \\
.18\end{array}$ & $\begin{array}{r}.35 \\
.34 \\
.29 \\
.29 \\
.29\end{array}$ & $\begin{array}{r}.22 \\
.21 \\
.20 \\
.20 \\
.19\end{array}$ & $\begin{array}{r}.21 \\
.22 \\
.23 \\
.23 \\
.29\end{array}$ & $\begin{array}{l}.20 \\
.11 \\
.26 \\
.38 \\
.21\end{array}$ & $\begin{array}{l}.22 \\
.22 \\
.18 \\
.18 \\
.18\end{array}$ & $\begin{array}{r}.20 \\
.20 \\
.20 \\
.19 \\
.18\end{array}$ & $\begin{array}{r}.20 \\
.35 \\
.38 \\
.28 \\
.25\end{array}$ & $\begin{array}{r}.21 \\
.19 \\
.18 \\
.19 \\
.19\end{array}$ \\
\hline $\begin{array}{l}21 \\
22 \\
23 \\
24 \\
25\end{array}$ & $\begin{array}{l}.11 \\
.12 \\
.12 \\
112 \\
.12\end{array}$ & $\begin{array}{l}.17 \\
.17 \\
.20 \\
.15 \\
.19\end{array}$ & $\begin{array}{l}.21 \\
.18 \\
.17 \\
.16 \\
.16\end{array}$ & $\begin{array}{r}.18 \\
.18 \\
.17 \\
.17 \\
.23\end{array}$ & $\begin{array}{l}.28 \\
.28 \\
.27 \\
.24 \\
.22\end{array}$ & $\begin{array}{r}.20 \\
.23 \\
.23 \\
.24 \\
.29\end{array}$ & $\begin{array}{l}.23 \\
.23 \\
.21 \\
.26 \\
.32\end{array}$ & $\begin{array}{r}.12 \\
.12 \\
.28 \\
.36 \\
.24\end{array}$ & $\begin{array}{l}.18 \\
.22 \\
.22 \\
.22 \\
.18\end{array}$ & $\begin{array}{r}.18 \\
.18 \\
.22 \\
.22 \\
.18\end{array}$ & $\begin{array}{r}.15 \\
.18 \\
.31 \\
.26 \\
.20\end{array}$ & $\begin{array}{l}.19 \\
.20 \\
.20 \\
.21 \\
.21\end{array}$ \\
\hline $\begin{array}{l}26 \\
27 \\
28 \\
29 \\
30 \\
31\end{array}$ & $\begin{array}{l}.13 \\
.14 \\
.15 \\
.16 \\
.16 \\
.30\end{array}$ & $\begin{array}{l}.18 \\
.18 \\
.23 \\
.17 \\
.15 \\
---\end{array}$ & $\begin{array}{r}.16 \\
.18 \\
.17 \\
.14 \\
.18 \\
.18\end{array}$ & $\begin{array}{l}.23 \\
.14 \\
.14 \\
.18 \\
.24 \\
.13\end{array}$ & $\begin{array}{r}.25 \\
.29 \\
.27 \\
.31 \\
-.-- \\
-.-\end{array}$ & $\begin{array}{l}.40 \\
.33 \\
.25 \\
.24 \\
.24 \\
.23\end{array}$ & $\begin{array}{l}.37 \\
.27 \\
.23 \\
.24 \\
.26 \\
-.-2\end{array}$ & $\begin{array}{l}.20 \\
.21 \\
.20 \\
.22 \\
.28 \\
.29\end{array}$ & $\begin{array}{l}.22 \\
.21 \\
.17 \\
.23 \\
.18 \\
-.-\end{array}$ & $\begin{array}{l}.15 \\
.18 \\
.21 \\
.21 \\
.22 \\
.23\end{array}$ & $\begin{array}{r}.15 \\
.15 \\
.15 \\
.15 \\
.17 \\
.19\end{array}$ & $\begin{array}{l}.22 \\
83^{.22} \\
14 \\
.50 \\
-.-\end{array}$ \\
\hline $\begin{array}{l}\text { TOTAL } \\
\text { MEAN } \\
\text { MAX } \\
\text { MIN } \\
\text { AC-FT }\end{array}$ & $\begin{array}{r}4.26 \\
.14 \\
.30 \\
.11 \\
8.4\end{array}$ & $\begin{array}{r}5.50 \\
.19 \\
.23 \\
.15 \\
11\end{array}$ & $\begin{array}{r}5.98 \\
.19 \\
.37 \\
.14 \\
12\end{array}$ & $\begin{array}{r}5.72 \\
.18 \\
.28 \\
.13 \\
11\end{array}$ & $\begin{array}{r}83.65 \\
2.88 \\
53 \\
.14 \\
166\end{array}$ & $\begin{array}{r}29.94 \\
.97 \\
13 \\
.19 \\
59\end{array}$ & $\begin{array}{r}8.21 \\
.27 \\
.69 \\
.21 \\
16\end{array}$ & $\begin{array}{r}7.36 \\
.24 \\
.43 \\
.11 \\
115\end{array}$ & $\begin{array}{r}7.62 \\
.25 \\
.50 \\
.17 \\
15\end{array}$ & $\begin{array}{r}5.83 \\
.19 \\
.23 \\
.14\end{array}$ & $\begin{array}{r}8.73 \\
.28 \\
.53 \\
.15\end{array}$ & $\begin{array}{r}108.56 \\
3.62 \\
83 \\
.17 \\
215\end{array}$ \\
\hline
\end{tabular}

$\begin{array}{llllllllll}\text { CAL YR } & 1975 & \text { TOTAL } 142.41 & \text { MFAN } & 39 & \text { MAX } 15 & \text { MIN } & .09 & \text { AC-FT } 282 \\ \text { WTR YR } 1976 & \text { TOTAL } 2 A 1.36 & \text { MFAN } .77 & \text { MAX } 83 & \text { MIN } & 11 & \text { AC-FT } 558\end{array}$ 
11119750 MISSION CREEK NEAR MISSION STREET, AT SANTA BARBARA, CA

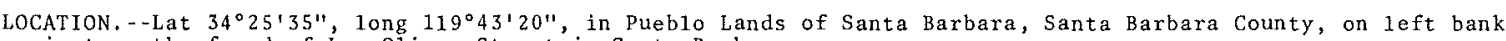
just south of end of Los olivos Street in Santa Barbara.

DRAINAGE AREA. $--8.38 \mathrm{mi}^{2}\left(21.70 \mathrm{~km}^{2}\right)$.

PERIOD OF RECORD.--October 1970 to current year.

GAGE. - Water-stage recorder. Concrete-1ined channe1. Altitude of gage is $105 \mathrm{ft}$ (32 m), from topographic map.

REMARKS. - Records fair. No regulation or diversion above station.

AVERAGE DISCHARGE. - -6 years, $2.28 \mathrm{ft}^{3} / \mathrm{s}\left(0.065 \mathrm{~m}^{3} / \mathrm{s}\right), 1,650 \mathrm{acre}-\mathrm{ft} / \mathrm{yr}^{2}\left(2.03 \mathrm{hm} / \mathrm{yr}^{3}\right)$.

EXTREMES FOR PERIOD OF RECORD. - Maximum discharge, $2,580 \mathrm{ft}^{3} / \mathrm{s}\left(73.1 \mathrm{~m}^{3} / \mathrm{s}\right) \mathrm{Jan}, 18,1973, \mathrm{gage} \mathrm{height}$, $4.97 \mathrm{ft}$ $(1.515 \mathrm{~m})$, from rating curve extended above $41 \mathrm{ft}^{3} / \mathrm{s}\left(1.16 \mathrm{~m}^{3} / \mathrm{s}\right)$ on basis of computation of flow in concretelined channe1; no flow most of each year.

EXTREMES FOR CURRENT YEAR. - Maximum discharge, $353 \mathrm{ft} / \mathrm{s}\left(10.0 \mathrm{~m}^{3} / \mathrm{s}\right)$ Feb. 9 , gage height, $2.30 \mathrm{ft}(0.701 \mathrm{~m}$ ), from rating curve extended above $41 \mathrm{ft}^{3} / \mathrm{s}\left(1.16 \mathrm{~m}^{3} / \mathrm{s}\right)$ on basis of computation of flow in concrete-1ined channel, no peak above base of $400 \mathrm{ft} / \mathrm{s}\left(11.3 \mathrm{~m}^{3} / \mathrm{s}\right)$; no flow for many months.

DISCHARGE, IN CUBIC FEET PER SECOND, WATER YEAR OCTOBER 1975 TO SEPTEMBER 1976 MEAN VALUES

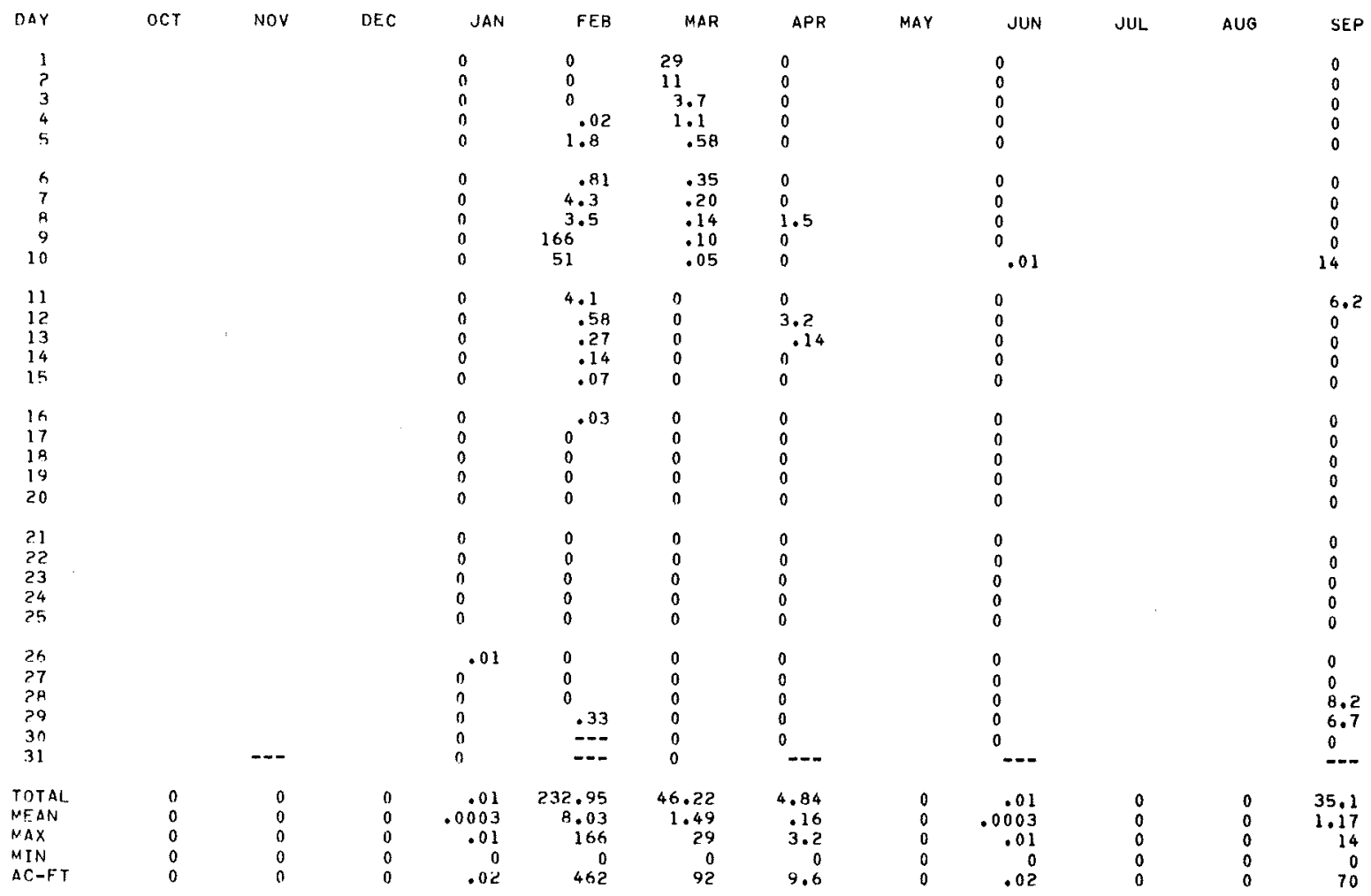

$\begin{array}{llllllllll}\text { CAL YR } 1975 & \text { TOTAL } 797.08 & \text { MEAN } 2.18 & \text { MAX } 110 & \text { MIN } 0 & \text { AC-FT } & 1580 \\ \text { WTR YR } 1976 & \text { TOTAL } 319.13 & \text { MEAN } & .87 & \text { MAX } 166 & \text { MIN } 0 & \text { AC-FT } & 633\end{array}$ 
LOCATION (Revised), - Lat $34^{\circ} 25^{\prime} 09^{\prime \prime}$, long $119^{\circ} 42^{\prime} 36^{\prime \prime}$, in Pueblo Lands of Santa Barbara, Santa Barbara County, near downstream end of culvert at intersection of Euclid Avenue and Victoria Street in Santa Barbara.

DRAINAGE AREA. $--0.625 \mathrm{mi}^{2}\left(1.619 \mathrm{~km}^{2}\right)$.

PERIOD OF RECORD.--October 1970 to current year. Prior to october 1972, pub1ished as "near Santa Barbara."

GAGE. - Water-stage recorder and culvert control. Datum of gage is $58.69 \mathrm{ft}$ (17.889 m) above mean sea 1eve1 (Santa Barbara County Flood Control and Water Conservation District bench mark).

REMARKS, - Records fair. Flow is from street drainage. During periods of heavy rainfall flood gates on the upper end of this watershed could be closed which would reduce the dratnage areaby 140 acres. (567,000 ${ }^{2}$ ).

EXTREMES FOR PERIOD OF RECORD.--Maximum discharge, $155 \mathrm{ft}^{3} / \mathrm{s}\left(4.39 \mathrm{~m}^{3} / \mathrm{s}\right) \mathrm{Feb} .27,1973$, gage height, $4.01 \mathrm{ft}$ $(1.222 \mathrm{~m})$; no flow most of each year.

EXTREMES OUTSIDE PERIOD OF RECORD, - Flood of Jan. 25, 1969, reached a stage of 4.26 ft (1.298 m), from floodmark, discharge, $178 \mathrm{ft}^{3} / \mathrm{s}\left(5.04 \mathrm{~m}^{3} / \mathrm{s}\right)$.

EXTREMES FOR CURRENT YEAR. - Maximum discharge, $100 \mathrm{ft}^{3} / \mathrm{s}\left(2.83 \mathrm{~m}^{3} / \mathrm{s}\right)$ Feb. 9 , gage height, $3.29 \mathrm{ft}(1.003 \mathrm{~m})$; no flow most of year.

DISCHARGE, IN CUBIC FEET PER SECOND, WATER YEAR OCTOBER 1975 TO SEPTEMBER 1976 MEAN VALUES

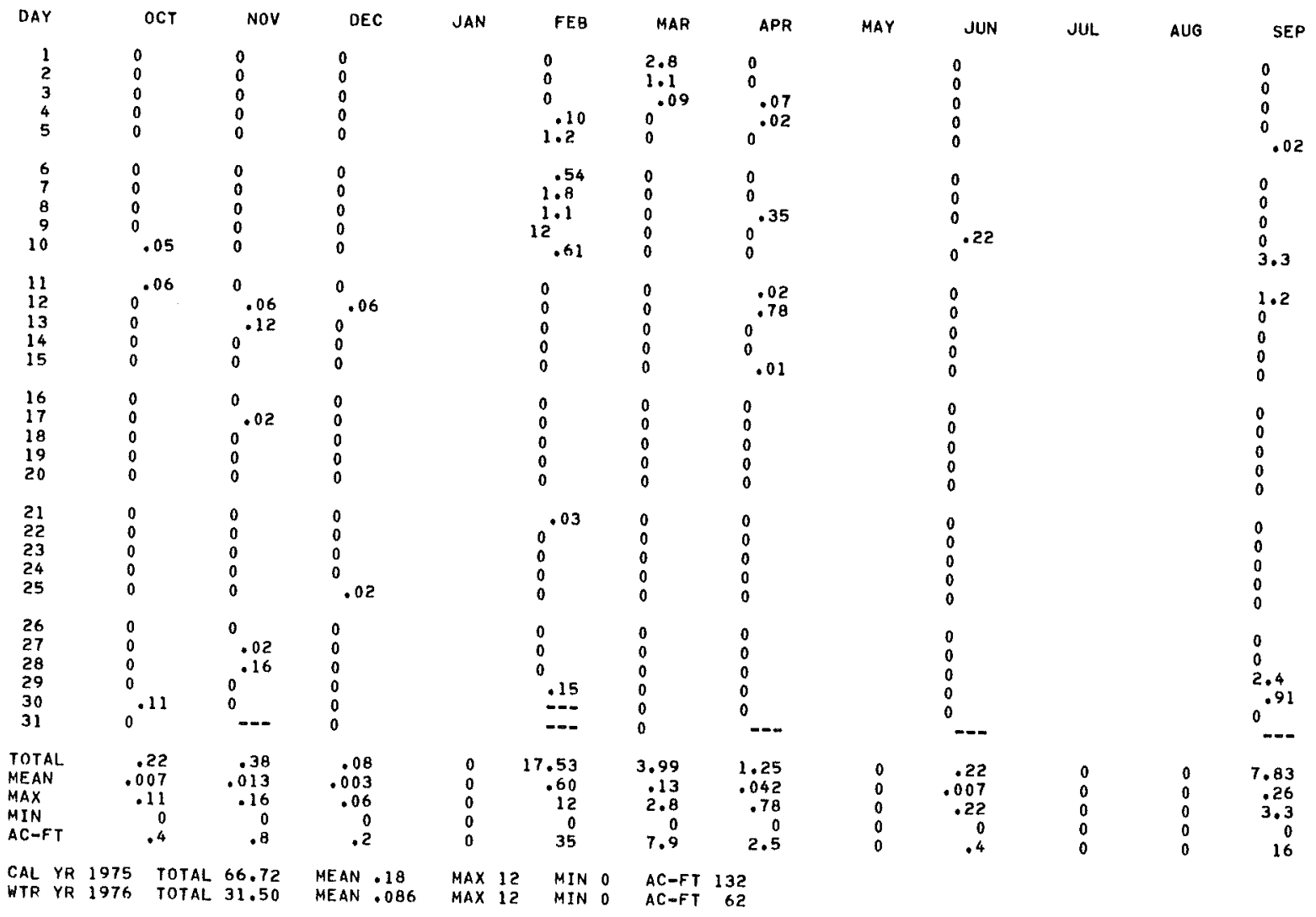


11119780 ARROYO BURRO CREEK AT SANTA BARBARA, CA

LOCATION.--Lat $34^{\circ} 26^{\prime} 13^{\prime \prime}$, long $119^{\circ} 44^{\prime} 44^{\prime \prime}$, in Pueblo Lands of Santa Barbara, Santa Barbara County, on right bank $0.4 \mathrm{mi}(0.6 \mathrm{~km})$ south of $\mathrm{State}$ Street on Hope Avenue in Santa Barbara.

DRAINAGE AREA. $-6.65 \mathrm{mi}^{2}\left(17.22 \mathrm{~km}^{2}\right)$.

PERIOD OF RECORD. - -October 1970 to current year.

GAGE. - Water-stage recorder. Concrete-1ined channe1 with a 1ow-water control. A1titude of gage is 160 ft (49 m), from topographic map.

REMARKS, - Records poor. Sma 11 amount of inflow occurs at times from large shopping center that empties water directly into the stream. partial regulation by Lauro Canyon Reservoir on San Roque Creek.

AVERAGE DISCHARGE.- -6 years, $1.98 \mathrm{t}^{3} / \mathrm{s}\left(0.056 \mathrm{~m}^{3} / \mathrm{s}\right), 1,430 \mathrm{acre}-\mathrm{ft} / \mathrm{yr}\left(1.76 \mathrm{hm} / \mathrm{yr}^{3}\right)$.

EXTREMES FOR PERIOD OF RECORD, --Maximum discharge, $1,510 \mathrm{ft}^{3} / \mathrm{s}\left(42.8 \mathrm{~m}^{3} / \mathrm{s}\right) \mathrm{Jan} .18,1973, \mathrm{gage} \mathrm{height,} 5.01 \mathrm{ft}$ $(1.527 \mathrm{~m})$; maximum gage height, $5.11 \mathrm{ft}(1.558 \mathrm{~m})$ Dec. 3 , 1974; no flow many days in each year.

EXTREMES FOR CURRENT YEAR, - MaXimum discharge, $305 \mathrm{ft}^{3} / \mathrm{s}\left(8.64 \mathrm{~m}^{3} / \mathrm{s}\right)$ Feb. 9 (0015 hrs), gage height $2.80 \mathrm{ft}$ $(0.853 \mathrm{~m})$, no other peaks above base of $300 \mathrm{ft}^{3} / \mathrm{s}\left(8.50 \mathrm{~m}^{3} / \mathrm{s}\right)$; no flow many days.

REVISIONS, - The maximum discharges for the water years 1974 and 1975 have been revised to $381 \mathrm{ft} / \mathrm{s}$ ( $10.8 \mathrm{~m} / \mathrm{s}$ ) Jan, 4, 1974, gage height, $2.98 \mathrm{ft}(0.908 \mathrm{~m})$ and $584 \mathrm{ft}^{3} / \mathrm{s}\left(16.5 \mathrm{~m}^{3} / \mathrm{s}\right)$ Dec. 28, 1974, gage height, $3.44 \mathrm{ft}$ $(1.049 \mathrm{~m})$, superseding figures published in WDR CA-74-1 and WDR CA-75-1.

OISCHARGE, IN CUBIC FEET PEA SECOND, WATER YEAR OCTOBER 1975 TO SEPTEMBER 1976 MEAN VALUES

\begin{tabular}{|c|c|c|c|c|c|c|c|c|c|c|c|c|}
\hline DAY & OCT & Nov & DEC & JAN & FEB & MAR & APR & MAY & JUN & JUL & AUG & SEP \\
\hline $\begin{array}{l}1 \\
2 \\
3 \\
4 \\
5\end{array}$ & $\begin{array}{l}.04 \\
.02 \\
.02 \\
.03 \\
.05\end{array}$ & $\begin{array}{l}.03 \\
.01 \\
.13\end{array}$ & $\begin{array}{l}0 \\
.11 \\
.25 \\
.01 \\
.13\end{array}$ & $\begin{array}{l}0 \\
.02 \\
.22 \\
.38 \\
.32\end{array}$ & $\begin{array}{l}0 \\
0.01 \\
0.56 \\
4.5\end{array}$ & $\begin{array}{r}20 \\
9.5 \\
2.5 \\
.90 \\
.63\end{array}$ & $\begin{array}{l}.05 \\
.01 \\
.21 \\
.19 \\
.01\end{array}$ & $\begin{array}{l}.03 \\
.02 \\
.02 \\
.02 \\
.04\end{array}$ & $\begin{array}{l}.02 \\
.02 \\
.03 \\
.04 \\
.05\end{array}$ & $\begin{array}{l}.02 \\
.02 \\
.05 \\
.04 \\
.04\end{array}$ & $\begin{array}{l}0 \\
.03 \\
.01 \\
.02 \\
.02\end{array}$ & $\begin{array}{l}.02 \\
.03 \\
.03 \\
.03 \\
.04\end{array}$ \\
\hline $\begin{array}{r}6 \\
7 \\
8 \\
9 \\
10\end{array}$ & $\begin{array}{l}.03 \\
.03 \\
.01 \\
.06 \\
.21\end{array}$ & $\begin{array}{l}.07 \\
.08 \\
.03 \\
.01 \\
.08\end{array}$ & $\begin{array}{l}.06 \\
0.01 \\
.19 \\
.26\end{array}$ & $\begin{array}{l}.07 \\
.01 \\
.01 \\
.21 \\
.11\end{array}$ & $\begin{array}{l}1.7 \\
6.6 \\
6.1 \\
91 \\
20\end{array}$ & $\begin{array}{l}.48 \\
.41 \\
.34 \\
.36 \\
.32\end{array}$ & $\begin{array}{l}0 \\
: 01 \\
1: 1 \\
0 \\
0\end{array}$ & $\begin{array}{l}.14 \\
.03 \\
0 \\
0 \\
.01\end{array}$ & $\begin{array}{l}.02 \\
.03 \\
.01 \\
.02 \\
.95\end{array}$ & $\begin{array}{l}.02 \\
0 \\
.02 \\
.04\end{array}$ & $\begin{array}{l}.02 \\
.03 \\
.05 \\
.04\end{array}$ & $\begin{array}{r}.04 \\
.05 \\
.05 \\
17^{.03}\end{array}$ \\
\hline $\begin{array}{l}11 \\
12 \\
13 \\
14 \\
15\end{array}$ & $\begin{array}{r}.17 \\
.01 \\
.01 \\
.01\end{array}$ & $\begin{array}{l}.01 \\
.05 \\
.03 \\
.14 \\
.02\end{array}$ & $\begin{array}{l}0 \\
.31 \\
.02 \\
0.011\end{array}$ & $\begin{array}{l}.05 \\
.01 \\
.01 \\
.14 \\
.08\end{array}$ & $\begin{array}{l}1.9 \\
.79 \\
.54 \\
.30 \\
.27\end{array}$ & $\begin{array}{l}.20 \\
.16 \\
.10 \\
.06 \\
.03\end{array}$ & $\begin{array}{l}.24 \\
3.4 \\
0.19 \\
.03\end{array}$ & $\begin{array}{l}.01 \\
.02 \\
.02 \\
.02 \\
.02\end{array}$ & $\begin{array}{l}.03 \\
.07 \\
.01 \\
.02 \\
.07\end{array}$ & $\begin{array}{l}.05 \\
.04 \\
.01 \\
.02 \\
.04\end{array}$ & $\begin{array}{l}.01 \\
.03 \\
.02 \\
.01 \\
.01\end{array}$ & $\begin{array}{l}6.8 \\
0 \\
0 \\
0 \\
.01\end{array}$ \\
\hline $\begin{array}{l}16 \\
17 \\
18 \\
19 \\
20\end{array}$ & $\begin{array}{r}.16 \\
0.03 \\
.13 \\
.05\end{array}$ & $\begin{array}{l}0 \\
.03 \\
.01 \\
.10 \\
.02\end{array}$ & $\begin{array}{r}.02 \\
.04 \\
.10 \\
0 \quad .03\end{array}$ & $\begin{array}{l}.02 \\
.02 \\
.01 \\
.11 \\
.01\end{array}$ & $\begin{array}{l}.13 \\
.01 \\
.01 \\
.14 \\
.05\end{array}$ & $\begin{array}{l}.06 \\
.02 \\
.02 \\
.08 \\
.02\end{array}$ & $\begin{array}{l}.04 \\
0.02 \\
0^{.03}\end{array}$ & $\begin{array}{r}.01 \\
.03 \\
.03 \\
.01\end{array}$ & $\begin{array}{l}.02 \\
.05 \\
.04 \\
.06 \\
.02\end{array}$ & $\begin{array}{l}.01 \\
.02 \\
.03 \\
0 \\
0\end{array}$ & $\begin{array}{r}.01 \\
.03 \\
0.01 \\
.03\end{array}$ & $\begin{array}{l}0 \\
0 \\
0.01 \\
.01\end{array}$ \\
\hline $\begin{array}{l}21 \\
22 \\
23 \\
24 \\
25\end{array}$ & $\begin{array}{r}.41 \\
.57 \\
1.3 \\
.77 \\
.75\end{array}$ & $\begin{array}{r}.05 \\
.03 \\
.02 \\
0.09\end{array}$ & $\begin{array}{l}.04 \\
.01 \\
.22 \\
.22 \\
.04\end{array}$ & $\begin{array}{l}.05 \\
.03 \\
.03 \\
.02 \\
.01\end{array}$ & $\begin{array}{l}0 \\
0 \\
.24 \\
.16 \\
0\end{array}$ & $\begin{array}{l}.04 \\
.06 \\
.04 \\
.04 \\
.04\end{array}$ & $\begin{array}{l}.01 \\
.01 \\
.01 \\
.02 \\
0\end{array}$ & $\begin{array}{l}.01 \\
.01 \\
.01 \\
.02 \\
.04\end{array}$ & $\begin{array}{l}.02 \\
.05 \\
.05 \\
.05 \\
.05\end{array}$ & $\begin{array}{l}0 \\
: 01 \\
0.01 \\
0 \\
0\end{array}$ & $\begin{array}{r}.01 \\
.03 \\
.02 \\
.01\end{array}$ & $\begin{array}{l}.01 \\
.02 \\
.01 \\
.02 \\
.01\end{array}$ \\
\hline $\begin{array}{l}26 \\
27 \\
28 \\
29 \\
30 \\
31\end{array}$ & $\begin{array}{l}.41 \\
.02 \\
.06 \\
.02 \\
.38 \\
.30\end{array}$ & $\begin{array}{r}.22 \\
.06 \\
.01 \\
0.06 \\
.0-\end{array}$ & $\begin{array}{l}.01 \\
.01 \\
.01 \\
.01 \\
.19 \\
.02\end{array}$ & $\begin{array}{l}.03 \\
.66 \\
.29 \\
.03 \\
.07 \\
.03\end{array}$ & $\begin{array}{r}0 \\
.06 \\
.02 \\
.91 \\
-. \\
-\end{array}$ & $\begin{array}{l}.06 \\
.07 \\
.04 \\
.07 \\
.07 \\
.07\end{array}$ & $\begin{array}{l}.02 \\
.01 \\
.01 \\
.01 \\
.03 \\
0-0\end{array}$ & $\begin{array}{l}.01 \\
.01 \\
.02 \\
.01 \\
.49 \\
.01\end{array}$ & $\begin{array}{l}.05 \\
.04 \\
.04 \\
.07 \\
.04 \\
.0\end{array}$ & $\begin{array}{r}.03 \\
.01 \\
.02 \\
.02 \\
0.03 \\
.03\end{array}$ & $\begin{array}{l}.01 \\
.01 \\
.06 \\
.03 \\
.04 \\
.07\end{array}$ & $\begin{array}{l}.01 \\
.01 \\
8.2 \\
4.4 \\
0\end{array}$ \\
\hline $\begin{array}{l}\text { TOTAL } \\
\text { MEAN } \\
\text { MAX } \\
\text { MIN } \\
\text { AC-FT }\end{array}$ & $\begin{array}{r}6.06 \\
.20 \\
i .3 \\
0 \\
12\end{array}$ & $\begin{array}{r}1.99 \\
.066 \\
.61 \\
0 \\
3.9\end{array}$ & $\begin{array}{r}2.43 \\
.078 \\
.31 \\
0 \\
4.8\end{array}$ & $\begin{array}{r}3.06 \\
.099 \\
.66 \\
0 \\
6.1\end{array}$ & $\begin{array}{r}136.00 \\
4.69 \\
91 \\
0 \\
270\end{array}$ & $\begin{array}{r}36.79 \\
1.19 \\
20 \\
.02 \\
73\end{array}$ & $\begin{array}{r}5.67 \\
.19 \\
3.4 \\
0 \\
11\end{array}$ & $\begin{array}{r}1.32 \\
.043 \\
.49 \\
0 \\
2.6\end{array}$ & $\begin{array}{r}2.04 \\
.068 \\
.95 \\
.01 \\
4.0\end{array}$ & $\begin{array}{r}.60 \\
.019 \\
.05 \\
0 \\
1.2\end{array}$ & $\begin{array}{r}.67 \\
.022 \\
.07 \\
0 \\
1.3\end{array}$ & $\begin{array}{r}36.84 \\
1.23 \\
17\end{array}$ \\
\hline
\end{tabular}

CAL YR 1975 TOTAL 867.13 MEAN 2.38 MAX 190 MIN O AC-FT 1720 WTP YR 1976 TOTAL 233.47 MEAN .64 MAX 91 MIN 0 AC-FT 463 
11119940 MARIA YGNACIO CREEK AT UNIVERSITY DRIVE, NEAR GOLETA, CA

LOCATION.--Lat $34^{\circ} 26^{\prime} 42^{\prime \prime}$, long $119^{\circ} 48^{\prime} 10^{\prime \prime}$, in Goleta Grant, Santa Barbara County, on right bank at University Drive, $0.2 \mathrm{mi}(0.3 \mathrm{~km})$ east of Patterson Avenue, and $1.5 \mathrm{mi}(2.4 \mathrm{~km})$ northeast of Goleta.

DRAINAGE AREA. $--6.35 \mathrm{mi}^{2}\left(16.4 \mathrm{~km}^{2}\right)$.

PERIOD OF RECORD, - - October 1970 to current year.

GAGE. - Water-stage recorder and concrete control. Altitude of gage is 60 ft (18 m), from topographic map.

REMARKS, - Records fair. No regulation. Some pumping for irrigation.

AVERAGE DISCHARGE. - -6 years, $1.18 \mathrm{ft}^{3} / \mathrm{s}\left(0.033 \mathrm{~m}^{3} / \mathrm{s}\right), 855 \mathrm{acre}-\mathrm{ft} / \mathrm{yr}\left(1.05 \mathrm{hm}^{3} / \mathrm{yr}^{2}\right)$.

EXTREMES FOR PERIOD OF RECORD, - Maximum discharge, $1,470 \mathrm{ft}^{3} / \mathrm{s}\left(41.6 \mathrm{~m}^{3} / \mathrm{s}\right) \mathrm{Jan}, 18,1973, \mathrm{gage}$ height, $4.06 \mathrm{ft}$ $(1.237 \mathrm{~m})$, from rating curve extended above $260 \mathrm{ft}^{3} / \mathrm{s}\left(7.36 \mathrm{~m}^{3} / \mathrm{s}\right)$ on basis of computation of $\mathrm{flow}$ in trapezoidal section; no flow most of each year.

EXTREMES FOR CURRENT YEAR. - Maximum discharge, $118 \mathrm{ft}^{3} / \mathrm{s}\left(3.34 \mathrm{~m}^{3} / \mathrm{s}\right.$ ) Feb. 9 (time unknown), gage height, $2.10 \mathrm{ft}$

$(0.640 \mathrm{~m})$, from outside high-water mark; no other peaks above base of $75 \mathrm{ft} / \mathrm{s}(2.12 \mathrm{~m} / \mathrm{s}) ; \mathrm{no} f 10 \mathrm{~m} \mathrm{many}$ days.

DISCHARGE, IN CUBIC FEET PER SECOND, WATER YEAR OCTOBER 1975 TO SEPYEMBER 1976 MEAN VALUES

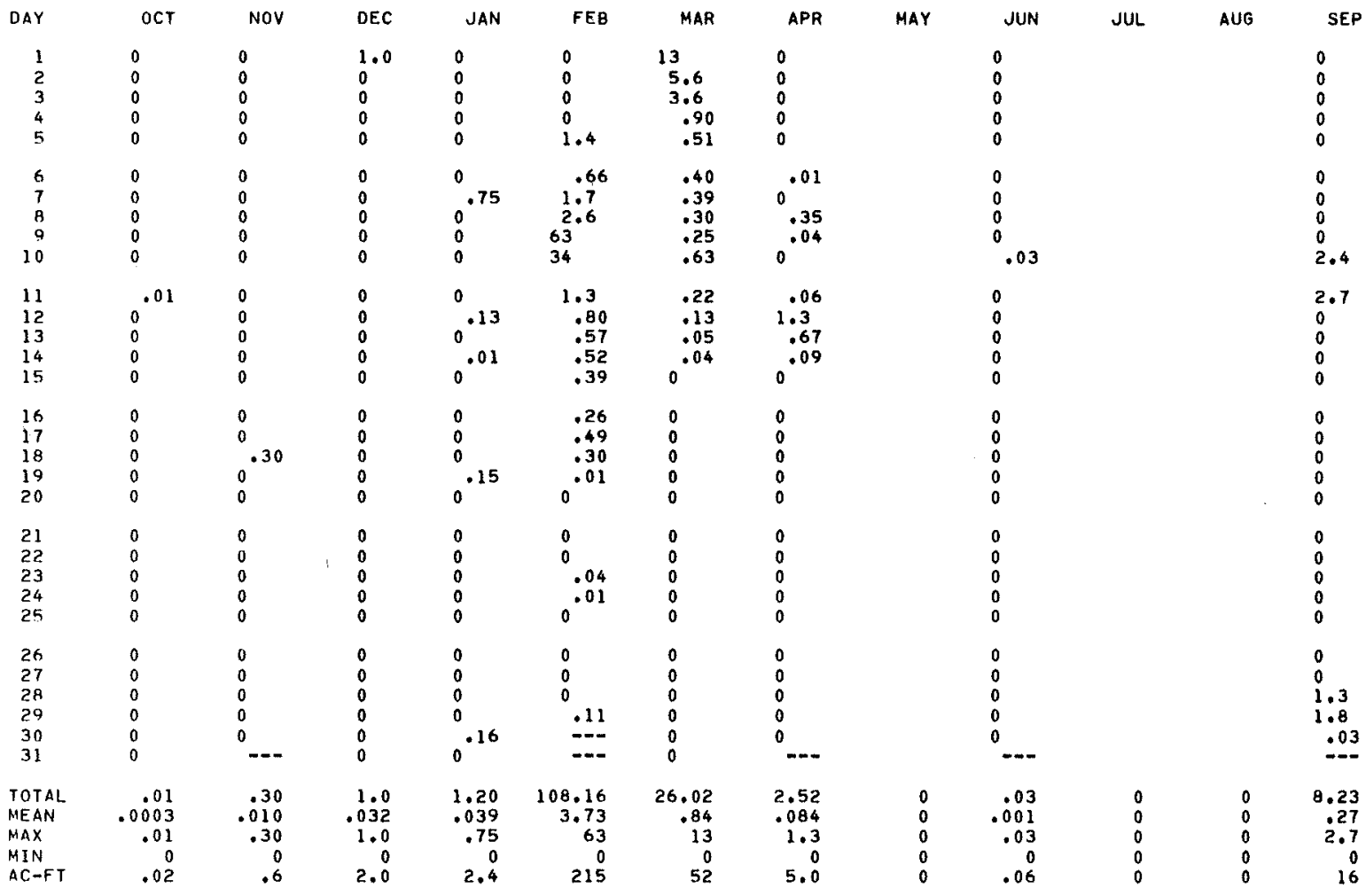

$\begin{array}{lrrrrrrrr}\text { CAL YR } 1975 & \text { TOTAL } 482.53 & \text { MEAN } 1.32 & \text { MAX } 105 & \text { MIN } 0 & \text { AC-FT } 957 \\ \text { WTR YR } 1976 & \text { TOTAL } 147.47 & \text { MEAN } & .40 & \text { MAX } & 63 & \text { MIN } & 0 & \text { AC-FT } 293\end{array}$ 
11120000 ATASCADERO CREEK NEAR GOLETA, CA

LOCATION, - - Lat $34^{\circ} 25^{\prime} 29^{\prime \prime}$, long $119^{\circ} 48^{\prime} 39^{\prime \prime}$, in La Goleta Grant, Santa Barbara County, on downstream side of center pier of county road bridge $100 \mathrm{ft}(30 \mathrm{~m})$ downstream from Maria Ygnacio Creek, $1.3 \mathrm{mi}$ (2.1 km) upstream from mouth, and $1.3 \mathrm{mi}(2.1 \mathrm{~km})$ southeast of Goleta.

DRAINAGE AREA. - - 18.9 $\mathrm{mi}^{2}\left(49.0 \mathrm{~km}^{2}\right)$.

PERIOD OF RECORD.--October 1941 to current year. Prior to October 1947, published as Alascadero Creek near Goleta.

GAGE. - Water-stage recorder. Datum of gage is $12.59 \mathrm{ft}(3.837 \mathrm{~m}$ ) above mean sea leve1 (Santa Barbara County bench mark). Prior to Dec, 14, 1967, at site $275 \mathrm{ft}(84 \mathrm{~m})$ downstream at same datum.

REMARKS. - Records poor. No regulation above station. Small diversions for irrigation above station. Some low flow results from return irrigation waste water.

AVERAGE DISCHARGE. -35 years, $4.36 \mathrm{ft}^{3} / \mathrm{s}\left(0.123 \mathrm{~m}^{3} / \mathrm{s}\right), 3,160$ acre-ft $/ \mathrm{yr}^{2}(3.90 \mathrm{hm} / \mathrm{yr})$.

EXTREMES FOR PERIOD OF RECORD.--Maximum discharge, $5,380 \mathrm{ft}^{3} / \mathrm{s}\left(152 \mathrm{~m}^{3} / \mathrm{s}\right) \mathrm{Jan}, 18,1973$, gage height, 13.1 ft $(3.99 \mathrm{~m})$, from rating curve extended above $2,300 \mathrm{ft}^{3} / \mathrm{s}\left(65.1 \mathrm{~m}^{3} / \mathrm{s}\right) ; \mathrm{maximum}$ gage height, $13.3 \mathrm{ft}(4.05 \mathrm{~m})$ from floodmark, Dec. 3, 1974; no flow some days in each year.

EXTREMES FOR CURRENT YEAR, - -Peak discharges above base of $100 \mathrm{ft} / \mathrm{s}\left(2.83 \mathrm{~m}^{3} / \mathrm{s}\right)$ and maximum(*), from rating curve extended above $192 \mathrm{ft}^{3} / \mathrm{s}\left(5.44 \mathrm{~m}^{3} / \mathrm{s}\right)$ on basis of slope-conveyance measurement of maximum flow:

\begin{tabular}{|c|c|c|c|c|c|c|c|}
\hline Date & Time & $\begin{array}{c}\text { Discharge } \\
\left(\mathrm{ft}^{3} / \mathrm{s}\right)\left(\mathrm{m}^{3} / \mathrm{s}\right)\end{array}$ & $\begin{array}{l}\text { Gage height } \\
(\mathrm{ft}) \\
(\mathrm{m})\end{array}$ & Date & Time & $\begin{array}{c}\text { Discharge } \\
\left(\mathrm{ft}^{3} / \mathrm{s}\right)\left(\mathrm{m}^{3} / \mathrm{s}\right)\end{array}$ & $\begin{array}{l}\text { Gage height } \\
\text { (ft) }\end{array}$ \\
\hline $\begin{array}{l}\text { eb. } 9 \\
\text { lar. } 1\end{array}$ & $\begin{array}{l}0645 \\
0245\end{array}$ & $\begin{array}{r}* 1380 \\
478\end{array}$ & $\begin{array}{l}1.085 \\
0.954\end{array}$ & $\begin{array}{l}\text { Sept. } 10 \\
\text { Sept. } 29\end{array}$ & $\begin{array}{l}2315 \\
0015\end{array}$ & $\begin{array}{r}10.6 \\
8.86\end{array}$ & $\begin{array}{l}0.927 \\
0.814\end{array}$ \\
\hline
\end{tabular}

Minimum daily discharge, no flow on some days.

DISCHARGE, IN CUBIC FEET PER SECOND, WATER YEAR OCTOBER 1975 TO SEPTEMBER 1976 MEAN VALUES

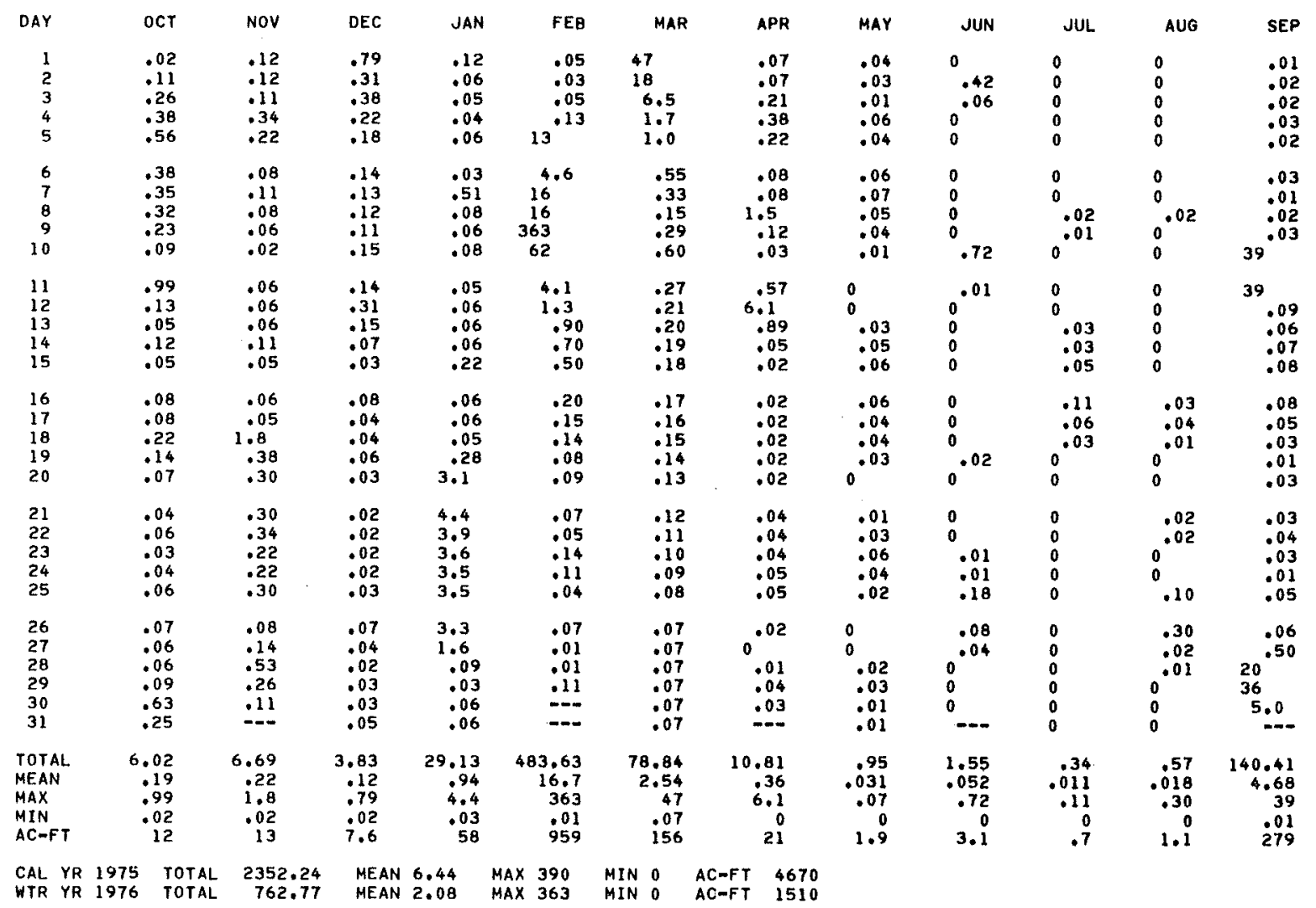


LOCATION. - Lat $34^{\circ} 27^{\prime} 33^{\prime \prime}$, long $119^{\circ} 48^{\prime} 29^{\prime \prime}$, in La Goleta Grant, Santa Barbara County, on right bank, 1.1 mi (1.8 km) downstream from unnamed tributary, and $1.7 \mathrm{mi}(2.7 \mathrm{~km})$ northeast of Goleta.

DRAINAGE AREA. $--5.51 \mathrm{mi}^{2}\left(14.27 \mathrm{~km}^{2}\right)$.

PERIOD OF RECORD. - -January 1941 to current year.

GAGE. - Water-stage recorder and concrete low-water control. Datum of gage is $95.61 \mathrm{ft}$ ( $29.142 \mathrm{~m}$ ) above mean sea leve1 (Santa Barbara County Road Department bench mark). Prior to Dec. 24, 1955 , at datum 5.50 ft (1.676 m) higher. Dec, 24, 1955, to Jan. 10, 1960, at datum $1.5 \mathrm{ft}(0.46 \mathrm{~m})$ higher. Prior to oct. 1, 1971, at site $75 \mathrm{ft}(23 \mathrm{~m})$ downstream at same datum.

REMARKS.--Records fair. No regulation above station. Many small diversions for irrigation above station. AVERAGE DISCHARGE. -35 years, $1.83 \mathrm{ft}^{3} / \mathrm{s}\left(0.052 \mathrm{~m}^{3} / \mathrm{s}\right), 1,330 \mathrm{acre}-\mathrm{ft} / \mathrm{yr}\left(1.64 \mathrm{hm} / \mathrm{yr}^{3}\right)$.

EXTREMES FOR PERIOD OF RECORD.--Maximum discharge, 2,000 $\mathrm{ft}^{3} / \mathrm{s}\left(56.6 \mathrm{~m}^{3} / \mathrm{s}\right) \mathrm{Jan} .25,1969, \mathrm{gage} \mathrm{height}, 10.10 \mathrm{ft}$ $(3.078 \mathrm{~m})$, from rating curve extended above $400 \mathrm{ft}^{3} / \mathrm{s}\left(11.3 \mathrm{~m}^{3} / \mathrm{s}\right)$ on basis of siope-area measurement at gage height $9.32 \mathrm{ft}(2.841 \mathrm{~m})$; maximum gage height, $12.74 \mathrm{ft}(3.883 \mathrm{~m})$, present datum, Jan. 21 , 1943 ; no f1ow at times in each year.

EXTREMES FOR CURRENT XEAR. - Maximum discharge, $192 \mathrm{ft}^{3} / \mathrm{s}\left(5.44 \mathrm{~m}^{3} / \mathrm{s}\right)$ Feb, 9 (2345 hrs), gage height, $4.47 \mathrm{ft}$ $(1.362 \mathrm{~m})$, from rating curve extended above $23 \mathrm{ft} / \mathrm{s}\left(0.65 \mathrm{~m}^{3} / \mathrm{s}\right)$ on basis of maximum discharge at old gage site $75 \mathrm{ft}(23 \mathrm{~m})$ downstream; no othex peaks above base of $100 \mathrm{ft} / \mathrm{s}\left(2.83 \mathrm{~m}^{3} / \mathrm{s}\right) ; \mathrm{no} f 10 \mathrm{foct}$. 2 .

DISCHARGE, IN CUBIC FEET PER SECOND, HATER YEAR OCTOBER 1975 TO SEPTEMBER 1976 MEAN VALUES

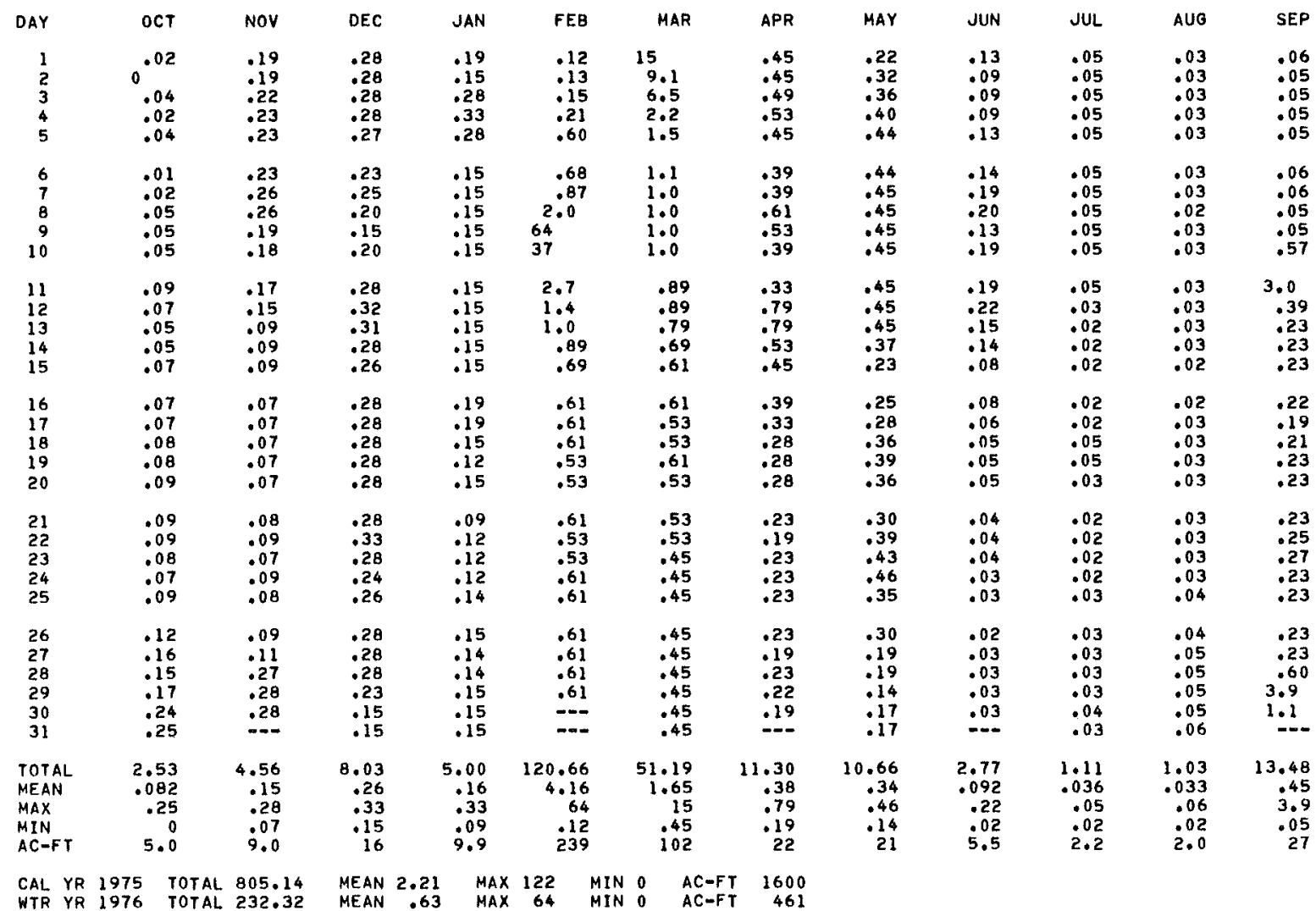


11120510 SAN JOSE CREEK AT GOLETA, CA

LOCATION.--Lat $34^{\circ} 25^{\prime} 49^{\prime \prime}$, long $119^{\circ} 49^{\prime} 16^{\prime \prime}$, in La Goleta Grant, Santa Barbara County, on right bank south of

Hollister Avenue on Kellogg Avenue, $0.5 \mathrm{mi}(0.8 \mathrm{~km})$ southeast of Goleta.

DRAINAGE AREA. $-9.42 \mathrm{mi}^{2}\left(24,40 \mathrm{~km}^{2}\right)$.

PERIOD OF RECORD. - October 1970 to current year.

REVISED RECORDS, - -WDR CA-73-1: $1973(\mathrm{M})$.

GAGE, - Water-stage recorder and concrete low-flow control. Altitude of gage is $10 \mathrm{ft}$ ( $3 \mathrm{~m}$ ), from topographic map.

REMARKS,--Records fair. No regulation above station. Diversions for irrigation and domestic use above station. AVERAGE Discharge. - -6 years, $2.22 \mathrm{ft}^{3} / \mathrm{s}\left(0.063 \mathrm{~m}^{3} / \mathrm{s}\right), 1,610 \mathrm{acre}-\mathrm{ft} / \mathrm{yr}^{2}\left(1.99 \mathrm{hm}^{3} / \mathrm{yr}^{\mathrm{r}}\right)$.

EXTREMES FOR PERIOD OF RECORD. - Maximum discharge, 1,950 $\mathrm{ft}^{3} / \mathrm{s}\left(55.2 \mathrm{~m}^{3} / \mathrm{s}\right) \mathrm{Jan}$. 18, 1973, gage height, $5.21 \mathrm{ft}$

$(1.588 \mathrm{~m})$, from rating curve extended above $400 \mathrm{ft} / \mathrm{s}\left(11.3 \mathrm{~m}^{3} / \mathrm{s}\right)$ on basis of siope-conveyance computation

of flow in concrete channel at gage height $8.00 \mathrm{ft}(2.438 \mathrm{~m})$; no flow for long periods in each year.

EXTREMES FOR CURRENT YEAR, - Peak discharges above base of $150 \mathrm{ft}^{3} / \mathrm{s}\left(4.25 \mathrm{~m}^{3} / \mathrm{s}\right)$ and maximum (*):

\begin{tabular}{|c|c|c|c|c|c|}
\hline Date & Time & $\begin{array}{r}\text { Disch } \\
\left(\mathrm{ft}^{3} / \mathrm{s}\right)\end{array}$ & $\left.e^{e} / s\right)$ & $\begin{array}{l}\text { Gage } \\
(f t)\end{array}$ & $\begin{array}{r}\text { height } \\
\text { (m) }\end{array}$ \\
\hline $\begin{array}{l}\text { Feb. } \\
\text { Sept, } 10\end{array}$ & $\begin{array}{l}0545 \\
2215\end{array}$ & $\begin{array}{r}* 239 \\
189\end{array}$ & $\begin{array}{l}6.77 \\
5.35\end{array}$ & $\begin{array}{l}2.34 \\
2.21\end{array}$ & $\begin{array}{l}0.713 \\
0.674\end{array}$ \\
\hline
\end{tabular}

Minimum daily discharge, no flow for many days.

DISCHARGE, IN CUBIC FEET PER SECOND, WATER YEAR OCTOBER 1975 TO SEPTEMBER 1976 MEAN VALUES

\begin{tabular}{|c|c|c|c|c|c|c|c|c|c|c|c|c|}
\hline DAY & $O C T$ & NOV & DEC & JAN & FEB & MAR & APR & MAY & JUN & JUL & AUG & SEP \\
\hline 1 & 0 & 0 & .08 & 0 & 0 & 16 & .11 & & 0 & 0 & & 0 \\
\hline 2 & 0 & 0 & 0 & 0 & 0 & 10 & .07 & & 0 & 0 & & 0 \\
\hline 3 & 0 & 0 & 0 & 0 & 0 & 6.6 & .31 & & 0 & 0 & & 0 \\
\hline 5 & 0 & 0 & 0 & 0 & 3.5 & $1 \cdot 2$ & .18 & & 0 & 0 & & 0 \\
\hline 6 & 0 & 0 & 0 & 0 & 1.3 & .83 & .12 & & 0 & 0 & & 0 \\
\hline 7 & 0 & 0 & 0 & .14 & 3.6 & .67 & .01 & & 0 & 0 & & 0 \\
\hline 8 & 0 & 0 & 0 & 0 & 6.1 & .61 & .81 & & 0 & 0 & & 0 \\
\hline 10 & .17 & 0 & 0 & 0 & 36 & .81 & .07 & & .13 & 0 & & 9.8 \\
\hline 11 & .26 & 0 & 0 & 0 & 2.3 & .47 & .30 & & 0 & 0 & & 7.5 \\
\hline 12 & 0 & 0 & .02 & 0 & 1.0 & .47 & 5.1 & & 0 & 0 & & .27 \\
\hline 13 & 0 & 0 & 0 & 0 & .75 & .40 & 1.1 & & 0 & 0 & & .12 \\
\hline 14 & 0 & 0 & 0 & 0 & .61 & .35 & .37 & & 0 & 0 & & 0 \\
\hline 15 & 0 & 0 & 0 & 0 & .48 & .32 & .27 & & 0 & .01 & & 0 \\
\hline 16 & 0 & 0 & 0 & 0 & .44 & .34 & .16 & & 0 & 0 & & 0 \\
\hline 17 & 0 & 0 & 0 & 0 & .38 & .28 & .12 & & 0 & 0 & & 0 \\
\hline 20 & 0 & 0 & 0 & 0 & .29 & .25 & 0 & & 0 & 0 & & 0 \\
\hline 21 & 0 & 0 & 0 & 0 & .24 & .24 & 0 & & 0 & 0 & & 0 \\
\hline 22 & 0 & 0 & 0 & 0 & .24 & .17 & 0 & & 0 & 0 & & 0 \\
\hline 23 & 0 & 0 & 0 & 0 & .27 & .16 & 0 & & 0 & 0 & & 0 \\
\hline 24 & 0 & 0 & 0 & 0 & .40 & .15 & 0 & & 0 & 0 & & 0 \\
\hline 25 & 0 & 0 & 0 & 0 & .24 & .11 & 0 & & 0 & 0 & & 0 \\
\hline 26 & 0 & 0 & 0 & 0 & .20 & .07 & 0 & & 0 & 0 & & 0 \\
\hline 27 & 0 & 0 & 0 & 0 & .18 & .07 & .01 & & 0 & 0 & & 0 \\
\hline 28 & 0 & .06 & 0 & 0 & .19 & .07 & .11 & & 0 & 0 & & 5.3 \\
\hline 29 & 0 & 0 & 0 & 0 & .31 & .10 & 0 & & 0 & 0 & & 6.9 \\
\hline 30 & .01 & 0 & 0 & .02 & -- & .12 & 0 & & 0 & 0 & & .68 \\
\hline 31 & 0 & -- & 0 & 0 & $-m$ & .08 & -- & & $\cdots$ & 0 & & $\ldots$ \\
\hline $\begin{array}{l}\text { TOTAL } \\
\text { MEAN }\end{array}$ & $\begin{array}{r}.44 \\
.014\end{array}$ & $\begin{array}{r}.08 \\
.003\end{array}$ & $\begin{array}{r}10 \\
.003\end{array}$ & .0 .16 & $\begin{array}{r}137.68 \\
4.75\end{array}$ & $\begin{array}{r}44.00 \\
1.42\end{array}$ & $\begin{array}{r}9.90 \\
.33\end{array}$ & $\begin{array}{l}0 \\
0\end{array}$ & $\begin{array}{r}.13 \\
.004\end{array}$ & $\begin{array}{r}.01 \\
.0003\end{array}$ & $\begin{array}{l}0 \\
0\end{array}$ & $\begin{array}{r}30.57 \\
1.02\end{array}$ \\
\hline MAX & .26 & .06 & .08 & .14 & 78 & 16 & 5.1 & 0 & .13 & .01 & 0 & 9.8 \\
\hline MIN & 0 & 0 & 0 & 0 & 0 & .07 & 0 & 0 & 0 & 0 & 0 & 0 \\
\hline$A C-F T$ & .9 & .2 & .2 & .3 & 273 & 87 & 20 & 0 & .3 & .02 & 0 & 61 \\
\hline
\end{tabular}

CAL YR 1975 TOTAL 721.11 MEAN 1.98 MAX 120 MIN O AC-FT 1430 WTR YR 1976 TOTAL 223.07 MEAN .61 MAX 7B MIN 0 AC-FT 442 
LOCATION. - Lat $34^{\circ} 29^{\prime} 16^{\prime \prime}$, long $120^{\circ} 13^{\prime} 34^{\prime \prime}$, in Nuestra Senora Del Refugio Grant, Santa Barbara County, on 1 eft

bank $1.3 \mathrm{mi}(2.1 \mathrm{~km})$ northwest of Gaviota, and $1.6 \mathrm{mi}(2.6 \mathrm{~km})$ upstream from mouth.

DRAINAGE AREA. $-18.8 \mathrm{mi}^{2}\left(48.7 . \mathrm{km}^{2}\right) \cdot$

PERIOD OF RECORD. - - October 1966 to current year.

GAGE. - Water-stage recorder and concrete control. Altitude of gage is $100 \mathrm{ft}$ ( $30 \mathrm{~m}$ ), from topograhic map.

REMARKS,--Records fair. No regulation. Small pumping for domestic and resort use.

AVERAGE DISCHARGE. - - 10 years, $5.06 \mathrm{ft}^{3} / \mathrm{s}\left(0.143 \mathrm{~m}^{3} / \mathrm{s}\right), 3,670 \mathrm{acre}-\mathrm{ft} / \mathrm{yr}\left(4.53 \mathrm{hm} / \mathrm{yr}^{3}\right)$.

EXTREMES FOR PERIOD OF RECORD.--Maximum discharge, 4,000 $\mathrm{ft}^{3} / \mathrm{s}\left(113 \mathrm{~m}^{3} / \mathrm{s}\right) \mathrm{Jan}, 24,1967$, gage height, 8.40 ft $(2.560 \mathrm{~m})$, from rating curve extended above $1,300 \mathrm{ft} / \mathrm{s}\left(36.8 \mathrm{~m}^{3} / \mathrm{s}\right)$ on basis of slope-area measurement of maximum flow; no flow at times in some years.

EXTREMES FOR CURRENT YEAR, --Maximum discharge, $1,730 \mathrm{ft}^{3} / \mathrm{s}\left(49.0 \mathrm{~m}^{3} / \mathrm{s}\right)$ Feb. 10 (0115 hrs), gage height, $7.07 \mathrm{ft}$ $(2.155 \mathrm{~m})$, no other peak above revised base of $200 \mathrm{ft}^{3} / \mathrm{s}\left(5.66 \mathrm{~m}^{3} / \mathrm{s}\right) ; \mathrm{minimum}$ daily, $0.13 \mathrm{ft} / \mathrm{s}(0.004 \mathrm{ft} / \mathrm{s})$

Aug. 30,31 , Sept. 8,9 .

DISCHARGE. IN CUBIC FEET PER SECOND, WATER YEAR OCTOBEA 1975 TO SEPTEMBER 1976 MEAN VALUES

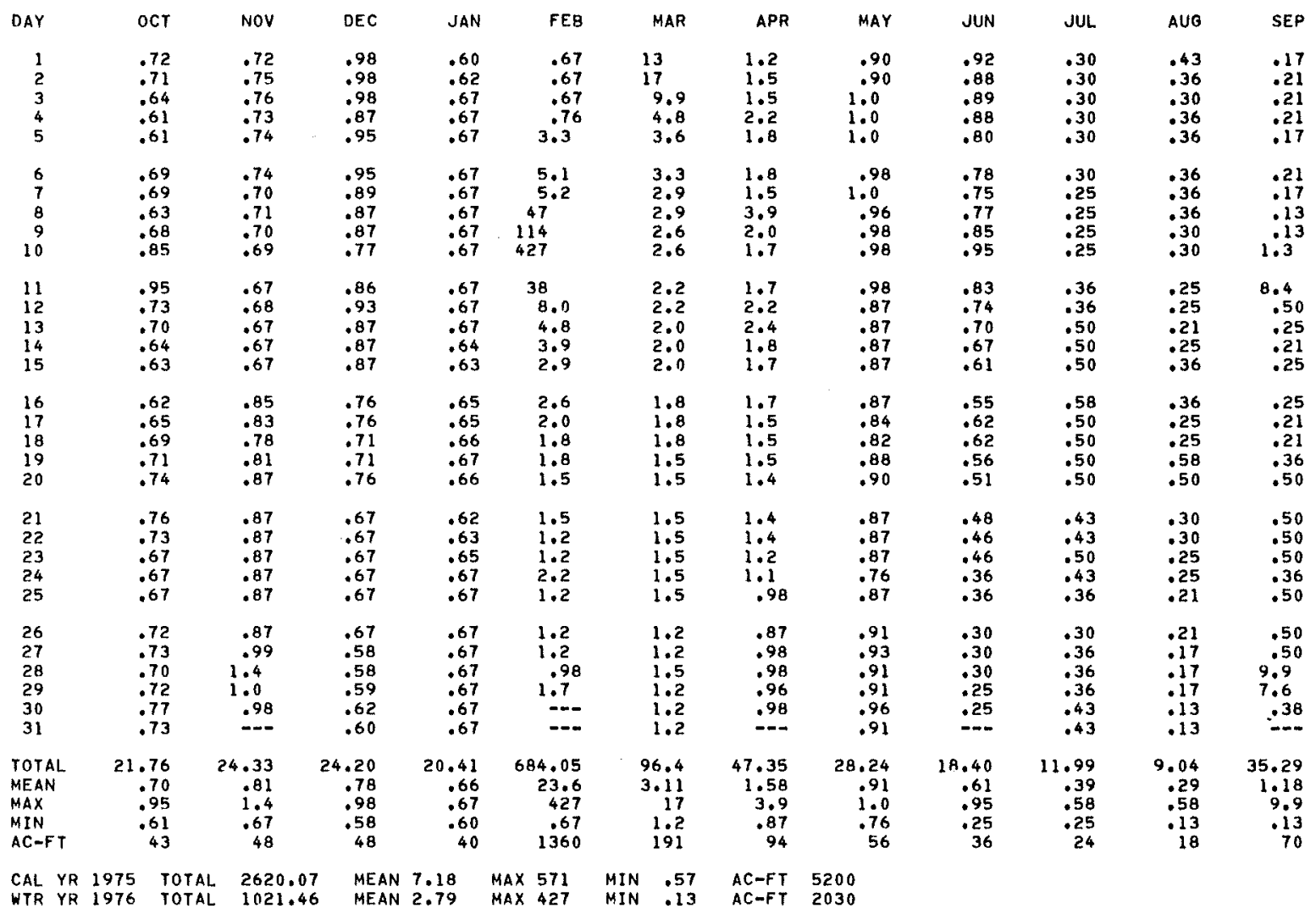


LOCATION, - Lat $34^{\circ} 30^{\prime} 50^{\prime \prime}$, long $120^{\circ} 29^{\prime} 02^{\prime \prime}$, in San Ju1ian Grant, Santa Barbara County, on downstream side of right bridge pier on Jalama Road, $0.6 \mathrm{mi}(1.0 \mathrm{~km})$ downstream from Gasper Creek, $1.4 \mathrm{mi}(2.3 \mathrm{~km})$ upstream from mouth, and $8.9 \mathrm{mi}(14.3 \mathrm{~km})$ southwest of Lompoc.

DRAINAGE AREA. $-20.5 \mathrm{mi}^{2}\left(53.1 \mathrm{~km}^{2}\right)$.

PERIOD OF RECORD. - -September 1965 to current year.

GAGE, - Water-stage recorder and concrete contro1. Altitude of gage is 80 ft (24 m), from topographic map.

REMARKS, - Records good. No regulation or diversion above station. Some pumping upstream from wells for irrigation of about 400 acres $\left(1.62 \mathrm{~km}^{2}\right)$.

AVERAGE DISCHARGE. - -11 years, $2.85 \mathrm{ft}^{3} / \mathrm{s}\left(0.081 \mathrm{~m}^{3} / \mathrm{s}\right), 2,060 \mathrm{acre}-\mathrm{ft} / \mathrm{yr}\left(2.54 \mathrm{hm}^{3} / \mathrm{yr}^{2}\right)$

EXTREMES FOR PERIOD OF RECORD.--Maximum discharge, 3,530 $\mathrm{ft}^{3} / \mathrm{s}\left(100 \mathrm{~m}^{3} / \mathrm{s}\right) \mathrm{Jan} .18$, 1973 , gage height, $9.97 \mathrm{ft}$

$(3.039 \mathrm{~m})$, from rating curve extended above $1,700 \mathrm{ft} / \mathrm{s}\left(48.1 \mathrm{~m}^{3} / \mathrm{s}\right)$ on basis of slope-area measurement at gage height $8.05 \mathrm{ft}(2.454 \mathrm{~m})$; no flow many days in most years.

EXTREMES FOR CURRENT YEAR. - Maximum discharge, $61 \mathrm{ft}^{3} / \mathrm{s}\left(1.73 \mathrm{~m}^{3} / \mathrm{s}\right)$ Feb. 10, gage height, $3.70 \mathrm{ft}(1.128 \mathrm{~m})$, no peak above base of $150 \mathrm{ft}^{3} / \mathrm{s}\left(4.25 \mathrm{~m}^{3} / \mathrm{s}\right)$; no flow June 23 to Sept. 27.

DISCHARGE, IN CUBIC FEET PER SECOND, WATER YEAR OCTOBER 1975 TO SEPTEMBER 1976 MEAN VALUES

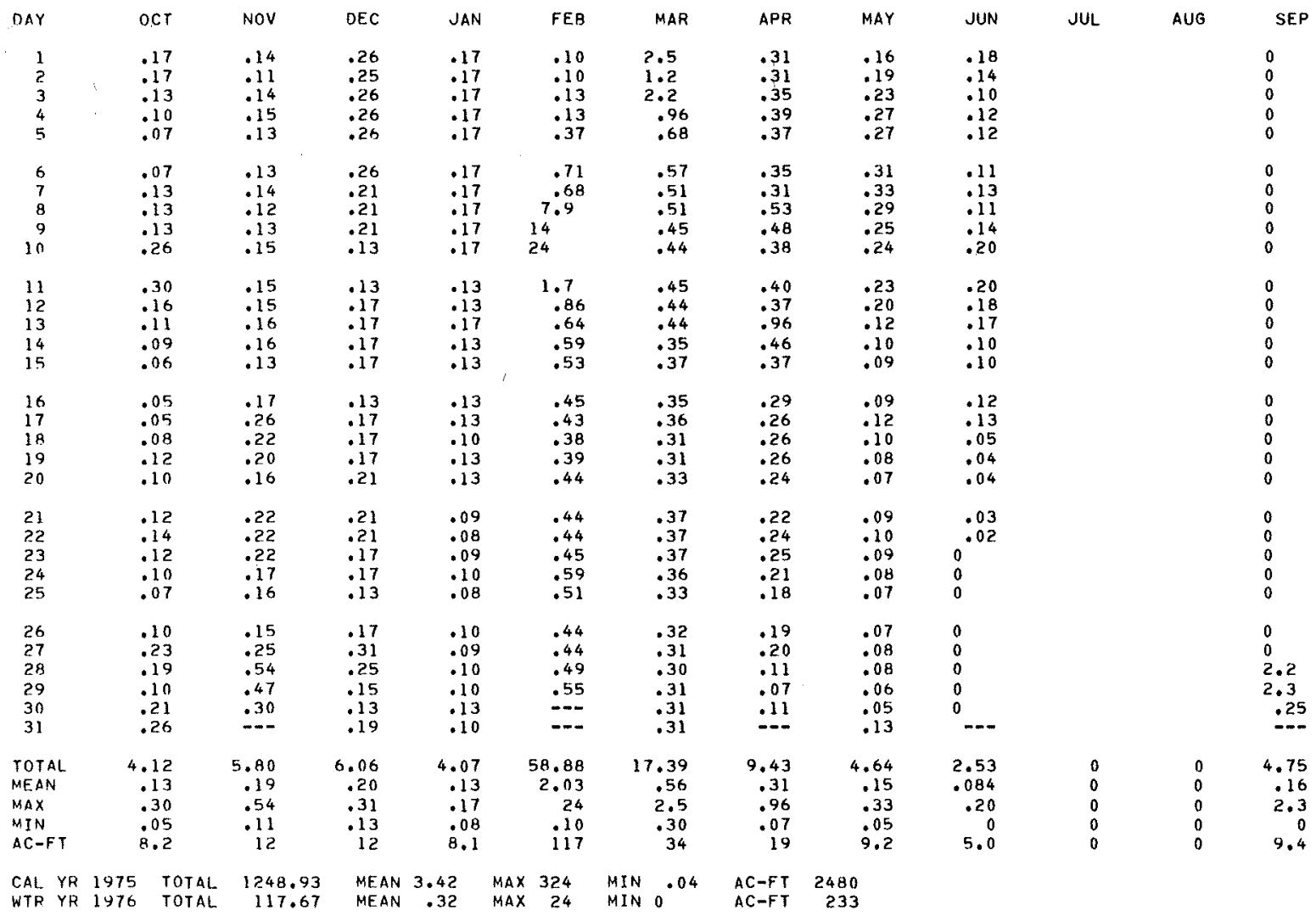


11121000 SANTA YNEZ RIVER AT JAMESON LAKE, NEAR MONTECITO, CA

LOCATION. - Lat $34^{\circ} 29^{\prime} 32^{\prime \prime}$, long $119^{\circ} 30^{\prime} 25^{\prime \prime}$, in SW/4E $\frac{1}{4} N W_{4}^{4}$ sec. 28 , T. 5 N., R. 25 W., Santa Barbara County, on upstrean face of Juncal Dam, $6.5 \mathrm{mi}(10.5 \mathrm{~km})$ north of Carpinteria, and 8 mi' (13 km) northeast of Montecito. DRAINAGE AREA. $--13.9 \mathrm{mi}^{2}\left(36.0 \mathrm{~km}^{2}\right)$, excludes that of Alder Creek.

PERIOD OF RECORD, - -December 1930 to current year. Prior to October 1938, pub1ished as "at Juncal Reservoir, near Montecito."

GAGE.--Two water-stage recorders. Datum of lake gage is $2,021.6 \mathrm{ft}(616.18 \mathrm{~m}$ ) above mean sea 1 evel (Bureau of Reclamation bench mark), or $2,000 \mathrm{ft}(609.6 \mathrm{~m})$ above arbitrary datun (called sea level) generally used for works in this vicinity. Supplementary gage and sharp-crested weir on outlet conduit of 1 ake release, at different datun.

REMARKS,--Records of total inflow represent all water reaching Jameson Lake including precipitation on the 1ake. Total inflow computed on basis of records of storage, diversion (draft) to the city of Montecito, spill and release to river, and evaporation. Records of net inflow exclude precipitation on lake surface. Monthly evaporation from lake surface computed on basis of evaporation from Colorado land pan using coefficient of evaporation from lake surface computed on basis of evaporation from Colorado land pan using coefficient of
0.80 . Area table is based on survey made in 1961 . Capacity table is based on survey made in 1969 . lake

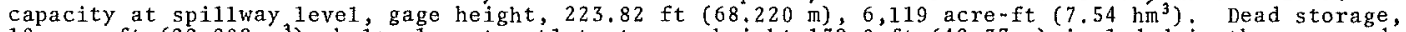
18 acre-ft $\left(22,200 \mathrm{~m}^{3}\right)$, below lowest outlet at gage height $139.0 \mathrm{ft}$ (42.37 m) included in these records. There is no regulation or diversion above station. At times flow of Alder Creek, which enters Santa Ynez River 2 mi (3 km) downstreal from Juncal Dam, is diverted at elevation, $2,250 \mathrm{ft}$ ( $686 \mathrm{~m}$ ) through a tunne1 to Jameson Lake and is included in these records.

COOPERATION. --Reservoir-operation records and related data were furnished by Montecito County Water District. AVERAGE DISCHARGE. -45 years (water years $1932-76), 6.36 \mathrm{ft}^{3} / \mathrm{s}\left(0.180 \mathrm{~m}^{3} / \mathrm{s}\right), 4,610 \mathrm{acre}-\mathrm{ft} / \mathrm{yr}\left(5.68 \mathrm{hm} / \mathrm{yr}^{3}\right)$.

MONTHLY NET DISCHARGE, WATER YEAR OCTOBER 1975 TO SEPTEMBER 1976

\begin{tabular}{|c|c|c|c|c|c|c|c|c|c|}
\hline ate & $\begin{array}{l}\text { Gage } \\
\text { height } \\
\text { (feet)a }\end{array}$ & $\begin{array}{c}\text { Contents } \\
\text { (acre- } \\
\text { feet) }\end{array}$ & $\begin{array}{c}\text { Change } \\
\text { in } \\
\text { contents } \\
\text { (acre- } \\
\text { feet) }\end{array}$ & $\begin{array}{l}\text { Draft } \\
\text { (acre- } \\
\text { feet) }\end{array}$ & $\begin{array}{c}\text { Spil1 } \\
\text { and } \\
\text { release } \\
\text { (acre- } \\
\text { feet) }\end{array}$ & $\begin{array}{l}\text { Evapo- } \\
\text { ration } \\
\text { (acre- } \\
\text { feet) }\end{array}$ & $\begin{array}{l}\text { Total } \\
\text { inflow } \\
\text { (acre- } \\
\text { feet) }\end{array}$ & $\begin{array}{l}\text { Rain on } \\
\text { reser- } \\
\text { voir } \\
\text { (acre- } \\
\text { feet) }\end{array}$ & $\begin{array}{c}\text { Net } \\
\text { inflow } \\
\text { (acre- } \\
\text { feet) }\end{array}$ \\
\hline
\end{tabular}

\begin{tabular}{|c|c|c|c|c|c|c|c|c|c|c|}
\hline $\begin{array}{l}\text { Sept. } \\
\text { Oct. } \\
\text { Nov. } \\
\text { Dec. }\end{array}$ & $\begin{array}{l}30 \ldots \ldots \ldots \ldots \\
31 \ldots \ldots \ldots \ldots \\
30 \ldots \ldots \ldots\end{array}$ & $\begin{array}{l}219.59 \\
218.43 \\
217.57 \\
216.82\end{array}$ & $\begin{array}{l}5550 \\
5410 \\
5300 \\
5200\end{array}$ & $\begin{array}{l}-- \\
-140 \\
-110 \\
-100\end{array}$ & $\begin{array}{l}-2 \\
76 \\
72 \\
77\end{array}$ & $\begin{array}{l}-- \\
0 \\
0 \\
0\end{array}$ & $\begin{array}{l}-2 \\
19 \\
13 \\
10\end{array}$ & $\begin{array}{l}-- \\
-45 \\
-25 \\
-13\end{array}$ & $\begin{array}{r}- \\
4 \\
1 \\
3\end{array}$ & $\begin{array}{l}-- \\
-49 \\
-26 \\
-16\end{array}$ \\
\hline $\mathrm{CAL}$ & YR $1975 \ldots \ldots$ & - & - & -350 & 1152 & 2266 & 348 & 3416 & 250 & 3166 \\
\hline $\begin{array}{l}\text { Jan. } \\
\text { Feb. } \\
\text { Mar. } \\
\text { Apr. } \\
\text { May } \\
\text { June } \\
\text { July } \\
\text { Aug. } \\
\text { Sept. }\end{array}$ & $\begin{array}{l}31 \ldots \ldots \ldots \ldots \\
29 \ldots \ldots \ldots \\
31 \ldots \ldots \ldots \\
30 \ldots \ldots \ldots \\
31 \ldots \ldots \ldots \\
30 \ldots \ldots \ldots \\
31 \ldots \ldots \ldots \\
31 \ldots \ldots \ldots \ldots \\
30 \ldots \ldots \ldots \ldots\end{array}$ & $\begin{array}{l}216.15 \\
223.90 \\
223.92 \\
224.14 \\
223.65 \\
222.41 \\
220.85 \\
219.65 \\
219.20\end{array}$ & $\begin{array}{l}5120 \\
6130 \\
6130 \\
6160 \\
6090 \\
5930 \\
5720 \\
5560 \\
5500\end{array}$ & $\begin{array}{r}-80 \\
+1010 \\
0 \\
+30 \\
-70 \\
-160 \\
-210 \\
-160 \\
-60\end{array}$ & $\begin{array}{r}80 \\
39 \\
44 \\
39 \\
62 \\
110 \\
110 \\
78 \\
79\end{array}$ & $\begin{array}{r}0 \\
297 \\
340 \\
0 \\
0 \\
0 \\
0 \\
0 \\
0\end{array}$ & $\begin{array}{l}13 \\
13 \\
26 \\
24 \\
42 \\
56 \\
57 \\
45 \\
22\end{array}$ & $\begin{array}{r}13 \\
1359 \\
410 \\
93 \\
34 \\
6 \\
-43 \\
-37 \\
41\end{array}$ & $\begin{array}{r}0 \\
140 \\
30 \\
16 \\
0 \\
2 \\
0 \\
0 \\
71\end{array}$ & $\begin{array}{r}13 \\
1219 \\
380 \\
77 \\
34 \\
4 \\
-43 \\
-37 \\
-30\end{array}$ \\
\hline WTR & YR $1976 \ldots \ldots \ldots$ & - & -- & -50 & 866 & 637 & 340 & 1793 & 267 & 1526 \\
\hline
\end{tabular}

a Gage height at 1800 .

NOTE.--For months when inflow to the lake was small and other quantities were 1 arge, discordant figures of net inflow may appear. This arises primarily from the difficulty of computing net inflow as the residual of several larger quantities, which are not susceptible to measurement with a precision necessary to produce a final answer within desirable inits of accuracy. 
11122000 SANTA YNEZ RIVER ABOVE GIBRALTAR DAM, NEAR SANTA BARBARA, CA

LOCATION. - Lat $34^{\circ} 31^{\prime} 34^{\prime \prime}$, long $119^{\circ} 41^{\prime} 08^{\prime \prime}$, in SWhNW'SW'a sec.11, T.5 N., R.27 W., Santa Barbara County, on upstream face of Gibraltar Dam, $7 \mathrm{mi}(11 \mathrm{~km})$ north of Santa Barbara.

DRAINAGE AREA. $-216 \mathrm{mi}^{2}\left(559 \mathrm{~km}^{2}\right)$.

PERIOD OF RECORD. - April 1920 to current year. November 1903 to November 1918 (fragmentary) at river station at damsite; records not equivalent because records since Aprit 1920 are based on operation of Gibraltar Reservoir, and since December 1930, Jameson Lake. Prior to October 1945, published as "Santa Ynez River near Santa Barbara."

GAGE. - Two water-stage recorders, Datum of reservoir gage is at mean sea level. Supplementary gage and sharpcrested weix on diversion from reservoir at different datum. See wsp 1735 for history of changes on both gages prior to oct. 1, 1955. Spill and release measured by river gaging station below dam (station 11123000).

REMARKS. - Records of tota1 inflow represent a11 water reaching Gibra1tar Reservoir, including precipitation on reservoir. Total inflow computed on basis of records of storage diversion (draft) to city of Santa Barbara, spill and release to river, and evaporation. Records of net inflow exclude precipitation on reservoir surface. Monthly evaporation from reservoir surface computed on basis of evaporation from Colorado 1 and pan using coefficient of 0.80 . Area and capacity tables are based on survey made in October 1973 . Reservoir

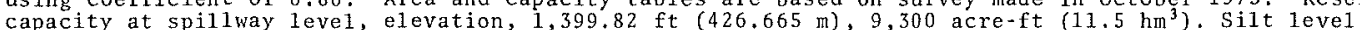
of reservoir at elevation $1,344 \mathrm{ft}(410 \mathrm{~m})$. Lowest outiet at elevation $1,333.86 \mathrm{ft}$ (406.561 $\mathrm{m}$ ). Flow of reservoir at elevation $1,344 \mathrm{ft}(410 \mathrm{~m})$. Lowest outlet at ele
regulated by Jameson Lake (station 11121000$)$ since December 1930.

COOPERATION, - - Reservoir-operation records and related data were furnished by city of Santa Barbara.

MONTHLY NET INFLOW, WATER YEAR OCTOBER 1975 TO SEPTEMBER 1976

\begin{tabular}{|c|c|c|c|c|c|c|c|c|c|c|}
\hline & Date & $\begin{array}{l}\text { Eleva- } \\
\text { tion } \\
\text { (feet)a }\end{array}$ & $\begin{array}{c}\text { Contents } \\
\text { (acre- } \\
\text { feet) }\end{array}$ & $\begin{array}{c}\text { Change } \\
\text { in } \\
\text { contents } \\
\text { (acre- } \\
\text { feet) }\end{array}$ & $\begin{array}{c}\text { Draft } \\
\text { (acre- } \\
\text { feet) }\end{array}$ & $\begin{array}{l}\text { Spil1 } \\
\text { and } \\
\text { release } \\
\text { (acre- } \\
\text { feet) }\end{array}$ & $\begin{array}{l}\text { Evapo- } \\
\text { ration } \\
\text { (acre- } \\
\text { feet) }\end{array}$ & $\begin{array}{l}\text { Total } \\
\text { inflow } \\
\text { (acre- } \\
\text { feet) }\end{array}$ & $\begin{array}{l}\text { Rain on } \\
\text { reservoir } \\
\text { (acre- } \\
\text { feet) }\end{array}$ & $\begin{array}{c}\text { Net } \\
\text { inflow } \\
\text { (acre- } \\
\text { feet) }\end{array}$ \\
\hline Sept. & $30 \ldots \ldots \ldots$ & 1389.47 & 6730 & - & - & $\cdots$ & -- & $\cdots$ & -- & -- \\
\hline oct. & $31, \ldots \ldots \ldots \ldots$ & 1388.25 & 6460 & -270 & 207 & 0 & 76 & 13 & 7 & 6 \\
\hline Nov. & $30 \ldots \ldots \ldots \ldots$ & 1387.33 & 6260 & -200 & 196 & 0 & 51 & 47 & 8 & 39 \\
\hline Dec. & $31 \ldots \ldots \ldots$ & 1384.83 & 5730 & -530 & 607 & 0 & 34 & 111 & 4 & 107 \\
\hline CAL & YR $1975 \ldots \ldots \ldots$ & -- & $\cdots$ & -140 & 5573 & 26253 & 1028 & 32714 & 333 & 32381 \\
\hline Jan. & $31 \ldots \ldots \ldots \ldots$ & 1382,10 & 5180 & -550 & 608 & 0 & 43 & 101 & 0 & 101 \\
\hline Feb. & $29 \ldots \ldots \ldots \ldots$ & 1395.91 & 8270 & +3090 & 329 & 0 & 36 & 3455 & 193 & 3262 \\
\hline Mar. & $31 \ldots \ldots \ldots \ldots$ & 1397.38 & 8650 & +380 & 567 & 0 & 75 & 1022 & 43 & 979 \\
\hline Apr. & $30 \ldots \ldots \ldots \ldots$ & 1396.76 & 8490 & -160 & 567 & 0 & 73 & 480 & 24 & 456 \\
\hline May & $31 \ldots \ldots \ldots \ldots$ & 1394.84 & 8000 & -490 & 590 & 0 & 116 & 216 & 0 & 216 \\
\hline June & $30 \ldots \ldots \ldots \ldots \ldots$ & 1391.85 & 7270 & -730 & 670 & 35 & 156 & 131 & 0 & 131 \\
\hline July & $31 \ldots \ldots \ldots \ldots$ & 1387.94 & 6400 & -870 & 662 & 180 & 142 & 114 & 0 & 114 \\
\hline Aug. & $31 \ldots \ldots \ldots \ldots$ & 1383.88 & 5540 & -860 & 676 & 138 & 114 & 68 & 1 & 67 \\
\hline Sept. & $30 \ldots \ldots \ldots$ & 1381.38 & 5040 & -500 & 602 & 128 & 66 & 296 & 70 & 226 \\
\hline WTR & YR $1976 \ldots \ldots \ldots$ & -- & -- & -1690 & 6281 & 481 & 982 & 6054 & 350 & 5704 \\
\hline
\end{tabular}

a Elevation at 1800 .

NOTE.- - For months when inflow to the reservoir was smal1 and other quantities were large, discordant figures of net inflow may appear. This arises primarily from the difficulty of computing net inflow as the residual of several larger quantities, which are not susceptible to measurement with a precision necessary to produce a final answer within desirable linits of accuracy. 
LOCATION, - Lat $34^{\circ} 31^{\prime} 28^{\prime \prime}$, long $11^{\circ} 41^{\prime} 11^{\prime \prime}$, in NW'SWtsWy sec.11, T.5 N., R.27 W., Santa Barbara County, on left bank $700 \mathrm{ft}(213 \mathrm{~m})$ downstream from Gibraltar Dam, and $7 \mathrm{mi}$ (11 km) north of Santa Barbara.

DRAINAGE AREA. $-216 \mathrm{mi}^{2}\left(559 \mathrm{~km}^{2}\right)$.

PERIOD OF RECORD.--April 1920 to current year (monthly discharge only prior to October 1941).

GAGE. - Two water-stage recorders. Datum of gage on main channe1 is $1,227 \mathrm{ft}$ ( $374 \mathrm{~m})$ above mean sea 1 eve1. Supplementary gage and sharp-crested wier on the release channel from Gibraltar Dam to river at different datum. See WSP 1735 for history of changes on both gages prior to May 20,1958 .

REMARKS. - Records good. F1ow regulated by Jameson Lake (see sta 11121000) and Gibraltar Reservoir (see sta $11122000)$. City of Santa Barbara diverted 6,280 acre-ft $\left(7.74 \mathrm{hm}^{3}\right)$ during current year from Gibraltar Reservoir; Montecito County Water District diverted 866 acre-ft $\left(1.07 \mathrm{hm}^{3}\right)$ during current year from James on Lake.

EXTREMES FOR PERIOD OF RECORD. - Maximum discharge, $54,200 \mathrm{ft}^{3} / \mathrm{s}\left(1,530 \mathrm{~m}^{3} / \mathrm{s}\right) \mathrm{Jan}$. $25,1969, \mathrm{gage} \mathrm{height,25.8} \mathrm{ft}$ $(7.86 \mathrm{~m})$, from rating curve extended above $2,100 \mathrm{ft} / \mathrm{s}\left(59.5 \mathrm{~m}^{3} / \mathrm{s}\right)$ on basis of computations of flow from gate openings and flow over dam at gage heights $17.5 \mathrm{ft}(5.33 \mathrm{~m})$ and $25.8 \mathrm{ft}(7.86 \mathrm{~m})$; no flow at times in most years.

EXTREMES FOR CURRENT YEAR. - Maximun discharge, $4.4 \mathrm{ft}^{3} / \mathrm{s}\left(0.12 \mathrm{~m}^{3} / \mathrm{s}\right)$ June 28 (gage height, unknown); no flow many months.

DISCHARGE, IN CUBIC FEET PER SECOND, WATER YEAR OCTOBER 1975 TO SEPTEMBER 1976 MEAN VALUES

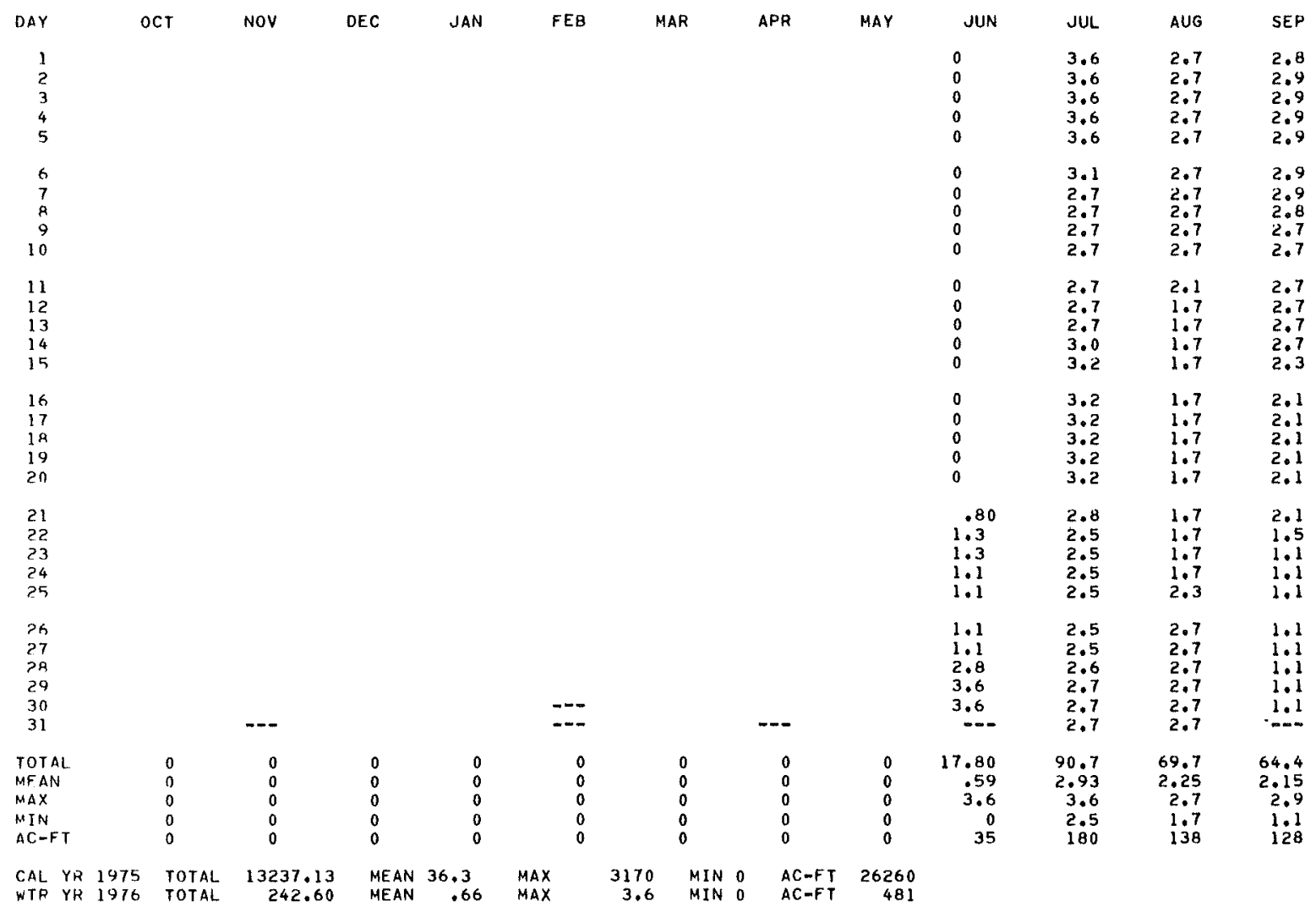


11123500 SANTA YNEZ RIVER BELOW LOS LAURELES CANYON, NEAR SANTA YNEZ, CA

LOCATION.--Lat $34^{\circ} 32^{\prime} 37^{\prime \prime}$, long 119 $51^{\prime} 50^{\prime \prime}$, in San Marcos Grant, Santa Barbara County, on 1eft bank 0.3 mi

$(0.5 \mathrm{~km})$ downstream from Los Laureles Canyon Creek, and $13.3 \mathrm{mi}(21.4 \mathrm{~km})$ east of Santa Ynez.

DRAINAGE AREA, $-277 \mathrm{mi}^{2}\left(717 \mathrm{~km}^{2}\right)$.

PERIOD OF RECORD.--April 1947 to current year. Monthly discharge only for some periods, published in WSP 1315-B.

GAGE. - Water-stage recorder. Datum of gage is $787.8 \mathrm{ft}(240.12 \mathrm{~m})$ above mean sea 1 evel.

REMARKS.--Records fair. Flow regulated by Jameson Lake and Gibra1tar Reservoir (stations 11121000, 11122000). Water diverted out of basin from these reservoirs to cities of Montecito and Santa Barbara for municipal supply. Low flow affected by intermittent pumping for irrigation from infiltration gallery in riverbed at station.

EXTREMES FOR PERIOD OF RECORD.--Maximum discharge, $67,500 \mathrm{ft}^{3} / \mathrm{s}\left(1,910 \mathrm{~m}^{3} / \mathrm{s}\right) \mathrm{Jan}$. $25,1969, \mathrm{gage} \mathrm{height}, 18.88 \mathrm{ft}$ $(5.755 \mathrm{~m})$, from rating curve extended above $11,600 \mathrm{ft}^{3} / \mathrm{s}(329 \mathrm{~m} / \mathrm{s})$ on basis of maximum flow for station below Gibraltar Dam plus tributary inflow; no flow for several months in each year.

EXTREMES FOR CURRENT YEAR. - Maximun discharge, $577 \mathrm{ft}^{3} / \mathrm{s}\left(16.3 \mathrm{~m}^{3} / \mathrm{s}\right)$ Feb. 10, gage height, $6.37 \mathrm{ft}(1.942 \mathrm{~m})$; no flow for several months.

DISCHARGE, IN CUBIC FEET PER SECOND, WATER YEAR OCTOBER 1975 TO SEPTEMBER 1976

\begin{tabular}{|c|c|c|c|c|c|c|c|c|c|c|c|c|}
\hline \multicolumn{13}{|c|}{ PIEAN VALULS } \\
\hline DAY & $\mathrm{OCT}$ & Nov & DEC & JAN & FEB & MAR & APR & HAY & JUN & JUL. & AUG & SEP \\
\hline $\begin{array}{l}1 \\
2 \\
3 \\
4 \\
5\end{array}$ & & & & & $\begin{array}{l}0 \\
0 \\
0 \\
0 \\
0\end{array}$ & $\begin{array}{l}5.6 \\
14 \\
32 \\
16 \\
12\end{array}$ & $\begin{array}{l}3.6 \\
3.4 \\
3.3 \\
3.3 \\
3.4\end{array}$ & $\begin{array}{l}1.6 \\
.15 \\
: 94 \\
1: 1 \\
0\end{array}$ & & & & \\
\hline $\begin{array}{r}6 \\
7 \\
8 \\
9 \\
10\end{array}$ & & & & & $\begin{array}{c}0 \\
0 \\
2.6 \\
280 \\
279\end{array}$ & $\begin{array}{l}9.7 \\
8.6 \\
7.9 \\
7.6 \\
7.3\end{array}$ & $\begin{array}{l}3.5 \\
3.4 \\
3.7 \\
3.9 \\
3.7\end{array}$ & $\begin{array}{l}0 \\
0 \\
0 \\
0 \\
.06\end{array}$ & & & & \\
\hline $\begin{array}{l}11 \\
12 \\
13 \\
14 \\
15\end{array}$ & & & & & $\begin{array}{l}46 \\
27 \\
18 \\
14 \\
12\end{array}$ & $\begin{array}{l}6.7 \\
6.4 \\
5.8 \\
5.5 \\
5.0\end{array}$ & $\begin{array}{l}3.5 \\
3.6 \\
5.3 \\
5.9 \\
5.3\end{array}$ & $\begin{array}{l}.43 \\
.61 \\
.47 \\
.10 \\
0\end{array}$ & & & & \\
\hline $\begin{array}{l}16 \\
17 \\
18 \\
19 \\
20\end{array}$ & & & & & $\begin{array}{l}10 \\
9.2 \\
8.4 \\
7.4 \\
7.0\end{array}$ & $\begin{array}{l}4.8 \\
4.5 \\
4.3 \\
4.1 \\
3.9\end{array}$ & $\begin{array}{l}4.9 \\
4.2 \\
3.8 \\
3.5 \\
3.2\end{array}$ & $\begin{array}{l}0 \\
0 \\
0 \\
0 \\
0\end{array}$ & & & & \\
\hline $\begin{array}{l}21 \\
22 \\
23 \\
24 \\
25\end{array}$ & & & & & $\begin{array}{l}6.8 \\
6.6 \\
6.0 \\
5.5 \\
5.5\end{array}$ & $\begin{array}{l}3.9 \\
3.7 \\
3.7 \\
3.7 \\
3.7\end{array}$ & $\begin{array}{l}3.0 \\
2.0 \\
1.1 \\
.91 \\
1.4\end{array}$ & $\begin{array}{l}0 \\
0 \\
0 \\
.04 \\
.05\end{array}$ & & & & \\
\hline $\begin{array}{l}26 \\
27 \\
28 \\
29 \\
30 \\
31\end{array}$ & & $\ldots$ & & & $\begin{array}{l}5.5 \\
5.4 \\
5.2 \\
5.0 \\
-.- \\
--\infty\end{array}$ & $\begin{array}{l}3.7 \\
3.9 \\
3.9 \\
3.9 \\
3.8 \\
3.7\end{array}$ & $\begin{array}{l}1.2 \\
.15 \\
.01 \\
1.4 \\
2.0 \\
. .-\end{array}$ & $\begin{array}{l}.05 \\
.03 \\
0 \\
0 \\
0 \\
0\end{array}$ & $-\infty$ & & & $-\infty$ \\
\hline $\begin{array}{l}\text { TOTAL } \\
\text { MEAN } \\
\text { MAX } \\
\text { MIN } \\
\text { AC-FT }\end{array}$ & $\begin{array}{l}0 \\
0 \\
0 \\
0 \\
0\end{array}$ & $\begin{array}{l}0 \\
0 \\
0 \\
0 \\
0\end{array}$ & $\begin{array}{l}0 \\
0 \\
0 \\
0 \\
0\end{array}$ & $\begin{array}{l}0 \\
0 \\
0 \\
0 \\
0\end{array}$ & $\begin{array}{r}780.1 \\
26.9 \\
288 \\
0 \\
1550\end{array}$ & $\begin{array}{r}213.3 \\
6.88 \\
32 \\
3.7 \\
423\end{array}$ & $\begin{array}{r}91.57 \\
3.05 \\
5.9 \\
.01 \\
182\end{array}$ & $\begin{array}{r}5.63 \\
.18 \\
1.6 \\
0 \\
11\end{array}$ & $\begin{array}{l}0 \\
0 \\
0 \\
0 \\
0\end{array}$ & $\begin{array}{l}0 \\
0 \\
0 \\
0 \\
0\end{array}$ & $\begin{array}{l}0 \\
0 \\
0 \\
0 \\
0\end{array}$ & $\begin{array}{l}0 \\
0 \\
0 \\
0 \\
0\end{array}$ \\
\hline
\end{tabular}


LOCATION. - Lat $34^{\circ} 35^{\prime} 48^{\prime \prime}$, long 119 $54^{\prime} 28^{\prime \prime}$, in San Marcos Grant, Santa Barbara County, on right bank 0.6 mi

$(1.0 \mathrm{~km})$ downstream from Pine Canyon, and $9.9 \mathrm{mi}(15.9 \mathrm{~km})$ east of Santa Ynez.

DRAINAGE AEEA. $-74.0 \mathrm{mi}^{2}\left(191.7 \mathrm{~km}^{2}\right)$.

PERIOD OF RECORD, - - October 1941 to current year. Month1y discharge only for some periods, published in WSP $1315-\mathrm{B}$.

GAGE, - Water-stage recorder. Datum of gage is $783.38 \mathrm{ft}(238.774 \mathrm{~m})$ above mean sea 1 eve1. See WSP 1735 for history of changes prior to Sept. 27, 1952. Sept. 27, 1952, to June 24, 1969, at datum $3.25 \mathrm{ft}$ (0.991 m) higher.

REMARKS.--Records fair. No regulation or diversion above station.

AVERAGE DISCHARGE. --35 years, $16.3 \mathrm{ft}^{3} / \mathrm{s}\left(0.462 \mathrm{~m}^{3} / \mathrm{s}\right), 11,810 \mathrm{acre}-\mathrm{ft} / \mathrm{yr}\left(14.6 \mathrm{hm}^{3} / \mathrm{\gamma r}^{2}\right)$.

EXTREMES FOR PERIOD OF RECORD, - Maximum discharge, $7,050 \mathrm{ft}^{3} / \mathrm{s}\left(200 \mathrm{~m}^{3} / \mathrm{s}\right)$ Feb. 24,1969 , gage height, $14.45 \mathrm{ft}$ $(4.404 \mathrm{~m})$, from floodmark, present datum, from rating curve extended above $2,500 \mathrm{ft} / \mathrm{s}(70.8 \mathrm{~m} / \mathrm{s})$ on basis of slope-area measurement at gage height $14.16 \mathrm{ft}(4.316 \mathrm{~m})$; no flow at times since 1953 .

EXTREMES FOR CURRENT YEAR. - -Maximum discharge, $234 \mathrm{ft}^{3} / \mathrm{s}\left(6.63 \mathrm{~m}^{3} / \mathrm{s}\right)$ Feb. 9 , (1000 hrs), gage height, $8.59 \mathrm{ft}$ $(2.618 \mathrm{~m})$, no other peaks above base of $100 \mathrm{ft}^{3} / \mathrm{s}\left(2.83 \mathrm{~m}^{3} / \mathrm{s}\right)$; no flow for several months.

DISCHARGE, IN CUBIC FEET PER SECOND, NATER YEAR OCTOBER 1975 TO SEPTEMBER 1976 MEAN VALUES

\begin{tabular}{|c|c|c|c|c|c|c|c|c|c|c|c|c|}
\hline DAY & $O C T$ & NOV & DEC & JAN & FEB & MAR & APR & MAY & JUN & JUL & AUG & SEP \\
\hline $\begin{array}{l}1 \\
2 \\
3 \\
4 \\
5\end{array}$ & & & & & $\begin{array}{l}0 \\
0 \\
0 \\
0 \\
0\end{array}$ & $\begin{array}{l}15 \\
16 \\
14 \\
8.6 \\
5.8\end{array}$ & $\begin{array}{l}3.0 \\
3.0 \\
3.1 \\
4.2 \\
4.5\end{array}$ & $\begin{array}{l}1.3 \\
1.3 \\
1.3 \\
1.3 \\
1.4\end{array}$ & $\begin{array}{r}.14 \\
.12 \\
.11 \\
.08 \\
.08\end{array}$ & $\begin{array}{l}0 \\
0 \\
0 \\
0\end{array}$ & & \\
\hline $\begin{array}{r}6 \\
7 \\
8 \\
9 \\
10\end{array}$ & & & & & $\begin{array}{c}0 \\
.59 \\
700^{\circ} \\
60\end{array}$ & $\begin{array}{l}4.9 \\
4.4 \\
4.2 \\
3.8 \\
3.6\end{array}$ & $\begin{array}{l}3.8 \\
3.3 \\
3.7 \\
3.6 \\
3.0\end{array}$ & $\begin{array}{l}1.3 \\
1.3 \\
1.1 \\
.97 \\
.90\end{array}$ & $\begin{array}{l}.08 \\
.08 \\
.08 \\
.08 \\
.08\end{array}$ & $\begin{array}{l}0 \\
0 \\
0 \\
0 \\
0\end{array}$ & & \\
\hline $\begin{array}{l}11 \\
12 \\
13 \\
14 \\
15\end{array}$ & & & & & $\begin{array}{l}20 \\
10 \\
6.4 \\
4.5 \\
4.3\end{array}$ & $\begin{array}{l}3.5 \\
3.4 \\
3.3 \\
3.3 \\
3.2\end{array}$ & $\begin{array}{l}3.1 \\
3.3 \\
5.1 \\
4.5 \\
3.8\end{array}$ & $\begin{array}{l}.86 \\
.68 \\
.56 \\
.55 \\
.55\end{array}$ & $\begin{array}{l}.07 \\
.05 \\
.05 \\
.05 \\
.06\end{array}$ & $\begin{array}{l}0 \\
0 \\
0 \\
0 \\
0\end{array}$ & & \\
\hline $\begin{array}{l}16 \\
17 \\
18 \\
19 \\
20\end{array}$ & & & & & $\begin{array}{l}3.7 \\
3.0 \\
2.6 \\
2.3 \\
2.3\end{array}$ & $\begin{array}{l}3.2 \\
3.2 \\
3.2 \\
3.2 \\
3.1\end{array}$ & $\begin{array}{l}3.4 \\
3.0 \\
2.7 \\
2.5 \\
2.2\end{array}$ & $\begin{array}{r}.42 \\
.44 \\
.42 \\
.42 \\
.42\end{array}$ & $\begin{array}{l}.06 \\
.05 \\
.05 \\
.07 \\
.08\end{array}$ & $\begin{array}{l}0 \\
0 \\
0 \\
0 \\
0\end{array}$ & & \\
\hline $\begin{array}{l}21 \\
22 \\
23 \\
24 \\
25\end{array}$ & & & & & $\begin{array}{l}2.1 \\
2.0 \\
2.2 \\
2.1 \\
2.2\end{array}$ & $\begin{array}{l}3.1 \\
3.1 \\
3.1 \\
3.1 \\
3.1\end{array}$ & $\begin{array}{l}2.1 \\
1.6 \\
1.6 \\
1.6 \\
1.4\end{array}$ & $\begin{array}{l}.42 \\
.42 \\
.30 \\
.25 \\
.24\end{array}$ & $\begin{array}{l}.08 \\
.08 \\
.05 \\
.05 \\
.05\end{array}$ & $\begin{array}{l}0 \\
0 \\
0 \\
0 \\
0\end{array}$ & & \\
\hline $\begin{array}{l}26 \\
27 \\
28 \\
29 \\
30 \\
31\end{array}$ & & $-\infty$ & & & $\begin{array}{c}2.2 \\
2.1 \\
2.0 \\
2.1 \\
-.- \\
=-\end{array}$ & $\begin{array}{l}3.1 \\
3.1 \\
3.1 \\
3.1 \\
3.1 \\
3.0\end{array}$ & $\begin{array}{l}1.3 \\
1.3 \\
1.5 \\
1.6 \\
1.5 \\
=.-\end{array}$ & $\begin{array}{l}.24 \\
.24 \\
.24 \\
.24 \\
.17 \\
.16\end{array}$ & $\begin{array}{l}.04 \\
.04 \\
.03 \\
.02 \\
.02 \\
.0\end{array}$ & $\begin{array}{l}0 \\
0 \\
0 \\
0 \\
0 \\
0\end{array}$ & & $-\infty$ \\
\hline $\begin{array}{l}\text { TOTAL } \\
\text { MEAN } \\
\text { MAX } \\
\text { MIN } \\
\text { AC-FT }\end{array}$ & $\begin{array}{l}0 \\
0 \\
0 \\
0 \\
0\end{array}$ & $\begin{array}{l}0 \\
0 \\
0 \\
0 \\
0\end{array}$ & $\begin{array}{l}0 \\
0 \\
0 \\
0 \\
0\end{array}$ & $\begin{array}{l}0 \\
0 \\
0 \\
0 \\
0\end{array}$ & $\begin{array}{r}246.39 \\
8.50 \\
100 \\
0 \\
489\end{array}$ & $\begin{array}{r}146.9 \\
4.74 \\
16 \\
3.0 \\
291\end{array}$ & $\begin{array}{r}84.3 \\
2.81 \\
5.1 \\
1.3 \\
167\end{array}$ & $\begin{array}{r}20.41 \\
.66 \\
1.46 \\
.160\end{array}$ & $\begin{array}{r}1.98 \\
.066 \\
.14 \\
.02 \\
3.9\end{array}$ & $\begin{array}{r}.01 \\
.0003 \\
.01 \\
0 \\
.02\end{array}$ & $\begin{array}{l}0 \\
0 \\
0 \\
0 \\
0\end{array}$ & $\begin{array}{l}0 \\
0 \\
0 \\
0 \\
0\end{array}$ \\
\hline
\end{tabular}

$\begin{array}{lrlrllllll}\text { CAL YR } 1975 & \text { TOTAL } & 4247.50 & \text { MEAN } 11.6 & \text { MAX } 680 & \text { MIN } 0 & \text { AC-FT } & 8420 \\ \text { WTR YR } 1976 & \text { TOTAL } & 499.99 & \text { MEAN } 1.37 & \text { MAX } 100 & \text { MIN } 0 & \text { AC-FT } & 992\end{array}$ 
LOCATION.--Lat $34^{\circ} 34^{\prime} 57^{\prime \prime}$, long $119^{\circ} 58^{\prime} 47^{\prime \prime}$, in Lomas de 1a Purification Grant, Santa Barbara County, at Cachuma Dam on Santa Ynez River, on upstream face near left end of dam, 6.1 mi (9.8 km) east of Santa Ynez.

DRAINAGE AREA. $-417 \mathrm{mi}^{2}\left(1,080 \mathrm{~km}^{2}\right)$.

PERIOD OF RECORD. - November 1952 to current year. Prior to October 1960, published as "at Cachuma Reservoir near Santa Ynez."

GAGE. - Water-stage recorder. Datum of gage is at mean sea level (Bureau of Reclamation bench mark). Prior to Oct. 1,1965 , nonrecording gage.

REMARKS. - Reservoir is formed by earthfill dam. Storage began November 1952 . Capacity table is based on surveys made in January 1953. Dead storage below outlet gage to river, elevation, $600 \mathrm{ft}$ (182.9 m), 3,114 acre-ft

$\left(3.84 \mathrm{hm}^{3}\right)$, included in contents. Capacity below sill of inlet to Tecolote tunnel, elevation, 660 ft

$(201.2 \mathrm{~m}), 32,514$ acre-ft $\left(40.1 \mathrm{hm}^{3}\right)$, below spillway level, elevation, $720 \mathrm{ft}(219.5 \mathrm{~m}), 125,292 \mathrm{acre}-\mathrm{ft}$ (154 $\left.\mathrm{hm}^{3}\right)$; below top of 4 radial gates, elevation, $750 \mathrm{ft}$ (228.6 m), $204,874 \mathrm{acre}-\mathrm{ft}(253 \mathrm{hm}$ ). Water is released from outlet to Santa Ynez River to satisfy downtream water rights. Water diverted to Tecolote tunnel for use by city of Santa Barbara and nearby communties, to Santa Ynez River Water Conservation District, and to Cachuma recreation area.

COOPERATION, - Reservoir elevation, contents, and diversion figures furnished by Bureau of Reclamation.

EXTREMES FOR PERIOD OF RECORD,--Maximum contents, 221,100 acre-ft $\left(273 \mathrm{hm}^{3}\right)$ Feb. 24 , 1969, elevation, 755.11 ft $(230.158 \mathrm{~m})$; minimum since initial filling in Apri1 1958, 116,900 acre-ft (144 hm $\left.{ }^{3}\right) \mathrm{Jan}^{2} 7,1973$, elevation, $716.19 \mathrm{ft}(218.295 \mathrm{~m})$.

EXTREMES FOR CURRENT YEAR,-.Maximum contents, 184,300 acre-ft $\left(227 \mathrm{hm}^{3}\right)$ Oct, 1 , elevation, $743.10 \mathrm{ft}$ (226.497 m); minimum, 145,200 acre-ft $\left(179 \mathrm{hm}^{3}\right)$ Sept. 30 , elevation, $728.43 \mathrm{ft}(222.025 \mathrm{~m})$.

MONTHEND ELEVATION AND CONTENTS, AT 0800, WATER YEAR OCTOBER 1975 TO SEPTEMBER 1976

Date

Sept. $30 \ldots \ldots \ldots \ldots \ldots \ldots$

Oct. $\quad 31 \ldots \ldots \ldots \ldots \ldots \ldots$

Nov. $30 \ldots \ldots \ldots \ldots \ldots \ldots$

Dec. $\quad 31 \ldots \ldots \ldots \ldots \ldots \ldots$

CAL YR $1975 \ldots \ldots \ldots \ldots$,

Jan $\quad 31 \ldots \ldots \ldots \ldots \ldots \ldots$

Feb. $\quad 29 \ldots \ldots \ldots \ldots \ldots \ldots$

Mar, $31 \ldots \ldots \ldots \ldots \ldots \ldots$

Apr,$\quad 30 \ldots \ldots \ldots \ldots \ldots \ldots$

May $\quad 31 \ldots \ldots \ldots \ldots \ldots$

June $30 \ldots \ldots \ldots \ldots \ldots \ldots$

July $31 \ldots \ldots \ldots \ldots \ldots \ldots$

Sept. $30 \ldots \ldots \ldots \ldots \ldots \ldots \ldots$

WTR YR 1976.

\section{Elevation \\ (feet)}

743.15

741.40

739.47

- -

738.32

39.16

738.84

738.15

736.47

734.54

732.49

729.60

728.43

$-$
Contents
(acre-feet)

184500

179500

176300

174100

$-$

170900

173200

172400

170500

165900

150800

155400

148100
145200

-.
Change in contents

(acre-feet)

$$
\begin{aligned}
& -5000 \\
& -3200 \\
& -2200
\end{aligned}
$$

$-5000$

$-3200$

$+2300$

-800
-1900

$-4600$

$-4600$

$-5100$

$-5400$

-7300
-2900

$-39300$
Tota1 diversions (acre-feet)

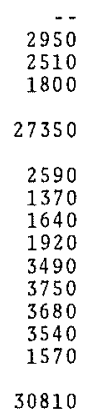


LOCATION. - Lat $34^{\circ} 35^{\prime} 21^{\prime \prime}$, long $119^{\circ} 59^{\prime} 16^{\prime \prime}$, in Canada de los Pinos Grant, Santa Barbara County, on right bank $0.7 \mathrm{mi}(1.1 \mathrm{~km})$ downstream from Cachuna Dan, and $5.5 \mathrm{mi}(8.8 \mathrm{~km})$ southeast of Santa Ynez.

DRAINAGE AREA. $-422 \mathrm{mi}^{2}\left(1,093 \mathrm{~km}^{2}\right)$.

PERIOD OF RECORD, --December 1928 to September 1931, October 1932 to September 1976 (discontinued).

GAGE. - Water-stage recorder. Datum of gage is $545.66 \mathrm{ft}(166.317 \mathrm{~m}$ ) above mean sea level (Bureau of Reclamation bench mark). Prior to Oct. 1, 1955, at site $2.5 \mathrm{mi}(4.0 \mathrm{~km})$ downstream at different datum. 0ct. 1 , 1955 , to Sept, 16, 1969, at site $0.4 \mathrm{mi}(0.6 \mathrm{~km})$ downstream at datum $7.2 \mathrm{ft}(2.19 \mathrm{~m}) \mathrm{higher}$.

REMARKS.--Records poor, F1ow regulated by Jameson Lake since December 1930, Gibra1tar Reservoir, and Lake Cachuma since November 1952 (stations 11121000,11122000 , 11125500). Water diverted out of basin from Jameson Lake, Gibraltar Reservoir, and Lake Cachuma to cities of Montecito, Santa Barbara, and to the Santa Ynez Valley for municipal supply. Some water pumped from wells along river banks for irrigation.

EXTREMES FOR PERIOD OF RECORD.- -Maximum discharge, $79,000 \mathrm{ft}^{3} / \mathrm{s}\left(2,240 \mathrm{~m}^{3} / \mathrm{s}\right) \mathrm{Jan} .25,1969, \mathrm{gage} \mathrm{height,} 22.00 \mathrm{ft}$ $(6.706 \mathrm{~m})$, from floodmark, present datum, on basis of computation of maximum flow over dam; no flow at times in some years.

EXTREMES FOR CURRENT YEAR,--Maximum discharge, $272 \mathrm{ft}^{3} / \mathrm{s}\left(7.70 \mathrm{~m}^{3} / \mathrm{s}\right)$ Aug. 16, gage height, $4.98 \mathrm{ft}$ (1.518 $\left.\mathrm{m}\right)$; no flow severa 1 months.

DISCHARGE, IN CUBIC FEET PER SECOND, HATER YEAR OCTOBER 1975 TO SEPTEMBER 1976 MEAN VALUES

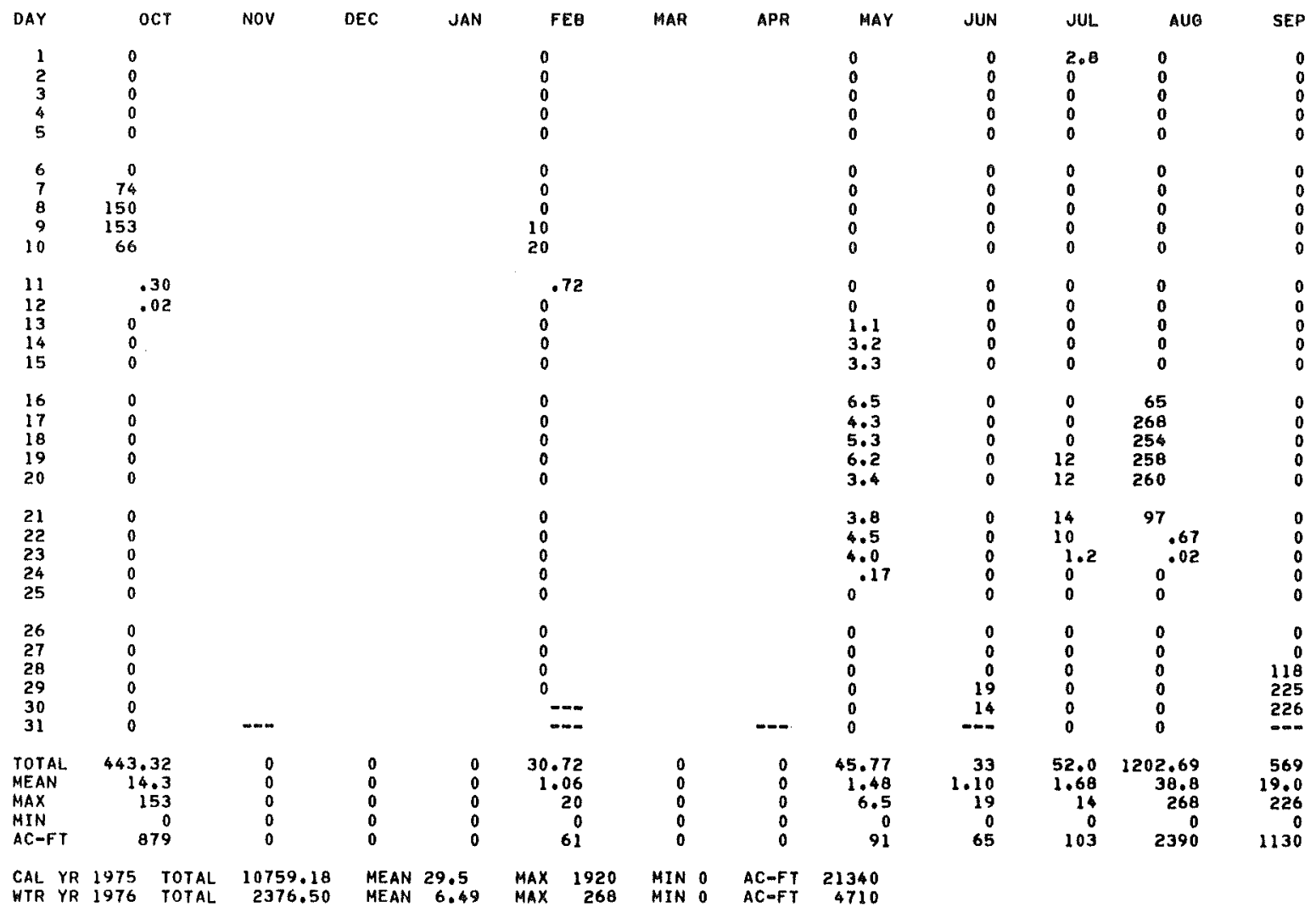


11128250 ALAMO PINTADO CREEK NEAR SOLVANG, CA

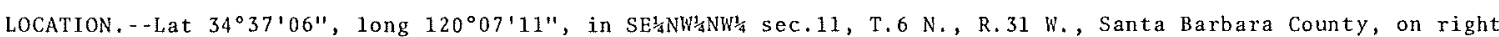
bank at downstrean side of bridge on Alamo Pintado Road, $1.5 \mathrm{mi}(2,4 \mathrm{~km})$ northeast of Solvang.

DRAINAGE AREA. $--29.4 \mathrm{mi}^{2}\left(76.1 \mathrm{~km}^{2}\right)$.

PERIOD OF RECORD,--October 1970 to current year. Records prior to October 1970 in files of Santa Barbara County Flood Control District.

GAGE. - Water-stage recorder. Datum of gage is $540.49 \mathrm{ft}$ (164.741 m) above mean sea level (Santa Barbara County bench mark).

REMARKS,--Records poor. No regulation above station. Pumping from wells along stream for irrigation.

AVERAGE DISCHARGE. -6 years, $0.081 \mathrm{ft}^{3} / \mathrm{s}\left(0.002 \mathrm{~m}^{3} / \mathrm{s}\right), 59$ acre-ft $/ y \mathrm{r}\left(72,700 \mathrm{~m}^{3} / \mathrm{yr}^{2}\right)$.

EXTREMES FOR PERIOD OF RECORD.--Maximum discharge, $466 \mathrm{ft}^{3} / \mathrm{s}\left(13.2 \mathrm{~m}^{3} / \mathrm{s}\right) \mathrm{Jan} .18$, 1973, gage height, $6.00 \mathrm{ft}$ $(1.829 \mathrm{~m})$, from $f l o o d m a r k$, from rating curve extended above $3.2 \mathrm{ft}^{3} / \mathrm{s}\left(0.091 \mathrm{~m}^{3} / \mathrm{s}\right)$ on basis of siope-area measurement of peak flow; no flow most of each year.

EXTREMES OUTSIDE PERIOD OF RECORD.--Flood of Jan. 25,1969 , reached a stage of $10.32 \mathrm{ft}$ ( $3.146 \mathrm{~m}$ ), from information by Santa Barbara County Flood Control District.

EXTREMES FOR CURRENT YEAR, --Maximum discharge, $8.8 \mathrm{ft}^{3} / \mathrm{s}\left(0.25 \mathrm{~m}^{3} / \mathrm{s}\right)$ Sept. 28 , gage height, $3.53 \mathrm{ft}(1.076 \mathrm{~m})$, no peak above base of $10 \mathrm{ft}^{3} / \mathrm{s}\left(0.28 \mathrm{~m}^{3} / \mathrm{s}\right) ;$ no flow most of year.

DISCHARGE, IN CUBIC FEET PER SECOND, WATER YEAR OCTOBER 1975 TO SEPTEMBER 1976 MEAN VALUES

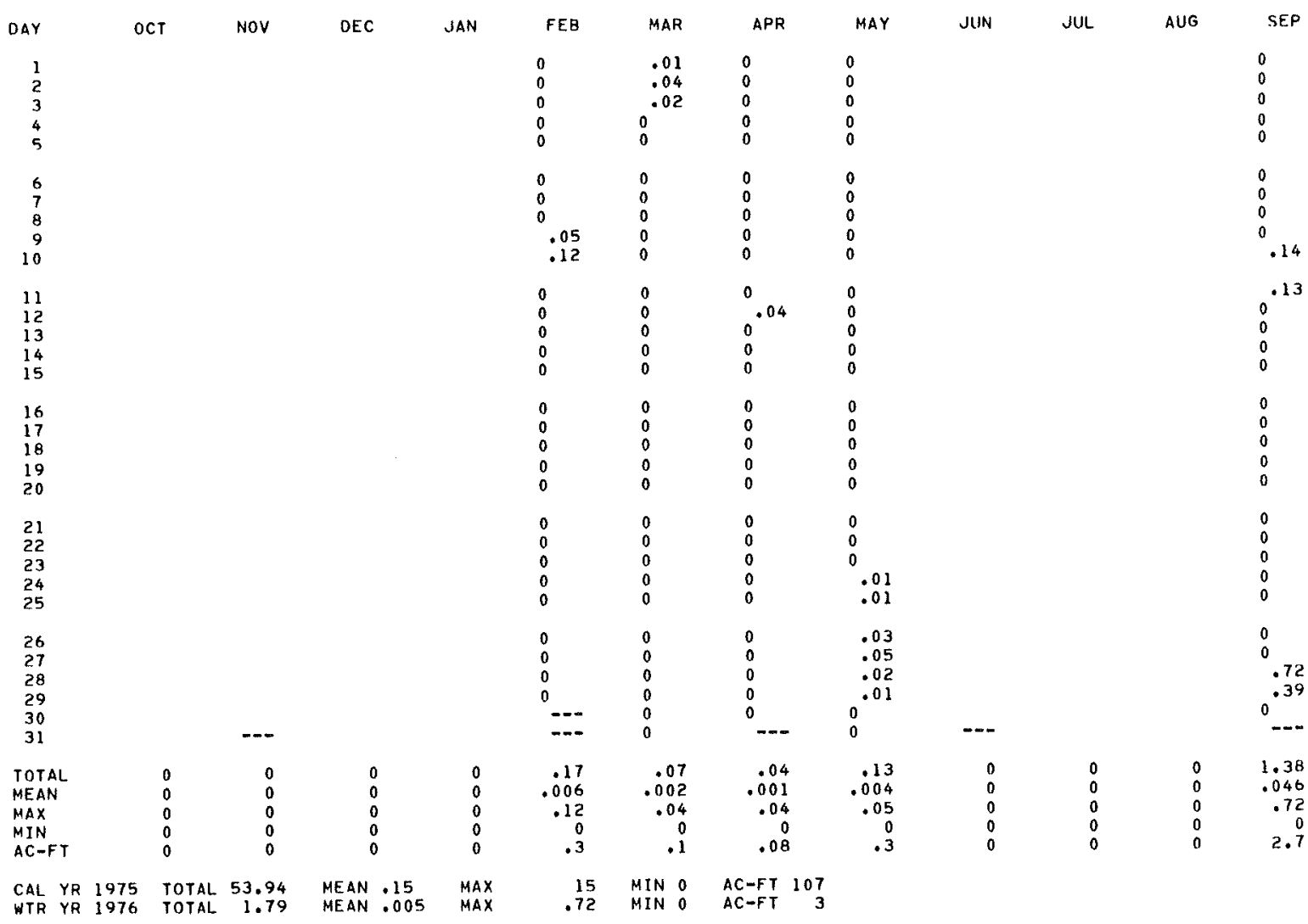


11128300 ALISAL RESERVOIR NEAR SOLVANG, CA

LOCATION, - Lat $34^{\circ} 32^{\prime} 56^{\prime \prime}$, long $120^{\circ} 07^{\prime} 45^{\prime \prime}$, in SE $\frac{1}{4}$ NE $\frac{1}{4} N W_{4}^{1}$ sec. 4, T.5 N., R. 31 W., Santa Barbara County, in cove, on right bank $0.4 \mathrm{mi}(0.6 \mathrm{~km})$ upstream' from reservoir spiliway, and $3 \mathrm{mi}$ ( 5 ' km) south of Solvang.

DRAINAGE AREA. $-7.83 \mathrm{mi}^{2}\left(20.28 \mathrm{~km}^{2}\right)$.

PERIOD OF RECORD, --December 1971 to current year.

GAGE. - Water-stage recorder. Datum of gage is at mean sea level,

REMARKS. - Lake is formed by earthfil1 dam. Storage began Dec, 19, 1970, Usable capacity, 2,260 acre-ft

$\left(2.79 \mathrm{hm}^{3}\right)$ between bottom of outlet gate at elevation $555.70 \mathrm{ft}(169.377 \mathrm{~m})$ and crest of spillway at elevation

$599.88 \mathrm{ft}(182.843 \mathrm{~m})$. Dead storage, $110 \mathrm{acre}-\mathrm{ft}\left(136,000 \mathrm{~m}^{3}\right)$. Infiow must total 150 acre-ft (185,000 $\left.{ }^{3}\right)$

during any one month between November and June to store flow for year.

EXTREMES FOR PERIOD OF RECORD. - Maximun contents, 2,650 acre-ft (3.27 hm $\left.{ }^{3}\right)$ Feb. 27, 1973 , elevation, 602.95 ft

$(183.779 \mathrm{~m})$; minimum, 748 acre-ft $\left(922,000 \mathrm{~m}^{3}\right)$ Nov. 8-10, 1972, elevation, $577.15 \mathrm{ft}$ (175.915 m).

EXTREMES FOR CURRENT YEAR.--Maximum contents, 2,520 acre-ft $\left(3.11 \mathrm{hm}^{3}\right)$ Feb. 10 , elevation, $601.55 \mathrm{ft}(183.352 \mathrm{~m})$; minimum, 2,190 acre-ft $\left(2.70 \mathrm{hm}^{3}\right)$ Sept. 10, elevation, $597.93 \mathrm{ft}(182.249 \mathrm{~m})$.

MONTHEND ELEVATION AND CONTENTS, AT 1800, WATER YEAR OCTOBER 1975 TO SEPTEMBER 1976

\begin{tabular}{|c|c|c|c|c|}
\hline & Date & $\begin{array}{l}\text { Elevation } \\
\text { (feet) }\end{array}$ & $\begin{array}{l}\text { Contents } \\
(\text { acre-feet })\end{array}$ & $\begin{array}{c}\text { Change in contents } \\
\text { (acre-feet) }\end{array}$ \\
\hline $\begin{array}{l}\text { Sept. } \\
\text { Oct. } \\
\text { Nov. } \\
\text { Dec. }\end{array}$ & $\begin{array}{l}30 \ldots \ldots \ldots \ldots \ldots \\
31 \ldots \ldots \ldots \ldots \\
30 \ldots \ldots \ldots \\
31 \ldots \ldots \ldots \ldots\end{array}$ & $\begin{array}{l}599.11 \\
598.80 \\
598.63 \\
598.53\end{array}$ & $\begin{array}{l}2300 \\
2270 \\
2260 \\
2250\end{array}$ & $\begin{array}{l}-- \\
-30 \\
-10 \\
-10\end{array}$ \\
\hline CAL & YR $1975 \ldots \ldots \ldots$ & - & -- & -170 \\
\hline $\begin{array}{l}\text { Jan. } \\
\text { Feb. } \\
\text { Mar. } \\
\text { Apr. } \\
\text { May } \\
\text { June } \\
\text { Juiy } \\
\text { Aug. } \\
\text { Sept. }\end{array}$ & $\begin{array}{l}31 \ldots \ldots \ldots \ldots \\
29 \ldots \ldots \\
31 \ldots \ldots \ldots \\
30 \ldots \ldots \ldots \\
31 \ldots \ldots \ldots \\
30 \ldots \ldots \ldots \\
31 \ldots \ldots \ldots \ldots \\
31 \ldots \ldots \ldots \\
30 \ldots \ldots \ldots\end{array}$ & $\begin{array}{l}598.46 \\
600.23 \\
600.16 \\
600.05 \\
599.70 \\
599.27 \\
598.61 \\
598.07 \\
598.42\end{array}$ & $\begin{array}{l}2240 \\
2400 \\
2390 \\
2380 \\
2350 \\
2310 \\
2250 \\
2210 \\
2240\end{array}$ & $\begin{array}{r}-10 \\
+160 \\
-10 \\
-10 \\
-30 \\
-40 \\
-60 \\
-40 \\
+30\end{array}$ \\
\hline WTR & YR $1976 \ldots \ldots \ldots$ & $\ldots$ & -- & -60 \\
\hline
\end{tabular}


11128500 SANTA YNEZ RIVER AT SOLVANG, CA

LOCATION. - Lat $34^{\circ} 35^{\prime} 06^{\prime \prime}$, long $120^{\circ} 08^{\prime} 37^{\prime \prime}$, in San Carlos de Jonata Grant, Santa Barbara County, on downstream side of right abutment of Mission bridge, $25 \mathrm{ft}(8 \mathrm{~m})$ downstream from Alisal Creek, $0.8 \mathrm{mi}$ ( $1.3 \mathrm{~km})$ southwest of Solvang, and $10 \mathrm{mi}(16 \mathrm{~km})$ downstream from Lake Cachuma.

DRAINAGE AREA. $-579 \mathrm{mi}^{2}\left(1,500 \mathrm{~km}^{2}\right)$.

PERIOD OF RECORD. - October 1928 to November 1936, June 1937 to November 1940 (irrigation seasons on1y), October 1946 to current year.

GAGE. - Water-stage recorder. Datum of gage is $362.43 \mathrm{ft}(110.469 \mathrm{~m})$ above mean sea level. Various datums used during period of record. July 29 to Sept. 30, 1953, auxiliary water-stage recorder $750 \mathrm{ft}$ (229 $\mathrm{m}$ ) upstream at different datum. Oct. 1, 1953, to Sept. 30, 1968 , water-stage recorder at datum 2.00 ft (0.610 m) higher.

REMARKS.--Records fair. Flow regulated by Jameson Lake, Gibraltar Reservoir, and since November 1952 by Lake Cachuma (stations 1i121000, 11122000, 11125500). Water diverted out of basin from Jameson Lake, Gibraltar Reservoir, and Lake Cachuma to cities of Montecito, Santa Barbara, and Goleta for municipal supply. Water for irrigation pumped from wells along banks of river in valley upstrean.

EXTREMES FOR PERIOD OF RECORD (1928-36 AND SINCE 1946).--Maximum discharge, $82,000 \mathrm{ft}^{3} / \mathrm{s}^{2}\left(2,320 \mathrm{~m}^{3} / \mathrm{s}\right)$, estimated, Jan. 25, 1969, gage height, $17.1 \mathrm{ft}(5.21 \mathrm{~m})$, from floodmark; no flow for several months in many years.

EXTREMES FOR CURRENT YEAR. - Maximum discharge, $644 \mathrm{ft}^{3} / \mathrm{s}\left(18.2 \mathrm{~m}^{3} / \mathrm{s}\right)$ Feb. 10, gage height, $5.39 \mathrm{ft}(1.643 \mathrm{~m})$; no. flow for several months.

DISCHARGE, IN CUBIC FEET PER SECOND, WATER YEAR OCTOBER 1975 TO SEPTEMBER 1976 MEAN VALUES

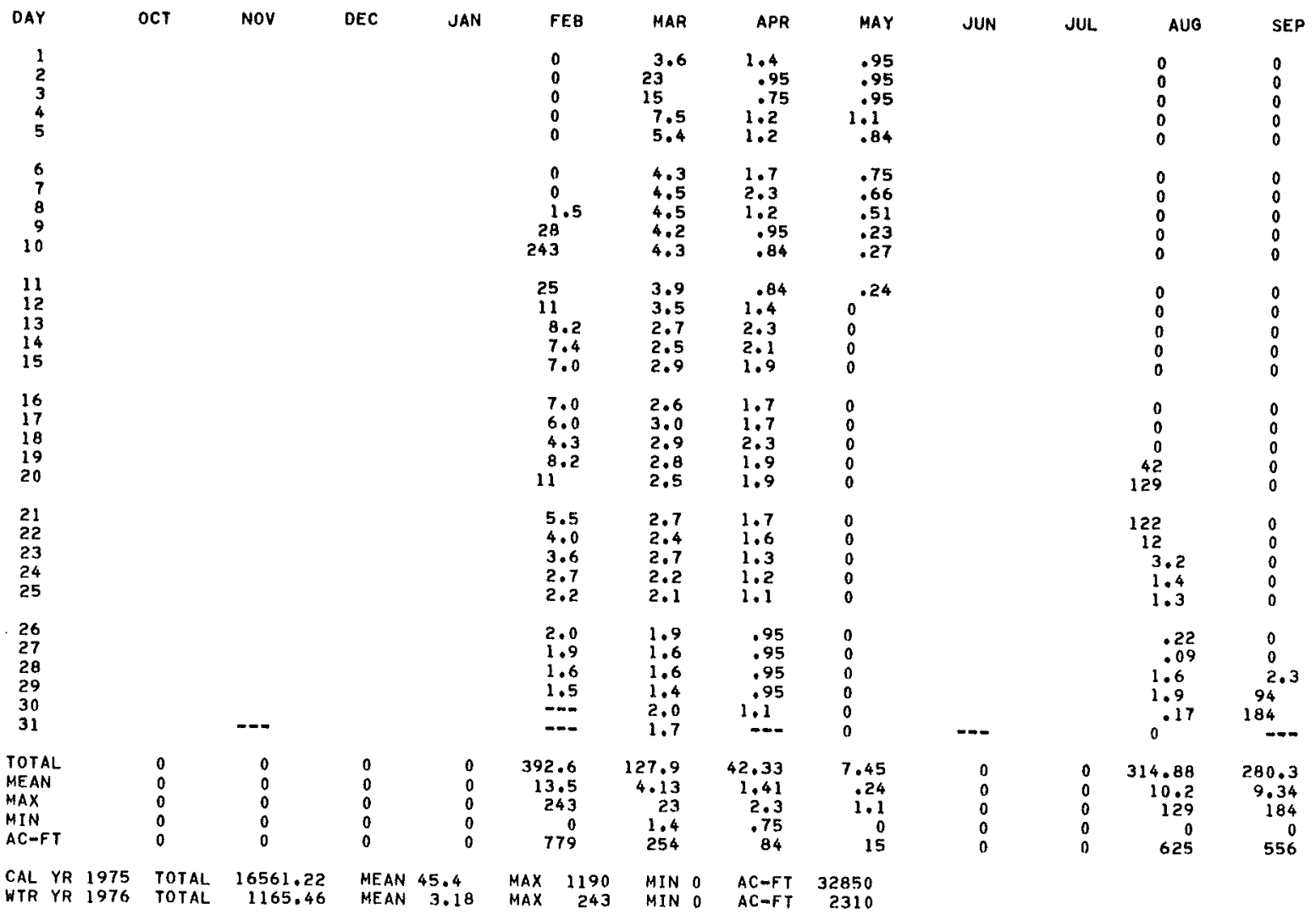


LOCATION. - Lat $34^{\circ} 38^{\prime} 55^{\prime \prime}$, long $120^{\circ} 11^{\prime} 00^{\prime \prime}$, in San Carlos de Jonata Grant, Santa Barbara County, on upstream end of left pier of bridge on frontage road, $0.9 \mathrm{mi}(1.4 \mathrm{~km})$ upstream from Dry Creek, $2.4 \mathrm{mi}$ (3.9 $\mathrm{km})$ north of Bueliton, and $4.0 \mathrm{mi}(6.4 \mathrm{~km})$ upstream from mouth.

DRAINAGE AREA. $--32.8 \mathrm{mi}^{2}\left(85.0 \mathrm{~km}^{2}\right)$.

PERIOD OF RECORD. --September 1963 to current year.

GAGE. - Water-stage recorder. Datum of gage is $471.54 \mathrm{ft}(143.725 \mathrm{~m})$ above mean sea 1 eve1.

REMARKS.--Records poor. Some pumping from wel1s along stream for irrigation above station.

AVERAGE DISCHARGE. - -13 years, $0.88 \mathrm{ft}^{3} / \mathrm{s}\left(0.025 \mathrm{~m}^{3} / \mathrm{s}\right), 638 \mathrm{acre}-\mathrm{ft} / \mathrm{yr}\left(787,000 \mathrm{~m} / \mathrm{yr}^{3}\right)$.

EXTREMES FOR PERIOD OF RECORD. - Maximum discharge, $1,390 \mathrm{ft}^{3} / \mathrm{s}\left(39.4 \mathrm{~m}^{3} / \mathrm{s}\right)$ Feb. 24,1969, gage height, $9.20 \mathrm{ft}$ $(2.804 \mathrm{~m})$; no flow most of each year.

EXTREMES FOR CURRENT YEAR. - Peak discharges above base of $10 \mathrm{ft}^{3} / \mathrm{s}\left(0.28 \mathrm{~m}^{3} / \mathrm{s}\right)$ and maximum (*):

\begin{tabular}{|c|c|c|c|c|c|}
\hline Date & Tine & $\begin{array}{r}\text { Discl } \\
\left(\mathrm{ft}^{3} / \mathrm{s}\right)\end{array}$ & $\underset{\left(m^{3} / s\right)}{r g e}$ & $\begin{array}{l}\text { Gage } \\
(f t)\end{array}$ & $\begin{array}{r}\text { height } \\
\text { (m) }\end{array}$ \\
\hline $\begin{array}{lr}\text { Feb. } & 9 \\
\text { Sept, } & 29\end{array}$ & $\begin{array}{l}2345 \\
0045\end{array}$ & $\begin{array}{r}33 \\
* 45\end{array}$ & $\begin{array}{l}0.93 \\
1.27\end{array}$ & $\begin{array}{l}2.83 \\
3.01\end{array}$ & $\begin{array}{l}0.862 \\
0.917\end{array}$ \\
\hline
\end{tabular}

Minimum daily discharge, no flow most of year.

DISCHARGE, IN CUBIC FEET PER SECOND, WATER YEAR OCTOBER 1975 TO SEPTEMBER 1976

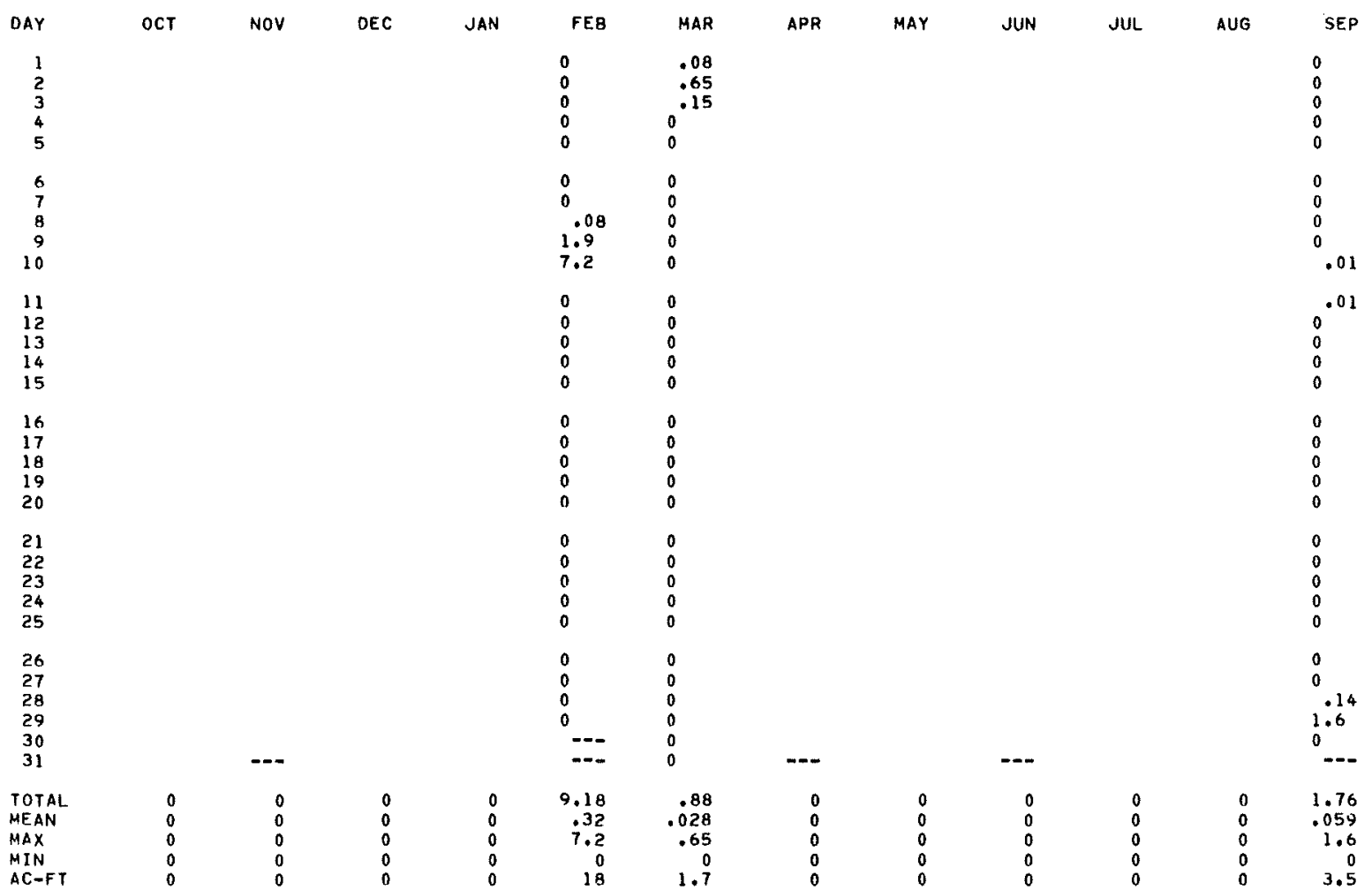

$\begin{array}{llllllll}\text { CAL YR } 1975 & \text { TOTAL } 59.04 & \text { MEAN } & 16 & \text { MAX } 8.0 & \text { MIN } 0 & \text { AC-FT } 117 \\ \text { WTR YR } 1976 & \text { TOTAL } 11.82 & \text { MEAN } .032 & \text { MAX } 7.2 & \text { MIN } 0 & \text { AC-FT } 23\end{array}$ 
11131500 SANTA YNEZ RIVER AT COOPER'S REEF, NEAR LOMPOC, CA

LOCATION. - Lat $34^{\circ} 36^{\prime} 48^{\prime \prime}$, long $120^{\circ} 21^{\prime} 23^{\prime \prime}$, near boundary of Canada de Salsipuedes Grant, Santa Barbara County, on right bank $0.6 \mathrm{mi}(1.0 \mathrm{~km})$ upstream from Canada de la Vina, $6 \mathrm{mi}$ (10 km) east of Lompoc, and $24 \mathrm{mi}$ ( $39 \mathrm{~km})$ downstrean from Lake Cachuma.

DRAINAGE AREA. $-708 \mathrm{mi}^{2}\left(1,830 \mathrm{~km}^{2}\right)$.

PERIOD OF RECORD. - October 1954 to September 1976 (discontinued).

GAGE, - Water-stage recorder. Altitude of gage is $160 \mathrm{ft}(49 \mathrm{~m})$, from topographic map. Prior to Sept. 18, 1969, at site $100 \mathrm{ft}(30 \mathrm{~m})$ downstream at datum about $0.6 \mathrm{ft}(0.18 \mathrm{~m})$ higher (reference marks destroyed by floods of $1969)$.

REMARKS.--Records fair. Flow regulated by Jameson Lake, Gibra1tar Reservoir, and Lake Cachuna (stations 11121000, $11122000,11125500)$. Water diverted out of basin from Jameson Lake, Gibraltar Reservoir, and Lake Cachuma to cities of Montecito, Santa Barbara, and Goleta for municipal supply. Water pumped from wells along banks of river for irrigation in valley upstream.

EXTREMES FOR PERIOD OF RECORD.--Maximum discharge, $81,000 \mathrm{ft}^{3} / \mathrm{s}\left(2,290 \mathrm{~m}^{3} / \mathrm{s}\right)$, estimated, Jan. 25, 1969, gage height, $22.5 \mathrm{ft}(6.86 \mathrm{~m})$ site and datum then in use, from floodmark; no flow at times in some years.

EXTREMES FOR CURRENT YEAR. - Maximun discharge, $661 \mathrm{ft}^{3} / \mathrm{s}\left(18.7 \mathrm{~m}^{3} / \mathrm{s}\right)$ Feb. 10, gage height, $8.24 \mathrm{ft}$ (2.512 $\left.\mathrm{m}\right)$, from rating curve extended above $130 \mathrm{ft}^{3} / \mathrm{s}\left(3.68 \mathrm{~m}^{3} / \mathrm{s}\right)$; no flow for several months.

DISCHARGE, IN CUBIC FEET PER SECOND, WATER YEAR OCTOBER 1975 TO SEPTEMBER 1976 MEAN VALUES

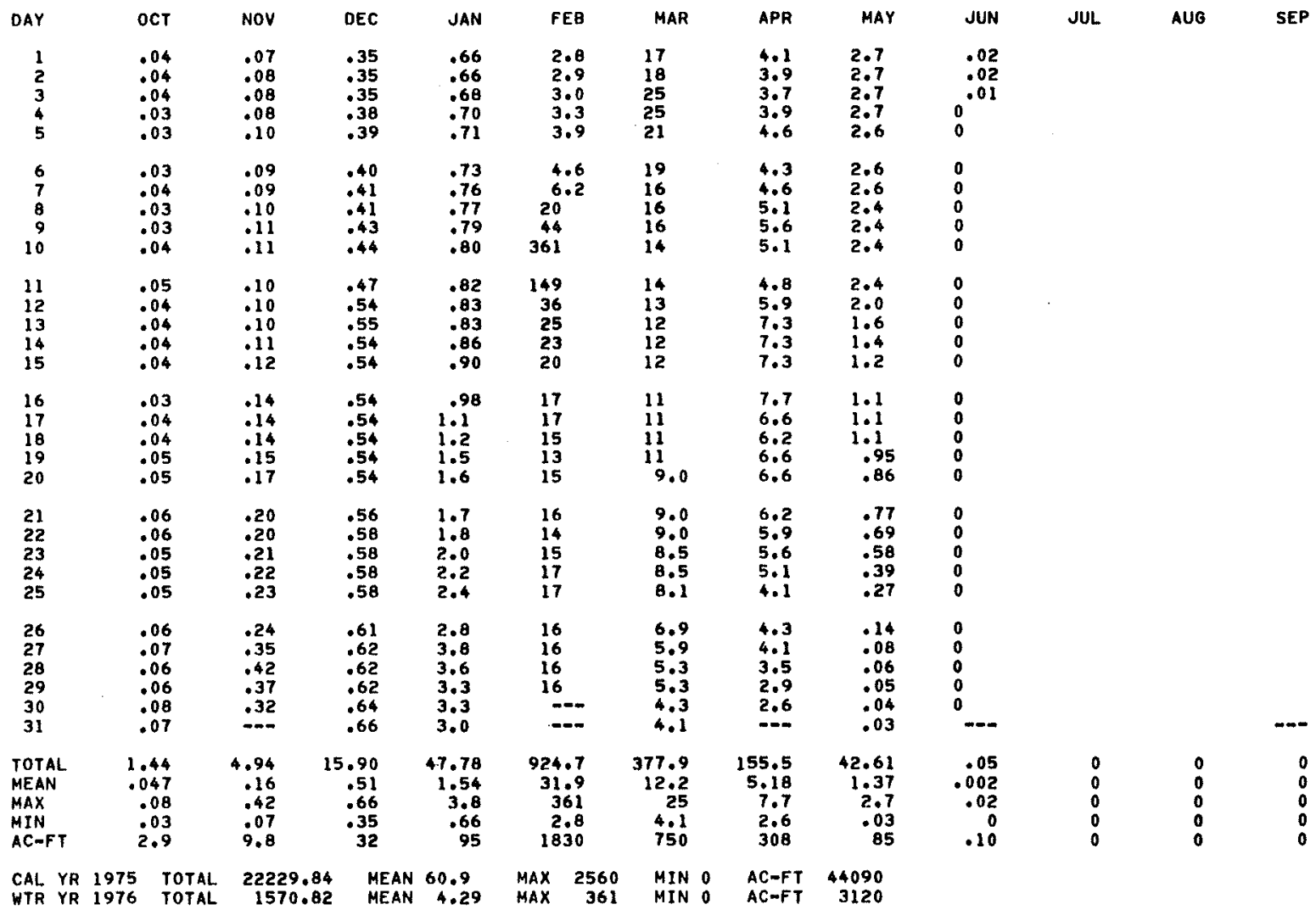


LOCATION, - - Lat $34^{\circ} 35^{\prime} 19^{\prime \prime}$, Long $120^{\circ} 24^{\prime} 27^{\prime \prime}$, in $W^{\frac{1}{2}}$ sec. 24, T.6 N., R. 34 W., Santa Barbara County, on right bank at bridge on Jalama Road, $0.4 \mathrm{mi}(0.6 \mathrm{~km})$ 'downstream from El Jaro Creek, and $4.4 \mathrm{mi}$ ( $7.1 \mathrm{~km}) \mathrm{southeast} \mathrm{of} \mathrm{Lompoc.}$ DRAINAGE AREA, $--47.1 \mathrm{mi}^{2}\left(122.0 \mathrm{~km}^{2}\right)$.

PERIOD OF RECORD. - -January 1941 to current year.

GAGE. - Water-stage recorder and concrete low-water control. Altitude of gage is $220 \mathrm{ft}$ ( $67 \mathrm{~m}$ ), from topographic map.

REMARKS,--Records good. No regulation above station. Sma11 diversions for irrigation above station.

AVERAGE DISCHARGE. -35 years, $8.58 \mathrm{ft} 3 / \mathrm{s}\left(0.243 \mathrm{~m}^{3} / \mathrm{s}\right), 6,220$ acre $-\mathrm{ft} / \mathrm{yr}\left(7.67 \mathrm{hm}^{3} / \mathrm{yr}^{3}\right)$.

EXTREMES FOR PERIOD OF RECORD. --Maximum discharge, $11,400 \mathrm{ft}^{3} / \mathrm{s}\left(323 \mathrm{~m}^{3} / \mathrm{s}\right) \mathrm{Mar} .15,1952, \mathrm{gage} \mathrm{height}, 20.8 \mathrm{ft}$

$(6.34 \mathrm{~m})$; no flow at times in some years.

EXTREMES FOR CURRENT YEAR. --Maximum discharge, $435 \mathrm{ft}^{3} / \mathrm{s}\left(12.3 \mathrm{~m}^{3} / \mathrm{s}\right)$ Feb, 10 (0600 hrs), gage height, 3.23 ft

$(0.985 \mathrm{~m})$, no peak above base of $700 \mathrm{ft}^{3} / \mathrm{s}\left(19.8 \mathrm{~m}^{3} / \mathrm{s}\right)$ revised; minimum daily, $0.05 \mathrm{ft} / \mathrm{s}(0.001 \mathrm{~m} / \mathrm{s}) \mathrm{July} 5-9$.

DISCHARGE, IN CUBIC FEET PER SECOND, HATER YEAR OCTOBER 1975 TO SEPTEMBER 1976

\begin{tabular}{|c|c|c|c|c|c|c|c|c|c|c|c|c|}
\hline DAY & OCT & NOV & DEC & JAN & FEB & MAR & APR & MAY & JUN & JUL & AUG & SEP \\
\hline $\begin{array}{l}1 \\
2 \\
3 \\
4 \\
5\end{array}$ & $\begin{array}{l}2.6 \\
2.2 \\
2.2 \\
1.9 \\
1.6\end{array}$ & $\begin{array}{l}1.6 \\
1.6 \\
1.6 \\
1.3 \\
1.6\end{array}$ & $\begin{array}{l}1.3 \\
1.3 \\
1 \cdot 3 \\
1.3 \\
1.6\end{array}$ & $\begin{array}{l}2.2 \\
1.9 \\
1.9 \\
2.2 \\
2.2\end{array}$ & $\begin{array}{l}1.9 \\
1.9 \\
1.9 \\
2.2 \\
2.6\end{array}$ & $\begin{array}{l}8.8 \\
11 \\
15 \\
6.0 \\
4.4\end{array}$ & $\begin{array}{l}2.2 \\
2.4 \\
2.3 \\
2.4 \\
2.9\end{array}$ & $\begin{array}{l}1.7 \\
1.6 \\
1.6 \\
1.6 \\
1.6\end{array}$ & $\begin{array}{l}.72 \\
.61 \\
.59 \\
.60 \\
.60\end{array}$ & $\begin{array}{l}.10 \\
.08 \\
.07 \\
.08 \\
.05\end{array}$ & $\begin{array}{r}.34 \\
.28 \\
.26 \\
.26 \\
.26\end{array}$ & $\begin{array}{l}.19 \\
.19 \\
.19 \\
.26 \\
.26\end{array}$ \\
\hline $\begin{array}{r}6 \\
7 \\
8 \\
9 \\
10\end{array}$ & $\begin{array}{l}1.9 \\
2.6 \\
2.6 \\
2.6 \\
3.0\end{array}$ & $\begin{array}{l}1.6 \\
1.6 \\
1.3 \\
1.6 \\
1.6\end{array}$ & $\begin{array}{l}1.6 \\
1.6 \\
1.1 \\
1.1 \\
1.1\end{array}$ & $\begin{array}{l}2.2 \\
1.9 \\
1.6 \\
2.2 \\
2.6\end{array}$ & $\begin{array}{c}2.6 \\
3.8 \\
27 \\
46 \\
124\end{array}$ & $\begin{array}{l}3.8 \\
3.4 \\
3.4 \\
3.4 \\
3.2\end{array}$ & $\begin{array}{l}2.5 \\
2.2 \\
3.4 \\
3.1 \\
2.5\end{array}$ & $\begin{array}{l}1.7 \\
1.9 \\
1.8 \\
1.6 \\
1.6\end{array}$ & $\begin{array}{l}.60 \\
.61 \\
.63 \\
.69 \\
.68\end{array}$ & $\begin{array}{l}.05 \\
.05 \\
.05 \\
.05 \\
.07\end{array}$ & $\begin{array}{r}.26 \\
.19 \\
.19 \\
.19 \\
.19\end{array}$ & $\begin{array}{l}.1 \\
11 \\
11 \\
11 \\
.3\end{array}$ \\
\hline $\begin{array}{l}11 \\
12 \\
13 \\
14 \\
15\end{array}$ & $\begin{array}{l}3.4 \\
1.6 \\
1.3 \\
1.3 \\
1.1\end{array}$ & $\begin{array}{l}1.3 \\
1.3 \\
1.3 \\
1.6 \\
1.6\end{array}$ & $\begin{array}{l}1.3 \\
1.6 \\
1.6 \\
1.6 \\
1.6\end{array}$ & $\begin{array}{l}3.0 \\
2.2 \\
2.2 \\
2.2 \\
1.9\end{array}$ & $\begin{array}{l}8.6 \\
5.2 \\
4.1 \\
4.2 \\
3.6\end{array}$ & $\begin{array}{l}2.7 \\
2.6 \\
2.5 \\
2.5 \\
2.6\end{array}$ & $\begin{array}{l}2.8 \\
3.5 \\
3.7 \\
2.6 \\
2.4\end{array}$ & $\begin{array}{l}1.6 \\
1.5 \\
1.2 \\
1.1 \\
1.1\end{array}$ & $\begin{array}{l}.75 \\
.64 \\
.51 \\
.48 \\
.39\end{array}$ & $\begin{array}{l}.07 \\
.08 \\
.10 \\
.16 \\
.20\end{array}$ & $\begin{array}{r}.19 \\
19 \\
19 \\
19 \\
119\end{array}$ & $\begin{array}{r}2.6 \\
1.1 \\
.34 \\
.34 \\
.26\end{array}$ \\
\hline $\begin{array}{l}16 \\
17 \\
18 \\
19 \\
20\end{array}$ & $\begin{array}{l}1.1 \\
1.1 \\
1.3 \\
1.3 \\
1.3\end{array}$ & $\begin{array}{l}1.9 \\
1.6 \\
1.6 \\
1.6 \\
1.6\end{array}$ & $\begin{array}{l}1.6 \\
1.9 \\
1.6 \\
1.9 \\
1.9\end{array}$ & $\begin{array}{l}1.9 \\
1.6 \\
1.6 \\
1.6 \\
1.6\end{array}$ & $\begin{array}{l}3.1 \\
3.0 \\
2.8 \\
2.9 \\
2.8\end{array}$ & $\begin{array}{l}2.4 \\
2.4 \\
2.4 \\
2.3 \\
2.2\end{array}$ & $\begin{array}{l}2.3 \\
2.2 \\
1.9 \\
2.0 \\
2.0\end{array}$ & $\begin{array}{l}1.2 \\
1.4 \\
1.3 \\
1.2 \\
1.2\end{array}$ & $\begin{array}{r}.36 \\
\cdot 36 \\
.36 \\
\cdot 35 \\
.32\end{array}$ & $\begin{array}{r}.31 \\
.36 \\
.38 \\
.38 \\
.36\end{array}$ & $\begin{array}{l}.17 \\
.14 \\
.14 \\
.20 \\
.18\end{array}$ & $\begin{array}{l}.2 \\
.2 \\
.2 \\
.2 \\
.2 \\
.2\end{array}$ \\
\hline $\begin{array}{l}21 \\
22 \\
23 \\
24 \\
25\end{array}$ & $\begin{array}{l}1.3 \\
1.6 \\
1.6 \\
1.3 \\
1.3\end{array}$ & $\begin{array}{l}1.6 \\
1.6 \\
1.3 \\
1.3 \\
1.3\end{array}$ & $\begin{array}{l}1.9 \\
1.9 \\
1.9 \\
1.9 \\
2.1\end{array}$ & $\begin{array}{l}1.6 \\
1.6 \\
1.8 \\
2.0 \\
2.2\end{array}$ & $\begin{array}{l}3.0 \\
2.8 \\
2.8 \\
3.1 \\
3.0\end{array}$ & $\begin{array}{l}2.2 \\
2.2 \\
2.2 \\
2.2 \\
2.1\end{array}$ & $\begin{array}{l}2.0 \\
2.1 \\
2.2 \\
1.9 \\
1.8\end{array}$ & $\begin{array}{l}1.3 \\
1.2 \\
1.2 \\
1.0 \\
1.0\end{array}$ & $\begin{array}{r}.28 \\
.27 \\
.25 \\
.25 \\
.26\end{array}$ & $\begin{array}{r}.30 \\
.26 \\
.32 \\
.30 \\
.20\end{array}$ & $\begin{array}{r}.29 \\
.21 \\
.18 \\
.19 \\
.19\end{array}$ & $\begin{array}{l}.26 \\
.26 \\
.34 \\
.33 \\
.43\end{array}$ \\
\hline $\begin{array}{l}26 \\
27 \\
28 \\
29 \\
30 \\
31\end{array}$ & $\begin{array}{l}1.6 \\
1.9 \\
1.5 \\
1.6 \\
1.9 \\
2.0\end{array}$ & $\begin{array}{l}1.3 \\
1.7 \\
2.2 \\
1.9 \\
1.3 \\
-.-0\end{array}$ & $\begin{array}{l}2.2 \\
2.2 \\
2.2 \\
2.2 \\
2.6 \\
2.2\end{array}$ & $\begin{array}{l}2.2 \\
2.2 \\
2.2 \\
2.2 \\
2.2 \\
2.2\end{array}$ & $\begin{array}{l}2.6 \\
2.6 \\
2.4 \\
2.6 \\
-.-\end{array}$ & $\begin{array}{l}2.1 \\
2.2 \\
2.1 \\
2.1 \\
2.1 \\
2.2\end{array}$ & $\begin{array}{l}1.5 \\
1.5 \\
1.6 \\
1.7 \\
1.7 \\
-.\end{array}$ & $\begin{array}{l}1.0 \\
.96 \\
.98 \\
.94 \\
.90 \\
.81\end{array}$ & $\begin{array}{l}.17 \\
.14 \\
.13 \\
.08 \\
.09 \\
.0-\end{array}$ & $\begin{array}{r}.10 \\
112 \\
119 \\
.19 \\
.22 \\
.30\end{array}$ & $\begin{array}{r}.19 \\
119 \\
119 \\
.19 \\
119 \\
119\end{array}$ & $\begin{array}{l}.69 \\
1.1 \\
2.6 \\
6.7 \\
1.6 \\
0\end{array}$ \\
\hline $\begin{array}{l}\text { TOTAL } \\
\text { MEAN } \\
\text { MAX } \\
\text { MIN } \\
\text { AC }-F T\end{array}$ & $\begin{array}{r}55.6 \\
1.79 \\
3.4 \\
1.1 \\
110\end{array}$ & $\begin{array}{r}46.3 \\
1.54 \\
2.2 \\
1.3 \\
92\end{array}$ & $\begin{array}{r}53.2 \\
1.72 \\
2.6 \\
1.1 \\
106\end{array}$ & $\begin{array}{r}63.1 \\
2.04 \\
3.0 \\
1.6 \\
125\end{array}$ & $\begin{array}{r}279.1 \\
9.62 \\
124 \\
1.9 \\
554\end{array}$ & $\begin{array}{r}110.7 \\
3.57 \\
15 \\
2.1 \\
220\end{array}$ & $\begin{array}{r}69.3 \\
2.31 \\
3.7 \\
1.5 \\
137\end{array}$ & $\begin{array}{r}40.79 \\
1.32 \\
1.9 \\
.81 \\
81\end{array}$ & $\begin{array}{r}12.77 \\
.43 \\
.75 \\
.08 \\
25\end{array}$ & $\begin{array}{r}5.55 \\
.18 \\
.38 \\
.05 \\
11\end{array}$ & $\begin{array}{r}6.40 \\
.21 \\
.34 \\
.14 \\
13\end{array}$ & $\begin{array}{r}22.39 \\
.75 \\
6.7 \\
.14 \\
44\end{array}$ \\
\hline
\end{tabular}

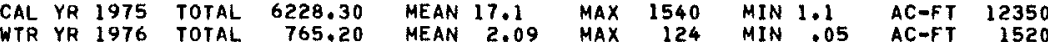


11133000 SANTA YNEZ RIVER AT NARROWS, NEAR LOMPOC, CA

LOCATION - - Lat $34^{\circ} 38^{\prime} 16^{\prime \prime}$, long $120^{\circ} 25^{\prime} 32^{\prime \prime}$, in Canada de Salsipuedes Grant, Santa Barbara County, on left bank $0.5 \mathrm{mi}(0.8 \mathrm{~km})$ upstream from state Highway $246,1.9 \mathrm{mi}(3.1 \mathrm{~km})$ east of Lompoc, $1.9 \mathrm{mi}(3.1 \mathrm{~km})$ downstream from Salsipuedes Creek, and $12.5 \mathrm{mi}(20.1 \mathrm{~km})$ downstreant from Lake Cachuma.

DRAINAGE AREA. $-789 \mathrm{mi}^{2}\left(2,040 \mathrm{~km}^{2}\right)$.

PERIOD OF RECORD.--May 1947 to November 1951 (irrigation seasons only). May 1952 to September 1963 , October 1964 to current year. Records equivalent, excepting low-f1ow periods, to those published as "near lompoc"

(station 11133500), November to December 1906, October 1907 to September 1918, May 1925 to September 1960.

GAGE. - Two water-stage recorders. Altitude of main gage is $90 \mathrm{ft}$ ( $27 \mathrm{~m})$, from topographic map. See WSP 1715 for history of changes prior to oct. 1, 1961. Since oct. 1, 1961, at various sites and datums within 0.1 mi

$(0.2 \mathrm{~km})$ of present site. Supplementary gage, used for high-water periods, at site $0.5 \mathrm{mi}(0.8 \mathrm{~km})$ downstream at datum $79.25 \mathrm{ft}(24.155 \mathrm{~m})$ above mean sea leve1.

REMARKS. - Records good. Flow regulated by Jameson Lake, Gibra1tar Reservoir, and since November 1952 by Lake Cachuma (stations $11121000,11122000,11125500$ ). Water diverted out of Jameson Lake, Gibraltar Reservoir, and Lake Cachuma to cities of Montecito, Santa Barbara, and Goleta for municipal supply. Water pumped from and Lake Cachuna to cities of Montecito, Santa Barbara, and G

EXTREMES FOR PERIOD OF RECORD,(1952-63 AND SINCE 1964).--Maximum discharge, $80,000 \mathrm{ft}^{3} / \mathrm{s}\left(2,270 \mathrm{~m}^{3} / \mathrm{s}\right)$ Jan, 25, 1969, gage height, $24.20 \mathrm{ft}(7.376 \mathrm{~m})$, from supplementary gage; no flow at times in each year.

EXTREMES OUTSIDE PERIOD OF RECORD. - Flood of Jan. $9,1907,120,000 \mathrm{ft}^{3} / \mathrm{s}\left(3,400 \mathrm{~m}^{3} / \mathrm{s}\right)$, gage height, $22.0 \mathrm{ft}$ $(6.71 \mathrm{~m})$ site and datum then in use, from mean-depth study.

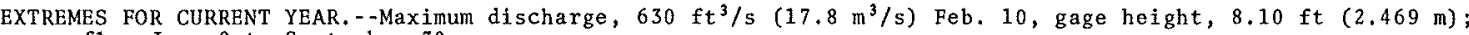
no flow June 8 to September 30 .

DISCHARGE, IN CUSIC FEET PER SECOND, MATER YEAR OCTOBER 1975 TO SEPTEMBER 1976 HEAN VALUES

\begin{tabular}{|c|c|c|c|c|c|c|c|c|c|c|c|c|c|}
\hline DAY & OCT & NOV & DEC & JAN & FEE & & MAR & APA & MAY & JUN & JUL & AUG & SEP \\
\hline $\begin{array}{l}1 \\
2 \\
3 \\
4 \\
5\end{array}$ & $\begin{array}{l}.60 \\
.67 \\
.65 \\
.57 \\
.61\end{array}$ & $\begin{array}{l}.95 \\
1.2 \\
1.1 \\
1.0 \\
1.1\end{array}$ & $\begin{array}{l}1.5 \\
1.5 \\
1.5 \\
1.5 \\
1.5\end{array}$ & $\begin{array}{l}1.8 \\
1.8 \\
1.7 \\
1.8 \\
1.8\end{array}$ & $\begin{array}{l}2.3 \\
2.3 \\
2.3 \\
2.3 \\
2.3\end{array}$ & & $\begin{array}{l}21 \\
22 \\
42 \\
32 \\
27\end{array}$ & $\begin{array}{l}4.2 \\
3.4 \\
2.7 \\
2.8 \\
3.0\end{array}$ & $\begin{array}{l}.92 \\
.81 \\
.73 \\
.73 \\
.77\end{array}$ & $\begin{array}{r}.31 \\
.29 \\
.26 \\
.20 \\
.08\end{array}$ & & & \\
\hline $\begin{array}{r}6 \\
7 \\
8 \\
9 \\
10\end{array}$ & $\begin{array}{l}.64 \\
.67 \\
.61 \\
.59 \\
.69\end{array}$ & $\begin{array}{l}1.0 \\
.90 \\
.97 \\
.97 \\
.98\end{array}$ & $\begin{array}{l}1.5 \\
1.5 \\
1.5 \\
1.5 \\
1.6\end{array}$ & $\begin{array}{l}1.8 \\
1.8 \\
1.9 \\
2.9 \\
1.9\end{array}$ & $\begin{array}{r}2 . \\
3 . \\
20 \\
53 \\
390\end{array}$ & & $\begin{array}{l}23 \\
21 \\
20 \\
19 \\
18\end{array}$ & $\begin{array}{l}2.6 \\
2.1 \\
2.8 \\
3.7 \\
4.1\end{array}$ & $\begin{array}{r}.90 \\
.88 \\
1.1 \\
1.2 \\
.93\end{array}$ & $\begin{array}{l}114 \\
0 \\
0 \\
0\end{array}$ & & & \\
\hline $\begin{array}{l}11 \\
12 \\
13 \\
14 \\
15\end{array}$ & $\begin{array}{r}.85 \\
.85 \\
.85 \\
.79 \\
.71\end{array}$ & $\begin{array}{r}.95 \\
.85 \\
.76 \\
.85 \\
.95\end{array}$ & $\begin{array}{l}1.7 \\
1.7 \\
1.8 \\
1.8 \\
1.7\end{array}$ & $\begin{array}{l}2.0 \\
2.0 \\
2.0 \\
2.0 \\
2.0\end{array}$ & $\begin{array}{r}231 \\
94 \\
61 \\
48 \\
40\end{array}$ & & $\begin{array}{l}17 \\
16 \\
15 \\
14 \\
14\end{array}$ & $\begin{array}{l}4.5 \\
4.6 \\
7.3 \\
7.3 \\
7.0\end{array}$ & $\begin{array}{r}.88 \\
.70 \\
.59 \\
.51 \\
.48\end{array}$ & $\begin{array}{l}0 \\
0 \\
0 \\
0 \\
0\end{array}$ & & & \\
\hline $\begin{array}{l}16 \\
17 \\
18 \\
19 \\
20\end{array}$ & $\begin{array}{r}.70 \\
.71 \\
.88 \\
.85 \\
.95\end{array}$ & $\begin{array}{l}1.0 \\
1.1 \\
.95 \\
.95 \\
.95\end{array}$ & $\begin{array}{l}1.8 \\
1.8 \\
1.8 \\
1.8 \\
1.8\end{array}$ & $\begin{array}{l}2.0 \\
1.9 \\
2.0 \\
2.0 \\
2.0\end{array}$ & $\begin{array}{l}33 \\
29 \\
26 \\
24 \\
21\end{array}$ & & $\begin{array}{l}13 \\
12 \\
11 \\
10 \\
9.9\end{array}$ & $\begin{array}{l}6.6 \\
5.0 \\
4.2 \\
3.9 \\
3.7\end{array}$ & $\begin{array}{r}.47 \\
.45 \\
.46 \\
.49 \\
.52\end{array}$ & $\begin{array}{l}0 \\
0 \\
0 \\
0 \\
0\end{array}$ & & & \\
\hline $\begin{array}{l}21 \\
22 \\
23 \\
24 \\
25\end{array}$ & $\begin{array}{r}.95 \\
.95 \\
.91 \\
.85 \\
.76\end{array}$ & $\begin{array}{l}1.2 \\
1.1 \\
1.2 \\
1.2 \\
1.3\end{array}$ & $\begin{array}{l}1.8 \\
2.0 \\
2.0 \\
1.0 \\
1.6\end{array}$ & $\begin{array}{l}2.1 \\
2.1 \\
2.1 \\
2.1 \\
2.2\end{array}$ & $\begin{array}{l}21 \\
19 \\
18 \\
18 \\
17\end{array}$ & & $\begin{array}{l}9.4 \\
9.4 \\
9.4 \\
9.0 \\
8.3\end{array}$ & $\begin{array}{l}3.4 \\
3.4 \\
3.4 \\
3.4 \\
3.1\end{array}$ & $\begin{array}{r}.50 \\
.44 \\
.46 \\
.44 \\
.39\end{array}$ & $\begin{array}{l}0 \\
0 \\
0 \\
0 \\
0\end{array}$ & & & \\
\hline $\begin{array}{l}26 \\
27 \\
28 \\
29 \\
30 \\
31\end{array}$ & $\begin{array}{r}.84 \\
.95 \\
.83 \\
.85 \\
.96 \\
.94\end{array}$ & $\begin{array}{l}1.3 \\
1.4 \\
1.5 \\
1.5 \\
1.5 \\
-.-\end{array}$ & $\begin{array}{l}1.8 \\
1.9 \\
2.1 \\
2.0 \\
2.0 \\
2.0\end{array}$ & $\begin{array}{l}2.2 \\
2.2 \\
2.2 \\
2.2 \\
2.2 \\
2.2\end{array}$ & $\begin{array}{l}14 \\
14 \\
14 \\
14 \\
=\end{array}$ & 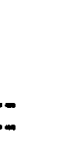 & $\begin{array}{l}8.1 \\
8.1 \\
8.1 \\
7.3 \\
5.9 \\
5.0\end{array}$ & $\begin{array}{l}2.5 \\
1.8 \\
1.4 \\
1.1 \\
.96 \\
-\end{array}$ & $\begin{array}{r}.36 \\
.37 \\
.35 \\
.33 \\
.31 \\
.32\end{array}$ & $\begin{array}{l}0 \\
0 \\
0 \\
0 \\
0 \\
\ldots\end{array}$ & & & $-\infty$ \\
\hline $\begin{array}{l}\text { TOTAL } \\
\text { MEAN } \\
\text { MAX } \\
\text { MIN } \\
\text { AC-FT }\end{array}$ & $\begin{array}{r}24.23 \\
.78 \\
.96 \\
.57 \\
48\end{array}$ & $\begin{array}{r}32.68 \\
1.09 \\
1.5 \\
.76 \\
65\end{array}$ & $\begin{array}{r}54.0 \\
1.74 \\
2.1 \\
1.5 \\
1.07\end{array}$ & $\begin{array}{r}62.4 \\
2.01 \\
2.4 \\
1.7 \\
124\end{array}$ & $\begin{array}{r}1236 \\
42 \\
39 \\
2 . \\
245\end{array}$ & & $\begin{array}{r}464.9 \\
15.0 \\
42 \\
5.0 \\
922\end{array}$ & $\begin{array}{r}109.96 \\
3.67 \\
7.3 \\
.96 \\
218\end{array}$ & $\begin{array}{r}18.79 \\
.61 \\
1.2 \\
.31 \\
37\end{array}$ & $\begin{array}{r}1.39 \\
.046 \\
.31 \\
0 \\
2.8\end{array}$ & $\begin{array}{l}0 \\
0 \\
0 \\
0 \\
0\end{array}$ & $\begin{array}{l}0 \\
0 \\
0 \\
0 \\
0\end{array}$ & $\begin{array}{l}0 \\
0 \\
0 \\
0 \\
0\end{array}$ \\
\hline
\end{tabular}


LOCATION. - Lat $34^{\circ} 37^{\prime} 57^{\prime \prime}$, long $120^{\circ} 27^{\prime} 51^{\prime \prime}$, in Lompoc Grant, Santa Barbara County, on right bank at upstream end of debris dam, and $1,500 \mathrm{ft}(457 \mathrm{~m})$ south of Lompoc Union High School.

DRAINAGE AREA. $--11.6 \mathrm{mi}^{2}\left(30.0 \mathrm{~km}^{2}\right)$.

PERIOD OF RECORD, --October 1970 to current year.

GAGE, - Water-stage recorder and concrete control. Datum of gage is $97.94 \mathrm{ft}$ ( $29.852 \mathrm{~m})$ above mean sea 1 evel (Santa Barbara County bench mark).

REMARKS.--Records fair. No regulation or diversion above station; some pumping from wells along stream for irrigation.

AVERAGE DISCHARGE. -6 years, $1.12 \mathrm{ft}^{3} / \mathrm{s}\left(0.032 \mathrm{~m}^{3} / \mathrm{s}\right), 811 \mathrm{acre}-\mathrm{ft} / \mathrm{yr}\left(1.00 \mathrm{hm}^{3} / \mathrm{yr}^{2}\right)$

EXTREMES FOR PERIOD OF RECORD. - Maximum discharge, $501 \mathrm{ft}^{3} / \mathrm{s}\left(14.2 \mathrm{~m}^{3} / \mathrm{s}\right) \mathrm{Feb}, 2,1975$, gage height, $5.34 \mathrm{ft}$ $(1.628 \mathrm{~m})$, from rating curve extended above $144 \mathrm{ft}^{3} / \mathrm{s}(4.08 \mathrm{~m} / \mathrm{s})$ on basis of slope-area measurement at gage height $5.02 \mathrm{ft}(1.530 \mathrm{~m})$; no flow many days in some years.

EXTREMES OUTSIDE PERIOD OF RECORD.-Flood of Jan. 25, 1969, reached a stage of 5.83 ft (1.777 m), from floodmark, discharge, $680 \mathrm{ft}^{3} / \mathrm{s}\left(19.3 \mathrm{~m}^{3} / \mathrm{s}\right)$.

EXTREMES FOR CURRENT YEAR. - -Maximum discharge, $144 \mathrm{ft}^{3} / \mathrm{s}\left(4,08 \mathrm{~m}^{3} / \mathrm{s}\right)$ Feb. 9 ( $\left.2130 \mathrm{hrs}\right)$, gage height, $2.92 \mathrm{ft}$ $(0.890 \mathrm{~m})$, no other peak above base of $100 \mathrm{ft}^{3} / \mathrm{s}\left(2.82 \mathrm{~m}^{3} / \mathrm{s}\right) ; \mathrm{minimum}$ daily, $0.05 \mathrm{ft}^{3} / \mathrm{s}\left(0.001 \mathrm{~m}^{3} / \mathrm{s}\right)$

several days from July to September.

DISCHARGE, IN CUBIC FEET PER SECOND, WATER YEAR OCTOBER 1975 TO SEPTEMBER 1976 MEAN VALUES

\begin{tabular}{|c|c|c|c|c|c|c|c|c|c|c|c|c|}
\hline DAY & OCT & NoV & DEC & JAN & FEB & MAR & APR & MAY & JUN & JUL & AUB & SEP \\
\hline $\begin{array}{l}1 \\
2 \\
3 \\
4 \\
5\end{array}$ & $\begin{array}{l}.56 \\
.46 \\
.35 \\
.26 \\
.41\end{array}$ & $\begin{array}{l}.17 \\
.18 \\
.26 \\
.16 \\
.16\end{array}$ & $\begin{array}{l}.41 \\
.41 \\
.26 \\
.26 \\
.26\end{array}$ & $\begin{array}{r}.32 \\
.33 \\
.46 \\
.44 \\
.39\end{array}$ & $\begin{array}{l}.26 \\
.26 \\
.26 \\
.26 \\
1.1\end{array}$ & $\begin{array}{l}2.8 \\
4.1 \\
2.0 \\
.83 \\
.60\end{array}$ & $\begin{array}{r}.16 \\
.19 \\
.16 \\
.16 \\
.17\end{array}$ & $\begin{array}{l}.26 \\
.26 \\
.26 \\
.26 \\
.20\end{array}$ & $\begin{array}{l}.16 \\
.16 \\
.16 \\
.16 \\
.26\end{array}$ & $\begin{array}{l}.09 \\
.08 \\
.08 \\
.08 \\
.08\end{array}$ & $\begin{array}{l}.07 \\
.08 \\
.08 \\
.08 \\
.08\end{array}$ & $\begin{array}{l}.05 \\
.05 \\
.08 \\
.08 \\
.08\end{array}$ \\
\hline $\begin{array}{r}6 \\
7 \\
8 \\
9 \\
10\end{array}$ & $\begin{array}{l}.41 \\
.41 \\
.26 \\
.26 \\
.41\end{array}$ & $\begin{array}{l}.16 \\
.16 \\
.16 \\
.26 \\
.26\end{array}$ & $\begin{array}{l}.26 \\
.26 \\
.26 \\
.26 \\
.26\end{array}$ & $\begin{array}{l}.26 \\
.26 \\
.26 \\
.26 \\
.41\end{array}$ & $\begin{array}{l}4.2 \\
1.1 \\
22 \\
23 \\
14\end{array}$ & $\begin{array}{l}.60 \\
.41 \\
.41 \\
.41 \\
.41\end{array}$ & $\begin{array}{l}.15 \\
.15 \\
.95 \\
.24 \\
.25\end{array}$ & $\begin{array}{l}.26 \\
.25 \\
.22 \\
.26 \\
.26\end{array}$ & $\begin{array}{l}.26 \\
.26 \\
.26 \\
.26 \\
.16\end{array}$ & $\begin{array}{l}.08 \\
.08 \\
.08 \\
.08 \\
.08\end{array}$ & $\begin{array}{l}.08 \\
.08 \\
.08 \\
.07 \\
.08\end{array}$ & $\begin{array}{l}.05 \\
.05 \\
.05 \\
.05 \\
1.3\end{array}$ \\
\hline $\begin{array}{l}11 \\
12 \\
13 \\
14 \\
15\end{array}$ & $\begin{array}{l}.83 \\
.41 \\
.41 \\
.41 \\
.41\end{array}$ & $\begin{array}{l}.26 \\
.26 \\
.26 \\
.16 \\
.26\end{array}$ & $\begin{array}{l}.26 \\
.44 \\
.26 \\
.26 \\
.26\end{array}$ & $\begin{array}{l}.41 \\
.41 \\
.41 \\
.26 \\
.26\end{array}$ & $\begin{array}{r}.83 \\
.60 \\
.26 \\
.60 \\
.26\end{array}$ & $\begin{array}{l}.41 \\
.41 \\
.26 \\
.41 \\
.41\end{array}$ & $\begin{array}{l}.15 \\
.59 \\
.22 \\
.14 \\
.22\end{array}$ & $\begin{array}{l}.26 \\
.16 \\
.16 \\
.16 \\
.16\end{array}$ & $\begin{array}{l}.08 \\
.08 \\
.08 \\
.08 \\
.08\end{array}$ & $\begin{array}{r}.08 \\
.04 \\
1.3 \\
.08 \\
.05\end{array}$ & $\begin{array}{l}.08 \\
.08 \\
.08 \\
.08 \\
.08\end{array}$ & $\begin{array}{r}4.3 \\
.08 \\
.08 \\
.08 \\
.08\end{array}$ \\
\hline $\begin{array}{l}16 \\
17 \\
18 \\
19 \\
20\end{array}$ & $\begin{array}{l}.41 \\
.41 \\
.41 \\
.41 \\
.41\end{array}$ & $\begin{array}{l}.26 \\
.41 \\
.26 \\
.26 \\
.26\end{array}$ & $\begin{array}{l}.41 \\
.26 \\
.26 \\
.26 \\
.26\end{array}$ & $\begin{array}{l}.26 \\
.16 \\
.26 \\
.26 \\
.26\end{array}$ & $\begin{array}{l}.26 \\
.26 \\
.26 \\
.26 \\
.26\end{array}$ & $\begin{array}{r}.26 \\
.26 \\
.26 \\
.26 \\
.26\end{array}$ & $\begin{array}{l}.16 \\
.16 \\
.26 \\
.26 \\
.26\end{array}$ & $\begin{array}{l}.16 \\
.26 \\
.26 \\
.26 \\
.26\end{array}$ & $\begin{array}{l}.08 \\
.08 \\
.08 \\
.08 \\
.09\end{array}$ & $\begin{array}{l}.05 \\
.05 \\
.05 \\
.05 \\
.05\end{array}$ & $\begin{array}{l}.08 \\
.08 \\
.08 \\
.03 \\
.05\end{array}$ & $\begin{array}{l}.08 \\
.08 \\
.08 \\
.08 \\
.08\end{array}$ \\
\hline $\begin{array}{l}21 \\
22 \\
23 \\
24 \\
25\end{array}$ & $\begin{array}{l}.41 \\
.41 \\
.26 \\
.26 \\
.41\end{array}$ & $\begin{array}{l}.26 \\
.32 \\
.35 \\
.37 \\
.34\end{array}$ & $\begin{array}{l}.26 \\
.26 \\
.26 \\
.26 \\
.26\end{array}$ & $\begin{array}{l}.28 \\
.39 \\
.33 \\
.26 \\
.26\end{array}$ & $\begin{array}{l}.26 \\
.26 \\
.22 \\
.26 \\
.26\end{array}$ & $\begin{array}{l}.26 \\
.26 \\
.26 \\
.26 \\
.26\end{array}$ & $\begin{array}{l}.16 \\
.16 \\
.15 \\
.12 \\
.11\end{array}$ & $\begin{array}{r}\cdot 26 \\
.26 \\
.26 \\
\cdot 26 \\
.20\end{array}$ & $\begin{array}{l}.09 \\
.09 \\
.11 \\
.09 \\
.10\end{array}$ & $\begin{array}{l}.05 \\
.05 \\
.05 \\
.05 \\
.06\end{array}$ & $\begin{array}{l}.05 \\
.08 \\
.08 \\
.08 \\
.08\end{array}$ & $\begin{array}{l}.08 \\
.08 \\
.08 \\
.05 \\
.08\end{array}$ \\
\hline $\begin{array}{l}26 \\
27 \\
28 \\
29 \\
30 \\
31\end{array}$ & $\begin{array}{l}.64 \\
.22 \\
.18 \\
.19 \\
.40 \\
.17\end{array}$ & $\begin{array}{r}.33 \\
.41 \\
1.2 \\
.41 \\
.41 \\
-\infty-\end{array}$ & $\begin{array}{l}.26 \\
.26 \\
.27 \\
.25 \\
.23 \\
. .26\end{array}$ & $\begin{array}{l}.26 \\
.26 \\
.26 \\
.24 \\
.25 \\
.25\end{array}$ & $\begin{array}{l}.26 \\
.25 \\
.40 \\
.41 \\
. .2 \\
. .-\end{array}$ & $\begin{array}{l}.21 \\
.20 \\
.28 \\
.29 \\
.24 \\
.17\end{array}$ & $\begin{array}{r}.14 \\
.13 \\
.16 \\
.30 \\
.31 \\
-.0\end{array}$ & $\begin{array}{l}.25 \\
.23 \\
.12 \\
.13 \\
.19 \\
.16\end{array}$ & $\begin{array}{l}.13 \\
.14 \\
.10 \\
.09 \\
.09 \\
-.0\end{array}$ & $\begin{array}{l}.08 \\
.08 \\
.07 \\
.10 \\
.08 \\
.07\end{array}$ & $\begin{array}{l}.05 \\
.05 \\
.05 \\
.05 \\
.08 \\
.05\end{array}$ & $\begin{array}{c}.08 \\
108 \\
12 \\
7.9 \\
.05 \\
=-\end{array}$ \\
\hline $\begin{array}{l}\text { TOTAL } \\
\text { MEAN } \\
\text { MAX } \\
\text { MIN } \\
\text { AC-FT }\end{array}$ & $\begin{array}{r}11.86 \\
.38 \\
.83 \\
.17 \\
24\end{array}$ & $\begin{array}{r}8.88 \\
.30 \\
1.1 \\
.16 \\
18\end{array}$ & $\begin{array}{r}0.66 \\
.28 \\
.44 \\
.23 \\
17\end{array}$ & $\begin{array}{r}9.40 \\
.30 \\
.46 \\
.16 \\
19\end{array}$ & $\begin{array}{r}72.87 \\
2.51 \\
23 \\
.22 \\
145\end{array}$ & $\begin{array}{r}16.46 \\
.60 \\
4.1 \\
.17 \\
37\end{array}$ & $\begin{array}{r}6.74 \\
.22 \\
.95 \\
.11 \\
13\end{array}$ & $\begin{array}{r}6.91 \\
.22 \\
.26 \\
.12 \\
14\end{array}$ & $\begin{array}{r}3.94 \\
.13 \\
.26 \\
.08 \\
7.8\end{array}$ & $\begin{array}{r}4.15 \\
.13 \\
1.3 \\
.05 \\
8.2\end{array}$ & $\begin{array}{r}3.00 \\
.097 \\
.03 \\
.05 \\
6.0\end{array}$ & $\begin{array}{r}27.34 \\
.91 \\
12 \\
.05 \\
54\end{array}$ \\
\hline
\end{tabular}

CAL YR 1975 TOTAL 744.43 MEAN 2.04 MAX 95 MIN 15 AC-FT 1480 WTR YA 1976 TOTAL 182.21 MEAN .50 MAX 23 MIN .05 ACWFT 361 
11135000 SANTA YNEZ RIVER AT PINE CANYON, NEAR LOMPOC, CA

LOCATION.--Lat $34^{\circ} 40^{\prime} 20^{\prime \prime}$, long $120^{\circ} 29^{\prime} 30^{\prime \prime}$, in Lompoc Grant, Santa Barbara County, on right bank at Floradale Avenue bridge, $2.1 \mathrm{mi}(3.4 \mathrm{~km})$ upstream from Santa Lucia Creek, $3 \mathrm{mi}$ ( $5 \mathrm{~km}$ ) northwest of Lompoc, and $7 \mathrm{mi}(11 \mathrm{~km})$ upstream from mouth at Pacific ocean.

DRAINAGE AREA. $--844 \mathrm{mi}^{2}\left(2,186 \mathrm{~km}^{2}\right)$.

PERIOD OF RECORD.--May 1941 to October 1946, August 1964 to current year. Month1y discharge only for some periods, published in WSP $1315-B$.

GAGE. - Water-stage recorder. Datum of gage is $40.78 \mathrm{ft}(12.430 \mathrm{~m})$ above mean sea 1 evel. Prior to Aug. 24 , 1964 , at different datum. Aug. 24, 1964, to Aug. 20, 1970, at datum $0.91 \mathrm{ft}(0.277 \mathrm{~m}) 10$ wer.

REMARKS. - Records fair. Flow regulated by Jameson Lake, Gibra1tar Reservoir, and Lake Cachuma (stations 11121000, $11122000,11125500)$. Water diverted out of basin from Jameson Lake, Gibraltar Reservoir, and Lake Cachuma to cities of Montecito, Santa Barbara, and Goleta for municipal supply. Water pumped from wells along bank for irrigation in valley upstream. Effluent from city of Lompoc contributes to low flow most months.

EXTREMES FOR PERIOD OF RECORD, - Maximum discharge, $78,000 \mathrm{ft}^{3} / \mathrm{s}\left(2,210 \mathrm{~m}^{3} / \mathrm{s}\right)$, estimated, Jan. 25 , 1969 , gage height, $24.91 \mathrm{ft}(7.593 \mathrm{~m})$, present datum, from floodmark; no flow at times in some years.

EXTREMES FOR CURRENT YEAR.--Maximum discharge, $670 \mathrm{ft}^{3} / \mathrm{s}\left(19.0 \mathrm{~m}^{3} / \mathrm{s}\right) \mathrm{Feb}$. 10 , gage height, $7.87 \mathrm{ft}(2.399 \mathrm{~m})$, from rating curve extended above $220 \mathrm{ft} / \mathrm{s}\left(6.23 \mathrm{~m}^{3} / \mathrm{s}\right) ;$ minimum daily, $1.1 \mathrm{ft} / \mathrm{s}\left(0.031 \mathrm{~m}^{3} / \mathrm{s}\right) \mathrm{Aug}$. $2-17$.

DISCHARGE, IN CUBIC FEET PER SECOND, HATER YEAR OCTOBER 1975 TO SEPTEMBER 1976 MEAN VALUES

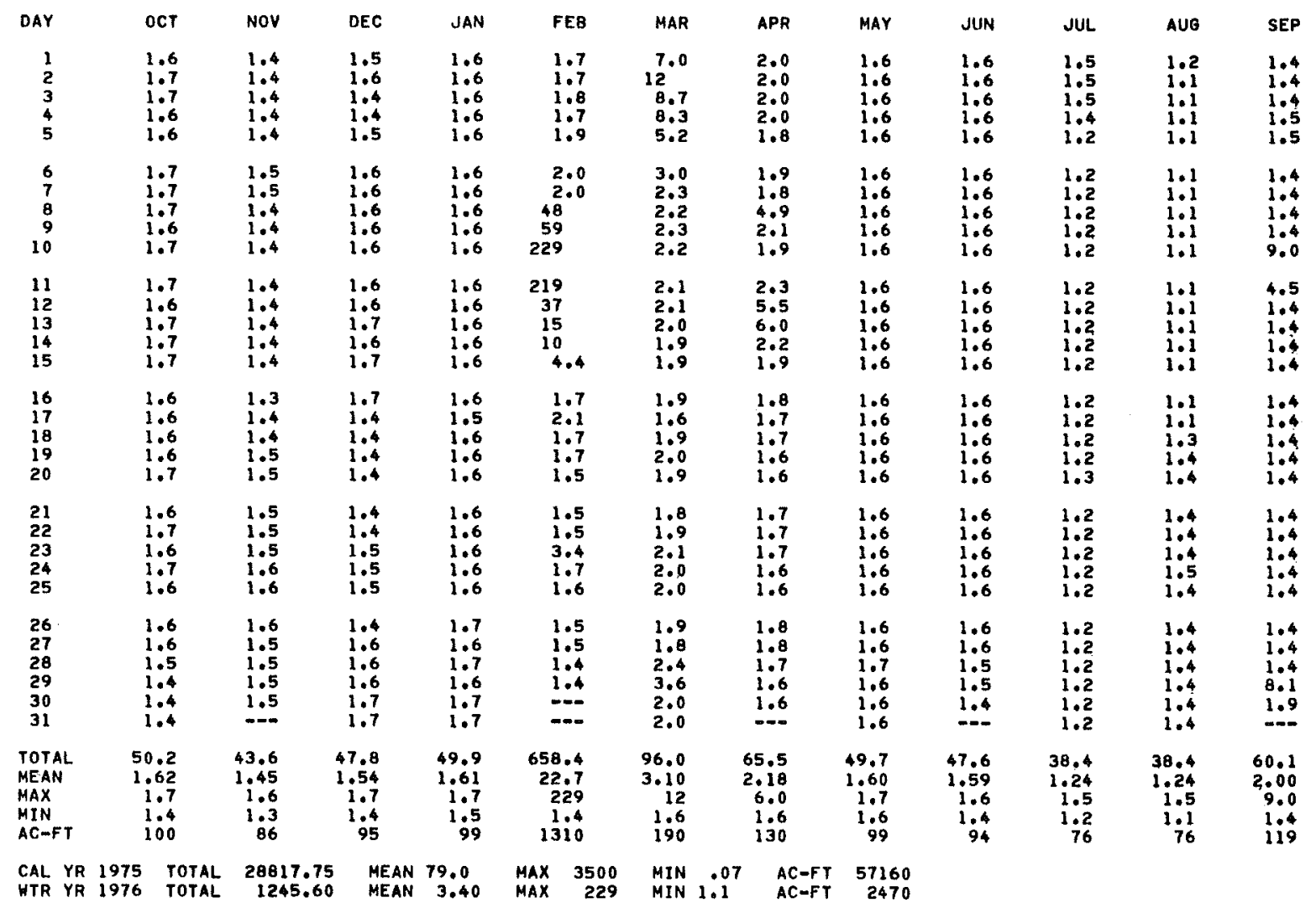


LOCATION.--Lat $34^{\circ} 44^{\prime} 36^{\prime \prime}$, long $120^{\circ} 16^{\prime} 12^{\prime \prime}$, in Los Alamos Grant, Santa Barbara County, on 1eft bank 100 ft ( $30 \mathrm{~m}$ ) upstream from bridge on northbound lane of Highway 101 at Los Alamos.

DRAINAGE AREA. $--34.9 \mathrm{mi}^{2}\left(90.4 \mathrm{~km}^{2}\right)$.

PERIOD OF RECORD, --October 1970 to current year.

GAGE. - Water-stage recorder. Altitude of gage is $580 \mathrm{ft}(177 \mathrm{~m})$, from topographic map.

REMARKS.--Records fair. No regulation above station. Pumping for irrigation of about 1,000 acres (4.05 km ${ }^{2}$ ) above station.

AVERAGE DISCHARGE. -6 years, $0.28 \mathrm{ft}^{3} / \mathrm{s}\left(0.008 \mathrm{~m}^{3} / \mathrm{s}\right), 203 \mathrm{acre}-\mathrm{ft} / \mathrm{yr}\left(250,000 \mathrm{~m}^{3} / \mathrm{yr}^{2}\right)$.

EXTREMES FOR PERIOD OF RECORD. - Maximum discharge, $233 \mathrm{ft}^{3} / \mathrm{s}\left(6.60 \mathrm{~m}^{3} / \mathrm{s}\right) \mathrm{Jan}, 18,1973$, gage height, $3.60 \mathrm{ft}$

$(1.097 \mathrm{~m})$, from rating curve extended above $3.0 \mathrm{ft}^{3} / \mathrm{s}\left(0.085 \mathrm{~m}^{3} / \mathrm{s}\right)$ on basis of slope-area measurements at gage heights, 2.16 ft $(0.658 \mathrm{~m})$ and $3.60 \mathrm{ft}(1.097 \mathrm{~m})$; no flow most of each year.

EXTREMES FOR CURRENT YEAR.-Maximum discharge, $21 \mathrm{ft}^{3} / \mathrm{s}\left(0.59 \mathrm{~m}^{3} / \mathrm{s}\right) \mathrm{Feb}$. 10, gage height, $1.87 \mathrm{ft}(0.570 \mathrm{~m})$, no peak above base of $30 \mathrm{ft} / \mathrm{s}\left(0.85 \mathrm{~m}^{3} / \mathrm{s}\right)$; no flow most of year.

DISCHARGE, IN CUBIC FEET PER SECOND, WATER YEAR OCTOBER 1975 TO SEPTEMBER 1976 MEAN VALUES

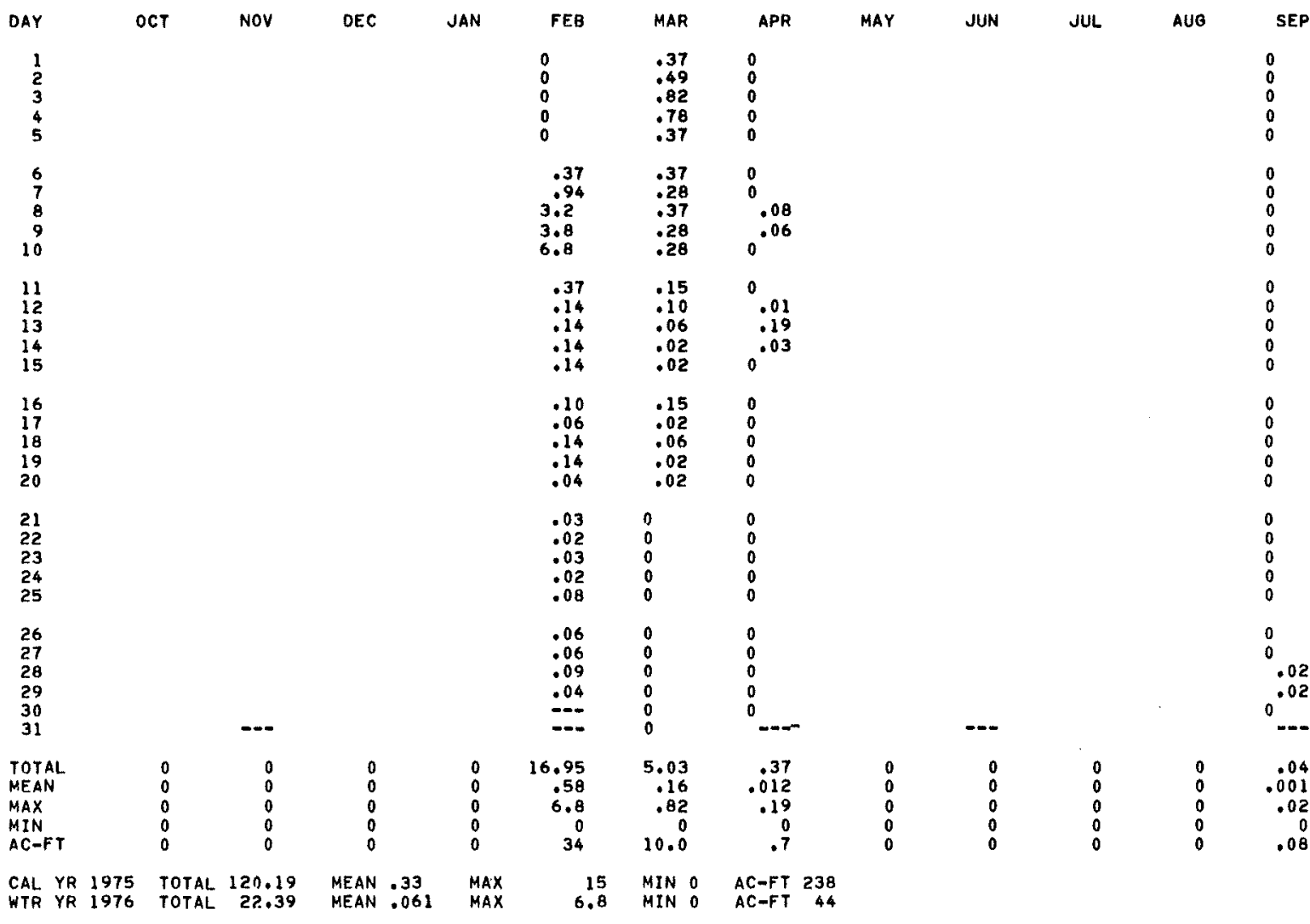


11136100 SAN ANTONTO CREEK NEAR CASMALIA, CA

LOCATION. - Lat $34^{\circ} 46^{\prime} 56^{\prime \prime}$, long $120^{\circ} 31^{\prime} 47^{\prime \prime}$, in Jesus Maria Grant, Santa Barbara County, on Vandenberg Military Reservation on downstream side of center pile bent of San Antonio Road bridge, $0.7 \mathrm{mi}$ (1.1 $\mathrm{km}$ ) east of junction of San Antonio Road and Lompoc-Casmalia Road, and $3.8 \mathrm{mi}$ ( $6.1 \mathrm{~km}$ ) south of Casma1ia.

DRAINAGE AREA. $--135 \mathrm{mi}^{2}\left(350 \mathrm{~km}^{2}\right)$.

PERIOD OF RECORD. - -October 1955 to current year.

GAGE. - Water-stage recorder. Concrete control since August 1970 . Altitude of gage is 160 ft (49 m), from topographic map. Prior to June 27, 1958, at datum $2.00 \mathrm{ft}(0.610 \mathrm{~m}) \mathrm{higher}$.

REMARKS. - Records good. No regulation above station. Flow affected by pumping from wells along stream for irrigation above station.

AVERAGE DISCHARGE. - -21 years, $5.11 \mathrm{ft} 3 / \mathrm{s}\left(0.145 \mathrm{~m}^{3} / \mathrm{s}\right), 3,700 \mathrm{acre}-\mathrm{ft} / \mathrm{yr}\left(4.56 \mathrm{hm}^{3} / \mathrm{yr}^{3}\right)$.

EXTREMES FOR PERIOD OF RECORD.--Maximum discharge, 2,300 $\mathrm{ft}^{3} / \mathrm{s}\left(65.1 \mathrm{~m}^{3} / \mathrm{s}\right)$ Feb. 25,1969 , gage height, $11.79 \mathrm{ft}$ (3.594 m); minimum daily, $0.10 \mathrm{ft}^{3} / \mathrm{s}\left(0.003 \mathrm{~m}^{3} / \mathrm{s}\right)$ June $19,20,1957$.

EXTREMES FOR CURRENT YEAR. - -Maximum discharge, $187 \mathrm{ft}^{3} / \mathrm{s}\left(5.30 \mathrm{~m}^{3} / \mathrm{s}\right)$ Feb. 10 (0945 hrs), gage height, $6.34 \mathrm{ft}$ $(1.932 \mathrm{~m})$, no other peak above base of $100 \mathrm{ft}^{3} / \mathrm{s}\left(2.83 \mathrm{~m}^{3} / \mathrm{s}\right) ; \mathrm{minimum} \mathrm{dai} 1 \mathrm{y}, 0.23 \mathrm{ft} / \mathrm{s}\left(0.007 \mathrm{~m}^{3} / \mathrm{s}\right) \mathrm{July} 29$.

DISCHARGE, IN CUBIC FEET PER SECOND, WATER YEAR OCTOBER 1975 TO SEPTEMBER 1976 MEAN VALUES

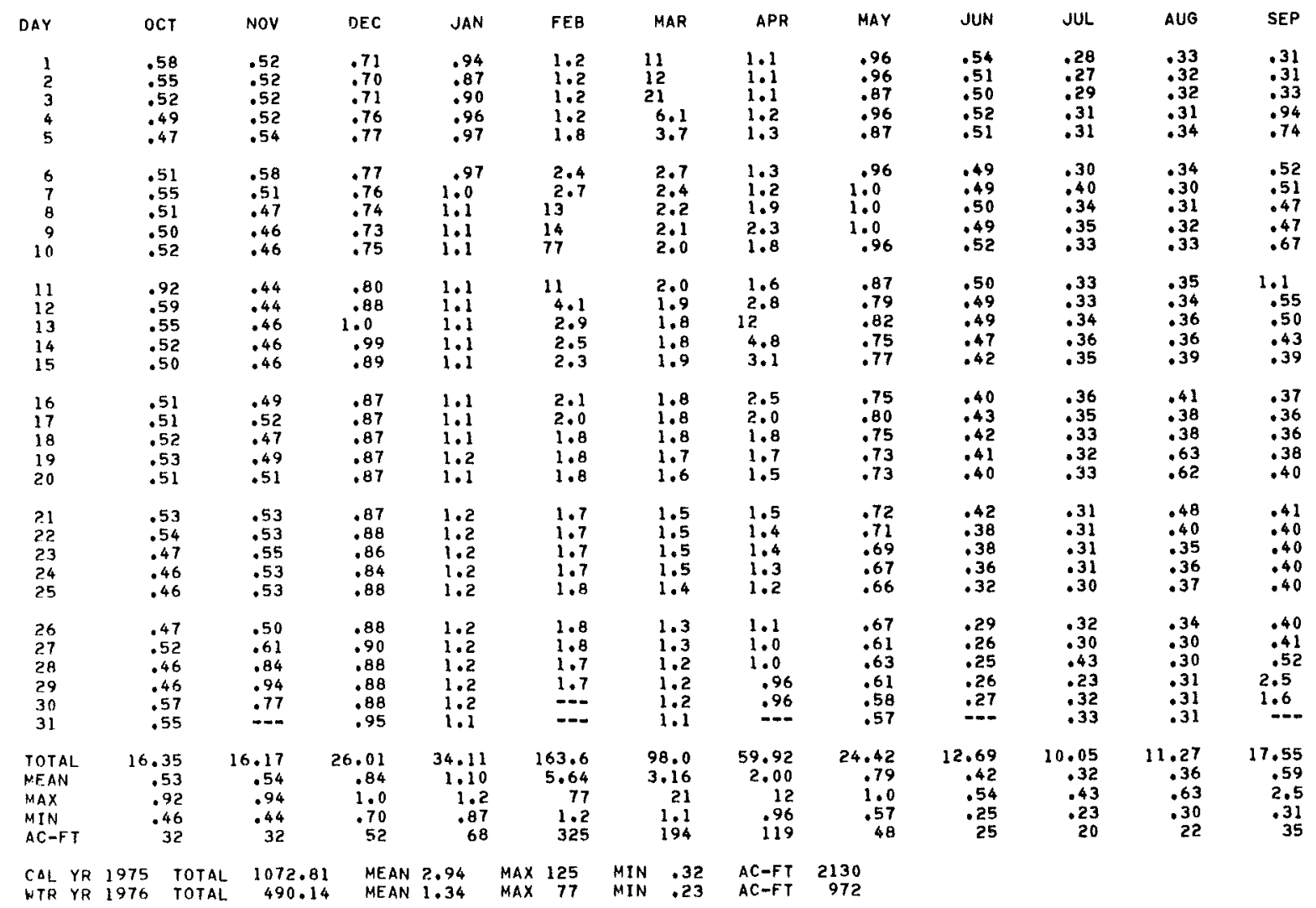


11136400 WAGON ROAD CREEK NEAR STAUFFER, CA

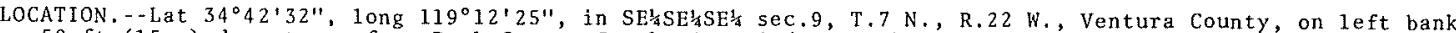
$50 \mathrm{ft}(15 \mathrm{~m})$ downstrean from Park Canyon Creek, $9.3 \mathrm{mi}$ (15.0 km) southwest of Stauffer, and $10 \mathrm{mi}$ ( $16 \mathrm{~km}$ ) east of Ozena Guard Station.

DRATNAGE AREA. $--17.9 \mathrm{mi}^{2}\left(46.4 \mathrm{~km}^{2}\right)$

PERIOD OF RECORD.--July 1972 to current year.

GAGE. - Water-stage recorder. Altitude of gage is 4,500 ft $(1,372 \mathrm{~m})$, from topographic map.

REMARKS, - Records poor. No diversion or regulation above station.

COOPERATION. - Seventeen discharge measurements were furnished by ventura County Flood Control District.

EXTREMES FOR PERIOD OF RECORD.--Maximun discharge, $860 \mathrm{ft}^{3} / \mathrm{s}\left(24.4 \mathrm{~m}^{3} / \mathrm{s}\right)$ Dec. 4 , 1974, from rating curve

extended above $80 \mathrm{ft}^{3} / \mathrm{s}\left(2.27 \mathrm{~m}^{3} / \mathrm{s}\right)$ on basis of slope-area measurement at gage height $4.76 \mathrm{ft}(1.451 \mathrm{~m})$

and Sept. 10,1976, on basis of slope-area measurement of peak flow; maximum gage height, 5.88 ft (1.792 m)

Sept. 10, 1976, from floodmarks; no flow many days in some years.

EXTREMES FOR CURRENT YEAR.--Peak discharges above base of $50 \mathrm{ft}^{3} / \mathrm{s}\left(1.42 \mathrm{~m}^{3} / \mathrm{s}\right)$ and maximum (*), from rating curve extended as explained above:

\begin{tabular}{|c|c|c|c|c|c|c|c|c|c|c|}
\hline Date & Time & $\begin{array}{c}\text { Discharge } \\
\left(\mathrm{ft}^{3} / \mathrm{s}\right)\left(\mathrm{It}^{3} / \mathrm{s}\right)\end{array}$ & $\begin{array}{l}\text { Gage } \\
(\mathrm{ft})\end{array}$ & $\begin{array}{l}\text { ight } \\
\text { (m) }\end{array}$ & Date & Time & $\begin{array}{r}D i s c \\
\left(\mathrm{ft}^{3} / \mathrm{s}\right.\end{array}$ & $\left(\mathrm{m}^{3} / \mathrm{s}\right)$ & $\begin{array}{l}\text { Gage } \\
(\mathrm{ft})\end{array}$ & $\underset{(m)}{\operatorname{height}}$ \\
\hline $\begin{array}{lr}\text { Feb, } & 8 \\
\text { Sept. } & 10\end{array}$ & $\begin{array}{l}0030 \\
\text { Unknown }\end{array}$ & $\begin{array}{r}374 \\
* 860\end{array}$ & $\begin{array}{l}4.02 \\
5.88\end{array}$ & $\begin{array}{l}1.225 \\
1.792\end{array}$ & Sept. 29 & 0745 & 270 & 7.65 & 4.37 & 1.332 \\
\hline
\end{tabular}

Minimum daily discharge, no flow many days during october, July through September.

DISCHARGE, IN CUBIC FEET PER SECOND, WATER YEAR OCTOBER 1975 TO SEPTEMBER 1976 MEAN VALUES

\begin{tabular}{|c|c|c|c|c|c|c|c|c|c|c|c|c|}
\hline DAY & OCT & NOV & DEC & JAN & FEB & MAR & APR & MAY & JUN & JUL & AUG & SEP \\
\hline $\begin{array}{l}1 \\
2 \\
3 \\
4 \\
5\end{array}$ & $\begin{array}{l}0 \\
0 \\
0 \\
0 \\
0\end{array}$ & $\begin{array}{l}.01 \\
.01 \\
.01 \\
.01 \\
.01\end{array}$ & $\begin{array}{l}.01 \\
.01 \\
.01 \\
.01 \\
.01\end{array}$ & $\begin{array}{l}.04 \\
.02 \\
.03 \\
.02 \\
.03\end{array}$ & $\begin{array}{l}.01 \\
.01 \\
.01 \\
.02 \\
.02\end{array}$ & $\begin{array}{l}1.2 \\
.68 \\
1.0 \\
1.5 \\
1.0\end{array}$ & $\begin{array}{l}.08 \\
.07 \\
.15 \\
.20 \\
.94\end{array}$ & $\begin{array}{l}.13 \\
112 \\
112 \\
.11 \\
.09\end{array}$ & $\begin{array}{r}.04 \\
.04 \\
.04 \\
.04 \\
.04\end{array}$ & $\begin{array}{l}.01 \\
.01 \\
.01 \\
.01 \\
.01 \\
.01\end{array}$ & $\begin{array}{l}0 \\
0 \\
0 \\
0 \\
0\end{array}$ & $\begin{array}{l}0 \\
4.0 \\
0 \\
0 \\
0\end{array}$ \\
\hline $\begin{array}{r}6 \\
7 \\
8 \\
9 \\
10\end{array}$ & $\begin{array}{l}0 \\
0 \\
0 \\
0 \\
0\end{array}$ & $\begin{array}{l}.02 \\
.02 \\
.02 \\
.02 \\
.02\end{array}$ & $\begin{array}{l}.01 \\
.01 \\
.01 \\
.01 \\
.01\end{array}$ & $\begin{array}{l}.01 \\
.01 \\
.01 \\
.01 \\
.01\end{array}$ & $\begin{array}{l}28^{.06} \\
153 \\
142 \\
39\end{array}$ & $\begin{array}{l}.83 \\
.68 \\
.43 \\
.34 \\
.55\end{array}$ & $\begin{array}{r}.20 \\
.10 \\
1.1 \\
.55 \\
.11\end{array}$ & $\begin{array}{l}.07 \\
.15 \\
.11 \\
.15 \\
.15\end{array}$ & $\begin{array}{r}.04 \\
.05 \\
.04 \\
.05 \\
.07\end{array}$ & $\begin{array}{l}.01 \\
0 \\
0 \\
0 \\
.01\end{array}$ & $\begin{array}{l}0 \\
.01 \\
.01 \\
.01 \\
0\end{array}$ & $\begin{array}{l}0^{.27} \\
0 \\
0 \\
36\end{array}$ \\
\hline $\begin{array}{l}11 \\
12 \\
13 \\
14 \\
15\end{array}$ & $\begin{array}{r}.01 \\
.01 \\
0.01 \\
.01\end{array}$ & $\begin{array}{l}.02 \\
.02 \\
.02 \\
.03 \\
.03\end{array}$ & $\begin{array}{l}.01 \\
.02 \\
.01 \\
.01 \\
.02\end{array}$ & $\begin{array}{l}.01 \\
.01 \\
.01 \\
.02 \\
.02\end{array}$ & $\begin{array}{r}14 \\
5.2 \\
1.9 \\
3.2 \\
2.8\end{array}$ & $\begin{array}{l}.68 \\
.43 \\
.43 \\
.11 \\
.15\end{array}$ & $\begin{array}{l}.06 \\
.05 \\
1.0 \\
3.0 \\
1.6\end{array}$ & $\begin{array}{l}.15 \\
.15 \\
.15 \\
.15 \\
.15\end{array}$ & $\begin{array}{l}.05 \\
.06 \\
.05 \\
.05 \\
.04\end{array}$ & $\begin{array}{l}.01 \\
0 \\
0 \\
0\end{array}$ & $\begin{array}{l}0 \\
0 \\
0 \\
0 \\
0\end{array}$ & $\begin{array}{l}1.0 \\
.01 \\
.01 \\
.01 \\
0\end{array}$ \\
\hline $\begin{array}{l}16 \\
17 \\
18 \\
19 \\
20\end{array}$ & $\begin{array}{l}.01 \\
.01 \\
.01 \\
.01 \\
.01\end{array}$ & $\begin{array}{l}.03 \\
.03 \\
.01 \\
.01 \\
.01\end{array}$ & $\begin{array}{l}.01 \\
.01 \\
.01 \\
.01 \\
.01\end{array}$ & $\begin{array}{l}.02 \\
.02 \\
.02 \\
.02 \\
.02\end{array}$ & $\begin{array}{l}.83 \\
1.2 \\
1.7 \\
1.5 \\
1.3\end{array}$ & $\begin{array}{l}.20 \\
.15 \\
.16 \\
.15 \\
.08\end{array}$ & $\begin{array}{l}3.6 \\
.68 \\
.20 \\
.15 \\
.11\end{array}$ & $\begin{array}{l}.15 \\
.11 \\
.08 \\
.08 \\
.08\end{array}$ & $\begin{array}{l}.04 \\
.04 \\
.04 \\
.03 \\
.03\end{array}$ & $\begin{array}{l}0 \\
0 \\
0 \\
0 \\
0\end{array}$ & $\begin{array}{l}0 \\
0 \\
0 \\
0 \\
0\end{array}$ & $\begin{array}{l}0 \\
0 \\
0 \\
0 \\
0\end{array}$ \\
\hline $\begin{array}{l}21 \\
22 \\
23 \\
24 \\
25\end{array}$ & $\begin{array}{l}.01 \\
.01 \\
.01 \\
0 \\
0\end{array}$ & $\begin{array}{l}.01 \\
.01 \\
.01 \\
.01 \\
.01\end{array}$ & $\begin{array}{l}.01 \\
.01 \\
.01 \\
.01 \\
.01\end{array}$ & $\begin{array}{l}.02 \\
.02 \\
.01 \\
.01 \\
.02\end{array}$ & $\begin{array}{l}1.2 \\
1.1 \\
.95 \\
.86 \\
.80\end{array}$ & $\begin{array}{l}.11 \\
.11 \\
.11 \\
.15 \\
.20\end{array}$ & $\begin{array}{l}.09 \\
.09 \\
.08 \\
.07 \\
.09\end{array}$ & $\begin{array}{l}.08 \\
.10 \\
.09 \\
.09 \\
.09\end{array}$ & $\begin{array}{l}.02 \\
.02 \\
.02 \\
.03 \\
.03\end{array}$ & $\begin{array}{l}0 \\
0 \\
0 \\
0 \\
0\end{array}$ & $\begin{array}{l}0 \\
0 \\
0 \\
0 \\
0\end{array}$ & $\begin{array}{l}0 \\
0 \\
0 \\
0 . \\
0\end{array}$ \\
\hline $\begin{array}{l}26 \\
27 \\
28 \\
29 \\
30 \\
31\end{array}$ & $\begin{array}{l}0 \\
.01 \\
0 \\
0 \\
.01 \\
.01\end{array}$ & $\begin{array}{l}.01 \\
.01 \\
.01 \\
.01 \\
.02 \\
.0\end{array}$ & $\begin{array}{l}.01 \\
.01 \\
.01 \\
.01 \\
.01 \\
.01\end{array}$ & $\begin{array}{l}.02 \\
.01 \\
.01 \\
.01 \\
.01 \\
.01\end{array}$ & $\begin{array}{l}.73 \\
.55 \\
.34 \\
.34 \\
-.- \\
-.-\end{array}$ & $\begin{array}{l}.16 \\
.20 \\
.13 \\
.11 \\
.11 \\
11\end{array}$ & $\begin{array}{l}.09 \\
.07 \\
.10 \\
.12 \\
.27 \\
.-2\end{array}$ & $\begin{array}{l}.07 \\
.07 \\
.07 \\
.06 \\
.06 \\
.04\end{array}$ & $\begin{array}{l}.03 \\
.02 \\
.01 \\
.02 \\
.02 \\
.0-\end{array}$ & $\begin{array}{l}0 \\
0 \\
0 \\
0 \\
0 \\
0\end{array}$ & $\begin{array}{l}0 \\
0 \\
0 \\
0 \\
0 \\
0\end{array}$ & $\begin{array}{r}0 \\
0 \\
21.01 \\
.03 \\
\end{array}$ \\
\hline $\begin{array}{l}\text { TOTAL } \\
\text { MEAN } \\
\text { MAX } \\
\text { MIN } \\
\text { AC-FT }\end{array}$ & $\begin{array}{r}.15 \\
.005 \\
.01 \\
0 \\
.3\end{array}$ & $\begin{array}{r}.47 \\
.016 \\
.03 \\
.01 \\
.9\end{array}$ & $\begin{array}{r}.33 \\
.011 \\
.02 \\
.01 \\
.7\end{array}$ & $\begin{array}{r}.51 \\
.017 \\
.04 \\
.01 \\
1.0\end{array}$ & $\begin{array}{r}402.63 \\
13.9 \\
153 \\
+01 \\
799\end{array}$ & $\begin{array}{r}12.25 \\
.40 \\
1.5 \\
.08 \\
24\end{array}$ & $\begin{array}{r}15.02 \\
.50 \\
3.6 \\
.05 \\
30\end{array}$ & $\begin{array}{r}3.27 \\
.11 \\
.15 \\
.04 \\
6.5\end{array}$ & $\begin{array}{r}1.10 \\
.037 \\
.07 \\
.01 \\
2.2\end{array}$ & $\begin{array}{r}.08 \\
.003 \\
.01 \\
0 \\
.2\end{array}$ & $\begin{array}{r}.03 \\
.001 \\
.01 \\
0 \\
.06\end{array}$ & $\begin{array}{r}62.34 \\
2.08 \\
36 \\
0 \\
124\end{array}$ \\
\hline
\end{tabular}

CAL YR 1975 TOTAL 409.70 MEAN 1.12 MAX 87 MIN 0 AC-FT 813 
11136480 REYES CREEK NEAR VENTUCOPA, CA

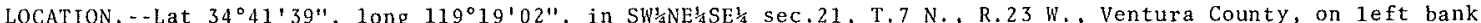
$800 \mathrm{ft}(244 \mathrm{~m})$ from Lockwood Ozena Road, $1,900 \mathrm{ft}(579 \mathrm{~m})$ upstream from mouth, $3 \mathrm{mi}$ ( $5 \mathrm{~km}$ ) east of $0 z$ ena Guard Station, and $13 \mathrm{mi}(21 \mathrm{~km})$ southeast of ventucopa.

DRAINAGE AREA. $-4.62 \mathrm{mi}^{2}\left(11.97 \mathrm{~km}^{2}\right)$.

PERIOD OF RECORD, - -JUIy 1972 to current year.

GAGE. - Water-stage recorder. A1titude of gage is $3,690 \mathrm{ft}(1,120 \mathrm{~m})$, from topographic map.

REMARKS,--Records fair. Smal1 diversion upstream for domestic use.

COOPERATION. - Twelve discharge measurements were furnished by Ventura County Flood control District.

EXTREMES FOR PERIOD OF RECORD.-Maximum discharge, $138 \mathrm{ft}^{3} / \mathrm{s}\left(3.91 \mathrm{~m}^{3} / \mathrm{s}\right) \mathrm{Feb} .11,1973$, gage height, $3.20 \mathrm{ft}$ $(0.975 \mathrm{~m})$; no flow at times in some years.

EXTRENES FOR CURRENT YEAR, - -Maximum discharge, $42 \mathrm{ft}^{3} / \mathrm{s}\left(1.19 \mathrm{~m}^{3} / \mathrm{s}\right)$ Feb. 9 (0430 hrs), gage height, $2.42 \mathrm{ft}$ $(0.738 \mathrm{~m})$, no other peaks above base of $20 \mathrm{ft}^{3} / \mathrm{s}\left(0.57 \mathrm{~m}^{3} / \mathrm{s}\right) ;$ no flow Aug. 28 to Sept. 5 .

DISCHARGE, IN CUBIC FEET PER SECOND, WATER YEAR OCTOBER 1975 TO SEPTEMBER 1976 MEAN VALUES

\begin{tabular}{|c|c|c|c|c|c|c|c|c|c|c|c|c|}
\hline DAY & OCT & Nov & DEC & JAN & FEB & MAR & APR & MAY & JUN & JUL & AUG & SEP \\
\hline $\begin{array}{l}1 \\
2 \\
3 \\
4 \\
5\end{array}$ & $\begin{array}{l}.14 \\
.16 \\
.16 \\
.14 \\
.16\end{array}$ & $\begin{array}{l}.71 \\
.66 \\
.66 \\
.61 \\
.56\end{array}$ & $\begin{array}{l}.76 \\
.76 \\
.76 \\
.76 \\
.76\end{array}$ & $\begin{array}{l}.87 \\
.92 \\
1.0 \\
1.0 \\
.92\end{array}$ & $\begin{array}{l}.81 \\
.81 \\
.81 \\
.81 \\
.92\end{array}$ & $\begin{array}{l}3.8 \\
3.7 \\
2.9 \\
2.5 \\
2.3\end{array}$ & $\begin{array}{l}1.7 \\
1.7 \\
1.9 \\
1.9 \\
1.8\end{array}$ & $\begin{array}{l}2.0 \\
2.0 \\
2.0 \\
2.0 \\
1.9\end{array}$ & $\begin{array}{r}.98 \\
.92 \\
.92 \\
.92 \\
.92\end{array}$ & $\begin{array}{l}.31 \\
.31 \\
.28 \\
.25 \\
.23\end{array}$ & $\begin{array}{l}.02 \\
.02 \\
.03 \\
.05 \\
.05\end{array}$ & $\begin{array}{l}0 \\
0 \\
0 \\
0 \\
0\end{array}$ \\
\hline $\begin{array}{r}6 \\
7 \\
8 \\
9 \\
10\end{array}$ & $\begin{array}{r}.18 \\
.28 \\
.41 \\
.41 \\
.37\end{array}$ & $\begin{array}{r}.52 \\
.56 \\
.52 \\
.56 \\
.56\end{array}$ & $\begin{array}{l}.71 \\
.71 \\
.71 \\
.71 \\
.71\end{array}$ & $\begin{array}{l}.92 \\
.92 \\
.87 \\
.87 \\
.87\end{array}$ & $\begin{array}{l}1.0 \\
2.3 \\
16 \\
26 \\
11\end{array}$ & $\begin{array}{l}2.1 \\
2.1 \\
2.1 \\
2.0 \\
2.0\end{array}$ & $\begin{array}{l}1.8 \\
1.8 \\
1.8 \\
1.7 \\
1.6\end{array}$ & $\begin{array}{l}1.9 \\
1.8 \\
1.8 \\
1.8 \\
1.8\end{array}$ & $\begin{array}{r}.92 \\
.92 \\
.92 \\
.92 \\
.92\end{array}$ & $\begin{array}{l}.16 \\
.16 \\
.16 \\
.15 \\
.14\end{array}$ & $\begin{array}{l}.05 \\
.05 \\
.04 \\
.04 \\
.03\end{array}$ & $\begin{array}{r}.06 \\
.48 \\
.20 \\
.16 \\
2.4\end{array}$ \\
\hline $\begin{array}{l}11 \\
12 \\
13 \\
14 \\
15\end{array}$ & $\begin{array}{l}.56 \\
.71 \\
.66 \\
.66 \\
.52\end{array}$ & $\begin{array}{l}.56 \\
.56 \\
.61 \\
.61 \\
.61\end{array}$ & $\begin{array}{l}.71 \\
.71 \\
.81 \\
.76 \\
.76\end{array}$ & $\begin{array}{l}.87 \\
.87 \\
.87 \\
.87 \\
.87\end{array}$ & $\begin{array}{l}6.0 \\
4.4 \\
3.5 \\
3.4 \\
3.4\end{array}$ & $\begin{array}{l}2.1 \\
2.0 \\
2.0 \\
2.0 \\
2.0\end{array}$ & $\begin{array}{l}1.7 \\
1.7 \\
1.8 \\
1.8 \\
1.8\end{array}$ & $\begin{array}{l}1.7 \\
1.7 \\
1.7 \\
1.8 \\
1.9\end{array}$ & $\begin{array}{r}.92 \\
.87 \\
.87 \\
.81 \\
.81\end{array}$ & $\begin{array}{r}.12 \\
.14 \\
.12 \\
.12 \\
.14\end{array}$ & $\begin{array}{l}.02 \\
.02 \\
.01 \\
.01 \\
.03\end{array}$ & $\begin{array}{r}4.2 \\
.92 \\
.56 \\
.41 \\
.37\end{array}$ \\
\hline $\begin{array}{l}16 \\
17 \\
18 \\
19 \\
20\end{array}$ & $\begin{array}{l}.44 \\
.44 \\
.48 \\
.52 \\
.48\end{array}$ & $\begin{array}{l}.61 \\
.66 \\
.71 \\
.71 \\
.76\end{array}$ & $\begin{array}{r}.76 \\
.76 \\
.76 \\
.76 \\
.76\end{array}$ & $\begin{array}{r}.87 \\
.87 \\
.87 \\
.92 \\
.87\end{array}$ & $\begin{array}{l}3.1 \\
3.0 \\
2.9 \\
2.8 \\
2.8\end{array}$ & $\begin{array}{l}2.2 \\
2.7 \\
2.8 \\
2.8 \\
2.7\end{array}$ & $\begin{array}{l}1.7 \\
1.8 \\
1.8 \\
1.8 \\
1.9\end{array}$ & $\begin{array}{l}1.8 \\
1.6 \\
1.5 \\
1.3 \\
1.2\end{array}$ & $\begin{array}{l}.81 \\
.76 \\
.76 \\
.66 \\
.66\end{array}$ & $\begin{array}{r}.12 \\
.12 \\
.10 \\
.10 \\
.09\end{array}$ & $\begin{array}{l}.04 \\
.05 \\
.06 \\
.08 \\
.06\end{array}$ & $\begin{array}{r}.37 \\
.37 \\
.34 \\
.31 \\
.31\end{array}$ \\
\hline $\begin{array}{l}21 \\
22 \\
23 \\
24 \\
25\end{array}$ & $\begin{array}{l}.44 \\
.48 \\
.56 \\
.61 \\
.66\end{array}$ & $\begin{array}{l}.76 \\
.76 \\
.76 \\
.76 \\
.76\end{array}$ & $\begin{array}{l}.76 \\
.76 \\
.76 \\
.76 \\
.76\end{array}$ & $\begin{array}{r}.87 \\
.87 \\
.87 \\
.87 \\
.87\end{array}$ & $\begin{array}{l}2.7 \\
2.5 \\
2.4 \\
2.3 \\
2.3\end{array}$ & $\begin{array}{l}2.3 \\
2.2 \\
2.1 \\
1.9 \\
2.0\end{array}$ & $\begin{array}{l}1.9 \\
1.9 \\
1.9 \\
1.9 \\
1.9\end{array}$ & $\begin{array}{l}1.2 \\
1.2 \\
1.2 \\
1.2 \\
1.2\end{array}$ & $\begin{array}{r}.56 \\
.56 \\
.56 \\
.52 \\
.41\end{array}$ & $\begin{array}{l}.08 \\
.08 \\
.10 \\
.06 \\
.04\end{array}$ & $\begin{array}{l}.04 \\
.03 \\
.03 \\
.02 \\
.02\end{array}$ & $\begin{array}{r}.34 \\
.34 \\
.28 \\
.31 \\
.34\end{array}$ \\
\hline $\begin{array}{l}26 \\
27 \\
28 \\
29 \\
30 \\
31\end{array}$ & $\begin{array}{l}.61 \\
.61 \\
.66 \\
.61 \\
.66 \\
.71\end{array}$ & $\begin{array}{l}.76 \\
.71 \\
.71 \\
.71 \\
.71 \\
-7 .\end{array}$ & $\begin{array}{l}.81 \\
.81 \\
.81 \\
.81 \\
.81 \\
.81\end{array}$ & $\begin{array}{r}.87 \\
.87 \\
.87 \\
.87 \\
.87 \\
.81\end{array}$ & $\begin{array}{c}2.3 \\
2.2 \\
2.2 \\
2.3 \\
-.- \\
-\end{array}$ & $\begin{array}{l}2.0 \\
1.9 \\
1.9 \\
1.8 \\
1.8 \\
1.7\end{array}$ & $\begin{array}{l}2.0 \\
2.0 \\
2.0 \\
2.0 \\
2.0 \\
-\end{array}$ & $\begin{array}{l}1.1 \\
1.1 \\
1.1 \\
1.1 \\
1.1 \\
1.0\end{array}$ & $\begin{array}{r}.37 \\
.32 \\
.29 \\
.25 \\
.28 \\
-.-\end{array}$ & $\begin{array}{l}.04 \\
.04 \\
.02 \\
.02 \\
.02 \\
.01\end{array}$ & $\begin{array}{l}.01 \\
.01 \\
0 \\
0 \\
0 \\
0\end{array}$ & $\begin{array}{r}.34 \\
.34 \\
.41 \\
5.6 \\
1.8 \\
.--0\end{array}$ \\
\hline $\begin{array}{l}\text { TOTAL } \\
\text { MEAN } \\
\text { MAX } \\
\text { MIN } \\
\text { AC-FT }\end{array}$ & $\begin{array}{r}14.49 \\
.47 \\
.71 \\
.14 \\
29\end{array}$ & $\begin{array}{r}19.72 \\
.66 \\
.76 \\
.52 \\
39\end{array}$ & $\begin{array}{r}23.56 \\
.76 \\
.81 \\
.71 \\
47\end{array}$ & $\begin{array}{r}27.42 \\
.88 \\
1.0 \\
.81 \\
54\end{array}$ & $\begin{array}{r}116.96 \\
4.03 \\
26 \\
.81 \\
232\end{array}$ & $\begin{array}{r}70.4 \\
2.27 \\
3.8 \\
1.7 \\
140\end{array}$ & $\begin{array}{r}55.0 \\
1.83 \\
2.0 \\
1.6 \\
1.09\end{array}$ & $\begin{array}{r}47.7 \\
1.54 \\
2.0 \\
1.0 \\
95\end{array}$ & $\begin{array}{r}21.31 \\
.71 \\
.98 \\
.25 \\
42\end{array}$ & $\begin{array}{r}3.83 \\
.12 \\
.31 \\
.01 \\
7.6\end{array}$ & $\begin{array}{r}.92 \\
.030 \\
.08 \\
0 \\
1.8\end{array}$ & $\begin{array}{r}21.56 \\
.72 \\
5.6 \\
0 \\
43\end{array}$ \\
\hline
\end{tabular}

$\begin{array}{lllllllll}\text { CAL YR } 1975 & \text { TOTAL } 745.99 & \text { MEAN } 2.04 & \text { MAX } 52 & \text { MIN } & .08 & \text { AC-FT } & 1480 \\ \text { HTR YR } 1976 & \text { TOTAL } & 22.87 & \text { MEAN } 1.16 & \text { MAX } 26 & \text { MIN } 0 & \text { AC-FT } & 839\end{array}$ 
11136800 CUYAMA RIVER BELOW BUCKHORN CANYON, NEAR SANTA MARIA, CA

LOCATION.--Lat $35^{\circ} 01^{\prime} 19^{\prime \prime}$, long $120^{\circ} 13^{\prime} 39^{\prime \prime}$, in SWh sec.14, T.11 N., R.32 K., San Luis Obispo-Santa Barbara County line, near right bank on downstream side of bridge on State Highway 166, $0.7 \mathrm{mi}$ (1.1 km) downstream from Buckhorn Canyon, and $13 \mathrm{mi}(21 \mathrm{~km})$ northeast of Santa Maria.

DRAINAGE AREA, $--886 \mathrm{mi}^{2}\left(2,295 \mathrm{~km}^{2}\right)$.

PERIOD OF RECORD, - October 1903 to December 1905 (published as Santa Maria River near Santa Maria), October 1959

to current year. Month1y discharge on $1 y$ for october 1903 and July 1904 and yearly estimate for water year

1941 (incomplete), published in WSP 1315-B.

GAGE.--Water-stage recorder. Altitude of gage is $760 \mathrm{ft}(232 \mathrm{~m})$, from topographic map. Prior to October 1959 , nonrecording gage at different site and datum.

REMARKS,--Records good. No regulation above station. pumping from wells along stream for irrigation of several thousand acres in Upper Cuyama Valley.

AVERAGE DISCHARGE. - -19 years (water years $1904,1905,1960-76) 20.2 \mathrm{ft}^{3} / \mathrm{s}\left(0.572 \mathrm{~m}^{3} / \mathrm{s}\right), 14,630$ acre-ft/yr $\left(18.0 \mathrm{hm}^{3} / \mathrm{yr}\right)$.

EXTREMES FOR PERIOD OF RECORD.--Maximum discharge, $17,800 \mathrm{ft}^{3} / \mathrm{s}\left(504 \mathrm{~m}^{3} / \mathrm{s}\right) \mathrm{Feb}, 25,1969, \mathrm{gage} \mathrm{height}, 13,70 \mathrm{ft}$ $(4.176 \mathrm{~m})$, from rating curve extended above $4,900 \mathrm{ft}^{3} / \mathrm{s}\left(139 \mathrm{~m}^{3} / \mathrm{s}\right)$ on basis of slope-area measurement at gage height $10.85 \mathrm{ft}(3.307 \mathrm{~m})$; no flow at times in most years.

EXTREMES FOR CURRENT YEAR, - -Peak discharges above base of $200 \mathrm{ft}^{3} / \mathrm{s}\left(5.66 \mathrm{~m}^{3} / \mathrm{s}\right)$ and $\mathrm{maximum}(*)$ :

\begin{tabular}{cllcrrr} 
Date & \multirow{2}{*}{ Time } & \multicolumn{2}{c}{$\begin{array}{c}\text { Discharge } \\
\left(\mathrm{ft}^{3} / \mathrm{s}\right)\end{array}$} & \multicolumn{2}{c}{$\begin{array}{c}\text { Gage } \\
\left(\mathrm{m}^{3} / \mathrm{s}\right)\end{array}$} & height \\
(ft) & (m) \\
Feb. 10 & 0330 & 904 & 25.6 & 7.63 & 2.326 \\
Sept. 30 & Unknown & $* 984$ & 27.9 & 7.68 & 2.341
\end{tabular}

Minimum daily discharge, no flow for several months during year.

DISCHARGE, IN CUBIC FEET PER SECOND, WATER YEAR OCTOBER 1975 TO SEPTEMBER 1976 MEAN VALUES

\begin{tabular}{|c|c|c|c|c|c|c|c|c|c|c|c|c|}
\hline DAY & $O C T$ & NOV & DEC & JAN & FEB & MAR & APR & MAY & JUN & JUL & AUG & SEP \\
\hline $\begin{array}{l}1 \\
2 \\
3 \\
4 \\
5\end{array}$ & $\begin{array}{l}.29 \\
.28 \\
.27 \\
.27 \\
.27\end{array}$ & $\begin{array}{r}.31 \\
.30 \\
.28 \\
.24 \\
.24\end{array}$ & $\begin{array}{l}.29 \\
.26 \\
.24 \\
.24 \\
.23\end{array}$ & $\begin{array}{r}.19 \\
119 \\
119 \\
.19 \\
.19\end{array}$ & $\begin{array}{l}.07 \\
.07 \\
.08 \\
.12 \\
.38\end{array}$ & $\begin{array}{l}1.4 \\
5.5 \\
8.5 \\
1.2 \\
.51\end{array}$ & $\begin{array}{l}.27 \\
.24 \\
.32 \\
.29 \\
.28\end{array}$ & $\begin{array}{l}.19 \\
.20 \\
.18 \\
.19 \\
.21\end{array}$ & $\begin{array}{l}.01 \\
.01 \\
.02 \\
.02 \\
.02\end{array}$ & & & $\begin{array}{l}0 \\
0 \\
0 \\
0 \\
0\end{array}$ \\
\hline $\begin{array}{r}6 \\
7 \\
8 \\
9 \\
10\end{array}$ & $\begin{array}{l}.29 \\
.31 \\
.30 \\
.30 \\
.37\end{array}$ & $\begin{array}{l}.24 \\
.26 \\
.26 \\
.26 \\
.26\end{array}$ & $\begin{array}{l}.24 \\
.22 \\
.20 \\
.20 \\
.20\end{array}$ & $\begin{array}{r}.18 \\
.18 \\
.17 \\
.19 \\
.18\end{array}$ & $\begin{array}{r}.25 \\
.22 \\
.31 \\
250\end{array}$ & $\begin{array}{r}.33 \\
.27 \\
.24 \\
.28 \\
.28\end{array}$ & $\begin{array}{l}.26 \\
.24 \\
.32 \\
.26 \\
.23\end{array}$ & $\begin{array}{l}.22 \\
.22 \\
.19 \\
.19 \\
.16\end{array}$ & $\begin{array}{l}.02 \\
.01 \\
.02 \\
.03 \\
.02\end{array}$ & & & $\begin{array}{l}0 \\
0 \\
0 \\
0 \\
0\end{array}$ \\
\hline $\begin{array}{l}11 \\
12 \\
13 \\
14 \\
15\end{array}$ & $\begin{array}{r}.40 \\
.32 \\
.31 \\
.30 \\
.29\end{array}$ & $\begin{array}{l}.26 \\
.25 \\
.25 \\
.25 \\
.25\end{array}$ & $\begin{array}{r}.19 \\
.20 \\
.19 \\
.19 \\
.19\end{array}$ & $\begin{array}{l}.19 \\
.17 \\
.17 \\
.17 \\
.15\end{array}$ & $\begin{array}{r}12 \\
2.7 \\
1.1 \\
.71 \\
.54\end{array}$ & $\begin{array}{l}.27 \\
.23 \\
.22 \\
.23 \\
.21\end{array}$ & $\begin{array}{r}.24 \\
.29 \\
.26 \\
.25 \\
.27\end{array}$ & $\begin{array}{l}.16 \\
.12 \\
.11 \\
.09 \\
.08\end{array}$ & $\begin{array}{l}.01 \\
0 \\
0 \\
0 \\
0\end{array}$ & & & $\begin{aligned} 0 \\
42 \\
2 . \\
.5 \\
.50 \\
.20\end{aligned}$ \\
\hline $\begin{array}{l}16 \\
17 \\
18 \\
19 \\
20\end{array}$ & $\begin{array}{l}.29 \\
.29 \\
.29 \\
.29 \\
.29\end{array}$ & $\begin{array}{l}.25 \\
.25 \\
.29 \\
.29 \\
.25\end{array}$ & $\begin{array}{r}.19 \\
.19 \\
19 \\
.19 \\
.19\end{array}$ & $\begin{array}{l}.14 \\
.14 \\
.14 \\
.15 \\
.13\end{array}$ & $\begin{array}{l}.48 \\
.43 \\
.44 \\
.44 \\
.38\end{array}$ & $\begin{array}{l}.21 \\
.22 \\
.23 \\
.24 \\
.24\end{array}$ & $\begin{array}{r}.24 \\
.23 \\
.22 \\
.19 \\
.19\end{array}$ & $\begin{array}{l}.09 \\
.09 \\
.08 \\
.09 \\
.10\end{array}$ & $\begin{array}{l}0 \\
0 \\
0 \\
0 \\
0\end{array}$ & & & $\begin{array}{l}.10 \\
.05 \\
.02 \\
.02 \\
.01\end{array}$ \\
\hline $\begin{array}{l}21 \\
22 \\
23 \\
24 \\
25\end{array}$ & $\begin{array}{l}.29 \\
.29 \\
.29 \\
.29 \\
.29\end{array}$ & $\begin{array}{l}.27 \\
.25 \\
.25 \\
.26 \\
.25\end{array}$ & $\begin{array}{l}.20 \\
.18 \\
.18 \\
.19 \\
.18\end{array}$ & $\begin{array}{l}.13 \\
.13 \\
12 \\
112 \\
.12\end{array}$ & $\begin{array}{r}.38 \\
.37 \\
.38 \\
.34 \\
.34\end{array}$ & $\begin{array}{l}.24 \\
.22 \\
.24 \\
.25 \\
.26\end{array}$ & $\begin{array}{r}.17 \\
.18 \\
.19 \\
.17 \\
.16\end{array}$ & $\begin{array}{l}.11 \\
.08 \\
.07 \\
.07 \\
.07\end{array}$ & $\begin{array}{l}0 \\
0 \\
0 \\
0 \\
0\end{array}$ & & & $\begin{array}{l}.01 \\
.01 \\
.01 \\
.01 \\
.01\end{array}$ \\
\hline $\begin{array}{l}26 \\
27 \\
28 \\
29 \\
30 \\
31\end{array}$ & $\begin{array}{l}.29 \\
.31 \\
.30 \\
.27 \\
.31 \\
.28\end{array}$ & $\begin{array}{l}.24 \\
.28 \\
.32 \\
.28 \\
.28 \\
-.-\end{array}$ & $\begin{array}{l}.18 \\
.17 \\
.16 \\
.15 \\
.16 \\
.17\end{array}$ & $\begin{array}{l}.12 \\
.12 \\
.10 \\
.10 \\
.08 \\
.08\end{array}$ & $\begin{array}{r}.34 \\
.34 \\
.34 \\
.43 \\
-.- \\
-.-\end{array}$ & $\begin{array}{l}.28 \\
.25 \\
.27 \\
.29 \\
.25 \\
.27\end{array}$ & $\begin{array}{l}.15 \\
.16 \\
.17 \\
.18 \\
.18 \\
.+-\end{array}$ & $\begin{array}{l}.06 \\
.04 \\
.04 \\
.04 \\
.04 \\
.03\end{array}$ & $\begin{array}{l}0 \\
0 \\
0 \\
0 \\
0 \\
-\cdots\end{array}$ & & & $\begin{array}{c}0 \\
0 \\
.03 \\
.07 \\
. .0\end{array}$ \\
\hline $\begin{array}{l}\text { TOTAL } \\
\text { MEAN } \\
\text { MAX } \\
\text { MIN } \\
\text { AC-FT }\end{array}$ & $\begin{array}{r}9.23 \\
.30 \\
.40 \\
.27 \\
18\end{array}$ & $\begin{array}{r}7.92 \\
.26 \\
.32 \\
.24 \\
16\end{array}$ & $\begin{array}{r}6.15 \\
.20 \\
.29 \\
.15 \\
12\end{array}$ & $\begin{array}{r}4.62 \\
.15 \\
.19 \\
.08 \\
9.2\end{array}$ & $\begin{array}{r}315.01 \\
10.9 \\
250 \\
.07 \\
625\end{array}$ & $\begin{array}{r}23.63 \\
.76 \\
8.5 \\
.21 \\
47\end{array}$ & $\begin{array}{r}6.80 \\
.23 \\
.32 \\
.15 \\
13\end{array}$ & $\begin{array}{r}3.61 \\
.12 \\
.22 \\
.03 \\
7.2\end{array}$ & $\begin{array}{r}.19 \\
.006 \\
.03 \\
0 \\
.4\end{array}$ & $\begin{array}{l}0 \\
0 \\
0 \\
0 \\
0\end{array}$ & $\begin{array}{l}0 \\
0 \\
0 \\
0 \\
0\end{array}$ & $\begin{array}{r}384.15 \\
12.8 \\
338 \\
0 \\
762\end{array}$ \\
\hline
\end{tabular}

CAL YR 1975 TOTAL 819.01 MEAN 2.24 MAX 267 MIN 15 AC-FT 1620

WTR YR 1976 TOTAL 761.31 MEAN 2.08 MAX 338 MIN $0^{\circ}$ AC-FT 1510 
11137400 ALAMO CREEK NEAR NIPOMO, CA

LOCATION.--Lat $35^{\circ} 02^{\prime} 55^{\prime \prime}$, long $120^{\circ} 18^{\prime} 05^{\prime \prime}$, in Huasna Grant, San Luis Obispo County, on right bank 3.2 mi (5.1 km) upstream from mouth, and $10 \mathrm{mi}(16 \mathrm{~km})$ east of Nipomo.

DRAINAGE AREA. $--83.3 \mathrm{mi}^{2}\left(215.7 \mathrm{~km}^{2}\right)$.

PERIOD OF RECORD, - March 1959 to current year.

GAGE. - Water-stage recorder. Altitude of gage is $650 \mathrm{ft}(198 \mathrm{~m})$, from topographic map. Prior to oct. 1 , 1966 , at datum $2.00 \mathrm{ft}(0.610 \mathrm{~m})$ higher.

REMARKS.--No flow since Mar. 22, 1975. No regulation or diversion above station.

AVERAGE DISCHARGE. --17 years, $7.56 \mathrm{ft}^{3} / \mathrm{s}\left(0.214 \mathrm{~m}^{3} / \mathrm{s}\right), 5,480 \mathrm{acre}-\mathrm{ft} / \mathrm{yr}\left(6.76 \mathrm{hm}^{3} / \mathrm{yr}^{3}\right)$.

EXTREMES FOR PERIOD OF RECORD.--Maximum discharge, $9,020 \mathrm{ft}^{3} / \mathrm{s}\left(255 \mathrm{~m}^{3} / \mathrm{s}\right) \mathrm{Jan}$. 25,1969 , gage height, 10.51 $\mathrm{ft}$

$(3.203 \mathrm{~m})$, from rating curve extended above $3,100 \mathrm{ft} / \mathrm{s}\left(87.8 \mathrm{~m}^{3} / \mathrm{s}\right)$ on basis of slope-area measurement at gage height $10.30 \mathrm{ft}(3.139 \mathrm{~m})$; no flow for all or part of each year.

EXTREMES FOR CURRENT YEAR. --No flow during year. 
LOCATION.--Lat $35^{\circ} 04^{\prime} 40^{\prime \prime}$, long $120^{\circ} 22^{\prime} 15^{\prime \prime}$, in Huasna Grant, San Luis Obispo County, on right bank 300 ft (91 m) downstream from Huasna Creek, and $12 \mathrm{mi}(19 \mathrm{~km})$ southeast of Arroyo Grande.

DRAINAGE AREA. - $-103 \mathrm{mi}^{2}\left(267 \mathrm{~km}^{2}\right)$.

PERIOD OF RECORD. - June 1959 to current year.

GAGE. - Water-stage recorder. A1titude of gage is $640 \mathrm{ft}(195 \mathrm{~m})$, from topographic map.

REMARKS. - Records fair except for period of no gage height record, Feb. 1-9, which is poor. No regulation above station. Some diversion above station into cattle ponds by two ranches upstream and one ranch at station.

Extensive diversions by pumping for irrigation above station.

AVERAGE DISCHARGE. - -17 years, $17.1 \mathrm{ft}^{3} / \mathrm{s}\left(0.484 \mathrm{~m}^{3} / \mathrm{s}\right), 12,390 \mathrm{acre}-\mathrm{ft} / \mathrm{yr}\left(15.3 \mathrm{hm}^{3} / \mathrm{yr}^{2}\right)$

EXTREMES FOR PERIOD OF RECORD.--Maximum discharge, $21,000 \mathrm{ft}^{3} / \mathrm{s}\left(595 \mathrm{~m}^{3} / \mathrm{s}\right) \mathrm{Jan} .25,1969$, gage height, $15.90 \mathrm{ft}$ $(4.846 \mathrm{~m})$, from rating curve extended above $1,300 \mathrm{ft}^{3} / \mathrm{s}(36.8 \mathrm{~m} / \mathrm{s})$ on basis of slope-area measurement of maximum flow; no flow at times in some years.

EXTREMES FOR CURRENT YEAR. - Maximum discharge, $9.9 \mathrm{ft}^{3} / \mathrm{s}\left(0.28 \mathrm{~m}^{3} / \mathrm{s}\right)$ Feb. 9 , gage height, $2.62 \mathrm{ft}(0.799 \mathrm{~m})$, no peak above base of $40 \mathrm{ft}^{3} / \mathrm{s}\left(1,13 \mathrm{~m}^{3} / \mathrm{s}\right) ;$ no fiow sept. 8 .

DISCHARGE, IN CUBIC FEET PER SECOND, HATER YEAR OCTOBER 1975 TO SEPTEMBER 1976 MEAN VALUES

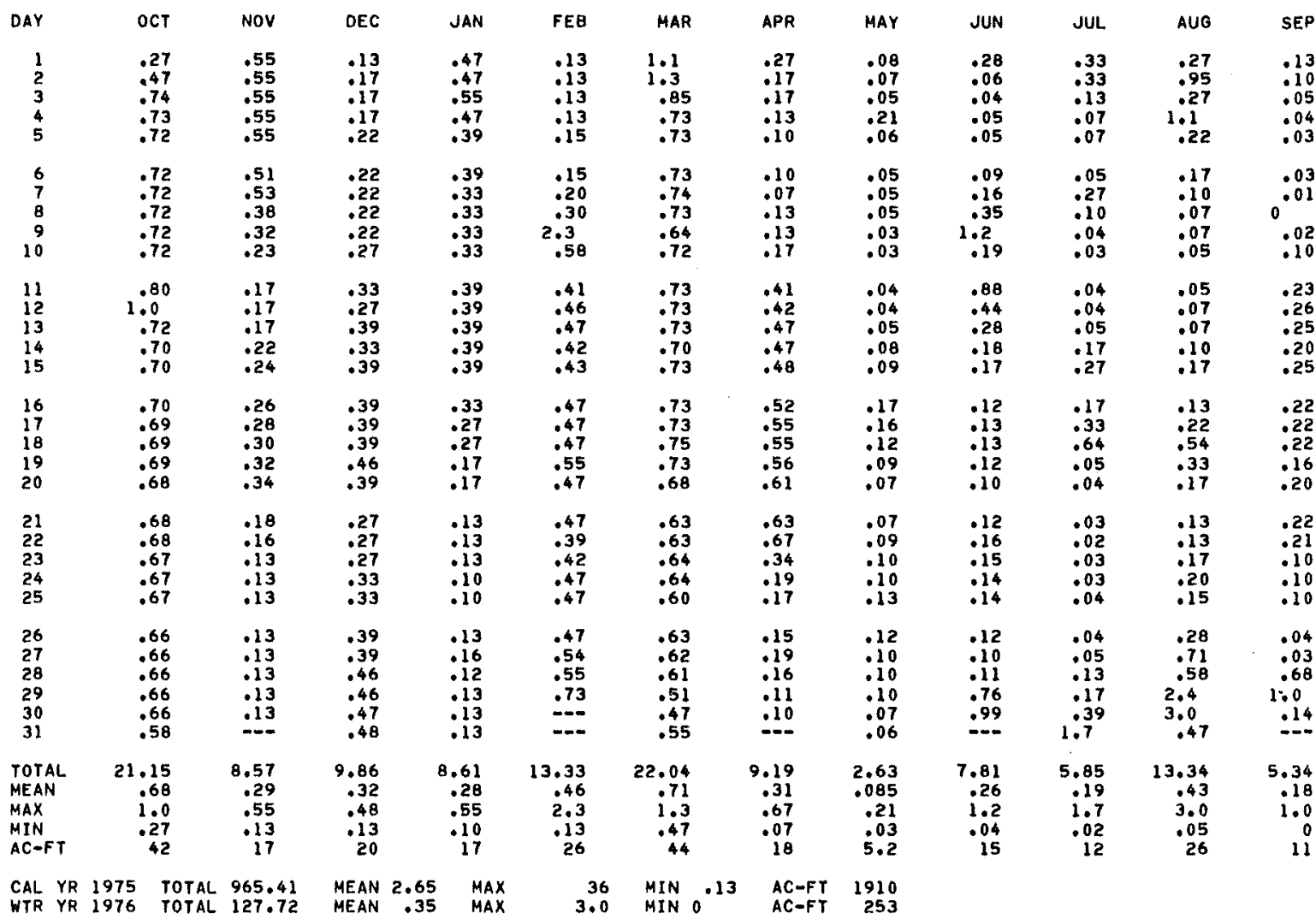


11138100 CUYAMA RIVER BELOW TWITCHELL DAM, CA

LOCATION, - Lat $34^{\circ} 56^{\prime} 40^{\prime \prime}$, long $120^{\circ} 17^{\prime} 30^{\prime \prime}$, in Suey Grant, Santa Barbara County, on left bank $3.5 \mathrm{mi}$ ( $5.6 \mathrm{~km}$ ) upstream from mouth, $4 \mathrm{mi}(6 \mathrm{~km})$ northeast of Garey, and $4.4 \mathrm{mi}(7.1 \mathrm{~km})$ downstream from Twitche11 Dam.

DRAINAGE AREA. - - 1, $132 \mathrm{mi}^{2}\left(2,932 \mathrm{~km}^{2}\right)$.

PERIOD OF RECORD.--October 1958 to current year.

GAGE,- Water-stage recorder. Datum of gage is $401.94 \mathrm{ft}(122.511 \mathrm{~m})$ above mean sea leve1 (Bureau of Reclamation bench mark).

REMARKS. - No flow since July 8, 1975. Flow regulated since February 1959 by Twitchel1 Reservoir, capacity 240,000 acre-ft $\left(296 \mathrm{hm}^{3}\right)$. Controlled releases are for ground-water recharge in Santa Maria Valley. Some pumping from wells along stream for irrigation above station. Discharge figures for calendar year ig75 are as follows: Total, $2,880.99 \mathrm{ft}^{3} / \mathrm{s}\left(81.6 \mathrm{~m}^{3} / \mathrm{s}\right), 5,720 \mathrm{acre}-\mathrm{ft} / \mathrm{yr}\left(6.49 \mathrm{hm}^{3} / \mathrm{yr}^{2} ; \mathrm{mean}^{2} 7.87 \mathrm{ft}{ }^{3} / \mathrm{s}(0.22 \mathrm{~m} / \mathrm{s}) ;\right.$ maximum daily, $161 \mathrm{ft}^{3} / \mathrm{s}\left(4.56 \mathrm{~m}^{3} / \mathrm{s}\right)$; minimum daily, no flow.

EXTREMES FOR PERIOD OF RECORD.--Maximum discharge, 9,100 $\mathrm{ft}^{3} / \mathrm{s}\left(258 \mathrm{~m}^{3} / \mathrm{s}\right) \mathrm{June} 13,1973$, gage height, $8.22 \mathrm{ft}$ $(2.505 \mathrm{~m})$, result of sluicing at dam; no flow at times in each year.

EXTREMES FOR CURRENT YEAR, - No flow during year. 
LOCATION,--Lat $34^{\circ} 50^{\prime} 23^{\prime \prime}$, long $120^{\circ} 10^{\prime} 02^{\prime \prime}$, in Sisquoc Grant, Santa Barbara County, on 1 eft bank 2.6 mi (4.2 km) upstream from La Brea Creek, and $7 \mathrm{mi}(11 \mathrm{~km})$ east of Sisquoc.

DRAINAGE AREA. - $-281 \mathrm{mi}^{2}\left(728 \mathrm{~km}^{2}\right)$.

PERIOD OF RECORD, - - October 1943 to current year. October 1929 to September 1933 , at site $0.2 \mathrm{mi}$ (0.3 km) downstream; low-flow records not equivalent owing to diversion immediately upstream. Monthly discharge only for some periods, published in WSP $1315-\mathrm{B}$

GAGE.-Water-stage recorder. Datum of gage is $624.30 \mathrm{ft}(190,287 \mathrm{~m})$ above mean sea leve1 (Corps of Engineers bench mark). See WSP 1735 for history of changes prior to Aug. 24, 1951.

REMARKS. - -Records poor. No regulation or diversion above station.

AVERAGE DISCHARGE. - -33 years, $40.0 \mathrm{ft}^{3} / \mathrm{s}\left(1.133 \mathrm{~m}^{3} / \mathrm{s}\right), 28,980 \mathrm{acre}-\mathrm{ft} / \mathrm{yr}\left(35.7 \mathrm{hm} / \mathrm{yr}^{3}\right)$

EXTREMES FOR PERIOD OF RECORD. - -Maximum discharge, 23,200 $\mathrm{ft}^{3} / \mathrm{s}\left(657 \mathrm{~m}^{3} / \mathrm{s}\right)$ Dec. 6, 1966 , gage height, $15.75 \mathrm{ft}$ $(4.801 \mathrm{~m})$, from rating curve extended above $1,700 \mathrm{ft} / \mathrm{s}\left(48.1 \mathrm{~m}^{3} / \mathrm{s}\right)$ on basis of slope-area measurements at gage heights $10.08 \mathrm{ft}(3.072 \mathrm{~m})$ and $15.75 \mathrm{ft}(4.801 \mathrm{~m})$; no flow Nov. $11-18,1967$

EXTREMES OUTSIDE PERIOD OF RECORD.--Flood of Mar, 2, 1938, 11,000 $\mathrm{ft}^{3} / \mathrm{s}\left(312 \mathrm{~m}^{3} / \mathrm{s}\right)$, gage height, $8.1 \mathrm{ft}$

$(2.47 \mathrm{~m})$ from high-water mark in gage we11, at site in use $1929-33$, from rating curve extended above $2,800 \mathrm{ft}^{3} / \mathrm{s}\left(79.3 \mathrm{~m}^{3} / \mathrm{s}\right)$.

EXTREMES FOR CURRENT YEAR. - - Peak discharges above base of $100 \mathrm{ft}^{3} / \mathrm{s}\left(2.83 \mathrm{~m}^{3} / \mathrm{s}\right)$ and $\mathrm{maximum}^{*}$ ):

$\begin{array}{llcc}\text { Date } & \text { Time } & \begin{array}{c}\text { Discharge } \\ \left(\mathrm{ft}^{3} / \mathrm{s}\right)\left(\mathrm{m}^{3} / \mathrm{s}\right)\end{array} & \begin{array}{c}\text { Gage height } \\ \text { (ft) }\end{array} \\ \text { Feb. } 9 & \text { Unknown } & * 360 \quad 10.2 & \text { Unknown } \\ \text { Sept. } 30 & 0145 & \text { Unknown } & \text { Unknown }\end{array}$

Minimum daily discharge, $0.86 \mathrm{ft}^{3} / \mathrm{s}\left(0.024 \mathrm{~m}^{3} / \mathrm{s}\right)$ June $24-26$

DISCHARGE, IN CUBIC FEET PER SECOND, WATER YEAR OCTOBER 1975 TO SEPTEMBER 1976 MEAN VALUES

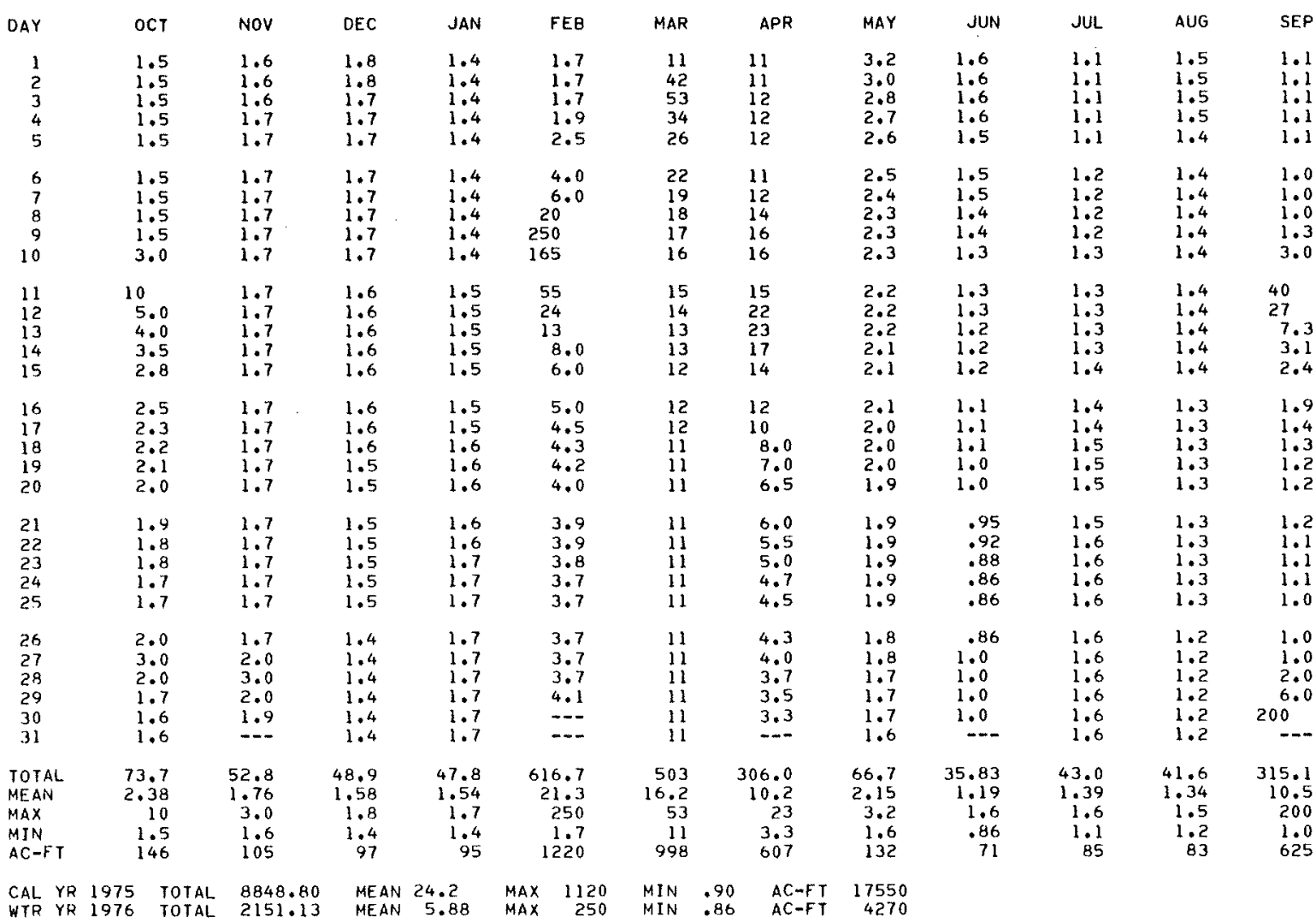


11139500 TEPUSQUET CREEK NEAR SISOUOC, CA

LOCATION,--Lat $34^{\circ} 52^{\prime} 21^{\prime \prime}$, long $120^{\circ} 14^{\prime} 37^{\prime \prime}$, in NE⿱ wingwal1 of right bridge abutment on Tepusquet Road (revised), $1.1 \mathrm{mi}$ ( $1.8 \mathrm{~km}$ ) upstream from mouth, and $3 \mathrm{mi}(5 \mathrm{~km})$ east of Sisquoc.

DRAINAGE AREA. $-28.7 \mathrm{mi}^{2}\left(74.3 \mathrm{~km}^{2}\right)$.

PERIOD OF RECORD. - October 1943 to current year.

GAGE. - Water-stage recorder. Altitude of gage is $500 \mathrm{ft}(152 \mathrm{~m})$, from topographic map. Prior to Dec. 9, 1948 , at datum 0.9 ft $(0.27 \mathrm{~m})$ higher.

REMARKS, - Records fair except those above $1.0 \mathrm{ft} / \mathrm{s}\left(0.028 \mathrm{~m}^{3} / \mathrm{s}\right)$, which are poor. No regulation above station. Some diversion by pumping from wells along stream to irrigate about 100 acres $\left(405,000 \mathrm{~m}^{2}\right)$ above gage.

AVERAGE DISCHARGE, -33 years, $1.51 \mathrm{ft}^{3} / \mathrm{s}\left(0.043 \mathrm{~m}^{3} / \mathrm{s}\right), 1,090 \mathrm{acre}-\mathrm{ft} / \mathrm{yr}(1.34 \mathrm{hm} / \mathrm{yr})$.

EXTREMES FOR PERIOD OF RECORD. - Maximum discharge, $788 \mathrm{ft}^{3} / \mathrm{s}\left(22.3 \mathrm{~m}^{3} / \mathrm{s}\right)$ Dec. 6,1966 , gage height, $5.48 \mathrm{ft}$ $(1.670 \mathrm{~m})$, from rating curve extended above $220 \mathrm{ft}^{3} / \mathrm{s}\left(6.23 \mathrm{~m}^{3} / \mathrm{s}\right)$ on basis of computation of maximum f1ow at contracted opening; no flow at times in some years.

EXTREMES FOR CURRENT YEAR. - Maximum discharge, $20 \mathrm{ft}^{3} / \mathrm{s}\left(0.57 \mathrm{~m}^{3} / \mathrm{s}\right)$ Sept. 29 , gage height, $3.58 \mathrm{ft}(1.091 \mathrm{~m})$, from rating curve extended above $1.0 \mathrm{ft}^{3} / \mathrm{s}\left(0.028 \mathrm{~m}^{3} / \mathrm{s}\right)$, no peak above base of $50 \mathrm{ft}^{3} / \mathrm{s}(1.42 \mathrm{~m} / \mathrm{s})$;

minimum daily, $0.06 \mathrm{ft}^{3} / \mathrm{s}\left(0.002 \mathrm{~m}^{3} / \mathrm{s}\right)$ July 27,28 , Aug. 10, 11 .

DISCHARGE, IN CUBIC FEET PER SECOND, WATER YEAR OCTOBER 1975 TO SEPTEMBER 1976 MEAN VALUES

\begin{tabular}{|c|c|c|c|c|c|c|c|c|c|c|c|c|}
\hline DAY & OCT & NOV & DEC & JAN & FEB & MAR & APR & MAY & JUN & JUL & AUO & SEP \\
\hline $\begin{array}{l}1 \\
2 \\
3 \\
4 \\
5\end{array}$ & $\begin{array}{r}.11 \\
.19 \\
.26 \\
.14 \\
.07\end{array}$ & $\begin{array}{r}.14 \\
.12 \\
.12 \\
.12 \\
.14\end{array}$ & $\begin{array}{r}.15 \\
.14 \\
.14 \\
.19 \\
.17\end{array}$ & $\begin{array}{l}.16 \\
.16 \\
.16 \\
.16 \\
.16\end{array}$ & $\begin{array}{l}.16 \\
.16 \\
.19 \\
.22 \\
.28\end{array}$ & $\begin{array}{r}.52 \\
.68 \\
.48 \\
.39 \\
.39\end{array}$ & $\begin{array}{r}.32 \\
.32 \\
.40 \\
.35 \\
.35\end{array}$ & $\begin{array}{r}.34 \\
.34 \\
.28 \\
.34 \\
.34\end{array}$ & $\begin{array}{l}.26 \\
.26 \\
.26 \\
.35 \\
.26\end{array}$ & $\begin{array}{r}.18 \\
.18 \\
.18 \\
18 \\
.18\end{array}$ & $\begin{array}{l}.10 \\
.10 \\
.09 \\
.09 \\
.09\end{array}$ & $\begin{array}{r}.08 \\
.09 \\
.10 \\
.10 \\
.12\end{array}$ \\
\hline $\begin{array}{r}6 \\
7 \\
8 \\
9 \\
10\end{array}$ & $\begin{array}{r}.14 \\
.26 \\
.35 \\
.45 \\
.71\end{array}$ & $\begin{array}{r}.14 \\
.14 \\
.14 \\
.12 \\
.12\end{array}$ & $\begin{array}{r}.19 \\
.14 \\
.14 \\
.19 \\
.22\end{array}$ & $\begin{array}{l}.14 \\
.14 \\
.16 \\
.16 \\
.16\end{array}$ & $\begin{array}{r}.35 \\
.35 \\
.60 \\
1.5 \\
1.1\end{array}$ & $\begin{array}{r}.32 \\
.32 \\
.32 \\
.32 \\
.32\end{array}$ & $\begin{array}{r}.35 \\
.35 \\
.57 \\
.45 \\
.45\end{array}$ & $\begin{array}{r}.37 \\
.34 \\
.34 \\
.34 \\
.34\end{array}$ & $\begin{array}{r}.26 \\
.26 \\
.35 \\
.35 \\
.26\end{array}$ & $\begin{array}{l}.16 \\
.14 \\
.16 \\
.16 \\
.16\end{array}$ & $\begin{array}{l}.09 \\
.10 \\
.09 \\
.08 \\
.06\end{array}$ & $\begin{array}{l}.13 \\
.13 \\
.12 \\
.08 \\
1.1\end{array}$ \\
\hline $\begin{array}{l}11 \\
12 \\
13 \\
14 \\
15\end{array}$ & $\begin{array}{r}1.3 \\
1.4 \\
.26 \\
.19 \\
.14\end{array}$ & $\begin{array}{l}.09 \\
.09 \\
.12 \\
.12 \\
.09\end{array}$ & $\begin{array}{r}.18 \\
.25 \\
.17 \\
.15 \\
.19\end{array}$ & $\begin{array}{l}.16 \\
.16 \\
.18 \\
.18 \\
.18\end{array}$ & $\begin{array}{r}.34 \\
.34 \\
.29 \\
.29 \\
.29\end{array}$ & $\begin{array}{l}.32 \\
.32 \\
.28 \\
.28 \\
.28\end{array}$ & $\begin{array}{l}.45 \\
.60 \\
.50 \\
.45 \\
.50\end{array}$ & $\begin{array}{l}.28 \\
.28 \\
.24 \\
.28 \\
.28\end{array}$ & $\begin{array}{r}.26 \\
.26 \\
.26 \\
.26 \\
.26\end{array}$ & $\begin{array}{l}.16 \\
.14 \\
.14 \\
.09 \\
.10\end{array}$ & $\begin{array}{l}.06 \\
.08 \\
.09 \\
.09 \\
.15\end{array}$ & $\begin{array}{r}1.5 \\
.20 \\
.20 \\
.17 \\
.20\end{array}$ \\
\hline $\begin{array}{l}16 \\
17 \\
18 \\
19 \\
20\end{array}$ & $\begin{array}{r}.14 \\
.14 \\
.19 \\
.14 \\
.14\end{array}$ & $\begin{array}{r}.12 \\
.09 \\
.12 \\
.12 \\
.12\end{array}$ & $\begin{array}{r}.14 \\
.14 \\
.19 \\
.19 \\
.26\end{array}$ & $\begin{array}{r}.18 \\
.16 \\
.16 \\
.18 \\
.18\end{array}$ & $\begin{array}{l}.25 \\
.29 \\
.25 \\
.25 \\
.21\end{array}$ & $\begin{array}{r}.28 \\
.28 \\
.28 \\
.28 \\
.24\end{array}$ & $\begin{array}{r}.37 \\
.34 \\
.34 \\
.37 \\
.34\end{array}$ & $\begin{array}{r}.34 \\
.28 \\
.28 \\
.28 \\
.28\end{array}$ & $\begin{array}{r}.26 \\
.35 \\
.35 \\
.26 \\
.35\end{array}$ & $\begin{array}{l}.10 \\
.10 \\
.12 \\
.12 \\
.12\end{array}$ & $\begin{array}{r}.12 \\
.10 \\
.12 \\
.17 \\
.15\end{array}$ & $\begin{array}{r}.20 \\
.24 \\
.24 \\
.24 \\
.28\end{array}$ \\
\hline $\begin{array}{l}21 \\
22 \\
23 \\
24 \\
25\end{array}$ & $\begin{array}{r}.19 \\
.19 \\
.09 \\
.09 \\
.09\end{array}$ & $\begin{array}{l}.16 \\
.23 \\
.16 \\
.12 \\
.13\end{array}$ & $\begin{array}{r}.16 \\
.12 \\
.15 \\
.15 \\
.15\end{array}$ & $\begin{array}{l}.18 \\
.21 \\
.21 \\
.23 \\
.23\end{array}$ & $\begin{array}{l}.25 \\
.21 \\
.25 \\
.25 \\
.25\end{array}$ & $\begin{array}{r}.24 \\
.24 \\
.28 \\
.28 \\
.24\end{array}$ & $\begin{array}{l}.34 \\
.34 \\
.37 \\
.34 \\
.28\end{array}$ & $\begin{array}{r}.34 \\
.34 \\
.13 \\
.34 \\
.20\end{array}$ & $\begin{array}{r}.35 \\
.34 \\
.27 \\
.20 \\
.18\end{array}$ & $\begin{array}{l}.12 \\
.14 \\
.14 \\
.10 \\
.12\end{array}$ & $\begin{array}{r}.13 \\
113 \\
112 \\
.13 \\
.10\end{array}$ & $\begin{array}{r}.24 \\
.24 \\
.24 \\
.24 \\
.24\end{array}$ \\
\hline $\begin{array}{l}26 \\
27 \\
28 \\
29 \\
30 \\
31\end{array}$ & $\begin{array}{r}.14 \\
.14 \\
.09 \\
.11 \\
.26 \\
.16\end{array}$ & $\begin{array}{l}.14 \\
.19 \\
.30 \\
.22 \\
.21 \\
.-1\end{array}$ & $\begin{array}{r}.14 \\
.14 \\
.11 \\
.16 \\
.14 \\
.14\end{array}$ & $\begin{array}{r}.23 \\
.23 \\
.19 \\
.19 \\
119 \\
.19\end{array}$ & $\begin{array}{r}.25 \\
+25 \\
.25 \\
.34 \\
-.- \\
---0\end{array}$ & $\begin{array}{r}.24 \\
.24 \\
.24 \\
.28 \\
.24 \\
.32\end{array}$ & $\begin{array}{r}.28 \\
.34 \\
.34 \\
.34 \\
.28 \\
-.-\end{array}$ & $\begin{array}{r}.21 \\
.57 \\
.32 \\
.32 \\
.38 \\
.26\end{array}$ & $\begin{array}{r}.18 \\
.16 \\
116 \\
116 \\
118 \\
-\end{array}$ & $\begin{array}{l}.09 \\
.06 \\
.06 \\
.09 \\
.09 \\
.09\end{array}$ & $\begin{array}{l}.09 \\
.09 \\
.09 \\
.09 \\
.09 \\
.08\end{array}$ & $\begin{array}{r}.24 \\
.28 \\
.83 \\
3.7 \\
.40 \\
.0-\end{array}$ \\
\hline $\begin{array}{l}\text { TOTAL } \\
\text { MEAN } \\
\text { MAX } \\
\text { MIN } \\
\text { AC }=F T\end{array}$ & $\begin{array}{r}8.27 \\
.27 \\
1.4 \\
.07 \\
16\end{array}$ & $\begin{array}{r}4.24 \\
.14 \\
.30 \\
.09 \\
8.4\end{array}$ & $\begin{array}{r}5.09 \\
.16 \\
.26 \\
.11 \\
10\end{array}$ & $\begin{array}{r}5.56 \\
.18 \\
.23 \\
.14 \\
11\end{array}$ & $\begin{array}{r}10.01 \\
.35 \\
1.5 \\
.16 \\
20\end{array}$ & $\begin{array}{r}9.74 \\
.31 \\
.68 \\
.24 \\
19\end{array}$ & $\begin{array}{r}11.42 \\
.38 \\
.60 \\
.28 \\
23\end{array}$ & $\begin{array}{r}9.60 \\
.31 \\
.57 \\
.13 \\
19\end{array}$ & $\begin{array}{r}7.92 \\
.26 \\
.35 \\
.16 \\
16\end{array}$ & $\begin{array}{r}3.97 \\
.13 \\
.18 \\
.06 \\
7.9\end{array}$ & $\begin{array}{l}3.16 \\
.10 \\
.17 \\
.06 \\
6.3\end{array}$ & $\begin{array}{r}12.17 \\
.41 \\
3.7 \\
.08 \\
24\end{array}$ \\
\hline
\end{tabular}

CAL YR 1975 TOTAL 220.53 MEAN .60 MAX 5.7 MIN 07 AC-FT 437 $\begin{array}{rrrrrrr}\text { CAL YR } 1975 & \text { TOTAL } 220.53 & \text { MEAN } .60 & \text { MAX } 5.7 & \text { MIN } & .07 & \text { AC-FT } 437 \\ \text { WTR YR } 1976 & \text { TOTAL } 91.15 & \text { MEAN } .25 & \text { MAX } 3.7 & \text { MIN } & .06 & \text { AC-FT } 181\end{array}$ 
LOCATION. - Lat $34^{\circ} 53^{\prime} 38^{\prime \prime}$, long $120^{\circ} 18^{\prime} 20^{\prime \prime}$, in SWl sec, 36, T. 10 N., R. 33 W. , Santa Barbara County, on downstream side of Santa Maria Mesa Road bridge (revised) near right bank, 0.6 mi (1.0 km) northeast of Garey, and 3 . 7 mi $(6.0 \mathrm{~km})$ downstrean from Tepusquet Creek.

DRAINAGE AREA, $--471 \mathrm{mi}^{2}\left(1,220 \mathrm{~km}^{2}\right)$.

FERIOD OF RECORD.--October 1940 to current year. Records for water year 1941 inconplete, yearly estimate and monthly discharge only for October 1940 and January 1941 , published in WSP $1315-B$.

GAGE, - - Two water-stage recorders, Datun of main gage is $354.8 \mathrm{ft}(108.14 \mathrm{~m})$ above mean sea 1 eve1 (Santa Barbara County bench mark). See WSP 1735 for history of changes prior to Oct. 1, 1959. 0ct. 1, 1959, to Dec. 30, 1965, at datum $6.00 \mathrm{ft}(1.829 \mathrm{~m})$ higher. Since Oct. 1,1959 , supplementary gage on downstream side of bridge near left bank at same datum.

REMARKS.--Records fair. No regulation above station. Pumping from wells along stream for irrigation of about 7,000 acres $\left(28,3 \mathrm{~km}^{2}\right)$ above station.

AVBRAGE DISCHARGE, -36 years, $38.5 \mathrm{ft}^{3} / \mathrm{s}\left(1.090 \mathrm{~m}^{3} / \mathrm{s}\right), 27,890 \mathrm{acre}-\mathrm{ft} / \mathrm{yr}\left(34.4 \mathrm{hm}^{3} / \mathrm{yr}^{2}\right)$.

EXTREMES FOR PERIOD OF RECORD,--Maximum discharge, $24,500 \mathrm{ft}^{3} / \mathrm{s}\left(694 \mathrm{~m}^{3} / \mathrm{s}\right) \mathrm{Jan} .25$, 1969 , gage height, $13.00 \mathrm{ft}$

$(3.962 \mathrm{~m})$; maximum gage height, $13.50 \mathrm{ft}(4.115 \mathrm{~m})$ Dec. 6,1966 ; no flow for several months in each year.

EXTREMES FOR CURRENT YEAR. - -Peak discharges above base of $100 \mathrm{ft}^{3} / \mathrm{s}\left(2.83 \mathrm{~m}^{3} / \mathrm{s}\right)$ and maximum(*):

\begin{tabular}{|c|c|c|c|c|c|}
\hline Date & Time & $\begin{array}{r}\text { Disc } \\
\left(\mathrm{ft}^{3} / \mathrm{s}\right.\end{array}$ & $\underset{\left(\mathrm{m}^{3} / \mathrm{s}\right)}{\operatorname{arge}}$ & $\begin{array}{l}\text { Gage } \\
\text { (ft) }\end{array}$ & $\begin{array}{c}\text { height } \\
\text { (In) }\end{array}$ \\
\hline $\begin{array}{ll}\text { eeb. } 1 \\
\text { jept. } 2\end{array}$ & $\begin{array}{l}0100 \\
0245\end{array}$ & $\begin{array}{r}* 389 \\
176\end{array}$ & $\begin{array}{l}11.0 \\
4.98\end{array}$ & $\begin{array}{l}4.73 \\
4.23\end{array}$ & $\begin{array}{l}1.442 \\
1.289\end{array}$ \\
\hline
\end{tabular}

Minimum daily discharge, no flow for several months.

DISCHARGE, IN CUBIC FEET PER SECOND, WATER YEAR OCTOBER 1975 TO SEPTEMBER 1976 MEAN VALUES

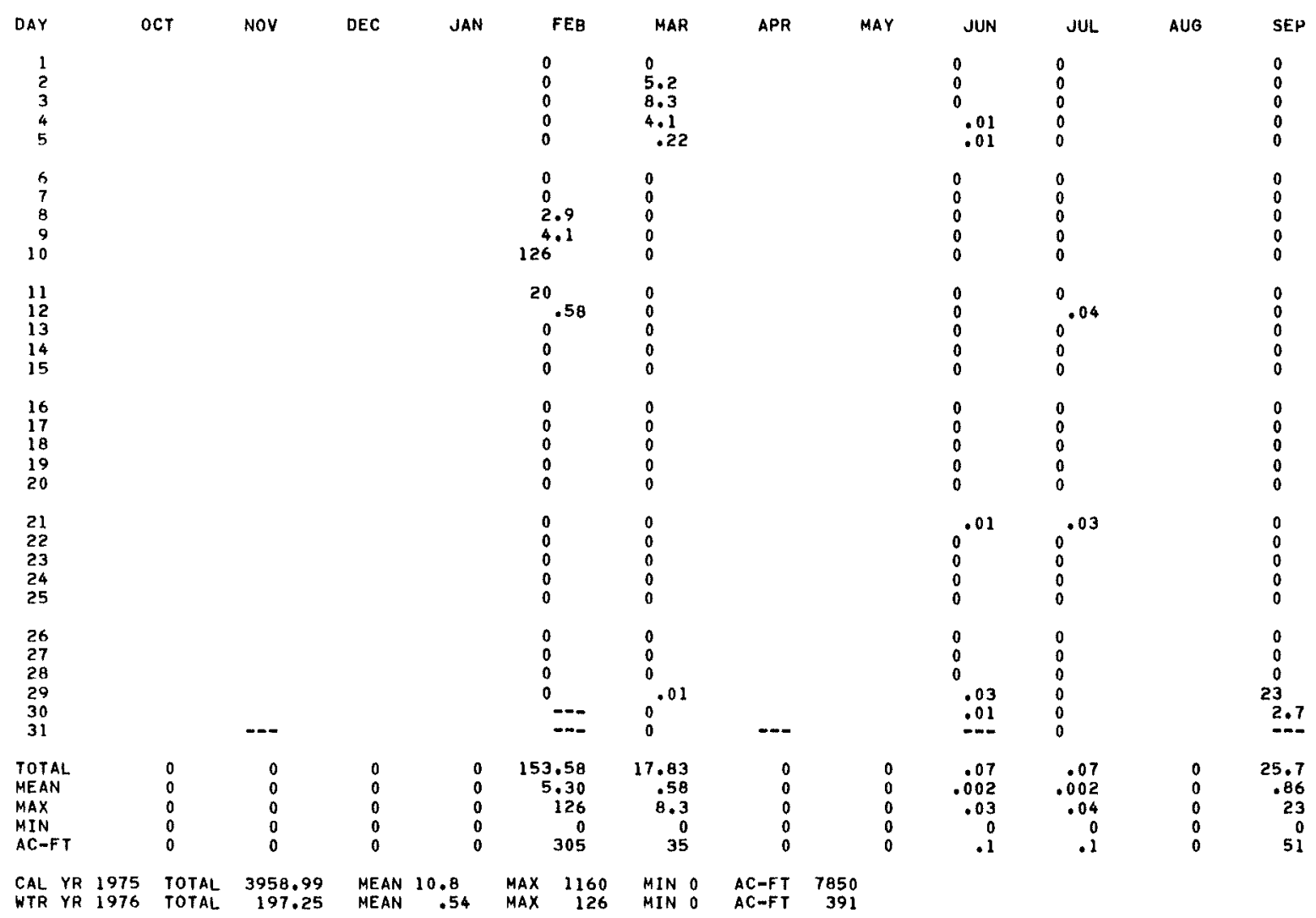


11140600 BRADLEY DITCH NEAR DONOVAN ROAD, AT SANTA MARIA, CA

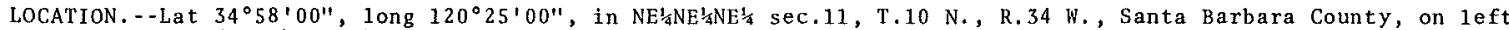
bank $250 \mathrm{ft}(76 \mathrm{~m})$ south of Donovan Road, and $0.2 \mathrm{mi}(0.3 \mathrm{~km})$ east of U.S. Highway 101 in Santa Maria.

PERIOD OF RECORD, - - October 1970 to current year.

GAGE, - Water-stage recorder on concrete-1ined channel. Altitude of gage is $225 \mathrm{ft}$ ( $69 \mathrm{~m}$ ), from topographic map. REMARKS.--Records poor.

AVERAGE DISCHARGE. -6 years, $0.91 \mathrm{ft}^{3} / \mathrm{s}\left(0.026 \mathrm{~m}^{3} / \mathrm{s}\right), 659 \mathrm{acre}-\mathrm{ft} / \mathrm{yr}\left(813,000 \mathrm{~m}^{3} / \mathrm{yr}^{2}\right)$.

EXTREMES FOR PERIOD OF RECORD.--Maximum discharge, $295 \mathrm{ft}^{3} / \mathrm{s}\left(8.35 \mathrm{~m}^{3} / \mathrm{s}\right)$ Dec. 4 , 1974 , gage height, $5.08 \mathrm{ft}$

$(1.548 \mathrm{~m})$, from rating curve based on computation of flow in concrete-1ined channel; no flow for several days in each year.

EXTREMES FOR CURRENT YEAR, - Maximum discharge, $230 \mathrm{ft}^{3} / \mathrm{s}\left(6.51 \mathrm{~m}^{3} / \mathrm{s}\right)$ Sept, 29 (0015 hrs), gage height, $4.51 \mathrm{ft}$ $(1.375 \mathrm{~m})$, from rating curve based on computation of flow in concrete-iined channel; no other peaks above

base of $100 \mathrm{ft}^{3} / \mathrm{s}\left(2.83 \mathrm{~m}^{3} / \mathrm{s}\right)$; no flow Feb. 13, 15, Sept. 14-16, 20 .

OISCHARGE, IN CUBIC FEET PER SECOND, HATER YEAR OCTOBER 1975 TO SEPTEMBER 1976 MEAN VALUES

\begin{tabular}{|c|c|c|c|c|c|c|c|c|c|c|c|c|}
\hline DAY & OCT & NOV & DEC & JAN & FEB & MAR & APR & MAY & JUN & JUL & AUG & SEP \\
\hline $\begin{array}{l}1 \\
2 \\
3 \\
4 \\
5\end{array}$ & $\begin{array}{l}.42 \\
.73 \\
.42 \\
.16 \\
.02\end{array}$ & $\begin{array}{l}.30 \\
.07 \\
.21 \\
.51 \\
.08\end{array}$ & $\begin{array}{l}.18 \\
.27 \\
.24 \\
.08 \\
.27\end{array}$ & $\begin{array}{l}.46 \\
.14 \\
.04 \\
.04 \\
.42\end{array}$ & $\begin{array}{l}.03 \\
.08 \\
.04 \\
.07 \\
.93\end{array}$ & $\begin{array}{l}2.0 \\
3.7 \\
1.4 \\
.03 \\
.01\end{array}$ & $\begin{array}{l}.30 \\
.30 \\
.21 \\
.02 \\
.18\end{array}$ & $\begin{array}{l}.42 \\
.21 \\
.21 \\
.21 \\
.10\end{array}$ & $\begin{array}{l}.06 \\
.15 \\
.42 \\
.36 \\
.18\end{array}$ & $\begin{array}{l}1.3 \\
1.0 \\
1.1 \\
.68 \\
.34\end{array}$ & $\begin{array}{r}.79 \\
.61 \\
.93 \\
1.0 \\
1.0\end{array}$ & $\begin{array}{l}.30 \\
.18 \\
.10 \\
.30 \\
.08\end{array}$ \\
\hline $\begin{array}{r}6 \\
7 \\
8 \\
9 \\
10\end{array}$ & $\begin{array}{l}.08 \\
.42 \\
.61 \\
.30 \\
.34\end{array}$ & $\begin{array}{l}.38 \\
.08 \\
.07 \\
.42 \\
.42\end{array}$ & $\begin{array}{l}.27 \\
.21 \\
.21 \\
.24 \\
.24\end{array}$ & $\begin{array}{l}.61 \\
.27 \\
.27 \\
.30 \\
.42\end{array}$ & $\begin{array}{c}1.3 \\
9.21 \\
9.9 \\
12 \\
14\end{array}$ & $\begin{array}{l}.01 \\
.01 \\
.01 \\
.01 \\
.02\end{array}$ & $\begin{array}{r}.30 \\
.46 \\
1.2 \\
.02 \\
.01\end{array}$ & $\begin{array}{l}.08 \\
.10 \\
.08 \\
.02 \\
.02\end{array}$ & $\begin{array}{r}.69 \\
.28 \\
.94 \\
.43 \\
1.1\end{array}$ & $\begin{array}{l}1.1 \\
1.4 \\
1.5 \\
1.2 \\
1.1\end{array}$ & $\begin{array}{l}1.1 \\
1.7 \\
.86 \\
1.5 \\
1.7\end{array}$ & $\begin{array}{r}.06 \\
.21 \\
.05 \\
.04 \\
6.3\end{array}$ \\
\hline $\begin{array}{l}11 \\
12 \\
13 \\
14 \\
15\end{array}$ & $\begin{array}{l}1.3 \\
.03 \\
.01 \\
.01 \\
.04\end{array}$ & $\begin{array}{l}.14 \\
.30 \\
.16 \\
.30 \\
.27\end{array}$ & $\begin{array}{l}.34 \\
.73 \\
.14 \\
.08 \\
.03\end{array}$ & $\begin{array}{l}.42 \\
1.0 \\
.56 \\
.21 \\
.27\end{array}$ & $\begin{array}{l}.03 \\
0.01 \\
0.02\end{array}$ & $\begin{array}{l}.07 \\
.10 \\
.14 \\
.02 \\
.18\end{array}$ & $\begin{array}{l}.06 \\
1.6 \\
.46 \\
.04 \\
.10\end{array}$ & $\begin{array}{l}.16 \\
.34 \\
.18 \\
.30 \\
.02\end{array}$ & $\begin{array}{l}1.2 \\
1.2 \\
.41 \\
.35 \\
.27\end{array}$ & $\begin{array}{l}.60 \\
.30 \\
.78 \\
.69 \\
.69\end{array}$ & $\begin{array}{l}2.4 \\
2.0 \\
1.9 \\
1.4 \\
.86\end{array}$ & $\begin{array}{l}17 \\
: 14 \\
0 \\
0 \\
0\end{array}$ \\
\hline $\begin{array}{l}16 \\
17 \\
18 \\
19 \\
20\end{array}$ & $\begin{array}{l}.27 \\
.86 \\
.56 \\
.08 \\
.04\end{array}$ & $\begin{array}{l}.30 \\
.30 \\
.24 \\
.21 \\
.61\end{array}$ & $\begin{array}{l}.24 \\
.06 \\
.42 \\
.61 \\
.42\end{array}$ & $\begin{array}{l}.61 \\
.51 \\
.04 \\
.27 \\
.38\end{array}$ & $\begin{array}{r}.08 \\
.46 \\
.32 \\
.31 \\
.01\end{array}$ & $\begin{array}{l}.24 \\
.02 \\
.24 \\
.24 \\
.17\end{array}$ & $\begin{array}{l}.03 \\
.01 \\
.18 \\
.03 \\
.03\end{array}$ & $\begin{array}{l}.08 \\
.02 \\
.03 \\
.06 \\
.08\end{array}$ & $\begin{array}{l}.33 \\
.86 \\
.55 \\
.33 \\
.28\end{array}$ & $\begin{array}{r}.84 \\
.72 \\
.59 \\
.92 \\
1.3\end{array}$ & $\begin{array}{c}. .51 \\
1.7 \\
16.4 \\
.51\end{array}$ & $\begin{array}{l}0 \\
.01 \\
.04 \\
.02 \\
0\end{array}$ \\
\hline $\begin{array}{l}21 \\
22 \\
23 \\
24 \\
25\end{array}$ & $\begin{array}{l}.03 \\
.21 \\
.27 \\
.21 \\
.51\end{array}$ & $\begin{array}{l}.18 \\
.24 \\
.27 \\
.51 \\
.27\end{array}$ & $\begin{array}{l}.24 \\
.08 \\
.10 \\
.34 \\
.07\end{array}$ & $\begin{array}{l}.42 \\
.27 \\
.24 \\
.42 \\
.07\end{array}$ & $\begin{array}{l}.11 \\
.07 \\
.08 \\
.24 \\
.46\end{array}$ & $\begin{array}{l}.38 \\
.18 \\
.06 \\
.16 \\
.38\end{array}$ & $\begin{array}{l}.03 \\
.08 \\
.14 \\
.14 \\
.18\end{array}$ & $\begin{array}{l}.06 \\
.10 \\
.73 \\
.42 \\
.38\end{array}$ & $\begin{array}{l}.46 \\
.55 \\
.95 \\
.51 \\
.66\end{array}$ & $\begin{array}{l}.84 \\
.73 \\
.52 \\
.59 \\
.36\end{array}$ & $\begin{array}{l}.06 \\
.02 \\
.01 \\
.02 \\
.02\end{array}$ & $\begin{array}{l}.01 \\
.34 \\
.03 \\
.51 \\
.42\end{array}$ \\
\hline $\begin{array}{l}26 \\
27 \\
28 \\
29 \\
30 \\
31\end{array}$ & $\begin{array}{l}.46 \\
.18 \\
.42 \\
.07 \\
.79 \\
.04\end{array}$ & $\begin{array}{l}.38 \\
.08 \\
.12 \\
.03 \\
.02 \\
-.0\end{array}$ & $\begin{array}{l}.34 \\
.24 \\
.18 \\
.18 \\
.46 \\
.42\end{array}$ & $\begin{array}{l}.21 \\
.14 \\
.21 \\
.27 \\
.38 \\
.27\end{array}$ & $\begin{array}{l}.21 \\
.18 \\
.30 \\
1.6 \\
-\infty-\infty\end{array}$ & $\begin{array}{l}.51 \\
.21 \\
.08 \\
.02 \\
.38 \\
.30\end{array}$ & $\begin{array}{l}.04 \\
.06 \\
.02 \\
.02 \\
.10 \\
.0\end{array}$ & $\begin{array}{l}.03 \\
.03 \\
.29 \\
.33 \\
.26 \\
.03\end{array}$ & $\begin{array}{r}.85 \\
.67 \\
1.1 \\
.49 \\
.51 \\
.0 .-\end{array}$ & $\begin{array}{l}.29 \\
.52 \\
1.0 \\
1.0 \\
.73 \\
.73\end{array}$ & $\begin{array}{l}.13 \\
.07 \\
.21 \\
.34 \\
.34 \\
.38\end{array}$ & $\begin{array}{r}.38 \\
.16 \\
9.9 \\
40 \\
2.5 \\
-\end{array}$ \\
\hline $\begin{array}{l}\text { TOTAL } \\
\text { MEAN } \\
\text { MAX } \\
\text { MIN } \\
\text { AC-FT }\end{array}$ & $\begin{array}{r}9.89 \\
.32 \\
1.3 \\
.01 \\
20\end{array}$ & $\begin{array}{r}7.47 \\
.25 \\
.61 \\
.02 \\
15\end{array}$ & $\begin{array}{r}7.93 \\
.26 \\
.73 \\
.03 \\
16\end{array}$ & $\begin{array}{r}10.14 \\
.33 \\
1.0 \\
.04 \\
20\end{array}$ & $\begin{array}{r}43.05 \\
1.48 \\
14 \\
0 \\
85\end{array}$ & $\begin{array}{r}11.28 \\
.36 \\
3.7 \\
.01 \\
22\end{array}$ & $\begin{array}{r}6.35 \\
.21 \\
1.6 \\
.01 \\
13\end{array}$ & $\begin{array}{r}5.38 \\
.17 \\
.73 \\
.02 \\
11\end{array}$ & $\begin{array}{r}17.14 \\
.57 \\
1.2 \\
.06 \\
34\end{array}$ & $\begin{array}{r}25.46 \\
.82 \\
1.5 \\
.29 \\
50\end{array}$ & $\begin{array}{r}41.47 \\
1.34 \\
16 \\
.01 \\
82\end{array}$ & $\begin{array}{r}79.10 \\
2.64 \\
40 \\
0 \\
157\end{array}$ \\
\hline
\end{tabular}

$\begin{array}{llllllll}\text { CAL YR } 1975 & \text { TOTAL } 210.33 & \text { MEAN } .56 & \text { MAX } 26 & \text { MIN } 0 & \text { ACFT } 417 \\ \text { WTR YR } 1976 & \text { TOTAL } 264.66 & \text { MEAN } .72 & \text { MAX } 40 & \text { MIN } 0 & \text { AC-FT } 525\end{array}$ 
11140800 BLOSSER DITCH NEAR DONOVAN ROAD, AT SANTA MARIA, CA

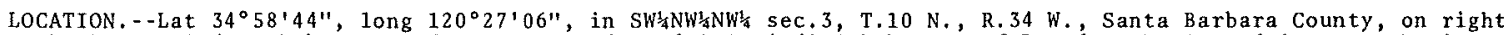
bank $0.8 \mathrm{mi}(1.3 \mathrm{~km})$ north of Donovan Road, and $1.0 \mathrm{mi}(1.6 \mathrm{~km})$ west of Broadway Boulevard in Santa Maria.

PERIOD OF RECORD, - October 1972 to September 1976 (discontinued). November 1962 to september 1972 in files of Santa Barbara County Flood Control and Water Conservation District.

GAGE, - Water-stage recorder and culvert control. Altitude of gage is $190 \mathrm{ft}$ ( $58 \mathrm{~m}$ ), from topographic map.

REMARKS.--Records good. Runoff affected by urbanization.

EXTREMES FOR PERIOD OF RECORD.--Maximum discharge, $230 \mathrm{ft}^{3} / \mathrm{s}\left(6.51 \mathrm{~m}^{3} / \mathrm{s}\right) \mathrm{Jan} .18,1973$, gage height, $6.88 \mathrm{ft}$

$(2.097 \mathrm{~m})$; no flow many days in each year.

EXTREMES FOR CURRENT YEAR. - Peak discharges above base of $100 \mathrm{ft}^{3} / \mathrm{s}\left(2.83 \mathrm{~m}^{3} / \mathrm{s}\right)$ and maximum (*):

\begin{tabular}{|c|c|c|c|c|c|c|c|c|c|}
\hline Date & Time & $\begin{array}{l}\text { Discharge } \\
\left(\mathrm{ft}^{3} / \mathrm{s}\right)\left(\mathrm{m}^{3} / \mathrm{s}\right)\end{array}$ & $\begin{array}{l}\text { Gage height } \\
\text { (ft) }\end{array}$ & Date & Time & $\begin{aligned} \text { Dis } \\
\left(f t^{3} /\right.\end{aligned}$ & $\left(\mathrm{m}^{3} / \mathrm{s}\right)$ & $\begin{array}{l}\text { Gage } \\
(\mathrm{ft})\end{array}$ & $\begin{array}{r}\text { height } \\
\text { (m) }\end{array}$ \\
\hline $\begin{array}{lr}\text { Feb. } & 8 \\
\text { Aug. } & 19\end{array}$ & $\begin{array}{l}0200 \\
1030\end{array}$ & $\begin{array}{l}3.09 \\
3.23\end{array}$ & $\begin{array}{ll}4.69 & 1.430 \\
4.80 & 1.463\end{array}$ & Sept. 29 & 0015 & * 210 & 5.95 & 6.85 & 2.088 \\
\hline
\end{tabular}

Minimum daily discharge, no flow many days.

DISCHARGE, IN CUBIC FEET PER SECOND, WATER YEAR OCTOBER 1975 TO SEPTEMEER 1976 MEAN VALUES

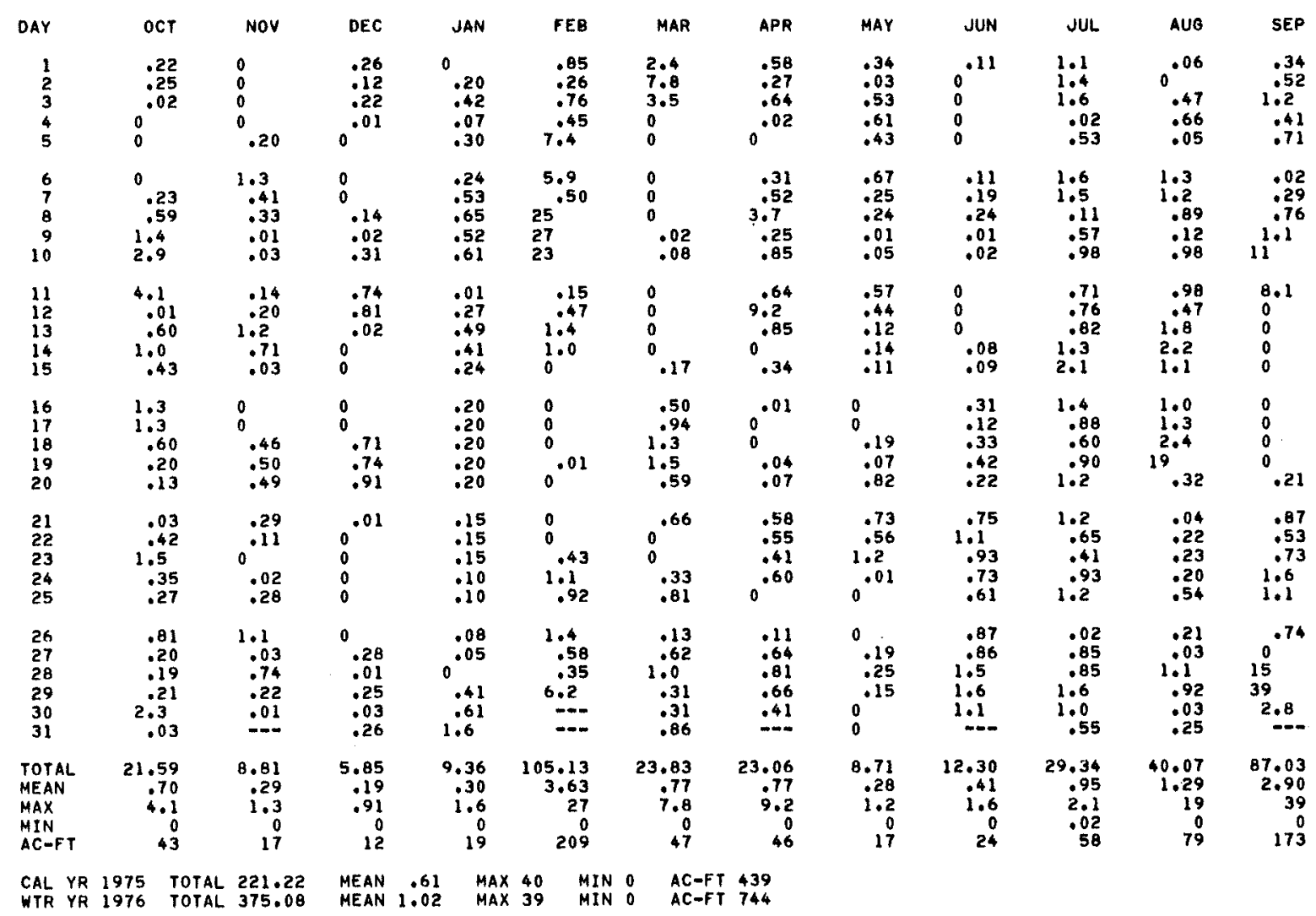


11141000 SANTA MARIA RIVER AT GUADALUPE, CA

LOCATION. - Lat $34^{\circ} 58^{\prime} 35^{\prime \prime}$, long $120^{\circ} 34^{\prime} 15^{\prime \prime}$, in Guadalupe Grant, Santa Barbara County, on downstream side of bridge on State Highway $1,0.5 \mathrm{mi}(0.8 \mathrm{~km})$ north of Guadalupe, and $4.5 \mathrm{mi}(7.2 \mathrm{~km})$ upstream from mouth.

DRAINAGE AREA. - - 1,741 $\mathrm{mi}^{2}\left(4,509 \mathrm{~km}^{2}\right)$.

PERIOD OF RECORD. - -October 1940 to current year. Monthiy discharge only october 1940 to January 1941 , published in WSP $1315-\mathrm{B}$.

GAGE. - Three water-stage recorders. Datum of main gage (left channel) is $64.92 \mathrm{ft}$ (19.788 $\mathrm{m}$ ) above mean sea 1eve1. Two supplementary gages; one on center chanel at datum $0.47 \mathrm{ft}(0.143 \mathrm{~m})$ higher than main gage, and one on right channe1 at datum $2.22 \mathrm{ft}(0.677 \mathrm{~m})$ higher than main gage. prior to Aug. 11, 1955 , main gage at site $100 \mathrm{ft}$ ( $30 \mathrm{~m}$ ) upstream at same datum. Supplementary gages started in igs6.

REMARKS. - No flow since Mar. 9, 1975. Cuyama River regulated since February 1959 by Twitchell Reservoir, capacity, 240,000 acre-ft $\left(296 \mathrm{hm}^{3}\right)$. Several small surface diversions and extensive pumping from wells for irrigation along stream above station. AVERAGE DISCHARGE represents flow to ocean, regardless of upstream development. along stream above station. AVERAGE DISCHARGE represents flow to ocean, regardless of upstream development.
Discharge figures for the calendar year 1975 are as follows: Total, $155 \mathrm{ft}^{3} / \mathrm{s}(4.39 \mathrm{~m} / \mathrm{s})$, 307 acre-ft/yr $\left(379,000 \mathrm{~m}^{3} / \mathrm{yr}\right)$; mean, $0.42 \mathrm{ft}^{3} / \mathrm{s}(0.012 \mathrm{~m} / \mathrm{s})$; maximum daily, $119 \mathrm{ft}^{3} / \mathrm{s}(3.37 \mathrm{~m} / \mathrm{s})$; minimum daily, no flow. AVERAGE DISCHARGE. - 36 years, $30.1 \mathrm{ft}^{3} / \mathrm{s}\left(0.852 \mathrm{~m}^{3} / \mathrm{s}\right), 21,810 \mathrm{acre}-\mathrm{ft} / \mathrm{yr}^{\mathrm{r}}\left(26.9 \mathrm{hm}^{3} / \mathrm{yr}^{3}\right)$.

EXTREMES FOR PERIOD OF RECORD. - Maximum discharge, 32,800 $\mathrm{ft}^{3} / \mathrm{s}\left(929 \mathrm{~m}^{3} / \mathrm{s}\right) \mathrm{Jan}, 16,1952$, gage height, $8.18 \mathrm{ft}$ $(2.493 \mathrm{~m})$; maximum gage height, $10.00 \mathrm{ft}(3.048 \mathrm{~m})$ Feb. 26,1969 ; no flow for ail or parts of each year.

EXTREMES FOR CURRENT YEAR.--No f1ow during year. 
The following table contains annual maximum discharges for crest-stage stations. A crest-stage gage is a device which will register the peak stage occurring between inspections of the gage. A stage-discharge relation for each gage is developed from discharge measurements made by indirect measurements of peak flow or by current meter. The date of the maximum discharge is not always certain, but is usually determined by comparison with nearby continuous-record stations, weather records, or local inquiry. Only the maximum discharge for the current water year is given. Information on some lower floods may have been obtained, but is not published herein. The years given in the period of record represent water years for which the annual maximum has been obtained

Annual maximum discharge at crest-stage partial-record stations during water year 1976

\begin{tabular}{|c|c|c|c|c|c|c|c|}
\hline $\begin{array}{l}\text { Station } \\
\text { No. }\end{array}$ & Station name & Location & $\begin{array}{l}\text { Drain } \\
\text { age } \\
\text { area } \\
\left(m i^{2}\right)\end{array}$ & $\begin{array}{l}\text { Period } \\
\text { of } \\
\text { record }\end{array}$ & Date & $\begin{array}{c}\text { Gage } \\
\text { height } \\
\text { (feet) }\end{array}$ & $\begin{array}{c}\text { Discharge } \\
\left(\mathrm{ft}^{3} / \mathrm{s}\right)\end{array}$ \\
\hline \multicolumn{8}{|c|}{ Dale Lake basin } \\
\hline 10253320 & $\begin{array}{l}\text { Quail Wash near } \\
\text { Joshua Tree, CA }\end{array}$ & 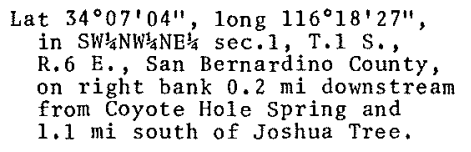 & 100 & $\begin{array}{l}1964-71 \ddagger \\
1972-76\end{array}$ & $9-10-76$ & 2.76 & 212 \\
\hline 10253350 & $\begin{array}{l}\text { Fortynine Palms } \\
\text { Creek near } \\
\text { Twentynine } \\
\text { Palms, CA }\end{array}$ & $\begin{array}{l}\text { Lat } 34^{\circ} 07^{\prime} 12^{\prime \prime}, \text { long } 116^{\circ} 05^{\prime} 43^{\prime \prime} \\
\text { (unsurveyed), San Bernardino } \\
\text { County, in Joshua Tree } \\
\text { Nationa1 Monument, on left } \\
\text { bank } 50 \text { ft upstream from } \\
\text { North Monument boundary, } \\
1.1 \text { mi downstream from } \\
\text { from Fortynine Palms Oasis, } \\
\text { and } 2.6 \text { mi southwest of } \\
\text { Twentynine Palms. }\end{array}$ & 8.55 & $\begin{array}{l}1962-71 \ddagger \\
1972-76\end{array}$ & $9-10-76$ & 1.15 & 8.8 \\
\hline \multicolumn{8}{|c|}{ Salton Sea basin } \\
\hline 10257800 & $\begin{array}{l}\text { Long Creek near } \\
\text { Desert Hot } \\
\text { Springs, CA }\end{array}$ & 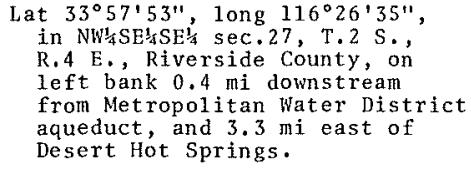 & 19.4 & $\begin{array}{l}1963-71 \ddagger \\
1972-76\end{array}$ & $9-10-76$ & 3.90 & 957 \\
\hline \multicolumn{8}{|c|}{ Emerson Lake basin } \\
\hline 10260200 & $\begin{array}{l}\text { Pipes Creek } \\
\text { near Yucca } \\
\text { Val1ey, CA }\end{array}$ & 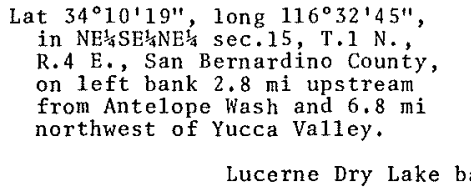 & asin & $\begin{array}{l}1958-71 \ddagger \\
1972-76\end{array}$ & -- & $\cdots$ & \\
\hline & & Indian Wells Valley & basin & & & & \\
\hline 10264780 & $\begin{array}{l}\text { E1 Paso Wash } \\
\text { near Inyokern, } \\
\text { CA }\end{array}$ & $\begin{array}{l}\mathrm{NW}_{4} \mathrm{SW}_{4} \text { sec.11, T. } 275 ., \mathrm{R} .39 \mathrm{E}, \text {, } \\
\text { Kern County, at culvert on } \\
\text { U.S. Highway } 395,4.5 \mathrm{mi} \\
\text { southeast of Inyokern. }\end{array}$ & 34.6 & 1976 & $9-29-76$ & 9.06 & 136 \\
\hline 10264785 & $\begin{array}{l}\text { E1 Paso Wash } \\
\text { tributary } \\
\text { No. } 5 \text { near } \\
\text { lnyokern, CA }\end{array}$ & 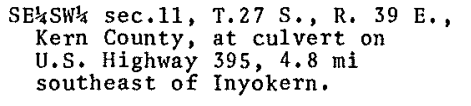 & .25 & 1976 & $9-29-76$ & 4.05 & 16 \\
\hline 10264790 & $\begin{array}{l}\text { E1 Paso Wash } \\
\text { tributary No. } \\
3 \text { near } \\
\text { Inyokern, CA }\end{array}$ & $\begin{array}{l}\text { NW/4SEt sec. } 3, \text { T.27S, R. ReE. } \\
\text { Kern County, at cuivert on } \\
\text { U.S. Highway } 395,3.6 \mathrm{mi} \\
\text { southeast of Inyokern. }\end{array}$ & 1.67 & 1976 & $9-29-76$ & 7.79 & 43 \\
\hline 10264795 & $\begin{array}{l}\text { E1 Paso Wash } \\
\text { tributary } \\
\text { No. } 4 \\
\text { near Inyokern, } \\
\text { CA }\end{array}$ & $\begin{array}{l}\text { NElaket sec.10, T.27 S., R. } 39 \mathrm{E} ., \\
\text { Kern County, at culvert on } \\
\text { U.S. Highway } 395,4.0 \mathrm{mi} \\
\text { southeast of Inyokern. }\end{array}$ & .37 & 1976 & $9-29-76$ & 4.30 & 1.4 \\
\hline
\end{tabular}

$\$$ Operated as a continuous-record gaging station. 
Annual maximum discharge at crest-stage partial-record stations during water year 1976--Continued

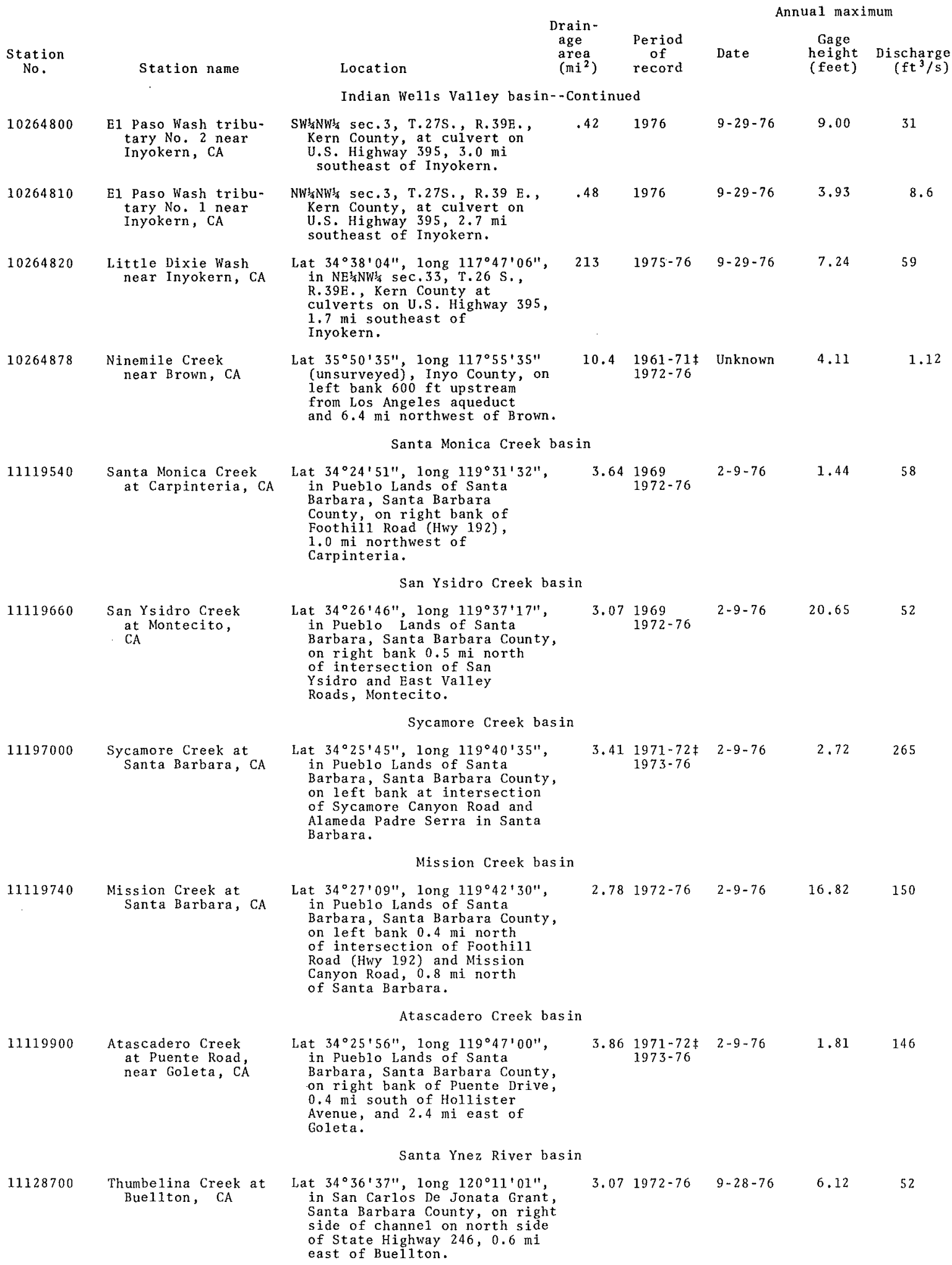

\$ Operated as continuous-record gaging station. 
Annual maximum discharge at crest-stage partial-record stations during water year 1976--Continued

\begin{tabular}{|c|c|c|c|c|c|c|c|}
\hline $\begin{array}{l}\text { Station } \\
\text { No. }\end{array}$ & Station name & Location & $\begin{array}{l}\text { Drain- } \\
\text { age } \\
\text { area } \\
\left(\mathrm{mi}^{2}\right)\end{array}$ & $\begin{array}{l}\text { Period } \\
\text { of } \\
\text { record }\end{array}$ & Date & $\begin{array}{c}\text { Gage } \\
\text { height } \\
\text { (feet) }\end{array}$ & $\begin{array}{r}\text { Discharge } \\
\left(\mathrm{ft}^{3} / \mathrm{s}\right)\end{array}$ \\
\hline \multicolumn{8}{|c|}{ Santa Ynez River basin--continued } \\
\hline 11131700 & $\begin{array}{l}\text { Santa Rita Creek } \\
\text { nr Lompoc, CA }\end{array}$ & $\begin{array}{l}\text { Lat } 34^{\circ} 38^{\prime} 41^{\prime \prime} \text {, long } 120^{\circ} 22^{\prime} 09^{\prime \prime} \text {, } \\
\text { in Santa Rita Grant, Santa } \\
\text { Barbara County, on left } \\
\text { bank } 2.4 \mathrm{mi} \text { from mouth and } \\
6.5 \mathrm{mi} \text { east of Lompoc. }\end{array}$ & 14.1 & 1976 & $2-10-76$ & 6.22 & 70 \\
\hline 11133700 & $\begin{array}{l}\text { Purisima Creek } \\
\text { near Lompoc, CA }\end{array}$ & $\begin{array}{l}\text { Lat } 34^{\circ} 41^{\prime} 34^{\prime \prime}, \text { long } 120^{\circ} 25^{\prime} 51^{\prime \prime} \text {, } \\
\text { in Purisima Grant, Santa } \\
\text { Barbara County, on right } \\
\text { bank, } 1.1 \text { mi northeast of } \\
\text { junction of Buener Road } \\
\text { and Lompoc-Casmalia Road, } \\
4.0 \text { mi northeast of Lompoc. }\end{array}$ & 4.75 & $\begin{array}{l}1972-75 \ddagger \\
1976\end{array}$ & $2-10-76$ & 1.64 & 21 \\
\hline
\end{tabular}

$¥$ Operated as a continuous-record gaging station. 
DISCHARGE MEASUREMENTS MADE AT MISCELLANEOUS SITES DURING WATER YEAR 1976

\begin{tabular}{|c|c|c|c|c|c|c|}
\hline \multirow[b]{2}{*}{ Stream } & \multirow[b]{2}{*}{ Tributary to } & \multirow[b]{2}{*}{ Location } & \multirow{2}{*}{$\begin{array}{l}\text { Drain- } \\
\text { age } \\
\text { area } \\
\left(m i^{2}\right)\end{array}$} & \multirow{2}{*}{$\begin{array}{l}\text { Measured } \\
\text { pre- } \\
\text { vious } 1 \text { y } \\
\text { (water } \\
\text { years) }\end{array}$} & \multicolumn{2}{|c|}{ Measurements } \\
\hline & & & & & Date & $\begin{array}{r}\text { Discharge } \\
\left(\mathrm{ft}^{3} / \mathrm{s}\right)\end{array}$ \\
\hline & & Salton Sea Basin & & & & \\
\hline Barton Creek & Salton Sea & $\begin{array}{l}\text { Lat } 33^{\circ} 26^{\prime} 48^{\prime \prime}, \text { Iong } 116^{\circ} 09^{\prime} 59^{\prime \prime} \text {, } \\
\text { Riverside County, } 1.3 \mathrm{mi} \\
\text { north of the Riverside-San } \\
\text { Diego County Iine and } 4.7 \mathrm{mi} \\
\text { southwest of Oasis. }\end{array}$ & 5.29 & & $9-10-76$ & 2,280 \\
\hline Carrizo Creek & Dead Indian Creek & $\begin{array}{l}\text { Lat } 33^{\circ} 39^{\prime} 41^{\prime \prime} \text {, long } 116^{\circ} 24^{\prime} 10^{\prime \prime} \text {, } \\
\text { Riverside County, } 0.9 \text { mi up-' } \\
\text { stream from junction with Dead } \\
\text { Indian Creek and } 4 \text { mi southwest } \\
\text { of Palm Desert. }\end{array}$ & 5.00 & & $9-10-76$ & 2,820 \\
\hline $\begin{array}{l}\text { Dead Indian } \\
\text { Creek }\end{array}$ & Deep Creek & $\begin{array}{l}\text { Lat } 33^{\circ} 40^{\prime} 07^{\prime \prime} \text {, long } 116^{\circ} 25^{\prime} 09^{\prime \prime} \text {, } \\
\text { Riverside County, } 0.7 \mathrm{mi} \text { up- } \\
\text { stream from the crossing with } \\
\text { State Highway } 74 \text { and } 4 \mathrm{mi} \text { south } \\
\text { east of Palm Desert. }\end{array}$ & 9.02 & & $9-10-76$ & 8,900 \\
\hline Edwards Creek & Salton Sea & $\begin{array}{l}\text { Lat } 33^{\circ} 24^{\prime} 24^{\prime \prime} \text {, long } 116^{\circ} 09^{\prime} 38^{\prime \prime} \text {, } \\
\text { San Diego County, } 1.4 \mathrm{mi} \text { south } \\
\text { of the Riverside-San Diego } \\
\text { County line and } 6.9 \mathrm{mi} \text { south- } \\
\text { west of Oasis. }\end{array}$ & 7.11 & & $9-10-76$ & 4,490 \\
\hline Martinez Creek & Salton Sea & $\begin{array}{l}\text { Lat } 33^{\circ} 30^{\prime} 50^{\prime \prime} \text {, long } 116^{\circ} 12^{\prime} 46^{\prime \prime} \text {, } \\
\text { Riverside County, just below } \\
\text { confluence with Agua Alta } \\
\text { Canyon, } 6 \text { mi north of River- } \\
\text { side-San Diego County line, } \\
\text { and } 4.2 \mathrm{mi} \text { southwest of } \\
\text { Valerie. }\end{array}$ & 48.8 & & $9-10-76$ & 21,400 \\
\hline Myer Creek & Coyote Wash & 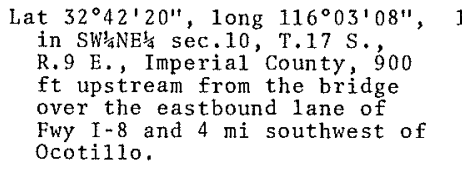 & 17.3 & & $9-10-76$ & 17,500 \\
\hline Sheep Creek & Salton Sea & $\begin{array}{l}\text { Lat } 33^{\circ} 27^{\prime} 33^{\prime \prime}, \text { long } 116^{\circ} 10^{\prime} 12^{\prime \prime} \text {, } \\
\text { Riverside County, } 2.2 \mathrm{mi} \text { north } \\
\text { of the Riverside-San Diego } \\
\text { County line and } 4.3 \mathrm{mi} \text { south- } \\
\text { west of Oasis. }\end{array}$ & 6.5 & & $9-10-76$ & 1,700 \\
\hline
\end{tabular}


344421118282201 , Local number, $8 \mathrm{~N} / 15 \mathrm{~W}-33 \mathrm{G} 1 \mathrm{~S}$.
LOCATION. - - at $34^{\circ} 44^{\prime} 21^{\prime \prime}$, long $118^{\circ} 28^{\prime} 22^{\prime \prime}$, west of Fairmont.

Owner: Fairmont Farms.

AQUIFER. - -A11 UVIUT .

WELL CHARACTERISTICS.--Drilled domestic water-table wel1, diameter 12 in (30 cm), depth $400 \mathrm{ft}$ ( $122 \mathrm{~m}$ ), previously reported $282 \mathrm{ft}(86 \mathrm{~m})$, cased with steel.

DATUM, - Altitude of land-surface datum is $2,930 \mathrm{ft}(893 \mathrm{~m})$ above mean sea level.

REMARKS. - -Records prior to 1968 furnished by California State Department of Water Resources.

PERIOD OF RECORD. - -January 1946 to April 1950 , June 1953 to April 1963 , Apri1 1967 to current year.

EXTREMES FOR PERIOD OF RECORD. - Highest water level measured, 194.00 ft ( 59.13 m) be low 1 and-surface datum, Jan. 23,$1946 ;$ lowest measured, $284.00 \mathrm{ft}(86.56 \mathrm{~m})$ below land-surface datum, Nov. 12, 1959.

WATER LEVEL, IN FEET BELOW LAND-SURFACE DATUM, WATER YEAR OCTOBER 1975 TO SEPTEMBER 1976

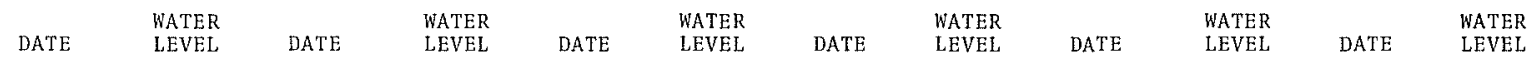

FEB $11 \quad 227.57$

340535117573501. Local number, 1S/10W-7R2 S (Key We11 U.S. 75).

LOCATION. - - Lat $34^{\circ} 05^{\prime} 35^{\prime \prime}$, 1ong $117^{\circ} 57^{\prime} 35^{\prime \prime}$, Baldwin Park.

Owner: Los Angeles County Flood Control District.

AQUIFER, - Fine sand to coarse gravel in alluvial deposits.

WELL CHARACTERISTICS.--Drilled observation water-table well, diameter 16 in (41 cm), depth $200 \mathrm{ft}$ (61 m), perforated 74 to $174 \mathrm{ft}(23$ to $53 \mathrm{~m}), 181$ to $196 \mathrm{ft}(55$ to $60 \mathrm{~m})$.

DATUM.--Altitude of land-surface datum is $387 \mathrm{ft}(118 \mathrm{~m})$ above mean sea level.

PERIOD OF RECORD. - 1903 to current year.

EXTREMES FOR PERIOD OF RECORD.--Highest water level measured, $56.0 \mathrm{ft}$ (17.1 m) below land-surface datum,

May 19,1916 ; lowest measured, $177.93 \mathrm{ft}(54.23 \mathrm{~m})$ below land-surface datum, 0ct. $5,1965$.

WATER LEVEL, IN FEET BELOW LAND-SURFACE DATUM, WATER YEAR OCTOBER 1975 TO SEPTEMBER 1976

\begin{tabular}{|c|c|c|c|c|c|c|c|c|c|c|c|}
\hline & WATER & & WATER & & WATER & & WATER & & WATER & & WATER \\
\hline DATE & LEVEL & DATE & LEVEL & DATE & LEVEL & DATE & LEVEL & DATE & LEVEL & DATE & LEVEL \\
\hline T 28 & 162.46 & $\begin{array}{cc}\text { DEC } & 23 \\
\text { JAN } & 26\end{array}$ & $\begin{array}{l}162.85 \\
163.38\end{array}$ & $\begin{array}{ll}\text { FEB } & 23 \\
M A R & 25\end{array}$ & $\begin{array}{l}164.23 \\
162.32\end{array}$ & $\begin{array}{ll}\text { APR } & 23 \\
M A Y & 25\end{array}$ & 160.90 & JUN 22 & $\begin{array}{l}165.46 \\
169.82\end{array}$ & $\begin{array}{ll}A \cup G & 24 \\
\text { SFP } & 20\end{array}$ & 171.53 \\
\hline
\end{tabular}

335506118083201 . Loca1 number, $35 / 12 \mathrm{~W}-813 \mathrm{~S}$.

LOCATION, - Lat 33 $33^{\circ} 06^{\prime \prime}$, long $118^{\circ} 08^{\prime} 32^{\prime \prime}$, near Downey.

Owner: Las Angeles County Farm.

AQUIFER. - Gaspur water-bearing zone of Holocene age and underlying deposits of pleistocene age.

WELL CHARACTERISTICS, - Drilled unused artesian we11, diameter 8 in (20 cm), depth $248 \mathrm{ft}$ ( $76 \mathrm{~m}$ ), cased with stee1. DATUM.--A1titude of land-surface datum is $92 \mathrm{ft}(28 \mathrm{~m})$ above mean sea level.

PERIOD OF RECORD. --January 1930 to current year.

EXTREMES FOR PERIOD OF RECORD.--Highest water level measured, $14.45 \mathrm{ft}(4.40 \mathrm{~m})$ below 1 and-surface datum,

Mar. 20, 1930; lowest measured, $83.69 \mathrm{ft}(25.51 \mathrm{~m})$ below land-surface datum, Aug. 27, 1962.

COOPERATION. - -Records were furnished by San Gabriel Valley protective Association.

WATER LEVEL, IN FEET BELOW LAND-SURFACE DATUM, WATER YEAR OCTOBER 1975 TO SFPTEMBER 1976

\begin{tabular}{|c|c|c|c|c|c|c|c|c|c|c|c|c|c|c|c|}
\hline DATE & $\begin{array}{l}\text { WATER } \\
\text { LEVEL }\end{array}$ & DATE & $\begin{array}{l}\text { WATER } \\
\text { LEVEL }\end{array}$ & $\mathrm{DA}^{\circ}$ & & $\begin{array}{l}\text { WATER } \\
\text { LEVEL }\end{array}$ & $\mathrm{DA}^{\top}$ & & $\begin{array}{l}\text { WATER } \\
\text { LEVEL }\end{array}$ & DA & & $\begin{array}{l}\text { WATER } \\
\text { LEVEL }\end{array}$ & $\mathrm{DA}$ & & $\begin{array}{l}\text { WATER } \\
\text { LEVEL }\end{array}$ \\
\hline $\begin{array}{ll}\text { OCT } & 6 \\
\text { NOV } & 3\end{array}$ & 66.0 & DEC 1 & 65.1 & FEB & 2 & 65.0 & APR & 5 & 65.0 & JUN & 7 & 66.1 & AUG & 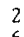 & 67. \\
\hline
\end{tabular}


344929118124401 . Local number, $4 \mathrm{~S} / 13 \mathrm{~W}-14 \mathrm{~L} 1 \mathrm{~S}$.

LOCATION. - Lat $34^{\circ} 49^{\prime} 29^{\prime \prime}$, long $118^{\circ} 12^{\prime} 44^{\prime \prime}$, Long Beach.

Owner: Southern California Edison Co,' Ltd.

AOUIFER. - Gasper water-bearing zone of Holocene age.

WELL CHARACTERISTICS. - Drilled unused artesian wel1, diameter 10 in (25 $\mathrm{cm})$, depth $116 \mathrm{ft}$ (35 $\mathrm{m})$, previous $1 \mathrm{y}$ reported $114 \mathrm{ft}(35 \mathrm{~m})$, perforated 90 to $116 \mathrm{ft}(27$ to $35 \mathrm{~m})$.

DATUM. - Land-surface datum is $28.55 \mathrm{ft}(8.70 \mathrm{~m})$ above mean sea level.

PERIOD OF RECORD. - - February 1930 to current year.

EXTREMES FOR PERIOD OF RECORD.--Highest water leve1 measured, $20.62 \mathrm{ft}$ (6.28 m) below 1and-surface datum, Apr. 5, 1941; lowest measured, $73.86 \mathrm{ft}(22.51 \mathrm{~m})$ below land-surface datum, Sept. $22,1971$.

COOPERATION. - Records were furnished by city of Long Beach.

WATER LEVEL, IN FEET BELOW LAND-SURFACE DATUM, WATER YEAR OCTOBER 1975 TO SEPTEMBER 1976

\begin{tabular}{|c|c|c|c|c|c|c|c|c|c|c|c|}
\hline DATE & $\begin{array}{l}\text { WATER } \\
\text { LEVEL }\end{array}$ & DATE & $\begin{array}{l}\text { WATER } \\
\text { LEVEL }\end{array}$ & DATE & $\begin{array}{l}\text { WATER } \\
\text { LEVEL }\end{array}$ & DATE & $\begin{array}{l}\text { WATER } \\
\text { LEVEL }\end{array}$ & DATE & $\begin{array}{l}\text { WATER } \\
\text { LEVEL }\end{array}$ & DATE & $\begin{array}{l}\text { WATER } \\
\text { LEVEL }\end{array}$ \\
\hline $\begin{array}{lr}\text { CT } & 22 \\
\text { OV } & 5\end{array}$ & $\begin{array}{l}56.82 \\
57.02\end{array}$ & $\begin{array}{lr}\text { DEC } & 17 \\
\text { JAN } & 7\end{array}$ & $\begin{array}{l}56.87 \\
56.77\end{array}$ & $\begin{array}{ll}\text { FEB } & 18 \\
\text { MAR } & 17\end{array}$ & $\begin{array}{l}56.62 \\
57.52\end{array}$ & $\begin{array}{ll}\text { APR } & 21 \\
\text { MAY } & 19\end{array}$ & $\begin{array}{l}58.42 \\
61.62\end{array}$ & $\begin{array}{ll}\text { JUN } & 16 \\
\text { JUL } & 21\end{array}$ & $\begin{array}{l}56.32 \\
56.22\end{array}$ & $\begin{array}{ll}\text { AUG } & 25 \\
\text { SEP } & 22\end{array}$ & $\begin{array}{l}56.32 \\
56.12\end{array}$ \\
\hline
\end{tabular}

334905118124601 . Local number, $4 \mathrm{~S} / 13 \mathrm{~W}-23 \mathrm{G2} \mathrm{S}$.

LOCATION. - Lat $33^{\circ} 49^{\prime} 05^{\prime \prime}$, 1 long $118^{\circ} 12^{\prime} 46^{\prime \prime}$, near Long Beach.

Owner: City of Long Beach.

AQUIFER, - Gravel in uppermost part of Silverado water-bearing zone of Pleistocene age.

WELL CHARACTERISTICS.--Drilled unused artesian wel1, diameter 26 to 16 in (66 to $41 \mathrm{~cm}$ ), depth $1,074 \mathrm{ft}$ ( $327 \mathrm{~m}$ ), perforated 650 to $900 \mathrm{ft}(198$ to $274 \mathrm{~m})$

DATUM. - Land-surface datum is $23.23 \mathrm{ft}(7.08 \mathrm{~m})$ above mean sea level.

PERIOD OF RECORD - -October 1932 to current year.

EXTREMES FOR PERIOD OF RECORD.--Highest water level measured, $52.93 \mathrm{ft}(16.13 \mathrm{~m})$ below 1 and-surface datum,

Feb. 6, 1939; lowest measured, $131.75 \mathrm{ft}(40.15 \mathrm{~m})$ below land-surface datum, Jan. $20,1953$.

COOPERATION. - -Records were furnished by city of Long Beach.

WATER LEVEL, IN FEET BELOW LAND-SURFACE DATUM, WATER YEAR OCTOBER 1975 TO SEPTEMBER 1976

\begin{tabular}{|c|c|c|c|c|c|c|c|c|c|c|c|}
\hline & WATER & & WATER & & WATER & & WATER & & WATER & & WATER \\
\hline DATE & LEVEL & DATE & LEVEL & DATE & LEVEL & DATE & LEVEL & DATE & LEVEL & DATE & LEVEL \\
\hline $\begin{array}{ll}\text { CT } & 22 \\
\text { OV } & 19\end{array}$ & $\begin{array}{l}124.08 \\
121.68\end{array}$ & $\begin{array}{ll}\text { DEC } & 17 \\
\text { JAN } & 21\end{array}$ & $\begin{array}{l}119.18 \\
120.78\end{array}$ & $\begin{array}{ll}\text { FEB } & 18 \\
\text { MAR } & 17\end{array}$ & $\begin{array}{l}121.28 \\
122.58\end{array}$ & $\begin{array}{ll}\text { APR } & 21 \\
\text { MAY } & 19\end{array}$ & $\begin{array}{l}123.48 \\
123.68\end{array}$ & $\begin{array}{ll}\text { JUN } & 23 \\
\text { JUL } & 21\end{array}$ & $\begin{array}{l}122.58 \\
122.68\end{array}$ & $\begin{array}{ll}\text { AUG } & 25 \\
\text { SEP } & 22\end{array}$ & $\begin{array}{l}122.18 \\
121.58\end{array}$ \\
\hline
\end{tabular}

ORANGE COUNTY

334837118040001. Local number, 4S/11W-19K1 S.

LOCATION. - Lat $33^{\circ} 48^{\prime} 37^{\prime \prime}$, long $118^{\circ} 04^{\prime} 00^{\prime \prime}$, near Los Alamitos.

Owner: Los Alamitos Sugar Co.
AQUIFER.--Deposits of Pleistocene age.

WELL CHARACTERISTICS.--Drilled unused artesian well, diameter 12 in (30 cm), depth $460 \mathrm{ft}$ (140 m), previously reported $448 \mathrm{ft}(137 \mathrm{~m})$, perforated 440 to $460 \mathrm{ft}(134$ to $140 \mathrm{~m})$

DATUM, - Land-surface datum is $28.50 \mathrm{ft}(8.69 \mathrm{~m})$ above mean sea level.

PERIOD OF RECORD. - - 1901, August 1903 , September 1929 to current year.

EXTREMES FOR PERIOD OF RECORD. - -Highest water level flowing, 1901; lowest measured, $73.53 \mathrm{ft}$ (22,41 m) below 1andsurface datum, July $22,1957$.

COOPERATION. - -Records were furnished by city of Long Beach.

WATER LEVEL, IN FEET BELOW LAND-SURFACE DATUM, WATER YEAR OCTOBER 1975 TO SEPTEMBER 1976

\begin{tabular}{|c|c|c|c|c|c|c|c|c|c|c|c|}
\hline DATE & $\begin{array}{l}\text { WATER } \\
\text { LEVEL }\end{array}$ & DATE & $\begin{array}{l}\text { WATER } \\
\text { LEVEL }\end{array}$ & DATE & $\begin{array}{l}\text { WATER } \\
\text { LEVEL }\end{array}$ & DATE & $\begin{array}{l}\text { WATER } \\
\text { LEVEL }\end{array}$ & DATE & $\begin{array}{l}\text { WATER } \\
\text { LEVEL }\end{array}$ & DATE & $\begin{array}{l}\text { WATER } \\
\text { LEVEL }\end{array}$ \\
\hline $\begin{array}{ll}\text { CT } & 28 \\
\text { OOV } & 19\end{array}$ & $\begin{array}{l}48.08 \\
44.38\end{array}$ & $\begin{array}{ll}\text { DEC } & 18 \\
\text { JAN } & 20\end{array}$ & $\begin{array}{l}44.58 \\
45.08\end{array}$ & $\begin{array}{cc}\text { FEB } & 18 \\
\text { MAR } & 16\end{array}$ & $\begin{array}{l}40.98 \\
41.18\end{array}$ & $\begin{array}{ll}\text { APR } & 26 \\
\text { MAY } & 18\end{array}$ & $\begin{array}{l}46.38 \\
47.18\end{array}$ & $\begin{array}{ll}\text { JUN } & 15 \\
\text { JUL } & 20\end{array}$ & $\begin{array}{l}55.98 \\
58.88\end{array}$ & $\begin{array}{ll}\text { AUG } & 25 \\
\text { SEP } & 21\end{array}$ & $\begin{array}{l}58.98 \\
52.08\end{array}$ \\
\hline
\end{tabular}


340039116105701. Local number, 2S/8E-7K1 S (Stokes No. 2)

LOCATION. - Lat $34^{\circ} 00^{\prime} 39^{\prime \prime}$, Iong $116^{\circ} 10^{\prime} 57^{\prime \prime}$, in narrow valley east of Hidden valley at west side of Lost Horse valley. Owner: National Park Service.

AQUIFER. - -Residuum

WELL CHARACTERISTICS. - -Drilled unused water-table we11, diameter 8 in $(20 \mathrm{~cm})$, depth $290 \mathrm{ft}(88 \mathrm{~m})$.

DATUM. - Altitude of land-surface datum is $4,100 \mathrm{ft}(1,250 \mathrm{~m})$ above mean sea leve1.

PERIOD OF RECORD. - -November 1961 to current year.

EXTREMES FOR CURRENT YEAR. - Highest water leve1 measured, $202.52 \mathrm{ft}(61.73 \mathrm{~m})$ below land-surface datum,

Sept. 10, 1962; lowest measured, $226.86 \mathrm{ft}(69.14 \mathrm{~m})$ below land-surface datum, Nov. $4,1976$.

WATER LEVEL, IN FEET BELOW LAND-SURFACE DATUM, WATER YEAR OCTOBER 1975 TO SEPTEMBER 1976

\begin{tabular}{|c|c|c|c|c|c|c|c|c|c|c|c|}
\hline DATE & $\begin{array}{l}\text { WATER } \\
\text { LEVEL }\end{array}$ & DATE & $\begin{array}{l}\text { WATER } \\
\text { LEVEL }\end{array}$ & DATE & WATER & DATE & WATER & DATE & WATER & DATE & WATER \\
\hline $10 \mathrm{~V} 13$ & 225.56 & MAR 25 & 226.00 & & & & & & & & \\
\hline
\end{tabular}

335612115243301 Local number, 3S/15E-4J1 S (Kaiser No, 2).

LOCATION. - - Lat $33^{\circ} 56^{\prime} 12^{\prime \prime}$, long $115^{\circ} 24^{\prime} 33^{\prime \prime}$, east end of Pinto basin near Kaiser Steel Co.'s Eagle Mountain we11s.

Owner: National Park Service.

AQUIFER, - -AIIUVium.

WELL CHARACTERISTICS, - -Drilled unused water-table well, diameter 16 in (41 cm), depth 575 ft ( $175 \mathrm{~m}$ ), perforated 250 to $520 \mathrm{ft}(76$ to $158 \mathrm{~m})$.

DATUM. - - Land-surface datum is $1,080.6$ (329.4 m) above mean sea level.

PERIOD OF RECORD.--December 1954 to current year.

EXTREMES FOR PERIOD OF RECORD, - - Highest water level measured, $150.00 \mathrm{ft}(45.72 \mathrm{~m})$ below 1 and-surface datum, Dec. 4, 1954; lowest measured, $168.91 \mathrm{ft}(51.48 \mathrm{~m})$ below land-surface datum, Nov. 4, 1976.

WATER LEVEL, IN FEET BELOW LAND-SURFACE DATUM, WATER YEAR OCTOBER 1975 TO SEPTEMBER 1976

DATE WATER WATER WATER WATER

NOV $12 \quad 160.00 \mathrm{C} \quad$ MAR $25 \quad 168.25 \mathrm{C}$

334712115485601 . Local number $4 \mathrm{~S} / 11 \mathrm{E}-27 \mathrm{Q} 1 \mathrm{~S}$ (Cottonwood We11).

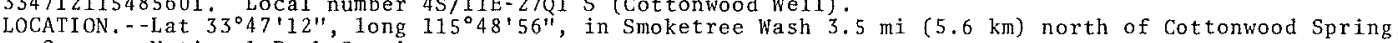

Owner: National Park'Service.

AQUTFER, - A11 Uvium.

WELL CHARACTERISTICS, - Drilled public-supply water-table we11, diameter 12 in (30 cm) $0 \mathrm{to} 232 \mathrm{ft}$ ( $71 \mathrm{~m}$ ), perforated 212 to $228 \mathrm{ft}(65$ to $69 \mathrm{~m})$, diameter 10 in $(25 \mathrm{~m})$, preperforated 208.75 to $402.75 \mathrm{ft}$ (63.63 to $122.76 \mathrm{~m})$,

depth $403 \mathrm{ft}(123 \mathrm{~m})$.
DATUM.--Altitude of 1 and-surface datum is $2,975 \mathrm{ft}(907 \mathrm{~m})$ above mean sea level.

PERIOD OF RECORD.--November 1958 to October 1961 , March 1963 to current year.

EXTREMES FOR PERIOD OF RECORD.--Highest water level measured, 170.29 ft ( $51.90 \mathrm{~m})$ below 1 and-surface datum,

$\mathrm{Mar}, 12,1959 ;$ lowest measured, $191.89 \mathrm{ft}(58.49 \mathrm{~m})$ below Iand-surface datum, June $15,1972$.

WATER LEVEL, IN FEET BELOW LAND-SURFACE DATUM, WATER YEAR OCTOBER 1975 TO SEPTEMBER 1976

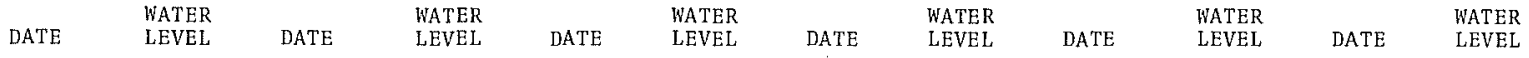

NOV $12 \quad 186.26 \quad$ MAR $25 \quad 185.90$

WATER QUALITY DATA, WATER YEAR OCTOBER 1975 TO SEPTEMBER 1976

\begin{tabular}{|c|c|c|c|c|c|c|c|c|c|c|}
\hline $\begin{array}{l}\text { LOCAL } \\
\text { IOENT- } \\
\text { I- } \\
\text { FIER }\end{array}$ & $\begin{array}{c}\text { DATE } \\
\text { OF } \\
\text { SAMPLE }\end{array}$ & $\begin{array}{l}\text { SPE- } \\
\text { CIFIC } \\
\text { CON- } \\
\text { OUCI- } \\
\text { ANCE } \\
\text { (MICRO- } \\
\text { MHOS) }\end{array}$ & $\begin{array}{l}\text { TEMPER - } \\
\text { ATURE } \\
\text { (DEG C) }\end{array}$ & $\begin{array}{l}\text { HARD - } \\
\text { NESS } \\
(C A, M G) \\
(M G / L)\end{array}$ & $\begin{array}{l}\text { NON- } \\
\text { CAR= } \\
\text { BONATE } \\
\text { HARD- } \\
\text { NESS } \\
(M G / L)\end{array}$ & $\begin{array}{l}\text { DIS- } \\
\text { SOLVED } \\
\text { CAL- } \\
\text { CIUM } \\
\text { (CA) } \\
\text { (MG/L) }\end{array}$ & $\begin{array}{l}\text { DIS- } \\
\text { SOLVED } \\
\text { MAG- } \\
\text { NE- } \\
\text { SIUM } \\
\text { (MG) } \\
(M G / L)\end{array}$ & $\begin{array}{l}\text { DIS- } \\
\text { SOLVED } \\
\text { SODIUM } \\
\text { (NA) } \\
\text { (MG/L) }\end{array}$ & $\begin{array}{r}\text { PERCENT } \\
\text { SOD IUM }\end{array}$ & $\begin{array}{l}\text { SODIUM } \\
\text { AD- } \\
\text { SORP- } \\
\text { TION } \\
\text { RATIO }\end{array}$ \\
\hline $0045011 E 27001 S$ & $75-11-12$ & 400 & 21.0 & 110 & 0 & 33 & 7.0 & 38 & 42 & 1.6 \\
\hline
\end{tabular}

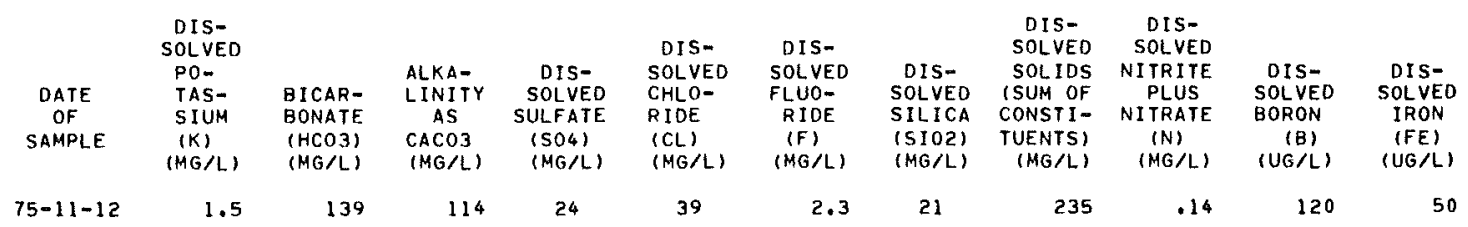

C Nearby well being pumped. 
SAN BERNARDINO COUNTY

340717117194601 , Local number, $1 \mathrm{~N} / 4 \mathrm{~W}-32 \mathrm{~N} 1 \mathrm{~S}$ (Base1ine We11)

LOCATION, - Lat $34^{\circ} 07^{\prime} 17^{\prime \prime}$, Iong $117^{\circ} 19^{\prime} 4^{\prime \prime}$, northwest of San Bernardino.

Owner: City of San Bernardino.

AQUIFER - -Alluvium of Pleistocene age.

WELL CHARACTERISTICS. - -Drilled observation water-table we11, diametex 20 in (51 cm), depth $581 \mathrm{ft}$ ( $177 \mathrm{~m}$ ),

perforated 126 to $184 \mathrm{ft}(38$ to $56 \mathrm{~m}), 224$ to $232 \mathrm{ft}(68$ to $71 \mathrm{~m}), 262$ to $304 \mathrm{ft}(80 \mathrm{fo} 93 \mathrm{~m})$, $312 \mathrm{fo} 372 \mathrm{ft}$ $(95$ to $113 \mathrm{~m}), 468$ to $476 \mathrm{ft}(143$ to $145 \mathrm{~m}), 540$ to $560 \mathrm{ft}(165$ to $171 \mathrm{~m})$, cased with stee 1 .

DATUM,--Land-surface datum is $1,184.8 \mathrm{ft}(361.1 \mathrm{~m})$ above mean sea level.

PERIOD OF RECORD. - -July 1946 to current year.

EXTREMES FOR PERIOD OF RECORD.--Highest water leve1 measured, $49.10 \mathrm{ft}$ (14.96 m) be1ow 1 and-surface datum,

Mar, 6, 1947; 1owest measured, $247.1 \mathrm{ft}(75.3 \mathrm{~m})$ below land-surface datum, Aug. $27,1968$.

COOPERATION. - Records were furnished by San Bernardino Municipal Water Department.

WATER LEVEL, IN FEET BELOW LAND-SURFACE DATUM, WATER YEAR OCTOBER 1975 TO SEPTEMBER 1976

\begin{tabular}{|c|c|c|c|c|c|c|c|c|c|c|c|}
\hline DATE & $\begin{array}{l}\text { WATER } \\
\text { LEVEL }\end{array}$ & DATE & $\begin{array}{l}\text { WATER } \\
\text { LEVEL }\end{array}$ & DATE & $\begin{array}{l}\text { WATER } \\
\text { LEVEL }\end{array}$ & DATE & $\begin{array}{l}\text { WATER } \\
\text { LEVEL }\end{array}$ & DATE & $\begin{array}{l}\text { WATER } \\
\text { LEVEL }\end{array}$ & DATE & $\begin{array}{l}\text { WATER } \\
\text { LEVEL }\end{array}$ \\
\hline $\begin{array}{ll}\text { OV } & 17 \\
\text { EC } & 24\end{array}$ & ${ }^{N}$ & $\begin{array}{ll}\text { JAN } & 23 \\
\text { FEB } & 11\end{array}$ & $\begin{array}{l}175.81 \\
171.11\end{array}$ & $\begin{array}{ll}\text { MAR } & 11 \\
\text { APR } & 23\end{array}$ & $\begin{array}{l}170.21 \\
216.81 \mathrm{~A}\end{array}$ & $\begin{array}{ll}\text { MAY } & 20 \\
\text { JUN } & 26\end{array}$ & $\begin{array}{l}217.51 \mathrm{~A} \\
221.91 \mathrm{~A}\end{array}$ & $\begin{array}{ll}\text { JUL } & 21 \\
\text { AUG } & 27\end{array}$ & $\begin{array}{l}221.61 \mathrm{~A} \\
224.81 \mathrm{~A}\end{array}$ & SEP 13 & $220.31 \mathrm{~A}$ \\
\hline
\end{tabular}

340328117185001. Loca1 number, 1S/4W-29H2 S (F1ume 1)

LOCATION. - Lat $34^{\circ} 03^{\prime} 28^{\prime \prime}$, long $117^{\circ} 18^{\prime} 50^{\prime \prime}$, south of Colton.

Owner: Riverside Watér Có.

AQUTFER - Alluvium of Pleistocene and Holocene age.

WELL CHARACTERISTICS.--Drilled irrigation water-table wel1, diameter 20 in ( $51 \mathrm{~cm}$ ), depth 189 ft (58 m), perforated

43 to $70 \mathrm{ft}(13$ to $21 \mathrm{~m}), 83$ to $97 \mathrm{ft}(25$ to $30 \mathrm{~m}), 131$ to $169 \mathrm{ft}$ (40 to $52 \mathrm{~m})$, cased with stee1.

DATUM, - - Land-surface datum is $934.4 \mathrm{ft}(284.8 \mathrm{~m})$ above mean sea level.

PERTOD OF RECORD. - -June 1928 to current year.

EXTREMES FOR PERIOD OF RECORD.--Highest water level measured, 2.90 ft $(0.88 \mathrm{~m})$ below 1 and-surface datum,

Apr. 8, 1938; lowest measured, $127.40 \mathrm{ft}(38.83 \mathrm{~m})$ below land-surface datum, 0ct. 30, 1964.

COOPERATION, - -Records were furnished by owner.

WATER LEVEL, IN FEET BELOW LAND-SURFACE DATUM, WATER YEAR OCTOBER 1975 TO SEPTEMBER 1976

\begin{tabular}{|c|c|c|c|c|c|c|c|c|c|c|c|c|c|c|}
\hline DATE & $\begin{array}{l}\text { WATER } \\
\text { LEVEL }\end{array}$ & $\mathrm{DA}$ & & $\begin{array}{l}\text { WATER } \\
\text { LEVEL }\end{array}$ & DA & & $\begin{array}{l}\text { WATER } \\
\text { LEVEL }\end{array}$ & DATE & $\begin{array}{l}\text { WATER } \\
\text { LEVEL }\end{array}$ & DATE & $\begin{array}{l}\text { WATER } \\
\text { LEVEL }\end{array}$ & DAT & & $\begin{array}{l}\text { WATER } \\
\text { LEVEL }\end{array}$ \\
\hline $\begin{array}{ll}\text { OC'T } & 1 \\
\text { NOV } & 4\end{array}$ & $\begin{array}{l}65.59 \\
65.19\end{array}$ & $\begin{array}{l}\text { DEC } \\
\text { JAN }\end{array}$ & $\begin{array}{l}2 \\
7\end{array}$ & $\begin{array}{l}64.19 \\
65.19\end{array}$ & $\begin{array}{l}\text { FEB } \\
\text { MAR }\end{array}$ & $\begin{array}{l}4 \\
1\end{array}$ & $\begin{array}{l}56.09 \\
49.49\end{array}$ & $\begin{array}{lr}\text { APR } & 1 \\
\text { MAY } & 11\end{array}$ & $\begin{array}{l}59.09 \\
64.19\end{array}$ & $\begin{array}{lr}\text { JUN } & 1 \\
\text { JUL } & 27\end{array}$ & $\begin{array}{l}67.89 \\
71.49\end{array}$ & $\begin{array}{l}\text { AUG } \\
\text { SEP }\end{array}$ & $\begin{array}{l}1 \\
1\end{array}$ & $\begin{array}{l}71.49 \\
76.39\end{array}$ \\
\hline
\end{tabular}

A Well being pumped.

$\mathrm{N}$ No measurement. 
332018117080701 . Local number, $10 \mathrm{~S} / 2 \mathrm{~W}-6 \mathrm{~F} 2 \mathrm{~S}$

LOCATION. - - Lat $33^{\circ} 20^{\prime} 18^{\prime \prime}$, Iong $117^{\circ} 08^{\prime} 07^{\prime \prime}$, Monserate Narrows, near gaging station.

Owner: San Luis Rey Ranch.

AQUIFER. - Alluvium of Holocene age.

WELL CHARACTERISTICS. - Drilled unused water-table well, diameter 12 in (30 $\mathrm{cm})$, depth $109 \mathrm{ft}$ (33 m), cased with stee1.

DATUM, - - Land-surface datum is $282.76 \mathrm{ft}(86.18 \mathrm{~m})$ above mean sea level.

REMARKS. - - Published measurements prior to 1951 are for wel1 $10 \mathrm{~S} / 2 \mathrm{~W}-6 \mathrm{~F} 6$.

PERIOD OF RECORD. - - January 1951 to March 1973, January 1975 to current year.

EXTREMES FOR PERIOD OF RECORD.--Highest water level measured, $6.92 \mathrm{ft}$ ( 2.11 m) below 1 and-surface datum, Mar. 11, 1969; 1owest, dry, Aug. 13, 1962, Aug. 17, 1964.

WATER LEVEL, IN FEET BELOW LAND-SURFACE DATUM, WATER YEAR OCTOBER 1975 TO SEPTEMBER 1976

\begin{tabular}{|c|c|c|c|c|c|c|c|c|c|c|c|}
\hline DATE & $\begin{array}{l}\text { WATER } \\
\text { LEVEL }\end{array}$ & DATE & $\begin{array}{l}\text { WATER } \\
\text { LEVEL }\end{array}$ & DATE & $\begin{array}{l}\text { WATER } \\
\text { LEVEL }\end{array}$ & DATE & $\begin{array}{l}\text { WATER } \\
\text { LEVEL }\end{array}$ & DATE & $\begin{array}{l}\text { WATER } \\
\text { LEVEL }\end{array}$ & DATE & $\begin{array}{l}\text { WATER } \\
\text { LEVEL }\end{array}$ \\
\hline NOV 6 & 11.64 & JAN 21 & 9.05 & MAR 30 & 7.60 & JUL 29 & $14.72 \mathrm{~A}$ & & & & \\
\hline
\end{tabular}

WATER QUALITY DATA, WATER YEAR OCTOBER 1975 TO SEPTEMBER 1976

LOCAL

IDENT -

FIER

$010 \$ 002 W 06 F 025$

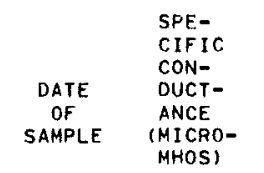

76-07-09

1450

TEMPER-

ATURE (DEG C)

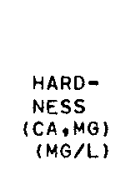

NON-
CAR-
BONATE
HARD-
NESS
(MG/L)

DIS-
SOLVED
CAL-
CIUM
(CA)
(MG/L)

DIS-

SOLVED

MAG - DIS-

NE- SOLVED

SIUM SODIUM

(MG) (NA)

(NA)

PERCEN SOD IUM

(MG/L)

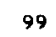

$28 \quad 1.8$
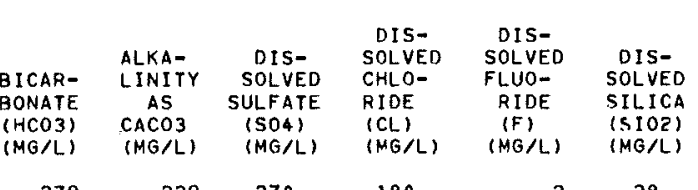

DIS-
SOLVED
SOLIDS

99

SOLVED

SOLVED

PAS

OF

SIUM

IMG/L

279

$229 \quad 270$

180

28

(SUM OF

UENTS)

PLUS

NITRATE

(N)

BORON IRON

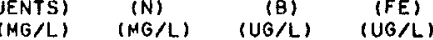

A Pumping. 
342414119274201 . Loca1 number, $4 \mathrm{~N} / 25 \mathrm{~W}-26 \mathrm{A1} \mathrm{S}$.

LOCATION. - Lat $34^{\circ} 24^{\prime} 14^{\prime \prime}$, long $119^{\circ} 27^{\prime} 42^{\prime \prime}$, about $3 \mathrm{mi}$ ( $5 \mathrm{~km}$ ) east of Carpinteria on Gobernador Road. Owner: Moses Mesa Associates Co.

AQUIFER. - Casitas Formation of pleistocene age.

WELL CHARACTERISTICS.--Drilled unused water-table we 11 , diameter 10 in $(25 \mathrm{~cm})$, depth $480 \mathrm{ft}(146 \mathrm{~m})$, cased to $480 \mathrm{ft}(146 \mathrm{~m})$, perforated 228 to $480 \mathrm{ft}(69$ to $146 \mathrm{~m})$.

DATUM. - Altitude of land-surface datum is $420 \mathrm{ft}(128 \mathrm{~m})$ above mean sea 1 eve 1

PERIOD OF RECORD. - -January 1940 to May 1941, June 1944 to current year.

EXTREMES FOR PERIOD OF RECORD.--Highest water leve1 measured, $185.40 \mathrm{ft}(56.51 \mathrm{~m})$ below 1 and-surface datum, Apr. 8, 1975; lowest measured, $387.00 \mathrm{ft}(117.96 \mathrm{~m})$ below land-surface datum, Nov. 28,1955 .

WATER LEVEL, IN FEET BELON LAND-SURFACE DATUM, WATER YEAR OCTOBER 1975 TO SEPTEMBER 1976

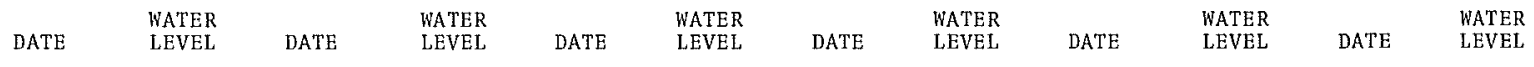

MAR $24 \quad 188.40$

343627120030801 . Local number, $6 \mathrm{~N} / 30 \mathrm{~W}-9 \mathrm{N1} \mathrm{S}$.

LOCATION. - Lat $34^{\circ} 36^{\prime} 27^{\prime \prime}$, long $120^{\circ} 03^{\prime} 08^{\prime \prime}$, near Santa Ynez.

Owner: San Lucas Ranch.

AQUTFER. - - Paso Robles(?) Formation of pliocene and pleistocene(?) age.

WELL CHARACTERISTICS. - -Drilled stock water-table we11, diameter 8 in (20 cm), depth $160 \mathrm{ft}(49 \mathrm{~m})$.

DATUM. - Land-surface datum is $660.01 \mathrm{ft}(201.17 \mathrm{~m})$ above mean sea level.

PERIOD OF RECORD,--December 1941 to current year.

EXTREMES FOR PERIOD OF RECORD. - - Highest water leve1 measured, $24.06 \mathrm{ft}$ ( 7.33 m) below 1 and-surface datum,

July 27,$1960 ;$ lowest measured, $46.75(14.25 \mathrm{~m})$ below land-surface datum, Mar. $31,1976$.

WATER LEVEL, IN FEET BELOW LAND-SURFACE DATUM, WATER YEAR OCTOBER 1975 TO SEPTEMBER 1976

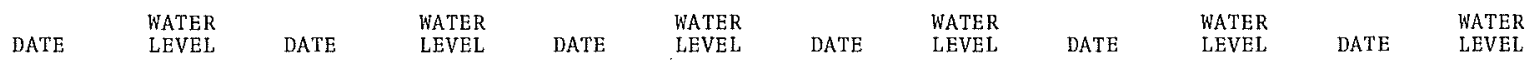

MAR $31 \quad 46.75$

343709120144701 . Local number, 6N/32W-9A2 S.

LOCATION. - Lat $34^{\circ} 37^{\prime} 09^{\prime \prime}$, long $120^{\circ} 14^{\prime} 47^{\prime \prime}$, near Buellton.

Owner: E. F. Airey.

AQUIFER, - -A11uvium.

WELL CHARACTERISTICS. - Drilled irrigation water-table well, diameter 12 in (30 $\mathrm{cm})$, depth $72 \mathrm{ft}(22 \mathrm{~m})$,

DATUM. - Land-surface datum is $308.03 \mathrm{ft}(93.95 \mathrm{~m})$ above mean sea level.

PERTOD OF RECORD. - Novenber 1941 to August 1942 , April 1945, September 1949 to August 1958 , August 1960 to current year.

EXTREMES FOR PERTOD OF RECORD.--Highest water leve1 measured, $29.23 \mathrm{ft}$ ( $8.91 \mathrm{~m}$ ) below 1 and-surface datum,

Jan. 16,$1952 ;$ 1owest measured, $42.30 \mathrm{ft}(12.89 \mathrm{~m})$ below 1 and-surface datum, Sept. $20,1971$.

WATER LEVEL, IN FEET BELOW LAND-SURFACE DATUM, WATER YEAR OCTOBER 1975 TO SEPTEMBER 1976

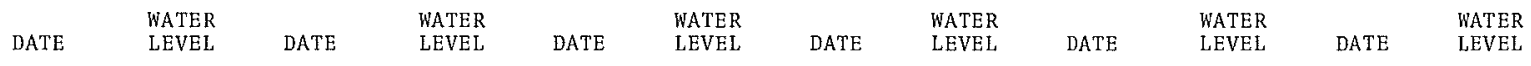

APR $5 \quad 36.70$

343831120055001 . Loca1 number, $7 \mathrm{~N} / 31 \mathrm{~W}-36 \mathrm{~L} 2 \mathrm{~S}$.

LOCATION. - Lat $34^{\circ} 38^{\prime} 31^{\prime \prime}$, long $120^{\circ} 05^{\prime} 50^{\prime \prime}$, Baseline and Grand (Refugio) Avenues, near Ballard.

Owner: D. B. Kilbourne.

AQUIFER. - -Paso Robles Formation.

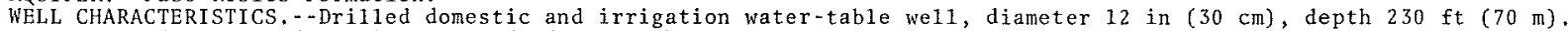
DATUM,--Land-surface datum is $720.64 \mathrm{ft}(219.65 \mathrm{~m})$ above mean sea level.

PERIOD OF RECORD. - October 1942 to current year.

EXTREMES FOR PERIOD OF RECORD, --Highest water level measured, $16.54 \mathrm{ft}$ ( $5.04 \mathrm{~m})$ below 1 and-surface datum, Apr. 7,1943 ; lowest measured, $128.20 \mathrm{ft}(39.07 \mathrm{~m})$ below iand-surface datum, 0ct. $14,1968$.

WATER LEVEL, IN FEET BELOW LAND-SURFACE DATUM, WATER YEAR OCTOBER 1975 TO SEPTEMBER 1976

DATE WATER WATER WATER WATE WATER WATER

MAR $31 \quad 82.7$ 
344219120250601 . Local number, $7 \mathrm{~N} / 34 \mathrm{~W}-12 \mathrm{E} 1 \mathrm{~S}$.

LOCATION, - Lat $34^{\circ} 42^{\prime} 19^{\prime \prime}$, long $120^{\circ} 25^{\prime} 06^{\prime \prime}$, near Lompoc, Union 0il Co., purisima Lease.

Owner: U. S. Geological Survey.

AQUIFER. - Careaga Sand of Pliocene age.

WELL CHARACTERISTICS. - -Drilled observation artesian well, diameter 8 to 16 in (20 to $41 \mathrm{~cm}$ ), depth $385 \mathrm{ft}$ ( $117 \mathrm{~m})$ cased to $385 \mathrm{ft}(117 \mathrm{~m})$, perforated 145 to $385 \mathrm{ft}(44$ to $117 \mathrm{~m})$.

DATUM. - - Land-surface datum is $385.83 \mathrm{ft}(117.60 \mathrm{~m})$ above mean sea level.

PERIOD OF RECORD,--June 1949 to July 1950, January 1956 to December 1956, January 1959 to December 1959 , January 1961 to October 1967, July 1970 to current year.

EXTREMES FOR PERIOD OF RECORD, - -Highest water level measured, $301.00 \mathrm{ft}$ ( $91.74 \mathrm{~m}$ ) below land-surface datum, June 19,$1949 ; 1$ owest dry, Mar. 29, Oct. 27, 1967.

WATER LEVEL, IN FEET BELOW LAND-SURFACE DATUM, WATER YEAR OCTOBER 1975 TO SEPTEMBER 1976

\begin{tabular}{|c|c|c|c|c|c|c|c|c|c|c|c|}
\hline DATE & $\begin{array}{l}\text { WATER } \\
\text { LEVEL }\end{array}$ & DATE & $\begin{array}{l}\text { WATER } \\
\text { LEVEL }\end{array}$ & DATE & $\begin{array}{l}\text { WATER } \\
\text { LEVEL }\end{array}$ & DATE & $\begin{array}{l}\text { WATER } \\
\text { LEVEL }\end{array}$ & DATE & $\begin{array}{l}\text { WATER } \\
\text { LEVEL }\end{array}$ & DATE & $\begin{array}{l}\text { WATER } \\
\text { LEVEL }\end{array}$ \\
\hline $\begin{array}{lr}\text { OCT } & 1 \\
\text { OCT } & 29\end{array}$ & $\begin{array}{l}317.40 \\
318.00\end{array}$ & $\begin{array}{ll}\text { NOV } & 26 \\
\text { DEC } & 30\end{array}$ & $\begin{array}{l}317.80 \\
317.90\end{array}$ & $\begin{array}{ll}\text { JAN } & 23 \\
\text { FEB } & 25\end{array}$ & $\begin{array}{l}318.00 \\
317.95\end{array}$ & $\begin{array}{ll}\text { MAR } & 24 \\
\text { APR } & 28\end{array}$ & $\begin{array}{l}317.90 \\
317.88\end{array}$ & $\begin{array}{ll}\text { MAY } & 24 \\
\text { JUN } & 24\end{array}$ & $\begin{array}{l}317.95 \\
317.95\end{array}$ & $\begin{array}{ll}\text { JUL } & 26 \\
\text { SEP } & 14\end{array}$ & $\begin{array}{l}318.12 \\
318.30\end{array}$ \\
\hline
\end{tabular}

343948120292002 , Local number, $7 \mathrm{~N} / 34 \mathrm{~W}-29 \mathrm{E} 4 \mathrm{~S}$

LOCATION, - Lat $34^{\circ} 39^{\prime} 48^{\prime \prime}$, long $120^{\circ} 29^{\prime} 20^{\prime \prime}$, Central and Floradale Avenues, near Lompoc.

Owner: W. H. Sanor.

AQUIFER - - A1l UVIUT .

WELL. CHARACTERISTICS. - Drilled irrigation artesian well, dianeter 16 in (41 cm), depth $176 \mathrm{ft}$ (54 $\mathrm{m})$

DATUM. - - Land-surface datum is $67.71 \mathrm{ft}(20.64 \mathrm{~m})$ above mean sea level.

PERIOD OF RECORD. - October 1945 to current year.

EXTREMES FOR PERIOD OF RECORD. - - Highest water leve1 measured, $18.36 \mathrm{ft}$ ( $5.60 \mathrm{~m}$ ) below 1 and-surface datum, Mar. 31, 1958; lowest measured, $48.14 \mathrm{ft}(14.67 \mathrm{~m})$ below land-surface datum, July $24,1963$.

WATER LEVEL, IN FEET BELOW LAND-SURFACE DATUM, WATER YEAR OCTOBER 1975 TO SEPTEMBER 1976

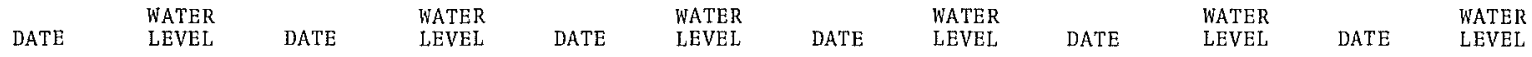

MAR $23 \quad 31.38$

344043120322402 . Local number, $7 \mathrm{~N} / 35 \mathrm{~W}-23 \mathrm{E} 4 \mathrm{~S}$.

LOCATION, - Lat $34^{\circ} 40^{\prime} 43^{\prime \prime}$, Iong $120^{\circ} 32^{\prime} 24^{\prime \prime}$, Ocean and Union Sugar Co. Avenues, near Lompoc.

Owner: U. S. Geologica1 Survey, Union'Sugar Co. property.

AQUI FER. - -Al luvium.

WELL CHARACTERISTICS.--Drilled observation water-table we1l, diameter 2 in ( $5 \mathrm{~cm}$ ), depth $28 \mathrm{ft}$ ( $9 \mathrm{~m}$ ),

DATUM. - Land-surface datum is $36.90 \mathrm{ft}(11.24 \mathrm{~m}$ ) above mean sea level.

PERIOD OF RECORD - -October 1947 to current year.

EXTREMES FOR PERIOD OF RECORD, - - Highest water level measured, 6.65 ft ( 2.03 m) below land-surface datum,

Mar. 23, 1976; lowest measured, $22.79 \mathrm{ft}(6.95 \mathrm{~m})$ below land-surface datum, Aug. 26,1948 .

WATER LEVEL, IN FEET BELOW LAND-SURFACE DATUM, WATER YEAR OCTOBER 1975 TO SEPTEMBER 1976

DATE WATER WATER WATER WATE WATER

MAR $23 \quad 6.65$

344546120252901 . Local number, $8 \mathrm{~N} / 34 \mathrm{~W}-23 \mathrm{~B} 1 \mathrm{~S}$

LOCATION, - - Lat $34^{\circ} 45^{\prime} 46^{\prime \prime}$, 1ong $120^{\circ} 25^{\prime} 29^{\prime \prime}$, Harris-los Alamos Road and State Highway 1 , near Los Alamos.

Owner: Josephine Harris Estate.

AQUIFER - - A1 luvium.

WELL CHARACTERISTICS.--Drilled unused artesian well, diameter 12 in (30 crit), depth $150 \mathrm{ft}$ (46 m).

DATUM. - A1titude of 1and-surface datum is $315 \mathrm{ft}(96 \mathrm{~m})$ above mean sea level.

PERIOD OF RECORD. - December 1943 to current year.

EXTREMES FOR PERIOD OF RECORD, - -Highest water level measured, $12.19 \mathrm{ft}$ ( $3.72 \mathrm{~m}$ ) below land-surface datum, Feb. 29 , $1944 ;$ lowest measured, 36.36 ft $(11.08 \mathrm{~m})$ below land-surface datum, Mar, 8, 1972.

WATER LEVEL, IN FEET BELOW LAND-SURFACE DATUM, WATER YEAR OCTOBER 1975 TO SEPTEMBER 1976

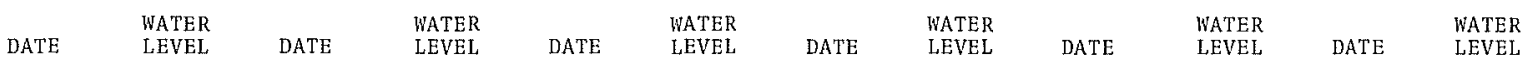

MAR $23 \quad 23.20$ 
345616120231001 . Local number, $10 \mathrm{~N} / 33 \mathrm{~W}-19 \mathrm{~B} 1 \mathrm{~S}$.

LOCATION, - - Lat $34^{\circ} 56^{\prime} 16^{\prime \prime}$, Iong $120^{\circ} 23^{\prime} 10^{\prime \prime}$, Battles and East Stowell Roads, near Santa Maria. Owner: Owen T. Rice.

AQUIFER. - Alluvium and Paso Robles Formation of Pliocene and Pleistocene age.

WELL CHARACTERISTICS.--Drilled irrigation water-table wel1, diameter 16 in (41 cm), depth $307 \mathrm{ft}$ (94 $\mathrm{m}$ ), perforated 92 to $97 \mathrm{ft}(28$ to $30 \mathrm{~m}), 116$ to $125 \mathrm{ft}(35$ to $38 \mathrm{~m}), 190$ to $215 \mathrm{ft}(58$ to $66 \mathrm{~m}), 238 \mathrm{fo} 248 \mathrm{ft}(73 \mathrm{to} 76 \mathrm{~m})$.

DATUM. - -Altitude of land-surface datum is $275 \mathrm{ft}(84 \mathrm{~m})$ above mean sea level.

PERIOD OF RECORD. - -December 1927 , August 1929 to current year.

EXTREMES FOR PERIOD OF RECORD. - - Highest water level measured, $72.70 \mathrm{ft}$ (22.16 m) below 1 and-surface datum,

Apr. 1, 1970; lowest measured, $191.3 \mathrm{ft}(58.3 \mathrm{~m})$ below land-surface datum, Aug. $30,1965$.

COOPERATION. - Reported measurements were furnished by Santa Maria Valley Water Conservation District.

WATER LEVEL, IN FEET BELOW LAND-SURFACE DATUM, WATER YEAR OCTOBER 1975 TO SEPTEMBER 1976

\begin{tabular}{|c|c|c|c|c|c|c|c|c|}
\hline 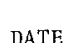 & WATER & DATE & $\begin{array}{l}\text { WATER } \\
\text { FVVE }\end{array}$ & DATE & $\begin{array}{l}\text { WATER } \\
\text { LEVEL }\end{array}$ & DATP & WATER & WATER \\
\hline
\end{tabular}

$\operatorname{OCT} 28$

$\begin{array}{llllll}140.5 \mathrm{G} & \text { JAN } 13 & 142.5 \mathrm{G} \quad \text { MAR } 26 & 120.70 \quad \text { MAR } 29\end{array}$

$143.0 \mathrm{G}$ JUL 22

$167.5 G$

345742120362501 , Local number, $10 \mathrm{~N} / 35 \mathrm{~W}-7 \mathrm{~F} 1 \mathrm{~S}$

LOCATION. - Lat $34^{\circ} 57^{\prime} 42^{\prime \prime}$, long $120^{\circ} 36^{\prime} 25^{\prime \prime}$, near Guadalupe.

Owner: M. J. E11 is

AQUIFER. -Aliuvium and Paso Robles Formation of Pliocene and Pleistocene(?) age

WELL CHARACTERISTICS. - -Drilled domestic and irrigation artesian wel1, diameter i2 in (30 $\mathrm{cm})$, depth $249 \mathrm{ft}$ ( $76 \mathrm{~m}$ ), perforated 140 to $145 \mathrm{ft}(43$ to $44 \mathrm{~m}), 200$ to $225 \mathrm{ft}(61$ to $69 \mathrm{~m})$.

DATUM. - Altitude of land-surface datum is $48 \mathrm{ft}(15 \mathrm{~m})$ above mean sea level.

PERIOD OF RECORD. - -August 1929 to August 1936, April 1938 to current year.

EXTREMES FOR PERIOD OF RECORD.--Highest water leve1 flowing, Jan. 1, 1942, Jan. 1, Feb. 29, Nov. 29, Dec. 28, 1944,

Jan. 1, Apr. 1, Dec, 28, 1945, Jan. 1, Dec, 28, 1946, Jan. 7, 1947 ; 1owest measured, 37.40 ft (11.40 m) below

Iand-surface datum

COOPERATION, --Reported measurements were furnished by Santa Maria Valley Water Conservation District.

WATER LEVEL, IN FEET BELOW LAND-SURFACE DATUM, WATER YEAR OCTOBER 1975 TO SEPTEMBER 1976

\begin{tabular}{|c|c|c|c|c|c|c|c|c|c|c|c|}
\hline DATE & $\begin{array}{l}\text { WATER } \\
\text { LEVEL }\end{array}$ & DATE & $\begin{array}{l}\text { WATER } \\
\text { LEVEL }\end{array}$ & DATE & $\begin{array}{l}\text { WATER } \\
\text { LEVEL }\end{array}$ & DATE & $\begin{array}{l}\text { WATER } \\
\text { LEVEL }\end{array}$ & DATE & $\begin{array}{l}\text { WATER } \\
\text { LEVEL }\end{array}$ & DATE & $\begin{array}{l}\text { WATER } \\
\text { LEVEL }\end{array}$ \\
\hline OCT 29 & $7.8 \mathrm{G}$ & JAN 14 & $9.2 \mathrm{G}$ & MAR 23 & 8.40 & MAR 29 & $8.2 \mathrm{G}$ & JUL 22 & $10.0 \mathrm{G}$ & & \\
\hline
\end{tabular}

G Measurement by another agency. 

Accuracy of field data and computed results....

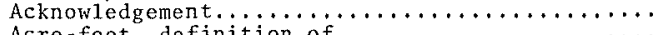
Acre-foot, definition of ............... Agua Caliente Creek near Warner Springs........ Alamo Creek near Nipomo.................

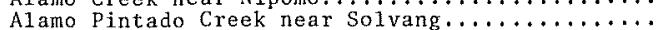
Alamo River near Niland..................

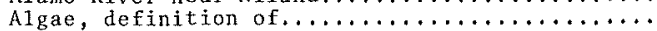
Alhambra Wash at Klingerman Street near Montebel1o.

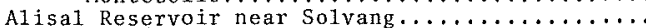

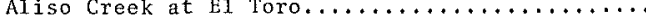
A11-American Cana1, below Pilot Knob wasteway... near Imperial Dam, Ariz,-Calif.............

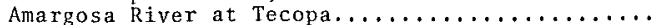
Andreas Creek near Palm Springs.............

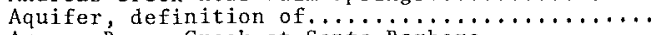
Arroyo Burro Creek at Santa Barbara........... Arroyo Seco (tributary to Los Angeles River)

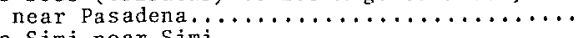

Arroyo Simi near Simi................. Arroyo Trabuco at San Juan Capistrano.......... Artesian, definition of ................ Atascadero Creek, at Puente Road, near Goleta... near Goleta... at Puente Road, near. Goleta... Atascadero Creek basin, crest-stage partial-

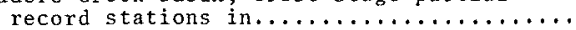

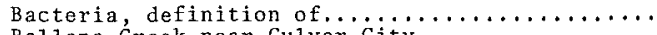
Ballona Creek near Culver City.............

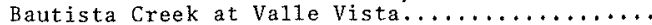

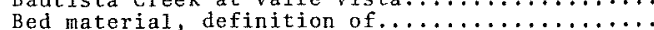

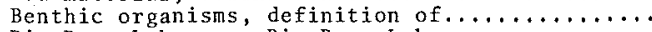

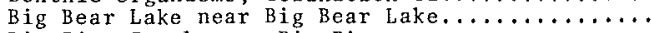

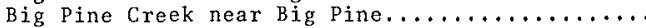

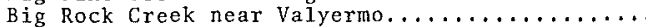
Big Tujunga Creek below Hansen Dam..........

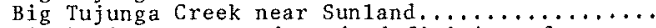
Biochemical oxygen demand, definition of .......

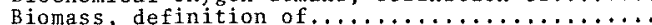
Bishop Creek below powerpiant No. 6 , near Bishop Blosser ditch near Donovan Road, at Santa Maria. Blosser ditch near Donovan Road, at Santa Maria. Bottom matertal, definition of . . . . . . . . . . Bradley ditch near Donovan Road, at Santa Maria. Brea Creek below Brea Dam, near Fullerton......

Cachuma, Lake, near Santa Ynez

Cajon Creek below Lone Pine Creek, near

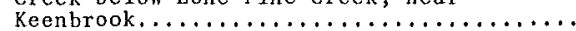
Calleguas Creek at Camariiio state Hospitai.....

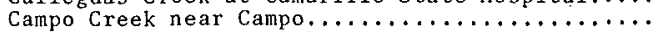
Carbon Creek below Carbon Canyon Dam........... Carpinteria Creek near Carpinteria........... Caruthers Creek near Ivanpah.............

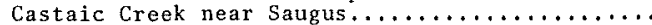
Castaic Creek near Saugus

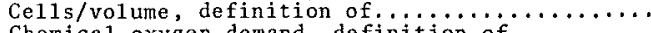
Chemical oxygen demand, definition of $\ldots \ldots \ldots \ldots$

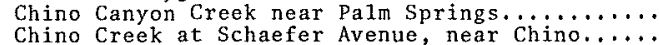

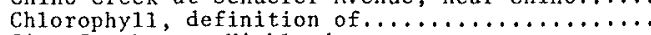

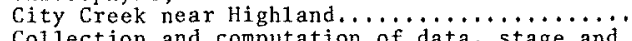
Collection and computation of data, stage and

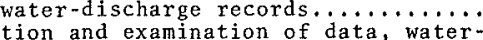

Collection and examination of data, water

Collection of the data, ground-water levels..... Colorado River, above Imperial Dam, Ariz.-Caij.

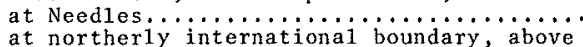

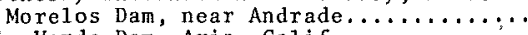

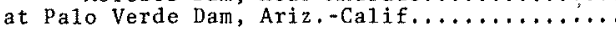

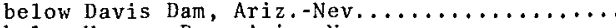

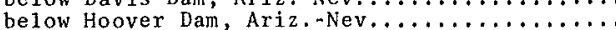

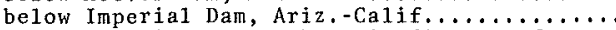
below Imperial Dam, schematic diagram of.....

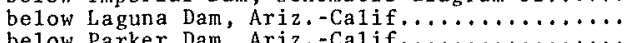
below Parker Dam, Ariz, -Calif............... neat Topock, Axiz ................. Colorado River aqueduct, near Parker Dam,

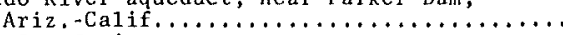

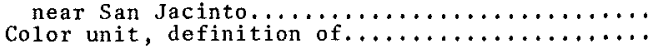

Conejo Creek above Highway 101, near Camarillo.. Page 505

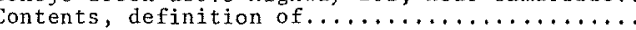

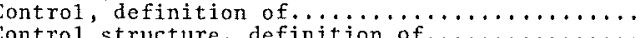

Convict

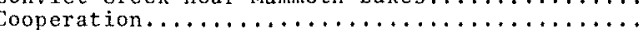

cottonwood Creek (head of Tijuana River) above Tecate Creek, near Dulzura............. 267 Cottonwood Creek (Owens Lake basin) near öiancha 260 Coyote Creek (tributary to Salton Sea) near

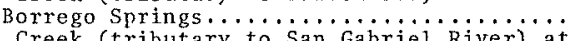
e Creek (tributary to San Gabriel River) at

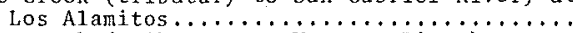

Coyote Creek (tributary to Ventura River), near

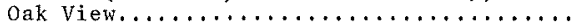

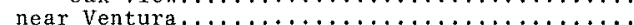
Crest-stage partiai-record stations, discharge at $\ldots \ldots \ldots \ldots \ldots \ldots \ldots \ldots$ Cubic foot per second, definition of .........

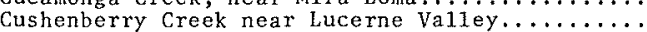
Cuyama River, below Buckhorn Canyon, near Santa

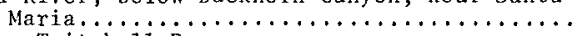

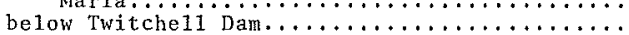

Dale Lake basin, crest-stage partial-record

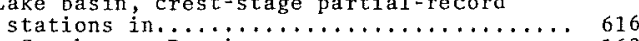

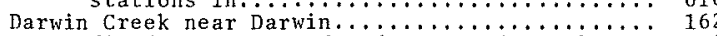

Data, field, accuracy of and computed results... 20

explanation of, ground-water levels........ 24

surface-water records............... 17

water-quality records $\ldots \ldots \ldots \ldots \ldots \ldots \ldots \ldots, 21$

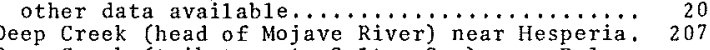

Deep Creek (tributary to Salton Sea) near Palm

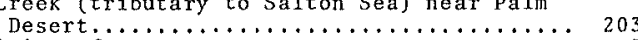

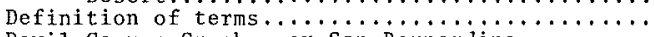

Devil Canyon Creek near San Bernardino........ 373

Discharge, partial-record stations and miscellaneous sites.................

crest-stage partia1-record stations.........

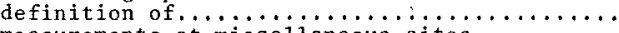
measurements at miscellaneous sites......... Dissolved, definition of $\ldots \ldots \ldots \ldots \ldots \ldots \ldots \ldots$ Diversity index, definition of $\ldots \ldots \ldots \ldots \ldots \ldots \ldots$ Downstream order and station number..........

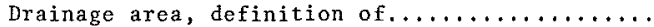

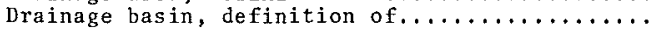

East Twin Creek near Arrowhead Springs........ E1 Capitan Reservoir near Lakeside.......... E1 Modena-I rvine Channe1 near Irvine...........

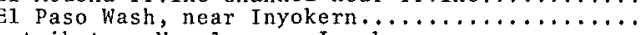
tributary No. 1 , near Inyokern........... tributary No. 2 , near Inyokern............. tributary No. 3, near Inyokern............ tributary No. 4 , near Inyokern........... tributary No, 5 , near Inyokern .... $\ldots \ldots \ldots \ldots \ldots$
merson Lake basin, crest-stage partiai-record Emerson Lake basin, crest-stage partial-record Explanation of, ground-water ievei records..... stage and water-discharge records $\ldots \ldots \ldots \ldots \ldots$ water-quality records..................

Fish Creek near Duarte.................. Fortynine palms Creek near Twentynine Palms.... Franklin Creek at Carpinteria.............. $\mathrm{Ft}^{3} / \mathrm{s}$-day, definition of....................

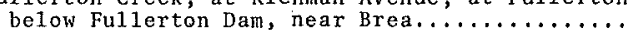

Gage height, definition of .............

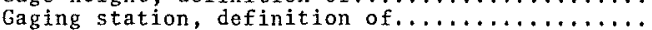

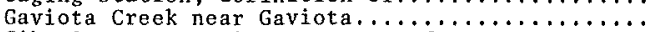
Gibraltar Reservoir, contents of....... Ariz.-Calif......................

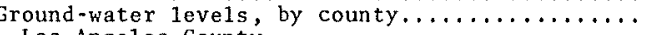
Los Angeles County .................. orange County $\ldots \ldots \ldots \ldots \ldots \ldots \ldots \ldots \ldots \ldots$

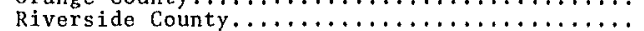
San Bernardino County................

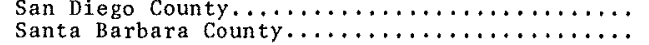
(n) . 565 567 400 616 606 616
7 .

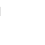

9

7

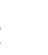


Guejito Creek near $\operatorname{san}$ Pasqual............ $\begin{array}{r}\text { Page } \\ 291\end{array}$

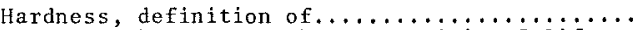
Havasu, Lake, near Parker, Dam, Ariz.-Calif....

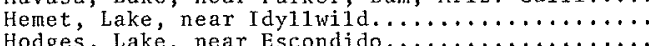

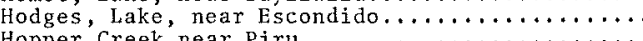

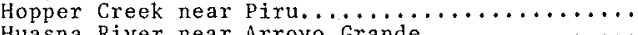
Huasna River near Arroyo Grande.

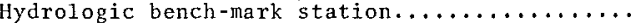

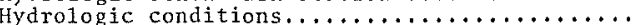

Independence Creek below Pinyon Creek, near

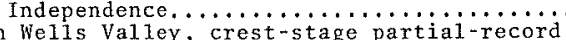
Indian Wells Valley, crest-stage partial-record

Jalama Creek near Lompoc.................

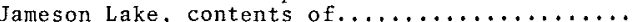

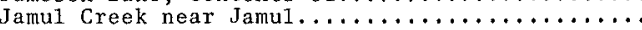

Keys Creek tributary at Valley Center.........

Lakes and reservoirs:

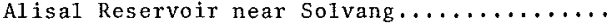

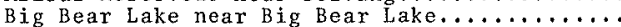

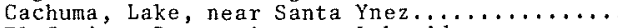

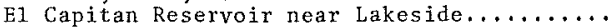

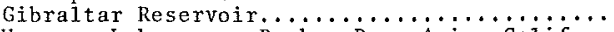
Havasu, Lake, near Parker Dam, Ariz.-Calif...

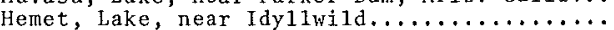

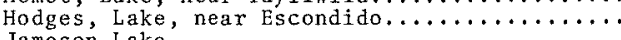

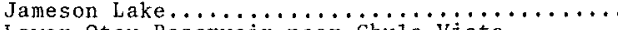
Lower Otay Reservoir near Chula Vista....... Matilija Reservoix at Matilija Hot Springs...

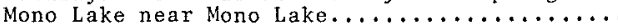

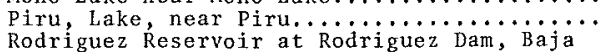

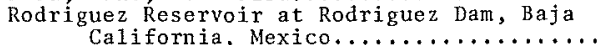

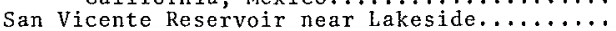
Sweetwater Reservoir near National City......

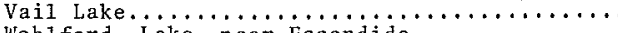
Wohlford, Lake, near Escondido.

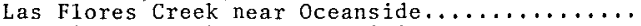

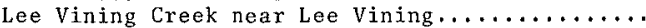

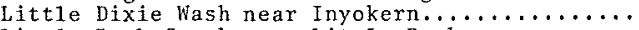

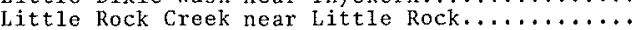
Little San Gorgonio Creek near Beaumont.........

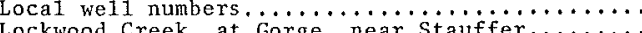

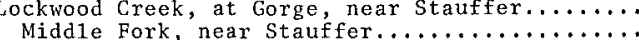

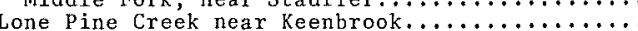

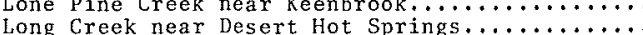
Long Creek near Desert Hot Springs ............. Los Angeles River, at Feliz Boulevard,

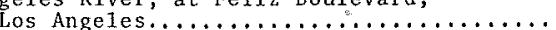

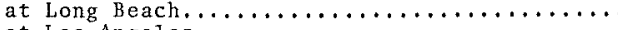

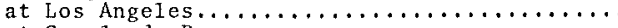

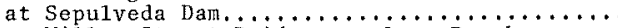
at Willow Street Bridge, at Long Beach.......

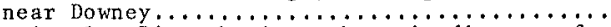
Los Angeles River basin, schematic diagram of.. Los Penasquitos Creek, below Poway Creek, near

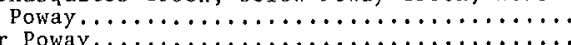

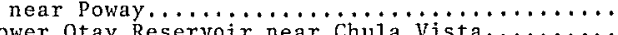
Lower Otay pry lake basin, crest-stage partiai-

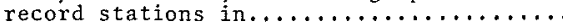

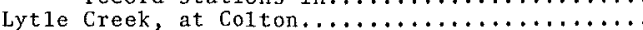

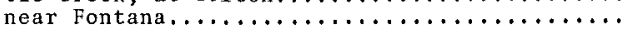

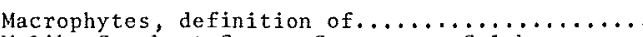
Malibu Creek at Crater Camp, near Calabasas.... Maria Ygnacio Creek at University Drive, near

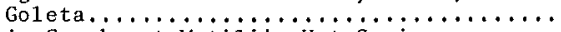
Matilija Creek, at Matiijja Hot Springs........ North Fork, at Matilija Hot Springs.......... Matilija Reservoir at Matilija Hot Springs...... Metanorphic stage, definition of.

Methylene blue active substance, definition of.

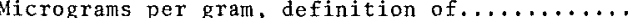

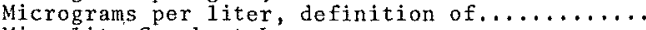
Miguelito Creek at Lompoc............... Mill Creek (tributary to Mono lake) beiow Lundy Lake, near Mono Lake............. Mill Creek (tributary to Santa Ana River) near

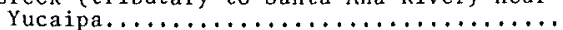

67

388

293

535

16

3

258

585

300

594

347

591

280

587
67

388

293

586

276

559
262

262
531

279

294

313

266

617
229

229
357

14
525

525
524

524
371

371
616

256

474

485
476

470

486
488

478

453

287
288

288
276

616

374

369

8
501

580

560

562

559
368

8
8

8

60.

263

351
Miscellaneous per liter, definition of ................... Mission Creek (Los Angeles River basin) near

585
586
275

270
281
279

368
8

Mission Creek (Saiton Sea basin) near Desert Hot

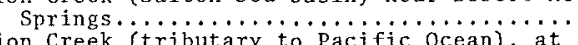

Mission Creek (tributary to Pacific Ocean), at

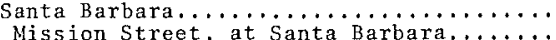

ission Creek basin, crest-stage partiai-record

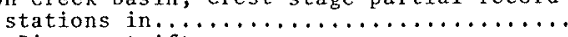

Mojave River, at Afton................

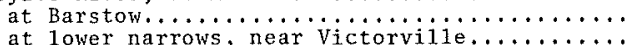

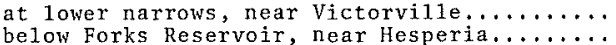

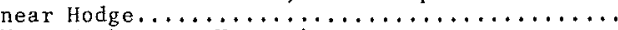

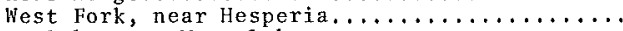

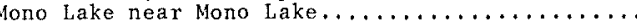

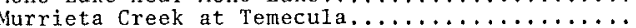

National stream-quality accounting network..... Nekton, definition of................. New River, at international boundary, at

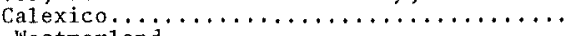

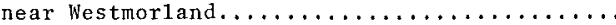

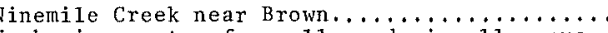

Numbering system for wells and miscellaneous

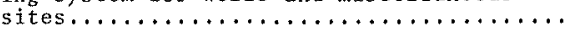

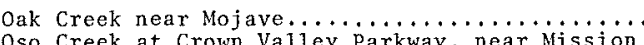

Oso Creek at Crown Valiey parkway, near Mission

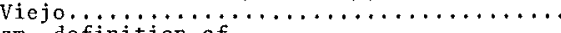
rganism, definition of $\ldots \ldots \ldots \ldots \ldots \ldots \ldots$ Owens River, at Keeler Bridge, near Lone pine.. below Tinemaha Reservoir, near Big Pine......

Pacoima Creek near San Fernando...........

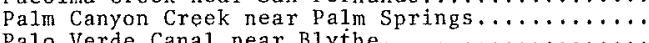
Palo Verde Canal near Blythe.......................

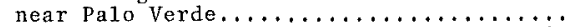

palo verde Irrigation District oijü

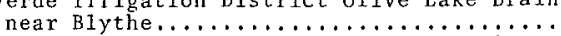

Palo verde Irrigation District outfaï Drain $\ldots$ nr

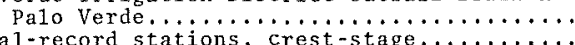
Partial-record stations, crest-stage.........

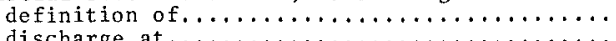

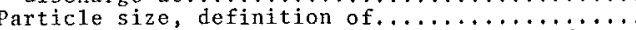

Particle-size classification, definition of....

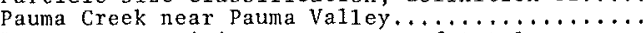
percent composition or percent of total,

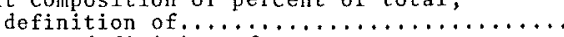

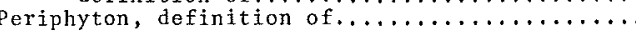

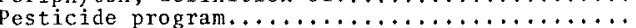

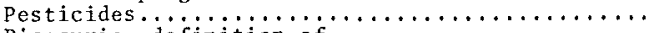

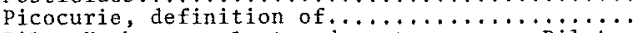
pilot Knob powerplant and wasteway near pilot

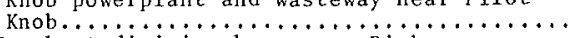

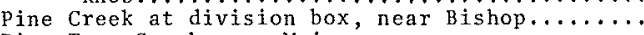

Pine Tree Creek near Mojave................

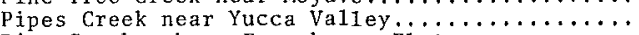

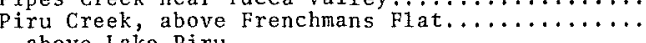

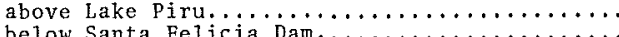
below Thorn Meadows, near stauffer..........

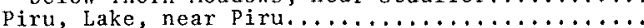
Plankton, definition of $\ldots \ldots \ldots \ldots \ldots \ldots \ldots \ldots \ldots \ldots$

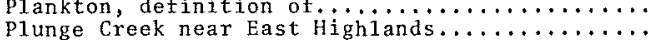

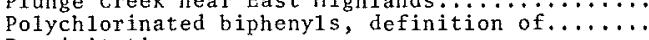
Precipitation:

Los Penasquitos Creek below Poway Creek, near

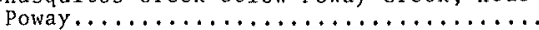

Mission Creek near Desert Hot Springs........

Pine Tree Creek near Mojave...............

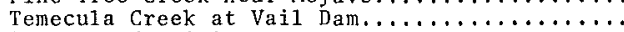

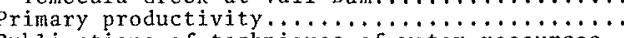
Publications of techniques of water-resources

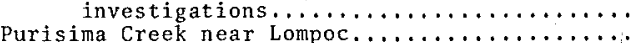
Quail Wash near Joshua Tree..............

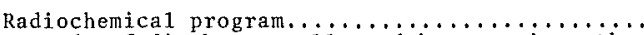
Records of discharge coilected by agencies other

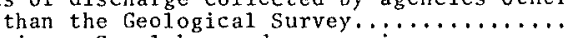
Reservoirs. See lakes and reservoirs:
Page

308

16
8

169

188

17

230

320

9
20
259

259

471

201
75

82

79

80

616

616

9

9

17
9

9

153

234

231
616

526

528

532
523

531

10

10

287

198

231

307
10

25

618

616

17

21 
Return surface flows below Imperia1 Dam,

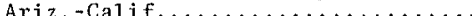

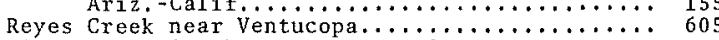
Rial to pipeline below Sar Antonio Dam, near

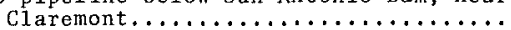

Rio Hondo, above Whittier Narrows Dam........

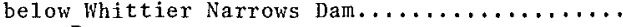

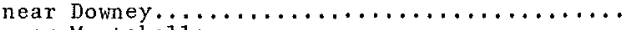
near Montebei1o.

Riverside Water Quality Control Plant at Riverside Narrows, near Arlington........ Rock Creek at Little Round Valley, near Bishop.. Rodeo-San Pasqual Creek near Lompoc............

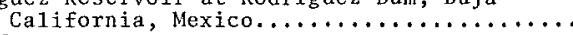

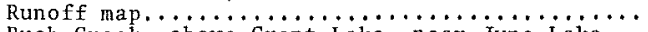
Rush Creek, above Grant Lake, near June Lake....
below Agnew Lake, near June Lake...........

Salsipuedes Creek (tributary to Santa Ynez

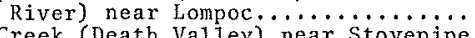

Salt Creek (Death Valley) near Stovepipe

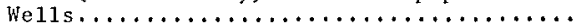

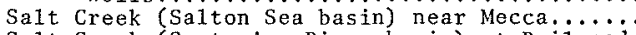

Salt Creek (Santa Ana River basin) at Railroad

Canyon Reservoir, near Elsinore........
Salton Sea, flow from Mexico at International Boundary . . . . . . . . . . . . . .

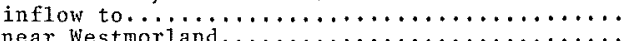

near Westmorland,.........

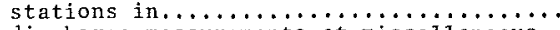
discharge measurements at miscellaneous

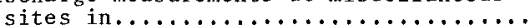

San Antonio Creek (Santa Ana River basin) below

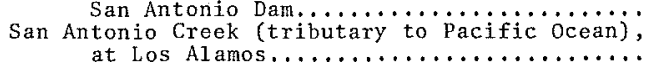
603

San Antonio Creek (Ventura River basin) at

San Bernardino Water Quaijty Contrö Piant at

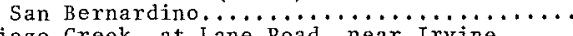

San Diego Creek, at Lane Road, near Irvine.....

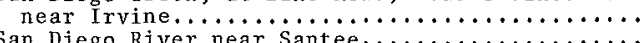
San Diego River near Santee $\ldots \ldots \ldots \ldots \ldots \ldots$

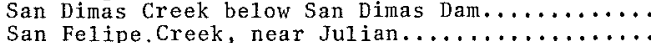

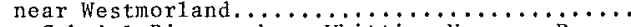

San Gabriel River, above Whittier Narrows Dam... at Azusa powerhouse, at Azusa............

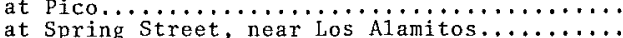

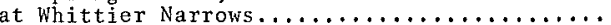
below Santa Fe Dam, near Baidwin Park.......... East Fork, near Camp Bonita............ West Fork, at Camp Rincon..............

San Gabriel River basin, schematic diagram of...

San Gorgonio River near white water............

San Jacinto River, at Railroad Canyon weir, near

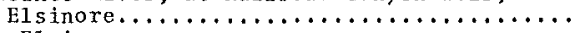

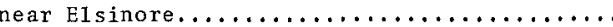
near San Jacinto.........

San Jose Creek (tributary to Pacific Ocean), at

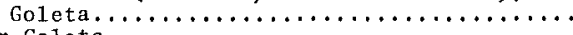

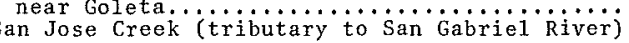

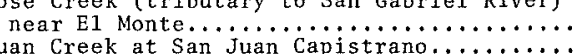

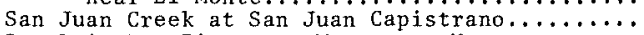

San Luis Rey River, at Monserate Narrows, near

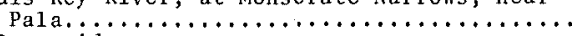

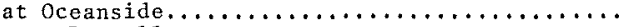

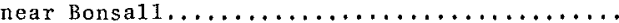
West Fork, near Warner springs............

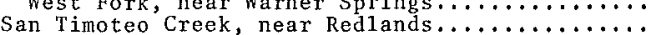
San Vicente Reservoir near Lakeside...........

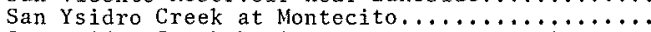
San Ysidro Creek basin, crest-stage partiai

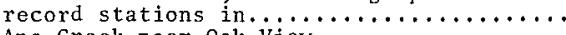

Santa Ana Creek near Oak View......

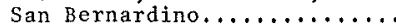

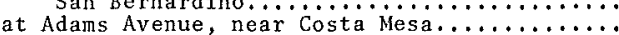

at Imperial Highway, near Anaheim..........

Santa Ana River at Mission Boulevard, at

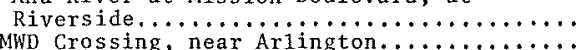

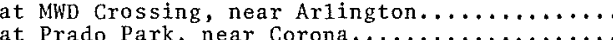

age

Santa Ana River, at Santa Ana.............

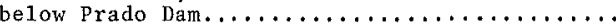

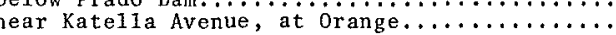

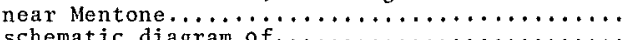
schematic diagram of ...................

Imperial Highway, near Anaheim..........

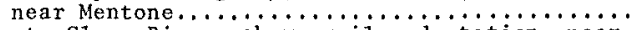

anta Clara River, above railroad station, near

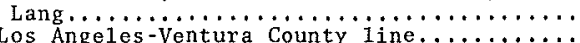

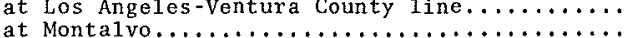
near santa ciära River, near santa Paula...... South Fork, at Saugus $\ldots \ldots \ldots \ldots \ldots \ldots \ldots \ldots$

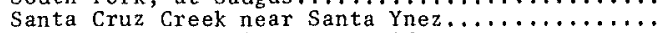

Santa Margarita River, at Ysidora.............

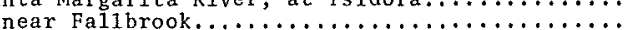

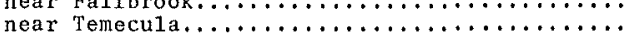
near Temecula $\ldots \ldots \ldots \ldots \ldots \ldots \ldots \ldots \ldots \ldots \ldots \ldots \ldots \ldots \ldots$

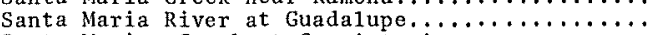

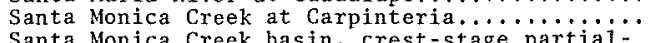

Santa Monica Creek basin, crest-stage partial-

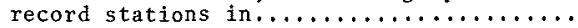

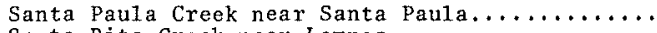

Santa Rita Creek near Lompoc..... W.......
Santa Ynez River, above Gibraitar Dam, near

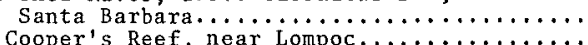

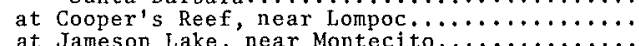

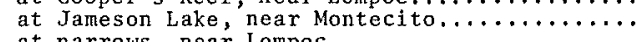
at narrows, near Lompoc..............

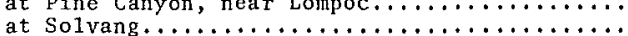
below Gibraitar Dam, near santa Barbara...... below Los Laureles Canyon, near Santa Ynez.... below Los Laureles Canyon, near Santa Ynez....

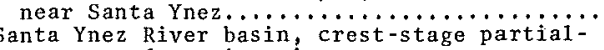

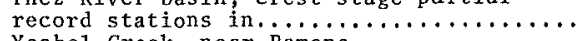

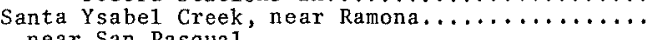
near San Pasqual................... Santiago Creek, at Modjeska............. at Santa Ana.......... $\ldots \ldots \ldots \ldots \ldots \ldots \ldots$

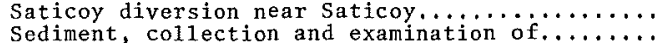
definition of $\ldots \ldots \ldots \ldots \ldots \ldots \ldots \ldots \ldots \ldots \ldots \ldots$

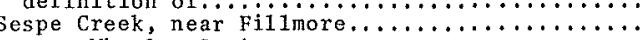
near wheeler springs $\ldots \ldots \ldots \ldots \ldots \ldots \ldots \ldots \ldots$

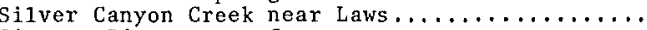
Sisquoc River, near Garey ...............

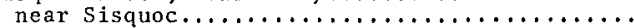

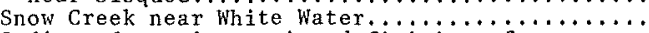
Sodium-adsorption-ratio, definition of ......... Solute, definition of $\ldots \ldots \ldots \ldots \ldots \ldots \ldots \ldots \ldots$

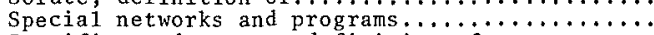

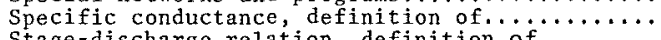
Stage-discharge relation, definition of $\ldots \ldots \ldots \ldots$

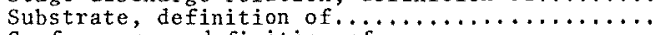

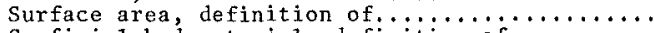

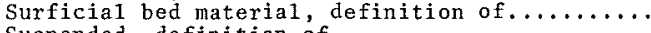
Suspended, definition of. $\ldots \ldots \ldots \ldots \ldots \ldots \ldots \ldots$ Sweetwater River near Descanso.............

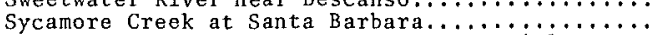
sycamore Creek basin, crest-stage partiai: record stations in .................

Tahquitz Greek near Palm Springs........... 200

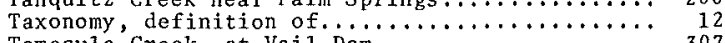

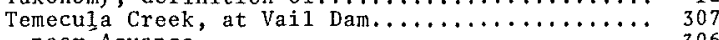

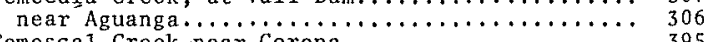

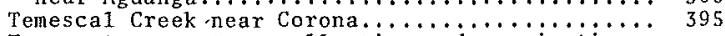

Temperature, water, collection and examination

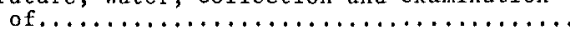

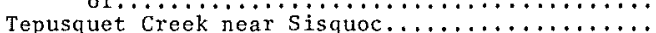

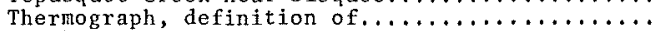

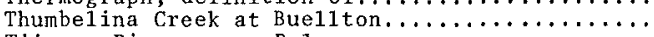

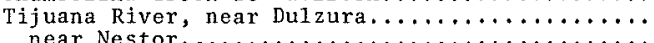

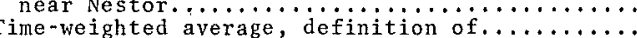

Tons per acre-foot, definition of ............

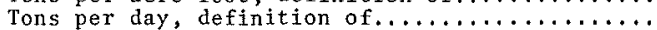

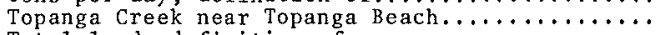

Total load, definition of..............

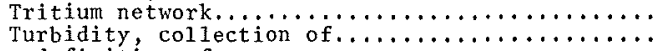

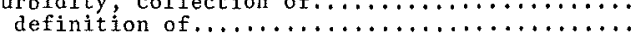




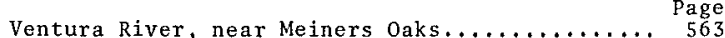
near Ventura.......................... 568 victoria Street drain at out $\ldots$ iet, at Santa Barbara...................... 578

Wagon Road Creek near Stauffer............. 604

Warm Creek, floodway at San Bernardino........ 361

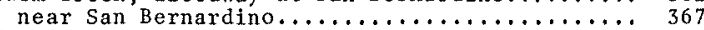

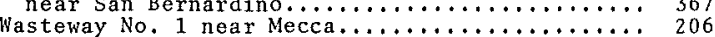

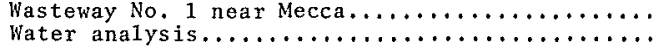

Waterman Canyon Creek near Arrowhead Springs..... 360

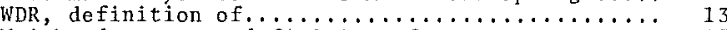

Weighted average, definition of $\ldots \ldots \ldots \ldots \ldots \ldots \ldots \ldots$

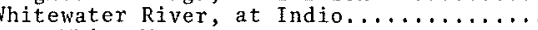

at White Water................... 194

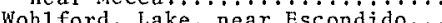

294

21 Zaca Creek near Bueliton................ 596 




\section{FACTORS FOR CONVERTING ENGLISH UNITS TO INTERNATIONAL SYSTEM UNITS (SI)}

The following factors may be used to convert the English units published herein to the International System of Units (SI). Subsequent reports will contain both the English and SI unit equivalents in the station manuscript descriptions until such time that all data will be published in SI units.

Multiply English units

\author{
inches (in) \\ feet $(\mathrm{ft})$ \\ miles (mi)
}

miles (mi)

acres

square miles $\left(\mathrm{mi}^{2}\right)$

gallons (gal)

million gallons $\left(10^{6} \mathrm{gal}\right)$

cubic feet $\left(\mathrm{ft}^{3}\right)$

cfs-days $\left[\left(\mathrm{ft}^{3} / \mathrm{s}\right) \cdot \mathrm{d}\right]$

acre-feet (acre-ft)
By

\section{Length}

$2.54 \times 10^{1}$

$2.54 \times 10^{-2}$

$3.048 \times 10^{-1}$

$1.609 \times 10^{0}$

Area

$4.047 \times 10^{3}$

$4.047 \times 10^{-1}$

$4.047 \times 10^{-1}$

$4.047 \times 10^{-3}$

$2.590 \times 10^{0}$

\section{Volume}

$3.785 \times 10^{0}$

$3.785 \times 10^{0}$

$3.785 \times 10^{-3}$

$3.785 \times 10^{3}$

$3.785 \times 10^{-3}$

$2.832 \times 10^{1}$

$2.832 \times 10^{-2}$

$2.447 \times 10^{3}$

$2.447 \times 10^{-3}$

$1.233 \times 10^{3}$

$1.233 \times 10^{-3}$

$1.233 \times 10^{-6}$

Flow

cubic feet per second $\left(\mathrm{ft}^{3} / \mathrm{s}\right)$

gallons per minute (gal/min)

million gallons per day (mgal/d)
$2.832 \times 10^{1}$

$2.832 \times 10^{1}$

$2.832 \times 10^{-2}$

$6.309 \times 10^{-2}$

$6.309 \times 10^{-2}$

$6.309 \times 10^{-5}$

$4.381 \times 10^{1}$

$4.381 \times 10^{-2}$

Mass millimeters $(\mathrm{mm})$

meters $(\mathrm{m})$

meters $(\mathrm{m})$

kilometers $(\mathrm{km})$

To obtain SI units

\author{
square meters $\left(\mathrm{m}^{2}\right)$ \\ * hectares (ha) \\ square hectometers $\left(\mathrm{hm}^{2}\right)$ \\ square kilometers $\left(\mathrm{km}^{2}\right)$ \\ square kilometers $\left(\mathrm{km}^{2}\right)$
}
**liters (1)
cubic decimeters $\left(\mathrm{dm}^{3}\right)$
cubic meters $\left(\mathrm{m}^{3}\right)$
cubic meters $\left(\mathrm{m}^{3}\right)$
cubic hectometers $\left(\mathrm{hm}^{3}\right)$
cubic decimeters $\left(\mathrm{dm}^{3}\right)$
cubic meters $\left(\mathrm{m}^{3}\right)$
cubic meters $\left(\mathrm{m}^{3}\right)$
cubic hectometers $\left(\mathrm{hm}^{3}\right)$
cubic meters $\left(\mathrm{m}^{3}\right)$
cubic hectometers $\left(\mathrm{hm}^{3}\right)$
cubic kilometers $\left(\mathrm{km}^{3}\right)$

tons (short)

$9.072 \times 10^{-1}$

liters per second $(1 / \mathrm{s})$

cubic decimeters per second $\left(\mathrm{dm}^{3} / \mathrm{s}\right)$

cubic meters per second $\left(\mathrm{m}^{3} / \mathrm{s}\right)$

liters per second $(1 / \mathrm{s})$

cubic decimeters per second $\left(\mathrm{dm}^{3} / \mathrm{s}\right)$

cubic meters per second $\left(\mathrm{m}^{3} / \mathrm{s}\right)$

cubic decimeters per second $\left(\mathrm{dm}^{3} / \mathrm{s}\right)$

cubic meters per second $\left(\mathrm{m}^{3} / \mathrm{s}\right)$

\footnotetext{
*The unit hectare is approved for use with the International System (SI) for a limited time. See NBS Special Bulletin 330, p.15, 1972 edition.

**The unit liter is accepted for use with the International System (SI). See NBS Special Bulletin 330, p. 13, 1972 edition.
} 
U.S. DEPARTMENT OF THE INTERIOR

Geological Survey

855 Oak Grove Avenue

Menlo Park CA 94025

POSTAGE AND FEES PAID

U.S. DEPARTMENT OF THE INTERIOR INT 413

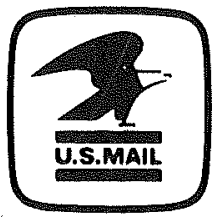

OFFICIAL BUSINESS

PENALTY FOR PRIVATE USE $\$ 300$ 